\title{
Noninvasive Nonpharmacological Treatment for Chronic Pain: A Systematic Review
}




\title{
Comparative Effectiveness Review
}

Number 209

\section{Noninvasive Nonpharmacological Treatment for Chronic Pain: A Systematic Review}

\author{
Prepared for: \\ Agency for Healthcare Research and Quality \\ U.S. Department of Health and Human Services \\ 5600 Fishers Lane \\ Rockville, MD 20857 \\ www.ahrq.gov
}

Contract No. 290-2015-00009-I

Prepared by:

Pacific Northwest Evidence-based Practice Center

Portland, OR

Investigators:

Andrea C. Skelly, Ph.D., M.P.H.

Roger Chou, M.D.

Joseph R. Dettori, Ph.D., M.P.H., M.P.T.

Judith A. Turner, Ph.D.

Janna L. Friedly, M.D.

Sean D. Rundell, Ph.D., D.P.T.

Rongwei Fu, Ph.D.

Erika D. Brodt, B.S.

Ngoc Wasson, M.P.H.

Cassandra Winter, B.S.

Aaron J. R. Ferguson, B.A.

AHRQ Publication No. 18-EHC013-EF

June 2018 


\section{Key Messages}

\section{Purpose of Review}

To assess which noninvasive nonpharmacological treatments for common chronic pain conditions improve function and pain for at least 1 month after treatment.

\section{Key Messages}

- Interventions that improved function and/or pain for at least 1 month when used for-

o Chronic low back pain: Exercise, psychological therapies (primarily cognitive behavioral therapy [CBT]), spinal manipulation, low-level laser therapy, massage, mindfulness-based stress reduction, yoga, acupuncture, multidisciplinary rehabilitation (MDR).

o Chronic neck pain: Exercise, low-level laser, Alexander Technique, acupuncture.

o Knee osteoarthritis: Exercise, ultrasound.

o Hip osteoarthritis: Exercise, manual therapies.

o Fibromyalgia: Exercise, CBT, myofascial release massage, tai chi, qigong, acupuncture, MDR.

o Chronic tension headache: Spinal manipulation.

- Most effects were small. Long-term evidence was sparse.

- There was no evidence suggesting serious harms from any of the interventions studied; data on harms were limited. 
This report is based on research conducted by the Pacific Northwest Evidence-based Practice Center (EPC) under contract to the Agency for Healthcare Research and Quality (AHRQ), Rockville, MD (Contract No. 290-2015-00009-I). The findings and conclusions in this document are those of the authors, who are responsible for its contents; the findings and conclusions do not necessarily represent the views of AHRQ. Therefore, no statement in this report should be construed as an official position of AHRQ or of the U.S. Department of Health and Human Services.

\section{None of the investigators have any affiliations or financial involvement that conflicts with the material presented in this report.}

The information in this report is intended to help health care decisionmakers - patients and clinicians, health system leaders, and policymakers, among others - make well-informed decisions and thereby improve the quality of health care services. This report is not intended to be a substitute for the application of clinical judgment. Anyone who makes decisions concerning the provision of clinical care should consider this report in the same way as any medical reference and in conjunction with all other pertinent information, i.e., in the context of available resources and circumstances presented by individual patients.

This report is made available to the public under the terms of a licensing agreement between the author and the Agency for Healthcare Research and Quality. This report may be used and reprinted without permission except those copyrighted materials that are clearly noted in the report. Further reproduction of those copyrighted materials is prohibited without the express permission of copyright holders.

AHRQ or U.S. Department of Health and Human Services endorsement of any derivative products that may be developed from this report, such as clinical practice guidelines, other quality enhancement tools, or reimbursement or coverage policies, may not be stated or implied.

This report may periodically be assessed for the currency of conclusions. If an assessment is done, the resulting surveillance report describing the methodology and findings will be found on the Effective Health Care Program Web site at www.effectivehealthcare.ahrq.gov. Search on the title of the report.

Persons using assistive technology may not be able to fully access information in this report. For assistance contact EffectiveHealthCare@ahrq.hhs.gov.

Suggested citation: Skelly AC, Chou R, Dettori JR, Turner JA, Friedly JL, Rundell SD, Fu R, Brodt ED, Wasson N, Winter C, Ferguson AJR. Noninvasive Nonpharmacological Treatment for Chronic Pain: A Systematic Review. Comparative Effectiveness Review No. 209. (Prepared by the Pacific Northwest Evidence-based Practice Center under Contract No. 290-2015-00009-I.) AHRQ Publication No 18-EHC013-EF. Rockville, MD: Agency for Healthcare Research and Quality; June 2018. Posted final reports are located on the Effective Health Care Program search page.

DOI: https://doi.org/10.23970/AHRQEPCCER209. 


\section{Preface}

The Agency for Healthcare Research and Quality (AHRQ), through its Evidence-based Practice Centers (EPCs), sponsors the development of evidence reports and technology assessments to assist public- and private-sector organizations in their efforts to improve the quality of health care in the United States. The Centers for Disease Control and Prevention and the Office of the Assistant Secretary for Planning and Evaluation requested this report from the EPC Program at AHRQ. AHRQ assigned this report to the following EPC: Pacific Northwest Evidence-based Practice Center (Contract Number: 290-2015-00009-I).

The reports and assessments provide organizations with comprehensive, evidence-based information on common medical conditions and new health care technologies and strategies. They also identify research gaps in the selected scientific area, identify methodological and scientific weaknesses, suggest research needs, and move the field forward through an unbiased, evidence-based assessment of the available literature. The EPCs systematically review the relevant scientific literature on topics assigned to them by AHRQ and conduct additional analyses when appropriate prior to developing their reports and assessments.

To bring the broadest range of experts into the development of evidence reports and health technology assessments, AHRQ encourages the EPCs to form partnerships and enter into collaborations with other medical and research organizations. The EPCs work with these partner organizations to ensure that the evidence reports and technology assessments they produce will become building blocks for health care quality improvement projects throughout the Nation. The reports undergo peer review and public comment prior to their release as a final report.

AHRQ expects that the EPC evidence reports and technology assessments, when appropriate, will inform individual health plans, providers, and purchasers as well as the health care system as a whole by providing important information to help improve health care quality.

If you have comments on this evidence report, they may be sent by mail to the Task Order Officers named below at: Agency for Healthcare Research and Quality, 5600 Fishers Lane, Rockville, MD 20857, or by email to epc@ahrq.hhs.gov.

Gopal Khanna, M.B.A.

Director

Agency for Healthcare Research and Quality

Stephanie Chang, M.D., M.P.H.

Director

Evidence-based Practice Center Program

Center for Evidence and Practice Improvement Agency for Healthcare Research and Quality
Arlene S. Bierman, M.D., M.S.

Director

Center for Evidence and Practice

Improvement

Agency for Healthcare Research and Quality

Elisabeth Kato, M.D., M.R.P.

Suchitra Iyer, Ph.D.

Task Order Officers

Center for Evidence and Practice Improvement

Agency for Healthcare Research and Quality 


\section{Investigator Affiliations}

Andrea C. Skelly, Ph.D., M.P.H.

Spectrum Research, Inc.

Roger Chou, M.D.

Department of Medical Informatics \&

Clinical Epidemiology

Oregon Health \& Science University

Joseph R. Dettori, Ph.D., M.P.H.

Spectrum Research, Inc.

Judith A. Turner, Ph.D.

Departments of Psychiatry and Behavioral

Sciences and Rehabilitation Medicine

University of Washington

Janna L. Friedly, M.D.

Department of Rehabilitation Medicine

University of Washington
Sean D. Rundell, Ph.D., D.P.T.

Department Rehabilitation Medicine

University of Washington

Roongwei Fu, Ph.D.

Department of Public Health \& Preventive

Medicine

Oregon Health \& Science University

Erika D. Brodt, B.S.

Spectrum Research, Inc.

Ngoc Wasson, M.P.H.

Oregon Health \& Science University

Cassandra Winter, B.S.

Spectrum Research, Inc.

Aaron J. R. Ferguson, B.S.

Spectrum Research, Inc.

\section{Acknowledgments}

The authors gratefully acknowledge the following individuals for their contributions to this project: Elaine Graham, M.L.S., for program guidance and collaborative support; Tracy Dana, M.L.S., for assistance with the literature search; Leah Williams, B.S., for editorial support; Paul Kraegel, M.S.W., for administrative assistance; Tamara Cheney, M.D., Jessica Griffin M.S., and Sara Grusing, B.A., for assistance with data abstraction; our Task Order Officers, Elisabeth Kato, M.D., M.R.P., and Suchitra Iyer, Ph.D., for their support and guidance in developing this report; and our Associate Editor, Timothy Wilt, M.D., M.P.H., for his review of this report.

\section{Key Informants}

In designing the study questions, the EPC consulted several Key Informants who represent the end-users of research. The EPC sought the Key Informant input on the priority areas for research and synthesis. Key Informants are not involved in the analysis of the evidence or the writing of the report. Therefore, in the end, study questions, design, methodological approaches, and/or conclusions do not necessarily represent the views of individual Key Informants.

Key Informants must disclose any financial conflicts of interest greater than \$5,000 and any other relevant business or professional conflicts of interest. Because of their role as end-users, individuals with potential conflicts may be retained. The TOO and the EPC work to balance, manage, or mitigate any conflicts of interest. 
The list of Key Informants who provided input to this report follows:

Matthew Bair, M.D., M.S.

Associate Professor of Medicine

Indiana University School of Medicine

Indianapolis, IN

Daniel Cherkin, Ph.D.

Senior Scientific Investigator

Kaiser Permanente Washington Health

Research Institute

Seattle, WA

Penny Cowan

Patient Advocate

Founder \& CEO, American Chronic Pain

Association

Pittsburgh, PA

Kurt Kroenke, M.D., M.A.C.P.

Professor of Medicine

Indiana University School of Medicine

Indianapolis, IN

Robert Nicholson, Ph.D., L.C.P., FAHS

Director, Department of Quality \& Safety

Mercy Health System

St. Louis, MO
Linda Porter, Ph.D.

Office of Pain Policy

National Institute of Neurological Disorders and Stroke

Bethesda, MD

Kathleen Sluka, Ph.D., P.T., FAPTA

Professor of Physical Therapy and

Rehabilitation Science

Neurobiology of Pain Lab

University of Iowa

Iowa City, IA

Lemeneh Tefera, M.D., M.Sc.

Medical Officer

Centers for Clinical Standards and Quality

Centers for Medicare \& Medicaid Services

Baltimore, MD

David Williams, Ph.D

Professor of Anesthesiology, Rheumatology,

Psychiatry, and Psychology

Associate Director of the Chronic Pain and

Fatigue Research Center

University of Michigan

Ann Arbor, MI

\section{Technical Expert Panel}

In designing the study questions and methodology at the outset of this report, the EPC consulted several technical and content experts. Broad expertise and perspectives were sought. Divergent and conflicted opinions are common and perceived as healthy scientific discourse that results in a thoughtful, relevant systematic review. Therefore, in the end, study questions, design, methodologic approaches, and/or conclusions do not necessarily represent the views of individual technical and content experts.

Technical Experts must disclose any financial conflicts of interest greater than $\$ 5,000$ and any other relevant business or professional conflicts of interest. Because of their unique clinical or content expertise, individuals with potential conflicts may be retained. The TOO and the EPC work to balance, manage, or mitigate any potential conflicts of interest identified. 
The list of Technical Experts who participated in reviewing the report follows:

Kelli Allen, Ph.D.*

Research Professor of Medicine

Division of Rheumatology Allergy and

Immunology

University of North Carolina School of

Medicine

Chapel Hill, NC

Center for Health Services Research in

Primary Care

Durham VA Health Care System

Durham, NC

Rowland Hazard, M.D.*

Professor of Orthopedics and of Medicine

Geisel School of Medicine, Dartmouth

College

Hanover, NH

Charles Helmick III, M.D.*

Senior Medical Epidemiologist

National Center for Chronic Disease

Prevention and Health Promotion

Centers for Disease Control and Prevention

Atlanta, GA

Kim Jones, Ph.D, F.N.P., FAAN*

Professor, School of Nursing

Oregon Health \& Science University

Portland, OR
Erin Krebs, M.D., M.P.H.

Center for Disease Outcomes Research

Minneapolis VA Healthcare System

Minneapolis, MN

Robert McLean, M.D.

Associate Clinical Professor of Medicine, Rheumatology

Yale School of Medicine

New Haven, CT

Robert Nicholson, Ph.D., L.C.P., FAHS*

Director, Department of Quality \& Safety

Mercy Health System

St. Louis, MO

Ellen Rosenquist, M.D.

Assistant Professor

Anesthesiology and Pain Medicine

Cleveland Clinic

Cleveland, $\mathrm{OH}$

James Witter, M.D., Ph.D., FACR

National Institute of Arthritis and

Musculoskeletal and Skin Disease

National Institute of Health

Bethesda, MD

*Provided input on draft report.

\section{Peer Reviewers}

Prior to publication of the final evidence report, EPCs sought input from independent Peer Reviewers without financial conflicts of interest. However, the conclusions and synthesis of the scientific literature presented in this report do not necessarily represent the views of individual reviewers.

Peer Reviewers must disclose any financial conflicts of interest greater than $\$ 5,000$ and any other relevant business or professional conflicts of interest. Because of their unique clinical or content expertise, individuals with potential nonfinancial conflicts may be retained. The TOO and the EPC work to balance, manage, or mitigate any potential nonfinancial conflicts of interest identified. 
The list of Peer Reviewers follows:

Julie Fritz, Ph.D., P.T.

Department of Physical Therapy and

Athletic Training

University of Utah, College of Health

Salt Lake City, UT

Robert Kerns, Ph.D.

Professor of Psychiatry, Neurology and

Psychology

Yale School of Medicine

New Haven, CT

Tianjing Li, Ph.D.

Associate Professor, Epidemiology

Johns Hopkins Bloomberg School of Public

Health

Baltimore, MD
Karen Sherman, Ph.D., M.P.H.

Affiliate Professor, Epidemiology

University of Washington

Senior Investigator

Kaiser Permanente Washington Health

Research Institute

Seattle, WA

David Tauben, M.D.

Chief of Pain Medicine

University of Washington

Seattle, WA 


\section{Noninvasive Nonpharmacological Treatment for Chronic Pain: A Systematic Review}

\section{Structured Abstract}

Objectives. Many interventions are available to manage chronic pain; understanding the durability of treatment effects may assist with treatment selection. We sought to assess which noninvasive nonpharmacological treatments for selected chronic pain conditions are associated with persistent improvement in function and pain outcomes at least 1 month after the completion of treatment.

Data sources. Electronic databases (Ovid MEDLINE ${ }^{\circledR}$, Cochrane Central Register of Controlled Trials, Cochrane Database of Systematic Reviews) through November 2017, reference lists, and ClinicalTrials.gov.

Review methods. Using predefined criteria, we selected randomized controlled trials of noninvasive nonpharmacological treatments for five common chronic pain conditions (chronic low back pain; chronic neck pain; osteoarthritis of the knee, hip, or hand; fibromyalgia; and tension headache) that addressed efficacy or harms compared with usual care, no treatment, waitlist, placebo, or sham intervention; compared with pharmacological therapy; or compared with exercise. Study quality was assessed, data extracted, and results summarized for function and pain. Only trials reporting results for at least 1 month post-intervention were included. We focused on the persistence of effects at short term ( 1 to $<6$ months following treatment completion), intermediate term ( $\geq 6$ to $<12$ months), and long term ( $\geq 12$ months).

Results. Two hundred eighteen publications (202 trials) were included. Many included trials were small. Evidence on outcomes beyond 1 year after treatment completion was sparse. Most trials enrolled patients with moderate baseline pain intensity (e.g., $>5$ on a 0 to 10 point numeric rating scale) and duration of symptoms ranging from 3 months to $>15$ years. The most common comparison was against usual care.

Chronic low back pain: At short term, massage, yoga, and psychological therapies (primarily $\mathrm{CBT}$ ) (strength of evidence [SOE]: moderate) and exercise, acupuncture, spinal manipulation, and multidisciplinary rehabilitation (SOE: low) were associated with slight improvements in function compared with usual care or inactive controls. Except for spinal manipulation, these interventions also improved pain.

Effects on intermediate-term function were sustained for yoga, spinal manipulation, multidisciplinary rehabilitation (SOE: low), and psychological therapies (SOE: moderate). Improvements in pain continued into intermediate term for exercise, massage, and yoga (moderate effect, SOE: low); mindfulness-based stress reduction (small effect, SOE: low); spinal manipulation, psychological therapies, and multidisciplinary rehabilitation (small effects, SOE: moderate). For acupuncture, there was no difference in pain at intermediate term, but a slight improvement at long term (SOE: low). Psychological therapies were associated with slightly greater improvement than usual care or an attention control on both function and pain at shortterm, intermediate-term, and long-term followup (SOE: moderate). At short and intermediate term, multidisciplinary rehabilitation slightly improved pain compared with exercise (SOE: 
moderate). High-intensity multidisciplinary rehabilitation ( $\geq 20$ hours/week or $>80$ hours total) was not clearly better than non-high-intensity programs.

Chronic neck pain: At short and intermediate terms, acupuncture and Alexander Technique were associated with slightly improved function compared with usual care (both interventions), sham acupuncture, or sham laser (SOE: low), but no improvement in pain was seen at any time (SOE: llow). Short-term low-level laser therapy was associated with moderate improvement in function and pain (SOE: moderate). Combination exercise (any 3 of the following: muscle performance, mobility, muscle re-education, aerobic) demonstrated a slight improvement in pain and function short and long term (SOE: low).

Osteoarthritis: For knee osteoarthritis, exercise and ultrasound demonstrated small shortterm improvements in function compared with usual care, an attention control, or sham procedure (SOE: moderate for exercise, low for ultrasound), which persisted into the intermediate term only for exercise (SOE: low). Exercise was also associated with moderate improvement in pain (SOE: low). Long term, the small improvement in function seen with exercise persisted, but there was no clear effect on pain (SOE: low). Evidence was sparse on interventions for hip and hand osteoarthritis. Exercise for hip osteoarthritis was associated with slightly greater function and pain improvement than usual care short term (SOE: low). The effect on function was sustained intermediate term (SOE: low).

Fibromyalgia: In the short term, acupuncture (SOE: moderate), CBT, tai chi, qigong, and exercise (SOE: low) were associated with slight improvements in function compared with an attention control, sham, no treatment, or usual care. Exercise (SOE: moderate) and CBT improved pain slightly, and tai chi and qigong (SOE: low) improved pain moderately in the short term. At intermediate term for exercise (SOE: moderate), acupuncture, and CBT (SOE: low), slight functional improvements persisted; they were also seen for myofascial release massage and multidisciplinary rehabilitation (SOE: low); pain was improved slightly with multidisciplinary rehabilitation in the intermediate term (SOE: low). In the long term, small improvements in function continued for multidisciplinary rehabilitation but not for exercise or massage (SOE: low for all); massage (SOE: low) improved long-term pain slightly, but no clear impact on pain for exercise (SOE: moderate) or multidisciplinary rehabilitation (SOE: low) was seen. Short-term CBT was associated with a slight improvement in function but not pain compared with pregabalin.

Chronic tension headache: Evidence was sparse and the majority of trials were of poor quality. Spinal manipulation slightly improved function and moderately improved pain short term versus usual care, and laser acupuncture was associated with slight pain improvement short term compared with sham (SOE: low).

There was no evidence suggesting increased risk for serious treatment-related harms for any of the interventions, although data on harms were limited.

Conclusions. Exercise, multidisciplinary rehabilitation, acupuncture, CBT, and mind-body practices were most consistently associated with durable slight to moderate improvements in function and pain for specific chronic pain conditions. Our findings provided some support for clinical strategies that focused on use of nonpharmacological therapies for specific chronic pain conditions. Additional comparative research on sustainability of effects beyond the immediate post-treatment period is needed, particularly for conditions other than low back pain. 


\section{Contents}

Evidence Summary ........................................................................................................................... ES-1

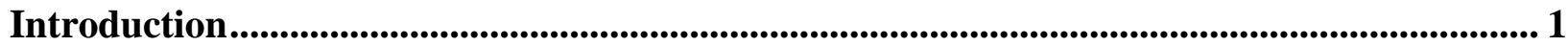

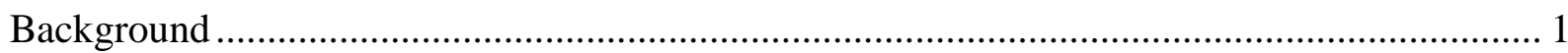

Nature and Burden of Chronic Pain ..................................................................................... 1

Management of Chronic Pain ........................................................................................... 1

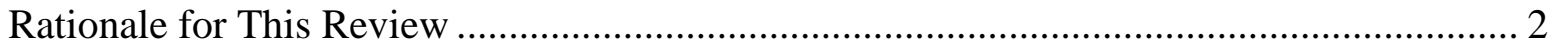

Scope and Key Questions ................................................................................................ 2

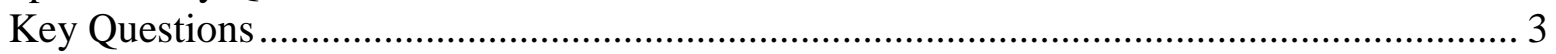

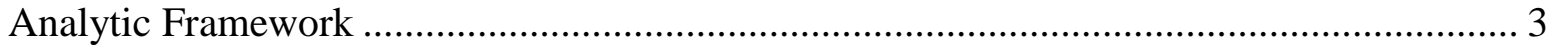

Methods............................................................................................................................................ 5

Topic Refinement and Review Protocol ............................................................................... 5

Literature Search Strategy …………………………......................................................... 5

Inclusion and Exclusion Criteria and Study Selection............................................................... 6

Data Abstraction and Data Management ................................................................................. 10

Quality (Risk of Bias) Assessment of Individual Studies........................................................ 10

Data Analysis and Synthesis................................................................................................ 11

Grading the Strength of Evidence for Major Comparisons and Outcomes ............................... 12

Assessing Applicability …………………………………...................................................... 13

Peer Review and Public Commentary …………………....................................................... 14

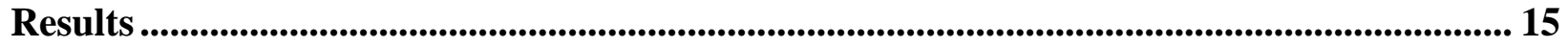

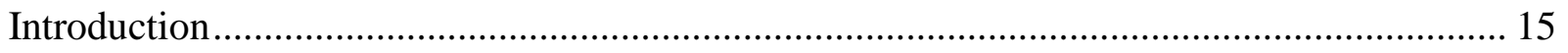

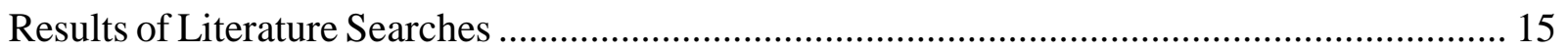

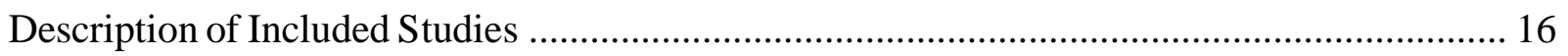

Key Question 1: Chronic Low Back Pain............................................................................. 19

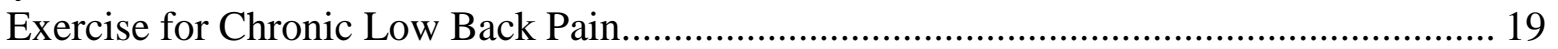

Psychological Therapies for Chronic Low Back Pain .................................................... 25

Physical Modalities for Chronic Low Back Pain..................................................................... 32

Manual Therapies for Chronic Low Back Pain .................................................................. 39

Mindfulness-Based Stress Reduction for Chronic Low Back Pain ...................................... 57

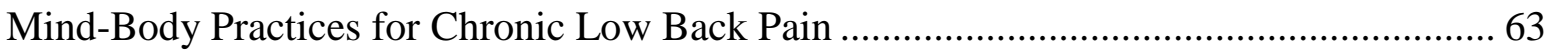

Acupuncture for Chronic Low Back Pain......................................................................... 74

Multidisciplinary Rehabilitation for Chronic Low Back Pain ............................................... 82

Key Question 2: Chronic Neck Pain........................................................................................ 97

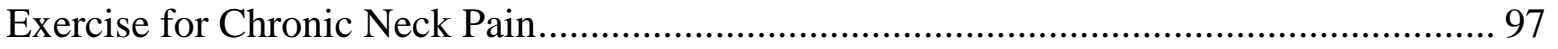

Psychological Therapies for Chronic Neck Pain ................................................................ 106

Physical Modalities for Chronic Neck Pain......................................................................... 108

Manual Therapies for Chronic Neck Pain ..................................................................... 114

Mind-Body Practices for Chronic Neck Pain .................................................................... 116

Acupuncture for Chronic Neck Pain ........................................................................... 121

Key Question 3: Osteoarthritis............................................................................................ 128

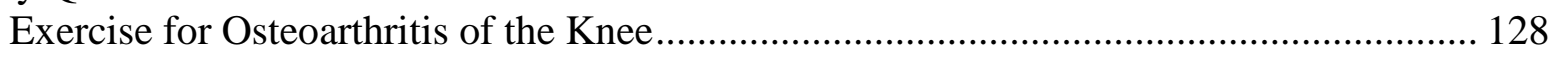

Psychological Therapy for Osteoarthritis of the Knee.......................................................... 146

Physical Modalities for Osteoarthritis of the Knee............................................................... 151

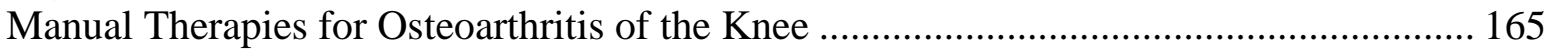

Mind-Body Therapies for Osteoarthritis of the Knee ........................................................... 169 
Acupuncture for Osteoarthritis of the Knee................................................................... 171

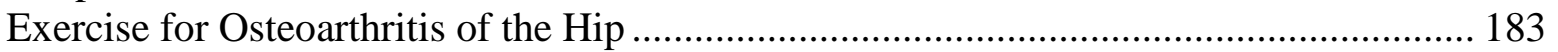

Manual Therapies for Osteoarthritis of the Hip................................................................... 189

Exercise for Osteoarthritis of the Hand ............................................................................ 192

Physical Modalities for Osteoarthritis of the Hand............................................................. 194

Multidisciplinary Rehabilitation for Osteoarthritis of the Hand.......................................... 196

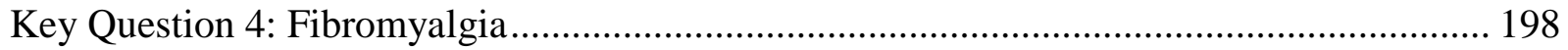

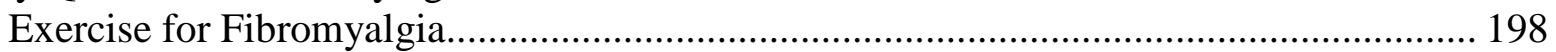

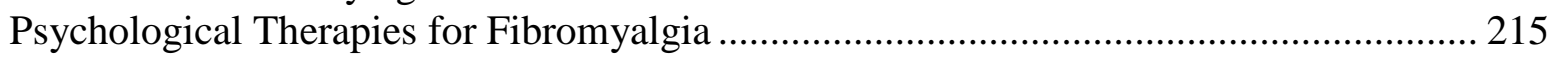

Physical Modalities for Fibromyalgia............................................................................... 234

Manual Therapies for Fibromyalgia ……………………............................................. 238

Mindfulness-Based Stress Reduction Therapy for Fibromyalgia ......................................... 242

Mind-Body Therapy for Fibromyalgia ............................................................................... 245

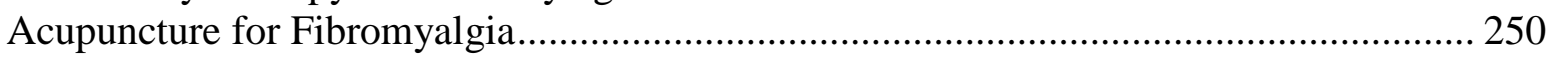

Multidisciplinary Rehabilitation for Fibromyalgia ......................................................... 256

Key Question 5: Chronic Tension Headache........................................................................ 265

Psychological Therapies for Chronic Tension Headache .................................................. 265

Physical Modalities for Chronic Tension Headache......................................................... 272

Manual Therapies for Chronic Tension Headache .......................................................... 274

Acupuncture for Chronic Tension Headache................................................................ 277

Key Question 6: Differential Efficacy …………………..................................................... 281

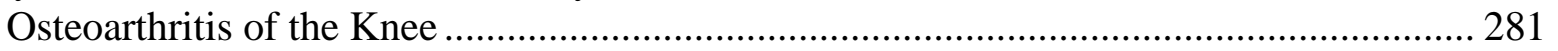

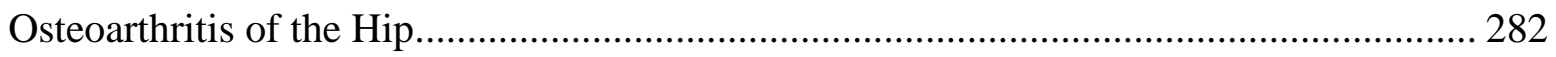

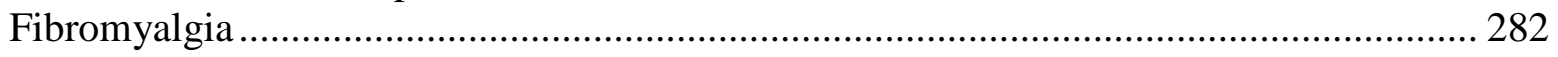

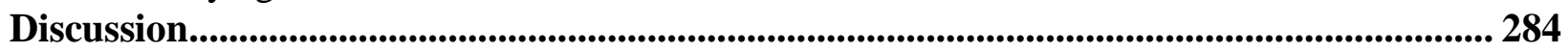

Key Findings and Strength of Evidence ........................................................................... 284

Findings in Relationship to What Is Already Known........................................................... 295

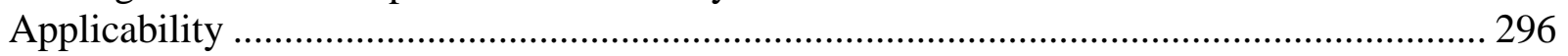

Limitations of the Evidence Base .............................................................................................. 297

Implications for Clinical and Policy Decisionmaking ........................................................... 298

Limitations of the Systematic Review Process ....................................................................... 299

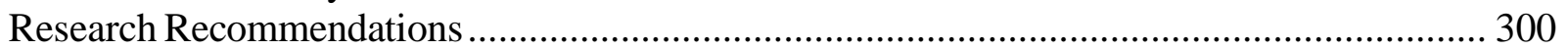

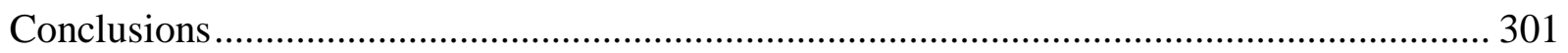

References............................................................................................................................................... 302

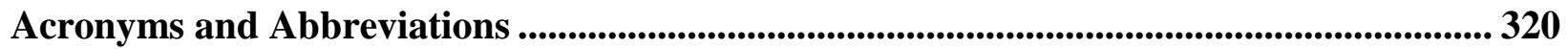

\section{Tables}

Table A. Chronic low back pain: effects of nonpharmacological interventions compared with usual care, placebo, sham, attention control, or waitlist ................................................................ Table B. Chronic low back pain: effects of nonpharmacological interventions compared with

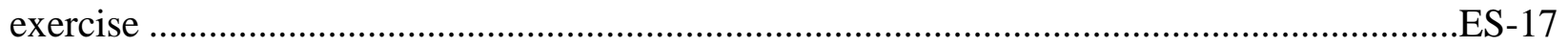

Table C. Chronic neck pain: effects of nonpharmacological interventions compared with usual care, placebo, sham, attention control, or waitlist..................................................................... Table D. Chronic neck pain: effects of nonpharmacological interventions compared with exercise ......................................................................................................................... Table E. Osteoarthritis of the knee: effects of nonpharmacological interventions compared with usual care, placebo, sham, attention control, or waitlist 
Table F. Osteoarthritis of the knee: effects of nonpharmacological interventions compared with

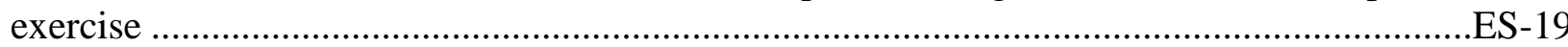

Table G. Osteoarthritis of the hip: effects of nonpharmacological interventions compared with usual care, placebo, sham, attention control, or waitlist ........................................................... Table H. Osteoarthritis of the hip: effects of nonpharmacological interventions compared with exercise

Table I. Osteoarthritis of the hand: effects of nonpharmacological interventions compared with usual care, placebo, sham, attention control, or waitlist ES-20 Table J. Fibromyalgia: effects of nonpharmacological interventions compared with usual care, placebo, sham, attention control, or waitlist ES-20 Table K. Fibromyalgia: effects of nonpharmacological interventions compared with pharmacological treatments

Table L. Fibromyalgia: effects of nonpharmacological interventions compared with exercise Table M. Chronic tension headache: effects of nonpharmacological interventions compared with usual care, placebo, sham, attention control, or waitlist ES-21 Table N. Summary of evidence gaps and research recommendations..................................... ES-25

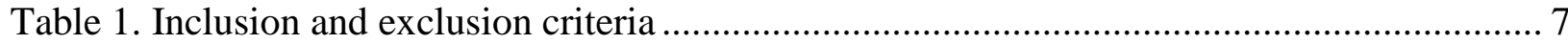

Table 2. Criteria for grading the quality of individual studies........................................................ 11

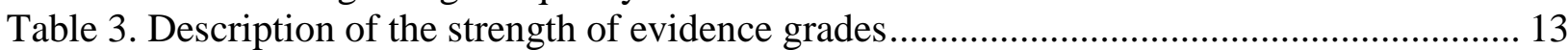

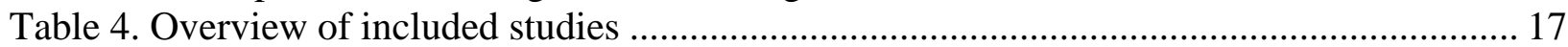

Table 5. Chronic low back pain: exercise .................................................................................... 20

Table 6. Chronic low back pain: psychological therapies ............................................................. 27

Table 7. Chronic low back pain: physical modalities (ultrasound) ................................................. 33

Table 8. Chronic low back pain: physical modalities (low-level laser therapy)............................. 35

Table 9. Chronic low back pain: physical modalities (traction) ................................................... 37

Table 10. Chronic low back pain: physical modalities (short-wave diathermy) ........................... 40

Table 11. Chronic low back pain: manual therapies (spinal manipulation) ..................................... 41

Table 12. Chronic low back pain: manual therapies (massage)....................................................... 51

Table 13. Chronic low back pain: mindfulness-based stress reduction .......................................... 58

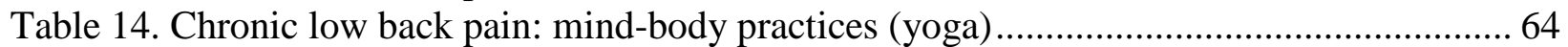

Table 15. Chronic low back pain: mind-body practices (qigong) ................................................. 73

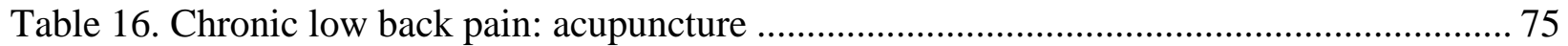

Table 17. Chronic low back pain: multidisciplinary rehabilitation ......................................... 84

Table 18. Chronic neck pain: exercise therapies .................................................................... 99

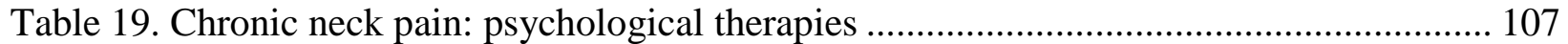

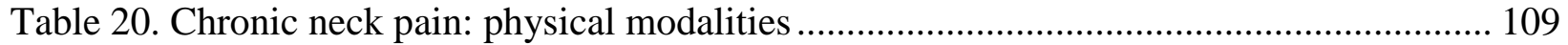

Table 21. Chronic neck pain: manual therapies..................................................................... 115

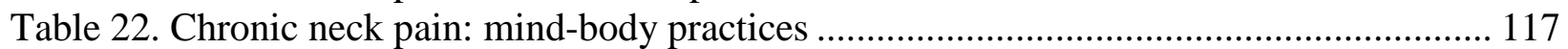

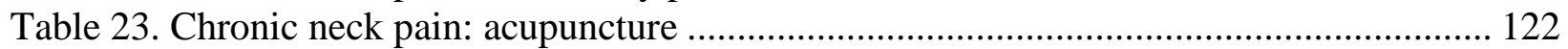

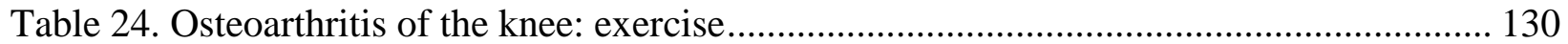

Table 25. Osteoarthritis of the knee: psychological therapies ...................................................... 148

Table 26. Osteoarthritis of the knee: physical modalities ............................................................ 153

Table 27. Osteoarthritis of the knee: manual therapies................................................................ 166

Table 28. Osteoarthritis of the knee: mind-body therapies.............................................................. 169

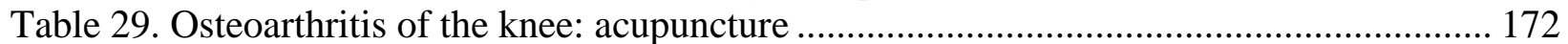

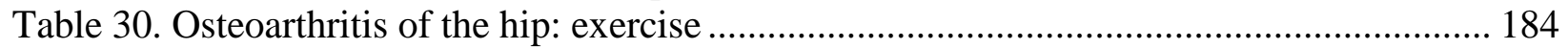




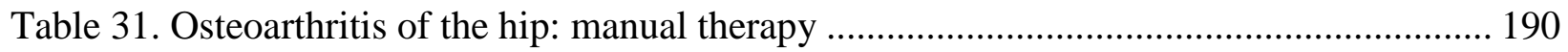

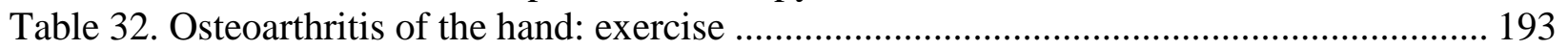

Table 33. Osteoarthritis of the hand: physical modalities............................................................. 194

Table 34. Osteoarthritis of the hand: multidisciplinary rehabilitation ........................................... 197

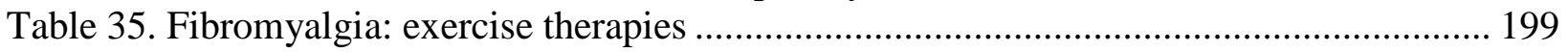

Table 36. Fibromyalgia: psychological therapies .................................................................. 217

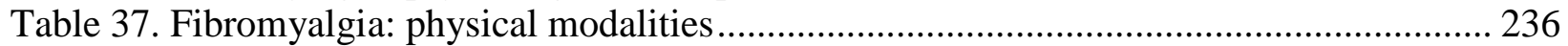

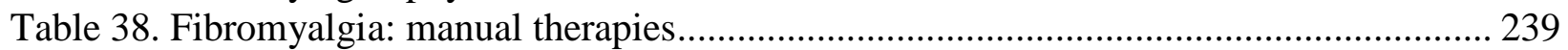

Table 39. Fibromyalgia: mindfulness-based stress reduction therapy ...................................... 243

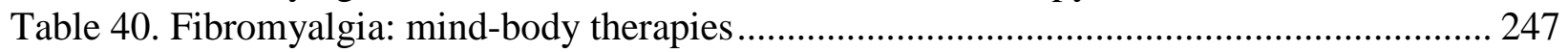

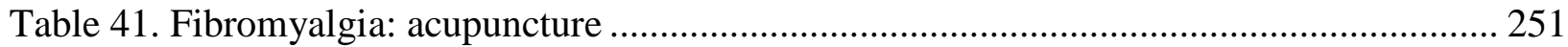

Table 42. Fibromyalgia: multidisciplinary rehabilitation .......................................................... 258

Table 43. Chronic tension headache: psychological therapies ..................................................... 267

Table 44. Chronic tension headache: physical modalities................................................... 273

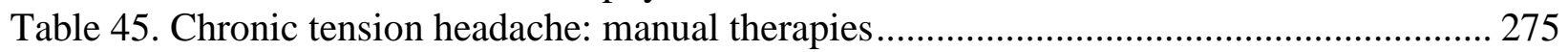

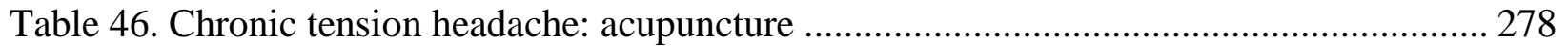

Table 47. Chronic low back pain: effects of nonpharmacological interventions compared with usual care, placebo, sham, attention control, or waitlist ............................................................ 285

Table 48. Chronic low back pain: effects of nonpharmacological interventions compared with

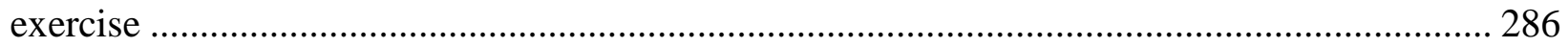

Table 49. Chronic neck pain: effects of nonpharmacological interventions compared with usual

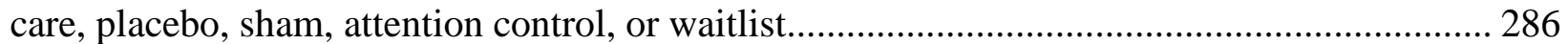

Table 50. Chronic neck pain: effects of nonpharmacological interventions compared with pharmacological treatments ...................................................................................................... 287

Table 51. Chronic neck pain: effects of nonpharmacological interventions compared with

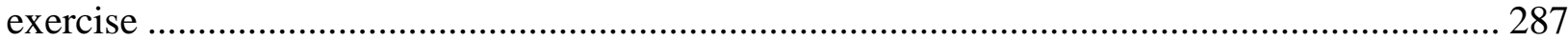

Table 52. Osteoarthritis of the knee: effects of nonpharmacological interventions compared with usual care, placebo, sham, attention control, or waitlist ............................................................. 288 Table 53. Osteoarthritis of the knee: effects of nonpharmacological interventions compared with

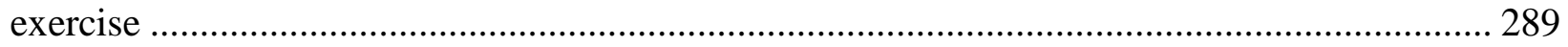

Table 54. Osteoarthritis of the hip: effects of nonpharmacological interventions compared with usual care, placebo, sham, attention control, or waitlist ............................................................ 289 Table 55. Osteoarthritis of the hip: effects of nonpharmacological interventions compared with

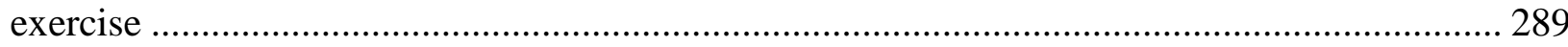
Table 56. Osteoarthritis of the hand: effects of nonpharmacological interventions compared with usual care, placebo, sham, attention control, or waitlist ............................................................ 290 Table 57. Fibromyalgia: effects of nonpharmacological interventions compared with usual care, placebo, sham, attention control, or waitlist ........................................................................... 290 Table 58. Fibromyalgia: effects of psychological therapies compared with pharmacological

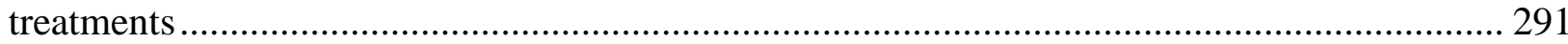
Table 59. Fibromyalgia: effects of nonpharmacological interventions compared with exercise 291 Table 60. Chronic tension headache: effects of nonpharmacological interventions compared with usual care, placebo, sham, attention control, or waitlist ............................................................ 292 Table 61. Chronic tension headache: effects of nonpharmacological interventions compared with pharmacological treatments ...................................................................................................... 292 Table 62. Summary of evidence gaps and research recommendations ....................................... 301 


\section{Figures}

Figure 1. Analytic framework ......................................................................................... 4

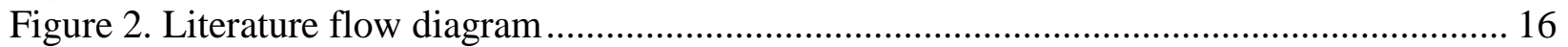

Figure 3. Overview and distribution of quality analysis ratings ................................................... 19

Figure 4. Exercise versus usual care, an attention control, or a placebo intervention for chronic

low back pain: effects on function ............................................................................................ 24

Figure 5. Exercise versus usual care, an attention control, or a placebo intervention for chronic

low back pain: effects on pain ............................................................................................ 26

Figure 6. Psychological therapy versus usual care or an attention control for chronic low back

pain: effects on function.............................................................................................................. 31

Figure 7. Psychological therapy versus usual care or an attention control for chronic low back

pain: effects on pain .............................................................................................................. 32

Figure 8. Spinal manipulation versus sham manipulation, usual care, an attention control, or a placebo intervention for chronic low back pain: effects on function.......................................... 47

Figure 9. Spinal manipulation versus sham manipulation, usual care, an attention control, or a

placebo intervention for chronic low back pain: effects on pain ................................................. 48

Figure 10. Spinal manipulation versus exercise for chronic low back pain: effects on function . 49

Figure 11. Spinal manipulation versus exercise for chronic low back pain: effects on pain........ 50

Figure 12. Massage versus sham massage, usual care, or attention control intervention for

chronic low back pain: effects on function ................................................................................. 56

Figure 13. Massage versus sham massage, usual care, or attention control for chronic low back

pain: effects on pain .......................................................................................................... 57

Figure 14. Mindfulness-based stress reduction versus usual care or an attention control for

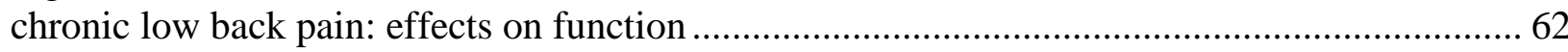

Figure 15. Mindfulness-based stress reduction versus usual care or an attention control for

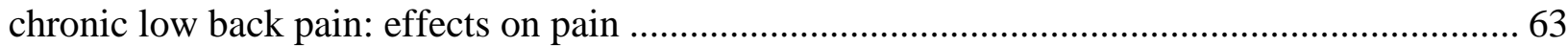

Figure 16. Yoga versus attention control or waitlist for chronic low back pain: effects on function

Figure 17. Yoga versus attention control or waitlist for chronic low back pain: effects on pain. 70

Figure 18. Yoga versus exercise for chronic low back pain: effects on function.......................... 71

Figure 19. Yoga versus exercise for chronic low back pain: effects on pain ............................... 72

Figure 20. Acupuncture versus sham acupuncture, usual care, attention control, or a placebo

intervention for chronic low back pain: effects on function .......................................................... 81

Figure 21. Acupuncture versus sham acupuncture, usual care, an attention control, or a placebo

intervention for chronic low back pain: effects on pain ............................................................. 82

Figure 22. Multidisciplinary rehabilitation versus usual care: effects on function......................... 94

Figure 23. Multidisciplinary rehabilitation versus usual care: effects on pain ............................... 95

Figure 24. Multidisciplinary rehabilitation versus exercise: effects on function............................ 96

Figure 25. Multidisciplinary rehabilitation versus exercise care: effects on pain ........................ 97

Figure 26. Exercise versus no treatment or an attention control for chronic neck pain: effects on

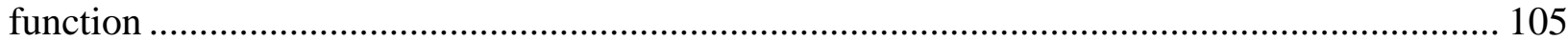

Figure 27. Exercise versus no treatment or an attention control for chronic neck pain: effects on

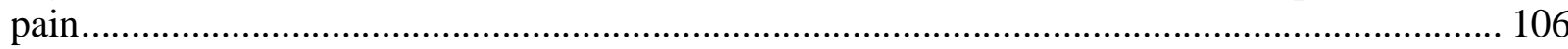

Figure 28. Low-level laser therapy versus sham for chronic neck pain: effects on function ...... 113

Figure 29. Low-level laser therapy versus sham for chronic neck pain: effects on pain............. 113 
Figure 30. Acupuncture versus sham acupuncture, a placebo intervention, or usual care for chronic neck pain: effects on function

Figure 31. Acupuncture versus sham acupuncture or a placebo intervention for chronic neck pain: effects on pain. 128

Figure 32. Exercise versus usual care, no treatment, sham, or an attention control for osteoarthritis of the knee: effects on function.... 145

Figure 33. Exercise versus usual care, no treatment, sham, or an attention control for osteoarthritis of the knee: effects on pain 146

Figure 34. Low-level laser therapy versus usual care or sham for osteoarthritis of the knee: effects on pain 165

Figure 35. Acupuncture versus usual care, waitlist, sham, or a placebo intervention in osteoarthritis of the knee: effects on function. 182

Figure 36. Acupuncture versus usual care, waitlist, sham, or a placebo intervention for osteoarthritis of the knee: effects on pain 183

Figure 37. Exercise versus usual care for osteoarthritis of the hip: effects on function ............. 188

Figure 38. Exercise versus usual care for osteoarthritis of the hip: effects on pain .................. 189

Figure 39. Exercise versus usual care, no treatment, waitlist, or an attention control for fibromyalgia: effects on function.....

Figure 40. Exercise versus usual care, no treatment, waitlist, or attention control for fibromyalgia: effects on pain . 215

Figure 41. Psychological therapies versus usual care or waitlist for fibromyalgia: effects on function

Figure 42. Psychological therapies versus usual care, waitlist, or attention control for

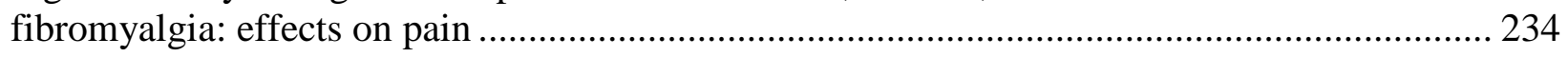

Figure 43. Myofascial release versus sham for fibromyalgia: effects on pain ......................... 242

Figure 44. Mind-body therapies for fibromyalgia: effects on function ................................ 249

Figure 45. Mind-body therapies for fibromyalgia: effects on pain........................................ 250

Figure 46. Acupuncture versus sham for fibromyalgia: effects on function ............................ 255

Figure 47. Acupuncture versus sham for fibromyalgia: effects on pain................................ 256

Figure 48. Multidisciplinary rehabilitation versus usual care or waitlist for fibromyalgia: effects

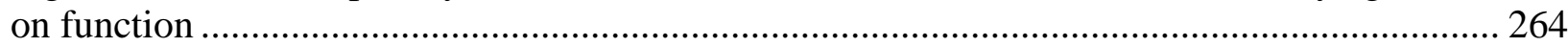

Figure 49. Multidisciplinary rehabilitation versus usual care or waitlist for fibromyalgia: effects

on pain... 265

Figure 50. Psychological therapies versus waitlist, attention control, placebo intervention, or pharmacological treatment for chronic tension headache: effects on pain (success) ................ 271 Figure 51. Psychological therapies versus waitlist, attention control, placebo intervention, or pharmacological treatment for chronic tension headache: effects on pain (mean difference) ... 272 Figure 52. Acupuncture versus sham for chronic tension headache: effects on pain..... 281

\author{
Appendixes \\ Appendix A. Search Strategies \\ Appendix B. Included Studies \\ Appendix C. Excluded Studies \\ Appendix D. Evidence Table \\ Appendix E. Quality Assessment \\ Appendix F. Exercise Categories \\ Appendix G. Strength of Evidence \\ Appendix H. Definitions for Magnitude of Effects
}




\section{Evidence Summary}

\section{Introduction}

Chronic pain substantially impacts physical and mental functioning, productivity, quality of life, and family relationships; it is the leading cause of disability and is often refractory to treatment. ${ }^{1,2}$ Chronic pain is often defined as pain lasting 3 months or longer or persisting past the normal time for tissue healing, though definitions vary. ${ }^{1,3}$ Chronic pain affects millions of adults in the United States, with an annual cost in personal and health system expenditures conservatively estimated at $\$ 560$ billion to $\$ 635$ billion. ${ }^{1}$ Chronic pain is multifaceted and is influenced by multiple factors (e.g., genetic, central nervous system, psychological, and environmental factors) and complex interactions, making pain assessment and management a challenge.

Many pharmacological and nonpharmacological treatments are available for management of chronic pain and include a variety of noninvasive as well as surgical and interventional procedures. The National Pain Strategy (NPS) report ${ }^{2}$ and 2011 Institute of Medicine (IOM) report ${ }^{1}$ describe the need for evidence-based strategies for the management of chronic pain that address the biopsychosocial nature of this problem, including nonpharmacological treatment. Recently, guidelines on opioid use for chronic pain by the Centers for Disease Control and Prevention (CDC) 4 included a recommendation on the preferred use of nonopioid treatment over opioid therapy. These initiatives, and others, speak to the importance of understanding current evidence on noninvasive nonpharmacological treatment of chronic pain.

Musculoskeletal pain, particularly related to joints and the back, is the most common type of chronic pain. ${ }^{1,5}$ This systematic review thus focuses on five of the most common causes of musculoskeletal pain: chronic low back pain, chronic neck pain, osteoarthritis, fibromyalgia and chronic tension headache.

This review focuses on noninvasive nonpharmacological treatments for chronic pain including exercise, mind-body practices, psychological therapies, multidisciplinary rehabilitation, mindfulness practices, manual therapies, physical modalities, and acupuncture. Many trials have examined the impact of these interventions on outcomes during or immediately after the course of treatment reporting improved function and reduced pain. However, given the persistence of chronic pain, understanding whether the benefits are durable would be very helpful for informing selection of therapies. Therefore, this report focuses on durability of treatment effects, defined as at least 1 month following the end of a course of treatment.

\section{Rationale for This Review}

Our review is intended to address some of the needs described in the NPS ${ }^{2}$ and IOM $^{1}$ reports and others for evidence to inform guidelines and health care policy (including reimbursement policy) related to use of noninvasive nonpharmacological treatments as possible alternatives to opioids and other pharmacological treatments. This review also aims to provide additional insights into research gaps related to use of noninvasive nonpharmacological alternatives for treating five of the most common chronic pain conditions.

\section{Scope and Key Questions}

This Comparative Effectiveness Review focused on noninvasive nonpharmacological therapy, with a Key Question (KQ) for each of five common chronic pain conditions: 
KQ 1: Chronic low back pain

KQ 2: Chronic neck pain

KQ 3: Osteoarthritis (knee, hip, hand)

KQ 4: Fibromyalgia

KQ 5: Chronic tension headache

KQ 6: Effects of age, sex, or presence of comorbidities (e.g., emotional or mood disorders) on estimates of benefits and harms.

For each condition, we addressed the following subquestions:

a. What are the benefits and harms of noninvasive nonpharmacological therapies compared with sham treatment, no treatment, waitlist, attention control, or usual care?

b. What are the benefits and harms of noninvasive nonpharmacological therapies compared with pharmacological therapy (e.g., opioids, NSAIDS, acetaminophen, antiseizure medications, antidepressants)?

c. What are the benefits and harms of noninvasive nonpharmacological therapies compared with exercise or (for headache) biofeedback? Exercise was chosen as a common comparator for all conditions except headache as it is recommended in most guidelines for these conditions and a frequent comparator in the chronic pain literature.

Interventions considered in the review include exercise (including aspects of physical therapy), mind-body practices (yoga, tai chi, qigong), psychological therapies (cognitivebehavioral therapy, biofeedback, relaxation techniques, acceptance and commitment therapy), multidisciplinary rehabilitation (including functional restoration), mindfulness practices (meditation, mindfulness-based stress reduction practices), musculoskeletal manipulation (e.g., chiropractic or osteopathic manipulation), and physical modalities (traction, ultrasound, transcutaneous electrical nerve stimulation [TENS], low-level laser therapy, interferential therapy, superficial heat or cold, bracing for knee, back or neck, electro-muscular stimulation and magnets), and acupuncture with a .focus common single active interventions and comparators. We assessed the persistence of effects for therapies at least 1 month following completion of a course of treatment. Studies of combination or adjunctive interventions were excluded. We categorized interventions a priori to provide a framework for the report realizing that there is some overlap and that other methods for such categorization are possible. We performed stratified analyses to evaluate specific techniques within broader intervention categories (e.g. we looked at different types of psychological therapies or exercise).

Details on the PICOTS (population, interventions, comparators, outcomes, timing, settings) inclusion and exclusion criteria are provided in the full report and in the published protocol.

\section{Methods}

The methods for this systematic review follow the Agency for Healthcare Research \& Quality (AHRQ) Methods Guide for Effectiveness and Comparative Effectiveness Reviews. ${ }^{6}$ See the review protocol (http://effectivehealthcare.ahrq.gov/index.cfm) and the full report of the review for additional details. 


\section{Topic Refinement and Review Protocol}

The review team developed initial KQs and PICOTS with input from the AHRQ Task Order Officer (TOO), representatives from the CDC and the Office of the Assistant Secretary for Planning and Evaluation (ASPE), and a group of Key Informants. The Evidence-based Practice Center review team considered the public comments received on the provisional Key Questions, PICOTS, and analytic framework (posted on the AHRQ Effective Health Care Web site), along with input from the AHRQ TOO, CDC and ASPE representatives, and a Technical Expert Panel convened for this report. The final version of the protocol for this review was posted on the AHRQ Effective Health Care Program Web site (www.effectivehealthcare.ahrq.gov) and registered in the PROSPERO international database of prospectively registered systematic reviews (CRD42017067729).

\section{Literature Search Strategy}

A research librarian conducted searches in Ovid ${ }^{\circledR}$ MEDLINE ${ }^{\circledR}$, Cochrane Central Register of Controlled Trials, and Cochrane Database of Systematic Reviews through November 1, 2017. ClinicalTrials.gov was searched for unpublished trials. A Federal Register notice was posted in an effort to identify unpublished data. No responses were received. Reference lists of included articles and the bibliographies of systematic reviews published since 2010 were reviewed for includable literature.

\section{Inclusion and Exclusion Criteria, Study Selection, and Data Abstraction}

Inclusion and exclusion criteria were developed a priori based on the Key Questions and PICOTS and are detailed in Table 1 of the report and the published protocol. We focused on randomized controlled trials (RCTs) reporting outcomes at least 1 month following the completion of a course of treatment. Trials comparing interventions with placebo/sham and trials where no active intervention was received (including usual care, waitlist control, minimal intervention) served as one set of comparators. To evaluate comparative effectiveness, exercise was chosen as a common active comparator for all conditions except headache, for which biofeedback was considered the common comparator, and we sought trials of intervention compared with pharmacological treatment.

Details regarding process and inclusion/exclusion of studies are provided in the full report and Appendixes B and C. We abstracted data on study characteristics, funding source, populations, interventions, comparators, and results.

\section{Quality Assessment of Individual Studies}

Study quality was independently assessed by two investigators using predefined criteria ${ }^{7,8}$ and based on methods recommended in the AHRQ Methods Guide for Effectiveness and Comparative Effectiveness Research. ${ }^{6}$ Studies were rated as “good," "fair," or "poor." (See Appendix E).

\section{Data Analysis and Synthesis}

Data were synthesized qualitatively (ranges and descriptive analysis) and quantitatively using meta-analysis where appropriate. ${ }^{9}$ Duration of followup post-intervention was reported and 
categorized as short term ( $<6$ months), intermediate term ( $\geq 6$ to $<12$ months) and long term ( $\geq 12$ months). Primary outcomes were function and pain.

Analyses were stratified by disease type, intervention, control group (usual care, exercise or pharmacological treatment) and length of followup (short, intermediate, and long term). We performed additional sensitivity and subgroup analyses based on specific interventions (e.g., type of acupuncture, type of exercise, intervention intensity etc.) and control types, and by excluding outlying studies and studies rated poor quality.

We categorized the magnitude of effects for function and pain using the system described in our previous reviews. ${ }^{10-12}$ We classified effects for measures with a 0-100 scale for pain or function as slight/small (5-10 points), moderate ( $>10-20$ points), or large/substantial ( $>20$ points). The moderate range for functional outcomes roughly corresponds to reported minimum clinically important differences for the measure. Small (slight) effects may not meet standard thresholds for minimal clinically important difference (MCID) but such thresholds may vary between patients and small average effects may be associated with larger effects in some patients. In some situations, interventions with small benefits may be warranted (e.g., when harms and costs are small). Additional information is found in the full report and Appendix H.

\section{Grading the Strength of Evidence for Major Comparisons and Outcomes}

The overall strength of evidence (SOE) for each KQ and primary outcome (pain, function) was graded high, moderate, low, or insufficient based on study limitations; consistency of results across studies; the directness of the evidence linking the interventions with health outcomes; effect estimate precision; and reporting bias. ${ }^{13,14}$ When all studies for a primary outcome were rated poor quality, we rated the SOE as insufficient (see Appendix G).

\section{Peer Review and Public Commentary}

Peer reviewers with expertise in primary care and management of the included chronic pain conditions were invited to provide written comments on the draft report. The AHRQ Task Order Officer and an Evidence-based Practice Center Associate Editor provided comments and editorial review. The draft report was posted on the AHRQ Web site for 4 weeks for public comment.

\section{Results}

\section{Results of Literature Searches}

Database searches resulted in 4,996 potentially relevant articles. After dual review of abstracts and titles, 1,193 articles were selected for full-text dual review and 218 publications (202 trials) met inclusion criteria. We included 68 trials (74 publication) on chronic low back pain, 25 trials on chronic neck pain, 53 trials (56 publications) on osteoarthritis, 47 trials (54 publications) on fibromyalgia, and nine trials on chronic tension headache. The majority of trials compared nonpharmacological interventions with usual care, waitlist, no treatment, attention control, or placebo/sham (93\%); few trials employed pharmacological treatments (5\%) or exercise (17\%) (Note: some trials had more than one comparator group). Little evidence beyond 12 months was available. 
The majority of trials (59\%) were rated fair quality, and 36 percent were rated as poor, with only 5 percent considered good quality. Attrition was greater than 20 percent in 28 percent of trials. For a number of interventions, providers and patients could not be effectively blinded. Other methodological shortcomings were unclear reporting of randomization or allocation concealment methods. Adherence to interventions was poorly reported.

Key points are presented in the following sections for interventions and outcomes for which there was low or moderate strength of evidence. All outcomes were considered to be direct. Interventions and outcomes with no or insufficient evidence are discussed in the full report. If differences were not statistically significant but confidence intervals were close to 0 (continuous outcomes) or 1 (dichotomous outcomes) results were interpreted as showing no clear difference, but favoring one treatment.

\section{Key Question 1: Chronic Low Back Pain}

\section{Exercise}

- Exercise was associated with slightly greater effects on short-term function than usual care, an attention control or a placebo intervention (6 trials, pooled standardized mean difference [SMD] $-0.31,95 \%$ confidence interval [CI] -0.58 to $-0.04, \mathrm{I}^{2}=57 \%$ ); there was no evidence of effects on intermediate-term function (3 trials, pooled SMD -0.15, 95\% CI -0.48 to $0.18, \mathrm{I}^{2}=51 \%$ ) or long-term function ( 1 trial, difference 0.00 on the 0 to 100 Oswestry Disability Index [ODI], 95\% CI -11.4 to 11.4) (SOE: Low).

- Exercise was associated with slightly to moderately greater effects on pain than usual care, an attention control or a placebo intervention at short-term (6 trials, pooled difference -0.81 on a 0 to 10 scale, $95 \%$ CI -1.26 to $-0 ., 36, \mathrm{I}^{2}=0 \%$ ), intermediate-term ( 3 trials, pooled difference $-1.37,95 \%$ CI -2.10 to $-0.65, \mathrm{I}^{2}=34 \%$ ), and long-term ( 1 trial, difference -1.55 , 95\% CI -2.378 to -0.32) followup (SOE: Moderate for short term, low for intermediate term and long term).

\section{Psychological Therapies}

- Psychological therapy was associated with slightly greater effects on function than usual care or an attention control at short-term (3 trials, pooled SMD -0.25, 95\% CI -0.38 to $0.12, \mathrm{I}^{2}=0 \%$ ), intermediate-term ( 3 trials, pooled SMD $-0.25,95 \%$ CI -0.37 to -0.13 , $\mathrm{I}^{2}=0 \%$ ), and long-term followup (3 trials, pooled SMD $-0.27,95 \%$ CI -0.39 to -0.15 , $\mathrm{I}^{2}=0 \%$ ) (SOE: Moderate).

- Psychological therapy was associated with slightly greater effects on pain than usual care or an attention control at short-term ( 3 trials, pooled difference -0.76 on a 0 to 10 scale, 95\% CI -0.99 to $-0.53, \mathrm{I}^{2}=0 \%$ ), intermediate-term ( 3 trials, pooled difference $-0.71,95 \%$ CI -0.94 to $-0.48, \mathrm{I}^{2}=0 \%$ ), or long-term followup ( 3 trials, pooled difference $-0.53,95 \%$ CI -0.78 to $-0.27, \mathrm{I}^{2}=0 \%$ ) (SOE: Moderate).

\section{Physical Modalities}

\section{Ultrasound}

- No evidence of difference was found between ultrasound versus sham ultrasound in short-term pain (2 trials, SOE: low). 


\section{Low-Level Laser Therapy}

- One trial found low-level laser therapy associated with slightly greater effects than sham laser on short-term function (difference -8.2 on the 0 to 100 ODI, 95\% CI -13.6 to -2.8) and moderately greater effects on pain (difference -16.0 on a 0 to 100 scale, $95 \%$ CI -28.3 to -3.7) (SOE: low).

\section{Traction}

- Two trials found no evidence of difference between traction versus sham traction in short-term pain or function (SOE: low).

\section{Manual Therapies}

\section{Spinal Manipulation}

- Spinal manipulation was associated with slightly greater effects than sham manipulation, usual care, an attention control, or a placebo intervention in short-term function (3 trials, pooled SMD -0.34, 95\% CI -0.63 to $-0.05, \mathrm{I}^{2}=61 \%$ ) and intermediate-term function (3 trials, pooled SMD -0.40 , 95\% CI -0.69 to $-0.11, \mathrm{I}^{2}=76 \%$ ) (SOE: low)

- There was no evidence of differences between spinal manipulation versus sham manipulation, usual care, an attention control or a placebo intervention in short-term pain ( 3 trials, pooled difference -0.20 on a 0 to 10 scale, $95 \%$ CI -0.66 to $0.26, I^{2}=58 \%$ ), but manipulation was associated with slightly greater effects than controls on intermediateterm pain ( 3 trials, pooled difference $-0.64,95 \%$ CI -0.92 to $-0.36, \mathrm{I}^{2}=0 \%$ ) (SOE: low for short term, moderate for intermediate term).

\section{Massage}

- Massage was associated with slightly greater effects on short-term function than sham massage or usual care ( 4 trials, SMD $-0.30,95 \%$ CI -0.46 to $-0.14, \mathrm{I}^{2}=0 \%$ ). There was no evidence of differences between massage versus controls in intermediate-term function (3 trials, SMD -0.09 , $95 \%$ CI -0.24 to $0.06, \mathrm{I}^{2}=0 \%$ ) (SOE: moderate for short term, low for intermediate term).

- Massage was associated with slightly greater effects on short-term pain than sham massage or usual care (4 trials, pooled difference -0.52 on a 0 to 10 scale, $95 \%$ CI -0.81 to $\left.-0.23, \mathrm{I}^{2}=0 \%\right)$. There was no evidence of differences between massage versus controls in intermediate-term pain ( 3 trials, difference -0.01 , $95 \%$ CI -0.40 to $0.38, \mathrm{I}^{2}=0 \%$ ) (SOE: moderate for short term, low for intermediate term).

\section{Mindfulness-Based Stress Reduction}

- There was no evidence of differences between mindfulness-based stress reduction (MBSR) versus usual care or an attention control in short-term function (4 trials, pooled SMD - 0.25 , $95 \%$ CI -0.53 to $0.04, I^{2}=53 \%$ ), intermediate-term function (1 trial, SMD $0.20,95 \%$ CI -0.47 to 0.06 ) or long-term function (1 trial, SMD - $0.20,95 \%$ CI -0.47 to $0.06)$ (SOE: low).

- MBSR was associated with slightly greater effects than usual care or an attention control on short-term pain ( 3 trials, pooled difference -0.73 on a 0 to 10 scale, $95 \%$ CI -1.18 to $0.28, \mathrm{I}^{2}=93 \%$ ), after excluding two poor-quality trials; MBSR was also associated with small effects on intermediate-term pain (1 trial, difference -0.75 , 95\% CI -1.17 to -0.33), 
with no statistically significant effects on long-term pain (1 trial, SMD -0.22, 95\% CI 0.64 to 0.20 ) (SOE: moderate for short term, low for intermediate and long term).

\section{Mind-Body Practices-Yoga}

- Yoga was associated with slightly greater effects on function than an attention or waitlist control at short-term (6 trials, pooled SMD $-0.50,95 \%$ CI -0.72 to $-0.29, \mathrm{I}^{2}=54 \%$ ) and intermediate-term ( 3 trials, pooled SMD -0.33, 95\% CI -0.49 to -0.16) followup (SOE: moderate for short term, low for intermediate term).

- Yoga was associated with moderately greater effects on pain than an attention or waitlist control at short-term (5 trials, pooled difference -1.10 on a 0 to 10 scale, $95 \%$ CI -1.77 to $-0.42, \mathrm{I}^{2}=74 \%$ ) and intermediate-term ( 2 trials, pooled difference $-1.17,95 \%$ CI -1.91 to $-0.44, \mathrm{I}^{2}=26 \%$ ) followup (SOE: low for short term, moderate for intermediate term).

\section{Acupuncture}

- Acupuncture was associated with slightly greater effects on short-term function than sham acupuncture or usual care (4 trials, pooled SMD -0.22, 95\% CI - 0.35 to -0.08 , $\mathrm{I}^{2}=44 \%$ ). There was no evidence of differences between acupuncture versus controls in intermediate-term function ( 3 trials, pooled SMD -0.08 , 95\% CI -0.36 to $0.20, \mathrm{I}^{2}=75 \%$ ) or long-term function ( 1 trial, adjusted difference -3.4 on the 0 to 100 ODI, $95 \%$ CI -7.8 to 1.0) (SOE: low).

- Acupuncture was associated with slightly greater effects on short-term pain than sham acupuncture, usual care, an attention control, or a placebo intervention (5 trials, pooled difference -0.55 on a 0 to 10 scale, $95 \%$ CI -0.86 to $-0.24, I^{2}=30 \%$ ). There was no evidence of a difference in intermediate-term pain ( 5 trials, pooled mean difference -0.25 , $95 \%$ CI -0.67 to $0.16, \mathrm{I}^{2}=33 \%$ ); one trial found acupuncture associated with greater effects on long-term pain (mean difference -0.83, 95\% CI -1.51 to -0.15) (SOE: moderate for short term, low for intermediate term and long term).

\section{Multidisciplinary Rehabilitation}

- Multidisciplinary rehabilitation was associated with slightly greater effects on function than usual care at short-term followup (4 trials, pooled SMD -0.31, 95\% CI -0.57 to $0.05, \mathrm{I}^{2}=70 \%$ ) and intermediate-term followup (4 trials, pooled SMD -0.37, 95\% CI - 0.64 to $-0.10, \mathrm{I}^{2}=50 \%$ ); there was no evidence of differences in long-term function ( 2 trials, pooled SMD -0.04, 95\% CI -0.31 to $0.24, \mathrm{I}^{2}=35 \%$ ) (SOE: low).

- Multidisciplinary rehabilitation was associated with slightly greater effects on pain than usual care at short-term followup (4 trials, pooled difference -0.51 on a 0 to 10 scale, $95 \%$ CI -0.89 to $-0.13, \mathrm{I}^{2}=23 \%$ ) and intermediate-term followup (4 trials, pooled difference $-0.63,95 \%$ CI -1.04 to $-0.22, \mathrm{I}^{2}=0 \%$ ); the long-term difference was smaller and not statistically significant ( 2 trials, pooled difference $-0.34,95 \%$ CI -0.86 to 0.18 , $\mathrm{I}^{2}=0 \%$ ) (SOE: moderate for short term and intermediate term, low for long term).

\section{Comparative Effectiveness of Interventions}

- One trial found no differences between low-level laser therapy versus exercise therapy in intermediate-term function or pain (SOE: low).

- There was no evidence of difference between spinal manipulation versus exercise in short-term function ( 3 trials, pooled SMD $0.01,95 \%$ CI -0.22 to 0.25 ; $\mathrm{I}^{2}=62 \%$ ) or 
intermediate-term function (4 trials, pooled SMD 0.02 , 95\% CI -0.13 to 0.18 ; $\mathrm{I}^{2}=48 \%$ ) (SOE: low).

- There was no evidence of difference between spinal manipulation versus exercise in short-term pain ( 3 trials, pooled difference 0.31 on a 0 to 10 scale, $95 \%$ CI -0.30 to 0.92 ; $\mathrm{I}^{2}=60 \%$ ) or intermediate-term pain ( 4 trials, pooled difference 0.22 , $95 \%$ CI -0.09 to 0.52 , $\left.\mathrm{I}^{2}=9.4 \%\right)$ (SOE: low).

- One trial found no differences between massage versus exercise in intermediate-term or function or pain (SOE: low).

- There was no statistically significant difference between yoga versus exercise in shortterm or intermediate-term function or pain (SOE: low).

- One trial found no evidence of differences between qigong versus exercise in short-term function (difference 0.9 on the RRoland-Morris Disability Questionnaire, 95\% CI -0.1 to 2.0), although intermediate-term results slightly favored exercise (difference 1.2, 95\% CI 0.1 to 2.3) (SOE: low).

- One trial found qigong associated with slightly lower effects on pain versus exercise at short-term followup (difference 7.7 on a 0 to 100 scale, 95\% CI 0.7 to 14.7), but the difference at intermediate-term was not statistically significant (difference 7.1, 95\% CI -1.0 to 15.2) (SOE: low).

- Multidisciplinary rehabilitation was associated with slightly greater effects than exercise on short-term function (6 trials, pooled SMD $-0.28,95 \%$ CI -0.54 to $-0.01, \mathrm{I}^{2}=39 \%$ ) and intermediate-term function (5 trials [excluding outlier trial], pooled SMD -0.22, 95\% CI 0.40 to $-0.03, \mathrm{I}^{2}=0 \%$ ); there was no effect on long-term function ( 2 trials [excluding outlier trial], pooled SMD $-0.06,95 \% \mathrm{CI}-0.36$ to $0.25, \mathrm{I}^{2}=0 \%$ ) (SOE: moderate for short term and intermediate term, low for long term).

- Multidisciplinary rehabilitation was associated with slightly greater effects than exercise on short-term pain (6 trials, pooled difference -0.75 on a 0 to 10 scale, $95 \%$ CI -1.18 to $0.31, \mathrm{I}^{2}=0 \%$ ) and intermediate-term pain ( 5 trials [excluding outlier trial], pooled difference $-0.55,95 \%$ CI -0.95 to $-0.15, \mathrm{I}^{2}=0 \%$ ); there was no effect on long-term pain (2 trials [excluding outlier trial], pooled difference $0.00,95 \%$ CI -0.94 to 0.95 ) (SOE: moderate for short term and intermediate term, low for long term).

\section{Key Question 2: Chronic Neck Pain}

\section{Exercise}

- Across types of exercise, there was no clear improvement in function (3 trials [excluding outlier trial], pooled SMD $-0.23,95 \%$ CI -0.71 to 0.15 ) or pain (3 trials [excluding outlier trial], pooled SMD $-0.72,95 \%$ CI -1.49 to 0.06 ) versus no treatment or advice alone in the short-term (SOE: low).

- A subgroup of two trials of combination exercises (including 3 of the following 4 exercise categories: muscle performance, mobility, muscle re-education, aerobic) suggests a slight benefit in function and pain versus no treatment or advice alone over the short term and function in the long term (SOE: low). 


\section{Psychological}

- No evidence of differences in function (Neck Disability Index, 0-80 scale) or pain (Visual Analog Scale for Pain [VAS], 0-10 scale) in the short term (adjusted difference 0.1, 95\% CI -2.9 to 3.2 and 0.2 , 95\% CI -0.4 to 0.8 , respectively) or intermediate term (adjusted difference 0.2 , 95\% CI -2.8 to 3.1 and 0.2 , 95\% CI -0.3 to 0.8 , respectively) from one trial comparing relaxation training and no intervention or exercise (SOE: low for all).

\section{Physical Modalities}

- Low-level laser therapy was associated with a moderate improvement in short-term function (2 trials, pooled difference -14.98 , 95\% CI -23.88 to $-6.07, \mathrm{I}^{2}=39 \%, 0-100$ scale) and pain (3 trials, pooled difference -1.81 on a $0-10$ scale, $95 \%$ CI -3.35 to -0.27 , $\mathrm{I}^{2}=75 \%$ ) compared with sham (SOE: moderate for function and pain).

\section{Manual Therapies}

- The effects of massage on function versus self-management attention control were slight and not statistically significant in one trial $(\mathrm{N}=64)$ in the short term $(\geq 5$ point improvement on the Neck Disability Index, 39\% versus 14\%, relative risk [RR] 2.7, 95\% CI 0.99 to 7.5 ) and intermediate term (57\% versus 31\%, RR 1.8, 95\% CI 0.97 to 3.5 ) (SOE: low for both time periods).

\section{Mind-Body Practices}

- Alexander Technique resulted in a slight improvement in function in the short term (difference -5.56 on a $0-100 \%$ scale, $95 \%$ CI -8.33 to -2.78 ) and intermediate term (difference -3.92, 95\% CI -6.87 to -0.97) compared with usual care alone based on one trial (SOE: low).

\section{Acupuncture}

- Acupuncture was associated with slightly greater effects on short-term and intermediateterm function versus sham acupuncture, placebo (sham laser) or usual care (short term, 5 trials, pooled SMD -0.40 , 95\% CI -0.64 to -0.17 , $\mathrm{I}^{2}=67.7 \%$; intermediate term, 3 trials, pooled SMD $-0.19,95 \%$ CI -0.35 to -0.02 ). One trial reported no difference in function in the long term (SMD -0.23, 95\% CI -0.61 to 0.16) (SOE: low for all time periods). A sham comparator was used in all but one trial.

- There was no evidence of differences in pain comparing acupuncture with sham acupuncture, or placebo interventions in the short term (4 trials [excluding outlier trial], pooled difference -0.2 on a $0-10$ scale, $95 \%$ CI -0.59 to $0.05, \mathrm{I}^{2}=2 \%$ ), intermediate term (3 trials, pooled difference 0.45 , 95\% CI -0.34 to $1.25, \mathrm{I}^{2}=59 \%$ ) or long term (1 trial, difference $-1.8,95 \%$ CI -1.34 to 0.64 ). (SOE: low for all time periods).

\section{Comparative Effectiveness of Interventions for Chronic Neck Pain}

- There was no clear evidence that massage improved pain in the intermediate term versus exercise ( $\mathrm{P}>0.05$, data not reported) in one trial (SOE: low).

- No clear evidence that basic body awareness therapy improved function in the short term versus exercise in one trial (SOE: low). 


\section{Key Question 3: Osteoarthritis}

\section{Exercise (Knee)}

- Exercise was associated with slightly greater improvement in function than usual care, no treatment or sham intervention short term (7 trials, pooled SMD -0.25, 95\% CI - 0.4 to $0.09, \mathrm{I}^{2}=0 \%$ ), at intermediate term ( 9 trials [excluding outlier trial] pooled SMD -0.78 , 95\%CI -1.37 to $-0.19, \mathrm{I}^{2}=91.4 \%$ ), and long term (2 trials, pooled SMD -0.24 , 95\%CI 0.37 to $-0.11 \mathrm{I}^{2}=0 \%$ ) (SOE: moderate for short term; low for intermediate and long term).

- Exercise was associated with a slight improvement in pain short term (7 trials, pooled difference -0.44 on a 0 to 10 scale, $95 \%$ CI -0.82 to $-0.05, \mathrm{I}^{2}=35 \%$ ) versus usual care, no treatment or sham intervention (SOE: moderate), and with moderately greater effect on pain in the intermediate term (9 trials, pooled difference -1.61 on a 0 to 10 scale, $95 \%$ CI -2.51 to $-0.72, \mathrm{I}^{2}=91 \%$ ) compared with usual care, an attention control, or no treatment (SOE: low). Long term, there was no clear difference between exercise and improvement in pain but data were limited (2 trials, difference $-0.24,95 \%$ CI -0.72 to 0.24 ) (SOE: low).

\section{Psychological Therapy (Knee)}

- Two trials of pain coping skills training and cognitive behavioral training versus usual care found no evidence of differences in function (Western Ontario and McMaster Universities Osteoarthritis Index [WOMAC] physical function, 0-100) or pain (WOMAC pain, 0-100); treatment effects were averaged over short term to intermediate term (difference $-0.3,95 \%$ CI -8.3 to 7.8 for function and $-3.9,95 \%$ CI -1.8 to 4.0 for pain) and intermediate term to long term (mean 35.2 , 95\% CI 31.8 to 38.6 vs. mean 37.5 , 95\% CI 33.9 to 41.2 , and mean 34.5, 95\% CI 30.8 to 38.2 vs. mean 38.0, 95\% CI 34.1 to 41.8), respectively (SOE: low).

\section{Physical Modalities (Knee)}

\section{Ultrasound}

- One trial found continuous and pulsed ultrasound was associated with better short-term function (difference of -6.2 , 95\% CI -8.36 to -4.20 , and $-5.71,95 \%$ CI -7.72 to -3.70 on a $0-24$ scale) and short-term pain intensity (difference $-3.3,95 \%$ CI -4.64 to -1.96 , and 3.37, $95 \%$ CI -4.73 to -2.01 on a $0-10$ scale) (SOE: low).

- One trial found no evidence of differences between continuous and pulsed ultrasound versus sham in intermediate-term function (difference -2.9, 95\% CI -9.19 to 3.39 and 1.6, 95\% CI -3.01 to 6.22, on a 0-68 scale) or pain (difference -1.6, 95\% CI -3.26 to 0.06 and $0.2,95 \%$ CI -1.34 to 1.74 , on a $0-20$ scale). There was also no evidence of difference between groups for VAS pain during rest or on movement (SOE: low).

\section{Transcutaneous Electrical Nerve Stimulation}

- There was no evidence of difference from one trial between transcutaneous electrical nerve stimulation (TENS) and placebo TENS in intermediate-term function as measured by the WOMAC function subscale (proportion of patients who achieved MCID ( $\geq 9.1)$, $38 \%$ vs. 39\%, RR 1.2 (95\% CI 0.6 to 2.2); and difference -1.9 (95\% CI -9.7 to 5.9) on a 0 -100 scale) or intermediate-term pain (proportion of patients who achieved MCID $(\geq 20)$ 
in VAS pain, 56\% vs 44\%, RR 1.3 (95\% CI 0.8 to 2.0); and mean difference -5.6 (95\%

CI -14.9 to 3.6) on the 0-100 WOMAC pain subscale) (SOE: low for function and pain).

\section{Electromagnetic Field}

- One trial found pulsed electromagnetic fields were associated with slight improvements in function (difference $-3.48,95 \%$ CI -4.44 to -2.51 on a $0-85$ WOMAC Activities of Daily Living subscale) and pain (difference $-0.84,95 \%$ CI -1.10 to -0.58 on a $0-25$ WOMAC pain subscale) versus sham short-term but differences may not be clinically significant (SOE: low).

\section{Acupuncture (Knee)}

- There was no evidence of differences between acupuncture versus control interventions (sham acupuncture, waitlist or usual care) on function in the short term (4 trials [excluding outlier trial], pooled SMD $-0.05,95 \%$ CI -0.32 to 0.38 ) or the intermediate term (4 trials, pooled SMD $-0.15,95 \%$ CI -0.31 to $0.02, \mathrm{I}^{2}=0 \%$ ) (SOE: low for short term; moderate for intermediate term). Stratified analysis showed no differences between acupuncture and sham treatments (4 trials) but moderate improvement in function compared with usual care (2 trials) short term.

- There was no evidence of differences between acupuncture versus control interventions (sham acupuncture, waitlist, or usual care) on pain in the short term (6 trials, pooled SMD $-0.27,95 \%$ CI -0.56 to $0.02, \mathrm{I}^{2}=75 \%$ ) or clinically meaningful differences in the intermediate term (4 trials, pooled SMD - $0.16,95 \%$ CI -0.31 to $0.02, \mathrm{I}^{2}=0 \%$ ); no individual trial was statistically significant. (SOE: low for short term; moderate for intermediate term). Short-term differences were significant for acupuncture versus usual care but not for acupuncture versus sham acupuncture.

\section{Exercise for Osteoarthritis of the Hip}

- Exercise was associated with a slight improvement in function versus usual care in the short term (3 trials, pooled SMD $-0.33,95 \%$ CI, -0.53 to $-0.12, \mathrm{I}^{2}=0.0 \%$ ) and intermediate term ( 2 trials, pooled SMD $-0.28,95 \% \mathrm{CI}-0.50$ to $-0.05, \mathrm{I}^{2}=0.0 \%$ ). (SOE: low for short and intermediate term).

- Exercise tended toward slightly greater improvement in short-term pain compared with usual care ( 3 trials, pooled SMD $-0.34,95 \% \mathrm{CI},-0.63$ to $-0.04, \mathrm{I}^{2}=48.2 \%$ ), but the results were no longer significant at intermediate term (2 trials, pooled SMD -0.14, 95\% CI -0.37 to $0.08, \mathrm{I}^{2}=0 \%$ ) (SOE: low for short and intermediate term).

\section{Physical Modalities for Osteoarthritis of the Hand}

- One trial of low-level laser treatment versus sham demonstrated no improvement in terms of function (difference $0.2,95 \%$ CI -0.2 to 0.6 ) or pain (difference $0.1,95 \%$ CI -0.3 to 0.5 ) in the short term (SOE: low).

\section{Multidisciplinary Rehabilitation for Osteoarthritis of the Hand}

- One trial of multidisciplinary rehabilitation versus waitlist control demonstrated no shortterm differences between groups in function (adjusted difference 0.49, 95\% CI, - 0.09 to 0.37 on $0-36$ scale), pain (adjusted difference $0.40,95 \%$ CI, -0.5 to 1.3 on a $0-20$ scale), or with regard to the proportion of Osteoarthritis Research Society International Outcome 
Measures in Rheumatology responders (odds ratio [OR] 0.82, 95\% CI, 0.42 to 1.61) (SOE: low for all outcomes).

\section{Comparative Effectiveness of Interventions for Osteoarthritis}

- Knee Osteoarthritis: One trial of pain coping skills training versus strengthening exercises found no evidence of differences in WOMAC physical function scores (0-68 scale) at short term (mean difference $2.0,95 \%$ CI -2.4 to 6.4) or intermediate term (mean difference 3.2, 95\% CI -0.6 to 7.0) or in WOMAC pain scores (0-20 scale) at short term (mean difference $-0.1,95 \% \mathrm{CI}-1.2$ to 1.0 ) or intermediate term (mean difference 0.4 , 95\% CI -0.8 to 1.6) (SOE low).

- Hip Osteoarthritis: Manual therapy was associated with slight improvements in shortterm (mean difference 11.1, 95\% CI 4.0 to 18.6, 0-100 scale Harris Hip Score) and intermediate-term (mean difference 9.7, 95\% CI, 1.5 to 17.9) function, and in short-term pain (mean differences of $-0.72,95 \%$ CI -1.38 to -0.05 for pain at rest; and $-1.21,95 \%$ CI -2.29 to -0.25 for pain walking) versus exercise (SOE: low for both function and pain).

\section{Key Question 4: Fibromyalgia}

\section{Exercise}

- Exercise was associated with slightly greater effects on function compared with an attention control, no treatment, or usual care in the short term ( 7 trials, pooled mean difference -7.61 on a 0 to 100 scale, $95 \%$ CI, -12.78 to $-2.43, \mathrm{I}^{2}=59.9 \%$ ) (SOE: low) and intermediate-term (8 trials, pooled mean difference, $-6.04,95 \%$ CI -9.05 to $-3.03, \mathrm{I}^{2}=0 \%$ ) (SOE: moderate). There were no clear effects long term (3 trials, pooled mean difference -4.33, 95\% CI -10.18 to $1.52, \mathrm{I}^{2}=0 \%$ ) (SOE: low).

- Exercise had a slightly greater effect on VAS pain (0-10 scale) compared with usual care, an attention control or no treatment short term ( 6 trials [excluding outlier trial] pooled mean difference $-0.89,95 \%$ CI -1.32 to $-0.46, \mathrm{I}^{2}=0 \%$ ) but there were no clear effects at intermediate term ( 7 trials, pooled mean difference $-0.41,95 \% \mathrm{CI}-0.87$ to $0.05, \mathrm{I}^{2}=9.5 \%$ ) or long term (4 trials, pooled mean difference -0.18 , $95 \%$ CI -0.77 to $0.42, \mathrm{I}^{2}=0 \%$ ) (SOE: moderate for all time frames).

\section{Psychological Therapies}

- Cognitive behavioral therapy (CBT) was associated with a slightly greater effect on the Fibromyalgia Impact Questionnaire (FIQ) Total Score than usual care or waitlist in the short-term ( 2 trials, pooled mean difference $-10.67,95 \%$ CI -17 to $-4.30, \mathrm{I}^{2}=0 \%, 0-100$ scale). The pooled estimate at intermediate term was not statistically significant due to heterogeneity, however individual trials showed a greater effect than usual care and a third trial using the 0 to 10 FIQ Physical Impairment Scale showed a greater effect of CBT than an attention control (mean difference -1.8, 95\% CI -2.9 to -0.70) (SOE: low for short term and intermediate term).

- CBT was associated with a slight improvement in pain (on a 0-10 scale) compared with usual care or waitlist in the short term ( 3 trials, pooled mean difference $-0.78,95 \%$ CI 1.30 to -0.17 ) but not in the intermediate term ( 2 trials, pooled mean difference -0.44 , 95\% CI -1.30 to 0.01) (SOE: low for short term and intermediate term). 


\section{Physical Modalities}

- One parallel trial showed no differences between magnetic mattress pads compared with sham or usual care in intermediate-term function (difference on the 0-80 scale FIQ -5.0, $95 \%$ CI -14.1 to 4.1 vs. sham and $-5.5,95 \%$ CI -14.4 to 3.4 vs. usual care) or pain (difference $-0.6,95 \%$ CI -1.9 to 0.7 and $-1.0,95 \%$ CI -2.2 to 0.2 , respectively on a $0-10$ scale) (SOE: low).

\section{Manual Therapies}

- Myofascial release therapy was associated with a slightly greater effect on intermediateterm function as measured by the FIQ (mean $58.6 \pm 16.3$ vs. $64.1 \pm 18.1$ on a 100 point scale, $\mathrm{P}=0.048$ for group by repeated measures [analysis of variance] ANOVA), but not long-term function (mean $62.8 \pm 20.1$ vs. $65.0 \pm 19.8$ on the FIQ, $0-100$ scale, $\mathrm{P}=0.329$ ), compared with sham in one trial (SOE: low).

- Myofascial release therapy was associated with slightly greater effects on long-term pain based on the sensory (mean $18.2 \pm 8.3$ vs. $21.2 \pm 7.9$ on a 0 -33 scale, $\mathrm{P}=0.038$ for group by repeated measures ANOVA) and evaluative (mean $23.2 \pm 7.6$ vs. $26.7 \pm 6.9$ on a 0-42 scale, $\mathrm{P}=0.036$ ) domains of the McGill Pain Questionnaire (MPQ) in one trial; there were no differences for the affective domain of the MPQ or for VAS pain (SOE: low).

\section{Mindfulness-Based Stress Reduction Therapy}

- No clear short-term effects of MBSR were seen on function compared with waitlist or an attention control (mean difference 0 to 0.06 on a $0-10$ scale) in two trials (SOE: moderate).

- No clear short-term effects of MBSR on pain (mean difference 0.1 on a 0-100 VAS pain scale in one trial; mean difference -1.38 to -1.59 on the affective and -0.28 to -0.71 on the sensory dimension [scales not reported] of the Pain Perception Scale in one trial) compared with waitlist or an attention control in two trials (SOE: moderate). Intermediate and long-term outcomes were not reported.

\section{Mind-Body Practices}

- Over the short term, two trials of mind-body practices reported a slight improvement in function for qigong compared with waitlist (mean difference -7.5, 95\% CI -13.3 to -1.68) and a large improvement for tai chi compared with attention control (mean difference 23.5, 95\% CI -30 to -17) based on 0-100 scale total FIQ score; heterogeneity may be explained by duration and intensity of intervention and control condition. Significantly more participants in the tai chi group also showed clinically meaningful improvement on total FIQ (RR 1.6, 95\% CI 1.1 to 2.3) consistent with a slight effect (SOE: low).

- Qigong and tai chi were associated with moderately greater improvement in pain (0-10 scale) compared with waitlist and an attention control in the short term (2 trials, pooled mean difference $-1.54,95 \%$ CI $\left.-2.67,-0.41, I^{2}=75 \%\right)$. Significantly more participants in the tai chi group also showed clinically meaningful improvement on VAS pain (RR 2.0, 95\% CI 1.1 to 3.8) consistent with a slight effect (SOE: low).

\section{Acupuncture}

- Acupuncture was associated with slightly greater effects on function based on 0-100 FIQ Total Score in patients with fibromyalgia than sham acupuncture in the short-term (2 
trials, pooled difference $-8.63,95 \% \mathrm{CI}=12.12$ to $\left.-5.13, \mathrm{I}^{2}=0 \%\right)$ and intermediate-term (2 trials, pooled mean difference $-9.41,95 \%$ CI -13.96 to $\left.-4.85, \mathrm{I}^{2}=27.4 \%\right)$ (SOE: moderate).

- There was no clear effect of acupuncture on pain (0-10 scale) versus sham acupuncture in the short term ( 3 trials, pooled mean difference -0.13 , 95\% CI -1.06 to $0.79, \mathrm{I}^{2}=72 \%$ ) or intermediate term (3 trials, pooled mean difference -0.53 , 95\% CI -1.15 to 0.09 , $\left.\mathrm{I}^{2}=45.5 \%\right)$ (SOE: low)

\section{Multidisciplinary Rehabilitation}

- Multidisciplinary treatment was associated with a slight improvement in function (based on a 0-100 FIQ total score) versus usual care or waitlist in the short term (3 trials, pooled mean difference $-6.52,95 \% \mathrm{CI}-12.84$ to $-0.21, \mathrm{I}^{2}=67.3 \%$ ) and versus usual care at intermediate term (3 trials, pooled mean difference -7.84 , 95\% CI - 11.43 to -4.25 , $\mathrm{I}^{2}=18.2 \%$ ) and long term ( 2 trials, pooled mean difference -8.42 , 95\% CI -13.76 to -3.08 , $\left.\mathrm{I}^{2}=24.9 \%\right)$. More multidisciplinary treatment participants experienced a clinically meaningful improvement in FIQ total score compared with usual care at short (odds ratio [OR] 3.1, 95\% CI 1.6 to 6.2), intermediate (OR 3.1, 95\% CI 1.5 to 6.4 ) and long term (OR 8.8, 95\% CI 2.5 to 30.9) in one trial (SOE: low for short, intermediate and long term).

- Multidisciplinary treatment was associated with a slight improvement in pain compared with usual care or waitlist at intermediate term ( 3 trials, pooled mean difference -0.68 , $95 \%$ CI -1.07 to $-0.30, \mathrm{I}^{2}=0 \%$ ); there were no clear differences compared with usual care or waitlist in the short term ( 2 trials [excluding an outlier trial], pooled mean difference on a $0-10$ scale $-0.24,95 \%$ CI -0.63 to $0.15, \mathrm{I}^{2}=0 \%$ ) or with usual care in the long-term (2 trials, pooled mean difference $-0.25,95 \% \mathrm{CI}-0.68$ to 0.17 , $\mathrm{I}^{2}=0 \%$ ) (SOE: low for short, intermediate and long term).

\section{Comparative Effectiveness of Interventions for Fibromyalgia}

- CBT was associated with a slight benefit compared with pharmacological treatment (pregabalin; duloxetine) for function (mean difference -4.0 on the 0-100 FIQ, 95\% CI 7.7 to -0.27 ), but not for pain (mean difference 0.2 on a $0-100$ VAS, $95 \%$ CI -4.0 to 4.4 ) at intermediate term in one trial (SOE: low).

- There was no evidence of an effect for multidisciplinary treatment versus aerobic exercise at long term for function (mean difference $-1.10,95 \%$ CI -8.40 to $6.20,0-100$ FIQ total score) or pain (mean difference $0.10,95 \%$ CI -0.67 to $0.87,0-10$ FIQ pain scale) in one trial (SOE: low).

\section{Key Question 5: Chronic Tension Headache}

\section{Manual Therapies}

- Spinal manipulation therapy was associated with slight to moderate improvements, respectively, compared with usual care in function (difference -5.0, 95\% CI -9.02 to -1.16 on the Headache Impact Test, scale 36-78 and difference -10.1, 95\% CI -19.5 to -0.64 on the Headache Disability Inventory, scale $0-100$ ) and pain intensity (difference -1.4 on a 0-10 Numerical Rating Scale scale, 95\% CI -2.69 to -0.16) over the short term in one trial (SOE: low). Approximately a quarter of the patients had comorbid migraine. 


\section{Acupuncture}

- Laser acupuncture was associated with slight improvement in pain intensity (median difference -2, IQR 6.3, on a 0-10 VAS scale) and in the number of headache days per month (median difference -8, IQR 21.5) over the short term versus sham in one trial (SOE: low).

\section{Comparative Effectiveness of Interventions for Chronic Tension Headache}

- No studies compared the interventions of interest to biofeedback and evidence from comparisons with pharmacological interventions was insufficient.

\section{Key Question 6: Differential Efficacy}

Evidence was insufficient to determine whether factors such as age, sex or comorbidities modify the effects of treatment.

\section{Harms}

Although data on harms were limited, no evidence suggested serious harms for the interventions included in the review. Many trials did not report harms, withdrawals due to adverse events, or differences between compared interventions in risk of harms or withdrawals. Trials that did report such data found infrequent or rare occurrences of nonserious treatmentrelated adverse events (e.g., discomfort, soreness, bruising, increased pain, worsening of symptoms), few withdrawals from nonpharmacological treatments due to adverse events, and no differences between comparison groups in frequency of intervention-related adverse events or withdrawals.

\section{Discussion}

\section{Key Findings and Strength of Evidence}

The key findings of this review, including SOE ratings, are summarized for each chronic pain condition in the Results and evidence summary Tables A-M. Interventions and comparators with insufficient evidence or no evidence (no RCTs meeting inclusion criteria) for either function or pain outcomes are not shown. Domains used to determine the overall SOE are shown in Appendix G of the full report. All outcomes were considered direct.

The strength of evidence was low (limited confidence in the estimates) or insufficient (no confidence in the estimated effects) for many interventions and was limited by small numbers of trials for specific comparisons at our specified time frames, particularly for long-term followup. We focused on evaluating the persistence of effects for therapies at least 1 month beyond the course of treatment, using the following definitions for post-intervention followup: short term (1 to $<6$ months), intermediate term ( $\geq 6$ to $<12$ months) and long term ( $\geq 12$ months). Evidence was particularly limited on long-term outcomes.

The majority of trials compared interventions with usual care, and very few trials employed pharmacological treatments or exercise as comparators. In general, effect sizes for most interventions were small, based on mean differences. There tended to be more evidence for the effects of interventions on pain than for function and effects on function were generally smaller or not clearly present. 
No trials directly compared interventions with opioids and few trials reported effects of interventions on opioid use. Our previous reviews found opioids associated with small to moderate effects on pain during treatment (effects would not be expected to persist) with evidence almost exclusively from short-term ( $\leq 3$ month) trials. ${ }^{10,11,15}$

Harms were poorly reported across interventions. No serious intervention-related adverse events requiring medical attention were identified; reported adverse events were generally minor (e.g., muscle soreness or increased pain with exercise, bruising with acupuncture) and timelimited (e.g., temporary worsening of pain).

Table A. Chronic low back pain: effects of nonpharmacological interventions compared with usual care, placebo, sham, attention control, or waitlist

\begin{tabular}{|c|c|c|c|c|c|c|}
\hline Intervention & $\begin{array}{l}\text { Function } \\
\text { Short-Term } \\
\\
\text { Effect Size } \\
\text { SOE } \\
\end{array}$ & $\begin{array}{c}\text { Function } \\
\text { Intermediate- } \\
\text { Term } \\
\text { Effect Size } \\
\text { SOE } \\
\end{array}$ & $\begin{array}{c}\text { Function } \\
\text { Long-Term }\end{array}$ & $\begin{array}{c}\text { Pain } \\
\text { Short-Term } \\
\text { Effect Size } \\
\text { SOE } \\
\end{array}$ & $\begin{array}{c}\text { Pain } \\
\text { Intermediate- } \\
\text { Term } \\
\text { Effect Size } \\
\text { SOE } \\
\end{array}$ & $\begin{array}{c}\text { Pain } \\
\text { Long-Term } \\
\text { Effect Size } \\
\text { SOE } \\
\end{array}$ \\
\hline Exercise & $\begin{array}{l}\text { slight } \\
+\end{array}$ & $\begin{array}{c}\text { none } \\
+\end{array}$ & $\begin{array}{c}\text { none } \\
+\end{array}$ & $\begin{array}{c}\text { slight } \\
++\end{array}$ & $\begin{array}{c}\text { moderate } \\
+\end{array}$ & $\begin{array}{c}\text { moderate } \\
+\end{array}$ \\
\hline $\begin{array}{l}\text { Psychological } \\
\text { Therapies: CBT } \\
\text { primarily }\end{array}$ & $\begin{array}{l}\text { slight } \\
++\end{array}$ & $\begin{array}{l}\text { slight } \\
++\end{array}$ & $\begin{array}{l}\text { slight } \\
++\end{array}$ & $\begin{array}{c}\text { slight } \\
++\end{array}$ & $\begin{array}{c}\text { slight } \\
++\end{array}$ & $\begin{array}{c}\text { slight } \\
++\end{array}$ \\
\hline $\begin{array}{l}\text { Physical } \\
\text { Modalities: } \\
\text { Ultrasound }\end{array}$ & $\begin{array}{l}\text { insufficient } \\
\text { evidence }\end{array}$ & no evidence & no evidence & $\begin{array}{c}\text { none } \\
+\end{array}$ & no evidence & no evidence \\
\hline $\begin{array}{l}\text { Physical } \\
\text { Modalities: Low- } \\
\text { Level Laser } \\
\text { Therapy }\end{array}$ & $\begin{array}{l}\text { slight } \\
+\end{array}$ & $\begin{array}{c}\text { none } \\
+\end{array}$ & no evidence & $\begin{array}{c}\text { moderate } \\
+\end{array}$ & $\begin{array}{c}\text { none } \\
+\end{array}$ & no evidence \\
\hline $\begin{array}{l}\text { Manual Therapies: } \\
\text { Spinal Manipulation }\end{array}$ & $\begin{array}{l}\text { slight } \\
+\end{array}$ & $\begin{array}{l}\text { slight } \\
+\end{array}$ & no evidence & $\begin{array}{c}\text { none } \\
+\end{array}$ & $\begin{array}{c}\text { slight } \\
++\end{array}$ & no evidence \\
\hline $\begin{array}{l}\text { Manual Therapies: } \\
\text { Massage }\end{array}$ & $\begin{array}{c}\text { slight } \\
++\end{array}$ & $\begin{array}{c}\text { none } \\
+\end{array}$ & no evidence & $\begin{array}{c}\text { slight } \\
++\end{array}$ & $\begin{array}{c}\text { none } \\
+\end{array}$ & no evidence \\
\hline $\begin{array}{l}\text { Manual Therapies: } \\
\text { Traction }\end{array}$ & $\begin{array}{c}\text { none } \\
+\end{array}$ & no evidence & no evidence & $\begin{array}{c}\text { none } \\
+\end{array}$ & no evidence & no evidence \\
\hline $\begin{array}{l}\text { Mindfulness } \\
\text { Practices: MBSR }\end{array}$ & $\begin{array}{c}\text { none } \\
+\end{array}$ & $\begin{array}{c}\text { none } \\
+\end{array}$ & $\begin{array}{c}\text { none } \\
+\end{array}$ & $\begin{array}{l}\text { slight } \\
++\end{array}$ & $\begin{array}{c}\text { slight } \\
+\end{array}$ & $\begin{array}{c}\text { none } \\
+\end{array}$ \\
\hline $\begin{array}{l}\text { Mind-Body } \\
\text { Practices: Yoga }\end{array}$ & $\begin{array}{l}\text { slight } \\
++\end{array}$ & $\begin{array}{l}\text { slight } \\
+\end{array}$ & no evidence & $\begin{array}{c}\text { moderate } \\
+\end{array}$ & $\begin{array}{c}\text { moderate } \\
++\end{array}$ & no evidence \\
\hline Acupuncture & $\begin{array}{l}\text { slight } \\
+\end{array}$ & $\begin{array}{c}\text { none } \\
+\end{array}$ & $\begin{array}{c}\text { none } \\
+\end{array}$ & $\begin{array}{c}\text { slight } \\
++\end{array}$ & $\begin{array}{c}\text { none } \\
+\end{array}$ & $\begin{array}{l}\text { slight } \\
+\end{array}$ \\
\hline $\begin{array}{l}\text { Multidisciplinary } \\
\text { Rehabilitation }\end{array}$ & $\begin{array}{l}\text { slight } \\
+\end{array}$ & $\begin{array}{l}\text { slight } \\
+\end{array}$ & $\begin{array}{c}\text { none } \\
+\end{array}$ & $\begin{array}{c}\text { slight } \\
++\end{array}$ & $\begin{array}{c}\text { slight } \\
++\end{array}$ & $\begin{array}{c}\text { none } \\
+\end{array}$ \\
\hline
\end{tabular}

Short-Term: 1 to $<6$ months; Intermediate-Term: $\geq 6$ to $<12$ months; Long-Term: $\geq 12$ months

Effect Size: none, slight/small, moderate, or large improvement

Strength of Evidence: $+=$ low, $++=$ moderate, $+++=$ high

$\mathrm{CBT}=$ cognitive behavioral therapy; MBSR = mindfulness-based stress reduction; none = no effect/no statistically significant effect; SOE = strength of evidence. 
Table B. Chronic low back pain: effects of nonpharmacological interventions compared with exercise

\begin{tabular}{|c|c|c|c|c|c|c|}
\hline Intervention & $\begin{array}{c}\text { Function } \\
\text { Short-Term } \\
\\
\text { Effect Size } \\
\text { SOE } \\
\end{array}$ & $\begin{array}{c}\text { Function } \\
\text { Intermediate- } \\
\text { Term } \\
\text { Effect Size } \\
\text { SOE }\end{array}$ & $\begin{array}{c}\text { Function } \\
\text { Long-Term } \\
\\
\text { Effect Size } \\
\text { SOE } \\
\end{array}$ & $\begin{array}{c}\text { Pain } \\
\text { Short-Term } \\
\\
\text { Effect Size } \\
\text { SOE } \\
\end{array}$ & $\begin{array}{c}\text { Pain } \\
\text { Intermediate- } \\
\text { Term } \\
\\
\text { Effect Size } \\
\text { SOE } \\
\end{array}$ & $\begin{array}{c}\text { Pain } \\
\text { Long-Term } \\
\\
\text { Effect Size } \\
\text { SOE } \\
\end{array}$ \\
\hline $\begin{array}{l}\text { Physical } \\
\text { Modalities: Low- } \\
\text { Level Laser } \\
\text { Therapy }\end{array}$ & no evidence & $\begin{array}{c}\text { none } \\
+\end{array}$ & no evidence & no evidence & $\begin{array}{l}\text { slight } \\
+\end{array}$ & no evidence \\
\hline $\begin{array}{l}\text { Manual Therapies: } \\
\text { Spinal Manipulation }\end{array}$ & $\begin{array}{c}\text { none } \\
+\end{array}$ & $\begin{array}{c}\text { none } \\
+\end{array}$ & no evidence & $\begin{array}{c}\text { none } \\
+\end{array}$ & $\begin{array}{c}\text { slight } \\
+\end{array}$ & no evidence \\
\hline $\begin{array}{l}\text { Manual Therapies: } \\
\text { Massage }\end{array}$ & no evidence & $\begin{array}{c}\text { none } \\
+\end{array}$ & no evidence & no evidence & $\begin{array}{c}\text { none } \\
+\end{array}$ & no evidence \\
\hline $\begin{array}{l}\text { Mind-Body } \\
\text { Practices: Yoga }\end{array}$ & $\begin{array}{c}\text { none } \\
+\end{array}$ & $\begin{array}{c}\text { none } \\
+\end{array}$ & no evidence & $\begin{array}{c}\text { slight } \\
+\end{array}$ & $\begin{array}{c}\text { none } \\
+\end{array}$ & no evidence \\
\hline $\begin{array}{l}\text { Mind-Body } \\
\text { Practices: Qigong }\end{array}$ & $\begin{array}{c}\text { none } \\
+\end{array}$ & $\begin{array}{c}\text { slight favoring } \\
\text { exercise } \\
+\end{array}$ & no evidence & $\begin{array}{c}\text { slight favoring } \\
\text { exercise } \\
+\end{array}$ & $\begin{array}{c}\text { none } \\
+\end{array}$ & no evidence \\
\hline $\begin{array}{l}\text { Multidisciplinary } \\
\text { Rehabilitation }\end{array}$ & $\begin{array}{c}\text { slight } \\
++\end{array}$ & $\begin{array}{c}\text { slight } \\
++\end{array}$ & $\begin{array}{c}\text { none } \\
+\end{array}$ & $\begin{array}{c}\text { slight } \\
++\end{array}$ & $\begin{array}{c}\text { slight } \\
++\end{array}$ & $\begin{array}{c}\text { none } \\
+\end{array}$ \\
\hline
\end{tabular}

Short-Term: 1 to $<6$ months; Intermediate-Term: $\geq 6$ to $<12$ months; Long-Term: $\geq 12$ months

Effect Size: none, slight/small, moderate, or large improvement

Strength of Evidence: $+=$ low, $++=$ moderate, $+++=$ high

none $=$ no effect/no statistically significant effect; SOE = strength of evidence.

Table C. Chronic neck pain: effects of nonpharmacological interventions compared with usual care, placebo, sham, attention control, or waitlist

\begin{tabular}{|c|c|c|c|c|c|c|}
\hline Intervention & $\begin{array}{c}\text { Function } \\
\text { Short-Term } \\
\\
\text { Effect Size } \\
\text { SOE } \\
\end{array}$ & $\begin{array}{c}\text { Function } \\
\text { Intermediate- } \\
\text { Term } \\
\text { Effect Size } \\
\text { SOE } \\
\end{array}$ & $\begin{array}{c}\text { Function } \\
\text { Long-Term } \\
\text { Effect Size } \\
\text { SOE } \\
\end{array}$ & $\begin{array}{c}\text { Pain } \\
\text { Short-Term } \\
\text { Effect Size } \\
\text { SOE } \\
\end{array}$ & $\begin{array}{c}\text { Pain } \\
\text { Intermediate- } \\
\text { Term } \\
\\
\text { Effect Size } \\
\text { SOE } \\
\end{array}$ & $\begin{array}{c}\text { Pain } \\
\text { Long-Term } \\
\\
\text { Effect Size } \\
\text { SOE } \\
\end{array}$ \\
\hline Exercise & $\begin{array}{c}\text { none } \\
+\end{array}$ & no evidence & no evidence & $\begin{array}{c}\text { none } \\
+\end{array}$ & no evidence & no evidence \\
\hline $\begin{array}{l}\text { Psychological } \\
\text { Therapies: PT-lead } \\
\text { relaxation training }\end{array}$ & $\begin{array}{c}\text { none } \\
+\end{array}$ & $\begin{array}{c}\text { none } \\
+\end{array}$ & no evidence & $\begin{array}{c}\text { none } \\
+\end{array}$ & $\begin{array}{c}\text { none } \\
+\end{array}$ & no evidence \\
\hline $\begin{array}{l}\text { Physical } \\
\text { Modalities: Low- } \\
\text { Level Laser Therapy }\end{array}$ & $\begin{array}{c}\text { moderate } \\
++\end{array}$ & no evidence & no evidence & $\begin{array}{c}\text { moderate } \\
++\end{array}$ & no evidence & no evidence \\
\hline $\begin{array}{l}\text { Manual Therapies: } \\
\text { Massage }\end{array}$ & $\begin{array}{c}\text { none } \\
+\end{array}$ & $\begin{array}{c}\text { none } \\
+\end{array}$ & no evidence & no evidence & no evidence & no evidence \\
\hline $\begin{array}{l}\text { Mind-Body } \\
\text { Practices: } \\
\text { Alexander } \\
\text { Technique }\end{array}$ & $\begin{array}{c}\text { slight } \\
+\end{array}$ & $\begin{array}{c}\text { slight } \\
+\end{array}$ & no evidence & no evidence & no evidence & no evidence \\
\hline Acupuncture & $\begin{array}{c}\text { slight } \\
+\end{array}$ & $\begin{array}{c}\text { slight } \\
+\end{array}$ & $\begin{array}{c}\text { none } \\
+\end{array}$ & $\begin{array}{c}\text { none } \\
+\end{array}$ & $\begin{array}{c}\text { none } \\
+\end{array}$ & $\begin{array}{c}\text { none } \\
+\end{array}$ \\
\hline
\end{tabular}

Short-Term: 1 to $<6$ months; Intermediate-Term: $\geq 6$ to $<12$ months; Long-Term: $\geq 12$ months

Effect Size: none, slight/small, moderate, or large improvement 
Strength of Evidence: $+=$ low, $++=$ moderate, $+++=$ high

none $=$ no effect $/$ no statistically significant effect; $\mathrm{PT}=$ physical therapist; $\mathrm{SOE}=$ strength of evidence .

Table D. Chronic neck pain: effects of nonpharmacological interventions compared with exercise

\begin{tabular}{|c|c|c|c|c|c|c|}
\hline Intervention & $\begin{array}{l}\text { Function } \\
\text { Short-Term } \\
\text { Effect Size } \\
\text { SOE }\end{array}$ & $\begin{array}{c}\text { Function } \\
\text { Intermediate- } \\
\text { Term } \\
\text { Effect Size } \\
\text { SOE }\end{array}$ & $\begin{array}{l}\text { Function } \\
\text { Long-Term }\end{array}$ & $\begin{array}{c}\text { Pain } \\
\text { Short-Term } \\
\text { Effect Size } \\
\text { SOE }\end{array}$ & $\begin{array}{c}\text { Pain } \\
\text { Intermediate- } \\
\text { Term } \\
\text { Effect Size } \\
\text { SOE }\end{array}$ & $\begin{array}{c}\text { Pain } \\
\text { Long-Term } \\
\text { Effect Size } \\
\text { SOE }\end{array}$ \\
\hline $\begin{array}{l}\text { Psychological } \\
\text { Therapies: PT-lead } \\
\text { relaxation training }\end{array}$ & $\begin{array}{c}\text { none } \\
+\end{array}$ & $\begin{array}{c}\text { none } \\
+\end{array}$ & no evidence & $\begin{array}{c}\text { none } \\
+\end{array}$ & $\begin{array}{c}\text { none } \\
+\end{array}$ & no evidence \\
\hline $\begin{array}{l}\text { Manual Therapies: } \\
\text { Massage }\end{array}$ & no evidence & no evidence & no evidence & no evidence & $\begin{array}{c}\text { none } \\
+\end{array}$ & no evidence \\
\hline $\begin{array}{l}\text { Mind-Body } \\
\text { Practices: Body } \\
\text { Awareness Therapy }\end{array}$ & $\begin{array}{c}\text { none } \\
+\end{array}$ & no evidence & no evidence & no evidence & no evidence & no evidence \\
\hline
\end{tabular}

Short-Term: 1 to $<6$ months; Intermediate-Term: $\geq 6$ to $<12$ months; Long-Term: $\geq 12$ months

Effect Size: none, slight/small, moderate, or large improvement

Strength of Evidence: $+=$ low, $++=$ moderate, $+++=$ high

none $=$ no effect $/$ no statistically significant effect; $\mathrm{PT}=$ physical therapist; $\mathrm{SOE}=$ strength of evidence .

Table E. Osteoarthritis of the knee: effects of nonpharmacological interventions compared with usual care, placebo, sham, attention control, or waitlist

\begin{tabular}{|c|c|c|c|c|c|c|}
\hline Intervention & $\begin{array}{c}\text { Function } \\
\text { Short-Term } \\
\\
\text { Effect Size } \\
\text { SOE } \\
\end{array}$ & $\begin{array}{c}\text { Function } \\
\text { Intermediate- } \\
\text { Term } \\
\text { Effect Size } \\
\text { SOE } \\
\end{array}$ & $\begin{array}{c}\text { Function } \\
\text { Long-Term } \\
\\
\text { Effect Size } \\
\text { SOE } \\
\end{array}$ & $\begin{array}{c}\text { Pain } \\
\text { Short-Term } \\
\\
\text { Effect Size } \\
\text { SOE } \\
\end{array}$ & $\begin{array}{c}\text { Pain } \\
\text { Intermediate- } \\
\text { Term } \\
\text { Effect Size } \\
\text { SOE } \\
\end{array}$ & $\begin{array}{c}\text { Pain } \\
\text { Long-Term } \\
\text { Effect Size } \\
\text { SOE } \\
\end{array}$ \\
\hline Exercise & $\begin{array}{l}\text { slight } \\
++\end{array}$ & $\begin{array}{l}\text { slight } \\
+\end{array}$ & $\begin{array}{l}\text { slight } \\
+\end{array}$ & $\begin{array}{c}\text { slight } \\
++\end{array}$ & $\begin{array}{c}\text { moderate } \\
+\end{array}$ & $\begin{array}{c}\text { none } \\
+\end{array}$ \\
\hline $\begin{array}{l}\text { Psychological } \\
\text { Therapies: Pain } \\
\text { coping, CBT }\end{array}$ & $\begin{array}{c}\text { none } \\
+\end{array}$ & $\begin{array}{c}\text { none } \\
+\end{array}$ & $\begin{array}{c}\text { none } \\
+\end{array}$ & $\begin{array}{c}\text { none } \\
+\end{array}$ & $\begin{array}{c}\text { none } \\
+\end{array}$ & $\begin{array}{c}\text { none } \\
+\end{array}$ \\
\hline $\begin{array}{l}\text { Physical } \\
\text { Modalities: } \\
\text { Ultrasound }\end{array}$ & $\begin{array}{l}\text { slight } \\
+\end{array}$ & $\begin{array}{c}\text { none } \\
+\end{array}$ & no evidence & $\begin{array}{l}\text { slight } \\
+\end{array}$ & $\begin{array}{c}\text { none } \\
+\end{array}$ & no evidence \\
\hline $\begin{array}{l}\text { Physical } \\
\text { Modalities: TENS }\end{array}$ & no evidence & $\begin{array}{c}\text { none } \\
+\end{array}$ & no evidence & no evidence & $\begin{array}{c}\text { none } \\
+\end{array}$ & no evidence \\
\hline $\begin{array}{l}\text { Physical } \\
\text { Modalities: } \\
\text { Electromagnetic } \\
\text { Field }\end{array}$ & $\begin{array}{c}\text { none } \\
+\end{array}$ & no evidence & no evidence & $\begin{array}{c}\text { none } \\
+\end{array}$ & no evidence & no evidence \\
\hline Acupuncture & $\begin{array}{c}\text { none } \\
+\end{array}$ & $\begin{array}{c}\text { none } \\
++\end{array}$ & no evidence & $\begin{array}{c}\text { none } \\
+\end{array}$ & $\begin{array}{c}\text { none } \\
++\end{array}$ & no evidence \\
\hline
\end{tabular}

Short-Term: 1 to $<6$ months; Intermediate-Term: $\geq 6$ to $<12$ months; Long-Term: $\geq 12$ months

Effect Size: none, slight/small, moderate, or large improvement

Strength of Evidence: $+=$ low, $++=$ moderate, $+++=$ high

$\mathrm{CBT}=$ cognitive-behavioral therapy; none $=$ no effect/no statistically significant effect; TENS = transcutaneous electrical nerve stimulation; $\mathrm{SOE}=$ strength of evidence 
Table F. Osteoarthritis of the knee: effects of nonpharmacological interventions compared with exercise

\begin{tabular}{|l|c|c|c|c|c|c|}
\hline Intervention & $\begin{array}{c}\text { Function } \\
\text { Short-Term }\end{array}$ & $\begin{array}{c}\text { Function } \\
\text { Intermediate- } \\
\text { Term }\end{array}$ & $\begin{array}{c}\text { Function } \\
\text { Long-Term }\end{array}$ & $\begin{array}{c}\text { Pain } \\
\text { Short-Term }\end{array}$ & $\begin{array}{c}\text { Pain } \\
\text { Intermediate- } \\
\text { Term }\end{array}$ & $\begin{array}{c}\text { Pain } \\
\text { Long-Term }\end{array}$ \\
& $\begin{array}{c}\text { Effect Size } \\
\text { SOE }\end{array}$ & $\begin{array}{c}\text { Effect Size } \\
\text { SOE }\end{array}$ & $\begin{array}{c}\text { Effect Size } \\
\text { SOE }\end{array}$ & $\begin{array}{c}\text { Effect Size } \\
\text { SOE }\end{array}$ & $\begin{array}{c}\text { Effect Size } \\
\text { SOE }\end{array}$ & $\begin{array}{c}\text { Effect Size } \\
\text { SOE }\end{array}$ \\
\hline $\begin{array}{l}\text { Psychological } \\
\begin{array}{l}\text { Therapies: Pain } \\
\text { coping }\end{array}\end{array}$ & $\begin{array}{c}\text { none } \\
+\end{array}$ & $\begin{array}{c}\text { none } \\
+\end{array}$ & no evidence & $\begin{array}{c}\text { none } \\
+\end{array}$ & $\begin{array}{c}\text { none } \\
+\end{array}$ & no evidence \\
\hline
\end{tabular}

Short-Term: 1 to $<6$ months; Intermediate-Term: $\geq 6$ to $<12$ months; Long-Term: $\geq 12$ months

Effect Size: none, slight/small, moderate, or large improvement

Strength of Evidence: $+=$ low, $++=$ moderate, $+++=$ high

none $=$ no effect/no statistically significant effect; SOE = strength of evidence

Table G. Osteoarthritis of the hip: effects of nonpharmacological interventions compared with usual care, placebo, sham, attention control, or waitlist

\begin{tabular}{|c|c|c|c|c|c|c|}
\hline Intervention & $\begin{array}{c}\text { Function } \\
\text { Short-Term } \\
\\
\text { Effect Size } \\
\text { SOE } \\
\end{array}$ & $\begin{array}{c}\text { Function } \\
\text { Intermediate- } \\
\text { Term } \\
\text { Effect Size } \\
\text { SOE } \\
\end{array}$ & $\begin{array}{l}\text { Function } \\
\text { Long-Term } \\
\\
\text { Effect Size } \\
\text { SOE } \\
\end{array}$ & $\begin{array}{c}\text { Pain } \\
\text { Short-Term } \\
\\
\text { Effect Size } \\
\text { SOE } \\
\end{array}$ & $\begin{array}{c}\text { Pain } \\
\text { Intermediate- } \\
\text { Term } \\
\text { Effect Size } \\
\text { SOE } \\
\end{array}$ & $\begin{array}{c}\text { Pain } \\
\text { Long-Term } \\
\\
\text { Effect Size } \\
\text { SOE } \\
\end{array}$ \\
\hline Exercise & $\begin{array}{c}\text { slight } \\
+\end{array}$ & $\begin{array}{l}\text { slight } \\
+\end{array}$ & $\begin{array}{l}\text { insufficient } \\
\text { evidence }\end{array}$ & $\begin{array}{l}\text { slight } \\
+\end{array}$ & $\begin{array}{c}\text { none } \\
+\end{array}$ & $\begin{array}{l}\text { insufficient } \\
\text { evidence }\end{array}$ \\
\hline
\end{tabular}

Short-Term: 1 to $<6$ months; Intermediate-Term: $\geq 6$ to $<12$ months; Long-Term: $\geq 12$ months

Effect Size: none, slight/small, moderate, or large improvement

Strength of Evidence: $+=$ low, $++=$ moderate, $+++=$ high

none $=$ no effect/no statistically significant effect; $\mathrm{SOE}=$ strength of evidence

Table H. Osteoarthritis of the hip: effects of nonpharmacological interventions compared with exercise

\begin{tabular}{|c|c|c|c|c|c|c|}
\hline Intervention & $\begin{array}{c}\text { Function } \\
\text { Short-Term } \\
\\
\text { Effect Size } \\
\text { SOE }\end{array}$ & $\begin{array}{c}\text { Function } \\
\text { Intermediate- } \\
\text { Term } \\
\text { Effect Size } \\
\text { SOE } \\
\end{array}$ & $\begin{array}{c}\text { Function } \\
\text { Long-Term } \\
\\
\text { Effect Size } \\
\text { SOE }\end{array}$ & $\begin{array}{c}\text { Pain } \\
\text { Short-Term } \\
\\
\text { Effect Size } \\
\text { SOE }\end{array}$ & $\begin{array}{c}\text { Pain } \\
\text { Intermediate- } \\
\text { Term } \\
\text { Effect Size } \\
\text { SOE } \\
\end{array}$ & $\begin{array}{c}\text { Pain } \\
\text { Long-Term } \\
\text { Effect Size } \\
\text { SOE } \\
\end{array}$ \\
\hline Manual Therapies & $\begin{array}{c}\text { slight } \\
+\end{array}$ & $\begin{array}{l}\text { slight } \\
+\end{array}$ & no evidence & $\begin{array}{l}\text { slight } \\
+\end{array}$ & $\begin{array}{c}\text { insufficient } \\
\text { evidence }\end{array}$ & no evidence \\
\hline
\end{tabular}

Short-Term: 1 to $<6$ months; Intermediate-Term: $\geq 6$ to $<12$ months; Long-Term: $\geq 12$ months

Effect Size: none, slight/small, moderate, or large improvement

Strength of Evidence: $+=$ low, $++=$ moderate, $+++=$ high

$\mathrm{SOE}=$ strength of evidence 
Table I. Osteoarthritis of the hand: effects of nonpharmacological interventions compared with usual care, placebo, sham, attention control, or waitlist

\begin{tabular}{|c|c|c|c|c|c|c|}
\hline Intervention & $\begin{array}{c}\text { Function } \\
\text { Short-Term } \\
\\
\text { Effect Size } \\
\text { SOE } \\
\end{array}$ & $\begin{array}{c}\text { Function } \\
\text { Intermediate- } \\
\text { Term } \\
\text { Effect Size } \\
\text { SOE } \\
\end{array}$ & $\begin{array}{c}\text { Function } \\
\text { Long-Term } \\
\\
\text { Effect Size } \\
\text { SOE } \\
\end{array}$ & $\begin{array}{c}\text { Pain } \\
\text { Short-Term } \\
\\
\text { Effect Size } \\
\text { SOE } \\
\end{array}$ & $\begin{array}{c}\text { Pain } \\
\text { Intermediate- } \\
\text { Term } \\
\\
\text { Effect Size } \\
\text { SOE } \\
\end{array}$ & $\begin{array}{c}\text { Pain } \\
\text { Long-Term } \\
\\
\text { Effect Size } \\
\text { SOE } \\
\end{array}$ \\
\hline $\begin{array}{l}\text { Physical } \\
\text { Modalities: Low- } \\
\text { Level Laser } \\
\text { Therapy }\end{array}$ & $\begin{array}{c}\text { none } \\
+\end{array}$ & no evidence & no evidence & $\begin{array}{c}\text { none } \\
+\end{array}$ & no evidence & no evidence \\
\hline $\begin{array}{l}\text { Multidisciplinary } \\
\text { Rehabilitation }\end{array}$ & $\begin{array}{c}\text { none } \\
+\end{array}$ & no evidence & no evidence & $\begin{array}{c}\text { none } \\
+\end{array}$ & no evidence & no evidence \\
\hline
\end{tabular}

Short-Term: 1 to $<6$ months; Intermediate-Term: $\geq 6$ to $<12$ months; Long-Term: $\geq 12$ months

Effect Size: none, slight/small, moderate, or large improvement

Strength of Evidence: $+=$ low, $++=$ moderate, $+++=$ high

none $=$ no effect $/$ no statistically significant effect; $\mathrm{SOE}=$ strength of evidence

Table J. Fibromyalgia: effects of nonpharmacological interventions compared with usual care, placebo, sham, attention control, or waitlist

\begin{tabular}{|c|c|c|c|c|c|c|}
\hline Intervention & $\begin{array}{l}\text { Function } \\
\text { Short-Term } \\
\text { Effect Size } \\
\text { SOE }\end{array}$ & $\begin{array}{c}\text { Function } \\
\text { Intermediate- } \\
\text { Term } \\
\text { Effect Size } \\
\text { SOE }\end{array}$ & $\begin{array}{l}\text { Function } \\
\text { Long-Term } \\
\text { Effect Size } \\
\text { SOE }\end{array}$ & $\begin{array}{c}\text { Pain } \\
\text { Short-Term } \\
\text { Effect Size } \\
\text { SOE }\end{array}$ & $\begin{array}{c}\text { Pain } \\
\text { Intermediate- } \\
\text { Term } \\
\\
\text { Effect Size } \\
\text { SOE }\end{array}$ & $\begin{array}{c}\text { Pain } \\
\text { Long-Term } \\
\text { Effect Size } \\
\text { SOE }\end{array}$ \\
\hline Exercise & $\begin{array}{l}\text { slight } \\
+\end{array}$ & $\begin{array}{c}\text { slight } \\
++\end{array}$ & $\begin{array}{c}\text { none } \\
+\end{array}$ & $\begin{array}{c}\text { slight } \\
++\end{array}$ & $\begin{array}{c}\text { none } \\
++\end{array}$ & $\begin{array}{c}\text { none } \\
++\end{array}$ \\
\hline $\begin{array}{l}\text { Psychological } \\
\text { Therapies: CBT }\end{array}$ & $\begin{array}{l}\text { slight } \\
+\end{array}$ & $\begin{array}{l}\text { slight } \\
+\end{array}$ & $\begin{array}{l}\text { insufficient } \\
\text { evidence }\end{array}$ & $\begin{array}{l}\text { slight } \\
+\end{array}$ & $\begin{array}{c}\text { none } \\
+\end{array}$ & $\begin{array}{l}\text { insufficient } \\
\text { evidence }\end{array}$ \\
\hline $\begin{array}{l}\text { Physical } \\
\text { Modalities: } \\
\text { Magnetic Pads }\end{array}$ & $\begin{array}{l}\text { insufficient } \\
\text { evidence }\end{array}$ & $\begin{array}{c}\text { none } \\
+\end{array}$ & no evidence & $\begin{array}{l}\text { insufficient } \\
\text { evidence }\end{array}$ & $\begin{array}{c}\text { none } \\
+\end{array}$ & no evidence \\
\hline $\begin{array}{l}\text { Manual Therapies: } \\
\text { Massage } \\
\text { (Myofascial } \\
\text { Release) }\end{array}$ & no evidence & $\begin{array}{l}\text { slight } \\
+\end{array}$ & $\begin{array}{c}\text { none } \\
+\end{array}$ & $\begin{array}{l}\text { insufficient } \\
\text { evidence }\end{array}$ & $\begin{array}{l}\text { insufficient } \\
\text { evidence }\end{array}$ & $\begin{array}{l}\text { slight } \\
+\end{array}$ \\
\hline $\begin{array}{l}\text { Mindfulness } \\
\text { Practices: MBSR }\end{array}$ & $\begin{array}{c}\text { none } \\
++\end{array}$ & no evidence & no evidence & $\begin{array}{c}\text { none } \\
++\end{array}$ & no evidence & no evidence \\
\hline $\begin{array}{l}\text { Mind-Body } \\
\text { Practices: Qigong, } \\
\text { Tai Chi }\end{array}$ & $\begin{array}{l}\text { slight } \\
+\end{array}$ & no evidence & no evidence & $\begin{array}{c}\text { moderate } \\
+\end{array}$ & no evidence & no evidence \\
\hline Acupuncture & $\begin{array}{c}\text { slight } \\
++\end{array}$ & $\begin{array}{c}\text { slight } \\
++\end{array}$ & no evidence & $\begin{array}{c}\text { none } \\
+\end{array}$ & $\begin{array}{c}\text { none } \\
+\end{array}$ & no evidence \\
\hline $\begin{array}{l}\text { Multidisciplinary } \\
\text { Rehabilitation }\end{array}$ & $\begin{array}{l}\text { slight } \\
+\end{array}$ & $\begin{array}{l}\text { slight } \\
+\end{array}$ & $\begin{array}{l}\text { slight } \\
+\end{array}$ & $\begin{array}{c}\text { none } \\
+\end{array}$ & $\begin{array}{l}\text { slight } \\
+\end{array}$ & $\begin{array}{c}\text { none } \\
+\end{array}$ \\
\hline
\end{tabular}

Short-Term: 1 to $<6$ months; Intermediate-Term: $\geq 6$ to $<12$ months; Long-Term: $\geq 12$ months

Effect Size: none, slight/small, moderate, or large improvement

Strength of Evidence: $+=$ low, $++=$ moderate, $+++=$ high

$\mathrm{CBT}$ = cognitive-behavioral therapy; MBSR = mindfulness-based stress reduction; none = no effect/no statistically significant effect; $\mathrm{SOE}=$ strength of evidence 
Table K. Fibromyalgia: effects of nonpharmacological interventions compared with pharmacological treatments

\begin{tabular}{|l|c|c|c|c|c|c|}
\hline Intervention & $\begin{array}{c}\text { Function } \\
\text { Short-Term }\end{array}$ & $\begin{array}{c}\text { Function } \\
\text { Intermediate- } \\
\text { Term }\end{array}$ & $\begin{array}{c}\text { Function } \\
\text { Long-Term }\end{array}$ & $\begin{array}{c}\text { Pain } \\
\text { Short-Term }\end{array}$ & $\begin{array}{c}\text { Pain } \\
\text { Intermediate- } \\
\text { Term }\end{array}$ & $\begin{array}{c}\text { Pain } \\
\text { Long-Term }\end{array}$ \\
& $\begin{array}{c}\text { Effect Size } \\
\text { SOE }\end{array}$ & $\begin{array}{c}\text { Effect Size } \\
\text { SOE }\end{array}$ & $\begin{array}{c}\text { Effect Size } \\
\text { SOE }\end{array}$ & $\begin{array}{c}\text { Effect Size } \\
\text { SOE }\end{array}$ & $\begin{array}{c}\text { Effect Size } \\
\text { SOE }\end{array}$ & $\begin{array}{c}\text { Effect Size } \\
\text { SOE }\end{array}$ \\
\hline $\begin{array}{l}\text { CBT vs. } \\
\text { pregabalin; } \\
\text { duloxetine }\end{array}$ & no evidence & $\begin{array}{c}\text { Slight } \\
+\end{array}$ & no evidence & no evidence & $\begin{array}{c}\text { none } \\
+\end{array}$ & no evidence \\
\hline
\end{tabular}

Short-Term: 1 to $<6$ months; Intermediate-Term: $\geq 6$ to $<12$ months; Long-Term: $\geq 12$ months

Effect Size: none, slight/small, moderate, or large improvement

Strength of Evidence: $+=$ low, $++=$ moderate, $+++=$ high

$\mathrm{CBT}=$ cognitive-behavioral therapy; none = no effect/no statistically significant effect; $\mathrm{SOE}=$ strength of evidence

Table L. Fibromyalgia: effects of nonpharmacological interventions compared with exercise

\begin{tabular}{|c|c|c|c|c|c|c|}
\hline Intervention & $\begin{array}{l}\text { Function } \\
\text { Short-Term } \\
\\
\text { Effect Size } \\
\text { SOE } \\
\end{array}$ & $\begin{array}{c}\text { Function } \\
\text { Intermediate- } \\
\text { Term } \\
\text { Effect Size } \\
\text { SOE } \\
\end{array}$ & $\begin{array}{l}\text { Function } \\
\text { Long-Term } \\
\\
\text { Effect Size } \\
\quad \text { SOE } \\
\end{array}$ & $\begin{array}{c}\text { Pain } \\
\text { Short-Term } \\
\\
\text { Effect Size } \\
\text { SOE } \\
\end{array}$ & $\begin{array}{c}\text { Pain } \\
\text { Intermediate- } \\
\text { Term } \\
\\
\text { Effect Size } \\
\text { SOE } \\
\end{array}$ & $\begin{array}{c}\text { Pain } \\
\text { Long-Term } \\
\\
\text { Effect Size } \\
\text { SOE } \\
\end{array}$ \\
\hline $\begin{array}{l}\text { Multidisciplinary } \\
\text { Rehabilitation }\end{array}$ & no evidence & no evidence & $\begin{array}{c}\text { none } \\
+\end{array}$ & no evidence & no evidence & $\begin{array}{c}\text { none } \\
+\end{array}$ \\
\hline
\end{tabular}

Short-Term: 1 to $<6$ months; Intermediate-Term: $\geq 6$ to $<12$ months; Long-Term: $\geq 12$ months

Effect Size: none, slight/small, moderate, or large improvement

Strength of Evidence: $+=$ low, $++=$ moderate, $+++=$ high

none = no effect/no statistically significant effect; SOE = strength of evidence

Table M. Chronic tension headache: effects of nonpharmacological interventions compared with usual care, placebo, sham, attention control, or waitlist

\begin{tabular}{|c|c|c|c|c|c|c|}
\hline Intervention & $\begin{array}{l}\text { Function } \\
\text { Short-Term } \\
\text { Effect Size } \\
\text { SOE }\end{array}$ & $\begin{array}{c}\text { Function } \\
\text { Intermediate- } \\
\text { Term } \\
\text { Effect Size } \\
\text { SOE }\end{array}$ & $\begin{array}{l}\text { Function } \\
\text { Long-Term } \\
\text { Effect Size } \\
\text { SOE }\end{array}$ & $\begin{array}{c}\text { Pain } \\
\text { Short-Term } \\
\text { Effect Size } \\
\text { SOE }\end{array}$ & $\begin{array}{c}\text { Pain } \\
\text { Intermediate- } \\
\text { Term } \\
\text { Effect Size } \\
\text { SOE }\end{array}$ & $\begin{array}{c}\text { Pain } \\
\text { Long-Term } \\
\text { Effect Size } \\
\text { SOE }\end{array}$ \\
\hline $\begin{array}{l}\text { Manual Therapies: } \\
\text { Spinal manipulation }\end{array}$ & $\begin{array}{c}\text { slight } \\
+\end{array}$ & no evidence & no evidence & $\begin{array}{c}\text { moderate } \\
+\end{array}$ & no evidence & no evidence \\
\hline Acupuncture & no evidence & no evidence & no evidence & $\begin{array}{c}\text { slight } \\
+ \\
\text { (laser) } \\
\text { insufficient } \\
\text { evidence } \\
\text { (needle) }\end{array}$ & $\begin{array}{c}\text { insufficient } \\
\text { evidence } \\
\text { (needle) }\end{array}$ & $\begin{array}{l}\text { insufficient } \\
\text { evidence } \\
\text { (needle) }\end{array}$ \\
\hline
\end{tabular}

Short-Term: 1 to $<6$ months; Intermediate-Term: $\geq 6$ to $<12$ months; Long-Term: $\geq 12$ months

Effect Size: none, slight/small, moderate, or large improvement

Strength of Evidence: $+=$ low, $++=$ moderate, $+++=$ high

$\mathrm{SOE}=$ strength of evidence 


\section{Findings in Relationship to What Is Already Known}

Many reviews have addressed the effects of interventions for chronic pain management during or immediately following treatments. We focused on evaluating the sustainability of effects for at least 1 month post-intervention.

This review updates our previous review on low back pain ${ }^{10}$ by incorporating new evidence on nonpharmacological treatments for chronic low back pain. Consistent with the prior review, we found exercise, yoga, various psychological therapies, acupuncture, spinal manipulation and low-level laser therapy associated with small to moderate effects on function and/or pain. This report differs from the prior review in and focusing on durability of treatment effects 1 month or longer after completion of a course of treatment, basing estimates on meta-analyses when poolable data were available, and conducting stratified and sensitivity analyses to evaluate sources of heterogeneity and robustness of findings. For example, subanalyses of specific interventions within a given category of intervention (e.g., aerobic exercise within the general category of exercise suggested that despite the inherent heterogeneity within some of the categories, effect estimates for specific interventions may be similar). Although we found some evidence that beneficial effects of some nonpharmacological therapies persist for up to 12 months following the end of a course of a treatment, data on longer-term ( $>12$ months) outcomes were very sparse.

Our findings indicate that a number of nonpharmacological treatments improve pain and/or function for specific chronic pain conditions included in this review. This is consistent with other reviews including a recent Institute for Clinical and Economic Review (ICER) review on chronic low back pain and neck pain, ${ }^{16}$ an AHRQ report on knee osteoarthritis treatment ${ }^{17}$ and with recent reviews that included a variety of chronic pain conditions which examined exercise, ${ }^{18}$ acupuncture, ${ }^{19}$ and complementary health approaches ${ }^{20}$ for chronic pain management, as well as a review of chronic pain treatment guidelines on the use of manual and physical therapies. ${ }^{21}$

\section{Applicability}

The applicability of our findings may be impacted by a number of factors. Included trials provided limited information on, symptom duration, clinical characteristics, comorbid conditions and concomitant treatments, thus it is not clear to what extent this reflects the populations seen in clinical practice or may how these factors impact our results. In addition, with the exception of fibromyalgia, information regarding diagnostic criteria for the pain condition of interest was limited. Information on presence of overlapping chronic pain conditions or psychosocial factors was generally not provided in included trials. The extent to which these characteristics were present in trial populations and their impact on our results is not clear. Across conditions, a majority of trial participants were female. The age of included populations generally reflected the ages impacted by the conditions. Evidence to evaluate how effectiveness varies by ages was limited. There was also heterogeneity in populations enrolled in the trials with regard to duration of chronic pain, severity of pain (most trials enrolled patients with at least moderate pain at baseline), as well as other factors (e.g., use of medications, medical and psychological comorbidities). Our findings are generally most applicable to persons without such comorbidities who have moderate or severe intensity pain that has persisted for $>1$ year. The heterogeneity in populations across included trials likely is consistent with the heterogeneity seen in clinical practice, so our findings may be applicable to most primary care clinical settings. 
Variability in interventions, comparators and co-interventions may impact applicability. For interventions, there was variability in the numbers of sessions, length of sessions, duration of treatment, methods of delivering the intervention and the experience and training of those providing the intervention. To address heterogeneity within intervention categories we abstracted details of techniques or methods used (e.g., specific type of psychological intervention or yoga) and attempted to stratify by them, however in most cases, data were insufficient to do so. We stratified by comparator where possible. In general, there were no clear differences in effects based on intervention factors or comparators; however analyses were limited by small numbers of trials. In clinical practice, most chronic pain patients likely use a combination of therapies and patients may continue to receive therapies if benefit is perceived It is unclear to what extent our findings represents conditions under which the various interventions are currently delivered. Evidence to identify optimal techniques and delivery of interventions is needed.

\section{Implications for Clinical and Policy Decisionmaking}

Our review provides some evidence that an array of nonpharmacological treatments provide small to moderate benefits in function and pain that are durable for more than 1 month for five chronic pain conditions addressed in this review. Musculoskeletal pain, particularly of back and joint pain, is the most common single type of chronic pain. Age-adjusted rates of adults reporting pain in the last three months were highest for low back pain (28\%), neck pain (15\%), knee pain (19.5\%), and severe headache or migraine (16\%). ${ }^{1,5}$ The evidence synthesized in this review may help inform guidelines and health care policy (including reimbursement policy) related to use of noninvasive nonpharmacological treatments, and inform policy decisions regarding funding priorities for future research.

Recent guidelines from the $\mathrm{CDC}^{4}$ in the United States and the Canadian Guidelines for Opioid Use in Chronic Non-Cancer Pain ${ }^{21}$ recommend nonopioid treatment as preferred treatment for chronic pain. Further, American College of Physicians guidelines recommend nonpharmacological therapies over medications for chronic back pain. ${ }^{12}$ Our findings support the feasibility of these guidelines by showing that there are nonpharmacological treatments for chronic pain that have evidence of sustained effectiveness after the completion of therapy. Importantly, some interventions, such as exercise, multidisciplinary rehabilitation, mind-body interventions, cognitive behavioral therapy and some complementary and integrative medicine therapies such as acupuncture and spinal manipulation also were associated with some sustained effects on function, although evidence beyond 12 months is sparse. At the same time, there was no evidence suggesting serious harms, although data on harms were limited.

Evidence reviewed in our report may also help inform decisions regarding prioritization of nonpharmacological therapies by clinicians selecting therapy. Consistent with a biopsychosocial understanding of chronic pain, ${ }^{1,2}$ evidence was somewhat more robust for "active" interventions that engage patients in movement and address psychological contributors to pain, particularly at longer-term followup, versus more "passive" treatments focused on symptom relief such as massage. Active interventions include exercise, multidisciplinary rehabilitation, psychological therapies (particularly cognitive-behavioral therapy), and mind-body interventions. This provides some support for clinical strategies that focus on "active" interventions as primary therapies, with "passive" interventions used in a more adjunctive or supplementary role. Research is needed to compare "active" versus "passive" strategies.

Our review also has policy implications related to treatment access and reimbursement. Given heterogeneity in chronic pain, variability in patient preferences for treatments, and 
differential responses to specific therapies in patients with a given chronic pain condition, policies that broaden access to a broader array of effective nonpharmacological treatments may have greater impact than those that focus on one or a few therapies. Several considerations could inform policy decisions regarding access to and coverage of nonpharmacological therapies. Efforts could prioritize access to interventions with evidence of persistent effectiveness across different pain conditions, such as exercise, multidisciplinary rehabilitation, psychological interventions, mind-body interventions, and acupuncture. Because the level of supporting evidence varies from condition to condition, policymakers may need to consider the degree to which evidence may be reasonably extrapolated across conditions (e.g., effectiveness of psychological therapies for chronic back pain may not necessarily be extrapolated to osteoarthritis). Although the Affordable Care Act has improved access to complementary and integrative medicine therapies, variability in reimbursement and authorization procedures remain a potential barrier. Although evidence supports the use of multidisciplinary rehabilitation over exercise therapy or usual care, primarily for low back pain, cost and availability remain important barriers, particularly in rural areas. Our report suggests that less-intensive multidisciplinary rehabilitation may be similarly effective to high-intensity multidisciplinary rehabilitation, which could inform decisions about more efficient methods for delivering this intervention. Not all patients may require multidisciplinary rehabilitation. ${ }^{22}$ Policy efforts that focus on use of multidisciplinary rehabilitation in persons more likely to benefit (e.g., severe functional deficits, failure to improve on standard nonmultidisciplinary therapies, significant psychosocial contributors to pain) could also inform efforts to deliver this modality efficiently.

\section{Limitations of the Evidence Base and the Systematic Review Process}

Evidence was sparse for most interventions. Data on long-term outcomes was particularly limited. There were also limited data on outcomes other than pain and function and on harms. Few trials directly compared an included intervention versus pharmacological therapy or the specified active comparator (exercise or biofeedback). Only 5 percent of included trials across conditions were considered to be of good quality; the majority were considered fair (59\%).

There were limitations in the systematic review process. We did not include trials of patients with chronic pain conditions other than those specified in the methods and excluded trials of patients with diffuse or mixed pain conditions. Some noninvasive nonpharmacological interventions (e.g., self-management education) were excluded, and we did not address invasive therapies. Trials that evaluated active comparators other than biofeedback (for headache) or exercise (all other conditions) or interventions as adjunctive treatment were excluded. Some meta-analyses were based on two or three trials; findings based on such meta-analyses must be interpreted with caution.

\section{Research Recommendations}

The gaps in the available evidence are many across the common conditions we included (Table N). Four primary issues relate to the need (1) to understand the longer-term sustainability of intervention effects; (2) for standardization of interventions for future trials; (3) for standardization of research protocols for collection and reporting of outcomes including harms; and (4) for comparisons of interventions with pharmacological interventions. For many of these areas, future research would benefit from considering recommendations from organizations such as the Initiative on Methods, Measurements, and Pain Assessment in Clinical Trials (IMMPACT) $^{23}$ and the Analgesic, Anesthetic, and Addiction Clinical Trials Translations, 
Innovations, Opportunities, and Networks (ACTTION) ${ }^{24}$ and the research priorities outlined in the recent Federal Pain Research Strategy. ${ }^{25}$

Table N. Summary of evidence gaps and research recommendations

\begin{tabular}{|c|c|c|}
\hline Research Component & Evidence Gap & Future Research Recommendation \\
\hline $\begin{array}{l}\text { Study Design Methods and } \\
\text { Reporting }\end{array}$ & $\begin{array}{l}\text { Sparse evidence on the sustainability } \\
\text { of effects; Limited information on } \\
\text { adherence and need to maximize } \\
\text { retention. }\end{array}$ & $\begin{array}{l}\text { Traditional (explanatory) and pragmatic } \\
\text { trials with long-term followup and use of } \\
\text { methods to enhance recruitment, } \\
\text { retention and adherence. Documentation } \\
\text { of adherence. } \\
\text { Consider recommendations from } \\
\text { IMMPACT, ACTTION and Federal Pain } \\
\text { Research Strategy }\end{array}$ \\
\hline Patient populations & $\begin{array}{l}\text { Information on overlapping chronic } \\
\text { pain conditions or psychosocial } \\
\text { factors was generally not provided in } \\
\text { included trials }\end{array}$ & $\begin{array}{l}\text { Documentation of coexisting conditions } \\
\text { and factors in trials with sufficient } \\
\text { sample-size to evaluate the differential } \\
\text { impact of conditions and factors. }\end{array}$ \\
\hline Interventions and comparators & $\begin{array}{l}\text { Lack of information on optimal } \\
\text { techniques, duration and frequency } \\
\text { of treatment; } \\
\text { Lack of evidence comparing } \\
\text { interventions to pharmacological } \\
\text { agents }\end{array}$ & $\begin{array}{l}\text { Research leading to standardization of } \\
\text { techniques and their delivery to be used } \\
\text { in future trials and understanding best } \\
\text { combinations of interventions. Pragmatic } \\
\text { trials may provide valuable information. } \\
\text { Trails comparing interventions with } \\
\text { pharmacological treatments. }\end{array}$ \\
\hline Outcomes measures & $\begin{array}{l}\text { Lack of consistency in types } \\
\text { outcomes measures used for } \\
\text { function and pain across trials makes } \\
\text { it challenging to compare results } \\
\text { across trials. } \\
\text { Commonly used VAS or NRS for } \\
\text { pain do not capture the impact of } \\
\text { pain or allow for accurate } \\
\text { classification or evaluation of } \\
\text { changes in chronic pain. } \\
\text { Common or know harms are not } \\
\text { routinely collected }\end{array}$ & $\begin{array}{l}\text { Standardized protocols for types of } \\
\text { outcomes to be assessed (including } \\
\text { harms). Use measures that incorporate } \\
\text { understanding of pathophysiological } \\
\text { mechanisms and address multiple } \\
\text { domains of pain. Report the proportions } \\
\text { of patients achieving a clinically } \\
\text { meaningful improvement for measures of } \\
\text { pain and function as well as outcomes } \\
\text { related to change in use of opioids, } \\
\text { health care utilization and quality of life. } \\
\text { Consider recommendations from } \\
\text { IMMPACT, ACTTION and Federal Pain } \\
\text { Research Strategy }\end{array}$ \\
\hline
\end{tabular}

ACTTION = Analgesic, Anesthetic, and Addiction Clinical Trials Translations, Innovations, Opportunities, and Networks; IMMPACT = Initiative on Methods, Measurements, and Pain Assessment in Clinical Trials; NRS = Numerical Rating Scale; VAS = Visual Analog Scale

\section{Conclusions}

Exercise, multidisciplinary rehabilitation, acupuncture, cognitive behavioral therapy, and mind-body practices were most consistently associated with durable slight to moderate improvements in function and pain for specific chronic pain conditions. Our findings provide some support for clinical strategies that focus on use of nonpharmacological therapies for specific chronic pain conditions. Additional comparative research on sustainability of effects beyond the immediate post-treatment period is needed, particularly for conditions other than low back pain. 


\section{References}

1. Institute of Medicine. Relieving Pain in America: A Blueprint for Transforming Prevention, Care, Education, and Research. Washington, DC: The National Academies Press; 2011.

2. National Pain Strategy Task Force. National Pain Strategy: A Comprehensive Population Health-Level Strategy for Pain. Interagency Pain Research Coordinating Committee (IPRCC), National Institutes of Health (NIH); 1-83. 2015. https://iprcc.nih.gov/National_Pain_Strategy /NPS_Main.htm.

3. [No authors listed]. Classification of chronic pain. Descriptions of chronic pain syndromes and definitions of pain terms. Prepared by the International Association for the Study of Pain, Subcommittee on Taxonomy. Pain Suppl. 1986;3:S1-226. PMID: 3461421.

4. Dowell D, Haegerich TM, Chou R. CDC Guideline for Prescribing Opioids for Chronic Pain--United States, 2016. JAMA. 2016 Apr 19;315(15):1624-45. doi: 10.1001/jama.2016.1464. PMID: 26977696.

5. National Center for Health Statistics. Health, United States, 2010: with special feature on death and dying. Hyattsville, MD: 2011. PMID: 21634072.

6. Methods Guide for Effectiveness and Comparative Effectiveness Reviews. AHRQ Publication No. 10(14)-EHC063-EF. Rockville, MD: Agency for Healthcare Research and Quality. January 2014. Chapters available at: www.effectivehealthcare.ahrq.gov.

7. Higgins JPT, Green S, eds. Cochrane Handbook for Systematic Reviews of Interventions. Version 5.1.0 [updated March 2011]. The Cochrane Collaboration. Available from http://handbook.cochrane.org.; 2011.

8. Furlan AD, Malmivaara A, Chou R, et al. 2015 Updated Method Guideline for Systematic Reviews in the Cochrane Back and Neck Group. Spine (Phila Pa 1976). 2015 Nov;40(21):1660-73. doi: 10.1097/BRS.0000000000001061. PMID: 26208232.
9. Fu R, Gartlehner G, Grant M, et al. Conducting quantitative synthesis when comparing medical interventions: AHRQ and the Effective Health Care Program. J Clin Epidemiol. 2011 Nov;64(11):1187-97. doi: 10.1016/j.jclinepi.2010.08.010. PMID: 21477993.

10. Chou R, Deyo R, Friedly J, et al. Noninvasive Treatment for Low Back Pain. Comparative Effectiveness Review No. 169. (Prepared by the Pacific Northwest Evidence-based Practice Center under Contract No. HHSA 290-2012-00014-I.) AHRQ Publication No. 16-EHC004-EF. Rockville, MD: Agency for Healthcare Research and Quality; February 2016. www.effectivehealthcare.ahrq.gov/reports/fi nal.cfm. PMID: 26985522.

11. Chou R, Deyo R, Friedly J, et al. Systemic pharmacologic therapies for low back pain: A systematic review for an American College of Physicians Clinical Practice Guideline. Ann Intern Med. 2017 Feb 14;166:[Epub ahead of print]. doi: 10.7326/M16-2458. PMID: 28192790.

12. Chou R, Deyo R, Friedly J, et al. Nonpharmacologic therapies for low back pain: A systematic review for an American College of Physicians Clinical Practice Guideline. Ann Intern Med. 2017 Feb 14;166:[Epub ahead of print]. doi: 10.7326/M16-2459. PMID: 28192793.

13. Berkman ND, Lohr KN, Ansari M, et al. Grading the Strength of a Body of Evidence When Assessing Health Care Interventions for the Effective Health Care Program of the Agency for Healthcare Research and Quality: An Update. Methods Guide for Effectiveness and Comparative Effectiveness Reviews. Rockville MD: Agency for Healthcare Research and Quality; 2008.

14. Berkman ND, Lohr KN, Ansari MT, et al. Grading the strength of a body of evidence when assessing health care interventions: an EPC update. J Clin Epidemiol. 2015 Nov;68(11):1312-24. doi: 10.1016/j.jclinepi.2014.11.023. PMID: 25721570. 
15. Chou R, Turner JA, Devine EB, et al. The effectiveness and risks of long-term opioid therapy for chronic pain: a systematic review for a National Institutes of Health Pathways to Prevention Workshop. Ann Intern Med. 2015 Feb 17;162(4):276-86. doi: 10.7326/M14-2559. PMID: 25581257.

16. Tice J, Kumar V, Otunoye I, et al. Cognitive and Mind-Body Therapies for Chronic Low Back and Neck Pain: Effectiveness and Value. Evidence Report. Prepared for The California Technology Assesment Forum. Boston, MA: The Institute for Clinical and Economic Review; 2017. https://icerreview.org/wpcontent/uploads/2017/03/CTAF_Chronic_Pa in Evidence_Report_100417.pdf. Accessed October 13, 2017.

17. Newberry SJ, FitzGerald J, SooHoo NF, et al. Treatment of Osteoarthritis of the Knee: An Update Review. Comparative Effectiveness Review No. 190. (Prepared by the RAND Southern California Evidencebased Practice Center under Contract No. 290-2015-00010-I.) AHRQ Publication No.17-EHC011-EF. Rockville, MD: Agency for Healthcare Research and Quality; 2017.

www.effectivehealthcare.ahrq.gov/reports/fi nal.cfmdoi: 10.23970/AHRQEPCCER190.

18. Geneen LJ, Moore RA, Clarke C, et al. Physical activity and exercise for chronic pain in adults: an overview of Cochrane Reviews. The Cochrane Library; 2017.
19. Vickers AJ, Cronin AM, Maschino AC, et al. Acupuncture for chronic pain: individual patient data meta-analysis. Arch Intern Med. 2012 Oct 22;172(19):1444-53. doi: 10.1001/archinternmed.2012.3654. PMID: 22965186.

20. Nahin RL, Boineau R, Khalsa PS, et al. Evidence-Based Evaluation of Complementary Health Approaches for Pain Management in the United States. Mayo Clin Proc. 2016 Sep;91(9):1292-306. doi: 10.1016/j.mayocp.2016.06.007. PMID: 27594189.

21. Busse J. The 2017 Canadian Guideline for Opioids for Chronic Non-Cancer Pain. 2017.

22. Hill JC, Whitehurst DG, Lewis M, et al. Comparison of stratified primary care management for low back pain with current best practice (STarT Back): a randomised controlled trial. Lancet. 2011 Oct 29;378(9802):1560-71. doi: 10.1016/S01406736(11)60937-9. PMID: 21963002.

23. Initiative on Methods, Measurement, and Pain Assessment in Clinical Trials (IMMPACT). Access at: www.impact.org

24. Analgesic, Anesthetic, and Addiction Clinical Trial Translations, Innovations, Opportunities, and Networks (ACTTION). Access at: www.acttion.org.

25. National Institute of Health Interagency Pain Research Coordinating Committee. Federal Pain Research Strategy. 2017. 


\section{Introduction}

\section{Background}

\section{Nature and Burden of Chronic Pain}

Chronic pain substantially impacts physical and mental functioning, productivity, quality of life, and family relationships; it is the leading cause of disability; and is often refractory to treatment. ${ }^{1,2}$ A monumental public health challenge, chronic pain affects millions of adults in the United States, with a conservative annual cost in personal and health system expenditures estimated at $\$ 560$ billion to $\$ 635$ billion. $^{3}$

Pain is usually regarded as chronic when it lasts or recurs for more than 3 to 6 months, however definitions vary. ${ }^{4,5}$ For purposes of this report, chronic pain is defined as pain lasting 3 months or longer, or persisting past the normal time for tissue healing. ${ }^{3,6}$ Nervous system changes that occur with chronic pain, combined with its psychological and cognitive impacts, have led to conceptualization of some types of chronic pain as a distinct disease entity. ${ }^{3}$ Chronic pain is multifaceted and influenced by multiple factors (e.g., genetic, central nervous system, psychological, and environmental factors) and complex interactions of factors, making pain assessment and management a challenge. A number of characteristics influence the development of and response to chronic pain, including sex, age, presence of comorbidities, and psychosocial factors. For example, women report chronic pain more frequently than do men, are at higher risk for some conditions such as fibromyalgia, ${ }^{3}$ and may respond to treatment differently than men. Older adults are more likely to have comorbidities and are more susceptible to polypharmacy, impacting choices and consequences of therapies. Pain is greatly influenced by psychosocial factors, which may predict who will develop chronic disabling pain, as well as who will respond to various treatments.

\section{Management of Chronic Pain}

Many pharmacological and nonpharmacological treatments are available for management of chronic pain and include a variety of noninvasive as well as surgical and interventional procedures. The National Pain Strategy Task Force report recommends that pain management be integrated, multimodal, interdisciplinary, evidence-based, and tailored to individual patient needs. ${ }^{7}$ In addition to addressing biological factors when known, optimal management of chronic pain must also address psychosocial contributors to pain, while taking into account individual susceptibility and treatment responses. Self-care is also an important part of chronic pain management.

Opioids have been used in the treatment of chronic pain. In the past 20 years, evidence shows only modest short-term benefits of these drugs. ${ }^{8-10}$ Lack of evidence on long-term effectiveness ${ }^{11}$ and safety concerns ${ }^{12}$ have been noted in the literature. The recent evidence-based Centers for Disease Control guidelines on opioid use for chronic pain, ${ }^{13}$ which include a recommendation on the preferred use of nonopioid treatment over opioid therapy, has prompted additional primary research on alternative methods of managing chronic pain.

Other pharmacological treatments for chronic pain include nonsteroidal anti-inflammatory drugs, acetaminophen, muscle relaxants, antiseizure medications, antidepressants, and corticosteroids, used alone or in combination with each other or with opioids. Each has potential side effects and contraindications. 
Nonpharmacological treatments for chronic pain examined in this review include exercise, mind-body practices, psychological therapies, multidisciplinary rehabilitation, mindfulness practices, manual therapies, physical modalities, and acupuncture.

\section{Rationale for This Review}

The review is intended to address some of the needs described in the National Pain Strategy Task Force $^{7}$ and Institute of Medicine ${ }^{3}$ reports and others for evidence to inform guidelines and health care policy (including reimbursement policy) related to use of noninvasive nonpharmacological treatments. Both the Institute of Medicine report and the National Pain Strategy Task Force report describe the need for evidence-based strategies for the treatment of chronic pain that address the biopsychosocial nature of this disease, including nonpharmacological treatment. These initiatives, and others, speak to the importance of understanding current evidence on noninvasive nonpharmacological treatment of chronic pain.

Many trials have examined the impact of interventions on outcomes during or immediately after the course of treatment. A number of them are associated with improved function and reduced pain. However, given the persistence of chronic pain, understanding whether the benefits are durable would be very helpful for informing selection of therapies. This review also aims to provide additional insights into research gaps related to use of noninvasive nonpharmacological alternatives for treating chronic pain. Musculoskeletal pain, particularly related to joints and the back, is the most common single type of chronic pain. ${ }^{3,14}$ This systematic review thus focuses on five of the most common causes of musculoskeletal pain: chronic low back pain, chronic neck pain, osteoarthritis (OA), fibromyalgia, and chronic tension headache.

\section{Scope and Key Questions}

This Comparative Effectiveness Review focused on noninvasive nonpharmacological therapy for five common chronic pain conditions: low back pain, neck pain, OA, fibromyalgia, and headache. Individual pain management strategies considered in the review include exercise (including aspects of physical therapy), mind-body practices (yoga, tai chi, qigong), psychological therapies (cognitive-behavioral therapy, biofeedback, relaxation techniques, acceptance, and commitment therapy), multidisciplinary rehabilitation (including functional restoration training), mindfulness practices (meditation, mindfulness-based stress reduction practices), manual therapies (e.g., musculoskeletal manipulation), physical modalities (traction, ultrasound, transcutaneous electrical nerve stimulation, low-level laser therapy, interferential therapy, superficial heat or cold, bracing for knee, back or neck, electro-muscular stimulation, and magnets), and acupuncture.

We focused on single active interventions and comparators over the long term. The Key Questions, PICOTS (populations, interventions, comparators, outcomes, timing, settings, and study designs), and analytic framework that guided this review are provided below.

\section{Key Questions}

Key Question 1: Adults with chronic low back pain

Key Question 2: Adults with chronic neck pain

Key Question 3: Adults with osteoarthritis-related pain 
Key Question 4: Adults with fibromyalgia

Key Question 5: Adults with chronic tension headache

Key Questions 1-5 incorporate the following subquestions:

a. What are the benefits and harms of noninvasive nonpharmacological therapies compared with sham treatment, no treatment, waitlist, attention control, or usual care?

b. What are the benefits and harms of noninvasive nonpharmacological therapies compared with pharmacological therapy (e.g., opioids, nonsteroidal antiinflammatory drugs, acetaminophen, antiseizure medications, antidepressants)?

c. What are the benefits and harms of noninvasive nonpharmacological therapies compared with exercise or, for headache, biofeedback?

The three-part format for Key Questions 1-5 reflects the following research concepts:

- Part "a" answers the question of whether the various interventions work overall compared with sham, waitlist control, attention control, no treatment, or usual care. For this review, usual care was defined as care that might be provided or recommended by a primary care provider.

- Part "b" answers the question of whether the various interventions work compared with pharmacological alternatives.

- Part "c" answers the question of how outcomes for individual interventions (e.g., acupuncture) compare with a common comparator. Exercise is the most frequent comparison in the literature for many chronic pain conditions, so it provides a common comparator for analysis. It is also recommended in most guidelines for conditions including low back pain, neck pain, fibromyalgia, and osteoarthritis and is widely available. Exercise served as common comparator for these conditions. For chronic headache, biofeedback provided a common comparator for analysis.

Key Question 6: Do estimates of benefits and harms differ by age, sex, or presence of comorbidities (e.g., emotional or mood disorders)?

\section{Analytic Framework}

The analytic framework (Figure 1) illustrates the population, interventions, outcomes, and adverse effects that guided the literature search and synthesis. 


\section{Figure 1. Analytic framework}

Interventions: Exercise, psychological therapies, physical modalities, manual therapies, mindfulness and mind-body practices, acupuncture, multidisciplinary rehabilitation (includes functional restoration)

Adults with the following chronic pain a conditions: low

back pain, neck pain, osteoarthritis, fibromyalgia, or headache

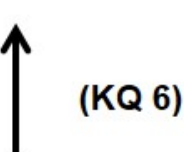

Age, sex, comorbidities

KQ = Key Question

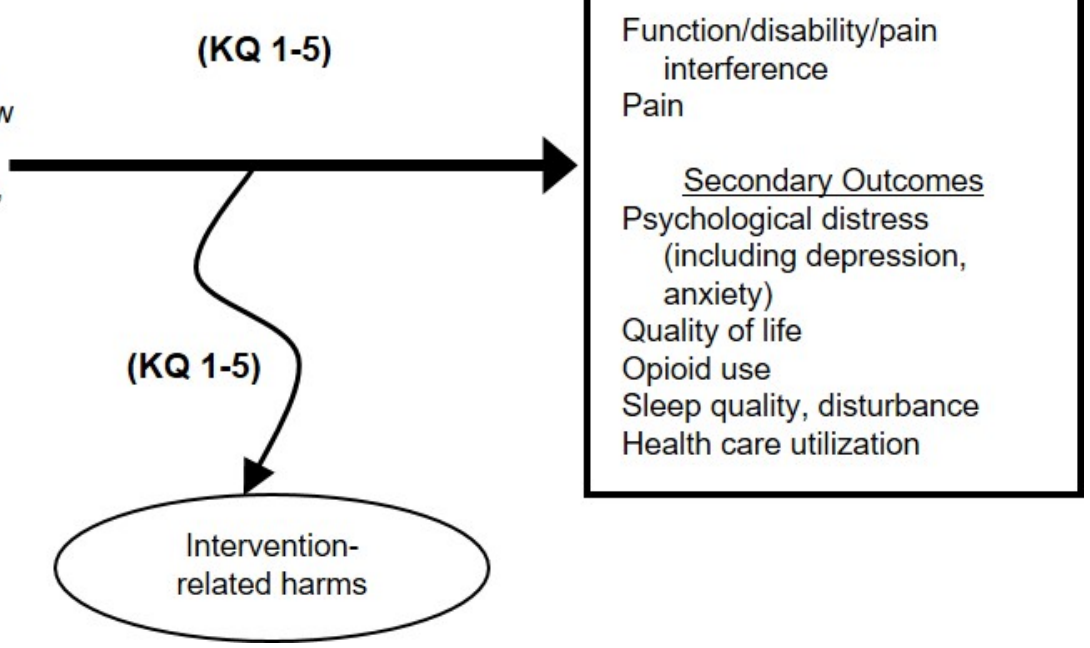

${ }^{a}$ Chronic pain is defined as pain lasting $\geq 12$ weeks or pain persisting past the normal time for tissue healing 


\section{Methods}

The methods for this systematic review follow the Agency for Healthcare Research and Quality (AHRQ) Methods Guide for Effectiveness and Comparative Effectiveness Reviews ${ }^{15}$ and the Preferred Reporting Items for Systamtic Reviews and Meta-Analyses (PRISMA) checklist. See the review protocol (http://effectivehealthcare.ahrq.gov/index.cfm) for details.

\section{Topic Refinement and Review Protocol}

The Evidence-based Practice Center (EPC) review team developed initial Key Questions and PICOTS (Populations, Interventions, Comparators, Outcomes, Timing, Studies, Settings) with input from the AHRQ Task Order Officer (TOO), representatives from the Centers for Disease Control and Prevention (CDC) and the Office of the Assistant Secretary for Planning and Evaluation (ASPE), and a group of Key Informants. The provisional Key Questions, PICOTS, and analytic framework were posted on the AHRQ Web site for public comment from December 27, 2016 to January 23, 2017.

After reviewing public comments, the EPC research team developed the final protocol with input from the AHRQ TOO, CDC and ASPE representatives, and a Technical Expert Panel (TEP) convened for this report. The TEP consisted of nine members with expertise in primary care, rheumatology, pain medicine, behavioral sciences, physical medicine and rehabilitation, and physical therapy. TEP members had expertise in treating patients with one or more of the five conditions included in this report. Suggestions for including additional chronic pain conditions and additional interventions were made; however, all were considered beyond the scope and resources for this review.

The final version of the protocol for this review was posted on the AHRQ Effective Health Care Program Web site (www.effectivehealthcare.ahrq.gov) on April 27, 2017. The protocol was also registered in the PROSPERO database of prospectively registered systematic reviews (CRD42017067729).

\section{Literature Search Strategy}

A research librarian conducted searches in Ovid ${ }^{\circledR}$ MEDLINE ${ }^{\circledR}$, Cochrane Central Register of Controlled Trials, and Cochrane Database of Systematic Reviews through November 1, 2017. Searches were conducted without publication date restrictions with the exception of studies of chronic low back pain, as we relied on a recent AHRQ review ${ }^{16}$ to identify primary studies for inclusion through 2016 (see Appendix A for full search strategies). As there are multiple manufacturers/sources for many of the devices examined in this review, a Federal Register notice was posted in an effort to identify unpublished data. We also searched for unpublished studies in ClinicalTrials.gov. Reference lists of included articles and the bibliographies of systematic reviews published since 2010 were reviewed for includable literature. Literature searches were updated during the public comment and peer review period to capture any new publications. Resulting citations and any suggested during peer review and public comment were evaluated against the inclusion/exclusion criteria following the same process of dual review as all other studies considered for inclusion in the report. Pertinent new literature was incorporated in the final report. 


\section{Inclusion and Exclusion Criteria and Study Selection}

Inclusion and exclusion criteria were developed a priori based on the Key Questions and PICOTS, in accordance with the AHRQ Methods Guide for Effectiveness and Comparative Effectiveness Reviews. ${ }^{15}$ Criteria are detailed below in Table 1 . Abstracts were reviewed by at least two investigators, and full-text articles were retrieved for all citations deemed potentially appropriate for inclusion by at least one of the reviewers. Two investigators then independently reviewed all full-text articles for final inclusion. Discrepancies were resolved by discussion and consensus. A list of the included studies appears in Appendix B; excluded studies and primary reason for exclusion are listed in Appendix C.

The focus of this review is on randomized controlled trials (RCTs) reporting on longer-term outcomes (at least 1 month post intervention) that otherwise meet our PICOTS criteria. 
Table 1. Inclusion and exclusion criteria

\begin{tabular}{|c|c|c|}
\hline PICOTS & Inclusion & Exclusion \\
\hline Population & $\begin{array}{l}\text { General Inclusion Criteria } \\
\text { - Adults with the following chronic pain } \\
\text { (defined as pain lasting } 12 \text { weeks or } \\
\text { longer or pain persisting past the time } \\
\text { for normal tissue healing) conditions: } \\
\text { low back pain, neck pain, } \\
\text { osteoarthritis pain, fibromyalgia, or } \\
\text { tension headache. } \\
\text { KQ1: Low back pain } \\
\text { - Adults with chronic, nonradicular low } \\
\text { back pain } \\
\text { KQ2: Neck pain } \\
\text { - Adults with chronic neck pain } \\
\text { KQ3: Osteoarthritis } \\
\text { - Adults with osteoarthritis-related pain } \\
\text { (primary or secondary osteoarthritis) } \\
\text { of the hip, knee or hand } \\
\text { KQ4: Fibromyalgia } \\
\text { - Adults with fibromyalgia } \\
\text { KQ5: Headache } \\
\text { - Adults with primary chronic tension } \\
\text { headache (International Classification } \\
\text { of Headache Disorders, 3rd edition } \\
\text { definition). } \\
\text { o Primary headaches are attributed } \\
\text { to the headache condition itself, } \\
\text { not headache caused by another } \\
\text { disease or medical condition. } \\
\text { Tension headaches are the most } \\
\text { common. } \\
\text { o Chronic headache is defined as } 15 \\
\text { or more days each month for at } \\
\text { least } 12 \text { weeks or history of } \\
\text { headache more than } 180 \text { days a } \\
\text { year. }\end{array}$ & 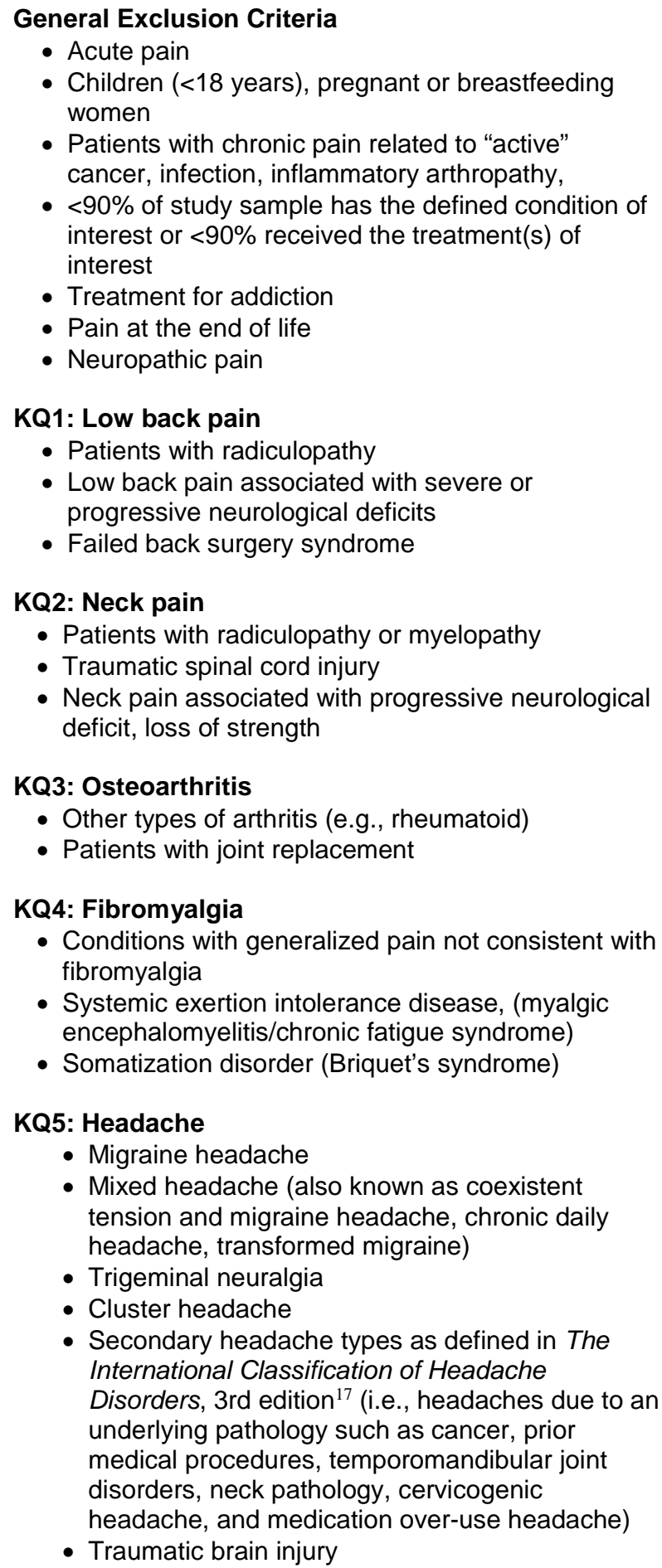 \\
\hline
\end{tabular}




\begin{tabular}{|c|c|c|}
\hline PICOTS & Inclusion & Exclusion \\
\hline Interventions & $\begin{array}{l}\text { All KQs: } \\
\text { - Exercise (exercise as part of physical } \\
\text { therapy, supervised exercise, home } \\
\text { exercise, group exercise, formal } \\
\text { exercise program) } \\
\text { - Psychological therapies (cognitive } \\
\text { and/or behavioral therapy, } \\
\text { biofeedback, relaxation training) } \\
\text { - Physical modalities (traction, } \\
\text { ultrasound, transcutaneous electrical } \\
\text { nerve stimulation, low-level laser } \\
\text { therapy, interferential therapy, electro- } \\
\text { muscular stimulation diathermy, } \\
\text { superficial heat or cold, bracing for } \\
\text { knee, back, neck, hand and magnets) } \\
\text { - Manual therapies (musculoskeletal } \\
\text { manipulation, massage) } \\
\text { - Mindfulness practices (meditation, } \\
\text { mindfulness-based stress reduction } \\
\text { practices) } \\
\text { - Mind-body practices (yoga, tai chi, } \\
\text { qigong) } \\
\text { - Acupuncture } \\
\text { Multidisciplinary/interdisciplinary } \\
\text { rehabilitationa }\end{array}$ & $\begin{array}{l}\text { All KQs: } \\
\text { - Invasive nonsurgical treatments (e.g., injections, } \\
\text { nerve block, spinal cord stimulators, parenterally- } \\
\text { administered medications) } \\
\text { - Surgical interventions (including minimally invasive } \\
\text { surgical interventions) } \\
\text { - Diet interventions or dietary supplementation } \\
\text { - Studies evaluating incremental value of adding a } \\
\text { noninvasive nonpharmacological intervention to } \\
\text { another noninvasive nonpharmacological } \\
\text { intervention } \\
\text { - Self-management interventions or programs, self- } \\
\text { management education programs } \\
\text { - Others not listed for inclusion }\end{array}$ \\
\hline Comparators & $\begin{array}{l}\text { All KQs, subquestion a } \\
\text { - Sham treatment } \\
\text { - Waitlist } \\
\text { - Usual care } \\
\text { - No treatment } \\
\text { - Attention control intended to control } \\
\text { for nonspecific effects (e.g., time, } \\
\text { attention, expectations); } \\
\text { All KQs subquestion b } \\
\text { - Nonopioid pharmacological therapy } \\
\quad \text { (NSAIDS, acetaminophen, anti- } \\
\text { seizure medications, antidepressants) } \\
\text { - Opioid analgesics } \\
\text { KQs 1-4,6 subquestion c } \\
\text { - Exercise } \\
\text { KQ 5, } 6 \text { subquestion c } \\
\text { - Biofeedback }\end{array}$ & $\begin{array}{l}\text { All KQs: } \\
\text { - Supplements (e.g., glucosamine, chondroitin, } \\
\text { d-ribose, herbal or homeopathic treatments) } \\
\text { - Over-the-counter topical agents (e.g., aloe, } \\
\text { capsaicin) } \\
\text { - Invasive nonsurgical treatments (e.g., injections, } \\
\text { nerve block, spinal cord stimulators, parenterally- } \\
\text { administered medications) } \\
\text { - Surgical interventions (including minimally invasive } \\
\text { surgical interventions) } \\
\text { - Studies evaluating incremental value of adding a } \\
\text { noninvasive nonpharmacological intervention to } \\
\text { another noninvasive nonpharmacological } \\
\text { intervention } \\
\text { - Comparisons within nonpharmacological intervention } \\
\text { types (e.g., comparisons of different types of } \\
\text { exercise with each other, different types of massage } \\
\text { with each other) } \\
\text { - Others not listed for inclusion }\end{array}$ \\
\hline
\end{tabular}




\begin{tabular}{|c|c|c|}
\hline PICOTS & Inclusion & Exclusion \\
\hline Outcomes & $\begin{array}{l}\text { All KQs: } \\
\text { Primary efficacy outcomes; we will focus } \\
\text { on outcomes from validated measures for } \\
\text { - Function/disability/pain interference }{ }^{d} \\
\text { - Pain }{ }^{d} \\
\text { Harms and Adverse effects } \\
\text { Secondary outcomes } \\
\text { - Psychological distress (including } \\
\text { - } \text { Quality of life } \\
\text { - Opioid use } \\
\text { - Sleep quality, sleep disturbance } \\
\text { - Health care utilization }\end{array}$ & $\begin{array}{l}\text { All KQs: } \\
\text { - Intermediate outcomes (e.g., biomarkers for } \\
\text { inflammation) } \\
\text { - Other nonclinical outcomes }\end{array}$ \\
\hline Timing & $\begin{array}{l}\text { Duration of followup: short term ( } 1 \text { to }<6 \\
\text { months), intermediate term ( } \geq 6 \text { to }<12 \\
\text { months) and long term }(\geq 12 \text { months); } \\
\text { focus on longer term ( }>12 \text { month) effects. } \\
\text { Trials lasting } \geq 6 \text { months that include a } \\
\text { supervised intervention followed by } \\
\text { continued home treatment as part of the } \\
\text { intervention will be included even though } \\
\text { the only followup occurs directly after the } \\
\text { intervention. }\end{array}$ & - Studies with $<1$ month followup after treatment \\
\hline Studies & $\begin{array}{l}\text { Randomized controlled trials or high } \\
\text { quality systematic reviews of randomized } \\
\text { controlled trials published in English; } \\
\text { cross-over trials with random assignment } \\
\text { of initial treatment will be considered. }\end{array}$ & $\begin{array}{l}\text { All KQs: } \\
\text { - Studies reporting on intermediate outcomes only } \\
\text { - Nonrandomized studies } \\
\text { - Abstracts, editorials, letters, conference proceedings } \\
\text { - Duplicate publications of the same study that do not } \\
\text { report on different outcomes } \\
\text { - Single site reports from multicenter trials } \\
\text { - White papers } \\
\text { - Narrative reviews } \\
\text { - Articles identified as preliminary reports when results } \\
\text { - Ine published in later versions } \\
\text { - Sturect comparisons } \\
\text { - Srm } \\
\text { - Systematic reviews on treatment of chronic neck } \\
\text { pain, fibromyalgia, chronic headache, or } \\
\text { osteoarthritis that are of low methodological quality. } \\
\text { Those that do not report outcomes or time frames of } \\
\text { interest may be excluded. Systematic reviews may } \\
\text { be excluded based on currency or relevance (e.g., if } \\
\text { there is a substantial new body of evidence reflected } \\
\text { in a later review). }\end{array}$ \\
\hline Settings & $\begin{array}{l}\text { Any nonhospital setting or in self-directed } \\
\text { care }\end{array}$ & $\begin{array}{l}\text { - Hospital care, hospice care, emergency department } \\
\text { care }\end{array}$ \\
\hline
\end{tabular}

KQ = Key Question; NSAID = nonsteroidal anti-inflammatory drug; PICOTS = population, interventions, comparators, outcomes, timing, studies, settings

a Multidisciplinary rehabilitation (MDR) (also known as interdisciplinary rehabilitation), is defined as a coordinated program with biopsychosocial treatment components (e.g., exercise therapy and cognitive-behavioral therapy) provided by professionals from at least two different specialties. Functional restoration training is included as part of MDR

b Different forms of exercise will not be compared to each other. Exercise will be compared with nonexercise interventions for low back pain, neck pain, fibromyalgia and osteoarthritis 
${ }^{\mathbf{c}}$ Different forms of biofeedback will not be compared to each other. Biofeedback will be compared with the noninvasive interventions for chronic headache

d The magnitude of effects for pain and function will be classified using the same system as in the AHRQ-funded noninvasive treatment for low back pain review recognizing that small effects using this system may not meet standard thresholds for clinically meaningful effects. A small/slight effect was defined for pain as a mean between-group difference following treatment of 5 to 10 points on a 0 - to 100 -point visual analog scale (VAS), 0.5 to 1.0 points on a 0 - to 10 -point numeric rating scale, or equivalent; for function as a mean difference of 5- to 10-point difference on the 0- to 100-point Oswestry Disability Index (ODI) or 1 to 2 points on the 0- to 24-point Roland-Morris Disability Questionnaire (RDQ), or equivalent; and for any outcome as a standardized mean difference (SMD) of 0.2 to 0.5 . A moderate effect was defined for pain as a mean difference of 10 to 20 points on a 0 - to 100-point VAS, for function as a mean difference of 10 to 20 points on the ODI or 2 to 5 points on the RDQ, and for any outcome as an SMD of 0.5 to 0.8 . Large/substantial effects were defined as greater than moderate. We will apply similar methodology to outcomes measures for the other condition. The clinical relevance of effects classified as small/slight might vary for individual patients depending on preferences, baseline symptom severity, harms, cost, and other factors

\section{Data Abstraction and Data Management}

Using templates, data from included trials were abstracted into categories that included but were not limited to: study design, year, setting, country, sample size, eligibility criteria, attrition, population and clinical characteristics (including age, sex, comorbidities, diagnostic classifications/information), intervention characteristics (including the type, number, intensity, duration of, and adherence to treatments), comparator characteristics, and results (including harms). We also recorded the funding source and role of the sponsor. All abstracted study data were verified for accuracy and completeness by a second team member (Appendix D). Details are further outlined in the protocol.

\section{Quality (Risk of Bias) Assessment of Individual Studies}

Predefined criteria were used to assess the quality of included trials. We focused on trials with the least potential for bias and the fewest limitations. RCTs were assessed based on criteria and methods established in the Cochrane Handbook for Systematic Reviews of Interventions (Chapter 8.5 Risk of Bias Tool), ${ }^{18}$ and precepts for appraisal developed by the Cochrane Back and Neck Group. ${ }^{19}$ These criteria and methods were used in conjunction with the approach recommended in the AHRQ Methods Guide for Effectiveness and Comparative Effectiveness Research. ${ }^{15}$ Two team members independently appraised each included study, with disagreements resolved by consensus. Studies were rated as "good," “fair,” or "poor” as described in Table 2. Assessments of included studies are in Appendix E. 
Table 2. Criteria for grading the quality of individual studies

\begin{tabular}{|l|l|}
\hline Rating & Description and criteria \\
\hline Good & $\begin{array}{l}\text { - Least risk of bias, results generally considered valid } \\
\text { - Employ valid methods for selection, inclusion, and allocation of patients to treatment; report } \\
\text { similar baseline characteristics in different treatment groups; clearly describe attrition and have } \\
\text { low attrition; use appropriate means for preventing bias (e.g., blinding of patients, care providers, } \\
\text { and outcomes assessors); and use appropriate analytic methods (e.g., intention-to-treat analysis) }\end{array}$ \\
\hline Fair & $\begin{array}{l}\text { - Susceptible to some bias but not enough to necessarily invalidate results } \\
\text { - May not meet all criteria for good quality, but no flaw is likely to cause major bias; the study may } \\
\text { be missing information making it difficult to assess limitations and potential problems }\end{array}$ \\
\hline - Category is broad; studies with this rating will vary in strengths and weaknesses; some fair-quality \\
studies are likely to be valid, while others may be only possibly valid
\end{tabular}

\section{Data Analysis and Synthesis}

Data were synthesized qualitatively (e.g., ranges and descriptive analysis) and quantitatively using meta-analysis where appropriate. Results are organized by Key Question (i.e., by condition) and intervention and then by comparators for each subquestion (e.g., intervention vs. waitlist or sham for subquestion a). To the extent that the interventions were distinct, we explored separating them out for analysis and reporting. For example, we categorized various forms of exercise based on their primary mechanisms of action (Appendix F). Interventions with similar characteristics were combined (e.g., cognitive-behavioral therapy [CBT] and acceptance and commitment therapy [ACT], which is a type of CBT).$^{20}$ Duration of followup postintervention was reported and categorized as short term ( 1 to $<6$ months), intermediate term ( $\geq 6$ to $<12$ months), and long term ( $\geq 12$ months).

Prioritized outcomes of function and pain, based on validated measures, are presented first. Based on input from stakeholders, improvement in function was prioritized as the most important outcome. There is overlap between functional outcome measures and quality of life measures. Short-Form 36 (SF-36) and EuroQoL-5 Dimensions (EQ-5D) are two such outcome measures and they were categorized as quality of life measures for this report. For some conditions, such as OA, results were organized by affected region (e.g., knee, hip, hand). Based on input from stakeholders, improvement in function was prioritized as the most important outcome.

Results for continuous outcomes as well as dichotomous outcomes were synthesized. Binary outcomes based on the proportion of patients achieving specific thresholds of success for improved function, or other measure of success as defined in the trials (e.g., $\geq 30 \%$ improvement in pain score), were reported and a risk ratio and $95 \%$ confidence interval were calculated to evaluate the presence of an association and estimate relative effect size using the Rothman Episheet. ${ }^{21}$ For continuous outcomes, mean differences between treatments and 95\% confidence intervals were calculated using GraphPad or Stata ${ }^{\circledR} /$ IC 12.1 (StataCorp, College Station, TX) to provide effect sizes and determine presence of a statistical association.

We conducted meta-analysis to quantitatively synthesize evidence. To determine the appropriateness of meta-analysis, we considered clinical and methodological diversity and assessed statistical heterogeneity. Two continuous primary outcomes (pain and function) and one 
secondary outcome (quality of life) provided adequate data for meta-analysis. Mean difference (MD) was used as the effect measure if the studies reported outcomes using the same scale, or if the outcomes could be converted to the same scale (e.g., 0-100 pain ratings were converted to 010 scale); otherwise, standardized mean difference (SMD) was used when the reported outcomes used different scales but measured the same underlying construct (e.g., function). In the primary analysis, MD and SMD were calculated using the followup score, and sensitivity analyses were conducted using the change score from the baseline. When standard deviation (SD) was not reported, or could not be calculated from the reported data, it was imputed using the average SD from the studies of the same meta-analysis, or using the SD value from the baseline if the baseline SD was reported and the followup SD was not.

We assumed random effects across studies and used both the Dersimonian-Laird method ${ }^{22}$ and the profile-likelihood model ${ }^{23}$ to combine studies. Statistical heterogeneity among the studies was assessed using the standard Cochran's chi-square test and the $I^{2}$ statistic. ${ }^{24}$ Primary analyses were stratified by disease type, intervention, control group (usual care, exercise, or pharmacological treatment) and length of followup (short, intermediate, and long term). Controls included usual care, waitlist, no treatment, placebo, sham treatment, attention control, or other groups that involved at most minimal active treatment. We performed additional sensitivity and subgroup analyses based on specific interventions (e.g., type of acupuncture, type of exercise, intervention intensity etc.) and control types (as described above) and by excluding outlying studies and studies rated as poor.

To facilitate interpretation of results across trials and interventions, we categorized the magnitude of effects for function and pain outcomes as in our previous reviews. ${ }^{16,25}$ In general we classified effects for measures with a 0 to 100 scale for pain or function as small/slight (5 to 10 points), moderate ( $>10$ to 20 points), or large/substantial ( $>20$ points) (see additional information in Assessing Applicability).

\section{Grading the Strength of Evidence for Major Comparisons and Outcomes}

The strength of evidence for each Key Question and primary outcome (function, pain, harms) was initially assessed by one researcher with experience in determining strength of evidence for each primary clinical outcome in accordance with AHRQ guidance ${ }^{26,27}$ and as described in the protocol. The initial assessment was independently reviewed by at least one other experienced senior investigator. The overall strength of evidence was determined based on assessment of study limitations (graded low, moderate, high); consistency of results across trials (graded consistent, inconsistent, or for single studies, unknown); the directness of the evidence linking the interventions with health outcomes (graded direct or indirect); effect estimate precision (graded precise or imprecise); and reporting bias (suspected or undetected). Bodies of evidence consisting of RCTs were initially considered high strength. All outcomes were considered direct.

The final strength of evidence grade was assigned by evaluating and weighing the combined results of the above domains and considering the highest quality evidence available. While studies rated as poor quality were not excluded, such studies were considered to be less reliable than higher quality studies when synthesizing the evidence, particularly when discrepancies across studies were noted. The strength of evidence was assigned an overall grade of high, moderate, low, or insufficient according to a four-level scale (Table 3). When all of the studies for a primary outcome were rated poor quality, we rated the strength of evidence as insufficient. Strength of evidence tables for primary outcomes are presented in Appendix G. 
Table 3. Description of the strength of evidence grades

\begin{tabular}{|c|c|}
\hline Strength of Evidence & Description \\
\hline High & $\begin{array}{l}\text { We are very confident that the estimate of effect lies close to the true effect for this } \\
\text { outcome. The body of evidence has few or no deficiencies. We believe that the findings } \\
\text { are stable, i.e., another study would not change the conclusions. }\end{array}$ \\
\hline Moderate & $\begin{array}{l}\text { We are moderately confident that the estimate of effect lies close to the true effect for } \\
\text { this outcome. The body of evidence has some deficiencies. We believe that the findings } \\
\text { are likely to be stable, but some doubt remains. }\end{array}$ \\
\hline Low & $\begin{array}{l}\text { We have limited confidence that the estimate of effect lies close to the true effect for this } \\
\text { outcome. The body of evidence has major or numerous deficiencies (or both). We } \\
\text { believe that additional evidence is needed before concluding either that the findings are } \\
\text { stable or that the estimate of effect is close to the true effect. }\end{array}$ \\
\hline Insufficient & $\begin{array}{l}\text { We have no evidence, we are unable to estimate an effect, or we have no confidence in } \\
\text { the estimate of effect for this outcome. No evidence is available or the body of evidence } \\
\text { has unacceptable deficiencies, precluding reaching a conclusion. }\end{array}$ \\
\hline
\end{tabular}

\section{Assessing Applicability}

Applicability was assessed using the PICOTS framework by examining the abstracted characteristics of the patient populations for each condition (e.g., demographic characteristics, condition-specific diagnostic criteria, symptoms, presence of medical and psychiatric comorbidities, and other psychosocial factors); the interventions (e.g., availability in the United States; dose, frequency, or intensity of treatment, and methods for administration); and clinical settings (e.g., primary care, specialty setting, or developing country vs. developed country) in which the included studies are performed.

The magnitude of effects for pain and function (Appendix $\mathrm{H}$ ) were classified with the system used in our previous AHRQ review on noninvasive treatment for low back pain, ${ }^{25}$ recognizing that small effects using this system may not meet standard thresholds for clinically meaningful effects. We applied the following definitions:

- Small/slight effect

o For pain: as a mean between-group difference following treatment of 5 to 10 points on a 0 -to 100 -point visual analog scale (VAS), 0.5 to 1.0 point on a 0 - to 10 -point numeric rating scale (NRS), or equivalent

o For function: as a mean difference of 5 to 10 points on the 0 - to 100-point Oswestry Disability Index (ODI) or Western Ontario and McMaters Universities Osteoarthritis Index (WOMAC) or 1 to 2 points on the 0- to 24-point Roland-Morris Disability Questionnaire (RDQ) or Lequesne Index (LI), or equivalent

o For any outcome: as a SMD of 0.2 to 0.5

- Moderate effect

o For pain: as a mean difference of 10 to 20 points on a 0 - to 100 -point VAS

o For function: as a mean difference of 10-20 points (on a 0-100 scale) on the ODI or WOMAC or 2-5 points on RDQ or LI, or equivalent

o For any outcome: as a SMD of $>0.5$ to 0.8 
- Large effect

o For pain: as a mean difference of $\geq 20$ points on a 0 - to 100 -point VAS

o For function: as a mean difference of $\geq 20$ (on a 0-100 scale) on the ODI or WOMAC or 5 points on RDQ or LI, or equivalent

o For any outcome: as a SMD of $>0.8$

Information regarding effect size definitions for other outcome measures is available in Appendix $\mathrm{H}$. There is variability across individual patients regarding what may constitute a clinically import effect, which is influenced by a number of factors such as preferences, duration and type of chronic pain, baseline symptom severity, harms, and costs.

\section{Peer Review and Public Commentary}

Peer reviewers with expertise in primary care and management of the included chronic pain conditions were invited to provide written comments on the draft report. The AHRQ TOO and an EPC Associate Editor provided comments and editorial review. The draft report was posted on the AHRQ Web site for 4 weeks for public comment. A disposition of comments report with authors' responses to the peer and public review comments will be posted after publication of the final Comparative Effectiveness Review on the AHRQ Web site. 


\section{Results}

\section{Introduction}

Results are organized by Key Question (i.e., by condition) and intervention and then organized by comparators for each subquestion. We categorized post-intervention followup as short term ( 1 to $<6$ months), intermediate term ( $\geq 6$ to $<12$ months) and long term ( $\geq 12$ months). We prioritized function and pain outcomes based on validated measures. For some conditions (e.g., osteoarthritis [OA]), results are organized by affected region.

We synthesized data qualitatively and quantitatively, using meta-analysis where appropriate. Two continuous primary outcomes (pain, function) provided adequate data for meta-analysis. For meta-analyses providing pooled estimates, we report results from heterogeneity testing. Isquared and corresponding P-values describe the degree and statistical significance of heterogeneity across studies; pooled (subtotal) estimates are statistically significant if the confidence interval does not include the value of 0 for mean differences (MDs) or the value of 1 for risk ratios (RR). (See the Methods section of this report and the protocol for additional details on data analysis and synthesis.) In general, if effect estimates tended to favor one treatment but failed to reach statistical significance with confidence interval crossing the null value of zero or one (perhaps due to sample size), the results are interpreted as showing no clear difference between treatments. If effect estimates are close to zero and not statistically significant, results are interpreted as no difference between groups.

A list of acronyms and abbreviations appears at the end of the report.

\section{Results of Literature Searches}

The search and selection of articles are summarized in the literature flow diagram (Figure 2). Database searches resulted in 4,996 potentially relevant articles. After dual review of abstracts and titles, 1,193 articles were selected for full-text dual review, and 218 publications were determined to meet inclusion criteria and were included in this review. One-fourth of the trials excluded at full text did not meet our criteria for followup duration (i.e., a minimum of 1 month of followup after termination of the intervention, or post-intervention if the intervention duration was at least 6 months). Other common reasons for exclusion of primary trials included ineligible population and ineligible intervention or comparator (i.e., combination of treatments or if treatments were additive in nature). Data abstraction and quality assessment tables for all included studies are available in Appendixes D and E. 


\section{Figure 2. Literature flow diagram}

Abstracts of potentially relevant articles identified through MEDLINE, Cochrane ${ }^{a}$,

PsychINFO, CINAHL, and other sources $(n=4996)$

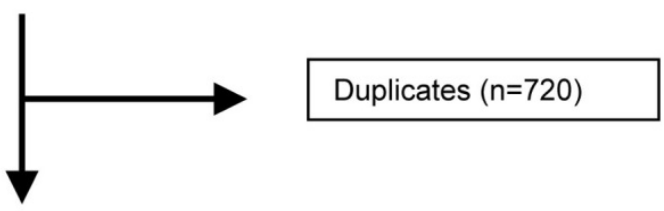

Abstracts of potentially relevant articles reviewed for relevance to Key Questions $(n=4276)$

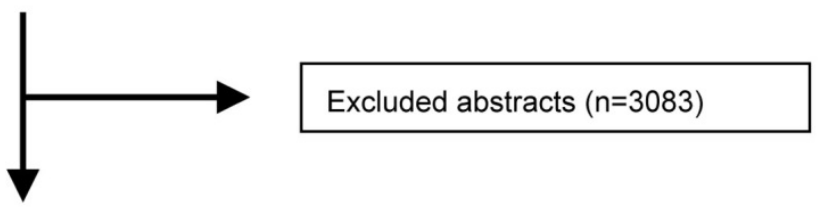

Full-text articles reviewed for relevance to Key Questions $(n=1193)$

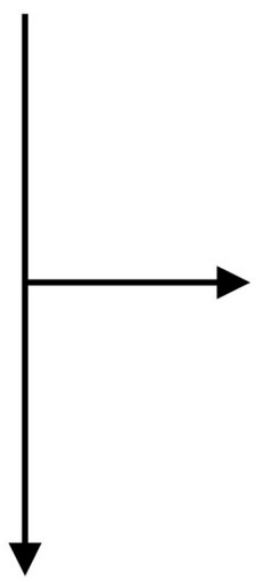

Articles excluded $^{c}(\mathrm{n}=975)$

Ineligible population: 177

Ineligible intervention: 101

Ineligible comparator: 97

Ineligible outcomes: 21

Ineligible study design: 62

Not a study (trial protocol, letter, editorial, nonsystematic review article): 45

Inadequate duration of follow-up: 227

Systematic review, not directly used ${ }^{\text {d }}: 241$

Not English but possibly relevant: 4

202 included trials (218 publications)

${ }^{a}$ Cochrane databases include the Cochrane Central Register of Controlled Trials and the Cochrane Database of Systematic

Reviews

${ }^{\mathrm{b}}$ Other sources include prior reports, reference lists of relevant articles, systematic reviews, etc.

${ }^{\text {c }}$ Publications may be included or excluded for multiple interventions

d Studies checked for inclusion

\section{Description of Included Studies}

A total of 202 trials (in 218 publications) were included. For each intervention category, the comparisons evaluated and their respective studies are listed in Table 4. 
Table 4. Overview of included studies

\begin{tabular}{|c|c|c|c|c|c|c|}
\hline Intervention & Comparator & $\begin{array}{l}\text { Chronic } \\
\text { Low Back } \\
\text { Pain: } \\
\text { n=68 (74 } \\
\text { Publications) }\end{array}$ & $\begin{array}{l}\text { Chronic } \\
\text { Neck } \\
\text { Pain: } \\
n=25\end{array}$ & $\begin{array}{l}\text { Osteoarthritis: } \\
n=53 \text { (56 } \\
\text { Publications) }\end{array}$ & $\begin{array}{l}\text { Fibromyalgia: } \\
\mathrm{n}=47 \text { (54 } \\
\text { Publications) }\end{array}$ & $\begin{array}{l}\text { Chronic } \\
\text { Tension } \\
\text { Headache } \\
: n=9\end{array}$ \\
\hline \multirow[t]{2}{*}{ Exercise } & $\begin{array}{l}\text { Sham, usual care, } \\
\text { waitlist, no } \\
\text { treatment, attention }\end{array}$ & $6^{28-33}$ & $6^{34-39}$ & $\begin{array}{l}\text { Knee OA: } 18 \\
(21)^{40-60} \\
\text { Hip OA: } 4^{40,61-63} \\
\text { Hand OA: } 1^{64}\end{array}$ & $21(23)^{65-87}$ & 0 \\
\hline & $\begin{array}{l}\text { Pharmacological } \\
\text { therapy }\end{array}$ & 0 & $1^{88}$ & 0 & $1^{82}$ & 0 \\
\hline \multirow[t]{3}{*}{$\begin{array}{l}\text { Psychological } \\
\text { Therapies }\end{array}$} & $\begin{array}{l}\text { Sham, usual care, } \\
\text { waitlist, no } \\
\text { treatment, attention }\end{array}$ & $5^{89-93}$ & $1^{38}$ & $\begin{array}{l}\text { Knee OA: } 2^{94,95} \\
\text { Hip, Hand OA: } 0\end{array}$ & $\begin{array}{l}10 \\
(11)^{67,86,87,96-} \\
103\end{array}$ & $2^{104,105}$ \\
\hline & $\begin{array}{l}\text { Pharmacological } \\
\text { therapy }\end{array}$ & 0 & 0 & 0 & $3^{96,106,107}$ & $2^{105,108}$ \\
\hline & $\begin{array}{l}\text { Exercise (or } \\
\text { biofeedback for } \\
\text { CTTH) }\end{array}$ & $1^{109}$ & $1^{38}$ & $\begin{array}{l}\text { Knee OA: } 1^{110} \\
\text { Hip, Hand OA: } 0\end{array}$ & $5^{67,86,87,111,112}$ & 0 \\
\hline \multirow[t]{3}{*}{$\begin{array}{l}\text { Physical } \\
\text { Modalities }\end{array}$} & $\begin{array}{l}\text { Sham, usual care, } \\
\text { waitlist, no } \\
\text { treatment, attention }\end{array}$ & $7^{113-119}$ & $5^{120-124}$ & $\begin{array}{l}\text { Knee OA: } 13^{125-} \\
137 \\
\text { Hip OA: } 0 \\
\text { Hand OA: } 2^{138,139}\end{array}$ & $2^{140,141}$ & $1^{142}$ \\
\hline & $\begin{array}{l}\text { Pharmacological } \\
\text { therapy }\end{array}$ & 0 & 0 & 0 & 0 & 0 \\
\hline & $\begin{array}{l}\text { Exercise (or } \\
\text { biofeedback for } \\
\text { CTTH) }\end{array}$ & $1^{143}$ & 0 & 0 & 0 & 0 \\
\hline \multirow[t]{3}{*}{$\begin{array}{l}\text { Manual } \\
\text { Therapies }\end{array}$} & $\begin{array}{l}\text { Sham, usual care, } \\
\text { waitlist, no } \\
\text { treatment, attention }\end{array}$ & $10^{93,119,144-151}$ & $2^{152,153}$ & $\begin{array}{l}\text { Knee OA: } 2^{40,154} \\
\text { Hip OA: } 1^{40} \\
\text { Hand OA: } 0\end{array}$ & $2^{155,156}$ & $1^{157}$ \\
\hline & $\begin{array}{l}\text { Pharmacological } \\
\text { therapy }\end{array}$ & 0 & 0 & 0 & 0 & $1^{158}$ \\
\hline & $\begin{array}{l}\text { Exercise (or } \\
\text { biofeedback for } \\
\text { CTTH) }\end{array}$ & $5^{147,159-162}$ & $1^{152}$ & $\begin{array}{l}\text { Knee OA: } 1^{40} \\
\text { Hip OA: } 2^{40,163} \\
\text { Hand OA: } 0\end{array}$ & 0 & 0 \\
\hline \multirow[t]{3}{*}{$\begin{array}{l}\text { Mindfulness } \\
\text { Practices }\end{array}$} & $\begin{array}{l}\text { Sham, usual care, } \\
\text { waitlist, no } \\
\text { treatment, attention }\end{array}$ & $5(7)^{89,164-169}$ & 0 & 0 & $2(3)^{170-172}$ & 0 \\
\hline & $\begin{array}{l}\text { Pharmacological } \\
\text { therapy }\end{array}$ & 0 & 0 & 0 & 0 & 0 \\
\hline & $\begin{array}{l}\text { Exercise (or } \\
\text { biofeedback for } \\
\text { CTTH) }\end{array}$ & 0 & 0 & 0 & 0 & 0 \\
\hline \multirow[t]{3}{*}{$\begin{array}{l}\text { Mind-body } \\
\text { Practices }\end{array}$} & $\begin{array}{l}\text { Sham, usual care, } \\
\text { waitlist, no } \\
\text { treatment, attention }\end{array}$ & $7^{173-179}$ & $1^{180}$ & $\begin{array}{l}\text { Knee OA: } 2^{181,182} \\
\text { Hip, Hand OA: } 0\end{array}$ & $2^{183,184}$ & 0 \\
\hline & $\begin{array}{l}\text { Pharmacological } \\
\text { therapy }\end{array}$ & 0 & 0 & 0 & 0 & 0 \\
\hline & $\begin{array}{l}\text { Exercise (or } \\
\text { biofeedback for } \\
\text { CTTH) }\end{array}$ & $5^{174-176,185,186}$ & $2^{187,188}$ & 0 & 0 & 0 \\
\hline \multirow[t]{3}{*}{ Acupuncture } & $\begin{array}{l}\text { Sham, usual care, } \\
\text { waitlist, no } \\
\text { treatment, attention }\end{array}$ & $8^{149,189-195}$ & $8^{180,196-202}$ & $\begin{array}{l}\text { Knee OA: 960,203- } \\
210 \\
\text { Hip, Hand OA: } 0\end{array}$ & $3^{211-213}$ & $3^{214-216}$ \\
\hline & $\begin{array}{l}\text { Pharmacological } \\
\text { therapy }\end{array}$ & 0 & $2^{196,217}$ & 0 & 0 & 0 \\
\hline & $\begin{array}{l}\text { Exercise (or } \\
\text { biofeedback for } \\
\text { CTTH) }\end{array}$ & 0 & 0 & $\begin{array}{l}\text { Knee OA: } \mathbf{1}^{\mathbf{6 0}} \\
\text { Hip, Hand OA: } 0\end{array}$ & 0 & 0 \\
\hline
\end{tabular}




\begin{tabular}{|c|c|c|c|c|c|c|}
\hline Intervention & Comparator & $\begin{array}{l}\text { Chronic } \\
\text { Low Back } \\
\text { Pain: } \\
\text { n=68 (74 } \\
\text { Publications) }\end{array}$ & $\begin{array}{l}\text { Chronic } \\
\text { Neck } \\
\text { Pain: } \\
n=25\end{array}$ & $\begin{array}{l}\text { Osteoarthritis: } \\
n=53 \text { (56 } \\
\text { Publications) }\end{array}$ & $\begin{array}{l}\text { Fibromyalgia: } \\
\mathrm{n}=47 \text { (54 } \\
\text { Publications) }\end{array}$ & $\begin{array}{l}\text { Chronic } \\
\text { Tension } \\
\text { Headache } \\
: n=9\end{array}$ \\
\hline \multirow[t]{3}{*}{$\begin{array}{l}\text { Function } \\
\text { Restoration } \\
\text { Training }\end{array}$} & $\begin{array}{l}\text { Sham, usual care, } \\
\text { waitlist, no } \\
\text { treatment, attention }\end{array}$ & 0 & 0 & 0 & 0 & 0 \\
\hline & $\begin{array}{l}\text { Pharmacological } \\
\text { therapy }\end{array}$ & 0 & 0 & 0 & 0 & 0 \\
\hline & $\begin{array}{l}\text { Exercise (or } \\
\text { biofeedback for } \\
\text { CTTH) }\end{array}$ & 0 & 0 & 0 & 0 & 0 \\
\hline \multirow[t]{3}{*}{$\begin{array}{l}\text { Multi- } \\
\text { disciplinary } \\
\text { Rehabilitation }\end{array}$} & $\begin{array}{l}\text { Sham, usual care, } \\
\text { waitlist, no } \\
\text { treatment, attention }\end{array}$ & $7^{218-223}$ & 0 & $\begin{array}{l}\text { Knee, Hip OA: } 0 \\
\text { Hand OA: } \mathbf{1}^{224}\end{array}$ & $6(8)^{85,225-231}$ & 0 \\
\hline & $\begin{array}{l}\text { Pharmacological } \\
\text { therapy }\end{array}$ & $1^{232}$ & 0 & 0 & 0 & 0 \\
\hline & $\begin{array}{l}\text { Exercise (or } \\
\text { biofeedback for } \\
\text { CTTH) }\end{array}$ & $\begin{array}{l}9(13)^{109,233-} \\
244\end{array}$ & 0 & 0 & $1^{85}$ & 0 \\
\hline
\end{tabular}

CTTH = chronic tension-type headache; OA = osteoarthritis

Thirty-five percent of the included trials were small ( $<70$ participants). Across trials, most patients were female ( $>57 \%$ ), with a mean ages ranging from 31 to 76 years; patients with OA tended to be older in general than those in the other conditions (range, 52 to 76 years). Mean pain duration for patients with chronic low back pain, chronic neck pain, and OA were similar and varied widely from 6 months to 15 years. Mean symptom duration in trials of fibromyalgia and chronic tension headache tended to be at least 4 years (up to 22 years). Exercise interventions were the most commonly studied for OA and fibromyalgia. Psychological therapies were most commonly studied for fibromyalgia, and manual therapies were most commonly studied for chronic low back pain. We identified trials of acupuncture for all included conditions.

Multidisciplinary rehabilitation was studied primarily for chronic low back pain and fibromyalgia. Most trials of multidisciplinary rehabilitation used a functional restoration approach either explicitly or implicitly. There were no trials of functional restoration training for any condition. Limited evidence was available for hip or hand OA or chronic tension headache. The majority of trials compared nonpharmacological interventions with usual care, waitlist, no treatment, attention control, or placebo/sham, with very few trials employing pharmacological treatments or exercise as comparators. Little long-term evidence was available across conditions and interventions.

The majority of trials (59\%) were rated fair quality with only 5 percent considered good quality (Figure 3). For chronic tension headache, no study was considered good quality. In the majority of trials (72\%), attrition was under 20 percent and therefore rated as acceptable. Across trials where attrition was not acceptable, the range was 20 to 63 percent. A primary methodological limitation in many trials was the inability to effectively blind participants and in many cases providers. Poor reporting of randomization and allocation concealment methods were common shortcomings. Acceptable adherence, defined as completion of a minimum of 80 percent of planned treatment, was reported in 44 percent of trials. It was either unclear (40\%) or unacceptable $(16 \%)$ in the majority of trials. 
Figure 3. Overview and distribution of quality analysis ratings

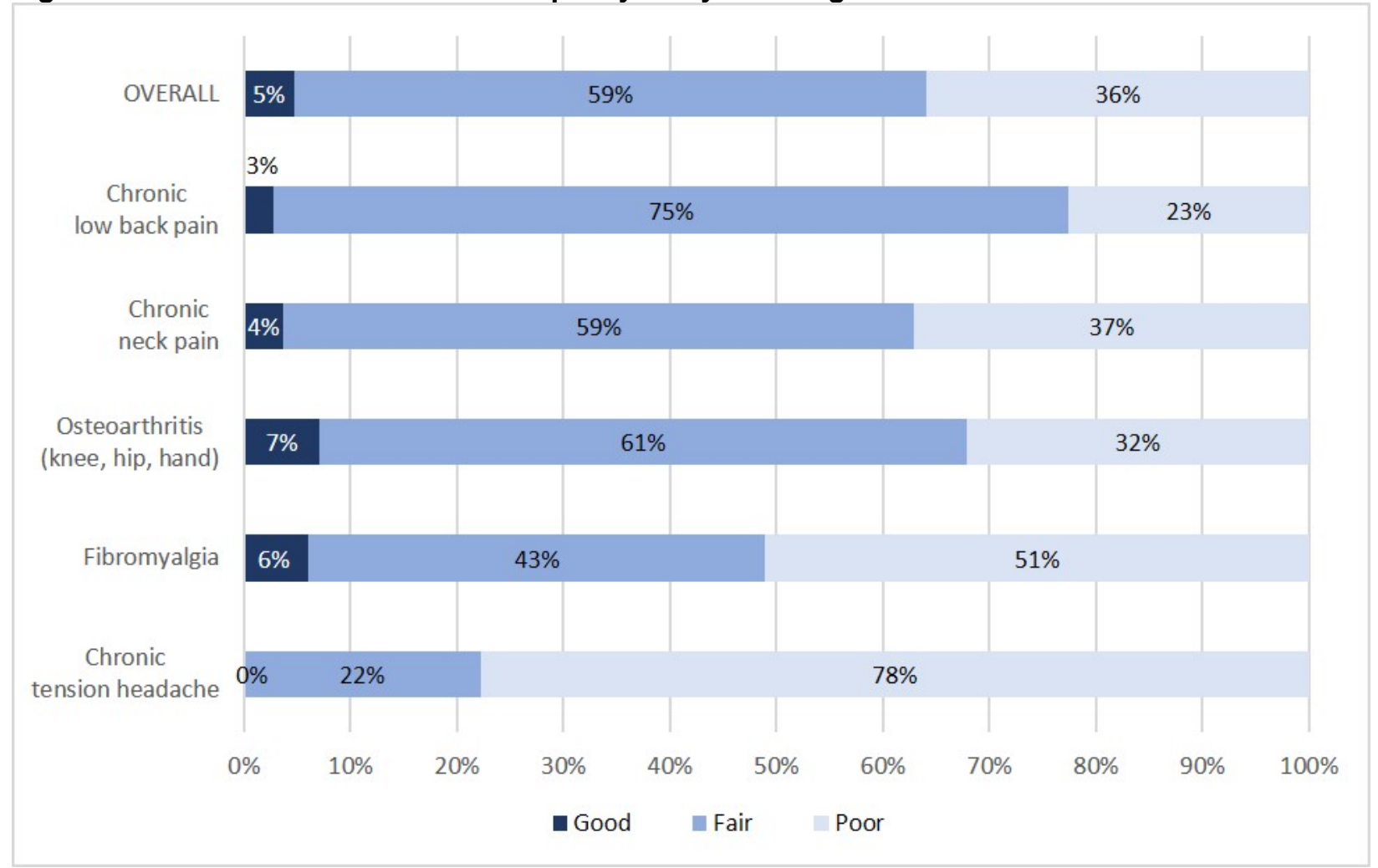

\section{Key Question 1: Chronic Low Back Pain}

\section{Exercise for Chronic Low Back Pain}

\section{Key Points}

- Exercise was associated with slightly greater effects on short-term function than usual care, an attention control, or a placebo intervention (6 trials, pooled standardized mean difference $[\mathrm{SMD}]-0.31,95 \%$ confidence interval $[\mathrm{CI}]-0.58$ to $-0.04, \mathrm{I}^{2}=57 \%$ ); there were no effects on intermediate-term function (3 trials, pooled SMD -0.15, 95\% CI -0.48 to $0.18, \mathrm{I}^{2}=51 \%$ ) or long-term function ( 1 trial, MD 0.00 on the 0 to 100 Oswestry Disability Index [ODI], 95\% CI -11.4 to 11.4) (strength of evidence [SOE]: low).

- Exercise was associated with slightly to moderately greater effects on pain than usual care, an attention control, or a placebo intervention at short-term (6 trials, pooled MD -0.81 on a 0 to 10 scale, $95 \%$ CI -1.26 to $-0.36, \mathrm{I}^{2}=0 \%$ ), intermediate-term ( 3 trials, pooled MD $-1.37,95 \% \mathrm{CI}-2.10$ to $-0.65, \mathrm{I}^{2}=34 \%$ ), and long-term ( 1 trial, MD -1.55 , 95\% CI -2.38 to -0.32) followup (SOE: moderate for short-term, low for intermediateterm and long-term).

- No trial evaluated exercise versus pharmacological therapy.

- Comparisons involving exercise versus other nonpharmacological therapies are addressed in the sections for the other therapies. 
- Harms were not reported in most trials; one trial did not find an association between exercise and increased pain versus placebo and one trial reported no adverse events (SOE: low).

\section{Detailed Synthesis}

Six trials of exercise therapy for low back pain met inclusion criteria (Table 5 and Appendix D). ${ }^{28-33}$ Two trials evaluated neuromuscular re-education exercise (motor control exercises), ${ }^{28,29}$ two trials muscle performance exercises (Pilates), ${ }^{32,33}$ and two trials combined exercise techniques. ${ }^{30,31}$ Sample sizes ranged from 60 to 154 (total sample=553). Three trials compared exercise versus an attention control; ${ }^{29,30,32}$ two trials compared exercise versus usual care; ${ }^{31,33}$ and one trial compared exercise versus a placebo intervention (detuned diathermy and ultrasound). ${ }^{28}$ Four trials were conducted in the United States, Europe, or Australia, and two trials ${ }^{32,33}$ were conducted in Brazil. The duration of exercise therapy ranged from 6 to 12 weeks and the number of exercise sessions ranged from 10 to 24 . One trial reported outcomes through long-term followup, ${ }^{29}$ three trials reported outcomes through intermediate-term followup, ${ }^{28,30}$ and the remainder only evaluated short-term outcomes.

Five trials were rated fair quality and one trial ${ }^{31}$ poor quality (Appendix E). In two fairquality trials, ${ }^{28,33}$ the main methodological limitation was the inability to blind interventions. Limitations in the other trials included unclear randomization and allocation concealment methods, high loss to followup, and baseline differences between intervention groups.

Table 5. Chronic low back pain: exercise

\begin{tabular}{|c|c|c|c|c|}
\hline $\begin{array}{l}\text { Author, Year, } \\
\text { Followup, } \\
\text { Pain } \\
\text { Duration, } \\
\text { Study Quality }\end{array}$ & Intervention & Population & Function and Pain Outcomes & Other Outcomes \\
\hline $\begin{array}{l}\text { Costa, } 2009^{28} \\
4 \text { and } 10 \\
\text { months } \\
\text { Duration of } \\
\text { pain: Mean } \\
328 \text { to } 335 \\
\text { weeks } \\
\text { Fair }\end{array}$ & $\begin{array}{l}\text { A: Neuromuscular } \\
\text { re-education } \\
\text { (motor control } \\
\text { exercise) ( } n=77 \text { ), } \\
12 \text { sessions over } 8 \\
\text { weeks } \\
\text { B: Placebo } \\
\text { (detuned } \\
\text { shortwave } \\
\text { diathermy and } \\
\text { detuned } \\
\text { ultrasound) ( } n=77 \text { ) } \\
12 \text { sessions, two } \\
\text { sessions/week for } \\
4 \text { weeks, then } 1 \\
\text { session/week for } 4 \\
\text { weeks }\end{array}$ & $\begin{array}{l}\text { A vs. B } \\
\text { Age: } 55 \text { vs. } 53 \\
\text { years } \\
\text { Female: } 58 \% \\
\text { vs. } 62 \% \\
\text { Baseline RDQ } \\
(0-24): 13.1 \text { vs. } \\
13.4 \\
\text { Baseline pain } \\
(0-10 \text { VAS): } 6.8 \\
\text { vs. } 6.6\end{array}$ & $\begin{array}{l}\frac{4 \text { months }}{\text { RDQ: } 5.3} \text { vs. } 4.3 \text {, adjusted } \\
\text { difference } 1.0 \text { (95\% } \mathrm{Cl} 0.3 \text { to } 1.8) \\
\text { Pain (0-10 VAS): } 5.0 \text { vs. } 5.6, \\
\text { adjusted difference } 1.4(95 \% \mathrm{Cl} \\
0.3 \text { to } 2.4) \\
10 \text { months } \\
\text { RDQ: } 11.4 \text { vs. } 12.3, \text { adjusted } \\
\text { difference }-1.0(95 \% \mathrm{Cl}-2.8 \text { to } \\
0.8) \\
\text { Pain: } 5.0 \text { vs. } 6.3 \text {, adjusted } \\
\text { difference }-1.0 \text { (95\% Cl }-1.9 \text { to } \\
-0.1)\end{array}$ & $\begin{array}{l}4 \text { months } \\
\text { Global impression of } \\
\text { recovery }(-5 \text { to }+5): 1.5 \text { vs. } \\
0.3 \text {, adjusted difference } 1.4 \\
\text { ( } 95 \% \text { Cl } 0.3 \text { to } 1.8) \\
10 \text { months } \\
\text { Global impression of } \\
\text { recovery: } 1.2 \text { vs. }-0.3 \text {, } \\
\text { adjusted difference } 1.6 \\
(95 \% \mathrm{Cl} 0.6 \text { to } 2.6)\end{array}$ \\
\hline
\end{tabular}




\begin{tabular}{|c|c|c|c|c|}
\hline $\begin{array}{l}\text { Author, Year, } \\
\text { Followup, } \\
\text { Pain } \\
\text { Duration, } \\
\text { Study Quality }\end{array}$ & Intervention & Population & Function and Pain Outcomes & Other Outcomes \\
\hline $\begin{array}{l}\text { Goldby, } \\
2006^{29} \\
3,6,12 \text { and } \\
24 \text { months } \\
\text { Duration of } \\
\text { pain: Mean } 11 \\
\text { to } 12 \text { years } \\
\text { Fair }\end{array}$ & $\begin{array}{l}\text { A: Neuromuscular } \\
\text { re-education } \\
\text { (motor control } \\
\text { exercise) }(n=84), \\
10 \text { sessions over } \\
10 \text { weeks } \\
\text { B: Attention control } \\
\text { (education) }(n=40)\end{array}$ & $\begin{array}{l}\text { A vs. B } \\
\text { Age: } 43 \text { vs. } 41 \\
\text { years } \\
\text { Female: } 68 \% \\
\text { vs. } 68 \% \\
\text { Race: } 80 \% \text { vs. } \\
62 \% \\
\text { Baseline ODI } \\
\text { (0-100): } 40.5 \\
\text { vs. } 33.5 \\
\text { Baseline LBO } \\
\text { (0-75): } 43.9 \text { vs. } \\
44.0 \text { vs. } 47.6 \\
\text { Baseline back } \\
\text { pain (0-100 } \\
\text { NRS): } 45.8 \text { vs. } \\
37.6\end{array}$ & 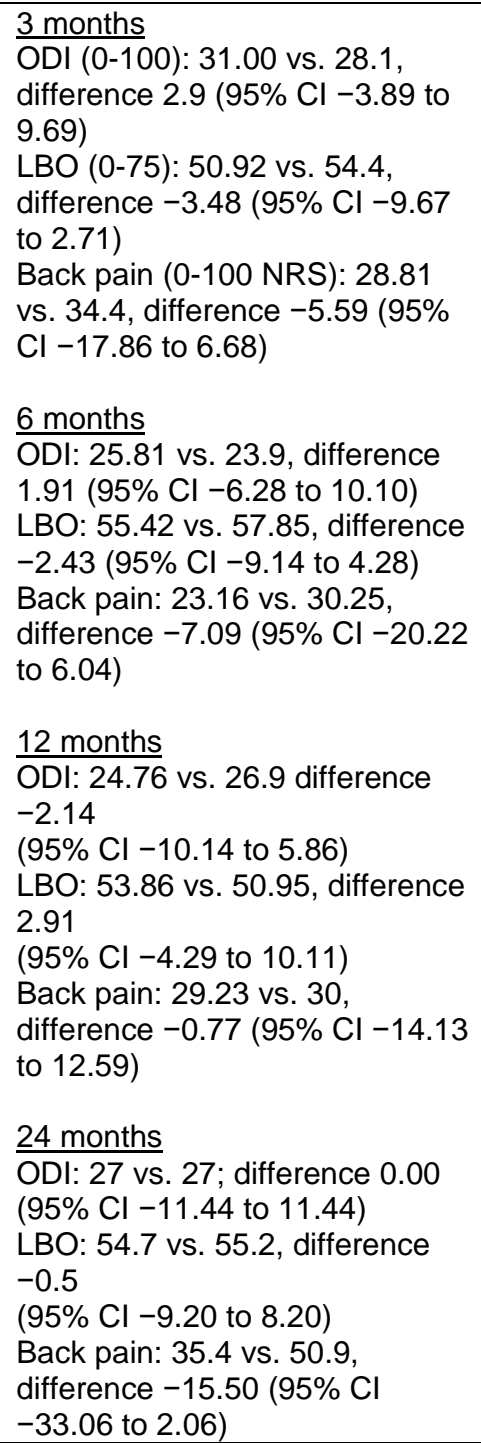 & 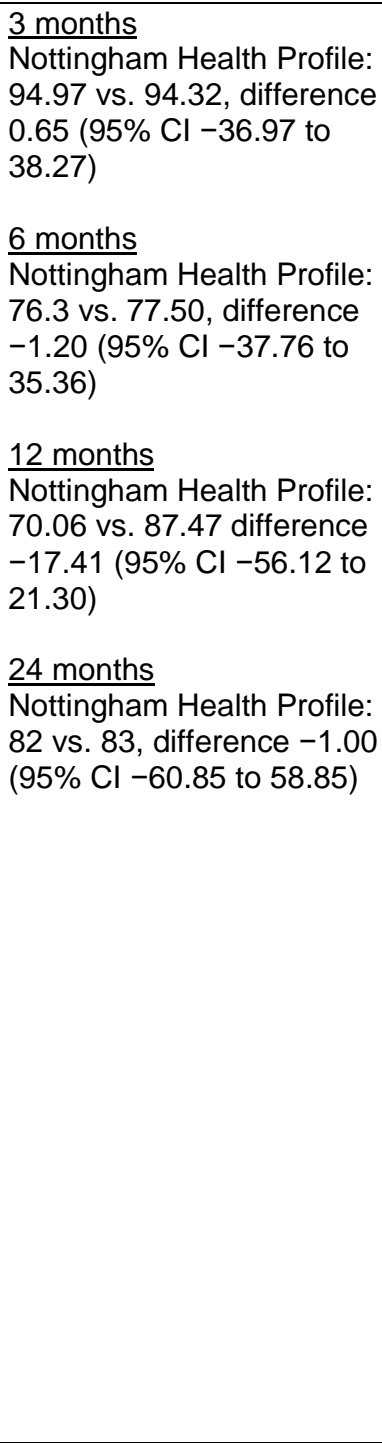 \\
\hline $\begin{array}{l}\text { Kankaaanpaa, } \\
1999^{30} \\
3 \text { and } 9 \\
\text { months } \\
\text { Duration of } \\
\text { pain: Mean } 7 \\
\text { to } 9 \text { years } \\
\text { Fair }\end{array}$ & $\begin{array}{l}\text { A. Combined } \\
\text { exercise } \\
\text { (exercises, } \\
\text { stretching, } \\
\text { relaxation, muscle } \\
\text { function and } \\
\text { ergonomic advice) } \\
\text { ( } n=30), 24 \\
\text { sessions over } 12 \\
\text { weeks } \\
\text { B. Attention } \\
\text { Control ( } n=24) \\
\text { (thermal therapy } \\
\text { and minimal } \\
\text { massage) }\end{array}$ & $\begin{array}{l}\text { A vs. B } \\
\text { Age: } 40 \text { vs. } 39 \\
\text { years } \\
\text { Female: } 36.6 \% \\
\text { vs. } 33.3 \% \\
\text { Baseline Pain } \\
\text { and Disability } \\
\text { Index (0-70 } \\
\text { PDI): } 13.2 \text { vs. } \\
9.5 \\
\text { Baseline back } \\
\text { pain (0-100 } \\
\text { mm VAS): } 55.2 \\
\text { vs. } 47.0\end{array}$ & $\begin{array}{l}\text { 3 months } \\
\text { Pain and Disability Index (0-70): } \\
5.7 \text { vs. } 12.6 \text {, difference }-6.9 \\
\text { (95\% } \mathrm{Cl}-11.69 \text { to }-2.11) \\
\text { Back pain }(0-100 \text { VAS): } 26.6 \text { vs. } \\
43.4 \text {; difference }-16.80(95 \% \mathrm{Cl} \\
-31.12 \text { to }-2.47) \\
9 \text { months } \\
\text { Pain and Disability Index: } 5.7 \text { vs. } \\
11.4 \text {, difference }-5.7(95 \% \mathrm{Cl} \\
-11.31 \text { to }-0.09) \\
\text { Back pain intensity: } 23.9 \text { vs. } \\
45.1 \text {, difference }-21.20(95 \% \mathrm{Cl} \\
-32.69 \text { to }-9.71)\end{array}$ & NR \\
\hline
\end{tabular}




\begin{tabular}{|c|c|c|c|c|}
\hline $\begin{array}{l}\text { Author, Year, } \\
\text { Followup, } \\
\text { Pain } \\
\text { Duration, } \\
\text { Study Quality }\end{array}$ & Intervention & Population & Function and Pain Outcomes & Other Outcomes \\
\hline $\begin{array}{l}\text { Miyamoto, } \\
2013^{32} \\
4.5 \text { months } \\
\text { Duration of } \\
\text { pain: Mean } 5 \\
\text { to } 6 \text { years } \\
\text { Fair }\end{array}$ & $\begin{array}{l}\text { A. Muscle } \\
\text { performance } \\
\text { (Pilates) }(n=43), 12 \\
\text { sessions over } 6 \\
\text { weeks } \\
\text { B. Attention control } \\
(n=43) \text { (education) }\end{array}$ & $\begin{array}{l}\text { A vs. B } \\
\text { Age: } 41 \text { vs. } 38 \\
\text { years } \\
\text { Female: } 84 \% \\
\text { vs. } 79 \% \\
\text { Baseline RDQ: } \\
9.7 \text { vs. } 10.5 \\
\text { Baseline pain } \\
\text { (0-10 VAS): } 6.6 \\
\text { vs. } 6.5\end{array}$ & $\begin{array}{l}4.5 \text { months } \\
\text { RDQ (0-24): } 4.5 \text { vs. } 6.7 \text {, adjusted } \\
\text { difference }-1.4(95 \% \mathrm{Cl}-3.1 \text { to } \\
0.03) \\
\text { Patient-Specific Functional Scale } \\
\text { (0-10): } 6.9 \text { vs. } 6.1 \text {, adjusted } \\
\text { difference } 0.2(95 \% \mathrm{Cl}-0.6 \text { to } \\
1.1) \\
\text { Pain (0-10 VAS): } 4.5 \text { vs. } 5.3 \text {, } \\
\text { adjusted difference }-0.9(95 \% \mathrm{Cl} \\
-1.9 \text { to } 0.1)\end{array}$ & $\begin{array}{l}4.5 \text { months } \\
\text { Global impression of } \\
\text { recovery }(-5 \text { to }+5): 2.4 \text { vs. } \\
1.7, \text { adjusted difference } 0.7 \\
(95 \% \mathrm{Cl}-0.4 \text { to } 1.8)\end{array}$ \\
\hline $\begin{array}{l}\text { Nassif, } 2011^{31} \\
4 \text { months } \\
\text { Duration of } \\
\text { pain: NR } \\
\text { Poor }\end{array}$ & $\begin{array}{l}\text { A. Combined } \\
\text { exercise (n=37) } \\
\text { (stretching, } \\
\text { stability, } \\
\text { coordination, and } \\
\text { muscle } \\
\text { strengthening } \\
\text { exercises), } 24 \\
\text { sessions over } 8 \\
\text { weeks } \\
\text { B. Usual care } \\
\text { (n=38) }\end{array}$ & $\begin{array}{l}\text { A vs. B } \\
\text { Age: } 45 \text { vs. } 45 \\
\text { Female: } 11 \% \\
\text { vs. } 21 \% \\
\text { Baseline RDQ: } \\
13.9 \text { vs. } 12.3 \\
\text { Baseline pain } \\
\text { (0-10 VAS): } 4.5 \\
\text { vs. } 4.9\end{array}$ & $\begin{array}{l}\frac{4 \text { months }}{\mathrm{RDQ}(0-24):} 10.0 \text { vs. } 10.6, \\
\text { difference }-0.6 \text { (95\% Cl }-3.5 \text { to } \\
2.3) \\
\text { Quebec Back Pain Disability } \\
\text { Questionnaire: } 27.2 \text { vs. } 30.2 \text {, } \\
\text { difference }-3.0 \text { (95\% Cl }-11.7 \text { to } \\
5.7) \\
\text { Pain (0-10 NRS): } 3.2(2.3) \text { vs. } \\
3.5(2.5), \text { difference }-0.3(95 \% \\
\mathrm{Cl}-1.6 \text { to } 1.0)\end{array}$ & $\begin{array}{l}\frac{4 \text { months }}{\text { Dallas Pain Questionnaire }} \\
\text { anxiety and depression: } \\
31.2 \text { vs. } 28.9 \text {, difference } 2.3 \\
(95 \% \mathrm{Cl}-8.2 \text { to } 12.8)\end{array}$ \\
\hline $\begin{array}{l}\text { Natour, } 2014^{33} \\
3 \text { months } \\
\text { Duration of } \\
\text { pain: >1 year } \\
\text { Fair }\end{array}$ & $\begin{array}{l}\text { A. Exercise } \\
\text { (Pilates) ( } n=30), 24 \\
\text { sessions over } 12 \\
\text { weeks } \\
\text { B. Usual care } \\
(n=30) \text { (no } \\
\text { treatment) }\end{array}$ & $\begin{array}{l}\text { A vs. B } \\
\text { Age: } 48 \text { vs. } 48 \\
\text { Female: } 80 \% \\
\text { vs. } 77 \% \\
\text { Baseline RDQ: } \\
1.1 \text { vs. } 10.6 \\
\text { Baseline pain } \\
\text { (0-10 VAS): } \\
5.5 \text { vs. } 5.8\end{array}$ & $\begin{array}{l}\frac{3 \text { months }}{\text { RDQ }(0-24): ~} 7.0 \text { vs. } 10.7 \\
\text { difference }-3.6, P<0.001 \\
\text { Pain (0-10 VAS): } 4.2 \text { vs. } 5.8 \text {, } \\
\text { difference }-1.6, P<0.001\end{array}$ & $\begin{array}{l}3 \text { months } \\
\text { SF-36 physical function (0- } \\
100): 65.4 \text { vs. } 59.6, \\
\text { difference } 5.8, P=0.026 \\
\text { SF-36 role physical: } 56.4 \\
\text { vs. } 40.0 \text {, difference } 16.4 \text {, } \\
P=0.086 \\
\text { SF-36 bodily pain: } 52.2 \text { vs. } \\
43.9, \text { difference } 8.3 \text {, } \\
P=0.030 \\
\text { SF-36 general health: } 65.2 \\
\text { vs. } 62.1 \text {, difference } 3.1 \text {, } \\
P=0.772 \\
\text { SF-36 mental health: } 67.9 \\
\text { vs. } 65.3 \text {, difference } 2.6 \text {, } \\
P=0.243 \\
\text { SF-36 social functioning: } \\
86.0 \text { vs. } 80.4 \text {, difference } \\
5.6, P=0.09 \\
\text { No differences on other SF- } \\
36 \text { subscales }\end{array}$ \\
\hline
\end{tabular}

CI = confidence interval; LBO = Low Back Outcome Score; NHP = Nottingham Health Profile; NR = not reported; ODI = Oswestry Disability Index; RDQ = Roland-Morris Disability Questionnaire; SF-36 = Short-Form 36 questionnaire; VAS = visual analog scale

${ }^{\mathrm{a}}$ Unless otherwise noted, followup time is calculated from the end of the treatment period

\section{Exercise Compared With Usual Care, an Attention Control, or a Placebo Intervention}

Exercise was associated with slightly greater effects on short-term function than controls (6 trials, pooled SMD $-0.31,95 \% \mathrm{CI}-0.58$ to $-0.04, \mathrm{I}^{2}=57 \%$ ) (Figure 4 ) ${ }^{28-33}$ Four trials that evaluated function using the Roland-Morris Disability Questionnaire (RDQ) (0 to 24 scale) reported a pooled $\mathrm{MD}$ of -1.96 points $(95 \% \mathrm{CI}-3.14$ to -0.78$),{ }^{28,31-33}$ and one trial that used the 
ODI ( 0 to 100 scale) reported a difference of 2.9 points (95\% CI -3.89 to 9.69$).{ }^{29}$ There were no clear differences in estimates when analyses were stratified according to the type of exercise (estimates ranged from -0.08 to -0.51 points) or the type of control and when the poor-quality trial was excluded. There were no differences between exercise versus controls in intermediateterm function ( 3 trials, pooled SMD -0.15 , 95\% CI -0.48 to $0.18, \mathrm{I}^{2}=51 \%$ ) ${ }^{28-30}$ or long-term function ( 1 trial, difference $0.00,95 \%$ CI -11.4 to 11.4 on the ODI). ${ }^{29}$

Exercise was associated with greater effects on short-term pain than usual care, an attention control, or a placebo intervention ( 6 trials, pooled difference -0.81 on a 0 to 10 scale, $95 \%$ CI -1.26 to $-0.36, \mathrm{I}^{2}=0 \%$ ) (Figure 5 ). ${ }^{28-33}$ There were no clear differences in estimates when analyses were stratified according to the type of exercise (difference $-0.52,95 \% \mathrm{CI}-1.41$ to 0.36 in 2 trials of neuromuscular re-education exercises, $-1.12,95 \% \mathrm{CI}-2.28$ to -0.14 in 2 trials of muscle performance exercises, and $-0.90,95 \%$ CI -2.63 to 0.68 in 2 trials of combined exercises), the type of control (usual care, attention control, or placebo intervention), and when the poor-quality trial was excluded. For intermediate-term pain ( 3 trials, pooled difference -1.37 , $95 \% \mathrm{CI}-2.10$ to $\left.-0.65, \mathrm{I}^{2}=34 \%\right)^{28-30}$ and long-term pain (1 trial, difference $-1.55,95 \% \mathrm{CI}-2.78$ to -0.32$),{ }^{29}$ effects of exercise on pain were moderate, but findings were based on small numbers of trials.

Data on effects of exercise on quality of life were limited. One trial ${ }^{29}$ found no differences between exercise versus an attention control on the Nottingham Health Profile at short-term, intermediate-term, or long-term followup, and one trial ${ }^{33}$ found exercise associated with higher scores on the Short-Form 36 (SF-36) physical functioning (difference 5.8 points on 0 to 100 scale, $\mathrm{P}=0.026$ ), bodily pain (difference 8.3 points, $\mathrm{P}=0.03$ ), and vitality subscales (difference 5.3 points, $\mathrm{P}=0.029$ ) at short-term followup; there were no differences on other SF-36 subscales (Table 5).

No trial evaluated effects of exercise on use of opioid therapies or health care utilization. There was insufficient evidence to determine effects of duration of exercise therapy or number of sessions on outcomes.

\section{Exercise Compared With Pharmacological Therapy}

No trial of exercise versus pharmacological therapy met inclusion criteria.

\section{Exercise Compared With Other Nonpharmacological Therapies}

Findings for exercise versus other nonpharmacological therapies are addressed in the sections for other nonpharmacological therapies.

\section{Harms}

Harms were not reported in most trials. One trial ${ }^{28}$ found no difference between exercise and a placebo intervention (detuned diathermy) in likelihood of increased pain, and another trial ${ }^{32}$ reported no adverse events (Appendix D). 
Figure 4. Exercise versus usual care, an attention control, or a placebo intervention for chronic low back pain: effects on function

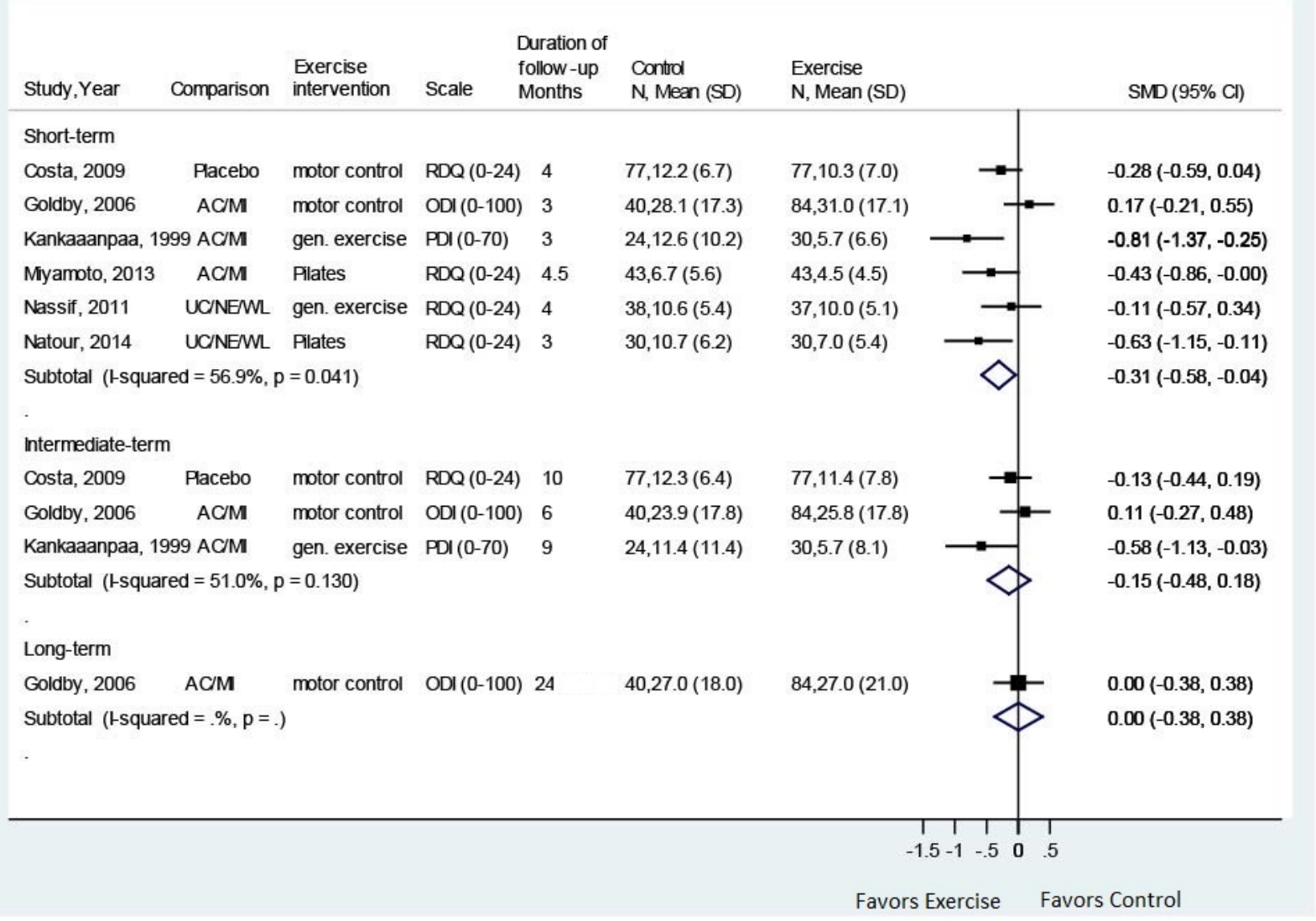

$\mathrm{AC}=$ attention control; $\mathrm{CI}=$ confidence interval; $\mathrm{MI}=$ minimal intervention; $\mathrm{N}=$ number; $\mathrm{NE}=$ no exercise; ODI = Oswestry Disability Index; PDI = Pain Disability Index; RDQ = Roland-Morris Disability Questionnaire; SD = standard deviation; SMD = standardized mean difference; UC = usual care; $\mathrm{WL}=$ waitlist 
Figure 5. Exercise versus usual care, an attention control, or a placebo intervention for chronic low back pain: effects on pain

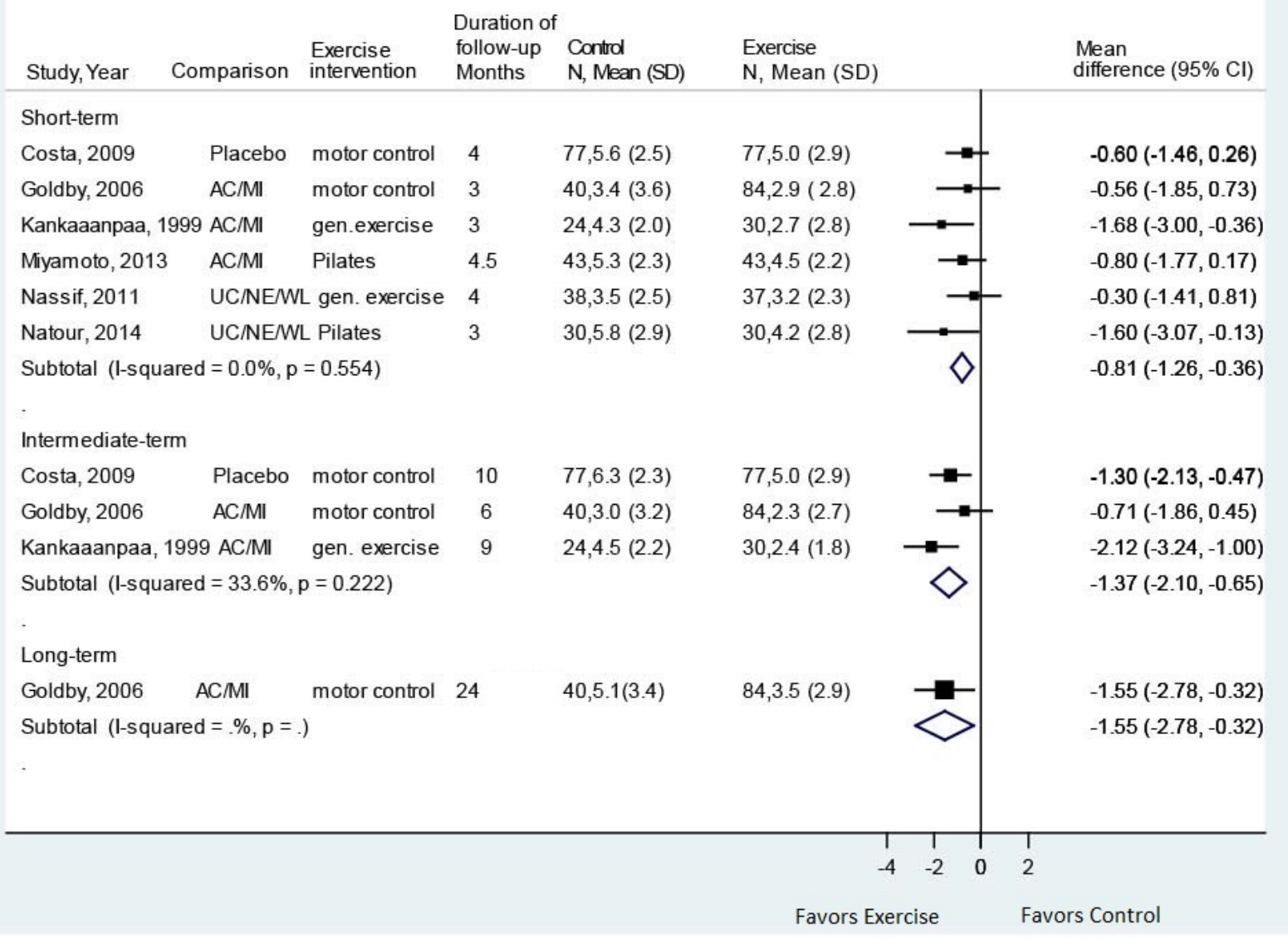

$\mathrm{AC}=$ attention control; $\mathrm{CI}=$ confidence interval; $\mathrm{MI}=$ minimal intervention; $\mathrm{N}=$ number; $\mathrm{NE}=$ no exercise; $\mathrm{SD}=$ standard deviation; $\mathrm{UC}=$ usual care; $\mathrm{WL}=$ waitlist

\section{Psychological Therapies for Chronic Low Back Pain}

\section{Key Points}

- Psychological therapy was associated with slightly greater effects on function than usual care or an attention control at short-term (3 trials, pooled SMD $-0.25,95 \%$ CI -0.38 to $-0.12, \mathrm{I}^{2}=0 \%$ ), intermediate-term ( 3 trials, pooled SMD $-0.25,95 \% \mathrm{CI}-0.37$ to -0.13 , $\mathrm{I}^{2}=0 \%$ ), and long-term followup ( 3 trials, pooled SMD $-0.27,95 \% \mathrm{CI}-0.39$ to -0.15 , $\mathrm{I}^{2}=0 \%$ ) (SOE: moderate).

- Psychological therapy was associated with slightly greater effects on pain than usual care or an attention control at short-term (3 trials, pooled MD -0.76 on a 0 to 10 scale, $95 \%$ $\mathrm{CI}-0.99$ to $-0.53, \mathrm{I}^{2}=0 \%$ ), intermediate-term ( 3 trials, pooled $\mathrm{MD}-0.71,95 \% \mathrm{CI}-0.94$ to $-0.48, \mathrm{I}^{2}=0 \%$ ), or long-term followup ( 3 trials, pooled $\mathrm{MD}-0.53,95 \% \mathrm{CI}-0.78$ to $-0.27, \mathrm{I}^{2}=0 \%$ ) (SOE: moderate).

- Evidence from one poor-quality trial was too unreliable to determine effects of psychological therapy versus exercise (SOE: insufficient). 
- One trial reported no serious adverse events and one withdrawal due to adverse events in 468 patients (SOE: low).

\section{Detailed Synthesis}

Five trials (reported in 6 publications) of psychological therapies for low back pain met inclusion criteria (Table 6 and Appendix D). ${ }^{89-93,109,165}$ Three trials evaluated group cognitivebehavioral therapy (CBT), ${ }^{89-92}$ one trial evaluated respondent therapy (progressive muscle relaxation), ${ }^{93}$ and one trial evaluated operant therapy. ${ }^{109}$ Sample sizes ranged from 49 to 701 (total sample=1,311). The number of psychological therapy sessions ranged from six to eight, and the duration of therapy ranged from 6 to 8 weeks. In one trial ${ }^{91,92}$ the duration of therapy was unclear. Three trials compared psychological therapies versus usual care, ${ }^{89,90,93}$ one trial compared psychological therapy versus an attention control (advice), ${ }^{91,92}$ and one trial compared psychological therapy versus exercise therapy. ${ }^{109}$ All trials were conducted in the United States or the United Kingdom. Four trials reported outcomes through long-term (12 to 34 months) followup, ${ }^{90-92,109,165}$ one trial evaluated outcomes through intermediate-term followup, ${ }^{89}$ and one trial only evaluated short-term outcomes. ${ }^{93}$

Three trials ${ }^{89-92}$ were rated fair quality and two trials poor quality (Appendix E). ${ }^{93,109}$ The major methodological limitation in the fair-quality trials was the inability to effectively blind patients and caregivers to the psychological intervention. Other methodological shortcomings in the poor-quality trials included unclear randomization and allocation concealment methods and high attrition. 
Table 6. Chronic low back pain: psychological therapies

\begin{tabular}{|c|c|c|c|c|}
\hline $\begin{array}{l}\text { Author, Year, } \\
\text { Followup,a } \\
\text { Pain } \\
\text { Duration, } \\
\text { Study } \\
\text { Quality }\end{array}$ & Intervention & Population & Function and Pain Outcomes & Other Outcomes \\
\hline $\begin{array}{l}\text { Cherkin, } \\
2016^{89} \\
\text { Herman, } \\
2017^{166} \\
\text { Cherkin, } \\
2017^{165} \text { (2 } \\
\text { year data } \\
\text { from Cherkin, } \\
2016) \\
22 \text { months } \\
\text { Duration of } \\
\text { pain: >3 } \\
\text { months } \\
\text { (>1 year in } \\
80 \% \text { of } \\
\text { patients) } \\
\text { Fair }\end{array}$ & $\begin{array}{l}\text { A. CBT }(n=116), 8 \\
\text { sessions over } 8 \\
\text { weeks } \\
\text { B. Usual care } \\
(n=112)\end{array}$ & $\begin{array}{l}\text { A vs. B } \\
49 \text { vs. } 49 \\
\text { years } \\
\text { Female: } 59 \% \\
\text { vs. } 66 \% \\
\text { Baseline } \\
\text { modified } \\
\text { RDQ (0-23): } \\
11.5 \text { vs. } 10.9 \\
\text { Baseline pain } \\
\text { bothersome- } \\
\text { ness (0-10): } \\
6.0 \text { vs. } 6.0\end{array}$ & 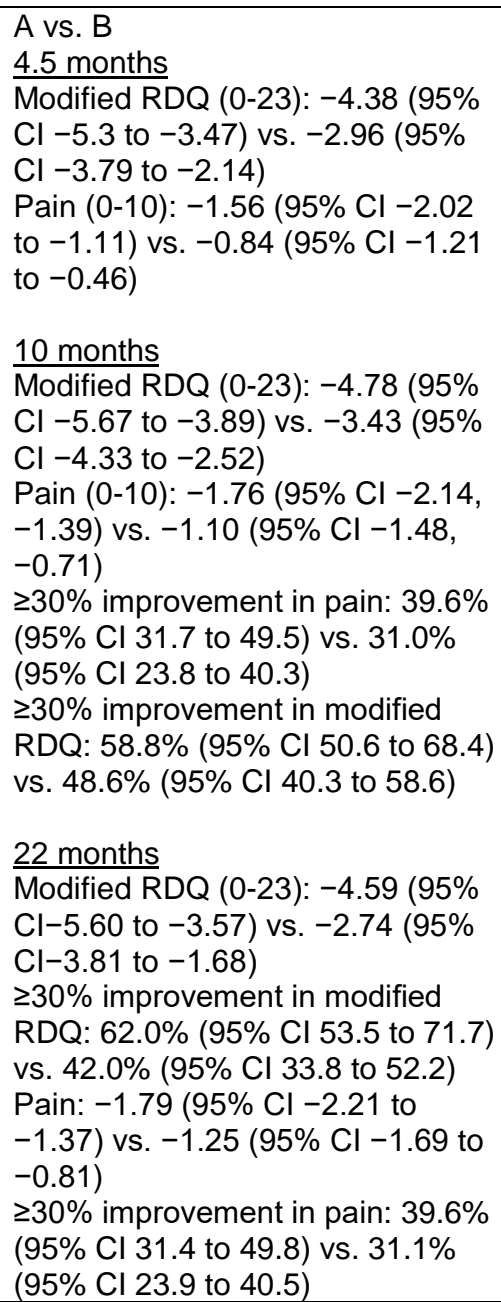 & 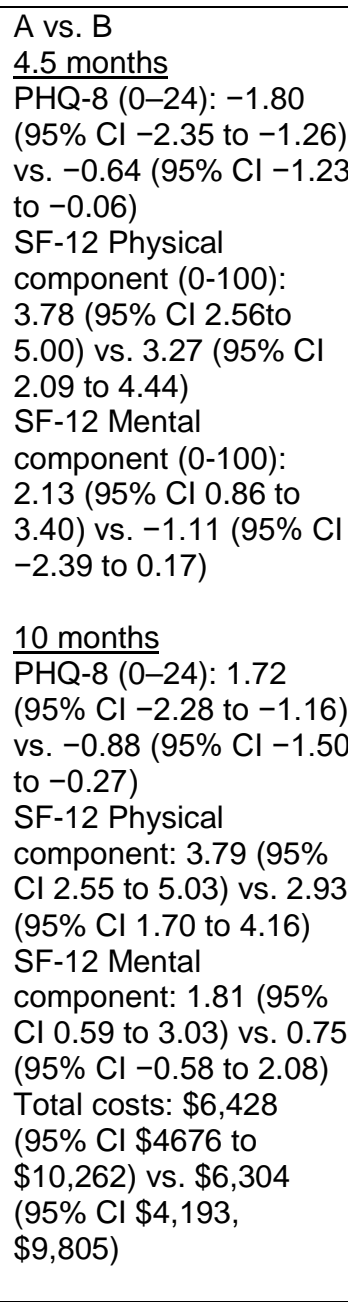 \\
\hline $\begin{array}{l}\text { Johnson, } \\
2007^{90} \\
12 \text { months } \\
\text { Duration of } \\
\text { pain: } 6 \\
\text { months } \\
\text { Fair }\end{array}$ & $\begin{array}{l}\text { A. CBT }(n=116), 8 \\
\text { sessions over } 6 \\
\text { weeks } \\
\text { B. Usual care } \\
(n=118)\end{array}$ & $\begin{array}{l}\text { A vs. B } \\
\text { Age: } 47 \text { vs. } \\
49 \\
\text { Female: } 61 \% \\
\text { vs. } 58 \% \\
\text { Baseline } \\
\text { RDQ (0-24): } \\
\text { 10.6 vs. } 10.9 \\
\text { Baseline pain } \\
\text { (0-100 VAS): } \\
44.9 \text { vs. } 51.6\end{array}$ & $\begin{array}{l}\text { A vs. B } \\
6 \text { months } \\
\text { RDQ (0-24): } 6.5 \text { vs. } 8.0 \text {, adjusted } \\
\text { difference }-1.09 \text { ( } 95 \% \mathrm{Cl}-2.28 \text { to } \\
0.09) \\
\text { Pain (0-100 VAS): } 26.1 \text { vs. } 35.0 \text {, } \\
\text { adjusted difference }-4.60 \text { (95\% Cl } \\
-11.07 \text { to } 1.88) \\
12 \text { months } \\
\text { RDQ (0-24): } 6.7 \text { vs. } 8.0 \text {, adjusted } \\
\text { difference }-0.93 \text { (95\% Cl }-2.30 \text { to } \\
0.45) \\
\text { Pain (0-100 VAS): } 27.9 \text { vs. } 36.4, \\
\text { adjusted difference }-5.49 \text { (95\% Cl } \\
-12.43 \text { to } 1.44)\end{array}$ & $\begin{array}{l}\text { A vs. B } \\
6 \text { months } \\
\text { Quality of life (0-1 EQ- } \\
\text { 5D): } 0.75 \text { vs. } 0.71 \text {, } \\
\text { adjusted difference } 0.03 \\
\text { (95\% Cl -0.05 to } 0.10) \\
12 \text { months } \\
\text { Quality of life (0-1 EQ- } \\
\text { 5D): } 0.75 \text { vs. } 0.71 \text {, } \\
\text { adjusted difference } 0.03 \\
\text { (95\% Cl }-0.04 \text { to } 0.09)\end{array}$ \\
\hline
\end{tabular}




\begin{tabular}{|c|c|c|c|c|}
\hline $\begin{array}{l}\text { Author, Year, } \\
\text { Followup, a } \\
\text { Pain } \\
\text { Duration, } \\
\text { Study } \\
\text { Quality }\end{array}$ & Intervention & Population & Function and Pain Outcomes & Other Outcomes \\
\hline $\begin{array}{l}\text { Lamb } 2010^{91} \\
\text { and } 2012^{92} \\
34 \text { months } \\
\text { Duration of } \\
\text { pain: } 13 \text { years } \\
\text { Fair }\end{array}$ & $\begin{array}{l}\text { A. CBT }(n=468), 8 \\
\text { sessions over } \\
\text { unclear number of } \\
\text { weeks } \\
\text { B. Attention control } \\
(n=233)\end{array}$ & $\begin{array}{l}\text { A vs. B } \\
\text { Age: } 53 \text { vs. } \\
54 \text { years } \\
\text { Female: } 59 \% \\
\text { vs. } 61 \% \\
\text { Korff } \\
\text { disability (0- } \\
100): 49 \text { vs. } \\
46 \\
\text { Baseline } \\
\text { RDQ (0-24): } \\
9 \text { vs. } 9 \\
\text { Baseline pain } \\
\text { (0-100 } \\
\text { Modified Von } \\
\text { Korff): } \\
59 \text { vs. } 59 \\
\text { Modified Von }\end{array}$ & 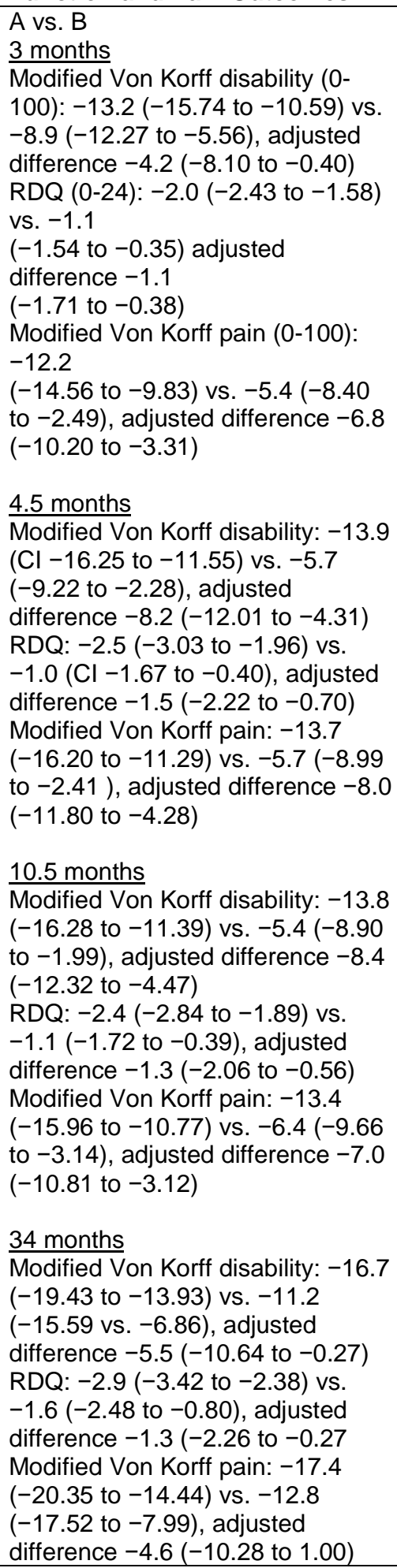 & 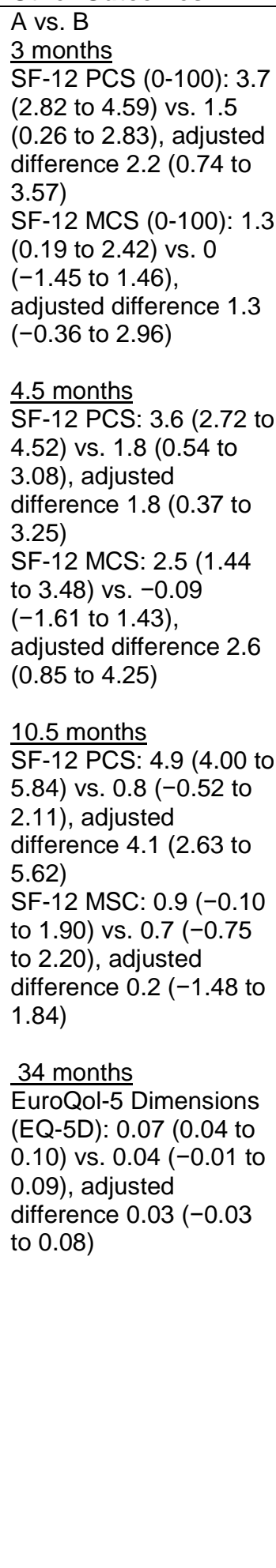 \\
\hline
\end{tabular}




\begin{tabular}{|c|c|c|c|c|}
\hline $\begin{array}{l}\text { Author, Year, } \\
\text { Followup, } \\
\text { Pain } \\
\text { Duration, } \\
\text { Study } \\
\text { Quality }\end{array}$ & Intervention & Population & Function and Pain Outcomes & Other Outcomes \\
\hline $\begin{array}{l}\text { Poole, } 2007^{93} \\
4.5 \text { months } \\
\text { Duration of } \\
\text { pain: } 10.6 \text { vs. } \\
9.5 \text { years } \\
\text { Poor }\end{array}$ & $\begin{array}{l}\text { A. Respondent } \\
\text { therapy } \\
\text { (progressive } \\
\text { muscle relaxation) } \\
\text { ( } n=54), 6 \text { sessions } \\
\text { over 6-8 weeks } \\
\text { B. Usual care } \\
(n=45)\end{array}$ & $\begin{array}{l}\text { A vs. B } \\
\text { Age: } 46 \text { vs. } \\
47 \\
\text { Female: } 65 \% \\
\text { vs. } 51 \% \\
\text { Baseline } \\
\text { Oswestry } \\
\text { Disability } \\
\text { Index (0- } \\
100 \% \text { ODI): } \\
33.2 \text { vs. 36.6 } \\
\text { Baseline pain } \\
\text { (0-100 VAS): } \\
40.7 \text { vs. } 40.6\end{array}$ & $\begin{array}{l}\text { A vs. B } \\
4.5 \text { month } \\
\text { ODI }(0-100): 31.3 \text { vs. } 32.9 \\
\text { Pain (0-100 VAS): } 41.3 \text { vs. } 42.7\end{array}$ & $\begin{array}{l}\text { A vs. B } \\
4.5 \text { month } \\
\text { Beck Depression } \\
\text { Inventory (0-63): } 12.6 \\
\text { vs. } 12.8 \\
\text { SF-36 physical } \\
\text { functioning (0-100): } \\
57.3 \text { vs. } 52.2 \\
\text { SF-36 social functioning } \\
\text { (0-100): } 66.7 \text { vs. } 61.5 \\
\text { SF-36 emotional role } \\
\text { limitations (0-100): } 63.0 \\
\text { vs. } 62.0 \\
\text { SF-36 pain (0-100): } \\
48.8 \text { vs. } 44.4 \\
\text { SF-36 mental health (0- } \\
\text { 100): } 64.4 \text { vs. } 67.7 \\
\text { SF-36 general health } \\
\text { perception (0-100): } 52.4 \\
\text { vs. } 55.0\end{array}$ \\
\hline $\begin{array}{l}\text { Turner, } \\
1990^{109} \\
12 \text { months } \\
\text { Duration of } \\
\text { pain: } 12.9 \\
\text { years } \\
\text { Poor }\end{array}$ & $\begin{array}{l}\text { A. Operant therapy } \\
(n=25), 8 \text { sessions } \\
\text { over } 8 \text { weeks } \\
\text { B. Exercise }(n=24)\end{array}$ & $\begin{array}{l}\text { Overall } \\
\text { Age: } 44 \\
\text { Female: } 48 \% \\
\text { A vs. B } \\
\text { Baseline } \\
\text { function (0- } \\
100 \text { SIP): } 7.9 \\
\text { vs. } 8.4 \\
\text { Baseline pain } \\
\text { (0-78 McGill } \\
\text { Pain Rating): } \\
21.0 \text { vs. } 19.4\end{array}$ & $\begin{array}{l}\text { A vs. B } \\
\underline{6 \text { months }} \\
\text { Sickness Impact Profile (0-100 } \\
\text { SIP): } 7.6 \text { vs. } 6.3 \\
\text { McGill Pain Questionnaire Pain } \\
\text { Rating Index (0-78): } 19.5 \text { vs. } 15.7 \\
12 \text { months } \\
\text { Sickness Impact Profile (0-100 } \\
\text { SIP): } 5.3 \text { vs. } 4.7 \\
\text { McGill Pain Questionnaire Pain } \\
\text { Rating Index: } 16.4 \text { vs. } 14.9\end{array}$ & $\begin{array}{l}\text { A vs. B } \\
6 \text { months } \\
\text { CES-D Scale }(0-60): \\
11.4 \text { vs. } 9.3 \\
\frac{12 \text { months }}{\text { CES-D Scale: } 8.3 \text { vs. }} \\
9.3\end{array}$ \\
\hline
\end{tabular}

BDI = Beck Depression Inventory; CBT = cognitive-behavioral therapy; CES-D = Center for Epidemiologic Studies-Depression; $\mathrm{CI}=$ confidence interval; MCS = Mental Component Score; NHP = Nottingham Health Profile; NR = not reported; ODI = Oswestry Disability Index; PCS = Physical Component Score; RDQ = Roland-Morris Disability Questionnaire; SF-36, ShortForm 36 Questionnaire; SIP = Sickness Impact Profile; VAS = visual analog scale

${ }^{\text {a }}$ Unless otherwise noted, followup time is calculated from the end of the treatment period

\section{Psychological Therapy Compared With Usual Care or an Attention Control}

Psychological therapy was associated with slightly greater effects on function than usual care or an attention control at short-term ( 3 trials, pooled SMD $-0.25,95 \%$ CI -0.38 to -0.12 , $\left.\mathrm{I}^{2}=0 \%\right),{ }^{89,91,93}$ intermediate-term ( 3 trials, pooled SMD $-0.25,95 \%$ CI -0.37 to $\left.-0.13, \mathrm{I}^{2}=0 \%\right),{ }^{89-}$ 91 and long-term followup ( 3 trials, pooled SMD $-0.27,95 \%$ CI -0.39 to $-0.15, \mathrm{I}^{2}=0 \%$ ) (Figure 6). ${ }^{90,91,165}$ Pooled differences on the RDQ or modified RDQ were -1.2 to -1.4 points at all time points. For short-term function, two fair-quality trials ${ }^{89,91,92}$ evaluated CBT and one poor-quality trial ${ }^{93}$ evaluated respondent therapy (progressive relaxation). Excluding the poorquality trial of progressive relaxation, ${ }^{93}$ which found no effect on short-term function (SMD -0.08 , 95\% CI -0.48 to 0.31 ), had no effect on the pooled estimate (2 trials, pooled SMD -0.27 , $95 \%$ CI -0.43 to -0.06$)$. 
Psychological therapy was associated with slightly greater effects on pain than usual care or an attention control at short-term ( 3 trials, pooled difference -0.76 on a 0 to 10 scale, $95 \%$ CI -0.99 to $\left.-0.53, \mathrm{I}^{2}=0 \%\right),{ }^{89,91,93}$ intermediate-term (3 trials, pooled difference $-0.71,95 \% \mathrm{CI}-0.94$ to $\left.-0.48, \mathrm{I}^{2}=0 \%\right),{ }^{89-91}$ or long-term followup ( 3 trials, pooled difference $-0.53,95 \% \mathrm{CI}-0.78$ to $-0.27, \mathrm{I}^{2}=0 \%$ ) (Figure 7). ${ }^{90,92,165}$ Excluding a poor-quality trial of progressive relaxation, which found no effect on short-term function (MD $-0.14,95 \% \mathrm{CI}-1.28$ to 1.00 ), did not change the pooled estimate ( 2 trials, pooled difference -0.78 , 95\% CI -1.06 to -0.49 ). For intermediateterm and long-term pain, all trials were fair quality and evaluated CBT.

Effects of psychological therapy on short-term or intermediate-term SF-36 Physical Component (PCS) or Mental Component (MCS) scores were small (differences 0 to 2 points on a 0 to 100 scale) and not statistically significant, except for short-term MCS (2 trials, pooled difference 2.12, 95\% CI 0.79 to 3.45) ${ }^{89,91}$ One trial found no effect of psychological therapy on work status or health care visits ${ }^{92}$ and one trial found no effect of psychological therapy on markers of health care utilization. ${ }^{166}$

\section{Psychological Therapy Compared With Pharmacological Therapy}

No trial of psychological versus pharmacological therapy met inclusion criteria.

\section{Psychological Therapy Compared With Exercise}

One poor-quality trial found no differences between psychological versus exercise therapy in intermediate-term or long-term function. ${ }^{109}$ Differences on the McGill Pain Questionnaire were less than 0.5 points on a 0 to 78 scale, and differences on the Sickness Impact Profile were 0.60 to 1.30 points on a 0 to 100 scale.

\section{Harms}

Data on harms were sparse. One trial reported no serious adverse events and one withdrawal due to adverse events among 468 patients randomized to CBT. ${ }^{91,92}$ 
Figure 6. Psychological therapy versus usual care or an attention control for chronic low back pain: effects on function

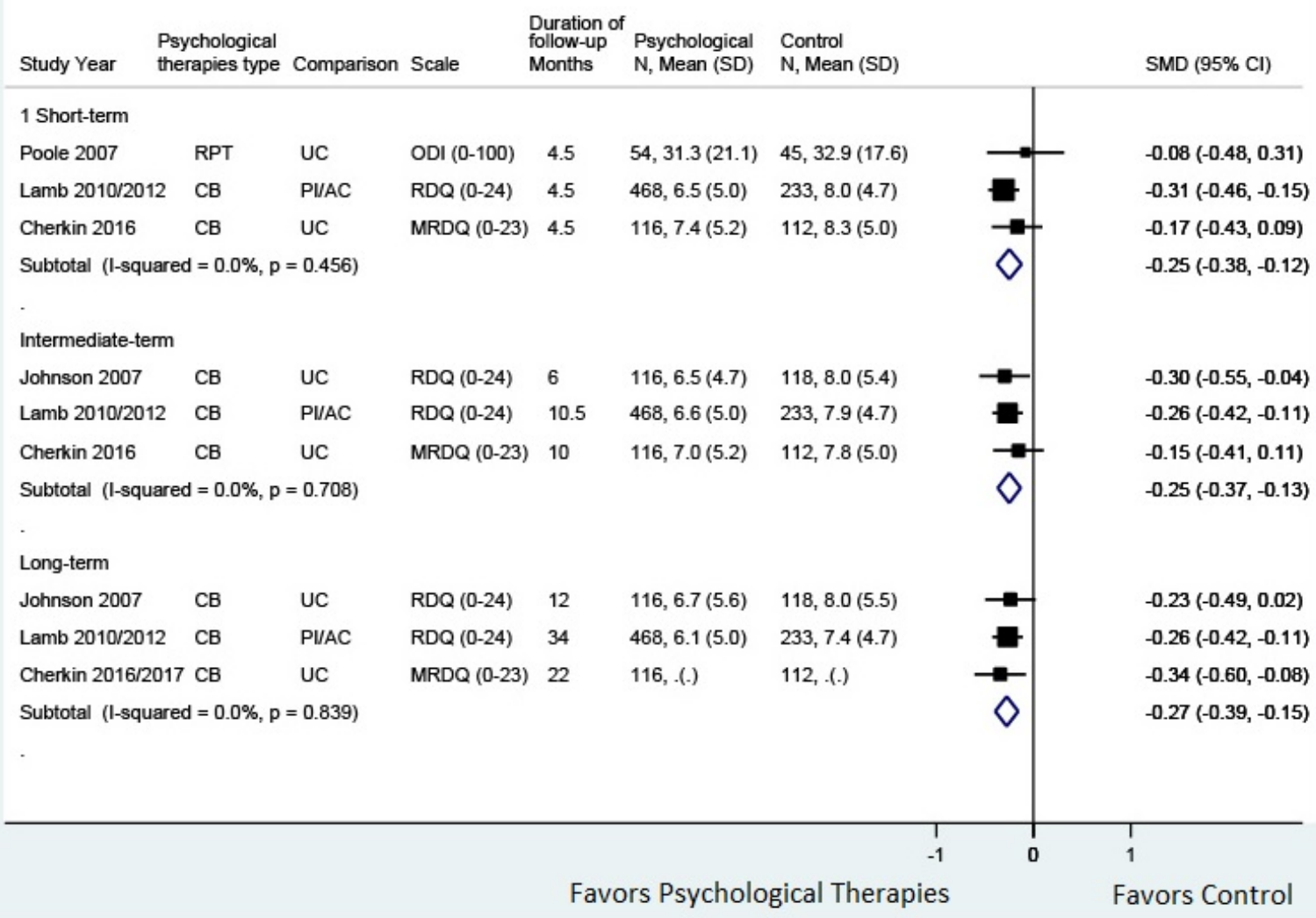

$\mathrm{AC}=$ attention control; $\mathrm{CB}=$ cognitive-behavioral therapy; $\mathrm{CI}=$ confidence interval; $\mathrm{MRDQ}=$ Modified Roland-Morris Disability Questionnaire; N = number; ODI = Oswestry Disability Index; PI = placebo intervention; RDQ = Roland-Morris Disability Questionnaire; RPT = respondent therapy (progressive relaxation); SD = standard deviation; SMD = standardized mean difference; $\mathrm{UC}=$ usual care 
Figure 7. Psychological therapy versus usual care or an attention control for chronic low back pain: effects on pain

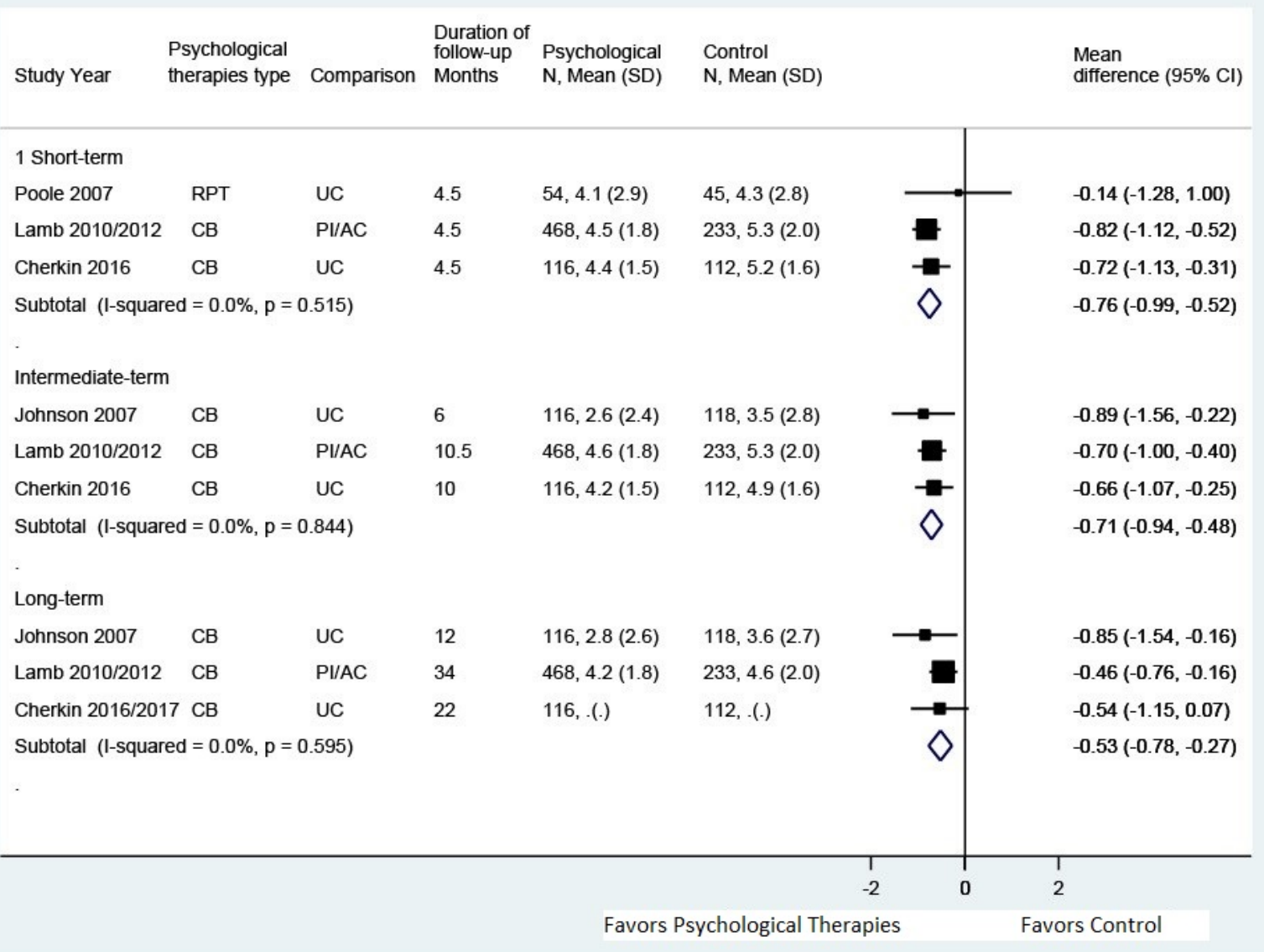

$\mathrm{AC}=$ attention control $\mathrm{CB}=$ cognitive-behavioral therapy; $\mathrm{CI}=$ confidence interval; $\mathrm{N}=$ number; $\mathrm{PI}=$ placebo intervention; $\mathrm{RPT}=$ respondent therapy (progressive relaxation); $\mathrm{SD}=$ standard deviation; $\mathrm{UC}=$ usual care

\section{Physical Modalities for Chronic Low Back Pain}

\section{Key Points}

\section{Ultrasound}

- Two trials found inconsistent effects of ultrasound versus sham ultrasound on short-term function (SOE: insufficient).Two trials found no differences between ultrasound versus sham ultrasound in short-term pain (SOE: low).

- One trial found no differences between ultrasound versus sham ultrasound in risk of any adverse events or risk of serious adverse events (SOE: low).

\section{Low-Level Laser Therapy}

- One trial found low-level laser therapy associated with moderately greater effects than sham laser on short-term pain (MD -16.0 on a 0 to 100 scale, $95 \%$ CI -28.3 to -3.7 ) and slightly greater effects on function (MD -8.2 on the 0 to 100 ODI, 95\% CI -13.6 to -2.8 ) (SOE: low). 
- One trial found no differences between low-level laser therapy versus exercise therapy in intermediate-term function or pain (SOE: low).

- One trial of low-level laser therapy reported no adverse events (SOE: low).

\section{Traction}

- Two trials found no differences between traction versus sham traction in short-term pain or function (SOE: low).

- Harms were not reported in either trial.

\section{Short-Wave Diathermy}

- Data from a small, poor-quality trial were insufficient to determine effects of short-wave diathermy versus sham (detuned) diathermy (SOE: insufficient).

\section{Detailed Synthesis}

\section{Ultrasound}

Two trials ( $n=50$ and $n=455$ ) of ultrasound versus sham ultrasound for low back pain met inclusion criteria (Table 7 and Appendix D). ${ }^{115,116}$ The duration of ultrasound therapy was 4 and 8 weeks and the number of sessions was 6 and 10. Both trials evaluated outcomes at short-term (1 month) followup. One good-quality trial ${ }^{116}$ was conducted in the United States and one fairquality trial $^{115}$ in Iran (Appendix E). Methodological limitations in the fair-quality trial included failure to blind care providers and unclear blinding of outcome assessors.

Table 7. Chronic low back pain: physical modalities (ultrasound)

\begin{tabular}{|c|c|c|c|c|}
\hline $\begin{array}{l}\text { Author, Year, } \\
\text { Followup, } \\
\text { Pain } \\
\text { Duration, } \\
\text { Study } \\
\text { Quality }\end{array}$ & Intervention & Population & Function and Pain Outcomes & Other Outcomes \\
\hline $\begin{array}{l}\text { Ebadi, } 2012^{115} \\
1 \text { month } \\
\text { Duration of } \\
\text { pain: Mean } 6 \\
\text { to } 8 \text { years } \\
\text { Fair }\end{array}$ & $\begin{array}{l}\text { A. Ultrasound } \\
(\mathrm{n}=25), 1.5 \mathrm{~W} / \mathrm{cm}^{2} \\
\text { at } 1 \mathrm{MHz}, 10 \\
\text { sessions over } 4 \\
\text { weeks } \\
\begin{array}{l}\text { B. Sham ultrasound } \\
(\mathrm{n}=25)\end{array}\end{array}$ & $\begin{array}{l}\text { A vs. B } \\
\text { Age: } 31 \text { vs. } 37 \\
\text { years } \\
\text { Female: } 25 \% \\
\text { vs. } 50 \% \\
\text { Functional } \\
\text { Rating Index } \\
\text { (mean, 0-100): } \\
41 \text { vs. } 44 \\
\text { Pain intensity } \\
\text { (mean, } 0-100 \\
\text { VAS): } 47 \text { vs. } \\
49\end{array}$ & $\begin{array}{l}\text { A vs. B } \\
1 \text { month } \\
\text { Functional Rating Index }(0-40): \\
22.8 \text { vs. } 30.5 ; P=0.004 \\
\text { Pain }(0-100 \text { VAS): } 27.7 \text { vs. } \\
25.5 ; P=0.48\end{array}$ & \\
\hline
\end{tabular}




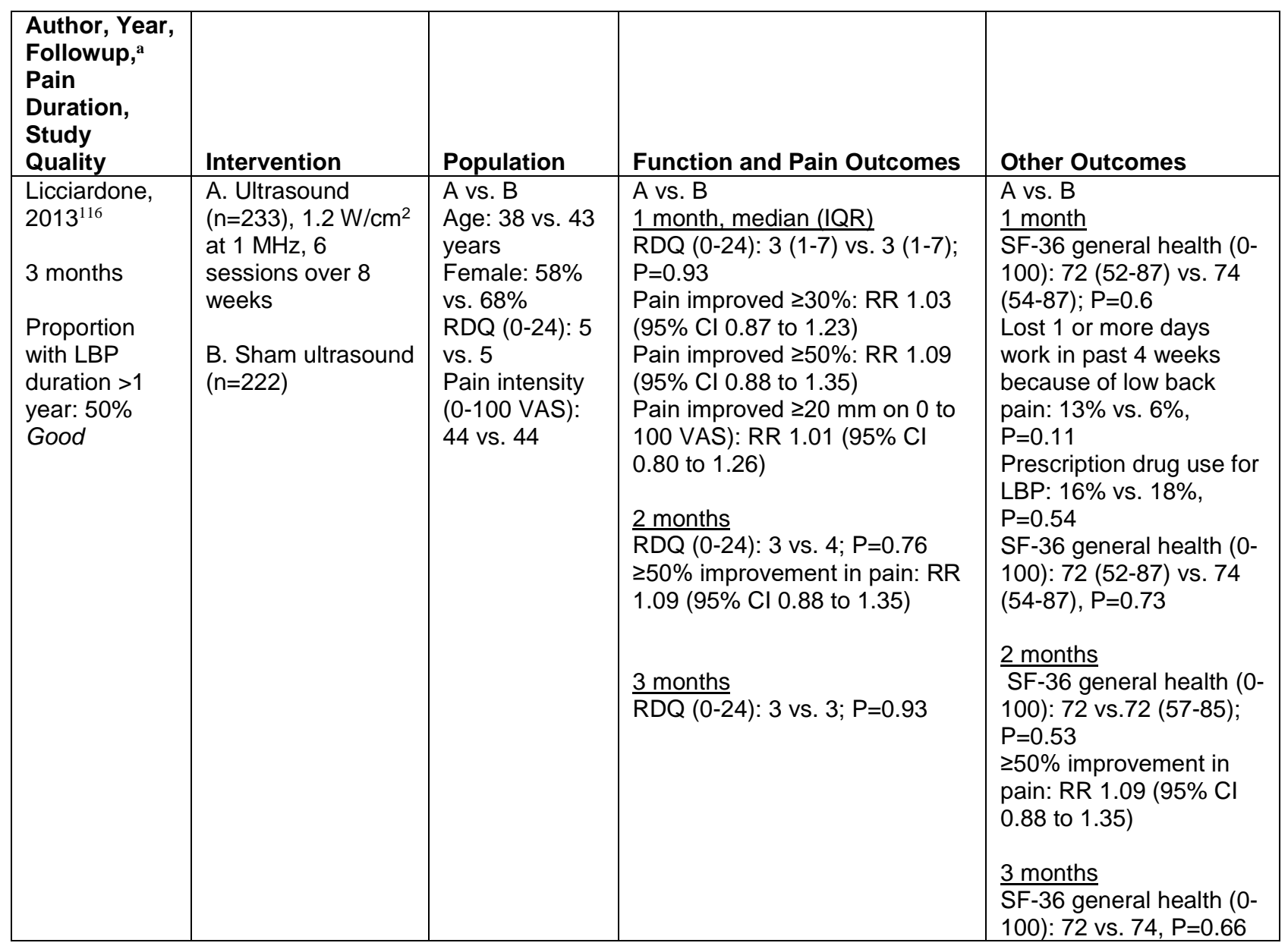

CI = confidence interval; NR = not reported; RDQ = Roland-Morris Disability Questionnaire; RR = relative risk; SF-36 = ShortForm 36 Questionnaire; VAS = visual analog scale

a Unless otherwise noted, followup time is calculated from the end of the treatment period

\section{Ultrasound Compared With Sham Ultrasound}

Limited evidence indicated no clear differences between ultrasound versus sham ultrasound at short-term followup. One good-quality trial $(\mathrm{n}=455)$ found no difference between ultrasound versus sham ultrasound in the RDQ (median 3 vs. $3, \mathrm{P}=0.93$ ), likelihood for $\geq 50$ percent improvement in pain (RR 1.09, 95\% CI 0.88 to 1.35), SF-36 general health (median 72 vs. 74), likelihood of prescription drug use for low back pain ( $16 \%$ vs. $18 \%, \mathrm{P}=0.54)$, or risk of serious adverse events ( $1.3 \%$ vs. $2.7 \%$, RR $0.48,95 \%$ CI 0.12 to 1.88 ) or any adverse event (6.0\% vs. $5.9 \%$, RR $1.03,95 \%$ CI 0.49 to 2.13$).{ }^{116}$ In the smaller $(n=50)$ fair-quality trial, there was no difference between ultrasound versus sham ultrasound in pain (mean 27.7 vs. 25.5 on a 0 to 100 scale, $\mathrm{P}=0.48$ ), although ultrasound was associated with better function (mean $22.8 \mathrm{vs.} 30.5$ on the 0 to 40 Functional Rating Index, $\mathrm{P}=0.004) .{ }^{115}$ No trial evaluated longer-term outcomes.

\section{Ultrasound Compared With Pharmacological Therapy or With Exercise}

No trial of ultrasound versus pharmacological therapy or versus exercise met inclusion criteria. 


\section{Harms}

One trial found no differences between ultrasound versus sham ultrasound in risk of any adverse event (RR 1.03, 95\% CI 0.49 to 2.13) or serious adverse event (RR $0.48,95 \%$ CI 0.12 to 1.88). ${ }^{116}$

\section{Low-Level Laser Therapy}

Three trials of low-level laser therapy $(n=34,56$, and 71) met inclusion criteria (Table 8 and Appendix D). ${ }^{117,118,143}$ One trial ${ }^{118}$ evaluated neodymium:yttrium-aluminum-garnet (Nd:YAG) laser and two trials ${ }^{117,143}$ evaluated gallium-arsenide (GaAs) laser. Two trials compared low-level laser therapy versus sham laser therapy ${ }^{117,118}$ and one trial low-level laser therapy versus exercise plus sham laser. ${ }^{143}$ One trial was conducted in the United States, ${ }^{118}$ one in Iran, ${ }^{143}$ and one in Argentina. ${ }^{117}$ The duration of laser therapy ranged from 2 to 6 weeks and the number of sessions ranged from 10 to 12 . One trial ${ }^{117}$ reported intermediate-term outcomes and the other two trials reported short-term outcomes.

Two trials ${ }^{118,143}$ were rated fair quality and one trial ${ }^{117}$ poor quality (Appendix E). The major methodological limitation in the fair-quality trials was unclear allocation concealment methods. ${ }^{118,143}$ The poor-quality trial also did not report randomization methods, did not conduct intention-to-treat analysis at intermediate-term followup, and reported high attrition; it was also unclear if timing of followup was the same in all patients. ${ }^{117}$

Table 8. Chronic low back pain: physical modalities (low-level laser therapy)

\begin{tabular}{|c|c|c|c|c|}
\hline $\begin{array}{l}\text { Author, Year, } \\
\text { Followup, } \\
\text { Pain } \\
\text { Duration, } \\
\text { Study } \\
\text { Quality }\end{array}$ & Intervention & Population & Function and Pain Outcomes & Other Outcomes \\
\hline $\begin{array}{l}\text { Basford, } \\
1999^{118} \\
2 \text { months } \\
\text { Duration of } \\
\text { pain: } 4.5 \text { vs. } \\
6.5 \text { months } \\
\text { Fair }\end{array}$ & $\begin{array}{l}\text { A. Nd:YAG laser } \\
\left(542 \mathrm{~mW} / \mathrm{cm}^{2}, 90\right. \\
\text { seconds, two sites, } \\
\text { applied to eight } \\
\text { points along } \mathrm{L} 2 \text { to } \\
\text { S3 paraspinal } \\
\text { tissues) ( } \mathrm{n}=27) 12 \\
\text { sessions over } 4 \\
\text { weeks } \\
\text { B. Sham laser } \\
(\mathrm{n}=29)\end{array}$ & $\begin{array}{l}\text { A vs. B } \\
\text { Age: } 48 \text { vs.48 } \\
\text { years } \\
\text { Female: } 40 \% \\
\text { vs. } 55 \% \\
\text { Baseline ODI: } \\
21 \text { vs. } 25 \\
\text { Baseline } \\
\text { maximal pain, } \\
\text { last } 24 \text { hours } \\
\text { (0-100 VAS): } \\
35.2 \text { vs. } 37.4\end{array}$ & $\begin{array}{l}\text { A vs. B } \\
2 \text { months } \\
\text { ODI (0-100): } 14.7 \text { vs. } 22.9 \text {, } \\
\text { difference }-8.2(95 \% \mathrm{Cl}-13.6 \text { to } \\
-2.8) ; \mathrm{P}=0.004 \\
\text { Maximal pain in last } 24 \text { hours } \\
\text { (0-100 VAS): } 19.1 \text { vs. } 35.1 \text {, } \\
\text { difference }-16.0(95 \% \mathrm{Cl}-28.3 \\
\text { to }-3.7) ; \mathrm{P}=0.012\end{array}$ & $\begin{array}{l}\text { A vs. B } \\
2 \text { months } \\
\text { Patient perception of } \\
\text { benefit (VAS, lower = } \\
\text { less pain): } 28.3 \text { vs. } 37.8 \\
(95 \% \mathrm{Cl}-20.9 \text { to } 1.9) ; \\
P=0.101\end{array}$ \\
\hline
\end{tabular}




\begin{tabular}{|c|c|c|c|c|}
\hline $\begin{array}{l}\text { Author, Year, } \\
\text { Followup, } \\
\text { Pain } \\
\text { Duration, } \\
\text { Study } \\
\text { Quality }\end{array}$ & Intervention & Population & Function and Pain Outcomes & Other Outcomes \\
\hline $\begin{array}{l}\text { Djavid, } \\
2007^{143} \\
1.5 \text { months } \\
\text { Duration of } \\
\text { pain: } 29 \\
\text { months vs. } 29 \\
\text { months vs. } 25 \\
\text { months } \\
\text { Fair }\end{array}$ & $\begin{array}{l}\text { A. GaAs laser } \\
\text { (wavelength } 810 \\
\text { nm, } 50 \mathrm{~mW} \text { wave, } \\
\text { and } 0.2211 \mathrm{~cm}^{2} \\
\text { spot area laser } \\
\text { applied to } 8 \text { points } \\
\text { along L2 to S2-S3 } \\
\text { paraspinal tissues, } \\
\text { dose } 27 \mathrm{~J} / \mathrm{cm}^{2} \text { ) } \\
\text { (n=16) } \\
12 \text { sessions over } 6 \\
\text { weeks } \\
\text { B. Low-level laser } \\
\text { therapy plus } \\
\text { exercise (n=19) } \\
\text { C. Exercise plus } \\
\text { sham laser } \\
\text { (strengthening, } \\
\text { stretching, } \\
\text { mobilizing, } \\
\text { coordination) } \\
\text { (n=18) }\end{array}$ & $\begin{array}{l}\text { A vs. B vs. C } \\
\text { Age: } 40 \text { vs. } 38 \\
\text { vs. } 36 \text { years } \\
\text { Female: } 5 \% \text { vs. } \\
7 \% \text { vs. } 2 \% \\
\text { Baseline ODI } \\
(0-100): 33.0 \\
\text { vs. } 31.8 \\
\text { Baseline pain } \\
(0-10 \text { VAS): } 7.3 \\
\text { vs. } 6.3\end{array}$ & $\begin{array}{l}\text { A vs. C } \\
1.5 \text { months } \\
\text { ODI }(0-100): 20.8 \text { vs. } 24.1, \\
\text { difference in change from } \\
\text { baseline }-4.4(95 \% \mathrm{Cl}-11.4 \text { to } \\
2.5) \\
\text { Pain (0-10 VAS): } 4.4 \text { vs. } 4.3 \text {, } \\
\text { difference in change from } \\
\text { baseline }-0.9 \text { ( } 95 \% \mathrm{Cl}-2.5 \text { to } \\
0.7) \\
\text { A vs. B } \\
1.5 \text { months } \\
\text { ODI (0-100): } 20.8 \text { vs. } 16.8 \\
\text { difference in change from } \\
\text { baseline }-4.4(95 \% \mathrm{Cl}-11.4 \text { to } \\
2.5) \\
\text { Pain (0-10 VAS): } 4.4 \text { vs. } 2.4, \\
\text { difference in change from } \\
\text { baseline }-0.9(95 \% \mathrm{Cl}-2.5 \text { to } \\
0.7)\end{array}$ & NR \\
\hline $\begin{array}{l}\text { Soriano, } \\
1998^{117} \\
6 \text { months } \\
\text { Duration of } \\
\text { pain: greater } \\
\text { than } 3 \text { months } \\
\text { Poor }\end{array}$ & $\begin{array}{l}\text { A GaAs laser } \\
\text { (wavelength } 904 \\
\text { nm, pulse } \\
\text { frequency } 10,000 \\
\mathrm{~Hz}, \text { pulse width } 200 \\
\text { nsec, peak power } \\
20 \mathrm{~W}, \text { average } \\
\text { power } 40 \mathrm{~mW}, \\
\text { administered at } \\
\text { dose of } 4 \mathrm{~J} / \mathrm{cm}^{2} \text { per } \\
\text { point to pain areas) } \\
\text { ( } \mathrm{n}=38 \text { ) } \\
10 \text { sessions over } 5 \\
\text { weeks } \\
\text { B. Sham laser } \\
(\mathrm{n}=33 \text { ) }\end{array}$ & $\begin{array}{l}\text { A vs. B } \\
\text { Age: } 63 \text { vs. } 64 \\
\text { years } \\
\text { Female: } 58 \% \\
\text { vs. } 52 \% \\
\text { Baseline } \\
\text { function: NR } \\
\text { Baseline pain } \\
\text { (1 to 10): } 7.9 \\
\text { vs. } 8.1\end{array}$ & $\begin{array}{l}6 \text { months } \\
\text { No pain: } 44.7 \% \text { vs. } 15 \% \text {; } \\
P<0.01\end{array}$ & $\begin{array}{l}\text { Pain recurrence in } \\
\text { subgroup of patients } \\
\text { with a good or excellent } \\
\text { response at end of } \\
\text { treatment: } 35 \% \text { vs. } \\
70 \% ; P=N R\end{array}$ \\
\hline
\end{tabular}

CI =confidence interval; NR = not reported; ODI = Oswestry Disability Index; RDQ, Roland-Morris Disability Questionnaire; VAS = visual analog scale

${ }^{\text {a }}$ Unless otherwise noted, followup time is calculated from the end of the treatment period

\section{Low-Level Laser Therapy Compared With Sham Laser}

One fair-quality trial found Nd:YAG laser therapy associated with moderately lower pain (difference -16.0 on a 0 to 100 scale, $95 \%$ CI -28.3 to -3.7 ) and slightly better function (difference -8.2 points on the 0 to $100 \mathrm{ODI}, 95 \% \mathrm{CI}-13.6$ to -2.8 ) at short-term followup. ${ }^{118} \mathrm{~A}$ poor-quality trial found GaAs laser therapy associated with increased likelihood of having no pain at intermediate-term followup ( $44.7 \%$ vs. $15 \%, \mathrm{P}<0.01)$, but the analysis was restricted to patients who reported that laser therapy was effective at the end of a 2-week course of treatment. ${ }^{117}$ 


\section{Low-Level Laser Therapy Compared With Pharmacological Therapy}

No trial of low-level laser therapy compared with pharmacological therapy met inclusion criteria.

\section{Low-Level Laser Therapy Compared With Exercise Therapy}

One fair-quality trial found no clear differences between GaAs laser therapy versus exercise plus sham laser in function (difference in change from baseline -4.4 on the 0 to $100 \mathrm{ODI}, 95 \%$ CI -11.4 to 2.5 ) or pain (difference in change from baseline -0.9 on a 0 to 10 scale, $95 \%$ CI -2.5 to 0.7 ) at intermediate-term followup. ${ }^{143}$ For pain, the difference at followup was similar to the baseline difference (mean 7.3 vs. 6.3), and final scores were very similar (4.4 vs. 4.3 ).

\section{Harms}

No adverse events were reported in any of the three trials of low-level laser therapy. ${ }^{117,118,143}$

\section{Traction}

Two trials of traction ( $\mathrm{n}=151$ and 60) met inclusion criteria (Table 9 and Appendix D). ${ }^{113,114}$ One trial ${ }^{113}$ evaluated continuous traction (12 sessions in 5 weeks) and the other ${ }^{114}$ evaluated intermittent traction (20 sessions in 6 weeks). The comparator in both trials was sham traction (traction at $<10 \%$ or $20 \%$ of body weight, compared with $35 \%$ to $50 \%$ for active traction). Both trials were conducted in the Netherlands and reported only short-term outcomes. The trials were rated fair quality due to failure to blind care providers (Appendix E).

Table 9. Chronic low back pain: physical modalities (traction)

\begin{tabular}{|c|c|c|c|c|}
\hline $\begin{array}{l}\text { Author, Year, } \\
\text { Followup, } \\
\text { Pain } \\
\text { Duration, } \\
\text { Study } \\
\text { Quality }\end{array}$ & Intervention & Population & Function and Pain Outcomes & Other Outcomes \\
\hline $\begin{array}{l}\text { Beurskens, } \\
1997^{113} \\
1.75 \text { and } 5 \\
\text { months } \\
\text { Duration of } \\
\text { pain: } 1.5 \\
\text { months } \\
\text { Fair }\end{array}$ & $\begin{array}{l}\text { A. Continuous } \\
\text { traction }(n=77) \\
\text { B. Sham traction } \\
(20 \% \text { body weight }) \\
(n=74) \\
12 \text { sessions, } 5 \\
\text { weeks }\end{array}$ & $\begin{array}{l}\text { A vs. B } \\
\text { Age: } 39 \text { vs. } 42 \\
\text { years } \\
\text { Female: } 44 \% \\
\text { vs. } 43 \% \\
\text { Baseline RDQ } \\
\text { (0-24): } 2 \text { vs. } 12 \\
\text { Baseline pain } \\
\text { (0-100 VAS): } \\
61 \text { vs. } 55\end{array}$ & $\begin{array}{l}\text { A vs. B } \\
1.75 \text { months } \\
\text { RDQ: } 4.4 \text { vs. } 4.3 \text {, difference } 0.1 \\
\text { (95\% } \mathrm{Cl}-1.8 \text { to } 1.9) \\
\text { Pain at the moment (0-100 } \\
\text { VAS): } 28.5 \text { vs. } 22.8 \text {, difference } \\
5.7 \text { ( } 95 \% \mathrm{Cl}-4.6 \text { to } 15.9 \text { ) } \\
5 \text { months } \\
\text { RDQ: } 4.7 \text { vs. } 4.0 \text {, difference } 0.7 \\
\text { (95\% } \mathrm{Cl}-1.1 \text { to } 2.6 \text { ) } \\
\text { Pain at the moment (0-100 } \\
\text { VAS): } 23.8 \text { vs. } 20.1 \text {, difference } \\
\text { 3.7 ( } 95 \% \mathrm{Cl}-8.4 \text { to } 15.8 \text { ) }\end{array}$ & $\begin{array}{l}\text { A vs. B } \\
1.75 \text { months } \\
\text { ADL disability ( } 0 \text { to } 100 \\
\text { VAS): } 27.1 \text { vs. } 29.4, \\
\text { difference }-2.4 \text { ( } 95 \% \mathrm{Cl} \\
-13.6 \text { to } 8.9 \text { ) } \\
\text { Work absence (days): } \\
23.5 \text { vs. } 27.8 \text {, difference } \\
-4.3 \text { (95\% } \mathrm{Cl}-14.7 \text { to } \\
6.1 \text { ) } \\
\text { Medical consumption: } \\
34 \% \text { vs. } 25 \% \text {, difference } \\
9 \% \text { (95\% } \mathrm{Cl}-6 \text { to } 24) \\
5 \text { months } \\
\text { ADL disability: } 25.7 \text { vs. } \\
25.8, \text { difference } 0.1 \\
\text { (95\% Cl -11.5.0 to } \\
11.2) \\
\text { Work absence (days): } \\
35.7 \text { vs. } 43.7, \text { difference } \\
-8.0 \text { (95\% } \mathrm{Cl}-27 \text { to } 11 \text { ) } \\
\text { Medical consumption: } \\
45 \% \text { vs. } 42 \% \text {, difference } \\
3 \% \text { (95\% Cl }-13 \% \text { to } \\
19 \% \text { ) }\end{array}$ \\
\hline
\end{tabular}




\begin{tabular}{|c|c|c|c|c|}
\hline $\begin{array}{l}\text { Author, Year, } \\
\text { Followup, } \\
\text { Pain } \\
\text { Duration, } \\
\text { Study } \\
\text { Quality }\end{array}$ & Intervention & Population & Function and Pain Outcomes & Other Outcomes \\
\hline $\begin{array}{l}\text { Schimmel, } \\
2009^{114} \\
2 \text { months } \\
\text { Duration of } \\
\text { pain: } 1 \text { year } \\
\text { Fair }\end{array}$ & $\begin{array}{l}\text { A. Intermittent } \\
\text { traction }(n=31) \\
\text { B. Sham traction } \\
\text { (<10\% body } \\
\text { weight) }(n=29) \\
20 \text { sessions, } 6 \\
\text { weeks }\end{array}$ & $\begin{array}{l}\text { A vs. B } \\
\text { Age (mean): } 42 \\
\text { vs. } 46 \text { years } \\
\text { Female: } 39 \% \\
\text { vs. } 52 \% \\
\text { Baseline ODI: } \\
36 \text { vs. } 33 \\
\text { Baseline back } \\
\text { pain (0-100 } \\
\text { VAS): } 61 \text { vs. } \\
53\end{array}$ & $\begin{array}{l}\text { A vs. B } \\
2 \text { months } \\
\text { ODI }(0-100): 25 \text { vs. } 23 \text { (SD, P } \\
\text { not reported) } \\
\text { Pain (0-100 VAS): } 32 \text { vs. } 36 ; \\
P=0.70\end{array}$ & $\begin{array}{l}\text { A vs. B } \\
2 \text { months } \\
\text { SF-36, total (0-100): } 66 \\
\text { vs. } 65 \text { (SD, P-value not } \\
\text { reported) }\end{array}$ \\
\hline
\end{tabular}

ADL = activities of daily living; CI = confidence interval; ODI = Oswestry Disability Index; RDQ = Roland-Morris Disability Questionnaire; SD = standard deviation; SF-36 =Short-Form 36 Questionnaire; VAS = visual analog scale

${ }^{a}$ Unless otherwise noted, followup time is calculated from the end of the treatment period

\section{Traction Compared With Sham Traction}

There were no differences between traction versus sham traction at short-term followup in function ( 25 vs. 23 on the 0 to $100 \mathrm{ODI}$ in one trial and 4.7 vs. 4.0 on the 0 to $24 \mathrm{RDQ}$, difference $0.7,95 \% \mathrm{CI}-1.1$ to 2.6 ) or pain (32 vs. 36 on a 0 to 100 scale, $\mathrm{P}=0.70$ and 24 vs. 20 , difference $3.7,95 \%$ CI -8.4 to 15.8$).{ }^{113,114}$ One trial ${ }^{114}$ also found no difference between intermittent traction versus sham on the total SF-36 (66 vs. 65 on a 0 to 100 scale) and one trial $^{113}$ found no difference between continuous traction versus sham in global perceived effect, work absence, or medical consumption.

\section{Traction Compared With Pharmacological Therapy or With Exercise}

No trial of low-level laser therapy compared with pharmacological therapy or with exercise met inclusion criteria.

\section{Harms}

Neither trial reported harms.

\section{Short-Wave Diathermy}

Data were insufficient from one poor-quality trial $(n=68)$ to evaluate effects of short-wave diathermy (3 times weekly for 4 weeks) versus sham (detuned) diathermy for low back pain (Table 10 and Appendix D). ${ }^{119}$ Methodological limitations included unclear randomization and allocation concealment methods, differential attrition, and baseline differences between groups (Appendix E). Although diathermy was associated with worse pain than sham treatment at shortterm (8 weeks after completion of therapy) followup (25 vs. 13); statistical significance was not reported. There were no statistically significant differences in likelihood of using analgesics ( $7 \%$ vs. $22 \%$, RR $0.34,95 \%$ CI 0.08 to 1.50 ) or being unable to work or having limited activities ( $7 \%$ vs. $19 \%$, RR $0.40,95 \%$ CI 0.09 to 1.80 ), but estimates were imprecise.

\section{Harms}

Adverse events were not evaluated in the trial. 
Table 10. Chronic low back pain: physical modalities (short-wave diathermy)

\begin{tabular}{|c|c|c|c|c|}
\hline $\begin{array}{l}\text { Author, Year, } \\
\text { Followup, } \\
\text { Pain } \\
\text { Duration, } \\
\text { Study } \\
\text { Quality }\end{array}$ & Intervention & Population & Function and Pain Outcomes & Other Outcomes \\
\hline $\begin{array}{l}\text { Gibson, } \\
1985^{119} \\
2 \text { months } \\
\text { Duration of } \\
\text { pain: } 2 \text { to } 12 \\
\text { months } \\
\text { Poor }\end{array}$ & $\begin{array}{l}\text { A. Short wave } \\
\text { diathermy (active } \\
\text { SWD) }(n=34), 12 \\
\text { sessions, } 3 \\
\text { session/per week } \\
\text { for } 4 \text { weeks } \\
\text { B. Placebo } \\
(\text { detuned SWD) } \\
(n=34)\end{array}$ & $\begin{array}{l}\text { A vs. B } \\
\text { Age: } 35 \text { vs. } 40 \\
\text { years } \\
\text { Female: } 47 \% \\
\text { vs. } 32 \% \\
\text { Pain (0-100 } \\
\text { VAS): } 45 \text { vs. } \\
48\end{array}$ & $\begin{array}{l}\text { A vs. B } \\
2 \text { months } \\
\text { Pain (0-100 VAS, median): } 25 \\
\text { vs. } 13 \text { (IQR not reported) } \\
\text { Unable to work or with limited } \\
\text { activities: } 7 \% \text { vs. } 19 \% \text { RR } 0.40 \text {, } \\
95 \% \text { CI } 0.09 \text { to } 1.80\end{array}$ & $\begin{array}{l}\text { A vs. B } \\
2 \text { months } \\
\text { Using analgesics: } 7 \% \\
\text { vs. } 22 \%, \text { RR } 0.34,95 \% \\
\text { Cl } 0.08 \text { to } 1.50\end{array}$ \\
\hline
\end{tabular}

$\mathrm{CI}$ = confidence interval; IQR = interquartile range; RR = relative risk; SWD = short wave diathermy; VAS = visual analog scale

${ }^{a}$ Unless otherwise noted, followup time is calculated from the end of the treatment period

\section{Manual Therapies for Chronic Low Back Pain}

\section{Key Points}

\section{Spinal Manipulation}

- Spinal manipulation was associated with slightly greater effects than sham manipulation, usual care, an attention control, or a placebo intervention in short-term function (3 trials, pooled SMD $-0.34,95 \%$ CI -0.63 to $-0.05, \mathrm{I}^{2}=61 \%$ ) and intermediate-term function (3 trials, pooled SMD $-0.40,95 \%$ CI -0.69 to $-0.11, \mathrm{I}^{2}=76 \%$ ) (SOE: low).

- There was no evidence of differences between spinal manipulation versus sham manipulation, usual care, an attention control, or a placebo intervention in short-term pain (3 trials, pooled MD -0.20 on a 0 to 10 scale, $95 \%$ CI -0.66 to $0.26, \mathrm{I}^{2}=58 \%$ ), but manipulation was associated with slightly greater effects than controls on intermediateterm pain ( 3 trials, pooled $\mathrm{MD}-0.64,95 \% \mathrm{CI}-0.92$ to $-0.36, \mathrm{I}^{2}=0 \%$ ) (SOE: low for short term, moderate for intermediate term).

- There was no evidence of differences between spinal manipulation versus exercise in short-term function ( 3 trials, pooled SMD 0.01 , 95\% CI -0.22 to 0.25 ; $\mathrm{I}^{2}=62 \%$ ) or intermediate-term function ( 4 trials, pooled SMD 0.02 , $95 \% \mathrm{CI}-0.13$ to $0.18 ; \mathrm{I}^{2}=48 \%$ ) (SOE: low).

- There was no evidence of differences between spinal manipulation versus exercise in short-term pain ( 3 trials, pooled MD 0.31 on a 0 to 10 scale, $95 \%$ CI -0.30 to 0.92 ; $\mathrm{I}^{2}=60 \%$ ) or intermediate-term pain ( 4 trials, pooled MD $0.22,95 \% \mathrm{CI}-0.09$ to 0.52 , $\left.\mathrm{I}^{2}=9.4 \%\right)$ (SOE: low).

- No serious adverse events or withdrawals due to adverse events were reported in seven trials; nonserious adverse events with manipulation (primarily increased pain) were reported in 3 trials (SOE: low).

\section{Massage}

- Massage was associated with slightly greater effects on short-term function than sham massage or usual care ( 4 trials, SMD $-0.30,95 \%$ CI -0.46 to $-0.14, \mathrm{I}^{2}=0 \%$ ). There was 
no evidence of differences between massage versus controls in intermediate-term function (3 trials, SMD $-0.09,95 \% \mathrm{CI}-0.24$ to $0.06, \mathrm{I}^{2}=0 \%$ ) (SOE: moderate for short term, low for intermediate term).

- Massage was associated with slightly greater effects on short-term pain than sham massage or usual care ( 4 trials, pooled MD -0.52 on a 0 to 10 scale, $95 \%$ CI -0.81 to $\left.-0.23, \mathrm{I}^{2}=0 \%\right)$. There was evidence of differences between massage versus controls in intermediate-term pain ( 3 trials, pooled MD $-0.01,95 \% \mathrm{CI}-0.40$ to $0.38, \mathrm{I}^{2}=0 \%$ ) (SOE: moderate for short term, low for intermediate term).

- One trial found no differences between massage versus exercise in intermediate-term function or pain (SOE: low).

- Two trials of massage reported no serious adverse events; in four trials, the proportion of massage patients who reported increased pain ranged from $<1$ to 26 percent (SOE: low).

\section{Detailed Synthesis}

\section{Spinal Manipulation}

Eight trials of spinal manipulation for low back pain met inclusion criteria (Table 11 and Appendix D). ${ }^{119,144-147,160-162}$ All of the trials evaluated standard (high-velocity low-amplitude) manipulation techniques; one trial ${ }^{162}$ evaluated flexion-distraction manipulation and one trial ${ }^{145}$ evaluated both high-velocity low-amplitude and flexion-distraction manipulation. Sample sizes ranged from 75 to 1,001 (total sample=2,586). The number of manipulation therapy sessions ranged from 4 to 24 and the duration of therapy ranged from 4 to 12 weeks. In one trial, patients were randomized to 12 manipulation sessions over 1 month or to 12 sessions over 1 month plus biweekly maintenance sessions for an additional 10 months. ${ }^{146}$ Two trials compared spinal manipulation versus usual care, ${ }^{145,147}$ one trial spinal manipulation versus an attention control (minimal massage), ${ }^{144}$ one trial spinal manipulation versus sham manipulation, ${ }^{146}$ one trial spinal manipulation versus a placebo treatment (sham short-wave diathermy), ${ }^{119}$ and four trials spinal manipulation versus exercise. ${ }^{147,160-162}$ One trial was conducted in Egypt ${ }^{146}$ and the rest in the United States, United Kingdom, or Australia. Six trials reported outcomes through intermediateterm followup, ${ }^{144,146,147,160-162}$ and two trials only evaluated short-term outcomes. ${ }^{119,145}$

Two trials ${ }^{119,146}$ were rated poor quality and the remainder fair quality (Appendix E). The major methodological limitation in the fair-quality trials was use of an unblinded design. Methodological shortcomings in the poor-quality trials included unclear randomization and allocation concealment methods, failure to report intention-to-treat analysis, and high attrition. 
Table 11. Chronic low back pain: manual therapies (spinal manipulation)

\begin{tabular}{|c|c|c|c|c|}
\hline $\begin{array}{l}\text { Author, Year, } \\
\text { Followup, }^{\mathrm{a}} \\
\text { Pain } \\
\text { Duration, } \\
\text { Study } \\
\text { Quality }\end{array}$ & Intervention & Population & $\begin{array}{l}\text { Function and Pain } \\
\text { Outcomes }\end{array}$ & Other Outcomes \\
\hline $\begin{array}{l}\text { Bronfort, } \\
2011^{160} \\
9 \text { months } \\
\text { Duration of } \\
\text { pain: } 5 \text { years } \\
\text { Fair }\end{array}$ & $\begin{array}{l}\text { A. Standard } \\
\text { manipulation } \\
(n=100), 12-24 \\
\text { sessions over } 12 \\
\text { weeks } \\
\text { B. Exercise } \\
\text { (supervised) } \\
(n=100) \\
\text { C. Exercise (home) } \\
(n=101)\end{array}$ & $\begin{array}{l}\text { A vs. B } \\
\text { Age: } 45.2 \text { vs. } \\
44.5 \text { vs. } 45.6 \\
\text { years } \\
\text { Female sex: } \\
67 \% \text { vs. } 57 \% \\
\text { vs. } 58 \% \\
\text { Baseline } \\
\text { Modified RDQ } \\
\text { (0-23): } 8.7 \text { vs. } \\
8.4 \text { vs. } 8.7 \\
\text { Baseline pain } \\
\text { (0-10 NRS): } \\
5.4 \text { vs. } 5.1 \text { vs. } \\
5.2\end{array}$ & 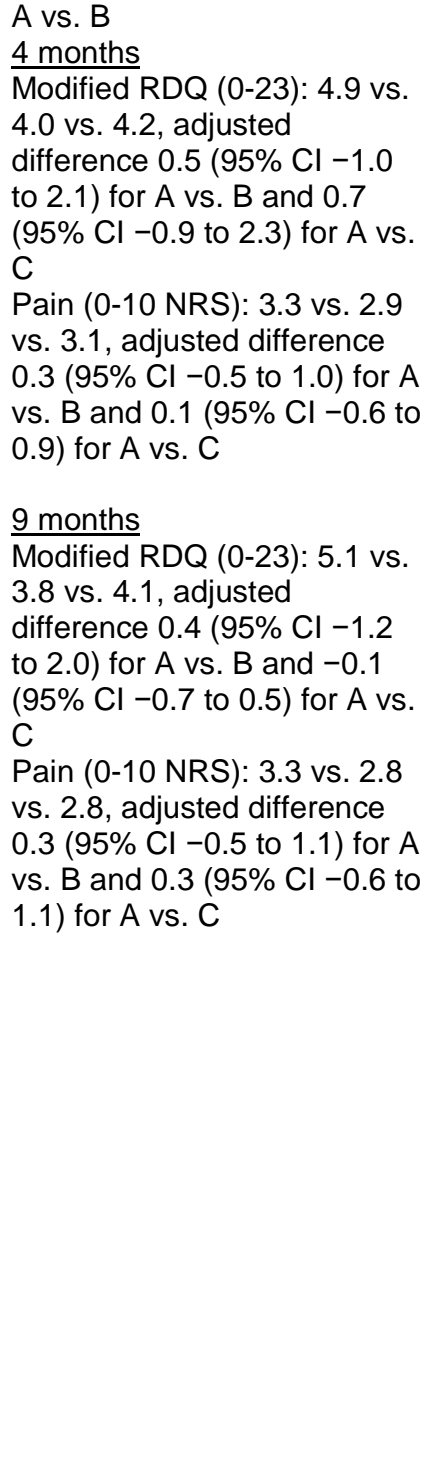 & 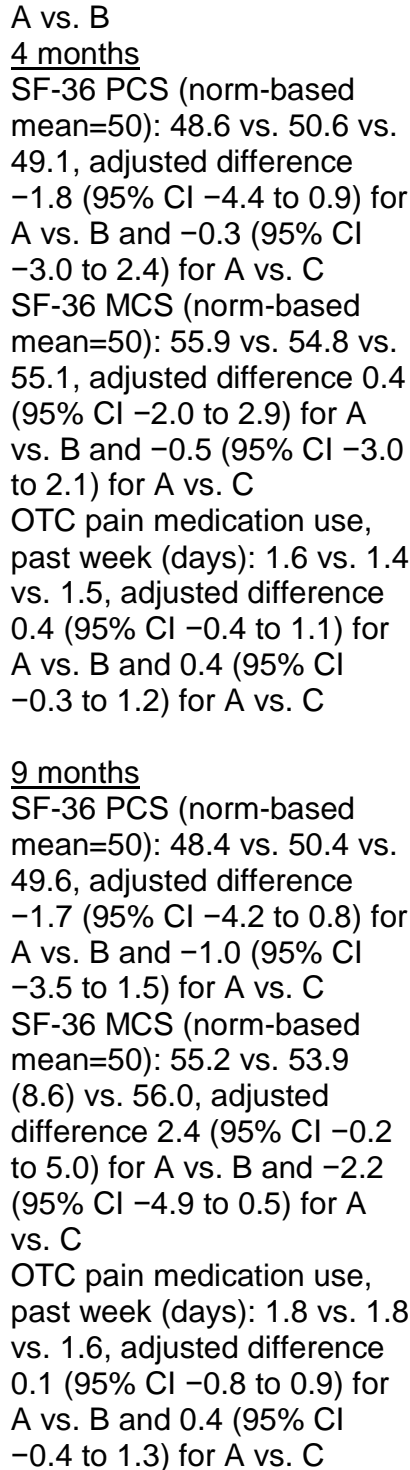 \\
\hline
\end{tabular}




\begin{tabular}{|c|c|c|c|c|}
\hline $\begin{array}{l}\text { Author, Year, } \\
\text { Followup, }^{\mathrm{a}} \\
\text { Pain } \\
\text { Duration, } \\
\text { Study } \\
\text { Quality }\end{array}$ & Intervention & Population & $\begin{array}{l}\text { Function and Pain } \\
\text { Outcomes }\end{array}$ & Other Outcomes \\
\hline $\begin{array}{l}\text { Ferreira, } \\
2007^{161} \\
10 \text { months } \\
\text { Duration of } \\
\text { pain: Not } \\
\text { reported } \\
\text { Fair }\end{array}$ & $\begin{array}{l}\text { A. Standard } \\
\text { manipulation and } \\
\text { mobilization }(n=80) \text {, } \\
12 \text { sessions over } 8 \\
\text { weeks } \\
\text { B. Exercise (motor } \\
\text { control) ( } n=80) \\
\text { C: Exercise } \\
\text { (general exercise) } \\
(n=80)\end{array}$ & $\begin{array}{l}\text { A vs. B vs. C } \\
\text { Age: } 54 \text { vs. } 52 \\
\text { vs. } 55 \text { years } \\
\text { Female: } 70 \% \\
\text { vs. } 66 \% \text { vs. } \\
70 \% \\
\text { Baseline RDQ } \\
\text { (0-24): } 12.4 \text { vs. } \\
14.0 \text { vs. } 14.1 \\
\text { Baseline pain } \\
\text { (0-10 VAS): } 6.2 \\
\text { vs. } 6.3 \text { vs. } 6.5\end{array}$ & 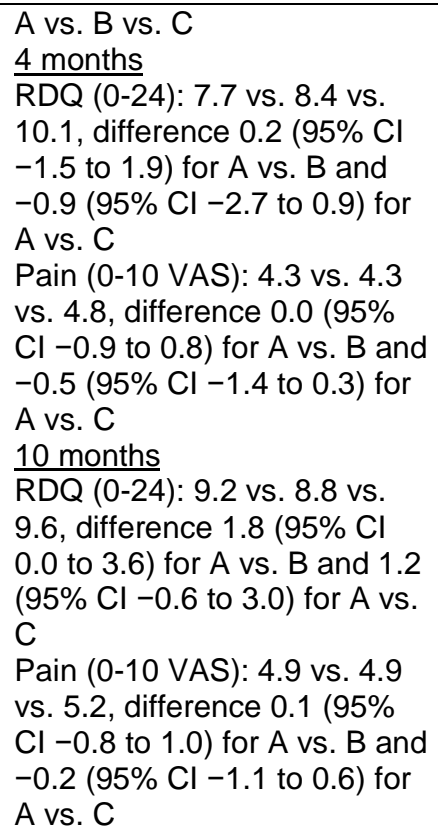 & $\begin{array}{l}\text { A vs. B vs. C } \\
4 \text { months } \\
\text { Patient Specific Functional } \\
\text { Scale (3-30): } 17.3 \text { vs. } 16.4 \\
\text { vs. } 15.0 \text {, difference } 0.7 \text { ( } 95 \% \\
\mathrm{Cl}-1.3 \text { to } 2.7) \text { for A vs. B } \\
\text { and } 1.7(95 \% \mathrm{Cl}-0.4 \text { to } \\
\text { 3.,8) for A vs. C } \\
10 \text { months } \\
\text { Patient Specific Functional } \\
\text { Scale (3-30): } 15.2 \text { vs. } 15.7 \\
\text { (6.8) vs. } 13.9, \text { difference } \\
-0.8 \text { (95\% Cl }-2.9 \text { to } 1.2) \text { for } \\
\text { A vs. B and } 0.3 \text { ( } 95 \% \text { Cl } \\
-1.7 \text { to } 2.3) \text { for A vs. C }\end{array}$ \\
\hline $\begin{array}{l}\text { Gibson, } \\
1985^{119} \\
2 \text { months } \\
\text { Duration of } \\
\text { pain: } 2 \text { to } 12 \\
\text { months } \\
\text { Poor }\end{array}$ & $\begin{array}{l}\text { A. Manipulation } \\
\text { (technique unclear) } \\
\text { and mobilization } \\
(\mathrm{n}=41), 4 \text { sessions } \\
\text { over } 4 \text { weeks } \\
\text { B. Placebo } \\
\text { (detuned short- } \\
\text { wave diathermy) } \\
\text { ( } n=34)\end{array}$ & $\begin{array}{l}\text { A vs. B } \\
34 \text { vs. } 40 \text { years } \\
\text { Female: } 61 \% \\
\text { vs. } 32 \% \\
\text { Baseline pain } \\
\text { (0-100 VAS): } \\
35 \text { vs. } 48\end{array}$ & $\begin{array}{l}\text { A vs. B } \\
\frac{1 \text { month }}{\text { Pain (median [range], 0-100 }} \\
\text { VAS): } 28(0-96) \text { vs. } 27(0-80) \\
\frac{3 \text { months }}{\text { Pain (median [range], } 0-100} \\
\text { VAS): } 25 \text { (4-90) vs. } 6(10-96) \\
\text { P<0.01 }\end{array}$ & $\begin{array}{l}\text { A vs. B } \\
\frac{1 \text { month }}{\text { Using analgesics: } 25 \% \text { vs. }} \\
50 \% \\
\frac{3 \text { months }}{\text { Using analgesics: } 18 \% \text { vs. }} \\
22 \%\end{array}$ \\
\hline $\begin{array}{l}\text { Gudavalli, } \\
2006^{162} \\
11 \text { months } \\
\text { Duration of } \\
\text { pain: }>3 \\
\text { months } \\
\text { Fair }\end{array}$ & $\begin{array}{l}\text { A. Flexion- } \\
\text { distraction } \\
\text { manipulation } \\
(n=123), 8-16 \\
\text { sessions over } 4 \\
\text { weeks } \\
\text { B. Exercise } \\
(n=112)\end{array}$ & $\begin{array}{l}\text { A vs. B } \\
\text { Age: } 42 \text { vs. } 41 \\
\text { years } \\
\text { Female: } 34 \% \\
\text { vs. } 41 \% \\
\text { Baseline RDQ } \\
(0-24): 6.64 \text { vs. } \\
6.84 \\
\text { Baseline pain } \\
\text { VAS (0-100: } \\
38.00 \text { vs. } 35.70\end{array}$ & $\begin{array}{l}\text { A vs. B } \\
2 \text { months } \\
\text { RDQ (0-24): } 3.50 \text { (SD 0.50) } \\
\text { vs. 3.75 (SD 0.51) } \\
\text { Pain (0-100 VAS): } 16.52 \text { (SD } \\
\text { 2.95) vs.12.04 (SD 2.53) } \\
\text { 5 months } \\
\text { RDQ (0-24): } 3.89 \text { (SD 0.46) } \\
\text { vs. 3.42 (SD 0.50) } \\
\text { Pain (0-100 VAS): } 18.26 \text { (SD } \\
\text { 2.64) vs. } 8.92 \text { (SD 2.89) } \\
11 \text { months } \\
\text { RDQ (0-24): } 3.90 \text { (SD 0.53) } \\
\text { vs. 3.77 (SD 0.44) } \\
\text { Pain (0-100 VAS): } 17.10 \text { (SD } \\
\text { 2.55) vs. 12.36 (SD 2.43) }\end{array}$ & NR \\
\hline
\end{tabular}




\begin{tabular}{|c|c|c|c|c|}
\hline $\begin{array}{l}\text { Author, Year, } \\
\text { Followup, } \\
\text { Pain } \\
\text { Duration, } \\
\text { Study } \\
\text { Quality }\end{array}$ & Intervention & Population & $\begin{array}{l}\text { Function and Pain } \\
\text { Outcomes }\end{array}$ & Other Outcomes \\
\hline $\begin{array}{l}\text { Haas, } 2014^{144} \\
10.5 \text { months } \\
\text { Duration of } \\
\text { pain: } 11 \text { to } 12 \\
\text { years } \\
\text { Fair }\end{array}$ & $\begin{array}{l}\text { A. Standard spinal } \\
\text { manipulation } \\
\text { ( } n=100), 6 \text { sessions } \\
\text { over } 6 \text { weeks } \\
\text { B. Standard } \\
\text { manipulation } \\
\text { ( } n=100), 12 \\
\text { sessions over } 6 \\
\text { weeks } \\
\text { C. Standard } \\
\text { manipulation } \\
\text { ( } n=100), 18 \\
\text { sessions over } 6 \\
\text { weeks } \\
\text { D: Attention control } \\
\text { (minimal massage) } \\
(n=100)\end{array}$ & $\begin{array}{l}\text { A vs. B vs. C } \\
\text { vs. D } \\
\text { Age: } 41 \text { vs. } 42 \\
\text { vs. } 41 \text { vs. } 41 \\
\text { Female: } 49 \% \\
\text { vs. } 49 \% \text { vs. } \\
52 \% \text { vs. } 49 \% \\
\text { Baseline } \\
\text { Modified Von } \\
\text { Korff functional } \\
\text { disability (0- } \\
\text { 100): } 44.8 \\
\text { vs.46.1 vs.45.2 } \\
\text { vs. } 45.2 \\
\text { Baseline Pain } \\
\text { (0-100 VAS): } \\
51.0 \text { vs. } 51.6 \\
\text { vs. } 51 . \text { vs. } 52.2 \\
\text { Baseline Von } \\
\text { Korff pain } \\
\text { intensity (0- } \\
100): 51.0 \text { vs. } \\
51.6 \text { vs. } 51.5 \\
\text { vs. } 52.2\end{array}$ & 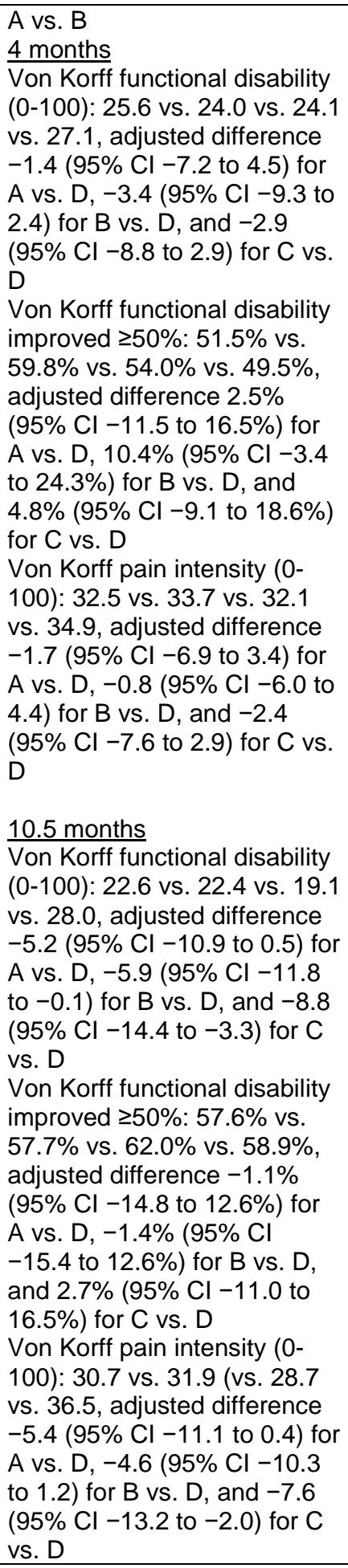 & 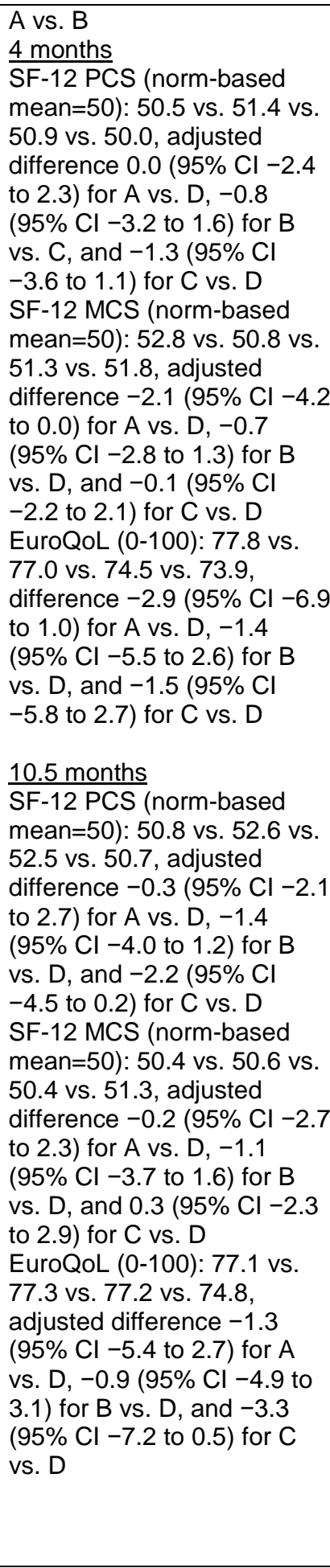 \\
\hline
\end{tabular}




\begin{tabular}{|c|c|c|c|c|}
\hline $\begin{array}{l}\text { Author, Year, } \\
\text { Followup, } \\
\text { Pain } \\
\text { Duration, } \\
\text { Study } \\
\text { Quality }\end{array}$ & Intervention & Population & $\begin{array}{l}\text { Function and Pain } \\
\text { Outcomes }\end{array}$ & Other Outcomes \\
\hline $\begin{array}{l}\text { Hondras, } \\
2009^{145} \\
4.5 \text { months } \\
\text { Duration of } \\
\text { pain: Mean } 9 \\
\text { to } 13 \text { years } \\
\text { Fair }\end{array}$ & $\begin{array}{l}\text { A. Standard } \\
\text { manipulation } \\
\text { ( } n=96), 12 \text { sessions } \\
\text { over } 6 \text { weeks } \\
\text { B. Flexion } \\
\text { distraction } \\
\text { manipulation } \\
\text { ( } n=95), 12 \text { sessions } \\
\text { over } 6 \text { weeks } \\
\text { C: Usual care } \\
(n=49)\end{array}$ & $\begin{array}{l}\text { A vs. B vs. C } \\
\text { Age: } 64 \text { vs. } 62 \\
\text { vs. } 63 \text { years } \\
\text { Female: } 45 \% \\
\text { vs. } 44 \% \text { vs. } \\
41 \% \\
\text { Baseline RDQ } \\
\text { (0-24), mean } \\
\text { (SD): } 6.5 \text { vs. } \\
6.6 \text { vs. } 5.7 \\
\text { Baseline pain } \\
\text { (0-100 VAS): } \\
42.1(23.6) \text { vs. } \\
42.5(25.2) \text { vs. } \\
42.4(24.5)\end{array}$ & 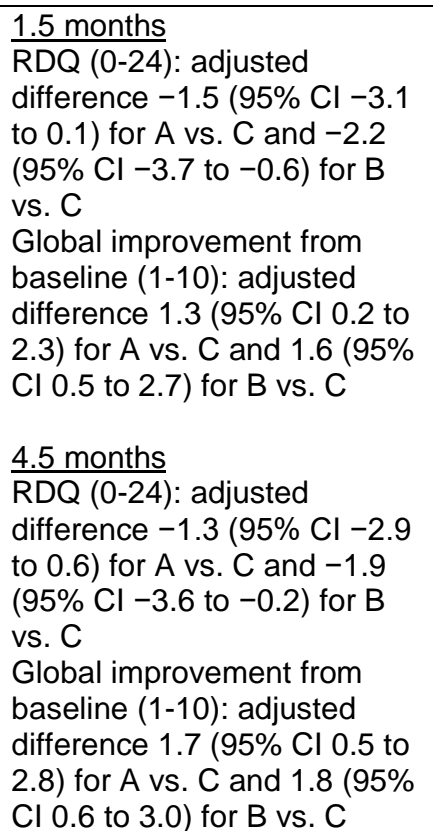 & NR \\
\hline $\begin{array}{l}\text { Senna, } \\
2011^{146} \\
9 \text { months } \\
\text { Duration of } \\
\text { pain: 18-19 } \\
\text { months } \\
\text { Poor }\end{array}$ & $\begin{array}{l}\text { A. Standard } \\
\text { manipulation } \\
(n=27), 12 \text { sessions } \\
\text { over } 4 \text { weeks } \\
\text { B. Standard } \\
\text { manipulation } \\
\text { maintained ( } n=27) \text {, } \\
12 \text { sessions over } 4 \\
\text { weeks, plus every } 2 \\
\text { weeks for } 9 \text { months } \\
\text { C. Sham } \\
\text { manipulation } \\
(n=40)\end{array}$ & $\begin{array}{l}\text { A vs. B } \\
\text { Age: } 40 \text { vs. } 42 \\
\text { vs. } 42 \text { years } \\
\text { Female: } 27 \% \\
\text { vs. } 24 \% \text { vs. } \\
24 \% \\
\text { Baseline } \\
\text { function (0-100 } \\
\text { ODI): } 39 \text { vs. } 40 \\
\text { vs. } 38 \\
\text { Baseline pain } \\
\text { (0-100 VAS): } \\
42 \text { vs. } 43 \text { vs. } \\
41\end{array}$ & $\begin{array}{l}\text { A vs. B } \\
3 \text { months } \\
\text { ODI }(0-100): 29.8 \text { vs. } 23.1 \text { vs. } \\
33.5 ; p>0.05 \\
\text { Pain ( } 0-100 \text { VAS): } 35.2 \text { vs. } \\
25.9 \text { vs. } 35.2 ; p>0.05 \\
6 \text { months } \\
\text { ODI (0-100): } 32.2 \text { vs. } 22.4 \text { vs. } \\
35.3 ; p>0.05 \\
\text { Pain (0-100 VAS): } 35.5 \text { vs. } \\
25.4 \text { vs. } 36.8 ; p>0.05 \\
9 \text { months } \\
\text { ODI (0-100): } 34.9 \text { vs. } 20.6 \text { vs. } \\
37.4 \\
\text { Pain (0-100 VAS): } 38.5 \text { vs. } \\
23.5 \text { vs. } 38.3\end{array}$ & 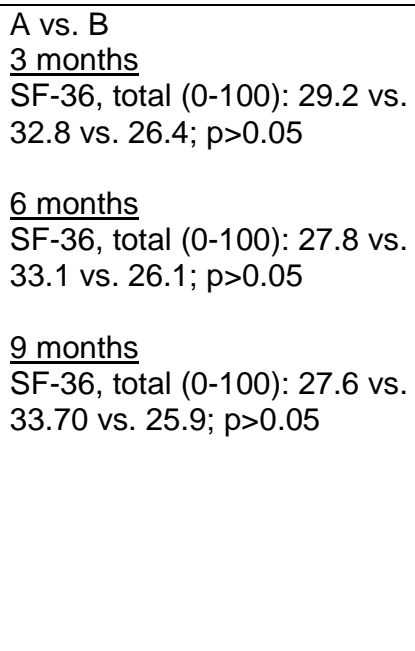 \\
\hline
\end{tabular}




\begin{tabular}{|c|c|c|c|c|}
\hline $\begin{array}{l}\text { Author, Year, } \\
\text { Followup, } \\
\text { Pain } \\
\text { Duration, } \\
\text { Study } \\
\text { Quality }\end{array}$ & Intervention & Population & $\begin{array}{l}\text { Function and Pain } \\
\text { Outcomes }\end{array}$ & Other Outcomes \\
\hline $\begin{array}{l}\text { UK BEAM } \\
\text { Trial Team, } \\
2004^{147} \\
9 \text { months } \\
\text { Duration of } \\
\text { pain: >3 } \\
\text { months in } \\
59 \% \\
\text { Fair }\end{array}$ & $\begin{array}{l}\text { A: Standard } \\
\text { manipulation } \\
(n=353), 8 \text { sessions } \\
\text { over } 12 \text { weeks } \\
\text { B: Usual care } \\
(n=338) \\
\text { C: Exercise } \\
(n=310)\end{array}$ & $\begin{array}{l}\text { A vs. B vs. C } \\
\text { Age: } 42 \text { vs. } 42 \\
\text { vs. } 44 \\
\text { Female: } 63 \% \\
\text { vs. } 53 \% \text { vs. } \\
55 \% \\
\text { Baseline RDQ } \\
(0-24): 8.9 \text { and } \\
8.9 \text { vs. } 9.0 \text { vs. } \\
9.2 \\
\text { Baseline Von } \\
\text { Korff Pain (0- } \\
100): 61.4 \text { and } \\
61.6 \text { vs. } 60.5 \\
\text { vs. } 60.8\end{array}$ & $\begin{array}{l}\text { A vs. B } \\
9 \text { months } \\
\text { RDQ (0-24): } 5.15 \text { vs. } 6.16, \\
\text { adjusted difference }-1.01 \\
\text { (95\% Cl }-1.81 \text { to }-0.22) \\
\text { Von Korff Disability (0-100): } \\
29.85 \text { vs. } 35.50 \text {, adjusted } \\
\text { difference }-5.65 \text { (95\% Cl } \\
-9.72 \text { to }-1.57) \\
\text { Von Korff Pain (0-100): } 41.68 \\
\text { vs. } 47.56, \text { adjusted difference } \\
-5.87(95 \% \text { Cl }-10.17 \text { to } \\
-1.58) \\
\text { A vs. C } \\
9 \text { months } \\
\text { RDQ (0-24): } 5.15 \text { (0.29) vs. } \\
5.74(0.31) \\
\text { Von Korff Disability (0-100): } \\
29.85(1.50) \text { vs. } 29.73(1.68) \\
\text { Von Korff Pain (0-100): } 41.68 \\
\text { (1.58) vs. 41.54 (1.84) }\end{array}$ & 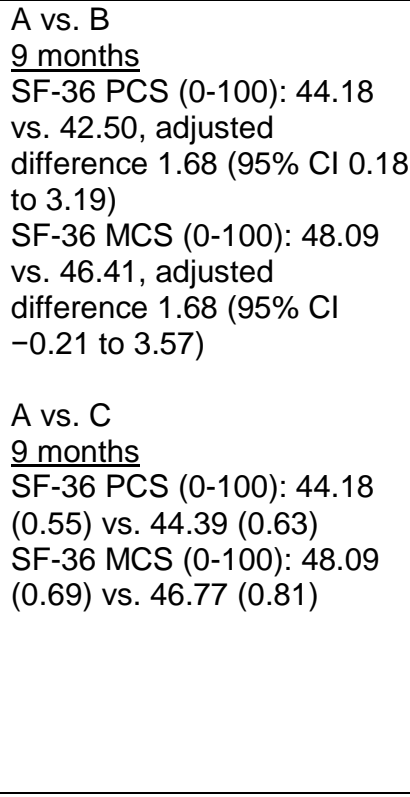 \\
\hline
\end{tabular}

CI = confidence interval; MCS = Mental Component Summary; NR = not reported; ODI = Oswestry Disability Index; OTC = over-the-counter; PCS = Physical Component Score; RDQ = Roland-Morris Disability Questionnaire; SF-36 = Short-Form 36 Questionnaire; VAS = visual analog scale

${ }^{a}$ Unless otherwise noted, followup time is calculated from the end of the treatment period

\section{Spinal Manipulation Compared With Sham Manipulation, Usual Care, an Attention Control, or a Placebo Intervention}

Spinal manipulation was associated with slightly greater effects on function than controls at short-term followup ( 3 trials, SMD $-0.34,95 \%$ CI -0.63 to $\left.-0.05, \mathrm{I}^{2}=61 \%\right)^{144-146}$ and intermediate-term followup (3 trials, SMD $-0.40,95 \%$ CI -0.69 to $\left.-0.11, \mathrm{I}^{2}=76 \%\right)^{144,146,147}$ (Figure 8). Based on the original 0 to 100 scales (ODI and Von Korff functional disability [VF]) used in the trials, the difference was -4.94 (95\% CI -9.36 to -0.53$)$ for short-term function and -9.19 (95\% CI -12.77 to -5.61$)$ for intermediate-term function. Estimates were similar when a poor-quality trial ${ }^{146}$ was excluded. For short-term function, one trial reported similar effects for standard manipulation (difference -1.3 on the RDQ, $95 \% \mathrm{CI}-2.9$ to 0.6 ) and flexion-distraction manipulation (differenced $-1.9,95 \%$ CI -3.6 to -0.2 ); therefore, results for both arms were combined for the pooled analysis. ${ }^{145}$

There was no clear difference between spinal manipulation versus sham manipulation, an attention control, or a placebo intervention in short-term pain ( 3 trials, pooled difference -0.20 on a 0 to 10 scale, $95 \%$ CI -0.66 to $0.26, I^{2}=58 \%$ ) (Figure 9). ${ }^{119,144,146}$ Two of the trials were rated poor quality; the results of the fair-quality trial ${ }^{144}$ were consistent with the overall estimate (difference $-0.21,95 \%$ CI -0.68 to 0.25 ). Manipulation was associated with slightly greater effects on intermediate-term pain than sham manipulation, usual care, or an attention control (3 trials, pooled difference -0.64 on a 0 to 10 scale, $95 \%$ CI -0.92 to $\left.-0.36, \mathrm{I}^{2}=0 \%\right) .{ }^{144,146,147}$ The estimate was similar when a poor-quality trial ${ }^{146}$ was excluded ( 2 trials, difference $-0.60,95 \%$ CI -0.98 to -0.22$){ }^{144,147}$ 
Two trials found no clear differences between spinal manipulation versus controls on the SF-36 MCS and PCS at short term. ${ }^{144,147}$ One trial ${ }^{144}$ found no differences at short-term or intermediate-term followup and the other ${ }^{147}$ found manipulation associated with slightly better PCS scores at intermediate-term followup, but the difference was very small (1.68 on a 0 to 100 scale, $95 \%$ CI 0.08 to 3.28).

\section{Spinal Manipulation Compared With Pharmacological Therapy}

No trial of spinal manipulation versus pharmacological therapy met inclusion criteria.

\section{Spinal Manipulation Compared With Exercise}

There were no differences between spinal manipulation versus exercise in function at shortterm (3 trials, SMD 0.01, 95\% CI -0.22 to $\left.0.25, \mathrm{I}^{2}=62 \%\right)^{160-162}$ or intermediate-term followup (4 trials, SMD 0.02, 95\% CI -0.13 to $\left.0.18, \mathrm{I}^{2}=48 \%\right)^{147,160-162}$ (Figure 10). Excluding one trial ${ }^{162}$ of flexion-distraction manipulation resulted in similar findings.

There were no differences between spinal manipulation versus exercise in short-term pain (3 trials, pooled difference $0.31,95 \% \mathrm{CI}-0.30$ to $\left.0.92, \mathrm{I}^{2}=60 \%\right)^{160-162}$ or intermediate-term pain (4 trials, pooled difference 0.22 , $95 \%$ CI -0.09 to $0.52, \mathrm{I}^{2}=9.4 \%$ ) (Figure 11$){ }^{147,160-162}$ Excluding one trial $^{162}$ of flexion-distraction manipulation resulted in similar findings.

Two trials found no clear differences between spinal manipulation versus controls on the SF-36 MCS and PCS at short term. ${ }^{147,160}$ One trial ${ }^{144}$ found no differences at short-term or intermediate-term followup, and the other ${ }^{147}$ found manipulation associated with slightly better PCS scores at intermediate-term followup, but the difference was very small (1.68 on a 0 to 100 scale, $95 \%$ CI 0.08 to 3.28).

\section{Harms}

Seven trials reported no serious adverse events or withdrawals due to adverse events. ${ }^{144-}$ 147,160-162 Nonserious adverse events (primarily increased pain) were reported in three trials. ${ }^{144,146,160}$ 
Figure 8. Spinal manipulation versus sham manipulation, usual care, an attention control, or a placebo intervention for chronic low back pain: effects on function

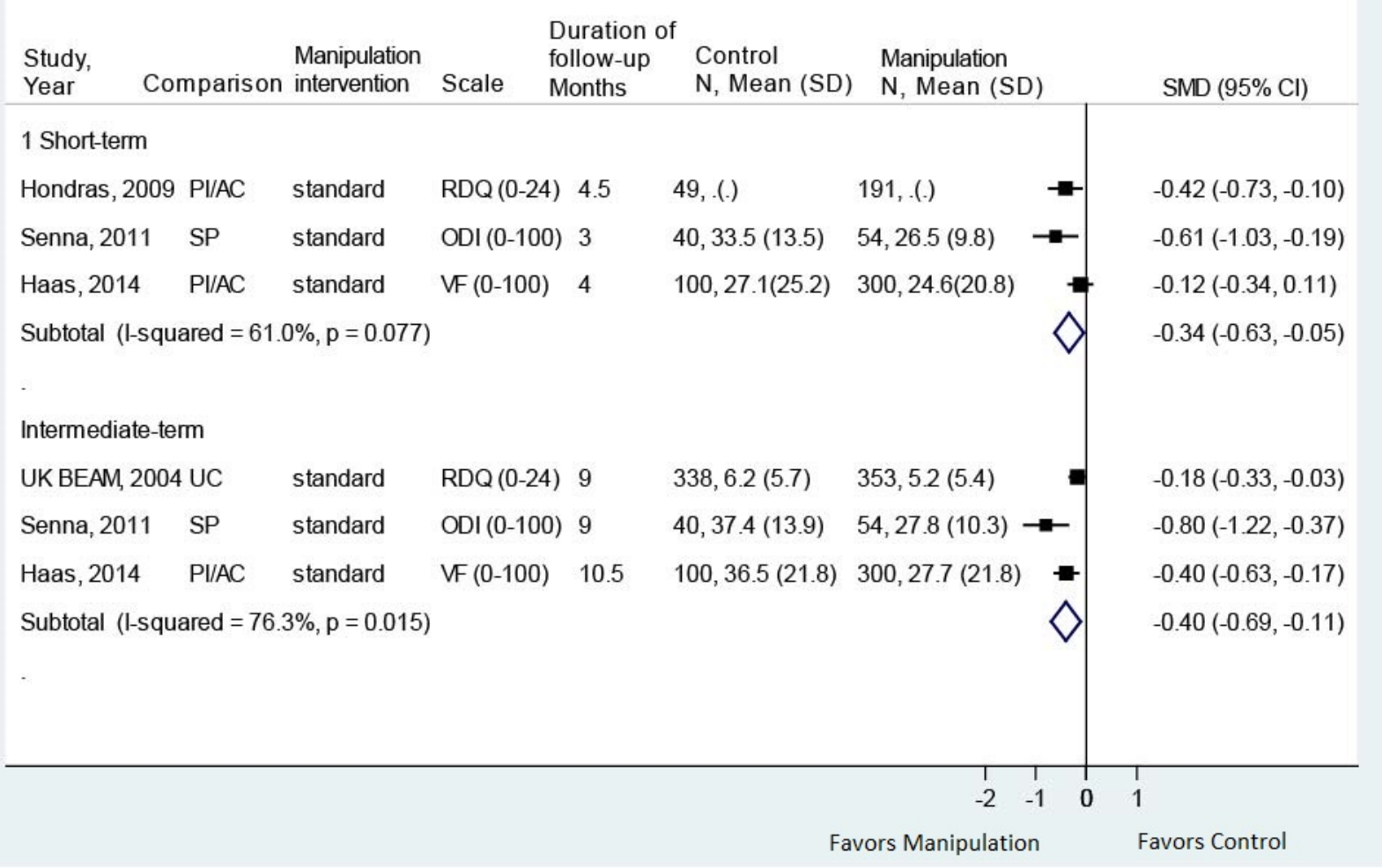

$\mathrm{AC}$ = attention control; $\mathrm{CI}=$ confidence interval; $\mathrm{N}$ = number; ODI = Oswestry Disability Index; PI = placebo intervention; RDQ = Roland-Morris Disability Questionnaire; SD = standard deviation; SMD = standardized mean difference; $\mathrm{SP}=$ sham manipulation; UC = usual care; UK BEAM = UK Back pain exercise and manipulation trial; VF = Von Korff functional disability 
Figure 9. Spinal manipulation versus sham manipulation, usual care, an attention control, or a placebo intervention for chronic low back pain: effects on pain

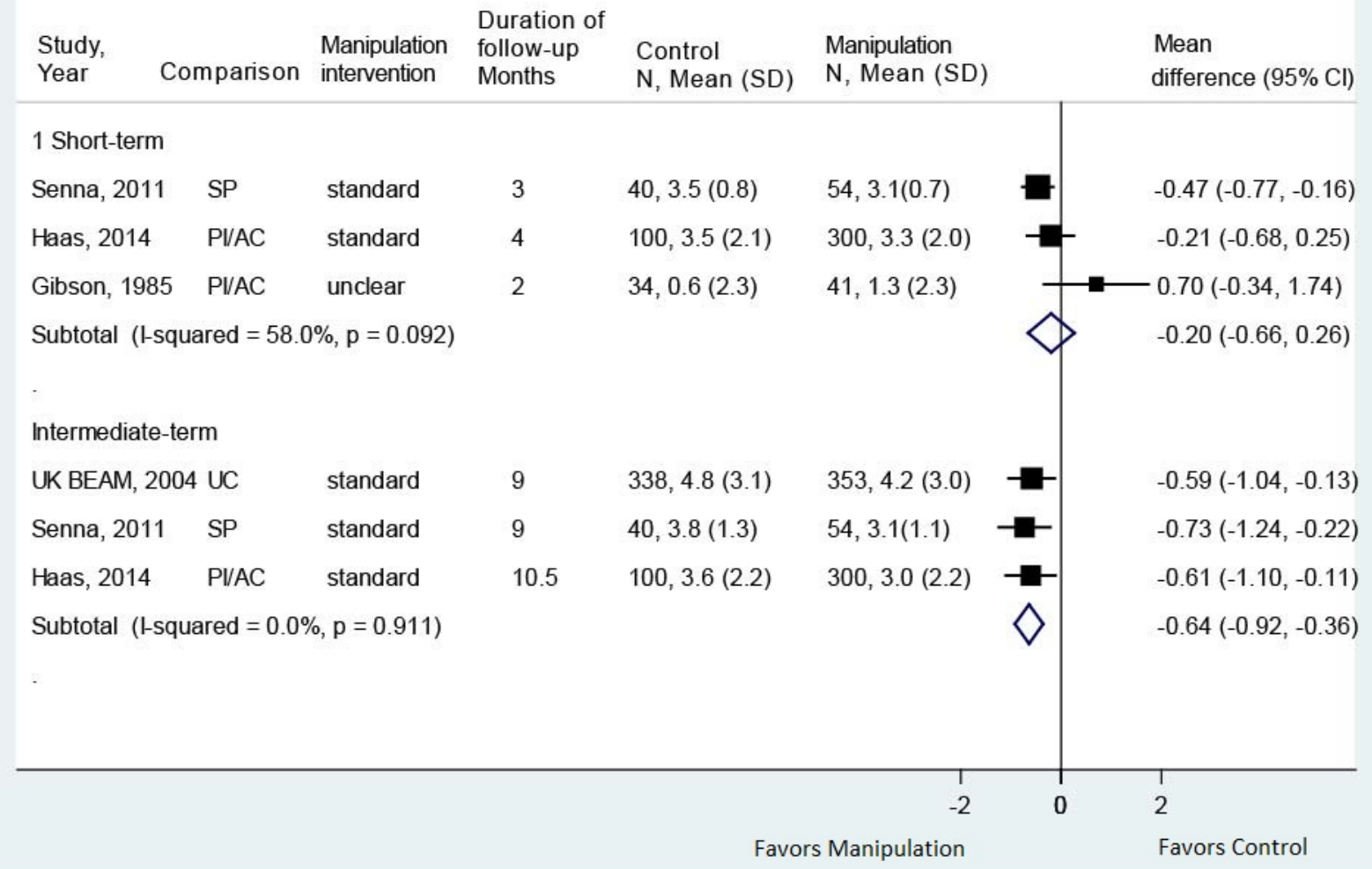

$\mathrm{AC}=$ attention control; $\mathrm{CI}$ = confidence interval; $\mathrm{N}$ = number; $\mathrm{PI}=$ placebo intervention; $\mathrm{SD}=$ standard deviation; $\mathrm{SP}=$ sham manipulation; UC = usual care; UK BEAM = UK Back pain exercise and manipulation trial 
Figure 10. Spinal manipulation versus exercise for chronic low back pain: effects on function

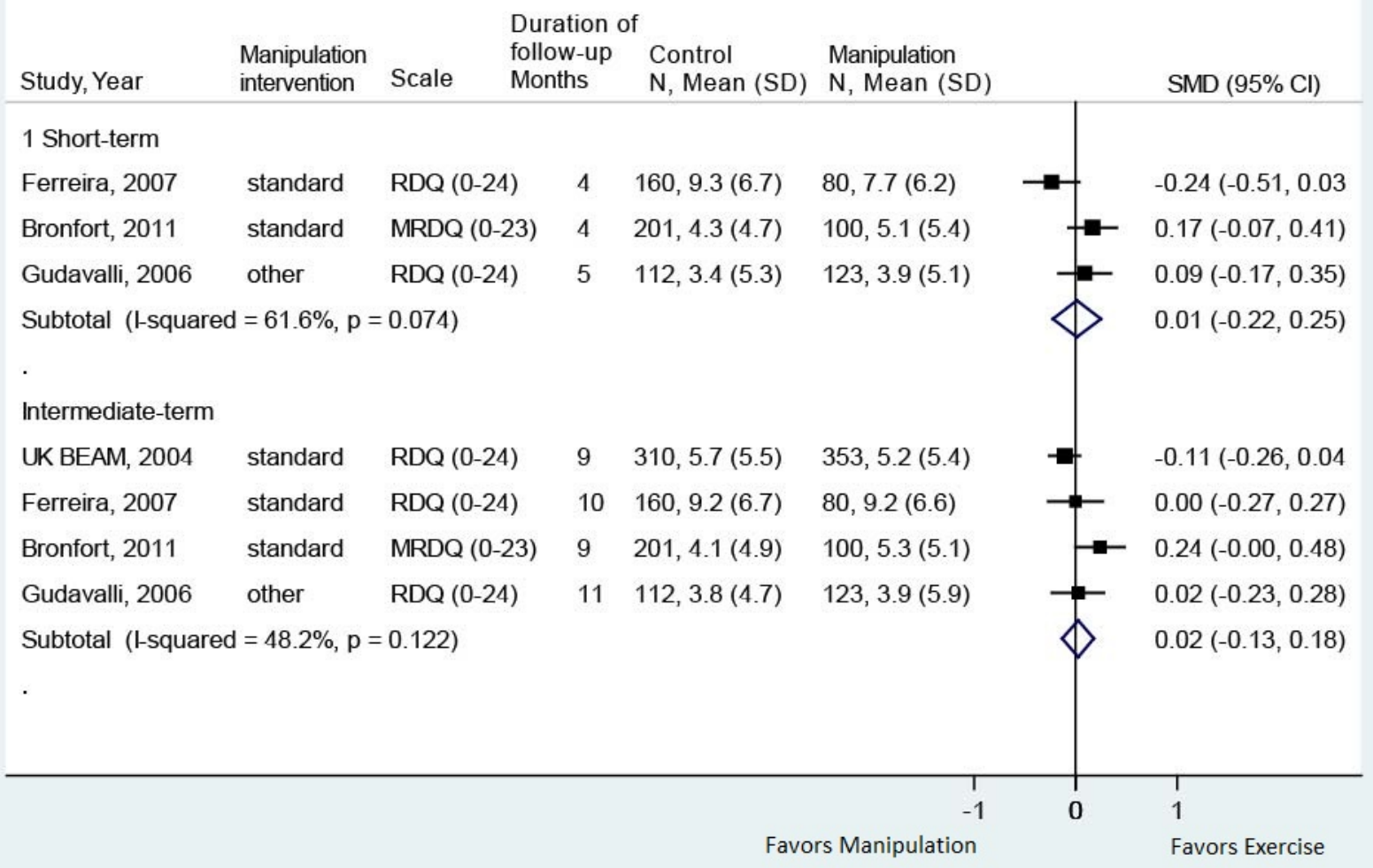

$\mathrm{CI}=$ confidence interval; MRDQ = Modified Roland-Morris Disability Questionnaire; N = number; RDQ = Roland-Morris Disability Questionnaire; SD = standard deviation; SMD = standardized mean difference; UK BEAM = UK Back pain exercise and manipulation trial 
Figure 11. Spinal manipulation versus exercise for chronic low back pain: effects on pain

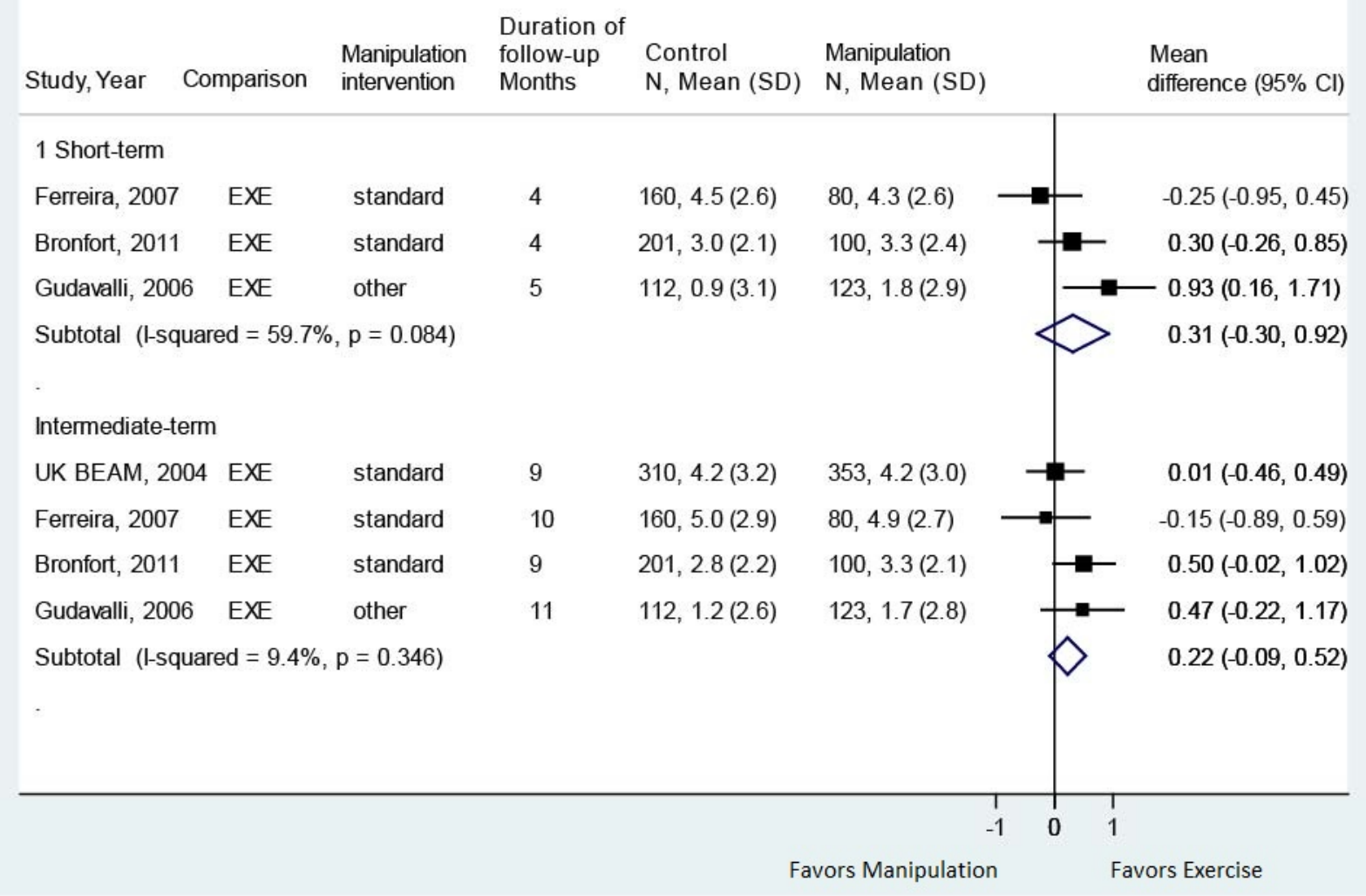

$\mathrm{CI}$ = confidence interval; $\mathrm{EXE}=$ exercise; $\mathrm{N}$ = number; $\mathrm{SD}$ = standard deviation; UK BEAM = UK Back pain exercise and manipulation trial

\section{Massage}

Six trials of massage for low back pain met inclusion criteria (Table 12 and Appendix D). ${ }^{93,148-151,159}$ Massage techniques varied across trials. Two trials evaluated reflexology, ${ }^{93,151}$ one trial myofascial release, ${ }^{148}$ one trial relaxation or structural massage, ${ }^{150}$ and two trials mixed massage techniques that included Swedish massage. ${ }^{149,159}$ Sample sizes ranged from 15 to 402 (total sample=1,027). Two trials compared massage versus sham massage, ${ }^{148,151}$ three trials massage versus usual care, ${ }^{93,150,159}$ and one trial compared massage versus an attention control (self-care education). ${ }^{149}$ One trial was conducted in India ${ }^{148}$ and the rest in the United States or Europe. The duration of massage therapy ranged from 6 to 10 weeks and the number of massage sessions ranged from 6 to 24. Three trials reported outcomes through intermediate-term followup, ${ }^{149,150,159}$ and three only reported short-term outcomes. ${ }^{93,148,151}$ No trial reported long-term outcomes.

All of the massage trials were rated fair-quality (Appendix E). Methodological limitations included unclear allocation concealment methods and unblinded design. One trial reported high loss to followup. ${ }^{93}$ 
Table 12. Chronic low back pain: manual therapies (massage)

\begin{tabular}{|c|c|c|c|c|}
\hline $\begin{array}{l}\text { Author, Year, } \\
\text { Followup, }^{\text {a }} \\
\text { Pain } \\
\text { Duration, } \\
\text { Study } \\
\text { Quality }\end{array}$ & Intervention & Population & Function and Pain Outcomes & Other Outcomes \\
\hline $\begin{array}{l}\text { Ajimsha, } \\
2014^{148} \\
1 \text { month } \\
\text { Duration of } \\
\text { pain: } 2.3 \text { vs. } \\
2.25 \text { years } \\
\text { Fair }\end{array}$ & $\begin{array}{l}\text { A. Myofascial } \\
\text { release }(n=38) \\
24 \text { sessions, } 3 \\
\text { session/week for } 8 \\
\text { weeks } \\
\text { B. Sham } \\
\text { myofascial release } \\
(n=36)\end{array}$ & $\begin{array}{l}\text { A vs. B } \\
\text { Age: } 36 \text { vs. } 34 \\
\text { years } \\
\text { Female: } 76 \% \\
\text { vs. } 78 \% \\
\text { Baseline } \\
\text { Quebec Back } \\
\text { Disability Scale } \\
\text { (0-100): } 37.1 \\
\text { vs. 35.3 } \\
\text { Baseline pain } \\
\text { (0-78 McGill } \\
\text { Pain): } 23.2 \text { vs. } \\
23.0\end{array}$ & $\begin{array}{l}\text { A vs. B } \\
1 \text { month } \\
\text { Quebec Back Disability Scale } \\
(0-100): 28.7 \text { vs. } 32.5, M D \\
-2.02, P<0.005 \\
\text { McGill Pain Questionnaire (0- } \\
78): 13.1 \text { vs. } 18.3, \text { MD }-3.25 \text {, } \\
P<0.005\end{array}$ & NR \\
\hline $\begin{array}{l}\text { Cherkin, } \\
2001^{149} \\
10.5 \text { months } \\
\text { Duration of } \\
\text { pain >1 year: } \\
64 \% \text { vs. } 62 \% \\
\text { Fair }\end{array}$ & $\begin{array}{l}\text { A. Mixed massage } \\
\text { (including Swedish) } \\
\text { ( } n=78) \text { Up to } 10 \\
\text { sessions over } 10 \\
\text { weeks } \\
\text { B. Attention control } \\
\text { (self-care } \\
\text { education) }(n=90)\end{array}$ & $\begin{array}{l}\text { A vs. B } \\
\text { Age: } 46 \text { vs. } 44 \\
\text { years } \\
\text { Female: } 69 \% \\
\text { vs. } 56 \% \\
\text { Baseline } \\
\text { modified RDQ } \\
(0-23): 11.8 \text { vs. } \\
12.0 \\
\text { Baseline } \\
\text { symptom } \\
\text { bothersomeness } \\
\text { (0-10): } 6.2 \text { vs. } \\
6.1\end{array}$ & $\begin{array}{l}\text { A vs. } B \\
10.5 \text { months } \\
\text { Modified RDQ }(0-23): 6.8 \text { vs. } \\
6.4, P=0.03 \\
\text { Symptom bothersomeness ( } 0 \text { - } \\
10): 3.2 \text { vs. } 3.8, P=0.003\end{array}$ & $\begin{array}{l}\text { A vs. B } \\
10.5 \text { months } \\
\text { Low back pain } \\
\text { medication: } 2.5 \text { vs. } 4.0 \text {, } \\
\mathrm{P}=0.69 \\
\text { SF-12 Mental } \\
\text { Component Score: no } \\
\text { differences, data not } \\
\text { shown }\end{array}$ \\
\hline
\end{tabular}




\begin{tabular}{|c|c|c|c|c|}
\hline $\begin{array}{l}\text { Author, Year, } \\
\text { Followup, } \\
\text { Pain } \\
\text { Duration, } \\
\text { Study } \\
\text { Quality }\end{array}$ & Intervention & Population & Function and Pain Outcomes & Other Outcomes \\
\hline $\begin{array}{l}\text { Cherkin, } \\
2011^{150} \\
9.5 \text { months } \\
\text { Duration of } \\
\text { pain } \geq 1 \text { year: } \\
77 \% \text { vs. } 72 \% \\
\text { vs. } 78 \% \\
\text { Fair }\end{array}$ & $\begin{array}{l}\text { A. Structural } \\
\text { massage }(n=132) \text { : } \\
\text { (myofascial, } \\
\text { neuromuscular, } \\
\text { and other soft- } \\
\text { tissue techniques) } \\
10 \text { sessions for ten } \\
\text { weeks } \\
\text { B. Relaxation } \\
\text { massage ( } n=136) \text { : } \\
10 \text { sessions for ten } \\
\text { weeks } \\
\text { C. Usual care } \\
(n=133)\end{array}$ & $\begin{array}{l}\text { A vs. B vs. C } \\
\text { Age: } 46 \text { vs. } 47 \\
\text { vs. } 48 \text { years } \\
\text { Female: } 66 \% \\
\text { vs. } 65 \% \text { vs. } \\
62 \% \\
\text { Symptom } \\
\text { bothersomeness } \\
\text { (0-10): } 5.6 \text { vs. } \\
5.6 \text { vs. } 5.8 \\
\text { Modified RDQ } \\
\text { (0-23): } 10.1 \text { vs. } \\
11.6 \text { vs. } 10.5\end{array}$ & $\begin{array}{l}\text { A vs. B vs. C } \\
9.5 \text { months } \\
\text { Symptom bothersomeness (0- } \\
\text { 10): } 4.6(95 \% \mathrm{Cl} 4.2 \text { to } 5.0) \text { vs. } \\
3.9(95 \% \mathrm{Cl} 3.5 \text { to } 4.3) \text { vs. } 4.2 \\
\text { ( } 95 \% \mathrm{Cl} 3.8 \text { to } 4.6) \\
\text { Modified RDQ }(0-23): 7.2(95 \% \\
\mathrm{Cl} 6.4,7.9) \text { vs. } 6.0(95 \% \mathrm{Cl} 5.2 \\
\text { to } 6.9) \text { vs. } 7.4(95 \% \mathrm{Cl} 6.6 \text { to } \\
8.3) \text {, adjusted difference }-0.3 \\
\text { (95\% } \mathrm{Cl}-1.4 \text { to } 0.9) \text { for A vs. C } \\
\text { and }-1.4(95 \% \mathrm{Cl}-2.6 \text { to }-0.2) \\
\text { for B vs. C }\end{array}$ & 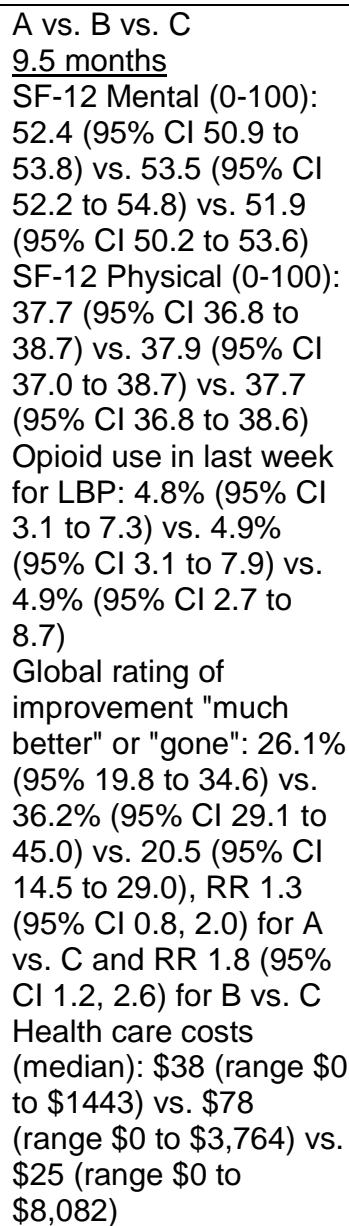 \\
\hline
\end{tabular}




\begin{tabular}{|c|c|c|c|c|}
\hline $\begin{array}{l}\text { Author, Year, } \\
\text { Followup, }{ }^{\text {a }} \\
\text { Pain } \\
\text { Duration, } \\
\text { Study } \\
\text { Quality }\end{array}$ & Intervention & Population & Function and Pain Outcomes & Other Outcomes \\
\hline $\begin{array}{l}\text { Little, } 2008^{159} \\
11.5 \text { months } \\
\text { Duration of } \\
\text { pain: NR } \\
\text { Fair }\end{array}$ & $\begin{array}{l}\text { A. Mixed massage } \\
\text { (including Swedish) } \\
\text { ( } n=72), 6 \text { sessions } \\
\text { over } 6 \text { weeks/ } \\
\text { B: Usual care } \\
\text { ( } n=72 \text { ) } \\
\text { C: Exercise } \\
\text { (regular exercise) } \\
\text { ( } n=72) 5 \text { times per } \\
\text { week }\end{array}$ & $\begin{array}{l}\text { Age: } 45-46 \\
\text { years } \\
\text { Female: } 64- \\
78 \% \\
\text { Baseline RDQ } \\
\text { (0-24): 10.8- } \\
11.3 \\
\text { Baseline Deyo } \\
\text { troublesome- } \\
\text { ness (1-5): } \\
3.3-3.4\end{array}$ & $\begin{array}{l}\text { A vs. B } \\
10.5 \text { months } \\
\text { RDQ (0-24): NR vs. } 9.23 \text { ( } 5.3) \text {, } \\
\text { difference }-0.45 \text { ( } 95 \% \mathrm{Cl}-2.3 \\
\text { to } 1.39) \\
\text { Von Korff disability (0-10): NR } \\
\text { vs. } 3.32(2.25) \text {, difference } 0.46 \\
\text { (95\% Cl }-0.43 \text { to } 1.35) \\
\text { Von Korff pain (0-10): NR vs. } \\
4.74(2.20) \text {, difference } 0.29 \\
\text { (95\% Cl }-0.58 \text { to } 1.16) \\
\text { A vs. C } \\
10.5 \text { months } \\
\text { RDQ: }-0.45 \text { (-2.3 to } 1.39) \text { vs. } \\
-1.65 \text { ( }-3.62 \text { to } 0.31) \\
\text { Von Korff disability: } 0.46(-0.43 \\
\text { to } 1.35) \text { vs. } 0.05(-0.92 \text { to } 1.02) \\
\text { Von Korff pain: } 0.29(-0.58 \text { to } \\
1.16) \text { vs. }-0.31(-1.26 \text { to } 0.63)\end{array}$ & 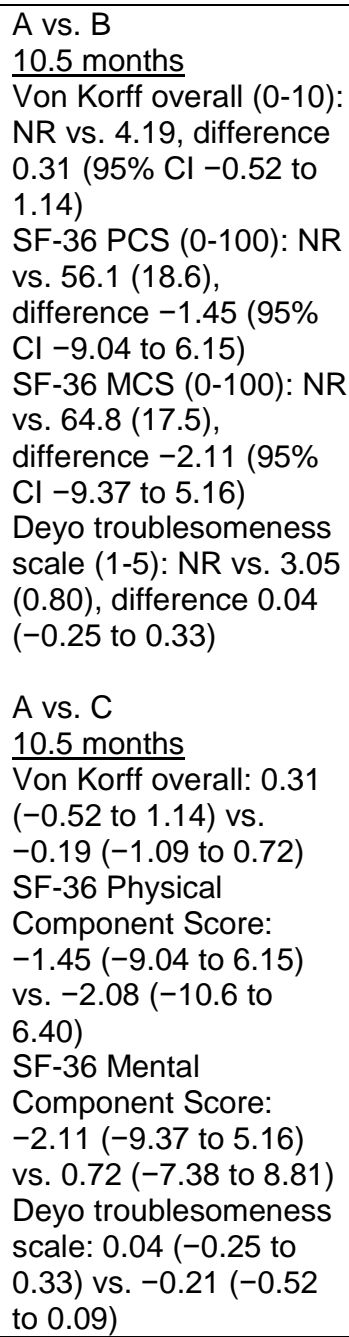 \\
\hline $\begin{array}{l}\text { Poole, } 2007^{93} \\
4.5 \text { months } \\
\text { Duration of } \\
\text { pain: } 10 \text { vs. } \\
11 \text { vs. } 9.5 \\
\text { years } \\
\text { Fair }\end{array}$ & $\begin{array}{l}\text { A. Reflexology } \\
(n=77) \\
6 \text { sessions over } \\
6-8 \text { weeks } \\
\begin{array}{l}\text { B. Usual care } \\
(n=75)\end{array}\end{array}$ & $\begin{array}{l}\text { A vs. B } \\
\text { Age: } 47 \text { vs. } 47 \\
\text { years } \\
\text { Female: } 62 \% \\
\text { vs. } 51 \% \\
\text { Baseline ODI: } \\
33.0 \text { vs. } 36.6 \\
\text { Baseline pain } \\
\text { (0-100 VAS): } \\
44.5 \text { vs. } 40.6\end{array}$ & $\begin{array}{l}\text { A vs. B } \\
4.5 \text { months } \\
\text { ODI (0-100): } 29.0(20.2) \text { vs. } \\
32.9(17.6) \\
\text { Pain (0-100 VAS): } 39.8 \text { (29.2) } \\
\text { vs. } 42.7(28.4)\end{array}$ & $\begin{array}{l}\text { A vs. B } \\
\text { 4.5 months } \\
\text { Beck Depression } \\
\text { Inventory (0-63): 11.6 } \\
\text { (10.9) vs. 12.8 (9.2) } \\
\text { SF-36 Physical } \\
\text { Functioning: } 57.1 \text { (31.8) } \\
\text { vs. } 52.2 \text { (29.5) } \\
\text { SF-36 Social } \\
\text { Functioning: } 68.1 \text { (31.8) } \\
\text { vs. } 61.5(30.8) \\
\text { SF-36 Physical } \\
\text { Limitations: } 48.2(46.4) \\
\text { vs. } 37.8(42.5) \\
\text { SF-36 Emotional } \\
\text { Limitations: } 55.0(46.5) \\
\text { vs. } 62.0(44.0)\end{array}$ \\
\hline
\end{tabular}




\begin{tabular}{|c|c|c|c|c|}
\hline $\begin{array}{l}\text { Author, Year, } \\
\text { Followup, }^{\text {a }} \\
\text { Pain } \\
\text { Duration, } \\
\text { Study } \\
\text { Quality }\end{array}$ & Intervention & Population & Function and Pain Outcomes & Other Outcomes \\
\hline $\begin{array}{l}\text { Quinn, } \\
2008^{151} \\
1.5 \text { and } 3 \\
\text { months } \\
\text { Duration of } \\
\text { pain: At least } \\
3 \text { months } \\
\text { Fair }\end{array}$ & $\begin{array}{l}\text { A. Reflexology } \\
\text { (pressure massage } \\
\text { stimulation) }(n=7) \\
6 \text { sessions over } 6 \\
\text { weeks } \\
\text { B. Sham } \\
\text { reflexology }(n=8)\end{array}$ & $\begin{array}{l}\text { A vs. B } \\
\text { Age (median): } \\
42 \text { vs. } 45 \\
\text { Female: } 86 \% \\
\text { vs. } 50 \% \\
\text { Baseline RDQ: } \\
5 \text { vs. } 7.5 \\
\text { Baseline pain } \\
\text { (0-10 VAS): } 4.7 \\
\text { vs. } 3.4\end{array}$ & $\begin{array}{l}\text { A vs. B } \\
1.5 \text { months, median (IQR) } \\
\text { RDQ: } 4 \text { (3 to } 4.5) \text { vs. } 4.5 \text { (1 to } 7) \\
\text { Pain (0-10 VAS): } 2.1 \text { ( } 1.5 \text { to } 4.9) \\
\text { vs. } 4.1 \text { ( } 2.7 \text { to } 5.1 \text { ) } \\
\text { McGill Pain Questionnaire (0- } \\
\text { 77): } 11 \text { (6 to 17) vs. } 6.5 \text { (5 to } \\
\text { 13) } \\
3 \text { months, median (IQR) } \\
\text { RDQ: } 4 \text { (2 to 5) vs. } 3.5 \text { ( } 1.8 \text { to } \\
4.8) \\
\text { VAS: } 2.2 \text { (1.6 to } 3.2) \text { vs. } 3.2 \text { ( } 2.6 \\
\text { to } 4.6) \\
\text { McGill Pain Questionnaire (0- } \\
\text { 77): } 6 \text { (4 to } 13 \text { ) vs. } 7.5 \text { (3.8 to } \\
\text { 9.8) }\end{array}$ & $\begin{array}{l}\text { A vs. B } \\
1.5 \text { months, median } \\
\text { (IQR) } \\
\text { SF-36 General health: } \\
52.9 \text { (49 to 54) vs. } 42.2 \\
\text { (40 to 51) } \\
\text { SF-36 Physical } \\
\text { functioning: } 48.6 \text { ( } 47 \text { to } \\
50) \text { vs. } 43.4 \text { ( } 40 \text { to } 50) \\
\text { SF-36 Mental health: } \\
47.2 \text { (43 to } 56) \text { vs. } 47.2 \\
\text { (42 to } 53) \\
3 \text { months, median (IQR) } \\
\text { SF-36 General health: } \\
48.2 \text { (46 to } 52) \text { vs. } 47.0 \\
\text { (38 to } 53) \\
\text { SF-36 Physical } \\
\text { functioning: } 50.7 \text { ( } 44 \text { to } \\
51) \text { vs. } 45.5 \text { (44 to } 50) \\
\text { SF-36 Mental health: } \\
52.8 \text { (39 to } 53 \text { ) vs. } 48.6 \\
\text { (44 to } 51)\end{array}$ \\
\hline
\end{tabular}

Abbreviations: CI = confidence interval; IQR = interquartile range; NR = not reported; MCS = Mental Component Summary; PCS = Physical Component Summary; ODI = Oswestry Disability Index; RDQ =Roland-Morris disability questionnaire; SF-36 = Short-Form 36 questionnaire; VAS = visual analog scale

${ }^{\text {a }}$ Unless otherwise noted, followup time is calculated from the end of the treatment period

\section{Massage Compared With Sham Massage, Usual Care, or an Attention Control}

Massage was associated with slightly greater effects on short-term function than sham massage or usual care ( 4 trials, SMD $-0.30,95 \% \mathrm{CI}-0.46$ to $-0.14, \mathrm{I}^{2}=0 \%$ ) (Figure 12). ${ }^{93,148,150,151}$ The massage technique was myofascial release in one trial (difference $-3.80,95 \%$ CI -8.20 to 0.60 on the 0 to 100 Quebec Back Disability Scale), ${ }^{148}$ structural or relaxation massage in one trial (difference -1.72 on the 0 to 23 modified RDQ, 95\% CI -2.78 to -0.66 ), ${ }^{150}$ and foot reflexology in two trials (difference 0.50 on the 0 to $24 \mathrm{RDQ}, 95 \% \mathrm{CI}-1.85$ to 2.85 in one trial ${ }^{151}$ and -3.90 on the 0 to $100 \mathrm{ODI}, 95 \% \mathrm{CI}-9.97$ to 2.17 in the other trial $\left.{ }^{93}\right)$. Estimates were similar when trials were stratified according to whether the comparator was sham massage or usual care. There was no effect on intermediate-term function (3 trials, SMD -0.09, 95\% CI -0.24 to $0.06, \mathrm{I}^{2}=0 \%$ ) (Figure 12 ). ${ }^{149,150,159}$

Massage was associated with slightly greater effects on short-term pain than sham massage or usual care ( 4 trials, pooled difference -0.52 on a 0 to 10 scale, $95 \%$ CI -0.81 to $-0.23, \mathrm{I}^{2}=0 \%$ ) (Figure 13). ${ }^{93,148,150,151}$ On a 0 to 10 scale, effects were -0.29 (95\% CI -1.21 to 0.63 ) and -1.00 ( $95 \%$ CI -2.41 to 0.41 ) points in two trials of foot reflexology, ${ }^{93,151}-0.67$ points (95\% CI -1.08 to -0.25 ) in a trial of myofascial release, ${ }^{148}$ and -0.35 points ( $95 \%$ CI -0.82 to 0.12 ) in a trial of relaxation or structural massage. ${ }^{150}$ Estimates were similar when trials were stratified according to whether the comparator was sham massage or usual care. There was no difference between massage (structural or relaxation massage or mixed massage techniques, including Swedish massage) versus an attention control or usual care in intermediate-term pain (3 trials, difference $-0.01,95 \%$ CI -0.40 to $\left.0.38, \mathrm{I}^{2}=0 \%\right) .{ }^{149,150,159}$ 
One trial found no difference between massage versus usual care in use of opioids at intermediate-term followup or health care costs. ${ }^{150}$ There was insufficient evidence to determine effects of duration of massage or number of massage sessions on findings. Two trials ${ }^{150,159}$ found no differences between massage versus usual care on the SF-36 MCS or PCS Scores at intermediate-term followup, and one trial ${ }^{93}$ found no effects on various SF-36 subscales or the Beck Depression Inventory at short-term followup.

\section{Massage Compared With Pharmacological Therapies}

No trial of massage versus pharmacological therapy met inclusion criteria.

\section{Massage Compared With Exercise}

One trial found no differences between massage versus exercise in intermediate-term function (difference 1.2 on the 0 to $24 \mathrm{RDQ}, 95 \% \mathrm{CI}-1.47$ to 3.87), pain (difference 0.60 on the 0 to 10 Von Korff pain scale, $95 \%$ CI -0.67 to 1.87 ), or the SF-36 MCS or PCS scores (differences 0 to 3 points on 0 to 100 scales, $\mathrm{P}>0.05$ ). ${ }^{159}$

\section{Harms}

Two trials ${ }^{148,149}$ reported no serious adverse events, and one trial ${ }^{151}$ reported no adverse events. In four trials, the proportion of massage patients who reported increased pain ranged from $<1$ to 26 percent. ${ }^{148-150,159}$ 
Figure 12. Massage versus sham massage, usual care, or attention control intervention for chronic low back pain: effects on function

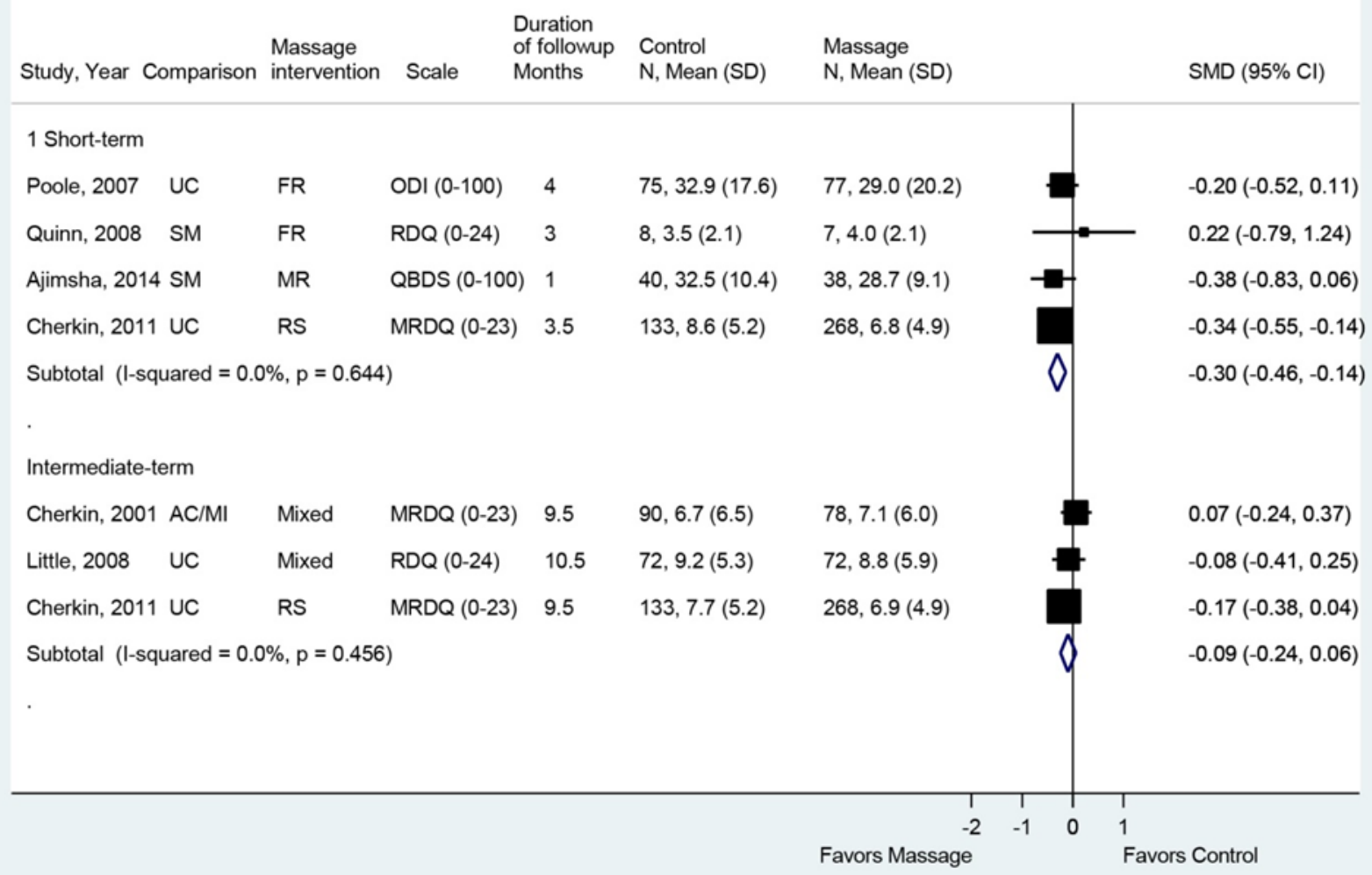

$\mathrm{AC}=$ attention control; $\mathrm{CI}=$ confidence interval; $\mathrm{FR}=$ foot reflexology; $\mathrm{MD}=$ mean difference; $\mathrm{MI}=$ minimal intervention; MRDQ = Modified Roland-Morris Disability Questionnaire; MR = myofascial release; N = number; QBDS = Quebec Back Pain Disability Scale; RDQ = Roland-Morris Disability Questionnaire; RS = relaxation/structural; SD = standard deviation; SM = sham massage, $\mathrm{SMD}=$ standardized mean difference; $\mathrm{UC}=$ usual care 
Figure 13. Massage versus sham massage, usual care, or attention control for chronic low back pain: effects on pain

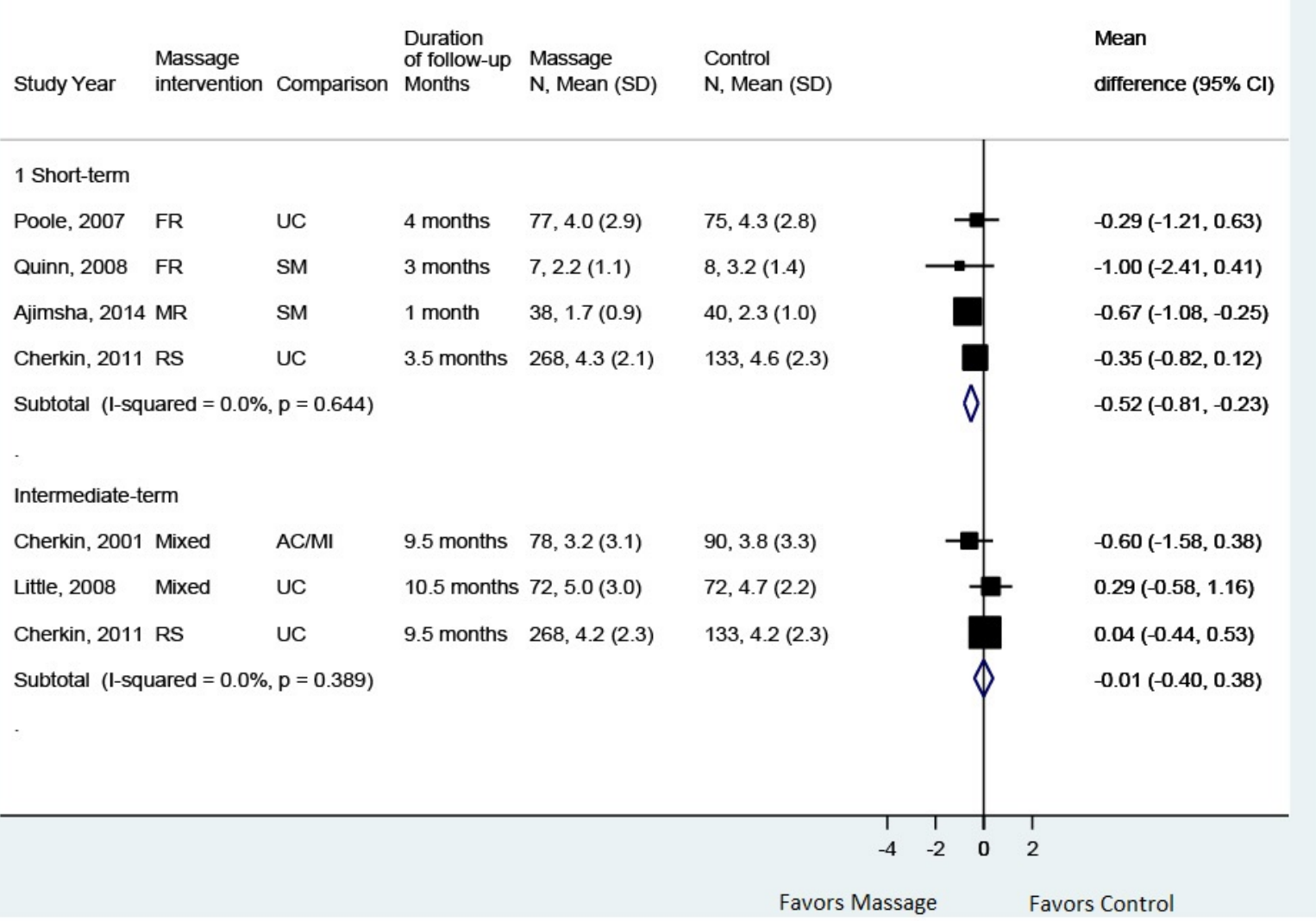

$\mathrm{AC}$ = attention control; $\mathrm{CI}$ = confidence interval; $\mathrm{FR}$ = foot reflexology; $\mathrm{MI}$ = minimal intervention; $\mathrm{MR}=$ myofascial release; $\mathrm{N}$ = number; $\mathrm{RS}$ = relaxation/structural; $\mathrm{SD}=$ standard deviation; $\mathrm{SM}=$ sham massage, $\mathrm{UC}=$ usual care

\section{Mindfulness-Based Stress Reduction for Chronic Low Back Pain}

\section{Key Points}

- There was no evidence of differences between mindfulness-based stress reduction (MBSR) versus usual care or attention control in short-term function (4 trials, pooled SMD -0.25 , 95\% CI -0.53 to $0.04, \mathrm{I}^{2}=53 \%$ ), intermediate-term function ( 1 trial, SMD $-0.20,95 \% \mathrm{CI}-0.47$ to 0.06 ), or long-term function ( 1 trial, SMD $-0.20,95 \% \mathrm{CI}-0.47$ to 0.06) (SOE: low).

- MBSR was associated with slightly greater effects than usual care or an attention control on short-term pain ( 3 trials, pooled MD -0.73 on a 0 to 10 scale, $95 \%$ CI -1.18 to -0.28 , $\mathrm{I}^{2}=93 \%$ ) after excluding two poor-quality trials; MBSR was also associated with small effects on intermediate-term pain ( 1 trial, MD -0.75 , $95 \%$ CI -1.17 to -0.33 ), with no statistically significant effects on long-term pain ( 1 trial, MD -0.22 , 95\% CI -0.64 to 0.20) (SOE: moderate for short term, low for intermediate and long term).

- One trial reported temporarily increased pain in 29 percent of patients undergoing MBSR, and three trials reported no harms (SOE: low). 


\section{Detailed Synthesis}

Five trials (7 publications) of MBSR for low back pain met inclusion criteria (Table 13 and Appendix D). ${ }^{89,164-169}$ In three trials, ${ }^{89,165-168}$ the MBSR intervention was closely modeled on the program developed by Kabat-Zinn; ${ }^{245}$ in the other two trials, the MBSR intervention appeared to have undergone some adaptations from the original Kabat-Zinn program. ${ }^{164,169}$ In all trials, the main intervention consisting of 1.5 to 2 hour weekly group sessions for 8 weeks. Sample sizes ranged from 35 to 282 (total sample=625). Three trials compared MBSR versus usual care ${ }^{89,164-}$ 166,169 and two trials compared MBSR versus an attention control (education). ${ }^{167,168}$ Four trials $^{89,165-169}$ were conducted in the United States and one trial ${ }^{164}$ in Iran. One trial focused on patients on opioid therapy for low back pain. ${ }^{169}$ One trial reported outcomes through long-term (22 months after 8-week MBSR course) followup, ${ }^{89,165,166}$ and the others only evaluated shortterm outcomes.

Three trials ${ }^{89,165-168}$ were rated fair quality and two trials poor quality (Appendix E). ${ }^{164,169}$ The major methodological limitation in the fair-quality trials was the inability to effectively blind patients and caregivers to the MBSR intervention. One poor-quality trial reported unclear randomization and allocation concealment methods and had high attrition, ${ }^{164}$ and another poorquality trial reported a large baseline difference in baseline pain scores (Brief Pain Inventory score 6.3 on a 0 to 10 scale with MBSR versus 4.9 with usual care). ${ }^{169}$

Table 13. Chronic low back pain: mindfulness-based stress reduction

\begin{tabular}{|c|c|c|c|c|}
\hline $\begin{array}{l}\text { Author, Year, } \\
\text { Followup, } \\
\text { Pain } \\
\text { Duration, } \\
\text { Study } \\
\text { Quality }\end{array}$ & Intervention & Population & Function and Pain Outcomes & Other Outcomes \\
\hline $\begin{array}{l}\text { Banth, } 2015^{164} \\
1 \text { month } \\
\text { Duration of } \\
\text { pain: } \geq 6 \\
\text { months } \\
\text { Poor }\end{array}$ & $\begin{array}{l}\text { A. Mindfulness- } \\
\text { based stress } \\
\text { reduction }(n=N R) \\
81.5 \text {-hour } \\
\text { sessions over } 8 \\
\text { weeks } \\
\text { B. Usual care } \\
\text { ( } n=N R) \\
48 \text { of } 88 \text { patients } \\
\text { were analyzed, } n \\
\text { for each group NR }\end{array}$ & $\begin{array}{l}\text { A vs. B (NR) } \\
\text { Age: } 40 \text { years } \\
\text { Female: } 100 \% \\
\text { Baseline } \\
\text { function: NR } \\
\text { McGill Pain } \\
\text { questionnaire } \\
\text { total score (0- } \\
45): 26.08 \text { vs. } \\
26.71\end{array}$ & $\begin{array}{l}\text { A vs. B } \\
1 \text { month } \\
\text { McGill Pain questionnaire total } \\
\text { score (0-45): } 13.58 \text { vs. } 23.60\end{array}$ & $\begin{array}{l}\text { A vs. B } \\
1 \text { month } \\
\text { SF-12 Mental } \\
\text { component (0-100): } \\
31.54 \text { (4.3) vs. } 24.29 \\
(5.2) \\
\text { SF-12 Physical } \\
\text { component (0-100): } \\
28.08 \text { (4.2) vs. } 21.08 \\
(3.3)\end{array}$ \\
\hline
\end{tabular}




\begin{tabular}{|c|c|c|c|c|}
\hline $\begin{array}{l}\text { Author, Year, } \\
\text { Followup, }^{\mathrm{a}} \\
\text { Pain } \\
\text { Duration, } \\
\text { Study } \\
\text { Quality }\end{array}$ & Intervention & Population & Function and Pain Outcomes & Other Outcomes \\
\hline $\begin{array}{l}\text { Cherkin, } \\
2016^{89} \\
\text { Herman, } \\
2017^{166} \\
\text { Cherkin, } \\
2017^{165}(2 \\
\text { year data } \\
\text { from Cherkin, } \\
2016) \\
22 \text { months } \\
\text { Duration of } \\
\text { pain: }>3 \\
\text { months } \\
\text { (>1 year in } \\
80 \% \text { of } \\
\text { patients) }\end{array}$ & $\begin{array}{l}\text { A. Mindfulness- } \\
\text { based stress } \\
\text { reduction ( } n=113) \text {, } \\
8 \text { 2-hour sessions } \\
\text { over } 8 \text { weeks } \\
\text { (optional } 6 \text { hour } \\
\text { retreat) } \\
\text { B. Usual care } \\
(n=112)\end{array}$ & $\begin{array}{l}\text { A vs. B } \\
50 \text { vs. } 49 \text { years } \\
\text { Female: } 61 \% \text { vs. } \\
66 \% \\
\text { Baseline } \\
\text { modified RDQ } \\
(0-23): 11.8 \text { vs. } \\
10.9 \\
\text { Baseline pain } \\
\text { bothersomeness } \\
(0-10): 6.1 \text { vs. } \\
6.0\end{array}$ & $\begin{array}{l}\text { A vs. B } \\
4.5 \text { months } \\
\text { Modified RDQ (0-23), mean } \\
\text { change from baseline: }-4.33 \\
(95 \% \mathrm{Cl}-5.16 \text { to }-3.51) \text { vs. } \\
-2.96(95 \% \mathrm{Cl}-3.79 \text { to }-2.14) \\
\text { Pain bothersomeness }(0-10) \text {, } \\
\text { mean change from baseline: } \\
-1.48 \text { ( } 95 \% \mathrm{Cl}-1.86 \text { to }-1.11) \\
\text { vs. }-0.84(95 \% \mathrm{Cl}-1.21 \text { to } \\
-0.46) \\
\geq 30 \% \text { improvement in RMDQ: } \\
60.5 \%(95 \% \mathrm{Cl} 52.0 \text { to } 70.3) \text { vs. } \\
44.1 \%(95 \% \mathrm{Cl} 35.9 \text { to } 54.2) \\
\geq 30 \% \text { improvement in pain } \\
\text { bothersomeness: } 43.6 \%(95 \% \\
\mathrm{Cl} 35.6 \text { to } 53.3) \text { vs. } 26.6 \%(95 \% \\
\mathrm{Cl} 19.8 \text { to } 35.9)\end{array}$ & $\begin{array}{l}\text { A vs. B } \\
4.5 \text { months } \\
\text { SF-12 MCS, mean } \\
\text { change from baseline } \\
(0-100): 0.45 \text { ( } 95 \% \mathrm{Cl} \\
-0.85 \text { to } 1.76) \text { vs. } 2.13 \\
(95 \% \mathrm{Cl} 0.86 \text { to } 3.40) \\
\text { vs. }-1.11(95 \% \mathrm{Cl} \\
-2.39 \text { to } 0.17) \\
\text { SF-12 PCS, mean } \\
\text { change from baseline } \\
(0-100): 3.58 \text { (95\% Cl } \\
2.15 \text { to } 5.01) \text { vs. } 3.27 \\
(95 \% \mathrm{Cl} 2.09 \text { to } 4.44) \\
\text { Used medications for } \\
\text { LBP: } 43.4 \% \text { (95\% Cl } \\
35.9 \text { to } 52.6) \text { vs. } 54.2 \\
\text { (95\% Cl } 46.2 \text { to } 63.6)\end{array}$ \\
\hline Fair & & & 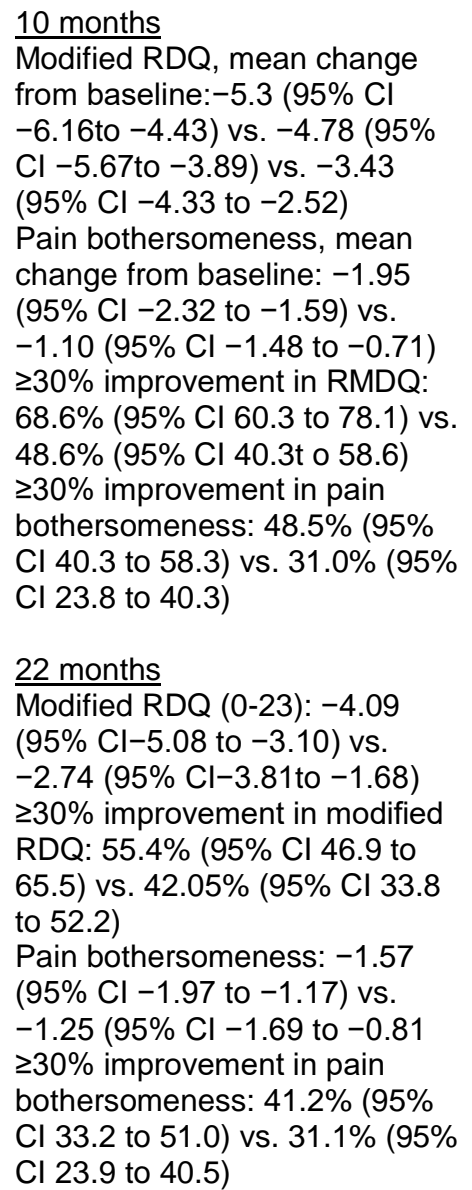 & $\begin{array}{l}10 \text { months } \\
\text { SF-12 MCS, mean } \\
\text { change from baseline: } \\
2.01 \text { ( } 95 \% \mathrm{Cl} 0.74 \text { to } \\
3.28) \text { vs. } 0.75 \text { (95\% Cl } \\
-0.58 \text { to } 2.08) \\
\text { SF-12 PCS, mean } \\
\text { change from baseline: } \\
3.87 \text { (95\% Cl } 2.55 \text { to } \\
5.19) \text { vs. } 2.93 \text { (95\% Cl } \\
1.70 \text { to } 4.16) \\
\text { Used medications for } \\
\text { LBP: } 46.8 \%(95 \% \mathrm{Cl} \\
39.2 \text { to } 55.9) \text { vs. } 52.9 \% \\
(95 \% \mathrm{Cl} 45.1 \text { to } 62.0) \\
\text { Total costs: } \$ 5,580 \\
(95 \% \mathrm{Cl} \$ 3,465, \\
\$ 8,343) \text { vs. } \$ 6,304 \\
(95 \% \mathrm{Cl} \$ 4,193, \\
\$ 9,805)\end{array}$ \\
\hline
\end{tabular}




\begin{tabular}{|c|c|c|c|c|}
\hline $\begin{array}{l}\text { Author, Year, } \\
\text { Followup, } \\
\text { Pain } \\
\text { Duration, } \\
\text { Study } \\
\text { Quality }\end{array}$ & Intervention & Population & Function and Pain Outcomes & Other Outcomes \\
\hline $\begin{array}{l}\text { Morone, } \\
2009^{168} \\
4 \text { months } \\
\text { Duration of } \\
\text { pain: Mean } \\
9.4 \text { to } 11 \\
\text { years } \\
\text { Fair }\end{array}$ & $\begin{array}{l}\text { A. Mindfulness- } \\
\text { based stress } \\
\text { reduction }(n=16) \text {, } \\
81.5 \text {-hour } \\
\text { sessions over } 8 \\
\text { weeks } \\
\text { B. Attention } \\
\text { control (education) } \\
(n=19)\end{array}$ & $\begin{array}{l}\text { A vs. B } \\
\text { Age } 78 \text { vs. } 73 \\
\text { years } \\
\text { Female: } 69 \% \text { vs. } \\
58 \% \\
\text { Baseline RDQ: } \\
8.8 \text { vs. } 11.3 \\
\text { Baseline McGill } \\
\text { Pain } \\
\text { Questionnaire } \\
\text { Current Pain (0- } \\
\text { 10): } 2.9 \text { vs. } 4.4 \\
\end{array}$ & $\begin{array}{l}\text { A vs. B } \\
4 \text { months } \\
\text { RDQ: } 7.6(95 \% \mathrm{Cl} 6.2 \text { to } 8.7) \\
\text { vs. } 10.0 \text { (95\% Cl } 8.7 \text { to } 11.2) \\
\text { McGill Pain Questionnaire Total } \\
\text { Score }(0-45): 12.4(95 \% \mathrm{Cl} 10.4 \\
\text { to } 14.6) \text { vs. } 12.0(95 \% \mathrm{Cl} 10.2 \\
\text { to } 13.7) \\
\text { McGill Pain Questionnaire } \\
\text { Current Pain (0-10): } 2.3(95 \% \\
\mathrm{Cl} 1.6 \text { to } 2.8) \text { vs. } 3.7(95 \% \mathrm{Cl} \\
3.1 \text { to } 4.3)\end{array}$ & $\begin{array}{l}\text { A vs. B } \\
4 \text { months } \\
\text { SF-36 Pain Score }(10- \\
62): 41.4(95 \% \mathrm{Cl} 39.8 \\
\text { to } 43.1) \text { vs. } 40.5(95 \% \\
\text { Cl } 38.7 \text { to } 42.2)\end{array}$ \\
\hline $\begin{array}{l}\text { Morone, } \\
2016^{167} \\
4.5 \text { months } \\
\text { Duration of } \\
\text { pain: Mean } 11 \\
\text { years } \\
\text { Fair }\end{array}$ & $\begin{array}{l}\text { A. Mindfulness- } \\
\text { based stress } \\
\text { reduction }(n=140) \text {, } \\
8 \text { 1.5-hour } \\
\text { sessions over } 8 \\
\text { weeks, with } 6 \\
\text { monthly booster } \\
\text { sessions } \\
\text { B. Control, (health } \\
\text { education) } \\
(n=142)\end{array}$ & $\begin{array}{l}\text { A vs. B } \\
\text { Age: } 75 \text { vs. } 74 \\
\text { years } \\
\text { Female: } 66 \% \text { vs. } \\
66 \% \\
\text { Baseline RDQ } \\
(0-24): 15.6 \text { vs. } \\
15.4 \\
\text { Baseline Pain } \\
(0-20 \text { NRS): } \\
11.0 \text { vs. } 10.5\end{array}$ & $\begin{array}{l}\text { A vs. B } \\
4.5 \text { months } \\
\text { RDQ: } 12.2 \text { vs. } 12.6 \text {, adjusted } \\
\text { difference }-0.4(95 \% \mathrm{Cl}-1.5 \text { to } \\
0.7) \\
\text { RDQ improved } \geq 2.5 \text { points: } \\
49.2 \%(58 / 117) \text { vs. } 48.9 \% \\
(66 / 135), P=0.97 \\
\text { Pain }(0-20 \text { NRS): } 9.5 \text { vs. } 10.6 \text {, } \\
\text { adjusted difference }-1.1(95 \% \\
\mathrm{Cl}-2.2 \text { to }-0.01) \\
\text { Pain improved } \geq 30 \%: 36.7 \% \\
\text { (43/117) vs. } 26.7 \%(36 / 135) \\
P=0.09\end{array}$ & $\begin{array}{l}\text { A vs. B } \\
4.5 \text { months } \\
\text { SF-36 Global Health } \\
\text { Composite (9-67): } 42.4 \\
\text { vs. } 41.2 \text {, adjusted } \\
\text { difference } 0.2 \text { ( } 95 \% \mathrm{Cl} \\
-1.9 \text { to } 2.4) \\
\text { SF-36 Physical Health } \\
\text { Composite (20 to } 65): \\
41.2 \text { vs. } 41.2 \text {, adjusted } \\
\text { difference }-0.1 \text { (95\% Cl } \\
-1.9 \text { to } 1.8)\end{array}$ \\
\hline $\begin{array}{l}\text { Zgierska, } \\
2016^{169} \\
4.5 \text { months } \\
\text { Duration of } \\
\text { pain: Mean } 14 \\
\text { years } \\
\text { Poor }\end{array}$ & $\begin{array}{l}\text { A. Mindfulness- } \\
\text { based stress } \\
\text { reduction }(n=21) \text { : } \\
8 \text { weekly } 2 \text { hour } \\
\text { group sessions } \\
\text { plus } 30 \\
\text { minutes/day, } 6 \\
\text { days/week of at } \\
\text { home practice } \\
\text { B. Usual care } \\
(n=14)\end{array}$ & $\begin{array}{l}\text { Overall } \\
\text { Age: } 51.8 \text { years } \\
\text { Female: } 80 \% \\
\text { Baseline ODI (0- } \\
\text { 100): } 68.1 \text { vs. } \\
64.5 \\
\text { Baseline Brief } \\
\text { Pain Inventory } \\
\text { pain intensity (0- } \\
\text { 10): } 6.3 \text { vs. } 4.9 \\
\text { Baseline Opioid } \\
\text { dose } 166.9 \text { vs. } \\
120.3\end{array}$ & $\begin{array}{l}\text { A vs. B } \\
4.5 \text { months } \\
\text { ODI (0-100): }-5.0(95 \% \mathrm{Cl} 9.7 \\
\text { to } 0.2) \text { vs. } 1.6(95 \% \mathrm{Cl}-4.3 \text { to } \\
7.4) \\
\text { Brief Pain Inventory pain } \\
\text { intensity: }-0.5(95 \% \mathrm{Cl}-1.1 \text { to } \\
0.02) \text { vs. } 0.5(95 \% \mathrm{Cl} 0.2 \text { to } 1.2)\end{array}$ & $\begin{array}{l}\text { A vs. B } \\
4.5 \text { months } \\
\text { Opioid dose (mg } \\
\text { morphine equivalents): } \\
-10.1 \text { ( } 95 \% \mathrm{Cl}-35.5 \text { to } \\
15.2) \text { vs. }-0.2(95 \% \mathrm{Cl} \\
-31.4 \text { to } 30.9)\end{array}$ \\
\hline
\end{tabular}

CI = confidence interval; MCS = Mental Component Summary; NR = not reported; NRS = numeric rating scale; ODI = Oswestry Disability Index; PCS = Physical Component Summary; RDQ = Roland-Morris Disability Questionnaire; SF-36 = Short-Form 36 Questionnaire; VAS = visual analog scale

${ }^{a}$ Unless otherwise noted, followup time is calculated from the end of the treatment period

\section{MBSR Compared With Usual Care or an Attention Control}

MBSR was associated with no statistically significant differences in short-term function compared with usual care or an attention control (4 trials, pooled SMD $-0.25,95 \%$ CI -0.53 to $0.04, \mathrm{I}^{2}=53 \%$ ) (Figure 14). ${ }^{89,167,168}$ Three trials ${ }^{89,167,168}$ evaluated function using the RDQ (pooled difference -0.95 points on a 0 to 24 scale, $95 \%$ CI -2.07 to 0.17 ), and one trial ${ }^{169}$ used the ODI (difference -3.00 points on a 0 to 100 scale, $95 \%$ CI -11.39 to 5.39 ). One trial found no difference between MBSR versus an attention control in intermediate-term (SMD -0.20, 95\% CI -0.47 to 0.06 ) or long-term function (SMD $-0.20,95 \%$ CI -0.47 to 0.06 ). ${ }^{89,165}$ There was no 
clear difference between MBSR versus controls in likelihood of a clinically meaningful effect on function ( $\geq 30 \%$ improvement in RDQ or RDQ improved by $\geq 2.5$ points) at short term ( 2 trials, 1.17, $95 \%$ CI 0.88 to 1.57 ). ${ }^{89,167}$ Data were restricted to one trial for intermediate-term (RR 1.41, 95\% CI 1.13 to 1.77 ) ${ }^{89}$ and long-term followup (RR 1.32, 95\% CI 1.00 to 1.74). ${ }^{165}$

MBSR was associated with no statistically significant effects on short-term pain compared with usual care or an attention control, when all trials were included in the analysis ( 5 trials, pooled difference -0.88 on a 0 to 10 scale, $95 \%$ CI -1.82 to 0.05 , $I^{2}=93 \%$ ) (Figure 15 )..$^{89,164,167-}$

${ }^{169}$ However, statistical heterogeneity was substantial. Excluding two poor-quality trials, ${ }^{164,169}$ which reported the largest effect in favor of MBSR (-1.40 points) as well as the only trial with results that favored usual care ( 0.40 points), resulted in a small effect on short-term pain ( 3 trials, pooled difference $-0.73,95 \% \mathrm{CI}-1.18$ to $-0.28, \mathrm{I}^{2}=45 \%$ ) and reduced statistical heterogeneity. ${ }^{89,167,168}$ Estimates were similar when analyses were stratified according to whether the trial evaluated usual care or an attention control comparator. One trial found MBSR associated with slightly greater effects than an attention control on intermediate-term pain (difference -0.75 on a 0 to 10 scale, $95 \%$ CI -1.17 to -0.33 ); there was no statistically significant effect on long-term pain (difference -0.22 , 95\% CI -0.64 to 0.20 ). ${ }^{165}$ MBSR was associated with greater likelihood of a clinically meaningful effect on pain (defined as $\geq 30 \%$ improvement) at short-term (2 trials, RR $1.49,95 \%$ CI 1.14 to $\left.1.95, \mathrm{I}^{2}=0 \%\right)^{89,167}$ and intermediate-term followup (1 trial, RR 1.56, 95\% CI 1.14 to 2.14), ${ }^{89}$ but not at long-term followup ( $41 \%$ vs. $31 \%$, RR 1.32, $95 \%$ CI 0.95 to 1.85 ). ${ }^{165}$

Three trials found no clear differences between MBSR versus usual care or an attention control on quality of life measured by the SF-12 or SF-36. ${ }^{89,164,167}$ One trial found MBSR associated with less medication use for low back pain at short term (43\% vs. 54\%) but not at intermediate term (47\% vs. $53 \%)$; MBSR was associated with slightly greater decrease in severity of depression (difference 0.63 points on the PHQ-8 at intermediate-term), with no clear differences in measures of health care utilization. ${ }^{89,166}$

\section{MBSR Compared With Pharmacological Therapy or With Exercise}

No trial of MBSR versus pharmacological or versus exercise therapy met inclusion criteria.

\section{Harms}

In one trial, 29 percent of MBSR patients reported temporarily increased pain. ${ }^{89}$ Three trials ${ }^{167-169}$ reported no adverse events and one trial ${ }^{164}$ did not report adverse events. 
Figure 14. Mindfulness-based stress reduction versus usual care or an attention control for chronic low back pain: effects on function

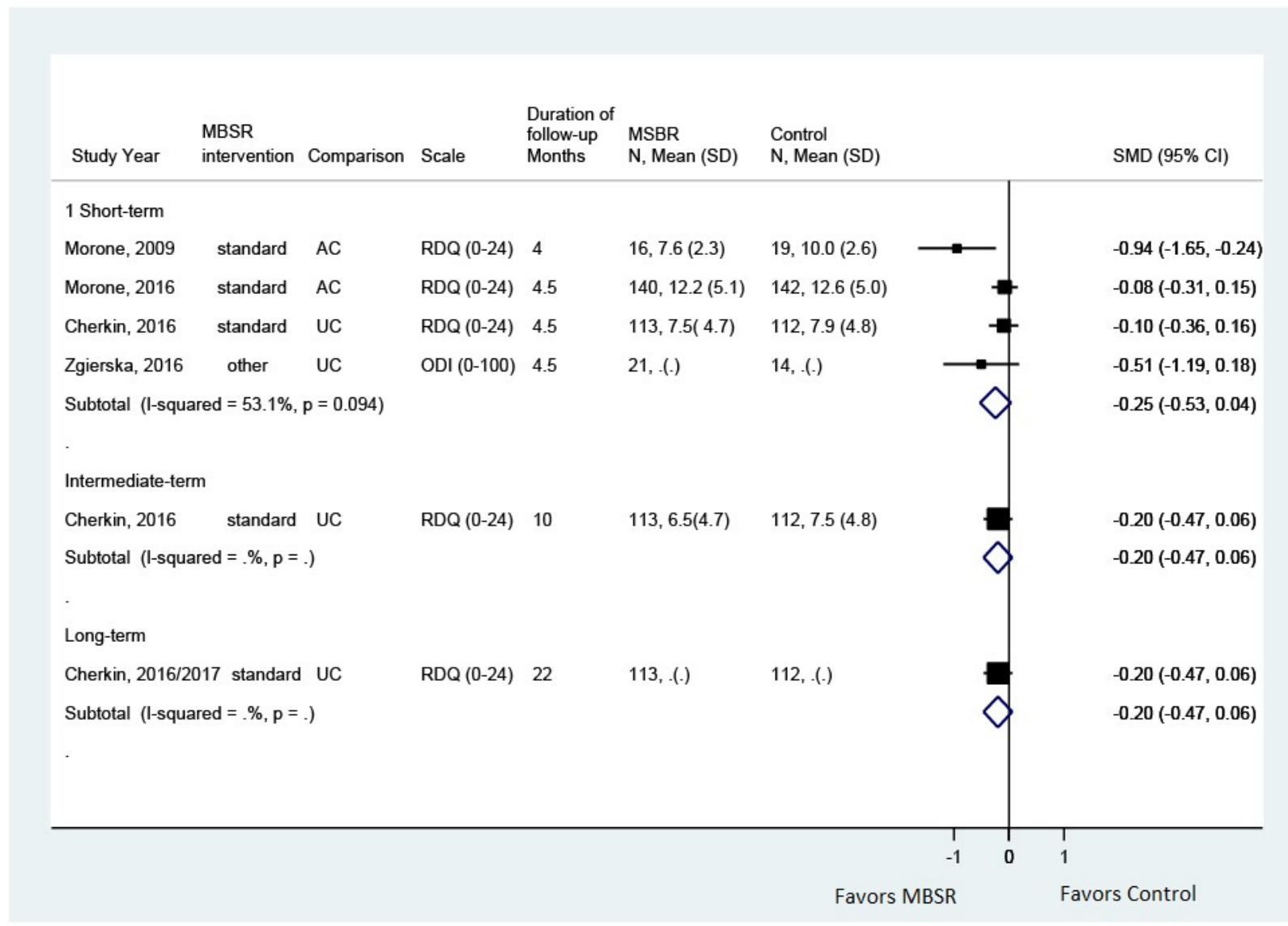

$\mathrm{AC}=$ attention control; $\mathrm{CI}$ = confidence interval; $\mathrm{MBSR}=$ mindfulness-based stress reduction; $\mathrm{N}=$ number; ODI = Oswestry Disability Index; RDQ = Roland-Morris Disability Questionnaire; SD = standard deviation; SMD = standardized mean difference; $\mathrm{UC}=$ usual care 
Figure 15. Mindfulness-based stress reduction versus usual care or an attention control for chronic low back pain: effects on pain

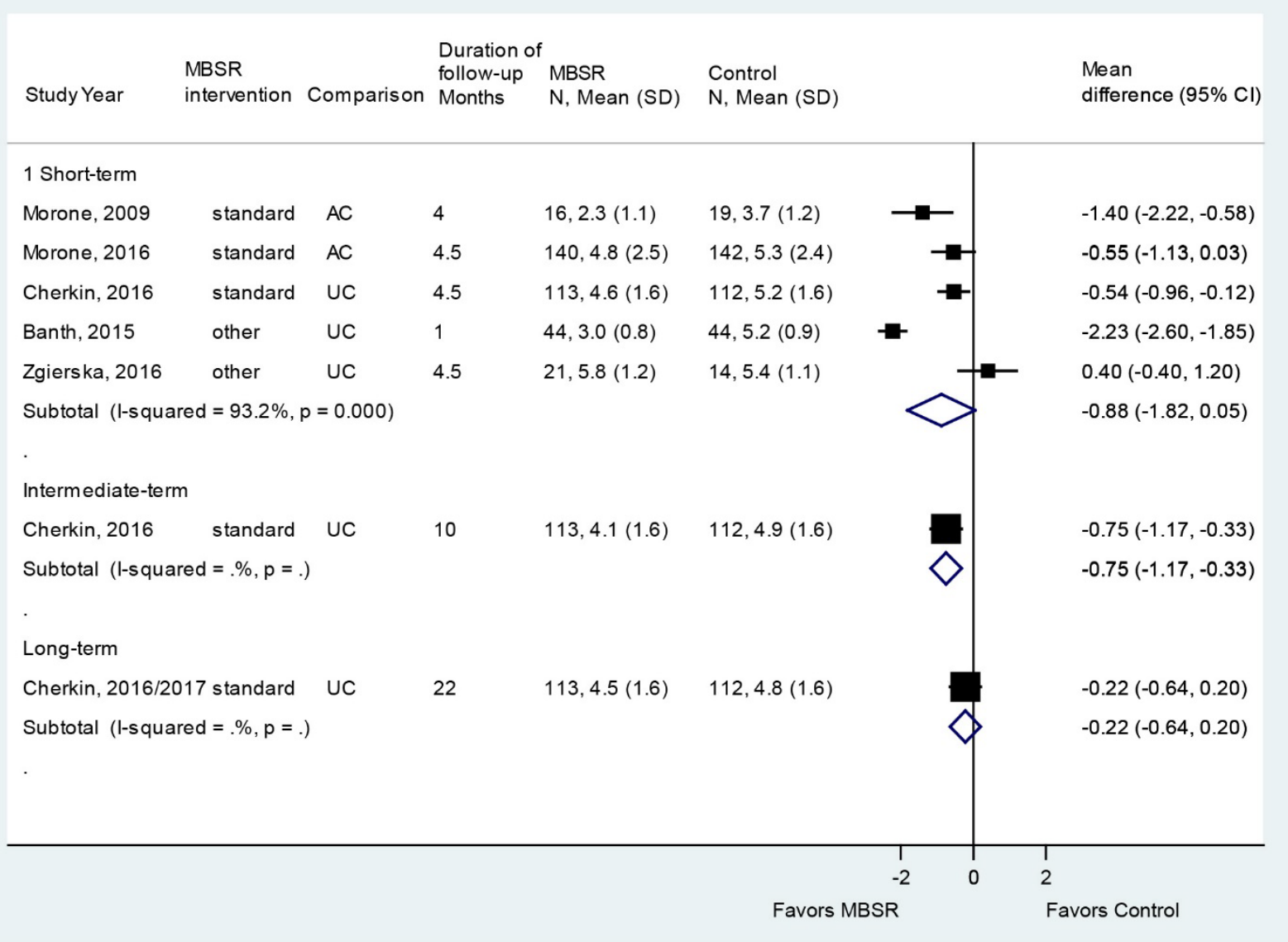

$\mathrm{AC}=$ attention control; $\mathrm{CI}=$ confidence interval; $\mathrm{MBSR}=$ mindfulness-based stress reduction; $\mathrm{N}=$ number; $\mathrm{SD}=$ standard deviation; UC = usual care

\section{Mind-Body Practices for Chronic Low Back Pain}

\section{Key Points}

\section{Yoga}

- Yoga was associated with slightly greater effects on function than an attention or waitlist control at short-term ( 6 trials, pooled SMD $-0.50,95 \%$ CI -0.72 to $-0.29, \mathrm{I}^{2}=54 \%$ ) and intermediate-term (3 trials, pooled SMD -0.33 , 95\% CI -0.49 to -0.16 ) followup (SOE: moderate for short term, low for intermediate term).

- Yoga was associated with moderately greater effects on pain than an attention or waitlist control at short-term ( 5 trials, pooled MD -1.10 on a 0 to 10 scale, $95 \% \mathrm{CI}$ -1.77 to $-0.42, \mathrm{I}^{2}=74 \%$ ) and intermediate-term ( 2 trials, pooled $\mathrm{MD}-1.17,95 \% \mathrm{CI}$ -1.91 to $-0.44, \mathrm{I}^{2}=26 \%$ ) followup (SOE: low for short term, moderate for intermediate term).

- Yoga was associated with no statistically significant differences versus exercise in shortterm or intermediate-term pain or function (SOE: low). 
- Yoga was not associated with increased risk of harms versus controls (SOE: low).

\section{Qigong}

- One trial found no evidence of differences between qigong versus exercise in short-term function (MD 0.9 on the RDQ, 95\% CI - 0.1 to 2.0), although intermediate-term results slightly favored exercise (MD 1.2, 95\% CI 0.1 to 2.3) (SOE: low).

- One trial found qigong associated with slightly lower effects on pain versus exercise at short-term followup (MD 7.7 on a 0 to 100 scale, $95 \%$ CI 0.7 to 14.7), but the difference at intermediate-term was not statistically significant (MD 7.1, 95\% CI -1.0 to 15.2) (SOE: low).

- One trial found no difference between qigong versus exercise in risk of adverse events (SOE: low).

\section{Detailed Synthesis}

\section{Yoga}

Eight trials of yoga for low back pain met inclusion criteria (Table 14, Appendix D). ${ }^{173-179,186}$ Four trials evaluated Iyengar yoga, ${ }^{177-179,186}$ two trials Viniyoga, ${ }^{175,176}$ and two trials Hatha yoga. ${ }^{173,174}$ Sample sizes ranged from 60 to 313 (total sample=1,466). Five trials compared yoga versus an attention control (education), ${ }^{174-177,179}$ two trials yoga versus wait list control, ${ }^{173,178}$ and four trials yoga versus exercise. ${ }^{174-176,186}$ One trial was conducted in India ${ }^{186}$ and the rest in the United States or Europe. The duration of yoga therapy ranged from 4 to 24 weeks and the number of sessions ranged from 4 to 48. In one trial, patients who received 12 weeks of yoga therapy were randomized to ongoing once-weekly maintenance sessions or to no maintenance. ${ }^{174}$ Three trials reported outcomes through intermediate-term followup, ${ }^{174,177,178}$ and five only reported short-term outcomes. ${ }^{173,175,176,179,186}$

All of the trials were rated fair quality (Appendix E). Trials could not effectively blind patients; other methodological limitations included unclear allocation or randomization methods and high attrition.

Table 14. Chronic low back pain: mind-body practices (yoga)

\begin{tabular}{|c|c|c|c|c|}
\hline $\begin{array}{l}\text { Author, Year, } \\
\text { Followup, }^{\text {a }} \\
\text { Pain } \\
\text { Duration, } \\
\text { Study } \\
\text { Quality }\end{array}$ & Intervention & Population & Function and Pain Outcomes & Other Outcomes \\
\hline $\begin{array}{l}\text { Groessl, } \\
2017^{173} \\
3.5 \text { months } \\
\text { Duration of } \\
\text { pain: >6 } \\
\text { months } \\
\text { Fair }\end{array}$ & $\begin{array}{l}\text { A. Hatha yoga } \\
\text { (n=75): Two } \\
\text { sessions per } \\
\text { week for } 12 \\
\text { weeks, 15-20 } \\
\text { minutes of home } \\
\text { practice on days } \\
\text { without sessions } \\
\text { B. Wait list } \\
\text { (n=75): Usual } \\
\text { care, with yoga } \\
\text { started after } 6 \\
\text { months }\end{array}$ & $\begin{array}{l}\text { A vs. B } \\
\text { Age: } 53 \text { vs. } 54 \\
\text { years } \\
\text { Female: } 27 \% \text { vs. } \\
25 \% \\
\text { Baseline RDQ } \\
(0-24): 9.40 \text { vs. } \\
10.3 \\
\text { Baseline pain (0- } \\
10 \text { Brief Pain } \\
\text { Inventory): } 4.64 \\
\text { vs. } 4.68\end{array}$ & $\begin{array}{l}\text { A vs. B } \\
3.5 \text { months } \\
\text { RDQ (0-24): }-3.37(95 \% \mathrm{Cl} \\
-4.51 \text { to }-2.23) \text { vs. }-0.89(95 \% \\
\mathrm{Cl}-2.02 \text { to } 0.23) \text {; between } \\
\text { group difference }-2.48(95 \% \mathrm{Cl} \\
-4.08 \text { to }-0.87) \\
\text { Pain intensity, Brief Pain } \\
\text { Inventory (0-10): }-0.44(95 \% \\
\mathrm{Cl}-0.78 \text { to }-0.11) \text { vs. } 0.15(95 \% \\
\mathrm{Cl}-0.18 \text { to } 0.47) ; \text { between- } \\
\text { group difference }-0.59(95 \% \mathrm{Cl} \\
-1.05 \text { to }-0.13)\end{array}$ & $\begin{array}{l}\text { A vs. } B \\
3.5 \text { months } \\
\text { Opioid medication use: } \\
9 \% \text { vs. } 7 \%, P=0.40 \\
\text { Other medical } \\
\text { treatments for pain: } \\
39 \% \text { vs. } 37, P=0.42\end{array}$ \\
\hline
\end{tabular}




\begin{tabular}{|c|c|c|c|c|}
\hline $\begin{array}{l}\text { Author, Year, } \\
\text { Followup, }^{\text {a }} \\
\text { Pain } \\
\text { Duration, } \\
\text { Study } \\
\text { Quality }\end{array}$ & Intervention & Population & Function and Pain Outcomes & Other Outcomes \\
\hline $\begin{array}{l}\text { Nambi, } \\
2014^{186} \\
5.5 \text { months } \\
\text { Duration of } \\
\text { pain: }>3 \\
\text { months } \\
\text { Fair }\end{array}$ & $\begin{array}{l}\text { A. lyengar yoga } \\
\text { ( } 29 \text { poses) }(n=30) \\
5 \text { sessions a week } \\
\text { for } 4 \text { weeks } \\
\text { B. Exercise } \\
\text { (stretching } \\
\text { exercises for soft } \\
\text { tissue flexibility } \\
\text { and range of } \\
\text { motion) }(n=30)\end{array}$ & $\begin{array}{l}\text { A vs. B } \\
\text { Age: } 44 \text { vs. } 43 \\
\text { years } \\
\text { Female: } 63 \% \text { vs. } \\
43 \% \\
\text { Baseline } \\
\text { function, } \\
\text { Physically } \\
\text { unhealthy days: } \\
18.0 \text { vs. } 17.8 \\
\text { Baseline pain (0- } \\
10 \text { VAS): } 6.7 \text { vs. } \\
6.7\end{array}$ & $\begin{array}{l}\text { A vs. B } \\
5 \text { months } \\
\text { Physically unhealthy days: } 2.6 \\
\text { vs. } 6.9, P=0.001 \\
\text { Pain (0-10 VAS): } 1.8 \text { vs. } 3.8, \\
P=0.001\end{array}$ & $\begin{array}{l}\text { A vs. } B \\
5 \text { months } \\
\text { Mentally unhealthy } \\
\text { days: } 2.1 \text { vs. } 5.0, \\
P=0.001 \\
\text { Activity limitation (days): } \\
2.0 \text { vs. } 5.0, P=0.001\end{array}$ \\
\hline $\begin{array}{l}\text { Saper, } \\
2017^{174} \\
10 \text { months } \\
\text { Duration of } \\
\text { pain: }>3 \\
\text { months } \\
\text { Fair }\end{array}$ & $\begin{array}{l}\text { A. Hatha yoga } \\
(\mathrm{n}=127) \\
12 \text { sessions over } \\
12 \text { weeks, with or } \\
\text { without ongoing } \\
\text { weekly } \\
\text { maintenance } \\
\text { sessions } \\
\text { B. Exercise } \\
(\mathrm{n}=129) \\
\text { C. Attention } \\
\text { control } \\
\text { (education) } \\
\text { ( } \mathrm{n}=64)\end{array}$ & $\begin{array}{l}\text { A vs. B vs. C } \\
\text { Age: } 46 \text { vs. } 46 \\
\text { vs. } 44 \\
\text { Female: } 57 \% \text { vs. } \\
70 \% \text { vs. } 66 \% \\
\text { Baseline } \\
\text { modified RDQ: } \\
13.9 \text { vs. } 15.6 \text { vs. } \\
15.0 \\
\text { Baseline pain (0- } \\
10 \text { NRS): } 7.1 \text { vs. } \\
7.2 \text { vs. } 7.0\end{array}$ & 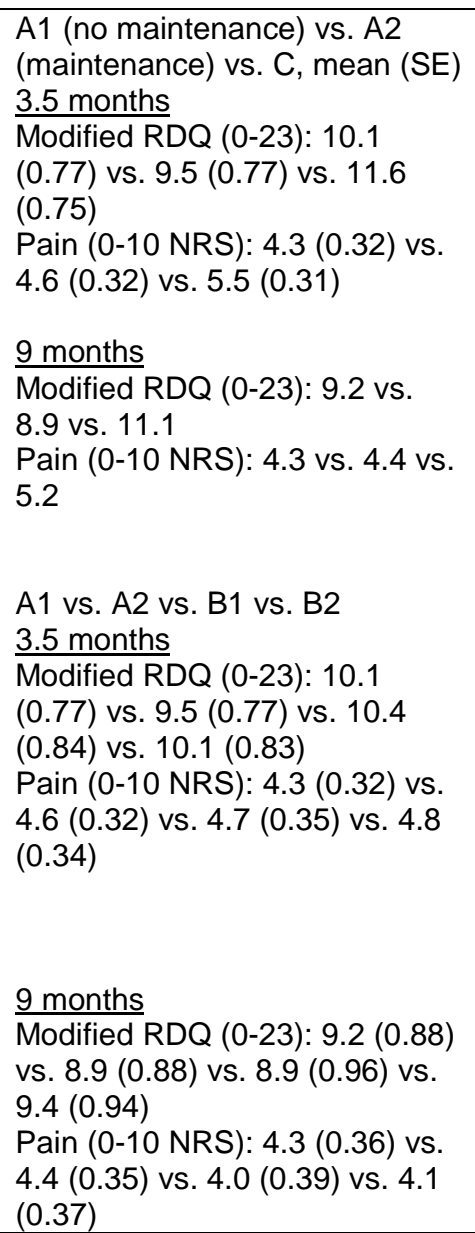 & NR \\
\hline
\end{tabular}




\begin{tabular}{|c|c|c|c|c|}
\hline $\begin{array}{l}\text { Author, Year, } \\
\text { Followup, }{ }^{\mathrm{a}} \text {, } \\
\text { Pain } \\
\text { Duration, } \\
\text { Study } \\
\text { Quality }\end{array}$ & Intervention & Population & Function and Pain Outcomes & Other Outcomes \\
\hline $\begin{array}{l}\text { Sherman, } \\
2005^{175} \\
3.5 \text { months } \\
\text { Duration of } \\
\text { pain: } 3 \text { to } 15 \\
\text { months } \\
\text { Fair }\end{array}$ & $\begin{array}{l}\text { A. Viniyoga } \\
(n=36) \\
12 \text { sessions } 1 \\
\text { session/week for } \\
12 \text { weeks } \\
\text { B. Exercise } \\
(n=35) \\
\text { C. Attention } \\
\text { control (self-care } \\
\text { advice) }(n=30)\end{array}$ & $\begin{array}{l}\text { A vs. B vs. C } \\
\text { Age: } 44 \text { vs. } 42 \\
\text { vs. } 45 \\
\text { Female: } 69 \% \text { vs. } \\
63 \% \text { vs. } 67 \% \\
\text { Baseline RDQ: } \\
8.1 \text { vs. } 9.0 \text { vs. } \\
8.0 \\
\text { Baseline } \\
\text { symptom } \\
\text { bothersomeness } \\
\text { (0-10): } 5.4 \text { vs. } \\
5.7 \text { vs. } 5.4\end{array}$ & 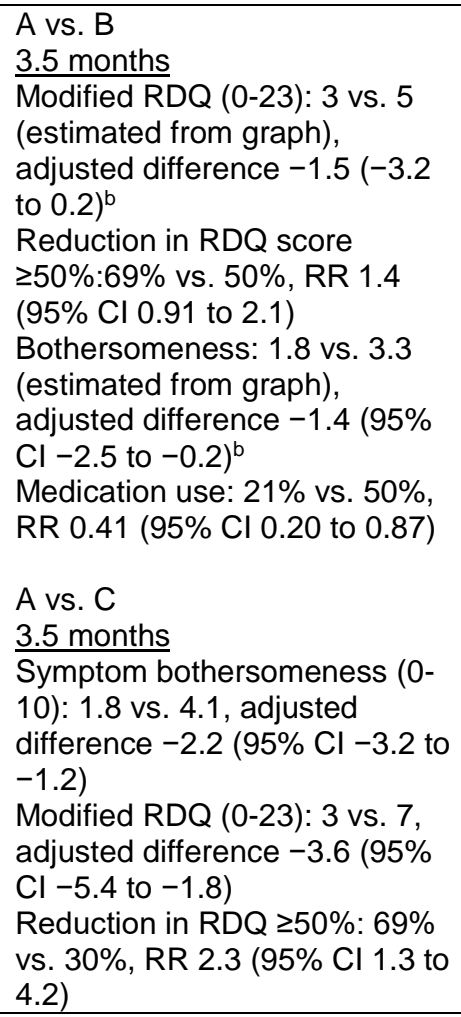 & $\begin{array}{l}\text { A vs. B } \\
3.5 \text { months } \\
\text { Medication use: } 21 \% \\
\text { vs. } 59 \% \text {, RR } 0.35 \text { ( } 95 \% \\
\text { Cl } 0.15 \text { to } 0.73 \text { ) } \\
\text { SF-36: No significant } \\
\text { differences (data not } \\
\text { provided) }\end{array}$ \\
\hline $\begin{array}{l}\text { Sherman, } \\
2011^{176} \\
3.5 \text { months } \\
\text { Duration of } \\
\text { pain: } 3 \text { to } 6 \\
\text { months } \\
\text { Fair }\end{array}$ & $\begin{array}{l}\begin{array}{l}\text { A. Viniyoga } \\
(n=92)\end{array} \\
12 \text { sessions } 1 \\
\text { session/week for } \\
12 \text { weeks } \\
\text { B. Exercise } \\
(n=91) \\
\text { C. Attention } \\
\text { control (self-care } \\
\text { advice) }(n=30)\end{array}$ & $\begin{array}{l}\text { A vs. B } \\
\text { Age: } 47 \text { vs. } 49 \\
\text { vs. } 50 \\
\text { Female: } 67 \% \text { vs. } \\
63 \% \text { vs. } 60 \% \\
\text { Baseline RDQ: } \\
9.8 \text { vs. } 8.6 \text { vs. } \\
9.0 \\
\\
\text { Baseline } \\
\text { symptom } \\
\text { bothersomeness } \\
\text { (0-10): } 4.9 \text { vs. } \\
4.5 \text { vs. } 4.7\end{array}$ & 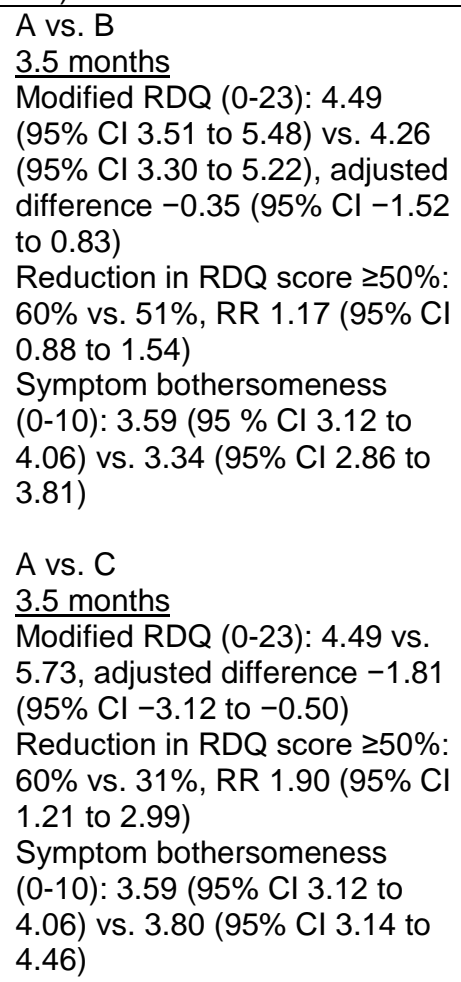 & $\begin{array}{l}\text { A vs. B } \\
3.5 \text { months } \\
\text { LBP better, much } \\
\text { better, or completely } \\
\text { gone: } 51 \% \text { vs. } 51 \% \text {, RR } \\
1.00 \text { ( } 95 \% \text { Cl } 0.75 \text { to } \\
1.34) \\
\text { A vs. C } \\
\text { LBP better, much } \\
\text { better, or completely } \\
\text { gone: } 51 \% \text { vs. } 20 \% \text {, RR } \\
2.57,95 \% \mathrm{Cl} 1.39 \text { to } \\
4.78)\end{array}$ \\
\hline
\end{tabular}




\begin{tabular}{|c|c|c|c|c|}
\hline $\begin{array}{l}\text { Author, Year, } \\
\text { Followup, }^{\text {a }} \\
\text { Pain } \\
\text { Duration, } \\
\text { Study } \\
\text { Quality }\end{array}$ & Intervention & Population & Function and Pain Outcomes & Other Outcomes \\
\hline $\begin{array}{l}\text { Tilbrook, } \\
2011^{177} \\
3 \text { and } 6 \\
\text { months } \\
\text { Duration of } \\
\text { pain: } 96 \text { vs. } 72 \\
\text { months } \\
\text { Fair }\end{array}$ & $\begin{array}{l}\text { A. lyengar yoga } \\
(n=156) \\
12 \text { sessions } 1 \\
\text { session/week for } \\
12 \text { weeks } \\
\text { B. Attention } \\
\text { control (self-care } \\
\text { advice) ( } n=157)\end{array}$ & $\begin{array}{l}\text { A vs. B } \\
\text { Age: } 46 \text { vs. } 46 \\
\text { Female: } 68 \% \text { vs. } \\
73 \% \\
\text { Baseline RDQ } \\
(0-24): 7.84 \text { vs. } \\
7.75 \\
\text { Baseline } \\
\text { Aberdeen Back } \\
\text { Pain Scale (0- } \\
\text { 100): } 25.36 \text { vs. } \\
26.69\end{array}$ & $\begin{array}{l}\text { A vs. B } \\
\text { MD in change from baseline } \\
(95 \% \mathrm{Cl}) \\
\frac{3 \text { months }}{\text { RDQ }(0-24):-1.48(-2.62 \text { to }} \\
-0.33) \\
\text { Aberdeen Back Pain Scale (0 to } \\
100):-1.74(-4.32 \text { to } 0.84) \\
\frac{6 \text { months }}{\text { RDQ }(0-24):-1.57(-2.71 \text { to }} \\
-0.42) \\
\text { Aberdeen Back Pain Scale: } \\
-0.73(-3.30 \text { to } 1.84)\end{array}$ & $\begin{array}{l}\text { A vS. B } \\
\text { MD in change from } \\
\text { baseline }(95 \% \mathrm{Cl}) \\
\frac{3 \text { months }}{\text { SF-12 PCS }(0-100):} \\
1.24(-0.83 \text { to } 3.33) \\
\text { SF-12 MCS }(0-100): \\
2.02(-0.34 \text { to } 4.37) \\
\frac{6 \text { months }}{\text { SF-12 PCS: } 0.80(-1.28} \\
\text { to } 2.87) \\
\text { SF-12 MCS: } 0.42 \\
(-1.92 \text { to } 2.77)\end{array}$ \\
\hline $\begin{array}{l}\text { Williams, } \\
2005^{179} \\
3 \text { months } \\
\text { Duration of } \\
\text { pain: } 11.3 \text { vs. } \\
11.0 \text { years } \\
\text { Fair }\end{array}$ & $\begin{array}{l}\begin{array}{l}\text { A. lyengar yoga } \\
(n=30),\end{array} \\
16 \text { sessions } 1 \\
\text { session/week for } \\
16 \text { weeks } \\
\text { B. Attention } \\
\text { control } \\
\text { (education) } \\
(n=30)\end{array}$ & $\begin{array}{l}\text { A vs. B } \\
\text { Age: } 49 \text { vs. } 48 \\
\text { Female: } 65 \% \text { vs. } \\
70 \% \\
\text { Pain Disability } \\
\text { Index (7-70): } \\
14.3 \text { vs. } 21.2 \\
\text { Pain intensity, } \\
\text { McGill Pain } \\
\text { Questionnaire } \\
\text { (0-10 VAS): } 2.3 \\
\text { vs. } 3.2\end{array}$ & $\begin{array}{l}\text { A vs. B } \\
\frac{3 \text { months }}{\text { Pain Disability Index (7-70): } 3.9} \\
\text { vs. } 12.7, P=0.009 \\
\text { Pain, McGill Pain Questionnaire } \\
(0-10 \text { VAS): } 0.6 \text { vs. } 2.0, \\
P=0.039 \\
\text { Present Pain Index (0-5): } 0.5 \\
\text { vs. } 1.1, P=0.013\end{array}$ & $\begin{array}{l}\text { A vs. B } \\
3 \text { months } \\
\text { Stopped or decreased } \\
\text { medication use: } 50 \% \\
\text { vs. } 33 \%, P=0.007\end{array}$ \\
\hline $\begin{array}{l}\text { Duration of } \\
\text { pain: } 47 \text { vs. } \\
78 \text { months } \\
\text { Fair }\end{array}$ & $\begin{array}{l}\begin{array}{l}\text { A. lyengar yoga } \\
(n=43)\end{array} \\
48 \text { sessions for } \\
24 \text { weeks } \\
\text { B. Waitlist } \\
\text { (standard medical } \\
\text { care) }(n=47)\end{array}$ & $\begin{array}{l}\text { A vs. B } \\
\text { Age: } 48 \text { vs. } 48 \\
\text { years } \\
\text { Female: } 74 \% \text { vs. } \\
79 \% \\
\text { Oswestry } \\
\text { Disability Index } \\
\text { (0-100): } 25.2 \text { vs. } \\
23.1 \\
\text { Pain (0-100 } \\
\text { VAS): } 41.9 \text { vs. } \\
41.2\end{array}$ & $\begin{array}{l}\text { A vs. B } \\
\frac{6 \text { months }}{\text { Oswestry Disability Index (0- }} \\
100): 19.3 \text { vs. } 23.5, P=0.001 \\
\text { Pain }(0-100 \text { VAS): } 22.2 \text { vs. } \\
38.3, P=0.0009\end{array}$ & $\begin{array}{l}\text { A vs. B } \\
6 \text { months } \\
\text { Beck Depression } \\
\text { Inventory }(0-63): 4.6 \text { vs. } \\
7.8, P=0.0004\end{array}$ \\
\hline
\end{tabular}

CI = confidence interval; EQ = EuroQol; LBP = low back pain; NR = not reported; NRS = numeric rating scale; ODI = Oswestry Disability Index; RDQ = Roland-Morris Disability Questionnaire; RR = risk ratio; VAS = visual analog scale

${ }^{a}$ Unless otherwise noted, followup time is calculated from the end of the treatment period

b Adjusted for baseline scores

\section{Yoga Compared With an Attention Control or Waitlist}

Yoga was associated with slightly greater effects on short-term function than controls (6 trials, pooled SMD $-0.50,95 \%$ CI -0.72 to $-0.29, \mathrm{I}^{2}=54 \%$ ) (Figure 16$) .{ }^{173-177,179}$ Results were similar when trials were stratified according to whether they evaluated Viniyoga (2 trials, pooled SMD $-0.56,95 \%$ CI -1.38 to 0.19$),{ }^{175,176}$ Hatha yoga (2 trials, SMD $-0.44,95 \%$ CI -0.82 to $-0.08),{ }^{173,174}$ or Iyengar yoga ( 2 trials, SMD $-0.54,95 \%$ CI -1.41 to 0.14$)$. ${ }^{177,179}$ All trials evaluated function using the RDQ or modified RDQ, with a MD on a 0 to 24 or 0 to 23 scale of $-2.24\left(95 \% \mathrm{CI}-3.30\right.$ to $\left.-1.18, \mathrm{I}^{2}=52 \%\right) .{ }^{173-177}$ Yoga was also associated with greater effects on 
intermediate-term function than controls (3 trials, pooled SMD -0.33 , 95\% CI -0.49 to -0.16 , $\left.\mathrm{I}^{2}=0 \%\right) .{ }^{174,177,178}$ In two trials that evaluated function with the RDQ or modified RDQ, the MD was -1.58 points $\left(95 \% \mathrm{CI}-2.47\right.$ to $\left.-0.70, \mathrm{I}^{2}=0 \%\right){ }^{174,177}$

Yoga was associated with moderately greater effects on short-term pain than an attention or wait list control (5 trials, pooled difference $-1.10,95 \%$ CI -1.77 to -0.42 on a 0 to 10 scale, $\mathrm{I}^{2}=74 \%$ ) (Figure 17). ${ }^{173-176,179}$ Estimates were similar from two trials of Viniyoga (pooled difference -1.25 , 95\% CI -3.78 to 1.27 ), ${ }^{175,176}$ two trials of Hatha yoga (difference -0.80 , 95\% $\mathrm{CI}-1.46$ to -0.20$),{ }^{173,174}$ and one trial of Iyengar yoga (MD $-1.40,95 \% \mathrm{CI}-2.27$ to -0.53$) .{ }^{179}$ No trials were rated poor quality. Yoga was also associated with greater effects on intermediateterm pain than controls, based on two trials (pooled MD $-1.17,95 \% \mathrm{CI}-1.91$ to -0.44 , $\left.\mathrm{I}^{2}=26 \%\right)^{174,178}$

Data on effects of yoga on quality of life were limited. One trial found no difference between yoga versus an attention control on the SF-36 Physical and Mental Component Summaries at short-term or intermediate-term followup (differences 0.42 to 2.02 points on a 0 to 100 scale). ${ }^{177}$ One other trial found no differences between yoga versus an attention control on the SF-36, but data were not provided. ${ }^{175}$

One trial found yoga associated with lower (better) scores on the Beck Depression Inventory than waitlist at intermediate-term followup (mean 4.6 vs. 7.8 on a 0 to 63 scale, $P=0.004)^{178}$ and one trial found no difference between yoga versus waitlist in opioid use $(9 \% \mathrm{vs.} 7 \%, \mathrm{P}=0.40)$ or other medical treatments for pain (39\% vs. 37\%, $\mathrm{P}=0.42)$ at short-term followup. ${ }^{173}$

\section{Yoga Compared With Pharmacological Therapy}

No trial of yoga versus pharmacological therapy met inclusion criteria.

\section{Yoga Compared With Exercise}

There were no differences between yoga versus exercise in short-term function (3 trials, pooled SMD -0.10 , 95\% CI -0.34 to $\left.0.13, \mathrm{I}^{2}=38 \%\right)^{174-176}$ or intermediate-term function ( 1 trial, SMD $-0.01,95 \%$ CI -0.26 to 0.24$)^{174}$ (Figure 18). One trial found no difference between yoga versus exercise on the SF-36 at short-term followup (data not provided). ${ }^{175}$

Effects of yoga versus exercise on short-term pain were not statistically significant and there was marked heterogeneity (4 trials, pooled difference -0.89 on a 0 to 10 scale, $95 \%$ CI -1.99 to $0.21, \mathrm{I}^{2}=92 \%$ ) (Figure 19). ${ }^{174-176,186}$ In one trial of Viniyoga, ${ }^{176}$ results favored exercise (difference $0.25,95 \%$ CI -0.41 to 0.91 ), and in three trials (one each of Viniyoga, Iyengar yoga, and Hatha yoga) ${ }^{174,175,186}$ effects favored yoga (MDs of -0.30 to -2.00 ). No trials were rated poor quality. One trial found no difference between yoga versus exercise in intermediate-term pain (difference $0.30,95 \%$ CI -0.39 to 0.99 ). ${ }^{174}$

\section{Harms}

Data on harms were limited, but trials reported no clear difference between yoga versus control interventions in risk of any adverse event. ${ }^{174,176,177}$ For serious adverse events, one trial reported a case of cellulitis in a patient randomized to yoga. ${ }^{174}$ 
Figure 16. Yoga versus attention control or waitlist for chronic low back pain: effects on function

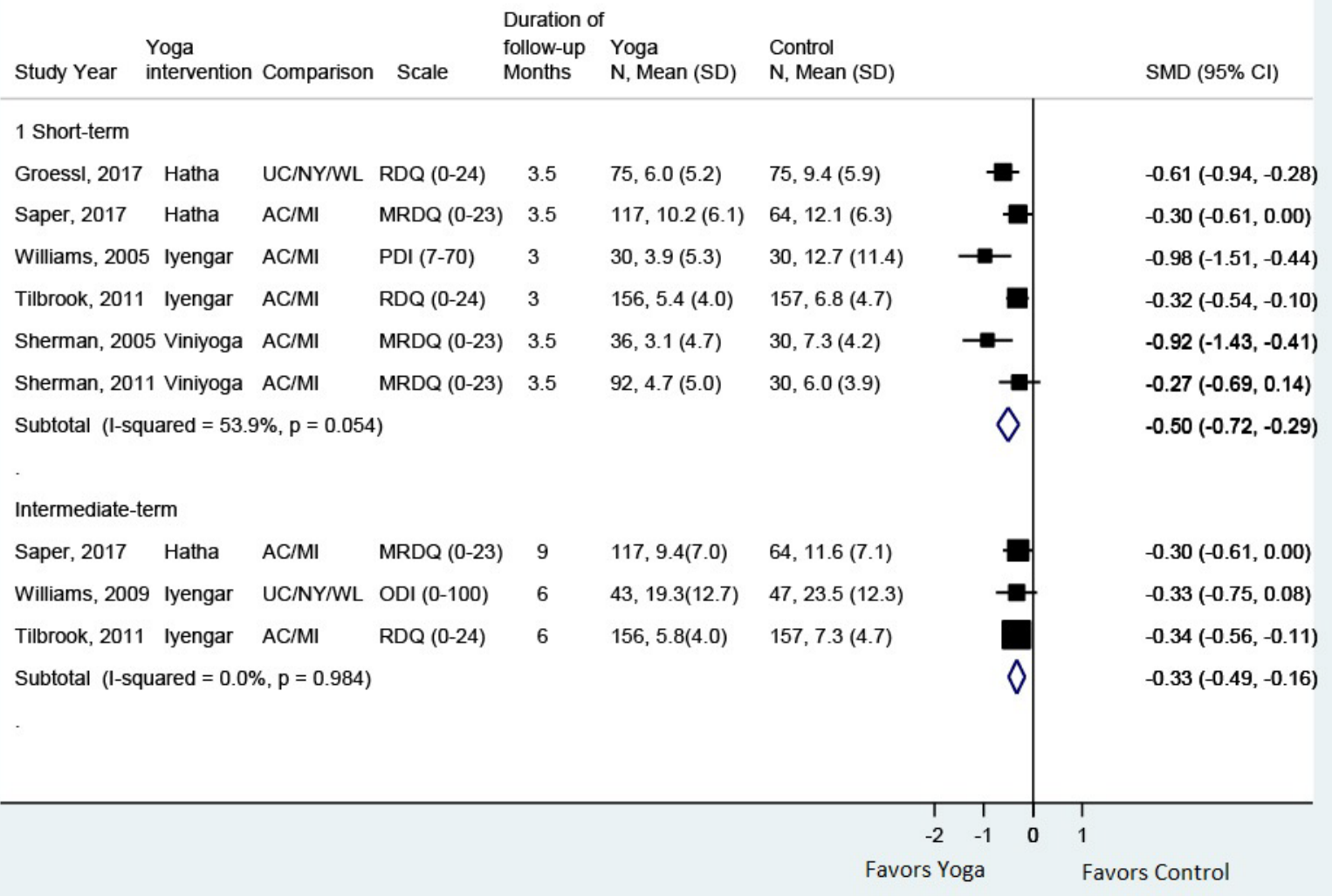

$\mathrm{AC}=$ attention control; $\mathrm{CI}=$ confidence interval; $\mathrm{MI}=$ minimal intervention; $\mathrm{MRDQ}=$ Modified Roland-Morris Disability Questionnaire; $\mathrm{N}=$ number; $\mathrm{NY}=$ no yoga; $\mathrm{RDQ}=$ Roland-Morris Disability Questionnaire; $\mathrm{SD}$ = standard deviation; $\mathrm{SMD}=$ standardized mean difference; UC = usual care; $\mathrm{WL}$ = waitlist 
Figure 17. Yoga versus attention control or waitlist for chronic low back pain: effects on pain

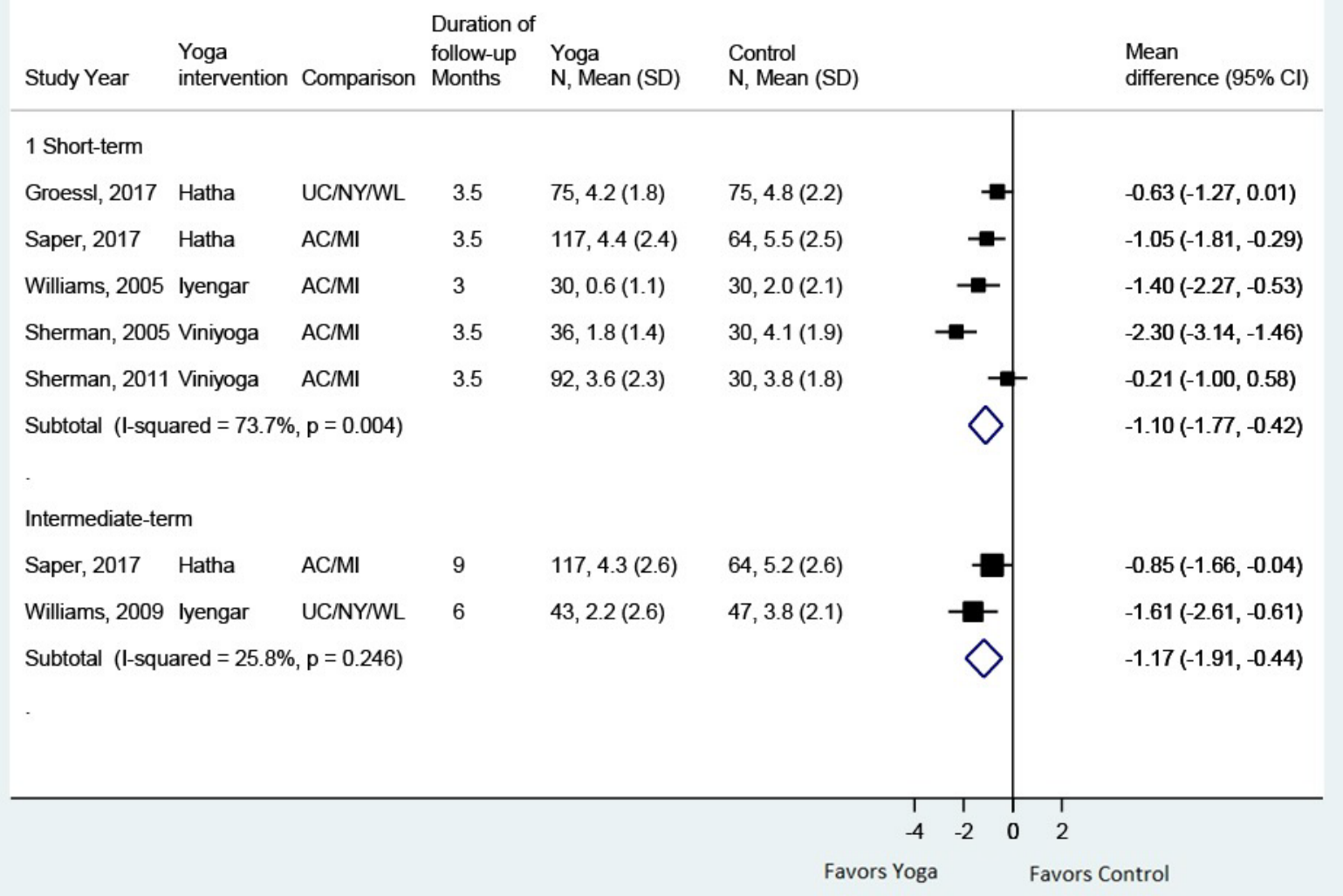

$\mathrm{AC}=$ attention control; $\mathrm{CI}=$ confidence interval; $\mathrm{MI}=$ minimal intervention; $\mathrm{N}=$ number; $\mathrm{NY}=$ no yoga; $\mathrm{RDQ}=\mathrm{Roland}-\mathrm{Morris}$ Disability Questionnaire; SD = standard deviation; UC = usual care; WL = waitlist 
Figure 18. Yoga versus exercise for chronic low back pain: effects on function

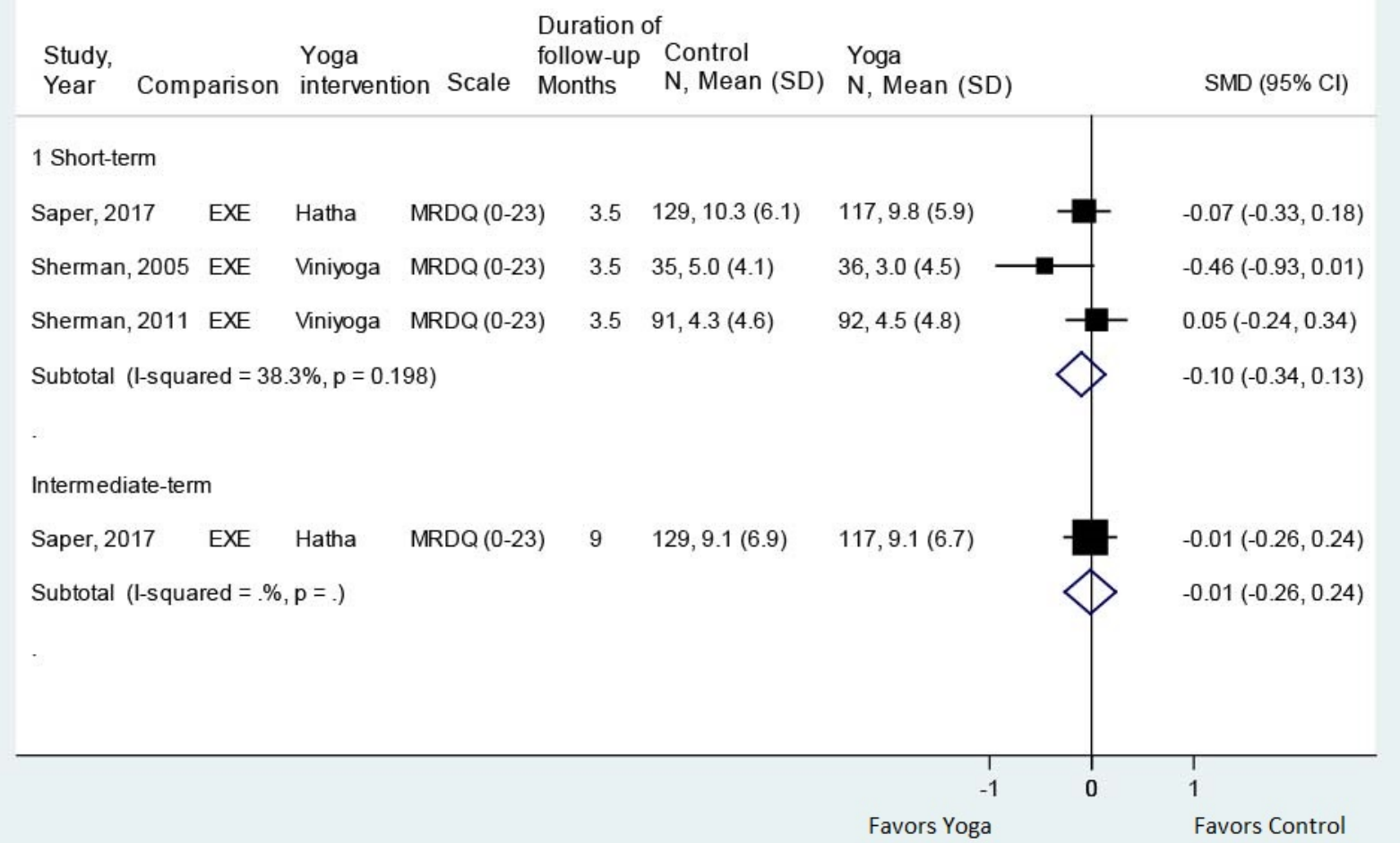

$\mathrm{CI}$ = confidence interval; EXE = exercise; $\mathrm{MRDQ}=$ Modified Roland-Morris Disability Questionnaire; $\mathrm{N}=$ number; $\mathrm{SD}=$ standard deviation; SMD = standardized mean difference 
Figure 19. Yoga versus exercise for chronic low back pain: effects on pain

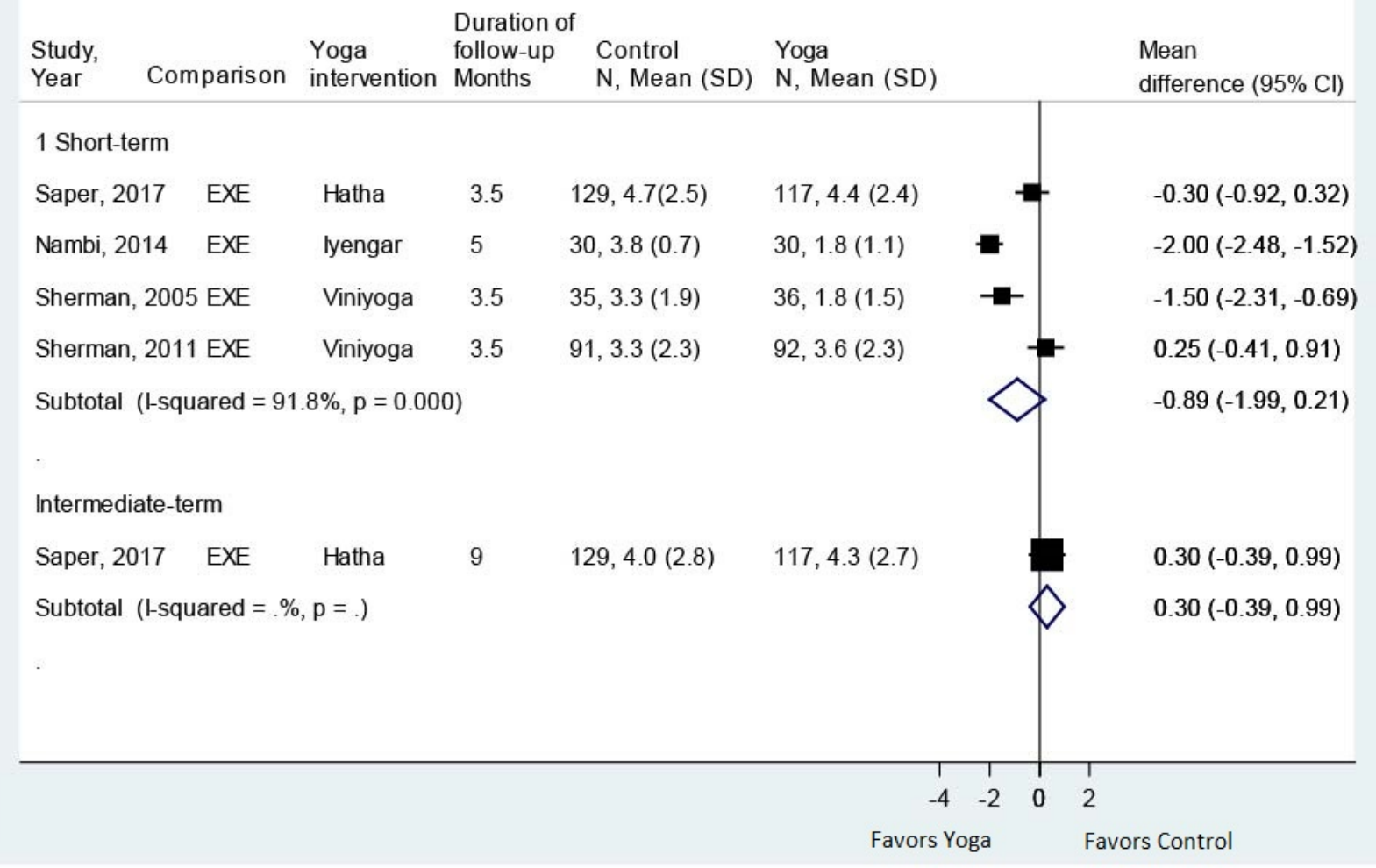

$\mathrm{CI}=$ confidence interval; EXE = exercise; $\mathrm{N}$ = number; $\mathrm{SD}=$ standard deviation

\section{Qigong}

There was no difference between qigong versus exercise in short-term function (difference 0.9 on the 0 to $24 \mathrm{RDQ}, 95 \% \mathrm{CI}-0.1$ to 2.0), although intermediate-term results slightly favored exercise (difference 1.2, 95\% CI 0.1 to 2.3$)$. One German trial $(n=125)$ compared qigong (weekly sessions for 3 months) versus exercise therapy (including stretching and strengthening) (Table 15 and Appendix D). ${ }^{185}$ It was rated fair quality due to baseline differences between groups, unblinded design, and suboptimal compliance (Appendix E). Qigong was associated with slightly worse pain versus exercise at short-term followup (MD 7.7 on a 0 to 100 scale, 95\% CI 0.7 to 14.7 ), but the difference at intermediate-term was not statistically significant (MD 7.1, 95\% CI -1.0 to 15.2). There were no differences in sleep, measures of the SF-36 PCS or MCS scores, or in risk of adverse events. 
Table 15. Chronic low back pain: mind-body practices (qigong)

\begin{tabular}{|c|c|c|c|c|}
\hline $\begin{array}{l}\text { Author, Year, } \\
\text { Followup, } \\
\text { Pain } \\
\text { Duration, } \\
\text { Study } \\
\text { Quality }\end{array}$ & Intervention & Population & Function and Pain Outcomes & Other Outcomes \\
\hline $\begin{array}{l}\text { Blodt, } 2015^{185} \\
3 \text { and } 9 \\
\text { months } \\
\text { Duration of } \\
\text { pain: Mean } 3 \\
\text { years } \\
\text { Fair }\end{array}$ & $\begin{array}{l}\text { A. Qigong } \\
\text { (movement } \\
\text { exercises and } \\
\text { exercise to change } \\
\text { "qi") ( } n=64) \\
12 \text { sessions over } \\
12 \text { weeks } \\
\text { B. Exercise } \\
\text { (strengthening, } \\
\text { stretching and } \\
\text { relaxation } \\
\text { exercises) (n=63) }\end{array}$ & $\begin{array}{l}\text { A vs. B } \\
\text { Age (mean): } 46 \\
\text { vs. } 48 \text { years } \\
\text { Female: } 91 \% \\
\text { vs. } 70 \% \\
\text { Baseline RDQ: } \\
6.2 \text { vs. } 5.7 \\
\text { Baseline pain } \\
\text { (0-100 VAS): } \\
55.6 \text { vs. } 52.1\end{array}$ & $\begin{array}{l}\text { A vs. B } \\
3 \text { months } \\
\text { RDQ (0-24): } 4.1 \text { vs. } 3.1 \text {, } \\
\text { difference } 0.9 \text { ( } 95 \% \mathrm{Cl}-0.1 \text { to } \\
2.0) \\
\text { Average low back pain (0-100 } \\
\text { VAS): } 35.1 \text { vs. } 27.4 \text {, difference } \\
7.7 \text { (95\% Cl } 0.7 \text { to } 14.7) \\
9 \text { months } \\
\text { RDQ: } 4.3 \text { vs. } 3.1 \text {, difference } 1.2 \\
\text { (95\% Cl } 0.1 \text { to } 2.3) \\
\text { Average low back pain (0-100 } \\
\text { VAS): } 35.9 \text { vs. } 28.8 \text {, difference } \\
7.1 \text { (95\% Cl }-1.0 \text { to } 15.2)\end{array}$ & 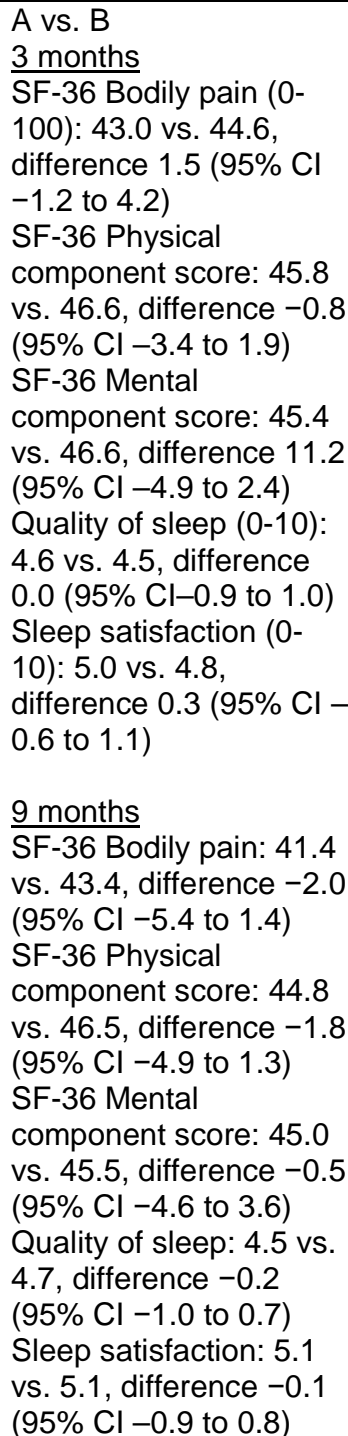 \\
\hline
\end{tabular}

$\mathrm{CI}$ = confidence interval; RDQ = Roland-Morris Disability Questionnaire; SF-36 = Short-Form 36 Questionnaire; VAS = visual analog scale

${ }^{\text {a }}$ Unless otherwise noted, followup time is calculated from the end of the treatment period 


\section{Acupuncture for Chronic Low Back Pain}

\section{Key Points}

- Acupuncture was associated with slightly greater effects on short-term function than sham acupuncture or usual care ( 4 trials, pooled SMD $-0.22,95 \%$ CI -0.35 to -0.08 , $\mathrm{I}^{2}=44 \%$ ). There was no evidence of differences between acupuncture versus controls in intermediate-term function ( 3 trials, pooled SMD $-0.08,95 \%$ CI -0.36 to $0.20, \mathrm{I}^{2}=75 \%$ ) or long-term function (1 trial, adjusted MD -3.4 on the 0 to 100 ODI, $95 \%$ CI -7.8 to 1.0) (SOE: low).

- Acupuncture was associated with slightly greater effects on short-term pain than sham acupuncture, usual care, an attention control, or a placebo intervention ( 5 trials, pooled $\mathrm{MD}-0.55$ on a 0 to 10 scale, $95 \% \mathrm{CI}-0.86$ to $-0.24, \mathrm{I}^{2}=30 \%$ ). There was no evidence of differences in intermediate-term pain ( 5 trials, pooled MD -0.25 , $95 \%$ CI -0.67 to 0.16 , $\mathrm{I}^{2}=33 \%$ ); one trial found acupuncture associated with greater effects on long-term pain (MD - 0.83, 95\% CI -1.51 to -0.15) (SOE: moderate for short term, low for intermediate term and long term).

- There was no clear difference between acupuncture versus control interventions in risk of withdrawal due to adverse events. Serious adverse events were rare with acupuncture and control interventions (SOE: low).

\section{Detailed Synthesis}

Eight trials of acupuncture for low back pain met inclusion criteria (Table 16 and Appendix D). ${ }^{149,189-195}$ All trials evaluated needle acupuncture to body acupoints; one trial also evaluated electroacupuncture. ${ }^{190}$ Sample sizes ranged from 40 to 1,162 (total sample=2,621). Four trials compared acupuncture versus sham acupuncture, ${ }^{189,191-193}$ three trials acupuncture versus usual care, ${ }^{191,193,195}$ two trials acupuncture versus a placebo intervention (sham transcutaneous electrical nerve stimulation [TENS]), ${ }^{190,194}$ and one trial acupuncture versus an attention control (self-care education) ${ }^{149}$ One trial was conducted in Asia ${ }^{192}$ and the rest in the United States or Europe. The duration of acupuncture therapy ranged from 6 to 12 weeks and the number of acupuncture sessions ranged from 6 to 15 . One trial reported outcomes through long-term followup, ${ }^{195}$ four trials through intermediate-term followup, ${ }^{149,189-191}$ and the remainder only evaluated short-term outcomes.

One trial was rated good quality, ${ }^{189}$ five trials fair quality, ${ }^{149,191-193,195}$ and two trials ${ }^{190,194}$ poor quality (Appendix E). Limitations in the fair-quality and poor-quality trials included unblinded design, unclear randomization or allocation concealment methods, and high attrition. 
Table 16. Chronic low back pain: acupuncture

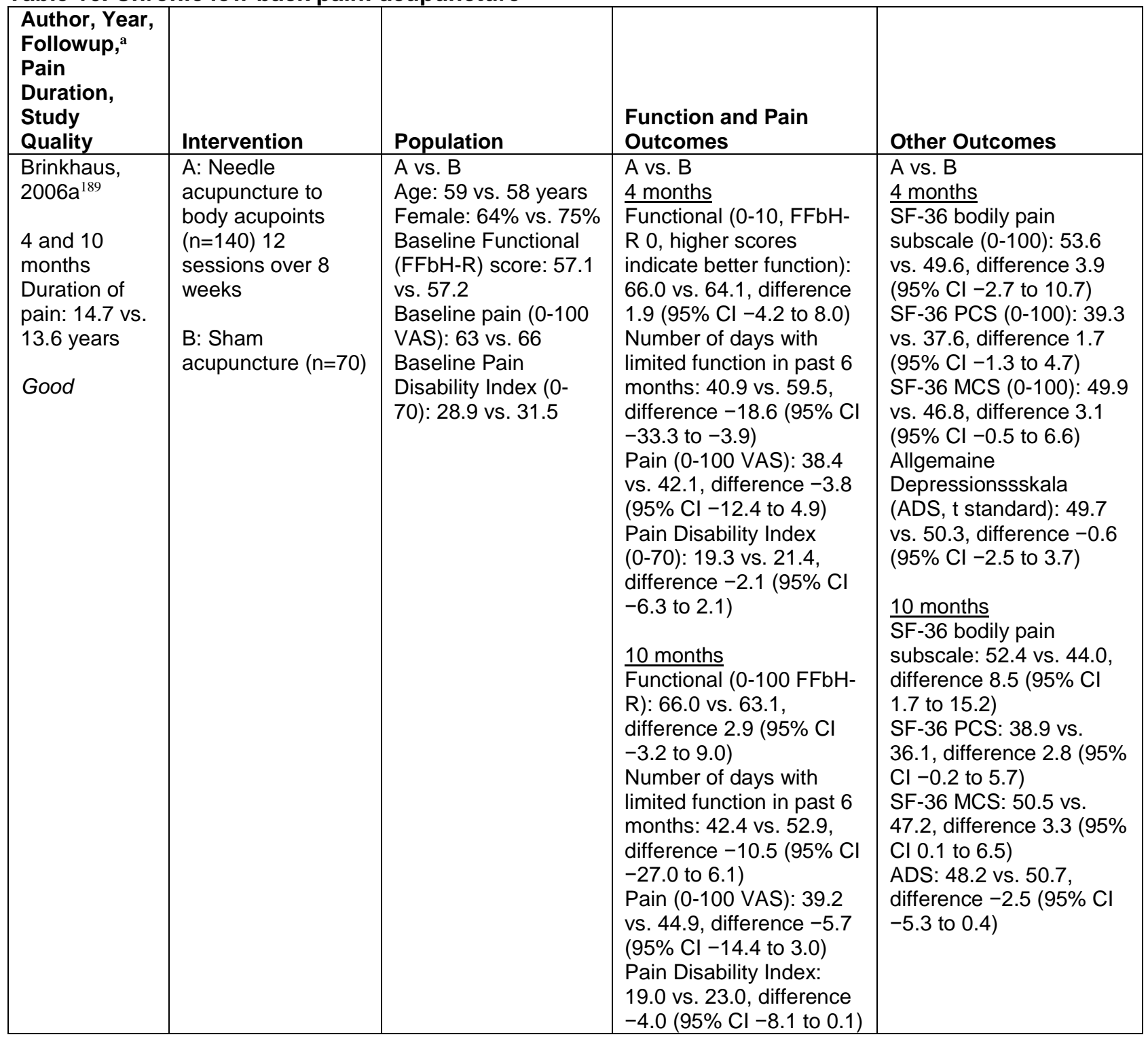




\begin{tabular}{|c|c|c|c|c|}
\hline $\begin{array}{l}\text { Author, Year, } \\
\text { Followup, } \\
\text { Pain } \\
\text { Duration, } \\
\text { Study } \\
\text { Quality }\end{array}$ & Intervention & Population & $\begin{array}{l}\text { Function and Pain } \\
\text { Outcomes }\end{array}$ & Other Outcomes \\
\hline $\begin{array}{l}\text { Carlsson, } \\
2001^{190} \\
1,3,6 \text { months } \\
\text { Duration of } \\
\text { pain: } 6 \\
\text { months or } \\
\text { longer } \\
\text { Poor }\end{array}$ & $\begin{array}{l}\text { A. Needle } \\
\text { acupuncture or } \\
\text { electroacupuncture } \\
\text { ( } n=34), 8 \text { sessions } \\
\text { over } 8 \text { weeks, with } \\
\text { followup session at } \\
3 \text { and } 6 \text { months } \\
\\
\text { B. Placebo (sham } \\
\text { transcutaneous } \\
\text { electrical nerve } \\
\text { stimulation) }(n=16)\end{array}$ & $\begin{array}{l}\text { A vs. B (NR) } \\
\text { Age: } 50 \text { years } \\
\text { Female: } 66 \% \\
\text { Baseline function: NR } \\
\text { Baseline Pain (0-100 } \\
\text { VAS): } 57 \text { vs. } 46\end{array}$ & 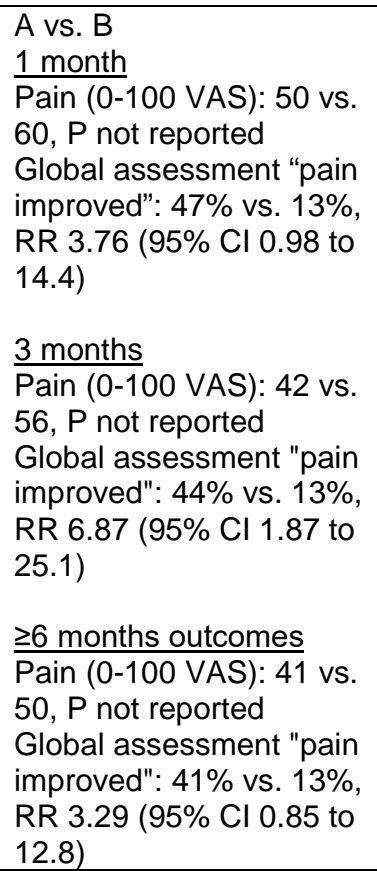 & $\begin{array}{l}\text { A vs. B } \\
\geq 6 \text { months } \\
\text { Analgesic intake (tablets } \\
\text { per week): } 21.4 \text { vs. } 21.5 \\
\text { Work full time: } 32 \% \text { vs. } \\
31 \%\end{array}$ \\
\hline $\begin{array}{l}\text { Cherkin, } \\
2001^{149} \\
9.5 \text { months } \\
\text { Duration of } \\
\text { pain: } 3 \text { to } 12 \\
\text { months, mean } \\
\text { not reported } \\
\text { Fair }\end{array}$ & $\begin{array}{l}\text { A. Needle } \\
\text { acupuncture } \\
(n=94), 10 \text { sessions } \\
\text { over } 10 \text { weeks } \\
\text { B. Attention control } \\
\text { (education) }(n=90)\end{array}$ & $\begin{array}{l}\text { A vs. B } \\
\text { Age: } 54 \text { vs. } 44 \text { years } \\
\text { Female: } 52 \% \text { vs. } 44 \% \\
\text { Baseline symptom } \\
\text { bothersomeness ( } 0- \\
\text { 10): } 6.2 \text { vs. } 6.1 \\
\text { Baseline modified } \\
\text { RDQ (0-23): } 12 . \text { vs. } \\
12.0\end{array}$ & $\begin{array}{l}\text { A vs. B } \\
9.5 \text { months } \\
\text { Symptom } \\
\text { bothersomeness }(0-10): \\
4.5 \text { vs. } 3.8, \text { adjusted } \\
P=0.002 \\
\text { Modified RDQ (0-23): } 8.0 \\
\text { vs. } 6.4 \text {, adjusted } P=0.05\end{array}$ & $\begin{array}{l}\text { A vs. B } \\
9.5 \text { months } \\
\geq 1 \text { work-loss day due to } \\
\text { LBP in past month: No } \\
\text { difference (data not } \\
\text { reported) } \\
\text { Medication use: } 51 \% \text { vs. } \\
62 \%, \text { P<0.05 } \\
\text { Provider visits: } 1.9 \text { (SD } \\
\text { 3.7) vs. } 1.5 \text { (SD 4.0) } \\
\text { LBP medication fills: } 4.4 \\
\text { (SD 8.9) vs. } 4.0 \text { (SD 8.6) } \\
\text { Imaging studies: } 0.2 \text { (SD } \\
0.4 \text { ) vs. 0.1 (SD 0.4) } \\
\text { Cost of services (1998 } \\
\text { \$): } 252 \text { (SD 46) vs. } 200 \\
\text { (SD 45) }\end{array}$ \\
\hline
\end{tabular}




\begin{tabular}{|c|c|c|c|c|}
\hline $\begin{array}{l}\text { Author, Year, } \\
\text { Followup, }{ }^{\mathrm{a}} \\
\text { Pain } \\
\text { Duration, } \\
\text { Study } \\
\text { Quality }\end{array}$ & Intervention & Population & $\begin{array}{l}\text { Function and Pain } \\
\text { Outcomes }\end{array}$ & Other Outcomes \\
\hline $\begin{array}{l}\text { Cherkin, } \\
2009191 \\
4.5 \text { and } 10.5 \\
\text { months } \\
\text { Duration of } \\
\text { pain: } 3 \text { to12 } \\
\text { months, mean } \\
\text { not reported } \\
\text { Fair }\end{array}$ & $\begin{array}{l}\text { A. Needle } \\
\text { acupuncture } \\
\text { (individualized) } \\
\text { (n=157), 10 } \\
\text { sessions over } 7 \\
\text { weeks } \\
\text { B. Needle } \\
\text { acupuncture } \\
\text { (standardized) } \\
\text { (n=158), 10 } \\
\text { sessions over } 7 \\
\text { weeks } \\
\text { C. Sham } \\
\text { acupuncture } \\
\text { (n=162) } \\
\text { D. Usual care } \\
\text { (n=161) }\end{array}$ & $\begin{array}{l}\text { A vs. B vs. C vs. D } \\
\text { Age: } 47 \text { vs. } 49 \text { vs. } 47 \\
\text { vs. } 46 \text { years } \\
\text { Female: } 68 \% \text { vs. } 56 \% \\
\text { vs. } 60 \% \text { vs. } 64 \% \\
\text { Symptom } \\
\text { bothersomeness (0- } \\
10): 5.0 \text { vs. } 5.0 \text { vs. } \\
4.9 \text { vs. } 5.4 \\
\text { Baseline pain ( } 0-10 \\
\text { VAS): } 5.0 \text { vs. } 5.0 \text { vs. } \\
4.9 \text { vs. } 5.3 \\
\text { Baseline modified } \\
\text { RDQ (0-23): } 10.8 \text { vs. } \\
10.8 \text { vs. } 9.8 \text { vs. } 11.0\end{array}$ & 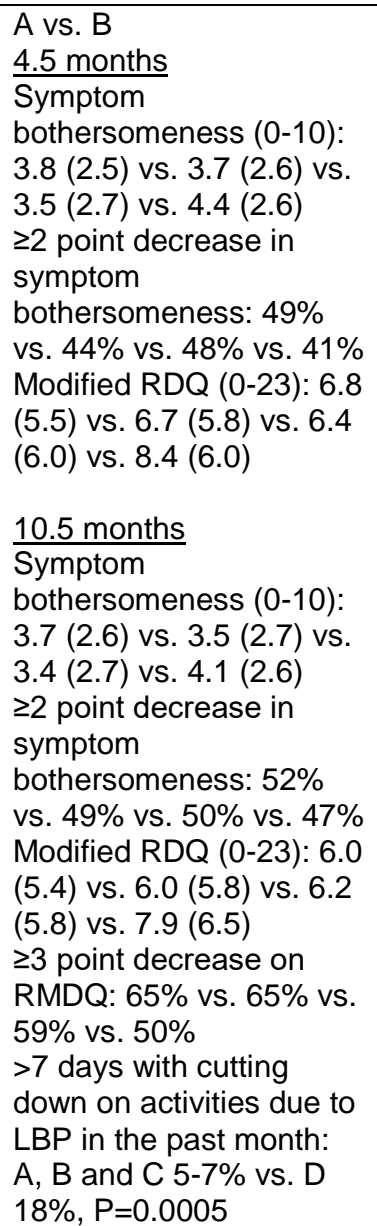 & $\begin{array}{l}\text { A vs. B } \\
10.5 \text { months } \\
\text { SF-36 PCS: No } \\
\text { differences, data not } \\
\text { provided } \\
\text { SF-36 MCS: No } \\
\text { differences, data not } \\
\text { provided } \\
\text { Missed work/school for } \\
>1 \text { day in past month: } A \text {, } \\
\text { B and C } 5-10 \% \text { vs. D } \\
16 \%, P=0.01 \\
\text { Mean total costs of back- } \\
\text { related health services: } \\
\$ 160-221 \text { across groups, } \\
\mathrm{P}=0.65\end{array}$ \\
\hline $\begin{array}{l}\text { Cho, } 2013^{192} \\
1.5 \text { and } 4 \\
\text { months } \\
\text { Duration of } \\
\text { pain: } 3 \\
\text { months } \\
\text { Fair }\end{array}$ & $\begin{array}{l}\text { A. Needle } \\
\text { acupuncture } \\
\text { ( } n=57), 12 \text { sessions } \\
\text { over } 6 \text { weeks } \\
\text { B. Sham } \\
\text { acupuncture }(n=59)\end{array}$ & $\begin{array}{l}\text { A vs. B } \\
\text { Age: } 42 \text { vs. } 42 \text { years } \\
\text { Female: } 83 \% \text { vs. } 86 \% \\
\text { Baseline ODI }(0-100): \\
28.2 \text { vs. } 24.2 \\
\text { Baseline pain }(0-10 \\
\text { VAS): } 6.5 \text { vs. } 6.4\end{array}$ & $\begin{array}{l}\text { A vs. B } \\
1.5 \text { months } \\
\text { ODI (0-100): } 15.5 \text { vs. } \\
15.5, \text { SD not reported } \\
\text { Symptom } \\
\text { bothersomeness (0-10 } \\
\text { VAS): } 2.83 \text { (2.34) vs. } \\
3.99 \text { (2.06) } \\
\text { Pain (0-10 VAS): } 2.78 \\
\text { (2.32) vs. } 4.06 \text { (2.19) } \\
4 \text { months } \\
\text { ODI: } 15.3 \text { vs. } 15.3, \text { SD } \\
\text { not reported } \\
\text { Symptom } \\
\text { bothersomeness: } 2.85 \\
\text { (2.44) vs. } 3.63(2.37) \\
\text { Pain (0-10 VAS): } 2.79 \\
\text { (2.44) vs. } 3.52(2.53)\end{array}$ & $\begin{array}{l}\text { A vs. B } \\
1.5 \text { months } \\
\text { Beck Depression } \\
\text { Inventory }(0-63): 6 \text { vs. } \\
7.5, \text { SD not reported } \\
\frac{4 \text { months }}{\text { Beck Depression }} \\
\text { Inventory: } 6 \text { vs. } 7, \text { SD not } \\
\text { reported }\end{array}$ \\
\hline
\end{tabular}




\begin{tabular}{|c|c|c|c|c|}
\hline $\begin{array}{l}\text { Author, Year, } \\
\text { Followup, }{ }^{\mathrm{a}} \\
\text { Pain } \\
\text { Duration, } \\
\text { Study } \\
\text { Quality }\end{array}$ & Intervention & Population & $\begin{array}{l}\text { Function and Pain } \\
\text { Outcomes }\end{array}$ & Other Outcomes \\
\hline $\begin{array}{l}\text { Haake, } \\
2007^{193} \\
1.5 \text { and } 4.5 \\
\text { months } \\
\text { Duration of } \\
\text { pain: Mean } 8 \\
\text { years } \\
\text { Fair }\end{array}$ & 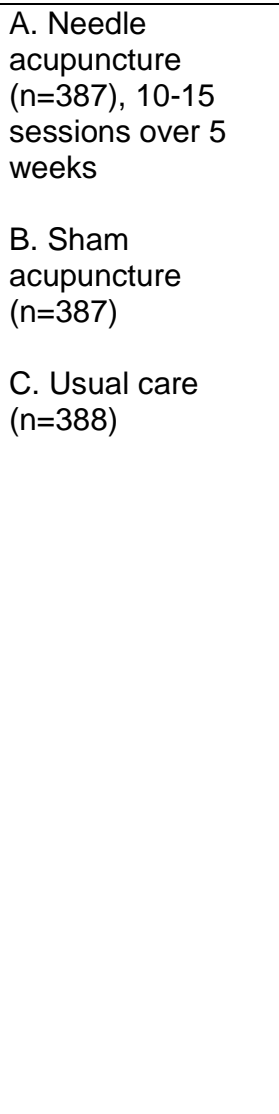 & $\begin{array}{l}\text { A vs. B vs. C } \\
\text { Age: } 50 \text { vs. } 49 \text { vs. } 51 \\
\text { years } \\
\text { Female: } 57 \% \text { vs. } 64 \% \\
\text { vs. } 58 \% \\
\text { Baseline Hannover } \\
\text { Functional Ability } \\
\text { Questionnaire (0- } \\
100): 46.3 \text { vs. } 46.3 \\
\text { vs. } 46.7 \\
\text { Baseline Von Korff } \\
\text { Chronic Pain Grade } \\
\text { Scale (0-100): } 67.7 \\
\text { vs. } 67.8 \text { vs. } 67.8\end{array}$ & $\begin{array}{l}\text { A vs. B } \\
1.5 \text { months } \\
\text { Hannover Functional } \\
\text { Ability (0-100): } 65.4 \\
\text { (22.9) vs. 61.3 (22.7) vs. } \\
56.0(22.0) \\
\text { Von Korff Chronic Pain } \\
\text { Grade Scale (0-100): } \\
45.4 \text { (19.4) vs. 48.5 } \\
(19.5) \text { vs. } 54.8(18.4) \\
4.5 \text { months } \\
\text { Hannover Functional } \\
\text { Ability (0-100): } 66.8 \\
\text { (23.1) vs. 62.2 (23.0) vs. } \\
55.7 \text { (22.7) } \\
\text { Von Korff Chronic Pain } \\
\text { Grade Scale: } 40.2(22.5) \\
\text { vs. 43.3 (23.0) vs. } 52.3 \\
\text { (21.2) }\end{array}$ & 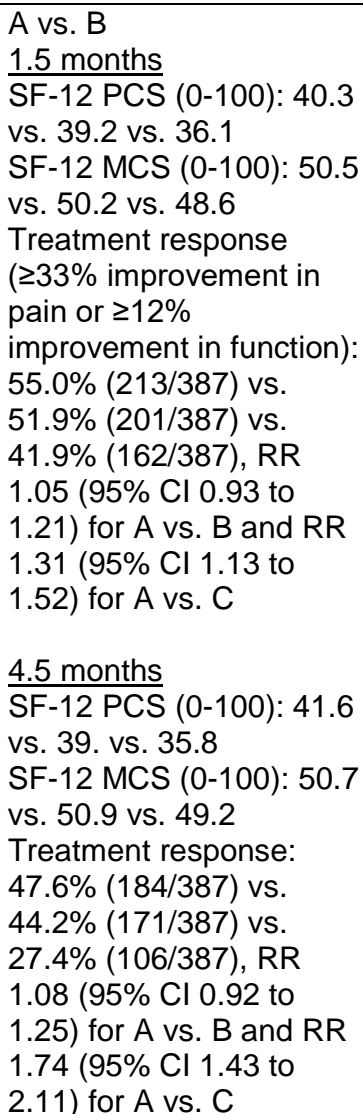 \\
\hline $\begin{array}{l}\text { Kerr, } 2003^{194} \\
4.5 \text { months } \\
\text { Duration of } \\
\text { pain: Mean } \\
86 \text { vs. } 73 \\
\text { months } \\
\text { Poor }\end{array}$ & $\begin{array}{l}\text { A. Needle } \\
\text { acupuncture } \\
\text { ( } \mathrm{n}=26), 6 \text { sessions } \\
\text { over } 6 \text { weeks } \\
\text { B. Placebo (sham } \\
\text { TENS) }(\mathrm{n}=20)\end{array}$ & $\begin{array}{l}\text { A vs. B } \\
\text { Age: } 43 \text { vs. } 43 \text { years } \\
\text { Female: } 50 \% \text { vs. } 35 \% \\
\text { Baseline function: NR } \\
\text { Baseline pain (0-100 } \\
\text { VAS): } 79.7 \text { vs. } 76\end{array}$ & $\begin{array}{l}\text { A vs. B } \\
4.5 \text { months } \\
\text { Pain relief "yes": } 91 \% \text { vs. } \\
75 \%, \text { RR } 1.19(95 \% \mathrm{Cl} \\
0.89 \text { to } 1.60)\end{array}$ & \\
\hline
\end{tabular}




\begin{tabular}{|c|c|c|c|c|}
\hline $\begin{array}{l}\text { Author, Year, } \\
\text { Followup, } \\
\text { Pain } \\
\text { Duration, } \\
\text { Study } \\
\text { Quality }\end{array}$ & Intervention & Population & $\begin{array}{l}\text { Function and Pain } \\
\text { Outcomes }\end{array}$ & Other Outcomes \\
\hline $\begin{array}{l}\text { Thomas, } \\
2006^{195} \\
9 \text { and } 21 \\
\text { months } \\
\text { Duration of } \\
\text { pain: Mean } 17 \\
\text { weeks } \\
\text { Fair }\end{array}$ & $\begin{array}{l}\text { A. Needle } \\
\text { acupuncture } \\
\text { (n=147), } 10 \\
\text { sessions over } 12 \\
\text { weeks } \\
\begin{array}{l}\text { B. Usual care } \\
(n=68)\end{array}\end{array}$ & $\begin{array}{l}\text { A vs. B } \\
\text { Age: } 42 \text { vs. } 44 \\
\text { Female: } 62 \% \text { vs. } 58 \% \\
\text { Baseline ODI (0-100): } \\
33.7 \text { vs. } 31.4 \\
\text { Baseline McGill } \\
\text { Present Pain Index } \\
(0-5): 2.64 \text { vs. } 2.70\end{array}$ & $\begin{array}{l}\text { A vs. B } \\
9 \text { months } \\
\text { ODI (0-100): } 20.6 \text { vs. } \\
\text { 19.6, adjusted difference } \\
-0.5(-5.1 \text { to } 4.2) \\
\text { McGill Present Pain } \\
\text { Index (0-5): } 1.43 \text { vs. } \\
1.53 \text {, adjusted difference } \\
-0.1 \text { (-0.4 to } 0.3) \\
21 \text { months } \\
\text { ODI: } 18.3 \text { vs. } 21.0, \\
\text { adjusted difference }-3.4 \\
\text { (-7.8 to } 1.0) \\
\text { McGill Present Pain } \\
\text { Index: } 1.42(1.1) \text { vs. } \\
1.71 \text {, adjusted difference } \\
-0.2 \text { ( }-0.6 \text { to } 0.1)\end{array}$ & $\begin{array}{l}\text { A vs. B } \\
9 \text { months } \\
\text { SF-36 bodily pain (0- } \\
\text { 100): } 64.0 \text { vs. } 58.3, \\
\text { adjusted difference } 5.6 \\
\text { ( } 95 \% \mathrm{Cl}-0.2 \text { to } 11.4) \\
21 \text { months } \\
\text { Used medication for LBP } \\
\text { in the past } 4 \text { weeks: } 40 \% \\
\text { vs. } 59 \% \text {, difference } \\
-19 \% \text { ( } 35 \text { to }-3), \\
\text { P=0.03 } \\
21 \text { months } \\
\text { SF-36 bodily pain: } 67.8 \\
\text { vs. } 59.5 \text {, adjusted } \\
\text { difference } 8.0 \text { ( } 2.8 \text { to } \\
13.2 \text { ) }\end{array}$ \\
\hline
\end{tabular}

CI = confidence interval; FFbH-R = Funktionsfragebogen Hannover-Rücken (Hannover Functional Ability Questionnaire-back); MCS = Mental Component Summary; NR = not reported; ODI = Oswestry Disability Index; PCS = Physical Component Summary; RDQ = Roland-Morris Disability Questionnaire; RR = Relative risk; SF-36 = Short-Form 36 Questionnaire; TENS = transcutaneous electrical nerve stimulation; VAS = visual analog scale

${ }^{\text {a }}$ Unless otherwise noted, followup time is calculated from the end of the treatment period

\section{Acupuncture Compared With Sham Acupuncture, Usual Care, an Attention Control, or a Placebo Intervention}

Acupuncture was associated with slightly greater effects on short-term function than sham acupuncture or usual care ( 4 trials, pooled SMD -0.22 , $95 \%$ CI -0.35 to $-0.08, \mathrm{I}^{2}=44 \%$ ) (Figure 20). ${ }^{189,191-193}$ Each trial measured function using a different scale; across trials the SMD ranged from -0.34 to 0.00 . Differences were slightly greater in trials that compared acupuncture against usual care ( 2 trials, SMD -0.42 , $95 \%$ CI -0.60 to -0.21$)^{191,193}$ than against sham acupuncture (4 trials, SMD $-0.13,95 \%$ CI -0.24 to 0.01 ). ${ }^{189,191-193}$ None of the trials were rated poor quality. There were no differences between acupuncture versus controls in intermediateterm function (3 trials, pooled SMD $-0.08,95 \%$ CI -0.36 to $\left.0.20, \mathrm{I}^{2}=75 \%\right)^{149,189,191}$ or long-term function (1 trial, adjusted difference -3.4 on the 0 to $100 \mathrm{ODI}, 95 \%$ CI -7.8 to 1.0 ). ${ }^{195}$

Acupuncture was associated with slightly greater effects on short-term pain than sham acupuncture, usual care, an attention control, or a placebo intervention ( 5 trials, pooled difference -0.55 on a 0 to 10 scale, $95 \%$ CI -0.86 to $-0.24, \mathrm{I}^{2}=30 \%$ ) (Figure 21). ${ }^{189-193}$ The pooled estimate was similar when poor-quality trials were excluded. When stratified according to the type of control intervention, acupuncture was associated with greater effects when compared with usual care ( 2 trials, pooled MD $-1.00,95 \%$ CI -1.60 to -0.28$)^{191,193}$ than when compared with sham acupuncture (4 trials, pooled MD $-0.20,95 \%$ CI -0.66 to 0.19 ). ${ }^{189,191-193}$ There was no difference between acupuncture versus controls in intermediate-term pain (5 trials, pooled MD $-0.25,95 \%$ CI -0.67 to $\left.0.16, \mathrm{I}^{2}=33 \%\right) .{ }^{149,189-191,195}$ One trial found acupuncture associated with greater effects on long-term pain than usual care (MD $-0.83,95 \%$ CI -1.51 to -0.15 ). ${ }^{195}$

Data on effects of acupuncture on quality of life were limited. In two trials, differences between acupuncture versus sham acupuncture or usual care on short-term or intermediate-term 
SF-36 PCS and MCS scores were small (range 0.65 to 3.95 points on a 0 to 100 scale), and most differences were not statistically significant. ${ }^{189,193}$ Two trials found no clear effects of acupuncture and controls on measures of depression. ${ }^{189,192}$

Two trials found no clear differences between acupuncture versus an attention control in measures of health care utilization (provider visits, medication fills, imaging studies, costs of services), ${ }^{149,191}$ and one trial found no clear differences at intermediate-term followup between acupuncture versus placebo TENS in likelihood of working full time. ${ }^{190}$

One trial found acupuncture associated with a higher likelihood of short-term (4.5 months) treatment response (defined as $\geq 33 \%$ pain improvement and $\geq 12 \%$ functional improvement) versus usual care (48\% vs. $27 \%$, RR $1.74,95 \%$ CI 1.43 to 2.11 ), but there was no difference versus sham acupuncture (RR 1.08, 95\% CI 0.92 to 1.25$).{ }^{193}$

No trial evaluated effects of acupuncture on use of opioid therapies or health care utilization. There was insufficient evidence to determine effects of duration of acupuncture or number of acupuncture sessions on findings.

\section{Acupuncture Compared With Pharmacological Therapy or With Exercise}

No trial of acupuncture versus pharmacological therapy or versus exercise met inclusion criteria.

\section{Harms}

Data on harms were limited but indicated no clear difference between acupuncture versus control interventions in risk of withdrawal due to adverse events. ${ }^{191,195}$ Serious adverse events were rare with acupuncture and control interventions. ${ }^{149,189,191-193}$ 
Figure 20. Acupuncture versus sham acupuncture, usual care, attention control, or a placebo intervention for chronic low back pain: effects on function

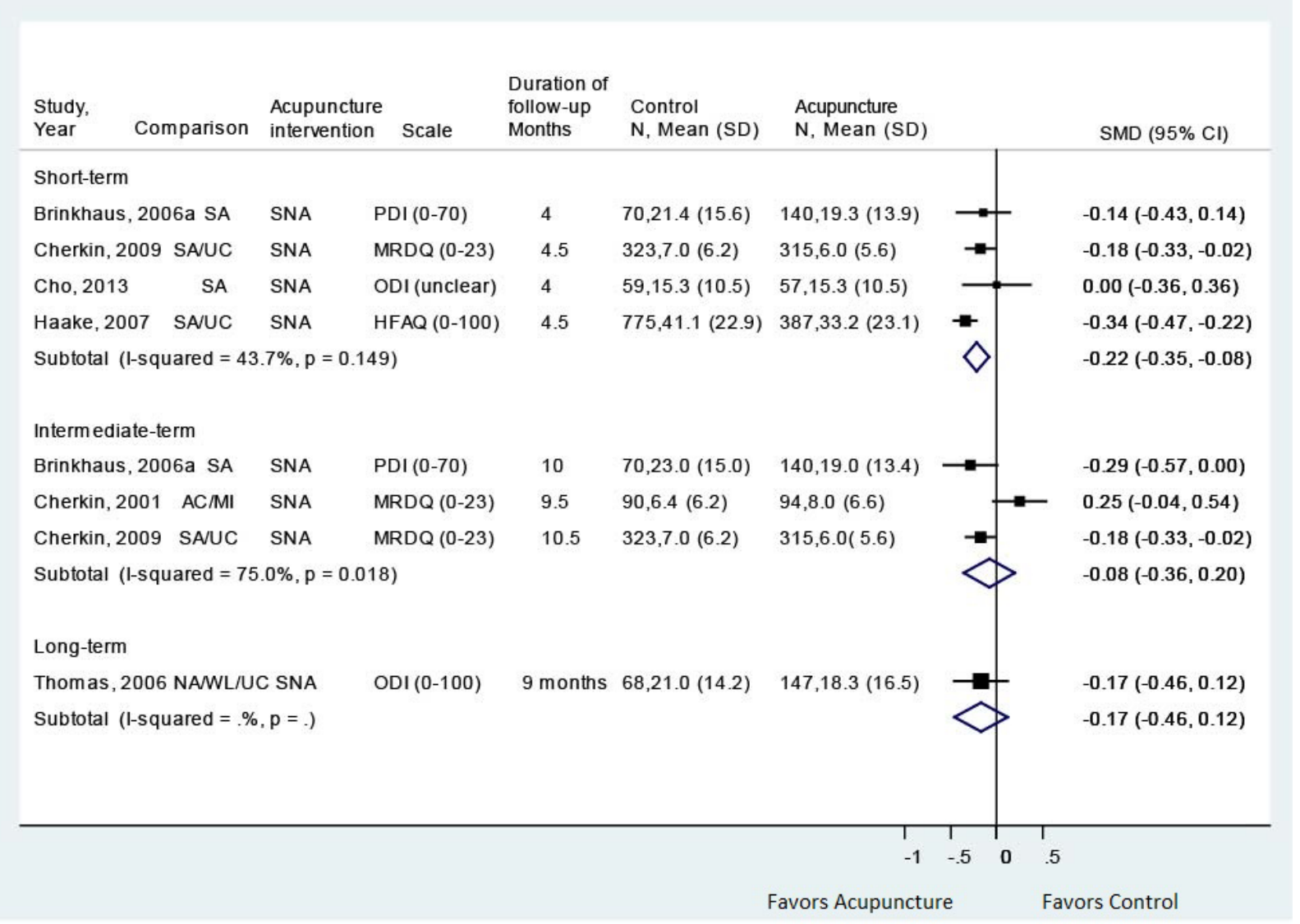

$\mathrm{AC}=$ attention control; $\mathrm{CI}=$ confidence interval; HFAQ = Hannover Functional Ability Questionnaire; $\mathrm{MI}=$ minimal intervention; MRDQ = Modified Roland-Morris Disability Questionnaire; N = number; NE = no exercise; ODI = Oswestry Disability Index; PDI = Pain Disability Index; SA=sham acupuncture; SD = standard deviation; SMD = standardized mean difference; SNA =standard needle acupuncture; UC = usual care; $\mathrm{WL}=$ waitlist 
Figure 21. Acupuncture versus sham acupuncture, usual care, an attention control, or a placebo intervention for chronic low back pain: effects on pain

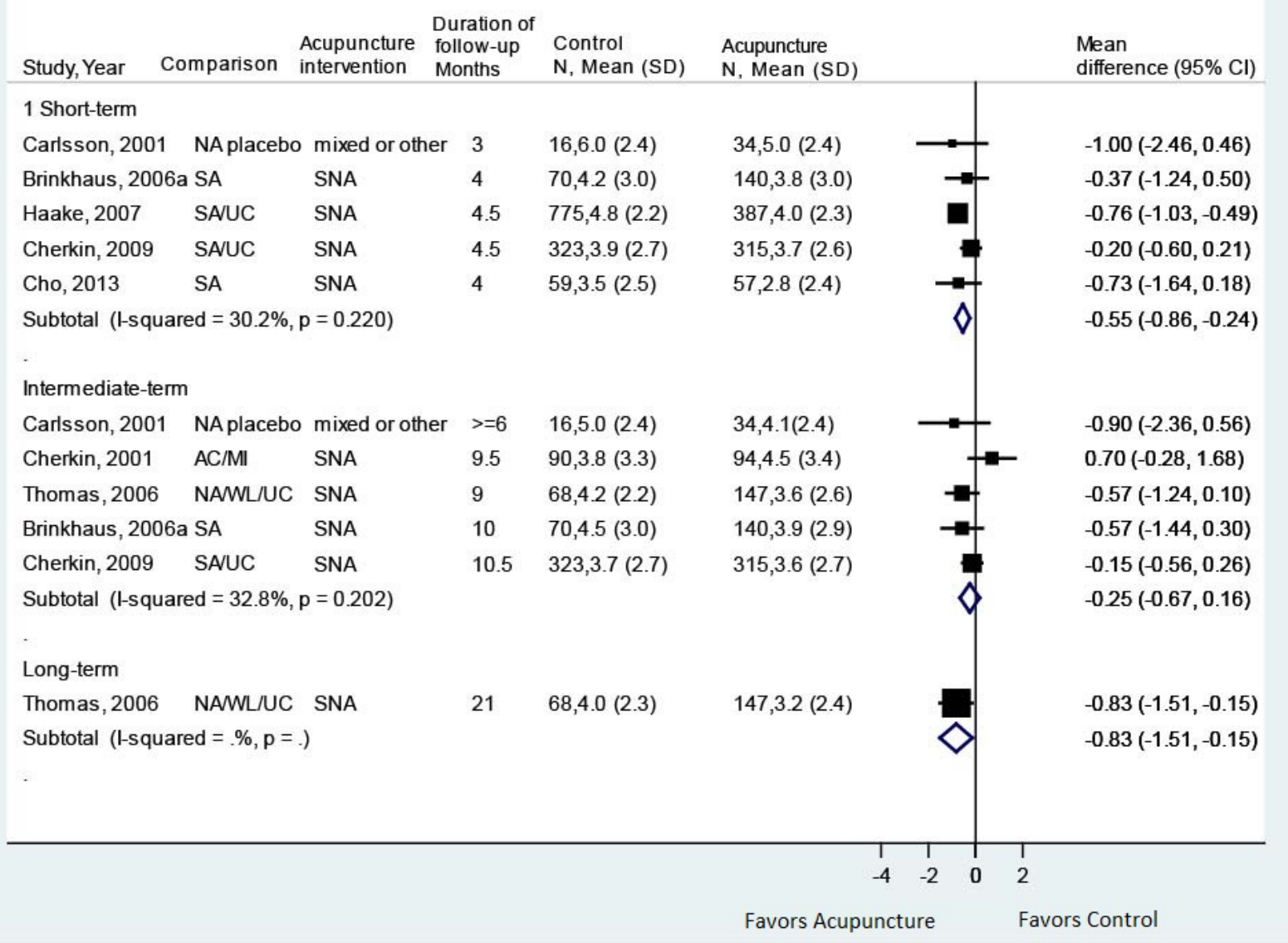

$\mathrm{AC}=$ attention control; $\mathrm{CI}=$ confidence interval; $\mathrm{MI}=$ minimal intervention; $\mathrm{N}=$ number; $\mathrm{NA}=$ needle acupuncture; $\mathrm{SA}=$ sham acupuncture; SD = standard deviation; SNA = standard needle acupuncture; UC = usual care; WL = waitlist

\section{Multidisciplinary Rehabilitation for Chronic Low Back Pain}

\section{Key Points}

- Multidisciplinary rehabilitation was associated with slightly greater effects on function than usual care at short-term (4 trials, pooled SMD $-0.31,95 \%$ CI -0.57 to -0.05 , $\mathrm{I}^{2}=70 \%$ ) and intermediate-term followup ( 4 trials, pooled SMD $-0.37,95 \%$ CI -0.64 to $-0.10, \mathrm{I}^{2}=50 \%$ ); there was no evidence of differences in long-term function ( 2 trials, pooled SMD -0.04 , 95\% CI -0.31 to $0.24, \mathrm{I}^{2}=35 \%$ ) (SOE: low).

- Multidisciplinary rehabilitation was associated with slightly greater effects on pain than usual care at short-term followup ( 4 trials, pooled MD -0.51 on a 0 to 10 scale, $95 \%$ CI -0.89 to $-0.13, \mathrm{I}^{2}=23 \%$ ) and intermediate-term followup (4 trials, pooled MD -0.63 , $95 \% \mathrm{CI}-1.04$ to $\left.-0.22, \mathrm{I}^{2}=0 \%\right)$; the long-term difference was smaller and not statistically significant ( 2 trials, pooled MD $-0.34,95 \%$ CI -0.86 to $0.18, \mathrm{I}^{2}=0 \%$ ) (SOE: moderate for short term and intermediate term, low for long term). 
- Multidisciplinary rehabilitation was associated with slightly greater effects than exercise on short-term function ( 6 trials, pooled SMD $-0.28,95 \%$ CI -0.54 to $-0.01, \mathrm{I}^{2}=39 \%$ ) and intermediate-term function ( 5 trials [excluding outlier trial], pooled SMD $-0.22,95 \%$ CI -0.40 to $-0.03, \mathrm{I}^{2}=0 \%$ ); there was no effect on long-term function ( 2 trials [excluding outlier trial], pooled SMD $-0.06,95 \% \mathrm{CI}-0.36$ to $0.25, \mathrm{I}^{2}=0 \%$ ) (SOE: moderate for short term and intermediate term, low for long term).

- Multidisciplinary rehabilitation was associated with slightly greater effects than exercise on short-term pain ( 6 trials, pooled MD -0.75 on a 0 to 10 scale, $95 \%$ CI -1.18 to -0.31 , $\mathrm{I}^{2}=0 \%$ ) and intermediate-term pain ( 5 trials [excluding outlier trial], pooled MD -0.55 , $95 \%$ CI -0.95 to $-0.15, \mathrm{I}^{2}=0 \%$ ); there was no effect on long-term pain ( 2 trials [excluding outlier trial], pooled MD $0.00,95 \% \mathrm{CI}-0.94$ to 0.95 ) (SOE: moderate for short term and intermediate term, low for long term).

- Data on harms were sparse; no serious harms were reported (SOE: insufficient).

\section{Detailed Synthesis}

Sixteen trials (reported in 21 publications) of multidisciplinary rehabilitation for low back pain met inclusion criteria (Table 17 and Appendix D). ${ }^{32,109,116,159,218-223,232-244 ~ I n ~ a c c o r d a n c e ~ w i t h ~}$ our definition for multidisciplinary rehabilitation, the intervention in all trials included a psychological therapy and an exercise therapy component, with therapy developed by clinicians from at least two disciplines. Most multidisciplinary rehabilitation interventions incorporated techniques and approaches consistent with principles of functional restoration. ${ }^{246}$ The intensity of multidisciplinary rehabilitation varied substantially, with treatment ranging from 4 to 150 hours. Five trials evaluated a multidisciplinary rehabilitation intervention that met our criteria for high intensity ( $\geq 20$ hours/week or $>80$ hours total). ${ }^{218,223,233,234,241}$ The duration of therapy ranged from 4 days to up to 13 weeks. Sample sizes ranged from 20 to 459 (total sample=1,904). Six trials compared multidisciplinary rehabilitation versus usual care, ${ }^{218-223}$ nine trials compared multidisciplinary rehabilitation versus exercise therapy, ${ }^{109,220,233,234,236-241}$ and one trial compared multidisciplinary rehabilitation versus oral medications. ${ }^{232}$ One trial ${ }^{232}$ was conducted in Iran and the remainder were conducted in the United States, the United Kingdom, or Australia. Five trials reported outcomes through long-term (12 to 60 months) followup, ${ }^{109,218,232,233,239}$ eight trials evaluated outcomes through intermediate-term followup, ${ }^{109,221-223,234,236,238,241,242}$ and three trials only evaluated short-term outcomes. ${ }^{219,237,240}$

Ten trials ${ }^{218,220,221,233,234,237-241}$ were rated fair quality and six trials poor quality (Appendix E). ${ }^{109,219,222,223,232,236}$ The major methodological limitation in the fair-quality trials was the inability to effectively blind patients and caregivers to the multidisciplinary rehabilitation. Other methodological shortcomings included unclear randomization and allocation concealment methods and high attrition. 
Table 17. Chronic low back pain: multidisciplinary rehabilitation

\begin{tabular}{|c|c|c|c|c|}
\hline $\begin{array}{l}\text { Author, Year, } \\
\text { Followup, }^{\text {a }} \\
\text { Pain Duration, } \\
\text { Study Quality }\end{array}$ & Intervention & Population & Function and Pain Outcomes & Other Outcomes \\
\hline $\begin{array}{l}\text { Abbassi, } \\
2012^{222} \\
10.25 \text { months } \\
\text { Duration of } \\
\text { pain: 6 years } \\
\text { Poor }\end{array}$ & $\begin{array}{l}\text { A. Multidisciplinary } \\
\text { rehabilitation } \\
(n=12), 7 \text { sessions } \\
\text { over } 7 \text { weeks } \\
\text { B. Multidisciplinary } \\
\text { pain management } \\
\text { (spouse-assisted) } \\
\text { ( } n=10) .7 \text { sessions } \\
\text { over } 7 \text { weeks } \\
\text { C: Usual care } \\
(n=11)\end{array}$ & $\begin{array}{l}\text { A + B + C } \\
\text { Overall } \\
\text { Age (mean): } \\
45 \text { years } \\
\text { Female: } 88 \% \\
\text { A vs. B vs. C } \\
\text { Baseline RDQ } \\
\text { (0-24): } 12.1 \\
\text { vs. 11.2 vs. } 8.4 \\
\text { Baseline pain } \\
\text { (0-10 VAS): } \\
4.6 \text { vs. } 5 \text { vs. } \\
3.6\end{array}$ & $\begin{array}{l}\text { A vs. B vs. C } \\
10.25 \text { months } \\
\text { RDQ (0-24): } 8.8 \text { vs. } 8.2 \text { vs. } \\
10.4, P=0.44 \\
\text { Pain }(0-10 \text { VAS): } 3.7 \text { vs. } 2.8 \\
\text { vs. } 4.3, P=0.44\end{array}$ & NR \\
\hline $\begin{array}{l}\text { Bendix, } \\
\text { 1995, } \\
1997,243 \\
1998^{244} \\
60 \text { months } \\
\text { Duration of } \\
\text { pain: >6 } \\
\text { months } \\
\text { Fair }\end{array}$ & $\begin{array}{l}\text { A. Multidisciplinary } \\
\text { rehabilitation } \\
\text { ( } n=46), 18 \text { sessions } \\
\text { over } 6 \text { weeks (total } \\
\sim 135 \text { hours) } \\
\text { B. Multidisciplinary } \\
\text { rehabilitation } \\
\text { ( } n=43), 12 \text { sessions } \\
\text { over } 6 \text { weeks (total } \\
24 \text { hours) } \\
\text { C. Exercise }(n=43)\end{array}$ & $\begin{array}{l}\text { A vs. B vs. C } \\
\text { Age: } 40 \text { vs. } 44 \\
\text { vs. } 42 \\
\text { Female: } 75 \% \\
\text { vs. } 77 \% \text { vs. } \\
74 \% \\
\text { Baseline pain } \\
(0-10 \text { NRS): } \\
5.3 \text { vs. } 5.9 \text { vs. } \\
5.4 \\
\text { Baseline Low } \\
\text { Back Pain } \\
\text { Rating Scale } \\
\text { (0-30): } 15.5 \text { vs. } \\
15.3 \text { vs. } 14.4\end{array}$ & $\begin{array}{l}\text { A vs. B vs. } C \\
3.25 \text { months } \\
\text { Back pain }(0-10 \text { NRS): } 2.7 \text { vs. } \\
5.6 \text { vs. } 4.4, P<0.001 \\
\text { Low Back Pain Rating Scale } \\
\text { (0-30): } 8.5 \text { vs. } 16.1 \text { vs. } 13.5, \\
P=0.002 \\
12 \text { months } \\
\text { Back pain (0-10 NRS): } 3.3 \text { vs. } \\
6.5 \text { vs. } 5.3, P=0.005 \\
\text { Low Back Pain Rating Scale } \\
\text { (0-30): } 8.9 \text { vs. } 16.4 \text { vs. } 13.7, \\
P<0.001 \\
24 \text { months } \\
\text { Back pain (0-10 NRS): } 3 \text { vs. } 6 \\
\text { vs. } 5, P=0.08 \\
\text { Low Back Pain Rating Scale } \\
\text { (0-30): } 10 \text { vs. } 17 \text { vs. } 14, \\
P=0.003\end{array}$ & 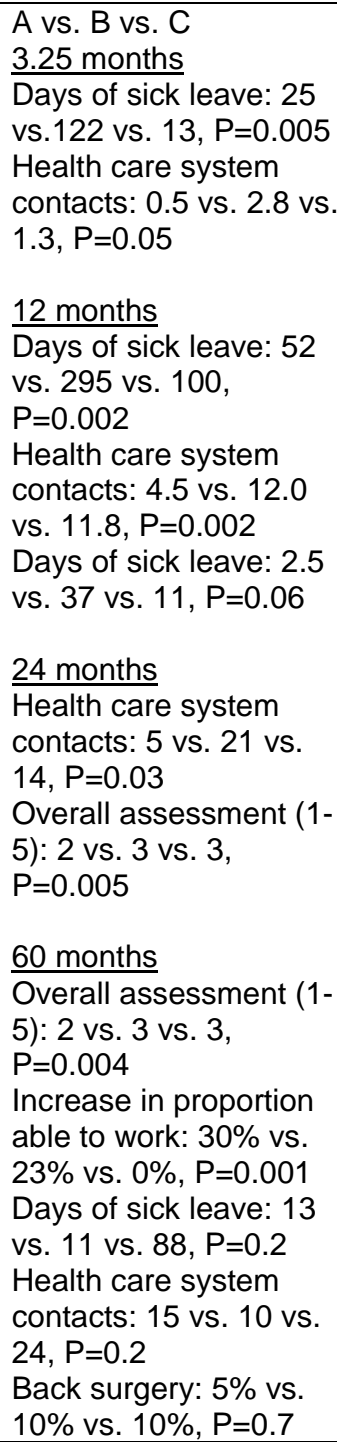 \\
\hline
\end{tabular}




\begin{tabular}{|c|c|c|c|c|}
\hline $\begin{array}{l}\text { Author, Year, } \\
\text { Followup, } \\
\text { Pain Duration, } \\
\text { Study Quality }\end{array}$ & Intervention & Population & Function and Pain Outcomes & Other Outcomes \\
\hline $\begin{array}{l}\text { Bendix,1996, }{ }^{218} \\
1998^{244} \\
60 \text { months } \\
\text { Duration of } \\
\text { pain: }>6 \\
\text { months } \\
\text { Fair }\end{array}$ & $\begin{array}{l}\text { A. Multidisciplinary } \\
\text { rehabilitation } \\
\text { ( } n=55), 18 \text { sessions } \\
\text { over } 6 \text { weeks (total } \\
\text { 135 hours) } \\
\text { B. Usual care } \\
(n=51)\end{array}$ & $\begin{array}{l}\text { A vs. B } \\
\text { Age } 41 \text { vs.40 } \\
\text { years } \\
\text { Female: } 71 \% \\
\text { vs. } 69 \% \\
\text { Baseline pain } \\
\text { (0-10 NRS): } \\
6.1 \text { vs. } 6.1 \\
\text { Baseline Low } \\
\text { Back Pain } \\
\text { Rating Scale } \\
\text { (0-30): } 16.9 \text { vs. } \\
15.9\end{array}$ & $\begin{array}{l}\text { A vs. B } \\
3.25 \text { months } \\
\text { Back pain }(0-10 \text { NRS): } 5.7 \text { vs. } \\
6.9, P=0.05 \\
\text { Low Back Pain Rating Scale } \\
(0-30): 12.1 \text { vs. } 16.8, P<0.001 \\
24 \text { months } \\
\text { Back pain ( } 0-10 \text { NRS): } 6 \text { vs. } \\
6.5, P=0.5 \\
\text { Low Back Pain Rating Scale } \\
\text { (0-30): } 16 \text { vs. } 15, P=0.9 \\
60 \text { months } \\
\text { Back pain (0-10 NRS): } 5 \text { vs. } 5 \text {, } \\
P=1.0 \\
\text { Low Back Pain Rating Scale } \\
\text { (0-30): } 12 \text { vs. } 16, P=0.2\end{array}$ & $\begin{array}{l}\text { A vs. B } \\
3.25 \text { months } \\
\text { Days of sick leave: } 10 \\
\text { vs. } 122, P=0.02 \\
\text { Contacts to health-care } \\
\text { system: } 1.6 \text { vs. } 5.3 \text {, } \\
\text { P<0.001 } \\
24 \text { months } \\
\text { Days of sick leave: } 15 \\
\text { vs. } 123, P<0.001 \\
\text { Health care system } \\
\text { contacts: } 12 \text { vs. } 26, \\
P<0.001 \\
60 \text { months } \\
\text { Days of sick leave: } 10 \\
\text { vs. } 50, P=0.4 \\
\text { Health care system } \\
\text { contacts: } 16 \text { vs. } 48, \\
P=0.1 \\
\text { Back surgery: } 7 \% \text { vs. } \\
12 \%, P=0.4\end{array}$ \\
\hline $\begin{array}{l}\text { Bendix, } 2000^{234} \\
10 \text { months } \\
\text { Duration of } \\
\text { pain: Not } \\
\text { reported } \\
\text { Fair }\end{array}$ & $\begin{array}{l}\text { A. Multidisciplinary } \\
\text { rehabilitation } \\
\text { ( } n=59), 18 \text { sessions } \\
\text { over } 8 \text { weeks (total } \\
\sim 139 \text { hours) } \\
\text { B. Exercise }(n=68)\end{array}$ & $\begin{array}{l}\text { A vs. B } \\
\text { Age: } 40 \text { vs. } 43 \\
\text { years } \\
\text { Female: } 66 \% \\
\text { vs. } 65 \% \\
\text { Baseline } \\
\text { function: NR } \\
\text { Baseline pain: } \\
\text { NR } \\
\end{array}$ & $\begin{array}{l}\text { A vs. } B \\
10 \text { months } \\
\text { Back pain }(0-10): 5.1 \text { vs. } 5.7 \\
P=0.33 \\
\text { Low Back Pain Rating Scale } \\
(0-30 \text { ADL): } 12 \text { vs. } 13, P=0.41\end{array}$ & $\begin{array}{l}\text { A vs. B } \\
10 \text { months } \\
\text { Overall assessment }(1- \\
\text { 5): } 1.7 \text { vs. } 2.7, P=0.03 \\
\text { Work capable: } 75 \% \text { vs. } \\
69 \%, P=0.64 \\
\text { Health care contacts } \\
\text { (number): } 2.5 \text { vs. } 4, \\
P=0.28\end{array}$ \\
\hline $\begin{array}{l}\text { Harkapaa, } \\
1989^{219} \\
1 \text { month } \\
\text { Duration of } \\
\text { pain: }>2 \text { years } \\
\text { Poor }\end{array}$ & $\begin{array}{l}\text { A. Multidisciplinary } \\
\text { rehabilitation } \\
\text { (inpatient) ( } n=156) \text {, } \\
3 \text { weeks (number } \\
\text { of sessions and } \\
\text { total hours unclear) } \\
\text { B. Multidisciplinary } \\
\text { rehabilitation } \\
\text { (outpatient) } \\
\text { ( } n=150), 15 \\
\text { sessions over } 8 \\
\text { weeks (total hours } \\
\text { unclear) } \\
\text { C. Usual care } \\
\text { (n=153) }\end{array}$ & $\begin{array}{l}\text { A vs. B vs. C } \\
\text { Age: } 45 \text { vs. } 45 \\
\text { vs. } 45 \text { years } \\
\text { Female: } 37 \% \\
\text { vs. } 39 \% \text { vs. } \\
35 \% \\
\text { Baseline } \\
\text { function, LBP } \\
\text { Disability Index } \\
\text { (0-45): } 16.7 \text { vs. } \\
17.6 \text { vs. } 16.7 \\
\text { Baseline Pain } \\
\text { Index (0-400): } \\
184.9 \text { vs. } 178.6 \\
\text { vs. } 175.8\end{array}$ & $\begin{array}{l}\text { A vs. B vs. C } \\
1 \text { month } \\
\text { LBP Disability Index }(0-45): \\
13.8 \text { vs. } 14.7 \text { vs. } 17.3, P<0.004 \\
\text { for } A \text { vs. } C \text { and } P<0.01 \text { for } B \\
\text { vs. C } \\
\text { Pain Index }(0-400) \text { : } 127 \text { vs. } 145 \\
\text { vs. } 160, P<0.001 \text { for } A \text { vs. C } \\
\text { and } P<0.04 \text { for } B \text { vs. C }\end{array}$ & NR \\
\hline
\end{tabular}




\begin{tabular}{|c|c|c|c|c|}
\hline $\begin{array}{l}\text { Author, Year, } \\
\text { Followup, } \\
\text { Pain Duration, } \\
\text { Study Quality }\end{array}$ & Intervention & Population & Function and Pain Outcomes & Other Outcomes \\
\hline $\begin{array}{l}\text { Jousset, } \\
2004^{235} \\
5 \text { months } \\
\text { Duration of } \\
\text { pain: }>4 \\
\text { months } \\
\text { Poor }\end{array}$ & $\begin{array}{l}\text { A. Multidisciplinary } \\
\text { rehabilitation } \\
(n=44), 25 \text { sessions } \\
\text { over } 5 \text { weeks (total } \\
150 \text { hours) } \\
\text { B. Exercise }(n=42)\end{array}$ & $\begin{array}{l}\text { A vs. B } \\
\text { Age: } 41 \text { vs. } 40 \\
\text { years } \\
\text { Female: } 30 \% \\
\text { vs. } 37 \% \\
\text { Baseline } \\
\text { function } \\
\text { Quebec } \\
\text { Disability Scale } \\
\text { (0-100): } 34.6 \\
\text { vs. } 31.6 \\
\text { Baseline pain } \\
\text { (0-10 NRS): } \\
5.0 \text { vs. } 4.6\end{array}$ & $\begin{array}{l}\text { A vs. B } \\
5 \text { months } \\
\text { Quebec Disability Scale }(0- \\
\text { 100): } 22.0 \text { vs. } 22.9, P=0.80 \\
\text { Pain ( } 0-10 \text { NRS): } 3.1 \text { vs. } 4.0, \\
P=0.01 \\
\text { Dallas Pain Questionnaire ADL } \\
\text { (0-100): } 36.7 \text { vs. } 41.5, P=0.36\end{array}$ & $\begin{array}{l}\text { A vs. B } \\
5 \text { months } \\
\text { Hospital Anxiety } \\
\text { Depression Scale (0- } \\
21): 12.7 \text { vs. } 13.4(6.4) \text {, } \\
\mathrm{P}=0.62 \\
\text { Dallas Pain } \\
\text { Questionnaire Social } \\
\text { interest }(0-100): 19.6 \\
\text { vs. } 24.3, P=0.37\end{array}$ \\
\hline $\begin{array}{l}\text { Lambeek } \\
2010^{221} \\
9 \text { months } \\
\text { Duration of } \\
\text { pain: }>4 \\
\text { months } \\
\text { Fair }\end{array}$ & $\begin{array}{l}\text { A. Multidisciplinary } \\
\text { rehabilitation } \\
(n=66), 26+ \\
\text { sessions over up to } \\
13 \text { weeks (total } \\
\text { hours unclear) } \\
\text { B. Usual care } \\
(n=68)\end{array}$ & $\begin{array}{l}\text { A vs. B } \\
\text { Age: } 46 \text { vs. } 47 \\
\text { years } \\
\text { Female: } 44 \% \\
\text { vs. } 40 \% \\
\text { Baseline } \\
\text { modified RDQ } \\
\text { (0-23): } 14.7 \text { vs. } \\
15.0 \text { Baseline } \\
\text { pain (0-10 } \\
\text { VAS): } 5.7 \text { vs. } \\
6.3\end{array}$ & $\begin{array}{l}\text { A vs. B } \\
3 \text { months } \\
\text { Modified RDQ (0-23): } 4.8 \text { vs. } \\
5.0(0.9), \text { adjusted difference } \\
0.06,95 \% \mathrm{Cl}-2.3 \text { to } 2.5 \\
\text { Pain (0-10 VAS): } 1.3 \text { vs. } 2.3 \text {, } \\
\text { adjusted difference } 0.5,95 \% \mathrm{Cl} \\
-0.6 \text { to } 1.6 \\
9 \text { months } \\
\text { Modified RDQ (0-23): } 7.2 \text { vs. } \\
4.4, \text { adjusted difference }-2.9, \\
95 \% \text { Cl }-4.9 \text { to }-0.9 \\
\text { Pain (0-10 VAS): } 1.6 \text { vs. } 1.9, \\
\text { adjusted difference } 0.21,95 \% \\
\mathrm{Cl}-0.8 \text { to } 1.2\end{array}$ & $\begin{array}{l}\text { A vs. B } \\
9 \text { months } \\
\text { General practitioner } \\
\text { visits (\# of patients): } 13 \\
\text { vs. } 29 \\
\text { Medical specialist visits } \\
\text { (\# of patients): } 13 \text { vs. } \\
29 \\
\text { Total costs (pounds): } \\
13,165 \text { (SD 13,600) vs. } \\
18,475 \text { (SD 13,616), } \\
\text { MD }-5,310(95 \% \mathrm{Cl} \\
-10,042 \text { to }-391)\end{array}$ \\
\hline
\end{tabular}




\begin{tabular}{|c|c|c|c|c|}
\hline $\begin{array}{l}\text { Author, Year, } \\
\text { Followup, }^{\text {a }} \\
\text { Pain Duration, } \\
\text { Study Quality }\end{array}$ & Intervention & Population & Function and Pain Outcomes & Other Outcomes \\
\hline $\begin{array}{l}\text { Monticone } \\
2013^{239} \\
23 \text { months } \\
\text { Duration of } \\
\text { pain: } 25 \text { vs. } 26 \\
\text { months } \\
\text { Fair }\end{array}$ & $\begin{array}{l}\text { A. Multidisciplinary } \\
\text { rehabilitation } \\
\text { ( } n=45), 26 \text { sessions } \\
\text { over } 5 \text { weeks (total } \\
26 \text { hours) } \\
\text { B. Exercise }(n=45)\end{array}$ & $\begin{array}{l}\text { A vs. B } \\
\text { Age: } 49 \text { vs. } 50 \\
\text { years } \\
\text { Female: } 60 \% \\
\text { vs. } 56 \% \\
\text { Baseline RDQ } \\
\text { (0-24): } 15.3 \text { vs. } \\
15.0 \text { Baseline } \\
\text { pain (0-10 } \\
\text { VAS): } 7.0 \text { vs. } \\
7.0\end{array}$ & 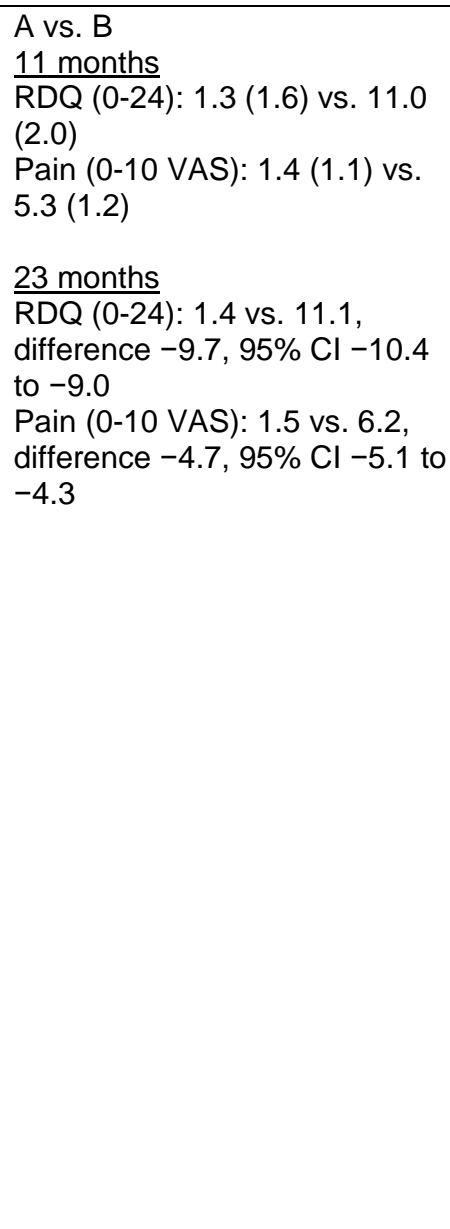 & $\begin{array}{l}\text { A vs. B } \\
11 \text { months } \\
\text { SF-36 physical pain (0- } \\
100): 79.0 \text { (14.6) vs. } \\
52.0(16.2) \\
\text { SF-36 physical } \\
\text { functioning (0-100): } \\
85.7(19.6) \text { vs. } 62.1 \\
(19.4) \\
\text { SF-36 general health } \\
\text { (0-100): 85.0 (13.8) vs. } \\
56.4(15.9) \\
\text { SF-36 mental health (0- } \\
100): 89.8 \text { (13.0) vs. } \\
54.1 \text { (11.9) } \\
23 \text { months } \\
\text { SF-36 physical pain: } \\
80.4 \text { vs. } 61.8, \text { difference } \\
18.6,95 \% \text { Cl } 12.8 \text { to } \\
24.3 \\
\text { SF-36 physical } \\
\text { functioning (0-100): } \\
87.6 \text { vs. } 65.0, \text { difference } \\
22.6,95 \% \text { Cl 15.0 to } \\
30.1 \\
\text { SF-36 general health: } \\
86.3 \text { vs. } 63.1 \text {, difference } \\
23.2,95 \% \text { Cl } 17.3 \text { to } \\
29.1 \\
\text { SF-36 mental health: } \\
91.0 \text { vs. } 58.8, \text { difference } \\
32.2,95 \% \text { Cl } 27.4 \text { to } \\
37.0)\end{array}$ \\
\hline $\begin{array}{l}\text { Monticone } \\
2014^{240} \\
3 \text { months } \\
\text { Duration of } \\
\text { pain: } 15 \text { vs. } 14 \\
\text { months } \\
\text { Fair }\end{array}$ & $\begin{array}{l}\text { A. Multidisciplinary } \\
\text { rehabilitation } \\
\text { ( } n=10), 16 \text { sessions } \\
\text { over } 8 \text { weeks (total } \\
16 \text { hours) } \\
\text { B. Exercise }(n=10)\end{array}$ & $\begin{array}{l}\text { A vs. B } \\
\text { Age: } 59 \text { vs. } 57 \\
\text { years } \\
\text { Female: } 7 \% \\
\text { vs. } 4 \% \\
\text { Baseline } \\
\text { function (0-100 } \\
\text { ODI): } 26 \text { vs. } 24 \\
\text { Baseline pain } \\
\text { (0-10 NRS): } 5 \\
\text { vs. } 4\end{array}$ & $\begin{array}{l}\text { A vs. B } \\
3 \text { months } \\
\text { ODI }(0-100): 8 \text { vs. } 15, P=0.027 \\
\text { Pain (0-10 NRS): } 2 \text { vs. } 3, \\
P=1.0\end{array}$ & 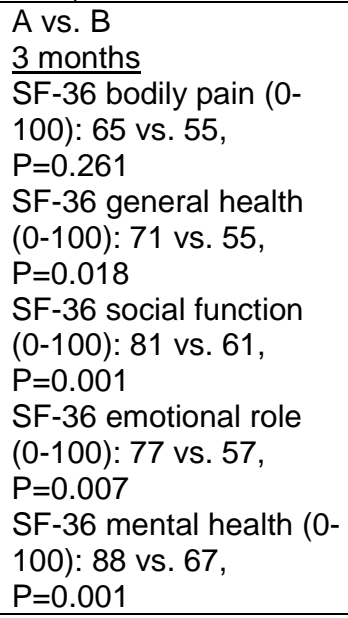 \\
\hline
\end{tabular}




\begin{tabular}{|c|c|c|c|c|}
\hline $\begin{array}{l}\text { Author, Year, } \\
\text { Followup, } \\
\text { Pain Duration, } \\
\text { Study Quality }\end{array}$ & Intervention & Population & Function and Pain Outcomes & Other Outcomes \\
\hline $\begin{array}{l}\text { Nicholas, } \\
1991^{236} \\
11 \text { months } \\
\text { Duration of } \\
\text { pain: } 7 \text { years } \\
\text { Poor }\end{array}$ & $\begin{array}{l}\text { A. Multidisciplinary } \\
\text { rehabilitation } \\
\text { (cognitive } \\
\text { treatment) ( } n=10 \text { ) } \\
\text { B. Multidisciplinary } \\
\text { rehabilitation } \\
\text { (behavioral } \\
\text { treatment) ( } n=10 \text { ) } \\
\text { C. Multidisciplinary } \\
\text { rehabilitation } \\
\text { (cognitive } \\
\text { treatment and } \\
\text { relaxation } \\
\text { treatment) ( } n=8 \text { ) } \\
\text { D. Multidisciplinary } \\
\text { rehabilitation } \\
\text { (behavioral } \\
\text { treatment and } \\
\text { relaxation training) } \\
\text { ( } n=9 \text { ) } \\
\text { E. Exercise }+ \\
\text { attention control } \\
\text { (psychologist-led } \\
\text { group discussions) } \\
\text { ( } n=10 \text { ) } \\
\text { F. Exercise ( }=11 \text { ) } \\
\text { For all } \\
\text { multidisciplinary } \\
\text { rehabilitation } \\
\text { interventions, 19 } \\
\text { sessions over } 5 \\
\text { weeks (total } 21.5 \\
\text { hours) }\end{array}$ & $\begin{array}{l}\text { Overall } \\
\text { Age: } 41 \text { years } \\
\text { Female: } 51 \% \\
\text { A vs. B vs. C } \\
\text { vs. D vs. } \\
\text { E vs. F } \\
\text { Baseline } \\
\text { function, (0- } \\
100 \text { Sickness } \\
\text { Impact Profile): } \\
37.13 \text { vs. } 34.24 \\
\text { vs. } 33.41 \text { vs. } \\
20.53 \text { vs. } 27.12 \\
\text { vs. } 28.06 \\
\text { Baseline pain } \\
(0-5 \\
\text { categorical } \\
\text { scale): } 2.78 \text { vs. } \\
2.96 \text { vs. } 3.80 \\
\text { vs. } 2.27 \text { vs. } \\
2.84 \text { vs. } 2.77\end{array}$ & $\begin{array}{l}\text { A vs. B vs. C vs. D vs. } \\
\text { E vs. F } \\
5 \text { months } \\
\text { Sickness Impact Profile (0- } \\
100): 24.42(11.78) \text { vs. } 15.44 \\
(14.12) \text { vs. } 25.69(8.50) \text { vs. } \\
14.86(9.08) \text { vs. } 19.40(6.89) \\
\text { vs. } 29.78(8.76) \\
\text { Pain (0-5 categorical scale): } \\
2.18(0.55) \text { vs. } 1.87(0.73) \text { vs. } \\
3.20(0.93) \text { vs. } 2.22(0.48) \text { vs. } \\
2.64(0.90) \text { vs. } 3.18(0.72)\end{array}$ & 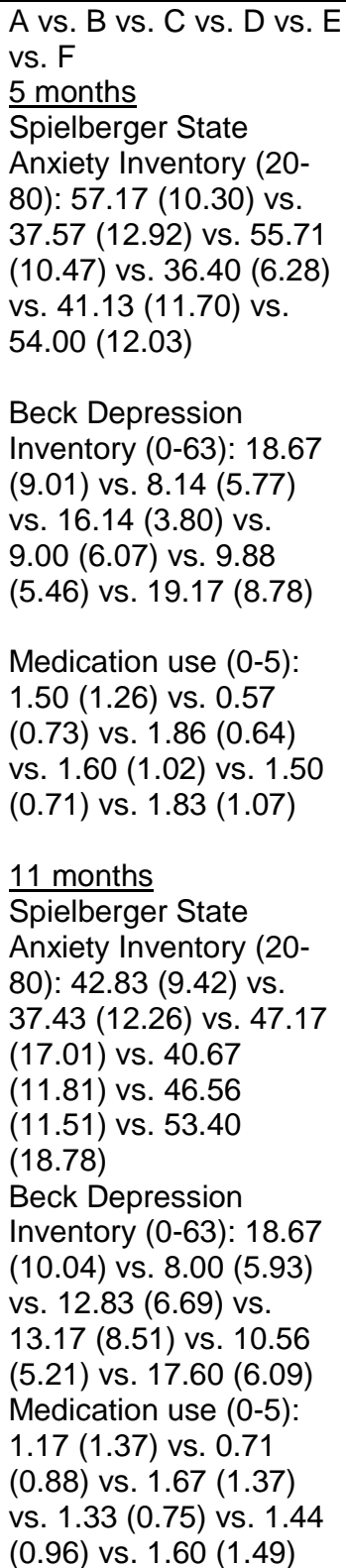 \\
\hline
\end{tabular}




\begin{tabular}{|c|c|c|c|c|}
\hline $\begin{array}{l}\text { Author, Year, } \\
\text { Followup, } \\
\text { Pain Duration, } \\
\text { Study Quality }\end{array}$ & Intervention & Population & Function and Pain Outcomes & Other Outcomes \\
\hline $\begin{array}{l}\text { Nicholas, } \\
1992^{237} \\
5 \text { months } \\
\text { Duration of } \\
\text { pain: } 5.5 \text { years } \\
\text { Fair }\end{array}$ & $\begin{array}{l}\text { A. Multidisciplinary } \\
\text { rehabilitation } \\
(n=10), 18 \text { sessions } \\
\text { over } 5 \text { weeks, (total } \\
31.5 \text { hours) } \\
\text { B. Exercise + } \\
\text { attention control } \\
\text { (psychologist-led } \\
\text { group discussions) } \\
(n=10)\end{array}$ & $\begin{array}{l}\text { Overall } \\
\text { Age: } 44 \text { years } \\
\text { Female: } 45 \% \\
\text { A vs. B } \\
\text { Baseline } \\
\text { function (0-100 } \\
\text { Sickness } \\
\text { Impact Profile): } \\
30.87 \text { vs. } 32.10 \\
\text { Baseline pain } \\
\text { (0-5 } \\
\text { categorical } \\
\text { scale): } 3.13 \text { vs. } \\
2.84\end{array}$ & $\begin{array}{l}\text { A vs. B } \\
5 \text { months } \\
\text { Pain intensity (0-5 categorical } \\
\text { scale): } 2.89(0.64) \text { vs. } 2.75 \\
(1.11)\end{array}$ & $\begin{array}{l}\text { A vs. B } \\
5 \text { months } \\
\text { Beck Depression } \\
\text { Inventory (0-63): } 14.44 \\
\text { (5.98) vs. 18.50 (9.26) } \\
\text { Using medication: } 44 \% \\
\text { vs. } 88 \%\end{array}$ \\
\hline $\begin{array}{l}\text { Roche, } \\
2007,{ }^{241} \\
2011^{242} \\
10.75 \text { months } \\
\text { Duration of } \\
\text { pain: }>4 \\
\text { months } \\
\text { Fair }\end{array}$ & $\begin{array}{l}\text { A. Multidisciplinary } \\
\text { rehabilitation } \\
\text { ( } n=68), 25 \text { sessions } \\
\text { over } 5 \text { weeks (total } \\
150 \text { hours) } \\
\begin{array}{l}\text { B. Exercise therapy } \\
(n=64)\end{array}\end{array}$ & $\begin{array}{l}\text { A vs. B } \\
\text { Age: } 41 \text { vs. } 39 \\
\text { years } \\
\text { Female: } 32 \% \\
\text { vs. } 38 \% \\
\text { Baseline } \\
\text { function (0-100 } \\
\text { Dallas Pain } \\
\text { Questionnaire } \\
\text { daily activities } \\
\text { (0-100): } 51.8 \\
\text { vs. } 51 \text { Baseline } \\
\text { Pain (0-10 } \\
\text { VAS): } 4.7 \text { vs. } \\
4.5\end{array}$ & $\begin{array}{l}\text { A vs. B } \\
10.75 \text { months } \\
\text { Dallas Pain Questionnaire daily } \\
\text { activities }(0-100): 31.4 \text { vs. } 39.1 \text {, } \\
\text { difference }-7.7 \text { ( } 95 \% \mathrm{Cl}-16.15 \\
\text { to } 0.75) \\
\text { Pain (0-10 VAS): } 2.9 \text { vs. } 3.5 \text {, } \\
\text { difference }-0.6(95 \% \mathrm{Cl}-1.49 \\
\text { to } 0.29)\end{array}$ & $\begin{array}{l}\text { A vs. B } \\
10.75 \text { months } \\
\text { Dallas Pain } \\
\text { Questionnaire } \\
\text { anxiety/depression (0- } \\
\text { 100): } 21.9 \text { vs. } 25.5, \\
\text { difference }-3.6(95 \% \mathrm{Cl} \\
-12.56 \text { to } 5.36)\end{array}$ \\
\hline $\begin{array}{l}\text { Strand, } 2001^{223} \\
11 \text { months } \\
\text { Duration of } \\
\text { pain: } 10 \text { vs. } 9 \\
\text { years } \\
\text { Fair }\end{array}$ & $\begin{array}{l}\text { A. Multidisciplinary } \\
\text { rehabilitation } \\
(n=81), 20 \text { sessions } \\
\text { over } 4 \text { weeks (total } \\
120 \text { hours) } \\
\begin{array}{l}\text { B. Usual Care } \\
(n=36)\end{array}\end{array}$ & $\begin{array}{l}\text { A vs. B } \\
\text { Age: } 45 \text { vs. } 42 \\
\text { years } \\
\text { Female: } 59 \% \\
\text { vs. } 64 \% \\
\text { Baseline } \\
\text { function (0-100 } \\
\text { Disability } \\
\text { Rating Index): } \\
55.6 \text { vs. } 58.3 \\
\text { Baseline pain } \\
\text { (0-100 VAS): } \\
48.3 \text { vs. } 53.0\end{array}$ & $\begin{array}{l}\text { A vs. B } \\
11 \text { months } \\
\text { Disability Rating Index }(0-100) \text { : } \\
-27.3(95 \% \mathrm{Cl}-34 \text { to }-21) \text { vs. } \\
-3.3(95 \% \mathrm{Cl}-10 \text { to } 14) \text { vs. } \\
-16.4(95 \% \mathrm{Cl}-26 \text { to }-7.3) \text { vs. } \\
0.2(95 \% \mathrm{Cl}-14 \text { to } 14) \text {, } \\
\text { difference }-3.8(95 \% \mathrm{Cl}-13.9 \\
\text { to } 6.3) \\
\mathrm{Pain}(0-100 \mathrm{VAS}):-21.1(95 \% \\
\mathrm{Cl}-31 \text { to }-11) \text { vs. }-2.3(95 \% \\
\mathrm{Cl}-9.4 \text { to } 4.8) \text { vs. }-23.1(95 \% \\
\mathrm{Cl}-37 \text { to } 9.2) \text { vs. } 7.1(95 \% \mathrm{Cl} \\
-7.7 \text { to } 22), \text { difference }-1.0 \\
(95 \% \mathrm{Cl}-11.7 \text { to } 9.6)\end{array}$ & $\begin{array}{l}\text { A vs. B } \\
11 \text { months } \\
\text { Working: } 47 \% \text { vs. } 58 \% \\
\text { difference }-11 \%(95 \% \\
\mathrm{Cl}-8 \text { to } 30)\end{array}$ \\
\hline
\end{tabular}




\begin{tabular}{|c|c|c|c|c|}
\hline $\begin{array}{l}\text { Author, Year, } \\
\text { Followup, } \\
\text { Pain Duration, } \\
\text { Study Quality }\end{array}$ & Intervention & Population & Function and Pain Outcomes & Other Outcomes \\
\hline $\begin{array}{l}\text { Tavafian, } \\
2008^{232} \\
12 \text { months } \\
\text { Duration of } \\
\text { pain: } 9 \text { months } \\
\text { Poor }\end{array}$ & $\begin{array}{l}\text { A. Multidisciplinary } \\
\text { program ( } n=37), 5 \\
\text { sessions over } 0.5 \\
\text { weeks (total hours } \\
\text { unclear) } \\
\text { B. Medications } \\
\text { (acetaminophen, } \\
\text { NSAID and } \\
\text { chlordiazepoxide) } \\
(n=37)\end{array}$ & $\begin{array}{l}\text { A vs. B } \\
\text { Age: } 43 \text { vs. } 45 \\
\text { years } \\
\text { Female, \%: } \\
100 \text { vs. } 100 \\
\text { Baseline SF-36 } \\
\text { Physical (0- } \\
100): 41.2 \text { vs. } \\
42.3 \\
\text { Baseline SF-36 } \\
\text { Mental (0-100): } \\
47.5 \text { vs. } 47.7\end{array}$ & NR & $\begin{array}{l}\text { A vs. B } \\
3 \text { months } \\
\text { SF-36 Physical (0-100): } \\
76.7 \text { vs. } 51.2 \text {, difference } \\
25.5 \text { (95\% Cl } 14.69 \text { to } \\
36.31) \\
\text { SF-36 MCS (0-100): } \\
80.4 \text { vs. } 57.4 \text {, difference } \\
23.0 \text { (95\% Cl 10.78 to } \\
35.22) \\
6 \text { months } \\
\text { SF-36 PCS (0-100): } \\
66.6 \text { vs. } 51.2, \text { difference } \\
15.4(95 \% \mathrm{Cl} 2.35 \text { to } \\
28.45) \\
\text { SF-36 MCS (0-100): } \\
66.9 \text { vs. } 57.9, \text { difference } \\
9.0(95 \% \mathrm{Cl}-3.88 \text { to } \\
21.88) \\
6 \text { months } \\
\text { SF-36 PCS (0-100): } \\
64.7 \text { v s. } 51.1, \\
\text { difference } 13.6 \text { (95\% Cl } \\
-1.48 \text { to } 28.68) \\
\text { SF-36 MCS (0-100): } \\
65.1 \text { vs. } 60.2, \text { difference } \\
4.9 \text { (95\% Cl -7.57 to } \\
17.37)\end{array}$ \\
\hline $\begin{array}{l}\text { Turner, } 1990^{109} \\
12 \text { months } \\
\text { Duration of } \\
\text { pain: } 12.9 \\
\text { years } \\
\text { Poor }\end{array}$ & $\begin{array}{l}\text { A. Multidisciplinary } \\
\text { rehabilitation } \\
(n=24), 16 \text { sessions } \\
\text { over } 2 \text { weeks (total } \\
32 \text { hours) } \\
\text { B. Exercise }(n=24)\end{array}$ & $\begin{array}{l}\text { Overall } \\
\text { Age: } 44 \text { years } \\
\text { Female: } 48 \% \\
\text { A vs. B } \\
\text { Baseline } \\
\text { function } \\
\text { (Sickness } \\
\text { Impact Profile): } \\
\text { 8.5 vs. } 8.4 \\
\text { Baseline pain } \\
\text { (0-78 MPQ): } \\
25.5 \text { vs. } 19.4\end{array}$ & $\begin{array}{l}\text { A vs. B } \\
6 \text { months } \\
\text { Sickness Impact Profile (0- } \\
100): 4.5 \text { vs. } 6.3 \\
\text { McGill Pain Questionnaire Pain } \\
\text { Rating Index (0-78): } 13.3 \text { vs. } \\
15.7 \\
12 \text { months } \\
\text { Sickness Impact Profile (0- } \\
100): 4.8 \text { vs. } 4.7 \\
\text { McGill Pain Questionnaire Pain } \\
\text { Rating Index (0-78): } 18.2 \text { vs. } \\
14.9\end{array}$ & $\begin{array}{l}\text { A vs. B } \\
6 \text { months } \\
\text { Center for } \\
\text { Epidemiologic Studies- } \\
\text { Depression Scale (0- } \\
60): 8.3 \text { vs. } 9.3 \\
12 \text { months } \\
\text { Center for } \\
\text { Epidemiologic Studies- } \\
\text { Depression Scale (0- } \\
60): 10.0 \text { vs. } 9.3\end{array}$ \\
\hline
\end{tabular}




\begin{tabular}{|c|c|c|c|c|}
\hline $\begin{array}{l}\text { Author, Year, } \\
\text { Followup, }^{\text {a }} \\
\text { Pain Duration, } \\
\text { Study Quality }\end{array}$ & Intervention & Population & Function and Pain Outcomes & Other Outcomes \\
\hline $\begin{array}{l}\text { van der Roer, } \\
2008^{238} \\
10 \text { months } \\
\text { Duration of } \\
\text { pain: 50 } \\
\text { weeks } \\
\text { Fair }\end{array}$ & $\begin{array}{l}\text { A. Multidisciplinary } \\
\text { rehabilitation } \\
(n=60), 30 \text { sessions } \\
\text { over } 10 \text { weeks } \\
\text { (total hours } \\
\text { unclear) } \\
\text { B. Exercise }(n=54)\end{array}$ & $\begin{array}{l}\text { A vs. B } \\
\text { Age: } 42 \text { vs. } 42 \\
\text { years } \\
\text { Female: } 55 \% \\
\text { vs. } 48 \% \\
\text { Baseline } \\
\text { function RDQ } \\
(0-24): 11.6 \text { vs. } \\
12.1 \\
\text { Baseline pain } \\
(0-10 \text { NRS): } \\
6.2 \text { vs. } 5.9\end{array}$ & $\begin{array}{l}\text { A vs. B } \\
4 \text { months } \\
\text { RDQ (0-24): } 7.4 \text { vs. } 7.7, \\
\text { adjusted difference } 0.13 \text { (95\% } \\
\mathrm{Cl}-2.24 \text { to } 2.50) \\
\text { Pain (0-10 NRS): } 4.1 \text { vs. } 4.8, \\
\text { adjusted difference }-0.97 \text { (95\% } \\
\mathrm{Cl}-1.88 \text { to }-0.06) \\
10 \text { months } \\
\text { RDQ (0-24): } 6.7 \text { vs. } 7.1, \\
\text { adjusted difference } 0.06(-2.22 \\
\text { to } 2.34) \\
\text { Pain (0-10 VAS): } 3.9 \text { vs. } 4.6, \\
\text { adjusted difference }-1.02 \\
\text { (-2.14 to 0.09) }\end{array}$ & $\begin{array}{l}\text { A vs. B } \\
4 \text { months } \\
\text { Global Perceived Effect } \\
\text { positive (\%): } 38.2 \% \text { vs. } \\
39.8 \% \text {, OR } 0.93(95 \% \\
\text { Cl } 0.36 \text { to } 2.43) \\
10 \text { months } \\
\text { Global Perceived Effect } \\
\text { positive (\%): } 45.0 \% \text { vs. } \\
32.3 \%, \text { OR } 1.71(95 \% \\
\text { Cl } 0.67 \text { to } 4.38)\end{array}$ \\
\hline $\begin{array}{l}\text { Von Korff, } \\
2005^{220} \\
22.5 \text { months } \\
\text { Duration of } \\
\text { pain: >3 } \\
\text { months } \\
\text { Fair }\end{array}$ & $\begin{array}{l}\text { A. Multidisciplinary } \\
\text { rehabilitation } \\
\text { ( } n=119), 4 \text { sessions } \\
\text { over } 5 \text { weeks (total } \\
4 \text { hours) } \\
\begin{array}{l}\text { B. Usual care } \\
(n=121)\end{array}\end{array}$ & $\begin{array}{l}\text { A vs. B } \\
\text { Age: } 50 \text { vs. } 50 \\
\text { years } \\
\text { Female: } 65 \% \\
\text { vs. } 60 \% \\
\text { Modified RDQ } \\
\text { (0-23): } 12.3 \text { vs. } \\
\text { 11.4 Baseline } \\
\text { pain (0-10 } \\
\text { NRS): } 5.7 \text { vs. } \\
5.8\end{array}$ & $\begin{array}{l}\text { A vs. B } \\
4.5 \text { months } \\
\text { Function } \\
\text { Modified RDQ (0-23): } 9.2 \text { (6.6) } \\
\text { vs. } 10.1(6.4), P=0.0003 \\
>1 / 3 \text { reduction in RDQ: } 42.2 \% \\
\text { vs. } 23.7 \% \text {, adjusted OR } 3.5, \\
P=0.0007 \\
\text { Pain (0-10 NRS): } 4.2 \text { (2.0) vs. } \\
4.7 \text { ( } 2.2), P=0.007 \\
10.5 \text { months } \\
\text { Modified RDQ (0-23): } 8.4 \text { vs. } \\
9.1, P=0.0063 \\
>1 / 3 \text { reduction in RDQ: } 44.6 \% \\
\text { vs. } 22.7 \%, \text { adjusted OR } 2.1, \\
P=0.03 \\
P \text { ain }(0-10 \text { NRS): } 4.0 \text { vs. } 4.7 \\
P=0.004 \\
22.5 \text { months } \\
\text { Modified RDQ (0-23): } 8.1 \text { vs. } \\
9.1, P=0.0078 \\
>1 / 3 \text { reduction in RDQ: } 49.4 \% \\
\text { vs. } 37.0 \%, \text { adjusted OR } 1.8, \\
P=0.08 \\
P a i n(0-10 \text { NRS): } 4.3 \text { vs. } 4.6, \\
P=0.115\end{array}$ & $\begin{array}{l}\text { A vs. B } \\
4.5 \text { months } \\
\text { SF-36 Social } \\
\text { Functioning }(0-100) \text { : } \\
74.4 \text { vs. } 73.6, P=0.26 \\
\text { SF-36 Mental Health (0- } \\
100): 70.3 \text { vs. } 69.5 \text {, } \\
P=0.23 \\
10.5 \text { months } \\
\text { SF-36 Social } \\
\text { Functioning }(0-100) \text { : } \\
74.4 \text { vs. } 73.6, P=0.26 \\
\text { SF-36 Mental Health }(0- \\
100): 70.3 \text { vs. } 69.5 \text {, } \\
P=0.23 \\
22.5 \text { months } \\
\text { SF-36 Social } \\
\text { Functioning }(0-100): \\
76.7 \text { vs. } 76.3, P=0.28 \\
\text { SF-36 Mental Health }(0- \\
100): 71.0 \text { vs. } 72.4 \text {, } \\
P=0.98\end{array}$ \\
\hline
\end{tabular}

ADL = activity of daily living; $\mathrm{CI}$ = confidence interval; $\mathrm{LBO}=$ Low Back Outcome Score; MCS = Mental Component Summary; MPQ = McGill Pain Questionnaire; NHP = Nottingham Health Profile; NR = not reported; NSAID = nonsteroidal anti-inflammatory drug; ODI = Oswestry Disability Index; PCS = Physical Component Summary; RDQ = Roland-Morris Disability Questionnaire; SF-36 = Short-Form 36Q; STAI-S = Spielberger State Anxiety Inventory; VAS = visual analog scale

${ }^{a}$ Unless otherwise noted, followup time is calculated from the end of the treatment period

\section{Multidisciplinary Rehabilitation Compared With Usual Care}

Multidisciplinary rehabilitation was associated with slightly greater effects on function than controls at short-term ( 4 trials, pooled SMD $-0.31,95 \%$ CI -0.57 to $-0.05, \mathrm{I}^{2}=70 \%$ ), ${ }^{218-221}$ and intermediate-term followup (4 trials, pooled SMD $-0.37,95 \%$ CI -0.64 to $-0.10, \mathrm{I}^{2}=50 \%$ ) (Figure 22). ${ }^{220-223}$ There was no difference in long-term function (2 trials, pooled SMD -0.04 , $95 \% \mathrm{CI}-0.31$ to $\left.0.24, \mathrm{I}^{2}=35 \%\right) .{ }^{218,220}$ In trials that measured function using the RDQ, the 
difference was 0.70 points at short term and 1.9 points at intermediate term. Evaluation of a high-intensity multidisciplinary rehabilitation intervention or exclusion of poor-quality trials had little effect on estimates. At short-term followup, effects on function were somewhat larger with high intensity multidisciplinary rehabilitation interventions (2 trials, pooled SMD $-0.51,95 \%$ CI -0.93 to -0.22$)^{218,219}$ than with nonhigh intensity interventions (3 trials, pooled difference -0.20 , $95 \% \mathrm{CI}-0.38$ to 0.03$),{ }^{219-221}$ but the interaction was not statistically significant $(\mathrm{P}=0.18)$. At intermediate term, there were no clear differences between high intensity ( 1 trial, SMD -0.59 , $95 \%$ CI -0.99 to -0.19$)^{223}$ and nonhigh intensity ( 3 trials, pooled difference -0.29 , 95\% CI -0.68 to 0.06$)^{220-222}$ interventions $(\mathrm{P}=0.47$ for interaction).

Multidisciplinary rehabilitation was associated with slightly greater effects than usual care on pain at short-term ( 4 trials, pooled difference -0.51 on a 0 to 10 scale, $95 \%$ CI -0.89 to -0.13 , $\left.\mathrm{I}^{2}=23 \%\right)^{218-221}$ and intermediate-term followup (4 trials, pooled difference $-0.63,95 \% \mathrm{CI}-1.04$ to $\left.-0.22, \mathrm{I}^{2}=0 \%\right)^{220-223}$ (Figure 23). The long-term difference was smaller and not statistically significant ( 2 trials, pooled difference $-0.34,95 \% \mathrm{CI}-0.86$ to $0.18, \mathrm{I}^{2}=0 \%$ ). ${ }^{218,220}$ Excluding poor-quality trials ${ }^{219,222,223}$ had little effect on estimates. At short-term followup, effects on pain were somewhat larger with high intensity multidisciplinary rehabilitation interventions (2 trials, pooled difference -0.87 , $95 \%$ CI -1.56 to -0.33$)^{218,219}$ than with nonhigh intensity interventions ( 3 trials, pooled difference $-0.35,95 \%$ CI -0.70 to 0.14 ), ${ }^{219-221}$ but the interaction between intensity and effects of multidisciplinary rehabilitation was not statistically significant $(\mathrm{P}=0.45)$. At intermediate term, estimates were similar for high intensity ( 1 trial, difference $-0.53,95 \%$ CI -1.36 to 0.30$)^{223}$ and nonhigh intensity (3 trials, pooled difference $-0.66,95 \%$ CI -1.19 to -0.12 ) interventions $\left(\mathrm{P}=0.81\right.$ for interaction). ${ }^{220-222}$

Data on other outcomes was limited. One trial found no differences between multidisciplinary rehabilitation versus usual care on the SF-36 Social Functioning or Mental Functioning subscales. ${ }^{220}$ Three trials reported inconsistent effects on work or disability/sick leave status. ${ }^{218,220,223}$ Two trials found multidisciplinary rehabilitation associated with fewer health system contacts versus usual care. ${ }^{218,221}$

\section{Multidisciplinary Rehabilitation Compared With Pharmacological Therapy}

One poor-quality trial ( $n=74)$ found multidisciplinary rehabilitation (intensity unclear) associated with greater effects on short-term quality of life than oral medications (acetaminophen, NSAIDs, and chlordiazepoxide). ${ }^{232}$ The difference on the SF-36 PCS was 25.5 points (95\% CI 14.7 to 36.3) and on the SF-36 MCS was 23.0 points (95\% CI 10.8 to 35.2). Effects were smaller at intermediate term and statistically significant for the SF-36 PCS (difference 15.4, 95\% CI 2.35 to 28.45) but not for the SF-36 MCS (difference 9.0, 95\% CI -3.88 to 21.9). Effects were not statistically significant at long-term (12 month) followup (differences 13.6 and 4.9 points, respectively).

\section{Multidisciplinary Rehabilitation Compared With Exercise}

Multidisciplinary rehabilitation was associated with slightly greater effects on short-term function than exercise ( 6 trials, pooled SMD $-0.28,95 \%$ CI -0.54 to $-0.01, \mathrm{I}^{2}=39 \%$ ) (Figure 24). ${ }^{233,235-238,240}$ Estimates were similar when a poor-quality trial ${ }^{236}$ was excluded and when analyses were restricted to trials of high-intensity multidisciplinary rehabilitation (2 trials, pooled difference $-0.14,95 \%$ CI -0.47 to 0.20$).{ }^{233,235}$ Multidisciplinary rehabilitation was associated with substantially greater effects than exercise on intermediate-term function (6 trials, pooled SMD $-1.01,95 \%$ CI -1.93 to $-0.09, \mathrm{I}^{2}=96 \%$ ), but statistical heterogeneity was very large. ${ }^{109,234,236,238,239,241,242}$ Excluding an outlier trial (SMD -5.31, 95\% CI -6.20 to -4.42$)^{239}$ 
eliminated statistical heterogeneity and resulted in a markedly attenuated (small) effect (5 trials, pooled SMD $-0.22,95 \% \mathrm{CI}-0.40$ to $-0.03, \mathrm{I}^{2}=0 \%$ ). There was no difference between multidisciplinary rehabilitation versus exercise in long-term function ( 3 trials, pooled SMD $-1.80,95 \% \mathrm{CI}-4.36$ to $\left.0.76, \mathrm{I}^{2}=98 \%\right) .{ }^{109,233,239}$ Excluding an outlier trial ${ }^{239}$ resulted in a pooled SMD close to 0 ( $-0.06,95 \%$ CI -0.36 to $\left.0.25, \mathrm{I}^{2}=0 \%\right)$.

Multidisciplinary rehabilitation was associated with slightly greater effects on short-term pain versus exercise ( 6 trials, pooled difference -0.75 on a 0 to 10 scale, $95 \%$ CI -1.18 to -0.31 , $\mathrm{I}^{2}=0 \%$ ) (Figure 25). Estimates were similar when one poor-quality trial ${ }^{236}$ was excluded ( 5 trials, pooled difference $-0.50,95 \% \mathrm{CI}-1.07$ to 0.11 ), and there were no clear differences when analyses were stratified according to intensity of multidisciplinary rehabilitation. In two trials that evaluated high intensity multidisciplinary rehabilitation, the pooled difference was -0.56 (95\% CI -1.53 to 0.36 ). ${ }^{233,235}$ Estimates at intermediate term (6 trials, pooled difference -1.17 points, $95 \% \mathrm{CI}-2.70$ to $\left.0.36, \mathrm{I}^{2}=96 \%\right)^{234,236,238,240-242}$ and long term ( 3 trials, pooled difference $-1.63,95 \%$ CI -5.30 to $\left.2.05, \mathrm{I}^{2}=99 \%\right)^{109,233,239}$ favored multidisciplinary rehabilitation, but effects were not statistically significant. Substantial statistical heterogeneity was present in analyses of intermediate-term and long-term pain, with an outlier $\operatorname{trial}^{239}$ that reported substantially larger effects than the other trials. For intermediate term, the outlier trial reported a MD of -3.90 points, versus -0.31 to -0.78 points in the other trials. Excluding the outlier trial eliminated statistical heterogeneity and resulted in a small, statistically significant difference in intermediate-term pain that favored multidisciplinary rehabilitation ( 5 trials, pooled difference $-0.55,95 \%$ CI -0.95 to $-0.15, \mathrm{I}^{2}=0 \%$ ); there was no difference in long-term pain ( 2 trials, pooled difference $0.00,95 \% \mathrm{CI}-0.94$ to $0.95, \mathrm{I}^{2}=50 \%$ ). For intermediate-term pain, exclusion of a poor-quality trial ${ }^{236}$ ( 5 trials, pooled difference $-1.52,95 \%$ CI -3.34 to 0.39 ) or restriction of analyses to high intensity multidisciplinary rehabilitation interventions ( 2 trials, pooled difference $-0.60,95 \%$ CI -1.41 to 0.21$)^{234,241,242}$ did not reduce heterogeneity and differences remained not statistically significant.

Data on other outcomes was limited. One trial found multidisciplinary rehabilitation associated with better scores versus exercise on SF-36 subscales at short-term followup (differences 10 to 21 points). ${ }^{240}$ Four trials found no clear differences between multidisciplinary rehabilitation versus exercise on severity of depression. ${ }^{109,235-237}$ Two trials found no clear effects on work status ${ }^{233,241,242}$ and one trial found high intensity multidisciplinary rehabilitation associated with fewer days or sick leave than exercise, but nonhigh intensity rehabilitation associated with more days of sick leave. ${ }^{233}$ Two trials found inconsistent effects on number of health system contacts. ${ }^{233,234}$

\section{Harms}

Data on harms were sparse and reported in only two trials. One study reported no clear difference between multidisciplinary rehabilitation versus exercise in risk of transient worsening of pain, ${ }^{240}$ and one trial reported no harms with either multidisciplinary rehabilitation or medications alone. ${ }^{232}$ 
Figure 22. Multidisciplinary rehabilitation versus usual care: effects on function

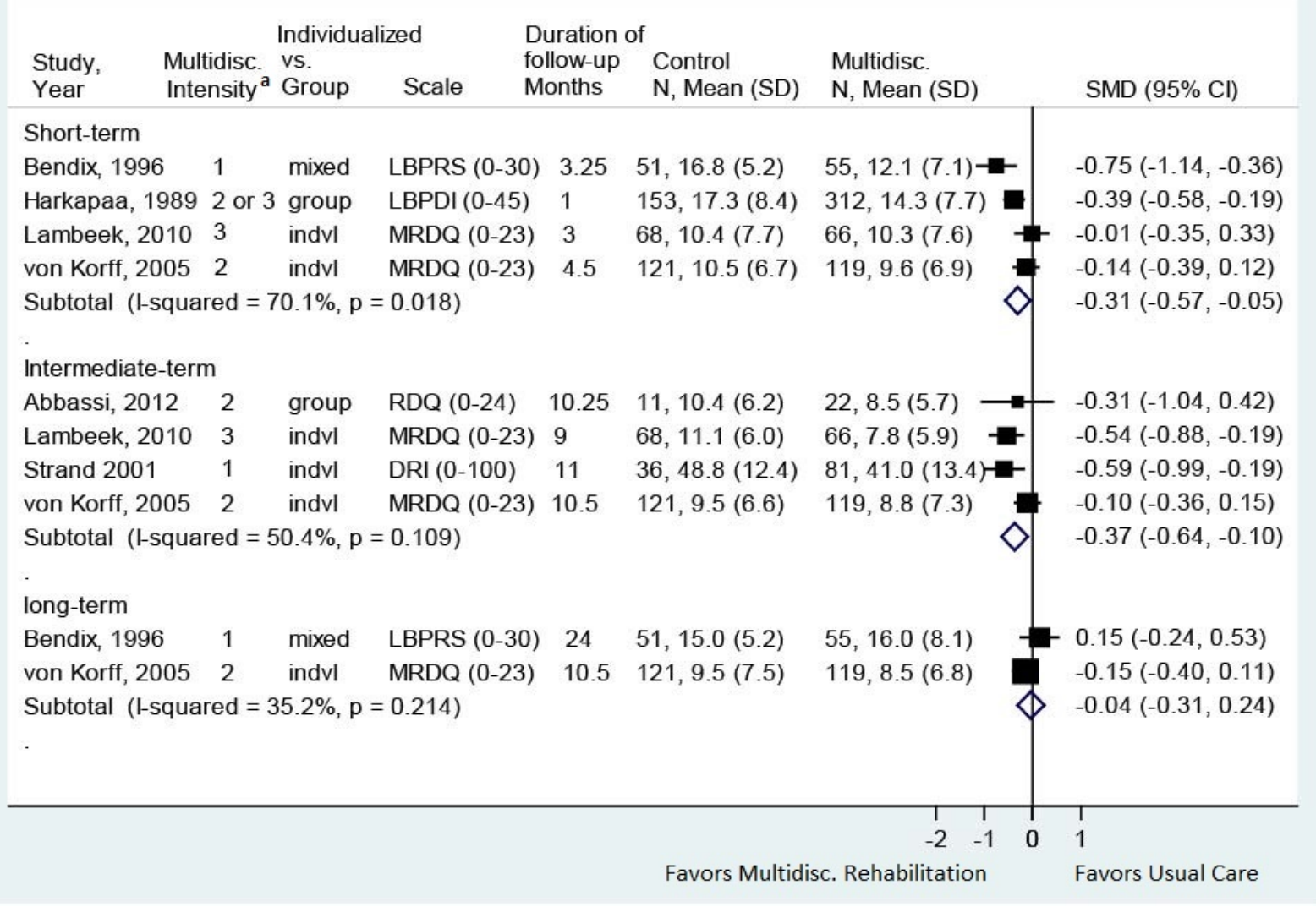

$\mathrm{CI}$ = confidence interval; DRI = Disability Rating Index; indvl = individual; LBPDI = low back pain disability index; LBPRS = low back pain rating scale; MRDQ = Modified Roland-Morris Disability Questionnaire; N = number; RDQ = Roland-Morris Disability Questionnaire; SD = standard deviation; SMD = standardized mean difference

${ }^{\text {a }}$ Multidisciplinary rehabilitation intensity: $1=$ high, $2=$ not high, $3=$ unclear or not reported 
Figure 23. Multidisciplinary rehabilitation versus usual care: effects on pain

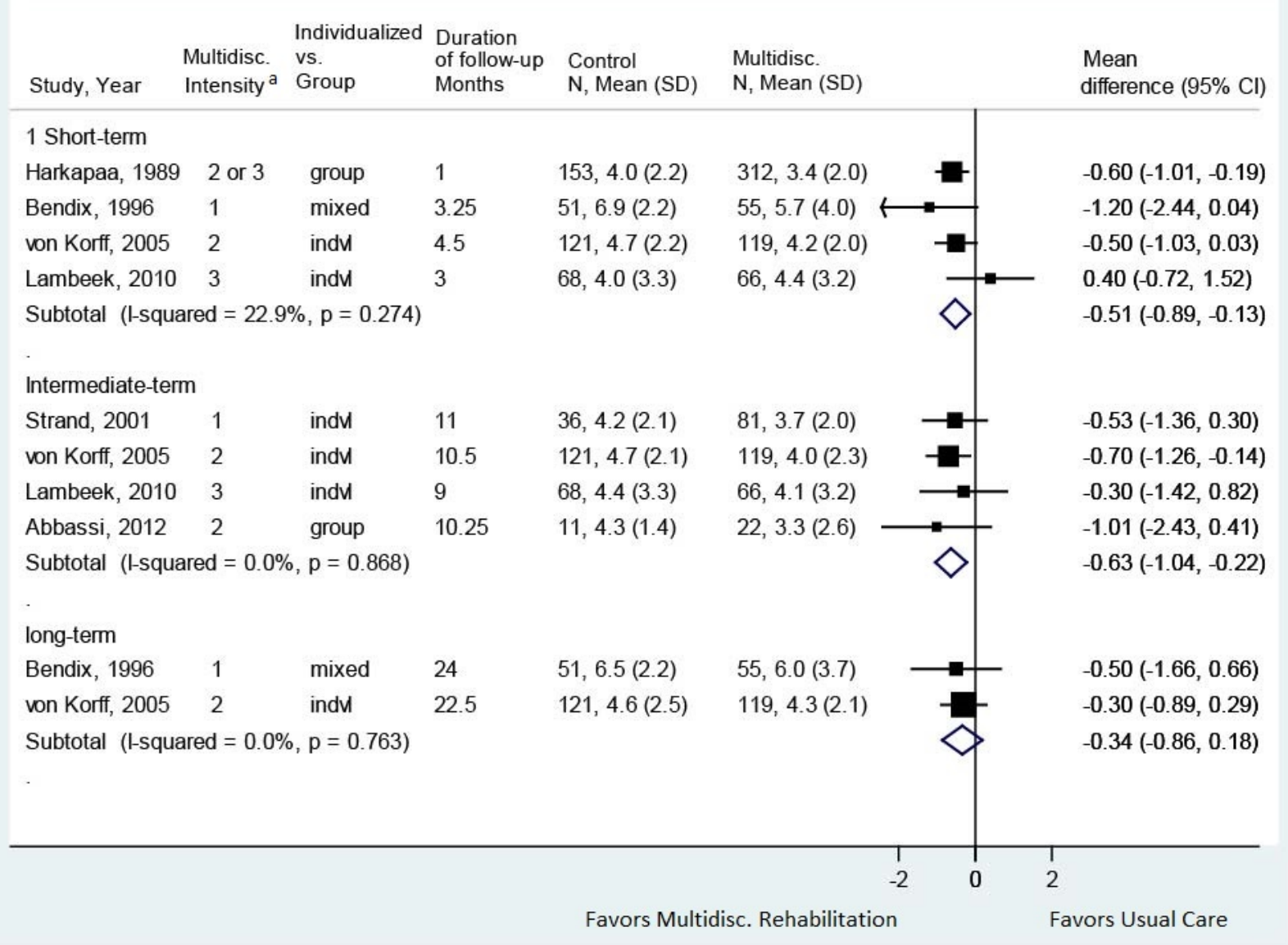

$\mathrm{CI}$ = confidence interval; indvl = individual; $\mathrm{N}=$ number; RDQ = Roland-Morris Disability Questionnaire; SD = standard deviation

${ }^{a}$ Multidisciplinary rehabilitation intensity: 1 = high, 2 = not high, 3 = unclear or not reported 
Figure 24. Multidisciplinary rehabilitation versus exercise: effects on function

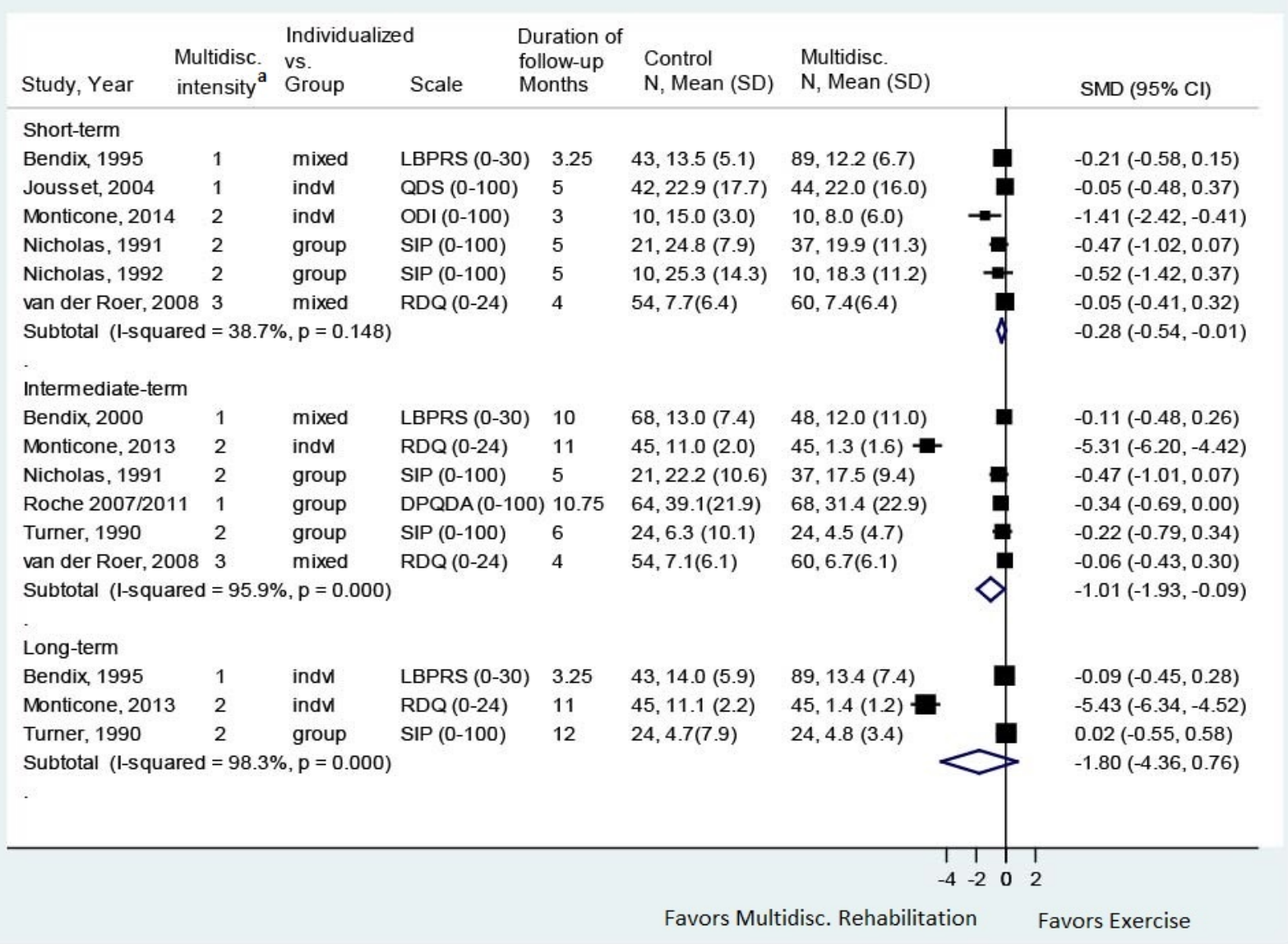

CI = confidence interval; DPQDA = Dallas Pain Questionnaire daily activities; indvl = individual; LBPRS = low back pain rating scale; N = number; ODI = Oswestry Disability Index; QDS = Quebec Disability Scale; RDQ = Roland-Morris Disability Questionnaire; SD = standard deviation; SIP = Sickness Impact Profile; SMD = standardized mean difference

a Multidisciplinary rehabilitation intensity: 1= high, 2= not high, 3= unclear or not reported 
Figure 25. Multidisciplinary rehabilitation versus exercise care: effects on pain

\begin{tabular}{|c|c|c|c|c|c|c|}
\hline \multirow{2}{*}{$\begin{array}{l}\text { Study, Year } \\
1 \text { Short-term }\end{array}$} & $\begin{array}{l}\text { Multidisc. } \\
\text { intensity }^{\text {a }}\end{array}$ & $\begin{array}{l}\text { Individualized } \\
\text { vs. } \\
\text { Group }\end{array}$ & $\begin{array}{l}\text { Duration of } \\
\text { follow-up } \\
\text { Months }\end{array}$ & $\begin{array}{l}\text { f Control } \\
\text { N, Mean (SD) }\end{array}$ & $\begin{array}{l}\text { Multidisc. } \\
\mathrm{N} \text {, Mean (SD) }\end{array}$ & $\begin{array}{l}\text { Mean } \\
\text { difference }(95 \% \mathrm{Cl})\end{array}$ \\
\hline & & & & & & \\
\hline Nicholas, 1991 & 2 & group & 5 & $21,5.8(1.6)$ & $37,4.7(1.4)$ & $-1.19(-2.03,-0.35)$ \\
\hline Nicholas, 1992 & 2 & group & 5 & $10,5.5(2.2)$ & $10,5.8(1.3)$ & $0.28(-1.42,1.98)$ \\
\hline Bendix, 1995 & 1 & mixed & 3.25 & $43,4.4(2.8)$ & $89,4.1(2.5)$ & $-0.30(-1.29,0.69)$ \\
\hline Jousset, 2004 & 1 & indvl & 5 & $42,4.0(2.8)$ & $44,3.1(2.5)$ & $-0.90(-2.04,0.24)$ \\
\hline van der Roer, 2008 & 3 & mixed & 4 & $54,4.8(2.4)$ & $60,4.1(2.4)$ & $-0.70(-1.61,0.21)$ \\
\hline Monticone, 2014 & 2 & indvl & 3 & $10,3.0(2.0)$ & $10,2.0(1.0)$ & $-1.00(-2.49,0.49)$ \\
\hline \multicolumn{3}{|c|}{ Subtotal $(l-$ squared $=0.0 \%, p=0.630)$} & & & & $-0.75(-1.18,-0.31)$ \\
\hline \multicolumn{7}{|l|}{ Intermediate-term } \\
\hline Turner, 1990 & 2 & group & 6 & $24,2.0(1.2)$ & $24,1.7(1.2)$ & $-0.31(-0.99,0.38)$ \\
\hline Nicholas, 1991 & 2 & group & 11 & $21,5.9(1.5)$ & $37,5.2(1.8)$ & $-0.78(-1.68,0.11)$ \\
\hline Bendix, 2000 & & mixed & 10 & $68,5.7(3.2)$ & $48,5.1(3.7)$ & $-0.60(-1.90,0.70)$ \\
\hline van der Roer, 2008 & 3 & mixed & 10 & $54,4.6(3.0)$ & $60,3.9(3.0)$ & $-0.70(-1.80,0.40)$ \\
\hline Roche 2007/2011 & 1 & group & 10.75 & $64,3.5(2.3)$ & $68,2.9(2.4)$ & $-0.60(-1.41,0.21)$ \\
\hline Monticone, 2013 & 2 & indvl & 11 & $45,5.3(1.2)$ & $45,1.4(1.1)$ & $-3.90(-4.38,-3.42)$ \\
\hline \multicolumn{4}{|c|}{ Subtotal (I-squared $=95.5 \%, p=0.000$ ) } & & & $-1.17(-2.70,0.36)$ \\
\hline \multicolumn{7}{|l|}{ Long-term } \\
\hline Turner, 1990 & 2 & group & 12 & $24,1.9(1.0)$ & $24,2.3(1.7)$ & $0.42(-0.39,1.24)$ \\
\hline Bendix, 1995 & 1 & mixed & 24 & $43,5.0(2.9)$ & $89,4.4(2.9)$ & $-0.55(-1.63,0.53)$ \\
\hline Monticone, 2013 & 2 & indvl & 23 & $45,6.2(0.9)$ & $45,1.5(1.1)$ & $-4.70(-5.12,-4.28)$ \\
\hline \multicolumn{3}{|c|}{ Subtotal $($ l-squared $=98.6 \%, p=0.000)$} & & & & $-1.63(-5.30,2.05)$ \\
\hline \multicolumn{7}{|l|}{ - } \\
\hline & & & & & & \\
\hline & & & & Favors $\mathrm{N}$ & Itidisc. Rehabil & rs Exercise \\
\hline
\end{tabular}

$\mathrm{CI}$ = confidence interval; indvl = individual; $\mathrm{N}=$ number; $\mathrm{SD}=$ standard deviation

a Multidisciplinary rehabilitation intensity: 1 = high, 2 = not high, 3 = unclear or not reported

\section{Key Question 2: Chronic Neck Pain}

\section{Exercise for Chronic Neck Pain}

\section{Key Points}

- Across types of exercise, there was no clear improvement in function (3 trials [excluding outlier trial], pooled SMD -0.23 , $95 \%$ CI -0.71 to 0.15 ) or pain (3 trials [excluding outlier trial], pooled SMD $-0.72,95 \% \mathrm{CI}-1.49$ to 0.06 ) versus no treatment or advice alone in the short term (SOE: low).

- A subgroup of two trials of combination exercises (including 3 of the following 4 exercise categories: muscle performance, mobility, muscle re-education, aerobic) suggests a slight benefit in function and pain versus no treatment or advice alone over the short term and function in the long term (SOE: low). 
- The effect of exercise versus NSAIDs and muscle relaxants on function and pain was indeterminate at short or intermediate term due to insufficient evidence from a single poor-quality trial (SOE: insufficient).

- Harms were poorly reported in trials of exercise with only two trials describing adverse events. No serious harms were reported in either trial. Minor complaints included muscle pain with exercise, knee pain, and lumbar spine pain (SOE: low).

\section{Detailed Synthesis}

Seven trials of exercise therapy for neck pain met inclusion criteria (Table 18 and Appendix D). ${ }^{34-39,88}$ Four trials evaluated participants with chronic neck pain associated with office work, ${ }^{34,36,38,39}$ one included patients with chronic neck pain following whiplash, ${ }^{37}$ one assessed participants with nonspecific neck pain, ${ }^{35}$ and one included patients with cervical arthritis. ${ }^{88}$ Across trials, participants were predominately female (>80\%) with mean ages ranging from 38 to 52 years.

Four trials evaluated muscle performance exercises (resistive training), ${ }^{34,36,38,39}$ and three combined exercise techniques. ${ }^{35,37,88}$ Sample sizes ranged from 40 to 230 (total sample=771). Four trials compared exercise versus an attention control, ${ }^{34,36,37,39}$ one versus no treatment, ${ }^{38}$ one versus waitlist, ${ }^{35}$ and one versus pharmacologic care. ${ }^{88}$ Four trials were conducted in Europe, ${ }^{34,35,38,39}$ one in Australia, ${ }^{37}$ one in China, ${ }^{36}$ and one in Turkey. ${ }^{88}$ The duration of exercise therapy ranged from 6 weeks to 12 months, and the number of supervised exercise sessions ranged from 3 to 52. Three trials reported outcomes through long-term followup, ${ }^{34,37,39}$ two through intermediate-term followup, ${ }^{38,88}$ and two evaluated only short-term outcomes. ${ }^{35,36}$

Three trials were rated fair quality ${ }^{36-38}$ and four poor quality ${ }^{34,35,39,88}$ (Appendix E). In the three fair-quality trials, the main methodological limitation was the inability to blind interventions. Limitations in the other trials included inability to blind interventions, unclear randomization and allocation concealment methods, unclear or high loss to followup, and baseline differences between intervention groups. 
Table 18. Chronic neck pain: exercise therapies

\begin{tabular}{|c|c|c|c|c|}
\hline $\begin{array}{l}\text { Author, Year, } \\
\text { Followup, } \\
\text { Pain Duration, } \\
\text { Study Quality }\end{array}$ & Intervention & Population & $\begin{array}{l}\text { Function and Pain } \\
\text { Outcomes }\end{array}$ & $\begin{array}{l}\text { Other } \\
\text { Outcomes }\end{array}$ \\
\hline $\begin{array}{l}\text { Andersen, } \\
2008^{\text {b34 }} \\
6 \text { and } 12 \text { months } \\
\text { Duration of pain, } \\
\text { NR } \\
\text { Poor }\end{array}$ & $\begin{array}{l}\text { A. Dynamic } \\
\text { strengthening } \\
\text { exercise (muscle } \\
\text { performance exercise) } \\
\text { (n=61): for the } \\
\text { neck/shoulder } \\
\text { muscles, performed in } \\
\text { in the workplace; } 20 \\
\text { minute sessions, } 3 \\
\text { times a week (2 of the } \\
3 \text { weekly sessions } \\
\text { were supervised by } \\
\text { experienced } \\
\text { instructors) } \\
\text { B. Lifestyle physical } \\
\text { exercise and activity } \\
\text { increase (combination } \\
\text { exercise) (n=59): } \\
\text { workplace activities } \\
\text { such as steppers } \\
\text { placed near the } \\
\text { copying machines, } \\
\text { punch bags in } \\
\text { the hall, group } \\
\text { sessions of Nordic } \\
\text { walking, and strength } \\
\text { and aerobic fitness } \\
\text { exercise programs } \\
\text { C. Control group } \\
\text { (n=62): ergonomics, } \\
\text { stress management, } \\
\text { organization of work, } \\
\text { cafeteria food quality } \\
\text { Treatment lasted } 1 \\
\text { year. All groups were } \\
\text { allowed } 1 \text { hour per } \\
\text { week during working } \\
\text { time for activities }\end{array}$ & $\begin{array}{l}\text { A + B + C } \\
\text { Age: } 45 \text { years } \\
\text { Female: } 78 \% \\
\text { Office workers: } \\
100 \% \\
\text { A vs. B vs. C } \\
\text { Pain VAS (0-10): } \\
5.0 \text { vs. } 5.0 \text { vs. } 4.7\end{array}$ & 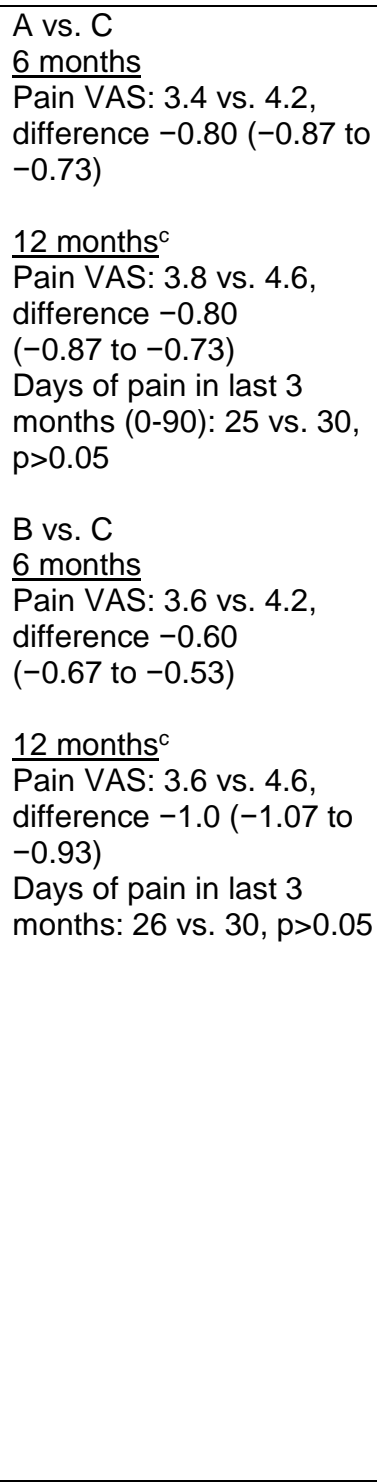 & NR \\
\hline
\end{tabular}




\begin{tabular}{|c|c|c|c|c|}
\hline $\begin{array}{l}\text { Author, Year, } \\
\text { Followup, } \\
\text { Pain Duration, } \\
\text { Study Quality }\end{array}$ & Intervention & Population & $\begin{array}{l}\text { Function and Pain } \\
\text { Outcomes }\end{array}$ & $\begin{array}{l}\text { Other } \\
\text { Outcomes }\end{array}$ \\
\hline $\begin{array}{l}\text { Aslan Telci, } \\
2012^{88} \\
6 \text { months } \\
\text { Pain duration: } \\
12 \text { months } \\
\text { Poor }\end{array}$ & $\begin{array}{l}\text { A. Combination } \\
\text { exercises ( } n=20) \text { : } \\
\text { consisting of posture, } \\
\text { active range of } \\
\text { motion, stretching, } \\
\text { isometric and dynamic } \\
\text { strengthening and } \\
\text { endurance exercises, } \\
\text { relaxation and } \\
\text { proprioception } \\
\text { exercises. Clinic } \\
\text { followup once a week } \\
\text { to maintain motivation } \\
\text { and check whether } \\
\text { exercises performed } \\
\text { correctly for a total of } \\
3 \text { weeks and home } \\
\text { exercise for at least } \\
\text { another month. } \\
\text { B. NSAIDs and } \\
\text { muscle relaxants for } \\
15 \text { days (n=20): all } \\
\text { patients received } \\
\text { verbal advice } \\
\text { regarding pain control, } \\
\text { posture, and } \\
\text { ergonomics. }\end{array}$ & $\begin{array}{l}\text { A vs. B } \\
\text { Age: } 48 \text { vs. } 52 \\
\text { years } \\
\text { Female: } 85 \% \text { vs. } \\
75 \% \\
\text { BMI: } 25 \text { vs. } 27 \\
\text { Employed: } 50 \% \text { vs. } \\
40 \% \\
\text { Education year: } 12 \\
\text { vs. } 11 \\
\text { NDI (0-50): } 14.0 \text { vs. } \\
10.7 \\
\text { Pain VAS (0-10): } \\
6.7 \text { vs. } 6.4\end{array}$ & 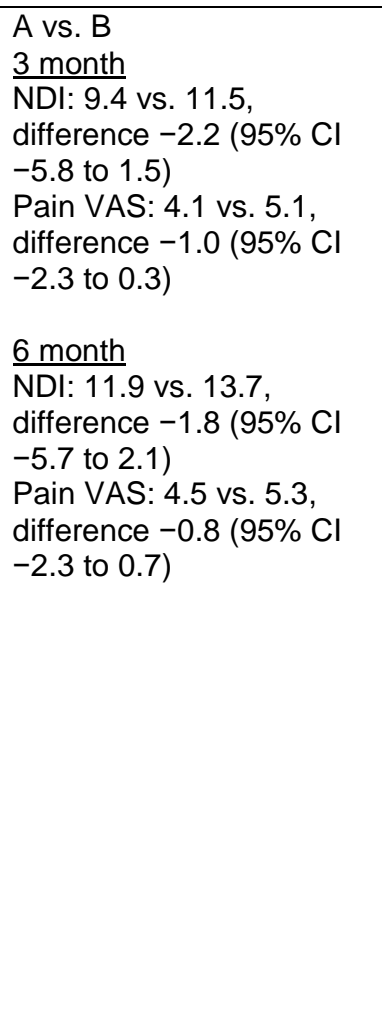 & $\begin{array}{l}\text { A vs. B } \\
3 \text { month } \\
\text { NHP (0-100): } \\
89.2 \text { vs. 230.0, } \\
\text { difference } \\
\text {-140.8 (95\% Cl } \\
\text {-214.0 to }-67.5) \\
\text { BDI (0-63): } 6.8 \\
\text { vs. 10.7, } \\
\text { difference }-4.0 \\
\text { (95\% Cl }-8.4 \text { to } \\
0.5) \\
6 \text { month } \\
\text { NHP: } 122.3 \text { vs. } \\
257.6, \text { difference } \\
-135.3(95 \% \mathrm{Cl} \\
-209.1 \text { to }-61.5) \\
\text { BDI: } 8.3 \text { vs. } \\
11.8, \text { difference } \\
-3.8 \text { (95\% Cl } \\
-8.5 \text { to 1.0) }\end{array}$ \\
\hline $\begin{array}{l}\text { Lauche, } 2016^{35} \\
3 \text { months } \\
\text { Pain duration: } \\
\text { NR } \\
\text { Poor }\end{array}$ & $\begin{array}{l}\text { A. Combination } \\
\text { exercises ( } n=37 \text { ): } \\
\text { weekly } 60-75 \text { minute } \\
\text { session for } 12 \text { weeks; } \\
\text { ergonomic principles, } \\
\text { proprioceptive } \\
\text { exercises, and } \\
\text { isometric and dynamic } \\
\text { mobilization, } \\
\text { stretching, } \\
\text { strengthening neck } \\
\text { and core exercises, } \\
\text { and relaxation } \\
\text { exercises; illustrated } \\
\text { written exercises for } \\
\text { home use } \geq 15 \\
\text { minutes/day. } \\
\text { B. Wait list ( } n=39 \text { ): } \\
\text { continuing usual } \\
\text { activities/therapies }\end{array}$ & $\begin{array}{l}\text { A vs. B } \\
\text { Age: } 47 \text { vs. } 49 \\
\text { years } \\
\text { Female: } 86 \% \text { vs. } \\
82 \% \text { years } \\
\\
\text { Pain recently (0- } \\
\text { 100): } 46.2 \text { vs. } 51.5 \\
\text { Pain considered } \\
\text { tolerable }(0-100): \\
20.5 \text { vs. } 20.7\end{array}$ & $\begin{array}{l}\text { A vs. B } \\
3 \text { month } \\
\text { NDI: } 25.1 \text { vs. } 29.4, \\
\text { difference }-4.3 \text { (95\% Cl } \\
\text {-10.2 to } 1.6) \\
\text { Recent pain VAS: } 33.1 \text { vs. } \\
44.6 \text {, difference }-11.5 \\
\text { (95\% } \mathrm{Cl}-20.8 \text { to }-2.2) \\
\text { Pain with motion VAS: } \\
34.9 \text { vs. } 45.5 \text {, difference } \\
-10.6 \text { ( } 95 \% \mathrm{Cl}-18.5 \text { to } \\
-2.7)\end{array}$ & $\begin{array}{l}\text { A vs. B } \\
3 \text { month } \\
\text { SF-36 PCS (0- } \\
100): \text { difference } \\
2.0(95 \% \mathrm{Cl} \\
-1.6 \text { to } 5.6) \\
\text { SF-36 MCS (0- } \\
100): \text { difference } \\
0.5(95 \% \mathrm{Cl} \\
-3.9 \text { to } 4.9)\end{array}$ \\
\hline
\end{tabular}




\begin{tabular}{|c|c|c|c|c|}
\hline $\begin{array}{l}\text { Author, Year, } \\
\text { Followup, } \\
\text { Pain Duration, } \\
\text { Study Quality }\end{array}$ & Intervention & Population & $\begin{array}{l}\text { Function and Pain } \\
\text { Outcomes }\end{array}$ & $\begin{array}{l}\text { Other } \\
\text { Outcomes }\end{array}$ \\
\hline $\begin{array}{l}\text { Li } 2017^{36} \\
1.5 \text { months } \\
\text { Duration of pain, } \\
4 \text { years } \\
\text { Fair }\end{array}$ & $\begin{array}{l}\text { A. Progressive } \\
\text { resistance training } \\
\text { (muscle performance } \\
\text { exercise) (38 } \\
\text { randomized/36 } \\
\text { analyzed) } \geq 3 \text { sessions } \\
\text { per week for six } \\
\text { weeks. Sessions } \\
\text { consisted of four } \\
\text { cervical isometric } \\
\text { exercises, each } \\
\text { repeated 8-12 times. } \\
\text { Resistance } \\
\text { progressively } \\
\text { increased every } 2 \\
\text { weeks, starting at } \\
30 \% \text { of maximal } \\
\text { strength and } \\
\text { increased to } 70 \% \text {. } \\
\text { B. Fixed resistance } \\
\text { training (muscle } \\
\text { performance exercise) } \\
\text { (35 randomized/32 } \\
\text { analyzed) } \geq 3 \text { sessions } \\
\text { per week for six } \\
\text { weeks. Sessions } \\
\text { consisted of four } \\
\text { cervical isometric } \\
\text { exercises, each } \\
\text { repeated 8-12 times. } \\
\text { Resistance was fixed } \\
\text { at } 70 \% \text { of the } \\
\text { participant's maximal } \\
\text { strength. } \\
\text { C. Attention control } \\
\text { (36 randomized/34 } \\
\text { analyzed). Subjected } \\
\text { received information } \\
\text { and had weekly } \\
\text { discussions about } \\
\text { workplace } \\
\text { ergonomics, stress } \\
\text { management, } \\
\text { relaxation, meditation, } \\
\text { and diet. } \\
\text { inged }\end{array}$ & $\begin{array}{l}\text { A vs. B vs. C } \\
\text { Age: } 36 \text { vs. } 34 \text { vs. } \\
34 \\
\text { BMI: } 21 \text { vs. } 22 \text { vs. } \\
22 \\
\text { Years working: } 9 \text { vs. } \\
9 \text { vs. } 10 \\
\text { Pain duration } \\
\text { (years): } 3 \text { vs. } 4 \text { vs. } 4 \\
\text { Work (days/week): } 5 \\
\text { vs. } 6 \text { vs. } 5 \\
\text { Computer use } \\
\text { (hours/day): } 7 \text { vs. } 8 \\
\text { vs. } 7 \\
\text { NDI (mean, } 0-50): \\
28.3 \text { vs. } 28.9 \text { vs. } \\
27.8 \\
\text { Pain VAS (mean } 0- \\
10): 5.3 \text { vs. } 5.4 \text { vs. } \\
5.2\end{array}$ & $\begin{array}{l}\text { A vs. C } \\
1.5 \text { month } \\
\text { NDI (mean, } 0-50): 14.9 \\
\text { (4.9) vs. } 26.6(5.4), P<0.05 \\
\text { Pain VAS (mean, } 0-10): \\
1.9(0.9) \text { vs. } 5.1(1.0), \\
\text { P<0.05 } \\
\text { B vs. C } \\
1.5 \text { month } \\
\text { NDI: } 15.8(4.8) \text { vs. } 26.6 \\
\text { (5.4), P<0.05 } \\
\text { Pain VAS: } 2.5 \text { (0.9) vs. } 5.1 \\
(1.0), P=N R\end{array}$ & None \\
\hline
\end{tabular}




\begin{tabular}{|c|c|c|c|c|}
\hline $\begin{array}{l}\text { Author, Year, } \\
\text { Followup, } \\
\text { Pain Duration, } \\
\text { Study Quality }\end{array}$ & Intervention & Population & $\begin{array}{l}\text { Function and Pain } \\
\text { Outcomes }\end{array}$ & $\begin{array}{l}\text { Other } \\
\text { Outcomes }\end{array}$ \\
\hline $\begin{array}{l}\text { Stewart, } 2007^{37} \\
1.5 \text { and } 12 \\
\text { months } \\
\text { Pain duration: } 9 \\
\text { months } \\
\text { Fair }\end{array}$ & $\begin{array}{l}\text { A. Combination } \\
\text { exercise, plus advice } \\
\text { ( } n=66 \text { ); aerobic, } \\
\text { stretching, functional, } \\
\text { speed and endurance, } \\
\text { trunk and limb } \\
\text { strengthening; } 1 \text { hour } \\
\text { per session for } 12 \\
\text { session over } 6 \text { weeks } \\
\text { B. Advice alone } \\
\text { ( } \mathrm{n}=68 \text { ): included } \\
\text { reassurance of a } \\
\text { favorable outcome } \\
\text { and encouragement } \\
\text { to resume light activity }\end{array}$ & $\begin{array}{l}\text { A vs. B } \\
\text { Age: } 44 \text { vs. } 43 \\
\text { years } \\
\text { Female: } 73 \% \text { vs. } \\
62 \% \\
\text { PSFS (0-10): } 3.9 \\
\text { vs. } 4.1 \\
\text { NDI (mean, } 0-50) \text { : } \\
\text { 18.2 vs. } 19.7 \\
\text { Pain VAS (mean, 0- } \\
\text { 10): } 5.2 \text { vs. } 5.3\end{array}$ & $\begin{array}{l}\text { A vs. B } \\
1.5 \text { months } \\
\text { PSFS: } 6.4 \text { vs. } 5.6, \\
\text { difference } 0.9(95 \% \mathrm{Cl} 0.3 \\
\text { to } 1.6) \\
\text { NDI: } 12.0 \text { vs. } 15.7, \\
\text { difference }-2.7(95 \% \mathrm{Cl} \\
-4.5 \text { to }-0.9) \\
\text { Pain VAS: } 3.2 \text { vs. } 4.3, \\
\text { difference }-1.1(95 \% \mathrm{Cl} \\
-1.8 \text { to }-0.3) \\
12 \text { months } \\
\text { PSFS: } 6.6 \text { vs. } 6.0, \\
\text { difference } 0.6(95 \% \mathrm{Cl} \\
-0.1 \text { to } 1.4) \\
\text { NDI: } 12.1 \text { vs. } 15.5, \\
\text { difference }-2.3(95 \% \mathrm{Cl} \\
-4.9 \text { to } 0.3) \\
\text { Pain VAS: } 3.5 \text { vs. } 3.8, \\
\text { difference }-0.2(95 \% \mathrm{Cl} \\
0.6 \text { to }-1.0)\end{array}$ & $\begin{array}{l}\text { A vs. B } \\
1.5 \text { months } \\
\text { Bothersomeness } \\
(0-10) 3.6 \text { vs. } \\
4.8, P=0.019 \\
\text { SF } 36 \text { physical } \\
(0-100): 42.1 \text { vs. } \\
38.9, P=0.003 \\
\text { SF } 36 \text { mental (0- } \\
100): 51.4 \text { vs. } \\
46.4, P=0.005 \\
\text { Global } \\
\text { Perceived Effect } \\
(-5 \text { to } 5) 2.5 \text { vs. } \\
1.5, P=0.006 \\
12 \text { months } \\
\text { Bothersomeness } \\
4.1 \text { vs. } 4.0, \\
P=0.480 \\
\text { SF } 36 \text { physical: } \\
42.3 \text { vs. } 38.9, \\
P=0.003 \\
S F 36 \text { mental: } \\
48.4 \text { vs. } 46.1, \\
P=0.33 \\
\text { Global } \\
\text { Perceived } \\
\text { Effect: } 2.3 \text { vs. } \\
1.9, P=0.48\end{array}$ \\
\hline $\begin{array}{l}\text { Viljanen, } 2003^{38} \\
3 \text { and } 9 \text { months } \\
\text { Pain duration: } \\
11 \text { years } \\
\text { Fair }\end{array}$ & $\begin{array}{l}\text { A. Dynamic } \\
\text { strengthening } \\
\text { exercises (muscle } \\
\text { performance } \\
\text { exercises) ( } n=135) \text { : } \\
\text { physical-therapist } \\
\text { guided; } 3 \text { times per } \\
\text { week for } 12 \text { weeks, } 30 \\
\text { minute sessions } \\
\text { B. No intervention } \\
(n=130)\end{array}$ & $\begin{array}{l}\text { A vs. B } \\
\text { Age: } 45 \text { vs. } 44 \\
\text { years } \\
\text { Female: } 100 \% \text { vs. } \\
100 \% \\
\text { Office workers: } \\
100 \% \\
\text { Computer work >6 } \\
\text { hours per day: } 33 \% \\
\text { vs. } 35 \% \\
\text { Depression index } \\
\text { (10-40): } 16 \text { vs. } 16 \\
\text { Neck disability } \\
\text { scale (0-80): } 29 \text { vs. } \\
26 \\
\text { Pain VAS (0-10): } \\
4.8 \text { vs. } 4.1\end{array}$ & $\begin{array}{l}\text { A vs. B } \\
3 \text { months } \\
\text { Neck disability scale }: 15 \\
\text { vs. } 14, \text { adjusted difference } \\
-0.1 \text { ( } 95 \% \mathrm{Cl}-3.1,2.9) \\
\text { Pain VAS: } 2.9 \text { vs. } 2.9, \\
\text { adjusted difference } 0.4 \\
\text { (95\% Cl }-0.3,1.0) \\
9 \text { months } \\
\text { Neck disability scale }: 19 \\
\text { vs. } 17, \text { adjusted difference } \\
-0.1 \text { (95\% Cl -3.0 to } 2.9) \\
\text { Pain VAS: } 3.1 \text { vs. } 3.2, \\
\text { adjusted difference } 0.5 \\
\text { (95\% Cl }-0.1 \text { to } 1.0)\end{array}$ & NR \\
\hline
\end{tabular}




\begin{tabular}{|c|c|c|c|c|}
\hline $\begin{array}{l}\text { Author, Year, } \\
\text { Followup, } \\
\text { Pain Duration, } \\
\text { Study Quality }\end{array}$ & Intervention & Population & $\begin{array}{l}\text { Function and Pain } \\
\text { Outcomes }\end{array}$ & $\begin{array}{l}\text { Other } \\
\text { Outcomes }\end{array}$ \\
\hline $\begin{array}{l}\text { Waling } 2002^{\mathrm{d} 39} \\
6 \text { and } 36 \text { months } \\
\text { Pain duration: } \\
6.8 \text { years } \\
\text { Poor }\end{array}$ & $\begin{array}{l}\text { A. Strength training } \\
\text { (muscle performance } \\
\text { exercise) ( } \mathrm{n}=29 \text { ): for } \\
\text { neck and shoulder } \\
\text { muscles, } 3 \text { times per } \\
\text { week for } 10 \text { weeks, } 1 \\
\text { hour/session } \\
\text { B. Endurance training } \\
\text { (muscle performance } \\
\text { exercise) (n=28): } \\
\text { using arm-cycling and } \\
\text { arm exercises, } 30 \\
\text { repetition maximum, } 3 \\
\text { times per week for } 10 \\
\text { weeks, } 1 \text { hour/session } \\
\text { C. Coordination } \\
\text { training } \\
\text { (neuromuscular } \\
\text { reeducation } \\
\text { exercises) (n=25): } \\
\text { focus on balance and } \\
\text { postural stability } 3 \\
\text { times per week for } 10 \\
\text { weeks, } 1 \text { hour/session } \\
\text { D. Reference group } \\
\text { ( } \mathrm{n}=21 \text { ): stress } \\
\text { management } 1 \text { time } \\
\text { per week for } 10 \\
\text { weeks, } 2 \text { hour/session }\end{array}$ & $\begin{array}{l}\text { A vs. B vs. C vs. D } \\
\text { Age: } 38 \text { vs. } 39 \text { vs. } \\
38 \text { vs. } 39 \text { years } \\
\text { Female: } 100 \% \text { all } \\
\text { groups } \\
\text { Office workers: } \\
100 \% \\
\text { Pain VAS at present } \\
\text { (0-10): } 2.6 \text { vs. } 2.8 \\
\text { vs. } 3.3 \text { vs. } 3.7\end{array}$ & $\begin{array}{l}\text { A vs. B vs. C vs. D } \\
6 \text { months } \\
\text { Frequent pain ( } \% \text { with pain } \\
\text { several times per week or } \\
\text { more): } 76 \% \text { vs. } 91 \% \text { vs. } 78 \\
\% \text { vs. } 73 \%, P=0.50 \\
36 \text { months } \\
\text { Pain VAS at present: } 3.1 \\
\text { vs. } 2.2 \text { vs. } 2.7 \text { vs. } 1.6, \\
P=0.073 \\
P a i n \text { VAS in general }(0- \\
10): 3.2 \text { vs. } 2.9 \text { vs. } 2.9 \text { vs. } \\
2.0, P=0.249 \\
P a i n \text { VAS at worst }(0-10): \\
6.1 \text { vs. } 5.8 \text { vs. } 5.7 \text { vs. } 5.8, \\
P=0.902 \\
\text { Frequent pain: } 47 \% \text { vs. } \\
50 \% \text { vs. } 58 \% \text { vs. } 39 \%, \\
P=0.66\end{array}$ & NR \\
\hline
\end{tabular}

BDI = Beck Depression Inventory; BMI = body mass index; CI = confidence interval; HADS = Hospital Anxiety and Depression Scale; MCS = Mental Component Summary; MD = mean difference; NDI = Neck Disability Index; NHP = Nottingham Health Profile; NR = not reported; NSAID = nonsteroidal anti-inflammatory drug; PCS = Physical Component Summary; PSFS = Patient Specific Functional Scale; SF-36 = Short-Form 36 questionnaire; VAS = visual analog scale

${ }^{a}$ Unless otherwise noted, followup time is calculated from the end of the treatment period

${ }^{\mathrm{b}}$ Cluster RCT where clusters were formed from participants working on the same floor

${ }^{\mathrm{c}}$ Intervention lasted 12 months and followup is at the end of the intervention

${ }^{\mathrm{d}}$ Cluster RCT where clusters were formed from participants selecting a time that best fit their schedule

e Neck disability scale was created by investigators from responses to eight questions related to functional limitations due to pain; this scale is not the same as the more common NDI

\section{Exercise Compared With No Treatment or an Attention Control}

Across types of exercise, there was no clear improvement in function versus no treatment, attention control, or advice alone in the short term (4 trials, pooled SMD $-0.73,95 \% \mathrm{CI}-1.57$ to $0.12, \mathrm{I}^{2}=95.1 \%$ ), but statistical heterogeneity was very large ${ }^{35-38}$ (Figure 26). Excluding an outlier trial (SMD $-2.22,95 \%$ CI -2.74 to -1.70$)^{36}$ reduced the statistical heterogeneity and resulted in an attenuated effect (SMD $-0.23,95 \%$ CI -0.61 to $0.15, \mathrm{I}^{2}=72.6 \%$ ). However, two studies that included combination exercises ( 3 of the following 4 exercise categories: muscle performance, mobility, muscle re-education, aerobic) found small improvement in function compared with controls ( 2 trials, pooled SMD $-0.44,95 \%$ CI -0.76 to -0.09 , data not shown in figure). ${ }^{35,37} \mathrm{~A}$ fair-quality study reported a continued small benefit with combination exercise in the long term (SMD $-0.38,95 \%$ CI -0.74 to -0.03$).{ }^{37}$ 
Exercise tended toward moderately greater effects on short-term pain compared with no treatment or an attention control (4 trials, pooled MD -1.31, 95\% CI - 2.76 to $0.14, \mathrm{I}^{2}=94.2 \%$ ), but statistical heterogeneity was very large, ${ }^{35-38}$ (Figure 27). Excluding an outlier trial (MD $-2.92,95 \% \mathrm{CI}-3.38$ to -2.46$)^{36}$ reduced the statistical heterogeneity and resulted in an attenuated effect (MD $-0.72,95 \% \mathrm{CI}-1.49$ to $0.06, \mathrm{I}^{2}=63.7 \%$ ). The effect of exercise on reducing pain was substantially greater in trials assessing combination exercises ( 2 trials, pooled MD -1.12, 95\% CI -1.82 to -0.43 ; data not shown in figure). ${ }^{35,37}$ There were no differences in pain comparing exercise versus controls in intermediate term (2 trials, pooled MD -0.25 , 95\% CI -0.71 to $\left.0.20, \mathrm{I}^{2}=0 \%\right)^{34,38}$ or long term ( 3 trials, pooled MD $0.12,95 \% \mathrm{CI}-0.52$ to 0.76 , $\left.\mathrm{I}^{2}=37.8 \%\right)^{34,37,39}$

Data on effects of exercise on quality of life were limited. One fair-quality trial $^{37}$ found significant improvement in SF-36 PCS and MCS in the short term (difference in change score 3.60 on a $0-100$ scale, $95 \%$ CI 1.23 to 5.97 and 4.00 , 95\% CI 1.24 to 6.77, respectively) and PCS in the long term (difference in change score 3.80, 95\% CI 1.30 to 6.30). A poor-quality trial found no difference in SF-36 PCS or MCS in the short term. ${ }^{35}$ No trial evaluated effects of exercise therapies on use of opioid therapies or health care utilization.

There was insufficient evidence to determine effects of duration of exercise therapy or number of sessions on outcomes.

\section{Exercise Compared With Pharmacological Therapy}

One poor-quality trial $(\mathrm{N}=40)^{88}$ comparing 1.5 months of home combination exercises (posture, stretching, strengthening and endurance exercises) versus ibuprofen plus thiocolchicoside for 15 days found no between-group difference in function (Neck Disability Index [NDI]) at 3-month (MD - 2.2 on 0-50 scale, 95\% CI -5.8 to 1.5) or 6-month followup (MD of $-1.8,95 \% \mathrm{CI}-5.7$ to 2.1 ). The study reported similar results for pain intensity (MD -1.0 on a $0-10$ scale, $95 \% \mathrm{CI}-2.3$ to 0.3 at 3-month and $\mathrm{MD}-0.8,95 \% \mathrm{CI}-2.3$ to 0.7 at 6 -month followup). The exercise group reported a better quality of life compared with the medication group at 3-month and 6-month followup using the Turkish version of the Nottingham Health Profile (MD -141, scale not stated though usual scale 0-100, 95\% CI -214 to -68; MD -135, $95 \%$ CI -209 to -62 , respectively). ${ }^{88}$ The groups scored comparably on the Beck Depression Inventory at both followup periods (Table 18).

\section{Exercise Compared With Other Nonpharmacological Therapies}

Findings for exercise versus other nonpharmacological therapies are addressed in the sections for other nonpharmacological therapies.

\section{Harms}

Only two exercise trials reported harms. One reported only mild complaints that included muscle pain with exercise (5\%), knee pain (3\%), and lumbar spine pain (3\%). ${ }^{37}$ None required referral to a medical practitioner. In the other, investigators reported no serious harms related to the intervention. ${ }^{35}$ One occurrence of minor knee pain was reported in the exercise group. 
Figure 26. Exercise versus no treatment or an attention control for chronic neck pain: effects on function

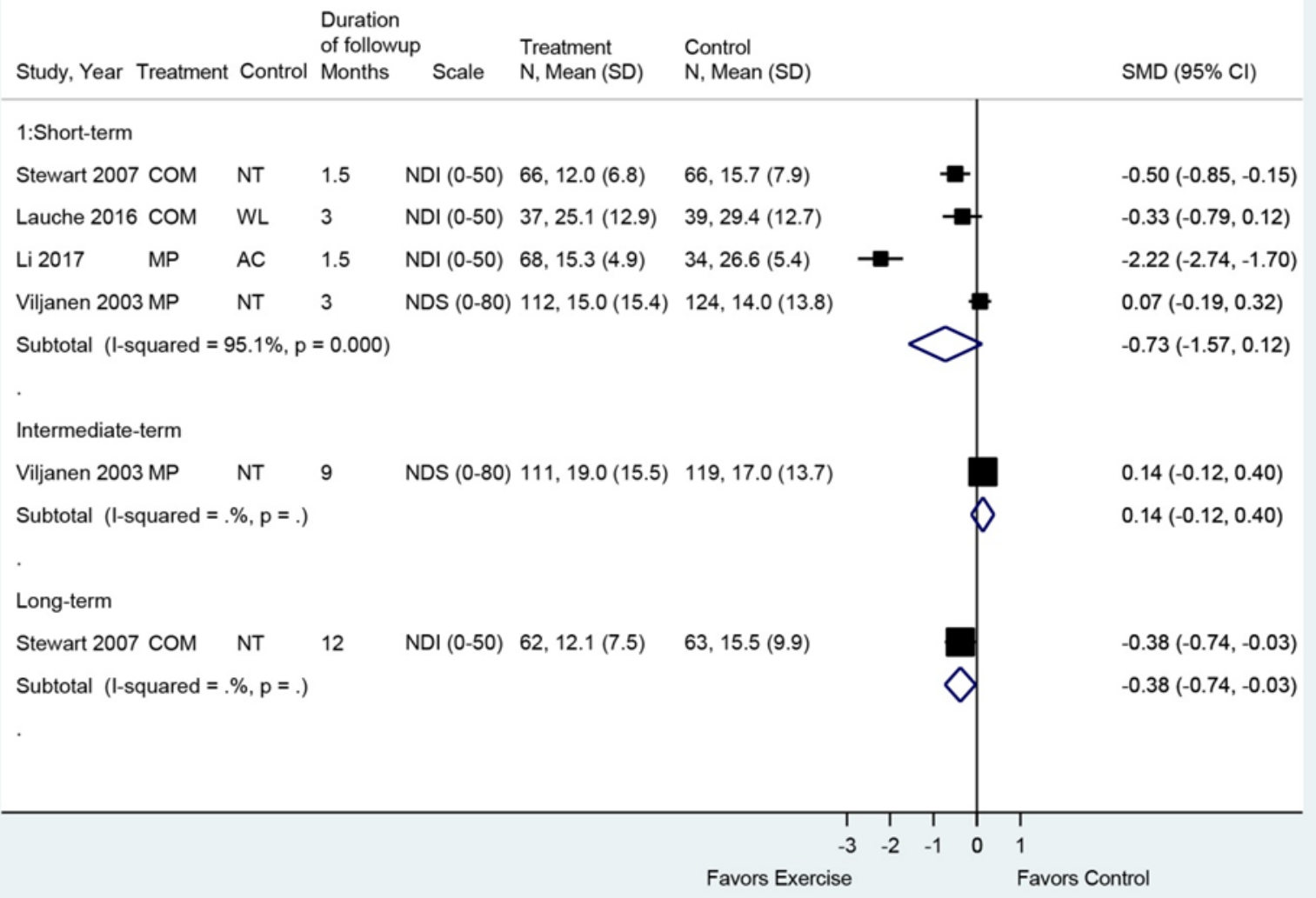

$\mathrm{CI}=$ confidence interval; $\mathrm{COM}=$ combination exercise therapy; $\mathrm{MP}=$ muscle performance exercise; $\mathrm{NDI}=$ Neck Disability Index; NDS = neck disability scale; NT = no treatment; $\mathrm{SD}=$ standard deviation; $\mathrm{SMD}=$ standardized mean difference; $\mathrm{WL}=$ waitlist. 
Figure 27. Exercise versus no treatment or an attention control for chronic neck pain: effects on pain

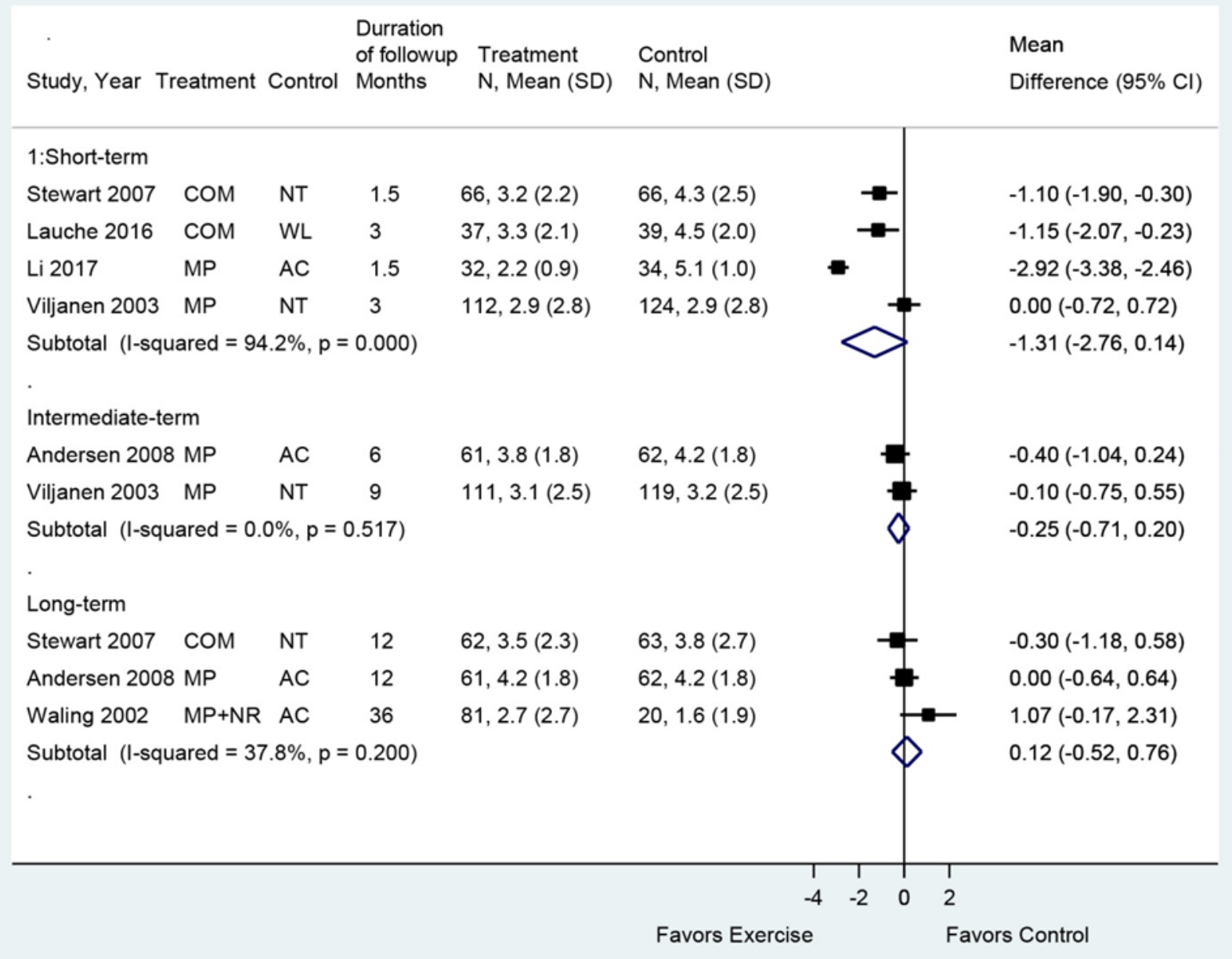

$\mathrm{AC}=$ attention control; $\mathrm{CI}=$ confidence interval; $\mathrm{COM}=$ combination exercise therapy; $\mathrm{MP}$ = muscle performance exercise; $\mathrm{MP}+\mathrm{NR}=$ muscle performance plus neuromuscular rehabilitation exercise; $\mathrm{NT}=$ no treatment; $\mathrm{SD}=$ standard deviation; $\mathrm{WL}=$ waitlist

\section{Psychological Therapies for Chronic Neck Pain}

\section{Key Points}

- No evidence of differences was found in function (NDI, 0-80 scale) or pain (visual analog scale [VAS], 0-10 scale) in the short term (adjusted difference $0.1,95 \%$ CI -2.9 to 3.2 and 0.2 , 95\% CI -0.4 to 0.8 , respectively) or intermediate term (adjusted difference $0.2,95 \% \mathrm{CI}-2.8$ to 3.1 and $0.2,95 \% \mathrm{CI}-0.3$ to 0.8 , respectively) from one fair-quality study comparing relaxation training and no intervention or exercise (SOE: low for all). We found no trials with outcomes assessed in the long term.

- We found no evidence comparing relaxation training with pharmacological therapy.

- The only trial of relaxation training did not report harms. 


\section{Detailed Synthesis}

We found one trial comparing the effects of relaxation training versus no intervention $(\mathrm{N}=258)$ or exercise therapy $(\mathrm{N}=263)$ in female office workers with chronic neck pain ${ }^{38}$ (Table 19 and Appendix D). Relaxation training and muscle performance exercise therapy were done in 30-minute sessions three times per week for 12 weeks, with 1 week of reinforcement training 6 months after randomization. Patients in the no-treatment group were instructed not to change their usual activities. Adherence to the relaxation schedule during the intervention period was 42 percent of the scheduled sessions. The nature of the intervention and control precluded blinding of participants and people administering the interventions; therefore, this trial was rated as fair quality.

Table 19. Chronic neck pain: psychological therapies

\begin{tabular}{|c|c|c|c|c|}
\hline $\begin{array}{l}\text { Author, } \\
\text { Year, } \\
\text { Followup, } \\
\text { Pain } \\
\text { Duration, } \\
\text { Study } \\
\text { Quality }\end{array}$ & Intervention & Population & Function and Pain Outcomes & $\begin{array}{l}\text { Other } \\
\text { Outcomes }\end{array}$ \\
\hline $\begin{array}{l}\text { Viljanen, } \\
2003^{38} \\
3 \text { and } 9 \\
\text { months } \\
\text { Pain } \\
\text { duration: } \\
11 \text { years } \\
\text { Fair }\end{array}$ & $\begin{array}{l}\text { A. Physical therapist } \\
\text { guided relaxation } \\
\text { training ( } \mathrm{n}=128 \text { ): } \\
\text { progressive relaxation, } \\
\text { autogenic } \\
\text { training, functional } \\
\text { relaxation, and } \\
\text { systematic desensi- } \\
\text { tization (goal was to } \\
\text { teach correct activation } \\
\text { and relaxation of } \\
\text { muscles used in daily } \\
\text { activities); } 3 \text { times per } \\
\text { week for } 12 \text { weeks, } 30 \\
\text { minute sessions } \\
\text { B. Physical therapist } \\
\text { guided dynamic } \\
\text { strengthening } \\
\text { exercises of the } \\
\text { shoulder and cervical } \\
\text { musculature (muscle } \\
\text { performance exercises) } \\
\text { ( } \mathrm{n}=135 \text { ): } 3 \text { times per } \\
\text { week for } 12 \text { weeks, } 30 \\
\text { minute sessions } \\
\text { C. No intervention } \\
\text { (n=130) }\end{array}$ & $\begin{array}{l}\text { A vs. B vs. C } \\
\text { Age: } 43 \text { vs. } 45 \text { vs. } 44 \\
\text { years } \\
\text { Female: } 100 \% \\
\text { Performing physical } \\
\text { activity } \geq 3 x / \text { week: } 34 \% \\
\text { vs. } 44 \% \text { vs. } 41 \% \\
\text { Duration of office work: } \\
20 \text { vs. } 23 \text { vs. } 21 \text { years } \\
\text { Sedentary work }>6 \\
\text { hours per day: } 75 \% \text { vs. } \\
76 \% \text { vs. vs. } 73 \% \\
\text { Computer work }>6 \\
\text { hours per day: } 39 \% \text { vs. } \\
33 \% \text { vs. vs. } 35 \% \\
\text { Absent from work due } \\
\text { to neck pain: } 12 \% \text { vs. } \\
12 \% \text { vs. } 12 \% \\
\text { Pain duration: } 11 \text { vs. } 11 \\
\text { vs. } 10 \text { years } \\
\text { Neck disability scale } \\
\text { (0-80): } 29 \text { vs. } 29 \text { vs. } 26 \\
\text { Pain VAS (0-10): } 4.8 \\
\text { vs. } 4.8 \text { vs. } 4.1 \\
\text { Depression index: } 16 \\
\text { vs. } 16 \text { vs. } 16\end{array}$ & 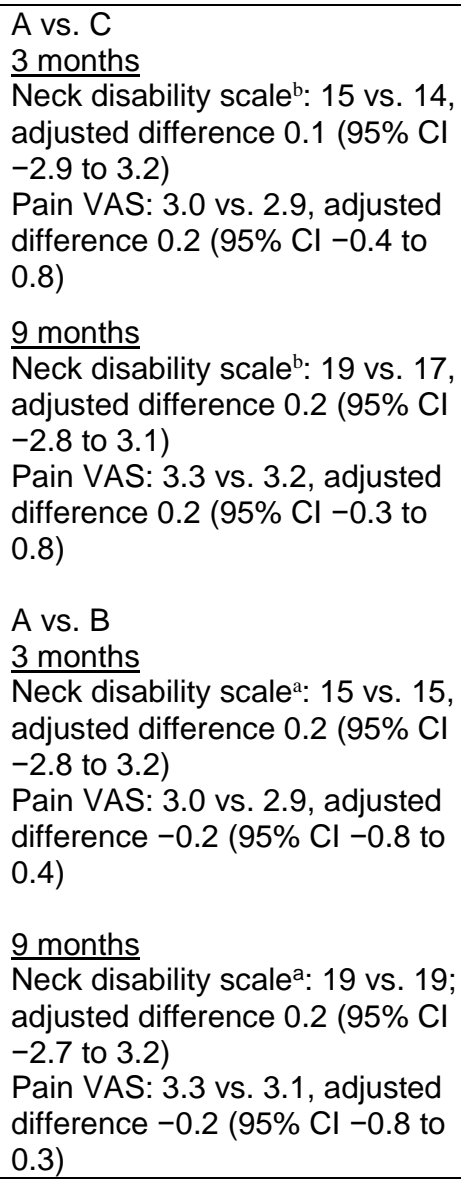 & NR \\
\hline
\end{tabular}

$\mathrm{CI}=$ confidence interval; VAS = visual analog scale

a Unless otherwise noted, followup time is calculated from the end of the treatment period

${ }^{\mathrm{b}}$ Neck disability scale was created by investigators from responses to eight questions related to functional limitations due to pain. This scale is not the same as the more common Neck Disability Index (NDI) 


\section{Relaxation Training Compared With No Treatment}

The one fair-quality trial found no between-group differences in the short term (3 months) or intermediate term (9 months) as measured by a neck disability scale (MD 0.1 on a 0-80 scale, 95\% CI -2.9 to 3.2, and MD 0.2, 95\% CI -2.8 to 3.1, respectively) ${ }^{38}$ (Table 19). The neck disability scale, a nonvalidated instrument, asked whether the participant had pain or difficulty on eight functional activities, with each activity scored from 0 (no pain or hindrance) to 10 (unbearable pain or maximum hindrance), for a total of 80 points. Likewise, there were no differences in pain intensity between groups at the same time frames, (MD 0.2 on a 10-point scale, $95 \% \mathrm{CI}-0.4$ to 0.8 , and MD 0.2 , $95 \% \mathrm{CI}-0.3$ to 0.8 , respectively). There were no trials evaluating relaxation in the long term.

\section{Relaxation Training Compared With Pharmacological Therapy}

We did not find any trials meeting our criteria that compared a relaxation training with pharmacological therapy.

\section{Relaxation Training Compared With Exercise Therapy}

The one fair-quality trial found no differences between relaxation training and exercise therapy in the short term (3 months) or intermediate term (9 months) as measured by a neck disability scale described above (MD 0.2 on a $0-80$ scale, $95 \%$ CI -2.8 to 3.2, and MD 0.2, 95\% CI -2.7 to 3.2, respectively) ${ }^{38}$ (Table 19). Similarly, there were no differences in pain intensity between groups at the same time frames (MD -0.2 on a 10 -point scale, $95 \% \mathrm{CI}-0.8$ to 0.4 , and MD $-0.2,95 \%$ CI -0.8 to 0.3 , respectively). There were no trials comparing relaxation with exercise therapy in the long term.

\section{Harms}

The trial on relaxation therapy did not report harms. ${ }^{38}$

\section{Physical Modalities for Chronic Neck Pain}

\section{Key Points}

- Low-level laser therapy was associated with a moderate improvement in short-term function ( 2 trials, pooled difference -14.98 , 95\% CI -23.88 to $-6.07, \mathrm{I}^{2}=39 \%, 0-100$ scale) and pain ( 3 trials, pooled difference -1.81 on a $0-10$ scale, $95 \%$ CI -3.35 to -0.27 , $\mathrm{I}^{2}=75 \%$ ) compared with sham (SOE: moderate for function and pain).

- Data from two small, poor-quality trials, one evaluating cervical traction versus attention control (infrared irradiation) and the other electromagnetic fields versus sham, were insufficient to determine effects on function or pain over the short term (SOE: insufficient).

- No trials assessed outcomes in the intermediate term or long term, or compared a physical modality to pharmacological therapy or exercise.

- Harms were poorly reported in trials of low-level laser. Adverse effects occurred with similar frequency in the laser and sham groups in the one trial reporting such effects. The most frequently reported adverse effects included mild (78\%) or moderately $(60 \%)$ increased neck pain, increased pain elsewhere (78\%), mild headache (60\%), and tiredness (24\%) (SOE: low).

- The trials of cervical traction and electromagnetic fields did not report harms. 


\section{Detailed Synthesis}

A total of five trials ( $\mathrm{N}=53$ to 90$)^{120-124}$ evaluating physical modalities for the treatment of chronic neck pain met inclusion criteria (Table 20 and Appendixes D and E). Interventions included traction, laser therapy, and electromagnetic field therapy.

One trial ( $\mathrm{N}=79)$ conducted in Hong Kong compared intermittent cervical traction versus attention control (infrared irradiation). ${ }^{121}$ Each treatment was administered for 20 minutes twice weekly for 6 weeks. This trial was considered poor quality due to lack of patient and caregiver blinding, high and unequal attrition (41\% in traction group, 58\% in control), and dissimilar baseline characteristics between groups.

Three trials ( $\mathrm{N}=53$ to 90$)^{120,122,123}$ compared low-level laser therapy with sham. The mean duration of pain varied from 4 years in two trials ${ }^{120,123}$ to 15 years in a third. ${ }^{122}$ Treatment consisted of laser application (wavelength range, 830 to $904 \mathrm{~nm}$ ) over several myofascial tender points; across the trials, duration ranged from 30 seconds to 3 minutes per tender point and frequency varied from daily to twice weekly over periods of 2 or 7 weeks. One trial was rated good quality ${ }^{122}$ and two fair quality. ${ }^{120,123}$ Common methodological limitations in the two fairquality trials included inadequate reporting of treatment allocation and no or unclear blinding of the care provider. In addition, baseline characteristics were not similar in one trial, in which the intervention group tended to have more pain and tenderness and longer duration of symptoms. ${ }^{120}$

One trial ( $\mathrm{N}=81$ ) compared the effects of eighteen 30-minute sessions (3-5 times per week) of low frequency pulsed electromagnetic fields versus sham. ${ }^{124}$ The treatment consisted of an electromagnetic coil against the back of the neck while the participants were lying on a pillow. The investigators covered the set of light emitting diodes that pulse to signal the coil being energized in order to blind the participants to the treatment or sham. This trial was rated as poor quality due to several factors: failure to describe the number randomized in each group; inadequate reporting of treatment compliance and information to calculate participant attrition and intent to treat analysis; care provider not blinded to treatment; and baseline characteristics dissimilar between groups.

Table 20. Chronic neck pain: physical modalities

\begin{tabular}{|c|c|c|c|c|}
\hline $\begin{array}{l}\text { Author, Year, } \\
\text { Followup } \\
\text { Pain } \\
\text { Duration, } \\
\text { Study Quality }\end{array}$ & Intervention & Population & $\begin{array}{l}\text { Function and } \\
\text { Pain Outcomes }\end{array}$ & Other Outcomes \\
\hline $\begin{array}{l}\text { Altan, } 2005^{120} \\
3 \text { months } \\
\text { Pain duration: } \\
4.5 \text { years } \\
\text { Fair }\end{array}$ & $\begin{array}{l}\text { A. GaAs low-level laser } \\
\text { treatment }(n=26) \text { : over the } 3 \\
\text { trigger points bilaterally and } 1 \\
\text { point in the taut bands in } \\
\text { trapezius muscle bilaterally for } 2 \\
\text { min over each point once a day } \\
\text { for } 2 \text { weeks. Laser wavelength } \\
\text { of } 904 \mathrm{~nm} \text {. } \\
\text { B. Sham laser treatment }(n=27)\end{array}$ & $\begin{array}{l}\text { A vs. B } \\
\text { Age: } 43 \text { vs. } 43 \\
\text { years } \\
\text { Female: } 87 \% \text { vs. } \\
48 \% \\
\text { Pain duration: } 4.7 \\
\text { vs. } 4.4 \text { years } \\
\text { Pain (VAS 0-10): } \\
6.85 \text { vs. } 6.24 \\
\text { Pain (5-point } \\
\text { scale, 0-5): } 2.35 \\
\text { vs. } 2.20\end{array}$ & $\begin{array}{l}\text { A vs. B } \\
3 \text { months: } \\
\text { Pain (VAS): } 3.17 \\
\text { vs. } 3.80, \\
\text { difference }-0.63 \\
\text { ( } 95 \% \mathrm{Cl}-0.95 \text { to } \\
-0.31) \\
\text { Pain (5 point } \\
\text { scale): } 1.09 \text { vs. } \\
1.16, \text { difference } \\
-0.07 \text { (95\% Cl } \\
-0.19 \text { to } 0.05)\end{array}$ & NR \\
\hline
\end{tabular}




\begin{tabular}{|c|c|c|c|c|}
\hline $\begin{array}{l}\text { Author, Year, } \\
\text { Followup } \\
\text { Pain } \\
\text { Duration, } \\
\text { Study Quality }\end{array}$ & Intervention & Population & $\begin{array}{l}\text { Function and } \\
\text { Pain Outcomes }\end{array}$ & Other Outcomes \\
\hline $\begin{array}{l}\text { Chiu, } 2011^{121} \\
1.5 \text { months } \\
\text { Duration of } \\
\text { pain: NR } \\
\text { Poor }\end{array}$ & $\begin{array}{l}\text { A. Cervical Traction } \\
\text { (intermittent) ( } n=39 \text { ): ranging } \\
\text { from } 10-20 \% \text { of patient body } \\
\text { weight, holding time } 10-25 \\
\text { seconds; resting time } 20-50 \% \text { of } \\
\text { holding time; twice/week for } 6 \\
\text { weeks; sessions lasting } 20 \\
\text { minutes. } \\
\text { B. Infrared Irradiation Control } \\
(n=40) \text { : via infrared lamp } \\
\text { positioned so that patients } \\
\text { reported minimal warmth over } \\
\text { the back of their neck; } \\
\text { twice/week for } 6 \text { weeks; } \\
\text { sessions lasting: } 20 \text { minutes. }\end{array}$ & $\begin{array}{l}\text { A vs. B } \\
\text { Age: } 50.9 \text { vs. } 46.8 \\
\text { years } \\
\text { Female: } 65.2 \% \text { vs. } \\
76.5 \% \\
\text { NPQ }(0-100 \%): \\
46.1 \text { vs. } 38.5 \\
\text { NPS (0-10): } 5.8 \\
\text { vs. } 5.2\end{array}$ & $\begin{array}{l}\text { A vs. B } \\
1.5 \text { months } \\
\text { NPQ Disability: } \\
31.4 \text { vs. } 29.6 ; \\
\text { P>0.05, } 95 \% \mathrm{Cl} \\
29.66 \text { to } 37.50 \text {, } \\
\text { power=0.15 } \\
\text { NPS Pain } \\
\text { Severityb: } 3.5 \text { vs. } \\
2.8 ; \text { P }>0.05, \\
95 \% \text { Cl } 3.29 \text { to } \\
4.50, \\
\text { power }=0.17\end{array}$ & NR \\
\hline $\begin{array}{l}\text { Chow, } 2006^{122} \\
1 \text { month } \\
\text { Pain duration: } \\
15 \text { years } \\
\text { Good }\end{array}$ & $\begin{array}{l}\text { A. Low-level laser therapy } \\
(\mathrm{n}=45) \text { : } 2 x / \text { week for } 7 \\
\text { consecutive weeks, maximum } \\
\text { half hour per treatment. Up to } \\
50 \text { tender points in the neck } \\
\text { were treated for } 30 \text { seconds per } \\
\text { point. Laser wavelength of } 830 \\
\mathrm{~nm} \text {. } \\
\text { B. Sham laser }(\mathrm{n}=45)\end{array}$ & $\begin{array}{l}\text { A vs. B } \\
\text { Age: } 57 \text { vs. } 55 \\
\text { years } \\
\text { Female: } 64 \% \text { vs. } \\
67 \% \\
\text { Pain duration: } 17 \\
\text { vs. } 13 \text { years } \\
\text { Pain (VAS } 0-10 \text { ): } \\
5.9 \text { vs. } 4.0\end{array}$ & $\begin{array}{l}\text { A vs. B } \\
1 \text { month } \\
\text { NPQ (0-100\%): } \\
-3.5 \text { vs. }-0.6, \\
\text { difference }-3.0 \\
\text { (95\% Cl }-5.0 \text { to } \\
-0.9) \\
\text { NPAD (0-100): } \\
-15.2 \text { vs. } \\
-3.1 \text {, difference } \\
-12.1 \text { (95\% Cl } \\
-19.3 \text { to }-4.8) \\
\text { Pain, VAS: }-2.7 \\
\text { vs. 0.3, } \\
\text { difference } 3.0 \\
\text { (95\% CI }-3.8 \text { to } \\
-2.1) \\
\text { MPQ VAS (1-5): } \\
-2.1 \text { vs. } 0.1 \text {, } \\
\text { difference }-2.2 \\
\text { (95\% CI }-3.5 \text { to } \\
-0.9) \\
\text { Improved pain } \\
<-3(\%): 40 \% \\
\text { vs. } 7 \%, \text { RR } 6.0 \\
\text { (95\% Cl } 1.9 \text { to } \\
19.0)\end{array}$ & $\begin{array}{l}\text { A vs. B } \\
1 \text { month } \\
\text { SF36 PCS: } 3.2 \text { vs. } \\
-1.3 \text {, difference } 4.5 \\
\text { (95\% } \mathrm{Cl} 0.7 \text { to } 8.2) \\
\text { SF } 36 \mathrm{MCS}: 2.4 \text { vs. } \\
5.4 \text {, difference }-2.9 \\
\text { (95\% } \mathrm{Cl}-7.2 \text { to } \\
1.3) \text {, } \\
\text { MPQ sensory (0- } \\
33 \text { ): } \\
-3.4 \text { vs. }-1.9 \text {, } \\
\text { difference } \\
-1.5(95 \% \mathrm{Cl}-4.5 \\
\text { to } 1.5) \\
\text { MPQ affective (0- } \\
12): \\
-1.3 \text { vs. }-0.7, \\
\text { difference } \\
-0.6 \text { (95\% } \mathrm{Cl}-2.3 \\
\text { to } 1.1)\end{array}$ \\
\hline
\end{tabular}




\begin{tabular}{|c|c|c|c|c|}
\hline $\begin{array}{l}\text { Author, Year, } \\
\text { Followup } \\
\text { Pain } \\
\text { Duration, } \\
\text { Study Quality }\end{array}$ & Intervention & Population & $\begin{array}{l}\text { Function and } \\
\text { Pain Outcomes }\end{array}$ & Other Outcomes \\
\hline $\begin{array}{l}\text { Gur, } 2004^{123} \\
2.5 \text { months } \\
\text { Pain duration: } \\
43 \text { months } \\
\text { Fair }\end{array}$ & $\begin{array}{l}\text { A. Active Ga-As low-level laser } \\
\text { therapy }(n=30) \text { : daily for } 2 \\
\text { weeks, } 3 \text { minutes each } \\
\text { myofascial tender point. Laser } \\
\text { wavelength of } 904 \mathrm{~nm} \text {. } \\
\text { B. Sham laser }(n=30)\end{array}$ & $\begin{array}{l}\text { A vs. B } \\
\text { Age: } 32 \text { vs. } 31 \\
\text { years } \\
\text { Female: } 82 \% \\
\text { (total pop only) } \\
\text { Pain duration: } 43 \\
\text { vs. } 43 \text { months } \\
\text { Employed: } 12 \% \\
\text { vs. } 17 \% \\
\text { Pain at rest (VAS } \\
0-10): 7.43 \text { vs. } \\
6.87 \\
\text { Pain at movement } \\
\text { (VAS 0-10): } 7.43 \\
\text { vs. } 7.19 \\
\text { NPAD (0-100): } \\
65.36 \text { vs. } 68.52 \\
\text { NHP (0-100): } 78.9 \\
\text { vs. } 75.5 \\
\text { BDI (0-63): } 21.56 \\
\text { vs. } 20.81\end{array}$ & $\begin{array}{l}\text { A vs. B } \\
2.5 \text { months } \\
\text { NPAD: } 41.14 \text { vs. } \\
63.29, \text { difference } \\
-22.15(95 \% \mathrm{Cl} \\
-36.7 \text { to }-7.6) \\
\text { Pain at rest } \\
\text { (VAS): } 4.18 \text { vs. } \\
6.29, \text { difference } \\
-2.11 \text { (95\% Cl } \\
-3.80 \text { to }-0.42) \\
\text { Pain at } \\
\text { movement } \\
\text { (VAS): } 5.26 \text { vs. } \\
7.28, \text { difference } \\
-2.02 \text { ( } 95 \% \mathrm{Cl} \\
-3.31 \text { to } \\
-0.73)\end{array}$ & $\begin{array}{l}\text { A vs. B } \\
2.5 \text { months } \\
\text { BDI: } 14.72 \text { vs. } \\
21.38, \text { difference } \\
-6.66(95 \% \mathrm{Cl} \\
-13.24 \text { to }-0.08) \\
\text { NHP: } 56.41 \text { vs. } \\
72.48 \text {, difference } \\
-16.1(95 \% \mathrm{Cl} \\
-30.9 \text { to }-1.3)\end{array}$ \\
\hline $\begin{array}{l}\text { Trock, } 1994^{124} \\
1 \text { month } \\
\text { Pain duration: } \\
7.5 \text { years } \\
\text { Poor }\end{array}$ & $\begin{array}{l}\text { A. Pulsed electromagnetic fields } \\
\text { ( } n=42 \text { treated): extremely low } \\
\text { frequency (<2 A, } 120 \mathrm{~V} \text { ) applied } \\
\text { with stepwise energy } \\
\text { characteristics as follows: } 5 \mathrm{~Hz} \text {, } \\
0-15 \text { gauss for } 10 \text { minutes; } 10 \\
\mathrm{~Hz}, 15-25 \text { gauss for } 10 \text { minutes; } \\
\text { and } 12 \mathrm{~Hz}, 15-25 \text { gauss for } 10 \\
\text { minutes. Maximum number of } \\
\text { pulses/burst was } 20 . \\
\text { B. Sham (n=39 treated) } \\
\text { Treatments were given for } 30 \\
\text { minute periods, } 3-5 \text { times per } \\
\text { week for } 18 \text { treatments. }\end{array}$ & $\begin{array}{l}\text { A vs. B } \\
\text { Age: } 61 \text { vs. } 67 \\
\text { years } \\
\text { Female: } 71 \% \text { vs. } \\
67 \% \\
\text { Weight (lb): } 161 \\
\text { vs. } 162 \\
\text { Duration of } \\
\text { symptoms: } 7 \text { vs. } 8 \\
\text { years } \\
\text { ADL difficulty (0- } \\
24) 11.9 \text { vs. } 11.5 \\
\text { Pain }(0-10): 7.20 \\
\text { vs. } 6.23\end{array}$ & $\begin{array}{l}\text { A vs. B } \\
1 \text { month: } \\
\text { ADL difficulty: } \\
3.78 \text { vs. } 2.14, \\
\text { difference } 1.6 \\
\text { (95\% } \mathrm{Cl}-1.5 \text { to } \\
4.8) \\
\text { Pain: } 2.59 \text { vs. } \\
1.47 \text {, difference } \\
1.12 \text { (95\% } \mathrm{Cl} \\
-0.31 \text { to } 2.55 \text { ) }\end{array}$ & $\begin{array}{l}\text { A vs. B } \\
1 \text { month: } \\
\text { Patients' } \\
\text { assessment of } \\
\text { improvement ( } 0- \\
100): 41.2 \text { vs. } 40.0 \text {, } \\
\text { difference } 1.2(95 \% \\
\mathrm{Cl}-15.2 \text { to } 17.6)\end{array}$ \\
\hline
\end{tabular}

ADL = activity of daily living; BDI = Beck Depression Inventory; BMI = body mass index; CI = confidence interval; Ga-As = Gallium Arsenide; HADS = Hospital Anxiety and Depression Scale; MD = mean difference; MPQ = McGill Pain Questionnaire; NDI = Neck Disability Index; NHP = Nottingham Health Profile; NPAD = Neck Pain and Disability Scale; NPQ = Northwick Park Questionnaire; NPS = numeric pain scale; NR = not reported; PSFS = Patient Specific Functional Scale; RR = risk ratio; VAS = visual analog scale

${ }^{a}$ Unless otherwise noted, followup time is calculated from the end of the treatment period

${ }^{\mathrm{b}}$ Results of two-way repeated measures analysis of variance (ANOVA)

\section{Physical Modalities Compared With Attention Control or Sham}

Traction. One poor-quality trial found no short-term differences in function comparing intermittent cervical traction versus attention control (infrared irradiation) using the Northwick Park Questionnaire (NPQ) (MD -1.8, 95\% CI -10.8 to 7.2, 0-100\% scale). ${ }^{121}$ Likewise, there was no difference in pain intensity between groups (MD -0.7, 95\% CI -2.2 to 0.8, 10 point scale). There were no trials evaluating cervical traction in the intermediate term or long term. 
Low-Level Laser Therapy. Laser was associated with moderately greater effects compared with sham on short-term function ( 2 trials, pooled difference $-14.98,95 \%$ CI -23.88 to -6.07 , $\mathrm{I}^{2}=39 \%, 0-100$ scale) (Figure 28) ${ }^{122,123}$ and short-term pain ( 3 trials, pooled difference -1.81 , $95 \%$ CI -3.35 to $-0.27, I^{2}=75 \%, 0-10$ scale) (Figure 29). ${ }^{120,122,123}$ Pain improvement of greater than -3.0 on a 10-point VAS scale was substantially more common with laser therapy in the good-quality trial (RR 6.0, 95\% CI 1.9 to 19.0). ${ }^{122}$ Quality of life improvement also favored lowlevel laser as measured by the SF-36 PCS (MD 4.5, 95\% CI 0.7 to 8.2 ) ${ }^{122}$ and the Nottingham Health Profile (MD -16.1 on a $0-100$ scale, $95 \%$ CI -30.9 to -1.3 ). ${ }^{123}$ Measures demonstrating no difference between groups included the SF36 MCS and the McGill Pain Questionnaire component scores $^{122}$ (Table 20). There were no trials evaluating laser therapy in the intermediate term or long term.

Electromagnetic Fields. One poor-quality trial found no between-group differences in short-term difficulty with activities of daily living (ADLs) (MD 1.6 , 95\% CI -1.5 to 4.8, scale 0-24, nonvalidated measure). ${ }^{124}$ The ADL instrument asked whether the participant had pain or difficulty on eight activities scored from 0 (never) to 3 (always), for a total of 24 points. Likewise, there was no difference in pain intensity between groups (MD 1.1, 95\% CI -0.3 to 2.6, 0-10 scale) or in patients' assessment of improvement (MD 1.2, 95\% CI -15.2 to 17.6, 0-100 scale). ${ }^{124}$ There were no trials evaluating electromagnetic fields in the intermediate term or long term.

\section{Physical Modalities Compared With Pharmacological Therapy or With Exercise Therapy We did not find any trials meeting our criteria comparing a physical modality with pharmacological therapy or with exercise.}

\section{Harms}

Only one laser trial reported harms. ${ }^{122}$ The trial reported a large number of adverse effects with similar frequency in both groups. However, the sham group reported nausea significantly more frequently ( $42 \%$ vs. $20 \%$ ) while the laser group reported stiffness more frequently ( $20 \% \mathrm{vs.}$ $4 \%)$. The most frequently reported adverse effects included mild (78\%) or moderate (60\%) increased neck pain, increased pain elsewhere (78\%), mild headache (60\%), and tiredness (24\%). Harms were not reported by either trial evaluating cervical traction or electromagnetic fields. 
Figure 28. Low-level laser therapy versus sham for chronic neck pain: effects on function

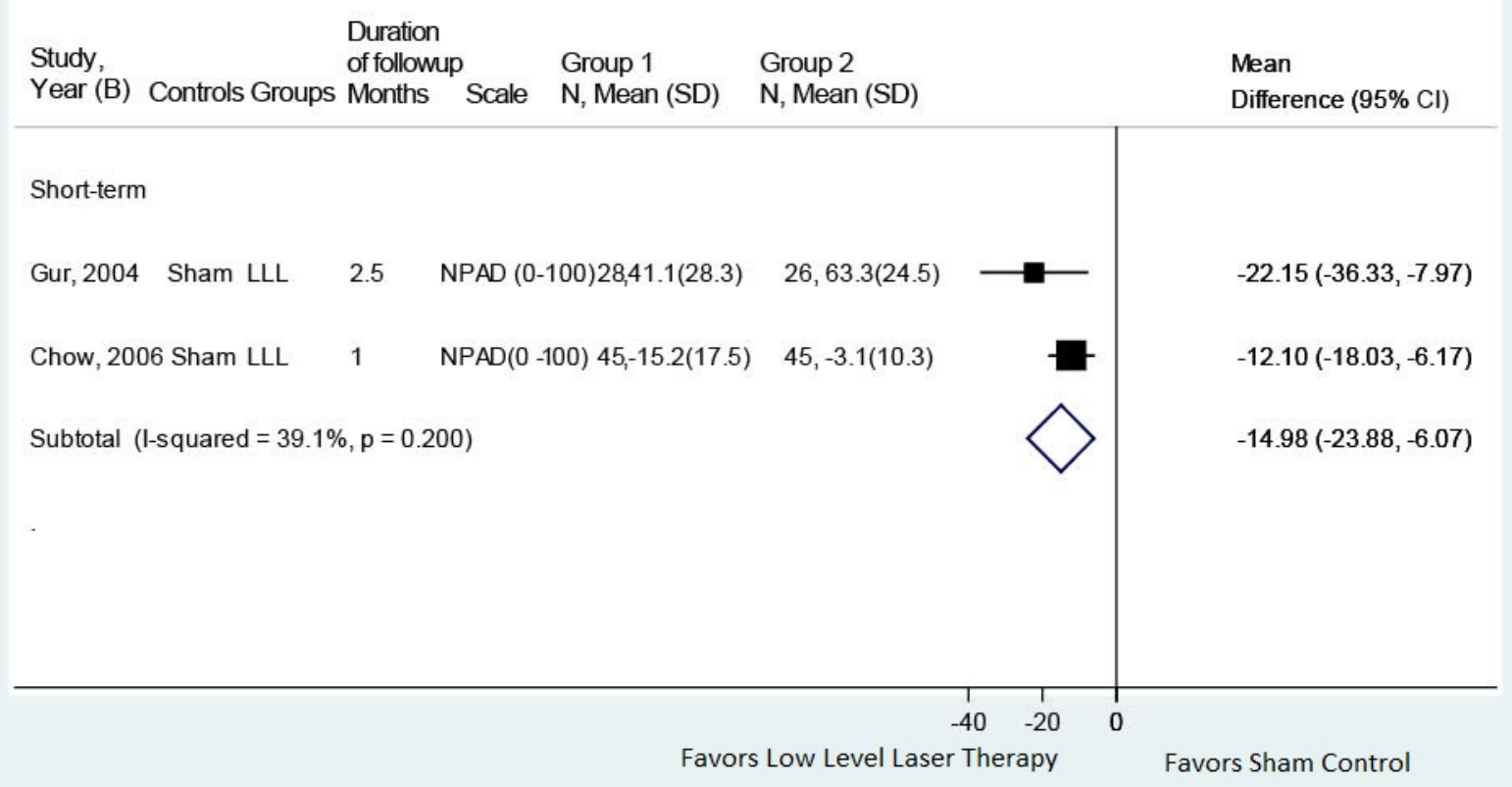

CI = confidence interval; LLL = low-level laser therapy; NPAD = Neck Pain and Disability Scale; SD = standard deviation

Figure 29. Low-level laser therapy versus sham for chronic neck pain: effects on pain

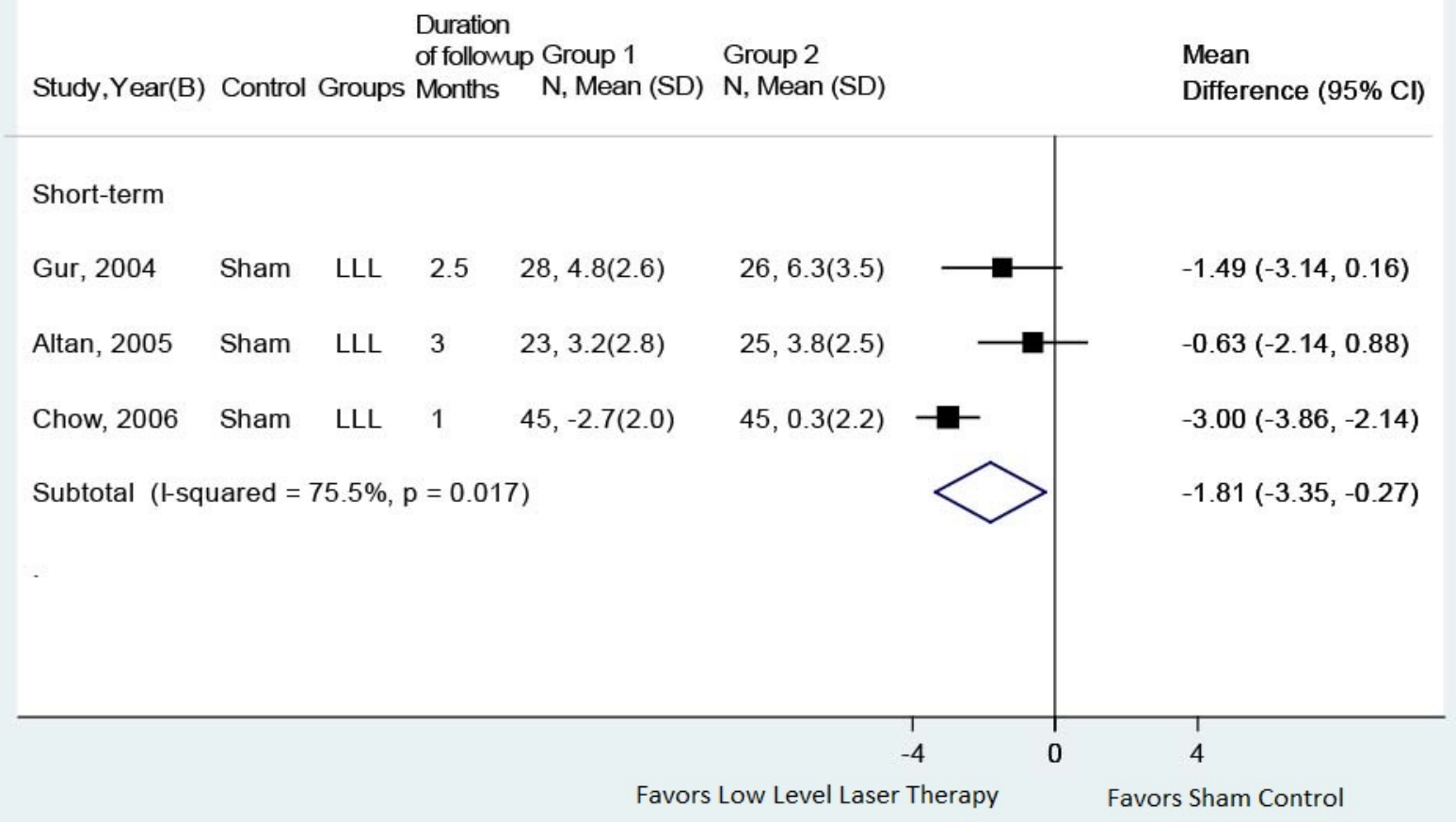

CI = confidence interval; LLL = low-level laser therapy; SD = standard deviation 


\section{Manual Therapies for Chronic Neck Pain}

\section{Key Points}

- The effects of massage on function versus self-management attention control were slight and not statistically significant in one trial $(\mathrm{N}=64)$ in the short term $(\geq 5$ point improvement on the NDI, $39 \%$ versus $14 \%$, RR $2.7,95 \%$ CI 0.99 to 7.5 ) and intermediate term ( $57 \%$ versus $31 \%$, RR $1.8,95 \%$ CI 0.97 to 3.5) (SOE: low for both time periods).

- No clear evidence that massage improved pain in the intermediate term versus exercise ( $\mathrm{P}>0.05$, data not reported) in one fair-quality trial (SOE: low).

- Two fair-quality trials reported no serious adverse effects, and more transient nonserious pain or soreness during or after exercise, but not massage (SOE: low).

\section{Detailed Synthesis}

Two trials of classical $(\mathrm{N}=85)^{152}$ or Swedish massage $(\mathrm{N}=58)^{153}$ met inclusion criteria (Table 21 and Appendix D). One trial compared massage versus attention control (self-care education), ${ }^{153}$ and one trial compared massage versus two types of exercise (muscle re-education and strength training targeting the neck and shoulder muscles). ${ }^{152}$ Muscle re-education was performed with a newly developed training device strapped to the head and consisted of a plate with 5 exchangeable surfaces that allow for progression of task difficulty. One trial was conducted in Sweden ${ }^{152}$ and one in the United States. ${ }^{153}$ One trial administered 10 massage treatments over 10 weeks, ${ }^{153}$ and the other trial 22 massage treatments over 11 weeks. ${ }^{152}$

Both trials were rated fair quality (Appendix E). Methodological limitations included the inability to blind interventions in both trials, and 21 percent attrition in the trial comparing massage with exercise. ${ }^{152}$ 
Table 21. Chronic neck pain: manual therapies

\begin{tabular}{|c|c|c|c|c|}
\hline $\begin{array}{l}\text { Author, Year, } \\
\text { Followup, } \\
\text { Pain Duration, } \\
\text { Study Quality }\end{array}$ & Intervention & Population & $\begin{array}{l}\text { Function and Pain } \\
\text { Outcomes }\end{array}$ & Other Outcomes \\
\hline $\begin{array}{l}\text { Rudolfsson, } \\
2014^{152} \\
6 \text { months } \\
\text { Duration of } \\
\text { pain: median } \\
84 \text { to } 123 \\
\text { months } \\
\text { Fair }\end{array}$ & $\begin{array}{l}\text { A. Massage, classical } \\
\text { ( } \mathrm{n}=36 \text { ): upper body } \\
\text { including the back, neck } \\
\text { and shoulders. } \\
\text { B. Neck coordination } \\
\text { exercise ( } \mathrm{n}=36 \text { ): } \\
\text { performed with a newly } \\
\text { developed training device } \\
\text { designed to improve the } \\
\text { fine movement control of } \\
\text { the cervical spine. } \\
\text { C. Strength training } \\
\text { ( } \mathrm{n}=36 \text { ): isometric and } \\
\text { dynamic exercises } \\
\text { targeting the neck and } \\
\text { shoulder regions. } \\
\text { All } 3 \text { interventions } \\
\text { consisted of } 22 \\
\text { individually supervised } \\
\text { single treatment sessions, } \\
30 \text { min each, distributed } \\
\text { over } 11 \text { weeks }\end{array}$ & $\begin{array}{l}\text { A vs. B vs. C } \\
\text { Age: } 51 \text { vs. } 52 \text { vs. } \\
51 \text { years } \\
\text { Female: } 100 \% \text { vs. } \\
100 \% \text { vs. } 100 \% \\
\text { Weight (kg): } 73 \\
\text { vs. } 74 \text { vs. } 74 \\
\text { Height (cm): } 167 \\
\text { vs. } 164 \text { vs. } 165 \\
\text { Pain duration: } 120 \\
\text { vs. } 123 \text { vs. } 84 \\
\text { months (median) } \\
\text { Pain NRS (0-10), } \\
5 \text { vs. } 6 \text { vs. } 6 \\
\text { (median) } \\
\text { NDI: } 26 \text { vs. } 29 \text { vs. } \\
31 \\
\text { SF-36 PCS (0- } \\
100): 43 \text { vs. } 39 \text { vs. } \\
39 \text { (median) } \\
\text { SF-36 MCS (0- } \\
100): 49 \text { vs. } 52 \text { vs. } \\
47 \text { (median) }\end{array}$ & $\begin{array}{l}\text { A vs. B: } \\
6 \text { months } \\
\text { Pain NRS (0-10): } 4.0 \text { vs. } \\
\text { 3.8, MD } 0.2(95 \% \mathrm{Cl}-0.82 \\
\text { to } 1.22) \\
\text { A vs. C: } \\
6 \text { months } \\
\text { Pain NRS (0-10): No data } \\
\text { given at } 6 \text { month, however, } \\
\text { authors state no difference } \\
\text { among A, B or C. }\end{array}$ & NR \\
\hline $\begin{array}{l}\text { Sherman, } \\
2009^{153} \\
2.5 \text { and } 6.5 \\
\text { months } \\
\text { Duration of pain } \\
>1 \text { year: } 81 \% \\
\text { Fair }\end{array}$ & $\begin{array}{l}\text { A. Massage }(n=32) \text { : } \\
\text { Swedish and clinical } \\
\text { techniques and self-care } \\
\text { recommendations; } 10 \\
\text { massage treatments over } \\
\text { a } 10 \text {-week period } \\
\text { B. Self-care book: ( } n=32) \\
\text { information on potential } \\
\text { causes of neck pain, } \\
\text { neck-related headaches, } \\
\text { whiplash, recommended } \\
\text { strengthening exercises, } \\
\text { body mechanics and } \\
\text { posture, conventional } \\
\text { treatment, complementary } \\
\text { therapies for neck pain, } \\
\text { and first aid for } \\
\text { intermittent flare-ups. }\end{array}$ & $\begin{array}{l}\text { A vs. B } \\
\text { Age: } 47 \text { vs. } 46 \\
\text { years } \\
\text { Female: } 69 \% \text { vs. } \\
69 \% \\
\text { White: } 87 \% \text { vs. } \\
81 \% \\
\text { Married: } 78 \% \text { vs. } \\
59 \% \\
\text { Smoker: } 9 \% \text { vs. } \\
6 \% \\
\text { Pain lasted > } 1 \\
\text { year: } 81 \% \text { vs. } \\
81 \% \\
\text { Symptom } \\
\text { bothersome (0- } \\
10): 4.8 \text { vs. } 4.9 \\
\text { NDI (0-50): } 14.2 \\
\text { vs. } 14.2 \\
\text { SF-36 PCS (0- } \\
100): 46.0 \text { vs. } 44.1 \\
\text { SF-36 MCS (0- } \\
100): 51.9 \text { vs. } 53.1\end{array}$ & $\begin{array}{l}\text { A vs. B } \\
2.5 \text { months } \\
\text { NDI, } \% \geq 5 \text { points: } 39 \% \text { vs. } \\
14 \%, \text { RR } 2.7 \text { ( } 95 \% \mathrm{Cl} 0.99 \\
\text { to } 7.5) \\
\mathrm{NDI}(0-50) \text { : MD }-2.3(95 \% \\
\mathrm{Cl}-4.7 \text { to } 0.15) \\
6.5 \text { months } \\
\text { NDI, \% } 25 \text { points: } 57 \% \text { vs. } \\
31 \%, \mathrm{RR} 1.8 \text { ( } 95 \% \mathrm{Cl} 0.97 \\
\text { to } 3.5) \\
\text { NDI: MD: }-1.9(95 \% \mathrm{Cl}-4.4 \\
\text { to } 0.63)\end{array}$ & $\begin{array}{l}\text { A vs. B } \\
2.5 \text { months } \\
\text { Bothersome score (0- } \\
\text { 10): MD }-1.2 \text { (95\% Cl } \\
-2.5 \text { to } 0.1) \\
\text { Bothersome } \\
\text { improvement } \geq 30 \%: 55 \% \\
\text { vs. } 25 \%, \mathrm{RR} 2.1 \text { (95\% Cl } \\
1.04 \text { to } 4.2) \\
\text { SF-36 PCS: } 52.8 \text { vs. } \\
53.3, \mathrm{P}=0.982 \\
\text { SF-36 MCS: } 45.9 \text { vs. } \\
45.3, \mathrm{P}=0.444 \\
6.5 \text { months } \\
\text { Bothersome score: MD } \\
-0.14 \text { (95\% Cl -1.5 to } \\
\text { 1.2) } \\
\text { Bothersome } \\
\text { improvement } \geq 30 \%: 43 \% \\
\text { vs. } 39 \%, \mathrm{RR} 1.1 \text { (95\% Cl } \\
\text { 0.6 to } 2.0) \\
\text { SF-36 PCS and MCS: } \\
\text { data not given, no } \\
\text { statistical difference } \\
\text { Medication use: No } \\
\text { change in group A, } 14 \% \\
\text { increase in group B }\end{array}$ \\
\hline
\end{tabular}

CI = confidence interval; MD = mean difference; NDI = Neck Disability Index; NR = not reported; NRS = numeric rating scale; SF-36 MCS = Short-Form 36 Mental Component Summary; SF-36 PCS = Short-Form 36 Physical Component Summary aUnless otherwise noted, followup time is calculated from the end of the treatment period. 


\section{Manual Therapies Compared With an Attention Control}

The effects of massage on function versus self-management attention control were small and not statistically significant in one trial $(\mathrm{N}=64)$ in the short term $(\geq 5$ point improvement on the NDI, 39\% versus $14 \%$, RR 2.7, 95\% CI 0.99 to 7.5 ) and intermediate term (57\% versus $31 \%$, RR 1.8, 95\% CI 0.97 to 3.5). ${ }^{153}$ A greater proportion of participants in the massage group reported improvement in a symptom bothersomeness scale $(\geq 30 \%)$ in the short term (55\% versus $25 \%$; RR 2.2, 95\% CI 1.04 to 4.2) but not intermediate term (RR 1.1, 95\% CI 0.6 to 2.0). There were no differences between groups in SF-36 PCS and MCS. Medication use did not change in the massage group while it increased in the self-management group (14\%).

\section{Manual Therapies Compared With Pharmacological Therapy}

No trial of manual therapy versus pharmacological therapy met inclusion criteria.

\section{Manual Therapies Compared With Exercise}

One fair-quality study reported no difference in intermediate-term pain comparing massage with neck coordination exercises (difference 0.2 , 95\% CI -0.82 to $1.22,0-10$ scale) or muscle performance exercises (no data given, $\mathrm{P}>0.05$ ). ${ }^{152}$

No trial evaluated effects of manual therapies on use of opioid therapies or health care utilization.

\section{Harms}

Neither trial reported serious adverse effects. Nonserious mild adverse effects included discomfort or pain during $(n=5)$ or after massage $(n=3)$ in one trial. ${ }^{153}$ There were no serious adverse effects in the massage group in the second trial, though there was transient neck or headache pain in the neuromuscular training exercise group $(n=10)$.

\section{Mind-Body Practices for Chronic Neck Pain}

\section{Key Points}

- Alexander Technique resulted in a small improvement in function in the short term (difference -5.56 on a $0-100 \%$ scale, $95 \%$ CI -8.33 to -2.78 ) and intermediate term (difference -3.92 , 95\% CI -6.87 to -0.97 ) compared with usual care alone, based on one fair-quality trial (SOE: low).

- There was no clear evidence that basic body awareness therapy improved function in the short term versus exercise in one fair-quality trial (SOE: low).

- There is insufficient evidence from one poor-quality trial to determine the effects of qigong on intermediate-term or long-term function or pain versus exercise; no data were available for short term outcomes (SOE: insufficient).

- Both fair-quality trials reported no serious treatment-related adverse events. The trial evaluating Alexander Technique versus usual care found no clear between-group difference for nonserious adverse events, such as pain and incapacity, knee injury, or muscle spasm (RR 2.25, 95\% CI 1.00 to 5.04). The other trial reported no differences between basic body awareness and exercise in any nonserious adverse effect (RR 0.65, 95\% CI 0.37 to 1.14 ) (SOE: low). 


\section{Detailed Synthesis}

Three trials of mind-body practices met inclusion criteria (Table 22 and Appendix D) ${ }^{180,187,188}$ One trial evaluated the Alexander Technique (a method of self-care developed to help people enhance their control of reaction and improve their way of going about everyday activities) plus usual care $(\mathrm{N}=344),{ }^{180}$ one trial basic body awareness therapy $(\mathrm{N}=115),{ }^{188}$ and one trial of qigong $(\mathrm{N}=134){ }^{187}$ One trial compared mind-body techniques versus usual care ${ }^{180}$ and two trials versus individually adjusted cervical and shoulder strengthening and stretching exercises, ${ }^{187}$ or group-led exercises for whole body strengthening, aerobic, and coordination exercises. ${ }^{188}$ Two trials were conducted in Sweden ${ }^{187,188}$ and one in England. ${ }^{180}$ The duration of mind-body treatment ranged from 10 to 20 weeks and the number of treatment sessions ranged from 12 to 20 . One trial reported outcomes during the intermediate term and long term, ${ }^{187}$ one short-term and intermediate-term outcomes, ${ }^{180}$ and one short-term outcomes only. ${ }^{188}$

Two of the trials were rated fair quality ${ }^{180,188}$ and one trial poor quality ${ }^{187}$ (Appendix E). In the two fair-quality trials, the main methodological limitation was the inability to blind interventions. Limitations in the other trial included the inability to blind interventions, high attrition, and unequal loss to followup between groups.

Table 22. Chronic neck pain: mind-body practices

\begin{tabular}{|c|c|c|c|c|}
\hline $\begin{array}{l}\text { Author, Year, } \\
\text { Followup, }{ }^{\mathrm{a}} \\
\text { Pain Duration, } \\
\text { Study Quality }\end{array}$ & Intervention & Population & $\begin{array}{l}\text { Function and Pain } \\
\text { Outcomes }\end{array}$ & Other Outcomes \\
\hline $\begin{array}{l}\text { Lansinger, } \\
2007^{187} \\
6 \text { and } 12 \\
\text { months } \\
\text { Pain duration: } \\
>5 \text { years, } 45 \% \\
\text { Poor }\end{array}$ & $\begin{array}{l}\text { A. Qigong (n=72): 10-12 } \\
\text { group sessions of } 10-15 \\
\text { people done } 1-2 \text { times } \\
\text { per week over } 3 \text { months. } \\
\text { Sessions were } 1 \text { hour } \\
\text { and consisted of } \\
\text { information of the } \\
\text { philosophy of medical } \\
\text { qigong followed by } \\
\text { exercises based on the } \\
\text { Biyun method } \\
\text { B. Exercise (n=67): 10- } \\
\text { 12 sessions } 1-2 \text { times } \\
\text { per week over } 3 \text { months. } \\
\text { Sessions were } 1 \text { hour } \\
\text { and individualized to } \\
\text { target } 30 \%-70 \% \text { of a } \\
\text { person's maximal } \\
\text { voluntary capacity, with } \\
\text { exercises aiming to } \\
\text { maintain/increase } \\
\text { circulation, endurance, } \\
\text { and strength. } \\
\text { All patients: Ergonomic } \\
\text { instructions and a } \\
\text { pamphlet containing } \\
\text { written information on } \\
\text { neck pain }\end{array}$ & $\begin{array}{l}\text { A vs. B } \\
\text { Age: } 45 \text { vs. } 43 \\
\text { Female: } 73 \% \text { vs. } \\
67 \% \\
\text { Duration of neck } \\
\text { pain: } \\
3 \text { mos-1 year: } \\
\text { 15\% vs. } 20 \% \\
\text { >1 year: } 38 \% \text { vs. } \\
37 \% \\
\text { >5 years: } 22 \% \text { vs. } \\
24 \% \\
\text { >10 years: } 25 \% \\
\text { vs. } 20 \% \\
\text { Physical activity: } \\
\text { No to light exercise: } \\
67 \% \text { vs. } 65 \% \\
\text { Med to hard } \\
\text { exercise: } \\
33 \% \text { vs. } 35 \% \\
\text { NDI (0-100\%), } \\
\text { median: } 26 \text { vs. } 22 \\
\text { Neck pain VAS (0- } \\
10), \text { median: } 45 \text { vs. } \\
39\end{array}$ & $\begin{array}{l}\text { A vs. B } \\
6 \text { months } \\
\text { NDI, median: } 22 \text { vs. } 18, \\
p>0.05 \\
\text { Neck pain VAS }(0-10), \\
\text { median: } 2.6 \text { vs. } 2.3, p>0.05 \\
12 \text { months } \\
\text { NDI, median: } 22 \text { vs. } 18, \\
\text { p>0.05 } \\
\text { Neck pain VAS, median: } \\
2.8 \text { vs. } 2.1, p>0.05\end{array}$ & NR \\
\hline
\end{tabular}




\begin{tabular}{|c|c|c|c|c|}
\hline $\begin{array}{l}\text { Author, Year, } \\
\text { Followup, } \\
\text { Pain Duration, } \\
\text { Study Quality }\end{array}$ & Intervention & Population & $\begin{array}{l}\text { Function and Pain } \\
\text { Outcomes }\end{array}$ & Other Outcomes \\
\hline $\begin{array}{l}\text { MacPherson, } \\
2015^{180} \\
1 \text { and } 7 \text { months } \\
\text { Duration of } \\
\text { pain, } 7 \text { years } \\
\text { Fair }\end{array}$ & $\begin{array}{l}\text { A. Alexander Technique } \\
\text { group ( } \mathrm{n}=172) \text { : up to } 20 \\
\text { one-to-one lessons of } 30 \\
\text { minutes' duration } \\
\text { ( } 600 \text { minutes total) plus } \\
\text { usual care, delivered } \\
\text { weekly, with the option } \\
\text { of being delivered } \\
\text { twice per week initially } \\
\text { and every } 2 \text { weeks later. } \\
\text { B. Usual care ( } n=172) \\
\text { including general and } \\
\text { neck pain-specific } \\
\text { treatments routinely } \\
\text { provided to primary care } \\
\text { patients, such as } \\
\text { prescribed medications } \\
\text { and visits to physical } \\
\text { therapists and other } \\
\text { health care } \\
\text { professionals. } \\
\text { Treatment was } 12 \\
\text { sessions over } 5 \text { months } \\
\text { lasting } 50 \text { minutes. }\end{array}$ & $\begin{array}{l}\text { A vs. B } \\
\text { Age: } 52 \text { vs. } 54 \\
\text { years } \\
\text { Female: } 69 \% \text { vs. } \\
69 \% \\
\text { White: } 93 \% \text { vs. } 89 \% \\
\text { Employed: } 61 \% \text { vs. } \\
62 \% \\
\text { Pain duration } \\
\text { (median): } 60 \text { vs. } 96 \\
\text { months } \\
\text { NPQ (0-100\%): } \\
39.64 \text { vs. } 40.46\end{array}$ & $\begin{array}{l}\text { A vs. B } \\
1 \text { month } \\
\text { NPQ: } 35.35 \text { vs. } 40.90, M D \\
-5.56(95 \% \mathrm{Cl}-8.33 \text { to } \\
-2.78) \\
\frac{7 \text { months }}{\text { NPQ: } 37.07 \text { vs. } 40.99, \mathrm{MD}} \\
-3.92(95 \% \mathrm{Cl}-6.87 \text { to } \\
-0.97)\end{array}$ & $\begin{array}{l}\text { A vs. B } \\
1 \text { month } \\
\text { SF-12v2 physical: data } \\
\text { NR, P=NS } \\
\text { SF-12v2 mental: data } \\
\text { NR, P=NS } \\
\\
7 \text { months } \\
\text { SF-12v2 physical: } 0.68 \\
\text { (95\% Cl }-1.08 \text { to } 2.44) \text {, } \\
\text { P=0.44 } \\
\text { SF-12v2 mental: } 1.76 \\
\text { (95\% Cl } 0.15 \text { to } 3.37), \\
P=0.033\end{array}$ \\
\hline
\end{tabular}




\begin{tabular}{|c|c|c|c|c|}
\hline $\begin{array}{l}\text { Author, Year, } \\
\text { Followup, } \\
\text { Pain Duration, } \\
\text { Study Quality }\end{array}$ & Intervention & Population & $\begin{array}{l}\text { Function and Pain } \\
\text { Outcomes }\end{array}$ & Other Outcomes \\
\hline $\begin{array}{l}\text { Seferiadis, }{ }^{188} \\
2015 \\
3 \text { months } \\
\text { Pain duration: } \\
9.5 \text { years } \\
\text { Fair }\end{array}$ & $\begin{array}{l}\text { A. Basic body } \\
\text { awareness therapy } \\
\text { ( } n=57): 1.5 \text { hour } \\
\text { sessions twice a week } \\
\text { for } 10 \text { weeks. Sessions } \\
\text { consisted of exercises } \\
\text { based on activities of } \\
\text { daily living, meditation, } \\
\text { and tai chi inspired } \\
\text { exercises aiming to } \\
\text { improve posture and } \\
\text { increase efficient } \\
\text { movement patterns } \\
\text { B. Exercise (n=56): } 1.5 \\
\text { hour sessions twice a } \\
\text { week for } 10 \text { weeks. } \\
\text { Sessions consisted of } \\
45 \text { minutes of muscle } \\
\text { strengthening, } 15 \\
\text { minutes of stretching, } \\
\text { and } 20 \text { minutes of } \\
\text { progressive muscle } \\
\text { relaxation }\end{array}$ & $\begin{array}{l}\text { A vs. B } \\
\text { Age: } 47 \text { vs. } 49 \\
\text { Female: } 66 \% \text { vs. } \\
77 \% \\
\text { Duration of } \\
\text { symptoms (years): } \\
10 \text { vs. } 9 \\
\text { WAD classification: } \\
\text { 1: } 0 \% \text { vs. } 2 \% \\
2: 23 \% \text { vs. } 28 \% \\
3: 77 \% \text { vs. } 70 \% \\
\text { NDI (0-50): } 20 \text { vs. } \\
18.8 \\
\text { SF-36v2 } \\
\text { physical functioning } \\
\text { (0-100): } 67.5 \text { vs. } \\
69.7 \\
\text { role-physical (0- } \\
100): 33.9 \text { vs. } 24.5 \\
\text { bodily pain (0-100): } \\
34.3 \text { vs. } 35.2 \\
\text { general health (0- } \\
100): 54.7 \text { vs. } 48.7 \\
\text { vitality (0-100): } 39.5 \\
\text { vs. } 35.1 \\
\text { social functioning } \\
\text { (0-100): } 60 \text { vs. } 59.4 \\
\text { role-emotional (0- } \\
100): 55.4 \text { vs. } 51.7 \\
\text { mental health (0- } \\
100): 65.9 \text { vs. } 62.7\end{array}$ & $\begin{array}{l}\text { A vs. B } \\
3 \text { months } \\
\text { NDI: Difference from } \\
\text { baseline }-2(95 \% \mathrm{Cl}-3.5 \text { to } \\
-0.5) \text { vs. }-1(95 \% \mathrm{Cl}-2.5 \\
\text { to } 0.4), p>0.05\end{array}$ & 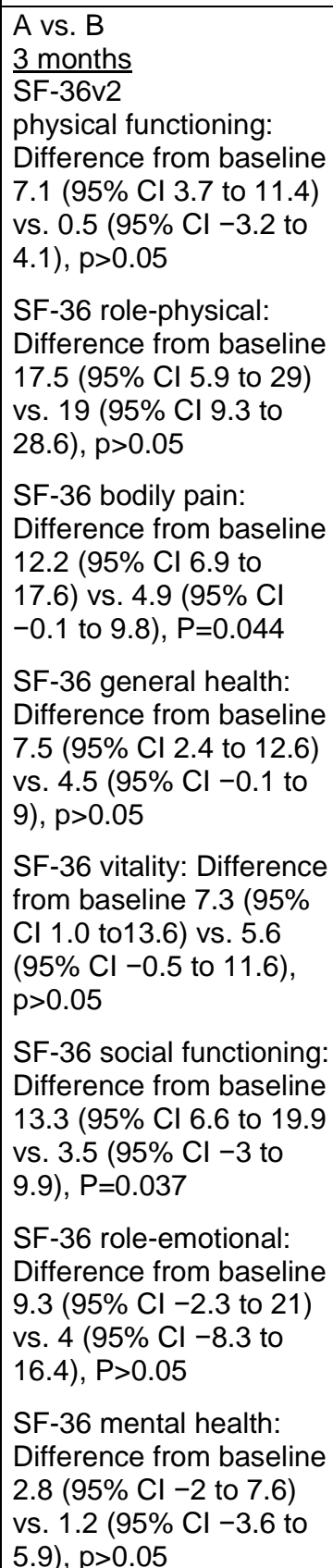 \\
\hline
\end{tabular}

CI = confidence interval; MD = mean difference; NDI = Neck Disability Index; NR = not reported; SF-36 =Short-Form 36 Questionnaire; VAS = visual analog scale; WAD = Whiplash Associated Disorders

${ }^{a}$ Unless otherwise noted, followup time is calculated from the end of the treatment period

\section{Mind-Body Practices Compared With Usual Care}

One fair-quality trial found a small improvement in function as measured by the NPQ in favor of the Alexander Technique plus usual care versus usual care alone in the short term (MD -5.56 on a $100 \%$ scale, $95 \%$ CI -8.33 to -2.78 ) and intermediate term (MD $-3.92,95 \%$ CI -6.87 to -0.97$).{ }^{180}$ There were no significant differences between the intervention group and 
usual care for the physical component score of the SF-12 v 2 at 1-month or 7-month followup. However, significantly larger improvements in the MCS occurred in the Alexander group versus the usual care group 7 months following treatment (MD, 2.12 on a $0-100$ scale, $95 \%$ CI 0.42 to 3.82). ${ }^{180}$

\section{Mind-Body Practices Compared With Pharmacological Therapy}

No trial of mind-body practice versus pharmacological therapy met inclusion criteria.

\section{Mind-Body Practices Compared With Exercise}

There were no differences in function as measured by the NDI between basic body awareness therapy ( 1 fair-quality study, $\mathrm{n}=113)^{188}$ in the short term (mean change from baseline -2 versus $-1, \mathrm{P}>0.05$ ) or qigong (poor-quality study, $\mathrm{n}=139)^{187}$ in the intermediate term or long term (median 22 versus 18, $\mathrm{P}>0.05$, at each time period) versus exercise therapy. The trial assessing qigong found no difference in pain at 6 or 12 months following treatment (median 2.6 versus 2.3 and 2.8 versus $2.3, \mathrm{P}>0.05$, respectively). ${ }^{187}$ Two of the eight sections of the SF-36v2 favored basic body awareness therapy versus exercise in the short term (bodily pain and social functioning) in the fair-quality trial. ${ }^{188}$ No other section of the SF-36v2 demonstrated a difference between groups.

No trial evaluated effects of mind-body practices on use of opioid therapies or health care utilization.

\section{Harms}

One trial of basic body awareness therapy reported no serious adverse effects. ${ }^{188}$ One patient in the basic body awareness group and four patients in the exercise group reported that they discontinued treatment due to increased neck symptoms or pain in other joints $(\mathrm{P}=0.363)$. The event risk for all nonserious adverse events was 0.27 in the body awareness therapy group and 0.40 in the exercise group (RR $0.65,95 \%$ CI 0.37 to 1.14 ).

\section{Acupuncture for Chronic Neck Pain}

\section{Key Points}

- Acupuncture was associated with slightly greater effects on short-term and intermediateterm function versus sham acupuncture, a placebo (sham laser), or usual care (short term, 5 trials, pooled SMD $-0.40,95 \%$ CI -0.64 to $-0.17, \mathrm{I}^{2}=67.7 \%$; intermediate term, 3 trials, pooled SMD $-0.19,95 \%$ CI -0.35 to -0.02 ). One trial reported no difference in function in the long term (SMD $-0.23,95 \%$ CI -0.61 to 0.16 ) (SOE: low for all time periods).

- There was no evidence of differences in pain in studies comparing acupuncture with sham acupuncture or placebo interventions in the short term (4 trials [excluding outlier trial], pooled difference -0.2 on a $0-10$ scale, $95 \%$ CI -0.59 to $0.05, \mathrm{I}^{2}=2 \%$ ), intermediate term ( 3 trials, pooled difference $0.45,95 \%$ CI -0.34 to $1.25, \mathrm{I}^{2}=59 \%$ ), or long term ( 1 trial, difference $-1.8,95 \% \mathrm{CI}-1.34$ to 0.64 ) (SOE: low for all time periods).

- There was insufficient evidence from two small poor-quality trials to draw conclusions regarding short-term function or pain for acupuncture versus NSAIDs (SOE: insufficient). 
- No serious adverse events were reported in five trials reporting harms. The most commonly reported nonserious adverse events in people receiving acupuncture included numbness/discomfort, fainting, and bruising (SOE: moderate).

\section{Detailed Synthesis}

We identified nine trials of acupuncture that met our inclusion criteria ${ }^{180,196-202,217}$ (Table 23 and Appendix D). All trials evaluated needle acupuncture to body acupoints; two also evaluated electroacupuncture. ${ }^{199,202}$ Control groups included sham acupuncture in five trials, ${ }^{196-}$ 199,201 placebo intervention (sham TENS ${ }^{200}$ and sham laser acupuncture ${ }^{202}$ ) in two trials, usual care in one trial, ${ }^{180}$ and pharmacological therapy (Zaltoprofen ${ }^{217}$ and Trilisate ${ }^{196}$ ) in two trials. The duration of acupuncture therapy ranged from 2 weeks to 5 months, and the number of sessions from 5 to 14. Sample sizes ranged from 30 to 355 (total sample=1,245). Across trials, participants were predominately female (from 60\% to 90\%) with mean ages ranging from 37 to 53 years. One trial was conducted in the United States, ${ }^{196}$ one in Turkey, ${ }^{199}$ and the rest in Asia ${ }^{197,198,202,217}$ or Europe. ${ }^{180,200,201}$ One trial reported outcomes through long-term followup, ${ }^{201}$ four trials through intermediate-term followup, ${ }^{180,200-202}$ and the remainder only evaluated shortterm outcomes. ${ }^{196-199,217}$

Seven trials were rated fair quality ${ }^{180,197-202}$ and two trials poor quality ${ }^{196,217}$ (Appendix E). Common limitations in the fair-quality trials included unclear allocation concealment methods and of care provider blinding; additionally, the poor-quality trials had baseline group dissimilarity (not controlled for) and high attrition. 
Table 23. Chronic neck pain: acupuncture

\begin{tabular}{|c|c|c|c|c|}
\hline $\begin{array}{l}\text { Author, Year, } \\
\text { Followup, } \\
\text { Pain Duration, } \\
\text { Study Quality }\end{array}$ & Intervention & Population & $\begin{array}{l}\text { Function and Pain } \\
\text { Outcomes }\end{array}$ & Other Outcomes \\
\hline $\begin{array}{l}\text { Birch, } 1998^{196} \\
3 \text { months } \\
\text { Duration of pain, } \\
7.5 \text { years } \\
\text { Poor }\end{array}$ & $\begin{array}{l}\text { A. Relevant acupuncture, } \\
\text { Japanese technique } \\
\text { ( } n=15) \text { : using bilateral } \\
\text { needles on hands and } \\
\text { feet known to be } \\
\text { associated with } \\
\text { treatment for neck pain } \\
\text { and followed by Infrared } \\
\text { lamp. } \\
\text { B. Irrelevant acupuncture } \\
\text { ( } n=16 \text { ): using bilateral } \\
\text { needles on hands and } \\
\text { feet in areas not } \\
\text { associated with } \\
\text { treatment for neck pain } \\
\text { and followed by light. } \\
\text { C. NSAIDs only ( } n=15 \text { ): } \\
500 m g \text { per day of } \\
\text { Trilisate } \\
30 \text { minute treatment } \\
\text { twice per week for } 4 \\
\text { weeks, then once per } \\
\text { week for } 4 \text { weeks, total } \\
14 \text { treatments }\end{array}$ & $\begin{array}{l}\text { A vs. B vs. C } \\
\text { Age: } 41 \text { vs. } 38 \text { vs. } 39 \\
\text { years } \\
\text { Female: } 86 \% \text { vs. } \\
77 \% \text { vs. } 86 \% \\
\text { Pain duration: } 82 \text { vs. } \\
92 \text { vs. } 91 \text { months } \\
\text { Married: } 36 \% \text { vs. } \\
23 \% \text { vs. } 50 \% \\
\text { Employed: } 86 \% \text { vs. } \\
69 \% \text { vs. } 77 \% \\
\text { Pain intensity (0-10) } \\
4.8 \text { vs. } 4.7 \text { vs. } 4.9\end{array}$ & $\begin{array}{l}\text { A vs. B } \\
\frac{3 \text { months }}{\text { SF-MPQ }}(0-33): 9.0 \\
\text { vs. } 15.1, P=N S \\
\text { A vs. C } \\
\frac{3 \text { months }}{\text { SF-MPQ: } 9.0 \text { vs. }} \\
\text { 18.0, P=NS }\end{array}$ & NR \\
\hline $\begin{array}{l}\text { Cho, } 2014^{217} \\
1 \text { month } \\
\text { Duration of pain, } \\
\text { NR } \\
\text { Poor }\end{array}$ & $\begin{array}{l}\text { A. Active acupuncture, } \\
\text { traditional Chinese ( } \mathrm{n}=15 \\
\text { randomized/15 } \\
\text { analyzed), 3x/week for } 3 \\
\text { weeks.(length of time for } \\
\text { each intervention not } \\
\text { reported) } \\
\text { B. Zaltoprofen ( } 80 \mathrm{mg}) \\
\text { alone ( } \mathrm{n}=15 \\
\text { randomized/15 analyzed) } \\
\text { 3x/day for } 3 \text { weeks. }\end{array}$ & $\begin{array}{l}\text { A vs. B } \\
\text { Age: } 38 \text { vs. } 39 \text { years } \\
\text { Female: } 60 \text { vs. } 80 \\
\text { NDI (0-50): } 22.3 \text { vs. } \\
26.3 \\
\text { Pain VAS (0-10): } 6.1 \\
\text { vs. } 7.1\end{array}$ & $\begin{array}{l}\text { A vs. B } \\
1 \text { month } \\
\text { NDI: } 17.3 \text { vs. } 17.7, \\
\text { difference }-0.40 \\
\text { (95\% } \mathrm{Cl}-4.55 \text { to } \\
3.75) \\
\text { Pain VAS: } 4.5 \text { vs. } 3.8 \text {, } \\
\text { difference } 0.7(95 \% \\
\mathrm{Cl}-0.74 \text { to } 2.14)\end{array}$ & $\begin{array}{l}\text { A vs. B } \\
1 \text { month } \\
\text { BDI }(0-63): 28.5 \\
\text { vs. } 27.2, P=N S \\
\text { SF-36 }(0-100): \\
88.6 \text { vs. } 84.3, \\
P=N S \\
\text { EQ-5D (scale } \\
\text { unclear): } 7.3 \text { vs. } \\
6.7, P=N S\end{array}$ \\
\hline
\end{tabular}




\begin{tabular}{|c|c|c|c|c|}
\hline $\begin{array}{l}\text { Author, Year, } \\
\text { Followup, }^{\text {a }} \\
\text { Pain Duration, } \\
\text { Study Quality }\end{array}$ & Intervention & Population & $\begin{array}{l}\text { Function and Pain } \\
\text { Outcomes }\end{array}$ & Other Outcomes \\
\hline $\begin{array}{l}\text { Ho } 2017^{197} \\
1 \text { month } \\
\text { Duration of pain: } \\
6 \text { years } \\
\text { Fair }\end{array}$ & $\begin{array}{l}\text { A. Acupuncture (77 } \\
\text { randomized/77 } \\
\text { analyzed), } 30 \text { sessions of } \\
\text { abdominal acupuncture } 3 \\
\text { times a week for } 2 \\
\text { weeks. The acupuncture } \\
\text { points CV12, CV4, KI17, } \\
\text { and ST24 were needled } \\
\text { for } 30 \text { minutes with } \\
\text { infrared therapeutic lamp } \\
\text { placed } 30 \text { cm above the } \\
\text { naval. } \\
\text { B. Sham acupuncture } \\
\text { (77 randomized/77 } \\
\text { analyzed), } 30 \text { sessions of } \\
\text { sham abdominal } \\
\text { acupuncture } 3 \text { times a } \\
\text { week for } 2 \text { weeks. Blunt } \\
\text { sham needles were } \\
\text { nonpenetrative and } \\
\text { administered at } \\
\text { nonacupuncture points. }\end{array}$ & $\begin{array}{l}\text { A vs. B } \\
\text { Age: } 46 \text { vs. } 45 \\
\text { Female: } 81 \% \text { vs. } \\
83 \% \\
\text { Pain duration } \\
\text { (years): } 6.0 \text { vs. } 6.0 \\
\text { Use of pain } \\
\text { medications: } 15 \% \text { vs. } \\
13 \% \\
\text { Previous } \\
\text { acupuncture use: } \\
42 \% \text { vs. } 44 \% \\
\text { NPQ, mean: } 41.3 \text { vs. } \\
41.0 \\
\text { Pain VAS, mean: } 6.4 \\
\text { vs. } 6.1 \\
\text { SF-36 PCS, mean: } \\
40.9 \text { vs. } 42.7 \\
\text { SF-36 MCS, mean: } \\
42.9 \text { vs. } 44.3\end{array}$ & $\begin{array}{l}\text { A vs. B } \\
1 \text { month } \\
\text { NPQ, mean } \Delta(95 \% \\
\mathrm{Cl}):-11.9(-14.6 \text { to } \\
-9.2) \text { vs. }-3.3(-5.5 \\
\text { to }-1.0), \mathrm{MD}-8.7 \\
(95 \% \mathrm{Cl}-12.1 \text { to } \\
-5.2) \mathrm{P}<0.001 \\
\text { Pain VAS, mean } \Delta \\
(95 \% \mathrm{Cl}):-2.4(-2.8 \\
\text { to }-1.9) \text { vs. }-0.6 \\
(-0.9 \text { to }-0.2), \mathrm{MD} \\
-1.8(95 \% \mathrm{Cl}-2.4 \text { to } \\
-1.2) \mathrm{P}<0.001\end{array}$ & $\begin{array}{l}\text { A vs. B } \\
1 \text { month } \\
\text { SF-36 PCS, mean } \\
\Delta(95 \% \mathrm{Cl}): 4.1 \\
(3.0 \text { to } 5.3) \text { vs. } 1.3 \\
(0.1 \text { to } 2.5), \mathrm{MD} \\
2.8(95 \% \mathrm{Cl} 1.2 \text { to } \\
4.5), \mathrm{P}=0.003 \\
\mathrm{SF}-36 \mathrm{MCS}, \text { mean } \\
\Delta(95 \% \mathrm{Cl}): 2.0 \\
(0.5 \text { to } 3.5) \text { vs. } \\
-0.3(-2.0 \text { to } 1.4), \\
\mathrm{MD} 2.3(95 \% \mathrm{Cl} \\
-0.0 \text { to } 4.5) \mathrm{P}=\mathrm{NR}\end{array}$ \\
\hline $\begin{array}{l}\text { Liang, } 2011^{198} \\
3 \text { months } \\
\text { Duration of pain, } \\
\text { NR } \\
\text { Fair }\end{array}$ & $\begin{array}{l}\text { A. Active acupuncture, } \\
\text { traditional Chinese, } \\
(\mathrm{n}=93) \\
\text { B. Sham acupuncture } \\
(\mathrm{n}=97) \\
\text { Treatment was } 3 \times \text { /week } \\
\text { for } 3 \text { weeks ( } 9 \text { treatments } \\
\text { total) lasting } 20 \text { minutes } \\
\text { after needling } \\
\text { Both groups received } \\
\text { infrared }\end{array}$ & $\begin{array}{l}\text { A vs. B } \\
\text { Age: } 37 \text { vs. } 37 \text { years } \\
\text { Female: } 72 \% \text { vs. } \\
73 \% \\
\text { NPQ }(0-100 \%): 32.7 \\
\text { vs. } 33.0 \\
\text { Pain VAS (0-10): } 5.3 \\
\text { vs. } 5.5\end{array}$ & $\begin{array}{l}\text { A vs. B } \\
3 \text { months } \\
\text { NPQ: } 19.1 \text { vs. } 25.5, \\
\text { difference }-6.4(95 \% \\
\mathrm{Cl}-9.9 \text { to }-2.9) \\
\text { Pain VAS: } 2.9 \text { vs. } 3.2 \text {, } \\
\text { difference }-0.3(95 \% \\
\mathrm{Cl}-0.75 \text { to } 0.15)\end{array}$ & $\begin{array}{l}\text { A vs. B } \\
3 \text { months } \\
\text { SF-36 physical } \\
\text { functioning (0- } \\
\text { 100): } 84.3 \text { vs. } \\
85.9, P=0.447 \\
\text { SF-36 mental (0- } \\
\text { 100): } 67.1 \text { vs. } \\
61.6, P=0.001\end{array}$ \\
\hline $\begin{array}{l}\text { MacPherson, } \\
2015^{180} \\
1 \text { and } 7 \text { months } \\
\text { Duration of pain, } \\
7 \text { years } \\
\text { Fair }\end{array}$ & $\begin{array}{l}\text { A. Active acupuncture, } \\
\text { traditional Chinese, } \\
\text { ( } n=173) \text { : plus usual care } \\
2 \text { weeks later. } \\
\text { B. Usual care ( } n=172) \text { : } \\
\text { including general and } \\
\text { neck pain-specific } \\
\text { treatments routinely } \\
\text { provided to primary care } \\
\text { patients, such as } \\
\text { prescribed medications } \\
\text { and visits to physical } \\
\text { therapists and other } \\
\text { health care } \\
\text { professionals. } \\
\text { Treatment was } 12 \\
\text { sessions over } 5 \text { months } \\
\text { lasting } 50 \text { minutes }\end{array}$ & $\begin{array}{l}\text { A vs. B } \\
\text { Age: } 52 \text { vs. } 54 \text { years } \\
\text { Female: } 69 \% \text { vs. } \\
69 \% \\
\text { White: } 93 \% \text { vs. } 89 \% \\
\text { Employed: } 61 \% \text { vs. } \\
62 \% \\
\text { Pain duration } \\
\text { (median): } 60 \text { vs. } 96 \\
\text { months } \\
\text { NPQ (0-100\%): } \\
39.64 \text { vs. } 40.46\end{array}$ & $\begin{array}{l}\text { A vs. B } \\
1 \text { month } \\
\text { NPQ: } 35.35 \text { vs. } \\
40.90, \text { difference } \\
-5.56(95 \% \mathrm{Cl}-8.33 \\
\text { to }-2.78) \\
7 \text { months } \\
\text { NPQ: } 37.07 \text { vs. } \\
40.99, \text { difference } \\
-3.92(95 \% \mathrm{Cl}-6.87 \\
\text { to }-0.97)\end{array}$ & $\begin{array}{l}\text { A vs. B } \\
1 \text { month } \\
\text { SF-12v2 physical: } \\
\text { data NR, P=NS } \\
\text { SF-12v2 mental: } \\
\text { data NR, P=NS } \\
7 \text { months } \\
\text { SF-12v2 physical } \\
(0-100): \text { MD } 0.68 \\
(95 \% \text { Cl } 1.08 \text { to } \\
2.44) \\
\text { SF-12v2 mental } \\
(0-100): \text { MD } 1.76 \\
(95 \% \text { Cl } 0.15 \text { to } \\
3.37)\end{array}$ \\
\hline
\end{tabular}




\begin{tabular}{|c|c|c|c|c|}
\hline $\begin{array}{l}\text { Author, Year, } \\
\text { Followup, }{ }^{\mathrm{a}} \\
\text { Pain Duration, } \\
\text { Study Quality }\end{array}$ & Intervention & Population & $\begin{array}{l}\text { Function and Pain } \\
\text { Outcomes }\end{array}$ & Other Outcomes \\
\hline $\begin{array}{l}\text { Sahin, } 2010^{199} \\
3 \text { months } \\
\text { Duration of pain, } \\
\text { NR } \\
\text { Fair }\end{array}$ & $\begin{array}{l}\begin{array}{l}\text { A. Electro-acupuncture } \\
(\mathrm{n}=15)\end{array} \\
\begin{array}{l}\text { B. Sham acupuncture } \\
(\mathrm{n}=16)\end{array} \\
\text { Treatment was } 10 \\
\text { sessions, } 3 \text { sessions per } \\
\text { week, lasting } 30 \text { minutes }\end{array}$ & $\begin{array}{l}\text { A vs. B } \\
\text { Age: } 39 \text { vs. } 35 \text { years } \\
\text { Female: } 100 \% \text { vs. } \\
81 \% \\
\text { University graduate: } \\
54 \% \text { vs. } 94 \% \\
\text { BMI: } 23.9 \text { vs. } 24.6 \\
\text { Pain with motion } \\
\text { VAS (0-10): } 7.38 \text { vs. } \\
6.19 \\
\text { Pain at rest VAS (0- } \\
10): 4.00 \text { vs. } 5.25\end{array}$ & $\begin{array}{l}\text { A vs. B } \\
3 \text { months } \\
\text { Pain with motion } \\
\text { VAS: } 4.50 \text { vs. } 5.38, \\
\text { difference }-0.88 \\
(95 \% \mathrm{Cl}-2.70 \text { to } \\
0.94) \\
\text { Pain at rest VAS: } \\
4.00 \text { vs. } 3.54 \\
\text { difference } 0.46(95 \% \\
\mathrm{Cl}-1.88 \text { to } 2.80)\end{array}$ & NR \\
\hline $\begin{array}{l}\text { Vas, } 2006^{200} \\
6 \text { months } \\
\text { Duration pain, } \\
3.8 \text { years } \\
\text { Fair }\end{array}$ & $\begin{array}{l}\text { A. Active acupuncture, } \\
\text { traditional Chinese, } \\
(n=61) \\
\text { B. Sham TENS ( } n=62) \\
\text { Treatment was } 5 \\
\text { sessions over } 3 \text { weeks } \\
\text { lasting } 30 \text { minutes }\end{array}$ & $\begin{array}{l}\text { A vs. B } \\
\text { Age: } 46 \text { vs. } 47 \text { years } \\
\text { Female: } 75 \% \text { vs. } \\
89 \% \\
\text { Pain duration: } 47 \text { vs. } \\
43 \text { months } \\
\text { Pain VAS with } \\
\text { motion (0-10): } 6.9 \\
\text { vs. } 7.2 \\
\text { NPQ (0-100): } 52.7 \\
\text { vs. } 56.5\end{array}$ & $\begin{array}{l}\text { A vs. B } \\
6 \text { months } \\
\text { (MD from baseline) } \\
\text { Pain VAS with } \\
\text { motion: } 4.1 \text { vs. } 2.7 \\
\text { difference } 1.4(95 \% \\
\text { Cl } 0.3 \text { to } 2.6)\end{array}$ & $\begin{array}{l}\text { A vs. B } \\
6 \text { months } \\
\text { SF-36 PCS: (0- } \\
\text { 100): } 9.3 \text { vs. } 5.3 \text {, } \\
P=0.054 \\
\text { SF-36 MCS: (0- } \\
\text { 100): } 8.0 \text { vs. 5.2, } \\
P=0.351 \\
\text { Rescue } \\
\text { medication (none } \\
\text { or occasional): } \\
87 \%(39 / 45) \text { vs. } \\
68 \%(27 / 40), \text { RR } \\
1.28(95 \% \text { Cl } 1.01 \\
\text { to } 1.64)\end{array}$ \\
\hline $\begin{array}{l}\text { White, } 2004^{201} \\
2,6,12 \text { months } \\
\text { Duration pain, } 6 \\
\text { years } \\
\text { Fair }\end{array}$ & $\begin{array}{l}\text { A. Active acupuncture, } \\
\text { Western technique } \\
\text { based on tender local } \\
\text { and distal points, ( } n=70 \\
\text { randomized/54 analyzed) } \\
\text { B. Sham electro- } \\
\text { acupuncture ( } n=65 \\
\text { randomized/53 analyzed) } \\
\text { Treatment was } 8 \\
\text { sessions over } 4 \text { weeks } \\
\text { lasting } 20 \text { minutes }\end{array}$ & $\begin{array}{l}\text { A vs. B } \\
\text { Age: } 54 \text { vs. } 53 \text { years } \\
\text { Female: } 66 \% \text { vs. } \\
63 \% \\
\text { Pain duration: } 4.8 \text { vs. } \\
7.7 \text { years } \\
\text { NDI (0-50): } 16.8 \text { vs. } \\
17.2 \\
\text { Pain VAS (0-10): } 5.0 \\
\text { vs. } 5.4\end{array}$ & $\begin{array}{l}\text { A vs. B } \\
2 \text { months } \\
\text { NDI: } 11.0 \text { vs. } 12.7, \\
\text { difference }-1.7(95 \% \\
\mathrm{Cl}-4.3 \text { to } 0.9) \\
\text { Pain VAS: } 1.7 \text { vs. } 2.3 \text {, } \\
\text { difference }-0.6 \text { (95\% } \\
\mathrm{Cl}-1.3 \text { to } 0.1) \\
6 \text { months } \\
\text { NDI: } 9.9 \text { vs. } 10.6, \\
\text { difference }-0.7(95 \% \\
\mathrm{Cl}-3.61 \text { to } 2.21) \\
\text { Pain VAS: } 1.9 \text { vs. } 2.1 \text {, } \\
\text { difference }-1.8 \text { (95\% } \\
\mathrm{Cl}-1.1 \text { to } 0.7) \\
12 \text { months } \\
\text { NDI: } 8.9 \text { vs. } 10.7, \\
\text { difference }-1.8(95 \% \\
\mathrm{Cl}-4.84 \text { to } 1.24) \\
\text { Pain VAS: } 2.1 \text { vs. } 2.4 \text {, } \\
\text { difference }-0.3(95 \% \\
\mathrm{Cl}-1.4 \text { to } 0.6)\end{array}$ & $\begin{array}{l}\text { A vs. B } \\
2 \text { months } \\
\text { SF-36 PCS (0- } \\
100): 42.5 \text { vs. } \\
43.8, P=N S \\
\text { SF-36 MCS (0- } \\
\text { 100): } 52.5 \text { vs. } \\
50.3, P=N S\end{array}$ \\
\hline
\end{tabular}




\begin{tabular}{|c|c|c|c|c|}
\hline $\begin{array}{l}\text { Author, Year, } \\
\text { Followup, } \\
\text { Pain Duration, } \\
\text { Study Quality }\end{array}$ & Intervention & Population & $\begin{array}{l}\text { Function and Pain } \\
\text { Outcomes }\end{array}$ & Other Outcomes \\
\hline $\begin{array}{l}\text { Zhang, } 2013^{202} \\
3 \text { and } 6 \text { months } \\
\text { Duration of pain, } \\
6.3 \text { years } \\
\text { Fair }\end{array}$ & $\begin{array}{l}\text { A. Electro-acupuncture, } \\
\text { traditional Chinese } \\
\text { ( } \mathrm{n}=103 \text { randomized/84 } \\
\text { analyzed) } \\
\text { B. Sham laser } \\
\text { acupuncture ( } \mathrm{n}=103 \\
\text { randomized/76 analyzed) } \\
\text { via a mock laser pen } \\
2 \text { minutes, with the pen } \\
\text { at a distance of } 0.5 \text { to } 1 \\
\text { cm from the skin. } \\
\text { Treatment } 3 \times \text { /week for } 3 \\
\text { weeks, } 45 \text { min for } \\
\text { electro-acupuncture and } \\
2 \text { min per point for sham } \\
\text { laser }\end{array}$ & $\begin{array}{l}\text { A vs. B } \\
\text { Age: } 46 \text { years (whole } \\
\text { population) } \\
\text { Female: } 70 \% \text { (whole } \\
\text { population) } \\
\text { NPQ (0-100\%): } 40.7 \\
\text { vs. } 41.1 \\
\text { Pain with motion (0- } \\
\text { 10): } 5.5 \text { vs. } 5.2\end{array}$ & 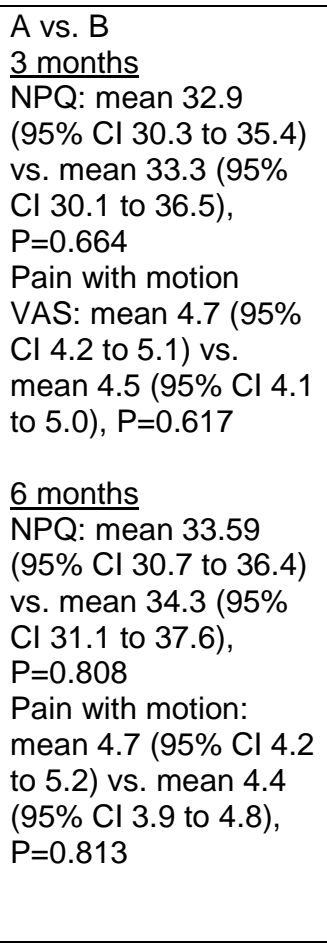 & $\begin{array}{l}\text { A vs. B } \\
3 \text { months } \\
\text { SF-36 PCS (0- } \\
100): \text { mean } 52.8 \\
(95 \% \mathrm{Cl} 53.0 \text { to } \\
53.7) \text { vs. mean } \\
53.3(95 \% \mathrm{Cl} 52.4 \\
\text { to } 54.2), \mathrm{P}=0.982 \\
\text { SF-36 MCS (0- } \\
100): \text { mean } 45.9 \\
(95 \% \mathrm{Cl} 46.0 \text { to } \\
46.8) \text { vs. mean } \\
45.3(95 \% \mathrm{Cl} 44.2 \\
\text { to } 46.4), \mathrm{P}=0.444 \\
\\
6 \text { months } \\
\text { SF-36 PCS: mean } \\
53.0(95 \% \mathrm{Cl} 52.0 \\
\text { to } 53.9) \mathrm{vs} \text {. mean } \\
53.2(95 \% \mathrm{Cl} 52.3 \\
\text { to } 54.0), \mathrm{P}=0.559 \\
\mathrm{SF}-36 \mathrm{MCS} \text { : mean } \\
45.4(95 \% \mathrm{Cl} 44.5 \\
\text { to } 46.3) \mathrm{vs} \text {. mean } \\
44,4(95 \% \mathrm{Cl} 43.4 \\
\text { to } 45.4), \mathrm{P}=0.246\end{array}$ \\
\hline
\end{tabular}

BDI = Beck Depression Inventory; CI = confidence interval; EQ-5D = Euroqol 5-D; MD = mean difference; NDI = Neck

Disability Index; NPQ = Northwick Park Neck Pain Questionnaire; NR = not reported; NS = not statistically significant; NSAID

= nonsteroidal anti-inflammatory drug; SF-36 MCS = Short Form-36 questionnaire Mental Component Summary; SF-36 PCS = Short Form-36 questionnaire Physical Component Summary; SF-MPQ = McGill Pain Questionnaire Short Form; VAS = visual analog scale

${ }^{\text {a }}$ Unless otherwise noted, followup time is calculated from the end of the treatment period

${ }^{\mathrm{b}}$ Estimated from Figure 1 in Birch et al. ${ }^{196}$

\section{Acupuncture Compared With Sham Acupuncture, Usual Care, or a Placebo Intervention}

Acupuncture was associated with slightly greater effects on short-term and intermediate-term function versus sham acupuncture, placebo (sham laser), or usual care (short term, 5 trials, ${ }^{180,197,198,201,202}$ pooled SMD $-0.40,95 \%$ CI -0.64 to -0.17 , $\mathrm{I}^{2}=67.7 \%$; intermediate term, 3 trials, ${ }^{180,201,202}$ pooled SMD $-0.19,95 \%$ CI -0.35 to $-0.02, \mathrm{I}^{2}=0.0 \%$ ) (Figure 30 ). Trials

measured function using the NDI or the NPQ; across trials the SMD ranged from -0.53 to -0.03 in the short term and -0.29 to -0.05 in the intermediate term. None of the trials were rated poor quality. One trial reported no difference in function in the long term (SMD $-0.23,95 \%$ CI -0.61 to 0.16$){ }^{201}$

Acupuncture was associated with slightly greater effect on short-term pain versus controls (5 trials, pooled MD $-0.67,95 \% \mathrm{CI}-1.41$ to $0.08, \mathrm{I}^{2}=83.9 \%$ ), but statistical heterogeneity was large. ${ }^{197-199,201,202}$ (Figure 31). Excluding an outlier trial (pooled MD -1.80, 95\% CI -2.36 to $-1.24)^{197}$ eliminated statistical heterogeneity and resulted in a markedly attenuated effect (MD $-0.27,95 \%$ CI -0.59 to $0.05, \mathrm{I}^{2}=2 \%$ ). Stratified analyses according to the type of control (sham or placebo laser) resulted in similar estimates. Trials reported no differences in pain between acupuncture versus controls in the intermediate term ( 3 trials, pooled MD $0.45,95 \% \mathrm{CI}-0.34$ to $\left.1.25, \mathrm{I}^{2}=58.5 \%\right)^{200-202}$ or long term ( 1 trial, $\mathrm{MD}-0.35,95 \% \mathrm{CI}-1.34$ to 0.64$) .{ }^{201}$ 
In general, acupuncture did not improve quality of life compared with sham intervention in the short term or intermediate term as reported in four trials ${ }^{198,200-202}$ (Table 23).

No trial evaluated effects of acupuncture on use of opioid therapies or health care utilization.

\section{Acupuncture Compared With Pharmacological Therapy}

Two small poor-quality trials evaluated acupuncture versus NSAIDs. One trial $(n=27)$ compared acupuncture three times per week for 3 weeks versus $80 \mathrm{mg}$ of Zaltoprofen alone three times per day for 3 weeks. ${ }^{217}$ The other trial $(n=30)$ compared 14 sessions of acupuncture versus $500 \mathrm{mg}$ of Trilisate per day for 8 weeks. ${ }^{196}$ In the short term, one trial reported no difference in NDI (MD -0.4, 95\% CI -4.6 to 3.8). ${ }^{217}$ Both trials reported no difference between groups in pain as measured by the McGill Pain Questionnaire ${ }^{196}$ or VAS. ${ }^{217}$ One trial found no differences between groups in the Beck Depression Index, the SF-36, or the EQ-5D in the short term ${ }^{217}$ (Table 23).

\section{Acupuncture Compared With Exercise Therapy}

No trial of acupuncture versus exercise met inclusion criteria.

\section{Harms}

Five of the eight trials assessing acupuncture reported harms. ${ }^{180,198,200-202}$ No serious adverse events (defined as involving death, hospitalization, persistent disability, or a life-threatening risk in one trial ${ }^{180}$ and undefined in the other four studies) were reported in any trial. The most commonly reported nonserious adverse effects in people receiving acupuncture included numbness/discomfort (2.7\%), fainting (1.1\%), and bruising (1.1\%). 
Figure 30. Acupuncture versus sham acupuncture, a placebo intervention, or usual care for chronic neck pain: effects on function

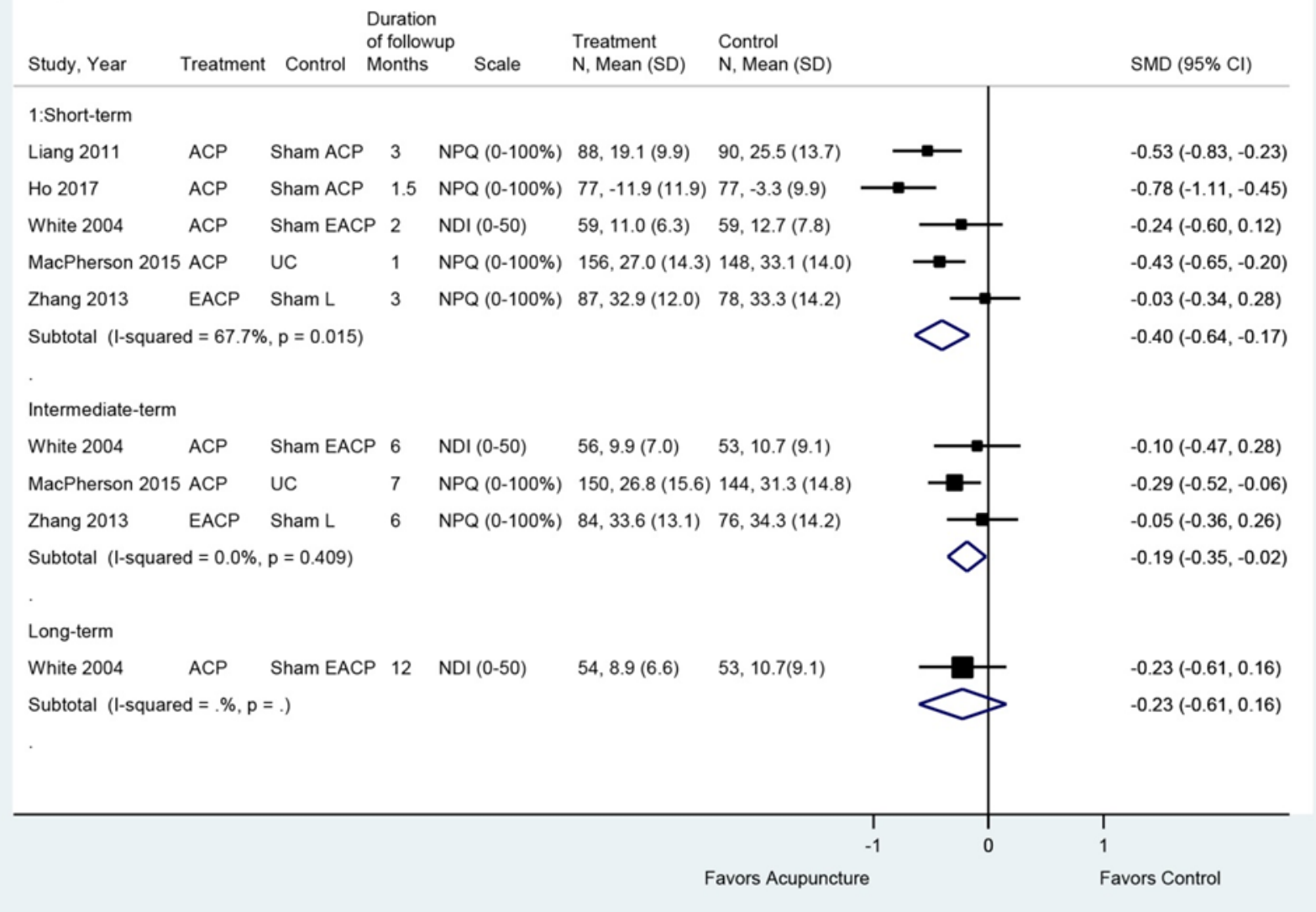

ACP = traditional needle acupuncture; CI = confidence interval; EACP = electroacupuncture; NDI = Neck Disability Index; NPQ = Northwick Park Questionnaire; SD = standard deviation; Sham L = sham laser; SMD = standardized mean difference; UC = usual care 
Figure 31. Acupuncture versus sham acupuncture or a placebo intervention for chronic neck pain: effects on pain

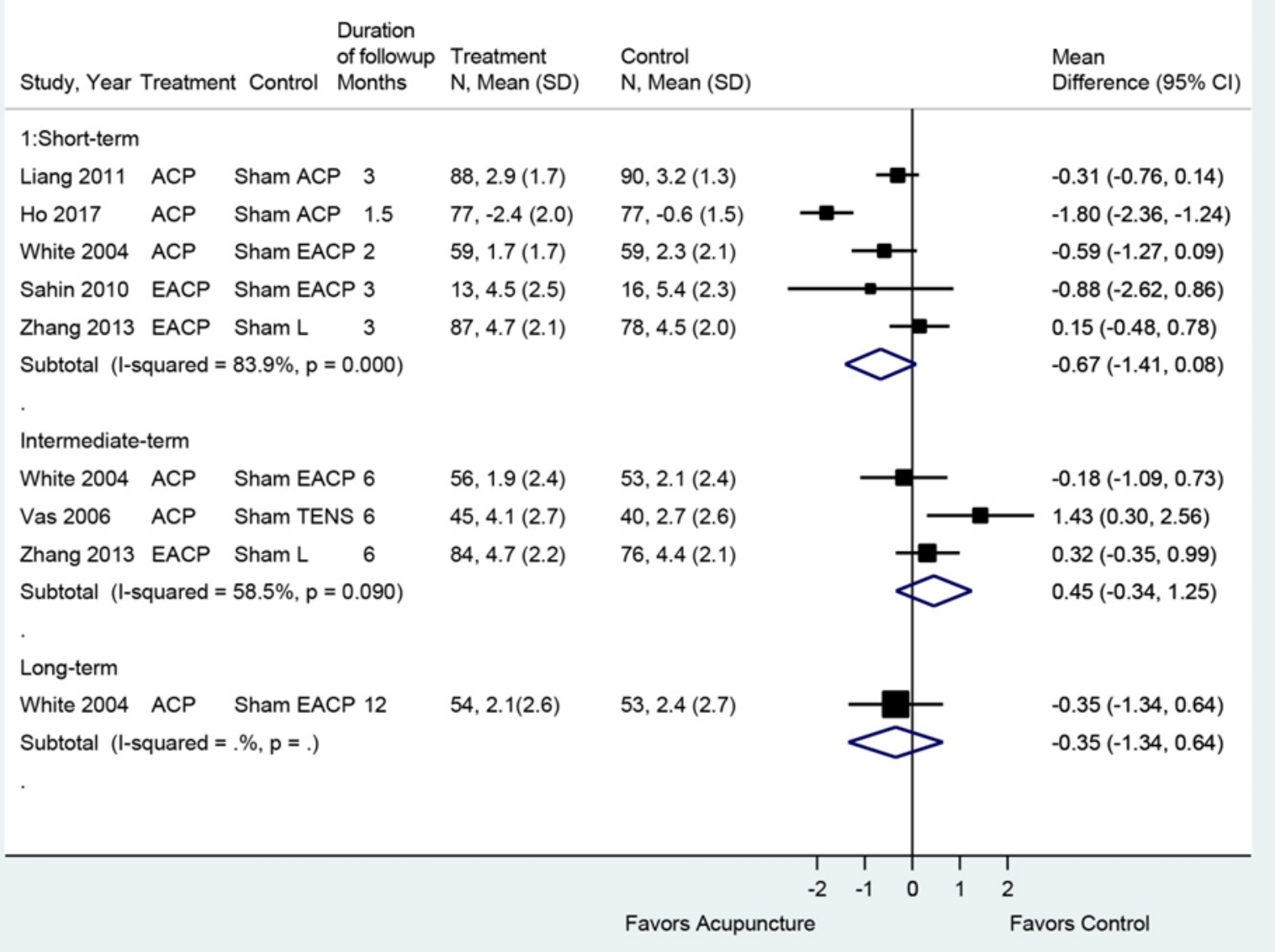

$\mathrm{ACP}$ = traditional needle acupuncture; $\mathrm{CI}=$ confidence interval; $\mathrm{EACP}=$ electroacupuncture; $\mathrm{SD}=$ standard deviation; $\mathrm{Sham} \mathrm{L}=$ sham laser; SMD = standardized mean difference; TENS = transcutaneous electrical stimulation; UC = usual care

\section{Key Question 3: Osteoarthritis}

\section{Exercise for Osteoarthritis of the Knee}

\section{Key Points}

- Exercise was associated with slightly greater improvement in function compared with usual care, no treatment, or sham intervention short term ( 7 trials, pooled SMD -0.25 , $95 \%$ CI -0.4 to $-0.09, \mathrm{I}^{2}=0 \%$ ), intermediate term ( 9 trials [excluding outlier trial] pooled SMD $-0.78,95 \%$ CI -1.37 to $-0.19, \mathrm{I}^{2}=91.4 \%$ ), and long term ( 2 trials, pooled SMD $-0.24,95 \% \mathrm{CI}-0.37$ to $-0.11, \mathrm{I}^{2}=0 \%$ ) (SOE: moderate for short term; low for intermediate and long term).

- Exercise was associated with a slight improvement in pain short term (7 trials, pooled difference -0.44 on a 0 to 10 scale, $95 \%$ CI -0.82 to $-0.05, \mathrm{I}^{2}=35 \%$ ) versus usual care, no treatment, or sham intervention (SOE: moderate), and with moderately greater effect 
on pain in the intermediate term ( 9 trials, pooled difference -1.61 on a 0 to 10 scale, $95 \%$ $\mathrm{CI}-2.51$ to $-0.72, \mathrm{I}^{2}=91 \%$ ) compared with usual care, an attention control, or no treatment (SOE: low). Long term, there was no clear difference between exercise and improvement in pain but data were limited ( 2 trials, difference $-0.24,95 \% \mathrm{CI}-0.72$ to 0.24) (SOE: low).

- No trial evaluated exercise versus pharmacological therapy.

- Harms were not well reported. Across seven trials, one reported minor temporary increase in pain with exercise, four others found no difference in worsening pain versus controls, and one reported no difference in falls or death (SOE: moderate).

\section{Detailed Synthesis}

Twenty-one publications from 18 randomized controlled trials ${ }^{40-60}$ that evaluated exercise interventions for the treatment of knee OA met the inclusion criteria (Table 24 and Appendix D). Seven trials evaluated muscle performance exercise versus attention control ${ }^{44,45,47,50,51,59}$ or no treatment. ${ }^{42,46,58}$ In six trials, the interventions consisted of combined exercise approaches compared with usual care, ${ }^{40,48,49,53,56}$ an attention control, ${ }^{57}$ or no treatment. ${ }^{43}$ Muscle performance exercises were a component of 6 trials. ${ }^{40,43,48,49,53,56,57}$ One trial had an aerobic exercise arm that consisted of a facility-based, 1-hour walking program three times per week over 3 months, and it used an attention control. ${ }^{44,50,51}$ A single trial evaluated a mobility exercise program based on Mechanical Diagnosis and Therapy (MDT) versus a waitlist comparator, where patients were allowed to continue receiving usual care. ${ }^{54}$ One trial evaluated gait training (guided strategies to optimize knee movements during treadmill walking with computerized motion analysis with visual feedback) versus usual care. ${ }^{55}$ Three trials tested exercise programs as a part of physiotherapy care compared to usual care or sham. ${ }^{41,52,60}$ The duration of exercise programs ranged from 2 to 24 weeks; the number of exercise sessions ranged from 4 to 36 . No trials comparing exercise with a pharmacological intervention were identified.

Sample sizes ranged from 50 to 786. Across the trials, the majority of patients were female (51\% to 88\%) with mean ages ranging from 56 to 75 years. Five trials specifically included patients with bilateral knee OA. ${ }^{42,45-47,59}$ Five trials were conducted in the United States or Canada, ${ }^{44,49-51,53-56}$ five in Europe, ${ }^{48,52,57,58,60}$ five in Taiwan, ${ }^{42,45-47,59}$ two in Australia or New Zealand, ${ }^{40,41}$ and one in Brazil. ${ }^{43}$ Most trials had short (6 trials) $)^{40,48,54,55,58,60}$ or intermediate followup (10 trials). ${ }^{42,43,45-47,49,55-57,59}$ Three trials reported long-term outcomes. ${ }^{49-51,53,57}$

Twelve trials were rated fair quality (one at short-term followup ${ }^{55}$ ), ${ }^{40,41,44,45,47-54,58}$ and eight trials poor quality, ${ }^{42,43,46,56,57,59,60}$ including one at intermediate-term followup ${ }^{55}$ (Appendix E). In the fair-quality trials, the main methodological limitation was a lack of blinding for the patients or care providers. Additional limitations in the poor-quality trials included unclear randomization and allocation concealment methods, unclear use of intention to treat, unclear baseline differences between intervention groups, and attrition not reported or unacceptable. 
Table 24. Osteoarthritis of the knee: exercise

\begin{tabular}{|c|c|c|c|c|}
\hline $\begin{array}{l}\text { Author, Year, } \\
\text { Followup, } \\
\text { Pain } \\
\text { Duration, Study } \\
\text { Quality }\end{array}$ & Intervention & Population & $\begin{array}{l}\text { Function and Pain } \\
\text { Outcomes }\end{array}$ & $\begin{array}{l}\text { Other } \\
\text { Outcomes }\end{array}$ \\
\hline $\begin{array}{l}\text { Abbott, } 2013^{40} \\
9.75 \text { months } \\
\text { Duration of } \\
\text { diagnosis: Mean } \\
2.5 \text { to } 2.8 \text { years } \\
\text { Fair }\end{array}$ & $\begin{array}{l}\text { A. Exercise ( } \mathrm{n}=51 / 29 \text { knee OA): } \\
7 \text { sessions of strengthening, } \\
\text { stretching, and neuromuscular } \\
\text { control over } 9 \text { weeks, with } 2 \\
\text { booster sessions at week } 16 \text {. } \\
\text { Individual exercises prescribed } \\
\text { as needed. Home exercise } \\
\text { prescribed } 3 \text { times weekly } \\
\text { B. Usual care ( } n=51 / 28 \text { knee } \\
\text { OA) }\end{array}$ & $\begin{array}{l}\text { A vs. B (total } \\
\text { population, } \\
\text { includes hip } \\
\text { OA) } \\
\text { Age: } 67 \text { vs. } 66 \\
\text { years } \\
\text { Female: 52\% } \\
\text { vs. } 58 \% \\
\text { Percent hip OA: } \\
\text { 43\% vs. } 45 \% \\
\text { Percent knee } \\
\text { OA: } 57 \% \text { vs. } \\
\text { 55\% } \\
\text { Percent both } \\
\text { hip OA and } \\
\text { knee OA: } 20 \% \\
\text { vs. } 26 \% \\
\text { Baseline } \\
\text { WOMAC } \\
\text { (0-240): } 95.5 \\
\text { vs. 93.8 }\end{array}$ & $\begin{array}{l}\text { A vs. B (knee OA only) } \\
\text { A vs. C } \\
9.75 \text { months } \\
\text { WOMAC mean change } \\
\text { from baseline: }-12.7 \text { vs. } \\
-31.5\end{array}$ & None \\
\hline
\end{tabular}




\begin{tabular}{|c|c|c|c|c|}
\hline $\begin{array}{l}\text { Author, Year, } \\
\text { Followup, } \\
\text { Pain } \\
\text { Duration, Study } \\
\text { Quality }\end{array}$ & Intervention & Population & $\begin{array}{l}\text { Function and Pain } \\
\text { Outcomes }\end{array}$ & $\begin{array}{l}\text { Other } \\
\text { Outcomes }\end{array}$ \\
\hline $\begin{array}{l}\text { Bennell, } 2005^{41} \\
3 \text { months } \\
\text { Duration of pain: } \\
9.6 \text { vs. } 8.7 \text { years } \\
\text { Fair }\end{array}$ & $\begin{array}{l}\text { A. Neuromuscular Re-education } \\
\text { (Physiotherapy) ( } \mathrm{n}=73) \\
\text { Knee taping; exercises to retrain } \\
\text { the quadriceps, hip, and back } \\
\text { muscles; balance exercises; } \\
\text { thoracic spine mobilization; and } \\
\text { soft tissue massage. individual } \\
\text { sessions lasting } 30 \text { to } 45 \\
\text { minutes once weekly for four } \\
\text { weeks, then fortnightly for eight } \\
\text { weeks. Thrice-daily } \\
\text { standardized home exercises. } \\
\text { B. Control ( } n=67) \\
\text { Placebo: sham ultrasound and } \\
\text { topical nontherapeutic gel. } 30 \text { to } \\
45 \text { minutes once weekly for four } \\
\text { weeks, then fortnightly for eight } \\
\text { weeks. }\end{array}$ & $\begin{array}{l}\text { A vs. B } \\
\text { Age: } 67 \text { vs. } 70 \\
\text { years } \\
\text { Female: } 68 \% \\
\text { vs. } 66 \% \\
\text { WOMAC } \\
\text { Physical } \\
\text { Function (0-68): } \\
27.6 \text { vs. } 28.4 \\
\text { WOMAC Pain } \\
\text { (0-20): } 8.2 \text { vs. } \\
8.0 \\
\text { VAS Pain on } \\
\text { movement (0- } \\
10): 5.3 \text { vs. } 5.2 \\
\text { KPS (0-36): } \\
16.6 \text { vs. } 16.4 \\
\text { KPS Frequency } \\
\text { (0-30): } 23.5 \text { vs. } \\
22.8\end{array}$ & $\begin{array}{l}\text { A vs. B } \\
3 \text { months } \\
\text { Responders, global } \\
\text { improvement in pain: } \\
59 \% \text { vs. } 50 \%, P=0.309 \\
\text { Responders, VAS pain: } \\
58 \% \text { vs. } 42 \%, P=0.069 \\
\text { WOMAC, Physical } \\
\text { Function: } 20.0 \text { vs. } 21.7 \text {, } \\
\text { MD }-0.9 \text { ( } 95 \% \text { Cl }-4.4 \text { to } \\
2.7) \\
\text { WOMAC, Pain: } 5.8 \text { vs. } \\
6.0, \mathrm{MD}-0.4(95 \% \mathrm{Cl} \\
-1.5 \text { to } 0.7) \\
\text { VAS pain on movement: } \\
3.2 \text { vs. } 3.5, \mathrm{MD}-0.5 \\
\text { (95\% } \mathrm{Cl}-1.2 \text { to } 0.3) \\
\text { KPS, Severity: } 13.5 \text { vs. } \\
14.3, \mathrm{MD}-1.0(95 \% \mathrm{Cl} \\
-2.5 \text { to } 0.6) \\
\text { KPS, Frequency: } 19.4 \text { vs. } \\
20.3, \mathrm{MD}-1.7(95 \% \mathrm{Cl} \\
-3.5 \text { to } 0.1)\end{array}$ & 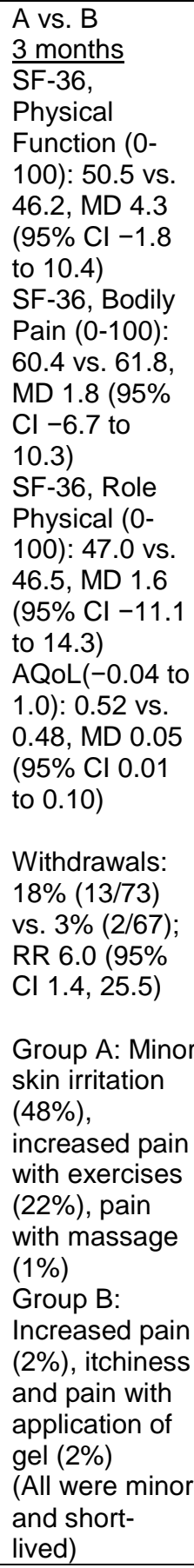 \\
\hline
\end{tabular}




\begin{tabular}{|c|c|c|c|c|}
\hline $\begin{array}{l}\text { Author, Year, } \\
\text { Followup, } \\
\text { Pain } \\
\text { Duration, Study } \\
\text { Quality }\end{array}$ & Intervention & Population & $\begin{array}{l}\text { Function and Pain } \\
\text { Outcomes }\end{array}$ & $\begin{array}{l}\text { Other } \\
\text { Outcomes }\end{array}$ \\
\hline $\begin{array}{l}\text { Chen, } 2014^{42} \\
6 \text { months } \\
\text { Duration of pain: } \\
10-144 \text { months } \\
\text { Poor }\end{array}$ & $\begin{array}{l}\text { A. Exercise }(n=30) \text { : } \\
3 \text { sessions per week for } 8 \\
\text { weeks. Sessions consisted of a } \\
20 \text { minutes of hot packs and } 5 \\
\text { minutes of passive range of } \\
\text { motion exercises on a stationary } \\
\text { bike, followed by an isokinetic } \\
\text { muscle-strengthening exercise } \\
\text { program } \\
\text { B. Control }(n=30): \\
\text { Details NR }\end{array}$ & $\begin{array}{l}\text { A + B } \\
\text { Age: } 63 \\
\text { Females: } 85 \% \\
\text { A vs. B } \\
\text { Lequesne Index } \\
(0-26): 7.8 \text { vs. } \\
8.0 \\
\text { Pain VAS (0- } \\
\text { 10): } 5.5 \text { vs. } 5.6\end{array}$ & $\begin{array}{l}\text { A vs. B } \\
6 \text { months } \\
\text { Lequesne Index: } 5.4 \text { vs. } \\
7.6,(\mathrm{MD}-2.2,95 \% \mathrm{Cl} \\
-3.1 \text { to }-1.3) \\
\text { Pain VAS: } 4.0 \text { vs. } 6.5, \\
\text { (MD }-2.5,95 \% \mathrm{Cl}-3.3 \text { to } \\
-1.7)\end{array}$ & $\begin{array}{l}\text { A vs. B } \\
6 \text { months } \\
\frac{\text { Intolerable }}{\text { knee pain: }} \\
10 \%(3 / 30) \text { vs. } \\
0 \%(0 / 30) \\
\text { RR=infinity, } \\
P=0.08\end{array}$ \\
\hline $\begin{array}{l}\text { Dias, } 2003^{43} \\
6 \text { months } \\
\text { Duration of pain: } \\
\text { NR } \\
\text { Poor }\end{array}$ & $\begin{array}{l}\text { A. Exercise ( } n=25) \text { : } \\
12 \text { exercise sessions twice a } \\
\text { week for the } 6 \text { month study } \\
\text { period in addition to three } \\
\text { supervised walks of } 40 \text { minutes } \\
\text { each week. Exercise sessions } \\
\text { consisted stretching, concentric } \\
\text { and eccentric isotonic } \\
\text { progressive resistance } \\
\text { exercises, and closed kinetic } \\
\text { chain weight-bearing exercises } \\
\text { B. Control group (n=25): } \\
\text { Subjects were instructed to } \\
\text { follow the instructions given at } \\
\text { an educational session that all } \\
\text { participants attended (see } \\
\text { information below) } \\
\text { All patients: One-hour } \\
\text { educational session consisting } \\
\text { of a lecture on disease } \\
\text { characteristics, joint protection, } \\
\text { pain management, and } \\
\text { strategies to overcome } \\
\text { difficulties in activities of daily } \\
\text { life }\end{array}$ & $\begin{array}{l}\text { A vs. B } \\
\text { Age, median: } \\
74 \text { vs. } 76 \\
\text { Female: } 84 \% \\
\text { vs. } 92 \% \\
\\
\text { Lequesne } \\
\text { Index, median } \\
\text { (0-24): } 12 \text { vs. } \\
12.5 \\
\text { HAQ, median } \\
\text { (0-3): } 1 \text { vs. } 1\end{array}$ & $\begin{array}{l}\text { A vs. } B \\
6 \text { months } \\
\text { Lequesne Index, median: } \\
4.3 \text { vs. } 13, P=0.001 \\
\text { HAQ, median: } 0.3 \text { vs. } \\
1.1, P=0.006\end{array}$ & $\begin{array}{l}\text { A vs. B } \\
6 \text { months } \\
\text { SF-36 } \\
\text { functional } \\
\text { capacity, } \\
\text { median (0- } \\
\text { 100): } 77.5 \text { vs. } \\
40, P<0.001 \\
\text { SF-36 physical } \\
\text { role limitation, } \\
\text { median (0- } \\
100): 92.5 \text { vs. } \\
75, P=0.001 \\
\text { SF-36 bodily } \\
\text { pain, median } \\
\text { (0-100): } 100 \\
\text { vs. } 0, P=0.002 \\
\text { SF-36 general } \\
\text { health, median } \\
(0-100): 100.5 \\
\text { vs. } 51, \\
P=0.021 \\
S F-36 \text { vitality, } \\
\text { median }(0- \\
100): 93.5 \text { vs. } \\
87, P=0.027 \\
\text { Adverse } \\
\text { Events: NR }\end{array}$ \\
\hline
\end{tabular}




\begin{tabular}{|c|c|c|c|c|}
\hline $\begin{array}{l}\text { Author, Year, } \\
\text { Followup, }{ }^{\text {a }} \\
\text { Pain } \\
\text { Duration, Study } \\
\text { Quality }\end{array}$ & Intervention & Population & $\begin{array}{l}\text { Function and Pain } \\
\text { Outcomes }\end{array}$ & $\begin{array}{l}\text { Other } \\
\text { Outcomes }\end{array}$ \\
\hline $\begin{array}{l}\text { Ettinger, } 1997^{44} \\
\text { (index trial) } \\
\text { Pennix 2002 } 2^{51} \\
\text { (substudy looking } \\
\text { at baseline } \\
\text { depressive } \\
\text { symptoms) } \\
\text { FAST trial } \\
6 \text { months, } 15 \\
\text { months } \\
\text { Duration of pain: } \\
\text { NR } \\
\text { Fair }\end{array}$ & $\begin{array}{l}\text { A. Aerobic Exercise Program } \\
\text { (n=144) } \\
\text { 3-month facility-based walking } \\
\text { program of } 3 \text { times per week for } \\
1 \text { hour. Each session consisted } \\
\text { of a 10-minute warm-up and } \\
\text { cool-down phase, including slow } \\
\text { walking and flexibility stretches, } \\
\text { and a 40-minute period of } \\
\text { walking at an intensity } \\
\text { equivalent to } 50 \% \text { to } 70 \% \text { of the } \\
\text { participants' heart rate reserve. } \\
\text { Followed by 15-month home- } \\
\text { based walking program. } \\
\text { B. Resistance Exercise } \\
\text { Program (n=146) } \\
3-\text { month supervised facility- } \\
\text { based program, with } 3 \text { one-hour } \\
\text { sessions per week, and a15- } \\
\text { month home-based program. } \\
\text { Each session consisted of a 10- } \\
\text { minute warm-up and cool-down } \\
\text { phase and a } 40-\text { minute phase } \\
\text { consisting of } 2 \text { sets of } 12 \\
\text { repetitions of } 9 \text { exercises. } \\
\text { C. Attention Control (n=149) } \\
\text { attended, during the first } 3 \\
\text { months, monthly group sessions } \\
\text { on education related to arthritis } \\
\text { management, including time for } \\
\text { discussions and social } \\
\text { gathering. Later, participants } \\
\text { were called bimonthly (months } \\
4-6) \text { or monthly (months } 7-18 \text { ) to } \\
\text { maintain health updates and } \\
\text { provide support }\end{array}$ & $\begin{array}{l}\text { A vs. B vs. C } \\
\text { Age: } 69 \text { vs. } 68 \\
\text { vs. } 69 \text { years } \\
\text { Female: } 69 \% \\
\text { vs. } 73 \% \text { vs. } \\
69 \% \\
\text { African- } \\
\text { American: } 24 \% \\
\text { vs. } 28 \% \text { vs. } \\
26 \% \\
\text { Baseline } \\
\text { function NR }\end{array}$ & $\begin{array}{l}\text { A vs. C } \\
\text { Average across all time- } \\
\text { points: } \\
\text { FAST Physical Disability } \\
\text { Scale } \\
\text { Total: } 1.72 \text { vs. } 1.90 \\
\text { Ambulation subscale: } \\
2.22 \text { vs. } 2.64 \\
\text { Transfers subscale: } 1.75 \\
\text { vs. } 1.92 \\
\text { Pain: } 2.14 \text { vs. } 2.40 \\
\text { B vs. C } \\
\text { Average across all time- } \\
\text { points: } \\
\text { FAST Physical Disability } \\
\text { Scale } \\
\text { Total: } 1.74 \text { vs. } 1.90 \\
\text { Ambulation subscale: } \\
2.37 \text { vs. } 2.64 \\
\text { Transfers subscale: } 1.72 \\
\text { vs. } 1.92 \\
\text { Pain: } 2.2 \text { vs. } 2.40\end{array}$ & 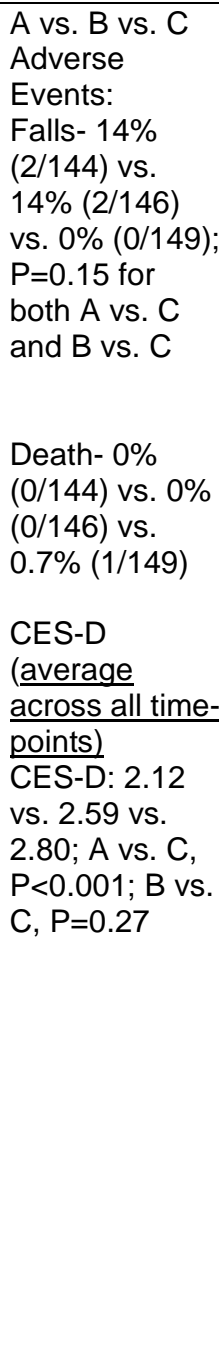 \\
\hline
\end{tabular}




\begin{tabular}{|c|c|c|c|c|}
\hline $\begin{array}{l}\text { Author, Year, } \\
\text { Followup, } \\
\text { Pain } \\
\text { Duration, Study } \\
\text { Quality }\end{array}$ & Intervention & Population & $\begin{array}{l}\text { Function and Pain } \\
\text { Outcomes }\end{array}$ & $\begin{array}{l}\text { Other } \\
\text { Outcomes }\end{array}$ \\
\hline $\begin{array}{l}\text { FAST trial (same } \\
\text { trial as Ettinger } \\
1997 \text { and Pennix } \\
2002 \text { above): } \\
\text { substudy in only } \\
\text { patients with no } \\
\text { baseline ADL } \\
\text { disability } \\
6 \text { and } 15 \text { months } \\
\text { Duration of pain: } \\
\text { NR } \\
\text { Fair }\end{array}$ & $\begin{array}{l}\text { A. Aerobic Exercise Program } \\
\text { (n=88) } \\
\text { 3-month facility-based walking } \\
\text { program of } 3 \text { times per week for } \\
1 \text { hour. Each session consisted } \\
\text { of a } 10 \text {-minute warm-up and } \\
\text { cool-down phase, including slow } \\
\text { walking and flexibility stretches, } \\
\text { and a 40-minute period of } \\
\text { walking at an intensity } \\
\text { equivalent to } 50 \% \text { to } 70 \% \text { of the } \\
\text { participants' heart rate reserve. } \\
\text { Followed by } 15-\text { month home- } \\
\text { based walking program. } \\
\text { B. Resistance Exercise } \\
\text { Program (n=82) } \\
3 \text {-month supervised facility- } \\
\text { based program, with } 3 \text { one-hour } \\
\text { sessions per week, and a15- } \\
\text { month home-based program. } \\
\text { Each session consisted of a } 10- \\
\text { minute warm-up and cool-down } \\
\text { phase and a } 40-\text {-minute phase } \\
\text { consisting of } 2 \text { sets of } 12 \\
\text { repetitions of } 9 \text { exercises. } \\
\text { C. Attention Control (n=80) } \\
\text { attended, during the first } 3 \\
\text { months, monthly group sessions } \\
\text { on education related to arthritis } \\
\text { management, including time for } \\
\text { discussions and social } \\
\text { gathering. Later, participants } \\
\text { were called bimonthly (months } \\
4-6) \text { or monthly (months } 7-18 \text { ) to } \\
\text { maintain health updates and } \\
\text { provide support }\end{array}$ & $\begin{array}{l}\text { A vs. B vs. C } \\
\text { Age: } 70 \text { vs. } 69 \\
\text { vs. } 69 \text { years } \\
\text { Female: } 66 \% \\
\text { vs. } 72 \% \text { vs. } \\
66 \% \\
\text { African- } \\
\text { American: } 25 \% \\
\text { vs. } 21 \% \text { vs. } \\
28 \% \\
\text { Disability (scale } \\
\text { NR): } 1.7 \text { vs. } 1.7 \\
\text { vs. } 1.6 \\
\text { Pain intensity } \\
\text { (1-6): } 2.2 \text { vs. } \\
2.1 \text { vs. } 2.1\end{array}$ & 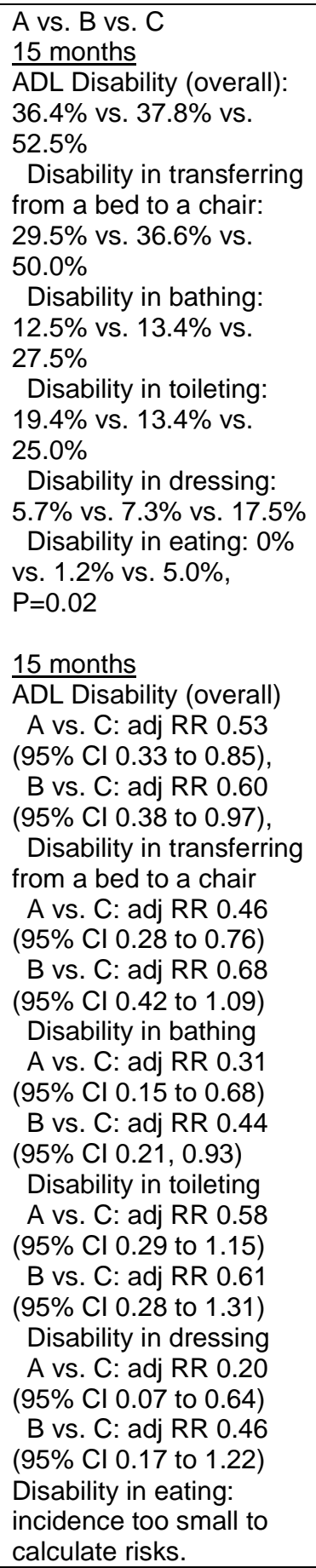 & $\begin{array}{l}\text { A vs. B vs. C } \\
15 \text { months } \\
\text { Increased } \\
\text { severity of } \\
\text { knee OA } \\
\text { leading to } \\
\text { withdrawal: } \\
n=3 \text { (not } \\
\text { reported by } \\
\text { exercise } \\
\text { group) }\end{array}$ \\
\hline
\end{tabular}




\begin{tabular}{|c|c|c|c|c|}
\hline $\begin{array}{l}\text { Author, Year, } \\
\text { Followup, } \\
\text { Pain } \\
\text { Duration, Study } \\
\text { Quality }\end{array}$ & Intervention & Population & $\begin{array}{l}\text { Function and Pain } \\
\text { Outcomes }\end{array}$ & $\begin{array}{l}\text { Other } \\
\text { Outcomes }\end{array}$ \\
\hline $\begin{array}{l}\text { Huang, } 2003^{46} \\
10 \text { months } \\
\text { Duration of pain: } \\
\text { range, } 0.33(4 \\
\text { months) to } 9 \text { years } \\
\text { Poor }\end{array}$ & 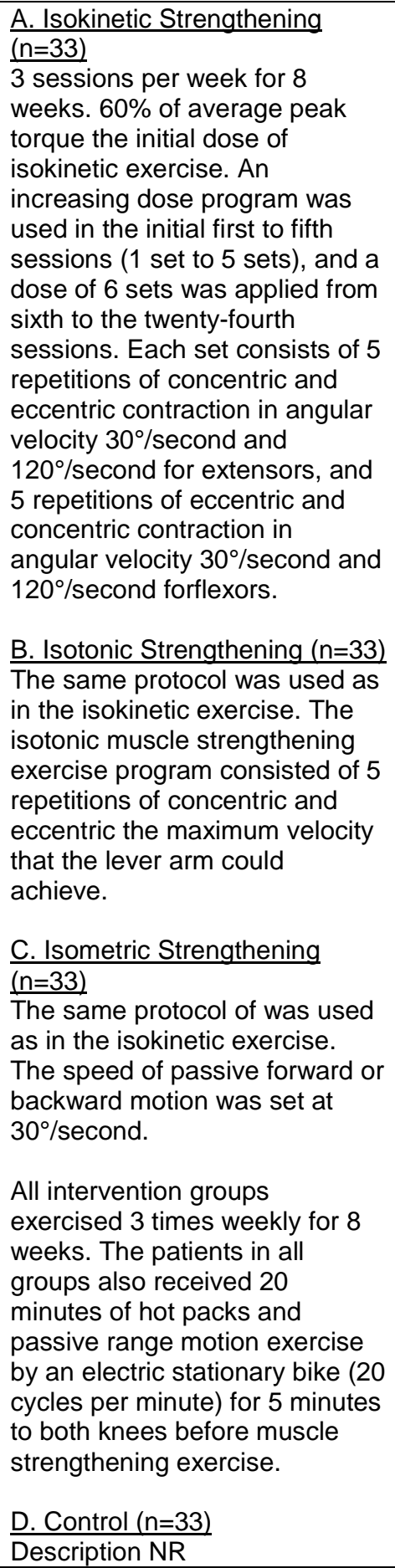 & $\begin{array}{l}\text { A+B+C+D } \\
\text { Age: } 62 \text { years } \\
\text { Female: } 70 \% \\
\text { A vs. B vs. C } \\
\text { vs. D } \\
\text { Lequesne Index } \\
\text { (0-26): } 6.9 \text { vs. } \\
7.1 \text { vs. } 6.8 \text { vs. } \\
7.2 \\
\text { VAS pain (0- } \\
10): 4.8 \text { vs. } 4.6 \\
\text { vs. } 4.7 \text { vs. } 4.6\end{array}$ & $\begin{array}{l}\text { A vs. D } \\
10 \text { months } \\
\text { Lequesne Index: } \\
3.1 \text { vs. } 7.6, \mathrm{MD}-4.5 \\
\text { ( } 95 \% \mathrm{Cl}-5.3 \text { to }-3.7) \text {, } \\
\text { VAS Pain: } 2.5 \text { vs. } 6.1 ; \\
\text { P<0.05 } \\
\text { B vs. D } \\
10 \text { months } \\
\text { Lequesne Index: } 3.1 \text { vs. } \\
7.6, \text { MD }-3.6 \text { (95\% Cl } \\
-4.4 \text { to }-2.8) \\
\text { VAS Pain: } 2.0 \text { vs. } 6.1 ; \\
\text { P<0.05 } \\
\text { C vs. D } \\
10 \text { months } \\
\text { Lequesne Index: } 4.8 \text { vs. } \\
7.6, \text { MD }-2.8 \text { (95\% Cl } \\
-3.6 \text { to }-2.0) \\
\text { VAS Pain: } 3.2 \text { vs. } 6.1 ; \\
\text { P<0.05 }\end{array}$ & $\begin{array}{l}\text { A vs. B vs. C } \\
\text { vs. D } \\
10 \text { months } \\
\text { Withdrawals: } \\
3 \%(1 / 33) \text { vs. } \\
6 \%(2 / 33) \text { vs. } \\
3 \%(1 / 33) \text { vs. } \\
18 \%(6 / 33) \\
\text { Withdrawals } \\
\text { RR (95\% Cl): } \\
\text { A vs. D: } 0.17 \\
(0.02,1.3) \\
\text { B vs. D: } 0.33 \\
(0.07,1.53) \\
\text { C vs. D: } 0.17 \\
\text { (0.02, 1.3) } \\
\text { Stopped } \\
\text { therapeutic } \\
\text { exercise due to } \\
\text { intolerable pain } \\
\text { during } \\
\text { exercise: } \\
12.1 \%(4 / 33) \\
\text { vs. } 6.1 \%(2 / 33) \\
\text { vs. } 6.1 \%(2 / 33)\end{array}$ \\
\hline
\end{tabular}




\begin{tabular}{|c|c|c|c|c|}
\hline $\begin{array}{l}\text { Author, Year, } \\
\text { Followup, } \\
\text { Pain } \\
\text { Duration, Study } \\
\text { Quality }\end{array}$ & Intervention & Population & $\begin{array}{l}\text { Function and Pain } \\
\text { Outcomes }\end{array}$ & $\begin{array}{l}\text { Other } \\
\text { Outcomes }\end{array}$ \\
\hline $\begin{array}{l}\text { Huang, } 2005^{47} \\
10 \text { months } \\
\text { Duration of pain: } \\
0.42 \text { (5 months) to } \\
12 \text { years } \\
\text { Fair }\end{array}$ & $\begin{array}{l}\text { A. Isokinetic Exercise ( } n=35) \\
3 \text { times per week for } 8 \text { weeks. } \\
\text { Began with } 60 \% \text { of the mean } \\
\text { peak torque, increasing dose } \\
\text { program was used in the first } 5 \\
\text { sessions ( } 1 \text { set to } 5 \text { sets), and a } \\
\text { dose of } 6 \text { sets was applied from } \\
\text { the sixth to twenty-fourth } \\
\text { sessions, with the density rising } \\
\text { from } 60 \% \text { to } 80 \% \text { of the mean } \\
\text { peak torque as the patient was } \\
\text { able. Each set consisted of } 5 \\
\text { repetitions of concentric } \\
\text { contraction in angular velocities } \\
\text { of } 30 \% / s e c o n d \text { and } 120 \% \text { second } \\
\text { for extensors, and } 5 \text { repetitions } \\
\text { of eccentric and concentric } \\
\text { (Ecc/Con) contractions in } \\
\text { angular velocities of } 30^{\circ} / \text { second } \\
\text { and } 120 \% / s e c o n d \text { for flexors. } \\
\text { B. Control ( } n=35 \text { ) } \\
\text { Warm-up exercises only }\end{array}$ & $\begin{array}{l}\text { A+B } \\
\text { Age: } 65 \text { years } \\
\text { Female: } 81 \% \\
\text { A vs. B } \\
\text { Lequesne } \\
\text { Index(1-26): } 7.6 \\
\text { vs. } 7.4 \\
\text { VAS pain(0-10): } \\
5.3 \text { vs. } 5.4\end{array}$ & $\begin{array}{l}\text { A vs. B } \\
10 \text { months } \\
\text { Lequesne Index: } 5.8 \text { vs. } \\
8.1, \mathrm{MD}-2.3(95 \% \mathrm{Cl} \\
-3.2 \text { to }-1.4) \\
\text { VAS Pain: } 3.9 \text { vs. } 6.6 \\
P<0.05\end{array}$ & $\begin{array}{l}\text { A vs. B } \\
10 \text { months } \\
\text { Withdrawals } \\
11 \%(4 / 35) \text { vs. } \\
11 \%(4 / 35) \\
\text { Discontinuation } \\
\text { of exercise due } \\
\text { to intolerable } \\
\text { pain during } \\
\text { exercise: } 14 \% \\
\text { (5/35) vs. NA }\end{array}$ \\
\hline $\begin{array}{l}\text { Huang } 2005^{45} \\
10 \text { months } \\
\text { Duration of pain: } \\
0.5 \text { ( } 6 \text { mos.) to } 11 \\
\text { years } \\
\text { Fair }\end{array}$ & $\begin{array}{l}\text { A. Isokinetic Exercise ( } n=30) \\
3 \text { times per week for } 8 \text { weeks. } \\
\text { Began with } 60 \% \text { of the average } \\
\text { peak torque. Intensity of } \\
\text { isokinetic exercise increased } \\
\text { from } 1 \text { set to } 5 \text { sets during the } \\
\text { first through fifth sessions and } \\
\text { remained at } 6 \text { sets for the } \\
\text { remaining } 6 \text { th through } 24 \text { th } \\
\text { sessions. Each set consisted of } \\
5 \text { repetitions of concentric } \\
\text { contraction in angular velocities } \\
\text { of } 30 \% \text { and } 120 \% \text { for } \\
\text { extensors, and } 5 \text { repetitions of } \\
\text { eccentric and concentric } \\
\text { contractions in angular } \\
\text { velocities of } 30 \% \text { and } 120 \% \text { for } \\
\text { flexors. } \\
\text { B. Control ( } n=30 \text { ) } \\
\text { Heat for } 20 \text { minutes and } 5 \\
\text { minutes of passive range of } \\
\text { motion on bike only. }\end{array}$ & $\begin{array}{l}\text { A+B } \\
\text { Age: } 62 \text { (range, } \\
\text { 42-72) years } \\
\text { Female: } 81 \% \\
\text { A vs. B } \\
\text { Lequesne } \\
\text { Index(1-26): } 6.7 \\
\text { vs. } 7.0 \\
\text { VAS pain(0-10): } \\
4.9 \text { vs. } 4.8\end{array}$ & $\begin{array}{l}\text { A vs. B } \\
10 \text { months } \\
\text { Lequesne Index: } 5.1 \text { vs. } \\
7.8, \mathrm{MD}-2.7(95 \% \mathrm{Cl} \\
-3.8 \text { to }-1.6) \\
\text { VAS Pain: } 3.5 \text { vs. } 6.0 \text {; } \\
\text { P<0.05 }\end{array}$ & $\begin{array}{l}\text { A vs. B } \\
10 \text { months } \\
\text { Withdrawals } \\
13 \%(4 / 30) \text { vs. } \\
13 \%(4 / 30) \\
\text { Discontinuation } \\
\text { of exercise due } \\
\text { to intolerable } \\
\text { pain during } \\
\text { exercise: } 17 \% \\
(5 / 30) \text { vs. NA }\end{array}$ \\
\hline
\end{tabular}




\begin{tabular}{|c|c|c|c|c|}
\hline $\begin{array}{l}\text { Author, Year, } \\
\text { Followup, } \\
\text { Pain } \\
\text { Duration, Study } \\
\text { Quality }\end{array}$ & Intervention & Population & $\begin{array}{l}\text { Function and Pain } \\
\text { Outcomes }\end{array}$ & $\begin{array}{l}\text { Other } \\
\text { Outcomes }\end{array}$ \\
\hline $\begin{array}{l}\text { Lund, } 2008^{48} \\
3 \text { months } \\
\text { Duration of pain: } \\
8.5 \text { vs. } 7.8 \text { vs. } 4.5\end{array}$ & $\begin{array}{l}\text { A. Aquatic Exercise ( } n=27): 2 x \\
\text { per week for } 8 \text { weeks. warm-up, } \\
\text { strengthening and endurance } \\
\text { exercise, balance exercise and } \\
\text { stretching exercise. Each } \\
\text { session lasted } 50 \text { min, } \\
\text { comprising } 10 \text { min warm-up, } 20 \\
\text { min resistance exercises, } 10 \\
\text { min balance and stabilizing } \\
\text { exercises, } 5 \text { min lower limb } \\
\text { stretches and } 5 \text { min cool-down } \\
\text { period. Compliance was } 92 \% \text {. } \\
\text { B. Land-based Exercise ( }=25 \text { ): } \\
2 x \text { per week for } 8 \text { weeks. warm- } \\
\text { up, strengthening/endurance } \\
\text { exercise, balance exercise and } \\
\text { stretching exercise. Each } \\
\text { session lasted } 50 \text { min, } \\
\text { comprising } 10 \text { min warm-up, } 20 \\
\text { min resistance exercises, } 10 \\
\text { min balance and stabilizing } \\
\text { exercises, } 5 \text { min lower limb } \\
\text { stretches and } 5 \text { min cool-down } \\
\text { period. Compliance was } 85 \% \text {. } \\
\text { C. Control ( } n=27 \text { ): } \\
\text { No exercise } \\
\text { All } 3 \text { groups were asked to } \\
\text { continue any other treatment as } \\
\text { usual. }\end{array}$ & $\begin{array}{l}\text { A vs. B vs. C } \\
\text { Age: } 65 \text { vs. } 68 \\
\text { vs. } 70 \text { years } \\
\text { Female: } 83 \% \\
\text { vs. } 88 \% \text { vs. } \\
66 \% \\
\text { KOOS } \\
\text { symptom (0- } \\
100): 50.5 \text { vs. } \\
50.9 \text { vs. } 50.1 \\
\text { KOOS pain (0- } \\
100): 47.1 \text { vs. } \\
41.0 \text { vs. } 37.9 \\
\text { KOOS Activities } \\
\text { of Daily Living } \\
\text { (0-100): } 44.7 \\
\text { vs. } 40.6 \text { vs. } \\
39.6 \\
\text { KOOS Sport (0- } \\
100): 79.1 \text { vs. } \\
75.6 \text { vs. } 70.0 \\
\text { KOOS Quality } \\
\text { of Life (0-100): } \\
63.7 \text { vs. } 57.0 \\
\text { vs. } 60.8 \\
\text { VAS Pain at } \\
\text { rest (0-100): } \\
29.8 \text { vs. } 23.3 \\
\text { vs. } 15.5 \\
\text { VAS Pain } \\
\text { during walking } \\
\text { (0-100): } 59.8 \\
\text { vs. } 53.0 \text { vs. } \\
48.5\end{array}$ & 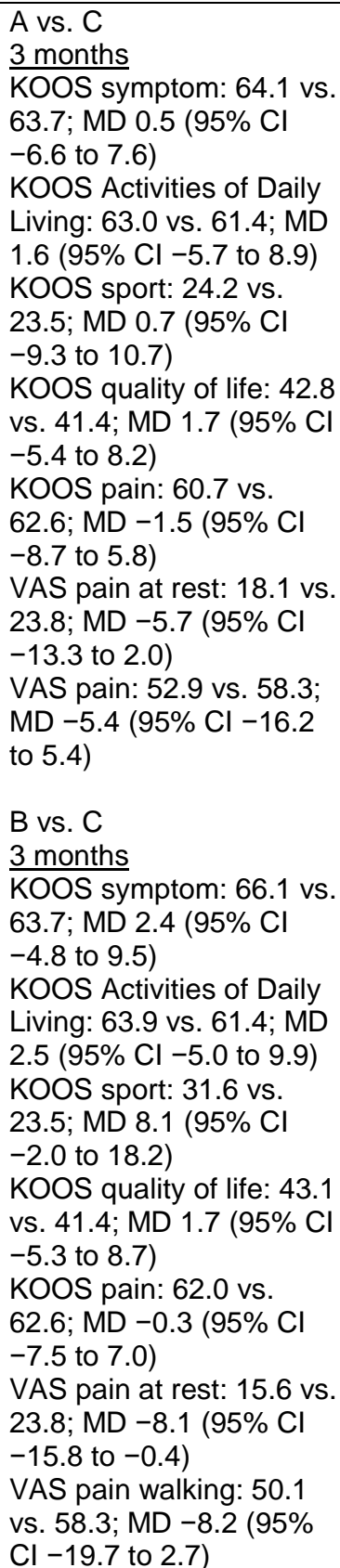 & $\begin{array}{l}\text { A vs. B vs. C } \\
3 \text { months } \\
\text { Withdrawals: } \\
4 \%(1 / 27) \text { vs. } \\
20 \%(5 / 25) \text { vs. } \\
7 \%(2 / 27) \\
\text { A vs. C: RR } \\
0.5(95 \% \mathrm{Cl} \\
0.05,5.2) \\
\text { B vs. C: RR } \\
2.5 \text { (95\% Cl } \\
0.6,12.7) \\
\text { Increased pain } \\
\text { during and } \\
\text { after exercise: } \\
11 \%(3 / 27) \text { vs. } \\
32 \% \text { (8/25) vs. } \\
\text { NR } \\
\text { Swollen knees: } \\
0 \%(0 / 27) \text { vs. } \\
12 \% \text { (3/25) vs. } \\
\text { NR } \\
\text { Withdrawals } \\
\text { due to adverse } \\
\text { events: 0\% } \\
\text { (0/27) vs. } 12 \% \\
\text { (3/25) vs. NR }\end{array}$ \\
\hline
\end{tabular}




\begin{tabular}{|c|c|c|c|c|}
\hline $\begin{array}{l}\text { Author, Year, } \\
\text { Followup, } \\
\text { Pain } \\
\text { Duration, Study } \\
\text { Quality }\end{array}$ & Intervention & Population & $\begin{array}{l}\text { Function and Pain } \\
\text { Outcomes }\end{array}$ & $\begin{array}{l}\text { Other } \\
\text { Outcomes }\end{array}$ \\
\hline $\begin{array}{l}\text { Messier, } 2004^{49} \\
\text { Rejeski, } 2002^{53} \\
3,6 \text { and18 months } \\
\text { Duration of pain: } \\
\text { NR } \\
\text { Fair }\end{array}$ & $\begin{array}{l}\text { A. Exercise ( } \mathrm{n}=80 \text { ): } \\
\text { Three 1-hour sessions per week } \\
\text { done at the study facility for } 4 \\
\text { months. Option to undergo a } 2 \\
\text { month transition phase } \\
\text { alternating between facility and } \\
\text { home sessions, after which they } \\
\text { carried out the program at } \\
\text { home. Sessions consisted of } 15 \\
\text { minutes of aerobic exercises, } 15 \\
\text { minutes of resistance-training, } \\
\text { an additional } 15 \text { minutes of } \\
\text { aerobic exercises, and a } 15 \\
\text { minute cool down phase. } \\
\text { B. Control (n=78): } \\
1 \text { hour sessions monthly for } \\
\text { three months consisting of } \\
\text { presentations on OA, obesity, } \\
\text { and exercise and a question } \\
\text { and answer session. Monthly } \\
\text { phone contact was maintained } \\
\text { for months } 4-6 \text { and bimonthly } \\
\text { phone contact was maintained } \\
\text { for months } 7-18 \text {. } \\
\text { All subjects: Instructed to } \\
\text { continue use of all medications } \\
\text { and other treatments as } \\
\text { prescribed by their personal } \\
\text { physicians }\end{array}$ & $\begin{array}{l}\text { A vs. B } \\
\text { Age: } 69 \text { vs. } 69 \\
\text { Female: } 74 \% \\
\text { vs. } 68 \% \\
\text { WOMAC } \\
\text { physical } \\
\text { function (0-68): } \\
24.0 \text { vs. } 26.0 \\
\text { WOMAC pain } \\
(0-20): 6.6 \text { vs. } \\
7.3\end{array}$ & $\begin{array}{l}\text { A vs. B } \\
6 \text { months } \\
\text { WOMAC physical } \\
\text { function*: } 22.0 \text { vs. } 22.0 \\
\text { WOMAC pain: } 6.2 \text { vs. } \\
6.2, \text { MD } 0.0(95 \% \mathrm{Cl}-0.2 \\
\text { to } 0.2) \\
18 \text { months } \\
\text { WOMAC physical } \\
\text { function: } 21.0 \text { vs. } 22.6 \\
\text { WOMAC physical } \\
\text { function, mean change: } \\
3.1 \text { vs. } 3.4 \\
\text { WOMAC pain: } 6.2 \text { vs. } \\
6.0, \text { MD } 0.2(95 \% \text { Cl } 0.04 \\
\text { to } 0.4)\end{array}$ & $\begin{array}{l}\text { A vs. B } \\
3 \text { months } \\
\text { Accident } \\
\text { related to } \\
\text { treatment: } 1 \% \\
(1 / 80) \text { vs. } 0 \% \\
(0 / 78) \\
6-18 \text { months } \\
\text { (average; } \\
\text { reported by } \\
\text { Rejeski 2002) } \\
\text { SF-36 PCS: } \\
37.1 \text { vs. 34.4 } \\
\text { SF-36 PCS, } \\
\text { adjusted mean: } \\
37.6 \text { vs. } 35.3 \\
\text { SF-36 MCS: } \\
52.9 \text { vs. } 53.5 \\
\text { SF-36 MCS, } \\
\text { adjusted mean: } \\
54.1 \text { vs. } 53.7\end{array}$ \\
\hline $\begin{array}{l}\text { Quilty, } 2003^{52} \\
2.5 \text { months, } 10.5 \\
\text { months } \\
\text { Duration of pain: } \\
\text { NR } \\
\text { Fair }\end{array}$ & $\begin{array}{l}\frac{\text { A. Combination (Physiotherapy) }}{(\mathrm{n}=40)} \\
9 \text { sessions over a } 10 \text { week } \\
\text { period. Sessions consisted of } \\
\text { patellar taping, } 7 \text { individualized } \\
\text { exercises, posture correction, } \\
\text { and footwear advice. All } \\
\text { exercises were performed } 10 \\
\text { times each, } 5 \text { times a day } \\
\text { B. Control ( } n=43 \text { ): } \\
\text { Baseline discussion with the } \\
\text { physiotherapist concerning } \\
\text { diagnosis, prognosis, footwear, } \\
\text { weight reduction, and activity. } \\
\text { General exercise was } \\
\text { encouraged but no specific } \\
\text { quadriceps exercises were } \\
\text { advised }\end{array}$ & $\begin{array}{l}\text { A vs. B } \\
\text { Age: } 69 \text { vs. } 67 \\
\text { years } \\
\text { WOMAC } \\
\text { Function (0-68): } \\
27.4 \text { vs. } 27.8 \\
\text { VAS pain (0- } \\
\text { 100): } 51.0 \text { vs. } \\
53.4\end{array}$ & $\begin{array}{l}\text { A vs. B } \\
2.5 \text { months } \\
\text { WOMAC function: } 26.5 \\
\text { vs. 27.5; Adjusted MD } \\
\text {-0.6 (95\% Cl -3.7, 2.4) } \\
\text { VAS Pain: } 42.8 \text { vs. 50.5; } \\
\text { Adjusted MD -6.4 (95\% } \\
\text { Cl -15.3, 2.4) } \\
10.5 \text { months } \\
\text { WOMAC function: } 29.7 \\
\text { vs. 28.3; Adjusted MD } \\
\text { 1.7 (95\% Cl -1.8, 5.2) } \\
\text { VAS Pain: 48.1 vs. 54.1; } \\
\text { Adjusted MD -4.9 (95\% } \\
\text { Cl -13.6, 3.8) }\end{array}$ & $\begin{array}{l}\text { A vs. B } \\
\text { Withdrawals } \\
2 \%(1 / 43) \text { vs. } \\
0 \%(0 / 44) \\
\text { Adverse } \\
\text { Events: None }\end{array}$ \\
\hline
\end{tabular}




\begin{tabular}{|c|c|c|c|c|}
\hline $\begin{array}{l}\text { Author, Year, } \\
\text { Followup, } \\
\text { Pain } \\
\text { Duration, Study } \\
\text { Quality }\end{array}$ & Intervention & Population & $\begin{array}{l}\text { Function and Pain } \\
\text { Outcomes }\end{array}$ & $\begin{array}{l}\text { Other } \\
\text { Outcomes }\end{array}$ \\
\hline $\begin{array}{l}\text { Rosedale, } 2014^{54} \\
2.5 \text { months } \\
\text { Duration of pain: } \\
\text { NR } \\
\text { Fair }\end{array}$ & $\begin{array}{l}\text { A. Exercise ( } n=120 \text { ): } \\
\text { given end-range exercises in } \\
\text { the direction they had } \\
\text { responded to, to be performed } \\
10 \text { times every } 2 \text { to } 3 \text { hours. A } \\
\text { nonresponder subgroup was } \\
\text { given exercises to strengthen } \\
\text { quadriceps and aerobic } \\
\text { exercises. All subjects in the } \\
\text { exercise group attended } 4 \text { to } 6 \\
\text { physiotherapy sessions, } 2 \text { to } 3 \\
\text { assessment sessions lasting up } \\
\text { to } 1 \text { hour and the rest followup } \\
\text { sessions lasting } 20 \text { minutes, } \\
\text { over a } 2 \text { week period. } \\
\text { B. Waiting list (n=60): Subjects } \\
\text { were followed up in the } \\
\text { orthopedic department at the } \\
\text { surgeon's discretion and } \\
\text { continued receiving their usual } \\
\text { care. }\end{array}$ & $\begin{array}{l}\text { A vs. B vs. C } \\
\text { Age: } 66 \text { vs. } 64 \\
\text { Female: } 56 \% \\
\text { vs. } 60 \% \\
\text { Median } \\
\text { comorbidities: } 3 \\
\text { vs. } 3 \\
\text { KOOS function } \\
\text { (0-100): } 56 \text { vs. } \\
51 \\
\text { KOOS function } \\
\text { in sport and } \\
\text { recreation(0- } \\
100): 22 \text { vs. } 20 \\
\text { KOOS pain(0- } \\
100): 51 \text { vs. } 46 \\
\text { P4 pain scale: } \\
21 \text { vs. } 23 \\
\text { KOOS knee } \\
\text { symptoms(0- } \\
100): 50 \text { vs. } 48 \\
\text { KOOS quality } \\
\text { of life(0-100): } \\
28 \text { vs. } 27\end{array}$ & 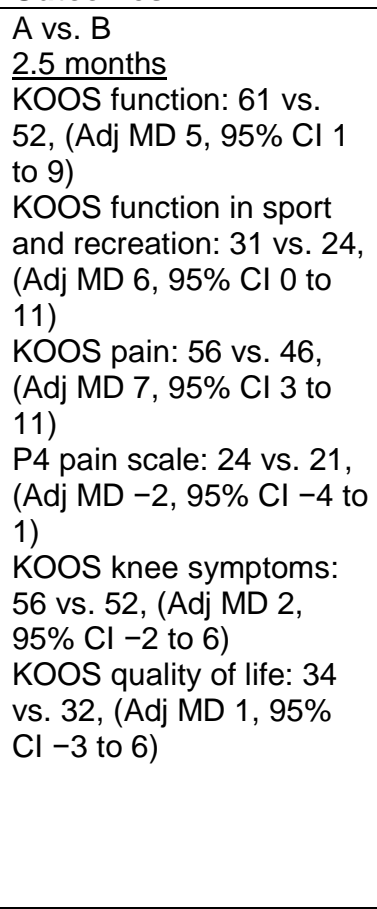 & NR \\
\hline $\begin{array}{l}\text { Segal, } 2015^{55} \\
3 \text { and } 9 \text { months } \\
\text { Duration of pain: } \\
\text { NR } \\
\text { Fair (3 months) } \\
\text { Poor (9 months) }\end{array}$ & $\begin{array}{l}\text { A. Gait Training ( } \mathrm{n}=24) \text { : } \\
\text { guided strategies to optimize } \\
\text { knee movements during } \\
\text { treadmill walking; computerized } \\
\text { motion analysis with visual } \\
\text { biofeedback; individualized } \\
\text { home programs from physical } \\
\text { therapist; Twice weekly } \\
\text { sessions (45 minutes) for } 12 \\
\text { weeks ( } 24 \text { total sessions) } \\
\text { B. Usual Care (n=18) } \\
\text { Usual care for knee OA and } \\
\text { were not asked to make } \\
\text { changes in their lifestyle (e.g., } \\
\text { annual visit to their physician, } \\
\text { use of pain medications, knee } \\
\text { surgery and/or physical } \\
\text { therapy); ask to keep a diary }\end{array}$ & $\begin{array}{l}\text { A vs. B } \\
\text { Age: } 70 \text { vs. } 69 \\
\text { years } \\
\text { Female: } 76 \% \\
\text { vs. } 53 \% \\
\text { Race: NR } \\
\text { LLFDI basic } \\
\text { lower limb } \\
\text { function score: } \\
65.8 \text { vs. } 63.5 \\
\text { KOOS Pain: } \\
62.7 \text { vs. } 59.8 \\
\text { KOOS } \\
\text { Symptoms: } \\
60.1 \text { vs. } 63.0\end{array}$ & $\begin{array}{l}\text { A vs. B, between group } \\
\text { difference in change } \\
\text { score compared with } \\
\text { baseline } \\
3 \text { months } \\
\text { LLFDI basic lower limb } \\
\text { function score: } 2.3 \text { (95\% } \\
\text { Cl -1.8 to } 6.3) \\
\text { KOOS Pain: } 3.7 \text { (95\% Cl } \\
-4.7 \text { to } 12.1) \\
\text { KOOS Symptoms: } 6.2 \\
\text { (95\% Cl -2.9 to } 15.4) \\
9 \text { months } \\
\text { LLFDI basic lower limb } \\
\text { function score: } 1.0(95 \% \\
\text { Cl -7.4 to } 9.4) \\
\text { KOOS Pain: } 7.2 \text { (95\% Cl } \\
-2.0 \text { to } 16.5) \\
\text { KOOS Symptoms: } 6.0 \\
\text { (95\% Cl -6.2 to } 18.2)\end{array}$ & NR \\
\hline
\end{tabular}




\begin{tabular}{|c|c|c|c|c|}
\hline $\begin{array}{l}\text { Author, Year, } \\
\text { Followup, } \\
\text { Pain } \\
\text { Duration, Study } \\
\text { Quality }\end{array}$ & Intervention & Population & $\begin{array}{l}\text { Function and Pain } \\
\text { Outcomes }\end{array}$ & $\begin{array}{l}\text { Other } \\
\text { Outcomes }\end{array}$ \\
\hline $\begin{array}{l}\text { Sullivan, } 1998^{56} \\
10 \text { months } \\
\text { Duration of pain: } \\
\text { NR } \\
\text { Poor }\end{array}$ & $\begin{array}{l}\text { A. Exercise ( } n=52 \text { ): } \\
3 \text { group sessions of } 10-15 \\
\text { subjects per week were done } \\
\text { for } 8 \text { weeks. Sessions were } \\
\text { structured as a hospital-based } \\
\text { supervised fitness walking and } \\
\text { supportive patient education } \\
\text { program. Sessions consisted of } \\
\text { stretching and strengthening } \\
\text { exercises, expert speakers, } \\
\text { group discussions, instructions } \\
\text { in safe walking techniques, and } \\
\text { up to } 30 \text { minutes of walking. At } \\
\text { the end of the } 8 \text { week treatment } \\
\text { period, subjects were } \\
\text { encouraged to continue walking } \\
\text { and given guidelines for } \\
\text { managing individualized } \\
\text { programs of fitness walking. } \\
\text { B. Usual care (n=50): Subjects } \\
\text { continued to receive the } \\
\text { standard routine medical care } \\
\text { they had been receiving prior to } \\
\text { enrollment in the study. } \\
\text { Subjects were interviewed } \\
\text { weekly during the } 8 \text { week } \\
\text { treatment period about their } \\
\text { functional and daily activities. }\end{array}$ & $\begin{array}{l}\text { A vs. B } \\
\text { Age: } 71 \text { vs. } 68 \\
\text { Female: } 77 \% \\
\text { vs. } 90 \% \\
\text { AIMS physical } \\
\text { activity } \\
\text { subscale (0- } \\
\text { 10): } 6.3 \text { vs. } 6.4 \\
\text { AIMS arthritis } \\
\text { impact } \\
\text { subscale (0- } \\
\text { 10): } 4.6 \text { vs. } 4.5 \\
\text { AIMS pain } \\
\text { subscale (0- } \\
\text { 10): } 4.9 \text { vs. } 5.5 \\
\text { Pain VAS (0- } \\
\text { 10): } 4.1 \text { vs. } 6.3 \\
\text { AIMS general } \\
\text { health } \\
\text { perception } \\
\text { subscale (0- } \\
\text { 10): NR }\end{array}$ & $\begin{array}{l}\text { A vs. B } \\
10 \text { months } \\
\text { AIMS physical activity } \\
\text { subscale: } 6.1 \text { vs. } 6.2, \mathrm{MD} \\
-0.1,(95 \% \mathrm{Cl}-1.7 \text { to } \\
1.5) \\
\text { AIMS arthritis impact } \\
\text { subscale: } 3.3 \text { vs. } 3.8, \mathrm{MD} \\
-0.5,(95 \% \mathrm{Cl}-1.8 \text { to } \\
0.8) \\
\text { AIMS pain subscale: } 4.6 \\
\text { vs. } 5.5, \mathrm{MD}-0.9,(95 \% \\
\mathrm{CI}-2.2 \text { to } 0.4) \\
\text { Pain VAS: } 5.0 \text { vs. } 5.4, \\
\text { MD }-0.4,(95 \% \mathrm{Cl}-2.0 \text { to } \\
1.2) \\
\text { AIMS general health } \\
\text { perception subscale: } 3.7 \\
\text { vs. } 3.3, \mathrm{MD} 0.4(95 \% \mathrm{Cl} \\
-1.0 \text { to } 1.8)\end{array}$ & NR \\
\hline
\end{tabular}




\begin{tabular}{|c|c|c|c|c|}
\hline $\begin{array}{l}\text { Author, Year, } \\
\text { Followup, } \\
\text { Pain } \\
\text { Duration, Study } \\
\text { Quality }\end{array}$ & Intervention & Population & $\begin{array}{l}\text { Function and Pain } \\
\text { Outcomes }\end{array}$ & $\begin{array}{l}\text { Other } \\
\text { Outcomes }\end{array}$ \\
\hline $\begin{array}{l}\text { Thomas, } 2002^{57} \\
6 \text { months, } 12 \\
\text { months, } 18 \text { months, } \\
24 \text { months } \\
\text { Duration of pain: } \\
\text { NR } \\
\text { Poor }\end{array}$ & $\begin{array}{l}\text { A. Exercise ( } \mathrm{n}=470 \text { ): } \\
\text { Two year, self-paced program } \\
\text { that started with four } 30 \text { minute } \\
\text { visits in the first } 2 \text { months } \\
\text { followed by visits every } 6 \\
\text { months. Designed to maintain } \\
\text { and improve strength of } \\
\text { muscles around the knee, range } \\
\text { of motion at the knee joint, and } \\
\text { locomotor function. } 121 \text { of the } \\
470 \text { patients also received } \\
\text { attention control which } \\
\text { consisted of monthly phone } \\
\text { calls by a study researcher that } \\
\text { sought to monitor symptoms } \\
\text { and offer simple advice on knee } \\
\text { pain management. } 114 \text { of the } \\
470 \text { patients received the } \\
\text { attention control and a placebo } \\
\text { tablet in addition to the exercise } \\
\text { program. The remaining } 235 \\
\text { participate in the exercise } \\
\text { program only.* } \\
\text { B. Control (n=316): } \\
160 \text { subjects received attention } \\
\text { control consisted of monthly } \\
\text { phone calls by a study } \\
\text { researcher that sought to } \\
\text { monitor symptoms and offer } \\
\text { simple advice on knee pain } \\
\text { management. } 78 \text { subjects took } \\
\text { a placebo tablet. } 78 \text { patients } \\
\text { had no contact with the } \\
\text { researchers between } \\
\text { assessment visits. }\end{array}$ & $\begin{array}{l}\text { A vs. B } \\
\text { Age: } 62 \text { vs. } 62 \\
\text { Female: } 63 \% \\
\text { vs. } 66 \% \\
\text { WOMAC pain } \\
\text { score(0-20): } \\
7.15 \text { vs. } 7.35\end{array}$ & $\begin{array}{l}\text { A vs. B } \\
6 \text { months } \\
\text { WOMAC physical } \\
\text { function, MD }(95 \% \mathrm{Cl}) \text { : } \\
\text { NR } \\
\text { WOMAC pain, MD }(95 \% \\
\mathrm{Cl}):-0.6(-1.0 \text { to }-0.2) \\
24 \text { months } \\
\text { WOMAC physical } \\
\text { function, MD }(95 \% \mathrm{Cl}) \text { : } \\
-2.6(-4.1 \text { to }-1.1) \\
\text { WOMAC pain: }-0.82 \\
(-1.3 \text { to }-0.3)\end{array}$ & $\begin{array}{l}\text { A vs. B } \\
6 \text { months } \\
\text { HADS: NR } \\
\text { SF-36: NR } \\
24 \text { months } \\
\text { HADS: NR } \\
\text { (NS) } \\
\text { SF-36: NR } \\
\text { (NS) }\end{array}$ \\
\hline $\begin{array}{l}\text { Thorstensson, } \\
2005^{58} \\
5 \text { months } \\
\text { Duration of pain: } \\
\text { NR } \\
\text { Fair }\end{array}$ & $\begin{array}{l}\text { A. Exercise }(n=30): 1 \text { hour } \\
\text { group exercise sessions of } 2 \text { to } \\
9 \text { participants, twice a week for } \\
6 \text { weeks. Sessions consisted of } \\
\text { weight-bearing exercises to } \\
\text { increase postural control and to } \\
\text { increase endurance and } \\
\text { strength in the lower extremity. } \\
\text { Patients were given daily } \\
\text { exercises to perform at home. } \\
\text { B. Control group ( } n=31) \text { : } \\
\text { Subjects were told not to make } \\
\text { any lifestyle changes. Subjects } \\
\text { met with the physical therapist } \\
\text { at baseline, at } 6 \text { weeks, and at } 6 \\
\text { months }\end{array}$ & $\begin{array}{l}\text { A vs. B } \\
\text { Age: } 55 \text { vs. } 57 \\
\text { Female: } 50 \% \\
\text { vs. } 52 \% \\
\text { KOOS ADL (0- } \\
\text { 100): } 69 \text { vs. } 71 \\
\text { KOOS Pain (0- } \\
\text { 100): } 60 \text { vs. } 64 \\
\text { KOOS } \\
\text { Symptoms (0- } \\
\text { 100): } 63 \text { vs. } 66 \\
\text { KOOS sports } \\
\text { and recreation } \\
\text { (0-100): } 34 \text { vs. } \\
37\end{array}$ & $\begin{array}{l}\text { A vs. } B \\
5 \text { months } \\
\text { KOOS ADL, mean } \\
\text { change: } 0.9 \text { vs. }-1.9, \\
P=0.61 \\
\text { KOOS pain, mean } \\
\text { change: } 3.1 \text { vs. }-1.1 \text {, } \\
P=0.32 \\
\text { KOOS symptoms, mean } \\
\text { change: } 1.0 \text { vs. }-3.4, \\
P=0.31 \\
\text { KOOS sports and } \\
\text { recreation, mean change: } \\
0.5 \text { vs. }-8.3, P=0.32\end{array}$ & $\begin{array}{l}\text { A vs. B } \\
5 \text { months } \\
\text { KOOS QOL, } \\
\text { mean change } \\
(0-100): 5.1 \text { vs. } \\
-2.3, P=0.02 \\
\text { SF-36 PCS, } \\
\text { mean change } \\
(0-100): 3.0 \text { vs. } \\
-0.7, P=0.09 \\
\text { SF-36 MCS, } \\
\text { mean change } \\
(0-100): 0.7 \text { vs. } \\
-0.7, P=0.40 \\
\text { Adverse } \\
\text { Events: } \\
\text { A vs. B } \\
\text { Increased knee } \\
\text { pain: } 3 \%(1 / 30) \\
\text { vs. } 0 \%(0 / 31)\end{array}$ \\
\hline
\end{tabular}




\begin{tabular}{|c|c|c|c|c|}
\hline $\begin{array}{l}\text { Author, Year, } \\
\text { Followup, } \\
\text { Pain } \\
\text { Duration, Study } \\
\text { Quality }\end{array}$ & Intervention & Population & $\begin{array}{l}\text { Function and Pain } \\
\text { Outcomes }\end{array}$ & $\begin{array}{l}\text { Other } \\
\text { Outcomes }\end{array}$ \\
\hline $\begin{array}{l}\text { Weng, }{ }^{59} 2009 \\
10 \text { months } \\
\text { Duration of pain: } \\
42.5 \text { months } \\
\text { Poor }\end{array}$ & $\begin{array}{l}\text { A. Isokinetic exercise }(n=33): 3 \\
\text { sessions a week for } 8 \text { weeks. } \\
\text { Sessions consisted of sets of } \\
\text { concentric and eccentric } \\
\text { contractions at varying angular } \\
\text { velocities and start and stop } \\
\text { angles. Hot packs for } 10 \\
\text { minutes and passive range of } \\
\text { motion exercises } \\
\text { B. No intervention }(n=33) \text { : } \\
\text { Warm-up cycling for } 10 \text { minutes. } \\
\text { Hot packs for } 10 \text { minutes and } \\
\text { passive range of motion } \\
\text { exercises }\end{array}$ & $\begin{array}{l}\text { A+B } \\
\text { Age: } 64 \\
\text { Female: } 75 \% \\
\text { A vs. B } \\
\text { Lequesne Index } \\
\text { (0-24): } 7.3 \text { vs. } \\
7.1 \\
\text { Pain VAS (0- } \\
\text { 10): } 4.7 \text { vs. } 4.5\end{array}$ & $\begin{array}{l}\text { A vs. B } \\
10 \text { months } \\
\text { Lequesne Index: } 6.3 \text { vs. } \\
7.3 \\
\text { Pain VAS: } 3.6 \text { vs. } 5.0\end{array}$ & $\begin{array}{l}\text { A vs. B } \\
10 \text { months } \\
\text { Treatment } \\
\text { related pain } \\
\text { causing } \\
\text { withdrawal: } 9 \% \\
(3 / 33) \text { vs. } 0 \% \\
(0 / 33) \\
R R=\text { infinity, } \\
P=0.08\end{array}$ \\
\hline $\begin{array}{l}\text { Williamson, } 2007^{60} \\
1.5 \text { months } \\
\text { Duration of pain: } \\
\text { NR } \\
\text { Poor }\end{array}$ & $\begin{array}{l}\text { A. Combination (Physiotherapy) } \\
\text { (n=60): Groups of } 6-10 \\
\text { patients, hourly, once a week } \\
\text { for } 6 \text { weeks. Exercise circuit of } \\
\text { static quadriceps contractions; } \\
\text { inner range quadriceps } \\
\text { contractions; straight leg raises; } \\
\text { sit to stands, stair climbing; calf } \\
\text { stretches; theraband resisted } \\
\text { knee extensions; wobble board } \\
\text { balance training; knee } \\
\text { flexion/extension sitting on gym } \\
\text { ball and free standing peddle } \\
\text { revolutions. } \\
\text { B. Control (n=61): } \\
\text { Usual Care (home exercise and } \\
\text { advice leaflet) }\end{array}$ & $\begin{array}{l}\text { A vs. B } \\
\text { Age: } 70 \text { vs. } 70 \\
\text { years } \\
\text { Female: } 52 \% \\
\text { vs. } 54 \% \\
\text { OKS (0-48): } \\
39.3 \text { vs. } 40.5 \\
\text { WOMAC } \\
\text { (unclear scale): } \\
50.2 \text { vs. } 51.1 \\
\text { VAS pain }(0- \\
\text { 10): } 6.8 \text { vs. } 6.9\end{array}$ & $\begin{array}{l}\text { A vs. B } \\
1.5 \text { months } \\
\text { OKS: } 38.8 \text { vs. } 40.8 \\
\text { WOMAC: } 49.4 \text { vs. } 52.3 \\
\text { VAS Pain: } 6.4 \text { vs. } 7.2\end{array}$ & $\begin{array}{l}\text { A vs. B } \\
1.5 \text { months } \\
\text { HAD Anxiety } \\
(0-21): 7.1 \text { vs. } \\
6.5 \\
\text { HAD } \\
\text { Depression (0- } \\
21): 6.8 \text { vs. } 7.1 \\
\text { Withdrawals: } \\
17 \%(10 / 60) \\
\text { vs. } 0 \%(0 / 61) \\
\text { Adverse } \\
\text { Events: None }\end{array}$ \\
\hline
\end{tabular}

ADL = activity of daily living; AIMS = Arthritis Impact Measurement Scale; AQoL = Assessment of Quality of Life; CES-D = Center for Epidemiologic Studies Depression; CI = confidence interval; HADS = Hospital Anxiety and Depression Scale; HAQ = Health Assessment Questionnaire; ITT = intention-to-treat; KOOS = Knee Injury and Osteoarthritis Outcome Score; KPS = Knee Pain Scale; LLFDI = Late-Life Function and Disability Instrument; MCS = Mental Component Score; MD = mean difference; $\mathrm{NA}=$ not applicable; $\mathrm{NR}=$ not reported; NS = not significant; OA = osteoarthritis; OKS = Oxford Knee Score; PCS = Physical Component Score; RR = risk ratio; QoL = quality of life; SF-36 = Short-Form-36; VAS, visual analog scale; WOMAC = Western Ontario and McMaster Universities Osteoarthritis Index

${ }^{a}$ Unless otherwise noted, followup time is calculated from the end of the treatment period

\section{Exercise Compared With Usual Care, No Treatment, Sham, or an Attention Control}

Functional Outcomes. Exercise was associated with slightly greater short-term impact on function (assessed across various measures) than usual care, no treatment, or sham intervention ( 7 trials, pooled SMD $-0.25,95 \%$ CI -0.4 to $\left.-0.09, \mathrm{I}^{2}=0 \%\right)^{41,48,52,54,55,58,60}$ (Figure 32). Estimates were similar following exclusion of poor-quality trials and when analyses were stratified by exercise and control type. In the short term, a small improvement in the Knee Injury and Osteoarthritis Outcome Score (KOOS) Sport and Recreation scale (0-100) with exercise 
compared with usual care or no treatment was seen (3 trials, pooled MD 5.88, 95\% CI 0.80 to 10.96, $\mathrm{I}^{2}=0 \%$, plot not shown). ${ }^{48,54,58}$

Exercise was also associated with moderately greater effect on function (assessed across various measures) than usual care, no treatment, or attention control at intermediate term (10 trials, pooled SMD -1.15 , 95\% CI -1.85 to $\left.-0.46, \mathrm{I}^{2}=93.9 \%\right)^{42,43,45-47,49,52,55,56,59}$ (Figure 32). Substantial heterogeneity was present with one outlier trial ${ }^{43}$ of combination exercise versus no treatment in elderly patients (median age 75 years) which had higher (worse) baseline Lequesne Index scores compared with other studies and a larger change from baseline scores in the intervention group. Removal of this poor quality trial did not improve heterogeneity but did attenuate the pooled estimate ( 9 trials, pooled SMD -0.78 , 95\% CI -1.37 to $-0.19, \mathrm{I}^{2}=91.4 \%$ ). Stratification by exercise type and control type may partially explain the heterogeneity. Muscle performance exercise was associated with a moderately greater effect on function compared with attention control or no treatment (5 trials, pooled SMD -1.44 , 95\% CI -2.08 to -0.17$)^{42,45-47,59}$ and when compared with attention control only ( 3 trials, pooled SMD -1.12 , 95\% CI -1.83 to $-0.47) .{ }^{45,47,59}$ No difference was seen across studies of exercise versus usual care (4 trials, pooled SMD 0.02 , $95 \%$ CI -0.20 to 0.24$){ }^{49,52,55,56}$

Analyses confined to trials that evaluated function on the 0-24 point Lequesne Index also suggests a moderately greater effect on function compared with attention control or no treatment (6 trials, pooled MD -3.42, 95\% CI -5.49 to -1.35 , $\mathrm{I}^{2}=97 \%$, plot not shown). ${ }^{42,43,45-47,59}$ Again, removal of the poor quality outlier trial ${ }^{43}$ did not impact the heterogeneity, but yielded a slightly lower effect estimate (5 trials, pooled MD -2.40, $95 \mathrm{CI}-3.32$ to -1.44), still consistent with a moderate effect for exercise. Results were similar to this estimate for muscle performance exercise, use of attention control, and when the two fair-quality trials were retained.

One fair-quality trial ( $n=101$ with knee OA $)^{40}$ compared combined exercise programs to usual care for intermediate-term function using the Western Ontario and McMaster Universities Osteoarthritis Index (WOMAC). The exercise group had improvement in function from baseline, which was not statistically significant (mean change from baseline -12.7, 95\% CI -27.1 to 1.7), while the usual care group had no change in function (mean change from baseline 1.6, 95\% CI -10.5 to 13.7). Data were insufficient to determine effect size or include in the meta-analysis.

One trial separately analyzed participants free of disability for ADLs at baseline $(n=250)$ and followed them to compare cumulative incidence of disability over 15 months. The aerobic exercise group had decreased risk of disability compared to the attention control group, RR 0.53 (95\% CI 0.33, 0.85), as did the muscle performance exercise group compared to the attention control group, RR 0.60 (95\% CI 0.38, 0.97). ${ }^{50}$

A small improvement in function long term was seen across two trials of combination exercise compared with usual care, one fair ${ }^{49}$ and the other poor quality ${ }^{57}$ (pooled SMD -0.24 , $95 \%$ CI -0.37 to $-0.11, \mathrm{I}^{2}=0 \%$ ), although separately neither trial reached statistical significance (Figure 32).

Pain Outcomes. Exercise was associated with slight improvement in short-term pain compared with usual care, no treatment, or sham in seven trials (pooled difference on a 0-10 scale -0.44 , $95 \%$ CI -0.82 to $-0.05, \mathrm{I}^{2}=35 \%$ ) (Figure 33 ). Six trials were fair quality ${ }^{41,48,52,54,55,58}$ and one was poor quality. ${ }^{60}$ Across studies comparing exercise with usual care, results were also similar ( 5 trials, pooled difference -0.53 , 95\% CI -1.07 to -0.02 ). ${ }^{48,52,54,55,60}$ The estimate was similar following exclusion of the poor-quality trials, but results were no longer significant (5 trials, pooled difference $-0.40,95 \% \mathrm{CI}-0.85$ to 0.08 ). One trial found no difference between exercise 
or sham procedure in the percentage of patients who reported clinically relevant reduction in VAS pain (58\% versus $42 \%, \mathrm{P}=0.069)$ or global improvement $(59 \%$ versus $50 \%, \mathrm{P}=0.309) .{ }^{41}$

Exercise was associated with moderately greater effect on intermediate-term pain compared with usual care, attention control, or no treatment across pain measures ( 9 trials, pooled difference $-1.61,95 \%$ CI -2.51 to $-0.72, \mathrm{I}^{2}=91 \%$ on a $0-10$ scale) across four fair-quality trials $^{45,47,49,52}$ and five poor-quality trials ${ }^{42,46,55,56,59}$ (Figure 33). Results differed somewhat by type of exercise and type of control. Three trials showed no difference between combination exercise and usual care; ${ }^{49,52,56}$ however, a substantial effect on pain was seen across trials comparing muscle performance exercise with an attention control (3 trials, pooled difference $-2.18,95 \% \mathrm{CI}-3.15$ to -1.24$)^{45,47,59}$ and with no treatment (2 poor quality trials, pooled difference $-3.01,95 \%$ CI -4.0 to -1.90$).{ }^{42,46}$ Substantial improvement in pain was seen across trials of muscle performance exercise versus attention control or no treatment ( 5 trials, pooled difference on $0-10$ scale $-2.53,95 \%$ CI -3.23 to -1.80$).{ }^{42,45-47,59}$ Results were no longer significant when four poor-quality trials ${ }^{42,46,56,59}$ were excluded ( 3 trials, pooled difference on a 0 -10 scale -1.69 , $95 \%$ CI -3.74 to 0.30$).{ }^{45,47,49}$

There was no clear difference between exercise and usual care or attention control on longterm pain (pooled difference -0.24 on a 0 to 10 scale, $95 \%$ CI -0.72 to $0.24, \mathrm{I}^{2}=54.9 \%$ ), but data were limited to two trials, the largest of which was of poor quality ${ }^{49,57}$ (Figure 33).

Most trials evaluated pain using a traditional 0 to 10 VAS. A small improvement in shortterm pain was observed across three trials ( 2 fair, 1 poor quality, pooled difference -0.51 , $95 \%$ $\mathrm{CI}-1.01$ to $\left.-0.01, \mathrm{I}^{2}=0 \%\right),{ }^{41,52,60}$ but was marginally statistically significant. Findings for intermediate-term pain were similar to the above findings across pain measures, showing a moderate improvement in pain (6 trials, pooled difference $-2.29,95 \% \mathrm{CI}-3.02$ to -1.55 , $\left.\mathrm{I}^{2}=78 \%\right)^{42,45-47,56,59}$ The pooled estimate was slightly larger when four poor-quality trials ${ }^{42,46,56,59}$ were excluded, leaving two fair-quality trials (pooled difference $-2.62,95 \% \mathrm{CI}-3.33$ to -1.89). ${ }^{45,47}$ Stratification by control type among studies reporting VAS pain yielded similar findings to those across multiple measures. Estimates were similar when analyses were stratified according to the type of exercise. No trial employing VAS reported on long-term pain.

Other Outcomes. Health-related quality of life outcomes had mixed results (Table 24). Two fairquality trials found no association between exercise and short-term quality of life on the KOOS 0 to 100 scale (pooled difference $1.76,95 \% \mathrm{CI}-2.45$ to $5.97, \mathrm{I}^{2}=0 \%$, plot not shown). ${ }^{48,54}$ A fairquality trial $(\mathrm{n}=65)$ reported no differences in mean change for short term SF-36 PCS (mean change of 3.0 [95\% CI -5.9 to 16.3 ] versus -0.7 [95\% CI -14.8 to 9.8]) and SF-36 MCS (mean change of 0.7 [95\% CI -18.1 to 13.2 ] vs. -0.7 [95\% CI -16.8 to 12.8 ]). ${ }^{58}$ One fair-quality trial $(n=158)$ reported similar health-related quality of life scores between a combined exercise group and usual care using averaged intermediate- and long-term scores. The adjusted mean (standard error [SE]) SF-36 PCS were 37.6 (0.9) vs. 35.3 (0.8), respectively, and adjusted mean (SE) SF36 MCS were $54.1(0.8)$ vs. 53.7 (0.8), respectively. ${ }^{53}$ A poor-quality trial $(n=50)$ reported intermediate-term SF-36 scores for individual domains. Functional capacity, physical role, bodily pain, general health, and vitality were slightly improved with exercise versus attention control. ${ }^{43}$

A fair-quality trial ( $n=438)$ reported no difference in depressive symptoms compared with attention control (2.59 vs. 2.80, $\mathrm{P}=0.27$ ) for muscle performance exercise, while aerobic exercise was associated with fewer depressive symptoms on the Center for Epidemiologic Studies Depression (CES-D) questionnaire compared to attention control $(2.12$ vs. $2.80, \mathrm{P}<0.001) .{ }^{51}$ 
There was insufficient evidence to determine effects of duration of exercise therapy or number of sessions on outcomes. No trials reported on changes in opioid use as a result of exercise programs.

\section{Exercise Compared With Pharmacological Therapy or With Other Nonpharmacological Therapies}

No trial of exercise therapy versus pharmacological therapy met inclusion criteria. Findings for exercise versus other nonpharmacological therapies are addressed in the sections for other nonpharmacological therapies.

\section{Harms}

Most trials did not report harms. One trial reported greater temporary, minor increases in pain in the exercise group versus a sham group (RR 14.7, 95\% CI 2.0 to 107.7); however, the confidence interval is wide. ${ }^{41}$ Four studies found no difference in worsening of pain symptoms with exercise versus comparators. ${ }^{42,46,58,59}$ One trial found no difference in falls or deaths. ${ }^{44}$

\section{Figure 32. Exercise versus usual care, no treatment, sham, or an attention control for osteoarthritis of the knee: effects on function}

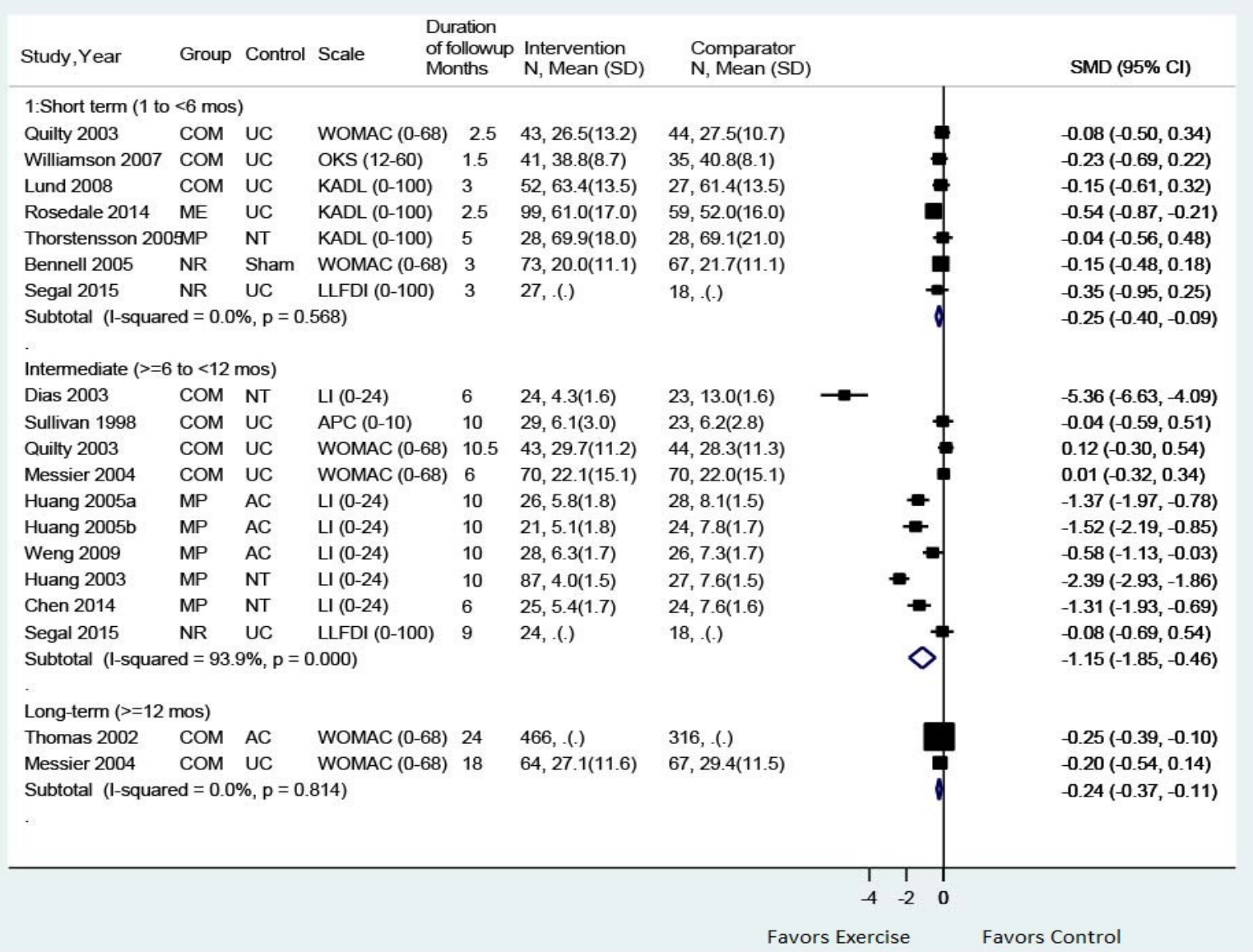

AC = attention control; APC = Arthritis Impact Measurement Scale (AIMS) physical activity component; $\mathrm{CI}=$ confidence interval; $\mathrm{COM}=$ combination exercise therapy; KADL = Knee Injury and Osteoarthritis Outcome Score (KOOS) ADL subscore; LI = Lequesne Index; LLFDI = Late Life Function and Disability Index Basic Lower Limb Function Score; ME = mobility exercise; MP = muscle performance exercise; NR = neuromuscular reeducation exercise; NT = no treatment; OKS = Oxford Knee Score; SD = standard deviation; SMD = standardized mean difference; UC = usual care; WOMAC = Western Ontario and McMaster's Universities Osteoarthritis Index 
Figure 33. Exercise versus usual care, no treatment, sham, or an attention control for osteoarthritis of the knee: effects on pain

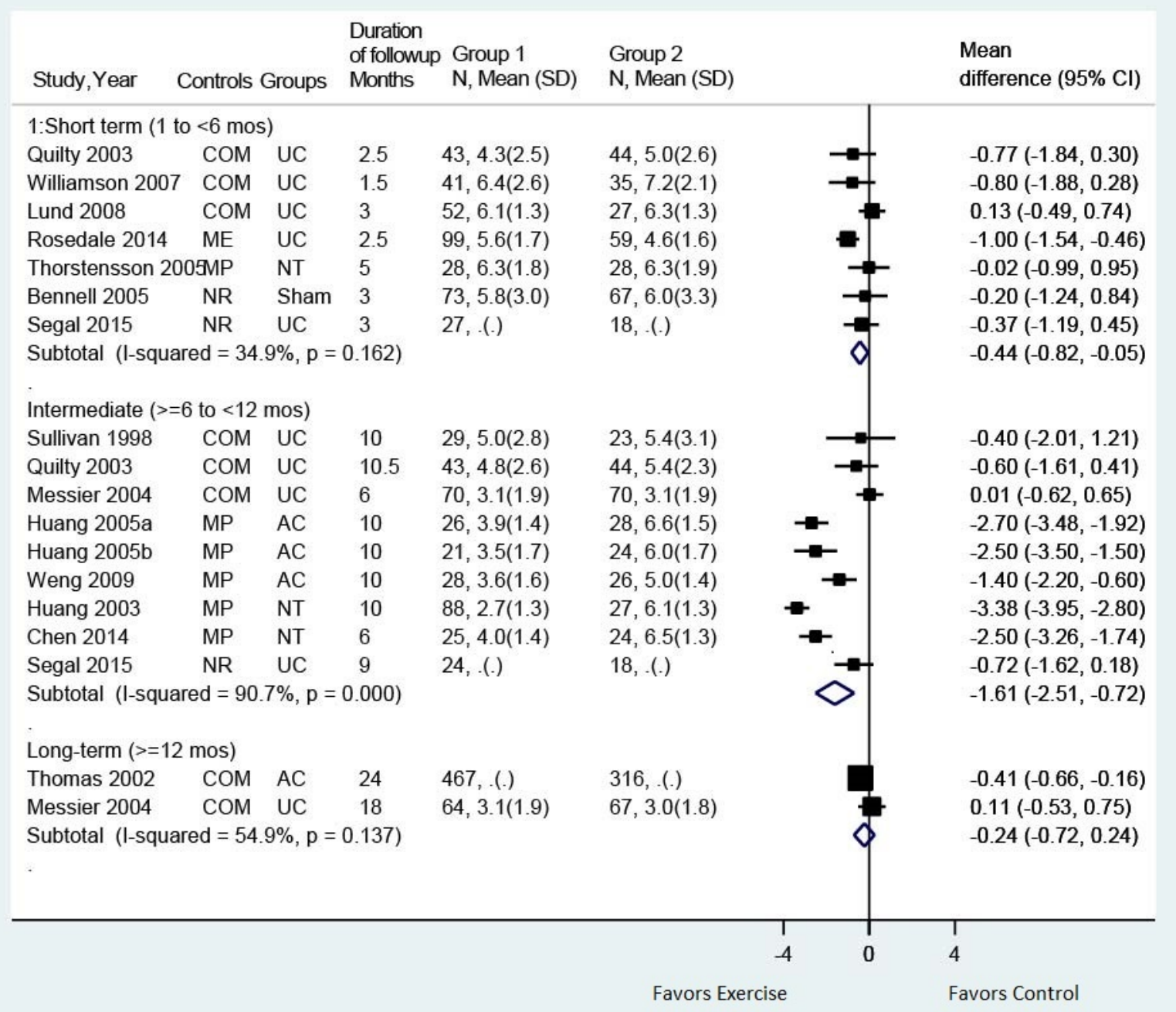

$\mathrm{AC}=$ attention control; $\mathrm{CI}=$ confidence interval; $\mathrm{COM}=$ combination exercise therapy; $\mathrm{ME}=$ mobility exercise; $\mathrm{MP}=$ muscle performance exercise; $\mathrm{NR}=$ neuromuscular re-education exercise; $\mathrm{NT}=$ no treatment; $\mathrm{SD}=$ standard deviation; $\mathrm{SMD}=$ standardized mean difference; UC = usual care

\section{Psychological Therapy for Osteoarthritis of the Knee}

\section{Key Points}

- Two trials of pain coping skills training and CBT versus usual care found no evidence of differences in function (WOMAC physical function, 0-100) or pain (WOMAC pain, 0100 ); treatment effects were averaged over short term to intermediate term (difference $-0.3,95 \%$ CI -8.3 to 7.8 for function and $-3.9,95 \%$ CI -1.8 to 4.0 for pain) and intermediate term to long term (mean 35.2 , $95 \%$ CI 31.8 to 38.6 vs. mean $37.5,95 \%$ CI 33.9 to 41.2 , and mean 34.5 , $95 \%$ CI 30.8 to 38.2 vs. mean $38.0,95 \%$ CI 34.1 to 41.8 ), respectively (SOE: low).

- One trial of pain coping skills training versus strengthening exercises found no evidence of differences in WOMAC physical function scores (0-68 scale) at short term (MD 2.0, $95 \%$ CI -2.4 to 6.4 ) or intermediate term (MD 3.2, 95\% CI -0.6 to 7.0) or in WOMAC 
pain scores ( 0 -20 scale) at short term (MD -0.1, 95\% CI -1.2 to 1.0) or intermediate term (MD 0.4, 95\% CI -0.8 to 1.6). (SOE: low).

- No serious harms were reported in either trial (SOE: low).

\section{Detailed Synthesis}

Three trials (total $n=371)^{94,95,110}$ of psychological therapies for knee OA met inclusion criteria (Table 25 and Appendix D). One was conducted in the United States, ${ }^{95}$ one in Finland, ${ }^{94}$ and one in Australia. ${ }^{110}$ Across the trials, participants were predominately female (60\% to $72 \%$ ) with mean ages ranging from 58 to 64 years. Two trials ( $n=111$ for both) ${ }^{94,95}$ evaluated group therapy consisting of CBT or pain coping skills training with usual care. The number and duration of psychological sessions varied between the trials (six 2-hour sessions versus eighteen 1-hour sessions, respectively), as did the total duration of therapy (6 and 24 weeks). Usual care was defined as routine care provided by the patient's primary care doctor and was not well-described in either trial. The third trial $(n=149)^{110}$ compared pain coping skills training (ten 45 -minute sessions) with strengthening exercises (ten 25-minute sessions); all sessions were conducted on an individual basis over a treatment period of 12 weeks. Participants randomized to receive PCST were told to practice skills daily and then as needed during followup; those in the exercise group were instructed to perform exercises four times a week during 12-week intervention and three times a week during the followup period.

Two trials were rated fair quality ${ }^{94,110}$ and the other was rated poor quality ${ }^{95}$ (see Appendix E for quality ratings). The primary methodological limitation in the fair-quality trials were the inability to effectively blind care providers, outcome assessors, and/or patients. Additional methodological shortcomings in the poor-quality trial included poor treatment compliance and high attrition (32\%). 
Table 25. Osteoarthritis of the knee: psychological therapies

\begin{tabular}{|c|c|c|c|c|}
\hline $\begin{array}{l}\text { Author, Year, } \\
\text { Followup, } \\
\text { Pain Duration, } \\
\text { Study Quality }\end{array}$ & Intervention & Population & $\begin{array}{l}\text { Function and Pain } \\
\text { Outcomes }\end{array}$ & Other Outcomes \\
\hline $\begin{array}{l}\text { Bennell } 2016^{110} \\
5 \text { and } 9 \text { months } \\
\text { Duration of } \\
\text { pain: } 6 \text { years } \\
\text { Fair }\end{array}$ & $\begin{array}{l}\text { A. Pain coping skills } \\
\text { training ( } n=74) \text { : } \\
\text { 10, } 45-\text {-minute } \\
\text { sessions over } 12 \\
\text { weeks; consisted of } \\
\text { pain education and } \\
\text { cognitive and } \\
\text { behavioral pain } \\
\text { coping skills training } \\
\text { B. Exercise }(n=75) \text { : } \\
\text { 10, } 25 \text { minute } \\
\text { sessions over } 12 \\
\text { week; consisted of } 6 \\
\text { strengthening } \\
\text { exercises. }\end{array}$ & $\begin{array}{l}\text { A vs. B } \\
\text { Age, years: } 63 \text { vs. } 63 \\
\text { Female: } 61 \% \text { vs. } 59 \% \\
\text { Radiographic disease } \\
\text { severity: } \\
\text { Grade } 2: 45 \% \text { vs. } \\
40 \% \\
\text { Grade } 3: 28 \% \text { vs. } \\
25 \% \\
\text { Grade } 4: 27 \% \text { vs. } \\
35 \% \\
\text { Opioid use: } 4 \% \text { vs. } 1 \%\end{array}$ & 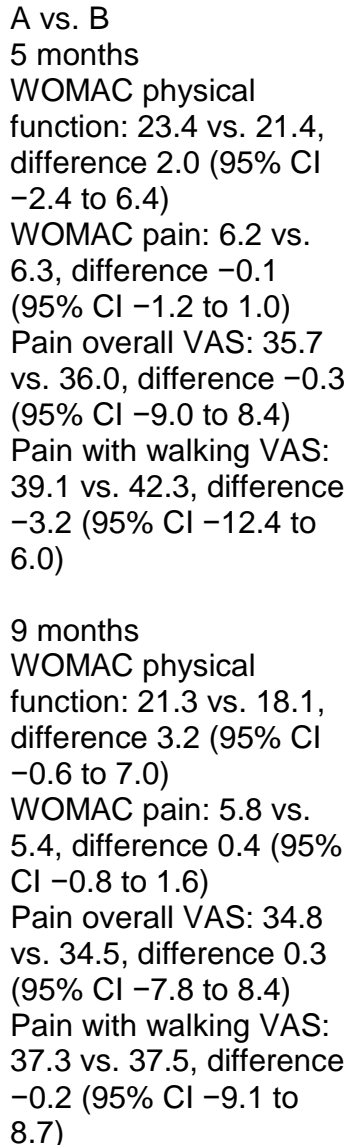 & 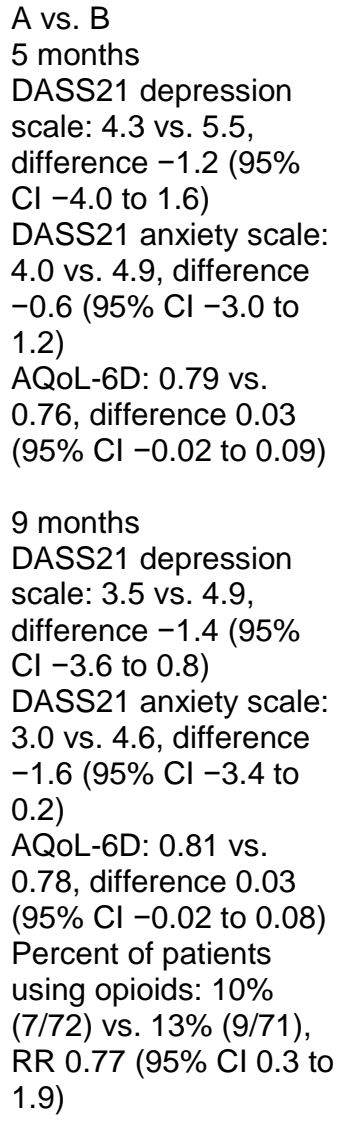 \\
\hline
\end{tabular}




\begin{tabular}{|c|c|c|c|c|}
\hline $\begin{array}{l}\text { Author, Year, } \\
\text { Followup, } \\
\text { Pain Duration, } \\
\text { Study Quality }\end{array}$ & Intervention & Population & $\begin{array}{l}\text { Function and Pain } \\
\text { Outcomes }\end{array}$ & Other Outcomes \\
\hline $\begin{array}{l}\text { Helminen, } \\
2015^{94} \\
31.5 \text { to } 10.5 \\
\text { months } \\
\text { Duration of } \\
\text { pain: } 7.8 \text { years } \\
\text { Fair }\end{array}$ & $\begin{array}{l}\text { Cognitive-Behavioral } \\
\text { Training plus usual } \\
\text { care ( } n=55) \text { : } \\
\text { 2-hour groups } \\
\text { sessions, weekly for } \\
6 \text { weeks (6 sessions } \\
\text { total); included } \\
\text { attention diversion } \\
\text { methods (relaxation, } \\
\text { imagery, distraction), } \\
\text { activity-rest cycling } \\
\text { and pleasant activity } \\
\text { scheduling, cognitive } \\
\text { restructuring, and } \\
\text { homework } \\
\text { assignments } \\
\text { B. Usual Care ( } n=56)\end{array}$ & $\begin{array}{l}\text { A vs. B } \\
\text { Age: } 64.5 \text { vs. } 63 \text { years } \\
\text { Female: } 71 \% \text { vs. } 68 \% \\
\text { BMl: } 30 \text { vs. } 30 \mathrm{~kg} / \mathrm{m}^{2} \\
\text { Bilateral knee OA: } \\
33 \% \text { vs. } 30 \% \\
\text { Kellgren-Lawrence } \\
\text { grade } 2: 60 \% \text { vs. } 61 \% \\
\text { Duration of Chronicity: } \\
6.6 \text { vs. } 8.9 \text { years } \\
\text { WOMAC Function (0- } \\
\text { 100): } 53.0 \text { vs. } 48.4 \\
\text { WOMAC Pain (0-100): } \\
57.6 \text { vs. } 56.4 \\
\text { WOMAC Function: } \\
53.0 \text { (48.1-57.9) vs. } \\
\text { NRS pain (0-10), } \\
\text { average past week: } \\
6.6 \text { vs. } 6.4 \\
\text { NRS pain (0-10), } \\
\text { worst past week: } 8.0 \\
\text { vs. } 7.5 \\
\text { NRS pain (0-10), } \\
\text { average } 3 \text { months: } 6.8 \\
\text { vs. } 6.6 \\
\text { NRS pain (0-10), } \\
\text { worst } 3 \text { months: } 8.2 \\
\text { vs. } 8.0\end{array}$ & 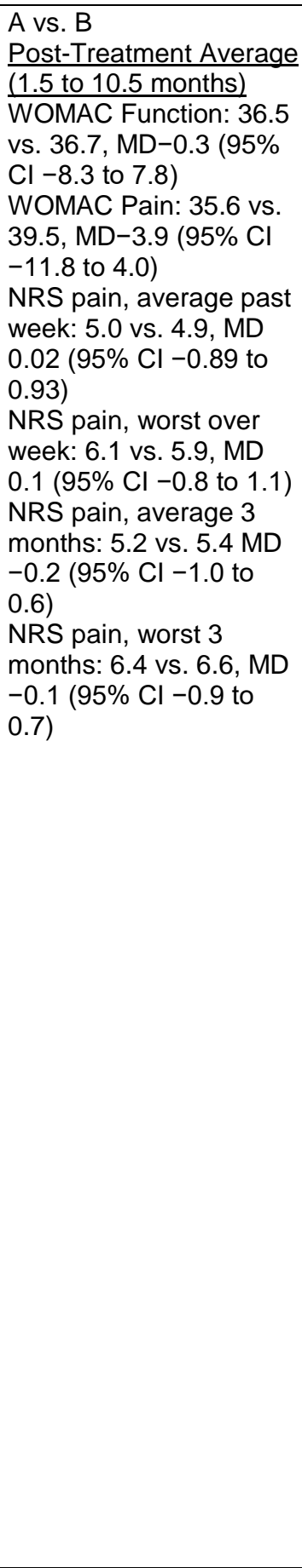 & 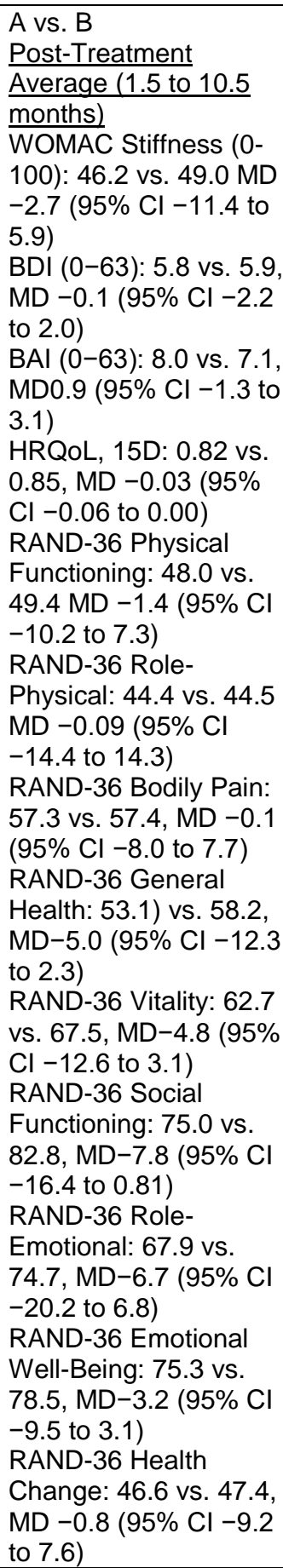 \\
\hline
\end{tabular}




\begin{tabular}{|c|c|c|c|c|}
\hline $\begin{array}{l}\text { Author, Year, } \\
\text { Followup, } \\
\text { Pain Duration, } \\
\text { Study Quality }\end{array}$ & Intervention & Population & $\begin{array}{l}\text { Function and Pain } \\
\text { Outcomes }\end{array}$ & Other Outcomes \\
\hline $\begin{array}{l}\text { Somers, } 2012^{95} \\
6-12 \text { months } \\
\text { Duration of } \\
\text { pain: NR } \\
\text { Poor }\end{array}$ & $\begin{array}{l}\text { A. Pain Coping Skills } \\
\text { Training ( } \mathrm{n}=60) \text { ) } 1- \\
\text { hour group sessions, } \\
\text { weekly for } 12 \text { weeks } \\
\text { then every other } \\
\text { week for } 12 \text { weeks } \\
\text { (total of } 18 \text { sessions } \\
\text { over } 24 \text { weeks); } \\
\text { consisted of } \\
\text { informational } \\
\text { lectures, problem } \\
\text { solving, skills } \\
\text { training, relaxation } \\
\text { exercises, homework } \\
\text { assignments, and } \\
\text { feedback } \\
\text { B. Usual Care ( } n=51 \text { ) }\end{array}$ & $\begin{array}{l}\text { A vs. B } \\
\text { Age: } 58 \text { vs. } 58 \text { years } \\
\text { Female: } 67 \% \text { vs. } 78 \% \\
\text { Caucasian: } 62 \% \text { vs. } \\
61 \% \\
\text { Mean Duration of } \\
\text { Chronicity: NR } \\
\text { Kellgren-Lawrence } \\
\text { score (0-4): } 2.5 \text { vs. } 2.3 \\
\text { WOMAC function } \\
\text { subscale (0-100): } 46.2 \\
\text { vs. } 46.1 \\
\text { WOMAC pain } \\
\text { subscale (0-100): } 42.8 \\
\text { vs. } 43.4\end{array}$ & $\begin{array}{l}\text { A vs. B } \\
\text { Post-treatment Average } \\
\frac{\text { (6-12 months) }}{\text { WOMAC function: } 35.2} \\
\text { vs. } 37.5, P=N S \\
\text { AIMS physical disability } \\
\text { subscale: } 1.5 \text { vs. } 1.4, \\
\text { P=NS } \\
\text { WOMAC pain subscale: } \\
34.5 \text { vs. } 38.0, P=N S \\
\text { AIMS pain subscale: } 4.4 \\
\text { vs. } 4.7, P=N S\end{array}$ & $\begin{array}{l}\text { A vs. B } \\
\text { Post-treatment } \\
\text { Average (6-12 months) } \\
\text { WOMAC stiffness } \\
\text { subscale: } 44.5 \text { vs. } 46.4 \text {, } \\
\text { P=NS } \\
\text { AIMS psychological } \\
\text { subscale: } 2.6 \text { vs. } 2.5 \text {, } \\
P=N S\end{array}$ \\
\hline
\end{tabular}

AIMS = Arthritis Impact Measurement Scale; BAI = Beck Anxiety Inventory; BDI = Beck Depression Inventory; CI = confidence interval; HRQoL = health-related quality of life; $\mathrm{MD}=$ mean difference; $\mathrm{NR}=$ not reported; NRS = numeric rating scale; NS = not statistically significant; OA = osteoarthritis; $\mathrm{RR}=$ risk ratio; WOMAC = Western Ontario and McMaster Universities Osteoarthritis index

a Unless otherwise noted, followup time is calculated from the end of the treatment period

\section{Psychological Therapies Compared With Usual Care}

Both trials reported outcomes averaged over all post-treatment followup times; the trial of CBT averaged results from 1.5 to 10.5 months post treatment (spanning short to intermediate term $)^{94}$ and the trial of pain coping skills training averaged results from 6 to 12 months post treatment (spanning intermediate to long term).$^{95}$

No significant differences in function or pain were found between the psychological therapy and the usual care groups in either trial. Function was measured using the WOMAC physical function subscale (0-100) in both trials, over the short to intermediate term (MD $-0.3,95 \% \mathrm{CI}$ -8.3 to 7.8 ) ${ }^{94}$ and intermediate to long term (mean 35.2 , 95\% CI 31.8 to 38.6 vs. mean 37.5 , 95\% CI 33.9 to 41.2), ${ }^{95}$ and using the Arthritis Impact Measurement Scale (AIMS) physical disability subscale in one trial ${ }^{95}$ (Table 25). Both trials measured pain using the WOMAC pain subscale (0100), one trial over short- to intermediate-term followup (MD $-3.9,95 \% \mathrm{CI}-11.8$ to 4.0$)^{94}$ and the other over intermediate- to long-term followup (mean 34.5, 95\% CI 30.8 to 38.2 vs. mean 38.0, 95\% CI 34.1 to 41.8$).{ }^{95}$ Results were similar for the AIMS pain subscale and the numeric rating scale (NRS) pain scale, reported by one trial each (Table 25). Neither trial reported any differences between groups in any secondary outcome measure.

No trial evaluated effects of psychological therapies on use of opioid therapies or health care utilization.

\section{Psychological Therapies Compared With Pharmacological Therapy}

No trial of psychological therapy versus pharmacological therapy met inclusion criteria.

\section{Psychological Therapies Compared With Exercise Therapy}

One fair-quality trial ${ }^{110}$ of pain coping skills training versus strengthening exercise found no between-group differences in function or pain in the short term (WOMAC physical function, MD 
2.0, 95\% CI -2.4 to 6.4 on a $0-68$ scale and WOMAC pain, MD $-0.1,95 \%$ CI -1.2 to 1.0 on a 0 20 scale) or the intermediate term (WOMAC physical function, MD 3.2, 95\% CI -0.6 to 7.0 and WOMAC pain, MD 0.4, 95\% CI -0.8 to 1.6) (Table 25). Results were similar for overall pain and pain with walking, both measured on a 0-100 VAS. There were also no differences between groups on any other secondary outcome measure including opioid use at short-term or intermediate-term follow up.

\section{Harms}

In the two trials of psychological interventions versus usual care, ${ }^{94,95}$ no adverse events were observed. In the third trial, ${ }^{110}$ fewer participants in the pain coping skills training group compared with the exercise group experienced pain in the knee (3\% vs. $31 \%, \mathrm{P}<0.001)$ and in other body regions (4\% vs. $15 \%, \mathrm{P}=0.02$ ) during treatment; during followup, only the frequency of pain in other body areas differed between groups ( $0 \%$ vs. $11 \%$, respectively, $\mathrm{P}<0.05$; knee pain, $7 \%$ vs. $10 \%, \mathrm{P}=0.53)$. Pain was most mostly mild and transient.

\section{Physical Modalities for Osteoarthritis of the Knee}

\section{Key Points}

\section{Ultrasound}

- One fair-quality trial found continuous and pulsed ultrasound was associated with slightly better short-term function (difference $-6.2,95 \%$ CI -8.36 to -4.20 , and $-5.71,95 \%$ CI -7.72 to -3.70 on a $0-24$ scale) and short-term pain intensity (difference $-3.3,95 \% \mathrm{CI}$ -4.64 to -1.96 , and $-3.37,95 \%$ CI -4.73 to -2.01 on a $0-10$ scale) (SOE: low).

- One fair-quality trial found no evidence of differences between continuous and pulsed ultrasound versus sham in intermediate-term function (difference -2.9 , 95\% CI -9.19 to 3.39 and $1.6,95 \% \mathrm{CI}-3.01$ to 6.22 , on a $0-68$ scale) or pain (difference $-1.6,95 \% \mathrm{CI}$ -3.26 to 0.06 and $0.2,95 \%$ CI -1.34 to 1.74 , on a $0-20$ scale). There was also no difference between groups for VAS pain during rest or on movement (SOE: low).

- No adverse events were reported during the two trials (SOE: low).

\section{Transcutaneous Electrical Nerve Stimulation}

- One trial found no evidence of differences between TENS and placebo TENS in intermediate-term function (proportion of patients who achieved a MCID on the WOMAC function subscale [ $\geq 9.1$ ], $38 \%$ vs. $39 \%$, RR $1.2,95 \%$ CI 0.6 to 2.2 ; and MD $-1.9,95 \%$ CI -9.7 to 5.9 on the $0-100$ WOMAC function subscale) or intermediate-term pain (proportion of patients who achieved MCID [ $\geq 20]$ in VAS pain, 56\% vs. 44\%, RR 1.3, $95 \%$ CI 0.8 to 2.0 ; and $\mathrm{MD}-5.6,95 \% \mathrm{CI}-14.9$ to 3.6 on the $0-100$ WOMAC pain subscale) (SOE: low for function and pain).

- One trial of TENS reported no difference in the risk of minor adverse events (RR 1.06 (95\% CI 0.38 to 2.97) (SOE: low).

\section{Low-Level Laser Therapy}

- Evidence was insufficient from one small fair-quality and two poor-quality trials to determine effects or harms of low-level laser therapy in the short or intermediate term; No data were available for the long term (SOE: insufficient) 


\section{Microwave Diathermy}

- There was insufficient evidence to determine short-term effects or harms from one small, fair-quality trial (SOE: insufficient).

\section{Pulsed Short-Wave Diathermy}

- There was insufficient evidence to determine effects or harms from one poor-quality trial in the short term or from another poor quality trial in the long term (SOE: insufficient).

\section{Electromagnetic Field}

- One fair-quality trial found pulsed electromagnetic fields were associated with slight improvements in function (difference -3.48 , $95 \% \mathrm{CI}-4.44$ to -2.51 on a $0-85$ WOMAC ADL subscale) and pain (difference $-0.84,95 \%$ CI -1.10 to -0.58 on a $0-25$ WOMAC pain subscale) versus sham short-term but differences may not be clinically significant (SOE: low).

- More patients who received real versus sham electromagnetic field therapy reported throbbing or warming sensations or aggravation of pain (29\% versus $7 \%$ ); however, the difference was not significant (RR 1.95, 95\% CI 0.81 to 4.71) (SOE: low).

\section{Superficial Heat}

- Evidence was insufficient from one small fair-quality trial to determine effects or harms of trial superficial heat versus placebo in short-term pain (SOE: insufficient).

\section{Braces}

- There is insufficient evidence from one poor-quality study to determine the effects of bracing versus usual care for intermediate-term and long-term function or pain (SOE: insufficient).

- Harms were not reported.

\section{Detailed Synthesis}

A total of 13 trials ${ }^{125-137}$ reported the use of a physical modality for the treatment of knee OA (Table 26 and Appendixes D and E). Physical modalities evaluated included ultrasound, TENS, low-level laser therapy, microwave diathermy, pulsed short-wave diathermy, electromagnetic fields, superficial heat, and bracing. All but one intervention (bracing vs. usual care) ${ }^{127}$ were compared to a sham procedure. 
Table 26. Osteoarthritis of the knee: physical modalities

\begin{tabular}{|c|c|c|c|c|}
\hline $\begin{array}{l}\text { Author, Year, } \\
\text { Followup, }{ }^{\text {a }} \\
\text { Pain Duration, Study } \\
\text { Quality }\end{array}$ & Intervention & Population & $\begin{array}{l}\text { Function and Pain } \\
\text { Outcomes }\end{array}$ & $\begin{array}{l}\text { Other } \\
\text { Outcomes }\end{array}$ \\
\hline $\begin{array}{l}\text { Al Rashoud, } 2014^{125} \\
1.5 \text { and } 6 \text { months } \\
\text { Duration of pain: } 11 \\
\text { years } \\
\text { Fair }\end{array}$ & $\begin{array}{l}\text { A. Low-level laser therapy } \\
\text { ( } \mathrm{n}=26), \text { continuous laser (30 } \\
\text { mW, } 830 \mathrm{~nm} \text { wavelength) } \\
\text { applied to } 5 \text { acupuncture } \\
\text { points over approximately of } \\
10 \text { sessions } \\
\text { B. Placebo laser ( } \mathrm{n}=23) \text {, } \\
\text { placebo laser applied to } 5 \\
\text { acupuncture points over } \\
\text { approximately } 10 \text { sessions }\end{array}$ & $\begin{array}{l}\text { A vs. B } \\
\text { Age: } 52 \text { vs. } 56 \\
\text { years } \\
\text { Female: } 62 \% \text { vs. } \\
65 \% \\
\text { Baseline pain on } \\
\text { movement VAS } \\
\text { (0-10): } 6.4 \text { vs. } 5.9 \\
\text { Baseline Saudi } \\
\text { Knee Function } \\
\text { Scale (SKFS) (0- } \\
112), \text { median: } \\
61.0 \text { vs. } 60.0\end{array}$ & $\begin{array}{l}\text { A vs. B } \\
1.5 \text { months } \\
\text { Pain on movement VAS: } \\
3.0 \text { vs. } 4.2^{\text {b }} \\
\text { SKFS, median: } 31 \text { vs. } 40 \text {, } \\
\text { median difference }-10 \\
(95 \% \mathrm{Cl}-23 \text { to }-4) \\
\text { P=0.054 } \\
6 \text { months } \\
\text { Pain on movement VAS: } \\
3.4 \text { vs. } 5.2^{\text {b }} \\
\text { SKFS, median: } 31 \text { vs. } 51 \text {, } \\
\text { median difference }-21 \\
(95 \% \text { CI }-34 \text { to }-7) \\
\text { P=0.006 }\end{array}$ & NR \\
\hline $\begin{array}{l}\text { Battisti, } 2004^{126} \\
1 \text { month } \\
\text { Duration of pain: } 11 \\
\text { years } \\
\text { Poor }\end{array}$ & $\begin{array}{l}\text { A. Therapeutic Application of } \\
\text { Musically Modulated } \\
\text { Electromagnetic Field } \\
\text { (TAMMEF) ( } n=30 \text { ) } \\
\text { The anatomical region } \\
\text { treated is placed between } \\
\text { opposing faces of low } \\
\text { frequency electromagnets } \\
\text { (3x4 cm). The current from } \\
\text { amplifier B feeds a loud } \\
\text { speaker that plays music. } \\
\text { The music modifies } \\
\text { parameters (frequency, } \\
\text { intensity, waveform) of the } \\
\text { electromagnetic field in time, } \\
\text { randomly varying within } \\
\text { respective ranges. } 15 \\
\text { consecutive daily sessions, } \\
30 \text { minutes each } \\
\text { B. Extremely Low Frequency } \\
\text { (ELF) ( } n=30 \text { ) } \\
\text { Similar treatment as } \\
\text { Intervention A except the } \\
\text { electromagnetic field is } \\
\text { stabilized at a frequency of } \\
100 H z \text { in a sinusoidal } \\
\text { waveform. } 15 \text { consecutive } \\
\text { daily sessions, } 30 \text { minutes } \\
\text { each } \\
\text { C. Simulated (Sham) } \\
\text { Frequency Field ( } n=30 \text { ) } \\
\text { Functionally similar } \\
\text { operation to the other groups } \\
\text { except a simulated } \\
\text { (noneffective) field is used, } \\
\text { but the patients remain } \\
\text { blinded to its effectiveness. } \\
15 \text { consecutive daily } \\
\text { sessions, } 30 \text { minutes each }\end{array}$ & $\begin{array}{l}\text { A + B + C } \\
\text { Age: } 58.9(7.4) \\
\text { Female: } 70 \% \\
\text { Race: NR } \\
\text { Mean Duration of } \\
\text { Chronicity: } 11 \\
(3.1) \\
\text { A vs. B vs. C } \\
\text { Mean Lequesne } \\
\text { Function Score (0- } \\
\text { 10) } 3.65 \text { vs. } 4.28 \\
\text { vs. } 3.48 \\
\text { Mean Lequesne } \\
\text { Pain Score (0- } \\
\text { 10)' } 6.88 \text { vs. } 6.28 \\
\text { vs. } 6.15\end{array}$ & $\begin{array}{l}\text { A vs. C } \\
1 \text { month } \\
\text { Mean Lequesne } \\
\text { Functionality: } 6.5 \text { vs. } 3.83 \\
\text { Mean Lequesne Pain } \\
\text { Score: } 1.4 \text { vs. } 6.85 \\
\text { B vs. C } \\
1 \text { month } \\
\text { Mean Lequesne } \\
\text { Functionality: } 7.1 \text { vs. } 3.83 \\
\text { Mean Lequesne Pain } \\
\text { Score: } 1.4 \text { vs. } 6.85\end{array}$ & NR \\
\hline
\end{tabular}




\begin{tabular}{|c|c|c|c|c|}
\hline $\begin{array}{l}\text { Author, Year, } \\
\text { Followup, }{ }^{a} \\
\text { Pain Duration, Study } \\
\text { Quality }\end{array}$ & Intervention & Population & $\begin{array}{l}\text { Function and Pain } \\
\text { Outcomes }\end{array}$ & $\begin{array}{l}\text { Other } \\
\text { Outcomes }\end{array}$ \\
\hline $\begin{array}{l}\text { Brouwer, } 2006^{127} \\
6 \text { and } 12 \text { months } \\
\text { Duration of pain: } 6.7 \text { vs. } \\
4.9 \text { years } \\
\text { Poor }\end{array}$ & $\begin{array}{l}\text { A. Brace ( } \mathrm{n}=60) \\
\text { Patients were fitted with a } \\
\text { commercially available knee } \\
\text { brace that allowed medial } \\
\text { unloading or lateral } \\
\text { unloading and also received } \\
\text { usual care. } \\
\text { Device: Oasys brace, } \\
\text { Innovation Sports, Irvine, } \\
\text { CA, USA } \\
\text { B. Usual Care ( } \mathrm{n}=57 \text { ) } \\
\text { Usual care was identical in } \\
\text { both groups and consisted of } \\
\text { patient education } \\
\text { (adaptation of activities } \\
\text { and/or weight loss), and (if } \\
\text { needed) physical therapy } \\
\text { and analgesic }\end{array}$ & $\begin{array}{l}\text { A vs. B } \\
\text { Agef: } 59.2 \\
\text { Female: } 48 \% \text { vs. } \\
51 \% \\
\text { Race: NR } \\
\text { HSS Knee } \\
\text { Function Score (0- } \\
100): 64.9 \text { vs. } \\
69.0 \\
\text { VAS Pain Severity } \\
(0-10): 6.6 \text { vs. } 5.5\end{array}$ & $\begin{array}{l}\text { A vS. B } \\
6 \text { months } \\
\text { HSS Knee Function: } \\
\text { difference } 3.2 \text { ( } 95 \% \mathrm{Cl} \\
\text {-0.58 to } 6.98) \\
\text { VAS Pain Severity: } \\
\text { difference }-0.58 \text { (95\% Cl } \\
\text {-1.48 to 0.32) } \\
12 \text { months } \\
\text { HSS Knee Function: } \\
\text { difference } 3.0(95 \% \mathrm{Cl} \\
-1.05 \text { to } 7.05) \\
\text { VAS Pain Severity: } \\
\text { difference }-0.81(95 \% \mathrm{Cl} \\
-1.76 \text { to } 0.14)\end{array}$ & $\begin{array}{l}\text { A vs. B } \\
6 \text { months } \\
\text { EQ-5D: } \\
\text { difference } \\
0.01(95 \% \mathrm{Cl} \\
-0.08 \text { to } \\
0.10) \\
12 \text { months } \\
\text { EQ-5D: } \\
\text { difference } \\
0.01 \text { (95\% Cl } \\
-0.08 \text { to } \\
0.10)\end{array}$ \\
\hline $\begin{array}{l}\text { Cakir, } 2014^{128} \\
6 \text { months } \\
\text { Duration of pain: Mean } \\
4.0 \text { to } 5.1 \text { years } \\
\text { Fair }\end{array}$ & $\begin{array}{l}\text { A. Continuous ultrasound } \\
(n=20), \text { Therapeutic } \\
\text { ultrasound given } 5 \text { times a } \\
\text { week for } 2 \text { weeks } \\
\text { B. Pulsed ultrasound }(n=20) \text {, } \\
\text { Therapeutic pulsed } \\
\text { ultrasound given } 5 \text { times a } \\
\text { week for } 2 \text { weeks } \\
\text { C. Sham ( } n=20), \text { Sham } \\
\text { ultrasound given } 5 \text { times a } \\
\text { week for } 2 \text { weeks } \\
\text { All patients performed home } \\
\text { exercise program } 3 \text { days a } \\
\text { week for } 8 \text { weeks }\end{array}$ & $\begin{array}{l}\text { A vs. B vs. C } \\
\text { Age: } 57 \text { vs. } 58 \text { vs. } \\
57 \text { years } \\
\text { Female: } 70 \% \text { vs. } \\
80 \% \text { vs. } 85 \% \\
\text { WOMAC physical } \\
\text { mean function (0- } \\
68): 55.7 \text { vs. } 52.4 \\
\text { vs. } 52.5 \\
\text { WOMAC pain (0- } \\
20): 15.9 \text { vs. } 14.5 \\
\text { vs. } 14.9 \\
\text { WOMAC stiffness } \\
\text { (0-8): NR } \\
\text { Pain at rest VAS } \\
\text { (0-10): } 57.9 \text { vs. } \\
55.7 \text { vs. } 53.6 \\
\text { Pain on } \\
\text { movement VAS } \\
\text { (0-10): } 75.5 \text { vs. } \\
73.0 \text { vs. } 72.2 \\
\text { Disease severity } \\
\text { VAS (0-10): } 73.9 \\
\text { vs. } 67.9 \text { vs. } 68.4\end{array}$ & 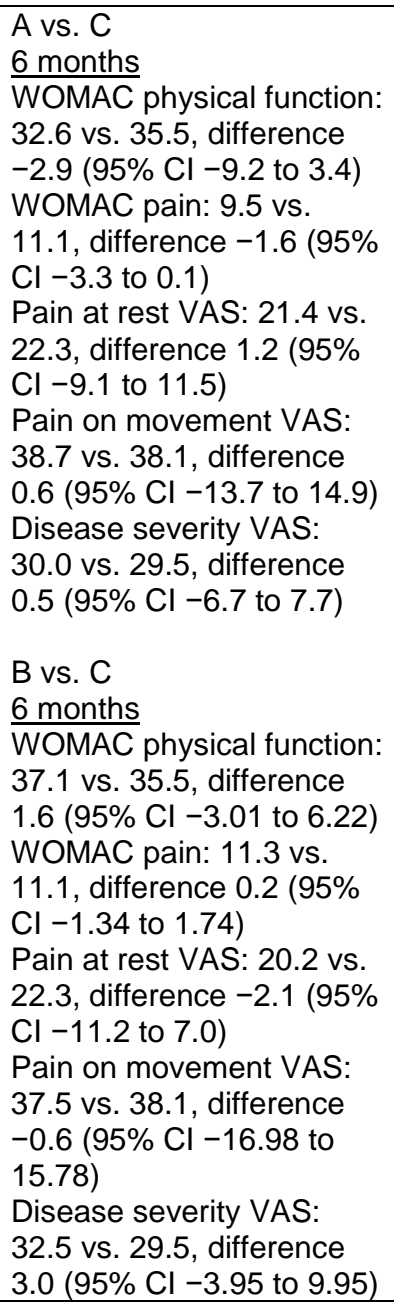 & NR \\
\hline
\end{tabular}




\begin{tabular}{|c|c|c|c|c|}
\hline $\begin{array}{l}\text { Author, Year, } \\
\text { Followup, }{ }^{\text {a }} \\
\text { Pain Duration, Study } \\
\text { Quality }\end{array}$ & Intervention & Population & $\begin{array}{l}\text { Function and Pain } \\
\text { Outcomes }\end{array}$ & $\begin{array}{l}\text { Other } \\
\text { Outcomes }\end{array}$ \\
\hline $\begin{array}{l}\text { Fary, } 2011^{129} 6.5 \text { months } \\
\text { Duration of pain: } 12 \\
\text { years } \\
\text { Good }\end{array}$ & $\begin{array}{l}\text { A. Pulsed electrical } \\
\text { stimulation }(n=34), \text { pulsed } \\
\text { electrical stimulator worn } 7 \\
\text { hours a day daily for } 26 \\
\text { weeks } \\
\text { B. Placebo electrical } \\
\text { stimulation }(n=36), \text { placebo } \\
\text { pulsed electrical stimulator } \\
\text { worn } 7 \text { hours a day daily for } \\
26 \text { weeks }\end{array}$ & $\begin{array}{l}\text { A vs. B } \\
\text { Age: } 71 \text { vs. } 69 \\
\text { years } \\
\text { Female: } 50 \% \text { vs. } \\
44 \% \\
\text { Baseline WOMAC } \\
\text { total (0-100): } 36 \\
\text { vs. } 34 \\
\text { Baseline WOMAC } \\
\text { function (0-100): } \\
35 \text { vs. } 34 \\
\text { Baseline WOMAC } \\
\text { stiffness (0-100): } \\
45 \text { vs. 41 } \\
\text { Baseline WOMAC } \\
\text { pain (0-100): } 35 \\
\text { vs. } 36 \\
\text { Baseline pain } \\
\text { VAS (0-100): } 51 \\
\text { vs. } 52\end{array}$ & 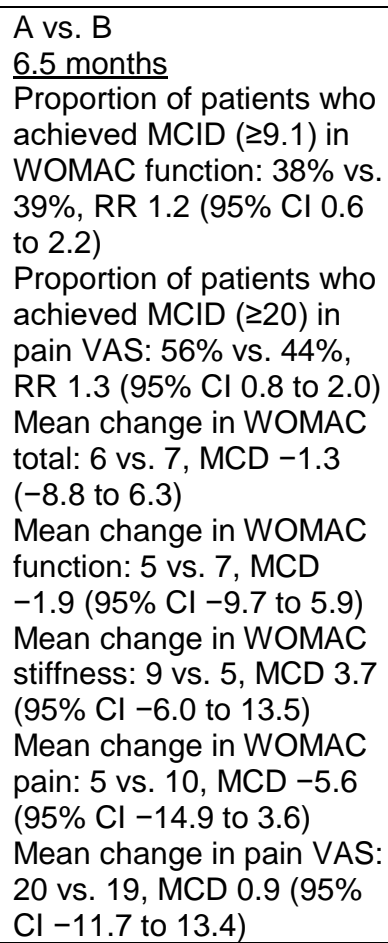 & $\begin{array}{l}\text { A vs. B } \\
6.5 \text { months } \\
\text { Mean } \\
\text { change in } \\
\text { SF-36 } \\
\text { physical } \\
\text { component } \\
\text { score (0- } \\
100):-1.0 \\
\text { vs. }-2.6, \\
\text { MCD } 1.7 \\
\text { (95\% Cl }-1.5 \\
\text { to } 4.8) \\
\text { Mean } \\
\text { change in } \\
\text { SF-36 } \\
\text { mental } \\
\text { component } \\
\text { score }(0- \\
100):-1.2 \\
\text { vs. }-2.4 \\
\text { MCD } 1.2 \\
\text { (95\% Cl }-2.9 \\
\text { to 5.4) }\end{array}$ \\
\hline
\end{tabular}




\begin{tabular}{|c|c|c|c|c|}
\hline $\begin{array}{l}\text { Author, Year, } \\
\text { Followup, }{ }^{\text {a }} \\
\text { Pain Duration, Study } \\
\text { Quality }\end{array}$ & Intervention & Population & $\begin{array}{l}\text { Function and Pain } \\
\text { Outcomes }\end{array}$ & $\begin{array}{l}\text { Other } \\
\text { Outcomes }\end{array}$ \\
\hline $\begin{array}{l}\text { Fukuda, }{ }^{130} 2011 \\
12 \text { months } \\
\text { Duration of pain: NR } \\
\text { Poor }\end{array}$ & $\begin{array}{l}\text { A. Low-dose Pulsed Short } \\
\text { Wave (PSW) (n=32) } \\
\text { Patients administered a } \\
\text { precalibrated device to the } \\
\text { anterior area of the thigh, } 5 \\
\text { cm above superior border of } \\
\text { the patella. Device was set } \\
\text { to output a specific } \\
\text { frequency and pulse } \\
\text { duration, with a care } \\
\text { provider nearby but without } \\
\text { direct input from care } \\
\text { provider. Three, } 19 \text { minute } \\
\text { applications per week for } \\
\text { three weeks ( } 9 \text { total) } \\
\text { Total Energy: } 17 \text { kJ } \\
\text { Frequency: } 27.12 \text { MHz } \\
\text { Mean Power Output: } 14.5 \text { W } \\
\text { Pulse Duration: } 400 \\
\text { microseconds } \\
\text { Pulse Frequency: } 145 \mathrm{~Hz} \\
\text { B. High-dose PSW (n=31) } \\
\text { Treatment characteristics } \\
\text { were identical to Group A } \\
\text { except length of treatment } \\
\text { (and received total energy) } \\
\text { were doubled. Three, } 38 \text { min } \\
\text { applications per week for } \\
\text { three weeks ( } 9 \text { total) } \\
\text { Total Energy: } 33 \text { kJ } \\
\text { C. Sham (n=23) } \\
\text { Treatment characteristics } \\
\text { were identical to Group A } \\
\text { except the device was kept } \\
\text { in standby mode without any } \\
\text { electrical current applied. } \\
\text { Three, } 19 \text { min applications } \\
\text { per week for } 3 \text { weeks ( } 9 \\
\text { total) }\end{array}$ & $\begin{array}{l}\text { A vs. B vs. C } \\
\text { Age: } 62 \text { vs. } 63 \text { vs. } \\
57 \\
\text { Female: } 100 \% \\
\text { Race: NR } \\
\text { Knee Injury and } \\
\text { Osteoarthritis } \\
\text { Outcome Score } \\
\text { Symptoms } \\
\text { Subscale (0-100): } \\
46.5 \text { vs. } 47.0 \text { vs. } \\
42.0 \\
\text { KOOS Daily } \\
\text { Activities } \\
\text { Subscale (0-100): } \\
45.8 \text { vs. } 51.7 \text { vs. } \\
45.7 \\
\text { KOOS } \\
\text { Recreational } \\
\text { Activities } \\
\text { Subscale (0-100): } \\
16.6 \text { vs. } 15.3 \text { vs. } \\
18.2 \\
\text { KOOS Pain } \\
\text { Subscale (0-100): } \\
37.4 \text { vs. } 42.5 \text { vs. } \\
38.0 \\
\text { NRS Pain(0-10): } \\
7.1 \text { vs. } 6.7 \text { vs. } 7.7 \\
\text { KOOS Quality of } \\
\text { Life Subscale (0- } \\
100): 26.1 \text { vs. } \\
32.4 \text { vs. } 27.8 \\
\text { (a) }\end{array}$ & 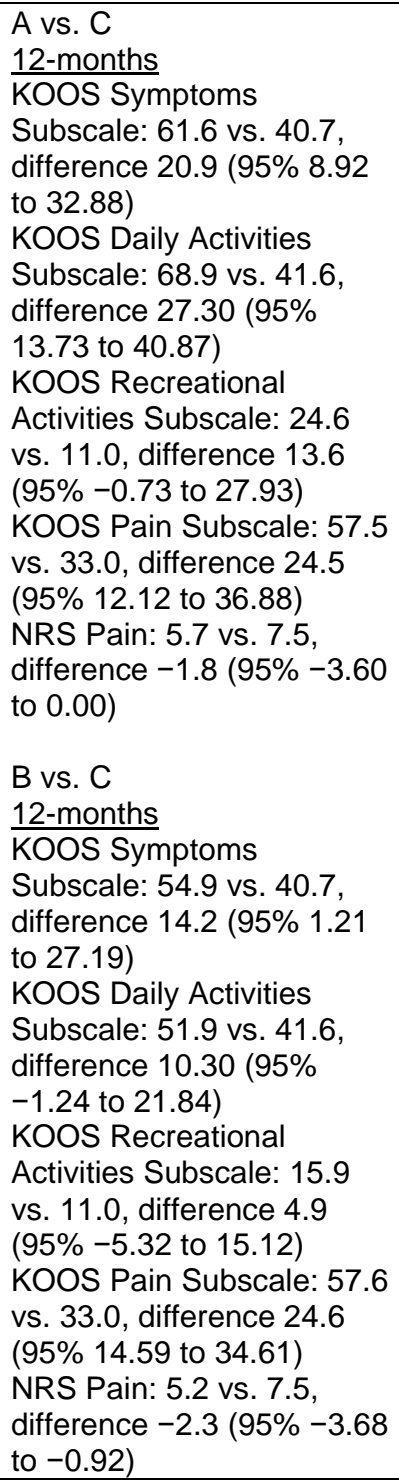 & $\begin{array}{l}\text { A vs. C } \\
\text { 12-months } \\
\text { KOOS } \\
\text { Quality of } \\
\text { Life } \\
\text { Subscale: } \\
31.8 \text { vs. } 33.0 \\
\text { B vs. C } \\
12-\text {-months } \\
\text { KOOS } \\
\text { Quality of } \\
\text { Life } \\
\text { Subscale: } \\
41.2 \text { vs. 33.0 } \\
\text { A vs. B vs. C } \\
\text { Adverse } \\
\text { Events: } \\
\text { Went on to } \\
\text { have a Total } \\
\text { Knee } \\
\text { Replacement } \\
\text { during 12 } \\
\text { month } \\
\text { followup: } \\
3.1 \% \text { (1/32) } \\
\text { vs. 6.5\% } \\
\text { (2/31) vs. } \\
4.3 \% \text { (1/23) }\end{array}$ \\
\hline
\end{tabular}




\begin{tabular}{|c|c|c|c|c|}
\hline $\begin{array}{l}\text { Author, Year, } \\
\text { Followup, }{ }^{\text {a }} \\
\text { Pain Duration, Study } \\
\text { Quality }\end{array}$ & Intervention & Population & $\begin{array}{l}\text { Function and Pain } \\
\text { Outcomes }\end{array}$ & $\begin{array}{l}\text { Other } \\
\text { Outcomes }\end{array}$ \\
\hline $\begin{array}{l}\text { Giombini, } 2011^{131} \\
3 \text { months } \\
\text { Duration of pain: } 3 \text { years } \\
\text { Fair }\end{array}$ & $\begin{array}{l}\frac{\text { A. Microwave diathermy }}{(n=29)} \\
\text { hyperthermic treatment } 3 \\
\text { times a week for } 4 \text { weeks } \\
\text { B. Sham diathermy }(n=25) \\
\text { sham hyperthermic } \\
\text { treatment } 3 \text { times a week for } \\
4 \text { weeks }\end{array}$ & $\begin{array}{l}\text { A vs. B } \\
\text { Age: } 67 \text { vs. } 67 \\
\text { years } \\
\text { Female: } 66 \% \text { vs. } \\
68 \% \\
\text { Baseline WOMAC } \\
\text { total (0-1.20): } \\
\text { 103.1 vs. 101.3 } \\
\text { Baseline WOMAC } \\
\text { pain (0-25): } 19.2 \\
\text { vs. 18.5 } \\
\text { Baseline WOMAC } \\
\text { stiffness (0-10): } \\
9.7 \text { vs. 9.7 } \\
\text { Baseline WOMAC } \\
\text { ADL (0-85): } 74.3 \\
\text { vs. } 73.1\end{array}$ & $\begin{array}{l}\text { A vs. B } \\
3 \text { months } \\
\text { Mean change in WOMAC } \\
\text { total: }-46.8 \text { vs. }-0.4, \\
\text { difference }-46.4(95 \% \mathrm{Cl} \\
-58.3 \text { to }-34.5) \\
\text { Mean change in WOMAC } \\
\text { pain; }-8.6 \text { vs. }-0.6, \\
\text { difference }-8.1 \text { (95\% Cl } \\
-10.7 \text { to }-5.3) \\
\text { Mean change in WOMAC } \\
\text { ADLs: }-33 \text { vs. } 0.3, \\
\text { difference }-33.2 \text { (95\% Cl } \\
-42.0 \text { to }-24.6) \\
\text { Mean change in WOMAC } \\
\text { stiffness: }-5.2 \text { vs. }-0.1, \\
\text { difference }-5.1, \text { P<0.01 }\end{array}$ & NR \\
\hline $\begin{array}{l}\text { Hegedus, } 2009^{132} \\
2 \text { months } \\
\text { Duration of pain NR } \\
\text { Poor }\end{array}$ & $\begin{array}{l}\text { A. Low-Level Laser Therapy } \\
\text { (n=18): } \\
50 \mathrm{~mW} \text {, continuous wave } \\
\text { laser (wavelength } 830 \mathrm{~nm}) \text {. } \\
\text { Treatment provided over the } \\
\text { femoral and tibial condyles. } \\
\text { Total dose of } 48 \mathrm{~J} / \mathrm{cm} 2 \text { per } \\
\text { session. Twice a week for } \\
\text { four weeks. } \\
\text { B. Placebo ( }=17) \text { : } \\
\text { Placebo probe }(0.5 \mathrm{~mW} \\
\text { power output) used twice a } \\
\text { week for four weeks. }\end{array}$ & $\begin{array}{l}\text { Age: } 49 \\
\text { Female: } 81 \% \\
\text { A vs. B } \\
\text { Pain VAS }(0-10): \\
5.75 \text { vs. } 5.62\end{array}$ & $\begin{array}{l}\text { A vs. B } \\
2 \text { months } \\
\text { Pain VAS: } 1.18 \text { vs. } 4.12 \text {, } \\
\text { difference }-2.94 \\
\text { (no estimate of variability } \\
\text { provided or calculable) }\end{array}$ & NR \\
\hline
\end{tabular}




\begin{tabular}{|c|c|c|c|c|}
\hline $\begin{array}{l}\text { Author, Year, } \\
\text { Followup, }{ }^{\text {a }} \\
\text { Pain Duration, Study } \\
\text { Quality }\end{array}$ & Intervention & Population & $\begin{array}{l}\text { Function and Pain } \\
\text { Outcomes }\end{array}$ & $\begin{array}{l}\text { Other } \\
\text { Outcomes }\end{array}$ \\
\hline $\begin{array}{l}\text { Laufer, } 2005^{133} \\
3 \text { months } \\
\text { Duration of pain: NR } \\
\text { Poor }\end{array}$ & $\begin{array}{l}\text { A. Low Intensity Pulsed } \\
\text { Shortwave Diathermy ( } \mathrm{n}=38 \text { ) } \\
\text { Treatment Protocol: } \\
\text { Shortwave diathermy was } \\
\text { applied to anterior aspect of } \\
\text { the affected knee; Three, } 20 \\
\text { min sessions per week for } 3 \\
\text { weeks (9 total) } \\
\text { Pulse Duration: } 82 \mu \mathrm{s} \\
\text { Pulse Frequency: } 110 \mathrm{~Hz} \\
\text { Peak Power: } 200 \mathrm{~W} \text { (mean } \\
\text { 1.8W)) } \\
\text { B. High Intensity Pulsed } \\
\text { Shortwave Diathermy (n=32) } \\
\text { Treatment protocol identical } \\
\text { to Group A except with a } \\
\text { higher intensity (pulse } \\
\text { duration and frequency) } \\
\text { Pulse Duration: } 300 \mu \mathrm{s} \\
\text { Pulse Frequency: } 300 \mathrm{~Hz} \\
\text { Peak Power: } 200 \mathrm{~W} \text { (mean } \\
\text { 18W) } \\
\text { C. Sham Shortwave } \\
\text { Diathermy ( }=33 \text { ) } \\
\text { Identical treatment except } \\
\text { the apparatus was turned on } \\
\text { but the power output was not } \\
\text { raised. }\end{array}$ & $\begin{array}{l}\text { A vs. B vs. C } \\
\text { Age: } 75 \text { vs. } 73 \text { vs. } \\
73 \\
\text { Female: } 82 \% \text { vs. } \\
90.6 \% \text { vs. } 67 \% \\
\text { Race: NR } \\
\text { Western Ontario } \\
\text { and McMaster } \\
\text { Universities } \\
\text { Osteoarthritis } \\
\text { Index (WOMAC) } \\
\text { Overall: 5.13 vs. } \\
4.60 \text { vs. 5.02 } \\
\text { WOMAC Pain: } \\
4.89(3.30) \text { vs. } \\
\text { 4.43(3.35) vs. } \\
4.97(3.52) ; \\
\text { WOMAC Stiffness } \\
: 4.87(3.50) \text { vs. } \\
4.25(3.47) \text { vs. } \\
\text { 4.92(3.58) } \\
\text { WOMAC Activities } \\
\text { of Daily Living: } \\
5.16(3.52) \text { vs. } \\
4.69(3.41) \text { vs. } \\
5.05(3.45) ;\end{array}$ & 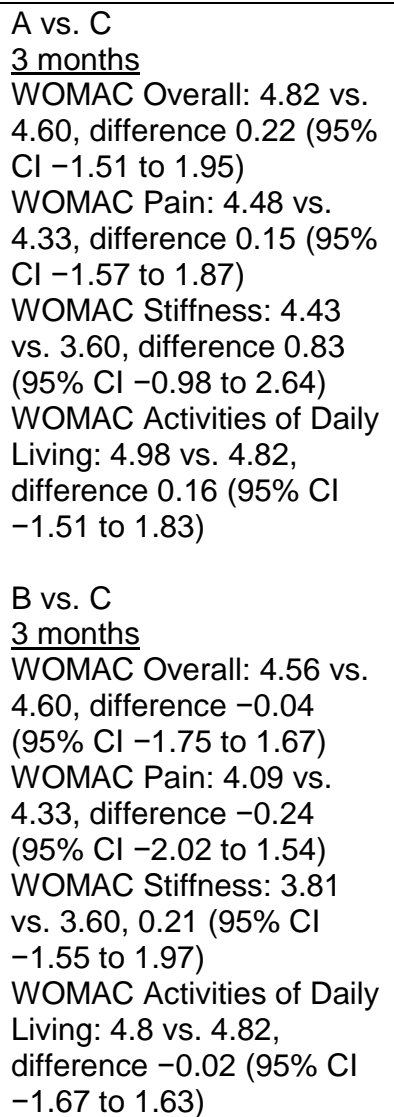 & $\begin{array}{l}\text { A vs. B vs. C } \\
\text { Adverse } \\
\text { Events: } \\
\text { No adverse } \\
\text { reactions to } \\
\text { the treatment } \\
\text { were } \\
\text { reported by } \\
\text { the subjects. }\end{array}$ \\
\hline $\begin{array}{l}\text { Mazzuca, } 2004^{134} \\
1 \text { month } \\
\text { Duration of } \\
\text { pain: NR } \\
\text { Fair }\end{array}$ & $\begin{array}{l}\text { A. Superficial Heat (sleeve) } \\
\frac{(\mathrm{n}=25)}{\text { Participants word a cotton }} \\
\text { and lycra sleeve with a heat } \\
\text { retaining polyester and } \\
\text { aluminum substrate. } \\
\text { Patients were asked to wear } \\
\text { the sleeve at least } 12 \text { hours } \\
\text { each day and to continue } \\
\text { their usual pain } \\
\text { medication(s). } \\
\text { B. Placebo Sleeve ( } \mathrm{n}=24) \\
\text { Placebo sleeves and } \\
\text { treatment protocol were } \\
\text { identical except placebo } \\
\text { sleeves did not contain the } \\
\text { heat retaining substrate } \\
\text { layer. }\end{array}$ & $\begin{array}{l}\text { A + B } \\
\text { Age: } 62.7 \\
\text { Female: } 77 \% \\
\text { Race: } 67 \% \text { white } \\
\\
\text { WOMAC Function } \\
(17-85)^{\mathrm{e}}: 51.8 \\
(11.8) \\
\text { WOMAC Pain (5- } \\
25)^{\mathrm{d}:} \text { 15.2 vs. } \\
\text { 14.7* } \\
\text { WOMAC Stiffness } \\
(2-10)^{\mathrm{e}}: 6.5(1.4)\end{array}$ & $\begin{array}{l}\text { A vs. B } \\
\frac{1 \text { month }}{\text { WOMAC Pain: } 13.7 \text { vs. }} \\
13.9\end{array}$ & NR \\
\hline
\end{tabular}




\begin{tabular}{|c|c|c|c|c|}
\hline $\begin{array}{l}\text { Author, Year, } \\
\text { Followup, }{ }^{\text {a }} \\
\text { Pain Duration, Study } \\
\text { Quality }\end{array}$ & Intervention & Population & $\begin{array}{l}\text { Function and Pain } \\
\text { Outcomes }\end{array}$ & $\begin{array}{l}\text { Other } \\
\text { Outcomes }\end{array}$ \\
\hline $\begin{array}{l}\text { Tascioglu, } 2004^{135} \\
6 \text { months } \\
\text { Duration of pain: } 7 \text { years } \\
\text { Poor }\end{array}$ & $\begin{array}{l}\text { A. Active laser } 3 \text { joule }(\mathrm{n}=20) \\
\text { continuous laser therapy }(50 \\
\mathrm{mW}, 830 \mathrm{~mm} \text { wavelength) } \\
\text { applied to } 5 \text { painful points } 5 \\
\text { days a week for } 2 \text { weeks } \\
\frac{\text { B. Active laser } 1.5 \text { joule }}{(\mathrm{n}=20)} \\
\text { continuous laser therapy } \\
(50 \mathrm{~mW}, 830 \mathrm{~mm} \\
\text { wavelength) applied to } 5 \\
\text { painful points } 5 \text { days a week } \\
\text { for } 2 \text { weeks } \\
\text { C. Placebo laser ( } \mathrm{n}=20) \text {, } \\
\text { sham laser therapy applied } \\
\text { to } 5 \text { painful points } 5 \text { days a } \\
\text { week for } 2 \text { weeks }\end{array}$ & $\begin{array}{l}\text { A vs. B vs. C } \\
\text { Age: } 63 \text { vs. } 60 \text { vs. } \\
64 \text { years } \\
\text { Female: } 70 \% \text { vs. } \\
75 \% \text { vs. } 65 \% \\
\text { Baseline WOMAC } \\
\text { function (0- } \\
68): 36.6 \text { vs. } 38.0 \\
\text { vs. } 39.5 \\
\text { Baseline WOMAC } \\
\text { stiffness (0-8): } 4.1 \\
\text { vs. } 4.6 \text { vs. } 4.5 \\
\text { Baseline WOMAC } \\
\text { pain (0-20): } 10.3 \\
\text { vs. } 11.6 \text { vs. } 9.6 \\
\text { Baseline pain at } \\
\text { rest VAS (0-100): } \\
39.1 \text { vs. } 41.6 \text { vs. } \\
37.9 \\
\text { Baseline pain at } \\
\text { activation VAS (0- } \\
100): 68.0 \text { vs. } \\
65.7 \text { vs. } 63.9\end{array}$ & $\begin{array}{l}\text { A vs. C } \\
6 \text { months } \\
\text { WOMAC function: } 34.8 \text { vs. } \\
38.7 \text {, difference }-3.8 \text { ( } 95 \% \\
\mathrm{Cl}-9.8 \text { to } 2.1) \\
\text { WOMAC stiffness: } 3.9 \text { vs. } \\
4.2 \text {, difference }-0.3 \text { (95\% } \\
\mathrm{Cl}-1.6 \text { to } 0.9) \\
\text { WOMAC pain: } 10.4 \text { vs. } \\
9.9 \text {, difference } 0.6 \text { (95\% Cl } \\
-1.5 \text { to } 2.7) \\
\text { Pain at rest VAS: } 38.7 \text { vs. } \\
38.9 \text {, difference }-0.3 \text { ( } 95 \% \\
\text { Cl }-9.8 \text { to } 9.3) \\
\text { Pain at activation VAS: } \\
66.8 \text { vs. } 62.0, \text { difference } \\
4.8 \text { (95\% Cl }-4.9 \text { to } 14.5) \\
\text { B vs. C } \\
6 \text { months } \\
\text { WOMAC function: } 38.5 \text { vs. } \\
38.7 \\
\text { WOMAC stiffness: } 4.5 \text { vs. } \\
4.2 \\
\text { WOMAC pain: } 11.3 \text { vs. } 9.9 \\
\text { Pain at rest VAS: } 40.0 \text { vs. } \\
38.9 \\
\text { Pain at activation VAS: } \\
61.8 \text { vs. } 62.0\end{array}$ & NR \\
\hline $\begin{array}{l}\text { Thamsborg, }{ }^{136} 2005 \\
1.5 \text { month } \\
\text { Duration of pain, } 8 \text { years } \\
\text { Fair }\end{array}$ & $\begin{array}{l}\text { A. Pulsed Electromagnetic } \\
\text { Fields (PEMF) ( } n=42 \text { ) } \\
\text { Two sets of two adjacent } \\
\text { coils were placed on the } \\
\text { medial and lateral regions of } \\
\text { the study knee, with the } \\
\text { interspace between the coils } \\
\text { being at the level of the koin } \\
\text { line. The coils were placed } \\
\text { on an insulating bandage of } \\
3-5 \text { mm thickness. } \\
2 \text {-hour daily treatment } 5 \\
\text { days per week for } 6 \text { weeks } \\
30 \text { total } \\
\text { Device: } \pm 50 \mathrm{~V} \text { in } 50 \mathrm{~Hz} \text { pulses } \\
\text { changing voltage in } 3 \text { ms } \\
\text { intervals. } \\
\text { B. Sham Electromagnetic } \\
\text { Field ( } \mathrm{n}=41 \text { ) } \\
\text { Patients in the control group } \\
\text { were subjected to a } \\
\text { noneffective placebo } \\
\text { electromagnetic field. } \\
\text { No. of Treatments: daily } \\
\text { treatment } 5 \text { days per week } \\
\text { for } 6 \text { weeks ( } 30 \text { total } \\
\text { Length of Treatments: } 2 \\
\text { hours each }\end{array}$ & $\begin{array}{l}\text { A vs. B } \\
\text { Age: } 60 \text { vs. } 60 \\
\text { Female: } 47.6 \% \\
\text { vs. } 61 \% \\
\text { Race: NR } \\
\text { WOMAC Activities } \\
\text { of Daily Living (0- } \\
85): 43.83 \text { vs. } \\
46.49 \\
\text { WOMAC Stiffness } \\
\text { (0-10): } 5.74 \text { vs. } \\
5.85 \\
\text { WOMAC Joint } \\
\text { Pain (0-25): } 13.15 \\
\text { vs. } 14.49\end{array}$ & $\begin{array}{l}\text { A vs. B } \\
1.5 \text { months } \\
\text { WOMAC Activities of Daily } \\
\text { Living: } 37.89 \text { vs. } 41.3, \\
\text { difference }-3.48(95 \% \mathrm{Cl} \\
-4.44 \text { to }-2.51) \\
\text { WOMAC Stiffness: } 4.81 \\
\text { vs. } 5.15 \text {, difference }-0.34 \\
\text { (95\% Cl }-0.48 \text { to }-0.20) \\
\text { WOMAC Joint Pain: } 11.40 \\
\text { vs. } 12.24 \text {, difference }-0.84 \\
\text { ( } 95 \% \mathrm{Cl}-1.10 \text { to }-0.58)\end{array}$ & $\begin{array}{l}\text { A vs. B } \\
\text { Adverse } \\
\text { Events: } \\
\text { throbbing } \\
\text { sensation, } \\
\text { warming } \\
\text { sensations } \\
\text { or } \\
\text { aggravation } \\
\text { of pain } \\
28.5 \% \\
(12 / 42) \text { vs. } \\
14.6 \%(6 / 41)\end{array}$ \\
\hline
\end{tabular}




\begin{tabular}{|c|c|c|c|c|}
\hline $\begin{array}{l}\text { Author, Year, } \\
\text { Followup, }{ }^{\text {a }} \\
\text { Pain Duration, Study } \\
\text { Quality }\end{array}$ & Intervention & Population & $\begin{array}{l}\text { Function and Pain } \\
\text { Outcomes }\end{array}$ & $\begin{array}{l}\text { Other } \\
\text { Outcomes }\end{array}$ \\
\hline $\begin{array}{l}\text { Yildiz, }{ }^{137} 2015 \\
2 \text { months } \\
\text { Duration of pain: Mean } \\
2.8 \text { to } 5.1 \text { years } \\
\text { Fair }\end{array}$ & $\begin{array}{l}\text { A. Continuous ultrasound } \\
(\mathrm{n}=30), \text { Therapeutic } \\
\text { ultrasound given } 5 \text { times a } \\
\text { week for } 2 \text { weeks } \\
\text { B. Pulsed ultrasound }(n=30) \text {, } \\
\text { Therapeutic pulsed } \\
\text { ultrasound given } 5 \text { times a } \\
\text { week for } 2 \text { weeks } \\
\text { C. Sham ( } n=30), \text { Sham } \\
\text { ultrasound given } 5 \text { times a } \\
\text { week for } 2 \text { weeks } \\
\text { All patients performed home } \\
\text { exercise program } 3 \text { days a } \\
\text { week for } 8 \text { weeks }\end{array}$ & $\begin{array}{l}\text { A vs. B vs. C } \\
\text { Age: } 56 \text { vs. } 55 \text { vs. } \\
58 \text { years } \\
\text { Female: } 83 \% \text { vs. } \\
80 \% \text { vs. } 87 \% \\
\text { Lequesne Index } \\
\text { score (0-24): } 13.2 \\
\text { vs. } 12.9 \text { vs. } 12.4 \\
\text { Pain at rest VAS } \\
\text { (0-10): NR } \\
\text { Pain on } \\
\text { movement VAS } \\
\text { (0-10): } 9.0 \text { vs. } 8.6 \\
\text { vs. } 8.9\end{array}$ & $\begin{array}{l}\text { A vs. C } \\
2 \text { months } \\
\text { Lequesne Index: } 5.5 \text { vs. } \\
11.7 \text {, difference }-6.2 \text { ( } 95 \% \\
\mathrm{Cl}-8.4 \text { to } 4.2) \\
\text { Pain at rest VAS: NR } \\
\text { Pain on movement VAS: } \\
3.9 \text { vs. } 7.2 \text {, difference }-3.3 \\
\text { (95\% Cl }-4.6 \text { to }-2.0) \\
\text { B vs. C } \\
2 \text { months } \\
\text { Lequesne Index: } 6.0 \text { vs. } \\
11.7, \text { difference }-5.7 \text { ( } 95 \% \\
\text { Cl }-7.7 \text { to }-3.7) \\
\text { Pain at rest VAS: NR } \\
\text { Pain on movement VAS: } \\
3.8 \text { vs. } 7.2 \text {, difference }-3.4 \\
\text { (95\% Cl }-4.7 \text { to }-2.0)\end{array}$ & NR \\
\hline
\end{tabular}

ADL = activity of daily living; EQ-5D = EuroQol Quality of Life Instrument 5-D; HSS = Hospital for Special Surgery; Hz = hertz; KOOS = Knee Injury and Osteoarthritis Outcome Score; MCID = minimal clinically important difference; MD = difference between means; NR = not reported; NRS = numeric rating scale; RR = risk ratio; SKFS = Saudi Knee Function Score; SF-36 = Short Form 36 Questionnaire; VAS = visual analog scale; W = watts; WOMAC = Western Ontario and McMaster Universities Osteoarthritis Index; $\mu$ s = microsecond

${ }^{\text {a }}$ Unless otherwise noted, followup time is calculated from the end of the treatment period

${ }^{\mathrm{b}}$ Values estimated from graph

${ }^{c}$ The study separated outcome values out into slight, moderate and severe disease patient groups for each treatment arm. These values are combined values for each intervention groups estimated from graphs in the study.

d Values estimated from graph

e Separate group baseline values not given for stiffness and function subscales

${ }_{\mathrm{f}}^{\mathrm{f}}$ Age only reported for population as a whole

Two fair-quality randomized controlled trials that evaluated ultrasound for knee OA met the inclusion criteria. ${ }^{128,137}$ Both trials required grade 2 or 3 radiographic knee OA using the Kellgren-Lawrence criteria for inclusion. Both trials had a continuous and a pulsed ultrasound group, which they compared to sham ultrasound. Both ultrasound groups received $1 \mathrm{MHz}$ treatments five times per week for 2 weeks at an intensity of either 1 or $1.5 \mathrm{~W} / \mathrm{cm}^{2}$. Sham ultrasound used the same protocols, but the power was switched off. All participants were also instructed to perform a home exercise program of mostly muscle performance exercises three times per week. Compliance with the intervention protocol was not reported. One trial reported short-term outcomes, ${ }^{137}$ the other intermediate-term outcomes. The methodological shortcomings were unclear adherence to an intention-to-treat analysis, ${ }^{137}$ and unclear blinding of the provider or assessor. ${ }^{128}$

We found one good-quality $(n=70)$ trial that compared active TENS with sham TENS for knee OA. ${ }^{129}$ Inclusion criteria required a confirmed diagnosis of knee OA using the American College of Rheumatology criteria. The TENS protocol had patients wear a pulsed TENS device 7 hours daily for 26 weeks. The sham TENS groups followed the same protocol as the active treatment, but the device turned off after 3 minutes. Compliance was unacceptable for time the TENS device was worn.

We identified three small trials ( $n=30,49$, and 60) that investigated low-level laser therapy versus sham laser for knee OA. ${ }^{125,132,135}$ The mean age ranged from 49 to 64 years and most 
patients were female (62\% to $75 \%$ ). Two studies included patients meeting the American College of Rheumatology criteria for knee OA. ${ }^{125,135}$ Two trials also required an average pain intensity of greater than 3 or 4 on a $0-10$ VAS, ${ }^{125}$ while the other trial had an additional inclusion criteria of radiographic knee OA of Kellgren-Lawrence grade of 2 or $3 .{ }^{135}$ Treatment duration ranged from 2 to 4 weeks and the number of total sessions from eight to ten. Low-level laser therapy protocols differed across the trials with doses ranging from 1.2 to 6 Joules per point (range, 5 to 6 points) and length of irradiation from 40 seconds to 2 minutes; all trials used a continuous laser beam. The sham laser comparison groups followed the same respective protocols, but the device was inactive. One trial was rated fair quality ${ }^{125}$ and two poor quality. ${ }^{132,135}$ In the fair-quality trial, blinding of the care provider was unclear. The two poorquality trials suffered from insufficient descriptions of allocation concealment methods, unclear application of intention to treat, lack of clarity regarding patient blinding, and no reporting of or unacceptable attrition.

One small ( $n=63)$, fair-quality trial compared microwave diathermy (three 30-minute sessions per week for 4 weeks) to sham. ${ }^{131}$ The inclusion criteria required radiographic knee OA of a Kellgren and Lawrence grade 2 or 3 . The power was set to 50 watts. Sham diathermy followed the same protocol, but the machine was set to off. Compliance with the treatment regimen for each group was unclear. Methodological limitations of this study included no blinding of the care providers.

Two trials ( $\mathrm{n}=86$ and 115) examined pulsed short-wave diathermy compared to sham diathermy. ${ }^{130,133}$ The mean age ranged from 62 to 75 years, and the proportion of female participants ranged from 67 to 100 percent. Both trials included patients meeting radiographic criteria for knee OA. Each trial compared two doses of short-wave diathermy to a sham diathermy group; dosages varied by intensity in one trial (mean power output of either 1.8 or 18 Watts for 20 minutes) ${ }^{133}$ or by length of session (19 or 38 minutes at 14.5 Watts) in the other. ${ }^{130}$ Both trials applied diathermy three times per week for 3 weeks (total of 9 sessions). Each sham diathermy group followed the same treatment protocol, but the electrical current was not applied. Compliance with the treatment regimens was acceptable for both trials. Both trials were rated poor quality due to unclear concealment of treatment allocation, a lack of care provider blinding, and unacceptable attrition.

Two trials ( $\mathrm{n}=90$ for both) compared the application of electromagnetic fields to sham interventions for knee OA. ${ }^{126,136}$ The mean age of participants was 59 and 60 years, and the proportion of female participants ranged from 48 to 70 percent. The mean duration of chronicity ranged from 9 to 11 years. The good-quality trial enrolled participants meeting the American College of Rheumatology criteria for knee OA. ${ }^{136}$ The inclusion criteria was not clearly presented in the poor-quality trial. ${ }^{126}$ The intervention group in the good-quality study received 2 hours of pulsed electromagnetic fields 5 days a week for 6 weeks. ${ }^{136}$ The poor-quality trial had a musically modulated electromagnetic field group that received 15 daily 30-minute sessions. Music from a connected speaker modulated the parameters of the electromagnetic field. The study also had an extremely low frequency electromagnetic field group that had 15 daily 30 minutes sessions, but the electromagnetic field was set at a frequency of $100 \mathrm{~Hz} .{ }^{126}$ The sham group in each trial followed the same respective treatment protocol, but used a noneffective electromagnetic field during the sessions. Compliance to the treatment sessions was acceptable in both trials. One trial was rated fair quality ${ }^{136}$ and the other was rated poor quality. ${ }^{126}$ Methodological limitations in both trials included unclear methods for allocation concealment. 
Additionally, in the poor-quality trial, there were baseline dissimilarities between groups, no blinding of patients, providers, or outcome assessors, and attrition was not reported. ${ }^{126}$

A single trial compared superficial heat with placebo $(n=52) .{ }^{134}$ Participants were included if they had grade 2 or higher using the Kellgren-Lawrence grading for radiographic knee OA. Superficial heat was provided using a knee sleeve with a heat retaining polyester and aluminum substrate. Participants were instructed to wear the sleeve at least 12 hours per day. The placebo sleeves were identical and participants received the same instructions, but the sleeve did not contain the heat retaining substrate; the extent to which patients could be truly blinded is unclear (sleeve may retain body heat and feel warmer). Compliance with wearing the sleeve was acceptable. This trial was rated fair quality due to unclear concealment of treatment allocation, and a lack of clarity regarding whether it was the provider or outcomes assessor that was blinded.

We identified one trial comparing use of a knee brace to usual care $(n=118) .{ }^{127}$ Inclusion criteria required unicompartmental knee OA, and either a varus or valgus malalignment. Patients in the intervention group were fitted with a commercially available knee brace that allowed medial unloading or lateral unloading. Usual care consisted of patient education and physical therapy and analgesics as needed. Compliance with continued use of the brace was unacceptable. This trial was rated poor quality due to lack of patient, provider, or assessor blinding, and unacceptable attrition.

\section{Physical Modalities Compared With Sham or Usual Care}

Ultrasound. One fair-quality trial reported short-term function using Lequesne Index (0-24) and VAS pain (0-10) during activity. ${ }^{137}$ Both the continuous ultrasound group and the pulsed ultrasound group had substantially better short-term function versus sham ultrasound (MD -6.2, $95 \%$ CI -8.36 to -4.20 , and -5.71 , $95 \%$ CI -7.72 to -3.70 , respectively). Continuous and pulsed ultrasound was also associated with substantially less pain during activity compared to sham ultrasound (MD -3.3, 95\% CI -4.64 to -1.96 , and $-3.37,95 \%$ CI -4.73 to -2.01 , respectively, on a 0 to 10 scale).

Intermediate-term results at 6 months from the other fair-quality trial showed no difference on the WOMAC Physical Function subscale (0 to 100) between either the continuous or pulsed ultrasound group versus sham ultrasound (MD -4.5, 95\% CI -10.34 to 1.34, and -2.9, 95\% CI -9.19 to 3.39 , respectively). ${ }^{128}$ Results for pain intensity were not consistent with regard to ultrasound method. The continuous ultrasound group had slightly less pain on the WOMAC pain scale compared to sham (MD -1.8, 95\% CI -3.34 to -0.26), but no statistical difference was seen between pulsed ultrasound and sham (MD -1.6, 95\% CI -3.26 to 0.06). There was no difference between either ultrasound group versus sham ultrasound for VAS pain during rest or on movement (Table 26).

Transcutaneous Electrical Nerve Stimulation. No effect was seen for TENS versus placebo TENS for function or pain over the intermediate term for any outcome measured in one goodquality trial. ${ }^{129}$ Function was measured via the WOMAC-function subscale (0 to 100); the difference in mean change scores was -1.9 (95\% CI -9.7 to 5.9) and the proportion of patients who achieved a MCID $\geq 9.1$ was 38 percent versus 39 percent (RR 1.2, 95\% CI 0.6 to 2.2). Pain was measured using a VAS pain scale (difference 0.9 on a scale of 0 to $10,95 \%$ CI -11.7 to 13.4) and the WOMAC pain subscale (difference -5.6 on a 0 to 100 scale, $95 \%$ CI -14.9 to 3.6). The proportion of patients who achieved MCID ( $\geq 20)$ in pain VAS was 56 percent versus 44 percent (RR 1.3, 95\% CI 0.8 to 2.0). Health-related quality of life measured with the SF-36 was 
not different between the two groups for the physical component and mental component score (Table 26).

Low-Level Laser Therapy. One fair-quality trial reported no difference between low-level laser therapy and sham for short-term function based on median Saudi Knee Function Scale scores (range 0-112 with higher scores indicating greater severity), median difference -10 (interquartile range of -23 to -4$), P=0.054$. $^{125}$ There were inconclusive results for intermediate-term function. One fair-quality trial reported the low-level laser therapy group had less functional severity at 6 months compared to sham on the Saudi Knee Function Scale (median difference -21.0, 95\% CI -34.0 to -7.0 ), $\mathrm{P}=0.006 .{ }^{125}$ For the other poor-quality trial, neither the higher dose nor the lower dose low-level laser therapy group differed from sham on the WOMAC physical function (0 to 96) subscale (MD -3.82 , 95\% CI -9.75 to 2.11 and -0.14 , 95\% CI -6.59 to 6.31 , respectively). ${ }^{135}$ However, the evidence was considered insufficient for function.

Low-level laser therapy was associated with moderately less pain over the short term in one fair-quality and one poor-quality trial (pooled difference -2.03 , 95\% CI -3.74 to -0.33 ) (Figure 34). ${ }^{125,132}$ There was no difference between low-level laser therapy versus sham for intermediate-term pain (pooled difference -0.93 , 95\% CI -2.82 to 0.96 ). ${ }^{125,135}$ However, the evidence was considered insufficient for pain.

Microwave Diathermy. Data were insufficient from one small, fair-quality trial evaluating microwave diathermy. ${ }^{131}$ The microwave diathermy group showed substantial short-term improvement compared with sham for function (difference -33.2 on a 0-85 scale, $95 \%$ CI -42.0 to -24.6 , WOMAC ADL subscale) and pain (difference -8.1 on a $0-25$ scale, $95 \%$ CI -10.7 to -5.3, WOMAC pain subscale). Substantial imprecision was noted.

Pulsed Short-Wave Diathermy. Data were insufficient for pulsed short-wave diathermy compared with sham. There was no difference in short-term function or pain for either the low intensity or high intensity group compared to sham diathermy based on the WOMAC in one poor-quality trial. ${ }^{131}$ There was no difference on the WOMAC function subscale (0 to 10) between either the low intensity group versus sham (MD 0.16, 95\% CI -1.51 to 1.83), or the high intensity group versus sham (MD -0.02, 95\% CI -1.67 to 1.63). There was also no difference on the WOMAC pain subscale (0 to 10) for either the low or high intensity group versus sham (MD 0.15, 95\% CI -1.57 to 1.87 and -0.24 , 95\% CI -2.02 to 1.54 , respectively).

The other trial found inconsistent results among the high and low dose groups for long-term function using the KOOS (0 to 100$){ }^{130}$ The low dose group had substantially greater improvement on the KOOS-Daily Activities subscale compared to sham (MD 27.30, 95\% CI 13.73 to 40.87), but there was no difference between the high dose group and sham on the KOOS-Daily Activities subscale (MD 10.30, 95\% CI -1.24 to 21.84). Neither the low or high dose group differed from sham on the KOOS-recreational activities subscale (Table 26). Regarding pain intensity, the low dose group had moderately better pain NRS (0 to 10) that was not statistically significant (MD -1.8, 95\% CI -3.60 to 0.00). The high dose group experienced substantially greater pain reduction than the sham group (MD $-2.3,95 \% \mathrm{CI}-3.68$ to -0.92 ).

Electromagnetic Fields. The fair-quality trial found use of pulsed electromagnetic fields did not appear to provide clinically meaningful short-term improvements in function or pain compared with sham, although statistical significance was achieved. The pulsed electromagnetic field 
group had better function on the WOMAC ADL subscale (0 to 85) compared with the sham group, (MD -3.48, 95\% CI -4.44 to -2.51), and it had lower scores on the WOMAC pain subscale ( 0 to 25 ) versus sham (MD $-0.84,95 \%$ CI -1.10 to -0.58 ). ${ }^{136}$ Based on estimated values from a graph for the poor-quality trial, ${ }^{126}$ each group using electromagnetic fields had better function and substantially less pain in the short term on the Lequesne Index. The musically modulated electromagnetic field group had moderately better Lequesne Function scores (0-10) versus sham (mean of 6.5 vs. 3.8) and substantially lower Lequesne Pain scores (0 to 10) (mean of 1.4 vs. 6.9). The low frequency electromagnetic field group had similar benefits for function (mean of 7.1 vs. 3.83) and pain (mean of 1.4 vs. 6.85, standard deviation and statistical testing not reported), compared with sham.

Superficial Heat. Evidence from one small fair-quality trial was insufficient to determine the effects of superficial heat on short-term pain. WOMAC pain subscale scores were similar between the heat and placebo group at 1 month post treatment (13.7 versus 13.9 , respectively). ${ }^{134}$

Brace. Evidence from one small poor-quality trial was insufficient to determine the effects of brace treatment. There was no difference between bracing and usual care for intermediate-term or long-term function, pain, and quality of life outcomes. ${ }^{127}$ Function was measured using the Hospital for Special Surgery (HSS) score (MD 3.2, 95\% CI -0.58 to 6.98 for intermediate-term function and 3.0, 95\% CI -1.05 to 7.05 for long-term function). Pain intensity was assessed using a VAS. The MD was -0.58 ( $95 \%$ CI -1.48 to 0.32 ) for intermediate-term pain and -0.81 (95\% CI -1.76 to 0.14 ) for long-term pain. Health-related quality of life was measured using the Euro-Qol 5-Dimensions (EQ-5D) (MD 0.01, 95\% CI -0.08 to 0.10 for both intermediate-term and long-term health-related quality of life).

\section{Physical Modalities Compared With Pharmacological Therapy or With Exercise Therapy}

No trial of physical modalities versus pharmacological therapy or versus exercise met inclusion criteria.

\section{Harms}

In general, harms were poorly reported across the physical modality trials. Six trials (2 of low-level laser therapy, ${ }^{125,135} 2$ of ultrasound therapy, ${ }^{128,137} 1$ of pulsed short-wave diathermy, ${ }^{133}$ and 1 of superficial heat ${ }^{134}$ ) reported that no adverse events or side effects occurred in either group. The good-quality trial that evaluated TENS found no difference between active and sham TENS in the risk of localized, mild rashes (18\% vs.17\%; RR 1.06, 95\% CI 0.38 to 2.97 ). ${ }^{129}$ One trial of microwave diathermy reported two cases of symptom aggravation in the intervention group; the events were transient and neither patient withdrew from the trial. ${ }^{131}$ More patients who received real versus sham electromagnetic field therapy reported throbbing or warming sensations or aggravation of pain ( $29 \%$ versus $7 \%$ ); however, the difference was not significant (RR $1.95,95 \%$ CI 0.81 to 4.71 ) in one fair-quality trial. ${ }^{136}$ 
Figure 34. Low-level laser therapy versus usual care or sham for osteoarthritis of the knee: effects on pain

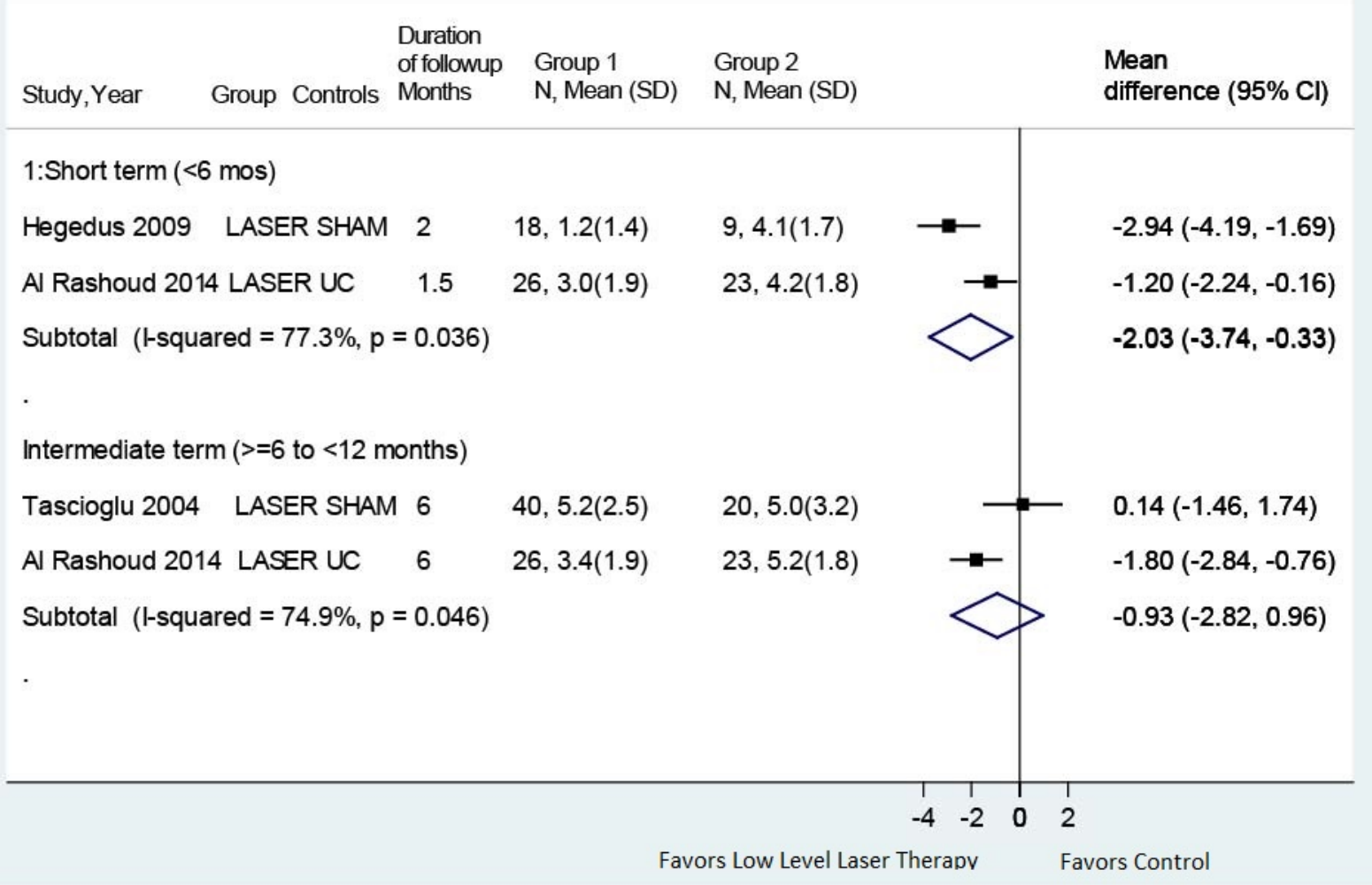

$\mathrm{CI}=$ confidence interval; $\mathrm{SD}$ = standard deviation; $\mathrm{UC}=$ usual care

\section{Manual Therapies for Osteoarthritis of the Knee}

\section{Key Points}

- There was insufficient evidence from one trial to determine the effects of joint manipulation on intermediate-term function or harms versus usual care or versus exercise due to inadequate data to determine effect sizes or statistical significance (SOE: insufficient).

- There was insufficient evidence from one trial to determine the effects of massage versus usual care on short-term function, pain, or harms, or to evaluate the effect of varying dosages of massage on outcomes (SOE: insufficient).

\section{Detailed Synthesis}

Two trials were identified that met inclusion criteria and evaluated manual therapies for the treatment of knee $\mathrm{OA}^{40,154}$ (Table 27 and Appendixes D and E); both trials required patients to have radiographically established knee OA meeting the American College of Rheumatology criteria. 
Table 27. Osteoarthritis of the knee: manual therapies

\begin{tabular}{|c|c|c|c|c|}
\hline $\begin{array}{l}\text { Author, Year, } \\
\text { Followup, } \\
\text { Pain Duration, } \\
\text { Study Quality }\end{array}$ & Intervention & Population & $\begin{array}{l}\text { Function and Pain } \\
\text { Outcomes }\end{array}$ & Other Outcomes \\
\hline $\begin{array}{l}\text { Abbott, } 2013^{40} \\
9.75 \text { months } \\
\text { Duration of } \\
\text { diagnosis: } 2.6 \\
\text { years } \\
\text { Fair }\end{array}$ & $\begin{array}{l}\text { A. Manual therapy } \\
(n=54 / 30 \text { knee OA): } 7 \\
\text { manual therapy } \\
\text { sessions in } 9 \text { weeks } \\
\text { with } 2 \text { additional } \\
\text { booster sessions } \\
\text { B. Exercise ( } n=51 / 29 \\
\text { knee OA), } 7 \text { exercise } \\
\text { sessions in } 9 \text { weeks } \\
\text { with } 2 \text { additional } \\
\text { booster sessions } \\
\text { C. Usual care }(n=51 / 28 \\
\text { knee OA) }\end{array}$ & $\begin{array}{l}\text { A vs. B vs. C (total } \\
\text { population, includes } \\
\text { hip OA) } \\
\text { Age: } 67 \text { vs. } 67 \text { vs. } 66 \\
\text { years } \\
\text { Female: } 49 \% \text { vs. } 52 \% \\
\text { vs. } 58 \% \\
\text { Percent knee OA: } \\
56 \% \text { vs. } 57 \% \text { vs. } 55 \% \\
\text { Percent hip OA: } 44 \% \\
\text { vs. } 43 \% \text { vs. } 45 \% \\
\text { Percent both hip OA } \\
\text { and knee OA: } 22 \% \text { vs. } \\
20 \% \text { vs. } 26 \% \\
\text { Baseline WOMAC (0- } \\
240): 114.8 \text { vs. } 95.5 \\
\text { vs. } 93.8\end{array}$ & $\begin{array}{l}\text { A vs. C (knee OA only) } \\
9.75 \text { months } \\
\text { WOMAC mean change } \\
\text { from baseline: }-31.5 \text { vs. } \\
1.6, P=N R \\
\text { A vs. B } \\
\frac{9.75 \text { months }}{\text { WOMAC mean change }} \\
\text { from baseline: }-31.5 \text { vs. } \\
-12.7, P=N R\end{array}$ & NR \\
\hline
\end{tabular}




\begin{tabular}{|c|c|c|c|c|}
\hline $\begin{array}{l}\text { Author, Year, } \\
\text { Followup, }^{\text {a }} \\
\text { Pain Duration, } \\
\text { Study Quality }\end{array}$ & Intervention & Population & $\begin{array}{l}\text { Function and Pain } \\
\text { Outcomes }\end{array}$ & Other Outcomes \\
\hline $\begin{array}{l}\text { Perlman, }{ }^{154} \\
2012 \\
4 \text { months } \\
\text { Duration of } \\
\text { pain: NR } \\
\text { Fair }\end{array}$ & 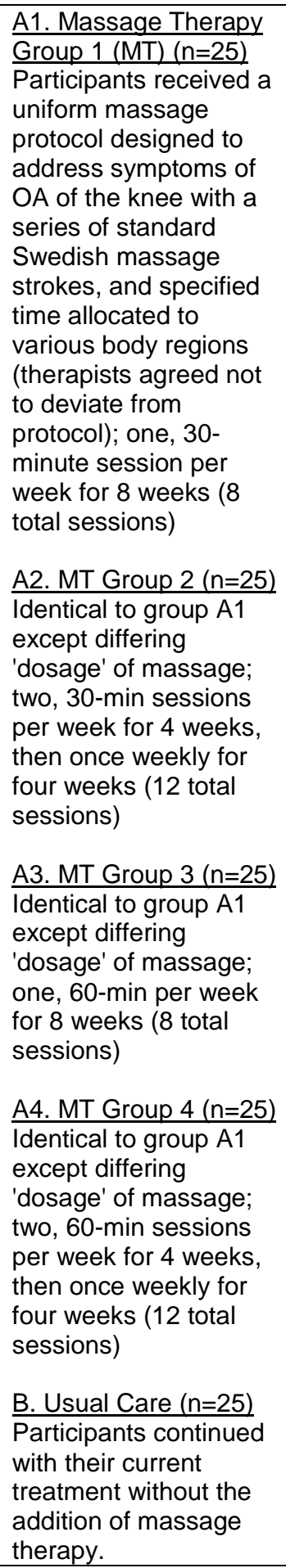 & $\begin{array}{l}\text { A1 vs. A2 vs. A3 vs. } \\
\text { A4 vs. B } \\
\text { Age: } 70 \text { vs. } 62 \text { vs. } 63 \\
\text { vs. } 64 \text { vs. } 64 \\
\text { Female: } 60 \% \text { vs. } 72 \% \\
\text { vs. } 76 \% \text { vs. } 68 \% \text { vs. } \\
76 \% \\
\text { Race: } 92 \% \text { vs. } 88 \% \\
\text { vs. } 76 \% \text { vs. } 80 \% \text { vs. } \\
88 \% \text { white } \\
\text { WOMAC Total (0- } \\
100): 52.9 \text { vs. } 50.2 \text { vs. } \\
53.6 \text { vs. } 48.0 \text { vs. } 53.2 \\
\text { WOMAC Physical } \\
\text { Function (0-100): } 52.9 \\
\text { vs. } 49.5 \text { vs. } 49.8 \text { vs. } \\
48.3 \text { vs. } 50.5 \\
\text { WOMAC Pain (0-100): } \\
52.3 \text { vs. } 42.4 \text { vs. } 52.5 \\
\text { vs. } 44.4 \text { vs. } 46.3 \\
\text { VAS Pain (0-100): } \\
61.2 \text { vs. } 64.0 \text { vs. } 66.4 \\
\text { vs. } 59.2 \text { vs. } 57.6\end{array}$ & 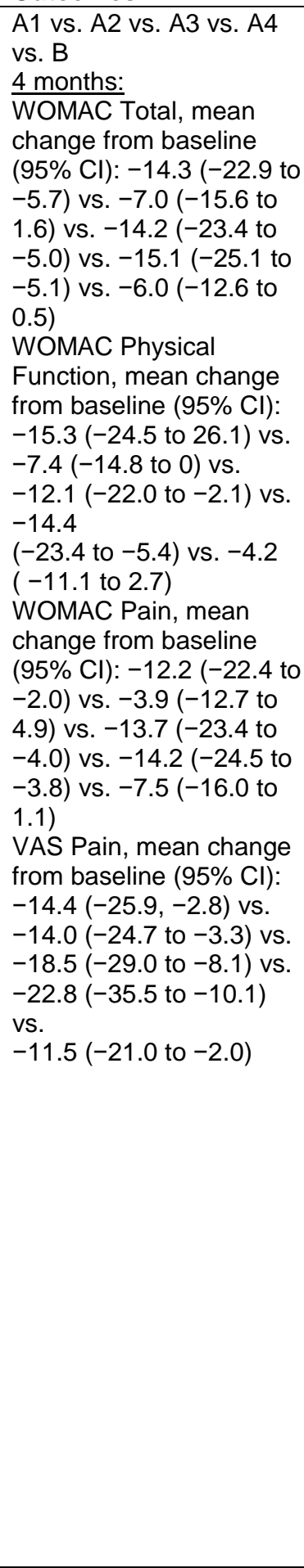 & $\begin{array}{l}\text { A1 vs. A2 vs. A3 } \\
\text { vs. A4 vs. B } \\
4 \text { months: } \\
\text { WOMAC } \\
\text { Stiffness, mean } \\
\text { change from } \\
\text { baseline }(95 \% \\
\text { Cl): }-15.4(-26.4 \\
\text { to } \\
-4.5) \text { vs. }-9.6 \\
(-20.6 \text { to } 1.3) \text { vs. } \\
-16.9(-28.5 \text { to } \\
-5.2) \text { vs. }-16.8 \\
(-29.7 \text { to }-3.9) \text { vs. } \\
-6.4(-13.2 \text { to } \\
0.4)\end{array}$ \\
\hline
\end{tabular}

$\mathrm{CI}$ = confidence interval; $\mathrm{NR}$ = not reported; $\mathrm{OA}$ = osteoarthritis; VAS = visual analog scale; WOMAC = Western Ontario and McMaster Universities Arthritis Index

${ }^{a}$ Unless otherwise noted, followup time is calculated from the end of the treatment period 
One fair-quality trial ( $\mathrm{N}=58$ with knee $\mathrm{OA}$ ) compared manual therapy with usual care (continued routine care from general practitioner and other providers) and with combination exercise. ${ }^{40}$ The manual therapy intervention consisted of nine 50 -minute sessions. Seven were delivered in the first 9 weeks and two booster sessions at week 16. All participants were prescribed a home exercise program three times per week. Compliance with the intervention was acceptable in all groups, and the methodological shortcoming of this trial was a lack of blinding for the patients and care providers. Only intermediate-term outcomes were reported.

One fair-quality trial $(\mathrm{N}=125)$ compared four different dosages of massage therapy with usual care (continued current treatment). ${ }^{154}$ The massage protocol consisted of standard Swedish massage strokes applied in each intervention group over 8 weeks. The dosage varied from 240 to 720 minutes based on the frequency (once or twice per week) and duration of massage (30-60 minutes per session). Compliance was acceptable in all groups, and the methodological shortcoming of this trial was a lack of blinding for the patients and care providers in the usual care arm. Only short-term outcomes were reported.

\section{Manual Therapies Compared With Usual Care}

Manual Therapy. Data were insufficient from one fair-quality trial ( $\mathrm{n}=58$ with knee $\mathrm{OA})^{40}$ to evaluate effects of joint manipulation versus usual care over the intermediate term. Although the manual therapy group showed a statistically significant improvement from baseline in function as measured by the WOMAC (mean change -31.5 on a $0-240$ scale, $95 \%$ CI -52.7 to -10.3 ), whereas the usual care group showed no improvement (mean change 1.6, 95\% CI -10.5 to 13.7), insufficient data was provided to calculate an effect estimate (number of patients with knee OA in each group were not provided). Pain outcomes were not reported.

Massage. Data were insufficient from one fair-quality trial $(\mathrm{n}=125)$ to evaluate the short-term effects of massage therapy (4 different dosages) compared with usual care. ${ }^{154}$ Function was measured using the WOMAC total and physical function subscale scores (both 0 to 100 scales) and pain was measured using the WOMAC pain subscale and the VAS (both 0 to 10). No significant effects were seen in any outcome measure at 4 months post-massage treatment versus usual care (Table 27). Authors reported a trend for greater magnitude of change in function and pain with higher massage dosages versus lower massage dosages and versus usual care (statistical tests not provided).

\section{Manual Therapies Compared With Pharmacological Therapy}

No trial of manual therapy versus pharmacological therapy met inclusion criteria.

\section{Manual Therapies Compared With Exercise Therapy}

The trial evaluating manual therapy also included an exercise group that received aerobic warm-up, muscle strengthening, muscle stretching, and neuromuscular control exercises. ${ }^{40}$ Both groups showed improvement from baseline in function (WOMAC) over the intermediate term, but the change was statistically significant in the manual therapy group only (mean change of -31.5 , $95 \%$ CI -52.7 to -10.3 versus -12.7 , 95\% CI -27.1 to 1.7 ) for exercise. However, insufficient data was provided to calculate an effect estimate (number of patients with knee OA in each group were not provided). Pain outcomes were not reported. 


\section{Harms}

No serious treatment-related adverse events occurred in either trial; ${ }^{40,154}$ one nontrial-related death was reported in the usual care group in the trial evaluating manual therapy. ${ }^{40}$

\section{Mind-Body Therapies for Osteoarthritis of the Knee}

\section{Key Points}

- Data were insufficient from two small, unblinded trials to determine the effects or harms of tai chi versus attention control in the short or intermediate terms. No data on long-term outcomes were available (SOE: insufficient).

\section{Detailed Synthesis}

Two small trials ( $n=41$ and 40 ) of tai chi versus attention control in older adults met the inclusion criteria ${ }^{181,182}$ (Table 28 and Appendix D). Tai chi was practiced 40 to 60 minutes two or three times per week for 24 or 36 sessions. Attention control consisted of group education classes with one trial ${ }^{182}$ including 20 minutes of stretching for sessions 18 to 24 . Blinding was not possible in either trial and was the primary methodological limitation in one fair-quality trial. ${ }^{182}$ Additional methodological concerns in the other poor-quality trial included unclear concealment of treatment allocation and high attrition ${ }^{181}$ (Appendix E).

Table 28. Osteoarthritis of the knee: mind-body therapies

\begin{tabular}{|c|c|c|c|c|}
\hline $\begin{array}{l}\text { Author, Year, } \\
\text { Followup, } \\
\text { Pain Duration, } \\
\text { Study Quality }\end{array}$ & Intervention & Population & $\begin{array}{l}\text { Function and Pain } \\
\text { Outcomes }\end{array}$ & Other Outcomes \\
\hline $\begin{array}{l}\text { Brismee, } \\
2007^{181} \\
1.5 \text { months } \\
\text { Duration of pain: } \\
\text { NR } \\
\text { Poor }\end{array}$ & $\begin{array}{l}\text { A. Tai chi ( } n=18 \text { ) } \\
\text { Subjects in the tai chi } \\
\text { group attended group tai } \\
\text { chi classes for } 6 \text { weeks } \\
\text { followed by } 6 \text { weeks of } \\
\text { home video tai chi } \\
\text { practice. } \\
\text { No. of Treatments: } \\
\text { 3/week for } 12 \text { weeks (36 } \\
\text { total) } \\
\text { Length of Treatments: } 40 \\
\text { min/session } \\
\text { B. Attention Control } \\
\text { (n=13) } \\
\text { Subjects in the attention } \\
\text { control group attended } \\
\text { group lectures and } \\
\text { discussions covering } \\
\text { health-related topics. } \\
\text { They did not take part in } \\
\text { any further activity past } 6 \\
\text { week group period. } \\
\text { No. of Treatments: } \\
\text { 3/week for } 6 \text { weeks (18 } \\
\text { total) } \\
\text { Length of Treatments: } 40 \\
\text { min/session }\end{array}$ & $\begin{array}{l}\text { A vs. B } \\
\text { Age: } 71 \text { vs. } 69 \\
\text { Female: } 86.4 \% \\
\text { vs. } 78.9 \% \\
\text { Race: NR } \\
\text { WOMAC Total } \\
\text { (26-13)]: } 64.6 \text { vs. } \\
59.6 \\
\text { WOMAC Physical } \\
\text { Function (17-85): } \\
42.7 \text { vs. } 37.6 \\
\text { WOMAC Pain } \\
\text { (7-35): } 16.5 \text { vs. } \\
\text { 16.9 } \\
\text { VAS Pain (0-10): } \\
4.7 \text { vs. } 4.2 \\
\text { WOMAC Stiffness } \\
\text { (2-10): } 5.6 \text { vs. } 5.1\end{array}$ & $\begin{array}{l}\text { A vs. B } \\
1.5 \text { months } \\
\text { WOMAC Total: } 60.28 \text { vs. } \\
\text { 57.73m P=NS } \\
\text { WOMAC Physical Function: } \\
38.61 \text { vs. } 37.58, P=N S \\
\text { WOMAC Pain: } 16.39 \text { vs. } 16 \text {, } \\
\text { P=NS } \\
\text { VAS Pain: } 3.46 \text { vs. } 3.19 \\
\text { P=NS } \\
\text { WOMAC Stiffness: } 5.28 \text { vs. } \\
\text { 4.54, P=NS }\end{array}$ & NR \\
\hline
\end{tabular}




\begin{tabular}{|c|c|c|c|c|}
\hline $\begin{array}{l}\text { Author, Year, } \\
\text { Followup, } \\
\text { Pain Duration, } \\
\text { Study Quality }\end{array}$ & Intervention & Population & $\begin{array}{l}\text { Function and Pain } \\
\text { Outcomes }\end{array}$ & Other Outcomes \\
\hline $\begin{array}{l}\text { Wang, } 2009^{182} \\
3 \text { and } 9 \text { months } \\
\text { Duration of pain: } \\
9.7 \text { years } \\
\text { Fair }\end{array}$ & $\begin{array}{l}\text { A. Tai chi (n=20) } \\
\text { Subjects in the tai chi } \\
\text { group attended group tai } \\
\text { chi classes where they } \\
\text { learned } 10 \text { forms from the } \\
\text { classic Yang style tai chi. } \\
\text { They were also instructed } \\
\text { to practice tai chi at least } \\
20 \text { minutes per day at } \\
\text { home with a tai chi DVD. } \\
\text { Home practice continued } \\
\text { after group sessions } \\
\text { ended until the } 48 \text { week } \\
\text { followup. } \\
\text { B. Attention Control } \\
\text { (n=20) } \\
\text { Subjects in the attention } \\
\text { control group attended } \\
\text { group classes where they } \\
\text { received nutritional and } \\
\text { medical information } \\
\text { paired with } 20 \text { minutes of } \\
\text { stretching. Instruction to } \\
\text { practice at least } 20 \\
\text { minutes of stretching } \\
\text { exercises per day at } \\
\text { home. } \\
\text { In both groups, } \\
\text { treatments were } 2 x / \text { week } \\
\text { for } 12 \text { weeks ( } 24 \text { total), } \\
60 \text { minute sessions }\end{array}$ & $\begin{array}{l}\text { A vs. B } \\
\text { Age: } 63 \text { vs. } 68 \\
\text { Female: } 80 \% \text { vs. } \\
70 \% \\
\text { Race: NR } \\
\\
\text { WOMAC Physical } \\
\text { Function } \\
\text { (0-1,700): } 707.6 \\
\text { vs. 827 } \\
\text { WOMAC Pain (0- } \\
500): 209.3 \text { vs. } \\
220.4 \\
\text { VAS Patient- } \\
\text { Assessed Pain } \\
\text { (0-10): } 4.2 \text { vs. } 4.8 \\
\text { VAS Physician- } \\
\text { Assessed Pain } \\
\text { (0-10): } 4.8 \text { vs. } 5.8 \\
\text { WOMAC Stiffness } \\
\text { (0-200): } 105.7 \text { vs. } \\
\text { 120.7 }\end{array}$ & 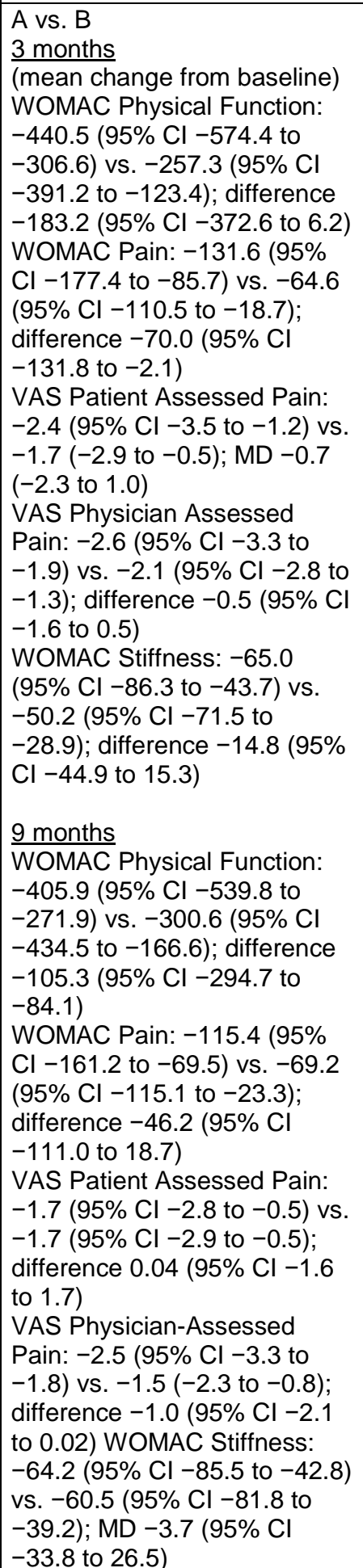 & 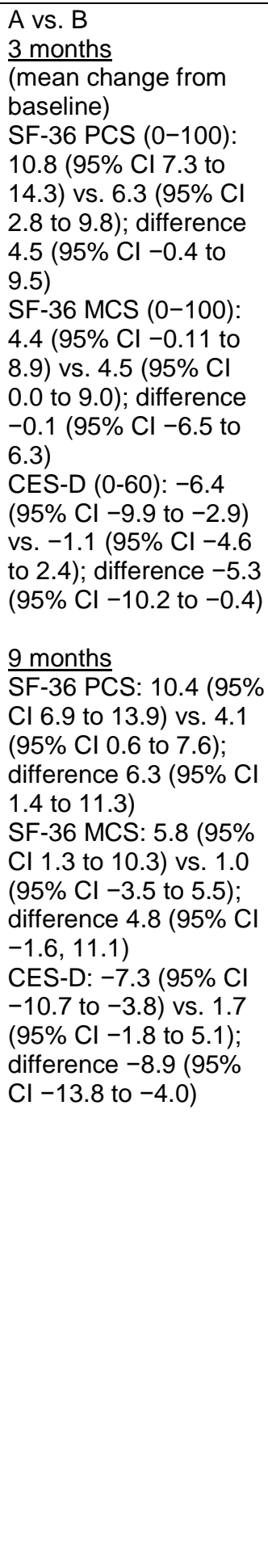 \\
\hline
\end{tabular}

AIMS = Arthritis Impact Measurement Scale; BAI = Beck Anxiety Inventory; BDI = Beck Depression Inventory; CI = confidence interval; HRQoL = health-related quality of life; NR = not reported; NRS = numeric rating scale; NS = not statistically significant; OA = osteoarthritis; WOMAC = Western Ontario and McMaster Universities Osteoarthritis index ${ }^{\text {a }}$ Unless otherwise noted, followup time is calculated from the end of the treatment period 


\section{Mind-Body Therapies Compared With Attention Control}

There is no clear difference between tai chi and an attention control on functional outcomes across the two trials over the short term on a WOMAC physical function 0- to 85-point scale (difference $1.03,95 \%$ CI -9.87 to 11.93$)^{181}$ or WOMAC physical function 0 - to 1700 -point scale (difference $-183.2,95 \% \mathrm{CI}-372.6$ to 6.2 ), ${ }^{182}$ or at intermediate term in one of the trials (difference -105.3 , 95\% CI -294.7 to $-84.1,0$ to 1700 scale). ${ }^{182}$ Results for short-term pain improvement were inconsistent with no difference between groups on WOMAC pain scale in one trial (difference 0.39 on a $0-35$ point scale, $95 \%$ CI -4.21 to 4.99 ) ${ }^{181}$ and the other marginally favoring tai chi on 0 to 500 point WOMAC pain scale (difference -67.0 , 95\% CI -131.8 to -2.1$),{ }^{182}$ but demonstrating no difference between the groups in 0 to 10 VAS pain (difference $-0.65,95 \%$ CI -2.31 to 1.02 ). ${ }^{182}$ There were no differences between groups at intermediate term in this latter trial (WOMAC pain 0 to 500 scale, difference -183.2, 95\% CI -372.6 to 6.2 ). ${ }^{182}$ One trial noted improvement in health-related quality of life (SF-36) in the intermediate term only and depression (CES-D) and self-efficacy in the short and intermediate terms.

\section{Mind-Body Therapies Compared With Pharmacological Therapy or With Exercise Therapy}

No trial of mind-body therapy versus pharmacological therapy or versus exercise met inclusion criteria.

\section{Harms}

In the two trials of mind-body interventions, harms were poorly reported. One trial reported no serious adverse events ${ }^{182}$ and the other reported sporadic complaints of muscle soreness and foot or knee pain. ${ }^{181}$

\section{Acupuncture for Osteoarthritis of the Knee}

\section{Key Points}

- There was no evidence of differences between acupuncture versus control interventions (sham acupuncture, waitlist, or usual care) on function in the short term (4 trials [excluding outlier trial], pooled SMD $-0.05,95 \% \mathrm{CI}-0.32$ to 0.38 ) or the intermediate term (4 trials, pooled SMD $-0.15,95 \% \mathrm{CI}-0.30$ to $0.01, \mathrm{I}^{2}=0 \%$ ) (SOE: low for short term; moderate for intermediate term). Stratified analysis showed no differences between acupuncture and sham treatments (4 trials) but moderate improvement in function compared with usual care (2 trials) short term.

- There was no evidence of differences between acupuncture versus control interventions (sham acupuncture, waitlist, or usual care) on pain in the short term (6 trials, pooled SMD $-0.27,95 \% \mathrm{CI}-0.56$ to $0.02, \mathrm{I}^{2}=75 \%$ ) or clinically meaningful differences in the intermediate term ( 4 trials, pooled SMD $-0.16,95 \%$ CI -0.31 to $0.02, \mathrm{I}^{2}=0 \%$ ) (SOE: low for short term; moderate for intermediate term). Short-term differences were significant for acupuncture versus usual care but not for acupuncture versus sham acupuncture.

- Data from one poor-quality trial were insufficient to determine the effects of acupuncture versus exercise (SOE: insufficient).

- There was no evidence of differences in risk of serious adverse events between any form of acupuncture and the control group. Worsening of symptoms (7\% to $14 \%$ ) and mild 
bruising, swelling, or pain at the acupuncture site (1\% to $18 \%)$ were most common; one case of infection at an electroacupuncture site was reported (SOE: moderate).

\section{Detailed Synthesis}

Nine trials of acupuncture for knee OA were identified that met inclusion criteria ${ }^{60,203-210}$ (Table 29 and Appendix D). Four trials evaluated traditional acupuncture, ${ }^{60,205,207,209}$ four electroacupuncture, ${ }^{203,204,206,208}$ and two laser acupuncture. ${ }^{205,210}$ Three trials compared acupuncture with usual care (provision of educational leaflets, instructions to remain on current oral medications, or no changes to their ongoing treatments) ${ }^{60,203,207}$ and one trial each to no treatment ${ }^{205}$ or to waitlist control. ${ }^{208}$ Six trials compared acupuncture with sham procedures, which consisted of inactive laser treatment (red light on but no power applied), ${ }^{205,210}$ superficial needling, or acupuncture performed at nonmeridian sites, ${ }^{204,208,209}$ or nonpenetrating sham acupuncture. ${ }^{206}$ No trials of acupuncture versus pharmacologic therapy or exercise were identified. Sample sizes ranged from 30 to 455 (total sample 1,364). Duration of acupuncture treatment ranged from 2 to 12 weeks, with the number of sessions ranging from 6 to 16 . Four studies were conducted in Europe, ${ }^{60,206,207,209}$ three in the United States, ${ }^{203,204,208}$ and one study each was conducted in Australia ${ }^{205}$ and Turkey. ${ }^{210}$ Short-term outcomes were reported by six trials ${ }^{60,203,206,208-210}$ and intermediate-term outcomes by four; ${ }^{204,205,207,209}$ no trial reported outcomes over the long term.

Trials were rated good quality (for the comparison of acupuncture versus sham only). ${ }^{205,208}$ Seven trials were rated fair quality (to include the comparison of acupuncture with no

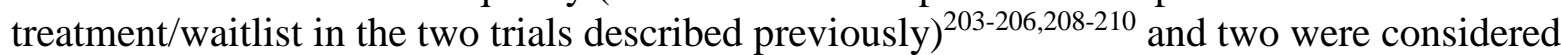
poor quality ${ }^{60,207}$ (Appendix E). The primary methodological shortcoming in the fair-quality trials was lack of blinding; additionally, the poor-quality trials suffered from unclear allocation concealment methods and high rates of attrition (30\% to 35\%).

Table 29. Osteoarthritis of the knee: acupuncture

\begin{tabular}{|c|c|c|c|c|}
\hline $\begin{array}{l}\text { Author, Year, } \\
\text { Followup, } \\
\text { Pain Duration, } \\
\text { Study Quality }\end{array}$ & Intervention & Population & Function and Pain Outcomes & Other Outcomes \\
\hline
\end{tabular}




\begin{tabular}{|c|c|c|c|c|}
\hline $\begin{array}{l}\text { Author, Year, } \\
\text { Followup, } \\
\text { Pain Duration, } \\
\text { Study Quality }\end{array}$ & Intervention & Population & Function and Pain Outcomes & Other Outcomes \\
\hline
\end{tabular}




\begin{tabular}{|c|c|c|c|c|}
\hline $\begin{array}{l}\text { Author, Year, } \\
\text { Followup, } \\
\text { Pain Duration, } \\
\text { Study Quality }\end{array}$ & Intervention & Population & Function and Pain Outcomes & Other Outcomes \\
\hline $\begin{array}{l}\text { Hinman, } 2014^{205} \\
9 \text { months } \\
\text { Duration of pain: } \\
\text { mean } 7.2 \text { years } \\
\text { Good (sham) } \\
\text { Fair (no } \\
\text { treatment) }\end{array}$ & $\begin{array}{l}\text { A. Needle acupuncture } \\
\text { (n=70): combination of } \\
\text { Western and traditional } \\
\text { Chinese acupuncture; } \\
\text { maximum of } 6 \text { points ( } 4 \text { on } \\
\text { study limb and } 2 \text { distal } \\
\text { points) at initial session, in } \\
\text { other sessions points were } \\
\text { added at therapist's } \\
\text { discretion. Needles were } \\
\text { left in while patient rested. } \\
\text { B. Laser acupuncture } \\
\text { (n=71): combination of } \\
\text { Western and traditional } \\
\text { Chinese acupuncture; } \\
\text { delivered to selected } \\
\text { points using standard } \\
\text { Class 3B laser devices } \\
\text { (measured output } 10 m W \\
\text { and energy output } 0.2 \\
\text { J/point) } \\
\text { C. No treatment (n=71): } \\
\text { did not receive } \\
\text { acupuncture; continued in } \\
\text { an observational study, } \\
\text { unaware they were in an } \\
\text { acupuncture trial } \\
\text { D. Sham laser } \\
\text { acupuncture (n=70): same } \\
\text { as true laser but no laser } \\
\text { was emitted, only red } \\
\text { nonlaser light at the probe } \\
\text { tip lit up. } \\
\text { For all acupuncture and } \\
\text { sham groups, sessions } \\
\text { were } 20 \text { minutes in } \\
\text { duration, } 1-2 \text { times per } \\
\text { week for } 12 \text { weeks ( } 8 \text { to } 12 \\
\text { sessions total) }\end{array}$ & $\begin{array}{l}\text { A vs. B vs. C vs. } \\
\text { D } \\
\text { Age: } 64 \text { vs. } 63 \\
\text { vs. } 63 \text { vs. } 64 \\
\text { years } \\
\text { Female: } 46 \% \text { vs. } \\
39 \% \text { vs. } 56 \% \text { vs. } \\
56 \% \\
\text { Duration of } \\
\text { symptoms } \geq 10 \\
\text { years: } 41 \% \text { vs. } \\
38 \% \text { vs. } 27 \% \text { vs. } \\
50 \% \\
\text { Bilateral } \\
\text { symptoms: } 64 \% \\
\text { vs. } 66 \% \text { vs. } 51 \% \\
\text { vs. } 63 \% \\
\text { Opioid use: } 1 \% \\
\text { vs. } 3 \% \text { vs. } 1 \% \text { vs. } \\
1 \% \\
\text { Previous } \\
\text { acupuncture for } \\
\text { knee pain: } 7 \% \text { vs. } \\
13 \% \text { vs. } 7 \% \text { vs. } \\
3 \% \\
\text { WOMAC function } \\
\text { W- } 68): 31.3 \text { vs. } \\
27.0 \text { vs. } 26.1 \text { vs. } \\
27.5 \\
\text { NRS activity } \\
\text { restriction (0-10): } \\
5.0 \text { vs. } 4.3 \text { vs. } 4.1 \\
\text { vs. } 4.5 \\
\text { WOMAC pain (0- } \\
20): 9.0 \text { vs. } 8.3 \\
\text { vs. } 7.8 \text { vs. } 8.6 \\
\text { NRS average } \\
\text { pain overall (0- } \\
10): 5.3 \text { vs. } 4.9 \\
\text { vs. } 5.1 \text { vs. } 5.0 \\
\text { NRS pain on } \\
\text { walking (0-10): } \\
5.5 \text { vs. } 4.8 \text { vs. } 4.8 \\
\text { vs. } 5.2 \\
\text { NRS pain on } \\
\text { standing (0-10): } \\
\text { vs. } 3.8 \text { vs. } 4.1 \\
\text { (3) }\end{array}$ & 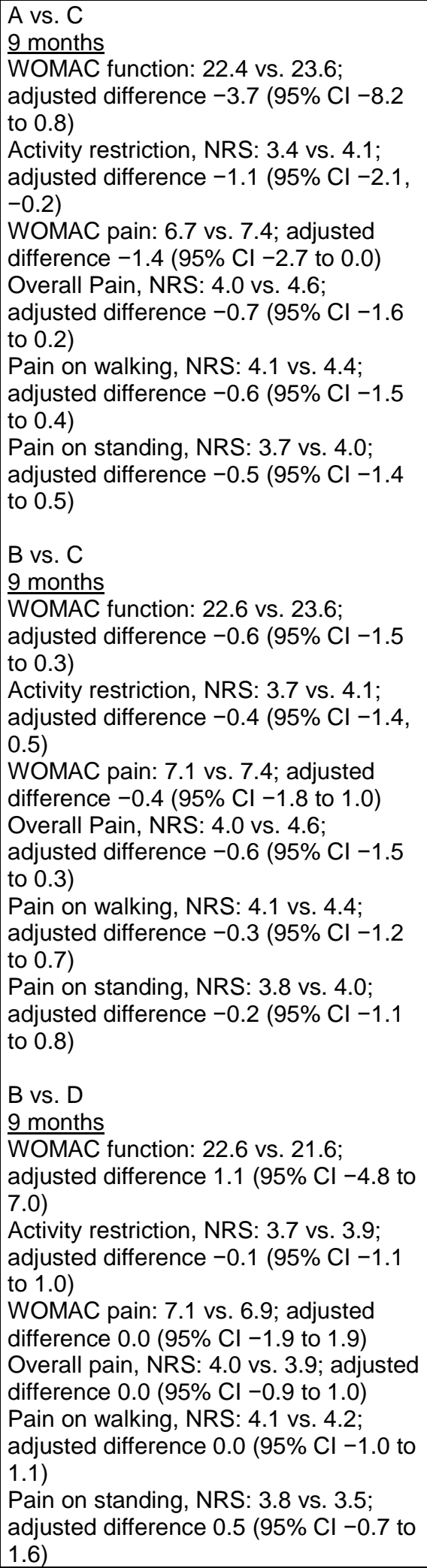 & 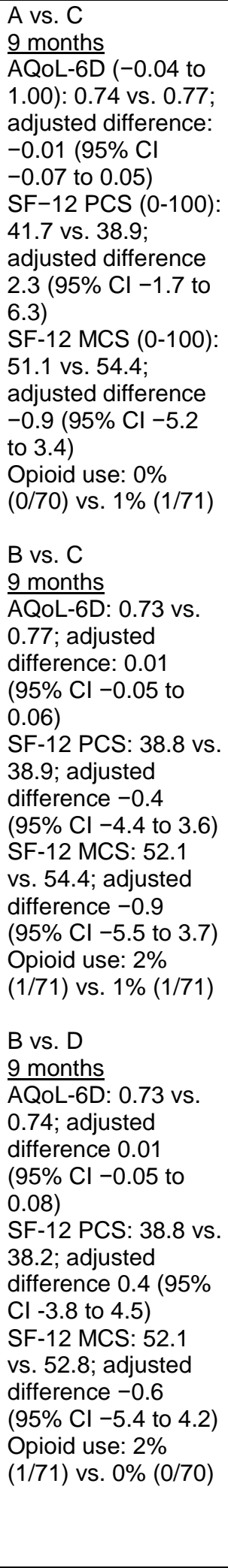 \\
\hline
\end{tabular}




\begin{tabular}{|c|c|c|c|c|}
\hline $\begin{array}{l}\text { Author, Year, } \\
\text { Followup, } \\
\text { Pain Duration, } \\
\text { Study Quality }\end{array}$ & Intervention & Population & Function and Pain Outcomes & Other Outcomes \\
\hline
\end{tabular}




\begin{tabular}{|c|c|c|c|c|}
\hline $\begin{array}{l}\text { Author, Year, } \\
\text { Followup, } \\
\text { Pain Duration, } \\
\text { Study Quality }\end{array}$ & Intervention & Population & Function and Pain Outcomes & Other Outcomes \\
\hline $\begin{array}{l}\text { Lansdown, } \\
2009^{207} \\
9.5 \text { months } \\
\text { Duration of pain } \\
\text { NR } \\
\text { Poor }\end{array}$ & $\begin{array}{l}\text { A. Acupuncture + usual } \\
\text { care ( } \mathrm{n}=15) \text { : once per } \\
\text { week for up to } 10 \text { weeks, } \\
\text { with maximum of } 10 \\
\text { sessions, which varied in } \\
\text { length and content (mean } \\
\text { number of acupoints was } \\
12, \text { range } 4-24 ; \text { de qi was } \\
\text { usually elicited; variety of } \\
\text { stimulation methods used } \\
\text { including tonification and } \\
\text { reduction; retention time } \\
\text { for needles ranged from } \\
10-30 \text { minutes); auxiliary } \\
\text { treatment included } \\
\text { moxibustion (3/14, } 21 \%) \\
\text { and acupressure massage } \\
\text { (3/14, } 21 \%) ; \text { life style } \\
\text { advice } 11 / 14 \text { ( } 79 \%) \\
\text { B. Usual care (n=15): any } \\
\text { appointments, medications } \\
\text { prescribed or over the } \\
\text { counter) and interventions } \\
\text { sought by participants } \\
\text { from any health } \\
\text { practitioner }\end{array}$ & $\begin{array}{l}\text { A vs. B } \\
\text { Age: } 63 \text { vs. } 64 \\
\text { years } \\
\text { Female: } 60 \% \text { vs. } \\
60 \% \\
\text { Caucasian: } 100 \% \\
\text { vs. } 100 \% \\
\text { Duration of } \\
\text { symptoms: NR } \\
\text { WOMAC total (0- } \\
96): 31 \text { vs. } 37.5 \\
\text { WOMAC function } \\
\text { (0-68): } 20.5 \text { vs. } \\
26.3 \\
\text { OKS (12-60): } \\
\text { 30.9 vs. } 30.6 \\
\text { WOMAC pain (0- } \\
20): 7.3 \text { vs. } 7.4\end{array}$ & $\begin{array}{l}\text { A vs. B } \\
9.5 \text { months } \\
\text { WOMAC total: } 24.8 \text { vs. } 25.6(17.6) \text {, } \\
\text { adjusted difference }-2.9 \text { (95\% Cl } 9.5 \text { to } \\
-15.4) \\
\text { WOMAC function: } 17.4 \text { vs. } 17.6 \text {, } \\
\text { adjusted difference }-1.36 \text { (95\% Cl } 8.7 \text {, } \\
-11.4) \\
\text { WOMAC pain: } 4.7 \text { vs. } 5.3(3.9) \text {, } \\
\text { adjusted difference }-1.4 \text { (95\% Cl } 0.8 \text { to } \\
-3.6) \\
\text { OKS: } 24.5 \text { vs. } 28.1 \text {; difference }-3.6 \\
\text { (95\% Cl }-9.8 \text { to } 2.6)\end{array}$ & 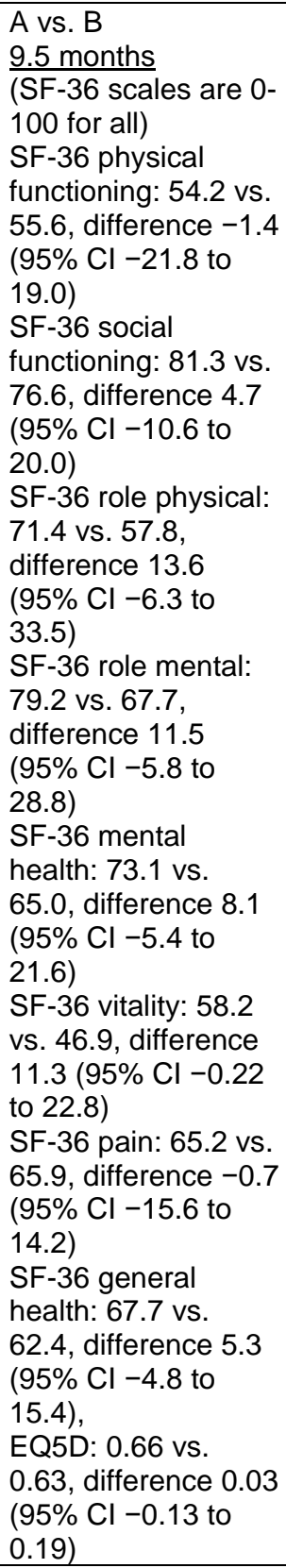 \\
\hline
\end{tabular}




\begin{tabular}{|c|c|c|c|c|}
\hline $\begin{array}{l}\text { Author, Year, } \\
\text { Followup, } \\
\text { Pain Duration, } \\
\text { Study Quality }\end{array}$ & Intervention & Population & Function and Pain Outcomes & Other Outcomes \\
\hline $\begin{array}{l}\text { Suarez-Almazo, } \\
2010^{208} \\
1.5 \text { months } \\
\text { Duration of pain: } \\
\text { mean } 8 \text { years } \\
\text { Good (sham) } \\
\text { Fair (waitlist) }\end{array}$ & $\begin{array}{l}\text { A. Electro-acupuncture } \\
\text { ( } n=153 \text { ): } \\
\text { Traditional Chinese } \\
\text { Medicine points; TENS } \\
\text { equipment emitted a } \\
\text { dense disperse wave } \\
\text { (50Hz, dispersed at } 15 \mathrm{~Hz}, \\
20 \text { cycles/minute); voltage } \\
\text { increased from } 5 \mathrm{~V} \text { to } 60 \mathrm{~V} \\
\text { until maximal tolerance } \\
\text { achieved. Patients rested } \\
\text { for } 20 \text { minutes with } \\
\text { needles retaining and with } \\
\text { continuing TENS. } \\
\text { B. Sham (n= 302) } \\
\text { 40Hz adjustable wave; } \\
\text { voltage increased until the } \\
\text { patient could feel it and } \\
\text { then immediately turned } \\
\text { off. Patients rested for } 20 \\
\text { minutes with the needles } \\
\text { retained, but without TENS } \\
\text { stimulation; nonrelevant } \\
\text { acupoints used and depth } \\
\text { of needle placement was } \\
\text { shallow } \\
\text { c. Waitlist ( } n=72 \text { ) }\end{array}$ & $\begin{array}{l}\text { A vs. B vs. C } \\
\text { Age: } 65 \text { vs. } 65 \\
\text { vs. } 64 \\
\text { Female: } 66 \% \text { vs. } \\
65 \% \text { vs. } 58 \% \\
\text { Caucasian: } 70 \% \\
\text { vs. } 68 \% \text { vs. } 65 \% \\
\text { Mean duration of } \\
\text { chronicity: } 9.2 \text { vs. } \\
8.6 \text { vs. } 11.5 \text { years } \\
\\
\text { WOMAC function } \\
\text { (0-100): } 42.9 \text { vs. } \\
44.6 \text { vs. } 40.1 \\
\text { WOMAC pain (0- } \\
\text { 100): } 44.5 \text { vs. } \\
45.0 \text { vs. } 44.1 \\
\text { VAS pain }(0- \\
100): 58.3 \text { vs. } \\
57.4 \text { vs. } 54.6 \\
\text { J-MAP (1-7): } 4.4 \\
\text { vs. } 4.4 \text { vs. } 4.3\end{array}$ & 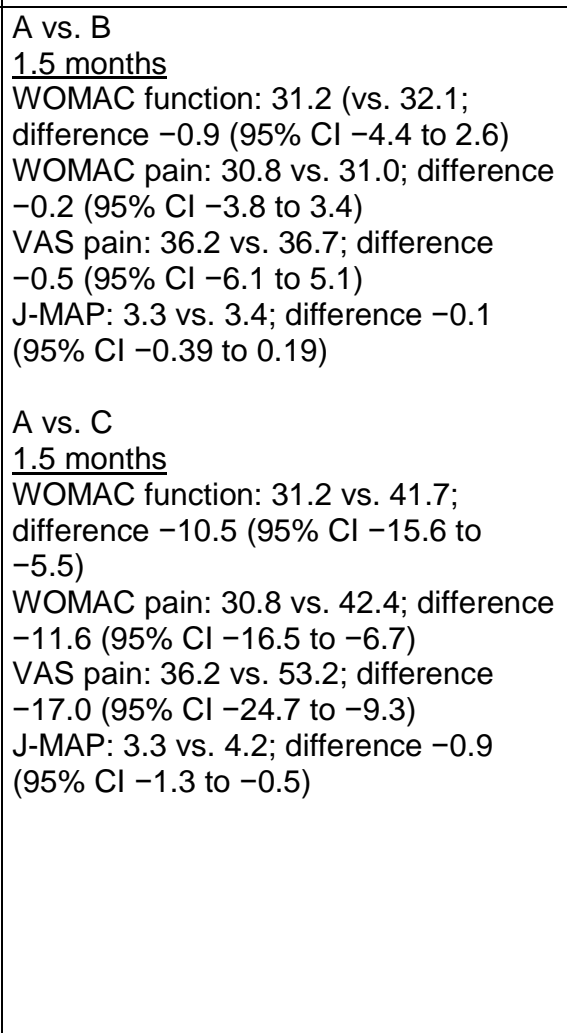 & 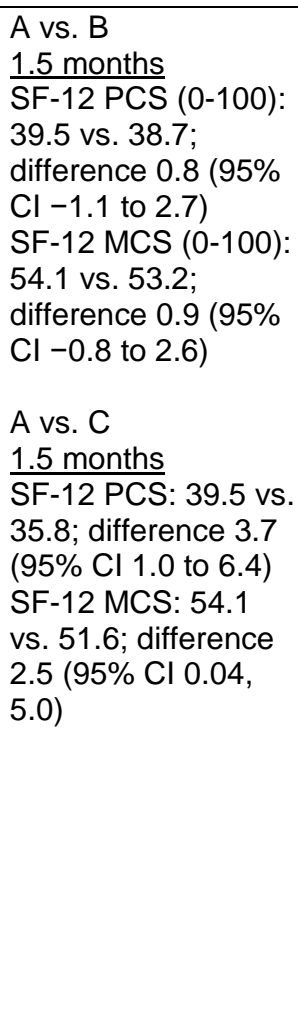 \\
\hline $\begin{array}{l}\text { Williamson, } \\
2007^{60} \\
1.5 \text { months } \\
\text { Duration of } \\
\text { symptoms: NR } \\
\text { Poor }\end{array}$ & $\begin{array}{l}\text { A. Acupuncture (n=60): } \\
\text { conducted by a } \\
\text { physiotherapist in a group } \\
\text { setting (6-10 patients); } \\
\text { needles inserted into } 7 \\
\text { acupoints until de qi was } \\
\text { achieved and left in place } \\
\text { for } 20 \text { minutes; treatments } \\
\text { were once per week for } 6 \\
\text { weeks, with } 6 \text { sessions in } \\
\text { total } \\
\text { B. Combination Exercise } \\
\text { (Physiotherapy) (n=60): } \\
\text { supervised group (6-10 } \\
\text { people) exercise } \\
\text { comprised of } \\
\text { strengthening, aerobic, } \\
\text { stretching, and balance } \\
\text { training; } 60 \text { minutes, once } \\
\text { per week for } 6 \text { weeks; } \\
\text { C. Usual care (n=61): } \\
\text { exercise and advice } \\
\text { leaflet; told they were } \\
\text { enrolled in the "home } \\
\text { exercise group" }\end{array}$ & $\begin{array}{l}\text { A vs. B vs. C } \\
\text { Age: } 72 \text { vs. } 70 \\
\text { vs. } 70 \text { years } \\
\text { Female: } 55 \% \text { vs. } \\
52 \% \text { vs. } 54 \% \\
\text { BMI: } 30.9 \text { vs. } \\
32.8 \text { vs. } 32.7 \\
\text { WOMAC total } \\
\text { (scale unclear): } \\
50.9 \text { vs. } 50.2 \text { vs. } \\
51.1 \\
\text { OKS (12-60): } \\
40.2 \text { vs. } 39.3 \text { vs. } \\
40.5 \\
\text { Pain VAS (0-10): } \\
7.3 \text { vs. } 6.8 \text { vs. } \\
6.9 \\
\text { HAD Anxiety (0- } \\
21): 7.3 \text { vs. } 7.5 \\
\text { vs. } 6.7 \\
\text { HAD Depression } \\
\text { (0-21): } 7.1 \text { vs. } \\
7.1 \text { vs. } 7.4\end{array}$ & $\begin{array}{l}\text { A vs. B } \\
1.5 \text { months } \\
\text { WOMAC: } 48.4 \text { vs. } 49.4 \text {, difference }-1.0 \\
\text { (95\% Cl }-6.7 \text { to } 4.7) \\
\text { OKS: } 38.1 \text { vs. } 38.8 \text {, difference }-0.7 \\
\text { (95\% Cl }-3.5 \text { to } 2.1 \text { ) } \\
\text { Pain VAS: } 6.6 \text { vs. } 6.4 \text {, difference } 0.22 \\
\text { (95\% Cl }-0.67 \text { to } 1.11 \text { ) } \\
\\
\text { A vs. C } \\
1.5 \text { months } \\
\text { WOMAC: } 48.4 \text { vs. } 52.3 \text {, difference }-3.9 \\
\text { (95\% Cl }-9.5 \text { to } 1.6) \\
\text { OKS: } 38.1 \text { vs. } 40.8, \text { difference }-2.6 \\
\text { (95\% Cl }-5.4 \text { to } 0.1 \text { ) } \\
\text { Pain VAS: } 6.6 \text { vs. } 7.2 \text {, difference }-0.66 \\
\text { (95\% Cl }-1.45 \text { to } 0.12 \text { ) }\end{array}$ & $\begin{array}{l}\text { A vs. B } \\
1.5 \text { months } \\
\text { HAD Anxiety: } 6.9 \text { vs. } \\
7.1, \text { difference }-0.20 \\
\text { (95\% } \mathrm{Cl}-1.89 \text { to } \\
1.49) \\
\text { HAD Depression: } \\
6.7 \text { vs. } 6.8, \\
\text { difference }-0.03 \\
\text { (95\% Cl }-1.30 \text { to } \\
1.24) \\
\\
\text { A vs. C } \\
1.5 \text { months } \\
\text { HAD Anxiety: } 6.9 \text { vs. } \\
6.5, \text { difference } 0.34 \\
\text { (95\% Cl }-1.11 \text { to } \\
1.8) \\
\text { HAD Depression: } \\
6.7 \text { vs. } 7.1, \\
\text { difference, }-0.41 \\
\text { (95\% Cl }-1.63 \text { to } \\
0.8)\end{array}$ \\
\hline
\end{tabular}




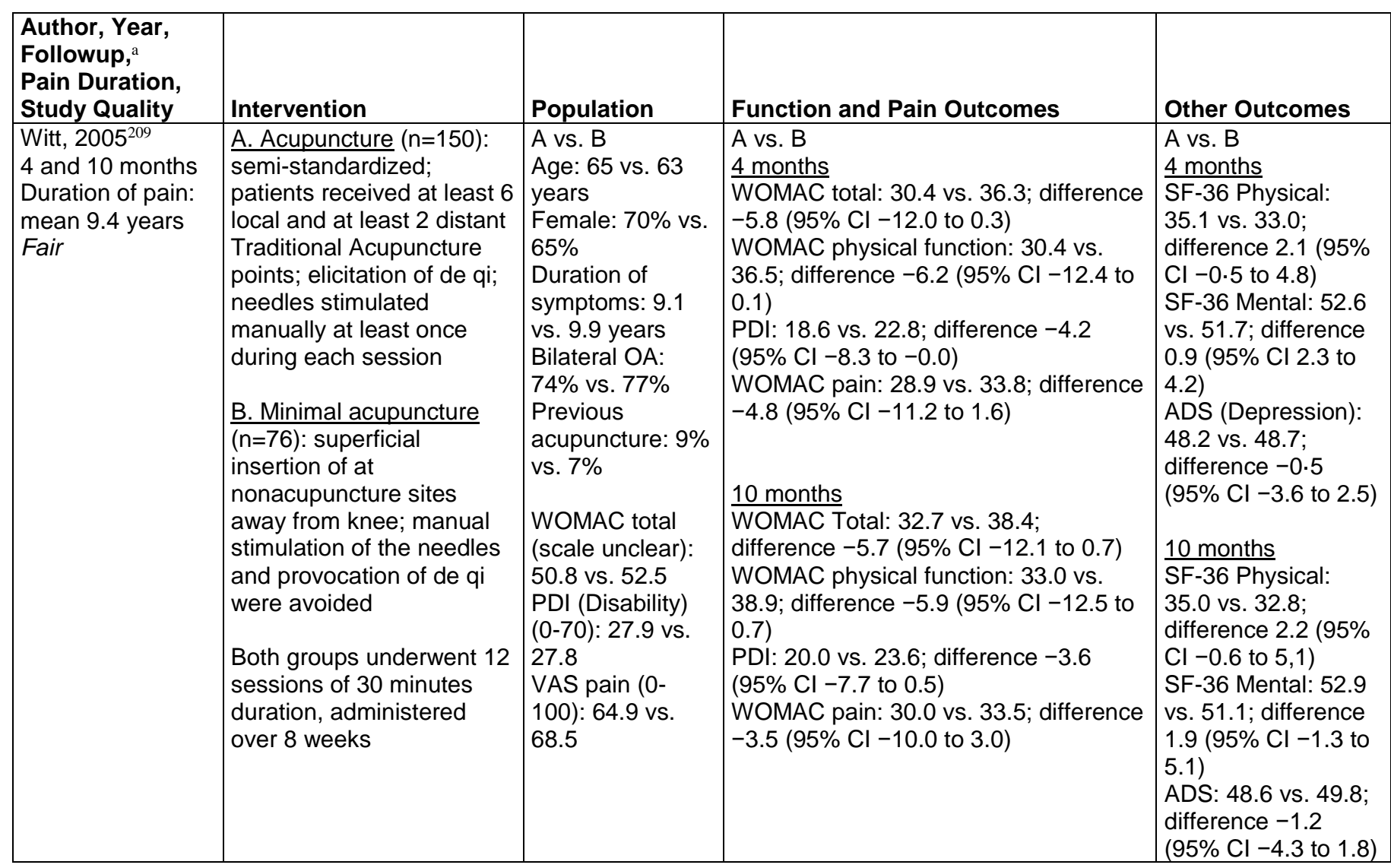




\begin{tabular}{|c|c|c|c|c|}
\hline $\begin{array}{l}\text { Author, Year, } \\
\text { Followup, } \\
\text { Pain Duration, } \\
\text { Study Quality }\end{array}$ & Intervention & Population & Function and Pain Outcomes & Other Outcomes \\
\hline
\end{tabular}

ADS = Anxiety and Depression Scale; AIMS = Arthritis Impact Measurement Scale; BAI = Beck Anxiety Inventory; BDI = Beck Depression Inventory; CI = confidence interval; HAD = Hospital Anxiety and Depression Scale; HRQoL = health-related quality of life; J-MAP = Joint-specific Multidimensional Assessment of Pain; NHP = Nottingham health profile; NR = not reported; NRS = numeric rating scale; NS = not statistically significant; OA = osteoarthritis; OKS = Oxford Knee Score; SF36/12 = Short Form 36/12; VAS = Visual Analog Scale; WOMAC = Western Ontario and McMaster Universities Osteoarthritis index

${ }^{\text {a }}$ Unless otherwise noted, followup time is calculated from the end of the treatment period

\section{Acupuncture Compared With Usual Care, Waitlist, or Sham}

Functional Outcomes. There was no evidence of differences between acupuncture versus control interventions (sham acupuncture, usual care, waitlist, no treatment) on WOMAC function score in the short term ( 5 trials, pooled SMD -0.18 , $95 \%$ CI -0.55 to $\left.0.20, \mathrm{I}^{2}=82 \%\right)^{203,206,208-210}$ (Figure 35). All trials were considered fair quality. Removal of one outlier trial (Berman 1999) ${ }^{203}$ attenuated the effect estimate size (4 trials, pooled SMD $-0.05,95 \%$ CI -0.32 to 0.38 ); results remained insignificant. No differences were found when the results were analyzed by the type of acupuncture used: electroacupuncture ( 3 trials, pooled SMD $-0.34,95 \%$ CI -1.17 to $0.46),{ }^{203,206,208}$ standard needle acupuncture (SMD $-0.28,95 \%$ CI -0.55 to 0.00 ), ${ }^{209}$ or laser acupuncture (SMD $0.55,95 \%$ CI -0.01 to 1.10$)^{210}$ compared with control interventions. When 
stratified by control type no differences were found between any form of acupuncture and sham treatment (4 trials, pooled SMD -0.02 , 95\% CI -0.28 to 0.39 ); ${ }^{206,208-210}$ however, when acupuncture was compared with waitlist and usual care, estimates suggested moderate improvement in function ( 2 trials, pooled SMD -0.74 , 95\% CI -1.40 to -0.24 , plot not shown). ${ }^{203,208}$ In one small, fair-quality trial ${ }^{210}$ of low-level laser acupuncture the authors reported a difference in WOMAC function score that favored the sham control (Table 29).

Similarly, based on WOMAC total score, there were no differences in short-term function between acupuncture and sham, waitlist, and usual care across trials ( 4 trials, pooled SMD -0.30 , 95\% CI -0.81 to 0.21 , $\mathrm{I}^{2}=85 \%$, plot not shown). ${ }^{60,203,209,210}$ Removal of one outlier trial (Berman 1999) ${ }^{203}$ attenuated the effect estimate size ( 3 trials, pooled SMD -0.10 , 95\% CI -0.54 to 0.49 ); results remained insignificant. Stratification by acupuncture type, control type, and exclusion of one poor-quality trial yielded similar estimates. Results according to other measures of function were mixed. In two small, fair-quality trials authors reported significant results (Table 29), one favoring electroacupuncture compared with usual care based on the Lequesne Index (0 to 24 scale), ${ }^{203}$ and the second favoring the sham control comparing low-level laser acupuncture based on the WOMAC total score. ${ }^{210}$ Five additional trials reported no differences between acupuncture and any of the control conditions across other measures of function ${ }^{60,205-207,209}$ (Table 29).

In the intermediate term, there was no difference between acupuncture versus control conditions (sham acupuncture, usual care, waitlist) on the WOMAC function score (4 trials, pooled SMD -0.15 , 95\% CI -0.30 to -0.01 , $\left.\mathrm{I}^{2}=0 \%\right)^{204,205,207,209}$ (Figure 35); the estimate using the more conservative proximal likelihood method yielded a SMD of -0.15 (95\% CI -0.31 to 0.02). Estimates were similar when stratified by study quality, acupuncture type, and control type; however, sensitivity analyses were limited by the small number of trials. Similarly, no differences in WOMAC total score were found for standard needle acupuncture versus usual care or sham at intermediate-term followup (2 trials, pooled SMD $-0.23,95 \%$ CI -0.49 to 0.03 , $\mathrm{I}^{2}=0 \%$, plot not shown). ${ }^{207,209}$ Across other measures of function, no differences were seen at intermediate term between standard needle acupuncture versus sham acupuncture on the Pain Disability Index (MD -3.5 on a $0-70$ scale, $95 \%$ CI -7.7 to 0.5 ) in one fair-quality trial ${ }^{209}$ or versus usual care on the Oxford Knee Score (MD 3.6 on a 12 to 60 scale, 95\% CI -9.8 to 2.6) in one small poor-quality trial. ${ }^{207}$

No trials reported data on long-term function.

Pain Outcomes. There was no evidence of differences between acupuncture versus control interventions (sham acupuncture, usual care, waitlist) on pain in the short term (6 trials, pooled SMD $-0.27,95 \%$ CI -0.56 to $\left.0.02, \mathrm{I}^{2}=75 \%\right)^{60,203,206,208-210}$ (Figure 36). All but one trial used the WOMAC pain score. Removal of one outlier trial (Berman 1999) ${ }^{203}$ attenuated the effect estimate size ( 5 trials, pooled SMD -0.15 , $95 \%$ CI -0.29 to 0.00 ); results remained insignificant. Estimates were similar after exclusion of one poor-quality trial and for stratification by acupuncture type and for analyses of VAS or NRS instead of WOMAC pain score if more than one pain measure was reported. When stratified by control type, no differences were seen between acupuncture and sham acupuncture ( 4 trials, pooled SMD -0.06 , 95\% CI -0.24 to $0.14) ;{ }^{206,208-210}$ however, when acupuncture was compared with waitlist or usual care, the 
estimate suggested moderate effects on pain (2 trials, pooled SMD $-0.68,95 \%$ CI -1.28 to $-0.15) .^{203,208}$

There were no clinically meaningful differences between acupuncture and control interventions for pain in the intermediate term ( 4 trials, pooled SMD $-0.16,95 \% \mathrm{CI}-0.31$ to $\left.-0.02, \mathrm{I}^{2}=0 \%\right){ }^{204,205,207,209}$ individually no trial reached statistical significance (Figure 36). Stratification based on acupuncture type, type of control intervention, and study quality yielded similar results.

No trial reported data on long-term pain.

Other Outcomes. Data on the effects of acupuncture on quality of life were limited (plots not shown). A slight effect favoring acupuncture versus control conditions (sham acupuncture, usual care, waitlist, no treatment) was seen for the SF-12/SF-36 PCS (0-100 scale) in both the short term ( 2 trials, pooled difference $1.6,95 \%$ CI 0.08 to $\left.3.11, \mathrm{I}^{2}=0 \%\right)^{208,209}$ and the intermediate term ( 2 trials, pooled difference $1.94,95 \%$ CI 0.03 to $3.86, \mathrm{I}^{2}=0 \%$ ), ${ }^{205,209}$ but no difference was seen in the SF-12/SF-36 MCS (0-100 scale) at either timepoint: short term (2 trials, pooled difference $1.14,95 \%$ CI -0.27 to $\left.2.56, \mathrm{I}^{2}=0 \%\right)^{208,209}$ and intermediate term (2 trials, pooled difference $-0.25,95 \%$ CI -4.05 to $\left.3.54, \mathrm{I}^{2}=70.8 \%\right) .{ }^{205,209}$ For individual trials, the effects were slight and not statistically significant for either outcome (SF-12 or SF-36 PCS or MCS). There were no differences between acupuncture and control interventions on other quality of life measures or on measures of anxiety or depression over either the short or intermediate term (Table 29).

In one trial, ${ }^{205}$ a small (1\%) change in opioid use at intermediate term was seen with needle acupuncture (decrease from $1 \%$ to $0 \%$ ), laser acupuncture (decrease from $3 \%$ to $2 \%$ ), and sham acupuncture (decrease from $1 \%$ to $0 \%$ ) while use remained the same in the no treatment group (Table 29).

\section{Acupuncture Compared With Pharmacological Therapy}

No trial of acupuncture versus pharmacological therapy met inclusion criteria.

\section{Acupuncture Compared With Exercise Therapy}

Data were insufficient from one poor-quality trial $(n=120)^{60}$ to evaluate the effects of weekly acupuncture versus 60 minutes of combination exercise (strengthening, aerobics, stretching, and balance training) for 6 weeks for knee OA (Table 29 and Appendix D). Methodological limitations included lack of patient or care provider blinding, unclear adherence, unacceptable attrition, and differential loss to followup (Appendix E). There were no differences between groups with regard to function on the Oxford Knee Score questionnaire (difference $-0.7,95 \%$ CI -3.5 to 2.1 on $12-60$ scale) or WOMAC score (difference $-1.0,95 \%$ CI -6.7 to 4.7 ; scale not provided by author). Similarly there was no difference between treatments for VAS pain on a 0 to 10 scale (difference $0.22,95 \%$ CI -0.67 to 1.11 ) or for anxiety or depression based on the Hospital Anxiety and Depression Scale.

\section{Harms}

All trials reported adverse events. One trial reported similar rates of serious adverse events in patients who received real versus sham acupuncture (2.1\% vs. $2.7 \%$, respectively; RR $0.75,95 \%$ CI 0.13 to 4.39), to include hospitalizations and one case of death from myocardial infarction in the control group; none were considered to be related to the study condition or treatment. ${ }^{209}$ All other events reported were classified as mild and there was no apparent difference in risk of adverse events between any form of acupuncture and the control groups. The most common 
adverse events reported were worsening of symptoms (7\% to 14\%) in three trials ${ }^{205,207,208}$ and mild bruising, swelling, or pain at the acupuncture site (1\% to 18\%) in five trials. ${ }^{60,205,207-209}$ One trial reported one case of an infection at the electroacupuncture site $(n=455$ for real and sham acupuncture groups). ${ }^{208}$ In only one trial did an adverse event (not treatment related) lead to withdrawal: one patient (3\%) in the acupuncture group had a flare-up of synovitis (nonseptic). ${ }^{206}$

\section{Figure 35. Acupuncture versus usual care, waitlist, sham, or a placebo intervention in osteoarthritis of the knee: effects on function}

\begin{tabular}{|c|c|c|c|c|c|c|c|}
\hline Study, Year & Intervention & Comparison & $\begin{array}{l}\text { Dur } \\
\text { of } f \\
\text { Mo }\end{array}$ & $\begin{array}{l}\text { atin } \\
\text { llowup } \\
\text { ths }\end{array}$ & $\begin{array}{l}\text { Intervention } \\
\mathrm{N}, \text { Mean (SD) }\end{array}$ & $\begin{array}{l}\text { Control } \\
\text { N, Mean (SD) }\end{array}$ & SMD (95\% Cl) \\
\hline \multicolumn{8}{|l|}{ 1:Short-term } \\
\hline Berman 1999 & EA & NAWL/UC & WOMAC, NR & 1 & $36,23.2(13.9)$ & $37,36.8(10.7)$ & $-1.09(-1.58,-0.59)$ \\
\hline Jubb 2008 & EA & SA & WOMAC, NR & 1 & $34,891.0(277.0)$ & $34,845.0(313.0)$ & $0.15(-0.32,0.63)$ \\
\hline Suarez-Almazo 2010 & 0 EA & SA/NAWLIUC & WOMAC, NR & 1.5 & $153,31.2(17.9)$ & $374,33.9(18.2)$ & $-0.15(-0.34,0.04)$ \\
\hline Yurturan 2007 & LA & SA & WOMAC, NR & 3 & $27,44.2(15.8)$ & $25,35.3(16.6)$ & $0.55(-0.01,1.10)$ \\
\hline Witt 2005 & SNA & SA & WOMAC, NR & 4 & $149,30.4(21.4)$ & $75,36.5(23.2)$ & $-0.28(-0.55,0.00)$ \\
\hline \multicolumn{7}{|c|}{ Subtotal $(I-$ squared $=81.8 \%, p=0.000)$} & $-0.18(-0.55,0.20)$ \\
\hline \multicolumn{8}{|l|}{ Intermediate-term } \\
\hline Berman 2004 & EA & SA & WOMAC (0-68) & 6 & $142,18.9(12.1)$ & $141,21.4(12.0)$ & $-0.21(-0.44,0.02)$ \\
\hline Lansdown 2009 & SNA & NAWL/UC & WOMAC (0-68) & 9.5 & $15,17.4(13.9)$ & $15,17.6(12.6)$ & $-0.01(-0.73,0.70)$ \\
\hline Witt 2005 & SNA & SA & WOMAC, NR & 10 & $149,33.0(23.0)$ & $75,38.9(23.8)$ & $-0.25(-0.53,0.03)$ \\
\hline Hinman 2014 & SNAVLA & SANNAWLIUC & WOMAC (0-68) & 9 & $117,22.5(13.6)$ & $113,22.7(13.5)$ & $-0.01(-0.27,0.24)$ \\
\hline \multicolumn{7}{|c|}{ Subtotal $(\mathrm{I}$-squared $=0.0 \%, \mathrm{p}=0.581$ ) } & $-0.15(-0.30,-0.01)^{\mathrm{a}}$ \\
\hline \multicolumn{8}{|l|}{ - } \\
\hline & & & & & & -2 & 2 \\
\hline & & & & & & Favors Acupuncture & Favors Control \\
\hline
\end{tabular}

A = electroacupuncture; LA = laser acupuncture; NR = not reported; SA = sham acupuncture; SNA = standard needle acupuncture; SD = standard deviation; SMD = standardized mean difference; $\mathrm{NR}=$ not reported; UC = usual care; $\mathrm{WL}=$ waitlist; WOMAC = Western Ontario and McMaster’s Universities Osteoarthritis Index

${ }^{\mathrm{a}}$ The estimate using the more conservative proximal likelihood method yielded a SMD of -0.15 (95\% CI -0.31 to 0.02 ) 
Figure 36. Acupuncture versus usual care, waitlist, sham, or a placebo intervention for osteoarthritis of the knee: effects on pain

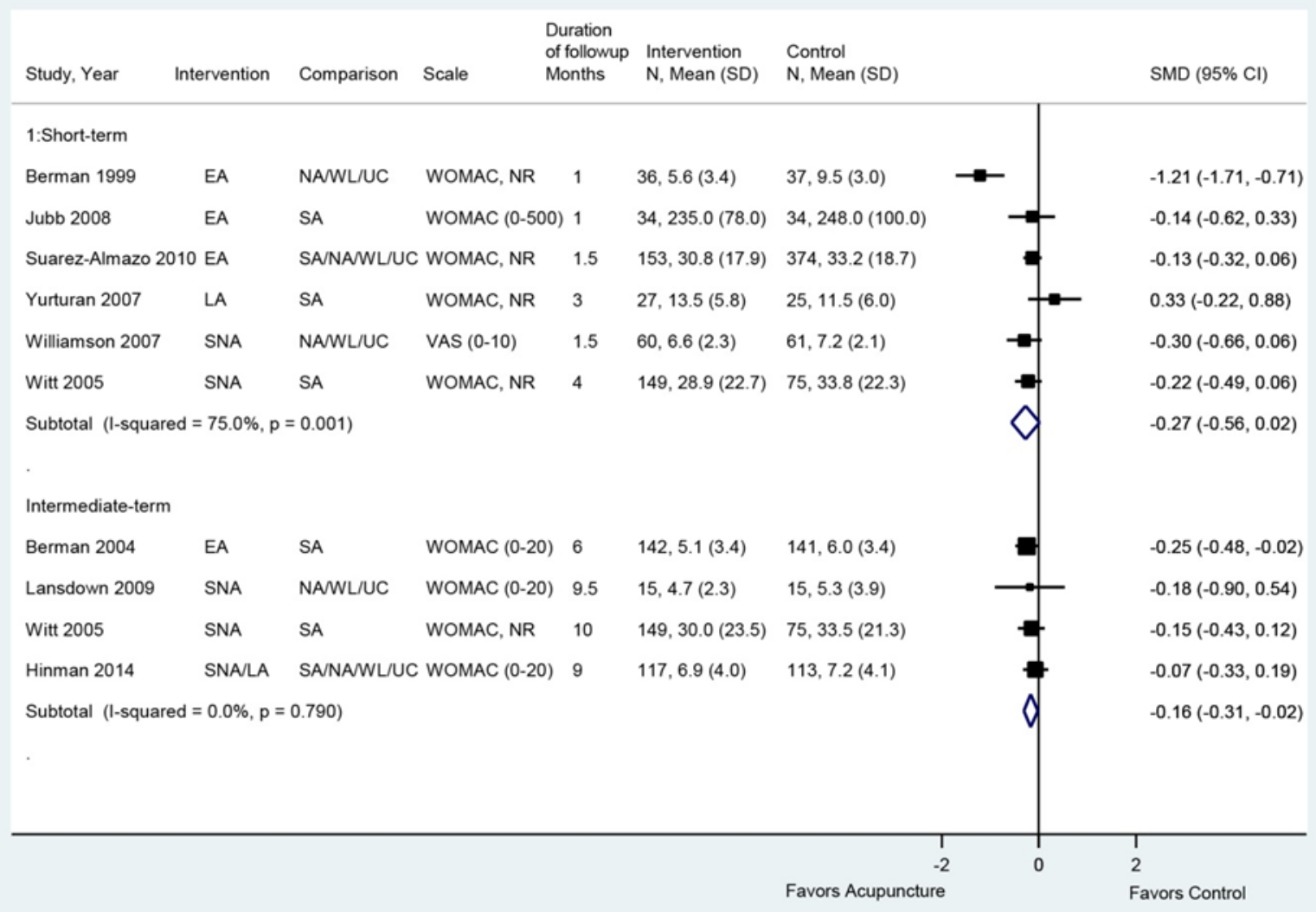

EA = electroacupucnture; LA = laser acupuncture; NR = not reported; SA = sham acupuncture; SNA = standard needle acupuncture; SD = standard deviation; SMD = standardized mean difference; $\mathrm{NR}=$ not reported; UC = usual care; WL = waitlist; WOMAC = Western Ontario and McMaster’s Universities Osteoarthritis Index

\section{Exercise for Osteoarthritis of the Hip}

\section{Key Points}

- Exercise was associated with a slight improvement in function versus usual care in the short term ( 3 trials, pooled SMD $-0.33,95 \% \mathrm{CI}-0.53$ to $-0.12, \mathrm{I}^{2}=0.0 \%$ ), intermediate term ( 2 trials, pooled SMD $-0.28,95 \%$ CI -0.50 to $\left.-0.05, \mathrm{I}^{2}=0.0 \%\right)$, and long term (1 trial, SMD $-0.37,95 \%$ CI -0.74 to -0.01 ) (SOE: low for short and intermediate term, insufficient for long term).

- Exercise tended toward slightly greater improvement in short-term pain compared with usual care ( 3 trials, pooled SMD $-0.34,95 \%$ CI -0.63 to $-0.04, \mathrm{I}^{2}=48.2 \%$ ) but the results were no longer significant at intermediate term (2 trials, pooled SMD -0.14, 95\% CI -0.37 to $0.08, \mathrm{I}^{2}=0 \%$ ) or long term ( 1 trial, SMD -0.25 , 95\% CI -0.62 to 0.11 ) (SOE: low for short and intermediate term, insufficient for long term).

- Evidence for harms was insufficient in trials of exercise with only two trials describing adverse events. However, no serious harms were reported in either trial (SOE: insufficient). 


\section{Detailed Synthesis}

Four trials of exercise therapy for hip OA met the inclusion criteria; three were conducted in Europe $^{61-63}$ and the other in New Zealand ${ }^{40}$ (Table 30 and Appendix D). Three trials evaluated participants with chronic hip pain diagnosed as OA using American College of Radiology criteria $^{40,61,63}$ and one assessed participants with hip OA diagnosed clinically who were on a waitlist for hip replacement. ${ }^{62}$ Sample sizes ranged from 45 to 203 (total number randomized $=477)$. Across trials, participants were predominately female ( $>50 \%)$ with mean ages ranging from 64 to 69 years. Three trials were conducted in Europe ${ }^{61-63}$ and the other in New Zealand. ${ }^{40}$

All trials compared exercise with usual care, defined as care routinely provided by the patient's primary care physician, which could include physical therapy referral. Two trials also provided education about hip OA to all participants. ${ }^{61,63}$ The exercise interventions included 8 to 12 supervised sessions of 30 to 60 minutes duration once per week over 8 to 12 weeks; the interventions were comprised of strengthening and stretching exercises (all studies), as well as neuromuscular control exercises in one trial ${ }^{40}$ and endurance exercise in another. ${ }^{63}$ All trials reported compliance rates with the scheduled exercise sessions between 76 and 88 percent. However, in one trial, ${ }^{40}$ although 88 percent of patients completed more than 80 percent of the scheduled sessions, only 44 percent of participants returned logbooks to demonstrate compliance with the recommended home exercises.

Three trials were rated fair quality ${ }^{40,61,63}$ and one was rated poor quality ${ }^{62}$ (Appendix E). In all trials, the nature of the intervention and control precluded blinding of participants and researchers; patient-reported outcomes were therefore not blinded. Additionally, in the poorquality trial, ${ }^{62}$ concealed allocation was unclear and outcomes were poorly reported, as were attrition rates, which were substantial for pain (68\%) and function (73\%) outcomes.

Table 30. Osteoarthritis of the hip: exercise

\begin{tabular}{|c|c|c|c|c|}
\hline $\begin{array}{l}\text { Author, } \\
\text { Year, } \\
\text { Followup, } \\
\text { Pain } \\
\text { Duration, } \\
\text { Study } \\
\text { Quality }\end{array}$ & Intervention & Population & $\begin{array}{l}\text { Function and Pain } \\
\text { Outcomes }\end{array}$ & Other Outcomes \\
\hline $\begin{array}{l}\text { Abbott, } \\
2013^{40} \\
9.75 \text { months } \\
\text { Duration } \\
\text { of pain: } 9 \\
\text { months } \\
\text { Fair }\end{array}$ & $\begin{array}{l}\text { A. Exercise therapy } \\
\text { ( } n=51 / 22 \text { hip OA): } 7 \\
\text { sessions of } \\
\text { strengthening, } \\
\text { stretching, and } \\
\text { neuromuscular control } \\
\text { over } 9 \text { weeks, with } 2 \\
\text { booster sessions at } \\
\text { week } 16 \text {. Individual } \\
\text { exercises prescribed } \\
\text { as needed. Home } \\
\text { exercise prescribed } 3 \\
\text { times weekly } \\
\text { B. Usual care } \\
\text { (n=51/23 hip OA): } \\
\text { Routine care provided } \\
\text { by patient's own GP } \\
\text { and other health care } \\
\text { providers }\end{array}$ & $\begin{array}{l}\text { A vs. B (total } \\
\text { population, } \\
\text { includes knee OA) } \\
\text { Age: } 67 \text { vs. } 66 \\
\text { Females: } 49 \% \text { vs. } \\
63 \% \\
\% \text { hip OA: } 43.1 \% \\
\text { vs. } 45.1 \% \\
\text { WOMAC }(0-240): \\
95.5 \text { vs. } 93.8\end{array}$ & $\begin{array}{l}\text { A vs. B (hip OA only) } \\
\frac{9.75 \text { months }}{\text { WOMAC mean change from }} \\
\text { baseline: }-12.4 \text { vs. } 6.6\end{array}$ & NR \\
\hline
\end{tabular}




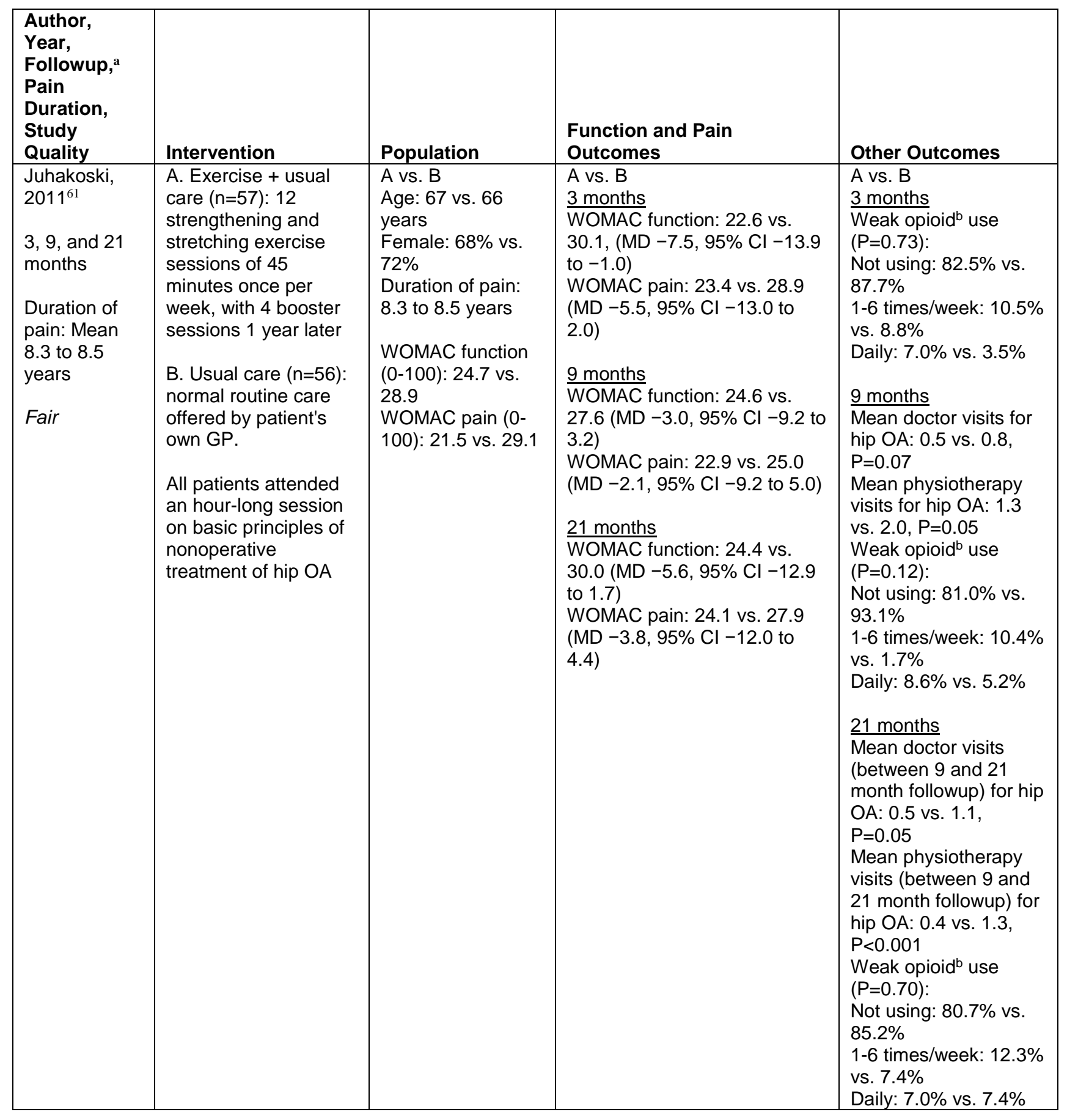




\begin{tabular}{|c|c|c|c|c|}
\hline $\begin{array}{l}\text { Author, } \\
\text { Year, } \\
\text { Followup, } \\
\text { Pain } \\
\text { Duration, } \\
\text { Study } \\
\text { Quality }\end{array}$ & Intervention & Population & $\begin{array}{l}\text { Function and Pain } \\
\text { Outcomes }\end{array}$ & Other Outcomes \\
\hline $\begin{array}{l}\text { Tak, }{ }^{62} 2005^{c} \\
6 \text { months, } 3 \\
\text { years } \\
\text { Mean } \\
\text { duration of } \\
\text { pain: NR } \\
\text { Poor }\end{array}$ & $\begin{array}{l}\text { A. Exercise ( } n=45) \text { : } \\
\text { Eight weekly group } \\
\text { sessions of strength } \\
\text { training, information } \\
\text { on a home exercise } \\
\text { program, ergonomic } \\
\text { advice, and dietary } \\
\text { advice } \\
\text { B. Usual care }(n=49) \text { : } \\
\text { Subject-initiated } \\
\text { contact with GP. } \\
\text { Reference group } \\
\text { ( } n=N R) \text { consisting of } \\
\text { weekly stress } \\
\text { management sessions } \\
\text { for } 10 \text { weeks }\end{array}$ & $\begin{array}{l}\text { A vs. B } \\
\text { Age: } 68 \text { vs. } 69 \\
\text { Female: } 64 \% \text { vs. } \\
71 \% \\
\text { HHS (0-100): } 71.1 \\
\text { vs. } 71.0 \\
\text { GARS (18-72): } \\
22.8 \text { vs. } 25.3 \\
\text { SIP-136 physical } \\
\text { (0-100): } 7.2 \text { vs. } 7.6 \\
\text { Pain VAS (0-10): } \\
\text { 3.8 vs. } 4.2 \\
\text { HHS pain subscale } \\
\text { (0-44): } 27.9 \text { vs. } \\
28.8\end{array}$ & $\begin{array}{l}\text { A vs. B } \\
3 \text { months } \\
\text { HHS: } 75.4 \text { vs. } 71.1,(\mathrm{MD} 4.3 \text {, } \\
95 \% \mathrm{Cl}-2.2 \text { to } 10.8) \\
\text { GARS: } 23.7 \text { vs. } 26.3,(\mathrm{MD} \\
\text {-2.6, } 95 \% \mathrm{Cl}-6.0 \text { to } 0.8) \\
\text { SIP-136 physical: } 5.1 \text { vs. } 8.4 \text {, } \\
\text { (MD }-3.3,95 \% \mathrm{Cl}-5.3 \text { to } \\
\text {-1.3) } \\
\text { Pain VAS: } 3.5 \text { vs. } 5.1,(\mathrm{MD} \\
-1.6,95 \% \mathrm{Cl}-2.6 \text { to }-0.6) \\
\text { HHS pain subscale: } 29.6 \text { vs. } \\
26.9,(\mathrm{MD}-0.9,95 \% \mathrm{Cl}-4.7 \\
\text { to } 2.9)\end{array}$ & $\begin{array}{l}\text { A vs. B } \\
3 \text { months } \\
\text { QoL VAS (0-10): } 5.0 \\
\text { vs. } 4.2 \text {, (MD } 1.4,95 \% \\
\mathrm{Cl}-0.2 \text { to } 3.0) \\
\text { HRQoL (7-39): } 28.6 \\
\text { vs. } 27.3 \text {, (MD } 0.9,95 \% \\
\mathrm{Cl}-0.4 \text { to } 2.2)\end{array}$ \\
\hline $\begin{array}{l}\text { Teirlinck, } \\
2016^{63} \\
3 \text { and } 9 \\
\text { months } \\
\text { Duration of } \\
\text { pain: Median } \\
1 \text { year } \\
\text { Fair }\end{array}$ & $\begin{array}{l}\text { A. Exercise therapy } \\
(\mathrm{n}=101) \text { : } 12 \text { sessions } \\
\text { over } 3 \text { months } \\
\text { consisting of } \\
\text { strengthening, } \\
\text { stretching, and } \\
\text { aerobic exercise } \\
\text { B. Usual care ( } n=102) \text { : } \\
\text { Routine care provided } \\
\text { by patient's own GP }\end{array}$ & $\begin{array}{l}\text { A vs. B } \\
\text { Age: } 64 \text { vs. } 67 \\
\text { Females: } 62 \% \text { vs. } \\
55 \% \\
\text { Pain duration } \\
\text { median (IQR): } 365 \\
\text { (810) vs. } 365 \text { (819) } \\
\text { days } \\
\text { HOOS function (0- } \\
\text { 100): } 35.4 \text { vs. } 32.2 \\
\text { HOOS pain (0- } \\
\text { 100): } 37.6 \text { vs. } 38.9 \\
\text { ICOAP constant } \\
\text { pain (0-20): } 5.4 \text { vs. } \\
5.8 \\
\text { ICOAP intermittent } \\
\text { pain (0-24): } 8.0 \text { vs. } \\
8.4 \\
\text { ICOAP total pain } \\
\text { (0-100): } 30.4 \text { vs. } \\
32.2\end{array}$ & 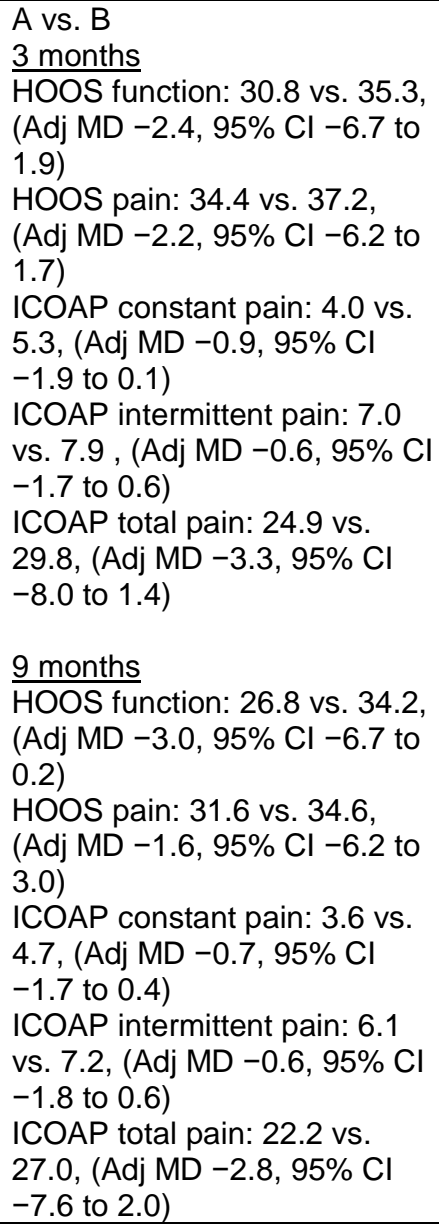 & $\begin{array}{l}\text { A vs. B } \\
3 \text { months } \\
\text { EuroQol 5D-3L } \\
\text { (-0.329-1.0): } 0.77 \text { vs. } \\
0.76, \text { (Adj MD -0.01, } \\
95 \% \mathrm{Cl}-0.06 \text { to 0.04) } \\
9 \text { months } \\
\text { EuroQol 5D-3L: } 0.78 \\
\text { vs. } 0.78,(\text { Adj MD } \\
-0.01,95 \% \mathrm{Cl}-0.06 \\
\text { to } 0.04) \\
\text { Total hip } \\
\text { replacements: } 6 \text { vs. } 9\end{array}$ \\
\hline
\end{tabular}

CI = confidence interval; GARS = gait abnormality rating scale; GP = general practitioner; HHS = Harris Hip Score; HOOS = hip disability and osteoarthritis outcome score; HRQoL = Health Related Quality of Life; ICOA = intermittent and constant pain score; $\mathrm{MD}$ = mean difference; NR = not reported; OA = osteoarthritis; QoL = quality of life; SIP-136 = Sickness Impact Profile136; VAS = visual analog scale; WOMAC= Western Ontario and McMaster Universities Osteoarthritis Index 
${ }^{\text {a }}$ Unless otherwise noted, followup time is calculated from the end of the treatment period

${ }^{\mathrm{b}}$ Authors defined weak opioids as tramadol or codeine

${ }^{\mathrm{c}}$ Cluster RCT where clusters were formed from participants selecting a time that best fit their schedule

\section{Exercise Compared With Usual Care}

Exercise was associated with a slightly greater effect on function versus usual care in the short term (3 trials, pooled SMD $-0.33,95 \%$ CI -0.53 to $-0.12, \mathrm{I}^{2}=0.0 \%$ ), ${ }^{61-63}$ intermediate term ( 2 trials, pooled SMD -0.28 , 95\% CI -0.50 to $\left.-0.05, \mathrm{I}^{2}=0.0 \%\right)^{61,63}$ and long term ( 1 trial, SMD $-0.37,95 \%$ CI -0.74 to -0.01$)^{61}$ (Figure 37 ). The intermediate-term findings were consistent with the additional trial not included in the meta-analysis (authors did not provide sufficient data), ${ }^{40}$ although the small improvement in function in this trial did not reach statistical significance in those with hip OA. The small number of trials precluded meaningful sensitivity analysis.

Exercise tended toward slightly greater improvement on short-term pain compared with usual care (3 trials, pooled SMD -0.34 , 95\% CI -0.63 to $\left.-0.04, \mathrm{I}^{2}=48 \%\right)^{61-63}$ (Figure 38), but not at intermediate term ( 2 trials, pooled SMD -0.14 , 95\% CI -0.37 to $0.08, \mathrm{I}^{2}=0 \%$ ). ${ }^{61,63}$ There was moderate heterogeneity between studies and the short-term improvement in pain was observed in only one poor-quality study, ${ }^{62}$ whereas the two fair-quality studies did not demonstrate any significant differences in short-term pain relief. ${ }^{61,63}$ There were no identifiable differences in methodology between the studies to explain these inconsistent findings, although the poorquality study only reported pain outcomes for 68 percent of participants, which may have biased results. There was no difference between exercise versus usual care in the long term based on a single study (SMD -0.25 , $95 \%$ CI -0.62 to 0.11 ). ${ }^{61}$ The small number of trials precluded meaningful sensitivity analysis.

Data on effects of exercise on quality of life were limited and were reported in only two trials. ${ }^{62,63}$ One fair-quality trial ${ }^{63}$ found no differences in health-related quality of life between groups in the short term and intermediate term and one poor-quality study ${ }^{62}$ found no differences between groups in the short term. One fair-quality study found no differences between groups in terms of opioid use at any time point (proportion of patients using tramadol or codeine daily: $7.0 \%$ vs. $3.5 \%$ at 3 months, $8.6 \%$ vs. $5.2 \%$ at 9 months, and $7.0 \%$ vs. $7.4 \%$ at 21 months, $\mathrm{P}=0.73$ ), but did report slightly fewer followup physical therapy visits in the exercise group in the intermediate and long terms ${ }^{61}$ (Table 30).

There was insufficient evidence to determine effects of duration of exercise therapy or number of sessions on outcomes.

\section{Exercise Compared With Pharmacological Therapy or With Other Nonpharmacological Therapies}

No trial of exercise versus pharmacological therapy met inclusion criteria. Findings for exercise versus other nonpharmacological therapies are addressed in the sections for other nonpharmacological therapies.

\section{Harms}

Only two exercise trials reported on harms, and neither reported adverse events in either the exercise group or usual care groups. ${ }^{40,62}$ 
Figure 37. Exercise versus usual care for osteoarthritis of the hip: effects on function

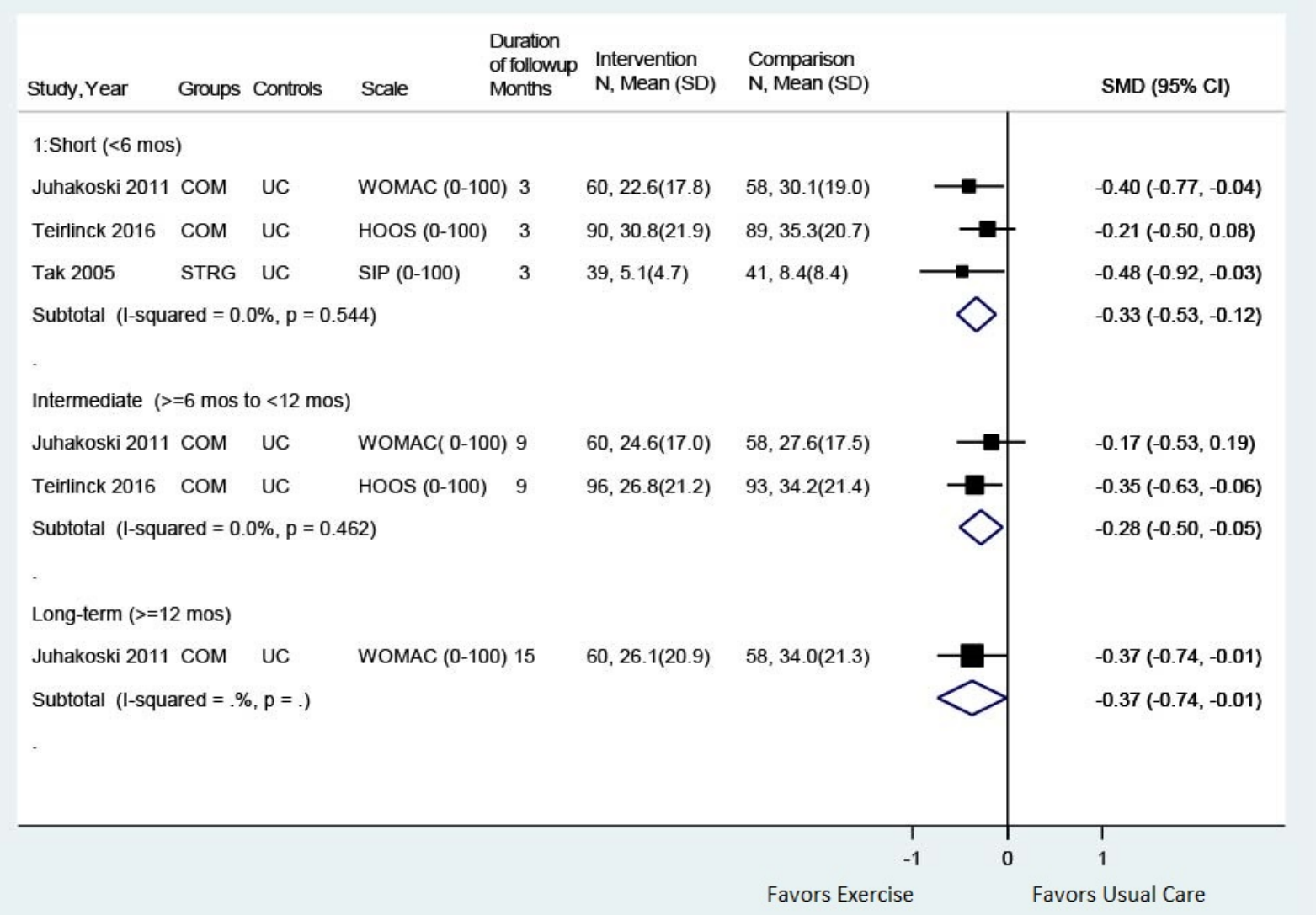

$\mathrm{CI}=$ confidence interval; $\mathrm{COM}$ = combination exercise therapy; HOOS = Hip disability and Osteoarthritis Outcomes Score; SD = standard deviation; SIP = Sickness Impact Profile physical function score; SMD = standardized mean difference; STRG = strength training exercise; UC = usual care; WOMAC = Western Ontario and McMaster's Universities Osteoarthritis Index 
Figure 38. Exercise versus usual care for osteoarthritis of the hip: effects on pain

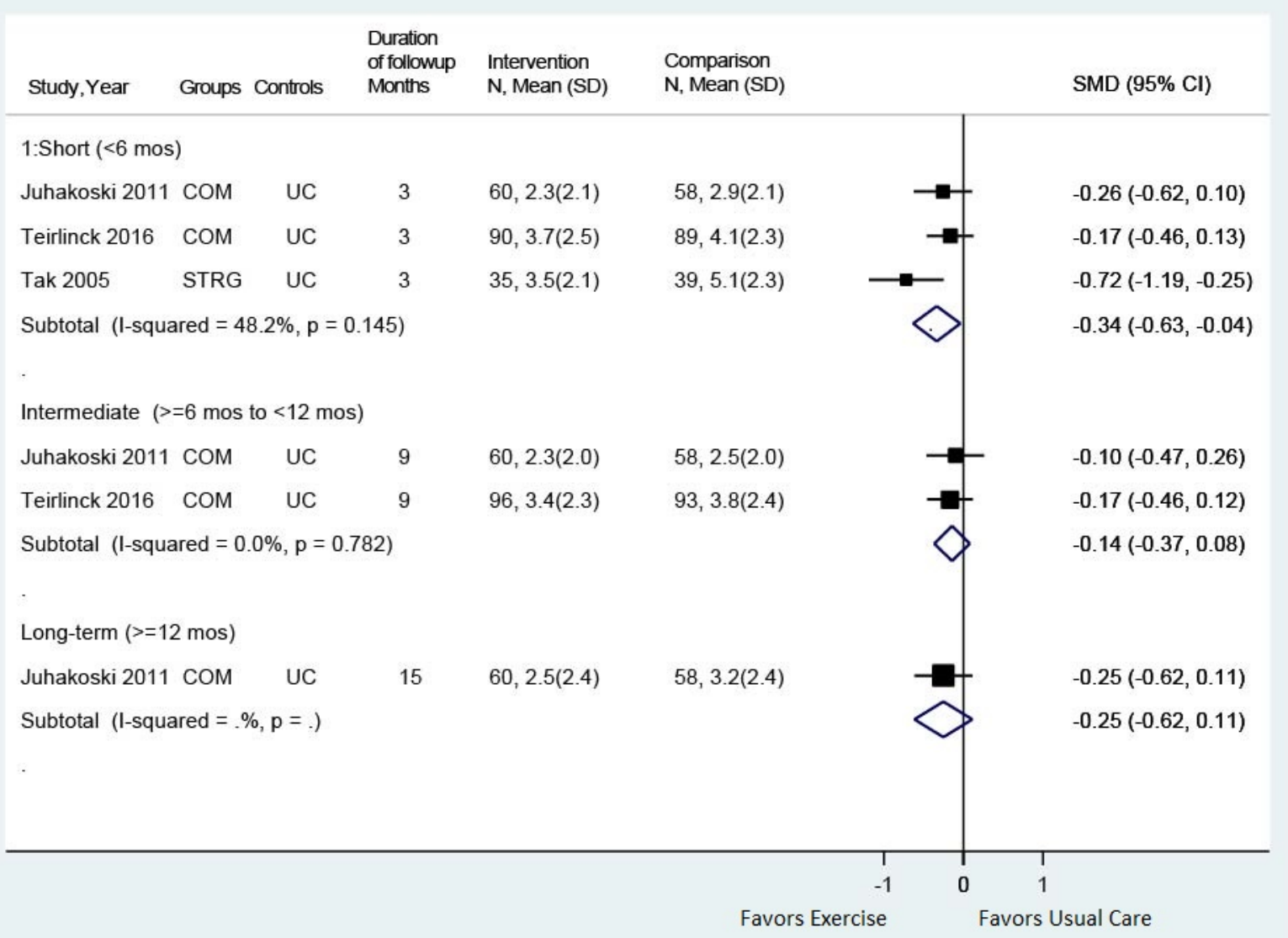

$\mathrm{CI}=$ confidence interval; $\mathrm{COM}$ = combination exercise therapy; $\mathrm{SD}=$ standard deviation; $\mathrm{SMD}$ = standardized mean difference; STRG = strength training exercise; $\mathrm{UC}=$ usual care

\section{Manual Therapies for Osteoarthritis of the Hip}

\section{Key Points}

- There were insufficient data to determine the effects or harms of manual therapy compared with usual care at intermediate term. No effect size could be calculated (SOE: insufficient).

- Manual therapy was associated with slight improvements in short-term (MD 11.1, 95\% CI 4.0 to 18.6, 0-100 scale Harris Hip Score) and intermediate-term (MD 9.7, 95\% CI 1.5 to 17.9) function versus exercise (SOE: low).

- Manual therapy was associated with a small effect on pain in the short term (MD -0.72 [95\% CI -1.38 to -0.05 ] for pain at rest and -1.21 [95\% CI -2.29 to -0.25 ] for pain walking) versus exercise (SOE: low). The impact on pain is not clear at intermediate term; there was no evidence of differences in pain at rest (adjusted difference $-7.0,95 \%$ CI -20.3 to 5.9 , 0-100 scale) but there was small improvement in pain while walking (adjusted difference $-12.7,95 \%$ CI -24.0 to -1.9 ) (SOE: insufficient).

- No trials evaluated manual therapies versus pharmacological therapy. 
- One trial reported that no treatment related-serious adverse events were detected and in the other, no difference in study withdrawal due to symptom aggravation was seen between manual therapy and exercise (RR 1.42, 95\% CI 0.25 to 8.16) (SOE: low).

\section{Detailed Synthesis}

We identified two trials ( $n=69$ and 109) of manual therapy for hip OA that met inclusion criteria (Table 31 and Appendix D); one was conducted in New Zealand ${ }^{40}$ and the other in the Netherlands. ${ }^{163}$ Mean patient age ranged from 66 to 72 years and females comprised 49 to 72 percent of the populations. Both trials required a diagnosis of hip OA meeting the American College of Rheumatology (ACR) criteria for inclusion. The duration of manual therapy ranged from 5 to 16 weeks with a total of nine sessions in both groups; in one trial this included seven sessions over the first 9 weeks and two booster sessions at week $16 .{ }^{40}$ One trial compared manual therapy to usual care (continued routine care from a general practitioner and other providers) ${ }^{40}$ and both trials compared manual therapy to combination exercise programs. ${ }^{40,163}$ The number of exercise sessions matched the manual therapy group of that respective study. All participants were prescribed a home exercise program three times per week. One trial reported short-term outcomes $^{163}$ and both reported intermediate-term outcomes.

Both trials were rated fair quality (Appendix E). Compliance with the intervention was acceptable in all groups, and the methodological shortcomings of these trials included a lack of blinding for the patients and care providers.

Table 31. Osteoarthritis of the hip: manual therapy

\begin{tabular}{|c|c|c|c|c|}
\hline $\begin{array}{l}\text { Author, Year, } \\
\text { Followup, } \\
\text { Pain Duration, } \\
\text { Study Quality }\end{array}$ & Intervention & Population & $\begin{array}{l}\text { Function and Pain } \\
\text { Outcomes }\end{array}$ & Other Outcomes \\
\hline $\begin{array}{l}\text { Abbott, } 2013^{40} \\
9.75 \text { months } \\
\text { Duration of } \\
\text { diagnosis: } 2.6 \\
\text { years } \\
\text { Fair }\end{array}$ & $\begin{array}{l}\text { A. Manual therapy } \\
(n=54 / 24 \text { hip OA): } 7 \\
\text { manual therapy } \\
\text { sessions in } 9 \text { weeks } \\
\text { with } 2 \text { additional } \\
\text { booster sessions } \\
\text { B. Exercise ( } n=51 / 22 \\
\text { hip OA), } 7 \text { exercise } \\
\text { sessions in } 9 \text { weeks } \\
\text { with } 2 \text { additional } \\
\text { booster sessions } \\
\text { C. Usual care } \\
(n=51 / 23 \text { hip OA) }\end{array}$ & $\begin{array}{l}\text { A vs. B vs. C (total } \\
\text { population, includes } \\
\text { knee OA) } \\
\text { Age: } 67 \text { vs. } 67 \text { vs. } 66 \\
\text { years } \\
\text { Female: } 49 \% \text { vs. } 52 \% \\
\text { vs. } 58 \% \\
\text { Percent knee OA: } \\
56 \% \text { vs. } 57 \% \text { vs. } 55 \% \\
\text { Percent hip OA: } 44 \% \\
\text { vs. } 43 \% \text { vs. } 45 \% \\
\text { Percent both hip OA } \\
\text { and knee OA: } 22 \% \text { vs. } \\
20 \% \text { vs. } 26 \% \\
\text { Baseline WOMAC (0- } \\
240 \text { ): } 114.8 \text { vs. } 95.5 \\
\text { vs. } 93.8\end{array}$ & $\begin{array}{l}\text { A vs. B (hip OA only) } \\
9.75 \text { months } \\
\text { WOMAC, mean change } \\
\text { from baseline: }-22.9 \text { vs. } \\
-12.4, P=N R \\
\text { A vs. C (hip OA only) } \\
9.75 \text { months } \\
\text { WOMAC, mean change } \\
\text { from baseline: }-22.9 \text { vs. } \\
6.6, P=N R\end{array}$ & None \\
\hline
\end{tabular}




\begin{tabular}{|c|c|c|c|c|}
\hline $\begin{array}{l}\text { Author, Year, } \\
\text { Followup, } \\
\text { Pain Duration, } \\
\text { Study Quality }\end{array}$ & Intervention & Population & $\begin{array}{l}\text { Function and Pain } \\
\text { Outcomes }\end{array}$ & Other Outcomes \\
\hline $\begin{array}{l}\text { Hoeksma, } \\
2004^{163} \\
3 \text { and } 6 \text { months } \\
\text { Duration of } \\
\text { symptoms: } \\
\text { mean NR } \\
\text { Fair }\end{array}$ & $\begin{array}{l}\text { A. Manual therapy } \\
\text { ( } n=56) \text { : Sessions } \\
\text { consisted of } \\
\text { stretching followed } \\
\text { by traction } \\
\text { manipulation in each } \\
\text { limited position (high } \\
\text { velocity thrust } \\
\text { technique). } \\
\text { B. Exercise therapy } \\
\text { ( } n=53 \text { ): Sessions } \\
\text { implemented } \\
\text { exercises for muscle } \\
\text { functions, muscle } \\
\text { length, joint mobility, } \\
\text { pain relief, and } \\
\text { walking ability and } \\
\text { were tailored to the } \\
\text { specific needs of the } \\
\text { patient. Instructions } \\
\text { for home exercises } \\
\text { were given. } \\
\text { Both groups received } \\
2 \text { sessions per week } \\
\text { for } 5 \text { weeks (9 } \\
\text { sessions in total). }\end{array}$ & $\begin{array}{l}\text { Age: } 72 \text { vs. } 71 \text { years } \\
\text { Females: } 68 \% \text { vs. } \\
72 \% \\
\text { Symptom duration of } \\
1 \text { month to } 5 \text { years: } \\
76 \% \text { vs. } 81 \% \\
\text { Severe OA on } \\
\text { radiography: } 45 \% \text { vs. } \\
38 \% \\
\text { HHS (0-100): } 54 \text { vs. } \\
53 \\
\text { Pain at rest VAS (0- } \\
100): 22.5 \text { vs. } 23.0 \\
\text { Pain walking VAS (0- } \\
100): 34.0 \text { vs. } 28.8\end{array}$ & $\begin{array}{l}\text { A vs. B } \\
3 \text { months } \\
\text { HHS: } 68.4 \text { vs. } 56.0, \\
\text { adjusted difference } 11.1 \text {, } \\
95 \% \mathrm{Cl} 4.0 \text { to } 18.6 \\
\text { Pain at rest VAS: } 19.1 \\
\text { vs. } 26.9 \text {, adjusted } \\
\text { difference }-7.2,95 \% \mathrm{Cl} \\
-13.8 \text { to }-0.5 \\
\text { Pain walking VAS: } 16.4 \\
\text { vs. } 23.7 \text {, adjusted } \\
\text { difference }-12.1,95 \% \mathrm{Cl} \\
-22.9 \text { to }-2.5 \\
6 \text { months } \\
\text { HHS: } 70.2 \text { vs. } 59.7, \\
\text { adjusted difference } 9.7, \\
95 \% \mathrm{Cl} 1.5 \text { to } 17.9 \\
\text { Pain at rest VAS: } 14.0 \\
\text { vs. } 21.6, \text { adjusted } \\
\text { difference }-7.0,95 \% \mathrm{Cl} \\
-20.3 \text { to } 5.9 \\
\text { Pain walking VAS: } 17.0 \\
\text { vs. } 24.3 \text {, adjusted } \\
\text { difference }-12.7,95 \% \mathrm{Cl} \\
-24.0 \text { to }-1.9\end{array}$ & $\begin{array}{l}\text { A vs. B } \\
3 \text { months } \\
\text { SF-36 physical } \\
\text { function: } 45.3 \text { vs. } \\
46.6 \text {, adjusted } \\
\text { difference }-2.1 \text {, } \\
95 \% \text { CI }-11.7 \text { to } \\
7.7 \\
\text { SF-36 role } \\
\text { physical function: } \\
25.4 \text { vs. } 29.8 \text {, } \\
\text { adjusted } \\
\text { difference }-23.5 \\
\text { to } 10.2 \\
\text { SF-36 bodily pain: } \\
47.4 \text { vs. } 46.1 \text {, } \\
\text { adjusted } \\
\text { difference }-3.2, \\
95 \% \text { CI }-13.1 \text { to } \\
6.8 \\
6 \text { months } \\
\text { SF-36 physical } \\
\text { function: } 50.4 \text { vs. } \\
45.3 \text {, adjusted } \\
\text { difference } 3.1 \text {, } \\
95 \% \text { CI }-4.1 \text { to } \\
10.5 \\
\text { SF-36 role } \\
\text { physical function: } \\
36.7 \text { vs. } 32.4, \\
\text { adjusted } \\
\text { difference } 2.2, \\
95 \% \text { CI }-16.8 \text { to } \\
21.1 \\
\text { SF-36 bodily pain: } \\
51.4 \text { vs. } 49.9, \\
\text { adjusted } \\
\text { difference }-1.5, \\
95 \% \text { Cl }-11.1 \text { to } \\
7.7\end{array}$ \\
\hline
\end{tabular}

CI = confidence interval; HHS = Harris Hip Score; NR = not reported; OA = osteoarthritis; SF-36 = Short Form 36 Questionnaire; VAS = visual analog scale; WOMAC =Western Ontario and McMaster Universities Arthritis Index ${ }^{a}$ Unless otherwise noted, followup time is calculated from the end of the treatment period

\section{Manual Therapies Compared With Usual Care}

A single fair-quality trial ( $\mathrm{n}=69$ with hip $\mathrm{OA})^{40}$ found that manual therapy resulted in an improvement in function at intermediate term using the total WOMAC score (0 to 240) in the manual therapy group (mean change from baseline -22.9 , 95\% CI -43.3 to -2.6 ), while the usual care group showed little change from baseline (mean change -7.9, 95\% CI -30.9 to 15.3). Lack of information on the number of patients precluded calculation of effect size, and results of statistical testing between groups was not presented.

\section{Manual Therapies Compared With Pharmacological Therapy}

No trial of manual therapy versus pharmacological therapy met inclusion criteria. 


\section{Manual Therapies Compared With Exercise}

One trial found that manual therapy resulted in slightly better short-term function compared with exercise (adjusted MD on the 0-100 scale Harris Hip Score [HHS] of 11.1, 95\% CI 4.0 to 18.6). Regarding intermediate-term function, manual therapy conferred a slight benefit in both trials. The adjusted MD on the HHS was 9.7 (95\% CI 1.5 to 17.9$)$ in one trial. ${ }^{163}$ The other trial compared function using the total WOMAC score (0 to 240), and the manual therapy group experienced a statistically significant improvement from baseline (mean change of $-22.9,95 \%$ CI -43.3 to -2.6 ), while the exercise group did not (mean change -12.4 , 95\% CI -27.1 to 2.3 ). ${ }^{40}$

Only one of the trials reported pain outcomes. Manual therapy was associated with slightly better short-term pain at rest and during walking compared to exercise (adjusted MDs on a VAS (0 to 10 ) of $-0.72,95 \%$ CI -1.38 to -0.05 , and $-1.21,95 \%$ CI -2.29 to -0.25 , respectively). ${ }^{163}$ Intermediate-term pain results were inconsistent. A moderate effect on VAS pain during walking was seen following manual therapy compared to exercise (adjusted MD $-1.27,95 \%$ CI -2.40 to -0.19 ), but there was no difference for pain at rest (adjusted MD $-0.70,95 \%$ CI -2.03 to $0.59){ }^{163}$

There was no difference in one trial ${ }^{163}$ between manual therapy and exercise for short-term or intermediate-term quality of life measured with the SF-36 physical function, role physical, or bodily pain subscales (Table 31).

\section{Harms}

No trial-related serious adverse events were detected in one trial, ${ }^{40}$ and there was no difference in symptom aggravation leading to withdrawal (5\% vs. $4 \%$; RR 1.42, 95\% CI 0.25 to 8.16) in the other trial. ${ }^{163}$

\section{Exercise for Osteoarthritis of the Hand}

\section{Key Points}

- Data from one poor-quality trial were insufficient to determine the effects or harms (though no serious harms were reported) of exercise versus usual care in the short term (SOE: insufficient).

\section{Detailed Synthesis}

One Norwegian trial $(n=130)$ that evaluated the effects of strengthening and range of motion exercise (3 times weekly for 3 months plus 4 group sessions) versus usual care (treatment recommended by the patient's general practitioner) met inclusion criteria ${ }^{64}$ (Table 32 and Appendix D). This trial was rated poor quality due to lack of patient blinding, baseline differences in mental health conditions, and large differential attrition between groups (exercise $29 \%$ vs. usual care 7\%) (Appendix E). Only short-term data was reported. 
Table 32. Osteoarthritis of the hand: exercise

\begin{tabular}{|c|c|c|c|c|}
\hline $\begin{array}{l}\text { Author, } \\
\text { Year, } \\
\text { Followup, } \\
\text { Pain } \\
\text { Duration, } \\
\text { Study } \\
\text { Quality }\end{array}$ & Intervention & Population & $\begin{array}{l}\text { Function and Pain } \\
\text { Outcomes }\end{array}$ & Other Outcomes \\
\hline $\begin{array}{l}\text { Osteras, } \\
2014^{64} \\
3 \text { months } \\
\text { Duration of } \\
\text { pain: NR } \\
\text { Poor }\end{array}$ & $\begin{array}{l}\text { A. Exercise }(n=46) \text { : } \\
\text { ROM/strength } \\
\text { exercises, } 4 \text { group } \\
\text { sessions } \\
\text { supplemented by } \\
\text { instructions for home } \\
\text { exercise } 3 \text { times per } \\
\text { week for } 12 \text { weeks } \\
\text { B. Usual care ( } n=64) \text { : } \\
\text { Subjects received no } \\
\text { particular attention, } \\
\text { referral, or treatment } \\
\text { from the study. }\end{array}$ & $\begin{array}{l}\text { A vs. B } \\
\text { Age: } 67 \text { vs. } 65 \text { years } \\
\text { Females: } 89 \% \text { vs. } \\
91 \% \\
\text { Fulfillment of ACR } \\
\text { criteria for hand OA } \\
91 \% \text { vs. } 91 \% \\
\text { Self-reported hip } \\
\text { OA: } 39 \% \text { vs. } 46 \% \\
\text { Self-reported knee } \\
\text { OA: } 40 \% \text { vs. } 51 \% \\
\text { Other rheumatic } \\
\text { disease: } 13 \% \text { vs. } \\
\text { 15\% } \\
\text { Severe mental } \\
\text { distress: } 17 \% \text { vs. } \\
39 \% \\
\text { FIHOA (0-30): } 10.8 \\
\text { vs. } 9.8 \\
\text { PSFS (0-10): } 3.5 \text { vs. } \\
3.9 \\
\text { Hand pain NRS (0- } \\
10): 4.2 \text { vs. } 3.9\end{array}$ & $\begin{array}{l}\text { A vs. B } \\
3 \text { months } \\
\text { FIHOA: } 10.9 \text { vs. } 10.5 ; \\
\text { adjusted difference }-0.5 \\
\text { (95\% } \mathrm{Cl}-1.9 \text { to } 0.8) \\
\text { Hand pain NRS: } 4.3 \text { vs. } 4.3 \text {; } \\
\text { adjusted difference }-0.2 \\
\text { (95\% CI }-0.8 \text { to } 0.3) \\
\text { OARSI OMERACT no. of } \\
\text { responders: } 30 \% \text { vs. } 28 \% \\
\text { (NS) }\end{array}$ & $\begin{array}{l}\text { A vs. B } \\
3 \text { months } \\
\text { PSFS: } 4.3 \text { vs. } 4.4 \text {; } \\
\text { adjusted difference } \\
0.1(95 \% \mathrm{Cl}-0.7 \text { to } \\
1.0) \\
\text { Patient global } \\
\text { assessment of } \\
\text { disease activity: } 4.2 \\
\text { vs. } 4.1 ; \text { adjusted } \\
\text { difference } 0.1 \text { (95\% } \\
\text { Cl }-0.5,0.7) \\
\text { Patient global } \\
\text { assessment of } \\
\text { disease activity } \\
\text { affecting ADL: } 3.8 \\
\text { vs. } 3.8 ; \text { adjusted } \\
\text { difference }-0.2 \\
\text { (95\% Cl -0.8 to } \\
0.4)\end{array}$ \\
\hline
\end{tabular}

ACR = American College of Radiology; ADL = activity of daily living; CI = confidence interval; FIHOA = Functional Index for Hand OsteoArthritis; NR = not reported; NRS = numeric rating scale; NS = not statistically significant; OA = osteoarthritis; OARSI OMERACT = Osteoarthritis Research Society International Outcome Measures in Rheumatology; PSFS = patientspecific function scale; $\mathrm{ROM}=$ range of motion

${ }^{a}$ Unless otherwise noted, followup time is calculated from the end of the treatment period

\section{Exercise Compared With Usual Care}

Data were insufficient from one poor-quality trial. No differences between exercise and usual care were observed for function according to the Functional Index for Hand OsteoArthritis (adjusted MD -0.5 on a $0-30$ scale, $95 \%$ CI -1.9 to 0.8 ), or for pain (adjusted MD -0.2 on a 0 to 10 VAS pain scale, $95 \% \mathrm{CI}-0.8$ to 0.3 ) at 3 months. ${ }^{64}$ Similarly, there were no differences between groups in the proportion of OARSI OMERACT responders (30\% versus $28 \%$ ). There were also no differences between groups in any secondary outcome measure, including the patient-specific function scale, hand stiffness, or patient global assessment of disease activity.

The effects of exercise on use of opioid therapies or health care utilization were not reported. There was insufficient evidence to determine effects of duration of exercise therapy or number of sessions on outcomes.

\section{Exercise Compared With Pharmacological Therapy or Other Nonpharmacological Therapies}

No trial of exercise versus pharmacological therapy met inclusion criteria. Findings for exercise versus other nonpharmacological therapies are addressed in the sections for other nonpharmacological therapies. 


\section{Harms}

In this trial, ${ }^{64}$ no serious adverse events were reported; 8/130 (6\%) patients reported increased pain (3 in hand, 5 in neck/shoulders) but adverse events were not reported by group.

\section{Physical Modalities for Osteoarthritis of the Hand}

\section{Key Points}

- One good-quality study of low-level laser treatment versus sham found no evidence of differences in function (MD 0.2, 95\% CI -0.2 to 0.6 ) or pain (MD 0.1, 95\% CI -0.3 to 0.5 ) in the short term (SOE: low).

- Data were insufficient from one fair-quality trial to determine effects or harms of heat therapy using paraffin compared to no treatment on function or pain in the short term (SOE: insufficient).

- No serious harms were reported in the trial of low-level laser therapy (SOE: low).

\section{Detailed Synthesis}

We identified two trials of physical modality use for hand OA (Table 33 and Appendixes D and E). One good-quality double-blind Canadian trial $(\mathrm{N}=88)^{138}$ compared three, 20 -minute sessions of low-level laser treatment to a sham laser probe over a 6-week period. Identical treatment procedures were used in each group. All participants attended three sham laser treatment sessions prior to randomization to ensure ability to comply with the treatment protocol.

One fair-quality trial $(n=56)$ conducted in Turkey compared 15 minutes of paraffin wrapping 5 days per week for 3 weeks with a no treatment control group. ${ }^{139}$ Both groups received information about joint protection strategies. Methodological limitations included lack of patient blinding, unclear compliance with treatment, and poorly reported analyses.

Table 33. Osteoarthritis of the hand: physical modalities

\begin{tabular}{|c|c|c|c|c|}
\hline $\begin{array}{l}\text { Author, } \\
\text { Year, } \\
\text { Followup,a } \\
\text { Pain } \\
\text { Duration, } \\
\text { Study } \\
\text { Quality }\end{array}$ & Intervention & Population & $\begin{array}{l}\text { Function and Pain } \\
\text { Outcomes }\end{array}$ & Other Outcomes \\
\hline $\begin{array}{l}\text { Brosseau, }{ }^{138} \\
2005 \\
4.5 \text { months } \\
\text { Duration of } \\
\text { pain: NR } \\
\text { Good }\end{array}$ & $\begin{array}{l}\text { A. Low-level laser } \\
\text { therapy ( } \mathrm{n}=42 \text { ): } 3 \\
\mathrm{~J} / \mathrm{cm}^{2} \text { applied for } 1 \\
\text { second each to the } \\
\text { skin overlying the } \\
\text { radial, medial and } \\
\text { ulnar nerves (total of } \\
15 \text { points irradiated); } \\
3 \text { sessions lasting } 20 \\
\text { minutes per week for } \\
6 \text { weeks } \\
\text { B. Sham low-level } \\
\text { laser therapy ( }=46) \text { : } \\
\text { same procedure as } \\
\text { the active treatment } \\
\text { but a sham laser } \\
\text { probe was used. }\end{array}$ & 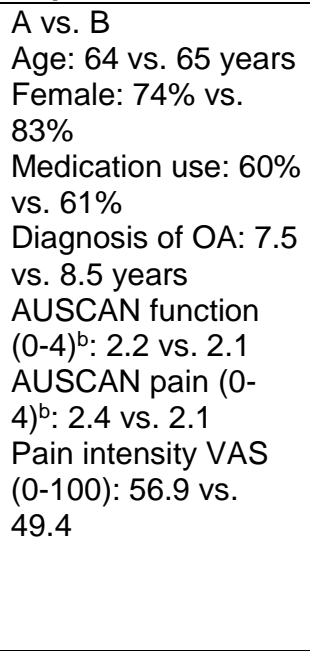 & $\begin{array}{l}\text { A vS. B } \\
4.5 \text { months } \\
\text { AUSCAN function: } 1.9 \text { vs. } \\
1.7 \text {, difference } 0.2 \text { ( } 95 \% \mathrm{Cl} \\
-0.2 \text { to } 0.6) \\
\text { AUSCAN pain: } 1.9 \text { vs. } 1.8, \\
\text { difference } 0.1(95 \% \mathrm{Cl}-0.3 \\
\text { to } 0.5) \\
\text { Pain VAS: NR }\end{array}$ & $\begin{array}{l}\text { A vs. B } \\
4.5 \text { months } \\
\text { Patient global } \\
\text { assessment: } \\
\text { Fully improved: } 0 \% \\
\text { vs. } 3 \% \\
\text { Partially improved: } \\
40 \% \text { vs. } 33.3 \% \\
\text { No improvement: } \\
60 \% \text { vs. } 52 \%\end{array}$ \\
\hline
\end{tabular}




\begin{tabular}{|c|c|c|c|c|}
\hline $\begin{array}{l}\text { Author, } \\
\text { Year, } \\
\text { Followup, } \\
\text { Pain } \\
\text { Duration, } \\
\text { Study } \\
\text { Quality }\end{array}$ & Intervention & Population & $\begin{array}{l}\text { Function and Pain } \\
\text { Outcomes }\end{array}$ & Other Outcomes \\
\hline $\begin{array}{l}\text { Dilek, } \\
2013^{139} \\
2.25 \text { months } \\
\text { Duration of } \\
\text { pain: } 5.5 \\
\text { years } \\
\text { Fair }\end{array}$ & $\begin{array}{l}\text { A. Dip-wrap paraffin } \\
\text { bath therapy }(\mathrm{n}=24) \text { : } \\
\text { patients dip both } \\
\text { hands into } 50^{\circ} \mathrm{C} \\
\text { paraffin bath } 10 \\
\text { times, paraffin left on } \\
\text { for } 15 \text { minutes, } \\
\text { treatment } \\
\text { administered } 5 \text { days } \\
\text { per week for } 3 \text { weeks } \\
\text { B. Control group } \\
\text { (n=22): Details NR; } \\
\text { assumed to be no } \\
\text { treatment } \\
\text { Only paracetamol } \\
\text { intake was permitted } \\
\text { during the study }\end{array}$ & $\begin{array}{l}\text { A vs. B } \\
\text { Age: } 59 \text { vs. } 60 \text { years } \\
\text { Female: } 83 \% \text { vs. } \\
91 \% \\
\text { AUSCAN function } \\
\text { (0-36) } 16.2 \text { vs. } 17.1 \\
\text { AUSCAN pain (0- } \\
\text { 20) } 10.7 \text { vs. } 9.8 \\
\text { Pain at rest, median } \\
\text { (VAS 0-10): } 5.0 \text { vs. } \\
4.0 \\
\text { Pain during ADL, } \\
\text { median (VAS 0-10): } \\
7.0 \text { vs. } 8.0\end{array}$ & $\begin{array}{l}\text { A vs. B } \\
2.25 \text { months } \\
\text { AUSCAN function: } 13.8 \text { vs. } \\
17.8 \text {, difference }-4.0 \text { ( } 95 \% \\
\mathrm{Cl}-8.6 \text { to } 0.6) \\
\text { AUSCAN pain: } 6.5 \text { vs. } 9.5 \text {, } \\
\text { difference }-3(95 \% \mathrm{CI}-5.5 \\
\text { to }-0.5) \\
\text { Pain VAS at rest, median: } \\
0.0 \text { vs. } 5.0, P<0.001 \\
\text { Pain VAS during ADL, } \\
\text { median: } 5.0 \text { vs. } 7.0, P=0.05\end{array}$ & NR \\
\hline
\end{tabular}

ADL = activity of daily living; AUSCAN = Australian Canadian Osteoarthritis Hand Index; CI =confidence interval; DFI = Dreiser Functional Index; NR = not reported; VAS = visual analog scale

${ }^{\text {a }}$ Unless otherwise noted, followup time is calculated from the end of the treatment period

${ }^{\mathrm{b}}$ Data for the AUSCAN was presented as an average of all responses, on a 5-point Likert scale (0-4), for both the physical function (9 items) and pain (5 items) subscale

${ }^{\mathrm{c}}$ Data for the AUSCAN was presented as a sum of the values across all items within the physical function (9 items) and pain (5 items) subscales; a 5-point Likert scale (0-4) was used to rate each item resulting in score ranges of 0-36 and 0-20, respectively

\section{Physical Modalities Compared With Sham or No Treatment}

Low-Level Laser Therapy. In the one good-quality trial of low-level laser treatment versus sham $(\mathrm{n}=88),{ }^{138}$ there were no differences in short-term function (MD 0.2 on a $0-4$ Australian Canadian Osteoarthritis Hand Index [AUSCAN] functional subscale, $95 \% \mathrm{CI}-0.2$ to 0.6 ) or pain (MD 0.1 on a $0-4$ AUSCAN pain subscale, $95 \%$ CI -0.3 to 0.5 ) at 4.5 months. Likewise, no difference was seen between groups in improvement based on patient global assessment.

Paraffin Treatment. One fair-quality trial $(\mathrm{N}=56)^{139}$ of paraffin heat treatment demonstrated no difference compared with no treatment on the AUSCAN function scale (0-36) (MD -4.0, 95\% CI -8.6 to 0.6 at short-term [2.25-month] followup). Regarding pain, no clear difference was identified between the groups over the short term as there was inconsistency across measures used and analyses for outcomes were poorly reported; findings were considered insufficient. ${ }^{139}$ While heat treatment was slightly favored based on the AUSCAN pain subscale (MD -3 on a 0 20 scale, $95 \%$ CI -5.5 to -0.5 ), it was not statistically significant in the author's intention-totreat (ITT) analysis $(\mathrm{P}=0.07)$. VAS pain at rest suggested more improvement with heat therapy versus control in the ITT analysis (median 0 vs. 5.0 on a $0-10$ scale, $\mathrm{P}<0.001$ ); however, there was no clear difference between groups on VAS pain during ADL (median 5.0 vs. 7.0, $\mathrm{P}=0.09$ for per protocol analysis, $\mathrm{P}=0.05$ for ITT).

No trial evaluated effects of physical modalities on use of opioid therapies or health care utilization. 
Physical Modalities Compared With Pharmacological Therapy or With Exercise Therapy

No trial of a physical modality versus pharmacological therapy or versus exercise met inclusion criteria.

\section{Harms}

Only the low-level laser therapy trial reported adverse events; no serious harms were reported. ${ }^{138}$ One patient (2\%) who received low-level laser treatment experienced erythema at the site.

\section{Multidisciplinary Rehabilitation for Osteoarthritis of the Hand}

\section{Key Points}

- One fair-quality trial of multidisciplinary rehabilitation versus waitlist control found no evidence of differences between groups over the short term in function (adjusted difference $0.49,95 \% \mathrm{CI}-0.09$ to 0.37 on $0-36$ scale) or pain (adjusted difference 0.40 , $95 \%$ CI -0.5 to 1.3 on a $0-20$ scale), or with regard to the proportion of OARSI OMERACT responders (OR 0.82, 95\% CI 0.42 to 1.61) (SOE: low for all outcomes).

- Data on harms were insufficient, although no serious adverse events were reported in the one trial of multidisciplinary rehabilitation versus waitlist control (SOE: insufficient).

\section{Detailed Synthesis}

One fair-quality trial ( $\mathrm{n}=151)$ compared four, 2.5- to 3-hour group-based sessions, delivered by an occupational therapist and a specialized nurse, consisting of self-management techniques, ergonomic principles, daily home exercises, and splint (optional) versus a waitlist control ${ }^{224}$ (Table 34 and Appendix D). Waitlist control consisted of one 30-minute explanation of OA followed by a 3-month waiting period. Effect estimates were adjusted for baseline function or pain, body mass index (BMI), gender, and presence of erosive arthritis. Methodological limitations included lack of patient blinding and unreported compliance to treatment (Appendix E).

Of note, this intervention appeared to focus on functional restoration and while it met our broad definition of multidisciplinary rehabilitation (see footnote in Table 1), it was not consistent with how multidisciplinary rehabilitation is generally delivered clinically. 
Table 34. Osteoarthritis of the hand: multidisciplinary rehabilitation

\begin{tabular}{|c|c|c|c|c|}
\hline $\begin{array}{l}\text { Author, Year, } \\
\text { Followup, } \\
\text { Pain } \\
\text { Duration, } \\
\text { Study Quality }\end{array}$ & Intervention & Population & $\begin{array}{l}\text { Function and Pain } \\
\text { Outcomes }\end{array}$ & Other Outcomes \\
\hline $\begin{array}{l}\text { Stukstette }^{224} \\
2013 \\
3 \text { months } \\
\text { Duration of } \\
\text { pain: } 4 \text { years } \\
\text { Fair }\end{array}$ & $\begin{array}{l}\text { A. Multidisciplinary } \\
\text { treatment program } \\
(\mathrm{n}=75): 4 \text { group } \\
\text { based therapy } \\
\text { sessions of } 2.5-3 \\
\text { hours duration (time } \\
\text { period NR), } \\
\text { supervised by a } \\
\text { specialized nurse } \\
\text { and occupational } \\
\text { therapist } \\
\text { B. Waiting list ( } n=72 \text { ) } \\
\text { All patients: } 30 \\
\text { minute explanation of } \\
\text { written information } \\
\text { about OA }\end{array}$ & $\begin{array}{l}\text { A vs. B } \\
\text { Age: } 60 \text { vs. } 58 \\
\text { Female: } 18 \% \text { vs. } \\
16 \% \\
\text { Mean duration of } \\
\text { diagnosis: } 4 \text { vs. } 4 \\
\text { years } \\
\text { Proportion taking } \\
\text { opioids: } 3 \% \text { vs. } 4 \% \\
\text { AUSCAN function } \\
\text { (0-36): } 21.0 \text { vs. } 21.8 \\
\text { AUSCAN pain (0- } \\
\text { 20):10.4 vs. } 10.2\end{array}$ & $\begin{array}{l}\text { A vs. B } \\
3 \text { months } \\
\text { AUSCAN function: } 18.6 \\
\text { vs. } 18.8 \text {, adjusted MD } \\
0.49 \text { (95\% } \mathrm{Cl}-0.09 \text { to } \\
0.37) \\
\text { AUSCAN pain: } 9.4 \text { vs. } \\
9.0, \text { adjusted MD } 0.40 \\
\text { (95\% Cl }-0.5 \text { to } 1.3) \\
\text { OARSI OMERACT } \\
\text { responders: } 33 \% \text { vs. } 37 \% \text {, } \\
\text { OR 0.82 (95\% Cl } 0.42 \text { to } \\
1.61)\end{array}$ & $\begin{array}{l}\text { A vs. B } \\
3 \text { months } \\
\text { Patient global } \\
\text { assessment: } 60.4 \text { vs. } \\
66.0 \text {, adjusted MD } \\
-5.2 \text { (95\% Cl }-11.4 \text {, } \\
\text { 1.0) } \\
\text { SF-36 PCS: } 39.8 \text { vs. } \\
39.9, \text { adjusted MD } \\
-0.14 \text { (95\% Cl -1.62 } \\
\text { to } 1.35) \\
\text { SF-36 MCS: } 50.3 \text { vs. } \\
51.6, \text { adjusted MD } \\
0.27 \text { (95\% Cl }-2.13 \text { to } \\
2.67)\end{array}$ \\
\hline
\end{tabular}

AUSCAN = Australian Canadian Osteoarthritis Hand Index; $\mathrm{MD}=$ mean difference; NR = not reported; OARSI-OMERACT = Osteoarthritis Research Society International Outcome Measures in Rheumatology; SF-36 MCS = Short-Form 36 Mental Component Summary score; SF-36 PCS = Short-Form 36 Physical Component Summary score

${ }^{a}$ Unless otherwise noted, followup time is calculated from the end of the treatment period

\section{Multidisciplinary Rehabilitation Compared With Waitlist}

No short-term (3 months) differences in function on the AUSCAN functional subscale (adjusted MD $0.49,95 \%$ CI -0.09 to 0.37 on 0 -36 scale) or on the AUSCAN pain subscale (adjusted MD 0.40, 95\% CI -0.5 to 1.3 , scale 0 -20) were reported. ${ }^{224}$

There was no difference in the proportion of OARSI OMERACT responders (OR 0.82, 95\% CO 0.42 to 1.61) between groups or on any secondary outcome measure, including ADLs (Canadian Occupational Measurement Scales), health-related quality of life (SF-36), arthritis self-efficacy, pain coping, muscle strength, or joint mobility. ${ }^{224}$

The effect of multidisciplinary rehabilitation on use of opioid therapies or health care utilization was not evaluated in any of the included studies.

\section{Multidisciplinary Rehabilitation Compared With Pharmacological Therapy or With Exercise Therapy}

No trial of a multidisciplinary rehabilitation program versus pharmacological therapy or versus exercise met inclusion criteria.

\section{Harms}

No serious adverse events were reported. One patient reported a swollen hand and increased pain after the second treatment session. ${ }^{224}$ 


\section{Key Question 4: Fibromyalgia}

\section{Exercise for Fibromyalgia}

\section{Key Points}

- Exercise was associated with slightly greater effects on function compared with attention control, no treatment, or usual care in the short term (7 trials, pooled MD -7.61 on a 0 to 100 scale, $95 \%$ CI -12.78 to $-2.43, \mathrm{I}^{2}=59.9 \%$ ) (SOE: low) and intermediate term (8 trials, pooled MD $-6.04,95 \% \mathrm{CI}-9.05$ to -3.03 , $\mathrm{I}^{2=} 0 \%$ ) (SOE: moderate). There were no clear effects in the long term (3 trials, pooled MD -4.33 , 95\% CI -10.18 to 1.52 , $\mathrm{I}^{2=} 0 \%$ ) (SOE: low).

- Exercise had a slightly greater effect on VAS pain (0 to 10 scale) compared with usual care, attention control, or no treatment short term (6 trials [excluding outlier trial], pooled $\mathrm{MD}-0.89,95 \% \mathrm{CI}-1.32$ to $-0.46, \mathrm{I}^{2}=0 \%$ ), but there were no clear effects at intermediate term (7 trials, pooled MD -0.41 , 95\% CI -0.87 to $0.05, \mathrm{I}^{2=} 9.5 \%$ ) or long term (4 trials, pooled MD -0.18 , 95\% CI -0.77 to 0.42 , $\mathrm{I}^{2=} 0 \%$ ) (SOE: moderate for all time frames).

- There was insufficient evidence from one small, poor-quality trial to determine the effects of aerobic exercise versus pharmacological therapy (paroxetine) on pain in the intermediate term (SOE: insufficient). There was no data on short- or long-term effects.

- Data on harms were insufficient. Most trials of exercise did not report on adverse events at all. One trial reported one nonstudy-related adverse event. Two trials reported no adverse events (SOE: insufficient).

\section{Detailed Synthesis}

Twenty-one trials (across 23 publications) of exercise therapy for fibromyalgia met inclusion criteria $^{65-87}$ (Table 35 and Appendix D). The exercise interventions varied across the trials and included combinations of different exercise types (11 trials), ${ }^{66,67,69,72,74,78,80,81,83-86}$ aerobic exercise (10 trials), ${ }^{68,70,71,73,75-77,79,81,82,87}$ muscle performance exercise/strength training $(1 \mathrm{trial}),{ }^{75}$ and Pilates ( 1 trial). ${ }^{65}$ The duration of exercise therapy ranged from 1 to 8 months across the trials and the total number of exercise sessions ranged from 4 to 96 (at a frequency of 1 to 5 times per week). Many trials also included instruction for home exercise practice. Exercise was compared to usual care in eight trials, ${ }^{68,69,79-81,85-87}$ no treatment in six trials, ${ }^{72-75,78,83,84}$ attention control in five trials, ${ }^{65,67,70,71,76,77}$ and to waitlist, ${ }^{66}$ sham (i.e., transcutaneous electrical stimulation), ${ }^{82}$ and pharmacological care ${ }^{82}$ in one trial each (the latter two groups were separate arms of the same trial). Usual care generally included medical treatment for fibromyalgia and continued normal daily activities (which often specifically excluded the exercise intervention being evaluated). Attention control conditions consisted of fibromyalgia education sessions, social support, instructions in coping strategies, relaxation and stretching exercises, and physical activity planning.

Sample sizes ranged from 32 to 166 across the trials (total number randomized=1,343). Patient mean age ranged from 35 to 57 years, and the majority were female (89\% to 100\%). Twelve trials were conducted in Europe, ${ }^{68,72,74,77-81,83-87}$ five in North America, ${ }^{67,69-71,73,76}$ two in Brazil, ${ }^{66,75}$ and two in Turkey. ${ }^{65,82}$

Eleven trials were rated fair quality ${ }^{65,66,68-71,75,77,78,81,85,87}$ and ten poor quality ${ }^{67,72-74,76,79,80,82-}$ ${ }^{84,86}$ (Appendix E). Methodological limitations in the fair-quality trials were primarily related to 
unclear allocation concealment methods and lack of blinding (the nature of interventions precluded blinding of participants and researchers). Additionally, poor-quality trials also suffered from unclear randomization methods and high rates of attrition and/or differential attrition.

Table 35. Fibromyalgia: exercise therapies

\begin{tabular}{|c|c|c|c|c|}
\hline $\begin{array}{l}\text { Author, Year, } \\
\text { Followup, } \\
\text { Pain Duration, } \\
\text { Study Quality }\end{array}$ & Intervention & Population & $\begin{array}{l}\text { Function and Pain } \\
\text { Outcomes }\end{array}$ & Other Outcomes \\
\hline $\begin{array}{l}\text { Altan, } 2009^{65} \\
3 \text { months } \\
\text { Pain duration NR } \\
\text { Fair }\end{array}$ & $\begin{array}{l}\text { A. Pilates ( } n=25) \text { : } 1 \\
\text { hour session } 3 \\
\text { times per week for } \\
3 \text { months: Pilates } \\
\text { postural education, } \\
\text { search for neutral } \\
\text { position, sitting, } \\
\text { antalgic, stretching } \\
\text { and, proproceptivity } \\
\text { improvement } \\
\text { exercises, and } \\
\text { breathing education } \\
\text { B. Attention control } \\
\text { (n=25): Instructions } \\
\text { in home exercise } \\
\text { relaxation/stretching } \\
\text { program of } 1 \text { hour } \\
\text { sessions } 3 \text { times } \\
\text { per week for } 3 \\
\text { months } \\
\text { All patients: } \\
\text { Education session } \\
\text { about available } \\
\text { diagnosis and } \\
\text { treatment of FM }\end{array}$ & $\begin{array}{l}\text { A vs. B } \\
\text { Age: } 48 \text { vs. } 50 \\
\text { years } \\
\text { Female: } 100 \% \text { vs. } \\
100 \% \\
\text { FIQ (0-100): } 80.8 \\
\text { vs. } 80.1 \\
\text { Pain VAS (0-10): } \\
6.1 \text { vs. } 6.3\end{array}$ & $\begin{array}{l}\text { A vs. B } \\
3 \text { months: } \\
\text { FIQ: } 69.3 \text { vs. } 77.6, \\
\text { difference }-8.3 \text { (95\% } \\
\mathrm{CI}-21.8 \text { to } 5.2) \\
\text { Pain VAS: } 5.2 \text { vs. } 6.5 \text {, } \\
\text { difference }-1.3 \text { (95\% } \\
\mathrm{Cl}-2.6 \text { to } 0.03)\end{array}$ & $\begin{array}{l}\text { A vs. B } \\
3 \text { months: } \\
\text { NHP (0-100): } 224.2 \\
\text { vs. } 246.3 \text {, difference } \\
-22.1(95 \% \mathrm{Cl}-96.0 \\
\text { to } 51.8)\end{array}$ \\
\hline
\end{tabular}




\begin{tabular}{|c|c|c|c|c|}
\hline $\begin{array}{l}\text { Author, Year, } \\
\text { Followup, } \\
\text { Pain Duration, } \\
\text { Study Quality }\end{array}$ & Intervention & Population & $\begin{array}{l}\text { Function and Pain } \\
\text { Outcomes }\end{array}$ & Other Outcomes \\
\hline $\begin{array}{l}\text { Baptista, } 2012^{66} \\
4 \text { months } \\
\text { Pain duration NR } \\
\text { Fair }\end{array}$ & $\begin{array}{l}\text { A. Belly dance } \\
\text { ( } n=40) \text { : One hour } \\
\text { belly dance classes } \\
\text { twice a week for } 16 \\
\text { weeks } \\
\text { (combination } \\
\text { exercise) } \\
\text { B. Waiting list } \\
\text { control ( } n=40 \text { ): } \\
\text { dance offered at } \\
\text { end of the study }\end{array}$ & $\begin{array}{l}\text { A vs. B: } \\
\text { Age: } 50 \text { vs. } 49 \\
\text { years } \\
\text { Female: } 100 \% \text { vs. } \\
100 \% \\
\text { Race: NR } \\
\text { FIQ (0-10): } 5.9 \text { vs. } \\
6.3 \\
\text { Pain VAS (0-10): } \\
7.7 \text { vs. } 7.5\end{array}$ & $\begin{array}{l}\text { A vs. B } \\
4 \text { months } \\
\text { FIQ: } 4.3 \text { vs. } 5.9 ; \\
\text { difference }-1.6(95 \% \\
\mathrm{Cl}-2.45 \text { to }-0.75) \\
\text { Pain VAS: } 4.7 \text { vs. } 7.3 \text {; } \\
\text { difference }-2.6(95 \% \\
\mathrm{Cl}-3.61 \text { to }-1.59)\end{array}$ & 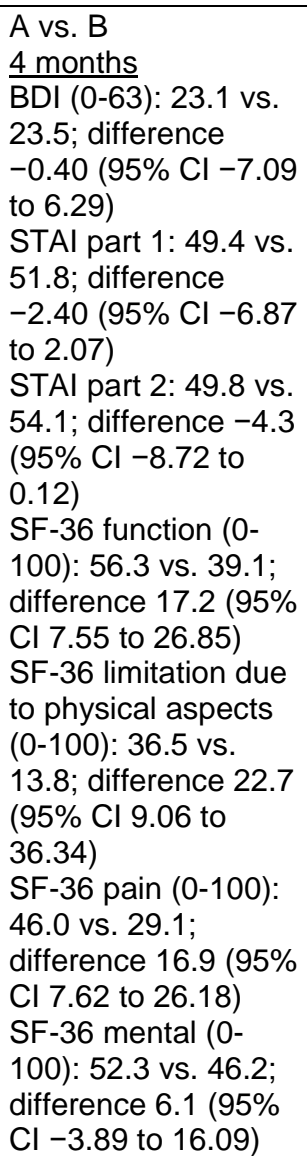 \\
\hline
\end{tabular}




\begin{tabular}{|c|c|c|c|c|}
\hline $\begin{array}{l}\text { Author, Year, } \\
\text { Followup, } \\
\text { Pain Duration, } \\
\text { Study Quality }\end{array}$ & Intervention & Population & $\begin{array}{l}\text { Function and Pain } \\
\text { Outcomes }\end{array}$ & Other Outcomes \\
\hline $\begin{array}{l}\text { Buckelew, } 1998^{67} \\
3 \text { and } 24 \text { months } \\
\text { Duration of } \\
\text { symptoms, } 11 \\
\text { years } \\
\text { Poor }\end{array}$ & $\begin{array}{l}\text { A. Combination } \\
\text { exercise ( } n=30 \text { ): } \\
\text { included active } \\
\text { range of motion } \\
\text { exercises, } \\
\text { strengthening } \\
\text { exercises, low to } \\
\text { moderate intensity } \\
\text { aerobic exercise, } \\
\text { proper posture and } \\
\text { body mechanics } \\
\text { instruction, and } \\
\text { instructions on use } \\
\text { of heat, cold, and } \\
\text { massage; one } 90 \\
\text { minute session per } \\
\text { week for } 1.5 \\
\text { months and } \\
\text { instructions to train } \\
2 \text { additional times } \\
\text { independently per } \\
\text { week then } 24 \\
\text { months of monthly } \\
\text { one-hour groups. } \\
\text { B. Attention control } \\
\text { ( } n=30 \text { ): one } 90-180 \\
\text { minute education } \\
\text { session weekly for } \\
1.5 \text { months }\end{array}$ & $\begin{array}{l}\text { A vs. B } \\
\text { Age: } 46 \text { vs. } 44 \\
\text { years } \\
\text { Female: } 93 \% \text { vs. } \\
90 \% \\
\text { Duration of } \\
\text { symptoms: } 12 \text { vs. } \\
10 \text { years } \\
\text { Duration of } \\
\text { diagnosis: } 3.0 \text { vs. } \\
2.5 \text { years } \\
\text { AlMS physical } \\
\text { activity subscale (0- } \\
10): \text { median } 4.0 \text { vs. } \\
6.0 \\
\text { Pain VAS (0-10): } \\
\text { median } 6.3 \text { vs. } 5.9\end{array}$ & $\begin{array}{l}\text { A vs. B } \\
3 \text { months: } \\
\text { AIMS physical activity } \\
\text { subscale: median } 4.0 \\
\text { vs. } 6.0 ; \text { median } \\
\text { change from baseline } \\
0 \text { vs. } 0 \\
\text { Pain VAS: median } 5.4 \\
\text { vs. } 5.8, \text { median } \\
\text { change from baseline } \\
-0.8 \text { vs. }-0.5 \\
24 \text { months } \\
\text { AIMS physical activity } \\
\text { subscale: median } 4.0 \\
\text { vs. } 6.0, \text { median } \\
\text { change from baseline } \\
0 \text { vs. } 0 \\
\text { Pain VAS: median } 5.5 \\
\text { vs. } 5.4, \text { median } \\
\text { change from baseline } \\
-1.2 \text { vs. }-0.6\end{array}$ & $\begin{array}{l}\text { A vs. B } \\
3 \text { months: } \\
\text { SCL-90-R Global } \\
\text { Severity Index (0-90): } \\
\text { median } 65.5 \text { vs. } 65.0, \\
\text { median change from } \\
\text { baseline }-3 \text { vs. } 0 \\
\text { CES-D (0-60): } \\
\text { median } 13.5 \text { vs. } 13.0 \text {, } \\
\text { median change from } \\
\text { baseline }-2.5 \text { vs. } 3 \\
\text { Sleep scale (0-12), } \\
\text { median } 8.0 \text { vs. } 5.0, \\
\text { median change from } \\
\text { baseline } 0 \text { vs. } 0 \\
24 \text { months } \\
\text { SCL-90-R Global } \\
\text { Severity Index: } \\
\text { median } 65.5 \text { vs. } 67.0, \\
\text { median change from } \\
\text { baseline }-2.5 \text { vs. }-1 \\
\text { CES-D: median } 11.5 \\
\text { vs. } 12.0, \text { median } \\
\text { change from baseline } \\
-3.5 \text { vs. }-2 \\
\text { Sleep scale: median } \\
7.5 \text { vs. } 6.0, \text { median } \\
\text { change from baseline } \\
0 \text { vs. } 0\end{array}$ \\
\hline
\end{tabular}




\begin{tabular}{|c|c|c|c|c|}
\hline $\begin{array}{l}\text { Author, Year, } \\
\text { Followup, } \\
\text { Pain Duration, } \\
\text { Study Quality }\end{array}$ & Intervention & Population & $\begin{array}{l}\text { Function and Pain } \\
\text { Outcomes }\end{array}$ & Other Outcomes \\
\hline $\begin{array}{l}\text { Clarke-Jenssen, } \\
2014^{68} \\
3 \text { and } 12 \text { months } \\
\text { Symptom } \\
\text { Duration, } \\
14 \text { years } \\
\text { Fair }\end{array}$ & $\begin{array}{l}\text { A. Aerobic exercise } \\
\text { ( } \mathrm{n}=44 \text { ): conducted } \\
\text { on land and in } \\
\text { warm water } \\
\text { provided in a warm } \\
\text { climate; also } \\
\text { stretching, } \\
\text { relaxation, and } \\
\text { education; provided } \\
\text { in groups } 5 \text { days } \\
\text { per week for } 4 \\
\text { weeks } \\
\text { B. Aerobic exercise } \\
\text { ( } \mathrm{n}=44 \text { ): on land and } \\
\text { in warm water } \\
\text { provided in a cold } \\
\text { climate; also } \\
\text { stretching, } \\
\text { relaxation, } \\
\text { education, provided } \\
\text { in groups } 5 \text { days } \\
\text { per week for } 4 \\
\text { weeks } \\
\text { C. Usual Care } \\
\text { ( } \mathrm{n}=44 \text { ): no } \\
\text { intervention }\end{array}$ & $\begin{array}{l}\text { A vs. B vs. C: } \\
\text { Age: } 46 \text { vs. } 46 \text { vs. } \\
45 \text { years } \\
\text { Female: } 88 \% \text { vs. } \\
93 \% \text { vs. } 96 \% \\
\text { Symptom duration: } \\
17 \text { vs. } 13 \text { vs.12 } \\
\text { years } \\
\text { Pain VAS (mean, 0- } \\
\text { 10): } 6.6 \text { vs. } 6.9 \text { vs. } \\
6.6\end{array}$ & 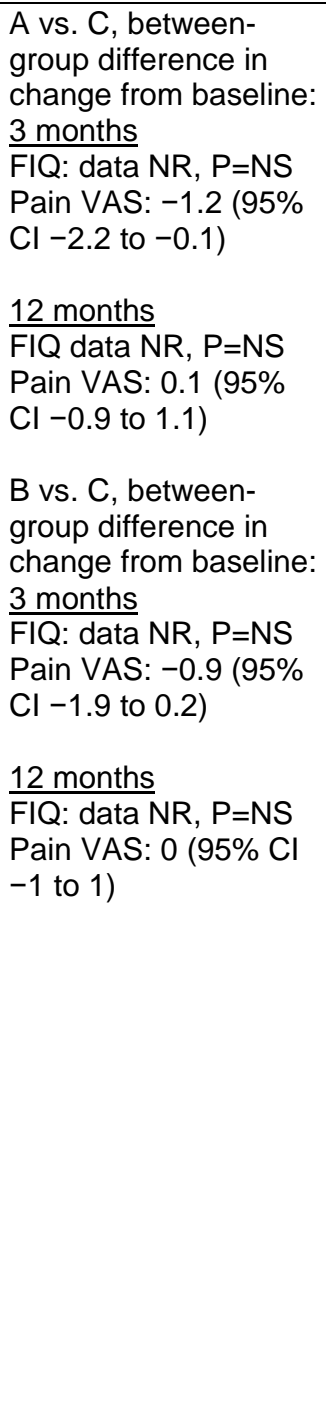 & $\begin{array}{l}\text { A vs. C, between- } \\
\text { group difference in } \\
\text { change from } \\
\text { baseline: } \\
3 \text { months } \\
\text { HADS: data NR, } \\
\text { P=NS } \\
\text { SF-36 Physical: data } \\
\text { NR, P=NS } \\
\text { SF-36 Mental: data } \\
\text { NR, P=NS } \\
\text { 12 months } \\
\text { HADS: data NR, } \\
\text { P=NS } \\
\text { SF-36 Physical: data } \\
\text { NR, P=NS } \\
\text { SF-36 Mental: data } \\
\text { NR, P=NS } \\
\text { B vs. C, between- } \\
\text { group difference in } \\
\text { change from } \\
\text { baseline: } \\
3 \text { months } \\
\text { HADS: data NR, } \\
\text { P=NS } \\
\text { SF-36 Physical: data } \\
\text { NR, P=NS } \\
\text { SF-36 Mental: data } \\
\text { NR, P=NS } \\
12 \text { months } \\
\text { HADS: data NR, } \\
\text { P=NS } \\
\text { SF-36 Physical: data } \\
\text { NR, P=NS } \\
\text { SF-36 Mental: data } \\
\text { NR, P=NS }\end{array}$ \\
\hline
\end{tabular}




\begin{tabular}{|c|c|c|c|c|}
\hline $\begin{array}{l}\text { Author, Year, } \\
\text { Followup, } \\
\text { Pain Duration, } \\
\text { Study Quality }\end{array}$ & Intervention & Population & $\begin{array}{l}\text { Function and Pain } \\
\text { Outcomes }\end{array}$ & Other Outcomes \\
\hline $\begin{array}{l}\text { Da Costa, } 2005^{69} \\
3 \text { and } 9 \text { months } \\
\text { Symptom duration, } \\
\text { years: } \\
11 \text { years } \\
\text { Fair }\end{array}$ & $\begin{array}{l}\text { A. Combination } \\
\text { Exercise ( } \mathrm{n}=39 \text { ): } \\
\text { aerobic exercise, } \\
\text { stretching, and } \\
\text { strength exercises; } \\
4 \text { visits (initial } 90 \\
\text { minutes, others } 30 \\
\text { minutes) over } 12 \\
\text { weeks with exercise } \\
\text { physiologist; } \\
\text { individualized } \\
\text { home-based } \\
\text { program. } \\
\text { B. Usual care } \\
\text { ( } \mathrm{n}=41 \text { ): subjects } \\
\text { asked to record } \\
\text { exercise activity } \\
\text { weekly during the } \\
\text { 12-week } \\
\text { intervention phase } \\
\text { and monthly } \\
\text { thereafter. }\end{array}$ & $\begin{array}{l}\text { A vs. B } \\
\text { Age, years: } 49 \text { vs. } \\
52 \\
\text { Female: } 100 \% \text { vs. } \\
100 \% \\
\text { Symptom duration: } \\
10.5 \text { vs. } 11.2 \text { years } \\
\text { FIQ (0-100): } 55.1 \\
\text { vs. } 48.6 \\
\text { Upper body pain } \\
\text { VAS (0-100): } 49.5 \\
\text { vs. } 47.4 \\
\text { Lower body pain } \\
\text { VAS (0-100): } 47.0 \\
\text { vs. } 47.0\end{array}$ & 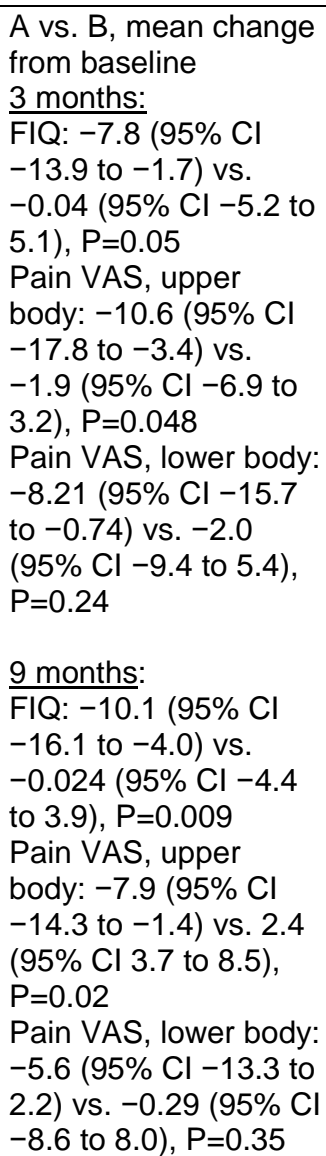 & $\begin{array}{l}\text { A vs. B, mean } \\
\text { change from baseline } \\
3 \text { months: } \\
\text { SCL } 90-\mathrm{R} \text { GSI } \\
(30-81):-0.02(95 \% \\
\mathrm{Cl}-0.3 \text { to }-0.04) \text { vs. } \\
-0.07(95 \% \mathrm{Cl}-0.2 \\
\text { to } 0.05), \mathrm{P}=0.26 \\
9 \text { months: } \\
\text { SCL } 90-\mathrm{R} \text { GSI }(30- \\
81):-0.16(95 \% \mathrm{Cl} \\
-0.28 \text { to } 0.35) \text { vs. } \\
-0.09(95 \% \mathrm{Cl}-0.21 \\
\text { to } 0.03), \mathrm{P}=0.39\end{array}$ \\
\hline $\begin{array}{l}\text { Fontaine, } 2010, \\
2011^{70,71} \\
6 \text { and } 12 \text { months } \\
\text { Mean duration of } \\
\text { fibromyalgia } 7.4 \\
\text { years } \\
\text { Fair }\end{array}$ & $\begin{array}{l}\text { A. Aerobic Exercise } \\
\text { (n=30): Lifestyle } \\
\text { Physical Activity; } 6 \text {, } \\
60 \text {-minute group } \\
\text { sessions over } 3 \\
\text { months with the } \\
\text { goal to increase } \\
\text { moderate-intensity } \\
\text { physical exercise by } \\
\text { accumulating short } \\
\text { bursts of physical } \\
\text { activity throughout } \\
\text { the day to } 30 \\
\text { minutes } 5-7 \text { days } \\
\text { per week. } \\
\text { B. Attention control } \\
\text { (n=23): FM } \\
\text { education, monthly } \\
\text { sessions for } 3 \\
\text { months. Included } \\
\text { education about FM } \\
\text { and social support. }\end{array}$ & $\begin{array}{l}\text { A vs. B } \\
\text { Age: } 46 \text { vs. } 49 \\
\text { years } \\
\text { Female: } 94 \% \text { vs. } \\
100 \% \\
\text { Race, white: } 78 \% \\
\text { vs. } 82 \% \\
\text { Years since } \\
\text { diagnosis: } 5.9 \text { vs. } \\
9.6 \\
\text { FIQ (scale NR): } \\
67.5 \text { vs. } 69.7 \\
\text { Pain VAS (0-100): } \\
54.6 \text { vs. } 58.9\end{array}$ & $\begin{array}{l}\text { A vs. B } \\
6 \text { months: } \\
\text { FIQ: } 65.3 \text { vs. } 63.9, \\
\text { difference } 1.4(95 \% \mathrm{Cl} \\
\text {-10.0 to } 12.8) \\
\text { Pain VAS: } 54.9 \text { vs. } \\
49.4 \text {, difference } 5.5 \\
\text { (95\% Cl }-7.8 \text { to } 18.8) \\
12 \text { months: } \\
\text { FIQ: } 64.4 \text { vs. } 65.1, \\
\text { difference }-0.7(95 \% \\
\text { Cl }-13.6 \text { to } 12.2) \\
\text { Pain VAS: } 51.6 \text { vs. } \\
50.9, \text { difference } 0.7 \\
\text { (95\% Cl }-12.9 \text { to } \\
14.3)\end{array}$ & $\begin{array}{l}\text { A vs. B } \\
6 \text { months: } \\
\text { CES-D (scale NR): } \\
18.1 \text { vs. } 19.9 \\
\text { difference }-1.8(95 \% \\
\mathrm{Cl}-7.5 \text { to } 3.9) \\
12 \text { months: } \\
\text { CES-D: } 19.8 \text { vs. } \\
20.6, \text { difference }-0.8 \\
(95 \% \mathrm{Cl}-7.1 \text { to } 5.5)\end{array}$ \\
\hline
\end{tabular}




\begin{tabular}{|c|c|c|c|c|}
\hline $\begin{array}{l}\text { Author, Year, } \\
\text { Followup, } \\
\text { Pain Duration, } \\
\text { Study Quality }\end{array}$ & Intervention & Population & $\begin{array}{l}\text { Function and Pain } \\
\text { Outcomes }\end{array}$ & Other Outcomes \\
\hline $\begin{array}{l}\text { Giannotti, } 2014^{72} \\
1 \text { and } 6 \text { months } \\
\text { Pain duration NR } \\
\text { Poor }\end{array}$ & $\begin{array}{l}\text { A. Combination } \\
\text { exercise }(n=21) \text { : } \\
\text { stretching, } \\
\text { strengthening, } \\
\text { active and passive } \\
\text { mobilization, spine } \\
\text { flexibility, and } \\
\text { aerobic training plus } \\
\text { education } 2 \text { days a } \\
\text { week ( } 60 \text { minutes } \\
\text { per session) for } 10 \\
\text { weeks; instructions } \\
\text { to perform at home } \\
\text { the exercise } \\
\text { program at least } 3 \\
\text { times per week. } \\
\text { B. No intervention } \\
\text { ( } \mathrm{n}=20 \text { ) }\end{array}$ & $\begin{array}{l}\text { A vs. B } \\
\text { Age: } 53 \text { vs. } 51 \\
\text { years } \\
\text { Female: } 95 \% \text { vs. } \\
92 \% \\
\text { FIQ (0-100): } 62.7 \\
\text { vs. } 59.1 \\
\text { Pain VAS (0-10): } \\
6.1 \text { vs. } 6.1\end{array}$ & $\begin{array}{l}\text { A vs. B } \\
1 \text { month: } \\
\text { FIQ: } 55.5 \text { vs. } 50.9, \\
\text { difference } 4.6(95 \% \mathrm{Cl} \\
\text {-6.38 to } 15.58) \\
\text { Pain VAS: } 5.3 \text { vs. } 5.5 \text {, } \\
\text { difference }-0.20(95 \% \\
\mathrm{Cl}-1.87 \text { to } 1.47) \\
\text { 6 months } \\
\text { FIQ: } 48.8 \text { vs. } 56.9, \\
\text { difference }-8.1(95 \% \\
\mathrm{Cl}-20.33 \text { to } 4.13) \\
\text { Pain VAS: } 5.8 \text { vs. } 5.4, \\
\text { difference } 0.4(95 \% \mathrm{Cl} \\
-1.4 \text { to } 2.2)\end{array}$ & $\begin{array}{l}\text { A vs. B } \\
1 \text { month } \\
\text { Sleep VAS }(0-10) \text { : } \\
4.6 \text { vs. } 5.0, \text { difference } \\
-0.40(95 \% \mathrm{Cl}-2.51 \\
\text { to } 1.71) \\
6 \text { months } \\
\text { Sleep VAS }(0-10) \text { : } \\
6.3 \text { vs. } 6.1, \text { difference } \\
0.20(95 \% \mathrm{Cl}-2.15 \\
\text { to } 2.55)\end{array}$ \\
\hline $\begin{array}{l}\text { Gowans, } 2001^{73} \\
6 \text { months } \\
\text { Duration of } \\
\text { symptoms, } 9 \text { years } \\
\text { Poor }\end{array}$ & $\begin{array}{l}\text { A. Aerobic exercise } \\
\text { ( } n=30): 3 \text { pool and } \\
\text { walking exercise } \\
\text { classes (plus } \\
\text { stretching) per } \\
\text { week for } 6 \text { months } \\
\text { B. Control group } \\
(n=27) \text { : continued } \\
\text { ad libitum activity }\end{array}$ & $\begin{array}{l}\text { A vs. B } \\
\text { Age: } 45 \text { vs. } 50 \\
\text { years } \\
\text { Female: } 89 \% \text { vs. } \\
87 \% \\
\text { FIQ (0-80): } 57.7 \text { vs. } \\
56.6\end{array}$ & $\begin{array}{l}\text { A vs. B } \\
6 \text { months: } \\
\text { FIQ: } 48.6 \text { vs. } 54.9, \\
p^{\star \star<}<0.05 ; \text { difference } \\
-6.3(95 \% \mathrm{Cl}-14.8 \text { to } \\
2.2)\end{array}$ & $\begin{array}{l}\text { A vs. B } \\
6 \text { months: } \\
\text { BDI (0-63): } 16.9 \text { vs. } \\
21.3, p^{\star *}<0.05 \\
\text { difference }-4.4(95 \% \\
\mathrm{Cl}-10.4 \text { to } 1.6) \\
\mathrm{P}=0.15 \\
\text { STAI }(20-80): 41.3 \\
\text { vs. } 51.7, \mathrm{P}^{\star *}<0.05 \\
\text { difference }-10.4 \\
\text { (95\% } \mathrm{Cl}-18.2 \text { to } \\
-2.6), \mathrm{P}=0.01\end{array}$ \\
\hline $\begin{array}{l}\text { Gusi, } 2006^{74} \\
3 \text { months } \\
\text { Duration of } \\
\text { symptoms, } 22 \\
\text { years } \\
\text { Poor }\end{array}$ & $\begin{array}{l}\text { A. Combination } \\
\text { exercise (n=18): 1- } \\
\text { hour pool exercise } \\
\text { (warm up, aerobic } \\
\text { exercise, mobility } \\
\text { and lower-limb } \\
\text { strength exercises, } \\
\text { cool down) } 3 \text { times } \\
\text { per week for } 12 \\
\text { weeks (subjects } \\
\text { instructed to avoid } \\
\text { physical exercise } \\
\text { for the next } 12 \\
\text { weeks) } \\
\text { B. Control (n=17): } \\
\text { Normal daily } \\
\text { activities, which did } \\
\text { not include any } \\
\text { exercise related to } \\
\text { those in the } \\
\text { therapy. }\end{array}$ & $\begin{array}{l}\text { A vs. B } \\
\text { Age, years: } 51 \text { vs. } \\
51 \\
\text { Female: } 100 \% \text { vs. } \\
100 \% \\
\text { Pain VAS (0-100): } \\
63.1 \text { vs. } 63.9\end{array}$ & $\begin{array}{l}\text { A vs. B } \\
\text { Change from baseline } \\
3 \text { months } \\
\text { Pain VAS: }-1.6(95 \% \\
\mathrm{Cl}-12.7 \text { to } 0.9) \text { vs. } \\
0.9(95 \% \mathrm{Cl}-7.3 \text { to } \\
9.2), P=0.69\end{array}$ & $\begin{array}{l}\text { A vs. B } \\
\text { Change from } \\
\text { baseline } \\
3 \text { months } \\
E Q-5 D(0-1): 0.14 \\
(95 \% \mathrm{Cl}-0.03 \text { to } \\
0.32) \text { vs. }-0.02 \\
(-0.17 \text { to } 0.13) \text {, } \\
P=0.14 \\
E Q-5 D \\
P a i n / d i s c o m f o r t ~(1-3) \text { : } \\
-0.1(95 \% \mathrm{Cl}-0.4 \text { to } \\
0.3) \text { vs. } 0((95 \% \mathrm{Cl} \\
-0.3 \text { to } 0.3), \mathrm{P}=0.79 \\
\mathrm{EQ}-5 \mathrm{D} \\
\mathrm{Anxiety/depression} \\
(1-3):-0.5(95 \% \mathrm{Cl} \\
-0.8 \text { to }-0.1) \text { vs. } 0 \\
(95 \% \mathrm{Cl}-0.2 \text { to } 0.2) \text {, } \\
P=0.01\end{array}$ \\
\hline
\end{tabular}




\begin{tabular}{|c|c|c|c|c|}
\hline $\begin{array}{l}\text { Author, Year, } \\
\text { Followup, } \\
\text { Pain Duration, } \\
\text { Study Quality }\end{array}$ & Intervention & Population & $\begin{array}{l}\text { Function and Pain } \\
\text { Outcomes }\end{array}$ & Other Outcomes \\
\hline $\begin{array}{l}\text { Kayo, } 2012^{75} \\
3 \text { months } \\
\text { Duration of } \\
\text { symptoms, } 5 \text { years } \\
\text { Fair }\end{array}$ & $\begin{array}{l}\text { A. Aerobic exercise } \\
\text { ( } \mathrm{n}=30 \text { ): Walking } \\
\text { program, } 60 \\
\text { minutes } 3 \text { times per } \\
\text { week for } 16 \text { weeks, } \\
\text { supervised by } \\
\text { physical therapist. } \\
\text { B. Muscle } \\
\text { strengthening } \\
\text { exercise ( } \mathrm{n}=30) \text { : } 60 \\
\text { minutes } 3 \text { times per } \\
\text { week for } 16 \text { weeks, } \\
\text { supervised by } \\
\text { physical therapist. } \\
\text { C. No treatment } \\
(\mathrm{n}=30)\end{array}$ & $\begin{array}{l}\text { A vs. B: } \\
\text { Age: } 48 \text { vs. } 47 \text { vs. } \\
46 \text { years } \\
\text { Symptom duration: } \\
4.0 \text { vs. } 4.7 \text { vs. } 5.4 \\
\text { FIQ total (0-100): } \\
63.1 \text { vs. } 67.3 \text { vs. } \\
63.8 \\
\text { Pain VAS (0-10): } \\
8.6 \text { vs. } 8.7 \text { vs. } 8.4\end{array}$ & $\begin{array}{l}\text { A vs. C } \\
3 \text { months } \\
\text { FIQ: } 38.5 \text { vs. } 57.7 ; \\
\text { overall group X time } \\
\text { interaction P=NS } \\
\text { Pain VAS: } 4.8 \text { vs. } 6.7 \text {; } \\
\text { overall group X time } \\
\text { interaction P=NS } \\
\text { B vs. C } \\
3 \text { months } \\
\text { FIQ: } 50.5 \text { vs. } 57.7 \text {; } \\
\text { overall group X time } \\
\text { interaction } P=N S \\
\text { Pain VAS: } 5.9 \text { vs. } 6.7 \text {; } \\
\text { overall group X time } \\
\text { interaction } P=N S\end{array}$ & NR \\
\hline $\begin{array}{l}\text { King, } 2002^{76} \\
3 \text { months } \\
\text { Duration of } \\
\text { symptoms, } 8.5 \\
\text { years } \\
\text { Poor }\end{array}$ & $\begin{array}{l}\text { A. Aerobic exercise } \\
\text { ( } n=30 \text { ): aerobic land } \\
\text { and water activities; } \\
\text { three, 10-40 minute } \\
\text { supervised exercise } \\
\text { sessions per week } \\
\text { for } 3 \text { months } \\
\text { B. Control ( } n=18) \text { : } \\
\text { instructions on } \\
\text { stretches and } \\
\text { coping strategies } \\
\text { and contacted 1-2 } \\
\text { times during the } 3 \\
\text { month treatment } \\
\text { period to answer } \\
\text { any questions }\end{array}$ & $\begin{array}{l}\text { A vs. B } \\
\text { Age: } 45 \text { vs. } 47 \\
\text { years } \\
\text { Female: } 100 \% \text { vs. } \\
\text { 100\% } \\
\text { Duration of } \\
\text { symptoms: } 7.8 \text { vs. } \\
9.6 \text { years } \\
\text { FIQ (0-80): } 52.4 \text { vs. } \\
55.2\end{array}$ & $\begin{array}{l}\text { A vs. B } \\
3 \text { months } \\
\text { FIQ: } 47.5 \text { vs. } 51.5, \\
\text { difference }-4.0(95 \% \\
\mathrm{Cl}-12.2 \text { to } 4.2)\end{array}$ & NR \\
\hline
\end{tabular}




\begin{tabular}{|c|c|c|c|c|}
\hline $\begin{array}{l}\text { Author, Year, } \\
\text { Followup, } \\
\text { Pain Duration, } \\
\text { Study Quality }\end{array}$ & Intervention & Population & $\begin{array}{l}\text { Function and Pain } \\
\text { Outcomes }\end{array}$ & Other Outcomes \\
\hline $\begin{array}{l}\text { Mannerkorpi, } \\
2009^{77} \\
6-7 \text { months } \\
\text { Pain duration NR } \\
\text { Fair }\end{array}$ & $\begin{array}{l}\text { A. Aerobic exercise } \\
\text { ( } \mathrm{n}=81 \text { ): One } 45 \\
\text { minute pool aerobic } \\
\text { exercise session } \\
\text { per week for } 20 \\
\text { weeks, stretching } \\
\text { exercise also, plus } \\
\text { six } 1 \text { hour weekly } \\
\text { sessions of } \\
\text { strategies to cope } \\
\text { with FM symptoms, } \\
\text { plan for physical } \\
\text { activity for the } \\
\text { following week and } \\
\text { short relaxation } \\
\text { exercise } \\
\text { B. Education control } \\
\text { ( } \mathrm{n}=85 \text { ): six } 1 \text { hour } \\
\text { weekly sessions of } \\
\text { strategies to cope } \\
\text { with FM symptoms, } \\
\text { plan for physical } \\
\text { activity for the } \\
\text { following week and } \\
\text { short relaxation } \\
\text { exercise }\end{array}$ & $\begin{array}{l}\text { A vs. B } \\
\text { Age: } 45 \text { vs. } 47 \\
\text { years } \\
\text { Female: } 100 \% \text { vs. } \\
\text { 100\% } \\
\text { FIQ (0-100): } 61.6 \\
\text { vs. } 66.6 \\
\text { FIQ pain subscale } \\
(0-100): 67.7 \text { vs. } \\
70.4\end{array}$ & $\begin{array}{l}\text { A vs. } B \\
6-7 \text { months } \\
\text { FIQ: mean change } \\
\text { from baseline: }-3.9 \\
\text { Vs. }-4.5, P=0.04 \\
\text { FIQ pain: mean } \\
\text { change from baseline: } \\
-6.5 \text { vs. }-2.5 \text {, } \\
P=0.018\end{array}$ & $\begin{array}{l}\text { A vs. B } \\
6-7 \text { months } \\
\text { HADS depression } \\
\text { scale }(0-21) \text { : mean } \\
\text { change from baseline } \\
-0.4 \text { vs. } 0.0, P=0.99 \\
\text { HADS anxiety scale } \\
\text { (0-21): mean change } \\
\text { from baseline }-0.7 \\
\text { vs. } 0.4, P=0.15 \\
\text { SF-36 PCS ( } 0-100): \\
\text { mean change from } \\
\text { baseline } 2.9 \text { vs. } 1.3, \\
P=0.13 \\
S F-36 \text { MCS (0-100): } \\
\text { mean change from } \\
\text { baseline } 0.5 \text { vs. } 1.3 \text {, } \\
P=0.15 \\
S F-36 \text { physical } \\
\text { functioning ( } 0-100): \\
\text { mean change from } \\
\text { baseline } 2.2 \text { vs. } 1.3 \text {, } \\
P=0.70 \\
\text { SF-36 role-physical } \\
(0-100): \text { mean } \\
\text { change from baseline } \\
12.1 \text { vs. } 9.3, P=0.72 \\
S F-36 \text { bodily pain }(0- \\
100): \text { mean change } \\
\text { from baseline } 5.0 \text { vs. } \\
3.6, P=0.24\end{array}$ \\
\hline $\begin{array}{l}\text { Paolucci, } 2015^{78} \\
\text { Duration of } \\
\text { symptoms: NR } \\
3 \text { months } \\
\text { Fair }\end{array}$ & $\begin{array}{l}\text { A. Combination } \\
\text { exercise ( } \mathrm{n}=19 \text { ): } \\
\text { Low-impact aerobic } \\
\text { training, agility } \\
\text { training balance } \\
\text { and postural } \\
\text { exercises, hip flexor } \\
\text { strengthening, static } \\
\text { stretching, } \\
\text { diaphragmatic } \\
\text { breathing, and } \\
\text { relaxation; } 10,60- \\
\text { minute sessions, } \\
\text { twice a week for } 5 \\
\text { weeks } \\
\text { B. Control (n=18): } \\
\text { No rehabilitation } \\
\text { interventions, } \\
\text { continued normal } \\
\text { activities }\end{array}$ & $\begin{array}{l}\text { A vs. B } \\
\text { Age: } 50 \text { vs. } 48 \\
\text { years } \\
\text { Female: } 100 \% \text { vs. } \\
100 \% \\
\text { FIQ total }(0-100) \text { : } \\
64.8 \text { vs. } 63.9\end{array}$ & $\begin{array}{l}\text { A vs. B } \\
3 \text { months: } \\
\text { FIQ total: } 53.8 \text { vs. } \\
64.3 \text {, difference } \\
-10.50(95 \% \mathrm{Cl} \\
-17.77,-3.23)\end{array}$ & $\mathrm{NR}$ \\
\hline
\end{tabular}




\begin{tabular}{|c|c|c|c|c|}
\hline $\begin{array}{l}\text { Author, Year, } \\
\text { Followup, } \\
\text { Pain Duration, } \\
\text { Study Quality }\end{array}$ & Intervention & Population & $\begin{array}{l}\text { Function and Pain } \\
\text { Outcomes }\end{array}$ & Other Outcomes \\
\hline $\begin{array}{l}\text { Sanudo, } 2010^{81} \\
6 \text { months } \\
\text { Pain duration NR } \\
\text { Fair }\end{array}$ & $\begin{array}{l}\text { A. Combination } \\
\text { exercise ( } \mathrm{n}=21 \text { ): } \\
\text { supervised aerobic, } \\
\text { muscle } \\
\text { strengthening, and } \\
\text { flexibility exercises; } \\
\text { twice-weekly } \\
\text { sessions for } 24 \\
\text { weeks } \\
\text { B. Aerobic exercise } \\
\text { (n=22): warm-up, } \\
\text { aerobic exercise, } \\
\text { cool down; two, } 45- \\
60 \text { minute } \\
\text { sessions/week for } 6 \\
\text { months } \\
\text { C. Usual care } \\
\text { control ( } n=21) \text { : } \\
\text { medical treatment } \\
\text { for FM and } \\
\text { continued normal } \\
\text { daily activities, } \\
\text { which did not } \\
\text { include aerobic } \\
\text { exercise. }\end{array}$ & $\begin{array}{l}\text { A vs. B vs. C } \\
\text { Age: } 56 \text { vs. } 56 \text { vs. } \\
57 \text { years } \\
\text { FIQ (0-100): } 62.2 \\
\text { vs. } 60.9 \text { vs. } 60.5\end{array}$ & $\begin{array}{l}\text { A vs. C } \\
6 \text { months } \\
\text { FIQ: mean change } \\
\text { from baseline }-8.8 \text { vs. } \\
\text { NR; } P<0.01 \\
\text { B vs. C } \\
\frac{6 \text { months }}{\text { FIQ: mean change }} \\
\text { from baseline }-8.8 \text { vs. } \\
\text { NR; } P<0.05\end{array}$ & $\begin{array}{l}\text { A vs. C } \\
6 \text { months } \\
\text { BDI }(0-63): \text { mean } \\
\text { change from baseline } \\
-6.4 \text { vs. NR; } P<0.01 \\
\text { SF-36 total }(0-100): \\
\text { mean change from } \\
\text { baseline } 8.4 \text { vs. NR; } \\
\text { P<0.01 } \\
\text { B vs. C } \\
6 \text { months } \\
\text { BDI: }-8.5 \text { vs. NR; } \\
\text { P<0.01 } \\
\text { SF-36 total: } 8.9 \text { vs. } \\
\text { NR; P<0.05 }\end{array}$ \\
\hline $\begin{array}{l}\text { Sanudo, } 2012^{80} \\
6,18 \text { and } 30 \\
\text { months } \\
\text { Pain duration NR } \\
\text { Poor }\end{array}$ & $\begin{array}{l}\text { A. Combination } \\
\text { exercise ( } n=21) \text { : } \\
\text { Twice-weekly 45- to } \\
60 \text {-minute sessions } \\
\text { of exercise (warm } \\
\text { up, aerobic } \\
\text { exercise, muscle } \\
\text { strengthening } \\
\text { exercise, flexibility } \\
\text { exercises) for } 6 \\
\text { months. } \\
\text { B. Usual care } \\
\text { (n=20): alternated } \\
\text { between } 6 \text { months } \\
\text { of training and } 6 \\
\text { months with no } \\
\text { exercise } \\
\text { intervention (asked } \\
\text { not to participate in } \\
\text { any structured } \\
\text { exercise program) } \\
\text { for } 30 \text { months. }\end{array}$ & $\begin{array}{l}\text { A vs. B } \\
\text { Female: } 100 \% \text { vs. } \\
100 \% \\
\text { FIQ (0-80): } 58.6 \text { vs. } \\
55.6\end{array}$ & $\begin{array}{l}\text { A vs. B } \\
6 \text { months: } \\
\text { FIQ: } 48.5 \text { vs. 55.4, } \\
\text { P<0.0005; difference } \\
\text {-6.9 (95\% Cl }-14.35 \\
\text { to } 0.55), P=0.07 \\
18 \text { months: } \\
\text { FIQ: } 45.6 \text { vs. } 51.3 \text {, } \\
\text { P=NR; difference }-5.7 \\
\text { (95\% Cl -14.6 to 3.2), } \\
P=0.20 \\
30 \text { months } \\
\text { FIQ: } 38.5 \text { vs. } 49.5, p \\
\text { NS; difference }-11.0 \\
\text { (95\% Cl -19.93 to } \\
-2.07), P=0.02\end{array}$ & 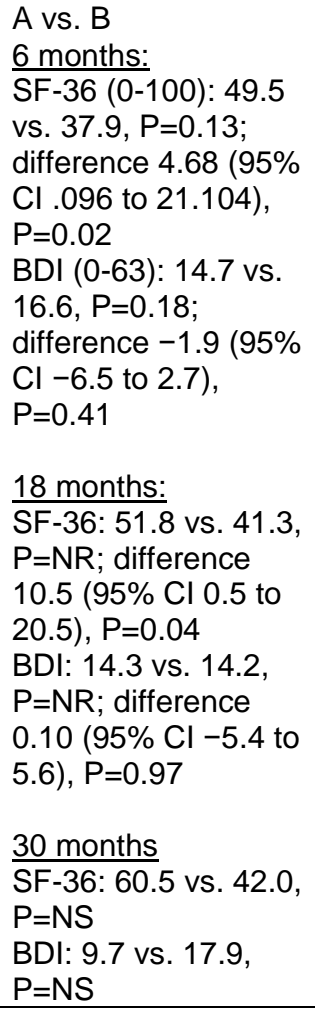 \\
\hline
\end{tabular}




\begin{tabular}{|c|c|c|c|c|}
\hline $\begin{array}{l}\text { Author, Year, } \\
\text { Followup, } \\
\text { Pain Duration, } \\
\text { Study Quality }\end{array}$ & Intervention & Population & $\begin{array}{l}\text { Function and Pain } \\
\text { Outcomes }\end{array}$ & Other Outcomes \\
\hline $\begin{array}{l}\text { Sanudo, } 2015^{79} \\
6 \text { months } \\
\text { Pain duration NR } \\
\text { Poor }\end{array}$ & $\begin{array}{l}\text { A. Aerobic exercise } \\
\text { ( } \mathrm{n}=16 \text { ): consisted of } \\
\text { warm up, steady } \\
\text { state exercise at } \\
60-65 \% \text { of } \\
\text { predicted maximum } \\
\text { heart rate, interval } \\
\text { training at } 75-80 \% \\
\text { of predicted } \\
\text { maximum heart } \\
\text { rate, and cool- } \\
\text { down; } 2,45-60 \\
\text { minute sessions per } \\
\text { week for } 6 \text { months } \\
\text { B. Usual care } \\
\text { ( } n=16 \text { ): normal } \\
\text { activities, which did } \\
\text { not include } \\
\text { structured exercise. }\end{array}$ & $\begin{array}{l}\text { A vs. B } \\
\text { Age: } 55 \text { vs. } 58 \\
\text { years } \\
\text { Female: } 100 \% \text { vs. } \\
100 \% \\
\text { Pain VAS }(0-10): \\
7.4 \text { vs. } 7.2\end{array}$ & $\begin{array}{l}\text { A vs. B } \\
6 \text { months: } \\
\text { Pain VAS: } 6.7 \text { vs. } 7.0 \text {, } \\
\text { difference }-0.3 \text { (95\% } \\
\mathrm{Cl}-6.3 \text { to } 5.7)\end{array}$ & $\begin{array}{l}\text { A vs. B } \\
6 \text { months } \\
\text { Anxiety VAS (0-10): } \\
5.7 \text { vs. } 7.5, \text { difference } \\
-1.8(95 \% \mathrm{Cl}-10.8 \\
\text { to } 7.2) \\
\text { Depression VAS (0- } \\
\text { 10): } 5.6 \text { vs. } 6.7(2.2) \text {, } \\
\text { difference }-1.1 \text { (95\% } \\
\mathrm{Cl}-10.1 \text { to } 7.9) \\
\text { Sleep disturbance } \\
\text { VAS (0-10): } 7.2 \text { vs. } \\
8.6(1.9), \text { difference } \\
-1.4(95 \% \mathrm{Cl}-8.9 \text { to } \\
6.1)\end{array}$ \\
\hline $\begin{array}{l}\text { Sencan, } 2004 \\
6 \text { months } \\
\text { Duration of pain: } \\
5.4 \text { years } \\
\text { Poor }\end{array}$ & $\begin{array}{l}\text { A. Exercise group } \\
\text { ( } n=14) \text { : } 3 \text { 40-minute } \\
\text { aerobic exercise } \\
\text { sessions per week } \\
\text { for } 6 \text { weeks } \\
\text { B. Paroxetine } \\
\text { ( } n=18) \text { : } 20 / \mathrm{mg} \\
\text { paroxetine/day for } 6 \\
\text { weeks } \\
\text { C. Sham (n=20): } \\
\text { placebo TENS with } \\
\text { electrodes applied } \\
\text { to two most painful } \\
\text { tender points for } 20 \\
\text { minutes, } 3 \\
\text { times/week for } 6 \\
\text { weeks. } \\
\text { All patients } \\
\text { instructed to take } \\
\text { paracetamol as a } \\
\text { rescue medication } \\
\text { throughout the } \\
\text { study. }\end{array}$ & $\begin{array}{l}\text { A vs. B vs. C } \\
\text { Age: } 35 \text { vs. } 36 \text { vs. } \\
36 \text { years } \\
\text { Female: } 100 \% \text { vs. } \\
100 \% \text { vs. } 100 \% \\
\text { BMI: } 24 \text { vs. } 24 \text { vs. } \\
15 \\
\text { Duration of } \\
\text { symptoms: } 4.7 \text { vs. } \\
6.5 \text { vs. } 5.1 \text { years } \\
\text { VAS (0-10): } 6.85 \\
\text { vs. } 6.62 \text { vs. } 7.70 \\
\text { Beck Depression } \\
\text { Index (BDI } 0-60): \\
16.20 \text { vs. } 20.80 \text { vs. } \\
18.50\end{array}$ & $\begin{array}{l}\text { A vs. C } \\
6 \text { months } \\
\text { VAS: } 4.75 \text { vs. } 5.01 \text {, } \\
\text { difference }-0.26 \text { (95\% } \\
\mathrm{Cl}-1.46 \text { to } 0.94) \\
\text { A vs. B } \\
6 \text { months } \\
\text { VAS: } 4.75 \text { vs. } 5.84, \\
\text { difference }-1.09 \text { (95\% } \\
\mathrm{Cl}-2.37 \text { to } 0.19)\end{array}$ & $\begin{array}{l}\text { A vs. C } \\
6 \text { months } \\
\text { BDI: } 9.95 \text { vs. } 15.15, \\
\text { difference }-5.2 \text { (95\% } \\
\mathrm{Cl}-7.41 \text { to }-2.99) \\
\text { Analgesic } \\
\text { Consumption: } 1.15 \\
\text { vs. } 4.35 \text {, difference } \\
-3.17 \text { (95\% Cl }-3.79 \\
\text { to }-2.55) \\
\text { A vs. B } \\
6 \text { months } \\
\text { BDI: } 9.95 \text { vs. } 10.12, \\
\text { difference }-0.17 \\
\text { (95\% Cl -2.09 to } \\
1.75) \\
\text { Analgesic } \\
\text { Consumption: } 1.15 \\
\text { vs. } 2.40, \text { difference } \\
-1.25 \text { (95\% Cl -1.39 } \\
\text { to }-1.11 \text { ) }\end{array}$ \\
\hline
\end{tabular}




\begin{tabular}{|c|c|c|c|c|}
\hline $\begin{array}{l}\text { Author, Year, } \\
\text { Followup, } \\
\text { Pain Duration, } \\
\text { Study Quality }\end{array}$ & Intervention & Population & $\begin{array}{l}\text { Function and Pain } \\
\text { Outcomes }\end{array}$ & Other Outcomes \\
\hline $\begin{array}{l}\text { Tomas-Carus, } \\
2008 / 2009^{83,84} \\
8 \text { months } \\
\text { Symptom duration } \\
20 \text { years } \\
\text { Poor }\end{array}$ & $\begin{array}{l}\text { A. Combination } \\
\text { exercise ( } \mathrm{n}=17) \text { : } \\
\text { Pool exercise in } 1 \\
\text { hour sessions } 3 \\
\text { times per week for } \\
8 \text { months (warm up, } \\
\text { aerobic exercise, } \\
\text { mobility and lower } \\
\text { limb strength } \\
\text { exercises using } \\
\text { water resistance } \\
\text { and upper limb } \\
\text { strength exercises } \\
\text { without water } \\
\text { resistance, cool } \\
\text { down) } \\
\text { B. Control ( } n=16 \text { ): } \\
\text { normal activities for } \\
8 \text { months, which did } \\
\text { not include exercise } \\
\text { similar to that in } \\
\text { group A. }\end{array}$ & $\begin{array}{l}\text { A vs. B } \\
\text { Age: } 51 \text { vs. } 51 \\
\text { years } \\
\text { Female: } 100 \% \text { vs. } \\
100 \% \\
\text { FIQ Total (0-10): } \\
6.1 \text { vs. } 6.3 \\
\text { FIQ Physical } \\
\text { Function (0-10): } 3.0 \\
\text { vs. } 3.7 \\
\text { FIQ Pain (0-10): } 5.6 \\
\text { vs. } 6.4\end{array}$ & $\begin{array}{l}\text { A vs. B } \\
8 \text { months } \\
\text { FIQ Total: } 5.2 \text { vs. } 6.5 \text {, } \\
\text { difference }-1.3(95 \% \\
\mathrm{Cl}-0.23 \text { to }-0.3) \\
\text { FIQ Physical } \\
\text { Function: } 2.4 \text { vs. } 3.7 \text {, } \\
\text { difference }-1.3(95 \% \\
\mathrm{Cl}-2.7 \text { to } 0.09) \\
\text { FIQ Pain: } 5.3 \text { vs. } 6.6 \text {, } \\
\text { difference }-1.3(95 \% \\
\mathrm{Cl}-2.5 \text { to }-0.09)\end{array}$ & 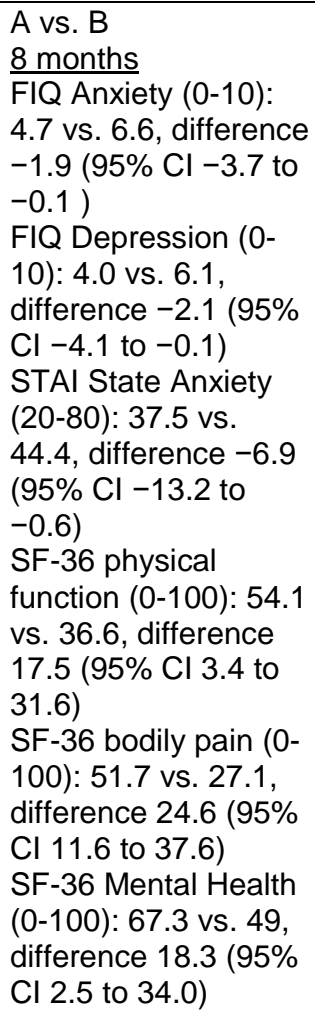 \\
\hline
\end{tabular}




\begin{tabular}{|c|c|c|c|c|}
\hline $\begin{array}{l}\text { Author, Year, } \\
\text { Followup, } \\
\text { Pain Duration, } \\
\text { Study Quality }\end{array}$ & Intervention & Population & $\begin{array}{l}\text { Function and Pain } \\
\text { Outcomes }\end{array}$ & Other Outcomes \\
\hline $\begin{array}{l}\text { van Eijk-Hustings, } \\
2013^{85} \\
18 \text { months } \\
\text { Pain duration NR } \\
\text { Fair }\end{array}$ & $\begin{array}{l}\text { A. Aerobic exercise } \\
\text { ( } \mathrm{n}=47 \text { ): two group } \\
\text { sessions per week } \\
\text { for } 12 \text { weeks (warm } \\
\text { up, aerobic } \\
\text { exercise, resistance } \\
\text { training to } \\
\text { strengthen muscles, } \\
\text { cool down). } \\
\text { Subjects were } \\
\text { asked to practice } \\
\text { exercises at home } \\
\text { with videodisc once } \\
\text { a week. } \\
\text { B. Usual care } \\
\text { ( } \mathrm{n}=48 \text { ): } \\
\text { individualized FM } \\
\text { education and } \\
\text { lifestyle advice } \\
\text { within 1-2 } \\
\text { consultations, plus } \\
\text { care as usual }\end{array}$ & $\begin{array}{l}\text { A vs. B } \\
\text { Age: } 44 \text { vs. } 43 \\
\text { years } \\
\text { Female: } 100 \% \text { vs. } \\
98 \% \\
\text { FIQ total }(0-100) \text { : } \\
60.0 \text { vs. } 55.4 \\
\text { FIQ physical } \\
\text { function }(0-10): 3.6 \\
\text { vs. } 3.4 \\
\text { FIQ Pain }(0-10): 6.2 \\
\text { vs. } 5.5\end{array}$ & $\begin{array}{l}\text { A vs. B } \\
18 \text { months: } \\
\text { FIQ total: } 52.0 \text { vs. } \\
56.2, \text { ES }=0.22 \text { ( } 95 \% \\
\mathrm{CI}-0.20 \text { to } 0.61) \\
\text { FIQ physical function: } \\
3.6 \text { vs. } 3.9, \text { ES }=0.11 \\
(95 \% \mathrm{Cl}-0.29 \text { to } \\
0.52) \\
\text { FIQ pain: } 5.2 \text { vs. } 5.3 \text {, } \\
E S=0.05(95 \% \mathrm{Cl} \\
-0.36 \text { to } 0.44)\end{array}$ & 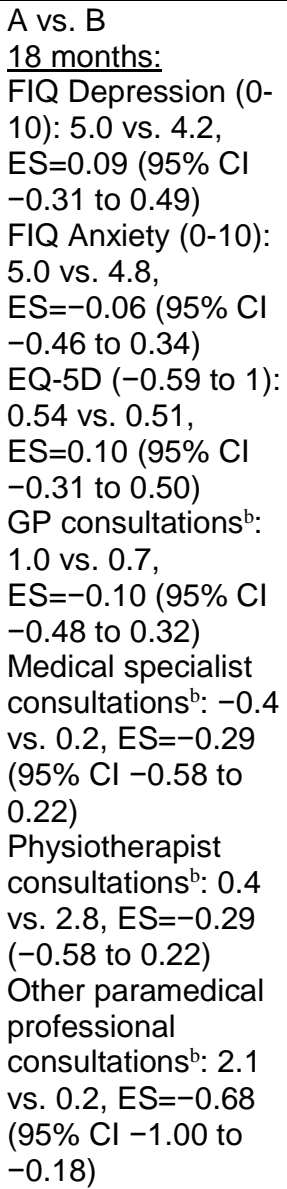 \\
\hline
\end{tabular}




\begin{tabular}{|c|c|c|c|c|}
\hline $\begin{array}{l}\text { Author, Year, } \\
\text { Followup, } \\
\text { Pain Duration, } \\
\text { Study Quality }\end{array}$ & Intervention & Population & $\begin{array}{l}\text { Function and Pain } \\
\text { Outcomes }\end{array}$ & Other Outcomes \\
\hline $\begin{array}{l}\text { van Santen, } \\
2002^{86} \\
6 \text { months } \\
\text { Duration of } \\
\text { symptoms: } 12 \\
\text { years } \\
\text { Poor }\end{array}$ & $\begin{array}{l}\text { A. Combination } \\
\text { exercise (n=58): } \\
\text { group sessions (60 } \\
\text { minutes) twice a } \\
\text { week for } 24 \text { weeks } \\
\text { (aerobic exercises, } \\
\text { stretching, general } \\
\text { flexibility and } \\
\text { balance exercises, } \\
\text { and isometric } \\
\text { muscle } \\
\text { strengthening); } \\
\text { encouraged to } \\
\text { attend a third, } \\
\text { unsupervised, } 60 \\
\text { minute session } \\
\text { weekly and to use } \\
\text { sauna or swimming } \\
\text { pool after all } \\
\text { sessions. } \\
\text { B. Usual care } \\
\text { (n=29): analgesics } \\
\text { NSAIDs, or tricyclic } \\
\text { antidepressants, if } \\
\text { appropriate; GPs } \\
\text { informed that } \\
\text { aerobic exercises } \\
\text { and relaxation } \\
\text { should not be } \\
\text { prescribed or } \\
\text { encouraged }\end{array}$ & $\begin{array}{l}\text { A vs. B } \\
\text { Age: } 46 \text { vs. } 43 \\
\text { years } \\
\text { Female: } 100 \% \text { vs. } \\
100 \% \\
\text { Duration of } \\
\text { symptoms: } 9.7 \text { vs. } \\
\text { 15.4 years } \\
\text { SIP physical score } \\
\text { (mean, 0-100): } 11.3 \\
\text { vs. } 9.8 \\
\text { SIP total score } \\
\text { (mean, 0-100): } 14.4 \\
\text { vs. } 11.4 \\
\text { AIMS (mean, 0-10): } \\
\text { 1.9 vs. } 5.4 \\
\text { Pain VAS (mean, 0- } \\
\text { 100): } 66.8 \text { vs. } 62.4\end{array}$ & $\begin{array}{l}\text { A vs. } \mathrm{B} \text {, mean change } \\
\text { from baseline } \\
6 \text { months: } \\
\text { SIP physical score: } \\
-1.7(95 \% \mathrm{Cl}-3.7 \text { to } \\
0.3) \text { vs. }-0.6(95 \% \mathrm{Cl} \\
-2.9 \text { to } 1.7), \mathrm{P}=\mathrm{NS} \\
\text { SIP total score: }-1.9 \\
(95 \% \mathrm{Cl}-3.9 \text { to } 0.1) \\
\text { vs. }-1.4(95 \% \mathrm{Cl}-3.4 \\
\text { to } 0.6) \mathrm{P}=\mathrm{NS} \\
\text { AIMS: } 0.1(95 \% \mathrm{Cl} \\
-0.6 \text { to } 0.8) \text { vs. } 0.8 \\
(95 \% \mathrm{Cl}-1.8 \text { to }-0.2) \text {, } \\
\mathrm{P}=\mathrm{NS} \\
\mathrm{Pain} \mathrm{VAS}:-5.5(95 \% \\
\mathrm{Cl}-10.9 \text { to }-0.1) \text { vS. } \\
1.3(95 \% \mathrm{Cl}-4.5 \text { to } \\
7.1), \mathrm{P}=\mathrm{NS}\end{array}$ & $\begin{array}{l}\text { A vs. B, mean } \\
\text { change from baseline } \\
6 \text { months: } \\
\text { SCL-90-R Global } \\
\text { Severity Index (scale } \\
\text { unclear): }-6.8(95 \% \\
\mathrm{Cl}-20.1 \text { to } 6.5) \text { vs. } \\
-8.1(95 \% \mathrm{Cl}-19.8 \\
\text { to } 3.6), \mathrm{P}=\mathrm{NS} \\
\text { SIP psychosocial } \\
\text { score }(0-100):-3.2 \\
\text { (95\% } \mathrm{Cl}-6.2 \text { to } 0.2) \\
\text { vs. }-3.5(95 \% \mathrm{Cl}-7.0 \\
\text { to } 0.0), \mathrm{P}=\mathrm{NS} \\
\mathrm{Patient} \text { global } \\
\text { assessment }(1-5): \\
0.5(95 \% \mathrm{Cl} 0.2 \text { to } \\
0.8) \text { vs. } 0.5(95 \% \mathrm{Cl} \\
0.2 \text { to } 0.8), \mathrm{P}=\mathrm{NS}\end{array}$ \\
\hline $\begin{array}{l}\text { Wigers, } 1996^{87} \\
48 \text { months } \\
\text { Duration of } \\
\text { symptoms: } 10 \\
\text { years } \\
\text { Fair }\end{array}$ & $\begin{array}{l}\text { A. Aerobic exercise } \\
\text { ( } n=20) \text { : sessions } \\
\text { consisted of training } \\
\text { to music (further } \\
\text { details not given) } \\
\text { and aerobic games; } \\
45 \text { minute group } \\
\text { sessions } 3 \text { times a } \\
\text { week for } 14 \text { weeks } \\
\text { B. Treatment as } \\
\text { usual }(n=20)\end{array}$ & $\begin{array}{l}\text { A vs. B } \\
\text { Age: } 43 \text { vs. } 46 \\
\text { years } \\
\text { Female: } 90 \% \text { vs. } \\
95 \% \\
\text { Duration of } \\
\text { symptoms: } 9 \text { vs. } 11 \\
\text { years } \\
\text { Pain VAS (0-100): } \\
72 \text { vs. } 65\end{array}$ & $\begin{array}{l}\text { A vs. B } \\
48 \text { months: } \\
\text { Pain VAS: } 68 \text { vs. } 69, \\
\text { difference }-1.0(95 \% \\
\mathrm{Cl}-16.3 \text { to } 14.4)\end{array}$ & $\begin{array}{l}\text { A vs. B } \\
48 \text { months } \\
\text { Depression VAS (0- } \\
100): 32 \text { vs. } 30, \\
\text { difference } 2.0 \text { ( } 95 \% \\
\mathrm{Cl}-18.8 \text { to } 22.8) \\
\text { Global subjective } \\
\text { improvement: } 75 \% \\
\text { vs. } 12 \%, \text { RR } 5.9 \\
\text { ( } 95 \% \mathrm{Cl} 1.5 \text { to } 22.2)\end{array}$ \\
\hline
\end{tabular}

AIMS = Arthritis Impact Measurement Scale; BDI = Beck Depression Inventory; CES-D: Center for Epidemiologic Studies Depression Scale Revised; CI = confidence interval; EQ5D = EuroQoL 5 Dimensions; ES = effect size; FIQ = Fibromyalgia Impact Questionnaire; FM = fibromyalgia; GP = general practitioner; HADS = Hospital Anxiety and Depression Scale; NHP = Nottingham Health Profile; NR = not reported; NS = not statistically significant; NSAID = nonsteroidal anti-inflammatory drug; SCL-90-R = Symptom Checklist-90-Revised; SF-36 = Short-Form 36 Questionnaire; SIP = Sickness Impact Profile; STAI = State-Trait Anxiety Inventory; VAS = visual analog scale

${ }^{a}$ Unless otherwise noted, followup time is calculated from the end of the treatment period

b Total number of consultations over a period of 2 months prior to measurement 


\section{Exercise Compared With Usual Care, Waitlist, an Attention Control, or No Treatment}

Functional Outcomes. Exercise was associated with a slightly greater effect on short-term function compared with usual care, an attention control, or no treatment based on Fibromyalgia Impact Questionnaire (FIQ) total scores (7 trials, pooled MD -7.61 on a 0 to 100 scale, 95\% CI -12.78 to $\left.-2.43, \mathrm{I}^{2}=59.9 \%\right)^{65,66,69,72,75,76,78}$ (Figure 39). The estimate across fair-quality trials (i.e., not including the poor-quality trials) was somewhat higher (5 trials, pooled MD $-9.91,95 \%$ CI -15.75 to -4.07$){ }^{65,66,69,75,78}$

Exercise was associated with slightly greater effects on intermediate-term function versus controls for FIQ total score (8 trials, pooled MD on 0-100 scale, $-6.04,95 \%$ CI -9.05 to $\left.-3.03 .10, \mathrm{I}^{2}=0 \%\right)^{69,71-73,77,80,81,83}$ (Figure 39). Estimates were slightly smaller across the fairquality trials only (4 trials, pooled MD $-4.04,95 \%$ CI -7.90 to -0.03 ). ${ }^{69,71,77,81}$ Stratification by exercise type yielded similar results for combination exercise ( 7 trials, pooled MD -5.75 , 95\% CI -9.29 to -2.54$),{ }^{69,71,72,77,80,81,83}$ but there was no clear difference between aerobic exercise and no treatment or usual care ( 2 trials, pooled MD $-8.13,95 \% \mathrm{CI}-16.24$ to 0.28 ). ${ }^{73,81}$ Estimates were consistent with a slightly greater effect of exercise on function when compared with usual care (3 trials, pooled MD -6.13 , 95\% CI -11.71 to -1.06$)^{69,80,81}$ or no treatment (3 poor quality trials, pooled MD $-9.97,95 \%$ CI -16.24 to -3.45$),{ }^{72,73,83}$ but there was no clear difference in two fair-quality trials using attention controls (pooled MD -3.25, 95\% CI -99.32 to 5.20). ${ }^{71,77}$

Exercise had a small effect on long-term function compared with controls but results were no longer statistically significant based on the FIQ total score (3 trials, pooled MD on 0 to 100 scale, -4.33 , $95 \%$ CI -10.18 to $\left.1.52, \mathrm{I}^{2}=0 \%\right)^{71,80,85}$ (Figure 39). There were no clear differences in estimates when analyses were stratified according to the type of exercise (2 trials of combination exercise, pooled MD -4.45 , 95\% CI - 14.39 to 6.24 ), ${ }^{71,80}$ type of comparison (2 trials of usual care, pooled MD $-5.34,95 \% \mathrm{CI}-13.4$ to 2.32$),{ }^{80,85}$ or after the exclusion of one poor-quality trial (2 trials, pooled MD -3.11 , 95\% CI -11.26 to 5.86). ${ }^{71,85}$ Findings are based on a small number of trials.

Pain Outcomes. Exercise had a moderately greater effect on pain (0 to 10 VAS) in the short term compared with usual care, attention control, or no treatment (7 trials, pooled MD $-1.07,95 \%$ CI -1.73 to $\left.-0.41, \mathrm{I}^{2}=58.7 \%\right)^{65-67,69,72,74,75}$ (Figure 40 ). Substantial heterogeneity was noted with one outlier trial of belly dance (combination exercise) versus waitlist control, reporting substantially higher estimates. ${ }^{66}$ Excluding the outlier trial reduced heterogeneity and led to an effect size consistent with a small effect (6 trials, pooled MD $-0.89,95 \% \mathrm{CI}-1.32$ to $-0.46, \mathrm{I}^{2}=0 \%$ ). Estimates were similar when stratified by exercise type and control type. Across the fair-quality trials, the estimate was somewhat larger (4 trials, pooled MD $-1.44,95 \% \mathrm{CI}-2.4$ to -0.49 , including the outlier). ${ }^{65,66,69,71,75}$

There was no effect of exercise on VAS pain at intermediate term ( 7 trials, pooled MD -0.41 on a $0-10$ scale, $95 \%$ CI -0.87 to $\left.0.05, \mathrm{I}^{2}=9.5 \%\right)^{69,71,72,79,82,83,86}$ (Figure 40 ). Removal of poorquality trials $^{72,79,82,83}$ and stratification by exercise and control types yielded similar estimates (MDs ranged from -0.10 to -0.71 ) with no clear difference identified.

There was no effect of exercise on pain long term (4 trials, pooled MD -0.18 on a $0-10$ scale, $95 \%$ CI -0.77 to $\left.0.42, I^{2}=0 \%\right)^{67,71,85,87}$ (Figure 40 ). Similar estimates were obtained and no clear differences were seen following exclusion of one poor quality-trial or for the comparisons of aerobic exercise with usual care or combination exercise with attention control; pooled differences ranged from -0.5 to -0.26 . 
Other Outcomes. Data on the effects of exercise on anxiety, depression, and quality of life were often poorly reported (Table 35) and results are mixed. Exercise had no clear effect in the short term on measures of mental health, depression, anxiety, psychological distress, or sleep disturbance VAS across five trials, ${ }^{65-69}$ with only one small poor-quality trial favoring exercise on the EuroQol 5-Dimensions (EQ-5D) anxiety/depression scale. ${ }^{74}$ Similarly, exercise had no clear effect on quality of life.

At intermediate term, exercise was associated with a small improvement in depression measured by the Beck Depression Inventory (BDI) compared with no treatment or usual care (4 trials, pooled $\mathrm{MD}-4.86$ on a $0-63$ scale, $95 \% \mathrm{CI}-7.55$ to $-2.17, \mathrm{I}^{2}=33.1 \%$, plot not shown); ${ }^{73,80-82}$ three of the four trials were poor quality. Results were similar for aerobic exercise (3 trials, pooled MD $-5.34,95 \%$ CI -8.42 to -3.03 ) but no difference between groups was seen in the pooled estimate for the two trials using combination exercise or when any exercise was compared with usual care only ( 2 trials). Across various other measures, exercise had no clear effect on depression in five trials, ${ }^{67,68,71,77,79}$ however one poor-quality trial favored exercise based on the FIQ depression subscale versus usual care. ${ }^{83}$ Results for anxiety were mixed: two trials (one fair- and one poor-quality) ${ }^{77,79}$ reported no difference between groups while two small, poor-quality trials reported a greater improvement in anxiety on the State-Trait Anxiety Inventory (STAI) and the FIQ anxiety subscale with exercise versus usual care. ${ }^{73,83}$ Exercise was associated with improved quality of life (SF-36) in three small trials, ${ }^{80,81,84}$ but not in a fourth larger fair-quality trial ${ }^{77}$ (Table 35). Exercise had no clear effect on psychological problems in two trials ${ }^{67,69}$ or sleep in three trials. ${ }^{67,72,79}$ One trial reported no between-group difference in analgesic consumption by 6 months, although patients who underwent aerobic exercise showed a significant reduction from baseline use. ${ }^{82}$

Long term, exercise had no clear effect on measures of depression, anxiety, or psychological problems in all but one poor-quality trial. ${ }^{80}$ This same trial also reported improvement in SF-36 total scores, whereas one larger fair-quality trial did not. ${ }^{68}$ No differences between groups in health care utilization were seen in the 2 months prior to the final measurement at 18 months in one trial ${ }^{85}$ (Table 35).

\section{Exercise Compared With Pharmacological Therapy}

One small, poor-quality trial ( $\mathrm{N}=32$ analyzed) comparing 1.5 months of aerobic exercise (40 minutes on bicycle ergometer three times per week) versus paroxetine $20 \mathrm{mg}$ daily found no between-group difference in pain on VAS at intermediate-term followup (MD -0.26 on a 0-10 scale, $95 \%$ CI -1.46 to 0.94 ). Regarding secondary outcomes, no differences were seen for depression (BDI) or mean analgesic consumption over the intermediate term, although the exercise group showed a greater reduction from baseline in analgesic use compared with the paroxetine group.

\section{Exercise Compared With Other Nonpharmacological Therapies}

Findings for exercise versus other nonpharmacological therapies are addressed in the sections for other nonpharmacological therapies.

\section{Harms}

Most trials of exercise did not report on adverse events at all. One trial reported one nonstudy-related adverse event. ${ }^{74}$ Two trials reported no adverse events. ${ }^{75,78}$ 
Figure 39. Exercise versus usual care, no treatment, waitlist, or an attention control for fibromyalgia: effects on function

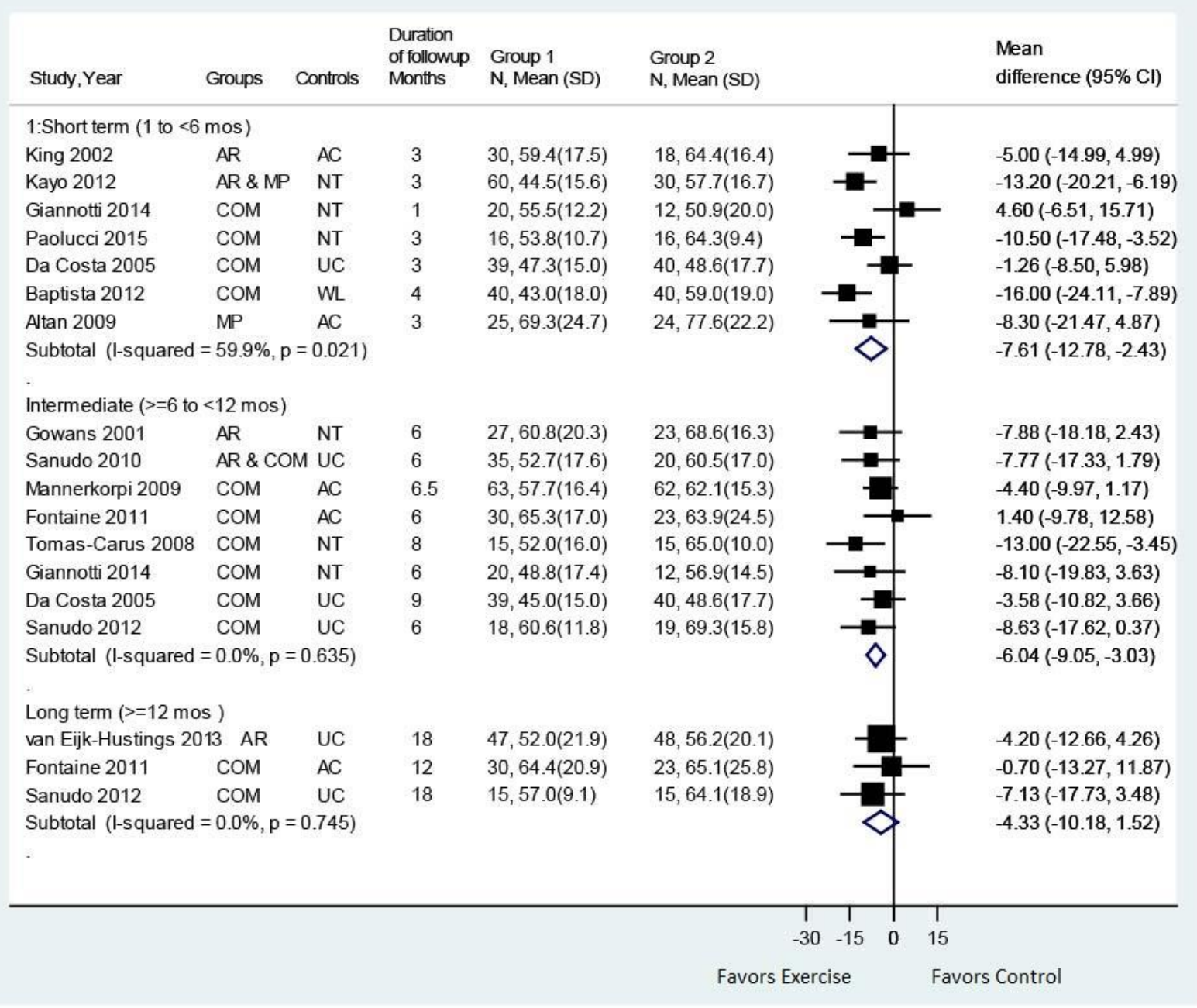

$\mathrm{AC}=$ attention control; $\mathrm{AR}=$ aerobic exercise; $\mathrm{AR} \& \mathrm{COM}=$ aerobic exercise in one arm and combination exercise in another arm; AR \& MP = aerobic exercise in one arm and muscle performance exercise in another arm; $\mathrm{CI}=$ confidence interval; $\mathrm{COM}=$ combination exercise therapy; $\mathrm{MP}=$ muscle performance exercise; $\mathrm{MP}+\mathrm{NR}=$ muscle performance plus neuromuscular rehabilitation exercise; $\mathrm{NT}=$ no treatment; $\mathrm{SD}=$ standard deviation; $\mathrm{UC}=$ usual care; $\mathrm{WL}=$ waitlist 
Figure 40. Exercise versus usual care, no treatment, waitlist, or attention control for fibromyalgia: effects on pain

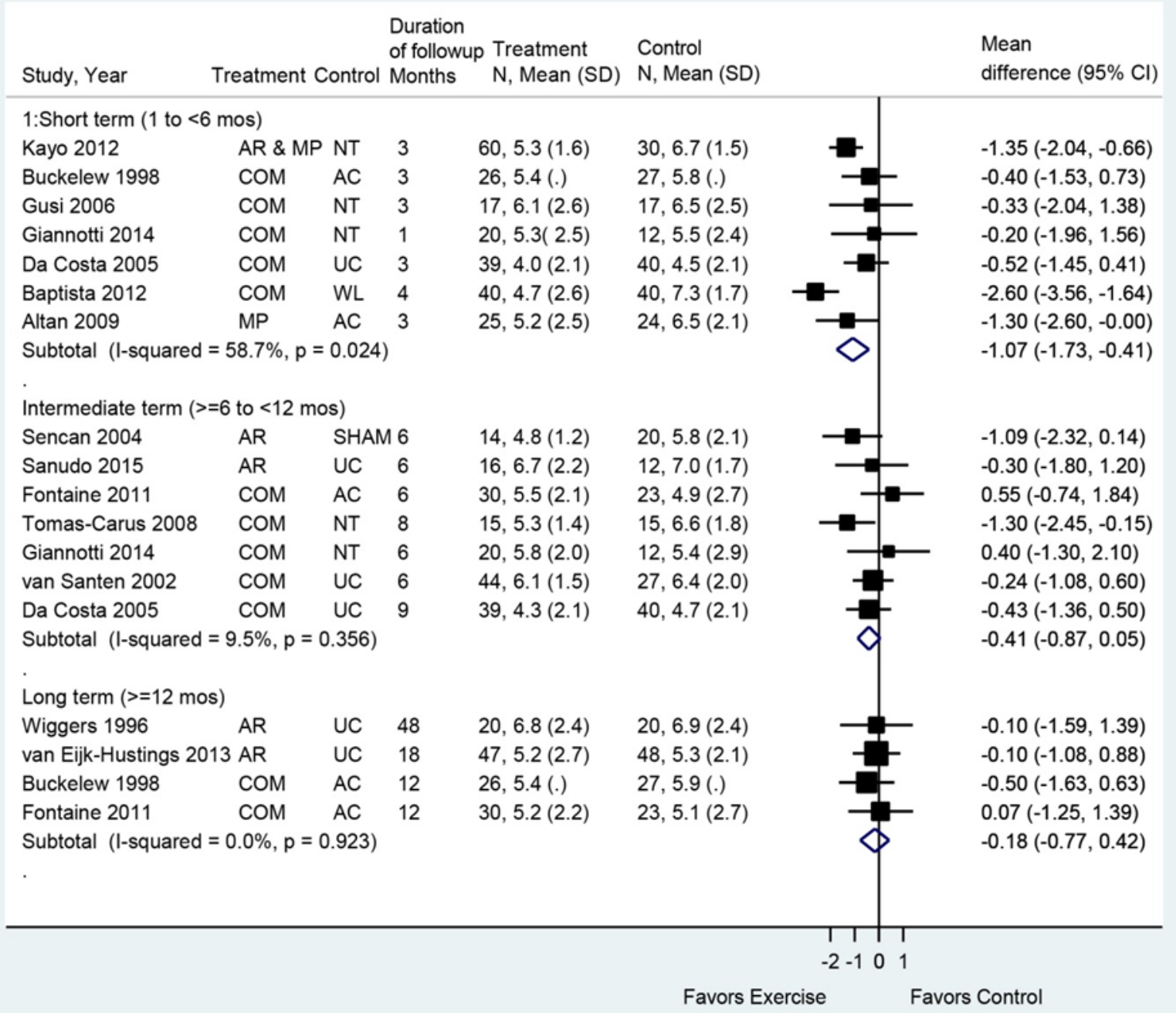

$\mathrm{AC}=$ attention control; $\mathrm{AR}=$ aerobic exercise; $\mathrm{AR} \& \mathrm{MP}=$ aerobic exercise in one arm and muscle performance exercise in another arm; $\mathrm{CI}=$ confidence interval; $\mathrm{COM}=$ combination exercise therapy; $\mathrm{MP}=$ muscle performance exercise; $\mathrm{MP}+\mathrm{NR}=$ muscle performance plus neuromuscular rehabilitation exercise; $\mathrm{NT}=$ no treatment; $\mathrm{SD}=$ standard deviation; UC = usual care; $\mathrm{WL}=$ waitlist

\section{Psychological Therapies for Fibromyalgia}

\section{Key Points}

- CBT was associated with a slightly greater effect on function (FIQ Total Score) compared with usual care or waitlist in the short term (2 trials, pooled MD -10.67, 95\% CI -17 to $-4.30, \mathrm{I}^{2}=0 \%, 0-100$ scale). The pooled estimate at intermediate term was not statistically significant due to heterogeneity, however, individual trials showed a greater effect than usual care, and a third trial using the 0 to 10 FIQ Physical Impairment Scale showed a greater effect of CBT than attention control (MD -1.8, 95\% CI -2.9 to -0.70); evidence from two poor-quality trials was insufficient to determine effects on long-term function (SOE: low for short term and intermediate term, insufficient for long term). 
- CBT was associated with a slight improvement in pain (on a 0-10 scale) compared with usual care or waitlist in the short term (3 trials, pooled MD $-0.78,95 \% \mathrm{CI}-1.30$ to -0.17 ), but not in the intermediate term ( 2 trials, pooled MD $-0.44,95 \% \mathrm{CI}-1.30$ to 0.01 ); evidence from one poor-quality trial was insufficient to determine effects on longterm pain (SOE: low for short term and intermediate term, insufficient for long term).

- Data were insufficient to determine the effects of EMG biofeedback on function and pain compared with attention controls in the short and long term (1 poor-quality trial) and with usual care in the intermediate term (1 poor-quality trial), and for the impact of guided imagery versus attention control in the short term (1 poor-quality trial) (SOE: insufficient for all comparisons and time points).

- CBT was associated with a slight benefit compared with pharmacological treatment (pregabalin, duloxetine) for function (MD -4.0 on the $0-100 \mathrm{FIQ}, 95 \% \mathrm{CI}-7.7$ to -0.27 ), but not for pain (MD 0.2 on a $0-100 \mathrm{VAS}, 95 \% \mathrm{CI}-4.0$ to 4.4 ) at intermediate term (SOE: low).

- There was insufficient evidence to determine the impact on pain and function for the following: CBT versus pharmacological treatment (amitriptyline) over the short term (fair-quality trial) and EEG biofeedback versus pharmacological treatment (escitalopram) over the short and intermediate term (poor-quality trial) (SOE: insufficient); long-term data were not reported.

- There was insufficient evidence to determine the effects of psychological therapies versus exercise on function and pain in the short term (1 small trial of biofeedback), intermediate term (2 trials of CBT and biofeedback) and long term ( 3 trials of CBT, biofeedback, and relaxation for function; 4 trials of CBT [2], biofeedback, and relaxation for pain). All trials were considered poor quality (SOE: insufficient for function and pain at all time points).

- Data on harms were insufficient. Adverse events were poorly reported across the five poor-quality trials but were overall minor and occurred at similar frequencies between groups. In one trial, however, fewer patients who received stress management (4.8\%) compared with usual care (50\%) withdrew from the trial, citing increased depression and worsening of symptoms, respectively (SOE: insufficient).

\section{Detailed Synthesis}

A total of 14 trials of psychological therapy for fibromyalgia met our inclusion criteria: nine trials (across 10 publications) featured a CBT component, ${ }^{87,96-100,102,103,106,112}$ three trials included biofeedback (electromyography [EMG] or electroencephalography [EEG]), ${ }^{67,86,107}$ and one trial each included relaxation training ${ }^{111}$ or guided imagery ${ }^{101}$ (Table 36 and Appendix D). The various psychological interventions were compared with usual care, waitlist control or attention control groups (10 trials), ${ }^{67,86,87,96-103}$ pharmacological therapy (3 trials), ${ }^{96,106,107}$ or exercise therapy (5 trials). ${ }^{67,86,87,111,112}$

The majority of subjects in all the trials were female (range $90 \%$ to $100 \%$ ) and mean ages ranged from 32 to 52 years. Sample sizes ranged between 32 and 169 subjects (total sample $=1,167)$. Therapy duration and frequency in CBT trials ranged from 6 weekly sessions to 20 sessions over 14 weeks. CBT was delivered in groups in eight studies ${ }^{96,98-100,102,103,106,112}$ and by telephone ${ }^{97}$ in another. All CBT studies except two were of CBT as traditionally delivered for the treatment of pain problems. The two exceptions were a study of Acceptance and Commitment Therapy (ACT), and a Stress Management Therapy (SMT) intervention that spent 
equal time between presentations on stress mechanisms and training on pain coping and relaxation strategies; however, the interventions were similar enough to standard CBT to be included in this analysis. Session lengths ranged from 30 minutes up to 120 minutes. In the five trials of biofeedback and associated interventions, therapy duration ranged from 4 to 16 weeks and was delivered individually in the three biofeedback trials and in groups for the remaining two trials. The frequency ranged from one to five times per week with sessions as short as 25 minutes and as long as 3 hours. Short-term outcomes ( $<6$ months) were reported by three CBT studies ${ }^{97,99,102,106}$ and three biofeedback trials. ${ }^{67,101,107}$ Intermediate outcomes ( 6 to $<12$ months) were reported by four CBT trials ${ }^{96,98,100,112}$ and one trial of biofeedback. ${ }^{86}$ Long-term outcomes ( $\geq 12$ months) were reported by four CBT trials ${ }^{87,100,103,112}$ and two biofeedback trials. ${ }^{67,111}$

Studies were conducted in Brazil, the Netherlands, Norway, Spain, Sweden, Turkey, and the United States.

Of the nine CBT trials, three were considered fair quality, ${ }^{96,99,102,106}$ while the remaining six were rated poor quality ${ }^{87,97,98,100,103,112}$ (Appendix E). Among the remaining trials of biofeedback, relaxation, and guided imagery interventions, all were rated poor quality. ${ }^{67,86,101,107,111}$

Methodological shortcomings included lack of blinding in fair-quality and poor-quality trials, and unclear allocation concealment methods, poor compliance, and high attrition in the poorquality trials. The nature of the intervention types precluded blinding of participants in all trials.

Table 36. Fibromyalgia: psychological therapies

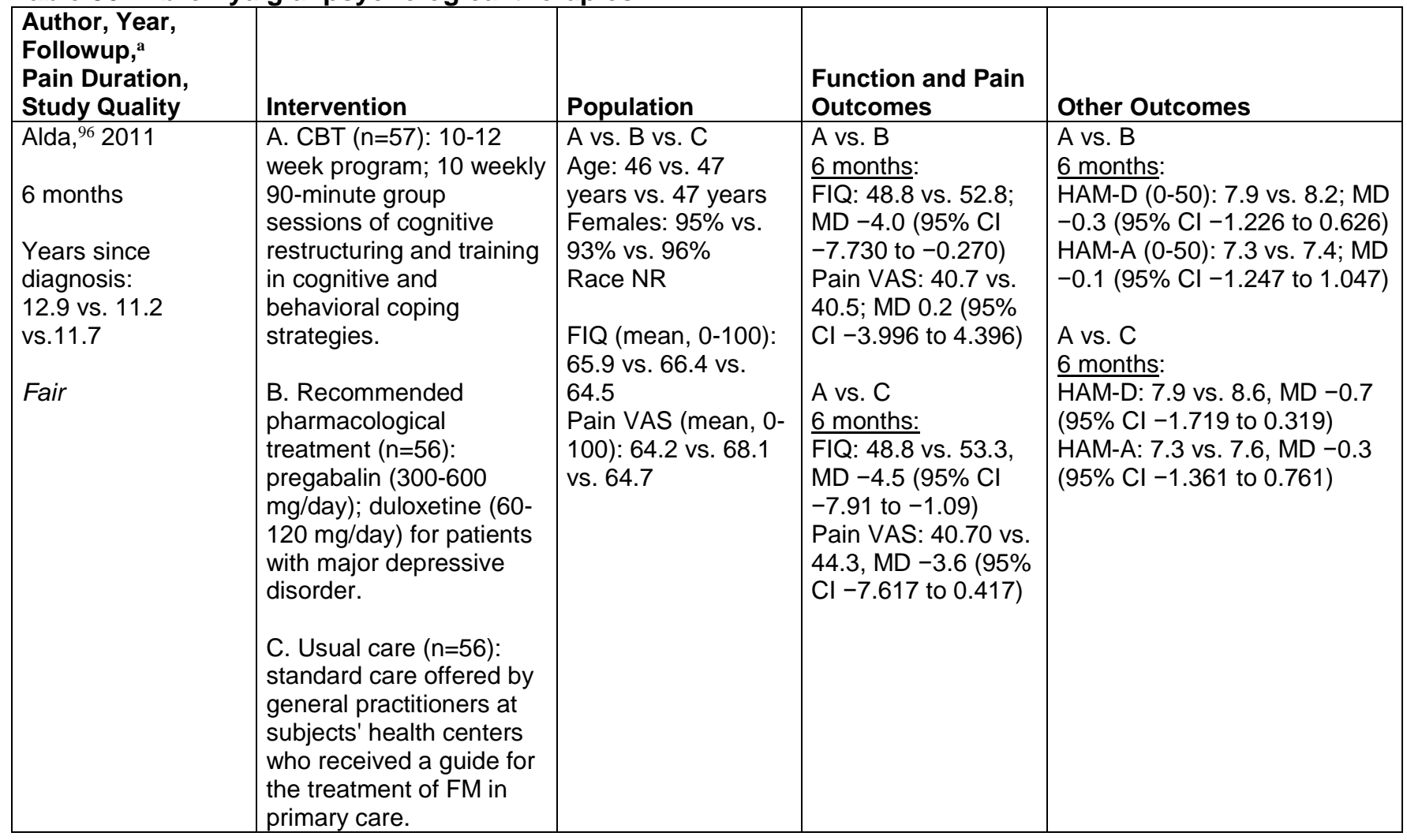




\begin{tabular}{|c|c|c|c|c|}
\hline $\begin{array}{l}\text { Author, Year, } \\
\text { Followup, }^{\text {a }} \\
\text { Pain Duration, } \\
\text { Study Quality }\end{array}$ & Intervention & Population & $\begin{array}{l}\text { Function and Pain } \\
\text { Outcomes }\end{array}$ & Other Outcomes \\
\hline $\begin{array}{l}\text { Ang, } 2010^{97} \\
1.5 \text { months } \\
\text { Duration of } \\
\text { fibromyalgia, years: } \\
11.8 \text { vs. } 12.3 \\
\text { Poor }\end{array}$ & $\begin{array}{l}\text { A. CBT ( } \mathrm{n}=17 \text { ): } 6 \text { weekly } \\
30-40 \text { minute sessions of } \\
\text { telephone-delivered CBT } \\
\text { (activity pacing, pleasant } \\
\text { activity scheduling, } \\
\text { relaxation, automatic } \\
\text { thoughts and pain, } \\
\text { cognitive restructuring, } \\
\text { and stress management) } \\
\text { B. Usual care ( } \mathrm{n}=15 \text { ): } \\
\text { customary care from } \\
\text { subject's treating } \\
\text { physician }\end{array}$ & $\begin{array}{l}\text { A vs. B } \\
\text { Age: } 51 \text { vs. } 47 \\
\text { years } \\
\text { Female: } 100 \% \text { vs. } \\
\text { 100\% } \\
\text { White: } 81 \% \text { vs. } 80 \% \\
\text { FIQ total (mean, 0- } \\
\text { 100): } 62.2 \text { vs. } 67.8 \\
\text { FIQ Physical } \\
\text { Impairment (PI) (0- } \\
\text { 10): } 5.6 \text { vs. 5.4 } \\
\text { FIQ Pain (0-10): } 7.6 \\
\text { vs. } 7.8\end{array}$ & $\begin{array}{l}\text { A vs. B } \\
1.5 \text { months: } \\
\text { Proportion of } \\
\text { patients with } \\
\text { clinically meaningful } \\
\text { improvement from } \\
\text { baseline FIQ total } \\
(14 \%): 33 \% \text { vs. } \\
15 \%, \text { RR } 2.2 \text { (95\% } \\
\text { Cl } 0.5 \text { to } 9.3) \\
\text { mean change from } \\
\text { baseline: } \\
\text { FIQ PI: }-0.6 \text { vs. } 0.5, \\
\text { adjusted } P=0.13 ; \\
\text { FIQ Pain: }-0.6(1.6) \\
\text { vs. }-0.3(1.7), \\
\text { adjusted } P=0.60\end{array}$ & $\begin{array}{l}\text { A vs. B } \\
1.5 \text { months: } \\
\text { PHQ-8 (0-24): mean change } \\
\text { from baseline }-0.9(5.2) \text { vs. } \\
0.0(4.1) \text {, adjusted } P=0.80 ; \\
\text { overall effect size }=0.60\end{array}$ \\
\hline
\end{tabular}




\begin{tabular}{|c|c|c|c|c|}
\hline $\begin{array}{l}\text { Author, Year, } \\
\text { Followup, } \\
\text { Pain Duration, } \\
\text { Study Quality }\end{array}$ & Intervention & Population & $\begin{array}{l}\text { Function and Pain } \\
\text { Outcomes }\end{array}$ & Other Outcomes \\
\hline $\begin{array}{l}\text { Buckelew } 1998^{67} \\
3,12 \text {, and } 24 \\
\text { months } \\
\text { Duration of } \\
\text { symptoms, years: } \\
11.6 \text { vs. } 10.0 \text { vs. } \\
11.6 \\
\text { Poor }\end{array}$ & 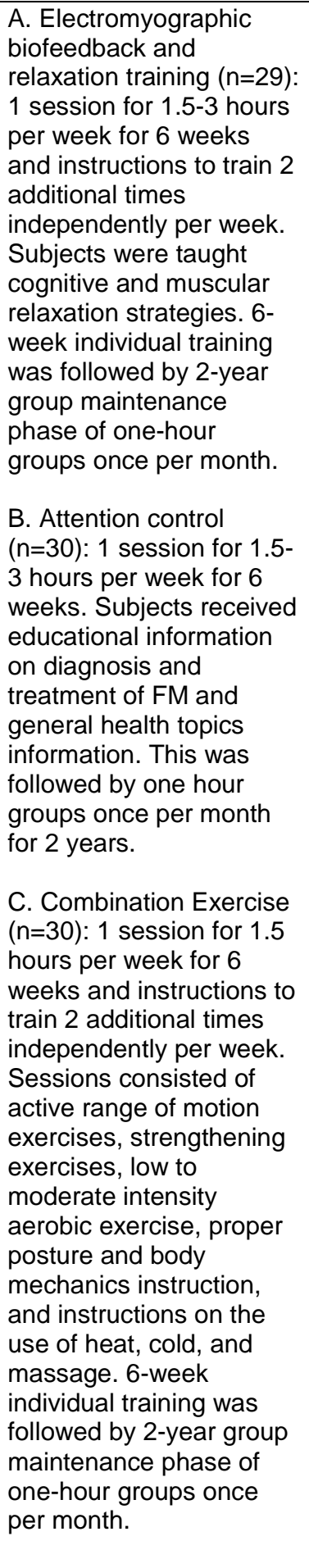 & $\begin{array}{l}\text { A vs. B vs. C } \\
\text { Age: } 44 \text { vs. } 44 \text { vs. } \\
46 \text { years } \\
\text { Female: } 97 \% \text { vs. } \\
90 \% \text { vs. } 93 \% \\
\text { Race NR } \\
\text { AIMS physical } \\
\text { activity subscale } \\
\text { (median, } 0-10): 6.0 \\
\text { vs. } 6.0 \text { vs. } 4.0 \\
\text { Pain VAS (median, } \\
0-10): 5.8 \text { vs. } 5.9 \text { vs. } \\
6.3\end{array}$ & 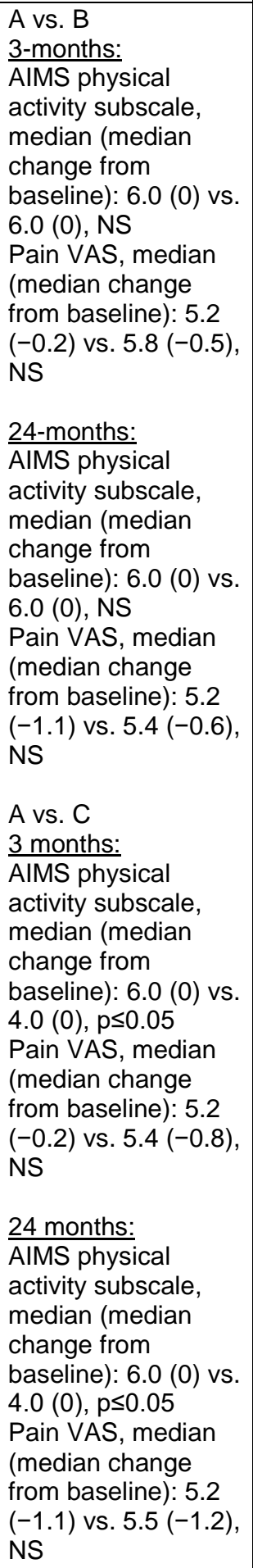 & 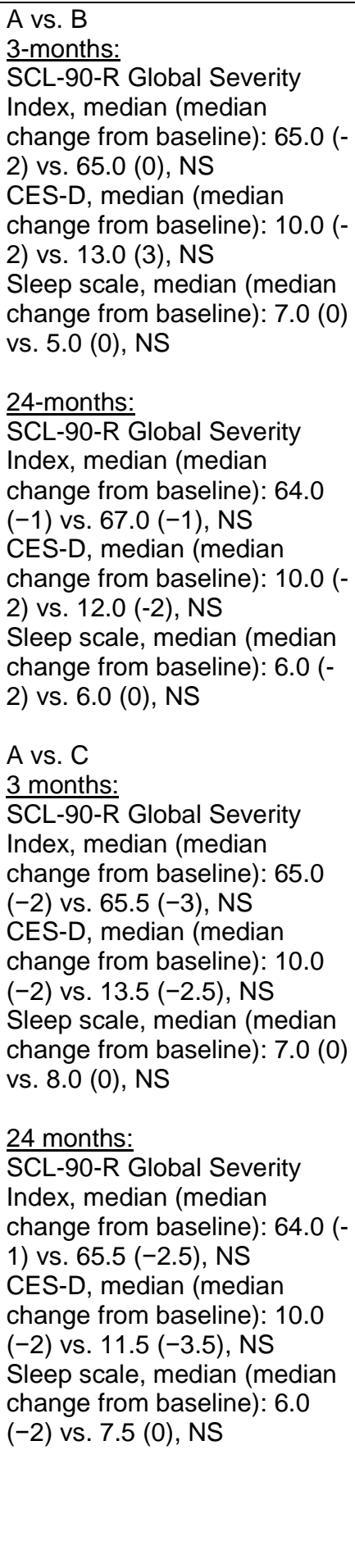 \\
\hline
\end{tabular}




\begin{tabular}{|c|c|c|c|c|}
\hline $\begin{array}{l}\text { Author, Year, } \\
\text { Followup, } \\
\text { Pain Duration, } \\
\text { Study Quality }\end{array}$ & Intervention & Population & $\begin{array}{l}\text { Function and Pain } \\
\text { Outcomes }\end{array}$ & Other Outcomes \\
\hline $\begin{array}{l}\text { Castel, }{ }^{98} 2012 \\
3 \text { and } 6 \text { months } \\
\text { A vs. B } \\
\text { Pain duration, } \\
\text { years: } 13.6 \text { vs. } 11.6 \\
\text { Poor }\end{array}$ & $\begin{array}{l}\text { A. CBT plus usual } \\
\text { pharmacological care } \\
\text { ( } n=34 \text { ): CBT conducted } \\
\text { in groups (except for one } \\
\text { individual session); } 14 \\
\text { weekly } 2 \text { hour sessions. } \\
\text { CBT included education } \\
\text { about FM and pain, } \\
\text { autogenic training, } \\
\text { cognitive restructuring, } \\
\text { CBT for insomnia, } \\
\text { assertiveness training, } \\
\text { activity pacing, pleasant } \\
\text { activity scheduling, goal } \\
\text { setting, and relapse } \\
\text { prevention. } \\
\text { B. Usual care (n=30): } \\
\text { usual pharmacological } \\
\text { care, including } \\
\text { analgesics, } \\
\text { antidepressants, } \\
\text { anticonvulsants, and } \\
\text { myorelaxants }\end{array}$ & $\begin{array}{l}\text { A vs. B } \\
\text { Age: } 50 \text { vs. } 49 \\
\text { years } \\
\text { Female: } 94 \% \text { vs. } \\
100 \% \\
\text { White: } 100 \% \text { vs. } \\
100 \% \\
\text { FIQ (scale NR): } \\
62.7 \text { vs. } 66.1 \\
\text { Pain NRS (0-10): } \\
6.1 \text { vs. } 6.9\end{array}$ & 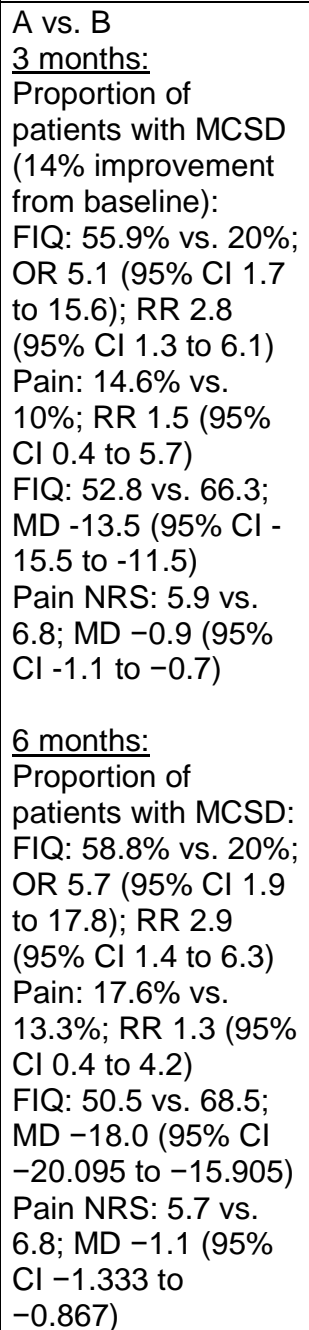 & 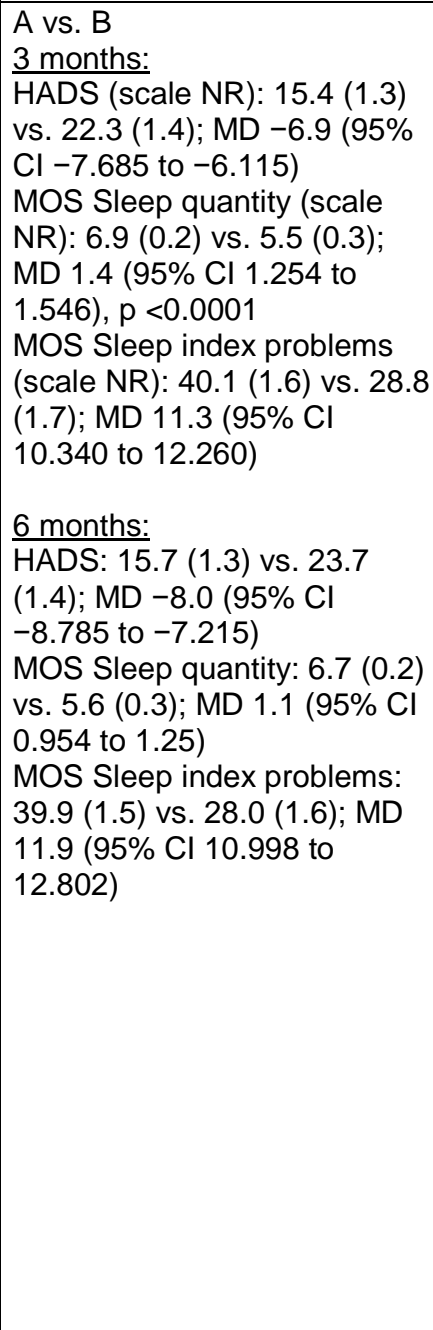 \\
\hline
\end{tabular}




\begin{tabular}{|c|c|c|c|c|}
\hline $\begin{array}{l}\text { Author, Year, } \\
\text { Followup, } \\
\text { Pain Duration, } \\
\text { Study Quality }\end{array}$ & Intervention & Population & $\begin{array}{l}\text { Function and Pain } \\
\text { Outcomes }\end{array}$ & Other Outcomes \\
\hline $\begin{array}{l}\text { Falcão, } 2008^{106} \\
3 \text { months } \\
\text { Disease duration, } \\
\text { years: } 3.5 \text { vs. } 3.7 \\
\text { Fair }\end{array}$ & $\begin{array}{l}\text { A. CBT plus Amitriptyline } \\
\text { ( } \mathrm{n}=30 \text { ): amitriptyline } \\
12.5 / \text { mg per day during } \\
\text { first week, then increase } \\
\text { dose to } 25 \text { mg/day. } \\
\text { Those with intolerance or } \\
\text { side effects to } \\
\text { amitriptyline were given } \\
\text { cyclobenzaprine } 5 \\
\text { mg/day in the first week } \\
\text { and then } 10 \text { mg/day. } \\
\text { Routine medical visits } \\
\text { once a week for } 10 \\
\text { weeks for brief } \\
\text { discussions with the } \\
\text { doctors. Immediately } \\
\text { after each visit, they had } \\
\text { a group CBT session, } \\
\text { consisting of progressive } \\
\text { relaxation training with } \\
\text { electromyographic } \\
\text { biofeedback, cognitive } \\
\text { restructuring, and stress } \\
\text { management. } \\
\text { B. Amitriptyline only } \\
\text { (control) (n=30): } \\
\text { amitriptyline } 12.5 / m g \text { per } \\
\text { day during first week, } \\
\text { then increase dose to } 25 \\
\text { mg/day. Those with } \\
\text { intolerance or side } \\
\text { effects to amitriptyline } \\
\text { were given } \\
\text { cyclobenzaprine } 5 \\
\text { mg/day in the first week } \\
\text { and then } 10 \text { mg/day. } \\
\text { Routine medical visits } \\
\text { once a week for } 10 \\
\text { weeks for brief } \\
\text { discussions with the } \\
\text { doctors. }\end{array}$ & $\begin{array}{l}\text { A vs. B } \\
\text { Age: } 45 \text { vs. } 46 \\
\text { years } \\
\text { Female: } 100 \% \text { vs. } \\
100 \% \\
\text { Caucasian: } 80 \% \text { vs. } \\
77 \% \\
\text { FIQ (0-100): } 64.9 \\
\text { vs. } 69.6 \\
\text { Pain VAS (0-10): } \\
6.9 \text { vs. } 7.0\end{array}$ & $\begin{array}{l}\text { A vs. B } \\
3 \text { months: } \\
\text { FIQ: } 38.7 \text { vs. } 42.8 ; \\
\text { MD }-4.1(95 \% \mathrm{Cl} \\
\text {-18.765 to } 10.565) \\
\text { Pain VAS: } 4.4 \text { vs. } \\
5.1 ; \text { MD }-0.7(95 \% \\
\text { Cl }-2.841 \text { to } 1.441)\end{array}$ & 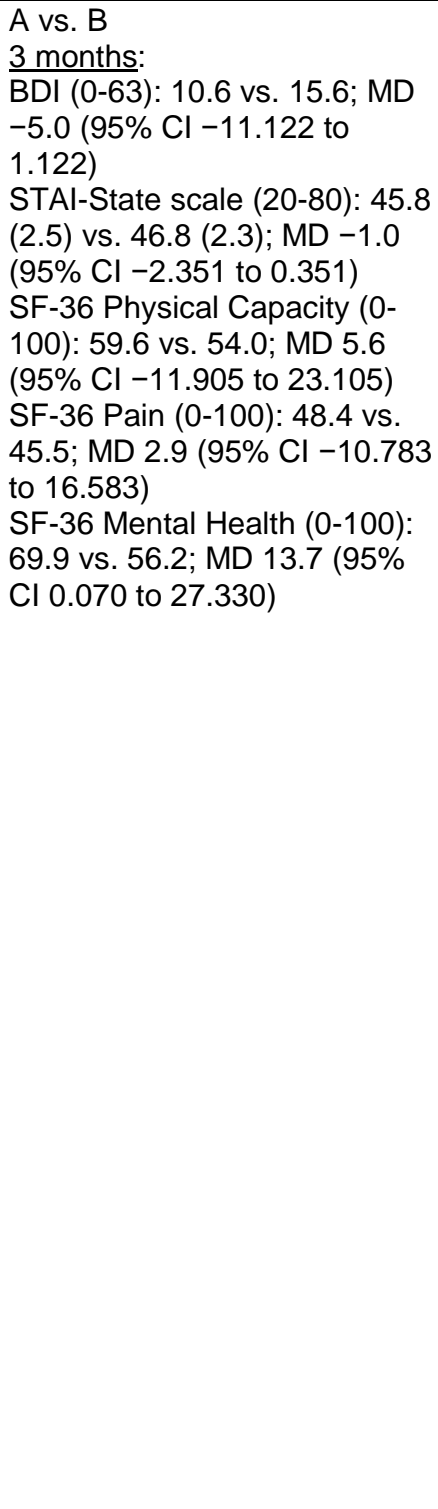 \\
\hline
\end{tabular}




\begin{tabular}{|c|c|c|c|c|}
\hline $\begin{array}{l}\text { Author, Year, } \\
\text { Followup, }^{\text {a }} \\
\text { Pain Duration, } \\
\text { Study Quality }\end{array}$ & Intervention & Population & $\begin{array}{l}\text { Function and Pain } \\
\text { Outcomes }\end{array}$ & Other Outcomes \\
\hline $\begin{array}{l}\text { Jensen 2012,99 } \\
\text { Wicksell 2013 } \\
\text { 3-4 months } \\
\text { Time since FM } \\
\text { onset, years: } 10.5 \\
\text { vs. } 11.8 \\
\text { Fair }\end{array}$ & $\begin{array}{l}\text { A. Acceptance and } \\
\text { Commitment Therapy } \\
\text { (ACT) ( } n=25): 12 \text { weekly } \\
\text { 90-minute group } \\
\text { sessions: exposure to } \\
\text { personally important } \\
\text { situations and activities } \\
\text { previously avoided due to } \\
\text { pain and distress, } \\
\text { training to distance self } \\
\text { from pain and distress. } \\
\\
\text { B. Waiting list control } \\
\text { (n=18) }\end{array}$ & $\begin{array}{l}\text { A vs. B } \\
\text { Age: } 45 \text { vs. } 47 \\
\text { years } \\
\text { Female: } 100 \% \text { vs. } \\
100 \% \\
\text { FIQ (0-100): } 49.3 \\
\text { vs. } 48.7 \\
\text { PDI (scale NR): } \\
40.0 \text { vs. 39.0 } \\
\text { Pain VAS (0-100): } \\
61 \text { vs. } 65.0 \text { Pain } \\
\text { NRS (0-10): } 4.2 \text { vs. } \\
4.3\end{array}$ & $\begin{array}{l}\text { A vs. B } \\
3-4 \text { months } \\
\text { FIQ: } 37.4 \text { vs. } 45.7, \\
\text { Cohen's d=0.66 } \\
\text { (95\% Cl }-0.06 \text { to } \\
1.37) ; \mathrm{MD}-8.3 \\
(95 \% \mathrm{Cl}-17.056 \text { to } \\
0.456) \\
\text { PDI: } 28.1 \text { vs. } 38.1 \text {, } \\
\text { Cohen's d=0.73 } \\
\text { (95\% Cl }-0.00 \text { to } \\
1.44) ; \mathrm{MD}-10.0 \\
\text { (95\% Cl }-19.740 \text { to } \\
-0.260) \\
\text { Pain VAS: means } \\
\text { NR but group X time } \\
\text { interaction P=0.26 } \\
\text { Pain NRS: } 3.9 \text { vs. } \\
4.8, \text { Cohen's d= } \\
0.82 \text { (95\% Cl } 0.08 \\
\text { to 1.54); MD }-0.90 \\
\text { (95\% Cl -1.674 to } \\
\text {-0.126) }\end{array}$ & $\begin{array}{l}\text { A vs. B } \\
\text { 3-4 months } \\
\text { BDI (0-63): } 10.7 \text { vs. } 16.4, \\
\text { Cohen's d=0.64 (95\% Cl } \\
-0.08 \text { to } 1.35) ; \mathrm{MD}-5.7(95 \% \\
\mathrm{Cl}-12.044 \text { to } 0.644) \\
\text { STAl-State: } 39.8 \text { vs. } 45.4 ; \\
\text { Cohen's d=0.55 (95\% Cl } \\
-0.17 \text { to } 1.26) ; \mathrm{MD}-5.6 \text { (95\% } \\
\mathrm{Cl}-12.751 \text { to } 1.551) \\
\text { SF-36 Mental: } 46.0 \text { vs. } 34.7 \\
\text { Cohen's d=1.06 (95\% Cl } 0.28 \\
\text { to } 1.82) ; \mathrm{MD} 11.3 \text { (95\% Cl } \\
\text { 3.761 to } 18.839) \\
\text { SF-36 Physical (0-100): } 28.4 \\
\text { vs. 31.1, Cohen's d=0.28 } \\
\text { (95\% Cl }-0.45 \text { to } 1.00) ; \mathrm{MD} \\
-2.7(95 \% \mathrm{Cl}-9.401 \text { to } \\
4.001),\end{array}$ \\
\hline $\begin{array}{l}\text { Kayiran } 2010^{107} \\
4 \text { to } 5 \text { months } \\
\text { Duration of } \\
\text { symptoms: } \\
5 \text { years } \\
\text { Poor }\end{array}$ & $\begin{array}{l}\text { A. EEG Biofeedback } \\
\text { (Neurofeedback) }(n=20) \text { : } \\
5 \text { sessions based on } \\
\text { sensorimotor rhythm } \\
\text { training protocol per } \\
\text { week for } 4 \text { weeks. Each } \\
\text { session consisted of } 10 \\
\text { sensorimotor rhythm } \\
\text { training periods lasting } \\
\text { for } 3 \text { minutes for a total of } \\
30 \text { minutes } \\
\\
\text { B. Escitalopram ( } n=20) \text { : } \\
10 \text { mg/day for } 8 \text { weeks } \\
\text { (control group) }\end{array}$ & $\begin{array}{l}\text { A vs. B } \\
\text { Age: } 32 \text { vs. } 32 \\
\text { years } \\
\text { Female: } 100 \% \text { vs. } \\
100 \% \\
\text { FIQ (mean, 0-100): } \\
70 \text { vs. } 74^{*} \\
\text { Pain VAS (mean, } \\
0-10): 8.9 \text { vs. } 9.1\end{array}$ & $\begin{array}{l}\text { A vs. B } \\
\text { 4-5 months: } \\
\text { FIQ: } 19 \text { vs. } 48^{\star} \\
\text { P=NR } \\
\text { Pain VAS: } 2.6 \text { vs. } \\
\text { 5.3; MD }-2.7(95 \% \\
\text { Cl }-3.7 \text { to }-1.7)\end{array}$ & 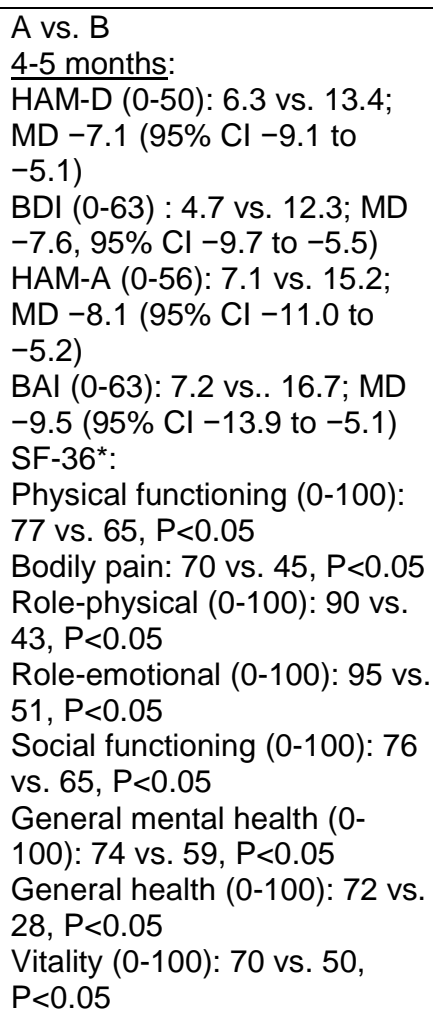 \\
\hline
\end{tabular}




\begin{tabular}{|c|c|c|c|c|}
\hline $\begin{array}{l}\text { Author, Year, } \\
\text { Followup, } \\
\text { Pain Duration, } \\
\text { Study Quality }\end{array}$ & Intervention & Population & $\begin{array}{l}\text { Function and Pain } \\
\text { Outcomes }\end{array}$ & Other Outcomes \\
\hline $\begin{array}{l}\text { Larsson } 2015^{111} \\
13 \text { to } 18 \text { months } \\
\text { Duration of } \\
\text { symptoms: } \\
10 \text { years } \\
\text { Poor }\end{array}$ & $\begin{array}{l}\text { A. Relaxation therapy } \\
\text { ( } n=63 \text { ): Two group } \\
\text { sessions of 5-8 subjects } \\
\text { per week for } 15 \text { weeks. } \\
\text { The intervention was } \\
\text { preceded by an individual } \\
\text { meeting covering } \\
\text { instructions and allowing } \\
\text { for adjustments to the } \\
\text { intervention. The } \\
\text { sessions lasted } 25 \\
\text { minutes and consisted of } \\
\text { autogenic training guided } \\
\text { by physiotherapist and } \\
\text { were followed by } \\
\text { stretching. } \\
\text { B. Resistance exercise } \\
\text { (Strength) (n=67): Two } \\
\text { group sessions of } 5-7 \\
\text { subjects per week for } 15 \\
\text { weeks. The intervention } \\
\text { was preceded by an } \\
\text { individual meeting going } \\
\text { over instructions on the } \\
\text { intervention, testing, and } \\
\text { modifications of specific } \\
\text { exercises. Sessions were } \\
\text { based on a resistance } \\
\text { exercise program aiming } \\
\text { to improve muscle } \\
\text { strength, focusing on } \\
\text { large muscle groups in } \\
\text { the lower extremity. }\end{array}$ & $\begin{array}{l}\text { A vs. B } \\
\text { Age: } 52 \text { vs. } 51 \\
\text { Female: } 100 \% \text { vs. } \\
100 \% \\
\text { FIQ (0-100): } 61.1 \\
\text { vs. } 60.5 \\
\text { Pain VAS (0-100): } \\
52.4 \text { vs. } 49.3 \\
\text { PDI (0-70): } 35.0 \text { vs. } \\
35.3\end{array}$ & $\begin{array}{l}\text { A vs. B } \\
\text { 13-18 months } \\
\text { FIQ: } 55.4 \text { vs. } 57.1 \text {, } \\
\text { (MD }-1.7,95 \% \mathrm{Cl} \\
\text {-9.3 to } 5.9) \\
\text { Pain VAS: } 52.1 \text { vs. } \\
49.2 \text {, (MD } 2.9,95 \% \\
\mathrm{Cl}-5.5 \text { to } 11.3 \text { ) } \\
\text { PDI: } 33.7 \text { vs. } 33.0 \\
\text { (MD } 0.7,95 \% \mathrm{Cl} \\
-4.0 \text { to } 5.4)\end{array}$ & $\begin{array}{l}\text { A vs. B } \\
13-18 \text { months } \\
\text { SF-36 PCS }(0-100): 32.0 \text { vs. } \\
32.2,(\mathrm{MD}-0.2,95 \% \mathrm{Cl}-3.8 \\
\text { to } 3.4) \\
\text { SF-36 MCS }(0-100): 40.0 \text { vs. } \\
39.2,(\mathrm{MD} 0.8,95 \% \mathrm{Cl}-4.6 \text { to } \\
6.2) \\
\text { Patient global impression of } \\
\text { change (mean, } 1-7) \text { : Values } \\
\text { NR but difference was NS }\end{array}$ \\
\hline
\end{tabular}




\begin{tabular}{|c|c|c|c|c|}
\hline $\begin{array}{l}\text { Author, Year, } \\
\text { Followup, } \\
\text { Pain Duration, } \\
\text { Study Quality }\end{array}$ & Intervention & Population & $\begin{array}{l}\text { Function and Pain } \\
\text { Outcomes }\end{array}$ & Other Outcomes \\
\hline $\begin{array}{l}\text { Redondo, } 2004^{112} \\
6 \text { and } 12 \text { months } \\
\text { Pain duration NR } \\
\text { Poor }\end{array}$ & $\begin{array}{l}\text { A. CBT (n=21): 1, } 2.5 \\
\text { hour session per week } \\
\text { for } 8 \text { weeks. Sessions } \\
\text { included information } \\
\text { about chronic pain and } \\
\text { FM, relaxation } \\
\text { techniques, and pain } \\
\text { coping strategies } \\
\text { training. } \\
\text { B. Combination Exercise } \\
\text { (n=19): } 5,45-\text { minute } \\
\text { sessions per week for } 8 \\
\text { weeks. Each week } \\
\text { included } 1 \text { session of } \\
\text { aquatic exercises, } 2 \\
\text { sessions of flexibility and } \\
\text { endurance exercises, } \\
\text { and } 2 \text { sessions of } \\
\text { cardiovascular exercises. } \\
\text { All subjects: Offered } \\
\text { ibuprofen or diclofenac, } \\
25 \text { mg of amitriptyline a } \\
\text { day, and acetaminophen. }\end{array}$ & $\begin{array}{l}\text { A vs. B } \\
\text { Age NR } \\
\text { Female: } 100 \% \text { vs. } \\
\text { 100\% } \\
\text { FIQ total (mean, 0- } \\
\text { 80): } 52.0 \text { vs. } 52.0 \\
\text { FIQ pain (mean, 0- } \\
\text { 10): } 7.3 \text { vs. } 6.8 \\
\text { FIQ depression } \\
\text { (mean, 0-10): } 5.2 \\
\text { vs. } 5.3 \\
\text { FIQ anxiety (mean, } \\
0-10 \text { ): } 6.4 \text { vs. } 6.3\end{array}$ & $\begin{array}{l}\text { A vs. B } \\
6 \text { months: } \\
\text { FIQ total: } 47.4 \text { vs. } \\
48.0,(\mathrm{MD}-0.6 \\
95 \% \mathrm{Cl}-12.6 \text { to } \\
11.4) \\
\text { FIQ pain: } 5.9 \text { vs. } \\
6.9,(\mathrm{MD}-1.0,95 \% \\
\mathrm{Cl}-2.8 \text { to } 0.8) \\
12 \text { months: } \\
\text { FIQ: } 47.8 \text { vs. } 47.7 ; \\
\text { (MD } 0.1,95 \% \mathrm{Cl} \\
-10.5 \text { to } 10.7) \\
\text { FIQ pain: } 6.3 \text { vs. } \\
6.6 ;(\mathrm{MD}-0.3,95 \% \\
\mathrm{Cl}-2.0 \text { to } 1.3)\end{array}$ & 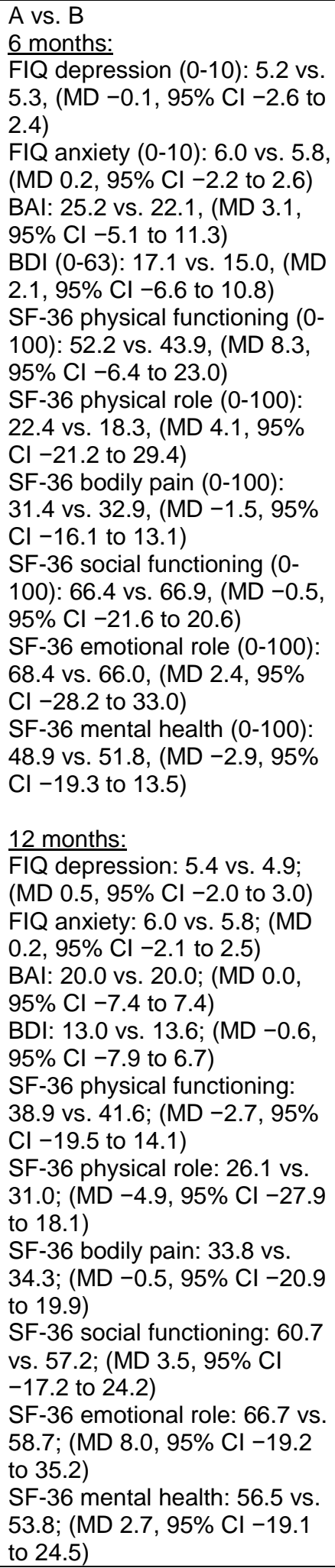 \\
\hline
\end{tabular}




\begin{tabular}{|c|c|c|c|c|}
\hline $\begin{array}{l}\text { Author, Year, } \\
\text { Followup, } \\
\text { Pain Duration, } \\
\text { Study Quality }\end{array}$ & Intervention & Population & $\begin{array}{l}\text { Function and Pain } \\
\text { Outcomes }\end{array}$ & Other Outcomes \\
\hline $\begin{array}{l}\text { Thieme, } 2006^{100} \\
6 \text { and } 12 \text { months } \\
\text { Duration of } \\
\text { symptoms, years: } \\
9.1 \text { vs. } 8.7 \\
\text { Poor }\end{array}$ & $\begin{array}{l}\text { A. CBT (n=42): 2-hour } \\
\text { group sessions weekly } \\
\text { for } 15 \text { weeks. Sessions } \\
\text { focused on changing } \\
\text { patients' thinking and } \\
\text { problem-solving, stress } \\
\text { and pain coping } \\
\text { strategies, and relaxation } \\
\text { exercises performed } \\
\text { during and between } \\
\text { sessions. } \\
\text { B. Attention control } \\
\text { (n=40): 2-hour group } \\
\text { sessions weekly for } 15 \\
\text { weeks: general } \\
\text { discussions about } \\
\text { medical and } \\
\text { psychosocial problems of } \\
\text { fibromyalgia. }\end{array}$ & $\begin{array}{l}\text { A vs. B } \\
\text { Age: } 49 \text { vs. } 47 \\
\text { years } \\
\text { Female: } 100 \% \text { vs. } \\
100 \% \\
\text { FIQ physical } \\
\text { impairment (mean, } \\
\text { 0-10): } 4.4 \text { vs. } 4.2 \\
\text { WHYMPI pain } \\
\text { intensity (mean, } 0- \\
\text { 6): } 4.2 \text { vs. } 3.8\end{array}$ & $\begin{array}{l}\text { A vs. B } \\
6 \text { months } \\
\text { FIQ physical } \\
\text { impairment: } 3.0 \text { vs. } \\
4.8 \text {; MD -1.8 (95\% } \\
\text { Cl -2.899 to } \\
-0.701) \\
\text { WHYMPI pain } \\
\text { intensity: } 3.7 \text { vs. 4.1; } \\
\text { MD -0.4 (95\% Cl } \\
-0.841 \text { to } 0.041) \\
12 \text { months } \\
\text { FIQ physical } \\
\text { impairment: } 3.4 \text { vs. } \\
5.2 ; \text { MD }-1.8 \text { (95\% } \\
\text { Cl -2.855 to } \\
-0.745) \\
\text { WHYMPI pain } \\
\text { intensity: } 3.2 \text { vs. } 4.1 \text {; } \\
\text { MD -0.9 (95\% Cl } \\
-1.537 \text { to }-0.263)\end{array}$ & $\begin{array}{l}\text { A vs. B } \\
\frac{6 \text { months }}{\text { WHYMPI affective distress: }} \\
2.6 \text { vs. } 4.0 ; \mathrm{MD}-1.4(95 \% \mathrm{Cl} \\
-1.952 \text { to }-0.848) \\
12 \text { months } \\
\text { WHYMPI affective distress: } \\
2.6 \text { vs. } 4.2 ; \mathrm{MD}-1.6(95 \% \mathrm{Cl} \\
-2.172 \text { to }-1.028)\end{array}$ \\
\hline
\end{tabular}




\begin{tabular}{|c|c|c|c|c|}
\hline $\begin{array}{l}\text { Author, Year, } \\
\text { Followup, } \\
\text { Pain Duration, } \\
\text { Study Quality }\end{array}$ & Intervention & Population & $\begin{array}{l}\text { Function and Pain } \\
\text { Outcomes }\end{array}$ & Other Outcomes \\
\hline $\begin{array}{l}\text { Van Santen } 2002^{86} \\
\text { Post 6-month } \\
\text { intervention } \\
\text { Duration of } \\
\text { symptoms, years: } \\
10.1 \text { vs. } 15.4 \text { vs. } \\
15.4 \\
\text { Poor }\end{array}$ & $\begin{array}{l}\text { A. Electromyographic } \\
\text { biofeedback (n=56): } \\
\text { Progressive muscle } \\
\text { relaxation and frontalis } \\
\text { EMG biofeedback; 30- } \\
\text { minute individual } \\
\text { sessions } 2 \text { times per } \\
\text { week for } 8 \text { weeks; } \\
\text { subjects encouraged to } \\
\text { practice at home twice } \\
\text { daily for the } 8 \text { weeks then } \\
\text { for } 16 \text { more weeks. } \\
\text { Subjects randomized to } \\
\text { education aimed at } \\
\text { compliance with } \\
\text { biofeedback training (6 } \\
90-\text { minute sessions over } \\
24 \text { weeks). } \\
\text { B. Usual care (n=29): } \\
\text { General physicians } \\
\text { informed not to prescribe } \\
\text { or encourage aerobic } \\
\text { exercises and relaxation. } \\
\text { Intervention duration: } 6 \\
\text { months } \\
\text { C. Combination Exercise } \\
\text { (n=58): } 60 \text {-minute group } \\
\text { sessions of twice a week } \\
\text { for } 24 \text { weeks; aerobic } \\
\text { exercises, postural } \\
\text { strengthening, general } \\
\text { flexibility and balance } \\
\text { exercises, and isometric } \\
\text { muscle strengthening; } \\
\text { subjects encouraged to } \\
\text { attend third, } \\
\text { unsupervised, } 60-\text { minute } \\
\text { session and to use sauna } \\
\text { or swimming pool after } \\
\text { sessions. }\end{array}$ & $\begin{array}{l}\text { A vs. B } \\
\text { Age: } 44 \text { vs. } 43 \text { vs. } \\
46 \text { years } \\
\text { Female: } 100 \% \text { vs. } \\
100 \% \text { vs. } 100 \% \\
\text { Race NR } \\
\text { SIP Physical score } \\
\text { (0-100): } 11.4 \text { vs. } 9.8 \\
\text { vs.11.3 } \\
\text { Pain VAS (0-100): } \\
59.1 \text { vs. } 62.4 \text { vs. } \\
66.8 \\
\text { AIMS (0-10): } 3.1 \text { vs. } \\
5.4 \text { vs. } 1.9 \\
\text { SIP Total score (0- } \\
100): 14.0 \text { vs. } 11.4 \\
\text { vs. } 14.4 \\
\text { SIP Psychosocial } \\
\text { score (0-100): } 15.8 \\
\text { vs. } 18.1 \text { vs. } 16.3\end{array}$ & 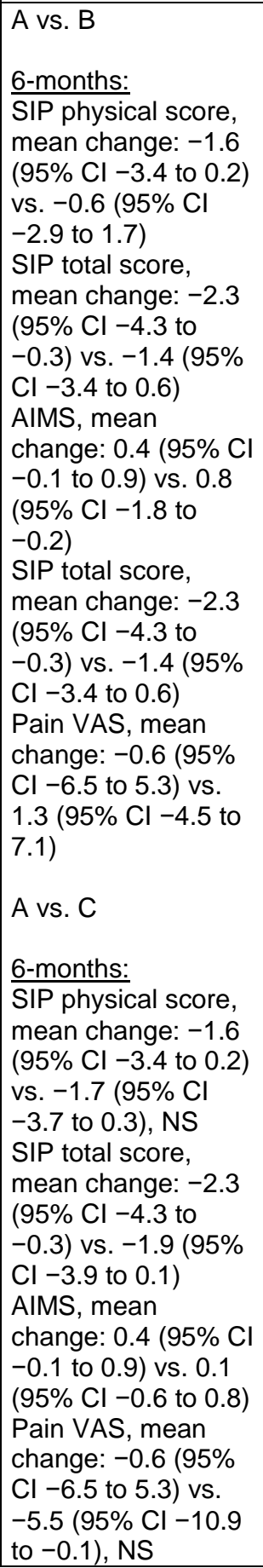 & $\begin{array}{l}\text { A vs. B } \\
\text { 6-months: } \\
\text { SIP psychosocial score, mean } \\
\text { change: }-3.7(95 \% \mathrm{Cl}-4.9 \text { to } \\
-2.5) \text { vs. }-3.5(95 \% \mathrm{Cl}-7.0 \text { to } \\
\text { 0.0) } \\
\text { Patient global assessment of } \\
\text { well-being, mean change: } 0.3 \\
\text { (95\% Cl } 0.0 \text { to } 0.6) \text { vs. } 0.5 \\
\text { (95\% Cl } 0.2 \text { to } 0.8) \\
\text { A vs. C } \\
6 \text {-months: } \\
\text { SIP psychosocial score, mean } \\
\text { change: }-3.7 \text { (95\% Cl }-4.9 \text { to } \\
-2.5) \text { vs. }-3.2(95 \% \mathrm{Cl}-6.2 \text { to } \\
0.2) \\
\text { Patient global assessment of } \\
\text { well-being, mean change: } 0.3 \\
\text { (95\% Cl } 0.0 \text { to } 0.6) \text { vs. } 0.5 \\
\text { (95\% Cl } 0.2 \text { to 0.8) }\end{array}$ \\
\hline
\end{tabular}




\begin{tabular}{|c|c|c|c|c|}
\hline $\begin{array}{l}\text { Author, Year, } \\
\text { Followup, } \\
\text { Pain Duration, } \\
\text { Study Quality }\end{array}$ & Intervention & Population & $\begin{array}{l}\text { Function and Pain } \\
\text { Outcomes }\end{array}$ & Other Outcomes \\
\hline $\begin{array}{l}\text { Verkaik, } 2014^{101} \\
1.5 \text { months } \\
\text { Duration of } \\
\text { symptoms, NR } \\
\text { Poor }\end{array}$ & $\begin{array}{l}\text { A. Guided imagery } \\
\text { (n=33): Two } 1.5 \text { hour } \\
\text { group sessions of } 6-12 \\
\text { subjects. The first } \\
\text { sessions consisted of } \\
\text { group discussion, the } \\
\text { theoretical background of } \\
\text { guided imagery, and } \\
\text { instructions to practice at } \\
\text { least one exercise daily } \\
\text { for } 4 \text { weeks. Each } \\
\text { exercise was a CD and } \\
\text { contained relaxation } \\
\text { techniques, music, } \\
\text { positive imagery, and } \\
\text { pain management } \\
\text { techniques. The second } \\
\text { group session took place } \\
\text { after the } 4 \text { weeks and } \\
\text { consisted of a group } \\
\text { discussion. } \\
\text { B. Attention control } \\
\text { (n=37): Two } 1.5 \text { hour } \\
\text { group sessions of } 6-12 \\
\text { subjects held } 4 \text { weeks } \\
\text { apart. Group sessions } \\
\text { were a group discussion } \\
\text { and did not contain any } \\
\text { information or training on } \\
\text { guided imagery. }\end{array}$ & $\begin{array}{l}\text { A vs. B } \\
\text { Age: } 47 \text { vs. } 48 \\
\text { Female: } 100 \% \text { vs. } \\
97 \% \\
\text { FIQ( } 0-100): 53.7 \\
\text { vs. } 56.4 \\
\text { Pain VAS (0-10): } \\
5.9 \text { vs. } 5.8\end{array}$ & $\begin{array}{l}\text { A vs. B } \\
1.5 \text { months } \\
\text { FIQ: } 54.2 \text { vs. } 53.0 \\
\text { MD } 1.2,95 \% \mathrm{Cl} \\
-0.2 \text { to } 2.6) \\
\text { Pain VAS: NR }\end{array}$ & NR \\
\hline
\end{tabular}




\begin{tabular}{|c|c|c|c|c|}
\hline $\begin{array}{l}\text { Author, Year, } \\
\text { Followup, } \\
\text { Pain Duration, } \\
\text { Study Quality }\end{array}$ & Intervention & Population & $\begin{array}{l}\text { Function and Pain } \\
\text { Outcomes }\end{array}$ & Other Outcomes \\
\hline $\begin{array}{l}\text { Wigers, } 1996^{87} \\
48 \text { months } \\
\text { Fibromyalgia } \\
\text { duration } \\
\text { A vs. B vs. C } \\
\text { Mean: } 11 \text { vs. } 9 \\
\text { years } \\
\text { Poor }\end{array}$ & $\begin{array}{l}\text { A. Stress management } \\
\text { ( } n=20 \text { ): } 90 \text { minute group } \\
\text { sessions of } 10 \text { patients } \\
\text { done } 2 \text { times a week for } \\
6 \text { weeks followed by } 1 \\
\text { session per week for the } \\
\text { next } 8 \text { weeks. Sessions } \\
\text { consisted of equal } \\
\text { portions of presentations } \\
\text { stress mechanisms and } \\
\text { strategies for improving } \\
\text { quality of life, group } \\
\text { discussions on patients' } \\
\text { experiences of stress } \\
\text { and coping with pain, and } \\
\text { relaxation training aimed } \\
\text { at helping cope with } \\
\text { stress and pain. } \\
\text { B. Usual care (n=20): } \\
\text { Subjects continued } \\
\text { treatments they had been } \\
\text { using at baseline. } \\
\text { C. Aerobic exercise } \\
\text { ( } n=20 \text { ): } 45 \text { minute group } \\
\text { sessions of } 10 \text { patients } \\
\text { done } 3 \text { times a week for } \\
14 \text { weeks. The exercise } \\
\text { program involved the } \\
\text { whole body and aimed to } \\
\text { minimize eccentric } \\
\text { muscle strain. Sessions } \\
\text { consisted of training to } \\
\text { music (further details not } \\
\text { given) and aerobic } \\
\text { games. }\end{array}$ & $\begin{array}{l}\text { A vs. B } \\
\text { Age: } 44 \text { vs. } 46 \text { vs. } \\
43 \text { years } \\
\text { Female: } 90 \% \text { vs. } \\
95 \% \text { vs.. } 90 \% \\
\text { Pain VAS (0-100): } \\
72 \text { vs. } 65 \text { vs. } 72\end{array}$ & 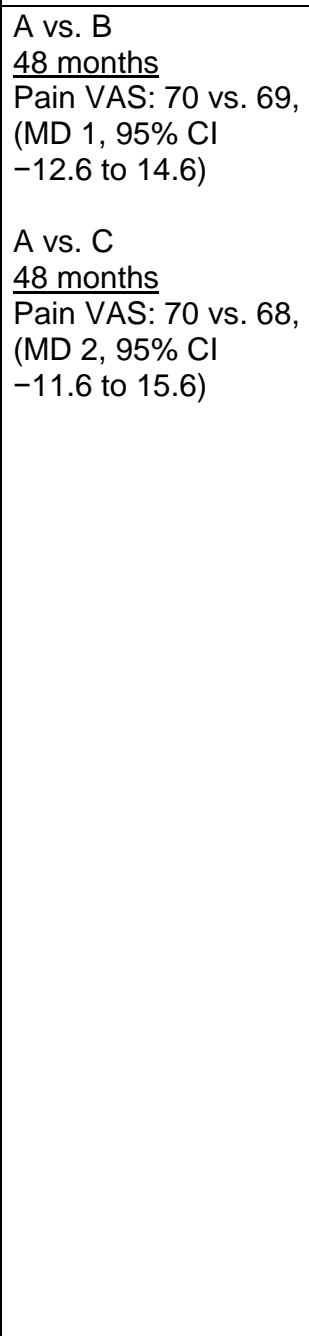 & $\begin{array}{l}\text { A vs. B } \\
\frac{48 \text { months }}{\text { Depression VAS }(0-100): 40} \\
\text { vs. } 30,(\mathrm{MD} 10,95 \% \mathrm{Cl}-8.9 \\
\text { to } 28.9) \\
\text { Global subjective } \\
\text { improvement: } 47 \%(6 / 13) \text { vs. } \\
12 \%(2 / 16),(\mathrm{RR} 3.7,95 \% \mathrm{Cl} \\
0.9 \text { to } 15.3) \\
\text { A vs. C } \\
48 \text { months } \\
\text { Depression VAS: } 40 \text { vs. } 32, \\
\text { (MD 8, 95\% Cl }-11.9 \text { to } 27.9) \\
\text { Global subjective } \\
\text { improvement: } 47 \%(6 / 13) \text { vs. } \\
75 \%(11 / 15),(R R 0.6,95 \% \mathrm{Cl} \\
0.3 \text { to } 1.2)\end{array}$ \\
\hline
\end{tabular}




\begin{tabular}{|c|c|c|c|c|}
\hline $\begin{array}{l}\text { Author, Year, } \\
\text { Followup, } \\
\text { Pain Duration, } \\
\text { Study Quality }\end{array}$ & Intervention & Population & $\begin{array}{l}\text { Function and Pain } \\
\text { Outcomes }\end{array}$ & Other Outcomes \\
\hline $\begin{array}{l}\text { Williams, } 2002^{103} \\
12 \text { months } \\
\text { Fibromyalgia } \\
\text { duration, } 8.6 \text { years } \\
\text { Poor }\end{array}$ & $\begin{array}{l}\text { A. Group CBT plus Usual } \\
\text { Care ( } \mathrm{n}=76 \text { ): } 6 \text { 1-hour } \\
\text { group sessions over 4- } \\
\text { week period: progressive } \\
\text { muscle relaxation, } \\
\text { imagery, activity pacing, } \\
\text { pleasant activity } \\
\text { scheduling, } \\
\text { communication skills and } \\
\text { assertiveness training, } \\
\text { cognitive restructuring, } \\
\text { stress management and } \\
\text { problem-solving. } \\
\text { B. Usual Care (n=69): } \\
\text { Standard } \\
\text { pharmacological } \\
\text { management (typically } \\
\text { low-dose tricyclic } \\
\text { antidepressant } \\
\text { medication, analgesics, } \\
\text { and/or antidepressants) } \\
\text { plus suggestions to } \\
\text { engage in aerobic } \\
\text { fitness. }\end{array}$ & $\begin{array}{l}\text { A + B } \\
\text { Age, mean, years: } \\
47.7 \\
\text { Females: } 90 \% \\
\text { Race: White non- } \\
\text { Hispanic } 88 \% \text {, black } \\
\text { non-Hispanic } 9 \% \text {, } \\
\text { Hispanic } 2 \%, \text { Asian } \\
\text { American } 1 \% \\
\text { MPQ-Sensory } \\
\text { (scale NR): } 14.8 \\
\text { MPQ-Affective pain } \\
\text { score (scale NR): } \\
4.6\end{array}$ & $\begin{array}{l}\text { A vs. B } \\
12 \text { months } \\
\text { Mean (SD): NR } \\
\text { Proportion of } \\
\text { subjects who } \\
\text { improved more than } \\
12 \text { points from } \\
\text { baseline on MPQ- } \\
\text { Sensory scale: } 3.9 \% \\
\text { vs. } 7.2 \% \text {; RR } 0.54 \\
\text { (95\% CI } 0.14 \text { to } 2.2 \text { ) }\end{array}$ & $\begin{array}{l}\text { A vs. B } \\
\frac{12 \text { months }}{\text { Mean (SD) NR }} \\
\text { Proportion of subjects who } \\
\text { improved more than } 6.5 \text { points } \\
\text { from baseline on SF-36 PCS } \\
\text { Score: } 25 \% \text { vs. } 11.6 \% \text {, OR } \\
2.9 ; \text { RR } 2.2 \text { (95\% CI } 0.98 \text { to } \\
4.99) \\
\text { Proportion of subjects who } \\
\text { improved more than } 5 \text { points } \\
\text { from baseline on MPQ- } \\
\text { Affective scale: } 9.2 \% \text { vs. } \\
\text { 8.7\%, RR } 1.1 \text { ( } 95 \% \text { Cl } 0.37 \text { to } \\
3.0)\end{array}$ \\
\hline
\end{tabular}

AIMS = Arthritis Impact Measurement Scales; BAI = Beck Anxiety Inventory; BDI = Beck Depression Inventory; CBT = cognitive-behavioral therapy; CES-D = Center for Epidemiologic Studies Depression Scale; CI = confidence interval; FIQ = Fibromyalgia Impact Questionnaire; HAM-D = Hamilton Rating Scale for Depression; HAM-A = Hamilton Anxiety Rating Scale; HADS = Hospital Anxiety and Depression Scale; MCSD = Minimal Clinically Significant Difference; MD = mean difference; MPQ = McGill Pain Questionnaire; PDI = Pain Disability Index; PHQ = Patient Health Questionnaire; PI = Physical Impairment; RR = risk ratio; SCL-90-R = Symptoms Checklist 90-Revised; SD = standard deviation; SIP = Sickness Impact Profile; SF-36 = Short-Form 36 questionnaire; SF-36 PCS = Short-Form 36 Physical Component Summary Score; SF-36 MCS = Short-Form 36 Mental Component Summary Score; STAI = State-Trait Anxiety Inventory; VAS = visual analog scale ${ }^{\text {a }}$ Unless otherwise noted, followup time is calculated from the end of the treatment period

\section{Psychological Therapies Compared With Usual Care or Sham}

Ten trials compared psychological interventions versus usual care, waitlist, or attention control. ${ }^{67,86,87,96-103}$ All but one trial ${ }^{99,102}$ were considered poor quality.

Functional Outcomes. Across types of psychological therapies, results for function were not consistent over the short term (Table 36). One trial reported that significantly more patients in the CBT group attained a clinically important improvement ( $\geq 14 \%$ on the FIQ total, $0-100$ scale) from baseline compared with usual care (RR 2.8, 95\% CI 1.3 to 6.1), ${ }^{98}$ while another smaller trial did not (RR 2.2, 95\% CI 0.5 to 9.3) ${ }^{97}$ CBT was associated with a small improvement in function compared with usual care or waitlist in the short term (2 trials, pooled MD $-10.67,95 \%$ CI -17 to $-4.30, \mathrm{I}^{2}=0 \%$, FIQ total score, $0-100$ scale) ${ }^{98,99,102}$ (Figure 41), but no differences were seen in trial each of guided imagery (FIQ total, 0 to 100 scale, MD 1.2, 95\% CI -0.2 to 2.6) ${ }^{101}$ and EMG biofeedback (median change from baseline 6.0 for both groups, Arthritis Impact Measurement Scales [AIMS] physical activity subscale, 0-10 scale) ${ }^{67}$ versus attention control.

At intermediate term, one trial reported that substantially more CBT patients achieved a clinically important difference ( $\geq 14 \%$ on the FIQ total, $0-100$ scale) compared with usual care (RR 2.9, 95\% CI 1.9 to 17.8 ) ${ }^{98}$ Individual trials showed CBT had a statistically greater effect on 
function than usual care at intermediate term based on FIQ total score; however, the pooled estimate was not statistically significant due to heterogeneity ( 2 trials, pooled MD $-10.36,95 \%$ CI -23.52 to $2.80, \mathrm{I}^{2}=84.5 \%, 0-100$ scale) ${ }^{96,98}$ (Figure 41). Findings from an additional trial suggested a greater effect of CBT on function compared with attention control based on a 0 to 10 FIQ Physical Impairment Scale (MD -1.8, 95\% CI -2.9 to -0.70). ${ }^{100}$ There was no clear difference between biofeedback and usual care on function according to the Sickness Impact Profile (SIP) physical score in one trial (mean change $-1.6,95 \%$ CI -3.4 to 0.2 versus $-0.6,95 \%$ CI -2.9 to 1.7 , respectively, on a $0-100$ scale). ${ }^{86}$

Data from three poor-quality trials were insufficient to determine the long-term effects of psychological therapies on function. One trial found no difference between CBT and usual care in the proportion of participants achieving a clinically meaningful change of 12 points from baseline on the McGill Pain Questionnaire (MPQ) Sensory Scale (RR 0.54, 95\% CI 0.14 to 2.2) ${ }^{103} \mathrm{~A}$ second trial reported that CBT resulted in greater improvement compared with attention control on the FIQ Physical Impairment Scale (MD -1.8 on a 0-10 scale, 95\% CI -2.85 to -0.745$)$. ${ }^{100} \mathrm{~A}$ trial of biofeedback versus usual care reported median change in the AIMS Physical Activity subscale of 6.0 in both groups. ${ }^{67}$

Pain Outcomes. Psychological therapies (CBT and EMG biofeedback) were associated with a small improvement in pain compared with usual care, waitlist, or attention control at short-term followup (4 trials, pooled MD $-0.74,95 \% \mathrm{CI}-1.20$ to $\left.-0.28, \mathrm{I}^{2}=0 \%\right)^{67,97-99,102}$ (Figure 42); the estimate was similar when only trials of CBT were considered ( 3 trials, pooled MD $-0.78,95 \%$ CI -1.30 to -0.17 , plot not shown). ${ }^{97-99,102}$ When stratified by type of control (usual care), estimates were also similar, but results were no longer statistically significant. Psychological therapies (CBT, EMG biofeedback) were also associated with a small improvement in pain compared with usual care at intermediate term (3 trials, pooled MD $-0.67,95 \% \mathrm{CI}-1.21$ to $\left.-0.31, \mathrm{I}^{2}=36.7 \%\right)^{86,96,98}$ (Figure 42). Estimates were similar when the two CBT trials were pooled, but no longer statistically significant. Long term, there was no clear difference between psychological therapies (CBT or biofeedback) and attention control or usual care (2 trials, pooled MD $0.04,95 \%$ CI -0.77 to $\left.0.84, I^{2}=0 \%\right) ; 67,87$ however, evidence across the two poor-quality trials was considered insufficient (Figure 42).

Other Outcomes. Results were mixed across trials for effects of CBT or ACT on secondary outcomes (Table 36). Only two trials were of fair quality.

In one fair-quality trial of ACT versus waitlist there were no differences between groups over the short term on the following: BDI, STAI-State scale or SF-36 PCS; ACT was associated with improvement in the SF-36 MCS. ${ }^{99,102}$

Another fair-quality trial reported intermediate-term outcomes and found no differences in either the Hospital Anxiety and Depression Scale (HAM-D) or Hamilton Anxiety Rating Scale (HAM-A) for the comparison of CBT versus usual care. ${ }^{96}$ Across the poor-quality trials results were mixed across various secondary outcomes measures (Table 36).

Two poor-quality studies compared EMG biofeedback to attention control conditions; neither found differences on secondary outcomes including the Symptoms Checklist 90-Revised Global Severity Index, SIP psychosocial score, global assessment of well-being, Center for Epidemiologic Studies Depression Scale (CED-S), and a sleep scale. ${ }^{67,86}$ 


\section{Psychological Therapies Compared With Pharmacological Therapy}

Two fair-quality ${ }^{96,106}$ and one poor-quality trial ${ }^{107}$ compared a psychological therapy with pharmacological treatment. Two trials reported functional outcomes over the short term with differing results. No clear effect was seen for CBT (plus amitriptyline) compared with amitriptyline alone at 3 months in one fair-quality trial (MD -4.1, 95\% CI -18.8 to 10.6 on the FIQ total score [0 to 100] scale). ${ }^{106}$ One poor-quality trial, comparing EEG biofeedback with escitalopram, reported better mean FIQ total scores in the biofeedback group at 4 to 5 months followup (19 versus 48, 0 to 100 scale), but did not provide enough data to calculate an effect estimate. ${ }^{107}$ Intermediate-term function was reported by one fair-quality trial, which found a small benefit for CBT compared with pregabalin (plus duloxetine as needed) on the FIQ at 6 months (difference -4.0 on a $0-100$ scale, $95 \%$ CI -7.7 to -0.27 ). ${ }^{96}$

The pattern for pain outcomes was similar over the short term. No differences were seen between groups in the trial of CBT versus amitriptyline (difference -0.7 on a $0-10 \mathrm{VAS}, 95 \% \mathrm{CI}$ -2.8 to 1.4$),{ }^{106}$ whereas a moderate effect was seen for EEG biofeedback compared with escitalopram (difference -2.7 on a $0-10$ VAS, $95 \%$ CI -3.7 to -1.7 ) in the poor-quality trial. ${ }^{107}$ At intermediate-term, VAS pain scores were similar between the CBT and pregabalin groups in the third trial (difference 0.2 on a $0-100$ scale, -4.0 to 4.4$).{ }^{96}$ It is unclear how many patients in the pharmacological group received concomitant duloxetine for major depressive disorder.

Regarding secondary outcomes, EEG biofeedback was associated with significantly better outcomes on various measures of anxiety, depression, and quality of life compared with escitalopram over short-term followup in the poor-quality trial, ${ }^{107}$ whereas the two fair-quality trials evaluating CBT (versus amitriptyline and versus pregabalin) ${ }^{96,106}$ found no differences between groups over the short or intermediate term, with the exception of SF-36 Mental Health scores at short-term followup in one trial (difference 13.7 on a $0-100$ scale, $95 \%$ CI 0.07 to 27.3). ${ }^{106}$

\section{Psychological Therapies Compared With Exercise}

Five poor-quality trials compared psychological interventions with exercise; two trials evaluated compared CBT, ${ }^{87,112}$ two trials evaluated biofeedback, ${ }^{67,86}$ and one evaluated relaxation training ${ }^{111}$ (Table 36).

Data were insufficient from one poor-quality trial to determine the effects of biofeedback versus combination exercise on function. The trial reported improved function based on the AIMS physical activity subscale (median change from baseline 6.0 versus $4.0, \mathrm{P}<0.05$ ). ${ }^{67}$ Intermediate-term data from two poor-quality trials were insufficient to determine effects of psychological therapies on function and no clear differences in function were seen for CBT (MD $-0.6,95 \%$ CI -12.6 to 11.4 on $0-100$ FIQ total score) ${ }^{112}$ or biofeedback (mean change $-1.6,95 \%$ CI -3.4 to 0.2 vs. $-0.6,95 \%$ CI -2.9 to 1.7 on $0-100$ SIP Physical score) ${ }^{86}$ versus combination exercise. Similarly, no clear differences between psychological therapies and exercise were seen across three trials at longer term and evidence was considered insufficient. Results from two trials were not statistically significant (CBT vs. combination exercise [MD $0.1,95 \%$ CI -10.5 to 10.7 on $0-100$ FIQ total scale] ${ }^{112}$ and relaxation training versus strength training [MD $-1.7,95 \%$ CI -9.3 to 5.9, on 0-100 FIQ Total Score]). ${ }^{111}$ The third trial of biofeedback versus combination exercise reported improvement in function, but limited data were provided (median change from baseline, 6.0 versus $4.0, \mathrm{P}<0.05){ }^{67}$

Data were insufficient from one poor-quality trial to determine the effects of biofeedback versus combination exercise pain (median change from baseline, 5.2 vs. 5.4 on $0-10$ VAS) ${ }^{67}$ Across two poor-quality trials at intermediate term, no clear differences were seen for CBT (MD 
$-1.0,95 \%$ CI -2.8 to 0.8$)^{112}$ or biofeedback (mean change $-0.6,95 \%$ CI -6.5 to 5.3 vs. -5.5 , $95 \% \mathrm{CI}-10.9$ to $-0.1, \mathrm{P}=\mathrm{NS})^{86}$ compared with combination exercise; evidence was considered insufficient. There were no clear differences between any of the psychological therapies and exercise for pain on a 0 to 10 scale across four trials long term, including CBT versus combination exercise (MD 0.3, 95\% CI -2.0 to 1.3 ) ${ }^{112}$ or aerobic exercise (difference 2, 95\% CI -11.6 to 15.6$),{ }^{87}$ biofeedback versus combination exercise (median change: 5.2 vs. $5.5, P=N S$ ) ${ }^{67}$ and relaxation training versus strength training (difference $2.9,95 \% \mathrm{CI}-5.5$ to 11.3 ). ${ }^{111}$

There were generally no significant differences on measures of mental health, depression or anxiety, or on SF-36 scales, at any time frame across five poor-quality trials. ${ }^{67,86,87,111,112}$ Some trials did not provide data for determination of effect sizes between treatment groups or report results of significance tests (Table 36).

\section{Harms}

Only five trials (1 fair-quality and 4 poor-quality) reported harms, which were poorly described in general. Two trials compared CBT with usual care; one trial reported no withdrawals due to adverse events in the CBT group compared with two (3.6\%) in the control group (not further described) ${ }^{96}$ and the other trial reported two withdrawals, one in each group, because the nociceptive flexion reflex test being used was too painful. ${ }^{97}$ One trial comparing CBT with attention control reported that 4.8 percent (due to depression) versus 50 percent (due to worsening of symptoms) of patients, respectively, withdrew from the study. ${ }^{100}$ One trial compared stress management to usual care and reported one withdrawal due to cancer (unrelated to the treatment) in the intervention group compared with no withdrawals or adverse events in the control. ${ }^{87}$

One of the above trials also compared CBT to pharmacological therapy (pregabalin) and reported no withdrawals due to adverse events in the CBT group compared with three (5.5\%) in the control group, two due to digestive problems and one due to dizziness. ${ }^{96}$

Two trials compared psychological therapies with exercise. One trial reported no adverse effects with relaxation therapy, but five (7.5\%) adverse effect reports following strengthening exercises (due to increased pain), resulting in three withdrawals from the trial. ${ }^{111}$ The other trial reported one withdrawal due to cancer (unrelated to the treatment) in the intervention group compared with three withdrawals in the exercise group (1 death, 1 gastritis, 1 ischialgia). ${ }^{87}$ 
Figure 41. Psychological therapies versus usual care or waitlist for fibromyalgia: effects on function

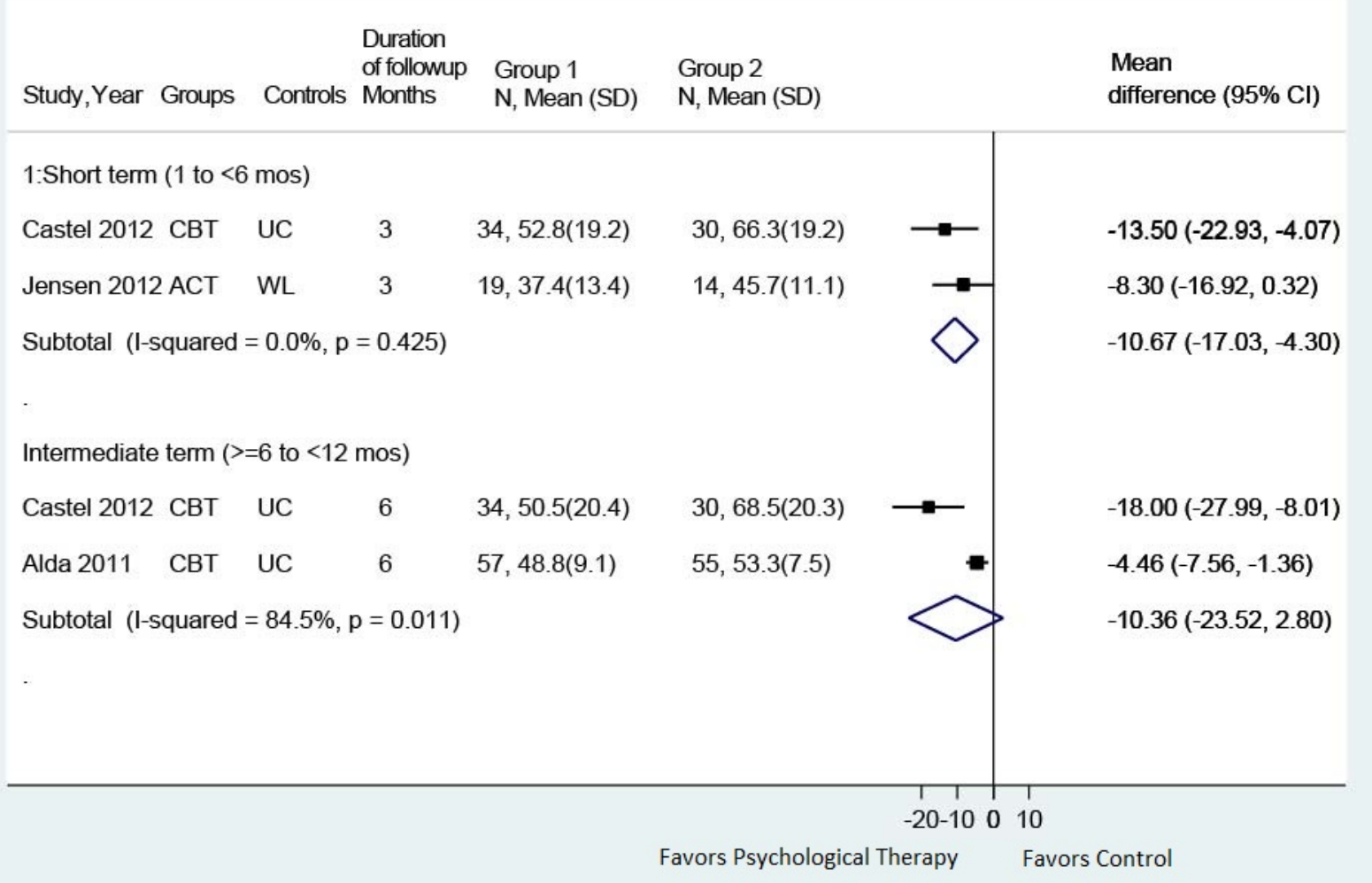

ACT = Acceptance and Commitment Therapy; CBT = cognitive-behavioral therapy; $\mathrm{CI}=$ confidence interval; $\mathrm{SD}=$ standard deviation; UC = usual care; $\mathrm{WL}=$ waitlist 
Figure 42. Psychological therapies versus usual care, waitlist, or attention control for fibromyalgia: effects on pain

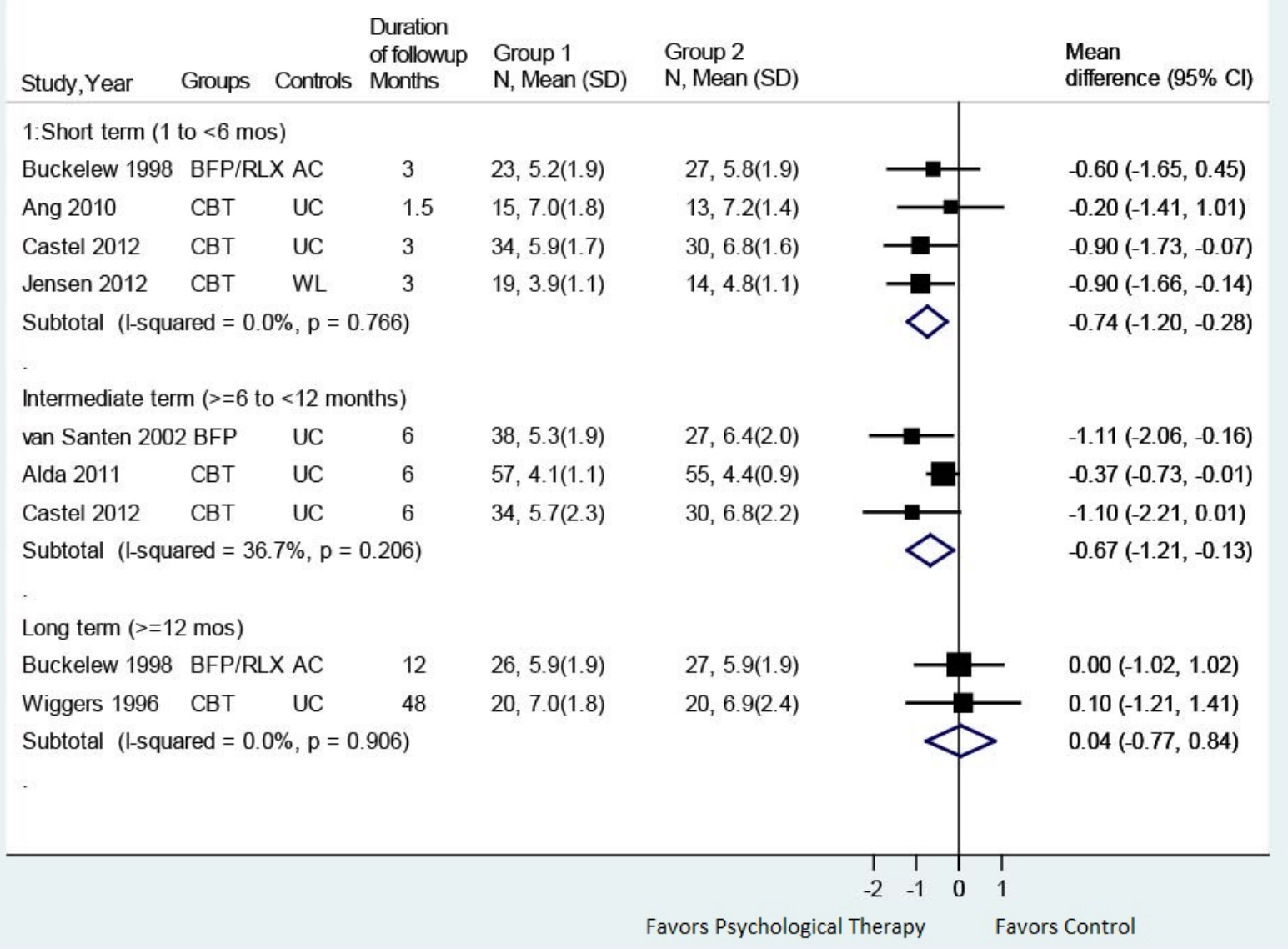

AC = attention control; BFP = Biofeedback; BFP/RLX = Biofeedback with a Relaxation component; CBT = cognitive-behavioral therapy; $\mathrm{CI}$ = confidence interval; $\mathrm{SD}=$ standard deviation; $\mathrm{UC}=$ usual care; $\mathrm{WL}=$ waitlist

\section{Physical Modalities for Fibromyalgia}

\section{Key Points}

- One fair-quality parallel trial found no evidence of differences between magnetic mattress pads compared with sham or usual care in intermediate-term function (MD on the 0 to 80 scale FIQ $-5.0,95 \%$ CI -14.1 to 4.1 vs. sham and $-5.5,95 \% \mathrm{CI}-14.4$ to 3.4 vs. usual care) or pain ( $\mathrm{MD}-0.6,95 \% \mathrm{CI}-1.9$ to 0.7 and $-1.0,95 \% \mathrm{CI}-2.2$ to 0.2 , respectively on a 0 to $10 \mathrm{NRS}$ ) (SOE: low). Data from one small, poor-quality crossover trial were insufficient to determine the effects of a magnetic mattress versus sham on function and pain in the short term (SOE: insufficient).

- There were no differences in adverse events between the functional and sham magnetic mattress pad groups (data not reported); none of the events were deemed to be related to the treatments (SOE: low). 


\section{Detailed Synthesis}

Two trials, ${ }^{140,141}$ one parallel and one cross-over design, evaluating the efficacy of magnetic fields for the treatment of fibromyalgia met inclusion criteria (Table 37 and Appendix D). In both trials, the majority of patients were female (93\% and 100\%) with mean ages of 45 and 50 years; symptom duration was 6 years in one trial and was not reported by the other trial. Due to the differences in trial designs we could not pool the data; therefore, these trials are reported separately.

One parallel trial $(n=119),{ }^{140}$ conducted in the United States, compared two different magnetic mattress pads (one with a low, uniform magnetic field of negative polarity and the other a low, static magnetic field that varied spatially and in polarity) versus sham (mattress pads with demagnetized magnets) and versus usual care (management by primary care provider). All pads were used for 6 months and outcomes were measured immediately post-treatment. This trial was rated fair quality due to deviations from the randomization protocol and unacceptable attrition rate (21\%) (Appendix E).

A second small, crossover trial $(\mathrm{N}=33)^{141}$ evaluated the effects of an extremely low frequency magnetic mattress compared with a sham mattress (no magnetic field delivered). The trial was conducted in Italy. The intervention periods were 1 month and the washout period between the first and second period was 1 month; no further information was provided about the washout period. Outcomes were measured 1 month after the end of each treatment cycle (i.e., at the beginning of the second treatment cycle, after a 1 month washout, and 1 month after the end of the second treatment cycle).This trial was rated poor quality for the following reasons: unclear randomization sequence generation and allocation concealment, and loss-to-followup of greater than $20 \%$ through the second treatment period; additional sources of bias in this crossover trial include no details regarding handling of missing data and no analysis of carryover effect. 
Table 37. Fibromyalgia: physical modalities

\begin{tabular}{|c|c|c|c|c|}
\hline $\begin{array}{l}\text { Author, } \\
\text { Year, } \\
\text { Followup, } \\
\text { Pain } \\
\text { Duration, } \\
\text { Study } \\
\text { Quality }\end{array}$ & Intervention & Population & Function and Pain Outcomes & $\begin{array}{l}\text { Other } \\
\text { Outcomes }\end{array}$ \\
\hline $\begin{array}{l}\text { Alfano, } \\
2001^{140} \\
6 \text { months } \\
\text { Duration of } \\
\text { pain: >3 } \\
\text { months } \\
\text { (mean NR) } \\
\text { Fair }\end{array}$ & $\begin{array}{l}\text { A. Magnetic } \\
\text { mattress pad } \\
\text { designed to expose } \\
\text { body to a uniform } \\
\text { magnetic field of } \\
\text { negative polarity } \\
\text { ( } n=37 \text { ) } \\
\text { B. Magnetic } \\
\text { mattress pad } \\
\text { exposing body to } \\
\text { magnetic field that } \\
\text { varied spatially and } \\
\text { in polarity ( } n=33 \text { ) } \\
\text { C. Sham magnetic } \\
\text { field ( } n=32 \text { ): } \\
\text { combined group of } \\
2 \text { sham magnetic } \\
\text { mattress pads; } \\
\text { identical in } \\
\text { appearance to real } \\
\text { magnetic pads but } \\
\text { contained } \\
\text { demagnetized } \\
\text { magnets. } \\
\text { D. Usual care } \\
\text { ( } n=17 \text { ): maintain } \\
\text { current treatment } \\
\text { under PCP, refrain } \\
\text { from new } \\
\text { treatments } \\
\text { Treatment period } \\
\text { was } 6 \text { months for } \\
\text { all groups. }\end{array}$ & $\begin{array}{l}\text { A vs. B vs. C vs. D } \\
\text { Age: } 44 \text { vs. } 47 \text { vs. } \\
46 \text { vs. } 45 \text { years } \\
\text { Female: } 92 \% \text { vs. } \\
87 \% \text { vs. } 96 \% \text { vs. } \\
100 \% \\
\text { FIQ (0-80): } 51.6 \text { vs. } \\
55.5 \text { vs. } 51.5 \text { vs. } \\
53.9 \\
\text { Pain intensity FIQ } \\
\text { NRS (0-10): } 7.1 \text { vs. } \\
7.0 \text { vs. } 6.7 \text { vs. } 7.0\end{array}$ & 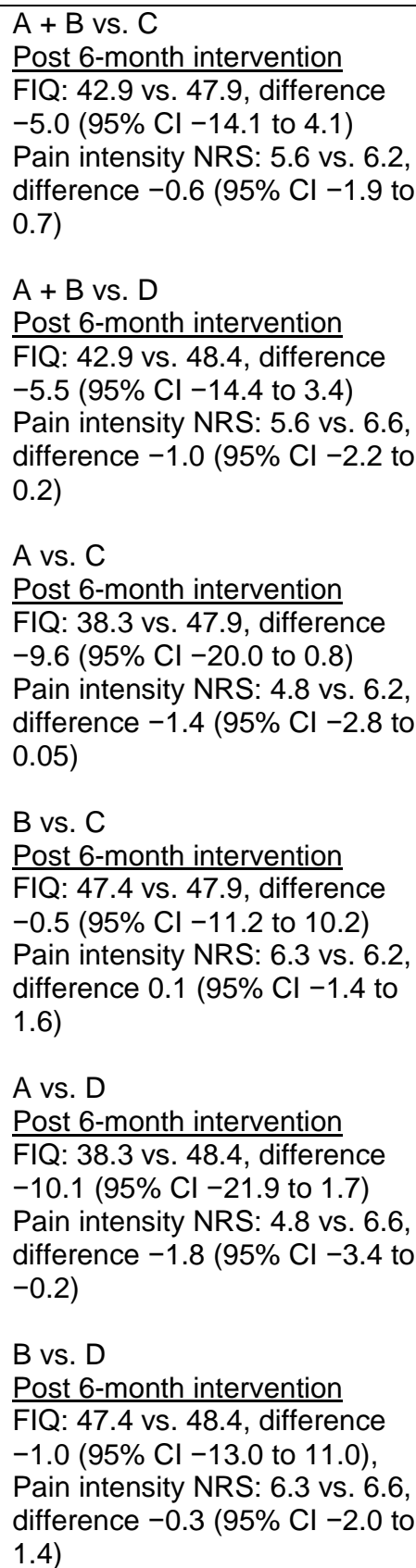 & NR \\
\hline
\end{tabular}




\begin{tabular}{|c|c|c|c|c|}
\hline $\begin{array}{l}\text { Author, } \\
\text { Year, } \\
\text { Followup, } \\
\text { Pain } \\
\text { Duration, } \\
\text { Study } \\
\text { Quality }\end{array}$ & Intervention & Population & Function and Pain Outcomes & $\begin{array}{l}\text { Other } \\
\text { Outcomes }\end{array}$ \\
\hline $\begin{array}{l}\text { Paolucci } \\
2016 \\
1 \text { month } \\
\text { Duration of } \\
\text { pain: } \\
\text { Poor }\end{array}$ & $\begin{array}{l}\text { A. Extremely low- } \\
\text { frequency magnetic } \\
\text { field first ( } n=16 \text { ): } 3 \\
\text { thirty minute } \\
\text { sessions per week } \\
\text { for } 4 \text { weeks (12 } \\
\text { sessions total). } \\
\text { Patients laid on a } \\
\text { bed with multi-low- } \\
\text { frequency mattress } \\
\text { that delivered a } \\
\text { magnetic field at an } \\
\text { intensity of } 100 \text { uT } \\
\text { and a } \\
\text { multifrequency of } 1 \\
\text { to } 80 \text { Hz. } \\
\text { B. Sham extremely } \\
\text { low-frequency } \\
\text { magnetic field first } \\
\text { ( } n=17) \text { : } 3 \text { thirty } \\
\text { minute sessions } \\
\text { per week for } 4 \\
\text { weeks (12 sessions } \\
\text { total). Patients laid } \\
\text { on a bed with multi- } \\
\text { low-frequency } \\
\text { mattress but no } \\
\text { magnetic field was } \\
\text { delivered. } \\
\text { Washout period: } 1 \\
\text { month }\end{array}$ & $\begin{array}{l}\text { A vs. B } \\
\text { Age, years: } 50 \text { vs. } \\
51 \\
\text { Female: } 100 \% \text { vs. } \\
\text { 100\% } \\
\text { Fibromyalgia } \\
\text { duration, years: } 7 \\
\text { vs. } 5 \\
\text { FIQ: } 58.7(11.3) \text { vs. } \\
57.2(12.3) \\
\text { FIQ pain: NR } \\
\text { Pain VAS: } 4.9(1.4) \\
\text { vs. } 4.8(1.2) \\
\text { FAS (0-10): } 6.1 \\
\text { (1.7) vs. } 6.4(1.4) \\
\text { HAQ (0-3): } 0.7 \\
\text { (0.3) vs. } 1.1(0.8)\end{array}$ & 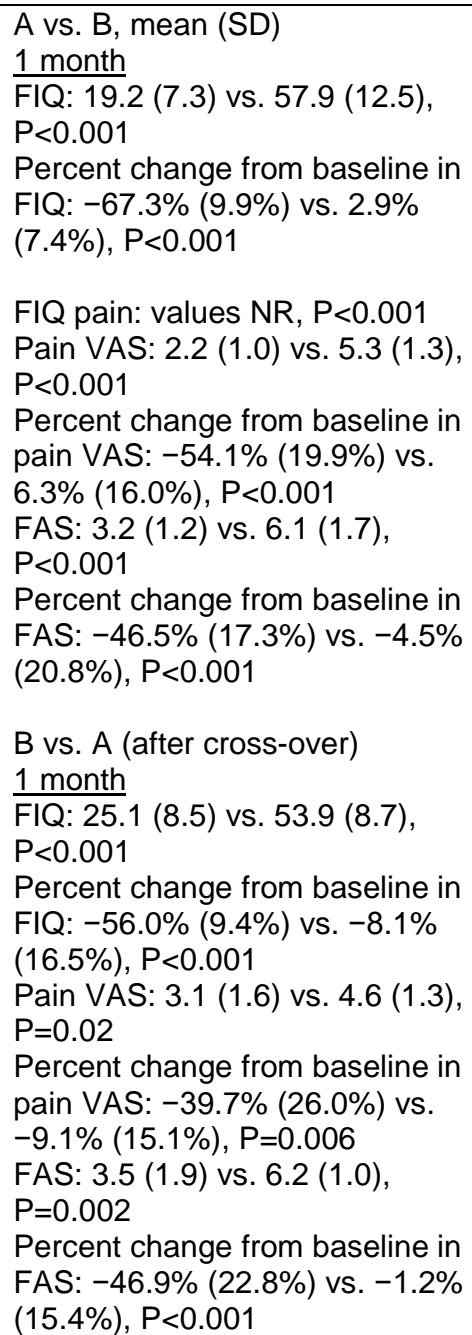 & $\begin{array}{l}\text { A vs. B } \\
1 \text { month } \\
\text { HAQ: } 0.3(0.2) \\
\text { vs. } 1.1(0.9), \\
\text { P=0.03 } \\
\text { Percent change } \\
\text { from baseline in } \\
\text { HAQ: NR } \\
\text { B vs. A (after } \\
\text { cross-over) } \\
1 \text { month } \\
\text { HAQ: } 0.7(0.7) \\
\text { vs. } 0.8 \text { (0.3), } \\
\text { P=0.41 } \\
\text { Percent change } \\
\text { from baseline in } \\
\text { HAQ: NR }\end{array}$ \\
\hline
\end{tabular}

CI = confidence interval; FAS = Fibromyalgia Assessment Status; FIQ = Fibromyalgia Impact Questionnaire; HAQ = Health Assessment Questionnaire; NR = not reported; NRS = numeric rating scale; $\mathrm{PCP}=$ primary care physician; $\mathrm{SD}=$ standard deviation; VAS = Visual Analog Scale

${ }^{a}$ Unless otherwise noted, followup time is calculated from the end of the treatment period

\section{Physical Modalities Compared With Usual Care or Sham}

The magnetic mattress pads offered no intermediate-term benefit for either function or pain compared with both sham and usual care in the one parallel trial. ${ }^{140}$ The MD between groups on the 0 to 80 scale FIQ at 6 months was -5.0 (95\% CI -14.1 to 4.1 ) (versus sham) and -5.5 (95\% CI -14.4 to 3.4) (usual care). Regarding pain, the between-group differences were -0.6 (95\% CI -1.9 to 0.7$)$ and -1.0 (95\% CI -2.2 to 0.2$)$, respectively, on a 0 to 10 NRS. When the intervention groups were considered separately, only the magnetic mattress pad designed to expose the body to a uniform magnetic field of negative polarity resulted in lower FIQ and NRS 
pain scores compared with controls; however, the MDs between groups were not statistically significant.

The crossover trial ${ }^{141}$ reported statistically significant improvement in both function and pain favoring the magnetic mattress 1 month after the end of both treatment periods (i.e., over the short term); however, the evidence is considered insufficient. For patients that received magnetic therapy during the first and second (i.e. after crossing-over) treatment periods, mean FIQ scores were 19.2 and 25.1 on a $0-100$ scale, respectively, compared with 57.9 and 53.9 for those receiving sham during the same treatment periods $(\mathrm{P}<0.001$ for both). For VAS pain, respective scores were 2.2 and 3.1 versus 5.3 and 4.6 on a $0-10$ scale $(\mathrm{P}<0.001$ for both). Results were similar for both the Fibromyalgia Assessment Scale and the Health Assessment Questionnaire (Table 37).

\section{Physical Modalities Compared With Pharmacological Therapy or Exercise}

No trial of physical modality versus pharmacological therapy or versus exercise met inclusion criteria.

\section{Harms}

In the parallel trial, there were no differences in adverse events between the magnetic mattress pad and sham pad groups. ${ }^{140}$ Type of adverse events was not reported, but none of the events were judged to be due to magnetic treatments. The crossover trial only stated that no side effects were recorded during the study. ${ }^{141}$

\section{Manual Therapies for Fibromyalgia}

\section{Key Points}

- Myofascial release therapy was associated with a slightly greater effect on intermediateterm function as measured by the FIQ (mean $58.6 \pm 16.3$ vs. $64.1 \pm 18.1$ on a 100 point scale, $\mathrm{P}=0.048$ for group by repeated measures ANOVA), but not long-term function (mean $62.8 \pm 20.1$ vs. $65.0 \pm 19.8$ on the FIQ, 0-100 scale, $\mathrm{P}=0.329$ ), compared with sham in one fair-quality trial (SOE: low). Short-term function was not reported.

- There was insufficient evidence to determine the effects of myofascial release therapy on short-term pain (1 poor-quality trial) and intermediate-term pain (1 fair-quality and 1 poor-quality trial) compared with sham; there were inconsistencies in effect estimates between the intermediate-term trials (SOE: insufficient).

- Myofascial release therapy was associated with slightly greater improvement in longterm pain compared with sham based on the sensory (mean $18.2 \pm 8.3$ vs. $21.2 \pm 7.9$ on a 0 -33 scale, $\mathrm{P}=0.038$ for group by repeated measures ANOVA) and evaluative (mean 23.2 \pm 7.6 vs. $26.7 \pm 6.9$ on a $0-42$ scale, $P=0.036$ ) domains of the MPQ in one fair-quality trial; there were no differences for the affective domain of the MPQ or for VAS pain (SOE: low).

- Data were insufficient for harms; however, no adverse effect occurred in one fair-quality trial (SOE: insufficient)

\section{Detailed Synthesis}

Two trials $(n=64,94)^{155,156}$ evaluating myofascial release therapy versus sham therapy for fibromyalgia met inclusion criteria (Table 38 and Appendix D). Mean patient ages were 48 and 55 years. Baseline pain history characteristics were poorly described in both trials. The duration 
of myofascial release therapy was 20 weeks in both trials; sessions ranged in length from 60 to 90 minutes and were conducted twice or once a week, respectively. The sham conditions included short-wave and ultrasound electrotherapy or sham (disconnected) magnotherapy. Both trials reported intermediate-term outcomes; short-term and long-term outcomes were also reported by one trial each. One trial was rated fair quality and the other poor quality (Appendix E). Unclear allocation concealment methods and lack of blinding were the major methodological shortcoming in both trials. Additionally, the poor-quality trial did not describe the randomization process employed.

Table 38. Fibromyalgia: manual therapies

\begin{tabular}{|c|c|c|c|c|}
\hline $\begin{array}{l}\text { Author, Year, } \\
\text { Followup, } \\
\text { Pain Duration, } \\
\text { Study Quality }\end{array}$ & Intervention & Population & $\begin{array}{l}\text { Function and } \\
\text { Pain Outcomes }\end{array}$ & Other Outcomes \\
\hline $\begin{array}{l}\text { Castro- } \\
\text { Sanchez, } \\
2011 a^{155} \\
6 \text { and } 12 \\
\text { months } \\
\text { Duration of } \\
\text { pain, NR } \\
\text { Fair }\end{array}$ & $\begin{array}{l}\text { A. Myofascial } \\
\text { Release ( } n=47 \text { ): } \\
\text { myofascial release } \\
\text { (across } 10 \text { pain } \\
\text { regions) } \\
\text { administered by a } \\
\text { physiotherapist; } \\
60 \text { minutes } \\
\text { sessions twice } \\
\text { weekly for } 20 \\
\text { weeks } \\
\text { B. Sham short- } \\
\text { wave and } \\
\text { ultrasound } \\
\text { electrotherapy } \\
\text { ( } n=47 \text { ): both } \\
\text { applied to the } \\
\text { cervical, dorsal } \\
\text { and lumbar } \\
\text { regions using } \\
\text { disconnected } \\
\text { equipment; } 30 \\
\text { minute sessions } \\
\text { (10 minutes each } \\
\text { region), twice } \\
\text { weekly for } 20 \\
\text { weeks }\end{array}$ & $\begin{array}{l}\text { A vs. B } \\
\text { Age: } 55 \text { vs. } 54 \\
\text { years } \\
\text { Female: NR } \\
\text { Race: NR } \\
\text { Mean duration of } \\
\text { pain: NR } \\
\text { FIQ total (0-100): } \\
65.0 \text { vs. } 63.9 \\
\text { Pain (FIQ, 0-10): } \\
9.2 \text { vs. } 8.9 \\
\text { Pain (VAS, 0-10): } \\
9.1 \text { vs. } 8.9 \\
\text { MPQ sensory } \\
\text { dimension (0-33): } \\
19.3 \text { vs. } 19.9 \\
\text { MPQ affective } \\
\text { dimension (0-12): } \\
5.6 \text { vs. } 4.9 \\
\text { MPQ evaluative } \\
\text { (sensory + } \\
\text { affective) } \\
\text { dimension (0-45): } \\
24.9 \text { vs. } 25.3\end{array}$ & $\begin{array}{l}\text { A vs. B } \\
6 \text { months } \\
\text { FIQ Total: } 58.6 \text { vs. } \\
64.1, P=0.048 \\
\text { FIQ pain: } 8.5 \text { vs. } \\
\text { 8.0, } P=0.042 \\
\text { VAS pain: } 8.25 \text { vs. } \\
\text { 8.94, } P=0.043 \\
\text { MPQ sensory: } \\
17.3 \text { vs. } 20.7, \\
P=0.042 \\
\text { MPQ affective: } 4.5 \\
\text { vs. } 5.2, P=0.042 \\
\text { MPQ evaluative: } \\
21.9 \text { vs. } 26.2, \\
P=0.022 \\
12 \text { months } \\
\text { FIQ Total: } 62.8 \text { vs. } \\
65.0, P=0.329 \\
\text { FIQ pain: } 8.8 \text { vs. } \\
8.7, P=0.519 \\
\text { VAS pain: } 8.74 \text { vs. } \\
8.92, P=0.306 \\
\text { MPQ sensory: } \\
18.2 \text { vs. } 21.2, \\
P=0.038 \\
\text { MPQ affective: } 4.8 \\
\text { vs. 5.1, } P=0.232 \\
\text { MPQ evaluative: } \\
23.2 \text { vs. } 26.7, \\
P=0.036 \\
P-\text { values are from } \\
\text { authors' ANOVAb }\end{array}$ & $\begin{array}{l}\text { A vs. B } \\
6 \text { months } \\
\text { Clinical Global Impression Severity } \\
\text { Scale (Likert, } 1-7): 5.3 \text { vs. } 6.0, P=0.048 \\
\text { Clinical Global Impression Improvement } \\
\text { Scale (Likert, } 1-7): 5.6 \text { vs. } 6.3, P=0.046 \\
12 \text { months } \\
\text { Clinical Global Impression Severity } \\
\text { Scale: } 5.5 \text { vs. } 6.2 \mathrm{P}=0.147 \\
\text { Clinical Global Impression Improvement } \\
\text { Scale: } 5.8 \text { vs. } 6.5, P=0.049 \\
\text { P-values are from authors' ANOVA }\end{array}$ \\
\hline
\end{tabular}




\begin{tabular}{|c|c|c|c|c|}
\hline $\begin{array}{l}\text { Author, Year, } \\
\text { Followup, } \\
\text { Pain Duration, } \\
\text { Study Quality }\end{array}$ & Intervention & Population & $\begin{array}{l}\text { Function and } \\
\text { Pain Outcomes }\end{array}$ & Other Outcomes \\
\hline $\begin{array}{l}\text { Castro- } \\
\text { Sanchez, } \\
2011 b^{156} \\
1 \text { and } 6 \text { months } \\
\text { Duration of } \\
\text { pain, NR } \\
\text { Poor }\end{array}$ & $\begin{array}{l}\text { A. Massage- } \\
\text { Myofascial } \\
\text { Release ( } n=32 \text { ): } \\
\text { Massage- } \\
\text { Myofascial release } \\
\text { therapy (across } 18 \\
\text { pain regions) } \\
\text { administered by a } \\
\text { physiotherapist; } \\
\text { weekly } 90-\text { minute } \\
\text { session for } 20 \\
\text { weeks. } \\
\text { B. Sham } \\
\text { magnotherapy } \\
\text { ( } \mathrm{n}=32 \text { ): weekly } 30- \\
\text { minute session of } \\
\text { disconnected } \\
\text { magnotherapy } \\
\text { (applied on } \\
\text { cervical and } \\
\text { lumbar area for } 15 \\
\text { minutes each) for } \\
20 \text { weeks. }\end{array}$ & $\begin{array}{l}\text { A vs. B } \\
\text { Age: } 49 \text { vs. } 46 \\
\text { years } \\
\text { Female: } 94 \% \text { vs. } \\
96 \% \\
\text { Race: NR } \\
\text { Mean duration of } \\
\text { pain: NR } \\
\text { Pain Intensity } \\
\text { (VAS, 0-10)c: } 9.1 \\
\text { vs. } 9.6\end{array}$ & $\begin{array}{l}\text { A vs. B } \\
\frac{1 \text { month }}{\text { VAS painc: } 8.4 \text { vs. }} \\
9.4, P<0.043 \\
\frac{6 \text { months }}{\text { VAS painc: } 8.8 \text { vs. }} \\
9.7, P=N S \\
\text { P-values are from } \\
\text { authors' ANOVA }\end{array}$ & 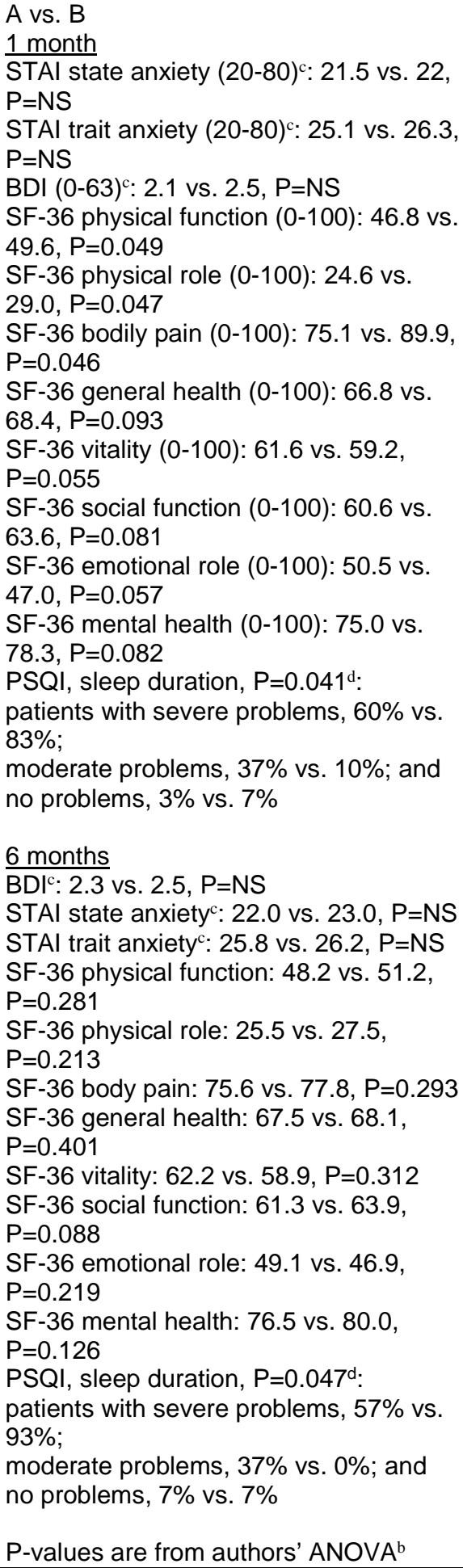 \\
\hline
\end{tabular}

ANOVA = repeated-measures analysis of variance; BDI = Beck Depression Inventory; FIQ = Fibromyalgia Impact Questionnaire; MPQ = McGill Pain Questionnaire; NR = not reported; NS = not statistically significant; PSQI = Pittsburgh sleep quality index; SF-36 = Short-Form 36 health questionnaire; STAI = State-Trait Anxiety Inventory; VAS = visual analog scale ${ }^{a}$ Unless otherwise noted, followup time is calculated from the end of the treatment period 
${ }^{\mathrm{b}}$ Changes in scores were analyzed by using a 2 (groups: experimental and placebo) X 4 (time points: baseline, immediately postintervention, at 1 and 6 months) repeated-measures analysis of variance

${ }^{c}$ Values estimated from figures in the article.

${ }^{\mathrm{d}}$ For all other dimensions of the PSQI (subjective sleep quality, sleep latency, habitual sleep efficiency, sleep disturbance, daily dysfunction), there were no statistically significant difference between groups in the proportion of patients experiencing severe, moderate or no problems in the authors' analysis of variance (ANOVA).

\section{Myofascial Release Therapy Compared With Sham}

Myofascial release therapy was associated with a slightly greater effect on intermediate-term function compared with sham as measured by the FIQ (58.6 \pm 16.3 vs. $64.1 \pm 18.1$ on a 100 point scale, $\mathrm{P}=0.048$ for group by time repeated measures ANOVA) in one fair-quality trial ${ }^{155}$; this effect did not persist to the long term (62.8 \pm 20.1 vs. $65.0 \pm 19.8, \mathrm{P}=0.329$, at 12 months). Function was not reported over the short term.

Regarding pain outcomes, one poor-quality trial reported a small effect for myofascial release compared with sham therapy over the short term (8.4 vs. 9.4 on a $0-10$ VAS at 1 month, $\mathrm{P}=0.048$ for group by time repeated measures ANOVA). ${ }^{156}$ Intermediate-term results were inconsistent across the trials as measured on a 0 to 10 VAS pain scale with one fair-quality trial reporting a slightly greater effect for myofascial release versus sham $(8.25 \pm 1.13$ vs. $8.94 \pm 1.34$, $\mathrm{P}=0.043)^{155}$ at 6 months and the other (poor quality) reporting no significant difference between groups (8.8 vs. 9.7, $\mathrm{P}=$ not significant) (Figure 43). ${ }^{156}$ Additional pain measures were reported over the intermediate-term by the fair-quality trial, all of which showed a small benefit in favor of myofascial release: FIQ pain $(8.5 \pm 0.7$ vs. $8.0 \pm 1.3, \mathrm{P}=0.042$ for group by time repeated measures ANOVA) and the McGill Pain Questionnaire (MPQ) sensory (17.3 \pm 7.8 vs. $20.7 \pm 7.1$ on a 0 -33 scale, $\mathrm{P}=0.04)$, affective ( $4.5 \pm 2.9$ vs. $5.2 \pm 3.8$ on a $0-12$ scale, $\mathrm{P}=0.04)$ and evaluative ( $21.9 \pm 7.2$ vs. $26.2 \pm 6.8$ on a $0-42$ scale, $\mathrm{P}=0.02$ ) dimensions. ${ }^{155}$ This effect persisted at long-term followup for the sensory and evaluative dimension of the MPQ only; no differences were seen between groups regarding VAS pain of the affective dimension of the MPQ at long term following in this trial (Table 38).

Depression, anxiety, and sleep outcomes were evaluated in one poor-quality trial, with significant improvement seen in the myofascial release versus the sham group on some subscales of the Short-Form-36 and on the sleep duration subscale of the Pittsburgh Sleep Quality Index (PSQI) over the short-term, ${ }^{156}$ but no differences between groups on the STAI or Beck Depression Index (Table 38); at intermediate followup, only PSQI sleep duration remained significantly improved following myofascial release versus sham.

\section{Manual Therapy Compared With Pharmacological Therapy or Exercise}

No trial of manual therapy versus pharmacological therapy or versus exercise met inclusion criteria.

\section{Harms}

In one trial, no patient experienced an adverse effect (details not reported). ${ }^{155}$ There was no information on harms reported by the other trial. 
Figure 43. Myofascial release versus sham for fibromyalgia: effects on pain

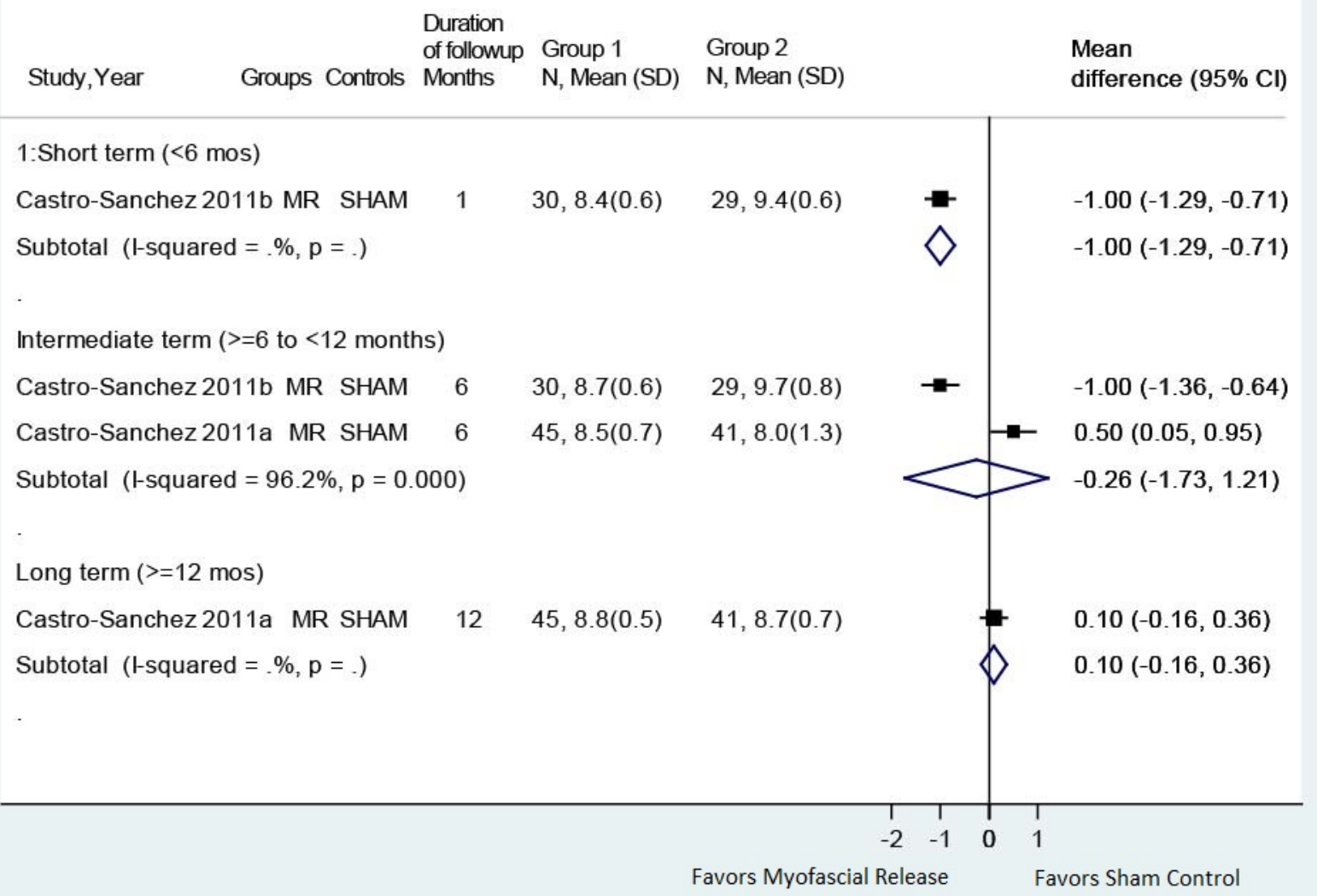

$\mathrm{CI}=$ confidence interval; $\mathrm{MR}=$ myofascial release; $\mathrm{SD}=$ standard deviation

\section{Mindfulness-Based Stress Reduction Therapy for Fibromyalgia}

\section{Key Points}

- No clear short-term effects of mindfulness-based stress reduction (MBSR) were seen on function compared with waitlist or attention control (MD 0 to 0.06 on a 0-10 scale) in two trials (one fair and one poor quality) (SOE: moderate).

- No clear short-term effects of MBSR on pain (MD 0.1 on a 0-100 VAS pain scale in one poor quality trial; $\mathrm{MD}-1.38$ to -1.59 on the affective and -0.28 to -0.71 on the sensory dimension [scales not reported] of the Pain Perception Scale in one fair-quality trial) compared with waitlist or attention control in two trials (SOE: moderate). Intermediateterm and long-term outcomes were not reported.

- No trial of MBSR versus pharmacological therapy or versus exercise met inclusion criteria.

- Harms were not reported.

\section{Detailed Synthesis}

We identified two trials (3 publications) of mindfulness-based stress reduction (MBSR) for fibromyalgia that met inclusion criteria (Table 39 and Appendix D). ${ }^{170-172}$ One study was conducted in the United States ${ }^{170,172}$ and the other in Germany. ${ }^{171}$ In both trials, MBSR was modeled after the program developed by Kabat-Zinn. The intervention lasted 8 weeks, with 
weekly 2.5-hour sessions, daily homework assignments, and a single 7-hour session. Sample sizes ranged from 91 to 177, age ranged from 48 to 53 years, and all participants were female. Both studies compared MBSR versus waitlist control; the German study ${ }^{171}$ also compared MBSR to an attention control group that consisted of education, relaxation, and stretching. Both studies reported only short-term outcomes.

One study was considered fair quality ${ }^{171}$ and the other was considered poor quality ${ }^{170,172}$ (Appendix E). Methodological shortcomings in both studies were the lack of long-term followup and the inability to blind patients and providers. The poor-quality study also had a high rate of overall attrition as well as differential attrition between the groups.

Table 39. Fibromyalgia: mindfulness-based stress reduction therapy

\begin{tabular}{|c|c|c|c|c|}
\hline $\begin{array}{l}\text { Author, Year, } \\
\text { Followup, } \\
\text { Pain Duration, } \\
\text { Study Quality }\end{array}$ & Intervention & Population & $\begin{array}{l}\text { Function and Pain } \\
\text { Outcomes }\end{array}$ & Other Outcomes \\
\hline $\begin{array}{l}\text { Cash } 2015,{ }^{170} \\
\text { Sephton } \\
2007^{172, b} \\
2 \text { months } \\
\text { Duration of pain } \\
\text { NR } \\
\text { Poor }\end{array}$ & $\begin{array}{l}\text { A. Mindfulness-based } \\
\text { Stress Reduction } \\
\text { (n=51) } \\
\text { 8-week group-based } \\
\text { program with one } 2.5 \\
\text { hour session/week } \\
\text { including instruction in } \\
\text { techniques, meditation, } \\
\text { and simple yoga } \\
\text { positions to encourage } \\
\text { relaxation. Participants } \\
\text { were asked to } \\
\text { complete daily } \\
\text { practices with } \\
\text { workbook and } \\
\text { audiotapes for } 45 \text { min } \\
\text { a day for } 6 \text { days a } \\
\text { week. } \\
\text { B. Waitlist control } \\
\text { group (n=39) } \\
\text { Participants were } \\
\text { offered the intervention } \\
\text { program only after the } \\
\text { conclusion of the study } \\
\text { and followup. }\end{array}$ & $\begin{array}{l}\text { A vs. B } \\
\text { Age: } 48 \text { vs. } 48 \\
\text { years } \\
\text { Female: } 100 \% \text { vs. } \\
100 \% \\
\text { Caucasian: } 94 \% \\
\text { vs. } 93 \% \\
\text { FIQ Physical } \\
\text { Functioning (0-10): } \\
1.3 \text { vs. } 1.2 \\
\text { Pain VAS (0-100): } \\
68.1 \text { vs. } 69.2 \\
\text { FIQ Severity (0- } \\
100) \text { c: } 67.5 \text { vs. } \\
62.5\end{array}$ & $\begin{array}{l}\text { A vs. B } \\
2 \text { months: } \\
\text { FIQ Physical } \\
\text { Functioning: } 1.2 \text { vs. } \\
\text { 1.2; difference } 0.0 \\
\text { (95\% Cl }-0.32 \text { to } \\
0.32) \\
\text { Pain VAS: } 65.2 \text { vs. } \\
65.1 ; \text { difference } 0.1 \\
\text { (95\% Cl }-9.96 \text { to } \\
10.16) \\
\text { FIQ Severityc: } 62.0 \\
\text { vs. } 66.7 ; \text { difference } \\
-4.7 \text { (95\% Cl - } \\
12.24 \text { to } 2.84)\end{array}$ & 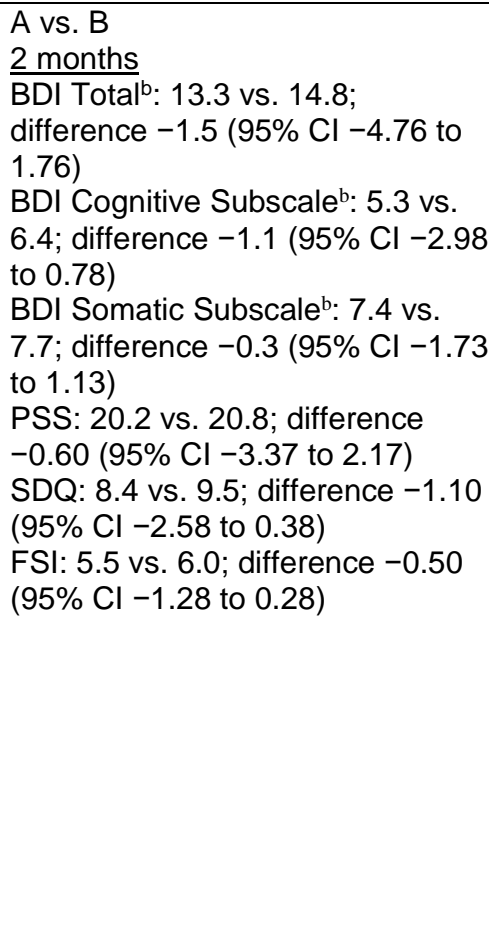 \\
\hline
\end{tabular}




\begin{tabular}{|c|c|c|c|c|}
\hline $\begin{array}{l}\text { Author, Year, } \\
\text { Followup, } \\
\text { Pain Duration, } \\
\text { Study Quality }\end{array}$ & Intervention & Population & $\begin{array}{l}\text { Function and Pain } \\
\text { Outcomes }\end{array}$ & Other Outcomes \\
\hline $\begin{array}{l}\text { Schmidt, } \\
2011^{171} \\
2 \text { months } \\
\text { Duration of } \\
\text { fibromyalgia, } \\
\text { years: } 14 \text { years } \\
\text { Fair }\end{array}$ & $\begin{array}{l}\text { A. Mindfulness-based } \\
\text { Stress Reduction } \\
\text { (n=53) } \\
\text { 8-week group-based } \\
\text { program with one } 2.5 \\
\text { hour session/week and } \\
\text { one } 7 \text { hour all-day } \\
\text { session covering } \\
\text { training in specific } \\
\text { exercises and topics of } \\
\text { mindfulness practices. } \\
\text { Participants were } \\
\text { asked to complete } \\
\text { daily practices of } 45-60 \\
\text { minutes each } \\
\text { B. Active-control } \\
\text { Intervention (n=56) } \\
\text { Controlled for } \\
\text { nonspecific aspects of } \\
\text { the MBSR program } \\
\text { with similar meeting } \\
\text { structure and format to } \\
\text { MBSR treatment arm. } \\
\text { Equivalent levels of } \\
\text { social support and } \\
\text { weekly topical } \\
\text { education was } \\
\text { provided along with } \\
\text { Jacobson Progressive } \\
\text { Muscle Relaxation } \\
\text { training and } \\
\text { fibromyalgia-specific } \\
\text { gentle stretching } \\
\text { exercises. Participants } \\
\text { were asked to } \\
\text { complete daily } \\
\text { homework } \\
\text { assignments with the } \\
\text { same duration as } \\
\text { MBSR group. } \\
\text { C. Waitlist (n=59) } \\
\text { Received no active } \\
\text { treatment but were } \\
\text { intervention at the } \\
\text { conclusion of the } \\
\text { followup period. }\end{array}$ & $\begin{array}{l}\text { A vs. B vs. C } \\
\text { Age: } 53 \text { vs. } 52 \\
\text { years } \\
\text { Female: } 100 \% \text { (all } \\
\text { female study) } \\
\text { Race: NR } \\
\text { A vs. C } \\
\text { FIQ Total (0-10): } \\
5.8 \text { vs. } 5.7 ; \\
\text { PPS Affective } \\
\text { (scale unclear): } \\
35.5 \text { vs. } 34.8 \\
\text { PPS Sensory } \\
\text { (scale unclear): } \\
22.4 \text { vs. } 22.6\end{array}$ & 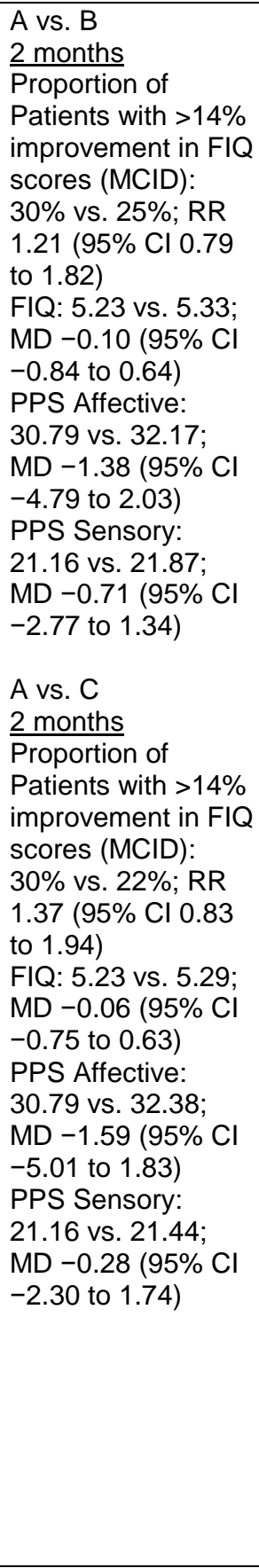 & 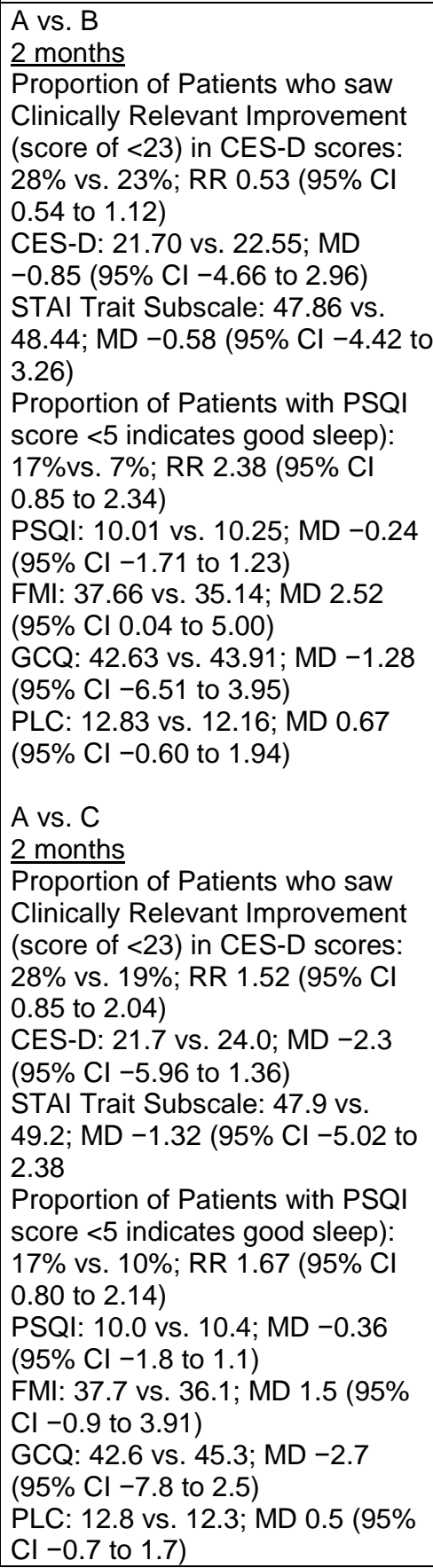 \\
\hline
\end{tabular}

BDI = Beck Depression Inventory; CES-D = Center for Epidemiological Studies Depression Scale; CI = confidence interval; FSI= Fatigue Symptom Inventory; FIQ = Fibromyalgia Impact Questionnaire; FMI = Freiburg Mindfulness Inventory; GCQ = Giessen Complaint Questionnaire; MCID = minimal clinically important difference; MD = mean difference; PLC = Profile for the Chronically Ill; PPS = Pain Perception Scale; PSQI = Pittsburgh Sleep Quality Index; PSS = Perceived Stress Scale; RR = risk ratio; SDQ $=$ Stanford Sleep Disorders Questionnaire; STAI = State-Trait-Anxiety-Inventory; VAS = visual analog scale a Unless otherwise noted, followup time is calculated from the end of the treatment period

${ }^{\mathrm{b}}$ Sephton is the same population as Cash 2015 but the focus of the study was on depression (Beck Depression Inventory).

${ }^{\text {c }}$ FIQ symptom severity is comprised of visual analog ratings of pain, fatigue, morning sleepiness, stiffness, anxiety, and depression 


\section{Mindfulness-Based Stress Reduction Therapy Compared With Waitlist or Attention Control}

There were no clear short-term effects of MBSR on any function or pain measure reported compared with waitlist or attention control. Both trials compared MBSR to waitlist and reported function using the FIQ, one reporting the physical function subscale (difference 0 on a 0-10 scale, $95 \%$ CI -0.32 to 0.32$)^{170}$ and the other reporting the total score (difference -0.06 on a $0-10$ scale, $95 \%$ CI -0.75 to 0.63$).{ }^{171}$ The latter fair-quality trial also reported the proportion of patients who achieved a 14percent or greater improvement in FIQ total scores: 30 percent versus 22 percent, RR 1.37 (95\% CI 0.83 to 1.94). ${ }^{171}$ Regarding pain, one trial reported a MD 0.1 (95\% CI -9.96 to 10.16 ) on a 0 to 100 VAS pain scale ${ }^{170}$ between the MBSR and waitlist groups, while the other reported pain using the affective (difference $-1.59,95 \%$ CI -5.01 to 1.83 ) and sensory (difference $-0.28,95 \%$ CI -2.30 to 1.74 ) domains of the Pain Perception Scale (scale not reported). ${ }^{171}$ Estimates for function and pain were similar for the comparison of MBSR versus attention control in the fair-quality trial ${ }^{171}$ (Table 39).

Secondary outcomes (measures of depression, anxiety, sleep, fatigue) did not differ significantly between MBSR and waitlist or attention control in either trial ${ }^{170-172}$ (Table 39). The fair-quality trial compared medication use (analgesics, anti-depressants, and sleep medication) between baseline and short-term followup; only antidepressant medication was reduced significantly from baseline ( $46 \%$ to $35 \%, \mathrm{P}=0.01$ ) but there was no group effect (data not reported). ${ }^{171}$

\section{Mindfulness-Based Stress Reduction Therapy Compared With Pharmacological Therapy or Exercise}

No trial of MBSR versus pharmacological therapy or versus exercise met inclusion criteria.

\section{Harms}

Neither trial reported harms.

\section{Mind-Body Therapy for Fibromyalgia}

\section{Key Points}

- Over the short-term, two trials of mind-body practices reported slight improvement in function for qigong compared with waitlist (MD -7.5, 95\% CI -13.3 to -1.68) and for tai chi compared with attention control (MD -23.5, 95\% CI -30 to -17) based on 0 to 100 scale total FIQ score; heterogeneity may be explained by duration and intensity of intervention and control condition. Significantly more participants in the tai chi group also showed clinically meaningful improvement on total FIQ (RR 1.6, 95\% CI 1.1 to 2.3) consistent with a slight effect (SOE: low).

- Qigong and tai chi were associated with moderately greater improvement in pain (0-10 scale) compared with waitlist and attention control in the short term (2 trials, pooled MD $-1.54,95 \%$ CI $-2.67,-0.41, I^{2}=75 \%$ ). Significantly more participants in the tai chi group also showed clinically meaningful improvement on VAS pain (RR 2.0, 95\% CI 1.1 to 3.8) consistent with a slight effect (SOE: low).

- No evidence in the intermediate or long term.

- Data for harms were insufficient. However, one trial reported two adverse events (in two patients) judged to be possibly related to qigong practice: an increase in shoulder pain 
and plantar fasciitis; neither participant withdrew from the study. In the trial of tai chi, no adverse events were reported. (SOE: insufficient)

\section{Detailed Synthesis}

Two trials ${ }^{183,184}$ that evaluated mind-body therapies for fibromyalgia met inclusion criteria (Table 40 and Appendix D). Across trials, the participants were predominately female ( $87 \%$ to 96\%), with mean ages between 51 to 52 years. Prior to study enrollment, participants in both trials were being treated with several drugs from major analgesic and adjuvant drug groups such as analgesics/NSAIDs (53\% to $73 \%$ ), antidepressants (35\% to $48 \%$ ), and anticonvulsants ( $21 \%$ to $27 \%$ ); in one trial, approximately 30 percent of participants were taking opioids and many participants had tried a variety of other therapies (including acupuncture, chiropractic, naturopathic/homeopathic/osteopathic therapies, massage therapy, and psychological therapies). ${ }^{183}$

One trial compared qigong ( 3 consecutive half-day training sessions, then weekly practice/review sessions for 8 weeks plus daily at-home practice for 45 to 60 minutes) to a waiting list control condition. ${ }^{183}$ The other trial compared tai chi (60-minute sessions twice per week for 12 weeks) to an attention control condition (40 minutes of wellness education and 20 minutes of supervised stretching exercises) ${ }^{184}$ In both trials, patients were instructed to continue the practice at home throughout the followup period. In the tai chi study, the average percent of sessions attended during the 12-week intervention was 77 percent for the tai chi group and 70 percent for the control group. ${ }^{184}$ In the qigong trial, the mean self-reported practice time per week for all participants who completed the trial was 4.9 hours at 2 months, 2.9 hours at 4 months, and 2.7 hours at 6 months. ${ }^{183}$

Both trials were rated fair quality (Appendix E). Due to the nature of the intervention and control groups, blinding was not possible in the two studies. Other methodological concerns included differential attrition between groups in the qigong trial (qigong 19\% vs. waitlist $4 \%$ at 6 months). ${ }^{183}$ 
Table 40. Fibromyalgia: mind-body therapies

\begin{tabular}{|c|c|c|c|c|}
\hline $\begin{array}{l}\text { Author, } \\
\text { Year, } \\
\text { Followup, } \\
\text { Pain } \\
\text { Duration, } \\
\text { Study } \\
\text { Quality }\end{array}$ & Intervention & Population & $\begin{array}{l}\text { Function and Pain } \\
\text { Outcomes }\end{array}$ & Other Outcomes \\
\hline $\begin{array}{l}\text { Lynch, } \\
2012^{183} \\
(\mathrm{~N}=100) \\
4 \text { months } \\
\text { Duration of } \\
\text { fibromyalgia, } \\
\text { mean: } 9.6 \\
\text { years } \\
\text { Fair }\end{array}$ & $\begin{array}{l}\text { A. Qigong ( } n=53) \\
\text { Chaoyi Fanhuan } \\
\text { Qigong; } \\
\text { Three consecutive half- } \\
\text { day training sessions } \\
\text { then weekly } \\
\text { practice/review sessions } \\
\text { for } 8 \text { weeks plus daily at- } \\
\text { home practice for } 45 \text { to } \\
60 \text { minutes. } \\
\text { B. Waitlist ( } n=47) \\
\text { Continued with usual } \\
\text { care; offered qigong } \\
\text { after the trial ended }\end{array}$ & $\begin{array}{l}\text { A vs. B } \\
\text { Age: } 53 \text { vs. } 52 \text { years } \\
\text { Female: } 94 \% \text { vs. } 98 \% \\
\text { Previous opioid therapy: } \\
42 \% \text { vs. } 30 \% \\
\text { Current opioid therapy: } \\
36 \% \text { vs. } 23 \% \\
\text { Current NSAID therapy: } \\
49 \% \text { vs. } 57 \% \\
\text { FIQ (0-100): } 65.5 \text { vs. } 61.8 \\
\text { NRS pain (0-10): } 6.5 \text { vs. } \\
6.6 \\
\text { SF-36 PCS (0-100): } 30.0 \\
\text { vs. } 32.6 \\
\text { SF-36 MCS (0-100): } 38.1 \\
\text { vs. } 40.4 \\
\text { PSQI (0-21): } 13.8 \text { vs. } 13.1\end{array}$ & $\begin{array}{l}\text { A vs. B } \\
4 \text { months } \\
\text { Mean change from } \\
\text { baseline: } \\
\text { FIQ: }-16.1 \text { vs. }-4.8 ; \\
\text { difference }-11.3(95 \% \\
\mathrm{Cl}-19.3 \text { to }-3.3) \\
\mathrm{NRS} \text { pain: }-1.21 \text { vs. } \\
-0.27 \text {; difference }-0.9 \\
(95 \% \mathrm{Cl}-1.7 \text { to }-0.1)\end{array}$ & $\begin{array}{l}\text { A vs. B } \\
4 \text { months } \\
\text { Mean change from } \\
\text { baseline: } \\
\text { SF-36 PCS: } 4.6 \text { vs. } \\
0.2 ; \text { difference } 4.4 \\
\text { (95\% Cl } 1.5 \text { to } 7.3) \\
\text { SF-36 MCS: } 4.4 \text { vs. } \\
0.7 ; \text { difference } 3.7 \\
\text { (95\% Cl }-0.3 \text { to } 7.7) \\
\text { PSQI: }-3.3 \text { vs. }-1.1 ; \\
\text { difference }-2.2(95 \% \\
\text { Cl -3.6 to }-0.8)\end{array}$ \\
\hline $\begin{array}{l}\text { Wang, } \\
2010^{184} \\
(\mathrm{~N}=66) \\
3 \text { months } \\
\text { Duration of } \\
\text { fibromyalgia } \\
\text { pain: } 11 \\
\text { years } \\
\text { Fair }\end{array}$ & $\begin{array}{l}\text { A. Tai chi ( } n=33 \text { ) } \\
\text { Classic Yang style tai } \\
\text { chi; at home practice for } \\
\text { at least } 20 \text { minutes a } \\
\text { day; encouraged to } \\
\text { maintain tai chi practice } \\
\text { using an instructional } \\
\text { video. } \\
\text { B. Attention control } \\
\frac{\text { (n=33) }}{40 \text { minutes of education }} \\
\text { then } 20 \text { minutes of } \\
\text { supervised stretching } \\
\text { (upper body, trunk, and } \\
\text { lower body); plus } 20 \\
\text { minutes of daily at-home } \\
\text { stretching } \\
\text { Both groups had } 60- \\
\text { minute sessions twice a } \\
\text { week for } 12 \text { weeks and } \\
\text { continued regular } \\
\text { medications and routine } \\
\text { activities. }\end{array}$ & $\begin{array}{l}\text { A vs. B } \\
\text { Age: } 50 \text { vs. } 51 \text { years } \\
\text { Female: } 85 \% \text { vs. } 88 \% \\
\text { Analgesic use: } 88 \% \text { vs. } \\
73 \% \\
\text { FIQ (0-100): } 62.9 \text { vs. } 68.0 \\
\text { VAS pain (0-10): } 5.8 \text { vs. } \\
6.3 \\
\text { CES-D (0-60): } 22.6 \text { vs. } \\
27.8 \\
\text { SF-36 PCS (0-100): } 28.5 \\
\text { vs. } 28.0 \\
\text { SF-36 MCS (0-100): } 42.6 \\
\text { vs. } 37.8 \\
\text { PSQI (0-21): } 13.9 \text { vs. } 13.5\end{array}$ & $\begin{array}{l}\text { A vs. B } \\
3 \text { months } \\
\text { Proportion with } \\
\text { clinically meaningful } \\
\text { improvement: } \\
\text { FIQb: } 81.8 \% \text { vs. } \\
51.5 \% \text {; RR } 1.6 \text { (95\% } \\
\text { CI } 1.1 \text { to } 2.3 \text { ) } \\
\text { VAS painc: } 54.5 \% \text { vs. } \\
27.3 \% \text {; RR } 2.0 \text { (95\% } \\
\text { CI } 1.1 \text { to } 3.8) \\
\text { Mean change from } \\
\text { baseline: FIQ: }-28.6 \\
\text { vs. }-10.2 ; \text { difference } \\
-18.3 \text { (95\% Cl }-27.1 \\
\text { to }-9.6) \\
\text { VAS pain: }-2.4 \text { vs. } \\
-0.7 ; \text { difference }-1.7 \\
\text { (95\% CI }-2.7 \text { to }-0.8)\end{array}$ & 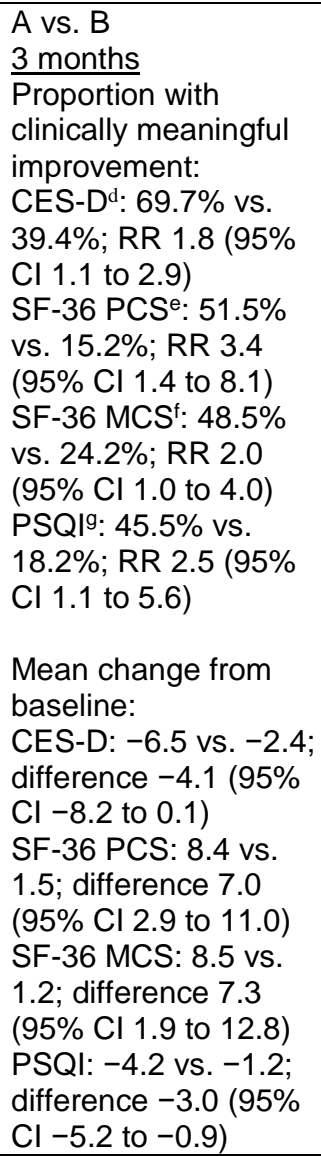 \\
\hline
\end{tabular}

CES-D = Center for Epidemiologic Studies Depression index; CI = confidence interval; FIQ = Fibromyalgia Impact Questionnaire; NRS = numeric rating scale; NSAIDs = nonsteroidal anti-inflammatory drugs; PSQI = Pittsburgh Sleep Quality Index; RR = risk ratio; SF-36 MCS = Short-Form-36 Mental Component Summary; SF-36 PCS = Short-Form-36 Physical Component Summary; VAS = visual analog scale 
${ }^{a}$ Unless otherwise noted, followup time is calculated from the end of the treatment period

${ }^{b}$ A reduction of $\geq 8.1$ points from baseline on the FIQ was considered a clinically meaningful improvement

${ }^{c}$ A reduction of $\geq 2$ points from baseline on the VAS was considered a clinically meaningful improvement

${ }^{d}$ A reduction of $\geq 6$ points from baseline on the CES-D was considered a clinically meaningful improvement

e An increase of $\geq 6.5$ points from baseline on the SF-36 PCS was considered a clinically meaningful improvement

${ }^{\mathrm{f}}$ An increase of $\geq 7.9$ points from baseline on the SF-36 MCS was considered a clinically meaningful improvement

${ }^{g}$ A reduction of $>5$ points from baseline on the PSQI was considered a clinically meaningful improvement

\section{Mind-Body Therapies Compared With Waitlist or Attention Control}

Short-term improvement in function on 0 to 100 scale total FIQ score was reported for qigong (slight improvement, $\mathrm{MD}-7.5,95 \% \mathrm{CI}-13.3$ to -1.68$)^{183}$ and for tai chi (substantial improvement, MD $-23.5,95 \%$ CI -30 to -17$)^{184}$ compared with waitlist or attention control. Substantial heterogeneity ( $\mathrm{I}^{2}=92 \%$ ), precluded meaningful pooling for this outcome (Figure 44 ). Significantly more participants in the tai chi group also showed clinically meaningful improvement (reduction of $\geq 8.1$ points from baseline) on total FIQ (RR 1.6, 95\% CI 1.1 to 2.3) consistent with a slight effect. Tai chi and qigong were associated with a moderate improvement in pain (0 to 10 scale) compared with wait list or attention control (2 trials, pooled difference $-1.54,95 \%$ CI -2.67 to $-0.41, \mathrm{I}^{2}=75 \%$ ) (Figure 45 ). Significantly more participants in the tai chi group also showed clinically meaningful improvement (reduction of $\geq 2$ points from baseline) in VAS pain (RR 2.0, 95\% CI 1.1 to 3.8) consistent with a slight effect. Heterogeneity may in part be due to differences in duration and intensity of the intervention.

Mind-body therapy resulted in significant improvement in most secondary outcomes measured. Participants who received tai chi group showed clinically meaningful improvement in depressive symptoms as measured by the Center for Epidemiological Studies-Depression scale (RR 1.8, 95\% CI 1.1 to 2.9), in sleep quality as measured by the Pittsburg Sleep Quality Index (PSQI) (RR 2.5, 95\% CI 1.1 to 5.6), and in quality of life as measured by the SF-36 PCS (RR 3.4, 95\% CI 1.4 to 8.1) and MCS (RR 2.0, 95\% CI 1.0 to 4.0) compared with controls; similar results were seen for mean followup scores on these measures (Table 40). ${ }^{184}$ In the second trial, ${ }^{183}$ compared to a waitlist control, qigong resulted in significantly improved quality of life as measured by the SF-36 PCS (difference in change from baseline 4.4, 95\% CI 1.5 to 7.3) and in sleep quality as measured by the PSQI (difference in change from baseline -2.2, 95\% CI -3.6 to -0.8). The change in SF-36 MCS scores did not differ between groups.

\section{Mind-Body Therapies Compared With Pharmacological Therapy or Exercise}

No trials comparing mind-body therapies with pharmacological therapy or with exercise met inclusion criteria.

\section{Harms}

In the trial of qigong, ${ }^{183}$ there were two adverse events judged to be possibly related to the practice. One participant reported an increase in shoulder pain and another experienced plantar fasciitis; neither participant withdrew from the study. In the trial of tai chi, no adverse events were reported. ${ }^{184}$ 
Figure 44. Mind-body therapies for fibromyalgia: effects on function

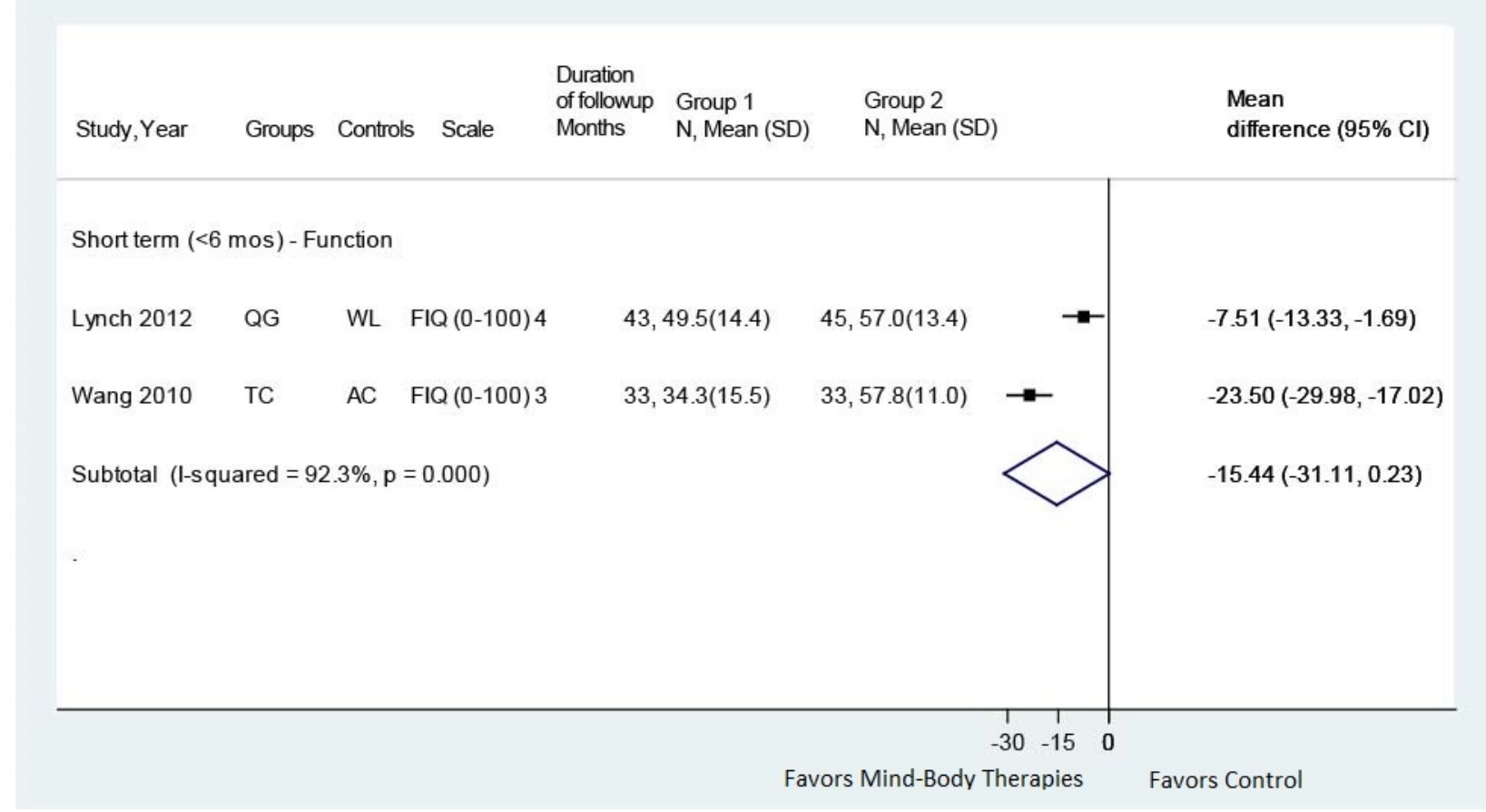

AC = attention control; CI = confidence interval; FIQ = Fibromyalgia Impact Questionnaire; QG = qigong; SD = standard deviation; $\mathrm{TC}=$ tai chi; $\mathrm{WL}=$ waitlist 
Figure 45. Mind-body therapies for fibromyalgia: effects on pain

$\begin{array}{lllll} & & \text { Duration } & & \text { Mean } \\ \text { Study, Year Groups Controls Scale } & \text { of followup Group 1 } & \text { Group 2 } & \text { difference (95\% Cl) }\end{array}$

\begin{tabular}{|c|c|c|c|c|c|}
\hline \multicolumn{6}{|c|}{ Short term ( $<6 \mathrm{mos})$ - Pain } \\
\hline Lynch 2012 & QG & mL & NRS (0-10) 4 & $43,5.2(1.5)$ & $45,6.3(1.1)$ \\
\hline Vang 2010 & TC & $A C$ & NRS (0-10) 3 & $33.3 .4(2.3)$ & $33,5.6(1.8)$ \\
\hline
\end{tabular}

Subtotal (I-squared $=75.3 \%, \mathrm{p}=0.044)$
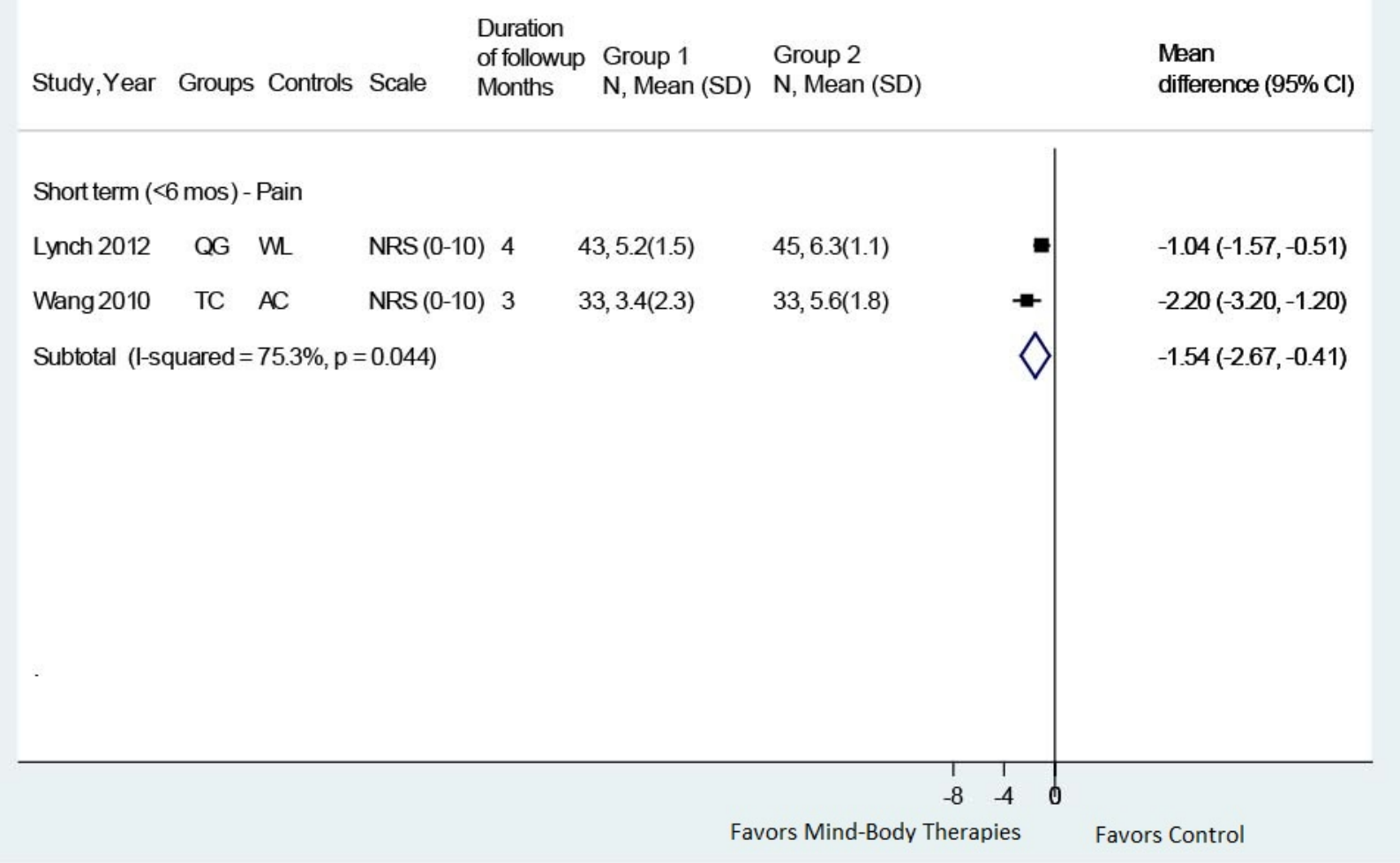

$\mathrm{AC}=$ attention control; $\mathrm{CI}$ = confidence interval; $\mathrm{QG}=$ qigong; $\mathrm{SD}$ = standard deviation; $\mathrm{TC}$ = tai chi; $\mathrm{WL}$ = waitlist

\section{Acupuncture for Fibromyalgia}

\section{Key Points}

- Acupuncture was associated with slightly greater improvements in function based on 0 to 100 FIQ Total Score compared with sham acupuncture in the short term (2 trials, pooled MD -8.63 , 95\% CI -12.12 to $-5.13, \mathrm{I}^{2}=0 \%$ ) and intermediate term ( 2 trials, pooled MD $-9.41,95 \%$ CI -13.96 to $-4.85, \mathrm{I}^{2}=27.4 \%$ ) (SOE: moderate).

- There was no clear effect of acupuncture on pain (0 to 10 scale) versus sham acupuncture in the short term ( 3 trials, pooled MD $-0.13,95 \% \mathrm{CI}-1.06$ to $0.79, \mathrm{I}^{2}=72 \%$ ) or intermediate term ( 3 trials, pooled MD -0.53 , 95\% CI -1.15 to 0.09 , $\mathrm{I}^{2}=45.5 \%$ ) (SOE: low).

- No data on long-term effects were reported.

- Discomfort and bruising were the most common adverse events. Discomfort was substantially more common for acupuncture or sham needling (61\% to 70\%) compared with simulated acupuncture (29\%). Vasovagal symptoms and aggravation of fibromyalgia symptoms were less common (4\%, 2.5 of sessions) (SOE: moderate). 


\section{Detailed Synthesis}

Three trials of acupuncture for fibromyalgia were identified that met inclusion criteria; one was conducted in Spain ${ }^{213}$ and two were conducted in the United States ${ }^{211,212}$ (Table 41 and Appendix D). Two trials evaluated traditional Chinese needle acupuncture ${ }^{211,213}$ and the third evaluated acupuncture with electrical stimulation. ${ }^{212}$ All three studies compared acupuncture to sham. One study ${ }^{211}$ employed three different types of sham treatments (needling for an unrelated condition, sham needling, and simulated acupuncture), one used sham needling ${ }^{212}$ and one used simulated acupuncture. ${ }^{213}$ Sample sizes ranged from 50 to 164 (total sample=314), mean ages from 47 to 53 years, and the proportion of females ranged from 95 percent to 100 percent. The duration of acupuncture treatment ranged from 3 to 12 weeks, with the total number of sessions ranging from six to 24 . All studies reported short-term and intermediate-term outcomes; no trial had long-term followup.

All three studies were considered good quality (Appendix E). Limitations of all studies were lack of long-term followup and that the person administering acupuncture was not blinded to treatment allocation.

Table 41. Fibromyalgia: acupuncture

\begin{tabular}{|c|c|c|c|c|}
\hline $\begin{array}{l}\text { Author, } \\
\text { Year, } \\
\text { Followup, } \\
\text { Pain } \\
\text { Duration, } \\
\text { Study } \\
\text { Quality }\end{array}$ & Intervention & Population & $\begin{array}{l}\text { Function and Pain } \\
\text { Outcomes }\end{array}$ & Other Outcomes \\
\hline $\begin{array}{l}\text { Assefi, } \\
2005^{211} \\
3 \text { and } 6 \\
\text { months } \\
\text { Mean } \\
\text { duration of } \\
\text { pain: } 9 \text { to } 12 \\
\text { years } \\
\text { Good }\end{array}$ & 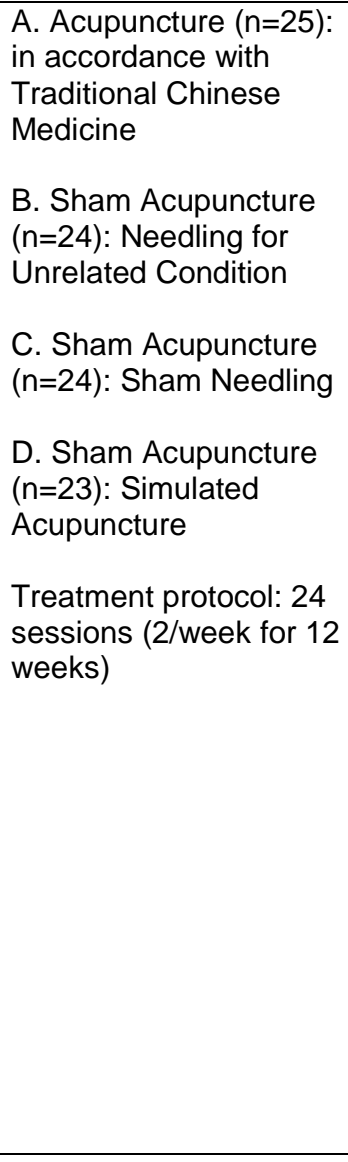 & $\begin{array}{l}\text { A vs. B vs. C vs. } \\
\text { D } \\
\text { Mean age: } 46 \\
\text { vs. } 46 \text { vs. } 49 \text { vs. } \\
48 \text { years } \\
\text { Female: } 88 \% \text { vs. } \\
96 \% \text { vs. } 100 \% \\
\text { vs. } 96 \% \\
\text { Race (white): } \\
96 \% \text { vs. } 88 \% \text { vs. } \\
96 \% \text { vs. } 92 \% \\
\text { Mean duration of } \\
\text { pain: } 12 \text { vs. } 9 \text { vs. } \\
9 \text { vs. } 10 \text { years } \\
\text { Pain Intensity } \\
\text { VAS (0-10): } 7.0 \\
\text { vs. } 6.9 \text { vs. } 6.8 \\
\text { vs. } 7.3\end{array}$ & $\begin{array}{l}\text { A. vs. B vs. C vs. D } \\
3 \text { months } \\
\text { Pain Intensity VAS } \\
6.0 \text { vs. } 5.4 \text { vs. } 5.4 \text { vs. } \\
4.5 \\
6 \text { months } \\
\text { Pain Intensity VAS: } \\
5.7 \text { vs. } 6.0 \text { vs. } 5.2 \text { vs. } \\
5.2\end{array}$ & 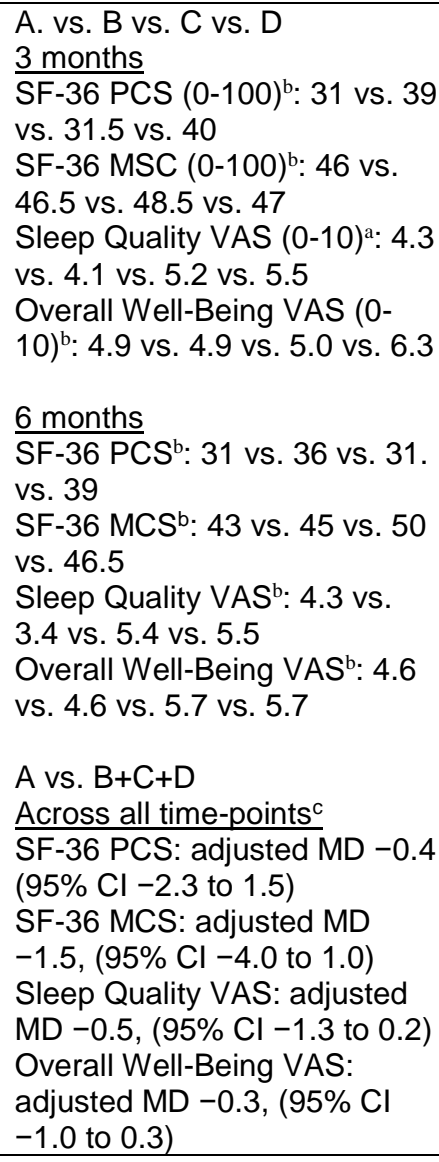 \\
\hline
\end{tabular}




\begin{tabular}{|c|c|c|c|c|}
\hline $\begin{array}{l}\text { Author, } \\
\text { Year, } \\
\text { Followup, }{ }^{\text {a }} \\
\text { Pain } \\
\text { Duration, } \\
\text { Study } \\
\text { Quality }\end{array}$ & Intervention & Population & $\begin{array}{l}\text { Function and Pain } \\
\text { Outcomes }\end{array}$ & Other Outcomes \\
\hline $\begin{array}{l}\text { Martin, } \\
2006^{212} \\
1 \text { and } 7 \\
\text { months } \\
\text { Duration of } \\
\text { pain: NR } \\
\text { Good }\end{array}$ & $\begin{array}{l}\text { A. Acupuncture }(n=25) \\
\text { B. Sham Acupuncture: } \\
\text { Sham Needling }(n=25) \\
\text { Treatment protocol: } 6 \\
\text { treatments over } 2 \text { to } 3 \\
\text { weeks }\end{array}$ & $\begin{array}{l}\text { A vs. B } \\
\text { Age: } 48 \text { vs. } 52 \\
\text { years } \\
\text { Female: } 100 \% \\
\text { vs. } 96 \% \\
\text { Race: } 96 \% \text { vs. } \\
100 \% \text { white } \\
\\
\text { FIQ total (0-80): } \\
42.4 \text { vs. } 44.0 \\
\text { FIQ Physical } \\
\text { Function (0-10): } \\
4.1 \text { vs. 3.6 } \\
\text { MPI Interference } \\
\text { (scale NR): } 42.6 \\
\text { vs. } 36.9 \\
\text { MPI General } \\
\text { Activity Level } \\
\text { (scale NR): } 55.7 \\
\text { vs. } 56.6 \\
\text { MPI Pain } \\
\text { Severity (scale } \\
\text { NR): } 40.4 \text { vs. } \\
43.0 \\
\text { FIQ Pain (0-10): } \\
6.2 \text { vs. } 6.5\end{array}$ & 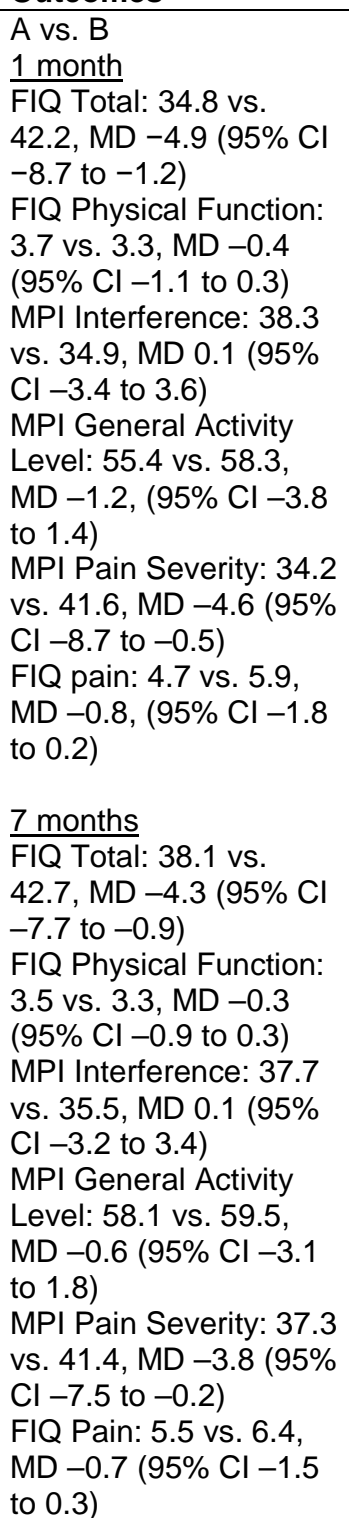 & 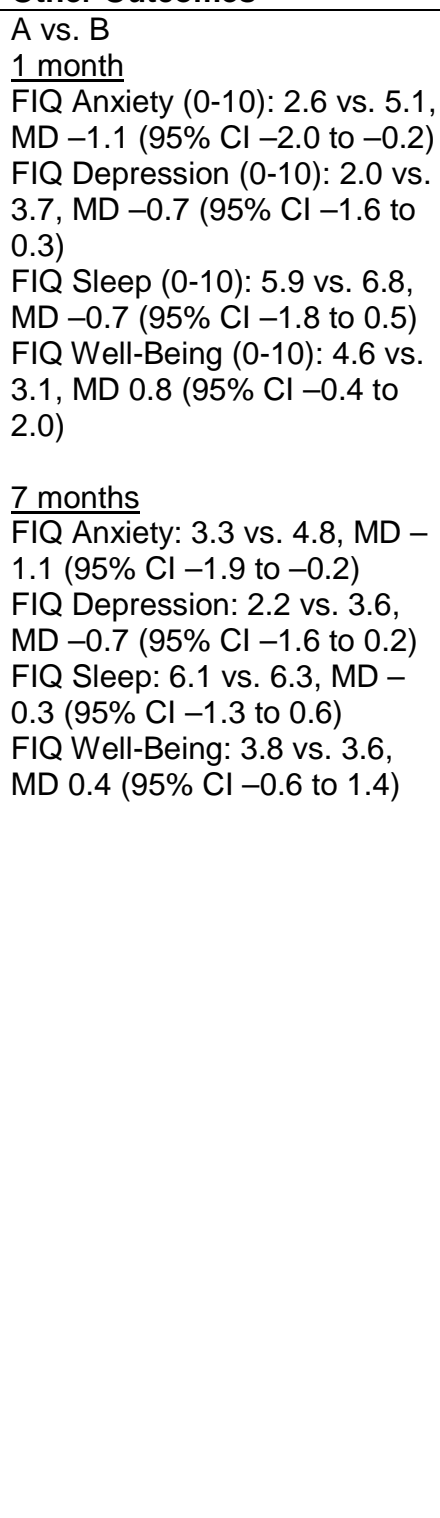 \\
\hline
\end{tabular}




\begin{tabular}{|c|c|c|c|c|}
\hline $\begin{array}{l}\text { Author, } \\
\text { Year, } \\
\text { Followup, } \\
\text { Pain } \\
\text { Duration, } \\
\text { Study } \\
\text { Quality }\end{array}$ & Intervention & Population & $\begin{array}{l}\text { Function and Pain } \\
\text { Outcomes }\end{array}$ & Other Outcomes \\
\hline $\begin{array}{l}\text { Vas, }{ }^{213} 2016 \\
3.75 \text { and } \\
9.75 \text { months } \\
\text { Duration of } \\
\text { pain: NR } \\
\text { Good }\end{array}$ & $\begin{array}{l}\text { A. Acupuncture }(n=82) \\
\text { B. Sham Acupuncture: } \\
\text { Simulated Acupuncture } \\
(n=82) \\
\text { Treatment protocol: } \\
\text { One } 20 \text { min session } \\
\text { per week for } 9 \text { weeks. } \\
\text { Participants also } \\
\text { received } \\
\text { pharmacological } \\
\text { treatment as prescribed } \\
\text { by GP. }\end{array}$ & $\begin{array}{l}\text { A vs. B } \\
\text { Age: } 52.3 \text { vs. } \\
53.2 \text { years } \\
\text { Female: } 100 \% \\
\text { vs. } 100 \% \\
\text { FIQ (0-100): } \\
71.7 \text { vs. } 70.1 \\
\text { Pain Intensity } \\
\text { VAS (0-100): } \\
79.3 \text { vs. } 75.8\end{array}$ & $\begin{array}{l}\text { A vs. B } \\
3.75 \text { months } \\
\text { FIQ \% mean relative } \\
\text { change: }-25.0 \text { vs. } \\
\text {-11.2, Cohen's } d=0.58 \\
\text { Pain Intensity VAS \% } \\
\text { mean relative change: } \\
-23.6 \text { vs. }-16.6, \\
\text { Cohen's d=0.28 } \\
9.75 \text { months } \\
\text { FIQ \% mean relative } \\
\text { change (\%): }-22.2 \text { vs. } \\
-4.9, \text { Cohen's d=0.80, } \\
\text { Pain intensity VAS \% } \\
\text { mean relative change: } \\
-19.9 \text { vs. }-6.2, \\
\text { Cohen's d=0.62 }\end{array}$ & $\begin{array}{l}\text { A vs. B } \\
3.75 \text { months } \\
\text { HDRS \% mean relative } \\
\text { change: NR } \\
\text { SF-12 MCS \% mean relative } \\
\text { change: } 30.6 \text { vs. } 13.9, \\
\text { Cohen's d=0.38 } \\
\text { SF-12 PCS \% mean relative } \\
\text { change: } 37.0 \text { vs. } 15.5 \text {, } \\
\text { Cohen's d=0.56 } \\
\text { 9.75 months } \\
\text { HDRS \% mean relative } \\
\text { change: }-19.1 \text { vs. }-5.9, \\
\text { Cohen's d=0.22 } \\
\text { SF-12 PCS \% mean relative } \\
\text { change: } 37.2 \text { vs. } 11.4, \\
\text { Cohen's d=0.58 } \\
\text { SF-12 MCS \% mean relative } \\
\text { change: } 23.0 \text { vs. } 9.4 \text {, Cohen's } \\
\text { d=0.36 }\end{array}$ \\
\hline
\end{tabular}

CI = confidence interval; FIQ = Fibromyalgia Impact Questionnaire; GP = general practitioner; HDRS = Hamilton Depression Rating Scale; MCS = Mental Component Score; MD = mean difference; MPI = Multidimensional Pain Inventory; NR = not reported; PCS = Physical Component Score; SF-12 = Short-Form-12; SF-36 = Short-Form 36; VAS = visual analog scale

${ }^{\text {a }}$ Unless otherwise noted, followup time is calculated from the end of the treatment period

${ }^{\mathrm{b}}$ Outcome values were estimated from graphs.

c Authors combined the three sham control groups and calculated the adjusted least-square mean difference between the acupuncture group and combined control groups. Treatment-by-time interaction was not included in the models; therefore data reflects results across all time-points.

\section{Acupuncture Compared With Sham}

Acupuncture was associated with slightly greater improvement in function compared with sham acupuncture based on the FIQ Total Score (0 to 100) at short-term followup (2 trials, pooled difference $-8.63,95 \% \mathrm{CI}-12.12$ to $-5.13, \mathrm{I}^{2}=0 \%$ ) and intermediate-term followup ( 2 trials, pooled difference on $0-100$ scale, $-9.41,95 \%$ CI -13.96 to $-4.85, \mathrm{I}^{2}=27.4 \%$ ) across the same trials $^{212,213}$ (Figure 46). There was, however, no clear effect of acupuncture on pain (0 to 10 scale) versus sham acupuncture in the short term (3 trials, pooled difference -0.13 , 95\% CI -1.06 to $0.79, \mathrm{I}^{2}=72 \%$ ) or intermediate term ( 3 trials, pooled difference $-0.53,95 \% \mathrm{CI}-1.15$ to $\left.0.09, \mathrm{I}^{2}=45.5 \%\right)^{211-213}$ (Figure 47 ). All trials were considered good quality.

Results for secondary outcomes across two trials of acupuncture versus sham were inconsistent, with each reporting effects in the opposite direction. In the trial of acupuncture versus three different types of sham acupuncture, ${ }^{211}$ there was no significant benefit of acupuncture versus the combined sham groups on the SF-36 MCS score, a measure of sleep quality, or a measure of overall well-being. In the trial of six acupuncture treatments over 2 to 3 weeks, there was a benefit for true versus sham acupuncture at 1 and 7 months on the FIQ subscale of anxiety, but not depression, sleep, or well-being. ${ }^{212}$ In the trial of one 20-minute session per week for 9 weeks plus pharmacological treatment as prescribed by a general practitioner, there was a benefit for true versus sham acupuncture at 1 month for the SF-12 MCS 
scale (mean relative change $30.6 \%$, 95\% CI 19.7 to 41.5 vs. $13.9 \%$, 95\% CI 5.4 to 22.5 ), Cohen's d $=0.38, \mathrm{P}=0.01$ ), and at 9.75 months for the Hamilton Rating Scale for Depression (mean relative change $-19.1 \%$, $95 \%$ CI -34.2 to -3.9 vs. $-5.9 \%$, $95 \%$ CI -16.6 to -4.8 , Cohen's $\mathrm{d}=0.22, \mathrm{P}=0.01$ ) and the SF-12 Mental Component scale (mean relative change, $23.0 \%$, 95\% CI 13.7 to 32.4 vs. $9.4 \%$, $95 \%$ CI 1.9 to 16.9 , Cohen's $d=0.36, \mathrm{P}=0.01) .{ }^{213}$

\section{Acupuncture Compared With Pharmacological Therapy or Exercise}

No trial of acupuncture versus pharmacological therapy or versus exercise met inclusion criteria.

\section{Harms}

Discomfort and bruising were the most common reported adverse events. In one trial, ${ }^{211} 89$ of 96 treated (true or sham acupuncture) participants reported adverse events; 35 of 96 (37\%) reported discomfort at needle insertion sites, 29 of 96 (30\%) reported bruising, 3 of 96 (3\%) reported nausea, and 1 of $96(0.3 \%)$ felt faint at some point during the study. For patients assigned to simulated acupuncture, 5 of 19 (29\%) had significantly less discomfort than those in directed acupuncture (14 of 23, 61\%), acupuncture for unrelated condition (15 of 22, 70\%) or sham needling ( 14 of $22,64 \%$ ); $\mathrm{P}=0.02$. In one trial, ${ }^{212} 2$ of $50(4 \%)$ experienced mild vasovagal symptoms and 1 of 50 (2\%) experienced a pulmonary embolism believed to be unrelated to treatment. Mild bruising and soreness were reported to be more common in the true acupuncture group, but rates were not reported. In one study, ${ }^{213} 2.6$ percent of sessions led to aggravation of fibromyalgia symptoms and 0.5 percent led to headache. In the true acupuncture group, pain, bruising, and vagal symptoms presented after 4.7 percent of sessions. 
Figure 46. Acupuncture versus sham for fibromyalgia: effects on function

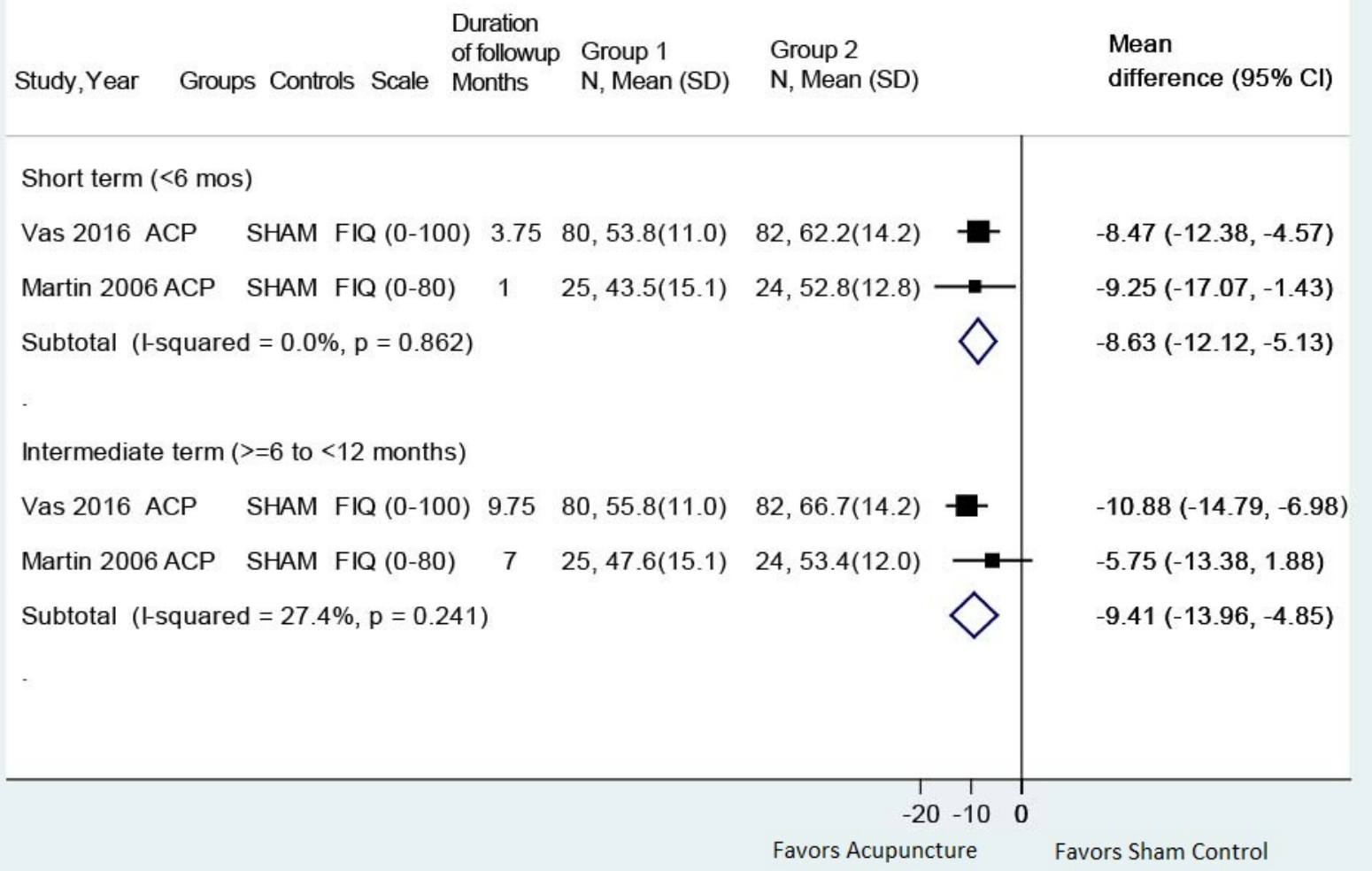

ACP = acupuncture; $\mathrm{CI}$ = confidence interval; FIQ = Fibromyalgia Impact Questionnaire; SD = standard deviation 
Figure 47. Acupuncture versus sham for fibromyalgia: effects on pain

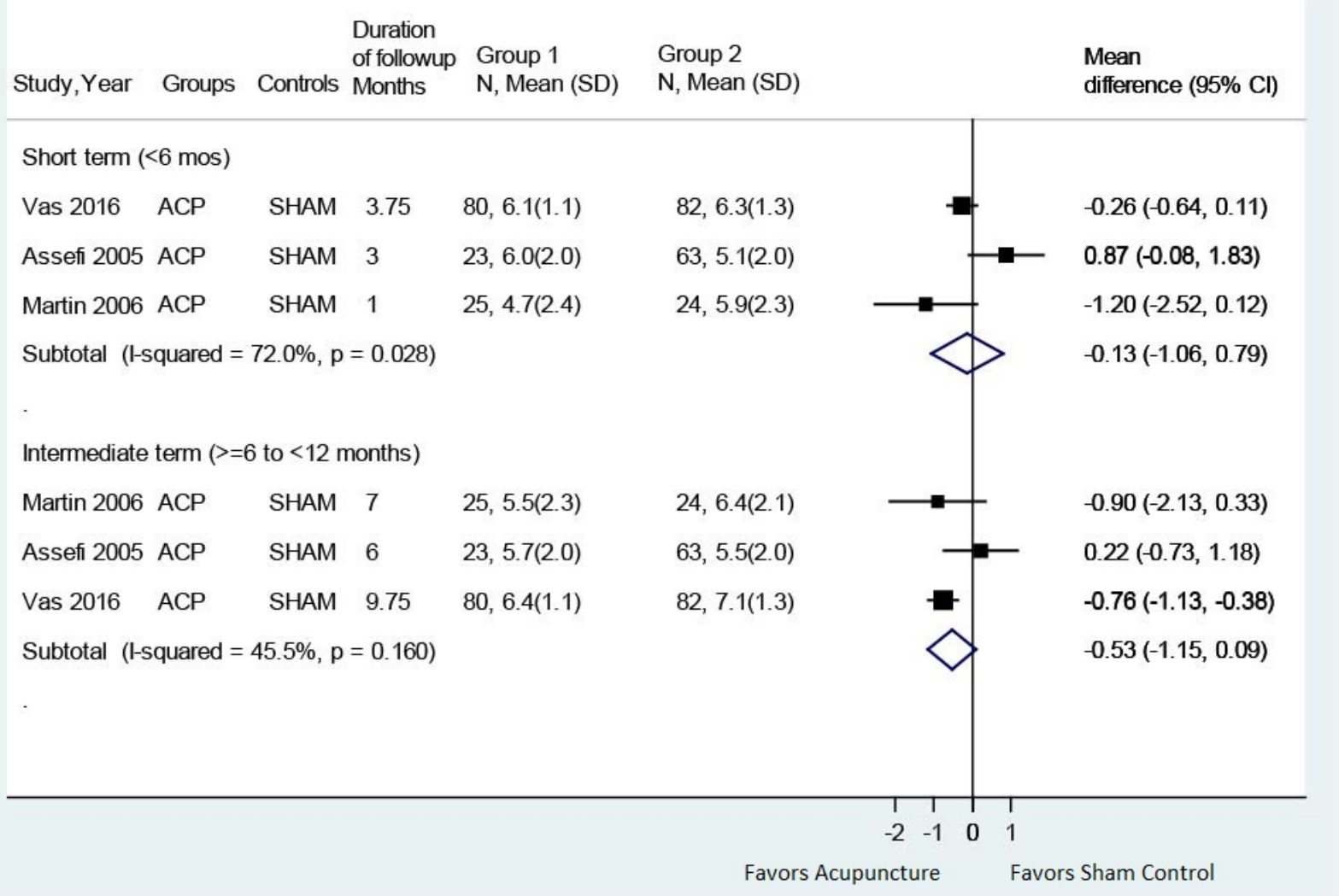

$\mathrm{ACP}=$ acupuncture; $\mathrm{CI}$ = confidence interval; $\mathrm{SD}=$ standard deviation

\section{Multidisciplinary Rehabilitation for Fibromyalgia}

\section{Key Points}

- More multidisciplinary treatment participants experienced a clinically meaningful improvement in FIQ total score ( $\geq 14 \%$ change) compared with usual care at short (odds ratio [OR] 3.1, 95\% CI 1.6 to 6.2), intermediate (OR 3.1, 95\% CI 1.5 to 6.4 ) and long term (OR 8.8, 95\% CI 2.5 to 30.9) in one poor-quality trial. Multidisciplinary treatment was associated with a slight improvement in function (based on a 0-100 FIQ total score) versus usual care or waitlist in the short-term ( 3 trials, pooled MD $-6.52,95 \%$ CI -12.84 to $-0.21, \mathrm{I}^{2}=67.3 \%$ ), and versus usual care at intermediate term ( 3 trials, pooled MD $-7.84,95 \% \mathrm{CI}-11.43$ to $-4.25, \mathrm{I}^{2}=18.2 \%$ ) and long term ( 2 trials, pooled $\mathrm{MD}-8.42$, 95\% CI -13.76 to $-3.08, \mathrm{I}^{2=} 24.9 \%$ ) (SOE: low for short, intermediate and long term).

- Multidisciplinary treatment was associated with a slight improvement in pain compared with usual care or waitlist at intermediate term (3 trials, pooled MD $-0.68,95 \% \mathrm{CI}-1.07$ to $-0.30, \mathrm{I}^{2}=0 \%$ ); there were no clear differences compared with usual care or waitlist in the short term (2 trials [excluding an outlier trial], pooled MD on a $0-10$ scale $-0.24,95 \%$ $\mathrm{CI}-0.63$ to $0.15, \mathrm{I}^{2}=0 \%$ ) or with usual care in the long term ( 2 trials, pooled $\mathrm{MD}-0.25$, $95 \%$ CI -0.68 to $0.17, \mathrm{I}^{2}=0 \%$ ) (SOE: low for short, intermediate and long-term). 
- There was no evidence of an effect for multidisciplinary pain treatment versus aerobic exercise at long term in one fair-quality trial for function (MD -1.10, 95\% CI -8.40 to 6.20, 0-100 FIQ total score) or pain (MD 0.10, 95\% CI -0.67 to 0.87, 0-10 FIQ pain scale) (SOE: low).

- Data were insufficient for harms. However, one poor-quality study reported on adverse events stating that $19 \%$ of participants randomized to multidisciplinary treatment withdrew (versus $0 \%$ for waiting list) and 2 of these 16 patients gave increased pain as the reason. Reasons for other withdrawals were not given and there was not systematic reporting of adverse events (SOE: insufficient).

\section{Detailed Synthesis}

We identified six trials (across 8 publications) of multidisciplinary treatments that met inclusion criteria (Table 42 and Appendix D); five were conducted in Europe $\mathrm{e}^{85,225-230}$ and one in Turkey. ${ }^{231}$ Across trials, sample sizes ranged from 66 to 203 (total randomized=959) and participants were predominantly (>90\%) female with mean ages between 40 to 50 years. The multidisciplinary treatments included physical therapy or exercise training in all trials, as well as CBT and pharmacological therapy (2 trials), ${ }^{226,229} \mathrm{CBT}$ and an educational program (1 trial), ${ }^{231}$ sociotherapy, psychotherapy, and creative arts therapy $(1$ trial $),{ }^{85}$ relaxation exercises $(1$ trial $),{ }^{228}$ and education and group discussions ( 1 trial). ${ }^{225}$ All trials compared multidisciplinary treatment with usual care or waitlist; in addition, one trial compared it with exercise. ${ }^{85}$ Treatment duration ranged from 2 to 12 weeks and the frequency of sessions from once a week to daily (total number of sessions ranged from 12 to 24 with durations between 1.5 to 5 hours). One of the trials included two intervention arms. ${ }^{231}$ The long-term multidisciplinary arm (2 days of education and exercise followed by 10 weeks of CBT) was determined to be most consistent with interventions employed by the other trials and was included in the pooled estimates below; results for the short-term group (2 days of education, exercise, and CBT programs) were similar to those of the long-term group and can be found in Table 42. Three trials reported outcomes over the short term ( 3 to 5.5 months), ${ }^{225,226,231}$ three over the intermediate term (6 months), ${ }^{226,228,229}$ and two over the long term (12 and 18 months). ${ }^{85,226}$

Three trials were judged to be of fair quality ${ }^{85,225,231}$ and three trials were rated poor quality ${ }^{226,228,229}$ (Appendix E). The nature of the intervention precluded blinding of participants and of people administering the treatments. Additional methodological shortcomings in the poor quality trials included unclear allocation concealment methods and unacceptable rates of overall attrition (21\% to $43 \%)$ and differential attrition between groups (12\% to $13 \%)$. 
Table 42. Fibromyalgia: multidisciplinary rehabilitation

\begin{tabular}{|c|c|c|c|c|}
\hline $\begin{array}{l}\text { Author, Year, } \\
\text { Followup, } \\
\text { Pain Duration, } \\
\text { Study Quality }\end{array}$ & Intervention & Population & $\begin{array}{l}\text { Function and Pain } \\
\text { Outcomes }\end{array}$ & Other Outcomes \\
\hline $\begin{array}{l}\text { Amris, } 2014^{225} \\
5.5 \text { months } \\
\text { Duration of pain: } \\
\text { median } 10 \text { to } 11 \\
\text { years } \\
\text { Fair }\end{array}$ & $\begin{array}{l}\text { A. Multidisciplinary } \\
\text { treatment ( } n=84), 3 \\
\text { to } 5 \text { hours of } \\
\text { education, sleep } \\
\text { hygiene, group } \\
\text { discussions, and } \\
\text { physical therapy } \\
\text { per day over } 2 \\
\text { weeks } \\
\text { B. Wait list }(n=86)\end{array}$ & $\begin{array}{l}\text { A vs. B } \\
\text { Age: } 44 \text { vs. } 44 \\
\text { years } \\
\text { Female: } 100 \% \text { vs. } \\
100 \% \\
\text { Baseline } \\
\text { Fibromyalgia } \\
\text { Impact } \\
\text { Questionnaire } \\
\text { Total (FIQ, 0-100): } \\
64.0 \text { vs. 65.7 } \\
\text { Baseline FIQ pain } \\
\text { VAS (0-10): } 7.1 \\
\text { vs. } 7.4\end{array}$ & $\begin{array}{l}\text { A vs. B } \\
5.5 \text { months } \\
\text { Change in FIQ total from } \\
\text { baseline: }-1.3 \text { vs. }-1.4, \\
\text { difference } 0.1(95 \% \mathrm{Cl}-3.6 \\
\text { to } 3.8) \\
\text { Change in FIQ pain VAS } \\
\text { from baseline: } 0.1 \text { vs. }-0.1 \text {, } \\
\text { difference } 0.2(95 \% \mathrm{Cl}-0.3 \\
\text { to } 0.7)\end{array}$ & 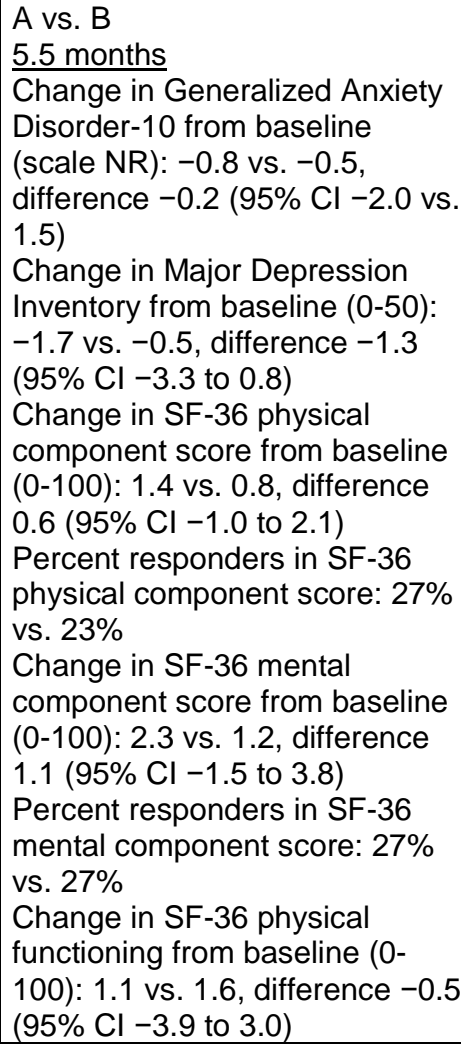 \\
\hline
\end{tabular}




\begin{tabular}{|c|c|c|c|c|}
\hline $\begin{array}{l}\text { Author, Year, } \\
\text { Followup, }{ }^{a} \\
\text { Pain Duration, } \\
\text { Study Quality }\end{array}$ & Intervention & Population & $\begin{array}{l}\text { Function and Pain } \\
\text { Outcomes }\end{array}$ & Other Outcomes \\
\hline $\begin{array}{l}\text { Castel, } 2013^{226} \\
\text { Salvat } 2017^{230} \\
3,6 \text { and } 12 \\
\text { months } \\
\text { Duration of pain: } \\
\text { Mean } 10.8 \text { to } \\
12.5 \text { years } \\
\text { Poor }\end{array}$ & $\begin{array}{l}\text { A. Multidisciplinary } \\
\text { treatment ( } \mathrm{n}=53) \text {, } \\
\text { conventional } \\
\text { pharmacological } \\
\text { treatment, } 24 \\
\text { sessions of group } \\
\text { CBT and physical } \\
\text { therapy over } 12 \\
\text { weeks. } \\
\text { B. Usual care } \\
\text { (conventional } \\
\text { pharmacological } \\
\text { treatment) (n=35), } \\
\text { including } \\
\text { analgesics, } \\
\text { antidepressants, } \\
\text { benzodiazepines, } \\
\text { and } \\
\text { nonbenzodiazepine } \\
\text { hypnotics }\end{array}$ & $\begin{array}{l}\text { A vs. B } \\
\text { Age: } 49 \text { vs. } 49 \\
\text { years } \\
\text { Female: } 100 \% \text { vs. } \\
100 \% \\
\text { Baseline FIQ (0- } \\
\text { 100): } 64.6 \text { vs. } 66.6 \\
\text { Baseline pain } \\
\text { NRS (0-10): } 6.8 \\
\text { vs. } 7.1\end{array}$ & 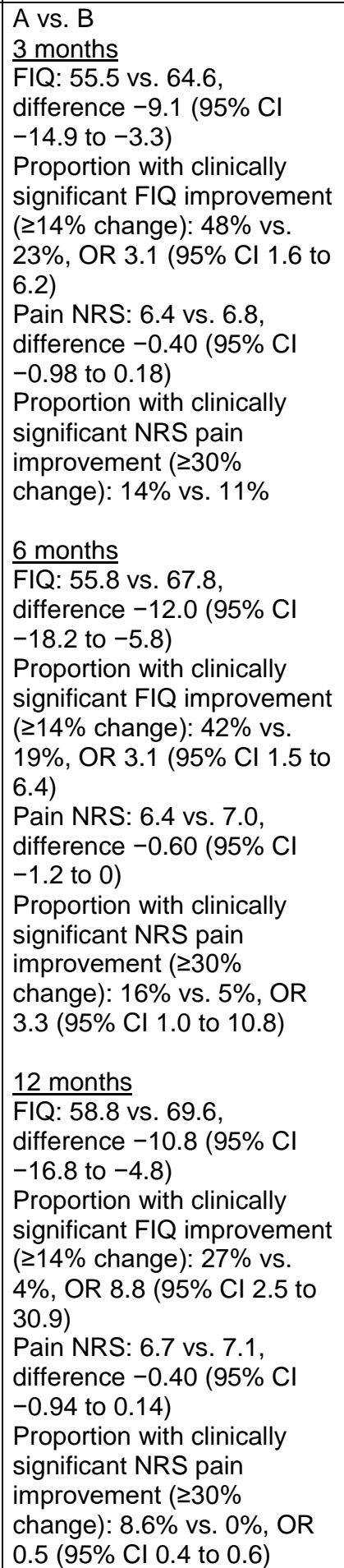 & 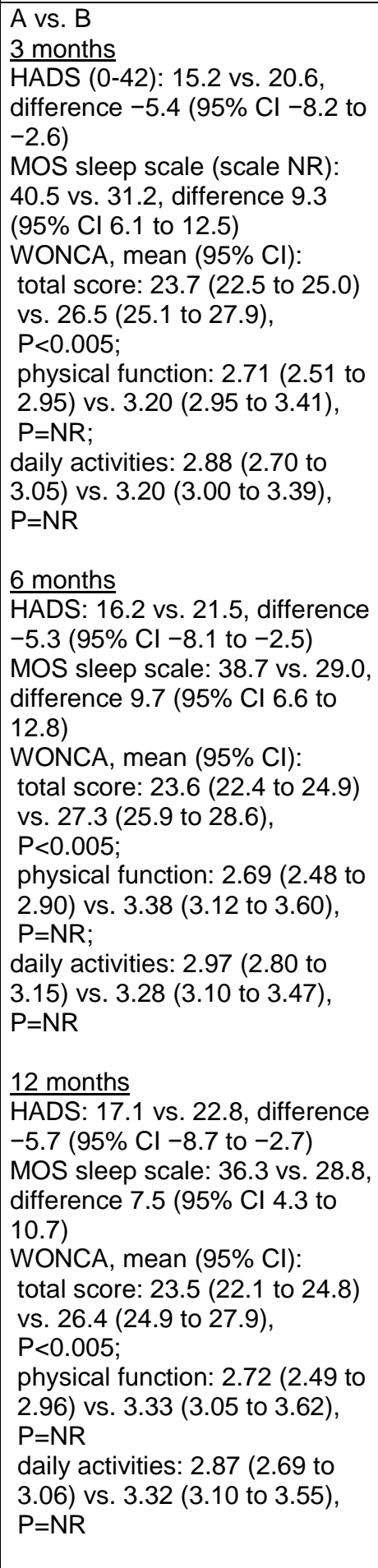 \\
\hline
\end{tabular}




\begin{tabular}{|c|c|c|c|c|}
\hline $\begin{array}{l}\text { Author, Year, } \\
\text { Followup, } \\
\text { Pain Duration, } \\
\text { Study Quality }\end{array}$ & Intervention & Population & $\begin{array}{l}\text { Function and Pain } \\
\text { Outcomes }\end{array}$ & Other Outcomes \\
\hline $\begin{array}{l}\text { Cedraschi, } \\
2004^{228} \\
6 \text { months } \\
\text { Duration of pain: } \\
\text { Mean } 8.4 \text { to } 9.5 \\
\text { years } \\
\text { Poor }\end{array}$ & $\begin{array}{l}\text { A. Multidisciplinary } \\
\text { treatment }(n=84) \text { : } \\
12 \text { group pool } \\
\text { sessions of } \\
\text { physiotherapy, } \\
\text { relaxation } \\
\text { exercises, and } \\
\text { exercise over } 6 \\
\text { weeks } \\
\text { B. Usual care } \\
\text { (n=80) } \\
\text { Regular care, } \\
\text { including physical } \\
\text { therapy, drug } \\
\text { treatment and, in } \\
\text { some cases, } \\
\text { psychotherapy. }\end{array}$ & $\begin{array}{l}\text { A vs. B } \\
\text { Age: } 49 \text { vs. } 50 \\
\text { years } \\
\text { Female: } 93 \% \text { vs. } \\
93 \% \\
\text { FIQ total (0-10): } \\
5.5 \text { vs. } 5.6 \\
\text { FIQ physical } \\
\text { function (0-10): } \\
4.2 \text { vs. } 4.5 \\
\text { FIQ pain (0-10): } \\
6.3 \text { vs. } 6.0 \\
\text { FIQ depression } \\
\text { (0-10): } 5.5 \text { vs. } 5.9 \\
\text { FIQ anxiety (0- } \\
10): 6.4 \text { vs. } 7.1 \\
\text { Regional Pain } \\
\text { Score (0-105): } \\
63.9 \text { vs. } 67.0\end{array}$ & $\begin{array}{l}\text { A vs. B } \\
6 \text { months } \\
\text { FIQ total: } 4.9 \text { vs. } 5.5, \\
\text { difference }-0.6(95 \% \mathrm{Cl} \\
-1.1 \text { to }-0.09) \\
\text { FIQ physical function: } 4.3 \\
\text { vs. } 4.8 \text {, difference }-0.5 \\
\text { (95\% Cl }-1.3 \text { to } 0.3) \\
\text { FIQ pain: } 6.1 \text { vs. } 6.6, \\
\text { difference }-0.5(95 \% \mathrm{Cl} \\
-1.2 \text { to } 0.2) \\
\text { Regional Pain Score: } 62.6 \\
\text { vs. } 68.4, \text { difference }-5.8 \\
\text { (95\% } \mathrm{Cl}-12.1 \text { to } 0.5)\end{array}$ & $\begin{array}{l}\text { A vs. B } \\
6 \text { months } \\
\text { Psychological General } \\
\text { Wellbeing Index total (0-110): } \\
51.1 \text { vs. } 43.8 \text {, difference } 7.3 \\
\text { (95\% Cl } 0.2 \text { to } 14.3) \\
\text { Psychological General } \\
\text { Wellbeing Index anxiety (0-25): } \\
13.0 \text { vs. } 10.3 \text {, difference } 2.7 \\
\text { (95\% Cl } 0.6 \text { to } 4.8) \\
\text { Psychological General } \\
\text { Wellbeing Index depression (0- } \\
15): 9.0 \text { vs. } 7.7, \text { difference } 1.3 \\
\text { (95\% CI }-0.1 \text { to } 2.7) \\
\text { SF-36 physical function }(0-100) \text { : } \\
42.2 \text { vs. } 43.9, \text { difference }-1.7 \\
\text { (95\% Cl }-8.6 \text { to } 5.2) \\
\text { FIQ depression: } 4.6 \text { vs. } 6.1 \\
\text { FIQ anxiety: } 5.1 \text { vs. } 6.7, \\
\text { difference }-1.6 \text { (95\% CI }-2.6 \text { to } \\
-0.6)\end{array}$ \\
\hline $\begin{array}{l}\text { Martin, } 2012^{229} \\
6 \text { months } \\
\text { Duration of pain: } \\
\text { Mean } 14 \text { to } 15 \\
\text { years } \\
\text { Poor }\end{array}$ & $\begin{array}{l}\text { A. Multidisciplinary } \\
\text { treatment }(n=54), \\
\text { conventional } \\
\text { pharmacological } \\
\text { treatment, } 12 \\
\text { sessions of CBT, } \\
\text { education, and } \\
\text { physiotherapy over } \\
6 \text { weeks } \\
\text { B. Usual care } \\
\text { (conventional } \\
\text { pharmacological } \\
\text { treatment) ( }=56 \text { ), } \\
\text { included } \\
\text { amitriptyline, } \\
\text { paracetamol, and } \\
\text { tramadol }\end{array}$ & $\begin{array}{l}\text { A vs. B } \\
\text { Age: } 49 \text { vs. } 52 \\
\text { years } \\
\text { Female: } 91 \% \text { vs. } \\
91 \% \\
\text { FIQ total }(0-100) \text { : } \\
76.3 \text { vs. } 76.2 \\
\text { FIQ physical } \\
\text { functioning }(0-10) \text { : } \\
5.5 \text { vs. } 5.4 \\
\text { FIQ pain }(0-10): \\
7.5 \text { vs. } 7.5\end{array}$ & $\begin{array}{l}\text { A vs. B } \\
6 \text { months } \\
\text { FIQ total: } 70.3 \text { vs. } 76.8, \\
\text { difference }-6.5(95 \% \mathrm{Cl}- \\
12.3 \text { to }-0.7) \\
\text { FIQ physical function: } 5.2 \\
\text { vs. } 5.9 \text {, difference }-0.7 \\
\text { (95\% Cl }-1.4 \text { to }-0.04) \\
\text { FIQ pain: } 7.2 \text { vs. } 8.2, \\
\text { difference }-1.0(95 \% \mathrm{Cl}-1.7 \\
\text { to }-0.3)\end{array}$ & $\begin{array}{l}\text { A vs. B } \\
6 \text { months } \\
\text { Hospital Anxiety and } \\
\text { Depression Scale anxiety } \\
\text { (HADS, } 0-21): 13.4 \mathrm{vs} .12 .8, \\
\text { difference } 0.66(95 \% \mathrm{Cl}-1.02 \\
\text { to } 2.34) \\
\text { HADS depression }(0-21): 9.8 \mathrm{vs} \text {. } \\
10.2 \text {, difference }-0.43(95 \% \mathrm{Cl} \\
-2.00 \text { to } 1.14)\end{array}$ \\
\hline
\end{tabular}




\begin{tabular}{|c|c|c|c|c|}
\hline $\begin{array}{l}\text { Author, Year, } \\
\text { Followup, } \\
\text { Pain Duration, } \\
\text { Study Quality }\end{array}$ & Intervention & Population & $\begin{array}{l}\text { Function and Pain } \\
\text { Outcomes }\end{array}$ & Other Outcomes \\
\hline $\begin{array}{l}\text { Saral } 2016^{231} \\
6 \text { months; } \\
4 \text { months based } \\
\text { on intervention } \\
\text { group } \\
\text { Duration of pain: } \\
7.5 \text { years } \\
\text { Fair }\end{array}$ & $\begin{array}{l}\text { A. Long term } \\
\text { interdisciplinary } \\
\text { group ( } n=22) \text { : } \\
\text { educational } \\
\text { program (1 full } \\
\text { day), exercise } \\
\text { program (1 full } \\
\text { day), and CBT (1, } \\
\text { 3-hour session per } \\
\text { week for 10 } \\
\text { weeks); plus home } \\
\text { strengthening and } \\
\text { stretching } \\
\text { exercises and } \\
\text { relaxation } \\
\text { B. Short term } \\
\text { interdisciplinary } \\
\text { group ( } n=22) \text { : } \\
\text { education, } \\
\text { exercise, and CBT } \\
\text { over } 2 \text { full days; } \\
\text { plus home } \\
\text { strengthening and } \\
\text { stretching } \\
\text { exercises and } \\
\text { relaxation } \\
\text { C. Usual care } \\
\text { ( } n=22 \text { ): Patients } \\
\text { continued current } \\
\text { medical treatments, } \\
\text { normal daily living, } \\
\text { and current } \\
\text { physical activity } \\
\text { levels }\end{array}$ & $\begin{array}{l}\text { A vs. B vs. C } \\
\text { Age, years: } 38 \text { vs. } \\
43 \text { vs. } 44 \\
\text { Female: } 100 \% \text { vs. } \\
100 \% \text { vs. } 100 \% \\
\text { Symptom } \\
\text { duration, months: } \\
69 \text { vs. } 113 \text { vs. } 88 \\
\text { FIQ (0-100): } 71.6 \\
\text { vs. } 67.7 \text { vs. } 65.5 \\
\text { Pain VAS (0-10): } \\
8.2 \text { vs. } 7.6 \text { vs. } 7.5\end{array}$ & 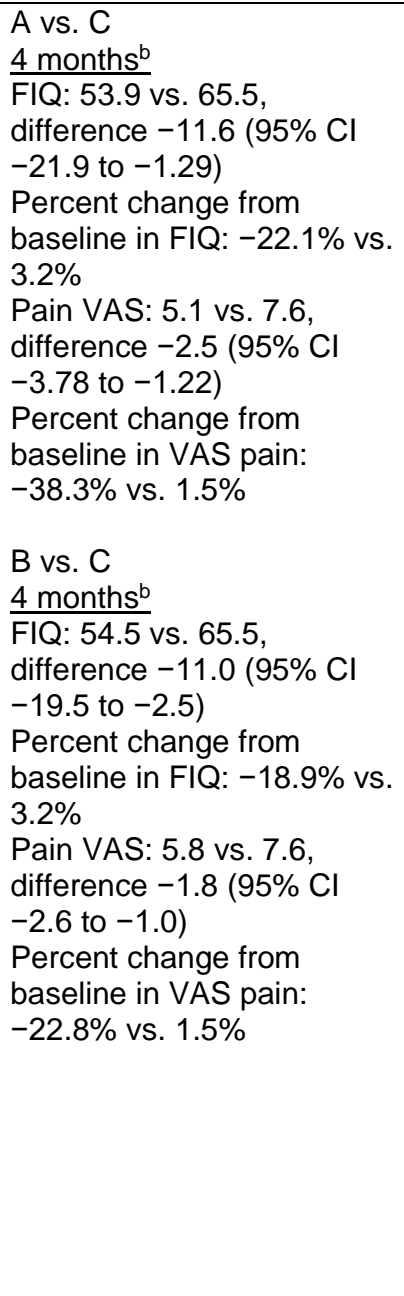 & 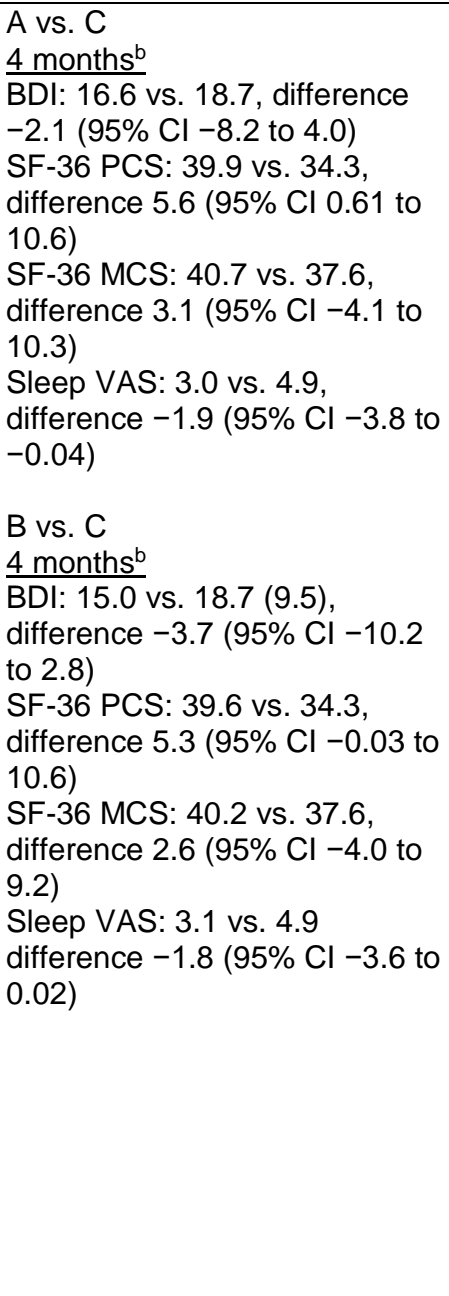 \\
\hline
\end{tabular}




\begin{tabular}{|c|c|c|c|c|}
\hline $\begin{array}{l}\text { Author, Year, } \\
\text { Followup, } \\
\text { Pain Duration, } \\
\text { Study Quality }\end{array}$ & Intervention & Population & $\begin{array}{l}\text { Function and Pain } \\
\text { Outcomes }\end{array}$ & Other Outcomes \\
\hline $\begin{array}{l}\text { Van Eijk- } \\
\text { Hustings, } 2013^{85} \\
18 \text { months } \\
\text { Duration of pain: } \\
\text { Mean of } 6.1 \text { to } \\
7.1 \text { years } \\
\text { Fair }\end{array}$ & $\begin{array}{l}\text { A. Multidisciplinary } \\
\text { intervention } \\
\text { ( } n=108), 36 \text { days of } \\
\text { sessions of } \\
\text { sociotherapy, } \\
\text { physiotherapy, } \\
\text { psychotherapy, and } \\
\text { creative arts } \\
\text { therapy over } 12 \\
\text { weeks } \\
\text { B. Aerobic exercise } \\
\text { ( } n=47) \text { : } 24 \text { sessions } \\
\text { over } 12 \text { weeks } \\
\text { C. Usual care } \\
\text { ( } n=48 \text { ), education } \\
\text { and lifestyle advice } \\
\text { in addition to usual } \\
\text { care }\end{array}$ & $\begin{array}{l}\text { A vs. B vs. C } \\
\text { Age: } 41 \text { vs. } 39 \text { vs. } \\
43 \text { years } \\
\text { Female: } 93 \% \text { vs. } \\
100 \% \text { vs. } 98 \% \\
\text { FIQ physical } \\
\text { function }(0-10): \\
4.2 \text { vs. } 3.6 \text { vs. } 3.4 \\
\text { FIQ total }(0-100): \\
64.5 \text { vs. } 60.0 \text { vs. } \\
55.4 \\
\text { FIQ pain }(0-10): \\
6.3 \text { vs. } 6.2 \text { vs. } 5.5\end{array}$ & $\begin{array}{l}\text { A vs. } B^{c} \\
18 \text { months } \\
\text { FIQ physical function: } 3.6 \\
\text { vs. } 3.6 \text {, difference } 0(95 \% \mathrm{Cl} \\
-0.79 \text { to } 0.79) \\
\text { FIQ total: } 50.9 \text { vs. } 52.0 \text {, } \\
\text { difference }-1.10(95 \% \mathrm{Cl} \\
-8.40 \text { to } 6.20) \\
\text { FIQ pain: } 5.3 \text { vs. } 5.2 \text {, } \\
\text { difference } 0.10(95 \% \mathrm{Cl} \\
-0.67 \text { to } 0.87) \\
\text { A vs. C } \\
18 \text { months } \\
\text { FIQ physical function: } 3.6 \\
\text { vs. } 3.9, \mathrm{ES} 0.12(-0.22 \text { to } \\
0.46) \\
\text { FIQ total: } 50.9 \text { vs. } 56.2 \text {, ES } \\
0.25 \text { ( } 95 \% \mathrm{Cl}-0.09 \text { to } 0.59) \\
\text { FIQ pain: } 5.3 \text { vs. } 5.3 \text {, ES } \\
-0.01 \text { (95\% } \mathrm{Cl}-0.35 \text { to } \\
0.34)\end{array}$ & 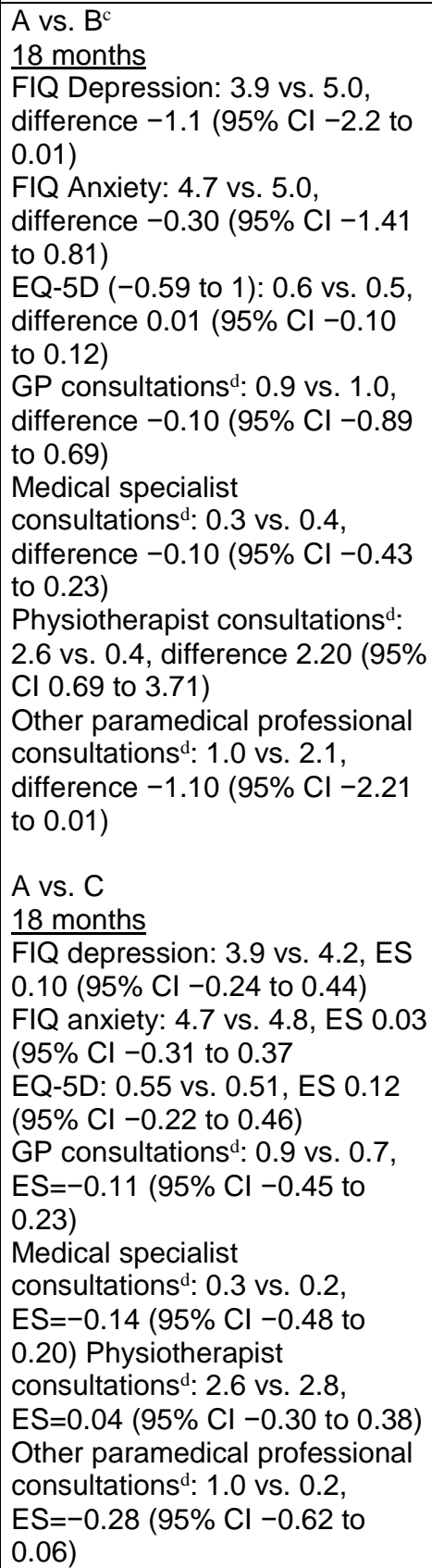 \\
\hline
\end{tabular}

CBT = cognitive behavioral therapy; CI = confidence interval; ES = effect size; EQ-5D = EuroQol-5D; FIQ = Fibromyalgia Impact Questionnaire; GP = general practitioner; HADS = Hospital Anxiety and Depression Scale; MOS = Medical Outcomes Study; NR = not reported; OR = odds ratio; SF-36 = Short-Form 36; VAS = visual analog scale

${ }^{a}$ Unless otherwise noted, followup time is calculated from the end of the treatment period

${ }^{\mathrm{b}}$ Long term multidisciplinary group was followed up at 4 months from end of intervention and the short term multidisciplinary and control groups were followed up at 6 months from end up intervention

${ }^{c}$ Authors did not provide effect estimates for the comparison of multidisciplinary rehabilitation versus exercise; mean differences were calculated by the EPC

${ }^{d}$ Total number of consultations over a period of 2 months prior to measurement 


\section{Multidisciplinary Rehabilitation Compared With Usual Care or Waitlist}

Clinically important FIQ improvement ( $\geq 14 \%$ change) was significantly more common for multidisciplinary treatment compared with usual care at short- (odds ratio [OR] 3.1, 95\% CI 1.6 to 6.2), intermediate- (OR 3.1, 95\% CI 1.5 to 6.4) and long-term followup (OR 8.8, 95\% CI 2.5 to 30.9 ) in one poor-quality trial. ${ }^{226}$ Multidisciplinary treatment for fibromyalgia was associated with a small improvement in function versus usual care or waitlist based on a 0 to 100 FIQ total score in the short term ( 3 trials, pooled MD $-6.52,95 \%$ CI -12.84 to $-0.21, \mathrm{I}^{2}=67.3 \%$ ), ${ }^{225,226,231}$ and versus usual care in the intermediate term ( 3 trials, pooled MD $-7.84,95 \% \mathrm{CI}-11.43$ to $\left.-4.25, \mathrm{I}^{2}=18.2 \%\right)^{226,228,229}$ (Figure 48). The short-term estimate for trials of multidisciplinary treatment versus usual care only was similar ( 2 trials, pooled MD $-9.74,95 \% \mathrm{CI}-16.38$ to -3.83). ${ }^{226,231}$ The slightly smaller effect of multidisciplinary rehabilitation versus usual care persisted over the long term (2 trials, pooled MD on 0-100 scale $-8.42,95 \%$ CI -13.76 to -3.08 , $\left.\mathrm{I}^{2=} 24.9 \%\right){ }^{85,226}$ Only one poor-quality trial reported short-term, intermediate-term, and long-term effects on function, showing a significant result for each time frame. ${ }^{226}$

Clinically important improvement in pain ( $\geq 30 \%$ change on a $0-10$ scale) was more common for multidisciplinary treatment compared with usual care at intermediate-term followup in one poor-quality trial, OR 3.4 (95\% CI 1.0 to 10.8$)^{226}$; no statistical differences were seen between groups at short- or long-term followup. There were no clear effects of multidisciplinary treatment for fibromyalgia on pain versus usual care or waitlist in the short term ( 3 trials, pooled MD on a 0 -10 scale -0.83 , 95\% CI -1.85 to $\left.0.18, \mathrm{I}^{2}=83.6 \%\right),{ }^{225,226,231}$ but statistical heterogeneity was very large (Figure 49). Excluding an outlier trial (MD $-2.50,95 \% \mathrm{CI}-3.73$ to -1.27$)^{231}$ reduced the statistical heterogeneity and resulted in an attenuated effect (pooled MD -0.24, 95\% CI -0.63 to $\left.0.15, \mathrm{I}^{2}=0 \%\right)$. At intermediate term, multidisciplinary treatment was associated with a slightly smaller effect on pain compared with usual care (3 trials, pooled MD 0-10 scale -0.68 , $95 \%$ CI -1.07 to $\left.-0.30, \mathrm{I}^{2}=0 \%\right){ }^{226,228,229}$ Long term, there were no clear effects of multidisciplinary treatment on pain versus usual care ( 2 trials, pooled difference -0.25 , 95\% CI -0.68 to $\left.0.17, \mathrm{I}^{2}=0 \%\right){ }^{85,226}$ Only one poor-quality trial reported short-, intermediate-, and longterm effects on pain, showing a significant result for each time frame. ${ }^{26}$

Results were mixed across the six trials for effects of multidisciplinary treatment on secondary outcomes. Three trials were fair quality. ${ }^{85,225,231}$ Across the three fair-quality trials, there were no significant differences between multidisciplinary treatment and usual care or waitlist on measures of anxiety (Generalized Anxiety Disorder-10, FIQ anxiety subscale) in two trials $^{85,225}$ and depression (Major Depression Inventory, FIQ depression subscale, BDI) in three trials $^{85,225,231}$ over short-term or long-term followup. Regarding quality of life, two of these trials reported no differences between groups on the SF-36 PCS and MCS and the EQ-5D ${ }^{85,225}$ while the third reported significant improvement on the SF-36 PCS but not the MCS. ${ }^{231}$ One trial reported no difference in health care utilization between groups during the 2 months prior to the final measurement at 18 months. ${ }^{85}$

\section{Multidisciplinary Rehabilitation Compared With Pharmacological Therapy}

No trial of multidisciplinary rehabilitation versus pharmacological therapy met inclusion criteria.

\section{Multidisciplinary Rehabilitation Compared With Exercise}

There was no clear effect of multidisciplinary pain treatment versus aerobic exercise at long term in one fair-quality trial ${ }^{85}$ for physical function on the FIQ physical function scale (difference 0 on a $0-10$ scale, $95 \%$ CI -0.79 to 0.79 ) or the FIQ total score (difference -1.10 on 
a $0-100$ scale, $95 \%$ CI -8.40 to 6.20$)$. Similarly, there were no significant differences on the FIQ pain scale (difference 0.10 on a $0-10$ scale, $95 \%$ CI -0.67 to 0.87 ), secondary outcomes of quality of life, depression or anxiety, or health care utilization, with the exception of physiotherapist consultations, which was higher for the multidisciplinary group in the 2 months prior to the final measurement at 18 months (Table 42).

\section{Harms}

Adverse events were poorly reported by the included trials. One trial that compared multidisciplinary treatment (group pool sessions of physiotherapy, relaxation exercises, and exercise) with usual care (physical therapy, drug treatment and, in some cases, psychotherapy) ${ }^{228}$ reported that 16 of 84 (19\%) multidisciplinary participants withdrew (versus 0\% for waiting list) and two of these gave increased pain as the reason. Reasons for other withdrawals were not given and there was not systematic reporting of adverse events.

Figure 48. Multidisciplinary rehabilitation versus usual care or waitlist for fibromyalgia: effects on function

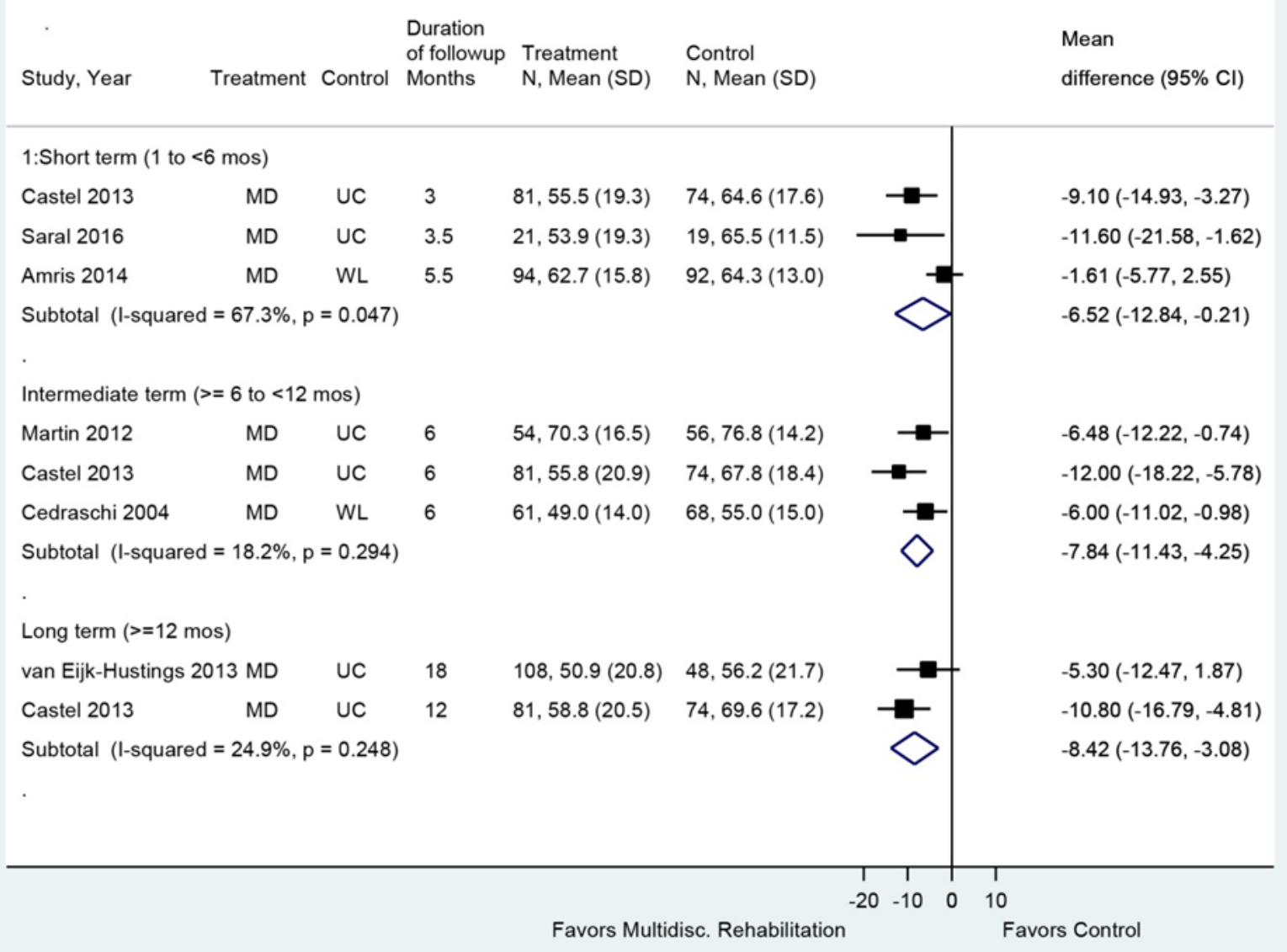

$\mathrm{CI}$ = confidence interval; $\mathrm{MD}=$ multidisciplinary rehabilitation; $\mathrm{SD}=$ standard deviation; $\mathrm{UC}=$ usual care; $\mathrm{WL}=$ waitlist 
Figure 49. Multidisciplinary rehabilitation versus usual care or waitlist for fibromyalgia: effects on pain

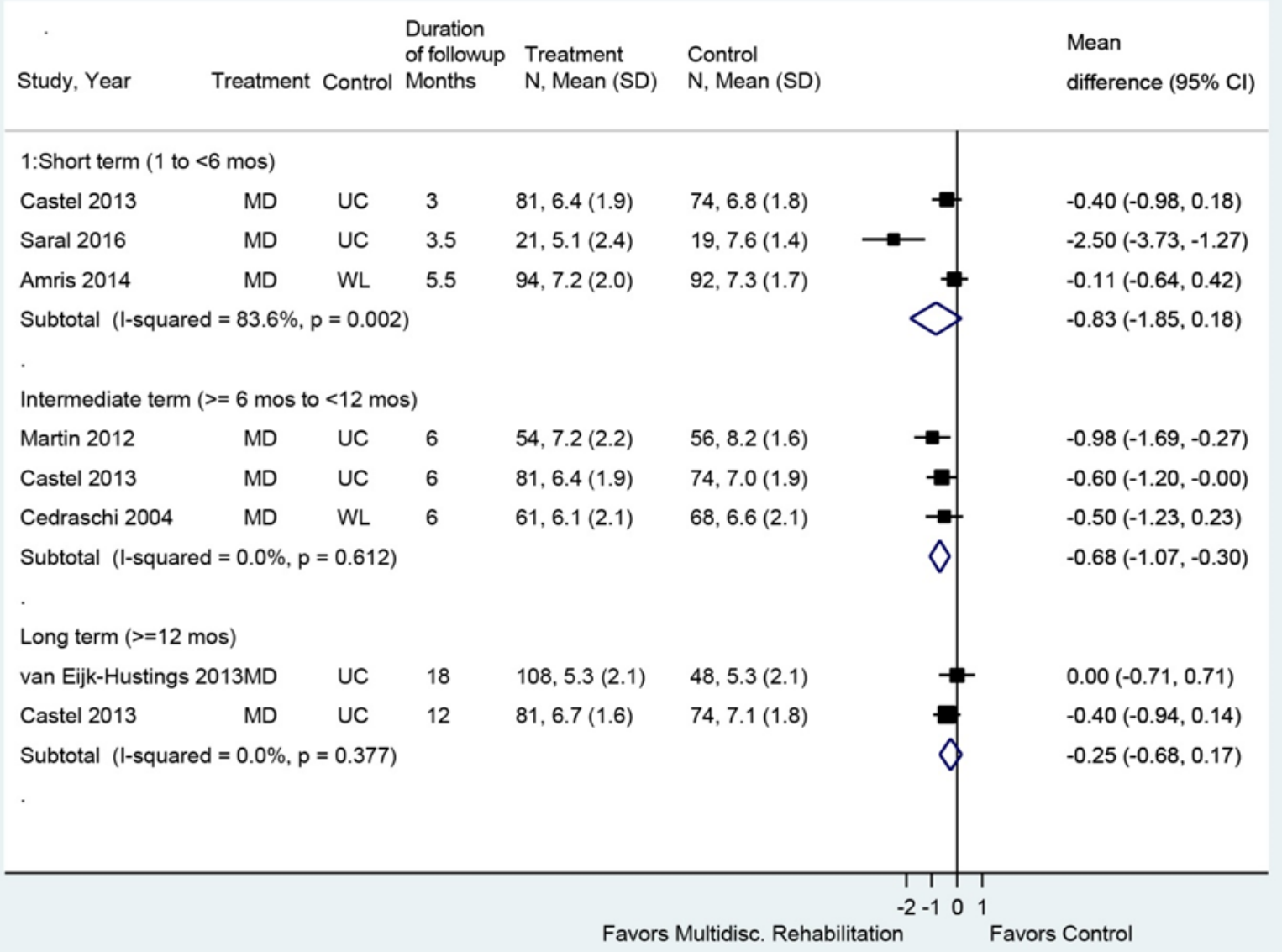

$\mathrm{CI}=$ confidence interval; $\mathrm{MD}=$ multidisciplinary rehabilitation; $\mathrm{SD}=$ standard deviation; $\mathrm{UC}=$ usual care; $\mathrm{WL}=$ waitlist

\section{Key Question 5: Chronic Tension Headache}

\section{Psychological Therapies for Chronic Tension Headache}

\section{Key Points}

- There is insufficient evidence from three poor quality trials to determine the effects of psychological therapies (CBT, relaxation) on short-term or intermediate-term function or pain compared with waitlist, placebo or attention control (SOE: insufficient).

- There is insufficient evidence from two poor-quality trials to determine the effects of CBT on short-term or intermediate-term function or pain compared with antidepressant medication (SOE: insufficient).

- No long-term outcomes were reported and no trials comparing psychological therapies to biofeedback were identified that met inclusion criteria.

- Data were insufficient for harms. Results were mixed across two poor-quality trials comparing CBT with antidepressant medication, with one trial reporting a lower risk of “at least mild” adverse events in the CBT group (0\% vs. 59\%), four of which led to 
withdrawal from the trial, and the second trial reporting a similar low risk of withdrawal due to adverse events ( $2 \%$ to $6 \%$ across groups to include placebo) (SOE: insufficient).

\section{Detailed Synthesis}

Three trials, all conducted in the United States, ${ }^{104,105,108}$ of CBT for chronic tension headache met inclusion criteria (Table 43 and Appendix D). Sample sizes ranged from 41 to 150; the mean age across trials varied from 32 to 42 years and most participants were female (56\% to $80 \%$ ). Duration since the onset of headache pain ranged from 10.7 to 14.5 years. All trials either excluded patients with concomitant migraines or required that they suffer from no more than one migraine per month. Two trials also specifically excluded patients with medication overuse (analgesic-abuse) headaches and required that patients be free from prophylactic headache medication upon study entry. ${ }^{105,108}$

All three trials evaluated some variation of stress management therapy/cognitive coping skills training with a relaxation component; one trial $(n=77)$ also included an additional relaxation only arm. ${ }^{104}$ In two trials $(n=41,150)$, patients received three 60 -minute sessions of CBT and training in home-based relaxation, ${ }^{105,108}$ and in the third trial $(\mathrm{n}=77)$, patients underwent 11 sessions (1-2 per week) of CBT plus progressive muscle relaxation training (session duration varied from 45 to 90 minutes). ${ }^{104}$ In all trials, the interventions were administered by a psychologist or counselor over a 2-month period. Two trials compared CBT with placebo (placebo pill), ${ }^{105}$ attention control (pseudomeditation/body awareness training) ${ }^{104}$ and waitlist (monitoring via phone and clinical visits) control groups. ${ }^{104}$ Two trials compared CBT with amitriptyline (25-75 mg/day). ${ }^{105,108}$ All trials reported short-term results; one trial also provided outcomes at intermediate-term followup. ${ }^{105}$

All three trials were considered poor quality (Appendix E) due to lack of blinding and large differential attrition between groups (in one trial, overall attrition was also substantial ${ }^{105}$ ). Additionally, randomization, concealment, and intention-to-treat processes were unclear in one trial. ${ }^{108}$ 
Table 43. Chronic tension headache: psychological therapies

\begin{tabular}{|c|c|c|c|c|}
\hline $\begin{array}{l}\text { Author, Year, } \\
\text { Followup, } \\
\text { Pain } \\
\text { Duration, } \\
\text { Study Quality }\end{array}$ & Intervention & Population & Function and Pain Outcomes & Other Outcomes \\
\hline $\begin{array}{l}\text { Blanchard, } \\
1^{1990^{104}} \\
(\mathrm{n}=77) \\
1 \text { month } \\
\text { Duration of } \\
\text { pain: mean } \\
14.2 \text { years } \\
\text { Poor }\end{array}$ & $\begin{array}{l}\text { A. Cognitive Stress } \\
\text { Coping Training + } \\
\text { PMR ( } n=17): 11 \text {, } \\
45-90 \text { minute } \\
\text { sessions once or } \\
\text { twice per week for } \\
8 \text { weeks } \\
\text { B. PMR alone } \\
\text { (n=22): 10, 30-70 } \\
\text { minute sessions } \\
\text { twice weekly for } 3 \\
\text { weeks followed by } \\
\text { once weekly for } 3 \\
\text { weeks with a final } \\
\text { session at week } 8 \\
\text { C. } \\
\text { Pseudomeditation } \\
\text { (attention control) } \\
\text { ( } n=19 \text { ): body } \\
\text { awareness and } \\
\text { mental control } \\
\text { training; } 11 \\
\text { sessions over } 8 \\
\text { weeks, } 40-45 \\
\text { minutes each } \\
D . \text { Waitlist ( } n=19 \text { ): } \\
\text { monitoring via } \\
\text { phone, clinical } \\
\text { visits and patient } \\
\text { diaries. }\end{array}$ & $\begin{array}{l}\text { A vs. B vs. C vs. D } \\
\text { Age: } 38 \text { vs. } 43 \text { vs. } \\
39 \text { vs. } 37 \text { years } \\
\text { Female: } 56 \% \text { vs. } \\
58 \% \text { vs. } 45 \% \text { vs. } \\
66 \% \\
\text { Mean duration of } \\
\text { chronicity: } 13.0 \text { vs. } \\
13.9 \text { vs. } 15.3 \text { vs. } \\
14.3 \text { years } \\
\text { Headache Index } \\
\text { Scores: mean } \\
5.82 \text { vs. } 5.63 \text { vs. } \\
5.23 \text { vs. } 5.05 \\
\text { Medication Index } \\
\text { Scores: mean } \\
39.8 \text { vs. } 16.9 \text { vs. } \\
12.1 \text { vs. } 24.0\end{array}$ & 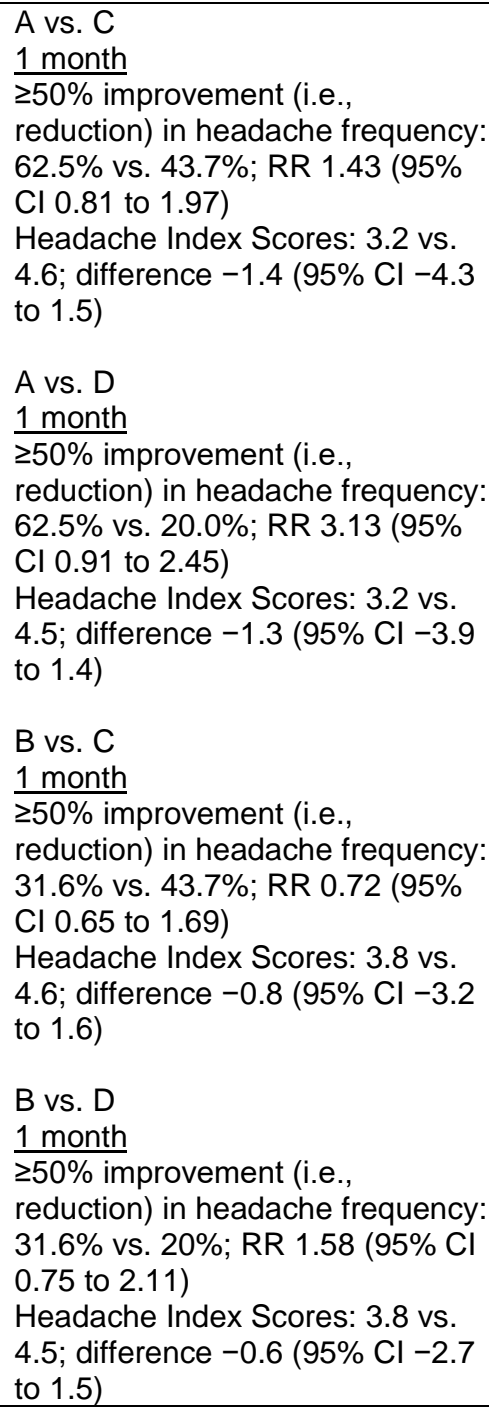 & $\begin{array}{l}\text { A vs. C } \\
1 \text { month } \\
\text { Medication Index } \\
\text { Scores: } 20.7 \text { vs. } \\
8.3 ; \text { difference } \\
12.4 \text { (95\% Cl } \\
-6.8 \text { to } 31.6) \\
\text { A vs. D } \\
1 \text { month } \\
\text { Medication Index } \\
\text { Scores: } 20.7 \text { vs. } \\
22.5 ; \text { difference } \\
-1.8 \text { (95\% Cl } \\
-23.8 \text { to } 20.2) \\
\text { B vs. C } \\
1 \text { month } \\
\text { Medication Index } \\
\text { Scores: } 9.8 \text { vs. } \\
8.3 ; \text { difference } 1.5 \\
\text { (95\% Cl }-6.8 \text { to } \\
9.8) \\
\text { B vs. D } \\
1 \text { month } \\
\text { Medication Index } \\
\text { Scores: } 9.8 \text { vs. } \\
22.5 ; \text { difference } \\
-12.7 \text { (95\% Cl } \\
-25.6 \text { to } 0.21)\end{array}$ \\
\hline
\end{tabular}




\begin{tabular}{|c|c|c|c|c|}
\hline $\begin{array}{l}\text { Author, Year, } \\
\text { Followup, }{ }^{a} \\
\text { Pain } \\
\text { Duration, } \\
\text { Study Quality }\end{array}$ & Intervention & Population & Function and Pain Outcomes & Other Outcomes \\
\hline $\begin{array}{l}\text { Holroyd, } \\
1991^{108} \\
(\mathrm{n}=41) \\
1 \text { month } \\
\text { Duration of } \\
\text { pain: mean } \\
10.7 \text { years } \\
\text { Poor }\end{array}$ & $\begin{array}{l}\text { A. CBT }(n=19) \text { : } \\
\text { three, } 1 \text { hour } \\
\text { sessions over } 8 \\
\text { weeks } \\
\text { B. Amitriptyline } \\
\text { therapy ( } n=17) \text { : } \\
\text { Individualized } \\
\text { dosage at } 25,50 \text {, } \\
\text { or } 75 \text { mg/day for } 8 \\
\text { weeks }\end{array}$ & $\begin{array}{l}\text { A + B } \\
\text { Age: } 32.3 \text { years } \\
\text { Female: } 80 \% \\
\text { A vs. B } \\
\% \text { of Headache- } \\
\text { free days: } 18.0 \text { vs. } \\
18.5 \\
\text { Headache Index } \\
\text { scores }(0-10): \\
2.17 \text { vs. } 2.04 \\
\text { Headache Pain } \\
\text { Peak scores } \\
\text { (0-10): } 6.41 \text { vs. } \\
6.36\end{array}$ & $\begin{array}{l}\text { A vs. B } \\
1 \text { month } \\
\text { Proportion with }>66 \% \text { reduction in } \\
\text { headaches (substantial } \\
\text { improvement): } 37 \% \text { vs. } 18 \% \text {; RR } \\
2.09 \text { ( } 95 \% \mathrm{Cl} 0.79 \text { to } 2.23 \text { ) } \\
\text { Proportion with } 33-66 \% \text { reduction } \\
\text { in headaches (moderate } \\
\text { improvement): } 53 \% \text { vs. } 35 \% \text {; RR } \\
1.49 \text { (95\% Cl } 0.80 \text { to } 2.03) \\
\% \text { of Headache-free days: } 54.7 \text { vs. } \\
42.3 \text {; difference } 12.4 \text { (95\% Cl } \\
-8.06 \text { to } 32.86) \\
\text { Headache Index scores: } 0.96 \text { vs. } \\
1.49 \text {; difference }-0.53 \text { (95\% Cl } \\
-1.14 \text { to } 0.08) \\
\text { Headache Peak scores: } 4.33 \text { vs. } \\
4.55 \text {; difference }-0.22 \text { ( } 95 \% \mathrm{Cl} \\
-1.70 \text { to } 1.26)\end{array}$ & 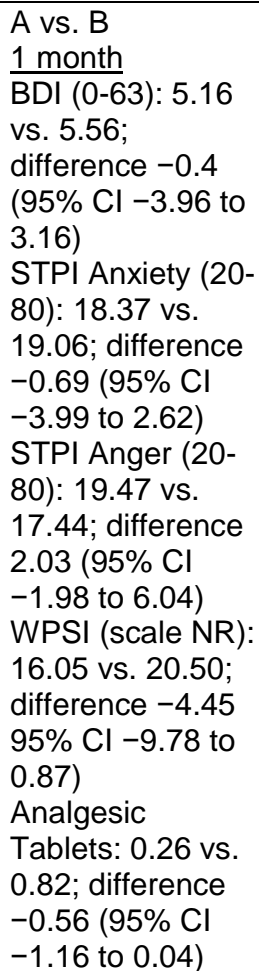 \\
\hline
\end{tabular}




\begin{tabular}{|c|c|c|c|c|}
\hline $\begin{array}{l}\text { Author, Year, } \\
\text { Followup, } \\
\text { Pain } \\
\text { Duration, } \\
\text { Study Quality }\end{array}$ & Intervention & Population & Function and Pain Outcomes & Other Outcomes \\
\hline $\begin{array}{l}\text { Holroyd, } \\
2001^{105} \\
(n=150) \\
1 \text { and } 6 \\
\text { months } \\
\text { Duration of } \\
\text { pain: mean } \\
11.8 \text { years } \\
\text { Poor }\end{array}$ & $\begin{array}{l}\text { A. Stress } \\
\text { Management } \\
\text { Therapy + Placebo } \\
(n=34) \text { : three, } 1 \\
\text { hour sessions } \\
\text { B. Placebo ( } n=26) \\
\text { Treatment Protocol: } \\
\text { identical to group C } \\
\text { C. Antidepressant } \\
\text { Medications } \\
\text { ( } n=44) \text { : } \\
\text { Low starting dose } \\
\text { (12.5 mg/day } \\
\text { increased to } 25 m g, \\
\text { then 50mg) with the } \\
\text { possibility to switch } \\
\text { to nortriptyline }\end{array}$ & $\begin{array}{l}\text { A vs. B vs. C } \\
\text { Age: } 37 \text { vs. } 38 \text { vs. } \\
36 \text { years } \\
\text { Female: } 80 \% \text { vs. } \\
79 \% \text { vs. } 66 \% \\
\text { Caucasian: } 91 \% \\
\text { vs. } 98 \% \text { vs. } 98 \% \\
\text { Duration of pain: } \\
12.3 \text { vs. } 11.1 \text { vs. } \\
11.9 \text { years } \\
\text { Headache } \\
\text { frequency, } \\
\text { days/month: } 26.5 \\
\text { vs. } 26.1 \text { vs. } 25.1 \\
\\
\text { Headache Index } \\
\text { (0-10): } 2.8 \text { vs. } 2.7 \\
\text { vs. } 2.8 \\
\text { Days/month with } \\
\text { at least } \\
\text { moderately severe } \\
\text { headache ( } \geq 5 \text { on } \\
0-10 \text { scale): } 13.5 \\
\text { vs. } 13.5 \text { vs. } 14.1\end{array}$ & 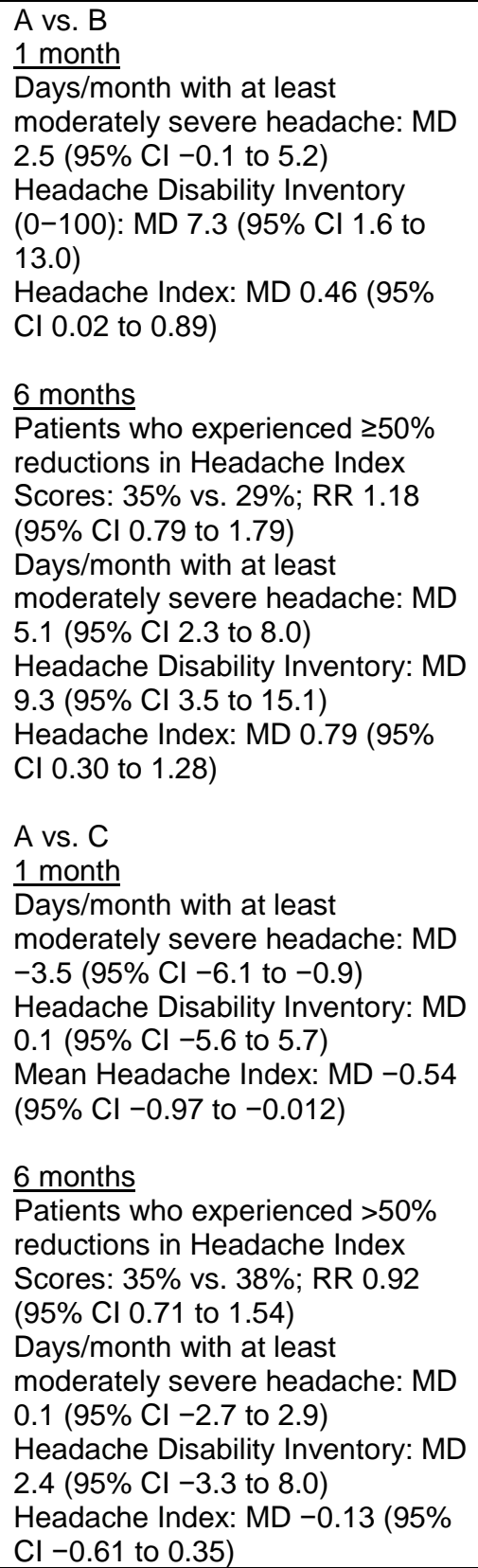 & $\begin{array}{l}\text { A vs. B } \\
1 \text { month } \\
\text { Weighted } \\
\text { analgesic use: } \\
\text { MD }-1.7 \text { (95\% Cl } \\
-12.0 \text { to } 8.6) \\
6 \text { months } \\
\text { Weighted } \\
\text { analgesic use: } \\
\text { MD } 11.8 \text { (95\% Cl } \\
1.5 \text { to } 22.1) \\
\text { A vs. C } \\
\frac{1 \text { month }}{\text { Weighted }} \\
\text { analgesic use: } \\
\text { MD -19.4 (95\% } \\
\text { Cl -29.5 to }-9.3) \\
6 \text { months } \\
\text { Weighted } \\
\text { analgesic use: } \\
\text { MD -6.2 (95\% Cl } \\
-16.2 \text { to 3.8) }\end{array}$ \\
\hline
\end{tabular}

BDI = Beck Depression Inventory; CBT = cognitive-behavioral therapy; CI = confidence interval; $\mathrm{MD}$ = mean difference; $\mathrm{NR}$ = not reported; PMR = Progressive Muscle Relaxation; RR = risk ratio; SD = standard deviation; STPI = State-Trait Personality Inventory; VAS = visual analog scale; WPSI = Wahler Physical Symptom Inventory

${ }^{\text {a }}$ Unless otherwise noted, followup time is calculated from the end of the treatment period

\section{Psychological Therapy Compared With Waitlist, Placebo, or Attention Control}

There was insufficient evidence from three poor-quality trials to draw conclusions regarding the effects of psychological therapies compared with waitlist, placebo, or attention control over the short term or intermediate term. 
CBT plus placebo was associated with a slightly greater effect on both short-term and intermediate-term function compared with placebo alone as measured by the Headache Disability Inventory (HDI) (scale 0-100) in one trial (MD 7.3, 95\% CI 1.6 to 13.0 at 1 month and 9.3, 95\% CI 3.5 to 15.1 at 6 months. ${ }^{105}$ Long-term function was not reported.

Various pain measures were reported across trials. In general, CBT (plus relaxation), but not relaxation alone, appeared to have a small effect on short-term pain compared with waitlist, placebo, or attention control (Table 43). CBT plus relaxation was associated with a slight improvement in pain on the Headache Index (HI) at 1 month compared with waitlist, attention control, or placebo across two trials (pooled SMD $-0.40,95 \%$ CI -0.74 to $-0.07, \mathrm{I}^{2}=0 \%$ ) ${ }^{104,105}$ (Figure 51). Relaxation only conferred no benefit for short-term pain compared with waitlist or attention control in one of these trials (difference -0.21 on a $0-20 \mathrm{HI}$ scale, $95 \% \mathrm{CI}-0.78$ to 0.36). ${ }^{104}$ Almost twice as many patients who received CBT plus relaxation achieved at least a 50 percent improvement in headache frequency compared with usual care or waitlist (risk ratio [RR] 1.94, 95\% CI 1.03 to 3.66) over the short term in one trial; however, there was no difference between groups when the intervention was relaxation alone (RR 0.98, 95\% CI 0.42 to 2.26$)^{104}$ (Figure 50). One trial reported similar favorable results regarding pain over the intermediateterm for CBT plus placebo compared with placebo alone, with the exception of "success" ( $\geq 50 \%$ improvement from baseline in HI score), which did not differ between groups (Table 43). ${ }^{105}$

Medication use did not differ significantly between the CBT and relaxation therapy groups and waitlist, placebo, or attention control groups over the short-term in two trials. ${ }^{104,105}$ Over the intermediate-term, CBT plus placebo resulted in a significant reduction in analgesic use compared with placebo alone (difference 11.8 , 95\% CI 1.5 to 22.1). ${ }^{105}$

\section{Psychological Therapy Compared With Pharmacological Therapy}

There was insufficient evidence from two poor-quality trials to draw conclusions regarding the effect of CBT versus pharmacological therapy through intermediate-term followup.

There was no effect for CBT plus placebo versus antidepressant medication over the shortterm or intermediate-term for function as measured by the HDI (scale 0-100) in one trial (MD $0.1,95 \% \mathrm{CI}-5.6$ to 5.7 at 1 month and $2.4,95 \% \mathrm{CI}-3.3$ to 8.0 at 6 months). ${ }^{105}$ Long-term function was not reported.

Regarding short-term pain, two trials reported HI index scores with differing results. One trial found that CBT plus placebo resulted in less improvement compared with antidepressant medication at 1 month (SMD 0.50, 95\% CI 0.11 to 0.89), ${ }^{105}$ whereas the other trial showed an improvement with CBT versus amitriptyline by 1 month, although the difference did not reach statistical significance (SMD -0.59 , $95 \%$ CI -1.26 to 0.08$)^{108}$ (Figure 51 ); due to the significant heterogeneity between groups we did not use the pooled estimate. There were no significant differences between CBT and pharmacological treatment for any other pain outcome reported over the short term in both trials ${ }^{105,108}$ or over the intermediate-term in one trial ${ }^{105}$ (Table 43).

Short-term results were mixed regarding medication use with one trial reporting no difference between CBT and amitriptyline ${ }^{108}$ and the other reporting a significant difference between groups favoring antidepressant therapy ${ }^{105}$; however, this difference did not persist to the intermediate term in the latter trial (Table 43).

\section{Psychological Therapy Compared With Biofeedback}

No trial of psychological therapy versus biofeedback met inclusion criteria. 


\section{Harms}

Harms were reported by the two poor-quality trials comparing CBT with antidepressant medication, ${ }^{108}$ and with placebo in one. ${ }^{105}$ No patient who underwent CBT experienced an adverse effect versus 10 of 17 (59\%) of those who took medication in one trial; ${ }^{108}$ six events were classified as mild, two as moderate, and two as substantial (no further details provided). Four of these patients withdrew from the trial. The risk of withdrawal due to adverse events was similar across groups in the second trial: CBT (2\%) versus antidepressant medication (2\%) and placebo (6\%); no other information was provided. ${ }^{105}$

Figure 50. Psychological therapies versus waitlist, attention control, placebo intervention, or pharmacological treatment for chronic tension headache: effects on pain (success)

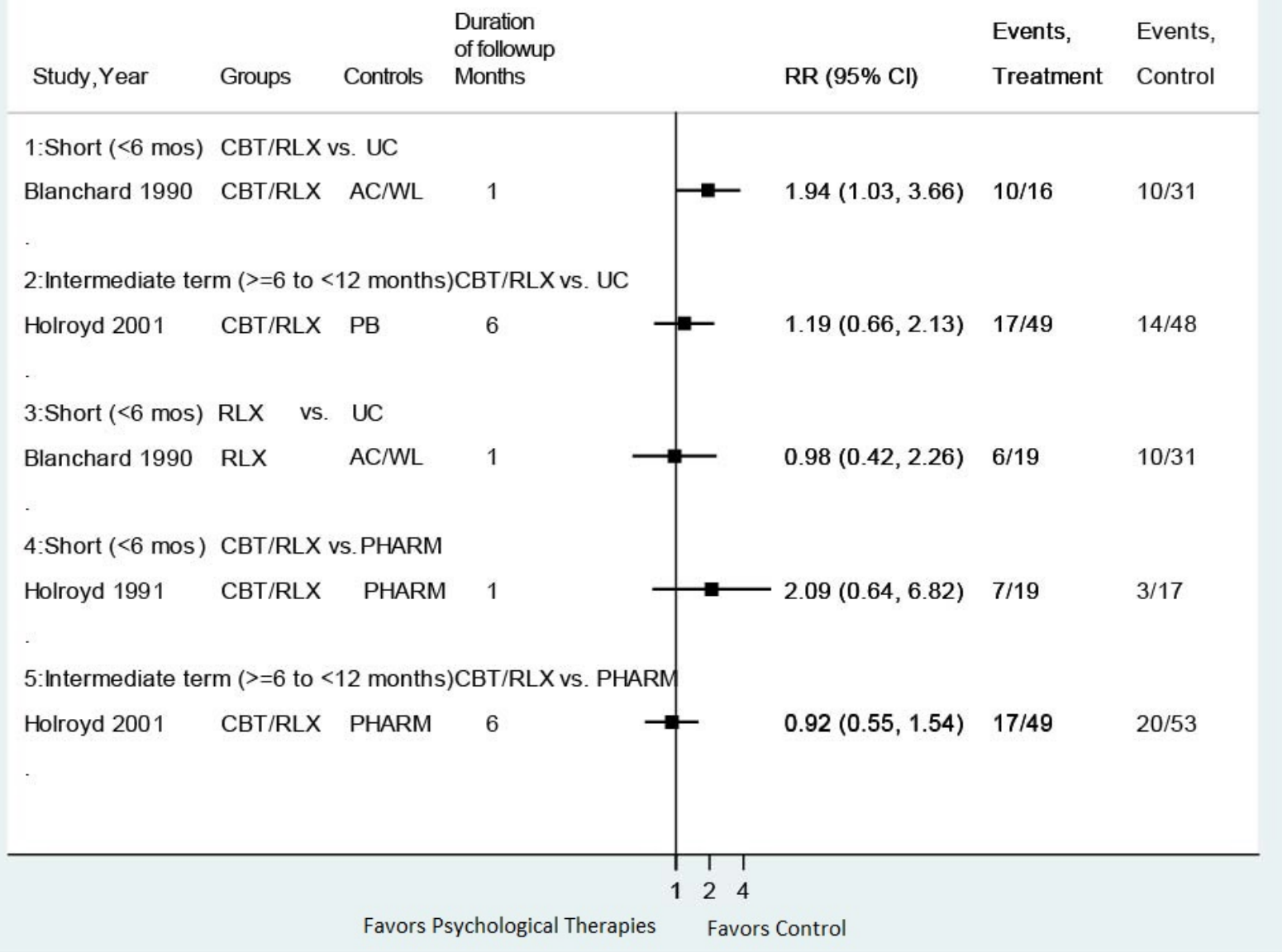

AC/WL = an attention control arm and a waitlist arm; CBT = cognitive-behavioral therapy; CBT/RLX = cognitive-behavioral therapy with a relaxation component; $\mathrm{CI}=$ confidence interval; $\mathrm{PB}=$ placebo (pill); PHARM = standard pharmacological therapy; RLX = relaxation therapy; $\mathrm{RR}=$ risk ratio; $\mathrm{UC}=$ usual care 
Figure 51. Psychological therapies versus waitlist, attention control, placebo intervention, or pharmacological treatment for chronic tension headache: effects on pain (mean difference)

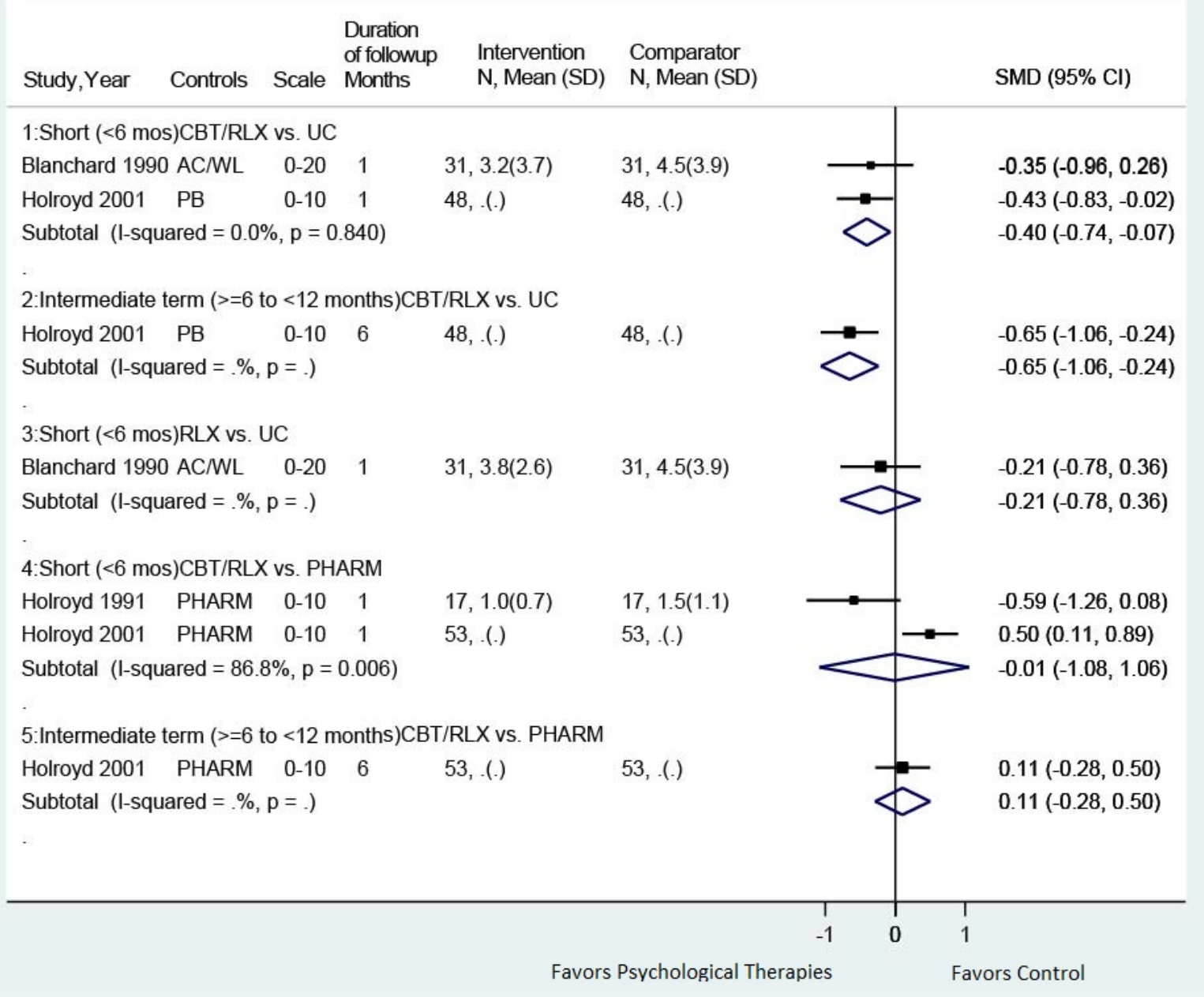

$\mathrm{AC} / \mathrm{WL}=$ an attention control arm and a waitlist arm; CBT = cognitive-behavioral therapy; CBT/RLX = cognitive-behavioral therapy with a relaxation component; $\mathrm{CI}=$ confidence interval; $\mathrm{PB}=$ placebo (pill); $\mathrm{PHARM}=$ standard pharmacological therapy; RLX = Relaxation therapy; SMD = standardized mean difference; UC = usual care

\section{Physical Modalities for Chronic Tension Headache}

\section{Key Points}

- There is insufficient evidence from one poor-quality trial to determine the effects occipital transcutaneous electrical stimulation (OTES) on short-term term function or pain compared with sham (SOE: insufficient).

- No longer-term outcomes were reported and no trials comparing physical modalities to pharmacological therapy or to biofeedback were identified that met inclusion criteria.

- Data were insufficient for harms; however, no adverse events occurred in either the real or the sham OTES group in one poor-quality trial (SOE: insufficient). 


\section{Detailed Synthesis}

Only one Italian trial ${ }^{142}$ was identified that investigated the efficacy of occipital transcutaneous electrical stimulation (OTES) versus sham (Table 44 and Appendix D). Patients were excluded if they had undergone prophylactic treatment in the prior 2 months or had previous treatment with OTES. Acute medications use was permitted during the study period, but other methods of pain control or new preventive treatments were prohibited. At baseline, 46 percent of patients were overusing medications. Identical devices and procedures were used for both the real and the sham OTES, and treatment consisted of 30-minute sessions, three times per day for two consecutive weeks. Limited information on the timing of outcomes was provided, but it was assumed that data was collected at 1 and 2 months post-treatment. This trial was rated poor quality due to unclear randomization sequence, failure to control for dissimilar proportion of females between groups, and no reporting of attrition (Appendix E). The focus of the trial was on allodonia, which was not of interest to this report.

Table 44. Chronic tension headache: physical modalities

\begin{tabular}{|c|c|c|c|c|}
\hline $\begin{array}{l}\text { Author, } \\
\text { Year, } \\
\text { Followup, } \\
\text { Pain } \\
\text { Duration, } \\
\text { Study } \\
\text { Quality }\end{array}$ & Intervention & Population & $\begin{array}{l}\text { Function and Pain } \\
\text { Outcomes }\end{array}$ & Other Outcomes \\
\hline $\begin{array}{l}\text { Bono, 2015 } \\
\text { (N=83) } \\
1 \text { month, } 2 \\
\text { months } \\
\text { Duration of } \\
\text { pain: >2 } \\
\text { years (mean } \\
\text { NR) } \\
\text { Poor }\end{array}$ & $\begin{array}{l}\text { A. Occipital TES } \\
\text { ( } \mathrm{n}=54) \text { : Electro- } \\
\text { stimulator } \\
\text { generated biphasic } \\
\text { impulses via } \\
\text { electrodes placed } \\
\text { on occipital region } \\
\text { bilaterally; pulse } \\
\text { width: } 250 \text { } 4 \mathrm{~s} \text {; } \\
\text { frequency: } 40 \mathrm{~Hz} \text {; } \\
\text { intensity } 20 \mathrm{~mA} \text {. } \\
\text { B. Sham ( } \mathrm{n}=29 \text { ): } \\
\text { Same device and } \\
\text { procedure, but no } \\
\text { current was } \\
\text { delivered. } \\
\text { Treatment protocol: } \\
30 \text { minute sessions } \\
3 \text { times daily for two } \\
\text { consecutive weeks } \\
\text { (42 sessions total) }\end{array}$ & $\begin{array}{l}\text { A vs. B } \\
\text { Age: } 42 \text { vs. } 40 \text { years } \\
\text { Female: } 81 \% \text { vs. } 66 \% \\
\text { Race: NR } \\
\text { Headache frequency: } \\
\text { mean } 29.0 \\
\text { days/month } \\
\text { Medication overuse: } \\
43 \% \text { vs. } 52 \% \\
\text { MIDAS }(0-21+): 63 \text { vs. } \\
50 \\
\text { VAS pain }(0-10): 8 \\
\text { vs. } 8\end{array}$ & $\begin{array}{l}\text { A vs. B } \\
1 \text { month } \\
\text { Patients who achieved } \\
>50 \% \text { reduction in } \\
\text { headache days: } 85 \% \text { vs. } \\
7 \% \text {; RR } 12.4(95 \% \mathrm{Cl} 3.2 \\
\text { to } 47.3) \\
2 \text { months } \\
\text { MIDAS: } 16 \text { vs. } 51 ; \\
\text { difference }-35.0 \text { ( } 95 \% \mathrm{Cl} \\
-42.6 \text { to }-27.4) \\
\text { VAS pain (0-10): } 3 \text { vs. 8; } \\
\text { difference }-5.0 \text { (95\% Cl } \\
-5.8 \text { to }-4.2) \\
\text { Proportion of patients still } \\
\text { overusing medications: } \\
7 \% \text { vs. } 48 \% \text {; RR } 0.15 \\
\text { (95\% Cl } 0.06 \text { to } 0.42)\end{array}$ & $\begin{array}{l}\text { A vs. B } \\
2 \text { months } \\
\text { BDI-II: } 7 \text { vs. } 8 ; \\
\text { difference }-1.0 \\
\text { (95\% Cl }-2.2 \text { to } \\
0.2) \\
\text { HAM-A: } 6 \text { vs. } 7 ; \\
\text { MD }-1.0(95 \% \mathrm{Cl} \\
-1.9 \text { to }-0.1)\end{array}$ \\
\hline
\end{tabular}

BDI-II = Beck Depression Inventory-II; CI = confidence interval; HAM-A = Hamilton Anxiety Rating Scale; Hz = Herta; $\mathrm{mA}$ = milliamps; MIDAS = Migraine Disability Assessment Questionnaire; NR = not reported; RR = risk ratio; SD = standard deviation; TES = transcutaneous electrical stimulation; VAS = visual analog scale; $\mu$ s = microsecond

${ }^{\text {a }}$ Unless otherwise noted, followup time is calculated from the end of the treatment period

\section{Physical Modalities Compared With Sham}

There was insufficient data from one poor-quality trial to determine the short-term effects of OTES compared with sham. ${ }^{142}$ OTES resulted in greater improvement in function at 2 months as measured by the Migraine Disability Assessment Questionnaire (MD -35.0, 95\% CI -42.6 to -27.4 , scale $0-21+$ ) and in pain intensity as measured by visual analog scale (VAS) (difference 
-5.0 on a $0-10$ scale, $95 \%$ CI -5.8 to -4.2 ) The proportion of patients who achieved a 50 percent or greater reduction in headache days also favored OTES (RR 12.4; 95\% CI 3.2 to 47.3). Measures of depression and anxiety were both somewhat better following OTES compared with sham at 2 months, however, the between-group difference was only statistically significant for anxiety (Table 44). The proportion of patients overusing medications at 2 months was also significantly lower in the OTES group.

\section{Physical Modalities Compared With Pharmacological Therapy or Biofeedback}

No trial of physical modalities versus pharmacological therapy and versus biofeedback met inclusion criteria.

\section{Harms}

Authors report that neither adverse events nor side effects occurred in either the real or the sham OTES group in one poor-quality trial. ${ }^{142}$

\section{Manual Therapies for Chronic Tension Headache}

\section{Key Points}

- Spinal manipulation therapy was associated with slight to moderate improvements, respectively, compared with usual care in function (difference $-5.0,95 \%$ CI -9.02 to -1.16 on the Headache Impact Test, scale 36-78 and difference $-10.1,95 \%$ CI -19.5 to -0.64 on the Headache Disability Inventory, scale 0 to 100) and pain intensity (difference -1.4 on a $0-10$ NRS scale, $95 \%$ CI -2.69 to -0.16 ) over the short term in one fair-quality trial (SOE: low). Approximately 25 percent of the patients had comorbid migraine.

- There is insufficient evidence from one poor-quality trial to determine the effects of spinal manipulation therapy on short-term pain compared with amitriptyline (SOE: insufficient).

- No longer-term outcomes were reported and no trials comparing physical modalities to pharmacological therapy or to biofeedback were identified that met inclusion criteria.

- No adverse events occurred in the trial comparing spinal manipulation to usual care, but significantly fewer adverse events were reported following manipulation versus amitriptyline in the other poor-quality trial (4.3\% vs. $82.1 \%$; RR 0.05 , 95\% CI 0.02 to $0.16)$. The risk of withdrawal due to adverse events was not significantly different $(1.4 \%$ vs. 8.9\%; RR 0.16, 95\% CI 0.02 to 1.33). Common complaints were neck stiffness in the manipulation group and dry mouth, dizziness, and weight gain in the medication group (SOE: low).

\section{Detailed Synthesis}

Two trials ( $\mathrm{n}=82$ and $\mathrm{n}=150)^{157,158}$ that evaluated spinal manipulation therapy (SMT) for the treatment of chronic tension headache met inclusion criteria (Table 45 and Appendix D). The majority of patients in both trials were female (61\% to $78 \%$ ) with mean ages ranging from 40 to 42 years and a mean headache duration of 13 years. Both trials included patients with comorbid migraine as long as their headache problem was determined by a physician to be predominantly tension-type in nature (this included $26 \%$ of patients in one trial; ${ }^{157}$ proportion not reported in the other trial). In one trial, patients were specifically excluded if they met the criteria for medication overuse or if they had received manual therapy in the 2 months prior to enrollment. ${ }^{157} \mathrm{At}$ 
baseline, prophylactic medication use was common. Current or past use of other treatments was not reported.

One Dutch trial compared a maximum of nine, 30-minute sessions of SMT over 8 weeks with usual care (information, reassurance and advice, discussion of lifestyle changes, and analgesics or NSAIDs provided by a general practitioner). ${ }^{157}$ The second trial, conducted in the United States, compared 12 SMT sessions of 20 minutes over a 6-week treatment period versus amitriptyline (maximum dose $30 \mathrm{mg} /$ day). ${ }^{158}$ Both trials reported only short-term outcomes. One trial was rated fair quality ${ }^{157}$ and one poor quality ${ }^{158}$ (Appendix E). Due to the nature of the interventions, blinding of patients and researchers was not possible. Additionally, the poor trial had a high rate of differential attrition (7\% SMT and 27\% amitriptyline).

Table 45. Chronic tension headache: manual therapies

\begin{tabular}{|c|c|c|c|c|}
\hline $\begin{array}{l}\text { Author, } \\
\text { Year, } \\
\text { Followup, } \\
\text { Pain } \\
\text { Duration, } \\
\text { Study } \\
\text { Quality }\end{array}$ & Intervention & Population & $\begin{array}{l}\text { Function and Pain } \\
\text { Outcomes }\end{array}$ & Other Outcomes \\
\hline $\begin{array}{l}\text { Boline, } \\
\text { 1995158 } \\
1 \text { month } \\
\text { Duration of } \\
\text { pain: } 13.5 \\
\text { years } \\
\text { Poor }\end{array}$ & $\begin{array}{l}\text { A. Spinal Manipulative } \\
\text { Therapy (n=70): short- } \\
\text { lever, low-amplitude, } \\
\text { high-velocity thrust } \\
\text { techniques on } \\
\text { cervical, thoracic or } \\
\text { lumbar spinal } \\
\text { segments. Moist heat } \\
\text { and light massage } \\
\text { preceded } \\
\text { manipulation; } 12,20 \\
\text { minute sessions ( } 2 \text { per } \\
\text { week for } 6 \text { weeks) } \\
\text { B. Amitriptyline } \\
\text { (n=56): dose titration } \\
\text { of amitriptyline for } 6 \\
\text { weeks. Nighttime, } \\
\text { daily doses began at } \\
\text { 10mg/day for first } \\
\text { week, then increased } \\
\text { to } 20 \text { mg/day in the } \\
\text { second, followed by } \\
30 \text { mg/day in the third } \\
\text { week and after; } \\
\text { continued use of OTC } \\
\text { medications as- } \\
\text { needed. }\end{array}$ & $\begin{array}{l}\text { A vs. B } \\
\text { Age: } 41 \text { vs. } 42 \\
\text { years } \\
\text { Female: } 54 \% \text { vs. } \\
70 \% \\
\text { Race: NR } \\
\text { Daily headache } \\
\text { intensity }(0-20)^{\mathrm{b}} \text { : } \\
5.6 \text { vs. } 5.0 \\
\text { Weekly headache } \\
\text { frequency }(0-28)^{\mathrm{c}} \text { : } \\
12.4 \text { vs. } 10.8\end{array}$ & $\begin{array}{l}\text { A vs. B } \\
1 \text { month } \\
\text { Daily headache intensity: } \\
\text { adjusted means } 3.8 \text { vs. } \\
5.2 \text {; difference } 1.4(95 \% \mathrm{Cl} \\
0.3,2.3) \\
\text { Weekly headache } \\
\text { frequencyc: adjusted } \\
\text { means } 7.6 \text { vs. } 11.8 ; \\
\text { difference } 4.2(95 \% \mathrm{Cl} 1.9, \\
6.5)\end{array}$ & $\begin{array}{l}\text { A vs. B } \\
1 \text { month } \\
\text { SF-36 Function } \\
\text { Health Status } \\
\text { Global Score (\% } \\
\text { points): adjusted } \\
\text { means } 78.8 \text { vs. } \\
73.9 ; \text { difference } 4.9 \\
\text { (95\% Cl 0.4, 9.4) } \\
\text { OTC medication } \\
\text { usage: adjusted } \\
\text { means } 1.3 \text { vs. } 2.2 ; \\
\text { difference } 0.9(95 \% \\
\text { Cl } 0.3,1.5)\end{array}$ \\
\hline
\end{tabular}




\begin{tabular}{|c|c|c|c|c|}
\hline $\begin{array}{l}\text { Author, } \\
\text { Year, } \\
\text { Followup, } \\
\text { Pain } \\
\text { Duration, } \\
\text { Study } \\
\text { Quality }\end{array}$ & Intervention & Population & $\begin{array}{l}\text { Function and Pain } \\
\text { Outcomes }\end{array}$ & Other Outcomes \\
\hline $\begin{array}{l}\text { Castien, } \\
2011^{157} \\
4.5 \text { months } \\
\text { Duration of } \\
\text { pain: } 13 \\
\text { years } \\
\text { Fair }\end{array}$ & $\begin{array}{l}\text { A. Spinal Manipulation } \\
\text { ( } \mathrm{n}=38 \text { ) } \\
\text { combination of } 3 \\
\text { approaches at the } \\
\text { therapist discretion: } \\
\text { mobilizations of the } \\
\text { cervical and thoracic } \\
\text { spine, craniocervical } \\
\text { muscle exercises and } \\
\text { posture correction; } \\
\text { maximum of } 9,30- \\
\text { minute sessions over } \\
2 \text { months } \\
\text { B. Usual Care ( } n=37 \text { ) } \\
2-3 \text { general } \\
\text { practitioner visits over } \\
2 \text { months }\end{array}$ & $\begin{array}{l}\text { A vs. B } \\
\text { Age, years: } 40 \text { vs. } \\
40 \text { years } \\
\text { Female: } 78 \% \text { vs. } \\
78 \% \\
\text { Race: NR } \\
\text { Mean frequency of } \\
\text { headache } \\
\text { (days/month): } 24 \\
\text { vs. } 24 \\
\text { NSAID use: } 29 \% \\
\text { (mean } 3 \\
\text { pills/week); } \\
\text { Analgesic use: } \\
59 \% \text { (mean } 1.5 \\
\text { pills/week) } \\
\text { HIT-6 (36-78): } 62.6 \\
\text { Vs. } 61.2 \\
\text { HDI (0-100): } 39.6 \\
\text { Vs. } 44.2 \\
\text { Pain intensity, } \\
\text { NRS (0-10): } 6.3 \text { vs. } \\
5.7\end{array}$ & $\begin{array}{l}\text { A vs. B } \\
4.5 \text { months } \\
\text { Proportion of patients with } \\
\geq 50 \% \text { reduction in } \\
\text { headache frequency: } \\
81.6 \% \text { vs. } 40.5 \% \text {; RR } 2.01 \\
\text { (95\% CI } 1.32 \text { to } 3.05) \\
\text { HIT-6, mean change from } \\
\text { baseline: }-10.6 \text { vs. }-5.5 ; \\
\text { difference } 5.0 \text { ( } 95 \% \text { Cl } \\
-9.02 \text { to }-1.16) \\
\text { HDI, mean change from } \\
\text { baseline: }-20.0 \text { vs. }-9.9 ; \\
\text { difference }-10.1 \text { ( } 95 \% \mathrm{Cl} \\
-19.5 \text { to }-0.64) \\
\text { Headache frequency } \\
\text { (days/14 days), mean } \\
\text { change from baseline: } \\
-9.1 \text { vs. }-4.1 \text {; difference } \\
-4.9 \text { (95\% Cl }-6.95 \text { to } \\
-2.98 \text { ) } \\
\text { Pain intensity mean } \\
\text { change from baseline: } \\
-3.1 \text { vs. }-1.7 ; \text { difference } \\
-1.4 \text { (95\% Cl }-2.69 \text { to } \\
-0.16) \\
\text { Headache duration } \\
\text { (hrs./day), mean change } \\
\text { from baseline: }-7.0 \text { vs. } \\
-3.5 ; \text { difference }-3.5 \text { ( } 95 \% \\
\text { Cl }-7.71 \text { to }-0.63 \text { ) }\end{array}$ & 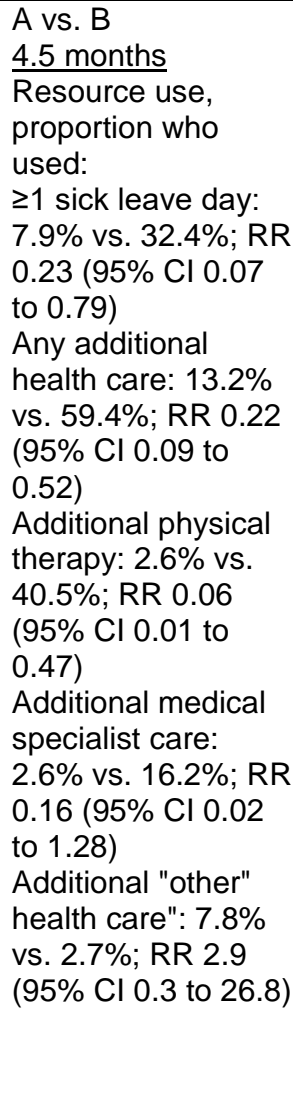 \\
\hline
\end{tabular}

CI = confidence interval; HDI = Headache Disability Index; HIT-6 = Headache Impact Test-6; NR = not reported; NR = not reported; NRS = numeric rating scale; NSAID = nonsteroidal anti-inflammatory drugs OTC = over-the-counter; RR = risk ratio; SF-36 = Short-Form-36 Questionnaire; VAS = visual analog scale

${ }^{a}$ Unless otherwise noted, followup time is calculated from the end of the treatment period

${ }^{\mathrm{b}}$ Headache intensity was calculated as the total ratings per period and divided by the number of days per period

c Headache frequency was calculated by summing all headache ratings 2 and above for the month

\section{Manual Therapies Compared With Usual Care}

Only short-term data from one fair-quality trial were reported. SMT resulted in small to moderate improvements in function compared with usual care at 4.5 months post-treatment as measured by the Headache Disability Inventory (HDI, scale 0 to 100) and the Headache Impact Test (HIT-6, scale 36 to 78), respectively (MD between groups in change scores from baseline, $-10.1,95 \%$ CI -19.5 to -0.64 and $-5.0,95 \%$ CI -9.02 to -1.16$).{ }^{157}$ Regarding pain outcomes, twice as many patients who received SMT experienced a $\geq 50 \%$ reduction from baseline in the number of headache days (per 2 weeks) compared with usual care: $81.6 \%$ versus $40.5 \%$; RR 2.0 (95\% CI 1.3 3.0). ${ }^{157}$ Similarly, a statistically greater reduction in the number of headache days (MD between groups in change scores from baseline, -4.9 ; 95\% CI -6.95 to -2.98 ) and in headache pain intensity (MD in change scores from baseline, -1.4 on a 0 to 10 NRS scale, $95 \%$ CI -2.69 to -0.16 ) was seen following SMT. Given that 29 percent of SMT patients and 22 
percent of usual care patients had comorbid migraine, it is unclear how the coexistence of these headache types may have affected the outcome.

The proportion of patients who used any additional health care services (e.g., physical therapy, medical specialists, other) was statistically lower in the SMT group compared with the usual care group (Table 45). ${ }^{157}$ Authors report no statistically significant differences between treatments in analgesic or NSAID use; data were not provided.

\section{Manual Therapies Compared With Pharmacological Therapy}

The evidence was insufficient from one poor-quality trial to determine the effects of spinal manipulation compared with amitriptyline over the short term. ${ }^{158}$ The spinal manipulation group showed more improvement compared with the amitriptyline group in daily headache intensity (adjusted difference $-1.4,95 \%$ CI -2.3 to -0.3 ), weekly headache frequency (adjusted difference -4.2, 95\% CI -6.5 to -1.9), Short Form-36 Function score (adjusted difference 4.9, 95\% CI 0.4 to 9.4), and over-the-counter medication use (difference $-0.9,95 \% \mathrm{CI}-1.5$ to -0.3 ) at 1 month. Attrition in the amitriptyline group was 27 percent, compared with 7 percent in the manipulation group.

\section{Manual Therapies Compared With Biofeedback}

No trial of physical modalities versus biofeedback met inclusion criteria.

\section{Harms}

No adverse events occurred in the trial comparing spinal manipulation to usual care. ${ }^{157}$ The other poor-quality trial reported significantly fewer adverse events following spinal manipulation compared with amitriptyline (4.3\% vs. 82.1\%; RR 0.05, 95\% CI 0.02 to 0.16 ) but the risk of withdrawal due to adverse events was not significantly different (1.4\% vs. 8.9\%; RR 0.16, 95\% CI 0.02 to 1.33). ${ }^{158}$ Patients in the manipulation group complained of neck stiffness which resolved in all cases and common side effects in the amitriptyline group included dry mouth, drowsiness, and weight gain.

\section{Acupuncture for Chronic Tension Headache}

\section{Key Points}

- There is insufficient evidence from two poor quality trials to determine the effects of Traditional Chinese needle acupuncture on short-term (2 trials), intermediate-term (1 trial) or long-term (1 trial) pain compared with sham acupuncture (SOE: insufficient).

- Laser acupuncture was associated with slight improvement in pain intensity (median difference -2, IQR 6.3, on a 0-10 VAS scale) and in the number of headache days per month (median difference -8 , IQR 21.5) over the short term versus sham in one fairquality trial (SOE: low).

- No trials comparing acupuncture to pharmacological therapy or to biofeedback were identified that met inclusion criteria.

- The fair-quality trial evaluating laser acupuncture reported that no adverse events occurred in either group (SOE: low).

\section{Detailed Synthesis}

Three small trials ( $\mathrm{n}=30$ to 50$)^{214-216}$ that evaluated acupuncture versus sham treatment for chronic tension headaches met inclusion criteria (Table 46 and Appendix D). Two trials 
employed traditional Chinese needle acupuncture, ${ }^{215,216}$ while one used low-energy laser acupuncture. ${ }^{214}$ The number of acupoints ranged from six to ten across studies. The duration of treatment ranged from 5 to 10 weeks, with the total number of sessions ranging from eight to ten (20 to 30 minutes duration, 1 to 3 times per week). Sham treatment consisted of irrelevant acupuncture (superficial needle insertion in areas without acupuncture points) and sham acupuncture (blunt needle that simulates puncturing of the skin, laser power output set to zero).

Across trials, participants were primarily female (49\% to 87\%), mean ages ranged from 33 to 49 years, and headache frequency from 18 to 27 days per month. Two trials specifically excluded patients with other causes of chronic headache ${ }^{214,215}$; the third trial did not note if any of the patients had concomitant headaches. ${ }^{216}$ One trial required patients to abstain from all other prophylactic therapies (with the exception of rescue analgesics), ${ }^{216}$ and one trial excluded patients who had received any treatment for their headache in the 2 weeks prior to enrollment. ${ }^{214}$ Concomitant (non-narcotic) medication was permitted in two trials, ${ }^{215,216}$ the third stated that no patient took concomitant analgesics. ${ }^{214}$ All trials assessed outcomes over the short term; one trial additionally provided intermediate- and long-term data. ${ }^{216}$

One trial was rated fair quality ${ }^{214}$ and two poor quality ${ }^{215,216}$ (Appendix E). In all three trials, random sequence generation and concealment of allocation were not clearly reported and the care providers were not blinded to treatment. Additional methodological concerns in the poor quality trials included unclear application of intention-to-treat methods, and failure to control for disproportionate baseline characteristics or to account for loss to followup in one trial each.

Table 46. Chronic tension headache: acupuncture

\begin{tabular}{|c|c|c|c|c|}
\hline $\begin{array}{l}\text { Author, Year, } \\
\text { Followup, } \\
\text { Pain } \\
\text { Duration, } \\
\text { Study Quality }\end{array}$ & Intervention & Population & Function and Pain Outcomes & $\begin{array}{l}\text { Other } \\
\text { Outcomes }\end{array}$ \\
\hline $\begin{array}{l}\text { Ebneshahidi, } \\
2005^{214} \\
3 \text { months } \\
\text { Duration of } \\
\text { pain: NR } \\
\text { Fair }\end{array}$ & $\begin{array}{l}\text { A. Low-Energy Laser } \\
\text { Acupuncture ( } \mathrm{n}=25) \text { : } \\
4 \text { acupoints (two } \\
\text { local and two distal), } \\
\text { bilaterally (8 total): } \\
\text { intensity } 1.3 \mathrm{~J} \text {, output } \\
\text { 100\%, continuous } \\
\text { mode, using vertical } \\
\text { contact with pressure } \\
\text { and a duration of } 43 \\
\text { seconds. } \\
\text { B. Sham Laser } \\
\text { Acupuncture (n=25): } \\
\text { Identical procedure } \\
\text { to real } \\
\text { electroacupuncture } \\
\text { except power output } \\
\text { set to } 0 \\
\text { Treatment Protocol: } \\
3 \text { sessions per week } \\
\text { for a total of } 10 \\
\text { sessions (session } \\
\text { length: NR) }\end{array}$ & $\begin{array}{l}\text { A vs. B } \\
\text { Age: } 33 \text { vs. } 39 \\
\text { years } \\
\text { Female: } 80 \% \text { vs. } \\
80 \% \\
\text { Race: NR } \\
\text { Number of } \\
\text { headache days per } \\
\text { month (0-28), } \\
\text { median: } 20 \text { vs. } 18 \\
\text { Pain intensity on } \\
\text { VAS (0-10), } \\
\text { median: } 10 \text { vs. } 10 \\
\text { Duration of attacks, } \\
\text { (hours), median: } 10 \\
\text { vs. } 8\end{array}$ & $\begin{array}{l}\text { A vs. B } \\
3 \text { months } \\
\text { Headache Days/Month, median } \\
\text { change from baseline: }-8 \text { vs. } 0 \text {, } \\
P<0.001 \\
\text { Headache Intensity (VAS), } \\
\text { median change from baseline: } \\
-2 \text { vs. } 0, P<0.001 \\
\text { Duration of attacks (hours), } \\
\text { median change from baseline: } \\
-4 \text { vs. } 0, P<0.001\end{array}$ & NR \\
\hline
\end{tabular}




\begin{tabular}{|c|c|c|c|c|}
\hline $\begin{array}{l}\text { Author, Year, } \\
\text { Followup, } \\
\text { Pain } \\
\text { Duration, } \\
\text { Study Quality }\end{array}$ & Intervention & Population & Function and Pain Outcomes & $\begin{array}{l}\text { Other } \\
\text { Outcomes }\end{array}$ \\
\hline $\begin{array}{l}\text { Karst, } 2000^{215} \\
1.5 \text { months } \\
\text { Duration of } \\
\text { pain: NR } \\
\text { Poor }\end{array}$ & $\begin{array}{l}\text { A. Acupuncture } \\
\text { ( } n=21) \\
\text { Traditional Chinese } \\
\text { acupuncture; } \\
\text { maximum of } 15 \\
\text { needles, } 10 \\
\text { acupoints } \\
\text { B. Sham } \\
\text { Acupuncture ( } n=18 \text { ): } \\
\text { blunt placebo } \\
\text { needles and elastic } \\
\text { foam were used to } \\
\text { simulate puncturing } \\
\text { and shield needle } \\
\text { type. } \\
\text { Treatment Protocol: } \\
\text { 30-minute sessions } \\
\text { twice weekly for } 5 \\
\text { weeks (10 sessions } \\
\text { total) }\end{array}$ & $\begin{array}{l}\text { A vs. B } \\
\text { Age: } 50 \text { vs. } 47 \\
\text { years } \\
\text { Female: } 38 \% \text { vs. } \\
61 \% \\
\text { Race: NR } \\
\text { Headache } \\
\text { frequency: } 27 \text { vs. } 27 \\
\text { days/month } \\
\text { VAS (0-10): } 6.2 \text { vs. } \\
6.3 \\
\text { Analgesic } \\
\text { Intake/Month: } 8.3 \\
\text { vs. } 10.2\end{array}$ & $\begin{array}{l}\text { A vs. B } \\
1.5 \text { months } \\
\text { Frequency of headache } \\
\text { attacks/month: } 22.1 \text { vs. } 22.0 ; \\
\text { difference } 0.1 \text { ( } 95 \% \mathrm{Cl}-6.6 \text { to } \\
6.8) \\
\text { Headache Severity, VAS: } 4.0 \\
\text { vs. } 3.9 ; \text { difference } 0.1 \text { (95\% Cl } \\
-11.9 \text { to } 12.1)\end{array}$ & $\begin{array}{l}\text { A vs. B } \\
1.5 \text { months } \\
\text { Analgesic } \\
\text { Intake/Month: } \\
13.7 \text { vs. } 21.2 ; \\
\text { difference }-7.5 \\
(95 \% \mathrm{Cl}-22.2 \text { to } \\
7.2)\end{array}$ \\
\hline $\begin{array}{l}\text { Tavola, } \\
1992^{216} \\
(\mathrm{n}=30) \\
1,6,12 \\
\text { months } \\
\text { Duration of } \\
\text { pain: } 8 \text { years } \\
\text { Poor }\end{array}$ & $\begin{array}{l}\text { A. Acupuncture } \\
\text { ( } n=15) \text { : } \\
\text { Traditional Chinese } \\
\text { acupuncture; } 6-10 \\
\text { acupoints chosen on } \\
\text { an individual basis; } \\
\text { insertion depth 10-20 } \\
\text { mm; needles were } \\
\text { left in place without } \\
\text { the use of any } \\
\text { manual or electrical } \\
\text { stimulation } \\
\text { B. Sham } \\
\text { Acupuncture (n=15): } \\
\text { same number of } \\
\text { needles, inserted } \\
\text { more superficially } \\
\text { (depth } 2-4 \text { mm), in } \\
\text { the same region } \\
\text { used in real } \\
\text { acupuncture group } \\
\text { but in areas without } \\
\text { acupuncture points } \\
\text { Treatment Protocol: } \\
\text { 20-minute sessions } \\
\text { once per week for } 8 \\
\text { weeks (8 sessions } \\
\text { total) }\end{array}$ & $\begin{array}{l}\text { A vs. B } \\
\text { Age: } 33 \text { vs. } 33 \\
\text { years } \\
\text { Female: } 87 \% \text { vs. } \\
87 \% \\
\text { Mean frequency of } \\
\text { headache attacks } \\
\text { per month: } 18 \text { vs. } \\
17 \\
\text { Mean analgesic } \\
\text { use: } 12 \text { vs. } 12 \\
\text { units/month } \\
\text { Mean HI (intensity X } \\
\text { duration X } \\
\text { frequency/30): } 4.3 \\
\text { vs. } 4.5 \\
\text { Mean duration of } \\
\text { attacks (sum of the } \\
\text { hours of headache } \\
\text { in a month/number } \\
\text { of attacks): } 3.3 \text { vs. } \\
4.4\end{array}$ & 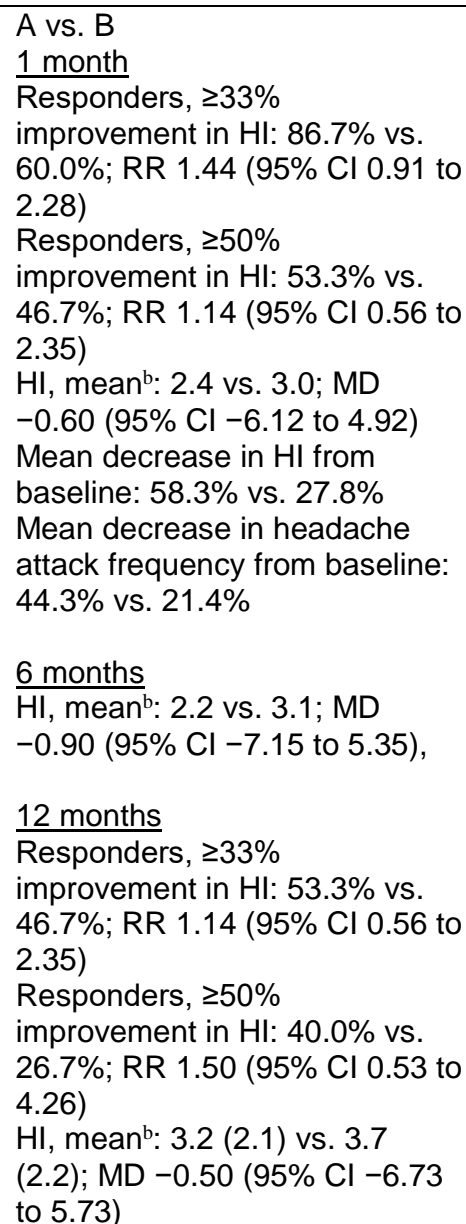 & $\begin{array}{l}\text { A vs. B } \\
1 \text { month } \\
\text { Mean decrease } \\
\text { in analgesic } \\
\text { consumption } \\
\text { from baseline: } \\
57.7 \% \text { vs. } 21.7 \%\end{array}$ \\
\hline
\end{tabular}


$\mathrm{CI}$ = confidence interval; $\mathrm{HI}=$ headache index; $\mathrm{MD}=$ mean difference; $\mathrm{NR}=$ not reported; $\mathrm{RR}=$ risk ratio; $\mathrm{VAS}=$ visual analog scale

${ }^{a}$ Unless otherwise noted, followup time is calculated from the end of the treatment period

${ }^{\mathrm{b}}$ Means and standard error of the means (not shown) estimated from graphs.

\section{Acupuncture Compared With Sham}

None of the trials reported on function. All three trials reported pain outcomes, although the specific measures varied across the trials. The results were mixed depending on the type of acupuncture used. No significant differences were found between needle acupuncture and sham for any pain outcome evaluated during the short term in two small poor-quality trials, ${ }^{215,216}$ or at intermediate and long-term followup in one of these trials ${ }^{216}$ (Table 46). In the third small fairquality trial, ${ }^{214}$ laser acupuncture resulted in a significant reduction in the number of headache days per month (median -8 , interquartile range [IQR] 21.5), in pain intensity on a 0 to $10 \mathrm{VAS}$ scale (median -2, IQR 6.3), and in the duration of attacks (median -4 hours, IQR 7.5) over the short term compared with the sham group, which reported no improvement from baseline on any outcome at the 3-month followup ( $\mathrm{P}<0.001$ for all) (Figure 52).

\section{Acupuncture Compared With Pharmacological Therapy or Biofeedback}

No trial of acupuncture versus pharmacological therapy and versus biofeedback met inclusion criteria.

\section{Harms}

Harms were generally not reported. The trial evaluating laser acupuncture reported that no adverse events occurred in either group. ${ }^{214}$

Figure 52. Acupuncture versus sham for chronic tension headache: effects on pain

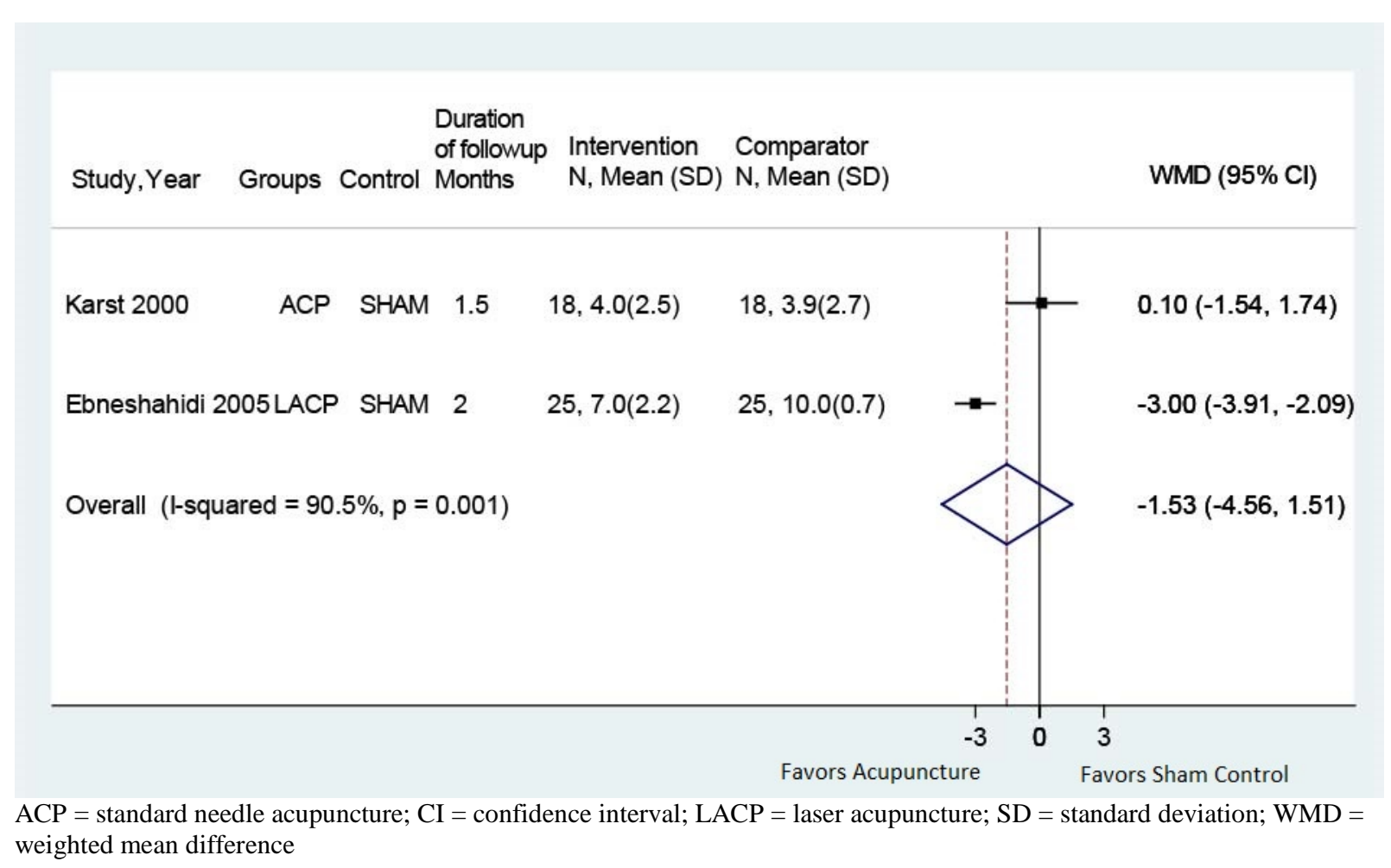




\section{Key Question 6: Differential Efficacy}

RCTs that stratified on patient characteristics of interest, permitting evaluation of factors that might modify the effect of treatment, were considered for inclusion. Factors included age, sex, and presence of comorbidities (e.g., emotional or mood disorders). If a comparison is not listed below there was either no evidence identified that met the inclusion criteria or the included trials did not provide information on differential efficacy or harms. Studies likely had insufficient sample size to evaluate differential efficacy or harms, and evidence was considered insufficient.

\section{Osteoarthritis of the Knee}

\section{Key Point}

- There is insufficient evidence from one fair-quality trial (across 3 publications) that age, sex, race, BMI, baseline disability, pain, or depression status modify the effects of exercise in patients with OA of the knee. Sample sizes in the subgroup analyses from the FAST trial were likely inadequate to effectively test for modification.

\section{Exercise Compared With Attention Control}

One fair-quality trial $(n=439)$ reported across three publications of the Fitness, Arthritis and Seniors Trial (FAST) ${ }^{44,50,51}$ included in Key Question 3 compared muscle performance (i.e., resistance training) and aerobic exercise programs to an attention control and formally evaluated factors that may modify treatment in patients with OA of the knee. Details regarding these study populations are available in the Results section for Key Question 3 and in Appendix D. Two of the reports performed formal tests for interaction; none of the demographic or clinical variables evaluated were found to modify the effect of either type of exercise. ${ }^{5,51}$ One trial explored whether age, sex, race, BMI, baseline disability, or baseline pain modified the effects of exercise on function based on ADL disability measures in a subgroup of patients who were free of ADL disability upon enrollment; however, no data were provided for evaluation. ${ }^{50}$ A second publication looked at whether the effects of exercise on pain, disability, and depression were modified by baseline depression status, that is, high versus low depressive symptomology according to the Center for Epidemiologic Studies Depression scale over time (using an adjusted repeated measures analysis of variance). However, the authors do not provide results that directly examined modification by baseline depression without the time component. ${ }^{51}$ The third FAST publication stratified on age, sex, race, and BMI and did not perform a formal statistical test for interaction. ${ }^{44}$ Upon visual inspection, the point estimates across groups and strata are similar, suggesting that the effect of exercise on physical disability and knee pain was not modified by any patient characteristic evaluated.

\section{Osteoarthritis of the Hip}

\section{Key Point}

- There is insufficient evidence from one fair-quality trial that age, sex, baseline pain, and the presence of radiographic OA modify the effects of exercise in patients with OA of the hip. Study authors only reported on effects that include evaluation of these factors over time. Sample size was likely inadequate to effectively test for modification. 


\section{Exercise Compared With Usual Care}

One fair-quality trial $(n=203)$ included for Key Question 3 compared combination exercise therapy (strengthening, stretching, and endurance exercises) to usual care and stratified on age, sex, race, and BMI, but it did not formally test for interaction. ${ }^{63}$ Details regarding this study population are available in the Results section for Key Question 3 and in Appendix D. Age, sex, education, self-reported knee OA, and baseline pain and Kellgren \& Lawrence radiographic OA scores were defined $a$ priori as subgroups of interest. Although older patients (age $\geq 65$ years), women, patients with a lower NRS pain score at baseline, and patients with radiographic OA showed somewhat larger effects of exercise therapy on function and pain, data were not systematically reported and, based on the data provided, overlapping confidence intervals suggest that the effect of exercise was not modified by any of these variables.

\section{Fibromyalgia}

\section{Key Point}

- There was insufficient evidence from one poor-quality trial that baseline BMI (normal, overweight, obese) modifies the effects of multidisciplinary rehabilitation in patients with fibromyalgia. Study authors only report on effects that include evaluation of these factors over time. Sample size was likely inadequate to effectively test for modification.

\section{Multidisciplinary Rehabilitation Compared With Usual Care}

An additional publication $(\mathrm{n}=130)^{227}$ of a poor-quality trial ${ }^{226}$ included for Key Question 4 that compared multidisciplinary rehabilitation to usual care assessed potential modification of treatment based on baseline BMI (normal, overweight, obese). No significant interactions were found for the effect of BMI on exercise over time for any pain or function measure evaluated; however, the authors do not provide results that exclude effects of time. Details regarding this study population are available in the section on efficacy and in Appendix D. 


\section{Discussion}

\section{Key Findings and Strength of Evidence}

The key findings of this review, including strength of evidence ratings, are summarized for each chronic pain condition in Tables 47-61 (interventions and comparators with no evidence for either function or pain outcomes are not shown); domains used to determine the overall strength of evidence are shown in Appendix G. All outcomes were considered direct. The strength of evidence was low or insufficient for many interventions and was limited by small numbers of trials for specific comparisons and for our specified time frames, particularly for long term. We focused on evaluating the persistence of effects for therapies beyond the course of treatment, using the following definitions for postintervention followup: short term ( 1 to $<6$ months), intermediate term ( $\geq 6$ to $<12$ months) and long term ( $\geq 12$ months). Evidence was particularly limited on effects on long-term outcomes.

The majority of trials compared interventions with usual care with very few trials employing pharmacological treatments or exercise as comparators. In general, effect sizes for most interventions were small, based on mean differences. There tended to be more evidence for the effects of interventions on pain than for function, and the effects on function were generally smaller or not clearly present.

No trials directly compared interventions with opioids and few trials reported effects of intervention on opioid use. Our previous reviews found opioids associated with small to moderate effects on pain during treatment (effects would not be expected to persist) with evidence almost exclusively from short-term ( $\leq 3$ month) trials. ${ }^{11,16,25,247}$ Information on adherence to interventions was not well-reported; poor adherence may have impacted some of our findings. Harms were poorly reported across interventions. No serious intervention-related adverse events requiring medical attention were identified; reported adverse events were generally minor (e.g., muscle soreness or increased pain with exercise, bruising with acupuncture) and time-limited (e.g., temporary worsening of pain). 
Table 47. Chronic low back pain: effects of nonpharmacological interventions compared with usual care, placebo, sham, attention control, or waitlist

\begin{tabular}{|c|c|c|c|c|c|c|}
\hline Intervention & $\begin{array}{l}\text { Function } \\
\text { Short-Term } \\
\\
\text { Effect Size } \\
\text { SOE } \\
\end{array}$ & $\begin{array}{c}\text { Function } \\
\text { Intermediate- } \\
\text { Term } \\
\text { Effect Size } \\
\text { SOE }\end{array}$ & $\begin{array}{c}\text { Function } \\
\text { Long-Term } \\
\\
\text { Effect Size } \\
\text { SOE } \\
\end{array}$ & $\begin{array}{c}\text { Pain } \\
\text { Short-Term } \\
\\
\text { Effect Size } \\
\text { SOE } \\
\end{array}$ & $\begin{array}{c}\text { Pain } \\
\text { Intermediate- } \\
\text { Term } \\
\text { Effect Size } \\
\text { SOE } \\
\end{array}$ & $\begin{array}{c}\text { Pain } \\
\text { Long-Term } \\
\\
\text { Effect Size } \\
\text { SOE } \\
\end{array}$ \\
\hline Exercise & $\begin{array}{l}\text { slight } \\
+\end{array}$ & $\begin{array}{c}\text { none } \\
+\end{array}$ & $\begin{array}{l}\text { none } \\
+\end{array}$ & $\begin{array}{c}\text { slight } \\
++\end{array}$ & $\begin{array}{c}\text { moderate } \\
+\end{array}$ & $\begin{array}{c}\text { moderate } \\
+\end{array}$ \\
\hline $\begin{array}{l}\text { Psychological } \\
\text { Therapies: CBT } \\
\text { primarily }\end{array}$ & $\begin{array}{l}\text { slight } \\
++\end{array}$ & $\begin{array}{l}\text { slight } \\
++\end{array}$ & $\begin{array}{c}\text { slight } \\
++\end{array}$ & $\begin{array}{c}\text { slight } \\
++\end{array}$ & $\begin{array}{c}\text { slight } \\
++\end{array}$ & $\begin{array}{c}\text { slight } \\
++\end{array}$ \\
\hline $\begin{array}{l}\text { Physical } \\
\text { Modalities: Short- } \\
\text { Wave Diathermy }\end{array}$ & $\begin{array}{l}\text { insufficient } \\
\text { evidence }\end{array}$ & no evidence & no evidence & $\begin{array}{l}\text { insufficient } \\
\text { evidence }\end{array}$ & no evidence & no evidence \\
\hline $\begin{array}{l}\text { Physical } \\
\text { Modalities: } \\
\text { Ultrasound }\end{array}$ & $\begin{array}{l}\text { insufficient } \\
\text { evidence }\end{array}$ & no evidence & no evidence & $\begin{array}{c}\text { none } \\
+\end{array}$ & no evidence & no evidence \\
\hline $\begin{array}{l}\text { Physical } \\
\text { Modalities: Low- } \\
\text { Level Laser } \\
\text { Therapy } \\
\end{array}$ & $\begin{array}{l}\text { slight } \\
+\end{array}$ & $\begin{array}{l}\text { none } \\
+\end{array}$ & no evidence & $\begin{array}{c}\text { moderate } \\
+\end{array}$ & $\begin{array}{c}\text { none } \\
+\end{array}$ & no evidence \\
\hline $\begin{array}{l}\text { Manual Therapies: } \\
\text { Spinal Manipulation }\end{array}$ & $\begin{array}{l}\text { slight } \\
+\end{array}$ & $\begin{array}{l}\text { slight } \\
+\end{array}$ & no evidence & $\begin{array}{c}\text { none } \\
+\end{array}$ & $\begin{array}{c}\text { slight } \\
++\end{array}$ & no evidence \\
\hline $\begin{array}{l}\text { Manual Therapies: } \\
\text { Massage }\end{array}$ & $\begin{array}{l}\text { slight } \\
++\end{array}$ & $\begin{array}{c}\text { none } \\
+\end{array}$ & no evidence & $\begin{array}{l}\text { slight } \\
++\end{array}$ & $\begin{array}{c}\text { none } \\
+\end{array}$ & no evidence \\
\hline $\begin{array}{l}\text { Manual Therapies: } \\
\text { Traction }\end{array}$ & $\begin{array}{c}\text { none } \\
+\end{array}$ & no evidence & no evidence & $\begin{array}{c}\text { none } \\
+\end{array}$ & no evidence & no evidence \\
\hline $\begin{array}{l}\text { Mindfulness } \\
\text { Practices: MBSR }\end{array}$ & $\begin{array}{c}\text { none } \\
+\end{array}$ & $\begin{array}{l}\text { none } \\
+\end{array}$ & $\begin{array}{l}\text { none } \\
+\end{array}$ & $\begin{array}{l}\text { slight } \\
++\end{array}$ & $\begin{array}{l}\text { slight } \\
+\end{array}$ & $\begin{array}{c}\text { none } \\
+\end{array}$ \\
\hline $\begin{array}{l}\text { Mind-Body } \\
\text { Practices: Yoga }\end{array}$ & $\begin{array}{l}\text { slight } \\
++\end{array}$ & $\begin{array}{l}\text { slight } \\
+\end{array}$ & no evidence & $\begin{array}{c}\text { moderate } \\
+\end{array}$ & $\begin{array}{c}\text { moderate } \\
++\end{array}$ & no evidence \\
\hline Acupuncture & $\begin{array}{l}\text { slight } \\
+\end{array}$ & $\begin{array}{c}\text { none } \\
+\end{array}$ & $\begin{array}{l}\text { none } \\
+\end{array}$ & $\begin{array}{c}\text { slight } \\
++\end{array}$ & $\begin{array}{c}\text { none } \\
+\end{array}$ & $\begin{array}{l}\text { slight } \\
+\end{array}$ \\
\hline $\begin{array}{l}\text { Multidisciplinary } \\
\text { Rehabilitation }\end{array}$ & $\begin{array}{l}\text { slight } \\
+\end{array}$ & $\begin{array}{l}\text { slight } \\
+\end{array}$ & $\begin{array}{c}\text { none } \\
+\end{array}$ & $\begin{array}{c}\text { slight } \\
++\end{array}$ & $\begin{array}{c}\text { slight } \\
++\end{array}$ & $\begin{array}{c}\text { none } \\
+\end{array}$ \\
\hline
\end{tabular}

Short-Term: 1 to $<6$ months; Intermediate-Term: $\geq 6$ to $<12$ months; Long-Term: $\geq 12$ months

Effect Size: none, slight/small, moderate, or large improvement

Strength of Evidence: $+=$ low, $++=$ moderate, $+++=$ high

CBT = cognitive-behavioral therapy; MBSR = mindfulness-based stress reduction; none = no effect/no statistically significant effect; $\mathrm{SOE}=$ strength of evidence. 
Table 48. Chronic low back pain: effects of nonpharmacological interventions compared with exercise

\begin{tabular}{|c|c|c|c|c|c|c|}
\hline Intervention & $\begin{array}{c}\text { Function } \\
\text { Short-Term } \\
\\
\text { Effect Size } \\
\text { SOE } \\
\end{array}$ & $\begin{array}{c}\text { Function } \\
\text { Intermediate- } \\
\text { Term } \\
\text { Effect Size } \\
\text { SOE }\end{array}$ & $\begin{array}{c}\begin{array}{c}\text { Function } \\
\text { Long-Term }\end{array} \\
\\
\text { Effect Size } \\
\text { SOE } \\
\end{array}$ & $\begin{array}{c}\text { Pain } \\
\text { Short-Term } \\
\\
\text { Effect Size } \\
\text { SOE } \\
\end{array}$ & \begin{tabular}{|c|} 
Pain \\
Intermediate- \\
Term \\
\\
Effect Size \\
SOE \\
\end{tabular} & $\begin{array}{c}\text { Pain } \\
\text { Long-Term } \\
\\
\text { Effect Size } \\
\text { SOE } \\
\end{array}$ \\
\hline $\begin{array}{l}\text { Psychological } \\
\text { Therapies: Operant } \\
\text { therapy }\end{array}$ & no evidence & $\begin{array}{l}\text { insufficient } \\
\text { evidence }\end{array}$ & $\begin{array}{l}\text { insufficient } \\
\text { evidence }\end{array}$ & no evidence & $\begin{array}{l}\text { insufficient } \\
\text { evidence }\end{array}$ & $\begin{array}{l}\text { insufficient } \\
\text { evidence }\end{array}$ \\
\hline $\begin{array}{l}\text { Physical } \\
\text { Modalities: Low- } \\
\text { Level Laser } \\
\text { Therapy }\end{array}$ & no evidence & $\begin{array}{c}\text { none } \\
+\end{array}$ & no evidence & no evidence & $\begin{array}{c}\text { slight } \\
+\end{array}$ & no evidence \\
\hline $\begin{array}{l}\text { Manual Therapies: } \\
\text { Spinal Manipulation }\end{array}$ & $\begin{array}{l}\text { none } \\
+\end{array}$ & $\begin{array}{c}\text { none } \\
+\end{array}$ & no evidence & $\begin{array}{c}\text { none } \\
+\end{array}$ & $\begin{array}{l}\text { slight } \\
+\end{array}$ & no evidence \\
\hline $\begin{array}{l}\text { Manual Therapies: } \\
\text { Massage }\end{array}$ & no evidence & $\begin{array}{c}\text { none } \\
+\end{array}$ & no evidence & no evidence & $\begin{array}{c}\text { none } \\
+\end{array}$ & no evidence \\
\hline $\begin{array}{l}\text { Mind-Body } \\
\text { Practices: Yoga }\end{array}$ & $\begin{array}{c}\text { none } \\
+\end{array}$ & $\begin{array}{c}\text { none } \\
+\end{array}$ & no evidence & $\begin{array}{c}\text { slight } \\
+\end{array}$ & $\begin{array}{c}\text { none } \\
+\end{array}$ & no evidence \\
\hline $\begin{array}{l}\text { Mind-Body } \\
\text { Practices: Qigong }\end{array}$ & $\begin{array}{c}\text { none } \\
+\end{array}$ & $\begin{array}{c}\text { slight favoring } \\
\text { exercise } \\
+\end{array}$ & no evidence & $\begin{array}{c}\text { slight } \\
\text { favoring } \\
\text { exercise } \\
+ \\
\end{array}$ & $\begin{array}{c}\text { none } \\
+\end{array}$ & no evidence \\
\hline $\begin{array}{l}\text { Multidisciplinary } \\
\text { Rehabilitation }\end{array}$ & $\begin{array}{c}\text { slight } \\
++\end{array}$ & $\begin{array}{c}\text { slight } \\
++\end{array}$ & $\begin{array}{c}\text { none } \\
+\end{array}$ & $\begin{array}{c}\text { slight } \\
++\end{array}$ & $\begin{array}{c}\text { slight } \\
++\end{array}$ & $\begin{array}{c}\text { none } \\
+\end{array}$ \\
\hline
\end{tabular}

Short-Term: 1 to $<6$ months; Intermediate-Term: $\geq 6$ to $<12$ months; Long-Term: $\geq 12$ months

Effect Size: none, slight/small, moderate, or large improvement

Strength of Evidence: $+=$ low, $++=$ moderate, $+++=$ high

none $=$ no effect/no statistically significant effect; SOE = strength of evidence.

Table 49. Chronic neck pain: effects of nonpharmacological interventions compared with usual care, placebo, sham, attention control, or waitlist

\begin{tabular}{|c|c|c|c|c|c|c|}
\hline Intervention & $\begin{array}{l}\text { Function } \\
\text { Short-Term } \\
\\
\text { Effect Size } \\
\text { SOE } \\
\end{array}$ & $\begin{array}{c}\text { Function } \\
\text { Intermediate- } \\
\text { Term } \\
\\
\text { Effect Size } \\
\text { SOE } \\
\end{array}$ & $\begin{array}{l}\text { Function } \\
\text { Long-Term } \\
\text { Effect Size } \\
\text { SOE } \\
\end{array}$ & $\begin{array}{c}\text { Pain } \\
\text { Short-Term } \\
\\
\text { Effect Size } \\
\text { SOE } \\
\end{array}$ & $\begin{array}{c}\text { Pain } \\
\text { Intermediate- } \\
\text { Term } \\
\text { Effect Size } \\
\text { SOE } \\
\end{array}$ & $\begin{array}{c}\text { Pain } \\
\text { Long-Term } \\
\text { Effect Size } \\
\text { SOE } \\
\end{array}$ \\
\hline Exercise & $\begin{array}{c}\text { none } \\
+\end{array}$ & no evidence & no evidence & $\begin{array}{c}\text { none } \\
+\end{array}$ & no evidence & no evidence \\
\hline $\begin{array}{l}\text { Psychological } \\
\text { Therapies: PT-lead } \\
\text { relaxation training }\end{array}$ & $\begin{array}{c}\text { none } \\
+\end{array}$ & $\begin{array}{c}\text { none } \\
+\end{array}$ & no evidence & $\begin{array}{c}\text { none } \\
+\end{array}$ & $\begin{array}{c}\text { none } \\
+\end{array}$ & no evidence \\
\hline $\begin{array}{l}\text { Physical } \\
\text { Modalities: Low- } \\
\text { Level Laser Therapy }\end{array}$ & $\begin{array}{c}\text { moderate } \\
++\end{array}$ & no evidence & no evidence & $\begin{array}{c}\text { moderate } \\
++\end{array}$ & no evidence & no evidence \\
\hline $\begin{array}{l}\text { Physical } \\
\text { Modalities: } \\
\text { Traction, } \\
\text { Electromagnetic } \\
\text { field } \\
\end{array}$ & $\begin{array}{l}\text { insufficient } \\
\text { evidence }\end{array}$ & no evidence & no evidence & $\begin{array}{l}\text { insufficient } \\
\text { evidence }\end{array}$ & no evidence & no evidence \\
\hline $\begin{array}{l}\text { Manual Therapies: } \\
\text { Massage }\end{array}$ & $\begin{array}{c}\text { none } \\
+\end{array}$ & $\begin{array}{c}\text { none } \\
+\end{array}$ & no evidence & no evidence & no evidence & no evidence \\
\hline
\end{tabular}




\begin{tabular}{|c|c|c|c|c|c|c|}
\hline Intervention & $\begin{array}{c}\text { Function } \\
\text { Short-Term } \\
\\
\text { Effect Size } \\
\text { SOE }\end{array}$ & $\begin{array}{c}\text { Function } \\
\text { Intermediate- } \\
\text { Term } \\
\text { Effect Size } \\
\text { SOE }\end{array}$ & $\begin{array}{l}\text { Function } \\
\text { Long-Term } \\
\text { Effect Size } \\
\text { SOE }\end{array}$ & $\begin{array}{c}\text { Pain } \\
\text { Short-Term } \\
\text { Effect Size } \\
\text { SOE }\end{array}$ & $\begin{array}{c}\text { Pain } \\
\text { Intermediate- } \\
\text { Term } \\
\text { Effect Size } \\
\text { SOE }\end{array}$ & $\begin{array}{c}\text { Pain } \\
\text { Long-Term } \\
\\
\text { Effect Size } \\
\text { SOE }\end{array}$ \\
\hline $\begin{array}{l}\text { Mind-Body } \\
\text { Practices: } \\
\text { Alexander } \\
\text { Technique }\end{array}$ & $\begin{array}{c}\text { slight } \\
+\end{array}$ & $\begin{array}{c}\text { slight } \\
+\end{array}$ & no evidence & no evidence & no evidence & no evidence \\
\hline Acupuncture & $\begin{array}{c}\text { slight } \\
+\end{array}$ & $\begin{array}{c}\text { slight } \\
+\end{array}$ & $\begin{array}{c}\text { none } \\
+\end{array}$ & $\begin{array}{c}\text { none } \\
+\end{array}$ & $\begin{array}{c}\text { none } \\
+\end{array}$ & $\begin{array}{c}\text { none } \\
+\end{array}$ \\
\hline
\end{tabular}

Short-Term: 1 to $<6$ months; Intermediate-Term: $\geq 6$ to $<12$ months; Long-Term: $\geq 12$ months

Effect Size: none, slight/small, moderate, or large improvement

Strength of Evidence: $+=$ low, $++=$ moderate, $+++=$ high

none = no effect/no statistically significant effect; PT = physical therapist; SOE = strength of evidence.

Table 50. Chronic neck pain: effects of nonpharmacological interventions compared with pharmacological treatments

\begin{tabular}{|l|c|c|c|c|c|c|}
\hline Intervention & $\begin{array}{c}\text { Function } \\
\text { Short-Term }\end{array}$ & $\begin{array}{c}\text { Function } \\
\text { Intermediate- } \\
\text { Term }\end{array}$ & $\begin{array}{c}\text { Function } \\
\text { Long-Term }\end{array}$ & $\begin{array}{c}\text { Pain } \\
\text { Short-Term }\end{array}$ & $\begin{array}{c}\text { Pain } \\
\text { Intermediate- } \\
\text { Term }\end{array}$ & $\begin{array}{c}\text { Pain } \\
\text { Long-Term }\end{array}$ \\
\hline Exercise & $\begin{array}{c}\text { SOE Size } \\
\text { Effect Size } \\
\text { SOE }\end{array}$ & $\begin{array}{c}\text { Effect Size } \\
\text { SOE }\end{array}$ & $\begin{array}{c}\text { Effect Size } \\
\text { SOE }\end{array}$ & $\begin{array}{c}\text { Effect Size } \\
\text { SOE }\end{array}$ & $\begin{array}{c}\text { Effect Size } \\
\text { SOE }\end{array}$ \\
\hline Acupuncture & $\begin{array}{c}\text { insufficient } \\
\text { evidence }\end{array}$ & $\begin{array}{c}\text { insufficient } \\
\text { evidence }\end{array}$ & no evidence & $\begin{array}{c}\text { insufficient } \\
\text { evidence }\end{array}$ & $\begin{array}{c}\text { insufficient } \\
\text { evidence }\end{array}$ & no evidence \\
\hline insufficient & no evidence & no evidence & $\begin{array}{c}\text { insufficient } \\
\text { evidence }\end{array}$ & no evidence & no evidence \\
\hline
\end{tabular}

Short-Term: 1 to $<6$ months; Intermediate-Term: $\geq 6$ to $<12$ months; Long-Term: $\geq 12$ months

Effect Size: none, slight/small, moderate, or large improvement

Strength of Evidence: $+=$ low, $++=$ moderate, $+++=$ high

none $=$ no effect/no statistically significant effect; SOE = strength of evidence.

Table 51. Chronic neck pain: effects of nonpharmacological interventions compared with exercise

\begin{tabular}{|c|c|c|c|c|c|c|}
\hline Intervention & $\begin{array}{l}\text { Function } \\
\text { Short-Term } \\
\\
\text { Effect Size } \\
\text { SOE }\end{array}$ & $\begin{array}{l}\text { Function } \\
\text { Intermediate- } \\
\text { Term } \\
\text { Effect Size } \\
\text { SOE }\end{array}$ & $\begin{array}{c}\text { Function } \\
\text { Long-Term } \\
\\
\text { Effect Size } \\
\text { SOE }\end{array}$ & $\begin{array}{c}\text { Pain } \\
\text { Short-Term } \\
\\
\text { Effect Size } \\
\text { SOE }\end{array}$ & $\begin{array}{c}\text { Pain } \\
\text { Intermediate- } \\
\text { Term } \\
\text { Effect Size } \\
\text { SOE }\end{array}$ & $\begin{array}{c}\text { Pain } \\
\text { Long-Term } \\
\\
\text { Effect Size } \\
\text { SOE }\end{array}$ \\
\hline $\begin{array}{l}\text { Psychological } \\
\text { Therapies: PT-lead } \\
\text { relaxation training }\end{array}$ & $\begin{array}{c}\text { none } \\
+\end{array}$ & $\begin{array}{c}\text { none } \\
+\end{array}$ & no evidence & $\begin{array}{c}\text { none } \\
+\end{array}$ & $\begin{array}{c}\text { none } \\
+\end{array}$ & no evidence \\
\hline $\begin{array}{l}\text { Manual Therapies: } \\
\text { Massage }\end{array}$ & no evidence & no evidence & no evidence & no evidence & $\begin{array}{c}\text { none } \\
+\end{array}$ & no evidence \\
\hline $\begin{array}{l}\text { Mind-Body } \\
\text { Practices: Body } \\
\text { Awareness Therapy }\end{array}$ & $\begin{array}{c}\text { none } \\
+\end{array}$ & no evidence & no evidence & no evidence & no evidence & no evidence \\
\hline $\begin{array}{l}\text { Mind-Body } \\
\text { Practices: Qigong }\end{array}$ & no evidence & $\begin{array}{l}\text { insufficient } \\
\text { evidence }\end{array}$ & $\begin{array}{l}\text { insufficient } \\
\text { evidence }\end{array}$ & no evidence & $\begin{array}{l}\text { insufficient } \\
\text { evidence }\end{array}$ & $\begin{array}{l}\text { insufficient } \\
\text { evidence }\end{array}$ \\
\hline
\end{tabular}

Short-Term: 1 to $<6$ months; Intermediate-Term: $\geq 6$ to $<12$ months; Long-Term: $\geq 12$ months

Effect Size: none, slight/small, moderate, or large improvement

Strength of Evidence: $+=$ low, $++=$ moderate, $+++=$ high

none $=$ no effect $/$ no statistically significant effect; $\mathrm{PT}=$ physical therapist; $\mathrm{SOE}=$ strength of evidence . 
Table 52. Osteoarthritis of the knee: effects of nonpharmacological interventions compared with usual care, placebo, sham, attention control, or waitlist

\begin{tabular}{|c|c|c|c|c|c|c|}
\hline Intervention & $\begin{array}{c}\text { Function } \\
\text { Short-Term } \\
\\
\text { Effect Size } \\
\text { SOE }\end{array}$ & $\begin{array}{c}\text { Function } \\
\text { Intermediate- } \\
\text { Term } \\
\text { Effect Size } \\
\text { SOE } \\
\end{array}$ & $\begin{array}{l}\text { Function } \\
\text { Long-Term } \\
\text { Effect Size } \\
\text { SOE }\end{array}$ & $\begin{array}{l}\text { Effect Size } \\
\text { SOE }\end{array}$ & $\begin{array}{c}\text { Pain } \\
\text { Intermediate- } \\
\text { Term } \\
\text { Effect Size } \\
\text { SOE } \\
\end{array}$ & $\begin{array}{c}\text { Pain } \\
\text { Long-Term } \\
\text { Effect Size } \\
\text { SOE }\end{array}$ \\
\hline Exercise & $\begin{array}{c}\text { slight } \\
++\end{array}$ & $\begin{array}{c}\text { slight } \\
+\end{array}$ & $\begin{array}{c}\text { slight } \\
+\end{array}$ & $\begin{array}{c}\text { slight } \\
++\end{array}$ & $\begin{array}{c}\text { moderate } \\
+\end{array}$ & $\begin{array}{c}\text { none } \\
+\end{array}$ \\
\hline $\begin{array}{l}\text { Psychological } \\
\text { Therapies: Pain } \\
\text { coping, CBT }\end{array}$ & $\begin{array}{c}\text { none } \\
+\end{array}$ & $\begin{array}{c}\text { none } \\
+\end{array}$ & $\begin{array}{c}\text { none } \\
+\end{array}$ & $\begin{array}{c}\text { none } \\
+\end{array}$ & $\begin{array}{c}\text { none } \\
+\end{array}$ & $\begin{array}{c}\text { none } \\
+\end{array}$ \\
\hline $\begin{array}{l}\text { Physical } \\
\text { Modalities: } \\
\text { Microwave } \\
\text { Diathermy }\end{array}$ & $\begin{array}{l}\text { insufficient } \\
\text { evidence }\end{array}$ & no evidence & no evidence & $\begin{array}{l}\text { insufficient } \\
\text { evidence }\end{array}$ & no evidence & no evidence \\
\hline $\begin{array}{l}\text { Physical } \\
\text { Modalities: Pulsed } \\
\text { Short-Wave } \\
\text { Diathermy } \\
\end{array}$ & $\begin{array}{l}\text { insufficient } \\
\text { evidence }\end{array}$ & no evidence & $\begin{array}{l}\text { insufficient } \\
\text { evidence }\end{array}$ & $\begin{array}{l}\text { insufficient } \\
\text { evidence }\end{array}$ & no evidence & $\begin{array}{l}\text { insufficient } \\
\text { evidence }\end{array}$ \\
\hline $\begin{array}{l}\text { Physical } \\
\text { Modalities: } \\
\text { Ultrasound } \\
\end{array}$ & $\begin{array}{l}\text { slight } \\
+\end{array}$ & $\begin{array}{c}\text { none } \\
+\end{array}$ & no evidence & $\begin{array}{l}\text { slight } \\
+\end{array}$ & $\begin{array}{c}\text { none } \\
+\end{array}$ & no evidence \\
\hline $\begin{array}{l}\text { Physical } \\
\text { Modalities: TENS }\end{array}$ & no evidence & $\begin{array}{c}\text { none } \\
+\end{array}$ & no evidence & no evidence & $\begin{array}{c}\text { none } \\
+\end{array}$ & no evidence \\
\hline $\begin{array}{l}\text { Physical } \\
\text { Modalities: Low- } \\
\text { Level Laser Therapy }\end{array}$ & $\begin{array}{l}\text { insufficient } \\
\text { evidence }\end{array}$ & $\begin{array}{l}\text { insufficient } \\
\text { evidence }\end{array}$ & no evidence & $\begin{array}{l}\text { insufficient } \\
\text { evidence }\end{array}$ & $\begin{array}{l}\text { insufficient } \\
\text { evidence }\end{array}$ & no evidence \\
\hline $\begin{array}{l}\text { Physical } \\
\text { Modalities: } \\
\text { Electromagnetic } \\
\text { Field }\end{array}$ & $\begin{array}{c}\text { none } \\
+\end{array}$ & no evidence & no evidence & $\begin{array}{c}\text { none } \\
+\end{array}$ & no evidence & no evidence \\
\hline $\begin{array}{l}\text { Physical } \\
\text { Modalities: } \\
\text { Superficial Heat }\end{array}$ & no evidence & no evidence & no evidence & $\begin{array}{l}\text { insufficient } \\
\text { evidence }\end{array}$ & no evidence & no evidence \\
\hline $\begin{array}{l}\text { Physical } \\
\text { Modalities: Braces }\end{array}$ & no evidence & $\begin{array}{l}\text { insufficient } \\
\text { evidence }\end{array}$ & $\begin{array}{l}\text { insufficient } \\
\text { evidence }\end{array}$ & $\begin{array}{l}\text { insufficient } \\
\text { evidence }\end{array}$ & $\begin{array}{l}\text { insufficient } \\
\text { evidence }\end{array}$ & no evidence \\
\hline $\begin{array}{l}\text { Manual Therapies: } \\
\text { Joint Manipulation }\end{array}$ & no evidence & $\begin{array}{l}\text { insufficient } \\
\text { evidence }\end{array}$ & no evidence & no evidence & no evidence & no evidence \\
\hline $\begin{array}{l}\text { Manual Therapies: } \\
\text { Massage }\end{array}$ & no evidence & $\begin{array}{l}\text { insufficient } \\
\text { evidence }\end{array}$ & no evidence & no evidence & $\begin{array}{l}\text { insufficient } \\
\text { evidence }\end{array}$ & no evidence \\
\hline $\begin{array}{l}\text { Mind-Body } \\
\text { Practices: Tai Chi }\end{array}$ & $\begin{array}{l}\text { insufficient } \\
\text { evidence }\end{array}$ & $\begin{array}{l}\text { insufficient } \\
\text { evidence }\end{array}$ & no evidence & $\begin{array}{l}\text { insufficient } \\
\text { evidence }\end{array}$ & $\begin{array}{l}\text { insufficient } \\
\text { evidence }\end{array}$ & no evidence \\
\hline Acupuncture & $\begin{array}{c}\text { none } \\
+\end{array}$ & $\begin{array}{c}\text { none } \\
++\end{array}$ & no evidence & $\begin{array}{c}\text { none } \\
+\end{array}$ & $\begin{array}{c}\text { none } \\
++\end{array}$ & no evidence \\
\hline
\end{tabular}

Short-Term: 1 to $<6$ months; Intermediate-Term: $\geq 6$ to $<12$ months; Long-Term: $\geq 12$ months

Effect Size: none, slight/small, moderate, or large improvement

Strength of Evidence: $+=$ low, $++=$ moderate, $+++=$ high

$\mathrm{CBT}=$ cognitive-behavioral therapy; none $=$ no effect/no statistically significant effect; TENS = transcutaneous electrical nerve

stimulation; $\mathrm{SOE}=$ strength of evidence 
Table 53. Osteoarthritis of the knee: effects of nonpharmacological interventions compared with exercise

\begin{tabular}{|c|c|c|c|c|c|c|}
\hline Intervention & $\begin{array}{l}\text { Function } \\
\text { Short-Term } \\
\\
\text { Effect Size } \\
\text { SOE }\end{array}$ & $\begin{array}{c}\text { Function } \\
\text { Intermediate- } \\
\text { Term } \\
\text { Effect Size } \\
\text { SOE } \\
\end{array}$ & $\begin{array}{c}\text { Function } \\
\text { Long-Term }\end{array}$ & $\begin{array}{c}\text { Pain } \\
\text { Short-Term } \\
\text { Effect Size } \\
\text { SOE }\end{array}$ & $\begin{array}{c}\text { Pain } \\
\text { Intermediate- } \\
\text { Term } \\
\\
\text { Effect Size } \\
\text { SOE } \\
\end{array}$ & $\begin{array}{l}\text { Effect Size } \\
\text { SOE }\end{array}$ \\
\hline $\begin{array}{l}\text { Psychological } \\
\text { Therapies: Pain } \\
\text { coping }\end{array}$ & $\begin{array}{c}\text { none } \\
+\end{array}$ & $\begin{array}{c}\text { none } \\
+\end{array}$ & no evidence & $\begin{array}{c}\text { none } \\
+\end{array}$ & $\begin{array}{c}\text { none } \\
+\end{array}$ & no evidence \\
\hline $\begin{array}{l}\text { Manual Therapies: } \\
\text { Joint Manipulation }\end{array}$ & no evidence & $\begin{array}{c}\text { insufficient } \\
\text { evidence }\end{array}$ & no evidence & no evidence & no evidence & no evidence \\
\hline Acupuncture & $\begin{array}{l}\text { insufficient } \\
\text { evidence }\end{array}$ & no evidence & no evidence & no evidence & no evidence & no evidence \\
\hline
\end{tabular}

Short-Term: 1 to $<6$ months; Intermediate-Term: $\geq 6$ to $<12$ months; Long-Term: $\geq 12$ months

Effect Size: none, slight/small, moderate, or large improvement

Strength of Evidence: $+=$ low, $++=$ moderate, $+++=$ high

none $=$ no effect/no statistically significant effect; SOE = strength of evidence

Table 54. Osteoarthritis of the hip: effects of nonpharmacological interventions compared with usual care, placebo, sham, attention control, or waitlist

\begin{tabular}{|c|c|c|c|c|c|c|}
\hline Intervention & $\begin{array}{c}\text { Function } \\
\text { Short-Term } \\
\\
\text { Effect Size } \\
\text { SOE }\end{array}$ & $\begin{array}{c}\text { Function } \\
\text { Intermediate- } \\
\text { Term } \\
\\
\text { Effect Size } \\
\text { SOE } \\
\end{array}$ & $\begin{array}{c}\text { Function } \\
\text { Long-Term } \\
\text { Effect Size } \\
\text { SOE }\end{array}$ & $\begin{array}{c}\text { Pain } \\
\text { Short-Term } \\
\\
\text { Effect Size } \\
\text { SOE } \\
\end{array}$ & $\begin{array}{c}\text { Pain } \\
\text { Intermediate- } \\
\text { Term } \\
\\
\text { Effect Size } \\
\text { SOE } \\
\end{array}$ & $\begin{array}{c}\text { Pain } \\
\text { Long-Term } \\
\\
\text { Effect Size } \\
\text { SOE }\end{array}$ \\
\hline Exercise & $\begin{array}{c}\text { slight } \\
+\end{array}$ & $\begin{array}{l}\text { slight } \\
+\end{array}$ & $\begin{array}{l}\text { insufficient } \\
\text { evidence }\end{array}$ & $\begin{array}{l}\text { slight } \\
+\end{array}$ & $\begin{array}{c}\text { none } \\
+\end{array}$ & $\begin{array}{l}\text { insufficient } \\
\text { evidence }\end{array}$ \\
\hline Manual Therapies & no evidence & $\begin{array}{c}\text { insufficient } \\
\text { evidence }\end{array}$ & no evidence & no evidence & no evidence & no evidence \\
\hline
\end{tabular}

Short-Term: 1 to $<6$ months; Intermediate-Term: $\geq 6$ to $<12$ months; Long-Term: $\geq 12$ months

Effect Size: none, slight/small, moderate, or large improvement

Strength of Evidence: $+=$ low, $++=$ moderate, $+++=$ high

none $=$ no effect/no statistically significant effect; SOE = strength of evidence

Table 55. Osteoarthritis of the hip: effects of nonpharmacological interventions compared with exercise

\begin{tabular}{|c|c|c|c|c|c|c|}
\hline Intervention & $\begin{array}{c}\text { Function } \\
\text { Short-Term } \\
\\
\text { Effect Size } \\
\text { SOE } \\
\end{array}$ & $\begin{array}{c}\text { Function } \\
\text { Intermediate- } \\
\text { Term } \\
\text { Effect Size } \\
\text { SOE } \\
\end{array}$ & $\begin{array}{c}\text { Function } \\
\text { Long-Term } \\
\\
\text { Effect Size } \\
\text { SOE } \\
\end{array}$ & $\begin{array}{c}\text { Pain } \\
\text { Short-Term } \\
\\
\text { Effect Size } \\
\text { SOE } \\
\end{array}$ & $\begin{array}{c}\text { Pain } \\
\text { Intermediate- } \\
\text { Term } \\
\text { Effect Size } \\
\text { SOE } \\
\end{array}$ & $\begin{array}{c}\text { Pain } \\
\text { Long-Term } \\
\\
\text { Effect Size } \\
\text { SOE } \\
\end{array}$ \\
\hline Manual Therapies & $\begin{array}{c}\text { slight } \\
+\end{array}$ & $\begin{array}{c}\text { slight } \\
+\end{array}$ & no evidence & $\begin{array}{c}\text { slight } \\
+\end{array}$ & $\begin{array}{l}\text { insufficient } \\
\text { evidence }\end{array}$ & no evidence \\
\hline
\end{tabular}

Short-Term: 1 to $<6$ months; Intermediate-Term: $\geq 6$ to $<12$ months; Long-Term: $\geq 12$ months

Effect Size: none, slight/small, moderate, or large improvement

Strength of Evidence: $+=$ low, $++=$ moderate, $+++=$ high

$\mathrm{SOE}=$ strength of evidence 
Table 56. Osteoarthritis of the hand: effects of nonpharmacological interventions compared with usual care, placebo, sham, attention control, or waitlist

\begin{tabular}{|c|c|c|c|c|c|c|}
\hline Intervention & $\begin{array}{c}\text { Function } \\
\text { Short-Term } \\
\\
\text { Effect Size } \\
\text { SOE }\end{array}$ & $\begin{array}{c}\text { Function } \\
\text { Intermediate- } \\
\text { Term } \\
\text { Effect Size } \\
\text { SOE } \\
\end{array}$ & $\begin{array}{c}\text { Function } \\
\text { Long-Term }\end{array}$ & $\begin{array}{c}\text { Pain } \\
\text { Short-Term } \\
\\
\text { Effect Size } \\
\text { SOE }\end{array}$ & $\begin{array}{c}\text { Pain } \\
\text { Intermediate- } \\
\text { Term } \\
\text { Effect Size } \\
\text { SOE } \\
\end{array}$ & $\begin{array}{c}\text { Pain } \\
\text { Long-Term } \\
\text { Effect Size } \\
\text { SOE }\end{array}$ \\
\hline Exercise & $\begin{array}{c}\text { insufficient } \\
\text { evidence }\end{array}$ & no evidence & no evidence & no evidence & no evidence & no evidence \\
\hline $\begin{array}{l}\text { Physical } \\
\text { Modalities: Low- } \\
\text { Level Laser } \\
\text { Therapy }\end{array}$ & $\begin{array}{c}\text { none } \\
+\end{array}$ & no evidence & no evidence & $\begin{array}{c}\text { none } \\
+\end{array}$ & no evidence & no evidence \\
\hline $\begin{array}{l}\text { Physical } \\
\text { Modalities: Heat } \\
\text { Therapy }\end{array}$ & $\begin{array}{l}\text { insufficient } \\
\text { evidence }\end{array}$ & no evidence & no evidence & no evidence & no evidence & no evidence \\
\hline $\begin{array}{l}\text { Multidisciplinary } \\
\text { Rehabilitation }\end{array}$ & $\begin{array}{c}\text { none } \\
+\end{array}$ & no evidence & no evidence & $\begin{array}{c}\text { none } \\
+\end{array}$ & no evidence & no evidence \\
\hline
\end{tabular}

Short-Term: 1 to $<6$ months; Intermediate-Term: $\geq 6$ to $<12$ months; Long-Term: $\geq 12$ months

Effect Size: none, slight/small, moderate, or large improvement

Strength of Evidence: $+=$ low, $++=$ moderate, $+++=$ high

none $=$ no effect/no statistically significant effect; SOE = strength of evidence

Table 57. Fibromyalgia: effects of nonpharmacological interventions compared with usual care, placebo, sham, attention control, or waitlist

\begin{tabular}{|c|c|c|c|c|c|c|}
\hline Intervention & $\begin{array}{c}\text { Function } \\
\text { Short-Term } \\
\text { Effect Size } \\
\text { SOE }\end{array}$ & $\begin{array}{c}\text { Function } \\
\text { Intermediate- } \\
\text { Term } \\
\text { Effect Size } \\
\text { SOE }\end{array}$ & $\begin{array}{c}\text { Function } \\
\text { Long-Term } \\
\text { Effect Size } \\
\text { SOE }\end{array}$ & $\begin{array}{c}\text { Pain } \\
\text { Short-Term } \\
\\
\text { Effect Size } \\
\text { SOE }\end{array}$ & $\begin{array}{c}\text { Pain } \\
\text { Intermediate- } \\
\text { Term } \\
\text { Effect Size } \\
\text { SOE }\end{array}$ & $\begin{array}{c}\text { Pain } \\
\text { Long-Term } \\
\text { Effect Size } \\
\text { SOE }\end{array}$ \\
\hline Exercise & $\begin{array}{l}\text { slight } \\
+\end{array}$ & $\begin{array}{l}\text { slight } \\
++\end{array}$ & $\begin{array}{c}\text { none } \\
+\end{array}$ & $\begin{array}{l}\text { slight } \\
++\end{array}$ & $\begin{array}{c}\text { none } \\
++\end{array}$ & $\begin{array}{c}\text { none } \\
++\end{array}$ \\
\hline $\begin{array}{l}\text { Psychological } \\
\text { Therapies: CBT }\end{array}$ & $\begin{array}{l}\text { slight } \\
+\end{array}$ & $\begin{array}{l}\text { slight } \\
+\end{array}$ & $\begin{array}{l}\text { insufficient } \\
\text { evidence }\end{array}$ & $\begin{array}{l}\text { slight } \\
+\end{array}$ & $\begin{array}{c}\text { none } \\
+\end{array}$ & $\begin{array}{l}\text { insufficient } \\
\text { evidence }\end{array}$ \\
\hline $\begin{array}{l}\text { Psychological } \\
\text { Therapies: } \\
\text { Biofeedback, } \\
\text { Imagery }\end{array}$ & $\begin{array}{l}\text { insufficient } \\
\text { evidence }\end{array}$ & $\begin{array}{l}\text { insufficient } \\
\text { evidence }\end{array}$ & $\begin{array}{l}\text { insufficient } \\
\text { evidence }\end{array}$ & $\begin{array}{l}\text { insufficient } \\
\text { evidence }\end{array}$ & $\begin{array}{l}\text { insufficient } \\
\text { evidence }\end{array}$ & $\begin{array}{l}\text { insufficient } \\
\text { evidence }\end{array}$ \\
\hline $\begin{array}{l}\text { Physical } \\
\text { Modalities: } \\
\text { Magnetic Pads }\end{array}$ & $\begin{array}{l}\text { insufficient } \\
\text { evidence }\end{array}$ & $\begin{array}{c}\text { none } \\
+\end{array}$ & no evidence & $\begin{array}{l}\text { insufficient } \\
\text { evidence }\end{array}$ & $\begin{array}{c}\text { none } \\
+\end{array}$ & no evidence \\
\hline $\begin{array}{l}\text { Manual Therapies: } \\
\text { Massage } \\
\text { (Myofascial } \\
\text { Release) }\end{array}$ & no evidence & $\begin{array}{l}\text { slight } \\
+\end{array}$ & $\begin{array}{c}\text { none } \\
+\end{array}$ & $\begin{array}{l}\text { insufficient } \\
\text { evidence }\end{array}$ & $\begin{array}{l}\text { insufficient } \\
\text { evidence }\end{array}$ & $\begin{array}{l}\text { slight } \\
+\end{array}$ \\
\hline $\begin{array}{l}\text { Mindfulness } \\
\text { Practices: MBSR }\end{array}$ & $\begin{array}{c}\text { none } \\
++\end{array}$ & no evidence & no evidence & $\begin{array}{c}\text { none } \\
++\end{array}$ & no evidence & no evidence \\
\hline $\begin{array}{l}\text { Mind-Body } \\
\text { Practices: Qigong, } \\
\text { Tai Chi }\end{array}$ & $\begin{array}{l}\text { slight } \\
+\end{array}$ & no evidence & no evidence & $\begin{array}{c}\text { moderate } \\
+\end{array}$ & no evidence & no evidence \\
\hline
\end{tabular}




\begin{tabular}{|l|c|c|c|c|c|c|}
\hline Intervention & $\begin{array}{c}\text { Function } \\
\text { Short-Term }\end{array}$ & $\begin{array}{c}\text { Function } \\
\text { Intermediate- } \\
\text { Term }\end{array}$ & $\begin{array}{c}\text { Function } \\
\text { Long-Term }\end{array}$ & $\begin{array}{c}\text { Pain } \\
\text { Short-Term }\end{array}$ & $\begin{array}{c}\text { Pain } \\
\text { Intermediate- } \\
\text { Term }\end{array}$ & $\begin{array}{c}\text { Pain } \\
\text { Long-Term }\end{array}$ \\
& $\begin{array}{c}\text { Effect Size } \\
\text { SOE }\end{array}$ & $\begin{array}{c}\text { Effect Size } \\
\text { SOE }\end{array}$ & $\begin{array}{c}\text { Effect Size } \\
\text { SOE }\end{array}$ & $\begin{array}{c}\text { Effect Size } \\
\text { SOE }\end{array}$ & $\begin{array}{c}\text { Effect Size } \\
\text { SOE }\end{array}$ & $\begin{array}{c}\text { Effect Size } \\
\text { SOE }\end{array}$ \\
\hline Acupuncture & slight & slight & no evidence & none & none & no evidence \\
++ & ++ & slight & slight \\
Multidisciplinary & slight & + & none & slight & none \\
Rehabilitation & + & + & + & + \\
\hline
\end{tabular}

Short-Term: 1 to $<6$ months; Intermediate-Term: $\geq 6$ to $<12$ months; Long-Term: $\geq 12$ months

Effect Size: none, slight/small, moderate, or large improvement

Strength of Evidence: $+=$ low, $++=$ moderate, $+++=$ high

CBT = cognitive-behavioral therapy; MBSR = mindfulness-based stress reduction; none = no effect/no statistically significant effect; SOE = strength of evidence

Table 58. Fibromyalgia: effects of psychological therapies compared with pharmacological treatments

\begin{tabular}{|c|c|c|c|c|c|c|}
\hline Intervention & $\begin{array}{c}\text { Function } \\
\text { Short-Term } \\
\\
\text { Effect Size } \\
\text { SOE } \\
\end{array}$ & $\begin{array}{c}\text { Function } \\
\text { Intermediate- } \\
\text { Term } \\
\text { Effect Size } \\
\text { SOE } \\
\end{array}$ & $\begin{array}{c}\text { Function } \\
\text { Long-Term } \\
\\
\text { Effect Size } \\
\text { SOE } \\
\end{array}$ & $\begin{array}{c}\text { Pain } \\
\text { Short-Term } \\
\\
\text { Effect Size } \\
\text { SOE } \\
\end{array}$ & $\begin{array}{c}\text { Pain } \\
\text { Intermediate- } \\
\text { Term } \\
\text { Effect Size } \\
\text { SOE } \\
\end{array}$ & $\begin{array}{c}\text { Pain } \\
\text { Long-Term } \\
\text { Effect Size } \\
\text { SOE } \\
\end{array}$ \\
\hline $\begin{array}{l}\text { Exercise vs. } \\
\text { paroxetine }\end{array}$ & no evidence & no evidence & no evidence & no evidence & $\begin{array}{l}\text { insufficient } \\
\text { evidence }\end{array}$ & no evidence \\
\hline $\begin{array}{l}\text { CBT vs. plus } \\
\text { amitriptyline }\end{array}$ & $\begin{array}{l}\text { insufficient } \\
\text { evidence }\end{array}$ & no evidence & no evidence & $\begin{array}{l}\text { insufficient } \\
\text { evidence }\end{array}$ & no evidence & no evidence \\
\hline $\begin{array}{l}\text { Biofeedback vs. } \\
\text { escitalopram }\end{array}$ & $\begin{array}{l}\text { insufficient } \\
\text { evidence }\end{array}$ & no evidence & no evidence & $\begin{array}{l}\text { insufficient } \\
\text { evidence }\end{array}$ & no evidence & no evidence \\
\hline $\begin{array}{l}\text { CBT vS. } \\
\text { pregabalin; } \\
\text { duloxetine }\end{array}$ & no evidence & $\begin{array}{c}\text { slight } \\
+\end{array}$ & no evidence & no evidence & $\begin{array}{c}\text { none } \\
+\end{array}$ & no evidence \\
\hline
\end{tabular}

Short-Term: 1 to $<6$ months; Intermediate-Term: $\geq 6$ to $<12$ months; Long-Term: $\geq 12$ months

Effect Size: none, slight/small, moderate, or large improvement

Strength of Evidence: $+=$ low, $++=$ moderate, $+++=$ high

$\mathrm{CBT}=$ cognitive-behavioral therapy; none = no effect/no statistically significant effect; $\mathrm{SOE}=$ strength of evidence

Table 59. Fibromyalgia: effects of nonpharmacological interventions compared with exercise

\begin{tabular}{|c|c|c|c|c|c|c|}
\hline Intervention & $\begin{array}{c}\text { Function } \\
\text { Short-Term } \\
\\
\text { Effect Size } \\
\text { SOE } \\
\end{array}$ & $\begin{array}{c}\text { Function } \\
\text { Intermediate- } \\
\text { Term } \\
\text { Effect Size } \\
\text { SOE } \\
\end{array}$ & $\begin{array}{l}\text { Function } \\
\text { Long-Term } \\
\\
\text { Effect Size } \\
\text { SOE } \\
\end{array}$ & $\begin{array}{c}\text { Pain } \\
\text { Short-Term } \\
\\
\text { Effect Size } \\
\text { SOE } \\
\end{array}$ & $\begin{array}{c}\text { Pain } \\
\text { Intermediate- } \\
\text { Term } \\
\text { Effect Size } \\
\text { SOE } \\
\end{array}$ & $\begin{array}{c}\text { Pain } \\
\text { Long-Term } \\
\\
\text { Effect Size } \\
\text { SOE } \\
\end{array}$ \\
\hline $\begin{array}{l}\text { Psychological } \\
\text { Therapy: CBT, } \\
\text { biofeedback, } \\
\text { relaxation }\end{array}$ & $\begin{array}{l}\text { insufficient } \\
\text { evidence }\end{array}$ & $\begin{array}{l}\text { insufficient } \\
\text { evidence }\end{array}$ & $\begin{array}{l}\text { insufficient } \\
\text { evidence }\end{array}$ & $\begin{array}{l}\text { insufficient } \\
\text { evidence }\end{array}$ & $\begin{array}{l}\text { insufficient } \\
\text { evidence }\end{array}$ & $\begin{array}{l}\text { insufficient } \\
\text { evidence }\end{array}$ \\
\hline $\begin{array}{l}\text { Multidisciplinary } \\
\text { Rehabilitation }\end{array}$ & no evidence & no evidence & $\begin{array}{c}\text { none } \\
+\end{array}$ & no evidence & no evidence & $\begin{array}{c}\text { none } \\
+\end{array}$ \\
\hline
\end{tabular}

Short-Term: 1 to $<6$ months; Intermediate-Term: $\geq 6$ to $<12$ months; Long-Term: $\geq 12$ months

Effect Size: none, slight/small, moderate, or large improvement

Strength of Evidence: $+=$ low, $++=$ moderate, $+++=$ high

$\mathrm{CBT}=$ cognitive-behavioral therapy; none $=$ no effect $/$ no statistically significant effect; $\mathrm{SOE}=$ strength of evidence 
Table 60. Chronic tension headache: effects of nonpharmacological interventions compared with usual care, placebo, sham, attention control, or waitlist

\begin{tabular}{|c|c|c|c|c|c|c|}
\hline Intervention & $\begin{array}{l}\text { Function } \\
\text { Short-Term } \\
\\
\text { Effect Size } \\
\text { SOE }\end{array}$ & $\begin{array}{l}\text { Function } \\
\text { Intermediate- } \\
\text { Term } \\
\text { Effect Size } \\
\text { SOE }\end{array}$ & $\begin{array}{c}\text { Function } \\
\text { Long-Term } \\
\\
\text { Effect Size } \\
\quad \text { SOE }\end{array}$ & $\begin{array}{l}\text { Pain } \\
\text { Short-Term } \\
\\
\text { Effect Size } \\
\text { SOE }\end{array}$ & $\begin{array}{c}\text { Pain } \\
\text { Intermediate- } \\
\text { Term } \\
\text { Effect Size } \\
\text { SOE }\end{array}$ & $\begin{array}{c}\text { Pain } \\
\text { Long-Term } \\
\\
\text { Effect Size } \\
\text { SOE }\end{array}$ \\
\hline $\begin{array}{l}\text { Psychological } \\
\text { Therapies: CBT } \\
\text { plus Relaxation }\end{array}$ & $\begin{array}{l}\text { insufficient } \\
\text { evidence }\end{array}$ & $\begin{array}{l}\text { insufficient } \\
\text { evidence }\end{array}$ & no evidence & $\begin{array}{l}\text { insufficient } \\
\text { evidence }\end{array}$ & $\begin{array}{l}\text { insufficient } \\
\text { evidence }\end{array}$ & no evidence \\
\hline $\begin{array}{l}\text { Psychological } \\
\text { Therapies: } \\
\text { Relaxation only }\end{array}$ & no evidence & no evidence & no evidence & $\begin{array}{l}\text { insufficient } \\
\text { evidence }\end{array}$ & no evidence & no evidence \\
\hline $\begin{array}{l}\text { Physical } \\
\text { Modalities: OTES }\end{array}$ & $\begin{array}{l}\text { insufficient } \\
\text { evidence }\end{array}$ & no evidence & no evidence & $\begin{array}{l}\text { insufficient } \\
\text { evidence }\end{array}$ & no evidence & no evidence \\
\hline $\begin{array}{l}\text { Manual Therapies: } \\
\text { Spinal manipulation }\end{array}$ & $\begin{array}{c}\text { slight } \\
+\end{array}$ & no evidence & no evidence & $\begin{array}{c}\text { moderate } \\
+\end{array}$ & no evidence & no evidence \\
\hline Acupuncture & no evidence & no evidence & no evidence & $\begin{array}{c}\text { slight } \\
+ \\
\text { (laser) } \\
\\
\text { insufficient } \\
\text { evidence } \\
\text { (needle) }\end{array}$ & $\begin{array}{l}\text { insufficient } \\
\text { evidence } \\
\text { (needle) }\end{array}$ & $\begin{array}{l}\text { insufficient } \\
\text { evidence } \\
\text { (needle) }\end{array}$ \\
\hline
\end{tabular}

Short-Term: 1 to $<6$ months; Intermediate-Term: $\geq 6$ to $<12$ months; Long-Term: $\geq 12$ months

Effect Size: none, slight/small, moderate, or large improvement

Strength of Evidence: $+=$ low, $++=$ moderate, $+++=$ high

$\mathrm{CBT}=$ cognitive-behavioral therapy; OTES = occipital transcutaneous electrical stimulation; SOE = strength of evidence

Table 61. Chronic tension headache: effects of nonpharmacological interventions compared with pharmacological treatments

\begin{tabular}{|c|c|c|c|c|c|c|}
\hline Intervention & $\begin{array}{l}\text { Function } \\
\text { Short-Term } \\
\text { Effect Size } \\
\text { SOE }\end{array}$ & $\begin{array}{c}\text { Function } \\
\text { Intermediate- } \\
\text { Term } \\
\text { Effect Size } \\
\text { SOE }\end{array}$ & $\begin{array}{l}\text { Function } \\
\text { Long-Term } \\
\text { Effect Size } \\
\text { SOE }\end{array}$ & $\begin{array}{c}\text { Pain } \\
\text { Short-Term } \\
\text { Effect Size } \\
\text { SOE }\end{array}$ & $\begin{array}{c}\text { Pain } \\
\text { Intermediate- } \\
\text { Term } \\
\\
\text { Effect Size } \\
\text { SOE } \\
\end{array}$ & $\begin{array}{c}\text { Pain } \\
\text { Long-Term } \\
\text { Effect Size } \\
\text { SOE }\end{array}$ \\
\hline $\begin{array}{l}\text { Psychological } \\
\text { Therapies: CBT }\end{array}$ & $\begin{array}{l}\text { insufficient } \\
\text { evidence }\end{array}$ & $\begin{array}{l}\text { insufficient } \\
\text { evidence }\end{array}$ & no evidence & $\begin{array}{l}\text { insufficient } \\
\text { evidence }\end{array}$ & $\begin{array}{l}\text { insufficient } \\
\text { evidence }\end{array}$ & no evidence \\
\hline $\begin{array}{l}\text { Manual Therapies: } \\
\text { Manipulation }\end{array}$ & no evidence & no evidence & no evidence & $\begin{array}{l}\text { insufficient } \\
\text { evidence }\end{array}$ & no evidence & no evidence \\
\hline
\end{tabular}

Short-Term: 1 to $<6$ months; Intermediate-Term: $\geq 6$ to $<12$ months; Long-Term: $\geq 12$ months

$\mathrm{CBT}=$ cognitive-behavioral therapy; $\mathrm{SOE}=$ strength of evidence

Low Back Pain. For chronic low back pain, compared with usual care, attention control, sham, or placebo, there was moderate evidence of slight improvement in function, at least in the short term, for massage, yoga, psychological therapies (cognitive-behavioral therapy [CBT]) (strength of evidence [SOE]: moderate) and low evidence for exercise, acupuncture, low-level laser therapy, spinal manipulation, multidisciplinary rehabilitation (SOE: low). With the exception of spinal manipulation, these interventions also showed slight improvement (exercise, acupuncture, massage, psychological therapies, multidisciplinary rehabilitation, SOE: low) or moderate 
improvements (yoga, low-level laser therapy, SOE: low) in pain short term. The slight improvements in function compared with controls were sustained into the intermediate term for yoga, spinal manipulation, psychological therapies, and multidisciplinary rehabilitation, with low strength of evidence for all but the psychological therapies, for which SOE was moderate. No clear improvement in function was seen at intermediate term for exercise, acupuncture, massage or low-level laser therapy (SOE: low for all). Improvements in pain were seen in the intermediate term for exercise (slight effect SOE moderate) and yoga (moderate effect, SOE low) and mindfulness-based stress reduction (MBSR) (slight effect, SOE: low) as well as spinal manipulation, psychological therapies and multidisciplinary rehabilitation (slight effects, SOE: moderate). Long-term evidence was available for four intervention categories: psychological therapies, multidisciplinary rehabilitation, exercise, and acupuncture. The strongest evidence was for psychological therapies (CBT primarily), which were associated with slightly greater effects than usual care or attention control on both function and pain at short, intermediate, and long term (SOE: moderate for all time frames). Neither exercise nor acupuncture was associated with improved function long term, even though both demonstrated continued pain improvement (SOE: low for all). For multidisciplinary rehabilitation, effects on function from earlier time frames were not sustained in the long term versus usual care (SOE: low). High intensity multidisciplinary rehabilitation ( $\geq 20$ hours/week or $>80$ hours total) was not clearly better than nonhigh intensity programs. Short-term effects on function and pain were somewhat larger with high intensity multidisciplinary rehabilitation than with nonhigh intensity interventions but the tests for interaction were not statistically significant. At intermediate term, estimates were similar for high intensity and nonhigh intensity programs.

In people with chronic low back pain, there were no clear differences in short-term function for comparisons of qigong, yoga, or spinal manipulation with exercise even though small improvements in pain were seen for yoga (SOE: low for all). Multidisciplinary rehabilitation was associated with small effects on function short term as well as pain (SOE: moderate). For Qigong, results for intermediate-term function and short-term pain slightly favored exercise (SOE: low for all). Again, multidisciplinary rehabilitation was associated with slight improvements in function and pain at intermediate term (SOE: moderate), but this was not sustained in the long term (SOE: low). Long-term data were only available for multidisciplinary rehabilitation.

Neck Pain. For chronic neck pain, in the short term, moderate effects on function and pain were seen for low-level laser therapy (SOE: moderate). In the short term and intermediate term, acupuncture and Alexander Technique were associated with slightly greater effect on function compared with usual care (both interventions), sham acupuncture or sham laser (SOE: low). The effect of acupuncture was not sustained long term (SOE: low) compared with sham acupuncture, sham laser, or usual care, and no improvement in pain was seen at any time frame (SOE: low). There were no clear improvements in function or pain across types of exercise (short term) or for psychological therapies or massage compared with usual care, sham procedures, or attention controls (SOE: low for all).

Knee Osteoarthritis. For knee osteoarthritis (OA), exercise, microwave diathermy and ultrasound were associated with functional improvement in the short term compared with usual care, attention control, or sham procedure; the effect size was small for exercise and ultrasound, and larger for diathermy (SOE: moderate for exercise, low for ultrasound, diathermy). While the 
small effects of exercise on function persisted into the intermediate and long term (SOE: low for both), there were no clear benefits to ultrasound at intermediate term (SOE: low). Similarly, small short-term effects of ultrasound on pain did not persist to intermediate term (SOE: low) in contrast to moderate improvement in pain for exercise (SOE: low). Long term, the small improvement in function seen with exercise was sustained, but there was no clear effect on pain (SOE: low). There were no clear differences in function or pain associated with electromagnetic fields (short-term SOE: low), with psychological therapies for any time frame (SOE: low), or with acupuncture at short (SOE: moderate) or intermediate term (SOE: low) versus usual care, attention control, or sham procedure. There was no difference in function or pain between pain coping skills training and exercise at short term or intermediate term in one trial (SOE: low).

Hip and Hand Osteoarthritis. Evidence was sparse on interventions for hip and hand OA. Exercise was associated with slightly greater function than usual care at short and intermediateterm (SOE: low), but data were in sufficient to determine long-term effects. For pain, a small effect was seen only at short term; no differences were seen at the other time points (SOE: low for short term and intermediate term, insufficient for long term). Compared with exercise, a small effect on function was seen with manual therapy in the short and intermediate term, and small improvement in pain short term (SOE: low for all). For hand OA, no clear differences were seen for low-level laser therapy versus sham or for multidisciplinary rehabilitation versus waitlist control at short term for either function or pain (SOE: low).

Fibromyalgia. Short term, in patients with fibromyalgia, there was low-quality evidence that slight improvements on function were associated with exercise, CBT, and mind-body practices of tai chi and qigong (SOE: low for all) compared with wait list and attention control, and moderate-quality evidence for slight functional improvement acupuncture compared with sham acupuncture (SOE: moderate). Improvements in short-term pain were seen with exercise (SOE: moderate) and mind body practices (SOE: low), but not with acupuncture. No clear differences in function or pain outcomes were seen for MBSR (SOE: moderate) or multidisciplinary rehabilitation (SOE: low). Slightly greater effects on function continued into the intermediate term for acupuncture and CBT and massage (SOE: low), and were seen for myofascial release massage and multidisciplinary rehabilitation; there was no clear effect of magnetic mattress pads versus sham pad (SOE: low for all). Slight improvement in pain intermediate-term were seen for massage and multidisciplinary rehabilitation (SOE: low), but not for exercise (SOE: moderate), acupuncture, or magnetic mattress pads (SOE: low). Long term, small improvements in function continued for multidisciplinary rehabilitation but not for exercise or massage (SOE: low for all), and there was no clear impact on pain for exercise (SOE: moderate) or multidisciplinary rehabilitation (SOE: low). No clear differences were seen between multidisciplinary rehabilitation and exercise for the long term on function or pain (SOE: low). CBT was associated with a small benefit for function but not for pain compared with pregabalin at intermediate term (SOE: low).

Chronic Tension Headache. Only nine trials of nonpharmacological treatments for chronic tension headache met the inclusion criteria and all but one was considered poor quality, resulting in a rating of insufficient evidence for comparisons of psychological therapies with waitlist or attention control, electrical stimulation versus sham, and acupuncture versus sham. One fairquality trial of laser acupuncture versus sham suggested moderate improvement in pain short 
term (SOE: low), and another fair-quality trial of spinal manipulation versus usual care suggested a small effect on short-term function based on the Headache Impact Test (SOE: low).

Approximately 25 percent of the patients in the trial had comorbid migraine headache.

Usual Care/Waitlist and Nonactive Comparators. For comparisons involving usual care/waitlist or nonactive comparators (placebo, sham, attention control), there were some differences depending on the specific comparator evaluated. For some interventions results different by control type. For example, in some analyses, acupuncture was associated with greater effects on pain in patients with chronic low back pain or OA when compared with usual care than when compared with sham acupuncture, suggesting that much of the benefit may be due to placebo or other nonspecific effect.

Harms. Harms were poorly reported across interventions. No serious intervention-related adverse events requiring medical attention were identified; reported adverse events were generally minor (e.g., muscle soreness with exercise, bruising with acupuncture) and time-limited (e.g., temporary worsening of pain).

Medication Use. Few trials compared opioid use pre- and post-intervention, and medication use in general was not well reported across trials.

Subgroups. One fair-quality trial in people with knee OA formally examined factors that might modify the effect of exercise on disability; the effect of exercise on activities of daily living disability did not appear to be modified by age, sex, baseline disability, knee pain score, body mass index, or race. ${ }^{50}$ The few trials that reported subgroup analyses either did not provide sufficient data to assess modification by demographic or other factors or did not formally test for modification; trials were generally too small to effectively evaluate outcomes in subgroups.

\section{Findings in Relationship to What Is Already Known}

Many reviews have addressed the effects of interventions for chronic pain management during or immediately following treatments. We focused on evaluating the sustainability of effects for at least 1 month postintervention.

This review updates our previous review on low back pain ${ }^{25}$ by incorporating new evidence on nonpharmacological treatments for chronic low back pain. Consistent with the prior review, we found exercise, yoga, various psychological therapies, acupuncture, spinal manipulation, and low-level laser therapy with small to moderate effects on function and/or pain. It differs from the prior review in focusing on durability of treatment effects 1 month or longer after completion of a course of treatment and basing estimates on meta-analyses when poolable data were available, and conducting stratified and sensitivity analyses to evaluate sources of heterogeneity and robustness of findings. For example, subanalyses of specific interventions within a given category of intervention (e.g., aerobic exercise within the general category of exercise suggests that despite the inherent heterogeneity within some of the categories, effect estimates results for specific interventions may be similar). Although we found some evidence that beneficial effects of some nonpharmacological therapies persist for up to 12 months following the end of a course of a treatment, data on longer-term ( $>1$ year) outcomes were very sparse.

A recent Institute for Clinical and Economic Review (ICER) review ${ }^{248}$ on chronic low back pain and neck pain used relevant portions of our previous review for chronic low back pain and 
updated it with new publications so the findings are generally consistent with our review for this condition. For chronic neck pain, this report and the ICER report both suggest a small benefit for acupuncture. The ICER report focuses on evaluating comparative value for interventions and suggests that cognitive and mind-body therapies for treatment of chronic low back pain and chronic neck pain would be cost-effective, would meet value-based price benchmarks, and may result in only a small increase (\$0.75) per member per month for a hypothetical payer plan covering 1 million members, compared with approximately $\$ 4.46$ per member per month for pain medication.

Our findings indicate that a number of nonpharmacological treatments improve pain and/or function for specific chronic pain conditions included in this review. This is consistent with other reviews, including recent reviews on exercise ${ }^{249}$ acupuncture, ${ }^{250}$ and complementary health approaches ${ }^{251}$ for chronic pain management across various conditions, an Agency for Healthcare Research and Quality (AHRQ) report on knee OA treatment, ${ }^{252}$ and a review of chronic pain treatment guidelines on the use of manual and physical therapies. ${ }^{253}$

The protocol for a systematic review and network meta-analysis of interventions for fibromyalgia was identified; ${ }^{254}$ no publication timeline for this review is currently available.

\section{Applicability}

The applicability of our findings may be impacted by a number of factors. Included trials provided limited information on symptom duration, clinical characteristics, comorbid conditions, and concomitant treatments, thus it is not clear to what extent these trials reflect the populations seen in clinical practice or how these impact our results. In addition, with the exception of fibromyalgia, information regarding diagnostic criteria for the pain condition of interest was limited. Information on the presence of overlapping chronic pain conditions or psychosocial factors was generally not provided in included trials, and the extent to which these characteristics were present in trial populations and their impact on our results is not clear. Across conditions, a majority of trial participants were female. The age of included populations generally reflected the ages impacted by the conditions. Evidence to how effectiveness varies by ages was limited. There was also heterogeneity in populations enrolled in the trials with regard to duration of chronic pain, severity of pain (most trials enrolled patients with at least moderate pain at baseline), as well as other factors (e.g., use of medications, medical and psychological comorbidities). Our findings are generally most applicable to people without such comorbidities who have moderate or severe intensity pain that has persisted for more than 12 months. The heterogeneity in populations across included trials likely is consistent with the heterogeneity seen in clinical practice, so our findings may be applicable to most primary care clinical settings.

Variability in interventions, comparators and cointerventions may impact our findings. For interventions, there was variability in the numbers of sessions, length of sessions, duration of treatment, methods of delivering the intervention and the experience and training of those providing the intervention. To address heterogeneity within intervention categories we abstracted details of techniques or methods used, (e.g. specific type of psychological intervention or Yoga) and attempted to stratify by them, however in most cases, data were insufficient to do so. In general, there were no clear differences in effects based on intervention factors or comparators; however analyses were limited by small numbers of trials. In clinical practice, most chronic pain patients likely use a combination of therapies and may continue to receive some types of therapies if benefit is perceived. It is unclear to what extent our findings represent the conditions 
under which the various interventions are currently delivered. Evidence to identify optimal techniques and delivery of interventions is needed.

To facilitate interpretation of results across trials and interventions, we categorized the magnitude of effects for function and pain outcomes using the system described in our previous

review. ${ }^{25}$ Using this system, beneficial effects identified were generally in the small or moderate range. We recognize that effects that we classified as small (e.g., 5 to 10 points on a 0 to 100 scale for pain or function) may be below some proposed thresholds for minimum clinically important differences for some measures. However, our classification provides some consistent and objective benchmarks to assess magnitude of smaller effects across trials and interventions. Interpretation of clinically important differences in mean change for continuous variables is challenging. If data were provided we also evaluated the proportion of patients who experienced a clinically important improvement in pain or function. This provides valuable insight regarding clinically important improvement. For example, one trial ${ }^{89}$ of MBSR versus usual care in low back pain reported a small improvement in function on a modified Roland Morris Disability questionnaire (1.87, 95\% CI -3.14 to -0.60 on 0 -23 scale); however, absolute difference between MBSR and usual care on the percentage of participants (20\%) achieving a minimally clinically meaningful ( $\geq 30 \%$ ) improvement from baseline (68.8\% to $48.6 \%$, risk ratio 1.56 , 95\% CI 1.14 to 2.14) suggests that the benefits may be more substantial.

\section{Limitations of the Evidence Base}

Evidence was sparse for most interventions. Data on long-term outcomes was particularly limited. There were also limited data on outcomes other than pain and function and on harms. Few trials directly compared an included intervention versus pharmacological therapy or the specified active comparator (exercise or biofeedback). Only 5 percent of included trials across conditions were considered to be of good quality; the majority were considered fair (59\%). No trial of treatment for chronic tension headache was considered to be of good quality. For some interventions, it is possible to effectively blind participants and providers (e.g. CBT, multidisciplinary rehabilitations, exercise); thus, observed effects may be due in part to placebo, attention, or other nonspecific effects and results may have been susceptible to performance and other biases. Many included trials were small (< 70 participants) and only few or single trials were available for some interventions (e.g., some physical modalities). The combination of these factors led to a determination that evidence was insufficient. There was no or little includable evidence for a number of interventions, including electromuscular simulation, traction, superficial heat or cold, bracing, use of magnets, interferential therapy, transcutaneous electrical nerve stimulation, and manual therapies (other than for low back pain). For most conditions, evidence was also sparse for mindfulness and mind-body practices. Evidence on interventions for hip and hand OA and chronic tension headache was very limited.

Heterogeneity in clinical diagnosis and presentation was present for most of the conditions, with the exception of fibromyalgia. It is likely that included patients may have additional conditions and/or psychological comorbidities that were not described in the trials. Details provided by trials were insufficient to conduct meaningful subanalyses.

Some of the limitations described for the review process reflect limitations of the evidence base, including those related to heterogeneity within and across interventions and heterogeneity within a given condition. Details of concurrent interventions and components of usual care were generally not reported or poorly reported. Additionally, it is assumed that most patients with chronic pain likely continued medications and other therapies or practices during the trials. These 
factors may have resulted in substantial mixing of effects of the intervention and cointerventions. These factors possibly attenuated observed effects.

Data on potential harms is sparse, although serious harms are not generally expected with the interventions included in this review. Serious treatment-related adverse events were not reported in any of the trials.

\section{Implications for Clinical and Policy Decisionmaking}

Our review provides some evidence that an array of nonpharmacological treatments provide small to moderate benefits function and pain that are durable for more than 1 month for the five common chronic pain conditions addressed in this review. Musculoskeletal pain, particularly of back and joint pain, is the most common single type of chronic pain. Age-adjusted rates of adults reporting pain in the last three months were highest for low back pain (28\%), neck pain (15\%), knee pain (19.5\%) and severe headache or migraine (16\%). ${ }^{3,14}$

The evidence synthesized in this review may help inform guidelines and health care policy (including reimbursement policy) related to use of noninvasive nonpharmacological treatments, and inform policy decisions regarding funding priorities for future research.

Recent guidelines ${ }^{13}$ from the Centers for Disease Control and Prevention (CDC) in the United States and the Canadian Guideline for Opioid Use in Chronic Non-Cancer Pain ${ }^{253}$ recommend nonopioid treatment as the preferred treatment for chronic pain. Further, guidelines from the American College of Physicians recommend nonpharmacological therapies over medications for chronic back pain. ${ }^{16}$ Our findings support the feasibility of implementing these guideline recommendations by showing that there are some nonpharmacological treatments for chronic pain that have evidence of sustained effectiveness after the completion of therapy. Importantly, some interventions, such as exercise, CBT, multidisciplinary rehabilitation, mindbody interventions, and some complementary and integrative medicine therapies, such as acupuncture and spinal manipulation, also were associated with some sustained effects on function, although evidence beyond 12 months is sparse. There was no evidence suggesting serious harms from these interventions, although harms data were limited.

Our report reviewed evidence that may also help inform decisions regarding prioritization of nonpharmacological therapies by clinicians selecting therapy. Consistent with a biopsychosocial understanding of chronic pain, 3,7 evidence was somewhat more robust for "active" interventions that engage patients in movement and address psychological contributors to pain, particularly at longer-term followup, versus more "passive" treatments focused on symptom relief such as massage. Active interventions include exercise, multidisciplinary rehabilitation, psychological therapies (particularly CBT), and mind-body interventions. This provides some support for clinical strategies that focus on "active" interventions as primary therapies, with "passive" interventions used in a more adjunctive or supplementary role. Research is needed to compare “active” vs. "passive” strategies.

Our review also has policy implications related to access to treatment and reimbursement. Given heterogeneity in chronic pain, variability in patient preferences for treatments, ${ }^{3,7}$ and differential responses to specific therapies in patients with a given chronic pain condition, policies that broaden access to a wider array of effective nonpharmacological treatments may have greater impact than those that focus on one or a few therapies. Several considerations could inform policy decisions regarding access to and coverage of nonpharmacological therapies. Policymakers could prioritize access to interventions with evidence of persistent effectiveness across different pain conditions, such as exercise, multidisciplinary rehabilitation, mind-body 
interventions, and acupuncture. Because the level of supporting evidence varies from condition to condition, policymakers may need to consider the degree to which evidence may be reasonably extrapolated across conditions (e.g., effectiveness of psychological therapies for chronic low back pain may not necessarily be extrapolated to OA). Although the Affordable Care Act has improved access to complementary and integrative therapies, variability in reimbursement and authorization procedures remain a potential barrier. Although evidence supports the use of multidisciplinary rehabilitation over exercise therapy or usual care, primarily for low back pain, cost and availability remain important barriers particularly in rural areas. Our report suggests that less-intensive multidisciplinary rehabilitation may be similarly effective to high-intensity multidisciplinary rehabilitation, which could inform decisions about more efficient methods for delivering this intervention. Not all patients may require multidisciplinary

rehabilitation. ${ }^{255}$ Policy efforts that focus on use of multidisciplinary rehabilitation in individuals more likely to benefit (e.g., severe functional deficits, failure to improve on standard nonmultidisciplinary therapies, significant psychosocial contributors to pain) could also inform efforts to deliver this modality efficiently.

\section{Limitations of the Systematic Review Process}

There were limitations in the systematic review process. Our analysis was restricted to trials that reported outcomes after at least 1 month following the end of therapy (except when therapy lasted at least 6 months; in these cases, we included assessments made immediately posttreatment). We did not include trials of patients with chronic pain conditions other than those specified in the methods and excluded trials of patients with diffuse or mixed pain conditions. Some noninvasive nonpharamcological interventions (e.g., self-management education) were excluded, and we did not address invasive therapies. Trials that evaluated active comparators other than biofeedback (for headache) or exercise (all other conditions) or interventions as adjunctive treatment were excluded. Some meta-analyses were based on two or three trials; findings based on such meta-analyses must be interpreted with caution.

The interventions were grouped a priori to provide an organizational framework for the report. There is some overlap between categories and there a many other methods of grouping interventions. We performed separate or stratified analyses to the extent possible to evaluate specific techniques/methods within broader categories (e.g., we looked at different types of psychological therapies and mind-body practices). We also performed stratified analyses by comparator type where data were available. Sparse literature for many of the interventions precluded extensive examination specific types of intervention within a given category.

We excluded non-English-language articles; however, we did not identify large numbers of non-English-language articles in our review of bibliographies. We searched ClinicalTrials.gov and identified some potentially relevant studies, but none had results available. We did not search conference proceedings or other sources. We were unable to assess for publication bias using graphical or statistical methods to evaluate any potential impact of small samples, methodological limitations in trials, or heterogeneity in interventions, populations or outcomes. Based on hand searches of reference lists, searches of ClinicalTrials.gov, and suggestions from technical experts, we did not find evidence indicating the presence of unpublished literature sufficient to impact conclusions. 


\section{Research Recommendations}

The gaps in the available evidence are many across the common conditions we included (Table 62). Four primary issues relate to (1) the need to understand the longer-term sustainability of intervention effects; (2) the need for standardization of interventions for future trials; (3) the standardization of research protocols for collection of and reporting of outcomes including harms; (4) the need for comparisons of interventions with pharmacological interventions. For many of these areas, future research would benefit from considering recommendations from organizations such as the Initiative on Methods, Measurements, and Pain Assessment in Clinical

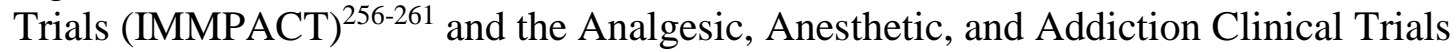
Translations, Innovations, Opportunities, and Networks (ACTTION) ${ }^{262,263}$ and the research priorities outlined in the recent Federal Pain Research Strategy. ${ }^{264}$

To understand the sustainability of effects, methodologically rigorous traditional (explanatory) trials with longer followup are needed to better understand whether benefits are sustained over time under ideal conditions. In addition, well-designed pragmatic trial designs with long-term followup could facilitate understanding of how interventions are delivered and continued in real-world settings as well as effect sustainability. Methods for enhancing recruitment, adherence and retention need to be incorporated for all trials. Education of researchers examining nonpharmacological approaches to pain management on clinical trial design, execution, and analysis may also assist with improving the quality of the evidence base for many of the interventions.

Research to identify optimal techniques and their delivery would help define more standardized interventions to evaluate in future trials is needed. In addition, there is a need to understand what combinations of interventions may be most logical for a given condition and standardization of methods to study adjunct therapies. Pragmatic trials may help provide insight into these questions.

Standardization of research protocols for reporting and outcomes measures and use of a standard set of measures would facilitate comparison of results across trials. Outcome measures such as the Visual Analog Scale or Numeric Rating Scale may not fully capture the impact of pain or allow for accurate classification or evaluation of changes in chronic pain. Inclusion of recommendations for pain assessment ${ }^{265}$ assessment that incorporate understanding of pathophysiological mechanisms and address multiple domains of pain, including temporal dimensions, sensory and affective qualities of pain and the location and bodily distribution of pain in trial planning and execution may facilitate more accurate classification and longitudinal tracking of response to interventions. Reporting the proportions of patients achieving a clinically meaningful improvement in pain, function, or quality of life as measures of "success" may provide additional clinical information to complement data on average changes in continuous measures of pain, function, and quality of life for which there is difficulty describing clinically important effects. Routine collection of common or known harms associated with interventions is needed in future trials.

There is heterogeneity with regard to research design, execution, and outcomes reporting in trials of interventions included in this review compared with well-funded trials of devices or pharmacological agents. Lack of funding to design methodologically sound studies with reasonable sample size of nonpharmacological interventions may have contributed to the general low quality of evidence. 
Table 62. Summary of evidence gaps and research recommendations

\begin{tabular}{|c|c|c|}
\hline Research Component & Evidence Gap & Future research recommendation \\
\hline $\begin{array}{l}\text { Study Design Methods and } \\
\text { Reporting }\end{array}$ & $\begin{array}{l}\text { Sparse evidence on the sustainability } \\
\text { of effects; Limited information on } \\
\text { adherence and need to maximize } \\
\text { retention. }\end{array}$ & $\begin{array}{l}\text { Traditional (explanatory) and pragmatic } \\
\text { trials with long-term followup and use of } \\
\text { methods to enhance recruitment, } \\
\text { retention and adherence. Documentation } \\
\text { of adherence. } \\
\text { Consider recommendations from } \\
\text { IMMPACT, ACTTION and Federal Pain } \\
\text { Research Strategy. }\end{array}$ \\
\hline Patient populations & $\begin{array}{l}\text { Information on overlapping chronic } \\
\text { pain conditions or psychosocial } \\
\text { factors was generally not provided in } \\
\text { included trials. }\end{array}$ & $\begin{array}{l}\text { Documentation of coexisting conditions } \\
\text { and factors in trials with sufficient } \\
\text { sample-size to evaluate the differential } \\
\text { impact of conditions and factors. }\end{array}$ \\
\hline Interventions and comparators & $\begin{array}{l}\text { Lack of information on optimal } \\
\text { techniques, duration and frequency } \\
\text { of treatment; } \\
\text { Lack of evidence comparing } \\
\text { interventions to pharmacological } \\
\text { agents. }\end{array}$ & $\begin{array}{l}\text { Research leading to standardization of } \\
\text { techniques and their delivery to be used } \\
\text { in future trials and understanding best } \\
\text { combinations of interventions. Pragmatic } \\
\text { trials may provide valuable information. } \\
\text { Trails comparing interventions with } \\
\text { pharmacological treatments. }\end{array}$ \\
\hline Outcomes measures & $\begin{array}{l}\text { Lack of consistency in types } \\
\text { outcomes measures used for } \\
\text { function and pain across trials makes } \\
\text { it challenging to compare results } \\
\text { across trials. } \\
\text { Commonly used VAS or NRS for } \\
\text { pain do not capture the impact of } \\
\text { pain or allow for accurate } \\
\text { classification or evaluation of } \\
\text { changes in chronic pain. } \\
\text { Common or know harms are not } \\
\text { routinely collected. }\end{array}$ & $\begin{array}{l}\text { Standardized protocols for types of } \\
\text { outcomes to be assessed (including } \\
\text { harms). Use measures that incorporate } \\
\text { understanding of pathophysiological } \\
\text { mechanisms and address multiple } \\
\text { domains of pain. Report the proportions } \\
\text { of patients achieving a clinically } \\
\text { meaningful improvement for measures of } \\
\text { pain and function as well as outcomes } \\
\text { related to change in use of opioids, } \\
\text { health care utilization and quality of life. } \\
\text { Consider recommendations from } \\
\text { IMMPACT, ACTTION and Federal Pain } \\
\text { Research Strategy. }\end{array}$ \\
\hline
\end{tabular}

ACTTION = Analgesic, Anesthetic, and Addiction Clinical Trials Translations, Innovations, Opportunities, and Networks; IMMPACT = Initiative on Methods, Measurements, and Pain Assessment in Clinical Trials; NRS = numeric rating scale; VAS = visual analog scale

\section{Conclusions}

Exercise, multidisciplinary rehabilitation, acupuncture, CBT, and mind-body practices were most consistently associated with durable slight to moderate improvements in function and pain for specific chronic pain conditions. Our findings provide some support for clinical strategies that focus on use of nonpharmacological therapies for specific chronic pain conditions. Additional comparative research on sustainability of effects beyond the immediate posttreatment period is needed, particularly for conditions other than low back pain. 


\section{References}

1. Ballantyne JC, Shin NS. Efficacy of opioids for chronic pain: a review of the evidence. Clin J Pain. 2008 Jul-Aug;24(6):469-78. doi: 10.1097/AJP.0b013e31816b2f26. PMID: 18574357.

2. Eriksen J, Sjogren P, Bruera E, et al. Critical issues on opioids in chronic non-cancer pain: an epidemiological study. Pain. 2006 Nov;125(1-2):172-9. doi: 10.1016/j.pain.2006.06.009. PMID: 16842922.

3. Institute of Medicine. Relieving Pain in America: A Blueprint for Transforming Prevention, Care, Education, and Research. Washington, DC: The National Academies Press; 2011.

4. Merskey H, Bogduk N, eds. Classification of chronic pain: Descriptions of chronic pain syndromes and definitions of pain terms. 2nd ed. Seattle: IASP Press; 1994.

5. Treede RD, Rief W, Barke A, et al. A classification of chronic pain for ICD-11. Pain. 2015 Jun;156(6):1003-7. doi: 10.1097/j.pain.0000000000000160. PMID: 25844555.

6. [No authors listed]. Classification of chronic pain. Descriptions of chronic pain syndromes and definitions of pain terms. Prepared by the International Association for the Study of Pain, Subcommittee on Taxonomy. Pain Suppl. 1986;3:S1-226. PMID: 3461421.

7. National Pain Strategy Task Force. National Pain Strategy: A Comprehensive Population Health-Level Strategy for Pain. Interagency Pain Research Coordinating Committee (IPRCC), National Institutes of Health (NIH); 1-83. 2015.

https://iprcc.nih.gov/National_Pain_Strategy /NPS_Main.htm.

8. Boudreau D, Von Korff M, Rutter CM, et al. Trends in long-term opioid therapy for chronic non-cancer pain.

Pharmacoepidemiol Drug Saf. 2009

Dec;18(12):1166-75. doi: 10.1002/pds.1833. PMID: 19718704.
9. Olsen Y, Daumit GL, Ford DE. Opioid prescriptions by U.S. primary care physicians from 1992 to 2001. J Pain. 2006 Apr;7(4):225-35. doi: 10.1016/j.jpain.2005.11.006. PMID: 16618466.

10. Sullivan MD, Edlund MJ, Fan MY, et al. Trends in use of opioids for non-cancer pain conditions 2000-2005 in commercial and Medicaid insurance plans: the TROUP study. Pain. 2008 Aug 31;138(2):440-9. doi: 10.1016/j.pain.2008.04.027. PMID: 18547726.

11. Chou R, Turner JA, Devine EB, et al. The effectiveness and risks of long-term opioid therapy for chronic pain: a systematic review for a National Institutes of Health Pathways to Prevention Workshop. Ann Intern Med. 2015 Feb 17;162(4):276-86. doi: 10.7326/M14-2559. PMID: 25581257.

12. Centers for Disease Control and Prevention. Vital signs: overdoses of prescription opioid pain relievers---United States, 1999--2008.

MMWR Morb Mortal Wkly Rep. 2011 Nov 4;60(43):1487-92. PMID: 22048730.

13. Dowell D, Haegerich TM, Chou R. CDC Guideline for Prescribing Opioids for Chronic Pain--United States, 2016. JAMA. 2016 Apr 19;315(15):1624-45. doi: 10.1001/jama.2016.1464. PMID: 26977696.

14. National Center for Health Statistics. Health, United States, 2010: with special feature on death and dying. Hyattsville, MD: 2011.

15. Methods Guide for Effectiveness and Comparative Effectiveness Reviews. AHRQ Publication No. 10(14)-EHC063-EF. Rockville, MD: Agency for Healthcare Research and Quality. January 2014. Chapters available at: www.effectivehealthcare.ahrq.gov.

16. Chou R, Deyo R, Friedly J, et al. Nonpharmacologic therapies for low back pain: A systematic review for an American College of Physicians Clinical Practice Guideline. Ann Intern Med. 2017 Feb 14;166:[Epub ahead of print]. doi: 10.7326/M16-2459. PMID: 28192793. 
17. Headache Classification Committee of the International Headache Society. The International Classification of Headache Disorders, 3rd edition (beta version). Cephalalgia. 2013;33(9):629-808.

18. Higgins JPT, Green S, eds. Cochrane Handbook for Systematic Reviews of Interventions. Version 5.1.0 [updated March 2011]. The Cochrane Collaboration. Available from http://handbook.cochrane.org.; 2011.

19. Furlan AD, Malmivaara A, Chou R, et al. 2015 Updated Method Guideline for Systematic Reviews in the Cochrane Back and Neck Group. Spine (Phila Pa 1976). 2015 Nov;40(21):1660-73. doi: 10.1097/BRS.0000000000001061. PMID: 26208232.

20. McCracken LM, Vowles KE. Acceptance and commitment therapy and mindfulness for chronic pain: model, process, and progress. Am Psychol. 2014 FebMar;69(2):178-87. doi: 10.1037/a0035623. PMID: 24547803.

21. A collection of $\mathrm{R}$ functions supporting the text book Modern Epidemiology, Second Edition, by Kenneth J. Rothman and Sander Greenland. GitHub, Inc.; 2017.

https://github.com/epijim/episheet. Accessed October 13, 2017.

22. DerSimonian R, Laird N. Meta-analysis in clinical trials. Control Clin Trials. 1986 Sep;7(3):177-88. PMID: 3802833.

23. Hardy RJ, Thompson SG. A likelihood approach to meta-analysis with random effects. Stat Med. 1996 Mar 30;15(6):61929. doi: 10.1002/(SICI)10970258(19960330)15:6<619::AIDSIM188>3.0.CO;2-A. PMID: 8731004.

24. Higgins JP, Thompson SG, Deeks JJ, et al. Measuring inconsistency in meta-analyses. BMJ. 2003 Sep 06;327(7414):557-60. doi: 10.1136/bmj.327.7414.557. PMID: 12958120 .
25. Chou R, Deyo R, Friedly J, et al.

Noninvasive Treatment for Low Back Pain. Comparative Effectiveness Review No. 169. (Prepared by the Pacific Northwest Evidence-based Practice Center under Contract No. HHSA 290-2012-00014-I.) AHRQ Publication No. 16-EHC004-EF. Rockville, MD: Agency for Healthcare Research and Quality. February 2016. www.effectivehealthcare.ahrq.gov/reports/fi nal.cfm. PMID: 26985522.

26. Berkman ND, Lohr KN, Ansari M, et al. Grading the Strength of a Body of Evidence When Assessing Health Care Interventions for the Effective Health Care Program of the Agency for Healthcare Research and Quality: An Update. Methods Guide for Effectiveness and Comparative Effectiveness Reviews. Rockville (MD); 2008.

27. Berkman ND, Lohr KN, Ansari MT, et al. Grading the strength of a body of evidence when assessing health care interventions: an EPC update. J Clin Epidemiol. 2015 Nov;68(11):1312-24. doi: 10.1016/j.jclinepi.2014.11.023. PMID: 25721570.

28. Costa LO, Maher CG, Latimer J, et al. Motor control exercise for chronic low back pain: a randomized placebo-controlled trial. Phys Ther. 2009 Dec;89(12):1275-86. doi: 10.2522/ptj.20090218. PMID: 19892856.

29. Goldby LJ, Moore AP, Doust J, et al. A randomized controlled trial investigating the efficiency of musculoskeletal physiotherapy on chronic low back disorder. Spine (Phila Pa 1976). 2006 May 01;31(10):1083-93. doi: 10.1097/01.brs.0000216464.37504.64. PMID: 16648741.

30. Kankaanpaa M, Taimela S, Airaksinen O, et al. The efficacy of active rehabilitation in chronic low back pain. Effect on pain intensity, self-experienced disability, and lumbar fatigability. Spine (Phila Pa 1976). 1999 May 15;24(10):1034-42. PMID: 10332798. 
31. Nassif H, Brosset N, Guillaume M, et al. Evaluation of a randomized controlled trial in the management of chronic lower back pain in a French automotive industry: an observational study. Arch Phys Med Rehabil. 2011 Dec;92(12):1927-36.e4. doi: 10.1016/j.apmr.2011.06.029. PMID: 22133239.

32. Miyamoto GC, Costa LO, Galvanin T, et al. Efficacy of the addition of modified Pilates exercises to a minimal intervention in patients with chronic low back pain: a randomized controlled trial. Phys Ther. 2013 Mar;93(3):310-20. doi: 10.2522/ptj.20120190. PMID: 23064732.

33. Natour J, Cazotti Lde A, Ribeiro LH, et al. Pilates improves pain, function and quality of life in patients with chronic low back pain: a randomized controlled trial. Clin Rehabil. 2015 Jan;29(1):59-68. doi: 10.1177/0269215514538981. PMID: 24965957.

34. Andersen LL, Jorgensen MB, Blangsted AK, et al. A randomized controlled intervention trial to relieve and prevent neck/shoulder pain. Med Sci Sports Exerc. 2008 Jun;40(6):983-90. doi:

10.1249/MSS.0b013e3181676640. PMID: 18461010 .

35. Lauche R, Stumpe C, Fehr J, et al. The Effects of Tai Chi and Neck Exercises in the Treatment of Chronic Nonspecific Neck Pain: A Randomized Controlled Trial. J Pain. 2016 Sep;17(9):1013-27. doi: 10.1016/j.jpain.2016.06.004. PMID: 27345663.

36. Li X, Lin C, Liu C, et al. Comparison of the effectiveness of resistance training in women with chronic computer-related neck pain: a randomized controlled study. Int Arch Occup Environ Health. 2017 May 20doi: 10.1007/s00420-017-1230-2. PMID: 28528354.

37. Stewart MJ, Maher CG, Refshauge KM, et al. Randomized controlled trial of exercise for chronic whiplash-associated disorders. Pain. 2007 Mar;128(1-2):59-68. PMID: 17029788.
38. Viljanen M, Malmivaara A, Uitti J, et al. Effectiveness of dynamic muscle training, relaxation training, or ordinary activity for chronic neck pain: randomised controlled trial. BMJ. 2003 Aug 30;327(7413):475. PMID: 12946968.

39. Waling K, Jarvholm B, Sundelin G. Effects of training on female trapezius Myalgia: An intervention study with a 3-year follow-up period. Spine. 2002 Apr 15;27(8):789-96. PMID: 11935098.

40. Abbott JH, Robertson MC, Chapple C, et al. Manual therapy, exercise therapy, or both, in addition to usual care, for osteoarthritis of the hip or knee: a randomized controlled trial. 1: clinical effectiveness. Osteoarthritis Cartilage. 2013 Apr;21(4):525-34. doi: 10.1016/j.joca.2012.12.014. PMID: 23313532.

41. Bennell KL, Hinman RS, Metcalf BR, et al. Efficacy of physiotherapy management of knee joint osteoarthritis: a randomised, double blind, placebo controlled trial. Ann Rheum Dis. 2005 Jun;64(6):906-12. PMID: 15897310 .

42. Chen TW, Lin CW, Lee CL, et al. The efficacy of shock wave therapy in patients with knee osteoarthritis and popliteal cyamella. Kaohsiung J Med Sci. 2014 Jul;30(7):362-70. doi: 10.1016/j.kjms.2014.03.006. PMID: 24924842.

43. Dias RC, Dias JM, Ramos LR. Impact of an exercise and walking protocol on quality of life for elderly people with OA of the knee. Physiother Res Int. 2003;8(3):121-30. PMID: 14533368.

44. Ettinger WH, Jr., Burns R, Messier SP, et al. A randomized trial comparing aerobic exercise and resistance exercise with a health education program in older adults with knee osteoarthritis. The Fitness Arthritis and Seniors Trial (FAST). JAMA. 1997 Jan 1;277(1):25-31. PMID: 8980206.

45. Huang MH, Lin YS, Lee CL, et al. Use of ultrasound to increase effectiveness of isokinetic exercise for knee osteoarthritis. Arch Phys Med Rehabil. 2005 Aug;86(8):1545-51. PMID: 16084806. 
46. Huang MH, Lin YS, Yang RC, et al. A comparison of various therapeutic exercises on the functional status of patients with knee osteoarthritis. Semin Arthritis Rheum. 2003 Jun;32(6):398-406. PMID: 12833248.

47. Huang MH, Yang RC, Lee CL, et al. Preliminary results of integrated therapy for patients with knee osteoarthritis. Arthritis Rheum. 2005 Dec 15;53(6):812-20. PMID: 16342083.

48. Lund H, Weile U, Christensen R, et al. A randomized controlled trial of aquatic and land-based exercise in patients with knee osteoarthritis. J Rehabil Med. 2008 Feb;40(2):137-44. doi: 10.2340/165019770134. PMID: 18509579.

49. Messier SP, Loeser RF, Miller GD, et al. Exercise and dietary weight loss in overweight and obese older adults with knee osteoarthritis: the Arthritis, Diet, and Activity Promotion Trial. Arthritis Rheum. 2004 May;50(5):1501-10. doi: 10.1002/art.20256. PMID: 15146420.

50. Penninx BW, Messier SP, Rejeski WJ, et al. Physical exercise and the prevention of disability in activities of daily living in older persons with osteoarthritis. Arch Intern Med. 2001 Oct 22;161(19):2309-16. PMID: 11606146.

51. Penninx BW, Rejeski WJ, Pandya J, et al. Exercise and depressive symptoms: a comparison of aerobic and resistance exercise effects on emotional and physical function in older persons with high and low depressive symptomatology. J Gerontol B Psychol Sci Soc Sci. 2002 Mar;57(2):P12432. PMID: 11867660.

52. Quilty B, Tucker M, Campbell R, et al. Physiotherapy, including quadriceps exercises and patellar taping, for knee osteoarthritis with predominant patellofemoral joint involvement: randomized controlled trial. J Rheumatol. 2003 Jun;30(6):1311-7. PMID: 12784408.

53. Rejeski WJ, Focht BC, Messier SP, et al. Obese, older adults with knee osteoarthritis: weight loss, exercise, and quality of life. Health Psychol. 2002 Sep;21(5):419-26. PMID: 12211508.
54. Rosedale R, Rastogi R, May S, et al. Efficacy of exercise intervention as determined by the McKenzie System of Mechanical Diagnosis and Therapy for knee osteoarthritis: a randomized controlled trial. J Orthop Sports Phys Ther. 2014 Mar;44(3):173-81, A1-6. doi: 10.2519/jospt.2014.4791. PMID: 24450370.

55. Segal NA, Glass NA, Teran-Yengle P, et al. Intensive gait training for older adults with symptomatic knee osteoarthritis. Am J Phys Med Rehabil. 2015 Oct;94(10 Suppl 1):84858. doi: 10.1097/PHM.0000000000000264. PMID: 25768068.

56. Sullivan T, Allegrante JP, Peterson MG, et al. One-year followup of patients with osteoarthritis of the knee who participated in a program of supervised fitness walking and supportive patient education. Arthritis Care Res. 1998 Aug;11(4):228-33. PMID: 9791321.

57. Thomas KS, Muir KR, Doherty M, et al. Home based exercise programme for knee pain and knee osteoarthritis: randomised controlled trial. BMJ. 2002 Oct 5;325(7367):752. PMID: 12364304.

58. Thorstensson CA, Roos EM, Petersson IF, et al. Six-week high-intensity exercise program for middle-aged patients with knee osteoarthritis: a randomized controlled trial [ISRCTN20244858]. BMC Musculoskelet Disord. 2005;6:27. PMID: 15924620.

59. Weng MC, Lee CL, Chen CH, et al. Effects of different stretching techniques on the outcomes of isokinetic exercise in patients with knee osteoarthritis. Kaohsiung J Med Sci. 2009 Jun;25(6):306-15. doi: 10.1016/S1607-551X(09)70521-2. PMID: 19560995.

60. Williamson L, Wyatt MR, Yein K, et al. Severe knee osteoarthritis: a randomized controlled trial of acupuncture, physiotherapy (supervised exercise) and standard management for patients awaiting knee replacement. Rheumatology. 2007 Sep;46(9):1445-9. PMID: 17604311. 
61. Juhakoski R, Tenhonen S, Malmivaara A, et al. A pragmatic randomized controlled study of the effectiveness and cost consequences of exercise therapy in hip osteoarthritis. Clinical Rehabilitation. 2011 Apr;25(4):37083. doi: 10.1177/0269215510388313. PMID: 21078702.

62. Tak E, Staats P, Van Hespen A, et al. The effects of an exercise program for older adults with osteoarthritis of the hip. $\mathrm{J}$ Rheumatol. 2005 Jun;32(6):1106-13. PMID: 15940775.

63. Teirlinck CH, Luijsterburg PA, Dekker J, et al. Effectiveness of exercise therapy added to general practitioner care in patients with hip osteoarthritis: a pragmatic randomized controlled trial. Osteoarthritis Cartilage. 2016 Jan;24(1):82-90. doi: 10.1016/j.joca.2015.07.023. PMID: 26254237.

64. Osteras N, Hagen KB, Grotle M, et al. Limited effects of exercises in people with hand osteoarthritis: results from a randomized controlled trial. Osteoarthritis Cartilage. 2014 Sep;22(9):1224-33. doi: 10.1016/j.joca.2014.06.036. PMID: 25008206.

65. Altan L, Korkmaz N, Bingol U, et al. Effect of pilates training on people with fibromyalgia syndrome: a pilot study. Arch Phys Med Rehabil. 2009 Dec;90(12):19838. doi: 10.1016/j.apmr.2009.06.021. PMID: 19969158.

66. Baptista AS, Villela AL, Jones A, et al. Effectiveness of dance in patients with fibromyalgia: a randomized, single-blind, controlled study. Clin Exp Rheumatol. 2012 Nov-Dec;30(6 Suppl 74):18-23. Epub 2012 Dec 14. PMID: 23020850.

67. Buckelew SP, Conway R, Parker J, et al. Biofeedback/relaxation training and exercise interventions for fibromyalgia: a prospective trial. Arthritis Care Res. 1998 Jun;11(3):196-209. PMID: 9782811.

68. Clarke-Jenssen AC, Mengshoel AM, Strumse YS, et al. Effect of a fibromyalgia rehabilitation programme in warm versus cold climate: a randomized controlled study. J Rehabil Med. 2014 Jul;46(7):676-83. doi: 10.2340/16501977-1819. PMID: 24788929.
69. Da Costa D, Abrahamowicz M, Lowensteyn I, et al. A randomized clinical trial of an individualized home-based exercise programme for women with fibromyalgia. Rheumatology (Oxford). 2005 Nov;44(11):1422-7. Epub 2005 Jul 19. PMID: 16030079.

70. Fontaine KR, Conn L, Clauw DJ. Effects of lifestyle physical activity on perceived symptoms and physical function in adults with fibromyalgia: results of a randomized trial. Arthritis Res Ther. 2010;12(2):R55. doi: 10.1186/ar2967. PMID: 20353551.

71. Fontaine KR, Conn L, Clauw DJ. Effects of lifestyle physical activity in adults with fibromyalgia: results at follow-up. J Clin Rheumatol. 2011 Mar;17(2):64-8. doi: 10.1097/RHU.0b013e31820e7ea7. PMID: 21325963.

72. Giannotti E, Koutsikos K, Pigatto M, et al. Medium-/long-term effects of a specific exercise protocol combined with patient education on spine mobility, chronic fatigue, pain, aerobic fitness and level of disability in fibromyalgia. BioMed Res Int. 2014;2014:474029. doi: 10.1155/2014/474029. PMID: 24616894.

73. Gowans SE, deHueck A, Voss S, et al. Effect of a randomized, controlled trial of exercise on mood and physical function in individuals with fibromyalgia. Arthritis Rheum. 2001 Dec;45(6):519-29. PMID: 11762688.

74. Gusi N, Tomas-Carus P, Häkkinen A, et al. Exercise in waist-high warm water decreases pain and improves health-related quality of life and strength in the lower extremities in women with fibromyalgia. Arthritis Care Res. 2006;55(1):66-73. PMID: 16463415.

75. Kayo AH, Peccin MS, Sanches CM, et al. Effectiveness of physical activity in reducing pain in patients with fibromyalgia: a blinded randomized clinical trial. Rheumatol Int. 2012 Aug;32(8):2285-92. doi: 10.1007/s00296-011-1958-z. PMID: 21594719.

76. King SJ, Wessel J, Bhambhani Y, et al. The effects of exercise and education, individually or combined, in women with fibromyalgia. J Rheumatol. 2002 Dec;29(12):2620-7. PMID: 12465163. 
77. Mannerkorpi K, Nordeman L, Ericsson A, et al. Pool exercise for patients with fibromyalgia or chronic widespread pain: a randomized controlled trial and subgroup analyses. J Rehabil Med. 2009 Sep;41(9):751-60. doi: 10.2340/165019770409. PMID: 19774310.

78. Paolucci T, Vetrano M, Zangrando F, et al. MMPI-2 profiles and illness perception in fibromyalgia syndrome: The role of therapeutic exercise as adapted physical activity. J Back Musculoskelet Rehabil. 2015;28(1):101-9. PMID: 25061029.

79. Sanudo B, Carrasco L, de Hoyo M, et al. Vagal modulation and symptomatology following a 6-month aerobic exercise program for women with fibromyalgia. Clin Exp Rheumatol. 2015 Jan-Feb;33(1 Suppl 88):S41-5. Epub 2015 Mar 17. PMID: 25786042.

80. Sanudo B, Carrasco L, de Hoyo M, et al. Effects of exercise training and detraining in patients with fibromyalgia syndrome: a 3-yr longitudinal study. Am J Phys Med Rehabil. 2012 Jul;91(7):561-9; quiz 70-3. doi: 10.1097/PHM.0b013e31824faa03. PMID: 22469880.

81. Sanudo B, Galiano D, Carrasco L, et al. Aerobic exercise versus combined exercise therapy in women with fibromyalgia syndrome: a randomized controlled trial. Arch Phys Med Rehabil. 2010 Dec;91(12):1838-43. doi: 10.016/j.apmr.2010.09.006. PMID: 21112423.

82. Sencan S, Ak S, Karan A, et al. A study to compare the therapeutic efficacy ofaerobic exercise and paroxetine in fibromyalgia syndrome. J Back Musculoskelet Rehabil. 2004;17(2):57-61.

83. Tomas-Carus P, Gusi N, Hakkinen A, et al. Eight months of physical training in warm water improves physical and mental health in women with fibromyalgia: a randomized controlled trial. J Rehabil Med. 2008 Apr;40(4):248-52. doi: 10.2340/165019770168. PMID: 18382819.
84. Tomas-Carus P, Gusi N, Hakkinen A, et al. Improvements of muscle strength predicted benefits in HRQOL and postural balance in women with fibromyalgia: an 8-month randomized controlled trial. Rheumatology (Oxford). 2009 Sep;48(9):1147-51. doi: 10.093/rheumatology/kep208. Epub 2009 Jul 14. PMID: 19605373.

85. van Eijk-Hustings Y, Kroese M, Tan F, et al. Challenges in demonstrating the effectiveness of multidisciplinary treatment on quality of life, participation and health care utilisation in patients with fibromyalgia: a randomised controlled trial. Clin Rheumatol. 2013 Feb;32(2):199-209. doi: 10.1007/s10067-012-2100-7. Epub 2012 Oct 10. PMID: 29053692.

86. van Santen M, Bolwijn P, Verstappen F, et al. A randomized clinical trial comparing fitness and biofeedback training versus basic treatment in patients with fibromyalgia. J Rheumatol. 2002 Mar;29(3):575-81. PMID: 11908576.

87. Wigers SH, Stiles TC, Vogel PA. Effects of aerobic exercise versus stress management treatment in fibromyalgia. A 4.5 year prospective study. Scand J Rheumatol. 1996;25(2):77-86. PMID: 8614771.

88. Aslan Telci E, Karaduman A. Effects of three different conservative treatments on pain, disability, quality of life, and mood in patients with cervical spondylosis. Rheumatology International. 2012 Apr;32(4):1033-40. doi: 10.1007/s00296010-1751-4. PMID: 21246365.

89. Cherkin DC, Sherman KJ, Balderson BH, et al. Effect of mindfulness-based stress reduction vs cognitive behavioral therapy or usual care on back pain and functional limitations in adults with chronic low back pain: a randomized clinical trial. JAMA. 2016 Mar 22-29;315(12):1240-9. doi: 10.1001/jama.2016.2323. PMID: 27002445.

90. Johnson RE, Jones GT, Wiles NJ, et al. Active exercise, education, and cognitive behavioral therapy for persistent disabling low back pain: a randomized controlled trial. Spine (Phila Pa 1976). 2007 Jul 01;32(15):1578-85. doi: 10.1097/BRS.0b013e318074f890. PMID: 17621203. 
91. Lamb SE, Hansen Z, Lall R, et al. Group cognitive behavioural treatment for lowback pain in primary care: a randomised controlled trial and cost-effectiveness analysis. Lancet. 2010 Mar 13;375(9718):916-23. doi: 10.1016/s01406736(09)62164-4. PMID: 20189241.

92. Lamb SE, Mistry D, Lall R, et al. Group cognitive behavioural interventions for low back pain in primary care: extended followup of the Back Skills Training Trial (ISRCTN54717854). Pain. 2012 Feb;153(2):494-501. doi: 10.1016/j.pain.2011.11.016. PMID: 22226729.

93. Poole H, Glenn S, Murphy P. A randomised controlled study of reflexology for the management of chronic low back pain. Eur $\mathrm{J}$ Pain. 2007 Nov;11(8):878-87. doi: 10.1016/j.ejpain.2007.01.006. PMID: 17459741.

94. Helminen EE, Sinikallio SH, Valjakka AL, et al. Effectiveness of a cognitivebehavioural group intervention for knee osteoarthritis pain: a randomized controlled trial. Clinical Rehabilitation. 2015 Sep;29(9):868-81. doi: 10.1177/0269215514558567. PMID: 25413168.

95. Somers TJ, Blumenthal JA, Guilak F, et al. Pain coping skills training and lifestyle behavioral weight management in patients with knee osteoarthritis: a randomized controlled study. Pain. 2012

Jun;153(6):1199-209. doi:

10.1016/j.pain.2012.02.023. PMID: 22503223.

96. Alda M, Luciano JV, Andres E, et al. Effectiveness of cognitive behaviour therapy for the treatment of catastrophisation in patients with fibromyalgia: a randomised controlled trial. Arthritis Res Ther. 2011;13(5):R173. doi: 10.1186/ar3496. PMID: 22018333.

97. Ang DC, Chakr R, Mazzuca S, et al. Cognitive-behavioral therapy attenuates nociceptive responding in patients with fibromyalgia: a pilot study. Arthritis Care Res. 2010 May;62(5):618-23. doi: 10.1002/acr.20119. PMID: 20191481.
98. Castel A, Cascon R, Padrol A, et al. Multicomponent cognitive-behavioral group therapy with hypnosis for the treatment of fibromyalgia: long-term outcome. J Pain. 2012 Mar;13(3):255-65. doi: 10.1016/j.jpain.2011.11.005. Epub 2 Jan 29. PMID: 22285609.

99. Jensen KB, Kosek E, Wicksell R, et al. Cognitive Behavioral Therapy increases pain-evoked activation of the prefrontal cortex in patients with fibromyalgia.[Erratum appears in Pain. 2012 Sep;153(9):1982]. Pain. 2012 Jul;153(7):1495-503. doi: 10.1016/j.pain.2012.04.010. PMID: 22617632.

100. Thieme K, Flor H, Turk DC. Psychological pain treatment in fibromyalgia syndrome: efficacy of operant behavioural and cognitive behavioural treatments. Arthritis Res Ther. 2006;8(4):R121. doi: 10.1186/ar2010. PMID: 16859516.

101. Verkaik R, Busch M, Koeneman T, et al. Guided imagery in people with fibromyalgia: a randomized controlled trial of effects on pain, functional status and selfefficacy. J Health Psychol. 2014 May;19(5):678-88. PMID: 23520350.

102. Wicksell RK, Kemani M, Jensen K, et al. Acceptance and commitment therapy for fibromyalgia: a randomized controlled trial. Eur J Pain. 2013 Apr;17(4):599-611. doi: 10.1002/j.1532-2149.2012.00224.x. PMID: 23090719.

103. Williams DA, Cary MA, Groner KH, et al. Improving physical functional status in patients with fibromyalgia: a brief cognitive behavioral intervention. J Rheumatol. 2002 Jun;29(6):1280-6. PMID: 12064847.

104. Blanchard EB, Appelbaum KA, Radnitz CL, et al. Placebo-controlled evaluation of abbreviated progressive muscle relaxation and of relaxation combined with cognitive therapy in the treatment of tension headache. J Consult Clin Psychol. 1990 Apr;58(2):210-5. PMID: 2186066. 
105. Holroyd KA, O'Donnell FJ, Stensland M, et al. Management of chronic tension-type headache with tricyclic antidepressant medication, stress management therapy, and their combination: a randomized controlled trial. JAMA. 2001 May 2;285(17):2208-15. PMID: 11325322.

106. Falcão DM, Sales L, Leite JR, et al. Cognitive behavioral therapy for the treatment of fibromyalgia syndrome: a randomized controlled trial. J Musculoskelet Pain. 2008;16(3):133-40.

107. Kayiran S, Dursun E, Dursun N, et al. Neurofeedback intervention in fibromyalgia syndrome; a randomized, controlled, rater blind clinical trial. Appl Psychophysiol Biofeedback. 2010 Dec;35(4):293-302. doi: 10.1007/s10484-010-9135-9. PMID: 20614235.

108. Holroyd KA, Nash JM, Pingel JD, et al. A comparison of pharmacological (amitriptyline HCL) and nonpharmacological (cognitive-behavioral) therapies for chronic tension headaches. J Consult Clin Psychol. 1991 Jun;59(3):38793. PMID: 2071723.

109. Turner JA, Clancy S, McQuade KJ, et al. Effectiveness of behavioral therapy for chronic low back pain: a component analysis. J Consult Clin Psychol. 1990 Oct;58(5):573-9. PMID: 2147702.

110. Bennell KL, Ahamed Y, Jull G, et al. Physical Therapist-Delivered Pain Coping Skills Training and Exercise for Knee Osteoarthritis: Randomized Controlled Trial. Arthritis Care Res (Hoboken). 2016 May;68(5):590-602. doi: 10.1002/acr.22744. PMID: 26417720.

111. Larsson A, Palstam A, Lofgren M, et al. Resistance exercise improves muscle strength, health status and pain intensity in fibromyalgia--a randomized controlled trial. Arthritis Res Ther. 2015 Jun 18;17:161.(doi)doi: 10.1186/s13075-0150679-1. PMID: 26084281.

112. Redondo JR, Justo CM, Moraleda FV, et al. Long-term efficacy of therapy in patients with fibromyalgia: a physical exercise-based program and a cognitive-behavioral approach. Arthritis Rheum. 2004 Apr 15;51(2):184-92. PMID: 15077258.
113. Beurskens AJ, de Vet HC, Koke AJ, et al. Efficacy of traction for nonspecific low back pain. 12-week and 6-month results of a randomized clinical trial. Spine (Phila $\mathrm{Pa}$ 1976). 1997 Dec 01;22(23):2756-62. PMID: 9431610.

114. Schimmel JJ, de Kleuver M, Horsting PP, et al. No effect of traction in patients with low back pain: a single centre, single blind, randomized controlled trial of Intervertebral Differential Dynamics Therapy. Eur Spine J. 2009 Dec;18(12):1843-50. doi: 10.1007/s00586-009-1044-3. PMID: 19484433.

115. Ebadi S, Ansari NN, Naghdi S, et al. The effect of continuous ultrasound on chronic non-specific low back pain: a single blind placebo-controlled randomized trial. BMC Musculoskelet Disord. 2012 Oct 02;13:192. doi: 10.1186/1471-2474-13-192. PMID: 23031570.

116. Licciardone JC, Minotti DE, Gatchel RJ, et al. Osteopathic manual treatment and ultrasound therapy for chronic low back pain: a randomized controlled trial. Ann Fam Med. 2013 Mar-Apr;11(2):122-9. doi: 10.1370/afm.1468. PMID: 23508598.

117. Soriano F, Ríos R. Gallium arsenide laser treatment of chronic low back pain: a prospective, randomized and double blind study. Laser Ther. 1998;10(4):175-80.

118. Basford JR, Sheffield CG, Harmsen WS. Laser therapy: a randomized, controlled trial of the effects of low-intensity Nd:YAG laser irradiation on musculoskeletal back pain. Arch Phys Med Rehabil. 1999 Jun;80(6):647-52. PMID: 10378490.

119. Gibson T, Grahame R, Harkness J, et al. Controlled comparison of short-wave diathermy treatment with osteopathic treatment in non-specific low back pain. Lancet. 1985 Jun 01;1(8440):1258-61. PMID: 2860453.

120. Altan L, Bingol U, Aykac M, et al. Investigation of the effect of GaAs laser therapy on cervical myofascial pain syndrome. Rheumatol Int. 2005 Jan;25(1):23-7. doi: 10.1007/s00296-0030396-y. PMID: 14673617. 
121. Chiu TT, Ng JK, Walther-Zhang B, et al. A randomized controlled trial on the efficacy of intermittent cervical traction for patients with chronic neck pain. Clinical

Rehabilitation. 2011 Sep;25(9):814-22. doi: 10.1177/0269215511399590. PMID: 21427150.

122. Chow RT, Heller GZ, Barnsley L. The effect of $300 \mathrm{~mW}, 830 \mathrm{~nm}$ laser on chronic neck pain: a double-blind, randomized, placebocontrolled study. Pain. 2006 Sep;124(12):201-10. doi: 10.1016/j.pain.2006.05.018. PMID: 16806710.

123. Gur A, Sarac AJ, Cevik R, et al. Efficacy of $904 \mathrm{~nm}$ gallium arsenide low level laser therapy in the management of chronic myofascial pain in the neck: a double-blind and randomize-controlled trial. Lasers Surg Med. 2004;35(3):229-35. doi: 10.1002/lsm.20082. PMID: 15389743.

124. Trock DH, Bollet AJ, Markoll R. The effect of pulsed electromagnetic fields in the treatment of osteoarthritis of the knee and cervical spine. Report of randomized, double blind, placebo controlled trials. J Rheumatol. 1994 Oct;21(10):1903-11. PMID: 7837158.

125. Al Rashoud AS, Abboud RJ, Wang W, et al. Efficacy of low-level laser therapy applied at acupuncture points in knee osteoarthritis: a randomised double-blind comparative trial. Physiotherapy. 2014 Sep;100(3):242-8. doi: 10.1016/j.physio.2013.09.007. PMID: 24418801.

126. Battisti E, Piazza E, Rigato M, et al. Efficacy and safety of a musically modulated electromagnetic field (TAMMEF) in patients affected by knee osteoarthritis. Clin Exp Rheumatol. 2004 Sep-Oct;22(5):568-72. PMID: 15485009.

127. Brouwer RW, van Raaij TM, Verhaar JA, et al. Brace treatment for osteoarthritis of the knee: a prospective randomized multi-centre trial. Osteoarthritis Cartilage. 2006 Aug;14(8):777-83. PMID: 16563810.

128. Cakir S, Hepguler S, Ozturk C, et al. Efficacy of therapeutic ultrasound for the management of knee osteoarthritis: a randomized, controlled, and double-blind study. Am J Phys Med Rehabil. 2014 May;93(5):405-12. PMID: 24322433.
129. Fary RE, Carroll GJ, Briffa TG, et al. The effectiveness of pulsed electrical stimulation in the management of osteoarthritis of the knee: results of a double-blind, randomized, placebo-controlled, repeated-measures trial. Arthritis Rheum. 2011 May;63(5):1333-42. doi: 10.1002/art.30258. PMID: 21312188.

130. Fukuda TY, Alves da Cunha R, Fukuda VO, et al. Pulsed shortwave treatment in women with knee osteoarthritis: a multicenter, randomized, placebo-controlled clinical trial. Phys Ther. 2011 Jul;91(7):1009-17. doi: 10.2522/ptj.20100306. PMID: 21642511.

131. Giombini A, Di Cesare A, Di Cesare M, et al. Localized hyperthermia induced by microwave diathermy in osteoarthritis of the knee: a randomized placebo-controlled double-blind clinical trial. Knee Surg Sports Traumatol Arthrosc. 2011 Jun;19(6):980-7. PMID: 21161171.

132. Hegedus B, Viharos L, Gervain M, et al. The effect of low-level laser in knee osteoarthritis: a double-blind, randomized, placebo-controlled trial. Photomed Laser Surg. 2009 Aug;27(4):577-84. doi: 10.1089/pho.2008.2297. PMID: 19530911.

133. Laufer Y, Zilberman R, Porat R, et al. Effect of pulsed short-wave diathermy on pain and function of subjects with osteoarthritis of the knee: a placebo-controlled double-blind clinical trial. Clinical rehabilitation. 2005 May;19(3):255-63. PMID: 15859526.

134. Mazzuca SA, Page MC, Meldrum RD, et al. Pilot study of the effects of a heat-retaining knee sleeve on joint pain, stiffness, and function in patients with knee osteoarthritis. Arthritis Rheum. 2004 Oct 15;51(5):716-21. PMID: 15478166.

135. Tascioglu F, Armagan O, Tabak Y, et al. Low power laser treatment in patients with knee osteoarthritis. Swiss Med Wkly. 2004 May 01;134(17-18):254-8. PMID: 15243853.

136. Thamsborg G, Florescu A, Oturai P, et al. Treatment of knee osteoarthritis with pulsed electromagnetic fields: a randomized, double-blind, placebo-controlled study. Osteoarthritis Cartilage. 2005 Jul;13(7):57581. PMID: 15979009. 
137. Yildiz SK, Ozkan FU, Aktas I, et al. The effectiveness of ultrasound treatment for the management of knee osteoarthritis: a randomized, placebo-controlled, doubleblind study. Turk J Med Sci. 2015;45(6):1187-91. PMID: 26775369.

138. Brosseau L, Wells G, Marchand S, et al. Randomized controlled trial on low level laser therapy (LLLT) in the treatment of osteoarthritis (OA) of the hand. Lasers Surg Med. 2005 Mar;36(3):210-9. doi: 10.1002/lsm.20137. PMID: 15704096.

139. Dilek B, Gozum M, Sahin E, et al. Efficacy of paraffin bath therapy in hand osteoarthritis: a single-blinded randomized controlled trial. Arch Phys Med Rehabil. 2013 Apr;94(4):642-9. doi: 10.1016/j.apmr.2012.11.024. PMID: 23187044.

140. Alfano AP, Taylor AG, Foresman PA, et al. Static magnetic fields for treatment of fibromyalgia: a randomized controlled trial. J Altern Complement Med. 2001 Feb;7(1):53-64. PMID: 11246937.

141. Paolucci T, Piccinini G, Iosa M, et al. Efficacy of extremely low-frequency magnetic field in fibromyalgia pain: A pilot study. J Rehabil Res Dev. 2016;53(6):102334. doi: 10.1682/JRRD.2015.04.0061. PMID: 28475205.

142. Bono F, Salvino D, Mazza MR, et al. The influence of ictal cutaneous allodynia on the response to occipital transcutaneous electrical stimulation in chronic migraine and chronic tension-type headache: a randomized, sham-controlled study. Cephalalgia. 2015 Apr;35(5):389-98. doi: 10.1177/0333102414544909. PMID: 25078717.

143. Djavid GE, Mehrdad R, Ghasemi M, et al. In chronic low back pain, low level laser therapy combined with exercise is more beneficial than exercise alone in the long term: a randomised trial. Aust J Physiother. 2007;53(3):155-60. PMID: 17725472.

144. Haas M, Vavrek D, Peterson D, et al. Doseresponse and efficacy of spinal manipulation for care of chronic low back pain: a randomized controlled trial. Spine J. 2014 Jul 01;14(7):1106-16. doi: 10.1016/j.spinee.2013.07.468. PMID: 24139233.
145. Hondras MA, Long CR, Cao Y, et al. A randomized controlled trial comparing 2 types of spinal manipulation and minimal conservative medical care for adults 55 years and older with subacute or chronic low back pain. J Manipulative Physiol Ther. 2009 Jun;32(5):330-43. doi: 10.1016/j.jmpt.2009.04.012. PMID: 19539115.

146. Senna MK, Machaly SA. Does maintained spinal manipulation therapy for chronic nonspecific low back pain result in better long-term outcome? Spine (Phila Pa 1976). 2011 Aug 15;36(18):1427-37. doi: 10.1097/BRS.0b013e3181f5dfe0. PMID: 21245790.

147. UK BEAM Trial Team. United Kingdom back pain exercise and manipulation (UK BEAM) randomised trial: effectiveness of physical treatments for back pain in primary care. BMJ. 2004 Dec 11;329(7479):1377. doi: 10.1136/bmj.38282.669225.AE. PMID: 15556955.

148. Ajimsha MS, Daniel B, Chithra S. Effectiveness of myofascial release in the management of chronic low back pain in nursing professionals. J Bodyw Mov Ther. 2014 Apr;18(2):273-81. doi: 10.1016/j.jbmt.2013.05.007. PMID: 24725797.

149. Cherkin DC, Eisenberg D, Sherman KJ, et al. Randomized trial comparing traditional Chinese medical acupuncture, therapeutic massage, and self-care education for chronic low back pain. Arch Intern Med. 2001 Apr 23;161(8):1081-8. PMID: 11322842.

150. Cherkin DC, Sherman KJ, Kahn J, et al. A comparison of the effects of 2 types of massage and usual care on chronic low back pain: a randomized, controlled trial. Ann Intern Med. 2011 Jul 5;155(1):1-9. doi: 10.7326/0003-4819-155-1-20110705000002. PMID: 21727288.

151. Quinn F, Hughes CM, Baxter GD. Reflexology in the management of low back pain: a pilot randomised controlled trial. Complement Ther Med. 2008 Feb;16(1):3-8. doi: 10.1016/j.ctim.2007.05.001. PMID: 18346622. 
152. Rudolfsson T, Djupsjobacka M, Hager C, et al. Effects of neck coordination exercise on sensorimotor function in chronic neck pain: a randomized controlled trial. J Rehabil Med. 2014 Oct;46(9):908-14. doi: 10.2340/16501977-1869. PMID: 25182501.

153. Sherman KJ, Cherkin DC, Hawkes RJ, et al. Randomized trial of therapeutic massage for chronic neck pain. Clin J Pain. 2009 MarApr;25(3):233-8. doi: 10.1097/AJP.0b013e31818b7912. PMID: 19333174.

154. Perlman AI, Ali A, Njike VY, et al. Massage therapy for osteoarthritis of the knee: a randomized dose-finding trial. PLoS ONE [Electronic Resource]. 2012;7(2):e30248. doi: 10.1371/journal.pone.0030248. PMID: 22347369.

155. Castro-Sanchez AM, Mataran-Penarrocha GA, Arroyo-Morales M, et al. Effects of myofascial release techniques on pain, physical function, and postural stability in patients with fibromyalgia: a randomized controlled trial. Clin Rehabil. 2011 Sep;25(9):800-13. doi: 10.1177/0269215511399476. PMID: 21673013.

156. Castro-Sanchez AM, Mataran-Penarrocha GA, Granero-Molina J, et al. Benefits of massage-myofascial release therapy on pain, anxiety, quality of sleep, depression, and quality of life in patients with fibromyalgia. Evid Based Complement Alternat Med. 2011;2011:561753. doi: 10.1155/2011/561753. PMID: 21234327.

157. Castien RF, van der Windt DA, Grooten A, et al. Effectiveness of manual therapy for chronic tension-type headache: a pragmatic, randomised, clinical trial. Cephalalgia. 2011 Jan;31(2):133-43. doi: 10.1177/0333102410377362. PMID: 20647241.

158. Boline PD, Kassak K, Bronfort G, et al. Spinal manipulation vs. amitriptyline for the treatment of chronic tension-type headaches: a randomized clinical trial. J Manipulative Physiol Ther. 1995 Mar-Apr;18(3):148-54. PMID: 7790794.
159. Little P, Lewith G, Webley F, et al. Randomised controlled trial of Alexander technique lessons, exercise, and massage (ATEAM) for chronic and recurrent back pain. BMJ. 2008 Aug 19;337:a884. doi: 10.1136/bmj.a884. PMID: 18713809.

160. Bronfort G, Maiers MJ, Evans RL, et al. Supervised exercise, spinal manipulation, and home exercise for chronic low back pain: a randomized clinical trial. Spine J. 2011 Jul;11(7):585-98. doi: 10.1016/j.spinee.2011.01.036. PMID: 21622028.

161. Ferreira ML, Ferreira PH, Latimer J, et al. Comparison of general exercise, motor control exercise and spinal manipulative therapy for chronic low back pain: A randomized trial. Pain. 2007 Sep;131(12):31-7. doi: 10.1016/j.pain.2006.12.008. PMID: 17250965.

162. Gudavalli MR, Cambron JA, McGregor M, et al. A randomized clinical trial and subgroup analysis to compare flexiondistraction with active exercise for chronic low back pain. Eur Spine J. 2006 Jul;15(7):1070-82. doi: 10.1007/s00586005-0021-8. PMID: 16341712.

163. Hoeksma HL, Dekker J, Ronday HK, et al. Comparison of manual therapy and exercise therapy in osteoarthritis of the hip: a randomized clinical trial. Arthritis Rheum. 2004 Oct 15;51(5):722-9. PMID: 15478147.

164. Banth S, Ardebil MD. Effectiveness of mindfulness meditation on pain and quality of life of patients with chronic low back pain. Int J Yoga. 2015 Jul-Dec;8(2):128-33. doi: 10.4103/0973-6131.158476. PMID: 26170592.

165. Cherkin DC, Anderson ML, Sherman KJ, et al. Two-Year Follow-up of a Randomized Clinical Trial of Mindfulness-Based Stress Reduction vs Cognitive Behavioral Therapy or Usual Care for Chronic Low Back Pain. JAMA. 2017 Feb 14;317(6):642-4. doi: 10.1001/jama.2016.17814. PMID: 28196244. 
166. Herman PM, Anderson ML, Sherman KJ, et al. Cost-effectiveness of Mindfulness-based Stress Reduction Versus Cognitive Behavioral Therapy or Usual Care Among Adults With Chronic Low Back Pain. Spine (Phila Pa 1976). 2017 Oct 15;42(20):151120. doi: 10.1097/BRS.0000000000002344. PMID: 28742756.

167. Morone NE, Greco CM, Moore CG, et al. A mind-body program for older adults with chronic low back pain: a randomized clinical trial. JAMA Intern Med. 2016

Mar;176(3):329-37. doi: 10.1001/jamainternmed.2015.8033. PMID: 26903081.

168. Morone NE, Rollman BL, Moore CG, et al. A mind-body program for older adults with chronic low back pain: results of a pilot study. Pain Med. 2009 Nov;10(8):1395-407. doi: 10.1111/j.1526-4637.2009.00746.x. PMID: 20021599.

169. Zgierska AE, Burzinski CA, Cox J, et al. Mindfulness Meditation and Cognitive Behavioral Therapy Intervention Reduces Pain Severity and Sensitivity in OpioidTreated Chronic Low Back Pain: Pilot Findings from a Randomized Controlled Trial. Pain Med. 2016 Oct;17(10):1865-81. doi: 10.1093/pm/pnw006. PMID: 26968850.

170. Cash E, Salmon P, Weissbecker I, et al. Mindfulness meditation alleviates fibromyalgia symptoms in women: results of a randomized clinical trial. Ann Behav Med. 2015 Jun;49(3):319-30. doi: 10.1007/s12160-014-9665-0. PMID: 25425224.

171. Schmidt S, Grossman P, Schwarzer B, et al. Treating fibromyalgia with mindfulnessbased stress reduction: results from a 3armed randomized controlled trial. Pain. 2011 Feb;152(2):361-9. doi: 10.1016/j.pain.2010.10.043. PMID: 21146930.

172. Sephton SE, Salmon P, Weissbecker I, et al. Mindfulness meditation alleviates depressive symptoms in women with fibromyalgia: results of a randomized clinical trial. Arthritis Rheum. 2007 Feb 15;57(1):77-85. doi: 10.1002/art.22478. PMID: 17266067.
173. Groessl EJ, Liu L, Chang DG, et al. Yoga for Military Veterans with Chronic Low Back Pain: A Randomized Clinical Trial. Am J Prev Med. 2017 Nov;53(5):599-608. doi: 10.1016/j.amepre.2017.05.019. PMID: 28735778.

174. Saper RB, Lemaster C, Delitto A, et al. Yoga, physical therapy, or education for chronic low back pain: A randomized noninferiority trial. Ann Intern Med. 2017 Jul 18;167(2):85-94. doi: 10.7326/m162579. PMID: 28631003.

175. Sherman KJ, Cherkin DC, Erro J, et al. Comparing yoga, exercise, and a self-care book for chronic low back pain: a randomized, controlled trial. Ann Intern Med. 2005 Dec 20;143(12):849-56. PMID: 16365466.

176. Sherman KJ, Cherkin DC, Wellman RD, et al. A randomized trial comparing yoga, stretching, and a self-care book for chronic low back pain. Arch Intern Med. 2011 Dec 12;171(22):2019-26. doi:

10.1001/archinternmed.2011.524. PMID: 22025101.

177. Tilbrook HE, Cox H, Hewitt CE, et al. Yoga for chronic low back pain: a randomized trial. Ann Intern Med. 2011 Nov 01;155(9):569-78. doi: 10.7326/0003-4819155-9-201111010-00003. PMID: 22041945.

178. Williams K, Abildso C, Steinberg L, et al. Evaluation of the effectiveness and efficacy of Iyengar yoga therapy on chronic low back pain. Spine (Phila Pa 1976). 2009 Sep 01;34(19):2066-76. doi: 10.1097/BRS.0b013e3181b315cc. PMID: 19701112.

179. Williams KA, Petronis J, Smith D, et al. Effect of Iyengar yoga therapy for chronic low back pain. Pain. 2005 May;115(12):107-17. doi: 10.1016/j.pain.2005.02.016. PMID: 15836974.

180. MacPherson H, Tilbrook H, Richmond S, et al. Alexander Technique Lessons or Acupuncture Sessions for Persons With Chronic Neck Pain: A Randomized Trial.[Summary for patients in Ann Intern Med. 2015 Nov 3;163(9):I30; PMID: 26524582]. Ann Intern Med. 2015 Nov 3;163(9):653-62. doi: 10.7326/M15-0667. PMID: 26524571. 
181. Brismee JM, Paige RL, Chyu MC, et al. Group and home-based tai chi in elderly subjects with knee osteoarthritis: a randomized controlled trial. Clinical Rehabilitation. 2007 Feb;21(2):99-111. PMID: 17264104.

182. Wang C, Schmid CH, Hibberd PL, et al. Tai Chi is effective in treating knee osteoarthritis: a randomized controlled trial. Arthritis Rheum. 2009 Nov 15;61(11):154553. doi: 10.1002/art.24832. PMID: 19877092.

183. Lynch M, Sawynok J, Hiew C, et al. A randomized controlled trial of qigong for fibromyalgia. Arthritis Res Ther. 2012;14(4):R178. doi: 10.1186/ar3931. PMID: 22863206.

184. Wang C, Schmid CH, Rones R, et al. A randomized trial of tai chi for fibromyalgia. N Engl J Med. 2010 Aug 19;363(8):743-54. doi: 10.1056/NEJMoa0912611. PMID: 20818876.

185. Blodt S, Pach D, Kaster T, et al. Qigong versus exercise therapy for chronic low back pain in adults--a randomized controlled noninferiority trial. Eur J Pain. 2015 Jan;19(1):123-31. doi: 10.1002/ejp.529. PMID: 24902673.

186. Nambi GS, Inbasekaran D, Khuman R, et al. Changes in pain intensity and health related quality of life with Iyengar yoga in nonspecific chronic low back pain: A randomized controlled study. Int J Yoga. 2014 Jan;7(1):48-53. doi: 10.4103/09736131.123481. PMID: 25035607.

187. Lansinger B, Larsson E, Persson LC, et al. Qigong and exercise therapy in patients with long-term neck pain: a prospective randomized trial. Spine. 2007 Oct 15;32(22):2415-22. PMID: 18090079.

188. Seferiadis A, Ohlin P, Billhult A, et al. Basic body awareness therapy or exercise therapy for the treatment of chronic whiplash associated disorders: a randomized comparative clinical trial. Disabil Rehabil. 2016;38(5):442-51. doi: 10.3109/09638288.2015.1044036. PMID: 25955823.
189. Brinkhaus B, Witt CM, Jena S, et al. Acupuncture in patients with chronic low back pain: a randomized controlled trial. Arch Intern Med. 2006 Feb 27;166(4):4507. doi: 10.1001/archinte.166.4.450. PMID: 16505266.

190. Carlsson CP, Sjolund BH. Acupuncture for chronic low back pain: a randomized placebo-controlled study with long-term follow-up. Clin J Pain. 2001 Dec;17(4):296305. PMID: 11783809.

191. Cherkin DC, Sherman KJ, Avins AL, et al. A randomized trial comparing acupuncture, simulated acupuncture, and usual care for chronic low back pain. Arch Intern Med. 2009 May 11;169(9):858-66. doi: 10.1001/archinternmed.2009.65. PMID: 19433697.

192. Cho YJ, Song YK, Cha YY, et al. Acupuncture for chronic low back pain: a multicenter, randomized, patient-assessor blind, sham-controlled clinical trial. Spine (Phila Pa 1976). 2013 Apr 01;38(7):549-57. doi: 10.1097/BRS.0b013e318275e601. PMID: 23026870.

193. Haake M, Muller HH, Schade-Brittinger C, et al. German Acupuncture Trials (GERAC) for chronic low back pain: randomized, multicenter, blinded, parallel-group trial with 3 groups. Arch Intern Med. 2007 Sep 24;167(17):1892-8. doi: 10.1001/archinte.167.17.1892. PMID: 17893311.

194. Kerr DP, Walsh DM, Baxter D. Acupuncture in the management of chronic low back pain: a blinded randomized controlled trial. Clin J Pain. 2003 NovDec;19(6):364-70. PMID: 14600536.

195. Thomas KJ, MacPherson H, Thorpe L, et al. Randomised controlled trial of a short course of traditional acupuncture compared with usual care for persistent non-specific low back pain. BMJ. 2006 Sep 23;333(7569):623. doi: 10.1136/bmj.38878.907361.7C. PMID: 16980316.

196. Birch S, Jamison RN. Controlled trial of Japanese acupuncture for chronic myofascial neck pain: assessment of specific and nonspecific effects of treatment. Clin J Pain. 1998 Sep;14(3):248-55. PMID: 9758075. 
197. Ho LF, Lin ZX, Leung AWN, et al. Efficacy of abdominal acupuncture for neck pain: A randomized controlled trial. PLoS One. 2017;12(7):e0181360. doi: 10.1371/journal.pone.0181360. PMID: 28715459 .

198. Liang Z, Zhu X, Yang X, et al. Assessment of a traditional acupuncture therapy for chronic neck pain: a pilot randomised controlled study. Complement Ther Med. 2011 Jan;19 Suppl 1:S26-32. doi: 10.1016/j.ctim.2010.11.005. PMID: 21195292.

199. Sahin N, Ozcan E, Sezen K, et al. Efficacy of acupunture in patients with chronic neck pain--a randomised, sham controlled trial. Acupunct Electrother Res. 2010;35(1-2):1727. PMID: 20578644.

200. Vas J, Perea-Milla E, Mendez C, et al. Efficacy and safety of acupuncture for chronic uncomplicated neck pain: a randomised controlled study. Pain. 2006 Dec 15;126(1-3):245-55. PMID: 16934402.

201. White P, Lewith G, Prescott P, et al. Acupuncture versus placebo for the treatment of chronic mechanical neck pain: a randomized, controlled trial.[Summary for patients in Ann Intern Med. 2004 Dec 21;141(12):I26; PMID: 15611483]. Ann Intern Med. 2004 Dec 21;141(12):911-9. PMID: 15611488.

202. Zhang SP, Chiu TT, Chiu SN. Long-term efficacy of electroacupuncture for chronic neck pain: a randomised controlled trial. Hong Kong Med J. 2013 Dec;19 Suppl 9:369. PMID: 24473589.

203. Berman BM, Singh BB, Lao L, et al. A randomized trial of acupuncture as an adjunctive therapy in osteoarthritis of the knee. Rheumatology. 1999 Apr;38(4):34654. PMID: 10378713.

204. Berman BM, Lao L, Langenberg P, et al. Effectiveness of acupuncture as adjunctive therapy in osteoarthritis of the knee: a randomized, controlled trial. Ann Intern Med. 2004 Dec 21;141(12):901-10. PMID: 15611487.
205. Hinman RS, McCrory P, Pirotta M, et al. Acupuncture for chronic knee pain: a randomized clinical trial.[Summary for patients in JAMA. 2014 Oct 1;312(13):1365; PMID: 25268455]. JAMA. 2014 Oct 1;312(13):1313-22. doi: 10.1001/jama.2014.12660. PMID: 25268438.

206. Jubb RW, Tukmachi ES, Jones PW, et al. A blinded randomised trial of acupuncture (manual and electroacupuncture) compared with a non-penetrating sham for the symptoms of osteoarthritis of the knee. Acupunct Med. 2008 Jun;26(2):69-78. PMID: 18591906.

207. Lansdown H, Howard K, Brealey S, et al. Acupuncture for pain and osteoarthritis of the knee: a pilot study for an open parallelarm randomised controlled trial. BMC Musculoskelet Disord. 2009;10:130. doi: 10.1186/1471-2474-10-130. PMID: 19852841.

208. Suarez-Almazor ME, Looney C, Liu Y, et al. A randomized controlled trial of acupuncture for osteoarthritis of the knee: effects of patient-provider communication. Arthritis Care Res. 2010 Sep;62(9):1229-36. doi: 10.1002/acr.20225. PMID: 20506122.

209. Witt C, Brinkhaus B, Jena S, et al. Acupuncture in patients with osteoarthritis of the knee: a randomised trial. Lancet. 2005 Jul 9-15;366(9480):136-43. PMID: 16005336.

210. Yurtkuran M, Alp A, Konur S, et al. Laser acupuncture in knee osteoarthritis: a doubleblind, randomized controlled study. Photomed Laser Surg. 2007 Feb;25(1):1420. PMID: 17352632.

211. Assefi NP, Sherman KJ, Jacobsen C, et al. A randomized clinical trial of acupuncture compared with sham acupuncture in fibromyalgia.[Summary for patients in Ann Intern Med. 2005 Jul 5;143(1):I24; PMID: 15998747]. Ann Intern Med. $2005 \mathrm{Jul}$ 5;143(1):10-9. PMID: 15998750.

212. Martin DP, Sletten CD, Williams BA, et al. Improvement in fibromyalgia symptoms with acupuncture: results of a randomized controlled trial. Mayo Clin Proc. 2006 Jun;81(6):749-57. doi: 10.4065/81.6.749. PMID: 16770975. 
213. Vas J, Santos-Rey K, Navarro-Pablo R, et al. Acupuncture for fibromyalgia in primary care: a randomised controlled trial. Acupunct Med. 2016 Aug;34(4):257-66. doi: 10.1136/acupmed-2015-010950. Epub 2016 Feb 15. PMID: 26879181.

214. Ebneshahidi NS, Heshmatipour M, Moghaddami A, et al. The effects of laser acupuncture on chronic tension headache--a randomised controlled trial. Acupunct Med. 2005 Mar;23(1):13-8. PMID: 15844435.

215. Karst M, Rollnik JD, Fink M, et al. Pressure pain threshold and needle acupuncture in chronic tension-type headache--a doubleblind placebo-controlled study. Pain. 2000 Nov;88(2):199-203. PMID: 11050375.

216. Tavola T, Gala C, Conte G, et al. Traditional Chinese acupuncture in tension-type headache: a controlled study. Pain. 1992 Mar;48(3):325-9. PMID: 1594255.

217. Cho JH, Nam DH, Kim KT, et al. Acupuncture with non-steroidal antiinflammatory drugs (NSAIDs) versus acupuncture or NSAIDs alone for the treatment of chronic neck pain: an assessorblinded randomised controlled pilot study. Acupunct Med. 2014 Feb;32(1):17-23. doi: 10.1136/acupmed-2013-010410. PMID: 24171895.

218. Bendix AF, Bendix T, Vaegter K, et al. Multidisciplinary intensive treatment for chronic low back pain: a randomized, prospective study. Cleve Clin J Med. 1996 Jan-Feb;63(1):62-9. PMID: 8590519.

219. Harkapaa K, Jarvikoski A, Mellin G, et al. A controlled study on the outcome of inpatient and outpatient treatment of low back pain. Part I. Pain, disability, compliance, and reported treatment benefits three months after treatment. Scand J Rehabil Med. 1989;21(2):81-9. PMID: 2526364.

220. Von Korff M, Balderson BH, Saunders K, et al. A trial of an activating intervention for chronic back pain in primary care and physical therapy settings. Pain. 2005 Feb;113(3):323-30. doi: 10.1016/j.pain.2004.11.007. PMID: 15661440 .
221. Lambeek LC, van Mechelen W, Knol DL, et al. Randomised controlled trial of integrated care to reduce disability from chronic low back pain in working and private life. BMJ. 2010 Mar 16;340:c1035. doi: 10.1136/bmj.c1035. PMID: 20234040.

222. Abbasi M, Dehghani M, Keefe FJ, et al. Spouse-assisted training in pain coping skills and the outcome of multidisciplinary pain management for chronic low back pain treatment: a 1-year randomized controlled trial. Eur J Pain. 2012 Aug;16(7):1033-43. doi: 10.1002/j.1532-2149.2011.00097.x. PMID: 22337646.

223. Strand LI, Ljunggren AE, Haldorsen EM, et al. The impact of physical function and pain on work status at 1-year follow-up in patients with back pain. Spine (Phila $\mathrm{Pa}$ 1976). 2001 Apr 01;26(7):800-8. PMID: 11295903.

224. Stukstette MJ, Dekker J, den Broeder AA, et al. No evidence for the effectiveness of a multidisciplinary group based treatment program in patients with osteoarthritis of hands on the short term; results of a randomized controlled trial. Osteoarthritis Cartilage. 2013 Jul;21(7):901-10. doi: 10.1016/j.joca.2013.03.016. PMID: 23583457.

225. Amris K, Waehrens EE, Christensen R, et al. Interdisciplinary rehabilitation of patients with chronic widespread pain: primary endpoint of the randomized, nonblinded, parallel-group IMPROvE trial. Pain. 2014 Jul;155(7):1356-64. doi: 10.1016/j.pain.2014.04.012. PMID: 24727345.

226. Castel A, Fontova R, Montull S, et al. Efficacy of a multidisciplinary fibromyalgia treatment adapted for women with low educational levels: a randomized controlled trial. Arthritis Care Res. 2013 Mar;65(3):421-31. doi: 10.1002/acr.21818. PMID: 22899402.

227. Castel A, Castro S, Fontova R, et al. Body mass index and response to a multidisciplinary treatment of fibromyalgia. Rheumatol Int. 2015 Feb;35(2):303-14. doi: 10.1007/s00296-014-3096-x. Epub 2014 Aug 1. PMID: 25080875. 
228. Cedraschi C, Desmeules J, Rapiti E, et al. Fibromyalgia: a randomised, controlled trial of a treatment programme based on self management. Ann Rheum Dis. 2004 Mar;63(3):290-6. PMID: 14962965.

229. Martin J, Torre F, Padierna A, et al. Six-and 12-month follow-up of an interdisciplinary fibromyalgia treatment programme: results of a randomised trial. Clin Exp Rheumatol. 2012 Nov-Dec;30(6 Suppl 74):103-11. Epub 2012 Dec 14. PMID: 23261008.

230. Salvat I, Zaldivar P, Monterde S, et al. Functional status, physical activity level, and exercise regularity in patients with fibromyalgia after Multidisciplinary treatment: retrospective analysis of a randomized controlled trial. Rheumatol Int. 2017 Mar;37(3):377-87. doi: 10.1007/s00296-016-3597-x. PMID: 27844124.

231. Saral I, Sindel D, Esmaeilzadeh S, et al. The effects of long- and short-term interdisciplinary treatment approaches in women with fibromyalgia: a randomized controlled trial. Rheumatol Int. 2016 Oct;36(10):1379-89. doi: 10.1007/s00296016-3473-8. PMID: 27055444.

232. Tavafian SS, Jamshidi AR, Montazeri A. A randomized study of back school in women with chronic low back pain: quality of life at three, six, and twelve months follow-up. Spine (Phila Pa 1976). 2008 Jul 01;33(15):1617-21. doi: 10.1097/BRS.0b013e31817bd31c. PMID: 18580739.

233. Bendix AF, Bendix T, Ostenfeld S, et al. Active treatment programs for patients with chronic low back pain: a prospective, randomized, observer-blinded study. Eur Spine J. 1995;4(3):148-52. PMID: 7552649.

234. Bendix T, Bendix A, Labriola M, et al. Functional restoration versus outpatient physical training in chronic low back pain: a randomized comparative study. Spine (Phila Pa 1976). 2000 Oct 01;25(19):2494-500. PMID: 11013502.

235. Jousset N, Fanello S, Bontoux L, et al. Effects of functional restoration versus 3 hours per week physical therapy: a randomized controlled study. Spine (Phila Pa 1976). 2004 Mar 01;29(5):487-93; discussion 94. PMID: 15129059.
236. Nicholas MK, Wilson PH, Goyen J. Operant-behavioural and cognitivebehavioural treatment for chronic low back pain. Behav Res Ther. 1991;29(3):225-38. PMID: 1831972.

237. Nicholas MK, Wilson PH, Goyen J. Comparison of cognitive-behavioral group treatment and an alternative nonpsychological treatment for chronic low back pain. Pain. 1992 Mar;48(3):339-47. PMID: 1534400.

238. van der Roer N, van Tulder M, Barendse J, et al. Intensive group training protocol versus guideline physiotherapy for patients with chronic low back pain: a randomised controlled trial. Eur Spine J. 2008 Sep;17(9):1193-200. doi: 10.1007/s00586008-0718-6. PMID: 18663487.

239. Monticone M, Ferrante S, Rocca B, et al. Effect of a long-lasting multidisciplinary program on disability and fear-avoidance behaviors in patients with chronic low back pain: results of a randomized controlled trial. Clin J Pain. 2013 Nov;29(11):929-38. doi: 10.1097/AJP.0b013e31827fef7e. PMID: 23328343.

240. Monticone M, Ambrosini E, Rocca B, et al. A multidisciplinary rehabilitation programme improves disability, kinesiophobia and walking ability in subjects with chronic low back pain: results of a randomised controlled pilot study. Eur Spine J. 2014 Oct;23(10):2105-13. doi: 10.1007/s00586-014-3478-5. PMID: 25064093.

241. Roche G, Ponthieux A, Parot-Shinkel E, et al. Comparison of a functional restoration program with active individual physical therapy for patients with chronic low back pain: a randomized controlled trial. Arch Phys Med Rehabil. 2007 Oct;88(10):122935. doi: 10.1016/j.apmr.2007.07.014. PMID: 17908562.

242. Roche-Leboucher G, Petit-Lemanac'h A, Bontoux L, et al. Multidisciplinary intensive functional restoration versus outpatient active physiotherapy in chronic low back pain: a randomized controlled trial. Spine (Phila Pa 1976). 2011 Dec 15;36(26):223542. doi: 10.1097/BRS.0b013e3182191e13. PMID: 21415807. 
243. Bendix AF, Bendix T, Lund C, et al. Comparison of three intensive programs for chronic low back pain patients: a prospective, randomized, observer-blinded study with one-year follow-up. Scand J Rehabil Med. 1997 Jun;29(2):81-9. PMID: 9198257.

244. Bendix AE, Bendix T, Haestrup C, et al. A prospective, randomized 5-year follow-up study of functional restoration in chronic low back pain patients. Eur Spine J. 1998;7(2):111-9. PMID: 9629934.

245. Kabat-Zinn J. Mindfulness-based interventions in context: past, present, and future. Clin Psychol Sci Pract. 2003;10(2):144-56. doi: 10.1093/clipsy.bpg016.

246. Gatchel RJ, Mayer TG. Evidence-informed management of chronic low back pain with functional restoration. Spine J. 2008 JanFeb;8(1):65-9. doi:

10.1016/j.spinee.2007.10.012. PMID: 18164455.

247. Chou R, Deyo R, Friedly J, et al. Systemic pharmacologic therapies for low back pain: A systematic review for an American College of Physicians Clinical Practice Guideline. Ann Intern Med. 2017 Feb 14;166:[Epub ahead of print]. doi: 10.7326/M16-2458. PMID: 28192790.

248. Tice J, Kumar V, Otunoye I, et al. Cognitive and Mind-Body Therapies for Chronic Low Back and Neck Pain: Effectiveness and Value. Evidence Report. Prepared for The California Technology Assesment Forum.

Boston, MA: The Institute for Clinical and Economic Review; 2017. https://icerreview.org/wpcontent/uploads/2017/03/CTAF_Chronic_Pa in_Evidence_Report_100417.pdf Accessed October 13, 2017.

249. Geneen LJ, Moore RA, Clarke C, et al. Physical activity and exercise for chronic pain in adults: an overview of Cochrane Reviews. The Cochrane Library. 2017.

250. Vickers AJ, Cronin AM, Maschino AC, et al. Acupuncture for chronic pain: individual patient data meta-analysis. Arch Intern Med. 2012 Oct 22;172(19):1444-53. doi: 10.1001/archinternmed.2012.3654. PMID: 22965186.
251. Nahin RL, Boineau R, Khalsa PS, et al. Evidence-Based Evaluation of Complementary Health Approaches for Pain Management in the United States. Mayo Clin Proc. 2016 Sep;91(9):1292-306. doi: 10.1016/j.mayocp.2016.06.007. PMID: 27594189.

252. Newberry SJ, FitzGerald J, SooHoo NF, et al. Treatment of Osteoarthritis of the Knee: An Update Review. Comparative Effectiveness Review No. 190. (Prepared by the RAND Southern California Evidencebased Practice Center under Contract No. 290-2015-00010-I.) AHRQ Publication No.17-EHC011-EF. Rockville, MD: Agency for Healthcare Research and Quality; 2017. www.effectivehealthcare.ahrq.gov/reports/fi nal.cfmdoi: 10.23970/AHRQEPCCER190.

253. Busse J. The 2017 Canadian Guideline for Opioids for Chronic Non-Cancer Pain. 2017.

254. Busse JW, Ebrahim S, Connell G, et al. Systematic review and network metaanalysis of interventions for fibromyalgia: a protocol. Syst Rev. 2013 Mar 13;2:18. doi: 10.1186/2046-4053-2-18. PMID: 23497523.

255. Hill JC, Whitehurst DG, Lewis M, et al. Comparison of stratified primary care management for low back pain with current best practice (STarT Back): a randomised controlled trial. Lancet. 2011 Oct 29;378(9802):1560-71. doi: 10.1016/S01406736(11)60937-9. PMID: 21963002.

256. Dworkin RH, Turk DC, Farrar JT, et al. Core outcome measures for chronic pain clinical trials: IMMPACT recommendations. Pain. 2005;113(1):9-19.

257. Dworkin RH, Turk DC, Peirce-Sandner S, et al. Research design considerations for confirmatory chronic pain clinical trials: IMMPACT recommendations. PAIN® . 2010;149(2):177-93.

258. Dworkin RH, Turk DC, Wyrwich KW, et al. Interpreting the clinical importance of treatment outcomes in chronic pain clinical trials: IMMPACT recommendations. The Journal of Pain. 2008;9(2):105-21.

259. Gewandter JS, Dworkin RH, Turk DC, et al. Research designs for proof-of-concept chronic pain clinical trials: IMMPACT recommendations. PAIN. 2014;155(9):168395. doi: 10.1016/j.pain.2014.05.025. PMID: 00006396-201409000-00004. 
260. Taylor AM, Phillips K, Patel KV, et al. Assessment of physical function and participation in chronic pain clinical trials: IMMPACT/OMERACT recommendations. Pain. 2016;157(9):1836-50.

261. Turk DC, Dworkin RH, McDermott MP, et al. Analyzing multiple endpoints in clinical trials of pain treatments: IMMPACT recommendations. Pain. 2008;139(3):48593.

262. Dworkin RH, Allen R, Kopko S, et al. A standard database format for clinical trials of pain treatments: An ACTTION-CDISC initiative. Pain. 2013;154(1):11-4.
263. Hunsinger M, Smith SM, Rothstein D, et al. Adverse event reporting in nonpharmacologic, noninterventional pain clinical trials: ACTTION systematic review. PAIN®. 2014;155(11):2253-62.

264. National Institute of Health Interagency Pain Research Coordinating Committee. Federal Pain Research Strategy. 2017.

265. Fillingim RB, Loeser JD, Baron R, et al. Assessment of Chronic Pain: Domains, Methods, and Mechanisms. J Pain. 2016 Sep;17(9 Suppl):T10-20. doi: 10.1016/j.jpain.2015.08.010. PMID: 27586827. 


\section{Acronyms and Abbreviations}

\begin{tabular}{|c|c|}
\hline Acronym/Abbreviation & Term \\
\hline $\mathrm{AC}$ & Attention Control \\
\hline ADL & Activities of daily living \\
\hline AIMS & Arthritis Impact Measurement Scale \\
\hline AQoL 6D & Assessment of Quality of Life version 6D \\
\hline AUSCAN & Australia Canadian Osteoarthritis Hand Index \\
\hline BAl & Beck Anxiety Inventory \\
\hline BDI & Beck Depression Inventory \\
\hline BMI & Body mass index \\
\hline $\mathrm{BPI}$ & Brief Pain Inventory \\
\hline BPI-SF & Brief Pain Inventory-Short Form \\
\hline CBT & Cognitive-behavioral therapy \\
\hline CDC HRQOL-4 & $\begin{array}{l}\text { Centers for Disease Control and Prevention's Health-Related Quality of Life } \\
\text { Questionnaire }\end{array}$ \\
\hline CES-D & Center for Epidemiologic Studies Depression Scale \\
\hline CGI-I & Clinical Global Impressions of Improvement Scale \\
\hline CGI-S & Clinical Global Impressions of Severity Scale \\
\hline $\mathrm{Cl}$ & Confidence interval \\
\hline CSQ & Coping Strategies Questionnaire \\
\hline DASS & Depression Anxiety Stress Scales \\
\hline DPQ & Dallas Pain Questionnaire \\
\hline DRI & Disability Rating Index \\
\hline DFI & Dreiser Functional Index \\
\hline EEG & Electroencephalography \\
\hline EMG & Electromyography \\
\hline EQ-5D & EuroQoL-5D \\
\hline FABQ & Fear Avoidance Beliefs Questionnaire \\
\hline FIHOA & Functional Index for Hand Osteoarthritis \\
\hline FIQ & Fibromyalgia Impact Questionnaire \\
\hline FMl & Freiburg Mindfulness Inventory \\
\hline FRI & Functional Rating Index \\
\hline FSI & Fatigue Symptom Inventory \\
\hline GAR & Groningen Activity Restriction Scale \\
\hline GCQ, GBB-24 & Giessen Complaint Questionnaire \\
\hline GDS & Geriatric Depression Scale \\
\hline GPE & Global Perceived Effect Scale \\
\hline GRADE & Grading of Recommendations Assessment, Development, and Evaluation \\
\hline GSI & Global Severity Index (Symptom Checklist-90-Revised) \\
\hline HADS & The Hospital Anxiety and Depression Scale \\
\hline HAM-A & Hamilton Anxiety Rating Scale (HAM-A) \\
\hline HAM-D & Hamilton Depression Rating Scale (HAM-D) \\
\hline HAQ & Health Assessment Questionnaire \\
\hline $\mathrm{HDI}$ & Headache Disability Inventory \\
\hline HHS & Harris Hip Score \\
\hline HFAQ & Hannover Functional Ability \\
\hline HIT-6 & Headache Impact Test- 6 \\
\hline HRQoL & Health-related quality of life \\
\hline HSCL-25 & Hopkin's Symptom Checklist \\
\hline HSS & Hospital for Special Surgery Knee Function \\
\hline IPAQ & International Physical Activity Questionnaire \\
\hline $\mathrm{IPQ}(-\mathrm{R})$ & Illness Perception Questionnaire(-Revised) \\
\hline IQR & Interquartile range \\
\hline ITT & Intention-to-treat \\
\hline KPS & Knee Pain Scale \\
\hline JLEQ & Japan Low Back Pain Evaluation Questionnaire \\
\hline JOA & Japanese Orthopedic Association \\
\hline LBP & Low back pain \\
\hline
\end{tabular}




\begin{tabular}{|c|c|}
\hline Acronym/Abbreviation & Term \\
\hline LBPOI & Low Back Pain Outcome Instrument \\
\hline LBPRS & Low back pain rating scale \\
\hline LLFDI & Late Life Function and Disability Instrument \\
\hline MACTAR & McMaster Toronto Arthritis patient preference questionnaire \\
\hline MASS & Mindful Attention Awareness Scale \\
\hline MBSR & Mindfulness-based stress reduction \\
\hline MCE & Motor control exercise \\
\hline MCID & Minimal clinically important difference \\
\hline MCS-12 & Mental component score of the SF-12 \\
\hline MD & Mean difference \\
\hline MIDAS & Migraine Disability Assessment questionnaire \\
\hline MRDQ & Modified Roland-Morris Disability Questionnaire \\
\hline MOS & Medical Outcome Study \\
\hline $\mathrm{MPI}$ & Multidimensional Pain Inventory \\
\hline MPQ(-SF) & McGill Pain Questionnaire(-Short Form) \\
\hline $\mathrm{NDI}$ & Neck Disability Index \\
\hline NHP & Nottingham Health Profile \\
\hline NIAMS & National Institute of Arthritis and Musculoskeletal and Skin Diseases \\
\hline $\mathrm{NIH}$ & National Institute of Health \\
\hline NPAD & Neck Pain and Disability Index \\
\hline NR & Not reported \\
\hline NRS & Numeric rating scale \\
\hline NS & Not statistically significant \\
\hline NSAID & Nonsteroidal anti-inflammatory drug \\
\hline NT & No treatment \\
\hline OA & Osteoarthritis \\
\hline OARSI-OMERACT & $\begin{array}{l}\text { Osteoarthritis Research Society International - Outcome Measures in } \\
\text { Rheumatology }\end{array}$ \\
\hline ODI & Oswestry Disability Index \\
\hline OKS & Oxford Knee Score \\
\hline PDI & Pain Disability Index \\
\hline PPS & Pain Perception Scale \\
\hline $\mathrm{PR}$ & Partial response \\
\hline PRISMA & Preferred Reporting Items for Systematic Reviews and Meta-Analyses \\
\hline PSEQ & Chronic Pain Self Efficacy Scale \\
\hline PSFS & Patient-Specific Functional Scale \\
\hline PSQI & Pittsburgh Sleep Quality Index \\
\hline PSS & Perceived Stress Scale \\
\hline PT & Physical therapy \\
\hline QBPDS & Quebec Back Pain Disability Scale \\
\hline QHS & Each night at bedtime \\
\hline $\mathrm{QOL}$ & Quality of life \\
\hline RAND-36 QoL & Quality of Life RAND-36 \\
\hline QoL VAS & Quality of Life Visual Analog Scale \\
\hline RCT & Randomized controlled trial \\
\hline RDQ & Roland-Morris Disability Questionnaire \\
\hline $\mathrm{RR}$ & Relative risk \\
\hline SD & Standard Deviation \\
\hline SA & Sham acupuncture \\
\hline SCL-90 & Symptom Checklist 90 \\
\hline SF-12, SF-12 MCS/PCS & Short Form-12, Physical Component Score/Mental Component Score \\
\hline SF-36, SF-36 MCS/PCS & Short Form-36, Physical Component Score/Mental Component Score \\
\hline SF-MPQ & McGill Pain Questionnaire Pain Rating Index-Short-Form \\
\hline $\mathrm{SHCl}$ & Subjective Health Complaint Inventory \\
\hline SIP & Sickness Impact Profile \\
\hline SKFS & Saudi version of the Knee Function Scale \\
\hline SMD & Standardized mean difference \\
\hline SOE & Strength of evidence \\
\hline
\end{tabular}




\begin{tabular}{|l|l|}
\hline Acronym/Abbreviation & \multicolumn{1}{c|}{ Term } \\
\hline SSDQ & Stanford Sleep Disorders Questionnaire \\
\hline SSS & Swiss Spinal Stenosis Questionnaire \\
\hline STAI & State-Trait Anxiety Inventory \\
\hline TENS & Transcutaneous electrical nerve stimulation \\
\hline UC & Usual Care \\
\hline VAS & Visual analog scale \\
\hline VF & Von Korff functional disability \\
\hline VKPS & Von Korff pain scale \\
\hline WHOQOL-BREF & World Health Organization Quality of Life-BREF instrument \\
\hline WL & Waitlist \\
\hline WMD & Weighted mean difference \\
\hline WPAI & Work activity impairment subscale \\
\hline WPSI & Wahler Physical Symptoms Inventory \\
\hline ZPS & Zung Self-Rating Depression Scale \\
\hline
\end{tabular}




\section{Appendix A. Search Strategies}

\section{Database: Ovid MEDLINE(R) without Revisions 1996 to May Week 2017}

Search Strategy:

1 exp Low Back Pain/

2 exp Chronic Pain/

32 and (back or spine or spinal or radicular).ti,ab.

4 or $1-3$

5 Neck Pain/ or neck.ti,ab.

6 exp Osteoarthritis/ or osteoarthritis.ti,ab.

7 Headache/ or headache.ti,ab.

8 Fibromyalgia/ or fibromyalgia.ti,ab.

9 exp Exercise Therapy/

10 exp Physical Therapy Modalities/

11 exp Braces/

12 exp Mind-Body Therapies/

13 exp Acupuncture Therapy/

14 exp Rehabilitation/

15 exp Psychotherapy/

16 exp Musculoskeletal Manipulations/

17 (noninvasive or non-invasive or nonpharmacologic* or non-pharmacologic*).ti,ab.

18 (exercise or physical therapy or cognitive or behavioral or feedback or relaxation or acceptance or commitment or traction or ultrasound or stimulation or laser or magnet* or inferential or electromuscular or diathermy or heat or cold or manipulation or manual or craniosacral or mindfulness or meditation or mind-body or yoga or pilates or Qigong or acupuncture or "functional restoration" or multidisciplin* or interdisciplin*).ti,ab.

19 rh.fs.

20 or $/ 9-19$

21 (or/5-8) and pain.mp.

2220 and 21

23 limit 22 to (meta analysis or systematic reviews)

24 limit 23 to (english language and humans)

25 limit 22 to randomized controlled trial

26 limit 25 to (english language and humans)

274 and 20

28 limit 27 to randomized controlled trial

29 limit 28 to yr="2016 - 2017"

30 limit 29 to (english language and humans)

3124 or 26 or 30

Database: EBM Reviews - Cochrane Central Register of Controlled Trials April 2017 1 exp Low Back Pain/

2 exp Chronic Pain/

32 and (back or spine or spinal or radicular).ti,ab.

4 or/ $1-3$

5 Neck Pain/ or neck.ti,ab.

6 exp Osteoarthritis/ or osteoarthritis.ti,ab. 
7 Headache/ or headache.ti,ab.

8 Fibromyalgia/ or fibromyalgia.ti,ab.

9 exp Exercise Therapy/

10 exp Physical Therapy Modalities/

11 exp Braces/

12 exp Mind-Body Therapies/

13 exp Acupuncture Therapy/

14 exp Rehabilitation/

15 exp Psychotherapy/

16 exp Musculoskeletal Manipulations/

17 (noninvasive or non-invasive or nonpharmacologic* or non-pharmacologic*).ti,ab.

18 (exercise or physical therapy or cognitive or behavioral or feedback or relaxation or acceptance or commitment or traction or ultrasound or stimulation or laser or magnet* or inferential or electromuscular or diathermy or heat or cold or manipulation or manual or craniosacral or mindfulness or meditation or mind-body or yoga or pilates or Qigong or acupuncture or functional restoration or multidisciplin* or interdisciplin*).ti,ab.

19 rh.fs.

20 or/9-19

21 (or/5-8) and pain.mp.

2220 and 21

23 limit 22 to randomized controlled trial

244 and 20

25 limit 24 to randomized controlled trial

26 limit 25 to $\mathrm{yr}=" 2016$ - 2017"

2723 or 26

28 limit 27 to english language

29 limit 28 to medline records

3028 not 29

Database: EBM Reviews - Cochrane Database of Systematic Reviews 2005 to December 21, 2016

1 chronic.ti,ab.

2 (back or spine or spinal or radicular or neck or osteoarthritis or fibromyalgia or headache).ti,ab.

3 (noninvasive or non-invasive or nonpharmacologic* or non-pharmacologic*).ti,ab.

4 (exercise or psychosocial or "cognitive behavioral therapy" or CBT or biofeedback or relaxation or "physical modal*" or traction or ultrasound or "transcutaneous electrical nerve stimulation" or TENS or laser or heat or cold or cryotherapy or magnet* or manual* or manipulation or massage or mindfulness or meditation or "mind-body" or "yoga to tai chi" or qigong or acupuncture or "functional restoration" or "occupational therapy" or multidisciplinary).ti,ab.

51 and 2

63 or 4

75 and 6 


\section{Appendix B. Included Studies}

1. Abbasi M, Dehghani M, Keefe FJ, et al. Spouse-assisted training in pain coping skills and the outcome of multidisciplinary pain management for chronic low back pain treatment: a 1-year randomized controlled trial. Eur J Pain. 2012 Aug;16(7):1033-43. doi: 10.1002/j.1532-2149.2011.00097.x. PMID: 22337646.

2. Abbott JH, Robertson MC, Chapple C, et al. Manual therapy, exercise therapy, or both, in addition to usual care, for osteoarthritis of the hip or knee: a randomized controlled trial. 1: clinical effectiveness. Osteoarthritis \& Cartilage. 2013 Apr;21(4):525-34. doi: http://dx.doi.org/10.1016/j.joca.2012.12.014. PMID: 23313532.

3. Ajimsha MS, Daniel B, Chithra S. Effectiveness of myofascial release in the management of chronic low back pain in nursing professionals. J Bodyw Mov Ther. 2014 Apr;18(2):273-81. doi: 10.1016/j.jbmt.2013.05.007. PMID: 24725797.

4. Al Rashoud AS, Abboud RJ, Wang W, et al. Efficacy of low-level laser therapy applied at acupuncture points in knee osteoarthritis: a randomised double-blind comparative trial. Physiotherapy. 2014 Sep;100(3):242-8. doi:

http://dx.doi.org/10.1016/j.physio.2013.09.0 07. PMID: 24418801.

5. Alda M, Luciano JV, Andres E, et al. Effectiveness of cognitive behaviour therapy for the treatment of catastrophisation in patients with fibromyalgia: a randomised controlled trial. Arthritis Res Ther. 2011;13(5):R173. doi: 10.1186/ar3496. PMID: 22018333.

6. Alfano AP, Taylor AG, Foresman PA, et al. Static magnetic fields for treatment of fibromyalgia: a randomized controlled trial. J Altern Complement Med. 2001 Feb;7(1):53-64.

7. Altan L, Bingol U, Aykac M, et al. Investigation of the effect of GaAs laser therapy on cervical myofascial pain syndrome. Rheumatol Int. 2005 Jan;25(1):23-7. doi: 10.1007/s00296-0030396-y. PMID: 14673617.
8. Altan L, Korkmaz N, Bingol U, et al. Effect of pilates training on people with fibromyalgia syndrome: a pilot study. Archives of Physical Medicine \& Rehabilitation. 2009 Dec;90(12):1983-8. doi:

http://dx.doi.org/10.1016/j.apmr.2009.06.02 1. PMID: 19969158.

9. Amris K, Waehrens EE, Christensen R, et al. Interdisciplinary rehabilitation of patients with chronic widespread pain: primary endpoint of the randomized, nonblinded, parallel-group IMPROvE trial. Pain. 2014 Jul;155(7):1356-64. doi: http://dx.doi.org/10.1016/j.pain.2014.04.012 . PMID: 24727345.

10. Andersen LL, Jorgensen MB, Blangsted AK, et al. A randomized controlled intervention trial to relieve and prevent neck/shoulder pain. Medicine \& Science in Sports \& Exercise. 2008 Jun;40(6):983-90. doi:

http://dx.doi.org/10.1249/MSS.0b013e3181 676640. PMID: 18461010.

11. Ang DC, Chakr R, Mazzuca S, et al. Cognitive-behavioral therapy attenuates nociceptive responding in patients with fibromyalgia: a pilot study. Arthritis Care Res (Hoboken). 2010 May;62(5):618-23. doi: 10.1002/acr.20119.

12. Aslan Telci E, Karaduman A. Effects of three different conservative treatments on pain, disability, quality of life, and mood in patients with cervical spondylosis.

Rheumatology International. 2012

Apr;32(4):1033-40. doi: http://dx.doi.org/10.1007/s00296-010-17514. PMID: 21246365.

13. Assefi NP, Sherman KJ, Jacobsen C, et al. A randomized clinical trial of acupuncture compared with sham acupuncture in fibromyalgia.[Summary for patients in Ann Intern Med. 2005 Jul 5;143(1):I24; PMID: 15998747]. Annals of Internal Medicine. 2005 Jul 5;143(1):10-9. PMID: 15998750.

14. Banth S, Ardebil MD. Effectiveness of mindfulness meditation on pain and quality of life of patients with chronic low back pain. Int J Yoga. 2015 Jul-Dec;8(2):128-33. doi: 10.4103/0973-6131.158476. PMID: 26170592. 
15. Baptista AS, Villela AL, Jones A, et al. Effectiveness of dance in patients with fibromyalgia: a randomized, single-blind, controlled study. Clin Exp Rheumatol. 2012 Nov-Dec;30(6 Suppl 74):18-23. Epub 2012 Dec 14.

16. Basford JR, Sheffield CG, Harmsen WS. Laser therapy: a randomized, controlled trial of the effects of low-intensity Nd:YAG laser irradiation on musculoskeletal back pain. Arch Phys Med Rehabil. 1999 Jun;80(6):647-52. PMID: 10378490.

17. Battisti E, Piazza E, Rigato M, et al. Efficacy and safety of a musically modulated electromagnetic field (TAMMEF) in patients affected by knee osteoarthritis. Clinical \& Experimental Rheumatology. 2004 Sep-Oct;22(5):568-72. PMID: 15485009.

18. Bendix AE, Bendix T, Haestrup C, et al. A prospective, randomized 5-year follow-up study of functional restoration in chronic low back pain patients. Eur Spine J. 1998;7(2):111-9. PMID: 9629934.

19. Bendix AF, Bendix T, Lund C, et al. Comparison of three intensive programs for chronic low back pain patients: a prospective, randomized, observer-blinded study with one-year follow-up. Scand J Rehabil Med. 1997 Jun;29(2):81-9. PMID: 9198257.

20. Bendix AF, Bendix T, Ostenfeld S, et al. Active treatment programs for patients with chronic low back pain: a prospective, randomized, observer-blinded study. Eur Spine J. 1995;4(3):148-52. PMID: 7552649.

21. Bendix AF, Bendix T, Vaegter K, et al. Multidisciplinary intensive treatment for chronic low back pain: a randomized, prospective study. Cleve Clin J Med. 1996 Jan-Feb;63(1):62-9. PMID: 8590519.

22. Bendix T, Bendix A, Labriola M, et al. Functional restoration versus outpatient physical training in chronic low back pain: a randomized comparative study. Spine (Phila Pa 1976). 2000 Oct 01;25(19):2494-500. PMID: 11013502.
23. Bennell KL, Ahamed Y, Jull G, et al. Physical Therapist-Delivered Pain Coping Skills Training and Exercise for Knee Osteoarthritis: Randomized Controlled Trial. Arthritis Care Res (Hoboken). 2016 May;68(5):590-602. doi: 10.1002/acr.22744. PMID: 26417720.

24. Bennell KL, Hinman RS, Metcalf BR, et al. Efficacy of physiotherapy management of knee joint osteoarthritis: a randomised, double blind, placebo controlled trial. Annals of the Rheumatic Diseases. 2005 Jun;64(6):906-12. PMID: 15897310.

25. Berman BM, Lao L, Langenberg P, et al. Effectiveness of acupuncture as adjunctive therapy in osteoarthritis of the knee: a randomized, controlled trial. Ann Intern Med. 2004 Dec 21;141(12):901-10. PMID: 15611487.

26. Berman BM, Singh BB, Lao L, et al. A randomized trial of acupuncture as an adjunctive therapy in osteoarthritis of the knee. Rheumatology. 1999 Apr;38(4):34654. PMID: 10378713.

27. Beurskens AJ, de Vet HC, Koke AJ, et al. Efficacy of traction for nonspecific low back pain. 12-week and 6-month results of a randomized clinical trial. Spine (Phila $\mathrm{Pa}$ 1976). 1997 Dec 01;22(23):2756-62. PMID: 9431610.

28. Birch S, Jamison RN. Controlled trial of Japanese acupuncture for chronic myofascial neck pain: assessment of specific and nonspecific effects of treatment. Clinical Journal of Pain. 1998 Sep;14(3):248-55. PMID: 9758075.

29. Blanchard EB, Appelbaum KA, Radnitz CL, et al. Placebo-controlled evaluation of abbreviated progressive muscle relaxation and of relaxation combined with cognitive therapy in the treatment of tension headache. J Consult Clin Psychol. 1990 Apr;58(2):210-5. PMID: 2186066.

30. Blodt S, Pach D, Kaster T, et al. Qigong versus exercise therapy for chronic low back pain in adults--a randomized controlled noninferiority trial. Eur J Pain. 2015 Jan;19(1):123-31. doi: 10.1002/ejp.529. PMID: 24902673. 
31. Boline PD, Kassak K, Bronfort G, et al. Spinal manipulation vs. amitriptyline for the treatment of chronic tension-type headaches: a randomized clinical trial. J Manipulative Physiol Ther. 1995 Mar-Apr;18(3):148-54. PMID: 7790794.

32. Bono F, Salvino D, Mazza MR, et al. The influence of ictal cutaneous allodynia on the response to occipital transcutaneous electrical stimulation in chronic migraine and chronic tension-type headache: a randomized, sham-controlled study. Cephalalgia. 2015 Apr;35(5):389-98. doi: http://dx.doi.org/10.1177/033310241454490 9. PMID: 25078717.

33. Brinkhaus B, Witt CM, Jena S, et al. Acupuncture in patients with chronic low back pain: a randomized controlled trial. Arch Intern Med. 2006 Feb 27;166(4):4507. doi: 10.1001/archinte.166.4.450. PMID: 16505266.

34. Brismee JM, Paige RL, Chyu MC, et al. Group and home-based tai chi in elderly subjects with knee osteoarthritis: a randomized controlled trial. Clinical Rehabilitation. 2007 Feb;21(2):99-111. PMID: 17264104.

35. Bronfort G, Maiers MJ, Evans RL, et al. Supervised exercise, spinal manipulation, and home exercise for chronic low back pain: a randomized clinical trial. Spine J. 2011 Jul;11(7):585-98. doi:

10.1016/j.spinee.2011.01.036. PMID: 21622028.

36. Brosseau L, Wells G, Marchand S, et al. Randomized controlled trial on low level laser therapy (LLLT) in the treatment of osteoarthritis (OA) of the hand. Lasers in Surgery \& Medicine. 2005 Mar;36(3):210-9. doi: https://dx.doi.org/10.1002/lsm.20137. PMID: 15704096.

37. Brouwer RW, van Raaij TM, Verhaar JA, et al. Brace treatment for osteoarthritis of the knee: a prospective randomized multi-centre trial. Osteoarthritis \& Cartilage. 2006 Aug;14(8):777-83. PMID: 16563810.

38. Buckelew SP, Conway R, Parker J, et al. Biofeedback/relaxation training and exercise interventions for fibromyalgia: a prospective trial. Arthritis Care Res. 1998 Jun;11(3):196-209. PMID: 9782811.
39. Cakir S, Hepguler S, Ozturk C, et al. Efficacy of therapeutic ultrasound for the management of knee osteoarthritis: a randomized, controlled, and double-blind study. American journal of physical medicine \& rehabilitation. 2014 May;93(5):405-12. PMID: CN-00992582 UPDATE.

40. Carlsson CP, Sjolund BH. Acupuncture for chronic low back pain: a randomized placebo-controlled study with long-term follow-up. Clin J Pain. 2001 Dec;17(4):296305. PMID: 11783809.

41. Cash E, Salmon P, Weissbecker I, et al. Mindfulness meditation alleviates fibromyalgia symptoms in women: results of a randomized clinical trial. Ann Behav Med. 2015 Jun;49(3):319-30. doi: 10.1007/s12160-014-9665-0.

42. Castel A, Cascon R, Padrol A, et al. Multicomponent cognitive-behavioral group therapy with hypnosis for the treatment of fibromyalgia: long-term outcome. J Pain. 2012 Mar;13(3):255-65. doi: 10.1016/j.jpain.2011.11.005. Epub 2 Jan 29.

43. Castel A, Castro S, Fontova R, et al. Body mass index and response to a multidisciplinary treatment of fibromyalgia. Rheumatol Int. 2015 Feb;35(2):303-14. doi: 10.1007/s00296-014-3096-x. Epub 2014

Aug 1.

44. Castel A, Fontova R, Montull S, et al. Efficacy of a multidisciplinary fibromyalgia treatment adapted for women with low educational levels: a randomized controlled trial. Arthritis Care Res (Hoboken). 2013 Mar;65(3):421-31. doi: 10.1002/acr.21818. PMID: 22899402.

45. Castien RF, van der Windt DA, Grooten A, et al. Effectiveness of manual therapy for chronic tension-type headache: a pragmatic, randomised, clinical trial. Cephalalgia. 2011 Jan;31(2):133-43. doi:

http://dx.doi.org/10.1177/033310241037736 2. PMID: 20647241. 
46. Castro-Sanchez AM, Mataran-Penarrocha GA, Arroyo-Morales M, et al. Effects of myofascial release techniques on pain, physical function, and postural stability in patients with fibromyalgia: a randomized controlled trial. Clin Rehabil. 2011 Sep;25(9):800-13. doi: 10.1177/0269215511399476. PMID: 21673013.

47. Castro-Sanchez AM, Mataran-Penarrocha GA, Granero-Molina J, et al. Benefits of massage-myofascial release therapy on pain, anxiety, quality of sleep, depression, and quality of life in patients with fibromyalgia. Evid Based Complement Alternat Med. 2011;2011:561753. doi: 10.1155/2011/561753. PMID: 21234327.

48. Cedraschi C, Desmeules J, Rapiti E, et al. Fibromyalgia: a randomised, controlled trial of a treatment programme based on self management. Ann Rheum Dis. 2004 Mar;63(3):290-6.

49. Chen TW, Lin CW, Lee CL, et al. The efficacy of shock wave therapy in patients with knee osteoarthritis and popliteal cyamella. Kaohsiung Journal of Medical Sciences. 2014 Jul;30(7):362-70. doi: https://dx.doi.org/10.1016/j.kjms.2014.03.00 6. PMID: 24924842.

50. Cherkin DC, Anderson ML, Sherman KJ, et al. Two-Year Follow-up of a Randomized Clinical Trial of Mindfulness-Based Stress Reduction vs Cognitive Behavioral Therapy or Usual Care for Chronic Low Back Pain. JAMA. 2017 Feb 14;317(6):642-4. doi: 10.1001/jama.2016.17814. PMID: 28196244.

51. Cherkin DC, Eisenberg D, Sherman KJ, et al. Randomized trial comparing traditional Chinese medical acupuncture, therapeutic massage, and self-care education for chronic low back pain. Arch Intern Med. 2001 Apr 23;161(8):1081-8. PMID: 11322842.

52. Cherkin DC, Sherman KJ, Avins AL, et al. A randomized trial comparing acupuncture, simulated acupuncture, and usual care for chronic low back pain. Arch Intern Med. 2009 May 11;169(9):858-66. doi: 10.1001/archinternmed.2009.65. PMID: 19433697.
53. Cherkin DC, Sherman KJ, Balderson BH, et al. Effect of mindfulness-based stress reduction vs cognitive behavioral therapy or usual care on back pain and functional limitations in adults with chronic low back pain: a randomized clinical trial. JAMA. 2016 Mar 22-29;315(12):1240-9. doi: 10.1001/jama.2016.2323. PMID: 27002445.

54. Cherkin DC, Sherman KJ, Kahn J, et al. A comparison of the effects of 2 types of massage and usual care on chronic low back pain: a randomized, controlled trial. Ann Intern Med. 2011 Jul 5;155(1):1-9. doi: 10.7326/0003-4819-155-1-20110705000002. PMID: 21727288.

55. Chiu TT, Ng JK, Walther-Zhang B, et al. A randomized controlled trial on the efficacy of intermittent cervical traction for patients with chronic neck pain. Clinical Rehabilitation. 2011 Sep;25(9):814-22. doi: https://dx.doi.org/10.1177/02692155113995 90. PMID: 21427150.

56. Cho JH, Nam DH, Kim KT, et al. Acupuncture with non-steroidal antiinflammatory drugs (NSAIDs) versus acupuncture or NSAIDs alone for the treatment of chronic neck pain: an assessorblinded randomised controlled pilot study. Acupuncture in Medicine. 2014 Feb;32(1):17-23. doi: http://dx.doi.org/10.1136/acupmed-2013010410 . PMID: 24171895.

57. Cho YJ, Song YK, Cha YY, et al. Acupuncture for chronic low back pain: a multicenter, randomized, patient-assessor blind, sham-controlled clinical trial. Spine (Phila Pa 1976). 2013 Apr 01;38(7):549-57. doi: 10.1097/BRS.0b013e318275e601. PMID: 23026870.

58. Chow RT, Heller GZ, Barnsley L. The effect of $300 \mathrm{~mW}, 830 \mathrm{~nm}$ laser on chronic neck pain: a double-blind, randomized, placebocontrolled study. Pain. 2006 Sep;124(12):201-10. doi: 10.1016/j.pain.2006.05.018. PMID: 16806710.

59. Clarke-Jenssen AC, Mengshoel AM, Strumse YS, et al. Effect of a fibromyalgia rehabilitation programme in warm versus cold climate: a randomized controlled study. J Rehabil Med. 2014 Jul;46(7):676-83. doi: 10.2340/16501977-1819. 
60. Costa LO, Maher CG, Latimer J, et al. Motor control exercise for chronic low back pain: a randomized placebo-controlled trial. Phys Ther. 2009 Dec;89(12):1275-86. doi: 10.2522/ptj.20090218. PMID: 19892856.

61. Da Costa D, Abrahamowicz M, Lowensteyn I, et al. A randomized clinical trial of an individualized home-based exercise programme for women with fibromyalgia. Rheumatology (Oxford). 2005 Nov;44(11):1422-7. Epub 2005 Jul 19.

62. Dias RC, Dias JM, Ramos LR. Impact of an exercise and walking protocol on quality of life for elderly people with OA of the knee. Physiotherapy Research International. 2003;8(3):121-30. PMID: 14533368.

63. Dilek B, Gozum M, Sahin E, et al. Efficacy of paraffin bath therapy in hand osteoarthritis: a single-blinded randomized controlled trial. Archives of Physical Medicine \& Rehabilitation. 2013 Apr;94(4):642-9. doi: http://dx.doi.org/10.1016/j.apmr.2012.11.02 4. PMID: 23187044.

64. Djavid GE, Mehrdad R, Ghasemi M, et al. In chronic low back pain, low level laser therapy combined with exercise is more beneficial than exercise alone in the long term: a randomised trial. Aust J Physiother. 2007;53(3):155-60. PMID: 17725472.

65. Ebadi S, Ansari NN, Naghdi S, et al. The effect of continuous ultrasound on chronic non-specific low back pain: a single blind placebo-controlled randomized trial. BMC Musculoskelet Disord. 2012 Oct 02;13:192. doi: 10.1186/1471-2474-13-192. PMID: 23031570 .

66. Ebneshahidi NS, Heshmatipour M, Moghaddami A, et al. The effects of laser acupuncture on chronic tension headache--a randomised controlled trial. Acupuncture in Medicine. 2005 Mar;23(1):13-8. PMID: 15844435.

67. Ettinger WH, Jr., Burns R, Messier SP, et al. A randomized trial comparing aerobic exercise and resistance exercise with a health education program in older adults with knee osteoarthritis. The Fitness Arthritis and Seniors Trial (FAST). JAMA. 1997 Jan 1;277(1):25-31. PMID: 8980206.
68. Falcão DM, Sales L, Leite JR, et al. Cognitive behavioral therapy for the treatment of fibromyalgia syndrome: a randomized controlled trial. Journal of Musculoskeletal Pain. 2008;16(3):133-40.

69. Fary RE, Carroll GJ, Briffa TG, et al. The effectiveness of pulsed electrical stimulation in the management of osteoarthritis of the knee: results of a double-blind, randomized, placebo-controlled, repeated-measures trial. Arthritis \& Rheumatism. 2011 May;63(5):1333-42. doi: http://dx.doi.org/10.1002/art.30258. PMID: 21312188.

70. Ferreira ML, Ferreira PH, Latimer J, et al. Comparison of general exercise, motor control exercise and spinal manipulative therapy for chronic low back pain: A randomized trial. Pain. 2007 Sep;131(12):31-7. doi: 10.1016/j.pain.2006.12.008. PMID: 17250965.

71. Fontaine KR, Conn L, Clauw DJ. Effects of lifestyle physical activity on perceived symptoms and physical function in adults with fibromyalgia: results of a randomized trial. Arthritis Res Ther. 2010;12(2):R55. doi: 10.1186/ar2967. PMID: 20353551.

72. Fontaine KR, Conn L, Clauw DJ. Effects of lifestyle physical activity in adults with fibromyalgia: results at follow-up. J Clin Rheumatol. 2011 Mar;17(2):64-8. doi: 10.1097/RHU.0b013e31820e7ea7.

73. Fukuda TY, Alves da Cunha R, Fukuda VO, et al. Pulsed shortwave treatment in women with knee osteoarthritis: a multicenter, randomized, placebo-controlled clinical trial. Physical Therapy. 2011 Jul;91(7):1009-17. doi: http://dx.doi.org/10.2522/ptj.20100306. PMID: 21642511.

74. Giannotti E, Koutsikos K, Pigatto M, et al. Medium-/long-term effects of a specific exercise protocol combined with patient education on spine mobility, chronic fatigue, pain, aerobic fitness and level of disability in fibromyalgia. BioMed Research International. 2014;2014:474029. doi: http://dx.doi.org/10.1155/2014/474029. PMID: 24616894. 
75. Gibson T, Grahame R, Harkness J, et al. Controlled comparison of short-wave diathermy treatment with osteopathic treatment in non-specific low back pain. Lancet. 1985 Jun 01;1(8440):1258-61. PMID: 2860453.

76. Giombini A, Di Cesare A, Di Cesare M, et al. Localized hyperthermia induced by microwave diathermy in osteoarthritis of the knee: a randomized placebo-controlled double-blind clinical trial. Knee surgery, sports traumatology, arthroscopy : official journal of the ESSKA. 2011 Jun;19(6):9807. PMID: CN-00802186 UPDATE.

77. Goldby LJ, Moore AP, Doust J, et al. A randomized controlled trial investigating the efficiency of musculoskeletal physiotherapy on chronic low back disorder. Spine (Phila Pa 1976). 2006 May 01;31(10):1083-93. doi: 10.1097/01.brs.0000216464.37504.64. PMID: 16648741.

78. Gowans SE, deHueck A, Voss S, et al. Effect of a randomized, controlled trial of exercise on mood and physical function in individuals with fibromyalgia. Arthritis Rheum. 2001 Dec;45(6):519-29.

79. Groessl EJ, Liu L, Chang DG, et al. Yoga for Military Veterans with Chronic Low Back Pain: A Randomized Clinical Trial. Am J Prev Med. 2017 Nov;53(5):599-608. doi: 10.1016/j.amepre.2017.05.019. PMID: 28735778.

80. Gudavalli MR, Cambron JA, McGregor M, et al. A randomized clinical trial and subgroup analysis to compare flexiondistraction with active exercise for chronic low back pain. Eur Spine J. 2006 Jul;15(7):1070-82. doi: 10.1007/s00586005-0021-8. PMID: 16341712.

81. Gur A, Sarac AJ, Cevik R, et al. Efficacy of $904 \mathrm{~nm}$ gallium arsenide low level laser therapy in the management of chronic myofascial pain in the neck: a double-blind and randomize-controlled trial. Lasers Surg Med. 2004;35(3):229-35. doi: 10.1002/lsm.20082. PMID: 15389743.
82. Gusi N, Tomas-Carus P, Häkkinen A, et al. Exercise in waist-high warm water decreases pain and improves health-related quality of life and strength in the lower extremities in women with fibromyalgia. Arthritis Care \& Research. 2006;55(1):6673.

83. Haake M, Muller HH, Schade-Brittinger C, et al. German Acupuncture Trials (GERAC) for chronic low back pain: randomized, multicenter, blinded, parallel-group trial with 3 groups. Arch Intern Med. 2007 Sep 24;167(17):1892-8. doi: 10.1001/archinte.167.17.1892. PMID: 17893311.

84. Haas M, Vavrek D, Peterson D, et al. Doseresponse and efficacy of spinal manipulation for care of chronic low back pain: a randomized controlled trial. Spine J. 2014 Jul 01;14(7):1106-16. doi: 10.1016/j.spinee.2013.07.468. PMID: 24139233.

85. Harkapaa K, Jarvikoski A, Mellin G, et al. A controlled study on the outcome of inpatient and outpatient treatment of low back pain. Part I. Pain, disability, compliance, and reported treatment benefits three months after treatment. Scand J Rehabil Med. 1989;21(2):81-9. PMID: 2526364.

86. Hegedus B, Viharos L, Gervain M, et al. The effect of low-level laser in knee osteoarthritis: a double-blind, randomized, placebo-controlled trial. Photomedicine and Laser Surgery. 2009 Aug;27(4):577-84. doi: https://dx.doi.org/10.1089/pho.2008.2297. PMID: 19530911.

87. Helminen EE, Sinikallio SH, Valjakka AL, et al. Effectiveness of a cognitivebehavioural group intervention for knee osteoarthritis pain: a randomized controlled trial. Clinical Rehabilitation. 2015 Sep;29(9):868-81. doi: http://dx.doi.org/10.1177/026921551455856 7. PMID: 25413168.

88. Herman PM, Anderson ML, Sherman KJ, et al. Cost-effectiveness of Mindfulness-based Stress Reduction Versus Cognitive Behavioral Therapy or Usual Care Among Adults With Chronic Low Back Pain. Spine (Phila Pa 1976). 2017 Oct 15;42(20):151120. doi: 10.1097/BRS.0000000000002344. PMID: 28742756. 
89. Hinman RS, McCrory P, Pirotta M, et al. Acupuncture for chronic knee pain: a randomized clinical trial.[Summary for patients in JAMA. 2014 Oct 1;312(13):1365; PMID: 25268455]. JAMA. 2014 Oct 1;312(13):1313-22. doi: http://dx.doi.org/10.1001/jama.2014.12660. PMID: 25268438.

90. Ho LF, Lin ZX, Leung AWN, et al. Efficacy of abdominal acupuncture for neck pain: A randomized controlled trial. PLoS One. 2017;12(7):e0181360. doi: 10.1371/journal.pone.0181360. PMID: 28715459.

91. Hoeksma HL, Dekker J, Ronday HK, et al. Comparison of manual therapy and exercise therapy in osteoarthritis of the hip: a randomized clinical trial. Arthritis \& Rheumatism. 2004 Oct 15;51(5):722-9. PMID: 15478147.

92. Holroyd KA, Nash JM, Pingel JD, et al. A comparison of pharmacological (amitriptyline HCL) and nonpharmacological (cognitive-behavioral) therapies for chronic tension headaches. J Consult Clin Psychol. 1991 Jun;59(3):38793. PMID: 2071723.

93. Holroyd KA, O'Donnell FJ, Stensland M, et al. Management of chronic tension-type headache with tricyclic antidepressant medication, stress management therapy, and their combination: a randomized controlled trial. JAMA. 2001 May 2;285(17):2208-15. PMID: 11325322.

94. Hondras MA, Long CR, Cao Y, et al. A randomized controlled trial comparing 2 types of spinal manipulation and minimal conservative medical care for adults 55 years and older with subacute or chronic low back pain. J Manipulative Physiol Ther. 2009 Jun;32(5):330-43. doi: 10.1016/j.jmpt.2009.04.012. PMID: 19539115.

95. Huang MH, Lin YS, Lee CL, et al. Use of ultrasound to increase effectiveness of isokinetic exercise for knee osteoarthritis. Archives of Physical Medicine \& Rehabilitation. 2005 Aug;86(8):1545-51. PMID: 16084806.
96. Huang MH, Lin YS, Yang RC, et al. A comparison of various therapeutic exercises on the functional status of patients with knee osteoarthritis. Seminars in Arthritis \& Rheumatism. 2003 Jun;32(6):398-406. PMID: 12833248.

97. Huang MH, Yang RC, Lee CL, et al. Preliminary results of integrated therapy for patients with knee osteoarthritis. Arthritis \& Rheumatism. 2005 Dec 15;53(6):812-20. PMID: 16342083.

98. Jensen KB, Kosek E, Wicksell R, et al. Cognitive Behavioral Therapy increases pain-evoked activation of the prefrontal cortex in patients with fibromyalgia.[Erratum appears in Pain. 2012 Sep;153(9):1982]. Pain. 2012 Jul;153(7):1495-503. doi: http://dx.doi.org/10.1016/j.pain.2012.04.010 . PMID: 22617632.

99. Johnson RE, Jones GT, Wiles NJ, et al. Active exercise, education, and cognitive behavioral therapy for persistent disabling low back pain: a randomized controlled trial. Spine (Phila Pa 1976). 2007 Jul 01;32(15):1578-85. doi: 10.1097/BRS.0b013e318074f890. PMID: 17621203.

100. Jousset N, Fanello S, Bontoux L, et al. Effects of functional restoration versus 3 hours per week physical therapy: a randomized controlled study. Spine (Phila Pa 1976). 2004 Mar 01;29(5):487-93; discussion 94. PMID: 15129059.

101. Jubb RW, Tukmachi ES, Jones PW, et al. A blinded randomised trial of acupuncture (manual and electroacupuncture) compared with a non-penetrating sham for the symptoms of osteoarthritis of the knee. Acupuncture in Medicine. 2008 Jun;26(2):69-78. PMID: 18591906.

102. Juhakoski R, Tenhonen S, Malmivaara A, et al. A pragmatic randomized controlled study of the effectiveness and cost consequences of exercise therapy in hip osteoarthritis. Clinical Rehabilitation. 2011 Apr;25(4):37083. doi: http://dx.doi.org/10.1177/026921551038831 3. PMID: 21078702. 
103. Kankaanpaa M, Taimela S, Airaksinen O, et al. The efficacy of active rehabilitation in chronic low back pain. Effect on pain intensity, self-experienced disability, and lumbar fatigability. Spine (Phila Pa 1976). 1999 May 15;24(10):1034-42. PMID: 10332798.

104. Karst M, Rollnik JD, Fink M, et al. Pressure pain threshold and needle acupuncture in chronic tension-type headache--a doubleblind placebo-controlled study. Pain. 2000 Nov;88(2):199-203. PMID: 11050375.

105. Kayiran S, Dursun E, Dursun N, et al. Neurofeedback intervention in fibromyalgia syndrome; a randomized, controlled, rater blind clinical trial. Appl Psychophysiol Biofeedback. 2010 Dec;35(4):293-302. doi: 10.1007/s10484-010-9135-9. PMID: 20614235.

106. Kayo AH, Peccin MS, Sanches CM, et al. Effectiveness of physical activity in reducing pain in patients with fibromyalgia: a blinded randomized clinical trial. Rheumatol Int. 2012 Aug;32(8):2285-92. doi: 10.1007/s00296-011-1958-z. PMID: 21594719.

107. Kerr DP, Walsh DM, Baxter D. Acupuncture in the management of chronic low back pain: a blinded randomized controlled trial. Clin J Pain. 2003 NovDec;19(6):364-70. PMID: 14600536.

108. King SJ, Wessel J, Bhambhani Y, et al. The effects of exercise and education, individually or combined, in women with fibromyalgia. J Rheumatol. 2002 Dec;29(12):2620-7.

109. Lamb SE, Hansen Z, Lall R, et al. Group cognitive behavioural treatment for lowback pain in primary care: a randomised controlled trial and cost-effectiveness analysis. Lancet. $2010 \mathrm{Mar}$ 13;375(9718):916-23. doi: 10.1016/s01406736(09)62164-4. PMID: 20189241.

110. Lamb SE, Mistry D, Lall R, et al. Group cognitive behavioural interventions for low back pain in primary care: extended followup of the Back Skills Training Trial (ISRCTN54717854). Pain. 2012

Feb;153(2):494-501. doi: 10.1016/j.pain.2011.11.016. PMID: 22226729.
111. Lambeek LC, Bosmans JE, Van Royen BJ, et al. Effect of integrated care for sick listed patients with chronic low back pain: economic evaluation alongside a randomised controlled trial. BMJ. 2010 Nov 30;341:c6414. doi: 10.1136/bmj.c6414. PMID: 21118874.

112. Lambeek LC, van Mechelen W, Knol DL, et al. Randomised controlled trial of integrated care to reduce disability from chronic low back pain in working and private life. BMJ. 2010 Mar 16;340:c1035. doi: 10.1136/bmj.c1035. PMID: 20234040.

113. Lansdown H, Howard K, Brealey S, et al. Acupuncture for pain and osteoarthritis of the knee: a pilot study for an open parallelarm randomised controlled trial. BMC Musculoskeletal Disorders. 2009;10:130. doi: http://dx.doi.org/10.1186/1471-247410-130. PMID: 19852841.

114. Lansinger B, Larsson E, Persson LC, et al. Qigong and exercise therapy in patients with long-term neck pain: a prospective randomized trial. Spine. 2007 Oct 15;32(22):2415-22. PMID: 18090079.

115. Larsson A, Palstam A, Lofgren M, et al. Resistance exercise improves muscle strength, health status and pain intensity in fibromyalgia--a randomized controlled trial. Arthritis Res Ther. 2015 Jun 18;17:161.(doi):10.1186/s13075-015-06791.

116. Lauche R, Stumpe C, Fehr J, et al. The Effects of Tai Chi and Neck Exercises in the Treatment of Chronic Nonspecific Neck Pain: A Randomized Controlled Trial. J Pain. 2016 Sep;17(9):1013-27. doi: 10.1016/j.jpain.2016.06.004. PMID: 27345663.

117. Laufer Y, Zilberman R, Porat R, et al. Effect of pulsed short-wave diathermy on pain and function of subjects with osteoarthritis of the knee: a placebo-controlled double-blind clinical trial. Clinical rehabilitation. 2005 May;19(3):255-63. PMID: CN-00513639 UPDATE. 
118. Li X, Lin C, Liu C, et al. Comparison of the effectiveness of resistance training in women with chronic computer-related neck pain: a randomized controlled study. Int Arch Occup Environ Health. 2017 May 20doi: 10.1007/s00420-017-1230-2. PMID: 28528354.

119. Liang Z, Zhu X, Yang X, et al. Assessment of a traditional acupuncture therapy for chronic neck pain: a pilot randomised controlled study. Complementary Therapies in Medicine. 2011 Jan;19 Suppl 1:S26-32. doi:

http://dx.doi.org/10.1016/j.ctim.2010.11.005 . PMID: 21195292.

120. Licciardone JC, Minotti DE, Gatchel RJ, et al. Osteopathic manual treatment and ultrasound therapy for chronic low back pain: a randomized controlled trial. Ann Fam Med. 2013 Mar-Apr;11(2):122-9. doi: 10.1370/afm.1468. PMID: 23508598.

121. Little P, Lewith G, Webley F, et al. Randomised controlled trial of Alexander technique lessons, exercise, and massage (ATEAM) for chronic and recurrent back pain. BMJ. 2008 Aug 19;337:a884. doi: 10.1136/bmj.a884. PMID: 18713809.

122. Lund H, Weile U, Christensen R, et al. A randomized controlled trial of aquatic and land-based exercise in patients with knee osteoarthritis. Journal of Rehabilitation Medicine. 2008 Feb;40(2):137-44. doi: http://dx.doi.org/10.2340/16501977-0134. PMID: 18509579.

123. Lynch M, Sawynok J, Hiew C, et al. A randomized controlled trial of qigong for fibromyalgia. Arthritis Res Ther. 2012 Aug 03

Aug 3;14(4):R178. doi: 10.1186/ar3931.

124. MacPherson H, Tilbrook H, Richmond S, et al. Alexander Technique Lessons or Acupuncture Sessions for Persons With Chronic Neck Pain: A Randomized Trial.[Summary for patients in Ann Intern Med. 2015 Nov 3;163(9):I30; PMID: 26524582]. Annals of Internal Medicine. 2015 Nov 3;163(9):653-62. doi: http://dx.doi.org/10.7326/M15-0667. PMID: 26524571.
125. Mannerkorpi K, Nordeman L, Ericsson A, et al. Pool exercise for patients with fibromyalgia or chronic widespread pain: a randomized controlled trial and subgroup analyses. Journal of Rehabilitation Medicine. 2009 Sep;41(9):751-60. doi: http://dx.doi.org/10.2340/16501977-0409. PMID: 19774310.

126. Martin DP, Sletten CD, Williams BA, et al. Improvement in fibromyalgia symptoms with acupuncture: results of a randomized controlled trial. Mayo Clin Proc. 2006 Jun;81(6):749-57. doi: 10.4065/81.6.749. PMID: 16770975.

127. Martin J, Torre F, Padierna A, et al. Six-and 12-month follow-up of an interdisciplinary fibromyalgia treatment programme: results of a randomised trial. Clin Exp Rheumatol. 2012 Nov-Dec;30(6 Suppl 74):103-11. Epub 2012 Dec 14.

128. Mazzuca SA, Page MC, Meldrum RD, et al. Pilot study of the effects of a heat-retaining knee sleeve on joint pain, stiffness, and function in patients with knee osteoarthritis. Arthritis and rheumatism. 2004 Oct 15;51(5):716-21. PMID: CN-00504445 UPDATE.

129. Messier SP, Loeser RF, Miller GD, et al. Exercise and dietary weight loss in overweight and obese older adults with knee osteoarthritis: the Arthritis, Diet, and Activity Promotion Trial. Arthritis \& Rheumatism. 2004 May;50(5):1501-10. doi: https://dx.doi.org/10.1002/art.20256. PMID: 15146420.

130. Miyamoto GC, Costa LO, Galvanin T, et al. Efficacy of the addition of modified Pilates exercises to a minimal intervention in patients with chronic low back pain: a randomized controlled trial. Phys Ther. 2013 Mar;93(3):310-20. doi: 10.2522/ptj.20120190. PMID: 23064732.

131. Monticone M, Ambrosini E, Rocca B, et al. A multidisciplinary rehabilitation programme improves disability, kinesiophobia and walking ability in subjects with chronic low back pain: results of a randomised controlled pilot study. Eur Spine J. 2014 Oct;23(10):2105-13. doi: 10.1007/s00586-014-3478-5. PMID: 25064093. 
132. Monticone M, Ferrante S, Rocca B, et al. Effect of a long-lasting multidisciplinary program on disability and fear-avoidance behaviors in patients with chronic low back pain: results of a randomized controlled trial. Clin J Pain. 2013 Nov;29(11):929-38. doi: 10.1097/AJP.0b013e31827fef7e. PMID: 23328343.

133. Morone NE, Greco CM, Moore CG, et al. A mind-body program for older adults with chronic low back pain: a randomized clinical trial. JAMA Intern Med. 2016

Mar;176(3):329-37. doi: 10.1001/jamainternmed.2015.8033. PMID: 26903081.

134. Morone NE, Rollman BL, Moore CG, et al. A mind-body program for older adults with chronic low back pain: results of a pilot study. Pain Med. 2009 Nov;10(8):1395-407. doi: 10.1111/j.1526-4637.2009.00746.x. PMID: 20021599.

135. Nambi GS, Inbasekaran D, Khuman R, et al. Changes in pain intensity and health related quality of life with Iyengar yoga in nonspecific chronic low back pain: A randomized controlled study. Int J Yoga. 2014 Jan;7(1):48-53. doi: 10.4103/09736131.123481. PMID: 25035607.

136. Nassif H, Brosset N, Guillaume M, et al. Evaluation of a randomized controlled trial in the management of chronic lower back pain in a French automotive industry: an observational study. Arch Phys Med Rehabil. 2011 Dec;92(12):1927-36.e4. doi: 10.1016/j.apmr.2011.06.029. PMID: 22133239.

137. Natour J, Cazotti Lde A, Ribeiro LH, et al. Pilates improves pain, function and quality of life in patients with chronic low back pain: a randomized controlled trial. Clin Rehabil. 2015 Jan;29(1):59-68. doi: 10.1177/0269215514538981. PMID: 24965957.

138. Nicholas MK, Wilson PH, Goyen J. Operant-behavioural and cognitivebehavioural treatment for chronic low back pain. Behav Res Ther. 1991;29(3):225-38. PMID: 1831972.
139. Nicholas MK, Wilson PH, Goyen J. Comparison of cognitive-behavioral group treatment and an alternative nonpsychological treatment for chronic low back pain. Pain. 1992 Mar;48(3):339-47. PMID: 1534400.

140. Osteras N, Hagen KB, Grotle M, et al. Limited effects of exercises in people with hand osteoarthritis: results from a randomized controlled trial. Osteoarthritis \& Cartilage. 2014 Sep;22(9):1224-33. doi: http://dx.doi.org/10.1016/j.joca.2014.06.036. PMID: 25008206.

141. Paolucci T, Piccinini G, Iosa M, et al. Efficacy of extremely low-frequency magnetic field in fibromyalgia pain: A pilot study. J Rehabil Res Dev. 2016;53(6):102334. doi: 10.1682/JRRD.2015.04.0061. PMID: 28475205.

142. Paolucci T, Vetrano M, Zangrando F, et al. MMPI-2 profiles and illness perception in fibromyalgia syndrome: The role of therapeutic exercise as adapted physical activity. J Back Musculoskelet Rehabil. 2015;28(1):101-9.

143. Penninx BW, Messier SP, Rejeski WJ, et al. Physical exercise and the prevention of disability in activities of daily living in older persons with osteoarthritis. Archives of Internal Medicine. 2001 Oct 22;161(19):2309-16. PMID: 11606146.

144. Penninx BW, Rejeski WJ, Pandya J, et al. Exercise and depressive symptoms: a comparison of aerobic and resistance exercise effects on emotional and physical function in older persons with high and low depressive symptomatology. Journals of Gerontology Series B-Psychological Sciences \& Social Sciences. 2002 Mar;57(2):P124-32. PMID: 11867660.

145. Perlman AI, Ali A, Njike VY, et al. Massage therapy for osteoarthritis of the knee: a randomized dose-finding trial. PLoS ONE [Electronic Resource]. 2012;7(2):e30248. doi:

http://dx.doi.org/10.1371/journal.pone.0030 248. PMID: 22347369. 
146. Poole H, Glenn S, Murphy P. A randomised controlled study of reflexology for the management of chronic low back pain. Eur J Pain. 2007 Nov;11(8):878-87. doi: 10.1016/j.ejpain.2007.01.006. PMID: 17459741.

147. Quilty B, Tucker M, Campbell R, et al. Physiotherapy, including quadriceps exercises and patellar taping, for knee osteoarthritis with predominant patellofemoral joint involvement: randomized controlled trial. Journal of Rheumatology. 2003 Jun;30(6):1311-7. PMID: 12784408.

148. Quinn F, Hughes CM, Baxter GD. Reflexology in the management of low back pain: a pilot randomised controlled trial. Complement Ther Med. 2008 Feb;16(1):3-8. doi: 10.1016/j.ctim.2007.05.001. PMID: 18346622.

149. Redondo JR, Justo CM, Moraleda FV, et al. Long-term efficacy of therapy in patients with fibromyalgia: a physical exercise-based program and a cognitive-behavioral approach. Arthritis \& Rheumatism. 2004 Apr 15;51(2):184-92. PMID: 15077258.

150. Rejeski WJ, Focht BC, Messier SP, et al. Obese, older adults with knee osteoarthritis: weight loss, exercise, and quality of life. Health Psychology. 2002 Sep;21(5):419-26. PMID: 12211508.

151. Roche G, Ponthieux A, Parot-Shinkel E, et al. Comparison of a functional restoration program with active individual physical therapy for patients with chronic low back pain: a randomized controlled trial. Arch Phys Med Rehabil. 2007 Oct;88(10):122935. doi: 10.1016/j.apmr.2007.07.014. PMID: 17908562.

152. Roche-Leboucher G, Petit-Lemanac'h A, Bontoux L, et al. Multidisciplinary intensive functional restoration versus outpatient active physiotherapy in chronic low back pain: a randomized controlled trial. Spine (Phila Pa 1976). 2011 Dec 15;36(26):223542. doi: 10.1097/BRS.0b013e3182191e13. PMID: 21415807.
153. Rosedale R, Rastogi R, May S, et al. Efficacy of exercise intervention as determined by the McKenzie System of Mechanical Diagnosis and Therapy for knee osteoarthritis: a randomized controlled trial. Journal of Orthopaedic \& Sports Physical Therapy. 2014 Mar;44(3):173-81, A1-6. doi: http://dx.doi.org/10.2519/jospt.2014.4791. PMID: 24450370.

154. Rudolfsson T, Djupsjobacka M, Hager C, et al. Effects of neck coordination exercise on sensorimotor function in chronic neck pain: a randomized controlled trial. Journal of Rehabilitation Medicine. 2014 Oct;46(9):908-14. doi: http://dx.doi.org/10.2340/16501977-1869. PMID: 25182501.

155. Sahin N, Ozcan E, Sezen K, et al. Efficacy of acupunture in patients with chronic neck pain--a randomised, sham controlled trial. Acupuncture \& Electro-Therapeutics Research. 2010;35(1-2):17-27. PMID: 20578644.

156. Salvat I, Zaldivar P, Monterde S, et al. Functional status, physical activity level, and exercise regularity in patients with fibromyalgia after Multidisciplinary treatment: retrospective analysis of a randomized controlled trial. Rheumatol Int. 2017 Mar;37(3):377-87. doi: 10.1007/s00296-016-3597-x. PMID: 27844124.

157. Sanudo B, Carrasco L, de Hoyo M, et al. Vagal modulation and symptomatology following a 6-month aerobic exercise program for women with fibromyalgia. Clin Exp Rheumatol. 2015 Jan-Feb;33(1 Suppl 88):S41-5. Epub 2015 Mar 17.

158. Sanudo B, Carrasco L, de Hoyo M, et al. Effects of exercise training and detraining in patients with fibromyalgia syndrome: a 3-yr longitudinal study. Am J Phys Med Rehabil. 2012 Jul;91(7):561-9; quiz 70-3. doi: 10.1097/PHM.0b013e31824faa03.

159. Sanudo B, Galiano D, Carrasco L, et al. Aerobic exercise versus combined exercise therapy in women with fibromyalgia syndrome: a randomized controlled trial. Arch Phys Med Rehabil. 2010 Dec;91(12):1838-43. doi: 10.016/j.apmr.2010.09.006. 
160. Saper RB, Lemaster C, Delitto A, et al. Yoga, Physical Therapy, or Education for Chronic Low Back Pain: A Randomized Noninferiority Trial. Ann Intern Med. 2017 Jul 18;167(2):85-94. doi: 10.7326/m162579. PMID: 28631003.

161. Saral I, Sindel D, Esmaeilzadeh S, et al. The effects of long- and short-term interdisciplinary treatment approaches in women with fibromyalgia: a randomized controlled trial. Rheumatol Int. 2016 Oct;36(10):1379-89. doi: 10.1007/s00296016-3473-8. PMID: 27055444.

162. Schimmel JJ, de Kleuver M, Horsting PP, et al. No effect of traction in patients with low back pain: a single centre, single blind, randomized controlled trial of Intervertebral Differential Dynamics Therapy. Eur Spine J. 2009 Dec;18(12):1843-50. doi: 10.1007/s00586-009-1044-3. PMID: 19484433.

163. Schmidt S, Grossman P, Schwarzer B, et al. Treating fibromyalgia with mindfulnessbased stress reduction: results from a 3armed randomized controlled trial. Pain. 2011 Feb;152(2):361-9. doi: http://dx.doi.org/10.1016/j.pain.2010.10.043 . PMID: 21146930.

164. Seferiadis A, Ohlin P, Billhult A, et al. Basic body awareness therapy or exercise therapy for the treatment of chronic whiplash associated disorders: a randomized comparative clinical trial. Disability \& Rehabilitation. 2016;38(5):442-51. doi: http://dx.doi.org/10.3109/09638288.2015.10 44036. PMID: 25955823.

165. Segal NA, Glass NA, Teran-Yengle P, et al. Intensive Gait Training for Older Adults with Symptomatic Knee Osteoarthritis. American Journal of Physical Medicine \& Rehabilitation. 2015 Oct;94(10 Suppl 1):848-58. doi: http://dx.doi.org/10.1097/PHM.0000000000 000264. PMID: 25768068.

166. Sencan S, Ak S, Karan A, et al. A study to compare the therapeutic efficacy ofaerobic exercise and paroxetine in fibromyalgia syndrome. J Back Musculoskelet Rehabil. 2004;17(2):57-61.
167. Senna MK, Machaly SA. Does maintained spinal manipulation therapy for chronic nonspecific low back pain result in better long-term outcome? Spine (Phila Pa 1976). 2011 Aug 15;36(18):1427-37. doi: 10.1097/BRS.0b013e3181f5dfe0. PMID: 21245790.

168. Sephton SE, Salmon P, Weissbecker I, et al. Mindfulness meditation alleviates depressive symptoms in women with fibromyalgia: results of a randomized clinical trial. Arthritis Rheum. 2007 Feb 15;57(1):77-85. doi: 10.1002/art.22478. PMID: 17266067.

169. Sherman KJ, Cherkin DC, Erro J, et al. Comparing yoga, exercise, and a self-care book for chronic low back pain: a randomized, controlled trial. Ann Intern Med. 2005 Dec 20;143(12):849-56. PMID: 16365466.

170. Sherman KJ, Cherkin DC, Hawkes RJ, et al. Randomized trial of therapeutic massage for chronic neck pain. Clinical Journal of Pain. 2009 Mar-Apr;25(3):233-8. doi: http://dx.doi.org/10.1097/AJP.0b013e31818 b7912. PMID: 19333174.

171. Sherman KJ, Cherkin DC, Wellman RD, et al. A randomized trial comparing yoga, stretching, and a self-care book for chronic low back pain. Arch Intern Med. 2011 Dec 12;171(22):2019-26. doi: 10.1001/archinternmed.2011.524. PMID: 22025101.

172. Somers TJ, Blumenthal JA, Guilak F, et al. Pain coping skills training and lifestyle behavioral weight management in patients with knee osteoarthritis: a randomized controlled study. Pain. 2012 Jun;153(6):1199-209. doi: https://dx.doi.org/10.1016/j.pain.2012.02.02 3. PMID: 22503223.

173. Soriano F, Ríos R. Gallium arsenide laser treatment of chronic low back pain: a prospective, randomized and double blind study. Laser Ther. 1998;10(4):175-80.

174. Stewart MJ, Maher CG, Refshauge KM, et al. Randomized controlled trial of exercise for chronic whiplash-associated disorders. Pain. 2007 Mar;128(1-2):59-68. PMID: 17029788. 
175. Strand LI, Ljunggren AE, Haldorsen EM, et al. The impact of physical function and pain on work status at 1-year follow-up in patients with back pain. Spine (Phila $\mathrm{Pa}$ 1976). 2001 Apr 01;26(7):800-8. PMID: 11295903.

176. Stukstette MJ, Dekker J, den Broeder AA, et al. No evidence for the effectiveness of a multidisciplinary group based treatment program in patients with osteoarthritis of hands on the short term; results of a randomized controlled trial. Osteoarthritis \& Cartilage. 2013 Jul;21(7):901-10. doi: http://dx.doi.org/10.1016/j.joca.2013.03.016. PMID: 23583457.

177. Suarez-Almazor ME, Looney C, Liu Y, et al. A randomized controlled trial of acupuncture for osteoarthritis of the knee: effects of patient-provider communication. Arthritis care \& research. 2010 Sep;62(9):1229-36. doi: http://dx.doi.org/10.1002/acr.20225. PMID: 20506122.

178. Sullivan T, Allegrante JP, Peterson MG, et al. One-year followup of patients with osteoarthritis of the knee who participated in a program of supervised fitness walking and supportive patient education. Arthritis Care \& Research. 1998 Aug;11(4):228-33. PMID: 9791321.

179. Tak E, Staats P, Van Hespen A, et al. The effects of an exercise program for older adults with osteoarthritis of the hip. Journal of Rheumatology. 2005 Jun;32(6):1106-13. PMID: 15940775.

180. Tascioglu F, Armagan O, Tabak Y, et al. Low power laser treatment in patients with knee osteoarthritis. Swiss Medical Weekly. 2004 May 01;134(17-18):254-8. doi: https://dx.doi.org/2004/17/smw-10518. PMID: 15243853.

181. Tavafian SS, Jamshidi AR, Montazeri A. A randomized study of back school in women with chronic low back pain: quality of life at three, six, and twelve months follow-up. Spine (Phila Pa 1976). 2008 Jul 01;33(15):1617-21. doi: 10.1097/BRS.0b013e31817bd31c. PMID: 18580739.
182. Tavola T, Gala C, Conte G, et al. Traditional Chinese acupuncture in tension-type headache: a controlled study. Pain. 1992 Mar;48(3):325-9. PMID: 1594255.

183. Teirlinck CH, Luijsterburg PA, Dekker J, et al. Effectiveness of exercise therapy added to general practitioner care in patients with hip osteoarthritis: a pragmatic randomized controlled trial. Osteoarthritis \& Cartilage. 2016 Jan;24(1):82-90. doi: http://dx.doi.org/10.1016/j.joca.2015.07.023. PMID: 26254237.

184. Thamsborg G, Florescu A, Oturai P, et al. Treatment of knee osteoarthritis with pulsed electromagnetic fields: a randomized, double-blind, placebo-controlled study. Osteoarthritis \& Cartilage. 2005 Jul;13(7):575-81. PMID: 15979009.

185. Thieme K, Flor H, Turk DC. Psychological pain treatment in fibromyalgia syndrome: efficacy of operant behavioural and cognitive behavioural treatments. Arthritis Res Ther. 2006;8(4):R121. doi: 10.1186/ar2010. PMID: 16859516.

186. Thomas KJ, MacPherson H, Thorpe L, et al. Randomised controlled trial of a short course of traditional acupuncture compared with usual care for persistent non-specific low back pain. BMJ. 2006 Sep 23;333(7569):623. doi: 10.1136/bmj.38878.907361.7C. PMID: 16980316.

187. Thomas KS, Muir KR, Doherty M, et al. Home based exercise programme for knee pain and knee osteoarthritis: randomised controlled trial. BMJ. 2002 Oct 5;325(7367):752. PMID: 12364304.

188. Thorstensson CA, Roos EM, Petersson IF, et al. Six-week high-intensity exercise program for middle-aged patients with knee osteoarthritis: a randomized controlled trial [ISRCTN20244858]. BMC Musculoskeletal Disorders. 2005;6:27. PMID: 15924620.

189. Tilbrook HE, Cox H, Hewitt CE, et al. Yoga for chronic low back pain: a randomized trial. Ann Intern Med. 2011 Nov 01;155(9):569-78. doi: 10.7326/0003-4819155-9-201111010-00003. PMID: 22041945. 
190. Tomas-Carus P, Gusi N, Hakkinen A, et al. Eight months of physical training in warm water improves physical and mental health in women with fibromyalgia: a randomized controlled trial. J Rehabil Med. 2008 Apr;40(4):248-52. doi: 10.2340/165019770168.

191. Tomas-Carus P, Gusi N, Hakkinen A, et al. Improvements of muscle strength predicted benefits in HRQOL and postural balance in women with fibromyalgia: an 8-month randomized controlled trial. Rheumatology (Oxford). 2009 Sep;48(9):1147-51. doi: 10.093/rheumatology/kep208. Epub 2009 Jul 14.

192. Trock DH, Bollet AJ, Markoll R. The effect of pulsed electromagnetic fields in the treatment of osteoarthritis of the knee and cervical spine. Report of randomized, double blind, placebo controlled trials. J Rheumatol. 1994 Oct;21(10):1903-11. PMID: 7837158.

193. Turner JA, Clancy S, McQuade KJ, et al. Effectiveness of behavioral therapy for chronic low back pain: a component analysis. J Consult Clin Psychol. 1990 Oct;58(5):573-9. PMID: 2147702.

194. UK BEAM Trial Team. United Kingdom back pain exercise and manipulation (UK BEAM) randomised trial: effectiveness of physical treatments for back pain in primary care. BMJ. 2004 Dec 11;329(7479):1377. doi: 10.1136/bmj.38282.669225.AE. PMID: 15556955.

195. van der Roer N, van Tulder M, Barendse J, et al. Intensive group training protocol versus guideline physiotherapy for patients with chronic low back pain: a randomised controlled trial. Eur Spine J. 2008 Sep;17(9):1193-200. doi: 10.1007/s00586008-0718-6. PMID: 18663487.

196. van Eijk-Hustings Y, Kroese M, Tan F, et al. Challenges in demonstrating the effectiveness of multidisciplinary treatment on quality of life, participation and health care utilisation in patients with fibromyalgia: a randomised controlled trial. Clin Rheumatol. 2013 Feb;32(2):199-209. doi: 10.1007/s10067-012-2100-7. Epub 2012 Oct 10.
197. van Santen M, Bolwijn P, Verstappen F, et al. A randomized clinical trial comparing fitness and biofeedback training versus basic treatment in patients with fibromyalgia. J Rheumatol. 2002 Mar;29(3):575-81.

198. Vas J, Perea-Milla E, Mendez C, et al. Efficacy and safety of acupuncture for chronic uncomplicated neck pain: a randomised controlled study. Pain. 2006 Dec 15;126(1-3):245-55. PMID: 16934402.

199. Vas J, Santos-Rey K, Navarro-Pablo R, et al. Acupuncture for fibromyalgia in primary care: a randomised controlled trial. Acupunct Med. 2016 Aug;34(4):257-66. doi: 10.1136/acupmed-2015-010950. Epub 2016 Feb 15.

200. Verkaik R, Busch M, Koeneman T, et al. Guided imagery in people with fibromyalgia: a randomized controlled trial of effects on pain, functional status and selfefficacy. Journal of health psychology. 2014 May;19(5):678-88. PMID: CN-01049006 UPDATE.

201. Viljanen M, Malmivaara A, Uitti J, et al. Effectiveness of dynamic muscle training, relaxation training, or ordinary activity for chronic neck pain: randomised controlled trial. BMJ. 2003 Aug 30;327(7413):475. PMID: 12946968.

202. Von Korff M, Balderson BH, Saunders K, et al. A trial of an activating intervention for chronic back pain in primary care and physical therapy settings. Pain. 2005 Feb;113(3):323-30. doi: 10.1016/j.pain.2004.11.007. PMID: 15661440.

203. Waling K, Jarvholm B, Sundelin G. Effects of training on female trapezius Myalgia: An intervention study with a 3-year follow-up period. Spine. 2002 Apr 15;27(8):789-96. PMID: 11935098.

204. Wang C, Schmid CH, Hibberd PL, et al. Tai Chi is effective in treating knee osteoarthritis: a randomized controlled trial. Arthritis \& Rheumatism. 2009 Nov 15;61(11):1545-53. doi: http://dx.doi.org/10.1002/art.24832. PMID: 19877092.

205. Wang C, Schmid CH, Rones R, et al. A randomized trial of tai chi for fibromyalgia. N Engl J Med. 2010 Aug 19;363(8):743-54. doi: 10.1056/NEJMoa0912611. 
206. Weng MC, Lee CL, Chen CH, et al. Effects of different stretching techniques on the outcomes of isokinetic exercise in patients with knee osteoarthritis. Kaohsiung Journal of Medical Sciences. 2009 Jun;25(6):30615. doi: http://dx.doi.org/10.1016/S1607551X(09)70521-2. PMID: 19560995.

207. White P, Lewith G, Prescott P, et al. Acupuncture versus placebo for the treatment of chronic mechanical neck pain: a randomized, controlled trial.[Summary for patients in Ann Intern Med. 2004 Dec 21;141(12):I26; PMID: 15611483]. Annals of Internal Medicine. 2004 Dec 21;141(12):911-9. PMID: 15611488.

208. Wicksell RK, Kemani M, Jensen K, et al. Acceptance and commitment therapy for fibromyalgia: a randomized controlled trial. European Journal of Pain. 2013 Apr;17(4):599-611. doi: http://dx.doi.org/10.1002/j.15322149.2012.00224.x. PMID: 23090719.

209. Wigers SH, Stiles TC, Vogel PA. Effects of aerobic exercise versus stress management treatment in fibromyalgia. A 4.5 year prospective study. Scand J Rheumatol. 1996;25(2):77-86.

210. Williams DA, Cary MA, Groner KH, et al. Improving physical functional status in patients with fibromyalgia: a brief cognitive behavioral intervention. J Rheumatol. 2002 Jun;29(6):1280-6.

211. Williams K, Abildso C, Steinberg L, et al. Evaluation of the effectiveness and efficacy of Iyengar yoga therapy on chronic low back pain. Spine (Phila Pa 1976). 2009 Sep 01;34(19):2066-76. doi: 10.1097/BRS.0b013e3181b315cc. PMID: 19701112.
212. Williams KA, Petronis J, Smith D, et al. Effect of Iyengar yoga therapy for chronic low back pain. Pain. 2005 May;115(12):107-17. doi: 10.1016/j.pain.2005.02.016. PMID: 15836974.

213. Williamson L, Wyatt MR, Yein K, et al. Severe knee osteoarthritis: a randomized controlled trial of acupuncture, physiotherapy (supervised exercise) and standard management for patients awaiting knee replacement. Rheumatology. 2007 Sep;46(9):1445-9. PMID: 17604311.

214. Witt C, Brinkhaus B, Jena S, et al. Acupuncture in patients with osteoarthritis of the knee: a randomised trial. Lancet. 2005 Jul 9-15;366(9480):136-43. PMID: 16005336.

215. Yildiz SK, Ozkan FU, Aktas I, et al. The effectiveness of ultrasound treatment for the management of knee osteoarthritis: a randomized, placebo-controlled, doubleblind study. Turkish Journal of Medical Sciences. 2015;45(6):1187-91. PMID: 26775369.

216. Yurtkuran M, Alp A, Konur S, et al. Laser acupuncture in knee osteoarthritis: a doubleblind, randomized controlled study. Photomedicine and Laser Surgery. 2007 Feb;25(1):14-20. PMID: 17352632.

217. Zgierska AE, Burzinski CA, Cox J, et al. Mindfulness Meditation and Cognitive Behavioral Therapy Intervention Reduces Pain Severity and Sensitivity in OpioidTreated Chronic Low Back Pain: Pilot Findings from a Randomized Controlled Trial. Pain Med. 2016 Oct;17(10):1865-81. doi: 10.1093/pm/pnw006. PMID: 26968850.

218. Zhang SP, Chiu TT, Chiu SN. Long-term efficacy of electroacupuncture for chronic neck pain: a randomised controlled trial. Hong Kong Medical Journal. 2013 Dec;19 Suppl 9:36-9. PMID: 24473589. 


\section{Appendix C. Excluded Studies}

\section{Exclusion Codes:}

$3=$ Ineligible population

$4=$ Ineligible intervention

$5=$ Ineligible comparator

$6=$ Ineligible outcomes

7 = Ineligible study design for Key Question

$8=$ Not a study (letter, editorial, non-systematic review article, etc.)

$9=$ Inadequate duration of followup

10 = Systematic review not directly used, but studies checked for inclusion

11 =Not English language, but possibly relevant

$12=$ Not English language and not relevant

1. Aas RW, Tuntland H, Holte KA, et al. Workplace interventions for neck pain in workers. Cochrane Database of Systematic Reviews. 2011(4):CD008160. doi: http://dx.doi.org/10.1002/14651858.CD0081 60.pub2. PMID: 21491405. Exclusion: 10

2. Abasolo L, Carmona L, Hernandez-Garcia C, et al. Musculoskeletal work disability for clinicians: time course and effectiveness of a specialized intervention program by diagnosis. Arthritis \& Rheumatism. 2007 Mar 15;57(2):335-42. doi: https://dx.doi.org/10.1002/art.22529. PMID: 17330282. Exclusion: 3

3. Abbott JH, Robertson MC, McKenzie JE, et al. Exercise therapy, manual therapy, or both, for osteoarthritis of the hip or knee: a factorial randomised controlled trial protocol. Trials. 2009 Feb 08;10:11. doi: 10.1186/1745-6215-10-11. PMID: 19200399. Exclusion: 8

4. Abdoli S, Rahzani K, Safaie M, et al. A randomized control trial: the effect of guided imagery with tape and perceived happy memory on chronic tension type headache. Scandinavian Journal of Caring Sciences. 2012 Jun;26(2):254-61. doi: http://dx.doi.org/10.1111/j.14716712.2011.00926.x. PMID: 21985338. Exclusion: 9
5. Abeles M, Solitar BM, Pillinger MH, et al. Update on fibromyalgia therapy. American Journal of Medicine. 2008 Jul;121(7):55561. doi: http://dx.doi.org/10.1016/j.amjmed.2008.02. 036. PMID: 18589048. Exclusion: 10

6. Aboagye E, Karlsson ML, Hagberg J, et al. Cost-effectiveness of early interventions for non-specific low back pain: a randomized controlled study investigating medical yoga, exercise therapy and self-care advice. $\mathrm{J}$ Rehabil Med. 2015 Feb;47(2):167-73. doi: 10.2340/16501977-1910. PMID: 25403347. Exclusion: 5

7. Acedo AA, Luduvice Antunes AC, Barros dos Santos A, et al. Upper trapezius relaxation induced by TENS and interferential current in computer users with chronic nonspecific neck discomfort: An electromyographic analysis. Journal of Back \& Musculoskeletal Rehabilitation. 2015;28(1):19-24. PMID: 24867904. Exclusion: 5

8. Adsuar JC, Del Pozo-Cruz B, Parraca JA, et al. Whole body vibration improves the single-leg stance static balance in women with fibromyalgia: a randomized controlled trial. J Sports Med Phys Fitness. 2012 Feb;52(1):85-91. Exclusion: 4 
9. Ahmed MS, Shakoor MA, Khan AA. Evaluation of the effects of shortwave diathermy in patients with chronic low back pain. Bangladesh Med Res Counc Bull. 2009;35(1):18-20. PMID: 19637541. Exclusion: 9

10. Ahn H, Woods AJ, Kunik ME, et al. Efficacy of transcranial direct current stimulation over primary motor cortex (anode) and contralateral supraorbital area (cathode) on clinical pain severity and mobility performance in persons with knee osteoarthritis: An experimenter- and participant-blinded, randomized, shamcontrolled pilot clinical study. Brain Stimulation. 2017 Sep - Oct;10(5):902-9. doi: https://dx.doi.org/10.1016/j.brs.2017.05.007. PMID: 28566193. Exclusion: 9

11. Ahsin S, Saleem S, Bhatti AM, et al. Clinical and endocrinological changes after electro-acupuncture treatment in patients with osteoarthritis of the knee. Pain. 2009 Dec 15;147(1-3):60-6. doi: http://dx.doi.org/10.1016/j.pain.2009.08.004 . PMID: 19766392. Exclusion: 9

12. Aker PD, Gross AR, Goldsmith $\mathrm{CH}$, et al. Conservative management of mechanical neck pain: systematic overview and metaanalysis. BMJ. 1996 Nov 23;313(7068):1291-6. PMID: 8942688. Exclusion: 10

13. Akhmadeeva L, Valeeva D, Kharisova E, et al. A double blind randomized placebo controlled trial for non-invasive dynamic trans-cutaneous electrical nerves stimulation in management of tension type headaches: The first results. Cephalalgia. START: 2015 May 14 CONFERENCE END: 2015 May 17, 17th Congress of the International Headache Society, IHC 2015 Valencia Spain;35(6 SUPPL. 1):71. PMID: CN01136421 NEW. Exclusion: 7

14. Alaranta H, Rytokoski U, Rissanen A, et al. Intensive physical and psychosocial training program for patients with chronic low back pain. A controlled clinical trial. Spine (Phila Pa 1976). 1994 Jun 15;19(12):1339-49. PMID: 8066514. Exclusion: 5
15. Alastair Gibson J, Ahmed M. The effectiveness of flexible and rigid supports in patients with lumbar backache. Journal of Orthopaedic Medicine. 2002;24(3):86-9. Exclusion: 9

16. Albornoz-Cabello M, Maya-Martin J, Dominguez-Maldonado G, et al. Effect of interferential current therapy on pain perception and disability level in subjects with chronic low back pain: a randomized controlled trial. Clinical Rehabilitation. 2017 Feb;31(2):242-9. doi: https://dx.doi.org/10.1177/02692155166396 53. PMID: 26975312. Exclusion: 9

17. Alexander A, Woolley SM, Bisesi M, et al. The effectiveness of back belts on occupational back injuries and worker perception. Professional Safety. 1995;40(9):22. Exclusion: 9

18. Alexandre NM, de Moraes MA, Correa Filho HR, et al. Evaluation of a program to reduce back pain in nursing personnel. Rev Saude Publica. 2001 Aug;35(4):356-61. PMID: 11600924. Exclusion: 9

19. Alghadir A, Omar MT, Al-Askar AB, et al. Effect of low-level laser therapy in patients with chronic knee osteoarthritis: a singleblinded randomized clinical study. Lasers in Medical Science. 2014 Mar;29(2):749-55. doi: https://dx.doi.org/10.1007/s10103-0131393-3. PMID: 23912778. Exclusion: 9

20. Ali SS, Ahmed SI, Khan M, et al. Comparing the effects of manual therapy versus electrophysical agents in the management of knee osteoarthritis. Pakistan Journal of Pharmaceutical Sciences. 2014 Jul;27(4 Suppl):1103-6. PMID: 25016274. Exclusion: 9

21. Allen KD, Bongiorni D, Walker TA, et al. Group physical therapy for veterans with knee osteoarthritis: study design and methodology. Contemporary Clinical Trials. 2013 Mar;34(2):296-304. doi: http://dx.doi.org/10.1016/j.cct.2012.12.007. PMID: 23279750. Exclusion: 8

22. Alnigenis MNY, Bradley JD, Wallick J, et al. Massage therapy in the management of fibromyalgia: a pilot study. Journal of Musculoskeletal Pain. 2001;9(2):55-67. Exclusion: 7 
23. Alpayci M, Ilter S. Isometric Exercise for the Cervical Extensors Can Help Restore Physiological Lordosis and Reduce Neck Pain: A Randomized Controlled Trial. Am J Phys Med Rehabil. 2017 Sep;96(9):621-6. Exclusion: 9

24. Alpayci M, Ozkan Y, Yazmalar L, et al. A randomized controlled trial on the efficacy of intermittent and continuous traction for patients with knee osteoarthritis. Clinical rehabilitation. 2013 Apr;27(4):347-54. PMID: CN-00916542 UPDATE. Exclusion: 5

25. Altmaier EM, Lehmann TR, Russell DW, et al. The effectiveness of psychological interventions for the rehabilitation of low back pain: a randomized controlled trial evaluation. Pain. 1992 Jun;49(3):329-35. PMID: 1408299. Exclusion: 5

26. Amorim AB, Pappas E, Simic M, et al. Integrating Mobile health and Physical Activity to reduce the burden of Chronic low back pain Trial (IMPACT): a pilot trial protocol. BMC Musculoskelet Disord. 2016 Jan 19;17:36. doi: 10.1186/s12891-0150852-3. PMID: 26787469. Exclusion: 8

27. Amris K, Luta G, Christensen R, et al. Predictors of improvement in observed functional ability in patients with fibromyalgia as an outcome of rehabilitation. Journal of Rehabilitation Medicine. 2016 Jan;48(1):65-71. doi: http://dx.doi.org/10.2340/16501977-2036. PMID: 26660148. Exclusion: 7

28. Andersen CH, Andersen LL, Gram B, et al. Influence of frequency and duration of strength training for effective management of neck and shoulder pain: a randomised controlled trial. British Journal of Sports Medicine. 2012 Nov;46(14):1004-10. doi: http://dx.doi.org/10.1136/bjsports-2011090813. PMID: 22753863. Exclusion: 9

29. Andersen CH, Andersen LL, Mortensen OS, et al. Protocol for shoulder function training reducing musculoskeletal pain in shoulder and neck: a randomized controlled trial. BMC Musculoskelet Disord. 2011 Jan 14;12:14. doi: 10.1186/1471-2474-12-14. PMID: 21235752. Exclusion: 8
30. Andersen CH, Andersen LL, Pedersen MT, et al. Dose-response of strengthening exercise for treatment of severe neck pain in women. Journal of Strength \& Conditioning Research. 2013 Dec;27(12):3322-8. doi: http://dx.doi.org/10.1519/JSC.0b013e31828f 12c6. PMID: 23478473. Exclusion: 7

31. Andersen CH, Andersen LL, Zebis MK, et al. Effect of scapular function training on chronic pain in the neck/shoulder region: a randomized controlled trial. Journal of Occupational Rehabilitation. 2014 Jun;24(2):316-24. doi: http://dx.doi.org/10.1007/s10926-013-94411. PMID: 23832167. Exclusion: 9

32. Andersen LL, Christensen KB, Holtermann A, et al. Effect of physical exercise interventions on musculoskeletal pain in all body regions among office workers: a oneyear randomized controlled trial. Manual Therapy. 2010 Feb;15(1):100-4. doi: http://dx.doi.org/10.1016/j.math.2009.08.00 4. PMID: 19716742. Exclusion: 3

33. Andersen LL, Mortensen OS, Zebis MK, et al. Effect of brief daily exercise on headache among adults--secondary analysis of a randomized controlled trial. Scandinavian Journal of Work, Environment \& Health. 2011 Nov;37(6):547-50. doi: https://dx.doi.org/10.5271/sjweh.3170. PMID: 21617837. Exclusion: 3

34. Andersen LL, Saervoll CA, Mortensen OS, et al. Effectiveness of small daily amounts of progressive resistance training for frequent neck/shoulder pain: randomised controlled trial. Pain. 2011 Feb;152(2):4406. doi: http://dx.doi.org/10.1016/j.pain.2010.11.016 . PMID: 21177034. Exclusion: 9

35. Andersen LL, Zebis MK, Pedersen MT, et al. Protocol for work place adjusted intelligent physical exercise reducing musculoskeletal pain in shoulder and neck (VIMS): a cluster randomized controlled trial. BMC Musculoskelet Disord. 2010 Aug 05;11:173. doi: 10.1186/1471-2474-11-173. PMID: 20687940. Exclusion: 8

36. Anderson BD. Randomized clinical trial comparing active versus passive approaches to the treatment of recurrent and chronic low back pain: University of Miami at Miami, FL; 2005. Exclusion: 9 
37. Andrade Ortega JA, Ceron Fernandez E, Garcia Llorent R, et al. Microwave diathermy for treating nonspecific chronic neck pain: a randomized controlled trial. The spine journal : official journal of the North American Spine Society. 2014 Aug 1;14(8):1712-21. PMID: CN-00998538 UPDATE. Exclusion: 4

38. Ang BO, Monnier A, Harms-Ringdahl K. Neck/shoulder exercise for neck pain in air force helicopter pilots: a randomized controlled trial. Spine. 2009 Jul 15;34(16):E544-51. doi: http://dx.doi.org/10.1097/BRS.0b013e3181a a6870. PMID: 19770596. Exclusion: 3

39. Anheyer D, Haller H, Barth J, et al. Mindfulness-based stress reduction for treating low back pain: a systematic review and meta-analysis. Ann Intern Med. 2017 Jun 06;166(11):799-807. doi: 10.7326/m161997. PMID: 28437793. Exclusion: 10

40. Ansari NN, Ebadi S, Talebian S, et al. A randomized, single blind placebo controlled clinical trial on the effect of continuous ultrasound on low back pain. Electromyogr Clin Neurophysiol. 2006 Nov;46(6):329-36. PMID: 17147074. Exclusion: 9

41. Anwer S, Alghadir A, Brismee JM. Effect of Home Exercise Program in Patients With Knee Osteoarthritis: A Systematic Review and Meta-analysis. Journal of Geriatric Physical Therapy. 2016 Jan-Mar;39(1):3848. doi: http://dx.doi.org/10.1519/JPT.00000000000 00045. PMID: 25695471. Exclusion: 10

42. Araujo FX, Scholl Schell M, Ribeiro DC. Effectiveness of Physiotherapy interventions plus Extrinsic Feedback for neck disorders: A systematic review with meta-analysis. Musculoskeletal Science \& Practice. 2017 Jun;29:132-43. doi: https://dx.doi.org/10.1016/j.msksp.2017.04. 005. PMID: 28412631. Exclusion: 10

43. Arnold CM, Faulkner RA. The effect of aquatic exercise and education on lowering fall risk in older adults with hip osteoarthritis. Journal of Aging \& Physical Activity. 2010 Jul;18(3):245-60. PMID: 20651413. Exclusion: 9
44. Astin JA, Ernst E. The effectiveness of spinal manipulation for the treatment of headache disorders: a systematic review of randomized clinical trials. Cephalalgia. 2002 Oct;22(8):617-23. PMID: 12383058. Exclusion: 10

45. Atamaz FC, Durmaz B, Baydar M, et al. Comparison of the efficacy of transcutaneous electrical nerve stimulation, interferential currents, and shortwave diathermy in knee osteoarthritis: a doubleblind, randomized, controlled, multicenter study. Archives of Physical Medicine \& Rehabilitation. 2012 May;93(5):748-56. doi: http://dx.doi.org/10.1016/j.apmr.2011.11.03 7. PMID: 22459699. Exclusion: 4

46. Ay S, Dogan SK, Evcik D. Is low-level laser therapy effective in acute or chronic low back pain? Clin Rheumatol. 2010 Aug;29(8):905-10. doi: 10.1007/s10067010-1460-0. PMID: 20414695. Exclusion: 5

47. Ay S, Evcik D. The effects of pulsed electromagnetic fields in the treatment of knee osteoarthritis: a randomized, placebocontrolled trial. Rheumatology International. 2009 Apr;29(6):663-6. doi: http://dx.doi.org/10.1007/s00296-008-0754x. PMID: 19015858. Exclusion: 9

48. Babu AS, Mathew E, Danda D, et al. Management of patients with fibromyalgia using biofeedback: a randomized control trial. Indian Journal of Medical Sciences. 2007 Aug;61(8):455-61. PMID: 17679735. Exclusion: 9

49. Bagnato GL, Miceli G, Atteritano M, et al. Far infrared emitting plaster in knee osteoarthritis: a single blinded, randomised clinical trial. Reumatismo. 2012;64(6):38894. doi: http://dx.doi.org/10.4081/reumatismo.2012. 388. PMID: 23285483. Exclusion: 4

50. Baillie LE, Gabriele JM, Penzien DB. A systematic review of behavioral headache interventions with an aerobic exercise component. Headache. 2014 Jan;54(1):4053. doi: http://dx.doi.org/10.1111/head.12204. PMID: 23992549. Exclusion: 10 
51. Baird CL, Murawski MM, Wu J. Efficacy of guided imagery with relaxation for osteoarthritis symptoms and medication intake. Pain Management Nursing. 2010 Mar;11(1):56-65. doi: http://dx.doi.org/10.1016/j.pmn.2009.04.002 . PMID: 20207328. Exclusion: 9

52. Baird CL, Sands L. A pilot study of the effectiveness of guided imagery with progressive muscle relaxation to reduce chronic pain and mobility difficulties of osteoarthritis. Pain Management Nursing. 2004 Sep;5(3):97-104. PMID: 15359221. Exclusion: 7

53. Baird CL, Sands LP. Effect of guided imagery with relaxation on health-related quality of life in older women with osteoarthritis. Research in Nursing \& Health. 2006 Oct;29(5):442-51. PMID: 16977642. Exclusion: 7

54. Baker KR, Nelson ME, Felson DT, et al. The efficacy of home based progressive strength training in older adults with knee osteoarthritis: a randomized controlled trial. Journal of Rheumatology. 2001 Jul;28(7):1655-65. PMID: 11469475. Exclusion: 9

55. Bakhshani NM, Amirani A, Amirifard H, et al. The Effectiveness of Mindfulness-Based Stress Reduction on Perceived Pain Intensity and Quality of Life in Patients With Chronic Headache. Global Journal of Health Science. 2016 Apr;8(4):142-51. doi: http://dx.doi.org/10.5539/gjhs.v8n4p142. PMID: 26573025. Exclusion: 9

56. Bartels EM, Lund H, Hagen KB, et al. Aquatic exercise for the treatment of knee and hip osteoarthritis. Cochrane Database of Systematic Reviews. 2007(4):CD005523. PMID: 17943863. Exclusion: 10

57. Bartels ME, Juhl CB, Christensen R, et al. Aquatic exercise for the treatment of knee and hip osteoarthritis. Cochrane Database of Systematic Reviews. 2016(3) PMID: 00075320-100000000-04544. Exclusion: 10
58. Bartholdy C, Juhl C, Christensen R, et al. The role of muscle strengthening in exercise therapy for knee osteoarthritis: A systematic review and meta-regression analysis of randomized trials. Semin Arthritis Rheum. 2017 Aug;47(1):9-21. doi: 10.1016/j.semarthrit.2017.03.007. PMID: 28438380. Exclusion: 10

59. Basford JR, Sheffield CG, Mair SD, et al. Low-energy helium neon laser treatment of thumb osteoarthritis. Archives of Physical Medicine \& Rehabilitation. 1987 Nov;68(11):794-7. PMID: 3314790. Exclusion: 9

60. Basler HD, Jakle C, Kroner-Herwig B. Incorporation of cognitive-behavioral treatment into the medical care of chronic low back patients: a controlled randomized study in German pain treatment centers. Patient Educ Couns. 1997 Jun;31(2):113-24. PMID: 9216352. Exclusion: 5

61. Baxter GD, Bleakley C, McDonough S. Clinical effectiveness of laser acupuncture: a systematic review. Jams Journal of Acupuncture \& Meridian Studies. 2008 Dec;1(2):65-82. doi: http://dx.doi.org/10.1016/S20052901(09)60026-1. PMID: 20633458. Exclusion: 10

62. Bearne LM, Walsh NE, Jessep S, et al. Feasibility of an exercise-based rehabilitation programme for chronic hip pain. Musculoskeletal Care. 2011 Sep;9(3):160-8. doi: http://dx.doi.org/10.1002/msc.209. PMID: 21695751. Exclusion: 4

63. Beaudreuil J, Bendaya S, Faucher M, et al. Clinical practice guidelines for rest orthosis, knee sleeves, and unloading knee braces in knee osteoarthritis. Joint, Bone, Spine: Revue du Rhumatisme. 2009 Dec;76(6):629-36. doi: http://dx.doi.org/10.1016/j.jbspin.2009.02.0 02. PMID: 19467901. Exclusion: 10

64. Beinert K, Preiss S, Huber M, et al. Cervical joint position sense in neck pain. Immediate effects of muscle vibration versus mental training interventions: a RCT. European journal of physical \& rehabilitation medicine. 2015 Dec;51(6):825-32. PMID: 25779914. Exclusion: 9 
65. Belza B, Topolski T, Kinne S, et al. Does adherence make a difference? Results from a community-based aquatic exercise program. Nursing Research. 2002 Sep-Oct;51(5):28591. PMID: 12352776 . Exclusion: 7

66. Bennell KL, Ahamed Y, Bryant C, et al. A physiotherapist-delivered integrated exercise and pain coping skills training intervention for individuals with knee osteoarthritis: a randomised controlled trial protocol. BMC Musculoskeletal Disorders. 2012;13:129. doi: http://dx.doi.org/10.1186/1471-247413-129. PMID: 22828288. Exclusion: 8

67. Bennell KL, Egerton T, Martin J, et al. Effect of physical therapy on pain and function in patients with hip osteoarthritis: a randomized clinical trial. JAMA. 2014 May 21;311(19):1987-97. doi: http://dx.doi.org/10.1001/jama.2014.4591. PMID: 24846036. Exclusion: 4

68. Bennell KL, Egerton T, Pua YH, et al. Efficacy of a multimodal physiotherapy treatment program for hip osteoarthritis: a randomised placebo-controlled trial protocol. BMC Musculoskeletal Disorders. 2010;11:238. doi: http://dx.doi.org/10.1186/1471-2474-11238. PMID: 20946621. Exclusion: 8

69. Bennell KL, Hunt MA, Wrigley TV, et al. Hip strengthening reduces symptoms but not knee load in people with medial knee osteoarthritis and varus malalignment: a randomised controlled trial. Osteoarthritis \& Cartilage. 2010 May;18(5):621-8. doi: http://dx.doi.org/10.1016/j.joca.2010.01.010. PMID: 20175973. Exclusion: 9

70. Berggren M, Joost-Davidsson A, Lindstrand $\mathrm{J}$, et al. Reduction in the need for operation after conservative treatment of osteoarthritis of the first carpometacarpal joint: a seven year prospective study. Scandinavian Journal of Plastic \& Reconstructive Surgery \& Hand Surgery. 2001 Dec;35(4):415-7. PMID: 11878178. Exclusion: 4

71. Bergstrom C, Jensen I, Hagberg J, et al. Effectiveness of different interventions using a psychosocial subgroup assignment in chronic neck and back pain patients: a 10year follow-up. Disability \& Rehabilitation. 2012;34(2):110-8. doi:

http://dx.doi.org/10.3109/09638288.2011.60 7218. PMID: 21988525. Exclusion: 3
72. Bernardy K, Klose P, Busch AJ, et al. Cognitive behavioural therapies for fibromyalgia. Cochrane Database of Systematic Reviews. 2013(9) PMID: 00075320-100000000-08144. Exclusion: 10

73. Bertozzi L, Gardenghi I, Turoni F, et al. Effect of therapeutic exercise on pain and disability in the management of chronic nonspecific neck pain: systematic review and meta-analysis of randomized trials. Physical Therapy. 2013 Aug;93(8):1026-36. doi: http://dx.doi.org/10.2522/ptj.20120412. PMID: 23559524. Exclusion: 10

74. Bertozzi L, Valdes K, Vanti C, et al. Investigation of the effect of conservative interventions in thumb carpometacarpal osteoarthritis: systematic review and metaanalysis. Disability \& Rehabilitation. 2015;37(22):2025-43. doi: http://dx.doi.org/10.3109/09638288.2014.99 6299. PMID: 25559974. Exclusion: 10

75. Beumer L, Wong J, Warden SJ, et al. Effects of exercise and manual therapy on pain associated with hip osteoarthritis: a systematic review and meta-analysis. British Journal of Sports Medicine. 2016 Apr;50(8):458-63. doi: http://dx.doi.org/10.1136/bjsports-2015095255. PMID: 26612846. Exclusion: 10

76. Bidonde J, Busch AJ, Schachter CL, et al. Aerobic exercise training for adults with fibromyalgia. Cochrane Database Syst Rev. 2017 Jun 21;6:CD012700. doi: 10.1002/14651858.CD012700. PMID: 28636204. Exclusion: 10

77. Bihaug O. Autotraksjon for ischialgpasienter: en kontrollert sammenlikning mellom effekten av Autotraksjon-B og isometriske ovelser ad modum Hume endall og enkins. Fysioterapeuten. 1978;45:377-9. Exclusion: 3

78. Binder AI. Neck pain. Clinical Evidence. 2008 PMID: 19445809. Exclusion: 10

79. Biondi DM. Physical treatments for headache: a structured review. Headache. 2005 Jun;45(6):738-46. doi: 10.1111/j.15264610.2005.05141.x. PMID: 15953306. Exclusion: 10 
80. Bischoff HA, Roos EM. Effectiveness and safety of strengthening, aerobic, and coordination exercises for patients with osteoarthritis. Current Opinion in Rheumatology. 2003 Mar;15(2):141-4. PMID: 12598802. Exclusion: 10

81. Bittar RG, Teddy PJ. Peripheral neuromodulation for pain. Journal of Clinical Neuroscience. 2009

Oct;16(10):1259-61. doi: http://dx.doi.org/10.1016/j.jocn.2009.02.004 . PMID: 19564116. Exclusion: 10

82. Bjordal JM, Johnson MI, Lopes-Martins RA, et al. Short-term efficacy of physical interventions in osteoarthritic knee pain. A systematic review and meta-analysis of randomised placebo-controlled trials. BMC Musculoskeletal Disorders. 2007;8:51. PMID: 17587446. Exclusion: 10

83. Blangsted AK, Sogaard K, Hansen EA, et al. One-year randomized controlled trial with different physical-activity programs to reduce musculoskeletal symptoms in the neck and shoulders among office workers. Scandinavian Journal of Work, Environment \& Health. 2008 Feb;34(1):55-65. PMID: 18427699. Exclusion: 9

84. Bloch B, Srinivasan S, Mangwani J. Current Concepts in the Management of Ankle Osteoarthritis: A Systematic Review. Journal of Foot \& Ankle Surgery. 2015 SepOct;54(5):932-9. doi:

http://dx.doi.org/10.1053/j.jfas.2014.12.042. PMID: 26028603. Exclusion: 10

85. Boeer J, Mueller O, Krauss I, et al. Effects of a sensory-motor exercise program for older adults with osteoarthritis or prosthesis of the hip using measurements made by the Posturomed oscillatory platform. Journal of Geriatric Physical Therapy. 2010 JanMar;33(1):10-5. PMID: 20503728.

Exclusion: 9

86. Borges J, Baptista AF, Santana N, et al. Pilates exercises improve low back pain and quality of life in patients with HTLV-1 virus: a randomized crossover clinical trial. J Bodyw Mov Ther. 2014 Jan;18(1):68-74. doi: 10.1016/j.jbmt.2013.05.010. PMID: 24411152. Exclusion: 9
87. Borges TP, Kurebayashi LF, Silva MJ. [Occupational low back pain in nursing workers: massage versus pain]. Rev Esc Enferm USP. 2014 Aug;48(4):669-75. PMID: 25338248. Exclusion: 9

88. Borjesson M, Robertson E, Weidenhielm L, et al. Physiotherapy in knee osteoarthrosis: effect on pain and walking. Physiotherapy Research International. 1996;1(2):89-97. PMID: 9238726. Exclusion: 9

89. Borman P, Keskin D, Bodur H. The efficacy of lumbar traction in the management of patients with low back pain. Rheumatol Int. 2003 Mar;23(2):82-6. doi: 10.1007/s00296002-0249-0. PMID: 12634941. Exclusion: 5

90. Bossen D, Veenhof C, Van Beek KE, et al. Effectiveness of a web-based physical activity intervention in patients with knee and/or hip osteoarthritis: randomized controlled trial. Journal of Medical Internet Research. 2013 Nov 22;15(11):e257. doi: https://dx.doi.org/10.2196/jmir.2662. PMID: 24269911. Exclusion: 3

91. Bougea A, Spandideas N, Thomaides T, et al. Chronic tension-type headache management with the emotional freedom technique. Journal of neurology. 2013;260(8) PMID: CN-01024173 UPDATE. Exclusion: 7

92. Bourgault P, Lacasse A, Marchand S, et al. Multicomponent interdisciplinary group intervention for self-management of fibromyalgia: a mixed-methods randomized controlled trial. PLoS One. 2015 May 15;10(5):e0126324. doi: 10.1371/journal.pone.. eCollection 2015. Exclusion: 4

93. Boyaci A, Tutoglu A, Boyaci N, et al. Comparison of the efficacy of ketoprofen phonophoresis, ultrasound, and short-wave diathermy in knee osteoarthritis. Rheumatology international. 2013 Nov;33(11):2811-8. PMID: CN-00996837 NEW. Exclusion: 9

94. Bramberg EB, Bergstrom G, Jensen I, et al. Effects of yoga, strength training and advice on back pain: a randomized controlled trial. BMC Musculoskelet Disord. 2017 Mar 29;18(1):132. PMID: Pmc5372262. Exclusion: 3 
95. Brattberg G. Connective tissue massage in the treatment of fibromyalgia. Eur J Pain. 1999 Jun;3(3):235-44. doi:

10.1053/eujp.1999.0123. PMID: 10700351. Exclusion: 7

96. Brinkhaus B, Witt CM, Jena S, et al. Interventions and physician characteristics in a randomized multicenter trial of acupuncture in patients with low-back pain. J Altern Complement Med. 2006

Sep;12(7):649-57. doi: 10.1089/acm.2006.12.649. PMID: 16970535. Exclusion: 6

97. Bronfort G, Assendelft WJ, Evans R, et al. Efficacy of spinal manipulation for chronic headache: a systematic review. Journal of Manipulative \& Physiological Therapeutics. 2001 Sep;24(7):457-66. PMID: 11562654.

Exclusion: 10

98. Bronfort G, Evans R, Nelson B, et al. A randomized clinical trial of exercise and spinal manipulation for patients with chronic neck pain. Spine. 2001 Apr 1;26(7):788-97; discussion 98-9. PMID: 11295901.

Exclusion: 3

99. Bronfort G, Haas M, Evans RL, et al. WITHDRAWN: Non-invasive physical treatments for chronic/recurrent headache. Cochrane Database of Systematic Reviews. 2014;8:CD001878. doi: http://dx.doi.org/10.1002/14651858.CD0018 78.pub3. PMID: 25157618. Exclusion: 10

100. Brooks C, Kennedy S, Marshall PW. Specific trunk and general exercise elicit similar changes in anticipatory postural adjustments in patients with chronic low back pain: a randomized controlled trial. Spine (Phila Pa 1976). 2012 Dec 01;37(25):E1543-50. doi: 10.1097/BRS.0b013e31826feac0. PMID: 22926279. Exclusion: 9

101. Brosseau L, Taki J, Desjardins B, et al. The Ottawa panel clinical practice guidelines for the management of knee osteoarthritis. Part one: introduction, and mind-body exercise programs. Clin Rehabil. 2017

May;31(5):582-95. doi: 10.1177/0269215517691083. PMID: 28183188. Exclusion: 10
102. Brosseau L, Taki J, Desjardins B, et al. The Ottawa panel clinical practice guidelines for the management of knee osteoarthritis. Part two: strengthening exercise programs. Clin Rehabil. 2017 May;31(5):596-611. doi: 10.1177/0269215517691084. PMID: 28183213. Exclusion: 10

103. Brosseau L, Wells GA, Kenny GP, et al. The implementation of a community-based aerobic walking program for mild to moderate knee osteoarthritis: a knowledge translation randomized controlled trial: part II: clinical outcomes. BMC Public Health. 2012;12:1073. doi: http://dx.doi.org/10.1186/1471-2458-121073. PMID: 23234575. Exclusion: 4

104. Brosseau L, Wells GA, Pugh AG, et al. Ottawa Panel evidence-based clinical practice guidelines for therapeutic exercise in the management of hip osteoarthritis. Clin Rehabil. 2016 Oct;30(10):935-46. doi: 10.1177/0269215515606198. PMID: 26400851. Exclusion: 10

105. Brosseau L, Wells GA, Tugwell P, et al. Ottawa Panel evidence-based clinical practice guidelines on therapeutic massage for neck pain. Journal of Bodywork \& Movement Therapies. 2012 Jul;16(3):30025. doi: http://dx.doi.org/10.1016/j.jbmt.2012.04.001 . PMID: 22703740. Exclusion: 10

106. Brouwer RW, Jakma TS, Verhagen AP, et al. Braces and orthoses for treating osteoarthritis of the knee. Cochrane Database of Systematic Reviews. 2005(1):CD004020. PMID: 15674927. Exclusion: 10

107. Brox JI, Sorensen R, Friis A, et al. Randomized clinical trial of lumbar instrumented fusion and cognitive intervention and exercises in patients with chronic low back pain and disc degeneration. Spine (Phila Pa 1976). 2003 Sep 01;28(17):1913-21. doi: 10.1097/01.brs.0000083234.62751.7a. PMID: 12973134. Exclusion: 5 
108. Bruce-Brand RA, Walls RJ, Ong JC, et al. Effects of home-based resistance training and neuromuscular electrical stimulation in knee osteoarthritis: a randomized controlled trial. BMC Musculoskeletal Disorders. 2012;13:118. doi: http://dx.doi.org/10.1186/1471-2474-13118. PMID: 22759883. Exclusion: 7

109. Buchmuller A, Navez M, Milletre-Bernardin $\mathrm{M}$, et al. Value of TENS for relief of chronic low back pain with or without radicular pain. Eur J Pain. 2012 May;16(5):656-65. doi: 10.1002/j.1532-2149.2011.00061.x. PMID: 22337531. Exclusion: 3

110. Budzynski TH, Stoyva JM, Adler CS, et al. EMG biofeedback and tension headache: a controlled outcome study. Semin Psychiatry. 1973 Nov;5(4):397-410. PMID: 4770570.

Exclusion: 7

111. Buford TW, Fillingim RB, Manini TM, et al. Kaatsu training to enhance physical function of older adults with knee osteoarthritis: Design of a randomized controlled trial. Contemporary Clinical Trials. 2015 Jul;43:217-22. doi: http://dx.doi.org/10.1016/j.cct.2015.06.016. PMID: 26111922. Exclusion: 8

112. Burckhardt CS, Clark SR, Bennett RM. Long-Term Follow-Up of Fibromyalgia Patients Who Completed a Structured Treatment Program versus Patients in Routine Treatment. Journal of Musculoskeletal Pain. 2005 2005/01/01;13(1):5-14. doi: 10.1300/J094v13n01_02. Exclusion: 7

113. Busch AJ, Barber ARK, Overend TJ, et al. Exercise for treating fibromyalgia syndrome. Cochrane Database of Systematic Reviews. 2009(4) PMID: 00075320100000000-02768. Exclusion: 10

114. Busch AJ, Schachter CL, Overend TJ, et al. Exercise for fibromyalgia: a systematic review. Journal of Rheumatology. 2008 Jun;35(6):1130-44. PMID: 18464301. Exclusion: 10

115. Busch AJ, Webber SC, Brachaniec M, et al. Exercise therapy for fibromyalgia. Current Pain \& Headache Reports. 2011 Oct;15(5):358-67. doi: http://dx.doi.org/10.1007/s11916-011-02142. PMID: 21725900. Exclusion: 10
116. Busch AJ, Webber SC, Richards RS, et al. Resistance exercise training for fibromyalgia. Cochrane Database of Systematic Reviews. 2013;12:CD010884. doi: http://dx.doi.org/10.1002/14651858.CD0108 84. PMID: 24362925. Exclusion: 10

117. Bush C, Ditto B, Feuerstein M. A controlled evaluation of paraspinal EMG biofeedback in the treatment of chronic low back pain. Health Psychol. 1985;4(4):307-21. PMID: 2932330. Exclusion: 6

118. Buttagat V, Eungpinichpong W, Chatchawan U, et al. The immediate effects of traditional Thai massage on heart rate variability and stress-related parameters in patients with back pain associated with myofascial trigger points. J Bodyw Mov Ther. 2011 Jan;15(1):15-23. doi: 10.1016/j.jbmt.2009.06.005. PMID: 21147414. Exclusion: 9

119. Button K, Roos PE, Spasic I, et al. The clinical effectiveness of self-care interventions with an exercise component to manage knee conditions: A systematic review. Knee. 2015 Oct;22(5):360-71. doi: http://dx.doi.org/10.1016/j.knee.2015.05.003 . PMID: 26056046. Exclusion: 10

120. Cadmus L, Patrick MB, Maciejewski ML, et al. Community-based aquatic exercise and quality of life in persons with osteoarthritis. Medicine \& Science in Sports \& Exercise. 2010 Jan;42(1):8-15. doi: http://dx.doi.org/10.1249/MSS.0b013e3181a e96a9. PMID: 20010135. Exclusion: 9

121. Cagnie B, Castelein B, Pollie F, et al. Evidence for the Use of Ischemic Compression and Dry Needling in the Management of Trigger Points of the Upper Trapezius in Patients with Neck Pain: A Systematic Review. American Journal of Physical Medicine \& Rehabilitation. 2015 Jul;94(7):573-83. doi: http://dx.doi.org/10.1097/PHM.0000000000 000266. PMID: 25768071. Exclusion: 10

122. Callaghan MJ, Parkes MJ, Felson DT. The Effect of Knee Braces on Quadriceps Strength and Inhibition in Subjects With Patellofemoral Osteoarthritis. Journal of Orthopaedic \& Sports Physical Therapy. 2016 Jan;46(1):19-25. doi: http://dx.doi.org/10.2519/jospt.2016.5093. PMID: 26556391. Exclusion: 6 
123. Callaghan MJ, Parkes MJ, Hutchinson CE, et al. A randomised trial of a brace for patellofemoral osteoarthritis targeting knee pain and bone marrow lesions. Annals of the Rheumatic Diseases. 2015 Jun;74(6):116470. doi: http://dx.doi.org/10.1136/annrheumdis2014-206376. PMID: 25596158. Exclusion: 9

124. Callahan LF, Mielenz T, Freburger J, et al. A randomized controlled trial of the people with arthritis can exercise program: symptoms, function, physical activity, and psychosocial outcomes. Arthritis Rheum. 2008 Jan 15;59(1):92-101. doi: 10.1002/art.23239. PMID: 18163409. Exclusion: 3

125. Calmels P, Queneau P, Hamonet C, et al. Effectiveness of a lumbar belt in subacute low back pain: an open, multicentric, and randomized clinical study. Spine (Phila $\mathrm{Pa}$ 1976). 2009 Feb 01;34(3):215-20. doi: 10.1097/BRS.0b013e31819577dc. PMID: 19179915. Exclusion: 3

126. Cameron ID, Wang E, Sindhusake D. A randomized trial comparing acupuncture and simulated acupuncture for subacute and chronic whiplash. Spine. 2011 Dec 15;36(26):E1659-65. doi: http://dx.doi.org/10.1097/BRS.0b013e31821 bf674. PMID: 21494196. Exclusion: 3

127. Cao L, Zhang XL, Gao YS, et al. Needle acupuncture for osteoarthritis of the knee. A systematic review and updated metaanalysis. Saudi Medical Journal. 2012 May;33(5):526-32. PMID: 22588814. Exclusion: 10

128. Carbonario F, Matsutani LA, Yuan SL, et al. Effectiveness of high-frequency transcutaneous electrical nerve stimulation at tender points as adjuvant therapy for patients with fibromyalgia. European journal of physical and rehabilitation medicine. 2013 Apr;49(2):197-204. PMID: CN00982619 UPDATE. Exclusion: 7

129. Carbonell-Baeza A, Aparicio VA, Ortega FB, et al. Does a 3-month multidisciplinary intervention improve pain, body composition and physical fitness in women with fibromyalgia? British journal of sports medicine. 2011 Dec;45(15):1189-95. PMID: CN-00813385 UPDATE. Exclusion: 7
130. Carlesso LC, Gross AR, Santaguida PL, et al. Adverse events associated with the use of cervical manipulation and mobilization for the treatment of neck pain in adults: a systematic review. Manual Therapy. 2010 Oct;15(5):434-44. doi: http://dx.doi.org/10.1016/j.math.2010.02.00 6. PMID: 20227325. Exclusion: 10

131. Carson JW, Carson KM, Jones KD, et al. A pilot randomized controlled trial of the Yoga of Awareness program in the management of fibromyalgia. Pain. 2010

Nov;151(2):530-9. doi: 10.1016/j.pain.2010.08.020. PMID: 20946990. Exclusion: 9

132. Castien RF, van der Windt DA, Dekker J, et al. Effectiveness of manual therapy compared to usual care by the general practitioner for chronic tension-type headache: design of a randomised clinical trial. BMC Musculoskelet Disord. 2009 Feb 12;10:21. doi: 10.1186/1471-2474-10-21. PMID: 19216763. Exclusion: 8

133. Castro-Sanchez AM, Mataran-Penarrocha GA, Sanchez-Labraca N, et al. A randomized controlled trial investigating the effects of craniosacral therapy on pain and heart rate variability in fibromyalgia patients. Clin Rehabil. 2011 Jan;25(1):2535. doi: 10.1177/0269215510375909. PMID: 20702514. Exclusion: 6

134. Cathcart S, Galatis N, Immink M, et al. Brief mindfulness-based therapy for chronic tension-type headache: a randomized controlled pilot study. Behavioural \& Cognitive Psychotherapy. 2014 Jan;42(1):115. doi: http://dx.doi.org/10.1017/S13524658130002 34. PMID: 23552390. Exclusion: 9

135. Ceccherelli F, Altafini L, Lo Castro G, et al. Diode laser in cervical myofascial pain: a double-blind study versus placebo. Clin J Pain. 1989 Dec;5(4):301-4. PMID: 2520419. Exclusion: 7

136. Cecchi F, Molino-Lova R, Chiti M, et al. Spinal manipulation compared with back school and with individually delivered physiotherapy for the treatment of chronic low back pain: a randomized trial with oneyear follow-up. Clin Rehabil. 2010 Jan;24(1):26-36. doi: 10.1177/0269215509342328. PMID: 20053720. Exclusion: 4 
137. Chaibi A, Russell MB. Manual therapies for primary chronic headaches: a systematic review of randomized controlled trials. Journal of Headache \& Pain. 2014;15:67. doi: http://dx.doi.org/10.1186/1129-237715-67. PMID: 25278005. Exclusion: 10

138. Chan DK, Johnson MI, Sun KO, et al. Electrical acustimulation of the wrist for chronic neck pain: a randomized, shamcontrolled trial using a wrist-ankle acustimulation device. Clinical Journal of Pain. 2009 May;25(4):320-6. doi: http://dx.doi.org/10.1097/AJP.0b013e31819 2ce39. PMID: 19590481. Exclusion: 4

139. Chang TF, Liou TH, Chen CH, et al. Effects of elastic-band exercise on lower-extremity function among female patients with osteoarthritis of the knee. Disability \& Rehabilitation. 2012;34(20):1727-35. doi: http://dx.doi.org/10.3109/09638288.2012.66 0598. PMID: 22397710. Exclusion: 9

140. Chang WJ, Bennell KL, Hodges PW, et al. Combined exercise and transcranial direct current stimulation intervention for knee osteoarthritis: protocol for a pilot randomised controlled trial. BMJ Open. 2015 Aug 21;5(8):e008482. doi: 10.1136/bmjopen-2015-008482. PMID: 26297371. Exclusion: 8

141. Chatchawan U, Eungpinichpong W, Sooktho S, et al. Effects of Thai traditional massage on pressure pain threshold and headache intensity in patients with chronic tension-type and migraine headaches. Journal of Alternative \& Complementary Medicine. 2014 Jun;20(6):486-92. doi: http://dx.doi.org/10.1089/acm.2013.0176. PMID: 24738648. Exclusion: 3

142. Chatchawan U, Thinkhamrop B, Kharmwan $\mathrm{S}$, et al. Effectiveness of traditional Thai massage versus Swedish massage among patients with back pain associated with myofascial trigger points. J Bodyw Mov Ther. 2005;9(4):298-309. Exclusion: 4

143. Cheing GL, Hui-Chan CW. Would the addition of TENS to exercise training produce better physical performance outcomes in people with knee osteoarthritis than either intervention alone? Clinical Rehabilitation. 2004 Aug;18(5):487-97. PMID: 15293483. Exclusion: 6
144. Cheing GL, Hui-Chan CW, Chan KM. Does four weeks of TENS and/or isometric exercise produce cumulative reduction of osteoarthritic knee pain? Clinical Rehabilitation. 2002 Nov;16(7):749-60. PMID: 12428824. Exclusion: 9

145. Cheing GL, Tsui AY, Lo SK, et al. Optimal stimulation duration of tens in the management of osteoarthritic knee pain. Journal of Rehabilitation Medicine. 2003 Mar;35(2):62-8. PMID: 12691335. Exclusion: 7

146. Chen CY, Chen CL, Hsu SC, et al. Effect of magnetic knee wrap on quadriceps strength in patients with symptomatic knee osteoarthritis. Archives of Physical Medicine \& Rehabilitation. 2008 Dec;89(12):2258-64. doi: https://dx.doi.org/10.1016/j.apmr.2008.05.0 19. PMID: 18976982. Exclusion: 9

147. Chen KW, Perlman A, Liao JG, et al. Effects of external qigong therapy on osteoarthritis of the knee. A randomized controlled trial. Clinical Rheumatology. 2008 Dec;27(12):1497-505. doi: http://dx.doi.org/10.1007/s10067-008-09554. PMID: 18654733. Exclusion: 7

148. Chen LX, Zhou ZR, Li YL, et al. Transcutaneous Electrical Nerve Stimulation in Patients With Knee Osteoarthritis: Evidence From Randomized-controlled Trials. Clinical Journal of Pain. 2016 Feb;32(2):146-54. doi: http://dx.doi.org/10.1097/AJP.00000000000 00233. PMID: 25803757. Exclusion: 10

149. Chen N, Wang J, Mucelli A, et al. ElectroAcupuncture is Beneficial for Knee Osteoarthritis: The Evidence from MetaAnalysis of Randomized Controlled Trials. Am J Chin Med. 2017;45(5):965-85. doi: 10.1142/S0192415X17500513. PMID: 28659033. Exclusion: 10

150. Chen YW, Hunt MA, Campbell KL, et al. The effect of Tai Chi on four chronic conditions-cancer, osteoarthritis, heart failure and chronic obstructive pulmonary disease: a systematic review and metaanalyses. British Journal of Sports Medicine. 2016 Apr;50(7):397-407. doi: http://dx.doi.org/10.1136/bjsports-2014094388. PMID: 26383108. Exclusion: 10 
151. Cherian JJ, Bhave A, Kapadia BH, et al. Strength and Functional Improvement Using Pneumatic Brace with Extension Assist for End-Stage Knee Osteoarthritis: A Prospective, Randomized trial. Journal of Arthroplasty. 2015 May;30(5):747-53. doi: http://dx.doi.org/10.1016/j.arth.2014.11.036. PMID: 25499679. Exclusion: 9

152. Cherian JJ, Jauregui JJ, Leichliter AK, et al. The effects of various physical nonoperative modalities on the pain in osteoarthritis of the knee. Bone \& Joint Journal. 2016 Jan;98-B(1 Suppl A):89-94. doi: http://dx.doi.org/10.1302/0301620X.98B1.36353. PMID: 26733650. Exclusion: 10

153. Cherian JJ, Kapadia BH, McElroy MJ, et al. Knee Osteoarthritis: Does Transcutaneous Electrical Nerve Stimulation Work? Orthopedics. 2016 Jan-Feb;39(1):e180-6. doi: http://dx.doi.org/10.3928/0147744720151222-02. PMID: 26726986. Exclusion: 5

154. Cheung C, Wyman JF, Bronas U, et al. Managing knee osteoarthritis with yoga or aerobic/strengthening exercise programs in older adults: a pilot randomized controlled trial. Rheumatology International. 2017 Mar;37(3):389-98. doi: https://dx.doi.org/10.1007/s00296-0163620-2. PMID: 27913870. Exclusion: 9

155. Cheung C, Wyman JF, Resnick B, et al. Yoga for managing knee osteoarthritis in older women: a pilot randomized controlled trial. BMC Complementary \& Alternative Medicine. 2014;14:160. doi: http://dx.doi.org/10.1186/1472-6882-14160. PMID: 24886638. Exclusion: 9

156. Chiranthanut N, Hanprasertpong N, Teekachunhatean S. Thai massage, and Thai herbal compress versus oral ibuprofen in symptomatic treatment of osteoarthritis of the knee: a randomized controlled trial. BioMed Research International. 2014;2014:490512. doi: http://dx.doi.org/10.1155/2014/490512. PMID: 25254207. Exclusion: 9
157. Chow RT, Johnson MI, Lopes-Martins RA, et al. Efficacy of low-level laser therapy in the management of neck pain: a systematic review and meta-analysis of randomised placebo or active-treatment controlled trials. Lancet. 2009 Dec 5;374(9705):1897-908. doi: http://dx.doi.org/10.1016/S01406736(09)61522-1. PMID: 19913903. Exclusion: 10

158. Chown M, Whittamore L, Rush M, et al. A prospective study of patients with chronic back pain randomised to group exercise, physiotherapy or osteopathy. Physiotherapy. 2008 2008/03/01/;94(1):21-8. doi: 10.1016/j.physio.2007.04.014. Exclusion: 4

159. Clausen B, Holsgaard-Larsen A, Sondergaard J, et al. The effect on kneejoint load of instruction in analgesic use compared with neuromuscular exercise in patients with knee osteoarthritis: study protocol for a randomized, single-blind, controlled trial (the EXERPHARMA trial). Trials [Electronic Resource]. 2014;15:444. doi: http://dx.doi.org/10.1186/1745-621515-444. PMID: 25399048. Exclusion: 8

160. Clauw DJ. Does acupuncture help reduce pain in patients with fibromyalgia? Nature Clinical Practice Rheumatology. 2005 Dec;1(2):76-7. doi: https://dx.doi.org/10.1038/ncprheum0065. PMID: 16932634. Exclusion: 8

161. Cleland JA, Childs JD, McRae M, et al. Immediate effects of thoracic manipulation in patients with neck pain: a randomized clinical trial. Manual Therapy. 2005 May;10(2):127-35. PMID: 15922233. Exclusion: 9

162. Coan RM, Wong G, Ku SL, et al. The acupuncture treatment of low back pain: a randomized controlled study. Am J Chin Med. 1980 Spring-Summer;8(1-2):181-9. PMID: 6446852. Exclusion: 5

163. Cochrane T, Davey RC, Matthes Edwards SM. Randomised controlled trial of the costeffectiveness of water-based therapy for lower limb osteoarthritis. Health Technology Assessment (Winchester, England). 2005 Aug;9(31):iii-iv, ix-xi, 1114. PMID: 16095546. Exclusion: 3 
164. Coeytaux RR, Kaufman JS, Kaptchuk TJ, et al. A randomized, controlled trial of acupuncture for chronic daily headache. Headache. 2005 Oct;45(9):1113-23. PMID: 16178942. Exclusion: 3

165. Coleman S, Briffa NK, Carroll G, et al. A randomised controlled trial of a selfmanagement education program for osteoarthritis of the knee delivered by health care professionals. Arthritis Research \& Therapy. 2012;14(1):R21. doi: http://dx.doi.org/10.1186/ar3703. PMID: 22284848. Exclusion: 4

166. Collacott EA, Zimmerman JT, White DW, et al. Bipolar permanent magnets for the treatment of chronic low back pain: a pilot study. Jama. 2000 Mar 08;283(10):1322-5. PMID: 10714732. Exclusion: 9

167. Collado-Mateo D, Dominguez-Munoz FJ, Adsuar JC, et al. Effects of Exergames on Quality of Life, Pain, and Disease Effect in Women With Fibromyalgia: A Randomized Controlled Trial. Archives of Physical Medicine \& Rehabilitation. 2017 Sep;98(9):1725-31. doi: https://dx.doi.org/10.1016/j.apmr.2017.02.0 11. PMID: 28322760. Exclusion: 9

168. Collado-Mateo D, Dominguez-Munoz FJ, Adsuar JC, et al. Exergames for women with fibromyalgia: a randomised controlled trial to evaluate the effects on mobility skills, balance and fear of falling. PeerJ. 2017;5:e3211. doi: https://dx.doi.org/10.7717/peerj.3211. PMID: 28439471. Exclusion: 9

169. Coole C, Drummond A, Watson PJ. Individual work support for employed patients with low back pain: a randomized controlled pilot trial. Clin Rehabil. 2013 Jan;27(1):40-50. doi: 10.1177/0269215512446839. PMID: 22701039. Exclusion: 5

170. Corbett MS, Rice SJ, Madurasinghe V, et al. Acupuncture and other physical treatments for the relief of pain due to osteoarthritis of the knee: network meta-analysis. Osteoarthritis \& Cartilage. 2013 Sep;21(9):1290-8. doi: http://dx.doi.org/10.1016/j.joca.2013.05.007. PMID: 23973143. Exclusion: 10
171. Coudeyre E, Jegu AG, Giustanini M, et al. Isokinetic muscle strengthening for knee osteoarthritis: A systematic review of randomized controlled trials with metaanalysis. Ann Phys Rehabil Med. 2016 Jun;59(3):207-15. doi: 10.1016/j.rehab.2016.01.013. PMID: 27079585. Exclusion: 10

172. Courtois I, Cools F, Calsius J. Effectiveness of body awareness interventions in fibromyalgia and chronic fatigue syndrome: a systematic review and meta-analysis. Journal of Bodywork \& Movement Therapies. 2015 Jan;19(1):35-56. doi: http://dx.doi.org/10.1016/j.jbmt.2014.04.003 . PMID: 25603742. Exclusion: 10

173. Cox H, Tilbrook H, Aplin J, et al. A randomised controlled trial of yoga for the treatment of chronic low back pain: results of a pilot study. Complement Ther Clin Pract. 2010 Nov;16(4):187-93. doi: 10.1016/j.ctcp.2010.05.007. PMID: 20920800. Exclusion: 9

174. Coxhead CE, Inskip H, Meade TW, et al. Multicentre trial of physiotherapy in the management of sciatic symptoms. Lancet. 1981 May 16;1(8229):1065-8. PMID: 6112444. Exclusion: 3

175. Cramer H, Klose P, Brinkhaus B, et al. Effects of yoga on chronic neck pain: a systematic review and meta-analysis. Clinical Rehabilitation. 2017

Nov;31(11):1457-65. doi: https://dx.doi.org/10.1177/02692155176987 35. PMID: 29050510. Exclusion: 10

176. Cramer H, Lauche R, Haller H, et al. A systematic review and meta-analysis of yoga for low back pain. Clin J Pain. 2013 May;29(5):450-60. doi: 10.1097/AJP.0b013e31825e1492. PMID: 23246998. Exclusion: 10

177. Cramer H, Lauche R, Hohmann C, et al. Yoga for chronic neck pain: a 12-month follow-up. Pain Medicine. 2013 Apr;14(4):541-8. doi: http://dx.doi.org/10.1111/pme.12053. PMID: 23387504. Exclusion: 7 
178. Cramer H, Lauche R, Hohmann C, et al. Randomized-controlled trial comparing yoga and home-based exercise for chronic neck pain. Clinical Journal of Pain. 2013 Mar;29(3):216-23. doi: http://dx.doi.org/10.1097/AJP.0b013e31825 1026c. PMID: 23249655. Exclusion: 9

179. Cross KM, Kuenze C, Grindstaff TL, et al. Thoracic spine thrust manipulation improves pain, range of motion, and self-reported function in patients with mechanical neck pain: a systematic review. Journal of Orthopaedic \& Sports Physical Therapy. 2011 Sep;41(9):633-42. doi: http://dx.doi.org/10.2519/jospt.2011.3670. PMID: 21885904. Exclusion: 10

180. Crossley KM, Vicenzino B, Lentzos J, et al. Exercise, education, manual-therapy and taping compared to education for patellofemoral osteoarthritis: a blinded, randomised clinical trial. Osteoarthritis \& Cartilage. 2015 Sep;23(9):1457-64. doi: http://dx.doi.org/10.1016/j.joca.2015.04.024. PMID: 25960116. Exclusion: 4

181. Cruz-Diaz D, Bergamin M, Gobbo S, et al. Comparative effects of 12 weeks of equipment based and mat Pilates in patients with Chronic Low Back Pain on pain, function and transversus abdominis activation. A randomized controlled trial. Complementary Therapies in Medicine. 2017 Aug;33:72-7. doi: https://dx.doi.org/10.1016/j.ctim.2017.06.00 4. PMID: 28735829. Exclusion: 5

182. da Fonseca JL, Magini M, de Freitas TH. Laboratory gait analysis in patients with low back pain before and after a pilates intervention. J Sport Rehabil. 2009 May;18(2):269-82. PMID: 19561369. Exclusion: 9

183. da Silva FS, de Melo FE, do Amaral MM, et al. Efficacy of simple integrated group rehabilitation program for patients with knee osteoarthritis: Single-blind randomized controlled trial. Journal of Rehabilitation Research \& Development. 2015;52(3):30922. doi: http://dx.doi.org/10.1682/JRRD.2014.08.01 99. PMID: 26237073. Exclusion: 9
184. Dailey DL, Rakel BA, Vance CG, et al. Transcutaneous electrical nerve stimulation reduces pain, fatigue and hyperalgesia while restoring central inhibition in primary fibromyalgia. Pain. 2013 Nov;154(11):255462. doi: 10.1016/j.pain.2013.07.043. Epub Jul 27. Exclusion: 9

185. Dalager T, Justesen JB, Sjogaard G. Intelligent Physical Exercise Training in a Workplace Setting Improves Muscle Strength and Musculoskeletal Pain: A Randomized Controlled Trial. Biomed Res Int. 2017;2017:7914134. PMID: Pmc5564061. Exclusion: 3

186. Dalichau S, Scheele K. [Effects of elastic lumbar belts on the effect of a muscle training program for patients with chronic back pain]. Z Orthop Ihre Grenzgeb. 2000 Jan-Feb;138(1):8-16. doi: 10.1055/s-200010106. PMID: 10730357. Exclusion: 5

187. Day MA, Thorn BE. Mindfulness-based cognitive therapy for headache pain: An evaluation of the long-term maintenance of effects. Complement Ther Med. 2017 Aug;33:94-8. doi: 10.1016/j.ctim.2017.06.009. PMID: 28735832. Exclusion: 3

188. Day MA, Thorn BE, Ward LC, et al. Mindfulness-based cognitive therapy for the treatment of headache pain: a pilot study.

The Clinical journal of pain. 2014 Feb;30(2):152-61. PMID: CN-00978978 UPDATE. Exclusion: 3

189. De Hertogh W, Vaes P, Devroey D, et al. Preliminary results, methodological considerations and recruitment difficulties of a randomised clinical trial comparing two treatment regimens for patients with headache and neck pain. BMC musculoskeletal disorders. 2009;10(115) PMID: CN-00742861 UPDATE. Exclusion: 3

190. Dehghan M, Farahbod F. The efficacy of thermotherapy and cryotherapy on pain relief in patients with acute low back pain, a clinical trial study. J Clin Diagn Res. 2014 Sep;8(9):Lc01-4. doi: 10.7860/jcdr/2014/7404.4818. PMID: 25386469. Exclusion: 5 
191. Deluze C, Bosia L, Zirbs A, et al. Electroacupuncture in fibromyalgia: results of a controlled trial. BMJ. 1992 Nov 21;305(6864):1249-52. PMID: 1477566. Exclusion: 9

192. Denegar CR, Schimizzi ME, Dougherty DR, et al. Responses to superficial heating and cooling differ in men and women with knee osteoarthritis. Physiotherapy Theory \& Practice. 2012 Apr;28(3):198-205. doi: https://dx.doi.org/10.3109/09593985.2011.5 86097. PMID: 21823994. Exclusion: 9

193. Denison B. Touch the pain away: new research on therapeutic touch and persons with fibromyalgia syndrome. Holistic Nursing Practice. 2004 May-Jun;18(3):14251. PMID: 15222602. Exclusion: 4

194. Desmoulin GT, Yasin NI, Chen DW. Spinal mechanisms of pain control. Clinical Journal of Pain. 2007 Sep;23(7):576-85. PMID: 17710007. Exclusion: 9

195. Devineni T, Blanchard EB. A randomized controlled trial of an internet-based treatment for chronic headache. Behaviour Research \& Therapy. 2005 Mar;43(3):27792. PMID: 15680926. Exclusion: 3

196. Devos-Comby L, Cronan T, Roesch SC. Do exercise and self-management interventions benefit patients with osteoarthritis of the knee? A metaanalytic review. Journal of Rheumatology. 2006 Apr;33(4):744-56. PMID: 16583478. Exclusion: 10

197. Deyle GD, Henderson NE, Matekel RL, et al. Effectiveness of manual physical therapy and exercise in osteoarthritis of the knee. A randomized, controlled trial. Annals of Internal Medicine. 2000 Feb 1;132(3):17381. PMID: 10651597. Exclusion: 4

198. Deyo RA, Walsh NE, Martin DC, et al. A controlled trial of transcutaneous electrical nerve stimulation (TENS) and exercise for chronic low back pain. N Engl J Med. 1990 Jun 07;322(23):1627-34. doi: 10.1056/nejm199006073222303. PMID: 2140432. Exclusion: 9

199. Dixon ASJ, Owen-Smith BD, Harrison RA. Cold-sensitive, non-specific, low back pain. A comparative trial of treatment. Clin Trials. 1972;9(4):16-21. Exclusion: 5
200. Dobson F, Hinman RS, French S, et al. Internet-mediated physiotherapy and pain coping skills training for people with persistent knee pain (IMPACT - knee pain): a randomised controlled trial protocol. BMC Musculoskelet Disord. 2014 Aug 13;15:279. doi: 10.1186/1471-2474-15-279. PMID: 25125068. Exclusion: 8

201. Doi T, Akai M, Fujino K, et al. Effect of home exercise of quadriceps on knee osteoarthritis compared with nonsteroidal antiinflammatory drugs: a randomized controlled trial. American Journal of Physical Medicine \& Rehabilitation. 2008 Apr;87(4):258-69. doi: http://dx.doi.org/10.1097/PHM.0b013e3181 68c02d. PMID: 18356618. Exclusion: 9

202. Donaldson S, Romney D, Donaldson M, et al. Randomized study of the application of single motor unit biofeedback training to chronic low back pain. J Occup Rehabil. 1994 Mar;4(1):23-37. doi: 10.1007/bf02109994. PMID: 24234261. Exclusion: 5

203. Doran DM, Newell DJ. Manipulation in treatment of low back pain: a multicentre study. Br Med J. 1975 Apr 26;2(5964):1614. PMID: 123815. Exclusion: 3

204. Duivenvoorden T, Brouwer RW, van Raaij TM, et al. Braces and orthoses for treating osteoarthritis of the knee. Cochrane Database of Systematic Reviews. 2015;3:CD004020. doi: http://dx.doi.org/10.1002/14651858.CD0040 20.pub3. PMID: 25773267. Exclusion: 10

205. Duman I, Taskaynatan MA, Mohur H, et al. Assessment of the impact of proprioceptive exercises on balance and proprioception in patients with advanced knee osteoarthritis. Rheumatology International. 2012

Dec;32(12):3793-8. doi: http://dx.doi.org/10.1007/s00296-011-22725. PMID: 22187058. Exclusion: 9

206. Durmus D. Effects of therapeutic ultrasound on pain, disability, walking performance, quality of life, and depression in patients with chronic low back pain: a randomized, placebo controlled trial. Turk J Rheumatol. 2010;25(2):82-7. doi: 10.5152/tjr.2010.06. Exclusion: 5 
207. Durmus D, Akyol Y, Alayli G, et al. Effects of electrical stimulation program on trunk muscle strength, functional capacity, quality of life, and depression in the patients with low back pain: a randomized controlled trial. Rheumatol Int. 2009 Jun;29(8):947-54. doi: 10.1007/s00296-008-0819-x. PMID: 19099308. Exclusion: 9

208. Durmus D, Alayli G, Goktepe AS, et al. Is phonophoresis effective in the treatment of chronic low back pain? A single-blind randomized controlled trial. Rheumatol Int. 2013 Jul;33(7):1737-44. doi: 10.1007/s00296-012-2634-7. PMID: 23283539. Exclusion: 5

209. Durmus D, Durmaz Y, Canturk F. Effects of therapeutic ultrasound and electrical stimulation program on pain, trunk muscle strength, disability, walking performance, quality of life, and depression in patients with low back pain: a randomized-controlled trial. Rheumatol Int. 2010 May;30(7):90110. doi: 10.1007/s00296-009-1072-7. PMID: 19644691. Exclusion: 5

210. Dwyer L, Parkin-Smith GF, Brantingham JW, et al. Manual and manipulative therapy in addition to rehabilitation for osteoarthritis of the knee: assessor-blind randomized pilot trial. Journal of Manipulative \& Physiological Therapeutics. 2015 Jan;38(1):1-21.e2. doi: http://dx.doi.org/10.1016/j.jmpt.2014.10.002 . PMID: 25455832. Exclusion: 9

211. Dziedzic K, Nicholls E, Hill S, et al. Selfmanagement approaches for osteoarthritis in the hand: a 2x2 factorial randomised trial. Annals of the Rheumatic Diseases. 2015 Jan;74(1):108-18. doi: http://dx.doi.org/10.1136/annrheumdis2013-203938. PMID: 24107979. Exclusion: 4

212. Dziedzic KS, Hill S, Nicholls E, et al. Self management, joint protection and exercises in hand osteoarthritis: a randomised controlled trial with cost effectiveness analyses. BMC Musculoskeletal Disorders. 2011;12:156. doi: http://dx.doi.org/10.1186/1471-2474-12156. PMID: 21745357. Exclusion: 8
213. Ebadi S, Henschke N, Nakhostin Ansari N, et al. Therapeutic ultrasound for chronic low-back pain. Cochrane Database Syst Rev. 2014 Mar 14(3):Cd009169. doi: 10.1002/14651858.CD009169.pub2. PMID: 24627326. Exclusion: 10

214. Edinger JD, Wohlgemuth WK, Krystal AD, et al. Behavioral insomnia therapy for fibromyalgia patients: a randomized clinical trial. Archives of Internal Medicine. 2005 Nov 28;165(21):2527-35. PMID: 16314551. Exclusion: 4

215. Eghbali M, Safari R, Nazari F, et al. The effects of reflexology on chronic low back pain intensity in nurses employed in hospitals affiliated with Isfahan University of Medical Sciences. Iran J Nurs Midwifery Res. 2012;17(3):239. PMID: 23833620. Exclusion: 9

216. Eisenberg DM, Buring JE, Hrbek AL, et al. A model of integrative care for low-back pain. J Altern Complement Med. 2012 Apr;18(4):354-62. doi: 10.1089/acm.2011.0408. PMID: 22455544. Exclusion: 3

217. Elliott TL, Marshall KS, Lake DA, et al. The Effect of Sitting on Stability Balls on Nonspecific Lower Back Pain, Disability, and Core Endurance: A Randomized Controlled Crossover Study. Spine. 2016 Sep 15;41(18):E1074-80. doi: https://dx.doi.org/10.1097/BRS.0000000000 001576. PMID: 27010995. Exclusion: 3

218. Elustondo SG, Fuertes RR, Mayor EE, et al. Satisfaction of patients with mechanical neck disorders attended to by primary care physical therapists. Journal of Evaluation in Clinical Practice. 2010 Jun;16(3):445-50. doi: https://dx.doi.org/10.1111/j.13652753.2009.01138.x. PMID: 20337831. Exclusion: 3

219. Endres HG, Bowing G, Diener HC, et al. Acupuncture for tension-type headache: a multicentre, sham-controlled, patient-and observer-blinded, randomised trial. J Headache Pain. 2007 Oct;8(5):306-14. doi: 10.1007/s10194-007-0416-5. PMID: 17955168. Exclusion: 3

220. Ernst E. Chiropractic spinal manipulation for neck pain: a systematic review. Journal of Pain. 2003 Oct;4(8):417-21. PMID: 14622659. Exclusion: 10 
221. Ernst E. Chiropractic manipulation for nonspinal pain--a systematic review. New Zealand Medical Journal. 2003 Aug 8;116(1179):U539. PMID: 14513080. Exclusion: 10

222. Escalante Y, Saavedra JM, Garcia-Hermoso A, et al. Physical exercise and reduction of pain in adults with lower limb osteoarthritis: a systematic review. Journal of Back \& Musculoskeletal Rehabilitation. 2010;23(4):175-86. doi: http://dx.doi.org/10.3233/BMR-2010-0267. PMID: 21079296. Exclusion: 10

223. Esmer G, Blum J, Rulf J, et al. Mindfulnessbased stress reduction for failed back surgery syndrome: a randomized controlled trial. J Am Osteopath Assoc. 2010 Nov;110(11):646-52. PMID: 21135196.

Exclusion: 9

224. Espi-Lopez GV, Gomez-Conesa A, Gomez AA, et al. Treatment of tension-type headache with articulatory and suboccipital soft tissue therapy: A double-blind, randomized, placebo-controlled clinical trial. Journal of bodywork and movement therapies. 2014 Oct;18(4):576-85. PMID: CN-01022354 UPDATE. Exclusion: 3

225. Espi-Lopez GV, Rodriguez-Blanco C, Oliva-Pascual-Vaca A, et al. Effect of manual therapy techniques on headache disability in patients with tension-type headache. Randomized controlled trial. European journal of physical \& rehabilitation medicine. 2014 Dec;50(6):641-7. PMID: 24785463. Exclusion: 9

226. Espi-Lopez GV, Rodriguez-Blanco C, Oliva-Pascual-Vaca A, et al. Do manual therapy techniques have a positive effect on quality of life in people with tension-type headache? A randomized controlled trial. Eur J Phys Rehabil Med. 2016 Aug;52(4):447-56. PMID: 26928164. Exclusion: 3

227. Evans DP, Burke MS, Lloyd KN, et al. Lumbar spinal manipulation on trial. Part I-clinical assessment. Rheumatol Rehabil. 1978 Feb;17(1):46-53. PMID: 153574. Exclusion: 3
228. Evans R, Bronfort G, Nelson B, et al. Twoyear follow-up of a randomized clinical trial of spinal manipulation and two types of exercise for patients with chronic neck pain. Spine. 2002 Nov 1;27(21):2383-9. PMID: 12438988. Exclusion: 3

229. Evcik D, Sonel B. Effectiveness of a homebased exercise therapy and walking program on osteoarthritis of the knee. Rheumatology international. 2002 Jul;22(3):103-6. PMID: CN-00445265 UPDATE. Exclusion: 7

230. Ezzo J, Hadhazy V, Birch S, et al. Acupuncture for osteoarthritis of the knee: a systematic review. Arthritis \& Rheumatism. 2001 Apr;44(4):819-25. PMID: 11315921. Exclusion: 10

231. Ezzo J, Haraldsson BG, Gross AR, et al. Massage for mechanical neck disorders: a systematic review. Spine. 2007 Feb 1;32(3):353-62. PMID: 17268268. Exclusion: 10

232. Facci LM, Nowotny JP, Tormem F, et al. Effects of transcutaneous electrical nerve stimulation (TENS) and interferential currents (IFC) in patients with nonspecific chronic low back pain: randomized clinical trial. Sao Paulo Med J. 2011;129(4):206-16. PMID: 21971895. Exclusion: 9

233. Fairbank J, Frost H, Wilson-MacDonald J, et al. Randomised controlled trial to compare surgical stabilisation of the lumbar spine with an intensive rehabilitation programme for patients with chronic low back pain: the MRC spine stabilisation trial. BMJ. 2005 May 28;330(7502):1233. doi: 10.1136/bmj.38441.620417.8F. PMID: 15911537. Exclusion: 5

234. Falconer J, Hayes KW, Chang RW. Effect of ultrasound on mobility in osteoarthritis of the knee. A randomized clinical trial.

Arthritis Care \& Research. 1992 Mar;5(1):29-35. PMID: 1581369. Exclusion: 4 
235. Falla D, Lindstrom R, Rechter L, et al. Effectiveness of an 8-week exercise programme on pain and specificity of neck muscle activity in patients with chronic neck pain: a randomized controlled study.

European Journal of Pain. 2013

Nov;17(10):1517-28. doi:

http://dx.doi.org/10.1002/j.1532-

2149.2013.00321.x. PMID: 23649799.

Exclusion: 9

236. Farasyn A, Meeusen R, Nijs J. A pilot randomized placebo-controlled trial of roptrotherapy in patients with subacute nonspecific low back pain. J Back

Musculoskelet Rehabil. 2006;19(4):111-7. Exclusion: 3

237. Fary RE, Carroll GJ, Briffa TG, et al. The effectiveness of pulsed electrical stimulation (E-PES) in the management of osteoarthritis of the knee: a protocol for a randomised controlled trial. BMC Musculoskelet Disord. 2008 Feb 04;9:18. doi: 10.1186/1471-24749-18. PMID: 18241355. Exclusion: 8

238. Feliu-Soler A, Borras X, Penarrubia-Maria MT, et al. Cost-utility and biological underpinnings of Mindfulness-Based Stress Reduction (MBSR) versus a psychoeducational programme (FibroQoL) for fibromyalgia: a 12-month randomised controlled trial (EUDAIMON study). BMC Complement Altern Med. 2016 Feb 27;16:81. doi: 10.1186/s12906-016-1068-2. PMID: 26921267. Exclusion: 8

239. Fernandez-de-Las-Penas C, Alonso-Blanco C, Cuadrado ML, et al. Are manual therapies effective in reducing pain from tension-type headache?: a systematic review. Clin J Pain. 2006 Mar-

Apr;22(3):278-85. doi: 10.1097/01.ajp.0000173017.64741.86. PMID: 16514329. Exclusion: 10

240. Ferragut-Garcias A, Plaza-Manzano G, Rodriguez-Blanco C, et al. Effectiveness of a Treatment Involving Soft Tissue Techniques and/or Neural Mobilization Techniques in the Management of TensionType Headache: A Randomized Controlled Trial. Arch Phys Med Rehabil. 2017

Feb;98(2):211-9 e2. doi: 10.1016/j.apmr.2016.08.466. PMID: 27623523. Exclusion: 3
241. Ferreira de Meneses SR, Hunter DJ, Young Docko E, et al. Effect of low-level laser therapy $(904 \mathrm{~nm})$ and static stretching in patients with knee osteoarthritis: a protocol of randomised controlled trial. BMC Musculoskeletal Disorders. 2015;16:252. doi: http://dx.doi.org/10.1186/s12891-0150709-9. PMID: 26369333. Exclusion: 8

242. Ferreira GE, Robinson CC, Wiebusch M, et al. The effect of exercise therapy on knee adduction moment in individuals with knee osteoarthritis: A systematic review. Clinical Biomechanics. 2015 Jul;30(6):521-7. doi: http://dx.doi.org/10.1016/j.clinbiomech.201 5.03.028. PMID: 25896448. Exclusion: 10

243. Field T, Delage J, Hernandez-Reif M. Movement and massage therapy reduce fibromyalgia pain. Journal of Bodywork and Movement Therapies. 2003;7(1):49-52. Exclusion: 9

244. Field T, Diego M, Gonzalez G, et al. Neck arthritis pain is reduced and range of motion is increased by massage therapy.

Complementary Therapies in Clinical Practice. 2014 Nov;20(4):219-23. doi: http://dx.doi.org/10.1016/j.ctcp.2014.09.001. PMID: 25444416. Exclusion: 9

245. Field T, Hernandez-Reif M, Diego M, et al. Lower back pain and sleep disturbance are reduced following massage therapy. $\mathrm{J}$ Bodyw Mov Ther. 2007;11(2):141-5. Exclusion: 9

246. Fink MG, Kunsebeck H, Wipperman B, et al. Non-specific effects of traditional Chinese acupuncture in osteoarthritis of the hip. Complementary Therapies in Medicine. 2001 Jun;9(2):82-9. PMID: 11444887. Exclusion: 5

247. Fjorback LO, Arendt M, Ornbol E, et al. Mindfulness therapy for somatization disorder and functional somatic syndromes: randomized trial with one-year follow-up. J Psychosom Res. 2013 Jan;74(1):31-40. doi: 10.1016/j.jpsychores.2012.09.006. PMID: 23272986. Exclusion: 3 
248. Focht BC, Garver MJ, Devor ST, et al. Improving maintenance of physical activity in older, knee osteoarthritis patients trialpilot (IMPACT-P): design and methods. Contemporary Clinical Trials. 2012

Sep;33(5):976-82. doi: http://dx.doi.org/10.1016/j.cct.2012.04.012. PMID: 22575796. Exclusion: 8

249. Focht BC, Rejeski WJ, Ambrosius WT, et al. Exercise, self-efficacy, and mobility performance in overweight and obese older adults with knee osteoarthritis. Arthritis \& Rheumatism. 2005 Oct 15;53(5):659-65. PMID: 16208674. Exclusion: 6

250. Foley A, Halbert J, Hewitt T, et al. Does hydrotherapy improve strength and physical function in patients with osteoarthritis--a randomised controlled trial comparing a gym based and a hydrotherapy based strengthening programme. Annals of the Rheumatic Diseases. 2003 Dec;62(12):11627. PMID: 14644853. Exclusion: 9

251. Foroughi N, Smith RM, Lange AK, et al. Lower limb muscle strengthening does not change frontal plane moments in women with knee osteoarthritis: A randomized controlled trial. Clinical Biomechanics. 2011 Feb;26(2):167-74. doi: http://dx.doi.org/10.1016/j.clinbiomech.201 0.08.011. PMID: 20888096. Exclusion: 5

252. Foroughi N, Smith RM, Lange AK, et al. Progressive resistance training and dynamic alignment in osteoarthritis: A single-blind randomised controlled trial. Clinical Biomechanics. 2011 Jan;26(1):71-7. doi: http://dx.doi.org/10.1016/j.clinbiomech.201 0.08.013. PMID: 20869141. Exclusion: 9

253. Franke A. Acupuncture massage vs Swedish massage and individual exercise vs group exercise in low back pain sufferers: a randomized controlled clinical trial in a $2 \times 2$ factorial design. Forsch Komplementarmed Klass Naturheilkd. 2000;7:286-93. Exclusion: 9

254. Fransen M, Crosbie J, Edmonds J. Physical therapy is effective for patients with osteoarthritis of the knee: a randomized controlled clinical trial. Journal of Rheumatology. 2001 Jan;28(1):156-64. PMID: 11196518. Exclusion: 9
255. Fransen M, McConnell S. Land-based exercise for osteoarthritis of the knee: a metaanalysis of randomized controlled trials. Journal of Rheumatology. 2009 Jun;36(6):1109-17. doi: http://dx.doi.org/10.3899/jrheum.090058. PMID: 19447940. Exclusion: 10

256. Fransen M, McConnell S, Bell M. Therapeutic exercise for people with osteoarthritis of the hip or knee. A systematic review. Journal of Rheumatology. 2002 Aug;29(8):1737-45. PMID: 12180738. Exclusion: 10

257. Fransen M, McConnell S, Harmer AR, et al. Exercise for osteoarthritis of the knee: a Cochrane systematic review. British Journal of Sports Medicine. 2015 Dec;49(24):15547. doi: http://dx.doi.org/10.1136/bjsports2015-095424. PMID: 26405113. Exclusion: 10

258. Fransen M, McConnell S, HernandezMolina G, et al. Does land-based exercise reduce pain and disability associated with hip osteoarthritis? A meta-analysis of randomized controlled trials. Osteoarthritis \& Cartilage. 2010 May;18(5):613-20. doi: http://dx.doi.org/10.1016/j.joca.2010.01.003. PMID: 20188228. Exclusion: 10

259. Fransen M, McConnell S, HernandezMolina G, et al. Exercise for osteoarthritis of the hip. Cochrane Database of Systematic Reviews. 2014;4:CD007912. doi: http://dx.doi.org/10.1002/14651858.CD0079 12.pub2. PMID: 24756895. Exclusion: 10

260. Fransen M, Nairn L, Winstanley J, et al. Physical activity for osteoarthritis management: a randomized controlled clinical trial evaluating hydrotherapy or Tai Chi classes. Arthritis \& Rheumatism. 2007 Apr 15;57(3):407-14. PMID: 17443749. Exclusion: 3

261. Fredin K, Loras H. Manual therapy, exercise therapy or combined treatment in the management of adult neck pain - A systematic review and meta-analysis. Musculoskeletal Science \& Practice. 2017 Oct;31:62-71. doi: https://dx.doi.org/10.1016/j.msksp.2017.07. 005. PMID: 28750310. Exclusion: 10 
262. French HP, Brennan A, White B, et al. Manual therapy for osteoarthritis of the hip or knee - a systematic review. Manual Therapy. 2011 Apr;16(2):109-17. doi: http://dx.doi.org/10.1016/j.math.2010.10.01 1. PMID: 21146444. Exclusion: 10

263. French HP, Cusack T, Brennan A, et al. Exercise and manual physiotherapy arthritis research trial (EMPART) for osteoarthritis of the hip: a multicenter randomized controlled trial.[Erratum appears in Arch Phys Med Rehabil. 2013 Mar;94(3):600 Note: Fitzpatrick, Martina [added]]. Archives of Physical Medicine \& Rehabilitation. 2013 Feb;94(2):302-14. doi: http://dx.doi.org/10.1016/j.apmr.2012.09.03 0. PMID: 23084955. Exclusion: 4

264. French HP, Cusack T, Brennan A, et al. Exercise and manual physiotherapy arthritis research trial (EMPART): a multicentre randomised controlled trial. BMC Musculoskelet Disord. 2009 Jan 19;10:9. doi: 10.1186/1471-2474-10-9. PMID: 19152689. Exclusion: 8

265. Friedrich M, Gittler G, Halberstadt Y, et al. Combined exercise and motivation program: effect on the compliance and level of disability of patients with chronic low back pain: a randomized controlled trial. Arch Phys Med Rehabil. 1998 May;79(5):475-87. PMID: 9596385. Exclusion: 5

266. Fritz JM, Lindsay W, Matheson JW, et al. Is there a subgroup of patients with low back pain likely to benefit from mechanical traction? Results of a randomized clinical trial and subgrouping analysis. Spine (Phila Pa 1976). 2007 Dec 15;32(26):E793-800. doi: 10.1097/BRS.0b013e31815d001a. PMID: 18091473. Exclusion: 3

267. Frost H, Lamb SE, Doll HA, et al. Randomised controlled trial of physiotherapy compared with advice for low back pain. BMJ. 2004 Sep 25;329(7468):708. doi: 10.1136/bmj.38216.868808.7C. PMID: 15377573. Exclusion: 3

268. Fu LM, Li JT, Wu WS. Randomized controlled trials of acupuncture for neck pain: systematic review and meta-analysis. Journal of Alternative \& Complementary Medicine. 2009 Feb;15(2):133-45. doi: http://dx.doi.org/10.1089/acm.2008.0135. PMID: 19216662. Exclusion: 10
269. Fu WB, Liang ZH, Zhu XP, et al. Analysis on the effect of acupuncture in treating cervical spondylosis with different syndrome types. Chin J Integr Med. 2009 Dec;15(6):426-30. doi: 10.1007/s11655009-0426-z. PMID: 20082247. Exclusion: 4

270. Furlan AD, Giraldo M, Baskwill A, et al. Massage for low-back pain. Cochrane Database Syst Rev. 2015 Sep 01(9):CD001929. doi: 10.1002/14651858.CD001929.pub3. PMID: 26329399. Exclusion: 10

271. Furlan AD, Imamura M, Dryden T, et al. Massage for low-back pain. Cochrane Database Syst Rev. 2008 Oct 08(4):CD001929. doi: 10.1002/14651858.CD001929.pub2. PMID: 18843627. Exclusion: 10

272. Furlan AD, Yazdi F, Tsertsvadze A, et al. Complementary and alternative therapies for back pain II. Evidence Report/Technology Assessment. 2010 Oct(194):1-764. PMID: 23126534. Exclusion: 10

273. Gaber W, Drozd A, Frauenrath-Volkers C, et al. Lifting and carrying with lumbar supports; end report of a project at the airfreight department of Frankfurt/Main airport [Heben und Tragen mit Rückenstützbandagen; Abschlussbericht zum Modellprojekt in der Luftfracht und der Flugzeugabfertigung, Flughafen Frankfurt/Main]. Airfreight department, Frankfurt/Main airport. 1999. Exclusion: 3

274. Gagnon LH. Efficacy of Pilates exercises as therapeutic intervention in treating patients with low back pain. PhD Diss: University of Tennessee; 2005. Exclusion: 9

275. Gaines JM, Metter EJ, Talbot LA. The effect of neuromuscular electrical stimulation on arthritis knee pain in older adults with osteoarthritis of the knee. Applied Nursing Research. 2004 Aug;17(3):201-6. PMID: 15343554. Exclusion: 5

276. Galantino ML, Bzdewka TM, Eissler-Russo JL, et al. The impact of modified Hatha yoga on chronic low back pain: a pilot study.

Altern Ther Health Med. 2004 MarApr;10(2):56-9. PMID: 15055095. Exclusion: 9 
277. Gamber RG, Shores JH, Russo DP, et al. Osteopathic manipulative treatment in conjunction with medication relieves pain associated with fibromyalgia syndrome: results of a randomized clinical pilot project. Journal of the American Osteopathic Association. 2002 Jun;102(6):321-5. PMID: 12090649. Exclusion: 7

278. Garcia AN, Costa Lda C, Hancock M, et al. Identifying Patients With Chronic Low Back Pain Who Respond Best to Mechanical Diagnosis and Therapy: Secondary Analysis of a Randomized Controlled Trial. Physical Therapy. 2016 May;96(5):623-30. doi: https://dx.doi.org/10.2522/ptj.20150295. PMID: 26494768. Exclusion: 5

279. Garcia-Palacios A, Herrero R, Vizcaino Y, et al. Integrating virtual reality with activity management for the treatment of fibromyalgia: acceptability and preliminary efficacy. Clinical Journal of Pain. 2015 Jun;31(6):564-72. doi: http://dx.doi.org/10.1097/AJP.00000000000 00196. PMID: 25551475. Exclusion: 9

280. Garland D, Holt P, Harrington JT, et al. A 3month, randomized, double-blind, placebocontrolled study to evaluate the safety and efficacy of a highly optimized, capacitively coupled, pulsed electrical stimulator in patients with osteoarthritis of the knee. Osteoarthritis \& Cartilage. 2007 Jun;15(6):630-7. PMID: 17303443. Exclusion: 9

281. Gatchel RJ, Polatin PB, Noe C, et al. Treatment- and cost-effectiveness of early intervention for acute low-back pain patients: a one-year prospective study. J Occup Rehabil. 2003 Mar;13(1):1-9. PMID: 12611026. Exclusion: 3

282. Gay MC, Philippot P, Luminet O. Differential effectiveness of psychological interventions for reducing osteoarthritis pain: a comparison of Erikson [correction of Erickson] hypnosis and Jacobson relaxation. European Journal of Pain. 2002;6(1):1-16. PMID: 11888223. Exclusion: 7

283. Geisser ME, Wiggert EA, Haig AJ, et al. A randomized, controlled trial of manual therapy and specific adjuvant exercise for chronic low back pain. Clin J Pain. 2005 Nov-Dec;21(6):463-70. PMID: 16215330. Exclusion: 9
284. Geneen LJ, Moore RA, Clarke C, et al. Physical activity and exercise for chronic pain in adults: an overview of Cochrane Reviews. Cochrane Database of Systematic Reviews. 201704 24;4:CD011279. doi: https://dx.doi.org/10.1002/14651858.CD011 279.pub3. PMID: 28436583. Exclusion: 10

285. Gerard S, Smith BH, Simpson JA. A randomized controlled trial of spiritual healing in restricted neck movement. Journal of Alternative \& Complementary Medicine. 2003 Aug;9(4):467-77. PMID: 14499022. Exclusion: 9

286. Ghoname EA, Craig WF, White PF, et al. Percutaneous electrical nerve stimulation for low back pain: a randomized crossover study. Jama. 1999 Mar 03;281(9):818-23. PMID: 10071003. Exclusion: 9

287. Gialanella B, Ettori T, Faustini S, et al. Home-Based Telemedicine in Patients with Chronic Neck Pain. American Journal of Physical Medicine \& Rehabilitation. 2017 May;96(5):327-32. doi: https://dx.doi.org/10.1097/PHM.000000000 0000610. PMID: 27584139. Exclusion: 4

288. Giggins O, Fullen B, Coughlan G. Neuromuscular electrical stimulation in the treatment of knee osteoarthritis: a systematic review and meta-analysis. Clinical Rehabilitation. 2012 Oct;26(10):867-81. doi: http://dx.doi.org/10.1177/026921551143190 2. PMID: 22324059. Exclusion: 10

289. Giles LG, Muller R. Chronic spinal pain: a randomized clinical trial comparing medication, acupuncture, and spinal manipulation. Spine (Phila Pa 1976). 2003 Jul 15;28(14):1490-502; discussion 502-3. PMID: 12865832. Exclusion: 9

290. Gladwell V, Head S, Haggar M, et al. Does a program of Pilates improve chronic nonspecific low back pain? J Sport Rehabil. 2006;15(4):338-50. Exclusion: 9

291. Glaser JA, Baltz MA, Nietert PJ, et al. Electrical muscle stimulation as an adjunct to exercise therapy in the treatment of nonacute low back pain: a randomized trial. J Pain. 2001 Oct;2(5):295-300. doi: 10.1054/jpai.2001.25523. PMID: 14622808. Exclusion: 5 
292. Goertz CM, Long CR, Hondras MA, et al. Adding chiropractic manipulative therapy to standard medical care for patients with acute low back pain: results of a pragmatic randomized comparative effectiveness study. Spine (Phila Pa 1976). 2013 Apr 15;38(8):627-34. doi: 10.1097/BRS.0b013e31827733e7. PMID: 23060056. Exclusion: 3

293. Goksen N, Calis M, Dogan S, et al. Magnetic resonance therapy for knee osteoarthritis: a randomized, double blind placebo controlled trial. European journal of physical \& rehabilitation medicine. 2016 Aug;52(4):431-9. PMID: 26799573. Exclusion: 4

294. Goldenberg DL, Kaplan KH, Nadeau MG, et al. A Controlled Study of a StressReduction, Cognitive-Behavioral Treatment Program in Fibromyalgia. J. Musculoskelet. Pain. 1994;2(2):53-66. Exclusion: 7

295. Gordon A, Merenstein JH, D'Amico F, et al. The effects of therapeutic touch on patients with osteoarthritis of the knee. Journal of Family Practice. 1998 Oct;47(4):271-7. PMID: 9789512. Exclusion: 7

296. Gowans SE, deHueck A, Voss S, et al. A randomized, controlled trial of exercise and education for individuals with fibromyalgia. Arthritis Care Res. 1999 Apr;12(2):120-8. Exclusion: 9

297. Gowans SE, Dehueck A, Voss S, et al. Sixmonth and one-year followup of 23 weeks of aerobic exercise for individuals with fibromyalgia. Arthritis Rheum. 2004 Dec 15;51(6):890-8. doi: 10.1002/art.20828. PMID: 15593364. Exclusion: 7

298. Graham N, Gross A, Goldsmith CH, et al. Mechanical traction for neck pain with or without radiculopathy. Cochrane Database of Systematic Reviews. 2011(2) PMID: 00075320-100000000-05064. Exclusion: 10

299. Graham N, Gross AR, Goldsmith C, et al. Mechanical traction for mechanical neck disorders: a systematic review. Journal of Rehabilitation Medicine. 2006 May;38(3):145-52. PMID: 16702080. Exclusion: 10
300. Griffin A, Leaver A, Moloney N. General Exercise Does Not Improve Long-Term Pain and Disability in Individuals With Whiplash-Associated Disorders: A Systematic Review. Journal of Orthopaedic \& Sports Physical Therapy. 2017 Jul;47(7):472-80. doi: https://dx.doi.org/10.2519/jospt.2017.7081. PMID: 28622749. Exclusion: 10

301. Groeneweg R, Kropman H, Leopold H, et al. The effectiveness and cost-evaluation of manual therapy and physical therapy in patients with sub-acute and chronic non specific neck pain. Rationale and design of a Randomized Controlled Trial (RCT). BMC Musculoskelet Disord. 2010 Jan 24;11:14. doi: 10.1186/1471-2474-11-14. PMID: 20096136. Exclusion: 8

302. Groeneweg R, van Assen L, Kropman H, et al. Manual therapy compared with physical therapy in patients with non-specific neck pain: a randomized controlled trial. Chiropractic \& manual therapies. 2017;25:12. doi: https://dx.doi.org/10.1186/s12998-0170141-3. PMID: 28465824. Exclusion: 3

303. Gross A, Kay TM, Paquin J, et al. Exercises for mechanical neck disorders. Cochrane Database of Systematic Reviews. 2015(1) PMID: 00075320-100000000-03158. Exclusion: 10

304. Gross A, Langevin P, Burnie SJ, et al. Manipulation and mobilisation for neck pain contrasted against an inactive control or another active treatment. Cochrane Database of Systematic Reviews. 2015;9:CD004249. doi: http://dx.doi.org/10.1002/14651858.CD0042 49.pub4. PMID: 26397370. Exclusion: 10

305. Gross A, Miller J, D'Sylva J, et al. Manipulation or mobilisation for neck pain: a Cochrane Review. Manual Therapy. 2010 Aug;15(4):315-33. doi: http://dx.doi.org/10.1016/j.math.2010.04.00 2. PMID: 20510644. Exclusion: 10

306. Gross AR, Aker PD, Goldsmith $\mathrm{CH}$, et al. Physical medicine modalities for mechanical neck disorders. Cochrane Database of Systematic Reviews. 2000(2):CD000961. PMID: 10796402. Exclusion: 10 
307. Gross AR, Dziengo S, Boers O, et al. Low Level Laser Therapy (LLLT) for Neck Pain: A Systematic Review and Meta-Regression. Open Orthop J. 2013;7:396-419. doi: 10.2174/1874325001307010396. PMID: 24155802. Exclusion: 10

308. Gross AR, Goldsmith C, Hoving JL, et al. Conservative management of mechanical neck disorders: a systematic review. Journal of Rheumatology. 2007 May;34(5):1083102. PMID: 17295434. Exclusion: 10

309. Gross AR, Hoving JL, Haines TA, et al. A Cochrane review of manipulation and mobilization for mechanical neck disorders. Spine. 2004 Jul 15;29(14):1541-8. PMID: 15247576. Exclusion: 10

310. Gross AR, Kay T, Hondras M, et al. Manual therapy for mechanical neck disorders: a systematic review. Manual Therapy. 2002 Aug;7(3):131-49. PMID: 12372310. Exclusion: 10

311. Gross AR, Paquin JP, Dupont G, et al. Exercises for mechanical neck disorders: A Cochrane review update. Man Ther. 2016 Aug;24:25-45. doi: 10.1016/j.math.2016.04.005. PMID: 27317503. Exclusion: 10

312. Grubisic F, Grazio S, Jajic Z, et al. [Therapeutic ultrasound in chronic low back pain treatment]. Reumatizam. 2006;53(1):18-21. PMID: 17580544. Exclusion: 11

313. Güevenol K, Tüzün Ç, Peker Ö, et al. A comparison of inverted spinal traction and conventional traction in the treatment of lumbar disc herniations. Physiother Theory Pract. 2000;16(3):151-60. doi: 10.1080/095939800750036079. Exclusion: 3

314. Gundog M, Atamaz F, Kanyilmaz S, et al. Interferential current therapy in patients with knee osteoarthritis: comparison of the effectiveness of different amplitudemodulated frequencies. American Journal of Physical Medicine \& Rehabilitation. 2012 Feb;91(2):107-13. doi: http://dx.doi.org/10.1097/PHM.0b013e3182 328687. PMID: 22019968. Exclusion: 4
315. Gunn CC, Milbrandt WE, Little AS, et al. Dry needling of muscle motor points for chronic low-back pain: a randomized clinical trial with long-term follow-up. Spine (Phila Pa 1976). 1980 May-Jun;5(3):279-91. PMID: 6446774. Exclusion: 4

316. Gur A, Karakoc M, Cevik R, et al. Efficacy of low power laser therapy and exercise on pain and functions in chronic low back pain. Lasers Surg Med. 2003;32(3):233-8. doi: 10.1002/lsm.10134. PMID: 12605431. Exclusion: 9

317. Gur A, Karakoc M, Nas K, et al. Effects of low power laser and low dose amitriptyline therapy on clinical symptoms and quality of life in fibromyalgia: a single-blind, placebocontrolled trial. Rheumatol Int. 2002 Sep;22(5):188-93. Epub 2002 Jul 6. Exclusion: 9

318. Gur A, Karakoc M, Nas K, et al. Efficacy of low power laser therapy in fibromyalgia: a single-blind, placebo-controlled trial. Lasers Med Sci. 2002;17(1):57-61. doi: 10.1007/s101030200010. PMID: 11845369. Exclusion: 9

319. Gusi N, Parraca JA, Olivares PR, et al. Tilt vibratory exercise and the dynamic balance in fibromyalgia: A randomized controlled trial. Arthritis Care Res (Hoboken). 2010 Aug;62(8):1072-8. doi: 10.02/acr.20180. Exclusion: 4

320. Gusi N, Tomas-Carus P. Cost-utility of an 8month aquatic training for women with fibromyalgia: a randomized controlled trial. Arthritis Res Ther. 2008;10(1):R24. doi: 10.1186/ar2377. Epub 008 Feb 22. Exclusion: 6

321. Gustavsson C, von Koch L. Applied relaxation in the treatment of long-lasting neck pain: a randomized controlled pilot study. Journal of Rehabilitation Medicine. 2006 Mar;38(2):100-7. PMID: 16546766. Exclusion: 4

322. Gworys K, Gasztych J, Puzder A, et al. Influence of various laser therapy methods on knee joint pain and function in patients with knee osteoarthritis. Ortopedia Traumatologia Rehabilitacja. 2012 MayJun;14(3):269-77. doi: https://dx.doi.org/10.5604/15093492.100225 7. PMID: 22764339. Exclusion: 9 
323. Haak T, Scott B. The effect of Qigong on fibromyalgia (FMS): a controlled randomized study. Disabil Rehabil. 2008;30(8):625-33. Exclusion: 9

324. Haines T, Bowles KA. Cost-effectiveness of using a motion-sensor biofeedback treatment approach for the management of sub-acute or chronic low back pain: economic evaluation alongside a randomised trial. BMC Musculoskeletal Disorders. 2017 Jan 17;18(1):18. doi: https://dx.doi.org/10.1186/s12891-0161371-6. PMID: 28095832. Exclusion: 3

325. Halbert J, Crotty M, Weller D, et al. Primary care-based physical activity programs: effectiveness in sedentary older patients with osteoarthritis symptoms. Arthritis \& Rheumatism. 2001 Jun;45(3):228-34. doi: https://dx.doi.org/10.1002/15290131(200106)45:3<228::AIDART253>3.0.CO;2-2. PMID: 11409662. Exclusion: 3

326. Hale LA, Waters D, Herbison P. A randomized controlled trial to investigate the effects of water-based exercise to improve falls risk and physical function in older adults with lower-extremity osteoarthritis. Archives of Physical Medicine \& Rehabilitation. 2012 Jan;93(1):27-34. doi: http://dx.doi.org/10.1016/j.apmr.2011.08.00 4. PMID: 21982325. Exclusion: 9

327. Hall AM, Maher CG, Lam P, et al. Tai chi exercise for treatment of pain and disability in people with persistent low back pain: a randomized controlled trial. Arthritis Care Res (Hoboken). 2011 Nov;63(11):1576-83. doi: 10.1002/acr.20594. PMID: 22034119. Exclusion: 9

328. Haller H, Lauche R, Cramer H, et al. Craniosacral Therapy for the Treatment of Chronic Neck Pain: A Randomized Shamcontrolled Trial. Clin J Pain. 2016

May;32(5):441-9. doi: 10.1097/AJP.0000000000000290. PMID: 26340656. Exclusion: 4

329. Hammond A, Freeman K. Community patient education and exercise for people with fibromyalgia: a parallel group randomized controlled trial. Clin Rehabil. 2006 Oct;20(10):835-46. Exclusion: 5
330. Hamnes B, Kjeken I, Mowinckel P, et al. Effects of a one week multidisciplinary inpatient self-management programme for patients with fibromyalgia: A randomised controlled trial. Annals of the Rheumatic Disease. 2012;71(6) PMID: CN-01011618 UPDATE. Exclusion: 9

331. Hansen IR, Sogaard K, Christensen R, et al. Neck exercises, physical and cognitive behavioural-graded activity as a treatment for adult whiplash patients with chronic neck pain: design of a randomised controlled trial. BMC Musculoskeletal Disorders. 2011;12:274. doi: http://dx.doi.org/10.1186/1471-2474-12274. PMID: 22136113. Exclusion: 8

332. Haraldsson BG, Gross AR, Myers CD, et al. Massage for mechanical neck disorders. Cochrane Database of Systematic Reviews. 2006(3):CD004871. PMID: 16856066. Exclusion: 10

333. Harris RE, Tian X, Williams DA, et al. Treatment of fibromyalgia with formula acupuncture: investigation of needle placement, needle stimulation, and treatment frequency. J Altern Complement Med. 2005 Aug;11(4):663-71. Exclusion: 5

334. Harris RE, Zubieta JK, Scott DJ, et al. Traditional Chinese acupuncture and placebo (sham) acupuncture are differentiated by their effects on mu-opioid receptors (MORs). Neuroimage. 2009 Sep;47(3):1077-85. doi: http://dx.doi.org/10.1016/j.neuroimage.2009 .05.083. PMID: 19501658. Exclusion: 7

335. Hart LE. Combination of manual physical therapy and exercises for osteoarthritis of the knee. Clinical Journal of Sport Medicine. 2000 Oct;10(4):305. PMID: 11086762. Exclusion: 8

336. Harte AA, Baxter GD, Gracey JH. The effectiveness of motorised lumbar traction in the management of LBP with lumbo sacral nerve root involvement: a feasibility study. BMC Musculoskelet Disord. 2007 Nov 29;8:118. doi: 10.1186/1471-2474-8-118. PMID: 18047650. Exclusion: 3 
337. Hartman CA, Manos TM, Winter C, et al. Effects of T'ai Chi training on function and quality of life indicators in older adults with osteoarthritis. Journal of the American Geriatrics Society. 2000 Dec;48(12):1553-9. PMID: 11129742. Exclusion: 9

338. Harts CC, Helmhout PH, de Bie RA, et al. A high-intensity lumbar extensor strengthening program is little better than a low-intensity program or a waiting list control group for chronic low back pain: a randomised clinical trial. Aust J Physiother. 2008;54(1):23-31. PMID: 18298356. Exclusion: 9

339. Haslam R. A comparison of acupuncture with advice and exercises on the symptomatic treatment of osteoarthritis of the hip--a randomised controlled trial. Acupuncture in Medicine. 2001 Jun;19(1):19-26. PMID: 11471578. Exclusion: 9

340. Hayden JA, van Tulder MW, Malmivaara A, et al. Exercise therapy for treatment of nonspecific low back pain. Cochrane Database Syst Rev. 2005 Jul 20(3):CD000335. doi: 10.1002/14651858.CD000335.pub2. PMID: 16034851. Exclusion: 10

341. He D, Hostmark AT, Veiersted KB, et al. Effect of intensive acupuncture on painrelated social and psychological variables for women with chronic neck and shoulder pain--an RCT with six month and three year follow up. Acupuncture in Medicine. 2005 Jun;23(2):52-61. PMID: 16025785. Exclusion: 7

342. He D, Veiersted KB, Hostmark AT, et al. Effect of acupuncture treatment on chronic neck and shoulder pain in sedentary female workers: a 6-month and 3-year follow-up study. Pain. 2004 Jun;109(3):299-307. PMID: 15157691. Exclusion: 7

343. Helewa A, Goldsmith CH, Smythe HA, et al. Effect of therapeutic exercise and sleeping neck support on patients with chronic neck pain: a randomized clinical trial. Journal of Rheumatology. 2007 Jan;34(1):151-8. PMID: 17216683. Exclusion: 5
344. Helminen EE, Sinikallio SH, Valjakka AL, et al. Determinants of pain and functioning in knee osteoarthritis: a one-year prospective study. Clinical Rehabilitation. 2016 Sep;30(9):890-900. doi: https://dx.doi.org/10.1177/02692155156196 60. PMID: 27496698. Exclusion: 7

345. Hemmila HM. Bone setting for prolonged neck pain: a randomized clinical trial. Journal of Manipulative \& Physiological Therapeutics. 2005 Sep;28(7):508-15. PMID: 16182025. Exclusion: 5

346. Henchoz Y, de Goumoens P, So AK, et al. Functional multidisciplinary rehabilitation versus outpatient physiotherapy for non specific low back pain: randomized controlled trial. Swiss Med Wkly. 2010 Dec 22;140:w13133. doi: 10.4414/smw.2010.13133. PMID: 21181567. Exclusion: 5

347. Hennig T, Haehre L, Hornburg VT, et al. Effect of home-based hand exercises in women with hand osteoarthritis: a randomised controlled trial. Annals of the Rheumatic Diseases. 2015 Aug;74(8):15018. doi: http://dx.doi.org/10.1136/annrheumdis2013-204808. PMID: 24667900. Exclusion: 9

348. Henriksen M, Klokker L, Graven-Nielsen T, et al. Association of exercise therapy and reduction of pain sensitivity in patients with knee osteoarthritis: a randomized controlled trial. Arthritis care \& research. 2014 Dec;66(12):1836-43. doi: http://dx.doi.org/10.1002/acr.22375. PMID: 24905427. Exclusion: 9

349. Hernandez-Molina G, Reichenbach S, Zhang B, et al. Effect of therapeutic exercise for hip osteoarthritis pain: results of a metaanalysis. Arthritis \& Rheumatism. 2008 Sep 15;59(9):1221-8. doi: http://dx.doi.org/10.1002/art.24010. PMID: 18759315. Exclusion: 10

350. Hernandez-Reif M, Field T, Krasnegor J, et al. Lower back pain is reduced and range of motion increased after massage therapy. Int J Neurosci. 2001;106(3-4):131-45. PMID: 11264915. Exclusion: 9 
351. Hertzman-Miller RP, Morgenstern H, Hurwitz EL, et al. Comparing the satisfaction of low back pain patients randomized to receive medical or chiropractic care: results from the UCLA low-back pain study. Am J Public Health. 2002 Oct;92(10):1628-33. PMID: 12356612. Exclusion: 3

352. Heuts PH, de Bie R, Drietelaar M, et al. Self-management in osteoarthritis of hip or knee: a randomized clinical trial in a primary healthcare setting. Journal of Rheumatology. 2005 Mar;32(3):543-9. PMID: 15742451. Exclusion: 4

353. Hidalgo B, Hall T, Bossert J, et al. The efficacy of manual therapy and exercise for treating non-specific neck pain: A systematic review. J Back Musculoskelet Rehabil. 2017 Nov 6;30(6):1149-69. doi: 10.3233/BMR-169615. PMID: 28826164. Exclusion: 10

354. Hill JC, Lewis M, Sim J, et al. Predictors of poor outcome in patients with neck pain treated by physical therapy. Clinical Journal of Pain. 2007 Oct;23(8):683-90. PMID: 17885347. Exclusion: 7

355. Hinman MR, Ford J, Heyl H. Effects of static magnets on chronic knee pain and physical function: a double-blind study. Alternative Therapies in Health \& Medicine. 2002 Jul-Aug;8(4):50-5. PMID: 12126173. Exclusion: 3

356. Hinman RS, Heywood SE, Day AR. Aquatic physical therapy for hip and knee osteoarthritis: results of a single-blind randomized controlled trial. Physical Therapy. 2007 Jan;87(1):32-43. PMID: 17142642. Exclusion: 9

357. Hiyama Y, Yamada M, Kitagawa A, et al. A four-week walking exercise programme in patients with knee osteoarthritis improves the ability of dual-task performance: a randomized controlled trial. Clinical Rehabilitation. 2012 May;26(5):403-12. doi: http://dx.doi.org/10.1177/026921551142102 8. PMID: 21975468. Exclusion: 9

358. Hobson WH, Shiraki R, Steiner D, et al. Spinal manipulation vs. amitriptyline for the treatment of chronic tension headache: a randomized clinical trial. J Manipulative Physiol Ther. 1996 May;19(4):278-9. PMID: 8926482. Exclusion: 8
359. Hoeksma HL, Dekker J, Ronday HK, et al. Manual therapy in osteoarthritis of the hip: outcome in subgroups of patients.

Rheumatology. 2005 Apr;44(4):461-4. PMID: 15695307. Exclusion: 9

360. Holroyd KA, Labus JS, Carlson B. Moderation and mediation in the psychological and drug treatment of chronic tension-type headache: the role of disorder severity and psychiatric comorbidity. Pain. 2009 Jun;143(3):213-22. PMID: CN00706512 UPDATE. Exclusion: 7

361. Hopman-Rock M, Westhoff MH. The effects of a health educational and exercise program for older adults with osteoarthritis for the hip or knee. Journal of Rheumatology. 2000 Aug;27(8):1947-54. PMID: 10955337. Exclusion: 3

362. Hoving JL, de Vet HC, Koes BW, et al. Manual therapy, physical therapy, or continued care by the general practitioner for patients with neck pain: long-term results from a pragmatic randomized clinical trial. Clinical Journal of Pain. 2006 May;22(4):370-7. PMID: 16691091. Exclusion: 3

363. Hoving JL, Koes BW, de Vet HC, et al. Manual therapy, physical therapy, or continued care by a general practitioner for patients with neck pain. A randomized, controlled trial.[Summary for patients in Ann Intern Med. 2002 May 21;136(10):I36; PMID: 12020157], [Summary for patients in Aust J Physiother. 2002;48(3):240-1; PMID: 12369567], [Summary for patients in Aust $J$ Physiother. 2002;48(3):241]. Annals of Internal Medicine. 2002 May 21;136(10):713-22. PMID: 12020139. Exclusion: 3

364. Hsiao-Wei Lo G, Balasubramanyam AS, Barbo A, et al. Link Between Positive Clinician-Conveyed Expectations of Treatment Effect and Pain Reduction in Knee Osteoarthritis, Mediated by Patient Self-Efficacy. Arthritis care \& research. 2016 Jul;68(7):952-7. doi: https://dx.doi.org/10.1002/acr.22775. PMID: 26554869. Exclusion: 7 
365. Hsieh CY, Phillips RB, Adams AH, et al. Functional outcomes of low back pain: comparison of four treatment groups in a randomized controlled trial. J Manipulative Physiol Ther. 1992 Jan;15(1):4-9. PMID: 1531488. Exclusion: 9

366. Hsieh LL, Kuo CH, Lee LH, et al. Treatment of low back pain by acupressure and physical therapy: randomised controlled trial. BMJ. 2006 Mar 25;332(7543):696700. doi: 10.1136/bmj.38744.672616.AE. PMID: 16488895. Exclusion: 5

367. Hsieh LL, Liou HH, Lee LH, et al. Effect of acupressure and trigger points in treating headache: a randomized controlled trial. American Journal of Chinese Medicine. 2010;38(1):1-14. PMID: 20128040.

Exclusion: 7

368. Hsieh LL-C, Kuo C-H, Yen M-F, et al. A randomized controlled clinical trial for low back pain treated by acupressure and physical therapy. Prev Med. 2004;39(1):168-76. doi: 10.1016/j.ypmed.2004.01.036. PMID: 15207999. Exclusion: 5

369. Hsieh RL, Lee WC. Short-term therapeutic effects of 890-nanometer light therapy for chronic low back pain: a double-blind randomized placebo-controlled study. Lasers Med Sci. 2014 Mar;29(2):671-9. doi: 10.1007/s10103-013-1378-2. PMID: 23820974. Exclusion: 9

370. Hsieh RL, Lo MT, Lee WC, et al. Therapeutic effects of short-term monochromatic infrared energy therapy on patients with knee osteoarthritis: a doubleblind, randomized, placebo-controlled study. Journal of Orthopaedic \& Sports Physical Therapy. 2012 Nov;42(11):947-56. doi: https://dx.doi.org/10.2519/jospt.2012.3881. PMID: 22960644. Exclusion: 9

371. Hughes SL, Seymour RB, Campbell R, et al. Impact of the fit and strong intervention on older adults with osteoarthritis. Gerontologist. 2004 Apr;44(2):217-28. PMID: 15075418. Exclusion: 7

372. Hughes SL, Seymour RB, Campbell RT, et al. Long-term impact of Fit and Strong! on older adults with osteoarthritis. Gerontologist. 2006 Dec;46(6):801-14. PMID: 17169935. Exclusion: 3
373. Huguet A, McGrath PJ, Stinson J, et al. Efficacy of psychological treatment for headaches: an overview of systematic reviews and analysis of potential modifiers of treatment efficacy. Clinical Journal of Pain. 2014 Apr;30(4):353-69. doi: http://dx.doi.org/10.1097/AJP.0b013e31829 8dd8b. PMID: 23823250. Exclusion: 10

374. Huisman PA, Speksnijder CM, de Wijer A. The effect of thoracic spine manipulation on pain and disability in patients with nonspecific neck pain: a systematic review. Disability \& Rehabilitation. 2013 Sep;35(20):1677-85. doi: http://dx.doi.org/10.3109/09638288.2012.75 0689. PMID: 23339721. Exclusion: 10

375. Hulme J, Robinson V, DeBie R, et al. Electromagnetic fields for the treatment of osteoarthritis. Cochrane Database of Systematic Reviews. 2002(1):CD003523. PMID: 11869668. Exclusion: 10

376. Hunter D, Gross KD, McCree P, et al. Realignment treatment for medial tibiofemoral osteoarthritis: randomised trial. Annals of the Rheumatic Diseases. 2012 Oct;71(10):1658-65. doi: http://dx.doi.org/10.1136/annrheumdis2011-200728. PMID: 22377805. Exclusion: 9

377. Hunter DJ, Beavers DP, Eckstein F, et al. The Intensive Diet and Exercise for Arthritis (IDEA) trial: 18-month radiographic and MRI outcomes. Osteoarthritis \& Cartilage. 2015 Jul;23(7):1090-8. doi: http://dx.doi.org/10.1016/j.joca.2015.03.034. PMID: 25887362. Exclusion: 6

378. Hurley DA, McDonough SM, Dempster M, et al. A randomized clinical trial of manipulative therapy and interferential therapy for acute low back pain. Spine (Phila Pa 1976). 2004 Oct 15;29(20):220716. PMID: 15480130. Exclusion: 3

379. Hurley DA, Minder PM, McDonough SM, et al. Interferential therapy electrode placement technique in acute low back pain: a preliminary investigation. Arch Phys Med Rehabil. 2001 Apr;82(4):485-93. doi: 10.1053/apmr.2001.21934. PMID: 11295009. Exclusion: 3 
380. Hurley MV, Walsh NE, Mitchell H, et al. Long-term outcomes and costs of an integrated rehabilitation program for chronic knee pain: a pragmatic, cluster randomized, controlled trial. Arthritis care \& research. 2012 Feb;64(2):238-47. doi: http://dx.doi.org/10.1002/acr.20642. PMID: 21954131. Exclusion: 3

381. Hurley MV, Walsh NE, Mitchell HL, et al. Clinical effectiveness of a rehabilitation program integrating exercise, selfmanagement, and active coping strategies for chronic knee pain: a cluster randomized trial. Arthritis \& Rheumatism. 2007 Oct 15;57(7):1211-9. PMID: 17907147.

Exclusion: 3

382. Hurley MV, Walsh NE, Mitchell HL, et al. Economic evaluation of a rehabilitation program integrating exercise, selfmanagement, and active coping strategies for chronic knee pain. Arthritis \& Rheumatism. 2007 Oct 15;57(7):1220-9. PMID: 17907207. Exclusion: 3

383. Hurwitz EL, Morgenstern H, Harber P, et al. A randomized trial of medical care with and without physical therapy and chiropractic care with and without physical modalities for patients with low back pain: 6-month follow-up outcomes from the UCLA low back pain study. Spine (Phila Pa 1976). 2002 Oct 15;27(20):2193-204. doi: 10.1097/01.brs.0000029253.40547.84. PMID: 12394892. Exclusion: 3

384. Hurwitz EL, Morgenstern H, Kominski GF, et al. A randomized trial of chiropractic and medical care for patients with low back pain: eighteen-month follow-up outcomes from the UCLA low back pain study. Spine (Phila Pa 1976). 2006 Mar 15;31(6):611-21; discussion 22. doi: 10.1097/01.brs.0000202559.41193.b2. PMID: 16540862. Exclusion: 3

385. Hyman RB, Feldman HR, Harris RB, et al. The effects of relaxation training on clinical symptoms: a meta-analysis. Nurs Res. 1989 Jul-Aug;38(4):216-20. PMID: 2664718. Exclusion: 5
386. Ilbuldu E, Cakmak A, Disci R, et al. Comparison of laser, dry needling, and placebo laser treatments in myofascial pain syndrome. Photomed Laser Surg. 2004 Aug;22(4):306-11. doi: 10.1089/pho.2004.22.306. PMID: 15345173. Exclusion: 4

387. Imoto AM, Peccin MS, Teixeira LE, et al. Is neuromuscular electrical stimulation effective for improving pain, function and activities of daily living of knee osteoarthritis patients? A randomized clinical trial. Sao Paulo Medical Journal = Revista Paulista de Medicina. 2013;131(2):80-7. PMID: 23657509. Exclusion: 9

388. Irnich D, Behrens N, Gleditsch JM, et al. Immediate effects of dry needling and acupuncture at distant points in chronic neck pain: results of a randomized, double-blind, sham-controlled crossover trial. Pain. 2002 Sep;99(1-2):83-9. PMID: 12237186. Exclusion: 7

389. Irnich D, Behrens $\mathrm{N}$, Molzen $\mathrm{H}$, et al. Randomised trial of acupuncture compared with conventional massage and "sham" laser acupuncture for treatment of chronic neck pain. BMJ. 2001 Jun 30;322(7302):1574-8. PMID: 11431299. Exclusion: 3

390. Itoh K, Hirota S, Katsumi Y, et al. Trigger point acupuncture for treatment of knee osteoarthritis--a preliminary RCT for a pragmatic trial. Acupuncture in Medicine. 2008 Mar;26(1):17-26. PMID: 18356795. Exclusion: 7

391. Itoh K, Katsumi Y, Hirota S, et al. Effects of trigger point acupuncture on chronic low back pain in elderly patients--a shamcontrolled randomised trial. Acupunct Med. 2006 Mar;24(1):5-12. PMID: 16618043. Exclusion: 9

392. Itoh K, Katsumi Y, Kitakoji H. Trigger point acupuncture treatment of chronic low back pain in elderly patients--a blinded RCT. Acupunct Med. 2004 Dec;22(4):170-7. PMID: 15628774. Exclusion: 5 
393. Jackel WH, Cziske R, Gerdes N, et al. [Assessment of the effectiveness of inpatient rehabilitation measures in patients with chronic low back pain: a prospective, randomized, controlled study].

Rehabilitation (Stuttg). 1990

May;29(2):129-33. PMID: 2142323.

Exclusion: 11

394. Jacobson JI, Gorman R, Yamanashi WS, et al. Low-amplitude, extremely low frequency magnetic fields for the treatment of osteoarthritic knees: a double-blind clinical study. Alternative Therapies in Health \& Medicine. 2001 Sep-Oct;7(5):54-64, 6-9. PMID: 11565402. Exclusion: 9

395. Jamtvedt G, Dahm KT, Christie A, et al. Physical therapy interventions for patients with osteoarthritis of the knee: an overview of systematic reviews. Physical Therapy. 2008 Jan;88(1):123-36. PMID: 17986496. Exclusion: 10

396. Jan MH, Lin CH, Lin YF, et al. Effects of weight-bearing versus nonweight-bearing exercise on function, walking speed, and position sense in participants with knee osteoarthritis: a randomized controlled trial. Archives of Physical Medicine \& Rehabilitation. 2009 Jun;90(6):897-904. doi: http://dx.doi.org/10.1016/j.apmr.2008.11.01 8. PMID: 19480863. Exclusion: 9

397. Jan MH, Lin JJ, Liau JJ, et al. Investigation of clinical effects of high- and lowresistance training for patients with knee osteoarthritis: a randomized controlled trial. Physical Therapy. 2008 Apr;88(4):427-36. doi: http://dx.doi.org/10.2522/ptj.20060300. PMID: 18218827. Exclusion: 9

398. Jan MH, Tang PF, Lin JJ, et al. Efficacy of a target-matching foot-stepping exercise on proprioception and function in patients with knee osteoarthritis. Journal of Orthopaedic \& Sports Physical Therapy. 2008 Jan;38(1):19-25. doi: https://dx.doi.org/10.2519/jospt.2008.2512. PMID: 18357655. Exclusion: 9
399. Jansen MJ, Viechtbauer W, Lenssen AF, et al. Strength training alone, exercise therapy alone, and exercise therapy with passive manual mobilisation each reduce pain and disability in people with knee osteoarthritis: a systematic review. Journal of Physiotherapy. 2011;57(1):11-20. doi: http://dx.doi.org/10.1016/S18369553(11)70002-9. PMID: 21402325. Exclusion: 10

400. Jarzem PF, Harvey EJ, Arcaro N, et al. Transcutaneous electrical nerve stimulation [TENS] for short-term treatment of low back pain-randomized double blind crossover study of sham versus conventional TENS. J Musculoskelet Pain. 2005;13(2):11-7. doi: 10.1300/J094v13n02_03. Exclusion: 7

401. Jay K, Frisch D, Hansen K, et al. Kettlebell training for musculoskeletal and cardiovascular health: a randomized controlled trial. Scandinavian Journal of Work, Environment \& Health. 2011 May;37(3):196-203. doi: http://dx.doi.org/10.5271/sjweh.3136. PMID: 21107513. Exclusion: 9

402. Jay K, Schraefel M, Andersen CH, et al. Effect of brief daily resistance training on rapid force development in painful neck and shoulder muscles: randomized controlled trial. Clinical Physiology \& Functional Imaging. 2013 Sep;33(5):386-92. doi: http://dx.doi.org/10.1111/cpf.12041. PMID: 23758661. Exclusion: 6

403. Jeitler M, Brunnhuber S, Meier L, et al. Effectiveness of jyoti meditation for patients with chronic neck pain and psychological distress--a randomized controlled clinical trial. Journal of Pain. 2015 Jan;16(1):77-86. doi:

http://dx.doi.org/10.1016/j.jpain.2014.10.00 9. PMID: 25451627. Exclusion: 9

404. Jena S, Witt CM, Brinkhaus B, et al. Acupuncture in patients with headache. Cephalalgia. 2008 Sep;28(9):969-79. doi: http://dx.doi.org/10.1111/j.14682982.2008.01640.x. PMID: 18624803. Exclusion: 3

405. Jensen IB, Bergstrom G, Ljungquist $\mathrm{T}$, et al. A 3-year follow-up of a multidisciplinary rehabilitation programme for back and neck pain. Pain. 2005 Jun;115(3):273-83. PMID: 15911154. Exclusion: 3 
406. Jessep SA, Walsh NE, Ratcliffe J, et al. Long-term clinical benefits and costs of an integrated rehabilitation programme compared with outpatient physiotherapy for chronic knee pain. Physiotherapy. 2009 Jun;95(2):94-102. doi: http://dx.doi.org/10.1016/j.physio.2009.01.0 05. PMID: 19627690. Exclusion: 5

407. Jones KD, Burckhardt CS, Deodhar AA, et al. A six-month randomized controlled trial of exercise and pyridostigmine in the treatment of fibromyalgia. Arthritis Rheum. 2008 Feb;58(2):612-22. doi: 10.1002/art.23203. Exclusion: 9

408. Jones KD, Sherman CA, Mist SD, et al. A randomized controlled trial of 8-form Tai chi improves symptoms and functional mobility in fibromyalgia patients. Clin Rheumatol. 2012 Aug;31(8):1205-14. doi: 10.007/s10067-012-1996-2. Epub 2012 May 13. Exclusion: 9

409. Jordan A, Bendix T, Nielsen $\mathrm{H}$, et al. Intensive training, physiotherapy, or manipulation for patients with chronic neck pain. A prospective, single-blinded, randomized clinical trial. Spine. 1998 Feb 1;23(3):311-8; discussion 9. PMID: 9507618. Exclusion: 5

410. Jorge RT, Souza MC, Chiari A, et al. Progressive resistance exercise in women with osteoarthritis of the knee: a randomized controlled trial. Clinical Rehabilitation. 2015 Mar;29(3):234-43. doi: http://dx.doi.org/10.1177/026921551454092 0. PMID: 24994768. Exclusion: 9

411. Juhakoski R, Malmivaara A, Lakka TA, et al. Determinants of pain and functioning in hip osteoarthritis - a two-year prospective study. Clinical Rehabilitation. 2013 Mar;27(3):281-7. doi: http://dx.doi.org/10.1177/026921551245306 0. PMID: 22843354. Exclusion: 7

412. Juhl C, Christensen R, Roos EM, et al. Impact of exercise type and dose on pain and disability in knee osteoarthritis: a systematic review and meta-regression analysis of randomized controlled trials. Arthritis \& Rheumatology. 2014 Mar;66(3):622-36. doi: http://dx.doi.org/10.1002/art.38290. PMID: 24574223. Exclusion: 10
413. Kaapa EH, Frantsi K, Sarna S, et al. Multidisciplinary group rehabilitation versus individual physiotherapy for chronic nonspecific low back pain: a randomized trial. Spine (Phila Pa 1976). 2006 Feb 15;31(4):371-6. doi: 10.1097/01.brs.0000200104.90759.8c. PMID: 16481945. Exclusion: 5

414. Kaleth AS, Saha CK, Jensen MP, et al. Effect of moderate to vigorous physical activity on long-term clinical outcomes and pain severity in fibromyalgia. Arthritis Care Res (Hoboken). 2013 Aug;65(8):1211-8. doi: 10.002/acr.21980. Exclusion: 4

415. Kalin S, Rausch-Osthoff AK, Bauer CM. What is the effect of sensory discrimination training on chronic low back pain? A systematic review. BMC Musculoskelet Disord. 2016 Apr 02;17:143. doi: 10.1186/s12891-016-0997-8. PMID: 27038609. Exclusion: 10

416. Kamali F, Panahi F, Ebrahimi S, et al. Comparison between massage and routine physical therapy in women with sub acute and chronic nonspecific low back pain. J Back Musculoskelet Rehabil. 2014;27(4):475-80. PMID: 24867893. Exclusion: 5

417. Kamper SJ, Apeldoorn AT, Chiarotto A, et al. Multidisciplinary biopsychosocial rehabilitation for chronic low back pain. Cochrane Database Syst Rev. 2014 Sep 02(9):CD000963. doi: 10.1002/14651858.CD000963.pub3. PMID: 25180773. Exclusion: 10

418. Kanai S, Taniguchi N, Okano H. Effect of magnetotherapeutic device on pain associated with neck and shoulder stiffness. Alternative Therapies in Health \& Medicine. 2011 Nov-Dec;17(6):44-8. PMID: 22314719. Exclusion: 9

419. Kanat E, Alp A, Yurtkuran M. Magnetotherapy in hand osteoarthritis: a pilot trial. Complementary Therapies in Medicine. 2013 Dec;21(6):603-8. doi: https://dx.doi.org/10.1016/j.ctim.2013.08.00 4. PMID: 24280467. Exclusion: 4 
420. Kao MJ, Wu MP, Tsai MW, et al. The effectiveness of a self-management program on quality of life for knee osteoarthritis (OA) patients. Archives of Gerontology \& Geriatrics. 2012 Mar-Apr;54(2):317-24. doi: http://dx.doi.org/10.1016/j.archger.2011.05. 018. PMID: 21726907. Exclusion: 4

421. Karjalainen K, Malmivaara A, van Tulder $\mathrm{M}$, et al. Multidisciplinary rehabilitation for fibromyalgia and musculoskeletal pain in working age adults. Cochrane Database of Systematic Reviews. 2000(2):CD001984. PMID: 10796458. Exclusion: 10

422. Karjalainen K, Malmivaara A, van Tulder $\mathrm{M}$, et al. Multidisciplinary biopsychosocial rehabilitation for neck and shoulder pain among working age adults: a systematic review within the framework of the Cochrane Collaboration Back Review Group. Spine. 2001 Jan 15;26(2):174-81. PMID: 11154538. Exclusion: 10

423. Karjalainen KA, Malmivaara A, van Tulder MW, et al. Multidisciplinary rehabilitation for fibromyalgia and musculoskeletal pain in working age adults. Cochrane Database of Systematic Reviews. 2009(1) PMID: 00075320-100000000-01349. Exclusion: 10

424. Kay TM, Gross A, Goldsmith CH, et al. Exercises for mechanical neck disorders. Cochrane Database of Systematic Reviews. 2012;8:CD004250. doi: http://dx.doi.org/10.1002/14651858.CD0042 50.pub4. PMID: 22895940. Exclusion: 10

425. Kaya Mutlu E, Mustafaoglu R, Birinci T, et al. Does Kinesio Taping of the Knee Improve Pain and Functionality in Patients with Knee Osteoarthritis?: A Randomized Controlled Clinical Trial. American Journal of Physical Medicine \& Rehabilitation. 2017 Jan;96(1):25-33. doi: https://dx.doi.org/10.1097/PHM.000000000 0000520. PMID: 27149590. Exclusion: 4

426. Keefe FJ, Blumenthal J, Baucom D, et al. Effects of spouse-assisted coping skills training and exercise training in patients with osteoarthritic knee pain: a randomized controlled study. Pain. 2004

Aug;110(3):539-49. PMID: 15288394.

Exclusion: 9
427. Keefe FJ, Caldwell DS, Baucom D, et al. Spouse-assisted coping skills training in the management of knee pain in osteoarthritis: long-term followup results. Arthritis Care \& Research. 1999 Apr;12(2):101-11. PMID: 10513498. Exclusion: 4

428. Kelley GA, Kelley KS. Exercise improves global well-being in adults with fibromyalgia: confirmation of previous meta-analytic results using a recently developed and novel varying coefficient model. Clinical \& Experimental Rheumatology. 2011 Nov-Dec;29(6 Suppl 69):S60-2. PMID: 22032521. Exclusion: 10

429. Kelley GA, Kelley KS. Effects of exercise on depressive symptoms in adults with arthritis and other rheumatic disease: a systematic review of meta-analyses. BMC Musculoskeletal Disorders. 2014;15:121. doi: http://dx.doi.org/10.1186/1471-247415-121. PMID: 24708605. Exclusion: 10

430. Kessler CS, Pinders L, Michalsen A, et al. Ayurvedic interventions for osteoarthritis: a systematic review and meta-analysis. Rheumatology International. 2015 Feb;35(2):211-32. doi: http://dx.doi.org/10.1007/s00296-014-3095y. PMID: 25062981. Exclusion: 10

431. Kettenmann B, Wille C, Lurie-Luke E, et al. Impact of continuous low level heatwrap therapy in acute low back pain patients: subjective and objective measurements. Clin J Pain. 2007 Oct;23(8):663-8. doi: 10.1097/AJP.0b013e31813543ef. PMID: 17885344. Exclusion: 3

432. Khadilkar A, Milne S, Brosseau L, et al. Transcutaneous electrical nerve stimulation (TENS) for chronic low-back pain.

Cochrane Database Syst Rev. 2005 Jul 20(3):CD003008. doi: 10.1002/14651858.CD003008.pub2. PMID: 16034883. Exclusion: 10

433. Khadilkar A, Odebiyi DO, Brosseau L, et al. Transcutaneous electrical nerve stimulation (TENS) versus placebo for chronic low-back pain. Cochrane Database Syst Rev. 2008 Oct 08(4):CD003008. doi: 10.1002/14651858.CD003008.pub3. PMID: 18843638. Exclusion: 10 
434. Khan M, Akhter S, Soomro RR, et al. The effectiveness of Cognitive Behavioral Therapy (CBT) with general exercises versus general exercises alone in the management of chronic low back pain. Pak J Pharm Sci. 2014 Jul;27(4 Suppl):1113-6. PMID: 25016276. Exclusion: 5

435. Kheshie AR, Alayat MS, Ali MM. Highintensity versus low-level laser therapy in the treatment of patients with knee osteoarthritis: a randomized controlled trial. Lasers in Medical Science. 2014 Jul;29(4):1371-6. doi: https://dx.doi.org/10.1007/s10103-0141529-0. PMID: 24487957. Exclusion: 4

436. Khoromi S, Blackman MR, Kingman A, et al. Low intensity permanent magnets in the treatment of chronic lumbar radicular pain. J Pain Symptom Manage. 2007

Oct;34(4):434-45. doi:

10.1016/j.jpainsymman.2006.12.008. PMID: 17618081. Exclusion: 3

437. Kim EJ, Lim CY, Lee EY, et al. Comparing the effects of individualized, standard, sham and no acupuncture in the treatment of knee osteoarthritis: a multicenter randomized controlled trial. Trials [Electronic Resource]. 2013;14:129. doi: http://dx.doi.org/10.1186/1745-6215-14129. PMID: 23782709. Exclusion: 8

438. Kim H, Suzuki T, Saito K, et al. Effectiveness of exercise with or without thermal therapy for community-dwelling elderly Japanese women with non-specific knee pain: a randomized controlled trial. Archives of Gerontology \& Geriatrics. 2013 Nov-Dec;57(3):352-9. doi: http://dx.doi.org/10.1016/j.archger.2013.06. 008. PMID: 23849900. Exclusion: 9

439. Kim TH, Lee CR, Choi TY, et al. Intramuscular stimulation therapy for healthcare: a systematic review of randomised controlled trials. Acupuncture in Medicine. 2012 Dec;30(4):286-90. doi: http://dx.doi.org/10.1136/acupmed-2012010182. PMID: 22871295. Exclusion: 10

440. Kiran, Girgla KK, Chalana H, et al. Effect of rajyoga meditation on chronic tension headache. Indian Journal of Physiology \& Pharmacology. 2014 Apr-Jun;58(2):157-61. PMID: 25509967. Exclusion: 7
441. Kitay GS, Koren MJ, Helfet DL, et al. Efficacy of combined local mechanical vibrations, continuous passive motion and thermotherapy in the management of osteoarthritis of the knee. Osteoarthritis \& Cartilage. 2009 Oct;17(10):1269-74. doi: http://dx.doi.org/10.1016/j.joca.2009.04.015. PMID: 19433134. Exclusion: 4

442. Kjeken I, Darre S, Smedslund G, et al. Effect of assistive technology in hand osteoarthritis: a randomised controlled trial. Annals of the Rheumatic Diseases. 2011 Aug;70(8):1447-52. doi: http://dx.doi.org/10.1136/ard.2010.148668. PMID: 21571733. Exclusion: 4

443. Kjeken I, Smedslund G, Moe RH, et al. Systematic review of design and effects of splints and exercise programs in hand osteoarthritis. Arthritis care \& research. 2011 Jun;63(6):834-48. doi: http://dx.doi.org/10.1002/acr.20427. PMID: 21630479. Exclusion: 10

444. Kjellman G, Oberg B. A randomized clinical trial comparing general exercise, McKenzie treatment and a control group in patients with neck pain. Journal of Rehabilitation Medicine. 2002 Jul;34(4):183-90. PMID: 12201614. Exclusion: 3

445. Kjellman GV, Skargren EI, Oberg BE. A critical analysis of randomised clinical trials on neck pain and treatment efficacy. A review of the literature. Scandinavian Journal of Rehabilitation Medicine. 1999 Sep;31(3):139-52. PMID: 10458312. Exclusion: 10

446. Klein R, Bareis A, Schneider A, et al. Strain-counterstrain to treat restrictions of the mobility of the cervical spine in patients with neck pain: a sham-controlled randomized trial. Complementary Therapies in Medicine. 2013 Feb;21(1):1-7. doi: http://dx.doi.org/10.1016/j.ctim.2012.11.003 . PMID: 23374199. Exclusion: 9

447. Klein RG, Eek BC. Low-energy laser treatment and exercise for chronic low back pain: double-blind controlled trial. Arch Phys Med Rehabil. 1990 Jan;71(1):34-7. PMID: 2136991. Exclusion: 5 
448. Kloek CJ, Bossen D, Veenhof C, et al. Effectiveness and cost-effectiveness of a blended exercise intervention for patients with hip and/or knee osteoarthritis: study protocol of a randomized controlled trial. BMC Musculoskelet Disord. 2014 Aug 08;15:269. doi: 10.1186/1471-2474-15-269. PMID: 25103686. Exclusion: 8

449. Koes BW, Bouter LM, van Mameren H, et al. The effectiveness of manual therapy, physiotherapy, and treatment by the general practitioner for nonspecific back and neck complaints. A randomized clinical trial. Spine (Phila Pa 1976). 1992 Jan;17(1):2835. PMID: 1531552. Exclusion: 3

450. Koes BW, Bouter LM, van Mameren H, et al. Randomised clinical trial of manipulative therapy and physiotherapy for persistent back and neck complaints: results of one year follow up. BMJ. $1992 \mathrm{Mar}$ 7;304(6827):601-5. PMID: 1532760. Exclusion: 3

451. Koldas Dogan S, Sonel Tur B, Kurtais Y, et al. Comparison of three different approaches in the treatment of chronic low back pain. Clin Rheumatol. 2008 Jul;27(7):873-81. doi: 10.1007/s10067-007-0815-7. PMID: 18188660. Exclusion: 4

452. Kole-Snijders AM, Vlaeyen JW, Goossens ME, et al. Chronic low-back pain: what does cognitive coping skills training add to operant behavioral treatment? Results of a randomized clinical trial. J Consult Clin Psychol. 1999 Dec;67(6):931-44. PMID: 10596514. Exclusion: 9

453. Kong LJ, Fang M, Zhan HS, et al. Chinese massage combined with herbal ointment for athletes with nonspecific low back pain: a randomized controlled trial. Evid Based Complement Alternat Med.

2012;2012:695726. doi: 10.1155/2012/695726. PMID: 23258996. Exclusion: 5

454. Konrad K, Tatrai T, Hunka A, et al. Controlled trial of balneotherapy in treatment of low back pain. Ann Rheum Dis. 1992 Jun;51(6):820-2. PMID: 1535495. Exclusion: 3
455. Kool J, Bachmann S, Oesch P, et al. Function-centered rehabilitation increases work days in patients with nonacute nonspecific low back pain: 1-year results from a randomized controlled trial. Arch Phys Med Rehabil. 2007 Sep;88(9):1089-94. doi: 10.1016/j.apmr.2007.05.022. PMID: 17826451. Exclusion: 5

456. Korshoj M, Birk Jorgensen M, Lidegaard M, et al. Decrease in musculoskeletal pain after 4 and 12 months of an aerobic exercise intervention: a worksite RCT among cleaners. Scand J Public Health. 2017 Jul 01:1403494817717833. Exclusion: 3

457. Korthals-de Bos IB, Hoving JL, van Tulder MW, et al. Cost effectiveness of physiotherapy, manual therapy, and general practitioner care for neck pain: economic evaluation alongside a randomised controlled trial. BMJ. 2003 Apr 26;326(7395):911. PMID: 12714472. Exclusion: 3

458. Kosterink SM, Huis in 't Veld RM, Cagnie $\mathrm{B}$, et al. The clinical effectiveness of a myofeedback-based teletreatment service in patients with non-specific neck and shoulder pain: a randomized controlled trial. Journal of Telemedicine $\&$ Telecare.

2010;16(6):316-21. doi: http://dx.doi.org/10.1258/jtt.2010.006005. PMID: 20798425. Exclusion: 4

459. Koybasi M, Borman P, Kocaoglu S, et al. The effect of additional therapeutic ultrasound in patients with primary hip osteoarthritis: a randomized placebocontrolled study. Clinical Rheumatology. 2010 Dec;29(12):1387-94. doi: http://dx.doi.org/10.1007/s10067-010-14685. PMID: 20499122. Exclusion: 4

460. Kraus I, Steinhilber B, Haupt G, et al. Exercise therapy in hip osteoarthritis--a randomized controlled trial. Deutsches Arzteblatt International. 2014 Sep 1;111(3536):592-9. doi:

http://dx.doi.org/10.3238/arztebl.2014.0592. PMID: 25249361. Exclusion: 9

461. Kraus JF, Schaffer KB, Rice T, et al. A field trial of back belts to reduce the incidence of acute low back injuries in New York City home attendants. Int $\mathrm{J}$ Occup Environ Health. 2002 Apr-Jun;8(2):97-104. doi: 10.1179/107735202800339073. PMID: 12019686. Exclusion: 3 
462. Kravitz HM, Esty ML, Katz RS, et al. Treatment of Fibromyalgia Syndrome Using Low-Intensity Neurofeedback with the Flexyx Neurotherapy System: A Randomized Controlled Clinical Trial. Journal of Neurotherapy: Investigations in Neuromodulation, Neurofeedback and Applied Neuroscience. 2006;10(2-3):41-58. Exclusion: 9

463. Krishnan A, Silver N. Headache (chronic tension-type). Clinical Evidence. 2009 PMID: 21696647. Exclusion: 10

464. Kristensen J, Franklyn-Miller A. Resistance training in musculoskeletal rehabilitation: a systematic review. British Journal of Sports Medicine. 2012 Aug;46(10):719-26. doi: http://dx.doi.org/10.1136/bjsm.2010.079376 . PMID: 21791457. Exclusion: 10

465. Kroeling P, Gross A, Goldsmith $\mathrm{CH}$, et al. Electrotherapy for neck pain. Cochrane Database of Systematic Reviews. 2009(4):CD004251. doi: http://dx.doi.org/10.1002/14651858.CD0042 51.pub4. PMID: 19821322. Exclusion: 10

466. Kroeling P, Gross A, Graham N, et al. Electrotherapy for neck pain. Cochrane Database of Systematic Reviews. 2013;8:CD004251. doi: http://dx.doi.org/10.1002/14651858.CD0042 51.pub5. PMID: 23979926. Exclusion: 10

467. Kroeling P, Gross A, Houghton PE, et al. Electrotherapy for neck disorders. Cochrane Database of Systematic Reviews. 2005(2):CD004251. PMID: 15846703. Exclusion: 10

468. Kroeling P, Gross AR, Goldsmith CH, et al. A Cochrane review of electrotherapy for mechanical neck disorders. Spine. 2005 Nov 1;30(21):E641-8. PMID: 16261102. Exclusion: 10

469. Kumnerddee W. Effectiveness comparison between Thai traditional massage and Chinese acupuncture for myofascial back pain in Thai military personnel: a preliminary report. J Med Assoc Thai. 2009;92(Suppl 1):S117-23. PMID: 21299184. Exclusion: 5
470. Kwon YD, Pittler MH, Ernst E. Acupuncture for peripheral joint osteoarthritis: a systematic review and metaanalysis. Rheumatology. 2006 Nov;45(11):1331-7. PMID: 16936326. Exclusion: 10

471. Lami MJ, Martinez MP, Sanchez AI. Systematic review of psychological treatment in fibromyalgia. Current Pain \& Headache Reports. 2013 Jul;17(7):345. doi: http://dx.doi.org/10.1007/s11916-013-03458. PMID: 23715945. Exclusion: 10

472. Landen BR. Heat or cold for the relief of low back pain? Phys Ther. 1967 Dec;47(12):1126-8. PMID: 4229712. Exclusion: 3

473. Landen Ludvigsson M, Peolsson A, Peterson G, et al. Cost-effectiveness of neck-specific exercise with or without a behavioral approach versus physical activity prescription in the treatment of chronic whiplash-associated disorders: Analyses of a randomized clinical trial. Medicine. 2017 Jun;96(25):e7274. doi: https://dx.doi.org/10.1097/MD.0000000000 007274. PMID: 28640136. Exclusion: 5

474. Lange AK, Vanwanseele B, Fiatarone Singh MA. Strength training for treatment of osteoarthritis of the knee: a systematic review. Arthritis \& Rheumatism. 2008 Oct 15;59(10):1488-94. doi: http://dx.doi.org/10.1002/art.24118. PMID: 18821647. Exclusion: 10

475. Lange AK, Vanwanseele B, Foroughi N, et al. Resistive Exercise for Arthritic Cartilage Health (REACH): a randomized doubleblind, sham-exercise controlled trial. BMC Geriatrics. 2009;9:1. doi: http://dx.doi.org/10.1186/1471-2318-9-1. PMID: 19144148. Exclusion: 8

476. Lange B, Toft P, Myburgh C, et al. Effect of targeted strength, endurance, and coordination exercise on neck and shoulder pain among fighter pilots: a randomizedcontrolled trial. Clinical Journal of Pain. 2013 Jan;29(1):50-9. doi: http://dx.doi.org/10.1097/AJP.0b013e31824 78678. PMID: 23221624. Exclusion: 9 
477. Langhorst J, Klose P, Dobos GJ, et al. Efficacy and safety of meditative movement therapies in fibromyalgia syndrome: a systematic review and meta-analysis of randomized controlled trials. Rheumatology International. 2013 Jan;33(1):193-207. doi: http://dx.doi.org/10.1007/s00296-012-23601. PMID: 22350253. Exclusion: 10

478. Lara-Palomo IC, Aguilar-Ferrandiz ME, Mataran-Penarrocha GA, et al. Short-term effects of interferential current electromassage in adults with chronic non-specific low back pain: a randomized controlled trial. Clin Rehabil. 2013 May;27(5):439-49. doi: 10.1177/0269215512460780. PMID: 23035006. Exclusion: 5

479. Larsman P, Hasenbring M, Sandsjo L, et al. Prognostic factors for the effect of a myofeedback-based teletreatment service. Journal of Telemedicine \& Telecare. 2010;16(6):336-43. doi: http://dx.doi.org/10.1258/jtt.2010.006008. PMID: 20798428. Exclusion: 3

480. Larsson U, Choler U, Lidstrom A, et al. Auto-traction for treatment of lumbagosciatica. A multicentre controlled investigation. Acta Orthop Scand. 1980 Oct;51(5):791-8. PMID: 6451138. Exclusion: 3

481. Latham N, Liu CJ. Strength training in older adults: the benefits for osteoarthritis. Clinics in Geriatric Medicine. 2010 Aug;26(3):44559. doi:

http://dx.doi.org/10.1016/j.cger.2010.03.006 . PMID: 20699165. Exclusion: 10

482. Lathia AT, Jung SM, Chen LX. Efficacy of acupuncture as a treatment for chronic shoulder pain. Journal of Alternative \& Complementary Medicine. 2009 Jun;15(6):613-8. doi: http://dx.doi.org/10.1089/acm.2008.0272. PMID: 19489707. Exclusion: 3

483. Latorre PA, Santos MA, Heredia-Jimenez JM, et al. Effect of a 24-week physical training programme (in water and on land) on pain, functional capacity, body composition and quality of life in women with fibromyalgia. Clinical and experimental rheumatology. 2013 NovDec;31(6 Suppl 79):S72-80. PMID: CN01119427 NEW. Exclusion: 9
484. Latorre Roman PA, Santos ECMA, GarciaPinillos F. Effects of functional training on pain, leg strength, and balance in women with fibromyalgia. Mod Rheumatol. 2015;25(6):943-7. doi: 10.3109/14397595.2015.1040614. Epub 2015 May 28. Exclusion: 9

485. Lau HM, Wing Chiu TT, Lam TH. The effectiveness of thoracic manipulation on patients with chronic mechanical neck pain a randomized controlled trial. Manual Therapy. 2011 Apr;16(2):141-7. doi: http://dx.doi.org/10.1016/j.math.2010.08.00 3. PMID: 20813577. Exclusion: 5

486. Lauche R, Cramer H, Choi KE, et al. The influence of a series of five dry cupping treatments on pain and mechanical thresholds in patients with chronic nonspecific neck pain--a randomised controlled pilot study. BMC Complementary \& Alternative Medicine. 2011;11:63. doi: http://dx.doi.org/10.1186/1472-6882-11-63. PMID: 21843336. Exclusion: 9

487. Lauche R, Cramer H, Dobos G, et al. A systematic review and meta-analysis of mindfulness-based stress reduction for the fibromyalgia syndrome. J Psychosom Res. 2013 Dec;75(6):500-10. doi: 10.1016/j.jpsychores.2013.10.010. PMID: 24290038. Exclusion: 10

488. Lauche R, Langhorst J, Dobos G, et al. A systematic review and meta-analysis of Tai Chi for osteoarthritis of the knee. Complementary Therapies in Medicine. 2013 Aug;21(4):396-406. doi: http://dx.doi.org/10.1016/j.ctim.2013.06.001 . PMID: 23876571. Exclusion: 10

489. Lauche R, Schuth M, Schwickert M, et al. Efficacy of the Alexander Technique in treating chronic non-specific neck pain: a randomized controlled trial. Clin Rehabil. 2016 Mar;30(3):247-58. doi: 10.1177/0269215515578699. PMID: 25834276. Exclusion: 5

490. Laufer Y, Shtraker H, Elboim Gabyzon M. The effects of exercise and neuromuscular electrical stimulation in subjects with knee osteoarthritis: a 3-month follow-up study. Clinical Interventions In Aging. 2014;9:1153-61. doi: http://dx.doi.org/10.2147/CIA.S64104. PMID: 25083133. Exclusion: 4 
491. Lauretti GR, Chubaci EF, Mattos AL. Efficacy of the use of two simultaneously TENS devices for fibromyalgia pain. Rheumatol Int. 2013 Aug;33(8):2117-22. doi: 10.1007/s00296-013-2699-y. PMID: 23423539. Exclusion: 7

492. Law PP, Cheing GL. Optimal stimulation frequency of transcutaneous electrical nerve stimulation on people with knee osteoarthritis. Journal of Rehabilitation Medicine. 2004 Sep;36(5):220-5. PMID: 15626162. Exclusion: 9

493. Leaver AM, Refshauge KM, Maher CG, et al. Conservative interventions provide shortterm relief for non-specific neck pain: a systematic review. Journal of Physiotherapy. 2010;56(2):73-85. PMID: 20482474.

Exclusion: 10

494. Lee AC, Harvey WF, Price LL, et al. Mindfulness Is Associated With Treatment Response From Nonpharmacologic Exercise Interventions in Knee Osteoarthritis. Archives of Physical Medicine \& Rehabilitation. 2017 Nov;98(11):226573.e1. doi: https://dx.doi.org/10.1016/j.apmr.2017.04.0 14. PMID: 28506776. Exclusion: 7

495. Lee AC, Harvey WF, Wong JB, et al. Effects of Tai Chi versus Physical Therapy on Mindfulness in Knee Osteoarthritis. Mindfulness. 2017 Oct;8(5):1195-205. doi: https://dx.doi.org/10.1007/s12671-0170692-3. PMID: 28959369. Exclusion: 5

496. Lee CY, Cho YH. Evaluation of a community health practitioner self-care program for rural Korean patients with osteoarthritis. Journal of Korean Academy of Nursing. 2012 Dec;42(7):965-73. doi: http://dx.doi.org/10.4040/jkan.2012.42.7.96 5. PMID: 23377592. Exclusion: 4

497. Lee HJ, Park HJ, Chae Y, et al. Tai Chi Qigong for the quality of life of patients with knee osteoarthritis: a pilot, randomized, waiting list controlled trial. Clinical Rehabilitation. 2009 Jun;23(6):504-11. doi: http://dx.doi.org/10.1177/026921550810174 6. PMID: 19389743. Exclusion: 9

498. Lee MS, Ernst E. Systematic reviews of t'ai chi: an overview. British Journal of Sports Medicine. 2012 Aug;46(10):713-8. doi: http://dx.doi.org/10.1136/bjsm.2010.080622 . PMID: 21586406. Exclusion: 10
499. Lee MS, Pittler MH, Ernst E. Tai chi for osteoarthritis: a systematic review. Clinical Rheumatology. 2008 Feb;27(2):211-8. PMID: 17874172. Exclusion: 10

500. Lee S, Nam D, Leem J, et al. Efficacy and safety of Myofascial-meridian Release Acupuncture (MMRA) for chronic neck pain: a study protocol for randomized, patient- and assessor-blinded, sham controlled trial. BMC Complement Altern Med. 2016 Feb 02;16:45. doi: 10.1186/s12906-016-1027-y. PMID: 26833397. Exclusion: 8

501. Leeuw M, Goossens ME, van Breukelen GJ, et al. Exposure in vivo versus operant graded activity in chronic low back pain patients: results of a randomized controlled trial. Pain. 2008 Aug 15;138(1):192-207. doi: 10.1016/j.pain.2007.12.009. PMID: 18242858. Exclusion: 5

502. Leibing E, Leonhardt U, Koster G, et al. Acupuncture treatment of chronic low-back pain -- a randomized, blinded, placebocontrolled trial with 9-month follow-up. Pain. 2002 Mar;96(1-2):189-96. PMID: 11932074. Exclusion: 4

503. Leininger B, McDonough C, Evans R, et al. Cost-effectiveness of spinal manipulative therapy, supervised exercise, and home exercise for older adults with chronic neck pain. Spine Journal: Official Journal of the North American Spine Society. 2016 Nov;16(11):1292-304. doi: https://dx.doi.org/10.1016/j.spinee.2016.06. 014. PMID: 27345747. Exclusion: 4

504. Lemstra M, Olszynski WP. The effectiveness of multidisciplinary rehabilitation in the treatment of fibromyalgia: a randomized controlled trial. Clin J Pain. 2005 Mar-Apr;21(2):166-74. PMID: 15722810. Exclusion: 9

505. Lerman SF, Finan PH, Smith MT, et al. Psychological interventions that target sleep reduce pain catastrophizing in knee osteoarthritis. Pain. 2017 Nov;158(11):2189-95. doi: https://dx.doi.org/10.1097/j.pain.000000000 0001023. PMID: 28767510. Exclusion: 4 
506. Letchuman R, Deusinger RH. Comparison of sacrospinalis myoelectric activity and pain levels in patients undergoing static and intermittent lumbar traction. Spine (Phila $\mathrm{Pa}$ 1976). 1993 Aug;18(10):1361-5. PMID: 8211369. Exclusion: 3

507. Lewis M, James M, Stokes E, et al. An economic evaluation of three physiotherapy treatments for non-specific neck disorders alongside a randomized trial. Rheumatology. 2007 Nov;46(11):1701-8. PMID:

17956916. Exclusion: 4

508. Li S, Yu B, Zhou D, et al. Electromagnetic fields for treating osteoarthritis. Cochrane Database of Systematic Reviews.

2013;12:CD003523. doi: http://dx.doi.org/10.1002/14651858.CD0035 23.pub2. PMID: 24338431. Exclusion: 10

509. Li Y, Su Y, Chen S, et al. The effects of resistance exercise in patients with knee osteoarthritis: a systematic review and metaanalysis. Clin Rehabil. 2016 Oct;30(10):947-59. doi: 10.1177/0269215515610039. PMID: 26471972. Exclusion: 10

510. Lidegaard M, Jensen RB, Andersen CH, et al. Effect of brief daily resistance training on occupational neck/shoulder muscle activity in office workers with chronic pain: randomized controlled trial. BioMed Research International. 2013;2013:262386. doi: http://dx.doi.org/10.1155/2013/262386. PMID: 24490152. Exclusion: 6

511. Lidstrom A, Zachrisson M. Physical therapy on low back pain and sciatica. An attempt at evaluation. Scand J Rehabil Med. 1970;2(1):37-42. PMID: 4257208. Exclusion: 3

512. Lim BW, Hinman RS, Wrigley TV, et al. Does knee malalignment mediate the effects of quadriceps strengthening on knee adduction moment, pain, and function in medial knee osteoarthritis? A randomized controlled trial. Arthritis \& Rheumatism. 2008 Jul 15;59(7):943-51. doi: http://dx.doi.org/10.1002/art.23823. PMID: 18576289. Exclusion: 9
513. Lim JY, Tchai E, Jang SN. Effectiveness of aquatic exercise for obese patients with knee osteoarthritis: a randomized controlled trial. Pm \& R. 2010 Aug;2(8):723-31; quiz 93. doi:

http://dx.doi.org/10.1016/j.pmrj.2010.04.004 . PMID: 20709301. Exclusion: 9

514. Lin DH, Lin CH, Lin YF, et al. Efficacy of 2 non-weight-bearing interventions, proprioception training versus strength training, for patients with knee osteoarthritis: a randomized clinical trial. Journal of Orthopaedic \& Sports Physical Therapy. 2009 Jun;39(6):450-7. doi: http://dx.doi.org/10.2519/jospt.2009.2923. PMID: 19531879. Exclusion: 9

515. Lin JH, Chiu TT, Hu J. Chinese manipulation for mechanical neck pain: a systematic review. Clinical Rehabilitation. 2012 Nov;26(11):963-73. doi: http://dx.doi.org/10.1177/026921551244148 5. PMID: 22473303. Exclusion: 10

516. Lin ML, Lin MH, Fen JJ, et al. A comparison between pulsed radiofrequency and electro-acupuncture for relieving pain in patients with chronic low back pain. Acupunct Electrother Res. 2010;35(34):133-46. PMID: 21319602. Exclusion: 9

517. Lind GA. Auto-traction: treatment of low back pain and sciatica: an electromyographic, radiographic and clinical study: Universitet; 1974. Exclusion: 3

518. Linde K, Allais G, Brinkhaus B, et al. Acupuncture for the prevention of tensiontype headache. Cochrane Database of Systematic Reviews. 2016;4:CD007587. doi:

http://dx.doi.org/10.1002/14651858.CD0075 87.pub2. PMID: 27092807. Exclusion: 10

519. Linde K, Allais G, Brinkhaus B, et al. Acupuncture for tension-type headache. Cochrane Database of Systematic Reviews. 2009(1):CD007587. doi: http://dx.doi.org/10.1002/14651858.CD0075 87. PMID: 19160338. Exclusion: 10 
520. Lindell O, Johansson SE, Strender LE.

Subacute and chronic, non-specific back and neck pain: cognitive-behavioural

rehabilitation versus primary care. A randomized controlled trial. BMC

Musculoskeletal Disorders. 2008;9:172. doi: http://dx.doi.org/10.1186/1471-2474-9-172.

PMID: 19116007. Exclusion: 3

521. Linton SJ, Boersma K, Jansson M, et al. The effects of cognitive-behavioral and physical therapy preventive interventions on painrelated sick leave: a randomized controlled trial. Clin J Pain. 2005 Mar-Apr;21(2):10919. PMID: 15722803. Exclusion: 3

522. Linton SJ, Bradley LA, Jensen I, et al. The secondary prevention of low back pain: a controlled study with follow-up. Pain. 1989 Feb;36(2):197-207. PMID: 2521930. Exclusion: 3

523. Linton SJ, Ryberg M. A cognitivebehavioral group intervention as prevention for persistent neck and back pain in a nonpatient population: a randomized controlled trial. Pain. 2001 Feb 1;90(1-2):83-90. PMID: 11166973. Exclusion: 3

524. Liu L, Huang QM, Liu QG, et al. Effectiveness of dry needling for myofascial trigger points associated with neck and shoulder pain: a systematic review and meta-analysis. Archives of Physical Medicine \& Rehabilitation. 2015 May;96(5):944-55. doi: http://dx.doi.org/10.1016/j.apmr.2014.12.01 5. PMID: 25576642. Exclusion: 10

525. Ljunggren AE, Walker L, Weber $\mathrm{H}$, et al. Manual traction versus isometric exercises in patients with herniated intervertebral lumbar discs. Physiother Theory Pract. 1992;8(4):207-13. Exclusion: 3

526. Ljunggren AE, Weber H, Larsen S. Autotraction versus manual traction in patients with prolapsed lumbar intervertebral discs. Scand J Rehabil Med. 1984;16(3):117-24. PMID: 6494835. Exclusion: 3
527. Lochting I, Storheim K, Werner EL, et al. Evaluation of individualized quality of life and illness perceptions in low back pain. A patient education cluster randomized controlled trial. Patient Education \& Counseling. 2016 Dec;99(12):1992-8. doi: https://dx.doi.org/10.1016/j.pec.2016.05.015 . PMID: 27486051. Exclusion: 3

528. Lopez-Lopez A, Alonso Perez JL, Gonzalez Gutierez JL, et al. Mobilization versus manipulations versus sustain apophyseal natural glide techniques and interaction with psychological factors for patients with chronic neck pain: randomized controlled trial. European journal of physical \& rehabilitation medicine. 2015 Apr;51(2):121-32. PMID: 25296741. Exclusion: 5

529. Lorig KR, Ritter PL, Laurent DD, et al. The internet-based arthritis self-management program: a one-year randomized trial for patients with arthritis or fibromyalgia. Arthritis Rheum. 2008 Jul 15;59(7):1009-17. doi: 10.1002/art.23817. PMID: 18576310. Exclusion: 3

530. Loyola-Sanchez A, Richardson J, Beattie $\mathrm{KA}$, et al. Effect of low-intensity pulsed ultrasound on the cartilage repair in people with mild to moderate knee osteoarthritis: a double-blinded, randomized, placebocontrolled pilot study. Archives of physical medicine and rehabilitation. 2012 Jan;93(1):35-42. PMID: CN-00804193 UPDATE. Exclusion: 7

531. Lu DF, Hart LK, Lutgendorf SK, et al. The effect of healing touch on the pain and mobility of persons with osteoarthritis: a feasibility study. Geriatric Nursing. 2013 Jul-Aug;34(4):314-22. doi: http://dx.doi.org/10.1016/j.gerinurse.2013.0 5.003. PMID: 23835011. Exclusion: 7

532. Lu M, Su Y, Zhang Y, et al. Effectiveness of aquatic exercise for treatment of knee osteoarthritis: Systematic review and metaanalysis. Zeitschrift fur Rheumatologie. 2015 Aug;74(6):543-52. doi: http://dx.doi.org/10.1007/s00393-014-15599. PMID: 25691109. Exclusion: 10 
533. Luciano JV, D'Amico F, Cerda-Lafont M, et al. Cost-utility of cognitive behavioral therapy versus U.S. Food and Drug Administration recommended drugs and usual care in the treatment of patients with fibromyalgia: an economic evaluation alongside a 6-month randomized controlled trial. Arthritis Res Ther. 2014 Oct 01

Oct 1;16(5):451. doi: 10.1186/s13075-014-0451-y. Exclusion: 6

534. Luciano JV, Guallar JA, Aguado J, et al. Effectiveness of group acceptance and commitment therapy for fibromyalgia: a 6month randomized controlled trial (EFFIGACT study). Pain. 2014 Apr;155(4):693-702. doi: 10.1016/j.pain.2013.12.029. Epub Dec 28. Exclusion: 7

535. Luciano JV, Sabes-Figuera R, Cardenosa E, et al. Cost-utility of a psychoeducational intervention in fibromyalgia patients compared with usual care: an economic evaluation alongside a 12-month randomized controlled trial. Clin J Pain. 2013 Aug;29(8):702-11. doi: 10.1097/AJP.0b013e318270f99a. Exclusion: 4

536. Ludvigsson ML, Peterson G, Dedering A, et al. One- and two-year follow-up of a randomized trial of neck-specific exercise with or without a behavioural approach compared with prescription of physical activity in chronic whiplash disorder. Journal of Rehabilitation Medicine. 2016 Jan;48(1):56-64. doi: http://dx.doi.org/10.2340/16501977-2041. PMID: 26660722. Exclusion: 5

537. Ludvigsson ML, Peterson G, O'Leary S, et al. The effect of neck-specific exercise with, or without a behavioral approach, on pain, disability, and self-efficacy in chronic whiplash-associated disorders: a randomized clinical trial. Clinical Journal of Pain. 2015 Apr;31(4):294-303. doi: http://dx.doi.org/10.1097/AJP.00000000000 00123. PMID: 24918474. Exclusion: 5

538. Lukinmaa A. Low back pain as a biopsychosocial problem. A controlled clinical trial and a cost-effectiveness analysis. Kansanelakelaitoksen julkaisuja 1989. Exclusion: 11
539. Luksurapan W, Boonhong J. Effects of phonophoresis of piroxicam and ultrasound on symptomatic knee osteoarthritis. Archives of physical medicine and rehabilitation. 2013 Feb;94(2):250-5. PMID: CN-00878572 UPDATE. Exclusion: 9

540. Lun V, Marsh A, Bray R, et al. Efficacy of Hip Strengthening Exercises Compared With Leg Strengthening Exercises on Knee Pain, Function, and Quality of Life in Patients With Knee Osteoarthritis. Clinical Journal of Sport Medicine. 2015 Nov;25(6):509-17. doi: http://dx.doi.org/10.1097/JSM.00000000000 00170. PMID: 25591130. Exclusion: 5

541. Lundqvist LO, Zetterlund C, Richter HO. Effects of Feldenkrais method on chronic neck/scapular pain in people with visual impairment: a randomized controlled trial with one-year follow-up. Archives of Physical Medicine \& Rehabilitation. 2014 Sep;95(9):1656-61. doi: http://dx.doi.org/10.1016/j.apmr.2014.05.01 3. PMID: 24907640. Exclusion: 4

542. Ma C, Szeto GP, Yan T, et al. Comparing biofeedback with active exercise and passive treatment for the management of workrelated neck and shoulder pain: a randomized controlled trial. Archives of Physical Medicine \& Rehabilitation. 2011 Jun;92(6):849-58. doi: http://dx.doi.org/10.1016/j.apmr.2010.12.03 7. PMID: 21621660. Exclusion: 3

543. Macfarlane GJ, Kronisch C, Dean LE, et al. EULAR revised recommendations for the management of fibromyalgia. Ann Rheum Dis. 2017 Feb;76(2):318-28. doi:

10.1136/annrheumdis-2016-209724. PMID: 27377815. Exclusion: 10

544. Machado GC, Maher CG, Ferreira PH, et al. Non-steroidal anti-inflammatory drugs for spinal pain: a systematic review and metaanalysis. Ann Rheum Dis. 2017 Jul;76(7):1269-78. Exclusion: 10

545. Machado LA, Azevedo DC, Capanema MB, et al. Client-centered therapy vs exercise therapy for chronic low back pain: a pilot randomized controlled trial in Brazil. Pain Med. 2007 Apr;8(3):251-8. doi: 10.1111/j.1526-4637.2006.00225.x. PMID: 17371412. Exclusion: 5 
546. MacIntyre L. The effect of Pilates on patients' chronic low back pain. A pilot study; 2006. Exclusion: 9

547. Mackawan S, Eungpinichpong W, Pantumethakul R, et al. Effects of traditional Thai massage versus joint mobilization on substance $\mathrm{P}$ and pain perception in patients with non-specific low back pain. J Bodyw Mov Ther. 2007;11(1):9-16. Exclusion: 9

548. Madson TJ, Cieslak KR, Gay RE. Joint mobilization vs massage for chronic mechanical neck pain: a pilot study to assess recruitment strategies and estimate outcome measure variability. Journal of Manipulative \& Physiological Therapeutics. 2010 NovDec;33(9):644-51. doi: http://dx.doi.org/10.1016/j.jmpt.2010.08.008 . PMID: 21109054. Exclusion: 5

549. Mahendira D, Towheed TE. Systematic review of non-surgical therapies for osteoarthritis of the hand: an update. Osteoarthritis \& Cartilage. 2009 Oct;17(10):1263-8. doi: http://dx.doi.org/10.1016/j.joca.2009.04.006. PMID: 19410030. Exclusion: 10

550. Maicki T, Bilski J, Szczygiel E, et al. PNF and manual therapy treatment results of patients with cervical spine osteoarthritis. J Back Musculoskelet Rehabil. 2017 Sep 22;30(5):1095-101. doi: 10.3233/BMR169718. PMID: 28946528. Exclusion: 4

551. Maiers M, Bronfort G, Evans R, et al. Spinal manipulative therapy and exercise for seniors with chronic neck pain. Spine Journal: Official Journal of the North American Spine Society. 2014 Sep 1;14(9):1879-89. doi: http://dx.doi.org/10.1016/j.spinee.2013.10.0 35. PMID: 24225010. Exclusion: 4

552. Maigne JY. Immediate effects of thoracic manipulation in patients with neck pain: a randomized clinical trial. Man Ther. 2007 Feb;12(1):e1. doi: 10.1016/j.math.2006.02.005. PMID: 16621668. Exclusion: 8

553. Makris UE, Abrams RC, Gurland B, et al. Management of persistent pain in the older patient: a clinical review. JAMA. 2014 Aug 27;312(8):825-36. doi: http://dx.doi.org/10.1001/jama.2014.9405. PMID: 25157726. Exclusion: 10
554. Malas FU, Ozcakar L, Kaymak B, et al. Effects of different strength training on muscle architecture: clinical and ultrasonographic evaluation in knee osteoarthritis. Pm \& R. 2013 Aug;5(8):65562. doi: http://dx.doi.org/10.1016/j.pmrj.2013.03.005 . PMID: 23474211. Exclusion: 9

555. Mangani I, Cesari M, Kritchevsky SB, et al. Physical exercise and comorbidity. Results from the Fitness and Arthritis in Seniors Trial (FAST). Aging-Clinical \& Experimental Research. 2006 Oct;18(5):374-80. PMID: 17167301. Exclusion: 7

556. Mangels M, Schwarz S, Worringen U, et al. Evaluation of a behavioral-medical inpatient rehabilitation treatment including booster sessions: a randomized controlled study. Clin J Pain. 2009 Jun;25(5):356-64. doi: 10.1097/AJP.0b013e3181925791. PMID: 19454868. Exclusion: 5

557. Manheimer E, Cheng K, Linde K, et al. Acupuncture for peripheral joint osteoarthritis. Cochrane Database of Systematic Reviews. 2010(1):CD001977. doi: http://dx.doi.org/10.1002/14651858.CD0019 77.pub2. PMID: 20091527. Exclusion: 10

558. Manheimer E, Linde K, Lao L, et al. Metaanalysis: acupuncture for osteoarthritis of the knee. Annals of Internal Medicine. 2007 Jun 19;146(12):868-77. PMID: 17577006. Exclusion: 10

559. Manias P, Tagaris G, Karageorgiou K. Acupuncture in headache: a critical review. Clinical Journal of Pain. 2000

Dec;16(4):334-9. PMID: 11153790. Exclusion: 10

560. Mannerkorpi K, Henriksson C. Nonpharmacological treatment of chronic widespread musculoskeletal pain. Best Practice \& Research in Clinical Rheumatology. 2007 Jun;21(3):513-34. PMID: 17602997. Exclusion: 10

561. Mannerkorpi K, Iversen MD. Physical exercise in fibromyalgia and related syndromes. Best Practice \& Research in Clinical Rheumatology. 2003 Aug;17(4):629-47. PMID: 12849716. Exclusion: 10 
562. Manyanga T, Froese M, Zarychanski R, et al. Pain management with acupuncture in osteoarthritis: a systematic review and metaanalysis. BMC Complementary \& Alternative Medicine. 2014;14:312. doi: http://dx.doi.org/10.1186/1472-6882-14312. PMID: 25151529. Exclusion: 10

563. Maquet D, Demoulin C, Croisier JL, et al. Benefits of physical training in fibromyalgia and related syndromes. Annales de Readaptation et de Medecine Physique. 2007 Jul;50(6):363-8, 56-62. PMID: 17467103. Exclusion: 10

564. Marcus DA. Fibromyalgia: diagnosis and treatment options. Gender Medicine. 2009;6 Suppl 2:139-51. doi:

http://dx.doi.org/10.1016/j.genm.2009.01.00 4. PMID: 19406366. Exclusion: 10

565. Marin TJ, Van Eerd D, Irvin E, et al. Multidisciplinary biopsychosocial rehabilitation for subacute low back pain. Cochrane Database of Systematic Reviews. 201706 28;6:CD002193. doi: https://dx.doi.org/10.1002/14651858.CD002 193.pub2. PMID: 28656659. Exclusion: 10

566. Marshall P, Murphy B. Self-report measures best explain changes in disability compared with physical measures after exercise rehabilitation for chronic low back pain. Spine (Phila Pa 1976). 2008 Feb 01;33(3):326-38. doi: 10.1097/BRS.0b013e31816233eb. PMID: 18303467. Exclusion: 4

567. Marshall PW, Kennedy S, Brooks C, et al. Pilates exercise or stationary cycling for chronic nonspecific low back pain: does it matter? a randomized controlled trial with 6month follow-up. Spine (Phila Pa 1976). 2013 Jul 01;38(15):E952-9. doi: 10.1097/BRS.0b013e318297c1e5. PMID: 23615384. Exclusion: 4

568. Martel J, Dugas C, Dubois JD, et al. A randomised controlled trial of preventive spinal manipulation with and without a home exercise program for patients with chronic neck pain. BMC Musculoskeletal Disorders. 2011;12:41. doi: http://dx.doi.org/10.1186/1471-2474-12-41. PMID: 21303529. Exclusion: 5
569. Martin J, Torre F, Aguirre U, et al. Evaluation of the interdisciplinary PSYMEPHY treatment on patients with fibromyalgia: a randomized control trial. Pain Medicine. 2014 Apr;15(4):682-91. doi: http://dx.doi.org/10.1111/pme.12375. PMID: 24576148. Exclusion: 7

570. Martin J, Torre F, Padierna A, et al. Impact of interdisciplinary treatment on physical and psychosocial parameters in patients with fibromyalgia: results of a randomised trial. Int J Clin Pract. 2014 May;68(5):618-27. Epub 2014 Feb 20. Exclusion: 7

571. Martin J, Torre F, Padierna A, et al. Interdisciplinary treatment of patients with fibromyalgia: improvement of their healthrelated quality of life. Pain Pract. 2014 Nov;14(8):721-31. doi: 10.1111/papr.12134. Epub 2013 Nov 27. Exclusion: 7

572. Martin L, Nutting A, MacIntosh BR, et al. An exercise program in the treatment of fibromyalgia. Journal of Rheumatology. 1996 Jun;23(6):1050-3. PMID: 8782139. Exclusion: 9

573. Martin PR, Forsyth MR, Reece J. Cognitivebehavioral therapy versus temporal pulse amplitude biofeedback training for recurrent headache. Behavior Therapy. 2007 Dec;38(4):350-63. PMID: 18021950. Exclusion: 3

574. Matarán-Peñarrocha GA, Castro-Sánchez AM, García GC, et al. Influence of craniosacral therapy on anxiety, depression and quality of life in patients with fibromyalgia. Evidence-Based Complementary and Alternative Medicine. 2011;2011. Exclusion: 4

575. Mathews JA, Hickling J. Lumbar traction: a double-blind controlled study for sciatica. Rheumatol Rehabil. 1975 Nov;14(4):222-5. PMID: 1105752. Exclusion: 3

576. Mathews W, Morkel M, Mathews J. Manipulation and traction for lumbago and sciatica: physiotherapeutic techniques used in two controlled trials. Physiotherapy Practice. 1988;4(4):201-6. Exclusion: 3

577. Maurer BT, Stern AG, Kinossian B, et al. Osteoarthritis of the knee: isokinetic quadriceps exercise versus an educational intervention. Archives of Physical Medicine \& Rehabilitation. 1999 Oct;80(10):1293-9. PMID: 10527090. Exclusion: 5 
578. Mavrommatis CI, Argyra E, Vadalouka A, et al. Acupuncture as an adjunctive therapy to pharmacological treatment in patients with chronic pain due to osteoarthritis of the knee: a 3-armed, randomized, placebocontrolled trial. Pain. 2012

Aug;153(8):1720-6. doi: http://dx.doi.org/10.1016/j.pain.2012.05.005 . PMID: 22727499. Exclusion: 4

579. Mayer JM, Ralph L, Look M, et al. Treating acute low back pain with continuous lowlevel heat wrap therapy and/or exercise: a randomized controlled trial. Spine J. 2005 Jul-Aug;5(4):395-403. doi: 10.1016/j.spinee.2005.03.009. PMID: 15996609. Exclusion: 3

580. McBeth J, Prescott G, Scotland G, et al. Cognitive behavior therapy, exercise, or both for treating chronic widespread pain. Arch Intern Med. 2012 Jan 09

Jan 9;172(1):48-57. doi: 10.1001/archinternmed.2011.555. Epub Nov 14. Exclusion: 3

581. McCarthy CJ, Callaghan MJ, Oldham JA. Pulsed electromagnetic energy treatment offers no clinical benefit in reducing the pain of knee osteoarthritis: a systematic review. BMC Musculoskeletal Disorders. 2006;7:51. PMID: 16776826. Exclusion: 10

582. McCauley JD, Thelen MH, Frank RG, et al. Hypnosis compared to relaxation in the outpatient management of chronic low back pain. Arch Phys Med Rehabil. 1983 Nov;64(11):548-52. PMID: 6227304. Exclusion: 5

583. McCurry SM, Shortreed SM, Von Korff M, et al. Who benefits from CBT for insomnia in primary care? Important patient selection and trial design lessons from longitudinal results of the Lifestyles trial. Sleep. 2014 Feb;37(2):299-308. doi: http://dx.doi.org/10.5665/sleep.3402. PMID: 24497658. Exclusion: 3

584. McDowell CP, Cook DB, Herring MP. The Effects of Exercise Training on Anxiety in Fibromyalgia Patients: A Meta-analysis. Med Sci Sports Exerc. 2017

Sep;49(9):1868-76. doi: 10.1249/MSS.0000000000001290. PMID: 28419024. Exclusion: 10
585. McKnight PE, Kasle S, Going S, et al. A comparison of strength training, selfmanagement, and the combination for early osteoarthritis of the knee. Arthritis care \& research. 2010 Jan 15;62(1):45-53. doi: http://dx.doi.org/10.1002/acr.20013. PMID: 20191490. Exclusion: 5

586. McLean SM, Klaber Moffett JA, Sharp DM, et al. A randomised controlled trial comparing graded exercise treatment and usual physiotherapy for patients with nonspecific neck pain (the GET UP neck pain trial). Manual Therapy. 2013 Jun;18(3):199205. doi:

http://dx.doi.org/10.1016/j.math.2012.09.00 5. PMID: 23085116. Exclusion: 5

587. McNair PJ, Simmonds MA, Boocock MG, et al. Exercise therapy for the management of osteoarthritis of the hip joint: a systematic review. Arthritis Research \& Therapy. 2009;11(3):R98. doi: http://dx.doi.org/10.1186/ar2743. PMID: 19555502. Exclusion: 10

588. Meade TW, Dyer S, Browne W, et al. Randomised comparison of chiropractic and hospital outpatient management for low back pain: results from extended follow up. BMJ. 1995 Aug 5;311(7001):349-51. PMID: 7640538. Exclusion: 3

589. Meade TW, Dyer S, Browne W, et al. Low back pain of mechanical origin: randomised comparison of chiropractic and hospital outpatient treatment. BMJ. 1990 Jun 2;300(6737):1431-7. PMID: 2143092. Exclusion: 3

590. Meeus M, Nijs J, Vanderheiden T, et al. The effect of relaxation therapy on autonomic functioning, symptoms and daily functioning, in patients with chronic fatigue syndrome or fibromyalgia: a systematic review. Clinical Rehabilitation. 2015 Mar;29(3):221-33. doi: http://dx.doi.org/10.1177/026921551454263 5. PMID: 25200878. Exclusion: 10

591. Melchart D, Linde K, Fischer P, et al. Acupuncture for idiopathic headache. Cochrane Database of Systematic Reviews. 2001(1):CD001218. PMID: 11279710. Exclusion: 10 
592. Melchart D, Linde K, Fischer P, et al. Acupuncture for recurrent headaches: a systematic review of randomized controlled trials.[Erratum appears in Cephalalgia 2000 Oct;20(8):762-3]. Cephalalgia. 1999 Nov;19(9):779-86; discussion 65. PMID: 10595286. Exclusion: 10

593. Melchart D, Streng A, Hoppe A, et al. Acupuncture in patients with tension-type headache: randomised controlled trial. BMJ. 2005 Aug 13;331(7513):376-82. PMID: 16055451. Exclusion: 3

594. Melzack R, Jeans ME, Stratford JG, et al. Ice massage and transcutaneous electrical stimulation: comparison of treatment for low-back pain. Pain. 1980 Oct;9(2):209-17. PMID: 6450393. Exclusion: 3

595. Meng K, Seekatz B, Roband H, et al. Intermediate and long-term effects of a standardized back school for inpatient orthopedic rehabilitation on illness knowledge and self-management behaviors: a randomized controlled trial. Clin J Pain. 2011 Mar-Apr;27(3):248-57. doi: 10.1097/AJP.0b013e3181ffbfaf. PMID: 21178600. Exclusion: 5

596. Meyer BB, Lemley KJ. Utilizing exercise to affect the symptomology of fibromyalgia: a pilot study. Med Sci Sports Exerc. 2000 Oct;32(10):1691-7. Exclusion: 7

597. Michalsen A, Kunz N, Jeitler M, et al. Effectiveness of focused meditation for patients with chronic low back pain-A randomized controlled clinical trial. Complementary Therapies in Medicine. 2016 Jun;26:79-84. doi: https://dx.doi.org/10.1016/j.ctim.2016.03.01 0. PMID: 27261986. Exclusion: 9

598. Michalsen A, Traitteur H, Ludtke R, et al. Yoga for chronic neck pain: a pilot randomized controlled clinical trial. Journal of Pain. 2012 Nov;13(11):1122-30. doi: http://dx.doi.org/10.1016/j.jpain.2012.08.00 4. PMID: 23117107. Exclusion: 9

599. Miller J, Gross A, D'Sylva J, et al. Manual therapy and exercise for neck pain: a systematic review. Manual Therapy. 2010 Aug;15(4):334-54. PMID: 20593537.

Exclusion: 10
600. Miller RC, Berman JS. The efficacy of cognitive behavior therapies: a quantitative review of the research evidence. Psychol Bull. 1983 Jul;94(1):39-53. PMID: 6353465. Exclusion: 5

601. Million R, Nilsen KH, Jayson MI, et al. Evaluation of low back pain and assessment of lumbar corsets with and without back supports. Ann Rheum Dis. 1981 Oct;40(5):449-54. PMID: 6458250. Exclusion: 5

602. Minelli A, Vaona A. Effectiveness of cognitive behavioral therapy in the treatment of fibromyalgia syndrome: a meta-analytic literature review. Reumatismo.

2012;64(3):151-7. doi: http://dx.doi.org/10.4081/reumatismo.2012. 151. PMID: 22842298. Exclusion: 10

603. Minen MT, Torous J, Raynowska J, et al. Electronic behavioral interventions for headache: a systematic review. Journal of Headache \& Pain. 2016;17:51. doi: http://dx.doi.org/10.1186/s10194-016-0608y. PMID: 27160107. Exclusion: 10

604. Mitchell RI, Carmen GM. The functional restoration approach to the treatment of chronic pain in patients with soft tissue and back injuries. Spine (Phila Pa 1976). 1994 Mar 15;19(6):633-42. PMID: 8009327. Exclusion: 6

605. Moe RH, Grotle M, Kjeken I, et al. Effectiveness of an Integrated Multidisciplinary Osteoarthritis Outpatient Program versus Outpatient Clinic as Usual: A Randomized Controlled Trial. Journal of Rheumatology. 2016 Feb;43(2):411-8. doi: https://dx.doi.org/10.3899/jrheum.150157. PMID: 26669917. Exclusion: 3

606. Moe RH, Haavardsholm EA, Christie A, et al. Effectiveness of nonpharmacological and nonsurgical interventions for hip osteoarthritis: an umbrella review of highquality systematic reviews. Physical Therapy. 2007 Dec;87(12):1716-27. PMID: 17906289. Exclusion: 10 
607. Moe RH, Kjeken I, Uhlig T, et al. There is inadequate evidence to determine the effectiveness of nonpharmacological and nonsurgical interventions for hand osteoarthritis: an overview of high-quality systematic reviews. Physical Therapy. 2009 Dec;89(12):1363-70. doi: http://dx.doi.org/10.2522/ptj.20080398. PMID: 19850713. Exclusion: 10

608. Mohseni-Bandpei MA, Critchley J, Staunton $\mathrm{T}$, et al. A prospective randomised controlled trial of spinal manipulation and ultrasound in the treatment of chronic low back pain. Physiotherapy. 2006;92(1):34-42. doi: 10.1016/j.physio.2005.05.005. Exclusion: 5

609. Moix J, Canellas M, Osorio C, et al. Efficacy of an interdisciplinary educational program in patients with chronic back pain. DOLOR BARCELONA. 2003;18(3):14957. Exclusion: 11

610. Moll LT, Jensen OK, Schiottz-Christensen B, et al. Return to Work in Employees on Sick Leave due to Neck or Shoulder Pain: A Randomized Clinical Trial Comparing Multidisciplinary and Brief Intervention with One-Year Register-Based Follow-Up. J Occup Rehabil. 2017 Aug 23. Exclusion: 3

611. Monro R, Bhardwaj AK, Gupta RK, et al. Disc extrusions and bulges in nonspecific low back pain and sciatica: Exploratory randomised controlled trial comparing yoga therapy and normal medical treatment. J Back Musculoskelet Rehabil. 2015;28(2):383-92. doi: 10.3233/bmr140531. PMID: 25271201. Exclusion: 3

612. Monticone M, Cedraschi C, Ambrosini E, et al. Cognitive-behavioural treatment for subacute and chronic neck pain. Cochrane Database of Systematic Reviews.

2015;5:CD010664. doi: http://dx.doi.org/10.1002/14651858.CD0106 64.pub2. PMID: 26006174. Exclusion: 10

613. Moonaz SH, Bingham CO, 3rd, Wissow L, et al. Yoga in Sedentary Adults with Arthritis: Effects of a Randomized Controlled Pragmatic Trial. Journal of Rheumatology. 2015 Jul;42(7):1194-202. doi: http://dx.doi.org/10.3899/jrheum.141129. PMID: 25834206. Exclusion: 3
614. Moore SR, Shurman J. Combined neuromuscular electrical stimulation and transcutaneous electrical nerve stimulation for treatment of chronic back pain: a doubleblind, repeated measures comparison. Arch Phys Med Rehabil. 1997 Jan;78(1):55-60. PMID: 9014958. Exclusion: 9

615. Moraska AF, Schmiege SJ, Mann JD, et al. Responsiveness of Myofascial Trigger Points to Single and Multiple Trigger Point Release Massages: A Randomized, Placebo Controlled Trial. Am J Phys Med Rehabil. 2017 Sep;96(9):639-45. doi: 10.1097/PHM.0000000000000728. PMID: 28248690. Exclusion: 3

616. Moraska AF, Stenerson L, Butryn N, et al. Myofascial trigger point-focused head and neck massage for recurrent tension-type headache: a randomized, placebo-controlled clinical trial. Clinical Journal of Pain. 2015 Feb;31(2):159-68. doi: http://dx.doi.org/10.1097/AJP.00000000000 00091. PMID: 25329141. Exclusion: 3

617. Morone G, Iosa M, Paolucci T, et al. Efficacy of perceptive rehabilitation in the treatment of chronic nonspecific low back pain through a new tool: a randomized clinical study. Clin Rehabil. 2012 Apr;26(4):339-50. doi: 10.1177/0269215511414443. PMID: 21965520. Exclusion: 4

618. Morone G, Paolucci T, Alcuri MR, et al. Quality of life improved by multidisciplinary back school program in patients with chronic non-specific low back pain: a single blind randomized controlled trial. Eur J Phys Rehabil Med. 2011 Dec;47(4):533-41. PMID: 21508915. Exclusion: 4

619. Morone NE, Greco CM, Weiner DK. Mindfulness meditation for the treatment of chronic low back pain in older adults: a randomized controlled pilot study. Pain. 2008 Feb;134(3):310-9. doi: 10.1016/j.pain.2007.04.038. PMID: 17544212. Exclusion: 6 
620. Morrisette DC, Cholewicki J, Logan S, et al. A randomized clinical trial comparing extensible and inextensible lumbosacral orthoses and standard care alone in the management of lower back pain. Spine (Phila Pa 1976). 2014 Oct 01;39(21):173342. doi: $10.1097 /$ brs.0000000000000521. PMID: 25054648. Exclusion: 3

621. Moseng T, Dagfinrud H, Smedslund G, et al. The importance of dose in land-based supervised exercise for people with hip osteoarthritis. A systematic review and meta-analysis. Osteoarthritis Cartilage. 2017 Oct;25(10):1563-76. doi: 10.1016/j.joca.2017.06.004. PMID: 28648741. Exclusion: 10

622. Moyer RF, Birmingham TB, Bryant DM, et al. Valgus bracing for knee osteoarthritis: a meta-analysis of randomized trials. Arthritis care \& research. 2015 Apr;67(4):493-501. doi: http://dx.doi.org/10.1002/acr.22472. PMID: 25201520. Exclusion: 10

623. Murray M, Lange B, Nornberg BR, et al. Self-administered physical exercise training as treatment of neck and shoulder pain among military helicopter pilots and crew: a randomized controlled trial. BMC Musculoskelet Disord. 2017 Apr 07;18(1):147. PMID: Pmc5383986. Exclusion: 9

624. Nadler SF, Steiner DJ, Erasala GN, et al. Continuous low-level heatwrap therapy for treating acute nonspecific low back pain. Arch Phys Med Rehabil. 2003

Mar;84(3):329-34. doi: 10.1053/apmr.2003.50102. PMID: 12638099. Exclusion: 3

625. Nadler SF, Steiner DJ, Erasala GN, et al. Continuous low-level heat wrap therapy provides more efficacy than Ibuprofen and acetaminophen for acute low back pain. Spine (Phila Pa 1976). 2002 May 15;27(10):1012-7. PMID: 12004166. Exclusion: 3

626. Nadler SF, Steiner DJ, Petty SR, et al. Overnight use of continuous low-level heatwrap therapy for relief of low back pain. Arch Phys Med Rehabil. 2003

Mar;84(3):335-42. doi: 10.1053/apmr.2003.50103. PMID: 12638100. Exclusion: 3
627. Nasiri A, Mahmodi MA, Nobakht Z. Effect of aromatherapy massage with lavender essential oil on pain in patients with osteoarthritis of the knee: A randomized controlled clinical trial. Complementary Therapies in Clinical Practice. 2016 Nov;25:75-80. doi: https://dx.doi.org/10.1016/j.ctcp.2016.08.00 2. PMID: 27863613. Exclusion: 4

628. Negm A, Lorbergs A, Macintyre NJ. Efficacy of low frequency pulsed subsensory threshold electrical stimulation vs placebo on pain and physical function in people with knee osteoarthritis: systematic review with meta-analysis. Osteoarthritis \& Cartilage. 2013 Sep;21(9):1281-9. doi: http://dx.doi.org/10.1016/j.joca.2013.06.015. PMID: 23973142. Exclusion: 10

629. Nelson DV, Bennett RM, Barkhuizen A, et al. Neurotherapy of fibromyalgia? Pain Med. 2010 Jun;11(6):912-9. doi: 10.1111/j.526-4637.2010.00862.x. Exclusion: 4

630. Nelson FR, Zvirbulis R, Pilla AA. Noninvasive electromagnetic field therapy produces rapid and substantial pain reduction in early knee osteoarthritis: a randomized double-blind pilot study. Rheumatology International. 2013 Aug;33(8):2169-73. doi: http://dx.doi.org/10.1007/s00296-012-23668. PMID: 22451021. Exclusion: 9

631. Nestoriuc Y, Rief W, Martin A. Metaanalysis of biofeedback for tension-type headache: efficacy, specificity, and treatment moderators. J Consult Clin Psychol. 2008 Jun;76(3):379-96. doi: 10.1037/0022-006X.76.3.379. PMID: 18540732. Exclusion: 10

632. Newton-John TR, Spence SH, Schotte D. Cognitive-behavioural therapy versus EMG biofeedback in the treatment of chronic low back pain. Behav Res Ther. 1995 Jul;33(6):691-7. PMID: 7654161. Exclusion: 9

633. Nicolakis P, Kollmitzer J, Crevenna R, et al. Pulsed magnetic field therapy for osteoarthritis of the knee--a double-blind sham-controlled trial. Wiener Klinische Wochenschrift. 2002 Aug 30;114(1516):678-84. PMID: 12602111. Exclusion: 9 
634. Niemisto L, Lahtinen-Suopanki T, Rissanen $\mathrm{P}$, et al. A randomized trial of combined manipulation, stabilizing exercises, and physician consultation compared to physician consultation alone for chronic low back pain. Spine (Phila Pa 1976). 2003 Oct 01;28(19):2185-91. doi: 10.1097/01.brs.0000085096.62603.61. PMID: 14520029. Exclusion: 4

635. Nikander R, Malkia E, Parkkari J, et al. Dose-response relationship of specific training to reduce chronic neck pain and disability. Medicine \& Science in Sports \& Exercise. 2006 Dec;38(12):2068-74. PMID: 17146312. Exclusion: 7

636. Nouwen A. EMG biofeedback used to reduce standing levels of paraspinal muscle tension in chronic low back pain. Pain. 1983 Dec;17(4):353-60. PMID: 6229707. Exclusion: 9

637. Nuhr M, Hoerauf K, Bertalanffy A, et al. Active warming during emergency transport relieves acute low back pain. Spine (Phila $\mathrm{Pa}$ 1976). 2004 Jul 15;29(14):1499-503. PMID: 15247569. Exclusion: 3

638. Nunez M, Nunez E, Segur JM, et al. The effect of an educational program to improve health-related quality of life in patients with osteoarthritis on waiting list for total knee replacement: a randomized study.

Osteoarthritis \& Cartilage. 2006

Mar;14(3):279-85. doi: https://dx.doi.org/10.1016/j.joca.2005.10.00 2. PMID: 16309929. Exclusion: 4

639. Oleske DM, Lavender SA, Andersson GB, et al. Are back supports plus education more effective than education alone in promoting recovery from low back pain?: Results from a randomized clinical trial. Spine (Phila Pa 1976). 2007 Sep 01;32(19):2050-7. doi: 10.1097/BRS.0b013e3181453fcc. PMID: 17762804. Exclusion: 3

640. Olivares PR, Gusi N, Parraca JA, et al. Tilting Whole Body Vibration improves quality of life in women with fibromyalgia: a randomized controlled trial. J Altern Complement Med. 2011 Aug;17(8):723-8. doi: 10.1089/acm.2010.0296. Epub 2011 Jul 12. Exclusion: 4
641. Oliveira AM, Peccin MS, Silva KN, et al. Impact of exercise on the functional capacity and pain of patients with knee osteoarthritis: a randomized clinical trial. Revista Brasileira de Reumatologia. 2012 Dec;52(6):876-82. PMID: 23223698. Exclusion: 9

642. Omar AS, Awadalla MA, El-Latif MA. Evaluation of pulsed electromagnetic field therapy in the management of patients with discogenic lumbar radiculopathy. Int $\mathrm{J}$ Rheum Dis. 2012 Oct;15(5):e101-8. doi: 10.1111/j.1756-185X.2012.01745.x. PMID: 23083041. Exclusion: 9

643. Onieva-Zafra MD, Castro-Sanchez AM, Mataran-Penarrocha GA, et al. Effect of music as nursing intervention for people diagnosed with fibromyalgia. Pain Management Nursing. 2013 Jun;14(2):e3946. doi:

http://dx.doi.org/10.1016/j.pmn.2010.09.004 . PMID: 23108015. Exclusion: 4

644. Onieva-Zafra MD, Garcia LH, Del Valle MG. Effectiveness of guided imagery relaxation on levels of pain and depression in patients diagnosed with fibromyalgia. Holistic Nursing Practice. 2015 JanFeb;29(1):13-21. doi: http://dx.doi.org/10.1097/HNP.0000000000 000062. PMID: 25470476. Exclusion: 9

645. Oppong R, Jowett S, Nicholls E, et al. Joint protection and hand exercises for hand osteoarthritis: an economic evaluation comparing methods for the analysis of factorial trials. Rheumatology. 2015 May;54(5):876-83. doi: http://dx.doi.org/10.1093/rheumatology/keu 389. PMID: 25339642. Exclusion: 4

646. O'Reilly SC, Muir KR, Doherty M. Effectiveness of home exercise on pain and disability from osteoarthritis of the knee: a randomised controlled trial. Annals of the Rheumatic Diseases. 1999 Jan;58(1):15-9. PMID: 10343535. Exclusion: 3

647. Osiri M, Welch V, Brosseau L, et al. Transcutaneous electrical nerve stimulation for knee osteoarthritis. Cochrane Database of Systematic Reviews. 2000(4):CD002823. PMID: 11034768. Exclusion: 10 
648. Osteras N, Kjeken I, Smedslund G, et al.

Exercise for Hand Osteoarthritis: A

Cochrane Systematic Review. J Rheumatol. 2017 Dec;44(12):1850-8. doi:

10.3899/jrheum.170424. PMID: 29032354.

Exclusion: 10

649. O'Sullivan PB, Phyty GD, Twomey LT, et al. Evaluation of specific stabilizing exercise in the treatment of chronic low back pain with radiologic diagnosis of spondylolysis or spondylolisthesis. Spine (Phila Pa 1976). 1997 Dec 15;22(24):2959-67. PMID: 9431633. Exclusion: 3

650. Ozdemir F, Birtane M, Kokino S. The clinical efficacy of low-power laser therapy on pain and function in cervical osteoarthritis. Clinical Rheumatology. 2001;20(3):181-4. PMID: 11434469. Exclusion: 9

651. Ozgonenel L, Aytekin E, Durmusoglu G. A double-blind trial of clinical effects of therapeutic ultrasound in knee osteoarthritis. Ultrasound in medicine \& biology. 2009 Jan;35(1):44-9. PMID: CN-00668261 UPDATE. Exclusion: 9

652. Ozturk B, Gunduz OH, Ozoran K, et al. Effect of continuous lumbar traction on the size of herniated disc material in lumbar disc herniation. Rheumatol Int. 2006 May;26(7):622-6. doi: 10.1007/s00296-0050035-x. PMID: 16249899. Exclusion: 3

653. Paatelma M, Kilpikoski S, Simonen R, et al. Orthopaedic manual therapy, McKenzie method or advice only for low back pain in working adults: a randomized controlled trial with one year follow-up. J Rehabil Med. 2008 Nov;40(10):858-63. doi: 10.2340/16501977-0262. PMID: 19242624. Exclusion: 3

654. Paige NM, Miake-Lye IM, Booth MS, et al. Association of Spinal Manipulative Therapy With Clinical Benefit and Harm for Acute Low Back Pain: Systematic Review and Meta-analysis. JAMA. 2017 Apr 11;317(14):1451-60. doi: https://dx.doi.org/10.1001/jama.2017.3086. PMID: 28399251. Exclusion: 10

655. Paiva T, Nunes JS, Moreira A, et al. Effects of frontalis EMG biofeedback and diazepam in the treatment of tension headache. Headache. 1982 Sep;22(5):216-20. PMID: 7141868. Exclusion: 7
656. Pal B, Mangion P, Hossain MA, et al. A controlled trial of continuous lumbar traction in the treatment of back pain and sciatica. Br J Rheumatol. 1986 May;25(2):181-3. PMID: 3011174. Exclusion: 3

657. Palmgren PJ, Sandstrom PJ, Lundqvist FJ, et al. Improvement after chiropractic care in cervicocephalic kinesthetic sensibility and subjective pain intensity in patients with nontraumatic chronic neck pain.[Erratum appears in J Manipulative Physiol Ther. 2006 May;29(4):340]. Journal of Manipulative \& Physiological Therapeutics. 2006 Feb;29(2):100-6. PMID: 16461168. Exclusion: 9

658. Palmieri-Smith RM, Thomas AC, Karvonen-Gutierrez C, et al. A clinical trial of neuromuscular electrical stimulation in improving quadriceps muscle strength and activation among women with mild and moderate osteoarthritis. Physical Therapy. 2010 Oct;90(10):1441-52. doi: http://dx.doi.org/10.2522/ptj.20090330. PMID: 20671100. Exclusion: 7

659. Papadopoulou D, Fassoulaki A, Tsoulas C, et al. A meta-analysis to determine the effect of pharmacological and nonpharmacological treatments on fibromyalgia symptoms comprising OMERACT-10 response criteria. Clin Rheumatol. 2016 Mar;35(3):573-86. doi: 10.1007/s10067015-3144-2. PMID: 26676810. Exclusion: 10

660. Park J, McCaffrey R, Dunn D, et al. Managing osteoarthritis: comparisons of chair yoga, Reiki, and education (pilot study). Holistic Nursing Practice. 2011 NovDec;25(6):316-26. doi: http://dx.doi.org/10.1097/HNP.0b013e31823 2c5f9. PMID: 22015342. Exclusion: 6

661. Park J, McCaffrey R, Newman D, et al. The effect of Sit ' $n$ ' Fit Chair Yoga among community-dwelling older adults with osteoarthritis. Holistic Nursing Practice. 2014 Jul-Aug;28(4):247-57. doi: http://dx.doi.org/10.1097/HNP.0000000000 000034. PMID: 24919095. Exclusion: 3 
662. Park J, McCaffrey R, Newman D, et al. A Pilot Randomized Controlled Trial of the Effects of Chair Yoga on Pain and Physical Function Among Community-Dwelling Older Adults With Lower Extremity Osteoarthritis. Journal of the American Geriatrics Society. 2017 Mar;65(3):592-7. doi: https://dx.doi.org/10.1111/jgs.14717. PMID: 28008603. Exclusion: 3

663. Park JM, Park SU, Jung WS, et al. Carthami-Semen acupuncture point injection for chronic daily headache: a pilot, randomised, double-blind, controlled trial. Complementary Therapies in Medicine. 2011 Jan;19 Suppl 1:S19-25. doi: http://dx.doi.org/10.1016/j.ctim.2010.09.004 . PMID: 21195291. Exclusion: 9

664. Passard A, Attal N, Benadhira R, et al. Effects of unilateral repetitive transcranial magnetic stimulation of the motor cortex on chronic widespread pain in fibromyalgia. Brain. 2007 Oct;130(Pt 10):2661-70. PMID: 17872930. Exclusion: 4

665. Patel KC, Gross A, Graham N, et al. Massage for mechanical neck disorders. Cochrane Database of Systematic Reviews. 2012;9:CD004871. doi: http://dx.doi.org/10.1002/14651858.CD0048 71.pub4. PMID: 22972078. Exclusion: 10

666. Patrick DL, Ramsey SD, Spencer AC, et al. Economic evaluation of aquatic exercise for persons with osteoarthritis. Medical Care. 2001 May;39(5):413-24. PMID: 11317090. Exclusion: 3

667. Pavlovic AS, Djurasic LM. The effect of low frequency pulsing electromagnetic field in treatment of patients with knee joint osteoarthritis. Acta Chirurgica Iugoslavica. 2012;59(3):81-3. PMID: 23654012. Exclusion: 9

668. Pelka RB, Jaenicke C, Gruenwald J. Impulse magnetic-field therapy for migraine and other headaches: a double-blind, placebocontrolled study. Advances in Therapy. 2001 May-Jun;18(3):101-9. PMID: 11571822. Exclusion: 3

669. Penrose KW, Chook K, Stump JL. Acute and chronic effects of pneumatic lumbar support on muscular strength, flexibility, and functional impairment index. Res Sports Med. 1991;2(2):121-9. Exclusion: 3
670. Peolsson A, Landen Ludvigsson M, Tigerfors AM, et al. Effects of NeckSpecific Exercises Compared to Waiting List for Individuals With Chronic WhiplashAssociated Disorders: A Prospective, Randomized Controlled Study. Archives of Physical Medicine \& Rehabilitation. 2016 Feb;97(2):189-95. doi: http://dx.doi.org/10.1016/j.apmr.2015.10.08 7. PMID: 26514296. Exclusion: 9

671. Perlman AI, Sabina A, Williams AL, et al. Massage therapy for osteoarthritis of the knee: a randomized controlled trial. Archives of Internal Medicine. 2006 Dec 11-25;166(22):2533-8. PMID: 17159021. Exclusion: 9

672. Petersen T, Larsen K, Nordsteen J, et al. The McKenzie method compared with manipulation when used adjunctive to information and advice in low back pain patients presenting with centralization or peripheralization: a randomized controlled trial. Spine (Phila Pa 1976). 2011 Nov 15;36(24):1999-2010. doi: 10.1097/BRS.0b013e318201ee8e. PMID: 21358492. Exclusion: 3

673. Peterson MG, Kovar-Toledano PA, Otis JC, et al. Effect of a walking program on gait characteristics in patients with osteoarthritis. Arthritis Care \& Research. 1993 Mar;6(1):11-6. PMID: 8443252. Exclusion: 9

674. Petrella RJ, Bartha C. Home based exercise therapy for older patients with knee osteoarthritis: a randomized clinical trial. Journal of Rheumatology. 2000 Sep;27(9):2215-21. PMID: 10990236. Exclusion: 9

675. Philips C. The modification of tension headache pain using EMG biofeedback. Behav Res Ther. 1977;15(2):119-29. PMID: 869862. Exclusion: 3

676. Pillastrini P, de Lima ESRF, Banchelli F, et al. Effectiveness of Global Postural Reeducation in Patients With Chronic Nonspecific Neck Pain: Randomized Controlled Trial. Physical Therapy. 2016 Sep;96(9):1408-16. doi: https://dx.doi.org/10.2522/ptj.20150501. PMID: 27013576. Exclusion: 4 
677. Pillastrini P, Mugnai R, Bertozzi L, et al. Effectiveness of an at-work exercise program in the prevention and management of neck and low back complaints in nursery school teachers. Industrial Health. 2009 Aug;47(4):349-54. PMID: 19672007. Exclusion: 3

678. Pinto D, Robertson MC, Abbott JH, et al. Manual therapy, exercise therapy, or both, in addition to usual care, for osteoarthritis of the hip or knee. 2: economic evaluation alongside a randomized controlled trial. Osteoarthritis \& Cartilage. 2013

Oct;21(10):1504-13. doi: http://dx.doi.org/10.1016/j.joca.2013.06.014. PMID: 23811491. Exclusion: 3

679. Pipitone N, Scott DL. Magnetic pulse treatment for knee osteoarthritis: a randomised, double-blind, placebocontrolled study. Current Medical Research \& Opinion. 2001;17(3):190-6. doi: https://dx.doi.org/10.1185/03007990391170 61. PMID: 11900312. Exclusion: 9

680. Pisters MF, Veenhof C, de Bakker DH, et al. Behavioural graded activity results in better exercise adherence and more physical activity than usual care in people with osteoarthritis: a cluster-randomised trial. Journal of Physiotherapy. 2010;56(1):41-7. PMID: 20500136. Exclusion: 3

681. Pisters MF, Veenhof C, Schellevis FG, et al. Long-term effectiveness of exercise therapy in patients with osteoarthritis of the hip or knee: a randomized controlled trial comparing two different physical therapy interventions. Osteoarthritis \& Cartilage. 2010 Aug;18(8):1019-26. doi: http://dx.doi.org/10.1016/j.joca.2010.05.008. PMID: 20488250. Exclusion: 4

682. Pisters MF, Veenhof C, van Meeteren NL, et al. Long-term effectiveness of exercise therapy in patients with osteoarthritis of the hip or knee: a systematic review. Arthritis \& Rheumatism. 2007 Oct 15;57(7):1245-53. PMID: 17907210. Exclusion: 10
683. Porter NS, Jason LA, Boulton A, et al. Alternative medical interventions used in the treatment and management of myalgic encephalomyelitis/chronic fatigue syndrome and fibromyalgia. Journal of Alternative \& Complementary Medicine. 2010 Mar;16(3):235-49. doi: http://dx.doi.org/10.1089/acm.2008.0376. PMID: 20192908. Exclusion: 10

684. Postacchini F, Facchini M, Palieri P. Efficacy of various forms of conservative treatment in low back pain. A comparative study. Neuro-Orthopedics. 1988;6(1):28-35. Exclusion: 3

685. Preyde M. Effectiveness of massage therapy for subacute low-back pain: a randomized controlled trial. Can Med Assoc J. 2000 Jun 27;162(13):1815-20. PMID: 10906914. Exclusion: 3

686. Price A, Burls A. Increased water intake to reduce headache: Learning from a critical appraisal. Journal of evaluation in clinical practice. 2015;21(6):1212-8. PMID: CN01137707 NEW. Exclusion: 10

687. Purepong N, Jitvimonrat A, Sitthipornvorakul E, et al. External validity in randomised controlled trials of acupuncture for osteoarthritis knee pain. Acupuncture in Medicine. 2012 Sep;30(3):187-94. doi: http://dx.doi.org/10.1136/acupmed-2012010140. PMID: 22759902. Exclusion: 10

688. Pushpika Attanayake AM, Somarathna KI, Vyas GH, et al. Clinical evaluation of selected Yogic procedures in individuals with low back pain. Ayu. 2010 Apr;31(2):245-50. doi: 10.4103/09748520.72409. PMID: 22131719. Exclusion: 9

689. Que Q, Ye X, Su Q, et al. Effectiveness of acupuncture intervention for neck pain caused by cervical spondylosis: study protocol for a randomized controlled trial. Trials. 2013 Jun 22;14:186. doi: 10.1186/1745-6215-14-186. PMID: 23800342. Exclusion: 8

690. Quicke JG, Foster NE, Thomas MJ, et al. Is long-term physical activity safe for older adults with knee pain?: a systematic review. Osteoarthritis \& Cartilage. 2015

Sep;23(9):1445-56. doi: http://dx.doi.org/10.1016/j.joca.2015.05.002. PMID: 26003947. Exclusion: 10 
691. Quinn JV. Influence of Pilates-based mat exercise on chronic lower back pain. 2005. Exclusion: 9

692. Quinn K, Barry S, Barry L. Do patients with chronic low back pain benefit from attending Pilates classes after completing conventional physiotherapy treatment? Physiother Pract Res. 2011;32(1):5-12. Exclusion: 9

693. Rabini A, De Sire A, Marzetti E, et al. Effects of focal muscle vibration on physical functioning in patients with knee osteoarthritis: a randomized controlled trial. European journal of physical \& rehabilitation medicine. 2015 Oct;51(5):51320. PMID: 25990196. Exclusion: 4

694. Raja K, Dewan N. Efficacy of knee braces and foot orthoses in conservative management of knee osteoarthritis: a systematic review. American Journal of Physical Medicine \& Rehabilitation. 2011 Mar;90(3):247-62. doi: http://dx.doi.org/10.1097/PHM.0b013e3182 06386b. PMID: 21273902. Exclusion: 10

695. Rajfur J, Pasternok M, Rajfur K, et al. Efficacy of Selected Electrical Therapies on Chronic Low Back Pain: A Comparative Clinical Pilot Study. Medical Science Monitor. 2017 Jan 07;23:85-100. PMID: 28062862. Exclusion: 9

696. Rajpal N, Arora M, Chauhan V. The study on efficacy of Pilates and McKenzie exercises in postural low back pain--a rehabilitative protocol. Physiother Occup Ther J. 2008;1(1):33-56. Exclusion: 9

697. Rasmussen-Barr E, Nilsson-Wikmar L, Arvidsson I. Stabilizing training compared with manual treatment in sub-acute and chronic low-back pain. Man Ther. 2003 Nov;8(4):233-41. PMID: 14559046. Exclusion: 4

698. Rasotto C, Bergamin M, Sieverdes JC, et al. A tailored workplace exercise program for women at risk for neck and upper limb musculoskeletal disorders: a randomized controlled trial. Journal of Occupational \& Environmental Medicine. 2015 Feb;57(2):178-83. doi: http://dx.doi.org/10.1097/JOM.0000000000 000329. PMID: 25654519. Exclusion: 3
699. Ravaud P, Giraudeau B, Logeart I, et al. Management of osteoarthritis (OA) with an unsupervised home based exercise programme and/or patient administered assessment tools. A cluster randomised controlled trial with a 2x2 factorial design. Annals of the Rheumatic Diseases. 2004 Jun;63(6):703-8. PMID: 15140778. Exclusion: 3

700. Rayegani SM, Raeissadat SA, Heidari S, et al. Safety and Effectiveness of Low-Level Laser Therapy in Patients With Knee Osteoarthritis: A Systematic Review and Meta-analysis. J Lasers Med Sci. 2017 Summer;8(Suppl 1):S12-S9. doi: 10.15171/jlms.2017.s3. PMID: 29071029. Exclusion: 10

701. Reddell CR, Congleton JJ, Huchingson RD, et al. An evaluation of a weightlifting belt and back injury prevention training class for airline baggage handlers. Appl Ergon. 1992;23(5):319-29. PMID: 15676878. Exclusion: 3

702. Reinhold T, Witt CM, Jena S, et al. Quality of life and cost-effectiveness of acupuncture treatment in patients with osteoarthritis pain. European Journal of Health Economics. 2008 Aug;9(3):209-19. doi: https://dx.doi.org/10.1007/s10198-0070062-5. PMID: 17638034. Exclusion: 7

703. Rejeski WJ, Ettinger WH, Jr., Martin K, et al. Treating disability in knee osteoarthritis with exercise therapy: a central role for selfefficacy and pain. Arthritis Care \& Research. 1998 Apr;11(2):94-101. PMID: 9668732. Exclusion: 9

704. Rendant D, Pach D, Ludtke R, et al. Qigong versus exercise versus no therapy for patients with chronic neck pain: a randomized controlled trial. Spine. 2011 Mar 15;36(6):419-27. doi: http://dx.doi.org/10.1097/BRS.0b013e3181d 51fca. PMID: 21178832. Exclusion: 9

705. Reust P, Chantraine A, Vischer TL. [Treatment of lumbar sciatica with or without neurological deficit using mechanical traction. A double-blind study]. Schweiz Med Wochenschr. 1988 Feb 27;118(8):271-4. PMID: 2965827. Exclusion: 3 
706. Revel M, Minguet M, Gregoy P, et al. Changes in cervicocephalic kinesthesia after a proprioceptive rehabilitation program in patients with neck pain: a randomized controlled study. Arch Phys Med Rehabil. 1994 Aug;75(8):895-9. PMID: 8053797. Exclusion: 5

707. Rewald S, Mesters I, Lenssen AF, et al. Effect of aqua-cycling on pain and physical functioning compared with usual care in patients with knee osteoarthritis: study protocol of a randomised controlled trial. BMC Musculoskelet Disord. 2016 Feb 18;17:88. doi: 10.1186/s12891-016-0939-5. PMID: 26887576. Exclusion: 8

708. Richmond SJ, Brown SR, Campion PD, et al. Therapeutic effects of magnetic and copper bracelets in osteoarthritis: a randomised placebo-controlled crossover trial. Complementary Therapies in Medicine. 2009 Oct-Dec;17(5-6):249-56. doi: https://dx.doi.org/10.1016/j.ctim.2009.07.00 2. PMID: 19942103. Exclusion: 3

709. Rigato M, Battisti E, Fortunato M, et al. Comparison between the analgesic and therapeutic effects of a musically modulated electromagnetic field (TAMMEF) and those of a $100 \mathrm{~Hz}$ electromagnetic field: blind experiment on patients suffering from cervical spondylosis or shoulder periarthritis. Journal of Medical Engineering \& Technology. 2002 Nov-Dec;26(6):253-8. PMID: 12490031. Exclusion: 9

710. Rini C, Porter LS, Somers TJ, et al. Automated Internet-based pain coping skills training to manage osteoarthritis pain: a randomized controlled trial. Pain. 2015 May;156(5):837-48. doi: http://dx.doi.org/10.1097/j.pain.0000000000 000121. PMID: 25734997. Exclusion: 4

711. Ris I, Sogaard K, Gram B, et al. Does a combination of physical training, specific exercises and pain education improve health-related quality of life in patients with chronic neck pain? A randomised control trial with a 4-month follow up. Man Ther. 2016 Dec;26:132-40. doi: 10.1016/j.math.2016.08.004. PMID: 27598552. Exclusion: 4
712. Roberts D, Walls C, VCarlile J, et al. Relief of chronic low back pain: heat versus cold. Aronoff GH. 2nd ed. Baltimore: Urban \& Schwarzenberg; 1992:263-6. Exclusion: 9

713. Roddy E, Zhang W, Doherty M. Aerobic walking or strengthening exercise for osteoarthritis of the knee? A systematic review. Annals of the Rheumatic Diseases. 2005 Apr;64(4):544-8. PMID: 15769914. Exclusion: 10

714. Roelofs PD, Bierma-Zeinstra SM, van Poppel MN, et al. Lumbar supports to prevent recurrent low back pain among home care workers: a randomized trial. Ann Intern Med. 2007 Nov 20;147(10):685-92. PMID: 18025444. Exclusion: 3

715. Roessler KK, Rugulies R, Bilberg R, et al. Does work-site physical activity improve self-reported psychosocial workplace factors and job satisfaction? A randomized controlled intervention study. International Archives of Occupational \& Environmental Health. 2013 Nov;86(8):861-4. doi: http://dx.doi.org/10.1007/s00420-012-0823z. PMID: 23064844. Exclusion: 9

716. Rogers MW, Wilder FV. Exercise and hand osteoarthritis symptomatology: a controlled crossover trial. Journal of Hand Therapy. 2009 Jan-Mar;22(1):10-7; discussion 9-20; quiz 18. doi: http://dx.doi.org/10.1016/j.jht.2008.09.002. PMID: 19013758. Exclusion: 9

717. Romanowski M, Romanowska J, Grzeskowiak M. A comparison of the effects of deep tissue massage and therapeutic massage on chronic low back pain. Stud Health Technol Inform. 2012;176:411-4. PMID: 22744541. Exclusion: 5

718. Romeo A, Parazza S, Boschi M, et al. Manual therapy and therapeutic exercise in the treatment of osteoarthritis of the hip: a systematic review. Reumatismo. 2013;65(2):63-74. doi: http://dx.doi.org/10.4081/reumatismo.2013. 63. PMID: 23877410. Exclusion: 10

719. Roos EM, Juhl CB. Osteoarthritis 2012 year in review: rehabilitation and outcomes. Osteoarthritis \& Cartilage. 2012 Dec;20(12):1477-83. doi: http://dx.doi.org/10.1016/j.joca.2012.08.028. PMID: 22960093. Exclusion: 10 
720. Rose MJ, Reilly JP, Pennie B, et al. Chronic low back pain rehabilitation programs: a study of the optimum duration of treatment and a comparison of group and individual therapy. Spine (Phila Pa 1976). 1997 Oct 01;22(19):2246-51; discussion 52-3. PMID: 9346145. Exclusion: 5

721. Rubinstein SM, van Eekelen R, Oosterhuis $\mathrm{T}$, et al. The risk of bias and sample size of trials of spinal manipulative therapy for low back and neck pain: analysis and recommendations. J Manipulative Physiol Ther. 2014 Oct;37(8):523-41. doi: 10.1016/j.jmpt.2014.07.007. PMID: 25194968. Exclusion: 10

722. Rutjes WSA, Nuesch E, Sterchi R, et al. Transcutaneous electrostimulation for osteoarthritis of the knee. Cochrane Database of Systematic Reviews. 2010(1) PMID: 00075320-100000000-01745. Exclusion: 10

723. Rydeard R, Leger A, Smith D. Pilates-based therapeutic exercise: effect on subjects with nonspecific chronic low back pain and functional disability: a randomized controlled trial. J Orthop Sports Phys Ther. 2006 Jul;36(7):472-84. doi:

10.2519/jospt.2006.2144. PMID: 16881464. Exclusion: 9

724. S GN, Kamal W, George J, et al. Radiological and biochemical effects (CTXII, MMP-3, 8, and 13) of low-level laser therapy (LLLT) in chronic osteoarthritis in Al-Kharj, Saudi Arabia. Lasers in Medical Science. 2017 Feb;32(2):297-303. doi: https://dx.doi.org/10.1007/s10103-0162114-5. PMID: 27913970. Exclusion: 4

725. Saeterbakken AH, Nordengen S, Andersen $\mathrm{V}$, et al. Nordic walking and specific strength training for neck- and shoulder pain in office workers: a pilot-study. Eur J Phys Rehabil Med. 2017 Jun 01. Exclusion: 7

726. Saha FJ, Schumann S, Cramer H, et al. The Effects of Cupping Massage in Patients with Chronic Neck Pain - A Randomised Controlled Trial. Complement Med Res. 2017;24(1):26-32. Exclusion: 9
727. Salacinski AJ, Krohn K, Lewis SF, et al. The effects of group cycling on gait and pain-related disability in individuals with mild-to-moderate knee osteoarthritis: a randomized controlled trial. Journal of Orthopaedic \& Sports Physical Therapy. 2012 Dec;42(12):985-95. doi: http://dx.doi.org/10.2519/jospt.2012.3813. PMID: 22951360. Exclusion: 9

728. Salaffi F, Ciapetti A, Gasparini S, et al. Web/Internet-based telemonitoring of a randomized controlled trial evaluating the time-integrated effects of a 24-week multicomponent intervention on key health outcomes in patients with fibromyalgia. Clin Exp Rheumatol. 2015 Jan-Feb;33(1 Suppl 88):S93-101. Epub 2015 Mar 18. Exclusion: 9

729. Salazar AP, Stein C, Marchese RR, et al. Electric Stimulation for Pain Relief in Patients with Fibromyalgia: A Systematic Review and Meta-analysis of Randomized Controlled Trials. Pain Physician. 2017 Feb;20(2):15-25. PMID: 28158150. Exclusion: 10

730. Salo PK, Hakkinen AH, Kautiainen H, et al. Effect of neck strength training on healthrelated quality of life in females with chronic neck pain: a randomized controlled 1-year follow-up study. Health \& Quality of Life Outcomes. 2010;8:48. doi: http://dx.doi.org/10.1186/1477-7525-8-48. PMID: 20465854. Exclusion: 9

731. Saltychev M, Laimi K. Effectiveness of repetitive transcranial magnetic stimulation in patients with fibromyalgia: a metaanalysis. Int J Rehabil Res. 2017 Mar;40(1):11-8. doi: 10.1097/MRR.0000000000000207. PMID: 27977465. Exclusion: 10

732. Sampath KK, Mani R, Miyamori T, et al. The effects of manual therapy or exercise therapy or both in people with hip osteoarthritis: a systematic review and metaanalysis. Clin Rehabil. 2016 Dec;30(12):1141-55. doi: 10.1177/0269215515622670. PMID: 26701903. Exclusion: 10 
733. Samut G, Dincer F, Ozdemir O. The effect of isokinetic and aerobic exercises on serum interleukin-6 and tumor necrosis factor alpha levels, pain, and functional activity in patients with knee osteoarthritis. Modern Rheumatology. 2015;25(6):919-24. doi: http://dx.doi.org/10.3109/14397595.2015.10 38425. PMID: 25849853. Exclusion: 9

734. Sandsjo L, Larsman P, Huis in 't Veld RM, et al. Clinical evaluation of a myofeedbackbased teletreatment service applied in the workplace: a randomized controlled trial. J Telemed Telecare. 2010;16(6):329-35. doi: 10.1258/jtt.2010.006007. PMID: 20798427. Exclusion: 5

735. Sangdee C, Teekachunhatean S, Sananpanich K, et al. Electroacupuncture versus diclofenac in symptomatic treatment of osteoarthritis of the knee: a randomized controlled trial. BMC Complementary \& Alternative Medicine. 2002 Mar 21;2:3. PMID: 11914160. Exclusion: 9

736. Sanudo B, Galiano D, Carrasco L, et al. Effects of a prolonged exercise program on key health outcomes in women with fibromyalgia: a randomized controlled trial. J Rehabil Med. 2011 May;43(6):521-6. doi: 10.2340/16501977-0814. PMID: 21533333. Exclusion: 9

737. Saper RB, Boah AR, Keosaian J, et al. Comparing once- versus twice-weekly yoga classes for chronic low back pain in predominantly low income minorities: a randomized dosing trial. Evid Based Complement Alternat Med. 2013;2013:658030. doi: 10.1155/2013/658030. PMID: 23878604. Exclusion: 5

738. Saper RB, Sherman KJ, Cullum-Dugan D, et al. Yoga for chronic low back pain in a predominantly minority population: a pilot randomized controlled trial. Altern Ther Health Med. 2009 Nov-Dec;15(6):18-27. PMID: 19943573. Exclusion: 9

739. Saragiotto BT, Maher CG, Yamato TP, et al. Motor control exercise for chronic nonspecific low-back pain. Cochrane Database Syst Rev. 2016 Jan 08(1):CD012004. doi: 10.1002/14651858.CD012004. PMID: 26742533. Exclusion: 10
740. Sarig-Bahat H. Evidence for exercise therapy in mechanical neck disorders. Manual Therapy. 2003 Feb;8(1):10-20. PMID: 12586557. Exclusion: 10

741. Sato N, Sekiguchi M, Kikuchi S, et al. Effects of long-term corset wearing on chronic low back pain. Fukushima J Med Sci. 2012;58(1):60-5. PMID: 22790893. Exclusion: 9

742. Sator-Katzenschlager SM, Scharbert G, Kozek-Langenecker SA, et al. The shortand long-term benefit in chronic low back pain through adjuvant electrical versus manual auricular acupuncture. Anesth Analg. 2004 May;98(5):1359-64, table of contents. PMID: 15105215. Exclusion: 5

743. Savolainen A, Ahlberg J, Nummila H, et al. Active or passive treatment for neckshoulder pain in occupational health care? A randomized controlled trial. Occupational Medicine (Oxford). 2004 Sep;54(6):422-4. PMID: 15358840. Exclusion: 3

744. Sayers SP, Gibson K, Cook CR. Effect of high-speed power training on muscle performance, function, and pain in older adults with knee osteoarthritis: a pilot investigation. Arthritis care \& research. 2012 Jan;64(1):46-53. doi: http://dx.doi.org/10.1002/acr.20675. PMID: 22012877. Exclusion: 7

745. Schachter CL, Busch AJ, Peloso PM, et al. Effects of short versus long bouts of aerobic exercise in sedentary women with fibromyalgia: a randomized controlled trial. Phys Ther. 2003 Apr;83(4):340-58. PMID: 12665405. Exclusion: 9

746. Schaller A, Dintsios CM, Icks A, et al. Promoting physical activity in low back pain patients: six months follow-up of a randomised controlled trial comparing a multicomponent intervention with a low intensity intervention. Clinical Rehabilitation. 2016 Sep;30(9):865-77. doi: https://dx.doi.org/10.1177/02692155156187 30. PMID: 27496696. Exclusion: 4

747. Scharf HP, Mansmann U, Streitberger K, et al. Acupuncture and knee osteoarthritis: a three-armed randomized trial.[Summary for patients in Ann Intern Med. 2006 Jul 4;145(1):I17; PMID: 16818921]. Annals of Internal Medicine. 2006 Jul 4;145(1):12-20. PMID: 16818924. Exclusion: 4 
748. Schellingerhout JM, Verhagen AP, Heymans MW, et al. Which subgroups of patients with non-specific neck pain are more likely to benefit from spinal manipulation therapy, physiotherapy, or usual care? Pain. 2008 Oct 31;139(3):67080. doi: http://dx.doi.org/10.1016/j.pain.2008.07.015 . PMID: 18774225. Exclusion: 10

749. Schencking M, Wilm S, Redaelli M. A comparison of Kneipp hydrotherapy with conventional physiotherapy in the treatment of osteoarthritis: a pilot trial. The Journal of Integrative Medicine. 2013 Jan;11(1):17-25. doi:

http://dx.doi.org/10.3736/jintegrmed201300 4. PMID: 23464642. Exclusion: 4

750. Schenkman ML, Jordan S, Akuthota V, et al. Functional movement training for recurrent low back pain: lessons from a pilot randomized controlled trial. Pm r. 2009

Feb;1(2):137-46. doi:

10.1016/j.pmrj.2008.10.004. PMID: 19627887. Exclusion: 3

751. Schilke JM, Johnson GO, Housh TJ, et al. Effects of muscle-strength training on the functional status of patients with osteoarthritis of the knee joint. Nursing Research. 1996 Mar-Apr;45(2):68-72. PMID: 8604366. Exclusion: 7

752. Schlenk EA, Lias JL, Sereika SM, et al. Improving physical activity and function in overweight and obese older adults with osteoarthritis of the knee: a feasibility study. Rehabilitation Nursing Journal. 2011 JanFeb;36(1):32-42. PMID: 21290963. Exclusion: 7

753. Scholten-Peeters GG, Thoomes E, Konings $\mathrm{S}$, et al. Is manipulative therapy more effective than sham manipulation in adults : a systematic review and meta-analysis. Chiropr Man Therap. 2013 Oct 02;21(1):34. doi: 10.1186/2045-709X-21-34. PMID: 24274314. Exclusion: 10

754. Schweikert B, Jacobi E, Seitz R, et al. Effectiveness and cost-effectiveness of adding a cognitive behavioral treatment to the rehabilitation of chronic low back pain. $\mathrm{J}$ Rheumatol. 2006 Dec;33(12):2519-26. PMID: 17143986. Exclusion: 5
755. Schwerla F, Bischoff A, Nurnberger A, et al. Osteopathic treatment of patients with chronic non-specific neck pain: a randomised controlled trial of efficacy. Forschende Komplementarmedizin (2006). 2008 Jun;15(3):138-45. doi: http://dx.doi.org/10.1159/000132397. PMID: 18617745. Exclusion: 4

756. Scott D, Kowalczyk A. Osteoarthritis of the knee. Clinical Evidence. 2007 PMID: 19450299. Exclusion: 10

757. Selfe TK, Bourguignon C, Taylor AG. Effects of noninvasive interactive neurostimulation on symptoms of osteoarthritis of the knee: a randomized, sham-controlled pilot study. Journal of Alternative \& Complementary Medicine. 2008 Nov;14(9):1075-81. doi: http://dx.doi.org/10.1089/acm.2008.0305. PMID: 19055333. Exclusion: 4

758. Selfe TK, Taylor AG. Acupuncture and osteoarthritis of the knee: a review of randomized, controlled trials. Family \& Community Health. 2008 Jul-Sep;31(3):24754. doi: http://dx.doi.org/10.1097/01.FCH.00003244 82.78577.0f. PMID: 18552606. Exclusion: 10

759. Seo BK, Lee JH, Kim PK, et al. Bee venom acupuncture, NSAIDs or combined treatment for chronic neck pain: study protocol for a randomized, assessor-blind trial. Trials. 2014 Apr 21;15:132. doi: 10.1186/1745-6215-15-132. PMID: 24746224. Exclusion: 8

760. Sevick MA, Bradham DD, Muender M, et al. Cost-effectiveness of aerobic and resistance exercise in seniors with knee osteoarthritis. Medicine \& Science in Sports \& Exercise. 2000 Sep;32(9):1534-40. PMID: 10994901. Exclusion: 6

761. Sevick MA, Miller GD, Loeser RF, et al. Cost-effectiveness of exercise and diet in overweight and obese adults with knee osteoarthritis. Medicine \& Science in Sports \& Exercise. 2009 Jun;41(6):1167-74. doi: https://dx.doi.org/10.1249/MSS.0b013e3181 97ece7. PMID: 19461553. Exclusion: 7 
762. Shakoor MA, Rahman MS, Moyeenuzzaman M. Effects of deep heat therapy on the patients with chronic low back pain. Mymensingh Med J. 2008 Jul;17(2 Suppl):S32-8. PMID: 18946448. Exclusion: 9

763. Shariat A, Cleland JA, Danaee M, et al. Effects of stretching exercise training and ergonomic modifications on musculoskeletal discomforts of office workers: a randomized controlled trial. Braz J Phys Ther. 2017 Sep 06. Exclusion: 3

764. Shearer HM, Carroll LJ, Wong JJ, et al. Are psychological interventions effective for the management of neck pain and whiplashassociated disorders? A systematic review by the Ontario Protocol for Traffic Injury Management (OPTIMa) Collaboration. Spine J. 2016 Dec;16(12):1566-81. doi: 10.1016/j.spinee.2015.08.011. PMID: 26279388. Exclusion: 10

765. Shen X, Zhao L, Ding G, et al. Effect of combined laser acupuncture on knee osteoarthritis: a pilot study. Lasers in Medical Science. 2009 Mar;24(2):129-36. doi: http://dx.doi.org/10.1007/s10103-0070536-9. PMID: 18180980. Exclusion: 9

766. Sherman KJ, Cook AJ, Wellman RD, et al. Five-week outcomes from a dosing trial of therapeutic massage for chronic neck pain. Annals of Family Medicine. 2014 MarApr;12(2):112-20. doi: http://dx.doi.org/10.1370/afm.1602. PMID: 24615306. Exclusion: 9

767. Sherry E, Kitchener P, Smart R. A prospective randomized controlled study of VAX-D and TENS for the treatment of chronic low back pain. Neurol Res. 2001 Oct;23(7):780-4. doi: 10.1179/016164101101199180. PMID: 11680522. Exclusion: 3

768. Shimoji K, Takahashi N, Nishio Y, et al. Pain relief by transcutaneous electric nerve stimulation with bidirectional modulated sine waves in patients with chronic back pain: a randomized, double-blind, shamcontrolled study. Neuromodulation. 2007 Jan;10(1):42-51. doi: 10.1111/j.15251403.2007.00086.x. PMID: 22151811. Exclusion: 9
769. Siemonsma PC, Stuive I, Roorda LD, et al. Cognitive treatment of illness perceptions in patients with chronic low back pain: a randomized controlled trial. Phys Ther. 2013 Apr;93(4):435-48. doi: 10.2522/ptj.20110150. PMID: 23162040. Exclusion: 9

770. Sierpina V, Astin J, Giordano J. Mind-body therapies for headache. American Family Physician. 2007 Nov 15;76(10):1518-22. PMID: 18052018. Exclusion: 10

771. Sihawong R, Janwantanakul P, Sitthipornvorakul E, et al. Exercise therapy for office workers with nonspecific neck pain: a systematic review. Journal of Manipulative \& Physiological Therapeutics. 2011 Jan;34(1):62-71. doi: http://dx.doi.org/10.1016/j.jmpt.2010.11.005 . PMID: 21237409. Exclusion: 10

772. Silva A, Serrao PR, Driusso P, et al. The effects of therapeutic exercise on the balance of women with knee osteoarthritis: a systematic review. Revista Brasileira de Fisioterapia. 2012 Jan-Feb;16(1):1-9. PMID: 22441221. Exclusion: 10

773. Simao AP, Avelar NC, Tossige-Gomes R, et al. Functional performance and inflammatory cytokines after squat exercises and whole-body vibration in elderly individuals with knee osteoarthritis. Archives of Physical Medicine \& Rehabilitation. 2012 Oct;93(10):1692-700. doi: http://dx.doi.org/10.1016/j.apmr.2012.04.01 7. PMID: 22546535. Exclusion: 7

774. Simmerman SM, Sizer PS, Dedrick GS, et al. Immediate changes in spinal height and pain after aquatic vertical traction in patients with persistent low back symptoms: a crossover clinical trial. Pm r. 2011 May;3(5):447-57. doi: 10.1016/j.pmrj.2011.01.010. PMID: 21570033. Exclusion: 3

775. Singh S, Pattnaik M, Mohanty P, et al. Effectiveness of hip abductor strengthening on health status, strength, endurance and six minute walk test in participants with medial compartment symptomatic knee osteoarthritis. Journal of Back \& Musculoskeletal Rehabilitation. 2016;29(1):65-75. doi: http://dx.doi.org/10.3233/BMR-150599. PMID: 26406217. Exclusion: 9 
776. Sjogren T, Nissinen KJ, Jarvenpaa SK, et al. Effects of a workplace physical exercise intervention on the intensity of headache and neck and shoulder symptoms and upper extremity muscular strength of office workers: a cluster randomized controlled cross-over trial. Pain. 2005 Jul;116(12):119-28. PMID: 15927388. Exclusion: 3

777. Skillgate E, Bill AS, Cote P, et al. The effect of massage therapy and/or exercise therapy on subacute or long-lasting neck pain--the Stockholm neck trial (STONE): study protocol for a randomized controlled trial. Trials. 2015 Sep 16;16:414. doi: 10.1186/s13063-015-0926-4. PMID: 26377322. Exclusion: 8

778. Skoglund L, Josephson M, Wahlstedt K, et al. Qigong training and effects on stress, neck-shoulder pain and life quality in a computerised office environment. Complementary Therapies in Clinical Practice. 2011 Feb;17(1):54-7. doi: http://dx.doi.org/10.1016/j.ctcp.2010.09.003. PMID: 21168116. Exclusion: 3

779. Skou ST, Rasmussen S, Laursen MB, et al. The efficacy of 12 weeks non-surgical treatment for patients not eligible for total knee replacement: a randomized controlled trial with 1-year follow-up. Osteoarthritis \& Cartilage. 2015 Sep;23(9):1465-75. doi: http://dx.doi.org/10.1016/j.joca.2015.04.021. PMID: 25937024. Exclusion: 4

780. Skou ST, Roos EM, Simonsen O, et al. The efficacy of non-surgical treatment on pain and sensitization in patients with knee osteoarthritis: a pre-defined ancillary analysis from a randomized controlled trial. Osteoarthritis \& Cartilage. 2016 Jan;24(1):108-16. doi: http://dx.doi.org/10.1016/j.joca.2015.07.013. PMID: 26241775. Exclusion: 9

781. Skouen JS, Grasdal A, Haldorsen EM. Return to work after comparing outpatient multidisciplinary treatment programs versus treatment in general practice for patients with chronic widespread pain. Eur J Pain. 2006 Feb;10(2):145-52. Exclusion: 3
782. Skouen JS, Grasdal AL, Haldorsen EM, et al. Relative cost-effectiveness of extensive and light multidisciplinary treatment programs versus treatment as usual for patients with chronic low back pain on longterm sick leave: randomized controlled study. Spine (Phila Pa 1976). 2002 May 01;27(9):901-9; discussion 9-10. PMID: 11979157. Exclusion: 3

783. Slavin-Spenny O, Lumley MA, Thakur ER, et al. Effects of anger awareness and expression training versus relaxation training on headaches: a randomized trial. Annals of Behavioral Medicine. 2013 Oct;46(2):181-92. doi: http://dx.doi.org/10.1007/s12160-013-9500z. PMID: 23620190. Exclusion: 3

784. Slawson D. Physical therapy no better than sham therapy for hip osteoarthritis. American Family Physician. 2014 Oct 1;90(7):497-502. PMID: 25369631. Exclusion: 8

785. Smania N, Corato E, Fiaschi A, et al. Repetitive magnetic stimulation: a novel therapeutic approach for myofascial pain syndrome. Journal of neurology. 2005 Mar;252(3):307-14. PMID: CN-00527860 UPDATE. Exclusion: 3

786. Smeets RJ, Vlaeyen JW, Hidding A, et al. Chronic low back pain: physical training, graded activity with problem solving training, or both? The one-year posttreatment results of a randomized controlled trial. Pain. 2008 Feb;134(3):263-76. doi: 10.1016/j.pain.2007.04.021. PMID: 17498879. Exclusion: 8

787. Smeets RJ, Vlaeyen JW, Hidding A, et al. Active rehabilitation for chronic low back pain: cognitive-behavioral, physical, or both? First direct post-treatment results from a randomized controlled trial [ISRCTN22714229]. BMC Musculoskelet Disord. 2006 Jan 20;7:5. doi: 10.1186/14712474-7-5. PMID: 16426449. Exclusion: 8

788. Smith MT, Finan PH, Buenaver LF, et al. Cognitive-behavioral therapy for insomnia in knee osteoarthritis: a randomized, doubleblind, active placebo-controlled clinical trial. Arthritis \& Rheumatology. 2015 May;67(5):1221-33. doi: http://dx.doi.org/10.1002/art.39048. PMID: 25623343. Exclusion: 3 
789. Smith TO, King JJ, Hing CB. The effectiveness of proprioceptive-based exercise for osteoarthritis of the knee: a systematic review and meta-analysis. Rheumatology International. 2012 Nov;32(11):3339-51. doi: http://dx.doi.org/10.1007/s00296-012-24807. PMID: 22821333. Exclusion: 10

790. Snodgrass SJ, Rivett DA, Sterling M, et al. Dose optimization for spinal treatment effectiveness: a randomized controlled trial investigating the effects of high and low mobilization forces in patients with neck pain. Journal of Orthopaedic \& Sports Physical Therapy. 2014 Mar;44(3):141-52. doi: http://dx.doi.org/10.2519/jospt.2014.4778. PMID: 24450365. Exclusion: 9

791. Soderberg E, Carlsson J, Stener-Victorin E. Chronic tension-type headache treated with acupuncture, physical training and relaxation training. Between-group differences. Cephalalgia. 2006 Nov;26(11):1320-9. PMID: 17059439. Exclusion: 5

792. Soderberg EI, Carlsson JY, Stener-Victorin $\mathrm{E}$, et al. Subjective well-being in patients with chronic tension-type headache: effect of acupuncture, physical training, and relaxation training. Clinical Journal of Pain. 2011 Jun;27(5):448-56. doi: http://dx.doi.org/10.1097/AJP.0b013e31820 8c8fe. PMID: 21317776. Exclusion: 5

793. Song R, Lee EO, Lam P, et al. Effects of tai chi exercise on pain, balance, muscle strength, and perceived difficulties in physical functioning in older women with osteoarthritis: a randomized clinical trial. Journal of Rheumatology. 2003 Sep;30(9):2039-44. PMID: 12966613. Exclusion: 9

794. Song R, Lee EO, Lam P, et al. Effects of a Sun-style Tai Chi exercise on arthritic symptoms, motivation and the performance of health behaviors in women with osteoarthritis. Daehan Ganho Haghoeji. 2007 Mar;37(2):249-56. PMID: 17435410. Exclusion: 9
795. Song R, Roberts BL, Lee EO, et al. A randomized study of the effects of t'ai chi on muscle strength, bone mineral density, and fear of falling in women with osteoarthritis. Journal of Alternative \& Complementary Medicine. 2010 Mar;16(3):227-33. doi: http://dx.doi.org/10.1089/acm.2009.0165. PMID: 20192907. Exclusion: 9

796. Southerst D, Nordin MC, Cote P, et al. Is exercise effective for the management of neck pain and associated disorders or whiplash-associated disorders? A systematic review by the Ontario Protocol for Traffic Injury Management (OPTIMa) Collaboration. Spine J. 2016 Dec;16(12):1503-23. doi: 10.1016/j.spinee.2014.02.014. PMID: 24534390. Exclusion: 10

797. Spaans AJ, van Minnen LP, Kon M, et al. Conservative treatment of thumb base osteoarthritis: a systematic review. Journal of Hand Surgery - American Volume. 2015 Jan;40(1):16-21.e1-6. doi: http://dx.doi.org/10.1016/j.jhsa.2014.08.047. PMID: 25534834. Exclusion: 10

798. Sritoomma N, Moyle W, Cooke M, et al. The effectiveness of Swedish massage with aromatic ginger oil in treating chronic low back pain in older adults: a randomized controlled trial. Complement Ther Med. 2014 Feb;22(1):26-33. doi: 10.1016/j.ctim.2013.11.002. PMID: 24559813. Exclusion: 5

799. Stark J, Petrofsky J, Berk L, et al. Continuous low-level heatwrap therapy relieves low back pain and reduces muscle stiffness. Phys Sportsmed. 2014 Nov;42(4):39-48. doi: 10.3810/psm.2014.11.2090. PMID: 25419887. Exclusion: 3

800. Stener-Victorin E, Kruse-Smidje C, Jung K. Comparison between electro-acupuncture and hydrotherapy, both in combination with patient education and patient education alone, on the symptomatic treatment of osteoarthritis of the hip. Clinical Journal of Pain. 2004 May-Jun;20(3):179-85. PMID: 15100594. Exclusion: 4

801. Stetter F, Kupper S. Autogenic training: a meta-analysis of clinical outcome studies. Appl Psychophysiol Biofeedback. 2002 Mar;27(1):45-98. PMID: 12001885. Exclusion: 10 
802. Stiller C. The effect of therapeutic touch on fibromyalgia pain and anxiety. 2006. Exclusion: 8

803. Street RL, Jr., Cox V, Kallen MA, et al. Exploring communication pathways to better health: clinician communication of expectations for acupuncture effectiveness. Patient Education \& Counseling. 2012 Nov;89(2):245-51. doi: http://dx.doi.org/10.1016/j.pec.2012.06.032. PMID: 22857778. Exclusion: 4

804. Streibelt M, Thren K, Müller-Fahrnow W. Effects of FCE-based multidisciplinary rehabilitation in patients with chronic musculoskeletal disorders-results of a randomized controlled trial. Physikalische Medizin, Rehabilitationsmedizin, Kurortmedizin. 2009;19(01):34-41. Exclusion: 5

805. Streitberger K, Witte S, Mansmann U, et al. Efficacy and safety of acupuncture for chronic pain caused by gonarthrosis: a study protocol of an ongoing multi-centre randomised controlled clinical trial [ISRCTN27450856]. BMC Complement Altern Med. 2004 Mar 24;4:6. doi: 10.1186/1472-6882-4-6. PMID: 15040805. Exclusion: 8

806. Strom L, Pettersson R, Andersson G. A controlled trial of self-help treatment of recurrent headache conducted via the Internet. Journal of Consulting \& Clinical Psychology. 2000 Aug;68(4):722-7. PMID: 10965647. Exclusion: 3

807. Strong J. Incorporating cognitive-behavioral therapy with occupational therapy: a comparative study with patients with low back pain. J Occup Rehabil. 1998;8(1):6171. Exclusion: 5

808. Stuckey SJ, Jacobs A, Goldfarb J. EMG biofeedback training, relaxation training, and placebo for the relief of chronic back pain. Percept Mot Skills. 1986

Dec;63(3):1023-36. doi:

10.2466/pms.1986.63.3.1023. PMID: 2949196. Exclusion: 6
809. Sun MY, Hsieh CL, Cheng YY, et al. The therapeutic effects of acupuncture on patients with chronic neck myofascial pain syndrome: a single-blind randomized controlled trial. American Journal of Chinese Medicine. 2010;38(5):849-59. PMID: 20821817. Exclusion: 3

810. Sun Y, Gan TJ. Acupuncture for the management of chronic headache: a systematic review. Anesthesia \& Analgesia. 2008 Dec;107(6):2038-47. doi: http://dx.doi.org/10.1213/ane.0b013e318187 c76a. PMID: 19020156. Exclusion: 10

811. Sun ZR, Yue JH, Zhang QH.

Electroacupuncture at Jing-jiaji points for neck pain caused by cervical spondylosis: a study protocol for a randomized controlled pilot trial. Trials. 2013 Oct 29;14:360. doi: 10.1186/1745-6215-14-360. PMID: 24168460. Exclusion: 8

812. Suni JH, Rinne M, Tokola K, et al. Effectiveness of a standardised exercise programme for recurrent neck and low back pain: a multicentre, randomised, two-arm, parallel group trial across 34 fitness clubs in Finland. BMJ Open Sport Exerc Med. 2017;3(1):e000233. PMID: Pmc5633732. Exclusion: 3

813. Suomi R, Collier D. Effects of arthritis exercise programs on functional fitness and perceived activities of daily living measures in older adults with arthritis. Archives of Physical Medicine \& Rehabilitation. 2003 Nov;84(11):1589-94. PMID: 14639556. Exclusion: 3

814. Surkitt LD, Ford JJ, Chan AY, et al. Effects of individualised directional preference management versus advice for reducible discogenic pain: A pre-planned secondary analysis of a randomised controlled trial. Manual Therapy. 2016 Sep;25:69-80. doi: https://dx.doi.org/10.1016/j.math.2016.06.00 2. PMID: 27422600. Exclusion: 4

815. Sutbeyaz ST, Sezer N, Koseoglu BF. The effect of pulsed electromagnetic fields in the treatment of cervical osteoarthritis: a randomized, double-blind, sham-controlled trial. Rheumatology International. 2006 Feb;26(4):320-4. PMID: 15986086. Exclusion: 9 
816. Sutbeyaz ST, Sezer N, Koseoglu F, et al. Low-frequency pulsed electromagnetic field therapy in fibromyalgia: a randomized, double-blind, sham-controlled clinical study. Clin J Pain. 2009 Oct;25(8):722-8. doi: 10.1097/AJP.0b013e3181a68a6c. Exclusion: 4

817. Sutton DA, Cote P, Wong JJ, et al. Is multimodal care effective for the management of patients with whiplashassociated disorders or neck pain and associated disorders? A systematic review by the Ontario Protocol for Traffic Injury Management (OPTIMa) Collaboration. Spine J. 2016 Dec;16(12):1541-65. doi: 10.1016/j.spinee.2014.06.019. PMID: 25014556. Exclusion: 10

818. Svege I, Fernandes L, Nordsletten L, et al. Long-Term Effect of Exercise Therapy and Patient Education on Impairments and Activity Limitations in People With Hip Osteoarthritis: Secondary Outcome Analysis of a Randomized Clinical Trial. Physical Therapy. 2016 Jun;96(6):818-27. doi: https://dx.doi.org/10.2522/ptj.20140520. PMID: 26678445. Exclusion: 5

819. Svege I, Nordsletten L, Fernandes L, et al. Exercise therapy may postpone total hip replacement surgery in patients with hip osteoarthritis: a long-term follow-up of a randomised trial. Annals of the Rheumatic Diseases. 2015 Jan;74(1):164-9. doi: http://dx.doi.org/10.1136/annrheumdis2013-203628. PMID: 24255546. Exclusion: 4

820. Sweetman BJ, Heinrich I, Anderson JAD. A randomized controlled trial of exercises, short wave diathermy, and traction for low back pain, with evidence of diagnosisrelated response to treatment. J Orthop Rheumatol. 1993;6(4):159-66. Exclusion: 3

821. Taimela S, Takala EP, Asklof T, et al. Active treatment of chronic neck pain: a prospective randomized intervention. Spine. 2000 Apr 15;25(8):1021-7. PMID: 10767816. Exclusion: 4
822. Takasaki H, May S. Mechanical diagnosis and therapy has similar effects on pain and disability as 'wait and see' and other approaches in people with neck pain: a systematic review. Journal of Physiotherapy. 2014 Jun;60(2):78-84. doi: http://dx.doi.org/10.1016/j.jphys.2014.05.00 6. PMID: 24952834. Exclusion: 10

823. Talbot LA, Gaines JM, Huynh TN, et al. A home-based pedometer-driven walking program to increase physical activity in older adults with osteoarthritis of the knee: a preliminary study. Journal of the American Geriatrics Society. 2003 Mar;51(3):387-92. PMID: 12588583. Exclusion: 5

824. Talbot LA, Gaines JM, Ling SM, et al. A home-based protocol of electrical muscle stimulation for quadriceps muscle strength in older adults with osteoarthritis of the knee. Journal of Rheumatology. 2003 Jul;30(7):1571-8. PMID: 12858461. Exclusion: 5

825. Tanaka R, Ozawa J, Kito N, et al. Efficacy of strengthening or aerobic exercise on pain relief in people with knee osteoarthritis: a systematic review and meta-analysis of randomized controlled trials. Clinical Rehabilitation. 2013 Dec;27(12):1059-71. doi: http://dx.doi.org/10.1177/026921551348889 8. PMID: 23828186. Exclusion: 10

826. Tanaka R, Ozawa J, Kito N, et al. Effects of exercise therapy on walking ability in individuals with knee osteoarthritis: a systematic review and meta-analysis of randomised controlled trials. Clinical Rehabilitation. 2016 Jan;30(1):36-52. doi: http://dx.doi.org/10.1177/026921551557009 8. PMID: 25691583. Exclusion: 10

827. Tang NK, Lereya ST, Boulton H, et al. Nonpharmacological Treatments of Insomnia for Long-Term Painful Conditions: A Systematic Review and Metaanalysis of Patient-Reported Outcomes in Randomized Controlled Trials. Sleep. 2015 Nov 01;38(11):1751-64. doi: 10.5665/sleep.5158. PMID: 25902806. Exclusion: 10 
828. Tao XG, Bernacki EJ. A randomized clinical trial of continuous low-level heat therapy for acute muscular low back pain in the workplace. J Occup Environ Med. 2005 Dec;47(12):1298-306. PMID: 16340712. Exclusion: 3

829. Targino RA, Imamura M, Kaziyama HH, et al. A randomized controlled trial of acupuncture added to usual treatment for fibromyalgia. J Rehabil Med. 2008 Jul;40(7):582-8. doi: 10.2340/165019770216. Exclusion: 4

830. Tascioglu F, Kuzgun S, Armagan O, et al. Short-term effectiveness of ultrasound therapy in knee osteoarthritis. The Journal of international medical research. $2010 \mathrm{Jul}-$ Aug;38(4):1233-42. PMID: CN-00772408 UPDATE. Exclusion: 9

831. Tavafian SS, Jamshidi AR, Mohammad K. Treatment of chronic low back pain: a randomized clinical trial comparing multidisciplinary group-based rehabilitation program and oral drug treatment with oral drug treatment alone. Clin J Pain. 2011 NovDec;27(9):811-8. doi: 10.1097/AJP.0b013e31821e7930. PMID: 21642845. Exclusion: 3

832. Taylor AG, Anderson JG, Riedel SL, et al. Cranial electrical stimulation improves symptoms and functional status in individuals with fibromyalgia. Pain Management Nursing. 2013 Dec;14(4):32735. doi: http://dx.doi.org/10.1016/j.pmn.2011.07.002 . PMID: 24315255. Exclusion: 4

833. Teasell RW, McClure JA, Walton D, et al. A research synthesis of therapeutic interventions for whiplash-associated disorder (WAD): part 4 - noninvasive interventions for chronic WAD. Pain Research \& Management. 2010 SepOct;15(5):313-22. PMID: 21038010. Exclusion: 10

834. Tekin L, Akarsu S, Durmus O, et al. The effect of dry needling in the treatment of myofascial pain syndrome: a randomized double-blinded placebo-controlled trial. Clin Rheumatol. 2013 Mar;32(3):309-15. doi: 10.1007/s10067-012-2112-3. PMID: 23138883. Exclusion: 3
835. Tekur P, Chametcha S, Hongasandra RN, et al. Effect of yoga on quality of life of CLBP patients: A randomized control study. Int J Yoga. 2010 Jan;3(1):10-7. doi: 10.4103/0973-6131.66773. PMID: 20948896. Exclusion: 9

836. ter Kuile MM, Spinhoven P, Linssen AC, et al. Autogenic training and cognitive selfhypnosis for the treatment of recurrent headaches in three different subject groups. Pain. 1994 Sep;58(3):331-40. PMID: 7838582. Exclusion: 5

837. Tesio L, Merlo A. Autotraction versus passive traction: an open controlled study in lumbar disc herniation. Arch Phys Med Rehabil. 1993 Aug;74(8):871-6. PMID: 8347073. Exclusion: 5

838. Thieme K, Gromnica-Ihle E, Flor H. Operant behavioral treatment of fibromyalgia: a controlled study. Arthritis Rheum. 2003 Jun 15;49(3):314-20. Exclusion: 7

839. Thomas KS, Miller P, Doherty M, et al. Cost effectiveness of a two-year home exercise program for the treatment of knee pain. Arthritis \& Rheumatism. 2005 Jun 15;53(3):388-94. PMID: 15934131. Exclusion: 6

840. Thorn BE, Pence LB, Ward LC, et al. A randomized clinical trial of targeted cognitive behavioral treatment to reduce catastrophizing in chronic headache sufferers. Journal of Pain. 2007 Dec;8(12):938-49. PMID: 17690017. Exclusion: 3

841. Tomas-Carus P, Hakkinen A, Gusi N, et al. Aquatic training and detraining on fitness and quality of life in fibromyalgia. Med Sci Sports Exerc. 2007 Jul;39(7):1044-50. doi: 10.1249/01.mss.0b0138059aec4. PMID: 17596770. Exclusion: 7

842. Topp R, Woolley S, Hornyak J, 3rd, et al. The effect of dynamic versus isometric resistance training on pain and functioning among adults with osteoarthritis of the knee. Archives of Physical Medicine \& Rehabilitation. 2002 Sep;83(9):1187-95. PMID: 12235596. Exclusion: 9 
843. Topuz O, Özfidan E, Ozgen M, et al. Efficacy of transcutaneous electrical nerve stimulation and percutaneous neuromodulation therapy in chronic low back pain. J Back Musculoskelet Rehabil. 2004;17(3-4):127-33. Exclusion: 9

844. Towheed TE. Systematic review of therapies for osteoarthritis of the hand. Osteoarthritis \& Cartilage. 2005 Jun;13(6):455-62. PMID: 15922179. Exclusion: 10

845. Toya S, Motegi M, Inomata K, et al. Report on a computer-randomized double blind clinical trial to determine the effectiveness of the GaAlAs (830 NM) diode laser for pain attenuation in selected pain groups. Laser Therapy. 1994;6(3):143-8. doi: 10.5978/islsm.94-OR-08. Exclusion: 9

846. Trans T, Aaboe J, Henriksen M, et al. Effect of whole body vibration exercise on muscle strength and proprioception in females with knee osteoarthritis. Knee. 2009

Aug;16(4):256-61. doi: http://dx.doi.org/10.1016/j.knee.2008.11.014 . PMID: 19147365. Exclusion: 9

847. Trinh K, Graham N, Gross A, et al. Acupuncture for neck disorders. Spine. 2007 Jan 15;32(2):236-43. PMID: 17224820. Exclusion: 10

848. Trinh K, Graham N, Irnich D, et al. Acupuncture for neck disorders. Cochrane Database of Systematic Reviews. 2016(5):CD004870. doi: http://dx.doi.org/10.1002/14651858.CD0048 70.pub4. PMID: 27145001. Exclusion: 10

849. Trinh KV, Graham N, Gross AR, et al. Acupuncture for neck disorders. Cochrane Database of Systematic Reviews. 2006(3):CD004870. PMID: 16856065. Exclusion: 10

850. Tsai PF, Chang JY, Beck C, et al. A pilot cluster-randomized trial of a 20-week Tai Chi program in elders with cognitive impairment and osteoarthritic knee: effects on pain and other health outcomes. Journal of Pain \& Symptom Management. 2013 Apr;45(4):660-9. doi: http://dx.doi.org/10.1016/j.jpainsymman.201 2.04.009. PMID: 23017610. Exclusion: 9
851. Tsai PF, Chang JY, Beck C, et al. A supplemental report to a randomized cluster trial of a 20-week Sun-style Tai Chi for osteoarthritic knee pain in elders with cognitive impairment. Complementary Therapies in Medicine. 2015 Aug;23(4):570-6. doi: http://dx.doi.org/10.1016/j.ctim.2015.06.001 . PMID: 26275650. Exclusion: 9

852. Tsui ML, Cheing GL. The effectiveness of electroacupuncture versus electrical heat acupuncture in the management of chronic low-back pain. J Altern Complement Med. 2004 Oct;10(5):803-9. doi: 10.1089/acm.2004.10.803. PMID: 15650469. Exclusion: 5

853. Tuchin P. A systematic literature review of intracranial hypotension following chiropractic. International Journal of Clinical Practice. 2014 Mar;68(3):396-402. doi: http://dx.doi.org/10.1111/ijcp.12247. PMID: 24372942. Exclusion: 10

854. Tunwattanapong P, Kongkasuwan R, Kuptniratsaikul V. The effectiveness of a neck and shoulder stretching exercise program among office workers with neck pain: a randomized controlled trial. Clinical Rehabilitation. 2016 Jan;30(1):64-72. doi: http://dx.doi.org/10.1177/026921551557574 7. PMID: 25780258. Exclusion: 9

855. Turner JA. Comparison of group progressive-relaxation training and cognitive-behavioral group therapy for chronic low back pain. J Consult Clin Psychol. 1982 Oct;50(5):757-65. PMID: 6216275. Exclusion: 9

856. Turner JA, Anderson ML, Balderson BH, et al. Mindfulness-based stress reduction and cognitive behavioral therapy for chronic low back pain: similar effects on mindfulness, catastrophizing, self-efficacy, and acceptance in a randomized controlled trial. Pain. 2016 Nov;157(11):2434-44. doi: 10.1097/j.pain.0000000000000635. PMID: 27257859. Exclusion: 6

857. Turner JA, Clancy S. Comparison of operant behavioral and cognitive-behavioral group treatment for chronic low back pain. J Consult Clin Psychol. 1988 Apr;56(2):2616. PMID: 2967314. Exclusion: 9 
858. Turner JA, Jensen MP. Efficacy of cognitive therapy for chronic low back pain. Pain. 1993 Feb;52(2):169-77. PMID: 8455964. Exclusion: 9

859. Ulus Y, Tander B, Akyol Y, et al. Therapeutic ultrasound versus sham ultrasound for the management of patients with knee osteoarthritis: a randomized double-blind controlled clinical study. International Journal of Rheumatic Diseases. 2012 Apr;15(2):197-206. doi: http://dx.doi.org/10.1111/j.1756185X.2012.01709.x. PMID: 22462424. Exclusion: 9

860. Unlu Z, Tasci S, Tarhan S, et al. Comparison of 3 physical therapy modalities for acute pain in lumbar disc herniation measured by clinical evaluation and magnetic resonance imaging. J Manipulative Physiol Ther. 2008 Mar;31(3):191-8. doi: 10.1016/j.jmpt.2008.02.001. PMID: 18394495. Exclusion: 3

861. Uthaikhup S, Assapun J, Watcharasaksilp K, et al. Effectiveness of physiotherapy for seniors with recurrent headaches associated with neck pain and dysfunction: a randomized controlled trial. Spine J. 2017 Jan;17(1):46-55. doi: 10.1016/j.spinee.2016.08.008. PMID: 27497890. Exclusion: 3

862. Uthman OA, van der Windt DA, Jordan JL, et al. Exercise for lower limb osteoarthritis: systematic review incorporating trial sequential analysis and network metaanalysis. BMJ. 2013;347:f5555. doi: http://dx.doi.org/10.1136/bmj.f5555. PMID: 24055922. Exclusion: 10

863. Valdes K, Marik T. A systematic review of conservative interventions for osteoarthritis of the hand. Journal of Hand Therapy. 2010 Oct-Dec;23(4):334-50; quiz 51. doi: http://dx.doi.org/10.1016/j.jht.2010.05.001. PMID: 20615662. Exclusion: 10

864. Valle-Jones JC, Walsh H, O'Hara J, et al. Controlled trial of a back support ('Lumbotrain') in patients with non-specific low back pain. Curr Med Res Opin. 1992;12(9):604-13. doi: 10.1185/03007999209111527. PMID: 1533832. Exclusion: 3
865. Vallone F, Benedicenti S, Sorrenti E, et al. Effect of diode laser in the treatment of patients with nonspecific chronic low back pain: a randomized controlled trial. Photomed Laser Surg. 2014 Sep;32(9):4904. doi: 10.1089/pho.2014.3715. PMID: 25141218. Exclusion: 5

866. van Baar ME, Assendelft WJ, Dekker J, et al. Effectiveness of exercise therapy in patients with osteoarthritis of the hip or knee: a systematic review of randomized clinical trials. Arthritis \& Rheumatism. 1999 Jul;42(7):1361-9. PMID: 10403263.

Exclusion: 10

867. van Baar ME, Dekker J, Oostendorp RA, et al. Effectiveness of exercise in patients with osteoarthritis of hip or knee: nine months' follow up. Annals of the Rheumatic Diseases. 2001 Dec;60(12):1123-30. PMID: 11709454. Exclusion: 3

868. van Baar ME, Dekker J, Oostendorp RA, et al. The effectiveness of exercise therapy in patients with osteoarthritis of the hip or knee: a randomized clinical trial. Journal of Rheumatology. 1998 Dec;25(12):2432-9. PMID: 9858441. Exclusion: 3

869. van den Hout JH, Vlaeyen JW, Heuts PH, et al. Secondary prevention of work-related disability in nonspecific low back pain: does problem-solving therapy help? A randomized clinical trial. Clin J Pain. 2003 Mar-Apr;19(2):87-96. PMID: 12616178. Exclusion: 5

870. van der Heijden G, Beurskens A, Dirx MJM, et al. Efficacy of lumbar traction: a randomised clinical trial. Physiotherapy. 1995;81(1):29-35. doi: 10.1016/S00319406(05)67032-0. Exclusion: 3

871. van der Velde G, Yu H, Paulden M, et al. Which interventions are cost-effective for the management of whiplash-associated and neck pain-associated disorders? A systematic review of the health economic literature by the Ontario Protocol for Traffic Injury Management (OPTIMa)

Collaboration. Spine J. 2016

Dec;16(12):1582-97. doi: 10.1016/j.spinee.2015.08.025. PMID: 26631759. Exclusion: 10 
872. van Es PP, Luijsterburg PA, Dekker J, et al. Cost-effectiveness of exercise therapy versus general practitioner care for osteoarthritis of the hip: design of a randomised clinical trial. BMC Musculoskeletal Disorders. 2011;12:232. doi: http://dx.doi.org/10.1186/1471-247412-232. PMID: 21992502. Exclusion: 8

873. van Jonbergen HP, Poolman RW, van Kampen A. Isolated patellofemoral osteoarthritis. Acta Orthopaedica. 2010 Apr;81(2):199-205. doi: http://dx.doi.org/10.3109/174536710036287 56. PMID: 20175647. Exclusion: 10

874. van Koulil S, van Lankveld W, Kraaimaat FW, et al. Tailored cognitive-behavioural therapy and exercise training improves the physical fitness of patients with fibromyalgia. Ann Rheum Dis. 2011 Dec;70(12):2131-3. doi: 10.1136/ard.2010.148577. Epub 2011 Sep 16. Exclusion: 6

875. van Koulil S, van Lankveld W, Kraaimaat FW, et al. Tailored cognitive-behavioral therapy and exercise training for high-risk patients with fibromyalgia. Arthritis care \& research. 2010 Oct;62(10):1377-85. doi: http://dx.doi.org/10.1002/acr.20268. PMID: 20521308. Exclusion: 4

876. van Poppel MN, Koes BW, van der Ploeg T, et al. Lumbar supports and education for the prevention of low back pain in industry: a randomized controlled trial. Jama. 1998 Jun 10;279(22):1789-94. PMID: 9628709. Exclusion: 3

877. Vance CG, Rakel BA, Blodgett NP, et al. Effects of transcutaneous electrical nerve stimulation on pain, pain sensitivity, and function in people with knee osteoarthritis: a randomized controlled trial. Physical Therapy. 2012 Jul;92(7):898-910. doi: http://dx.doi.org/10.2522/ptj.20110183. PMID: 22466027. Exclusion: 9

878. Vavken P, Arrich F, Schuhfried O, et al. Effectiveness of pulsed electromagnetic field therapy in the management of osteoarthritis of the knee: a meta-analysis of randomized controlled trials. Journal of Rehabilitation Medicine. 2009 May;41(6):406-11. doi: http://dx.doi.org/10.2340/16501977-0374. PMID: 19479151. Exclusion: 10
879. Vayvay ES, Tok D, Turgut E, et al. The effect of Laser and taping on pain, functional status and quality of life in patients with fibromyalgia syndrome: A placebo- randomized controlled clinical trial. J Back Musculoskelet Rehabil. 2016;29(1):77-83. doi: 10.3233/BMR150600. Exclusion: 9

880. Veenhof C, Koke AJ, Dekker J, et al. Effectiveness of behavioral graded activity in patients with osteoarthritis of the hip and/or knee: A randomized clinical trial. Arthritis \& Rheumatism. 2006 Dec 15;55(6):925-34. PMID: 17139639. Exclusion: 3

881. Veenhof C, Van den Ende CH, Dekker J, et al. Which patients with osteoarthritis of hip and/or knee benefit most from behavioral graded activity? International Journal of Behavioral Medicine. 2007;14(2):86-91. PMID: 17926436. Exclusion: 3

882. Verhagen AP, Bierma-Zeinstra SM, Burdorf A, et al. Conservative interventions for treating work-related complaints of the arm, neck or shoulder in adults. Cochrane Database Syst Rev. 2013 Dec 12(12):CD008742. doi: 10.1002/14651858.CD008742.pub2. PMID: 24338903. Exclusion: 10

883. Verhagen AP, Damen L, Berger MY, et al. Behavioral treatments of chronic tensiontype headache in adults: are they beneficial? CNS Neuroscience \& Therapeutics. 2009;15(2):183-205. PMID: 19499626. Exclusion: 10

884. Verhagen AP, ScholtenPeeters GGMG, van Wijngaarden $\mathrm{S}$, et al. Conservative treatments for whiplash. Cochrane Database of Systematic Reviews. 2011(2) PMID: 00075320-100000000-02365. Exclusion: 10

885. Vernon H, Humphreys BK. Manual therapy for neck pain: an overview of randomized clinical trials and systematic reviews. Europa Medicophysica. 2007 Mar;43(1):91118. PMID: 17369783. Exclusion: 10 
886. Vernon H, Humphreys K, Hagino C. Chronic mechanical neck pain in adults treated by manual therapy: a systematic review of change scores in randomized clinical trials. Journal of Manipulative \& Physiological Therapeutics. 2007 MarApr;30(3):215-27. PMID: 17416276. Exclusion: 10

887. Vernon H, McDermaid CS, Hagino C. Systematic review of randomized clinical trials of complementary/alternative therapies in the treatment of tension-type and cervicogenic headache. Complementary Therapies in Medicine. 1999 Sep;7(3):14255. PMID: 10581824. Exclusion: 10

888. Villadsen A, Overgaard S, Holsgaard-Larsen

A, et al. Immediate efficacy of neuromuscular exercise in patients with severe osteoarthritis of the hip or knee: a secondary analysis from a randomized controlled trial. Journal of Rheumatology. 2014 Jul;41(7):1385-94. doi: http://dx.doi.org/10.3899/jrheum.130642. PMID: 24931956. Exclusion: 9

889. Villafane JH, Silva GB, Diaz-Parreno SA, et al. Hypoalgesic and motor effects of kaltenborn mobilization on elderly patients with secondary thumb carpometacarpal osteoarthritis: a randomized controlled trial. Journal of Manipulative \& Physiological Therapeutics. 2011 Oct;34(8):547-56. doi: http://dx.doi.org/10.1016/j.jmpt.2011.08.005 . PMID: 21899891. Exclusion: 9

890. Villafane JH, Silva GB, Fernandez-Carnero J. Effect of thumb joint mobilization on pressure pain threshold in elderly patients with thumb carpometacarpal osteoarthritis. Journal of Manipulative \& Physiological Therapeutics. 2012 Feb;35(2):110-20. doi: http://dx.doi.org/10.1016/j.jmpt.2011.12.002 . PMID: 22257943. Exclusion: 9

891. Vincent K, Maigne JY, Fischhoff C, et al. Systematic review of manual therapies for nonspecific neck pain. Joint, Bone, Spine: Revue du Rhumatisme. 2013 Oct;80(5):50815. doi: http://dx.doi.org/10.1016/j.jbspin.2012.10.0 06. PMID: 23165183. Exclusion: 10
892. Vitiello MV, McCurry SM, Shortreed SM, et al. Cognitive-behavioral treatment for comorbid insomnia and osteoarthritis pain in primary care: the lifestyles randomized controlled trial. Journal of the American Geriatrics Society. 2013 Jun;61(6):947-56. doi: http://dx.doi.org/10.1111/jgs.12275. PMID: 23711168. Exclusion: 3

893. Vitiello MV, Rybarczyk B, Von Korff M, et al. Cognitive behavioral therapy for insomnia improves sleep and decreases pain in older adults with co-morbid insomnia and osteoarthritis. Journal of Clinical Sleep Medicine. 2009 Aug 15;5(4):355-62. PMID: 19968014. Exclusion: 3

894. Vlaeyen JW, Teeken-Gruben NJ, Goossens ME, et al. Cognitive-educational treatment of fibromyalgia: a randomized clinical trial. I. Clinical effects. J Rheumatol. 1996 Jul;23(7):1237-45. Exclusion: 4

895. Vollenbroek-Hutten MM, Hermens HJ, Wever D, et al. Differences in outcome of a multidisciplinary treatment between subgroups of chronic low back pain patients defined using two multiaxial assessment instruments: the multidimensional pain inventory and lumbar dynamometry. Clin Rehabil. 2004 Aug;18(5):566-79. doi: 10.1191/0269215504cr772oa. PMID: 15293491. Exclusion: 5

896. Von Korff M, Vitiello MV, McCurry SM, et al. Group interventions for co-morbid insomnia and osteoarthritis pain in primary care: the lifestyles cluster randomized trial design. Contemporary Clinical Trials. 2012 Jul;33(4):759-68. doi: http://dx.doi.org/10.1016/j.cct.2012.03.010. PMID: 22484341. Exclusion: 3

897. von Trott P, Wiedemann AM, Ludtke R, et al. Qigong and exercise therapy for elderly patients with chronic neck pain (QIBANE): a randomized controlled study. Journal of Pain. 2009 May;10(5):501-8. doi: http://dx.doi.org/10.1016/j.jpain.2008.11.00 4. PMID: 19231298. Exclusion: 4 
898. Vong SK, Cheing GL, Chan F, et al. Motivational enhancement therapy in addition to physical therapy improves motivational factors and treatment outcomes in people with low back pain: a randomized controlled trial. Arch Phys Med Rehabil. 2011 Feb;92(2):176-83. doi: 10.1016/j.apmr.2010.10.016. PMID: 21272712. Exclusion: 5

899. Vonk F, Verhagen AP, Twisk JW, et al. Effectiveness of a behaviour graded activity program versus conventional exercise for chronic neck pain patients. European Journal of Pain. 2009 May;13(5):533-41. doi: http://dx.doi.org/10.1016/j.ejpain.2008.06.0 08. PMID: 18692420. Exclusion: 5

900. Wajswelner H, Metcalf B, Bennell K. Clinical pilates versus general exercise for chronic low back pain: randomized trial. Med Sci Sports Exerc. 2012 Jul;44(7):1197205. doi: 10.1249/MSS.0b013e318248f665. PMID: 22246216. Exclusion: 4

901. Waling K, Sundelin G, Ahlgren C, et al. Perceived pain before and after three exercise programs--a controlled clinical trial of women with work-related trapezius myalgia. Pain. 2000 Mar;85(1-2):201-7. PMID: 10692619. Exclusion: 9

902. Walitt B, Klose P, Fitzcharles MA, et al. Cannabinoids for fibromyalgia. Cochrane Database Syst Rev. 2016 Jul

18;7:CD011694. doi: 10.1002/14651858.CD011694.pub2. PMID: 27428009. Exclusion: 10

903. Walker BF, Hebert JJ, Stomski NJ, et al. Outcomes of usual chiropractic. The OUCH randomized controlled trial of adverse events. Spine. 2013 Sep 15;38(20):1723-9. doi:

http://dx.doi.org/10.1097/BRS.0b013e31829 fefe4. PMID: 23778372. Exclusion: 4

904. Walker BF, Hebert JJ, Stomski NJ, et al. Short-term usual chiropractic care for spinal pain: a randomized controlled trial. Spine. 2013 Nov 15;38(24):2071-8. doi: http://dx.doi.org/10.1097/01.brs.000043503 2.73187.c7. PMID: 24026159. Exclusion: 3

905. Walker L, Svenkerud T, Weber H. Traksjonsbehandling ved lumbago-ischias: en kontrollert undersolske med Spina-trac. Fysioterapeuten. 1982;49:161-3. Exclusion: 3
906. Walker MJ, Boyles RE, Young BA, et al. The effectiveness of manual physical therapy and exercise for mechanical neck pain: a randomized clinical trial. Spine. 2008 Oct 15;33(22):2371-8. doi: http://dx.doi.org/10.1097/BRS.0b013e31818 3391e. PMID: 18923311. Exclusion: 3

907. Waller B, Ogonowska-Slodownik A, Vitor $\mathrm{M}$, et al. Effect of therapeutic aquatic exercise on symptoms and function associated with lower limb osteoarthritis: systematic review with meta-analysis. Physical Therapy. 2014 Oct;94(10):1383-95. doi: http://dx.doi.org/10.2522/ptj.20130417. PMID: 24903110. Exclusion: 10

908. Walsh NE, Schwartz RK. The influence of prophylactic orthoses on abdominal strength and low back injury in the workplace. Am J Phys Med Rehabil. 1990 Oct;69(5):245-50. PMID: 2145877. Exclusion: 3

909. Wang C, McAlindon T, Fielding RA, et al. A novel comparative effectiveness study of Tai Chi versus aerobic exercise for fibromyalgia: study protocol for a randomized controlled trial. Trials [Electronic Resource]. 2015;16:34. doi: http://dx.doi.org/10.1186/s13063-015-0548x. PMID: 25633475. Exclusion: 8

910. Wang C, Schmid CH, Hibberd PL, et al. Tai Chi for treating knee osteoarthritis: designing a long-term follow up randomized controlled trial. BMC Musculoskelet Disord. 2008 Jul 29;9:108. doi: 10.1186/1471-24749-108. PMID: 18664276. Exclusion: 8

911. Wang C, Schmid CH, Iversen MD, et al. Comparative Effectiveness of Tai Chi Versus Physical Therapy for Knee Osteoarthritis: A Randomized Trial. Annals of Internal Medicine. 2016 Jul 19;165(2):7786. doi: https://dx.doi.org/10.7326/M152143. PMID: 27183035. Exclusion: 5

912. Wang K, Svensson P, Arendt-Nielsen L. Effect of acupuncture-like electrical stimulation on chronic tension-type headache: a randomized, double-blinded, placebo-controlled trial. Clinical Journal of Pain. 2007 May;23(4):316-22. PMID: 17449992. Exclusion: 4 
913. Wang Q, Wang TT, Qi XF, et al. Manual Therapy for Hip Osteoarthritis: A Systematic Review and Meta-analysis. Pain Physician. 2015 Nov;18(6):E1005-20.

PMID: 26606015. Exclusion: 10

914. Wang SY, Olson-Kellogg B, Shamliyan TA, et al. Physical therapy interventions for knee pain secondary to osteoarthritis: a systematic review. Annals of Internal Medicine. 2012 Nov 6;157(9):632-44. doi: http://dx.doi.org/10.7326/0003-4819-157-9201211060-00007. PMID: 23128863.

Exclusion: 10

915. Wang TJ, Belza B, Elaine Thompson F, et al. Effects of aquatic exercise on flexibility, strength and aerobic fitness in adults with osteoarthritis of the hip or knee. Journal of Advanced Nursing. 2007 Jan;57(2):141-52. PMID: 17214750. Exclusion: 9

916. Wang XQ, Huang LY, Liu Y, et al. Effects of tai chi program on neuromuscular function for patients with knee osteoarthritis: study protocol for a randomized controlled trial. Trials. 2013 Nov 07;14:375. doi: 10.1186/1745-6215-14375. PMID: 24195862. Exclusion: 8

917. Waylonis GW, Wilke S, O'Toole D, et al. Chronic myofascial pain: management by low-output helium-neon laser therapy. Arch Phys Med Rehabil. 1988 Dec;69(12):101720. PMID: 3063230. Exclusion: 6

918. Weber H. Traction therapy in sciatica due to disc prolapse (does traction treatment have any positive effect on patients suffering from sciatica caused by disc prolapse?). J Oslo City Hosp. 1973 Oct;23(10):167-76. PMID: 4775527. Exclusion: 3

919. Weber H, Ljunggren AE, Walker L. Traction therapy in patients with herniated lumbar intervertebral discs. J Oslo City Hosp. 1984 Jul-Aug;34(7-8):61-70. PMID: 6481516. Exclusion: 3

920. Wegner I, Widyahening IS, van Tulder MW, et al. Traction for low-back pain with or without sciatica. Cochrane Database Syst Rev. 2013 Aug 19(8):CD003010. doi: 10.1002/14651858.CD003010.pub5. PMID: 23959683. Exclusion: 10
921. Weifen W, Muheremu A, Chaohui C, et al. Effectiveness of tai chi practice for nonspecific chronic low back pain on retired athletes: a randomized controlled study. J Musculoskelet Pain. 2013;21(1):37-45. doi: 10.3109/10582452.2013.763394. Exclusion: 9

922. Weissbecker I, Salmon P, Studts JL, et al. Mindfulness-based stress reduction and sense of coherence among women with fibromyalgia. Journal of Clinical Psychology in Medical Settings. 2002;9(4):297-307. Exclusion: 6

923. Werners R, Pynsent PB, Bulstrode CJ. Randomized trial comparing interferential therapy with motorized lumbar traction and massage in the management of low back pain in a primary care setting. Spine (Phila Pa 1976). 1999 Aug 01;24(15):1579-84. PMID: 10457578. Exclusion: 5

924. Wetzels R, van Weel C, Grol R, et al. Family practice nurses supporting selfmanagement in older patients with mild osteoarthritis: a randomized trial. BMC Family Practice. 2008;9:7. doi: http://dx.doi.org/10.1186/1471-2296-9-7. PMID: 18226255. Exclusion: 4

925. White A, Foster NE, Cummings M, et al. Acupuncture treatment for chronic knee pain: a systematic review. Rheumatology. 2007 Mar;46(3):384-90. PMID: 17215263. Exclusion: 10

926. White AR, Ernst E. A systematic review of randomized controlled trials of acupuncture for neck pain. Rheumatology. 1999 Feb;38(2):143-7. PMID: 10342627. Exclusion: 10

927. White P, Bishop FL, Prescott P, et al. Practice, practitioner, or placebo? A multifactorial, mixed-methods randomized controlled trial of acupuncture. Pain. 2012 Feb;153(2):455-62. doi: http://dx.doi.org/10.1016/j.pain.2011.11.007 . PMID: 22169359. Exclusion: 9

928. Williams DA. Utility of cognitive behavioral therapy as a treatment for insomnia in patients with fibromyalgia. Nature Clinical Practice Rheumatology. 2006 Apr;2(4):1901. doi: https://dx.doi.org/10.1038/ncprheum0163. PMID: 16932684. Exclusion: 8 
929. Williams QI, Gunn AH, Beaulieu JE, et al. Physical therapy vs. internet-based exercise training (PATH-IN) for patients with knee osteoarthritis: study protocol of a randomized controlled trial. BMC Musculoskelet Disord. 2015 Sep 28;16:264. doi: 10.1186/s12891-015-0725-9. PMID: 26416025. Exclusion: 8

930. Williamson W, Kluzek S, Roberts N, et al. Behavioural physical activity interventions in participants with lower-limb osteoarthritis: a systematic review with meta-analysis. BMJ Open. 2015;5(8):e007642. doi: http://dx.doi.org/10.1136/bmjopen-2015007642. PMID: 26260348. Exclusion: 10

931. Willich SN, Reinhold T, Selim D, et al. Cost-effectiveness of acupuncture treatment in patients with chronic neck pain. Pain. 2006 Nov;125(1-2):107-13. PMID: 16842918. Exclusion: 7

932. Witt CM, Jena S, Brinkhaus B, et al. Acupuncture for patients with chronic neck pain. Pain. 2006 Nov;125(1-2):98-106. PMID: 16781068. Exclusion: 5

933. Witt CM, Jena S, Brinkhaus B, et al. Acupuncture in patients with osteoarthritis of the knee or hip: a randomized, controlled trial with an additional nonrandomized arm. Arthritis \& Rheumatism. 2006

Nov;54(11):3485-93. doi: https://dx.doi.org/10.1002/art.22154. PMID: 17075849. Exclusion: 5

934. Witt CM, Jena S, Selim D, et al. Pragmatic randomized trial evaluating the clinical and economic effectiveness of acupuncture for chronic low back pain. Am J Epidemiol. 2006 Sep 01;164(5):487-96. doi: 10.1093/aje/kwj224. PMID: 16798792. Exclusion: 4

935. Witteveen AG, Hofstad CJ, Kerkhoffs GM. Hyaluronic acid and other conservative treatment options for osteoarthritis of the ankle. Cochrane Database of Systematic Reviews. 2015;10:CD010643. doi: http://dx.doi.org/10.1002/14651858.CD0106 43.pub2. PMID: 26475434. Exclusion: 4
936. Wonderling D, Vickers AJ, Grieve R, et al. Cost effectiveness analysis of a randomised trial of acupuncture for chronic headache in primary care. BMJ. 2004 Mar 27;328(7442):747. PMID: 15023830. Exclusion: 3

937. Wong JJ, Shearer HM, Mior S, et al. Are manual therapies, passive physical modalities, or acupuncture effective for the management of patients with whiplashassociated disorders or neck pain and associated disorders? An update of the Bone and Joint Decade Task Force on Neck Pain and Its Associated Disorders by the OPTIMa collaboration. Spine J. 2016

Dec;16(12):1598-630. doi: 10.1016/j.spinee.2015.08.024. PMID: 26707074. Exclusion: 10

938. Wu MX, Li XH, Lin MN, et al. Clinical study on the treatment of knee osteoarthritis of Shen-Sui insufficiency syndrome type by electroacupuncture. Chinese Journal of Integrative Medicine. 2010 Aug;16(4):2917. doi: http://dx.doi.org/10.1007/s11655010-0513-1. PMID: 20697938. Exclusion: 9

939. Wuschech $\mathrm{H}$, von Hehn U, Mikus E, et al. Effects of PEMF on patients with osteoarthritis: Results of a prospective, placebo-controlled, double-blind study. Bioelectromagnetics. 2015 Dec;36(8):57685. doi: https://dx.doi.org/10.1002/bem.21942. PMID: 26562074. Exclusion: 9

940. Yamato TP, Maher CG, Saragiotto BT, et al. Pilates for low back pain. Cochrane Database Syst Rev. 2015 Jul 02(7):CD010265. doi: 10.1002/14651858.CD010265.pub2. PMID: 26133923. Exclusion: 10

941. Yamato TP, Saragiotto BT, Maher C. Therapeutic exercise for chronic nonspecific neck pain: PEDro systematic review update. British Journal of Sports Medicine. 2015 Oct;49(20):1350. doi: http://dx.doi.org/10.1136/bjsports-2014093874. PMID: 25136081. Exclusion: 10

942. Yan JH, Gu WJ, Sun J, et al. Efficacy of Tai Chi on pain, stiffness and function in patients with osteoarthritis: a meta-analysis. PLoS ONE [Electronic Resource]. 2013;8(4):e61672. doi: http://dx.doi.org/10.1371/journal.pone.0061 672. PMID: 23620778. Exclusion: 10 
943. Yang PF, Li D, Zhang SM, et al. Efficacy of ultrasound in the treatment of osteoarthritis of the knee. Orthopaedic surgery. 2011 Aug;3(3):181-7. PMID: CN-00920135 UPDATE. Exclusion: 9

944. Yazigi F, Espanha M, Vieira F, et al. The PICO project: aquatic exercise for knee osteoarthritis in overweight and obese individuals. BMC Musculoskeletal Disorders. 2013;14:320. doi: http://dx.doi.org/10.1186/1471-2474-14320. PMID: 24219758. Exclusion: 8

945. Ye L, Kalichman L, Spittle A, et al. Effects of rehabilitative interventions on pain, function and physical impairments in people with hand osteoarthritis: a systematic review. Arthritis Research \& Therapy. 2011;13(1):R28. doi: http://dx.doi.org/10.1186/ar3254. PMID: 21332991. Exclusion: 10

946. Yelland MJ, Glasziou PP, Bogduk N, et al. Prolotherapy injections, saline injections, and exercises for chronic low-back pain: a randomized trial. Spine (Phila Pa 1976). 2004 Jan 01;29(1):9-16; discussion doi: 10.1097/01.brs.0000105529.07222.5b. PMID: 14699269. Exclusion: 5

947. Yildirim N, Filiz Ulusoy M, Bodur H. The effect of heat application on pain, stiffness, physical function and quality of life in patients with knee osteoarthritis. Journal of Clinical Nursing. 2010 Apr;19(7-8):111320. doi: http://dx.doi.org/10.1111/j.13652702.2009.03070.x. PMID: 20492056. Exclusion: 9

948. Yip YB, Tam AC. An experimental study on the effectiveness of massage with aromatic ginger and orange essential oil for moderateto-severe knee pain among the elderly in Hong Kong. Complementary Therapies in Medicine. 2008 Jun;16(3):131-8. doi: http://dx.doi.org/10.1016/j.ctim.2007.12.003 . PMID: 18534325. Exclusion: 3

949. Yip YB, Tse SH. The effectiveness of relaxation acupoint stimulation and acupressure with aromatic lavender essential oil for non-specific low back pain in Hong Kong: a randomised controlled trial. Complement Ther Med. 2004 Mar;12(1):2837. doi: 10.1016/j.ctim.2003.12.003. PMID: 15130569. Exclusion: 3
950. Ylinen J, Hakkinen A, Nykanen M, et al. Neck muscle training in the treatment of chronic neck pain: a three-year follow-up study. Europa Medicophysica. 2007 Jun;43(2):161-9. PMID: 17525699. Exclusion: 4

951. Ylinen J, Kautiainen H, Wiren K, et al. Stretching exercises vs manual therapy in treatment of chronic neck pain: a randomized, controlled cross-over trial. Journal of Rehabilitation Medicine. 2007 Mar;39(2):126-32. PMID: 17351694. Exclusion: 4

952. Ylinen J, Nikander R, Nykanen M, et al. Effect of neck exercises on cervicogenic headache: a randomized controlled trial. Journal of Rehabilitation Medicine. 2010 Apr;42(4):344-9. doi: http://dx.doi.org/10.2340/16501977-0527. PMID: 20461336. Exclusion: 3

953. Ylinen J, Takala EP, Kautiainen H, et al. Effect of long-term neck muscle training on pressure pain threshold: a randomized controlled trial. European Journal of Pain. 2005 Dec;9(6):673-81. PMID: 16246820. Exclusion: 9

954. Ylinen J, Takala EP, Nykanen M, et al. Active neck muscle training in the treatment of chronic neck pain in women: a randomized controlled trial. JAMA. 2003 May 21;289(19):2509-16. PMID: 12759322. Exclusion: 9

955. Ylinen JJ, Hakkinen AH, Takala EP, et al. Effects of neck muscle training in women with chronic neck pain: one-year follow-up study. Journal of Strength \& Conditioning Research. 2006 Feb;20(1):6-13. PMID: 16503693. Exclusion: 9

956. Yoon YS, Yu KP, Lee KJ, et al. Development and application of a newly designed massage instrument for deep crossfriction massage in chronic non-specific low back pain. Ann Rehabil Med. 2012 Feb;36(1):55-65. doi: 10.5535/arm.2012.36.1.55. PMID: 22506236. Exclusion: 5 
957. Yousefi-Nooraie R, Schonstein E, Heidari $\mathrm{K}$, et al. Low level laser therapy for nonspecific low-back pain. Cochrane Database Syst Rev. 2008 Apr

16(2):Cd005107. doi: 10.1002/14651858.CD005107.pub4. PMID: 18425909. Exclusion: 10

958. Youssef EF, Muaidi QI, Shanb AA. Effect of Laser Therapy on Chronic Osteoarthritis of the Knee in Older Subjects. J Lasers Med Sci. 2016 Spring;7(2):112-9. doi: 10.15171/jlms.2016.19. PMID: 27330707. Exclusion: 9

959. Yuan QL, Guo TM, Liu L, et al. Traditional Chinese medicine for neck pain and low back pain: a systematic review and metaanalysis. PLoS ONE [Electronic Resource]. 2015;10(2):e0117146. doi: http://dx.doi.org/10.1371/journal.pone.0117 146. PMID: 25710765. Exclusion: 10

960. Yun M, Shao Y, Zhang Y, et al. Hegu acupuncture for chronic low-back pain: a randomized controlled trial. J Altern Complement Med. 2012 Feb;18(2):130-6. doi: 10.1089/acm.2010.0779. PMID: 22339101. Exclusion: 4

961. Yun M, Xiong N, Guo M, et al. Acupuncture at the back-pain-acupoints for chronic low back pain of peacekeepers in Lebanon: a randomized controlled trial. J Musculoskelet Pain. 2012 2012/06/01;20(2):107-15. doi: 10.3109/10582452.2012.673544. Exclusion: 4

962. Yurtkuran M, Kocagil T. TENS, electroacupuncture and ice massage: comparison of treatment for osteoarthritis of the knee. American Journal of Acupuncture. 1999;27(3-4):133-40. PMID: 10729968.

Exclusion: 9

963. Zacharias A, Green RA, Semciw AI, et al. Efficacy of rehabilitation programs for improving muscle strength in people with hip or knee osteoarthritis: a systematic review with meta-analysis. Osteoarthritis \& Cartilage. 2014 Nov;22(11):1752-73. doi: http://dx.doi.org/10.1016/j.joca.2014.07.005. PMID: 25065642. Exclusion: 10
964. Zafar H, Alghadir A, Anwer S, et al. Therapeutic effects of whole-body vibration training in knee osteoarthritis: a systematic review and meta-analysis. Archives of Physical Medicine \& Rehabilitation. 2015 Aug;96(8):1525-32. doi: http://dx.doi.org/10.1016/j.apmr.2015.03.01 0. PMID: 25827655. Exclusion: 10

965. Zdrodowska B, Leszczynska-Filus M, Leszczynski R, et al. [Comparison of the effect of laser and magnetic therapy for pain level and the range of motion of the spine of people with osteoarthritis lower back]. Pol Merkur Lekarski. 2015 Jan;38(223):26-31. PMID: 25763584. Exclusion: 3

966. Zeada MA. Effects of Pilates on low back pain and urine catecholamine. Ovidius University Annals, Series Physiotherapy Education and Sport. 2011;12:41-7. Exclusion: 9

967. Zebis MK, Andersen CH, Sundstrup E, et al. Time-wise change in neck pain in response to rehabilitation with specific resistance training: implications for exercise prescription. PLoS ONE [Electronic Resource]. 2014;9(4):e93867. doi: http://dx.doi.org/10.1371/journal.pone.0093 867. PMID: 24709874. Exclusion: 9

968. Zebis MK, Andersen LL, Pedersen MT, et al. Implementation of neck/shoulder exercises for pain relief among industrial workers: a randomized controlled trial. BMC Musculoskeletal Disorders. 2011;12:205. doi: http://dx.doi.org/10.1186/1471-2474-12205. PMID: 21936939. Exclusion: 9

969. Zeng C, Li H, Yang T, et al. Electrical stimulation for pain relief in knee osteoarthritis: systematic review and network meta-analysis. Osteoarthritis \& Cartilage. 2015 Feb;23(2):189-202. doi: http://dx.doi.org/10.1016/j.joca.2014.11.014. PMID: 25497083. Exclusion: 10

970. Zhang C, Xie Y, Luo X, et al. Effects of therapeutic ultrasound on pain, physical functions and safety outcomes in patients with knee osteoarthritis: a systematic review and meta-analysis. Clin Rehabil. 2016 Oct;30(10):960-71. doi: 10.1177/0269215515609415. PMID: 26451008. Exclusion: 10 
971. Zhang W, Nuki G, Moskowitz RW, et al. OARSI recommendations for the management of hip and knee osteoarthritis: part III: Changes in evidence following systematic cumulative update of research published through January 2009.

Osteoarthritis \& Cartilage. 2010

Apr;18(4):476-99. doi:

http://dx.doi.org/10.1016/j.joca.2010.01.013.

PMID: 20170770. Exclusion: 10

972. Zhang Y, Tang S, Chen G, et al. Chinese massage combined with core stability exercises for nonspecific low back pain: a randomized controlled trial. Complement Ther Med. 2015 Feb;23(1):1-6. doi: 10.1016/j.ctim.2014.12.005. PMID: 25637146. Exclusion: 4
973. Zheng Z, Wang J, Gao Q, et al. Therapeutic evaluation of lumbar tender point deep massage for chronic non-specific low back pain. J Tradit Chin Med. 2012

Dec;32(4):534-7. PMID: 23427384. Exclusion: 5

974. Zhu XM, Polus B. A controlled trial on acupuncture for chronic neck pain. American Journal of Chinese Medicine. 2002;30(1):13-28. PMID: 12067088. Exclusion: 7

975. Zylbergold RS, Piper MC. Cervical spine disorders. A comparison of three types of traction. Spine. 1985 Dec;10(10):867-71. PMID: 3914085. Exclusion: 3 


\section{Appendix D. Evidence Table}

Table D-1. Data abstraction of randomized controlled trials

See Appendix B. Included Studies for references.

\begin{tabular}{|c|c|c|c|}
\hline Author, Year & $\begin{array}{c}\text { Country } \\
\text { Number of Centers } \\
\text { Setting }\end{array}$ & Inclusion/Exclusion Criteria & $\begin{array}{c}\text { Number Randomized, } \\
\text { Analyzed } \\
\text { Attrition }\end{array}$ \\
\hline Abbassi 2012 & $\begin{array}{l}\text { Iran } \\
\text { Number of centers: } 2 \\
\text { Outpatient clinic }\end{array}$ & $\begin{array}{l}\text { Married patients ages } 18 \text { to } 70 \text { with chronic LBP longer than } 6 \text { months } \\
\text { Exclude: Patients with unexplained pain, pregnancy, did not speak Persian language, } \\
\text { had active rheumatological disease, progressive neurological disease, serious } \\
\text { cardiac or other internal medical condition, malignant, basic diseases, acute traumas, } \\
\text { infections, or acute vascular catastrophes, major cognitive dysfunction, coexisting } \\
\text { psychiatric morbidity as determined by a } \\
\text { psychological screening interview and previous participation in a rehabilitation } \\
\text { cognitive behavioral program }\end{array}$ & $\begin{array}{l}\text { Randomized: } 36 \\
\text { Treated: } 32 \\
\text { Analyzed: } 32 \\
\text { Attrition: } 11 \%(4 / 36)\end{array}$ \\
\hline Abbott 2013 & $\begin{array}{l}\text { New Zealand } 2 \\
\text { centers } \\
1 \text { general practitioner, } \\
1 \text { outpatient }\end{array}$ & $\begin{array}{l}\text { Diagnosis of hip or knee OA fulfilling ACR criteria } \\
\text { Exclude: Rheumatoid arthritis, previous knee or hip joint replacement surgery of affected } \\
\text { joint, surgical procedure on lower limbs within } 6 \text { months, surgical procedure planned for } \\
\text { lower limbs within } 6 \text { months, opioid analgesia or corticosteroid or analgesic injection } \\
\text { intervention for hip or knee pain in past } 30 \text { days }\end{array}$ & $\begin{array}{l}\text { Randomized:156 (87 with knee } \\
\text { OA) } \\
\text { Treated: } 156 \\
\text { Analyzed: } 147 \\
\text { Attrition: } 6 \%(9 / 156)\end{array}$ \\
\hline
\end{tabular}




\begin{tabular}{|c|c|}
\hline Author, Year & Intervention, Comparator \\
\hline Abbassi 2012 & $\begin{array}{l}\text { A: Multidisciplinary pain management program }(\mathrm{n}=12): 7 \text { weekly } 2 \text { hour group sessions of training in pain coping and couple skills for the patient, } \\
\text { led by psychologist and focusing on self-management. Components included education, self-management strategies, coping skills. Also education } \\
\text { from orthopedic surgeon at second group session, medication management via private sessions with psychiatrist, and } 1 \text { group session with } \\
\text { physiotherapist plus an individualized appointment with tailored exercises. } \\
\text { B: Spouse-assisted multidisciplinary pain management program ( } n=10): 7 \text { weekly } 2 \text { hour group sessions of training in pain coping and couple skills } \\
\text { with spouses, otherwise similar to A. } \\
\text { C: Standard medical care }(n=11): \text { Routine medical treatment only }\end{array}$ \\
\hline Abbott 2013 & $\begin{array}{l}\text { A.Manual therapy }(\mathrm{n}=54)(30 \mathrm{knee} O A / 24 \text { hip OA): } 9 \text { total sessions of } 50 \text { minutes, } 7 \text { sessions in the initial } 9 \text { weeks of the trial with } 2 \text { booster } \\
\text { sessions at week } 16 \text {. The sessions aimed to modify the quality and ROM of the target joint and associated soft tissue structures. Additional manual } \\
\text { therapy interventions were prescribed individually as needed and all patients were prescribed a home program of joint range of motion exercises to } \\
\text { be done three times per week. } \\
\text { B. Exercise therapy }(n=51)(29 \mathrm{knee} O A / 22 \text { hip OA): } 9 \text { total sessions of } 50 \text { minutes, } 7 \text { sessions in the initial } 9 \text { weeks of the trial with } 2 \text { booster } \\
\text { sessions at week 16. The sessions consisted of an aerobic warm-up, muscle strengthening, muscle stretching, and neuromuscular control } \\
\text { exercises. Additional exercises were prescribed individually as needed and all subjects were prescribed a home exercise program to be done three } \\
\text { times per week. } \\
\text { C. Usual care }(n=51)(28 \text { knee OA/23 hip OA): Routine care from patients' own GP and other healthcare providers. Subjects participation in the use } \\
\text { of the interventions outside of the trial was not influenced or restricted, but it was monitored. } \\
\text { All subjects continued receiving usual care as above. }\end{array}$ \\
\hline
\end{tabular}




\begin{tabular}{|c|c|c|c|}
\hline Author, Year & Study Participants & Outcome Measures & $\begin{array}{l}\text { Duration of } \\
\text { Followup }\end{array}$ \\
\hline Abbassi 2012 & $\begin{array}{l}\text { Overall } \\
\text { Age (mean): } 45 \text { years } \\
\text { Female: } 88 \% \\
\text { Race: } \mathrm{NR}^{*}\end{array}$ & $\begin{array}{l}\text { Roland Disability Questionnaire (RDQ, 0-24) } \\
\text { Pain (0-10 VAS) } \\
\text { Depression Anxiety Stress Scale (DASS, } 0 \text { to 42, higher } \\
\text { score indicates greater level of depression, anxiety or } \\
\text { stress) }\end{array}$ & 10.25 months \\
\hline Abbott 2013 & $\begin{array}{l}\text { A vs B vs C (overall population) Age: } \\
67 \text { vs } 67 \text { vs } 66 \\
\text { Females: } 49 \% \text { vs } 52 \% \text { vs } 58 \% \\
\text { Years of OA diagnosis: } 2.5 \text { vs } 2.6 \text { vs } 2.8 \\
\% \text { hip OA: } 44.4 \% \text { vs } 43.1 \% \text { vs } 45.1 \% \\
\% \text { knee OA: } 55.6 \% \text { vs } 56.9 \% \text { vs } 54.9 \% \\
\text { Both hip and knee OA: } 22.2 \% \text { vs } 19.6 \% \text { vs } 25.5 \% \\
\text { Low risk of depression from depression screening test score: } 50.9 \% \text { vs } \\
52.9 \% \text { vs } 51.0 \% \\
\text { WOMAC: } 114.8(56.3) \text { vs } 95.5(57.3) \text { vs } 93.8(52.8)\end{array}$ & WOMAC (0-240, higher score=higher disability) & 9.75 months \\
\hline
\end{tabular}




\begin{tabular}{|c|c|}
\hline Author, Year & $\begin{array}{c}\text { Results - Subquestion a } \\
\text { (vs. sham, no treatment, waitlist, attention control) }\end{array}$ \\
\hline Abbassi 2012 & 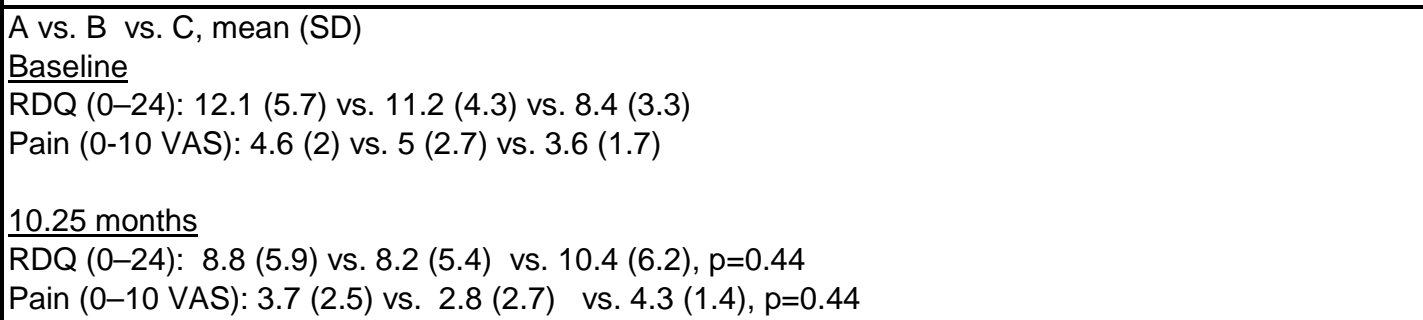 \\
\hline Abbott 2013 & 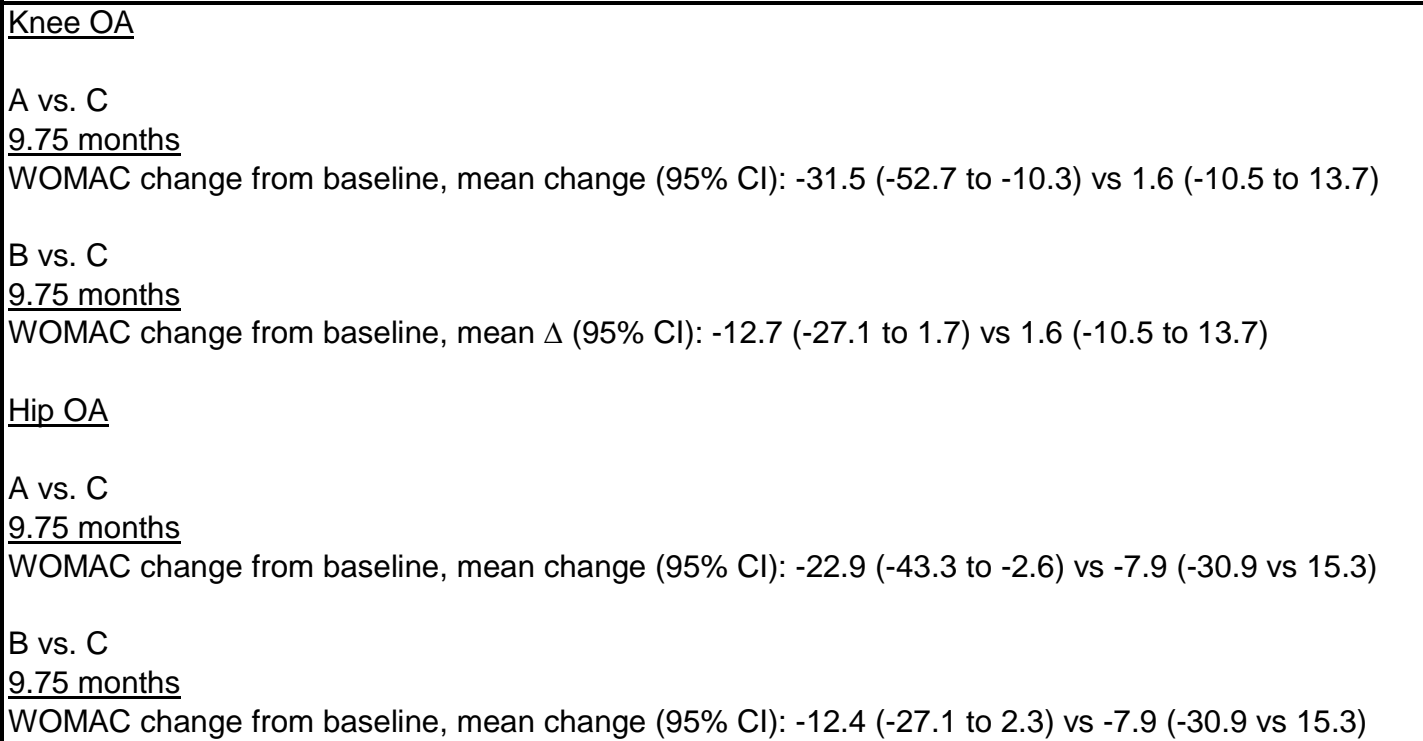 \\
\hline
\end{tabular}




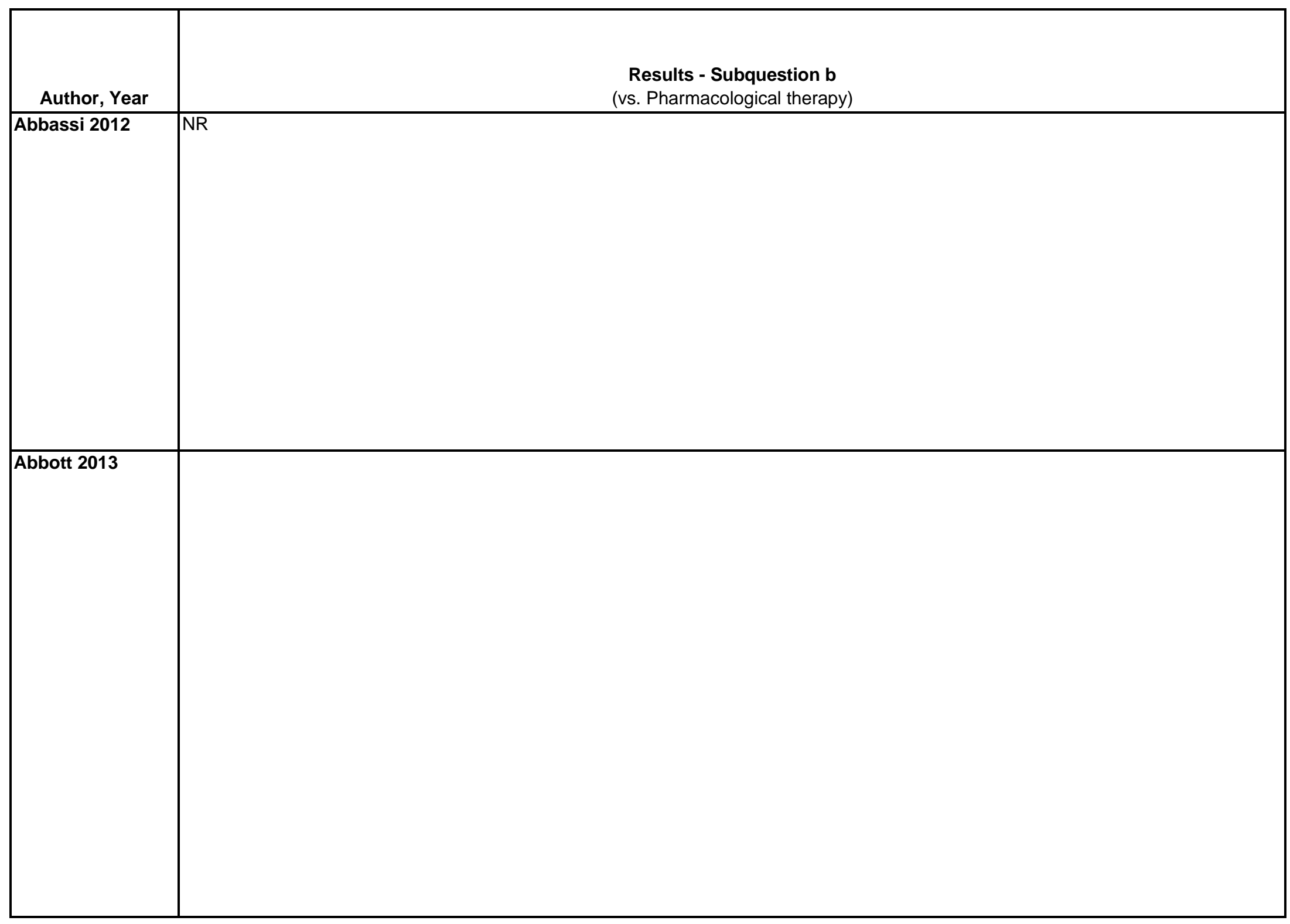

D-5 


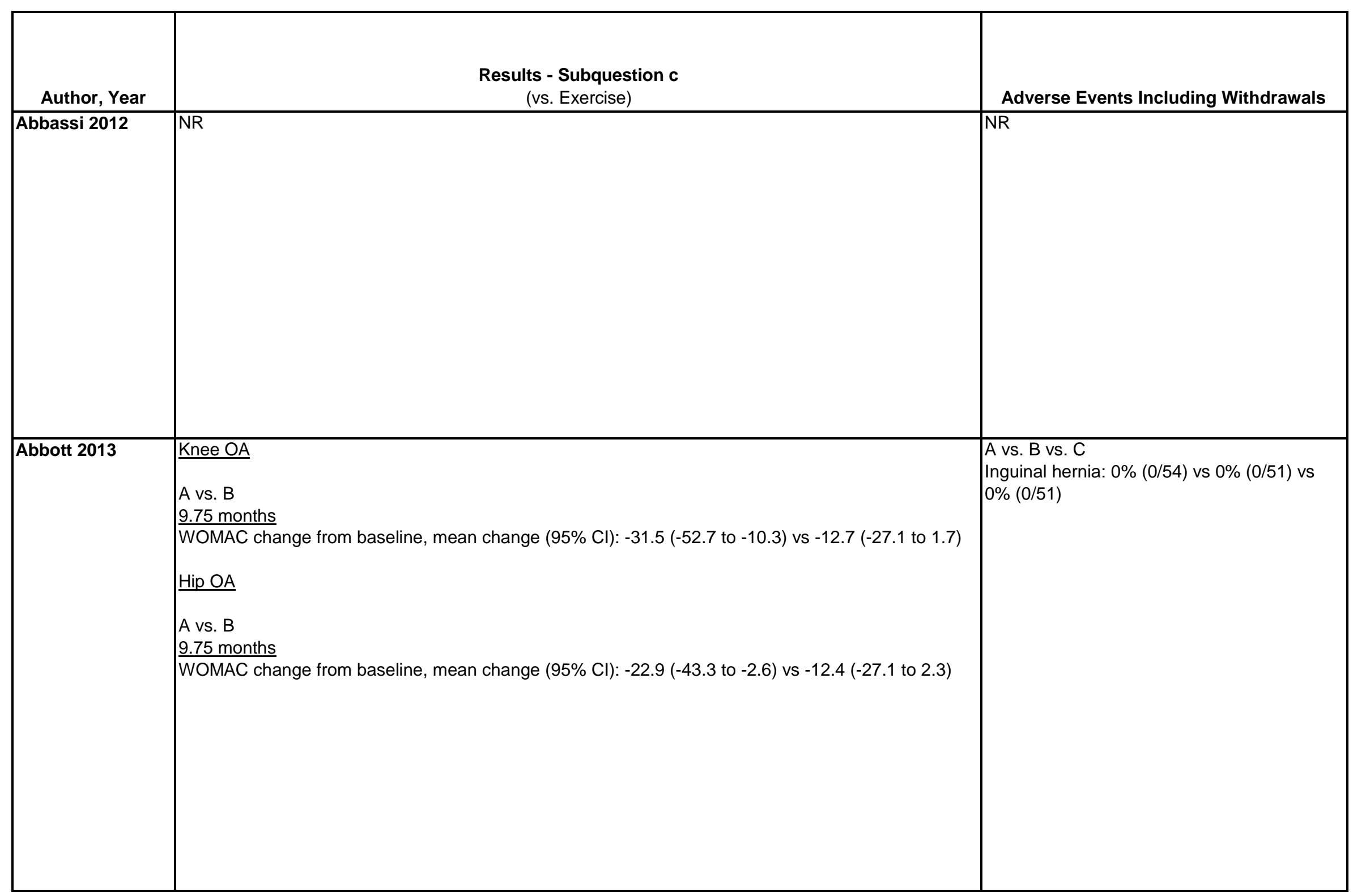




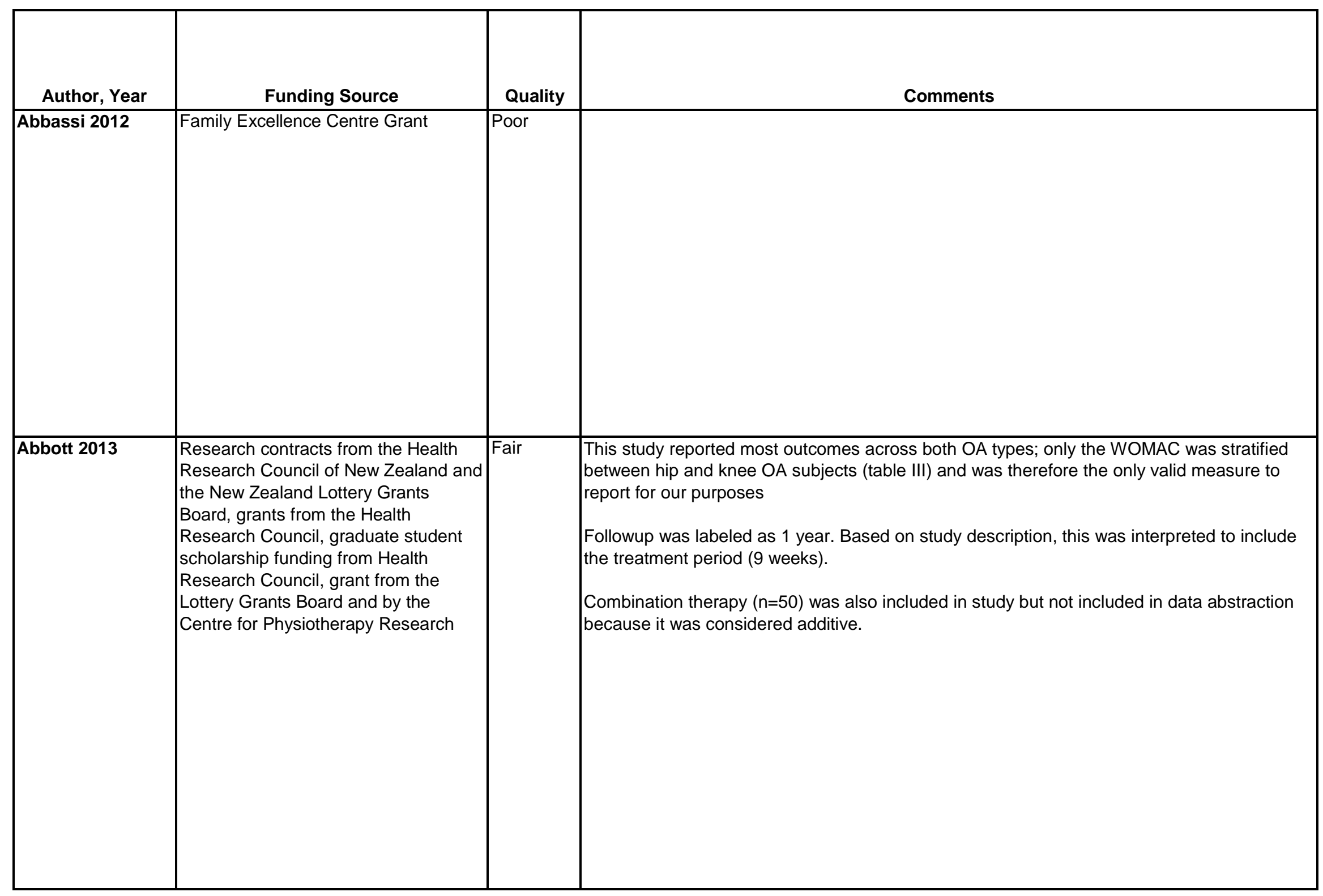




\begin{tabular}{|c|c|c|c|}
\hline Author, Year & $\begin{array}{c}\text { Country } \\
\text { Number of Centers } \\
\text { Setting }\end{array}$ & Inclusion/Exclusion Criteria & $\begin{array}{c}\text { Number Randomized, } \\
\text { Analyzed } \\
\text { Attrition }\end{array}$ \\
\hline Ajimsha 2014 & $\begin{array}{l}\text { India } \\
\text { Number of centers: } 1 \\
\text { Outpatient }\end{array}$ & $\begin{array}{l}\text { Nursing professional } \\
20-40 \text { years old; chronic musculoskeletal low back pain for } \geq 3 \text { months } \\
\text { Exclude: } \\
\text { Osteoporosis } \\
\text { Primary joint disease } \\
\text { Metabolic bone disease } \\
\text { Malignant bone disease } \\
\text { Fracture } \\
\text { Hyper mobility of the lumbar/sacral spine } \\
\text { Cardiovascular or other medical disorder preventing strenuous } \\
\text { exercise } \\
\text { Radiculopathy } \\
\text { Radiating pain } \\
\text { Pregnancy } \\
\text { Severe psychiatric disturbance } \\
\text { Oral/systemic steroids } \\
\text { Analgesics on }>10 \text { days per month for previous } 6 \text { months }\end{array}$ & \begin{tabular}{|l|} 
Randomized: 80 \\
Analyzed: 74 \\
Attrition: $7.5 \%(6 / 80)$
\end{tabular} \\
\hline Al Rashoud 2014 & $\begin{array}{l}\text { Saudi Arabia, single- } \\
\text { site, hospital }\end{array}$ & $\begin{array}{l}\text { Inclusion Criteria: } \\
\text { Patients with knee osteoarthritis (according to the American College of } \\
\text { Rheumatology criteria)with an average pain intensity of } \geq 3 \text { on a } 10-\mathrm{cm} \\
\text { visual analogue scale (VAS), ability to perform all movements included } \\
\text { in the evaluation forms, ability to read or understand the patient } \\
\text { information sheets, and ability to sign a consent form. For those } \\
\text { patients with bilateral knee osteoarthritis, the most painful knee } \\
\text { was assessed. } \\
\\
\text { Exclusion Criteria: } \\
\text { Exclusion criteria included previous knee surgery, serious valgus or } \\
\text { varus deformity, disease where laser treatment is contraindicated } \\
\text { (cancer, uncontrolled diabetes mellitus, hypertension, etc.), and } \\
\text { current use of medications that might interfere with LLLT treatment } \\
\text { (e.g. corticosteroid injections). }\end{array}$ & $\begin{array}{l}\text { Randomized: NR } \\
\text { Treated: } 49 \\
\text { Analyzed: } 49 \\
\text { Attrition: NR }\end{array}$ \\
\hline
\end{tabular}




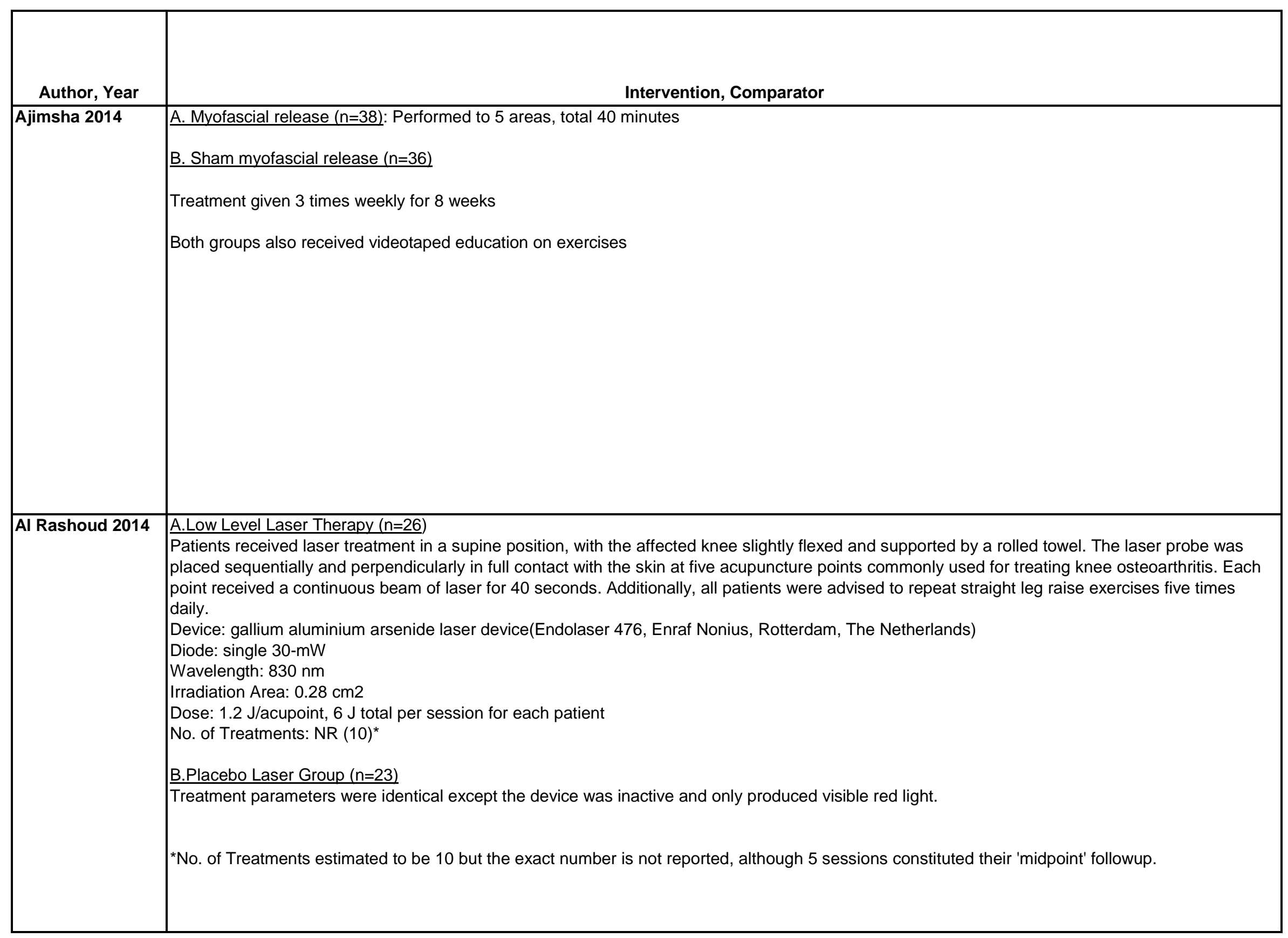




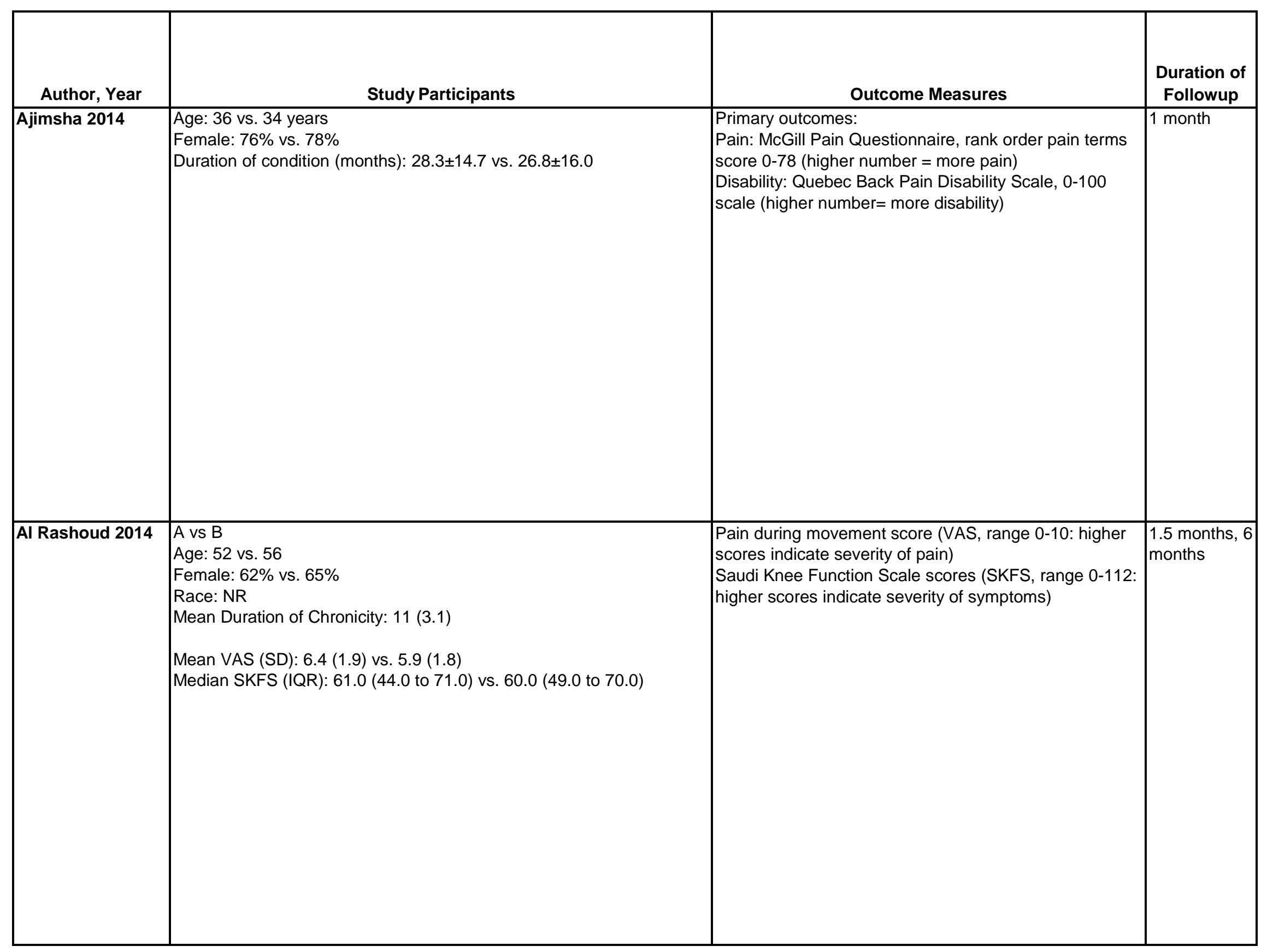




\begin{tabular}{|c|c|}
\hline Author, Year & $\begin{array}{c}\text { Results - Subquestion a } \\
\text { (vs. sham, no treatment, waitlist, attention control) }\end{array}$ \\
\hline Ajimsha 2014 & $\begin{array}{l}\text { A vs. B, mean (SD) } \\
\text { Baseline } \\
\text { McGill Pain Questionnaire (0-78): } 23.2(8.7) \text { vs. } 23.0(7.6), \text { mean difference }-1.00(p=0.13) \\
\text { Quebec Back Disability Scale (0-100): } 37.1(11.8) \text { vs. } 35.3(13.6), \text { mean difference }-0.97(p=0.47) \\
1 \text { month } \\
\text { McGill Pain Questionnaire (0-78): } 13.1(6.9) \text { vs. } 18.3(7.5) \text {, mean difference }-3.25(p<0.005) \\
\text { Quebec Back Disability Scale (0-100): } 28.7(9.1) \text { vs. } 32.5(10.4), \text { mean difference }-2.02(p<0.005)\end{array}$ \\
\hline Al Rashoud 2014 & $\begin{array}{l}\text { A vs. B } \\
\text { 1.5 months } \\
\text { Mean VAS Pain on Movement*: } 3 \text { vs. } 4.2 \\
\text { Median SKFS (IQR): } 31 \text { (12 to } 44) \text { vs. } 40 \text { ( } 29 \text { to } 54) \text {; median difference }-10(-23 \text { to }-4) p=0.054 \\
6 \text { months } \\
\text { Mean VAS Pain on Movement*: } 3.4 \text { vs. } 5.2 \\
\text { Median SKFS (IQR): } 31 \text { (19 to } 43 \text { ) vs. } 51 \text { ( } 33 \text { to } 55) \text {; median difference }-21.0(95 \% \mathrm{Cl}-34.0 \text { to }-7.0) p=0.006 \\
\text { ×Pain values were abstracted from a graph and no SD was given. }\end{array}$ \\
\hline
\end{tabular}




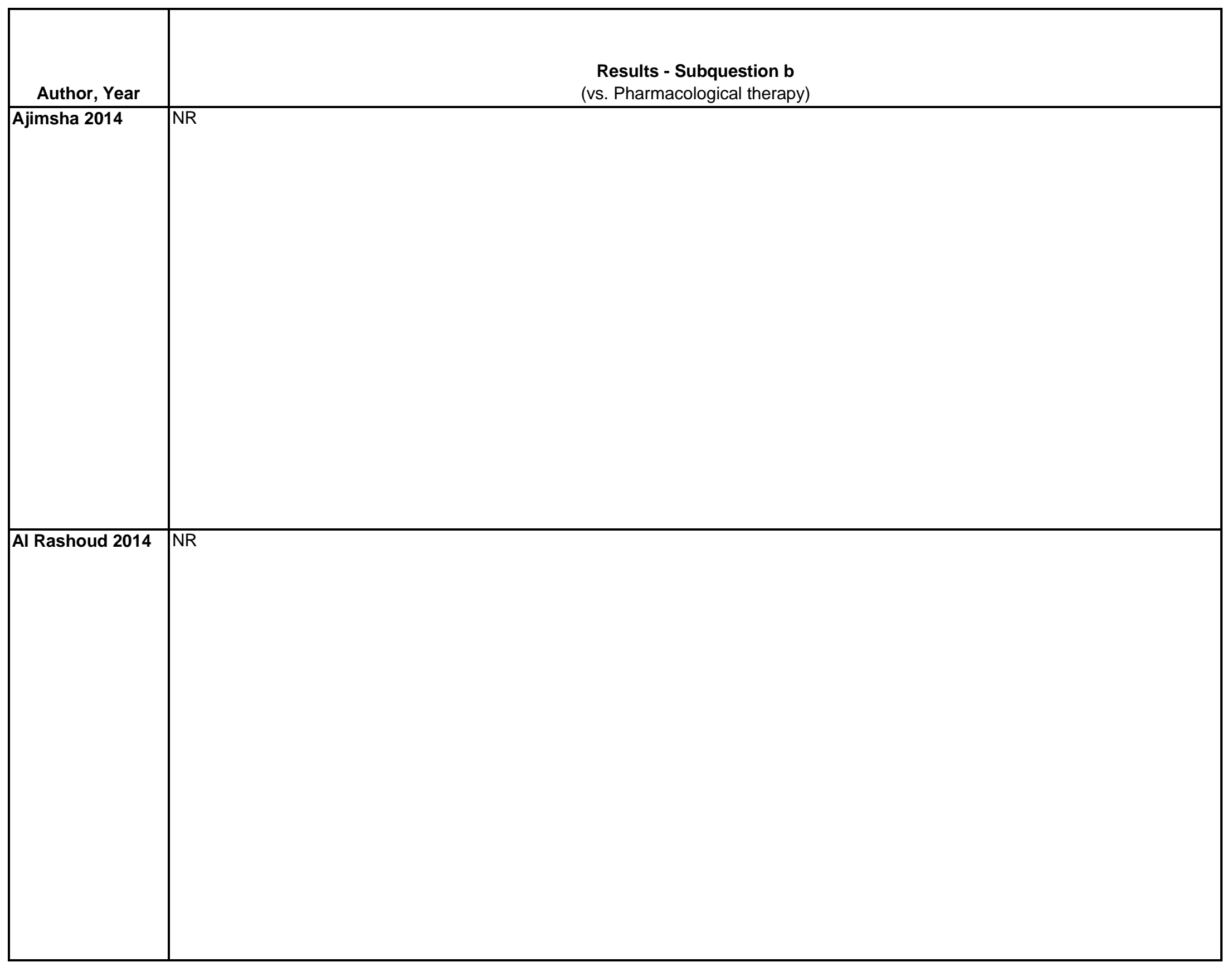

D-12 


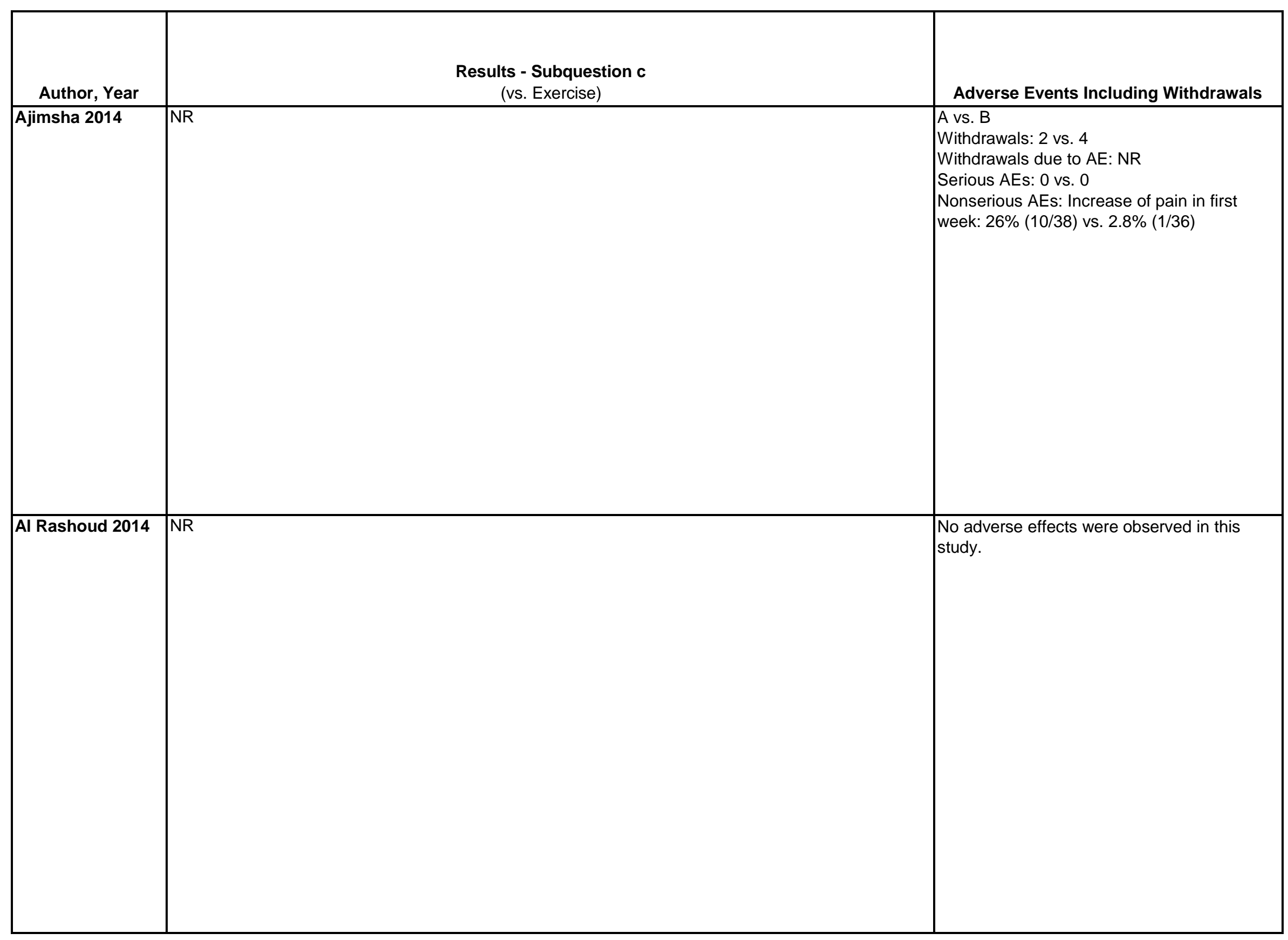




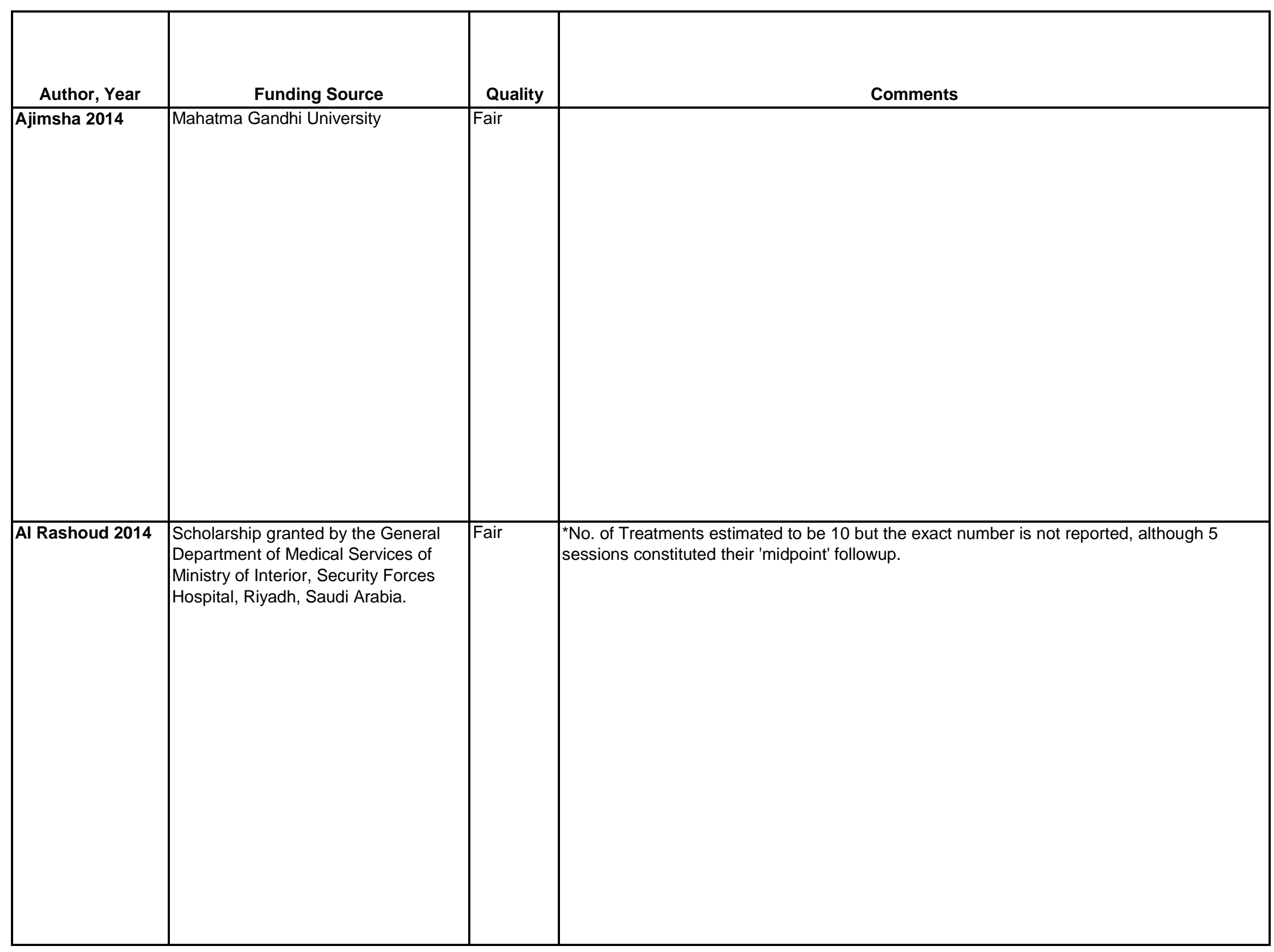




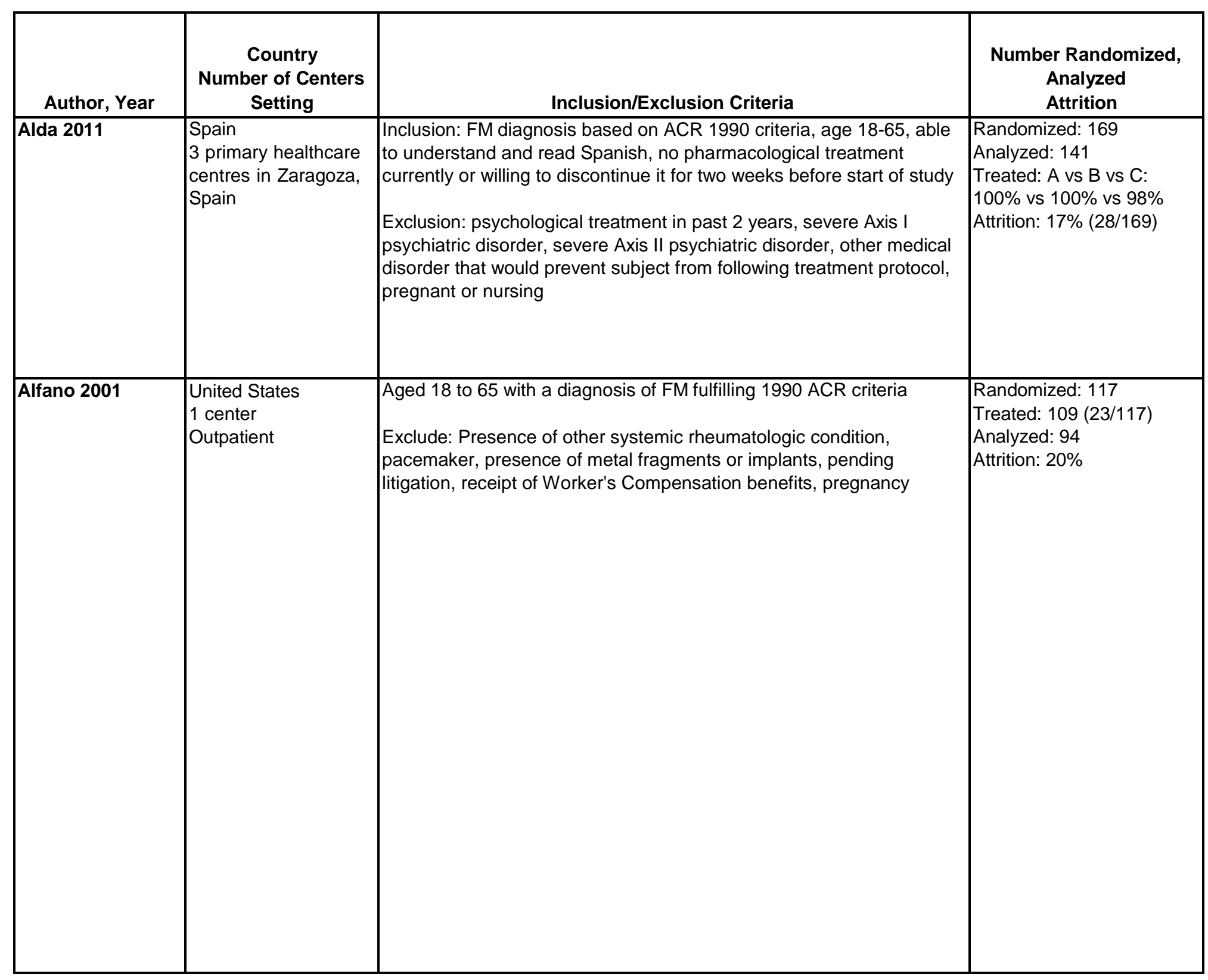




\begin{tabular}{|c|c|}
\hline Author, Year & Intervention, Comparator \\
\hline Alda 2011 & $\begin{array}{l}\text { A.CBT }(n=49) \text { : } 10-12 \text { week program consisting of } 10 \text { weekly } 90-\text { minute group sessions. Cognitive restructuring and training in cognitive and } \\
\text { behavioral coping strategies. Administered by "trained therapists." Of } 57 \text { randomized, } 1 \text { received } 1 \text { session, } 2 \text { received } 6 \text { sessions, } 6 \text { received } 7 \\
\text { sessions, } 5 \text { received } 8 \text { sessions, } 43 \text { received } 9 \text { sessions, } 84 \%(48 / 57) \text { received } 80 \% \text { of sessions. } \\
\text { B. Recommended pharmacological treatment ( } n=46) \text { : Treatment with pregabalin ( } 300-600 \mathrm{mg} / \mathrm{day}) \text {; in addition, duloxetine }(60-120 \mathrm{mg} / \text { day) was } \\
\text { administered to patients with major depressive disorder. A psychiatrist administered treatment and conducted followup with patients at baseline and } \\
\text { each month after baseline during the } 6 \text {-month study. Adherence to medication was NR, although withdrawals due to medication adverse effects } \\
\text { was reported. } \\
\text { C. Treatment as usual ( } n=46) \text { : standard care offered by general practitioners at subjects' health centres. The doctors received a guide for the } \\
\text { treatment of FM in primary care that recommended the same treatment as in B. }\end{array}$ \\
\hline Alfano 2001 & $\begin{array}{l}\text { A.Magnetic field with uniform polarity ( } \mathrm{n}=30 \text { ): A magnetic mattress composed of a grid of ceramic magnets with the dimensions } 2.5 \times 5.1 \times 1.0 \mathrm{~cm} \\
\text { produced a magnetic field of uniform south (negative) polarity ranging in a magnetic flux of } 0.6 \text { to } 0.3 \mathrm{mT} \text {. Subjects slept on the pad for } 6 \text { months } \\
\text { and it was placed between the subjects' mattress and box spring } \\
\text { B.Magnetic field with varied polarity ( } \mathrm{n}=26 \text { ): Disc shaped ceramic magnets, } 1.8 \mathrm{~cm} \text { in diameter and } 0.3 \mathrm{~cm} \text { thick, were spaced } 12.5 \mathrm{~cm} \text { apart on the } \\
\text { width and } 5 \mathrm{~cm} \text { apart on the length of a pad. Magnets were oriented so that the same pole faced the body and the magnetic flux of the field varied } \\
\text { with distance above the pad, ranging from } 0.03 \text { to } 0.28 \mathrm{mT} \text { above the pad. In the space between the magnetics, the field varied in polarity. Subjects } \\
\text { slept on the pad for } 6 \text { months and the pad was placed above the mattress. } \\
\text { C.Sham pad of magnetic field with uniform polarity ( } \mathrm{n}=24 \text { analyzed in the combined sham pad groups): Pad was identical in appearance to the pad } \\
\text { used in group A but magnets were demagnetized by heating to high temperatures. Subjects slept on the pad for } 6 \text { months and it was placed } \\
\text { between the subjects' mattress and box spring. } \\
\text { D.Sham pad of magnetic field with varied polarity ( } \mathrm{n}=24 \text { analyzed in the two combined sham pad groups): Pad was identical in appearance to the } \\
\text { pad used in group B but magnets were demagnetized by heating to high temperatures. Subjects slept on the pad for } 6 \text { months and it was placed } \\
\text { between the subjects' mattress and box spring } \\
\text { E.Usual care ( } n=14 \text { ): Subjects were instructed to maintain current FM treatment regimens that were reported at baseline } \\
\text { All subjects: Instructed to continue current FM treatment regimens but refrain from initiating additional therapies during the study*. }\end{array}$ \\
\hline
\end{tabular}




\begin{tabular}{|c|c|c|c|}
\hline Author, Year & Study Participants & Outcome Measures & $\begin{array}{c}\text { Duration of } \\
\text { Followup }\end{array}$ \\
\hline Alda 2011 & $\begin{array}{l}\text { A vs B vs C } \\
\text { Age: } 46 \text { vs } 47 \text { vs } 47 \\
\text { Females: } 95 \% \text { vs } 93 \% \text { vs } 96 \% \\
\text { Years since diagnosis: } 12.9(7.1) \text { vs } 11.2(3.9) \text { vs } 11.7(4.0) \\
\text { FlQ: } 65.9(10.9) \text { vs } 66.4(9.9) \text { vs } 64.5(10.5) \\
\text { Pain VAS: } 64.2(10.8) \text { vs } 68.1(9.8) \text { vs } 64.7(10.4) \\
\text { HAM-D: } 14.5(3.9) \text { vs } 14.9(4.0) \text { vs } 14.1(4.6) \\
\text { HARS: } 10.8(4.3) \text { vs } 11.2(3.8) \text { vs } 9.5(3.0) \\
\text { Comorbid major depressive disorder: } 47 \% \text { vs } 46 \% \text { vs } 55 \% \\
\text { Currently in litigation: } 30 \% \text { vs } 21 \% \text { vs } 29 \%\end{array}$ & $\begin{array}{l}\text { FIQ (0-100, higher scores= higher impairment) } \\
\text { Pain VAS (0-100, higher scores=greater pain) } \\
\text { Hamilton Rating Scale for Depression (HAM-D) (17-item } \\
\text { version, 0-50, higher scores=higher depression) } \\
\text { Hamilton Anxiety Rating Scale (HARS) (0-56, higher } \\
\text { scores=greater anxiety) }\end{array}$ & 6 months \\
\hline Alfano 2001 & \begin{tabular}{|l} 
A vs B vs C+D vs $E$ \\
Age: 44 vs 47 vs 46 vs 45 \\
Female: $92 \%$ vs $87 \%$ vs $96 \%$ vs $100 \%$ \\
FIQ: $51.6(13.2)$ vs $55.5(12.1)$ vs $51.5(14.1)$ vs $53.9(11.8)$ \\
FIQ score ranges: \\
$21-40: 24 \%$ vs $13 \%$ vs $22 \%$ vs $18 \%$ \\
$41-60: 43 \%$ vs $57 \%$ vs $56 \%$ vs $47 \%$ \\
$61-80: 32 \%$ vs $30 \%$ vs $22 \%$ vs $35 \%$ \\
Pain intensity NRS: $7.1(2.3)$ vs $7.0(2.4)$ vs $6.7(2.3)$ vs $7.0(2.3)$
\end{tabular} & $\begin{array}{l}\text { FIQ (0-80, higher score=higher impact); pain intensity } \\
\text { NRS (0-10, higher score=higher pain) }\end{array}$ & $\begin{array}{l}\text { Immediately } \\
\text { post } \\
\text { intervention } \\
\text { (treatment of } \\
6 \text { months) }\end{array}$ \\
\hline
\end{tabular}




\begin{tabular}{|c|c|}
\hline Author, Year & $\begin{array}{c}\text { Results - Subquestion a } \\
\text { (vs. sham, no treatment, waitlist, attention control) }\end{array}$ \\
\hline Alda 2011 & $\begin{array}{l}\text { A vs C } \\
6 \text { months, ITT analysis using LOCF method: } \\
\text { FIQ: } 48.8(9.1) \text { vs } 53.3(7.5), p<0.05 ; \text { MD }-4.5(95 \% \mathrm{Cl}-7.91 \text { to }-1.09), \mathrm{p}=0.01 \\
\text { Pain VAS: 40.7 (10.9) vs 44.3 (8.6), } \mathrm{p}>0.05 ; \mathrm{MD}-3.6(95 \% \mathrm{Cl}-7.617 \text { to } 0.417), \mathrm{p}=0.08 \\
\text { HAM-D: } 7.9(2.5) \text { vs } 8.6(2.5), \mathrm{p}<0.05 ; \mathrm{MD}-0.7(95 \% \mathrm{Cl}-1.719 \text { to } 0.319), \mathrm{p}=0.18 \\
\text { HARS: } 7.3(3.0) \text { vs } 7.6(2.1), \mathrm{p}<0.05 ; \mathrm{MD}-0.3(95 \% \mathrm{Cl}-1.361 \text { to } 0.761), \mathrm{p}=0.58\end{array}$ \\
\hline Alfano 2001 & 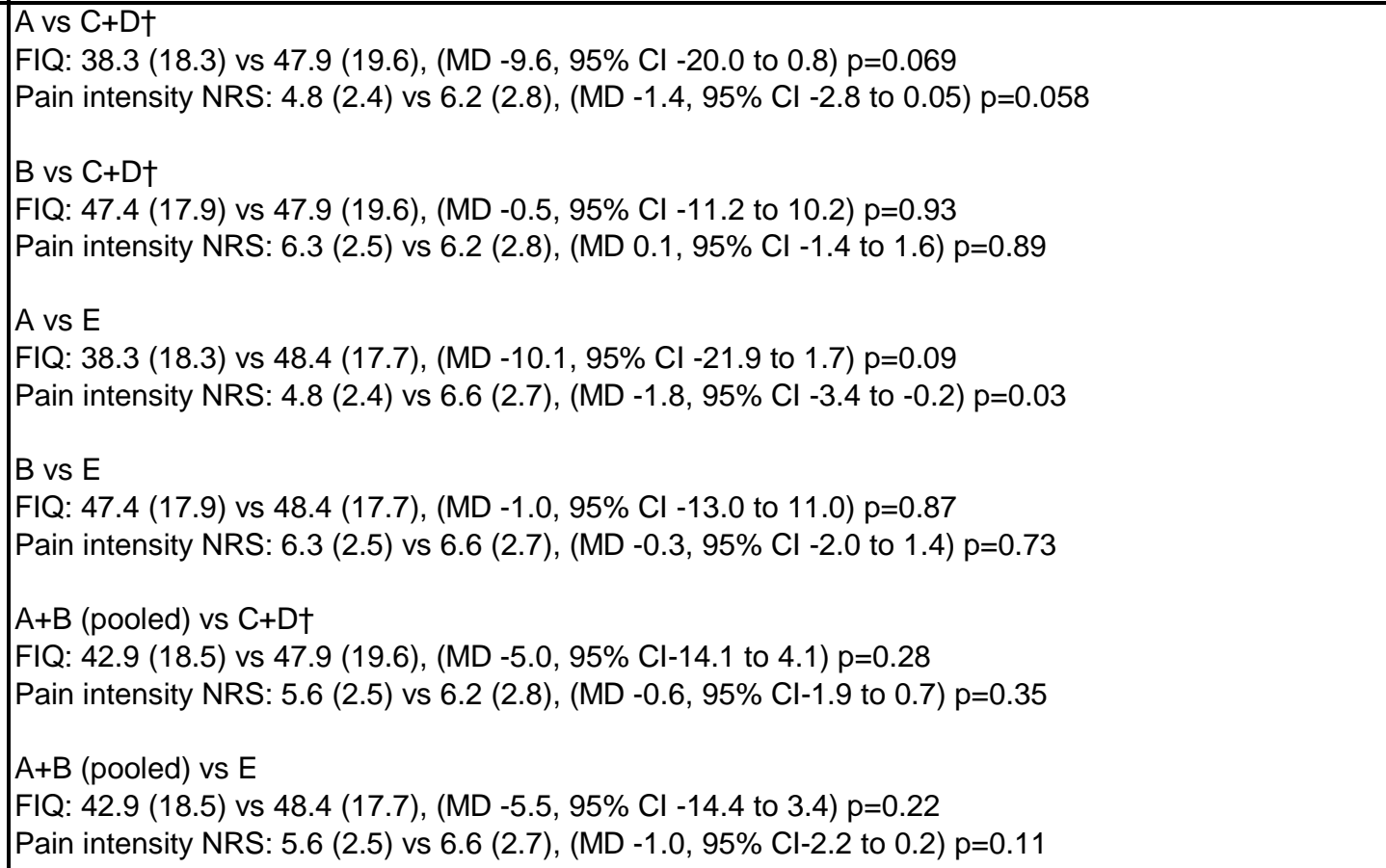 \\
\hline
\end{tabular}




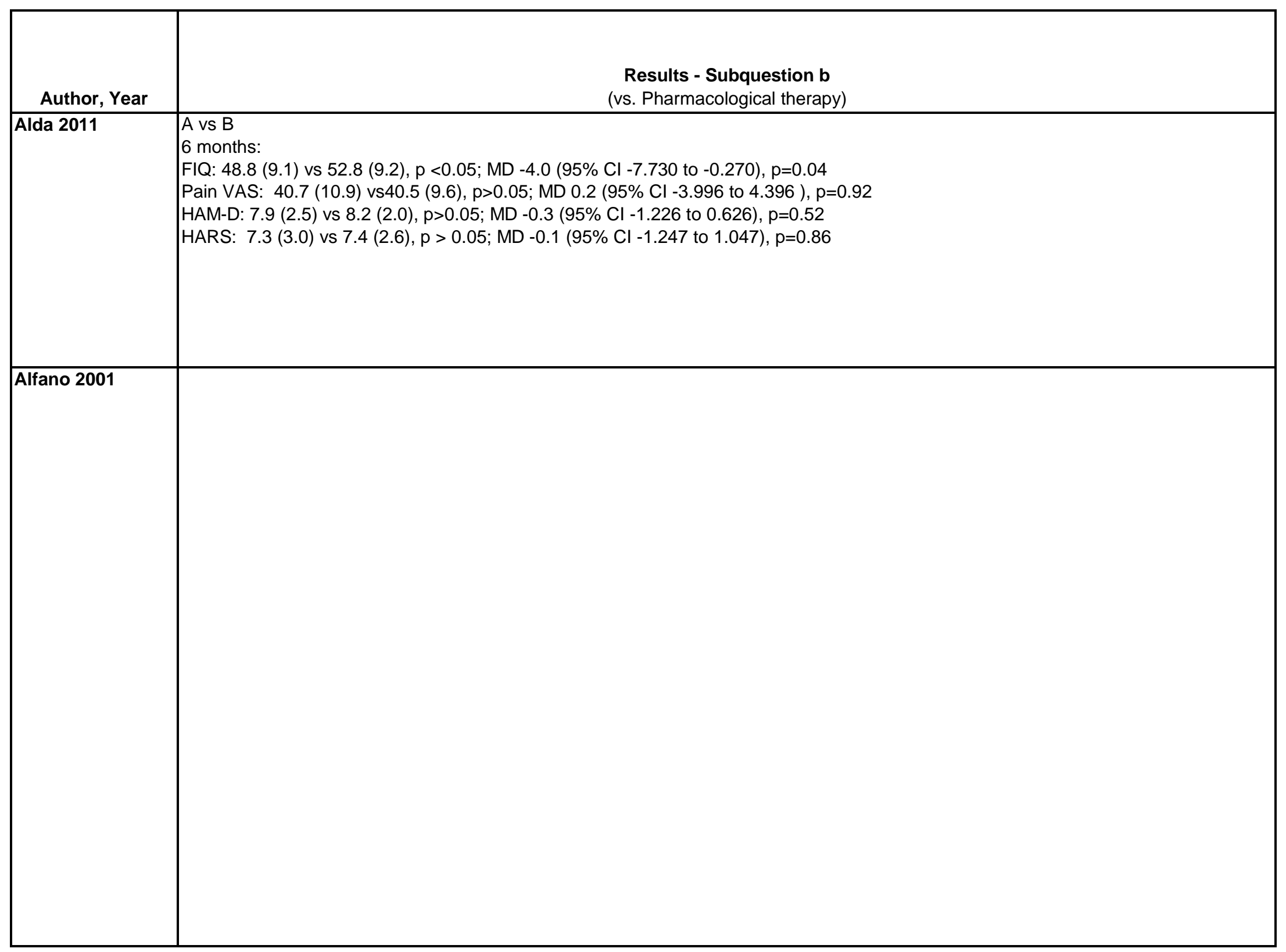




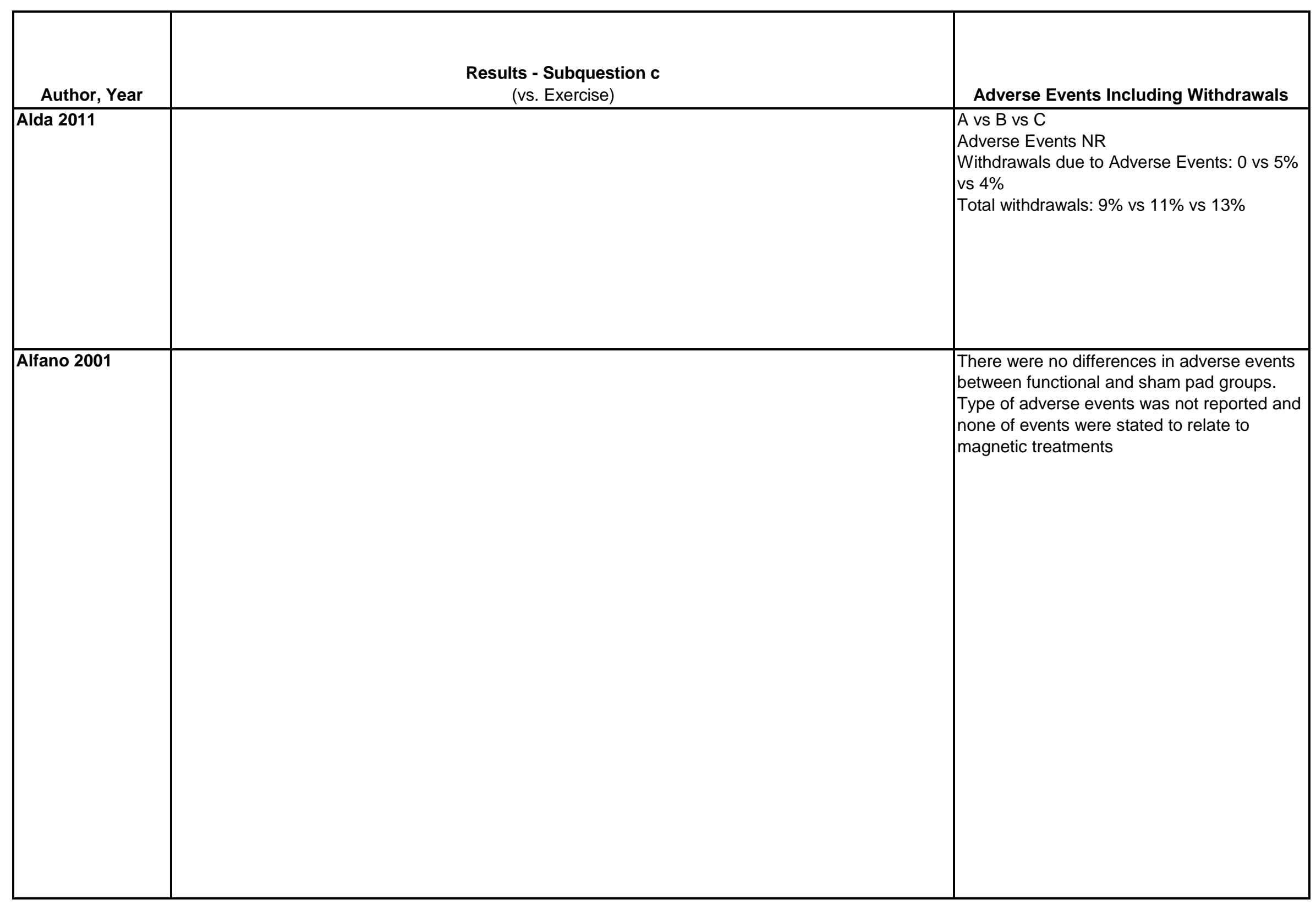




\begin{tabular}{|c|c|c|c|}
\hline Author, Year & Funding Source & Quality & Comments \\
\hline Alfano 2001 & $\begin{array}{l}\text { Grant (5 U24 DE 11924) from the } \\
\text { National Center for Complementary } \\
\text { and Alternative Medicine, funds from } \\
\text { the National Institutes of Health, and a } \\
\text { gift from a large private Canadian } \\
\text { charitable foundation }\end{array}$ & Fair (all) & $\begin{array}{l}\text { ×Primary care physicians of all subjects were asked to limit treatment of flareups to } \\
\text { modalities such as heat or cold when possible } \\
\text { tDemographics and results for the two sham pad groups were combined and reported } \\
\text { together } \\
\text { Report comparisons of pads separately and pooled (NOTE). Results were pooled given that } \\
\text { there were not statistically significant differences between the two groups. } \\
\text { MDs and } p \text { values calculated by AAl. N's used for calculations were as follows: } \\
\text { Pad A (A): } n=30 \\
\text { Pad B (B): } n=26 \\
\text { Sham (C+D): } n=24 \\
\text { Usual care }(E): n=14 \\
\text { Pooled A+B: } n=56\end{array}$ \\
\hline
\end{tabular}




\begin{tabular}{|c|c|c|c|}
\hline Author, Year & $\begin{array}{c}\text { Country } \\
\text { Number of Centers } \\
\text { Setting }\end{array}$ & Inclusion/Exclusion Criteria & $\begin{array}{c}\text { Number Randomized, } \\
\text { Analyzed } \\
\text { Attrition }\end{array}$ \\
\hline Altan 2005 & \begin{tabular}{|l|} 
Turkey \\
Setting NR
\end{tabular} & $\begin{array}{l}\text { Localized pain and taut bands in the neck for a } \geq 3 \text { months, bilateral } \\
\text { and significantly more tenderness in the } 3 \text { cervical trigger points } \\
\text { (upper trapezius, supraspinatus, and suboccipital muscles) compared } \\
\text { to the control point (a nontender point over deltoid muscle). } \\
\\
\text { Exclude: } \\
\text { Fibromyalgia diagnosis, cervical arthrosis, disc hernia, cervical } \\
\text { vertebral fracture, radiculopathy, or myelopathy, other major pathology }\end{array}$ & $\begin{array}{l}\text { Randomized: } 53 \\
\text { Treated: NR } \\
\text { Analyzed:: } 48 \\
\text { Attrition: } 12 \% \\
(6 / 51)\end{array}$ \\
\hline Altan 2009 & $\begin{array}{l}\text { Turkey } \\
1 \text { center } \\
\text { Outpatient }\end{array}$ & $\begin{array}{l}\text { Diagnosis of FM according to ACR criteria } \\
\text { Exclude: Accompanying rheumatoid disease, unstable hypertension, } \\
\text { severe cardiopulmonary problems, psychiatric disorder affecting } \\
\text { participant compliance }\end{array}$ & $\begin{array}{l}\text { Randomized: } 50 \\
\text { Treated: } 49 \\
\text { Analyzed: } 49 \\
\text { Attrition: } 2 \%(1 / 50)\end{array}$ \\
\hline Amris 2014 & \begin{tabular}{|l|} 
Denmark \\
1 Outpatient \\
rheumatology clinic
\end{tabular} & $\begin{array}{l}\text { Inclusion: age } 18+\text {, chronic widespread pain/fibromyalgia diagnosed } \\
\text { according to } 1990 \text { ACR criteria (i.e., reporting of pain axially and in a } \\
\text { minimum of } 3 \text { body quadrants), fluent in Danish } \\
\\
\text { Exclusions: psychiatric disorder, uncontrolled rheumatic or medical } \\
\text { disease capable of causing chronic widespread pain }\end{array}$ & \begin{tabular}{|l|} 
Randomized: 191 \\
Analyzed: 170 \\
Attrition: $12 \%(21 / 170)$
\end{tabular} \\
\hline
\end{tabular}




\begin{tabular}{|c|c|}
\hline Author, Year & Intervention, Comparator \\
\hline Altan 2005 & $\begin{array}{l}\text { A.GaAs laser treatment }(n=26 / 23) \text { over the } 3 \text { trigger points bilaterally and } 1 \text { point in the taut bands in trapezius muscle bilaterally for } 2 \text { min over } \\
\text { each point once a day for } 2 \text { weeks. Laser parameters: wavelength of } 904 \mathrm{~nm} \text {, frequency range of } 5-7000 \mathrm{~Hz} \text {, and } \\
\text { maximum power of } 27 \mathrm{~W}, 50 \mathrm{~W} \text {, or } 27 \times 4 \mathrm{~W} \\
\text { B. Sham laser treatment }(n=27 / 25) \text { using the same instrument in the same way over the same points as in group } 1 \text { but not turning it on. } \\
\text { All laser applications were performed by the same physiotherapist. All patients in both groups were instructed to perform daily isometric exercises } \\
\text { and stretching just short of pain for } 2 \text { weeks at home No analgesic during the treatment and control periods. }\end{array}$ \\
\hline Altan 2009 & $\begin{array}{l}\text { A.Pilates }(n=25) \text { : } 1 \text { hour Pilates program administered } 3 \text { times per week for } 12 \text { weeks. Program followed basic principles of Pilates method } \\
\text { consisting of postural education, search for neutral position, sitting exercise, antalgic exercises, stretching exercises, proprioceptivity improvement } \\
\text { exercises, and breathing education } \\
\text { B.Attention control }(n=24) \text { : Instruction in home exercise relaxation/stretching program of } 1 \text { hour sessions } 3 \text { times per week for } 12 \text { weeks. Exercise } \\
\text { program consisted of relaxation techniques, dynamic and active stretching, and passive stretching } \\
\text { All patients: Education session about available diagnosis and treatment of FM }\end{array}$ \\
\hline Amris 2014 & $\begin{array}{l}\text { A.Multidisciplinary treatment }(n=84): \text {-week program conducted by multidisciplinary team of rheumatologist, psychologist, nurse, and occupational } \\
\text { and physical therapists. Scheduled program each day, with daily time schedule between } 3 \text { and } 5 \text { hours; in total, } 35 \text { hours. Treatment aimed to } \\
\text { improve functional ability and pain coping. Program included education, sleep hygiene, group discussions, physical therapy including graded activity } \\
\text { and activity pacing, adaptations and modifications to increase participation in activities of daily living. } 53 \% \text { of subjects missed no sessions, and } \\
88 \% \text { attended } 5 \text { or more days. } \\
\text { B.Waiting list control group }(n=86) \text { : No treatment during first phase of study ( } 6 \text { months), then offered } A \text { at the end of the waiting list plus an } \\
\text { additional } 16 \text {-week course of either individualized physiotherapy or occupational therapy in the second study phase }\end{array}$ \\
\hline
\end{tabular}




\begin{tabular}{|c|c|c|c|}
\hline Author, Year & Study Participants & Outcome Measures & $\begin{array}{c}\text { Duration of } \\
\text { Followup }\end{array}$ \\
\hline Altan 2005 & \begin{tabular}{|l} 
A vs $B$ \\
Age: 43 vs 43 years \\
Female: $87 \%$ vs $48 \%$ \\
Pain duration: 4.7 vs 4.4 years \\
Pain $(0-10): 6.85(0.35)$ vs $6.24(0.32)$ \\
Pain (5-point scale): $2.35(0.16)$ vs $2.20(0.14)$ \\
Tenderness $(0-18$ points): $6.78(0.57)$ vs $6.68(0.71)$
\end{tabular} & $\begin{array}{l}\text { Pain severity (VAS 0-10, higher score worse pain) } \\
\text { Pain severity (VAS 0-5, } 0=\text { no pain, } 1=\text { mild, } \\
2=\text { moderate, } 3=\text { severe, or } 4=\text { =unbearable) }\end{array}$ & 3 months \\
\hline Altan 2009 & $\begin{array}{l}\text { A vs } B \\
\text { Age: } 48 \text { vs } 50 \\
\text { Female: } 100 \% \text { vs } 100 \% \\
\text { FIQ: } 80.8(17.2) \text { vs } 80.1(18.7) \\
\text { Pain VAS: } 6.1(1.7) \text { vs } 6.3(1.8) \\
\text { NHP: } 297.1(124.2) \text { vs } 280.3(86.6)\end{array}$ & $\begin{array}{l}\text { FIQ (0-100, higher score=higher disability); pain VAS (0- } \\
\text { 10, higher score=higher pain); Nottingham Health Profile } \\
\text { (NHP) (range NR) }\end{array}$ & 3 months \\
\hline Amris 2014 & \begin{tabular}{|l|} 
A vs B \\
Age: 44 vs 44 \\
Female: $100 \%$ vs $100 \%$ \\
Pain duration, years, median: 11 vs 10 \\
Years since FM diagnosis, median: 1 vs 1 \\
Fibromyalgia Impact Questionnaire: 64.0 (15.8) vs $65.7(13.0)$ \\
FlQ Pain VAS: 7.1 (2.0) vs $7.4(1.7)$ \\
Generalized Anxiety Disorder-10, Median (quartiles): $17.5(13-26)$ vs \\
17.0 (13-23) \\
Major Depression Inventory, Median (quartiles): $18.0(13-27)$ vs 21.0 \\
(15-27) \\
SF-36 Physical Composite Score: $27.1(6.9)$ vs $27.2(7.0)$ \\
SF-36 Mental Composite Score: $39.4(12.2)$ vs $37.8(9.8)$ \\
SF-36 Physical Functioning scale, Median (quartiles):: $40.0(25-55)$ vs \\
40.0 (25-50)
\end{tabular} & $\begin{array}{l}\text { Fibromyalgia Impact Questionnaire, (0-100, higher } \\
\text { scores = greater impact of FM) } \\
\text { FIQ-Pain VAS (0-10, higher scores=greater pain) } \\
\text { Generalized Anxiety Disorder-10 (scale NR, higher } \\
\text { scores=greater anxiety) } \\
\text { Major Depression Inventory (scale NR, higher scores = } \\
\text { greater depression) } \\
\text { SF-36 Physical Composite Score (scale NR, higher } \\
\text { scores = better function) } \\
\text { SF-36 PCS Responder: } \geq 4 \text { point improvement } \\
\text { SF-36 Mental Composite Score (scale NR, higher } \\
\text { scores = better function) } \\
\text { SF-36 MCS Responder: } \geq 6 \text { point improvement } \\
\text { SF-36 Physical Functioning scale (scale NR, higher } \\
\text { scores = better function) }\end{array}$ & 5.5 months \\
\hline
\end{tabular}




\begin{tabular}{|c|c|}
\hline Author, Year & $\begin{array}{c}\text { Results - Subquestion a } \\
\text { (vs. sham, no treatment, waitlist, attention control) }\end{array}$ \\
\hline Altan 2005 & $\begin{array}{l}\text { A vs B } \\
\text { 3 months: } \\
\text { Pain }(0-10): 3.17(0.58) \text { vs } 3.80(0.51), M D-0.63(95 \% \mathrm{Cl}-0.95 \text { to }-0.31) \mathrm{p}=0.0002 \\
\text { Pain }(0-5): 1.09(0.22) \text { vs } 1.16(0.20), \mathrm{MD}-0.07(95 \% \mathrm{Cl}-0.19 \text { to } .05), p=0.254\end{array}$ \\
\hline Altan 2009 & $\begin{array}{l}\text { A vs B } \\
\text { 3 months } \\
\text { FlQ: } 69.3(24.7) \text { vs } 77.6(22.2),(\mathrm{MD}-8.3,95 \% \mathrm{Cl}-21.8 \text { to } 5.2) \mathrm{p}=0.222 \\
\text { Pain VAS: } 5.2(2.5) \text { vs } 6.5(2.1),(\mathrm{MD}-1.3,95 \% \mathrm{Cl}-2.6 \text { to } 0.03) \mathrm{p}=0.055 \\
\text { NHP: } 224.2(129.1) \text { vs } 246.3(128.1),(\mathrm{MD}-22.1,95 \% \mathrm{Cl}-96.0 \text { to } 51.8), \mathrm{p}=0.551\end{array}$ \\
\hline Amris 2014 & 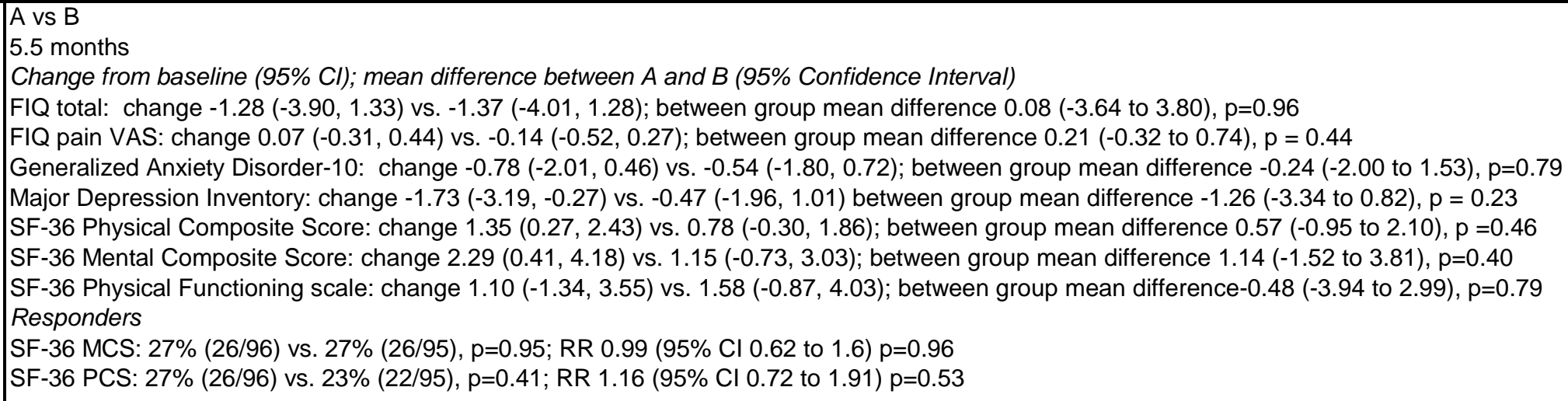 \\
\hline
\end{tabular}




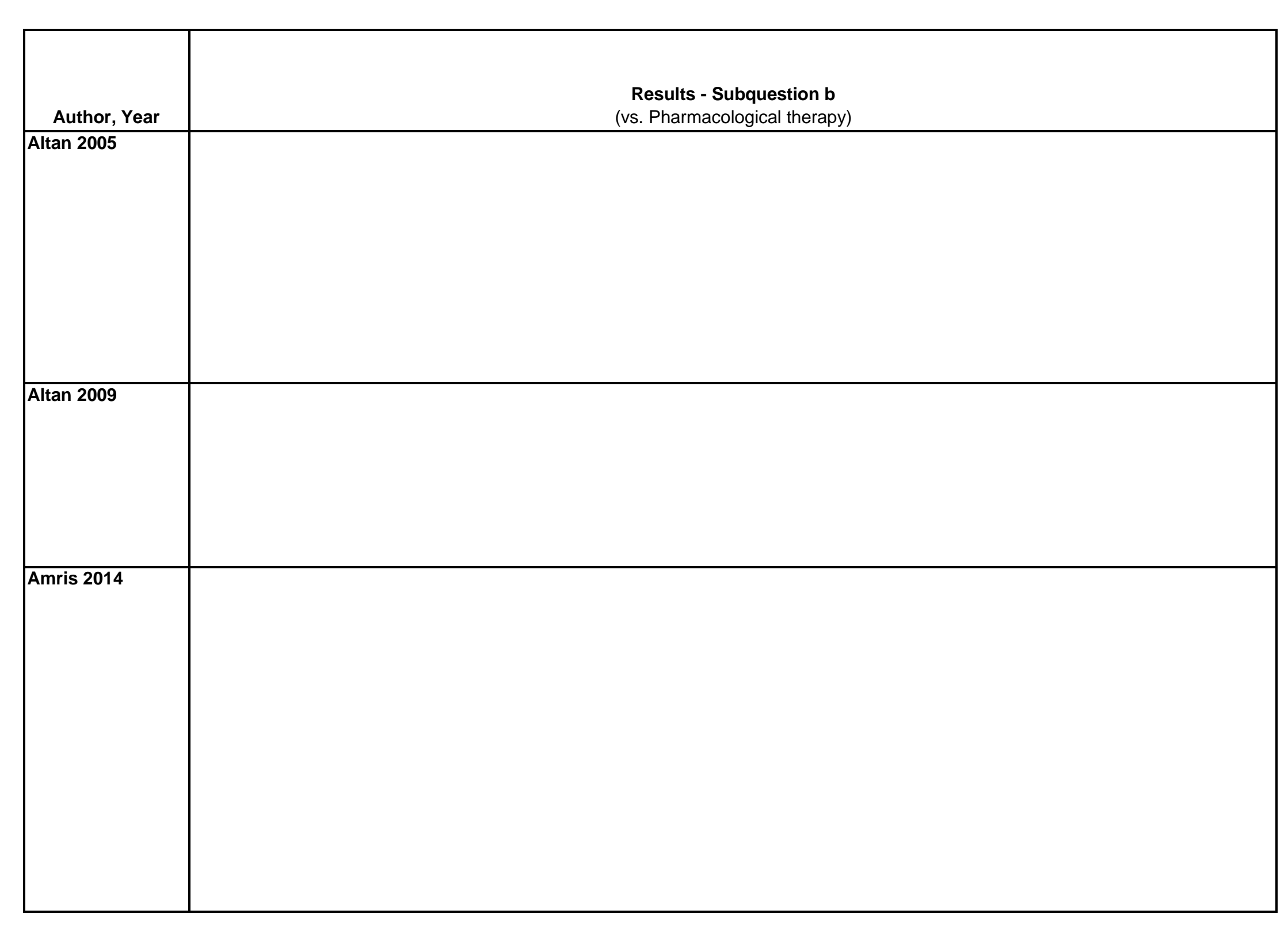




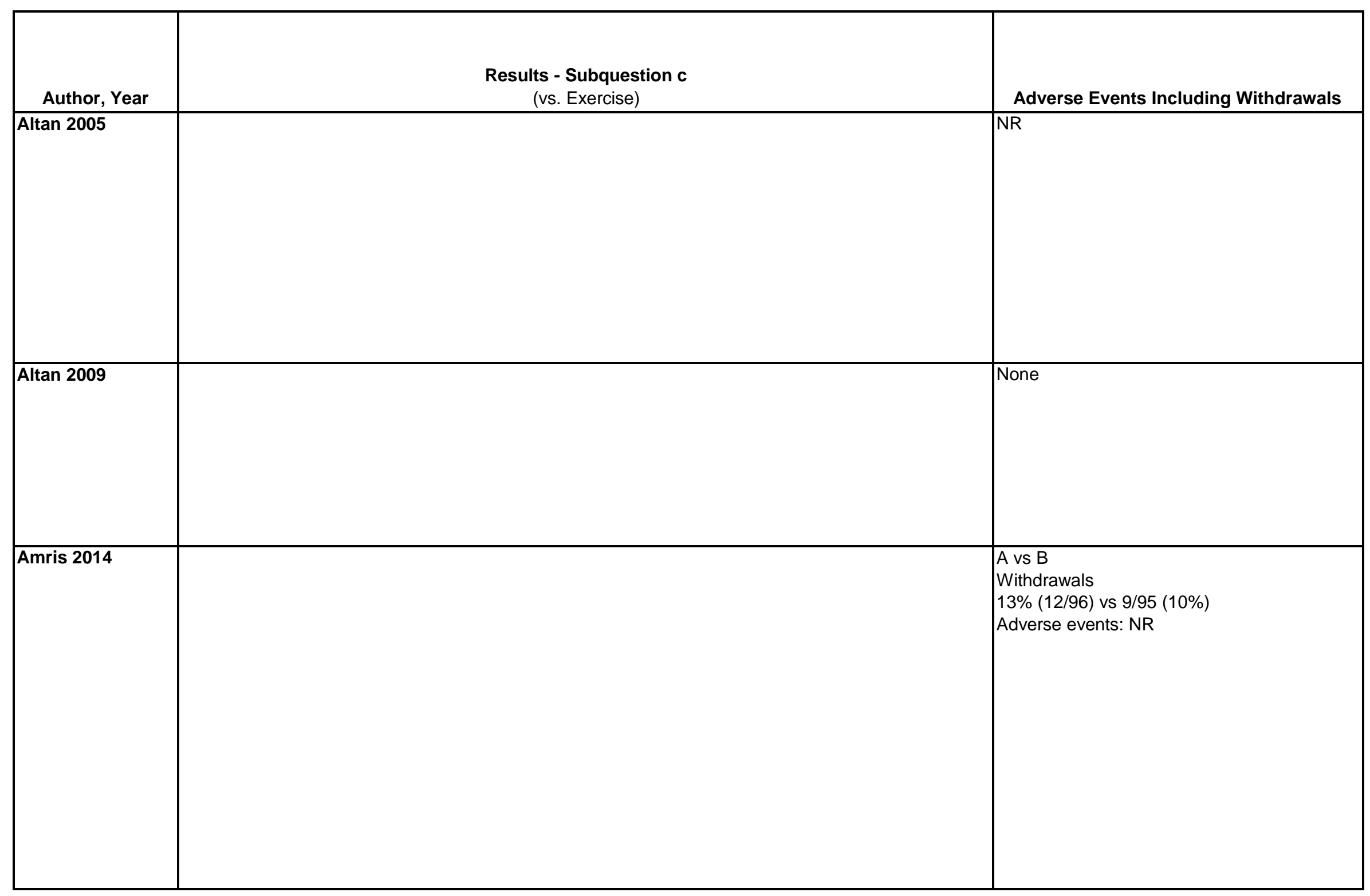




\begin{tabular}{|c|c|c|c|}
\hline Author, Year & Funding Source & Quality & Comments \\
\hline Altan 2009 & NR & Fair & $\begin{array}{l}\text { Outcomes not reported: number of tender points, algometric score, and chair stand test } \\
\text { MDs and } p \text { values calculated by AAl using } n=25 \text { for Pilates group and } n=24 \text { for the control } \\
\text { group } \\
\text { NHP had differences between groups at baseline, potentially significant enough for further } \\
\text { analysis }\end{array}$ \\
\hline Amris 2014 & \begin{tabular}{|l|} 
The Oak Foundation \\
Schioldanns Fond \\
Danish Rheumatism Association
\end{tabular} & Fair & \\
\hline
\end{tabular}




\begin{tabular}{|c|c|c|c|}
\hline Author, Year & $\begin{array}{c}\text { Country } \\
\text { Number of Centers } \\
\text { Setting }\end{array}$ & Inclusion/Exclusion Criteria & $\begin{array}{c}\text { Number Randomized, } \\
\text { Analyzed } \\
\text { Attrition }\end{array}$ \\
\hline Andersen 2008 & \begin{tabular}{|l} 
Denmark \\
12 different located \\
units of Danish public \\
administration \\
authority
\end{tabular} & $\begin{array}{l}\text { Office workers (some with and some without neck pain - we only } \\
\text { include those with neck pain) } \\
\text { Exclude: health risks (hypertension, disc prolapse, severe spinal } \\
\text { disorders, history of trauma, pregnancy), too few volunteers in a } \\
\text { specific unit }\end{array}$ & $\begin{array}{l}\text { Randomized: NR* } \\
\text { Treated: } 182 \\
\text { Analyzed: NR } \\
\text { Attrition: NR } \\
\\
\star \text { `Total patients randomized } \\
\text { ( } \mathrm{n}=549 \text { ) included patients } \\
\text { with and without neck pain. } \\
\text { Randomization of clusters } \\
\text { formed from workers on } \\
\text { the same work floor. }\end{array}$ \\
\hline Ang 2010 & \begin{tabular}{|l} 
USA \\
Subjects were \\
referred from \\
community \\
rheumatology offices
\end{tabular} & $\begin{array}{l}\text { Inclusion: FM diagnosis based on ACR } 1990 \text { criteria, FIQ pain score } \\
\text { >3, FIQ physical impairment score } \geq 2 \text {, taking stable doses of pain- } \\
\text { related medications for at least } 4 \text { weeks, female. } \\
\text { Exclusions: peripheral neuropathy, diabetes, demyelinating disorders, } \\
\text { inflammatory rheumatic diseases }\end{array}$ & $\begin{array}{l}\text { Randomized: } 32 \\
\text { Analyzed: } 28 \\
\text { Attrition: } 14 \%(4 / 28)\end{array}$ \\
\hline
\end{tabular}




\begin{tabular}{|c|c|}
\hline Author, Year & Intervention, Comparator \\
\hline Andersen 2008 & $\begin{array}{l}\text { A.Specific resistance training }(n=61) \text { : dynamic strengthening exercises for shoulder girdle and static exercises for neck muscles with progressive } \\
\text { resistance } \\
\text { B.All-round physical exercise }(n=59) \text { : increase activity as part of lifestyle such as riding bike to work; workplace activity such as steppers near copy } \\
\text { machine, punch bags in hall, group session of Nordic walking and programs for strength and aerobic fitness } \\
\text { C. Reference intervention ( } n=62) \text { : form groups to improve health and working conditions through workplace ergonomics, stress management, } \\
\text { organization of work, cafeteria food quality } \\
\text { Intervention for } 1 \text { year; all groups were allowed } 1 \text { hour per week during working time for activities, and each group received equal amount of } \\
\text { attention }\end{array}$ \\
\hline Ang 2010 & $\begin{array}{l}\text { A.CBT }(n=15) \text { : Usual care plus } 6 \text { weekly } 30-40 \text { minute sessions of CBT delivered by telephone by a psychology graduate student. The therapist } \\
\text { followed a manualized treatment protocol and subjects received a companion workbook. Components of CBT included activity pacing, pleasant } \\
\text { activity scheduling, relaxation, automatic thoughts and pain, cognitive restructuring, and stress management. } \\
\text { B.Usual care }(n=13) \text { : customary care from subject's treating physician } \\
\text { All subjects were asked to stay on the same pain-related medication regimen, including dosing, throughout the study period. }\end{array}$ \\
\hline
\end{tabular}




\begin{tabular}{|c|c|c|c|}
\hline Author, Year & Study Participants & Outcome Measures & $\begin{array}{l}\text { Duration of } \\
\text { Followup }\end{array}$ \\
\hline Andersen 2008 & $\begin{array}{l}\text { A }+B+C \\
\text { Age: } 45 \text { years } \\
\text { Female: } 78 \% \\
\text { Baseline information given for the groups combined } \\
\text { A vs B vs C } \\
\text { Pain intensity: } 5.0(0.2) \text { vs } 5.0(0.2) \text { vs } 4.7(0.2) \\
\text { A and B baseline pain intensity given in text, C baseline pain intensity } \\
\text { estimated from Figure } 4 A \\
\text { Duration of pain (number of days in last } 3 \text { months): } 45(2.9) \text { vs } 47(2.9) \\
\text { vs } 43(2.8)\end{array}$ & $\begin{array}{l}\text { Neck pain intensity during last } 3 \text { months (scale } 0-9 \text {, } \\
\text { higher score=worse pain) } \\
\text { Days of pain (number of days having neck trouble in } \\
\text { last } 3 \text { months), }\end{array}$ & $\begin{array}{l}6 \text { and } 12 \\
\text { months }\end{array}$ \\
\hline Ang 2010 & $\begin{array}{l}\text { A vs B } \\
\text { Age, years: } 51 \text { vs } 47 \\
\text { Female: } 100 \% \text { vs } 100 \% \\
\text { White: } 81 \% \text { vs } 80 \% \\
\text { Duration of FM, years: } 11.8(4.6) \text { vs } 12.3(7.9) \\
\text { FIQ total: } 62.2(15) \text { vs } 67.8(12) \\
\text { FIQ PI: } 5.6(1.8) \text { vs } 5.4(1.7) \\
\text { FIQ Pain: } 7.6(1.8) \text { vs } 7.8(1.4) \\
\text { PHQ-8: } 10(5.4) \text { vs } 13(4.5) \\
\text { Taking opioids: } 52 \% \text { vs } 40 \%\end{array}$ & $\begin{array}{l}\text { FIQ total (0-100, higher scores= higher impact of FM; } \\
\text { MCID 14\%) } \\
\text { FIQ PI (0-10, higher score=higher impact of FM) } \\
\text { FIQ Pain (Pain VAS): (0-10, higher score=higher pain) } \\
\text { PHQ-8 (0-24, higher scores=greater depression) }\end{array}$ & 1.5 months \\
\hline
\end{tabular}




\begin{tabular}{|c|c|}
\hline Author, Year & $\begin{array}{l}\text { Results - Subquestion a } \\
\text { (vs. sham, no treatment, waitlist, attention control) }\end{array}$ \\
\hline Andersen 2008 & 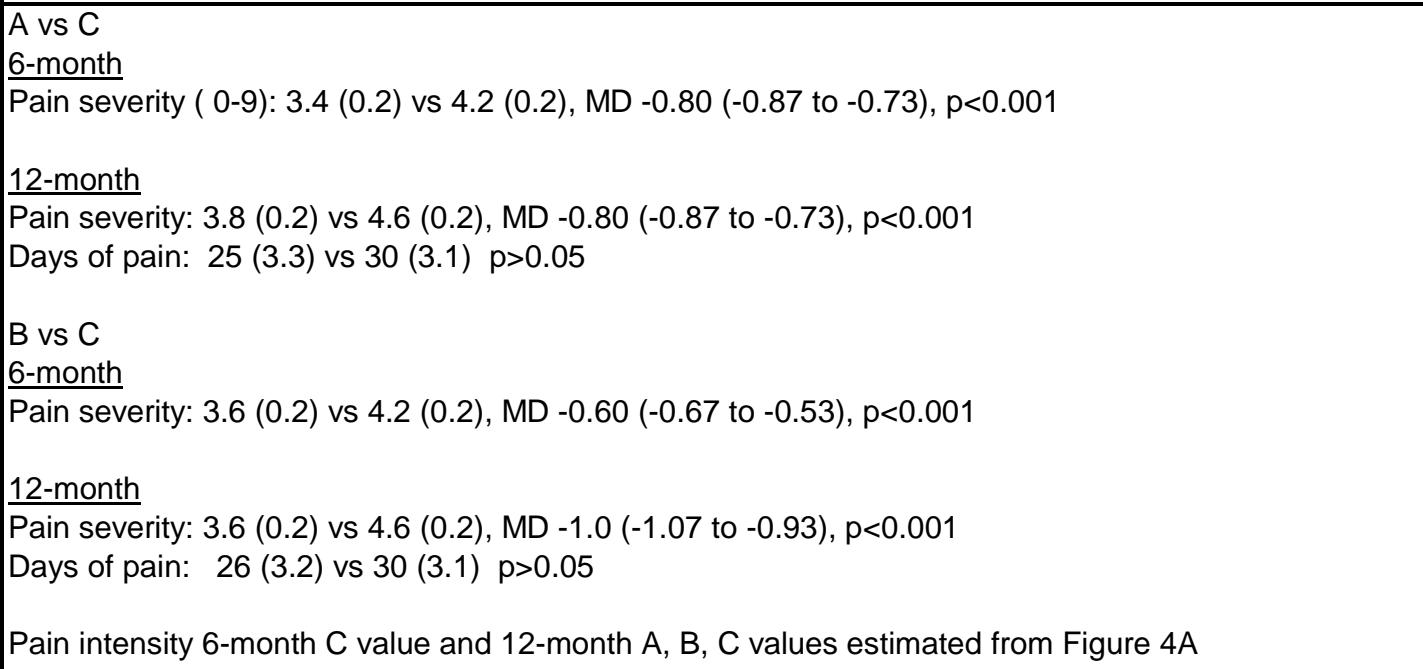 \\
\hline Ang 2010 & $\begin{array}{l}\text { A vs B } \\
1.5 \text { months, } \\
\text { proportion of patients with clinically meaningful improvement from baseline: } \\
\text { FIQ total: } 33 \%\left(5^{\star} / 15\right) \text { vs. } 15 \%,\left(2^{\star} / 13\right), p=0.3 ; \mathrm{RR} 2.2(95 \% \mathrm{Cl} 0.5,9.3) \\
{ }^{*} \mathrm{n} \text { 's back-calculated based on } \% \text { given and group } \mathrm{N} \\
\text { mean change from baseline: } \\
\text { FIQ PI: }-0.6(2.3) \text { vs. } 0.5(1.2) \text {, adjusted } \mathrm{p}=0.13 \text {; overall effect size }=0.5 \text { (moderate) } \\
\text { FIQ Pain: }-0.6(1.6) \text { vs. }-0.3(1.7) \text {, adjusted } \mathrm{p}=0.6 \text {; overall effect size }=0.2 \text { (small) } \\
\text { PHQ-8: }-0.9(5.2) \text { vs. } 0.0(4.1), \text { adjusted } \mathrm{p}=0.8 ; \text { overall effect size }=0.6\end{array}$ \\
\hline
\end{tabular}




$$
7=
$$




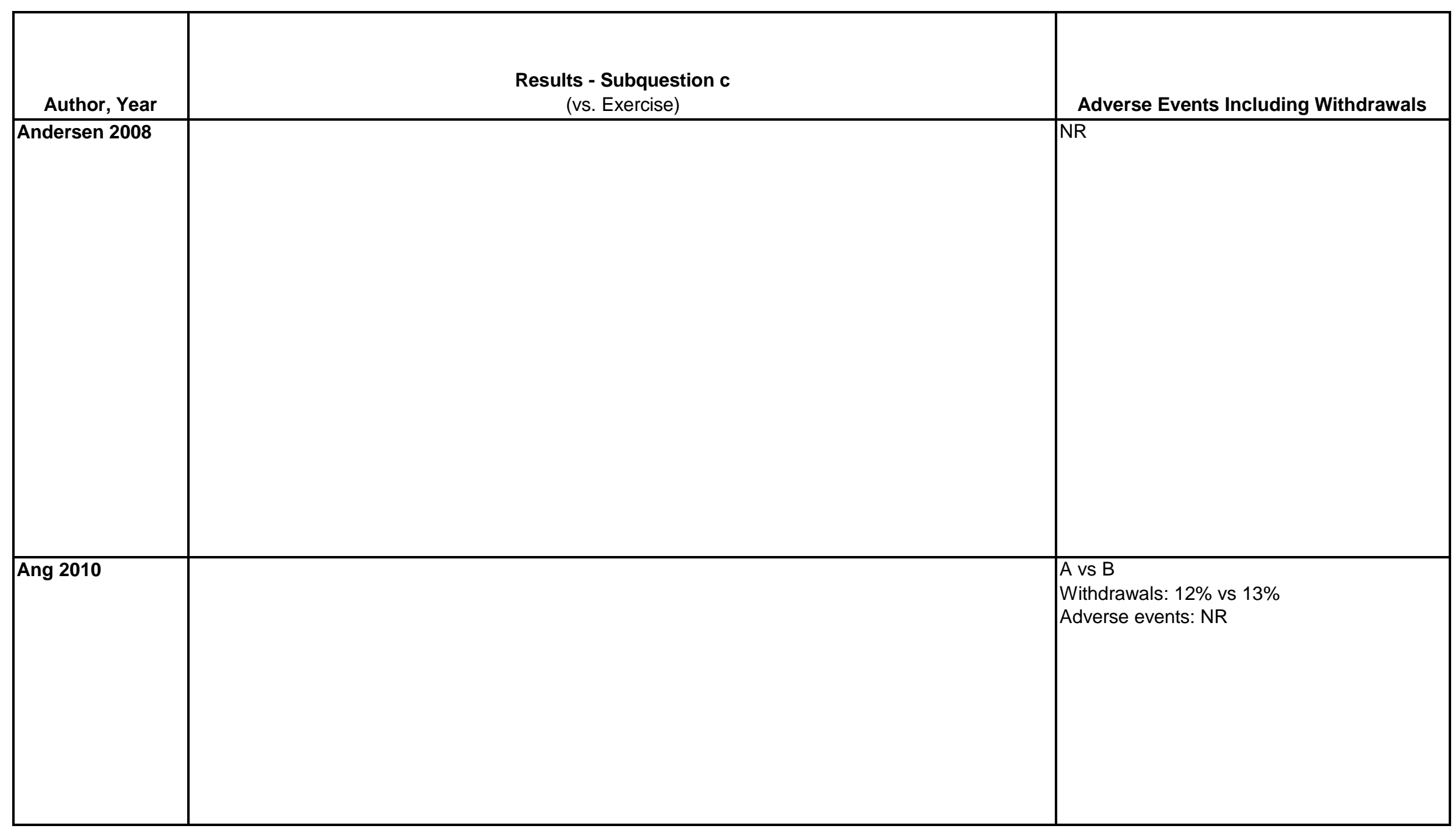




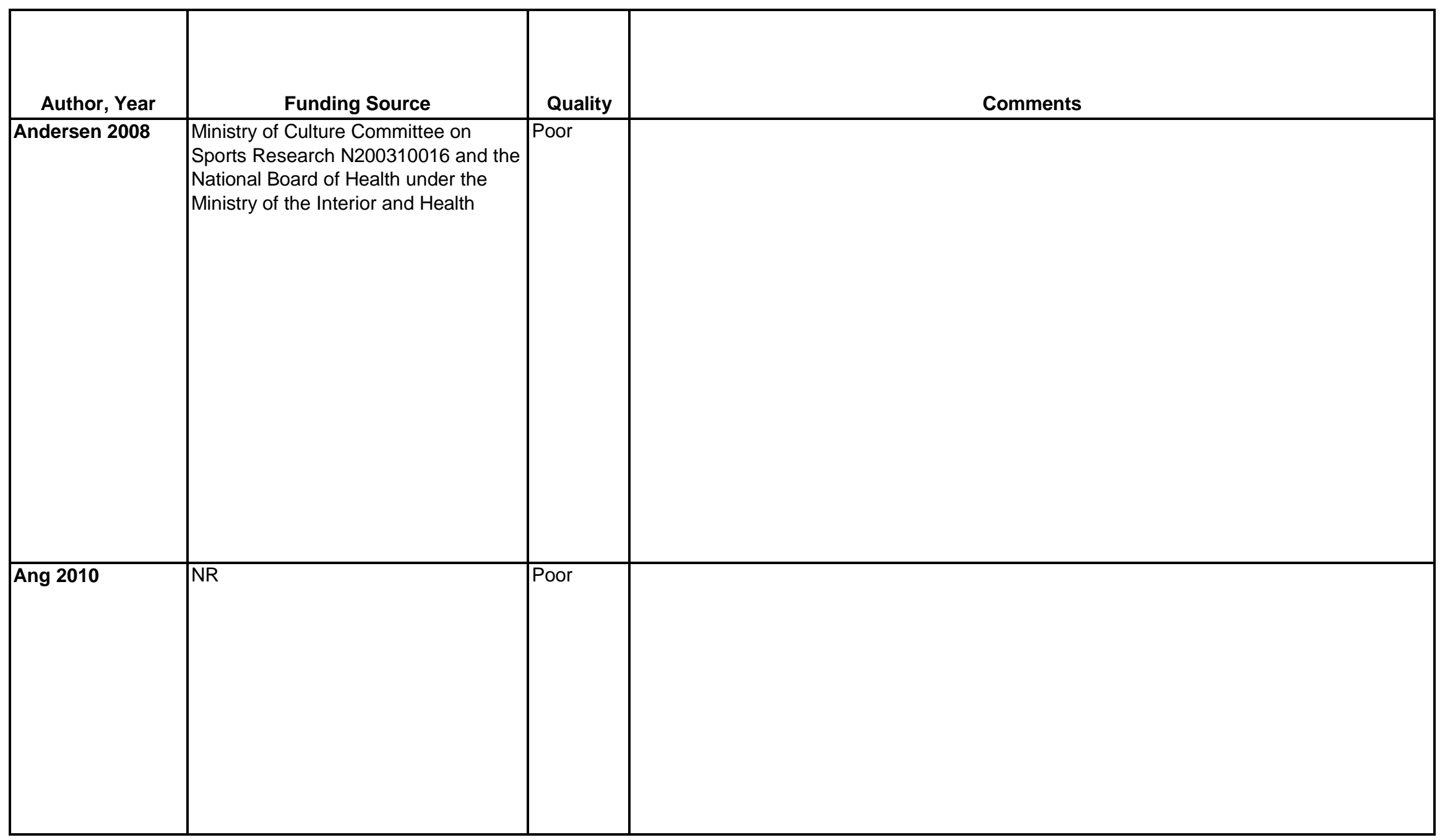

D-35 


\begin{tabular}{|c|c|c|c|}
\hline Author, Year & $\begin{array}{c}\text { Country } \\
\text { Number of Centers } \\
\text { Setting }\end{array}$ & Inclusion/Exclusion Criteria & $\begin{array}{c}\text { Number Randomized, } \\
\text { Analyzed } \\
\text { Attrition }\end{array}$ \\
\hline Aslan Telci 2012 & $\begin{array}{l}\text { Turkey } \\
\text { Setting NR }\end{array}$ & $\begin{array}{l}\text { Cervical arthritis with pain for at least } 6 \text { months } \\
\text { Exclude: } \\
\text { Pain or numbness radiating to the arms; impingement; thoracic outlet } \\
\text { syndrome; prior cervical surgery; conservative treatment within the } \\
\text { last } 6 \text { months; proven specific pathology such as a malignancy, } \\
\text { fracture or systemic rheumatoid disorder; impingement; thoracic outlet } \\
\text { syndrome }\end{array}$ & $\begin{array}{l}\text { Randomized: } 60 \\
\text { Treated: NR } \\
\text { Analyzed: NR } \\
\text { Attrition: NR }\end{array}$ \\
\hline
\end{tabular}




\begin{tabular}{|c|c|}
\hline Author, Year & Intervention, Comparator \\
\hline Aslan Telci 2012 & $\begin{array}{l}\text { A. Home exercises }(n=20) \text { consisting of active range of motion, stretching, isometric and dynamic strengthening and endurance exercises, } \\
\text { relaxation with breathing exercises, and proprioception. They attended clinic followup once a week for a total of } 3 \text { weeks and were asked to } \\
\text { continue their exercise program for at least another month ( } 1.5 \text { months in total). } \\
\text { B. Nonsteroidal anti-inflammatory drugs and muscle relaxants for } 15 \text { days }(n=20) \text {. All } \\
\text { patients received verbal advice regarding pain control, posture, and ergonomics. }\end{array}$ \\
\hline
\end{tabular}




\begin{tabular}{|c|c|c|c|}
\hline Author, Year & Study Participants & Outcome Measures & $\begin{array}{c}\text { Duration of } \\
\text { Followup }\end{array}$ \\
\hline Aslan Telci 2012 & $\begin{array}{l}\text { A vs B vs C } \\
\text { Age: } 48 \text { vs } 52 \text { years } \\
\text { Female: } 85 \% \text { vs } 75 \% \\
\text { Pain: } 6.67(1.87) \text { vs } 6.41(2.20) \\
\text { NDI: } 14.00(6.22) \text { vs } 10.70(5.87) \\
\text { Nottingham: } 179.7(116.4) \text { vs } 248.4(121.5) \\
\text { Beck: } 10.45(6.86) \text { vs } 10.35(7.31) \\
\text { Pain duration: } 12 \text { vs } 12 \text { months } \\
\text { BMl: } 25 \text { vs } 27 \\
\text { Employed: } 50 \% \text { vs } 40 \% \\
\text { Education year: } 12 \text { vs } 11\end{array}$ & $\begin{array}{l}\text { Pain severity (VAS scale 0-10, higher score worse pain) } \\
\text { NDI: (VAS scale 0-50, higher score greater disability) } \\
\text { Nottingham Health Profile (scale 0-100, lower score } \\
\text { greater disability) } \\
\text { Beck Depression Inventory (scale 0-63, higher score, } \\
\text { more severe the depression) }\end{array}$ & $\begin{array}{l}3 \text { and } 6 \\
\text { months }\end{array}$ \\
\hline
\end{tabular}




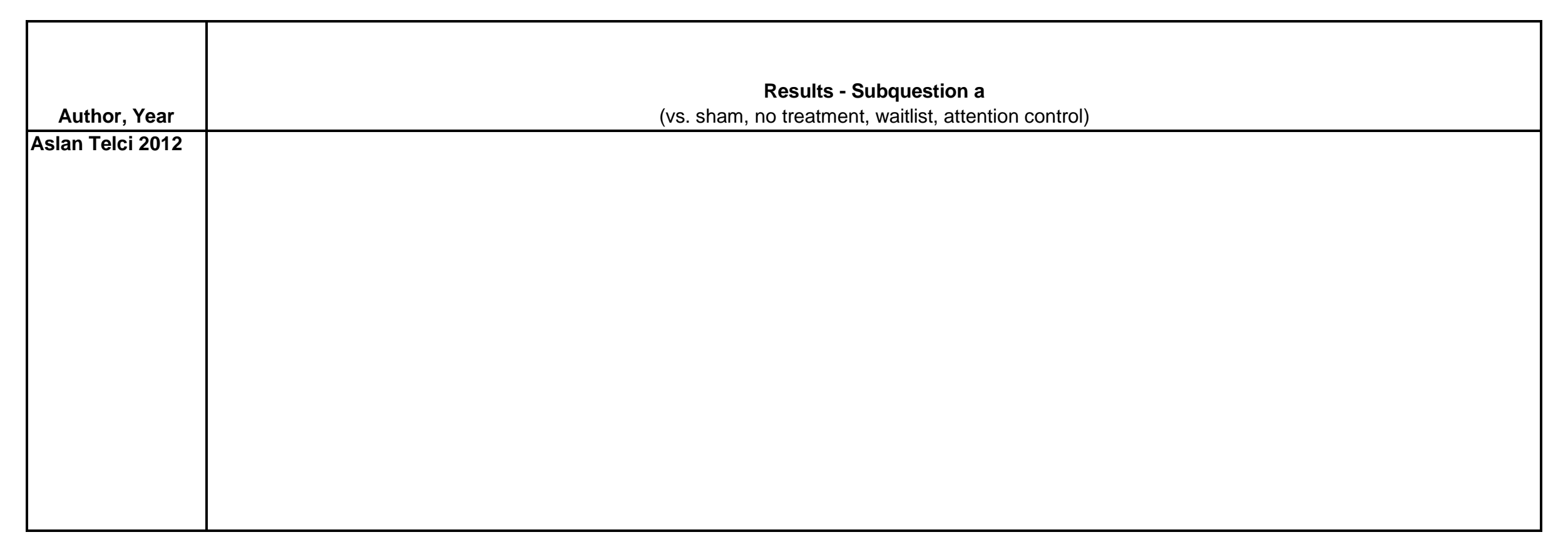




\begin{tabular}{|c|c|}
\hline Author, Year & $\begin{array}{l}\text { Results - Subquestion b } \\
\text { (vs. Pharmacological therapy) }\end{array}$ \\
\hline Aslan Telci 2012 & 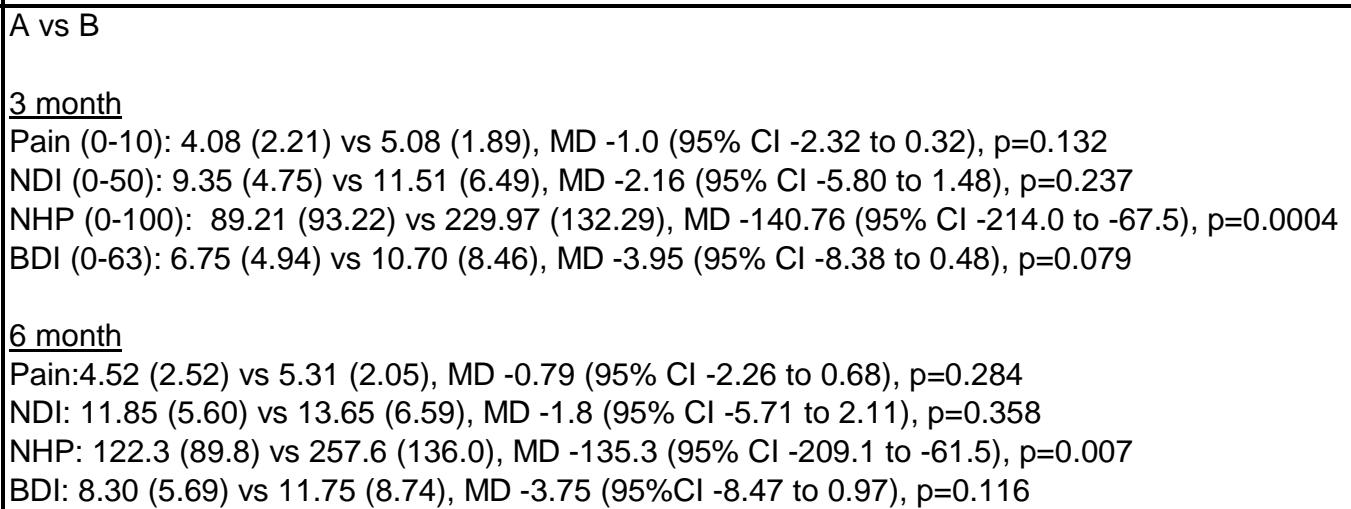 \\
\hline
\end{tabular}




\begin{tabular}{|c|c|c|}
\hline Author, Year & $\begin{array}{l}\text { Results - Subquestion c } \\
\text { (vs. Exercise) }\end{array}$ & Adverse Events Including Withdrawals \\
\hline Aslan Telci 2012 & & NR \\
\hline & & \\
\hline & & \\
\hline & & \\
\hline & & \\
\hline & & \\
\hline & & \\
\hline
\end{tabular}




\begin{tabular}{|c|c|c|c|}
\hline Author, Year & Funding Source & Quality & Comments \\
\hline
\end{tabular}




\begin{tabular}{|c|c|c|c|}
\hline Author, Year & $\begin{array}{c}\text { Country } \\
\text { Number of Centers } \\
\text { Setting }\end{array}$ & Inclusion/Exclusion Criteria & $\begin{array}{c}\text { Number Randomized, } \\
\text { Analyzed } \\
\text { Attrition }\end{array}$ \\
\hline Assefi 2005 & $\begin{array}{l}\text { United States, setting } \\
\text { not reported }\end{array}$ & $\begin{array}{l}\text { Inclusion Criteria: } \\
\text { English speaking adults }>18 \text { diagnosed with Fibromyalgia with } \\
\text { baseline global pain score of } 4 \text { or greater on a VAS }(0-10) \text {. Kept } \\
\text { fibromyalgia related treatments/therapies constant throughout study. } \\
\text { Exclusion Criteria: } \\
\text { Patients who reported other pain-related medical conditions or } \\
\text { potential contraindications to acupuncture, were pregnant or } \\
\text { breastfeeding, used narcotics that could blunt the effects of } \\
\text { acupuncture, were involved in litigation related to fibromyalgia or had } \\
\text { previously received acupuncture. }\end{array}$ & $\begin{array}{l}\text { Randomized: } 100 \\
\text { Treated: } 96 \\
\text { Analyzed: } 86 \\
\text { Attrition: } 14 \%(14 / 100)\end{array}$ \\
\hline
\end{tabular}




\begin{tabular}{|c|c|}
\hline Author, Year & Intervention, Comparator \\
\hline Assefi 2005 & $\begin{array}{l}\text { A.Acupuncture ( } \mathrm{n}=23 \text { ) } \\
\text { Patients randomized to intervention group received directed acupuncture in accordance with Traditional Chinese Medicine. } \\
\text { No. of Sessions: } 24 \text { (2/week for } 12 \text { weeks) } \\
\text { Needle Depth: Standard depth(?) } \\
\text { Length of Insertion: } 30 \text { min/acupoint } \\
\text { Needles: Disposable Chinese, Japanese or Korean needles, ( } 34 \text { to } 40 \text { gauge) according to practitioner preference. } \\
\text { Sham Acupuncture (groups B, C, D): } \\
\text { Participants were randomized to three different possible sham acupuncture treatments, each of which followed the same treatment protocol as the } \\
\text { intervention group. } \\
\text { B. Needling for Unrelated Condition ( } n=22) \\
\text { One controlled for acupoint specificity and involved acupuncture typically used to treat irregular menses (rather than fibromyalgia points), in } \\
\text { accordance with Traditional Chinese Medicine. } \\
\text { C.Sham Needling ( } n=22) \\
\text { Another sham intervention used body locations not recognized as true acupoints or meridians for needling (sham needling). } \\
\text { D.Simulated Acupuncture ( } n=19) \\
\begin{array}{l}\text { The third sham treatment controlled for needle insertion, and involved noninsertive simulated acupuncture at the same acupoints used in the } \\
\text { directed acupuncture. }\end{array}\end{array}$ \\
\hline
\end{tabular}




\begin{tabular}{|c|c|c|c|}
\hline Author, Year & Study Participants & Outcome Measures & $\begin{array}{l}\text { Duration of } \\
\text { Followup }\end{array}$ \\
\hline Assefi 2005 & $\begin{array}{l}\text { A vs. B vs. C vs. D } \\
\text { Age (SD): } 46 \text { vs. } 46 \text { vs. } 49 \text { vs. } 48 \text { years } \\
\text { Female: } 88 \% \text { vs. } 96 \% \text { vs. } 100 \% \text { vs. } 96 \% \\
\text { Race: } 96 \% \text { vs. } 88 \% \text { vs. } 96 \% \text { vs. } 92 \% \text { white } \\
\text { Mean (SD) duration of pain, years: } 12(18) \text { vs. } 9 \text { (7) vs. } 9 \text { (7) vs. } 10 \\
\text { (16) } \\
\text { Pain Intensity (VAS, } 0-10): 7.0(2) \text { vs. } 6.9(2) \text { vs. } 6.8(2) \text { vs. } 7.3(2) \\
\text { Fatigue Intensity (VAS, } 0-10): 7.5(2) \text { vs. } 8.1(1) \text { vs. } 7.3(2) \text { vs } 7.9(2) \\
\text { Sleep Quality (VAS, } 0-10): 4.0(2) \text { vs. } 2.8(2) \text { vs. } 3.7(2) \text { vs. } 2.6(2) \\
\text { Overall Well-Being (VAS, } 0-10): 4.2(2) \text { vs. } 4.7(2) \text { vs } 3.9(2) \text { vs. } 3.7(2) \\
\text { SF-36 Mean Summary Scores } \\
\text { Physical Component: } 28(8) \text { vs. } 31(9) \text { vs. } 31(8) \text { vs. } 32(9) \\
\text { Mental Component: } 42(11) \text { vs. } 41 \text { (12) vs. } 42(8) \text { vs. } 42(9) \\
\text { *Prior preventive therapy separated out by therapy type, these values } \\
\text { represent minimum percentage reported who sought prior therapies. }\end{array}$ & $\begin{array}{l}\text { Pain Intensity (VAS, 0-10: higher scores indicate } \\
\text { severity of pain) } \\
\text { Intensity of Fatigue (VAS, 0-10: higher scores indicate } \\
\text { severity of pain) } \\
\text { Sleep Quality (VAS, 0-10: higher scores indicate better } \\
\text { sleep) } \\
\text { Overall Well-Being (VAS, 0-10: higher scores indicate } \\
\text { better quality of life) } \\
\text { SF-36 Physical Component (SF-36 PCS; physical } \\
\text { health scores summed and negatively weighted by } \\
\text { mental health scores, higher scores indicate more } \\
\text { optimal health) } \\
\text { SF-36 Mental Component (SF-36 MCS; mental health } \\
\text { scores summed negatively weighted by physical health } \\
\text { scores, higher scores indicate more optimal health) }\end{array}$ & $\begin{array}{l}3 \text { and } 6 \\
\text { months }\end{array}$ \\
\hline
\end{tabular}




\begin{tabular}{|c|c|}
\hline Author, Year & $\begin{array}{c}\text { Results - Subquestion a } \\
\text { (vs. sham, no treatment, waitlist, attention control) }\end{array}$ \\
\hline Assefi 2005 & 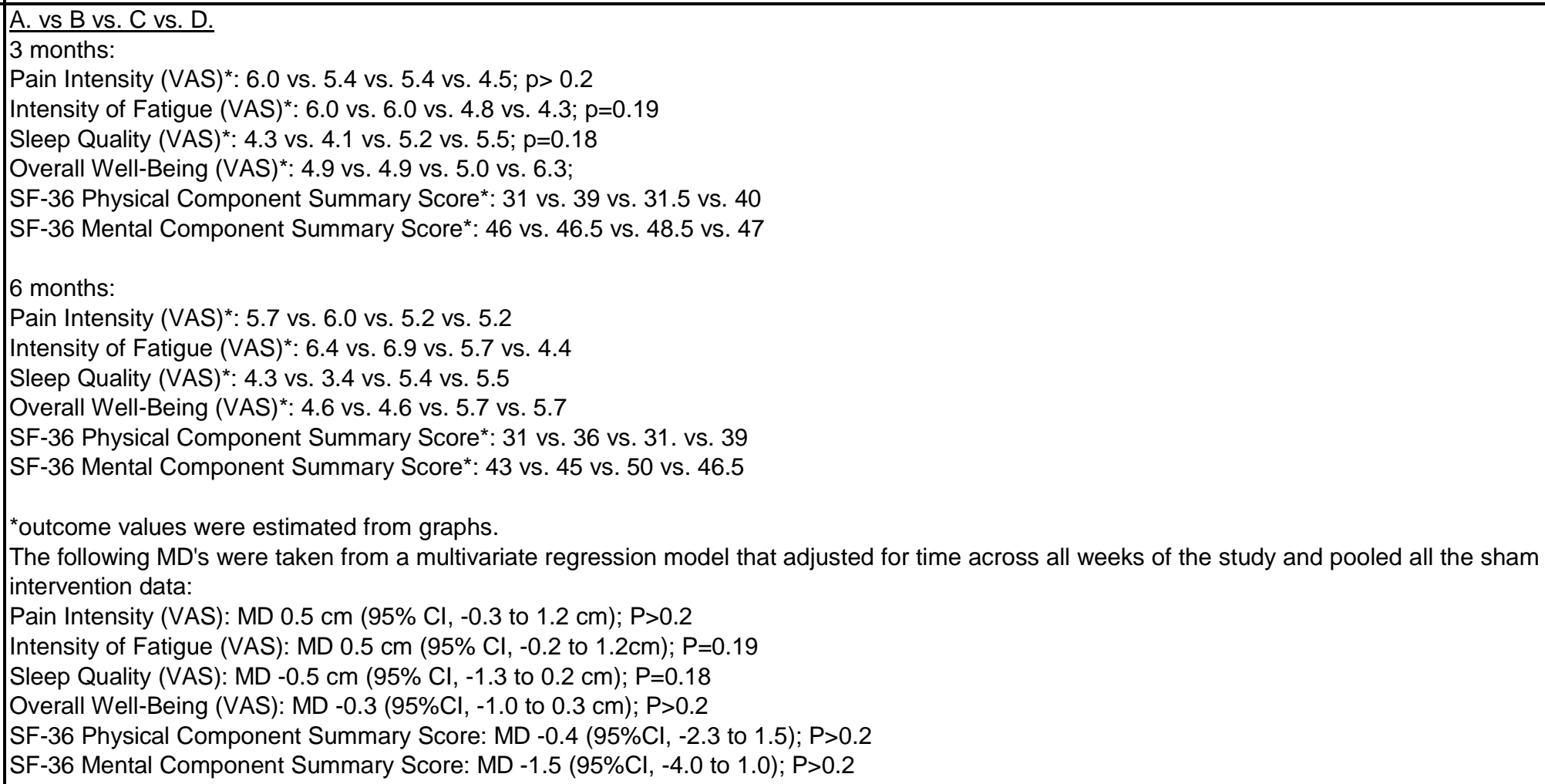 \\
\hline
\end{tabular}




\begin{tabular}{|l|l|}
\hline Author, Year & \multicolumn{2}{c|}{$\begin{array}{c}\text { Results - Subquestion b } \\
\text { (vs. Pharmacological therapy) }\end{array}$} \\
\hline Assefi 2005 & NR \\
& \\
& \\
\hline
\end{tabular}




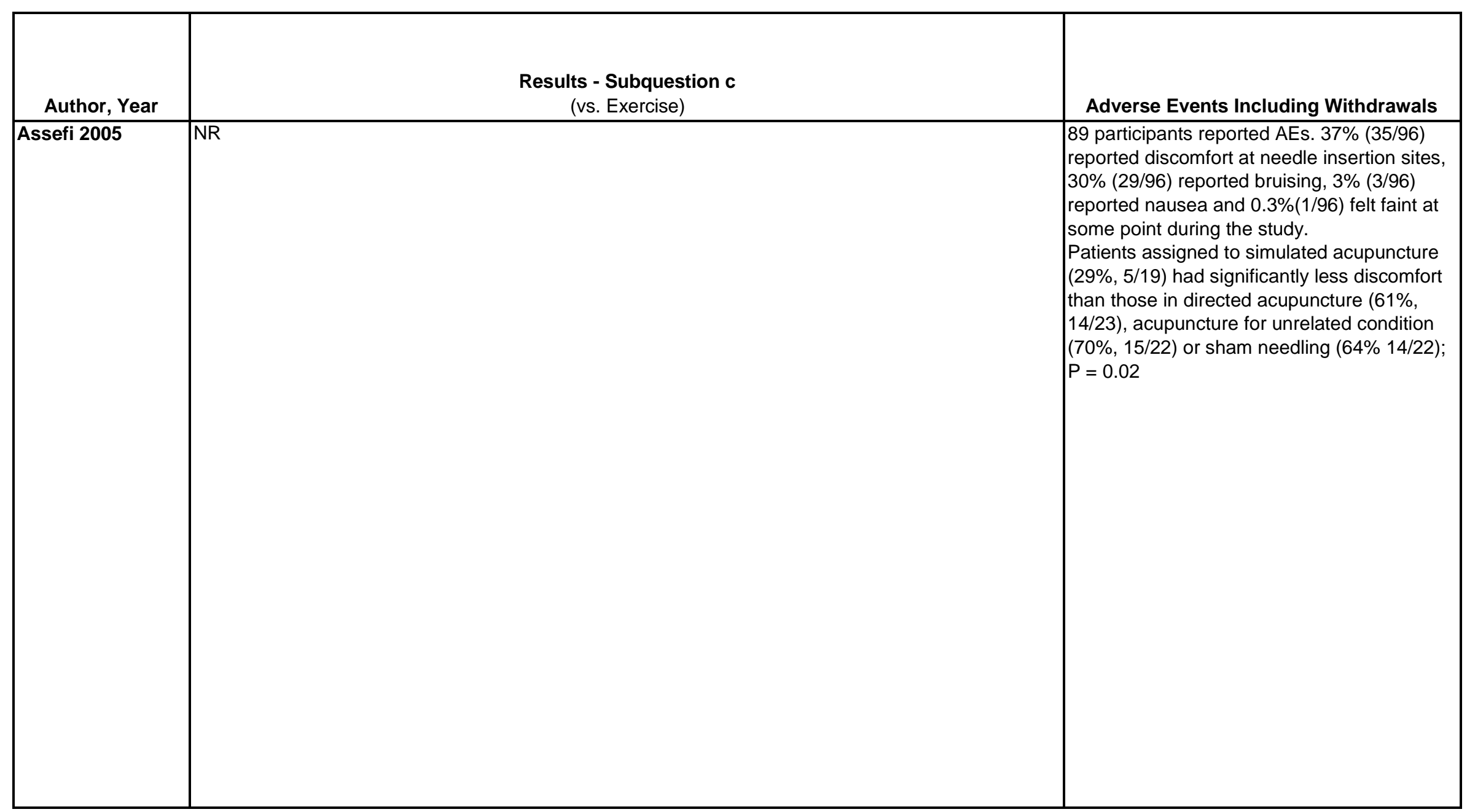




\begin{tabular}{|l|l|l|l|}
\hline \multicolumn{1}{|c|}{ Author, Year } & \multicolumn{1}{|c|}{ Funding Source } & Quality & \\
\hline Assefi 2005 & $\begin{array}{l}\text { This project was funded by Research } \\
\text { Grant RO1AT00003 from the National } \\
\text { Center for Complementary and } \\
\text { Alternative Medicine. }\end{array}$ & Good & \\
& & & \\
& & & \\
\end{tabular}




\begin{tabular}{|c|c|c|c|}
\hline Author, Year & $\begin{array}{c}\text { Country } \\
\text { Number of Centers } \\
\text { Setting }\end{array}$ & Inclusion/Exclusion Criteria & $\begin{array}{c}\text { Number Randomized, } \\
\text { Analyzed } \\
\text { Attrition }\end{array}$ \\
\hline Banth 2015 & $\begin{array}{l}\text { Iran } \\
\text { Number of centers: } \\
\text { unclear } \\
\text { Clinic and } \\
\text { Outpatient }\end{array}$ & $\begin{array}{l}\text { Patients age } 30-45 \text { years, history of nonspecific medical history of } \\
\text { NSCLBP, persisting pain for persisting for } \geq 6 \text { months, female, } \\
\text { educated at least up to high school } \\
\text { Exclude: History of spine surgery, } \\
\text { combination with other chronic disease, psychotherapy in the last } 2 \\
\text { years, unavailability in } 3 \text { months }\end{array}$ & $\begin{array}{l}\text { Randomized: } 88 \\
\text { Treated: } 88 \\
\text { Analyzed: } 48 \\
\text { Attrition: } 54 \% \text { (40/88) }\end{array}$ \\
\hline Baptista 2012 & \begin{tabular}{|l|} 
Brazil \\
Outpatient \\
rheumatology clinics
\end{tabular} & $\begin{array}{l}\text { Inclusion: FM diagnosis based on ACR } 1990 \text { criteria, female, age } \\
\text { between } 18 \text { and } 65 \text { years, not having altered treatment in past } 4 \\
\text { weeks } \\
\text { Exclusion: other rheumatic diseases, painful joint diseases, } \\
\text { uncontrolled cardiopulmonary diseases, diseases of the lower limbs, } \\
\text { uncontrolled diabetes }\end{array}$ & $\begin{array}{l}\text { Randomized: } 80 \\
\text { Analyzed: } 75 \\
\text { Attrition: } 6 \%(5 / 80)\end{array}$ \\
\hline
\end{tabular}




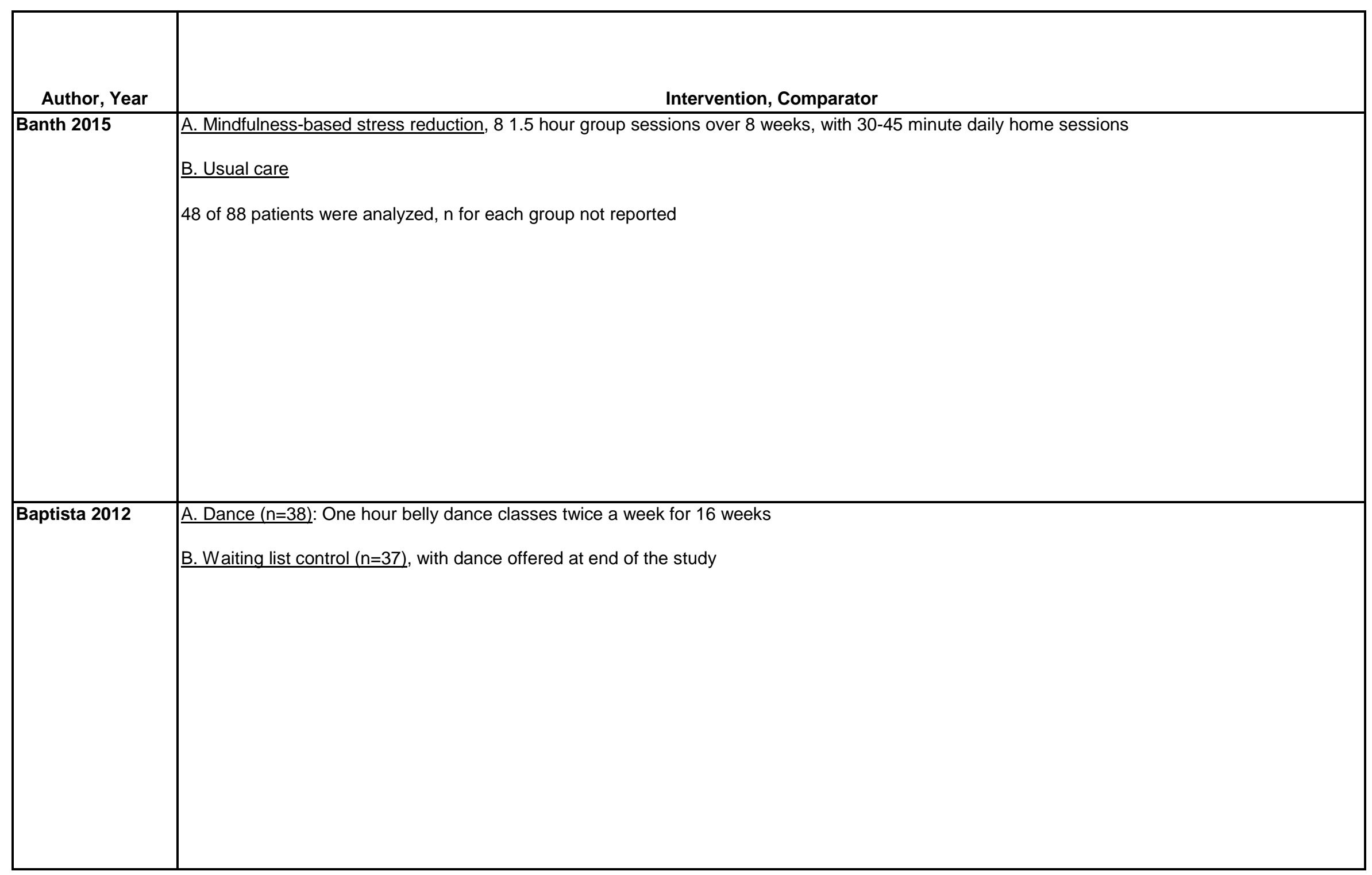




\begin{tabular}{|c|c|c|c|}
\hline Author, Year & Study Participants & Outcome Measures & $\begin{array}{c}\text { Duration of } \\
\text { Followup }\end{array}$ \\
\hline Banth 2015 & $\begin{array}{l}\text { A vs. B (NR) } \\
\text { Age: } 40 \text { years } \\
\text { Female: } 100 \% \\
\text { Race: NR } \\
\text { Duration of symptoms: } 6 \text { months } \\
\text { Very low physical quality of life: } 9.8 \% \\
\text { Low physical quality of life: } 54.8 \% \\
\text { Moderate physical quality of life: } 36.4 \%\end{array}$ & $\begin{array}{l}\text { McGill Pain questionnaire } \\
\text { total score (0 to 45) } \\
\text { Quality of life (SF-12) (eight health constructs Physical } \\
\text { functioning; role physical; bodily pain; general health; } \\
\text { vitality; social functioning; role emotional; and mental } \\
\text { health with scores from 0-100) }\end{array}$ & 1 month \\
\hline Baptista 2012 & $\begin{array}{l}\text { A vs B: } \\
\text { Age: } 50 \text { vs } 49 \\
\text { Female: } 100 \% \text { vs } 100 \% \\
\text { Race NR } \\
\text { FIQ: } 5.9 \text { vs } 6.3 \\
6 \text {-minute walk test: } 372.8 \text { vs } 332.0, p=0.015 \\
\text { Pain VAS: } 7.7 \text { vs } 7.5 \\
\text { SF-36 Pain: } 29.6 \text { vs } 25.7 \\
\text { BDI: } 23.9 \text { vs } 21.2 \\
\text { STAl part } 1: 50.5 \text { vs } 52.8 \\
\text { STAl part } 2: 51.1 \text { vs } 53.0, p=0.06 \\
\text { SF-36 Function: } 44.9 \text { vs } 32.6, p<0.001 \\
\text { SF-36 Limitation due to physical aspects: } 24.7 \text { vs } 8.8, p<0.001 \\
\\
\text { SF-36 Mental Health: } 46.0 \text { vs } 43.4\end{array}$ & $\begin{array}{l}\text { FIQ (0-10, higher scores=worse function and symptom } \\
\text { severity) } \\
6 \text { minute walk test (meters traveled on 20-meter course) } \\
\text { (higher scores =less impairment) } \\
\text { Pain VAS (0-10, higher scores=greater pain) } \\
\text { Beck Depression Inventory (0-21, higher scores=greater } \\
\text { depression) } \\
\text { State-Trait Anxiety Inventory (scale NR, higher } \\
\text { scores=greater anxiety) } \\
\text { SF-36 (0-100, higher scores = better quality of life) }\end{array}$ & 4 months \\
\hline
\end{tabular}




\begin{tabular}{|c|c|}
\hline Author, Year & $\begin{array}{l}\text { Results - Subquestion a } \\
\text { (vs. sham, no treatment, waitlist, attention control) }\end{array}$ \\
\hline Banth 2015 & \begin{tabular}{|l} 
A vs. B, (mean, SD) \\
Baseline \\
McGill Pain questionnaire (0-45) \\
26.08 (5.4) vs. $26.71(4.4)$ \\
SF-12 Mental component (0-100) \\
23.44 (4.0) vs. 22.38 (3.8) \\
SF-12 Physical component (0-100) \\
20.83 (4.6) vs. $19.96(3.5)$ \\
\\
1 month \\
McGill Pain questionnaire \\
13.58 (3.8) vs. $23.60(4.1)$ \\
SF-12 Mental component \\
31.54 (4.3) vs. $24.29(5.2)$ \\
SF-12 Physical component \\
28.08 (4.2) vs. $21.08(3.3)$
\end{tabular} \\
\hline Baptista 2012 & 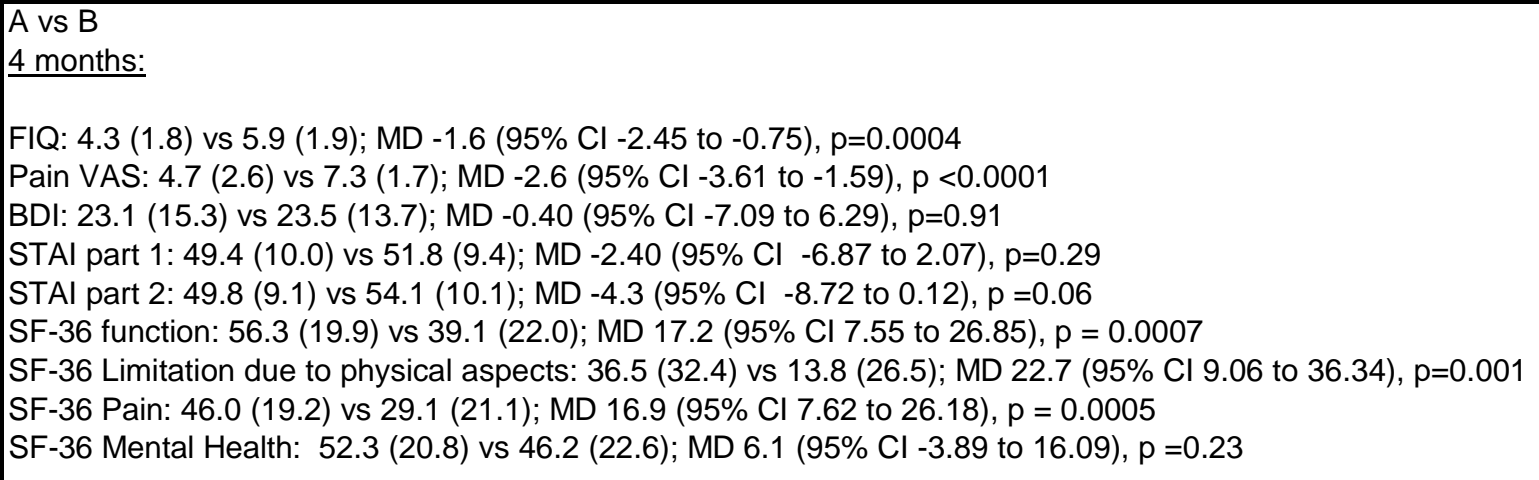 \\
\hline
\end{tabular}




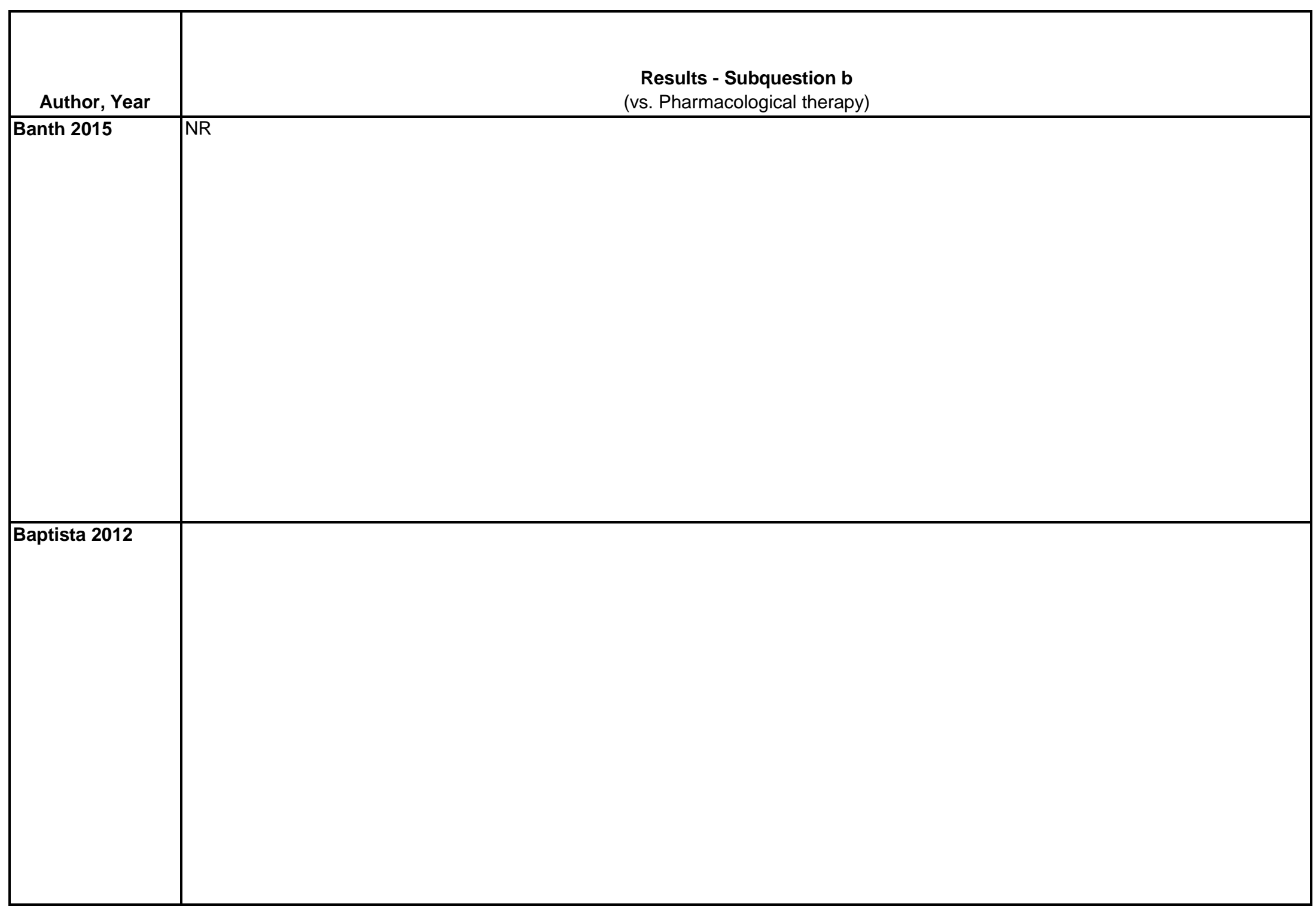

D-54 


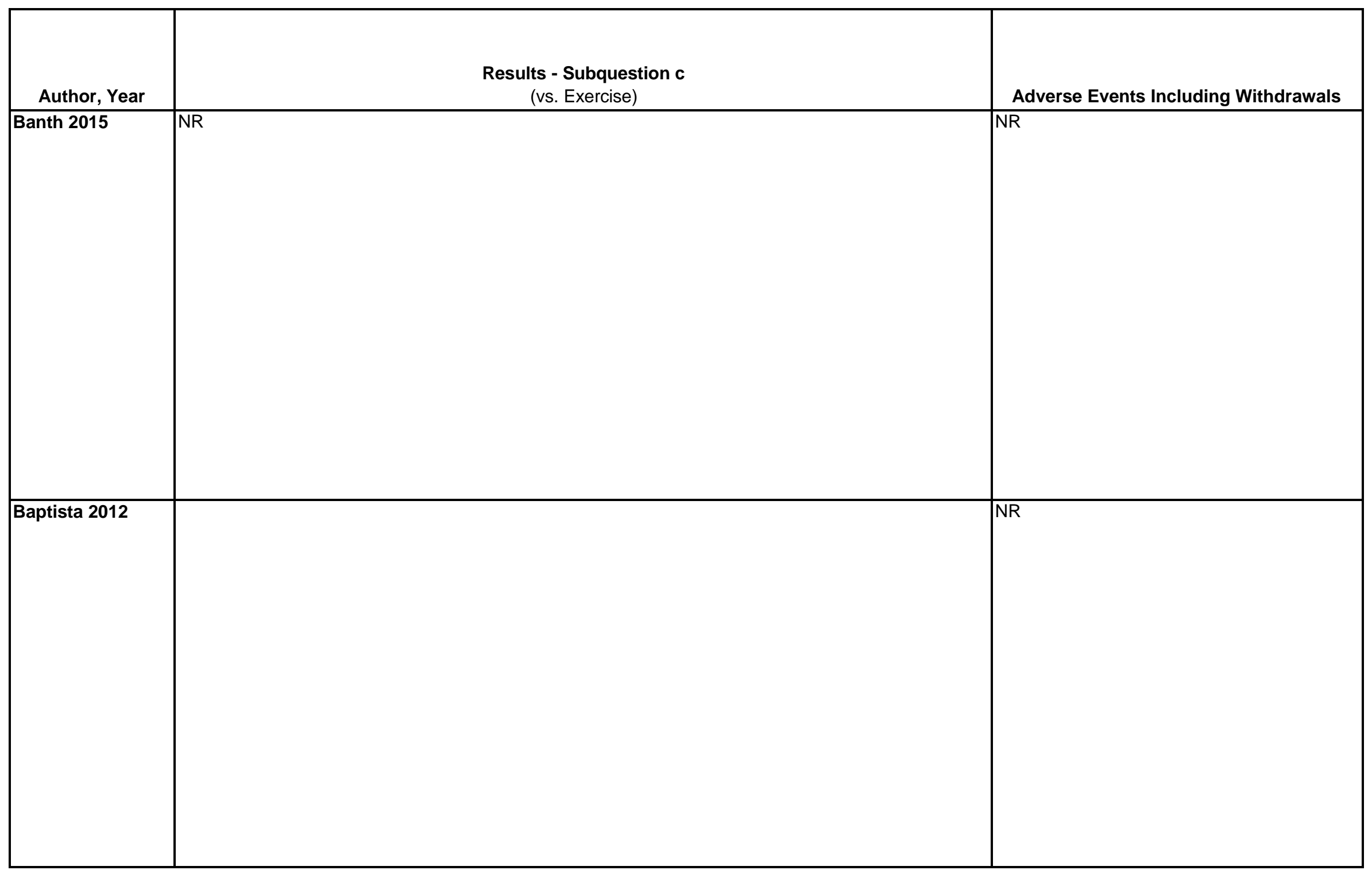

D-55 


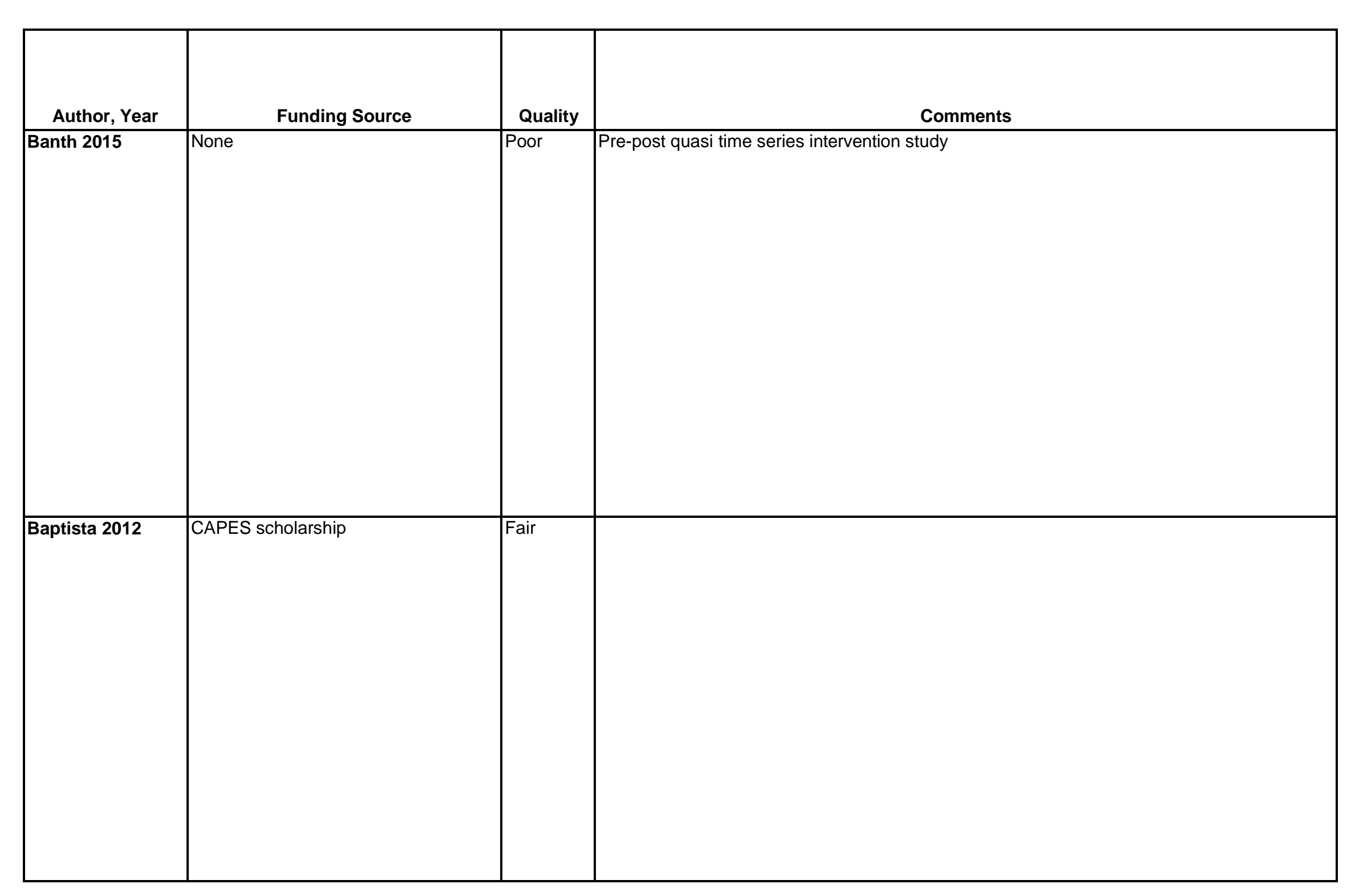




\begin{tabular}{|c|c|c|c|}
\hline Author, Year & $\begin{array}{c}\text { Country } \\
\text { Number of Centers } \\
\text { Setting }\end{array}$ & Inclusion/Exclusion Criteria & $\begin{array}{c}\text { Number Randomized, } \\
\text { Analyzed } \\
\text { Attrition } \\
\end{array}$ \\
\hline Basford 1999 & $\begin{array}{l}\text { US } \\
\text { Number of centers: } 1 \\
\text { Outpatient } \\
\text { rehabilitation clinic }\end{array}$ & $\begin{array}{l}\text { Healthy adults ages } 18-70 \text { years with nonradiating low back pain } \\
\text { more than } 30 \text { days. } \\
\text { Exclude: patients with litigation or workman's compensation issues } \\
\text { pending and/or received corticosteroids within last } 30 \text { days. }\end{array}$ & $\begin{array}{l}\text { Randomized: } 59 \\
\text { Treated: } 59 \\
\text { Analyzed: } 56 \\
\text { Attrition: } 5 \%(3 / 59)\end{array}$ \\
\hline Battisti 2004 & Italy, outpatient & $\begin{array}{l}\text { Inclusion Criteria: } \\
\text { NR } \\
\text { Exclusion Criteria: } \\
\text { NR }\end{array}$ & $\begin{array}{l}\text { Randomized: } 90 \\
\text { Treated: } 90 \\
\text { Analyzed: } 90 \\
\text { Attrition: } 0 \%(0 / 90)\end{array}$ \\
\hline
\end{tabular}




\begin{tabular}{|c|c|}
\hline Author, Year & Intervention, Comparator \\
\hline Basford 1999 & $\begin{array}{l}\text { A.Nd:YAG laser }(\mathrm{n}=27): 542 \mathrm{~mW} / \mathrm{cm}^{2} \text { for } 90 \text { seconds at two sites simultaneously at four equally spaced levels (a total of } 8 \text { points) along the } \mathrm{L} 2 \text { to } \\
\text { S3 Para spinal tissues; } 3 \text { times a week for } 4 \text { weeks. } \\
\text { B. Sham treatment }(\mathrm{n}=29) \text { : Same as above but irradiated with inactive probes. }\end{array}$ \\
\hline Battisti 2004 & $\begin{array}{l}\text { A.Therapeutic Application of Musically Modulated Electromagnetic Field (TAMMEF) }(n=30) \\
\text { Application of low frequency electromagnetic fields through two amplifiers }(A \text { and } B) \text { feeding two electromagnets. The anatomical region treated is } \\
\text { placed between opposing faces of the electromagnets }(3 \times 4 \mathrm{~cm}) \text {. The current from amplifier } B \text { feeds a loud speaker that plays music. The music } \\
\text { modifies parameters (frequency, intensity, waveform) of the electromagnetic field in time, randomly varying within respective ranges. } \\
\text { No. of Sessions: } 15 \text { daily sessions } \\
\text { Length of Sessions: } 30 \text { minutes each } \\
\text { B.Extremely Low Frequency }(E L F)(n=30) \\
\text { Similar treatment as Intervention A except the electromagnetic field is stabilized at a frequency of } 100 \mathrm{~Hz} \text { in a sinusoidal waveform. } \\
\text { No. of Sessions: } 15 \text { daily sessions } \\
\text { Length of Sessions: } 30 \text { minutes each } \\
\text { C.Simulated (Sham) Frequency Field ( } n=30) \\
\text { Functionally similar operation to the other groups except a simulated (noneffective) field is used, but the patients remain blinded to its effectiveness. } \\
\text { No. of Sessions: } 15 \text { daily sessions } \\
\text { Length of Sessions: } 30 \text { minutes each }\end{array}$ \\
\hline
\end{tabular}




\begin{tabular}{|c|c|c|c|}
\hline Author, Year & Study Participants & Outcome Measures & $\begin{array}{l}\text { Duration of } \\
\text { Followup }\end{array}$ \\
\hline Basford 1999 & $\begin{array}{l}\text { A vs. B } \\
\text { Age: } 48 \text { vs. } 48 \text { years } \\
\text { Female: } 40 \% \text { vs. } 55 \% \\
\text { Nature of pain (\% described as burning or aching: } 87 \% \text { vs. } 72 \% \\
\text { Symptom duration (months): } 4.5 \text { vs. } 6.5 \\
\text { Previous physical therapy, injection or chiropractic treatment: } 57 \text { vs. } \\
69 \\
\text { Analgesic use (number per day): } 4.6 \text { vs. } 4.4 \\
\text { Lumbar spine X-rays showing changes compatible with mild } \\
\text { to moderate degenerate spine disease (\%): } 70 \text { vs. } 86\end{array}$ & $\begin{array}{l}\text { Oswestry score (Oswestry Disability Questionnaire, total } \\
\text { scored/ } 50 \times 100=\% \text { ) } \\
\text { Patient perception of benefit } \\
\text { Lumbar mobility (Schober test, marking points } 5 \mathrm{~cm} \\
\text { above and } 5 \mathrm{~cm} \text { below the L5-SI junction standing in a } \\
\text { neutral position and measuring the excursion of points } \\
\text { when bending forward to their maximal extent) } \\
\text { Pain (Visual analog scales }(0 \mathrm{~mm} \text {, no pain; } 100 \mathrm{~mm} \text {, } \\
\text { incredibly severe pain) }\end{array}$ & $\begin{array}{l}\text { Short term } \\
1 \text { month }\end{array}$ \\
\hline Battisti 2004 & $\begin{array}{l}\text { A+B } \\
\text { Age: } 58.9(7.4) \\
\text { Female: } 70 \% \\
\text { Race: NR } \\
\text { Mean Duration of Chronicity: } 11(3.1) \\
\text { A vs. B } \\
\text { Mean Lequesne Pain Score*: } 6.88 \text { vs. } 6.28 \text { vs. } 6.15 \\
\text { Mean Lequesne Function Score*: } 3.65 \text { vs. } 4.28 \text { vs. } 3.48 \\
\text { *The study separated outcome values out into slight, moderate and } \\
\text { severe disease patient groups for each treatment arm. These values } \\
\text { are combined values for each intervention groups estimated from } \\
\text { graphs in the study. SD was not reported. }\end{array}$ & $\begin{array}{l}\text { Primary: } \\
\text { Lequesne Algo-Functional Index for Knee Osteoarthritis } \\
\text { Lequesne Pain (range 0-10: higher scores indicate } \\
\text { severity of pain) } \\
\text { Lequesne Function (range 0-10: higher scores indicate } \\
\text { better function) }\end{array}$ & $\begin{array}{l}\text { immediate } \\
\text { post- } \\
\text { treatment, } 1 \\
\text { month }\end{array}$ \\
\hline
\end{tabular}




\begin{tabular}{|c|c|}
\hline Author, Year & $\begin{array}{c}\text { Results - Subquestion a } \\
\text { (vs. sham, no treatment, waitlist, attention control) }\end{array}$ \\
\hline Basford 1999 & $\begin{array}{l}\text { A vs B, mean } \\
\text { Baseline } \\
\text { Oswestry Disability Index: } 21 \text { vs. } 25 \text {, mean difference }-3.5 \text { (95\% Cl }-7.8 \text { to } 0.8) \\
\text { Maximal pain in last } 24 \text { hours (0-100 VAS): } 35.2 \text { vs. } 37.4 \text {, mean difference }-2.5 \text { ( } 95 \% \mathrm{Cl}-14.9 \text { to } 10.0) \\
\text { 2-month outcomes } \\
\text { Oswestry Disability Index (0-100): } 14.7 \text { vs. } 22.9 \text {, difference }-8.2(95 \% \mathrm{Cl}-13.6 \text { to }-2.8) \\
\text { Maximal pain in last } 24 \text { hours (0-100 VAS): } 19.1 \text { vs. } 35.1 \text {, difference }-16.0(95 \% \mathrm{Cl}-28.3 \text { to }-3.7)\end{array}$ \\
\hline Battisti 2004 & $\begin{array}{l}\text { A vs. C } \\
\text { month } \\
\text { Mean Lequesne Pain Score*: } 1.4 \text { vs. } 6.85 \\
\text { Mean Lequesne Functionality*: } 6.5 \text { vs. } 3.83 \\
\text { B vs. C } \\
\frac{1 \text { month }}{\text { Mean Lequesne Pain Score*: } 1.4 \text { vs. } 6.85} \\
\text { Mean Lequesne Functionality*: } 7.1 \text { vs. } 3.83 \\
\text { *The study separated outcome values out into slight, moderate and severe disease patient groups for each treatment arm. These values are combined } \\
\text { values for each intervention groups estimated from graphs in the study. SD was not reported. }\end{array}$ \\
\hline
\end{tabular}




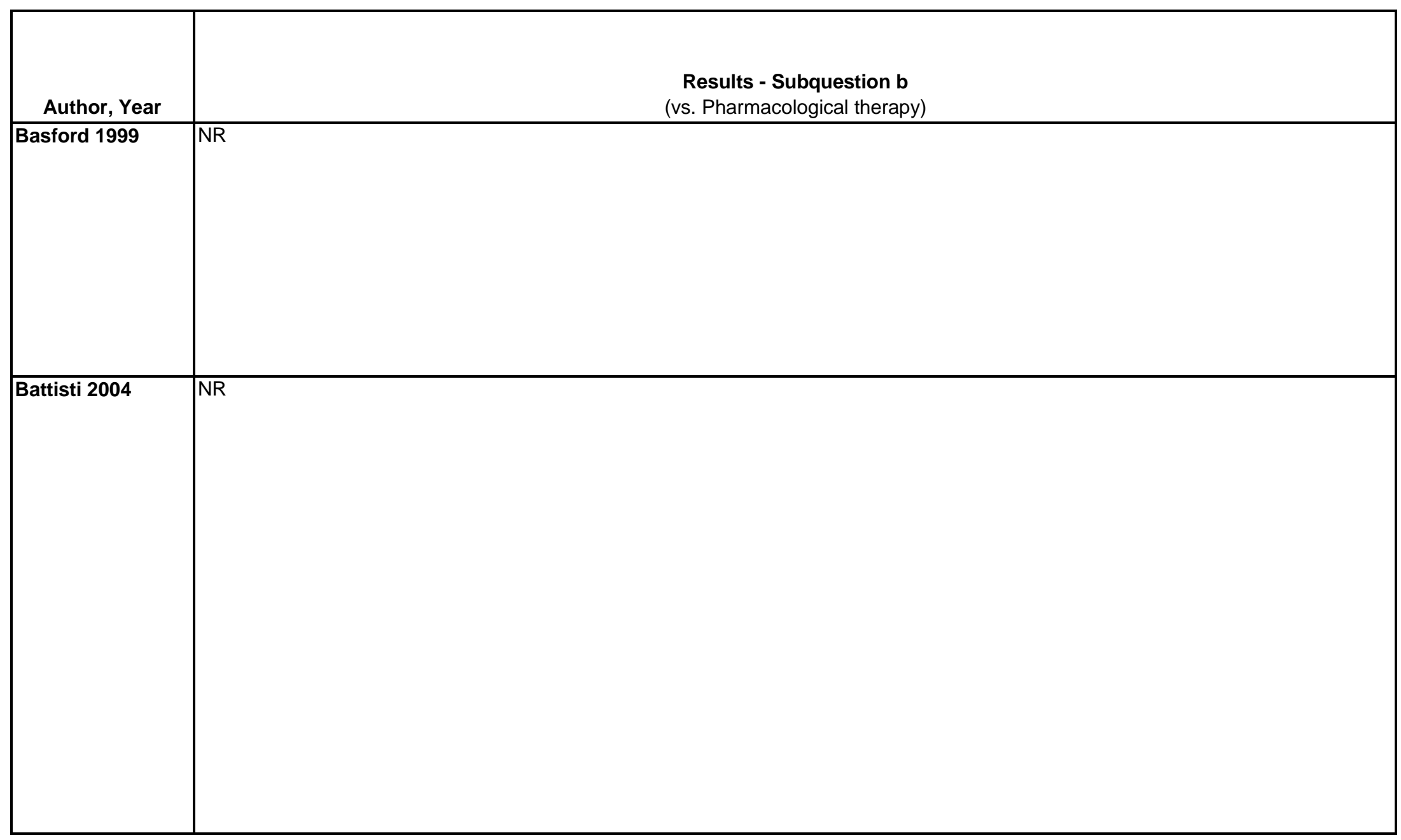

D-61 


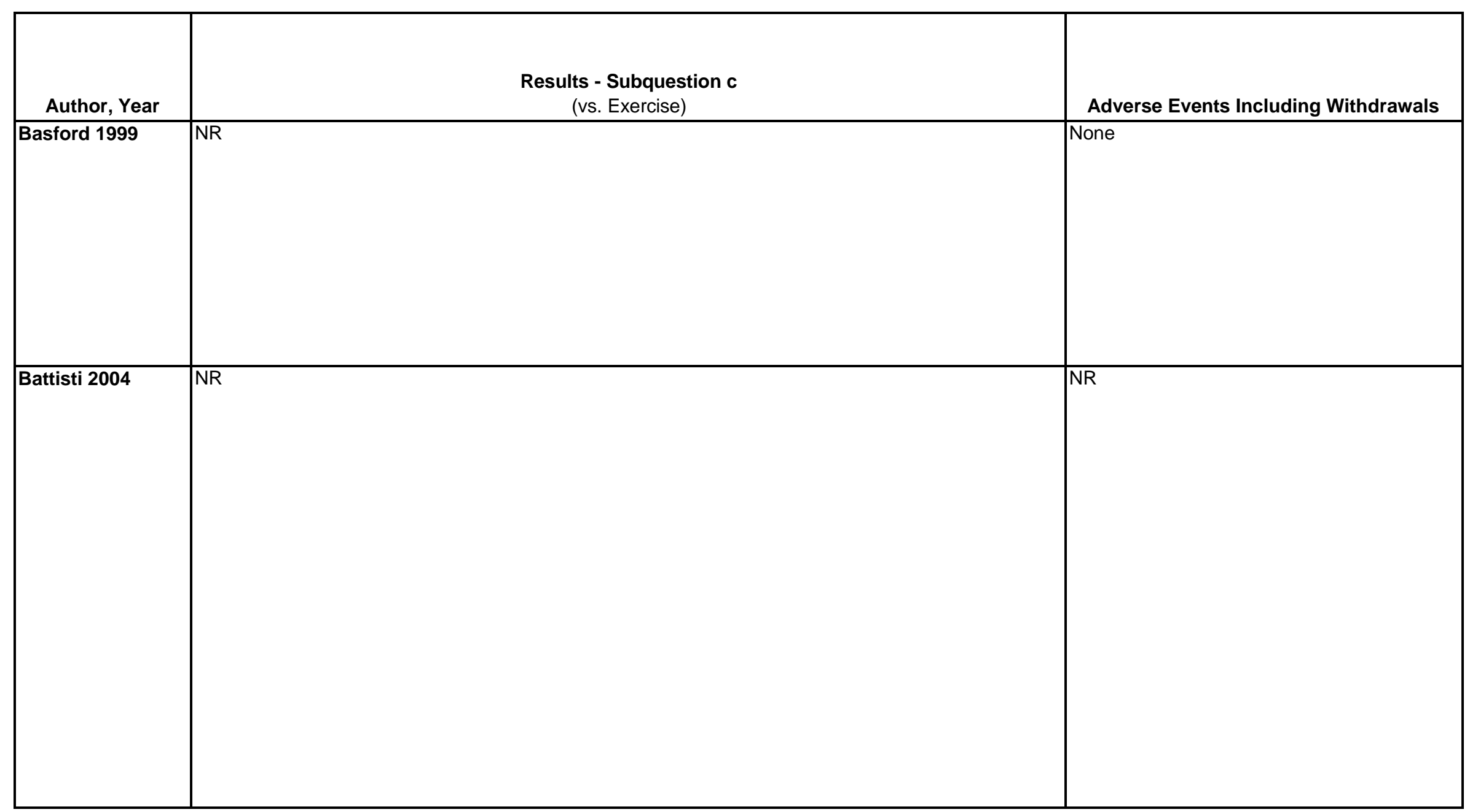




\begin{tabular}{|c|c|c|c|}
\hline Author, Year & Funding Source & Quality & Comments \\
\hline Battisti 2004 & $\begin{array}{l}\text { This study was supported in part by a } \\
\text { contribution from the "Fondazione del } \\
\text { Monte dei Paschi di Siena", Siena, } \\
\text { Italy. }\end{array}$ & Poor & $\begin{array}{l}\text { "The study separated values out into slight, moderate and severe disease patients for each } \\
\text { treatment arm. These values are combined values for each intervention groups estimated } \\
\text { from graphs in the study. SD was not reported. }\end{array}$ \\
\hline
\end{tabular}




\begin{tabular}{|c|c|c|c|}
\hline Author, Year & $\begin{array}{c}\text { Country } \\
\text { Number of Centers } \\
\text { Setting }\end{array}$ & Inclusion/Exclusion Criteria & $\begin{array}{c}\text { Number Randomized, } \\
\text { Analyzed } \\
\text { Attrition }\end{array}$ \\
\hline $\begin{array}{l}\text { Bendix } 19951997 \\
1998 \\
\\
\text { Note: Project B in } \\
\text { Bendix } 1998\end{array}$ & $\begin{array}{l}\text { Denmark } \\
\text { Number of centers: } \\
\text { Unclear } \\
\text { Inpatient }\end{array}$ & $\begin{array}{l}\text { Patients age } 18 \text { to } 59 \text { with chronic LBP for at least } 6 \text { months and } \\
\text { threatened job situation } \\
\text { Exclude: Patients with current disc herniation, surgically remediable } \\
\text { back lesions, inflammatory disease, pregnancy, cancer, clinically } \\
\text { relevant fractures, and social pension }\end{array}$ & $\begin{array}{l}\text { Randomized: } 132 \\
\text { Treated: } 106 \\
\text { Analyzed: } 106 \\
\text { Attrition: } 11 \%(14 / 132) \text { at } \\
3.25 \text { months, } 22 \% \text { at } 12 \\
\text { months }\end{array}$ \\
\hline
\end{tabular}




\begin{tabular}{|c|c|}
\hline Author, Year & Intervention, Comparator \\
\hline $\begin{array}{l}\text { Bendix } 19951997 \\
1998 \\
\text { Note: Project B in } \\
\text { Bendix } 1998\end{array}$ & $\begin{array}{l}\text { A: Multidisciplinary treatment ( } n=46) \text { : Muscle, psychological, and ADL testing, followed by exercise (fitness, endurance, coordination, stretching, } \\
\text { progressive weight training), occupational therapy (focused on work situations and work intensification), psychological treatment (behavioral } \\
\text { approach, daily relaxation, weekly individualized counseling), education, job analysis course, recreational activities. } 7.5 \text { hours/day daily for } 3 \text { weeks } \\
\text { (39 hours/per week), then one } 6 \text { hour session once weekly for } 3 \text { weeks, including psychological, physical, and ergonomic training. } \\
\text { B: Combined psycho-physical program ( } n=43) \text { : Psychological pain management, active } \\
\text { physical training: "warm-up" exercises, progressive } \\
\text { weight training, } 2 \text { hour sessions twice weekly for } 6 \text { weeks (total } 24 \text { hours) } \\
\text { C: Exercise ( } n=43) \text { : Aerobics, progressive weight training, and traditional Swedish "back to school "principles, } 2 \text { hour sessions twice weekly for } 6 \\
\text { weeks (total } 24 \text { hours) }\end{array}$ \\
\hline
\end{tabular}




\begin{tabular}{|c|c|c|c|}
\hline Author, Year & Study Participants & Outcome Measures & $\begin{array}{l}\text { Duration of } \\
\text { Followup }\end{array}$ \\
\hline \begin{tabular}{|l} 
Bendix 19951997 \\
1998 \\
Note: Project B in \\
Bendix 1998
\end{tabular} & \begin{tabular}{|l} 
A vs. B vs. C \\
Age (mean): 40 vs. 44 vs. 42 \\
Female: $75 \%$ vs. $77 \%$ vs. $74 \%$ \\
Race: NR \\
Medication: $75 \%$ vs. $66 \%$ vs. $74 \%$ \\
Back surgery: $15 \%$ vs. $17 \%$ vs. $32 \%$ \\
Back pain $(0-10): 5.3$ vs. 5.9 vs. 5.4
\end{tabular} & $\begin{array}{l}\text { Low Back Pain Rating Scale }(0-30, \text { higher score } \\
\text { indicates more disability) } \\
\text { Pain }(0-10 \text { NRS) } \\
\text { Overall assessment ( } 1=\text { much better to } 5=\text { much worse }) \\
\text { Prescription medication use }(0=\text { no medications to } \\
10=\text { morphine }>4 \text { days/week) } \\
\text { Increase in proportion able to work }\end{array}$ & $\begin{array}{l}3.25,12,24, \\
\text { and } 60 \\
\text { months }\end{array}$ \\
\hline
\end{tabular}




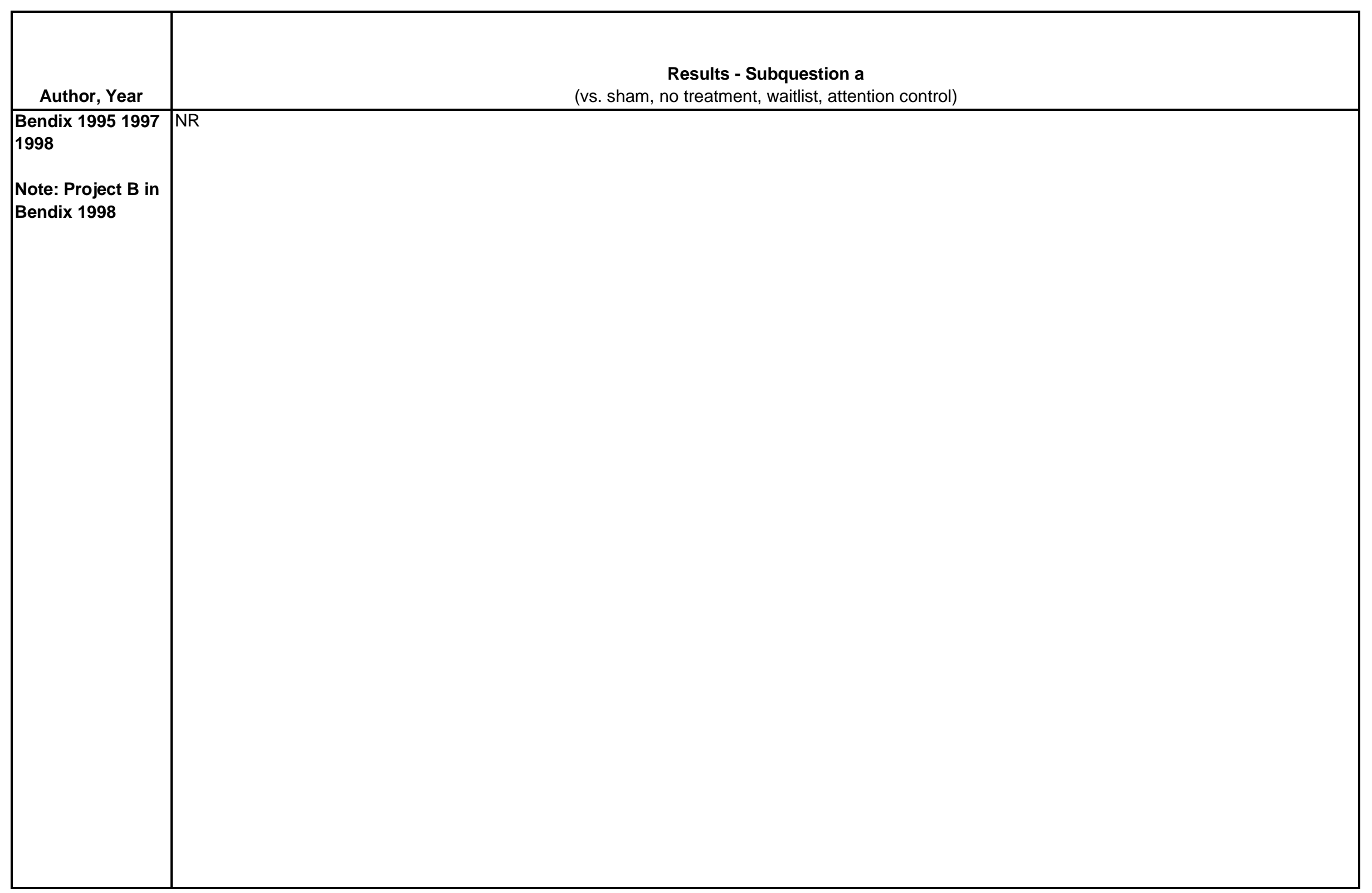




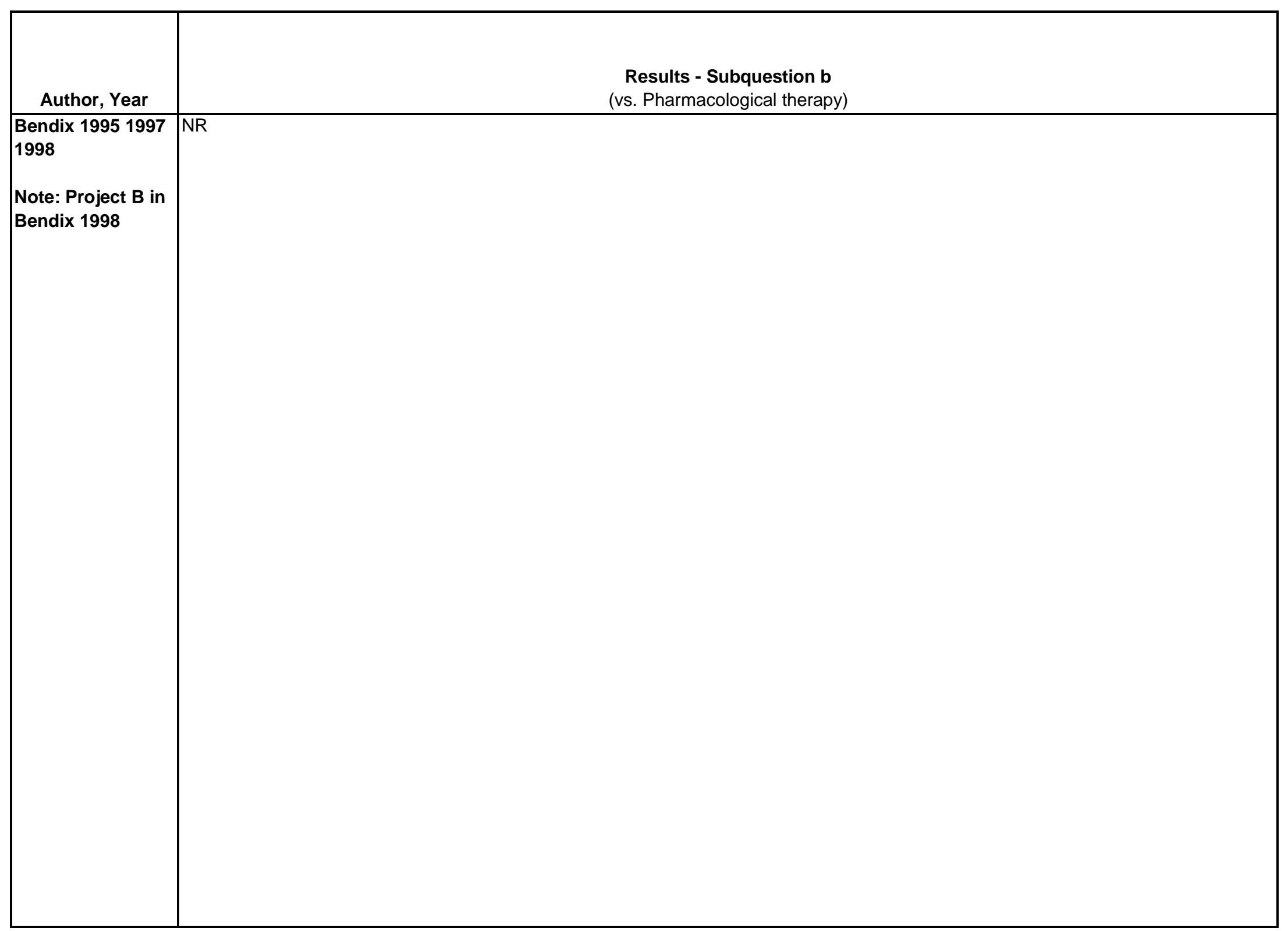




\begin{tabular}{|c|c|c|}
\hline Author, Year & $\begin{array}{c}\text { Results - Subquestion c } \\
\text { (vs. Exercise) }\end{array}$ & Adverse Events Including Withdrawals \\
\hline $\begin{array}{l}\text { Bendix } 19951997 \\
1998 \\
\text { Note: Project B in } \\
\text { Bendix } 1998\end{array}$ & 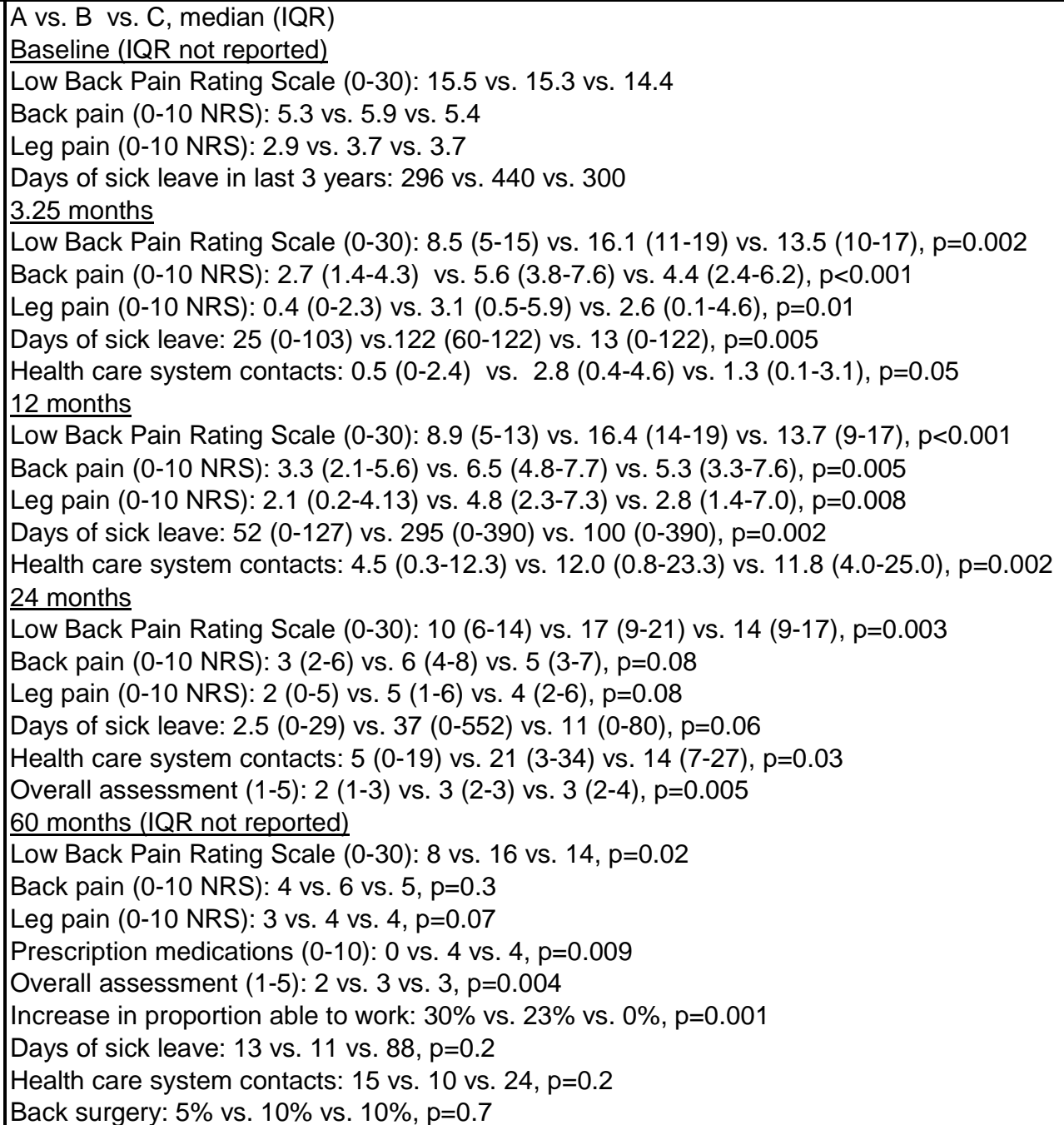 & NR \\
\hline
\end{tabular}




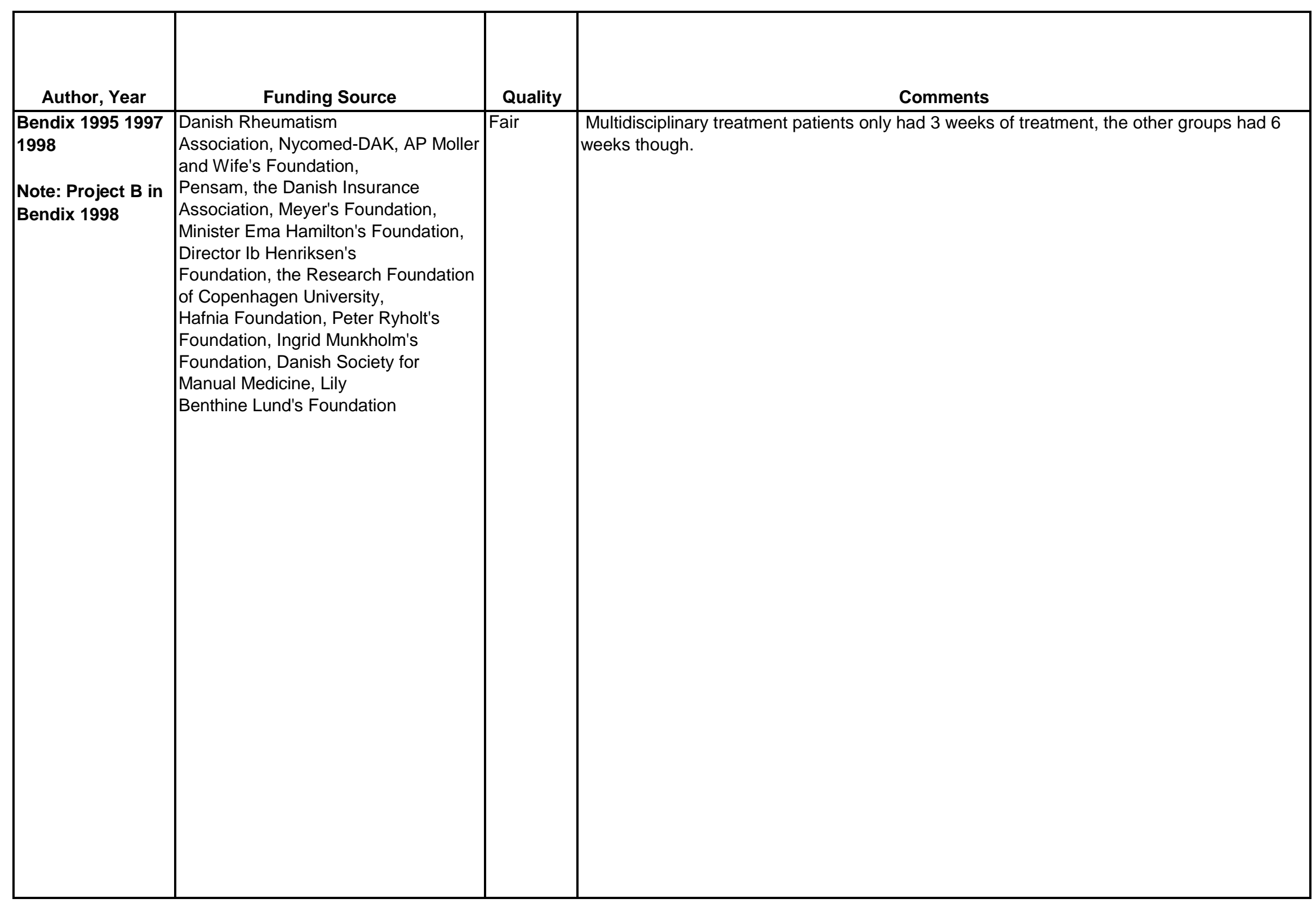




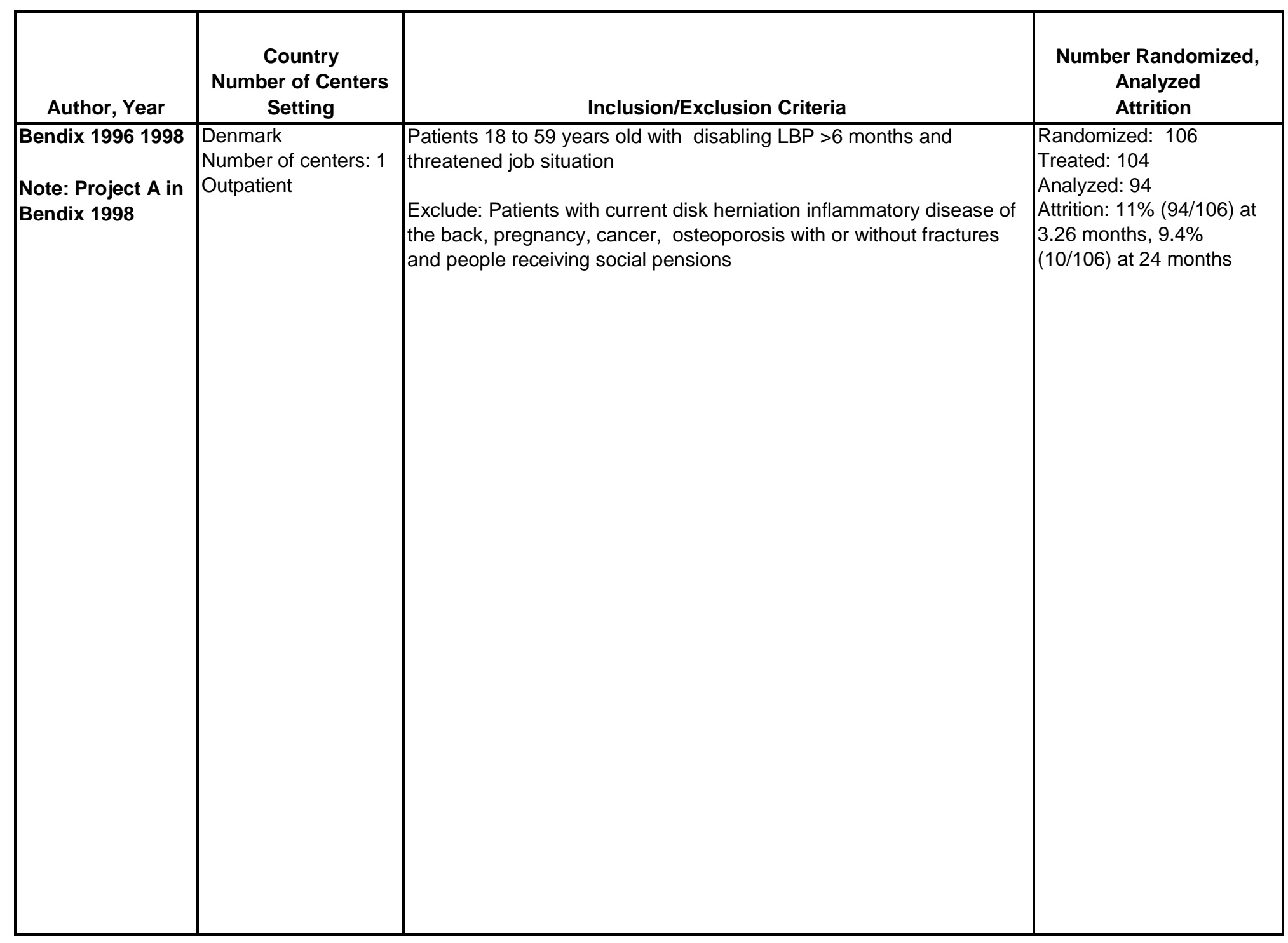




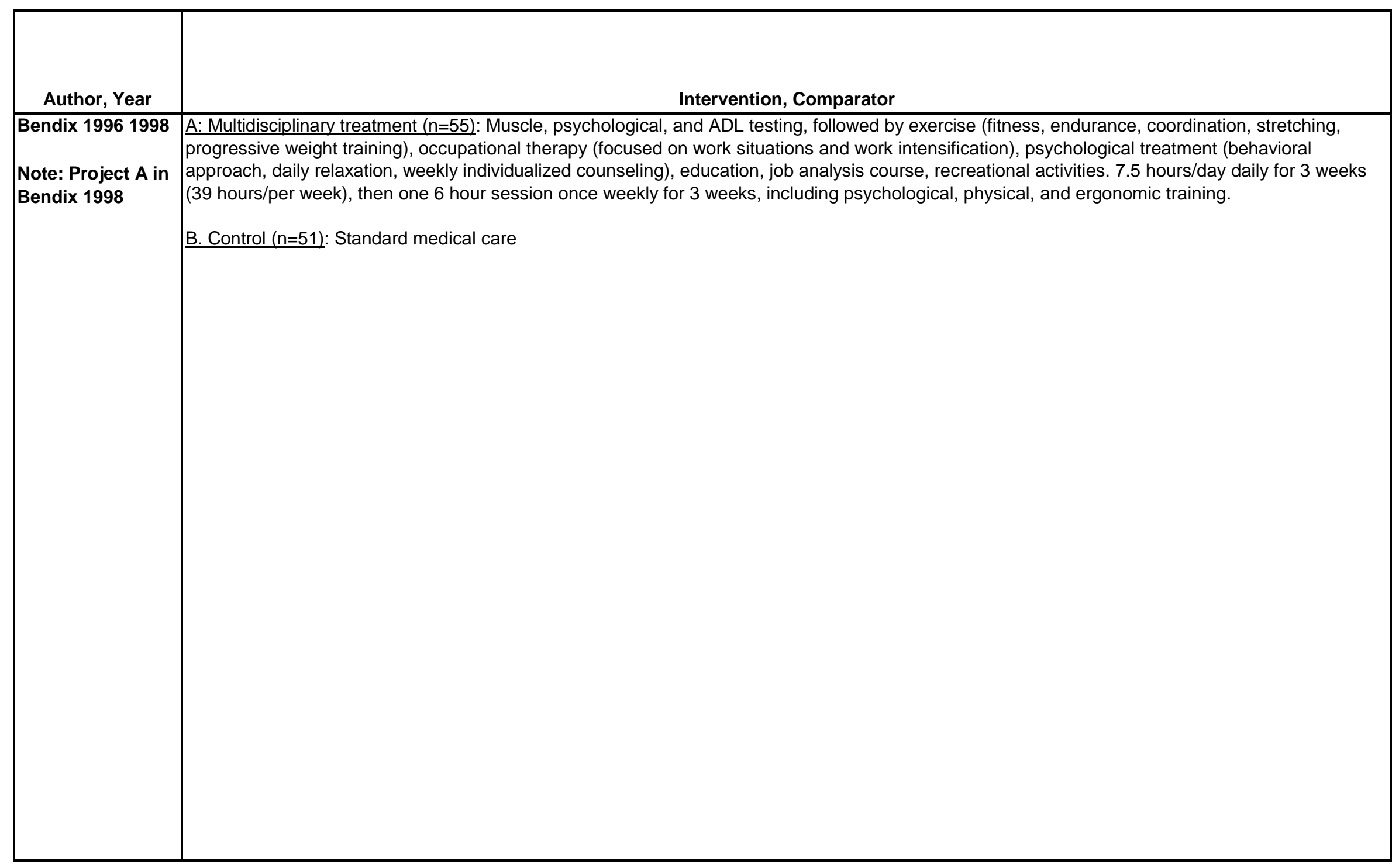




\begin{tabular}{|c|c|c|c|}
\hline Author, Year & Study Participants & Outcome Measures & $\begin{array}{l}\text { Duration of } \\
\text { Followup }\end{array}$ \\
\hline $\begin{array}{l}\text { Bendix } 19961998 \\
\text { Note: Project A in } \\
\text { Bendix } 1998\end{array}$ & $\begin{array}{l}\text { A vs. B } \\
\text { Age (median): } 41 \text { vs. } 40 \text { years } \\
\text { Female: } 71 \% \text { vs. } 69 \% \\
\text { Race: NR } \\
\text { Back pain (0-10): } 6.1 \text { vs. } 6.1 \\
\text { Medication for LBP: } 80 \% \text { vs. } 73 \% \\
\text { Previous back surgery: } 16 \% \text { vs. } 18 \%\end{array}$ & $\begin{array}{l}\text { Low Back Pain Rating Scale }(0-30, \text { higher score } \\
\text { indicates more disability) } \\
\text { Pain ( } 0-10 \text { NRS) } \\
\text { Days of sick leave } \\
\text { Health care system contacts } \\
\text { Overall assessment ( } 1=\text { much better to } 5=\text { much worse) } \\
\text { Prescription medication use }(0=\text { no medications to } \\
10=\text { morphine }>4 \text { days/week) } \\
\text { Increase in proportion able to work }\end{array}$ & $\begin{array}{l}3.25,24, \text { and } \\
60 \text { months }\end{array}$ \\
\hline
\end{tabular}




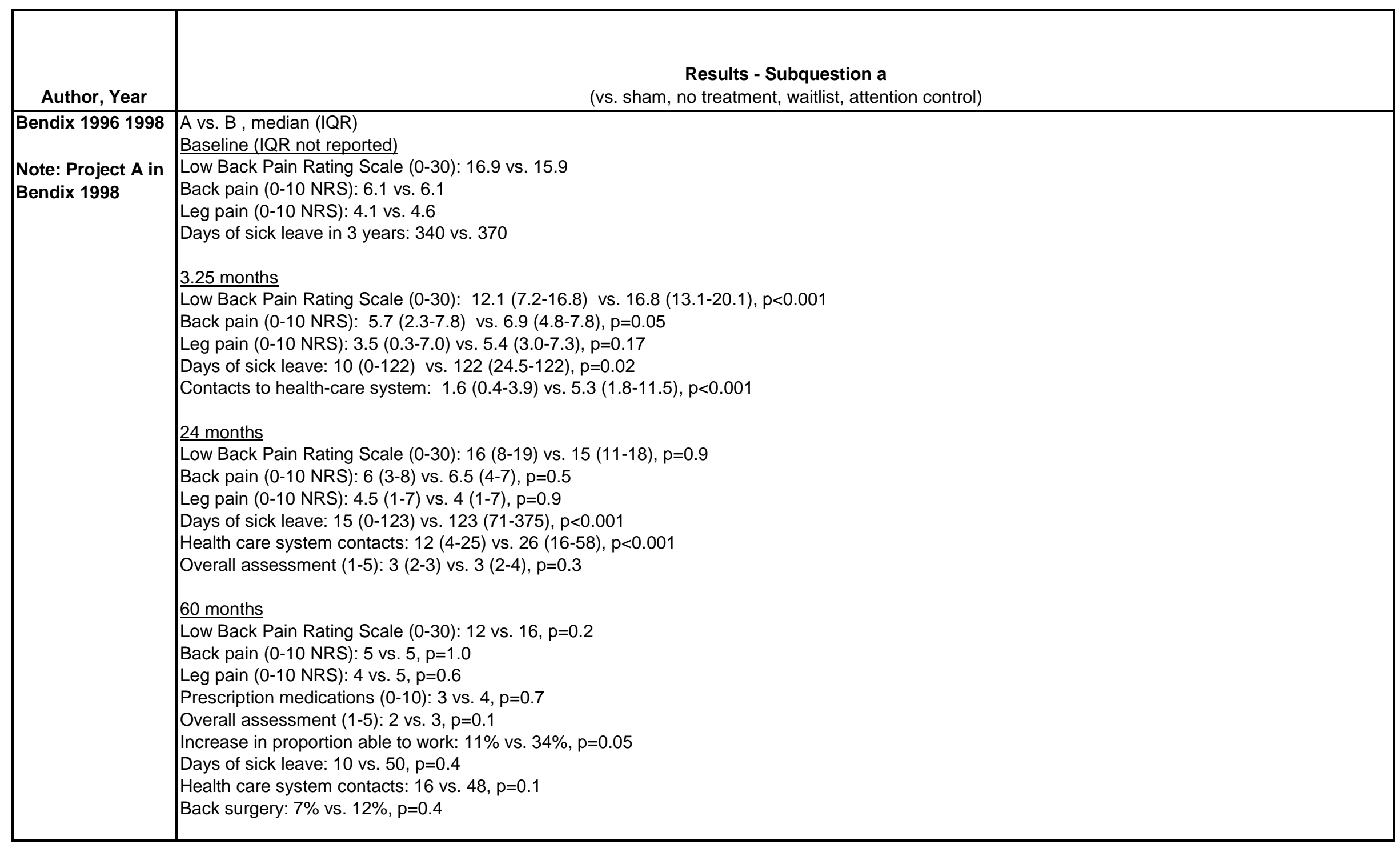




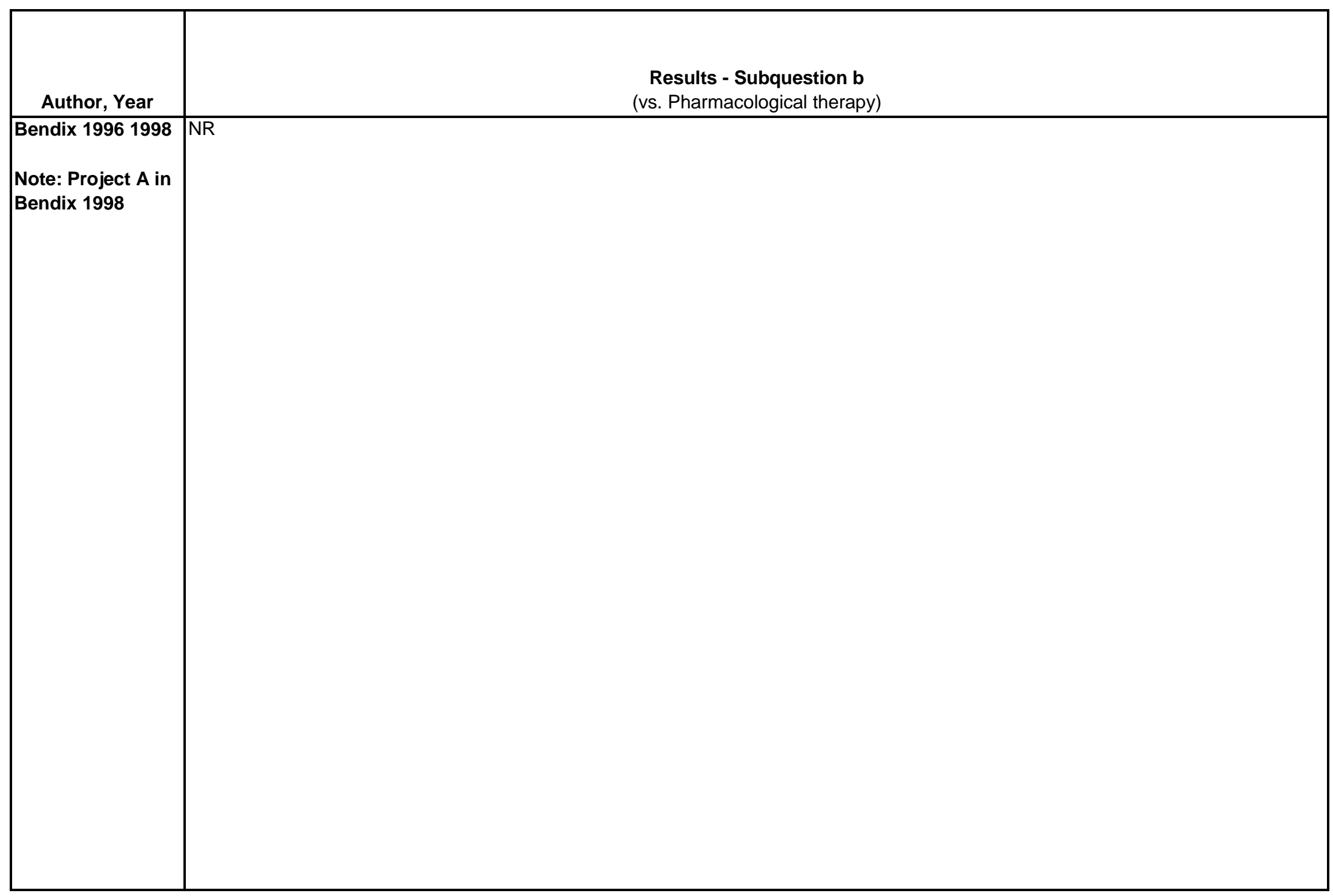

D-75 


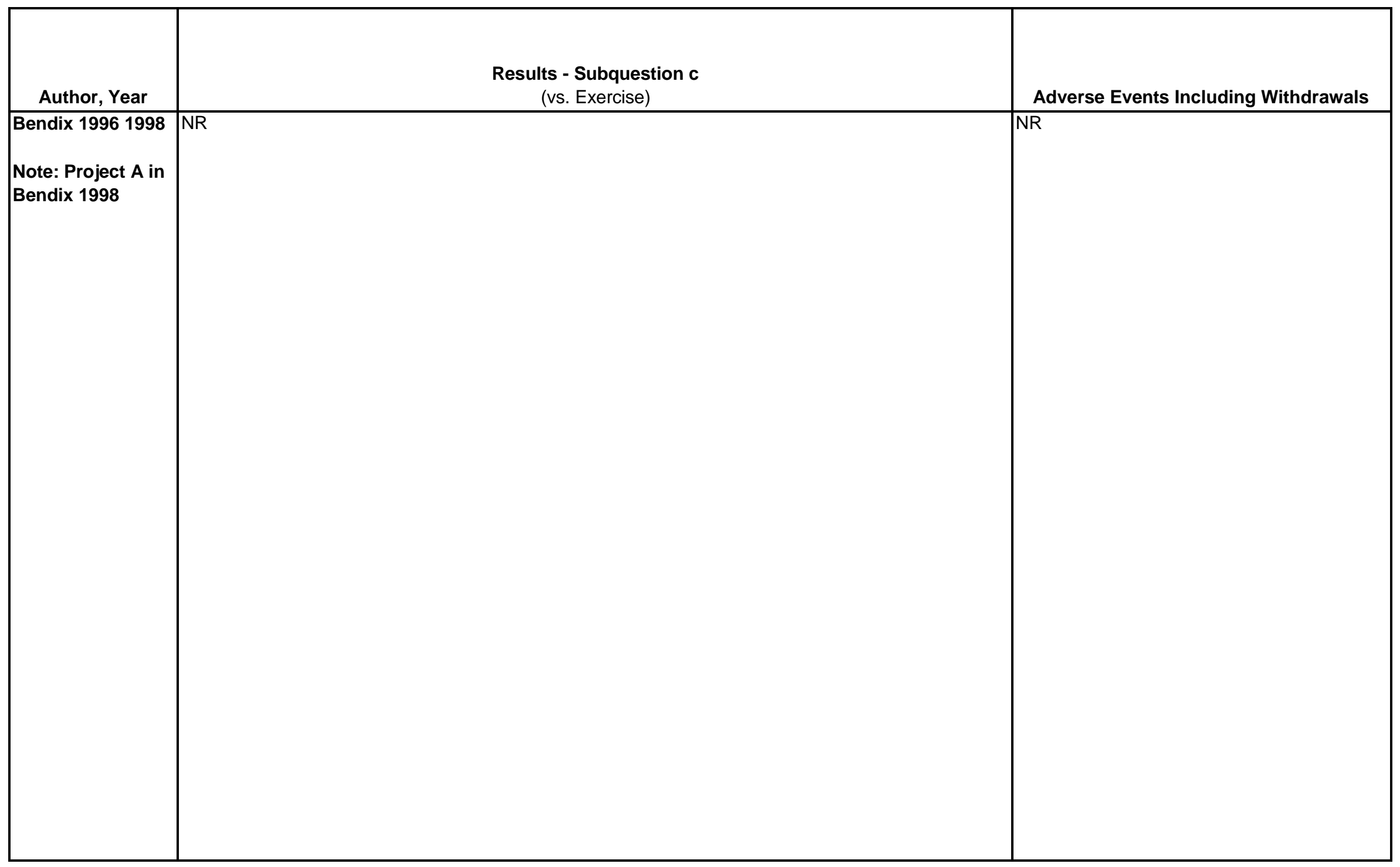

D-76 


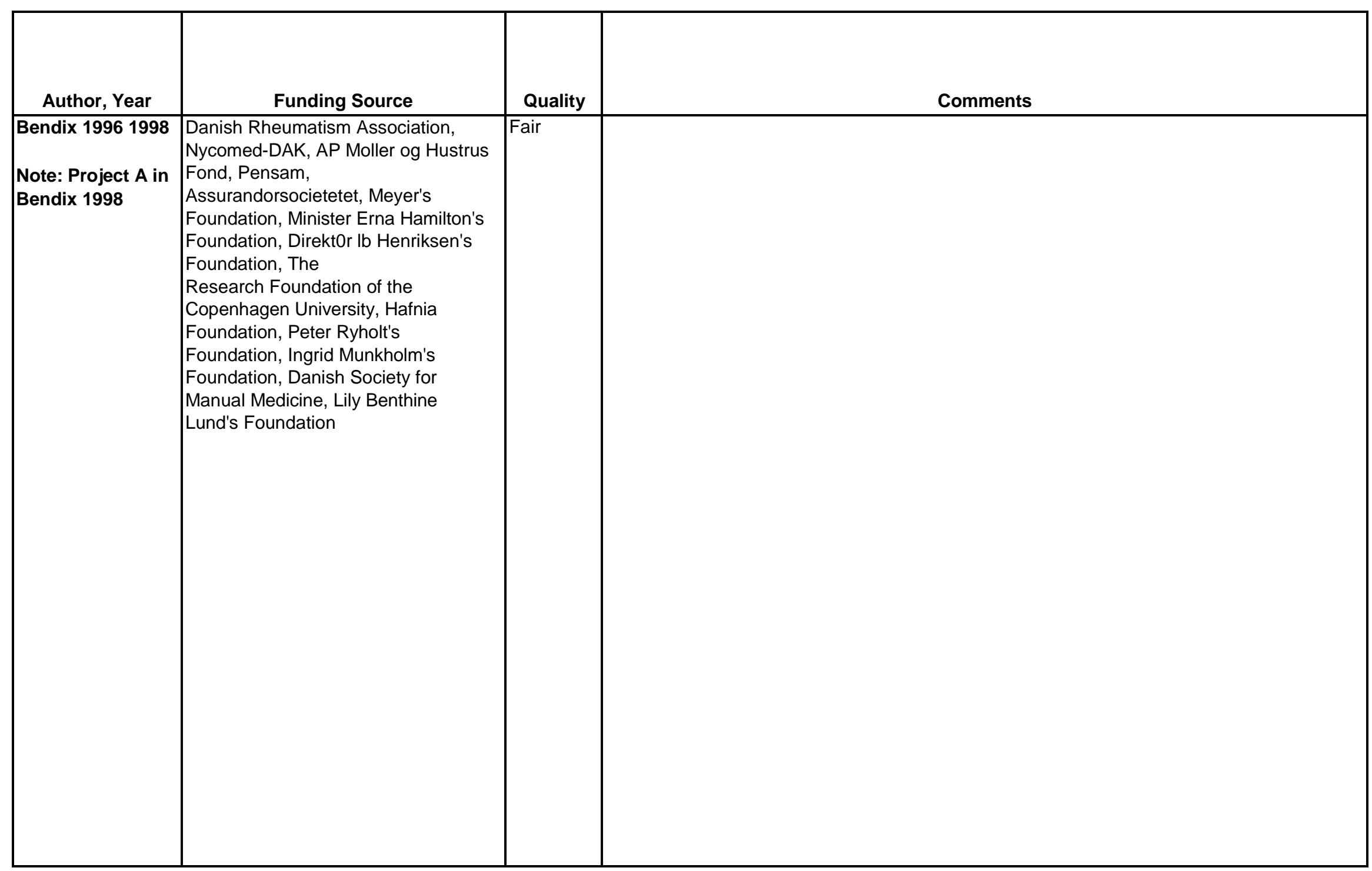




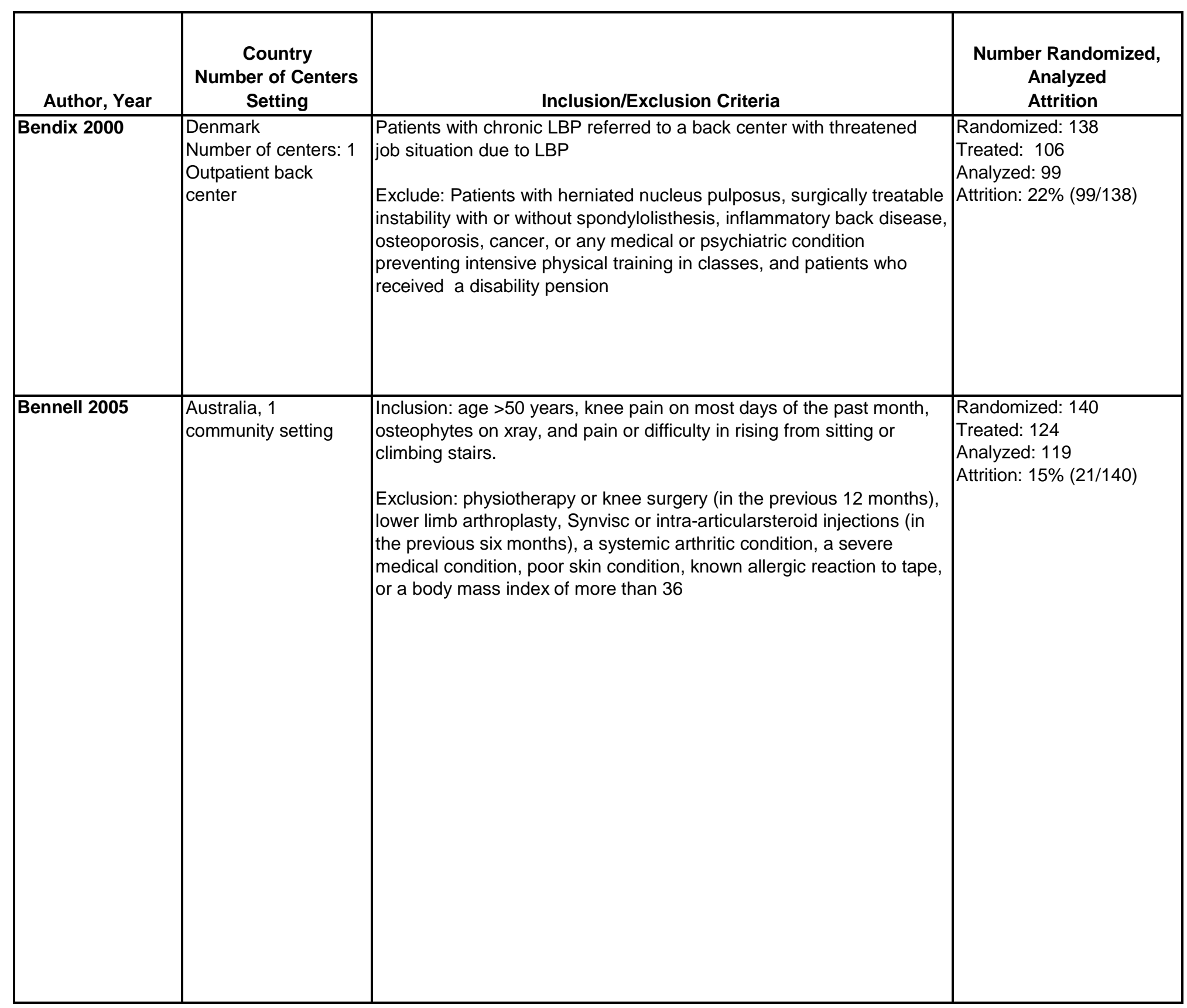




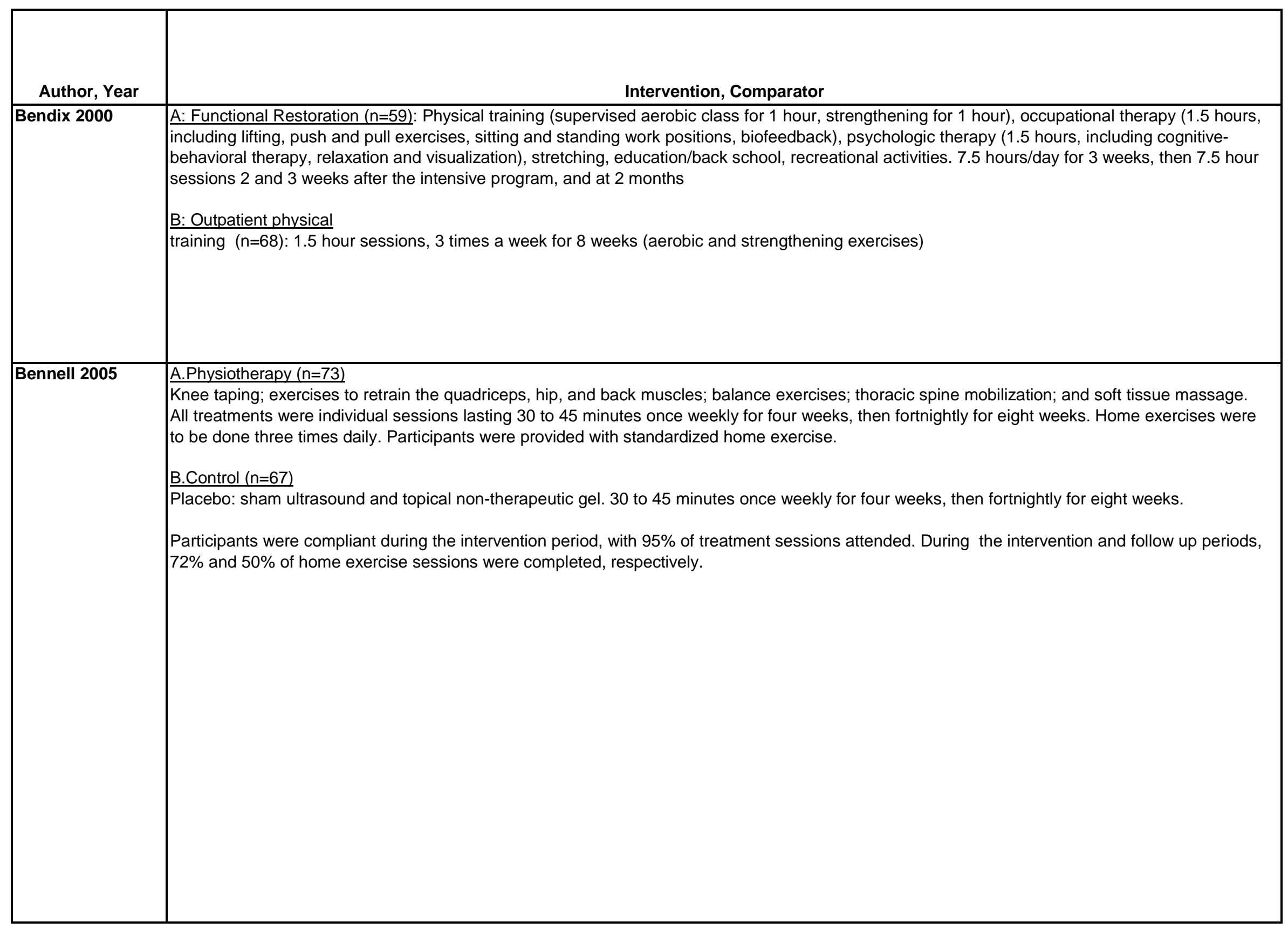




\begin{tabular}{|c|c|c|c|}
\hline Author, Year & Study Participants & Outcome Measures & $\begin{array}{l}\text { Duration of } \\
\text { Followup }\end{array}$ \\
\hline Bendix 2000 & $\begin{array}{l}\text { A vs. B } \\
\text { Age (median): } 40 \text { vs. } 43 \text { years } \\
\text { Female: } 66 \% \text { vs. } 65 \% \\
\text { Race: NR }\end{array}$ & $\begin{array}{l}\text { Back pain }(0-10) \\
\text { Leg pain }(0-10) \\
\text { Low Back Pain Rating Scale }(0-30) \\
\text { Sick leave (days) } \\
\text { Health care contacts }(\#) \\
\text { Overall assessment }(1-5,1=\text { much better and } 5=\text { much } \\
\text { worse) }\end{array}$ & 10 months \\
\hline Bennell 2005 & $\begin{array}{l}\text { A vs B } \\
\text { Age: } 67 \text { vs } 70 \text { years } \\
\text { Female: } 68 \% \text { vs } 66 \% \\
\text { BMl: } 29 \text { vs } 29 \\
\text { Duration of Symptoms: } 9.6 \text { vs } 8.7 \text { years } \\
\text { WOMAC, Physical Function (mean, } 95 \% \text { Cl): } 27.6(25.2,29.9) \text { vs } 28.4 \\
(26.0,30.7) \\
\text { WOMAC, Pain (mean, } 95 \% \text { Cl): } 8.2(7.5,8.9) \text { vs. } 8.0(7.3,8.6) \\
\text { VAS Pain on movement (mean, } 95 \% \text { Cl): } 5.3(4.8,5.7) \text { vs. } 5.2(4.8, \\
5.6) \\
\text { KPS, Severity (mean, } 95 \% \mathrm{Cl}): 16.6(15.5,17.7) \text { vs. } 16.4(15.5,17.3) \\
\text { KPS, Frequency (mean, } 95 \% \text { Cl): } 23.5(22.5,24.5) \text { vs. } 22.8(21.8, \\
23.7) \\
\text { SF-36, Physical Function (mean, } 95 \% \text { Cl): } 40.8(36.0,45.6) \text { vs. } 40.8 \\
(36.6,45.0) \\
\text { SF-36, Bodily Pain (mean, } 95 \% \mathrm{Cl}): 53.7(48.5,58.9) \text { vs. } 57.0(52.8, \\
61.1) \\
\text { SF-36, Role Physical (mean, } 95 \% \mathrm{Cl}): 33.7(24.6,42.8) \text { vs. } 34.7(24.8, \\
44.6) \\
\text { AQoL (mean, } 95 \% \mathrm{Cl}): 0.45(0.41,0.49) \text { vs. } 0.46(0.42,0.51)\end{array}$ & $\begin{array}{l}\text { Responders: global change in pain (proportion of } \\
\text { patients with a score of } 4 \text { or } 5 \text { on a } 5 \text { point Likert scale); } \\
\text { Responders: proportion of patients with a clinically } \\
\text { significant change of } \geq 1.75 \text { on VAS; } \\
\text { WOMAC physical function scores (scale 0-68; higher } \\
\text { score=worse function); } \\
\text { WOMAC pain scores (scale 0-20; higher score=more } \\
\text { severe pain); } \\
\text { Pain on movement over the past week (VAS, 0-10; } \\
\text { higher score=greater pain); } \\
\text { Knee Pain Scale (KPS), Severity subscale (scale 0-36, } \\
\text { higher scores=more severe pain); } \\
\text { Knee Pain Scale (KPS), Frequency subscale (scale 0- } \\
30 \text {, higher scores=more frequent pain); } \\
\text { Short Form } 36 \text { general health questionnaire (SF-36), } \\
\text { Physical Function, Physical Role, and Bodily Pain } \\
\text { subscales (scales 0-100, higher scores=better quality of } \\
\text { life); } \\
\text { Assessment of quality of life (AQoL) index (scale -0.04 } \\
\text { to 1.0, higher scores=greater quality of life) }\end{array}$ & 3 months \\
\hline
\end{tabular}




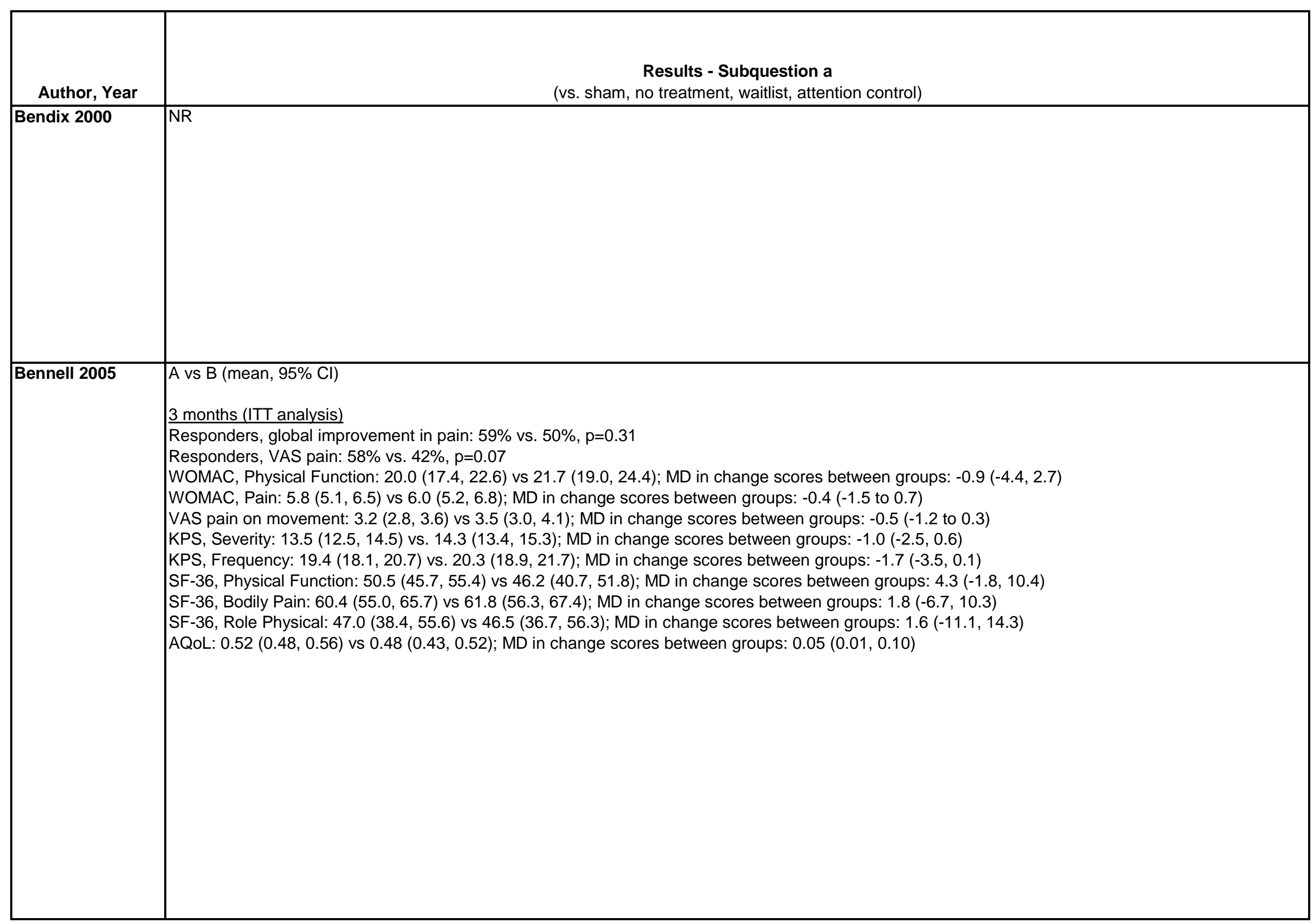




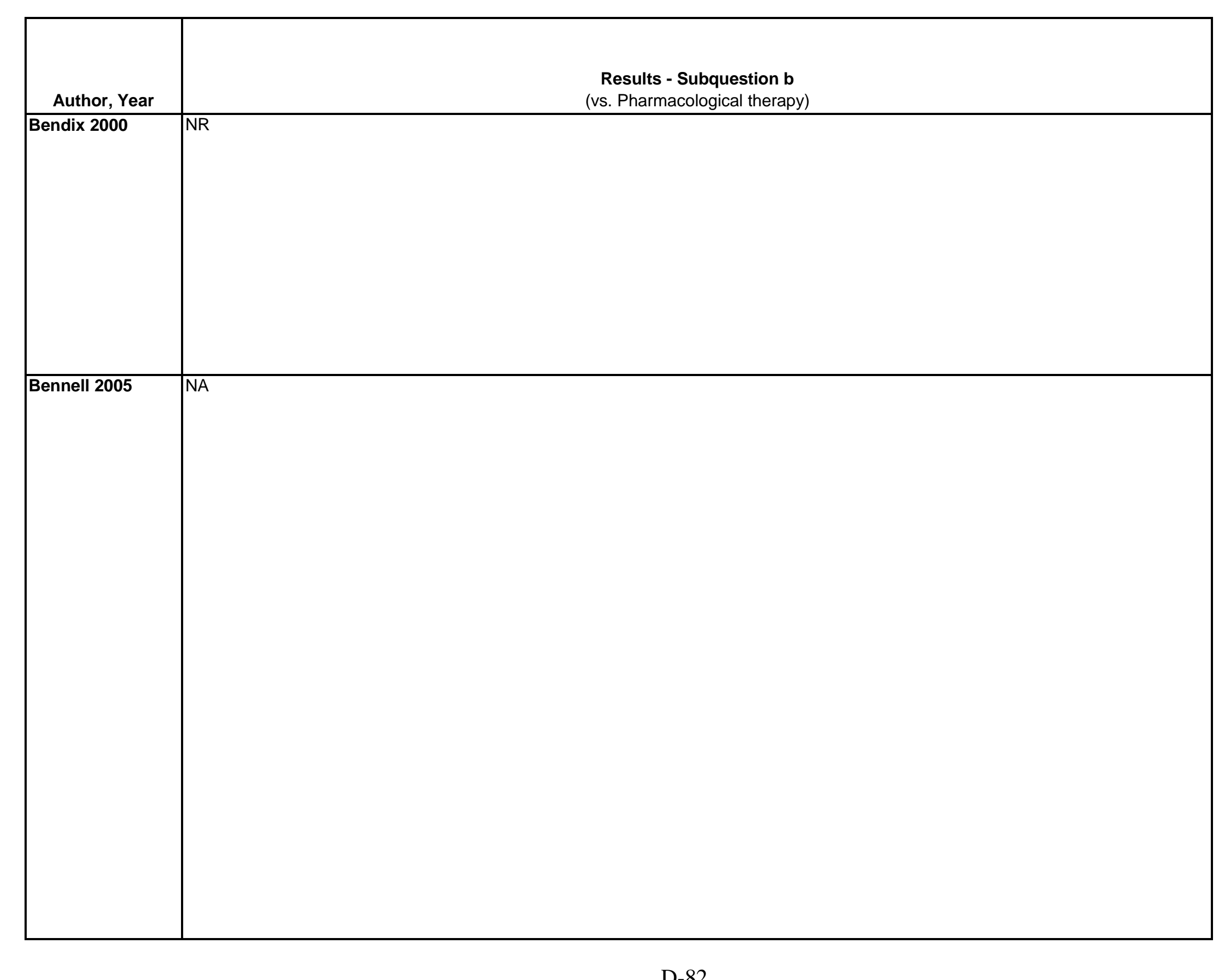




\begin{tabular}{|c|c|c|}
\hline Author, Year & $\begin{array}{c}\text { Results - Subquestion c } \\
\text { (vs. Exercise) }\end{array}$ & Adverse Events Including Withdrawals \\
\hline Bendix 2000 & $\begin{array}{l}\text { A vs. } B \text {, median (IQR) } \\
\text { Baseline not reported } \\
\\
10 \text { months } \\
\text { Back pain }(0-10): 5.1(2-7) \text { vs. } 5.7(3-7.3), p=0.33 \\
\text { Leg pain }(0-10): 2.8(0-7) \text { vs. } 3.5(1-6.3), p=0.43 \\
\text { Low Back Pain Rating Scale, ADL assessment }(0-30): 12(6-21) \text { vs. } 13 \text { (9-19), } p=0.41 \\
\text { Overall assessment (1-5): } 1.7(1-3) \text { vs. } 2.7(2-3.3), p=0.03 \\
\text { Sick leave (days): } 5.5(0-113) \text { vs. } 2.5(0-301), p=1.00 \\
\text { Health care contacts (\#): } 2.5(0-10) \text { vs. } 4(0-12.3), p=0.28 \\
\text { Work capable: } 75 \%(36 / 48) \text { vs. } 69 \%(35 / 51), p=0.64\end{array}$ & NR \\
\hline Bennell 2005 & NA & $\begin{array}{l}\text { A vs B } \\
\text { Withdrawals: } \\
23 \%(17 / 73) \text { vs } 6 \%(4 / 67) ; \text { RR } 6.0(95 \% \mathrm{Cl} \\
1.4,25.5) \\
\text { Group A: Minor skin irritation (48\%), } \\
\text { increased pain with exercises (22\%), pain } \\
\text { with massage (1\%) } \\
\text { Group B: Increased pain (2\%), itchiness and } \\
\text { pain with application of gel }(2 \%) \\
\text { (All were minor and short-lived) }\end{array}$ \\
\hline
\end{tabular}




\begin{tabular}{|c|c|c|c|}
\hline Author, Year & Funding Source & Quality & Comments \\
\hline Bennell 2005 & $\begin{array}{l}\text { National Health and Medical Research } \\
\text { Council (grant No 114277) }\end{array}$ & Fair & $\begin{array}{l}\text { The primary outcomes were reanalyzed using only the data from those who completed the } \\
\text { trial. At } 24 \text { weeks, a greater proportion of physiotherapy participants }(77 \%) \text { reported global } \\
\text { improvement (from baseline) compared with placebo participants }(49 \%)(p=0.005) \text { at this } \\
\text { time. More physiotherapy participants (66\%) reported a clinically relevant reduction in pain } \\
\text { on VAS than did placebo participants (48\%) ( } p=0.027) \text {. } \\
\text { Also report drug use (but not opioids specifically): drug use was similar between the } \\
\text { physiotherapy and placebo groups over the treatment period (analgesics, } 23 \% \mathrm{v} 21 \% \text {; non- } \\
\text { steroidal anti-inflammatory drugs, } 22 \% \mathrm{v} 24 \% \text {; glucosamine, } 3 \% \mathrm{v} 6 \%) \text {. }\end{array}$ \\
\hline
\end{tabular}




\begin{tabular}{|c|c|c|c|}
\hline Author, Year & $\begin{array}{c}\text { Country } \\
\text { Number of centers and setting }\end{array}$ & Inclusion/Exclusion Criteria & $\begin{array}{l}\text { Number randomized, } \\
\text { analyzed } \\
\text { Attrition }\end{array}$ \\
\hline Bennell 2016 & $\begin{array}{l}\text { Australia } \\
\text { Multiple centers, number NR } \\
\text { Type of center NR }\end{array}$ & $\begin{array}{l}\text { Inclusion: } \geq 50 \text { yars old, diagnosis of knee OA fulfilling ACR } \\
\text { criteria, knee pain } \geq 3 \text { months, average pain during previous } \\
\text { week } \geq 40 \text { on } 100 \text { mm VAS scale, at least moderate difficulty } \\
\text { with daily activities (WOMAC physical function subscale } \\
\geq 25 \text { ). } \\
\text { Exclusion: systematic arthritic conditions such as } \\
\text { rheumatoid arthritis, medical condition precluding safe } \\
\text { exercise, self-reported history of serioius mental illness, } \\
\text { self-reported diganosis of current clinical depression, } \\
\text { neurological condition, multiple sclerosis or stroke, knee } \\
\text { surgery or total joint replacement within past } 6 \text { months, } \\
\text { current or previous use within } 3 \text { months of oral or intra- } \\
\text { articular corticosteroid use, physiotherapy, chiropractic or } \\
\text { acupuncture treatment or exercises specifically for the knee } \\
\text { in past } 6 \text { months, walking exercise for }>30 \text { minutes } \\
\text { continuously daily, }>2 \text { times per week of structured and/or } \\
\text { supervised exercise program, participating in or previous } \\
\text { participation in a formal PCST program, inability to walk } \\
\text { unaided, inability to comply with the study protocol }\end{array}$ & $\begin{array}{l}\text { Randomized: } 149 \\
\text { Analyzed: } 122 \\
\text { Attrition: } 18 \%(27 / 149)\end{array}$ \\
\hline
\end{tabular}




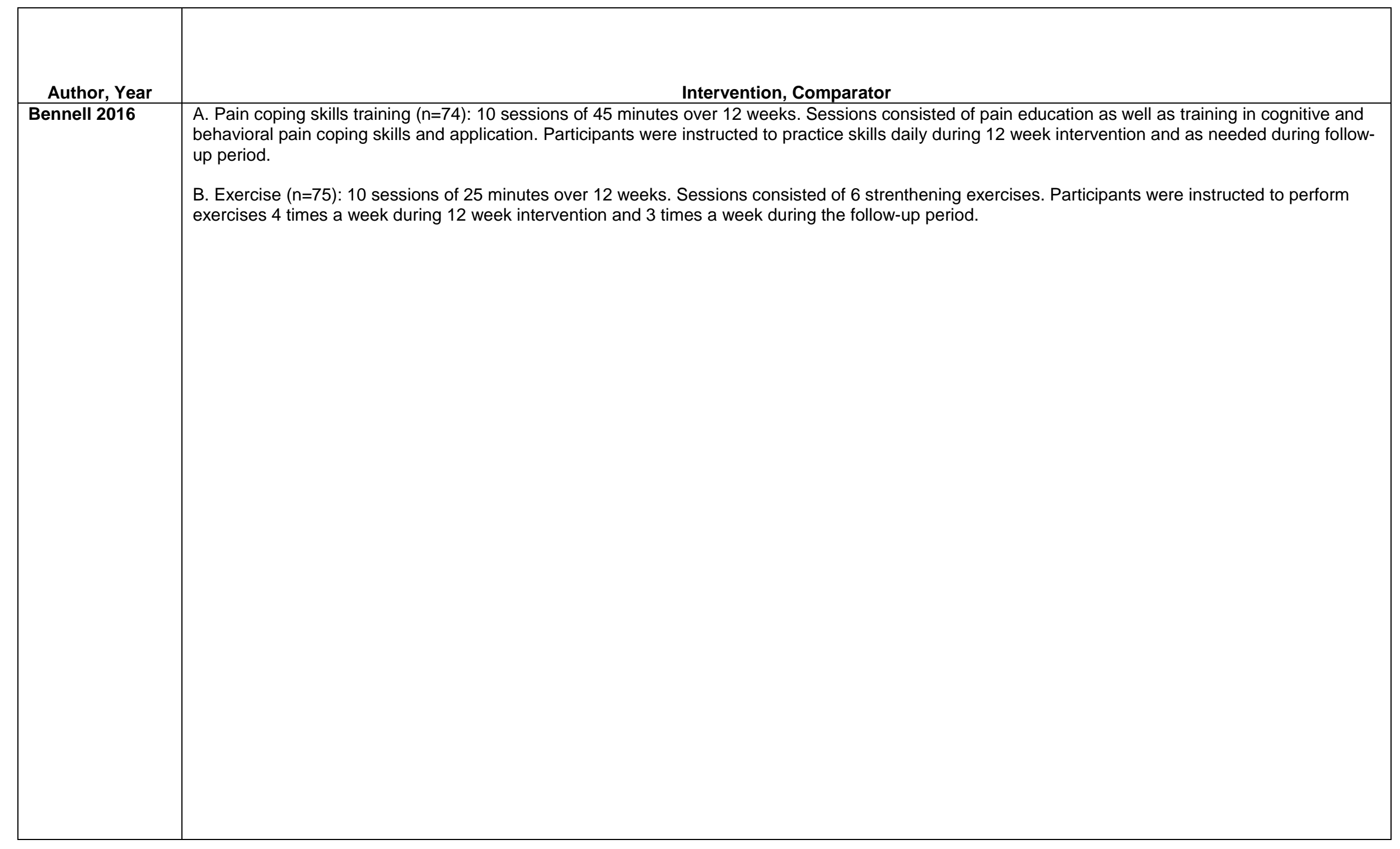




\begin{tabular}{|c|c|c|c|}
\hline Author, Year & Study participants & Outcome measures & $\begin{array}{l}\text { Duration of } \\
\text { followup }\end{array}$ \\
\hline Bennell 2016 & $\begin{array}{l}\text { A vs B } \\
\text { Age, years: } 63 \text { vs } 63 \\
\text { Female: } 61 \% \text { vs } 59 \% \\
\text { Duration of symptoms, years, median (IQR): } 6 \text { (4-10) vs } 6 \text { (3-10) } \\
\text { Radiographic disease severity, } \% \text { : } \\
\quad \text { Grade } 2: 45 \% \text { vs } 40 \% \\
\text { Grade } 3: 28 \% \text { vs } 25 \% \\
\text { Grade } 4: 27 \% \text { vs } 35 \% \\
\text { Opioid use, } \%: 4 \% \text { vs } 1 \% \\
\text { Employment status, \%: } \\
\quad \text { Currently employed: } 50 \% \text { vs } 52 \% \\
\text { Unable to work due to health: } 4 \% \text { vs } 12 \% \\
\text { Retired: } 39 \% \text { vs } 31 \% \\
\text { Not employed: } 7 \% \text { vs } 4 \% \\
\text { Comorbidities: } \\
\quad \text { Heart disease/hypertension: } 38 \% \text { vs } 41 \% \\
\text { Osteoporosis/osteopenia: } 14 \% \text { vs } 11 \% \\
\quad \text { Depression: } 10 \% \text { vs } 8 \% \\
\text { Stomach ulcer/pains: } 11 \% \text { vs } 13 \% \\
\text { Cancer: } 12 \% \text { vs } 4 \% \\
\text { WOMAC physical function: } 35.0 \text { (7.4) vs } 34.3(7.2) \\
\text { WOMAC pain: } 8.7(2.8) \text { vs } 8.6(2.7) \\
\text { Pain overall VAS: } 58.7(12.6) \text { vs } 59.1(12.4) \\
\text { Pain with walking VAS: } 61.3(17.3) \text { vs } 60.9(17.1) \\
\text { DASS21 depression scale: } 6.4(8.5) \text { vs } 5.7(7.1) \\
\text { DASS21 anxiety scale: } 6.5(6.5) \text { vs } 5.4(6.5) \\
\text { AQoL-6D: } 0.71 \text { (0.16) vs } 0.71(0.14)\end{array}$ & $\begin{array}{l}\text { WOMAC physical function (0-68, higher } \\
\text { score=lower function); WOMAC pain (0-20, } \\
\text { higher score=higher pain); pain overall VAS } \\
\text { (0-100, higher score=higher pain); pain on } \\
\text { walking VAS (0-100, higher score=higher } \\
\text { pain); DASS21 depression scale ( } 0-42 \text {, } \\
\text { higher score=higher depression); DASS21 } \\
\text { anxiety scale (0-42, higher score=higher } \\
\text { anxiety); patient overall global change (1-7, } \\
\text { higher score=higher improvement); patient } \\
\text { function global change (1-7, higher } \\
\text { score=higher improvement); patient pain } \\
\text { global change (1-7, higher score=higher } \\
\text { improvement) }\end{array}$ & 5 and 9 months \\
\hline
\end{tabular}




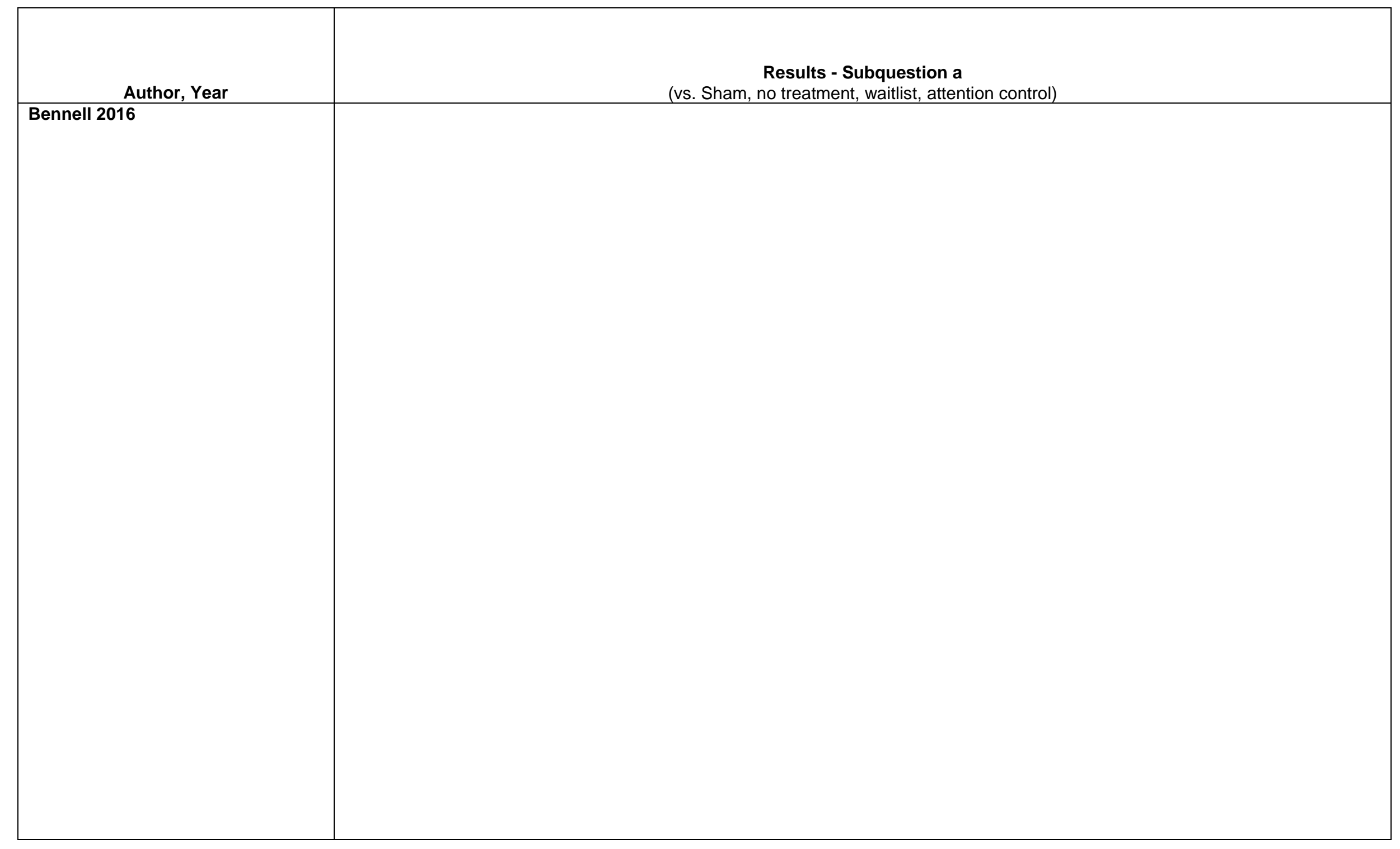




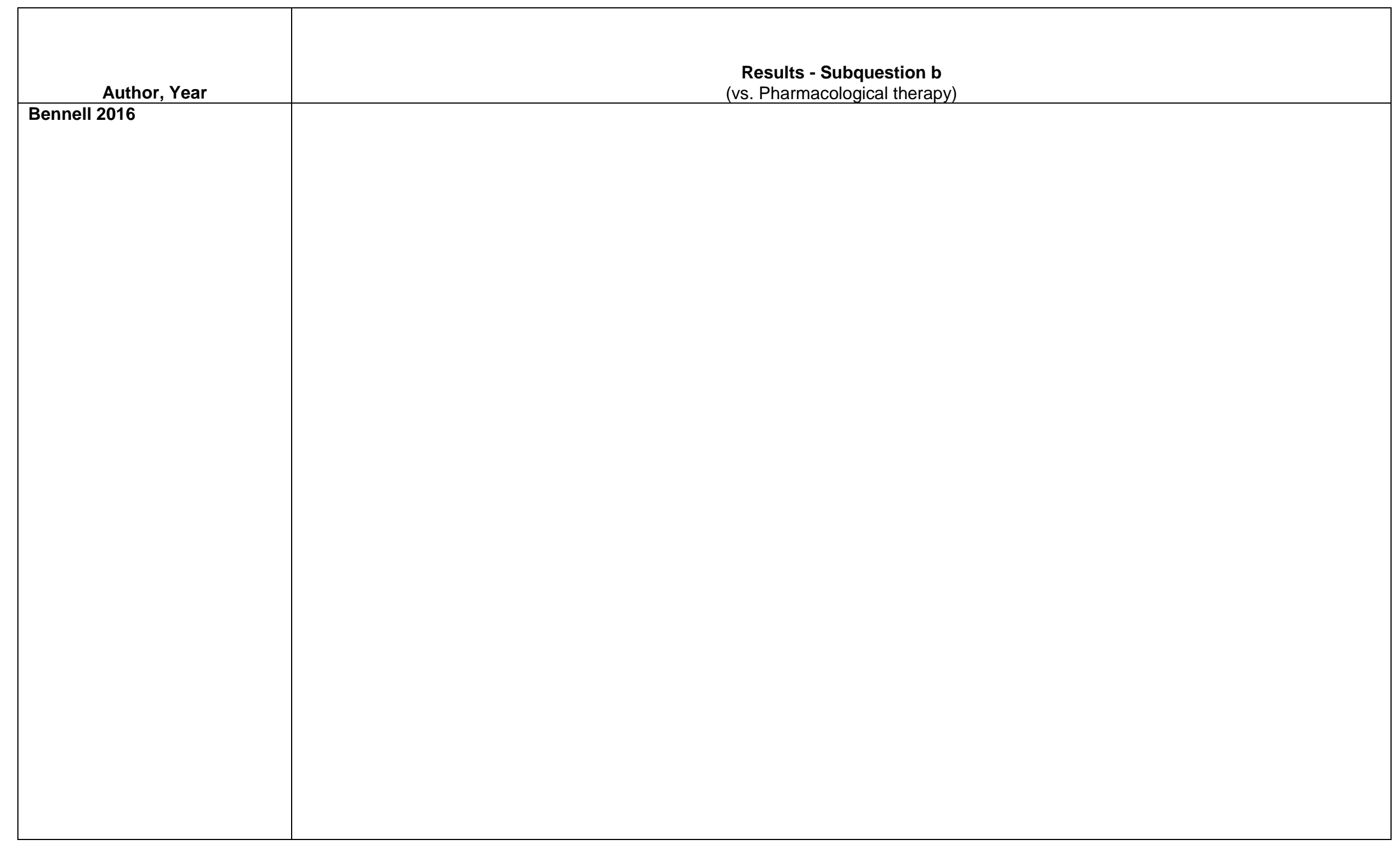




\begin{tabular}{|c|c|c|}
\hline Author, Year & $\begin{array}{c}\text { Results - Subquestion c } \\
\text { (vs. Exercise) }\end{array}$ & $\begin{array}{l}\text { Adverse events including } \\
\text { withdrawls }\end{array}$ \\
\hline Bennell 2016 & 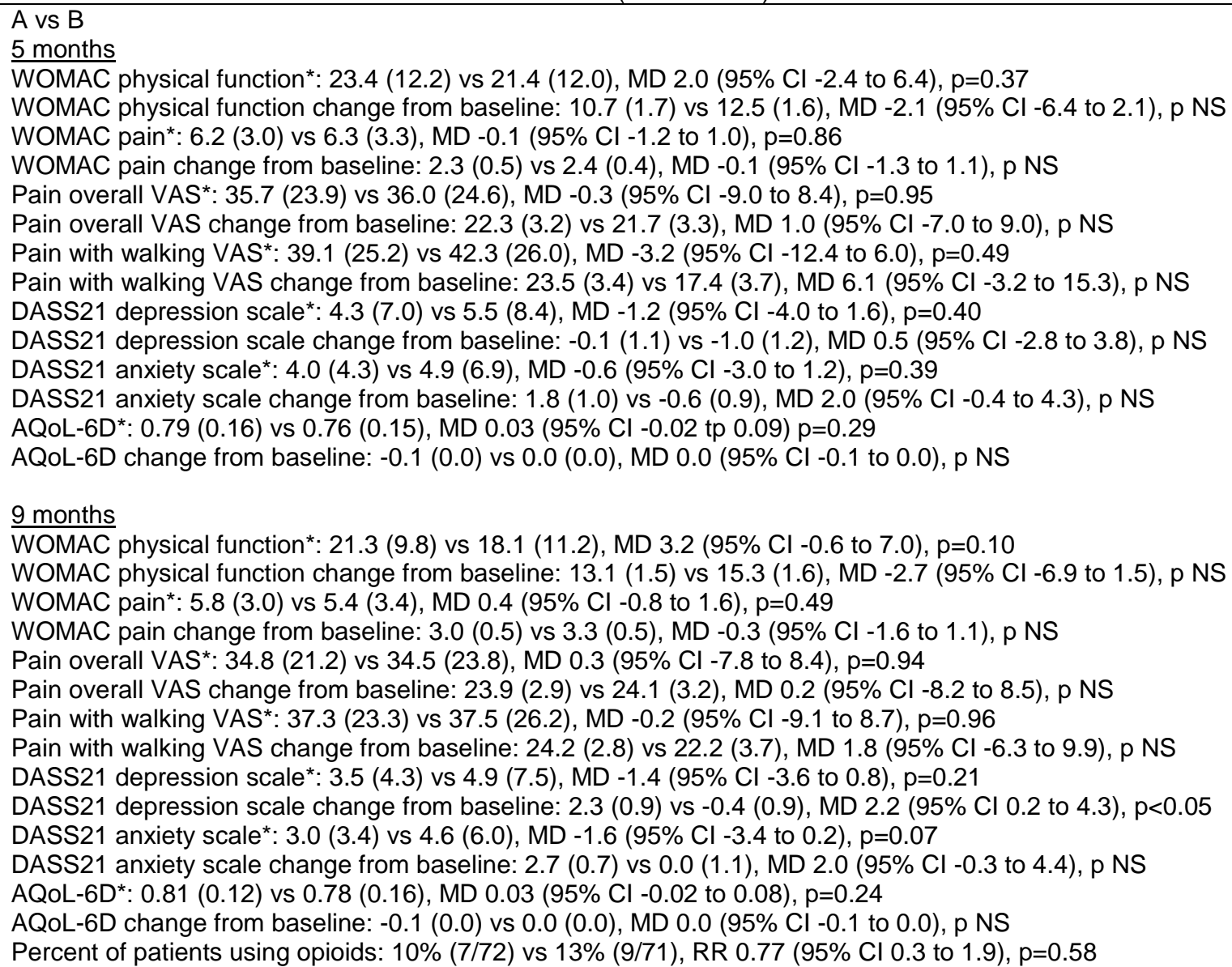 & 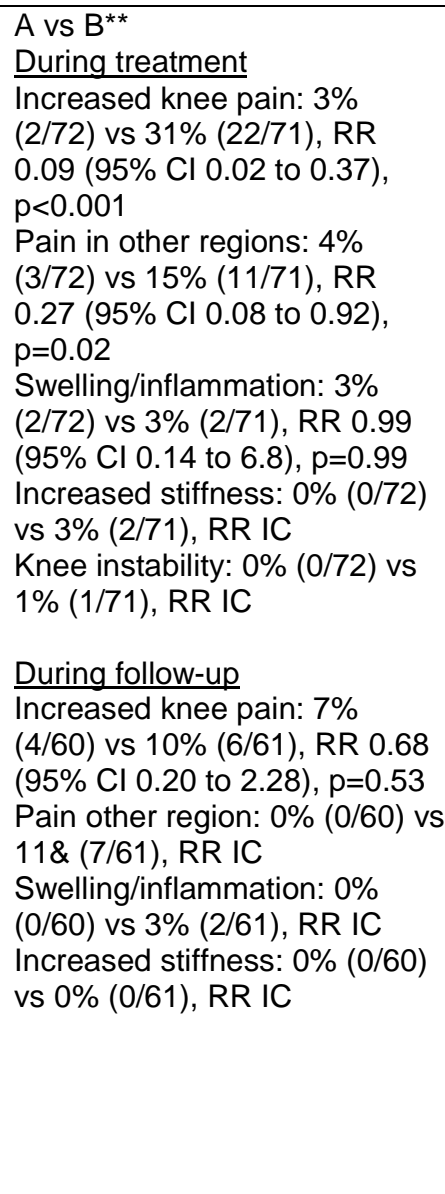 \\
\hline
\end{tabular}




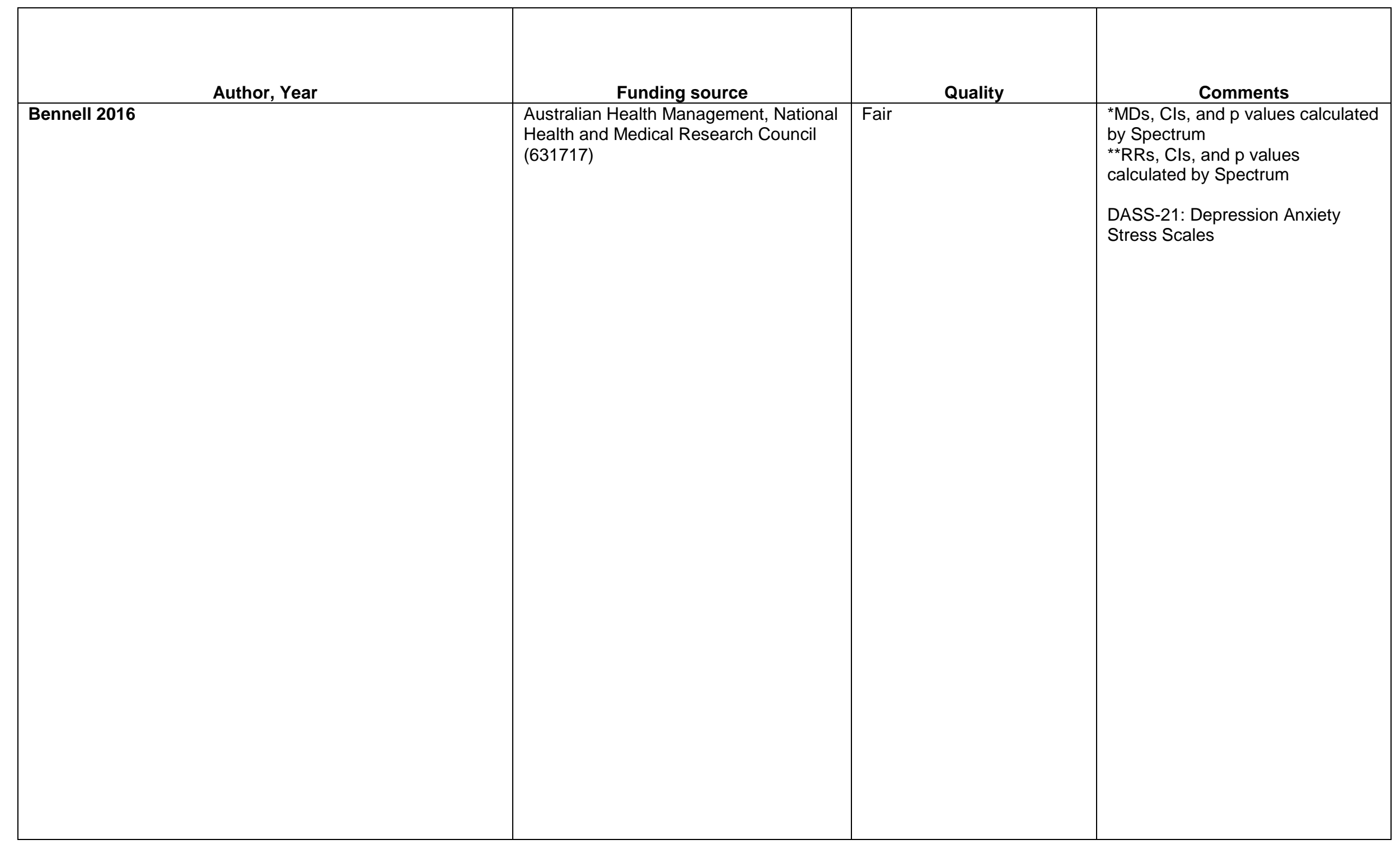




\begin{tabular}{|c|c|c|c|}
\hline Author, Year & $\begin{array}{l}\text { Country Number } \\
\text { of Centers } \\
\text { Setting }\end{array}$ & Inclusion/Exclusion Criteria & $\begin{array}{l}\text { Number Randomized, } \\
\text { Analyzed Attrition }\end{array}$ \\
\hline Berman 1999 & $\begin{array}{l}\text { USA, University of } \\
\text { Maryland }\end{array}$ & $\begin{array}{l}\text { Inclusion criteria: } 50+\text { years old, diagnosis of knee OA by ACR criteria, at least moderate pain } \\
6+\text { months, taking analgesics or NSAIDs of } 1+\text { month, Kellgren-Lawrence grade 2+ OA by xray, } \\
\text { Exclusion criteria: intra-articular steroid injection within } 4 \text { weeks, severe or uncontrolled } \\
\text { concomitant illness, history of bleeding diathesis or use of anticoagulant }\end{array}$ & $\begin{array}{l}\text { Randomized: } 73 \\
\text { Treated: } 73 \\
\text { Analyzed: } 73 \text { (ITT, last carrie } \\
\text { forward) } \\
\text { Attrition at } 1 \text { month: } 5 \% \text { (4/7 } \\
\text { Attrition at } 2 \text { months: } 11 \% \text { (8 } \\
\text { Attrition at } 3 \text { months: } 21 \% \\
\text { (15/73) (see comments) }\end{array}$ \\
\hline Berman 2004 & \begin{tabular}{|l} 
United States \\
Multi-site \\
two outpatient clinics at \\
an academic teaching \\
hospital and one clinical \\
trials facility
\end{tabular} & $\begin{array}{l}\text { Inclusion: age } 50 \text { years or older, diagnosis of osteoarthritis of the knee, radiographic evidence } \\
\text { of at least } 1 \text { osteophyte at the tibiofemoral joint (Kellgren-Lawrence grade } \geq 2 \text { ), moderate or } \\
\text { greater clinically significant knee pain on most days during past month } \\
\text { Exclusion: presence of serious medical conditions that precluded participation in study, } \\
\text { bleeding disorders that might contraindicate acupuncture, intra-articular corticosteroid or } \\
\text { hyaluronate injections (as well as any knee surgeries or concomitant use of topical capsaicin } \\
\text { cream) during past } 6 \text { months, previous experience with acupuncture, or any planned events } \\
\text { (including total knee replacement) that would interfere with participation in the study during the } \\
\text { following } 26 \text { weeks. }\end{array}$ & $\begin{array}{l}\text { Randomized: } 381 \\
\text { Analyzed: } 283 \\
\text { Attrition: } 23.8 \%(102 / 381)\end{array}$ \\
\hline Beurskens 1997 & $\begin{array}{l}\text { Netherlands } \\
\text { Number of centers: } 1\end{array}$ & $\begin{array}{l}\text { Patients with at least } 6 \text { weeks of nonspecific LBP, no traction treatment } \\
\text { Exclude: Patients whose conditions improved in the previous } 2 \text { weeks }\end{array}$ & $\begin{array}{l}\text { Randomized: } 151 \\
\text { Treated: } 150 \\
\text { Analyzed:150 } \\
\text { Attrition: <.0006\% (1/151) । } \\
\text { done }\end{array}$ \\
\hline
\end{tabular}




\begin{tabular}{|c|c|}
\hline Author, Year & Intervention, Comparator \\
\hline Berman 1999 & $\begin{array}{l}\text { A.Acupuncture }(n=37) \text { : based on the Traditional Chinese Medicine theory for treating } B i \text { syndrome; needles }(0.22 \mathrm{~mm}, 34 \text { gauge }) \text { inserted to a depth } \\
\text { of } 0.4-0.6 \text { inches at } 5 \text { local points and } 4 \text { distal points until elicitation of de qi; two electrodes were attached to needles at local points, electrical } \\
\text { stimulation with } 2.5 \text { to } 4 \mathrm{~Hz} \text {, pulses of } 1.0 \mathrm{~ms} \text { duration was used for } 20 \text { minutes; patients asked to remain on their baseline analgesic/anti- } \\
\text { inflammatory regimens and not to begin any new physiotherapy or exercise programs } \\
\text { B. Usual care }(n=36) \text { : asked to remain on their current level of oral therapy throughout the trial } \\
\text { Both groups received } 20 \text { minute treatments, } 2 / \text { week for } 8 \text { weeks }\end{array}$ \\
\hline Berman 2004 & $\begin{array}{l}\text { A. Acupuncture ( } \mathrm{n}=186) \text { : Gradually tapering treatment schedule }-8 \text { weeks of } 2 \text { treatments per week, followed by } 2 \text { weeks of } 1 \text { treatment per week, } 4 \\
\text { weeks of } 1 \text { treatment every other week, and } 12 \text { weeks of } 1 \text { treatment per month. Total of } 26 \text { weeks, } 25 \text { possible sessions. Additionally, } \\
\text { acupuncturists applied electrical stimulation at knee points Xiyan at low frequency ( } 8 \mathrm{~Hz} \text { and square biphasic pulses ( } 0.5 \text { ms puls width) for } 20 \\
\text { minutes. Screens at the waist were used in both groups to facilitate blinding and prevent observation of the procedures at the knee. } \\
\text { Acupoints: } 5 \text { local and } 4 \text { distal points. if both knees were affected, } 9 \text { needles were inserted in each leg } \\
\text { Needles: } 32 \text {-gauge }(0.25 \mathrm{~mm}) \\
\text { Insertion depth: } 0.3 \text { to } 1.0 \text { inch } \\
\text { B. Sham acupuncture ( } n=183) \text { : Overall schedule identical to group } 1 \text {. Modified combined insertion and noninsertion procedure. inserted } 3 \text { needles } \\
\text { into sham points in the abdominal area, } 3 \mathrm{~cm} \text { lateral and above the umbilicus and then applied } 2 \text { pieces of adhesive tape next to needles. in addition } \\
\text { they tapped a mock plastic needle guiding tube on the surface of the } 9 \text { 'true' acupoints in the leg to produce some discernible sensation then } \\
\text { immediately applied a needle with adhesive tape to the dermal surface without insertion. } 20 \text { minutes for each point. Additionally, a mock electric } \\
\text { stimulation was attached to sham needles at the knee. Screens at the waist were used in both groups to facilitate blinding and prevent observation of } \\
\text { the procedures at the knee. } \\
\text { Acupoints: } 5 \text { local and } 4 \text { distal points. if both knees were affected, } 9 \text { needles were inserted in each leg }\end{array}$ \\
\hline Beurskens 1997 & $\begin{array}{l}\text { A.Continuous traction }(n=77) \text { : Traction with Eltrac, DIMEC Delft Instrument, minimum force of } 35 \% \text { and maximum of } 50 \% \text { of body weight, } 12 \\
\text { sessions in } 5 \text { weeks, } 20 \text { minutes per session } \\
\text { B.Sham traction }(n=74) \text { : Similar treatment but } 20 \% \text { body weight }\end{array}$ \\
\hline
\end{tabular}




\begin{tabular}{|c|c|c|c|}
\hline Author, Year & Study Participants & Outcome Measures & $\begin{array}{c}\text { Duration of } \\
\text { Followup }\end{array}$ \\
\hline Berman 1999 & $\begin{array}{l}\text { A vs B } \\
\text { Age: } 66 \text { vs. } 66 \\
\text { Female: } 47 \% \text { vs. } 72 \% \\
\text { Caucasian: } 92 \% \text { vs. } 74 \% \\
\text { BMl: } 32 \text { vs. } 32 \\
\text { Duration of symptoms: } 7.5 \text { vs. } 6.9 \text { years WOMAC Total: } 48.4 \\
\text { (16.1) vs. } 51.4(12.3) \\
\text { WOMAC Disability: } 34.3(12.1) \text { vs. } 34.4(9.2) \\
\text { WOMAC Pain: } 9.6 \text { (3.3) vs. } 9.9(2.8) \\
\text { Lequesne Index: } 11.7(3.5) \text { vs. } 12.3(3.5)\end{array}$ & $\begin{array}{l}\text { WOMAC index (scales unclear; higher scores=worse disability) } \\
\text { Lequesne scale }(0-24, \text { higher scores=worse disability })\end{array}$ & 1 month \\
\hline Berman 2004 & $\begin{array}{l}\text { A vs B } \\
\text { Age, years: } 65.2(8.4) \text { vs } 66.2(8.7) \\
\text { Female: } 63.2 \% \text { vs } 61.8 \% \\
\text { non-Hispanic white: } 70 \% \text { vs. } 70.7 \% \\
2 \text { Target Knees: } 25.0 \% \text { vs. } 28.9 \% \\
\text { Length of diagnosis of osteoarthritis } \\
<5 \text { years (\%): } 53.8 \% \text { VS. } 53 \% \\
6-10 \text { years (\%): } 19.9 \% \text { vs. } 18.0 \% \\
\text { > } 10 \text { years (\%): } 25.8 \% \text { vs. } 29.0 \% \\
\% \text { using opioids: } 5.5 \% \text { vs. } 5.0 \% \\
\% \text { using simple analgesics: } 10.2 \% \\
\text { WOMAC Function: } 31.31(12.06) \text { vs. } 31.29(12.00) \\
\text { WOMAC Pain: } 8.92(3.42) \text { vs. } 8.90(3.39) \\
\text { SF-36 Physical Health Score: } 48.69(20.44) \text { vs. } 49.65(19.92) \\
\text { Patient Global Assessment: } 2.95(0.97) \text { vs. } 3.08(0.88)\end{array}$ & & \\
\hline \begin{tabular}{|l|} 
Beurskens \\
1997
\end{tabular} & $\begin{array}{l}\text { A vs. B } \\
\text { Age (mean): } 39 \text { vs. } 42 \text { years } \\
\text { Female: } 44 \% \text { vs. } 43 \% \text { Race: NR } \\
\text { Chronic pain }>6 \text { months: } 52 \% \text { vs. } 54 \% \\
\text { Previous LBP: } 86 \% \text { vs. } 77 \% \\
\text { General Heath Questionnaire } 0-36 \text { (mean): } 8.3 \text { vs. } 8.6 \\
\text { Severity, First main complaint } 100 \mathrm{~mm} \text { VAS (mean): } 75 \text { vs. } 73 \\
\text { Severity, Second main complaint } 100 \mathrm{~mm} \text { VAS (mean): } 74 \text { vs. } \\
70 \text { Pain score during measurement, } 100 \mathrm{~mm} \text { VAS (mean): } 61 \\
\text { vs. } 55 \text { Pain score last week, } 100 \mathrm{~mm} \text { VAS (mean): } 62 \text { vs. } 62 \\
\text { ADL disability VAS (mean): } 67 \text { vs. } 70 \text { RDQ (mean): } 12 \text { vs. } 12\end{array}$ & $\begin{array}{l}\text { Global perceived effect: ratings on a } 7 \text { point scale, dichotomized in } \\
\text { "improved" (completely recovered and much improved vs. "not improved } \\
\text { (slightly improved a, not changed, slightly worsened, and vastly worsened) } \\
\text { First main complaint: } 100 \mathrm{~mm} \text { VAS (best score 0, worse score 100) } \\
\text { Second main complaint: } 100 \mathrm{~mm} \text { VAS (best score 0, worse score 24) } \\
\text { Roland Disability: } 24 \text { item questionnaire (best score 0, worst score 10) } \\
\text { Pain at the moment: } 100 \mathrm{~mm} \text { VAS (best score 0, worse score 100) } \\
\text { Pain last week: } 100 \mathrm{~mm} \text { VAS (best score 0, worse score 100) } \\
\text { Severity of LBP: scored on an } 11 \text { point scale (best score 0, worst score 10) } \\
\text { Range of motion: degrees (mean) } \\
\text { Activities of Daily Living (ADL) disability: } 100 \mathrm{~mm} \text { VAS (best score 0, worse } \\
\text { score 100) } \\
\text { Work absence: days (mean) } \\
\text { Medical consumption: number and \% }\end{array}$ & $\begin{array}{l}1.75 \text { and } 5 \\
\text { months }\end{array}$ \\
\hline
\end{tabular}




\begin{tabular}{|c|c|}
\hline Author, Year & $\begin{array}{l}\text { Results - Subquestion a } \\
\text { (vs. sham, no treatment, waitlist, attention control) }\end{array}$ \\
\hline Berman 1999 & $\begin{array}{l}\text { A vs. B } \\
1 \text { month } \\
\text { WOMAC Total: } 31.58(18.27) \text { vs. } 50.43(14.1), \mathrm{p}<0.001 ; \mathrm{MD}-18.9(95 \% \mathrm{Cl}-26.5,-11.2) \\
\text { WOMAC Disability: } 23.17(13.92) \text { vs. } 36.78(10.71) ; \mathrm{p}<0.001 ; \mathrm{MD}-13.6(95 \% \mathrm{Cl}-19.4,-7.8) \\
\text { WOMAC Pain: } 5.56(3.44) \text { vs. } 9.51(3.01), \mathrm{p}<0.001 ; \mathrm{MD}-4.0(95 \% \mathrm{Cl}-5.5,-2.4) \\
\text { Lequesne Index: } 9.34 \text { (4.09) vs. } 12.41(3.47), \mathrm{p}<0.001 ; \mathrm{MD}-3.1(95 \% \mathrm{Cl}-4.8,-1.3)\end{array}$ \\
\hline Berman 2004 & $\begin{array}{l}\text { A vs. } \mathrm{B} \\
6 \text { months ( } \mathrm{n}=142 \text { vs } \mathrm{n}=141) \\
\Delta \text { from baseline, WOMAC Function: }-12.42(1.12) \text { vs. }-9.88(0.93), \mathrm{p}<0.01 \\
\Delta \text { from baseline, WOMAC Pain: }-3.79(0.33) \text { vs. }-2.92(0.30), \mathrm{p}<0.01 \\
\\
\Delta \text { from baseline, SF-36 Physical Health Score: } 10.7(1.6) \text { vs. } 8.2(1.5), \mathrm{p}=0.21 \\
\Delta \text { from baseline, Patient Global Assessment: } 0.45(0.08) \text { vs. } 0.19(0.09), \mathrm{p}=0.02\end{array}$ \\
\hline Beurskens 1997 & 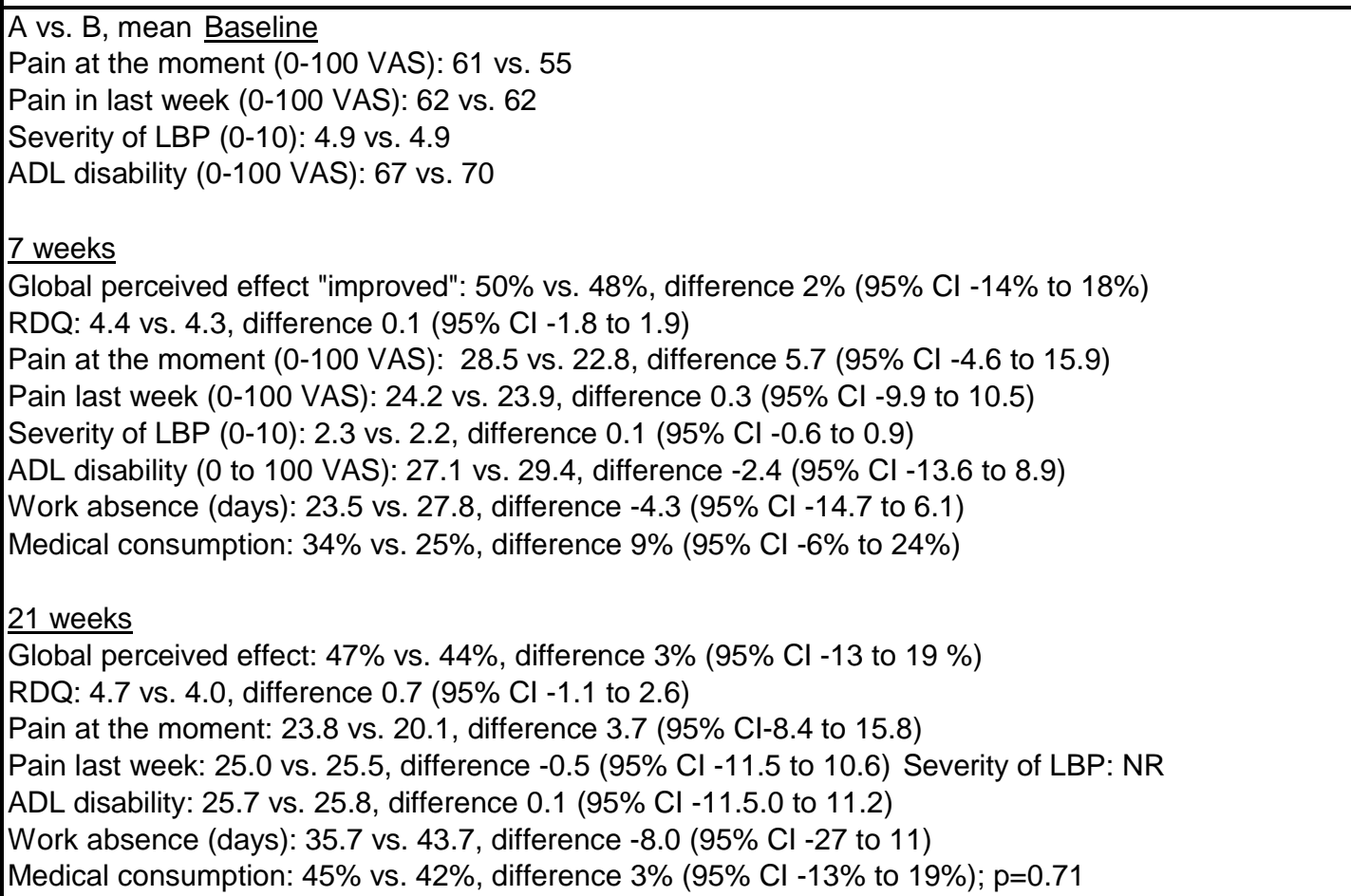 \\
\hline
\end{tabular}




\begin{tabular}{|l|l|}
\hline Author, Year & \multicolumn{1}{c|}{$\begin{array}{c}\text { Results - Subquestion b } \\
\text { (vs. Pharmacological therapy) }\end{array}$} \\
\hline Berman 1999 & \\
\hline Berman 2004 & \\
\hline Beurskens 1997 & NR \\
& \\
\hline
\end{tabular}




\begin{tabular}{|c|c|c|}
\hline Author, Year & $\begin{array}{l}\text { Results - Subquestion c } \\
\text { (vs. Exercise) }\end{array}$ & Adverse Events Including Withdrawals \\
\hline Berman 1999 & & $\begin{array}{l}\text { No patients reported side-effects from the } \\
\text { acupuncture sessions }\end{array}$ \\
\hline Berman 2004 & & $\begin{array}{l}\text { A vs. } B(n=142 \text { vs. } 141) \\
\text { Adverse Events, } n: \\
\text { Heart disease }-1 \text { vs } 0 \\
\text { Cancer }-2 \text { vs } 0 \\
\text { Non-study-related injuries }-3 \text { vs } 1 \\
\text { Exacerbation of knee pain }-0 \text { vs } 1 \\
\text { non-arthritis-related surgery - } 6 \text { vs } 3 \\
\text { Stroke }-1 \text { vs } 0 \\
\text { Pneumonia }-1 \text { vs } 0 \\
\text { Total, } n(\%)-14 \text { (7.4\%) vs } 5(2.6 \%) \\
\text { Withdrawals: } 33 \text { vs } 25\end{array}$ \\
\hline Beurskens 1997 & NR & $\mathrm{NR}$ \\
\hline
\end{tabular}




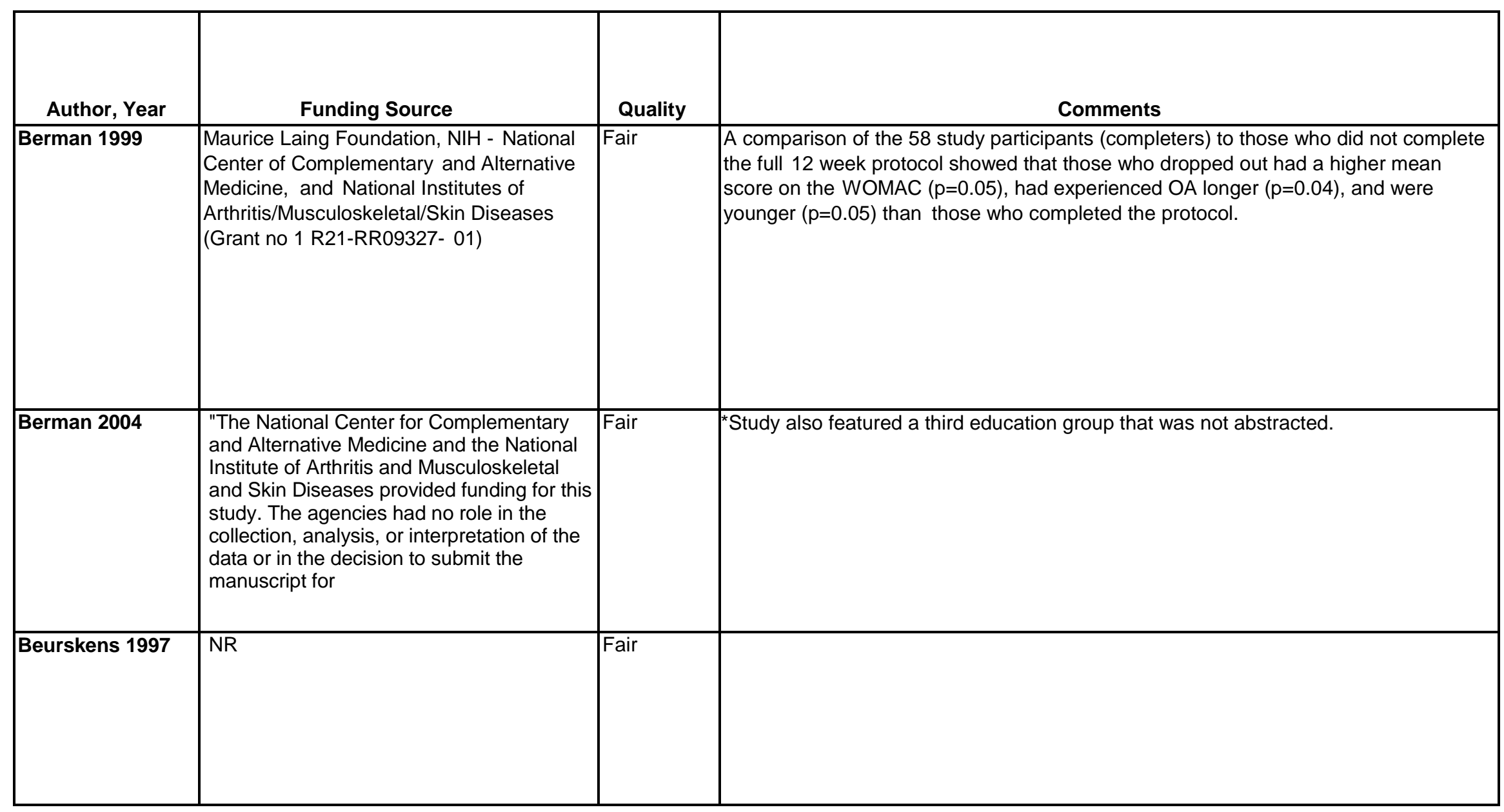




\begin{tabular}{|c|c|c|c|}
\hline Author, Year & $\begin{array}{c}\text { Country } \\
\text { Number of Centers } \\
\text { Setting }\end{array}$ & Inclusion/Exclusion Criteria & $\begin{array}{c}\text { Number Randomized, } \\
\text { Analyzed } \\
\text { Attrition }\end{array}$ \\
\hline Birch 1998 & $\begin{array}{l}\text { USA } \\
\text { Setting: Hospital- } \\
\text { based pain } \\
\text { management center } \\
\text { and neurology clinic }\end{array}$ & $\begin{array}{l}\text { Chronic myofascial neck pain > } 6 \text { months; painful area sensitive to } \\
\text { moderate touch; unsuccessful response to physical therapy, } \\
\text { medication, and a soft collar; age between } 18 \text { and } 65 \text { years; } \\
\text { willingness to participate in study. } \\
\text { Excluded: Disc herniation, cervical osteoarthritis, infection, } \\
\text { malignancy, collapsed vertebra, thoracic outlet syndrome, } \\
\text { temporomandibular joint dysfunction, collagen vascular disease, } \\
\text { brachial plexopathy, schizophrenia, delusional disorder, psychotic } \\
\text { disorder, dissociative disorder, bipolar disorder, or ongoing litigation } \\
\text { concerning their neck pain. }\end{array}$ & \begin{tabular}{|l|} 
Randomized: 46 \\
Treated: 46 \\
Analyzed:: 36 \\
Attrition:22\% \\
$(10 / 46)$
\end{tabular} \\
\hline
\end{tabular}




\begin{tabular}{|c|c|}
\hline Author, Year & Intervention, Comparator \\
\hline Birch 1998 & $\begin{array}{l}\text { A.Relevant acupuncture }(n=11) \text { in } 2 \text { stages: Stage 1, bilateral needles on hands and feet at SI3, BL62, GB41, and TW5. Needles in hand and foot } \\
\text { connected by copper wire through alligator clips with a silicone diode in one clip, and left in place for 10 minutes. Stage 2, needling on } 6 \\
\text { acupuncture points in the neck, shoulder, and upper back at left and right GB20, left and right GB21, left and right GB12, left and right BL10, left } \\
\text { and right BL11, and GV14. Infrared lamp applied over the needled area for } 10 \text { minutes. } \\
\text { B.Irrelevant acupuncture }(n=13) \text { in } 2 \text { stages: Stage 1, bilateral needles on hands and feet at LI5, GB42, TW8, and ST41. Needles connected by } \\
\text { cords that looked like the cords used in group A, but connections were severed. Needles and cords left in place for } 10 \text { minutes. Stage 2, needling } \\
\text { in shoulder and upper back on } 6 \text { acupuncture points, left and right BL16, left and right SI9, and left and right LI15. Light was shone over area } \\
\text { needled, but no heat was felt. Needles and light left in place for } 10 \text { minutes. } \\
\text { C.Medication only ( } n=12) \text {, nonsteroidal anti-inflammatory drug, Trilisate } \\
30 \text { minute treatment twice per week for } 4 \text { weeks, then once per week for } 4 \text { weeks, total } 14 \text { treatments }\end{array}$ \\
\hline
\end{tabular}




\begin{tabular}{|c|c|c|c|}
\hline Author, Year & Study Participants & Outcome Measures & $\begin{array}{c}\text { Duration of } \\
\text { Followup }\end{array}$ \\
\hline Birch 1998 & $\begin{array}{l}\text { A vs B vs C } \\
\text { Age: } 41 \text { vs } 38 \text { vs } 39 \text { years } \\
\text { Female: } 86 \% \text { vs } 77 \% \text { vs } 86 \% \\
\text { Pain duration: } 82 \text { vs } 92 \text { vs } 91 \text { months } \\
\text { Married: } 36 \% \text { vs } 23 \% \text { vs } 50 \% \\
\text { Employed: } 86 \% \text { vs } 69 \% \text { vs } 77 \% \\
\text { Completed high school: } 100 \% \text { vs } 100 \% \text { vs } 100 \% \\
\text { Pain intensity (0-10) } 4.8 \text { vs } 4.7 \text { vs } 4.9 \\
\text { SF-MPQ*: } 16.1 \text { vs } 16.2 \text { vs } 16.8 \\
\text { (*estimated from Fig } 1 ; \text { no sd provided) }\end{array}$ & $\begin{array}{l}\text { Comprehensive Pain Evaluation Questionnaire (CPEQ) } \\
\text { McGill Pain Questionnaire (MPQ) (scale: 0-33 sensory, } \\
\text { 0-12 affective, 0-5 present pain intensity; higher score = } \\
\text { greater pain) } \\
\text { Pain intensity rating hourly (scale, 0=no pain, 1-2= mild, } \\
\text { tolerable, low pain; 3-4=moderate pain, can be ignored } \\
\text { at times; 5-6=intense, distressing, just able to continue } \\
\text { activities; 7-8=very intense, difficulty concentrating, } \\
\text { interferes with activity; 9-10=excruciating, } \\
\text { incapacitating, worst pain possible) } \\
\text { Short-Form } 36 \text { (SF-36) (scale 0-100, higher } \\
\text { score=better QoL) } \\
\text { Symptom Checklist } 90 \text { (SCL-90-R) (9 subscales; } \\
\text { somatization, obsessionality, interpersonal sensitivity, } \\
\text { depression, anxiety, hostility, phobic anxiety, paranoia, } \\
\text { and psychoticism; higher scores=greater psychiatric } \\
\text { distress) }\end{array}$ & 3 months \\
\hline
\end{tabular}




\begin{tabular}{|l|l|}
\hline \multicolumn{1}{|c|}{ Author, Year } & \multicolumn{1}{c|}{$\begin{array}{c}\text { Results - Subquestion a } \\
\text { (vs. sham, no treatment, waitlist, attention control) }\end{array}$} \\
\hline Birch 1998 & $\begin{array}{l}\text { A vs B } \\
\text { 3 month outcomes } \\
\text { SF-MPQ (0-33): 9.0 vs } 15.1 \\
\text { (*estimated from Fig 1; no sd provided) }\end{array}$ \\
\hline
\end{tabular}




\begin{tabular}{|l|l|}
\hline \multicolumn{1}{|c|}{ Author, Year } & \multicolumn{1}{c|}{$\begin{array}{c}\text { Results - Subquestion b } \\
\text { (vs. Pharmacological therapy) }\end{array}$} \\
\hline Birch 1998 & $\begin{array}{l}\text { A vs C } \\
\text { 3 month outcomes } \\
\text { SF-MPQ* (0-33): 9.0 vs } 18.0 \\
\text { (*estimated from Fig 1; no sd provided) }\end{array}$ \\
\hline
\end{tabular}




\begin{tabular}{|c|c|c|}
\hline Author, Year & $\begin{array}{l}\text { Results - Subquestion c } \\
\text { (vs. Exercise) }\end{array}$ & Adverse Events Including Withdrawals \\
\hline Birch 1998 & & NR \\
\hline
\end{tabular}




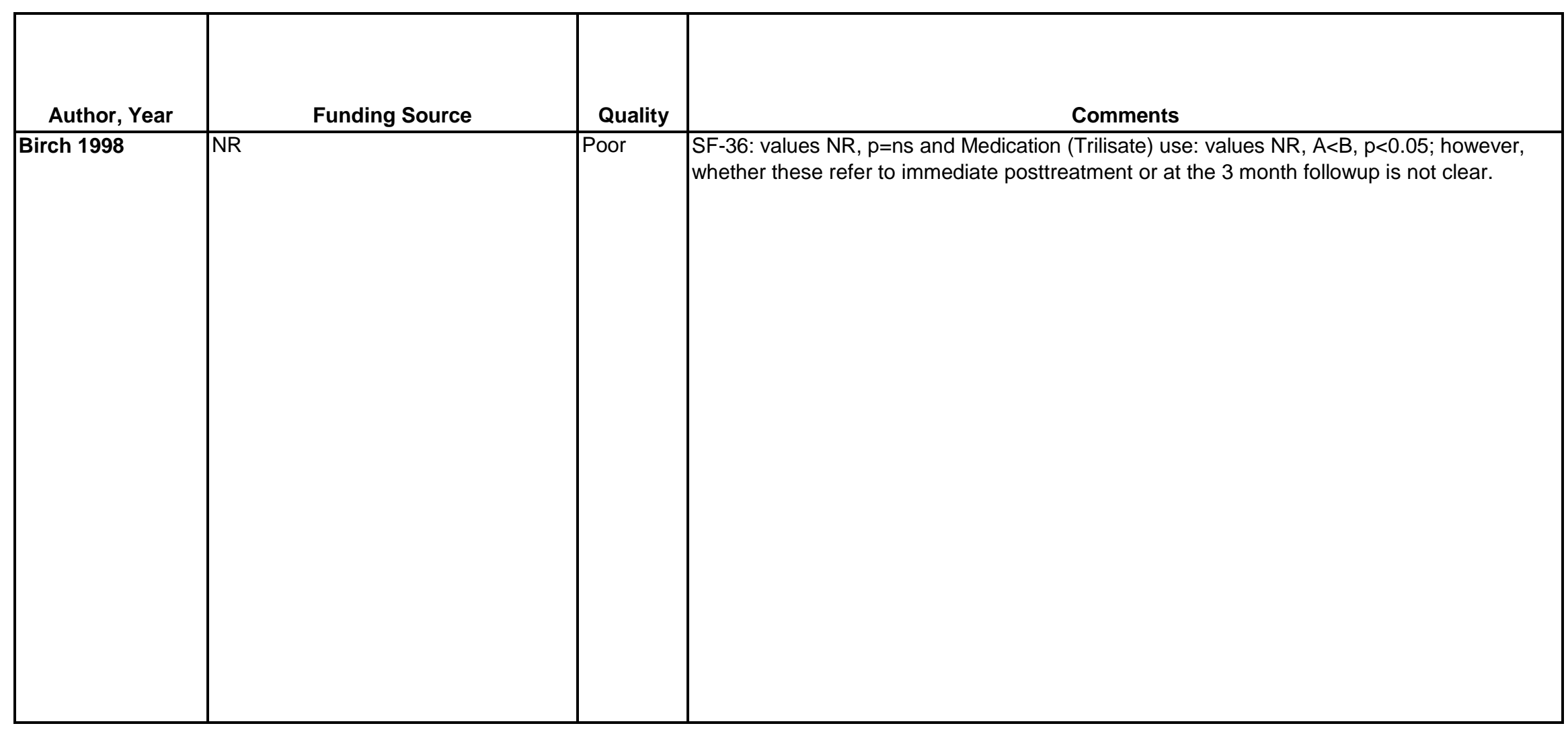




\begin{tabular}{|c|c|c|c|}
\hline Author, Year & $\begin{array}{c}\text { Country } \\
\text { Number of Centers } \\
\text { Setting } \\
\end{array}$ & Inclusion/Exclusion Criteria & $\begin{array}{c}\text { Number Randomized, } \\
\text { Analyzed } \\
\text { Attrition } \\
\end{array}$ \\
\hline Blanchard 1990 & $\begin{array}{l}\text { United States, number } \\
\text { of sites/setting not } \\
\text { reported }\end{array}$ & $\begin{array}{l}\text { Inclusion Criteria: } \\
\text { Patients with tension-type headache; patients required to report HA } \\
\text { activity for an average of } 4 \text { days/week over } 4 \text { week baseline } \\
\text { Exclusion Criteria: } \\
\text { Migraine or combined migraine and tension headache, other forms of } \\
\text { headache. }\end{array}$ & $\begin{array}{l}\text { Randomized: } 77 \\
\text { Treated: } 77 \\
\text { Analyzed: } 66 \\
\text { Attrition: } 14.2 \%(11 / 77)\end{array}$ \\
\hline
\end{tabular}




\begin{tabular}{|c|c|}
\hline Author, Year & Intervention, Comparator \\
\hline Blanchard 1990 & 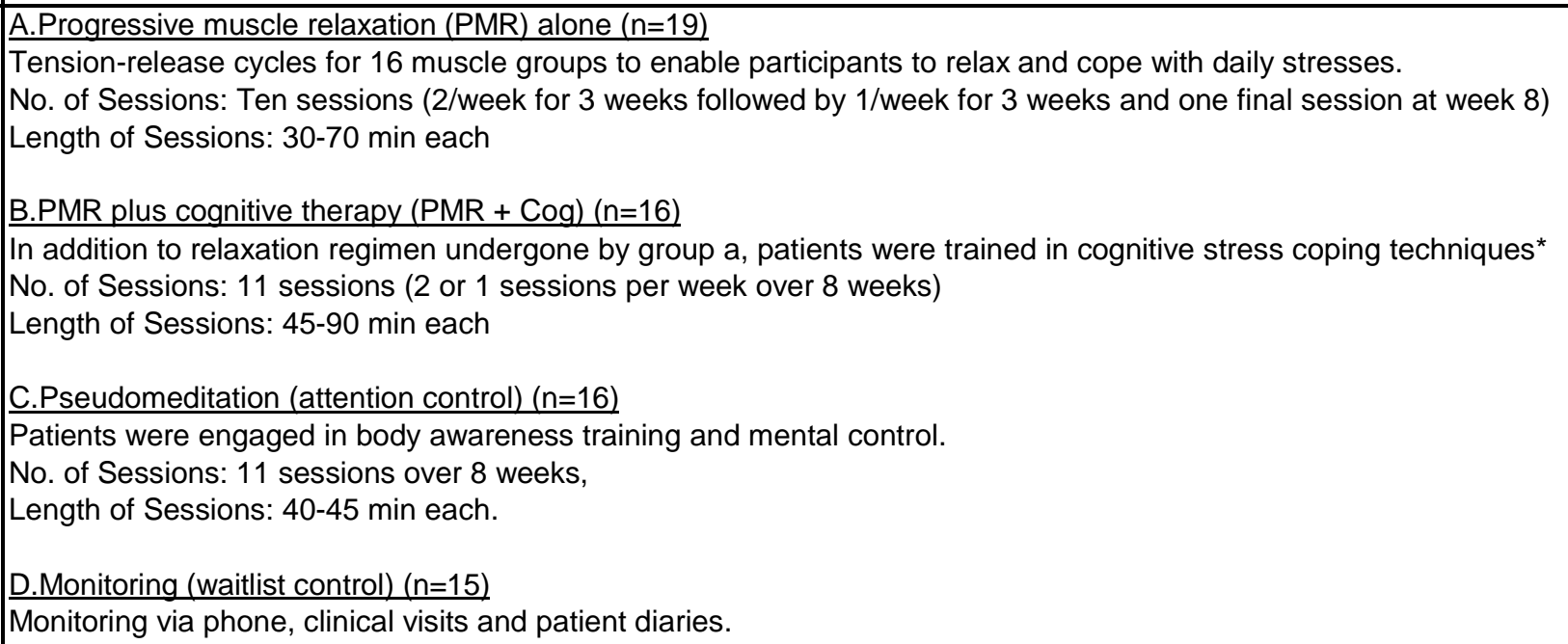 \\
\hline
\end{tabular}




\begin{tabular}{|c|c|c|c|}
\hline Author, Year & Study Participants & Outcome Measures & $\begin{array}{l}\text { Duration of } \\
\text { Followup }\end{array}$ \\
\hline Blanchard 1990 & $\begin{array}{l}\text { A vs. B vs. C vs. D } \\
\text { Age: } 43 \text { vs } 38 \text { vs } 39 \text { vs } 37 \text { years } \\
\text { Sex: } 58 \% \text { vs. } 56 \% \text { vs. } 45 \% \text { vs } 66 \% \text { female } \\
\text { Race: NR } \\
\text { Mean duration of chronicity: } 13.9 \text { vs } 13.0 \text { vs. } 15.3 \text { vs } 14.3 \text { years } \\
\text { Mean frequency of headache, days (SD): NR } \\
\text { Patients who had prior preventative treatments: } 100 \% \text { were seeking } \\
\text { nondrug treatments } \\
\text { Patients who overused medications: NR } \\
\text { Mean number of analgesic medications used at baseline (SD): NR } \\
\text { Headache Index Scores (SD): } 5.63 \text { (3.26) vs. } 5.82(4.08) \text { vs. } 5.23 \\
\text { (3.48) vs. } 5.05 \text { (3.44) } \\
\text { Medication Index Scores (SD): } 16.9(17.8) \text { vs. } 39.8(57.8) \text { vs. } 12.1 \\
\text { (11.0) vs. } 24.0(25.5)\end{array}$ & $\begin{array}{l}\text { Proportion of Patients with } \geq 50 \% \text { improvement in } \\
\text { Headache Index scores; } \\
\text { Headache Index (average daily headache activity [i.e., } \\
\text { score range from 0, no headache, to } 5 \text { intense, } \\
\text { incapacitation headache]; index score range: } 0-20 ; 28 \\
\text { weekly headache ratings / 7); } \\
\text { Medication index (average daily headache medication } \\
\text { consumption: medication potency x daily dose level) }\end{array}$ & 1 month \\
\hline
\end{tabular}




\begin{tabular}{|c|c|}
\hline Author, Year & $\begin{array}{l}\text { Results - Subquestion a } \\
\text { (vs. sham, no treatment, waitlist, attention control) }\end{array}$ \\
\hline Blanchard 1990 & 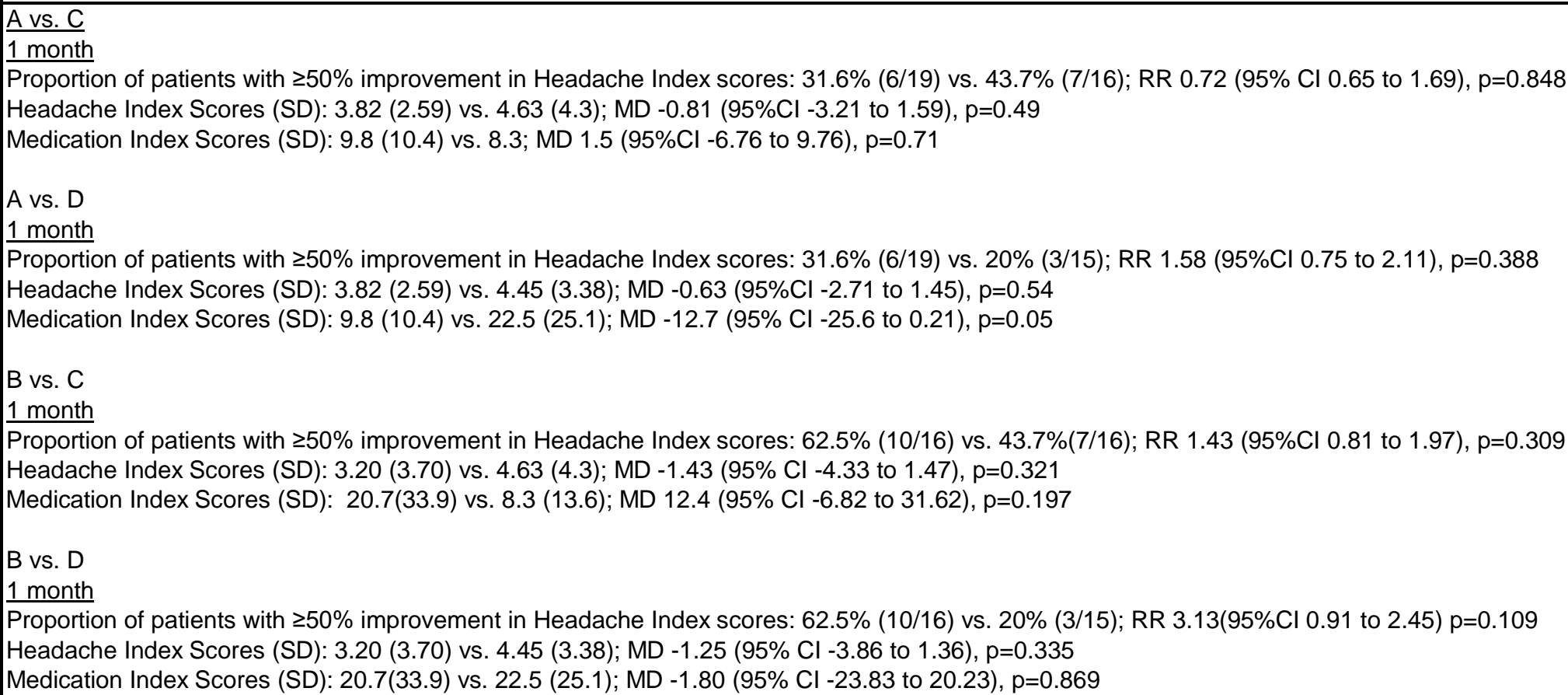 \\
\hline
\end{tabular}




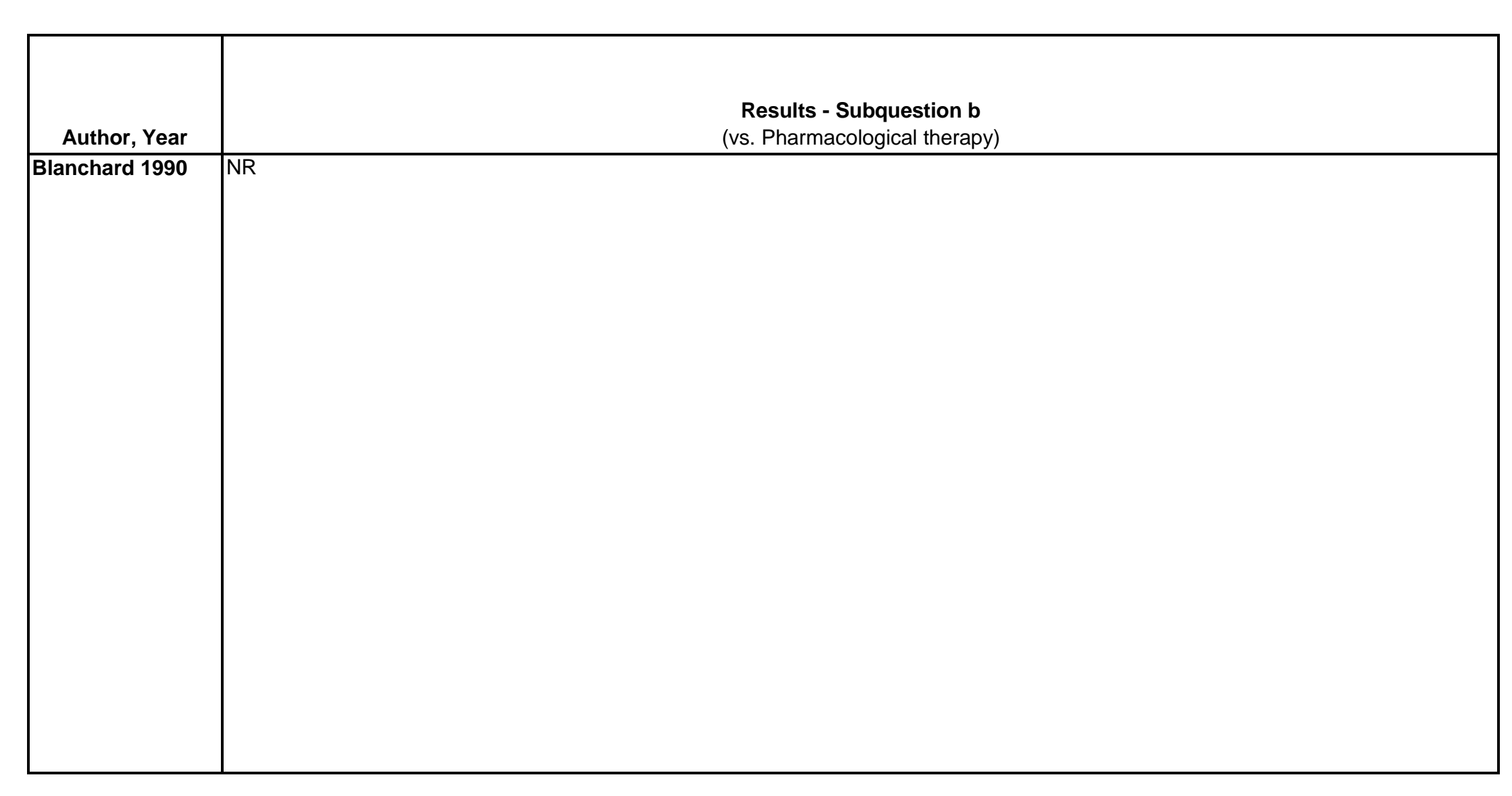

D-110 


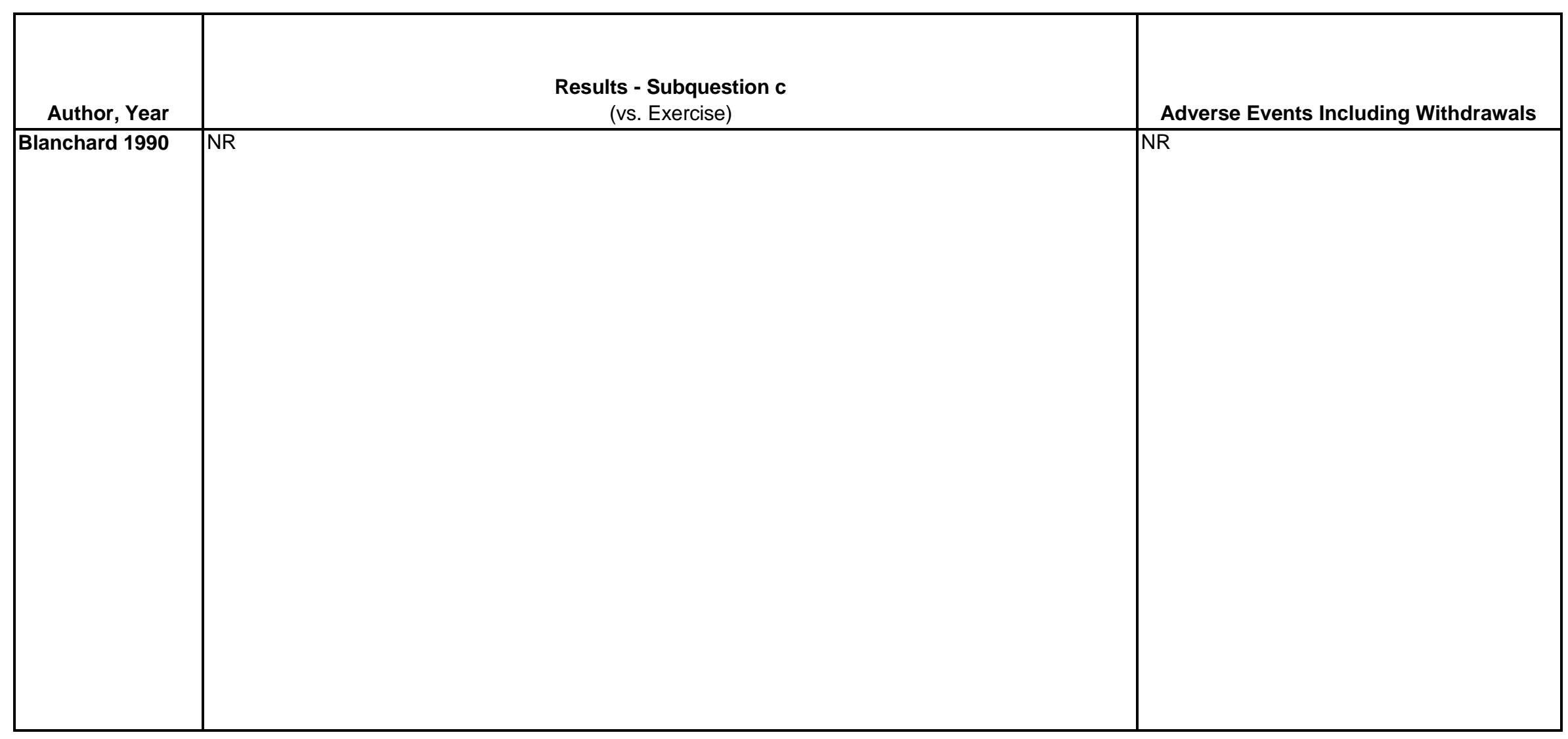

D-111 


\begin{tabular}{|c|l|c|l|}
\hline Author, Year & \multicolumn{1}{|c|}{ Funding Source } & Quality & \multicolumn{1}{c|}{ Comments } \\
\hline Blanchard 1990 & $\begin{array}{l}\text { National Institute of Neurological and } \\
\text { Communicative Disorders and Stroke } \\
\text { Grants NS-15235 and NS-23440, } \\
\text { National Institute of Mental Health } \\
\text { Grant MH-41341 }\end{array}$ & $\begin{array}{l}\text { Poor } \\
\text { ieadache Index reduction }>50 \% \text { were scheduled for 3, } 6 \text { and } 12 \text { month followup. 3 month } \\
\text { data was obtained for 26 patients. } \\
\text { This study included four comparator groups but we have excluded one (PMR+cognitive } \\
\text { therapy) because it does not match our protocol (e.g., incremental value of adding } \\
\text { interventions). } \\
\text { The dropouts (n=11) on average tended to be younger, to have had headaches for a shorter } \\
\text { duration, and to have less severe headaches than completers, all factors associated with } \\
\text { better outcome. }\end{array}$ \\
\hline
\end{tabular}




\begin{tabular}{|c|c|c|c|}
\hline Author, Year & $\begin{array}{c}\text { Country } \\
\text { Number of Centers } \\
\text { Setting }\end{array}$ & Inclusion/Exclusion Criteria & $\begin{array}{c}\text { Number Randomized, } \\
\text { Analyzed } \\
\text { Attrition }\end{array}$ \\
\hline Blodt, 2015 & $\begin{array}{l}\text { Germany } \\
\text { Number of centers: } 1 \\
\text { Rehabilitation clinic }\end{array}$ & $\begin{array}{l}\text { Patients age } 20 \text { to } 65 \text { years, LBP for at least } 3 \text { months but not longer } \\
\text { than } 5 \text { years, more prominent than pain in other spine areas, average } \\
\text { pain intensity in the previous } 7 \text { days } \geq 40 \text { mm measured on a VAS } \\
(0-100 \mathrm{~mm}) \text {. } \\
\text { Exclude: Patients with LBP due to accident or malignant disease, } \\
\text { inflammatory arthropathy, history of spine surgery, prolapsed vertebral } \\
\text { disc or spondylolisthesis with radicular symptoms, planned start of } \\
\text { physiotherapy and other therapies (e.g., acupuncture, massage, } \\
\text { spinal manipulation, neuroflexotherapy, feldenkrais) against LBP, } \\
\text { activities including swimming, yoga, Pilates, tai chi, kung fu, tai bo, } \\
\text { gymnastics, regular (> once a week) intake of analgesics, pregnancy } \\
\text { or planned pregnancy within the treatment period, severe acute or } \\
\text { chronic disorders (physical or mental), or alcohol abuse, current } \\
\text { participation in any qigong/or exercise therapy or within } 12 \text { months, } \\
\text { participation in another trial during the last } 6 \text { months, or a history of } \\
\text { participation in any qigong/or exercise therapy/low back pain study. }\end{array}$ & $\begin{array}{l}\text { Randomized: } 128 \\
\text { Treated: } 127 \\
\text { Analyzed: } 127 \\
\text { Attrition:10\% (13/128) }\end{array}$ \\
\hline
\end{tabular}




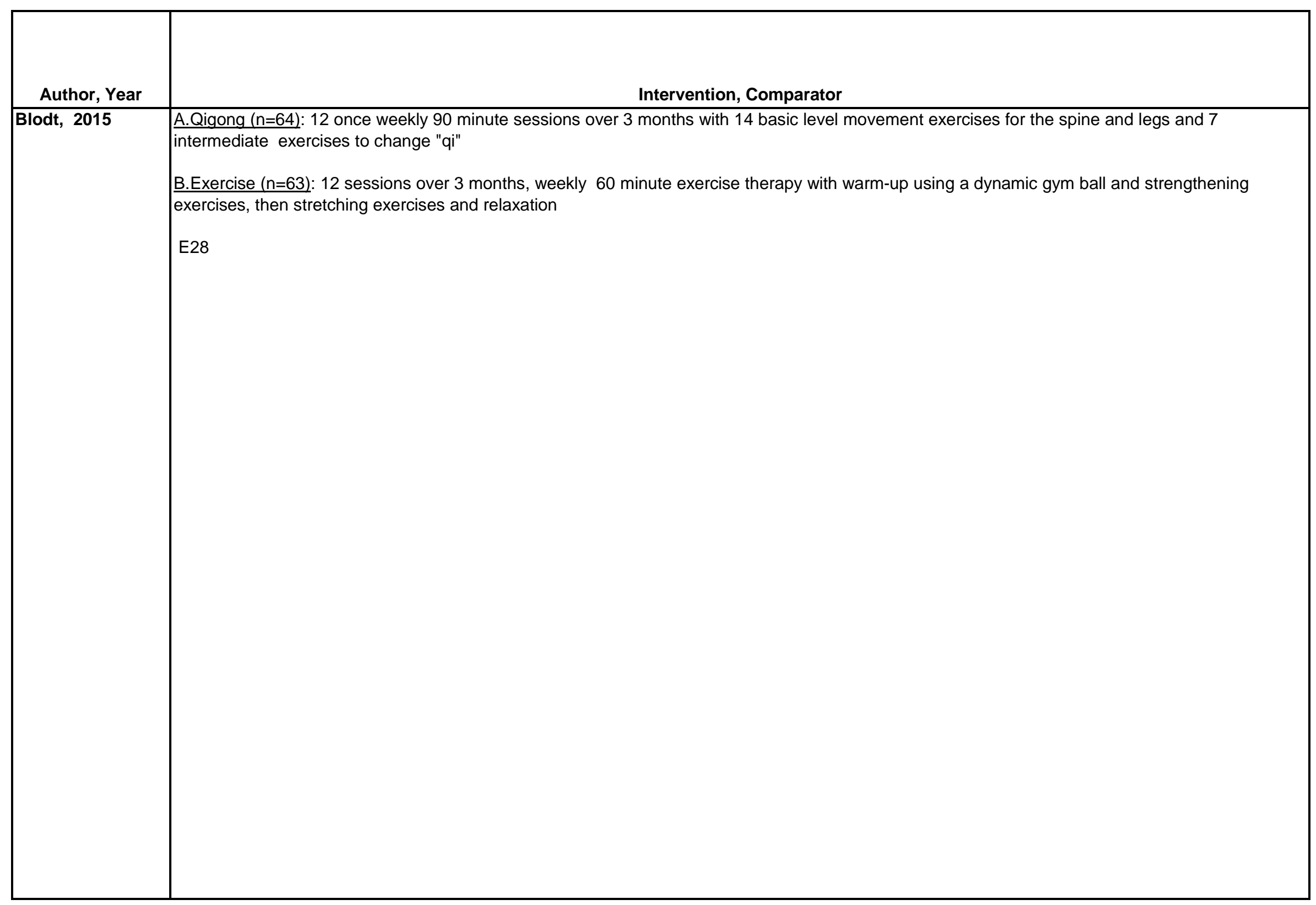




\begin{tabular}{|c|c|c|c|}
\hline Author, Year & Study Participants & Outcome Measures & $\begin{array}{c}\text { Duration of } \\
\text { Followup }\end{array}$ \\
\hline Blodt, 2015 & $\begin{array}{l}\text { A vs. B } \\
\text { Age (mean): } 46 \text { vs. } 48 \text { years } \\
\text { Female: } 91 \% \text { vs. } 70 \% \\
\text { Race: NR } \\
\text { Duration of low back pain: } 3 \text { vs. } 3 \text { years } \\
\text { Medication intake: } 38 \% \text { vs. } 44 \% \\
\text { Average low back pain (VAS; mean): } 55.6 \text { vs. } 52.1 \\
\text { Low back pain/disability (RMD; mean): } 6.2 \text { vs. } 5.7 \\
\text { Physical health (SF-36, mean): } 41.8 \text { vs. } 42.6 \\
\text { Mental health (SF-36, mean): } 46.3 \text { vs. } 49.2 \\
\text { Quality of sleep (mean): } 4.7 \text { vs. } 4.7 \\
\text { Sleep satisfaction (mean): } 4.9 \text { vs. } 5.1 \\
\text { Self-efficacy, Schützler \& Witt (mean): } 19.4 \text { vs. } 19.3\end{array}$ & $\begin{array}{l}\text { Pain (VAS 0-100 VAS) } \\
\text { Roland Morris Disability (RMD) Questionnaire (0-24) } \\
\text { SF-36 Bodily pain (0-100) } \\
\text { SF-36 Physical component }(0-100) \\
\text { SF-36 Mental component score }(0-100) \\
\text { Quality of sleep (0=very good to } 10=\text { very bad) } \\
\text { Sleep satisfaction (0=very satisfied to } 10=\text { not at } \\
\text { all satisfied) } \\
\text { Self-efficacy, Schützler \& Witt (Higher values indicate } \\
\text { better status) }\end{array}$ & $\begin{array}{l}3 \text { and } 9 \\
\text { months }\end{array}$ \\
\hline
\end{tabular}




\begin{tabular}{|l|l|}
\hline Author, Year & Results - Subquestion a \\
(vs. sham, no treatment, waitist, attention control)
\end{tabular}

D-116 


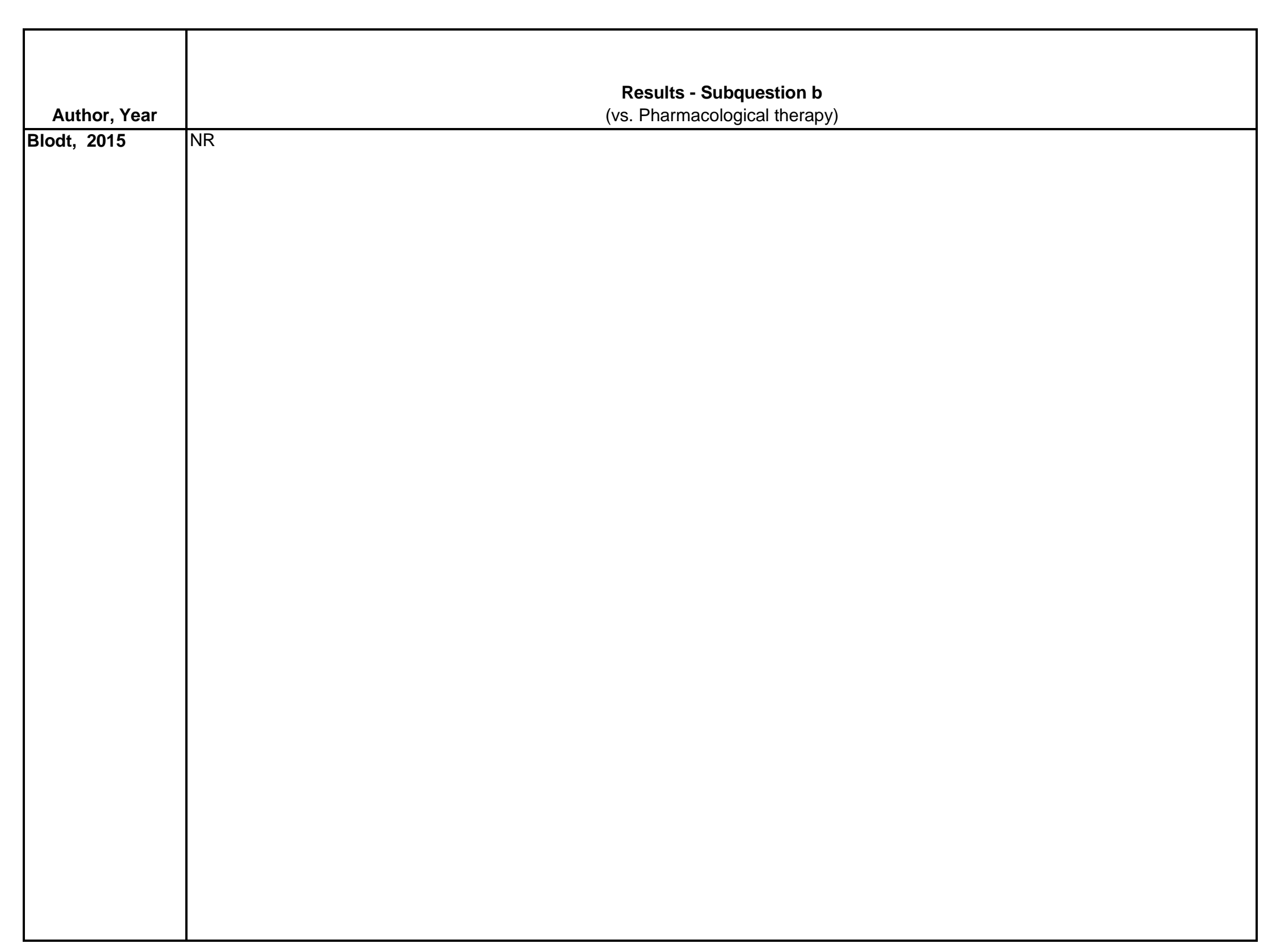

D-117 


\begin{tabular}{|c|c|c|}
\hline Author, Year & $\begin{array}{l}\text { Results - Subquestion c } \\
\text { (vs. Exercise) }\end{array}$ & Adverse Events Including Withdrawals \\
\hline Blodt, 2015 & 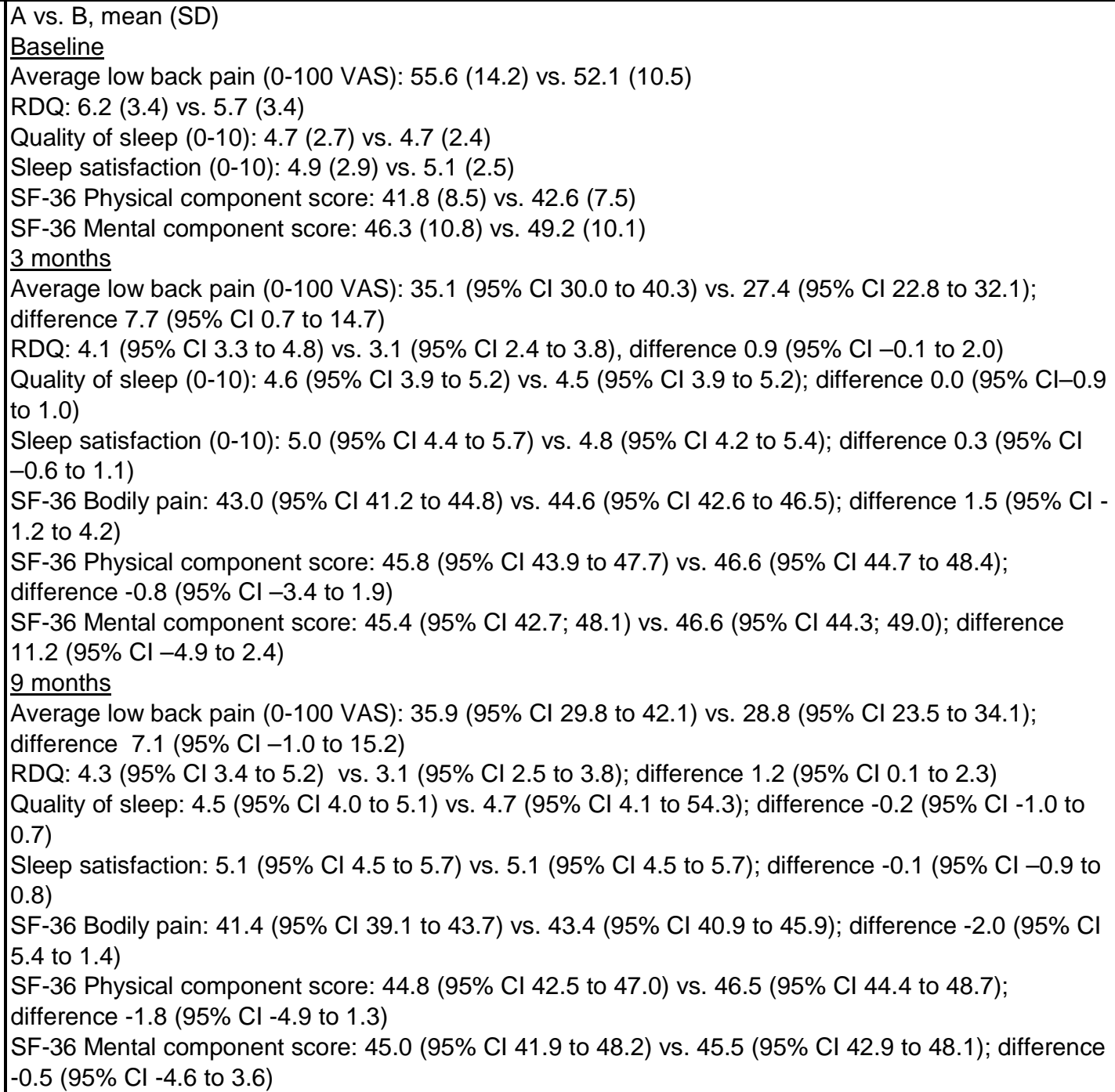 & $\begin{array}{l}\text { A vs. B } \\
\text { Adverse events: } 7 \%(10 / 127) \text { vs. } 7 \%(10 / 127)\end{array}$ \\
\hline
\end{tabular}




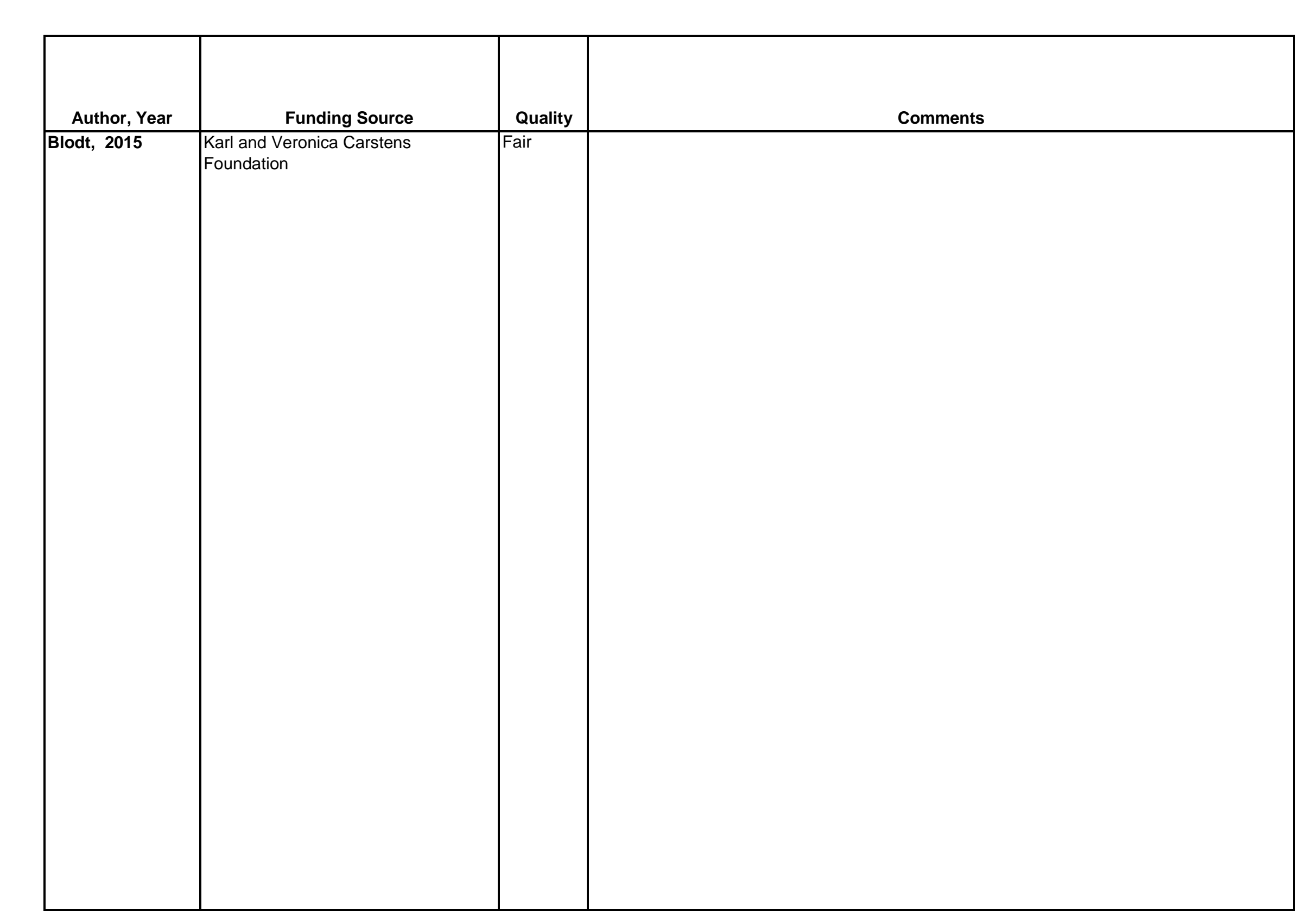




\begin{tabular}{|c|c|c|c|}
\hline Author, Year & $\begin{array}{c}\text { Country } \\
\text { Number of Centers } \\
\text { Setting }\end{array}$ & Inclusion/Exclusion Criteria & $\begin{array}{c}\text { Number Randomized, } \\
\text { Analyzed } \\
\text { Attrition }\end{array}$ \\
\hline Boline 1995 & $\begin{array}{l}\text { USA, single site, } \\
\text { outpatient clinic }\end{array}$ & $\begin{array}{l}\text { Inclusion Criteria: } \\
\text { Patients aged 18-70 with a headache duration of at least } 3 \text { months } \\
\text { and with at least one episode per week. CTTH Diagnosis was } \\
\text { determined by the examining team according to IHS criteria. Patients } \\
\text { with overlap in CM were included if examiners determined headache } \\
\text { problem was predominantly tension-type. } \\
\text { Exclusion Criteria: } \\
\text { Exclusion for pregnancy, active treatment for headaches within past } \\
\text { three months, contraindications to amitriptyline therapy (e.g. cardiac } \\
\text { arrhythmias and glaucoma) or spinal manipulative therapy (e.g. } \\
\text { metastases, fractures, inflammatory disease), as determined by } \\
\text { history, physical and radiological examination. }\end{array}$ & $\begin{array}{l}\text { Randomized: } 150 \\
\text { Treated: } 126 \\
\text { Analyzed: } 70 \text { vs. } 56 \\
\text { Attrition: } 16.0 \%(24 / 150)\end{array}$ \\
\hline Bono 2015 & $\begin{array}{l}\text { Italy, number of } \\
\text { sites/setting not } \\
\text { reported }\end{array}$ & $\begin{array}{l}\text { Inclusion Criteria: } \\
\text { >18 years old, at least two years of CTTH (by ICCHD classification), at } \\
\text { least four attacks/week, failure on at least three well-conducted } \\
\text { preventative drug treatments. } \\
\text { Exclusion Criteria: } \\
\text { Use of preventative treatment in the last two months, previous TES } \\
\text { treatment, severe anxiety or mood depression, severe sleep } \\
\text { disturbances, and associated disabling neurologic or other psychiatric } \\
\text { disorders. }\end{array}$ & $\begin{array}{l}\text { Randomized: } 83 \\
\text { Treated: } 83 \\
\text { Analyzed: } 83 \\
\text { Attrition: NR }\end{array}$ \\
\hline
\end{tabular}




\begin{tabular}{|c|c|}
\hline Author, Year & Intervention, Comparator \\
\hline Boline 1995 & $\begin{array}{l}\text { A.Spinal Manipulative Therapy }(\mathrm{n}=70) \\
\text { Participants received short-lever, low-amplitude, high-velocity thrust techniques. Doctor determined by manual palpation, the cervical, thoracic or } \\
\text { lumbar spinal segments to be manipulated. Moist heat and light massage preceded manipulation. } \\
\text { No. of Sessions: Twelve sessions ( } 2 / \text { week for } 6 \text { weeks) } \\
\text { Length of Sessions: } 20 \text { minutes each } \\
\text { B.Amitriptyline }(n=56)\end{array}$ \\
\hline Bono 2015 & $\begin{array}{l}\text { A.Occipital Transcutaneous electrical stimulation (OTES) }(\mathrm{n}=54) \\
\text { Electrostimulator generated biphasic impulses via } 50 \mathrm{~mm} \times 90 \mathrm{~mm} \text { self-adhesive electrodes placed on occipital region } \\
\text { Pulse Width: } 250 \mu \mathrm{s} \\
\text { Frequency: } 40 \mathrm{~Hz} \\
\text { Intensity: } 20 \mathrm{~mA} \\
\text { No. of Sessions: } 3 / \text { day for two consecutive weeks (total of } 42 \text { sessions) } \\
\text { Length of Sessions: } 30 \mathrm{~min} \\
\text { B.Sham OTES ( } \mathrm{n}=29) \\
\text { Same device/procedure, but no current was delivered. }\end{array}$ \\
\hline
\end{tabular}




\begin{tabular}{|c|c|c|c|}
\hline Author, Year & Study Participants & Outcome Measures & $\begin{array}{c}\text { Duration of } \\
\text { Followup }\end{array}$ \\
\hline Boline 1995 & $\begin{array}{l}\text { A vs. } B \\
\text { Age: } 40.9 \text { vs } 42.7 \\
\text { Female: } 54.3 \text { vs. } 69.6 \\
\text { Race: NR } \\
\text { Mean duration of chronicity: } 13.4 \text { vs } 13.6 \text { years } \\
\text { Daily Headache Intensity: } 5.6(2.7) \text { vs. } 5.0(3.3) \\
\text { Weekly headache frequency: } 12.4(7.4) \text { vs. } 10.8(7.5) \\
\text { OTC Medication Usage: } 1.7(1.7) \text { vs. } 2.1(2.3) \\
\text { SF-36 Function Health Status Global Score (\% points): } 67.2(14) \text { vs. } \\
71.3(13)\end{array}$ & $\begin{array}{l}\Delta \text { from baseline, Headache Intensity (range 0-20: total } \\
\text { ratings per period / number of days per period) } \\
\Delta \text { from baseline, Headache Frequency (range 0-28: } \\
\text { total of all headache ratings } 2 \text { or above) } \\
\Delta \text { from baseline, OTC medication usage (no. of } \\
\text { tablets/day) } \\
\text { SF-36 Functional Health Status Global Score } \\
\text { (summation of all SF-36 dimensions) }\end{array}$ & 1 month \\
\hline Bono 2015 & 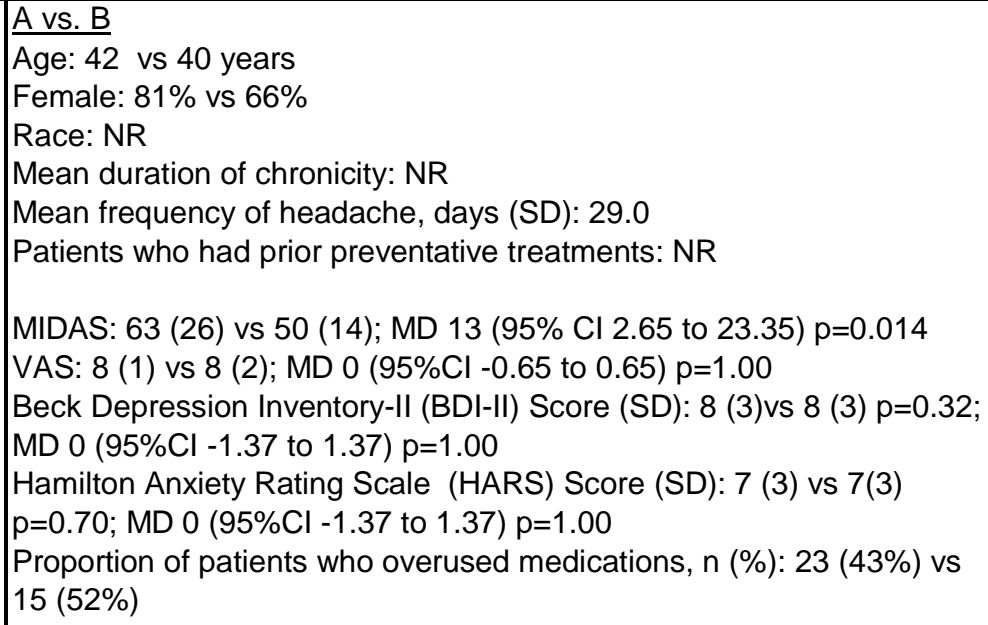 & $\begin{array}{l}\text { Migraine Disability Assessment (MIDAS, 0-21+ e.g. little } \\
\text { or no disability to severe disability); } \\
\text { Visual Analogue Scale (VAS, 0-10: higher scores } \\
\text { indicate severity of pain); } \\
\text { Beck Depression Inventory-II (BDI-II; total:0-63, higher } \\
\text { scores indicate severity of depressive symptoms); } \\
\text { Hamilton Anxiety Rating Scale (HAM-A, 14 ratings of 0- } \\
5 \text {, higher scores indicate severity of depressive } \\
\text { symptoms); } \\
\Delta \text { in monthly acute medications use }\end{array}$ & $\begin{array}{l}1 \text { month, } 2 \\
\text { months }\end{array}$ \\
\hline
\end{tabular}




\begin{tabular}{|c|c|}
\hline Author, Year & $\begin{array}{c}\text { Results - Subquestion a } \\
\text { (vs. sham, no treatment, waitlist, attention control) }\end{array}$ \\
\hline Boline 1995 & NR \\
\hline Bono 2015 & 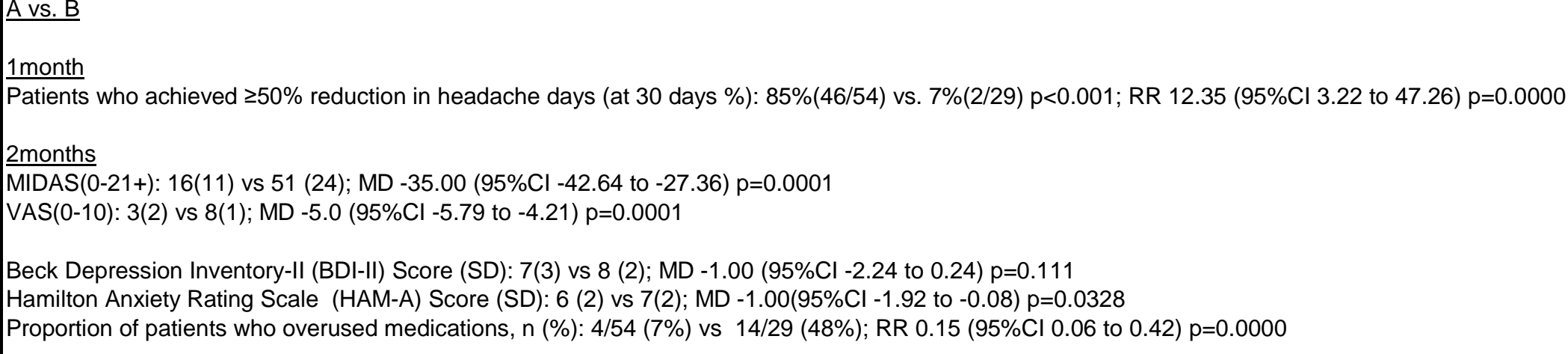 \\
\hline
\end{tabular}




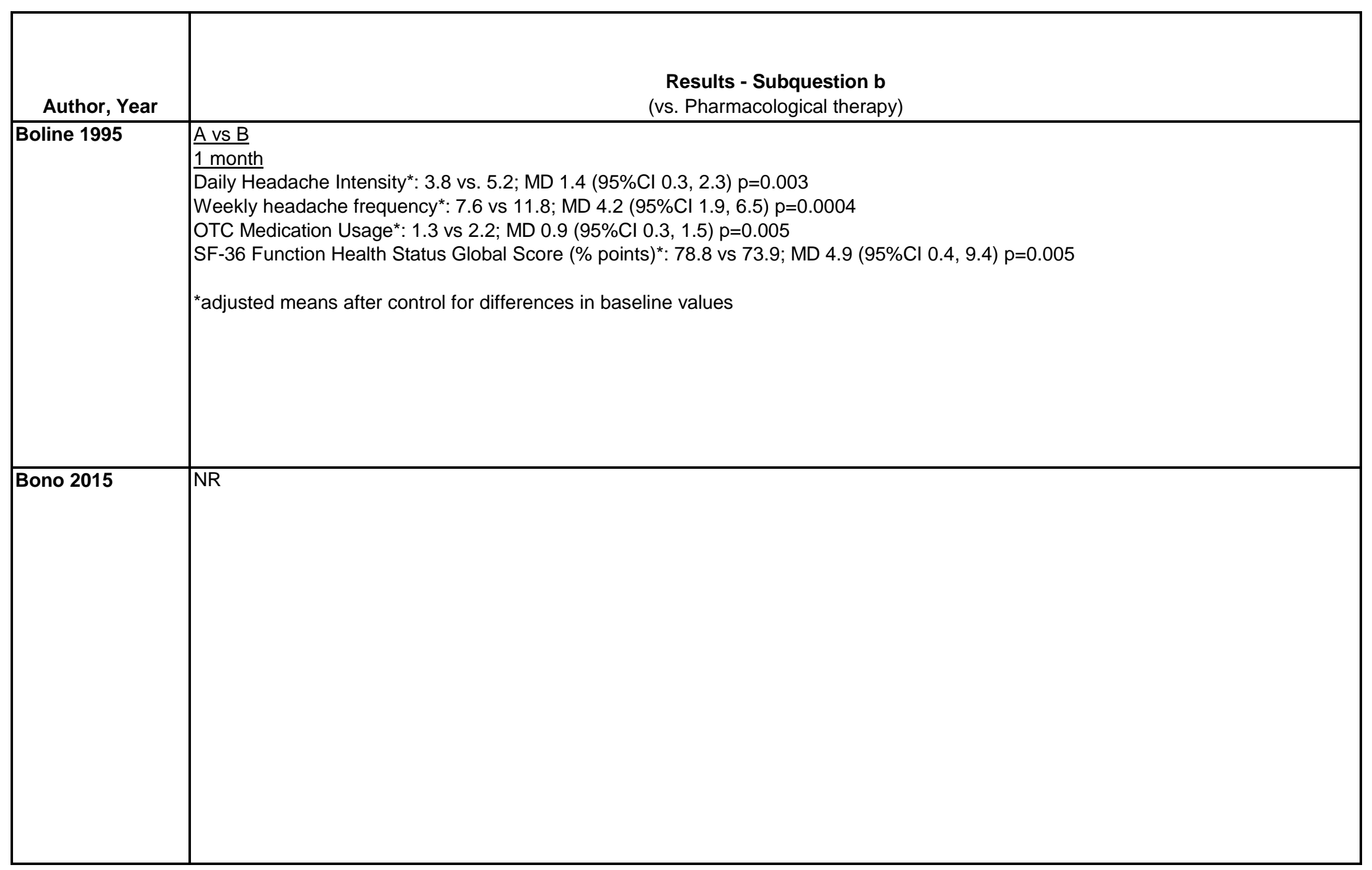




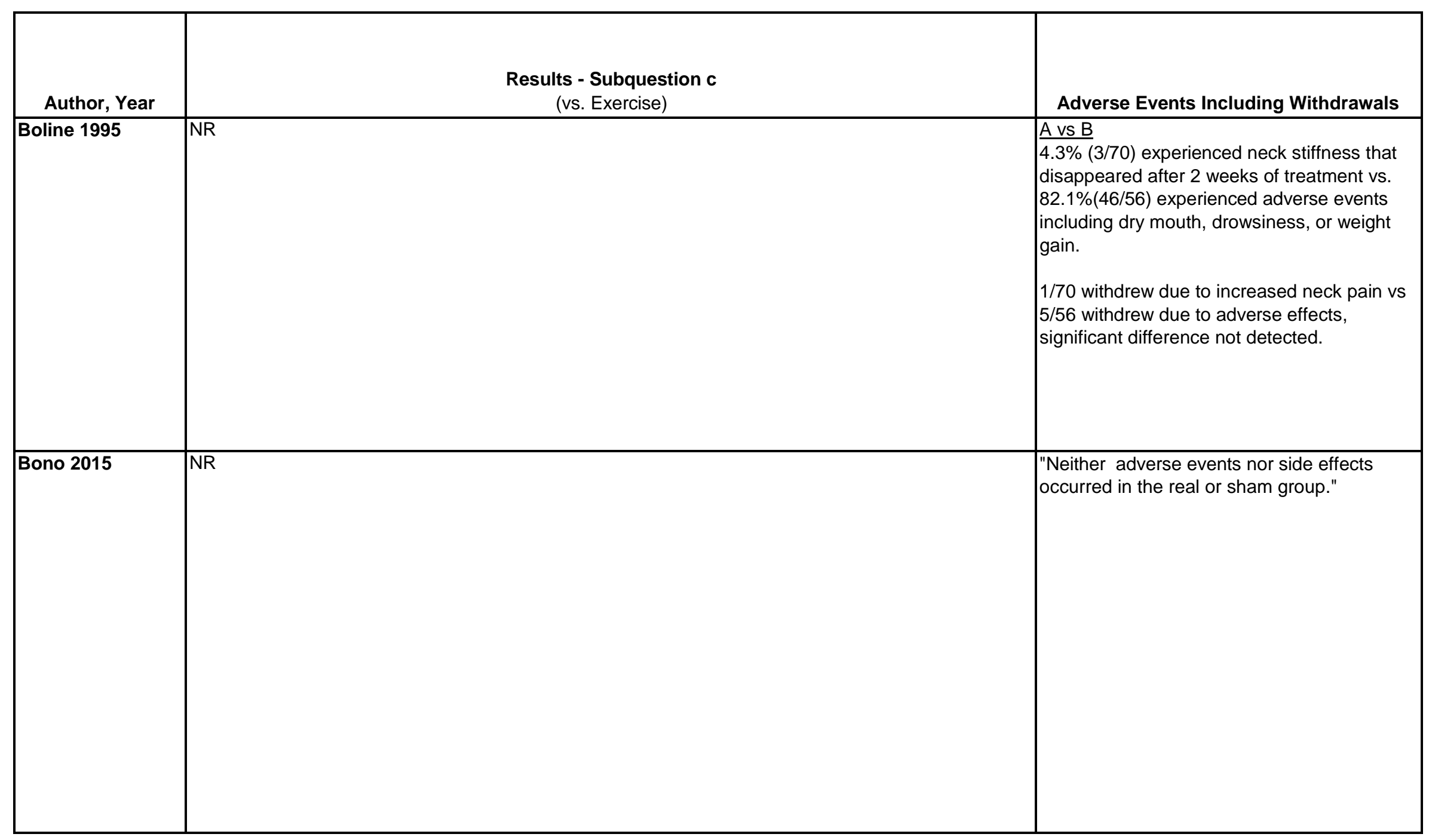




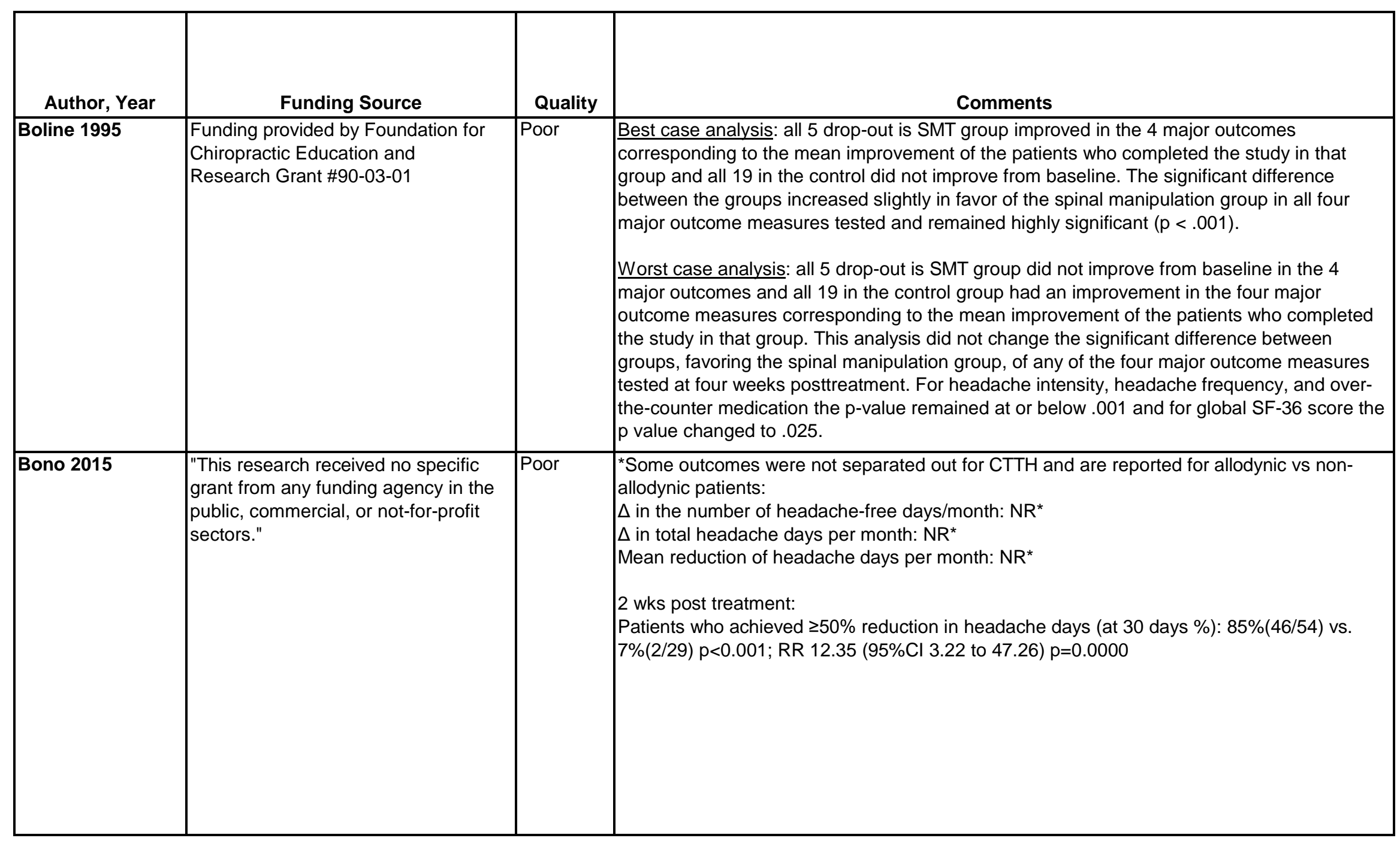




\begin{tabular}{|c|c|c|c|}
\hline Author, Year & $\begin{array}{c}\text { Country } \\
\text { Number of Centers } \\
\text { Setting }\end{array}$ & Inclusion/Exclusion Criteria & $\begin{array}{c}\text { Number Randomized, } \\
\text { Analyzed } \\
\text { Attrition }\end{array}$ \\
\hline Brinkhaus 2006a & \begin{tabular}{|l|} 
Germany \\
Number of centers: 30 \\
Outpatient \\
\\
\end{tabular} & $\begin{array}{l}\text { Clinical diagnosis of chronic LBP } \geq 6 \text { months } \\
\text { Age } 49-75 \text { years } \\
\text { Average pain intensity of } \geq 40 \text { on } 100 \text {-mm VAS on previous } 7 \text { days } \\
\text { Only oral non-steroidal anti-inflammatory drugs for pain treatment in } \\
\text { the } 4 \text { weeks before treatment } \\
\text { Exclude: } \\
\text { Protrusion or prolapse of } \geq 1 \text { intervertebral discs with concurrent } \\
\text { neurological symptoms } \\
\text { Radicular pain } \\
\text { Prior vertebral column surgery } \\
\text { Infectious spondylopathy } \\
\text { LBP caused by inflammatory, malignant, or autoimmune disease } \\
\text { Congenital deformation of the spine, except for slight lordosis or } \\
\text { scoliosis } \\
\text { Compression fracture caused by osteoporosis } \\
\text { Spinal stenosis } \\
\text { Spondylolysis or spondylolisthesis } \\
\text { Patients with Chinese medicine diagnoses warranting treatment with } \\
\text { moxibustion } \\
\text { Acupuncture treatment during the past } 12 \text { months }\end{array}$ & $\begin{array}{l}\text { Randomized: } 210 \\
\text { Treated: } 140 \\
\text { Analyzed: } 210 \\
\text { Attrition: } 0 \%(0 / 210)\end{array}$ \\
\hline
\end{tabular}




\begin{tabular}{|c|c|}
\hline Author, Year & Intervention, Comparator \\
\hline Brinkhaus 2006a & $\begin{array}{l}\text { A.Needle acupuncture ( } n=140) \text { : } 12 \text { acupuncture sessions, } 30 \text { minutes each, over } 8 \text { weeks (usually } 2 \text { sessions/week for } 4 \text { weeks then } 1 \\
\text { session/week for remaining } 4 \text { weeks). Acupuncture physicians had } \geq 140 \text { hours of acupuncture training and } \geq 3 \text { years of experience. } \\
\text { Semistandardized acupuncture treatment using sterile, disposable, } 1 \text {-time needles. Needle length and diameter were not defined. All patients were } \\
\text { treated with local and distant points including (bilaterally) } \geq 4 \text { local points and } \geq 2 \text { distant points from a set selection. Patients that were experiencing } \\
\text { local or pseudoradicular sensation, } \geq 2 \text { local points were acupunctured. Other acupuncture points (including ear and trigger points) could be chosen } \\
\text { individually. Physicians were instructed to achieve de qi if possible, and needles were to be stimulated manually at least once during each session. } \\
\\
\text { B.Sham (minimal) acupuncture }(n=70): 12 \text { sessions, } 30 \text { minutes each, over } 8 \text { weeks (the same as for the acupuncture group). Acupuncturists } \\
\text { received a videotape, oral instruction and brochure detailing minimal acupuncture. } \geq 6 \text { of } 10 \text { predefined nonacupuncture points were needled } \\
\text { bilaterally using superficial insertion with fine needles } 20-40 \mathrm{~mm} \text { in length. Points were not in area of the back where patients were experiencing } \\
\text { pain, and de qi and manual stimulation were avoided. } \\
\begin{array}{l}\text { All: Oral non-steroidal anti-inflammatory drugs were allowed for treatment of chronic LBP if needed; use of corticosteroids or pain-relieving drugs } \\
\text { that act through the central nervous system was prohibited. }\end{array}\end{array}$ \\
\hline
\end{tabular}




\begin{tabular}{|c|c|c|c|}
\hline Author, Year & Study Participants & Outcome Measures & $\begin{array}{c}\text { Duration of } \\
\text { Followup }\end{array}$ \\
\hline Brinkhaus 2006a & $\begin{array}{l}\text { A vs. B } \\
\text { Age: } 59 \text { vs. } 58 \\
\text { Female: } 64 \% \text { vs. } 75 \% \\
\text { Race: NR } \\
\text { Duration of LBP, years: } 14.7 \text { vs. } 13.6 \\
\text { Number of days with pain during past month: } 24.6 \text { vs. } 26.2 \\
\text { Number of days with limited function during past } 6 \text { months: } 88.0 \text { vs. } \\
103.3 \\
\text { Baseline PDI score: } 28.9 \text { vs. } 31.5 \\
\text { Baseline HFAQ (FFbH-R) score: } 57.1 \text { vs. } 57.2 \\
\text { Baseline VAS score for LBP intensity: } 63.2 \text { vs. } 66.6 \\
\text { Baseline SF-36 physical health score: } 32.8 \text { vs. } 31.8 \\
\text { Baseline SF-36 mental health score: } 48.5 \text { vs. } 48.0 \\
\text { Baseline SF-36 subscale pain score: } 35.2 \text { vs. } 32.5 \\
\text { Baseline SES affective pain score: } 50.2 \text { vs. } 50.9 \\
\text { Baseline SES sensory pain score: } 49.7 \text { vs. } 49.1 \\
\text { Baseline ADS score: } 53.0 \text { vs. } 53.0 \\
\text { Prior acupuncture treatment: } 32 \% \text { vs. } 36 \% \\
\text { Physiotherapy in the past } 6 \text { months: } 26 \% \text { vs. } 29 \% \\
\text { Use of analgesics in the past } 6 \text { months: } 40 \$ \text { vs. } 37 \%\end{array}$ & $\begin{array}{l}\text { Funktionsfragebogen Hannover-Rücken (FFbH-R) (0- } \\
\text { 100, higher scores indicate better function) } \\
\text { Pain Disability Index (0-70, higher scores indicate } \\
\text { greater disability) } \\
\text { Number of days with limited function } \\
\text { LBP intensity (0-100 VAS) } \\
\text { Days with pain } \\
\text { SF-36 physical component (0-100) } \\
\text { SF-36 mental component } \\
\text { SF-36 pain subscale } \\
\text { Allgemeine Depressionsskala depression scale } \\
\text { (reported as t-standard) }\end{array}$ & $\begin{array}{l}4 \text { months, } 10 \\
\text { months }\end{array}$ \\
\hline
\end{tabular}




\begin{tabular}{|c|c|}
\hline Author, Year & $\begin{array}{c}\text { Results - Subquestion a } \\
\text { (vs. sham, no treatment, waitlist, attention control) }\end{array}$ \\
\hline Brinkhaus 2006a & 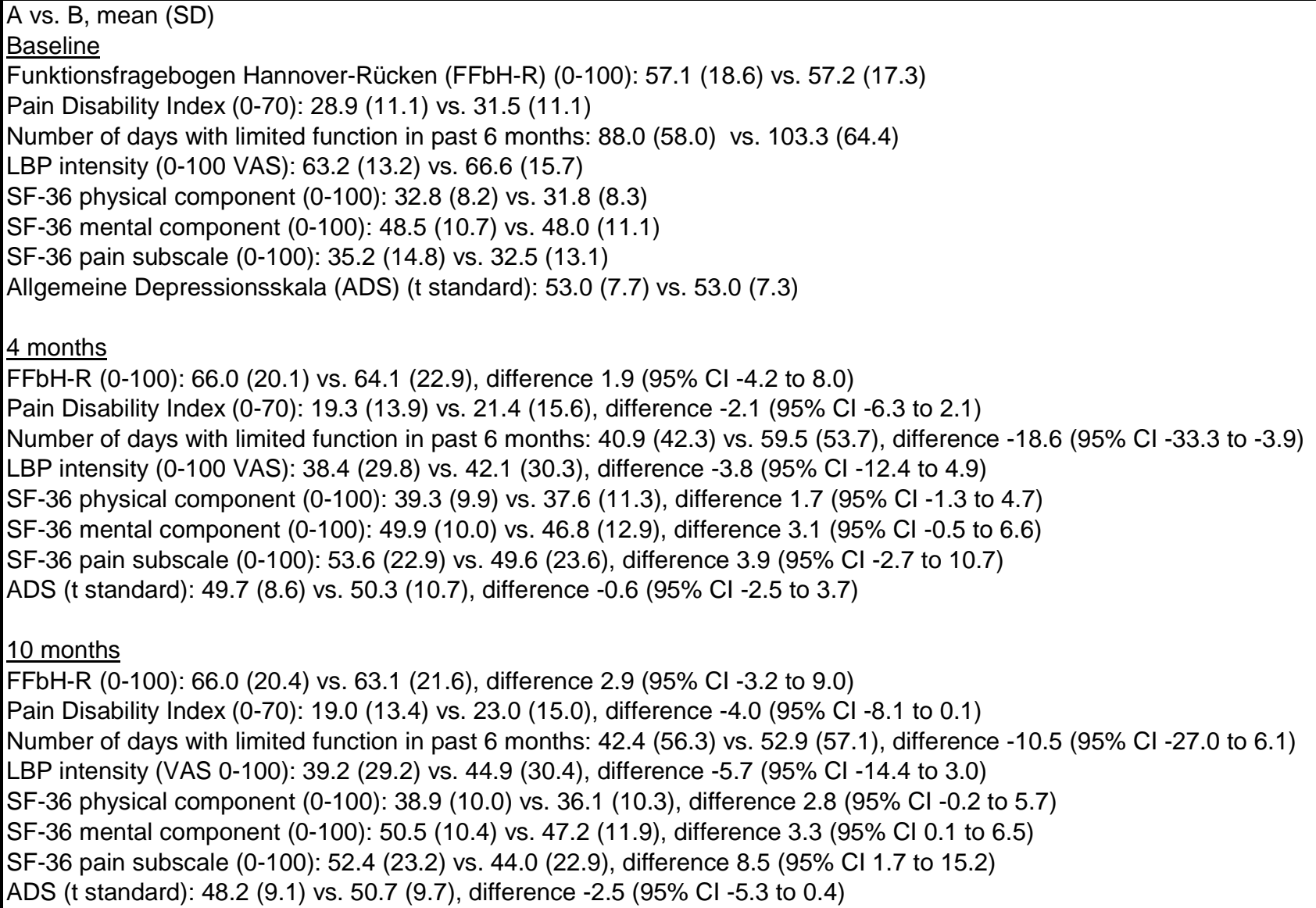 \\
\hline
\end{tabular}




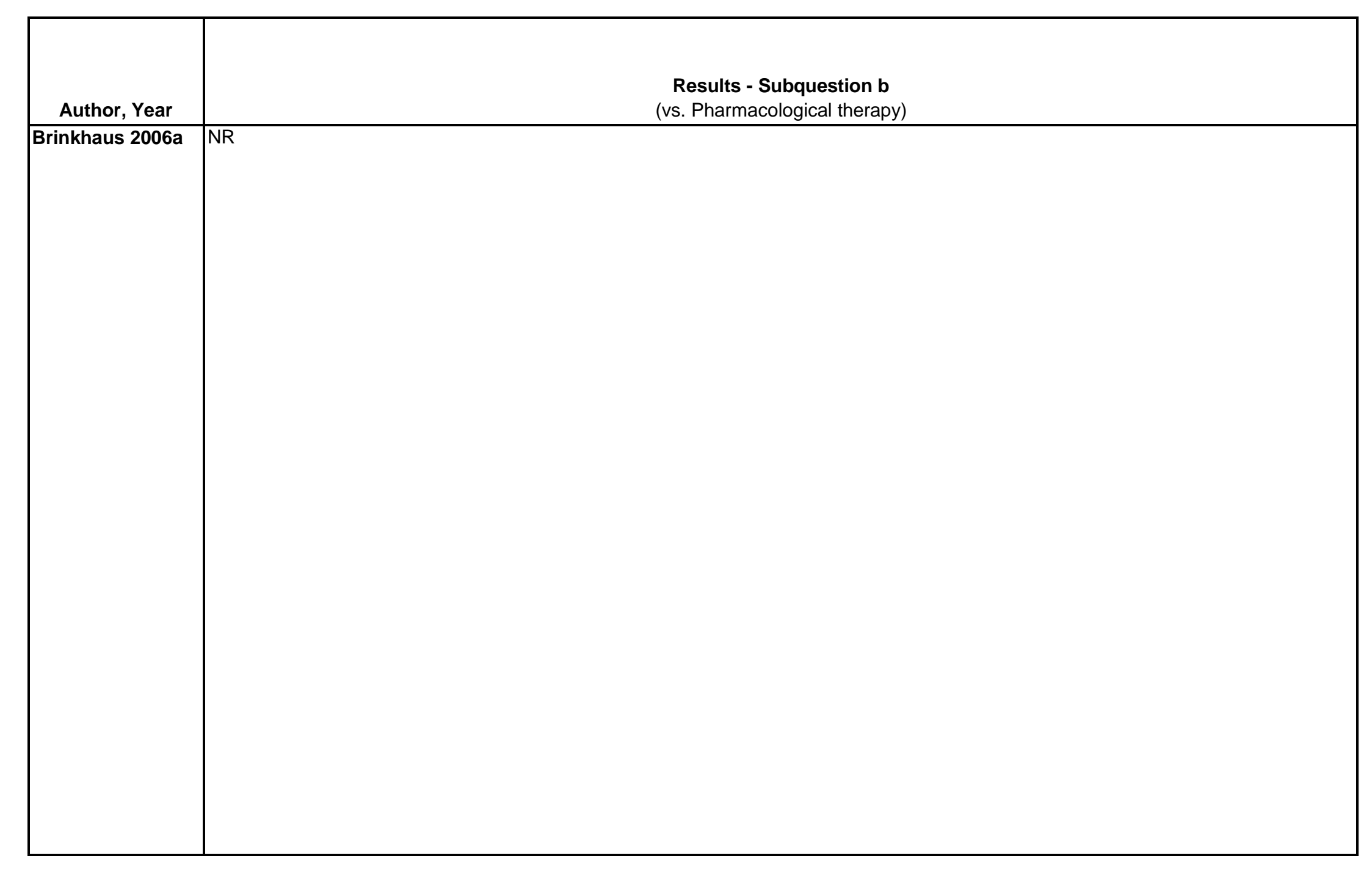

D-131 


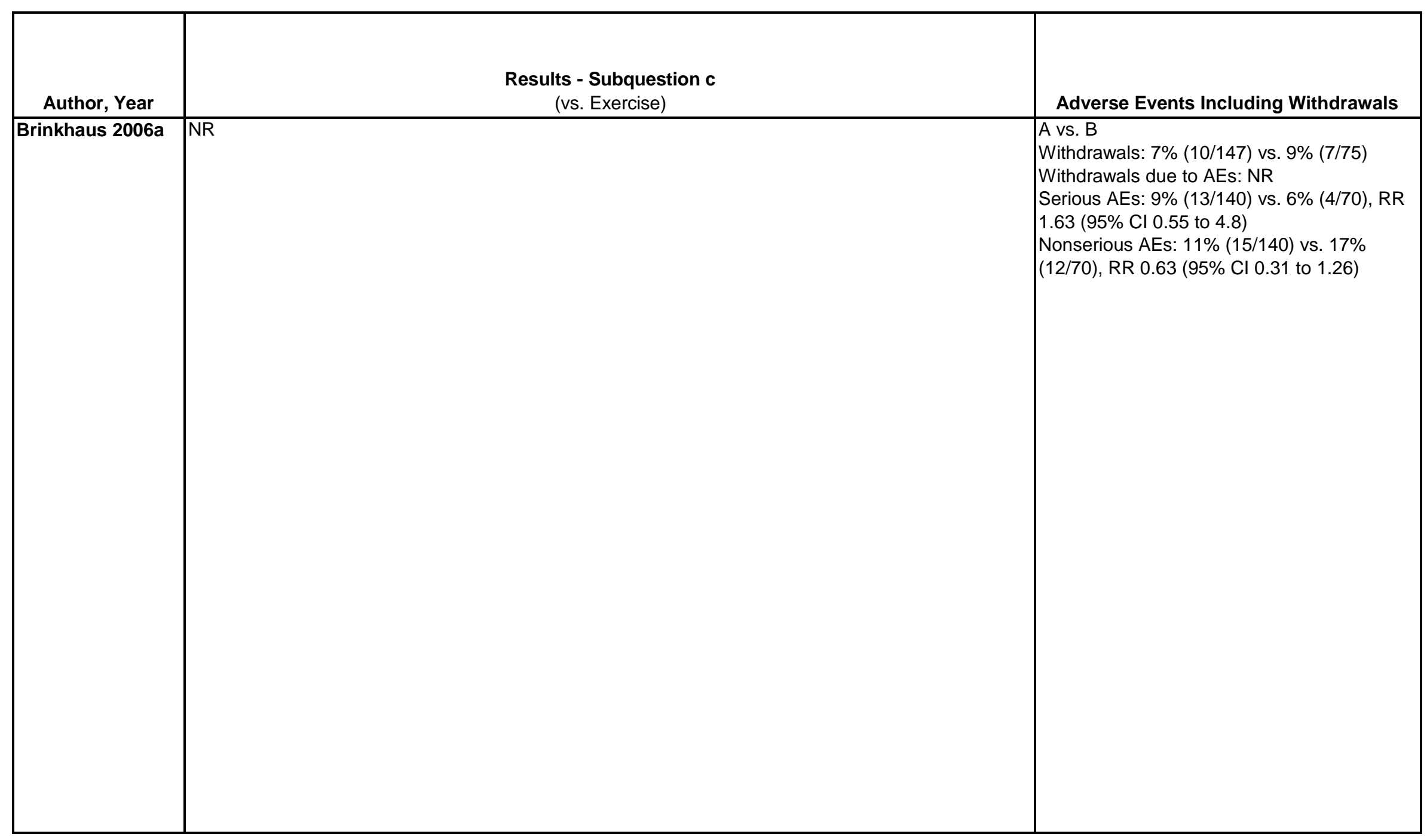




\begin{tabular}{|c|c|c|c|}
\hline Author, Year & Funding Source & Quality & Comments \\
\hline
\end{tabular}




\begin{tabular}{|c|c|c|c|}
\hline Author, Year & $\begin{array}{c}\text { Country } \\
\text { Number of Centers } \\
\text { Setting }\end{array}$ & Inclusion/Exclusion Criteria & $\begin{array}{c}\text { Number Randomized, } \\
\text { Analyzed } \\
\text { Attrition }\end{array}$ \\
\hline Brismee 2007 & \begin{tabular}{|l} 
United States, \\
"general community"
\end{tabular} & $\begin{array}{l}\text { Inclusion Criteria: } \\
\text { Subjects aged } 50 \text { years or older with knee pain. Selection of subjects } \\
\text { was based on the Classification Criteria of the American Rheumatism } \\
\text { Association for Osteoarthritis of the Knee. } \\
\text { Exclusion Criteria: } \\
\text { Exclusion if they could not read or write English, could not ambulate at } \\
\text { least } 25 \text { feet ( } 7.6 \mathrm{~m}) \text {, had a medical condition involving knee trauma or } \\
\text { intra-articular knee injection within one month, exercise-induced or } \\
\text { uncontrolled angina within three months, severe dyspnoea at rest, } \\
\text { terminal illness, uncontrolled hypertension, acute or chronic renal } \\
\text { failure, bilateral total knee arthroplasties, or a Mini- Mental State Exam } \\
\text { score of } 23 \text { or lower. }\end{array}$ & $\begin{array}{l}\text { Randomized: } 41 \\
\text { Treated: } 40 \\
\text { Analyzed: } 31 \\
\text { Attrition: } 24.3 \% \text { (10/41) }\end{array}$ \\
\hline Bronfort 2011 & $\begin{array}{l}\text { US, Minnesota } \\
\text { Number of centers: } 1 \\
\text { Outpatient and clinic }\end{array}$ & $\begin{array}{l}\text { Patients } 18 \text { to } 65 \text { years of age, who had a primary complaint of } \\
\text { mechanical LBP of at least } 6 \text {-week duration with or without radiating } \\
\text { pain to the lower extremity } \\
\text { Exclude: Patients with previous lumbar spine fusion surgery, } \\
\text { progressive neurological deficits, aortic } \\
\text { or peripheral vascular disease, pain scores of less than } 3 \\
(0-10 \text { scale), pending or current litigation, or ongoing treatment for } \\
\text { back pain by other health care providers. }\end{array}$ & $\begin{array}{l}\text { Randomized: } 301 \\
\text { Treated: } 245 \\
\text { Analyzed: } 245 \\
\text { Attrition: } 19 \%(57 / 301)\end{array}$ \\
\hline
\end{tabular}




\begin{tabular}{|c|c|}
\hline Author, Year & Intervention, Comparator \\
\hline Brismee 2007 & $\begin{array}{l}\text { A.Tai Chi }(\mathrm{n}=18) \\
\text { Subjects in the tai chi group attended group tai chi classes for six weeks followed by six weeks of home video tai chi practice. } \\
\text { No. of Treatments: } 3 / \text { week for } 12 \text { weeks ( } 36 \text { total) } \\
\text { Length of Treatments: } 40 \text { min/session } \\
\text { B.Attention Control ( } n=13) \\
\text { Subjects in the attention control group attended group lectures and discussions covering health-related topics. They did not take part in any further } \\
\text { activity past } 6 \text { week group period. } \\
\text { No. of Treatments: } 3 / \text { week for } 6 \text { weeks (18 total) } \\
\text { Length of Treatments: } 40 \text { min/session }\end{array}$ \\
\hline Bronfort 2011 & $\begin{array}{l}\text { A. Chiropractic spinal manipulation therapy, SMT ( } n=100) \text { : } 1 \text { to } 2 \text { times per week over } 12 \text { weeks, } 15 \text { to } 30 \text { minute short-lever, low-amplitude, high- } \\
\text { velocity SMT to low back } \\
\text { B: Supervised exercise therapy, SET ( } n=100) \text { : trunk } \\
\text { strengthening exercises with } 3 \text { sets of trunk extensions and leg extensions, trunk } \\
\text { lifted to } 5 \text { to } 10 \text { degrees past horizontal for a total range of motion of } 80 \text { to } 90 \text { degrees; approximately } 201 \text { hour sessions over } 12 \text { weeks } \\
\text { C. Home exercise and advice, HEA ( } n=101) \text { : Instruction in two } 1 \text { hour sessions on self care } \\
\text { measures; ice and heat, stretching and strengthening exercises, a book and laminated cards describing exercises to do daily }\end{array}$ \\
\hline
\end{tabular}




\begin{tabular}{|c|c|c|c|}
\hline Author, Year & Study Participants & Outcome Measures & $\begin{array}{c}\text { Duration of } \\
\text { Followup }\end{array}$ \\
\hline Brismee 2007 & $\begin{array}{l}\text { A vs B } \\
\text { Age: } 71 \text { vs. } 69 \\
\text { Female: } 86.4 \% \text { vs. } 78.9 \% \\
\text { Race: NR } \\
\text { Mean Duration of Chronicity: NR } \\
\\
\text { Overall (WOMAC): } 64.58(17.44) \text { vs. } 59.63(15.22) \\
\text { Physical Function (WOMAC): } 42.74(12.07) \text { vs. } 37.63(10.61) \\
\text { Stiffness (WOMAC): } 5.57(1.17) \text { vs. } 5.11(1.37) \\
\text { Pain (WOMAC): } 16.48(5.33) \text { vs. } 16.9(4.23) \\
\text { Pain (VAS): } 4.67(2.59) \text { vs. } 4.16(1.79)\end{array}$ & $\begin{array}{l}\text { Western Ontario and McMaster Osteoarthritis Index } \\
\text { Overall (WOMAC, range 26-130: higher scores } \\
\text { represent more pain, stiffness and disability) } \\
\text { Physical Function (WOMAC, range 17-85) } \\
\text { Stiffness (WOMAC, range 2-10) } \\
\text { Pain (WOMAC, range 7-35) } \\
\text { Pain (VAS) }\end{array}$ & 1.5 months \\
\hline Bronfort 2011 & $\begin{array}{l}\text { A vs. B vs. C } \\
\text { Mean age: } 45.2 \text { vs. } 44.5 \text { vs. } 45.6 \text { years } \\
\text { Female sex: } 67 \% \text { vs. } 57 \% \text { vs. } 58 \% \\
\text { Race: NR } \\
\text { Pain all or most of the time: } 55 \% \text { vs. } 51 \% \text { vs. } 60 \% \\
\text { Duration of back pain: } 5.0 \text { vs. } 4.8 \text { vs. } 5.0 \text { years } \\
\text { Mean pain severity score }(0-10): 5.4 \text { vs. } 5.1 \text { vs. } 5.2 \\
\text { Modified RDQ (0-23): } 8.7 \text { vs. } 8.4 \text { vs. } 8.7 \\
\text { SF- } 36 \text { PCS: } 43 \text { vs. } 44 \text { vs. } 43 \\
\text { SF- } 36 \text { MCS: } 55 \text { vs. } 54 \text { vs. } 54 \\
\text { Depression score } \\
\text { Scale) }(0=\text { no depression, } 16=\text { mild, } 60=\text { maximum): } 6.7 \text { vs. } 7.9 \text { vs. } 8.1\end{array}$ & $\begin{array}{l}\text { Pain (0-10 NRS) } \\
\text { Modified Roland Morris Disability Questionnaire (0=no } \\
\text { disability, 23=maximum disability) } \\
\text { SF- 36-Item Short Form Health Survey Physical } \\
\text { component (norm-based mean=50) } \\
\text { SF- 36-Item Short Form Health Survey Mental } \\
\text { component (norm-based mean=50) } \\
\text { Over-the-counter pain medication in past week (days) }\end{array}$ & \begin{tabular}{|l|}
4 and 9 \\
months
\end{tabular} \\
\hline
\end{tabular}




\begin{tabular}{|c|c|}
\hline Author, Year & $\begin{array}{l}\text { Results - Subquestion a } \\
\text { (vs. sham, no treatment, waitlist, attention control) }\end{array}$ \\
\hline Brismee 2007 & $\begin{array}{l}\text { A vs. B } \\
1.5 \text { months } \\
\text { Overall (WOMAC): } 60.28 \text { (23.8) vs. } 57.73(19.58) ; \mathrm{MD} 2.55(95 \% \mathrm{Cl}-13.94 \text { to } 19.04) \mathrm{p}=0.754 \\
\text { Physical Function (WOMAC): } 38.61 \text { (15.62) vs. } 37.58(13.12) ; \mathrm{MD} 1.03(95 \%-9.87 \text { to } 11.93) \mathrm{p}=0.848 \\
\text { Stiffness (WOMAC): } 5.28 \text { (1.53) vs. } 4.54(1.51) ; \mathrm{MD} 0.74(95 \% \mathrm{Cl}-0.39 \text { to } 1.87) \mathrm{p}=0.192 \\
\text { Pain (WOMAC): } 16.39 \text { (6.96) vs. } 16(4.88) ; \mathrm{MD} 0.39(95 \% \mathrm{Cl}-4.21 \text { to } 4.99) \mathrm{p}=0.390 \\
\text { Pain (VAS): } 3.46 \text { (2.45) vs. 3.19 (1.97); MD } 0.27(95 \% \mathrm{Cl}-1.42 \text { to } 1.96) \mathrm{p}=0.746\end{array}$ \\
\hline Bronfort 2011 & NR \\
\hline
\end{tabular}




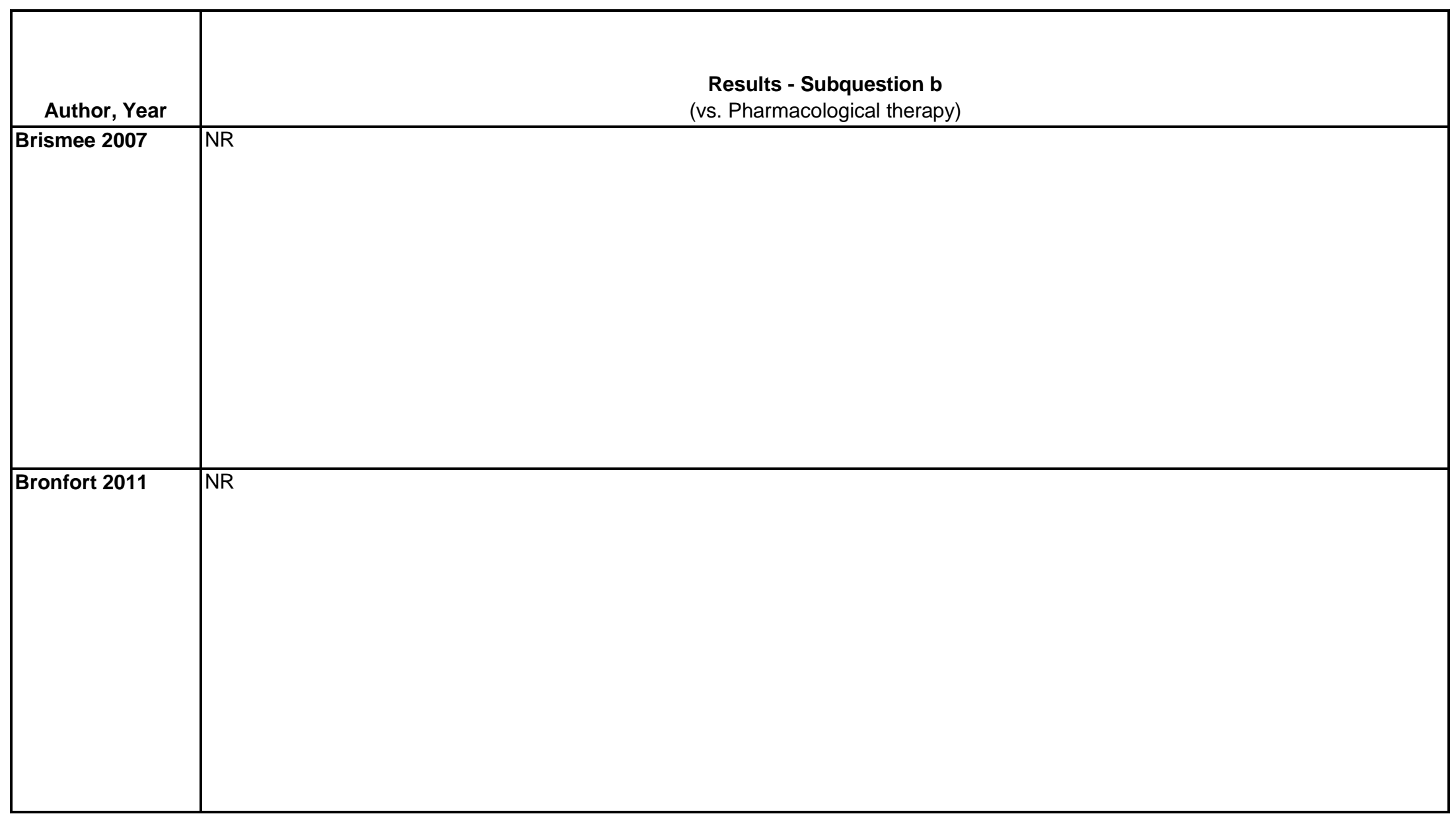

D-138 


\begin{tabular}{|c|c|c|}
\hline Author, Year & $\begin{array}{c}\text { Results - Subquestion c } \\
\text { (vs. Exercise) }\end{array}$ & Adverse Events Including Withdrawals \\
\hline Brismee 2007 & NR & $\begin{array}{l}\text { "Sporadic complaints of minor muscle } \\
\text { soreness and foot and knee pain were made } \\
\text { mainly during the first few days of the } \\
\text { intervention. No other adverse effect } \\
\text { associated with the practice of tai chi was } \\
\text { reported by the participants." }\end{array}$ \\
\hline Bronfort 2011 & 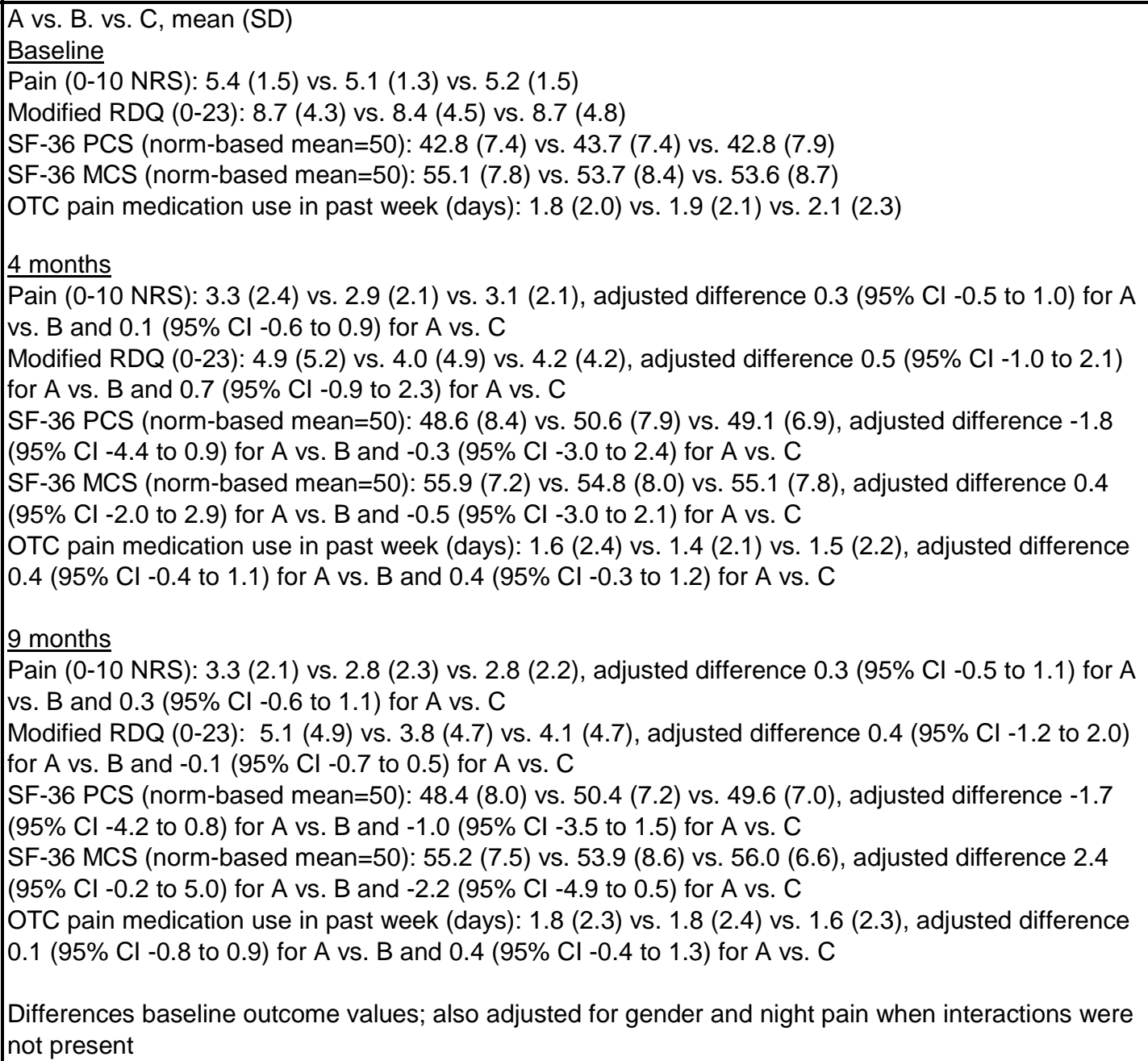 & $\begin{array}{l}\text { A vs. B vs. C } \\
\text { Nonserious adverse events: } 1 \%(1 / 100) \text { vs. } \\
1 \%(1 / 100) \text { vs. } 4 \%(4 / 101) \\
\text { All adverse events were considered non- } \\
\text { serious. }\end{array}$ \\
\hline
\end{tabular}

\section{D-139}




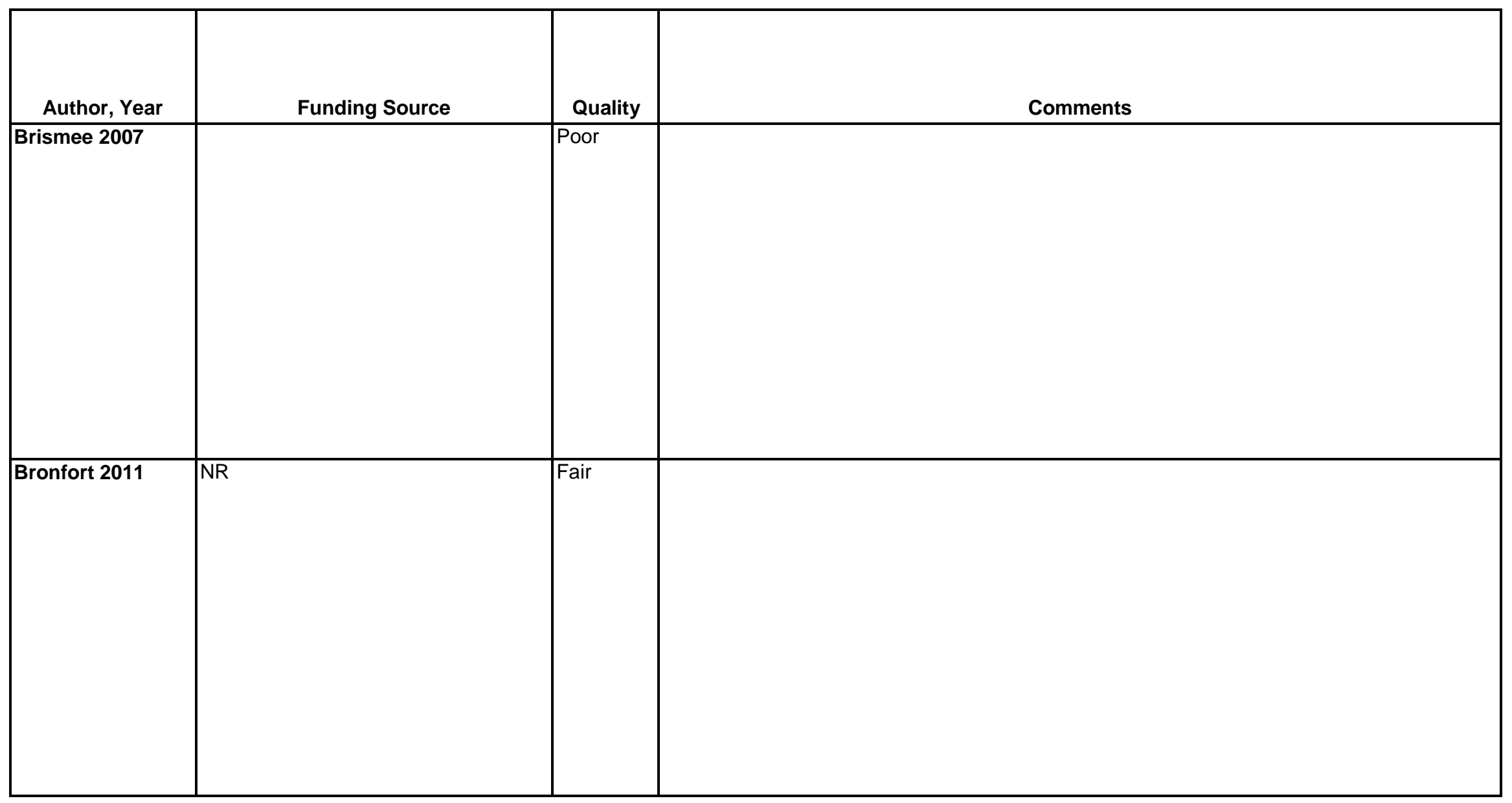

D-140 


\begin{tabular}{|c|c|c|c|}
\hline Author, Year & \begin{tabular}{|c|} 
Country \\
Number of Centers \\
Setting \\
\end{tabular} & \begin{tabular}{|c|} 
Inclusion/Exclusion Criteria \\
\end{tabular} & $\begin{array}{c}\text { Number Randomized, } \\
\text { Analyzed } \\
\text { Attrition }\end{array}$ \\
\hline Brosseau 2005 & \begin{tabular}{|l|} 
Canada \\
Number of \\
centers unclear \\
Rheumatology \\
treatment facilities
\end{tabular} & \begin{tabular}{|l|} 
Diagnosis of hand OA fulfilling ACR criteria, symptoms for at least 3 \\
months, aged 45 to 80 years old, pain VAS score of 4 or greater, $x-$ \\
ray evidence of joint space narrowing in the hands, available for the \\
study treatment schedule \\
Exclude: Orthopedic or rheumatologic comorbidities, evidence of \\
chondrocalcinosis, prior surgery for finger joints, acute disease, \\
uncontrolled diabetes mellitus, untreated hypertension, neurological \\
deficits or other mental disorders, anticipated change in type or \\
dosage or prescribed initial analgesic medication during study, current \\
rehabilitation treatment or other pain-related treatment (aside from \\
medication), previous experience with low-level laser therapy, \\
corticosteroid injection of finger joints within previous 12 months, \\
pregnancy, photosensitivity, cancer, plans to move within 6 months
\end{tabular} & $\begin{array}{l}\text { Randomized: } 88 \text { Treated: } \\
88 \\
\text { Analyzed: } 86 \\
\text { Attrition: } 5 \%(4 / 88)\end{array}$ \\
\hline Brouwer 2006 & $\begin{array}{l}\text { The Netherlands, } \\
\text { multi-center }\end{array}$ & \begin{tabular}{|l} 
Inclusion Criteria: \\
The inclusion criteria were symptomatic unicompartmental knee OA \\
and a malalignment in patients aged 18 years and over. We \\
diagnosed the OA as unicompartmental when the symptoms (pain \\
and tenderness of the joint margins) were located over the medial or \\
the lateral tibiofemoral compartment of the knee in combination with \\
osteoarthritic signs according to the Ahlback score (Ahlback $>0$ ) in the \\
same medial or lateral tibiofemoral compartment of the knee as well \\
as in combination with varus alignment (in combination with medial \\
compartment OA) or valgus alignment (in com-bination with lateral \\
compartment OA), respective \\
Exclusion Criteria: \\
Patients with concurrent symptomatic OA of medial and lateral \\
compartments, symptomatic patellofemoral OA(scored on the \\
lateral radiograph of the knee), no malalignment, rheumatoid arthritis, \\
previous high tibial osteotomy, symptomatic hip or ankle pathology, \\
and an insufficient command of the Dutch language were excluded.
\end{tabular} & $\begin{array}{l}\text { Randomized: } 118 \\
\text { Treated: (89) 49+40 } \\
\text { Analyzed: } 89 \\
\text { Attrition: } 25 \% \text { (29/118) }\end{array}$ \\
\hline
\end{tabular}




\begin{tabular}{|c|c|}
\hline Author, Year & Intervention, Comparator \\
\hline Brosseau 2005 & $\begin{array}{l}\text { A.Low-level laser therapy }(\mathrm{n}=42) \text { : } 3 \text { sessions lasting } 20 \text { minutes per week for } 6 \text { weeks } \text { In each session, a Gallium Aluminum Arsenide low level laser } \\
\text { was used on radial, median, and ulnar nerves on the most affected hand; each nerve had } 3 \text { points irradiated for } 1 \text { second each for a total of } 15 \\
\text { points. In addition, each painful joint on the most affected hand was irradiated at } 4 \text { points for } 1 \text { second each. } \\
\text { B.Sham low-level laser therapy ( } n=46) \text { : same procedure as the active treatment but a sham laser probe was used. } \\
\text { All patients: Attended three sham low-level laser therapy sessions prior to the treatment period }\end{array}$ \\
\hline Brouwer 2006 & $\begin{array}{l}\text { Brace }(n=60) \\
\text { Patients were fitted with a commercially available knee brace that allowed medial unloading or lateral unloading and also received usual care. } \\
\text { Device: Oasys brace, Innovation Sports, Irvine, CA, USA } \\
\text { Usual Care ( } n=57) \\
\text { Usual care was identical in both groups and consisted of patient education (ad-aptation of activities and/or weight loss), and (if needed) physical } \\
\text { therapy and analgesic }\end{array}$ \\
\hline
\end{tabular}




\begin{tabular}{|c|c|c|c|}
\hline Author, Year & Study Participants & Outcome Measures & $\begin{array}{l}\text { Duration of } \\
\text { Followup }\end{array}$ \\
\hline Brosseau 2005 & $\begin{array}{l}\text { A vs B } \\
\text { Age: } 64 \text { vs } 65 \\
\text { Female: } 74 \% \text { vs } 83 \% \\
\% \text { taking medications: } 60 \% \text { vs } 61 \% \\
\text { Diagnosis of OA, years: } 7.5(8.0) \text { vs } 8.5(8.6) \\
\text { Pain intensity VAS: } 56.9(18.4) \text { vs } 49.4(22.4) \\
\text { AUSCAN function: } 2.2(0.9) \text { vs } 2.1(0.7) \\
\text { AUSCAN pain: } 2.4(0.6) \text { vs } 2.1(0.7)\end{array}$ & $\begin{array}{l}\text { AUSCAN function (0-4, higher score=higher } \\
\text { dysfunction); AUSCAN pain intensity (0-4, higher } \\
\text { score=higher dysfunction); pain VAS (0-100, higher } \\
\text { score=higher pain); patient global assessment }\end{array}$ & $\begin{array}{l}1.5 \text { and } 4.5 \\
\text { months }\end{array}$ \\
\hline Brouwer 2006 & $\begin{array}{l}\text { A vs B } \\
\text { Age*: } 59.2 \\
\text { Female: } 48 \% \text { vs. } 51 \% \\
\text { Race: NR } \\
\text { Mean Duration of Chronicity: } 6.7 v s .4 .9 \text { years } \\
\text { Mean Pain Severity (VAS): } 6.6(2.4) \text { vs. } 5.5(2.0) \\
\text { Mean Knee Function (HSS): } 64.9(12.0) \text { vs. } 69.0(9.5) \\
\text { Quality of Life (EQ-5D): } 0.50(0.30) \text { vs. } 0.56(0.26) \\
\text { ^Age only reported for total population }\end{array}$ & $\begin{array}{l}\text { Pain Severity (VAS, range } 0-10) \\
\text { Hospital for special surgery score (HSS, range 0-100) } \\
\text { Quality of Life (EQ-5D, 0-1) }\end{array}$ & $\begin{array}{l}6 \text { months, } \\
\text { immediate } \\
\text { post- } \\
\text { treatment (12 } \\
\text { months) }\end{array}$ \\
\hline
\end{tabular}




\begin{tabular}{|c|c|}
\hline Author, Year & $\begin{array}{c}\text { Results - Subquestion a } \\
\text { (vs. sham, no treatment, waitlist, attention control) }\end{array}$ \\
\hline Brosseau 2005 & $\begin{array}{l}\text { A vs B } \\
4.5 \text { months } \\
\text { AUSCAN function: } 1.9(0.9) \text { vs } 1.7(0.8),(\mathrm{MD} 0.2,95 \% \mathrm{Cl}-0.2 \text { to } 0.6) \mathrm{p}=0.28 \\
\text { AUSCAN pain: } 1.9(0.9) \text { vs } 1.8(0.8),(\mathrm{MD} 0.1,95 \% \mathrm{Cl}-0.3 \text { to } 0.5) \mathrm{p}=0.59 \\
\text { Pain VAS: NR } \\
\text { Patient global assessment: } \\
\quad \text { Fully improved: } 0 \% \text { vs } 3 \% \\
\quad \text { Partially improved: } 40 \% \text { vs } 33.3 \% \\
\quad \text { No improvement: } 60 \% \text { vs } 52 \%\end{array}$ \\
\hline Brouwer 2006 & $\begin{array}{l}\text { A vs. B } \\
\text { 6 months } \\
\text { Pain Severity (VAS): MD }-0.58(95 \% \mathrm{Cl}-1.48 \text { to } 0.32) \\
\text { Knee Function (HSS): MD } 3.2(95 \% \mathrm{Cl}-0.58 \text { to } 6.98) \mathrm{p}<0.1 \\
\text { Quality of Life (EQ-5D): MD } 0.01(95 \% \mathrm{Cl}-0.08 \text { to } 0.10) \\
\\
12 \text { months (post-treatment) } \\
\text { Pain Severity (VAS): MD }-0.81(95 \% \mathrm{Cl}-1.76 \text { to } 0.14) \mathrm{p}<0.1 \\
\text { Knee Function (HSS): MD } 3.0(95 \% \mathrm{Cl}-1.05 \text { to } 7.05) \\
\text { Quality of Life (EQ-5D): MD } 0.01(95 \% \mathrm{Cl}-0.08 \text { to } 0.10)\end{array}$ \\
\hline
\end{tabular}




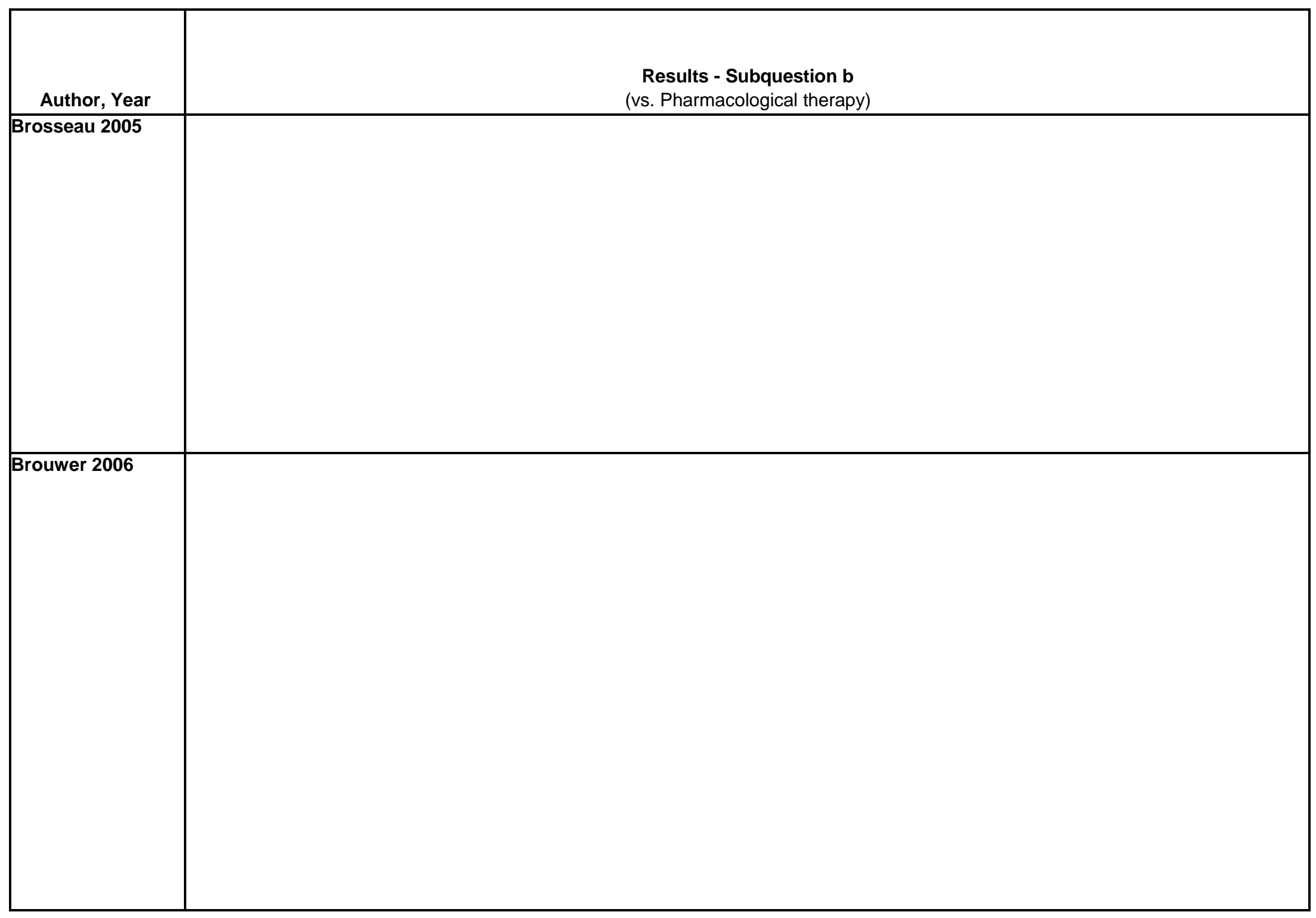

D-145 


\begin{tabular}{|l|l|l|}
\hline \multicolumn{1}{|c|}{ Author, Year } & \multicolumn{1}{|c|}{$\begin{array}{l}\text { Results - Subquestion c } \\
\text { (vs. Exercise) }\end{array}$} & \multicolumn{1}{c|}{ Adverse Events Including Withdrawals } \\
\hline Brosseau 2005 & & $\begin{array}{l}\text { A vs B } \\
\text { Erythema: } 2 \%(1 / 42) \text { vs } 0 \%(0 / 46) \\
\text { Start of period after menopause: } 2 \% \\
(1 / 42) \text { vs } 0 \%(0 / 46)\end{array}$ \\
\hline Brouwer 2006 & & \\
& & \\
\hline
\end{tabular}




\begin{tabular}{|l|l|l|l|}
\hline Author, Year & \multicolumn{1}{|c|}{ Funding Source } & Quality & \\
\hline Brosseau 2005 & $\begin{array}{l}\text { Grants from the Ontario Arthritis } \\
\text { Society (CANADA) (grant number TAS } \\
\text { 302), Ontario Ministry of Health and } \\
\text { Long-Term Care (grant number HRPD- } \\
\text { 05225), University Research Chair, } \\
\text { and Ministry of Human Resources }\end{array}$ & Good & MDs and p values calculated by using n=41 for intervention group and n=45 for control group \\
\hline Brouwer 2006 & & Poor & \\
\hline
\end{tabular}




\begin{tabular}{|c|c|c|c|}
\hline Author, Year & $\begin{array}{c}\text { Country } \\
\text { Number of Centers } \\
\text { Setting }\end{array}$ & Inclusion/Exclusion Criteria & $\begin{array}{c}\text { Number Randomized, } \\
\text { Analyzed } \\
\text { Attrition }\end{array}$ \\
\hline Buckelew 1998 & $\begin{array}{l}\text { United States } \\
2 \text { centers } \\
\text { Hospital and } \\
\text { outpatient }\end{array}$ & $\begin{array}{l}\text { Yunus' criteria for diagnosis of FM } \\
\text { Exclude: } \\
\text { Organic brain syndrome, psychotic disorder, unstable or uncontrolled } \\
\text { medical conditions, major communicative disorder, rheumatoid } \\
\text { arthritis, wide-spread osteoarthritis, subjective pain < } 4 \text { on } 0-10 \text { VAS, } \\
\text { regular aerobic exercise, biofeedback training within previous year }\end{array}$ & $\begin{array}{l}\text { Randomized: } 119 \\
\text { Treated: } 119 \\
\text { Analyzed: } 101 \\
\text { Attrition: } 15 \% \text { (18/119) }\end{array}$ \\
\hline
\end{tabular}




\begin{tabular}{|c|c|}
\hline Author, Year & Intervention, Comparator \\
\hline Buckelew 1998 & $\begin{array}{l}\text { A.Biofeedback }(n=25): 1 \text { session for } 1.5-3 \text { hours per week for } 6 \text { weeks and instructions to train } 2 \text { additional times independently per week. Subjects } \\
\text { were taught cognitive and muscular relaxation strategies. } \\
\text { B. Exercise }(n=26) \text { : } 1 \text { session for } 1.5-3 \text { hours per week for } 6 \text { weeks and instructions to train } 2 \text { additional times independently per week. Sessions } \\
\text { consisted of active range of motion exercises, strengthening exercises, low to moderate intensity aerobic exercise, proper posture and body } \\
\text { mechanic instruction, and instructions on the use of heat, cold, and massage } \\
\text { C.Attention control }(n=27): 1 \text { session for } 1.5-3 \text { hours per week for } 6 \text { weeks and instructions to train } 2 \text { additional times independently per week. } \\
\text { Subjects received educational information on diagnosis and treatment of FM and general health topics information }\end{array}$ \\
\hline
\end{tabular}




\begin{tabular}{|c|c|c|c|}
\hline Author, Year & Study Participants & Outcome Measures & $\begin{array}{l}\text { Duration of } \\
\text { Followup }\end{array}$ \\
\hline Buckelew 1998 & $\begin{array}{l}\text { A vs B vs C } \\
\text { Age: } 44 \text { vs } 46 \text { vs } 44 \\
\text { Female: } 97 \% \text { vs } 93 \% \text { vs } 90 \% \\
\text { Duration of symptoms (years): } 11.6 \text { ( } 10.0) \text { vs } 11.6(8.9) \text { vs } 10.0(9.0) \\
\text { Duration of diagnosis (years): } 2.5(2.9) \text { vs } 3.0(3.4) \text { vs } 2.5(2.4) \\
\text { AIMS physical activity subscale: } 6.0 \text { vs } 4.0 \text { vs } 6.0 \\
\text { Pain behavior observation measure: } 5.0 \text { vs } 4.0 \text { vs } 3.4 \\
\text { Pain VAS: } 5.8 \text { vs } 6.3 \text { vs } 5.9 \\
\text { SCL-90-R Global Severity Index: } 69.0 \text { vs } 72.5 \text { vs } 63.5 \\
\text { CES-D: } 16.0 \text { vs } 15.0 \text { vs } 12.5 \\
\text { Sleep scale: } 7.0 \text { vs } 8.0 \text { vs } 5.5\end{array}$ & $\begin{array}{l}\text { AIMS physical activity subscale (0-10, higher } \\
\text { score=lower activity); pain behavior observation method } \\
\text { (number of behaviors concomitant to pain counted in a } \\
\text { ten minute span, higher number=higher number of pain- } \\
\text { related behaviors observed); pain VAS (0-10, higher } \\
\text { score=higher pain); SCL-90-R Global Severity Index (0- } \\
360 \text {, higher score=more severe psychological } \\
\text { symptoms); CES-D (0-60, higher score=more severe } \\
\text { symptoms of depression); sleep scale (0-12, higher } \\
\text { score=worse sleep) }\end{array}$ & $\begin{array}{l}3,12, \text { and } 24 \\
\text { months }\end{array}$ \\
\hline
\end{tabular}




\begin{tabular}{|c|c|}
\hline Author, Year & $\begin{array}{c}\text { Results - Subquestion a } \\
\text { (vs. sham, no treatment, waitlist, attention control) }\end{array}$ \\
\hline Buckelew 1998 & $\begin{array}{l}\text { A vs C } \\
3 \text { months } \\
\text { AIMS physical activity subscale, median (median } \Delta \text { from baseline): } 6.0(0) \text { vs } 6.0(0) \\
\text { Pain behavior observation measure, median (median } \Delta \text { from baseline): } 2.5(-1) \text { vs } 3.0(0) \\
\text { Pain VAS, median (median } \Delta \text { from baseline): } 5.2(-0.2) \text { vs } 5.8(-0.5) \\
\text { SCL-90-R Global Severity Index, median (median } \Delta \text { from baseline): } 65.0(-2) \text { vs } 65.0(0) \\
\text { CES-D, median (median } \Delta \text { from baseline): } 10.0(-2) \text { vs } 13.0(3) \\
\text { Sleep scale, median (median } \Delta \text { from baseline): } 7.0(0) \text { vs } 5.0(0) \\
24 \text { months } \\
\text { AIMS physical activity subscale, median (median } \Delta \text { from baseline): } 6.0(0) \text { vs } 6.0(0) \\
\text { Pain behavior observation measure, median (median } \Delta \text { from baseline): } 2.5(-0.5) \text { vs } 3.0(1) \\
\text { Pain VAS, median (median } \Delta \text { from baseline): } 5.2(-1.1) \text { vs } 5.4(-0.6) \\
\text { SCL-90-R Global Severity Index, median (median } \Delta \text { from baseline): } 64.0(-1) \text { vs } 67.0(-1) \\
\text { CES-D, median (median } \Delta \text { from baseline): } 10.0(-2) \text { vs } 12.0(-2) \\
\text { Sleep scale, median (median } \Delta \text { from baseline): } 6.0(-2) \text { vs } 6.0(0) \\
\text { B vs C } \\
3 \text { months } \\
\text { AIMS physical activity subscale, median (median } \Delta \text { from baseline): } 4.0(0) \text { vs } 6.0(0) \\
\text { Pain VAS, median (median } \Delta \text { from baseline): } 5.4(-0.8) \text { vs } 5.8(-0.5) \\
\text { SCL-90-R Global Severity Index, median (median } \Delta \text { from baseline): } 65.5(-3) \text { vs } 65.0(0) \\
\text { CES-D, median (median } \Delta \text { from baseline): } 13.5(-2.5) \text { vs } 13.0(3) \\
\text { Sleep scale, median (median } \Delta \text { from baseline): } 8.0(0) \text { vs } 5.0(0) \\
24 \text { months } \\
\text { AlMS physical activity subscale, median (median } \Delta \text { from baseline): } 4.0(0) \text { vs } 6.0(0) \\
\text { Pain VAS, median (median } \Delta \text { from baseline): } 5.5(-1.2) \text { vs } 5.4(-0.6) \\
\text { SCL-90-R Global Severity Index, median (median } \Delta \text { from baseline): } 65.5(-2.5) \text { vs } 67.0(-1) \\
\text { CES-D, median (median } \Delta \text { from baseline): } 11.5(-3.5) \text { vs } 12.0(-2) \\
\text { Sleep scale, median (median } \Delta \text { from baseline): } 7.5(0) \text { vs } 6.0(0)\end{array}$ \\
\hline
\end{tabular}




$$
[-
$$




\begin{tabular}{|c|c|c|}
\hline Author, Year & $\begin{array}{l}\text { Results - Subquestion c } \\
\text { (vs. Exercise) }\end{array}$ & Adverse Events Including Withdrawals \\
\hline Buckelew 1998 & $\begin{array}{l}\text { A vs B } \\
3 \text { months } \\
\text { AIMS physical activity subscale, median (median } \Delta \text { from baseline): } 6.0(0) \text { vs } 4.0(0) \\
\text { Pain behavior observation measure, median (median } \Delta \text { from baseline): } 2.5(-1) \text { vs } 2.0(-1) \\
\text { Pain VAS, median (median } \Delta \text { from baseline): } 5.2(-0.2) \text { vs } 5.4(-0.8) \\
\text { SCL-90-R Global Severity Index, median (median } \Delta \text { from baseline): } 65.0(-2) \text { vs } 65.5(-3) \\
\text { CES-D, median (median } \Delta \text { from baseline): } 10.0(-2) \text { vs } 13.5(-2.5) \\
\text { Sleep scale, median (median } \Delta \text { from baseline): } 7.0(0) \text { vs } 8.0(0) \\
\\
24 \text { months } \\
\text { AIMS physical activity subscale, median (median } \Delta \text { from baseline): } 6.0(0) \text { vs } 4.0(0) \\
\text { Pain behavior observation measure, median (median } \Delta \text { from baseline): } 2.5(-0.5) \text { vs } 4.0(0) \\
\text { Pain VAS, median (median } \Delta \text { from baseline): } 5.2(-1.1 \text { vs } 5.5(-1.2) \\
\text { SCL-90-R Global Severity Index, median (median } \Delta \text { from baseline): } 64.0(-1) \text { vs } 65.5(-2.5) \\
\text { CES-D, median (median } \Delta \text { from baseline): } 10.0(-2) \text { vs } 11.5(-3.5) \\
\text { Sleep scale, median (median } \Delta \text { from baseline): } 6.0(-2) \text { vs } 7.5(0)\end{array}$ & NR \\
\hline
\end{tabular}




\begin{tabular}{|c|c|c|c|}
\hline Author, Year & Funding Source & Quality & Comments \\
\hline
\end{tabular}




\begin{tabular}{|c|c|c|c|}
\hline Author, Year & $\begin{array}{c}\text { Country } \\
\text { Number of Centers } \\
\text { Setting }\end{array}$ & Inclusion/Exclusion Criteria & $\begin{array}{c}\text { Number Randomized, } \\
\text { Analyzed } \\
\text { Attrition } \\
\end{array}$ \\
\hline Cakir 2014 & $\begin{array}{l}\text { Turkey, multi-site, } \\
\text { outpatient }\end{array}$ & $\begin{array}{l}\text { Inclusion Criteria: } \\
\text { Patients with pain for at least at } 6 \text { months least, diagnosed with knee } \\
\text { OA according to American College of Rheumatology guidelines, } \\
\text { confirmed with radiologically in Kellgren-Lawrence grades of } 2 \text { or } 3 \text {, } \\
\text { aged } 40-80 \text { years old were eligible. } \\
\text { Exclusion Criteria: } \\
\text { Patients were excluded if they had an experience of any physical } \\
\text { therapy agent, intra-articular corticosteroid therapy or } \\
\text { chondroprotective agents during the } 30 \text { days prior to the study or } \\
\text { viscosupplementation treatment within } 6 \text { months prior to the study, if } \\
\text { they had a diagnosis of joint infection, neoplasm, diabetes mellitus, } \\
\text { paresis, osteonecrosis, recent trauma, ascertained/suspected } \\
\text { pregnancy or lactating and poor general health status. Other exclusion } \\
\text { criteria were any history of contraindication of heat therapy or previous } \\
\text { major surgery. }\end{array}$ & $\begin{array}{l}\text { Randomized: } 60 \\
\text { Treated: } 60 \\
\text { Analyzed: } 58 \\
\text { Attrition: } 3.3 \%(2 / 60)\end{array}$ \\
\hline Carlsson 2001 & $\begin{array}{l}\text { Sweden } \\
\text { Number of centers: } 1 \\
\text { Outpatient pain clinic } \\
\text { in university hospital } \\
\text { setting }\end{array}$ & $\begin{array}{l}\text { Lumbar or lumbosacral low back pain for a duration of } 6 \text { months or } \\
\text { longer } \\
\text { No radiation of pain below the knee level } \\
\text { Normal neurologic examination findings of lumbosacral nerve function, } \\
\text { including deep tendon reflexes, plantar response, voluntary muscle } \\
\text { activation, straight leg raising, and sensory function. } \\
\text { Exclude: } \\
\text { Major trauma or systemic disease } \\
\text { Ongoing pregnancy } \\
\text { History of acupuncture treatment }\end{array}$ & $\begin{array}{l}\text { Randomized: } 51 \\
\text { Treated: } 34 \\
\text { Analyzed: } 50 \\
\text { Attrition: } 2 \% \text { (1/51) } \\
\text { Note on study design and } \\
\text { analysis: } \\
\text { Patients with a global } \\
\text { assessment of "worse" or } \\
\text { "unchanged" at the } 1 \\
\text { month or } 3 \text { month } \\
\text { followups were excluded } \\
\text { and labeled as } \\
\text { "unchanged" for the } \\
\text { remainder of the study. } \\
\text { - A: } 1 \text { month, } n=17 ; 3 \\
\text { months, } n=5 \\
\text { - B: } 1 \text { month, } n=14,3 \\
\text { months, } n=0\end{array}$ \\
\hline
\end{tabular}




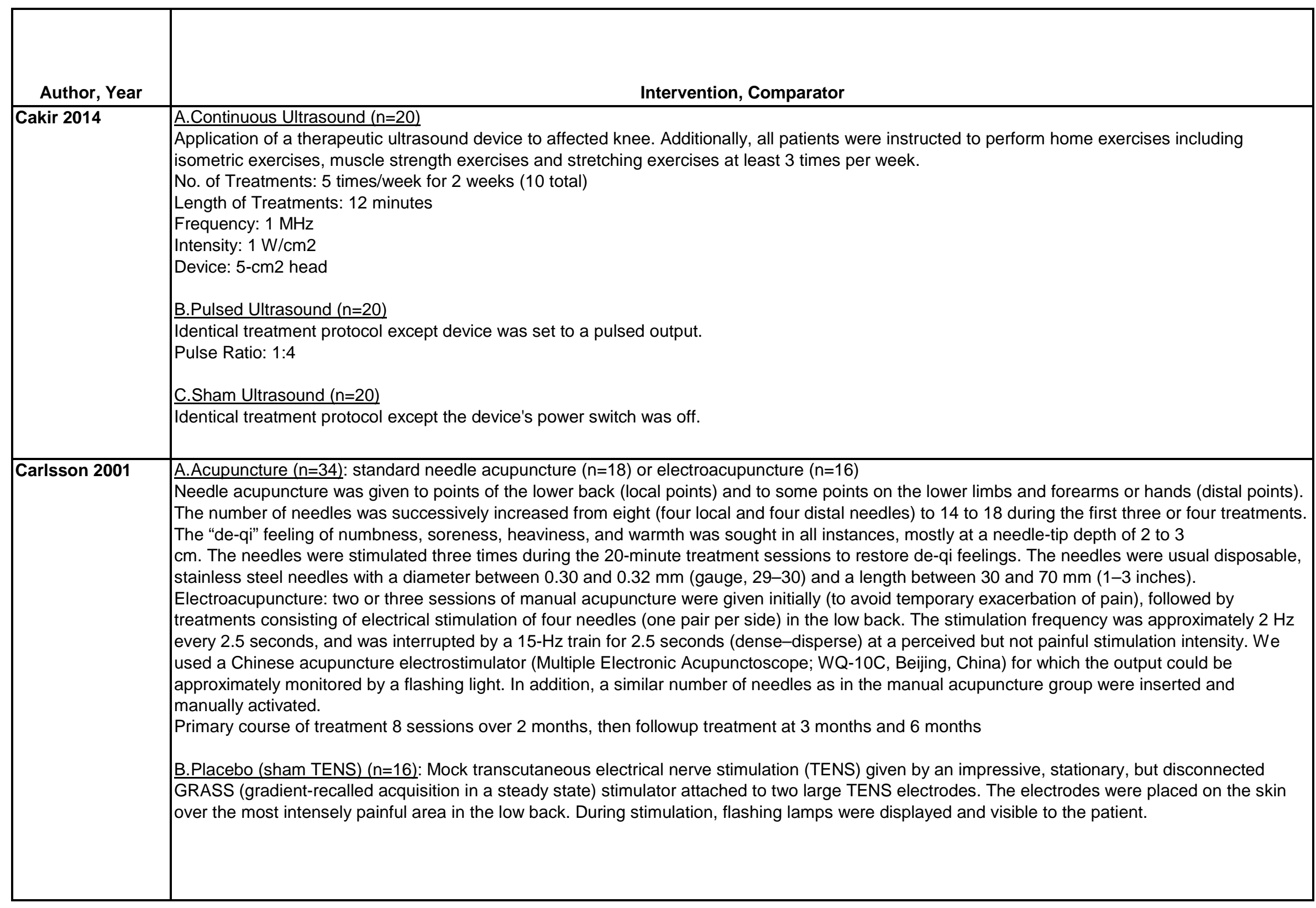




\begin{tabular}{|c|c|c|c|}
\hline Author, Year & \begin{tabular}{|c} 
Study Participants \\
\end{tabular} & Outcome Measures & $\begin{array}{c}\text { Duration of } \\
\text { Followup }\end{array}$ \\
\hline Cakir 2014 & $\begin{array}{l}\text { A vs B vs. C } \\
\text { Age: } 57 \text { vs. } 58 \text { vs. } 57 \\
\text { Female: } 70 \% \text { vs. } 80 \% \text { vs. } 85 \% \\
\text { Race: NR } \\
\text { Mean Duration of Chronicity: } 4.0(2.9) \text { vs. } 5.1 \text { (2.1) vs. } 4.5(3.8) \\
\\
\text { Physical Function (WOMAC): } 55.7(13.4) \text { vs. } 52.4(11.9) \text { vs. } 52.5(15.4) \\
\text { Pain (WOMAC): } 15.9(4.3) \text { vs. } 14.5(3.1) \text { vs. } 14.9(4.3) \\
\text { Pain at Rest (VAS): } 57.9(20.2) \text { vs. } 55.7(17.8) \text { vs. } 53.6(19.1) ; \\
\text { Pain on Movement (VAS): } 75.5(18.3) \text { vs. } 73.0(19.9) \text { vs. } 72.2(21.8) \\
\text { Disease Severity (VAS): } 73.9(19.2) \text { vs. } 67.9(18.7) \text { vs. } 68.4(20.5) ;\end{array}$ & $\begin{array}{l}\text { WOMAC } \\
\text { physical function (scale 0-68: higher score=worse } \\
\text { function) } \\
\text { Stiffness } \\
\text { WOMAC pain (range 0-20: higher score=greater pain) } \\
\text { Pain at rest (VAS, 0-10; higher score=greater pain) } \\
\text { Pain on Movement (VAS, 0-10; higher score=greater } \\
\text { pain) } \\
\text { Disease Severity (VAS, 0-10; higher score=greater } \\
\text { disability) }\end{array}$ & 6 months \\
\hline Carlsson 2001 & $\begin{array}{l}\text { Age: } 50 \text { years* } \\
\text { Female: } 66 \% \%^{\star} \\
\text { Race: NR } \\
\text { Pain duration (mean): } 9.5 \text { years* } \\
\text { Employment status: retired } 34 \% \text {, sick leave } 40 \% \text {, working full time } \\
\text { 24\%, unemployed } 2 \% \\
\text { Common LBP of presumed muscular origin: } 78 \% \\
\text { Number of treatment modalities tried prior to study (mean): } 2.8 \\
\text { Previous lumbar surgery: } 10 \% \\
\\
\text { ^ no significant difference among groups }\end{array}$ & $\begin{array}{l}\text { Global assessment by independent observer (pain } \\
\text { improved, unchanged, or worse) } \\
\text { Pain (0-100 VAS) } \\
\text { Analgesic intake: number tablets taken } \\
\text { Sleep quality (good, slightly disturbed by pain and woke } \\
1 \text { or } 2 \text { times, or badly disturbed by pain and work more } \\
\text { than twice) } \\
\text { Level of activity at work or at home }\end{array}$ & $\begin{array}{l}1,3, \text { and } \geq 6 \\
\text { months } \\
\text { (based on } \\
\text { primary } \\
\text { course of } \\
\text { treatment) }\end{array}$ \\
\hline
\end{tabular}




\begin{tabular}{|c|c|}
\hline Author, Year & $\begin{array}{c}\text { Results - Subquestion a } \\
\text { (vs. sham, no treatment, waitlist, attention control) }\end{array}$ \\
\hline Cakir 2014 & 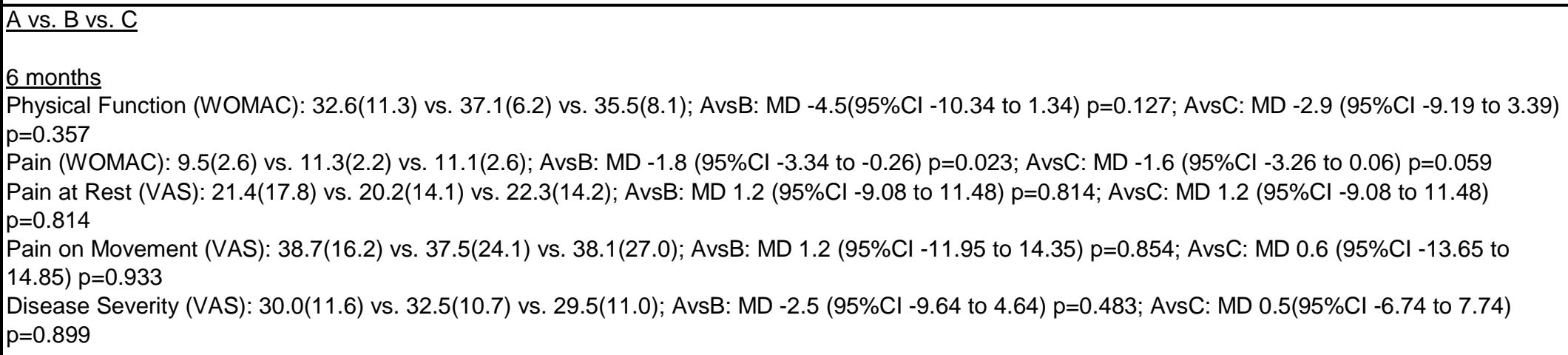 \\
\hline Carlsson 2001 & 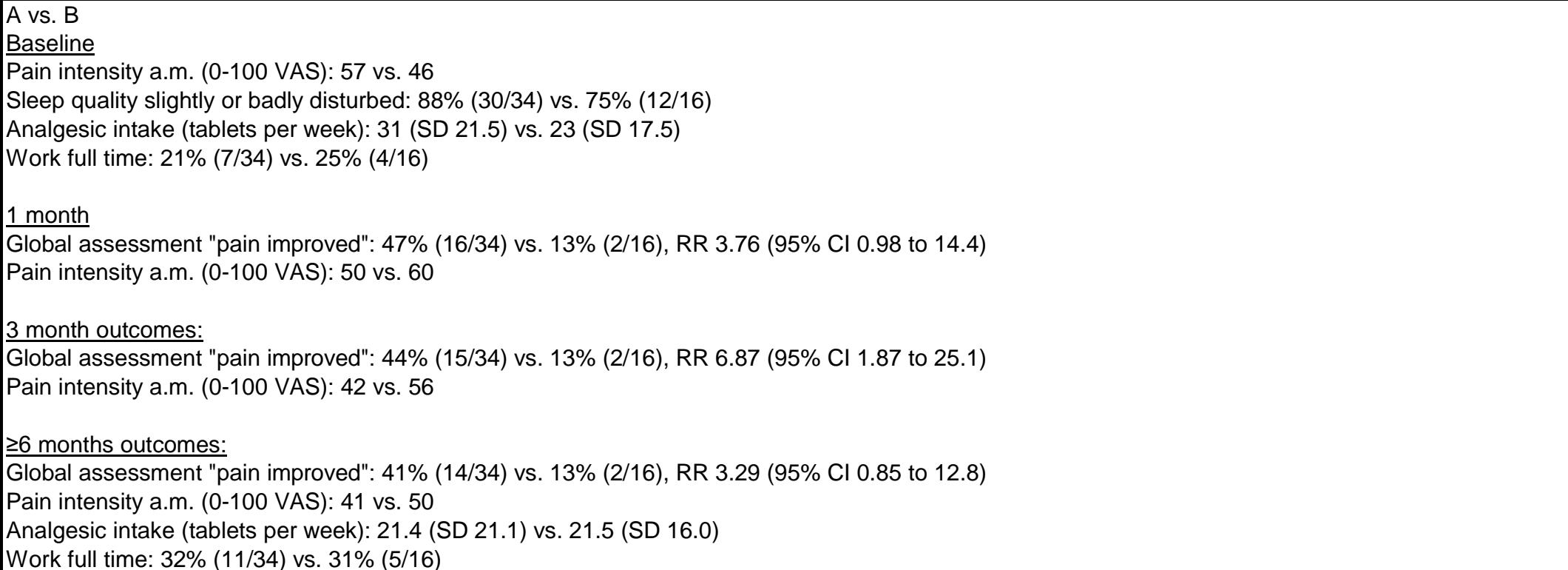 \\
\hline
\end{tabular}




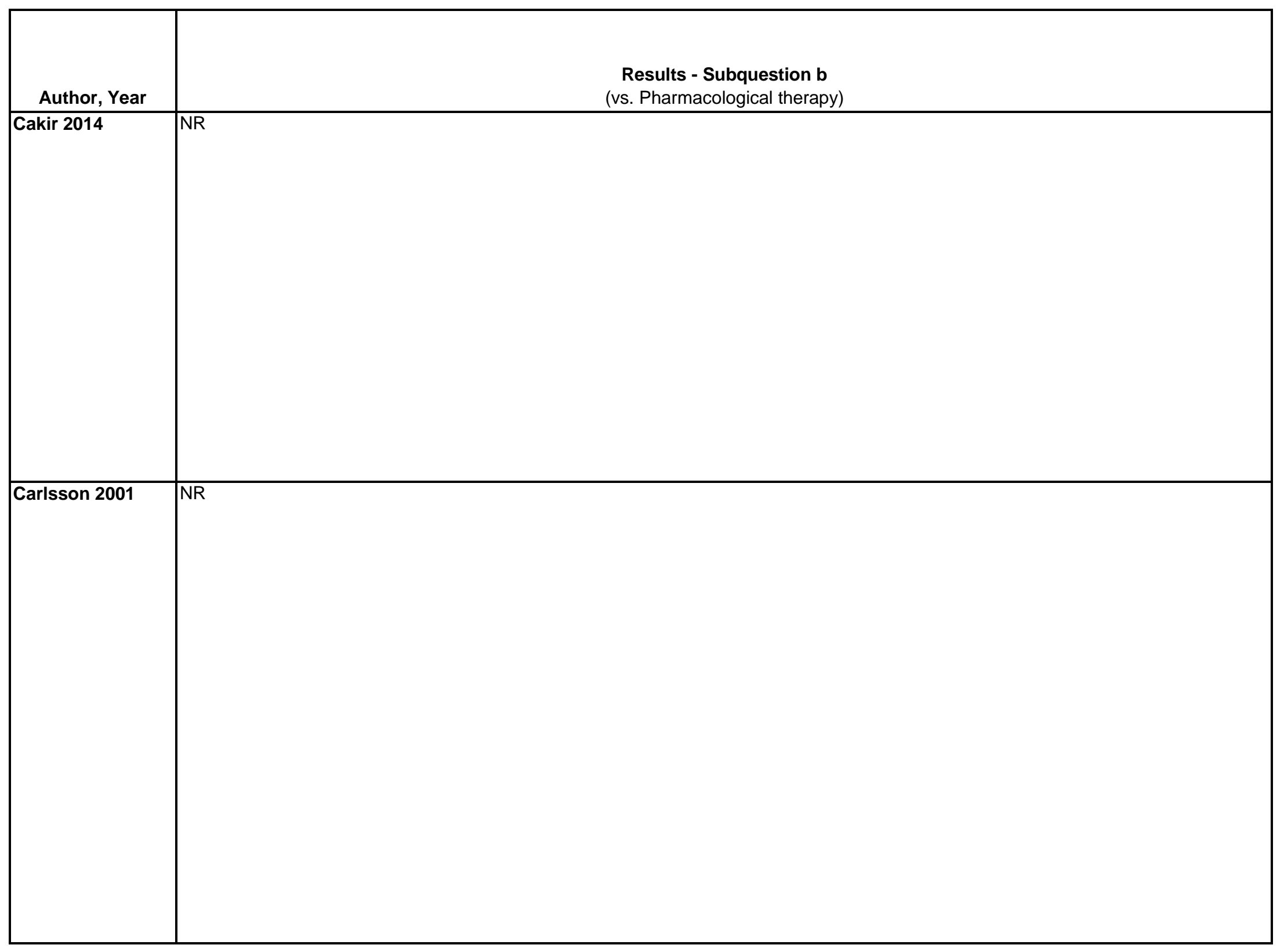

D-159 


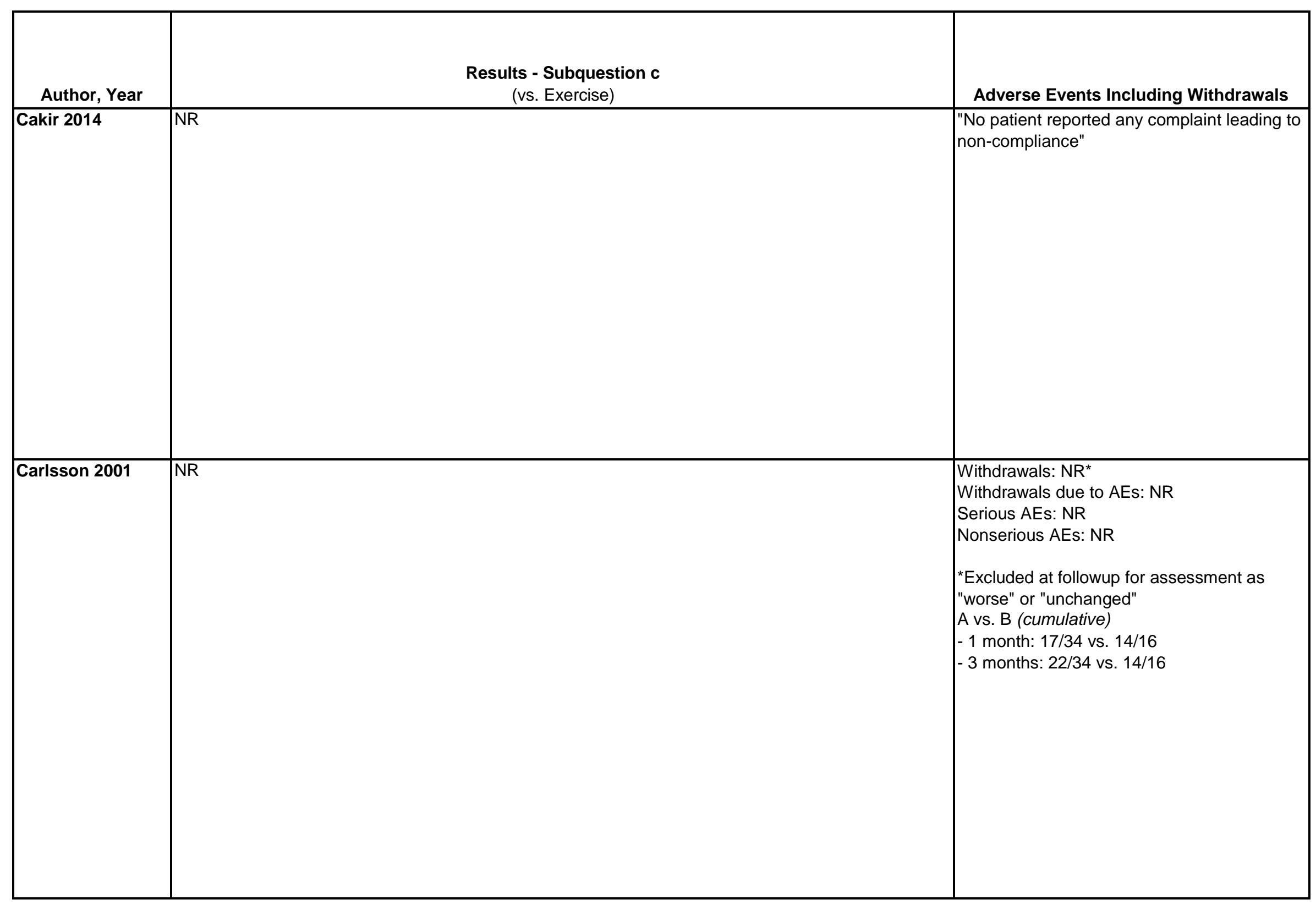




\begin{tabular}{|l|l|l|l|}
\hline \multicolumn{1}{|c|}{ Author, Year } & \multicolumn{1}{|c|}{ Funding Source } & Quality & \\
\hline Cakir 2014 & $\begin{array}{l}\text { Financial support provided by Ege } \\
\text { University for this project. No conflicts } \\
\text { of interest have been reported by the } \\
\text { authors or by any individuals in control } \\
\text { of the content of this article. }\end{array}$ & Comments \\
\hline Carlsson 2001 & $\begin{array}{l}\text { Partial support by grant No. 05658 } \\
\text { from the Swedish Medical Research } \\
\text { Council project. }\end{array}$ & Poor & $\begin{array}{l}\text { The results were not reported clearly. Means and percent changes were not reported as } \\
\text { values, just as graphs without any numbers for actual result. } \\
\text { - Figure 5 }\end{array}$ \\
& & & \\
\hline
\end{tabular}




\begin{tabular}{|c|c|c|c|}
\hline Author, Year & $\begin{array}{c}\text { Country } \\
\text { Number of Centers } \\
\text { Setting }\end{array}$ & Inclusion/Exclusion Criteria & $\begin{array}{c}\text { Number Randomized, } \\
\text { Analyzed } \\
\text { Attrition }\end{array}$ \\
\hline $\begin{array}{l}\text { Cash 2015, } \\
\text { Sephton } 2007\end{array}$ & $\begin{array}{l}\text { United States, setting } \\
\text { not reported }\end{array}$ & $\begin{array}{l}\text { Inclusion Criteria: } \\
\text { Women aged } 18 \text { and older, able to attend a weekly group with a } \\
\text { physician verified diagnosis of fibromyalgia. } \\
\text { Exclusion Criteria: } \\
\text { NR }\end{array}$ & $\begin{array}{l}\text { Randomized: } 91 \\
\text { Treated: } 82.3 \%(42 / 51) \\
\text { Analyzed: } 90 \text { (ITT) } \\
\text { Attrition: } 25 \%(23 / 91)\end{array}$ \\
\hline
\end{tabular}




\begin{tabular}{|l|l|}
\hline \multicolumn{1}{|c|}{ Author, Year } & \multicolumn{1}{c|}{$\quad$ Intervention, Comparator } \\
\hline $\begin{array}{l}\text { Cash 2015, } \\
\text { Sephton 2007 }\end{array}$ & $\begin{array}{l}\text { A. Mindfulness-based Stress Reduction }[\mathrm{MBSR}](\mathrm{n}=51) \\
\text { 8-week group-based program with one 2.5 hour session/week including instruction in techniques, meditation, and simple yoga positions to } \\
\text { encourage relaxation. Participants were asked to complete daily practices with workbook and audiotapes for } 45 \text { min a day for } 6 \text { days a week. } 42 \\
\text { participants (82\%) attended 4+ sessions, with mean attendance of 5.5 sessions. } \\
\text { B. Waitlist control group ( } \mathrm{n}=39)\end{array}$ \\
\begin{tabular}{l} 
Participants were offered the MBSR program only after the conclusion of the study and followup. \\
\hline
\end{tabular} \\
\hline
\end{tabular}




\begin{tabular}{|c|c|c|c|}
\hline Author, Year & Study Participants & Outcome Measures & $\begin{array}{c}\text { Duration of } \\
\text { Followup }\end{array}$ \\
\hline $\begin{array}{l}\text { Cash 2015, } \\
\text { Sephton } 2007\end{array}$ & $\begin{array}{l}\text { A vs. B } \\
\text { Age: NR } \\
\text { Female: } 100 \% \text { vs. } 100 \% \\
\text { Race: NR } \\
\text { Mean duration of chronicity: NR } \\
\\
\text { Physical Functioning (FIQ): } 1.3(.72) \text { vs. } 1.2(.75) \\
\text { Pain VAS: } 68.1 \text { (25.4) vs. } 69.2(19.6) \\
\text { Beck Depression Inventory (BDI) Total: } 15.6(7.0) \text { vs. 14.7(6.9) } \\
\text { Cognitive Subscale BDI (0-45): } 6.4(4.3) \text { vs. } 6.1(4.1) \\
\text { Somatic Subscale BDI (0-45): } 8.4(3.2) \text { vs. } 7.7(3.2) \\
\text { Perceived Stress Scale (PSS): } 22.0(6.2) \text { vs. } 21.4(7.4) \\
\text { Stanford Sleep Questionnaire (SSQ): } 9.0(3.2) \text { vs. } 9.3(3.1) \\
\text { FlQ Severity: } 67.5 \text { (15.8) vs. } 62.5(18.1) \\
\text { Fatigue Symptom Inventory (FSI): } 6.1(1.4) \text { vs. } 6.1(1.7)\end{array}$ & $\begin{array}{l}\text { Primary: } \\
\text { Fibromyalgia Impact Questionnaire (FIQ, range 0-100: } \\
\text { higher scores indicate severity of symptoms) } \\
\text { Severity (FIQ, range 0-100: higher scores indicate } \\
\text { severity of symptoms) } \\
\text { Physical Functioning (FIQ, range 0-10: higher scores } \\
\text { indicate severity of symptoms) } \\
\text { Pain (VAS, range 0-100mm: higher scores indicate } \\
\text { severity of pain) } \\
\text { Beck Depression Inventory (BDI; total:0-63, higher } \\
\text { scores indicate severity of depressive symptoms) } \\
\text { Perceived Stress Scale (PSS, range 0-40: higher scores } \\
\text { indicate severity of perceived stress) } \\
\text { Stanford Sleep Disorders Questionnaire (SDQ: scoring } \\
\text { information unavailable) } \\
\text { Fatigue Symptom Inventory (FSI, range 0-10: higher } \\
\text { scores indicate severity of fatigue) }\end{array}$ & 2 months \\
\hline
\end{tabular}




\begin{tabular}{|c|c|}
\hline Author, Year & $\begin{array}{l}\text { Results - Subquestion a } \\
\text { (vs. sham, no treatment, waitlist, attention control) }\end{array}$ \\
\hline $\begin{array}{l}\text { Cash 2015, } \\
\text { Sephton } 2007\end{array}$ & 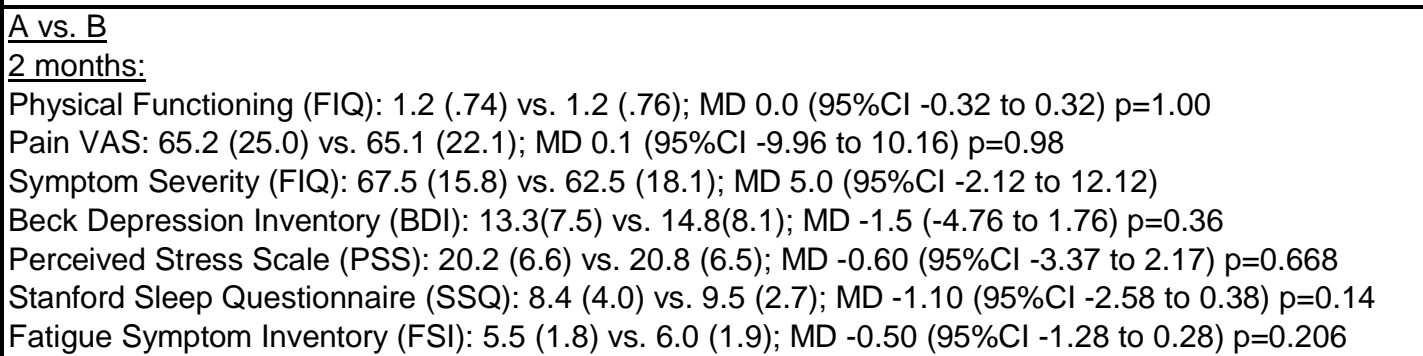 \\
\hline
\end{tabular}




\begin{tabular}{|l|l|}
\hline \multicolumn{1}{|c|}{ Author, Year } & \multicolumn{1}{c|}{$\begin{array}{c}\text { Results - Subquestion b } \\
\text { (vs. Pharmacological therapy) }\end{array}$} \\
\hline $\begin{array}{l}\text { Cash 2015, } \\
\text { Sephton 2007 }\end{array}$ & NR \\
& \\
& \\
& \\
\hline
\end{tabular}

D-166 


\begin{tabular}{|c|c|c|}
\hline Author, Year & $\begin{array}{l}\text { Results - Subquestion c } \\
\text { (vs. Exercise) }\end{array}$ & Adverse Events Including Withdrawals \\
\hline $\begin{array}{l}\text { Cash 2015, } \\
\text { Sephton } 2007\end{array}$ & NR & NR \\
\hline & & \\
\hline & & \\
\hline & & \\
\hline & & \\
\hline & & \\
\hline & & \\
\hline
\end{tabular}




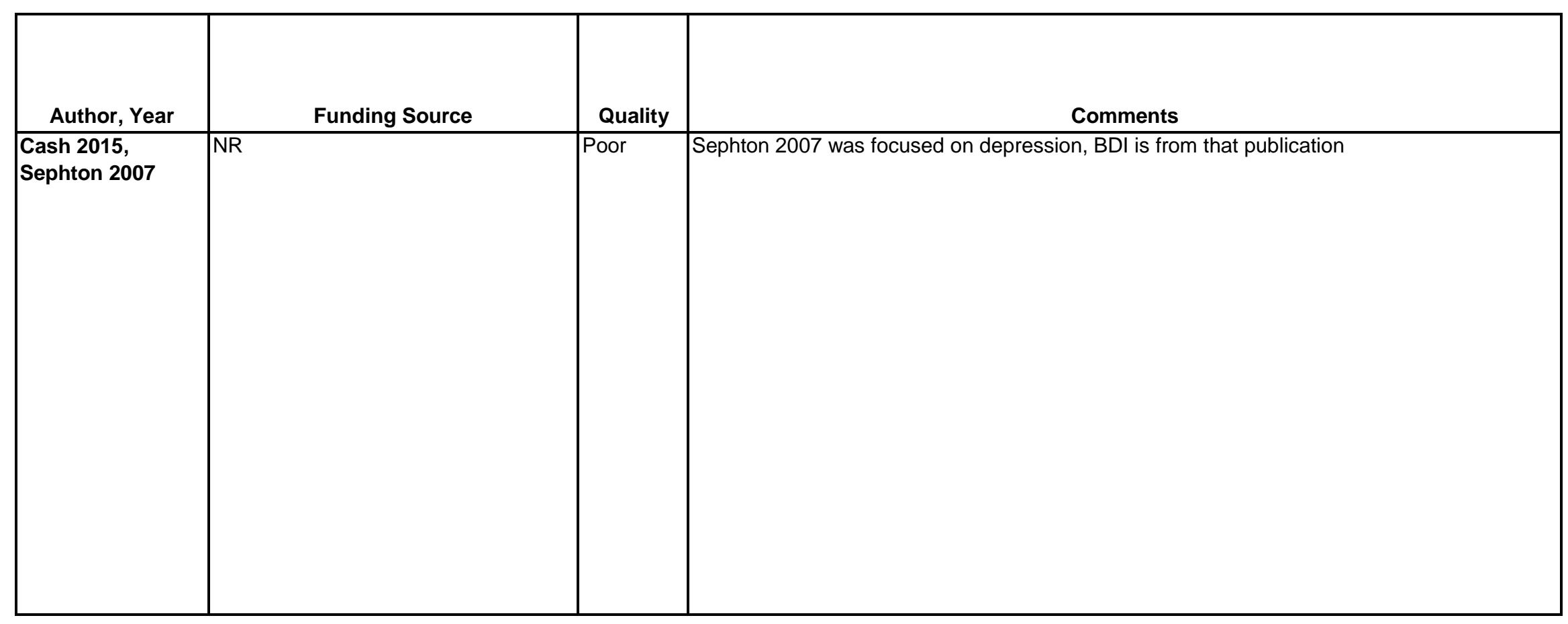




\begin{tabular}{|c|c|c|c|}
\hline Author, Year & $\begin{array}{c}\text { Country } \\
\text { Number of Centers } \\
\text { Setting }\end{array}$ & Inclusion/Exclusion Criteria & $\begin{array}{c}\text { Number Randomized, } \\
\text { Analyzed } \\
\text { Attrition }\end{array}$ \\
\hline Castel 2012 & $\begin{array}{l}\text { Spain } \\
\text { Setting NR }\end{array}$ & $\begin{array}{l}\text { Inclusion: } \\
\text { FM diagnosis based on ACR } 1990 \text { criteria, age 18-65 } \\
\text { Exclusion: additional severe chronic medical pain conditions, suicidal } \\
\text { ideation, severe psychopathology, moderate-to-severe cognitive } \\
\text { impairment }\end{array}$ & $\begin{array}{l}\text { Randomized: } 64 \\
\text { Analyzed: } 48 \\
\text { Attrition: } 25 \%(16 / 64)\end{array}$ \\
\hline
\end{tabular}




\begin{tabular}{|c|c|}
\hline Author, Year & Intervention, Comparator \\
\hline Castel 2012 & $\begin{array}{l}\text { A.CBT plus standard pharmacological care }(\mathrm{n}=26) \text {. CBT conducted in groups (except for session 2, which was individual); } 14 \text { weekly } 2 \text { hour } \\
\text { sessions. CBT included education about FM and pain, autogenic training, cognitive restructuring, CBT for insomnia, assertiveness training, activity } \\
\text { pacing, pleasant activity scheduling, goal setting, and relapse prevention. Subjects were given a manual and CD to practice autogenic training at } \\
\text { home. No difference was found between attendance in A (mean of } 12.3 \text { sessions and SD of 1.7) vs B (mean of } 12.0 \text { sessions, SD of 2.6). } \\
\text { B.Control }(n=22): \text { standard pharmacological care: conventional pharmacological management, including analgesics, antidepressants, } \\
\text { anticonvulsants, and myorelaxants }\end{array}$ \\
\hline
\end{tabular}




\begin{tabular}{|c|c|c|c|}
\hline Author, Year & Study Participants & Outcome Measures & $\begin{array}{l}\text { Duration of } \\
\text { Followup }\end{array}$ \\
\hline Castel 2012 & $\begin{array}{l}\text { A vs B } \\
\text { Age: } 50 \text { vs } 49 \\
\text { Female: } 94 \% \text { vs } 100 \% \\
\text { White: } 100 \% \text { vs } 100 \% \\
\text { Pain duration, years: } 13.6(9.2) \text { vs } 11.6(6.9) \\
\text { FIQ: } 62.7(2.8) \text { vs } 66.1(3.0) \\
\text { Pain NRS: } 6.1(0.3) \text { vs } 6.9(0.3) \\
\text { HADS: } 23.2(1.4) \text { vs } 24.2(1.5) \\
\text { MOS Sleep quantity: } 6.0(0.3) \text { vs } 5.5(0.3) \\
\text { MOS Sleep index problems: } 30.4(1.5) \text { vs } 27.9(1.6)\end{array}$ & $\begin{array}{l}\text { FIQ (0-100, higher scores=greater impact of FM; MCID } \\
14 \% \text { ) } \\
\text { Pain intensity NRS (mean of three 0-10 ratings of } \\
\text { maximum, minimum, and usual pain intensity in last } \\
\text { week, 0-10, higher scores=greater pain; MCID 30\%) } \\
\text { Hospital Anxiety and Depression Scale (HADS; scale } \\
\text { NR, higher scores=greater psychological distress) } \\
\text { MOS Sleep quantity (scale NR) } \\
\text { MOS Sleep index problems (scale NR) }\end{array}$ & \begin{tabular}{|l} 
Immediately \\
post- \\
treatment, \\
then 3 and 6 \\
months later.
\end{tabular} \\
\hline
\end{tabular}




\begin{tabular}{|c|c|}
\hline Author, Year & $\begin{array}{l}\text { Results - Subquestion a } \\
\text { (vs. sham, no treatment, waitlist, attention control) }\end{array}$ \\
\hline Castel 2012 & 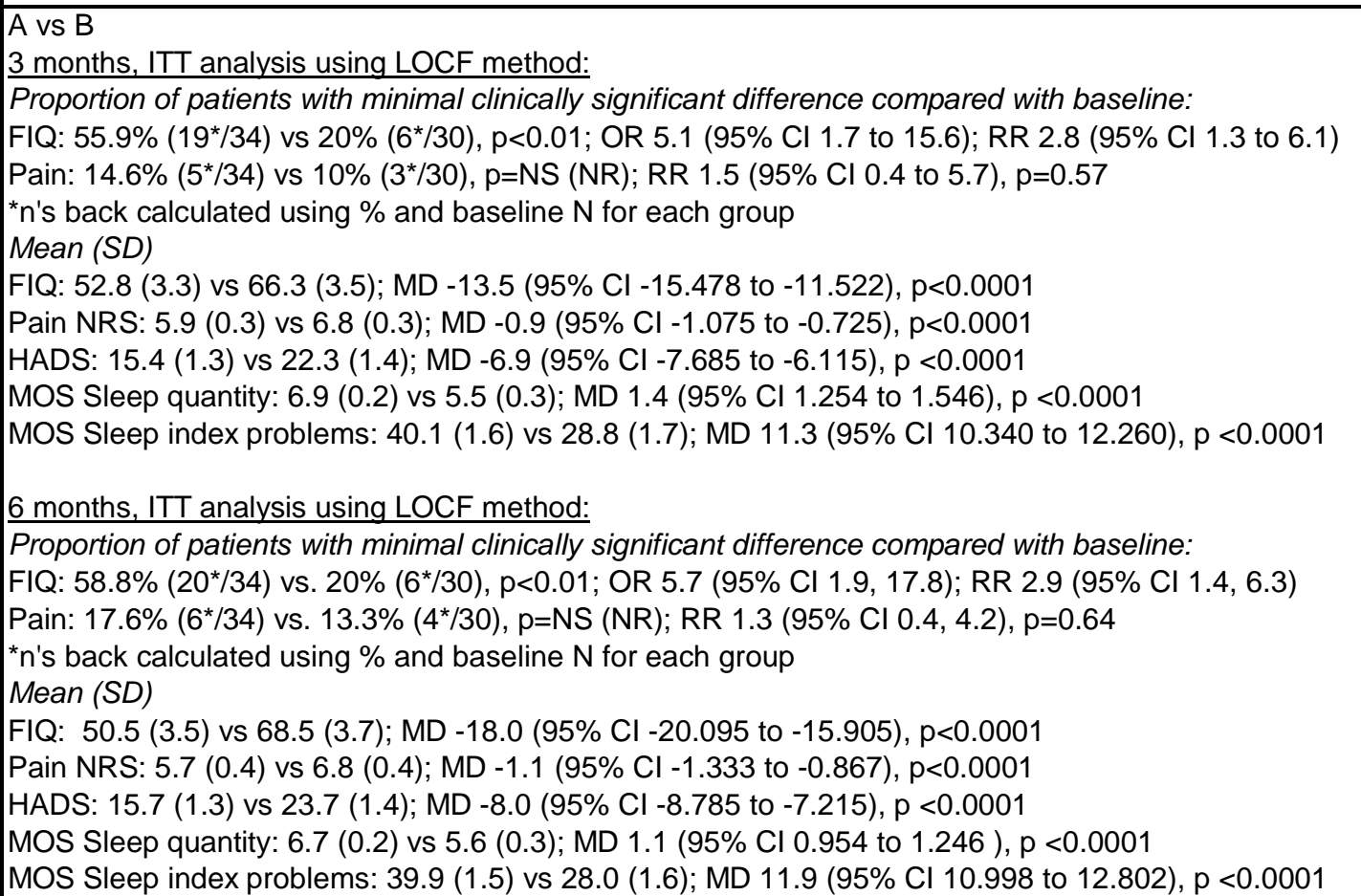 \\
\hline
\end{tabular}




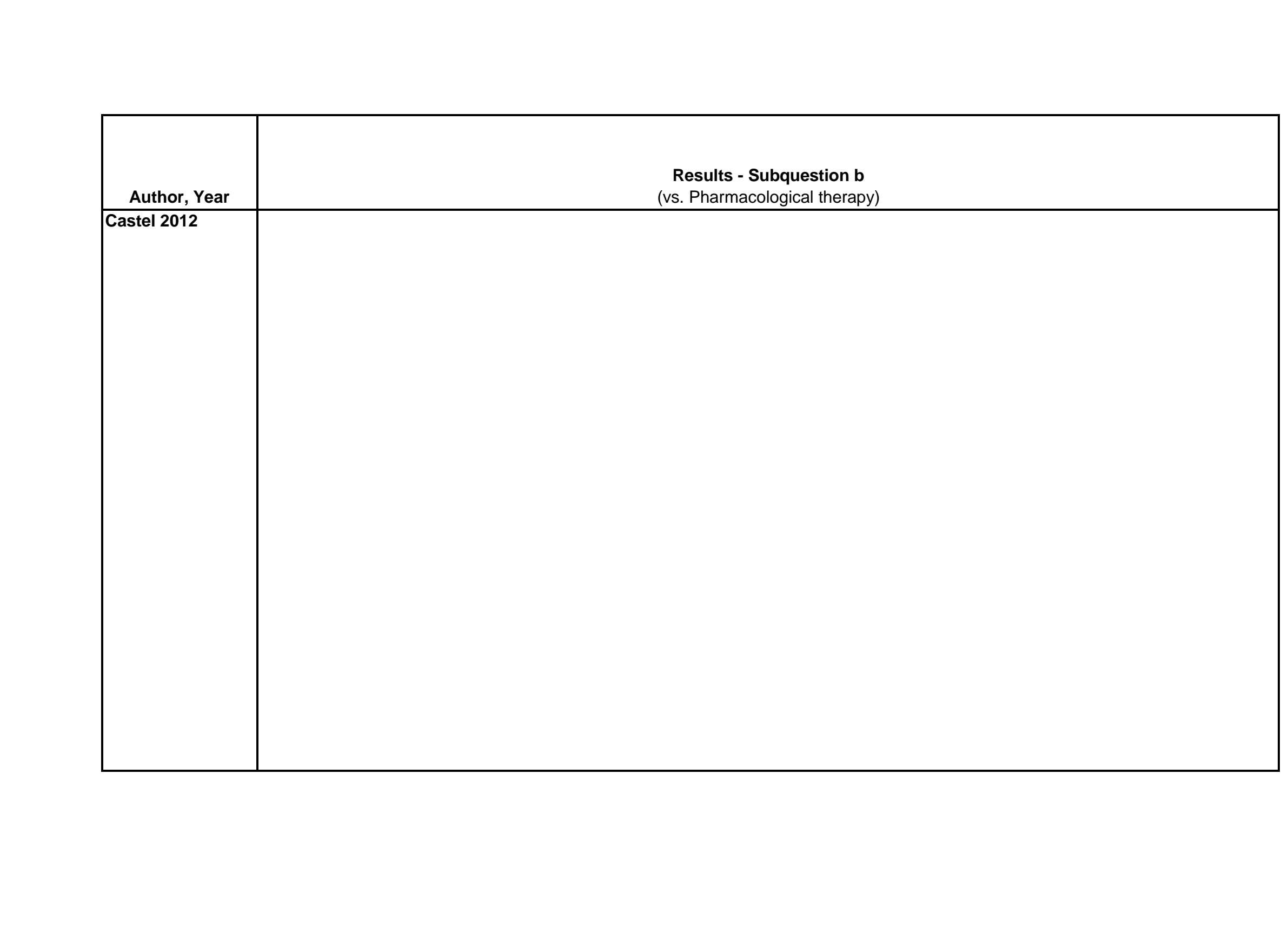




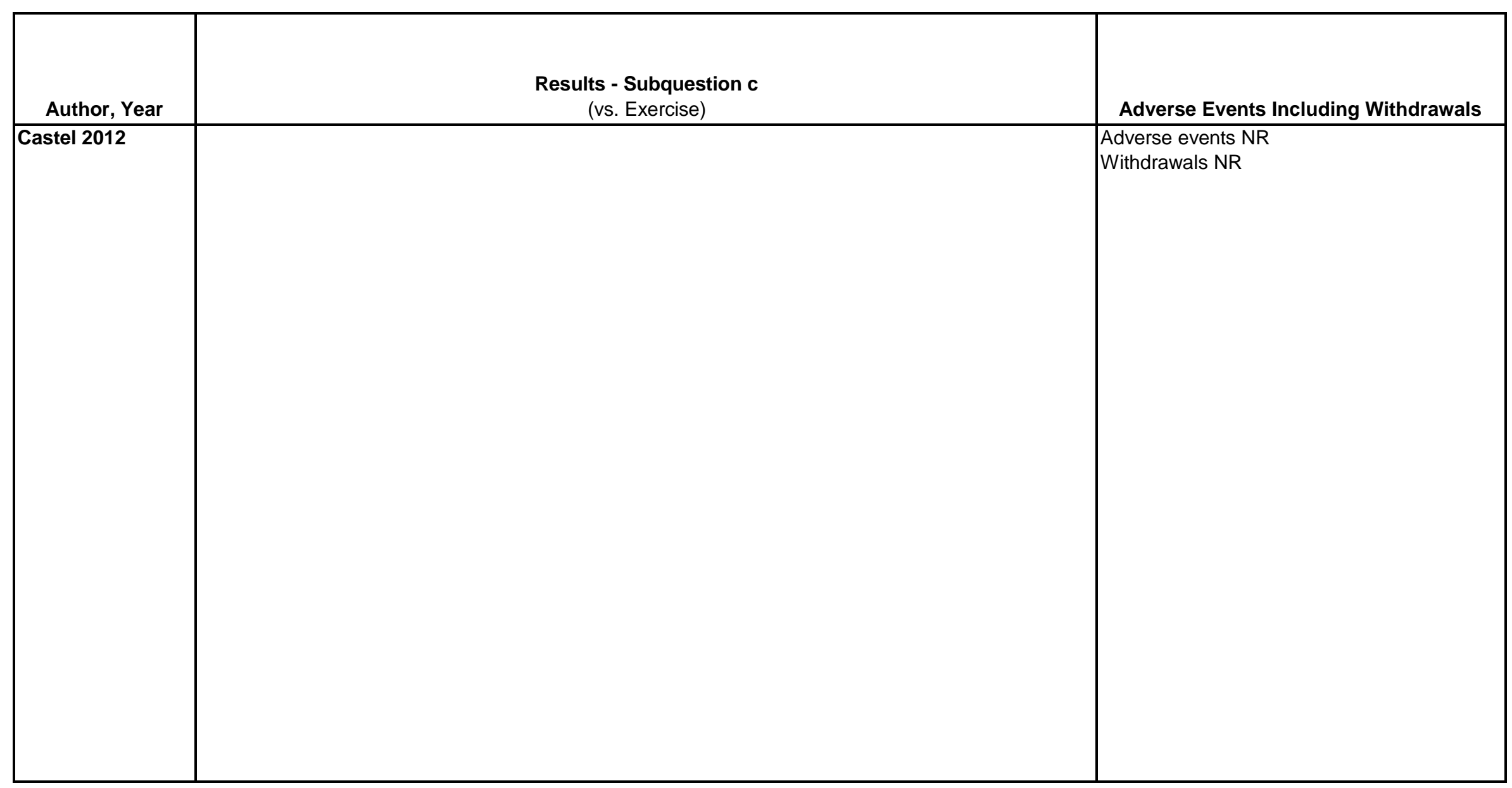




\begin{tabular}{|c|c|c|c|}
\hline Author, Year & Funding Source & Quality & Comments \\
\hline Castel 2012 & NR & Poor & RRs for 3 month followup results were calculated \\
\hline
\end{tabular}

D-175 


\begin{tabular}{|c|c|c|c|}
\hline Author, Year & $\begin{array}{l}\text { Country Number } \\
\text { of Centers } \\
\text { Setting }\end{array}$ & Inclusion/Exclusion Criteria & $\begin{array}{l}\text { Number Randomized, } \\
\text { Analyzed Attrition }\end{array}$ \\
\hline Castel 2013 & $\begin{array}{l}\text { Spain } \\
1 \text { center } \\
\text { Patients recruited from } \\
\text { rheumatologists }\end{array}$ & $\begin{array}{l}\text { Inclusion: } \\
\text { female, FM diagnosis based on } 1990 \text { ACR criteria; age 18-60; 3-8 years of } \\
\text { schooling } \\
\text { Exclusion: } \\
\text { other severe chronic medical pain condition; psychiatric or psychological treatment } \\
\text { in past } 3 \text { years for severe psychopathology; inflammatory rheumatic disease; } \\
\text { cognitive, sensorial, or physical impairment limitation to perform the treatments; } \\
\text { pending legal resolution for disability }\end{array}$ & $\begin{array}{l}\text { Randomized: } 155 \\
\text { Analyzed: } 88 \\
\text { Attrition: } 43 \%(67 / 155)\end{array}$ \\
\hline $\begin{array}{l}\text { Castel 2013/Salvat } \\
2017\end{array}$ & \begin{tabular}{|l} 
Spain \\
1 center \\
Patients recruited from \\
rheumatologists
\end{tabular} & $\begin{array}{l}\text { Inclusion: female, FM diagnosis based on } 1990 \text { ACR criteria; age 18-60; 3-8 years of } \\
\text { schooling } \\
\text { Exclusion: other severe chronic medical pain condition; psychiatric or psychological } \\
\text { treatment in past } 3 \text { years for severe psychopathology; inflammatory rheumatic disease; } \\
\text { cognitive, sensorial, or physical impairment limitation to perform the treatments; } \\
\text { pending legal resolution for disability }\end{array}$ & $\begin{array}{l}\text { Randomized: } 155 \\
\text { Analyzed: } 88 \\
\text { Attrition: } 43 \%(67 / 155)\end{array}$ \\
\hline
\end{tabular}




\begin{tabular}{|c|c|}
\hline Author, Year & Intervention, Comparator \\
\hline Castel 2013 & $\begin{array}{l}\text { A.Multidisciplinary treatment ( } \mathrm{n}=53 \text { ): Conventional pharmacological treatment, including analgesics, antidepressants, benzodiazepine and non- } \\
\text { benzodiazepine hypnotics; group CBT and group physical therapy ( } 1 \text { hour CBT and } 1 \text { hour physical therapy) } 2 \text { days/week for a total of } 24 \text { sessions. } \\
\text { CBT included education, cognitive restructuring, CBT for insomnia, assertiveness training, goal setting, activity pacing, pleasant activity scheduling, } \\
\text { and relapse prevention. Physical therapy emphasized aerobic capacity, muscle strengthening and flexibility, and hydrokinesiotherapy in a heated } \\
\text { pool. Participants attended a mean of } 22.3 \text { (SD 1.8) of the CBT sessions and a mean of } 21.6 \text { (SD 2.2) of the physical therapy sessions. } \\
\text { B.Conventional pharmacological treatment }(n=35) \text { : Conventional pharmacological treatment, including analgesics, antidepressants, } \\
\text { benzodiazepine and non-benzodiazepine hypnotics. }\end{array}$ \\
\hline $\begin{array}{l}\text { Castel 2013/Salvat } \\
2017\end{array}$ & $\begin{array}{l}\text { A. Multidisciplinary treatment ( } \mathrm{n}=53) \text { : Conventional pharmacological treatment, including analgesics, antidepressants, benzodiazepine and non- } \\
\text { benzodiazepine hypnotics; group CBT and group physical therapy ( } 1 \text { hour CBT and } 1 \text { hour physical therapy) } 2 \text { days/week for a total of } 24 \text { sessions. } \\
\text { CBT included education, cognitive restructuring, CBT for insomnia, assertiveness training, goal setting, activity pacing, pleasant activity scheduling, } \\
\text { and relapse prevention. Physical therapy emphasized aerobic capacity, muscle strengthening and flexibility, and hydrokinesiotherapy in a heated } \\
\text { pool. Participants attended a mean of } 22.3 \text { (SD 1.8) of the CBT sessions and a mean of } 21.6 \text { (SD 2.2) of the physical therapy sessions. } \\
\text { B. Conventional pharmacological treatment ( } n=35) \text { : Conventional pharmacological treatment, including analgesics, antidepressants, benzodiazepine } \\
\text { and non-benzodiazepine hypnotics. }\end{array}$ \\
\hline
\end{tabular}




\begin{tabular}{|c|c|c|c|}
\hline Author, Year & Study Participants & Outcome Measures & $\begin{array}{l}\text { Duration of } \\
\text { Followup }\end{array}$ \\
\hline Castel 2013 & $\begin{array}{l}\text { A vs B } \\
\text { Age, years: } 49 \text { vs } 49 \\
\text { Female: } 100 \% \text { vs } 100 \% \\
\text { Pain duration, years: } 12.5 \text { vs } 10.8 \\
\text { FIQ: } 64.6(16.0) \text { vs } 66.6(17.4) \\
\text { Pain intensity (NRS): } 6.8(1.4) \text { vs } 7.1(1.6) \\
\text { HADS: } 21.9(8.0) \text { vs } 23.2(8.1) \\
\text { Sleep index problems: } 29.0(8.9) \text { vs } 27.9(8.1)\end{array}$ & $\begin{array}{l}\text { Fibromyalgia Impact Questionnaire (FIQ) (scale NR, } \\
\text { higher scores=greater impact of FM) } \\
\text { FIQ clinically significant improvement: cutoff=14\% Pain } \\
\text { numerical rating scale (NRS), mean of maximum, } \\
\text { minimum, and usual pain intensity in past week (0-10 } \\
\text { scale, higher scores=greater pain) } \\
\text { Clinically significant pain improvement: } 30 \% \text { cutoff } \\
\text { Hospital Anxiety and Depression Scale (HADS) (scale NR, } \\
\text { higher scores=greater psychological distress) MOS Sleep } \\
\text { scale sleep problems index (scale NR, higher } \\
\text { scores=worse sleep) }\end{array}$ & $\begin{array}{l}3,6,12 \\
\text { months }\end{array}$ \\
\hline $\begin{array}{l}\text { Castel 2013/Salvat } \\
2017\end{array}$ & \begin{tabular}{|l|} 
A vs B \\
Age, years: 49 vs 49 \\
Female: $100 \%$ vs $100 \%$ \\
Pain duration, years: 12.5 vs 10.8 \\
FIQ: $64.6(16.0)$ vs $66.6(17.4)$ \\
Pain intensity (NRS): $6.8(1.4)$ vs 7.1 (1.6) \\
HADS: 21.9 (8.0) vs $23.2(8.1)$ \\
Sleep index problems: 29.0 (8.9) vs $27.9(8.1)$ \\
WONCA total score, median (IQR): $27.0(23.0$ to 31.0$)$ vs 28.0 (25.0 to 32.0$)$ \\
\end{tabular} & $\begin{array}{l}\text { Fibromyalgia Impact Questionnaire (FIQ) (scale NR, } \\
\text { higher scores=greater impact of FM), FIQ clinically } \\
\text { significant improvement: cutoff=14\%, WONCA total score } \\
\text { (9-45, higher score=lower function), WONCA physical } \\
\text { function (1-5, higher score=lower function), WONCA daily } \\
\text { activites (1-5, higher score=lower function), Pain } \\
\text { numerical rating scale (NRS), mean of maximum, } \\
\text { minimum, and usual pain intensity in past week (0-10 } \\
\text { scale, higher scores=greater pain), Clinically significant } \\
\text { pain improvement: } 30 \% \text { cutoff, Hospital Anxiety and } \\
\text { Depression Scale (HADS) (scale NR, higher } \\
\text { scores=greater psychological distress), MOS Sleep scale } \\
\text { sleep problems index (scale NR, higher scores=worse } \\
\text { sleep) }\end{array}$ & $\begin{array}{l}3,6,12 \\
\text { months }\end{array}$ \\
\hline
\end{tabular}




\begin{tabular}{|c|c|}
\hline Author, Year & $\begin{array}{l}\text { Results - Subquestion a } \\
\text { (vs. sham, no treatment, waitlist, attention control) }\end{array}$ \\
\hline Castel 2013 & 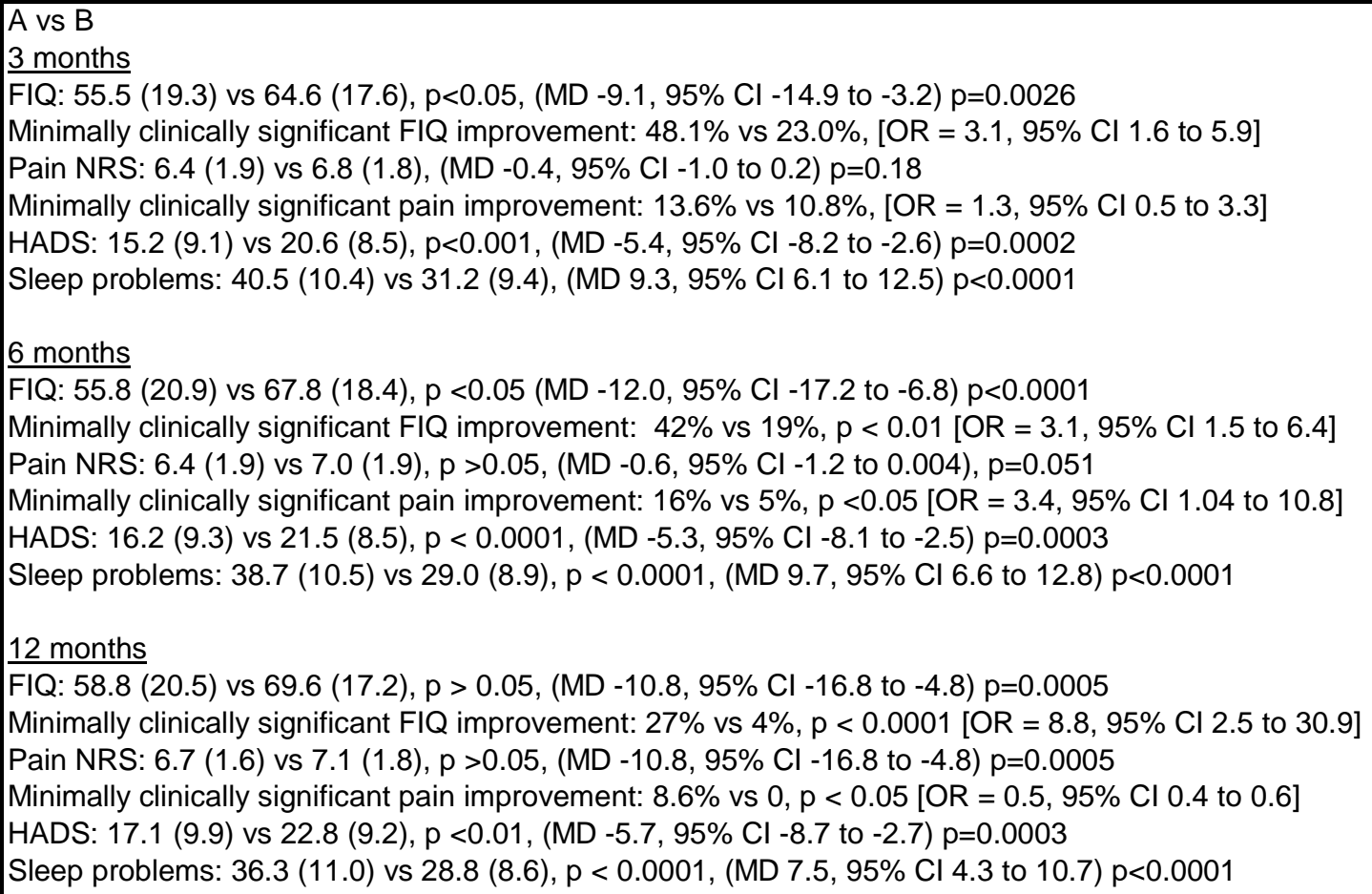 \\
\hline $\begin{array}{l}\text { Castel 2013/Salvat } \\
2017\end{array}$ & \\
\hline
\end{tabular}




\begin{tabular}{|c|c|}
\hline Author, Year & $\begin{array}{c}\text { Results - Subquestion b } \\
\text { (vs. Pharmacological therapy) }\end{array}$ \\
\hline Castel 2013 & \\
\hline $\begin{array}{l}\text { Castel 2013/Salvat } \\
2017\end{array}$ & 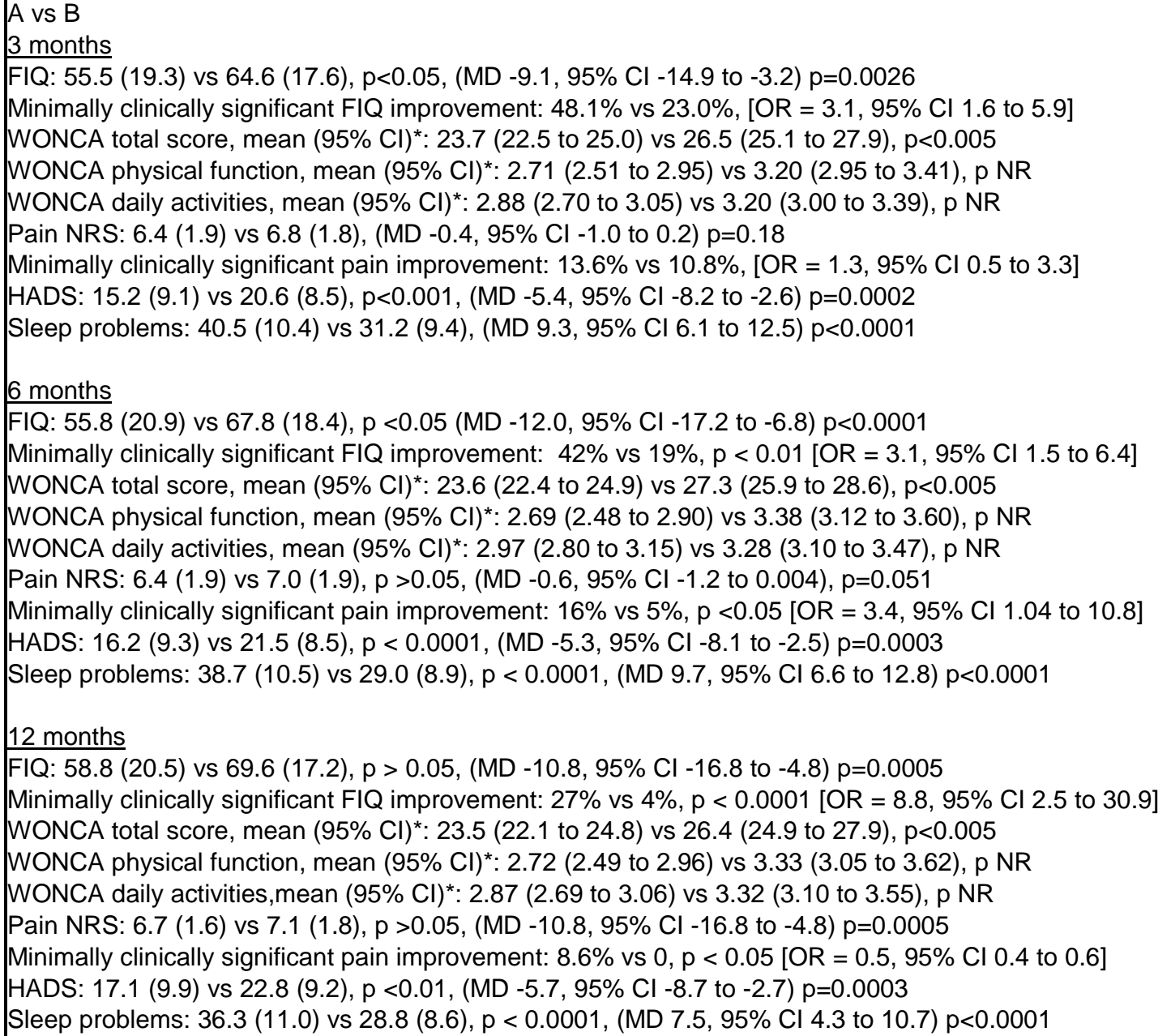 \\
\hline
\end{tabular}




\begin{tabular}{|c|c|c|}
\hline Author, Year & $\begin{array}{c}\text { Results - Subquestion c } \\
\text { (vs. Exercise) }\end{array}$ & Adverse Events Including Withdrawals \\
\hline Castel 2013 & & $\begin{array}{l}\text { Adverse events: NR } \\
\text { Withdrawals: NR }\end{array}$ \\
\hline $\begin{array}{l}\text { Castel 2013/Salvat } \\
2017\end{array}$ & & $\begin{array}{l}\text { Adverse events: NR } \\
\text { Withdrawals: NR }\end{array}$ \\
\hline
\end{tabular}




\begin{tabular}{|c|c|c|c|}
\hline Author, Year & Funding Source & Quality & Comments \\
\hline Castel 2013 & \begin{tabular}{|l|l|} 
Foundation Marato TV3 \\
\end{tabular} & Poor & \\
\hline $\mid \begin{array}{l}\text { Castel 2013/Salvat } \\
2017\end{array}$ & $\begin{array}{l}\text { Foundation Marato TV3, grant number } \\
\text { 070910 }\end{array}$ & Fair & $\begin{array}{l}\text { Given instructions in Column I, } 3 \text { month results were not abstracted } \\
\text { *Values estimated from figure }\end{array}$ \\
\hline
\end{tabular}




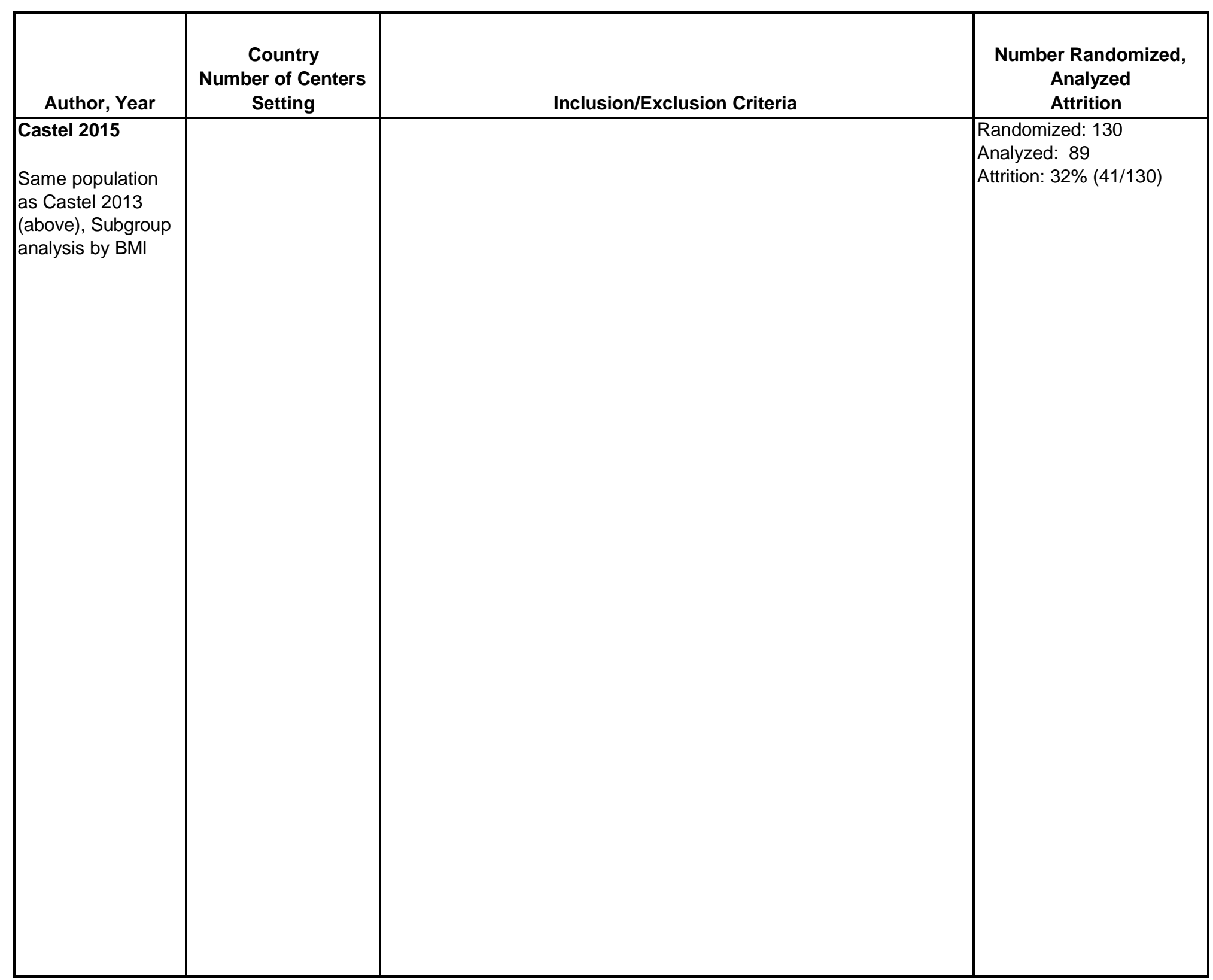




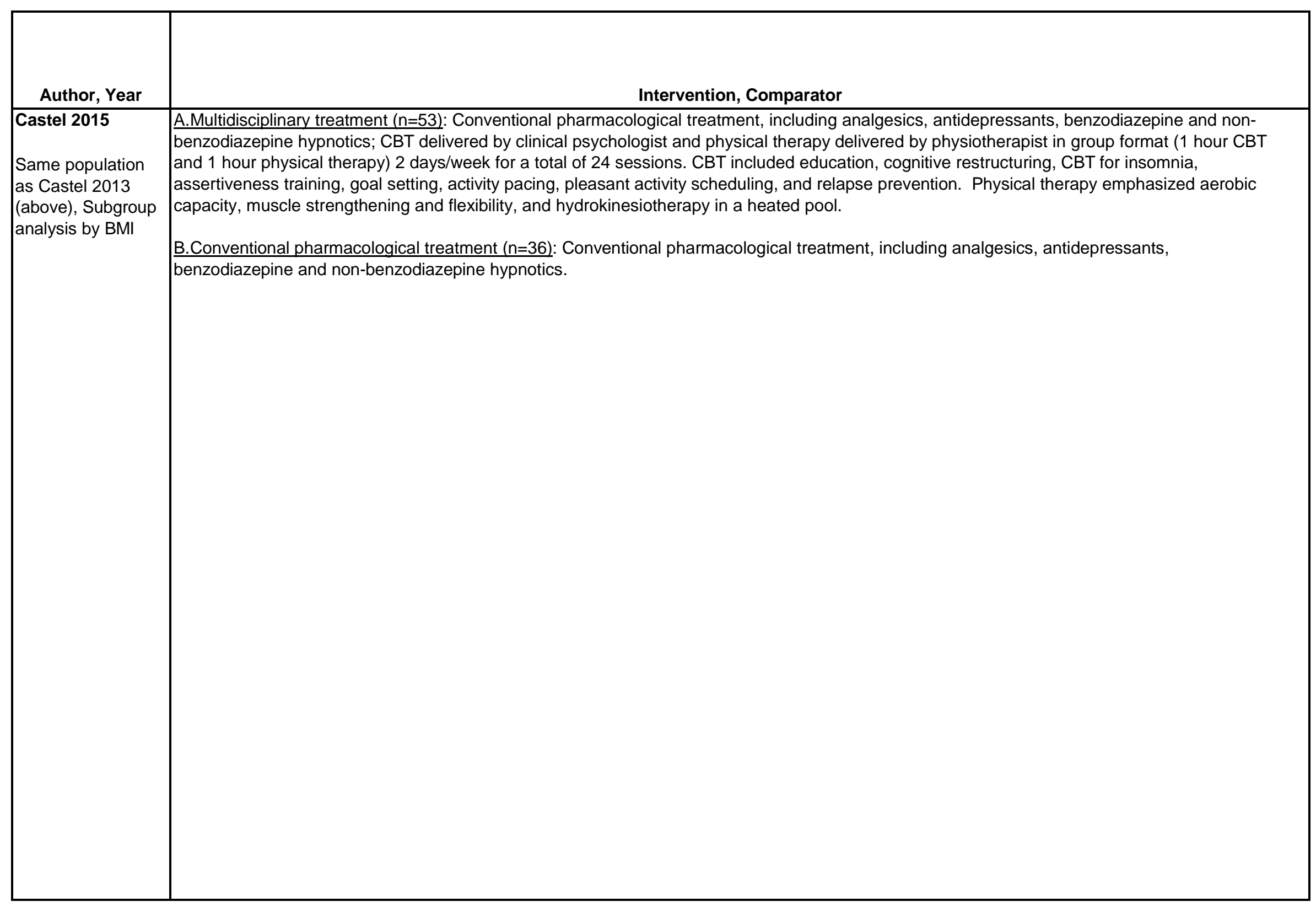




\begin{tabular}{|c|c|c|c|}
\hline Author, Year & Study Participants & Outcome Measures & $\begin{array}{c}\text { Duration of } \\
\text { Followup }\end{array}$ \\
\hline $\begin{array}{l}\text { Castel } 2015 \\
\text { Same population } \\
\text { as Castel } 2013 \\
\text { (above), Subgroup } \\
\text { analysis by BMI }\end{array}$ & $\begin{array}{l}\text { A vs B } \\
\text { BMl < } 25 \\
\text { Age: } 48 \text { vs } 49 \\
\text { Female: } 100 \% \text { vs } 100 \% \\
\text { FIQ: } 65.1(13.3) \text { vs } 66.9(13.0) \\
\text { Pain NRS: } 6.8(1.2) \text { vs } 7.4(1.3) \\
\text { HADS: } 22.9 \text { (8.0) vs } 21.8(7.8) \\
\text { MOS Sleep quantity: } 5.7(1.4) \text { vs } 4.6(1.2) \\
\text { MOS Sleep problems index: } 28.3 \text { (8.5) vs } 24.6(6.1) \\
\\
\text { BMI } 25.0-29.9 \\
\text { Age: } 50 \text { vs } 48 \\
\text { Female: } 100 \% \text { vs } 100 \% \\
\text { FIQ: } 59.8(17.2) \text { vs } 57.7(15.8) \\
\text { Pain NRS: } 6.3(1.3) \text { vs } 6.1(2.1) \\
\text { HADS: } 20.9 \text { (8.1) vs } 20.8(8.7) \\
\text { MOS Sleep quantity: } 5.9(1.5) \text { vs } 5.8(1.4) \\
\text { MOS Sleep problems index: } 32.4(8.4) \text { vs } 31.7 \text { (9.1) } \\
\text { BMI } \geq 30 \\
\text { Age: } 51 \text { vs } 50 \\
\text { Female: } 100 \% \text { vs } 100 \% \\
\text { FIQ: } 64.7(14.4) \text { vs } 67.2(17.2) \\
\text { Pain NRS: } 7.3(1.3) \text { vs } 7.2(1.2) \\
\text { HADS: } 20.2(8.4) \text { vs } 24.3(8.5) \\
\text { MOS Sleep quantity: } 5.0(1.7) \text { vs } 5.2(1.3) \\
\text { MOS Sleep problems index: } 28.9(9.1) \text { vs } 27.1 \text { (7.8) }\end{array}$ & $\begin{array}{l}\text { Fibromyalgia Impact Questionnaire (FIQ) (0-100 scale, } \\
\text { higher scores=greater impact of FM) } \\
\text { Pain numerical rating scale (NRS), mean of maximum, } \\
\text { minimum, and usual pain intensity in past week (0-10 } \\
\text { scale, higher scores=greater pain) } \\
\text { Hospital Anxiety and Depression Scale (HADS) (scale } \\
\text { NR, higher scores=greater psychological distress) } \\
\text { MOS Sleep scale sleep quantity (scale NR, higher } \\
\text { scores=worse sleep) } \\
\text { MOS Sleep scale sleep problems index (scale NR, } \\
\text { higher scores=worse sleep) }\end{array}$ & $\begin{array}{l}3,6, \text { and } 12 \\
\text { months }\end{array}$ \\
\hline
\end{tabular}




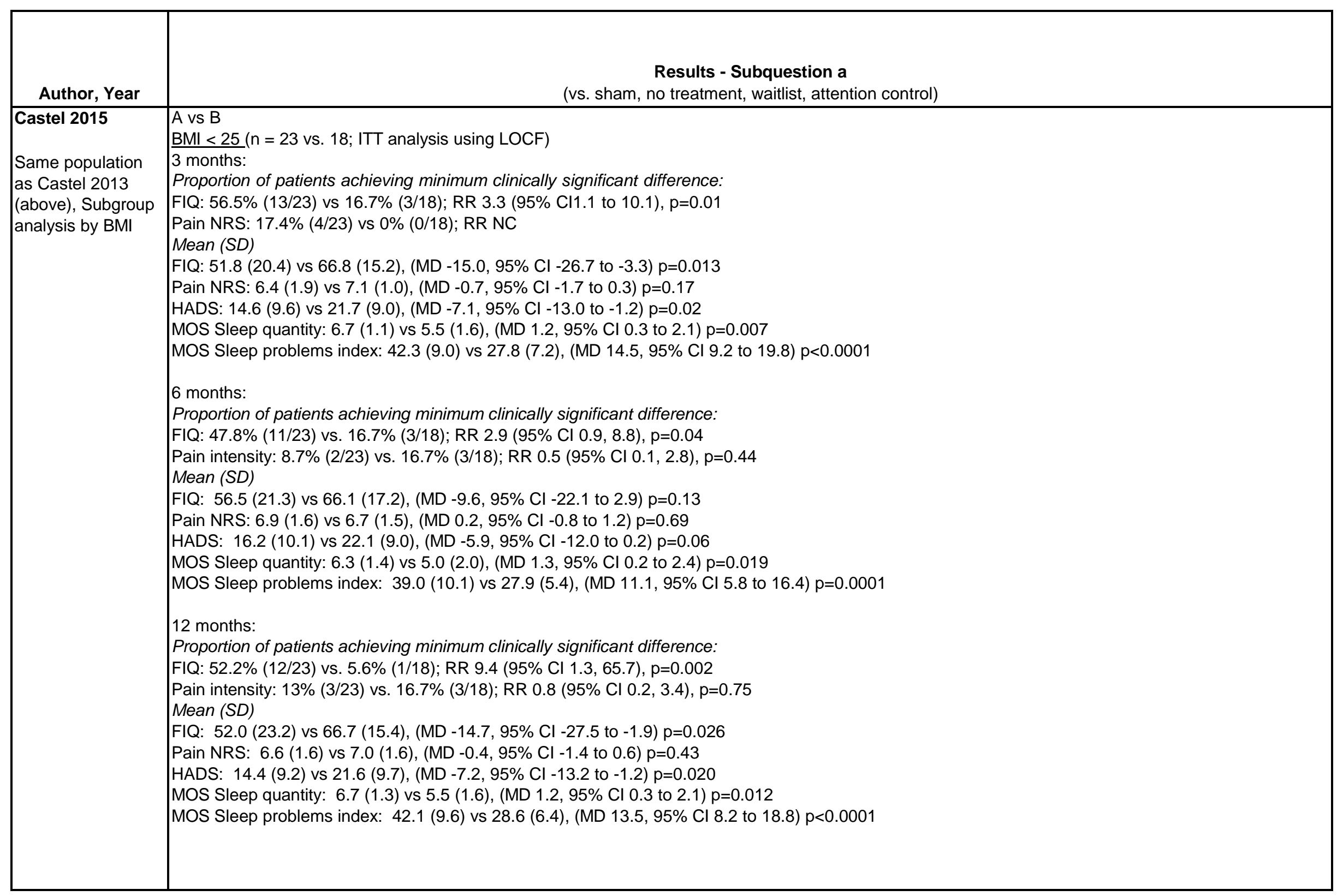




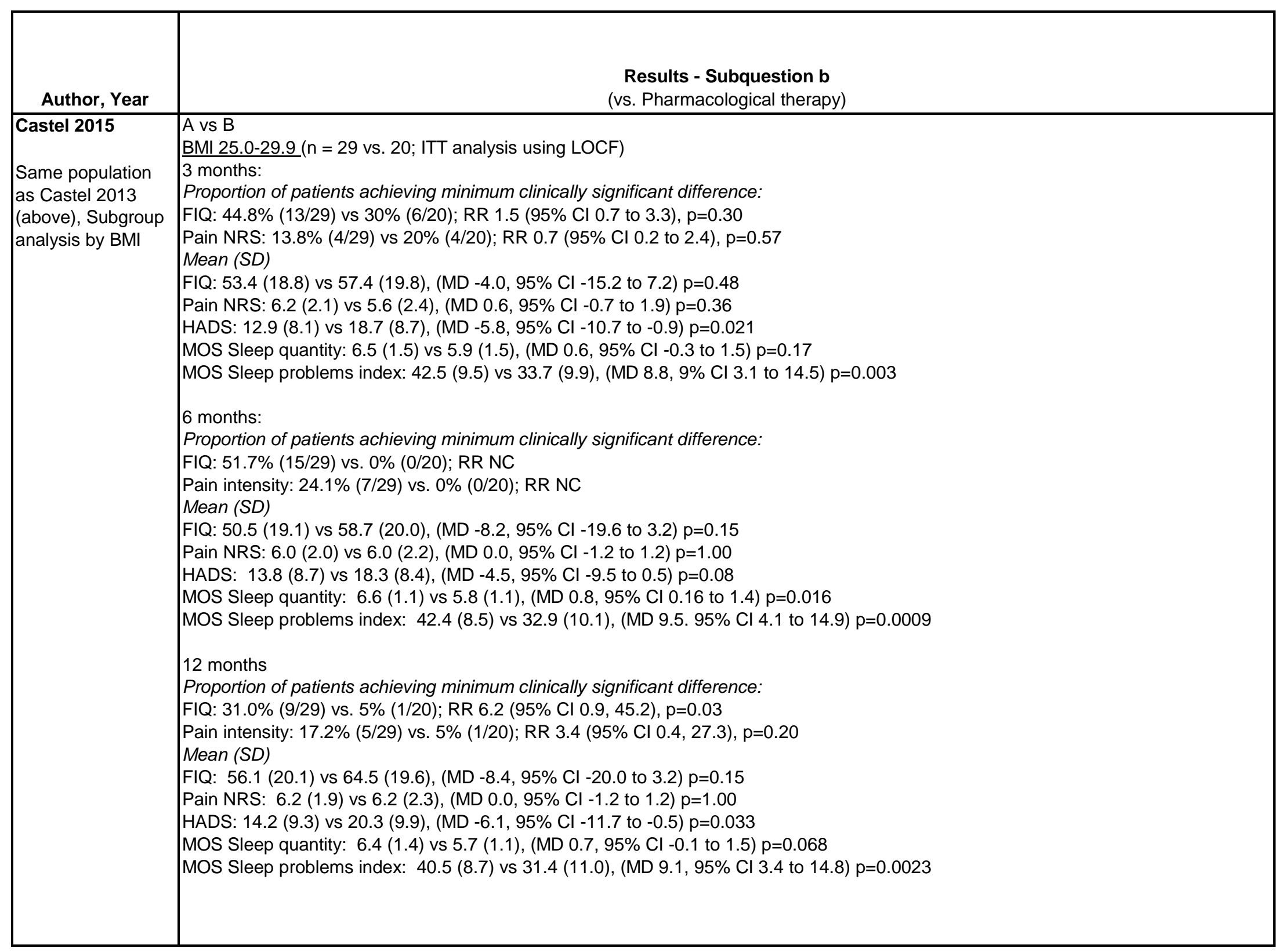




\begin{tabular}{|c|c|c|}
\hline Author, Year & $\begin{array}{l}\text { Results - Subquestion c } \\
\text { (vs. Exercise) }\end{array}$ & Adverse Events Including Withdrawals \\
\hline $\begin{array}{l}\text { Castel } 2015 \\
\text { Same population } \\
\text { as Castel } 2013 \\
\text { (above), Subgroup } \\
\text { analysis by BMI }\end{array}$ & 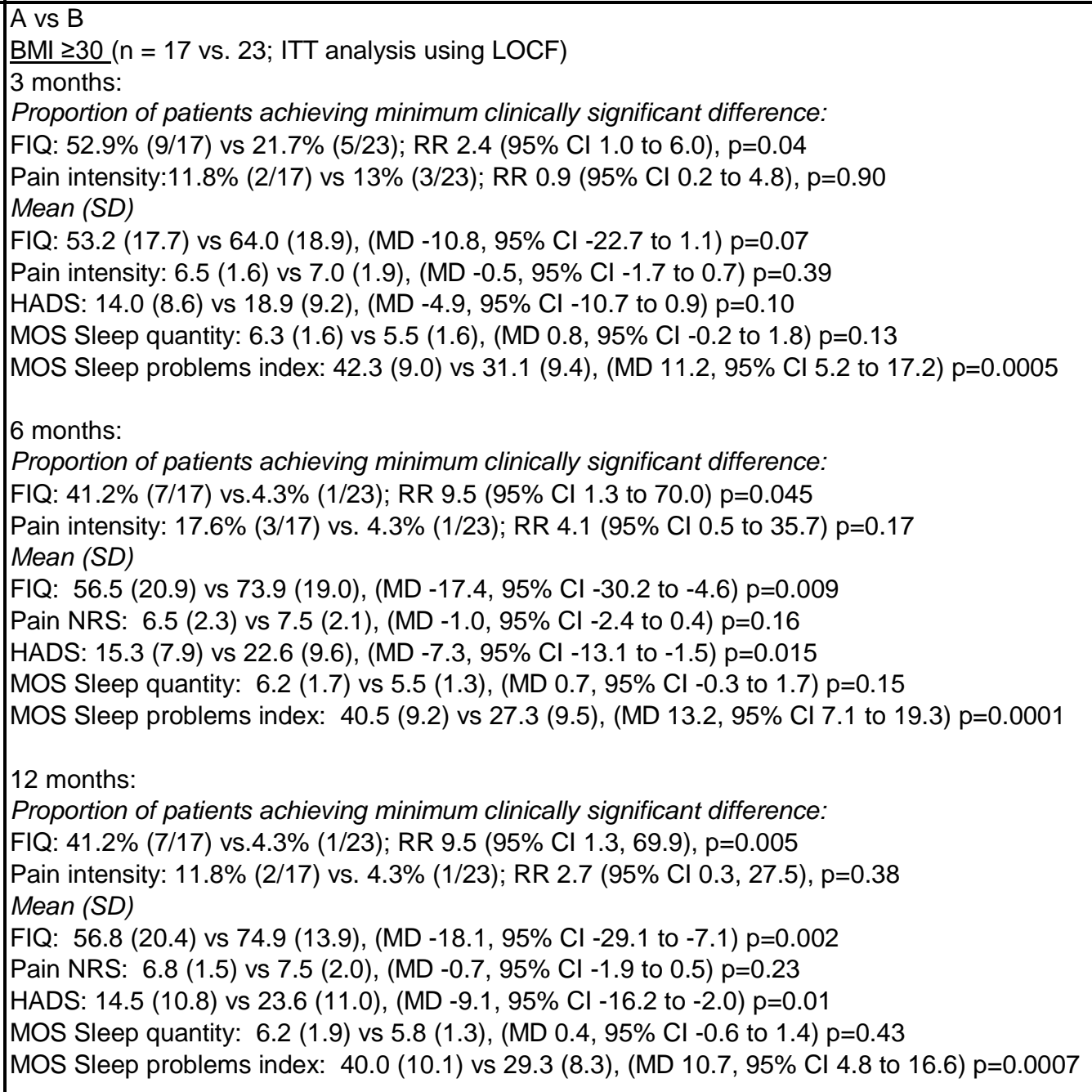 & $\begin{array}{l}\text { Withdrawals: NR } \\
\text { Adverse events: NR }\end{array}$ \\
\hline
\end{tabular}




\begin{tabular}{|c|c|c|c|}
\hline Author, Year & Funding Source & Quality & Comments \\
\hline $\begin{array}{l}\text { Castel } 2015 \\
\\
\text { Same population } \\
\text { as Castel 2013 } \\
\text { (above), Subgroup } \\
\text { analysis by BMI }\end{array}$ & Foundation Marato TV3 & Poor & $\begin{array}{l}\text { P values were not reported for the comparisons listed in the Results column. There was a } \\
\text { significant overall treatment } X \text { time interaction effect for pain intensity }(p<0.01) \text {, HADS }(p< \\
0.0001) \text {, sleep index problems }(p<0.0001) \text {. No significant interactions were found for BMI } X \\
\text { group treatment } X \text { time for any measure. } \\
\text { Not enough room in subquestion a column so the different BMI strata were included in the } 3 \\
\text { separate results columns } \\
\text { INCLUDE FOR KO } 6 \text { - Special Populations }\end{array}$ \\
\hline
\end{tabular}




\begin{tabular}{|c|c|c|c|}
\hline Author, Year & $\begin{array}{c}\text { Country } \\
\text { Number of Centers } \\
\text { Setting }\end{array}$ & Inclusion/Exclusion Criteria & $\begin{array}{c}\text { Number Randomized, } \\
\text { Analyzed } \\
\text { Attrition }\end{array}$ \\
\hline Castien 2011 & $\begin{array}{l}\text { The Netherlands } \\
\text { (multicenter) }\end{array}$ & $\begin{array}{l}\text { Inclusion Criteria: } \\
\text { >18 to } 65 \text { years old, diagnosed with CTTH according to IHS } \\
\text { classification } \\
\text { Exclusion criteria: } \\
\text { Rheumatoid arthritis, suspected malignancy, pregnancy, intake of } \\
\text { triptans, ergotamines, or opioids } \geq 10 \text { days per month, simple } \\
\text { analgesics } \geq 15 \text { days per month for } \geq 3 \text { months, manual therapy } \\
\text { treatment within } 2 \text { months of enrollment }\end{array}$ & $\begin{array}{l}\text { Randomized: } 82 \\
\text { Treated: } 80 \\
\text { Analyzed: } 75 \\
\text { Attrition: } 9 \%(7 / 82)\end{array}$ \\
\hline
\end{tabular}




\begin{tabular}{|c|c|}
\hline Author, Year & Intervention, Comparator \\
\hline Castien 2011 & $\begin{array}{l}\text { A.Manual therapy }(\mathrm{n}=38) \\
\text { No. sessions: Max of } 9 \text { over } 8 \text { weeks } \\
\text { Length of sessions: } 30 \mathrm{~min} \\
\text { Segments targeted: Cervical, thoracic, and lumbar spinal segments } \\
\text { Description of technique: combination of } 3 \text { approaches: mobilizations, craniocervical muscle exercises and posture correction } \\
\text { B.Usual Care }(\mathrm{n}=37) \\
\text { General practitioner provided information and advice, first prescribing life-style changes. Analgesics or NSAIDs were prescribed and pain } \\
\text { medication was changed as needed. Treatment spanned on average 2-3 visits }\end{array}$ \\
\hline
\end{tabular}




\begin{tabular}{|c|c|c|c|}
\hline Author, Year & \begin{tabular}{|c} 
Study Participants \\
\end{tabular} & Outcome Measures & $\begin{array}{c}\text { Duration of } \\
\text { Followup }\end{array}$ \\
\hline Castien 2011 & 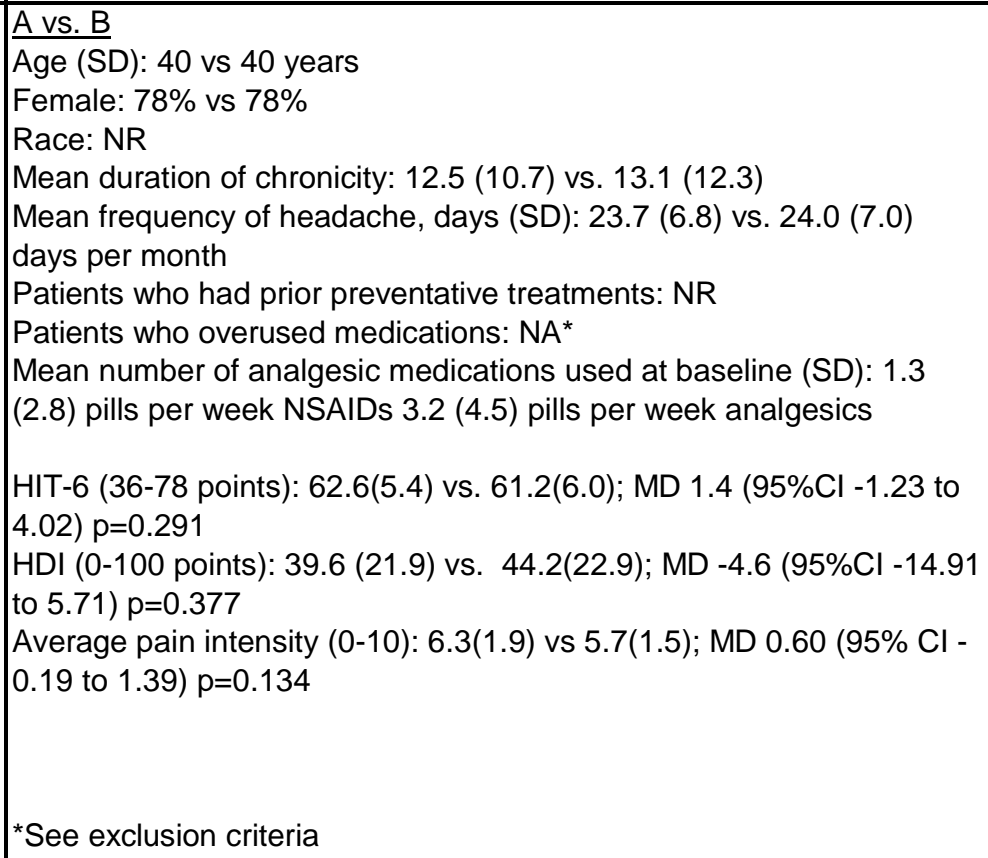 & $\begin{array}{l}\text { Proportion of patients with 50\% reduction in headache } \\
\text { frequency; } \\
\text { Headache Impact Test- } 6 \text { (HIT-6, range 36-78: from little } \\
\text { to no impact to severe impact); } \\
\text { Headache Disability Inventory (HDI, range 0-100: higher } \\
\text { scores indicate severity of symptoms); } \\
\text { Mean Headache frequency (days with headache in } 2 \\
\text { week time period); } \\
\text { Mean Headache intensity (Numeric Rating Scale, range } \\
\text { 0-10: higher scores indicate severity of pain); } \\
\text { Mean Headache Duration } \\
\text { Analgesic/NSAID use; } \\
\text { Healthcare Resource Utilization }\end{array}$ & 4.5 months \\
\hline
\end{tabular}




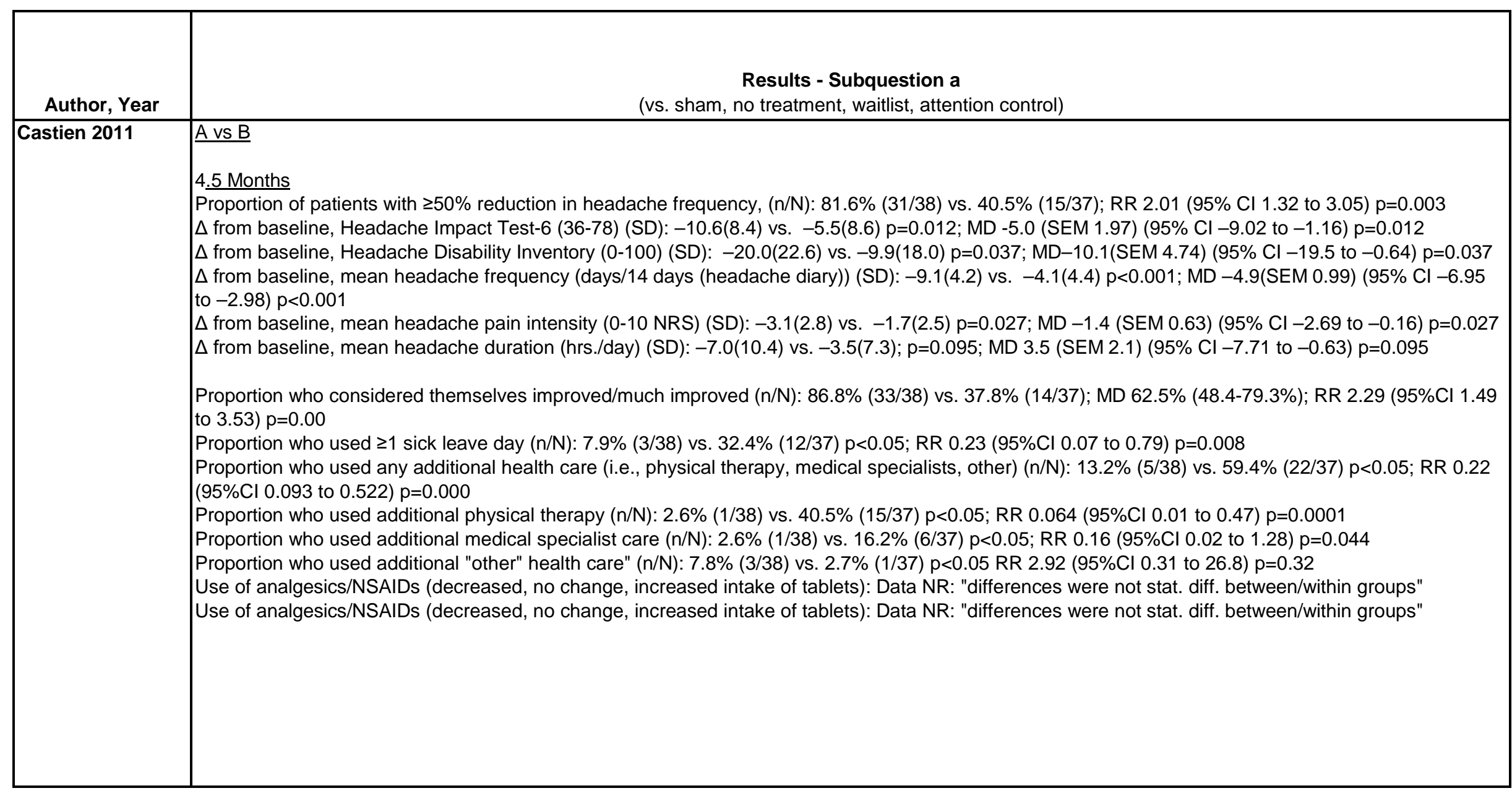




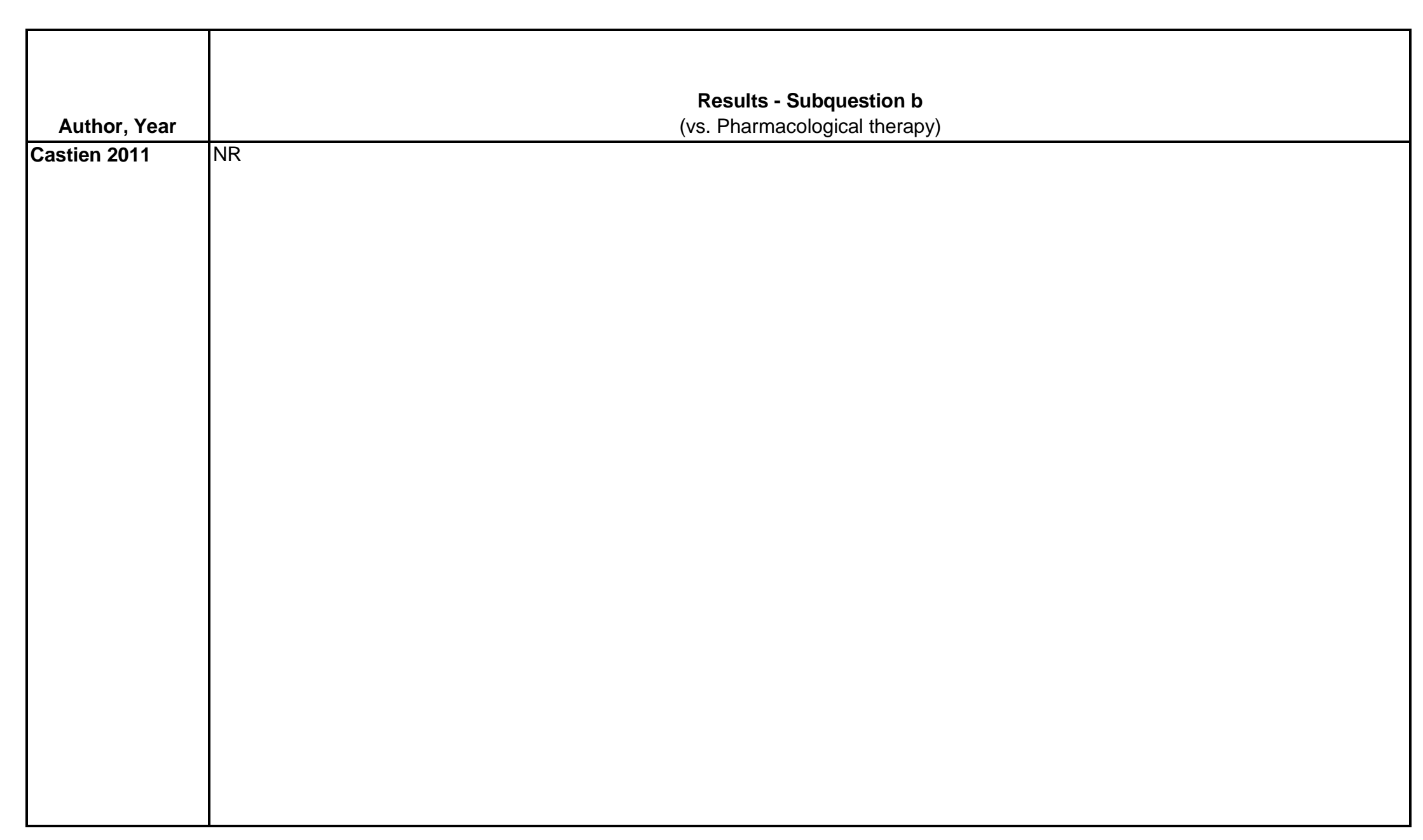

D-194 


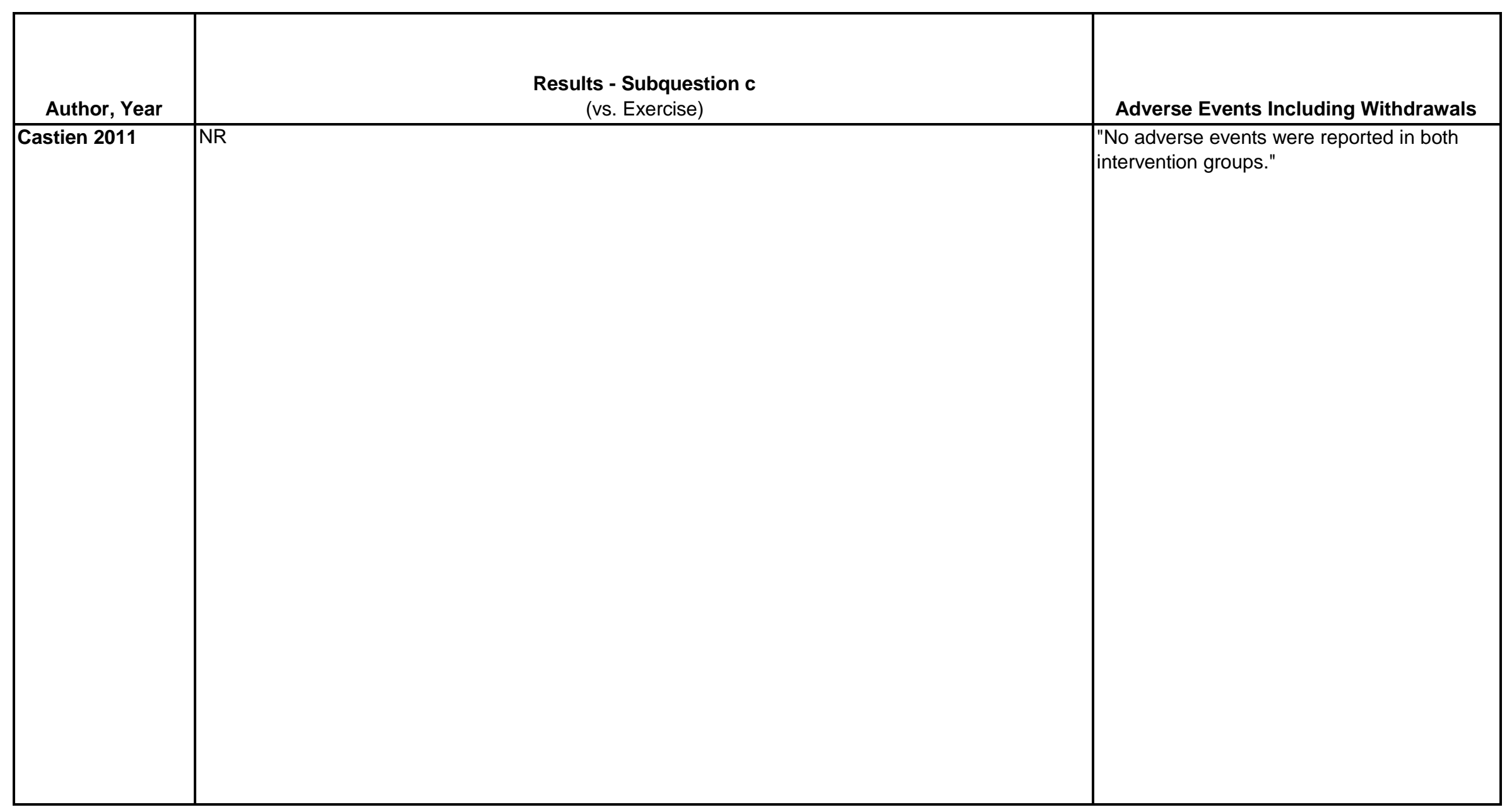




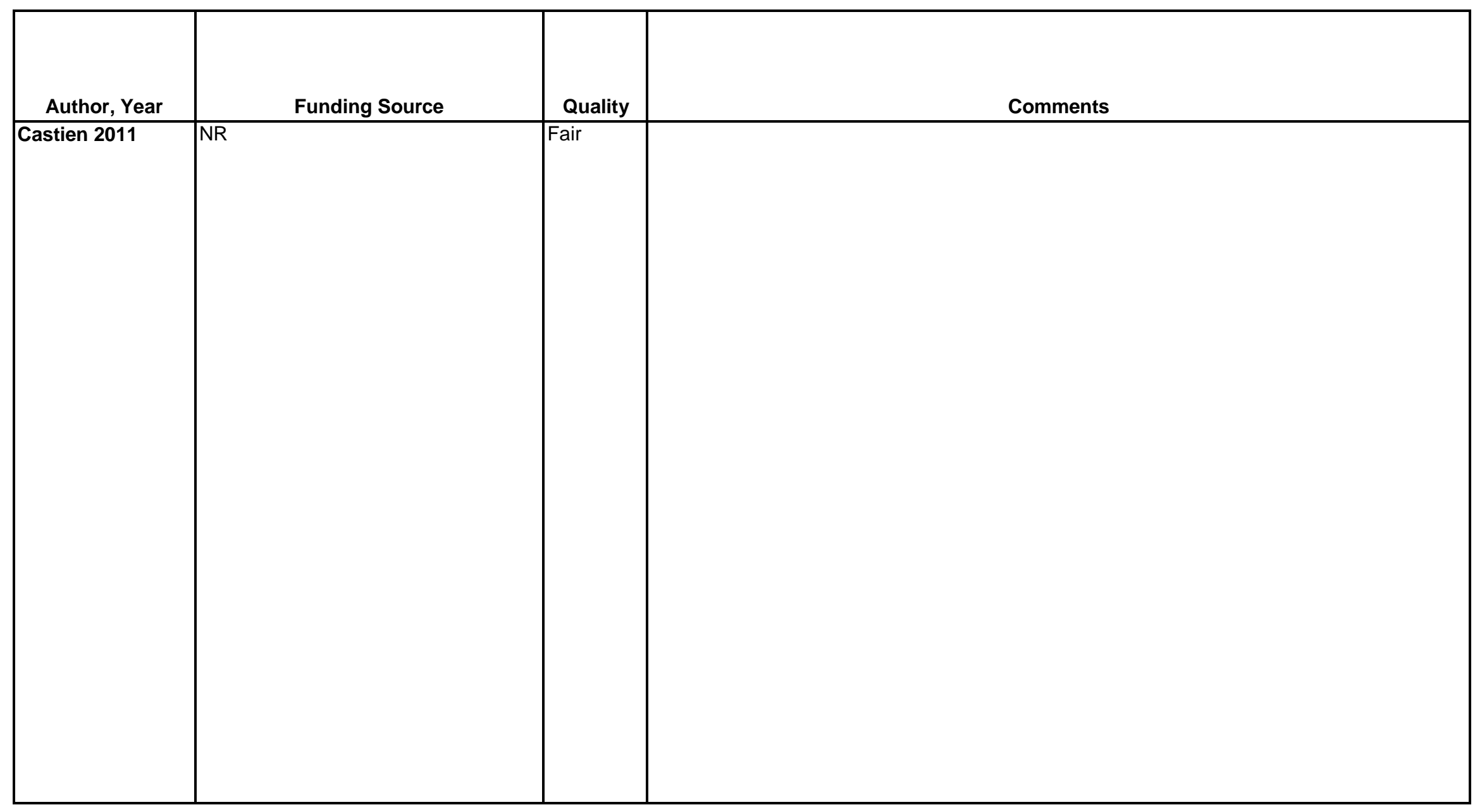

D-196 


\begin{tabular}{|c|c|c|c|}
\hline Author, Year & $\begin{array}{c}\text { Country } \\
\text { Number of Centers } \\
\text { Setting }\end{array}$ & Inclusion/Exclusion Criteria & $\begin{array}{c}\text { Number Randomized, } \\
\text { Analyzed } \\
\text { Attrition }\end{array}$ \\
\hline $\begin{array}{l}\text { Castro-Sanchez } \\
\text { 2011[a] }\end{array}$ & Spain & $\begin{array}{l}\text { Inclusion Criteria: } \\
\text { Adults age } 40 \text { to } 65 \text {, agreement to attend evening therapy sessions, } \\
\text { limitation of usual activities due to pain on at least } 1 \text { day in the } \\
\text { previous } 30 \text { days, and/or moderate or worse average pain level }(<=4 \\
\text { on a } 10-\text { point scale according to article; we assume they meant }>4) \text {. } \\
\\
\text { Exclusion Criteria: } \\
\text { Receipt of non-pharmaceutical therapies; presence of infection, fever, } \\
\text { hypotension, treatment-limiting respiratory disorders; and alterations } \\
\text { in cutaneous integrity. }\end{array}$ & $\begin{array}{l}\text { Randomized: } 94 \\
\text { Treated: } 94 \\
\text { Analyzed: } 86 \\
\text { Attrition: } 8.5 \% \text { (8/94) }\end{array}$ \\
\hline
\end{tabular}




\begin{tabular}{|c|c|}
\hline Author, Year & Intervention, Comparator \\
\hline $\begin{array}{l}\text { Castro-Sanchez } \\
\text { 2011[a] }\end{array}$ & $\begin{array}{l}\text { A.Myofascial Release }(\mathrm{n}=45) \\
\text { Deep fascia release } \\
\text { No. of Regions: Temporal region, suboccipital release, compression-decompression of temporomandibular join, global release of cervicodorsal } \\
\text { fascia, release of pectoral region, diaphragm release (transverse slide), transverse diaphragmatic plane, lumbosacral decompression, release of } \\
\text { psoas fascia and release of the lumbar square. } \\
\text { No. of Treatments: } 2 / \text { week for } 20 \text { weeks } \\
\text { Length of Treatments: } 1 \text { hour with } 10 \text { myofascial release modalities } \\
\text { B.Sham short-wave and Ultrasound Electrotherapy }(n=41) \\
\begin{array}{l}\text { No. of Treatments: } 2 / \text { week for } 20 \text { weeks } \\
\text { Length of Treatments: } 30 \text { minutes }\end{array}\end{array}$ \\
\hline
\end{tabular}




\begin{tabular}{|c|c|c|c|}
\hline Author, Year & Study Participants & Outcome Measures & $\begin{array}{l}\text { Duration of } \\
\text { Followup }\end{array}$ \\
\hline $\begin{array}{l}\text { Castro-Sanchez } \\
\text { 2011[a] }\end{array}$ & $\begin{array}{l}\text { A vs. B } \\
\text { Age (SD): } 55 \text { vs } 54 \text { years } \\
\text { Female: NR } \\
\text { Race: NR } \\
\text { Mean duration of chronicity: NR } \\
\\
\text { Total FIQ: } 64.95(18.2) \text { vs. } 63.94(16.4) \\
\text { Number of Days Feeling Good (FIQ): } 1.84(1.56) \text { vs. } 2.04(2.10) \\
\text { Pain (FIQ): } 9.2(0.6) \text { vs } 8.9(1.1) \\
\text { Fatigue (FIQ): } 8.1(1.5) \text { vs. } 8.6(1.3) \\
\text { Tiredness on waking: } 8.5(2.3) \text { vs. } 7.9(2.6) \\
\text { Stiffness: } 7.8(1.9) \text { vs. } 6.9(2.7) \\
\\
\text { Pain: McGill Pain Questionnaire (MPQ): } \\
\text { Sensory (0-33): } 19.3(9.2) \text { vs. } 19.9(10.6) \\
\text { Affective (0-12): } 5.6(3.4) \text { vs. } 4.9(4.2) \\
\text { Sensory+Affective (0-45): } 24.9(12.6) \text { vs. } 25.3(10.7) \\
\text { Pain (VAS): } 9.13(0.8) \text { vs } 8.90(1.3) \text { p=0.219 } \\
\text { Clinical Global Impression Severity Scale: } 6.25(0.73) \text { vs. } 5.92(0.84) \\
\text { Clinical Global Impression Improvement Scale: }-5.38(0.79) \text { vs. - } \\
5.47(0.46)\end{array}$ & $\begin{array}{l}\text { Fibromyalgia Impact Questionnaire Total (FIQ, 0-100) } \\
\text { Number of Days Feeling Good (FIQ, 0-10): } \\
\text { Pain (FIQ, 0-10) } \\
\text { Fatigue (FIQ, 0-10) } \\
\text { Tiredness on waking (FIQ, 0-10) } \\
\text { Stiffness (FIQ, 0-10) } \\
\text { McGill Pain Questionnaire (MPQ): } \\
\text { Sensory (MPQ, 0-33) } \\
\text { Affective (MPQ, 0-12) } \\
\text { Sensory+Affective (MPQ, 0-45) } \\
\text { Clinical Global Impression Severity Scale (Likert, 1-7, } \\
\text { higher scores indicate severity of illness) } \\
\text { Clinical Global Impression Improvement Scale (Likert, 1- } \\
\text { 7, higher scores indicate severity of illness) }\end{array}$ & $\begin{array}{l}6 \text { Months, } 12 \\
\text { months } \\
\end{array}$ \\
\hline
\end{tabular}




\begin{tabular}{|c|c|}
\hline Author, Year & $\begin{array}{c}\text { Results - Subquestion a } \\
\text { (vs. sham, no treatment, waitlist, attention control) }\end{array}$ \\
\hline $\begin{array}{l}\text { Castro-Sanchez } \\
\text { 2011[a] }\end{array}$ & 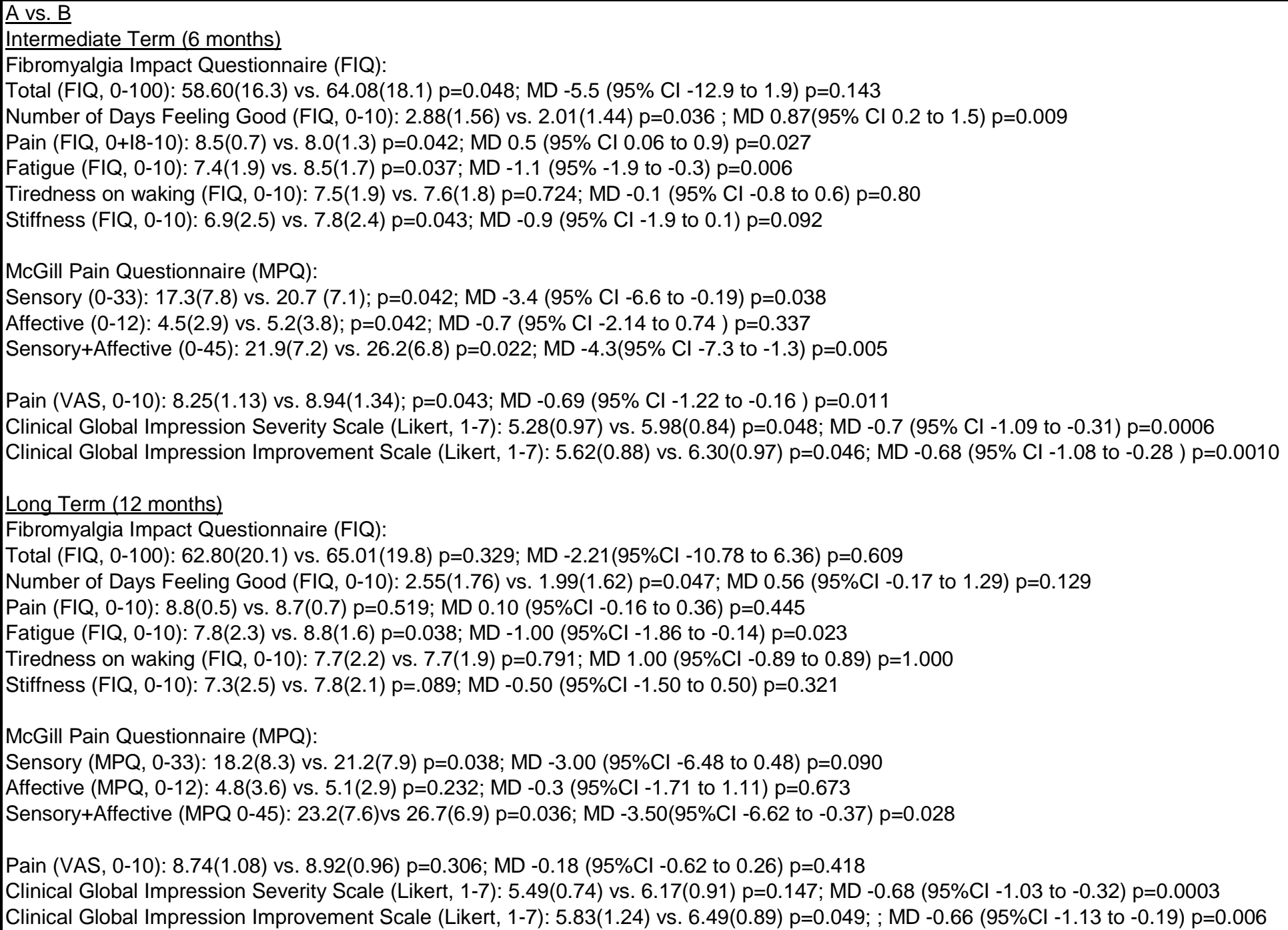 \\
\hline
\end{tabular}




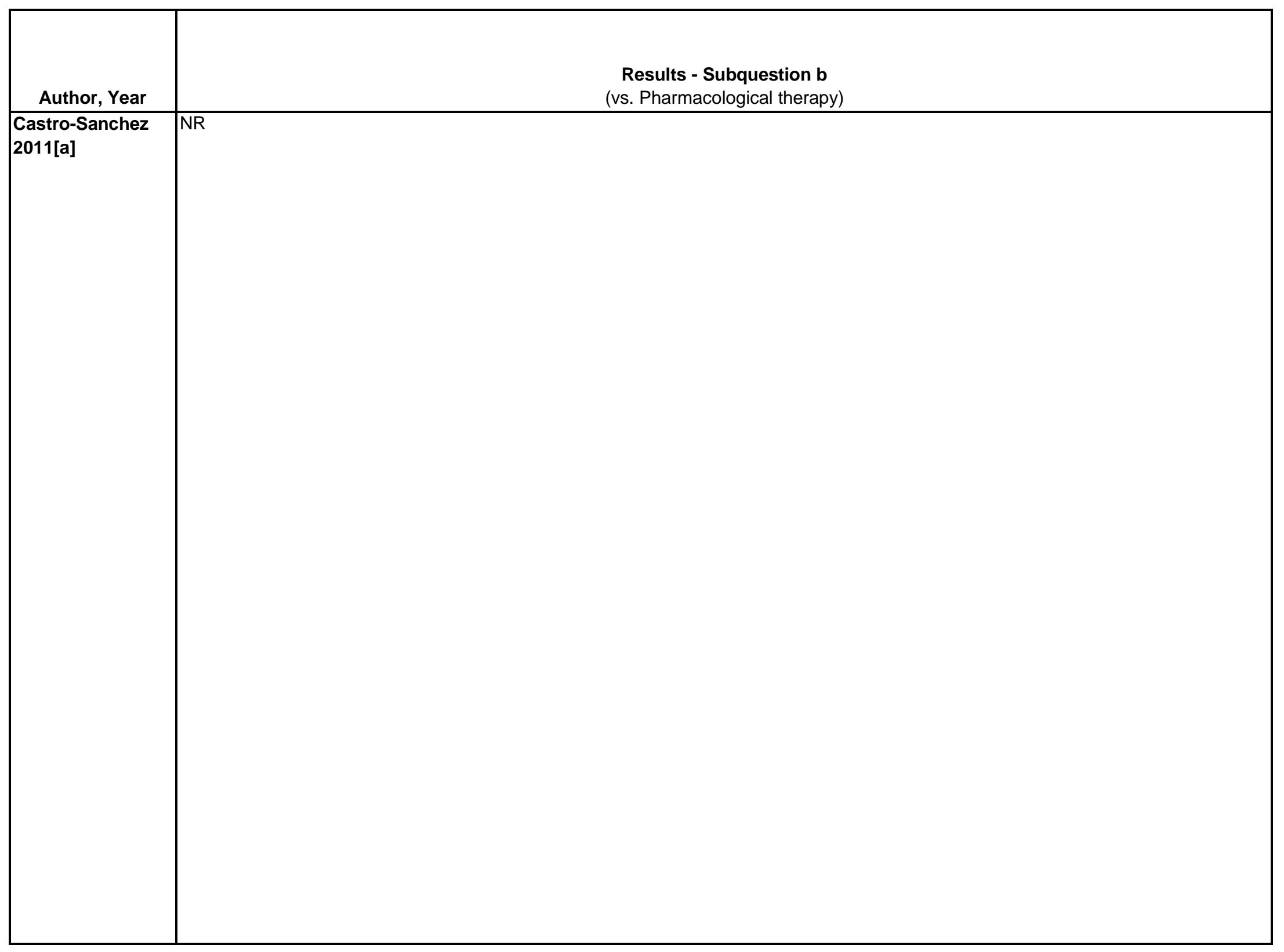

D-201 


\begin{tabular}{|c|c|c|}
\hline Author, Year & $\begin{array}{c}\text { Results - Subquestion c } \\
\text { (vs. Exercise) }\end{array}$ & Adverse Events Including Withdrawals \\
\hline $\begin{array}{l}\text { Castro-Sanchez } \\
\text { 2011[a] }\end{array}$ & 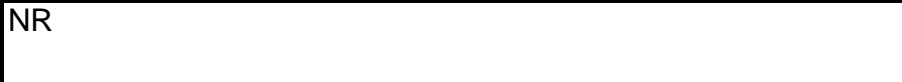 & $\begin{array}{l}\text { "None of the } 94 \text { participants reported adverse } \\
\text { effects" }\end{array}$ \\
\hline
\end{tabular}




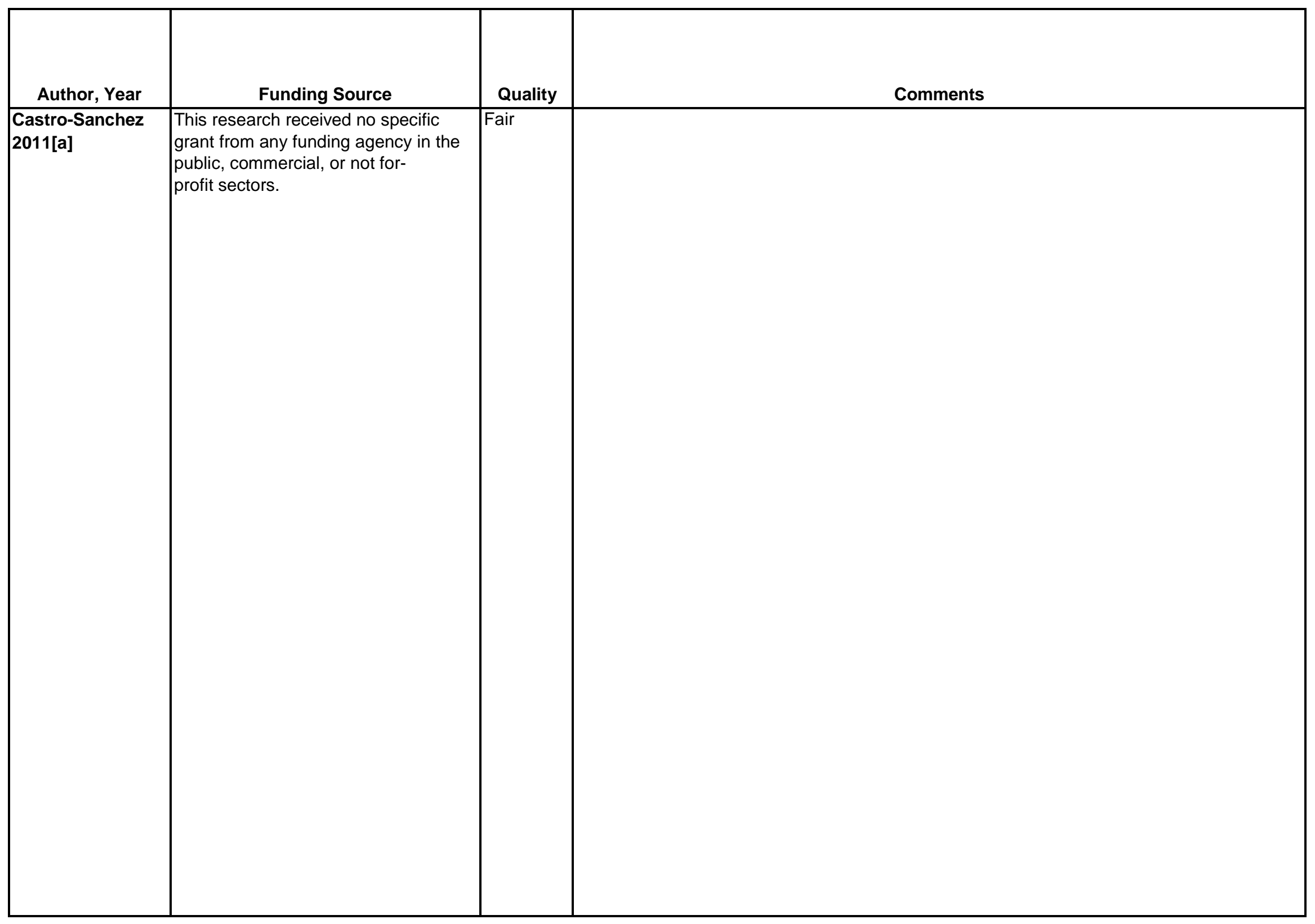

D-203 


\begin{tabular}{|c|c|c|c|}
\hline Author, Year & $\begin{array}{c}\text { Country } \\
\text { Number of Centers } \\
\text { Setting }\end{array}$ & Inclusion/Exclusion Criteria & $\begin{array}{c}\text { Number Randomized, } \\
\text { Analyzed } \\
\text { Attrition }\end{array}$ \\
\hline $\begin{array}{l}\text { Castro-Sanchez } \\
\text { 2011[b] }\end{array}$ & Spain & $\begin{array}{l}\text { Inclusion Criteria: } \\
\text { Adults age } 18 \text { to } 65, \text { no regular physical activity and agreement to } \\
\text { attend evening therapy sessions. } \\
\text { Exclusion Criteria: } \\
\text { Nonagreement to study participation; receipt of other } \\
\text { nonpharmacologic therapies; presence of cardiac, renal or hepatic } \\
\text { insufficiency; cardiovascular event during previous year and presence } \\
\text { of peripheral arterial or venuous insufficiency, physical or } \\
\text { psychological disease, infection fever, hypotension, respiratory } \\
\text { alterations limiting treatment application; skin integrity alterations and } \\
\text { failure to comply with prescribed pharmaceutical therapy. }\end{array}$ & $\begin{array}{l}\text { Randomized: } 64 \\
\text { Treated: } 59 \\
\text { Analyzed: } 59 \\
\text { Attrition: } 8 \%(5 / 64)\end{array}$ \\
\hline
\end{tabular}




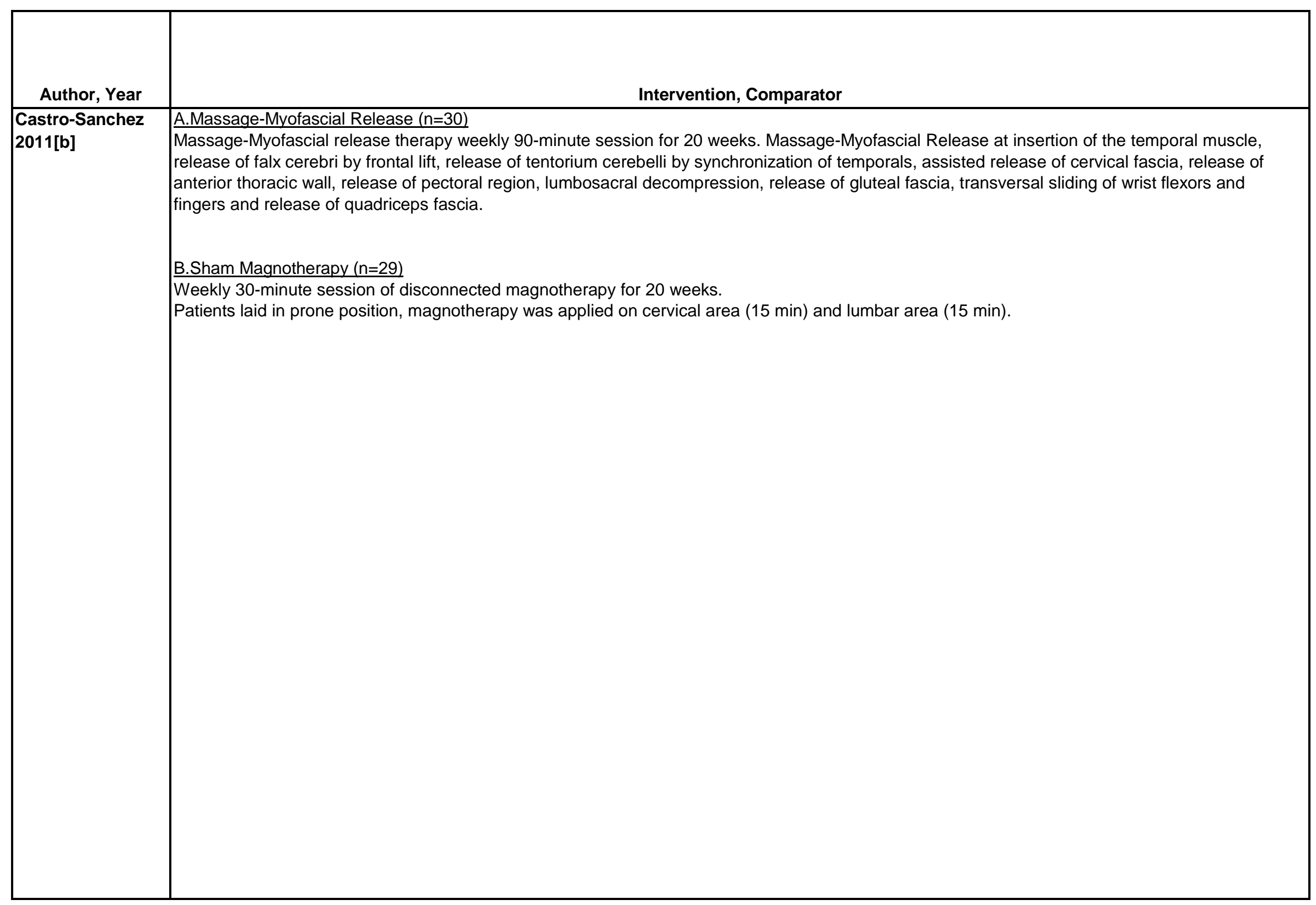




\begin{tabular}{|c|c|c|c|}
\hline Author, Year & Study Participants & Outcome Measures & $\begin{array}{c}\text { Duration of } \\
\text { Followup }\end{array}$ \\
\hline $\begin{array}{l}\text { Castro-Sanchez } \\
\text { 2011[b] }\end{array}$ & 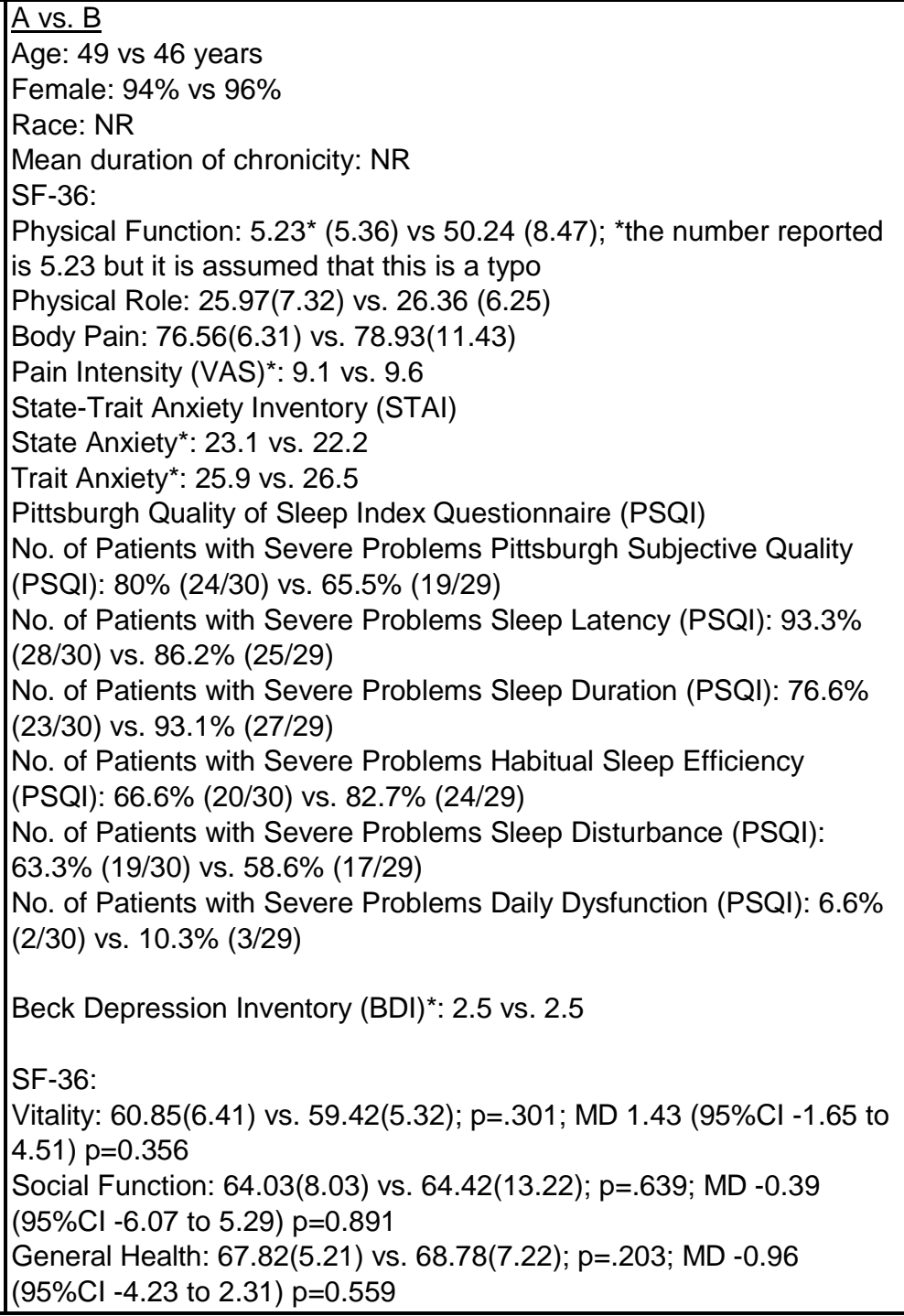 & $\begin{array}{l}\text { Primary: } \\
\text { Pain (VAS, range 0-10) } \\
\text { Secondary: } \\
\text { State-Trait Anxiety Inventory (STAI) } \\
\text { State Anxiety (range 20-80, higher scores indicate } \\
\text { higher anxiety levels): } \\
\text { Trait Anxiety (range 20-80, higher scores indicate higher } \\
\text { anxiety levels): } \\
\text { No. of Patients with Severe Problems on Pittsburgh } \\
\text { Quality of Sleep Index Questionnaire (PSQI, range 0- } \\
\text { 21: higher scores indicate worse sleep) } \\
\text { Beck Depression Inventory (BDI; total:0-63, higher } \\
\text { scores indicate severity of depressive symptoms) } \\
\text { SF-36 Quality of Life Questionnaire (SF-36, range 0- } \\
\text { 100: higher scores indicate optimal health status) }\end{array}$ & $\begin{array}{l}1 \text { month, } 6 \\
\text { months }\end{array}$ \\
\hline
\end{tabular}




\begin{tabular}{|c|c|}
\hline Author, Year & $\begin{array}{c}\text { Results - Subquestion a } \\
\text { (vs. sham, no treatment, waitlist, attention control) }\end{array}$ \\
\hline $\begin{array}{l}\text { Castro-Sanchez } \\
\text { 2011[b] }\end{array}$ & 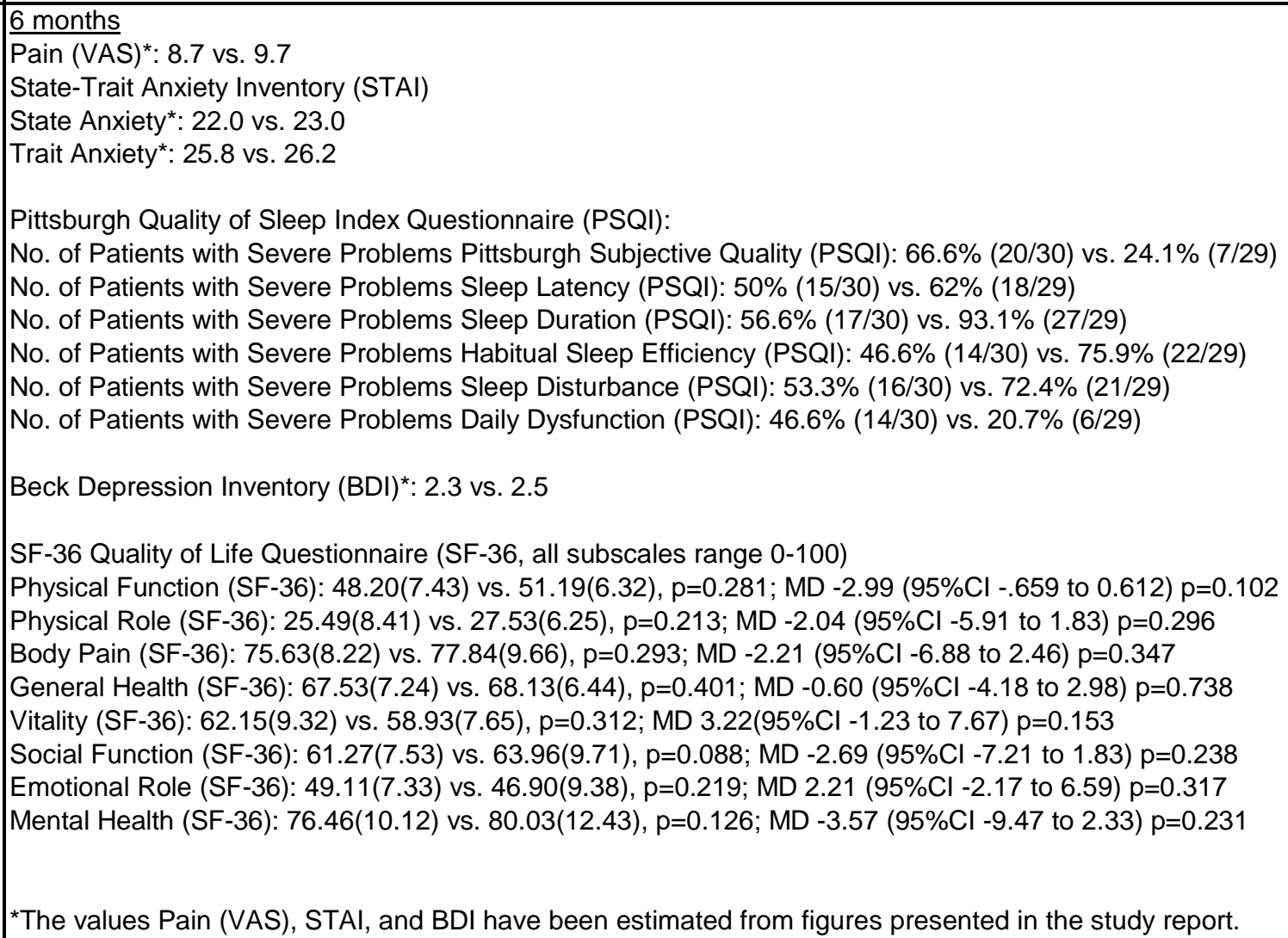 \\
\hline
\end{tabular}




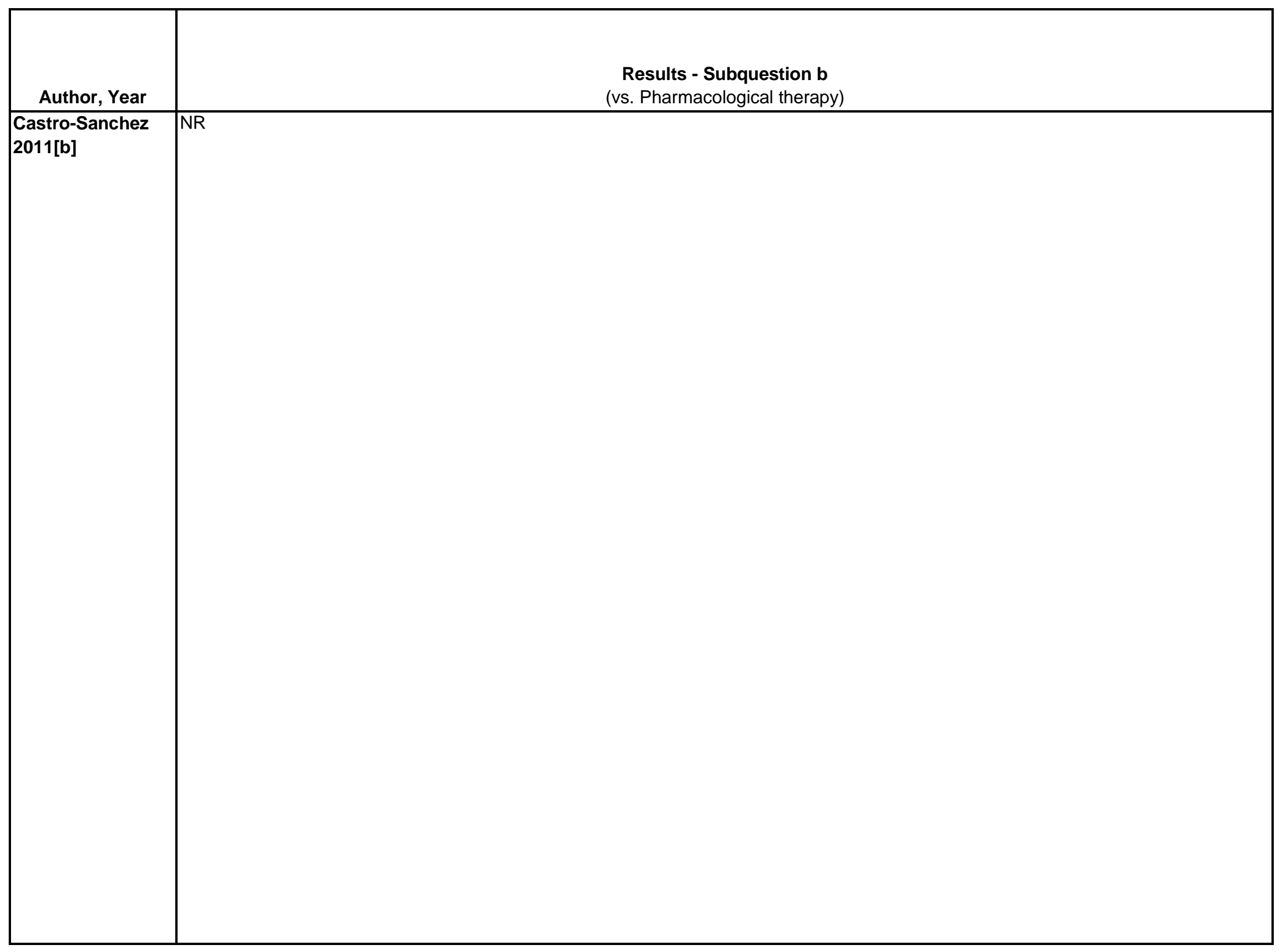

D-208 


$$
[7
$$




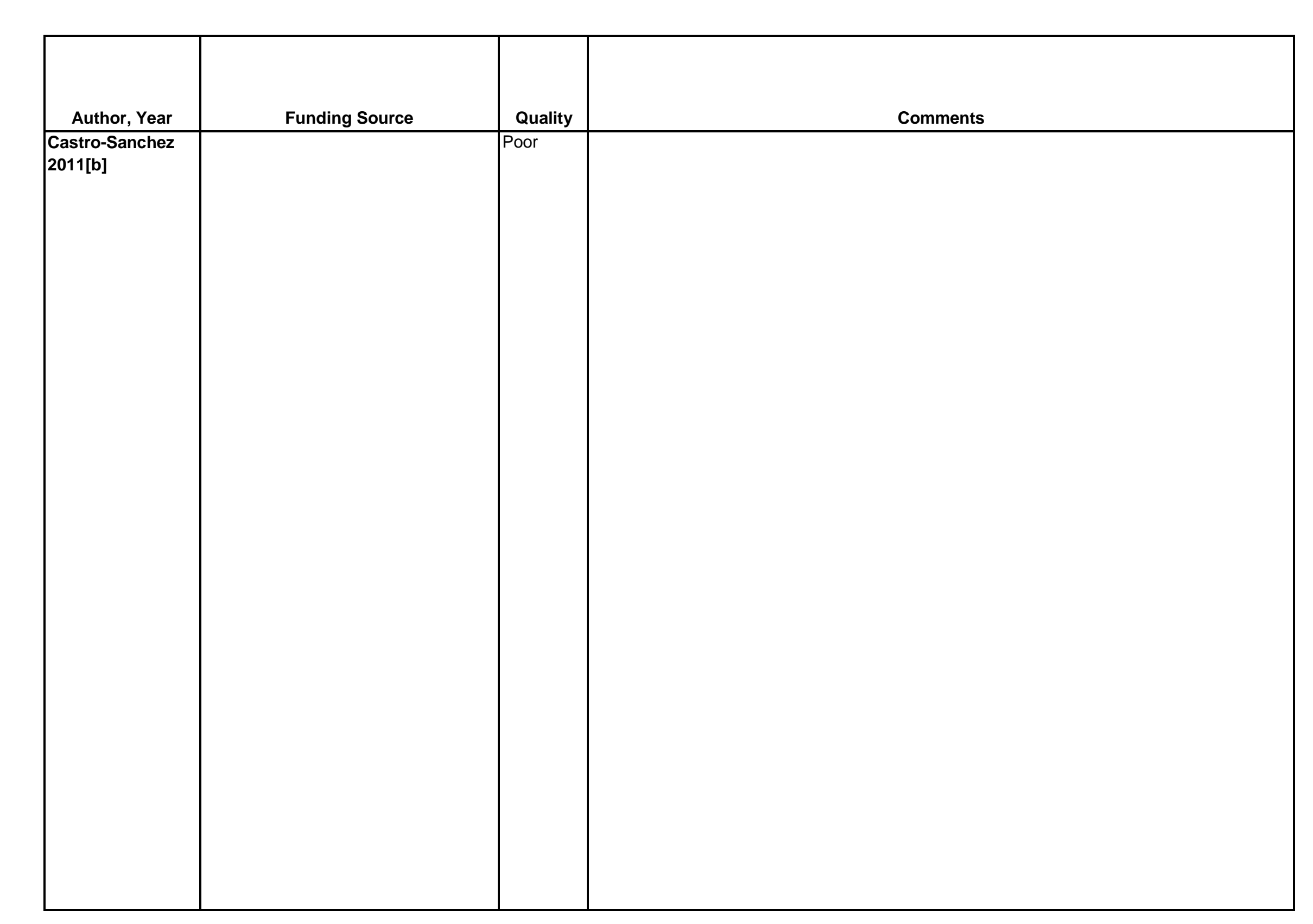




\begin{tabular}{|c|c|c|c|}
\hline Author, Year & $\begin{array}{c}\text { Country } \\
\text { Number of Centers } \\
\text { Setting }\end{array}$ & Inclusion/Exclusion Criteria & $\begin{array}{c}\text { Number Randomized, } \\
\text { Analyzed } \\
\text { Attrition }\end{array}$ \\
\hline Cedraschi 2004 & \begin{tabular}{|l} 
Switzerland \\
1 university hospital \\
rheumatology center
\end{tabular} & $\begin{array}{l}\text { Inclusion: } \\
\text { FM diagnosis based on } 1990 \text { ACR criteria, fluent in French } \\
\text { Exclusion: } \\
\text { Medical disorder requiring immediate treatment or preventing physical } \\
\text { activity or participation in pool sessions }\end{array}$ & \begin{tabular}{|l|} 
Randomized: 164 \\
analyzed: 129 \\
Attrition: $21 \%(35 / 164)$
\end{tabular} \\
\hline Chen 2014 & \begin{tabular}{|l} 
Taiwan \\
Number of centers \\
unclear \\
Setting type NR
\end{tabular} & $\begin{array}{l}\text { Aged } 40 \text { or older with bilateral moderate knee } \mathrm{OA}^{*} \text { and popliteal } \\
\text { cyamella. } \\
\text { Exclusion criteria NR }\end{array}$ & $\begin{array}{l}\text { Randomized: } 60 \\
\text { Treated: } 60 \\
\text { Analyzed: } 51 \\
\text { Attrition: } 15 \%(9 / 60)\end{array}$ \\
\hline
\end{tabular}




\begin{tabular}{|c|c|}
\hline Author, Year & Intervention, Comparator \\
\hline Cedraschi 2004 & $\begin{array}{l}\text { A.Multidisciplinary treatment ( } \mathrm{n}=61) \text { : } 6 \text {-week program, } 1290 \text {-minute group sessions, twice a week for } 6 \text { weeks. Program included pool sessions } \\
\text { led by physiotherapist, relaxation exercises, low impact exercise led by physiotherapist, sessions on activities of daily living led by occupational } \\
\text { therapist, and education. Team consisted of rheumatologist, psychologist, physiotherapist, occupational therapist. } 19 \% \text { withdrew, } 60 \% \text { completed } \\
\geq 10 \text { sessions. } \\
\text { B.Waiting list }(n=68) \text { : Usual care. Offered A after the 6-month followup. }\end{array}$ \\
\hline Chen 2014 & $\begin{array}{l}\text { A.Exercise ( } n=30) \text { : } 3 \text { sessions per week for } 8 \text { weeks. Sessions consisted of a } 20 \text { minutes of hot packs and } 5 \text { minutes of passive range of motion } \\
\text { exercises on a stationary bike, followed by an isokinetic muscle-strengthening exercise program } \\
\text { B.Control }(n=30) \text { : Details NR }\end{array}$ \\
\hline
\end{tabular}




\begin{tabular}{|c|c|c|c|}
\hline Author, Year & Study Participants & Outcome Measures & $\begin{array}{c}\text { Duration of } \\
\text { Followup }\end{array}$ \\
\hline Cedraschi 2004 & $\begin{array}{l}\text { A vs B } \\
\text { Age } 49 \text { vs } 50 \\
\text { Female: } 93 \% \text { vs } 93 \% \\
\text { Symptom duration, years: } 8.4 \text { vs } 9.5 \\
\text { FIQ total score: } 5.5(1.3) \text { vs } 5.6(1.6) \\
\text { FIQ Physical Function: } 4.2(2.0) \text { vs } 4.5(2.2) \\
\text { FIQ Pain: } 6.3(1.9) \text { vs } 6.0(2.1) \\
\text { FIQ Depression: } 5.5(3.1) \text { vs } 5.9(3.5) \\
\text { FIQ Anxiety: } 6.4(2.6) \text { vs } 7.1(2.7) \\
\text { Regional Pain Score: } 63.9(18.0) \text { vs } 67.0(15.7) \\
\text { Psychological General Wellbeing Index subscales: } \\
\text { Anxiety: } 11.4(5.3) \text { vs } 10.8(5.4) \\
\text { Depression: } 8.3(3.4) \text { vs } 7.6(4.0) \\
\text { Psychological General Wellbeing Index total score: } 45.9(17.6) \text { vs } \\
\text { 44.0 (19.3) } \\
\text { SF-36 Physical Function: } 41.8(18.1) \text { vs } 46.8(19.4)\end{array}$ & $\begin{array}{l}\text { FIQ total score (0-10, higher scores=greater impact of } \\
\text { FM) } \\
\text { FIQ Physical Function (0-10, higher scores=greater } \\
\text { impact of FM on physical function) } \\
\text { FIQ Pain (0-10, higher scores=greater pain) } \\
\text { FIQ Depression (0-10, higher scores=greater } \\
\text { depression) } \\
\text { FIQ Anxiety (0-10, higher scores=greater anxiety) } \\
\text { Regional Pain Score (0-105, higher score=more pain) } \\
\text { Psychological General Wellbeing Index total score 0- } \\
\text { 110, higher scores=worse wellbeing) } \\
\text { Psychological General Wellbeing Index subscales: } \\
\text { Anxiety (0-110, higher scores=greater anxiety) } \\
\text { Depression (0-110, higher scores=greater depression) } \\
\text { SF-36 Physical Function (0-100, higher scores=better } \\
\text { function) }\end{array}$ & 6 months \\
\hline Chen 2014 & $\begin{array}{l}\text { A vs B† } \\
\text { Age: } 63 \\
\text { Females: } 85 \% \\
\text { Duration of knee pain: } 10-144 \text { months } \\
\text { Lequesne Index: } 7.8 \text { (1.2) vs } 8.0(1.1) \\
\text { Pain VAS: } 5.5 \text { (1.4) vs } 5.6(1.4)\end{array}$ & $\begin{array}{l}\text { Lequesne Index (0-26, higher score=higher } \\
\text { dysfunction); pain VAS (0-10, higher score=higher pain) }\end{array}$ & 6 months \\
\hline
\end{tabular}




\begin{tabular}{|c|c|}
\hline Author, Year & $\begin{array}{l}\text { Results - Subquestion a } \\
\text { (vs. sham, no treatment, waitlist, attention control) }\end{array}$ \\
\hline Cedraschi 2004 & 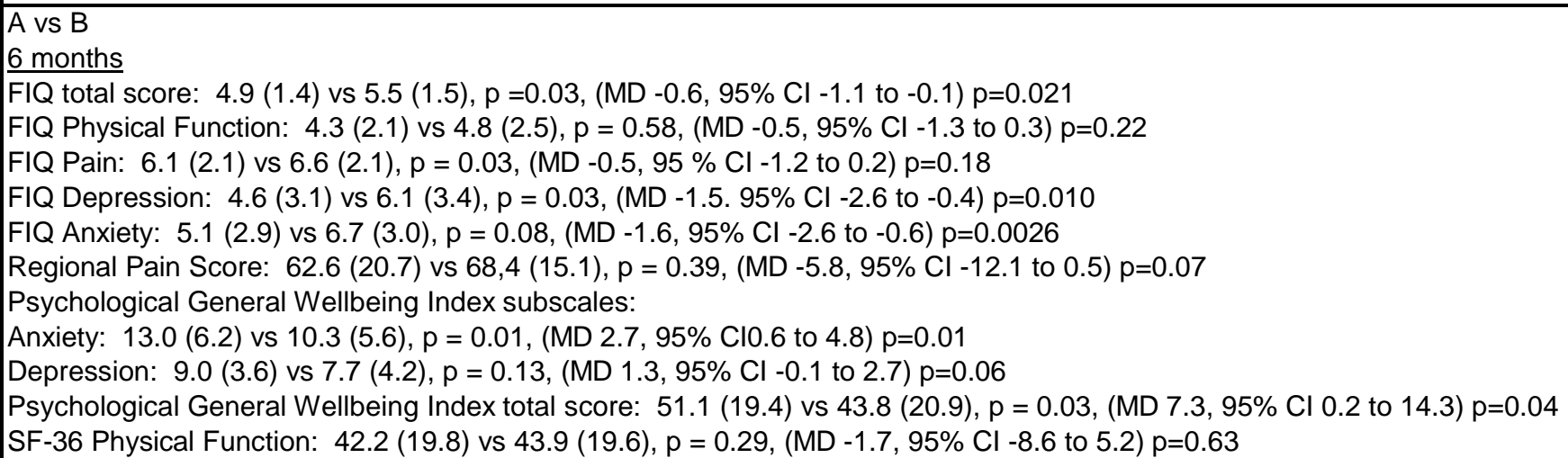 \\
\hline Chen 2014 & $\begin{array}{l}\text { A vs B } \\
\text { Lequesne Index: } 5.4(1.7) \text { vs } 7.6(1.6),(\mathrm{MD}-2.2,95 \% \mathrm{Cl}-3.1 \text { to }-1.3) \mathrm{p}<0.001 \\
\text { Pain VAS: } 4.0(1.4) \text { vs } 6.5(1.3),(\mathrm{MD}-2.5,95 \% \mathrm{Cl}-3.3 \text { to }-1.7) \mathrm{p}<0.001\end{array}$ \\
\hline
\end{tabular}




\begin{tabular}{|l|c|}
\hline Author, Year & $\begin{array}{c}\text { Results - Subquestion b } \\
\text { (vs. Pharmacological therapy) }\end{array}$ \\
\hline Cedraschi 2004 & \\
\hline Chen 2014 & \\
& \\
\hline
\end{tabular}

D-215 


\begin{tabular}{|l|l|l|}
\hline Author, Year & \multicolumn{1}{|c|}{$\begin{array}{c}\text { Results - Subquestion c } \\
\text { (vs. Exercise) }\end{array}$} & Adverse Events Including Withdrawals \\
\hline Cedraschi 2004 & & $\begin{array}{l}\text { Avs B } \\
\text { Withdrawals: 19\% (16/84) vs 0 } \\
\text { Adverse events: 2\% (2/84) vs 0 }\end{array}$ \\
& & \\
\hline Chen 2014 & & RR=inf, $\mathrm{p}=0.08$ \\
& & \\
\hline
\end{tabular}




\begin{tabular}{|c|c|c|c|}
\hline Author, Year & Funding Source & Quality & Comments \\
\hline
\end{tabular}




\begin{tabular}{|c|c|c|c|}
\hline Author, Year & $\begin{array}{c}\text { Country } \\
\text { Number of Centers } \\
\text { Setting }\end{array}$ & Inclusion/Exclusion Criteria & $\begin{array}{c}\text { Number Randomized, } \\
\text { Analyzed } \\
\text { Attrition }\end{array}$ \\
\hline Cherkin 2001 & $\begin{array}{l}\text { USA } \\
\text { Number of centers: } 7 \\
\text { Setting: Outpatient } \\
\text { offices of CAM } \\
\text { practitioners in HMO } \\
\text { network }\end{array}$ & $\begin{array}{l}\text { Inclusion: } \\
\text { Age } 20-70 \text { years } \\
\text { Primary care physician visit for low back pain } \\
\text { Exclude: } \\
\text { Sciatica } \\
\text { Acupuncture or massage for back pain within the past year } \\
\text { Back care from a specialist or CAM provider } \\
\text { Severe clotting disorders or anticoagulant therapy } \\
\text { Cardiac pacemakers } \\
\text { Underlying systemic or visceral disease } \\
\text { Pregnancy } \\
\text { Involvement with litigation or compensation claims for back pain } \\
\text { Inability to speak English } \\
\text { Severe or progressive neurologic deficits } \\
\text { Lumbar surgery within the past } 3 \text { years } \\
\text { Recent vertebral fracture } \\
\text { Serious comorbid conditions } \\
\text { Bothersomeness of back pain rated }<4 \text { on a scale of } 0-10\end{array}$ & $\begin{array}{l}\text { Randomized: } 184 \\
\text { Treated: } 94 \\
\text { Analyzed: } 184 \\
\text { Attrition: } 0 \%(0 / 184)\end{array}$ \\
\hline
\end{tabular}




\begin{tabular}{|c|c|}
\hline Author, Year & Intervention, Comparator \\
\hline Cherkin 2001 & $\begin{array}{l}\text { A. Needle acupuncture }(n=94) \text { : Traditional Chinese Medical (TCM) acupuncture treatment for up to } 10 \text { visits over } 10 \text { weeks using protocol; } \\
\text { permitted basic TCM needling techniques, electrical stimulation and manual manipulation of the needles, indirect moxibustion, infrared heat, } \\
\text { cupping, and exercise recommendations; did not allow massage (including acupressure), herbs, and treatments not considered common TCM } \\
\text { practice; number and location of needles were decided by provider. } \\
\text { B.Self-care education ( } n=90) \text { : Patients were mailed high-quality and relatively inexpensive educational materials designed for persons with chronic } \\
\text { low back pain: a book and } 2 \text { professionally produced videotapes (self-management of back pain, exercise demonstrations); materials included } \\
\text { information about back pain and its treatment, techniques for controlling and preventing pain and for improving quality of life, and suggestions for } \\
\text { coping with the emotional and interpersonal problems often accompanying chronic illness. }\end{array}$ \\
\hline
\end{tabular}




\begin{tabular}{|c|c|c|c|}
\hline Author, Year & Study Participants & Outcome Measures & $\begin{array}{c}\text { Duration of } \\
\text { Followup }\end{array}$ \\
\hline Cherkin 2001 & $\begin{array}{l}\text { A vs. B } \\
\text { Age: } 54 \text { vs. } 44 \\
\text { Female: } 52 \% \text { vs. } 44 \% \\
\text { Race - White: } 82 \% \text { vs. } 89 \% \\
\text { Pain has lasted < } 1 \text { year: } 57 \% \text { vs. } 62 \% \\
\text { >90 days of LBP in the past } 6 \text { months: } 63 \% \text { vs. } 66 \% \\
\text { Baseline Symptom bothersomeness score during past week: } 6.2 \text { vs. } \\
6.1 \\
\text { Baseline Roland Disability Scale: } 12.8 \text { vs. } 12.0 \\
\text { Baseline SF-12 Physical Health Scale: } 37.0 \text { vs. } 36.5 \\
\text { Baseline SF-12 Mental Health Scale: } 48.8 \text { vs. } 48.8 \\
\geq 1 \text { work-loss day due to LBP in past month: } 26 \% \text { vs. } 26 \% \\
>7 \text { days restricted activity due to LBP in past month: } 48 \% \text { vs. } 1 \% \\
\text { Previous hospitalization for back problem: } 11 \% \text { vs. } 7 \% \\
\text { Previous lower back operation: } 5 \% \text { vs. } 8 \% \\
\text { Pain travels below knee: } 24 \% \text { vs. } 30 \% \\
\text { Symptoms most of past } 24 \text { hours: } 53 \% \text { vs. } 62 \% \\
\text { Previous acupuncture for LBP: } 3 \% \text { vs. } 4 \% \\
\text { Previous massage for LBP: } 14 \% \text { vs. } 19 \% \\
\text { Used medication for LBP in the past week: } 69 \% \text { vs. } 63 \% \\
\text { Taking narcotic analgesics: } 9 \% \text { vs. } 9 \%\end{array}$ & $\begin{array}{l}\text { Symptom bothersomeness scale (0-10) } \\
\text { Modified Roland Disability Scale (RMDQ): } 0-23 \\
\text { SF-12 physical health summary scale } \\
\text { SF-12 mental health summary scale } \\
\geq 1 \text { work-loss day due to LBP in past month } \\
>7 \text { days restricted activity due to LBP in past month }\end{array}$ & 9.5 months \\
\hline
\end{tabular}




\begin{tabular}{|c|c|}
\hline Author, Year & $\begin{array}{c}\text { Results - Subquestion a } \\
\text { (vs. sham, no treatment, waitlist, attention control) }\end{array}$ \\
\hline Cherkin 2001 & 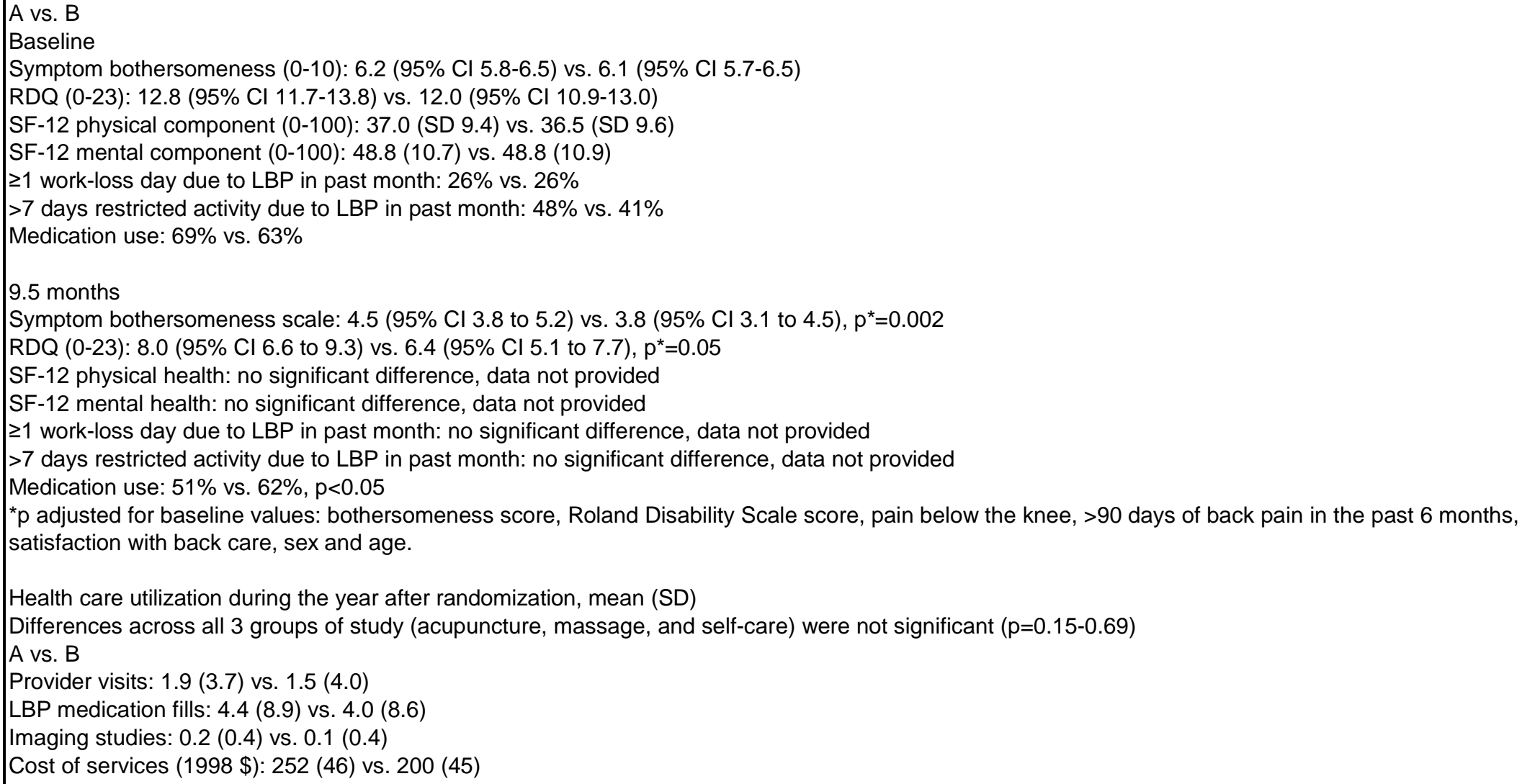 \\
\hline
\end{tabular}




\begin{tabular}{|l|l|}
\hline Author, Year & \multicolumn{2}{c|}{$\begin{array}{c}\text { Results - Subquestion b } \\
\text { (vs. Pharmacological therapy) }\end{array}$} \\
\hline Cherkin 2001 & NR \\
& \\
& \\
\hline
\end{tabular}




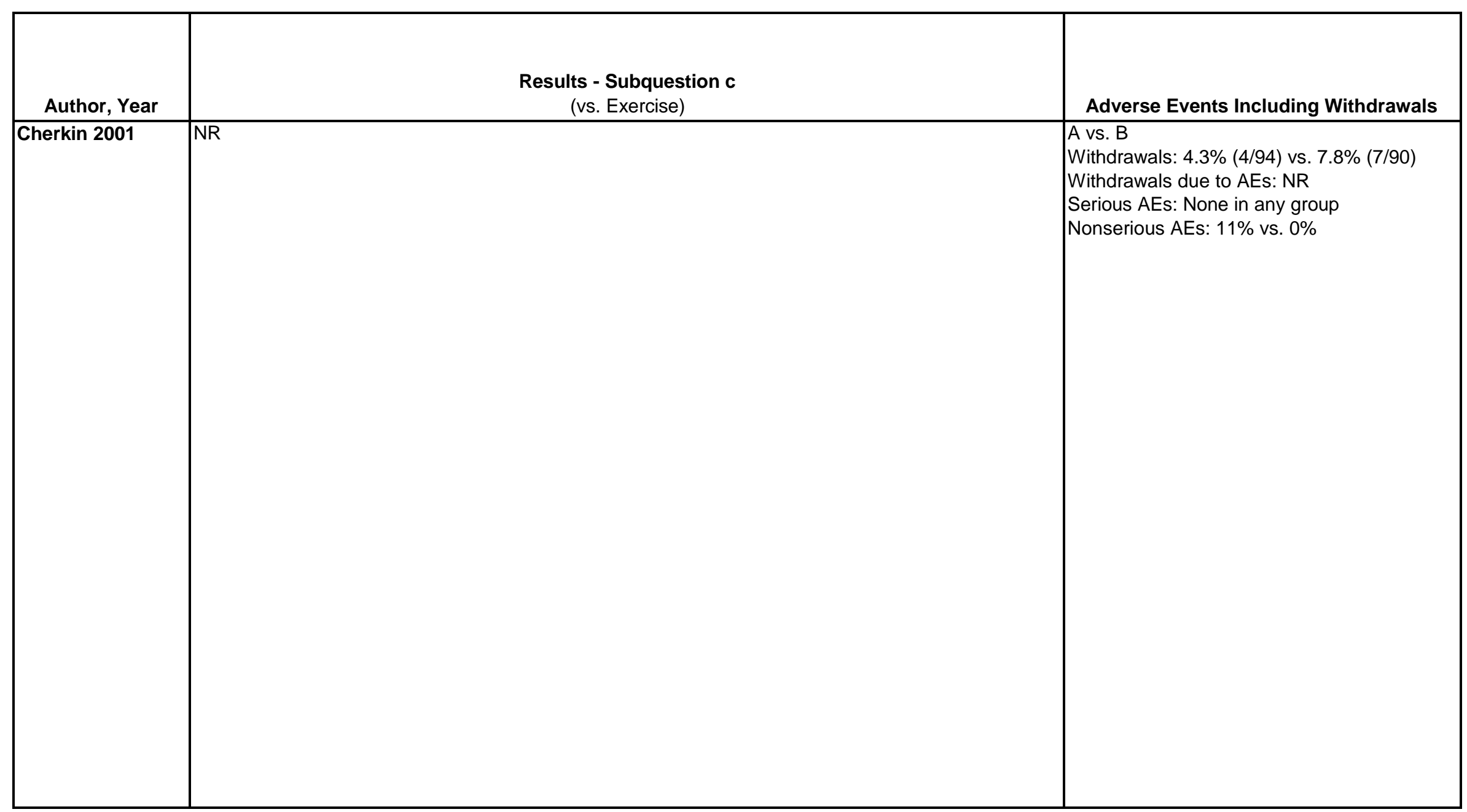




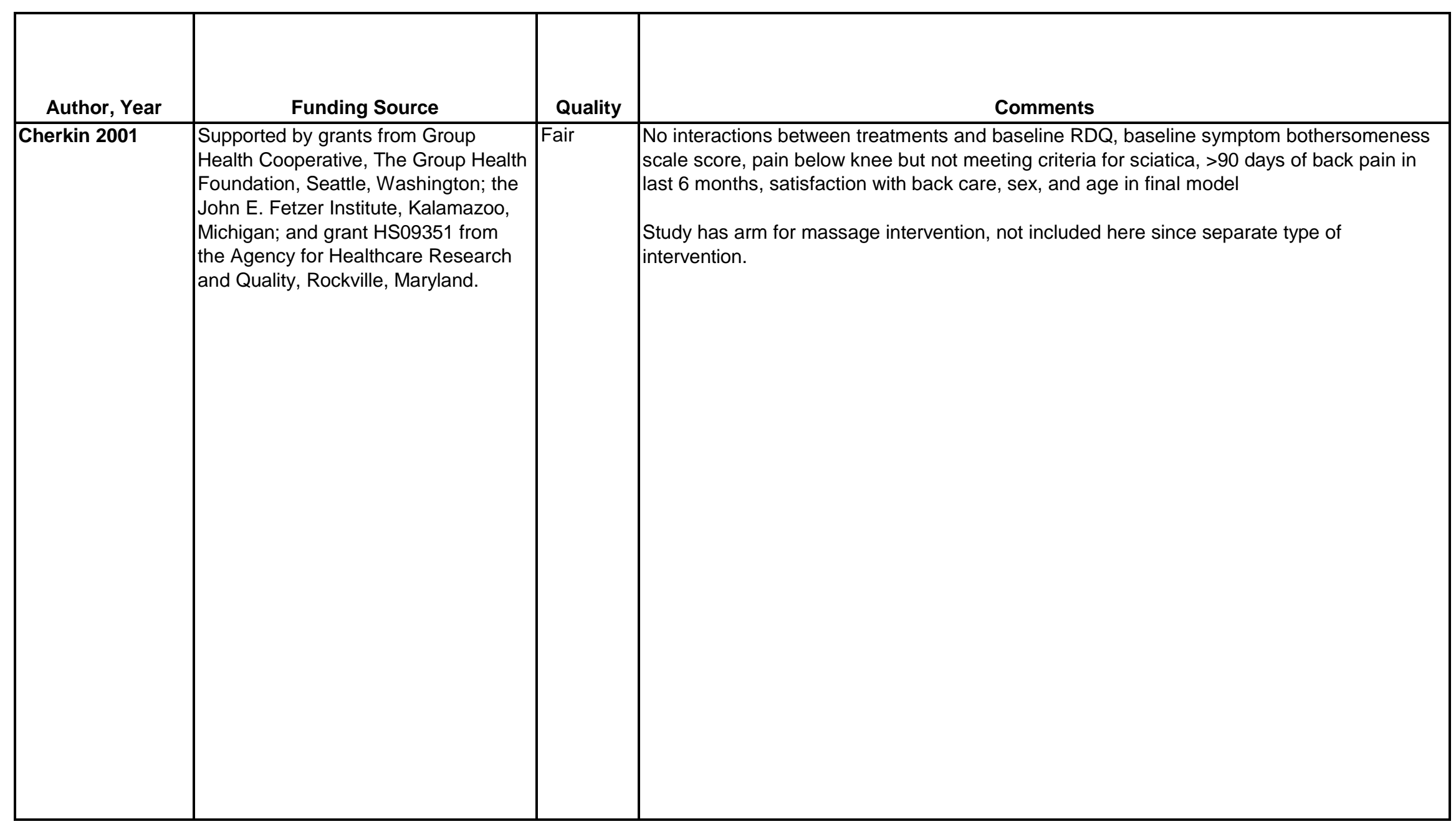




\begin{tabular}{|c|c|c|c|}
\hline Author, Year & $\begin{array}{c}\text { Country } \\
\text { Number of Centers } \\
\text { Setting }\end{array}$ & Inclusion/Exclusion Criteria & $\begin{array}{c}\text { Number Randomized, } \\
\text { Analyzed } \\
\text { Attrition }\end{array}$ \\
\hline Cherkin 2001 & $\begin{array}{l}\text { US } \\
\text { Number of centers } \\
\text { unclear } \\
\text { Outpatient }\end{array}$ & $\begin{array}{l}\text { Age } 20-70 \\
\text { Primary care visit for low back pain } \\
\text { Exclude: } \\
\text { Sciatica } \\
\text { Acupuncture or massage for back pain within the past year } \\
\text { Back care from a specialist or complementary and alternative } \\
\text { medicine provider } \\
\text { Severe clotting disorders or anticoagulant therapy } \\
\text { Cardiac pacemaker } \\
\text { Underlying systemic or visceral disease } \\
\text { Pregnancy } \\
\text { Involvement with litigation or compensation claims for back pain } \\
\text { Lumbar surgery within past } 3 \text { years } \\
\text { Recent vertebral fracture } \\
\text { Serious comorbid conditions } \\
\text { Bothersomeness of back pain rated }<4 \text { on } 0-10 \text { scale }\end{array}$ & $\begin{array}{l}\text { Randomized: } 262 \\
\text { Treated: } 252 \\
\text { Analyzed: } 262 \\
\text { Attrition at } 1 \text { year: } 5 \% \\
(13 / 262)\end{array}$ \\
\hline
\end{tabular}




\begin{tabular}{|c|c|}
\hline Author, Year & Intervention, Comparator \\
\hline Cherkin 2001 & 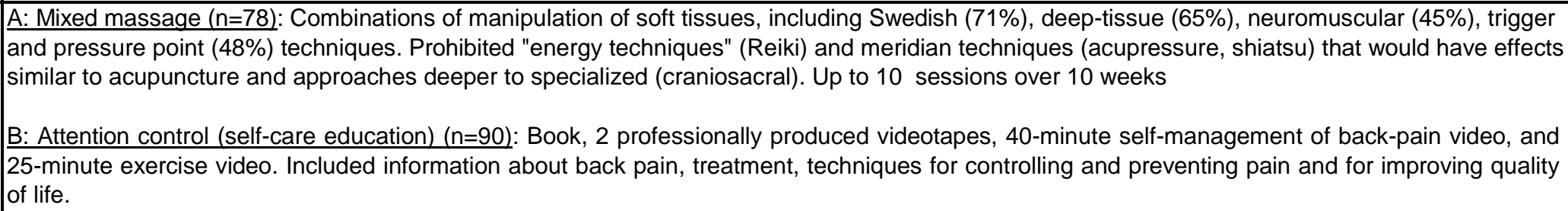 \\
\hline
\end{tabular}




\begin{tabular}{|l|l|l|}
\hline \multicolumn{1}{|c|}{ Author, Year } & \multicolumn{1}{|c|}{ Study Participants } & \multicolumn{1}{|c|}{ Outcome Measures } \\
\hline Cherkin 2001 & $\begin{array}{l}\text { Age: } 46 \text { vs. } 44 \text { years } \\
\text { Female: } 69 \% \text { vs. } 56 \% \\
\text { White: } 82 \% \text { vs. } 89 \% \\
\text { LBP care }>1 \text { year ago: } 81 \% \text { vs. } 85 \% \\
\text { Pain lasted }>1 \text { year: } 64 \% \text { vs. } 62 \% \\
\text { RDQ mean: } 11.8 \text { vs. } 12.0 \\
\text { Used medication for LBP in last week: } 73 \% \text { vs. } 63 \%\end{array}$ & $\begin{array}{l}\text { Duration of } \\
\text { Followup }\end{array}$ \\
\hline $\begin{array}{l}10.5 \text { months } \\
\text { Bothersomeness of back pain, leg pain, numbness or } \\
\text { tingling in prior week, } 0-10 \text { scale, score for most } \\
\text { bothersome symptom was used (higher number=more } \\
\text { bothersome) } \\
\text { Modified RDQ: positive answers to 23 questions on } \\
\text { limitation of daily activities attributable to back pain } \\
\text { (higher number=more dysfunction) }\end{array}$ \\
$\begin{array}{l}\text { Secondary outcomes: } \\
\text { Disability: National Health Interview Survey questions } \\
\text { modified to refer specifically to back-related restrictions. } \\
\text { Healthcare utilization: automated HMO data } \\
\text { Medication use } \\
\text { SF-12 Physical and Mental Health summary scales } \\
\text { Number of days of aerobic exercise and back exercise } \\
\text { in pervious week }\end{array}$ \\
\hline
\end{tabular}




\begin{tabular}{|c|c|}
\hline Author, Year & $\begin{array}{c}\text { Results - Subquestion a } \\
\text { (vs. sham, no treatment, waitlist, attention control) }\end{array}$ \\
\hline Cherkin 2001 & $\begin{array}{l}\text { A vs. B, mean }(95 \% \mathrm{Cl}) \\
\text { Baseline } \\
\text { Modified RMDQ (0-23): } 11.8(10.8 \text { to } 12.7) \text { vs. } 12.0(10.9 \text { to } 13.0) \\
\text { Symptom bothersomeness (0-10): } 6.2(5.8 \text { to } 6.6) \text { vs. } 6.1(5.7 \text { to } 6.5) \\
\text { SF-12 Mental Component Score: no differences, data not shown } \\
\text { 10.5 months } \\
\text { Modified RMDQ (0-23): } 6.8(5.5 \text { to } 8.1) \text { vs. } 6.4(5.1 \text { to } 7.7), p=0.03^{*} \\
\text { Symptom bothersomeness (0-10): } 3.2(2.5 \text { to } 3.9) \text { vs. } 3.8(3.1 \text { to } 4.5), p=0.003^{\star} \\
\text { Low back pain medication, mean (SD): } 2.5(3.6) \text { vs. } 4.0(8.6), p=0.69 \\
\star \text { Adjusted for baseline RMDQ score }\end{array}$ \\
\hline
\end{tabular}




\begin{tabular}{|c|c|c|}
\hline Author, Year & \multicolumn{1}{c|}{$\begin{array}{c}\text { Results - Subquestion b } \\
\text { (vs. Pharmacological therapy) }\end{array}$} \\
\hline Cherkin 2001 & NR \\
& \\
& \\
\hline
\end{tabular}




\begin{tabular}{|c|c|c|}
\hline Author, Year & \multicolumn{1}{|c|}{$\begin{array}{c}\text { Results - Subquestion c } \\
\text { (vs. Exercise) }\end{array}$} & Adverse Events Including Withdrawals \\
\hline Cherkin 2001 & NR & $\begin{array}{l}\text { Serious Adverse Events: } 0 \\
\text { Significant discomfort or pain shortly after } \\
\text { treatment: 13\% in massage group }\end{array}$ \\
& & \\
\hline
\end{tabular}




\begin{tabular}{|c|c|c|c|}
\hline Author, Year & Funding Source & Quality & Comments \\
\hline Cherkin 2001 & Group Health Cooperative and AHRQ & Fair & \\
\hline
\end{tabular}




\begin{tabular}{|c|c|c|c|}
\hline Author, Year & $\begin{array}{c}\text { Country } \\
\text { Number of Centers } \\
\text { Setting }\end{array}$ & Inclusion/Exclusion Criteria & $\begin{array}{c}\text { Number Randomized, } \\
\text { Analyzed } \\
\text { Attrition } \\
\end{array}$ \\
\hline Cherkin 2009 & \begin{tabular}{|l} 
USA \\
Number of centers: 2 \\
Setting: 2 integrated \\
health care delivery \\
systems
\end{tabular} & $\begin{array}{l}\text { 18-70 years old } \\
\text { Plans to continue enrollment in health plan } \\
\geq 1 \text { primary care visit for LBP within the past } 3-12 \text { months } \\
\text { Non-specific, uncomplicated low back pain } \\
\text { Exclude: } \\
\text { Previous acupuncture for any reason } \\
\text { LBP lasting <3 months } \\
\text { Mild symptoms (VAS for bothersomeness }<3 \text { on } 0-10 \text { scale) } \\
\text { Specific causes of back pain (cancer, fractures, spinal stenosis, } \\
\text { infections) } \\
\text { Complicated back problems (sciatica, prior back surgery, medico-legal } \\
\text { issues) } \\
\text { Possible contraindications for acupuncture (coagulation disorders, } \\
\text { cardiac pacemaker, pregnancy, seizure disorder) } \\
\text { Conditions making treatment difficult (paralysis, psychoses) } \\
\text { Conditions that might confound treatment effects or interpretation of } \\
\text { data (severe fibromyalgia, rheumatoid arthritis, concurrent care from } \\
\text { other providers) }\end{array}$ & $\begin{array}{l}\text { Randomized: } 641 \\
\text { Treated: } 315 \\
\text { Analyzed: } 638 \\
\text { Attrition: } 0.5 \%(3 / 641) \\
\\
\end{array}$ \\
\hline
\end{tabular}




\begin{tabular}{|c|c|}
\hline Author, Year & Intervention, Comparator \\
\hline Cherkin 2009 & 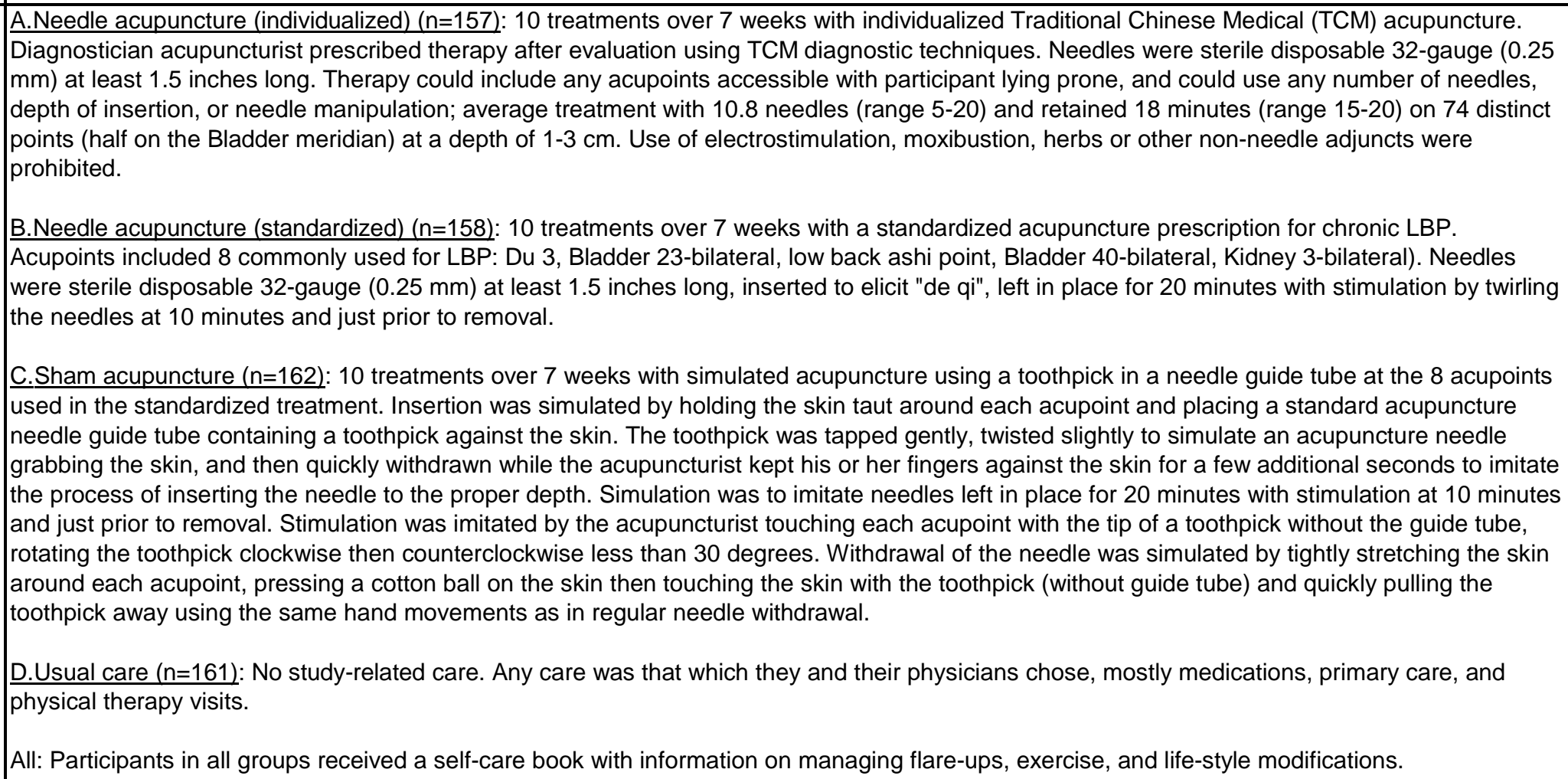 \\
\hline
\end{tabular}




\begin{tabular}{|c|c|c|c|}
\hline Author, Year & Study Participants & Outcome Measures & $\begin{array}{c}\text { Duration of } \\
\text { Followup }\end{array}$ \\
\hline Cherkin 2009 & $\begin{array}{l}\text { A vs. B vs. C vs. D } \\
\text { Age: } 47 \text { vs. } 49 \text { vs. } 47 \text { vs. } 46 \\
\text { Female: } 68 \% \text { vs. } 56 \% \text { vs. } 60 \% \text { vs. } 64 \% \\
\text { - White: } 67 \% \text { vs. } 69 \% \text { vs. } 72 \% \text { vs. } 65 \% \\
\text { - Hispanic origin: } 7 \% \text { vs. } 9 \% \text { vs. } 8 \% \text { vs. } 8 \% \\
\text { Chronic pain for } \geq 1 \text { year: } 69 \% \text { vs. } 74 \% \text { vs. } 60 \% \text { vs. } 70 \% \\
\text { Baseline modified RDQ: } 10.8 \text { vs. } 10.8 \text { vs. } 9.8 \text { vs. } 11.0 \\
\text { Baseline VAS ( } 0-10 \text { VAS): } 5.0 \text { vs. } 5.0 \text { vs. } 4.9 \text { vs. } 5.3 \\
\text { Baseline SF- } 36 \text { physical health score: } 41 \text { vs. } 42 \text { vs. } 42 \text { vs. } 42 \\
\text { Baseline SF- } 36 \text { mental health score: } 53 \text { vs. } 54 \text { vs. } 54 \text { vs. } 53 \\
\text { Medication use in past week: } 62 \% \text { vs. } 62 \% \text { vs. } 63 \% \text { vs. } 65 \% \\
\text { Reduced activity } \geq 7 \text { days in last } 3 \text { months due to LBP: } 29 \% \text { vs. } 23 \% \\
\text { vs. } 22 \% \text { vs. } 27 \% \\
\text { Reduced activity }>7 \text { days in last } 4 \text { weeks due to LBP: } 27 \% \text { vs. } 25 \% \text { vs. } \\
20 \% \text { vs. } 28 \% \\
\text { Kept in bed or lying down } \geq 1 \text { day in last } 4 \text { weeks due to LBP: } 17 \% \text { vs. } \\
22 \% \text { vs. } 21 \% \text { vs. } 22 \%\end{array}$ & $\begin{array}{l}\text { Modified Roland Morris Disability Questionnaire }(0-23) \\
\text { Symptom bothersomeness }(0-10 \text {, higher score = more } \\
\text { bothersome) } \\
\text { Self-reported medication use for back pain in the prior } \\
\text { week } \\
\text { SF-36 physical component }(0-100) \\
\text { SF-36 mental component }(0-100) \\
\text { Cost of health services for LBP during the year following } \\
\text { randomization }\end{array}$ & $\begin{array}{l}4.5 \text { months, } \\
10.5 \text { months }\end{array}$ \\
\hline
\end{tabular}




\begin{tabular}{|c|c|}
\hline Author, Year & $\begin{array}{c}\text { Results - Subquestion a } \\
\text { (vs. sham, no treatment, waitlist, attention control) }\end{array}$ \\
\hline Cherkin 2009 & 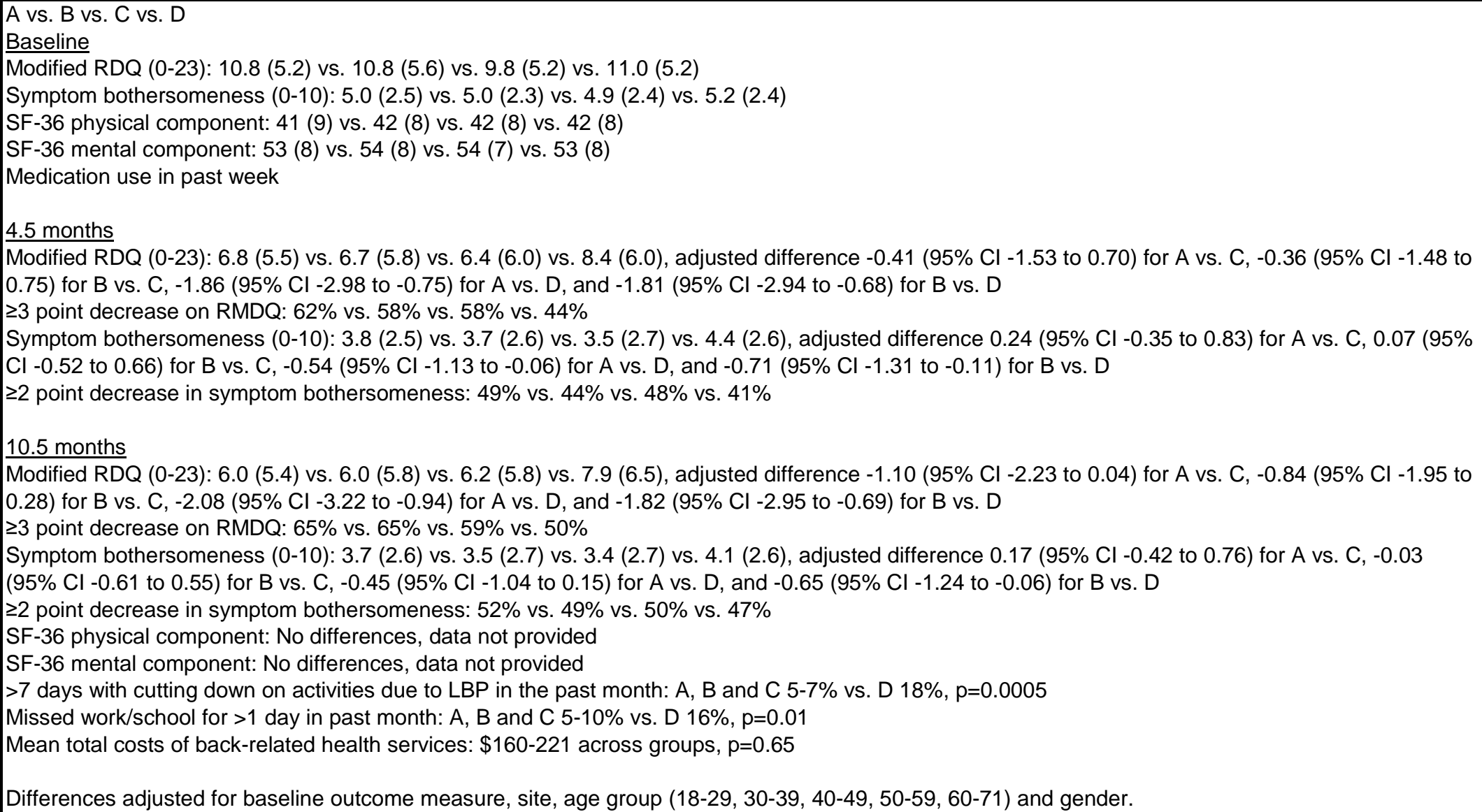 \\
\hline
\end{tabular}




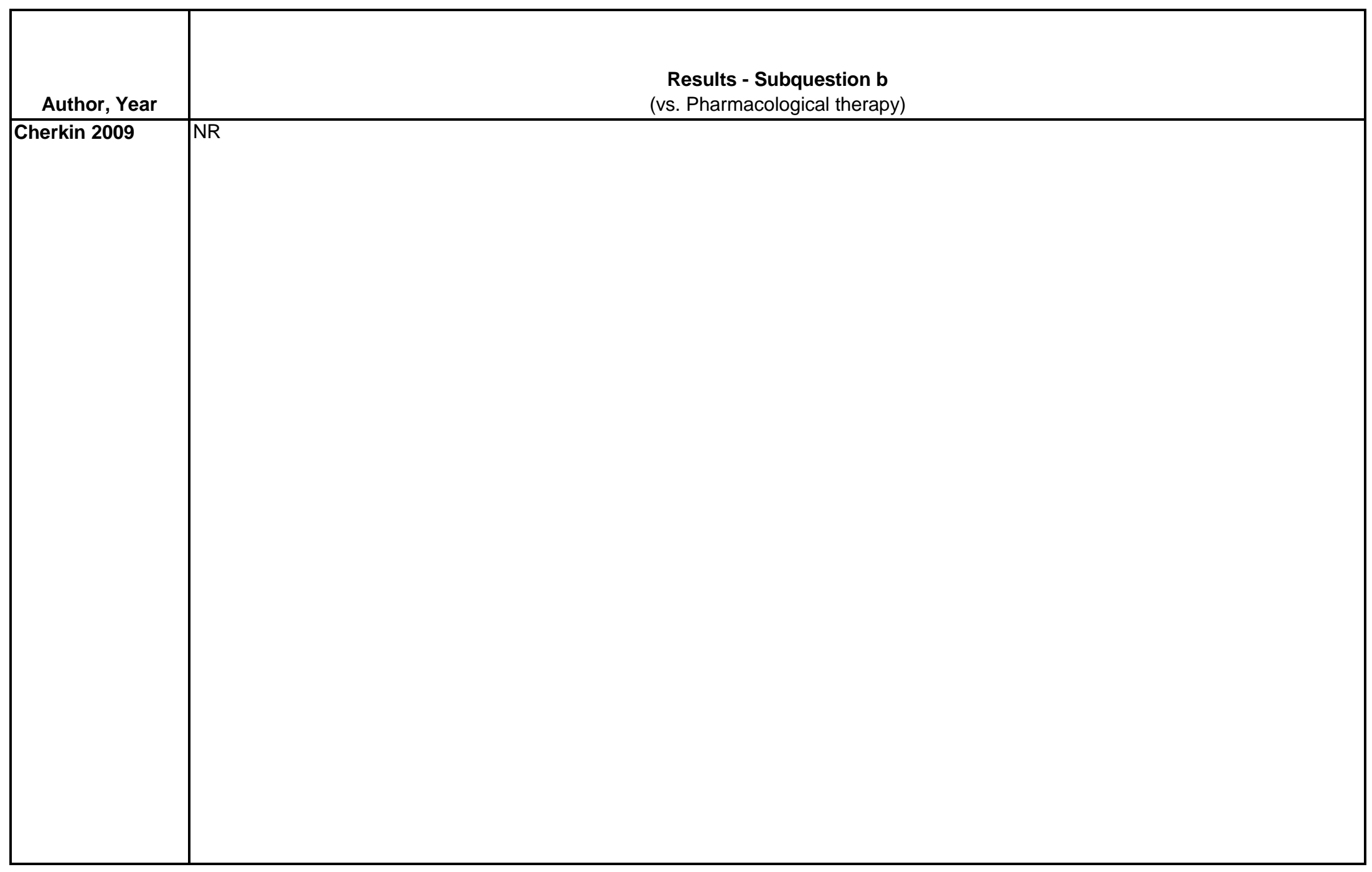

D-236 


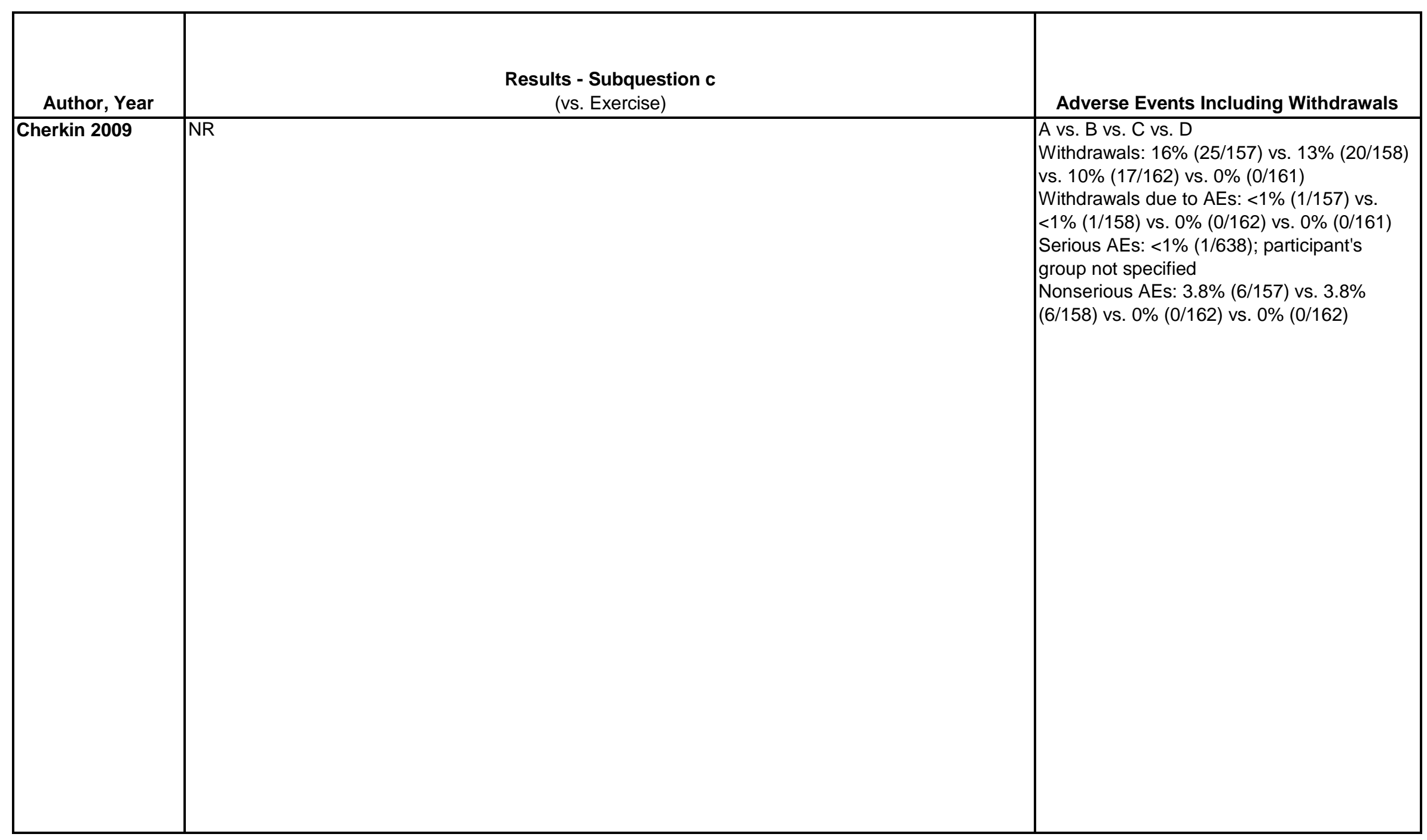




\begin{tabular}{|l|l|l|l|}
\hline Author, Year & \multicolumn{1}{|c|}{ Funding Source } & Quality & \\
\hline Cherkin 2009 & $\begin{array}{l}\text { Funded through an NIH Cooperative } \\
\text { Agreement (U01 AT O01110) with the } \\
\text { National Center for Complementary } \\
\text { and Alternative Medicine (NCCAM). } \\
\text { Seirin acupuncture needles used in } \\
\text { the study were donated by Lhasa } \\
\text { OMS (Weymouth, Massachusetts). }\end{array}$ & Comments \\
\hline & & & \\
\hline
\end{tabular}




\begin{tabular}{|c|c|c|c|}
\hline Author, Year & $\begin{array}{c}\text { Country } \\
\text { Number of Centers } \\
\text { Setting }\end{array}$ & Inclusion/Exclusion Criteria & $\begin{array}{c}\text { Number Randomized, } \\
\text { Analyzed } \\
\text { Attrition }\end{array}$ \\
\hline Cherkin, 2011 & $\begin{array}{l}\text { US } \\
\text { Number of centers: } 1 \\
\text { Outpatient }\end{array}$ & $\begin{array}{l}\text { Age } 20 \text { to } 65 \text { years with LBP } 3+ \\
\text { months without } 2 \text { or more pain- free weeks and pain bothersomeness } \\
\text { rated at least } 3 \text { on a scale of } 0 \text { to } 10 \\
\text { Exclude: specific causes of back pain, sciatica, back surgery in the } \\
\text { past } 3 \text { years, or medicolegal issues, conditions making treatment } \\
\text { difficult }\end{array}$ & $\begin{array}{l}\text { Randomized: } \\
402 \\
\text { Analyzed: } 366 \\
\text { Attrition: } 8.9 \% \text { (36/402) }\end{array}$ \\
\hline
\end{tabular}




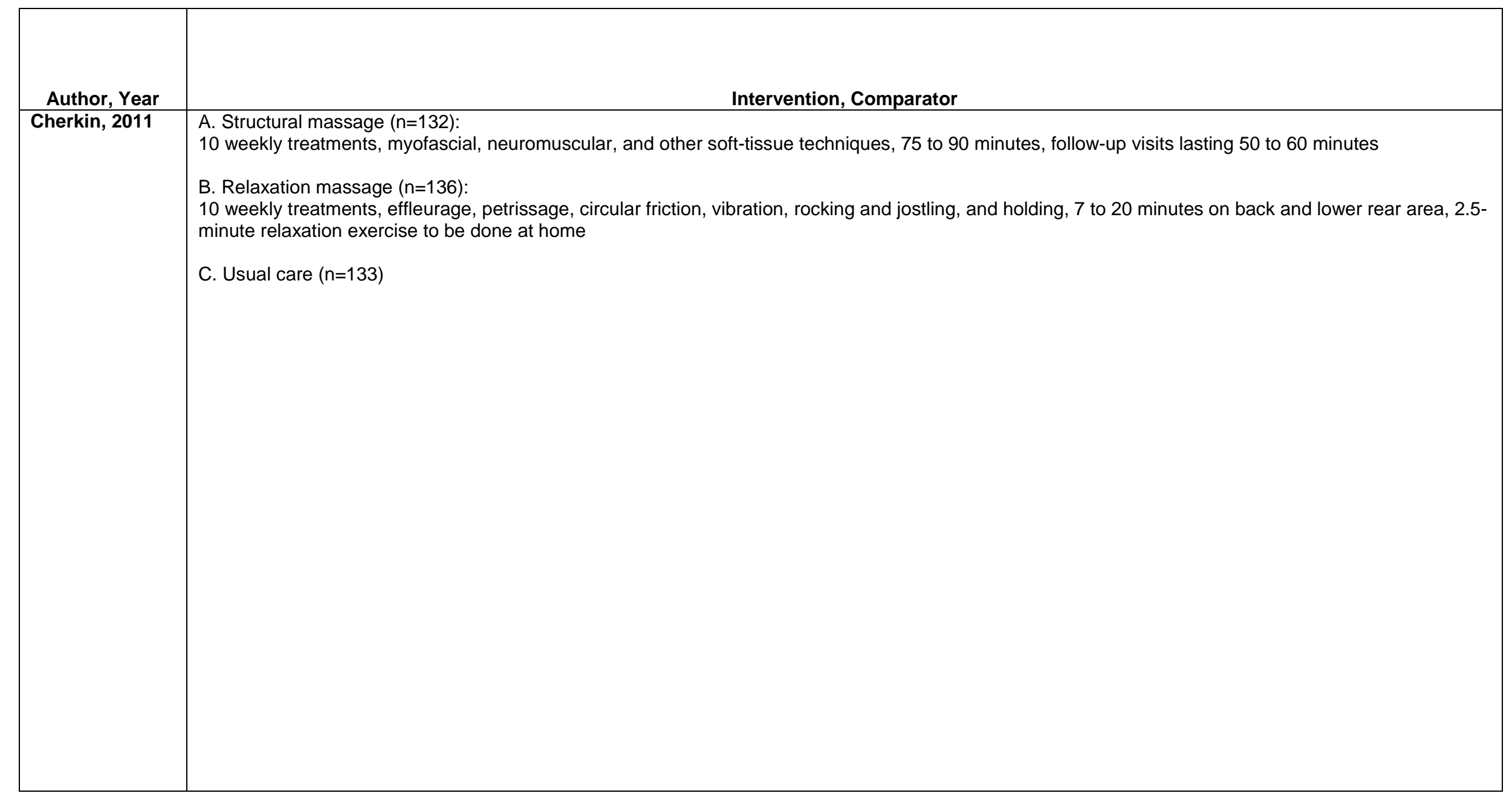




\begin{tabular}{|c|c|c|c|}
\hline Author, Year & Study Participants & Outcome Measures & $\begin{array}{l}\text { Duration of } \\
\text { Followup }\end{array}$ \\
\hline Cherkin, 2011 & $\begin{array}{l}\text { A vs. B vs. C } \\
\text { Mean age: } 46 \text { vs. } 47 \text { vs. } 48 \text { years } \\
\text { Female: } 66 \% \text { vs. } 65 \% \text { vs. } 62 \% \text { Race: } 86 \% \text { vs. } 87 \% \text { vs. } 86 \% \text { white } \\
\text { LBP for at least } 1 \text { year: } 77 \% \text { vs. } 72 \% \text { vs. } 78 \% \\
\text { Mean days with LBP in past the } 6 \text { months: } 133 \text { vs. } 128 \text { vs. } 131 \\
\text { LBP bothersomeness, VAS (0-10): } 5.6 \text { vs. } 5.6 \text { vs. } 5.8 \\
\text { Disability, mean RDQ score: } 10.1 \text { vs. } 11.6 \text { vs. } 10.5 \\
\text { NSAIDS in past week: } 50 \% \text { vs. } 57 \% \text { vs. } 55 \% \\
\text { Narcotic analgesics in past week: } 17 \% \text { vs. } 17 \% \text { vs. } 13 \% \\
\text { Mean SF-12 physical health component: } 40 \text { vs. } 38 \text { vs. } 39 \\
\text { Mean SF-12 mental health component: } 50 \text { vs. } 50 \text { vs. } 50\end{array}$ & $\begin{array}{l}\text { Modified RDQ }(0-23) \\
\text { Symptom bothersomeness }(0=\text { "not at all" to } 10= \\
\text { "extremely") } \\
\text { Opioid use in last week for LBP } \\
\text { Global rating of improvement ( } 7 \text { point categorical scale) } \\
\text { Health care costs }\end{array}$ & 3.5 and 9.5 months \\
\hline
\end{tabular}




\begin{tabular}{|c|c|}
\hline Author, Year & $\begin{array}{c}\text { Results - Subquestion a } \\
\text { (vs. Sham, no treatment, waitlist, attention control) }\end{array}$ \\
\hline Cherkin, 2011 & 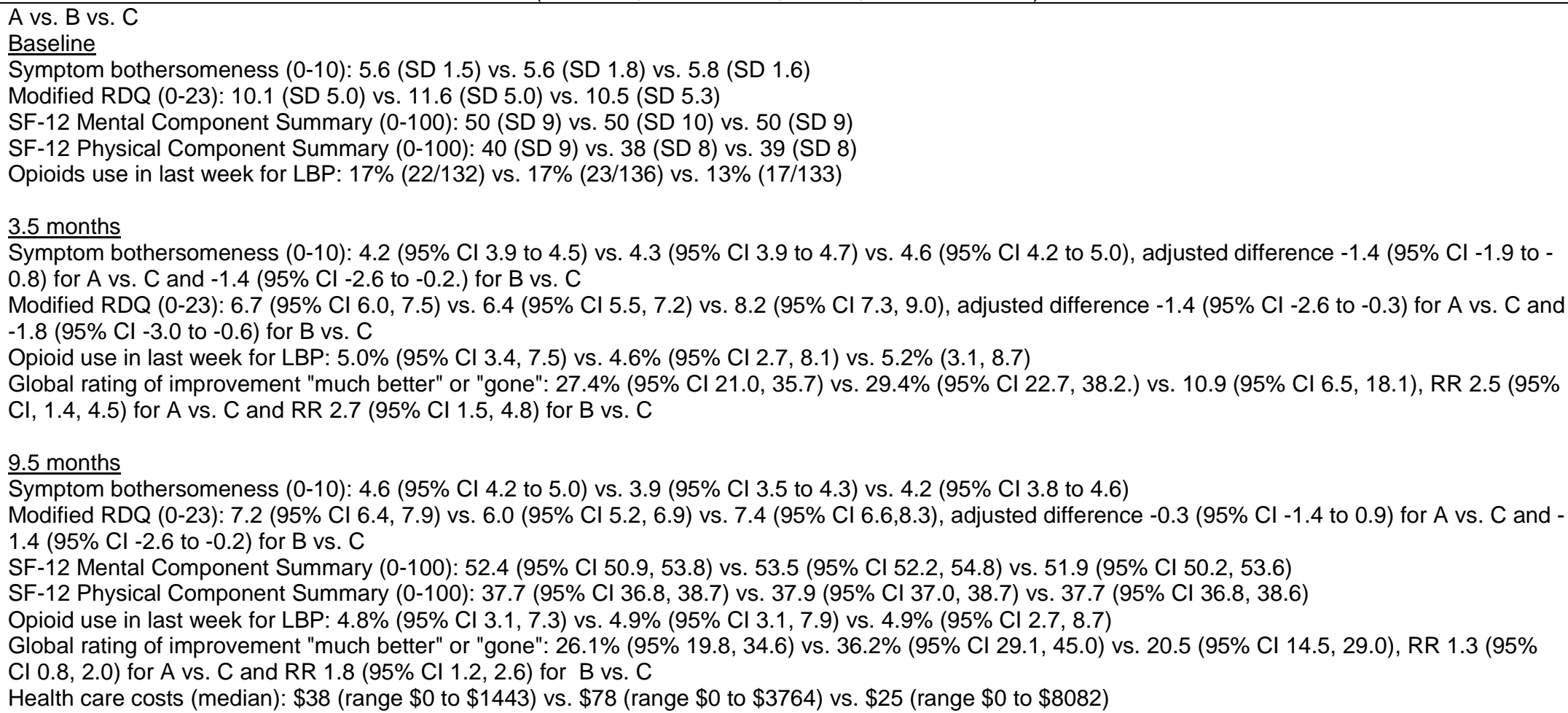 \\
\hline
\end{tabular}




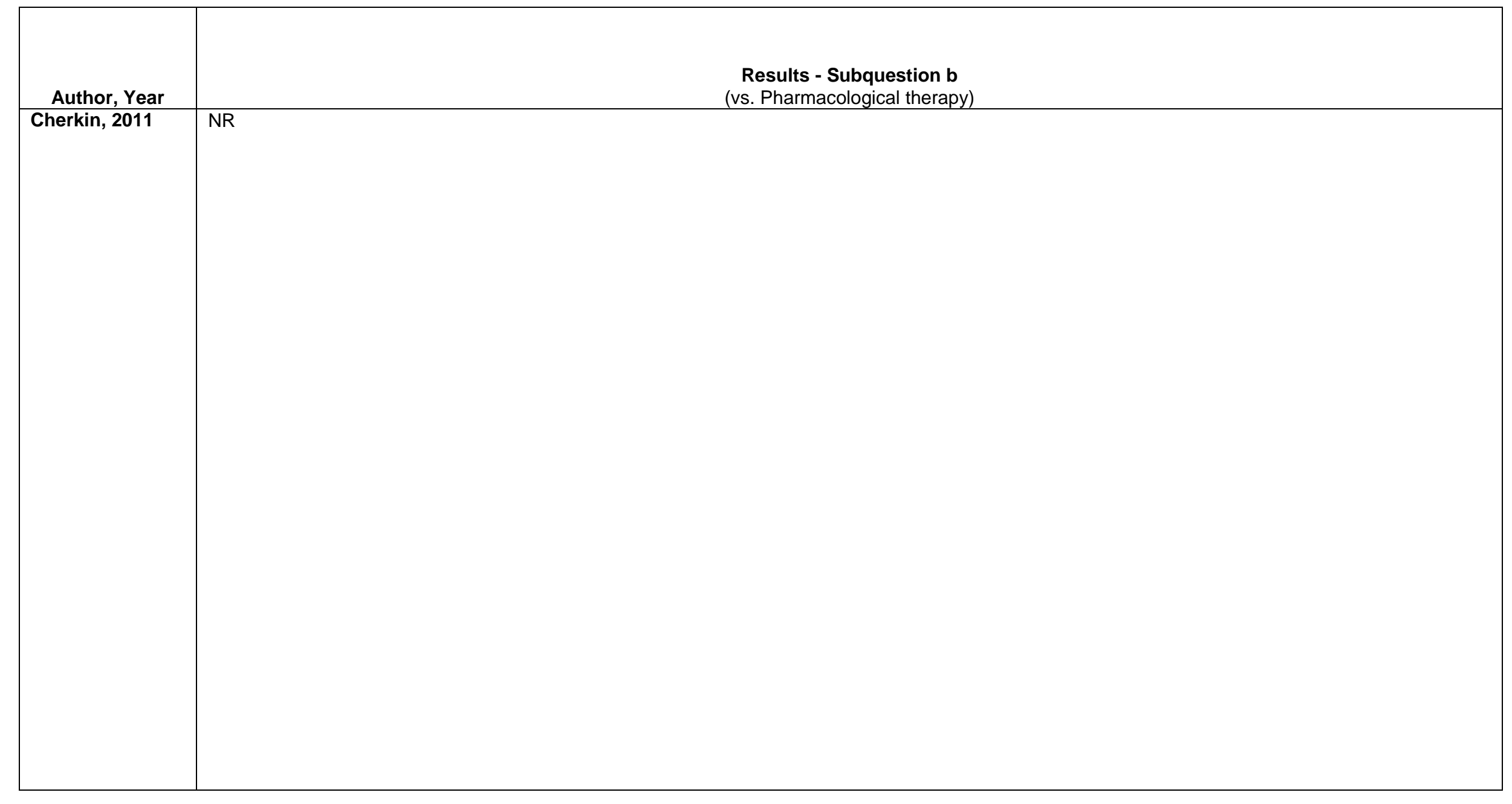




\begin{tabular}{|c|c|c|}
\hline $\begin{array}{c}\text { Author, Year } \\
\text { Cherkin, 2011 }\end{array}$ & $\begin{array}{l}\text { Results - Subquestion c } \\
\text { (vs. Exercise) }\end{array}$ & $\begin{array}{l}\text { Adverse Events Including Withdrawls } \\
\text { Adverse events possibly related to massage (primarily pain): } 7 \%(9 / 131) \text { vs. }\end{array}$ \\
\hline & TNR & $\begin{array}{l}\text { Aaverse enents } \\
4 \%(5 / 134) \text { vs. NR }\end{array}$ \\
\hline & & \\
\hline & & \\
\hline & & \\
\hline & & \\
\hline & & \\
\hline & & \\
\hline & & \\
\hline & & \\
\hline
\end{tabular}




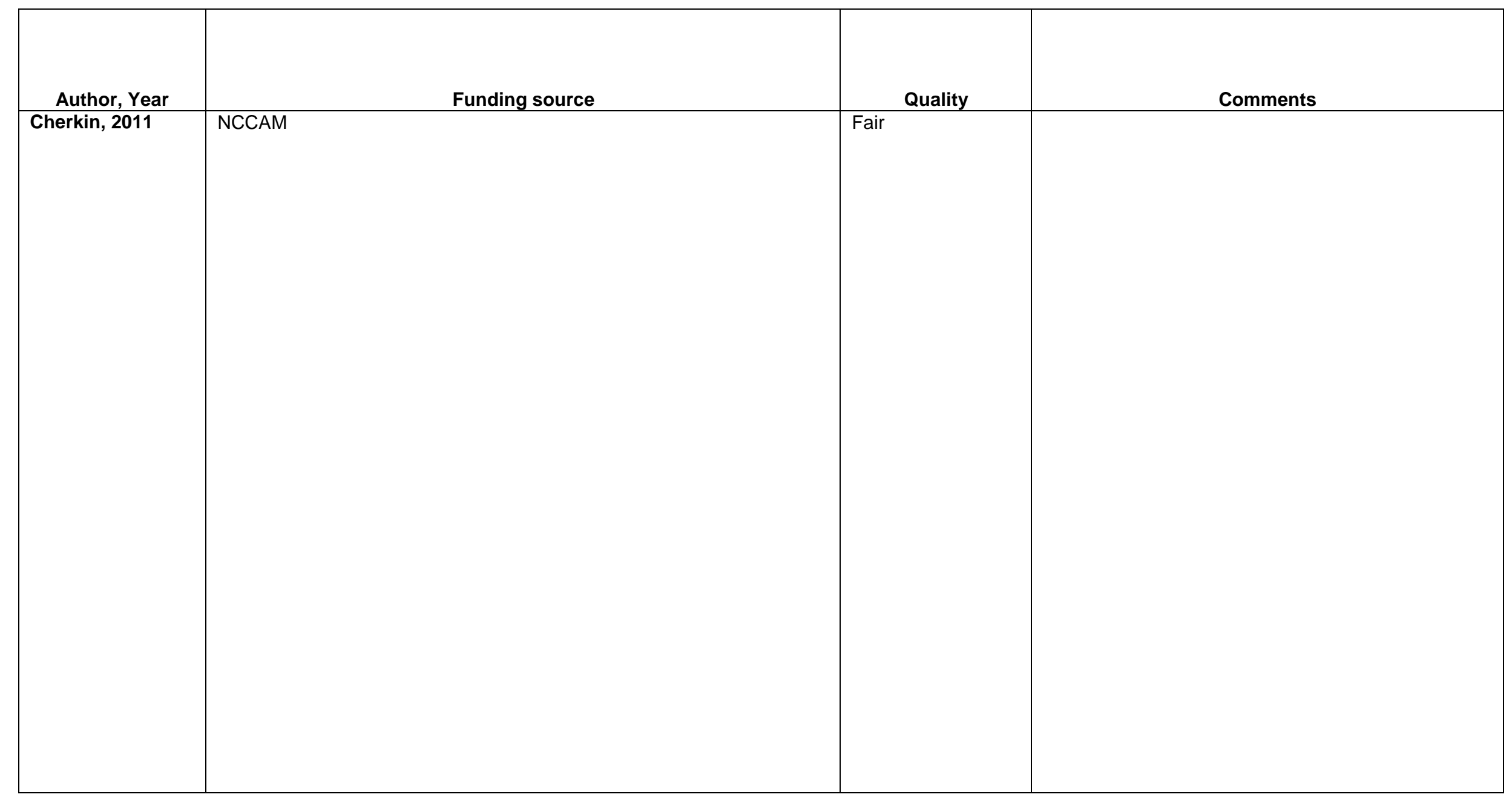




\begin{tabular}{|c|c|c|c|}
\hline Author, Year & $\begin{array}{l}\text { Country Number } \\
\text { of Centers } \\
\text { Setting }\end{array}$ & Inclusion/Exclusion Criteria & $\begin{array}{c}\text { Number Randomized, } \\
\text { Analyzed } \\
\text { Attrition }\end{array}$ \\
\hline $\begin{array}{l}\text { Cherkin, } 2016 \text { and } \\
2017 \text { and Herman, } \\
2017\end{array}$ & $\begin{array}{l}\text { US, Washington } \\
\text { Number of centers: } \\
\text { multiple } \\
\text { Clinic and } \\
\text { Outpatient }\end{array}$ & $\begin{array}{l}\text { Nonspecific low back pain persisting for }>3 \text { months, pain bothersomeness }>4 \text { on a } \\
\text { scale of } 0 \text { to } 10 \text {, and pain interference with activities } \geq 3 \text { on a scale of } 0 \text { to } 10 \\
\text { Exclude: Back pain specific diagnosis (spinal stenosis), compensation or litigation } \\
\text { issues, difficulty participating unable to speak English, unable to attend classes at the } \\
\text { scheduled time and location), or who rated pain bothersomeness }<4 \text { and/or pain } \\
\text { interference with activities } \\
<3 \text { on } 0-10 \text { scales }\end{array}$ & $\begin{array}{l}\text { Randomized: } 342 \\
\text { Treated: } 264 \text { Analyzed: } \\
341^{*} \text { Attrition: } 23 \%(78 / 342) \\
\star 1 \text { patient missing baseline data } \\
\text { excluded } \\
276 \text { participants }(81 \%) \text { at } 2 \text { year } \\
\text { followup }\end{array}$ \\
\hline
\end{tabular}




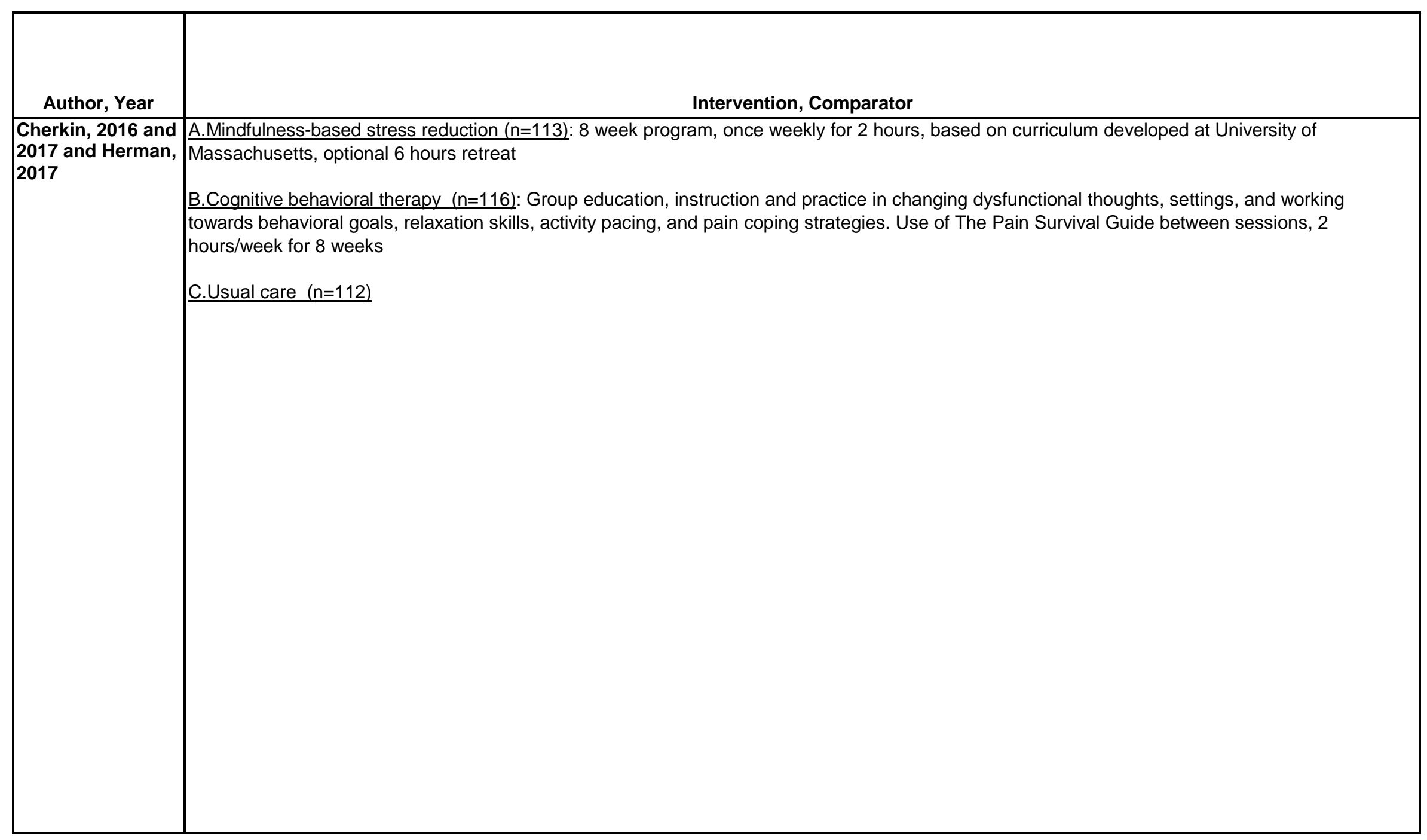




\begin{tabular}{|c|c|c|c|}
\hline Author, Year & Study Participants & Outcome Measures & $\begin{array}{l}\text { Duration of } \\
\text { Followup }\end{array}$ \\
\hline $\begin{array}{l}\text { Cherkin, } 2016 \text { and } \\
2017 \text { and Herman, } \\
2017\end{array}$ & $\begin{array}{l}\text { A vs. B vs. C } \\
\text { Age (mean): } \\
50 \text { vs. } 49 \text { vs. } 49 \text { years } \\
\text { Female: } 61 \% \text { vs. } 59 \% \text { vs. } 66 \% \\
\text { Race: } \\
\text { White: } 84 \% \text { vs. } 83 \% \text { vs. } 80 \% \\
\text { Asian: } 4 \% \text { vs. } 5 \% \text { vs. } 3 \% \\
\text { African-American: } 4 \% \text { vs. } 4 \% \text { vs. } 3 \% \\
\text { Other: } 9 \% \text { vs. } 8 \% \text { vs. } 15 \% \\
\text { Hispanic: } 4 \% \text { vs. } 9 \% \text { vs. } 7 \% \\
\text { Duration of symptoms: } 1 \text { year since one week without LBP } \\
80 \% \text { vs. } 80 \% \text { vs. } 76 \% \\
\text { Medication use for LBP in past week: } \\
\text { Any medication: } 73 \% \text { vs. } 76 \% \text { vs. } 73 \% \\
\text { Opioids: } 12 \% \text { vs. } 11 \% \text { vs. } 11 \%\end{array}$ & $\begin{array}{l}\text { Modified Roland Disability Questionnaire (RDQ) } 23 \\
\text { (versus original 24) higher scores (range 0-23) indicate } \\
\text { greater functional limitation } \\
\text { Depression (PHQ-8) range, 0-24; higher scores } \\
\text { indicate greater severity } \\
\text { Pain bothersomeness (range 0-10) } \\
\text { Patient Global Impression of Change scale, } \\
\text { improvement in pain on a 7-point scale ("completely } \\
\text { gone, much better, somewhat better, a little better, } \\
\text { about the same, a little worse, and much worse") } \\
\text { Quality of life (SF-12) 12-item Short-Form Health } \\
\text { Survey (SF-12) (0-100 scale; lower scores indicate } \\
\text { poorer health status) }\end{array}$ & $\begin{array}{l}4.5,10 \\
\text { and } 22 \\
\text { months }\end{array}$ \\
\hline
\end{tabular}




\begin{tabular}{|c|c|}
\hline Author, Year & $\begin{array}{c}\text { Results - Subquestion a } \\
\text { (vs. sham, no treatment, waitlist, attention control) }\end{array}$ \\
\hline $\begin{array}{l}\text { Cherkin, } 2016 \text { and } \\
2017 \text { and Herman, } \\
2017\end{array}$ & 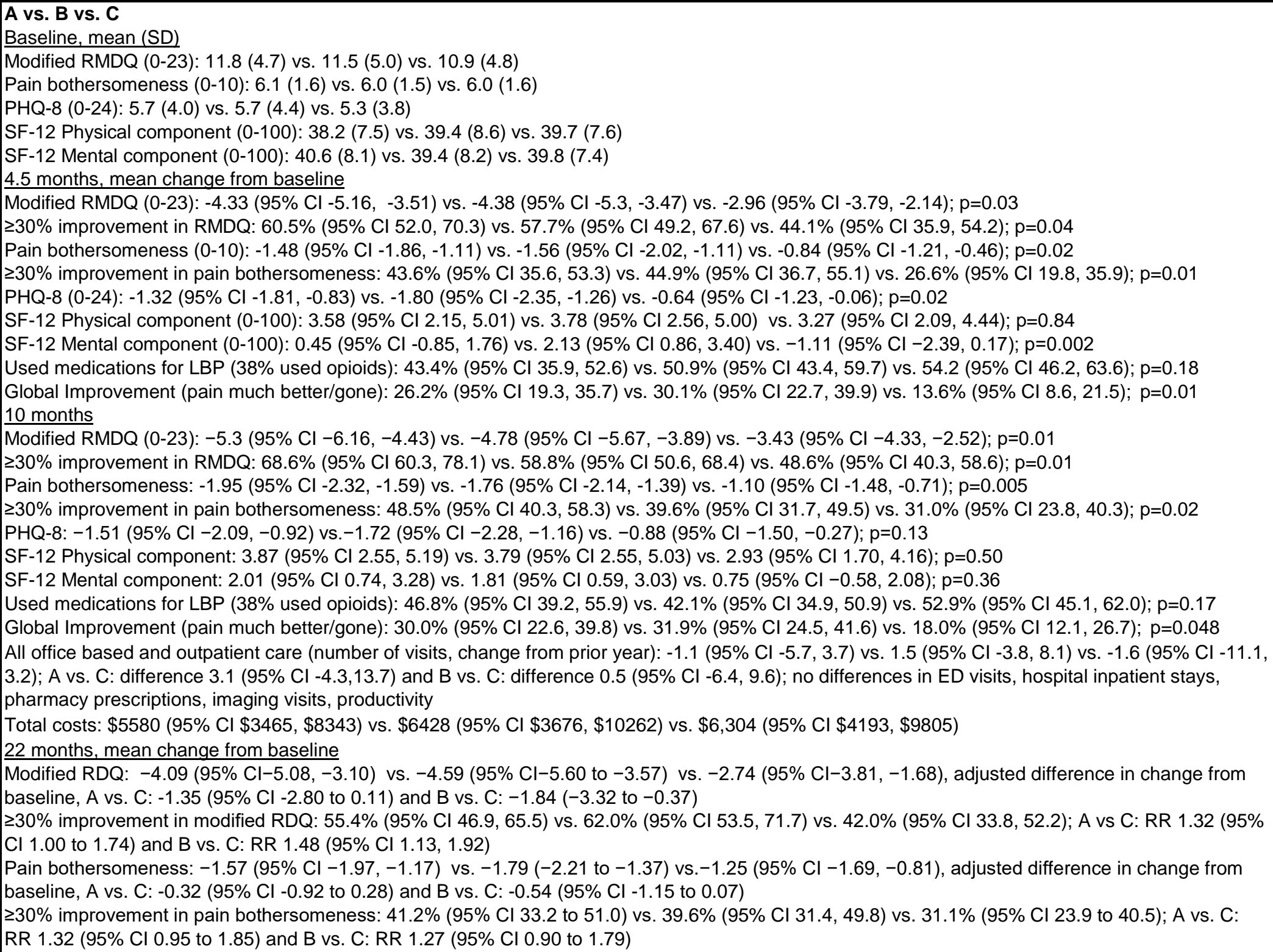 \\
\hline
\end{tabular}




\begin{tabular}{|l|l|}
\hline Author, Year & \multicolumn{2}{|c|}{$\begin{array}{c}\text { Results - Subquestion b } \\
\text { (vs. Pharmacological therapy) }\end{array}$} \\
\hline $\begin{array}{l}\text { Cherkin, 2016 and } \\
2017 \text { and Herman, } \\
2017\end{array}$ & \\
& \\
& \\
& \\
\hline
\end{tabular}




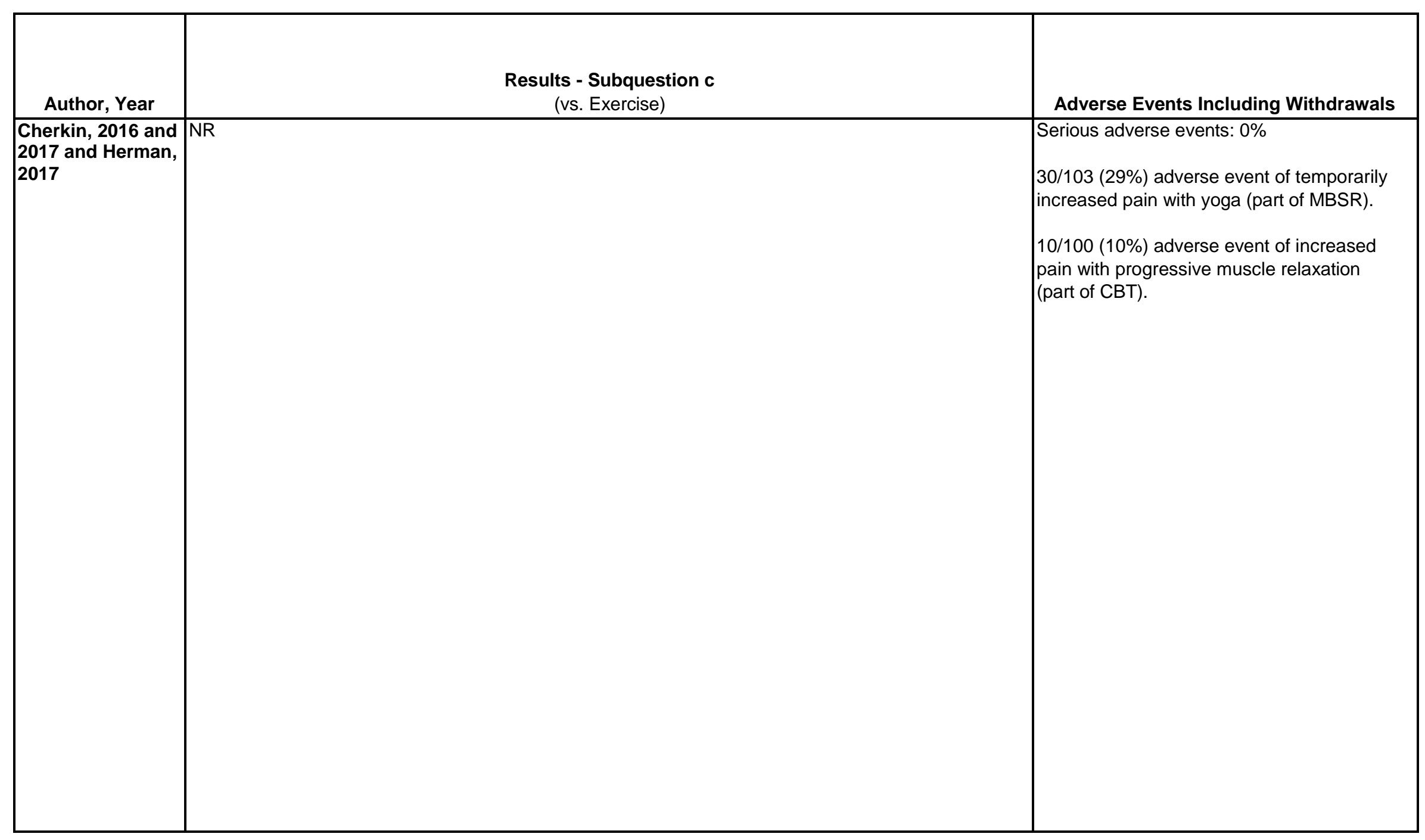




\begin{tabular}{|c|c|c|c|}
\hline Author, Year & Funding Source & Quality & Comments \\
\hline
\end{tabular}




\begin{tabular}{|c|c|c|c|}
\hline Author, Year & $\begin{array}{c}\text { Country } \\
\text { Number of Centers } \\
\text { Setting }\end{array}$ & Inclusion/Exclusion Criteria & $\begin{array}{c}\text { Number Randomized, } \\
\text { Analyzed } \\
\text { Attrition }\end{array}$ \\
\hline Chiu 2011 & $\begin{array}{l}\text { Hong Kong, } \\
\text { outpatient, single-site }\end{array}$ & $\begin{array}{l}\text { Inclusion Criteria: } \\
\text { Between ages of } 18 \text { to } 70 \text { years old, with history of neck pain }>3 \\
\text { months, can read Chinese. } \\
\text { Exclusion criteria: } \\
\text { history of injury to neck or upper back from T1 to T6, inflammatory } \\
\text { conditions (e.g. rheumatoid arthritis), previous surgery to the neck, } \\
\text { history of malignancy, congenital abnormality of the spine, other } \\
\text { concurrent musculoskeletal problems, receiving concurrent treatment } \\
\text { (e.g. physiotherapy manipulation, chiropractor or bone setter) or } \\
\text { received training because of the neck pain in prior } 3 \text { months. }\end{array}$ & $\begin{array}{l}\text { Randomized: } 79 \\
\text { Treated: } 45 \\
\text { Analyzed: } 79(\text { ITT) } \\
\text { Attrition: } 49.3 \%(39 / 79)\end{array}$ \\
\hline Cho 2013 & $\begin{array}{l}\text { Korea } \\
\text { Number of centers: } 3 \\
\text { Setting: Hospital }\end{array}$ & $\begin{array}{l}\text { Age 18-65 years } \\
\text { Chronic LBP for at least the last } 3 \text { months } \\
\text { VAS for bothersomeness of LBP } \geq 5 \\
\text { Nonspecific, uncomplicated LBP with intact neurological examination } \\
\text { Exclude: } \\
\text { Sciatic pain } \\
\text { Pain mainly below the knee } \\
\text { Serious spinal disorders, including malignancy, vertebral fracture, } \\
\text { spinal infection, inflammatory spondylitis and cauda equina } \\
\text { compression } \\
\text { History of previous spinal surgery } \\
\text { Scheduled surgery for a chronic disease that could interfere with } \\
\text { treatment effects (e.g., cardiovascular disease, diabetic neuropathy, } \\
\text { fibromyalgia, rheumatoid arthritis, dementia, and epilepsy) } \\
\text { Acupuncture treatment of LBP in the previous month } \\
\text { Conditions that could compromise the safety of acupuncture (e.g., } \\
\text { clotting disorders, taking anticoagulant agent, pregnancy, and seizure } \\
\text { disorders) } \\
\text { Severe psychiatric or psychological disorder } \\
\text { History of use of corticosteroids, narcotics, muscle relaxants, or herbal } \\
\text { medicine to treat LBP. }\end{array}$ & $\begin{array}{l}\text { Randomized: } 130 \\
\text { Treated: } 57 \\
\text { Analyzed: } 116 \\
\text { Attrition: } 11 \%(14 / 130)\end{array}$ \\
\hline
\end{tabular}




\begin{tabular}{|c|c|}
\hline Author, Year & Intervention, Comparator \\
\hline Chiu 2011 & $\begin{array}{l}\text { A.Intermittent Cervical Traction (ICT) }(\mathrm{n}=39) \\
\text { No. sessions: Twice/week for } 6 \text { wks } \\
\text { Length of sessions: } 20 \text { min } \\
\text { Segments targeted: } \\
\text { Description of technique: Received ICT using Tru-Trac series 92B machine under supervision of exp. physiotherapist. } \\
\text { Parameters: traction poundage ranging from 10-20\% of patient body weight, holding time } 10-25 \text { seconds; resting time } 20-50 \% \text { of holding; resting } \\
\text { poundage } 20-40 \% \text { of traction poundage. traction indvidualized within these ranges at physiotherapist' discretion } \\
\text { B.Infrared Irradiation Control }(\mathrm{n}=34) \\
\text { No. sessions: Twice/week for } 6 \text { wks } \\
\text { Length of sessions: } 20 \text { min } \\
\text { Description: Received only infrared irradiation as a placebo heat treatment. Posterior aspect of patients' neck were exposed in a sitting position, and } \\
\text { head was well supported by pillows. Center of infra-red lemp was placed directly above the spinous process of C4. Positioned so that patients } \\
\text { reported just minimal warmth over the back of their neck. }\end{array}$ \\
\hline Cho 2013 & $\begin{array}{l}\text { A. Needle acupuncture }(\mathrm{n}=57) \text { : } 12 \text { sessions, approximately } 2 \text { per week for } 6 \text { weeks, of individualized acupuncture treatment. Acupuncture points } \\
\text { according to the } 3 \text { types of meridian patterns: gallbladder, bladder, or mixed meridian pattern. Other acupuncture points could be used according to } \\
\text { the diagnosis. Needles were sterile, disposable stainless steel, } 40 \times 0.25 \mathrm{~mm} \text {, with the same tube used for the sham acupuncture device. Needles } \\
\text { were inserted perpendicular to a depth of } 5-20 \mathrm{~mm} \text {, followed by manual stimulation by bidirectional rotation to induce Deqi sensation, then left in } \\
\text { place for } 15-20 \text { minutes. } \\
\text { B: Sham acupuncture }(n=59): 12 \text { sessions, approximately } 2 \text { per week for } 6 \text { weeks, of sham acupuncture treatment, using nonpenetrating semi-blunt } \\
\text { sham needles. } 8 \text { predefined points at the lower back unrelated to traditional acupuncture points were used. } \\
\text { All: No additional therapy, such as analgesics or physical treatments were allowed. Acupuncturists had } \geq 3 \text { years experience with specialization in } \\
\text { Korean Rehabilitation Medicine. At the 1st visit, participants were given an exercise manual for patients with LBP and instructed about appropriate } \\
\text { posture and exercises; patients were requested to do exercises every day and maintain correct posture. }\end{array}$ \\
\hline
\end{tabular}




\begin{tabular}{|c|c|c|c|}
\hline Author, Year & Study Participants & Outcome Measures & $\begin{array}{l}\text { Duration of } \\
\text { Followup }\end{array}$ \\
\hline Chiu 2011 & $\begin{array}{l}\text { A vs. } B^{\star} \\
\text { Age (SD): } 50.9(10.5) \text { vs. } 46.8(10.4) \\
\text { Female: } 65.2 \% \text { vs. } 76.5 \% \\
\text { Race: NR } \\
\text { Mean duration of chronicity, years: NR } \\
\text { NPQ Disability (0-100): } 46.1(14.5) \text { vs. } 38.5(8.0) ; \text { ns } \\
\text { NPS Pain Severity(0-10): } 5.8(1.9) \text { vs. } 5.2(2.0) ; \text { ns } \\
\\
\text { *Baseline data only provided for } 23 / 39 \text { intervention participants and } \\
\text { 17/40 control patients. }\end{array}$ & $\begin{array}{l}\text { Northwick Park Neck Pain Questionnaire (NPQ, range 0- } \\
\text { 100: higher scores indicate greater disability) } \\
\text { verbal Numerical Pain Scale Pain Severity (NPS, range } \\
\text { 0-10: higher scores indicate severity of pain) }\end{array}$ & $\begin{array}{l}\text { intermediate } \\
\text { post- } \\
\text { intervention, } \\
1.5 \text { months }\end{array}$ \\
\hline Cho 2013 & \begin{tabular}{|l} 
A vs. B \\
Age: 42 vs. 42 \\
Female: $83 \%$ vs. $86 \%$ \\
Baseline pain (0-10 VAS): 6.5 vs. 6.4 \\
Baseline Korean ODI: 28.2 vs. 24.2 \\
Baseline SF-36: 107.7 vs. 110.4 \\
Baseline BDI: 11.3 vs. 11.8
\end{tabular} & $\begin{array}{l}\text { Symptom bothersomeness (0-10 VAS, higher=more } \\
\text { bothersome) } \\
\text { Pain intensity (0-10 VAS) } \\
\text { ODI, Korean version, excludes the sex life item (scale } \\
\text { unclear) } \\
\text { SF-36 total, Korean version (scale unclear) } \\
\text { Beck Depression Inventory, Korean version (0-63) }\end{array}$ & $\begin{array}{l}1.5 \text { and } 4 \\
\text { months }\end{array}$ \\
\hline
\end{tabular}




\begin{tabular}{|c|c|}
\hline Author, Year & $\begin{array}{c}\text { Results - Subquestion a } \\
\text { (vs. sham, no treatment, waitlist, attention control) }\end{array}$ \\
\hline Chiu 2011 & $\begin{array}{l}\text { A vs B } \\
1.5 \text { months } \\
\text { NPQ Disability: } 31.4(12.7) \text { vs. } 29.6(15.5) ; p>0.05,95 \% \mathrm{Cl}, 29.66-37.50, \text { power }=0.15 \text { * } \\
\text { NPS Pain Severity: } 3.5(2.6) \text { vs. } 2.8(2.0) ; p>0.05,95 \% \mathrm{Cl}, 3.29-4.50, \text { power }=0.17^{*} \\
\text { ^Results of two-way repeated measures ANOVA }\end{array}$ \\
\hline Cho 2013 & 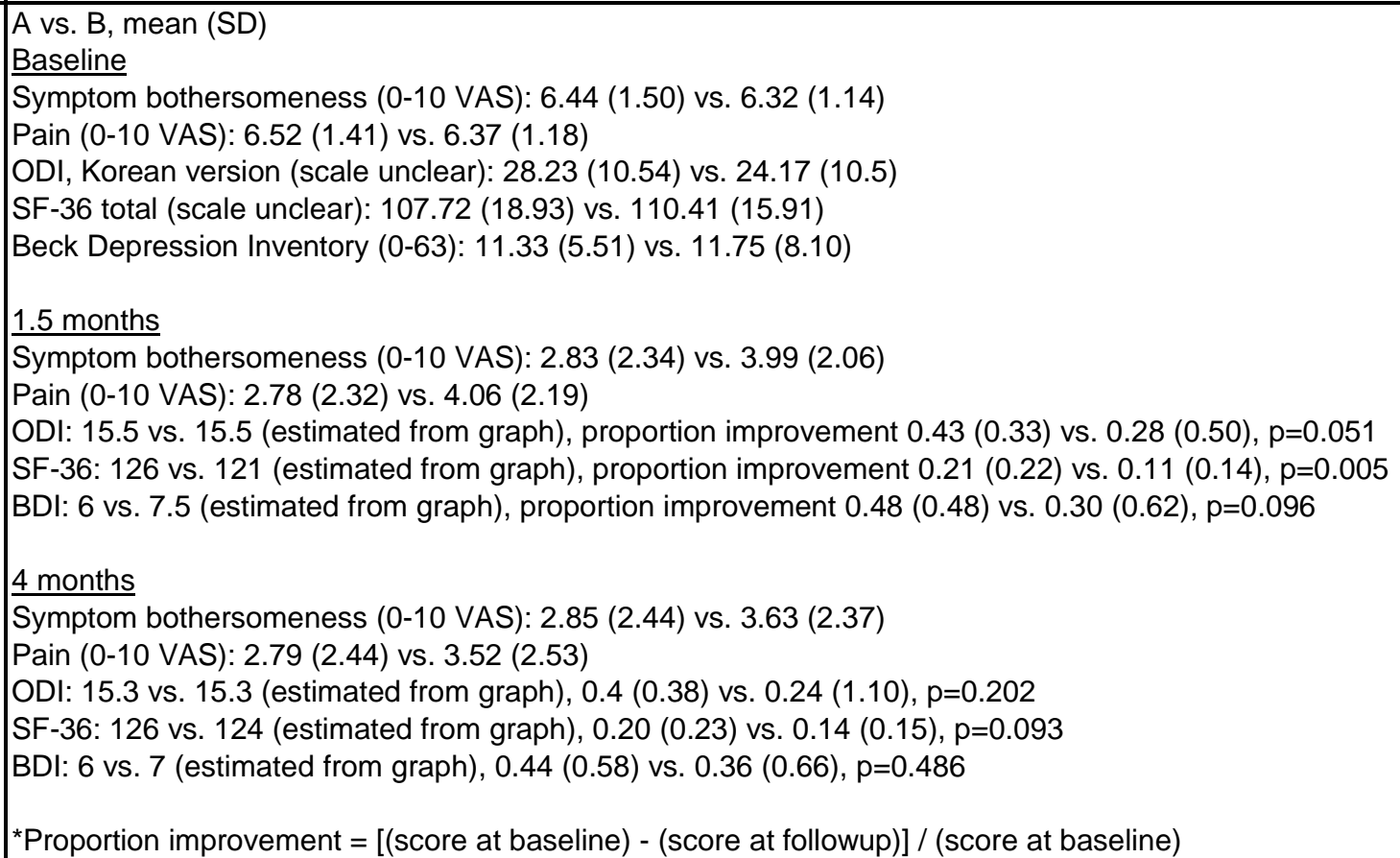 \\
\hline
\end{tabular}




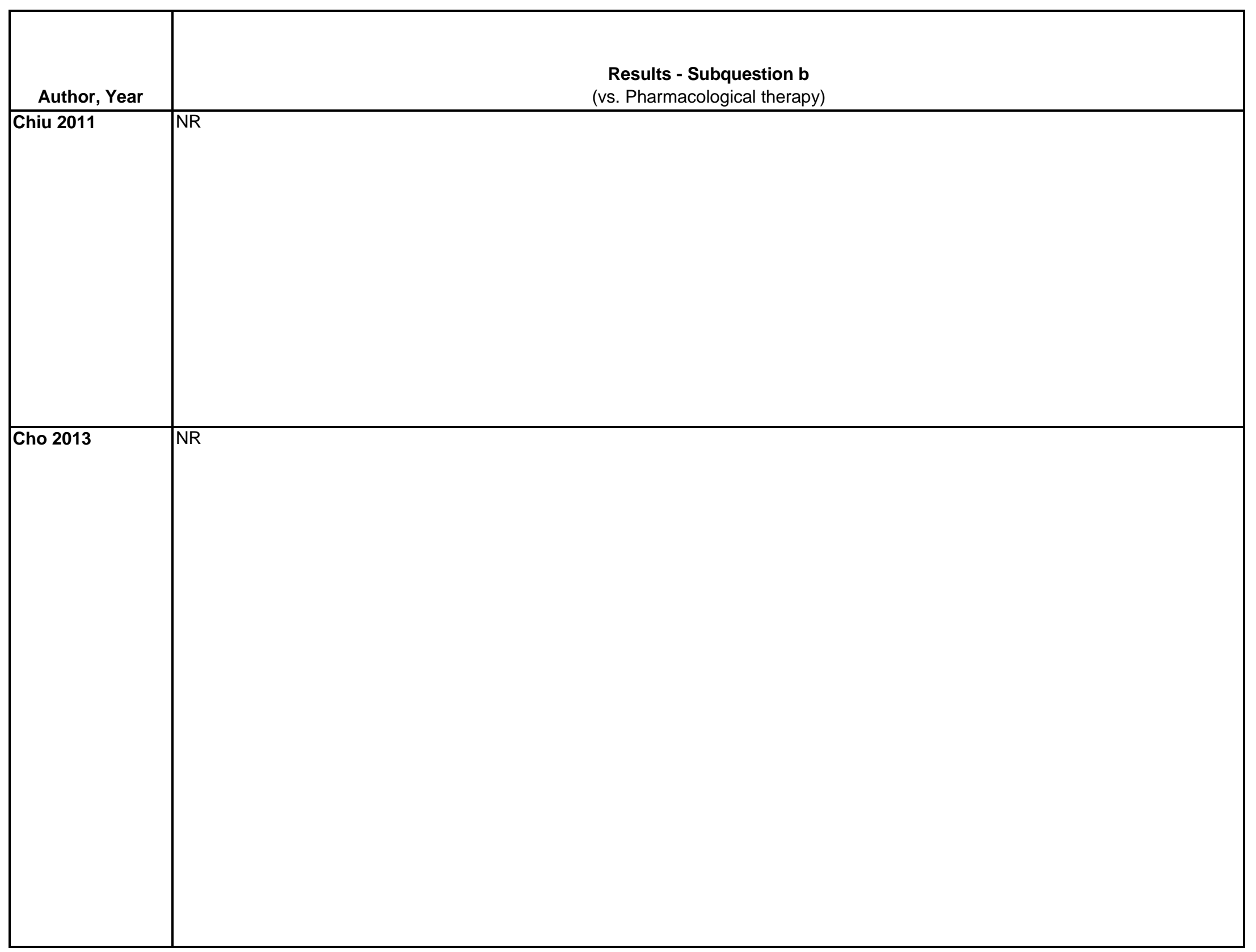

D-257 


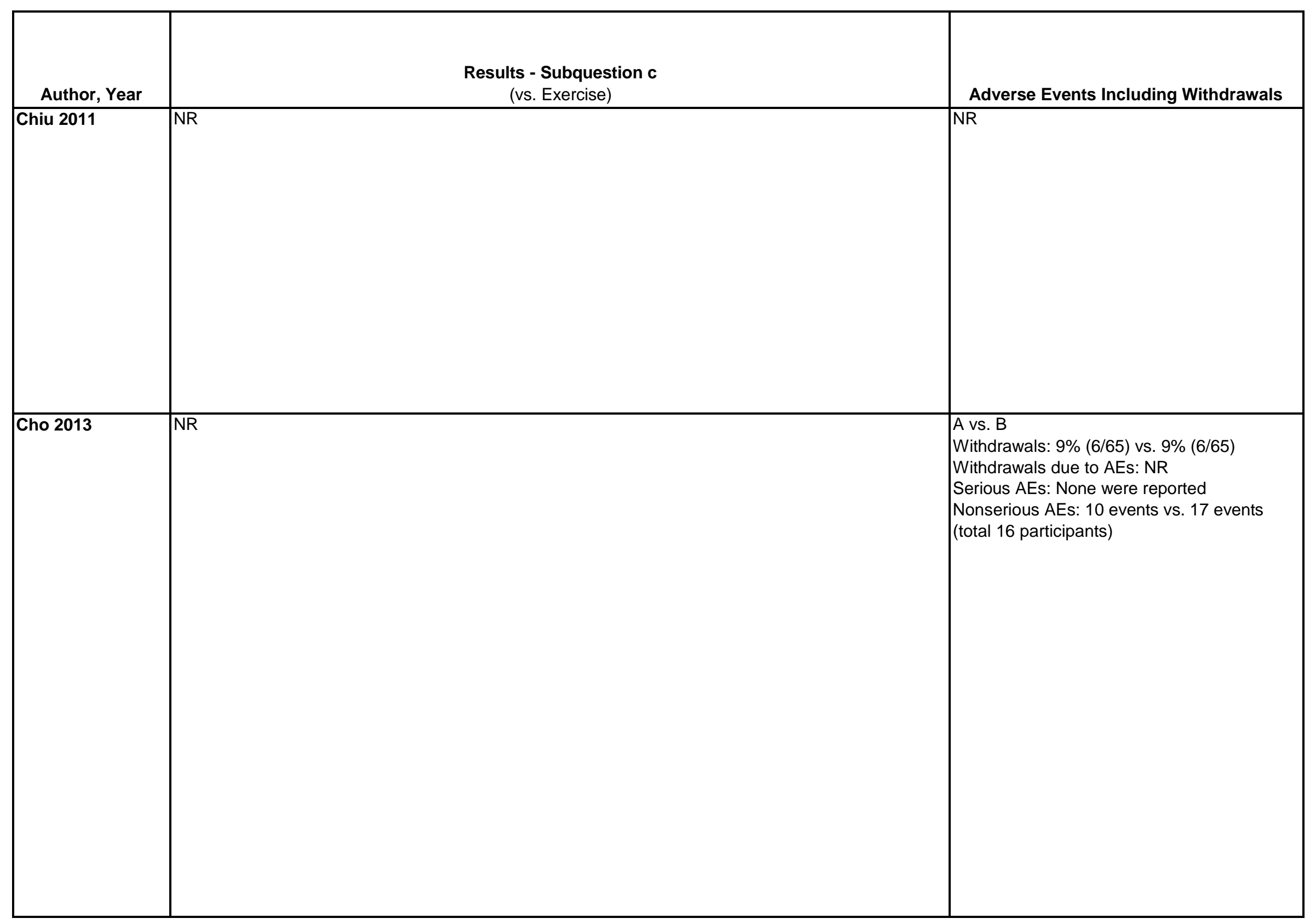




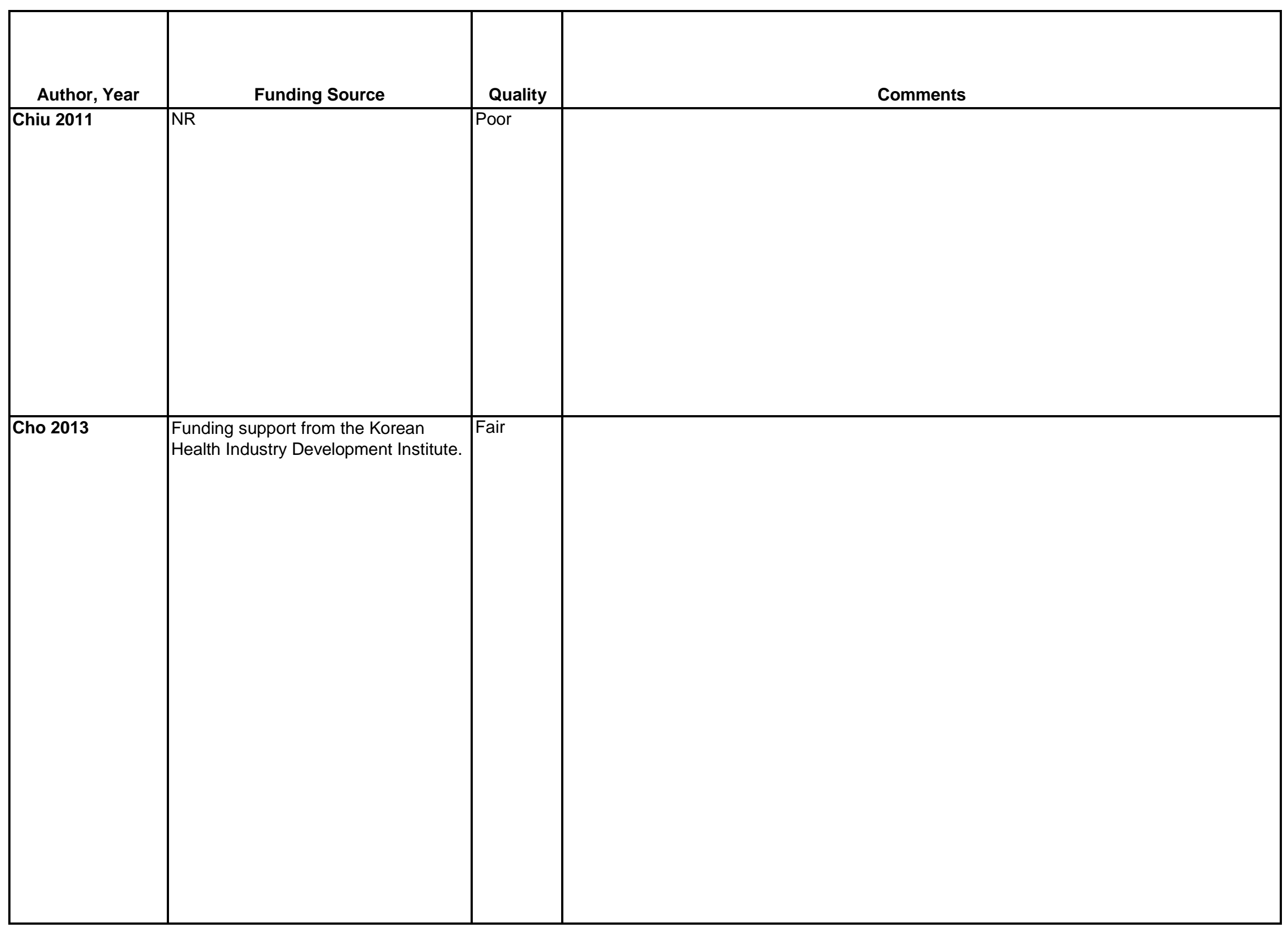

D-259 


\begin{tabular}{|c|c|c|c|}
\hline Author, Year & $\begin{array}{c}\text { Country } \\
\text { Number of Centers } \\
\text { Setting }\end{array}$ & Inclusion/Exclusion Criteria & $\begin{array}{c}\text { Number Randomized, } \\
\text { Analyzed } \\
\text { Attrition }\end{array}$ \\
\hline Cho 2014 & $\begin{array}{l}\text { Korea } \\
\text { Single hospital }\end{array}$ & $\begin{array}{l}\text { Men or women aged } 25-55 \text { years; neck pain or stiffness lasting for } \geq 3 \\
\text { months; (3) a score of } \geq 5 \text { on the visual analogue scale (VAS) at } \\
\text { baseline. } \\
\text { Excluded: } \\
\text { Received acupuncture or NSAID for neck pain within the past } 3 \\
\text { months; serious medical disease or cancer; history of spinal trauma, } \\
\text { had undergone surgery on the neck or had systematic neurological or } \\
\text { other skeletal disorders; pregnant or breast feeding. }\end{array}$ & $\begin{array}{l}\text { Randomized: } 45 \\
\text { Treated: } 45 \\
\text { Analyzed: } 38 \\
\text { Attrition: } 16 \%(7 / 45)\end{array}$ \\
\hline Chow 2006 & $\begin{array}{l}\text { Australia } \\
\text { Large single } \\
\text { suburban medical } \\
\text { center of } 17 \text { general } \\
\text { practitioners }\end{array}$ & $\begin{array}{l}\text { 218 years of age; chronic neck pain of more than } 3 \text { months duration; } \\
\text { able to attend a full course of } 14 \text { treatments given twice a week; able } \\
\text { to understand the nature of the trial and were naive to treatment with } \\
\text { LLLT (except laser acupuncture). } \\
\text { Exclusion: } \\
\text { Current litigation or compensation; neurological signs in the upper } \\
\text { limbs relating to nerve entrapment or impingement from the cervical } \\
\text { spine; unable to discontinue temporarily any activity which } \\
\text { exacerbated the pain; pregnancy; prior cervical spine surgery; } \\
\text { systemic rheumatic disease; neck pain which was part of a } \\
\text { widespread pain syndrome involving other areas; photosensitivity or } \\
\text { had other illnesses precluding involvement for practical reasons. }\end{array}$ & $\begin{array}{l}\text { Randomized: } 90 \\
\text { Treated: } 84 \\
\text { Analyzed:: } 84 \\
\text { Attrition: } 7 \% \\
(6 / 90)\end{array}$ \\
\hline
\end{tabular}




\begin{tabular}{|c|c|}
\hline Author, Year & Intervention, Comparator \\
\hline Cho 2014 & $\begin{array}{l}\text { A.Acupuncture and NSAIDs group ( } \mathrm{n}=15) \text {, acupuncture 3x/week and zaltoprofen (80mg) 3x/day } \\
\text { B.Acupuncture alone ( } \mathrm{n}=15) \text {, bilateral cervical points SI9, SI10, SI11, SI12, SI14, BL11, BL12, TE14, TE15, TE16, TE17 and GB21; and extremity } \\
\text { points SI3, SI4 and BL65 3x/week for } 3 \text { weeks. } \\
\text { C.Zaltoprofen (80mg) alone }(\mathrm{n}=15), 3 \times / \text { day for } 3 \text { weeks. }\end{array}$ \\
\hline Chow 2006 & $\begin{array}{l}\text { A.Active GaAlAs laser therapy }(\mathrm{n}=45) \text {, (wavelength of } 830 \mathrm{~nm} \text { and power of } 300 \mathrm{~mW} \text { in continuous wave mode at a Power Density (PD) of } 0.67 \\
\text { W/cm2) } 2 x / \text { week for } 7 \text { consecutive weeks, maximum half hour per treatment. Up to } 50 \text { tender points in the neck were treated for } 30 \text { seconds per } \\
\text { point. } \\
\text { B.Sham laser }(\mathrm{n}=45)\end{array}$ \\
\hline
\end{tabular}




\begin{tabular}{|c|c|c|c|}
\hline Author, Year & Study Participants & Outcome Measures & $\begin{array}{c}\text { Duration of } \\
\text { Followup }\end{array}$ \\
\hline Cho 2014 & $\begin{array}{l}\text { A vs B vs C } \\
\text { Age: } 39 \text { vs } 38 \text { vs } 39 \text { years } \\
\text { Female: } 53 \text { vs } 60 \text { vs } 80 \\
\text { Pain: } 6.7(0.7) \text { vs } 6.1(0.5) \text { vs } 7.1(1.3) \\
\text { NDI: } 23.2(5.9) \text { vs } 22.3(4.0) \text { vs } 26.3(5.0) \\
\text { SF-36: } 85.2(1.2) \text { vs } 86.2(2.0) \text { vs } 84.2(1.7) \\
\text { BDI: } 28.7(4.8) \text { vs } 30.7(5.6) \text { vs } 33.1(7.8) \\
\text { EQ-5D: } 7.4(1.7) \text { vs } 7.4(1.5) \text { vs } 7.5(1.3)\end{array}$ & $\begin{array}{l}\text { Pain intensity week prior to assessment (scale, 0-10, } \\
\text { higher score=greater pain) } \\
\text { NDI: (scale 0-50, higher score greater disability) } \\
\text { Beck Depression Inventory (scale 0-63, higher score, } \\
\text { more severe the depression) } \\
\text { Short-Form } 36 \text { (SF-36) (scale 0-100, higher } \\
\text { score=better QoL) } \\
\text { EQ-5D (scale 0-1, lower score, greater disability) }\end{array}$ & 1 month \\
\hline Chow 2006 & \begin{tabular}{|l} 
A vs B \\
Age: 57 vs 55 years \\
Female: $64 \%$ vs $67 \%$ \\
Pain duration: 17 vs 13 years \\
Pain $(0-10): 5.9$ vs 4.0
\end{tabular} & $\begin{array}{l}\text { Pain intensity (VAS 0-10, higher score worse pain) } \\
\text { Northwick Park Neck pain Questionnaire (NPNQ) } \\
\text { (scale: 0-100\%, higher percentage the greater the } \\
\text { disability) } \\
\text { Neck Pain and Disability Scale (NPAD) (scale: 0-100, } \\
\text { higher score = greater disability) } \\
\text { McGill Pain Questionnaire (MPQ) (scale: 0-33 sensory, } \\
\text { 0-12 affective, @1-5 present pain intensity; higher score } \\
=\text { greater pain) } \\
\text { Short-Form } 36 \text { (SF-36) (scale 0-100, higher } \\
\text { score=better QoL) }\end{array}$ & 1 month \\
\hline
\end{tabular}




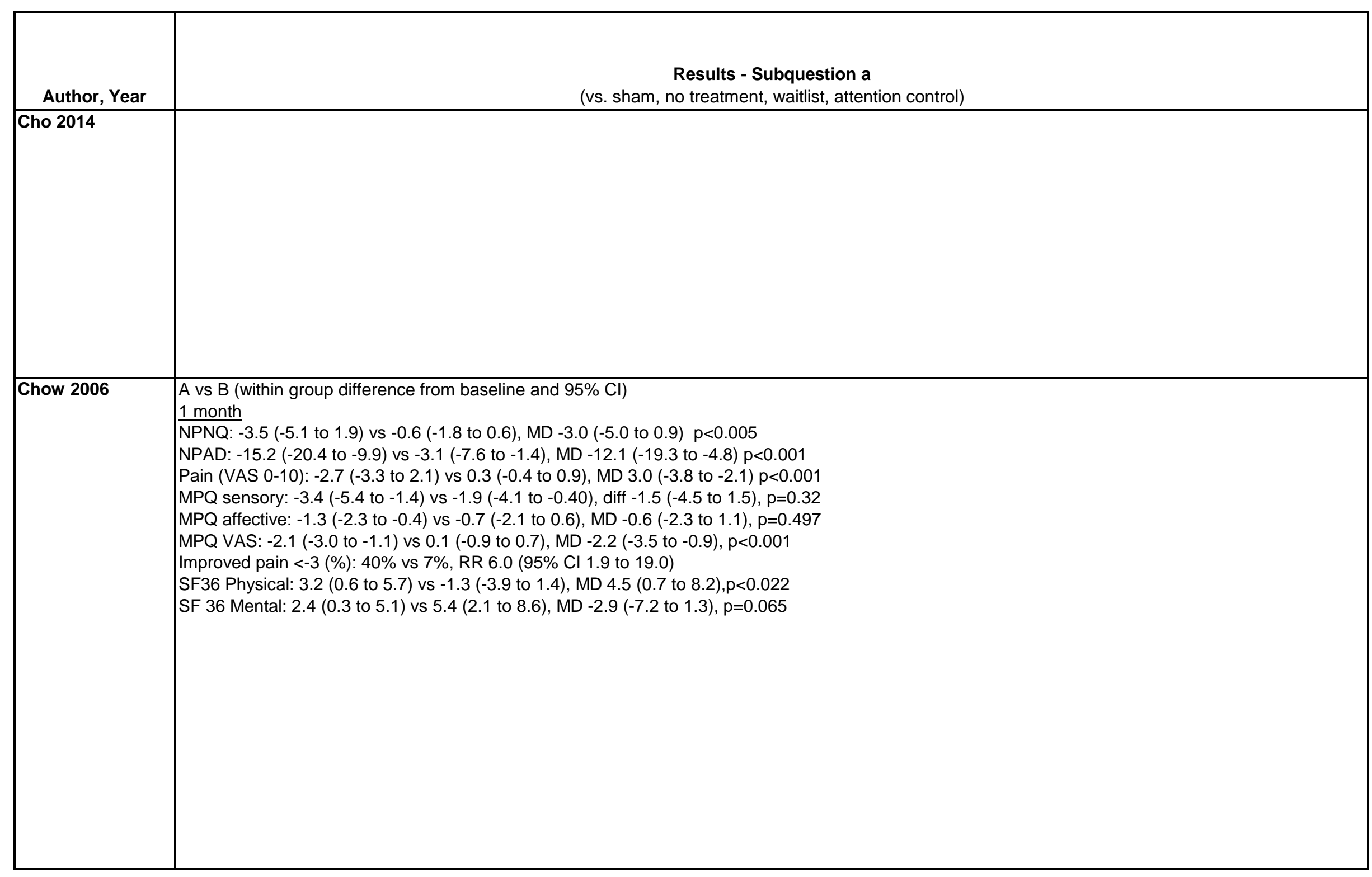




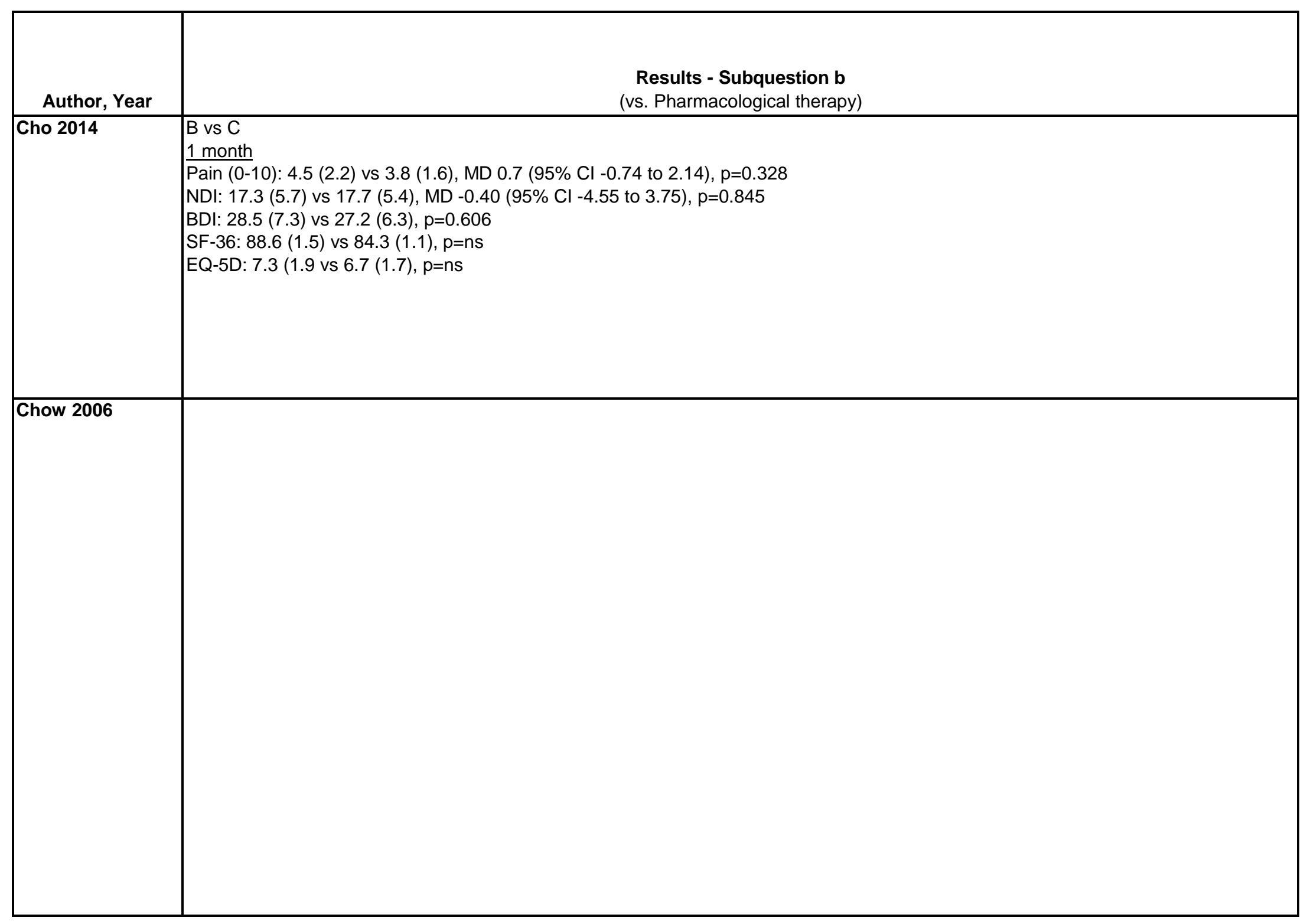




\begin{tabular}{|c|c|c|}
\hline Author, Year & $\begin{array}{l}\text { Results - Subquestion c } \\
\text { (vs. Exercise) }\end{array}$ & Adverse Events Including Withdrawals \\
\hline Cho 2014 & & NR \\
\hline Chow 2006 & & $\begin{array}{l}\text { A vs } B \text { (number of patients) } \\
\text { Mildly increased pain: } 35,29, \mathrm{p}=0.16 \\
\text { Moderately increased pain: } 27,23, \mathrm{p}=0.40 \\
\text { Severely increased pain: } 14,12, \mathrm{p}=0.64 \\
\text { Increased pain elsewher: } 35,28, \mathrm{p}=0.11 \\
\text { Mild headache: } 27,24, \mathrm{p}=0.5 \\
\text { Moderately increased headache: } 18,13, \\
\mathrm{p}=0.27 \\
\text { Severe headache: } 10,10, \mathrm{p}=1.0 \\
\text { Nausea: } 9,19, \mathrm{p}=0.02^{\star} \\
\text { Light-headed/dizzy: } 16,20, \mathrm{p}=0.39 \\
\text { Tingling in extremity: } 6,6, \mathrm{p}=0.56 \\
\text { "Spaced-out" feeling: } 14,10, \mathrm{p}=0.34 \\
\text { Sleepiness: } 18,19, \mathrm{p}=0.83 \\
\text { Tiredness: } 24,21, \mathrm{p}=0.53 \\
\text { Skin sensitivity: } 6,4, \mathrm{p}=0.50 \\
\text { Jaw pain: } 3,2, \mathrm{p}=0.65 \\
\text { Intercurrent infection: } 11,8, \mathrm{p}=0.44 \\
\text { Stiffness: } 9,2, \mathrm{p}=0.02^{\star} \\
\text { Depression: } 2,3, \mathrm{p}=0.65\end{array}$ \\
\hline
\end{tabular}




\begin{tabular}{|l|l|l|l|}
\hline \multicolumn{1}{|c|}{ Author, Year } & \multicolumn{1}{|c|}{ Funding Source } & Quality & \multicolumn{1}{c|}{ Comments } \\
\hline Cho 2014 & $\begin{array}{l}\text { Program of the Kyung } \\
\text { Hee University for young medical } \\
\text { researcher in 2009 } \\
\text { (KHU-20100763). }\end{array}$ & Poor & Missing values imputed via Stochastic Regression \\
\hline Chow 2006 & NR & Good & Last observation carried forward for analysis \\
& & & \\
\end{tabular}




\begin{tabular}{|c|c|c|c|}
\hline Author, Year & $\begin{array}{c}\text { Country } \\
\text { Number of Centers } \\
\text { Setting }\end{array}$ & Inclusion/Exclusion Criteria & $\begin{array}{c}\text { Number Randomized, } \\
\text { Analyzed } \\
\text { Attrition }\end{array}$ \\
\hline $\begin{array}{l}\text { Clarke-Jenssen } \\
2014\end{array}$ & $\begin{array}{l}\text { Norway } \\
1 \text { outpatient } \\
\text { Rheumatology clinic }\end{array}$ & $\begin{array}{l}\text { Inclusion: } \\
\text { ACR } 1990 \text { criteria for FM, age } 18-60 \text { years, independent in activities of } \\
\text { daily living, capable of participating in light exercise group on land and } \\
\text { in warm water, understand written and oral Norwegian } \\
\text { Exclusion: } \\
\text { Serious physical or psychiatric diagnosis, alcohol or drug abuse, } \\
\text { pregnant or breast-feeding, receiving more than } 50 \% \text { disability } \\
\text { pension }\end{array}$ & $\begin{array}{l}\text { Randomized: } 129 \\
\text { Analyzed: } 129 \\
\text { Attrition: } 9 \%(12 / 129) \\
\end{array}$ \\
\hline
\end{tabular}




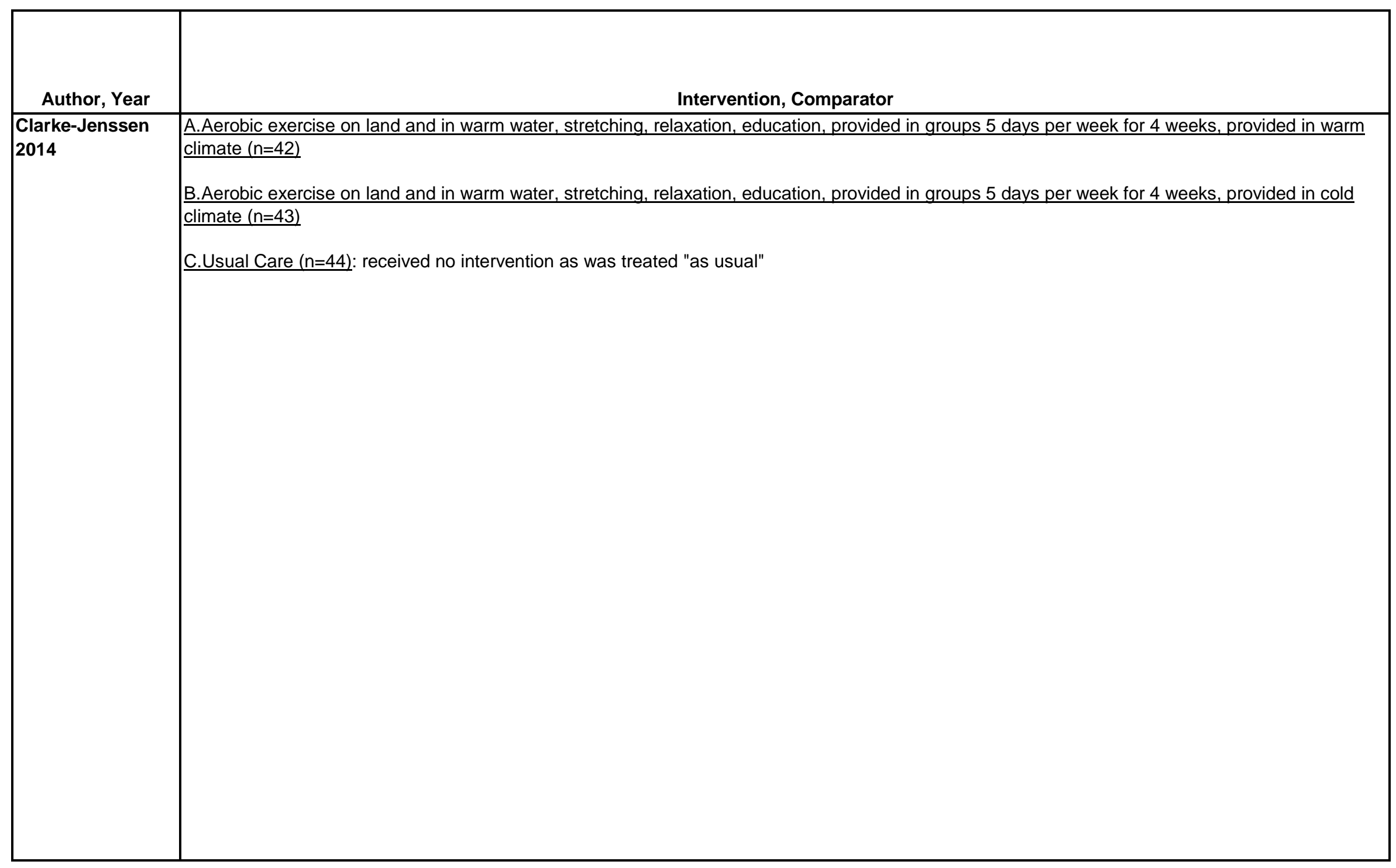




\begin{tabular}{|c|c|c|c|}
\hline Author, Year & Study Participants & Outcome Measures & $\begin{array}{l}\text { Duration of } \\
\text { Followup }\end{array}$ \\
\hline $\begin{array}{l}\text { Clarke-Jenssen } \\
2014\end{array}$ & 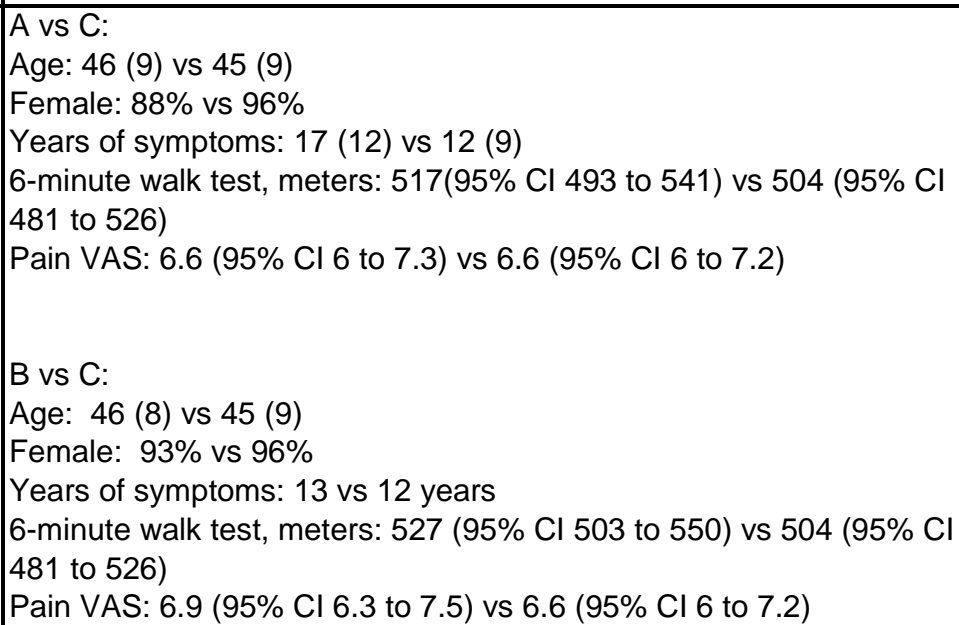 & $\begin{array}{l}\text { Fibromyalgia Impact Questionnaire (FIQ; 0-100, higher } \\
\text { scores = greater impact of FM on daily life) } \\
\text { Pain VAS (0-10, higher scores=higher pain) } \\
\text { Hospital Anxiety and Depression Scale (HADS; 0-21, } \\
\text { higher scores=greater anxiety and depression) } \\
\text { SF-36 Physical (0-100, higher scores=better qualify of } \\
\text { life) } \\
\text { SF-36 Mental (0-100; higher scores=better quality of } \\
\text { life) }\end{array}$ & $\begin{array}{l}3 \text { and } 12 \\
\text { months }\end{array}$ \\
\hline
\end{tabular}




\begin{tabular}{|c|c|}
\hline Author, Year & $\begin{array}{l}\text { Results - Subquestion a } \\
\text { (vs. sham, no treatment, waitlist, attention control) }\end{array}$ \\
\hline $\begin{array}{l}\text { Clarke-Jenssen } \\
2014\end{array}$ & $\begin{array}{l}\text { A vs C: } \\
\text { 3 months, between-group difference in change from baseline: } \\
\text { FIQ: not significant } \\
\text { Pain VAS: }-1.2 \text { ( } 95 \% \text { Cl }-2.2 \text { to }-0.1), p=0.02 \\
\text { HADS: not significant } \\
\text { SF-36 Physical: not significant } \\
\text { SF-36 Mental: not significant } \\
12 \text { months, between-group difference in change from baseline: } \\
\text { FIQ: not significant } \\
\text { Pain VAS: } 0.1 \text { ( } 95 \% \text { CI }-0.9 \text { to } 1.1), p=0.45 \\
\text { HADS: not significant } \\
\text { SF-36 Physical: not significant } \\
\text { SF-36 Mental: not significant } \\
\text { B vs C: } \\
3 \text { months, between-group difference in change from baseline: } \\
\text { FIQ: not significant } \\
\text { Pain VAS: }-0.9 \text { ( } 95 \% \text { Cl }-1.9 \text { to } 0.2), p=0.12 \\
\text { HADS: not significant } \\
\text { SF-36 Physical: not significant } \\
\text { SF-36 Mental: not significant } \\
12 \text { months, between-group difference in change from baseline: } \\
\text { FlQ: not significant } \\
\text { Pain VAS: } 0 \text { (95\% Cl }-1 \text { to } 1), p=0.99 \\
\text { HADS: not significant } \\
\text { SF-36 Physical: not significant } \\
\text { SF-36 Mental: not significant }\end{array}$ \\
\hline
\end{tabular}




$$
4=
$$




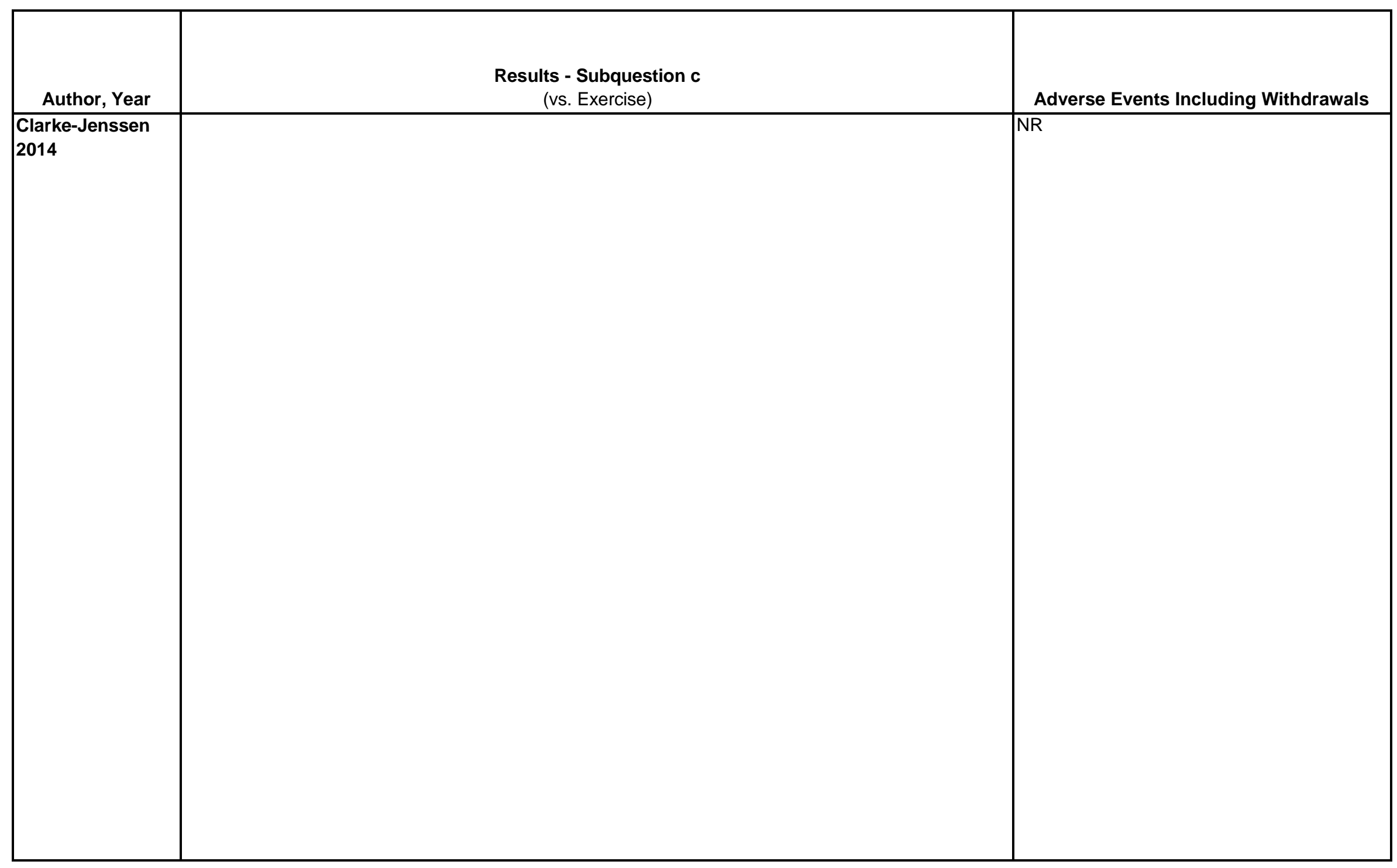




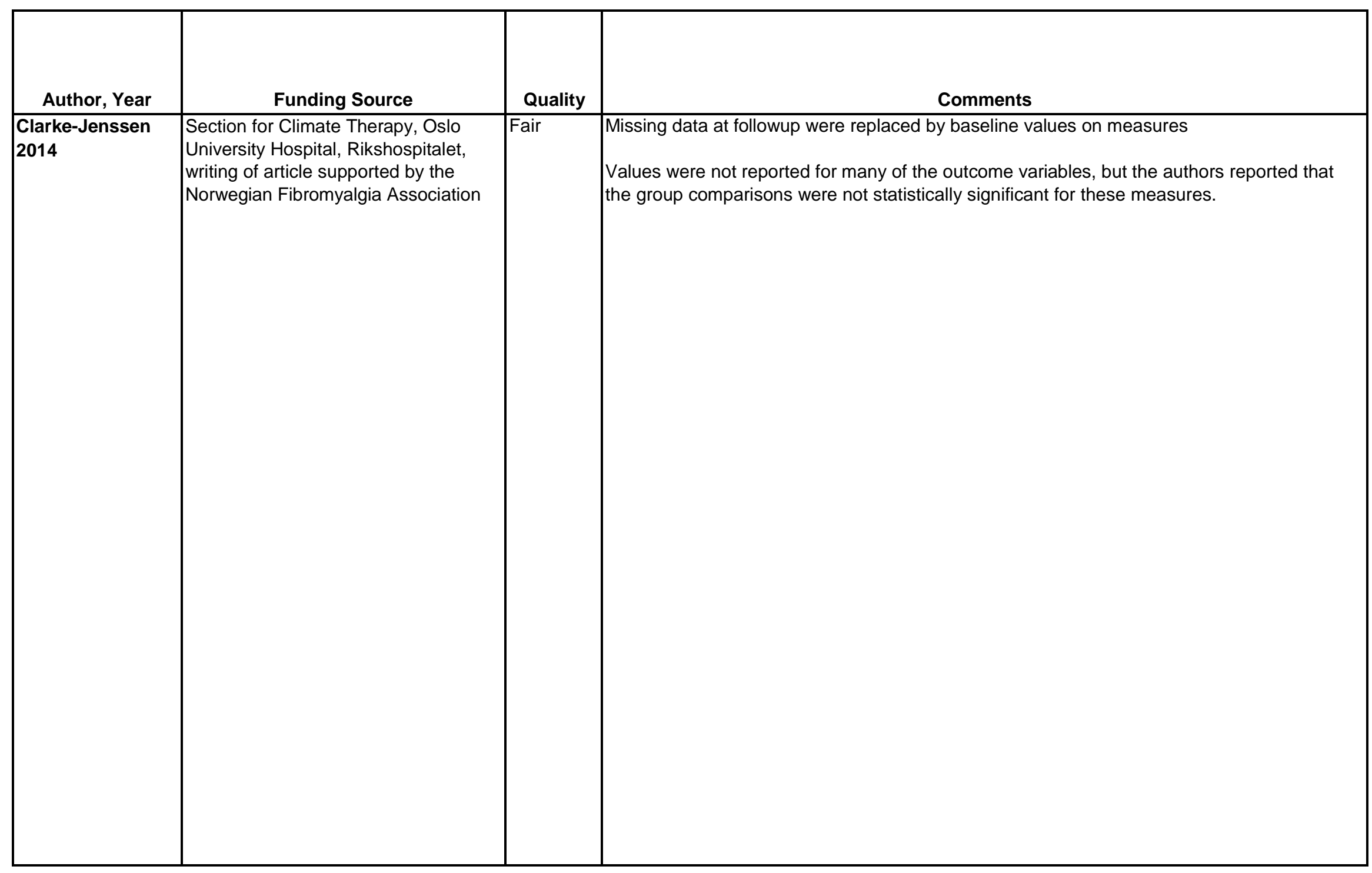




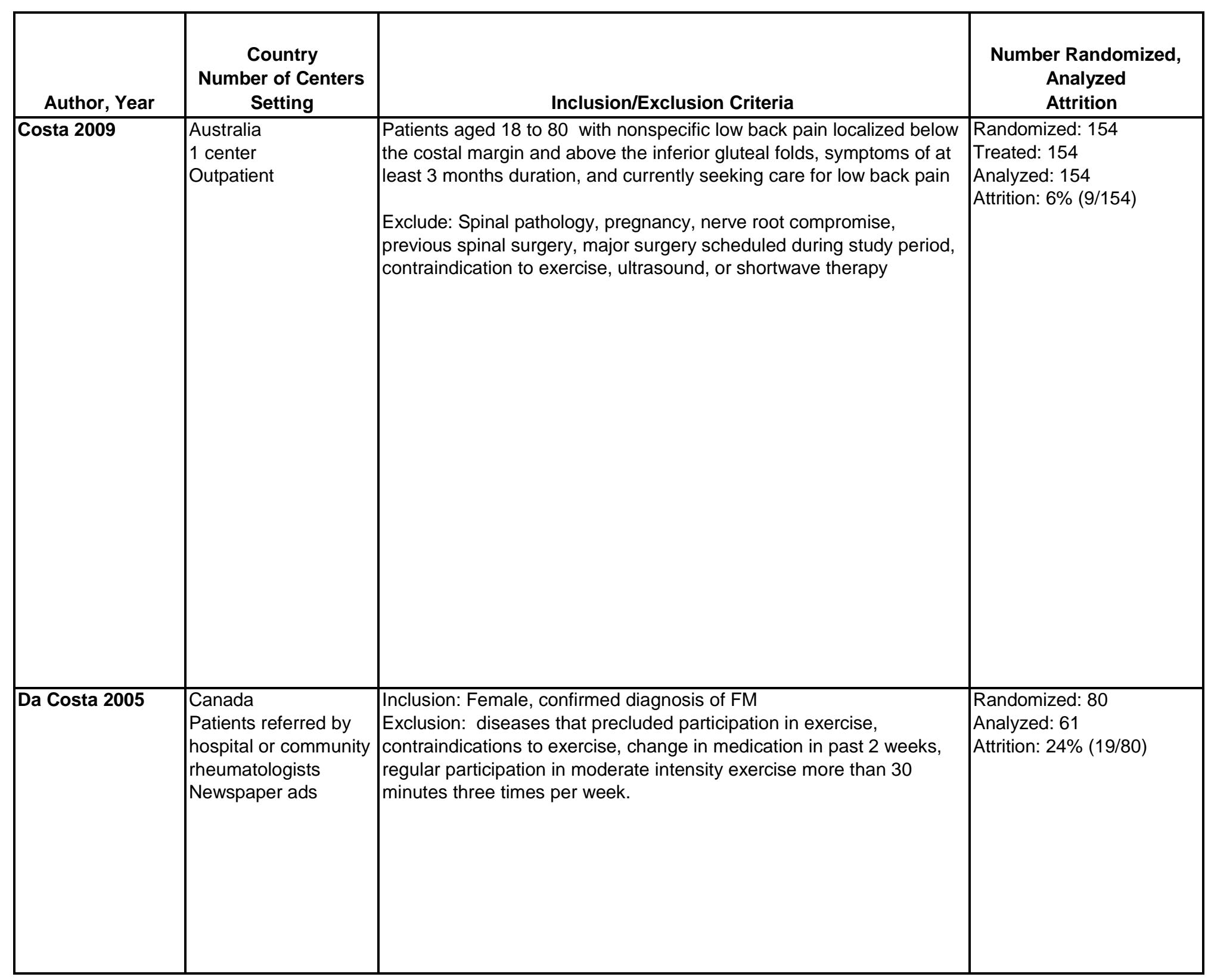




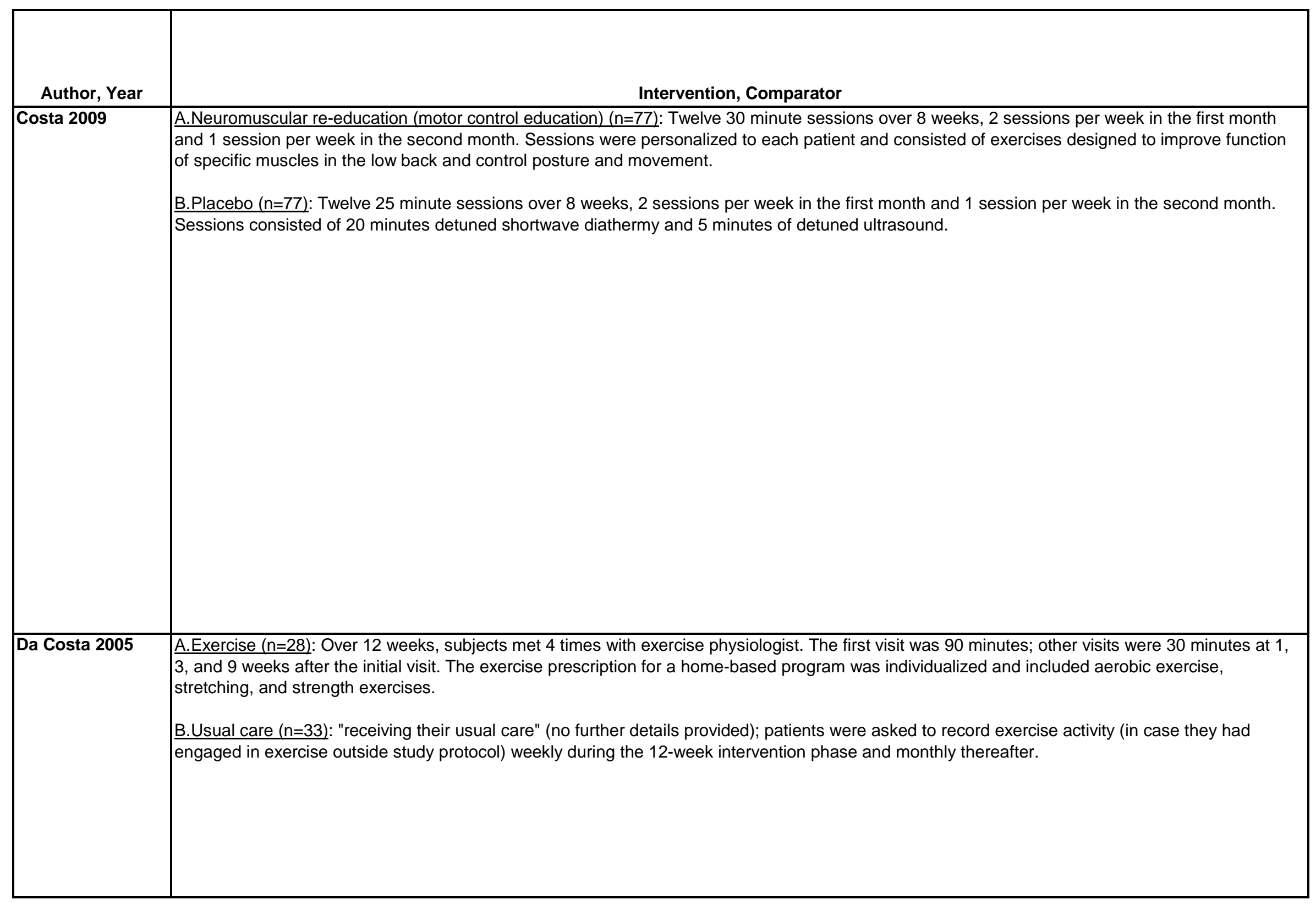




\begin{tabular}{|c|c|c|c|}
\hline Author, Year & Study Participants & Outcome Measures & $\begin{array}{c}\text { Duration of } \\
\text { Followup }\end{array}$ \\
\hline Costa 2009 & \begin{tabular}{|l} 
A vs B \\
Age: 55 vs 53 years \\
Female: $58 \%$ vs $62 \%$ \\
Duration of symptoms (weeks): 334.8 vs 328.2 \\
Work status: \\
$\quad$ Full-time: $8 \%$ vs $17 \%$ \\
$\quad$ Part-time: $7 \%$ vs $4 \%$ \\
$\quad$ Not working: $26 \%$ vs $16 \%$ \\
$\quad$ Not seeking employment: $60 \%$ vs $64 \%$ \\
General health status: \\
$\quad$ Excellent: $4 \%$ vs $10 \%$ \\
Very good: $23 \%$ vs $16 \%$ \\
$\quad$ Good: $49 \%$ vs $57 \%$ \\
Fair: $18 \%$ vs $9 \%$ \\
Poor: $5 \%$ vs $8 \%$ \\
Depression Anxiety Stress Scales (0-42): \\
Depression: $11.4(12.9)$ vs $11.2(13.4)$ \\
Anxiety: $11.9(11.1)$ vs $11.8(12.2)$ \\
Stress: $14.1(11.8)$ vs $14.4(12.5)$ \\
PSFS: $3.3(1.7)$ vs $3.3(! .8)$ \\
RMDQ: $13.1(5.0)$ vs $13.4(4.9)$ \\
Pain VAS: $6.8(2.1)$ vs $6.6(2.0)$ \\
Global impression of recovery: $-1.9(2.5)$ vs $-2.1(2.4)$
\end{tabular} & $\begin{array}{l}\text { Patient-Specific Functional Scale (0-10, higher } \\
\text { score=lower disability) } \\
\text { RDQ (0-24, higher score=higher disability } \\
\text { Pain (0-10 VAS, higher score=higher pain) } \\
\text { Global impression of recovery (-5 to }+5 \text {, higher } \\
\text { score=higher recovery) }\end{array}$ & $\begin{array}{l}\text { Short-term } \\
\text { and } \\
\text { intermediate } \\
\text { term } \\
4 \text { and } 10 \\
\text { months }\end{array}$ \\
\hline Da Costa 2005 & $\begin{array}{l}\text { A vs B } \\
49 \text { (8.7) vs } 52(10.8) \\
\text { Female: } 100 \% \text { vs } 100 \% \\
\text { Symptom duration, years: } 10.5(8.4) \text { vs } 11.2(7.6) \\
\text { Years since diagnosis: } 3.8(4.5) \text { vs } 4.9(4.1) \\
\text { FIQ: } 55.1 \text { (15.0) vs } 48.6(17.7) \\
\text { Upper body pain VAS: } 49.5(15.5) \text { vs } 47.4(18.9) \\
\text { Lower body pain VAS: } 47.0(25.8) \text { vs } 47.0(23.9) \\
\text { SCL-90 R GSI: } 64.3(6.3) \text { vs } 64.4(7.9)\end{array}$ & $\begin{array}{l}\text { Fibromyalgia Impact Questionnaire (FIQ; 0-100, higher } \\
\text { scores=more severe symptoms and disability) } \\
\text { Pain VAS, past week, upper body (0-100, higher } \\
\text { scores=greater pain) } \\
\text { Pain VAS, past week, lower body (0-100, higher } \\
\text { scores=greater pain) } \\
\text { Symptom Checklist } 90-R \text { GSI (SCL 90-R; 30-81, higher } \\
\text { scores=greater psychological distress) }\end{array}$ & $\begin{array}{l}3 \text { and } 9 \\
\text { months }\end{array}$ \\
\hline
\end{tabular}




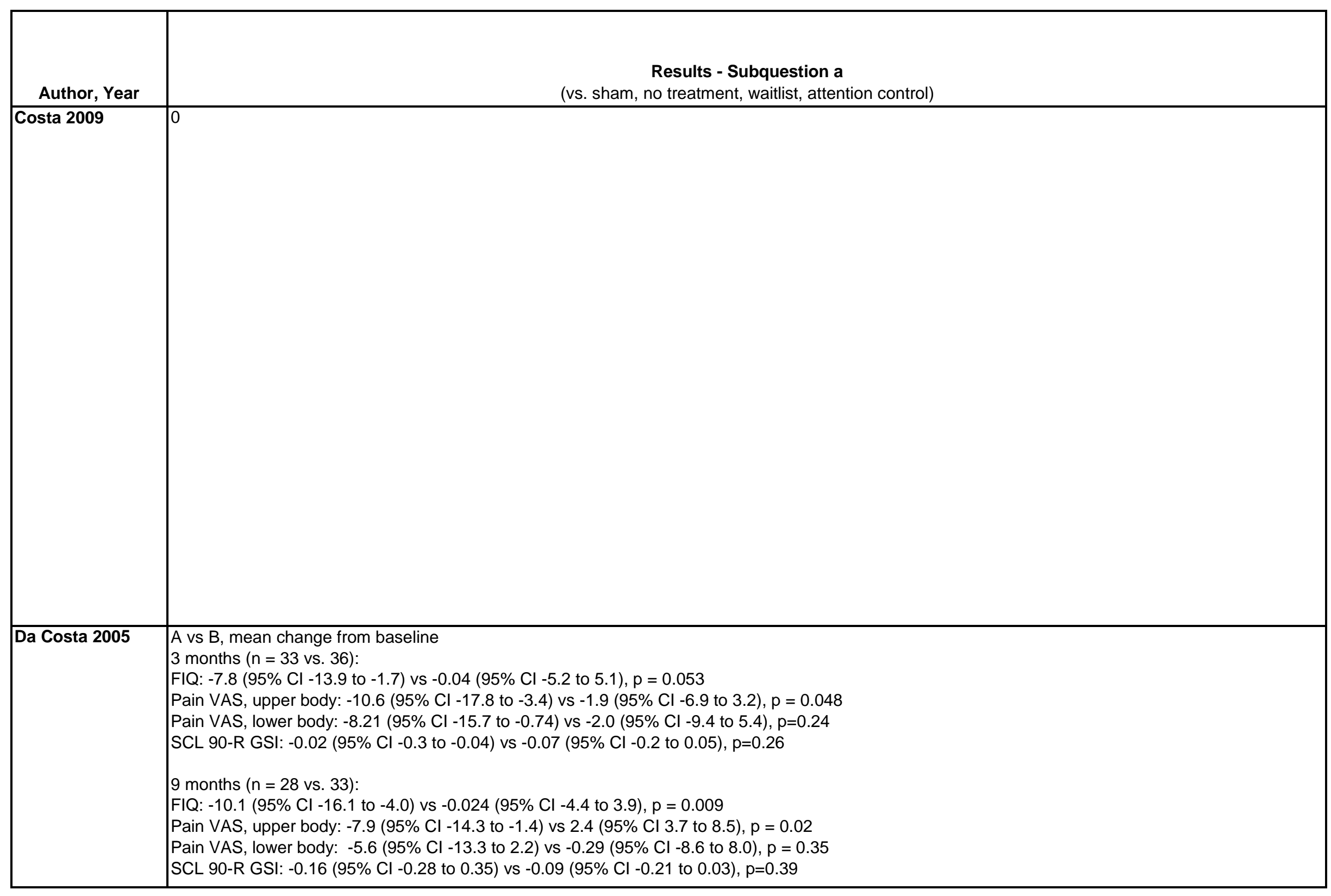




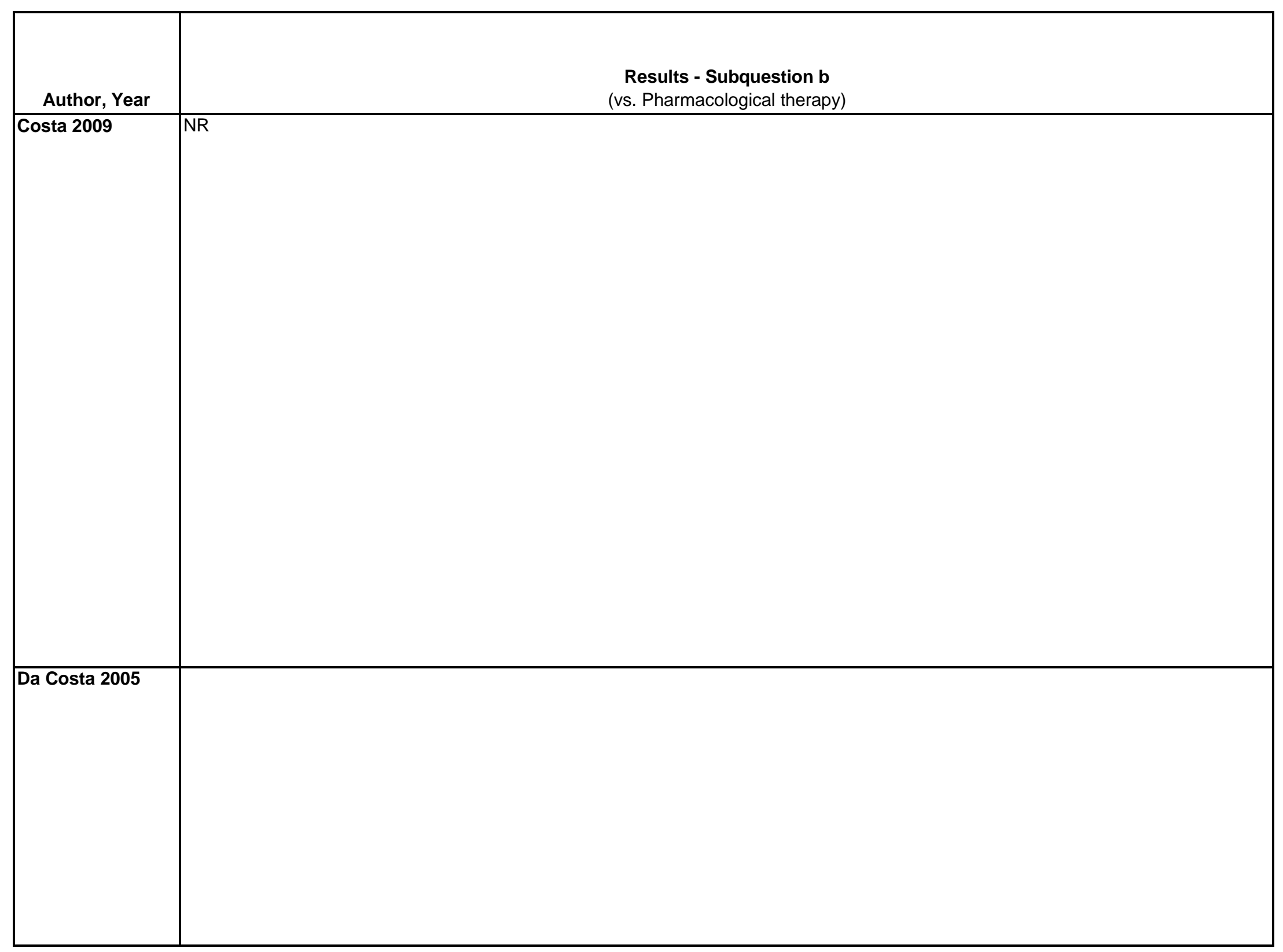




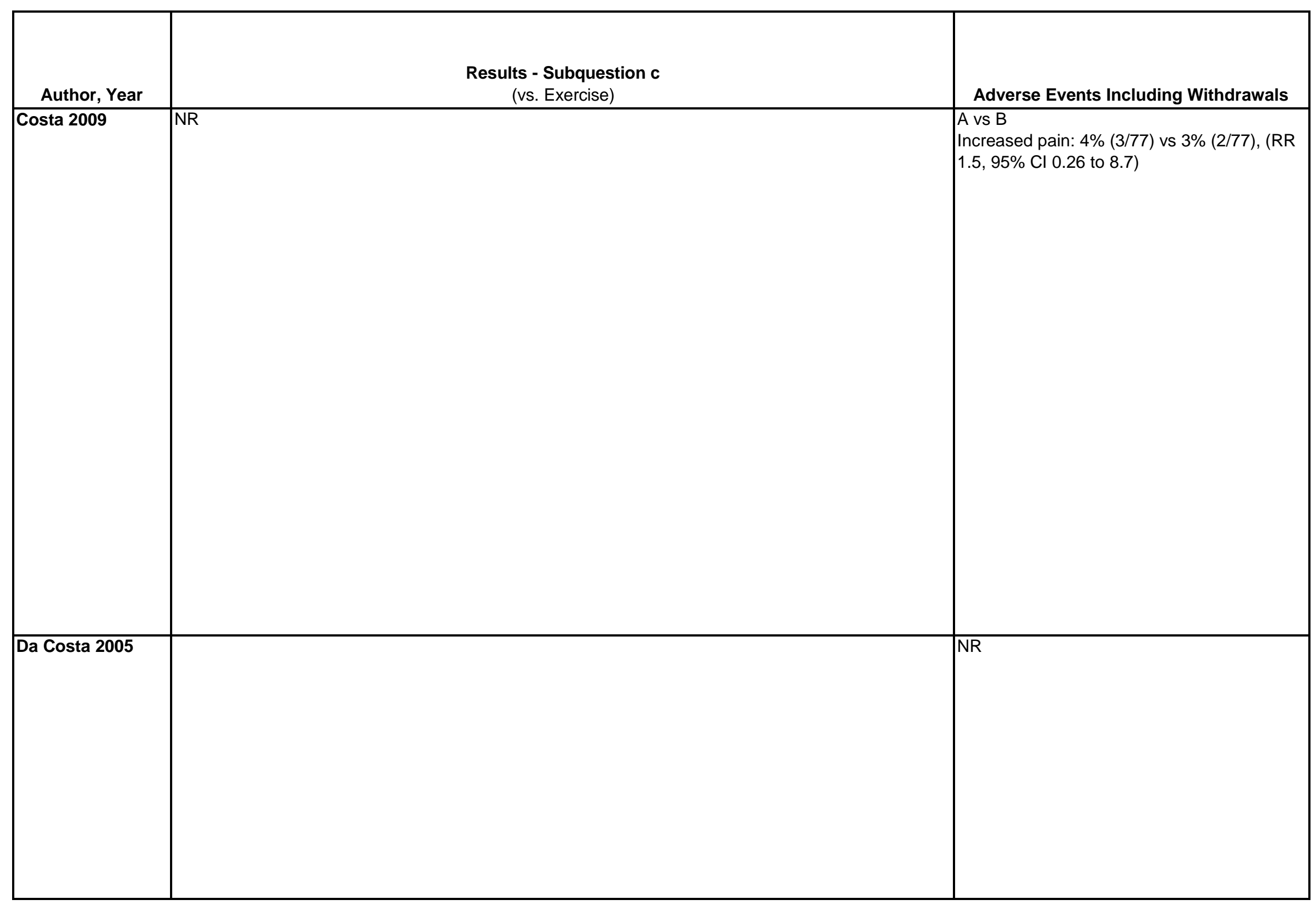




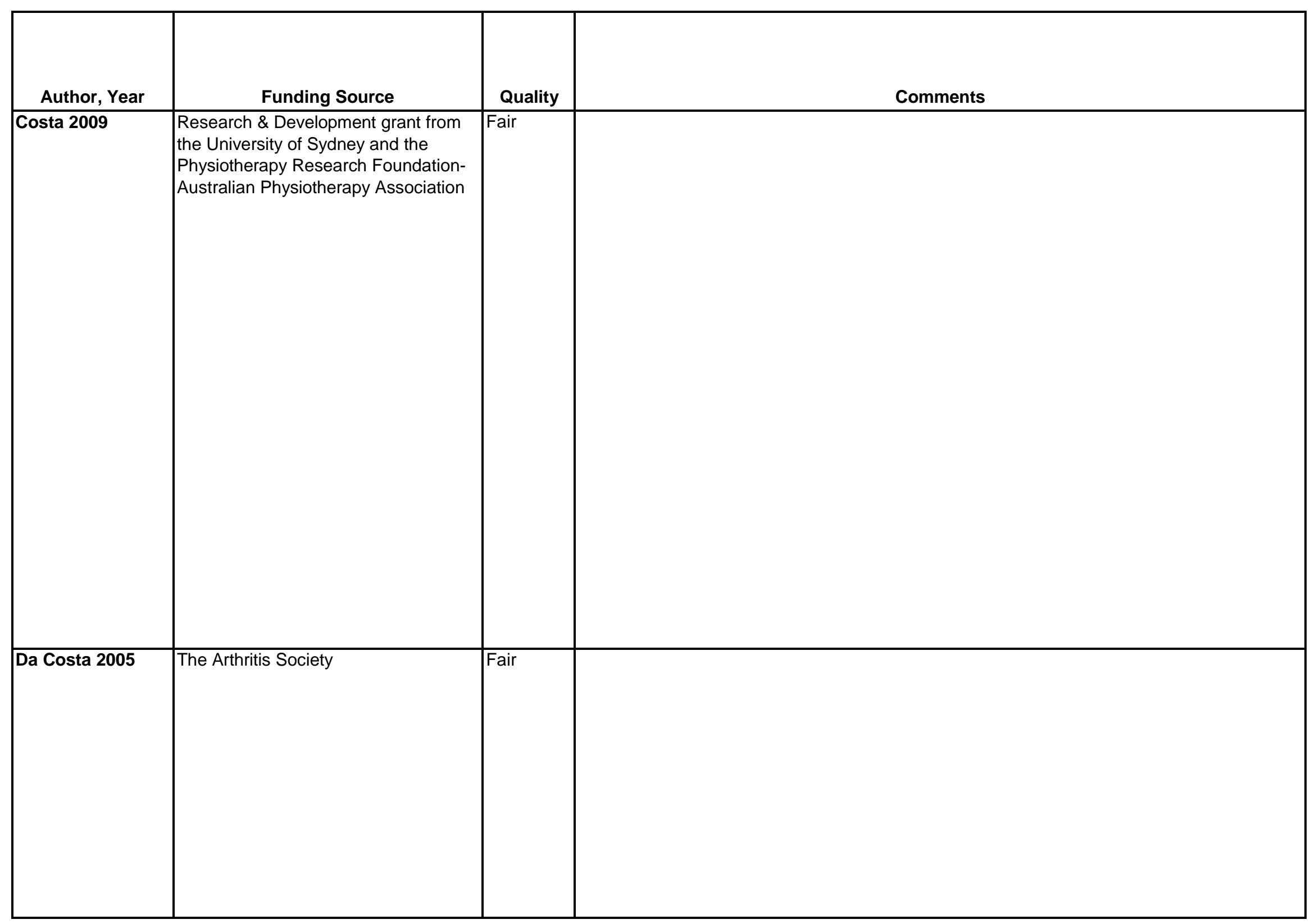




\begin{tabular}{|c|c|c|c|}
\hline Author, Year & $\begin{array}{c}\text { Country } \\
\text { Number of Centers } \\
\text { Setting }\end{array}$ & Inclusion/Exclusion Criteria & $\begin{array}{c}\text { Number Randomized, } \\
\text { Analyzed } \\
\text { Attrition }\end{array}$ \\
\hline Dias 2003 & $\begin{array}{l}\text { Brazil } \\
1 \text { center } \\
\text { Geriatric outpatient }\end{array}$ & $\begin{array}{l}\text { Aged } 65 \text { or older with a diagnosis of knee OA fulfilling ACR criteria } \\
\text { Exclude: History of previous knee surgery for OA, hip or knee } \\
\text { arthroplasty }\end{array}$ & $\begin{array}{l}\text { Randomized: } 50 \\
\text { Treated: } 50 \\
\text { Analyzed: } 47 \\
\text { Attrition: } 6 \%(3 / 50)\end{array}$ \\
\hline Dilek 2013 & $\begin{array}{l}\text { Turkey } \\
1 \text { center } \\
\text { Outpatient }\end{array}$ & $\begin{array}{l}\text { ACR criteria for bilateral hand osteoarthritis } \\
\text { Exclude: Acute inflammation, trauma or open wounds, steroid drug or } \\
\text { NSAID intake, sensory deficits, muscle weakness, malignancy, } \\
\text { Raynaud disease and phenomenon, atrophic skin, palmar } \\
\text { tenosynovitis, trigger finger, Dupuytren contracture, collagen } \\
\text { diseases, inflammatory arthritic diseases, high acute phase reactants, } \\
\text { steroid or hyaluronan injection to joints, history of physical therapy, } \\
\text { coagulation disorders }\end{array}$ & $\begin{array}{l}\text { Randomized: } 56 \\
\text { Treated: } 56 \\
\text { Analyzed: } 46 \\
\text { Attrition: } 18 \%(10 / 56)\end{array}$ \\
\hline Djavid 2007 & $\begin{array}{l}\text { Iran } \\
\text { Number of centers: } 1 \\
\text { Outpatient clinic and } \\
\text { patients home }\end{array}$ & $\begin{array}{l}\text { Patients } 20 \text { - } 60 \text { years, with low back pain for } 12 \text { weeks, able to give } \\
\text { consent, understand instructions, and co-operate with treatment. } \\
\text { Exclude: patients with degenerative disc disease, disc herniation, } \\
\text { fracture, spondylosis, and spinal stenosis, neurological deficits, } \\
\text { abnormal laboratory findings, systemic or psychiatric illness, and } \\
\text { pregnancy. }\end{array}$ & $\begin{array}{l}\text { Randomized: } 61 \\
\text { Treated: } 53 \\
\text { Analyzed: } 53 \\
\text { Attrition: } 13 \%(8 / 61)\end{array}$ \\
\hline
\end{tabular}




\begin{tabular}{|c|c|}
\hline Author, Year & Intervention, Comparator \\
\hline Dias 2003 & $\begin{array}{l}\text { A.Exercise }(n=25): 12 \text { exercise sessions twice a week for the } 6 \text { month study period in addition to three supervised walks of } 40 \text { minutes each week. } \\
\text { Exercise sessions consisted stretching, concentric and eccentric isotonic progressive resistance exercises, and closed kinetic chain weight-bearing } \\
\text { exercises } \\
\text { B.Control group }(n=25) \text { : Subjects were instructed to follow the instructions given at an educational session that all participants attended (see } \\
\text { information below) } \\
\text { All patients: One-hour educational session consisting of a lecture on disease characteristics, joint protection, pain management, and strategies to } \\
\text { overcome difficulties in activities of daily life }\end{array}$ \\
\hline Dilek 2013 & $\begin{array}{l}\text { A.Dip-wrap paraffin bath therapy }(\mathrm{n}=24) \text { : patients dip both hands into } 50^{\circ} \mathrm{C} \text { paraffin bath } 10 \text { times, paraffin left on for } 15 \text { minutes, treatment } \\
\text { administered } 5 \text { days per week for } 3 \text { weeks } \\
\text { B.Control group }(n=22) \text { : Details NR } \\
\text { All patients: received information about joint-protection techniques, only allowed paracetamol intake, asked to keep a drug diary }\end{array}$ \\
\hline Djavid 2007 & $\begin{array}{l}\text { A.GaAs laser }(\mathrm{n}=16): 810 \mathrm{~nm} \text { wavelength, } 50 \mathrm{~mW} \text {, continuous wave, and } 0.2211 \mathrm{~cm} 2 \mathrm{spot} \text { area laser applied to } 8 \text { points in the paravertebral } \\
\text { region (L2 to S2-S3) at dose of } 27 \mathrm{~J} / \mathrm{cm} 2 \text {, twice weekly for } 6 \text { weeks } \\
\text { B.Low level laser therapy plus exercise }(\mathrm{n}=19) \\
\text { C.Sham laser therapy plus exercise }(\mathrm{n}=18) \text {; included strengthening, stretching, mobilizing, coordination and stabilization of the abdominal, back, } \\
\text { pelvic, and lower limb muscles, first exercise session conducted by physiotherapist and the rest were at home }\end{array}$ \\
\hline
\end{tabular}




\begin{tabular}{|c|c|c|c|}
\hline Author, Year & Study Participants & Outcome Measures & $\begin{array}{c}\text { Duration of } \\
\text { Followup }\end{array}$ \\
\hline Dias 2003 & $\begin{array}{l}\text { A vs B } \\
\text { Age, median: } 74 \text { vs } 76 \\
\text { Female: } 84 \% \text { vs } 92 \% \\
\text { Lequesne Index, median: } 12 \text { vs } 12.5 \\
\text { HAQ, median: } 1 \text { vs } 1 \\
\text { SF-36 functional capacity, median: } 55 \text { vs } 45 \\
\text { SF-36 physical role limitation, median: } 25 \text { vs } 50 \\
\text { SF-36 bodily pain, median: } 74 \text { vs } 74 \\
\text { SF-36 general health, median: } 87 \text { vs } 77 \\
\text { SF-36 vitality, median: } 90 \text { vs } 85\end{array}$ & $\begin{array}{l}\text { Lequesne Index of Knee OA Severity (0-24, higher } \\
\text { score=higher severity of OA); HAQ (0-80, higher } \\
\text { score=higher disability); SF-36 (0-100, higher } \\
\text { score=higher quality of life) }\end{array}$ & $\begin{array}{l}\text { Immediately } \\
\text { post- } \\
\text { intervention } \\
\text { (treatment of } \\
6 \text { months) }\end{array}$ \\
\hline Dilek 2013 & $\begin{array}{l}\text { A vs B } \\
\text { Age: } 59 \text { vs } 60 \\
\text { Female: } 83 \% \text { vs } 91 \% \\
\text { Symptom duration (mos): } 64.4(57.2) \text { vs } 67.6(55.9) \\
\text { Heberden nodules (no): } 4.5(2.5) \text { vs } 4.0(2.6) \\
\text { Bouchard nodules (no): } 0.0(1.3) \text { vs } 0.0(2.2) \\
\text { AUSCAN function: } 16.2(7.0) \text { vs } 17.1(8.4), p=0.37 \\
\text { AUSCAN pain: } 10.7(3.3) \text { vs } 9.8(5.7), p=0.42 \\
\text { VAS at rest median (IQR): } 5.0(4.0-5.0) \text { vs } 4.0(3.0-8.0), p=0.71 \\
\text { VAS at ADL median (IQR): } 7.0(7.0-9.0) \text { vs } 8.0(6.0-8.0), p=0.88\end{array}$ & $\begin{array}{l}\text { AUSCAN function (0-36, higher score=worse pain): DFI } \\
\text { (0-30, higher score=worse function): AUSCAN pain (0- } \\
\text { 20, higher score=worse pain): pain VAS at rest (0-10, } \\
\text { higher score=worse pain): pain VAS during ADL (0-10, } \\
\text { higher score=worse pain) }\end{array}$ & 2.25 months \\
\hline Djavid 2007 & $\begin{array}{l}\text { A vs. B vs. C } \\
\text { Age: } 40 \text { vs. } 38 \text { vs. } 36 \text { years } \\
\text { Female: } 5 \% \text { vs. } 7 \% \text { vs. } 2 \% \\
\text { Duration of LBP: } 29 \text { months vs. } 29 \text { months vs. } 25 \text { months }\end{array}$ & $\begin{array}{l}\text { Pain severity (VAS) (score: 0-10) measures intensity } \\
\text { of pain (a higher were indicates higher pain intensity) } \\
\text { Lumbar range of motion (ROM) Schober Test } \\
\text { (centimeters) } \\
\text { Oswestry Disability Index (ODI) (score: 0-50) }\end{array}$ & $\begin{array}{l}\text { Short term } \\
6 \text { weeks }\end{array}$ \\
\hline
\end{tabular}




\begin{tabular}{|c|c|}
\hline Author, Year & $\begin{array}{c}\text { Results - Subquestion a } \\
\text { (vs. sham, no treatment, waitlist, attention control) }\end{array}$ \\
\hline Dias 2003 & $\begin{array}{l}\text { A vs } B \\
\text { Lequesne Index, median: } 4.3 \text { vs } 13, p=0.001 \\
\text { HAQ, median: } 0.3 \text { vs } 1.1, p=0.006 \\
\text { SF-36 functional capacity, median: } 77.5 \text { vs } 40, p<0.001 \\
\text { SF-36 physical role limitation, median: } 92.5 \text { vs } 75, p=0.001 \\
\text { SF-36 bodily pain, median: } 100 \text { vs } 0, p=0.002 \\
\text { SF-36 general health, median: } 100.5 \text { vs } 51, p=0.021 \\
\text { SF-36 vitality, median: } 93.5 \text { vs } 87, p=0.027\end{array}$ \\
\hline Dilek 2013 & $\begin{array}{l}\text { A vs B } \\
2.25 \text { month outcomes } \\
\text { AUSCAN function: } 13.8 \text { (7.0) vs } 17.8(8.4), p \text { value NR (MD }-4,95 \% \mathrm{Cl}-8.58 \text { to } 0.58) \mathrm{p} \text { value NR } \\
\text { DFI: Values NR, } \mathrm{p}=0.05 \\
\text { AUSCAN pain: } 6.5(4.0) \text { vs } 9.5(4.5)(\mathrm{MD}-3,95 \% \mathrm{Cl}-5.5 \text { to }-0.5) \mathrm{p}=0.05, \mathrm{p}=0.07 \text { for ITT } \\
\text { Pain VAS at rest, median (IQR): } 0.0(0.0-3.0) \text { vs } 5.0(1.0-6.0), p=0.003, p<0.001 \text { for ITT } \\
\text { Pain VAS during ADL, median (IQR): } 5.0(3.0-6.5) \text { vs } 7.0(5.0-8.0) ; p=0.09, p=0.05 \text { for ITT }\end{array}$ \\
\hline Djavid 2007 & $\begin{array}{l}\text { A vs. B, mean (SD) } \\
1.5 \text { months } \\
\text { Pain (0-10 VAS): } 4.4(2.0) \text { vs. } 2.4(1.4) \text {, difference in change from baseline }-0.9(95 \% \mathrm{Cl}-2.5 \text { to } 0.7) \\
\text { Oswestry Disability Index (0-100): } 20.8(4.4) \text { vs. } 16.8 \text { (3.7) difference in change from baseline }-4.4(95 \% \mathrm{Cl}-11.4 \text { to } 2.5)\end{array}$ \\
\hline
\end{tabular}




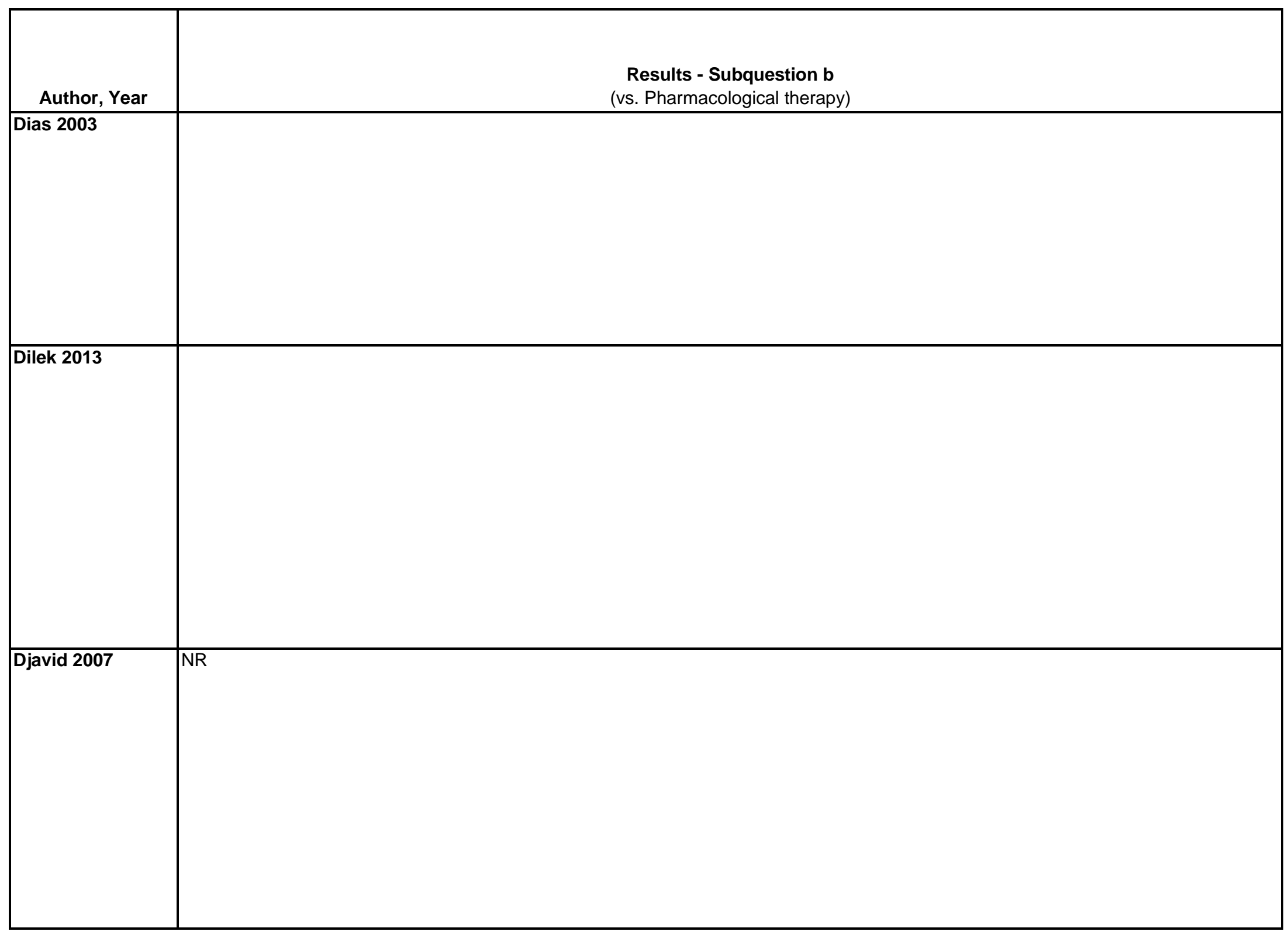

D-285 


\begin{tabular}{|c|c|c|}
\hline Author, Year & $\begin{array}{l}\text { Results - Subquestion c } \\
\text { (vs. Exercise) }\end{array}$ & Adverse Events Including Withdrawals \\
\hline Dias 2003 & & NR \\
\hline Dilek 2013 & & NR \\
\hline Djavid 2007 & 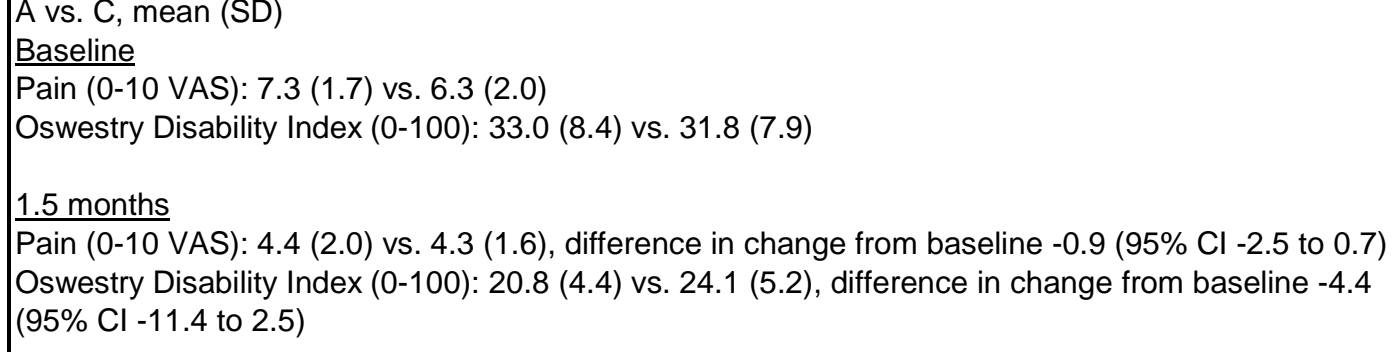 & None \\
\hline
\end{tabular}




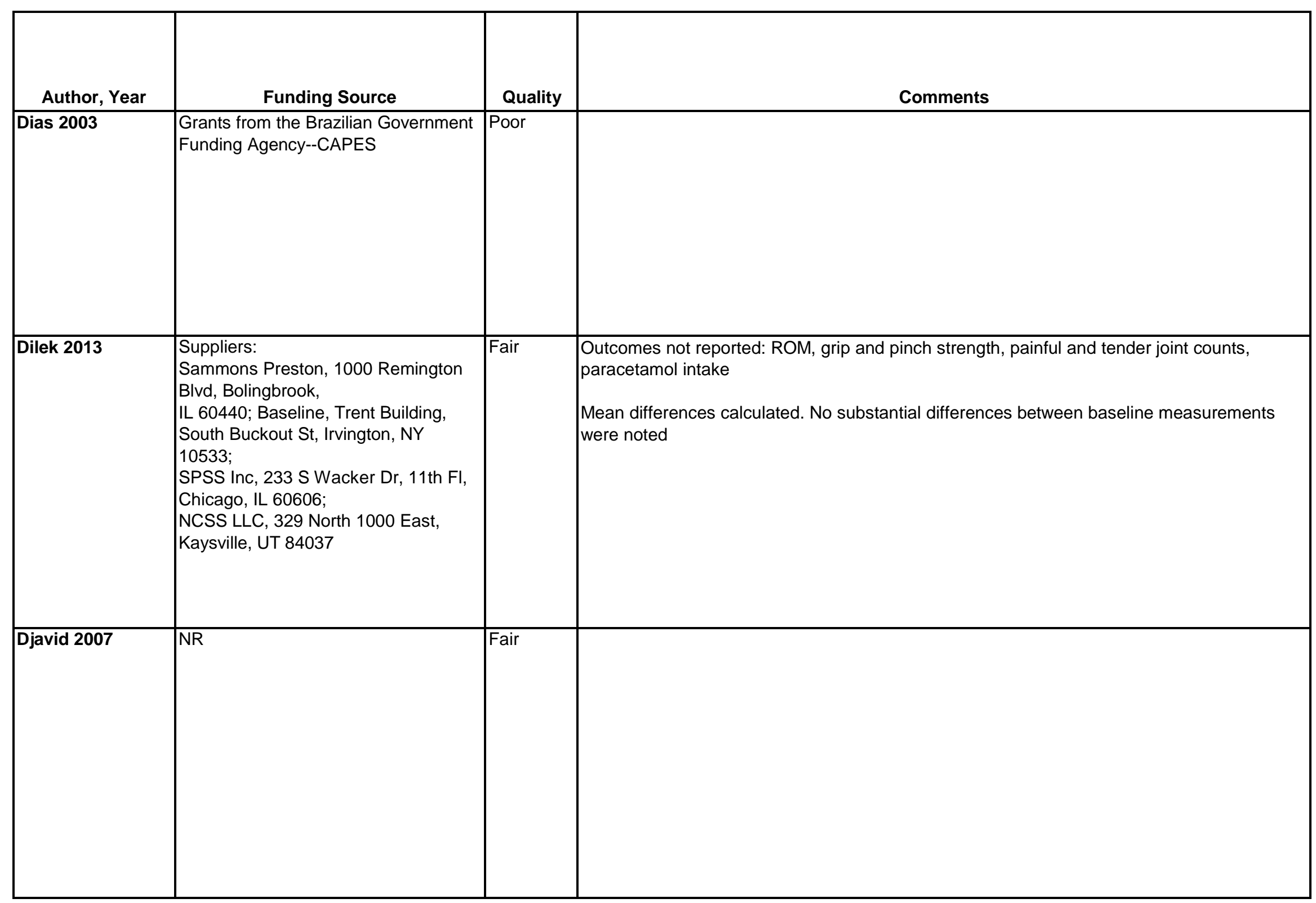




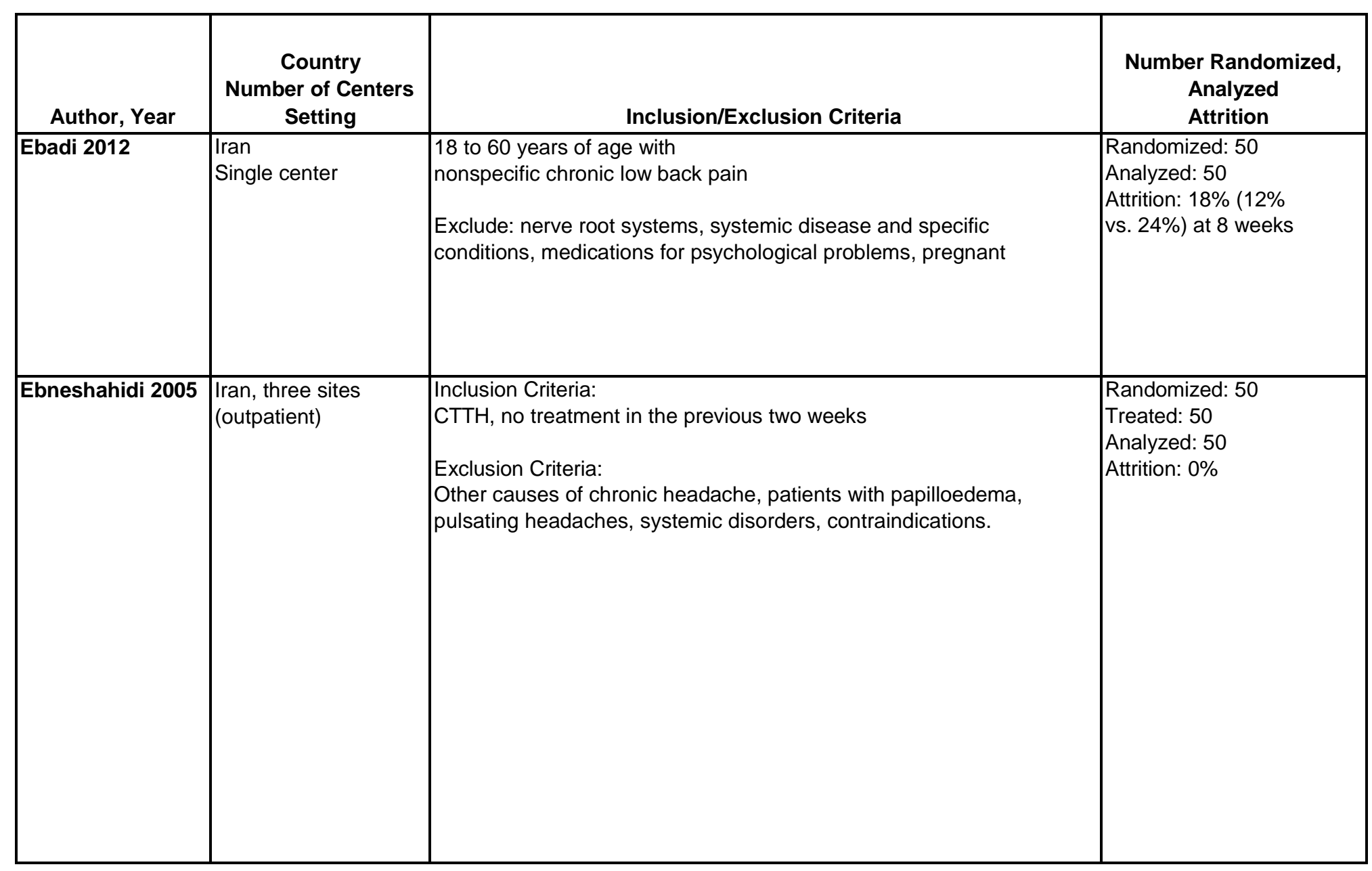




\begin{tabular}{|c|c|}
\hline Author, Year & Intervention, Comparator \\
\hline Ebadi 2012 & $\begin{array}{l}\text { A: Ultrasound } 1.5 \mathrm{~W} / \mathrm{cm}^{2} \text { at } 1 \mathrm{MHz} \text {; duration based on Grey's formula, } 10 \text { sessions over } 4 \text { weeks }(n=25) \\
\text { B: Sham ultrasound, same technique as A but no US }(n=22)\end{array}$ \\
\hline Ebneshahidi 2005 & $\begin{array}{l}\text { A.Low-Energy Laser Acupuncture }(\mathrm{n}=25) \\
\text { Laser acupuncture } \\
\text { No. of Sessions: } 3 \text { times/week for } 10 \text { sessions } \\
\text { Length of Sessions: NR } \\
\text { Output wave length: } 830 \mathrm{~nm} \text {; } \\
\text { Maximum intensity: } 39 \mathrm{~mW} / \mathrm{cm} \text { squared on } 8 \text { acupoints. } \\
\text { Acupoints: GB14, GB20, LI4, LU7 bilaterally (totaling } 8 \text { points) } \\
\text { B.Sham Laser Acupuncture ( } \mathrm{n}=25) \\
\text { Same procedure except power output was set to zero }\end{array}$ \\
\hline
\end{tabular}




\begin{tabular}{|c|c|c|c|}
\hline Author, Year & Study Participants & Outcome Measures & $\begin{array}{c}\text { Duration of } \\
\text { Followup }\end{array}$ \\
\hline Ebadi 2012 & $\begin{array}{l}\text { A vs. B } \\
\text { Mean age: } 31 \text { vs. } 37 \text { years } \\
25 \% \text { vs. } 50 \% \text { female } \\
\text { Race: Not reported } \\
\text { Pain intensity (mean, } 0-100 \\
\text { VAS): } 47 \text { vs. } 49 \\
\text { Functional Rating Index } \\
\text { (mean, } 0-100): 41 \text { vs. } 44\end{array}$ & $\begin{array}{l}\text { Pain (mean, 0-100 VAS) } \\
\text { Functional Rating Index (0-40) }\end{array}$ & 1 month \\
\hline Ebneshahidi 2005 & $\begin{array}{l}\text { A vs } B \\
\text { Age: } 33 \text { vs } 39 \text { years }(p=0.04) \\
\text { Female: } 80 \% \text { vs } 80 \% \\
\text { Race: NR } \\
\text { Duration of symptoms: NR } \\
\text { Median Number of Headache Days/Month (IQR): } 20 \text { (15.0) vs. } 18 \\
\text { (15.0) } p=0.5 \\
\text { Median VAS (IQR): } 10(3.0) \text { vs. } 10 \text { (1.0) p=0.1 } \\
\text { Median Duration of Attacks (IQR): } 10 \text { (4.0) vs. } 8(4.5) p=0.02\end{array}$ & $\begin{array}{l}\text { Number of Headache Days/Month; } \\
\text { Headache Intensity (VAS; 0-10: higher scores indicate } \\
\text { severity of pain); } \\
\text { Duration of Attacks (hours) }\end{array}$ & $\begin{array}{l}12 \text { and } 3 \\
\text { months }\end{array}$ \\
\hline
\end{tabular}




\begin{tabular}{|c|c|}
\hline Author, Year & $\begin{array}{c}\text { Results - Subquestion a } \\
\text { (vs. sham, no treatment, waitlist, attention control) }\end{array}$ \\
\hline Ebadi 2012 & 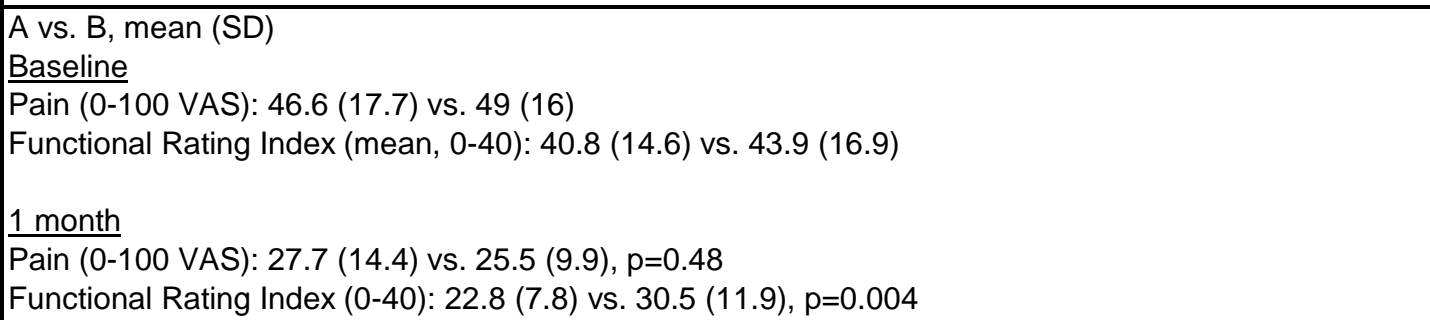 \\
\hline Ebneshahidi 2005 & $\begin{array}{l}\text { A vs. B } \\
\text { Imonths } \\
\Delta \text { Number of Headache Days/Month, median (IQR): }-15(16.5) \text { vs. }-2(5.0) p<0.001 \\
\Delta \text { in Headache Intensity (VAS), median (IQR): }-5(3.8) \text { vs. }-1(2.0) p<0.001 \\
\Delta \text { Duration of Attacks (hours), median (IQR): }-6 \text { (4.5) vs. }-1(2.0) p<0.001 \\
\text { 2months } \\
\Delta \Delta \text { Number of Headache Days/Month, median (IQR): }-10(20.0) \text { vs. } 0(5.0) p<0.001 \\
\Delta \text { in Headache Intensity (VAS), median (IQR): }-3(4.0) \text { vs. } 0(1.5) p<0.001 \\
\Delta \text { Duration of Attacks (hours), median (IQR): }-4(6.0) \text { vs. } 0(0.5) p<0.001 \\
\text { 3months } \\
\Delta \text { Number of Headache Days/Month, median (IQR): }-8(21.5) \text { vs. } 0(0.0) p<0.001 \\
\Delta \text { in Headache Intensity (VAS), median (IQR): }-2(6.3) \text { vs. } 0(0.0) p<0.001 \\
\Delta \text { Duration of Attacks (hours), median (IQR): }-4(7.5) \text { vs. } 0(0.0) p<0.001\end{array}$ \\
\hline
\end{tabular}




\begin{tabular}{|c|c|}
\hline Author, Year & $\begin{array}{l}\text { Results - Subquestion b } \\
\text { (vs. Pharmacological therapy) }\end{array}$ \\
\hline \begin{tabular}{|l|l|} 
Ebadi 2012 \\
\end{tabular} & 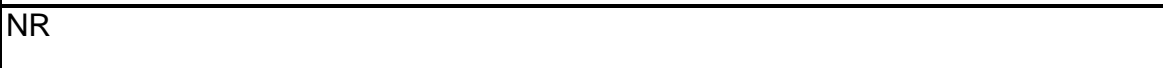 \\
\hline Ebneshahidi 2005 & NA \\
\hline & \\
\hline & \\
\hline & \\
\hline & \\
\hline & \\
\hline
\end{tabular}




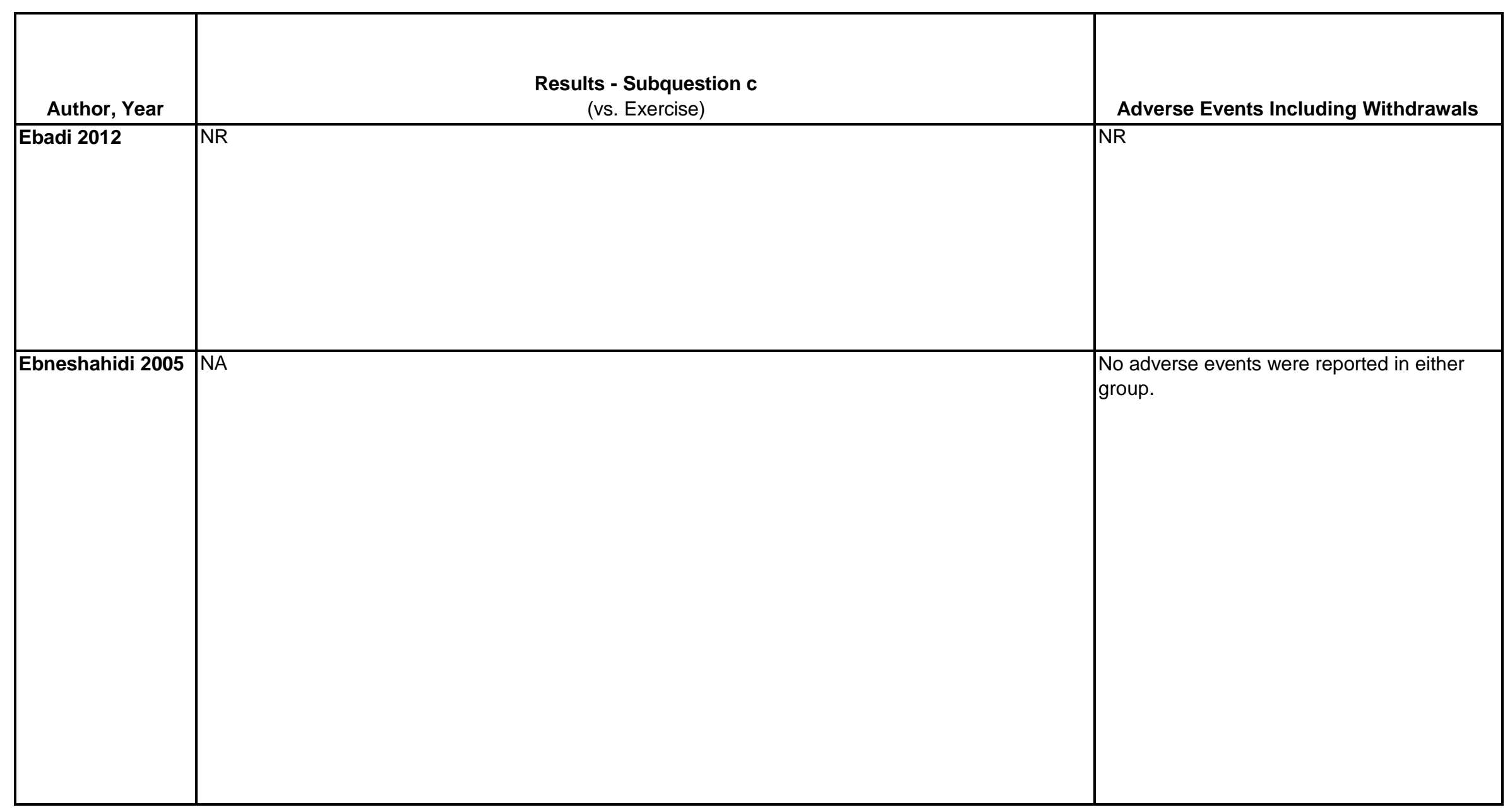




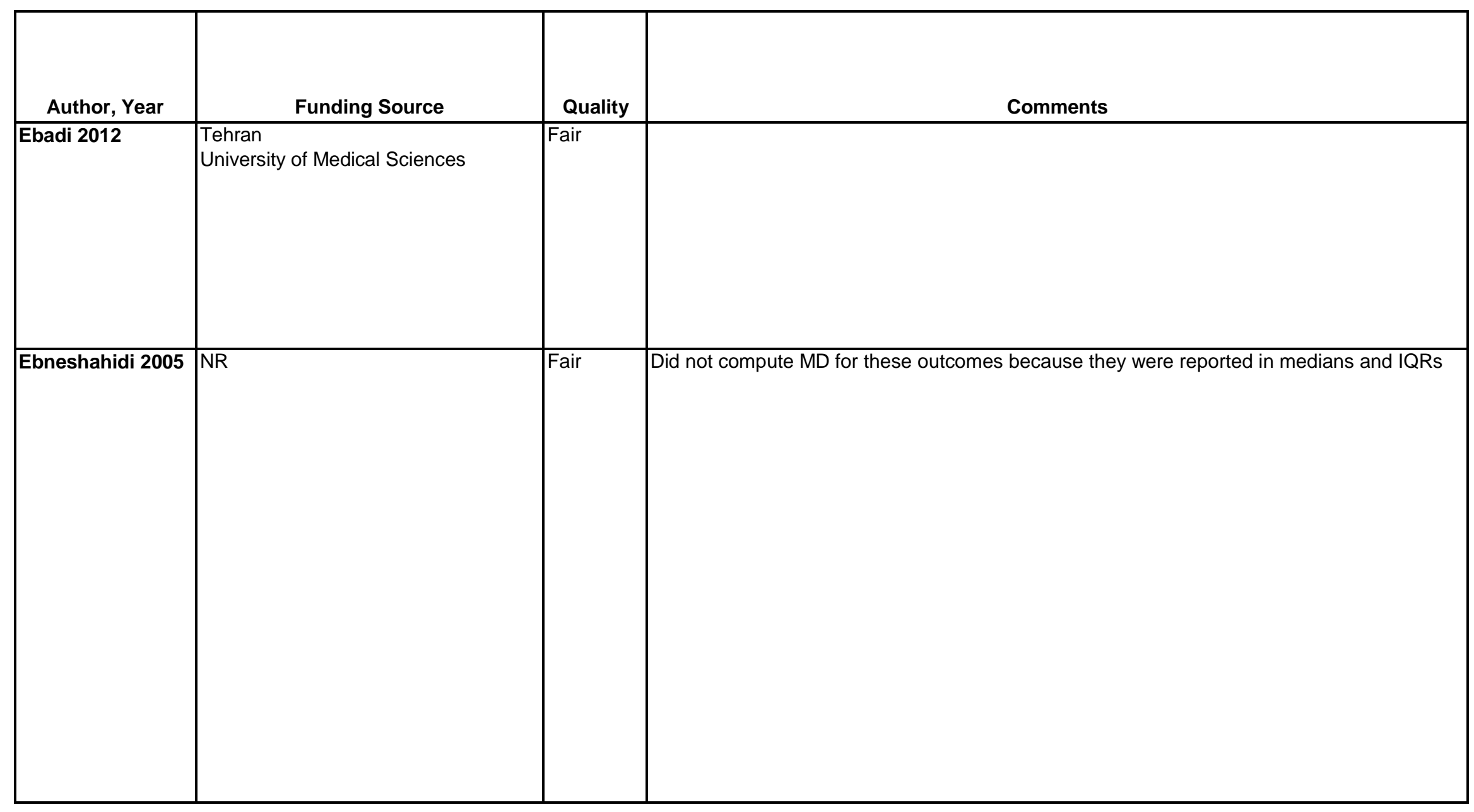

D-294 


\begin{tabular}{|c|c|c|c|}
\hline Author, Year & $\begin{array}{c}\text { Country } \\
\text { Number of Centers } \\
\text { Setting }\end{array}$ & Inclusion/Exclusion Criteria & $\begin{array}{c}\text { Number Randomized, } \\
\text { Analyzed } \\
\text { Attrition } \\
\end{array}$ \\
\hline $\begin{array}{l}\text { Ettinger } 1997 \\
\text { FAST trial (index } \\
\text { study) }\end{array}$ & \begin{tabular}{|l|} 
United States, 2 \\
centers, academic \\
medical centers
\end{tabular} & $\begin{array}{l}\text { Inclusion criteria: age } 60 \text { years or older; pain in the knee(s) on most } \\
\text { days of the month; difficulty with at least one of the following because } \\
\text { of knee pain: walking } 0.4 \mathrm{~km} \text {; climbing stairs; getting in and out of a } \\
\text { car, bath, orbed; rising from a chair; or performing shopping, cleaning, } \\
\text { or self-care activities; and radiographic evidence of knee } \\
\text { osteoarthritis. } \\
\text { Exclusion criteria: baseline ADL disability; the presence of a medical } \\
\text { condition that precluded safe participation in an exercise program } \\
\text { (e.g., recent myocardial infarction or stroke, severe chronic obstructive } \\
\text { pulmonary disease, or congestive heart failure); inflammatory arthritis; } \\
\text { regular exercise participation (1 time per week for at least } 20 \text { minutes); } \\
\text { and inability to walk on a treadmill or walk, unassisted, } 128 \text { m in } 6 \\
\text { minutes; participating in another research study; or resided in a long- } \\
\text { term care facility }\end{array}$ & $\begin{array}{l}\text { Randomized: } 439 \\
\text { Treated: } 439 \\
\text { Analyzed: } 364 \\
\text { Attrition: } 17 \%(75 / 439)\end{array}$ \\
\hline Falcao 2008 & \begin{tabular}{|l|} 
Brazil \\
1rheumatology \\
outpatient clinic
\end{tabular} & $\begin{array}{l}\text { Inclusion: Met ACR } 1990 \text { criteria for FM, female, age 18-65, 4+ years } \\
\text { of formal education, no previous treatment for FM } \\
\text { Exclusions: other rheumatic disease; known hypersensitivity to } \\
\text { amitriptyline, cyclobenzaprine, or paracetamol; using psychotropic } \\
\text { drug; psychiatric disease; work-related litigation }\end{array}$ & $\begin{array}{l}\text { Randomized: } 60 \\
\text { Analyzed: } 51 \\
\text { Attrition: } 15 \%(9 / 60)\end{array}$ \\
\hline
\end{tabular}




\begin{tabular}{|c|c|}
\hline Author, Year & Intervention, Comparator \\
\hline $\begin{array}{l}\text { Ettinger } 1997 \\
\text { FAST trial (index } \\
\text { study) }\end{array}$ & 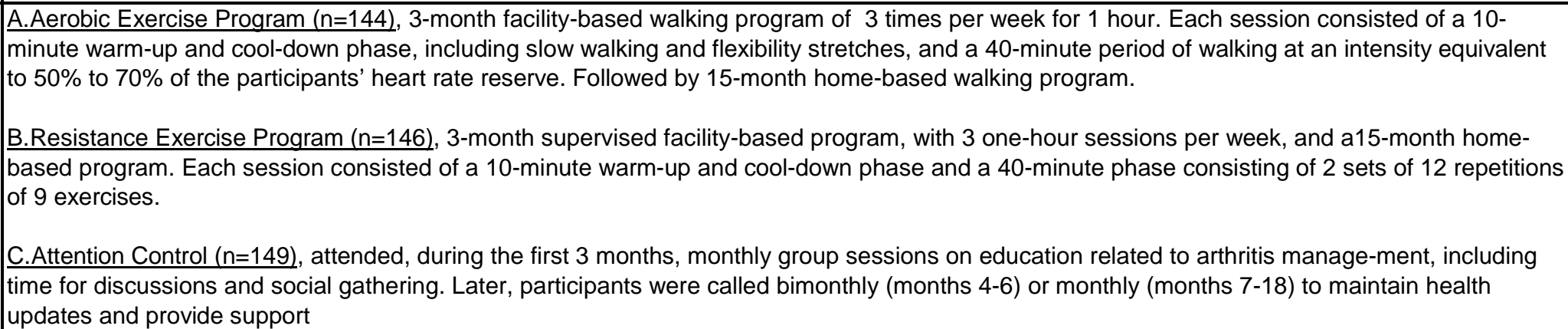 \\
\hline Falcao 2008 & $\begin{array}{l}\text { A.Amitriptyline plus CBT ( } \mathrm{n}=25 \text { ): amitriptyline } 12.5 / \mathrm{mg} \text { per day during first week, then increase dose to } 25 \mathrm{mg} / \text { day. Those with intolerance or side } \\
\text { effects to amitriptyline were given cyclobenzaprine } 5 \mathrm{mg} / \mathrm{day} \text { in the first week and then } 10 \mathrm{mg} / \mathrm{day} \text {. Subjects were also allowed to use paracetamol } \\
\text { if they had pain. Routine medical visits once a week for } 10 \text { weeks for brief discussions with the doctors. Immediately after each visit, they had a } \\
\text { CBT session, consisting of progressive relaxation training with electromyographic biofeedback, cognitive restructuring, and stress management. } \\
\text { Subjects who missed }>20 \% \text { of the treatment sessions and those who started new medications or did not come for evaluation were excluded from } \\
\text { analysis. } \\
\text { B.Amitriptyline only (control) }(\mathrm{n}=26 \text { ): amitriptyline } 12.5 / \mathrm{mg} \text { per day during first week, then increase dose to } 25 \mathrm{mg} / \text { day. Those with intolerance or } \\
\text { side eff+E66ects to amitriptyline were given cyclobenzaprine } 5 \mathrm{mg} / \mathrm{day} \text { in the first week and then } 10 \mathrm{mg} / \mathrm{day} \text {. Subjects were also allowed to use } \\
\text { paracetamol if they had pain. Routine medical visits once a week for } 10 \text { weeks for brief discussions with the doctors. }\end{array}$ \\
\hline
\end{tabular}




\begin{tabular}{|c|c|c|c|}
\hline Author, Year & Study Participants & Outcome Measures & $\begin{array}{c}\text { Duration of } \\
\text { Followup }\end{array}$ \\
\hline $\begin{array}{l}\text { Ettinger } 1997 \\
\text { FAST trial (index } \\
\text { study) }\end{array}$ & $\begin{array}{l}\text { A vs. B vs. C } \\
\text { Age: } 69 \text { vs. } 68 \text { vs. } 69 \text { years } \\
\text { Female: } 69 \% \text { vs. } 73 \% \text { vs. } 69 \% \\
\text { African-American: } 24 \% \text { vs } 28 \% \text { vs } 26 \% \\
\text { Education, >12 years: } 54 \% \text { vs. } 52 \% \text { vs. } 62 \% \\
\text { BMl >30: } 50 \% \text { vs. } 49 \% \text { vs. } 58 \%\end{array}$ & $\begin{array}{l}\text { Physical Disability. New disability questionnaire was } \\
\text { developed for use in FAST that combined } \\
23 \text { questions drawn from previous studies that } \\
\text { assessed difficulty with activities of daily living. The } \\
\text { scale used a Likert scale from } 1 \text { (usually done with no } \\
\text { difficulty) to } \\
5 \text { (unable to do). A composite disability score was } \\
\text { created by averaging scores on all } 23 \text { items. } \\
\text { Pain. Intensity of knee pain during the past week on } 6 \\
\text { activities of daily living on a Likert } \\
\text { scale from } 1 \text { (no pain) to } 6 \text { (excruciating } \\
\text { pain) during the } 6 \text { activities. Scores for } \\
\text { each activity were averaged to give summary pain } \\
\text { intensity scores for both ambulation and transfer } \\
\text { activities. }\end{array}$ & $\begin{array}{l}3 \\
\text { (immediately } \\
\text { post } \\
\text { treatment), } 6 \\
\text { and 15 } \\
\text { months }\end{array}$ \\
\hline Falcao 2008 & $\begin{array}{l}\text { A vs B } \\
\text { Age: } 45 \text { vs } 46 \\
\text { Female: } 100 \% \text { vs } 100 \% \\
\text { White: } 80 \% \text { vs } 77 \% \\
\text { Disease duration, years: } 3.5(2.4) \text { vs } 3.7(4.8) \\
\text { FIQ: } 64.9(15.5) \text { vs } 69.6(11.4) \\
\text { Pain VAS: } 6.9(2.3) \text { vs } 7.0(2.3) \\
\text { Beck Depression Inventory: } 20.6(10.0) \text { vs } 25.8(8.5) \\
\text { State-Trait Anxiety Inventory, state scale: } 47.4(3.2) \text { vs } 48.3(2.7) \\
\text { SF-36 physical capacity: } 45.4(24.2) \text { vs } 48.8(25.0) \\
\text { SF-36 Pain: } 28.0(17.5) \text { vs } 27.9(17.7) \\
\text { SF-36 Mental Health: } 44.0(20.4) \text { vs } 38.3(19.7)\end{array}$ & $\begin{array}{l}\text { FIQ (0-100, higher scores=greater impact of FM) } \\
\text { Pain VAS (0-10, higher scores=greater pain) } \\
\text { Beck Depression Inventory (BDI; 0-63, higher } \\
\text { scores=greater depression) } \\
\text { State-Trait Anxiety Inventory, state scale (20-80, higher } \\
\text { scores=greater anxiety) } \\
\text { SF-36 Physical Capacity (0-100, higher scores=better } \\
\text { outcomes) } \\
\text { SF-36 Pain (0-100, higher scores=better outcomes) } \\
\text { SF-36 Mental Health (0-100, higher scores=better } \\
\text { outcomes) }\end{array}$ & 3 months \\
\hline
\end{tabular}




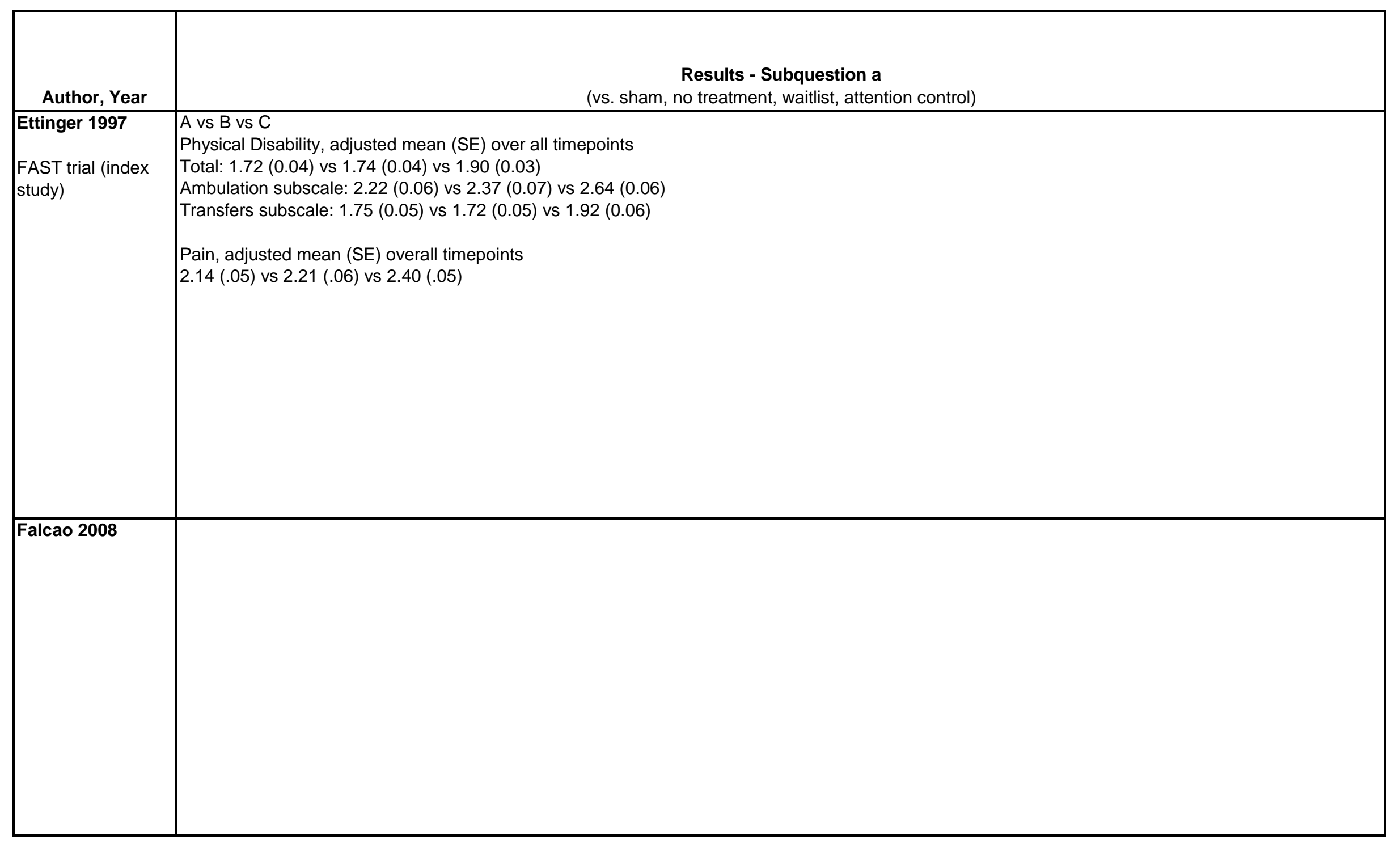




\begin{tabular}{|c|c|}
\hline Author, Year & $\begin{array}{l}\text { Results - Subquestion b } \\
\text { (vs. Pharmacological therapy) }\end{array}$ \\
\hline $\begin{array}{l}\text { Ettinger } 1997 \\
\text { FAST trial (index } \\
\text { study) }\end{array}$ & NR \\
\hline |Falcao 2008 & 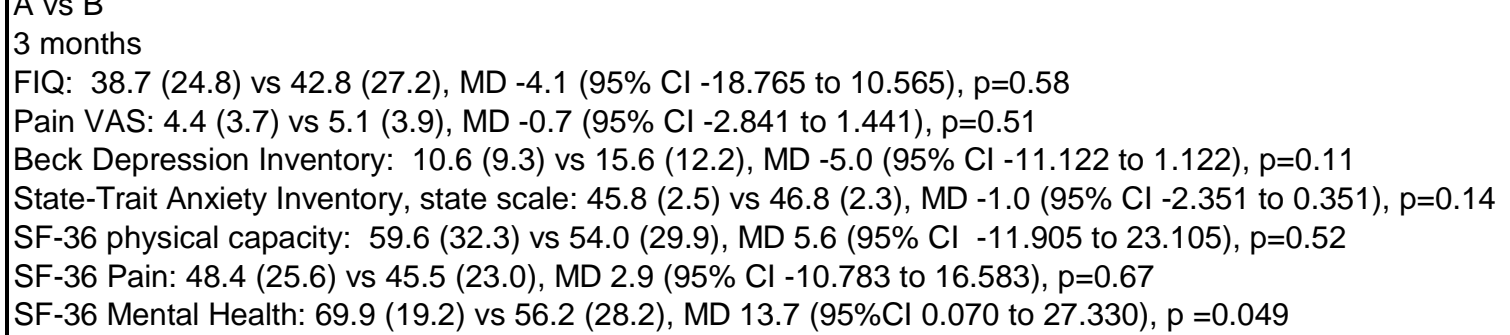 \\
\hline
\end{tabular}




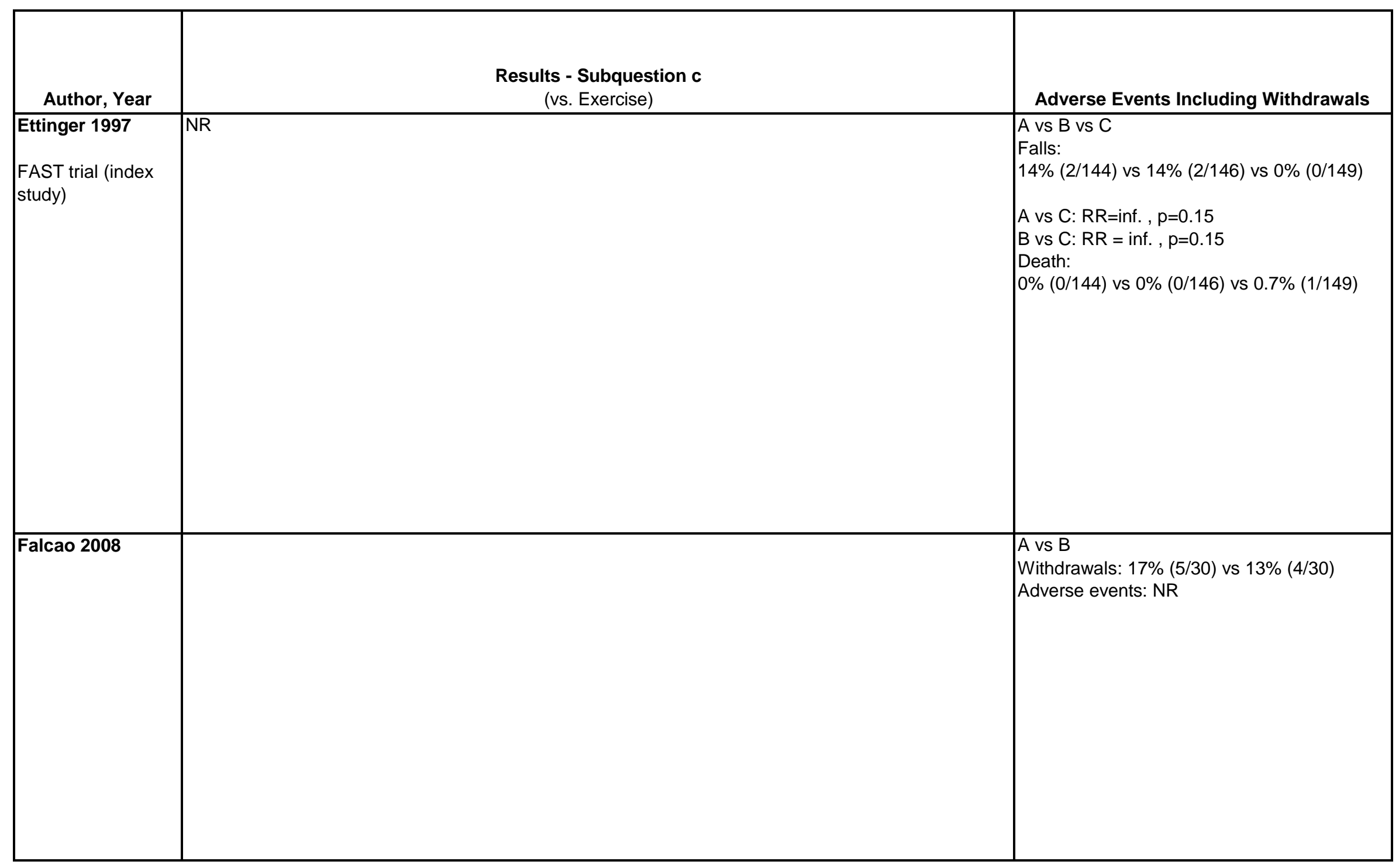




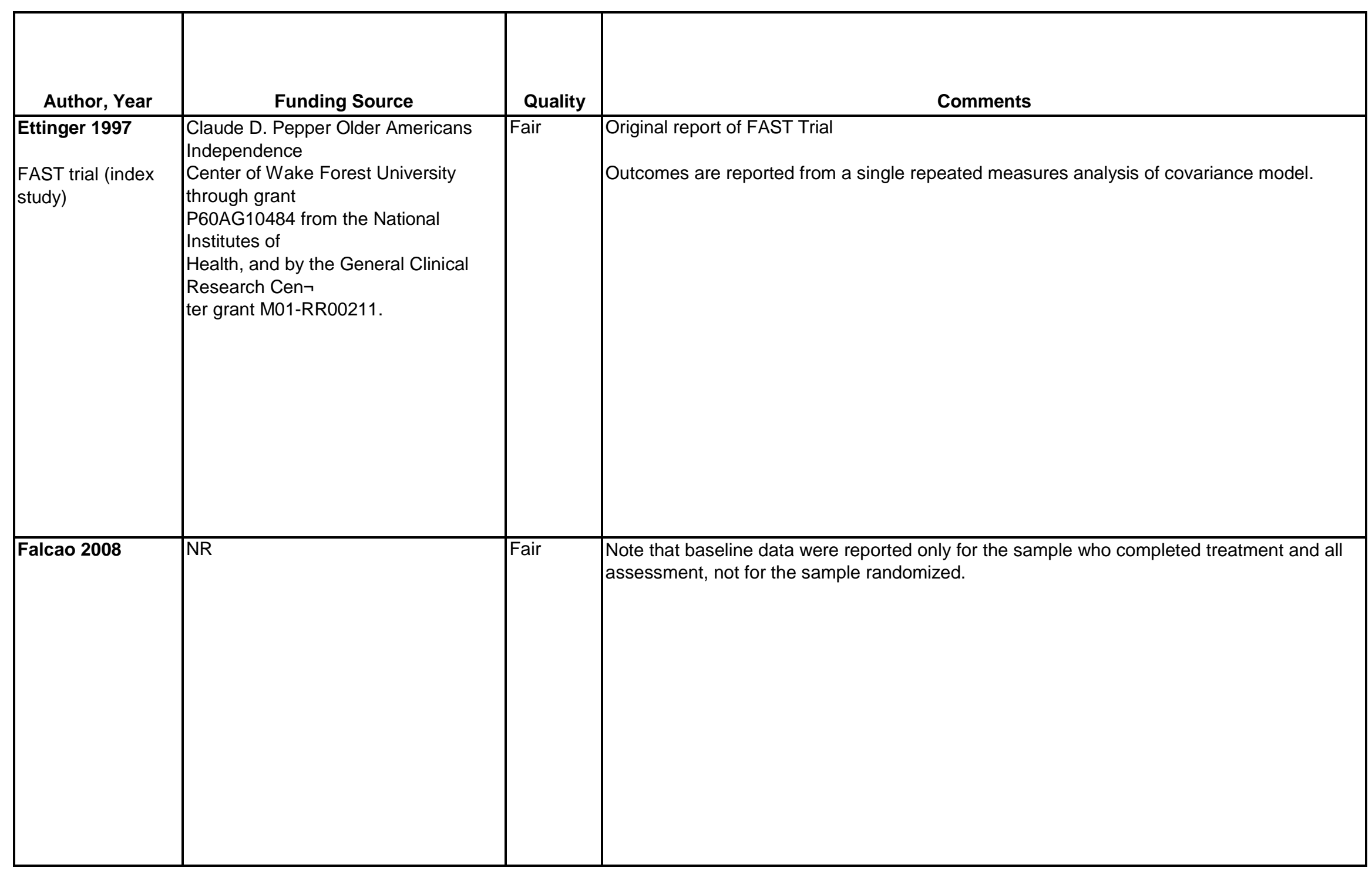




\begin{tabular}{|c|c|c|c|}
\hline Author, Year & $\begin{array}{c}\text { Country } \\
\text { Number of Centers } \\
\text { Setting }\end{array}$ & Inclusion/Exclusion Criteria & $\begin{array}{c}\text { Number Randomized, } \\
\text { Analyzed } \\
\text { Attrition } \\
\end{array}$ \\
\hline Fary 2011 & $\begin{array}{l}\text { Australia, setting not } \\
\text { reported }\end{array}$ & $\begin{array}{l}\text { Inclusion Criteria: } \\
\text { Confirmed diagnosis of knee OA (by American College of } \\
\text { Rheumatology criteria), persistent and stable pain(unchanging for } \\
\text { better or worse) for minimum of } 3 \text { months prior to study entry, with } \\
\text { baseline pain score of at least } 25 \mathrm{~mm} \text { on a } 100 \mathrm{~mm} \text { VAS. } \\
\\
\text { Exclusion Criteria: } \\
\text { Exclusion for coexisting inflammatory arthropathies, contraindications } \\
\text { to electrical stimulation, skin disorders in the vicinity of the knee to be } \\
\text { treated, total knee replacement scheduled during the study period, } \\
\text { and/or insufficient English to follow instructions and complete forms. }\end{array}$ & $\begin{array}{l}\text { Randomized: } 70 \\
\text { Treated: } 67 \\
\text { Analyzed: } 70 \text { (ITT) } \\
\text { Attrition: } 4.2 \%(3 / 70)\end{array}$ \\
\hline Ferreira, 2007 & $\begin{array}{l}\text { Australia } \\
\text { Number of centers: } 3 \\
\text { Outpatient clinic } \\
\text { physical therapy }\end{array}$ & $\begin{array}{l}\text { Patients with non-specific low back pain for at least } 3 \text { months, } 18 \text { to } 80 \\
\text { years old, with written informed } \\
\text { voluntary consent } \\
\text { Exclude: patients with neurological signs, specific spinal pathology } \\
\text { (e.g. malignancy, or inflammatory joint or bone disease) or previous } \\
\text { back surgery }\end{array}$ & $\begin{array}{l}\text { Randomized: } 240 \\
\text { Treated: } 240 \\
\text { Analyzed: } 240 \\
\text { Attrition: } 8 \%(211 / 240)\end{array}$ \\
\hline
\end{tabular}




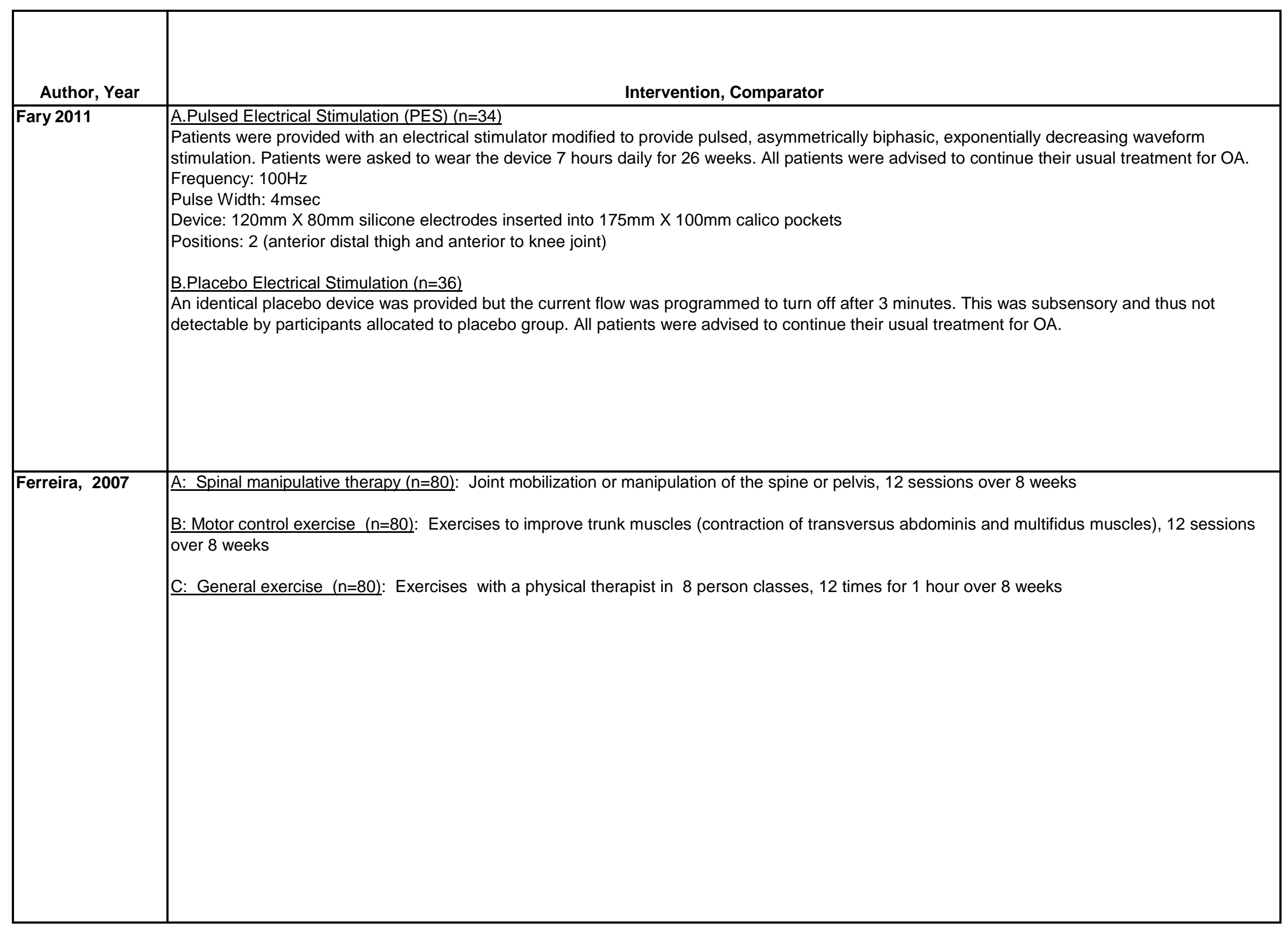




\begin{tabular}{|c|c|c|c|}
\hline Author, Year & Study Participants & Outcome Measures & $\begin{array}{l}\text { Duration of } \\
\text { Followup }\end{array}$ \\
\hline Fary 2011 & $\begin{array}{l}\text { A vs B } \\
\text { Age: } 71 \text { vs. } 69 \text { years } \\
\text { Female: } 50 \% \text { vs. } 44 \% \\
\text { Race: NR } \\
\text { Mean Duration of Chronicity: } 12.6 \text { vs. } 11.4 \text { years } \\
\text { Analgesic Medication Use: } 34 \% \text { vs. } 51 \% \\
\\
\text { Total (WOMAC): } 36(16.8) \text { vs. } 34(14.6) \\
\text { Function (WOMAC): } 35 \text { (17.6) vs. } 34(16.5) \\
\text { Stiffness (WOMAC): } 45(20.9) \text { vs. } 41(18.7) \\
\text { Pain Subscale (WOMAC): } 35(16.3) \text { vs. } 36(18.1) \\
\text { Pain (VAS, 0-100mm): } 51(17.2) \text { vs. } 52(18.2) \\
\text { SF-36 Physical Component: } 37.0(8.5) \text { vs. } 36.5(9.1) \\
\text { SF-36 Mental Component: } 52.7(11.0) \text { vs. 53.7(11.2) } \\
\text { Patient's Global Assessment of Disease Activity (VAS 0-100mm): } \\
44(19.3) \text { vs. } 47 \text { (24.5) }\end{array}$ & $\begin{array}{l}\text { WOMAC, all scores normalized to 0-100; higher } \\
\text { score=worse symptoms) } \\
\text { WOMAC total } \\
\text { WOMAC } \\
\text { physical function subscale WOMAC } \\
\text { stiffness subscale WOMAC } \\
\text { pain subscale } \\
\text { Pain on VAS (0-100; higher score=worse pain) } \\
\text { SF-36 Physical Component Summary Score (SF-36, } \\
\text { 0-100, higher score=improved state) } \\
\text { SF-36 Mental Component Summary Score (SF-36, } \\
0-100, \text { higher score=improved state) }\end{array}$ & 6.5 months \\
\hline Ferreira, 2007 & $\begin{array}{l}\text { A vs. B vs. C } \\
\text { Age: } 54 \text { vs. } 52 \text { vs. } 55 \text { years } \\
\text { Female: } 70 \% \text { vs. } 66 \% \text { vs. } 70 \% \\
\text { Low back pain duration } 3-12 \text { months: } 28 \% \text { vs. } 24 \% \text { vs. } 21 \% \\
\text { Low back pain duration } 13-36 \text { months: } 18 \% \text { vs. } 29 \% \text { vs. } 14 \% \\
\text { Low back pain duration }>36 \text { months: } 55 \% \text { vs. } 48 \% \text { vs. } 65 \%\end{array}$ & $\begin{array}{l}\text { Patient-Specific Functional Scale (PSFS): } 3 \text { (unable to } \\
\text { perform activities) to } 30 \text { (able to perform activities at pre- } \\
\text { injury level) } \\
\text { Pain (Average pain intensity over the last week, a visual } \\
\text { analogue scale, } 0=\text { no pain } 10=\text { worst pain possible) } \\
\text { Roland Morris Disability Questionnaire (RDQ) ( } 0=\text { no } \\
\text { disability to } 24=\text { severe disability ) }\end{array}$ & $\begin{array}{l}4 \text { and } 10 \\
\text { months }\end{array}$ \\
\hline
\end{tabular}




\begin{tabular}{|c|c|}
\hline Author, Year & $\begin{array}{c}\text { Results - Subquestion a } \\
\text { (vs. sham, no treatment, waitlist, attention control) }\end{array}$ \\
\hline Fary 2011 & 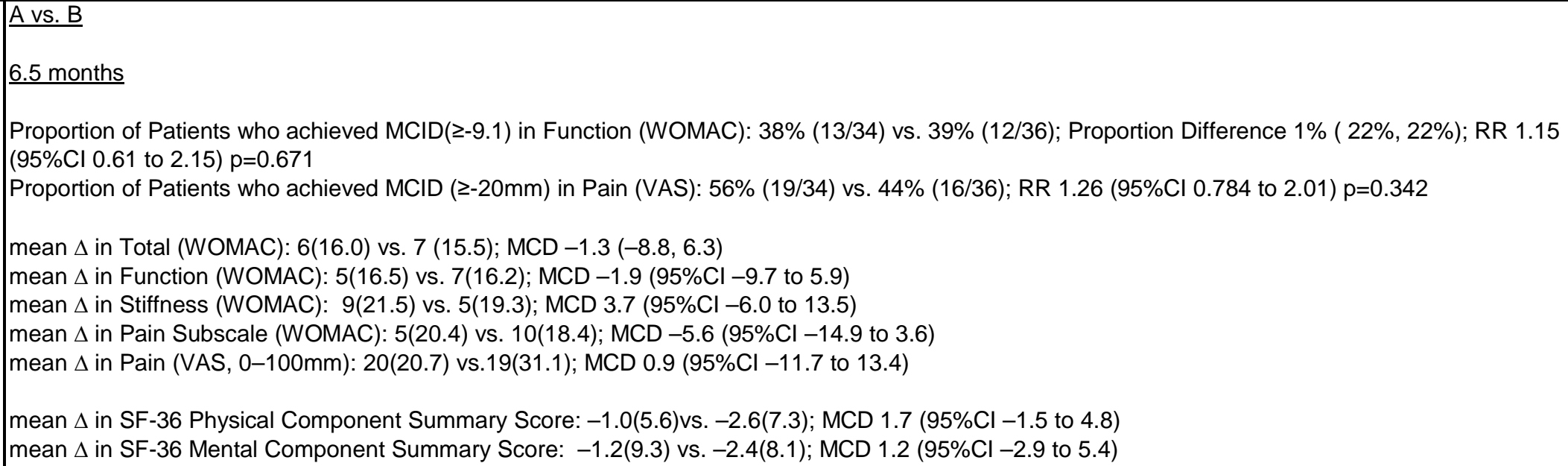 \\
\hline Ferreira, 2007 & NR \\
\hline
\end{tabular}




$$
E
$$




\begin{tabular}{|c|c|c|}
\hline Author, Year & $\begin{array}{l}\text { Results - Subquestion c } \\
\text { (vs. Exercise) }\end{array}$ & Adverse Events Including Withdrawals \\
\hline Fary 2011 & NR & $\begin{array}{l}18 \%(6 / 34) \text { in the treatment group vs. } 17 \% \\
\text { (6/36) in the control group experienced } \\
\text { localized, mild rashes; RR } 1.06(95 \% \mathrm{Cl} 0.378 \\
\text { to } 2.97) \mathrm{p}=0.914\end{array}$ \\
\hline Ferreira, 2007 & 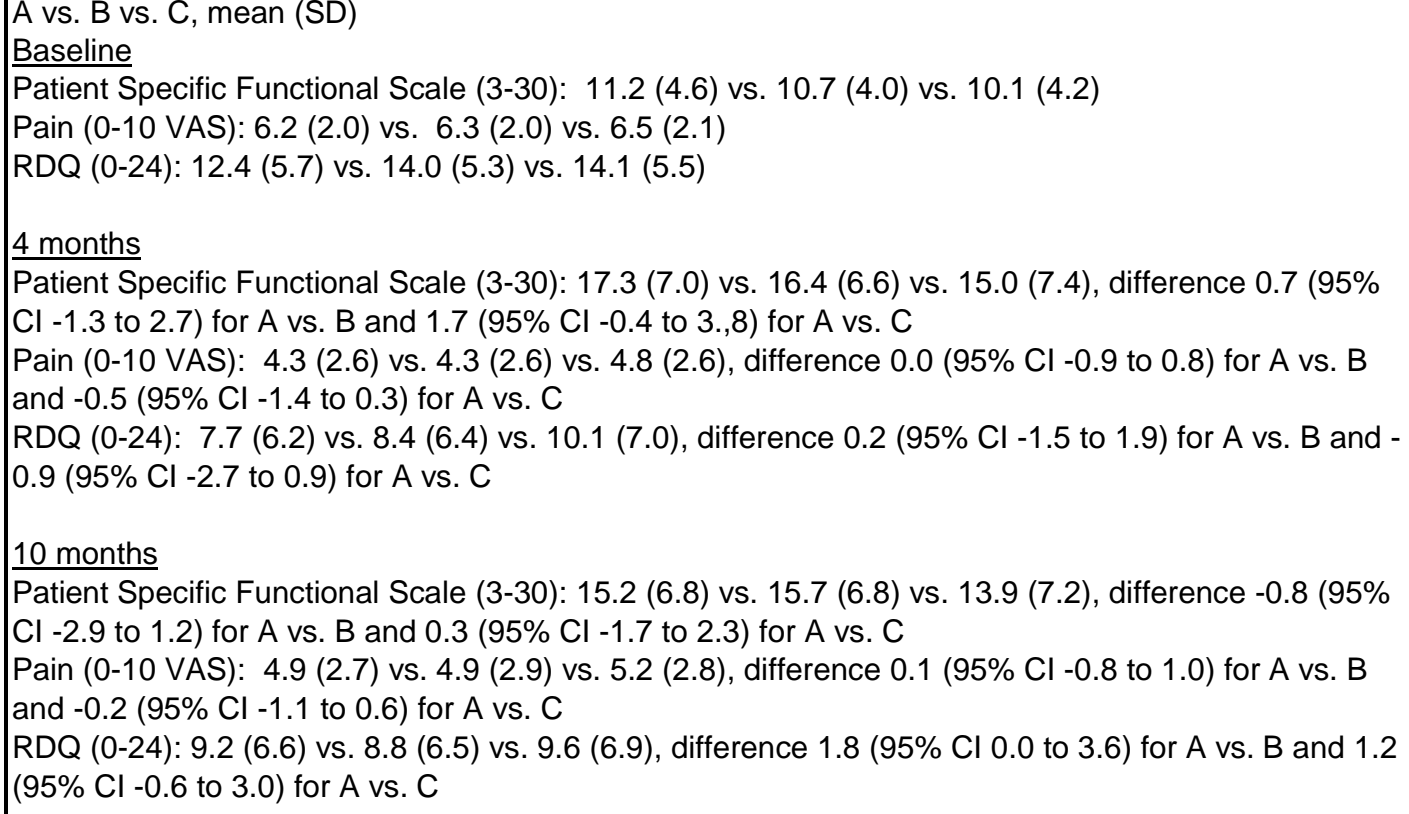 & No adverse events were reported \\
\hline
\end{tabular}




\begin{tabular}{|c|c|c|c|}
\hline Author, Year & Funding Source & Quality & Comments \\
\hline
\end{tabular}




\begin{tabular}{|c|c|c|c|}
\hline Author, Year & $\begin{array}{c}\text { Country } \\
\text { Number of Centers } \\
\text { Setting }\end{array}$ & Inclusion/Exclusion Criteria & $\begin{array}{c}\text { Number Randomized, } \\
\text { Analyzed } \\
\text { Attrition }\end{array}$ \\
\hline $\begin{array}{l}\text { Fontaine } 2010 \\
2011\end{array}$ & $\begin{array}{l}\text { United States } \\
\text { University medical } \\
\text { center Arthritis } \\
\text { Center, newspaper } \\
\text { ads, clinicaltrials.gov }\end{array}$ & $\begin{array}{l}\text { Met } 1990 \text { American College of Rheumatology diagnostic criteria for } \\
\text { FM, age } 18 \text { or older, not meeting US Surgeon General's } 1996 \\
\text { recommendations for physical activity } \\
\text { Exclude: medical conditions that could preclude active participation, } \\
\text { plans to change medication that might affect mood, intent to seek } \\
\text { professional attention for anxiety or depression during study period }\end{array}$ & $\begin{array}{l}\text { Randomized: } 84 \\
\text { Analyzed: } 53 \\
\text { Attrition: } 37 \% \text { (31/84) }\end{array}$ \\
\hline Fukuda 2011 & $\begin{array}{l}\text { Brazil, two site, } \\
\text { hospital }\end{array}$ & $\begin{array}{l}\text { Inclusion Criteria: } \\
\text { Patients }>40 \text { years old with primary grade II or II knee OA based on } \\
\text { Gupta and colleagues radiographic criteria, and had had joint or } \\
\text { anterior knee pain for at least } 3 \text { months } \\
\text { Exclusion Criteria: } \\
\text { Patients were exclude if they had a history of surgery or any invasive } \\
\text { procedure of the affected knee, physical therapy for knee injuries or } \\
\text { any medication that had changed in the last } 3 \text { months, or other } \\
\text { diseases affection functional nd patients who presented any } \\
\text { contraindication for application of PSW treatment, especially metallic } \\
\text { implants, pacemakers, lack of sensitivity or tumor. }\end{array}$ & $\begin{array}{l}\text { Randomized: } 86 \\
\text { Treated: } 86 \\
\text { Analyzed: } 51 \\
\text { Attrition: } 41 \%(35 / 86)\end{array}$ \\
\hline
\end{tabular}




\begin{tabular}{|c|c|}
\hline Author, Year & Intervention, Comparator \\
\hline $\begin{array}{l}\text { Fontaine } 2010 \\
2011\end{array}$ & $\begin{array}{l}\text { A.Lifestyle Physical Activity }(\mathrm{n}=30): 6,60 \text {-minute group sessions over } 12 \text { weeks. Goal was to help subjects increase moderate-intensity physical } \\
\text { exercise by accumulating short bursts of physical activity (e.g.,, walking, yard work, climbing stairs) throughout the day to } 30 \text { minutes } 5-7 \text { days per } \\
\text { week. } \\
\text { B.Fibromyalgia Education attention control condition }(n=23) \text { : met monthly for } 3 \text { months. Included education about FM and social support. }\end{array}$ \\
\hline Fukuda 2011 & $\begin{array}{l}\text { A.Low-dose Pulsed Short Wave (PSW) }(\mathrm{n}=32) \\
\text { Patients received a pre-calibrated device set to output a specific frequency and pulse duration. Patients administered the device with a care } \\
\text { provider nearby but without direct input from care provider. } \\
\text { No. of Treatments: } 3 \text { applications per week for } 3 \text { weeks }(9 \text { total) } \\
\text { Length of Treatment: } 19 \text { minutes per session } \\
\text { Total Energy: } 17 \mathrm{~kJ} \\
\text { Frequency: } 27.12 \mathrm{MHz} \\
\text { Mean Power Output: } 14.5 \mathrm{~W} \\
\text { Pulse Duration: } 400 \text { microseconds } \\
\text { Pulse Frequency: } 145 \mathrm{~Hz} \\
\text { Positions: Anterior area of the thigh, } 5 \mathrm{~cm} \text { above superior border of the patella } \\
\text { B.High-dose PSW ( } \mathrm{n}=31) \\
\text { Treatment characteristics were identical to Group A except length of treatment (and received total energy) were doubled } \\
\text { No. of Treatments: } 3 \text { applications per week for } 3 \text { weeks }(9 \text { total) } \\
\text { Length of Treatment: } 38 \text { minutes per session } \\
\text { Total Energy: } 33 \mathrm{~kJ} \\
\text { C.Sham ( } \mathrm{n}=23) \\
\text { Treatment characteristics were identical to Group A except the device was kept in standby mode without any electrical current applied. } \\
\text { No. of Treatments: } 3 \text { applications per week for } 3 \text { weeks }(9 \text { total) } \\
\text { Length of Treatment: } 19 \text { minutes per session }\end{array}$ \\
\hline
\end{tabular}




\begin{tabular}{|c|c|c|c|}
\hline Author, Year & Study Participants & Outcome Measures & $\begin{array}{c}\text { Duration of } \\
\text { Followup }\end{array}$ \\
\hline $\begin{array}{l}\text { Fontaine } 2010 \\
2011\end{array}$ & $\begin{array}{l}\text { A vs } B \\
\text { Age: } 46 \text { vs } 49 \\
\text { Female: } 94 \% \text { vs } 100 \% \\
\text { Race, white: } 78 \% \text { vs } 82 \% \\
\text { Years since diagnosis: } 5.9 \text { vs } 9.6, p=0.007 \\
\text { Fibromyalgia } \\
\text { FIQ: } 67.5(12.0) \text { vs } 69.7(13.4) \\
\text { Pain VAS: } 54.6(25.6) \text { vs } 58.9(25.0) \\
\text { CES-D: } 23.4(8.6) \text { vs } 24.0(10.0), p=0.06\end{array}$ & $\begin{array}{l}\text { Fibromyalgia Impact Questionnaire } \\
\text { Pain VAS (0-100, higher score=greater current pain) } \\
\text { Center for Epidemiological Studies Depression Scale } \\
\text { (CES-D; higher score=greater depression) }\end{array}$ & $\begin{array}{l}6 \text { and } 12 \\
\text { months }\end{array}$ \\
\hline Fukuda 2011 & $\begin{array}{l}\text { A. vs B. vs. C } \\
\text { Age: } 62 \text { vs. } 63 \text { vs. } 57 \\
\text { Female: } 100 \% \\
\text { Race: NR } \\
\text { Mean Duration of Chronicity: NR } \\
\text { KOOS Symptoms Subscale: } 46.5(19.8) \text { vs. } 47.0(18.0) \text { vs. } 42.0 \\
(17.9) ; \\
\text { KOOS Daily Activities Subscale: } 45.8(19.8) \text { vs. } 51.7(19.1) \text { vs. } \\
45.7(16.3) \\
\text { KOOS Recreational Activities Subscale: } 16.6(10.3) \text { vs. } 15.3(17.6) \text { vs. } \\
\text { 18.2(15.0) } \\
\text { KOOS Pain Subscale: } 37.4(17.4) \text { vs. } 42.5(16.0) \text { vs. } 38.0(13.5) \\
\text { Numerical Pain Rating Scale (NPRS) } 7.1(2.8) \text { vs. } 6.7(2.5) \text { vs. } 7.7(1.4) \\
\text { KOOS Quality of Life Subscale: } 26.1(12.0) \text { vs. } 32.4(15.0) \text { vs. } \\
27.8(29.7)\end{array}$ & $\begin{array}{l}\text { Primary } \\
\text { Knee Injury and Osteoarthritis Outcome Score (KOOS, } \\
\text { higher scores on the KOOS represents better function) } \\
\text { KOOS Symptoms Subscale (range, 0-100) } \\
\text { KOOS Daily Activities Subscale (range, 0-100) } \\
\text { KOOS Recreational Activities Subscale (range, 0-100) } \\
\text { KOOS Pain Subscale (range, 0-100) } \\
\text { Numerical Pain Rating Scale (NPRS, range 0-10: higher } \\
\text { scores indicate severity of pain) } \\
\text { Secondary } \\
\text { KOOS Quality of Life Subscale }\end{array}$ & 12 months \\
\hline
\end{tabular}




\begin{tabular}{|c|c|}
\hline Author, Year & $\begin{array}{c}\text { Results - Subquestion a } \\
\text { (vs. sham, no treatment, waitlist, attention control) }\end{array}$ \\
\hline $\begin{array}{l}\text { Fontaine } 2010 \\
2011\end{array}$ & 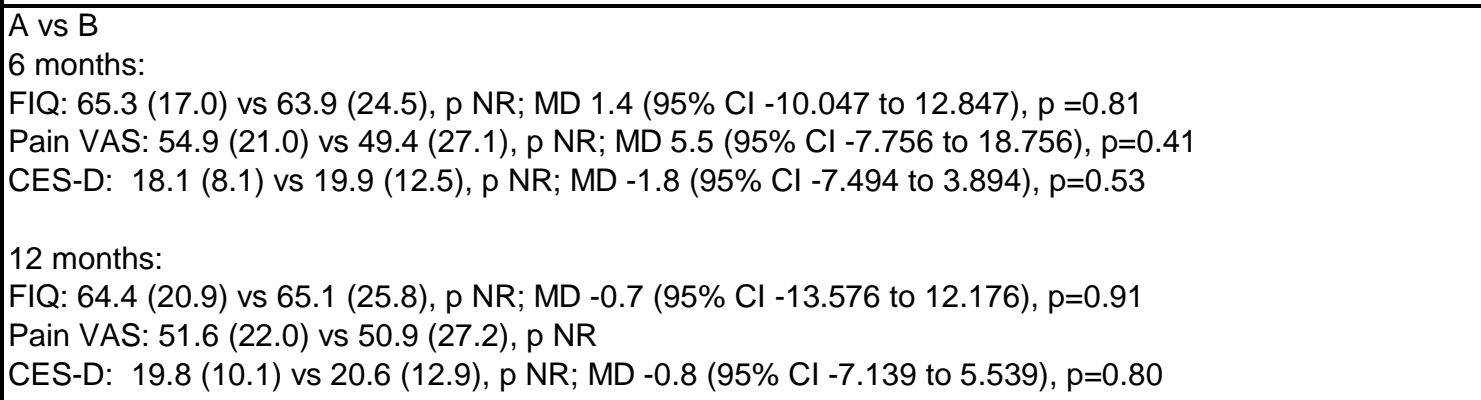 \\
\hline Fukuda 2011 & 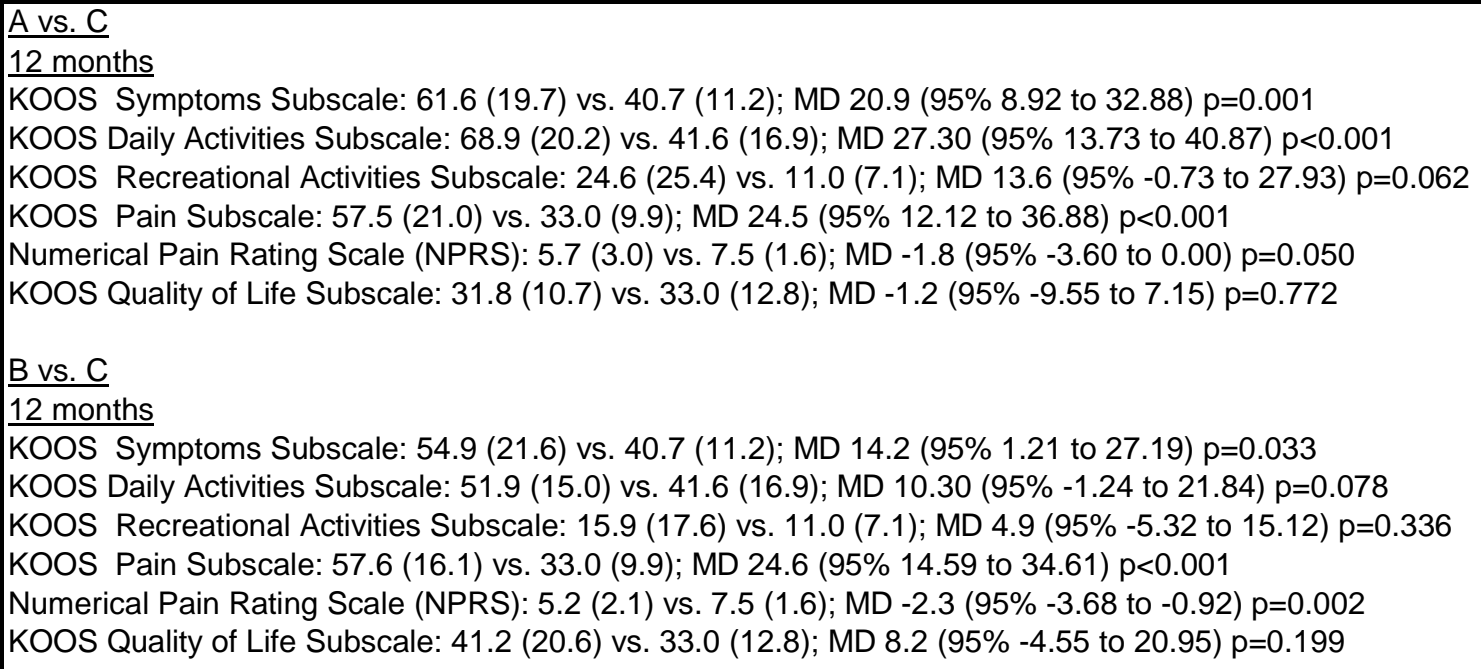 \\
\hline
\end{tabular}




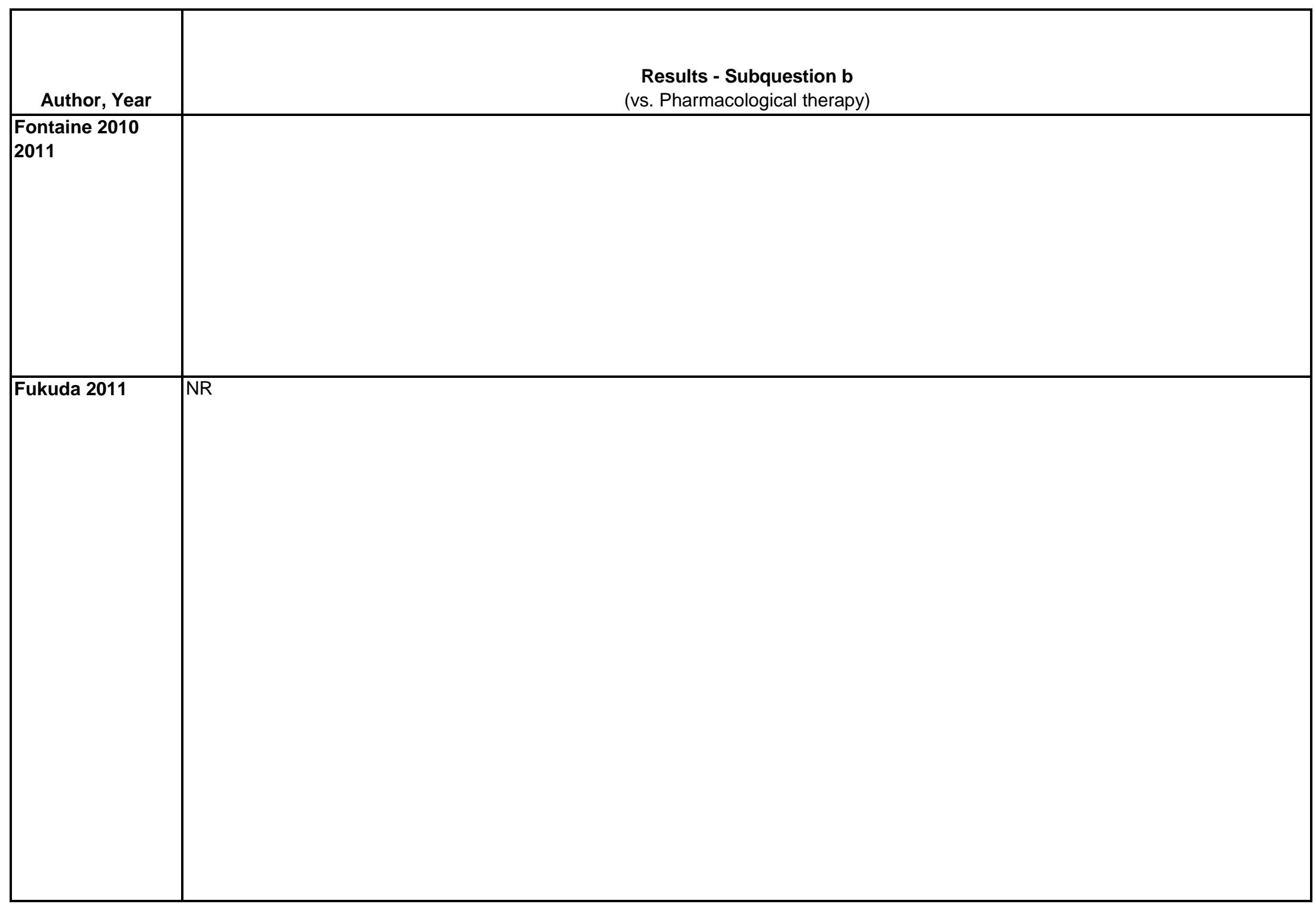

D-313 


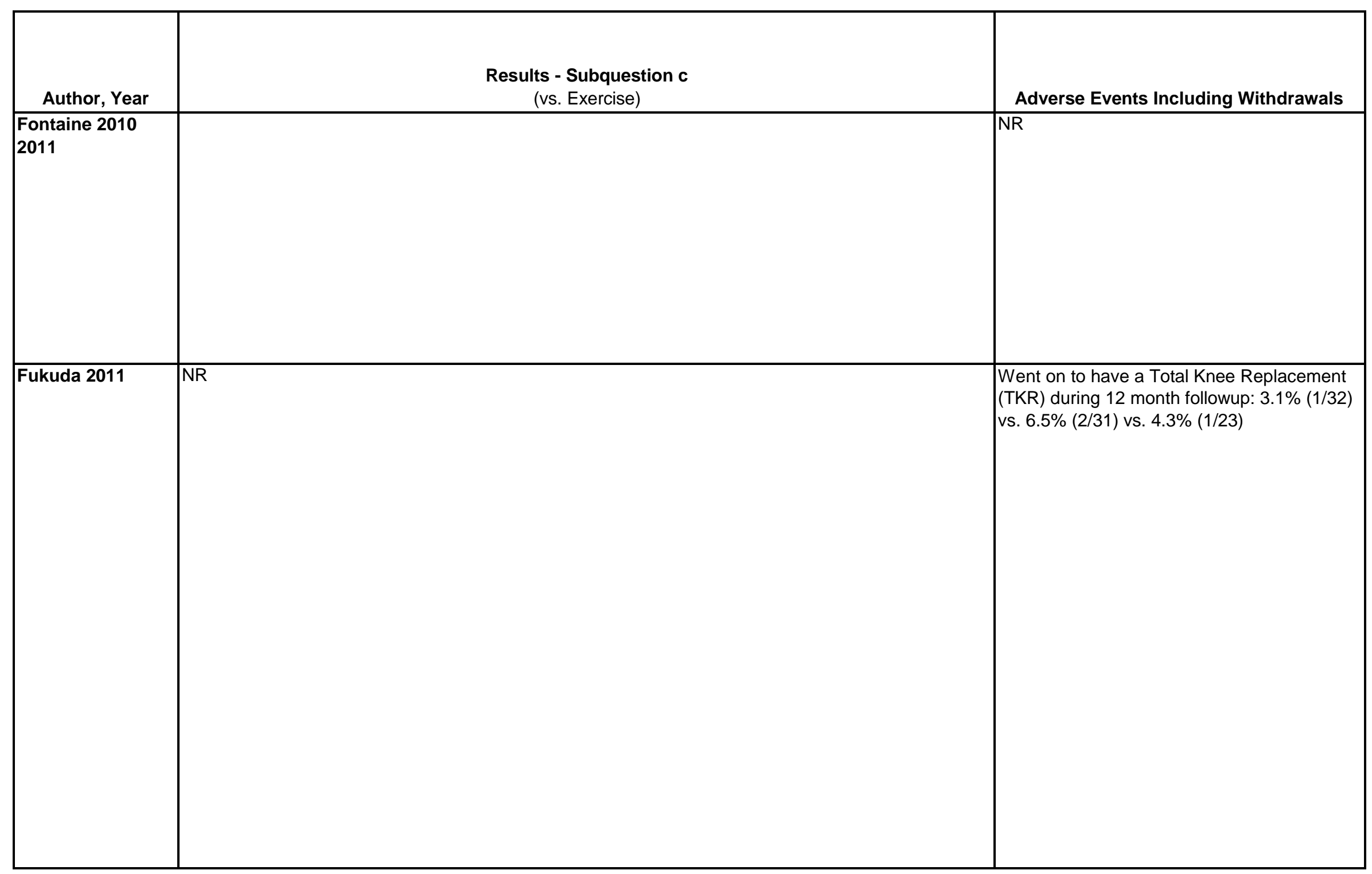




\begin{tabular}{|c|c|c|c|}
\hline Author, Year & Funding Source & Quality & Comments \\
\hline Fukuda 2011 & NR & Poor & $\begin{array}{l}\text { A } 12 \text { month followup was not performed for the no treatment group because after the } \\
\text { treatment phase ended they were referred to traditional physical therapy; therefore, this arm } \\
\text { was excluded due to insufficient followup (immediately post-intervention period only). }\end{array}$ \\
\hline
\end{tabular}




\begin{tabular}{|c|c|c|c|}
\hline Author, Year & $\begin{array}{c}\text { Country } \\
\text { Number of Centers } \\
\text { Setting }\end{array}$ & Inclusion/Exclusion Criteria & $\begin{array}{c}\text { Number Randomized, } \\
\text { Analyzed } \\
\text { Attrition }\end{array}$ \\
\hline Giannotti 2014 & $\begin{array}{l}\text { Italy } \\
\text { Centers and setting } \\
\text { NR }\end{array}$ & $\begin{array}{l}\text { Inclusion: FM diagnosis based on ACR 2010criteria, age 35-65, body } \\
\text { mass index } 18-35 \\
\text { Exclusion: diabetes, other rheumatic diseases including severe } \\
\text { osteoarthritis and severe osteoporosis, use of assistive device to } \\
\text { perform daily activities, orthopedic surgery in past year, attendance in } \\
\text { physical therapy and rehabilitation treatments or change in usual FM } \\
\text { pharmacologic therapy in past } 3 \text { months }\end{array}$ & $\begin{array}{l}\text { Randomized: } 41 \\
\text { Analyzed: } 32 \\
\text { Attrition: } 22 \%(9 / 41)\end{array}$ \\
\hline Gibson 1985 & $\begin{array}{l}\text { UK, London } \\
\text { Number of centers: } 1 \\
\text { Clinic }\end{array}$ & $\begin{array}{l}\text { Patients with chronic low back pain }>2 \text { months but }<12 \text { months. } \\
\text { Exclude: Patients with history of numbness, paresthesia, radicular } \\
\text { pain, and neurological deficit. }\end{array}$ & $\begin{array}{l}\text { Randomized: } 109 \\
\text { Treated: } 108 \\
\text { Analyzed: } 108 \\
\text { Attrition: } 16 \%(18 / 109)\end{array}$ \\
\hline Giombini 2011 & Italy & $\begin{array}{l}\text { Inclusion Criteria: } \\
\text { Inclusion criteria were age } 60 \text { and above of both sex; mono or bilateral } \\
\text { moderate knee OA (Kellgren and Lawrence grading system II and III), } \\
\text { knee pain for at least } 6 \text { months and no more than } 4 \text { years; } \\
\text { independent ambulation without a walking aid; no previous knee } \\
\text { surgery or injection of glucocorticoid and/or hyaluronic acid in the last } \\
3 \text { months, no physiotherapy treatment for knee problems in the last } \\
\text { month. } \\
\text { Exclusion Criteria: } \\
\text { Exclusion criteria were tumors, joint disease involving the knee such } \\
\text { as rheumatic or psoriatic arthritis, joint infections, previous lower limb } \\
\text { fractures, neurologic disorders, neck or low back pain with referred } \\
\text { pain to the study knee, impaired cutaneous thermal sensitivity, } \\
\text { previous deep vein thrombosis. Patients with a cardiac pacemaker or } \\
\text { metallic knee implants were not recruited to avoid possible } \\
\text { interactions between electromagnetic fields produced by the } \\
\text { hyperthermia equipment and these devices. }\end{array}$ & $\begin{array}{l}\text { Randomized: } 63 \\
\text { Treated: } 55 \\
\text { Analyzed: } 54 \text { (ITT) } \\
\text { Attrition: } 14.2 \%(9 / 63)\end{array}$ \\
\hline
\end{tabular}




\begin{tabular}{|c|c|}
\hline Author, Year & Intervention, Comparator \\
\hline Giannotti 2014 & $\begin{array}{l}\text { A. Rehabilitation protocol combining physical exercise and education } 2 \text { days a week ( } 60 \text { minutes per session) for } 10 \text { weeks }(n=20) \text {. Sessions were } \\
\text { conducted in a group and supervised by a physiotherapist. Strengthening exercises intensified from session } 8 \text {, and from session } 15 \text {, aerobic } \\
\text { exercises were added. Exercises included stretching, strengthening, active and passive mobilization, spine flexibility, and aerobic training. Goal was } \\
\text { to improve cardiovascular endurance, muscle strength and stretch, and joint range of motion. Subjects were instructed to perform at home the } \\
\text { exercise program at least } 3 \text { times per week. } \\
\text { B.Control group that did not receive A ( } n=12)\end{array}$ \\
\hline Gibson 1985 & $\begin{array}{l}\text { A: Spinal osteopathic manipulation }(n=41) \text {, once weekly for } 4 \text { weeks, including passive articulation of stiff spinal segments and manipulation of the } \\
\text { vertebra facet of sacroiliac joints using minimal rotation } \\
\text { B: Short wave diathermy }(S W D)(n=34), 3 \text { times weekly for } 4 \text { weeks } \\
\text { C. Placebo, detuned SWD }(n=34)\end{array}$ \\
\hline Giombini 2011 & $\begin{array}{l}\text { A.Microwave Diathermy }(\mathrm{n}=29) \\
\text { All participants received hyperthermic treatment (application of superficial heat and electromagnetic energy) from an ALBA Hyperthermia System. } \\
\text { No. of Treatments: } 3 \text { per week for } 4 \text { weeks (12 total) } \\
\text { Length of Treatments: } 30 \text { minutes each } \\
\text { Power Output: } 50 \mathrm{~W} \\
\text { Water Pad Temperature: } 38 \text { degrees Celsius } \\
\text { Pilot Temperature: } 41 \text { degrees Celsius } \\
\text { B.Sham Diathermy ( } n=25) \\
\text { All treatment parameters were identical except the device was set to off, but patients were unable to distinguish sham from real treatment. }\end{array}$ \\
\hline
\end{tabular}




\begin{tabular}{|c|c|c|c|}
\hline Author, Year & Study Participants & Outcome Measures & $\begin{array}{l}\text { Duration of } \\
\text { Followup }\end{array}$ \\
\hline Giannotti 2014 & $\begin{array}{l}\text { A vs B } \\
\text { Age: } 53 \text { vs } 51 \\
\text { Female: } 95 \% \text { vs } 92 \% \\
\text { Duration of FM symptoms before diagnosis, years: } 8 \text { vs } 7 \\
\text { FIQ (mean, } 0-100): 62.7 \text { (14.4) vs } 59.1 \text { (15.6) } \\
\text { Pain VAS: } 6.1(2.1) \text { vs } 6.1(1.6) \\
\text { Sleep VAS: } 6.8(2.7) \text { vs } 6.9(3.5)\end{array}$ & $\begin{array}{l}\text { FIQ (Italian version) (0-100, higher scores= higher } \\
\text { impairment) } \\
\text { Pain VAS ( 0-10, higher scores=greater pain) } \\
\text { Sleep VAS (0-10, higher scores=greater sleep } \\
\text { problems) }\end{array}$ & $\begin{array}{l}1 \text { and } 6 \\
\text { months }\end{array}$ \\
\hline Gibson 1985 & $\begin{array}{l}\text { A vs. B vs. C } \\
\text { Age (mean): } 34 \text { vs. } 35 \text { vs. } 40 \text { years } \\
\text { Female: } 61 \% \text { vs. } 47 \% \text { vs. } 32 \% \\
\text { Race: NR } \\
\text { Pain (median, } 0-100 \text { VAS): } 35 \text { vs. } 45 \text { vs. } 48 \\
\text { Using analgesics: } 25 \% \text { vs. } 18 \% \text { vs. } 50 \%\end{array}$ & $\begin{array}{l}\text { Pain scores (100 mm horizontal visual analogy scale } \\
\text { and spinal tenderness } 0-3, \text { none, mild, moderate, } \\
\text { severe) } \\
\text { Pain intensity } \\
\text { Need for analgesics }\end{array}$ & 2 months \\
\hline Giombini 2011 & $\begin{array}{l}\text { A. vs B. } \\
\text { Age: } 67 \text { vs. } 67 \text { years } \\
\text { Female: } 65.7 \% \text { vs. } 67.8 \% \\
\text { Race: NR } \\
\text { Mean Duration of Chronicity: } \\
\\
\text { Total (WOMAC): } 103.1(27.6) \text { vs. } 101.3(23.4) \\
\text { Pain (WOMAC): } 19.2 \text { (7.3) vs. } 18.5(7.1) \\
\text { Stiffness (WOMAC): } 9.7 \text { (4.1) vs. } 9.7(3.6) \\
\text { Activities of Daily Living (WOMAC): } 74.3(18.9) \text { vs. } 73.1(18.3)\end{array}$ & $\begin{array}{l}\text { Primary: } \\
\text { Western Ontario and McMaster Universities } \\
\text { Osteoarthritis Index (WOMAC, higher scores indicate } \\
\text { greater pain, stiffness or functional limitation) } \\
\text { Total (WOMAC, range } 0-120 \text { ) } \\
\text { Physical Function (WOMAC, range 0-85) } \\
\text { Stiffness (WOMAC, range 0-10 } \\
\text { Pain(WOMAC, range 0-25) }\end{array}$ & 3 months \\
\hline
\end{tabular}




\begin{tabular}{|c|c|}
\hline Author, Year & $\begin{array}{l}\text { Results - Subquestion a } \\
\text { (vs. sham, no treatment, waitlist, attention control) }\end{array}$ \\
\hline Giannotti 2014 & 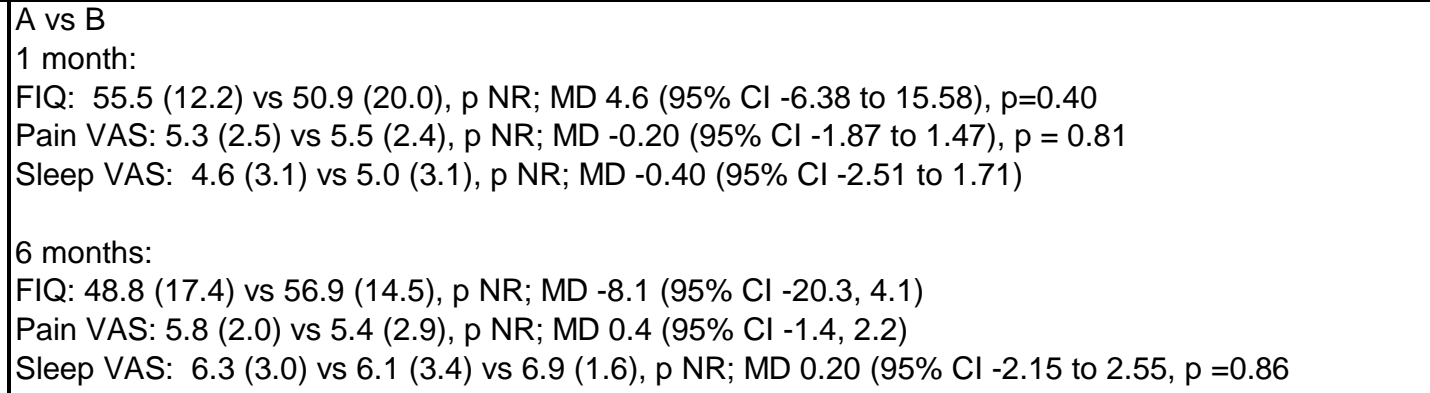 \\
\hline Gibson 1985 & 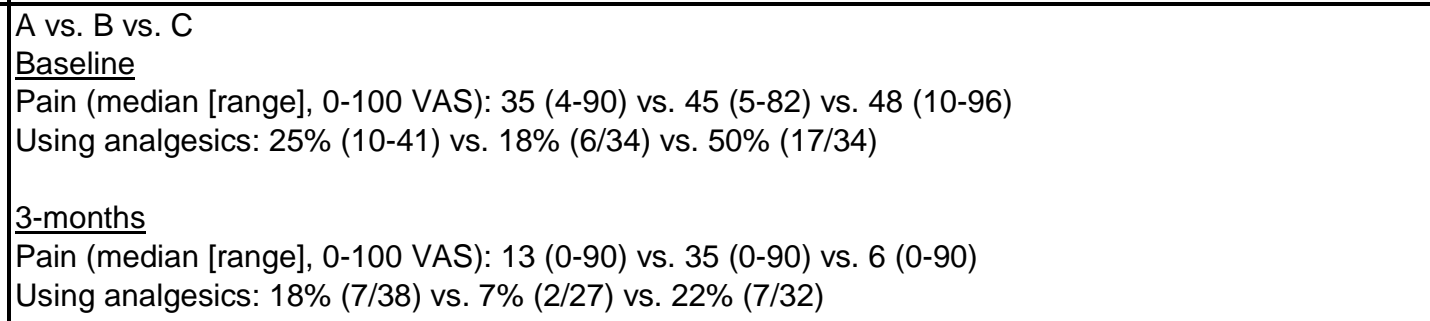 \\
\hline Giombini 2011 & \begin{tabular}{|l} 
A vs. $B$ \\
3 months \\
Mean $\Delta$ in Total (WOMAC): $-46.8(27.2)$ vs. $-0.4(12.7) ; M D-46.4 p<0.01$ \\
Mean $\Delta$ in Pain (WOMAC): -8.6(6.0) vs. -0.6(3.0); MD -8.1 $p<0.01$ \\
Mean $\Delta$ in Stiffness (WOMAC): -5.2(3.8) vs. -0.1(2.9); MD -5.1 $p<0.01$ \\
Mean $\Delta$ Function (WOMAC): -33(19.7) vs. 0.3(9.8); MD -33.2 $p<0.01$
\end{tabular} \\
\hline
\end{tabular}




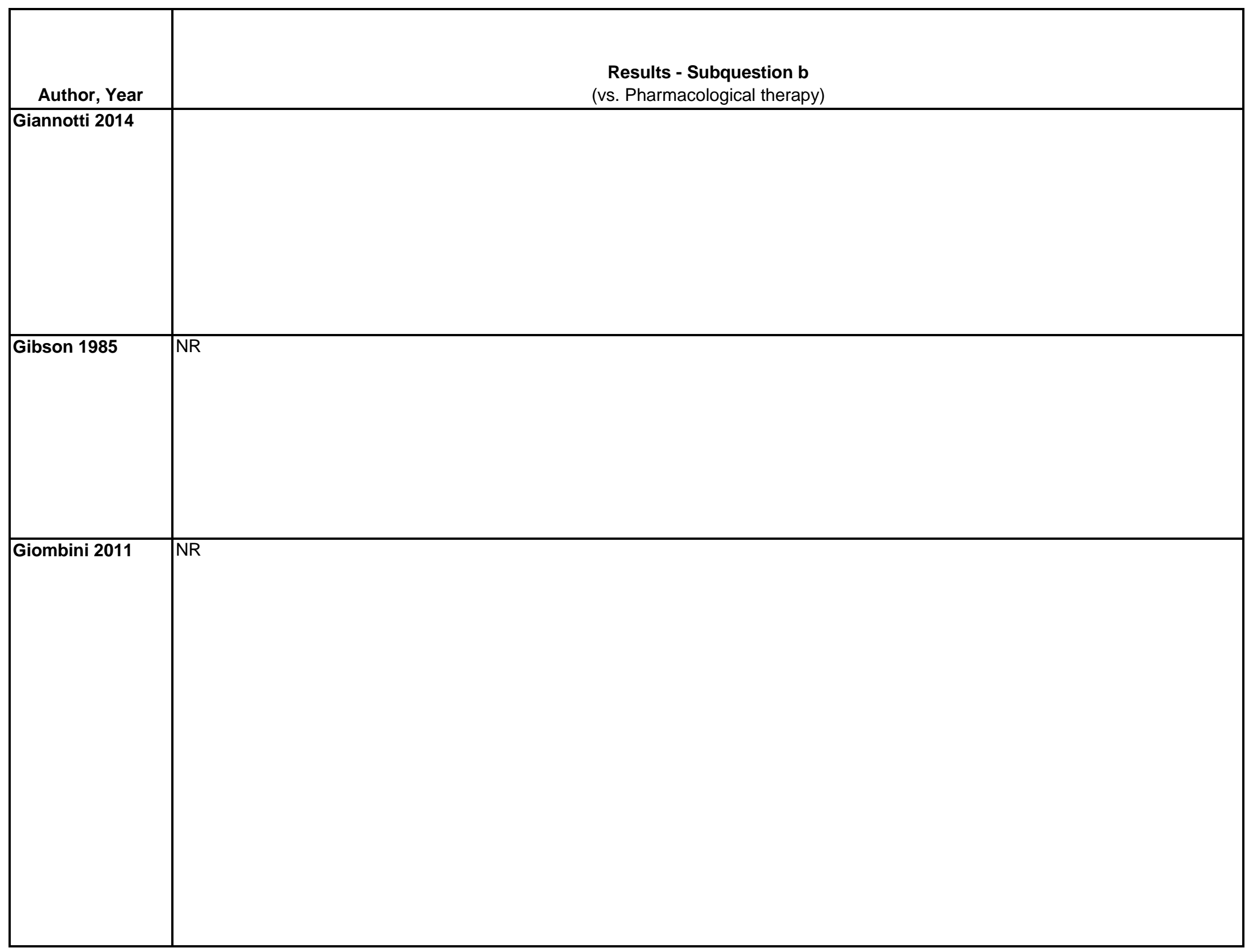

D-320 


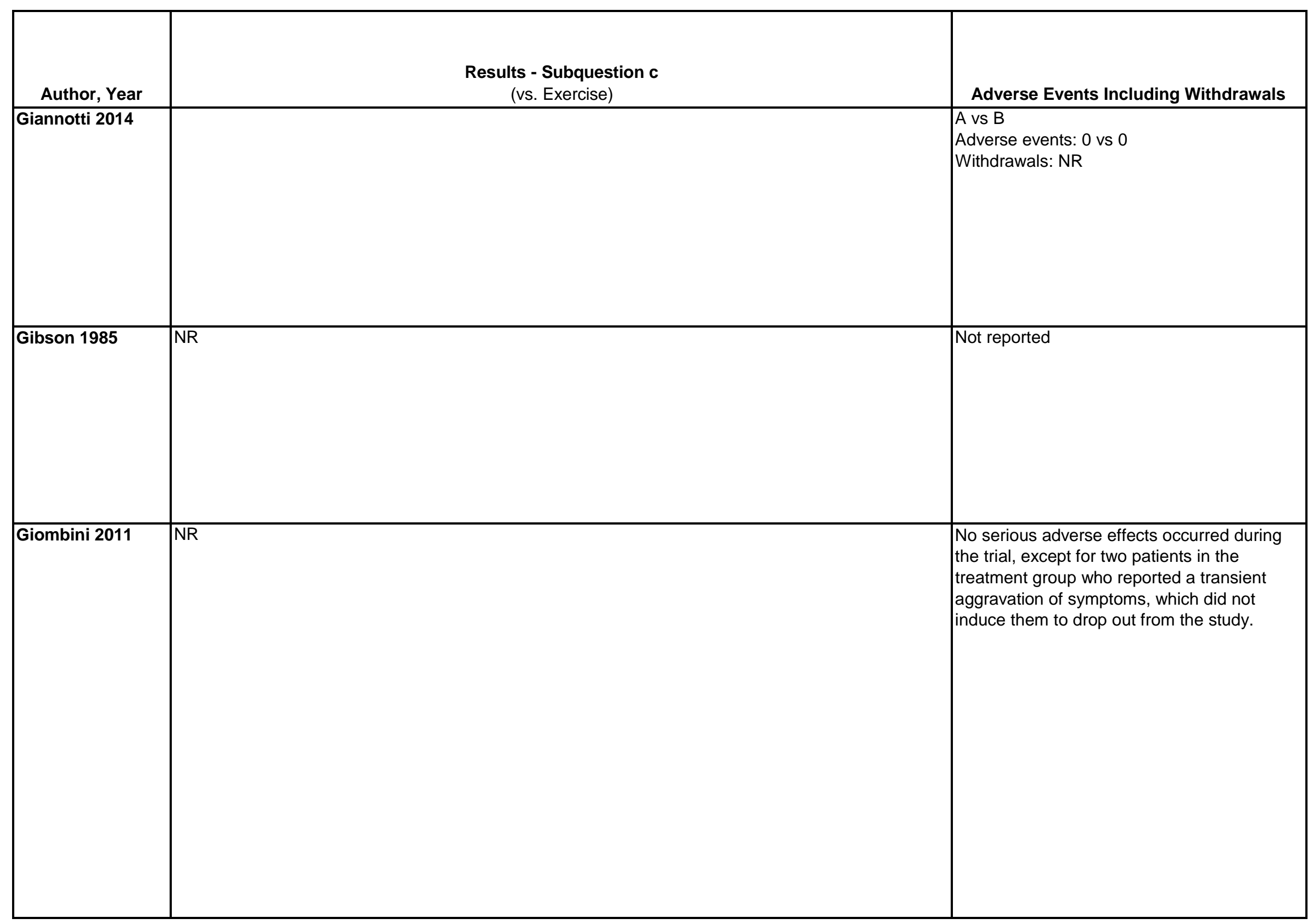




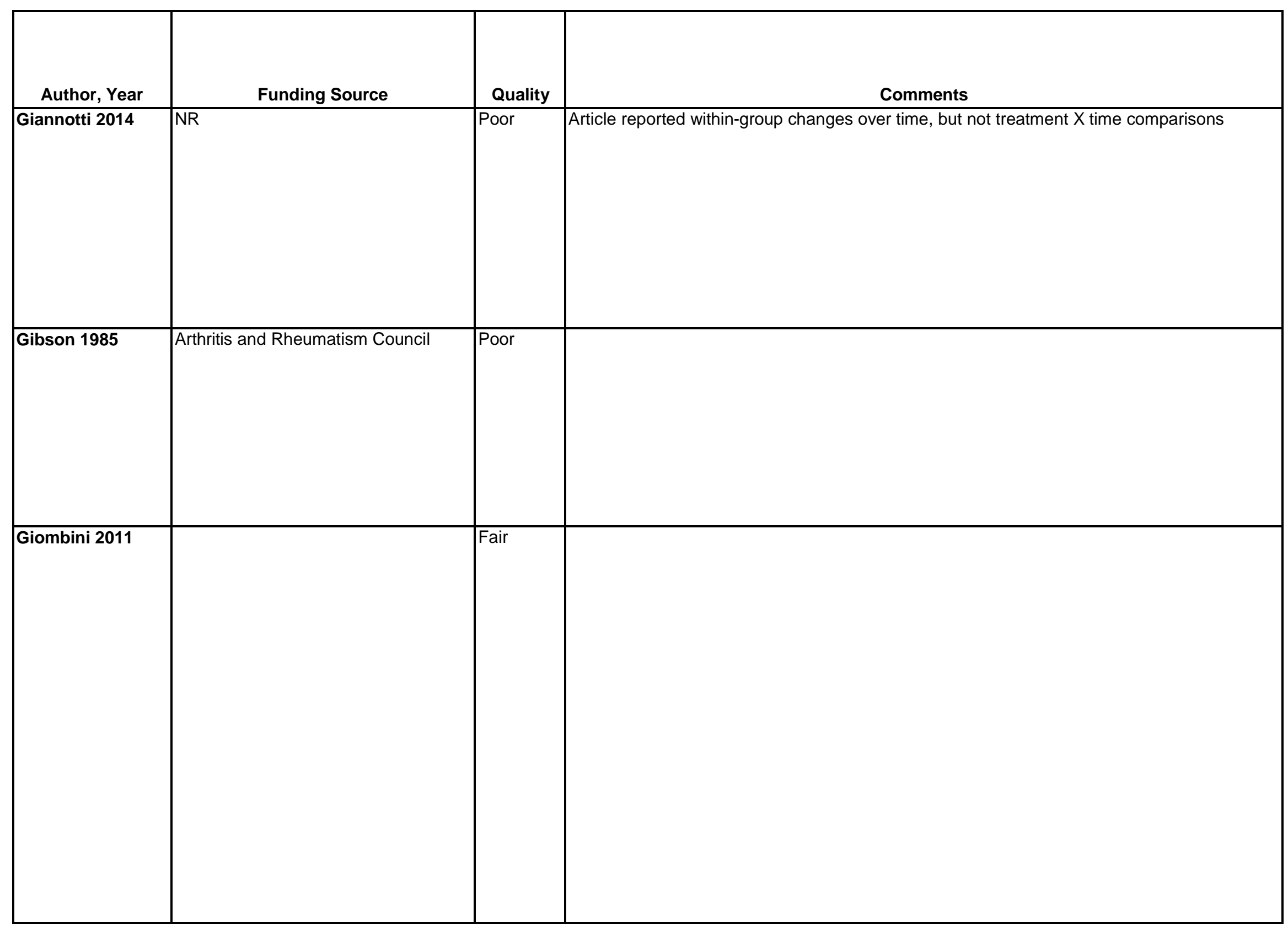




\begin{tabular}{|c|c|c|c|}
\hline Author, Year & $\begin{array}{c}\text { Country } \\
\text { Number of Centers } \\
\text { Setting } \\
\end{array}$ & Inclusion/Exclusion Criteria & $\begin{array}{c}\text { Number Randomized, } \\
\text { Analyzed } \\
\text { Attrition } \\
\end{array}$ \\
\hline Goldby 2006 & $\begin{array}{l}\text { United Kingdom, two- } \\
\text { site, hospital }\end{array}$ & $\begin{array}{l}\text { Inclusion Criteria: } \\
\text { All subjects had chronic low back disorder, with the current episode } \\
\text { lasting for a minimum of } 12 \text { weeks, were aged between } 18 \text { and } 65 \\
\text { years, and able to read and write English. } \\
\text { Exclusion Criteria: } \\
\text { All patients with nonmechanical low back pain were excluded. } \\
\text { Additional exclusion for Spinal stenosis, spondylolisthesis grades III } \\
\text { or IV, or recent fractures; significant or worsening signs of neurologic } \\
\text { deficit; evidence of inflammatory joint disease; lower limb pathology } \\
\text { likely to influence leg pain intensity; present or past history of } \\
\text { metastatic disease; medically unsuitable for participation in the } \\
\text { exercise class; chronic pain syndrome or a history of } 2 \text { operative } \\
\text { interventions for low back pain; history of anxiety neurosis; and } \\
\text { pregnancy. }\end{array}$ & $\begin{array}{l}\text { Randomized: } 323 \\
\text { Treated: } 213 \\
\text { Analyzed: } \\
\text { Attrition: } \\
3 \text { months - } 38 \%(123 / 323) \\
6 \text { months - } 46.1 \% \\
(149 / 323) \\
12 \text { months - } 46.4 \% \\
(150 / 323) \\
24 \text { months - } 71.8 \% \\
(232 / 323)\end{array}$ \\
\hline
\end{tabular}




\begin{tabular}{|c|c|}
\hline Author, Year & Intervention, Comparator \\
\hline Goldby 2006 & $\begin{array}{l}\text { A.Neuromuscular re-education (motor control exercise) }(\mathrm{n}=84) \\
\text { Participants gathered in classes of } 12 \text { participants and were exposed to a functionally progressive exercise class that emphasized the selective } \\
\text { retraining of various muscle groupings. } \\
\text { No. of Treatments: weekly sessions for } 10 \text { weeks (10 total) } \\
\text { Length of Treatments: } 1 \text { hour } \\
\text { B.Manual Therapy ( } n=89) \\
\text { Physiotherapists treated patients according to clinical reasoning. They were not allowed to prescribe exercises nor electrophysical methods. } \\
\text { Patients were discharged at the discretion of the physiotherapist or to a maximum of } 10 \text { interventions. } \\
\text { No. of Treatments: } 1-10 \text { sessions (physiotherapists discretion) } \\
\text { Length of Treatments: NR } \\
\text { C.Attention control (education) ( } n=40) \\
\text { Physiotherapists explained the contents of an educational booklet. } \\
\text { No. of Treatments: } 1 \text { initial consultation with physiotherapist } \\
\text { Additionally, patients in all } 3 \text { groups attended The Back School, which consisted of } 1 \text { group specific } 3 \text {-hour question and answer session on } \\
\text { anatomy and physiology, biomechanics and lifting, pathologies, and advice on education, exercise and general fitness. }\end{array}$ \\
\hline
\end{tabular}




\begin{tabular}{|c|c|c|c|}
\hline Author, Year & Study Participants & Outcome Measures & $\begin{array}{c}\text { Duration of } \\
\text { Followup }\end{array}$ \\
\hline Goldby 2006 & $\begin{array}{l}\text { A vs. B vs. C } \\
\text { Age: } 43 \text { vs. } 41 \text { vs. } 41 \text { years } \\
\text { Female: } 68 \% \text { vs. } 70 \% \text { vs. } 68 \% \\
\text { Race: } 79.8 \% \text { vs. } 75.3 \% \text { vs. } 61.5 \% \\
\text { Mean Duration of Chronicity: } 11.5 \text { vs. } 11.1 \text { vs. } 12.5 \text { years } \\
\\
\text { ODI: } 40.47 \text { (15.62) vs. } 39.17(13.73) \text { vs. } 33.54(12.21) \\
\text { LBO: } 43.86(13.97) \text { vs. } 44.02(13.16) \text { vs. } 47.55(15.58) \\
\text { Back Pain (NRS): } 45.75(27.54) \text { vs. } 55.67(28.35) \text { vs. } 37.6(33.99) \\
\text { Leg Pain (NRS): } 27.54(31.93) \text { vs. } 27.74(34.71) \text { vs. } 21.0(31.94) \\
\text { NHP: } 162.18(105.5) \text { vs. } 163.22(118.98) \text { vs. } 139.61(89.81)\end{array}$ & $\begin{array}{l}\text { Primary: } \\
\text { Oswestry Disability Index (ODI, range 0-100) } \\
\text { Low Back Outcome Score (0-75, higher=better status) } \\
\text { Back Pain (0-100 NRS, higher scores indicate worse } \\
\text { pain) } \\
\text { Leg Pain (0-100 NRS, higher scores indicate worse } \\
\text { pain) } \\
\text { Secondary: } \\
\begin{array}{l}\text { Nottingham Health Profile (NHP) (range unclear, usually } \\
\text { scored } 0 \text { to } 100,100=\text { maximal distress) }\end{array}\end{array}$ & $\begin{array}{l}\text { Short, } \\
\text { intermediate, } \\
\text { and long- } \\
\text { term } \\
3 \text { months, } 6 \\
\text { months, } 12 \\
\text { months, and } \\
24 \text { months } \\
\end{array}$ \\
\hline
\end{tabular}




\begin{tabular}{|c|c|}
\hline Author, Year & $\begin{array}{c}\text { Results - Subquestion a } \\
\text { (vs. sham, no treatment, waitlist, attention control) }\end{array}$ \\
\hline Goldby 2006 & 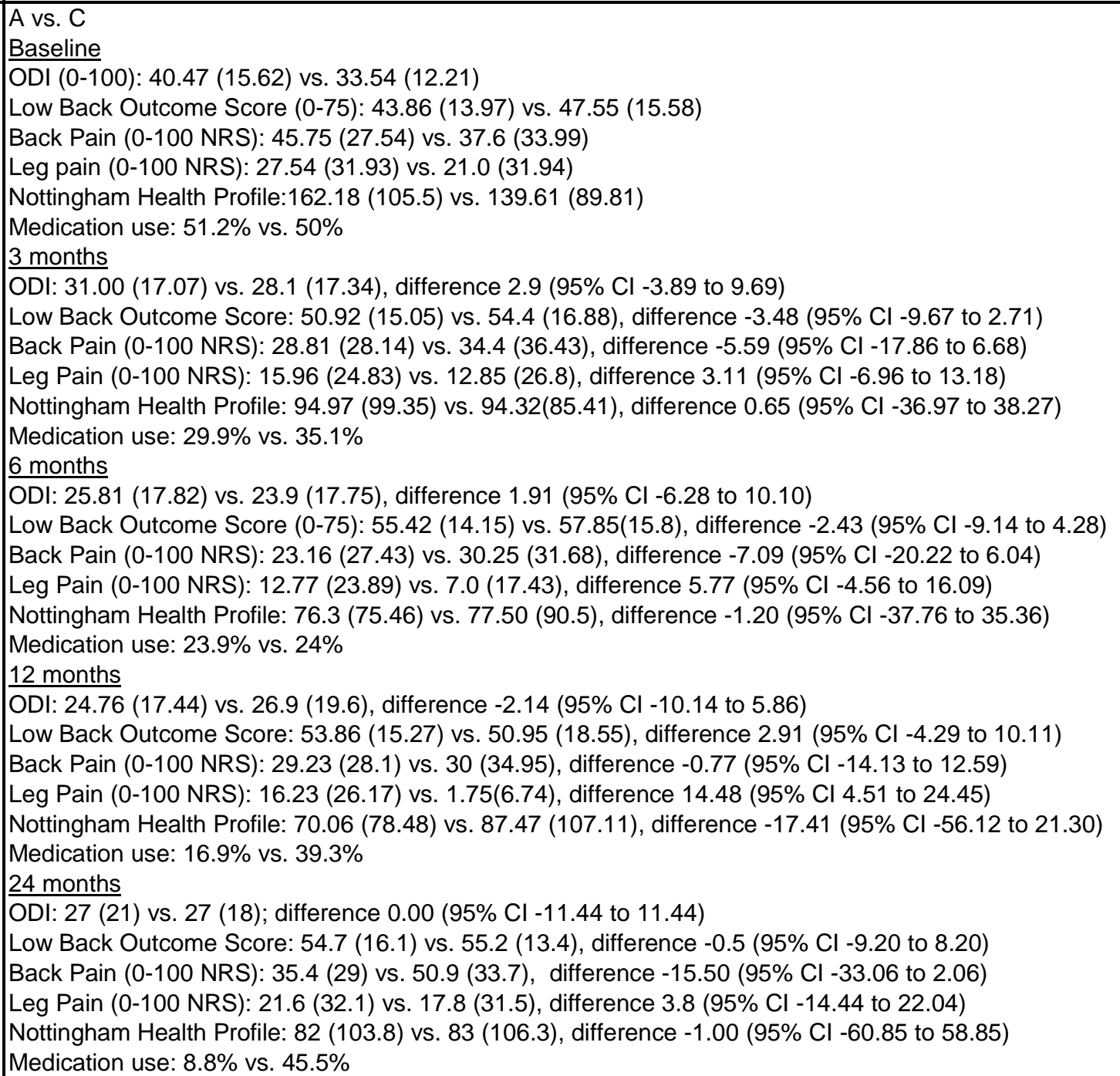 \\
\hline
\end{tabular}




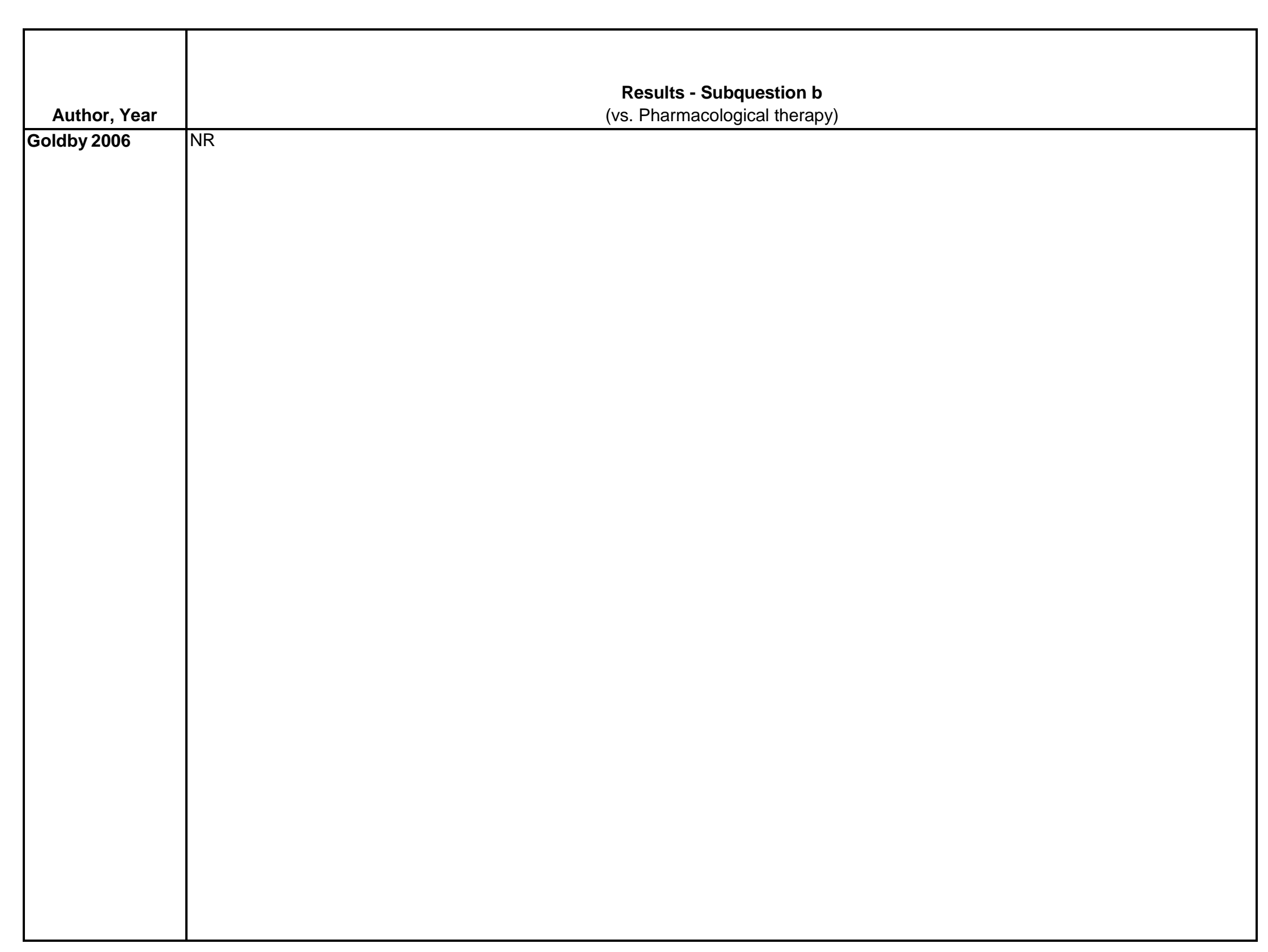

D-327 


\begin{tabular}{|c|c|c|}
\hline Author, Year & $\begin{array}{c}\text { Results - Subquestion c } \\
\text { (vs. Exercise) }\end{array}$ & Adverse Events Including Withdrawals \\
\hline Goldby 2006 & 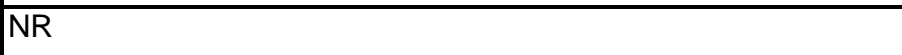 & NR \\
\hline
\end{tabular}




\begin{tabular}{|c|l|l|l|}
\hline Author, Year & \multicolumn{1}{|c|}{ Funding Source } & Quality & \multicolumn{1}{c|}{ Comments } \\
\hline Goldby 2006 & $\begin{array}{l}\text { "Professional Organizational funds } \\
\text { were received in support of this work. } \\
\text { No benefits in any form have been or } \\
\text { will be received from a commercial } \\
\text { party related directly or indirectly to } \\
\text { the subject of this manuscript" }\end{array}$ & $\begin{array}{l}\text { (EB) There is no mention of radiculopathy in the inclusion or exclusion criteria but Leg Pain } \\
\text { is an outcome. No further information is provided. } \\
\text { Abstract states that data were collected at baseline, and 3, 6, 12, and 24 months after } \\
\text { intervention. }\end{array}$ \\
\hline
\end{tabular}




\begin{tabular}{|c|c|c|c|}
\hline Author, Year & $\begin{array}{c}\text { Country } \\
\text { Number of Centers } \\
\text { Setting }\end{array}$ & Inclusion/Exclusion Criteria & $\begin{array}{c}\text { Number Randomized, } \\
\text { Analyzed } \\
\text { Attrition } \\
\end{array}$ \\
\hline Gowans 2001 & $\begin{array}{l}\text { Canada } \\
\text { Advertisements in } \\
\text { Rheumatology clinic } \\
\text { or large urban } \\
\text { teaching hospital and } \\
\text { local FM support } \\
\text { group newsletters }\end{array}$ & $\begin{array}{l}\text { Inclusion: FM diagnosis based on ACR } 1990 \text { criteria } \\
\text { Exclusion: high blood pressure or symptomatic cardiac disease, other } \\
\text { serious systemic disease, intent to change medications for anxiety or } \\
\text { depression, or seek professional treatment for anxiety or depression } \\
\text { during study period, enrolled in or intent to begin aerobic exercise } \\
\text { program }\end{array}$ & $\begin{array}{l}\text { Randomized: } 57 \\
\text { analyzed: } 50 \\
\text { Attrition: } 12 \% \text { (7/57) }\end{array}$ \\
\hline Groessl, 2017 & $\begin{array}{l}\text { US } \\
\text { Number of centers } 1 \\
\text { Outpatient }\end{array}$ & $\begin{array}{l}\text { Age }>18 \text { years with chronic LBP diagnosis }>6 \text { months } \\
\text { Exclude: } \\
\text { Back surgery in the last } 12 \text { months, back pain from systemic } \\
\text { conditions, morbid obesity, acute sciatica/nerve compression, } \\
\text { chronic lumbar radicular pain, serious unstable coexisting medical } \\
\text { or psychiatric conditions, potential metastatic disease, positive } \\
\text { Romberg test, or practiced yoga in the last year }\end{array}$ & $\begin{array}{l}\text { Randomized: } 152 \\
\text { Treated: } 150 \\
\text { Analyzed: } 150 \\
\text { Attrition: } 0.01 \%(2 / 152)\end{array}$ \\
\hline Gudavalli 2006 & $\begin{array}{l}\text { US, Illinois } \\
\text { Number of centers: } 1 \\
\text { Outpatient clinic }\end{array}$ & $\begin{array}{l}\text { Patients with LBP from L1 to SI joint for more that } 3 \text { months, palpatory } \\
\text { tenderness over one or more lumbar zygapophyseal joints, no narcotic } \\
\text { use during treatment phase, no NSAID use and/or muscle relaxant } \\
\text { use } 24 \text { hours prior to baseline or outcome measure assessment } \\
\text { Exclude: Patients younger than } 18 \text { years with central nervous system } \\
\text { disease, contraindication to manual therapy, severe osteoporosis, } \\
\text { lumbar fracture, systemic disease potentially affecting the } \\
\text { musculoskeletal system, failed fusion surgery with unstable } \\
\text { components, inability to undergo physical therapy or flexion- } \\
\text { distraction therapy, psychiatric illnesses or lack of cognitive abilities, } \\
\text { current and known substance abuse, not fluent and/or illiterate in the } \\
\text { English language, morbidly obese, pregnant, receiving care for LBP } \\
\text { other providers, chiropractor or physical therapist in past } 6 \text { months, } \\
\text { not willing to stop LBP care at other clinics, New York Heart } \\
\text { Association Classification grade III or IV }\end{array}$ & $\begin{array}{l}\text { Randomized: } 235 \\
\text { Treated: } 235 \\
\text { Analyzed: } 235 \\
\text { Attrition: } 17 \% \text { (197/235) }\end{array}$ \\
\hline
\end{tabular}




\begin{tabular}{|c|c|}
\hline Author, Year & Intervention, Comparator \\
\hline Gowans 2001 & $\begin{array}{l}\text { A.Supervised exercise group ( } n=27) \text { : } 3 \text { hospital-based exercise classes per week for } 23 \text { weeks. Classes consisted of } 10 \text { minutes stretching and } 20 \\
\text { minutes of aerobic exercise. Classes for the first } 6 \text { weeks were held in a warm therapeutic pool. At } 7 \text { weeks, subjects progressed to } 2 \text { walking } \\
\text { classes in a gym and one pool class. Subjects were taught to maintain their heart rates at } 60-75 \% \text { of age-adjusted maximum heart rates during the } \\
\text { aerobic component. Mean attendance at exercise classes over the } 23-\text { week period was 55\% (range 7-91\%). } \\
\text { B.Control group ( } n=23 \text { ): continued ad libitum activity }\end{array}$ \\
\hline Groessl, 2017 & $\begin{array}{l}\text { A. Hatha yoga ( } n=75) \text { : Two } 60 \text { minute sessions per week for } 12 \text { weeks, } 15-20 \text { minutes of home practice on days without sessions } \\
\text { B. Wait list }(n=75) \text { : Usual care, with yoga started after } 6 \text { months }\end{array}$ \\
\hline Gudavalli 2006 & $\begin{array}{l}\text { A.Flexion-distraction (FD) ( } n=123) \text { : Slow manual traction and mobilization, } 2-4 \text { times per week for } 4 \text { weeks. } \\
\text { B.Active trunk exercise program (ATEP) ( } n=112) \text { : Flexion or extension exercises, weight training, flexibility exercises, and cardiovascular } \\
\text { exercises dependent on patient symptoms, 2-4 times per week for } 4 \text { weeks. }\end{array}$ \\
\hline
\end{tabular}




\begin{tabular}{|c|c|c|c|}
\hline Author, Year & Study Participants & Outcome Measures & $\begin{array}{l}\text { Duration of } \\
\text { Followup }\end{array}$ \\
\hline Gowans 2001 & $\begin{array}{l}\text { A vs B } \\
\text { Age, years: } 45 \text { vs } 50, p<0.05 \\
\text { Female: } 89 \% \text { vs } 87 \% \\
\text { Duration of symptoms, years: } 9.6 \text { vs } 8.4 \\
\text { Duration of diagnosis, years: } 2.8 \text { vs } 4.2 \\
\text { FIQ: } 57.7(11.7) \text { vs } 56.6(12.9) \\
\text { 6-minute walk test: } 427.8(89.0) \text { vs } 414.1(81.6) \\
\text { BDI: } 22.9(12.2) \text { vs } 21.3(9.8) \\
\text { STAl: } 47.4(15.9) \text { vs } 47.0(14.6)\end{array}$ & $\begin{array}{l}\text { FIQ excluding job items (0-80, higher scores=greater } \\
\text { impairment) } \\
6 \text {-minute walk test (higher scores=greater distance } \\
\text { walked) } \\
\text { Beck Depression Inventory (0-63; higher scores=greater } \\
\text { depression) } \\
\text { State version of State-Trait Anxiety Inventory (20-80, } \\
\text { higher scores=greater anxiety) }\end{array}$ & $\begin{array}{l}\text { Immediately } \\
\text { post- } \\
\text { intervention } \\
\text { (6 months) }\end{array}$ \\
\hline Groessl, 2017 & $\begin{array}{l}\text { A vs. B } \\
\text { Mean age: } 53 \text { vs. } 54 \text { years } \\
\text { Female: } 27 \% \text { vs. } 25 \% \\
\text { Race: } \\
\text { African American or black: } 21 \% \text { vs. } 13 \% \\
\text { White: } 47 \% \text { vs. } 52 \% \\
\text { Native American: } 1.3 \% \text { vs. } 1.3 \% \\
\text { Hispanic: } 20 \% \text { vs. } 20 \% \\
\text { Asian/Pacific Islander: } 4 \% \text { vs. } 8 \% \\
\text { Years of LBP: } 15.4 \text { vs. } 14.6 \\
\text { Current opioid mediication use: } 56 \% \text { vs. } 47 \%\end{array}$ & $\begin{array}{l}\text { RDQ (0-24) } \\
\text { Pain intensity, Brief Pain Inventory (0-10) } \\
\text { Opioid medication use } \\
\text { Other medical treatments for pain }\end{array}$ & $\begin{array}{l}\text { Short term } \\
3.5 \text { months }\end{array}$ \\
\hline Gudavalli 2006 & $\begin{array}{l}\text { A vs B } \\
\text { Age: } 42 \text { vs. } 41 \text { years } \\
\text { Female: } 34 \% \text { vs. } 41 \% \\
\text { Race } \\
\text { Caucasian: } 83 \% \text { vs. } 82 \% \\
\text { Hispanic: } 4 \% \text { vs. } 6 \% \\
\text { African American: } 7 \% \text { vs. } 6 \% \\
\text { Asian: } 7 \% \text { vs. } 4 \% \\
\text { Other: } 0 \% \text { vs. } 2 \% \\
\text { Pain VAS (0-100), mean (SD): } 38.00(2.01) \text { vs. } 35.70(1.96) \\
\text { Roland Morris, mean (SD): } 6.64(0.43) \text { vs. } 6.84 \text { (0.42) } \\
\text { SF-36 Physical component score, mean (SD): } 41.77 \text { (0.74) vs.42.71 } \\
(0.84) \\
\text { SF-36 Mental component score mean (SD): } 51.18(0.83) \text { vs. } 48.49 \\
\text { (1.19) } \\
\text { Zung depression score, mean (SD): } 43.34(0.81) \text { vs. } 45.06(0.89) \\
\text { Radiculopathy: } 18 \% \text { vs. } 21 \%\end{array}$ & $\begin{array}{l}\text { Pain (0-100 VAS) } \\
\text { RDQ (0-24) }\end{array}$ & $\begin{array}{l}2,5, \text { and } 11 \\
\text { months }\end{array}$ \\
\hline
\end{tabular}




\begin{tabular}{|c|c|}
\hline Author, Year & $\begin{array}{c}\text { Results - Subquestion a } \\
\text { (vs. sham, no treatment, waitlist, attention control) }\end{array}$ \\
\hline Gowans 2001 & $\begin{array}{l}\text { A vs B } \\
6 \text { months, ITT analysis: } \\
\text { FIQ: } 48.6(16.2) \text { vs } 54.9(13.0), p<0.05 ; \mathrm{MD}-6.3(95 \% \mathrm{Cl}-14.8,2.2), \mathrm{p}=0.14 \\
\text { BDI: } 16.9(10.8) \text { vs } 21.3(10.3), \mathrm{p}<0.05 ; \mathrm{MD}-4.4(95 \% \mathrm{Cl}-10.4,1.6), \mathrm{p}=0.15 \\
\text { STAl: } 41.3(14.2) \text { vs } 51.7(13.1), \mathrm{p}<0.05 ; \mathrm{MD}-10.4(95 \% \mathrm{Cl}-18.2,-2.6), \mathrm{p}=0.01 \\
\text { p-values reported are from independent t-tests (A vs. B) of change scores (23 weeks-baseline) }\end{array}$ \\
\hline Groessl, 2017 & 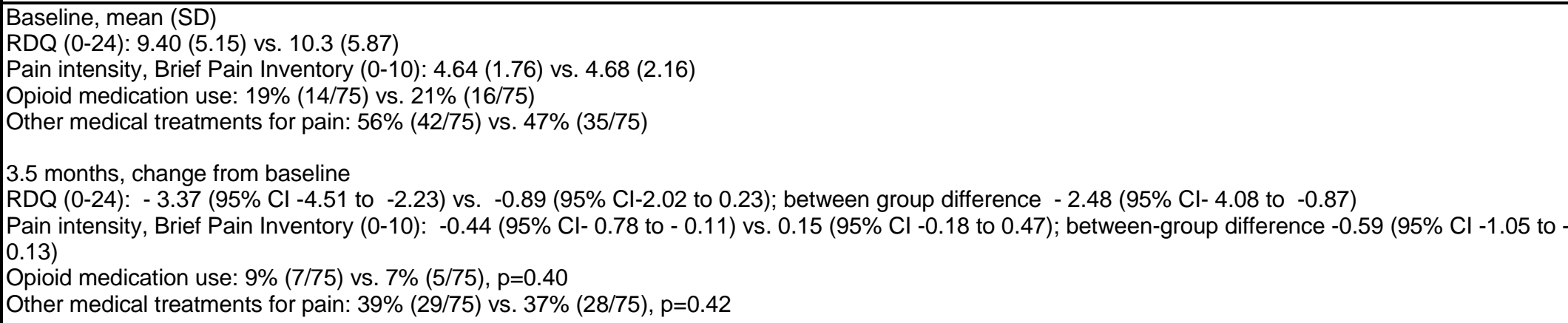 \\
\hline Gudavalli 2006 & NR \\
\hline
\end{tabular}




\begin{tabular}{|c|c|}
\hline Author, Year & $\begin{array}{l}\text { Results - Subquestion b } \\
\text { (vs. Pharmacological therapy) }\end{array}$ \\
\hline Gowans 2001 & \\
\hline Groessl, 2017 & NR \\
\hline Gudavalli 2006 & NR \\
\hline
\end{tabular}




\begin{tabular}{|c|c|c|}
\hline Author, Year & $\begin{array}{c}\text { Results - Subquestion c } \\
\text { (vs. Exercise) }\end{array}$ & Adverse Events Including Withdrawals \\
\hline Gowans 2001 & & $\begin{array}{l}\text { A vs B } \\
\text { Withdrawals: } 10 \%(3 / 30) \text { vs } 11 \%(3 / 27) \\
\text { Adverse Events: NR }\end{array}$ \\
\hline Groessl, 2017 & NR & None reported. \\
\hline Gudavalli 2006 & 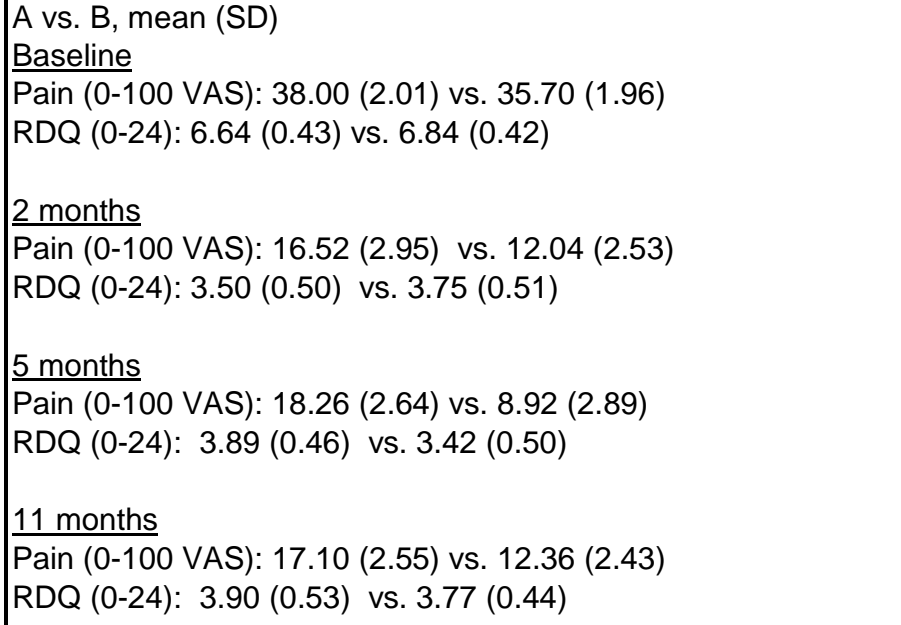 & No adverse events or side effects reported. \\
\hline
\end{tabular}




\begin{tabular}{|c|l|l|l|}
\hline Author, Year & \multicolumn{1}{|c|}{ Funding Source } & Quality & \\
\hline Gowans 2001 & $\begin{array}{l}\text { Toronto Hospital Auxiliary Women's } \\
\text { Health Project on Women and Arthritis }\end{array}$ & $\begin{array}{l}\text { Poor } \\
\text { Authors reported analyses were intent-to-treat but did not include subjects who withdrew } \\
\text { after randomization in baseline data analyses. }\end{array}$ \\
\hline Groessl, 2017 & $\begin{array}{l}\text { Veteran } \\
\text { Affairs Rehabilitation Research and } \\
\text { Development (Grant } \\
\text { \#RX000474) }\end{array}$ & Fair & \\
\hline Gudavalli 2006 & $\begin{array}{l}\text { Health Resources and } \\
\text { Services Administration (HRSA) Grant } \\
\text { \#R18 AH 10001 }\end{array}$ & Fair & \\
& & & \\
\hline
\end{tabular}




\begin{tabular}{|c|c|c|c|}
\hline Author, Year & $\begin{array}{c}\text { Country } \\
\text { Number of Centers } \\
\text { Setting }\end{array}$ & Inclusion/Exclusion Criteria & $\begin{array}{c}\text { Number Randomized, } \\
\text { Analyzed } \\
\text { Attrition }\end{array}$ \\
\hline Gur 2004 & \begin{tabular}{|l|} 
Turkey \\
Setting NR
\end{tabular} & $\begin{array}{l}\text { Age 17-55 years; pain lasting at least } 1 \text { year affecting work or daily } \\
\text { activity, arising from the neck and shoulder girdle; between 1-10 } \\
\text { myofascial tender points in the shoulder-girdle. } \\
\text { Exclusion: Fibromyalgia; patients aged below } 17 \text { or above } 55 \text { years; } \\
\text { mental retardation; neurological deficits involving the upper limbs; } \\
\text { advanced osteopathic or arthropathic disorder of the cervical spine or } \\
\text { the shoulder; cardiovascular disease, hypertension, coagulopathy, } \\
\text { ulcer, recent severe hemorrhage, renal insufficiency, severe hepatic } \\
\text { disease, neoplasia, epilepsy, cutaneous pathology or pain of central } \\
\text { origin, and pregnancy. }\end{array}$ & $\begin{array}{l}\text { Randomized: } 60 \\
\text { Treated: } 58 \\
\text { Analyzed:: } 54 \\
\text { Attrition:10\% } \\
(6 / 60)\end{array}$ \\
\hline Gusi 2006 & $\begin{array}{l}\text { Spain } \\
\text { Members of local FM } \\
\text { association }\end{array}$ & $\begin{array}{l}\text { Inclusion: female with FM diagnosis according to ACR } 1990 \text { criteria } \\
\text { Exclusion: severe spine disorder such as prolapsed disk or spinal } \\
\text { stenosis; history of severe trauma, frequent migraines, peripheral } \\
\text { nerve entrapment, inflammatory rheumatic disease, severe psychiatric } \\
\text { illness; other disease that prevents physical loading; pregnancy; } \\
\text { attendance at another psychological or physical therapy }\end{array}$ & $\begin{array}{l}\text { Randomized: } 35 \\
\text { Treated: } 35 \\
\text { Analyzed: } 34 \\
\text { Attrition: } 3 \%(1 / 35)\end{array}$ \\
\hline
\end{tabular}




\begin{tabular}{|c|c|}
\hline Author, Year & Intervention, Comparator \\
\hline Gur 2004 & $\begin{array}{l}\text { A.Active Ga-As laser therapy ( } \mathrm{n}=28) \text {, (20 W maximum output per pulse, } 904 \mathrm{~nm}, 200 \text { nanoseconds maximum pulse duration, } 2.8 \mathrm{kHz} \text { pulse } \\
\text { frequency, } 11.2 \mathrm{~mW} \text { average power, and } 1 \mathrm{~cm} 2 \text { surface) daily for } 2 \text { weeks, } 3 \text { minutes each myofascial tender point, approximately } 2 \mathrm{~J} / \mathrm{cm} 2 \mathrm{energy} \\
\text { density. } \\
\text { B.Sham laser ( } \mathrm{n}=26)\end{array}$ \\
\hline Gusi 2006 & $\begin{array}{l}\text { A.Exercise }(n=17) \text { : exercise in waist-high warm pool } 3 \text { times per week for } 12 \text { weeks. Each } 1 \text { hour session included } 10 \text { minutes warmup, } 10 \text { minutes } \\
\text { aerobic exercise at } 65-75 \% \text { of maximal heart rate, } 20 \text { minutes of overall mobility and lower-limb strength exercises, another set of } 10 \text { minutes of } \\
\text { aerobics, and } 10 \text { minutes cooldown. Heart rate was monitored with a pulse meter. At the end of the } 12 \text {-week therapy, all subjects were instructed to } \\
\text { avoid physical exercise for the next } 12 \text { weeks. The } 18 \text { participants randomized attended }>34 \text { of the } 36 \text { sessions. } \\
\text { B.Control }(n=17) \text { : Normal daily activities, which did not include any form of exercise related to those in the therapy. }\end{array}$ \\
\hline
\end{tabular}




\begin{tabular}{|c|c|c|c|}
\hline Author, Year & \begin{tabular}{|c} 
Study Participants \\
\end{tabular} & Outcome Measures & $\begin{array}{c}\text { Duration of } \\
\text { Followup }\end{array}$ \\
\hline Gur 2004 & \begin{tabular}{|l} 
A vs B \\
Age: 32 vs 31 years \\
Female: $82 \%$ (total pop only) \\
Pain duration: 43 vs 43 months \\
Pain at rest: 7.43 (2.65) vs $6.87(1.96)$ \\
Pain at movement: $7.43(2.65)$ vs $7.19(2.52)$ \\
NPAD: $65.36(24.83)$ vs $68.52(28.39)$ \\
NHP: $78.92(20.23)$ vs $75.47(26.15)$ \\
BDI: $21.56(13.49)$ vs $20.81(12.25)$ \\
Married: $40 \%$ vs $37 \%$ \\
Employed: $12 \%$ vs $17 \%$ \\
Student: $21 \%$ vs $25 \%$ \\
Secondary education or better: $54 \%$ vs $47 \%$
\end{tabular} & $\begin{array}{l}\text { Neck Pain and Disability Scale (NPAD) (scale: 0-100, } \\
\text { higher score = greater disability) } \\
\text { Pain at rest (VAS 0-10, higher score worse pain) } \\
\text { Pain at movement (VAS 0-10, higher score worse pain) } \\
\begin{array}{l}\text { Nottingham Health Profile (NHP) (scale 0-100, lower } \\
\text { score greater disability) } \\
\text { Beck Depression Inventory (BDI) (scale 0-63, higher } \\
\text { score, more severe the depression) }\end{array}\end{array}$ & 2.5 months \\
\hline Gusi 2006 & $\begin{array}{l}\text { A vs B } \\
\text { Age, years: } 51 \text { vs } 51 \\
\text { Female: } 100 \% \text { vs } 100 \% \\
\text { Duration of symptoms, years: } 24 \text { vs } 19 \\
\text { Pain VAS (mean, 0-100): } 63.1(26.0) \text { vs } 63.9(25.0) \\
\text { EQ-5D (mean, 0-1): } 0.29 \text { (0.28) vs } 0.32(0.32) \\
\\
\text { EQ-5D Pain/discomfort: } 2.5(0.5) \text { vs } 2.5(0.5) \\
\text { EQ-5D Anxiety/depression: } 2.2(0.6) \text { vs } 2.2(0.6)\end{array}$ & $\begin{array}{l}\text { Pain VAS (0-100; higher scores=worse pain) } \\
\text { EQ-5D (0-1; 0=death, 1=full functional quality of life) } \\
\text { EQ-5D Mobility (1-3; higher scores=more problems) } \\
\text { EQ-5D Pain/discomfort (1-3, higher scores=more } \\
\text { problems) } \\
\text { EQ-5D Anxiety/depression (1-3, higher scores=more } \\
\text { problems) }\end{array}$ & 6 months \\
\hline
\end{tabular}




\begin{tabular}{|c|c|}
\hline Author, Year & $\begin{array}{l}\text { Results - Subquestion a } \\
\text { (vs. sham, no treatment, waitlist, attention control) }\end{array}$ \\
\hline Gur 2004 & $\begin{array}{l}\text { A vs B } \\
\text { 2.5 months } \\
\text { NPAD }(0-100): 41.14(28.34) \text { vs } 63.29(24.50), M D-22.15(95 \% \mathrm{Cl}-36.7 \text { to }-7.6), p=0.004 \\
\text { NHP }(0-100): 56.41(29.18) \text { vs } 72.48(24.66), \mathrm{MD}-16.1(95 \% \mathrm{Cl}-30.9 \text { to }-1.3), \mathrm{p}=0.034 \\
\text { BDI: } 14.72(13.19) \text { vs } 21.38(10.65), \mathrm{MD}-6.66(95 \% \mathrm{Cl}-13.24 \text { to }-0.08), \mathrm{p}=0.047 \\
\text { Pain at rest (0-10) } 4.18(2.65) \text { vs } 6.29(3.52), \mathrm{MD}-2.11(95 \% \mathrm{Cl}-3.80 \text { to }-0.42), \mathrm{p}=0.016 \\
\text { Pain at movement }(0-10): 5.26(1.49) \text { vs } 7.28(3.03), \mathrm{MD}-2.02(95 \% \mathrm{Cl}-3.31 \text { to }-0.73), \mathrm{p}=0.003\end{array}$ \\
\hline Gusi 2006 & $\begin{array}{l}\text { A vs B } \\
6 \text { months (mean hange from baseline }(95 \% \mathrm{Cl}))(\mathrm{p} \text { is for difference between groups): } \\
\text { Pain VAS: }-1.6(95 \% \mathrm{Cl}-12.7 \text { to } 0.9) \text { vs } 0.9(95 \% \mathrm{Cl}-7.3 \text { to } 9.2), \mathrm{p}=0.69 \\
\text { EQ-5D: } 0.14(95 \% \mathrm{Cl}-0.03 \text { to } 0.32) \text { vs }-0.02(-0.17 \text { to } 0.13), \mathrm{p}=0.14 \\
\text { EQ-5D Mobility: }-0.2(-0.5 \text { to }-0.1) \text { vs } 0.1(95 \% \mathrm{Cl}-0.2 \text { to } 0.3), \mathrm{p}=0.056 \\
\text { EQ-5D Pain/discomfort: }-0.1(95 \% \mathrm{Cl}-0.4 \text { to } 0.3) \text { vs } 0((95 \% \mathrm{Cl}-0.3 \text { to } 0.3), \mathrm{p}=0.79 \\
\text { EQ-5D Anxiety/depression: }-0.5((95 \% \mathrm{Cl}-0.8 \text { to }-0.1) \text { vs } 0(95 \% \mathrm{Cl}-0.2 \text { to } 0.2), p=0.01\end{array}$ \\
\hline
\end{tabular}




\begin{tabular}{|l|c|}
\hline \multicolumn{1}{|c|}{ Author, Year } & $\begin{array}{c}\text { Results - Subquestion b } \\
\text { (vs. Pharmacological therapy) }\end{array}$ \\
\hline Gur 2004 & \\
& \\
& \\
\hline Gusi 2006 & \\
& \\
\hline
\end{tabular}




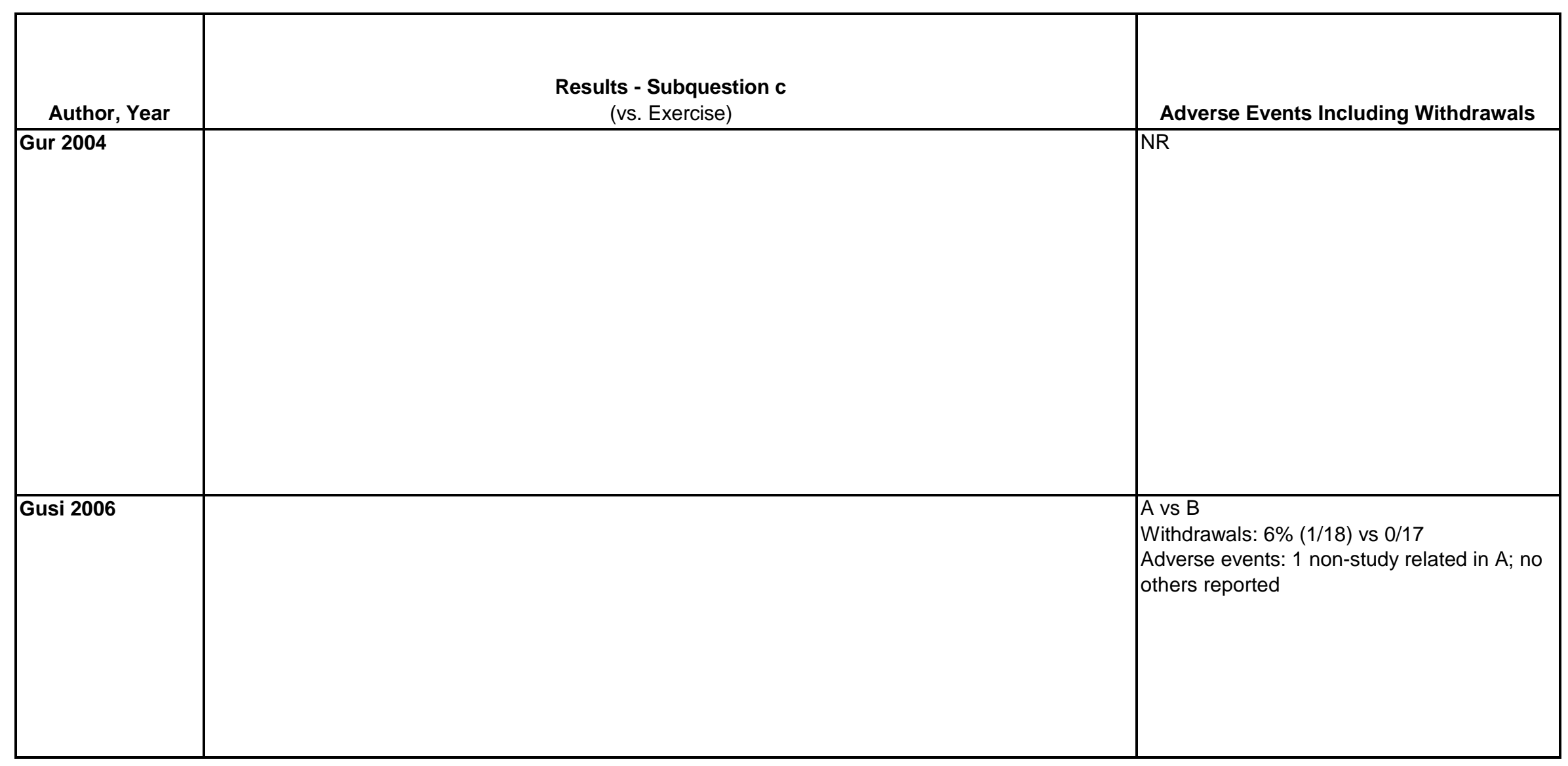




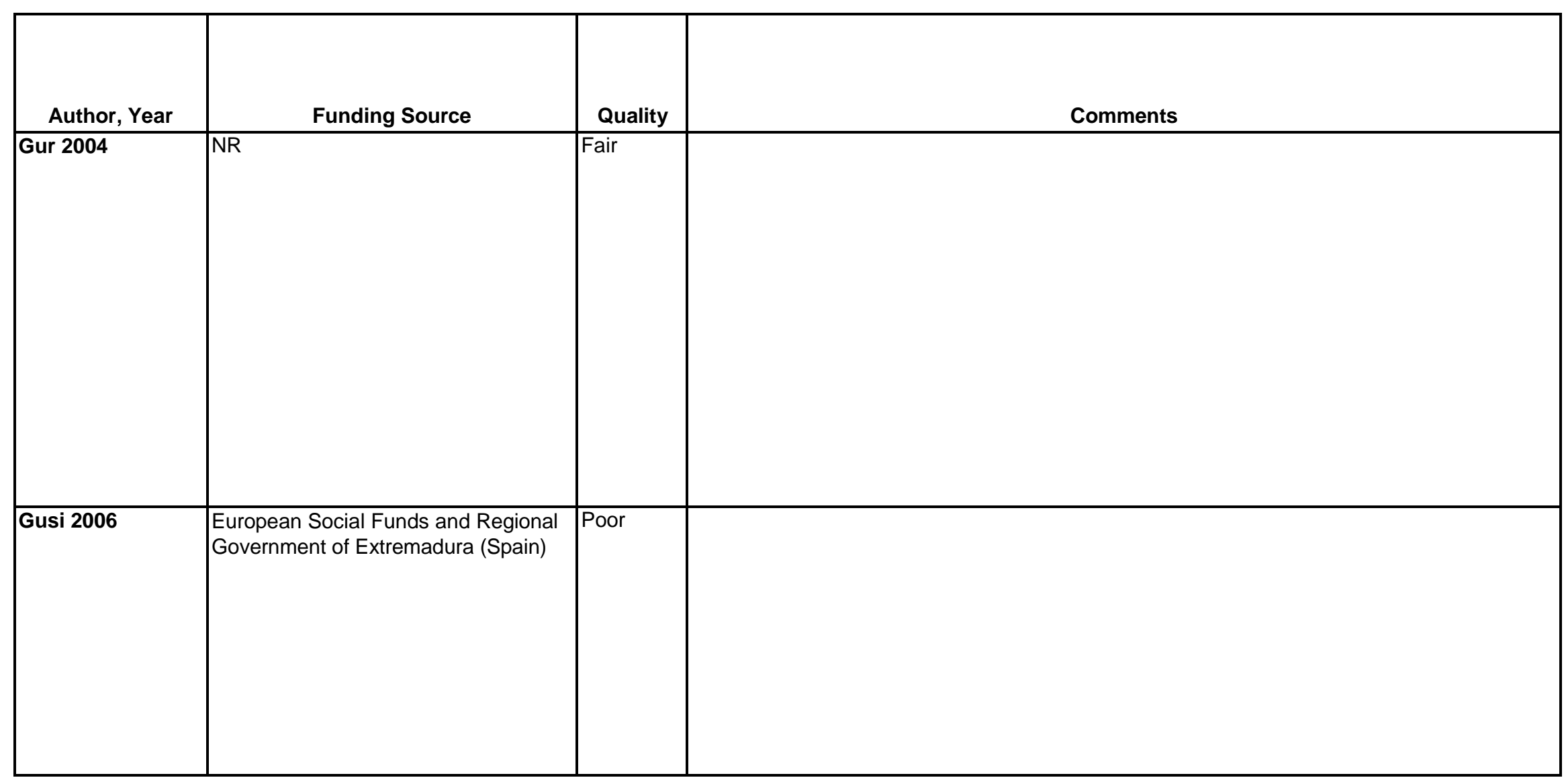




\begin{tabular}{|c|c|c|c|}
\hline Author, Year & $\begin{array}{c}\text { Country } \\
\text { Number of Centers } \\
\text { Setting }\end{array}$ & Inclusion/Exclusion Criteria & $\begin{array}{c}\text { Number Randomized, } \\
\text { Analyzed } \\
\text { Attrition }\end{array}$ \\
\hline Haake 2007 & $\begin{array}{l}\text { Germany } \\
\text { Number of centers: } \\
340 \\
\text { Outpatient }\end{array}$ & $\begin{array}{l}\text { Age } \geq 18 \text { years } \\
\text { Clinical diagnosis of chronic low back pain for } \geq 6 \text { months } \\
\text { Mean Von Korff Chronic Pain Grade Score (CPGS) of grade } \geq 1 \\
\text { Hannover Functional Ability Questionnaire (HFAQ) score }<70 \% \\
\text { No previous acupuncture for treatment of chronic low back pain } \\
\text { Ability to speak, read, and write German } \\
\text { Exclude: } \\
\text { Treatment with needle acupuncture for any other indication within the } \\
\text { last year } \\
\text { Previous spinal fracture, or disc or spinal surgery } \\
\text { Infectious or tumorous spondylopathy } \\
\text { Systemic bone or joint disorders } \\
\text { Scoliosis or kyphosis } \\
\text { Sciatica or chronic pain from other disease } \\
\text { Hemorrhagic disorders or anticoagulant therapy } \\
\text { Skin disease in the area of acupuncture } \\
\text { Abuse of drugs or pain medication } \\
\text { Pregnancy } \\
\text { Epilepsy } \\
\text { Patient included in any other studies }\end{array}$ & $\begin{array}{l}\text { Randomized: } 1162 \\
\text { Treated: } 387 \\
\text { Analyzed: } 1161 \\
\text { Attrition: <1\% (1/1162) }\end{array}$ \\
\hline
\end{tabular}




\begin{tabular}{|c|c|}
\hline Author, Year & Intervention, Comparator \\
\hline Haake 2007 & 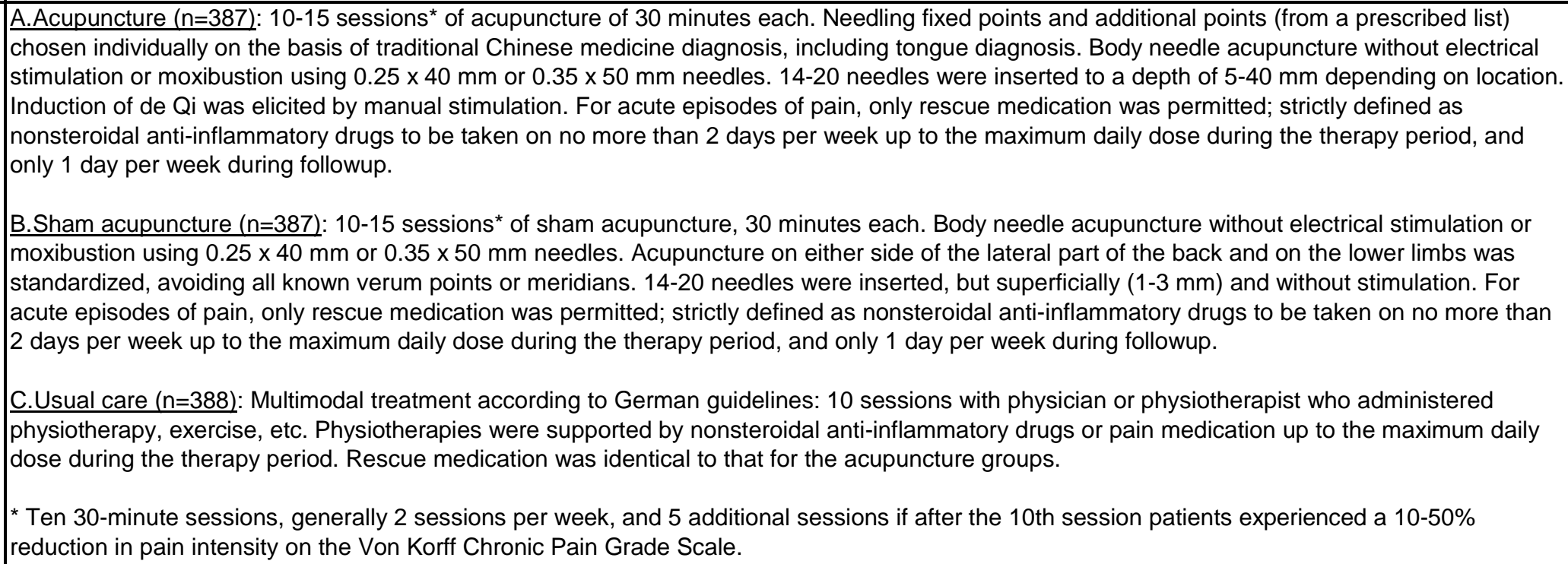 \\
\hline
\end{tabular}




\begin{tabular}{|c|c|c|c|}
\hline Author, Year & Study Participants & Outcome Measures & $\begin{array}{c}\text { Duration of } \\
\text { Followup }\end{array}$ \\
\hline Haake 2007 & $\begin{array}{l}\text { A vs. B vs. C } \\
\text { Age: } 50 \text { vs. } 49 \text { vs. } 51 \\
\text { Female: } 57 \% \text { vs. } 64 \% \text { vs. } 58 \% \\
\text { Race: NR } \\
\text { Duration of back pain: } 8.1 \text { vs. } 7.7 \text { vs. } 8.1 \text { years } \\
\text { Baseline CPGS: } 67.7 \text { vs. } 67.8 \text { vs. } 67.8 \\
\text { Baseline HFAQ: } 46.3 \text { vs. } 46.3 \text { vs. } 46.7 \\
\text { Baseline SF-12, physical component: } 31.8 \text { vs. } 31.5 \text { vs. } 31.6 \\
\text { Baseline SF-12, mental component: } 46.6 \text { vs. } 46.6 \text { vs. } 47.1\end{array}$ & $\begin{array}{l}\text { Treatment response: } \geq 33 \% \text { improvement in pain or } \\
\geq 12 \% \text { improvement in function } \\
\text { Von Korff Chronic Pain Grade Scale (0-100) } \\
\text { Hannover Functional Ability Questionnaire: } 0-100 \\
\text { (higher score = better function) } \\
\text { SF-12 physical and mental component } \\
\text { Global assessment of therapy effectiveness by patient: } \\
1 \text { (very good) to } 6 \text { (fail) }\end{array}$ & $\begin{array}{l}1.5 \text { and } 4.5 \\
\text { months }\end{array}$ \\
\hline
\end{tabular}




\begin{tabular}{|c|c|}
\hline Author, Year & $\begin{array}{c}\text { Results - Subquestion a } \\
\text { (vs. sham, no treatment, waitlist, attention control) }\end{array}$ \\
\hline Haake 2007 & 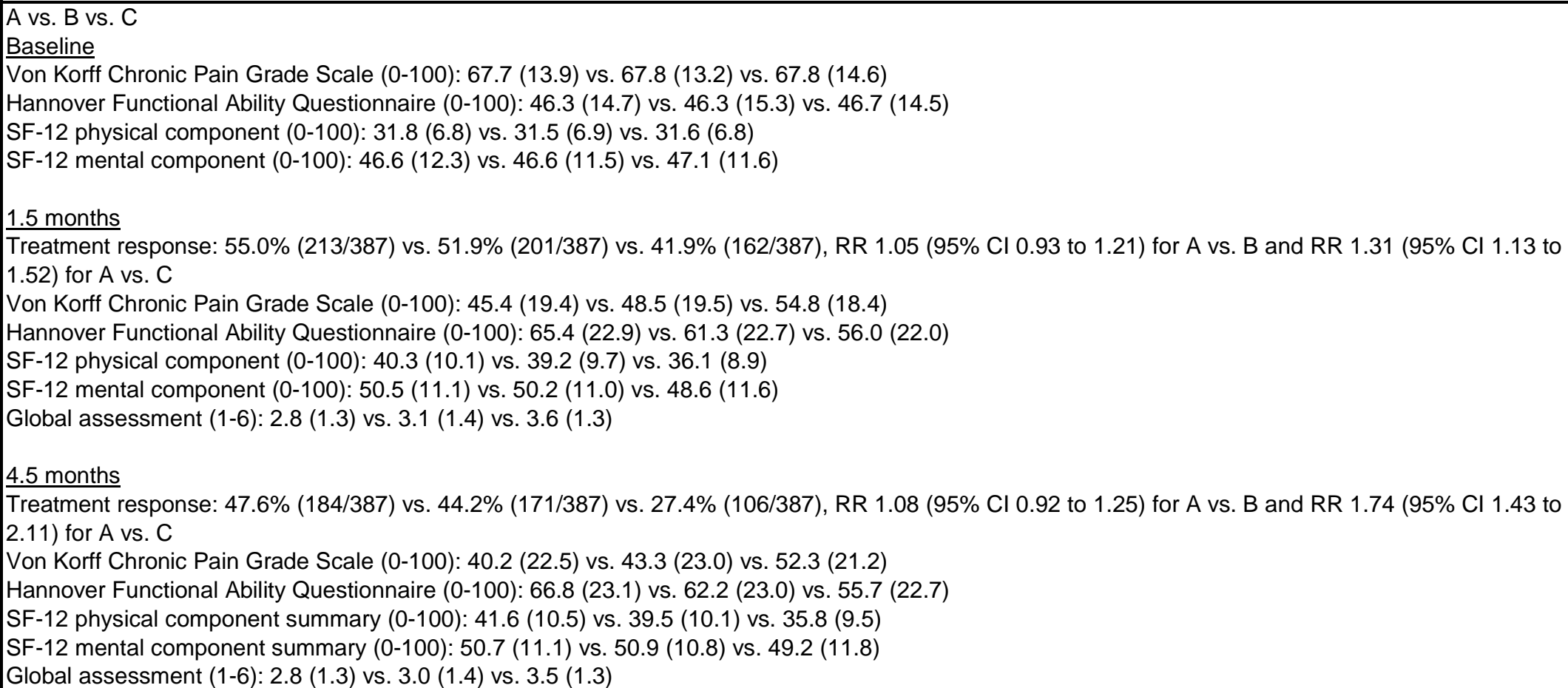 \\
\hline
\end{tabular}




\begin{tabular}{|c|c|c|}
\hline Author, Year & Results - Subquestion b \\
(vs. Pharmacological therapy)
\end{tabular}




\begin{tabular}{|c|c|c|}
\hline Author, Year & $\begin{array}{l}\text { Results - Subquestion c } \\
\text { (vs. Exercise) }\end{array}$ & Adverse Events Including Withdrawals \\
\hline Haake 2007 & 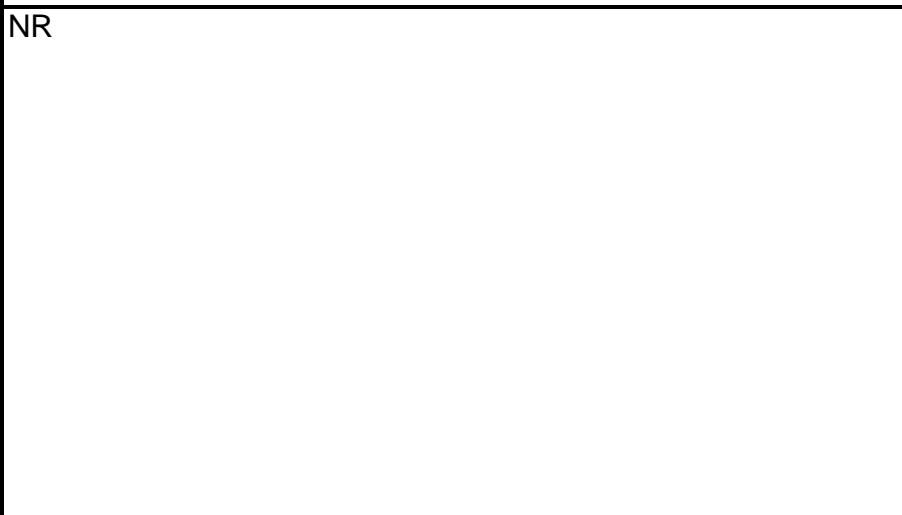 & 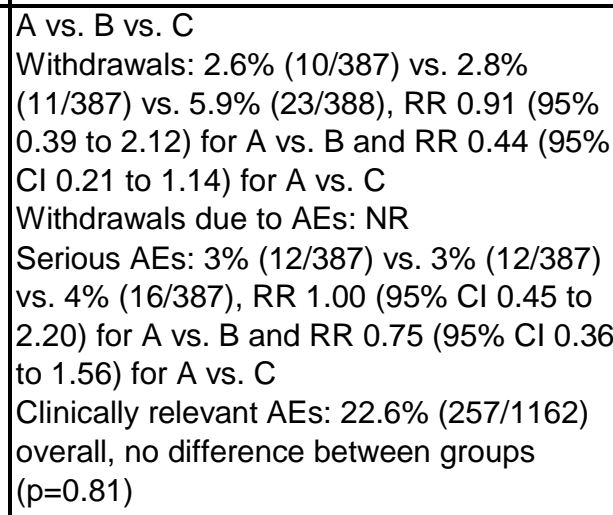 \\
\hline
\end{tabular}




\begin{tabular}{|c|l|l|l|}
\hline Author, Year & \multicolumn{1}{|c|}{ Funding Source } & Quality & \\
\hline Haake 2007 & $\begin{array}{l}\text { German public health insurance } \\
\text { companies: Allgeme- ine } \\
\text { Ortskrankenkasse, } \\
\text { Betriebskrankenkasse, Innungskran- } \\
\text { kenkasse, Bundesknapschaft, } \\
\text { Bundesverband der Land- } \\
\text { wirtschaftlichen Krankenkassen, and } \\
\text { Seekasse. }\end{array}$ & Fair & \\
& & & \\
\hline
\end{tabular}




\begin{tabular}{|c|c|c|c|}
\hline Author, Year & $\begin{array}{c}\text { Country } \\
\text { Number of Centers } \\
\text { Setting }\end{array}$ & Inclusion/Exclusion Criteria & $\begin{array}{c}\text { Number Randomized, } \\
\text { Analyzed } \\
\text { Attrition }\end{array}$ \\
\hline Haas 2014 & \begin{tabular}{|l|} 
US, Oregon \\
Number of centers: 1 \\
Outpatient clinic
\end{tabular} & $\begin{array}{l}\text { Patients } 18+\text { years old, } \\
\text { current episode of LBP of mechanical origin } 3+\text { months duration, } \\
\text { some LBP on } 30 \text { days in the previous } 6 \text { weeks and a minimum LBP } \\
\text { index of } 25 \text { on a } 100 \text {-point scale. } \\
\\
\text { Exclude: Patients who received manual therapy within } 90 \text { days } \\
\text { or for contraindications to study interventions, patients with active } \\
\text { cancer, spine pathology, inflammatory arthropathies, autoimmune } \\
\text { disorders, anticoagulant conditions, neurodegenerative diseases, pain } \\
\text { radiating below the knee, organic referred pain, pregnancy, and } \\
\text { disability compensation. }\end{array}$ & $\begin{array}{l}\text { Randomized: } 400 \\
\text { Treated: } 391 \\
\text { Analyzed: } 391 \\
\text { Attrition: } 2.3 \%(9 / 400)\end{array}$ \\
\hline
\end{tabular}




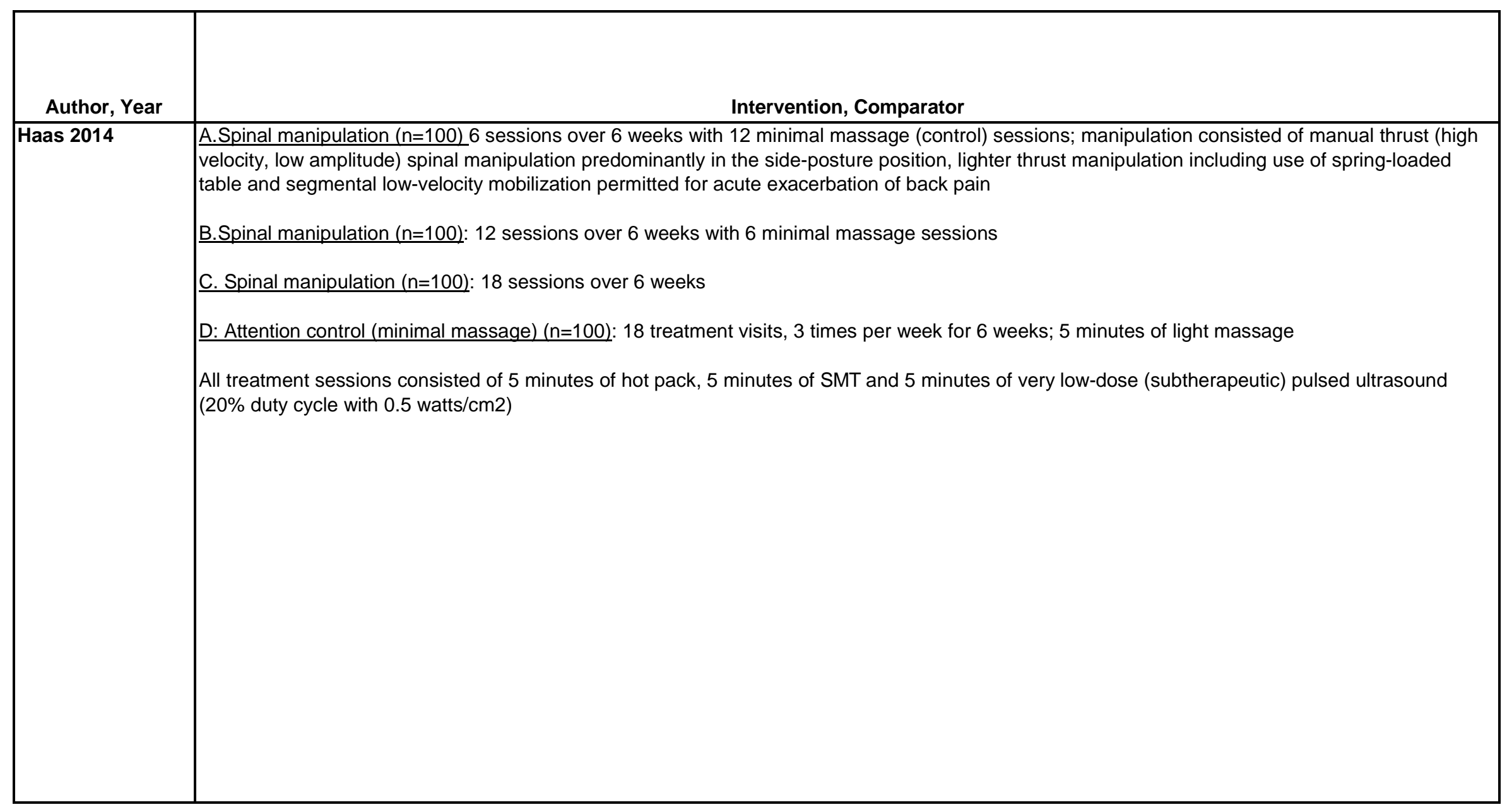




\begin{tabular}{|c|c|c|c|}
\hline Author, Year & Study Participants & Outcome Measures & $\begin{array}{l}\text { Duration of } \\
\text { Followup }\end{array}$ \\
\hline Haas 2014 & 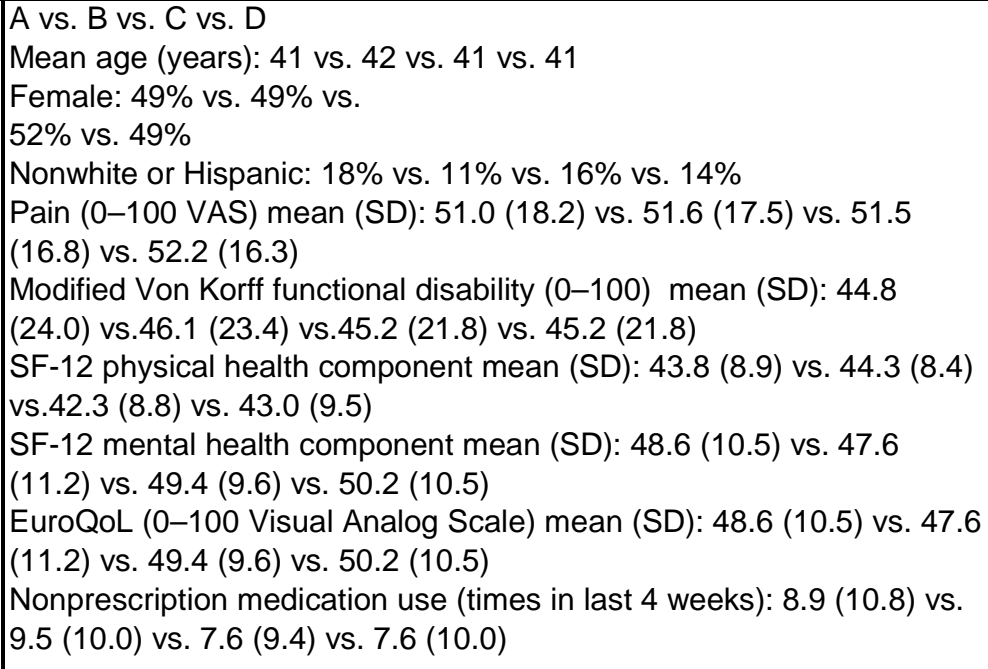 & $\begin{array}{l}\text { Von Korff pain intensity }(0-100) \\
\text { Von Korff functional disability }(0-100, \text { lower scores=less } \\
\text { disability) } \\
\text { SF-12 physical health component (norm-based } \\
\text { mean=50) } \\
\text { SF-12 mental health component (norm-based } \\
\text { mean=50) } \\
\text { EuroQol Health State }(0-100 \text { VAS, higher score is } \\
\text { more favorable) }\end{array}$ & $\begin{array}{l}4 \text { months and } \\
10.5 \text { months }\end{array}$ \\
\hline
\end{tabular}




\begin{tabular}{|c|c|}
\hline Author, Year & $\begin{array}{l}\text { Results - Subquestion a } \\
\text { (vs. sham, no treatment, waitlist, attention control) }\end{array}$ \\
\hline Haas 2014 & 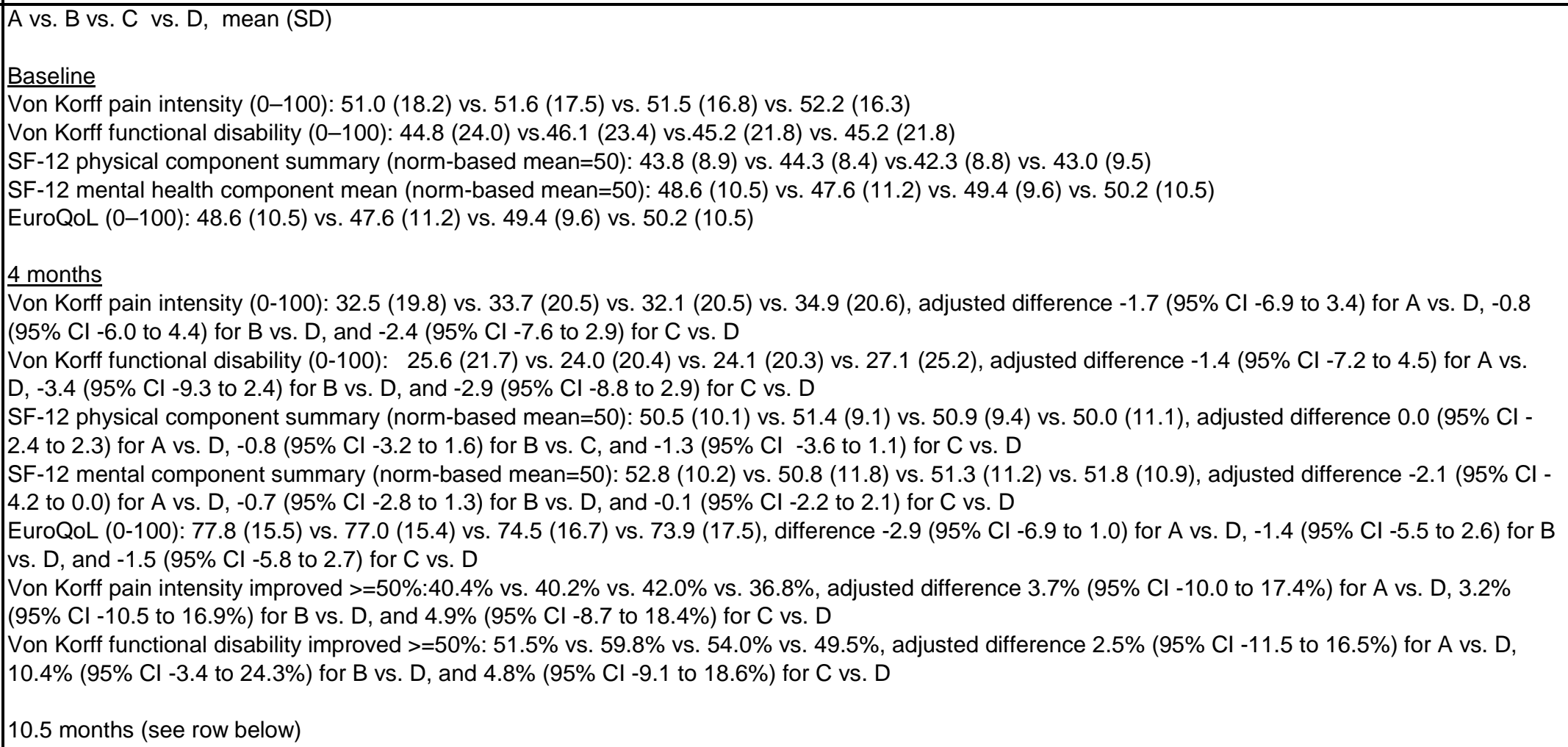 \\
\hline
\end{tabular}




\begin{tabular}{|l|l|}
\hline Author, Year & Results - Subquestion b \\
\hline Haas 2014 & (vs. Pharmacological therapy) \\
\hline & \\
\hline
\end{tabular}




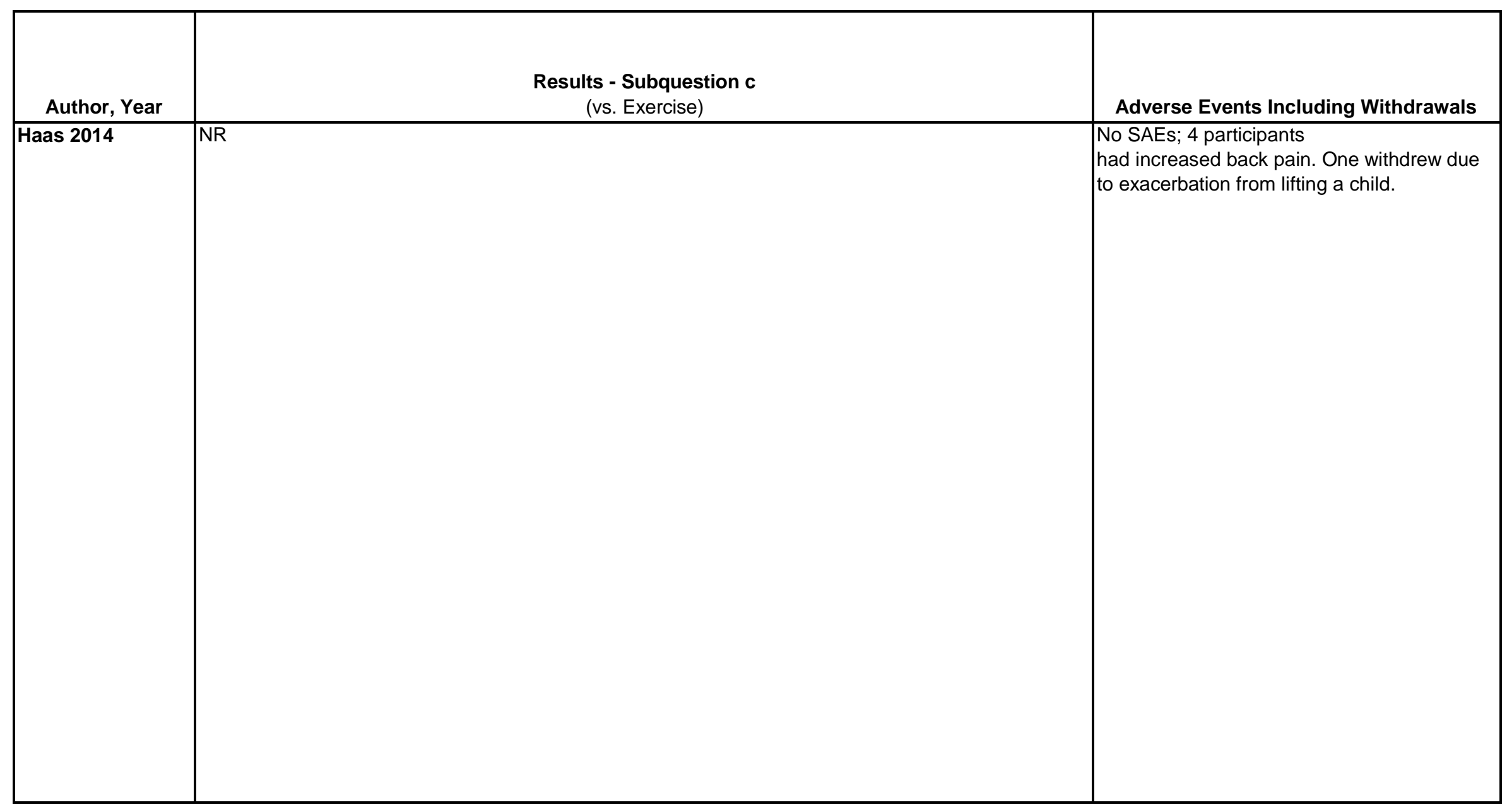




\begin{tabular}{|l|l|l|l|}
\hline Author, Year & \multicolumn{1}{|c|}{ Funding Source } & Quality & Comments \\
\hline Haas 2014 & $\begin{array}{l}\text { National Center of Complementary } \\
\text { and Alternative Medicine (NCCAM) } \\
\text { National } \\
\text { Institutes of Heatth (U01 ATOO1908) }\end{array}$ & Fair & \\
& & & \\
& & & \\
\hline
\end{tabular}




\begin{tabular}{|c|c|c|c|}
\hline Author, Year & $\begin{array}{c}\text { Country } \\
\text { Number of Centers } \\
\text { Setting }\end{array}$ & Inclusion/Exclusion Criteria & $\begin{array}{c}\text { Number Randomized, } \\
\text { Analyzed } \\
\text { Attrition }\end{array}$ \\
\hline \multicolumn{4}{|l|}{$\begin{array}{l}\text { Haas } 2014 \\
\text { (continued) }\end{array}$} \\
\hline Harkapaa 1989 & $\begin{array}{l}\text { Finland } \\
\text { Number of centers } \\
\text { In patient and } \\
\text { outpatient }\end{array}$ & $\begin{array}{l}\text { Patients with physically strenuous work and chronic or recurrent LBP } \\
\text { for }>2 \text { years and LBP caused sick leave } \\
\text { Exclusion criteria not reported }\end{array}$ & $\begin{array}{l}\text { Randomized: } 476 \\
\text { Treated: } 459 \\
\text { Analyzed: } 459 \\
\text { Attrition: } 4 \%(20 / 476)\end{array}$ \\
\hline Hegedus 2009 & $\begin{array}{l}\text { Hungary } \\
1 \text { center }\end{array}$ & $\begin{array}{l}\text { Inclusion: } \\
\text { Between the ages of } 30 \text { and } 65 \text {. Knee pain }>40 \mathrm{~mm} \text { on VAS and mild } \\
\text { to moderate knee OA confirmed by radiographs } \\
\text { Exclusion: } \\
\text { Considerable varus or valgus deformity, ankylosis, intense synovitis, } \\
\text { gonitis, Kellgren-Lawrence stage } 4 \text {, and contraindications to laser } \\
\text { therapy. }\end{array}$ & $\begin{array}{l}\text { Randomized: } 35 \\
\text { Treated: } 27 \\
\text { Analyzed: } 27 \\
\text { Attrition: } 8 / 35=23 \%\end{array}$ \\
\hline
\end{tabular}




\begin{tabular}{|c|c|}
\hline Author, Year & Intervention, Comparator \\
\hline $\begin{array}{l}\text { Haas } 2014 \\
\text { (continued) }\end{array}$ & \\
\hline Harkapaa 1989 & $\begin{array}{l}\text { A.Inpatient multidisciplinary rehabilitation }(\mathrm{n}=156) \text { : Groups sessions, } 4 \text { Swedish back school sessions, } 15 \text { sessions of back exercises, } 9 \text { sessions } \\
\text { of relaxation exercises, heat/electrotherapy, discussion groups on coping, discussion on back care, stretching, massage and strengthening and } \\
\text { physical exercises for } 3 \text { weeks; total hours not reported } \\
\text { B. Outpatient multidisciplinary rehabilitation ( } n=150): \\
15 \text { session back treatment same as above with program conducted at work or local health center, twice weekly for } 2 \text { months; total hours not } \\
\text { reported } \\
\text { C. Usual care ( } n=153) \text { : Exam and questionnaire plus oral instructions for ergonomics and back exercise }\end{array}$ \\
\hline Hegedus 2009 & $\begin{array}{l}\text { A.Low Level Laser Therapy }(\mathrm{n}=18) \\
50 \mathrm{~mW} \text {, continuous wave laser. Treatment provided over the femoral and tibial condyles. Total does of } 48 \mathrm{~J} / \mathrm{cm} 2 \text { per session. Twice a week for four } \\
\text { weeks. } \\
\text { B.Placebo }(n=17) \\
\text { Placebo probe used twice a week for four weeks. }\end{array}$ \\
\hline
\end{tabular}




\begin{tabular}{|c|c|c|c|}
\hline Author, Year & Study Participants & Outcome Measures & $\begin{array}{l}\text { Duration of } \\
\text { Followup }\end{array}$ \\
\hline \multicolumn{4}{|l|}{$\begin{array}{l}\text { Haas } 2014 \\
\text { (continued) }\end{array}$} \\
\hline Harkapaa 1989 & $\begin{array}{l}\text { A vs. B vs. C } \\
\text { Age (mean): } 45 \text { vs. } 45 \text { vs. } 45 \text { years } \\
\text { Female: } 37 \% \text { vs. } 39 \% \text { vs. } 35 \% \\
\text { Race: NR } \\
\text { Continuous LBP during the past year: } 42 \% \text { vs. } 39 \% \text { vs. } 41 \% \\
\text { Use of analgesics: } 62 \% \text { vs. } 65 \% \text { vs. } 67 \%\end{array}$ & $\begin{array}{l}\text { Pain Index (0-400, sum of } 40-100 \text { VAS scales }) \\
\text { LBP Disability Index (0-45, higher score=more disabled) }\end{array}$ & 1 month \\
\hline Hegedus 2009 & $\begin{array}{l}\text { A and } B \text { (for } n=27 \text { completers only) } \\
\text { Age: } 49 \\
\text { Female: } 81 \% \\
\text { A vs B } \\
\text { Mean Pain VAS (SD): } 5.75 \text { vs } 5.62\end{array}$ & Pain (VAS 0-10; higher score=greater pain) & 2 months \\
\hline
\end{tabular}




\begin{tabular}{|c|c|}
\hline Author, Year & $\begin{array}{c}\text { Results - Subquestion a } \\
\text { (vs. sham, no treatment, waitlist, attention control) }\end{array}$ \\
\hline $\begin{array}{l}\text { Haas } 2014 \\
\text { (continued) }\end{array}$ & 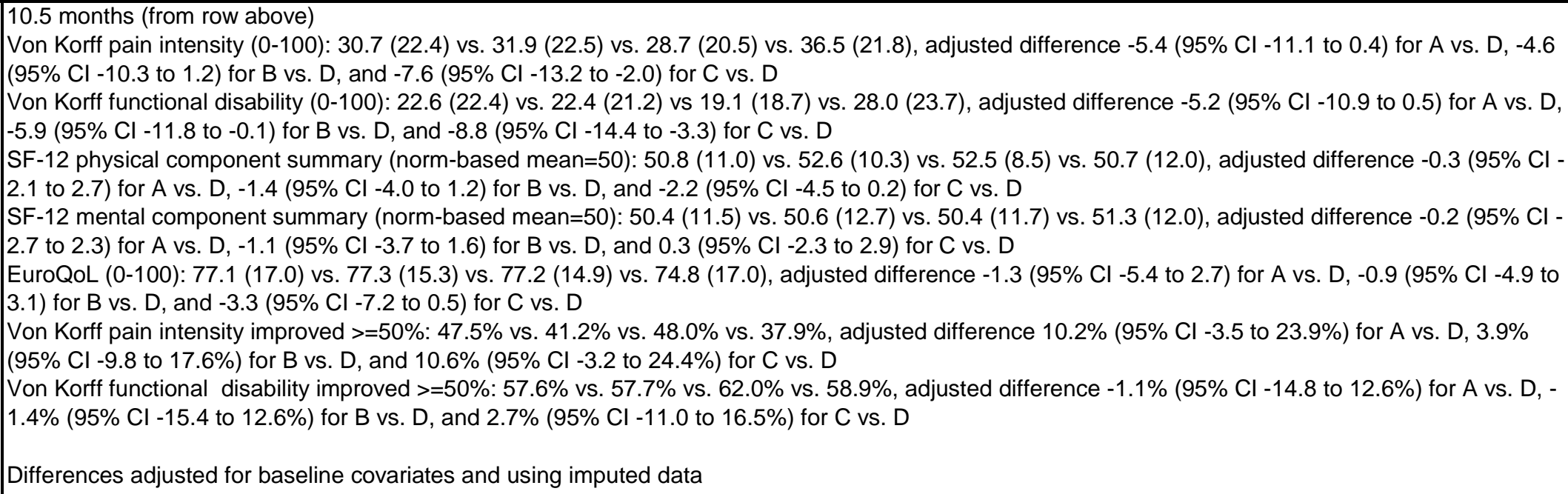 \\
\hline Harkapaa 1989 & 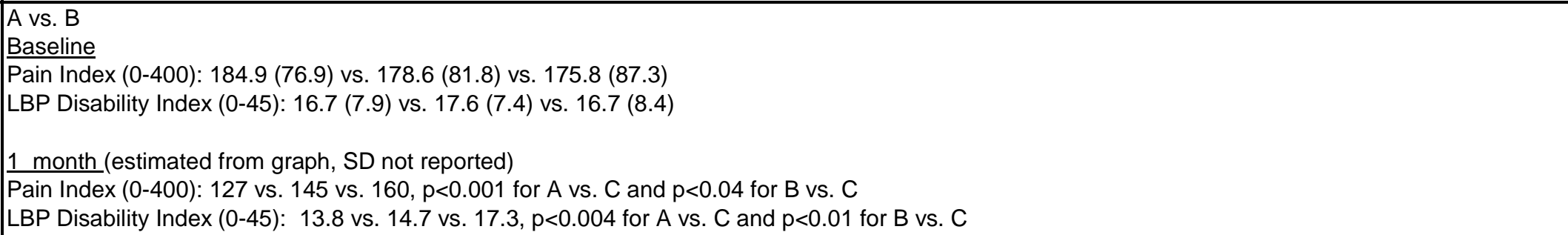 \\
\hline Hegedus 2009 & $\begin{array}{l}\text { A vs B } \\
\text { Mean Pain VAS: } 1.18 \text { vs } 4.12 \text {, } \\
\text { MD }=-2.94^{\star} \\
\text { *standard deviation not reported }\end{array}$ \\
\hline
\end{tabular}




\begin{tabular}{|l|l|}
\hline \multicolumn{1}{|c|}{} & \multicolumn{1}{c|}{$\begin{array}{c}\text { Results - Subquestion b } \\
\text { (vs. Pharmacological therapy) }\end{array}$} \\
\hline $\begin{array}{l}\text { Haanthor, Year } \\
\text { (continued) }\end{array}$ & \\
\hline Harkapaa 1989 & \\
\hline Hegedus 2009 & NR \\
\hline
\end{tabular}




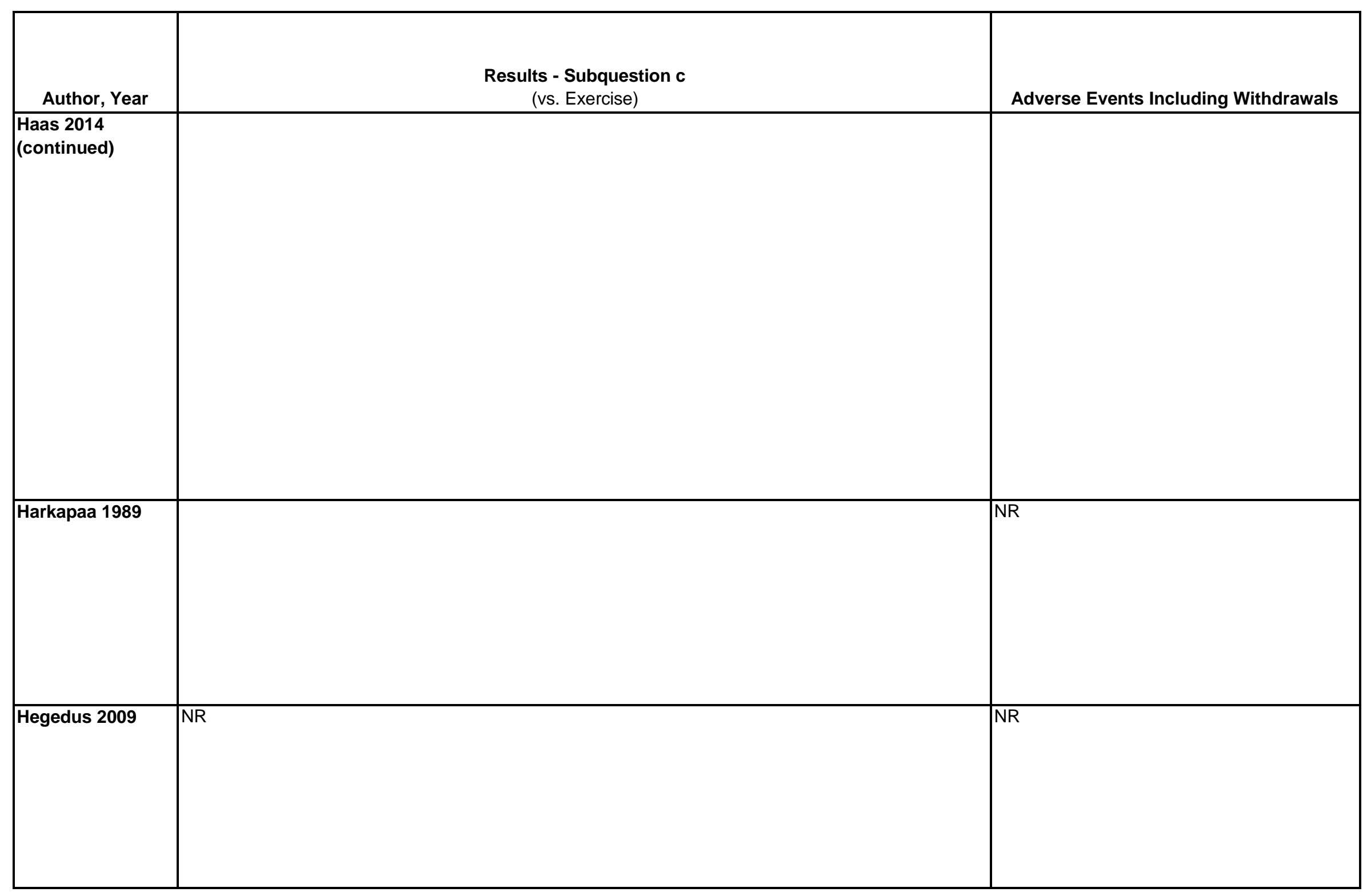




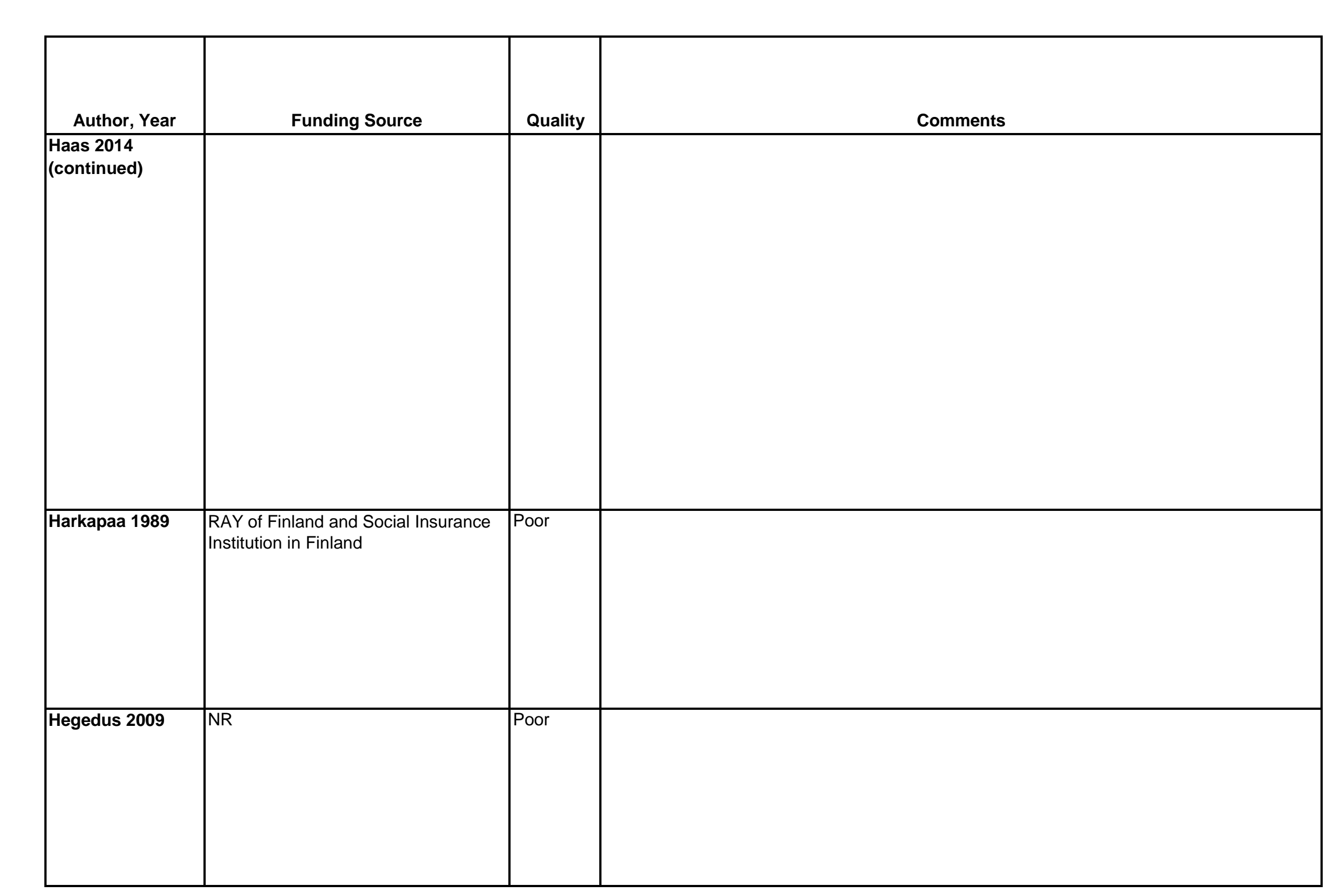




\begin{tabular}{|c|c|c|c|}
\hline Author, Year & $\begin{array}{c}\text { Country } \\
\text { Number of Centers } \\
\text { Setting }\end{array}$ & Inclusion/Exclusion Criteria & $\begin{array}{c}\text { Number Randomized, } \\
\text { Analyzed } \\
\text { Attrition } \\
\end{array}$ \\
\hline Helminen 2015 & $\begin{array}{l}\text { Finland, single site, } \\
\text { primary care }\end{array}$ & $\begin{array}{l}\text { Inclusion Criteria: } \\
\text { Patients aged between } 35 \text { and } 75 \text { years with clinical symptoms and } \\
\text { radiographic grading (Kellgren-Lawrence } 2-4 \text { ) of knee osteoarthritis } \\
\text { were eligible. } \\
\text { Exclusion Criteria: } \\
\text { Exclusion for severe psychiatric or psychological disorders that had } \\
\text { led to hospitalization or an inability to work, previous or planned lower } \\
\text { extremity joint surgery, and other back or lower limb pain symptoms } \\
\text { that had been more aggravating than the knee pain. }\end{array}$ & \begin{tabular}{|l|} 
Randomized: 111 \\
Treated: 111 \\
Analyzed: 111 (ITT) 3 \\
month: $90.9 \%(101 / 111)$ \\
12 months: $88.2 \%(98 / 111)$ \\
Attrition: $11.7 \%(13 / 111)$
\end{tabular} \\
\hline
\end{tabular}




\begin{tabular}{|c|c|}
\hline Author, Year & Intervention, Comparator \\
\hline Helminen 2015 & $\begin{array}{l}\text { A.Cognitive-Behavioral Training (CBT) (n=55) } \\
\text { Patients undertook group }(7-13 \text { people each) sessions of CBT led by trained psychologist and physiotherapist. Practices included knowledge } \\
\text { building, problem solving, skills training and homework assignments. In addition all patients were instructed to continue regular care. } \\
\text { No. of Treatments: weekkly sessions for } 6 \text { weeks ( } 6 \text { total) } \\
\text { Length of Treatment: } 2 \text { hours/session } \\
\text { B. Usual Care }(n=56) \\
\text { Both the intervention and control group continued usual care from their general practitioners. }\end{array}$ \\
\hline
\end{tabular}




\begin{tabular}{|c|c|c|c|}
\hline Author, Year & Study Participants & Outcome Measures & $\begin{array}{l}\text { Duration of } \\
\text { Followup }\end{array}$ \\
\hline Helminen 2015 & $\begin{array}{l}\text { A vs B } \\
\text { Age: } 64.5 \text { vs. } 63 \\
\text { Female: } 71 \% \text { vs. } 68 \% \\
\text { BMI: } \\
\text { Race: NR } \\
\text { Mean Duration of Chronicity: } 6.6(4.5) \text { vs. } 8.9(8.7) \\
\text { WOMAC Pain: } 57.6(53.9-61.3) \text { vs. } 56.4(52.9-60.0) \\
\text { WOMAC Stiffness: } 63.1(57.2-69.0) \text { vs. } 62.0(56.6-67.4) \\
\text { WOMAC Function: } 53.0(48.1-57.9) \text { vs. } 48.4(43.1-53.7) \\
\text { NPRS avg. last week: } 6.6(6.1-7.0) \text { vs. } 6.4(5.9-6.8) \\
\text { NPRS worst last week: } 8.0(7.6-8.4) \text { vs. } 7.5(7.1-7.9) \\
\text { NPRS average } 3 \text { months: } 6.8(6.3-7.3) \text { vs. } 6.6(6.1-7.0) \\
\text { NPRS worst } 3 \text { months: } 8.2(7.9-8.6) \text { vs. } 8.0(7.6-8.3) \\
\\
\text { HRQoL, } 15 D: 0.82 \text { (0.80-0.84) vs. } 0.83(0.80-0.86) \\
\text { RAND-36 Physical Functioning: } 44.4(38.5-50.3) \text { vs. } 49.8(44.2-55.5) \\
\text { RAND-36 Role-Physical: } 35.2(24.9-45.5) \text { vs. } 38.4(27.7-49.2) \\
\text { RAND-36 Bodily Pain: } 51.0(46.4-55.7) \text { vs. } 53.6(48.5-58.6) \\
\text { RAND-36 General Health: } 50.8(46.3-55.3) \text { vs. } 56.7(51.4-62.0) \\
\text { RAND-36 Vitality: } 62.2(57.4-67.0) \text { vs. } 67.1(62.3-71.8) \\
\text { RAND-36 Social Functioning: } 73.4(66.4-80.4) \text { vs. } 82.5(76.5-88.5) \\
\text { RAND-36 Role-Emotional: } 68.5(57.2-79.8) \text { vs. } 75.8(65.9-85.6) \\
\text { RAND-36 Emotional Well-Being: } 78.1(74.0-82.3) \text { vs. } 81.4 \\
\text { (77.8-85.0) } \\
\text { RAND-36 Health Change: } 40.9(35.7-46.2) \text { vs. } 45.0(38.3-51.7) \\
\text { Beck Depression Inventory }(0-63): 6.1(4.8-7.4) \text { vs. } 5.8(4.5-7.1) \\
\text { Beck Anxiety Inventory (0-63): } 9.0(7.2-10.8) \text { vs. } 7.1(5.7-8.5)\end{array}$ & $\begin{array}{l}\text { WOMAC } \\
\text { Physical Function (0-100; higher score=worse function) } \\
\text { WOMAC Stiffness (r0-100; higher score=worse } \\
\text { stiffness) } \\
\text { WOMAC Pain 0-100; higher score=greater pain) } \\
\text { Numeric Pain Rating Scales (NPRS, range 0-10; higher } \\
\text { score=greater pain) } \\
\text { Beck Depression Inventory (BDI, range 0-63; higher } \\
\text { score=worse depression) } \\
\text { Beck Anxiety Inventory (BAI, range 0-63; higher } \\
\text { score=worse anxiety) } \\
\text { Health Related Quality of Life 15D (HRQoL, range: 0-1) } \\
\text { Quality of Life RAND-36 (each subscale ranged 0-100, } \\
\text { higher scores indicate better health) }\end{array}$ & $\begin{array}{l}3 \text { and12 } \\
\text { months }\end{array}$ \\
\hline
\end{tabular}




\begin{tabular}{|c|c|}
\hline Author, Year & $\begin{array}{c}\text { Results - Subquestion a } \\
\text { (vs. sham, no treatment, waitlist, attention control) }\end{array}$ \\
\hline Helminen 2015 & 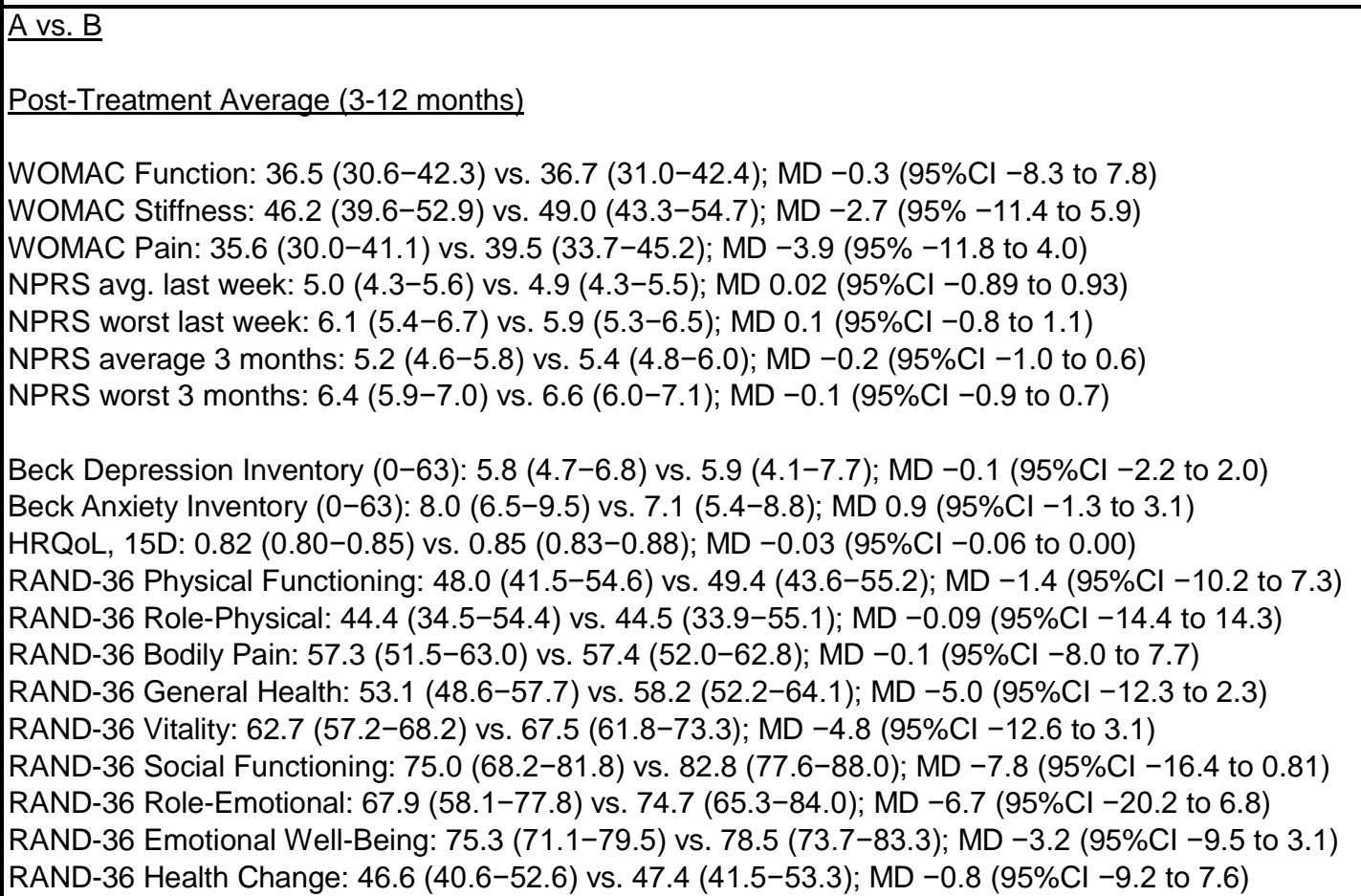 \\
\hline
\end{tabular}




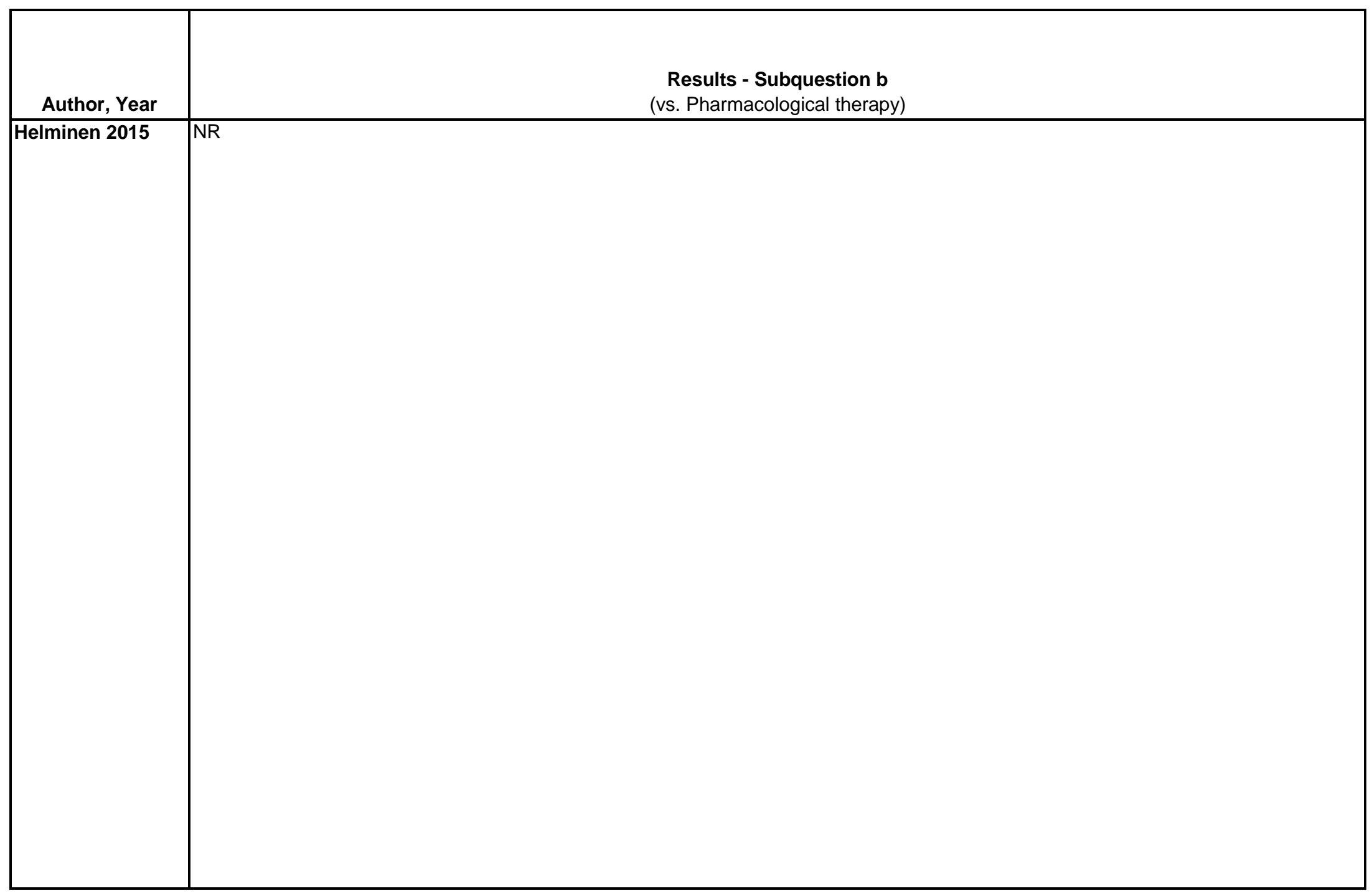

D-369 


\begin{tabular}{|c|c|c|}
\hline Author, Year & $\begin{array}{l}\text { Results - Subquestion c } \\
\text { (vs. Exercise) }\end{array}$ & Adverse Events Including Withdrawals \\
\hline Helminen 2015 & 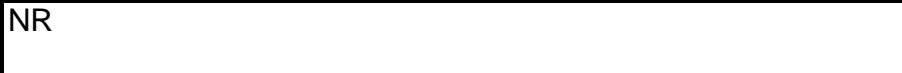 & $\begin{array}{l}\text { "No adverse events were recorded in either } \\
\text { of the study groups." }\end{array}$ \\
\hline
\end{tabular}




\begin{tabular}{|c|l|l|l|}
\hline Author, Year & \multicolumn{1}{|c|}{ Funding Source } & Quality & \multicolumn{1}{|c|}{ Comments } \\
\hline Helminen 2015 & $\begin{array}{l}\text { This study has been supported by an } \\
\text { EVO and a VTR grant from Kuopio } \\
\text { University Hospital }\end{array}$ & $\begin{array}{l}\text { Fair } \\
\text { Values reported for follow up are an agregated "post-treatment average" reflecting all } \\
\text { outcome values over 12 month period with no specific values for 3- or 12-month follow up } \\
\text { sessions. }\end{array}$ \\
& & & \\
\hline
\end{tabular}




\begin{tabular}{|c|c|c|c|}
\hline Author, Year & $\begin{array}{c}\text { Country } \\
\text { Number of Centers } \\
\text { Setting }\end{array}$ & Inclusion/Exclusion Criteria & $\begin{array}{c}\text { Number Randomized, } \\
\text { Analyzed } \\
\text { Attrition }\end{array}$ \\
\hline Hinman 2014 & $\begin{array}{l}\text { Australia, community } \\
\text { recruitment, ? } 1 \\
\text { center }\end{array}$ & $\begin{array}{l}\text { Inclusion Criteria: } \\
50 \text { years or older } \\
\text { knee pain }>3 \text { months } \\
\text { knee pain most days with average severity of } 4 \text { or more on } 0-10 \text { NRS } \\
\text { morning stiffness }<30 \text { minutes } \\
\text { Exclusion: in online table (need to access) }\end{array}$ & \begin{tabular}{|l|} 
Randomized: 282 \\
Treated: 248 \\
Analyzed: 282 (analyzed \\
all regardless of follow up) \\
Attrition: $24.5 \%$ (69/282)
\end{tabular} \\
\hline
\end{tabular}




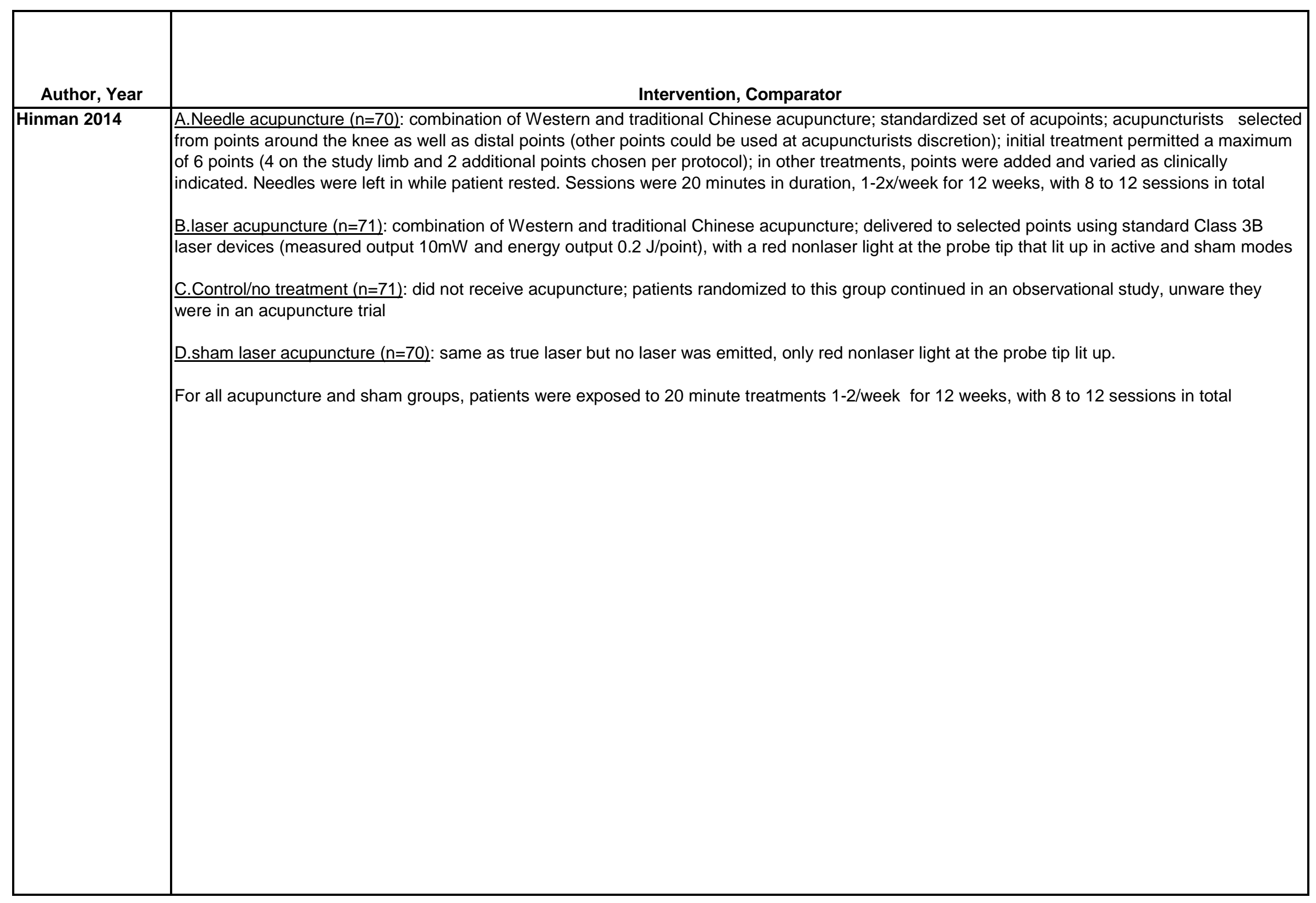




\begin{tabular}{|c|c|c|c|}
\hline Author, Year & Study Participants & Outcome Measures & $\begin{array}{l}\text { Duration of } \\
\text { Followup }\end{array}$ \\
\hline Hinman 2014 & $\begin{array}{l}\text { A vs B vs. C vs. D } \\
\text { Age: } 64 \text { vs. } 63 \text { vs. } 63 \text { vs. } 64 \text { years } \\
\text { Female: } 46 \% \text { vs. } 39 \% \text { vs. } 56 \% \text { vs. } 56 \% \\
\text { Race: NR } \\
\text { Duration of symptoms } \geq 10 \text { years: } 41 \% \text { vs. } 38 \% \text { vs. } 27 \% \text { vs. } 50 \% \\
\text { Unilateral symptoms: } 36 \% \text { vs. } 34 \% \text { vs. } 49 \% \text { vs. } 37 \% \\
\text { Opioid use: } 1 \% \text { vs. } 3 \% \text { vs. } 1 \% \text { vs. } 1 \% \\
\text { Previous acupuncture for knee pain: } 7 \% \text { vs. } 13 \% \text { vs. } 7 \% \text { vs. } 3 \% \\
\text { Previous injection therapy for knee pain: } 11 \% \text { vs. } 8 \% \text { vs. } 8 \% \text { vs. } 17 \% \\
\text { Previous surgery for knee pain: } 37 \% \text { vs. } 34 \% \text { vs. } 32 \% \text { vs. } 39 \% \\
\text { WOMAC function: } 31.3(11.8) \text { vs. } 27.0(11.3) \text { vs. } 26.1(12.4) \text { vs. } 27.5 \\
(12.4) \\
\text { NRS activity restriction: } 5.0(2.5) \text { vs. } 4.3(2.3) \text { vs. } 4.1(2.5) \text { vs. } 4.5(2.6) \\
\text { WOMAC pain: } 9.0(3.3) \text { vs. } 8.3(3.1) \text { vs. } 7.8(3.4) \text { vs. } 8.6(3.5) \\
\text { NRS average pain overall: } 5.3(1.9) \text { vs. } 4.9(1.9) \text { vs. } 5.1(2.1) \text { vs. } 5.0 \\
(2.1) \\
\text { NRS pain on walking: } 5.5(2.0) \text { vs. } 4.8(2.0) \text { vs. } 4.8(2.1) \text { vs. } 5.2(2.2) \\
\text { NRS pain on standing: } 4.6(2.2) \text { vs. } 3.8(2.1) \text { vs. } 4.1(2.4) \text { vs. } 4.3(2.3) \\
\text { AQoL-6D: } 0.72(0.15) \text { vs. } 0.70(0.16) \text { vs. } 0.77(0.16) \text { vs. } 0.73(0.15) \\
\text { SF-12 PCS: } 36.6(9.0) \text { vs. } 37.6(10.3) \text { vs. } 39.2(9.0) \text { vs. } 37.9(9.6) \\
\text { SF-12 MCS: } 51.3(11.4) \text { vs. } 52.5(11.1) \text { vs. } 55.6(10.2) \text { vs. } 52.4(19.5)\end{array}$ & $\begin{array}{l}\text { WOMAC function subscale (0-68; higher score=worse } \\
\text { function; MCID = } 6 \text { nonnormalized units); } \\
\text { WOMAC pain subscale (0-20; higher score=worse pain; } \\
\text { MCID } \geq 12 \% \text { improvement from baseline); } \\
\text { Average knee pain over previous week (NRS, 0-10; } \\
\text { higher score=greater pain; MCID = } 1.8 \text { points); } \\
\text { Average knee pain with standing and walking (NRS, 0- } \\
10 \text {; higher score=greater pain; MCID = } 1.8 \text { points) } \\
\text { Average daily activity restriction over previous week } \\
\text { (NRS, 0-10; higher score=more restriction) } \\
\text { Assessment } \\
\text { of Quality of Life instrument version } 2 \text { (AQol-6D; scale } \\
-0.04 \text { to } 1.00 \text {, higher scores= better quality of life; MCID } \\
=0.06 \text { ) } \\
\text { Physical and Mental Component Summary scores (PSC } \\
\text { and MSC) of the } 12 \text {-item Short Form Health Survey (SF- } \\
12, \text { scale } 0-100, \text { higher scores=better status; MCID } \\
\geq 12 \% \text { improvement } \\
\text { from baseline). }\end{array}$ & 9 months \\
\hline
\end{tabular}




\begin{tabular}{|c|c|}
\hline Author, Year & $\begin{array}{c}\text { Results - Subquestion a } \\
\text { (vs. sham, no treatment, waitlist, attention control) }\end{array}$ \\
\hline Hinman 2014 & 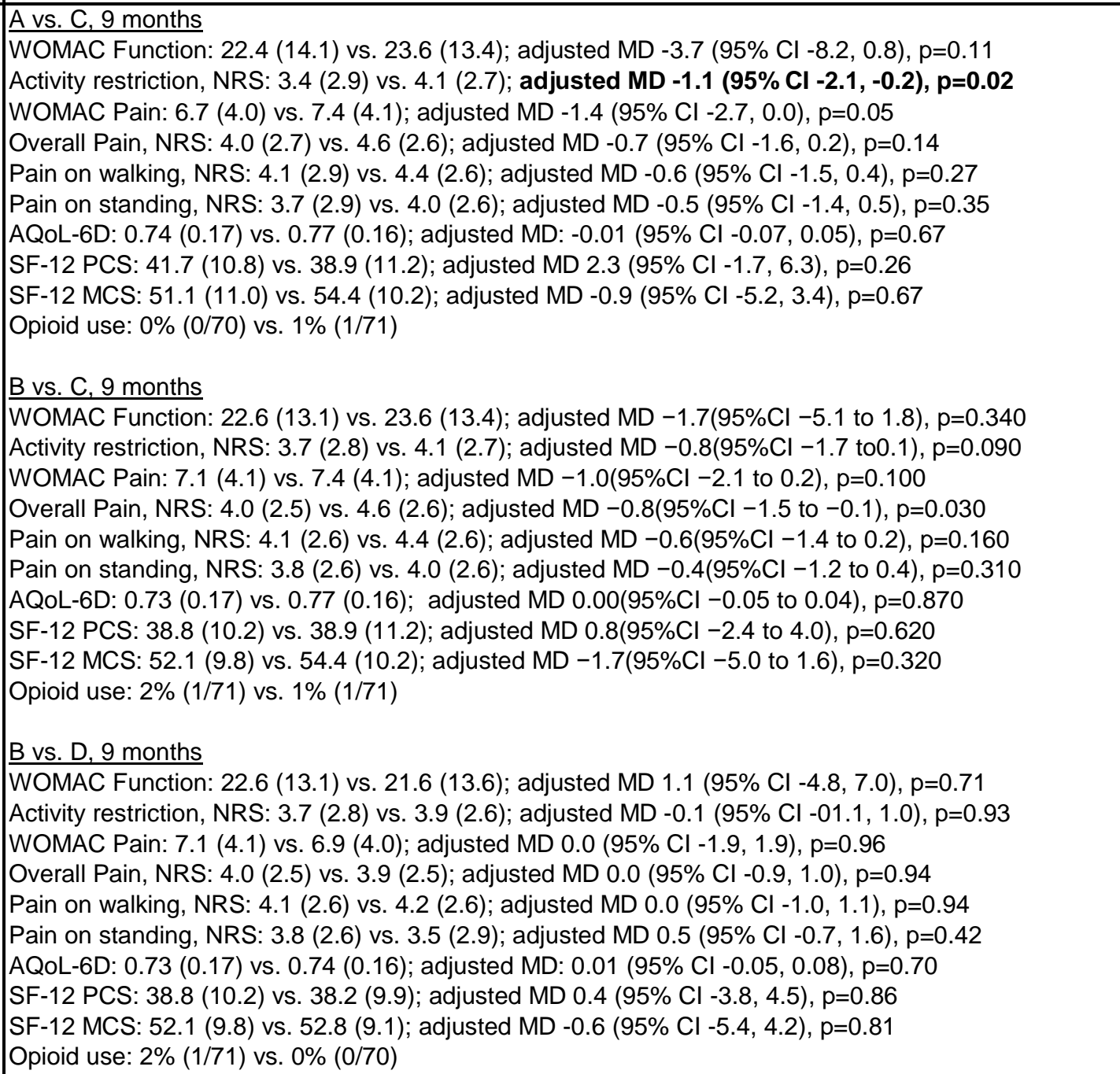 \\
\hline
\end{tabular}




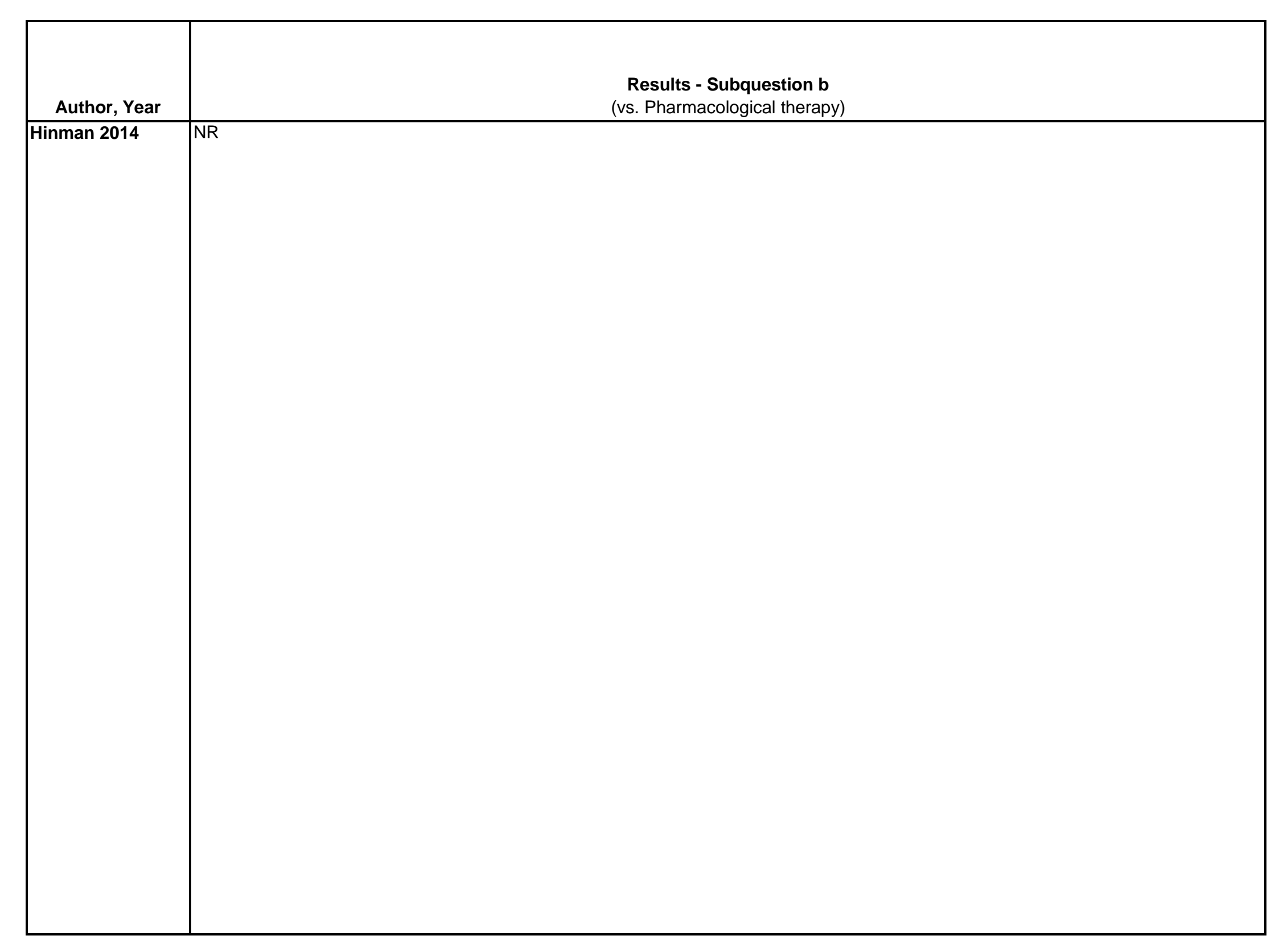

D-376 


\begin{tabular}{|c|c|c|}
\hline Author, Year & $\begin{array}{l}\text { Results - Subquestion c } \\
\text { (vs. Exercise) }\end{array}$ & Adverse Events Including Withdrawals \\
\hline Hinman 2014 & NR & 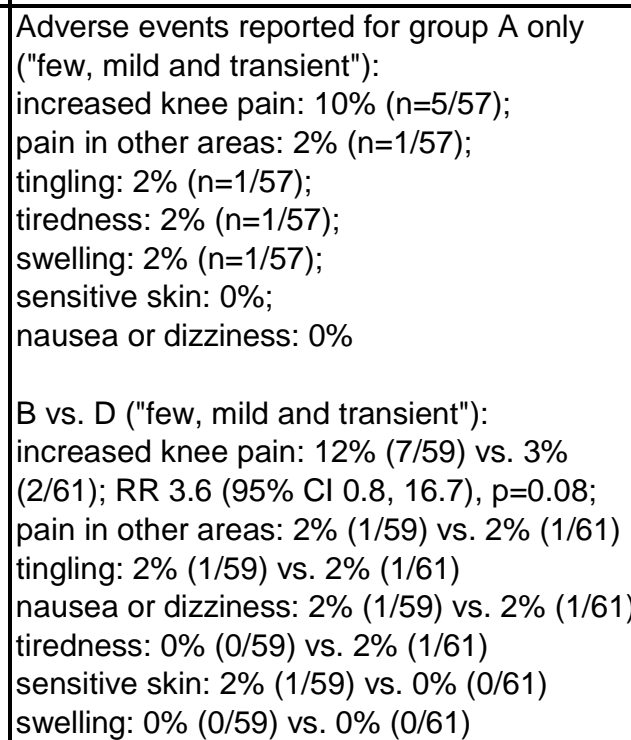 \\
\hline
\end{tabular}




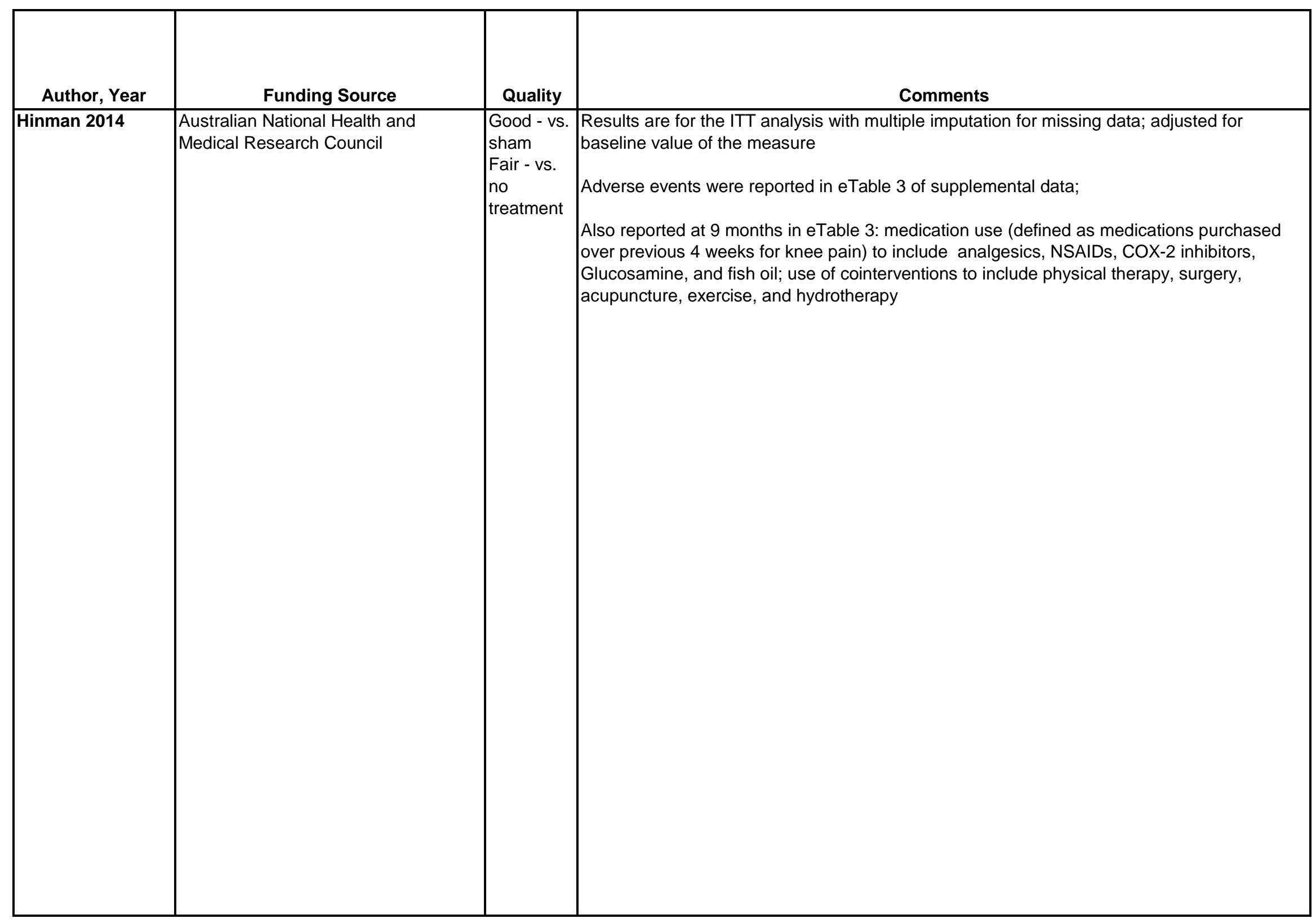




\begin{tabular}{|c|c|c|c|}
\hline Author, Year & $\begin{array}{l}\text { Country } \\
\text { Number of } \\
\text { centers and } \\
\text { setting }\end{array}$ & Inclusion/Exclusion Criteria & $\begin{array}{c}\text { Number randomized, analyzed } \\
\text { Attrition }\end{array}$ \\
\hline Ho 2017 & $\begin{array}{l}\text { China } \\
1 \text { center } \\
\text { Hospital }\end{array}$ & $\begin{array}{l}\text { 18-65 years old, no history of abdominal acupuncture, and VAS score } \geq 3 \\
\text { for neck pain casued by one or more of the following: neck pain, stiffness, } \\
\text { or tenderness, pain around the neck with radiation towards the occiput or } \\
\text { shoulder or ROM limited by neck pain, or neck pain with denegerative joint } \\
\text { disease or cervical sponylosis or both. } \\
\text { Exclude: Illness due to visceral pain in the neck, serious spinal disorders, } \\
\text { previous neck surgery or plan to get neck surgery during study, chronic } \\
\text { diseases that could interfere with abdominal acupuncture, cancer } \\
\text { diagnosis, chief pain complaint other than neck pain, unsafe conditions for } \\
\text { abdominal acupuncture, abdominal scars interfering with acupoints, } \\
\text { severe psychiatric or psychological disorders, acupuncture treatment } \\
\text { within } 1 \text { month to study start with conflicting or ongoing co-interventions, } \\
\text { participation in other clinical trials during study, pending neck-related } \\
\text { litigation or disability claims, inability to answer questionnaires and non- } \\
\text { responsiveness towards the assesor, pregnancy and breast feeding }\end{array}$ & $\begin{array}{l}\text { Randomized: } 154 \\
\text { Treated: } 154 \\
\text { Analyzed: } 154 \\
\text { Attrition: } 0 \%(0 / 154) \\
\\
\end{array}$ \\
\hline
\end{tabular}




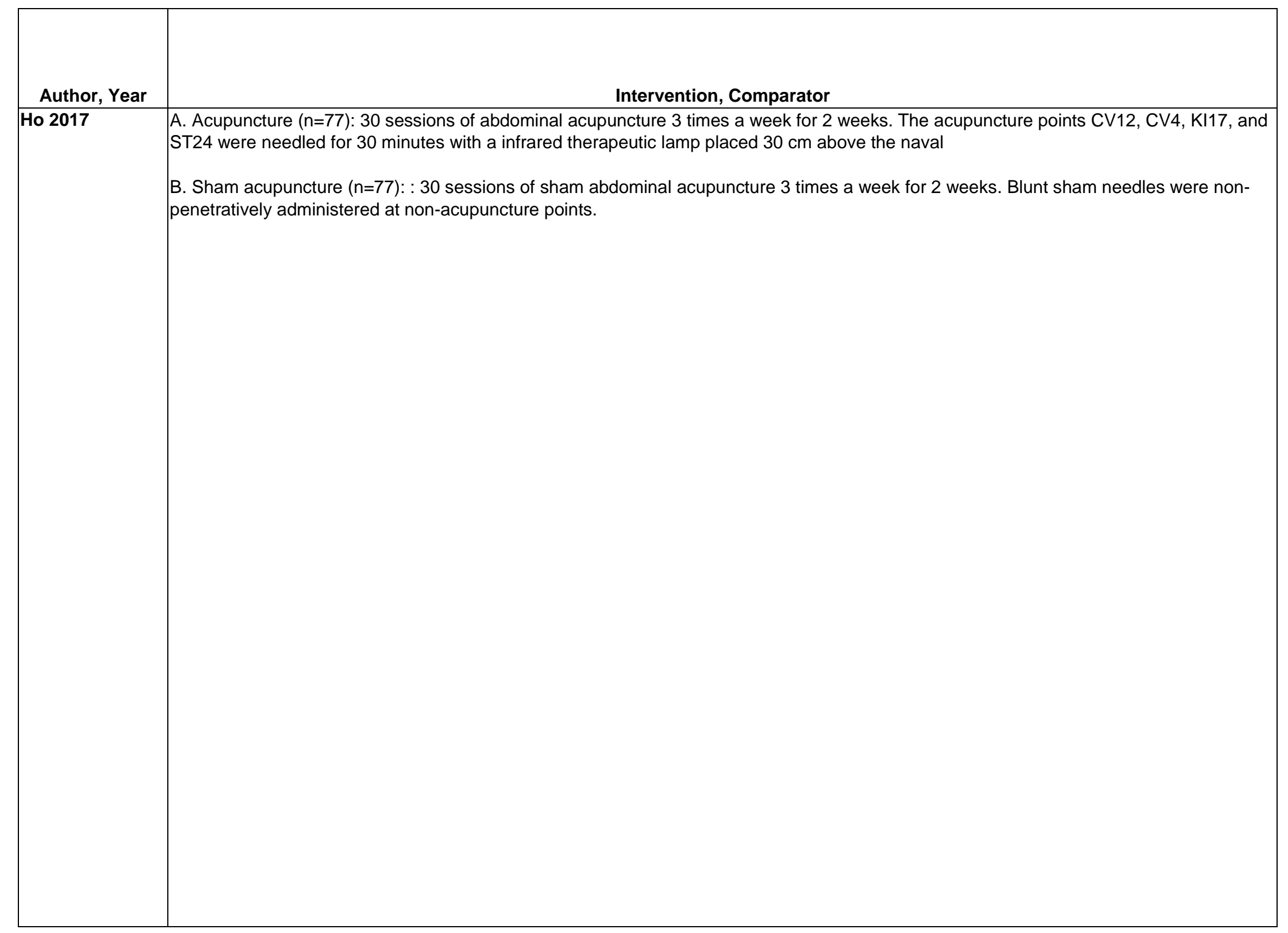




\begin{tabular}{|c|c|c|c|}
\hline Author, Year & Study participants & Outcome measures & $\begin{array}{c}\text { Duration of } \\
\text { followup }\end{array}$ \\
\hline Ho 2017 & 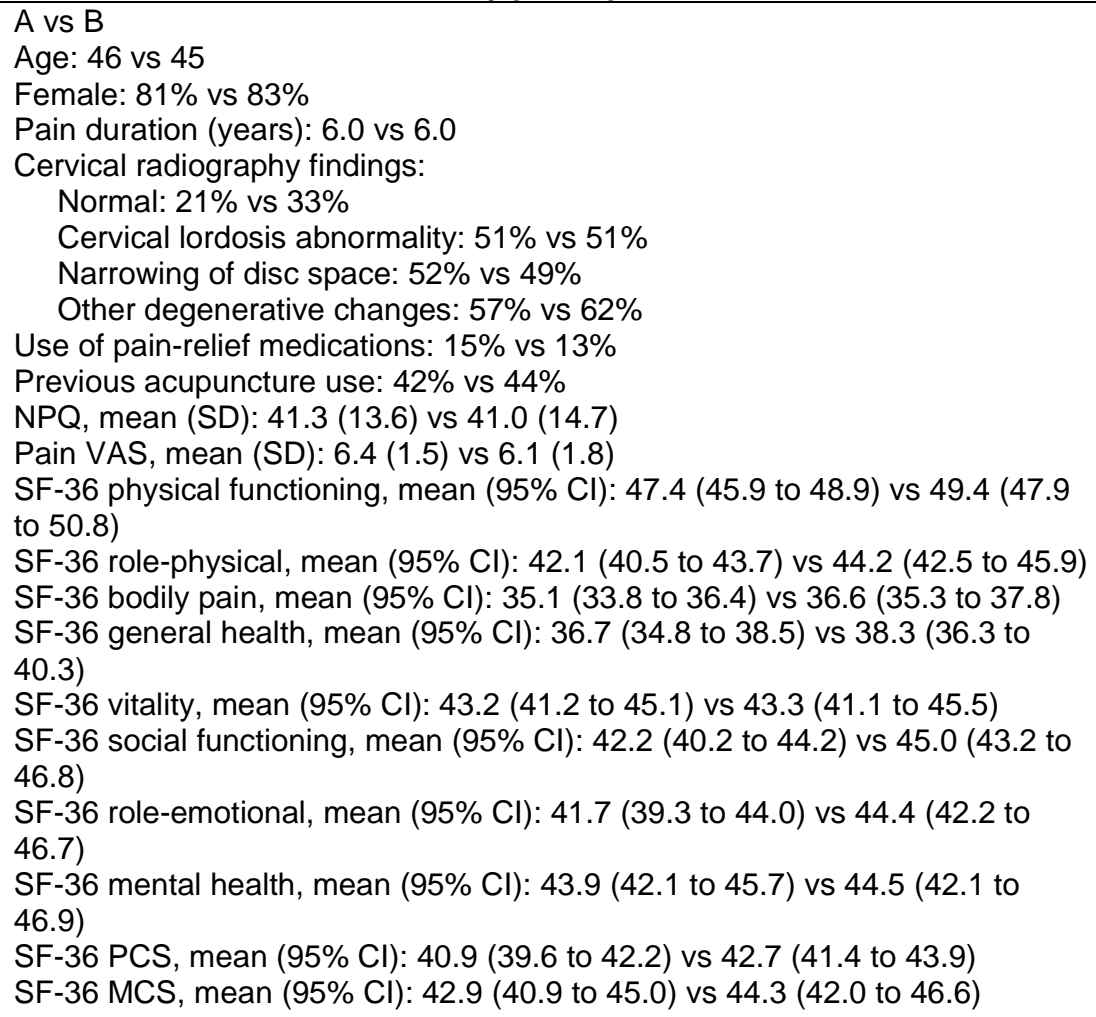 & $\begin{array}{l}\text { NPQ (0 to 100, higher } \\
\text { score=higher disability); pain } \\
\text { VAS (0-10, higher } \\
\text { score=higher pain); SF-36 } \\
\text { subscales (0-100, higher } \\
\text { score=higher quality of life) }\end{array}$ & 1 and 3 months \\
\hline
\end{tabular}




\begin{tabular}{|c|c|}
\hline Author, Year & $\begin{array}{c}\text { Results - Subquestion a } \\
\text { (vs. Sham, no treatment, waitlist, attention control) }\end{array}$ \\
\hline Ho 2017 & 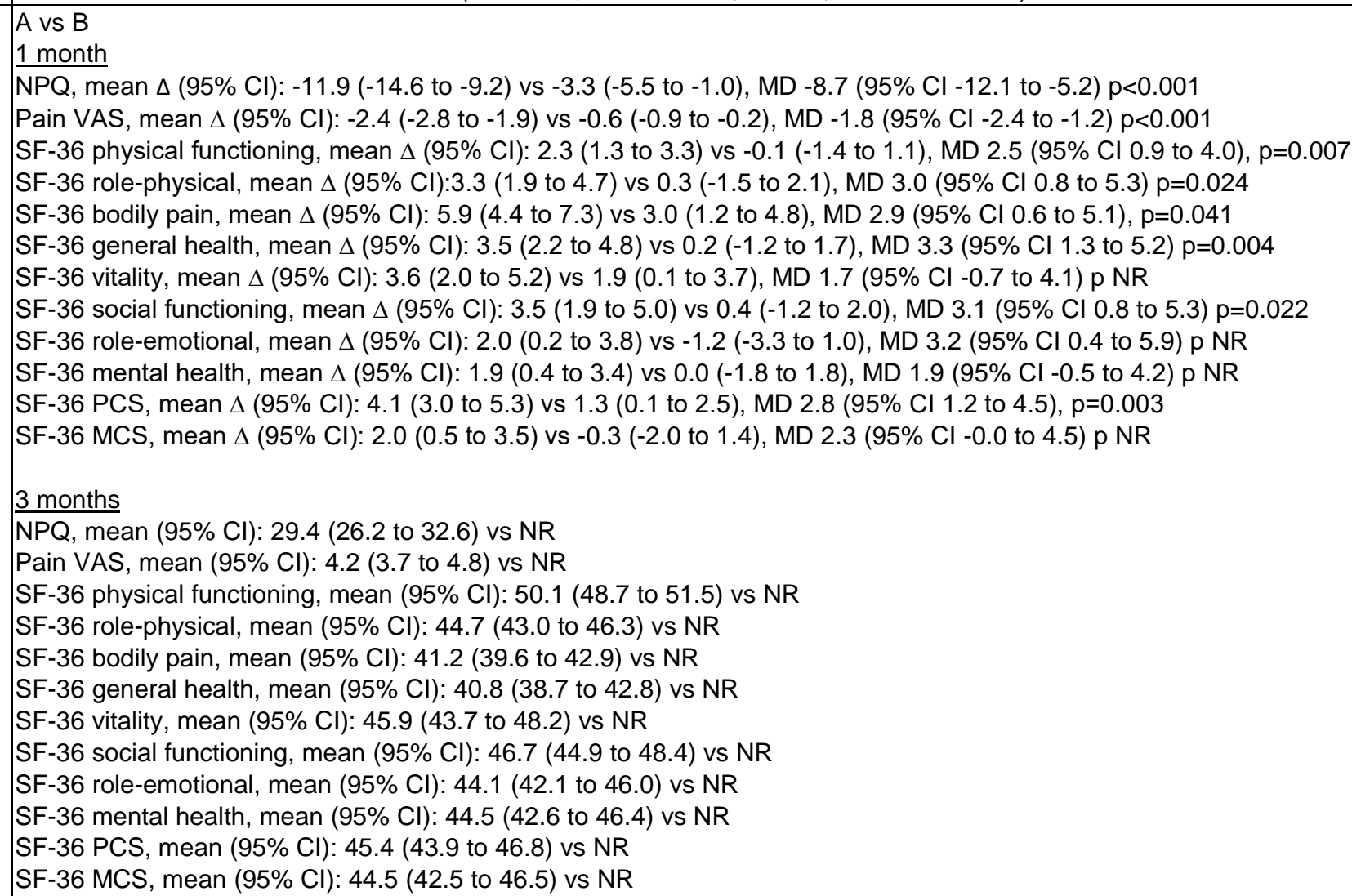 \\
\hline
\end{tabular}




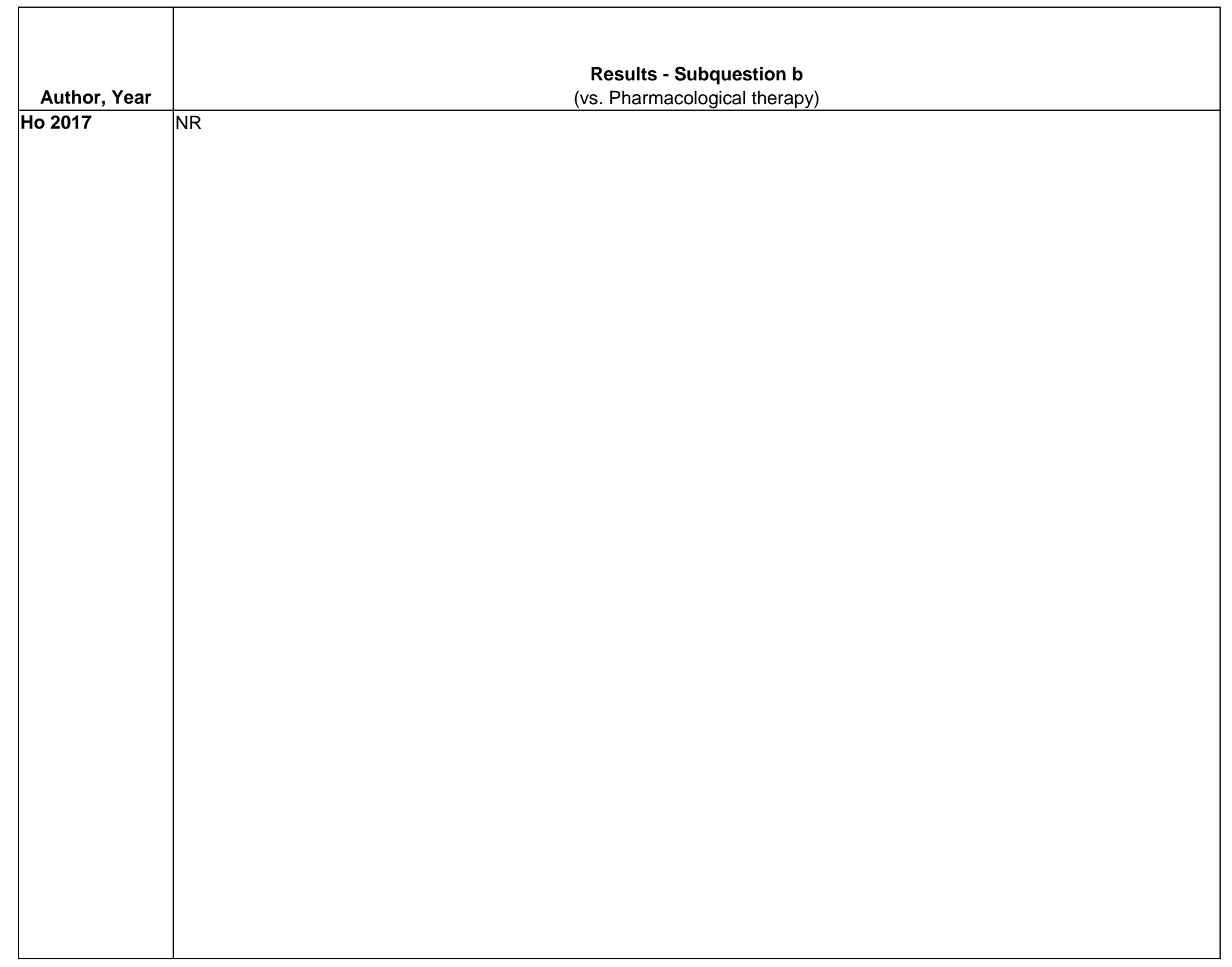




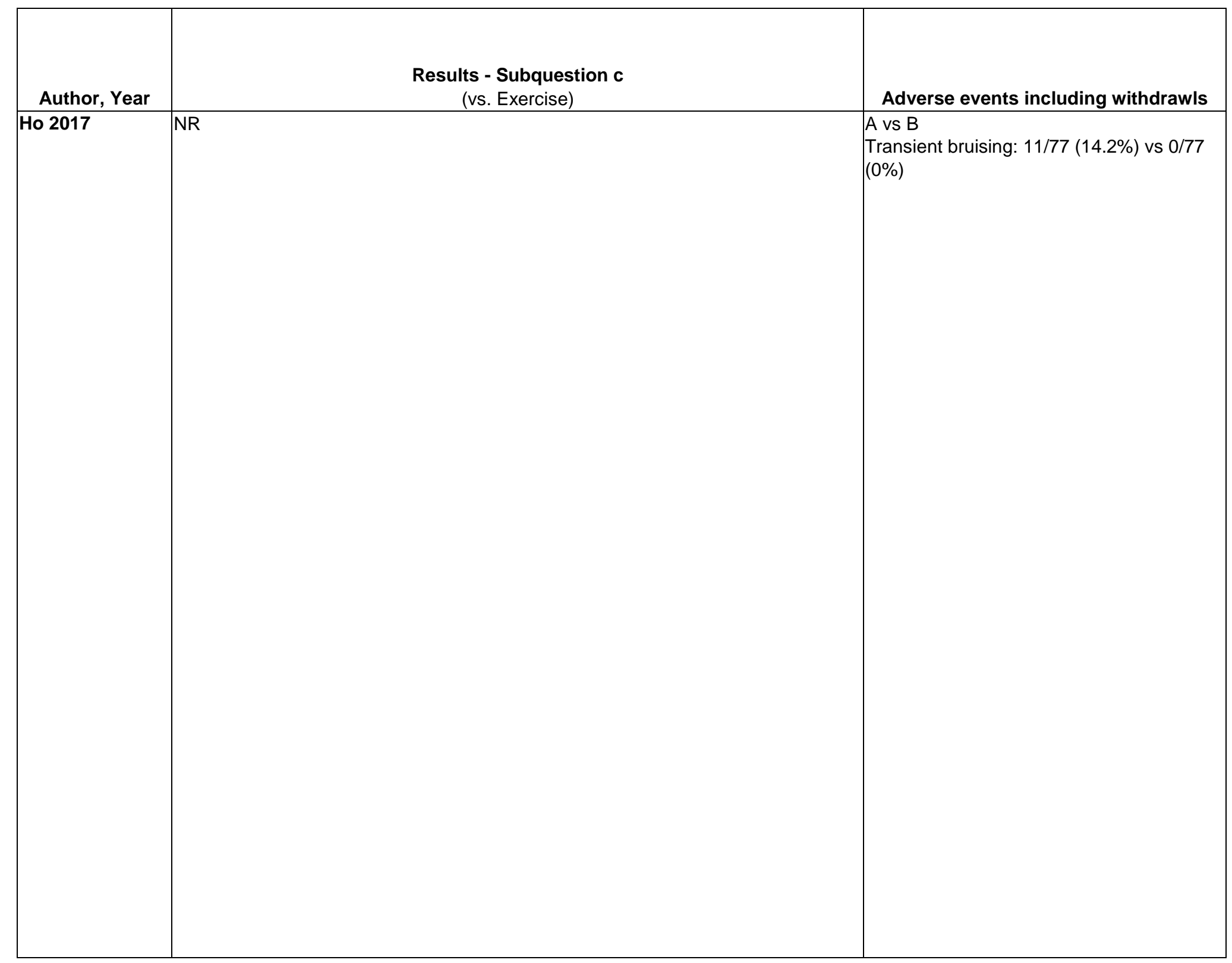




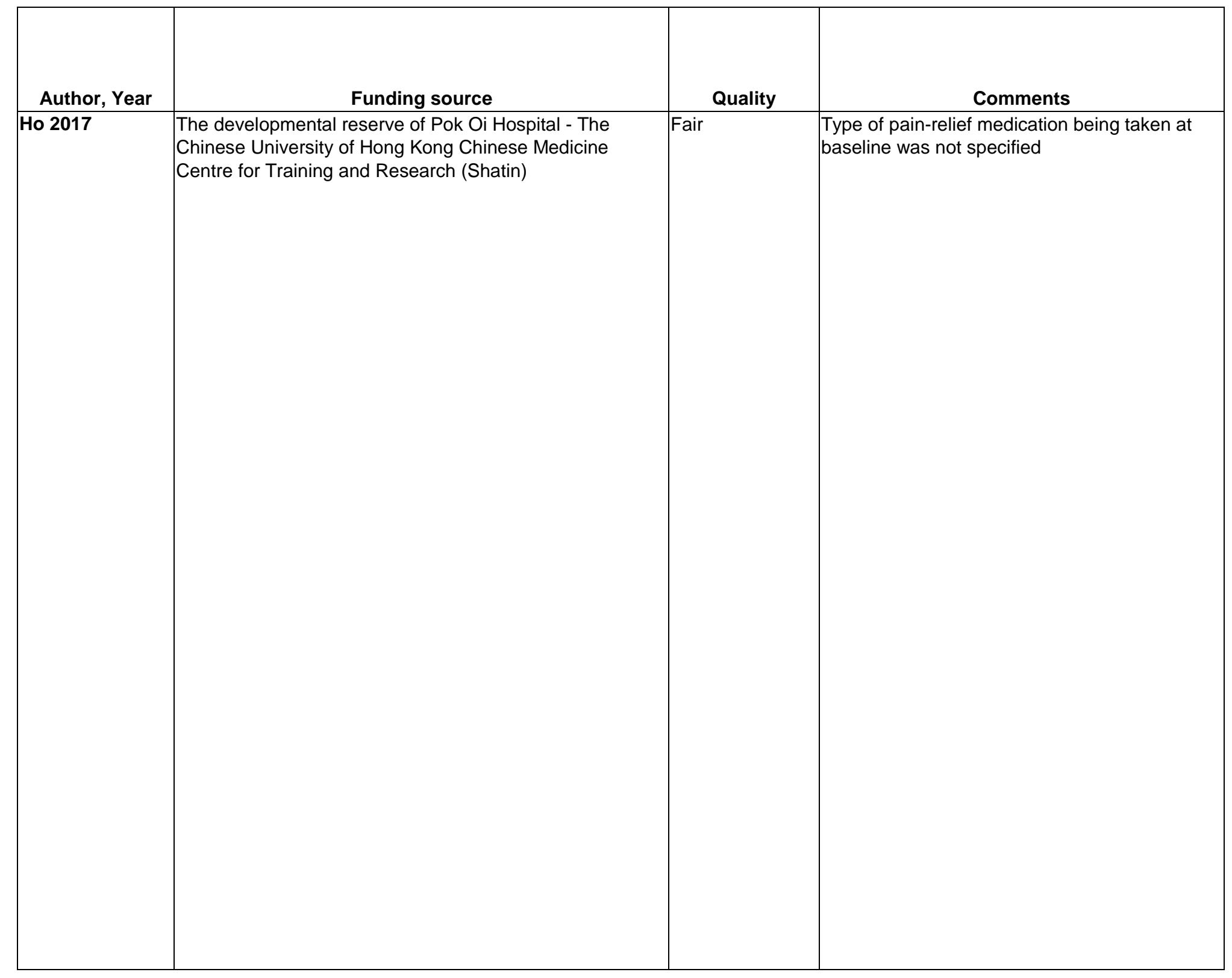




\begin{tabular}{|c|c|c|c|}
\hline Author, Year & $\begin{array}{c}\text { Country } \\
\text { Number of Centers } \\
\text { Setting }\end{array}$ & Inclusion/Exclusion Criteria & $\begin{array}{c}\text { Number Randomized, } \\
\text { Analyzed } \\
\text { Attrition } \\
\end{array}$ \\
\hline Hoeksma 2004 & $\begin{array}{l}\text { The Netherlands } \\
1 \text { center } \\
\text { Outpatient }\end{array}$ & $\begin{array}{l}\text { Diagnosis of hip OA fulfilling ACR criteria } \\
\text { Exclude: Bilateral symptoms, fear of manipulative surgery, age }<60 \text { or } \\
>85 \text { years, lower back pain, severe cardiopulmonary disease }\end{array}$ & Randomized: 109 \\
\hline Holroyd 1991 & $\begin{array}{l}\text { United States, single } \\
\text { site, clinic }\end{array}$ & $\begin{array}{l}\text { Inclusion Criteria: } \\
\text { Diagnosis of CTTH, >=3 days of headache/week, suffered from } \\
\text { headaches for at least } 1 \text { year } \\
\\
\text { Exclusion Criteria: } \\
\text { Prodromal symptoms commonly associated with vascular headache, } \\
\text { frequent unilateral pulsing or throbbing pain, typical sudden or abrupt } \\
\text { headache onset, indication of sinus headaches, headaches } \\
\text { associated with a disease state or head trauma, or aggravated by } \\
\text { analgesic abuse, free from prophylactic headache medication for at } \\
\text { least } 3 \text { months before entering the study. }\end{array}$ & Treated: 103 \\
\hline
\end{tabular}




\begin{tabular}{|c|c|}
\hline Author, Year & Intervention, Comparator \\
\hline Hoeksma 2004 & $\begin{array}{l}\text { A.Manual therapy }(n=56): 2 \text { sessions per week for } 5 \text { weeks with } 9 \text { sessions in total. Sessions consisted of stretching followed by traction } \\
\text { manipulation in each limited position (high velocity thrust technique). } \\
\text { B.Exercise therapy }(n=53): 2 \text { sessions per week for } 5 \text { weeks with } 9 \text { sessions in total. Sessions implemented exercises for muscle functions, muscle } \\
\text { length, joint mobility, pain relief, and walking ability and were tailored to the specific needs of the patient. Instructions for home exercises were given. }\end{array}$ \\
\hline Holroyd 1991 & $\begin{array}{l}\text { A.Cognitive Behavioral Therapy }(\mathrm{n}=19) \\
\text { Primarily home-based treatment protocol } \\
\text { No. of Treatments: Total of } 3 \text { sessions over } 8 \text { week treatment period. } \\
\text { Length of Treatment: } 1 \text { hour } \\
\text { B.Amitriptyline therapy }(n=17) \\
\text { Individualized dosage at } 25,50 \text {, or } 75 \mathrm{mg} / \text { day }\end{array}$ \\
\hline
\end{tabular}




\begin{tabular}{|c|c|c|c|}
\hline Author, Year & Study Participants & Outcome Measures & $\begin{array}{c}\text { Duration of } \\
\text { Followup }\end{array}$ \\
\hline Hoeksma 2004 & $\begin{array}{l}\text { A vs B } \\
\text { Age: } 72 \text { vs } 71 \\
\text { Females: } 68 \% \text { vs } 72 \% \\
\text { Symptom duration: } \\
\quad 1 \text { month to } 1 \text { year: } 39 \% \text { vs } 28 \% \\
\quad 1 \text { year to } 2 \text { years: } 21 \% \text { vs } 25 \% \\
2 \text { years to } 5 \text { years: } 16 \% \text { vs } 28 \% \\
5 \text { years to } 10 \text { years: } 18 \% \text { vs } 15 \% \\
\quad \text { } 10 \text { years: } 5 \% \text { vs } 4 \% \\
\text { Radiographic deterioration: } \\
\quad 0 \text { (no OA): } 9 \% \text { vs } 8 \% \\
\quad 1 \text { (mild OA): } 13 \% \text { vs } 11 \% \\
2 \text { (moderate OA): } 34 \% \text { vs } 43 \% \\
\quad 3 \text { (severe OA): } 45 \% \text { vs } 38 \% \\
\text { HHS: } 54 \text { (15) vs } 53(14) \\
\text { SF-36 physical function: } 42.1(23) \text { vs } 41.4(21) \\
\text { SF-36 role physical function: } 27.0(38) \text { vs } 24.7 \text { (36) } \\
\text { SF-36 bodily pain: } 41.1(18) \text { vs } 37.9(18) \\
\text { Pain at rest VAS: } 22.5 \text { (23) vs } 23.0(26) \\
\text { Pain walkina VAS: } 34.0 \text { (22) vs } 28.8 \text { (22) } \\
\end{array}$ & $\begin{array}{l}\text { HHS (0-100, higher score=higher function); SF-36 physical } \\
\text { function (0-100, higher score=worse function); SF-36 role } \\
\text { physical function (0-100, higher score=worse function); SF-36 } \\
\text { bodily pain (0-100, higher score=less pain); pain at rest VAS } \\
\text { (0-100, higher score=higher pain); pain walking VAS (0-100, } \\
\text { higher score=higher pain) }\end{array}$ & $\begin{array}{l}3 \text { and } 6 \\
\text { months }\end{array}$ \\
\hline Holroyd 1991 & $\begin{array}{l}\frac{A+B}{\text { Age: } 32.3 \text { years }} \\
\text { Female: } 80 \% \text { Race: NR } \\
\text { Duration of symptoms: } 10.7 \text { years } \\
\\
\text { \% of Headache-Free Days: } 18.0(16.0) \text { vs. } 18.5(14.3) \\
\text { Headache Index Scores }(0-10): 2.17(0.96) \text { vs. } 2.04(0.94) \\
\text { Headache Pain Peak Scores(0-10): } 6.41(1.67) \text { vs. } 6.36(1.23) \\
\text { Mean Number of Analgesic Tablets: } 0.82(0.89) \text { vs. } 1.59(1.77) \\
\text { Depression (BDI): } 9.26(5.41) \text { vs. } 7.69(5.88) \\
\text { Anxiety(STPI): } 22.63(6.04) \text { vs. } 20.62(6.82) \\
\text { Anger(STPI): } 20.68(5.65) \text { vs. } 19.06(5.08) \\
\text { Physical Complaints(WPSI): } 20.53(8.16) \text { vs. } 20.94(7.87)\end{array}$ & $\begin{array}{l}\text { \% of Headache-Free Days; } \\
\text { Proportion of Patients who Substantially Improved } \\
\text { (>66\% reduction;) } \\
\text { Proportion of Patients who Moderately Improved (33- 66\% } \\
\text { reduction); } \\
\text { Headache Index (mean headache recording for an } \\
\text { assessment period): measure of the average level of pain } \\
\text { (range 0-10: higher scores=more incapacitating the pain); } \\
\text { Headache Peak (highest pain rating for each week } \\
\text { averaged across an assessment period): measure of } \\
\text { patient's most intense pain (range 0-10; higher } \\
\text { scores=more intense the pain) } \\
\text { Mean Number of Analgesic Tablets (weighted by } \\
\text { medication potency); } \\
\text { Beck Depression Inventory (BDI; total: 0-63, higher scores } \\
\text { indicate severity of depressive symptoms); State-Trait } \\
\text { Personality Inventory (STPI, range 20-80: higher scores } \\
\text { indicate higher anxiety levels); } \\
\text { Wahler Physical Symptom Inventory (WPSI) }\end{array}$ & 1 month \\
\hline
\end{tabular}




\begin{tabular}{|l|l|}
\hline Author, Year & $\begin{array}{c}\text { Results - Subquestion a } \\
\text { (vs. sham, no treatment, watitist, attention control) }\end{array}$ \\
\hline Hoeksma 2004 & \\
\hline Holroyd 1991 & NA \\
& \\
\hline
\end{tabular}




\begin{tabular}{|c|c|}
\hline Author, Year & $\begin{array}{l}\text { Results - Subquestion b } \\
\text { (vs. Pharmacological therapy) }\end{array}$ \\
\hline Hoeksma 2004 & \\
\hline Holroyd 1991 & 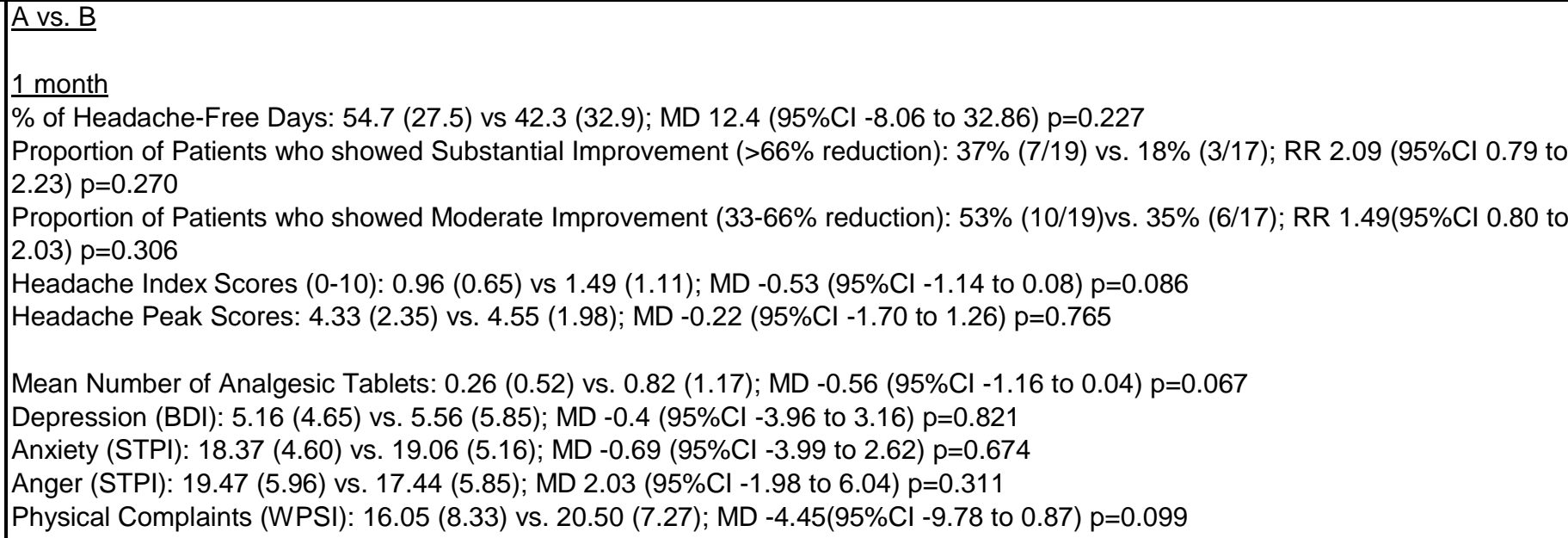 \\
\hline
\end{tabular}




\begin{tabular}{|c|c|c|}
\hline Author, Year & $\begin{array}{l}\text { Results - Subquestion c } \\
\text { (vs. Exercise) }\end{array}$ & Adverse Events Including Withdrawals \\
\hline Hoeksma 2004 & 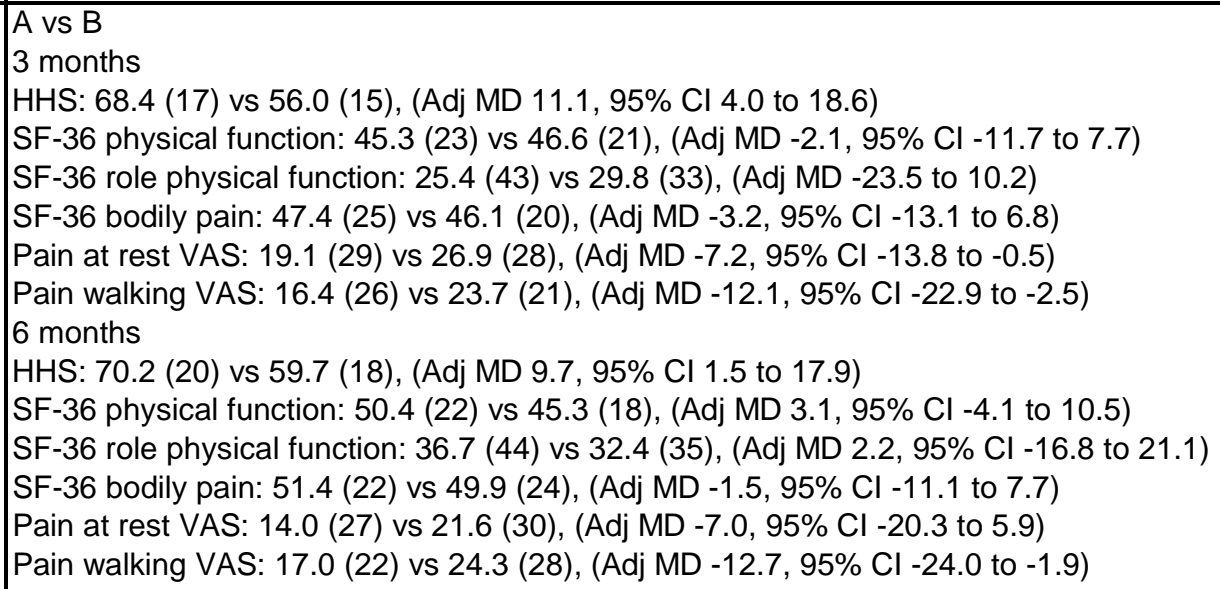 & $\begin{array}{l}\text { Increased complaints: } 3 / 56(5 \%) \text { vs 0/53 } \\
(0 \%)\end{array}$ \\
\hline Holroyd 1991 & NA & $\begin{array}{l}\text { Statistically significant difference in side } \\
\text { effects between groups, with } 58.8 \%(10 / 17) \\
\text { patients who received amitriptyline reporting } \\
\text { at least mild side effects ( } p<.001 \text { ) vs. } 0 \% \\
(0 / 19) \text { of the CBT group } \\
\\
\begin{array}{l}\text { Withdrawals: One patient }(1 / 20) \text { from the } \\
\text { CBT group (due to lack of time) vs. four } \\
\text { patients ( } 4 / 21) \text { in the amitriptyline group due } \\
\text { to medication side effects }\end{array}\end{array}$ \\
\hline
\end{tabular}




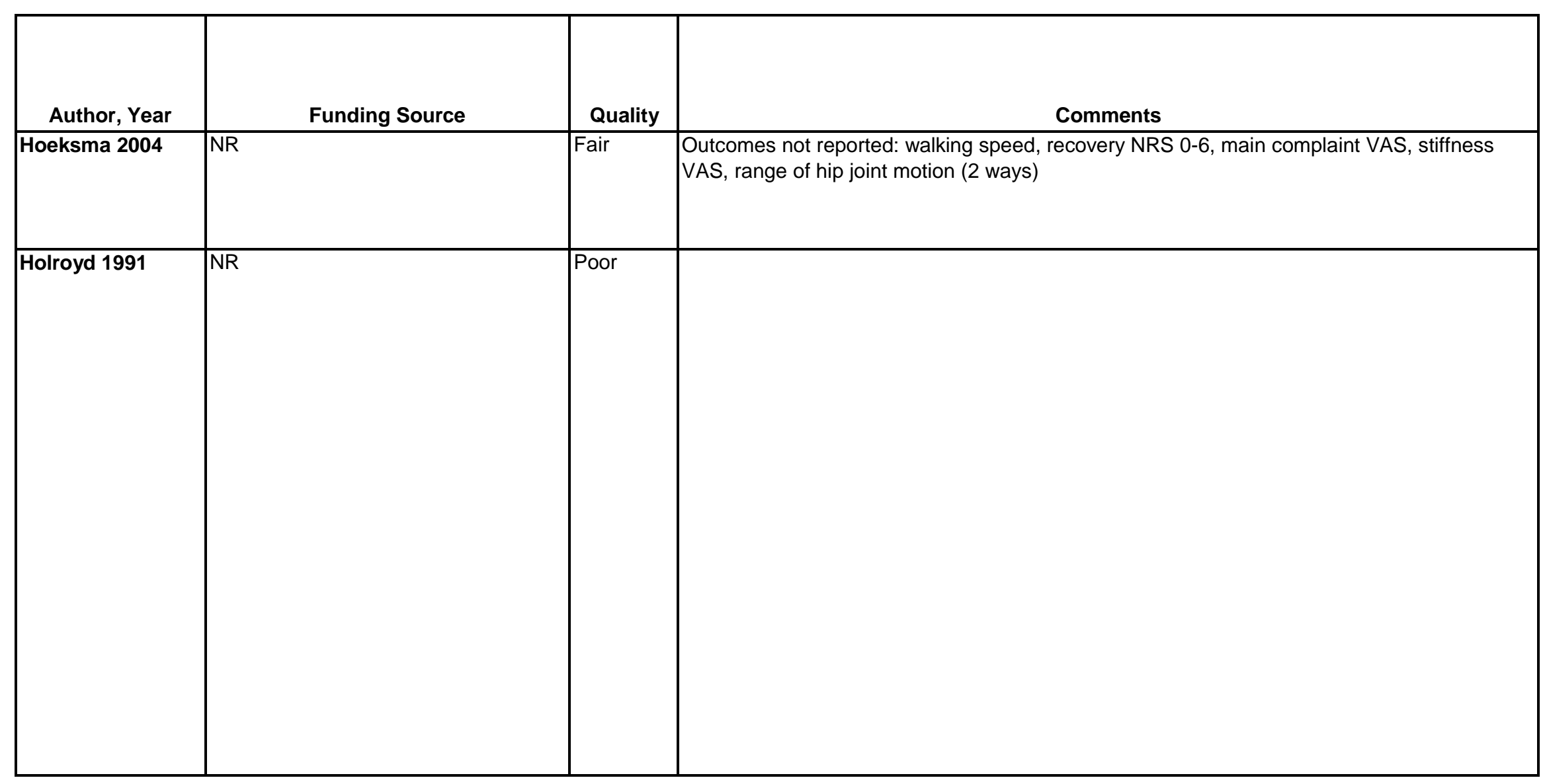




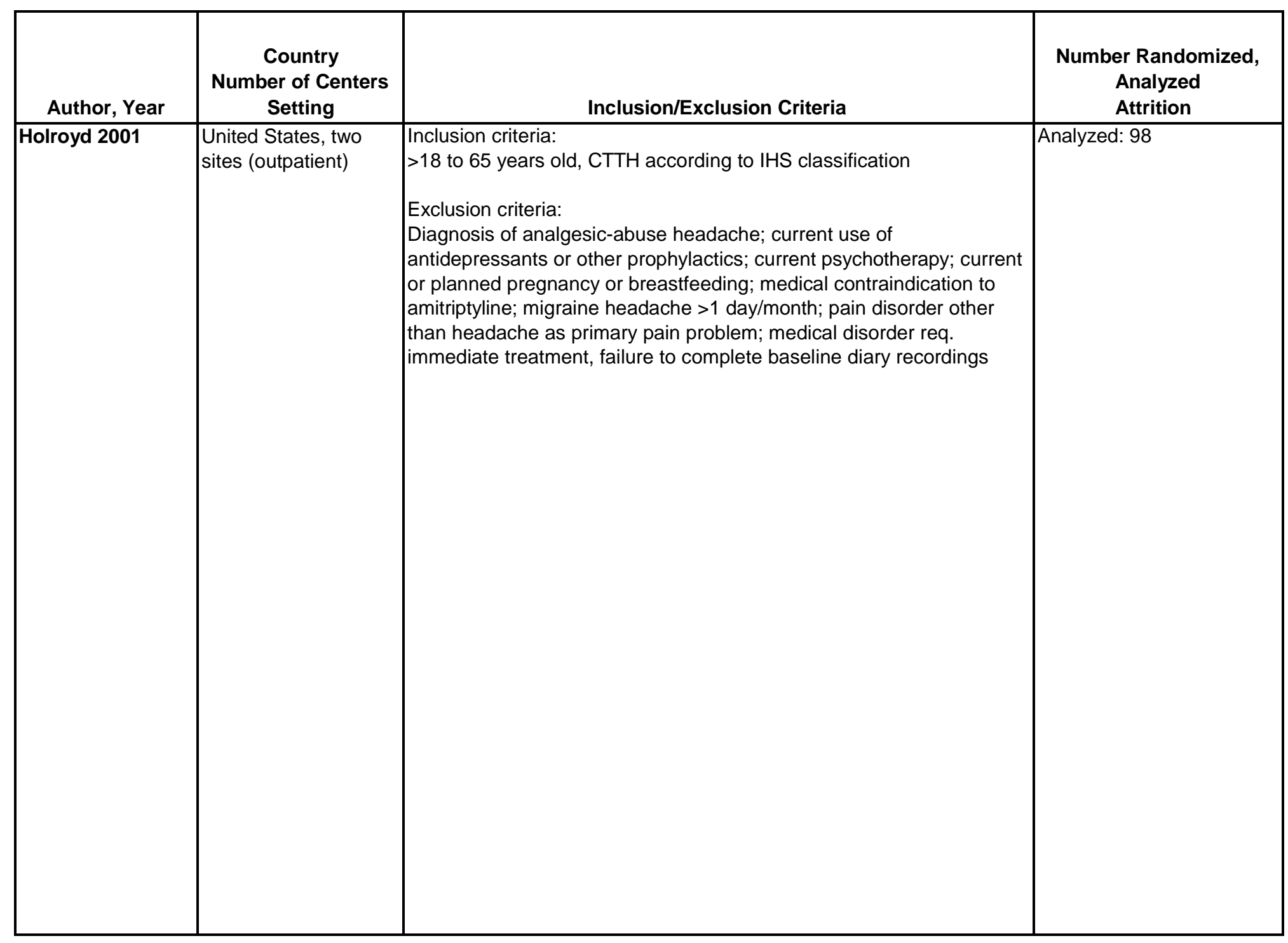




\begin{tabular}{|c|c|}
\hline Author, Year & Intervention, Comparator \\
\hline Holroyd 2001 & $\begin{array}{l}\text { A.Stress Management Therapy + Placebo ( } \mathrm{n}=34) \\
\text { Psychologist or counselor administered lessons on home-based relaxation and cognitive coping skills } \\
\text { No. of Sessions: } 3 \\
\text { Length of Sessions: } 1 \text { hour } \\
\text { B.Placebo ( } \mathrm{n}=26) \\
\text { Followed the same procedure as AM group but with placebo pills. } \\
\text { C.Antidepressant Medications ( } \mathrm{n}=44) \\
\text { Low starting dose }(12.5 \mathrm{mg} \text { increased to } 25 \mathrm{mg} \text {, then } 50 \mathrm{mg} \text { ) with the possibility to switch to nortriptyline }\end{array}$ \\
\hline
\end{tabular}




\begin{tabular}{|c|c|c|c|}
\hline Author, Year & Study Participants & Outcome Measures & $\begin{array}{l}\text { Duration of } \\
\text { Followup }\end{array}$ \\
\hline Holroyd 2001 & $\begin{array}{l}\text { A vs B vs C } \\
\text { Age: } 37 \text { vs } 38 \text { vs. } 36 \\
\text { Sex: } 80 \% \text { vs } 79 \% \text { vs. } 66 \% \text { female } \\
\text { Race: } 91 \% \text { vs } 98 \% \text { vs } 98 \% \text { white } \\
\text { Duration of symptoms: } 12.3 \text { vs. } 11.1 \text { vs } 11.9(p=0.44) \\
\text { Frequency of Headache, days per month: } 26.5(0.70) \text { vs. } 26.1(0.74) \\
\text { vs. } 25.1 \text { (0.72), } p=0.57 \\
\\
\text { Headache Index: } 2.8(0.20) \text { vs. } 2.7(0.21) \text { vs. } 2.8(0.18) \text {; Avs.B: MD } \\
0.10(95 \% \mathrm{Cl} 0.02 \text { to } 0.18) p=0.018 ; \text { Avs.C: MD } 0.0(95 \% \mathrm{Cl}-0.07 \text { to } \\
0.07) p=1.000 \\
\text { At least moderately severe headache days/month: } 13.5(1.2) \text { vs. } 13.5 \\
\text { (1.2)vs. } 14.1(1.1) ; \text { Avs.B: MD } 0.0(95 \% C l-0.48 \text { to } 0.48) p=1.000 ; \\
\text { Avs.C: } \text { MD }-0.6(95 \% C l-1.05 \text { to }-0.15) p=0.009 \\
\text { Weighted Analgesic use: NR } \\
\text { Headache Disability Inventory Score }(0-100): N R\end{array}$ & $\begin{array}{l}\text { Days/month with at least moderately severe ( } \geq 5 \text { pain } \\
\text { rating) headache; } \\
\text { Headache Disability Inventory Scores (HDI, range 0- } \\
\text { 100: higher scores indicate greater severity of } \\
\text { symptoms); } \\
\text { Headache Index Scores (mean of all headache diary } \\
\text { ratings for } 1 \text { month period; 0-10; higher score=greater } \\
\text { pain); } \\
\text { Analgesic Medication Use Scores (weighted by } \\
\text { medication potency) }\end{array}$ & $\begin{array}{l}1 \text { month, } 6 \\
\text { month }\end{array}$ \\
\hline
\end{tabular}




\begin{tabular}{|c|c|}
\hline Author, Year & $\begin{array}{l}\text { Results - Subquestion a } \\
\text { (vs. sham, no treatment, waitlist, attention control) }\end{array}$ \\
\hline Holroyd 2001 & 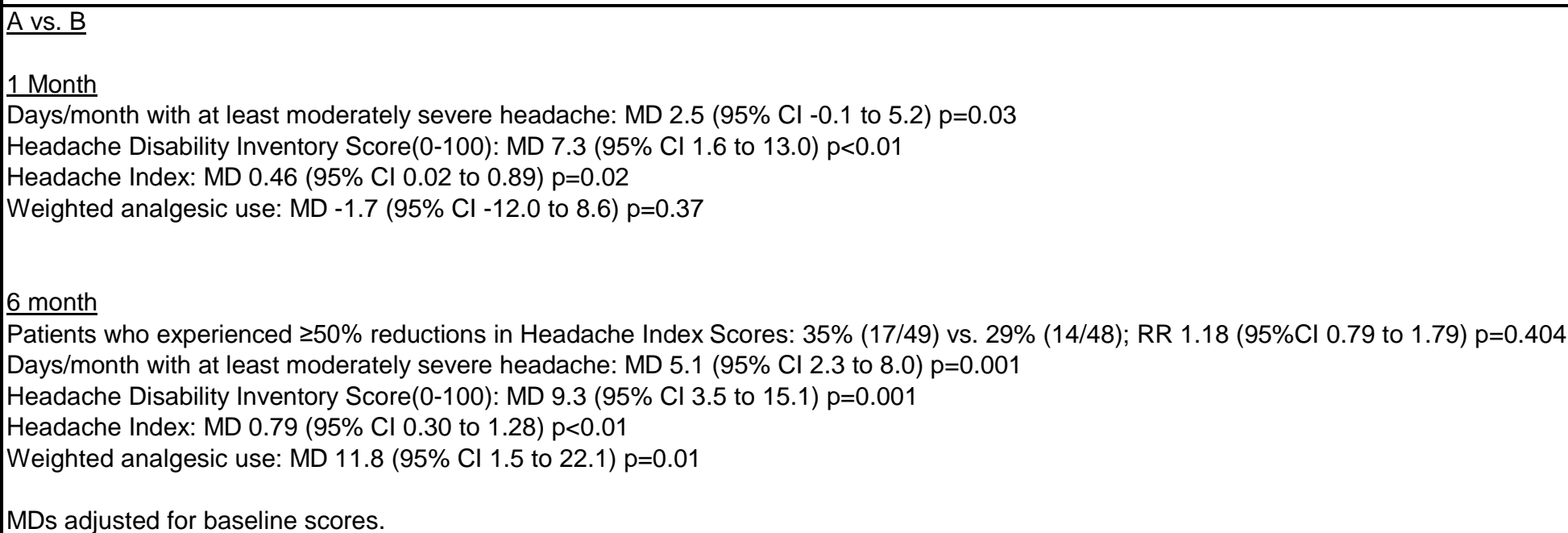 \\
\hline
\end{tabular}




\begin{tabular}{|c|c|}
\hline Author, Year & $\begin{array}{l}\text { Results - Subquestion b } \\
\text { (vs. Pharmacological therapy) }\end{array}$ \\
\hline Holroyd 2001 & 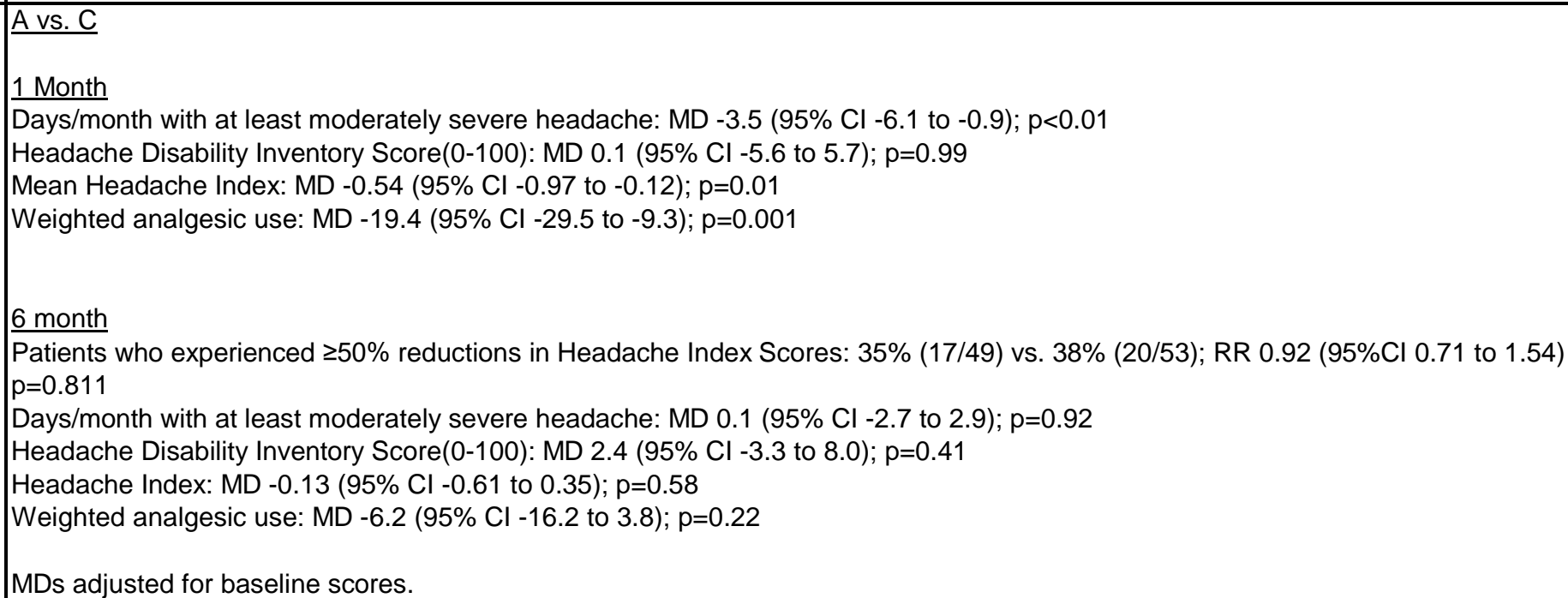 \\
\hline
\end{tabular}




\begin{tabular}{|c|c|c|}
\hline Author, Year & $\begin{array}{l}\text { Results - Subquestion c } \\
\text { (vs. Exercise) }\end{array}$ & Adverse Events Including Withdrawals \\
\hline Holroyd 2001 & & 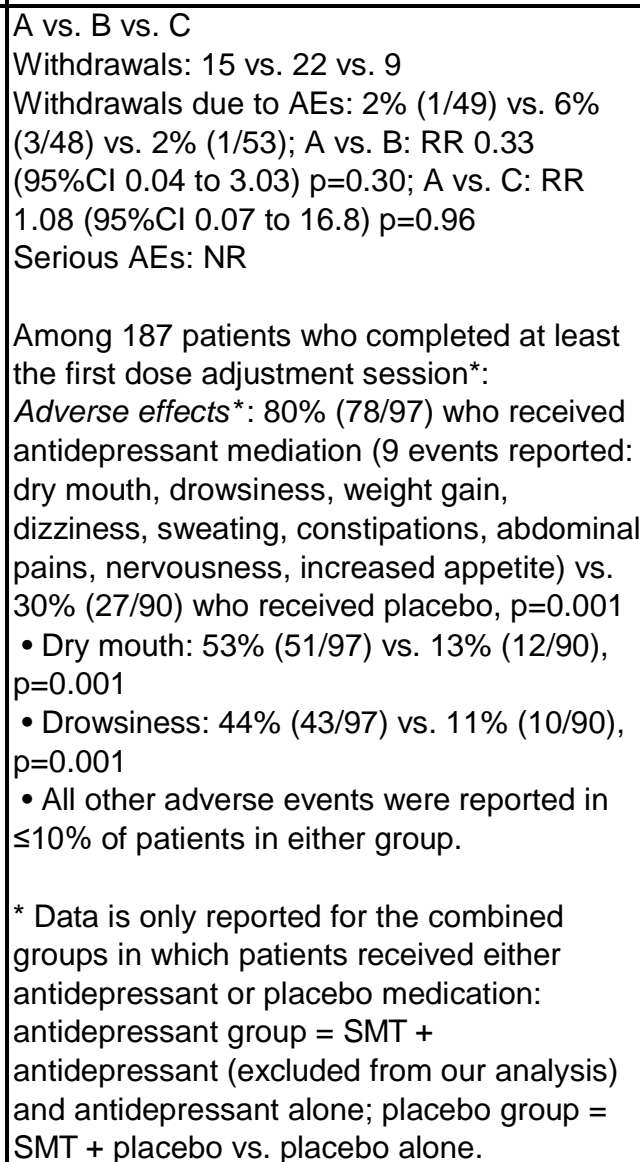 \\
\hline
\end{tabular}




\begin{tabular}{|l|l|l|l|}
\hline Author, Year & \multicolumn{1}{|c|}{ Funding Source } & Quality & \multicolumn{1}{|c|}{ Comments } \\
\hline Holroyd 2001 & $\begin{array}{l}\text { Grant NS32374 from the National } \\
\text { Institue of Neurological Disorders and } \\
\text { Stroke, National Institute of Heath }\end{array}$ & $\begin{array}{l}\text { This study involved 4 comparator groups, 1 of which was excluded for not meeting our } \\
\text { inclusion criteria (stress management + meds = additive). } \\
\text { Some patients who received AM also received SMT so AE cannot be separated. }\end{array}$ \\
& & & \\
\hline
\end{tabular}




\begin{tabular}{|c|c|c|c|}
\hline Author, Year & $\begin{array}{c}\text { Country } \\
\text { Number of Centers } \\
\text { Setting }\end{array}$ & Inclusion/Exclusion Criteria & $\begin{array}{c}\text { Number Randomized, } \\
\text { Analyzed } \\
\text { Attrition } \\
\end{array}$ \\
\hline Hondras 2009 & $\begin{array}{l}\text { US, lowa } \\
\text { Number of centers: } 1 \\
\text { Research clinic }\end{array}$ & $\begin{array}{l}\text { Patients } 55 \text { years old, with non-specific LBP for } 4 \text { weeks and } \\
\text { diagnostic classification of } 1 \text { (pain without radiation), } 2 \text { (pain plus } \\
\text { radiation to extremity, proximally), or } 3 \text { (pain plus radiation to } \\
\text { extremity, distally) according to the Quebec Task Force on Spinal } \\
\text { Disorders. } \\
\text { Exclude: Patients with frank radiculopathy or neurological signs, } \\
\text { comorbid conditions or general poor } \\
\text { Health, pregnancy, bleeding disorders, evidence of narcotic or other } \\
\text { drug abuse, major clinical depression scores greater than } 29 \text { on the } \\
\text { Beck Depression Inventory, bone or joint pathology, spinal fractures, } \\
\text { tumors, infections, arthropathies, and significant osteoporosis, } \\
\text { pacemaker, current or pending litigation related to LBP episode, } \\
\text { receiving disability, received SM within the past month; unwilling to } \\
\text { postpone use of manual therapies for LBP except those provided in } \\
\text { the study (including chiropractic and osteopathic manipulation, } \\
\text { physical therapy and massage). }\end{array}$ & Attrition: 10\% (11/109) \\
\hline Huang 2003 & $\begin{array}{l}\text { Taiwan, single center, } \\
\text { outpatient department } \\
\text { of rehabilitation }\end{array}$ & $\begin{array}{l}\text { Inclusion: moderate bilateral knee OA (Altman grade II } \\
\text { Exclusion: respiratory or cardiac dysfunction, or combined ankle or } \\
\text { hip pain }\end{array}$ & $\begin{array}{l}\text { Randomized: } 132 \\
\text { Treated: } 132 \\
\text { Analyzed: } 122 \\
\text { Attrition: } 8 \%(10 / 132)\end{array}$ \\
\hline
\end{tabular}




\begin{tabular}{|c|c|}
\hline Author, Year & Intervention, Comparator \\
\hline Hondras 2009 & $\begin{array}{l}\text { A: Spinal manipulation ( } n=96) \text { : Chiropractic high-velocity low amplitude spinal manipulation, side-lying diversified lumbar spine "adjustment", } 12 \\
\text { visits over } 6 \text { weeks } \\
\text { B: Flexion distraction manipulation ( } n=95) \text { : Chiropractic low-velocity variable amplitude spinal mobilization, flexion distraction technique (Cox } \\
\text { technique) with the application of up to } 15 \text { slow repetitions (low-velocity variable amplitude loads), } 12 \text { visits over } 6 \text { weeks } \\
\text { C: Usual care ( } n=49 \text { ): Consultation with medical provider within } 7 \text { days and at week } 3 \text { and week } 6 \text { plus a questionnaire } \\
\text { All groups received home exercise instruction at week } 3\end{array}$ \\
\hline Huang 2003 & 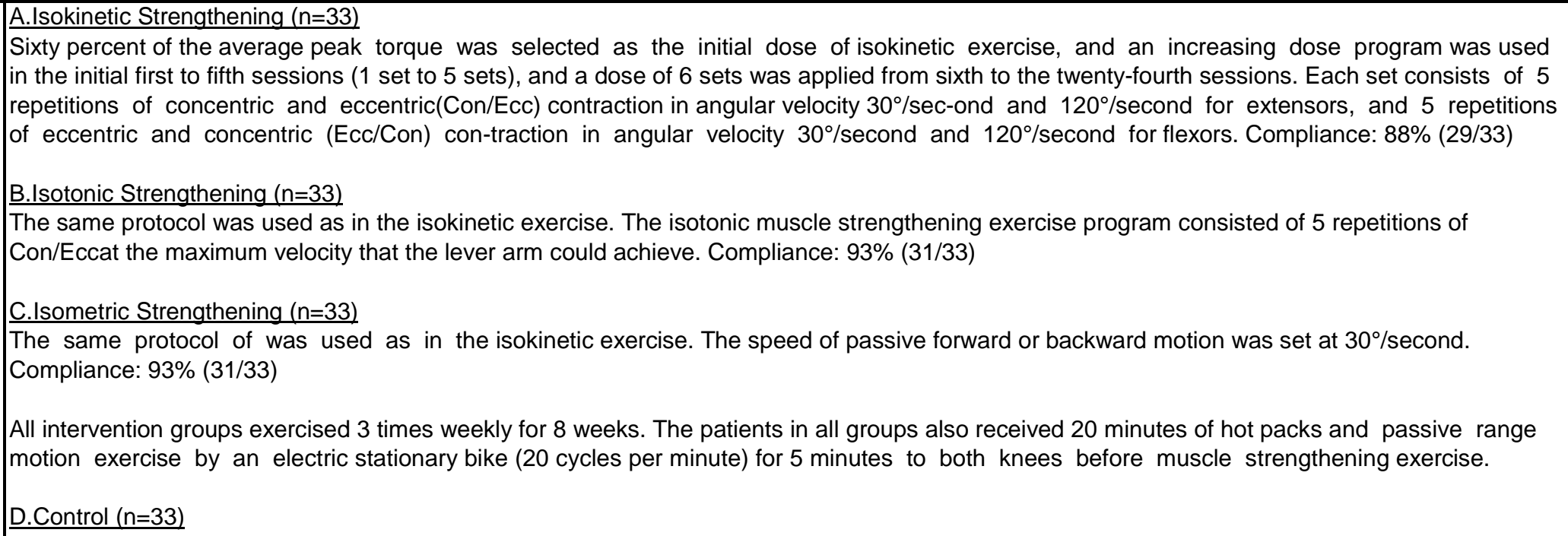 \\
\hline
\end{tabular}




\begin{tabular}{|c|c|c|c|}
\hline Author, Year & Study Participants & Outcome Measures & $\begin{array}{l}\text { Duration of } \\
\text { Followup }\end{array}$ \\
\hline Hondras 2009 & $\begin{array}{l}\text { A vs. B vs. C } \\
\text { Age: } 64 \text { vs. } 62 \text { vs. } 63 \text { years } \\
\text { Female: } 45 \% \text { vs. } 44 \% \text { vs. } 41 \% \\
\text { White race: } 96 \% \text { vs. } 96 \% \text { vs. } 98 \% \\
\text { Non-white: } 4 \% \text { vs. } 3 \% \text { vs. } 2 \% \\
\text { SF-36, Physical component summary, mean (SD): } 39.1 \text { (8.3) vs. } 38.8 \\
(8.1) \text { vs. } 40.7(8.7) \\
\text { SF-36, Mental component summary, mean (SD): } 51.7 \text { (8.6) vs. } 52.6 \\
\text { (8.7) vs. } 52.1(8.0) \\
\text { RDQ (0-24), mean (SD): } 6.5(4.1) \text { vs. } 6.6(4.6) \text { vs. } 5.7(4.0) \\
\text { Pain (0-100 VAS): } 42.1(23.6) \text { vs. } 42.5(25.2) \text { vs. } 42.4(24.5) \\
\text { SF-36 Physical Function (0-100): } 65.3(22.2) \text { vs. } 64.4(22.2) \text { vs. } 67.2 \\
\text { (21.6) } \\
\text { Beck Depression Inventory: } 7.3(5.6) \text { vs. } 8.2(6.9) \text { vs. } 6.9(6.3)\end{array}$ & $\begin{array}{l}\text { RDQ }(0-24) \\
\text { Global improvement from baseline (1= no improvement } \\
\text { to } 10=\text { complete improvement) }\end{array}$ & $\begin{array}{l}1.5 \text { and } 4.5 \\
\text { months }\end{array}$ \\
\hline Huang 2003 & $\begin{array}{l}\text { All Patients (not reported by treatment group) } \\
\text { Age: } 62 \text { (range, } 45-77) \text { years } \\
\text { Female: } 70 \% \\
\text { Duration of knee pain: range, } 0.33 \text { (4 mos.) to } 9 \text { years } \\
\text { A vs. B. vs. C vs. D. } \\
\text { Lequesne Index }(n=33 \text { patients per group): } 6.9(1.4) \text { vs. } 7.1(1.2) \text { vs. } \\
6.8(2.2) \text { vs. } 7.2(1.5) \\
\text { VAS pain }(n=66 \text { knees per group): } 4.8(1.4) \text { vs. } 4.6(1.7) \text { vs. } 4.7(1.4) \\
\text { vs. } 4.6(1.3)\end{array}$ & $\begin{array}{l}\text { Lequesne Index (Scale 1-26, higher score=greater } \\
\text { disability) (The disability may be graded as follows: }>14 \\
\text { points, extremely severe; } 11-13 \text { points, very severe; } 8- \\
10 \text { points, severe; } 4-7 \\
\text { points, moderate; } 1-3 \text { points, mild disability; }<7 \text { points is } \\
\text { considered acceptable function) } \\
\\
\begin{array}{l}\text { Pain Visual Analog Scale after } 5 \text { minutes of weight } \\
\text { bearing (Scale } 0-10 \text {, higher score=worse pain) }\end{array}\end{array}$ & 10 months \\
\hline
\end{tabular}




\begin{tabular}{|c|c|}
\hline Author, Year & $\begin{array}{c}\text { Results - Subquestion a } \\
\text { (vs. sham, no treatment, waitlist, attention control) }\end{array}$ \\
\hline Hondras 2009 & 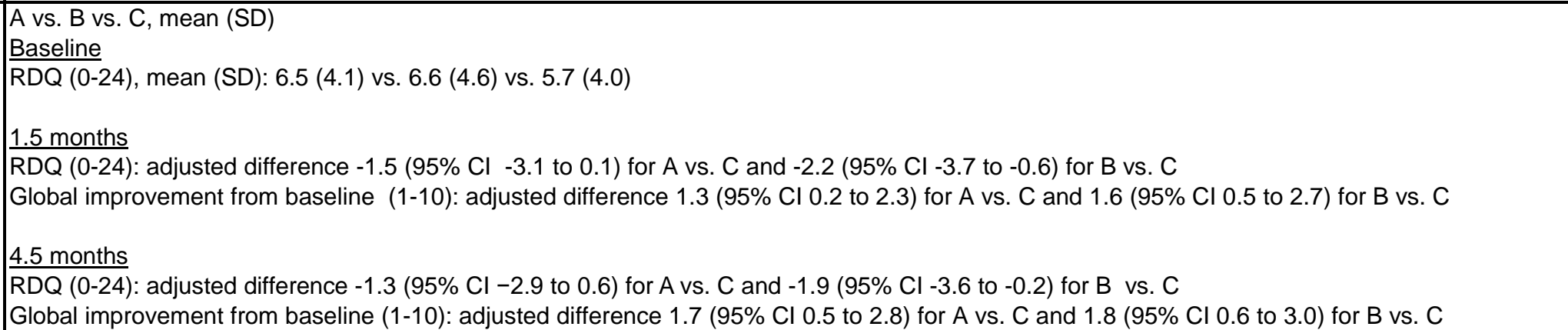 \\
\hline Huang 2003 & 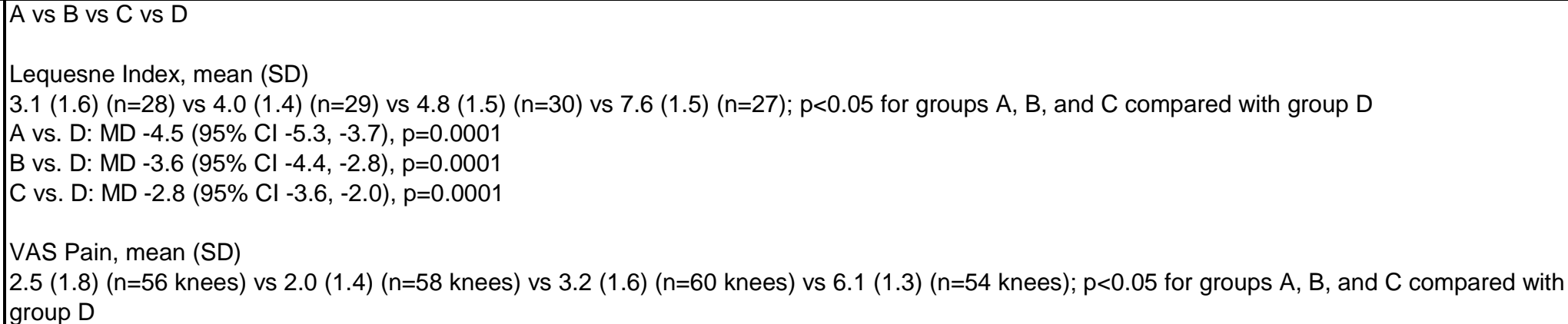 \\
\hline
\end{tabular}




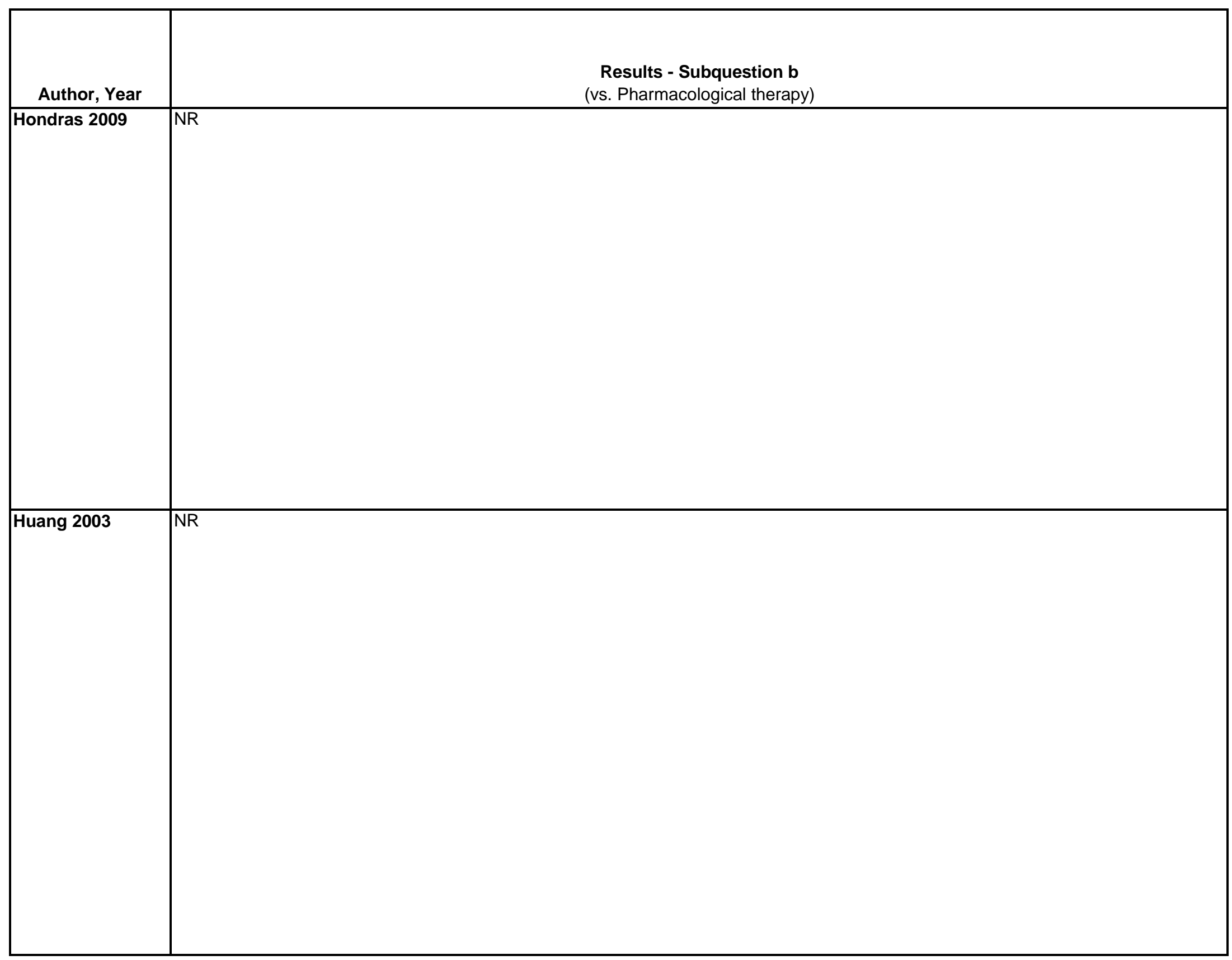

D-404 


\begin{tabular}{|c|c|c|}
\hline Author, Year & $\begin{array}{c}\text { Results - Subquestion c } \\
\text { (vs. Exercise) }\end{array}$ & Adverse Events Including Withdrawals \\
\hline Hondras 2009 & NR & No serious adverse events. \\
\hline Huang 2003 & NR & $\begin{array}{l}\text { A vs B vs C vs D } \\
\text { Withdrawals: } 3 \%(1 / 33) \text { vs } 6 \%(2 / 33) \text { vs } 3 \% \\
(1 / 33) \text { vs } 18 \%(6 / 33) \\
\text { Withdrawals RR }(95 \% \mathrm{Cl}) \text { : } \\
\text { A vs D: } 0.17(0.02,1.3) \\
\text { B vs D: } 0.33(0.07,1.53) \\
\text { C vs D: } 0.17(0.02,1.3) \\
\\
\text { Stopped therapeutic exercise due to } \\
\text { intolerable pain during exercise*: } \\
12.1 \%(4 / 33) \text { vs. } 6.1 \%(2 / 33) \text { vs. } 6.1 \%(2 / 33) \\
\\
\text { } \text { There was greater treatment compliance } \\
\text { in exercise groups B and C, and exercise- } \\
\text { induced knee pain was the major factor } \\
\text { causing discontinuation of treatment. }\end{array}$ \\
\hline
\end{tabular}




\begin{tabular}{|c|c|c|c|}
\hline Author, Year & Funding Source & Quality & Comments \\
\hline Huang 2003 & National Science Council of Taiwan & Poor & $\begin{array}{l}\text { Since VAS pain (mean }+/-\mathrm{SD} \text { ) is based on the number of knees and thus is a correlated } \\
\text { measures, we cannot calculate a MD. }\end{array}$ \\
\hline
\end{tabular}




\begin{tabular}{|c|c|c|c|}
\hline Author, Year & $\begin{array}{l}\text { Country } \\
\text { Number of Centers } \\
\text { Setting }\end{array}$ & Inclusion/Exclusion Criteria & $\begin{array}{l}\text { Number Randomized, } \\
\text { Analyzed } \\
\text { Attrition }\end{array}$ \\
\hline $\begin{array}{l}\text { Huang 2005a } \\
\text { Arthritis \& } \\
\text { Rheumatism }\end{array}$ & Taiwan & $\begin{array}{l}\text { Inclusion: bilateral moderate knee OA (Altman grade II } \\
\text { Exclusion: NR }\end{array}$ & $\begin{array}{l}\text { Randomized: } 70 \\
\text { Treated: } 70 \\
\text { Analyzed: } 54 \\
\text { Attrition: } 23 \%(16 / 70)\end{array}$ \\
\hline $\begin{array}{l}\text { Huang 2005b } \\
\text { Archives of PM\&R }\end{array}$ & Taiwan & $\begin{array}{l}\text { Inclusion: bilateral moderate knee OA } \\
\text { (Altman grade II) with periarticular soft tissue pain } \\
\text { Exclusion: NR }\end{array}$ & $\begin{array}{l}\text { Randomized: } 60 \\
\text { Treated: } 60 \\
\text { Analyzed: } 45 \\
\text { Attrition: } 25 \%(15 / 60)\end{array}$ \\
\hline $\begin{array}{l}\text { Jensen } 2012 \\
\text { Wicksell } 2013\end{array}$ & \begin{tabular}{|l} 
Sweden \\
Patient referred from \\
primary care \\
physicians in \\
Stockholm
\end{tabular} & $\begin{array}{l}\text { Inclusion: female, diagnosed with FM by } 1990 \text { ACR criteria, age 18- } \\
\text { 55, pain of at least } 40 \text { on 0-100 pain VAS } \\
\text { Exclusions: left-handed pregnant, breastfeeding, metal implant, } \\
\text { claustrophobia; use of antidepressants, mood stabilizers, analgesics, } \\
\text { strong opioids, anticonvulsants, centrally acting relaxants, joint } \\
\text { injections, trigger/tender point injections, biofeedback, transcutaneous } \\
\text { electrical nerve stimulation, severe psychiatric comorbidity }\end{array}$ & $\begin{array}{l}\text { Randomized: } 43 \\
\text { Analyzed: } 33 \\
\text { Attrition: } 23 \%(10 / 43)\end{array}$ \\
\hline
\end{tabular}




\begin{tabular}{|c|c|}
\hline Author, Year & Intervention, Comparator \\
\hline $\begin{array}{l}\text { Huang 2005a } \\
\text { Arthritis \& } \\
\text { Rheumatism }\end{array}$ & $\begin{array}{l}\text { A.Isokinetic Exercise }(n=35) 3 \\
\text { times per week for } 8 \text { weeks. } \\
\text { Began with } 60 \% \text { of the mean peak torque, increasing dose program was used in the first } 5 \text { sessions ( } 1 \text { set to } 5 \text { sets), and a dose of } 6 \text { sets was } \\
\text { applied from the sixth to twenty-fourth sessions, with the density rising from } 60 \% \text { to } 80 \% \text { of the mean peak torque as the patient was able. Each set } \\
\text { consisted of } 5 \text { repetitions of concentric contraction in angular velocities of } 30 \% \text { second and } 120 \% \text { second for extensors, and } 5 \text { repetitions of eccentric } \\
\text { and concentric (Ecc/Con) contractions in angular velocities of } 30 \% \text { second and } 120 \% / s e c o n d \text { for flexors. } \\
\text { B.Control }(n=35) \text { Warm-up exercises only }\end{array}$ \\
\hline $\begin{array}{l}\text { Huang 2005b } \\
\text { Archives of PM\&R }\end{array}$ & $\begin{array}{l}\text { A vs B } \\
\text { A.Isokinetic Exercise }(n=30) 3 \\
\text { times per week for } 8 \text { weeks. } \\
\text { Began with } 60 \% \text { of the average peak torque. Intensity of } \\
\text { isokinetic exercise increased from } 1 \text { set to } 5 \text { sets during the first } \\
\text { through fifth sessions and remained at } 6 \text { sets for the remaining } \\
6 \text { th through } 24 \text { th sessions. Each set consisted of } 5 \text { repetitions of } \\
\text { concentric contraction in angular velocities of } 30 \% \text { and } 120 \% \text { for extensors, and } 5 \text { repetitions of eccentric and concentric } \\
\text { contractions in angular velocities of } 30 \% / s \text { and } 120 \% \text { for flexors. } \\
\text { B.Control }(n=30) \text { Heat for } 20 \text { minutes and } 5 \text { minutes of passive range of motion on bike only. }\end{array}$ \\
\hline $\begin{array}{l}\text { Jensen } 2012 \\
\text { Wicksell } 2013\end{array}$ & $\begin{array}{l}\text { A.Acceptance and Commitment Therapy (ACT) ( } n=19) \text { : } 12 \text { weekly 90-minute group sessions: exposure to personally important situations and } \\
\text { activities previously avoided due to pain and distress, training to distance self from pain and distress. A physician conducted two sessions and a } \\
\text { psychologist conducted } 10 \text { sessions. } \\
\text { B.Waiting list control }(n=15)\end{array}$ \\
\hline
\end{tabular}




\begin{tabular}{|c|c|c|c|}
\hline Author, Year & Study Participants & Outcome Measures & $\begin{array}{c}\text { Duration of } \\
\text { Followup }\end{array}$ \\
\hline $\begin{array}{l}\text { Huang 2005a } \\
\text { Arthritis \& } \\
\text { Rheumatism }\end{array}$ & $\begin{array}{l}\text { All Patients, not reported by treatment group (see comment column } \\
\text { regarding study population) } \\
\text { Age: } 65 \text { (range, } 40-77 \text { ) years } \\
\text { Female: } 81 \% \\
\text { Duration of knee pain: range, } 0.42 \text { ( } 5 \text { mos.) to } 12 \text { years } \\
\text { A vs. B. } \\
\text { Lequesne Index ( } \mathrm{n}=35 \text { patients per group): } 7.6(1.2) \text { vs. } 7.4 \text { (1.1) } \\
\text { VAS pain ( } \mathrm{n}=70 \text { knees per group): } 5.3 \text { (1.5) vs. } 5.4(1.7)\end{array}$ & $\begin{array}{l}\text { Lequesne Index (Scale 1-26, higher score=greater } \\
\text { disability) (The disability may be graded as follows: }>14 \\
\text { points, extremely severe; } 11-13 \text { points, very severe; } 8- \\
10 \text { points, severe; } 4-7 \\
\text { points, moderate; } 1-3 \text { points, mild disability; }<7 \text { points is } \\
\text { considered acceptable function) } \\
\text { Pain Visual Analog Scale after } 5 \text { minutes of weight } \\
\text { bearing (Scale } 0-10, \text { higher score=worse pain) }\end{array}$ & 10 months \\
\hline $\begin{array}{l}\text { Huang 2005b } \\
\text { Archives of PM\&R }\end{array}$ & $\begin{array}{l}\text { All Patients, not reported by treatment group (see comment column } \\
\text { regarding study population) } \\
\text { Age: } 62 \text { (range, } 42-72 \text { ) years } \\
\text { Female: } 81 \% \\
\text { Duration of knee pain: range, } 0.5 \text { ( } 6 \text { mos.) to } 11 \text { years } \\
\text { A vs. B. } \\
\text { Lequesne Index ( } \mathrm{n}=30 \text { patients per group): } 6.7(2.1) \text { vs. } 7.0(1.1) \\
\text { VAS pain ( } \mathrm{n}=60 \text { knees per group): } 4.9 \text { (1.5) vs. } 4.8(1.8)\end{array}$ & $\begin{array}{l}\text { Pain Visual Analog Scale after } 5 \text { minutes of weight } \\
\text { bearing (Scale 0-10, higher is worse pain) } \\
\text { Lequesne Index (Scale 1-26, higher is greater } \\
\text { disability) }\end{array}$ & 10 months \\
\hline $\begin{array}{l}\text { Jensen } 2012 \\
\text { Wicksell } 2013\end{array}$ & $\begin{array}{l}\text { A vs B } \\
\text { Age: } 45 \text { vs } 47 \\
\text { Female: } 100 \% \text { vs } 100 \% \\
\text { Time since FM onset, years: } 10.5 \text { vs } 11.8 \\
\text { FIQ: } 49.3(9.7) \text { vs } 48.7(12.0) \\
\text { Pain Disability Index: } 40.0(10.9) \text { vs } 39.0(10.2) \\
\text { Pain VAS: } 61(20) \text { vs } 65.0(10) \\
\text { Pain NRS: } 4.2(1.0) \text { vs } 4.3(1.1) \\
\text { BDI: } 15.9(6.3) \text { vs } 19.3(13.0) \\
\text { STAl: } 45.7(12.0) \text { vs } 48.0(15.1) \\
\text { SF-36 Mental: } 40.1(9.1) \text { vs } 38.6(12.4) \\
\text { SF-36 Physical: } 25.2(6.6) \text { vs } 29.1(9.9)\end{array}$ & $\begin{array}{l}\text { Fibromyalgia Impact Questionnaire (FIQ) (0-100, higher } \\
\text { scores= greater impact of FM) } \\
\text { Pain Disability Index (scale NR, higher scores= greater } \\
\text { disability) } \\
\text { Pain VAS: (0-100 mm, higher scores=worse pain in past } \\
\text { week) } \\
\text { Pain NRS (0-10, higher scores=greater pain) } \\
\text { Beck Depression Inventory (BDI): (scale NR, higher } \\
\text { scores=greater depression) } \\
\text { State-Trait Anxiety Inventory State scale: (STAI-S): } \\
\text { (scale NR, higher scores=greater anxiety) } \\
\text { SF-36 (0-100, higher scores=better health-related } \\
\text { quality of life) }\end{array}$ & 3-4 months \\
\hline
\end{tabular}




\begin{tabular}{|c|c|}
\hline Author, Year & $\begin{array}{l}\text { Results - Subquestion a } \\
\text { (vs. sham, no treatment, waitlist, attention control) }\end{array}$ \\
\hline $\begin{array}{l}\text { Huang 2005a } \\
\text { Arthritis \& } \\
\text { Rheumatism }\end{array}$ & $\begin{array}{l}\text { A vs } B \\
\text { Lequesne Index, mean (SD) } \\
5.8(1.8)(n=26) \text { vs } 8.1(1.5)(n=28), p<0.05 \\
\text { MD }-2.3(95 \% \text { Cl }-3.2,-1.4), p=0.0001 \\
\text { VAS Pain, mean (SD) } \\
3.9(1.4)(n=52 \text { knees) vs } 6.6(1.5)(n=56 \text { knees), } p<0.05\end{array}$ \\
\hline $\begin{array}{l}\text { Huang 2005b } \\
\text { Archives of PM\&R }\end{array}$ & $\begin{array}{l}\text { A vs } B \\
\text { Lequesne Index, mean (SD) } \\
5.1(1.8)(n=21) \text { vs } 7.8(1.7)(n=24) \\
\text { MD -2.7 (95\% Cl -3.8, -1.6), } p=0.0001 \\
\text { VAS Pain, mean (SD) } \\
3.5(1.7)(n=42 \text { knees) vs } 6.0(1.3)(n=48 \text { knees); } p<0.05\end{array}$ \\
\hline $\begin{array}{l}\text { Jensen } 2012 \\
\text { Wicksell } 2013\end{array}$ & 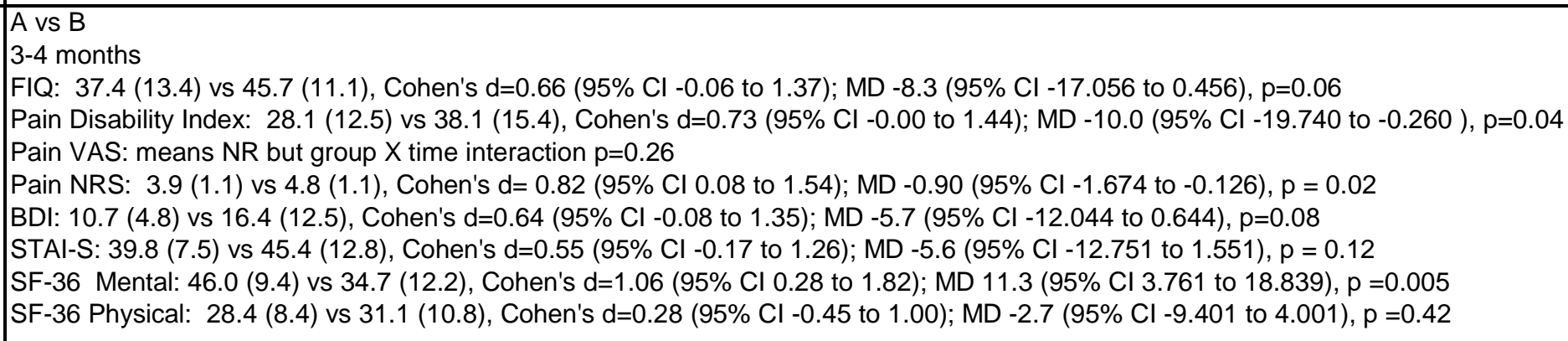 \\
\hline
\end{tabular}




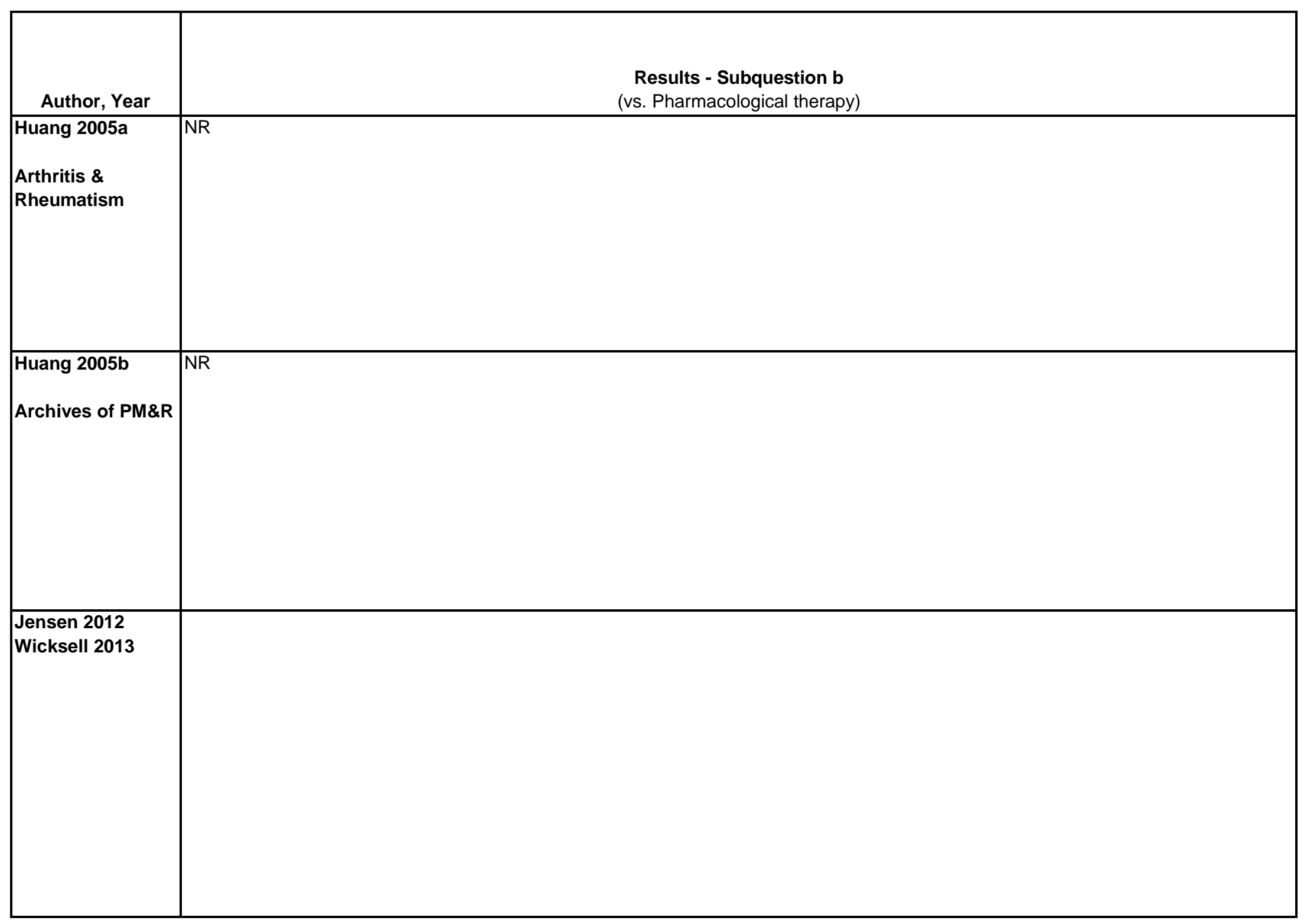




\begin{tabular}{|c|c|c|}
\hline Author, Year & $\begin{array}{l}\text { Results - Subquestion c } \\
\text { (vs. Exercise) }\end{array}$ & Adverse Events Including Withdrawals \\
\hline \begin{tabular}{|l} 
Huang 2005a \\
Arthritis \& \\
Rheumatism
\end{tabular} & NR & $\begin{array}{l}\text { A vs B } \\
\text { Withdrawals } \\
11 \%(4 / 35) \text { vs } 11 \%(4 / 35) \\
\text { Discontinuation of exercise due to intolerable } \\
\text { pain during exercise: } 14 \%(5 / 35) \text { vs. NA }\end{array}$ \\
\hline $\begin{array}{l}\text { Huang 2005b } \\
\text { Archives of PM\&R }\end{array}$ & NR & \begin{tabular}{|l} 
A vs B \\
Withdrawals \\
$13 \%(4 / 30)$ vs $13 \%(4 / 30)$ \\
Discontinuation of exercise due to intolerable \\
pain during exercise: $17 \%(5 / 30)$ vs. NA
\end{tabular} \\
\hline $\begin{array}{l}\text { Jensen } 2012 \\
\text { Wicksell } 2013\end{array}$ & & $\begin{array}{l}\text { Withdrawals } \\
\text { A vs B } \\
\text { Before treatment } 8 \%(2 / 25) \text { vs } 6 \%(1 / 18) \\
\text { During treatment: } \\
12 \%(3 / 25 \text { originally randomized) vs } 6 \% \\
(1 / 18 \text { originally randomized }) \\
\text { Adverse events NR }\end{array}$ \\
\hline
\end{tabular}




\begin{tabular}{|c|c|c|c|}
\hline Author, Year & Funding Source & Quality & Comments \\
\hline $\begin{array}{l}\text { Huang 2005b } \\
\text { Archives of PM\&R }\end{array}$ & $\begin{array}{l}\text { National Science Council of Taiwan } \\
\text { (grant no. NSC-92-2314-B-037- } \\
\text { 067) }\end{array}$ & Fair & $\begin{array}{l}\text { This trial had a total of } 4 \text { arms ( } \mathrm{N}=120 \text { total); } 2 \text { were excluded from our analysis because } \\
\text { they did not meet our inclusion criteria (additive/combination of treatments): } \\
\text { Group II ( } 30 \text { patients) = isokinetic exercise and } \\
\text { continuous Ultrasound; } \\
\text { Group III ( } 30 \text { patients) = isokinetic exercise and } \\
\text { pulsed Ultrasound } \\
\text { Since VAS pain (mean +/- SD) is based on the number of knees and thus is a correlated } \\
\text { measures, we cannot calculate a MD. }\end{array}$ \\
\hline \begin{tabular}{|l|} 
Jensen 2012 \\
Wicksell 2013
\end{tabular} & $\begin{array}{l}\text { Swedish Society for Medical Research } \\
\text { Swedish Council for Working Life and } \\
\text { Social Research } \\
\text { Swedish Research council } \\
\text { Stockholm City council } \\
\text { Swedish Rheumatism Association }\end{array}$ & $\begin{array}{l}\text { Fair } \\
\end{array}$ & $\begin{array}{l}\text { Note that the intervention was ACT, a form of CBT but a therapy that differs in content/goals } \\
\text { from traditional CBT for pain } \\
\text { Wicksell } 2013 \text { reports full study results for patient-reported outcome measures; Jensen } 2012 \\
\text { reports some patient-reported outcome measures and fMRI results. } \\
\text { Jensen } 2012 \text { reports } 25 \text { randomized to ACT and } 18 \text { randomized to WL; Wicksell } 2013 \text { did } \\
\text { not count the } 3 \text { participants who withdrew after randomization and instead reported } 23 \\
\text { randomized to ACT and } 17 \text { randomized to WL. For purposes of data abstraction, used the } \\
\text { originally-reported } 25 \text { randomized to CBT and } 18 \text { randomized to WL. }\end{array}$ \\
\hline
\end{tabular}




\begin{tabular}{|c|c|c|c|}
\hline Author, Year & $\begin{array}{c}\text { Country } \\
\text { Number of Centers } \\
\text { Setting }\end{array}$ & Inclusion/Exclusion Criteria & $\begin{array}{c}\text { Number Randomized, } \\
\text { Analyzed } \\
\text { Attrition }\end{array}$ \\
\hline Johnson 2007 & $\begin{array}{l}\text { UK } \\
\text { Number of centers: } 9 \\
\text { Setting: General } \\
\text { practices }\end{array}$ & $\begin{array}{l}\text { 18-65 years old } \\
\text { Persistent disabling LBP for } 3 \text { months, defined as: } 1 \text { ) Pain } \geq 20 \mathrm{~mm} \\
\text { (scale: } 0-100 \mathrm{~mm} \text { VAS), and 2) RMDQ disability score } \geq 5 \text { (scale: 0-24) } \\
\text { Exclude } \\
\text { Previous consultation for LBP in past } 6 \text { months } \\
\text { "Red flags" indicating signs of serious pathology } \\
\text { Pregnancy or recent childbirth } \\
\text { Major rheumatologic, neurologic, neoplastic or other conditions that } \\
\text { may prevent full participation in the intervention } \\
\text { Previous spinal surgery } \\
\text { Major psychiatric illness, diagnosed or such symptoms under } \\
\text { investigation } \\
\text { History of drug or alcohol abuse in past } 5 \text { years }\end{array}$ & $\begin{array}{l}\text { Randomized: } 234 \\
\text { Analyzed: } \\
\text { - } 6 \text { months: } 203 \\
\text { - } 12 \text { months: } 195 \\
\text { Attrition: } 16.7 \% \text { (39/234) } \\
\end{array}$ \\
\hline Jousset 2004 & \begin{tabular}{|l} 
France \\
Number of centers: 1 \\
Outpatient clinic
\end{tabular} & $\begin{array}{l}\text { Patients } 18 \text { to } 50 \text { years with LBP not relieved by conventional } \\
\text { treatment, threatened job situation. } \\
\text { Exclude: Patients with LBP of specific origin, less than } 4 \text { months, } \\
\text { spinal surgery, cardiac or respiratory abnormalities after exercise } \\
\text { stress tests on bicycle ergometers, psychiatric disorders precluding } \\
\text { group participation, or receiving disability pensions }\end{array}$ & $\begin{array}{l}\text { Randomized: } 86 \\
\text { Treated: } 84 \\
\text { Analyzed: } 83 \\
\text { Attrition: } 1.2 \%(1 / 83)\end{array}$ \\
\hline
\end{tabular}




\begin{tabular}{|c|c|}
\hline Author, Year & Intervention, Comparator \\
\hline Johnson 2007 & $\begin{array}{l}\text { A.Cognitive behavioral therapy (CBT) program ( } n=116) \text { : } 8 \text { group sessions, } 2 \text { hours each over } 6 \text { weeks in community-based program for active } \\
\text { exercise and education led by physiotherapist trained on CBT principles for LBP. Group discussions, case vignettes, and practical (physical) } \\
\text { activities, encouraging the self-management of back pain; focused on problem solving, pacing and regulation of activity, challenging distorted } \\
\text { cognitions about activity and harm, and helping patients identify helpful and unhelpful thoughts about pain and activity. Weekly homework was } \\
\text { assessed and discussed. Patients were to monitor thoughts associated with pain and work to recognize helpful and unhelpful thoughts associated } \\
\text { with the behavioral experiments. } \\
\text { B. Usual care ( } n=118) \text { : Treated as usual according to their general practitioner. } \\
\text { Both: Mailed an educational booklet and audio-cassette containing advice on self-management suitable for patients with persistent LBP. The } \\
\text { booklet had } 9 \text { "leaflets": pain and activity; pacing; goal setting; stress; posture and body mechanics; guidelines for sleep hygiene; beds and } \\
\text { sleeping; flare-up plans; when to see your general practitioner. }\end{array}$ \\
\hline Jousset 2004 & $\begin{array}{l}\text { A.Functional Restoration }(n=44) \\
\text { Exercise with physiotherapist; warm-up, stretching, flexibility, aerobic exercises strengthening, muscular endurance, coordination exercises, work } \\
\text { simulations, counselling, } 6 \text { hours a day, } 5 \text { days a week for } 5 \text { weeks } \\
\text { B.Active Individual Therapy }(n=42) \\
\text { Active exercise, flexibility, stretching, strengthening, proprioception exercises, endurance training, jogging, swimming, stretching, } 1 \text { hour, } 3 \text { times a } \\
\text { week for } 5\end{array}$ \\
\hline
\end{tabular}




\begin{tabular}{|c|c|c|c|}
\hline Author, Year & Study Participants & Outcome Measures & $\begin{array}{l}\text { Duration of } \\
\text { Followup }\end{array}$ \\
\hline Johnson 2007 & $\begin{array}{l}\text { A vs. B } \\
\text { Age: } 47 \text { vs. } 49 \\
\text { Female: } 61 \% \text { vs. } 58 \% \\
\text { Race: NR } \\
\text { History of LBP: } 90 \% \text { vs. } 87 \% \\
\text { <1 month LBP prior to consultation: } 54 \% \text { vs. } 38 \% \\
\text { Baseline VAS: } 44.9 \text { vs. } 51.6 \\
\text { Baseline RMDQ: } 10.6 \text { vs. } 10.9 \\
\text { Baseline EQ-5D: } 0.66 \text { vs. } 0.64 \\
12 \text {-item General Health Questionnaire score } \geq 22: 83 \% \text { vs. } 81 \% \\
\text { Paid employment: } 68 \% \text { vs. } 66 \% \\
\text { Routine and manual occupations: } 28 \% \text { vs. } 27 \%\end{array}$ & $\begin{array}{l}\text { Pain (0-100 VAS) } \\
\text { RDQ (0-24, } 0=\text { no disability) } \\
\text { EuroQol EQ-5D (0-1, } 1=\text { perfect health) }\end{array}$ & $\begin{array}{l}6 \text { and } 12 \\
\text { months }\end{array}$ \\
\hline Jousset 2004 & $\begin{array}{l}\text { A vs. B } \\
\text { Age (mean): } 41 \text { vs. } 40 \text { years } \\
\text { Female: } 30 \% \text { vs. } 37 \% \\
\text { Race: NR } \\
\text { Previous surgery } 34.9 \% \text { vs. } 14.6 \%\end{array}$ & $\begin{array}{l}\text { Pain (0-10 NRS) } \\
\text { Dallas Pain Questionnaire, } 4 \text { subscales (0-100, higher } \\
\text { scores=less favorable) } \\
\text { Quebec Disability Scale (0-100, higher score=more } \\
\text { disability) } \\
\text { Work status } \\
\text { Hospital Anxiety Depression scale (0-21), higher } \\
\text { score=less favorable) }\end{array}$ & 5 months \\
\hline
\end{tabular}




\begin{tabular}{|c|c|}
\hline Author, Year & $\begin{array}{c}\text { Results - Subquestion a } \\
\text { (vs. sham, no treatment, waitlist, attention control) }\end{array}$ \\
\hline Johnson 2007 & 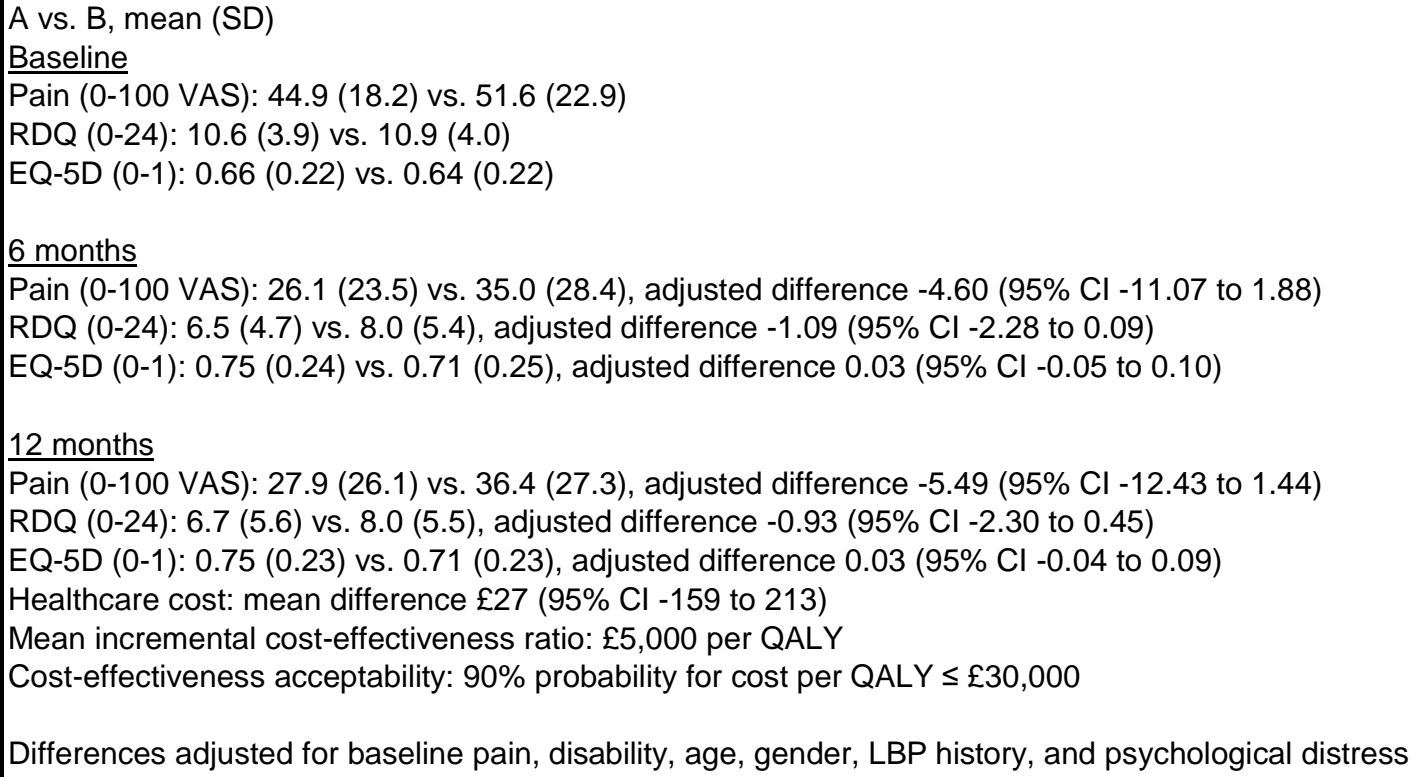 \\
\hline Jousset 2004 & NR \\
\hline
\end{tabular}




\begin{tabular}{|l|l|}
\hline Author, Year & \multicolumn{1}{|c|}{$\begin{array}{c}\text { Results - Subquestion b } \\
\text { (vs. Pharmacological therapy) }\end{array}$} \\
\hline Johnson 2007 & NR \\
\hline Jousset 2004 & NR \\
& \\
& \\
\hline
\end{tabular}




\begin{tabular}{|c|c|c|}
\hline Author, Year & $\begin{array}{l}\text { Results - Subquestion c } \\
\text { (vs. Exercise) }\end{array}$ & Adverse Events Including Withdrawals \\
\hline Johnson 2007 & NR & $\begin{array}{l}\text { A vs B } \\
\text { Withdrawal: } 12.1 \% \text { (14/116) vs. } 20.3 \% \\
\text { (24/118) } \\
\text { Withdrawal due to AEs: NR } \\
\text { Serious AEs: NR } \\
\text { Nonserious AEs: NR }\end{array}$ \\
\hline Jousset 2004 & 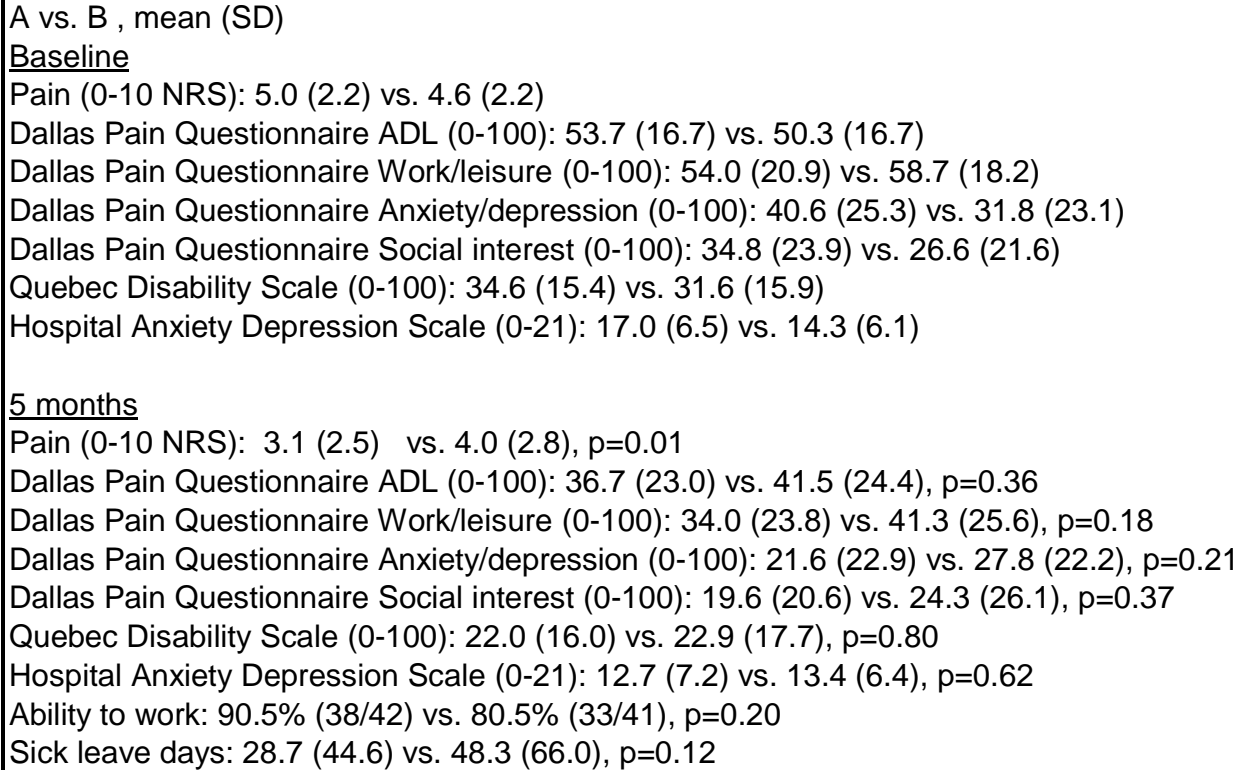 & NR \\
\hline
\end{tabular}




\begin{tabular}{|l|l|l|l|}
\hline Author, Year & \multicolumn{1}{|c|}{ Funding Source } & Quality & \\
\hline Johnson 2007 & $\begin{array}{l}\text { Supported by the Arthritis Research } \\
\text { Campaign, Chesterfield, UK and the } \\
\text { Epidemiology Unit at the University of } \\
\text { Manchester, UK. Charity funds were } \\
\text { received in support of the study. }\end{array}$ & Fair & \\
\hline Jousset 2004 & $\begin{array}{l}\text { Union } \\
\text { Regionale des Caisses } \\
\text { d'Assurance Maladie des Pays de } \\
\text { Loire }\end{array}$ & Poor & \\
\hline
\end{tabular}




\begin{tabular}{|c|c|c|c|}
\hline Author, Year & $\begin{array}{c}\text { Country } \\
\text { Number of Centers } \\
\text { Setting }\end{array}$ & Inclusion/Exclusion Criteria & $\begin{array}{c}\text { Number Randomized, } \\
\text { Analyzed } \\
\text { Attrition }\end{array}$ \\
\hline Jubb 2008 & $\begin{array}{l}\text { UK, Rheumatology } \\
\text { clinic attendees, } 1 \\
\text { center }\end{array}$ & $\begin{array}{l}\text { Inclusion Criteria: } \\
18 \text { years or older } \\
\text { symptomatic, radiological } \\
\text { knee OA > } 6 \text { months w/ inadequate response to 1+ conventional } \\
\text { medical treatments } \\
\text { Exclusion: previous acupuncture, regnancy } \\
\text { other forms of arthritis and the "usual contra-indications for } \\
\text { acupuncture" }\end{array}$ & $\begin{array}{l}\text { Randomized: } 68 \\
\text { Treated: } 64 \\
\text { Analyzed: } 62 \\
\text { Attrition: } 9 \%(6 / 68)\end{array}$ \\
\hline
\end{tabular}




\begin{tabular}{|c|c|}
\hline Author, Year & Intervention, Comparator \\
\hline Jubb 2008 & $\begin{array}{l}\text { A.Acupuncture ( } \mathrm{n}=34) \text { : } 10 \text { minutes of manual acupuncture (total of } 9 \text { points; } 3 \mathrm{~cm}, 30 \text { gauge solid stainless steel needles; insertion depth of } 1-1.5 \\
\mathrm{~cm} \text {; elicitation of de qi) and } 20 \text { minutes of electroacupuncture }(10 \text { mins. each on anterior and posterior part of the knee; low frequency, delivered at } \\
6 \mathrm{~Hz} \text { at a constant current; voltage set just above the pain threshold) } \\
\text { B.Sham acupuncture ( } \mathrm{n}=34) \text { : sham needle secured to the skin with a plastic ring covered by a sticking plaster (also used for those having verum } \\
\text { acupuncture), did not penetrate the skin; dummy mode of the electrical stimulation apparatus was used (produced sound signals but no electrical } \\
\text { current). } \\
\text { Both groups received } 30 \text { minute treatments, } 2 / \text { week for } 5 \text { weeks, with } 10 \text { sessions in total }\end{array}$ \\
\hline
\end{tabular}




\begin{tabular}{|c|c|c|c|}
\hline Author, Year & Study Participants & Outcome Measures & $\begin{array}{l}\text { Duration of } \\
\text { Followup }\end{array}$ \\
\hline Jubb 2008 & $\begin{array}{l}\text { A vs B } \\
\text { Age: } 64.1(1.6) \text { vs. } 66.1 \text { (1.9) } \\
\text { Female: } 85 \% \text { vs. } 76 \% \\
\text { Caucasian: } 74 \% \text { vs. } 85 \% \\
\text { Duration of symptoms: } 10 \text { vs. } 9.6 \text { years } \\
\text { WOMAC pain: } 294 \text { (78) vs. } 261(100) \\
\text { WOMAC function: } 1028 \text { (277) vs. } 979(313) \\
\text { EuroQoL VAS: } 63(22) \text { vs. } 54(20) \\
\text { Total Body Pain VAS: } 49 \text { (24) vs. } 49(26) \\
\text { Night Pain in Knee VAS: } 61 \text { (26) vs. } 52(28) \\
\text { Overall Pain in Knee VAS: } 63 \text { (19) vs. } 53(25) \\
\text { Weight Pain in Knee VAS: } 71(19) \text { vs. } 60(23)\end{array}$ & $\begin{array}{l}\text { WOMAC function (0-1700, non-normalized; higher } \\
\text { score=worse function) } \\
\text { WOMAC pain (0-500, non-normalized; higher } \\
\text { score=worse function) } \\
\text { Knee Pain on VAS (scale 0-100; higher score=worse } \\
\text { pain) } \\
\text { EuroQol - VAS (0-100; higher score=best health } \\
\text { imaginable) }\end{array}$ & 1 month \\
\hline
\end{tabular}




\begin{tabular}{|c|c|}
\hline Author, Year & $\begin{array}{c}\text { Results - Subquestion a } \\
\text { (vs. sham, no treatment, waitlist, attention control) }\end{array}$ \\
\hline Jubb 2008 & 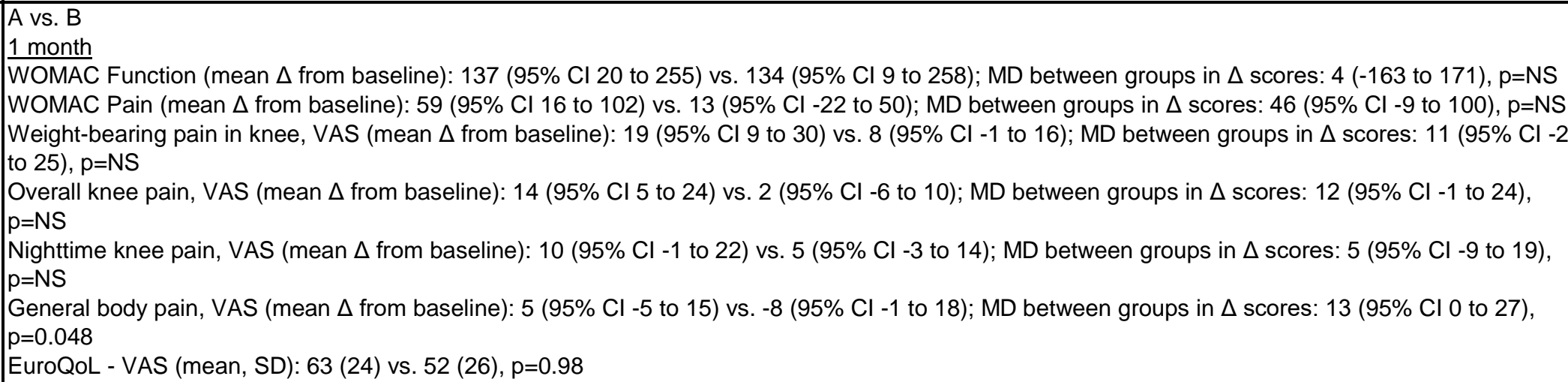 \\
\hline
\end{tabular}




\begin{tabular}{|l|c|}
\hline \multicolumn{1}{|c|}{ Author, Year } & $\begin{array}{c}\text { Results - Subquestion b } \\
\text { (vs. Pharmacological therapy) }\end{array}$ \\
\hline Jubb 2008 & \\
& \\
& \\
& \\
\hline
\end{tabular}




\begin{tabular}{|c|c|c|}
\hline Author, Year & $\begin{array}{c}\text { Results - Subquestion c } \\
\text { (vs. Exercise) }\end{array}$ & Adverse Events Including Withdrawals \\
\hline Jubb 2008 & & $\begin{array}{l}\text { Withdrawal: } 5.9 \% \text { (2/34) vs. } 5.9 \%(2 / 34) ; \\
\text { Withdrawal due to adverse events: } 2.9 \% \\
\text { (1/34) vs. } 0 \% \text { (0/34) (flare of synovitis, not } \\
\text { septic); } \\
\text { Adverse events (not specified): } 11.8 \%(4 / 34) \\
\text { vs. } 17.6 \%(6 / 34) ; \text { RR } 0.67 \text { (95\% Cl } 0.21,2.2) \text {, } \\
\text { p=0.50 } \\
\\
\text { No adverse events attributable to } \\
\text { acupuncture }\end{array}$ \\
\hline
\end{tabular}




\begin{tabular}{|l|l|l|l|}
\hline \multicolumn{1}{|c|}{ Author, Year } & \multicolumn{1}{|c|}{ Funding Source } & Quality & \\
\hline Jubb 2008 & $\begin{array}{l}\text { University Hospital Birmingham NHS } \\
\text { Foundation Trust, UK }\end{array}$ & Fair & \\
& & & \\
& & & \\
\hline
\end{tabular}




\begin{tabular}{|c|c|c|c|}
\hline Author, Year & $\begin{array}{c}\text { Country } \\
\text { Number of Centers } \\
\text { Setting }\end{array}$ & Inclusion/Exclusion Criteria & $\begin{array}{c}\text { Number Randomized, } \\
\text { Analyzed } \\
\text { Attrition }\end{array}$ \\
\hline Juhakoski 2011 & \begin{tabular}{|l|} 
Finland 2 \\
centers \\
Outpatient
\end{tabular} & $\begin{array}{l}\text { Aged 55-80 years, commitment to two year long study, radiological } \\
\text { evidence within } 3 \text { years of unilateral or bilateral hip Oawith Kellgren- } \\
\text { Lawrence grade } \geq 1 \text {, pain in hip region within previous month } \\
\text { consistent with ACR criteria } \\
\text { Exclude: Total hip replacement, rheumatoid arthritis, cognitive } \\
\text { impairment, major surgical operation to lower back or lower limb area } \\
\text { within previous } 6 \text { mos, acute or subacute lower back pain, } \\
\text { cardiovascular or pulmonary disease, chronic disease that would } \\
\text { prevent full participation }\end{array}$ & $\begin{array}{l}\text { Randomized: } 120 \\
\text { Treated: } 118 \\
\text { Analyzed: } 113 \\
\text { Attrition: } 6 \%(7 / 120)\end{array}$ \\
\hline
\end{tabular}




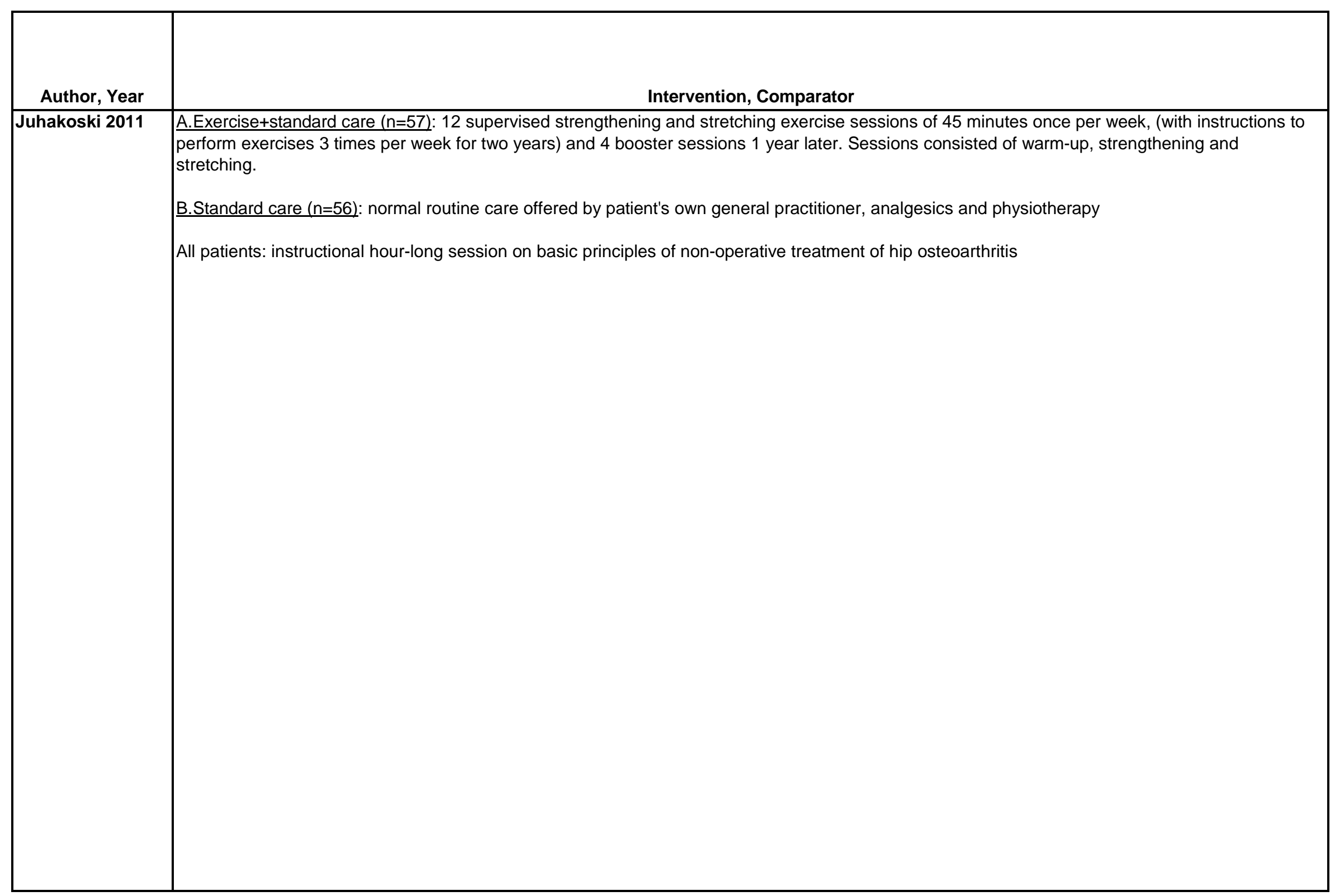




\begin{tabular}{|c|c|c|c|}
\hline Author, Year & Study Participants & Outcome Measures & $\begin{array}{c}\text { Duration of } \\
\text { Followup }\end{array}$ \\
\hline Juhakoski 2011 & $\begin{array}{l}\text { A vs B } \\
\text { Age: } 67 \text { vs } 66 \text { years } \\
\text { Female: } 68 \% \text { vs } 72 \% \\
\text { Duration of symptoms (yrs): } 8.3 \text { vs } 8.5 \\
\text { Knee OA and/or knee pain: } 38 \% \text { vs } 29 \% \\
\text { Comorbidities (chronic disease): } \\
\quad \text { None: } 40 \% \text { vs } 43 \% \\
\quad \text { One: } 47 \% \text { vs } 43 \% \\
\quad \text { Two or more: } 13 \% \text { vs } 14 \% \\
\text { Work status: } \\
\quad \text { No longer employed: } 77 \% \text { vs. } 67 \% \\
\quad \text { Part-time employment: } 12 \% \text { vs. } 9 \% \\
\text { Employed: } 10 \% \text { vs. } 24 \% \\
\text { WOMAC function: } 24.7 \text { (16.7) vs } 28.9(22.4) \\
\text { RAND-36 (SF-36) physical function: } 63.4(19.8) \text { vs } 61.2 \text { (20.8) } \\
\text { WOMAC pain: } 21.5(14.8 \text { ) vs } 29.1(20.2) \\
\text { Weak opioid (i.e. tramadol and codeine) use: } \\
\quad \text { Not using: } 81.7 \% \text { vs } 84.5 \% \\
\quad \text { Using less than daily: } 13.3 \% \text { vs } 6.9 \% \\
\text { Using daily: } 5.0 \% \text { vs } 8.6 \%\end{array}$ & $\begin{array}{l}\text { WOMAC physical function (0-100, higher score=higher } \\
\text { disability); SF-36 (0-100, higher score=higher QoL); } \\
\text { WOMAC pain (0-100, higher score=higher pain); } \\
\text { Weak opioid use; Physician visits attributable to hip OA }\end{array}$ & $\begin{array}{l}3,9,15 \text {, and } \\
21 \text { months }\end{array}$ \\
\hline
\end{tabular}




\begin{tabular}{|c|c|}
\hline Author, Year & $\begin{array}{c}\text { Results - Subquestion a } \\
\text { (vs. sham, no treatment, waitlist, attention control) }\end{array}$ \\
\hline Juhakoski 2011 & 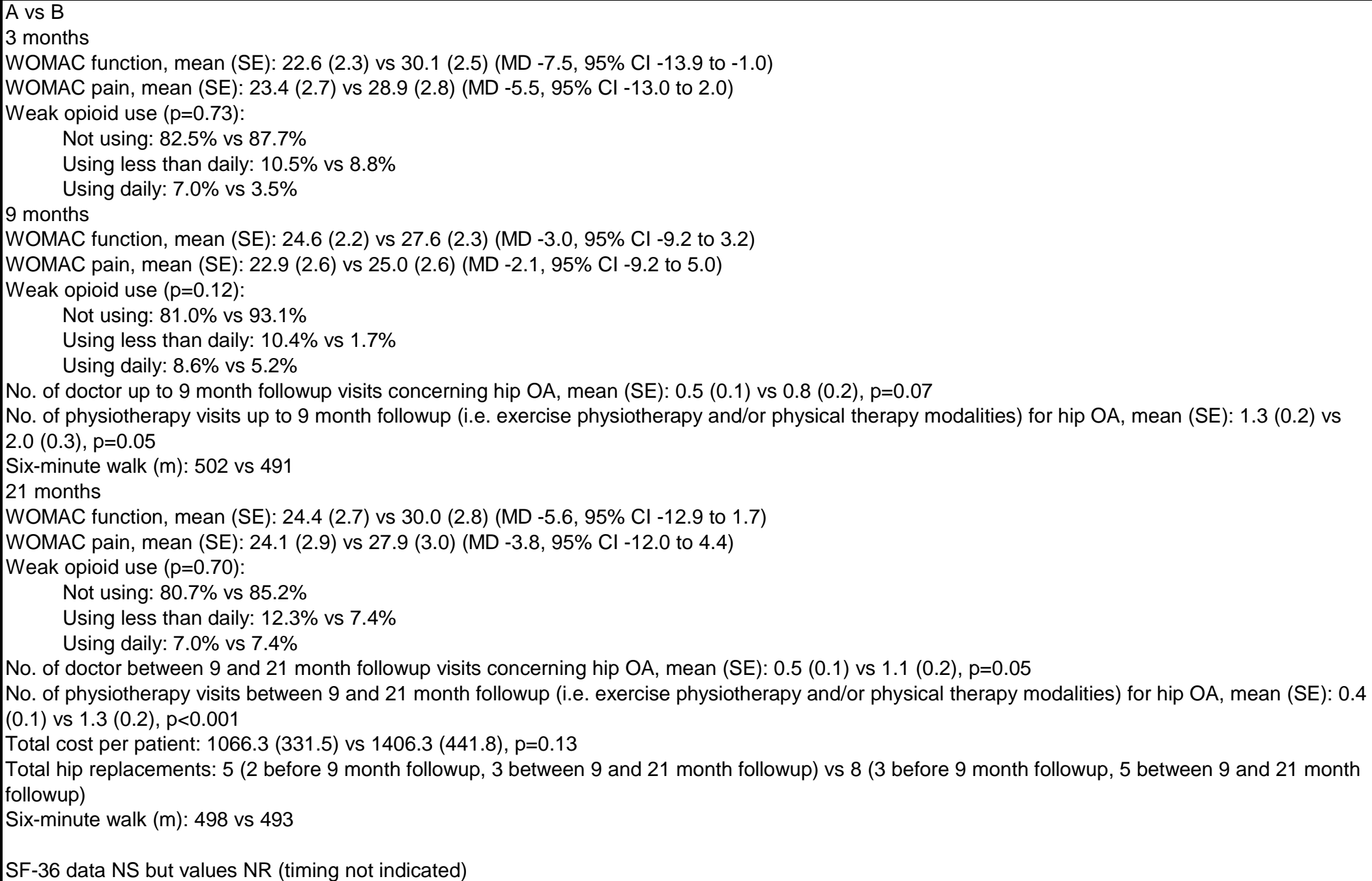 \\
\hline
\end{tabular}




$$
[-
$$




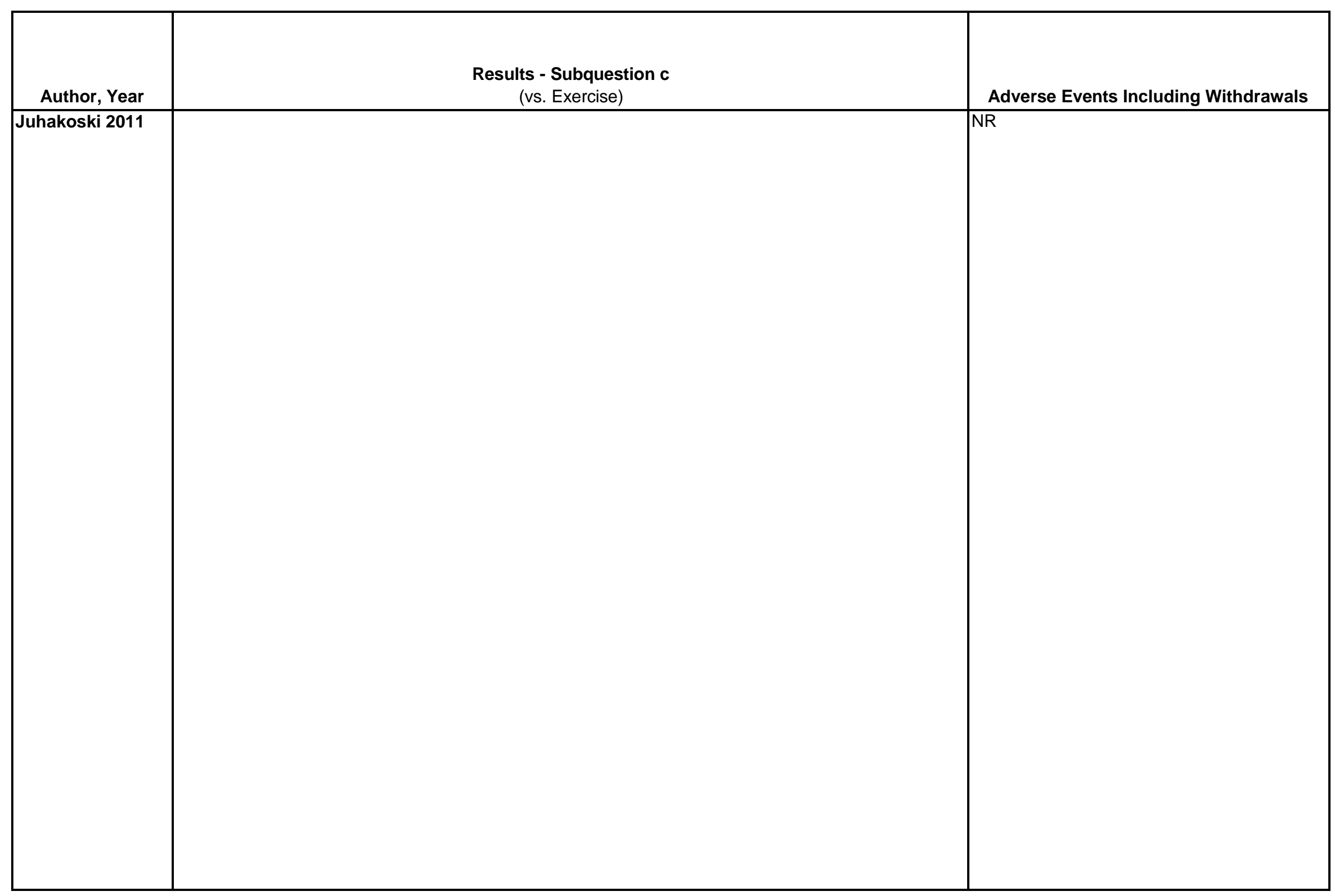




\begin{tabular}{|c|c|c|c|}
\hline Author, Year & \multicolumn{1}{|c|}{ Funding Source } & Quality & \multicolumn{1}{c|}{ Comments } \\
\hline Juhakoski 2011 & $\begin{array}{lll}\text { EVO-grant from Mikkeli Central } \\
\text { Hospital }\end{array}$ & Fair & $\begin{array}{l}\text { *Weak opioids evaluated were tramadol and codeine } \\
\text { Outcomes not reported: Direct medical costs, use of analgesics, use of NSAIDS, internal } \\
\text { rotation and flexion of the hip joint, extensor power of lower limb, 10 m walk test, Timed Up } \\
\text { and Go test, the Sock test }\end{array}$ \\
& & & \\
\end{tabular}




\begin{tabular}{|c|c|c|c|}
\hline Author, Year & $\begin{array}{c}\text { Country } \\
\text { Number of Centers } \\
\text { Setting }\end{array}$ & Inclusion/Exclusion Criteria & $\begin{array}{c}\text { Number Randomized, } \\
\text { Analyzed } \\
\text { Attrition }\end{array}$ \\
\hline Kankaanpaa 1999 & $\begin{array}{l}\text { Finland, single site, } \\
\text { health center }\end{array}$ & $\begin{array}{l}\text { Nonspecific, chronic LBP for greater than } 3 \text { months duration, and no } \\
\text { radicular symptoms } \\
\text { Exclude: nerve root compression, disc prolapse, severe scoliosis, } \\
\text { spondyloarthrosis, pervious back surgery, and other specific and } \\
\text { serious causes of back pain }\end{array}$ & $\begin{array}{l}\text { Randomized: } 59 \\
\text { Treated: } 54 \\
\text { Analyzed: } 54 \\
\text { Attrition: } \\
6 \text { month - } 15.3 \%(9 / 59) \\
12 \text { month - } 16.9 \%(10 / 59)\end{array}$ \\
\hline Karst 2000 & $\begin{array}{l}\text { Germany, number of } \\
\text { sites/setting not } \\
\text { reported }\end{array}$ & $\begin{array}{l}\text { Inclusion criteria: } \\
\text { CTTH according to IHS classification } \\
\text { Exclusion criteria: } \\
\text { Anticoagulation, predominantly operating factors, rebound analgesic } \\
\text { headache syndrome, symptomatic or other concomitant headaches, } \\
\text { history of or current migraines }\end{array}$ & $\begin{array}{l}\text { Randomized: NR } \\
\text { Treated: NR } \\
\text { Analyzed: } 39 \\
\text { Attrition: NR }\end{array}$ \\
\hline
\end{tabular}




\begin{tabular}{|c|c|}
\hline Author, Year & Intervention, Comparator \\
\hline Kankaanpaa 1999 & $\begin{array}{l}\text { A.Combined exercise }(\mathrm{n}=30) \\
\text { Active rehabilitation patients trained in groups of } 4 \text { to } 5 \text { under supervision of a physiotherapist. Patients learned exercises, stretching and relaxation } \\
\text { exercises, behavioral support and ergonomic advice. Four specially designed training units targeted trunk muscle function and coordination. } \\
\text { Progressive load increases we added over the course of the } 12 \text { weeks. } \\
\text { No. of Treatments: } 24 \text { sessions over } 12 \text { weeks } \\
\text { Length of Treatments: } 1.5 \text { hours } \\
\text { B.Attention Control }(n=24) \\
\text { Use of treatment methods, medication dosages and guidance presumed to be of minor efficacy, and thus considered as a placebo. This included } \\
\text { thermal therapy and minimal massage from physiotherapists. } \\
\text { No. of Treatments: Once weekly for } 4 \text { weeks ( } 4 \text { sessions total during the final } 4 \text { weeks of the } 12 \text { week active group) } \\
\text { Length of Treatments: NR }\end{array}$ \\
\hline Karst 2000 & $\begin{array}{l}\text { A. Acupuncture }(\mathrm{n}=21) \\
\text { No. of treatments: Twice per week for } 5 \text { weeks } \\
\text { Type of needle: Seirine Btype needle no. } 8(0.3 \times 0.3 \mathrm{~mm}) \text { and no. } 3(0.2 \times 0.15 \mathrm{~mm}) \\
\text { Acupoints: GB 20, L 14, LR } \\
3, \text { GB 8, GB 14, GB 21, GB } \\
\text { 41, UB 2, UB 10, UB 60 } \\
\text { No. of needles: Max of } 15 \\
\text { No. of insertions per } \\
\text { needle: NR } \\
\text { Insertion depth: NR } \\
\text { Time length of treatment: } 30 \text { min } \\
\text { B.Sham Acupuncture }(n=18) \\
\text { Blunt placebo needles simulated puncturing sensation without being inserted. Elastic foam was used to shield needle type. }\end{array}$ \\
\hline
\end{tabular}




\begin{tabular}{|c|c|c|c|}
\hline Author, Year & Study Participants & Outcome Measures & $\begin{array}{c}\text { Duration of } \\
\text { Followup }\end{array}$ \\
\hline Kankaanpaa 1999 & $\begin{array}{l}\text { A vs B } \\
\text { Age: } 40 \text { vs. } 39 \text { years } \\
\text { Female: } 36.6 \% \text { vs. } 33.3 \% \\
\text { Race: NR } \\
\text { Mean Duration of Chronicity: } 9.03 \text { vs. } 7 \\
\\
\text { Functional Disability (PDI): } 13.2(10.2) \text { vs. } 9.5(8.3) \\
\text { Back Pain Intensity (VAS): } 55.2(22.8) \text { vs. } 47.0(29.3)\end{array}$ & $\begin{array}{l}\text { Pain and Disability Index (PDI, range 0-70: higher } \\
\text { scores indicate worse disability) } \\
\text { Back Pain Intensity (VAS, range 0-100mm: higher } \\
\text { scores indicate worse pain) }\end{array}$ & $\begin{array}{l}\text { Short term } \\
\text { and } \\
\text { intermediate } \\
\text { term followup } \\
3 \text { and } 9 \\
\text { months }\end{array}$ \\
\hline Karst 2000 & $\begin{array}{l}\text { A vs. B } \\
\text { Age: } 50 \text { vs } 47 \text { years } \\
\text { Female: } 38 \% \text { vs. } 61 \% \\
\text { Race: NR } \\
\text { Mean duration of chronicity: NR } \\
\text { Mean frequency of headache: (SD): } 26.9 \text { vs } 27.2 \text { days/month } \\
\text { Patients who had prior preventative treatments: NR } \\
\text { Patients who overused medications: NR } \\
\\
\text { VAS at baseline: } 6.2(2.2) \text { vs } 6.3(2.2) \\
\text { Mean Analgesic Intake/Month at Baseline: } 8.3(11.8) \text { vs. } 10.2(12.0)\end{array}$ & $\begin{array}{l}\text { Frequency of headache attacks/month; } \\
\text { Headache severity (VAS, range 0-10: higher scores } \\
\text { indicate severity of pain); } \\
\text { Mean Analgesic Intake/Month }\end{array}$ & 1.5 months \\
\hline
\end{tabular}




\begin{tabular}{|c|c|}
\hline Author, Year & $\begin{array}{c}\text { Results - Subquestion a } \\
\text { (vs. sham, no treatment, waitlist, attention control) }\end{array}$ \\
\hline Kankaanpaa 1999 & 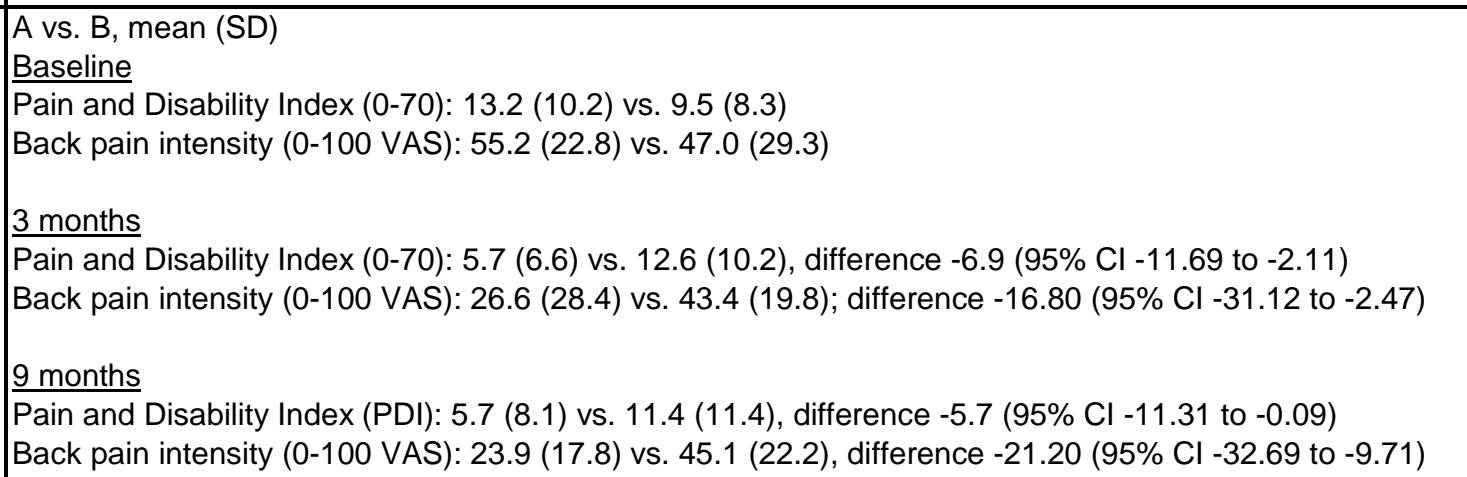 \\
\hline Karst 2000 & $\begin{array}{l}\text { A vs. B } \\
\text { 1.5 Months } \\
\text { Frequency of headache attacks/month: } 22.1(10.6) \text { vs. 22.0(9.9); MD } 0.10(95 \% \mathrm{Cl}-6.59 \text { to } 6.79) p=0.976 \\
\text { Mean Headache Severity VAS (0-10): } 4.0(2.5) \text { vs. 3.9(2.7); MD } 0.10(95 \% \mathrm{Cl}-11.92 \text { to } 12.12) p=0.987 \\
\text { Mean Analgesic Intake/Month: } 13.7(17.2) \text { vs. } 21.2(27.6) ; \mathrm{MD}-7.5(95 \% \mathrm{Cl}-22.20 \text { to } 7.20) \mathrm{p}=0.308\end{array}$ \\
\hline
\end{tabular}




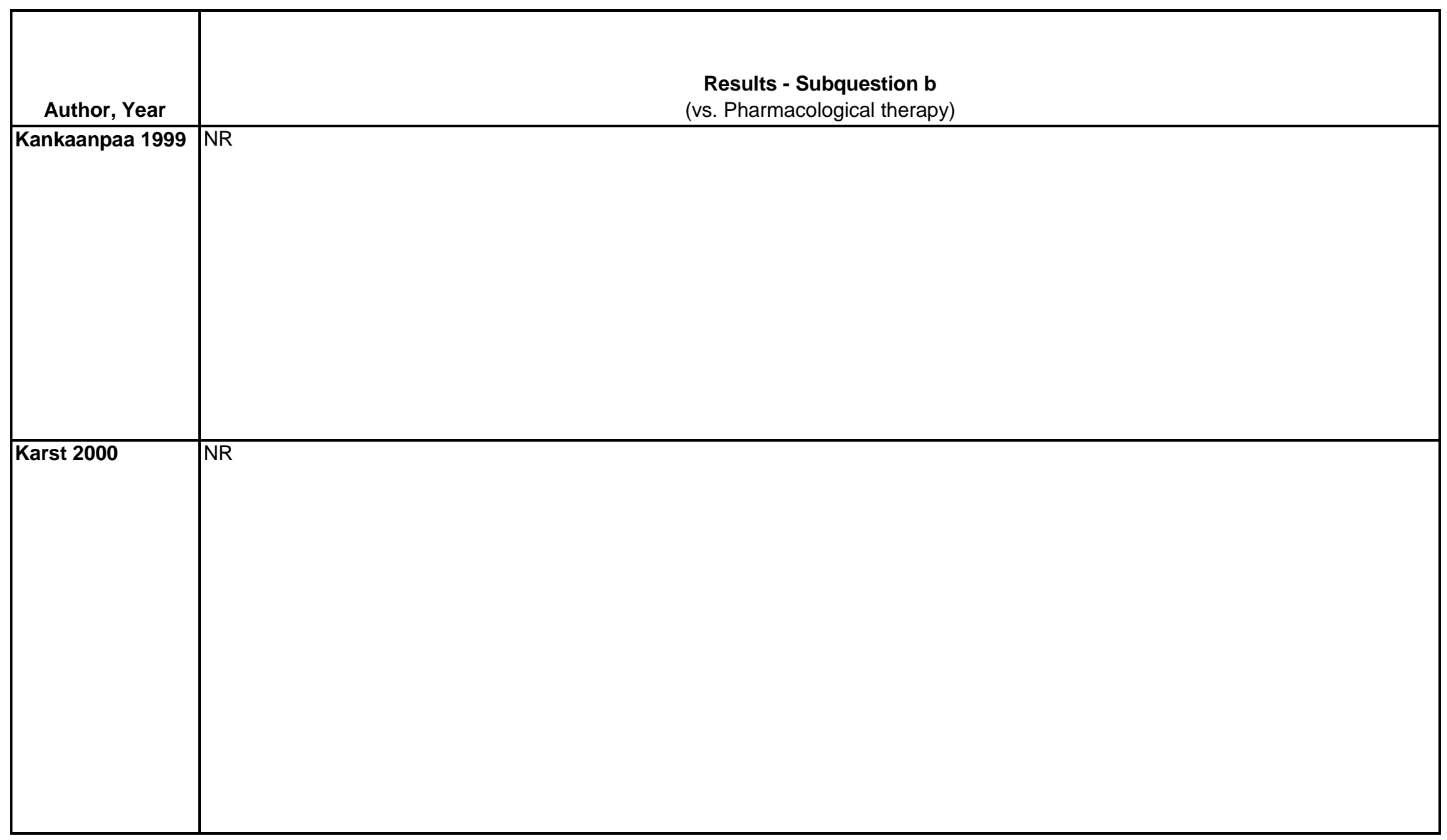

D-439 


\begin{tabular}{|c|c|c|}
\hline Author, Year & $\begin{array}{l}\text { Results - Subquestion c } \\
\text { (vs. Exercise) }\end{array}$ & Adverse Events Including Withdrawals \\
\hline Kankaanpaa 1999 & 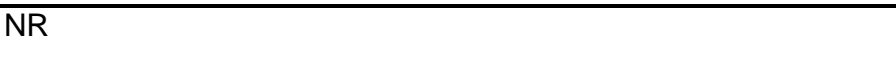 & NR \\
\hline Karst 2000 & $\mathrm{NR}$ & $\overline{N R}$ \\
\hline & & \\
\hline & & \\
\hline & & \\
\hline & & \\
\hline
\end{tabular}




\begin{tabular}{|c|c|c|c|}
\hline Author, Year & \begin{tabular}{|l} 
Funding Source \\
\end{tabular} & Quality & Comments \\
\hline Kankaanpaa 1999 & 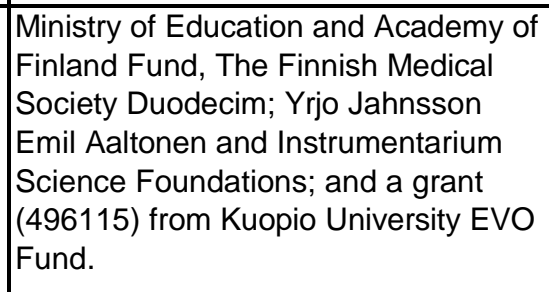 & Fair & \\
\hline Karst 2000 & NR & Poor & \\
\hline & & & \\
\hline & & & \\
\hline & & & \\
\hline & & & \\
\hline
\end{tabular}




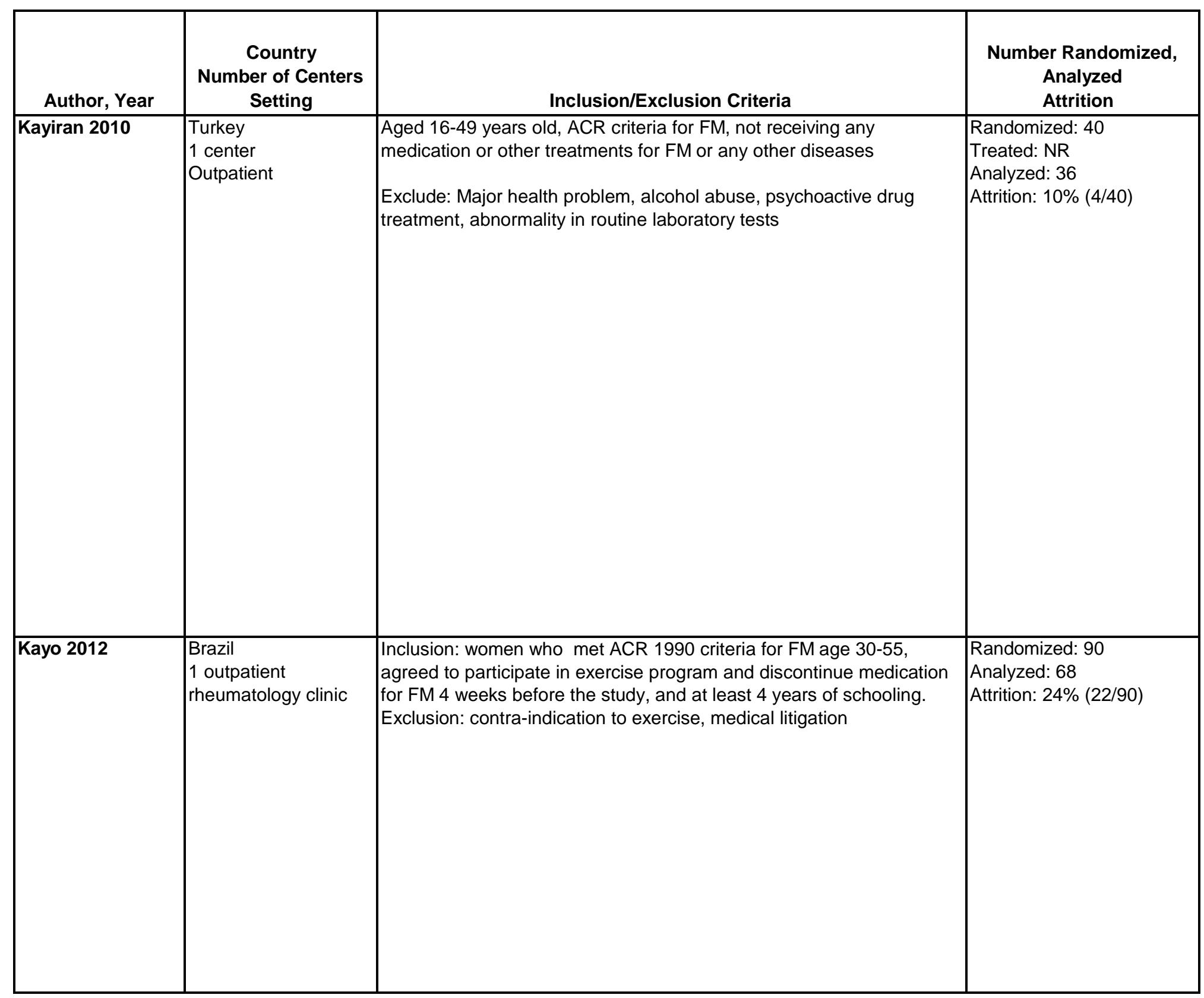




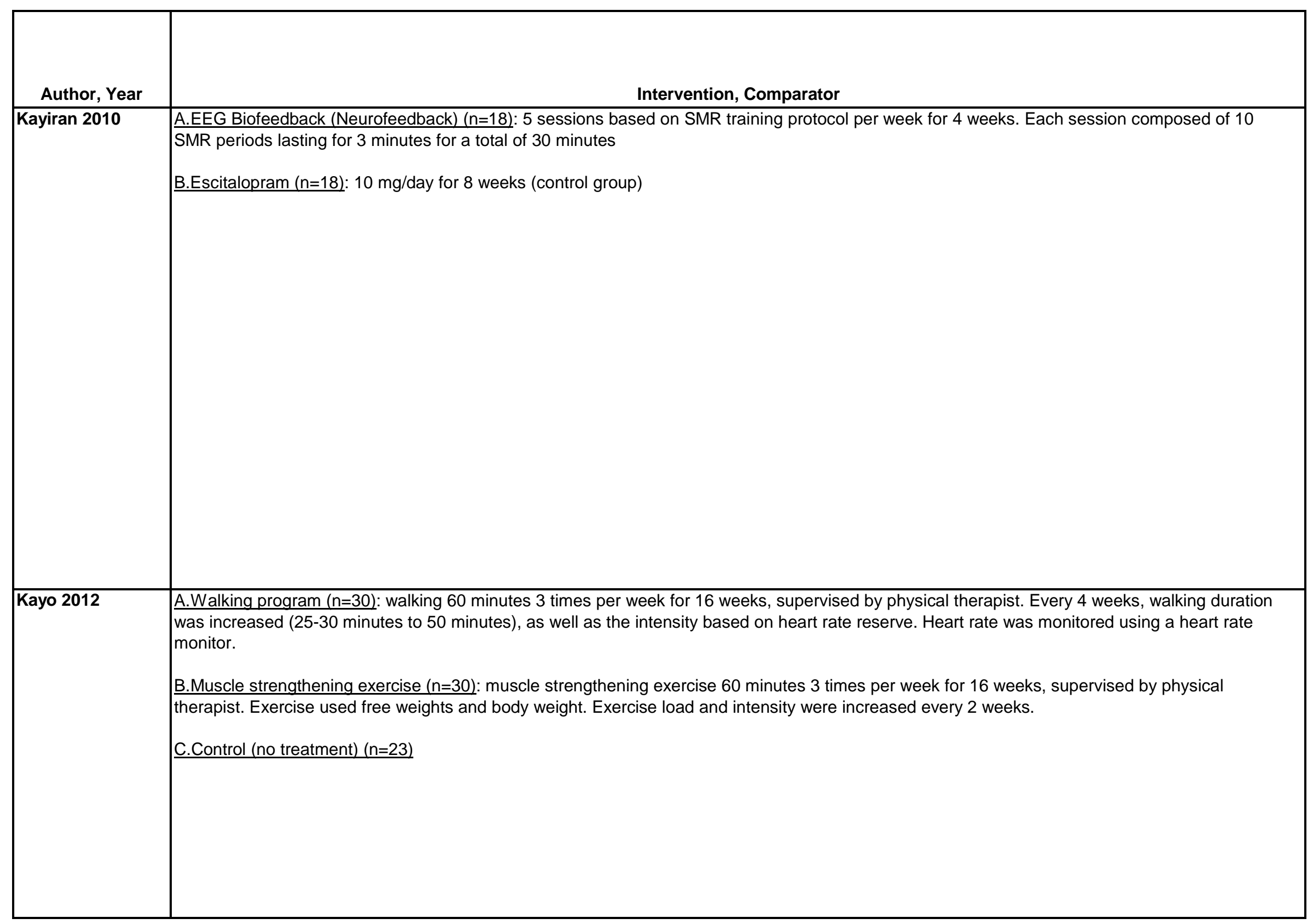




\begin{tabular}{|c|c|c|c|}
\hline Author, Year & Study Participants & Outcome Measures & $\begin{array}{l}\text { Duration of } \\
\text { Followup }\end{array}$ \\
\hline Kayiran 2010 & $\begin{array}{l}\text { A vs B } \\
\text { Age: } 32 \text { vs } 32 \\
\text { Female: } 100 \% \text { vs } 100 \% \\
\text { Duration of symptoms (years): } 4.6(2.5) \text { vs } 4.9(2.4) \\
\text { Major depressive disorder, n: } 9 \text { vs } 10 \\
\text { FIQ: } 70 \text { vs } 74^{*} \\
\text { Pain VAS, mean (SE): } 8.9 \text { (0.2) vs } 9.1(0.2) \\
\text { Hamilton Depression Scale, mean (SE): } 16.9(1.3) \text { vs } 20.8(0.7) \\
\text { Beck Depression Scale, mean (SE): } 21.5(2.6) \text { vs } 26.0(2.2) \\
\text { Hamilton Anxiety Scale, mean (SE): } 19.7(1.4) \text { vs } 25.1(1.3) \\
\text { Beck Anxiety Scale, mean (SE):26.2 (2.4) vs } 35.6(2.4) \\
\text { SF-36*: } \\
\text { Physical functioning: } 40 \text { vs } 39 \\
\text { Bodily pain: } 28 \text { vs } 25 \\
\text { Role-physical: } 2 \text { vs } 4 \\
\quad \text { Role-emotional: } 11 \text { vs } 8 \\
\quad \text { Social functioning: } 39 \text { vs } 25 \\
\quad \text { General mental health: } 35 \text { vs } 31 \\
\text { General health: } 38 \text { vs } 51 \\
\text { Vitality: } 23 \text { vs } 22\end{array}$ & $\begin{array}{l}\text { FIQ (0-100, higher score=higher disability); pain VAS (0- } \\
10 \text {, higher score=higher pain); Hamilton Depression } \\
\text { Scale (0-50, higher score=more severe symptoms of } \\
\text { depression); Beck Depression Scale (0-63, higher } \\
\text { score=more severe symptoms of depression); Hamilton } \\
\text { Anxiety Scale (0-56, higher score=more severe } \\
\text { symptoms of anxiety); Beck Anxiety Scale (0-63, higher } \\
\text { score=more severe symptoms of anxiety) }\end{array}$ & $4-5$ months \\
\hline Kayo 2012 & \begin{tabular}{|l} 
A vs C: \\
Age, years: $48(5.3)$ vs $46(6.4)$ \\
Duration of symptoms, years: $4.0(3.1)$ vs $5.4(3.5)$ \\
FIQ total: $63.1(14.7)$ vs $63.8(16.7)$ \\
Pain VAS: $8.6(1.6)$ vs $8.4(1.5)$ \\
SF-36 Physical Functioning: $39.3(18.6)$ vs $35.8(17.3)$ \\
SF-36 Mental Health: $51.3(24.3)$ vs 46.0 \\
\\
B vs C: \\
Age, years: $46.7(6.3)$ vs $46.1(6.4)$ \\
Duration of symptoms, years: $4.7(5.7)$ vs $5.4(3.5)$ \\
FIQ total: $67.3(16.5)$ vs $63.8(16.7)$ \\
Pain VAS: $8.7(1.6)$ vs $8.4(1.5)$ \\
SF-36 Physical Functioning: $37.3(17.6)$ vs $35.8(17.3)$ \\
SF-36 Mental Health: $46.0(22.8)$ vs $46.0(22.2)$
\end{tabular} & $\begin{array}{l}\text { FIQ (0-100, higher scores=greater disability) } \\
\text { Pain VAS }(0-10 \text {, higher scores=greater pain) } \\
\text { SF-36 (0-100, higher scores=better health status) }\end{array}$ & 3 months \\
\hline
\end{tabular}




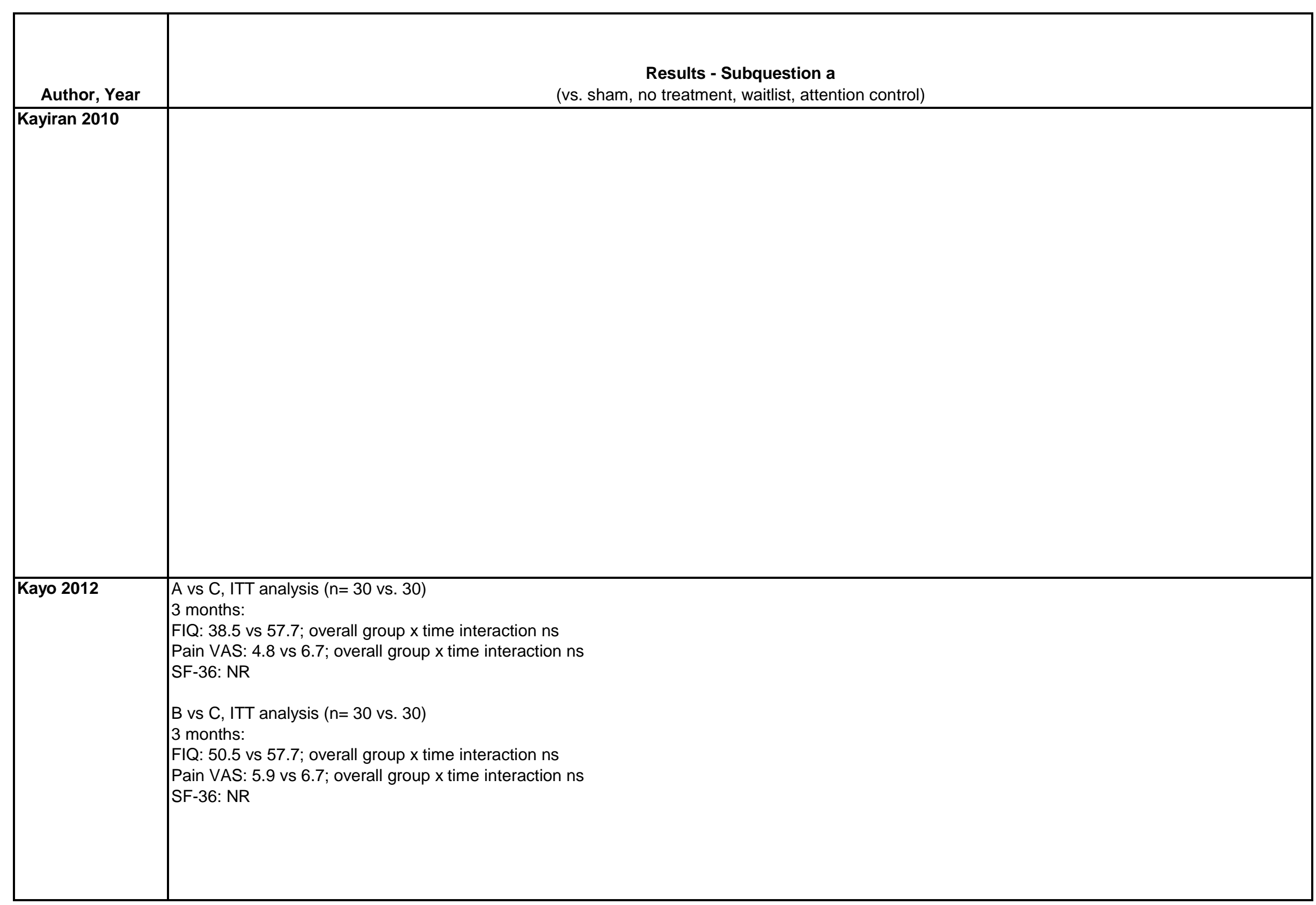




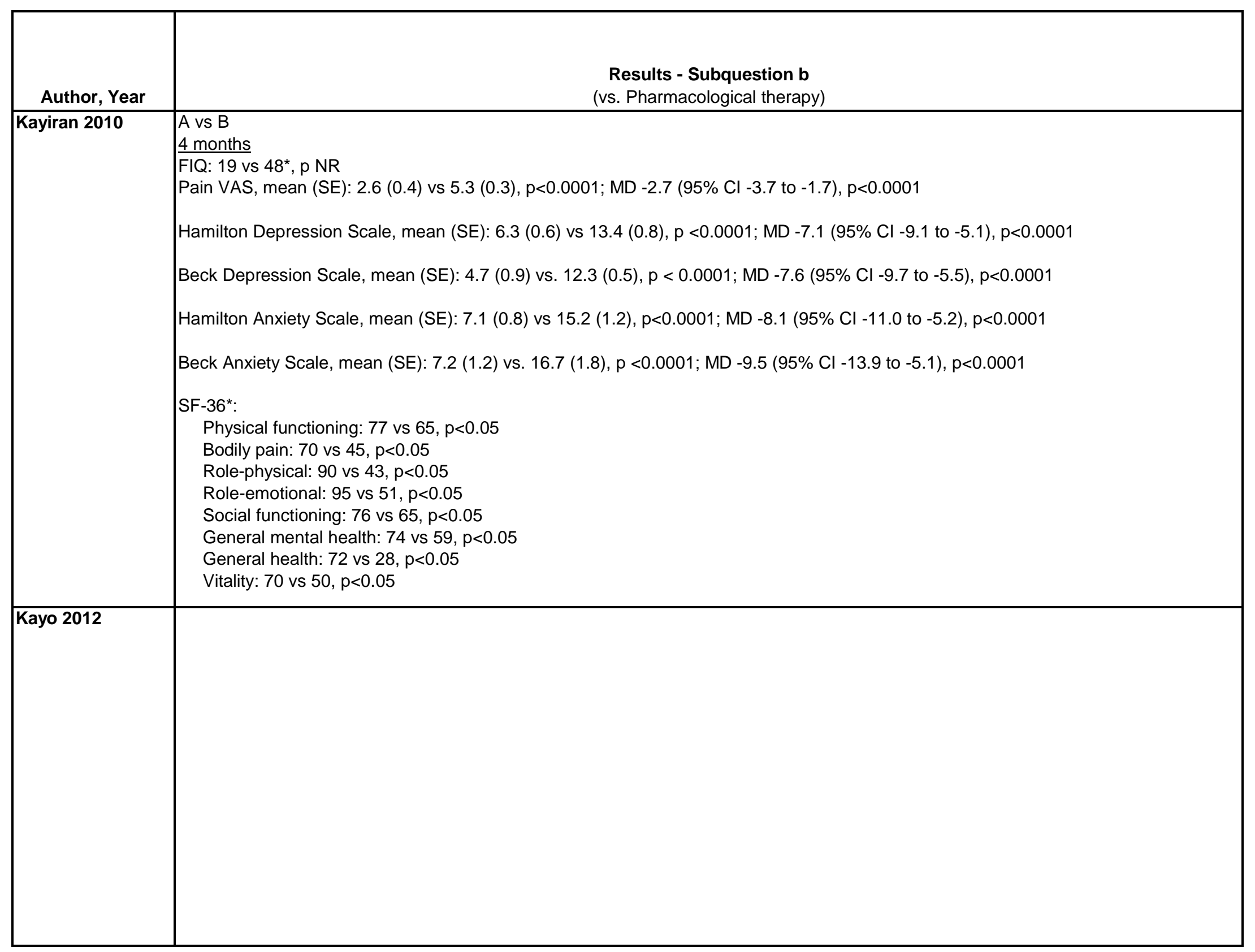




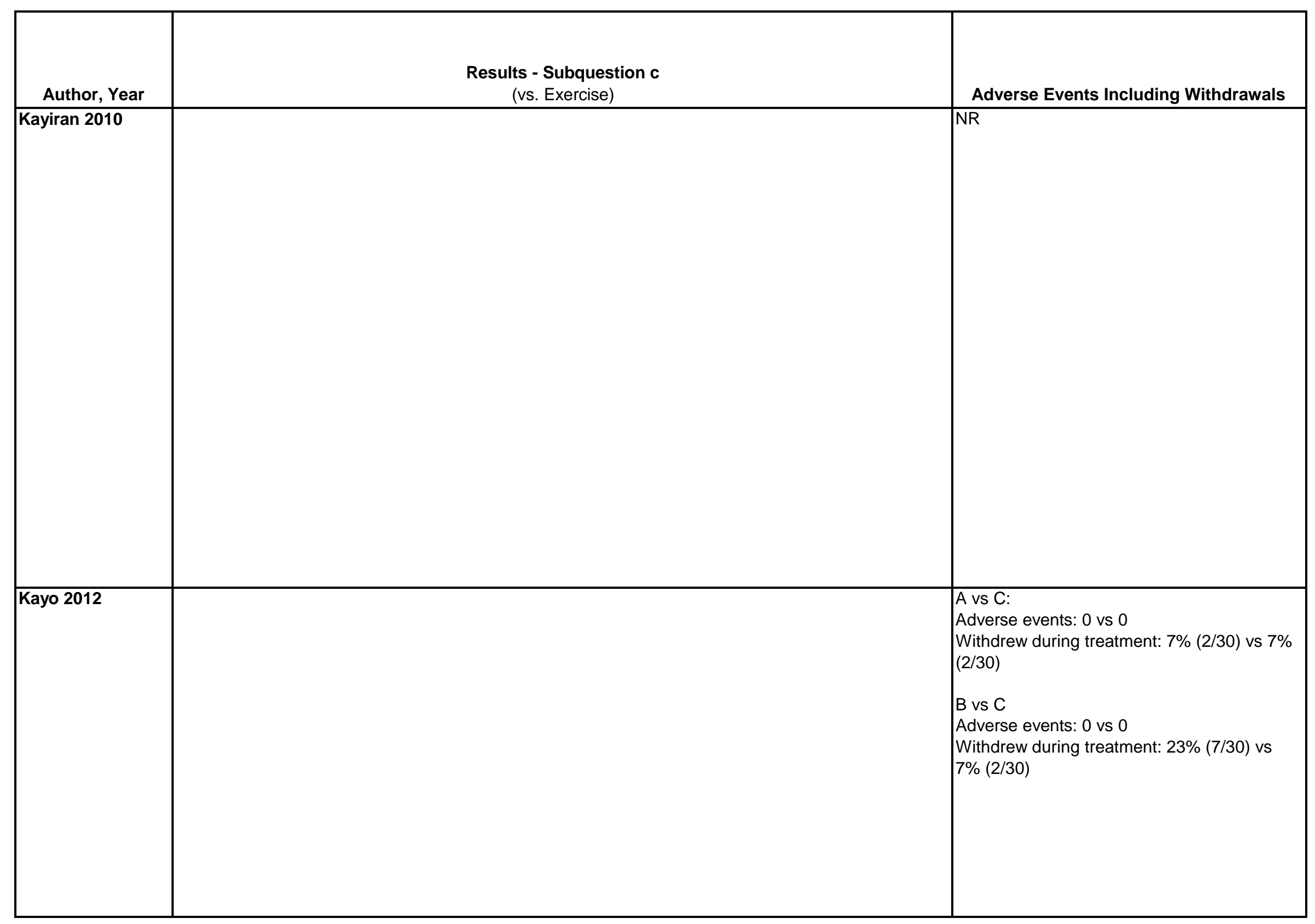




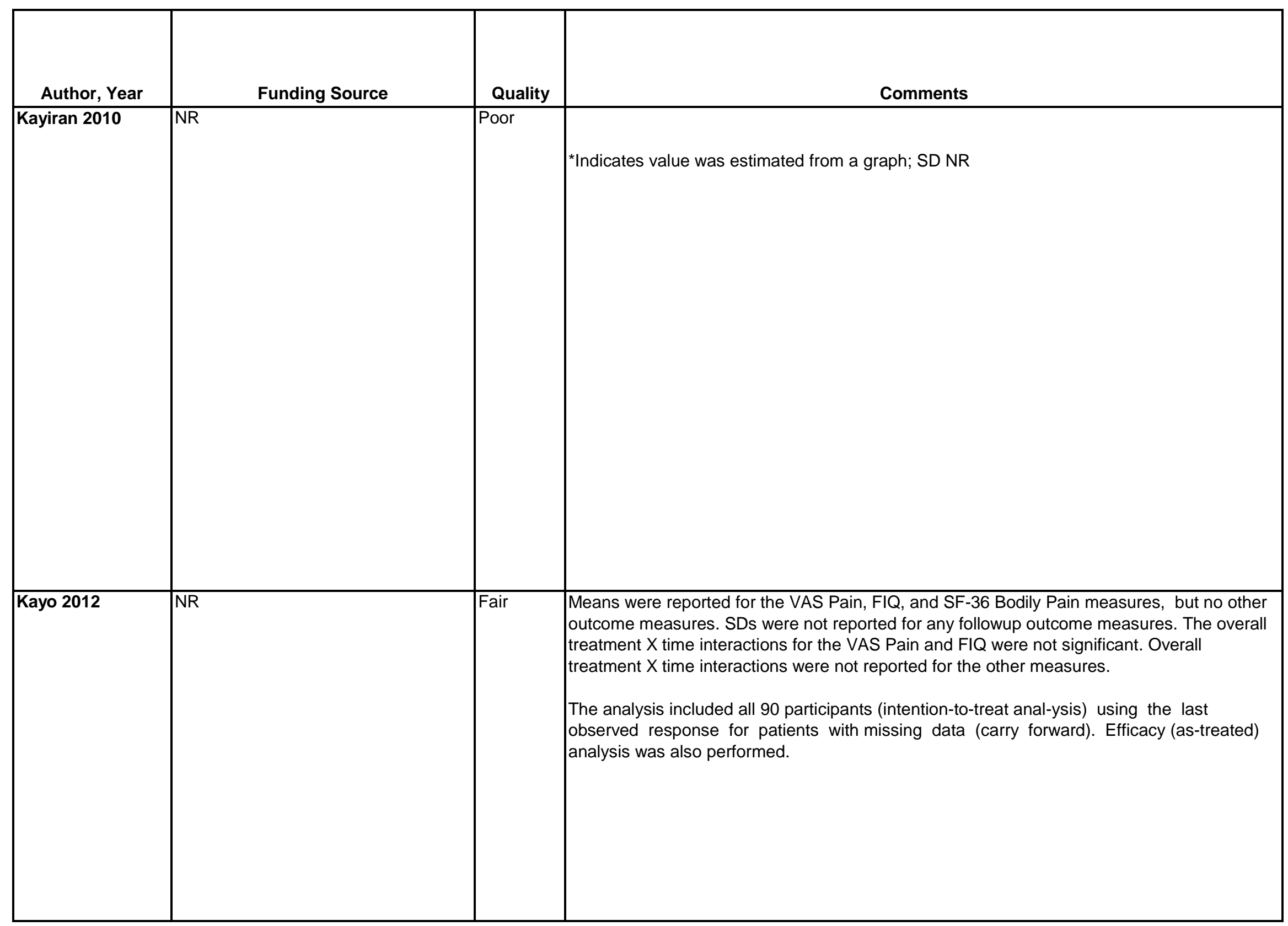




\begin{tabular}{|c|c|c|c|}
\hline Author, Year & $\begin{array}{c}\text { Country } \\
\text { Number of Centers } \\
\text { Setting }\end{array}$ & Inclusion/Exclusion Criteria & $\begin{array}{c}\text { Number Randomized, } \\
\text { Analyzed } \\
\text { Attrition }\end{array}$ \\
\hline Kerr 2003 & $\begin{array}{l}\text { UK } \\
\text { Number of centers: } \\
\text { Unclear } \\
\text { Setting: Unclear } \\
\text { Patients were } \\
\text { recruited as direct } \\
\text { referral from general } \\
\text { practitioner or from } \\
\text { the waitlist of an open } \\
\text { referral system for } \\
\text { outpatient } \\
\text { physiotherapy } \\
\text { services operated by } \\
\text { local general } \\
\text { practitioners and } \\
\text { hospitals. }\end{array}$ & $\begin{array}{l}\text { LBP symptoms } \geq 6 \text { months with or without leg pain } \\
\text { No neurologic deficits } \\
\text { Exclude } \\
\text { Contraindications to acupuncture therapy } \\
\text { Age }<18 \text { years } \\
\text { Pregnancy } \\
\text { Underlying systemic disorders } \\
\text { Rheumatoid arthritis } \\
\text { Osteoarthritis of the spine } \\
\text { Cancer }\end{array}$ & $\begin{array}{l}\text { Randomized: } 60 \\
\text { Treated: } 26 \\
\text { Analyzed: } 46 \text { (end of } \\
\text { treatment), } 40 \text { ( } 4.5 \\
\text { months) }\end{array}$ \\
\hline King 2002 & \begin{tabular}{|l|} 
United States \\
1 center \\
University setting
\end{tabular} & $\begin{array}{l}\text { Females with diagnosis of FM fulfilling ACR criteria } \\
\text { Exclude: Conditions that precluded ability to exercise, inflammatory } \\
\text { arthritis, systemic lupus erythematosus, rheumatoid arthritis }\end{array}$ & $\begin{array}{l}\text { Randomized: } \mathrm{NR}^{\star} \\
\text { Treated: } \mathrm{NR}^{\star} \\
\text { Analyzed: } 76 \\
\text { Attrition: Unclear* }\end{array}$ \\
\hline
\end{tabular}




\begin{tabular}{|c|c|}
\hline Author, Year & Intervention, Comparator \\
\hline Kerr 2003 & $\begin{array}{l}\text { A.Acupuncture ( } \mathrm{n}=26) \text { : } 6 \text { 30-minute sessions over } 6 \text { weeks using set acupuncture points performed by single provider. } 11 \text { needles used for each } \\
\text { patient, } 0.30 \times 50 \mathrm{~mm} \text { c-type, inserted with until the sensation of "ch'i" was produced, with patient in prone position. Needles were manually rotated } \\
\text { to produce "ch'i" sensation again at 10- and 20-minute intervals. Patients were also given a leaflet that included standardized advice and exercises } \\
\text { (identical for both groups). } \\
\text { B.Placebo (sham TENS) ( } \mathrm{n}=20): 630 \text {-minute sessions over } 6 \text { weeks. Nonfunctioning TENS unit attached to } 4 \text { electrodes }(3 \mathrm{~cm} \times 3 \mathrm{~cm} \text { carbon- } \\
\text { rubber with self-adhesive gel pads) and placed over the lumbar spine. The unit was switched on but the circuit was broken between the unit and the } \\
\text { patient. Patients were also given a leaflet that included standardized advice and exercises (identical for both groups). }\end{array}$ \\
\hline King 2002 & $\begin{array}{l}\text { A. Exercise }(n=30 \ddagger) \text { : } 3 \text { supervised exercise sessions per week for } 12 \text { weeks. Sessions were based on recommendations from the } 1990 \text { American } \\
\text { College of Sports Medicine recommendations on quantity and quality of exercise for developing cardiorespiratory fitness in healthy adults. } \\
\text { Exercises were aerobic and included both land and water activities. Sessions lasted from } 10-15 \text { minutes at the beginning of the treatment period } \\
\text { and were } 20-40 \text { minutes at the end of the treatment period. } \\
\text { B. Control }(n=18 \ddagger) \text { : Subjects were given basic instructions on stretches and coping strategies at the beginning of the treatment period. Subjects } \\
\text { were contacted 1-2 times during the treatment period to answer any questions. }\end{array}$ \\
\hline
\end{tabular}




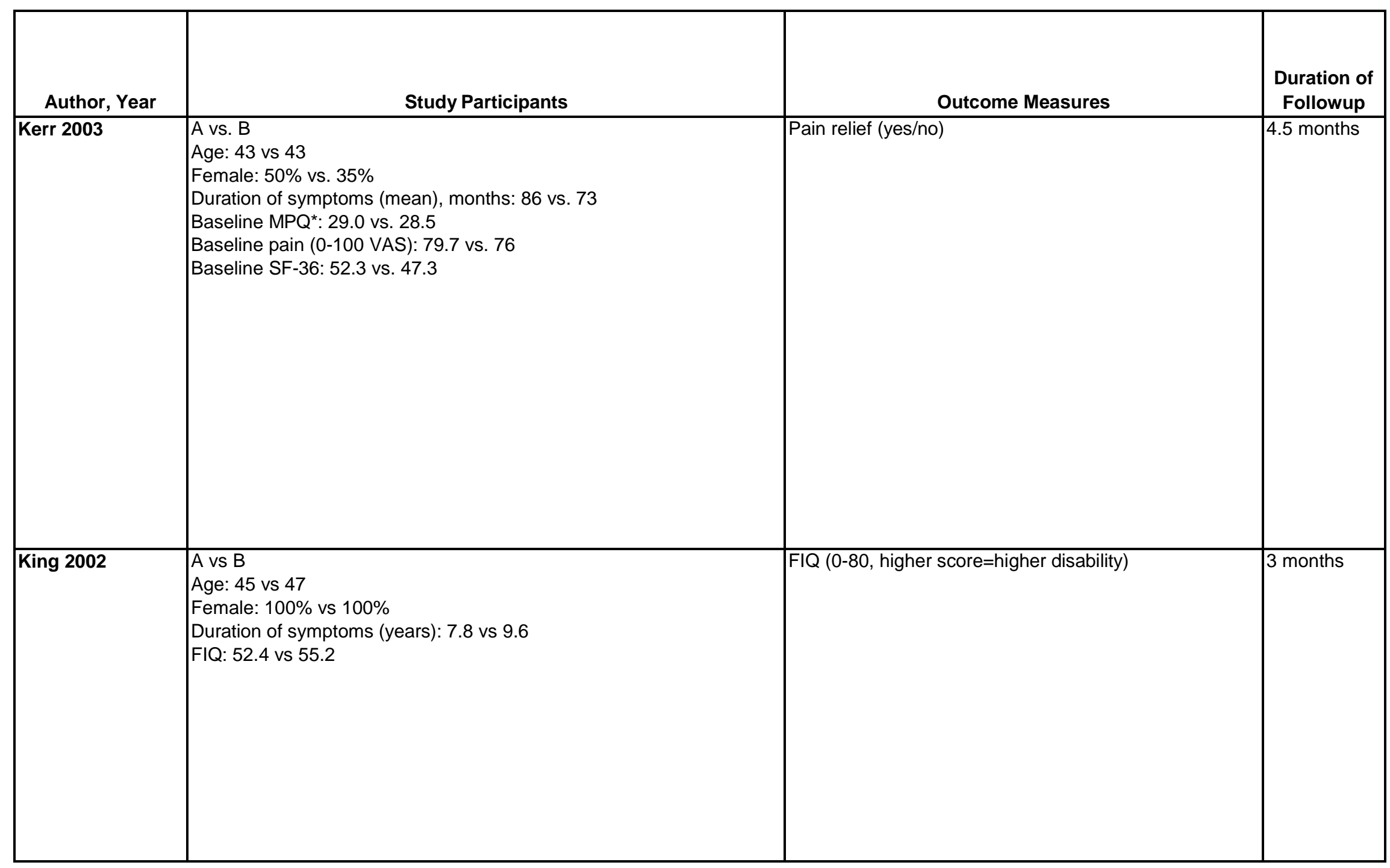




\begin{tabular}{|c|c|}
\hline Author, Year & $\begin{array}{l}\text { Results - Subquestion a } \\
\text { (vs. sham, no treatment, waitlist, attention control) }\end{array}$ \\
\hline Kerr 2003 & 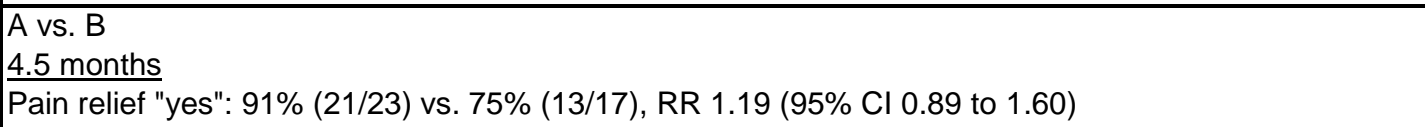 \\
\hline |King 2002 & $\begin{array}{l}\text { A vs B } \\
\text { FIQ: } 47.5 \text { (14.0) vs } 51.5 \text { (13.1), p ns; (MD -4.0, 95\% Cl -12.2 to 4.2) p=0.33 }\end{array}$ \\
\hline
\end{tabular}




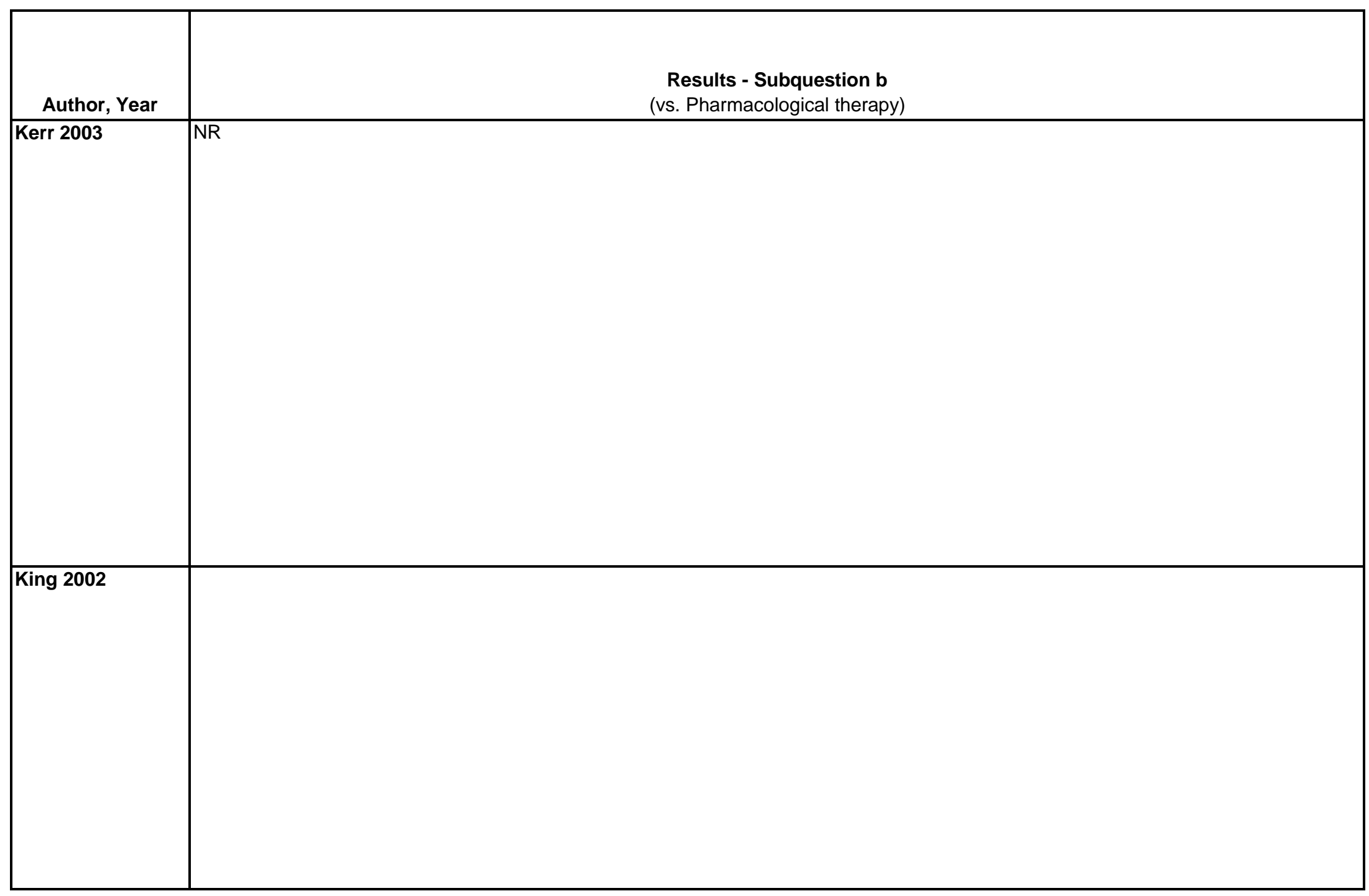

D-453 


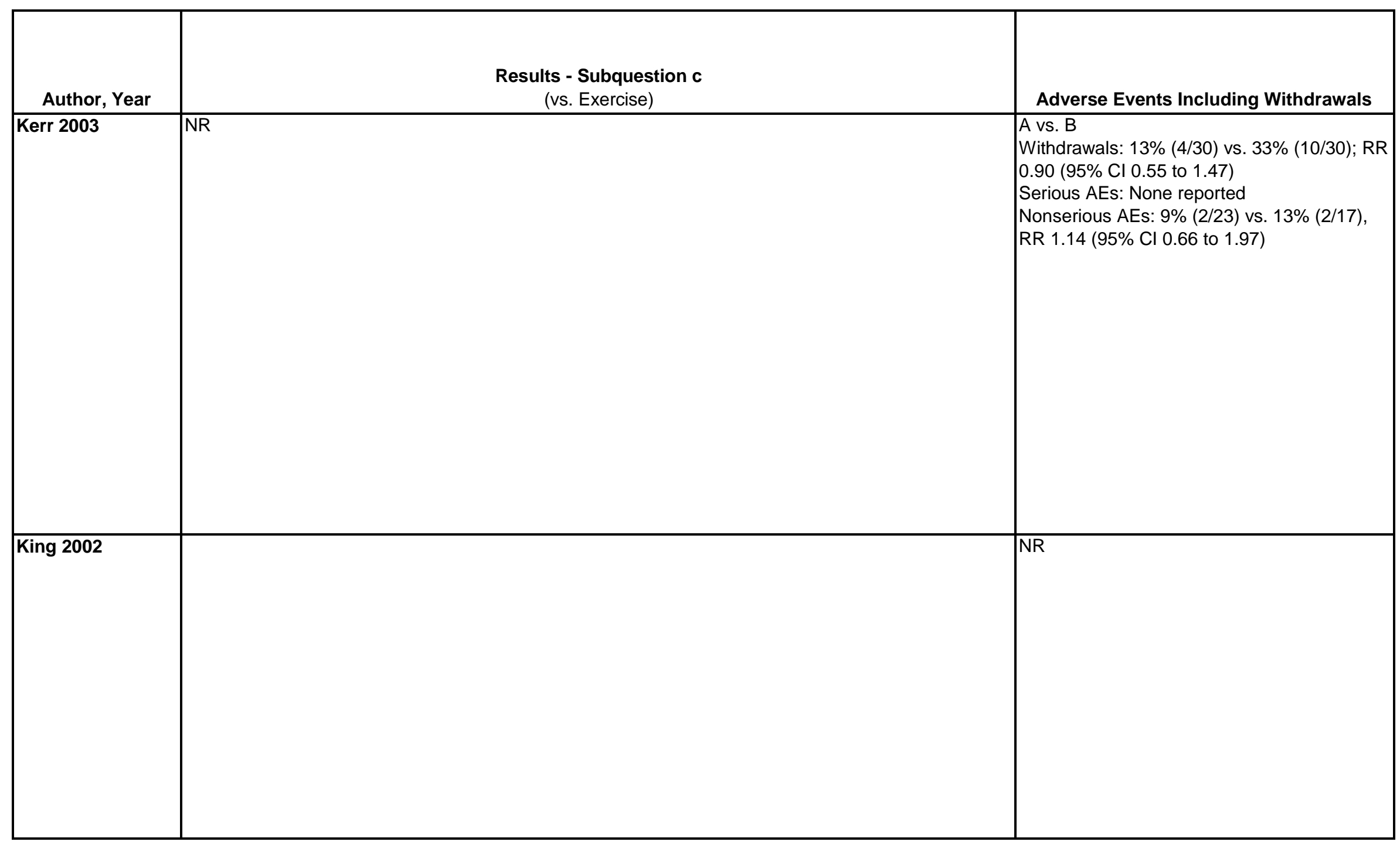




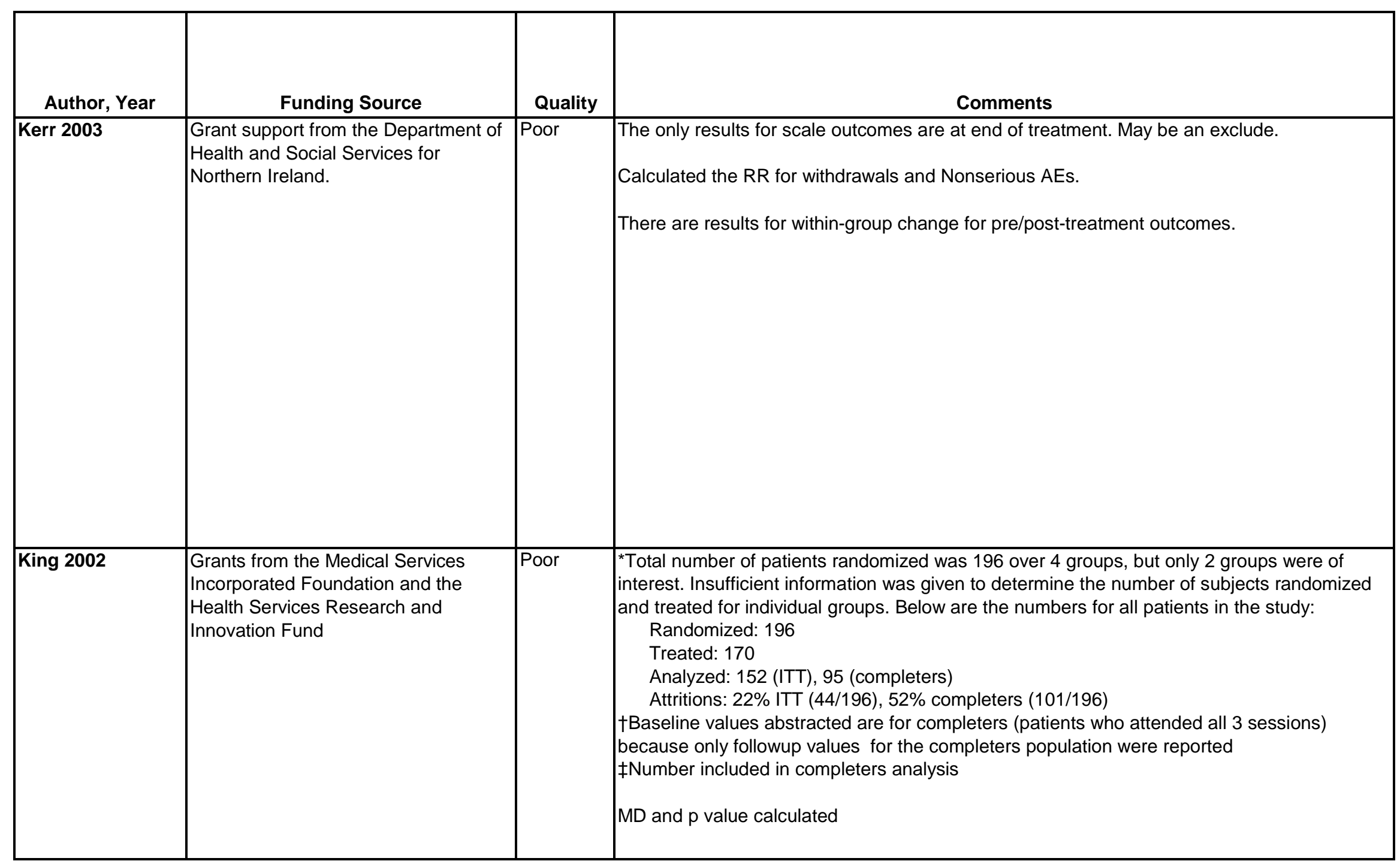




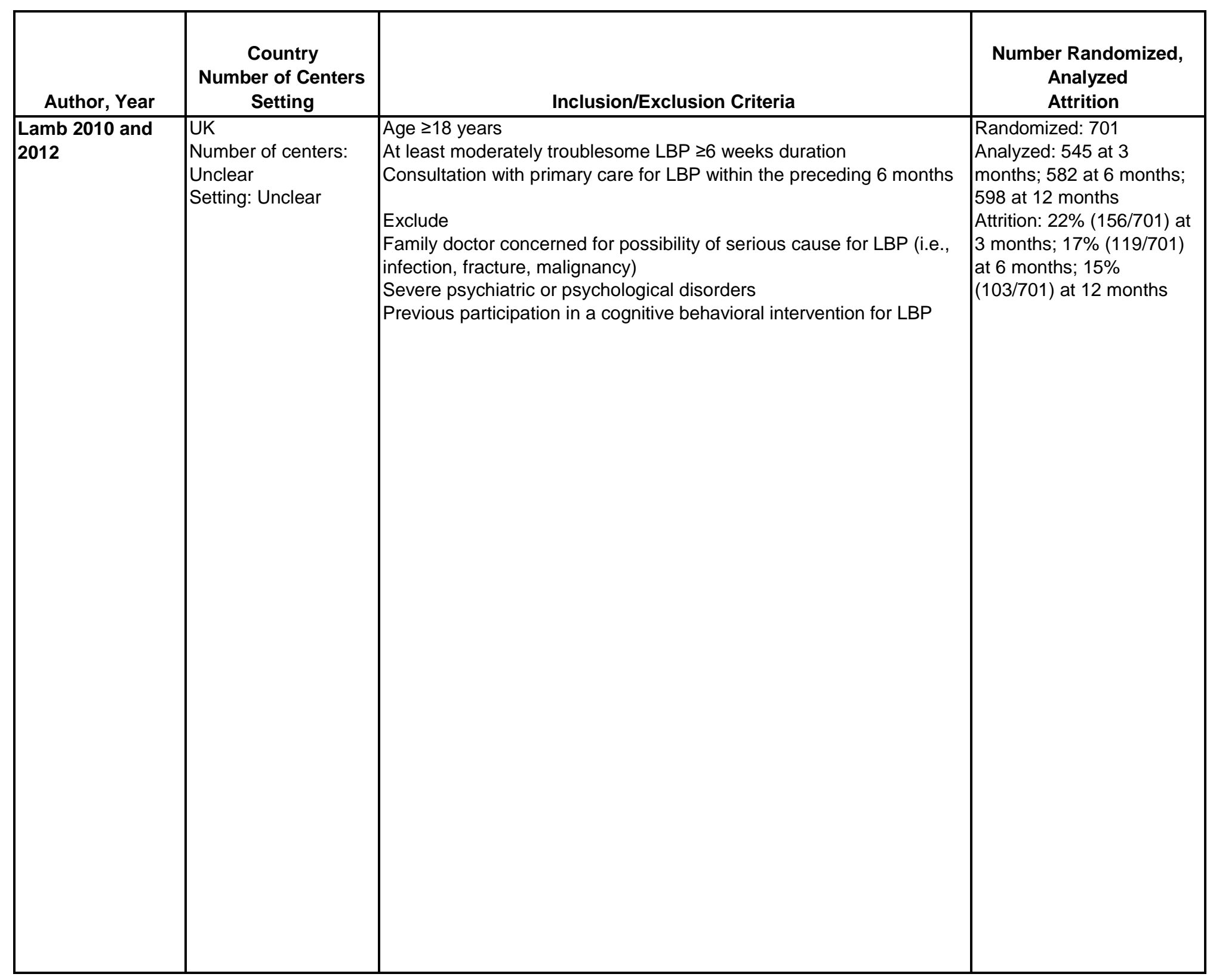




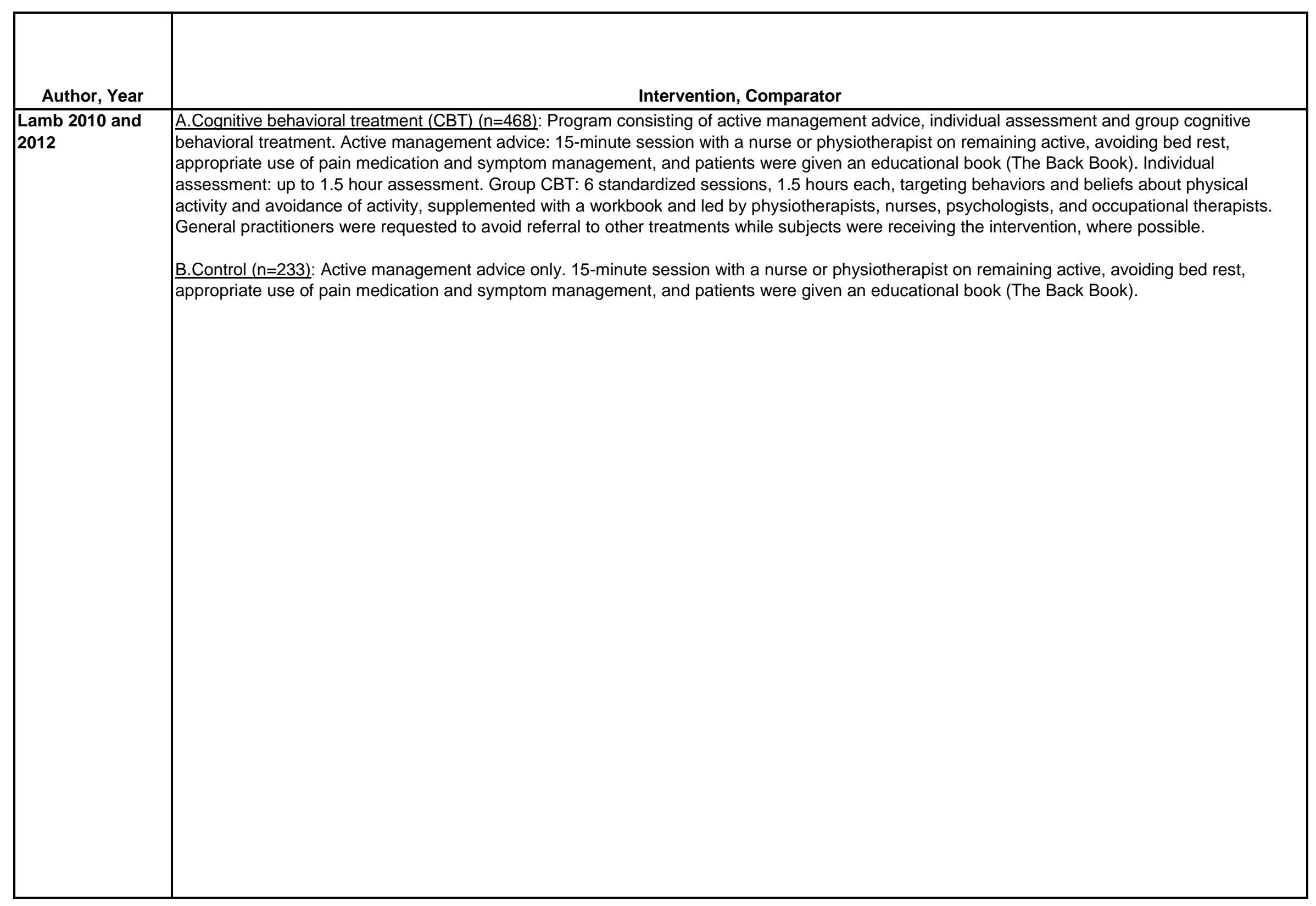




\begin{tabular}{|c|c|c|c|}
\hline Author, Year & Study Participants & Outcome Measures & $\begin{array}{c}\text { Duration of } \\
\text { Followup }\end{array}$ \\
\hline $\begin{array}{l}\text { Lamb } 2010 \text { and } \\
2012\end{array}$ & $\begin{array}{l}\text { A vs. B } \\
\text { Age: } 53 \text { vs. } 54 \text { years } \\
\text { Female: } 59 \% \text { vs. } 61 \% \\
\text { White race: } 88 \% \text { vs. } 88 \% \\
\text { Duration of back pain (years since first onset): } 13 \text { vs. } 13 \\
\text { Employed: } 51 \% \text { vs. } 47 \% \\
\text { Unable to work because of LBP: } 11 \% \text { vs. } 9 \% \\
\text { RDQ (0-24): } 9 \text { vs. } 9 \\
\text { Modified Von Korff disability (0-100): } 49 \text { vs. } 46 \\
\text { Modified Von Korff pain (0-100): } 59 \text { vs. } 59 \\
\text { SF-12 Physical component score (0-100): } 37 \text { vs. } 38 \\
\text { SF-12 Mental component score: } 45 \text { vs. } 46\end{array}$ & $\begin{array}{l}\text { Roland Morris Disability Questionnaire (RDQ, 0-24 } \\
\text { (higher scores indicate more disability) } \\
\text { Modified Von Korff disability (0-100) } \\
\text { Modified Von Korff pain (0-100) } \\
\text { SF-12 Physical component score (0-100, lower score } \\
\text { indicates poorer quality of life) } \\
\text { SF-12 Mental component score (0-100) } \\
\text { Health care resource use for LBP during followup year }\end{array}$ & $\begin{array}{l}1.5,4.5, \\
10.5, \text { and } \\
\text { mean } 34 \\
\text { months (see } \\
\text { Lamb 2012) }\end{array}$ \\
\hline
\end{tabular}




\begin{tabular}{|c|c|}
\hline Author, Year & $\begin{array}{c}\text { Results - Subquestion a } \\
\text { (vs. sham, no treatment, waitlist, attention control) }\end{array}$ \\
\hline $\begin{array}{l}\text { Lamb } 2010 \text { and } \\
2012\end{array}$ & 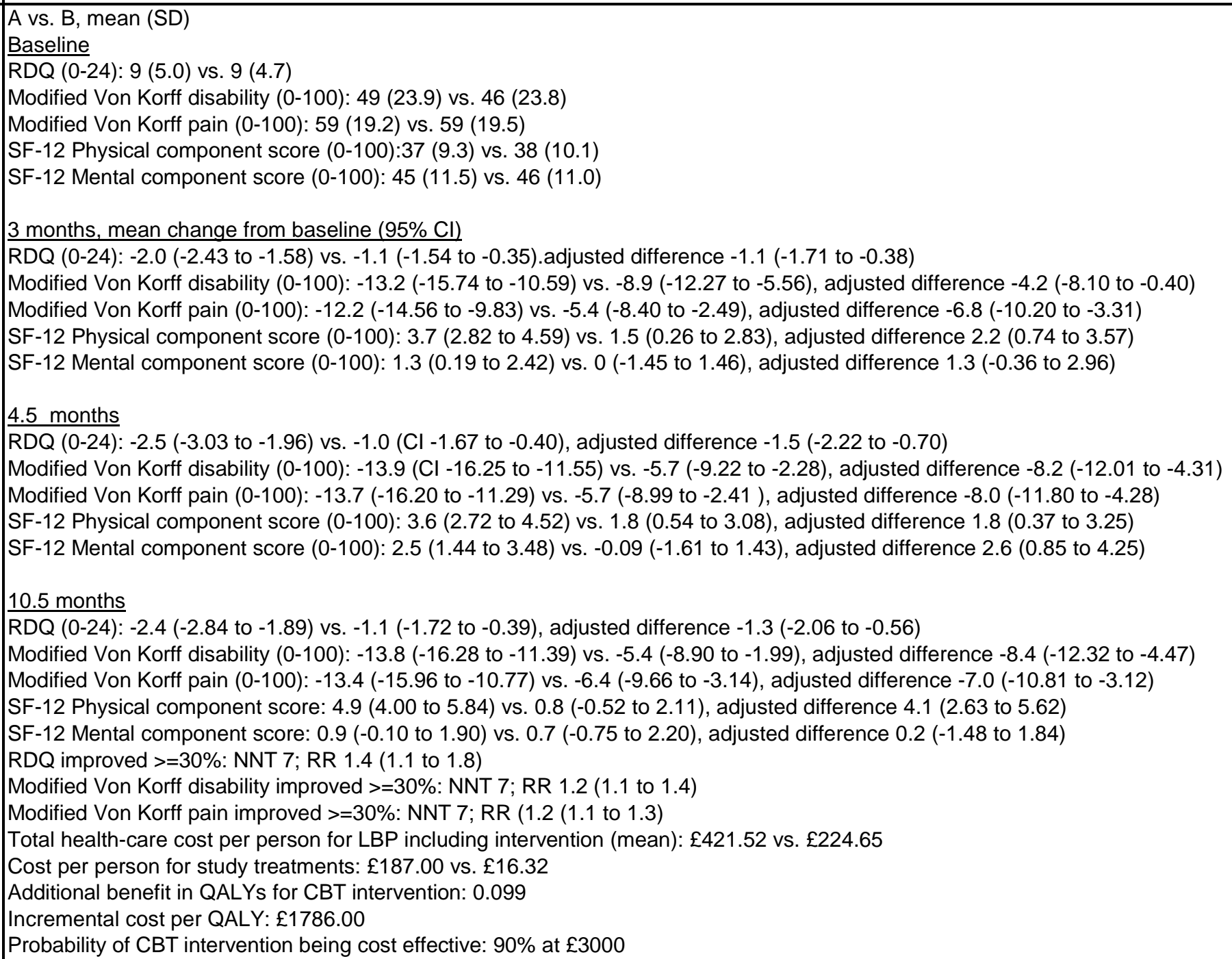 \\
\hline
\end{tabular}




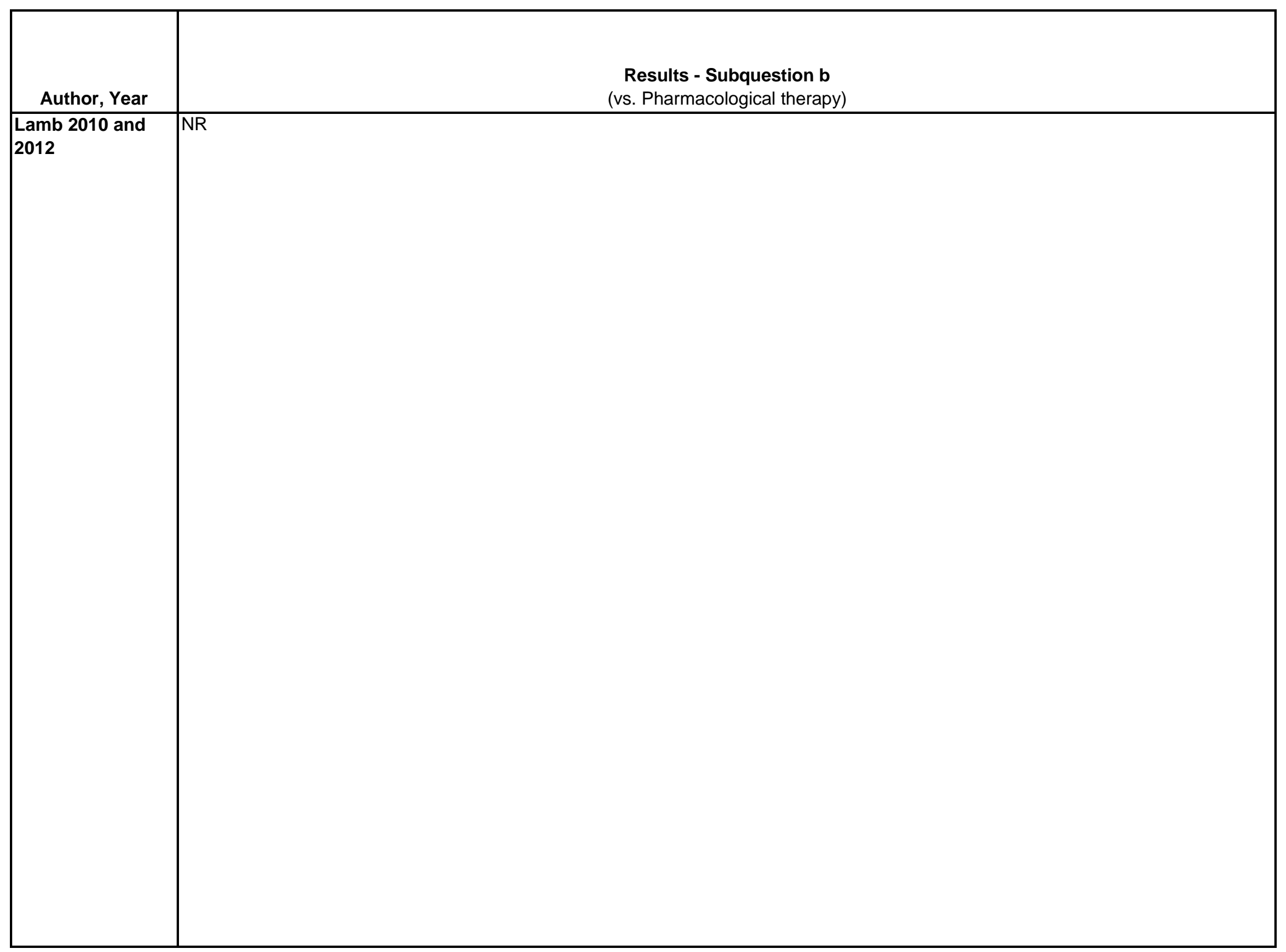




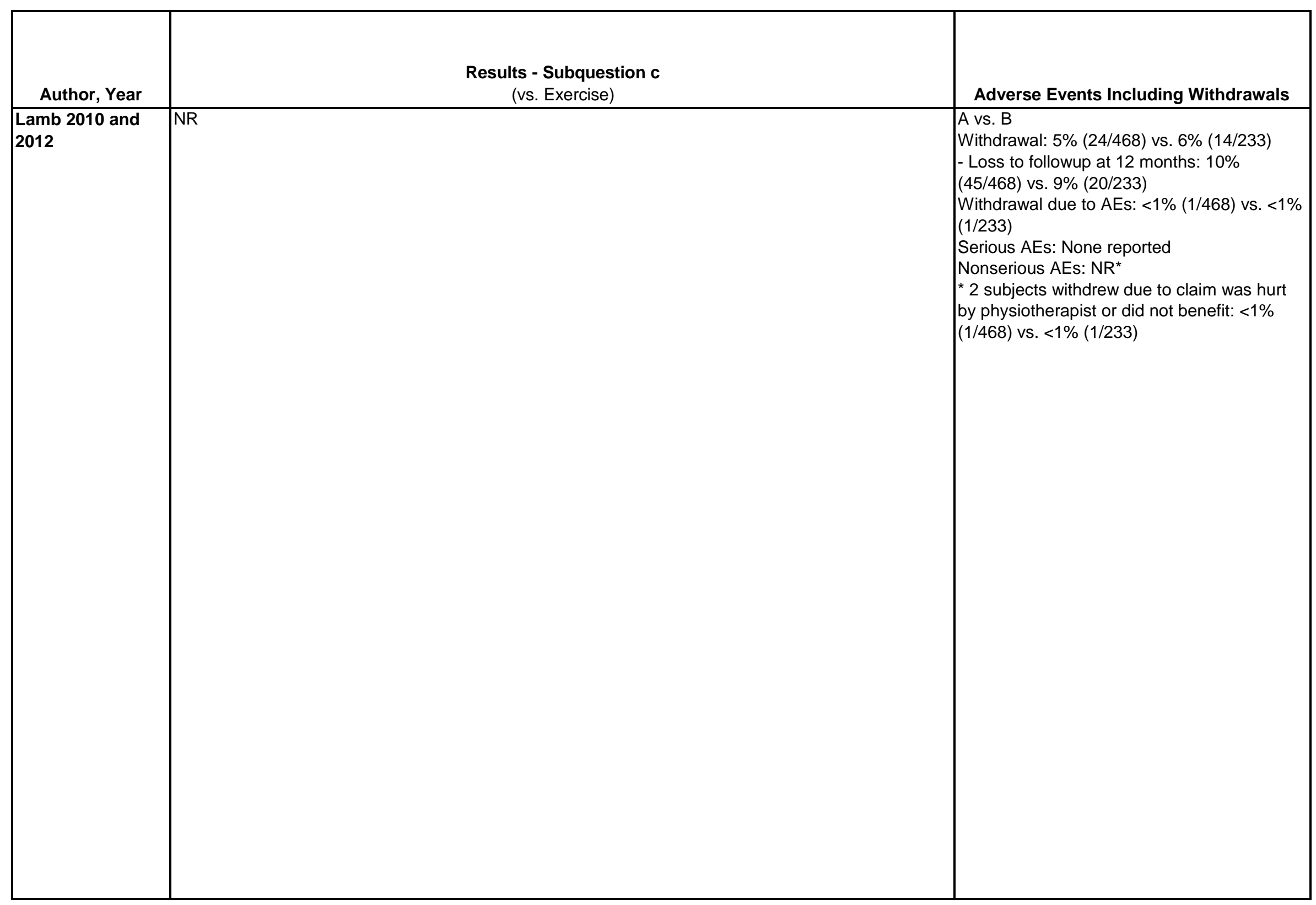




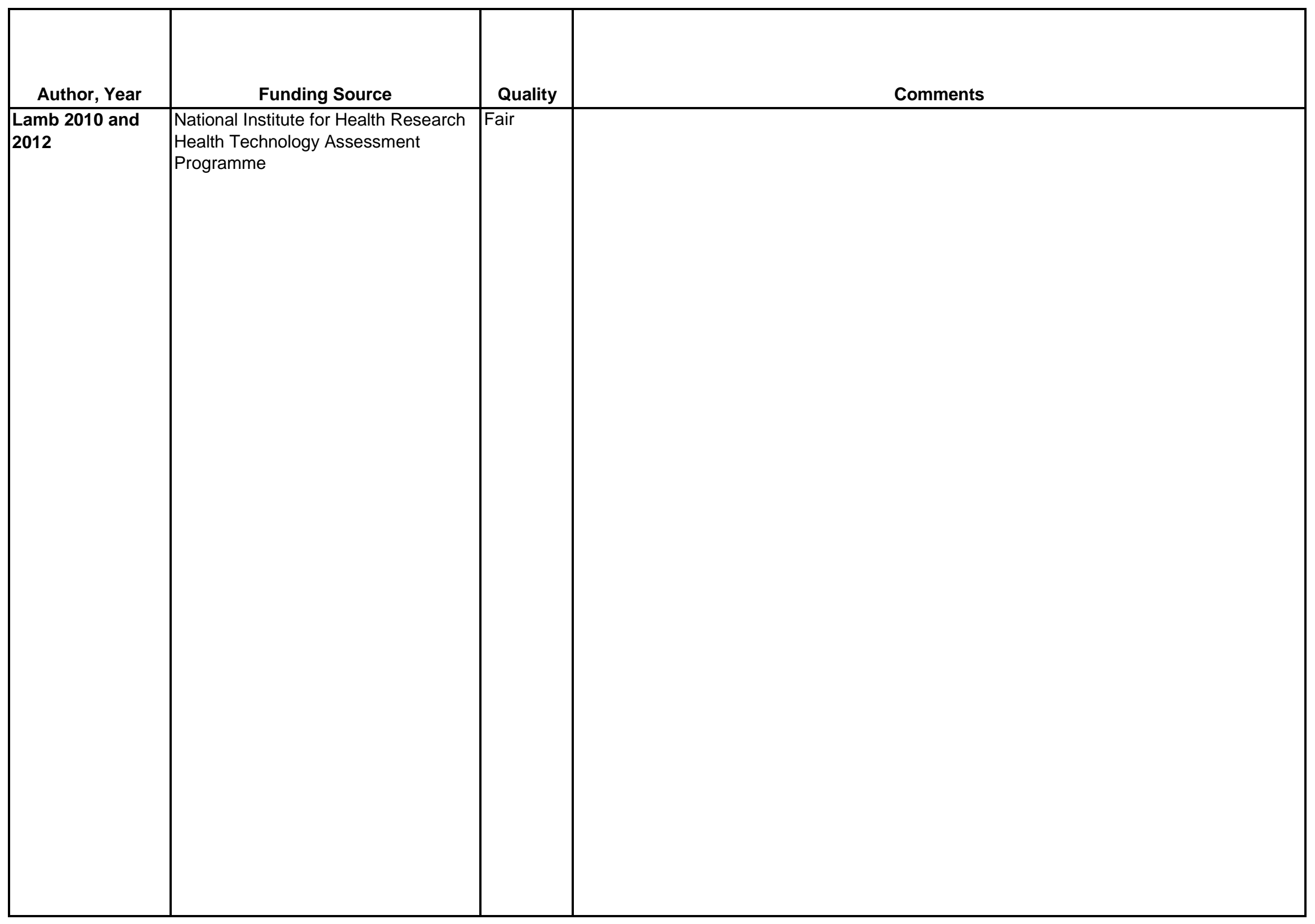

D-462 


\begin{tabular}{|c|c|c|c|}
\hline Author, Year & $\begin{array}{c}\text { Country } \\
\text { Number of Centers } \\
\text { Setting }\end{array}$ & Inclusion/Exclusion Criteria & $\begin{array}{c}\text { Number Randomized, } \\
\text { Analyzed } \\
\text { Attrition }\end{array}$ \\
\hline \begin{tabular}{|l} 
Lamb 2012 \\
Extended \\
followup of \\
subjects from \\
Lamb 2010
\end{tabular} & & & \begin{tabular}{|l|} 
Randomized: 701 \\
Analyzed: 395 \\
Attrition: $44 \%(306 / 701)$
\end{tabular} \\
\hline Lambeek 2010a & $\begin{array}{l}\text { The Netherlands } \\
17 \text { centers } \\
\text { Outpatient }\end{array}$ & $\begin{array}{l}\text { Patients aged } 18-65 \text { with low back pain for }>12 \text { weeks, were in paid } \\
\text { work for } \geq 8 \text { hours per week, and were absent or partially absent from } \\
\text { work. } \\
\text { Exclude: Patients who had been absent from work for }>2 \text { years, } \\
\text { worked temporarily for an employment agency without detachment, } \\
\text { specific low back pain due to infection, tumor, osteoporosis, } \\
\text { rheumatoid arthritis, fracture, or inflammatory process, lumbar spine } \\
\text { surgery within past } 6 \text { weeks or planned within } 3 \text { months, series } \\
\text { psychiatric cardiovascular illness, pregnancy, current lawsuit against } \\
\text { employer }\end{array}$ & $\begin{array}{l}\text { Randomized: } 134 \\
\text { Treated: } 129 \\
\text { Analyzed: } 117 \\
\text { Attrition: } 13 \% \text { (17/134) }\end{array}$ \\
\hline
\end{tabular}




\begin{tabular}{|c|c|}
\hline Author, Year & Intervention, Comparator \\
\hline \begin{tabular}{|l} 
Lamb 2012 \\
Extended \\
followup of \\
subjects from \\
Lamb 2010
\end{tabular} & \\
\hline Lambeek 2010a & $\begin{array}{l}\text { A: Multidisciplinary care }(\mathrm{n}=66) \text { : Intervention consisted of integrated care management by a clinical occupational physician, workplace intervention, } \\
\text { and a graded activity program. The integrated care management lasted a maximum of } 3 \text { months and consisted of developing a treatment plan to } \\
\text { aid the subject in returning to work. The workplace intervention lasted } 9 \text { weeks and consisted of an occupational therapist observing patient's in the } \\
\text { workplace and developing solutions for work-based obstacles. The graded activity was a program of up to } 26 \text { sessions that consisted of teaching } \\
\text { patients to manage pain during activity. } \\
\text { B: Usual care ( } n=68) \text { : Patients received usual care from their medical specialist, occupational physician, general practitioner, and/or allied health } \\
\text { professionals. }\end{array}$ \\
\hline
\end{tabular}




\begin{tabular}{|c|c|c|c|}
\hline Author, Year & Study Participants & Outcome Measures & $\begin{array}{c}\text { Duration of } \\
\text { Followup }\end{array}$ \\
\hline \begin{tabular}{|l|} 
Lamb 2012 \\
Extended \\
followup of \\
subjects from \\
Lamb 2010
\end{tabular} & & $\begin{array}{l}\text { As above, plus: } \\
\text { EuroQol-5 Dimensions (EQ-5D): - } 0.59 \text { to } 1 \text { (lower } \\
\text { scores indicate worsening health-related quality of life) }\end{array}$ & $\begin{array}{l}\text { Mean 34 } \\
\text { months }\end{array}$ \\
\hline Lambeek 2010a & $\begin{array}{l}\text { Age: } 46 \text { vs } 47 \\
\text { Female: } 44 \% \text { vs } 40 \% \\
\text { Demands of work: } \\
\quad \text { Physical: } 64 \% \text { vs } 62 \% \\
\quad \text { Mental: } 36 \% \text { vs } 38 \% \\
\text { Absence from work: } \\
\quad \text { Partial: } 52 \% \text { vs } 53 \% \\
\text { Full: } 49 \% \text { vs } 47 \% \text { Modified } \\
\text { Modified RDQ (0-23): } 14.7(5.0) \text { vs } 15.0(3.6) \\
\text { Pain (0-10 VAS): } 5.7(2.2) \text { vs } 6.3(2.1)\end{array}$ & \begin{tabular}{|l|} 
RMDQ $(0-24)$ \\
Pain (0-10 VAS) \\
Number of healthcare visits \\
Medications for back pain \\
Total costs
\end{tabular} & $\begin{array}{l}3 \text { and } 9 \\
\text { months }\end{array}$ \\
\hline
\end{tabular}




\begin{tabular}{|c|c|}
\hline Author, Year & $\begin{array}{c}\text { Results - Subquestion a } \\
\text { (vs. sham, no treatment, waitlist, attention control) }\end{array}$ \\
\hline $\begin{array}{l}\text { Lamb } 2012 \\
\text { Extended } \\
\text { followup of } \\
\text { subjects from } \\
\text { Lamb } 2010\end{array}$ & $\begin{array}{l}\text { A vs. B, mean change from baseline }(95 \% \mathrm{Cl}) \\
\text { RDQ }(0-24):-2.9(-3.42 \text { to }-2.38) \text { vs. }-1.6(-2.48 \text { to }-0.80) \text {, adjusted difference }-1.3(-2.26 \text { to }-0.27) \\
\text { Modified Von Korff disability }(0-100):-16.7(-19.43 \text { to }-13.93) \text { vs. }-11.2(-15.59 \text { vs. }-6.86) \text {, adjusted difference }-5.5(-10.64 \text { to }-0.27) \\
\text { Modified Von Korff pain (0-100): }-17.4(-20.35 \text { to }-14.44) \text { vs. }-12.8(-17.52 \text { to }-7.99) \text {, adjusted difference }-4.6(-10.28 \text { to } 1.00) \\
\text { EQ-5D: } 0.07(0.04 \text { to } 0.10) \text { vs. } 0.04(-0.01 \text { to } 0.09) \text {, adjusted difference } 0.03(-0.03 \text { to } 0.08) \\
>1 \text { night in hospital: } 2 \% \text { vs. } 4 \%, p=0.257 \\
\text { GP visit due to LBP: } 38 \% \text { vs. } 43 \%, p=0.356 \\
\text { Missed work because of LBP: } 9 \% \text { vs. } 13 \%, p=0.238 \\
\text { Decreased work hours because of LBP: } 3 \% \text { vs. } 6 \%, p=0.378\end{array}$ \\
\hline Lambeek 2010a & 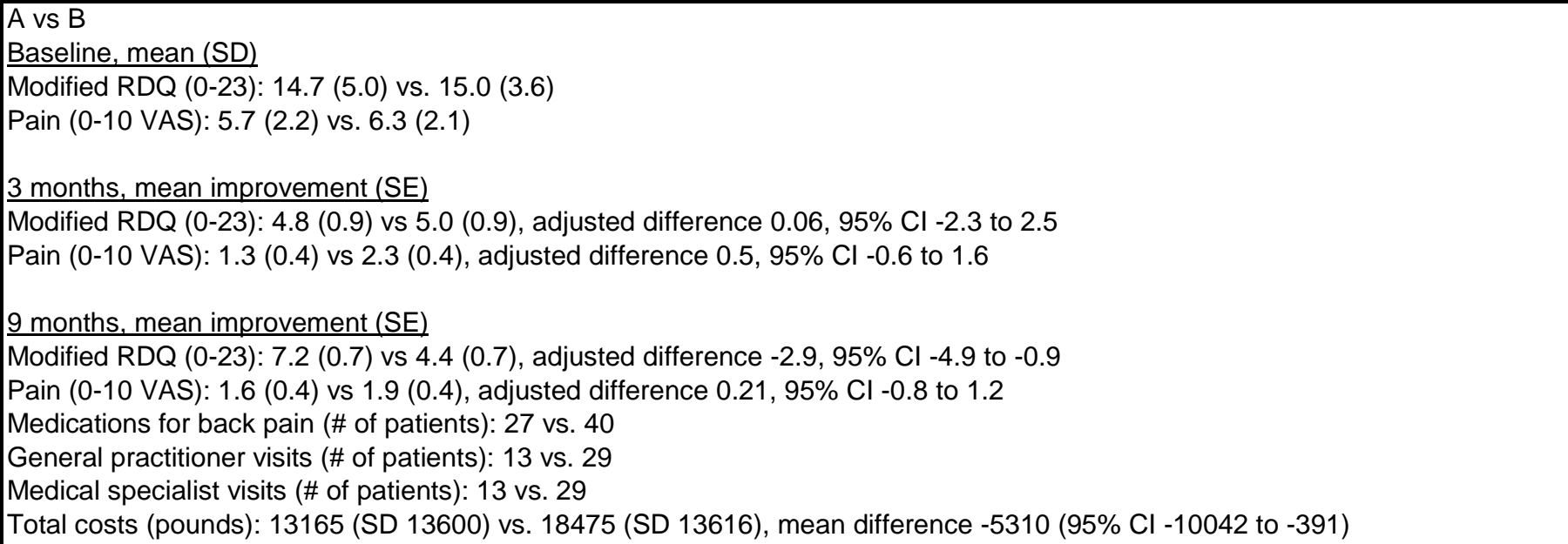 \\
\hline
\end{tabular}




\begin{tabular}{|l|l|}
\hline \multicolumn{1}{|c|}{ Author, Year } & \multicolumn{1}{c|}{$\begin{array}{c}\text { Results - Subquestion b } \\
\text { (vs. Pharmacological therapy) }\end{array}$} \\
\hline $\begin{array}{l}\text { Lamb 2012 } \\
\text { Extended } \\
\text { followup of } \\
\text { subjects from } \\
\text { Lamb 2010 }\end{array}$ & NR \\
\hline Lambeek 2010a & \\
& \\
\hline
\end{tabular}




\begin{tabular}{|l|l|l|}
\hline \multicolumn{1}{|c|}{$\begin{array}{c}\text { Results - Subquestion c } \\
\text { (vs. Exercise) }\end{array}$} & Adverse Events Including Withdrawals \\
\hline $\begin{array}{l}\text { Lamb 2012 } \\
\text { Extended } \\
\text { followup of } \\
\text { subjects from } \\
\text { Lamb 2010 }\end{array}$ & NR & $\begin{array}{l}\text { Avs. B } \\
\text { Withdrawal: 40\% (187/468) vs. 51\% } \\
\text { (119/233) } \\
\text { Withdrawal due to AEs: NR } \\
\text { Serious AEs: NR } \\
\text { Nonserious AEs: NR }\end{array}$ \\
\hline & & \\
\hline & & \\
\hline
\end{tabular}




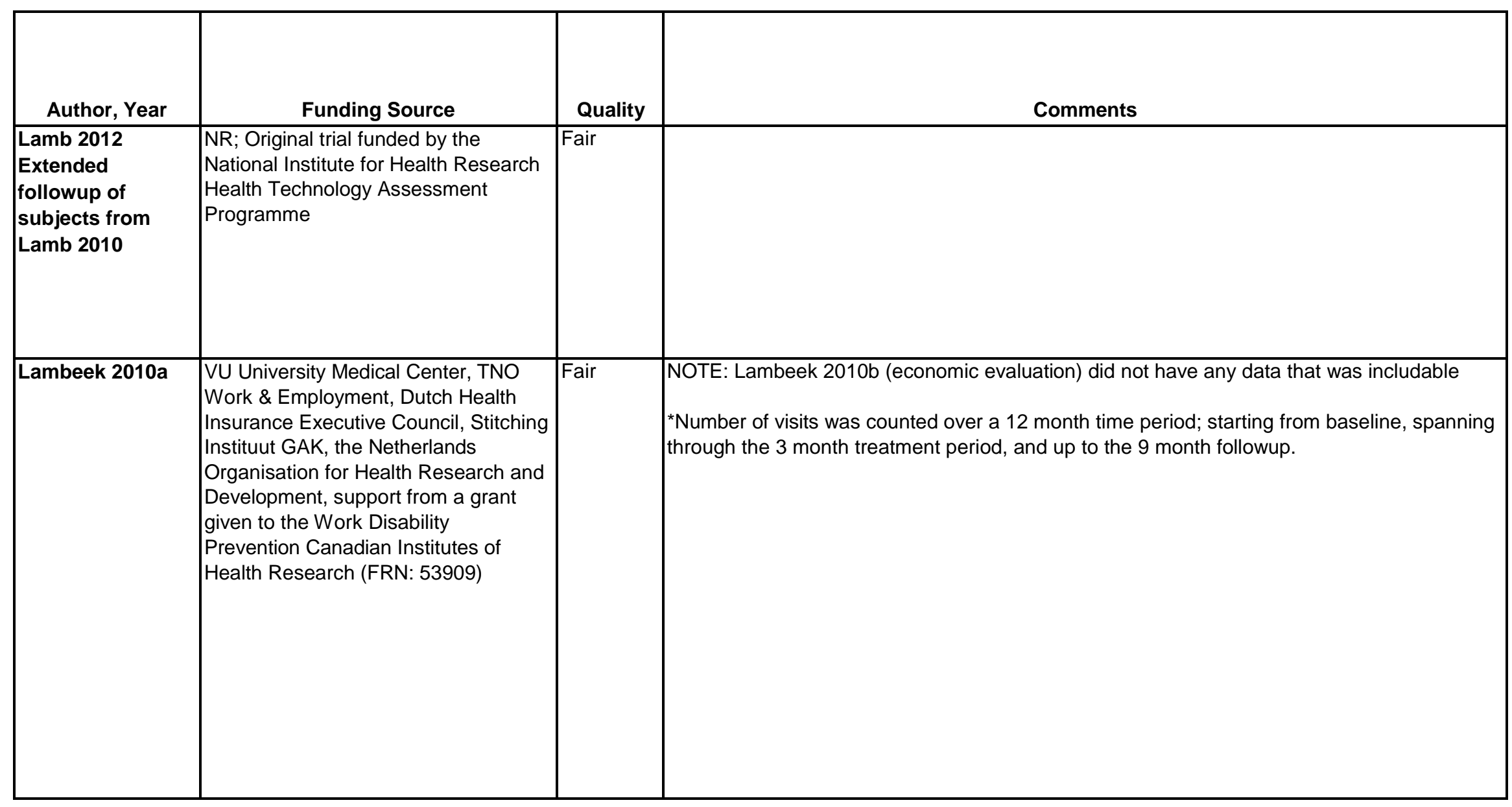




\begin{tabular}{|c|c|c|c|}
\hline Author, Year & $\begin{array}{c}\text { Country } \\
\text { Number of Centers } \\
\text { Setting }\end{array}$ & Inclusion/Exclusion Criteria & $\begin{array}{c}\text { Number Randomized, } \\
\text { Analyzed } \\
\text { Attrition } \\
\end{array}$ \\
\hline Lansdown 2009 & York, UK GP practice & $\begin{array}{l}\text { Inclusion criteria: } \geq 50 \text { years old who had consulted their GP in the } \\
\text { last } 3 \text { years with knee pain, using the READ codes of 'knee pain', } \\
\text { 'knee joint pain', 'osteoarthritis-tis of the knee', 'anterior knee pain', } \\
\text { 'other knee injury', 'painful right knee' and 'arthralgia'. } \\
\text { Exclusion criteria: taking anticoagulants, intra articular steroid injection } \\
\text { within } 2 \text { months, back pain with referred leg pain, ipsilateral hip OA, } \\
\text { skin conditions around knee, RA or having had PT or acupuncture } \\
\text { within last year }\end{array}$ & $\begin{array}{l}\text { Randomized: } 30 \\
\text { Treated: } 29 \\
\text { Analyzed: } 21(\mathrm{ITT} \mathrm{n}=30) \\
\text { Attrition: } 30 \%(9 / 30)^{*} \\
\text { *Attrition A vs. B: } 13 \% \\
\text { (2/15) vs. } 47 \%(7 / 15)\end{array}$ \\
\hline Lansinger 2007 & $\begin{array}{l}\text { Sweden } \\
\text { Multicenter (number } \\
\text { of centers unclear) } \\
\text { Outpatient }\end{array}$ & $\begin{array}{l}\text { Aged 18-65 years old, non-specific neck pain for }>3 \text { months, VAS > } \\
20 \mathrm{~mm} \text { on } 0-100 \mathrm{~mm} \text { scale } \\
\text { Exclude: Chronic tension-type headache, migraine, traumatic neck } \\
\text { injuries, neurologic signs or symptoms, rheumatic diseases, } \\
\text { fibromyalgia, physiologic or physical diseases, treatment with } \\
\text { antidepressive and anti-inflammatory drugs }\end{array}$ & $\begin{array}{l}\text { Randomized: } 139 \\
\text { Treated: } 122 \\
\text { Analyzed: } 121^{*} \\
\text { Attrition: } 28 \% \text { (39/139) }\end{array}$ \\
\hline
\end{tabular}




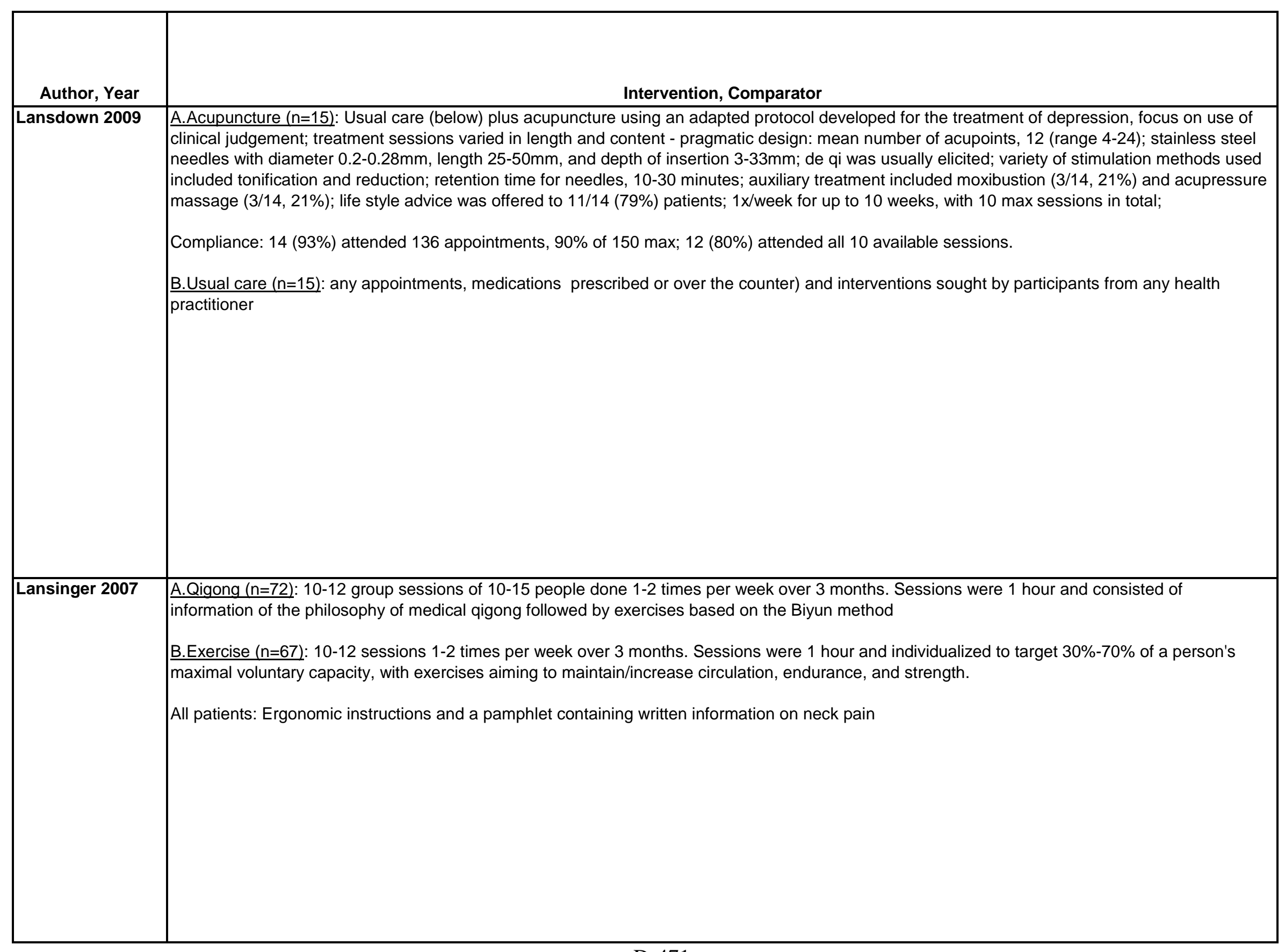




\begin{tabular}{|c|c|c|c|}
\hline Author, Year & Study Participants & Outcome Measures & $\begin{array}{c}\text { Duration of } \\
\text { Followup }\end{array}$ \\
\hline Lansdown 2009 & $\begin{array}{l}\text { A vs B } \\
\text { Age: } 63 \text { vs. } 64 \text { years } \\
\text { Female: } 60 \% \text { vs. } 60 \% \\
\text { Caucasian: } 100 \% \text { vs. } 100 \% \\
\text { Duration of symptoms: NR } \\
\text { WOMAC Total: } 31(15.7) \text { vs. } 57.5(18.2) \\
\text { WOMAC Function: } 20.5(12.7) \text { vs. } 26.3(14.0) \\
\text { WOMAC Pain: } 7.3(2.8) \text { vs. } 7.4(3.7) \\
\text { OKS: } 30.9 \text { (9.3) vs. } 30.6(9.3) \\
\text { SF-36 physical functioning: } 49.6(26.6) \text { vs. } 48.3(24.5) \\
\text { SF-36 social functioning: } 71.8(25.2) \text { vs. } 70(23.5) \\
\text { SF-36 role physical: } 62.5(28.4) \text { vs. } 52.9(25.4) \\
\text { SF-36 role mental: } 76.7(26.0) \text { vs. } 68.9(35.6) \\
\text { SF-36 mental health: } 76.3(15.4) \text { vs. } 69.3(18.7) \\
\text { SF-36 vitality: } 55(18.6) \text { vs. } 46.3(24.0) \\
\text { SF-36 pain: } 53.1(18.7) \text { vs. } 51.3(24.3) \\
\text { SF-36 general health: } 67.3(17.0) \text { vs. } 55.1(19.0) \\
\text { EQ5D: } 0.61(0.24) \text { vs. } 0.67(0.15)\end{array}$ & $\begin{array}{l}\text { WOMAC total (scale 0-96; higher score=worse } \\
\text { disability) } \\
\text { WOMAC function (scale 0-68; higher score=worse } \\
\text { function) } \\
\text { WOMAC pain (scale 0-20; higher score=worse pain) } \\
\text { Oxford Knee Scale (OKS) (higher score=worse } \\
\text { disability) } \\
\text { SF-36 (higher score=better quality of life) } \\
\text { EQ-5D (higher score=better quality of life) }\end{array}$ & 9.5 months \\
\hline Lansinger 2007 & \begin{tabular}{|l} 
A vs B \\
Age: 45 vs 43 \\
Female: $73 \%$ vs $67 \%$ \\
Duration of neck pain: \\
$\quad 3$ mos- 1 year: $15 \%$ vs $20 \%$ \\
$\quad>1$ year: $38 \%$ vs $37 \%$ \\
$\quad>5$ years: $22 \%$ vs $24 \%$ \\
>10 years: $25 \%$ vs $20 \%$ \\
Neck frequency (days/wk), median (range): 7 (2.5-7) vs 7 (1-7) \\
Physical activity: \\
$\quad$ Slightly no exercise: $22 \%$ vs $31 \%$ \\
$\quad$ Light exercise $<4$ hr/wk: $45 \%$ vs $34 \%$ \\
$\quad$ Med to hard exercise $1-4$ hrs/wk: $22 \%$ vs $29 \%$ \\
$\quad$ Hard exercise $\geq 3$ hrs/wk: $11 \%$ vs $6 \%$ \\
Neck Disability Index, median (IQR): 26 (6-60) vs 22 (8-52) \\
Neck pain VAS, median (IQR): 45 (2-100) vs 39 (3-76)
\end{tabular} & $\begin{array}{l}\text { Neck Disability Index (0-100\%, higher percent=higher } \\
\text { disability) } \\
\text { Neck pain VAS (0-100, higher score=higher pain) }\end{array}$ & $\begin{array}{l}6 \text { and } 12 \\
\text { months }\end{array}$ \\
\hline
\end{tabular}




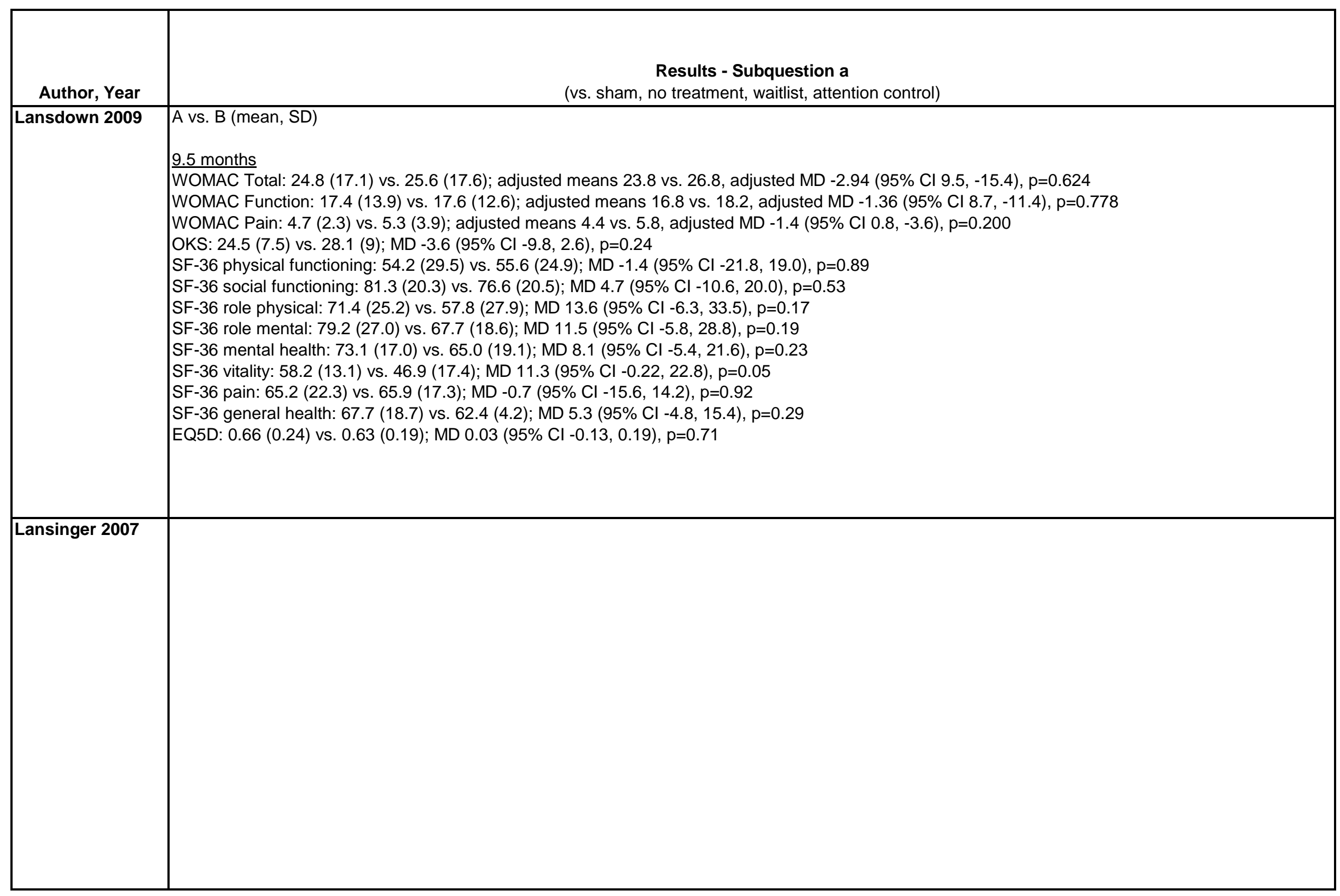




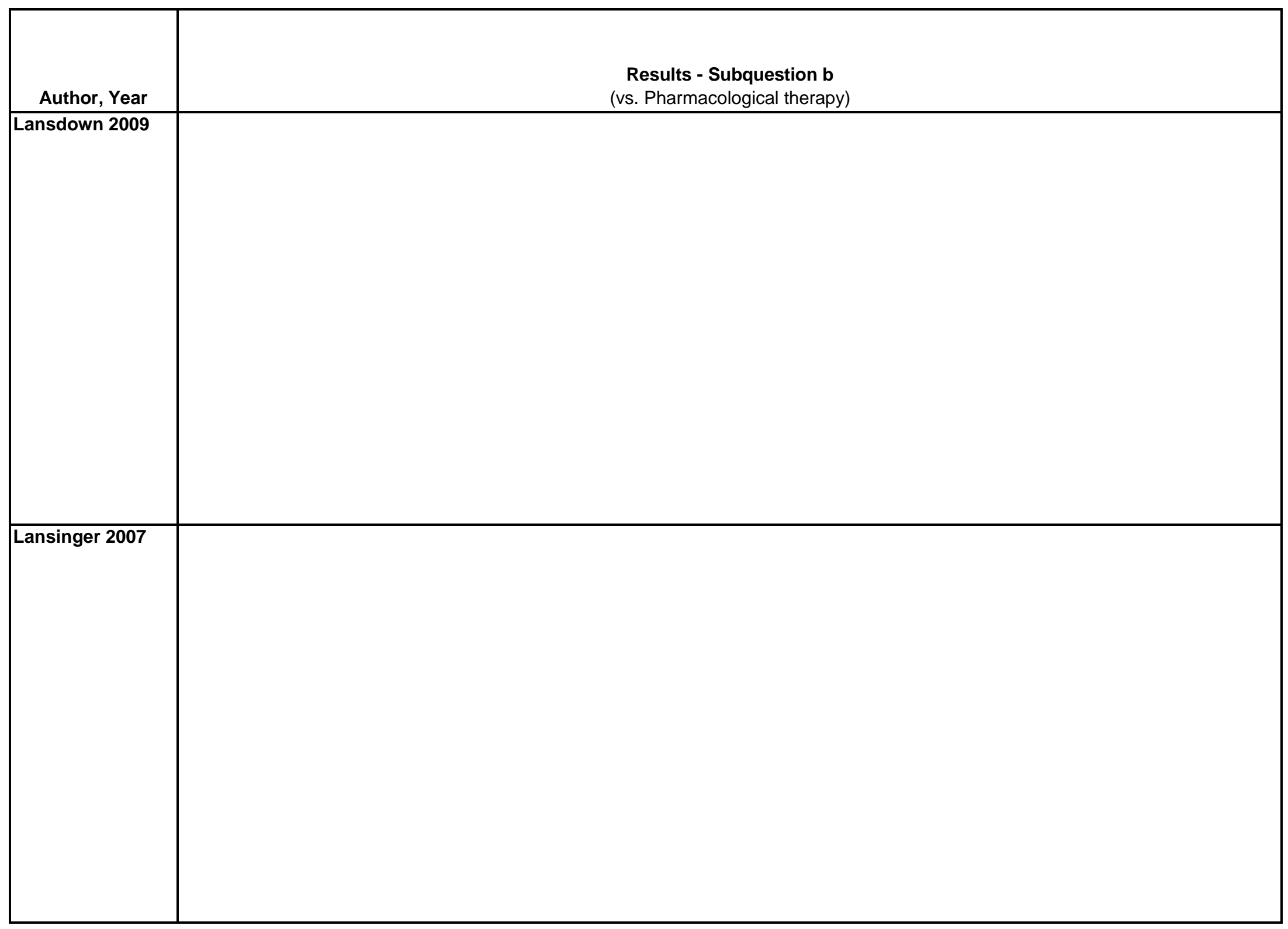

D-474 


\begin{tabular}{|c|c|c|}
\hline Author, Year & $\begin{array}{c}\text { Results - Subquestion c } \\
\text { (vs. Exercise) }\end{array}$ & Adverse Events Including Withdrawals \\
\hline Lansdown 2009 & & $\begin{array}{l}\text { No major AEs reported; } \\
7 \text { minor AEs in acupuncture group (none led } \\
\text { to a patient discontinuing treatment): } \\
\text { bruising, } 7 \%(1 / 14) ; \\
\text { faint, } 7 \%(1 / 14) ; \\
\text { worsening of symptoms, } 14 \%(2 / 14) \text {; } \\
\text { forgotten needle, } 7 \%(1 / 14) ; \\
\text { migraine, } 7 \%(1 / 14) ; \\
\text { pain at needle site, } 7 \%(1 / 14)\end{array}$ \\
\hline Lansinger 2007 & $\begin{array}{l}\text { A vs B } \\
6 \text { months } \\
\text { Neck Disability Index, median (range): } 22(0-64) \text { vs } 18(0-56) \\
\text { Neck pain VAS, median (range): } 26(0-90) \text { vs } 23(0-76) \\
12 \text { months } \\
\text { Neck Disability Index, median (range): } 22(0-54) \text { vs } 18(0-52) \\
\text { Neck pain VAS, median (range): } 28 \text { (0-86) vs } 21(0-86)\end{array}$ & NR \\
\hline
\end{tabular}




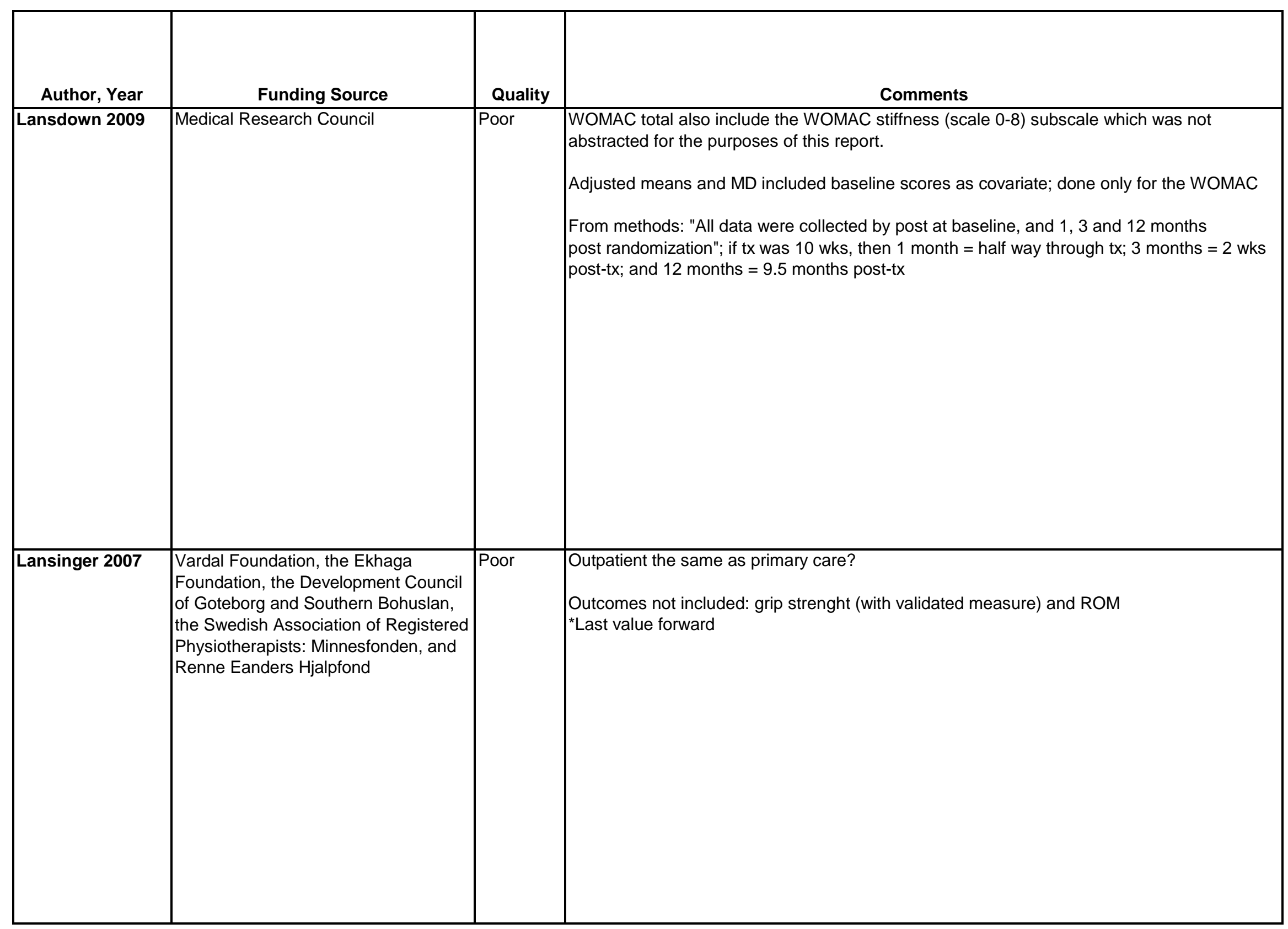




\begin{tabular}{|c|c|c|c|}
\hline Author, Year & $\begin{array}{c}\text { Country } \\
\text { Number of Centers } \\
\text { Setting }\end{array}$ & Inclusion/Exclusion Criteria & $\begin{array}{c}\text { Number Randomized, } \\
\text { Analyzed } \\
\text { Attrition }\end{array}$ \\
\hline Larsson 2015 & \begin{tabular}{|l|} 
Sweden \\
Number of centers \\
unclear \\
Type of center unclear
\end{tabular} & $\begin{array}{l}\text { Women aged 20-65 with a FM diagnosis fulfilling ACR criteria } \\
\text { Exclude: Blood pressure }>160 / 90 \mathrm{mmHg} \text { ), knee or hip osteoarthritis } \\
\text { confirmed radiologically and affecting activities of daily living, severe } \\
\text { somatic or psychiatric disorders, other dominating causes of pain } \\
\text { besides FM, alcohol use disorders identification test score }>6 \text {, } \\
\text { participation in a rehabilitation program within the past year, regular } \\
\text { resistance exercise or relaxation exercise two times a week or more, } \\
\text { inability to refrain from NSAIDs or hypnotic drugs } 48 \text { hours before } \\
\text { examinations }\end{array}$ & $\begin{array}{l}\text { Randomized: } 130 \\
\text { Treated: } 93 \\
\text { Analyzed: } 91 \\
\text { Attrition: } 30 \%(39 / 130)^{\star}\end{array}$ \\
\hline
\end{tabular}




\begin{tabular}{|c|c|}
\hline Author, Year & Intervention, Comparator \\
\hline Larsson 2015 & $\begin{array}{l}\text { A.Relaxation therapy ( } n=63) \text { : Two groups sessions of } 5-8 \text { subjects per week for } 15 \text { weeks. The intervention was preceded by an individual meeting } \\
\text { covering instructions and allowing for adjustments to the intervention. The sessions lasted } 25 \text { minutes and consisted of autogenic training guided by } \\
\text { physiotherapist and were followed by stretching. } \\
\\
\text { B.Resistance exercise ( } n=67) \text { : Two group sessions of } 5-7 \text { subjects per week for } 15 \text { weeks. The intervention was preceded by an individual meeting } \\
\text { going over instructions on the intervention, testing, and modifications of specific exercises. Sessions were based on a resistance exercise program } \\
\text { aiming to improve muscle strength, focusing on large muscle groups in the lower extremity. }\end{array}$ \\
\hline
\end{tabular}




\begin{tabular}{|c|c|c|c|}
\hline Author, Year & Study Participants & \begin{tabular}{|c} 
Outcome Measures \\
\end{tabular} & $\begin{array}{c}\text { Duration of } \\
\text { Followup }\end{array}$ \\
\hline Larsson 2015 & 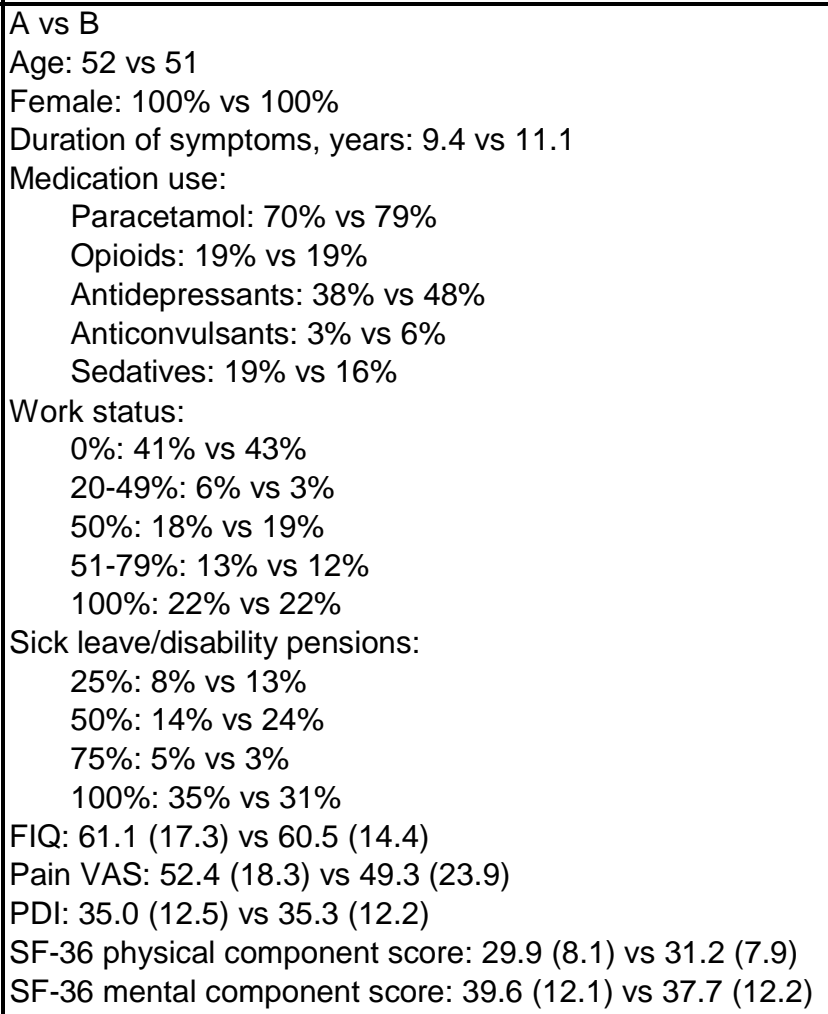 & $\begin{array}{l}\text { FIQ (0-100, higher score=lower function); pain VAS (0- } \\
100 \text {, higher score=worse pain); PDI (0-70, higher } \\
\text { score=higher disability from pain); SF-36 physical } \\
\text { component score (0-100, higher score=higher quality of } \\
\text { life); SF-35 mental component score (0-100, higher } \\
\text { score=higher quality of life); patient global impressions } \\
\text { of change (1-7, higher score=higher improvement) }\end{array}$ & $\begin{array}{l}13-18 \\
\text { months }\end{array}$ \\
\hline
\end{tabular}




\begin{tabular}{|l|c|}
\hline Author, Year & $\begin{array}{c}\text { Results - Subquestion a } \\
\text { (vs. sham, no treatment, watitist, attention control) }\end{array}$ \\
\hline Larsson 2015 & \\
& \\
& \\
\hline
\end{tabular}




\begin{tabular}{|l|c|}
\hline Author, Year & $\begin{array}{c}\text { Results - Subquestion b } \\
\text { (vs. Pharmacological therapy) }\end{array}$ \\
\hline Larsson 2015 & \\
& \\
&
\end{tabular}




\begin{tabular}{|c|c|c|}
\hline Author, Year & $\begin{array}{l}\text { Results - Subquestion c } \\
\text { (vs. Exercise) }\end{array}$ & Adverse Events Including Withdrawals \\
\hline Larsson 2015 & $\begin{array}{l}\text { A vs B } \\
\text { FlQ: } 55.4(17.0) \text { vs } 57.1(19.4),(\mathrm{MD}-1.7,95 \% \mathrm{Cl}-9.3 \text { to } 5.9) \mathrm{p}=0.65 \\
\text { Pain VAS: } 52.1 \text { (19.5) vs } 49.2(20.8),(\mathrm{MD} 2.9,95 \% \mathrm{Cl}-5.5 \text { to } 11.3) \mathrm{p}=0.50 \\
\text { PDI: } 33.7(10.9) \text { vs } 33.0(11.6),(\mathrm{MD} 0.7,95 \% \mathrm{Cl}-4.0 \text { to } 5.4) \mathrm{p}=0.77 \\
\text { SF-36 physical component score: } 32.0(9.4) \text { vs } 32.2(8.0),(\mathrm{MD}-0.2,95 \% \mathrm{Cl}-3.8 \text { to } 3.4) \mathrm{p}=0.91 \\
\text { SF-36 mental component score: } 40.0 \text { (11.9) vs } 39.2(13.9),(\mathrm{MD} 0.8,95 \% \mathrm{Cl}-4.6 \text { to } 6.2) \mathrm{p}=0.89 \\
\text { Patient global impression of change: Values NR but difference was NS }\end{array}$ & $\begin{array}{l}\text { Withdrawal due to increased pain: } 7 \%(5 / 67) \\
\text { vs } 0 \%(0 / 63)\end{array}$ \\
\hline
\end{tabular}




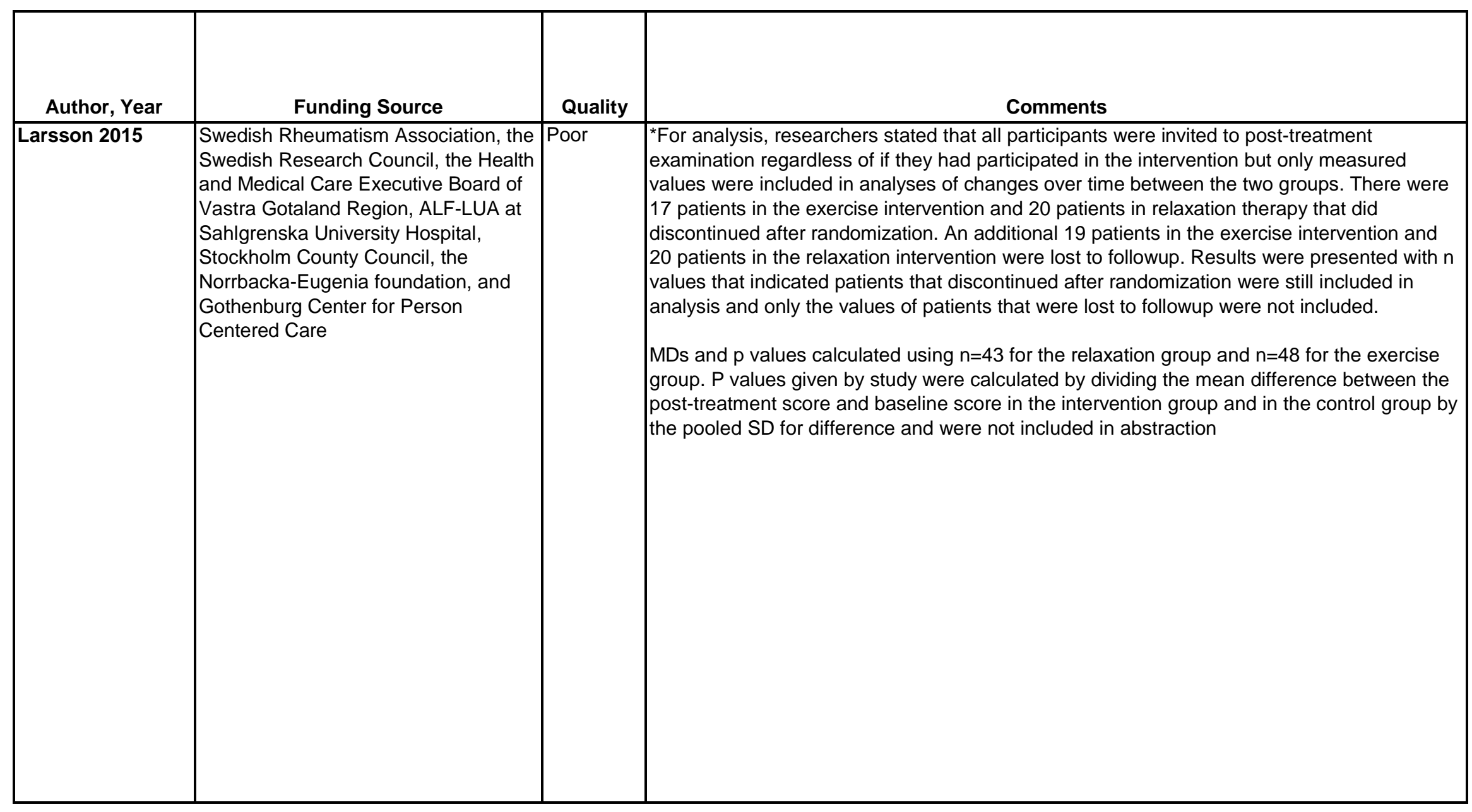




\begin{tabular}{|c|c|c|c|}
\hline Author, Year & $\begin{array}{c}\text { Country } \\
\text { Number of Centers } \\
\text { Setting }\end{array}$ & Inclusion/Exclusion Criteria & $\begin{array}{c}\text { Number Randomized, } \\
\text { Analyzed } \\
\text { Attrition } \\
\end{array}$ \\
\hline Lauche 2016 & $\begin{array}{l}\text { Germany } \\
\text { Setting NR }\end{array}$ & $\begin{array}{l}\geq 18 \text { years of age; chronic nonspecific neck pain } \geq 3 \text { consecutive } \\
\text { months } \geq 5 \text { days/week; moderate pain ( } \geq 45 \text { mm or higher on VAS 0- } \\
100 \mathrm{~mm}) \\
\text { Excluded: Neck pain caused by trauma, disc protrusion, whiplash, } \\
\text { congenital deformity of the spine, spinal stenosis, neoplasm, } \\
\text { inflammatory rheumatic disease, neurological disorder, active } \\
\text { oncologic disease, severe affective disorder, addiction, and psychosis; } \\
\text { pregnant; invasive treatment of the spine in previous } 4 \text { weeks or spinal } \\
\text { surgery within previous year; initiated /modified drug regimen recently; } \\
\text { taking opiates; regular practice of tai chi, Qi gong, or yoga in past } 6 \\
\text { months }\end{array}$ & $\begin{array}{l}\text { Randomized: } 114 \\
\text { Treated: } 104 \\
\text { Analyzed: } 114^{*} \\
\text { Attrition: } 23 \% \\
\text { (26/114) } \\
\\
\text { *missing values completed } \\
\text { via multiple imputation }\end{array}$ \\
\hline Laufer 2005 & $\begin{array}{l}\text { Israel, single-site, } \\
\text { outpatient }\end{array}$ & $\begin{array}{l}\text { Inclusion Criteria: } \\
\text { Patients age } 65 \text { and above; primary OA of one or both knee joints; } \\
\text { grade 2-3 knee OA, based on the Kellgren- Lawrence classification, } \\
\text { as evidenced by a radiograph and interpreted by a trained } \\
\text { rheumatologist blind to treatment allocation; knee pain for at least } \\
\text { three months; independent ambulation with or without an assistive } \\
\text { device; no physiotherapy treatment for knee problems in the last } \\
\text { month; no previous knee surgery or knee joint injection in the last } \\
\text { three months; no change in medication in the last month; normal } \\
\text { sensation for warmth in the knee region; no other orthopedic or } \\
\text { neurological disease that could affect pain and/or disability; and no } \\
\text { contraindication to SWD, particularly no presence of metal implants, } \\
\text { pacemakers, joint effusion or malignancy. } \\
\text { Exclusion Criteria: } \\
\text { Anything not fitting inclusion criteria. }\end{array}$ & $\begin{array}{l}\text { Randomized: } 115 \\
\text { Treated: } 103 \\
\text { Analyzed: } 95 \\
\text { Attrition: } 17.3 \% \text { (20/115) }\end{array}$ \\
\hline
\end{tabular}




\begin{tabular}{|c|c|}
\hline Author, Year & Intervention, Comparator \\
\hline Lauche 2016 & $\begin{array}{l}\text { A.Tai chi (Yang style) ( } n=38) \text { weekly } 75-90-m i n \text { session in a group format for } 12 \text { weeks; sessions included warm up, Tai Chi form practice, } \\
\text { relaxation period. educational units, breathing exercises, and relaxation music; illustrated written movement sequences for home Tai chi } \geq 15 \\
\text { mins/day. } \\
\text { B. Neck exercises ( } n=37) \\
\text { weekly } 60-75 \text { min session in a group format for } 12 \text { weeks; ergonomic principles, proprioceptive exercises, and isometric and dynamic mobilization, } \\
\text { stretching, strengthening neck and core exercises, and relaxation exercises; illustrated written exercises for home use } \geq 15 \text { mins/day. } \\
\text { C.Wait list ( } n=39 \text { ) continuing usual activities/therapies (Tai chi or neck exercises offered at end of study) }\end{array}$ \\
\hline Laufer 2005 & $\begin{array}{l}\text { A.Low Intensity Pulsed Shortwave Diathermy }(\mathrm{n}=38) \\
\text { Shortwave diathermy was applied to affected knee(s). Treatments were administered with one of two Curapuls } 670 \text { machines (manufactured by } \\
\text { Enraf-Nonius, Delft, The Netherlands). } \\
\text { No. of Treatments: } 3 \text { per week for } 3 \text { weeks ( } 9 \text { total) } \\
\text { Length of Treatments: } 20 \text { minutes each } \\
\text { Pulse Duration: } 82 \mu \mathrm{s} \\
\text { Pulse Frequency: } 110 \mathrm{~Hz} \\
\text { Peak Power: } 200 \mathrm{~W} \text { (mean } 1.8 \mathrm{~W}) \\
\text { Area: anterior aspect of the knee } \\
\text { B. High Intensity Pulsed Shortwave Diathermy ( } \mathrm{n}=32) \\
\text { Treatment protocol identical to Group A except with a higher intensity (pulse duration and frequency). } \\
\text { Pulse Duration: } 300 \mu \mathrm{s} \\
\text { Pulse Frequency: } 300 \mathrm{~Hz} \\
\text { Peak Power: } 200 \mathrm{~W} \text { (mean } 18 \mathrm{~W}) \\
\text { Area: anterior aspect of the knee } \\
\text { C.Sham Shortwave Diathermy ( } \mathrm{n}=33 \text { ) } \\
\text { Identical treatment except the apparatus was turned on but the power output was not raised. }\end{array}$ \\
\hline
\end{tabular}




\begin{tabular}{|c|c|c|c|}
\hline Author, Year & Study Participants & Outcome Measures & $\begin{array}{c}\text { Duration of } \\
\text { Followup }\end{array}$ \\
\hline Lauche 2016 & $\begin{array}{l}\text { A vs B vs C } \\
\text { Age: } 52 \text { vs } 47 \text { vs } 49 \text { years } \\
\text { Female: } 74 \% \text { vs } 86 \% \text { vs } 82 \% \\
\text { ars } \\
\text { Pain recently }(0-100): 54.2(20.5) \text { vs } 46.2(19.2) \text { vs } 51.5(21.1) \\
\text { Pain considered tolerable }(0-100): 21.7(14.5) \text { vs } 20.5(11.7) \text { vs } 20.7 \\
(12.1)\end{array}$ & $\begin{array}{l}\text { NDI (scale, 0-50) } \\
\text { Disability in days (VAS) } \\
\text { Everyday function (VAS) } \\
\text { Recent pain intensity, pain considered tolerable, pain } \\
\text { with motion VAS (scale, 0-100), higher score worse } \\
\text { pain) } \\
\text { SF-36 PCS, MCS } \\
\text { HADS depression }\end{array}$ & 3 months \\
\hline Laufer 2005 & $\begin{array}{l}\text { A vs B vs. C } \\
\text { Age: } 75 \text { vs. } 73 \text { vs. } 73 \\
\text { Female: } 82 \% \text { vs. } 90.6 \% \text { vs. } 67 \% \\
\text { Race: NR } \\
\text { Mean Duration of Chronicity: NR } \\
\text { Overall (WOMAC): } 5.13(3.49) \text { vs. } 4.60(3.40) \text { vs. } 5.02(3.40) \\
\text { Pain (WOMAC): } 4.89(3.30) \text { vs. } 4.43(3.35) \text { vs. } 4.97(3.52) \\
\text { Stiffness (WOMAC): } 4.87(3.50) \text { vs. } 4.25(3.47) \text { vs. } 4.92(3.58) \\
\text { Activities of Daily Living (WOMAC): } 5.16(3.52) \text { vs. } 4.69(3.41) \text { vs. } \\
5.05(3.45)\end{array}$ & $\begin{array}{l}\text { Primary: } \\
\text { Western Ontario and McMaster Universities } \\
\text { Osteoarthritis Index (WOMAC, higher scores indicate } \\
\text { greater pain, stiffness or functional limitation) } \\
\text { Overall (WOMAC): } \\
\text { Pain (WOMAC, range } 0-10 \text { ): } \\
\text { Stiffness (WOMAC, range 0-10): } \\
\text { Activities of Daily Living (WOMAC, range 0-10): }\end{array}$ & 3 months \\
\hline
\end{tabular}




\begin{tabular}{|c|c|}
\hline Author, Year & $\begin{array}{c}\text { Results - Subquestion a } \\
\text { (vs. sham, no treatment, waitlist, attention control) }\end{array}$ \\
\hline Lauche 2016 & 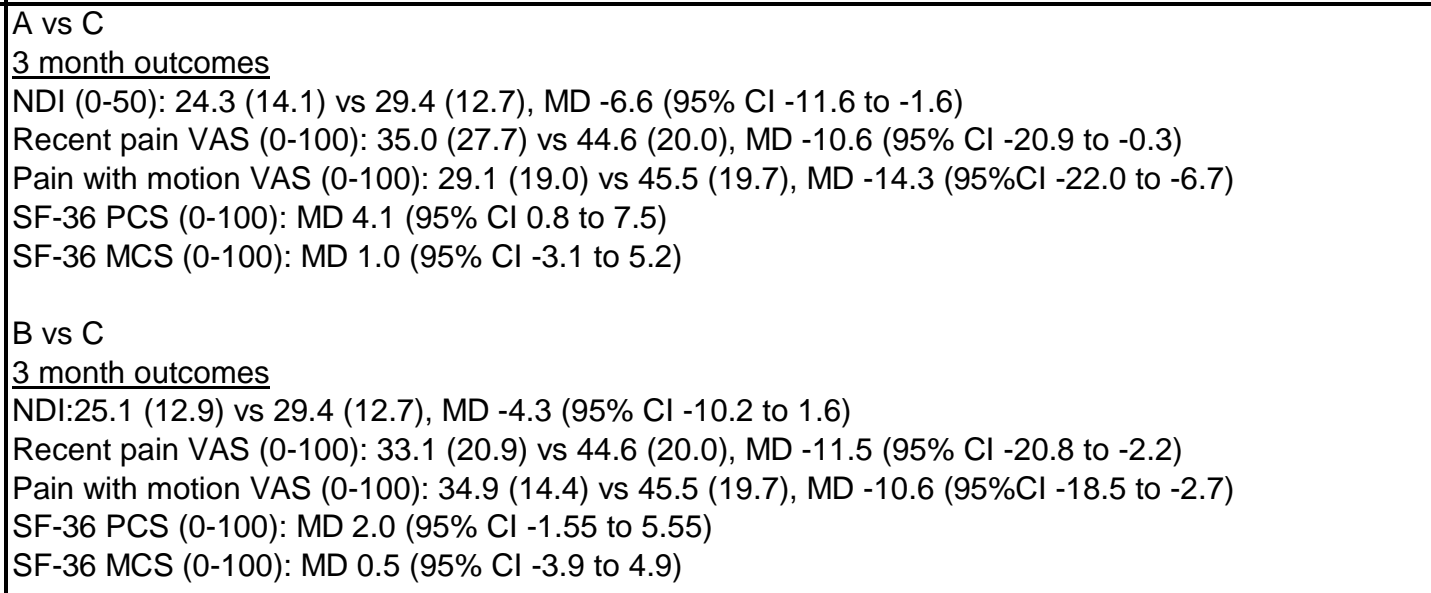 \\
\hline Laufer 2005 & $\begin{array}{l}\text { A vs. C } \\
\text { 3 months } \\
\text { Overall (WOMAC): } 4.82(3.71) \text { vs. } 4.60(3.58) ; \mathrm{MD} 0.22(95 \% \mathrm{Cl}-1.51 \text { to } 1.95) \mathrm{p}=0.801 \\
\text { Pain (WOMAC): } 4.48(3.58) \text { vs. } 4.33(3.69) ; \mathrm{MD} 0.15(95 \% \mathrm{Cl}-1.57 \text { to } 1.87) \mathrm{p}=0.863 \\
\text { Stiffness (WOMAC): } 4.43(3.85) \text { vs. } 3.60(3.78) ; \mathrm{MD} 0.83(95 \% \mathrm{Cl}-0.98 \text { to } 2.64) \mathrm{p}=0.364 \\
\text { Activities of Daily Living (WOMAC): } 4.98(3.61) \text { vs. } 4.82(3.42) ; \mathrm{MD} 0.16(95 \% \mathrm{Cl}-1.51 \text { to } 1.83) \mathrm{p}=0.849 \\
\\
\text { B vs. C } \\
\text { 3 months } \\
\text { Overall (WOMAC): } 4.56(3.31) \text { vs. } 4.60(3.58) ; \mathrm{MD}-0.04(95 \% \mathrm{Cl}-1.75 \text { to } 1.67) \mathrm{p}=0.963 \\
\text { Pain (WOMAC): } 4.09(3.49) \text { vs. } 4.33(3.69) ; \mathrm{MD}-0.24(95 \% \mathrm{Cl}-2.02 \text { to } 1.54) \mathrm{p}=0.788 \\
\text { Stiffness (WOMAC): } 3.81(3.28) \text { vs. } 3.60(3.78) ; \mathrm{MD} 0.21(95 \% \mathrm{Cl}-1.55 \text { to } 1.97) \mathrm{p}=0.812 \\
\text { Activities of Daily Living (WOMAC): } 4.8(3.25) \text { vs. } 4.82(3.42) ; \mathrm{MD}-0.02(95 \% \mathrm{Cl}-1.67 \text { to } 1.63) \mathrm{p}=0.981\end{array}$ \\
\hline
\end{tabular}




\begin{tabular}{|c|c|}
\hline Author, Year & $\begin{array}{l}\text { Results - Subquestion b } \\
\text { (vs. Pharmacological therapy) }\end{array}$ \\
\hline Lauche 2016 & \\
\hline \begin{tabular}{|l|l|l|l|l|} 
Laufer \\
\end{tabular} & INR \\
\hline & \\
\hline & \\
\hline & \\
\hline & \\
\hline & \\
\hline & \\
\hline
\end{tabular}




\begin{tabular}{|c|c|c|}
\hline Author, Year & $\begin{array}{l}\text { Results - Subquestion c } \\
\text { (vs. Exercise) }\end{array}$ & Adverse Events Including Withdrawals \\
\hline Lauche 2016 & $\begin{array}{l}\text { A vs B } \\
\frac{3 \text { month outcomes }}{\text { NDI:24.3 (14.1) vs } 25.1(12.9), \mathrm{MD}:-1.4(-6.7 \text { to } 4.0)} \\
\text { Recent pain VAS (0-100): } 35.0(27.7) \text { vs } 33.1(20.9), \mathrm{MD}-0.5(95 \% \mathrm{Cl}-11.8 \text { to } 10.7) \\
\text { Pain with motion VAS (0-100): } 29.1(19.0) \text { vs } 34.9(14.4), \mathrm{MD}-5.6(95 \% \mathrm{Cl}-13.0 \text { to } 1.8) \\
\text { SF-36 PCS (0-100): MD }-1.6(95 \% \mathrm{Cl}-4.8 \text { to } 8.0) \\
\text { SF-36 MCS (0-100): MD }-0.3(95 \% \mathrm{Cl}-12.0 \text { to } 12.6)\end{array}$ & $\begin{array}{l}\text { A vs } B \text { vs } C \\
\text { Likely related to intervention } \\
\text { Serious AEs: none } \\
\text { Minor AEs: } 4 \text { vs } 1 \text { vs } 0 \\
\text { A: Migraine attack }(n=1) \text {; Achilles tendon pain } \\
(n=3) \\
\text { B. Knee pain }(n=1) \\
\\
\text { Total serious AEs to include those not related } \\
\text { to intervention: } 2 \text { vs } 4 \text { vs } 0 \\
\text { Total minor AEs: } 8 \text { vs } 5 \text { vs } 0\end{array}$ \\
\hline Laufer 2005 & NR & $\begin{array}{l}\text { No adverse reactions to the treatment were } \\
\text { reported by the subjects. }\end{array}$ \\
\hline
\end{tabular}




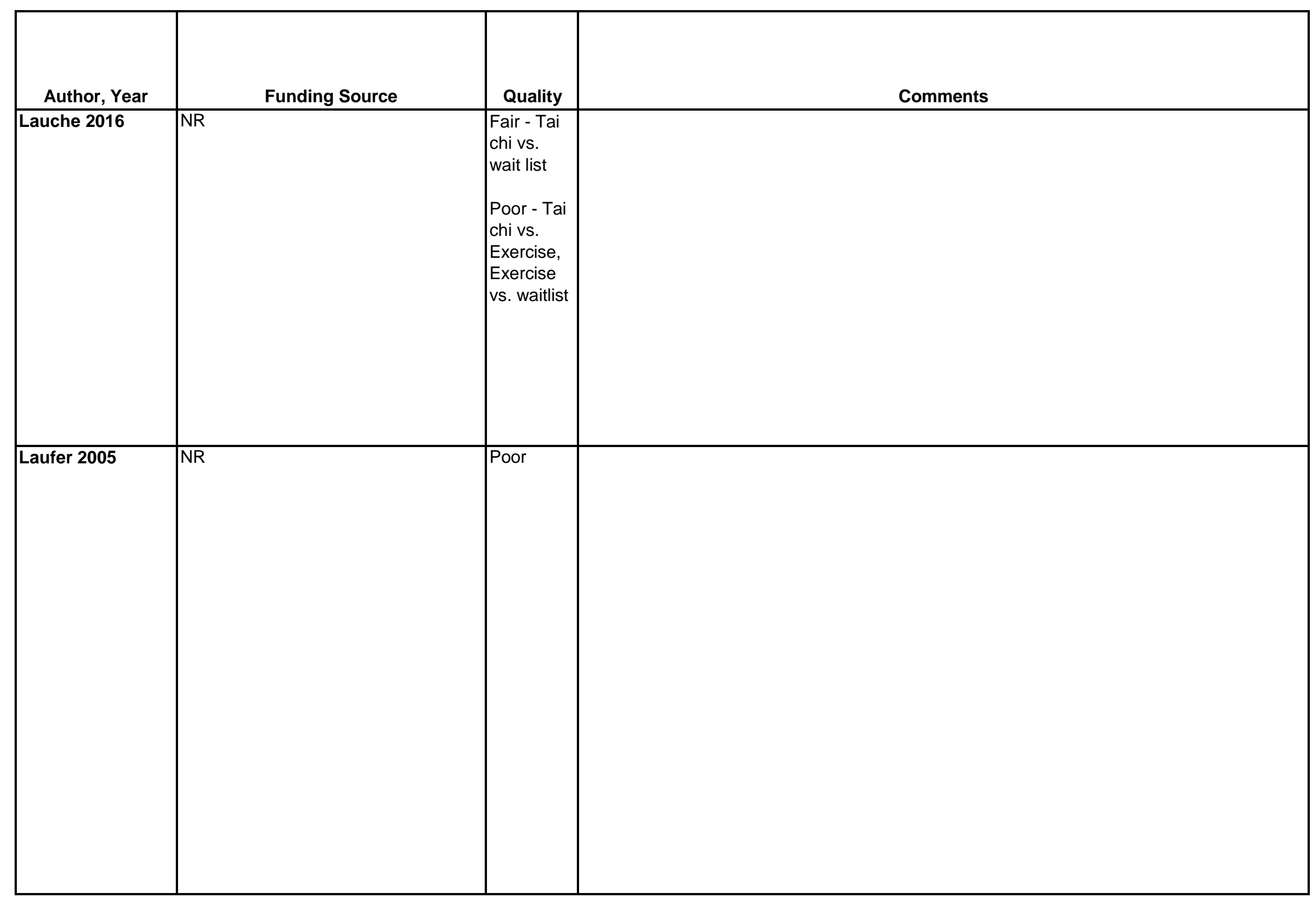




\begin{tabular}{|c|c|c|c|}
\hline Author, Year & $\begin{array}{c}\text { Country } \\
\text { Number of Centers } \\
\text { Setting }\end{array}$ & Inclusion/Exclusion Criteria & $\begin{array}{c}\text { Number Randomized, } \\
\text { Analyzed } \\
\text { Attrition }\end{array}$ \\
\hline Li 2017 & \begin{tabular}{l|} 
China \\
Number of centers NR \\
Type of center NR
\end{tabular} & $\begin{array}{l}\text { Females aged } 20-55 \text {, daily computer user with constantly or frequently } \\
\text { occurring computer-related neck pain for }>1 \text { year, worked on a } \\
\text { computer } \geq 3 \text { years, employed, motivated to continue working and } \\
\text { rehabilitation, not been sick for }>1 \text { month in the last year, working } \geq 20 \\
\text { hours per week, neck pain in the previous } 7 \text { days, self-reported pain } \\
\text { intesnity of } \geq 2 \text { or } 3-7 \text { days on a } 0-10 \text { scale. }\end{array}$ & $\begin{array}{l}\text { Randomized: } 109 \\
\text { Treated: } 109 \\
\text { Analyzed:102 } \\
\text { Attrition: } 6 \%(7 / 109) \\
\end{array}$ \\
\hline Liang 2011 & \begin{tabular}{|l|} 
China \\
Outpatient clinic of \\
Guangdong Provincial \\
Hospital of Chinese \\
Medicine 2007-2009 \\
\end{tabular} & $\begin{array}{l}18 \text { to } 60 \text { years of age, neck and shoulder pain or stiffness, frequent } \\
\text { attacks } \geq 1 / \text { month for } \geq 6 \text { months, baseline pain between } 3-7 \text { points on } \\
10 \text {-point VAS scale, no acupuncture within the last } 6 \text { months, willing to } \\
\text { join the study and sign an informed consent document. } \\
\text { Excluded: Received acupuncture due to neck pain in the past } 6 \\
\text { months, were unwilling to following the study protocol for treatment or } \\
\text { to provide informed consent, cervical or thoracic vertebral trauma, } \\
\text { surgery on the neck, neurological disorder, skeletal disorder, fear of } \\
\text { acupuncture treatment, pregnant or breast feeding, severe medical } \\
\text { disease or cancer. }\end{array}$ & $\begin{array}{l}\text { Randomized: } 190 \\
\text { Treated: } 183 \\
\text { Analyzed: } 178 \\
\text { Attrition: } 6 \%(12 / 190)\end{array}$ \\
\hline Licciardone 2013 & $\begin{array}{l}\text { United States } \\
\text { Single center }\end{array}$ & $\begin{array}{l}21 \text { to } 69 \text { years of age, nonpregnant, low back pain }>3 \\
\text { months. } \\
\text { Exclude: Cancer, spinal osteomyelitis, spinal fracture, herniated disc, } \\
\text { ankylosing spondylitis, cauda equina syndrome, low back surgery in } \\
\text { last year, workers' compensation benefits in the last } 3 \text { months, } \\
\text { ongoing litigation involving back problems, angina or congestive heart } \\
\text { failure symptoms with minimal activity, history of stroke or transient } \\
\text { ischemic attack in past year, implanted biomedical devices, bleeding } \\
\text { or infection in the lower back, corticosteroids in the last month, use of } \\
\text { manual treatment of ultrasound in the last } 3 \text { months or more than } 3 \\
\text { times in the past year, no signs of radiculopathy. }\end{array}$ & $\begin{array}{l}\text { Randomized: } 455 \\
\text { Analyzed: } 455 \\
\text { Attrition: } 7.4 \%(9.4 \% \text { vs. } \\
5.9 \%) \text { at } 12 \text { weeks }\end{array}$ \\
\hline
\end{tabular}




\begin{tabular}{|c|c|}
\hline Author, Year & Intervention, Comparator \\
\hline Li 2017 & $\begin{array}{l}\text { A. Progressive resistance training }(n=38) \text {. At least } 3 \text { sessions per week for six weeks. Sessions consisted of four cervical isometric neck resistance } \\
\text { exercises, with each exercise repeated } 8-12 \text { times. Resistance progressively increased every } 2 \text { weeks, starting at } 30 \% \text { of maximal strength and } \\
\text { increased to } 70 \% \text {. } \\
\text { B. Fixed resistance training }(n=35) \text { At least } 3 \text { sessions per week for six weeks. Sessions consisted of four cervical isometric neck resistance } \\
\text { exercises, with each exercise repeated } 8-12 \text { times. Resistnace was fixed at } 70 \% \text { of the participants maximal strength. } \\
\text { C. Attention control }(n=36) \text {. Subjected received information and had weekly discussions about workplace ergonomics, stress management, relaxation, } \\
\text { meditation, and diet. }\end{array}$ \\
\hline Liang 2011 & $\begin{array}{l}\text { A. Active acupuncture, traditional Chinese }(\mathrm{n}=88) 3 \mathrm{x} / \mathrm{week} \text { for } 3 \text { weeks }(9 \text { treatments total) lasting } 20 \text { minutes at the following points: bilateral DU14, } \\
\text { SI15 and Ex-HN15. Needles inserted to a depth of } 20 \mathrm{~mm} \text { and manipulated until numbness or other acupuncture sensation was felt. } \\
\text { B. Sham acupuncture }(\mathrm{n}=90) \text { for } 3 \mathrm{x} / \text { week for } 3 \text { weeks }(9 \text { treatments total) lasting } 20 \text { minutes } 1 \mathrm{~cm} \text { lateral to the points in treatment A. Needles } \\
\text { inserted to a depth of } 3 \mathrm{~mm} \text { without any manipulation. } \\
\text { Both groups received infrared irradiation in the cervical area. }\end{array}$ \\
\hline Licciardone 2013 & $\begin{array}{l}\text { A. Ultrasound } 1.2 \mathrm{~W} / \mathrm{cm}^{2} \text { at } 1 \mathrm{MHz} \text {; six } 10 \text { minute treatments over } 8 \text { weeks }(\mathrm{n}=233) \\
\text { B. Sham ultrasound, at } 0.1 \mathrm{~W} / \mathrm{cm}^{2} \text {, treatment otherwise identical to } \mathrm{A}(\mathrm{n}=222) \\
\text { Factorial design, patients also randomized to osteopathic manual treatment vs. sham treatment; no interaction between treatments }\end{array}$ \\
\hline
\end{tabular}




\begin{tabular}{|c|c|c|c|}
\hline Author, Year & Study Participants & Outcome Measures & $\begin{array}{c}\text { Duration of } \\
\text { Followup }\end{array}$ \\
\hline Li 2017 & $\begin{array}{l}\text { A vs B vs C } \\
\text { Age: } 36 \text { vs } 34 \text { vs } 34 \\
\text { BMl: } 21 \text { vs } 22 \text { vs } 22 \\
\text { Years working: } 9 \text { vs } 9 \text { vs } 10 \\
\text { Pain duration (years): } 3 \text { vs } 4 \text { vs } 4 \\
\text { Work (days/week): } 5 \text { vs } 6 \text { vs } 5 \\
\text { Computer use (hours/day): } 7 \text { vs } 8 \text { vs } 7 \\
\text { NDI: } 28.3 \text { (6.3) vs } 28.9 \text { (6.7) vs } 27.8(6.5) \\
\text { Pain VAS: } 5.3 \text { (1.3) vs } 5.4 \text { (1.1) vs } 5.2 \text { (1.2) }\end{array}$ & $\begin{array}{l}\mathrm{NDI}(0 \text { to } 100, \text { higher score=greater disability), } \\
\text { pain VAS }(0-10 \text {, higher score=higher pain) }\end{array}$ & $\begin{array}{l}1.5 \\
\text { months }\end{array}$ \\
\hline Liang 2011 & $\begin{array}{l}\text { A vs B } \\
\text { Age: } 37 \text { vs } 37 \text { years } \\
\text { Female: } 72 \% \text { vs. } 73 \% \\
\text { 25 pain attacks per month: } 58 \% \text { vs } 62 \% \\
\text { NPQ (0-100\%): } 32.7(12.5) \text { vs } 33.0(10.6) \\
\text { Pain (0-10): } 5.3(1.9) \text { vs } 5.5(1.6) \\
\text { SF-36 physical functioning: } 80.8(14.8) \text { vs } 79.2(19.1) \\
\text { SF-36 mental: } 63.5(15.4) \text { vs } 59.5(14.4)\end{array}$ & $\begin{array}{l}\text { Northwick Park Neck pain Questionnaire (NPNQ) } \\
\text { (scale: 0-100\%, higher percentage the greater the } \\
\text { disability) } \\
\text { Pain intensity (scale, 0-10, higher score=greater pain) } \\
\text { Short-Form } 36 \text { (SF-36) (scale 0-100, higher } \\
\text { score=better QoL) }\end{array}$ & $\begin{array}{l}1 \text { and } 3 \\
\text { month }\end{array}$ \\
\hline Licciardone 2013 & $\begin{array}{l}\text { A vs. B } \\
\text { Median age: } 38 \text { vs. } 43 \text { years } \\
\text { 58\% vs. } 68 \% \text { female } \\
\text { Race: Not reported } \\
\text { Pain (median, } 0-100 \text { VAS): } 44 \text { vs. } 44 \\
\text { RDQ (median, } 0-24 \text { ): } 5 \text { vs. } 5 \\
\text { SF-36 general health (median, } 0-100): 72 \text { vs. } 67 \\
\text { Duration of LBP >1 year: } 51 \% \text { vs. } 49 \%\end{array}$ & $\begin{array}{l}\text { RDQ (median, 0-24) } \\
\text { SF-36 general health } \\
\text { \% improvement in pain } \\
\text { Lost days of work } \\
\text { Very satisfied with back care }\end{array}$ & 1 month \\
\hline
\end{tabular}




\begin{tabular}{|c|c|}
\hline Author, Year & $\begin{array}{c}\text { Results - Subquestion a } \\
\text { (vs. sham, no treatment, waitlist, attention control) }\end{array}$ \\
\hline Li 2017 & $\begin{array}{l}\text { A vs C } \\
1.5 \text { month } \\
\text { NDI: } 14.9(4.9) \text { vs } 26.6(5.4), p<0.05 \\
\text { Pain VAS: } 1.9(0.9) \text { vs } 5.1(1.0), p<0.05 \\
\text { B vs C } \\
1.5 \text { month } \\
\text { NDI: } 15.8(4.8) \text { vs } 26.6(5.4), p<0.05 \\
\text { Pain VAS: } 2.5(0.9) \text { vs } 5.1(1.0), p \text { NR }\end{array}$ \\
\hline Liang 2011 & $\begin{array}{l}\text { A vs B } \\
\text { 3 months } \\
\text { NPNQ: } 19.1(9.9) \text { vs } 25.5(13.7), M D-6.4(95 \% \mathrm{Cl}-9.9 \text { to }-2.9), p<0.001 \\
\text { Pain }(0-10): 2.9(1.7) \text { vs } 3.2(1.3), \mathrm{MD}-0.3(95 \% \mathrm{Cl}-0.75 \text { to } 0.15), p=0.187 \\
\text { SF-36 physical functioning: } 84.3(15.2) \text { vs } 85.9(14.0), p=0.447 \\
\text { SF-36 mental: } 67.1 \text { (10.0) vs } 61.6(10.7), p=0.001\end{array}$ \\
\hline Licciardone 2013 & 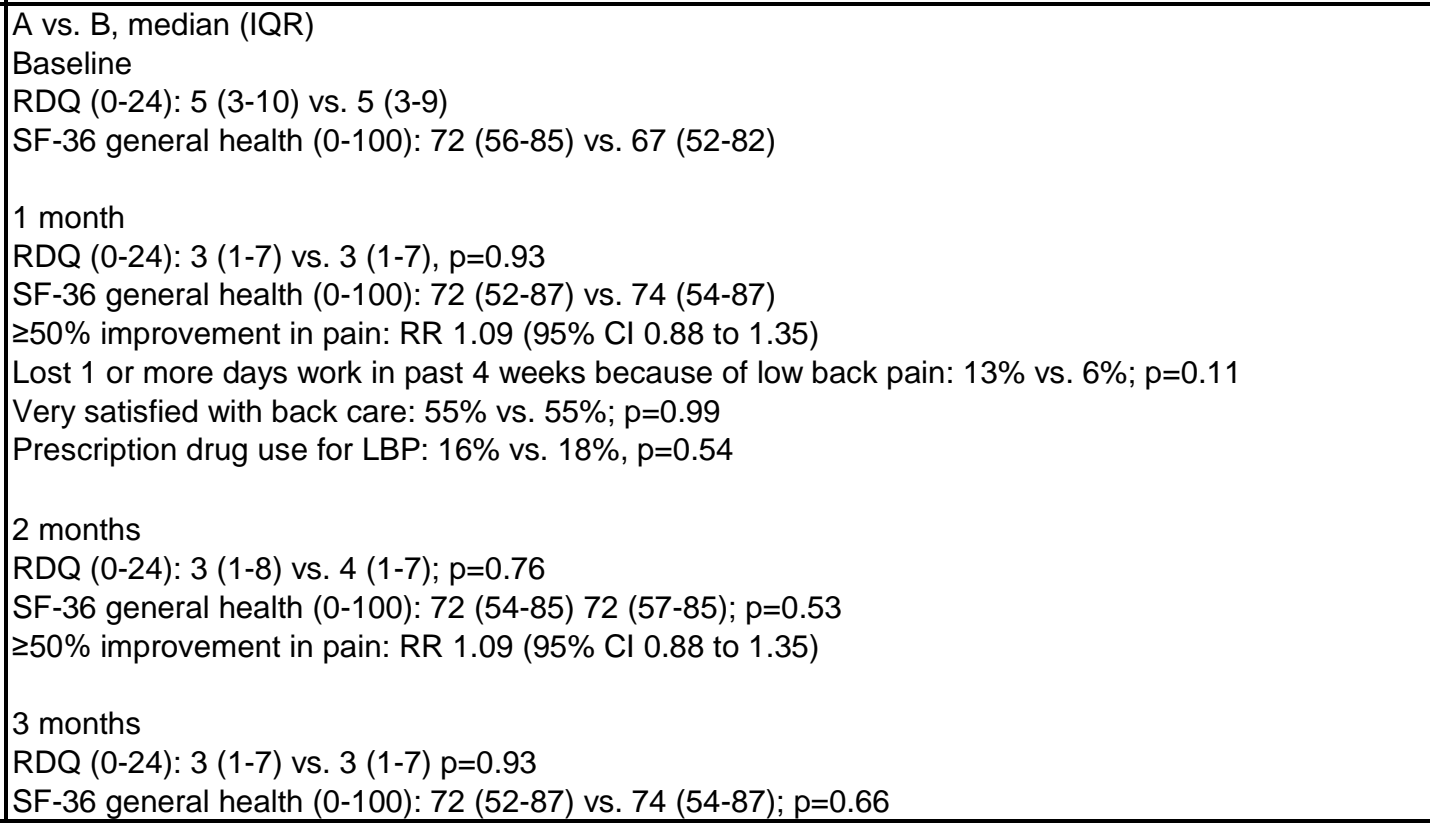 \\
\hline
\end{tabular}




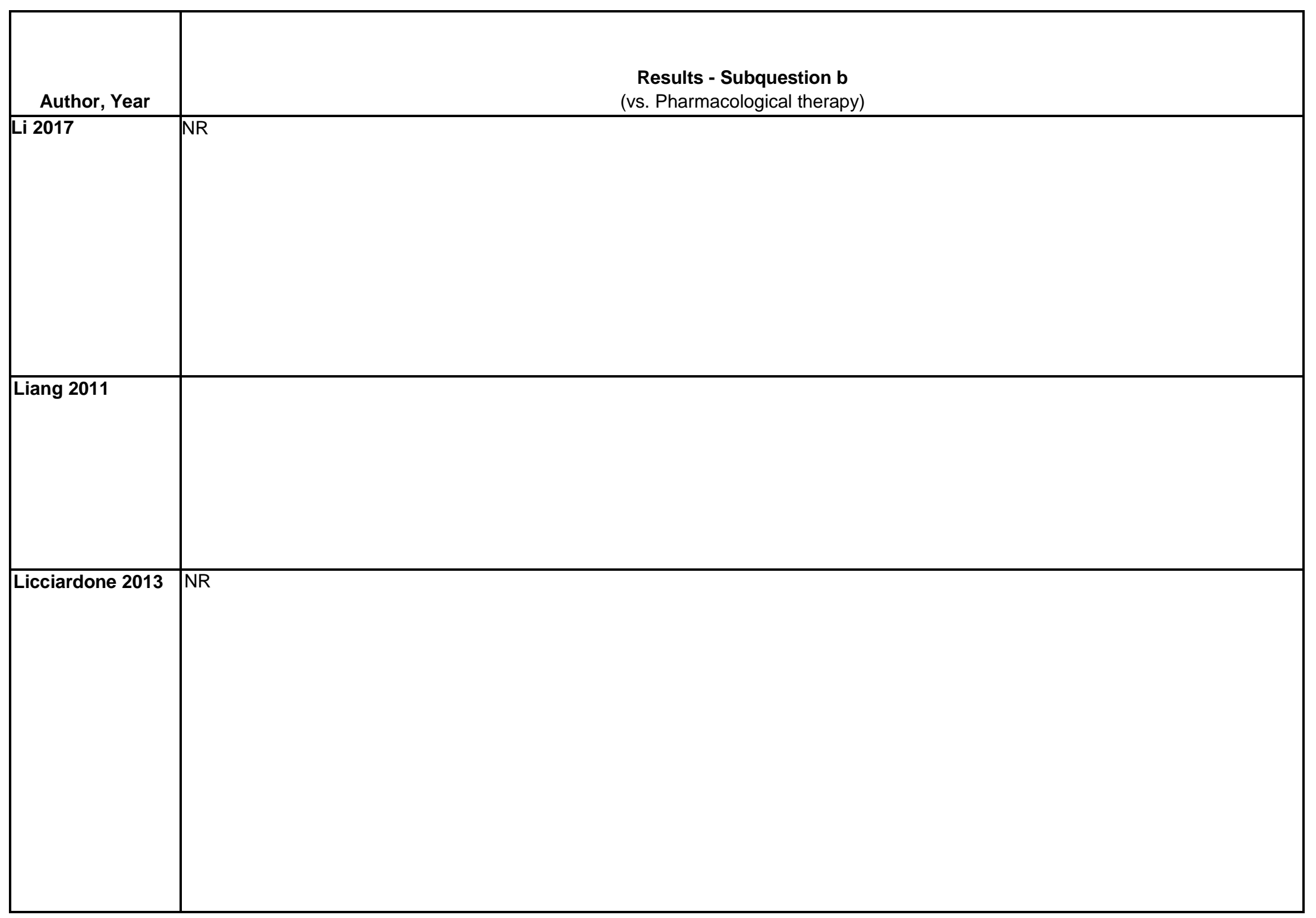

D-495 


\begin{tabular}{|c|c|c|}
\hline Author, Year & $\begin{array}{c}\text { Results - Subquestion c } \\
\text { (vs. Exercise) }\end{array}$ & Adverse Events Including Withdrawals \\
\hline Li 2017 & NR & $\begin{array}{l}\text { "Very few participants complained about the } \\
\text { arm or shoulder pain when stretching the } \\
\text { thera-bands. No other side effects were heard } \\
\text { in the process of training." }\end{array}$ \\
\hline Liang 2011 & & $\begin{array}{l}\text { Fainting: } n=3 \text { vs } n=4 \\
\text { Feeling numb and aching on treated points: } \\
n=4 \text { vs } n=2 \\
\text { Bleeding: Occurred, but frequency NR }\end{array}$ \\
\hline Licciardone 2013 & NR & $\begin{array}{l}\text { A vs. B } \\
\text { Withdrawal due to adverse event: Not } \\
\text { reported } \\
\text { Any adverse event: } 6.0 \%(14 / 233) \text { vs. } 5.9 \% \\
\text { (13/222), RR } 1.03 \text { ( } 95 \% \mathrm{Cl} 0.49 \text { to } 2.13) \\
\text { Serious adverse event: } \\
1.3 \% \text { (3/233) vs. } 2.7 \% \text { (6/222), RR } 0.48 \text { (95\% } \\
\text { Cl } 0.12 \text { to } 1.88)\end{array}$ \\
\hline
\end{tabular}




\begin{tabular}{|l|l|l|l|}
\hline \multicolumn{1}{|c|}{ Author, Year } & \multicolumn{1}{|c|}{ Funding Source } & Quality & \\
\hline Li 2017 & $\begin{array}{l}\text { Grant of National Science Foundation } \\
\text { of China (81171469 and 81671088) }\end{array}$ & Fair & Reducion in pain VAS $\geq 2$ was considered a clinically important difference. \\
\hline Liang 2011 & $\begin{array}{l}\text { State Ministry of Science and } \\
\text { Technology (No. 2006BAl12B04-1) } \\
\text { and the Scientific Project supported by } \\
\text { Guangdong Provincial Administration } \\
\text { of Science and Technology (No. } \\
\text { 2006B50107006) }\end{array}$ & Fair & \\
\hline Licciardone 2013 & $\begin{array}{l}\text { National } \\
\text { Institutes of Health- National Center } \\
\text { for Complementary and Alternative } \\
\text { Medicine and the Osteopathic } \\
\text { Heritage Foundation }\end{array}$ & Good & \\
\hline
\end{tabular}




\begin{tabular}{|c|c|c|c|}
\hline Author, Year & $\begin{array}{c}\text { Country } \\
\text { Number of Centers } \\
\text { Setting }\end{array}$ & Inclusion/Exclusion Criteria & $\begin{array}{c}\text { Number Randomized, } \\
\text { Analyzed } \\
\text { Attrition }\end{array}$ \\
\hline Little 2008 & $\begin{array}{l}\text { UK } \\
\text { Number of centers: } 2 \\
\text { Outpatient }\end{array}$ & $\begin{array}{l}\text { Age } 18-65 \\
\text { Primary care visit for low back pain more than three months previously } \\
\text { RDQ score } \geq 4 \\
\text { Current pain for } \geq 3 \text { weeks } \\
\text { Exclude: } \\
\text { Previous experience with Alexander technique } \\
\text { Clinical indicators of serious spinal disease } \\
\text { Current nerve root pain } \\
\text { History of psychosis or major alcohol misuse } \\
\text { Perceived inability to walk } 100 \text { meters }\end{array}$ & \begin{tabular}{|l} 
Randomized: 579 \\
Treated: 579 \\
Analyzed: 469
\end{tabular} \\
\hline Lund 2008 & $\begin{array}{l}\text { Denmark, Outpatient } \\
\text { General Praction }\end{array}$ & $\begin{array}{l}\text { Inclusion: OA criteria according to The American College of } \\
\text { Rheumatology, C-reactive protein within the reference range, and } \\
\text { a negative rheumatoid factor. } \\
\text { Exclusion: hydrophobia, incontinence, wounds, language or } \\
\text { intellectual problems, a history of periarticular knee fracture, total knee } \\
\text { replacement, inflammatory joint disease, heart or lung condition and } \\
\text { other medical diseases with possible contra-indication of exercise } \\
\text { and/or pool therapy, present participation in other clinical or exercise } \\
\text { trials, and secondary knee OA. }\end{array}$ & $\begin{array}{l}\text { Randomized: } 79 \\
\text { Treated: } 71 \\
\text { Analyzed: } 70 \\
\text { Attrition: } 11 \%(9 / 79)\end{array}$ \\
\hline
\end{tabular}




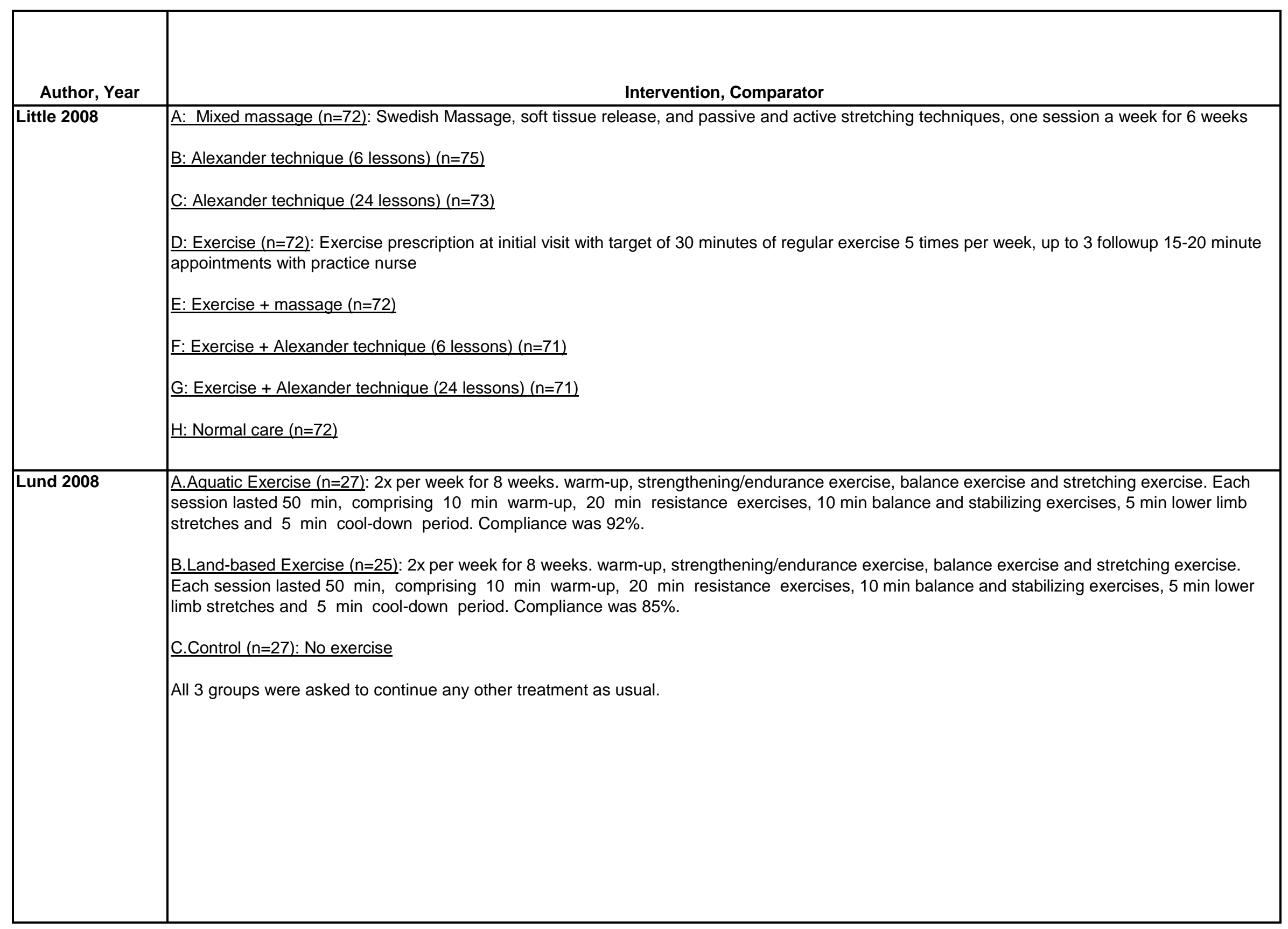




\begin{tabular}{|c|c|c|c|}
\hline Author, Year & Study Participants & Outcome Measures & $\begin{array}{l}\text { Duration of } \\
\text { Followup }\end{array}$ \\
\hline Little 2008 & $\begin{array}{l}\text { Baseline characteristics presented groups of study arms: } \\
\text { Controls }(H+D) \text { vs. Massage }(A+E) \text { vs. Alexander } 6 \text { lessons }(B+F) \text { vs. } \\
\text { Alexander } 24 \text { lessons }(C+G) \\
\text { Age: } 46 \text { vs. } 46 \text { vs. } 45 \text { vs. } 45 \\
\text { Female: } 73 \% \text { vs. } 78 \% \text { vs. } 63 \% \text { vs. } 64 \% \\
\text { Median number of days in pain in past } 4 \text { months: } 24.5 \text { vs. } 28 \text { vs. } 28 \\
\text { vs. } 28 \\
\text { Baseline Deyo troublesomeness: } 3.3-3.4 \\
\text { Baseline RDQ (0-24): } 10.8-11.3\end{array}$ & $\begin{array}{l}\text { Primary outcomes: } \\
\text { Disability: RDQ } \\
\text { Number of days in pain during the past four weeks } \\
\text { Secondary outcomes: } \\
\text { Quality of life: SF-36, higher score=better outcome } \\
\text { Back pain and disability: VonKorff scale and Deyo } \\
\text { "troublesomeness" scale, higher number = worse } \\
\text { outcome } \\
\text { Back Health Scale: developed by study to measure } \\
\text { enablement, } 0 \text { (worst) to } 7 \text { (best) }\end{array}$ & 10.5 months \\
\hline Lund 2008 & $\begin{array}{l}\text { A vs B vs C } \\
\text { Age: } 65 \text { vs } 68 \text { vs } 70 \text { years } \\
\text { Female: } 83 \% \text { vs } 88 \% \text { vs } 66 \% \\
\text { Duration of OA (median years): } 8.5 \text { vs } 7.8 \text { vs } 4.5 \\
\text { Pain at rest (VAS): } 29.8(23.5) \text { vs } 23.3(18.8) \text { vs } 15.5(20.1) \\
\text { Pain during walking (VAS): } 59.8(18.4) \text { vs. } 53.0(32.6) \text { vs. } 48.5(31.9) \\
\text { KOOS symptom: } 50.5 \text { (13.6) vs. } 50.9(12.7) \text { vs. } 50.1(13.6) \\
\text { KOOS pain: } 47.1(15.2) \text { vs. } 41.0(14.8) \text { vs. } 37.9(15.0) \\
\text { KOOS ADL: } 44.7(18.1) \text { vs. } 40.6(13.6) \text { vs. } 39.6(13.2) \\
\text { KOOS Sport: } 79.1(18.4) \text { vs. } 75.6(20.3) \text { vs. } 70.0(22.8) \\
\text { KOOS Quality of Life: } 63.7(11.8) \text { vs } 57.0(12.4) \text { vs } 60.8(13.1)\end{array}$ & $\begin{array}{l}\text { Pain at rest and during walking with Visual Analog Scale } \\
\text { (Scale 0-100, higher is worse pain) } \\
\text { Knee Injury and Osteoarthritis Outcome Score } \\
\text { questionnaire (KOOS) (Scale 0-100, higher is better } \\
\text { symptoms and function) }\end{array}$ & 3 months \\
\hline
\end{tabular}




\begin{tabular}{|c|c|}
\hline Author, Year & $\begin{array}{c}\text { Results - Subquestion a } \\
\text { (vs. sham, no treatment, waitlist, attention control) }\end{array}$ \\
\hline Little 2008 & 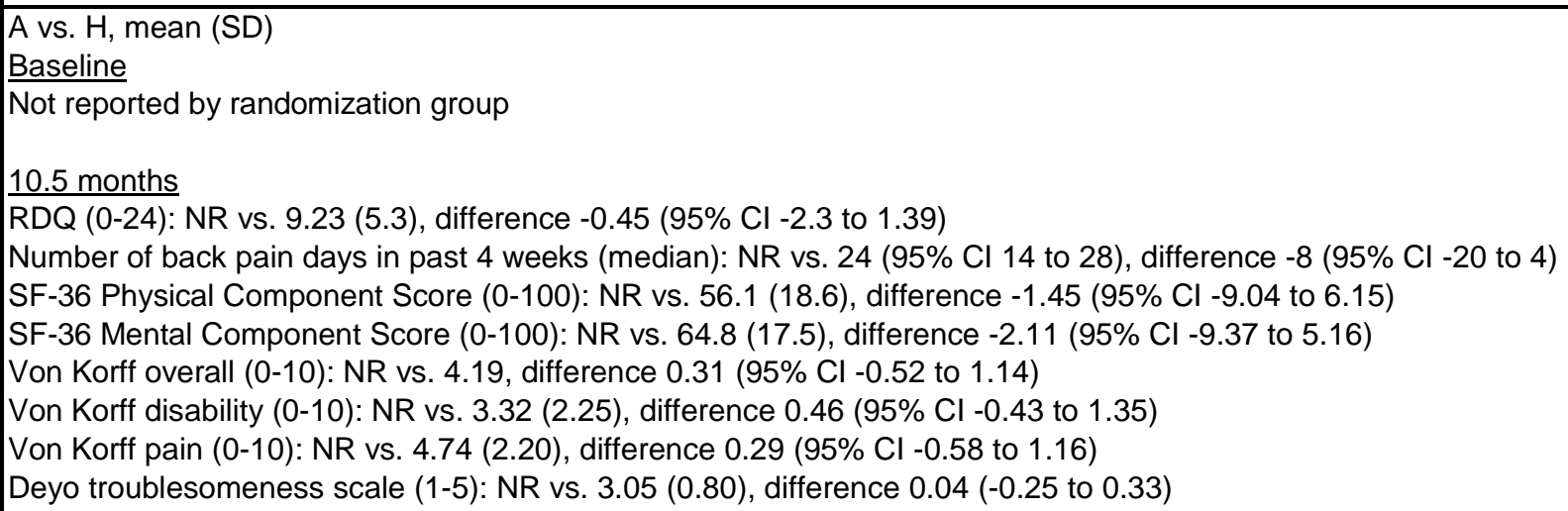 \\
\hline Lund 2008 & 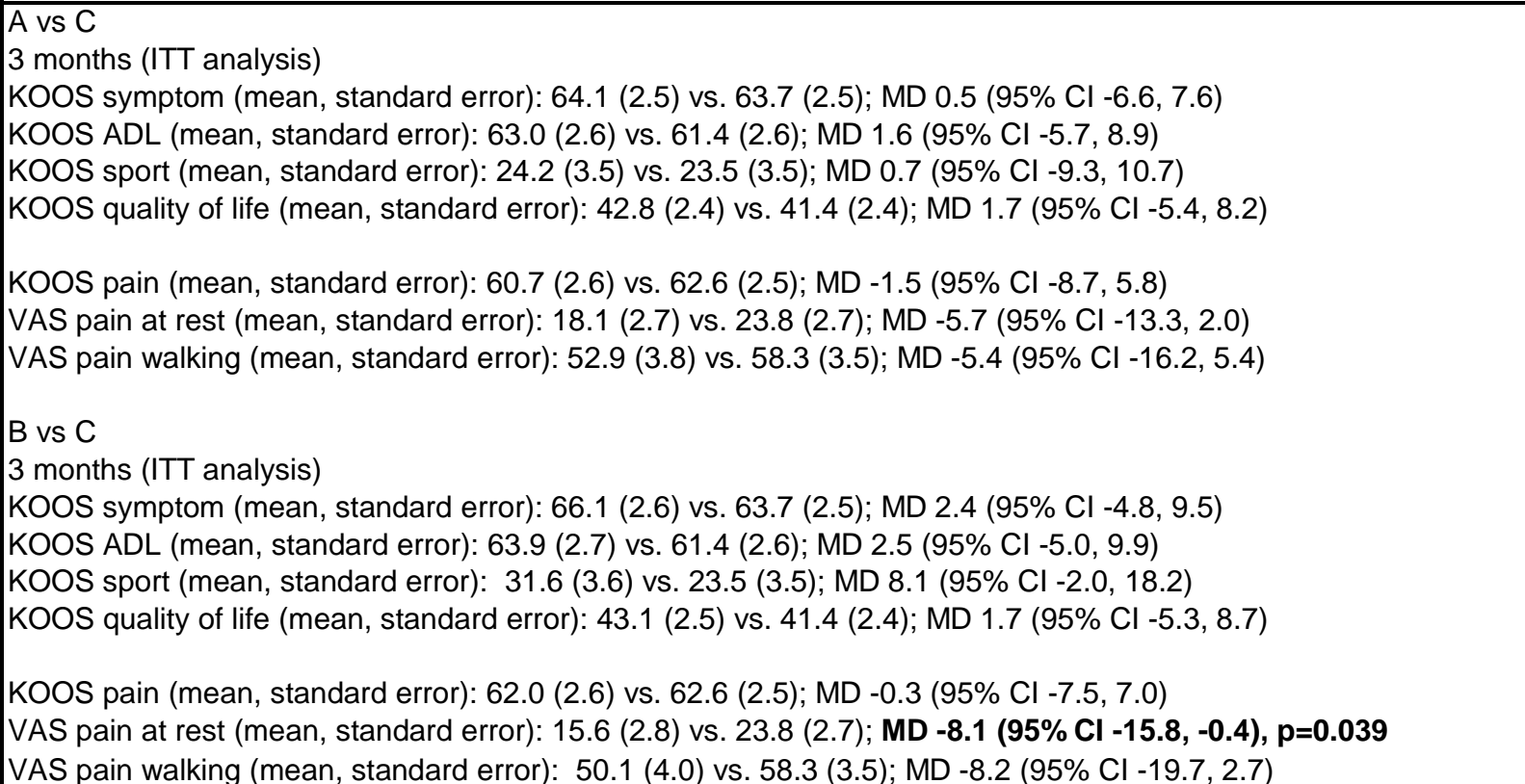 \\
\hline
\end{tabular}




\begin{tabular}{|l|l|}
\hline \multicolumn{1}{|c|}{ Author, Year } & \multicolumn{1}{c|}{$\begin{array}{c}\text { Results - Subquestion b } \\
\text { (vs. Pharmacological therapy) }\end{array}$} \\
\hline Little 2008 & NR \\
\hline Lund 2008 & NR \\
& \\
& \\
&
\end{tabular}




\begin{tabular}{|c|c|c|}
\hline Author, Year & $\begin{array}{c}\text { Results - Subquestion c } \\
\text { (vs. Exercise) }\end{array}$ & Adverse Events Including Withdrawals \\
\hline Little 2008 & $\begin{array}{l}\text { A vs. D, mean improvement versus usual care }(95 \% \mathrm{Cl}) \\
10.5 \text { months } \\
\text { RDQ: }-0.45(-2.3 \text { to } 1.39) \text { vs. }-1.65(-3.62 \text { to } 0.31) \\
\text { Number of back pain days in past } 4 \text { weeks (median): }-8(-20 \text { to } 4) \text { vs. }-11(-23 \text { to }-1) \\
\text { SF-36 Physical Component Score: }-1.45(-9.04 \text { to } 6.15) \text { vs. }-2.08(-10.6 \text { to } 6.40) \\
\text { SF-36 Mental Component Score: }-2.11(-9.37 \text { to } 5.16) \text { vs. } 0.72(-7.38 \text { to } 8.81) \\
\text { Von Korff overall: } 0.31(-0.52 \text { to } 1.14) \text { vs. }-0.19(-1.09 \text { to } 0.72) \\
\text { Von Korff disability: } 0.46(-0.43 \text { to } 1.35) \text { vs. } 0.05(-0.92 \text { to } 1.02) \\
\text { Von Korff pain: } 0.29(-0.58 \text { to } 1.16) \text { vs. }-0.31(-1.26 \text { to } 0.63) \\
\text { Deyo troublesomeness scale: } 0.04(-0.25 \text { to } 0.33) \text { vs. }-0.21(-0.52 \text { to } 0.09)\end{array}$ & $\begin{array}{l}\text { Increased back pain: } 0.7 \%(1 / 147) \text { in } \\
\text { massage group vs. } 0 \text { in all other groups }\end{array}$ \\
\hline Lund 2008 & NR & $\begin{array}{l}\text { A vs B vs C } \\
\text { Withdrawals } \\
4 \%(1 / 27) \text { vs. } 20 \%(5 / 25) \text { vs. } 7 \%(2 / 27) \\
\text { A vs C: RR } 0.5(95 \% \mathrm{Cl} 0.05,5.2) \\
\text { B vs C: RR } 2.5(95 \% \mathrm{Cl} 0.6,12.7) \\
\text { Increased pain during and after exercise: } \\
11 \%(3 / 27) \text { vs. } 32 \%(8 / 25) \text { vs. NR } \\
\text { Swollen knees: } 0 \%(0 / 27) \text { vs. } 12 \%(3 / 25) \text { vs. } \\
\text { NR } \\
\text { Withdrawals due to adverse events: } 0 \% \\
\text { (0/27) vs. } 12 \%(3 / 25) \text { vs. NR }\end{array}$ \\
\hline
\end{tabular}




\begin{tabular}{|l|l|l|l|}
\hline \multicolumn{1}{|c|}{ Author, Year } & \multicolumn{1}{|c|}{ Funding Source } & Quality & \\
\hline Little 2008 & Medical Research Council & Cair & \\
& & & \\
& & & \\
\hline Lund 2008 & $\begin{array}{l}\text { The Oak foundation, The Research } \\
\text { Foundation of the Danish } \\
\text { Physiotherapy Association, The } \\
\text { Danish Rheumatism Association, The } \\
\text { Spies Foundation and H:S Central } \\
\text { Research Fund. }\end{array}$ & Fair & Also report a Completers analysis in Table IV \\
& & & \\
\hline
\end{tabular}




\begin{tabular}{|c|c|c|c|}
\hline Author, Year & $\begin{array}{c}\text { Country } \\
\text { Number of Centers } \\
\text { Setting }\end{array}$ & Inclusion/Exclusion Criteria & $\begin{array}{c}\text { Number Randomized, } \\
\text { Analyzed } \\
\text { Attrition }\end{array}$ \\
\hline Lynch 2012 & $\begin{array}{l}\text { Canada } \\
1 \text { center } \\
\text { Outpatient }\end{array}$ & $\begin{array}{l}\text { Diagnosis of FM fulfilling } 1990 \text { ACR criteria, bilateral and widespread } \\
\text { pain above and below the waist and axial skeletal pain for at least } 3 \\
\text { months, at least } 11 \text { of } 18 \text { tender points, stable medications for at least } \\
14 \text { days prior, average } 7 \text { day pain score of at least } 4 \text { on an 11-point } \\
\text { NRS } \\
\text { Exclude: Already practicing qigong, significant medical disorder that } \\
\text { would compromise participant safety }\end{array}$ & $\begin{array}{l}\text { Randomized: } 100 \\
\text { Treated: } 100 \\
\text { Analyzed: } 88 \\
\text { Attrition: } 12 \%(12 / 100)\end{array}$ \\
\hline
\end{tabular}




\begin{tabular}{|l|l|}
\hline \multicolumn{1}{|c|}{ Author, Year } & \multicolumn{1}{c|}{ Intervention, Comparator } \\
\hline Lynch 2012 & $\begin{array}{l}\text { A.Q.igong (n=53): 1 group session per week for 8 weeks in addition to instructions for subjects to practice qigong daily at home for } 45 \text { to } 60 \\
\text { minutes. Sessions used Chaoyi Fanhuan Qigong. } \\
\text { B. Waitlist (n=47): Subjects continued with their usual care }\end{array}$ \\
\hline
\end{tabular}




\begin{tabular}{|c|c|c|c|}
\hline Author, Year & Study Participants & Outcome Measures & $\begin{array}{c}\text { Duration of } \\
\text { Followup }\end{array}$ \\
\hline Lynch 2012 & $\begin{array}{l}\text { A vs B } \\
\text { Age: } 53 \text { vs } 52 \\
\text { Female: } 94 \% \text { vs } 98 \% \\
\text { Duration of FM, years: } 9.7 \text { vs } 9.6 \\
\text { Pain condition comorbidities: } \\
\quad \text { Headache: } 59 \% \text { vs } 57 \% \\
\quad \text { Orofacial pain: } 43 \% \text { vs } 70 \% \\
\quad \text { Osteoarthritis: } 42 \% \text { vs } 36 \% \\
\quad \text { Rheumatoid arthritis: } 9 \% \text { vs } 9 \% \\
\quad \text { Other: } 30 \% \text { vs } 28 \% \\
\text { Previous opioid treatment: } 42 \% \text { vs } 30 \% \\
\text { Medication use: } \\
\quad \text { Anticonvulsants: } 25 \% \text { vs } 30 \% \\
\quad \text { Antidepressants: } 38 \% \text { vs } 32 \% \\
\quad \text { NSAIDs: } 49 \% \text { vs } 57 \% \\
\quad \text { Opioids: } 36 \% \text { vs } 23 \% \\
\quad \text { Other: } 55 \% \text { vs } 60 \% \\
\text { FIQ: } 65.5 \text { (14.4) vs } 61.8(13.4) \\
\text { Pain intensity NRS: } 6.5(1.5) \text { vs } 6.6(1.1) \\
\text { SF-36 physical component score: } 30.0(8.3) \text { vs } 32.6(8.8) \\
\text { SF-36 mental component score: } 38.1(9.6) \text { vs } 40.4(10.1) \\
\text { PSQI: } 13.8 \text { (3.0) vs } 13.1(3.8)\end{array}$ & $\begin{array}{l}\text { FIQ (0-100, higher score=more severe symptoms); pain } \\
\text { intensity NRS (0-10, higher score=higher pain); SF-36 } \\
\text { physical component score (0-100, higher score=higher } \\
\text { quality of life); SF-36 mental component score (0-100, } \\
\text { higher score=higher quality of life); PSQI (0-21, higher } \\
\text { scores=worse sleep quality) }\end{array}$ & \begin{tabular}{|l|}
2 and 4 \\
months
\end{tabular} \\
\hline
\end{tabular}




\begin{tabular}{|c|c|}
\hline Author, Year & $\begin{array}{c}\text { Results - Subquestion a } \\
\text { (vs. sham, no treatment, waitlist, attention control) }\end{array}$ \\
\hline Lynch 2012 & 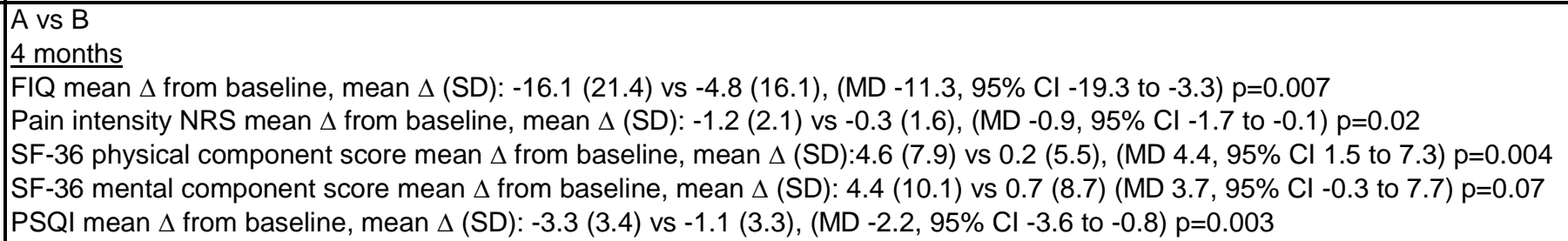 \\
\hline
\end{tabular}




\begin{tabular}{|l|c|}
\hline Author, Year & $\begin{array}{c}\text { Results - Subquestion b } \\
\text { (vs. Pharmacological therapy) }\end{array}$ \\
\hline Lynch 2012 & \\
& \\
& \\
& \\
\hline
\end{tabular}




\begin{tabular}{|l|c|l|}
\hline \multicolumn{1}{|c|}{ Author, Year } & $\begin{array}{c}\text { Results - Subquestion c } \\
\text { (vs. Exercise) }\end{array}$ & Adverse Events Including Withdrawals \\
\hline Lynch 2012 & & \begin{tabular}{|} 
A vs B \\
Treatment related pain: $2 \%(1 / 53)$ vs $0 \%$ \\
(0/47) \\
Plantar fasciitis: $2 \%(1 / 53)$ vs $0 \%(0 / 47)$
\end{tabular} \\
& & \\
& & \\
\hline
\end{tabular}




\begin{tabular}{|l|l|l|l|}
\hline Author, Year & \multicolumn{1}{|c|}{ Funding Source } & Quality & \multicolumn{1}{c|}{ Comments } \\
\hline Lynch 2012 & $\begin{array}{l}\text { Pfizer Neuropathic Pain Research } \\
\text { Award }\end{array}$ & Fair & $\begin{array}{l}\text { Majority of patients had tried previous treatments including anticonvulsants, antidepressants, } \\
\text { nerve blocks/injections, NSAIDS, acupuncture, chiropractic, } \\
\text { naturopath/homeopath/osteopath, massage therapy, physiological therapies, psychological } \\
\text { therapies } \\
\text { MDs were calculated, } \mathrm{p} \text { values were given by the study. N's used for calculations were } \mathrm{n}=43 \\
\text { for qigong group and } \mathrm{n}=45 \text { for wait list group. }\end{array}$ \\
\hline
\end{tabular}




\begin{tabular}{|c|c|c|c|}
\hline Author, Year & $\begin{array}{c}\text { Country } \\
\text { Number of Centers } \\
\text { Setting }\end{array}$ & Inclusion/Exclusion Criteria & $\begin{array}{c}\text { Number Randomized, } \\
\text { Analyzed } \\
\text { Attrition }\end{array}$ \\
\hline MacPherson 2015 & $\begin{array}{l}\text { England } \\
\text { General Practice }\end{array}$ & $\begin{array}{l}\text { Neck pain lasting } \geq 3 \text { months and a score of at } \geq 28 \% \text { on the Northwick } \\
\text { Park Questionnaire (NPQ) for neck pain and associated disability. } \\
\text { Excluded: serious underlying pathology, prior cervical spine surgery, } \\
\text { psychosis, rheumatoid arthritis, ankylosing spondylitis, osteoporosis, } \\
\text { hemophilia, cancer, HIV or hepatitis, current or recent alcohol or drug } \\
\text { dependency, compensation or litigation pending, unable to } \\
\text { communicate in English, participation in another clinical trial that might } \\
\text { interfere with the current study, currently receiving acupuncture for } \\
\text { neck pain, attendance at 1-to-1 alexander technique lessons in the } \\
\text { past } 2 \text { years. }\end{array}$ & $\begin{array}{l}\text { Randomized: } 517 \\
\text { Treated: } 483 \\
\text { Analyzed: } 439 \\
\text { Attrition:15\% } \\
\text { (78/517) } \\
\end{array}$ \\
\hline
\end{tabular}




\begin{tabular}{|c|c|}
\hline Author, Year & Intervention, Comparator \\
\hline MacPherson 2015 & $\begin{array}{l}\text { A.Needle acupuncture }(n=173) \text { at various points, most common (of } 259 \text { different points): GB-20, GB-21, LI-4, LIV-3, BL-10, SP-6, and SI-3. Twelve } \\
50 \text { minute session ( } 600 \text { minutes total) plus usual care, once per week initially and once every } 2 \text { weeks later. } \\
\text { B.Alexander Technique group ( } n=172) \text { : up to } 20 \text { one-to-one lessons of } 30 \text { minutes' duration } \\
(600 \text { minutes total) plus usual care, delivered weekly, with the option of being delivered } \\
\text { twice per week initially and every } 2 \text { weeks later. } \\
\text { C. Usual care }(n=171) \text { : general and neck pain-specific treatments routinely provided to primary care patients, such as prescribed medications and } \\
\text { visits to physical therapists and other health care professionals. } \\
\text { All intervention sessions were intended to be delivered within } 5 \text { months }\end{array}$ \\
\hline
\end{tabular}




\begin{tabular}{|c|c|c|c|}
\hline Author, Year & Study Participants & Outcome Measures & $\begin{array}{c}\text { Duration of } \\
\text { Followup }\end{array}$ \\
\hline MacPherson 2015 & $\begin{array}{l}\text { A vs B vs C } \\
\text { Age: } 52 \text { vs } 54 \text { vs } 54 \text { years } \\
\text { Female: } 69 \% \text { vs } 70 \% \text { vs } 69 \% \\
\text { White: } 93 \% \text { vs } 89 \% \text { vs } 89 \% \\
\text { Employed: } 61 \% \text { vs } 59 \% \text { vs } 62 \% \\
\text { Pain duration (median): } 60 \text { vs } 60 \text { vs } 96 \text { months) } \\
\text { NPQ ( } 39.64 \text { ( } 9.71) \text { vs } 39.38(11.91) \text { vs } 40.46(11.60) \\
\text { SF12v2 }(n=172 \text { vs } 169 \text { vs } 169): \\
\text { physical: } 39.99 \text { (9.83) vs } 39.87(9.75) \text { vs } 40.98(9.49) \\
\text { mental: } 45.07 \text { (11.00) vs } 45.63(12.22) \text { vs } 46.59(10.87)\end{array}$ & $\begin{array}{l}\text { Northwick Park Neck pain Questionnaire (NPQ) (scale: } \\
\text { 0-100\%, higher percentage the greater the disability) } \\
\text { Short-Form 12v2 (SF-12v2) (scale 0-100, higher } \\
\text { score=better QoL) }\end{array}$ & $\begin{array}{l}1 \text { and } 7 \\
\text { months }\end{array}$ \\
\hline
\end{tabular}




\begin{tabular}{|c|c|}
\hline Author, Year & $\begin{array}{l}\text { Results - Subquestion a } \\
\text { (vs. sham, no treatment, waitlist, attention control) }\end{array}$ \\
\hline MacPherson 2015 & 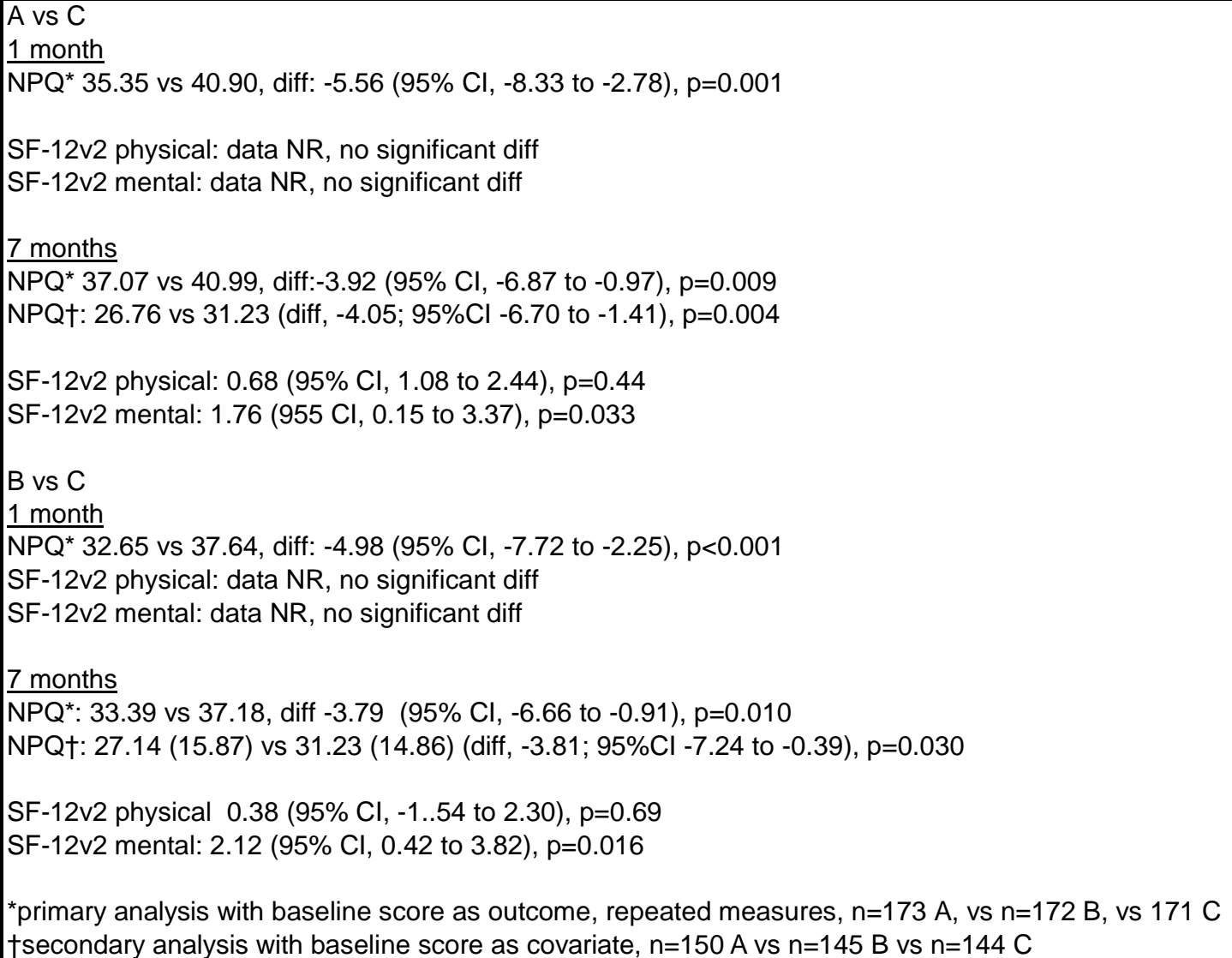 \\
\hline
\end{tabular}




$$
\text { I }
$$




\begin{tabular}{|c|c|c|}
\hline Author, Year & $\begin{array}{l}\text { Results - Subquestion c } \\
\text { (vs. Exercise) }\end{array}$ & Adverse Events Including Withdrawals \\
\hline MacPherson 2015 & & $\begin{array}{l}\text { A: Serious AEs: 0/173 (0.0\%) } \\
\text { Non-serious AEs: } 10 / 173(5.8 \%) \\
\text { Bruising, swelling or numbness: } \\
\text { 1/173 (0.6\%) } \\
\text { Muscle spasm: } 1 / 173(0.6 \%) \\
\text { Pain: } 7 / 173(4.0 \%) \\
\text { Respiratory problems 1/173 (0.6\%) } \\
\\
\text { B: Serious AEs: } 1 / 172(0.6 \%) \\
\text { Pain \& incapacity: } 1 / 172(0.6 \%) \\
\text { Non-serious AEs: } 2 / 173(1.2 \%) \\
\text { Injury at knee: } 11172(0.6 \%) \\
\text { Muscle spasm: } 1 / 172(0.6 \%) \\
\text { C: Serious AEs: } 2 / 172(1.2 \%) \\
\text { Complications after surgery: } 1 / 172 \\
\text { (0.66) } \\
\text { Pain \& incapacity: } 1 / 172(0.6 \%) \\
\text { Non-serious AEs:0/172 (0.0\%) }\end{array}$ \\
\hline
\end{tabular}




\begin{tabular}{|c|c|c|c|}
\hline Author, Year & Funding Source & Quality & Comments \\
\hline MacPherson 2015 & Arthritis Research, UK & Fair & Data are adjusted values with sensitivity analyses. Not sure what to use for meta-analysis. \\
\hline
\end{tabular}




\begin{tabular}{|c|l|l|l|}
\hline Author, Year & $\begin{array}{c}\text { Country } \\
\text { Number of Centers } \\
\text { Setting }\end{array}$ & \multicolumn{1}{|c|}{ Inclusion/Exclusion Criteria } & $\begin{array}{c}\text { Number Randomized, } \\
\text { Analyzed } \\
\text { Attrition }\end{array}$ \\
\hline Mannerkorpi 2009 & $\begin{array}{l}\text { Sweden } \\
\text { Number of centers } \\
\text { unclear } \\
\text { Primary care centers }\end{array}$ & $\begin{array}{l}\text { Females aged 18-60 years with FM or chronic widespread pain } \\
\text { Exclude: Severe somatic or psychiatric disorders, allergy to chlorine, } \\
\text { ongoing exercise therapy supervised by a physical therapist or plans } \\
\text { to start exercise therapy during study period }\end{array}$ & $\begin{array}{l}\text { Randomized: } 166 \\
\text { Treated: } 152 \\
\text { Analyzed: } 125 \\
\text { Attrition: 25\% (41/166) }\end{array}$ \\
\end{tabular}




\begin{tabular}{|c|c|}
\hline Author, Year & Intervention, Comparator \\
\hline Mannerkorpi 2009 & $\begin{array}{l}\text { A.Exercise and education ( } n=81 \text { randomized, } 75 \text { treated, } 63 \text { analyzed): One } 45 \text { minute pool exercise session per week for } 20 \text { weeks. Sessions } w \\
\text { consisted of stretching and aerobic exercises. All patients also attended six } 1 \text { hour sessions conducted weekly that introduced strategies to cope } \\
\text { with FM symptoms. At each sessions, patients developed a plan for physical activity for the following week and performed a short relaxation } \\
\text { exercise. } 58 \% \text { of participants assigned to the program were defined as active participants. } \\
\\
\text { B.Education control ( } n=85 \text { randomized, } 77 \text { received allocated intervention, } 62 \text { analyzed): six } 1 \text { hour sessions conducted weekly that introduced } \\
\text { strategies to cope with FM symptoms. At each sessions, patients developed a plan for physical activity for the following week and performed a short } \\
\text { relaxation exercise. } 66 \% \text { of participants assigned to the program were defined as active participants. }\end{array}$ \\
\hline
\end{tabular}




\begin{tabular}{|c|c|c|c|}
\hline Author, Year & Study Participants & Outcome Measures & $\begin{array}{l}\text { Duration of } \\
\text { Followup }\end{array}$ \\
\hline Mannerkorpi 2009 & $\begin{array}{l}\text { A vs } B \\
\text { Age: } 45 \text { vs } 47 \\
\text { Female: } 100 \% \text { vs } 100 \% \\
\text { Employment: } \\
\quad \text { Not working: } 55 \% \text { vs } 62 \% \\
\quad \text { Working part-time: } 35 \% \text { vs } 27 \% \\
\quad \text { Working full-time: } 10 \% \text { vs } 11 \% \\
\text { FIQ: } 61.6(16.42) \text { vs } 66.6(15.3) \\
\text { FIQ pain subscale: } 67.7(16.8) \text { vs } 70.4(20.1) \\
\text { HADS depression scale: } 6.4(4.0) \text { vs } 7.8(3.6) \\
\text { HADS anxiety scale: } 8.1(5.5) \text { vs } 9.1(4.8) \\
\text { SF-36 physical component score: } 30.8(8.1) \text { vs } 29.4(8.0) \\
\text { SF-36 mental component score: } 40.9(13.8) \text { vs } 36.6(12.3) \\
\text { SF-36 physical functioning: } 56.6(19.0) \text { vs } 50.9(18.3) \\
\text { SF-36 role-physical: } 22.8(32.2) \text { vs } 15.2(26.0) \\
\text { SF-36 bodily pain: } 28.6(14.3) \text { vs } 25.7(16.1) \\
\text { SF-36 vitality: } 28.4(21.1) \text { vs } 24.2(16.7)\end{array}$ & $\begin{array}{l}\text { FIQ (0-100, higher score=higher disability); FIQ pain } \\
\text { subscale (0-100, higher score=higher pain); HADS } \\
\text { depression subscale (0-21, higher score=higher } \\
\text { symptoms of depression); HADS anxiety subscale (0- } \\
21 \text {, higher score=higher symptoms of anxiety); SF-36 } \\
\text { physical component score (0-100, higher score=higher } \\
\text { quality of life); SF-36 mental component score (higher } \\
\text { score=higher quality of life) }\end{array}$ & 6-7 months \\
\hline
\end{tabular}




\begin{tabular}{|c|c|}
\hline Author, Year & $\begin{array}{l}\text { Results - Subquestion a } \\
\text { (vs. sham, no treatment, waitlist, attention control) }\end{array}$ \\
\hline Mannerkorpi 2009 & $\begin{array}{l}\text { A vS } B \\
\text { FIQ, mean change from baseline (SD): }-3.9 \text { (15.5) vs }-4.5(14.3), p=0.04 \\
\text { FIQ pain subscale, mean change from baseline (SD): }-6.5(23.7) \text { vs }-2.5(19.9), p=0.018 \\
\text { HADS depression scale, mean change from baseline (SD): }-0.4(3.3) \text { vs } 0.0(3.2), p=0.99 \\
\text { HADS anxiety scale, mean change from baseline (SD): }-0.7(3.3) \text { vs } 0.4(3.8), p=0.15 \\
\text { SF-36 physical component score, mean change from baseline (SD): } 2.9(8.6) \text { vs } 1.3(7.9), p=0.13 \\
\text { SF-36 mental component score, mean change from baseline (SD): } 0.5(13.9) \text { vs } 1.3(11.3), p=0.15 \\
\text { SF-36 physical functioning, mean change from baseline (SD): } 2.2(14.5) \text { v } 1.3(16.9), p=070 \\
\text { SF-36 role-physical, mean change from baseline (SD): } 12.1(40.7) \text { vs } 9.3(43.6), p=0.72 \\
\text { SF-36 bodily pain, mean change from baseline (SD): } 5.0(21.1) \text { vs } 3.6(18.2), p=0.24\end{array}$ \\
\hline
\end{tabular}




\begin{tabular}{|c|c|}
\hline Author, Year & $\begin{array}{c}\text { Results - Subquestion b } \\
\text { (vs. Pharmacological therapy) }\end{array}$ \\
\hline Mannerkorpi 2009 & \\
& \\
& \\
& \\
\hline
\end{tabular}




\begin{tabular}{|c|c|c|}
\hline Author, Year & $\begin{array}{l}\text { Results - Subquestion c } \\
\text { (vs. Exercise) }\end{array}$ & Adverse Events Including Withdrawals \\
\hline Mannerkorpi 2009 & & NR \\
\hline & & \\
\hline & & \\
\hline & & \\
\hline & & \\
\hline & & \\
\hline & & \\
\hline
\end{tabular}




\begin{tabular}{|c|l|l|l|}
\hline Author, Year & \multicolumn{1}{|c|}{ Funding Source } & Quality & \\
\hline Mannerkorpi 2009 & $\begin{array}{l}\text { The Swedish Research Council, The } \\
\text { Health and Medical Care Executive } \\
\text { Board of Vastra Gotaland Region, The } \\
\text { Läsförsäkringsbolagens Research } \\
\text { Foundation, The Rheumatic Pain } \\
\text { Society in Goteborg/RiG, The } \\
\text { Goteborg Region Foundation for } \\
\text { Rheumatology Research/GSFR and } \\
\text { ALF at Sahlgrenska University } \\
\text { Hospital }\end{array}$ & Comments \\
\hline
\end{tabular}




\begin{tabular}{|c|c|c|c|}
\hline Author, Year & $\begin{array}{c}\text { Country } \\
\text { Number of Centers } \\
\text { Setting }\end{array}$ & Inclusion/Exclusion Criteria & $\begin{array}{c}\text { Number Randomized, } \\
\text { Analyzed } \\
\text { Attrition }\end{array}$ \\
\hline Martin 2006 & $\begin{array}{l}\text { United States, Single- } \\
\text { Site }\end{array}$ & $\begin{array}{l}\text { Inclusion Criteria: } \\
\text { Confirmed diagnosis of Fibromyalgia } \\
\text { Exclusion Criteria: } \\
\text { Patients with prior experience of acupuncture or a bleeding diathesis, } \\
\text { cognitive ability to read consent form and complete survey } \\
\text { instruments, and within geographic range that allowed for participation } \\
\text { in treatment over 3-week period. }\end{array}$ & $\begin{array}{l}\text { Randomized: } 50 \\
\text { Treated: } 50 \\
\text { Analyzed: } 49 \\
\text { Attrition: } 2 \%(1 / 50)\end{array}$ \\
\hline
\end{tabular}




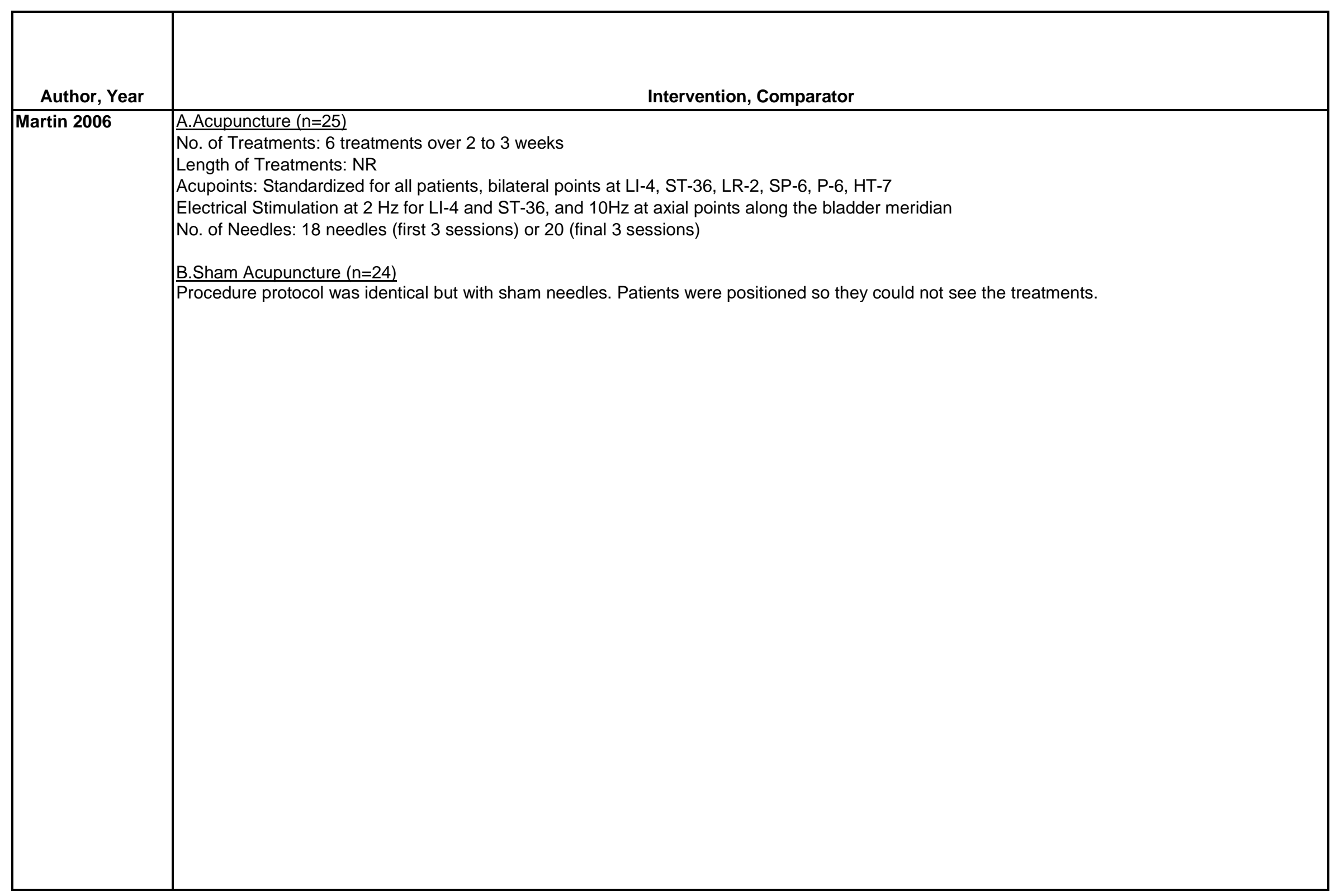




\begin{tabular}{|c|c|c|c|}
\hline Author, Year & Study Participants & Outcome Measures & $\begin{array}{c}\text { Duration of } \\
\text { Followup }\end{array}$ \\
\hline Martin 2006 & $\begin{array}{l}\text { A vs B } \\
\text { Age: } 48 \text { vs. } 52 \text { years; } p=.30 \\
\text { Female: } 100 \% \text { vs. } 96 \% \\
\text { Race: } 96 \% \text { vs. } 100 \% \text { white } \\
\text { Mean Duration of Chronicity: NR } \\
\\
\text { Total (FIQ, 0-80): } 42.4(11.0) \text { vs. } 44.0(9.8) \\
\text { Physical Function (FIQ): } 4.1(2.4) \text { vs } 3.6(2.5) \\
\text { Well-Being (FIQ): } 3.3(2.7) \text { vs. } 2.7(2.0) \\
\text { Pain (FIQ): 6.2(2.2) vs. 6.5(1.8) } \\
\text { Fatigue (FIQ): } 7.6(2.1) \text { vs. } 7.6(1.8) \\
\text { Sleep (FIQ): 6.9(2.1) vs. } 7.3(2.4) \\
\text { Stiffness (FIQ): } 7.2(1.9) \text { vs. } 6.8(2.0) \\
\text { Anxiety (FIQ): } 4.2(2.9) \text { vs. } 5.5(2.2) \\
\text { Depression (FIQ): } 2.9(3.0) \text { vs. 4.0(3.1) } \\
\\
\text { Pain Severity (MPI): } 40.4(10.3) \text { vs. 43.0(7.7) } \\
\text { Interference (MPI): 42.6(11.5) vs. } 36.9(11.7) \\
\text { Life Control (MPI): } 51.4(5.4) \text { vs. } 49.5(7.3) \\
\text { Affective Distress (MPI): } 42.6(7.7) \text { vs. } 46.1(8.1) \\
\text { General Activity Level (MPI): } 55.7(8.1) \text { vs. } 56.6(8.2)\end{array}$ & $\begin{array}{l}\text { Fibromyalgia Impact Questionnaire (FIQ, range 0-80: } \\
\text { higher scores represent severity of disability ) } \\
\text { Well-Being (FIQ, 0-10) } \\
\text { Pain (FIQ, 0-10) } \\
\text { Fatigue (FIQ, 0-10) } \\
\text { Sleep (FIQ, O-10) } \\
\text { Stiffness (FIQ, 0-10) } \\
\text { Anxiety (FIQ, 0-10) } \\
\text { Depression (FIQ, 0-10) } \\
\text { Multidisciplinary Pain Inventory (MPI): } \\
\text { Pain Severity (MPI) } \\
\text { Interference (MPI) } \\
\text { Life Control (MPI) } \\
\text { Affective Distress (MPI) } \\
\text { General Activity Level (MPI) }\end{array}$ & $\begin{array}{l}1 \text { and } 7 \\
\text { months }\end{array}$ \\
\hline
\end{tabular}




\begin{tabular}{|c|c|}
\hline Author, Year & $\begin{array}{l}\text { Results - Subquestion a } \\
\text { (vs. sham, no treatment, waitlist, attention control) }\end{array}$ \\
\hline Martin 2006 & 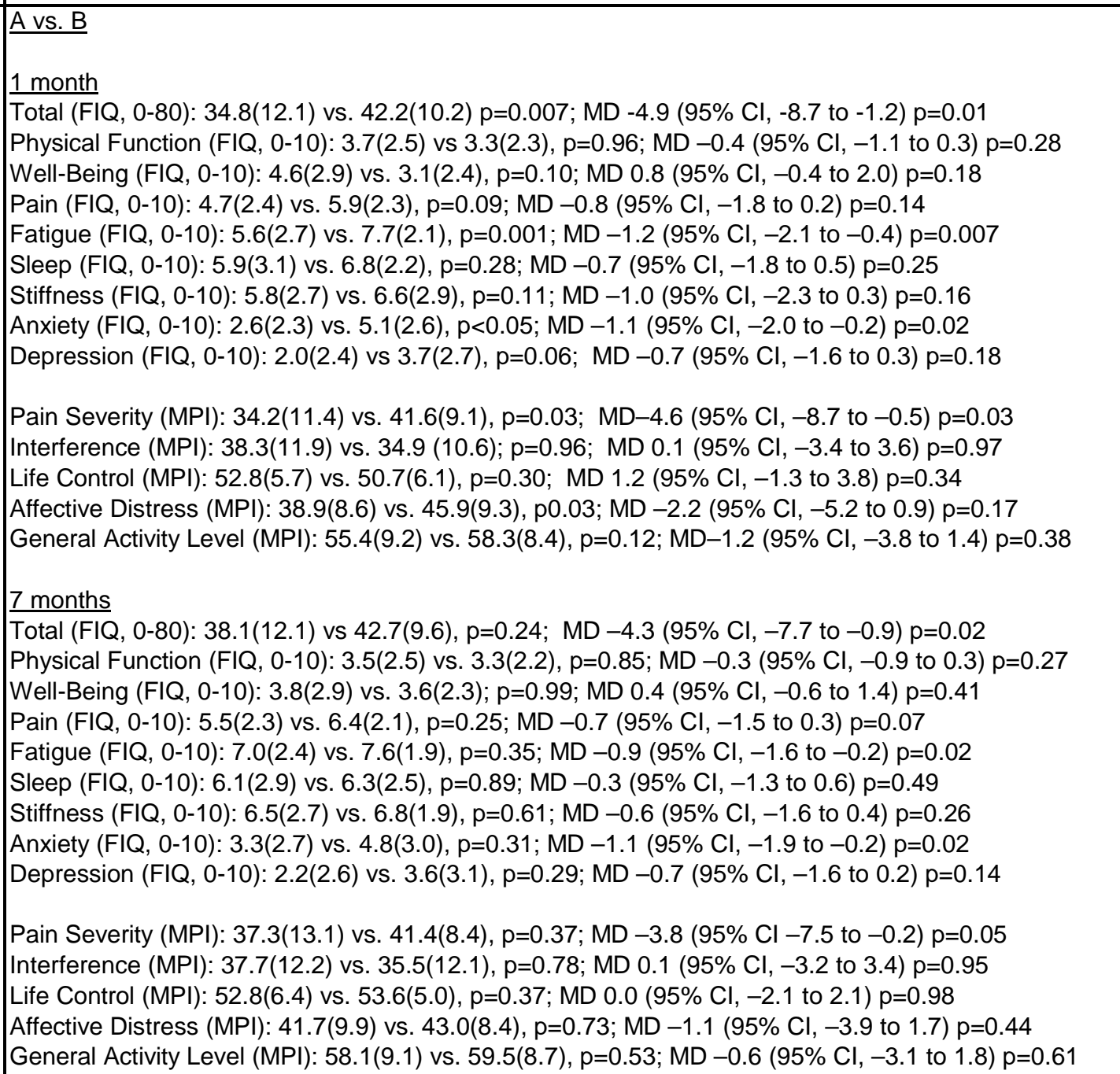 \\
\hline
\end{tabular}




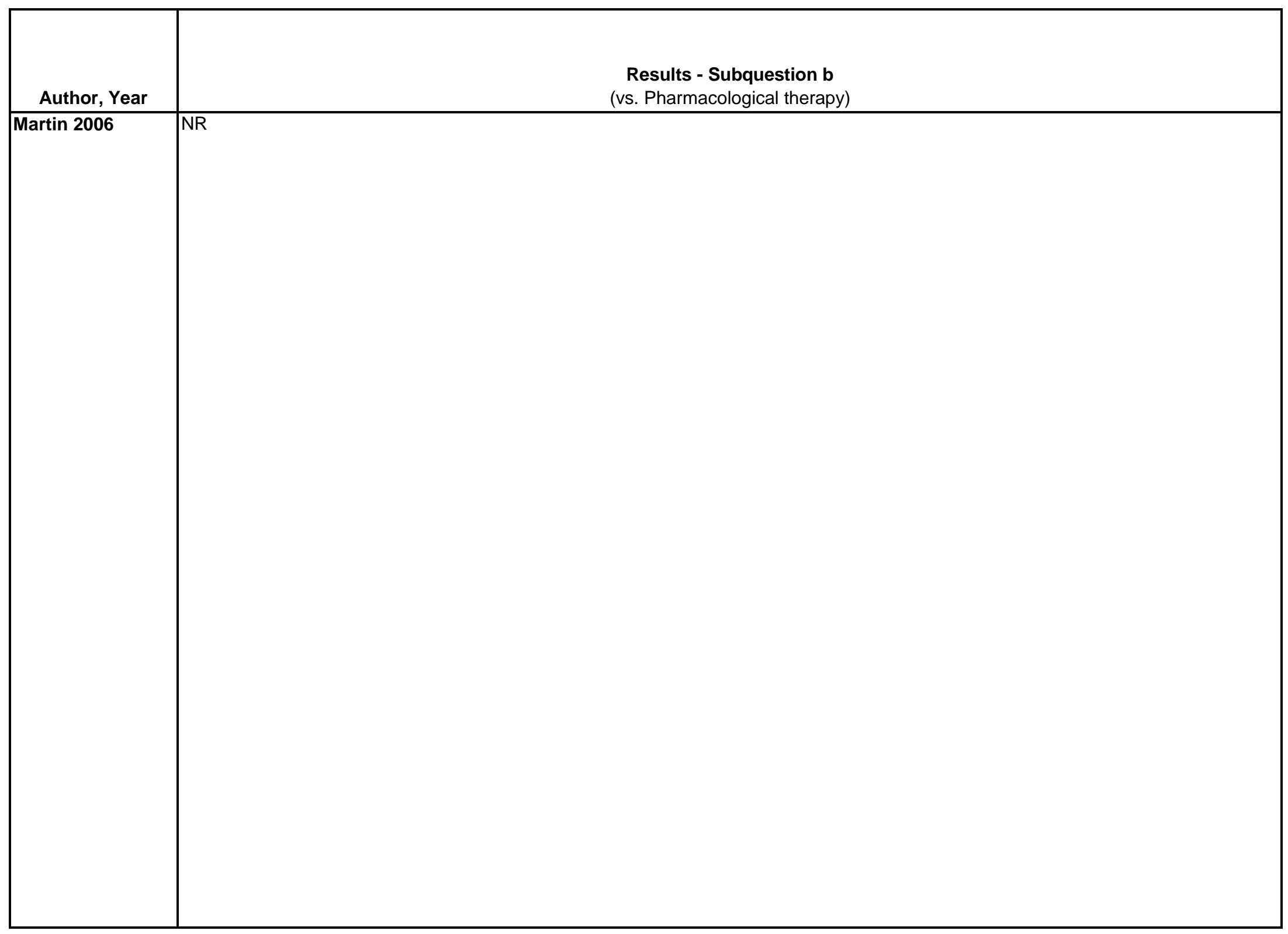

D-530 


\begin{tabular}{|c|c|c|}
\hline Author, Year & $\begin{array}{l}\text { Results - Subquestion c } \\
\text { (vs. Exercise) }\end{array}$ & Adverse Events Including Withdrawals \\
\hline Martin 2006 & NR & $\begin{array}{l}4 \%(2 / 50) \text { experienced mild vasovagal } \\
\text { symptoms } \\
2 \% \text { (1/50) experienced a pulmonary } \\
\text { embolism believed to be unrelated to } \\
\text { treatment }\end{array}$ \\
\hline
\end{tabular}




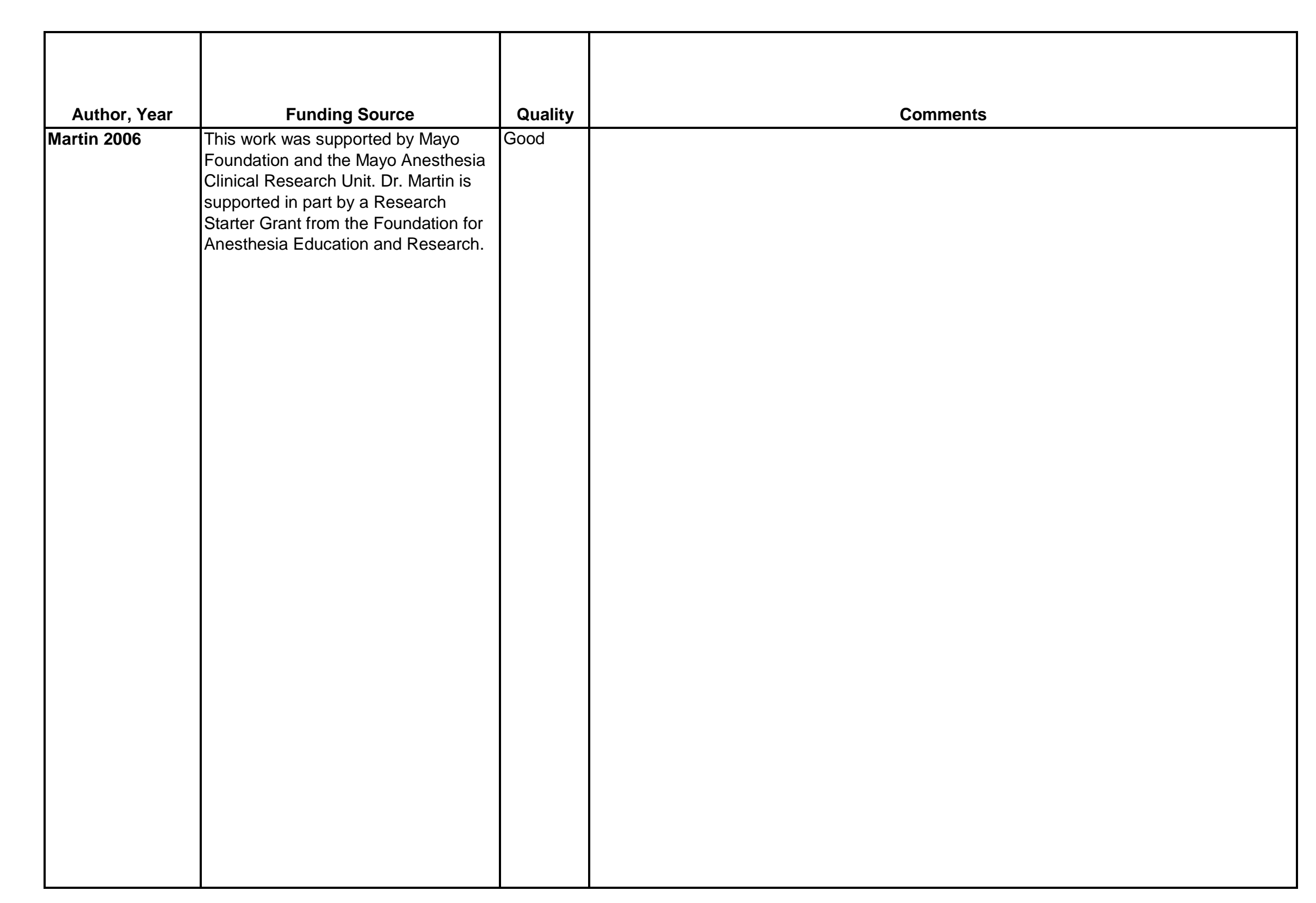




\begin{tabular}{|c|c|c|c|}
\hline Author, Year & $\begin{array}{c}\text { Country } \\
\text { Number of Centers } \\
\text { Setting }\end{array}$ & Inclusion/Exclusion Criteria & $\begin{array}{c}\text { Number Randomized, } \\
\text { Analyzed } \\
\text { Attrition }\end{array}$ \\
\hline Martin 2012 & $\begin{array}{l}\text { Spain } \\
1 \text { hospital pain } \\
\text { management unit }\end{array}$ & $\begin{array}{l}\text { Inclusion: FM diagnosis by ACR criteria, age }>18 \text { years, continuous } \\
\text { chronic pain for at least } 6 \text { months } \\
\text { Exclusion: severe psychiatric or organic disorder, employment-related } \\
\text { legal proceedings related to FM. }\end{array}$ & $\begin{array}{l}\text { Randomized: } 180 \text { (90 A, } \\
90 \text { B) } \\
\text { Analyzed: } 110 \text { (54 A, } 56 \text { B) } \\
\text { Attrition: } 39 \%(70 / 180)\end{array}$ \\
\hline Mazzuca 2004 & United States & $\begin{array}{l}\text { Inclusion Criteria: } \\
\text { Eligibility criteria were grade } 2 \text { or higher Kellgren and Lawrence (K/L) } \\
\text { radiographic severity of tibiofemoral OA in the standing } \\
\text { anteroposterior view and a total Western Ontario and McMaster } \\
\text { Universities Osteoarthritis Index (WOMAC) pain score } 8 \text { (possible } \\
\text { range 5-25). } \\
\text { Exclusion Criteria: } \\
\text { NR }\end{array}$ & $\begin{array}{l}\text { Randomized: } 52 \\
\text { Treated: } 51 \\
\text { Analyzed: } 49 \\
\text { Attrition: } 5.7 \%(3 / 52)\end{array}$ \\
\hline $\begin{array}{l}\text { Messier } 2004 \\
\text { ADAPT Trial (same } \\
\text { trial as Rejeski } \\
\text { 2002; reports pain } \\
\text { and function } \\
\text { outcomes) }\end{array}$ & $\begin{array}{l}\text { United States } \\
1 \text { center } \\
\text { University } \\
\end{array}$ & $\begin{array}{l}\text { Aged } 60 \text { or older, BMI greater or equal to } 28 \text {, knee pain on most days } \\
\text { of the month, sedentary lifestyle with less than } 20 \text { minutes of formal } \\
\text { exercise once a week for the past } 6 \text { months, self-reported difficulty in } \\
\text { at least one of the following activities due to knee pain: } 0.25 \text { mile walk, } \\
\text { climbing stairs, bending, stopping, kneeling, shopping, housecleaning, } \\
\text { other self-care or daily living activities, radiographic evidence of grad I- } \\
\text { III tibiofemoral or patellofemoral OA } \\
\text { Exclude: Serious medical condition preventing safe participation in an } \\
\text { exercise program, Mini-Mental score less than } 24 \text {, inability to complete } \\
18 \text { month study, inability to walk without a cane or assistive device, } \\
\text { participation in another research study, greater than or equal to } 14 \\
\text { alcoholic drinks per week, ST segment depression of at least } 2 \text { mm at } \\
\text { exercise level of } 4 \text { METS or less, hypotension or complex arrhythmias } \\
\text { during graded exercise test, inability to complete protocol }\end{array}$ & $\begin{array}{l}\text { Randomized: } 158 \\
\text { Treated: } 158 \\
\text { Analyzed: } 158 \\
\text { Attrition: } 17 \%(27 / 158)\end{array}$ \\
\hline
\end{tabular}




\begin{tabular}{|c|c|}
\hline Author, Year & Intervention, Comparator \\
\hline Martin 2012 & $\begin{array}{l}\text { A.Interdisciplinary pain treatment }(\mathrm{n}=54) \text { : current standard pharmacologic care for FM in Spain: amitriptyline maximum dose } 75 \mathrm{mg} / \mathrm{day}, \\
\text { paracetamol maximum dose } 4 \mathrm{gr} / \mathrm{day} \text {, and tramadol maximum dose of } 400 \mathrm{mg} / \mathrm{day} \text {. In addition: } 6 \text { week multidisciplinary treatment delivered by team } \\
\text { of physician, clinical psychologist, and physiotherapist and consisting of twice-weekly } 105-\mathrm{minute} \text { group sessions. Treatment included cognitive- } \\
\text { behavioral therapy (cognitive restructuring, breathing and relaxation exercises, communication skills, activity pacing), education, and physiotherapy. } \\
78 \%(70 / 90) \text { randomized completed the treatment. } \\
\text { B.Control ( } \mathrm{n}=56 \text { ): current standard pharmacologic care for FM in Spain: amitriptyline maximum dose } 75 \mathrm{mg} / \text { day, paracetamol maximum dose } \\
\text { 4gr/day, and tramadol maximum dose of } 400 \mathrm{mg} / \mathrm{day}\end{array}$ \\
\hline Mazzuca 2004 & 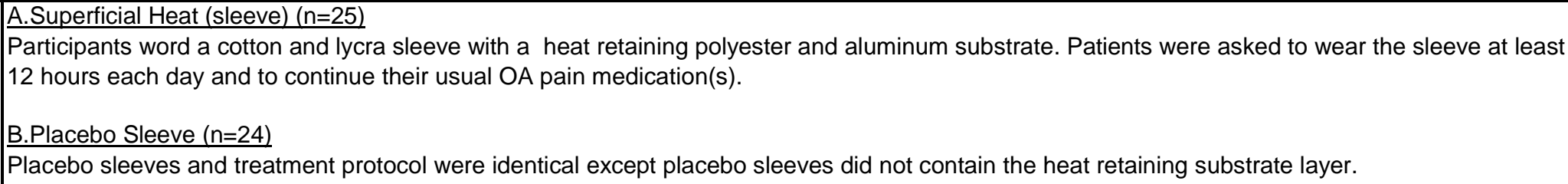 \\
\hline $\begin{array}{l}\text { Messier } 2004 \\
\text { ADAPT Trial (same } \\
\text { trial as Rejeski } \\
\text { 2002; reports pain } \\
\text { and function } \\
\text { outcomes) }\end{array}$ & 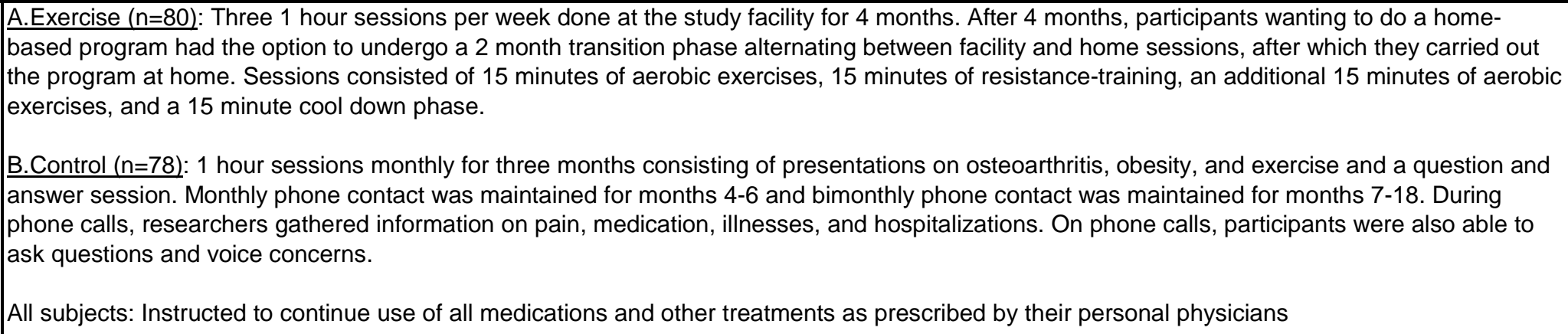 \\
\hline
\end{tabular}




\begin{tabular}{|c|c|c|c|}
\hline Author, Year & Study Participants & Outcome Measures & $\begin{array}{c}\text { Duration of } \\
\text { Followup }\end{array}$ \\
\hline Martin 2012 & $\begin{array}{l}\text { A vs B } \\
\text { Age: } 49 \text { vs } 52 \text { years } \\
\text { Female: } 91 \% \text { vs } 91 \% \\
\text { Race NR } \\
\text { Pain duration: } 15 \text { vs } 14 \text { years } \\
\text { FIQ total: } 76.3 \text { vs } 76.2 \\
\text { FIQ physical functioning: } 5.5 \text { vs } 5.4 \\
\text { FIQ Pain: } 7.5 \text { vs } 7.5 \\
\text { HAD Anxiety: } 13.8 \text { vs } 13.4 \\
\text { HAD Depression: } 10.6 \text { vs } 10.6\end{array}$ & $\begin{array}{l}\text { FIQ total (0-100, higher scores=greater impact of FM on } \\
\text { functioning) } \\
\text { FIQ physical functioning }(0-10, \text { higher scores=greater } \\
\text { impact of FM on physical functioning) } \\
\text { HAD Anxiety (scale NR) } \\
\text { HAD Depression (scale NR) }\end{array}$ & 6 months \\
\hline Mazzuca 2004 & $\begin{array}{l}\text { A+B } \\
\text { Age: } 62.7 \\
\text { Female: } 77 \% \\
\text { Race: } 67 \% \text { white } \\
\text { Mean Duration of Chronicity: NR } \\
\\
\text { Pain (WOMAC): } 15.2 \text { vs. } 14.7^{*} \\
\text { Stiffness (WOMAC): } 6.5(1.4) \\
\text { Function (WOMAC): } 51.8(11.8) \\
\text { ^Separate group baseline values not given for Stiffness and Function. } \\
\text { Mean pain estimated from graph. }\end{array}$ & $\begin{array}{l}\text { Western Ontario and McMaster Universities } \\
\text { Osteoarthritis Index (WOMAC, higher scores indicate } \\
\text { greater pain, stiffness or functional limitation) } \\
\text { Pain (WOMAC, range 5-25) } \\
\text { Stiffness (WOMAC, range 2-10) } \\
\text { Physical Function (WOMAC, range 17-85) }\end{array}$ & 1 month \\
\hline $\begin{array}{l}\text { Messier } 2004 \\
\text { ADAPT Trial (same } \\
\text { trial as Rejeski } \\
\text { 2002; reports pain } \\
\text { and function } \\
\text { outcomes) }\end{array}$ & $\begin{array}{l}\text { A vs B } \\
\text { Age: } 69 \text { vs } 69 \\
\text { Female: } 74 \% \text { vs } 68 \% \\
\text { Comorbidities: } \\
\left.\quad \text { Obesity (BMI } \geq 30 \mathrm{~kg} / \mathrm{m}^{2}\right): 84 \% \text { vs } 76 \% \\
\quad \text { Arthritis in other joints: } 55 \% \text { vs } 58 \% \\
\quad \text { Hypertension: } 54 \% \text { vs } 46 \% \\
\quad \text { Coronary heart disease: } 34 \% \text { vs } 28 \% \\
\quad \text { Diabetes: } 11 \% \text { vs } 9 \% \\
\text { Kellgren/Lawrence score: } 2.2(0.8) \text { vs } 2.2(0.09) \\
\text { WOMAC physical function, mean (SEM): } 24.0(1.3) \text { vs } 26.0(1.3) \\
\text { WOMAC pain, mean (SEM): } 6.6(0.4) \text { vs } 7.3(0.4)\end{array}$ & $\begin{array}{l}\text { WOMAC physical function subscale (0-68, higher } \\
\text { score=higher disability); WOMAC pain subscale (0-20, } \\
\text { higher score=higher pain) }\end{array}$ & $\begin{array}{l}6 \text { and } 18 \\
\text { months }\end{array}$ \\
\hline
\end{tabular}




\begin{tabular}{|c|c|}
\hline Author, Year & $\begin{array}{c}\text { Results - Subquestion a } \\
\text { (vs. sham, no treatment, waitlist, attention control) }\end{array}$ \\
\hline Martin 2012 & $\begin{array}{l}\text { A vs B } \\
\text { 6-month outcomes: } \\
\text { FIQ total: } 70.33(16.48) \text { vs } 76.81 \text { (14.18), } \mathrm{p}=0.04 ; \mathrm{MD}-6.48(95 \% \mathrm{Cl}-12.2837 \text { to }-0.6763), \mathrm{p}=0.03 \\
\text { FIQ physical function: } 5.19(1.83) \text { vs } 5.92(1.84), \mathrm{p}=0.01 ; \mathrm{MD}-0.73(95 \% \mathrm{Cl}-1.4238 \text { to }-0.0362), \mathrm{p}=0.04 \\
\text { FIQ pain: } 7.24(2.17) \text { vs } 8.22(1.62), \mathrm{p}=0.03 ; \mathrm{MD}-0.98(95 \% \mathrm{Cl}-1.7020 \text { to }-0.2580), \mathrm{p}=0.008 \\
\text { HADS Anxiety: } 13.41(4.31) \text { vs } 12.75(4.55), \mathrm{p}=0.72 \\
\text { HADS Depression: } 9.77(4.09) \text { vs. } 10.2(4.22), \mathrm{p}=0.19\end{array}$ \\
\hline Mazzuca 2004 & $\begin{array}{l}\frac{\text { A vs. B }}{1 \text { month }} \\
\text { Mean Pain (WOMAC): } 13.7 \text { vs. } 13.9\end{array}$ \\
\hline $\begin{array}{l}\text { Messier } 2004 \\
\text { ADAPT Trial (same } \\
\text { trial as Rejeski } \\
\text { 2002; reports pain } \\
\text { and function } \\
\text { outcomes) }\end{array}$ & 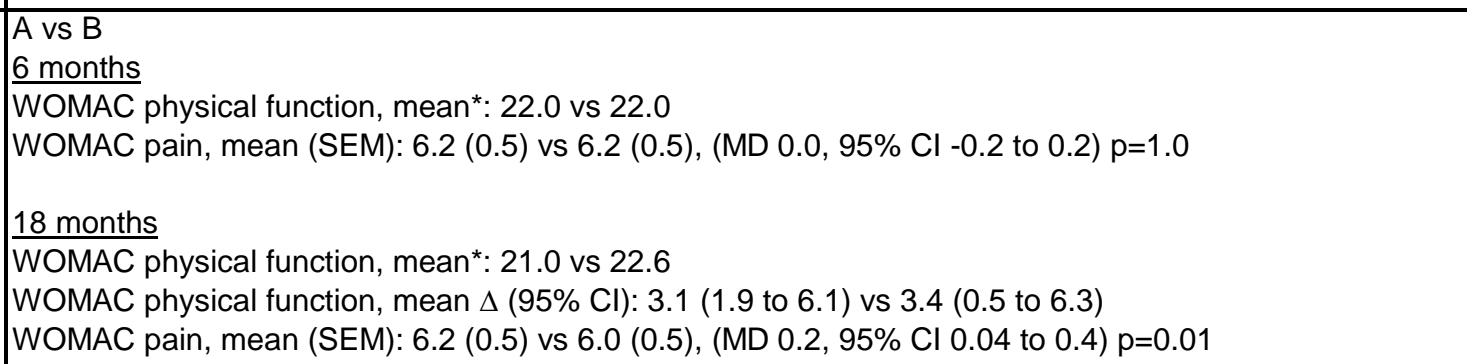 \\
\hline
\end{tabular}




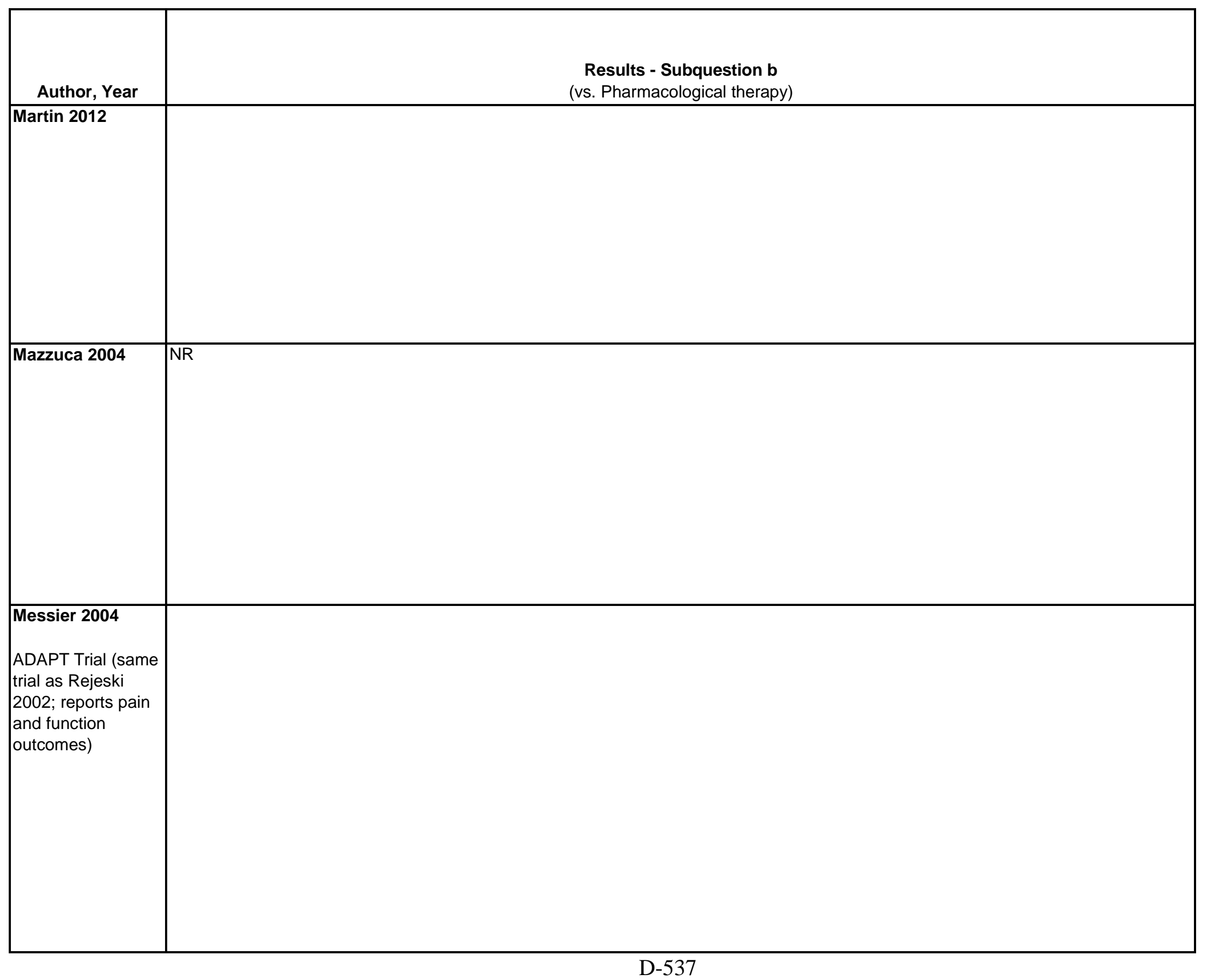




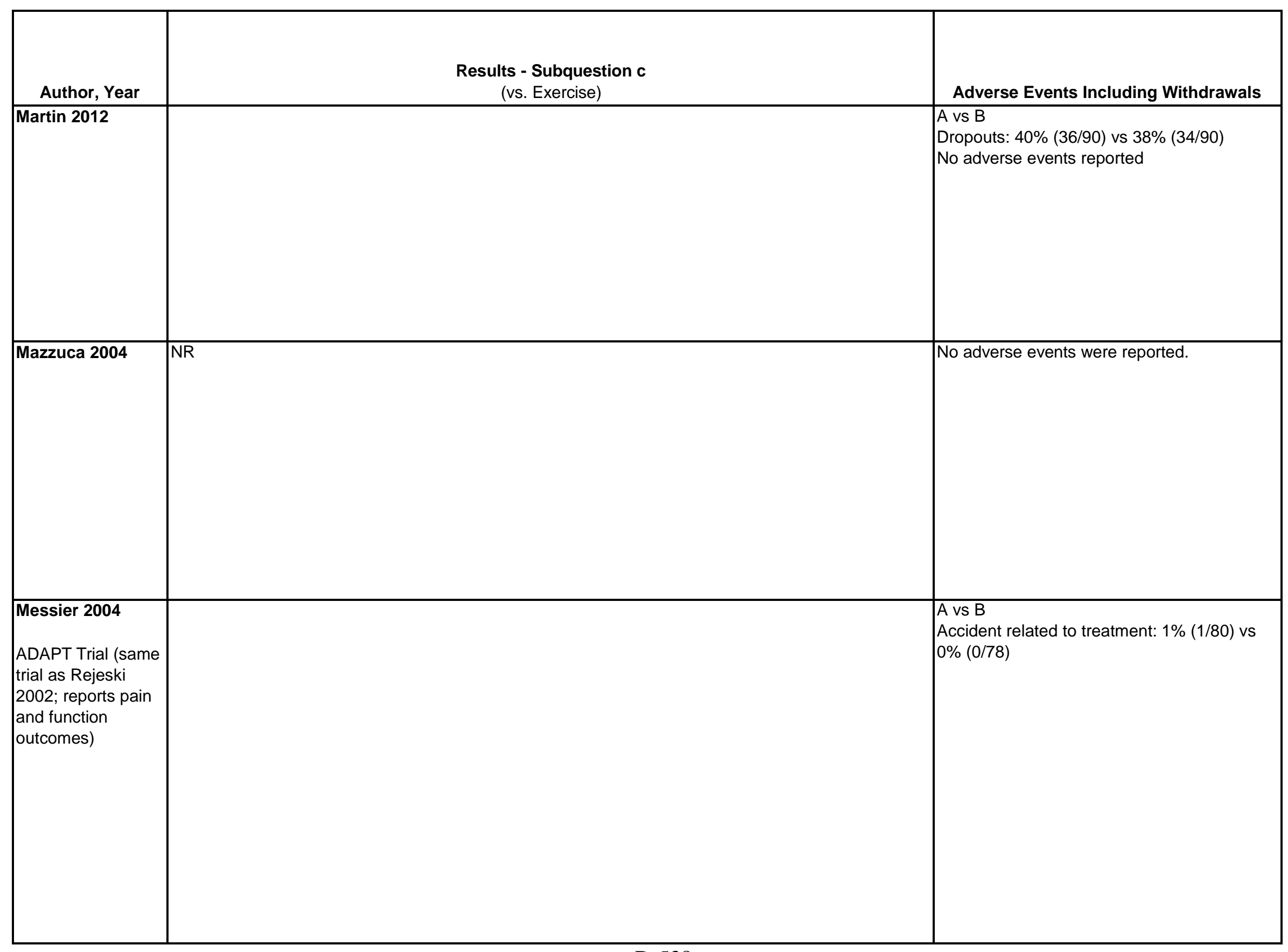




\begin{tabular}{|c|c|c|c|}
\hline Author, Year & Funding Source & Quality & Comments \\
\hline Mazzuca 2004 & & Fair & $\begin{array}{l}\text { Only results for mean WOMAC pain were given for } 1 \text { month post-treatment follow up. The } \\
\text { other scores given were at immediate follow up. Mean pain scores were estimated from a } \\
\text { graph. }\end{array}$ \\
\hline $\begin{array}{l}\text { Messier } 2004 \\
\text { ADAPT Trial (same } \\
\text { trial as Rejeski } \\
\text { 2002; reports pain } \\
\text { and function } \\
\text { outcomes) }\end{array}$ & $\begin{array}{l}\text { NIH grants from 5p60-AG-10484-07 } \\
\text { and M01-RR-00211 }\end{array}$ & Fair & $\begin{array}{l}\text { Means for WOMAC physical function scores were estimated from a graph } \\
\text { A diet group }(n=73) \text { and a diet+exercise group }(n=68) \text { were also included in the study but } \\
\text { data was not abstracted } \\
\text { Between group MDs calculated }\end{array}$ \\
\hline
\end{tabular}




\begin{tabular}{|c|c|c|c|}
\hline Author, Year & $\begin{array}{c}\text { Country } \\
\text { Number of Centers } \\
\text { Setting }\end{array}$ & Inclusion/Exclusion Criteria & $\begin{array}{c}\text { Number Randomized, } \\
\text { Analyzed } \\
\text { Attrition }\end{array}$ \\
\hline Miyamoto 2013 & \begin{tabular}{|l|} 
Brazil \\
1 center \\
Outpatient
\end{tabular} & $\begin{array}{l}\text { Patients aged } 18 \text { to } 60 \text { with chronic nonspecific low back pain for } 3 \\
\text { months or greater. } \\
\text { Exclude: Contraindication for physical exercise, previous regular } \\
\text { Pilates method training, pregnancy, serious spinal pathologies, } \\
\text { previous or scheduled spine surgery, low back pain from nerve root } \\
\text { compression, physical therapy for low back pain in previous } 6 \text { months }\end{array}$ & $\begin{array}{l}\text { Randomized: } 86 \\
\text { Treated: } 86 \\
\text { Analyzed: } 86 \\
\text { Attrition: } 0 \%(0 / 86)\end{array}$ \\
\hline
\end{tabular}




\begin{tabular}{|c|c|}
\hline Author, Year & Intervention, Comparator \\
\hline Miyamoto 2013 & $\begin{array}{l}\text { A.Muscle performance (Pilates) }(n=43): 2 \text { sessions of } 60 \text { minutes a week for } 6 \text { weeks. Sessions were individual and were based on the modified } \\
\text { Pilates method, with exercises aimed at improving breathing, core stability, motor control, posture, flexibility, and mobility with the spine in neutral } \\
\text { position. } \\
\text { B.Attention control (education) }(n=43) \text { : Instructed to not undergo treatments elsewhere. Subjects received twice-weekly phone calls regarding } \\
\text { education booklet instructions that all patients received. } \\
\text { All subjects: Received an educational booklet containing information on the anatomy of the spine and pelvis, information on low back pain, and } \\
\text { recommendations for posture and movements involved in the activities of daily living. }\end{array}$ \\
\hline
\end{tabular}




\begin{tabular}{|c|c|c|c|}
\hline Author, Year & Study Participants & Outcome Measures & $\begin{array}{c}\text { Duration of } \\
\text { Followup }\end{array}$ \\
\hline Miyamoto 2013 & $\begin{array}{l}\text { A vs B } \\
\text { Age: } 41 \text { vs } 38 \\
\text { Female: } 84 \% \text { vs } 79 \% \\
\text { Duration of symptoms (months): } 73.3 \text { vs } 56.7 \\
\text { Percent done previous physical therapy: } 42 \% \text { vs } 2 \% \\
\text { Percent used previous other treatment: } 9 \% \text { vs } 7 \% \\
\text { Percent using medication: } 40 \% \text { vs } 42 \% \\
\text { RMDQ: } 9.7(4.5) \text { vs } 10.5(5.4) \\
\text { PSFS: } 4.9 \text { (1.8) vs } 4.3(1.8) \\
\text { Pain VAS: } 6.6(1.5) \text { vs } 6.5(1.7) \\
\text { Global impression of recovery: }-1.0(2.3) \text { vs }-1.0(2.5)\end{array}$ & $\begin{array}{l}\text { RMDQ (0-24, higher score=higher disability) } \\
\text { Patient-Specific Functional Scale (0-10, higher } \\
\text { score=lower disability) } \\
\text { Pain (0-10 VAS, higher score=higher pain) } \\
\text { Global impression of recovery ( }-5 \text { to }+5 \text {, higher } \\
\text { score=greater recovery) }\end{array}$ & $\begin{array}{l}\text { Short-term } \\
\text { followup } \\
4.5 \text { months }\end{array}$ \\
\hline
\end{tabular}




\begin{tabular}{|c|c|}
\hline Author, Year & $\begin{array}{c}\text { Results - Subquestion a } \\
\text { (vs. sham, no treatment, waitlist, attention control) }\end{array}$ \\
\hline Miyamoto 2013 & 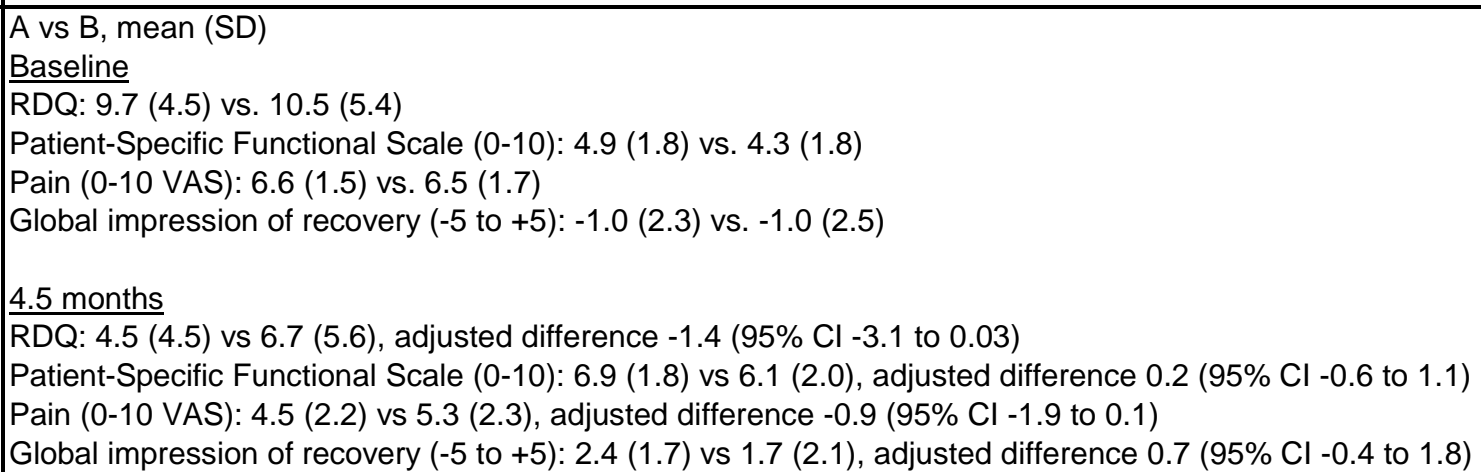 \\
\hline
\end{tabular}




\begin{tabular}{|c|c|c|}
\hline & & $\begin{array}{c}\text { Results - Subquestion b } \\
\text { (vs. Pharmacological therapy) }\end{array}$ \\
\hline Muthor, Year & & \\
& \\
& \\
\hline
\end{tabular}




\begin{tabular}{|c|c|c|}
\hline Author, Year & $\begin{array}{c}\text { Results - Subquestion c } \\
\text { (vs. Exercise) }\end{array}$ & Adverse Events Including Withdrawals \\
\hline Miyamoto 2013 & NR & \\
& & \\
\hline
\end{tabular}




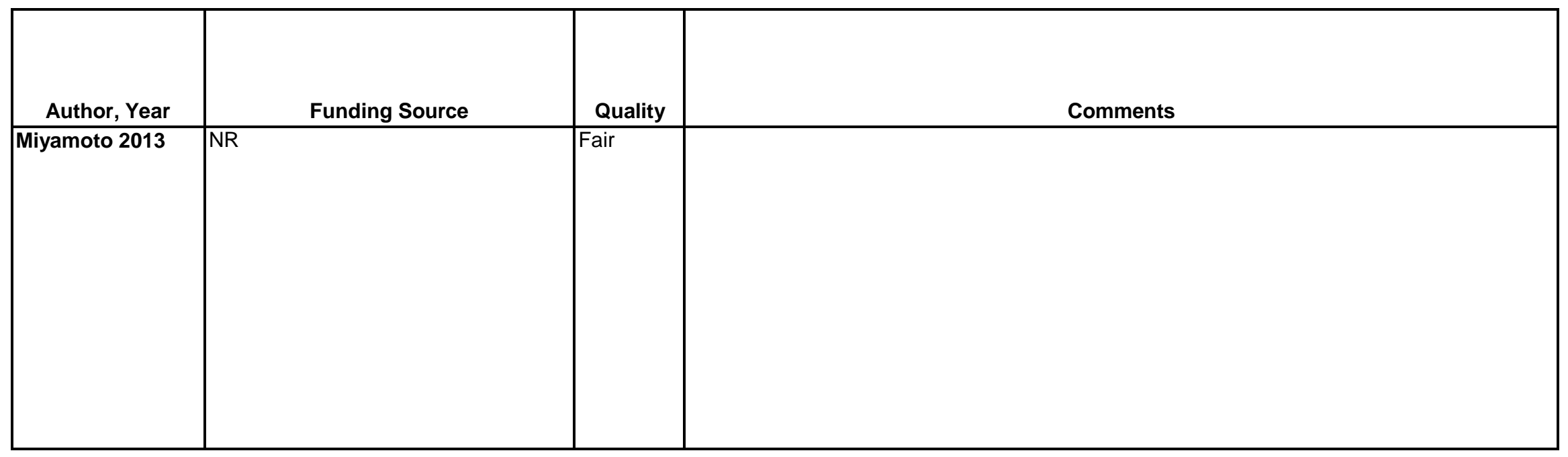

D-546 


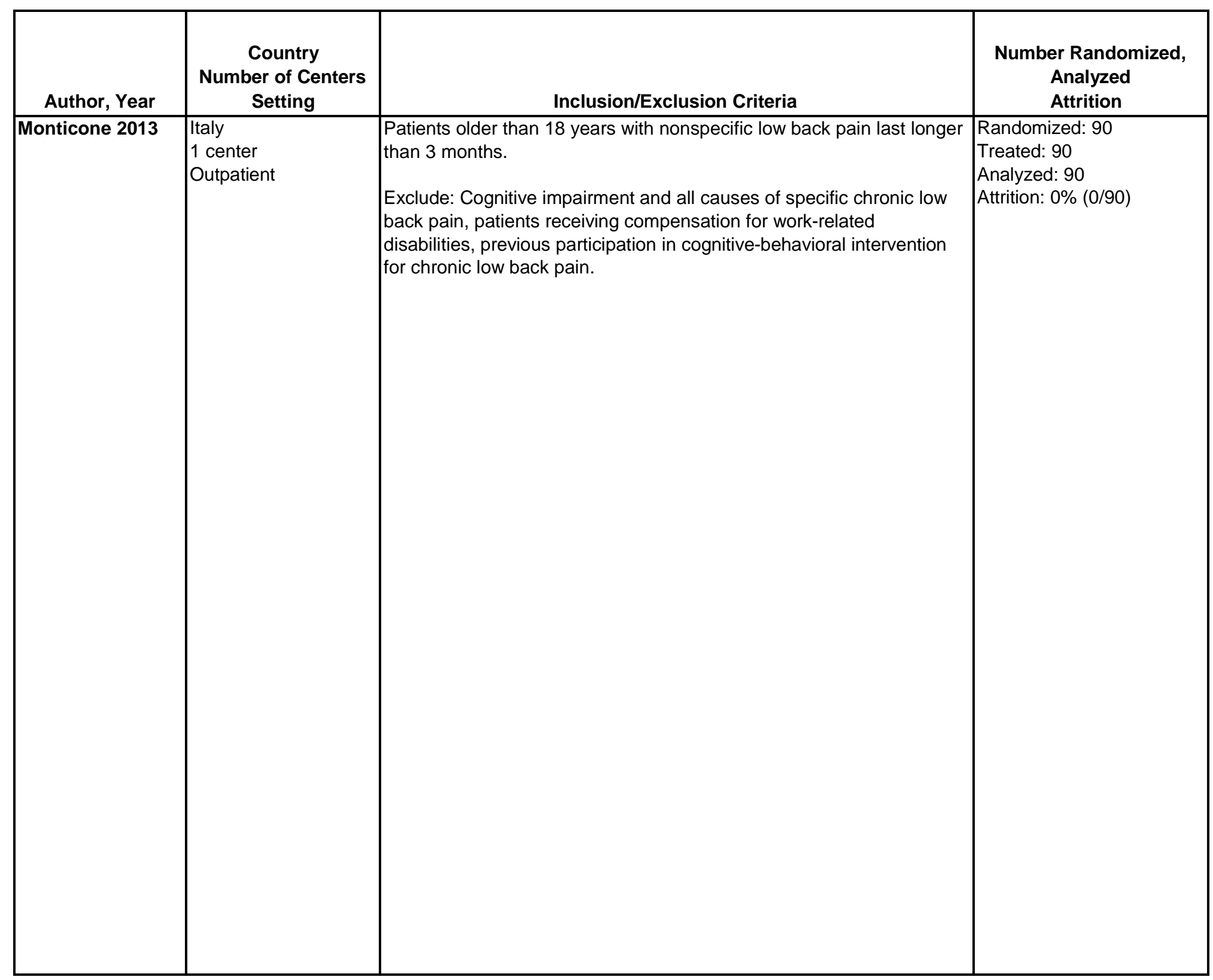




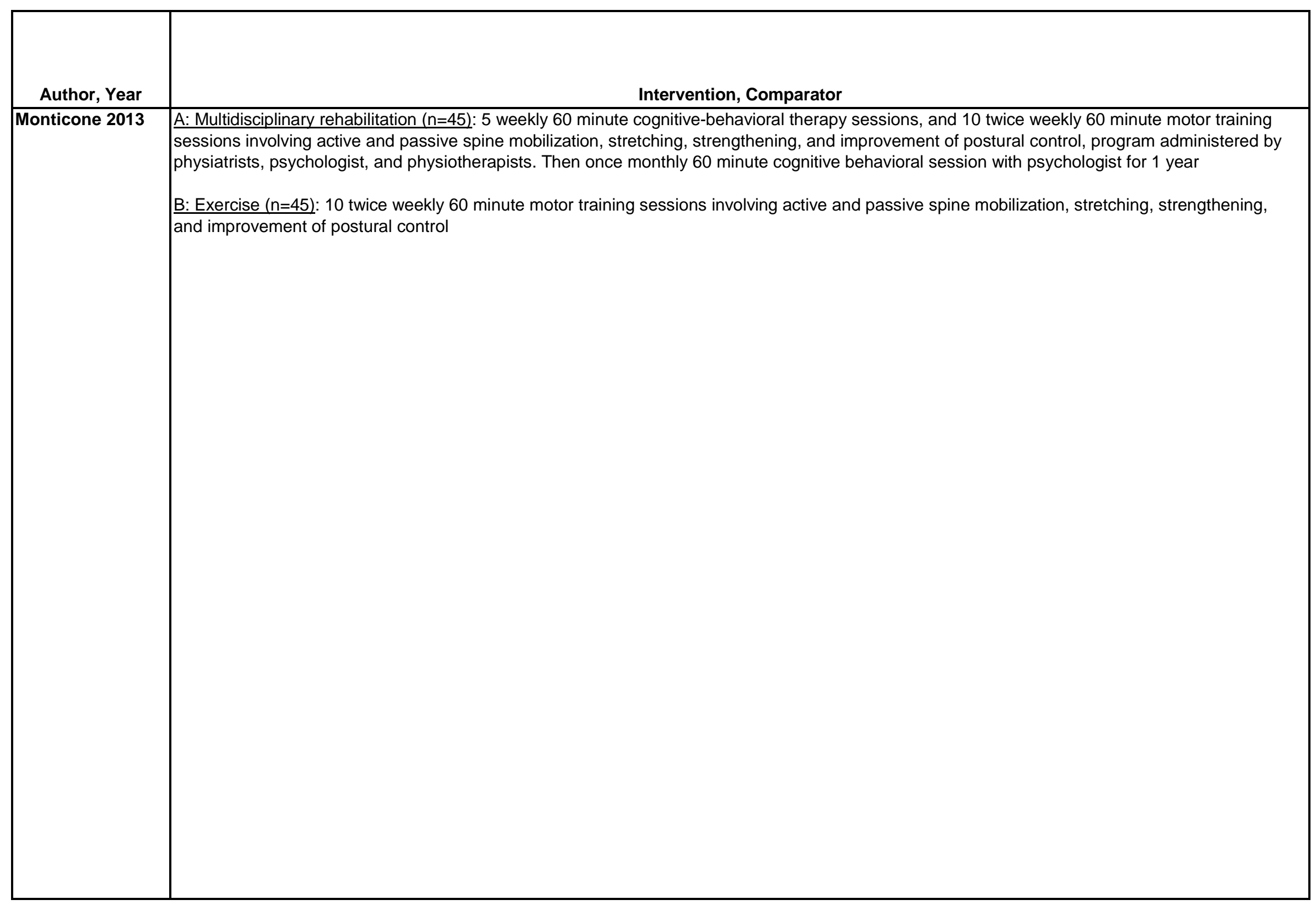




\begin{tabular}{|c|c|c|c|}
\hline Author, Year & Study Participants & Outcome Measures & $\begin{array}{l}\text { Duration of } \\
\text { Followup }\end{array}$ \\
\hline Monticone 2013 & \begin{tabular}{|l} 
A vs B \\
Age: 49 vs 50 \\
Female: $60 \%$ vs $56 \%$ \\
Comorbidity: \\
$\quad$ None: $47 \%$ vs $40 \%$ \\
$\quad$ Musculoskeletal: $18 \%$ vs $20 \%$ \\
$\quad$ Non-musculoskeletal: $11 \%$ vs $16 \%$ \\
Pain duration, months: $25.2(11.9)$ vs $26.3(11.7)$ \\
RDQ (0-24): $15.3(2.9)$ vs $15.0(2.9)$ \\
Pain (0-10 VAS): $7.0(1.1)$ vs $7.0(1.3)$ \\
SF-36 physical functioning: $47.2(27.3)$ vs $48.3(24.7)$ \\
SF-36 physical role: $29.4(35.5)$ vs $31.1(32.5)$ \\
SF-36 physical pain: $38.2(15.4)$ vs $41.4(17.9)$ \\
SF-36 general health: $34.0(17.7)$ vs $36.7(14.1)$ \\
SF-36 vitality: $52.0(16.9)$ vs $52.6(15.4)$ \\
SF-36 social functioning: $50.8(18.3)$ vs $51.6(17.7)$ \\
SF-36 emotional role: $39.3(35.0)$ vs $39.3(37.8)$ \\
SF-36 mental health: $50.1(11.6)$ vs $52.1(12.7)$
\end{tabular} & $\begin{array}{l}\text { RDQ (0-24) } \\
\text { Pain }(0-10 \text { VAS) } \\
\text { SF-36 subscales( } 0-100, \text { higher score=higher quality of } \\
\text { life) }\end{array}$ & \begin{tabular}{|l}
11 and 23 \\
months \\
(based on \\
time following \\
initial \\
intensive 5 \\
week \\
intervention)
\end{tabular} \\
\hline
\end{tabular}




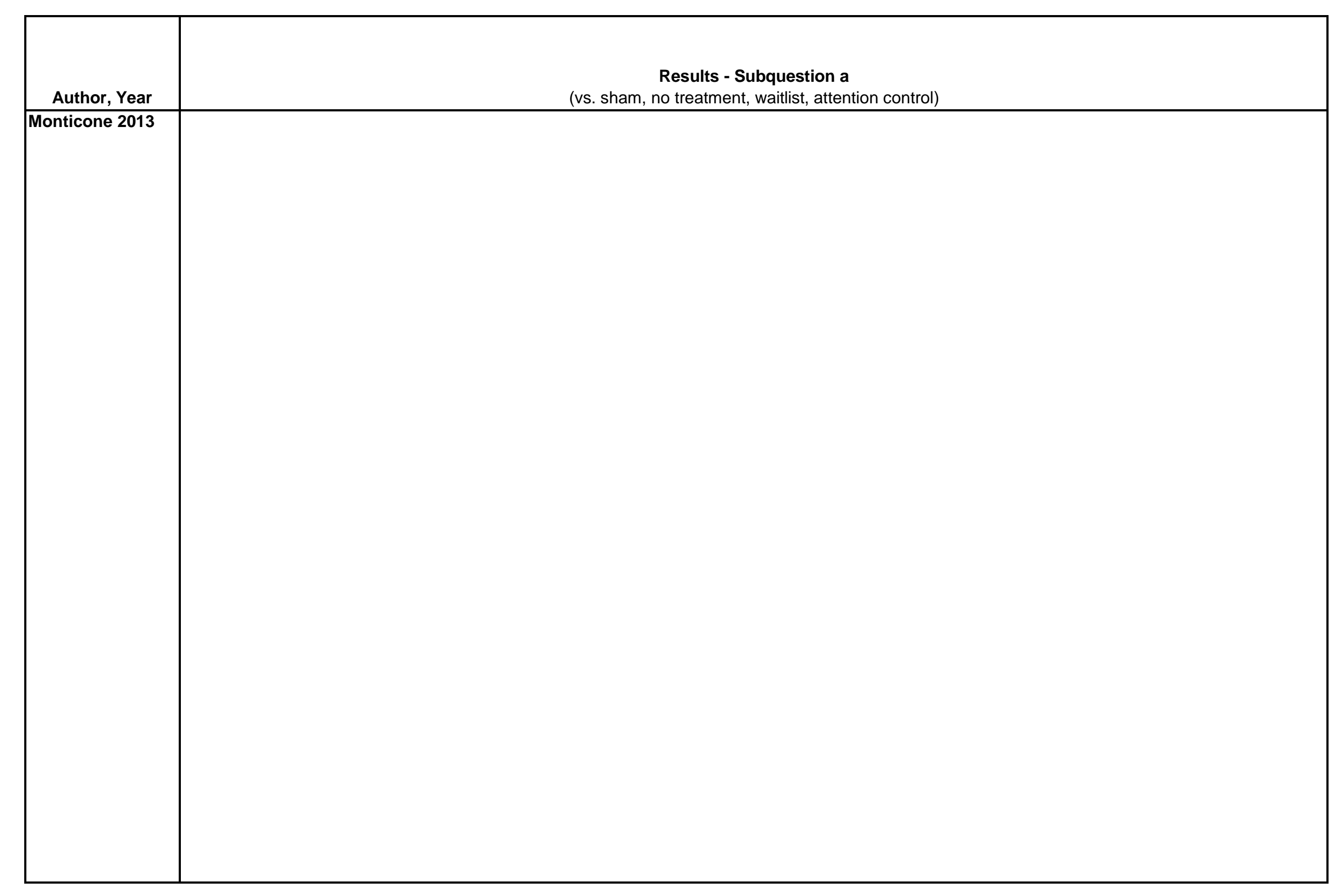

D-550 


$$
[-
$$




\begin{tabular}{|c|c|c|}
\hline Author, Year & $\begin{array}{l}\text { Results - Subquestion c } \\
\text { (vs. Exercise) }\end{array}$ & Adverse Events Including Withdrawals \\
\hline Monticone 2013 & 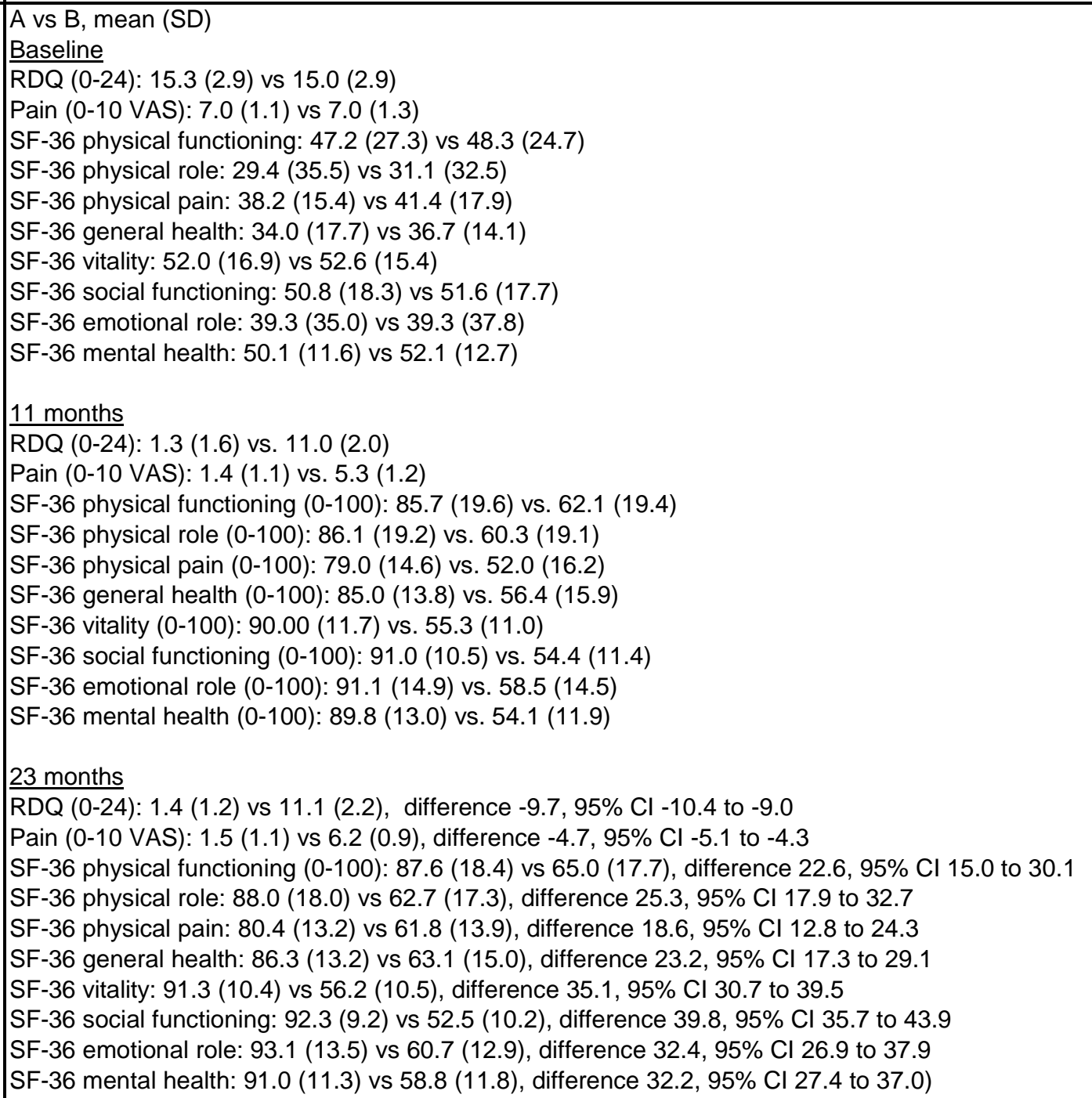 & NR \\
\hline
\end{tabular}




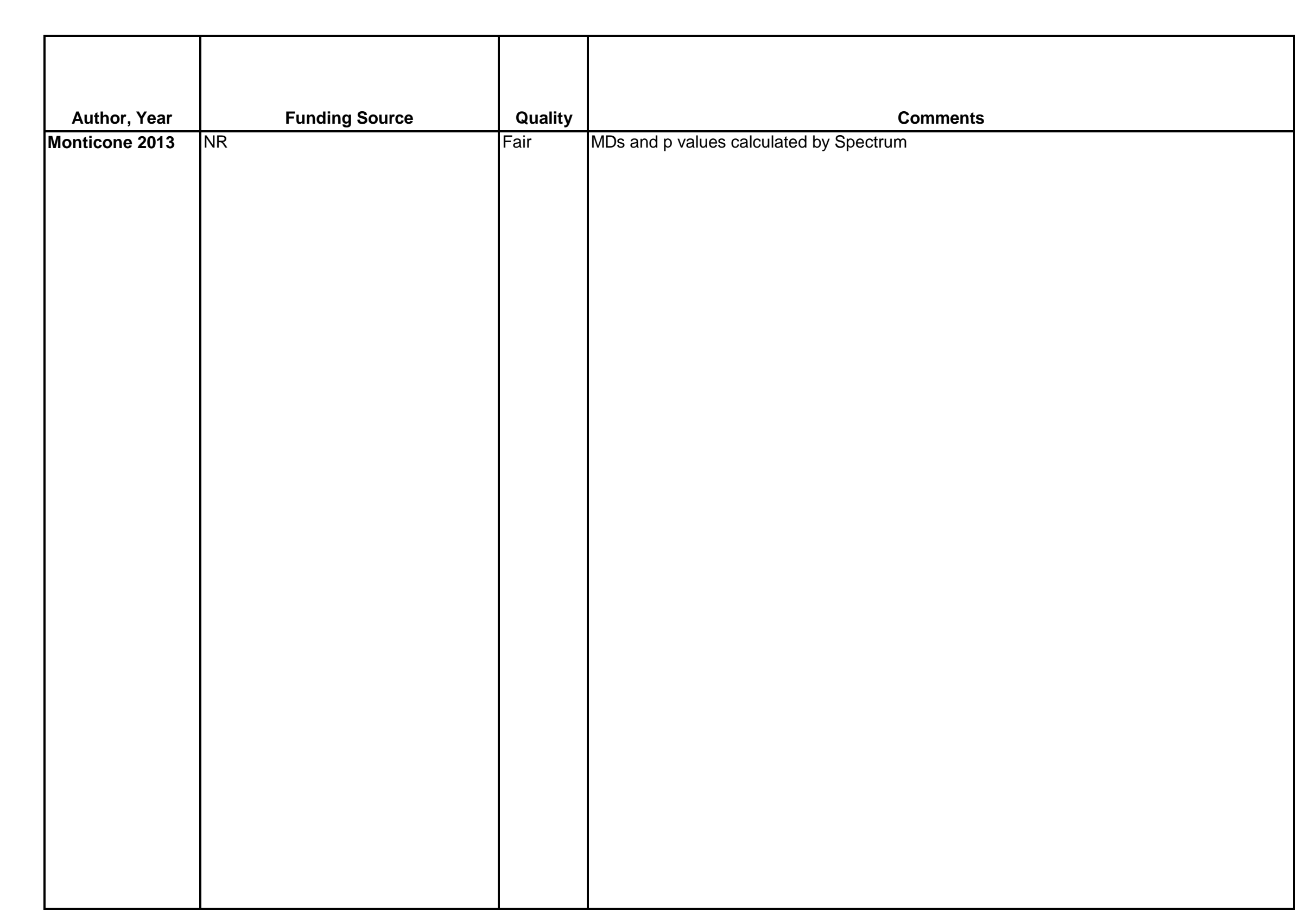




\begin{tabular}{|c|c|c|c|}
\hline Author, Year & $\begin{array}{c}\text { Country } \\
\text { Number of Centers } \\
\text { Setting }\end{array}$ & Inclusion/Exclusion Criteria & $\begin{array}{c}\text { Number Randomized, } \\
\text { Analyzed } \\
\text { Attrition }\end{array}$ \\
\hline Monticone 2014 & $\begin{array}{l}\text { Italy } \\
\text { Number of centers: } 1 \\
\text { Outpatient }\end{array}$ & $\begin{array}{l}\text { Patients age }>18 \\
\text { Nonspecific chronic ( }>3 \text { months) LBP } \\
\text { Exclude: } \\
\text { Central or peripheral neurological signs } \\
\text { Cognitive impairment } \\
\text { Severe cardiovascular and respiratory comorbidity } \\
\text { Prior spine surgery } \\
\text { Ambulation deficits due to neurological or orthopedic impairments } \\
\text { Pregnant } \\
\text { Previous participation in cognitive-behavioral interventions }\end{array}$ & $\begin{array}{l}\text { Randomized: } 20 \\
\text { Treated: } 20 \\
\text { Analyzed: } 20 \\
\text { Attrition: } 0 \%\end{array}$ \\
\hline Morone 2009 & $\begin{array}{l}\text { US, Pennsylvania } \\
\text { Number of centers } 1 \\
\text { Clinic and } \\
\text { Outpatient }\end{array}$ & $\begin{array}{l}\text { Patients age } \geq 65 \text { years, MMSE score } \geq 24 \text {, and chronic low back pain } \\
\text { (with moderate intensity for } \geq 3 \text { months) and intact cognition (Mini- } \\
\text { Mental Status Exam } \geq 24 \text { ) } \\
\\
\text { Exclude: non-English speaking, previous participation in mindfulness } \\
\text { meditation, serious hearing or vision impairment, medical instability } \\
\text { from heart or lung disease, multiple recent falls or inability to stand } \\
\text { independently, pain caused by an acute injury within previous } 3 \\
\text { months, possible serious underlying illness (unexplained weight loss, } \\
\text { fever, or sudden worsening of back pain) }\end{array}$ & $\begin{array}{l}\text { Randomized: } 40 \\
\text { Treated: } 35 \\
\text { Analyzed: } 35 \\
\text { Attrition: } 14 \%(5 / 35)\end{array}$ \\
\hline
\end{tabular}




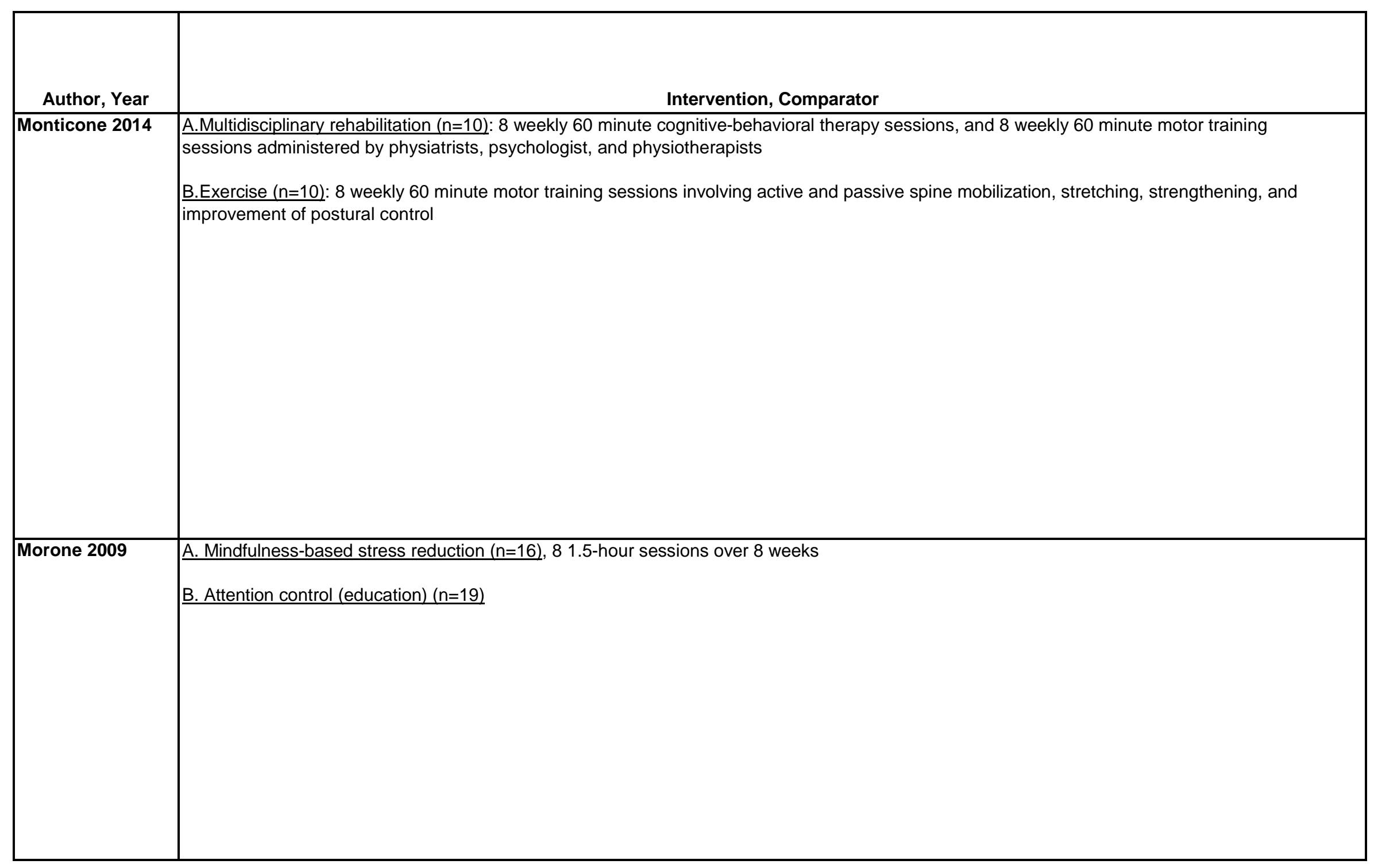




\begin{tabular}{|c|c|c|c|}
\hline Author, Year & Study Participants & Outcome Measures & $\begin{array}{c}\text { Duration of } \\
\text { Followup }\end{array}$ \\
\hline Monticone 2014 & $\begin{array}{l}\text { A vs. B } \\
\text { Age (mean): } 59 \text { vs. } 57 \text { years } \\
\text { Female: } 7 \% \text { vs. } 4 \% \\
\text { Race: NR } \\
\text { Pain duration (months): } 15 \text { vs. } 14\end{array}$ & $\begin{array}{l}\text { Oswestry Disability Index (ODI, 0-100, higher } \\
\text { number=greater disability } \\
\text { Pain (0-10 NRS) } \\
\text { Italian SF-36 (8 scales, each scored 1-100, higher } \\
\text { number = better health status) } \\
\text { Global perceived effect: treatment satisfaction } \\
\text { questions, higher number = worsening of symptoms }\end{array}$ & 3 months \\
\hline Morone 2009 & $\begin{array}{l}\text { A vs B } \\
\text { Age (mean): } 78 \text { vs. } 73 \text { years } \\
\text { Female: } 69 \% \text { vs. } 58 \% \\
\text { White: } 94 \% \text { vs. } 80 \% \\
\text { African American: } 5 \% \text { vs. } 15 \% \\
\text { Asian: } 0 \% \text { vs. } 5 \% \\
\text { Opioids: } 19 \% \text { vs. } 26 \%\end{array}$ & $\begin{array}{l}\text { Roland and Morris Disability Questionnaire (RMDQ, } \\
\text { range 0-24, higher scores indicate more disability } \\
\text { SF-36 Pain Score (10-62) } \\
\text { McGill Pain Questionnaire Total Score: Answer range } \\
\text { 0-45, lower scores indicate less pain } \\
\text { McGill Pain Questionnaire Current Pain Scale: Answer } \\
\text { range 0-10, lower scores indicate less pain }\end{array}$ & 4 months \\
\hline
\end{tabular}




\begin{tabular}{|c|c|}
\hline Author, Year & $\begin{array}{c}\text { Results - Subquestion a } \\
\text { (vs. sham, no treatment, waitlist, attention control) }\end{array}$ \\
\hline Monticone 2014 & NR \\
\hline Morone 2009 & 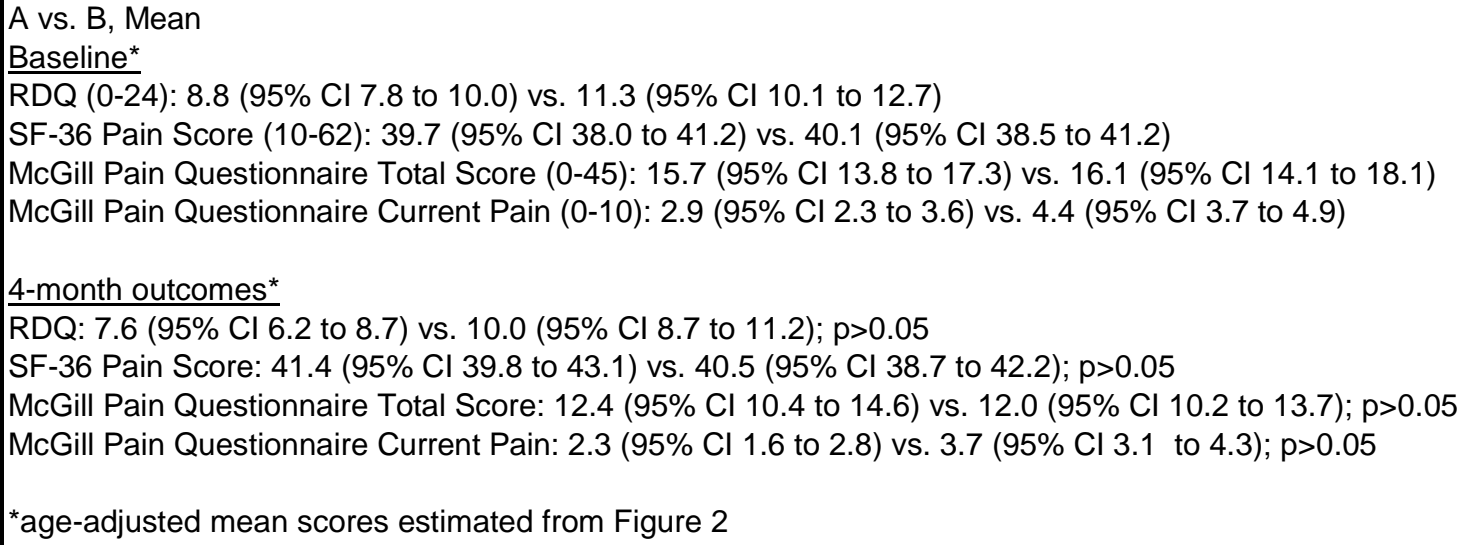 \\
\hline
\end{tabular}




\begin{tabular}{|l|l|}
\hline Author, Year & \multicolumn{1}{c|}{$\begin{array}{c}\text { Results - Subquestion b } \\
\text { (vs. Pharmacological therapy) }\end{array}$} \\
\hline Monticone 2014 & NR \\
& \\
\hline Morone 2009 & NR \\
\hline
\end{tabular}




\begin{tabular}{|c|c|c|}
\hline Author, Year & $\begin{array}{c}\text { Results - Subquestion c } \\
\text { (vs. Exercise) }\end{array}$ & Adverse Events Including Withdrawals \\
\hline Monticone 2014 & 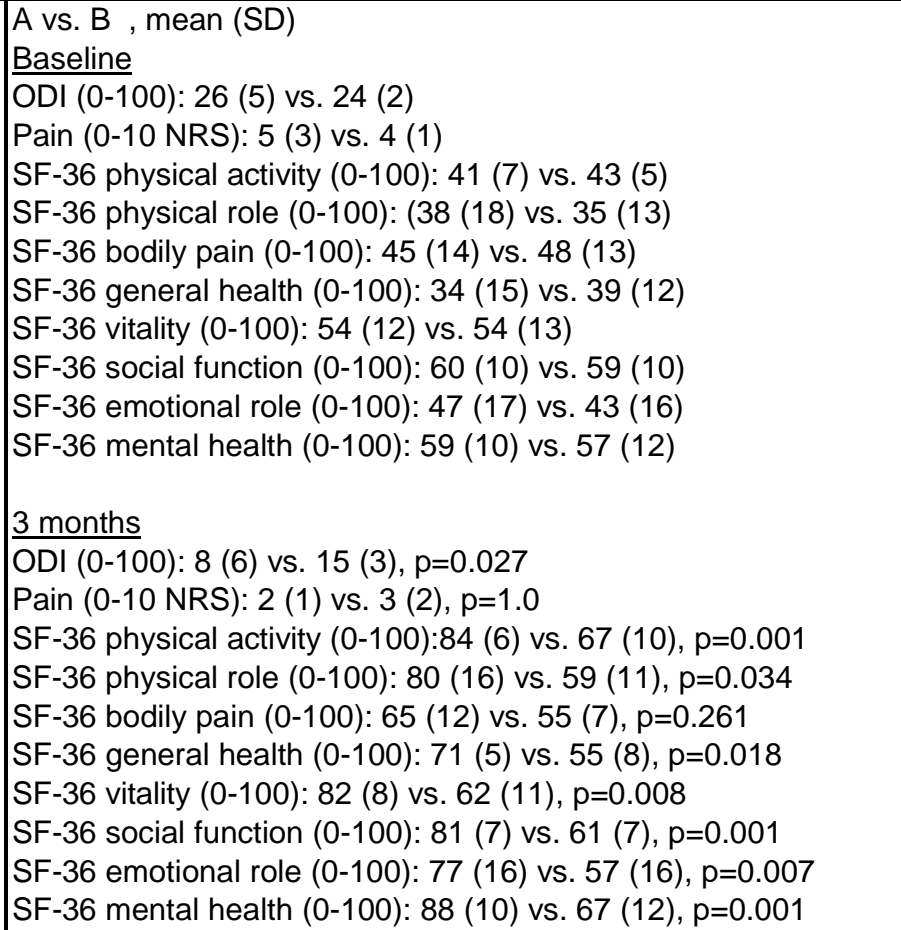 & $\begin{array}{l}\text { Withdrawals: } 0 \\
\text { Nonserious AEs: } \\
\text { Transitory pain worsening: } 3 / 10 \text { vs. } 2 / 10 \\
\text { Mood alterations: } 1 / 10 \text { vs. } 2 / 10\end{array}$ \\
\hline Morone 2009 & NR & No adverse events. \\
\hline
\end{tabular}




\begin{tabular}{|l|l|l|l|}
\hline Author, Year & Funding Source & Quality & \\
\hline Monticone 2014 & EuroSpine Task Force on Research & Fair & \\
& & & \\
& & & \\
\hline Morone 2009 & National Institutes of Health & Fair & \\
\hline
\end{tabular}




\begin{tabular}{|c|c|c|c|}
\hline Author, Year & $\begin{array}{c}\text { Country } \\
\text { Number of Centers } \\
\text { Setting }\end{array}$ & Inclusion/Exclusion Criteria & $\begin{array}{c}\text { Number Randomized, } \\
\text { Analyzed } \\
\text { Attrition }\end{array}$ \\
\hline Morone 2016 & $\begin{array}{l}\text { US, Pennsylvania } \\
\text { Number of centers } 1 \\
\text { Clinic }\end{array}$ & $\begin{array}{l}\text { Patients age } \geq 65 \text { years, MMSE score } \geq 24 \text {, and chronic low back pain } \\
\text { (with moderate intensity for } \geq 3 \text { months) and functional limitations } \\
\text { score of } \geq 11 \text { on the Roland and Morris } \\
\text { Disability Questionnaire } \\
\text { Exclude: Patients who participated } \\
\text { previous mindfulness meditation programs, or had serious illness } \\
\text { (malignant neoplasms, infection, unexplained fever, weight loss, or } \\
\text { recent trauma) or had moderate to severe depression. }\end{array}$ & $\begin{array}{l}\text { Randomized: } 282 \\
\text { Treated: } 273 \\
\text { Analyzed: } 282 \\
\text { Attrition: } 4 \% \\
(9 / 282)\end{array}$ \\
\hline Nambi 2014 & $\begin{array}{l}\text { India } \\
\text { Number of centers: } 1 \\
\text { Outpatient }\end{array}$ & $\begin{array}{l}\text { Age }>18 \text { years } \\
\text { Nonspecific LPB for } 3 \text { months; } \\
\text { Exclude: LBP due to nerve root compressing, disc prolapse, spinal } \\
\text { stenosis, tumor, spinal infection, ankylosing spondylosis, } \\
\text { spondylolisthesis, kyphosis or structural scoliosis, widespread } \\
\text { neurological disorder, pre-surgical candidates } \\
\text { Involved in litigation or compensation, Compromised cardiopulmonary } \\
\text { system } \\
\text { Pregnant } \\
\text { BMI >35 } \\
\text { Major depression or substance abuse } \\
\text { Yoga practitioners }\end{array}$ & $\begin{array}{l}\text { Randomized: } 60 \\
\text { Treated: } 60 \\
\text { Analyzed:54 } \\
\text { Attrition: } 10 \%(6 / 60)\end{array}$ \\
\hline
\end{tabular}




\begin{tabular}{|c|c|}
\hline Author, Year & Intervention, Comparator \\
\hline Morone 2016 & $\begin{array}{l}\text { A. Mindfulness-based stress reduction ( } n=140), 81.5 \text {-hour sessions over } 8 \text { weeks, followed by } 6 \text { monthly booster sessions } \\
\text { B. Attention control (education) }(n=142)\end{array}$ \\
\hline Nambi 2014 & $\begin{array}{l}\text { A: Iyengar yoga ( } n=30): 1 \text { hour lyengar class/week }+30 \text { minute home practice, } 5 \text { days/week for } 4 \text { weeks; with props; } 29 \text { poses introduced in } \\
\text { stages simple to progressively more challenging; At end of } 4 \text { weeks, participants encouraged to continue Yoga at home. } \\
\text { B: Exercise ( } n=30) \text { : Following } 5-10 \text { minute warm up (stretching exercises for soft tissue flexibility and range of motion); Taught specific exercises for } \\
\text { strengthening abdominal and back muscles (depending on clinical findings) } 3 \text { days/week with } 5 \text { repetitions in } 3 \text { sets with } 30 \text {-s pause per set; } \\
\text { repetitions gradually increased until reaching } 15 \text { for } 4 \text { weeks: instructed to refrain from other back exercises, strenuous activities outside of normal } \\
\text { activities of daily living during study. }\end{array}$ \\
\hline
\end{tabular}




\begin{tabular}{|c|c|c|c|}
\hline Author, Year & Study Participants & Outcome Measures & $\begin{array}{c}\text { Duration of } \\
\text { Followup }\end{array}$ \\
\hline Morone 2016 & $\begin{array}{l}\text { A vs } B \\
\text { Age (mean): } 75 \text { vs. } 74 \\
\text { Female: } 66 \% \text { vs. } 66 \% \\
\text { White: } 70 \% \text { vs. } 71 \% \\
\text { African American: } 30 \% \text { vs. } 27 \% \\
\text { Asian: } 0 \% \text { vs. } 2 \% \\
\text { Cumulative Illness Rating Scale score, mean (SD): } 3.4 \text { (2.1) vs. } 3.2 \\
\text { (1.8) } \\
\text { Geriatric Depression Scale score: } 5.7 \text { (4.3) vs. } 6.0 \text { (4.3) }\end{array}$ & $\begin{array}{l}\text { Disability (RMDQ Scores range from } 0 \text { to } 24 \text {, with } \\
\text { higher scores indicating increased limitations) } \\
\text { Average pain, NRS }(0-20) \\
\text { SF-36 Global Health Composite (9 to } 67) \\
\text { SF-36 Physical Health Composite (20 to } 65)\end{array}$ & 4.5 months \\
\hline Nambi 2014 & $\begin{array}{l}\text { A vs. B } \\
\text { Mean age: } 44 \text { vs. } 43 \\
\text { Female: } 63 \% \text { vs. } 43 \% \\
\text { Race: NR } \\
\text { Baseline } \\
\text { Pain intensity (10 cm VAS,0= no pain , } 10=\text { worst possible): } 6.7 \text { vs. } \\
6.7 \\
\text { Physically unhealthy days (from CDC HRQOL-4): } 18 \text { vs. } 17.8 \\
\text { Mentally unhealthy days (from CDC HRQOL-4): } 17.0 \text { vs. } 17.4 \\
\text { Activity limitation days (from CDC HRQOL- } 4 \text { ): } 16.7 \text { vs. } 17.1\end{array}$ & $\begin{array}{l}\text { Primary outcomes: } \\
\text { Pain intensity: Visual Analog Scale, } 0-10 \mathrm{~cm} \text { line, higher } \\
\text { number = more pain) } \\
\text { Health-related quality of life: HRQOL-4, dichotomized } \\
\text { answers into fair/poor vs. good/very good/excellent for } \\
\text { general health and into } 14 \text { days vs. }<14 \text { days for } \\
\text { frequency of physical distress, mental distress, activity } \\
\text { limitation. }\end{array}$ & 5 months \\
\hline
\end{tabular}




\begin{tabular}{|c|c|}
\hline Author, Year & $\begin{array}{c}\text { Results - Subquestion a } \\
\text { (vs. sham, no treatment, waitlist, attention control) }\end{array}$ \\
\hline Morone 2016 & 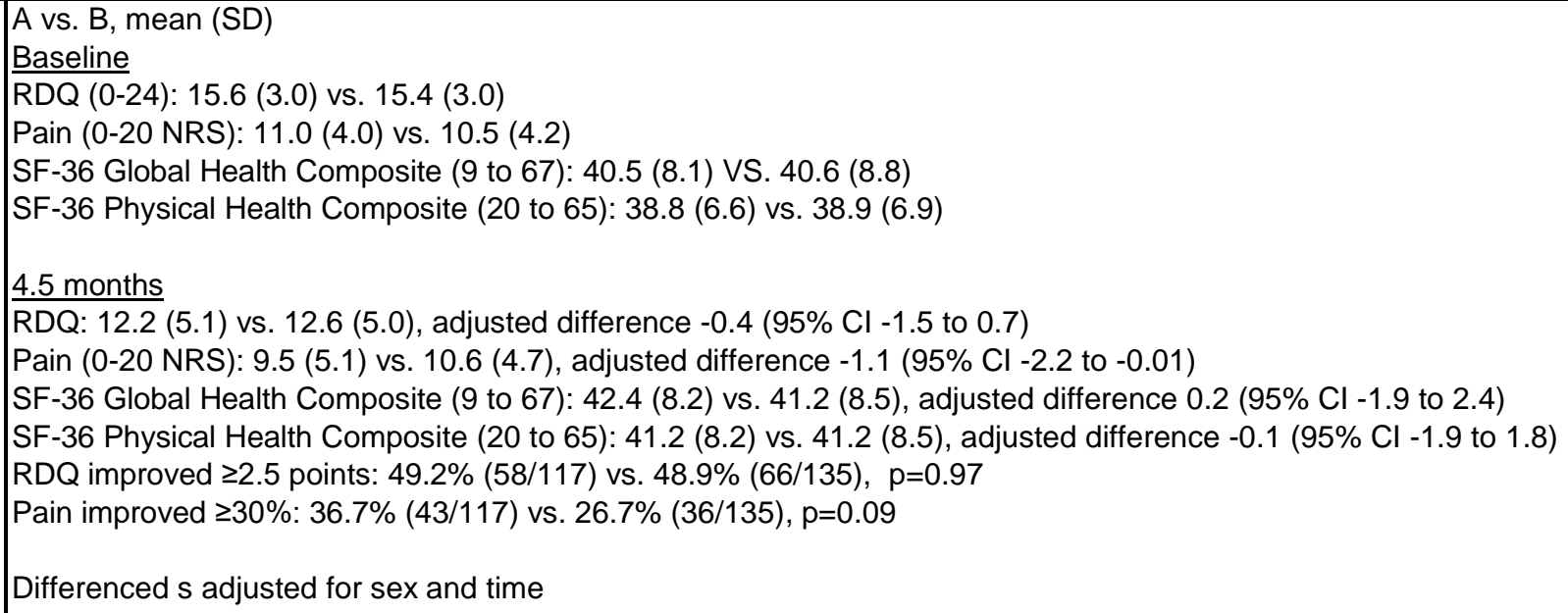 \\
\hline Nambi 2014 & NR \\
\hline
\end{tabular}




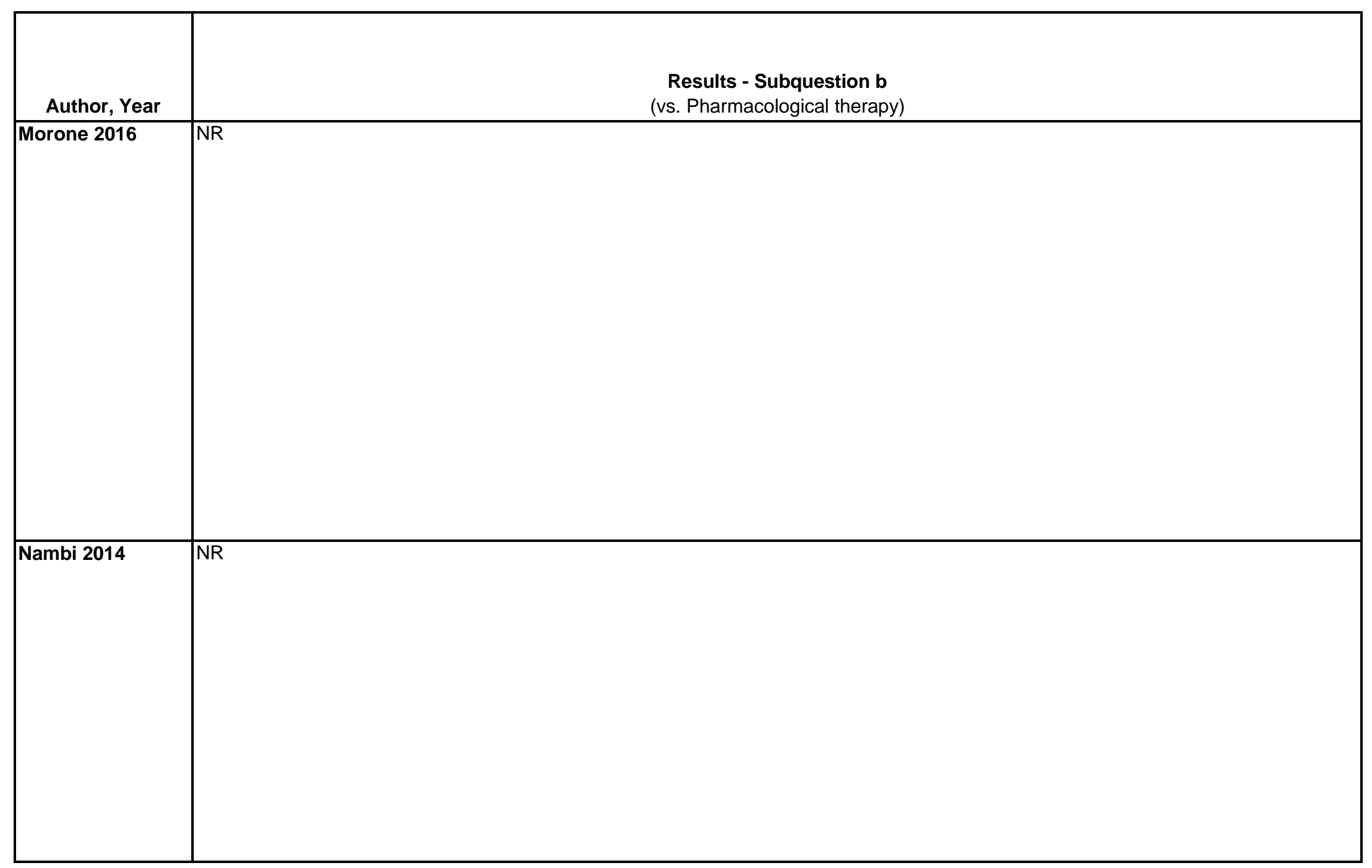




\begin{tabular}{|c|c|c|}
\hline Author, Year & $\begin{array}{l}\text { Results - Subquestion c } \\
\text { (vs. Exercise) }\end{array}$ & Adverse Events Including Withdrawals \\
\hline Morone 2016 & NR & No adverse events. \\
\hline [Nation & $\begin{array}{l}\text { Baseline } \\
\text { Pain intensity (VAS, } 0-10): 6.7(0.9) \text { vs. } 6.7(0.9) \\
\text { Physically unhealthy days: } 18.0(2.5) \text { vs. } 17.8(3.2) \\
\text { Mentally unhealthy days: } 17.0(2.3) \text { vs. } 17.4(2.2) \\
\text { Activity limitation days: } 16.7(2.6) \text { vs. } 17.1(2.5) \\
5 \text { months } \\
\text { Pain intensity (VAS, } 0-10): 1.8(1.1) \text { vs. } 3.8(0.7), p=0.001 \text { (repeated measures ANOVA) } \\
\text { Physically unhealthy days: } 2.6(3.1) \text { vs. } 6.9(3.2), p=0.001 \\
\text { Mentally unhealthy days: } 2.1(2.3) \text { vs. } 5.0(2.0), p=0.001 \\
\text { Activity limitation days: } 2.0(2.2) \text { vs. } 5.0(1.9), p=0.001\end{array}$ & \\
\hline
\end{tabular}




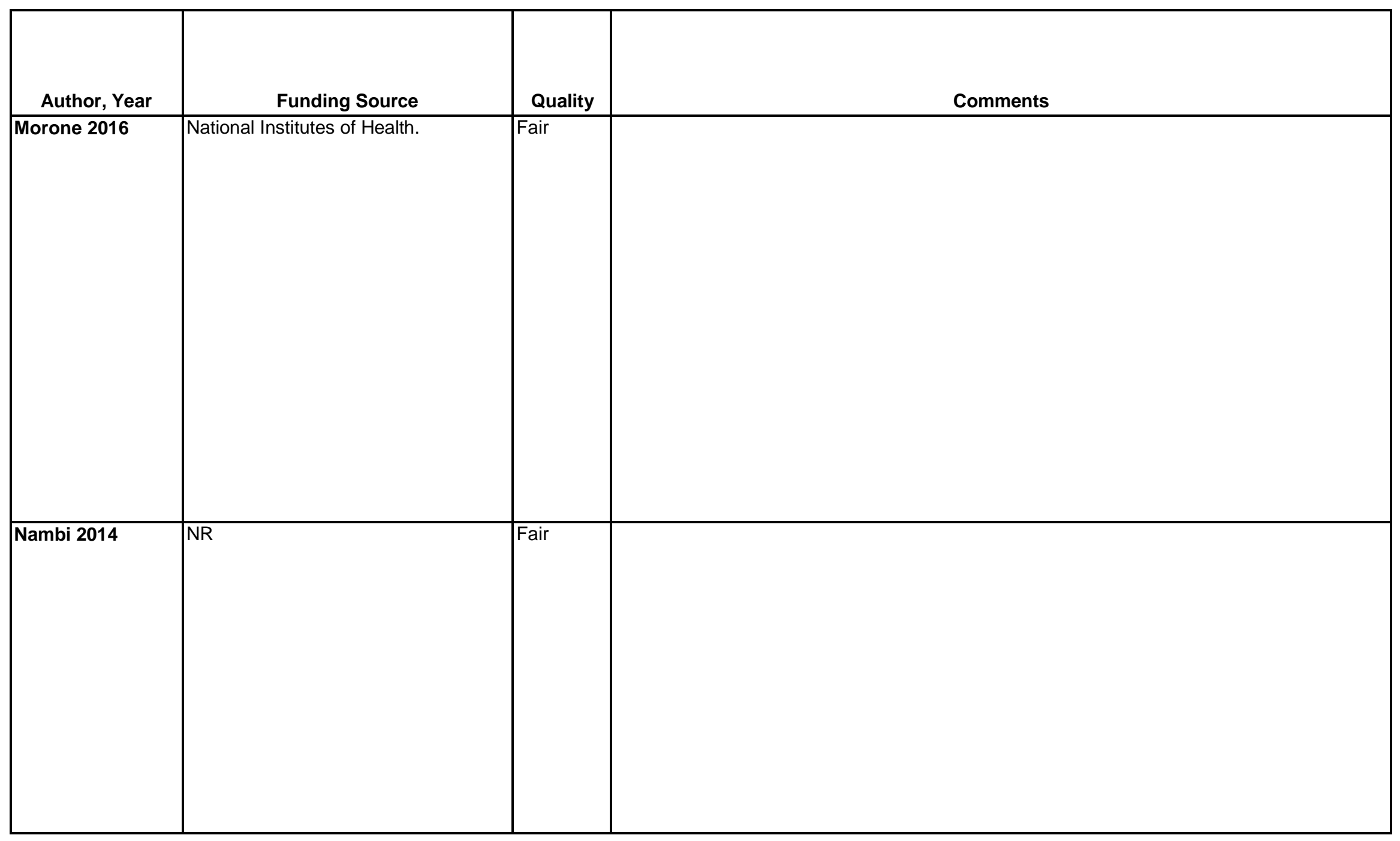

D-567 


\begin{tabular}{|c|c|c|c|}
\hline Author, Year & $\begin{array}{c}\text { Country } \\
\text { Number of Centers } \\
\text { Setting }\end{array}$ & Inclusion/Exclusion Criteria & $\begin{array}{c}\text { Number Randomized, } \\
\text { Analyzed } \\
\text { Attrition }\end{array}$ \\
\hline Nassif 2011 & \begin{tabular}{|l} 
France \\
1 center \\
Subjects' workplace \\
(factory)
\end{tabular} & $\begin{array}{l}\text { Workers aged } 18 \text { or older in the assembly line of a car manufacturing } \\
\text { company with chronic low back pain. } \\
\text { Exclude: Recent surgery or pathologic conditions related to the onset } \\
\text { of low back pain or interfering with the designed monitoring } \\
\text { measurements of the study. }\end{array}$ & $\begin{array}{l}\text { Randomized: } 75 \\
\text { Treated: } 75 \\
\text { Analyzed: } 52 \\
\text { Attrition: } 17 \%(13 / 75)\end{array}$ \\
\hline
\end{tabular}




\begin{tabular}{|c|c|}
\hline Author, Year & Intervention, Comparator \\
\hline Nassif 2011 & $\begin{array}{l}\text { A.Exercise ( } n=37) \text { : Three } 60 \text { minute group sessions of } 2 \text { to } 8 \text { participants per week for } 8 \text { weeks. In sessions, participants trained major muscle } \\
\text { groups through joint flexion and extension, stretching, stability, coordination, and muscle strengthening exercises. } \\
\text { B. Usual care }(n=38) \text { : Subjects received no direct intervention but were free to pursue treatments externally. } \\
\text { All subjects: Received medical and paramedical consultation on the benefits of physical activity and proper working posture positions }\end{array}$ \\
\hline
\end{tabular}




\begin{tabular}{|c|c|c|c|}
\hline Author, Year & Study Participants & Outcome Measures & $\begin{array}{l}\text { Duration of } \\
\text { Followup }\end{array}$ \\
\hline Nassif 2011 & $\begin{array}{l}\text { A vs B } \\
\text { Age: } 45 \text { vs } 45 \\
\text { Female: } 11 \% \text { vs } 21 \% \\
\text { Quebec Back Pain Disability Questionnaire: } 57.3(18.5) \text { vs } 36.2(17.1) \\
\text { RMDQ: } 13.9(4.6) \text { vs } 12.3(5.0) \\
\text { Pain VAS: } 4.5(2.7) \text { vs } 4.9(2.4) \\
\text { Dallas Pain Questionnaire daily activities: } 57.3(16.2) \text { vs } 53.2(19.6) \\
\text { Dallas Pain Questionnaire work and recreation: } 54.9(20.9) \text { vs } 48.8 \\
\text { (19.5) } \\
\text { Dallas Pain Questionnaire anxiety and depression: } 44.7(19.5) \text { vs } 36.5 \\
(23.0) \\
\text { Dallas Pain Questionnaire social: } 34.5(24.9) \text { vs } 31.8(24.1)\end{array}$ & $\begin{array}{l}\text { Quebec Back Pain Disability Questionnaire (0-100, } \\
\text { higher percent=higher disability) } \\
\text { RDQ (0-24, higher score=higher disability) } \\
\text { Pain (0-10 NRS, higher score=higher pain) } \\
\text { Dallas Pain Questionnaire (0-100\%, higher } \\
\text { percent=higher impact of pain) }\end{array}$ & $\begin{array}{l}\text { Short-term } \\
\text { followup } \\
4 \text { months }\end{array}$ \\
\hline
\end{tabular}




\begin{tabular}{|c|c|}
\hline Author, Year & $\begin{array}{c}\text { Results - Subquestion a } \\
\text { (vs. sham, no treatment, waitlist, attention control) }\end{array}$ \\
\hline Nassif 2011 & 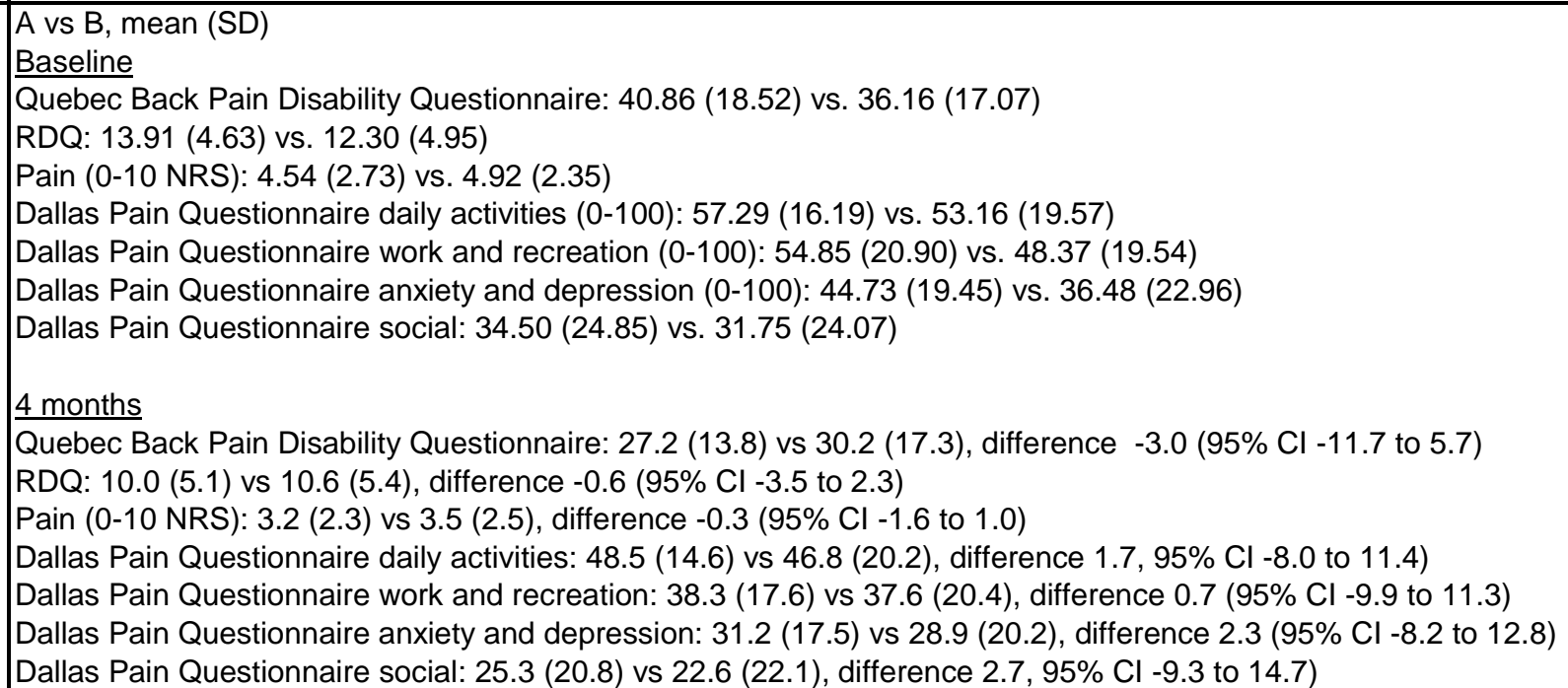 \\
\hline
\end{tabular}




$$
7-
$$




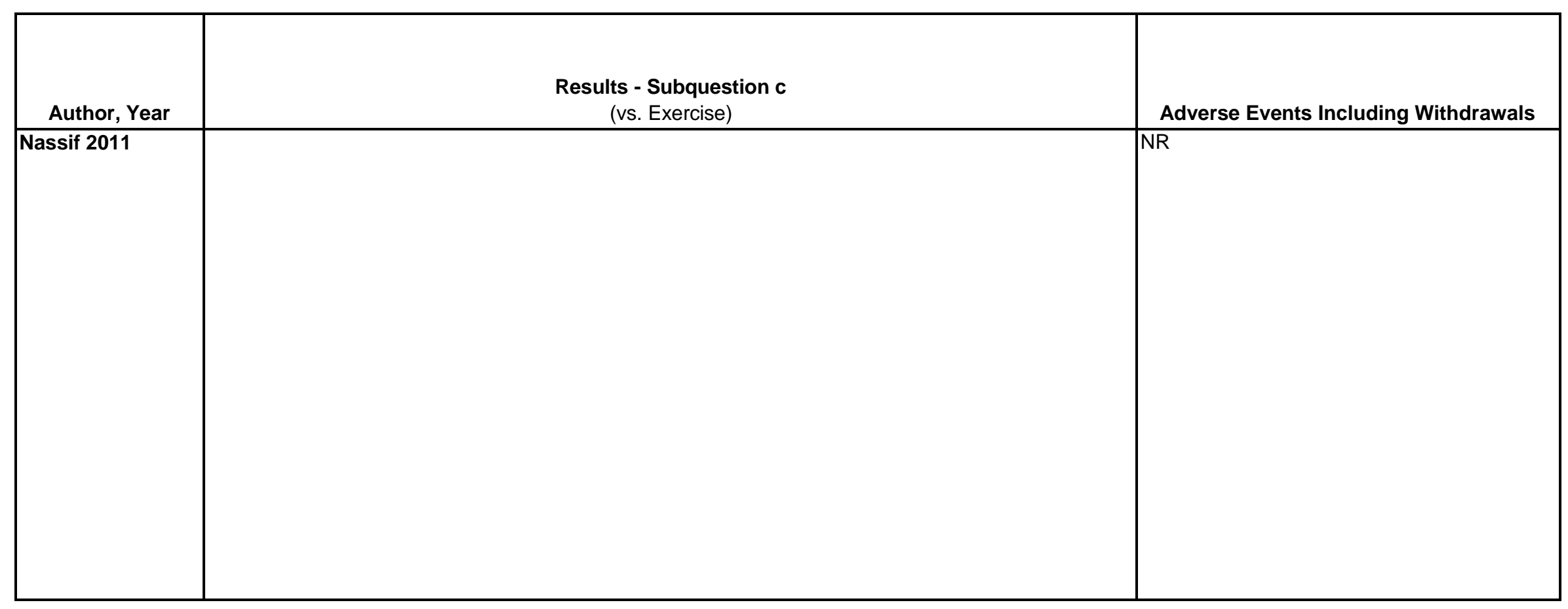




\begin{tabular}{|c|c|c|c|}
\hline Author, Year & Funding Source & Quality & Comments \\
\hline Nassif 2011 & Unclear & Poor & $\begin{array}{l}\text { MDs and p values calculated by AAI. Baseline values of outcome measures seem different } \\
\text { enough to potentially do adj MD }\end{array}$ \\
\hline
\end{tabular}




\begin{tabular}{|c|c|c|c|}
\hline Author, Year & $\begin{array}{c}\text { Country } \\
\text { Number of Centers } \\
\text { Setting }\end{array}$ & Inclusion/Exclusion Criteria & $\begin{array}{c}\text { Number Randomized, } \\
\text { Analyzed } \\
\text { Attrition }\end{array}$ \\
\hline Natour 2014 & $\begin{array}{l}\text { Brazil } \\
\text { Number of centers } \\
\text { unclear } \\
\text { Type of center unclear }\end{array}$ & $\begin{array}{l}\text { Patients with a diagnosis of chronic low back pain }{ }^{\star} \text {, nonspecific low } \\
\text { back pain with no signs of a serious underlying condition, no signs of } \\
\text { spinal stenosis or radiculopathy, pain that becomes accentuate with } \\
\text { physical effort and is relieve with rest, aged } 18 \text { to } 50 \text {, and a pain VAS } \\
\text { score between } 4 \text { and } 7 \\
\\
\text { Exclude: Diagnosis of low back pain due to other causes, } \\
\text { fibromyalgia, previous spine surgery, lawsuit, initiation or change to } \\
\text { regular physical activity in previous } 3 \text { months, body mass index }>30 \text {, } \\
\text { physical therapy or acupuncture treatment in the previous } 3 \text { months }\end{array}$ & $\begin{array}{l}\text { Randomized: } 60 \\
\text { Treated: } 60 \\
\text { Analyzed: } 60 \\
\text { Attrition: } 5 \%(3 / 60)\end{array}$ \\
\hline
\end{tabular}




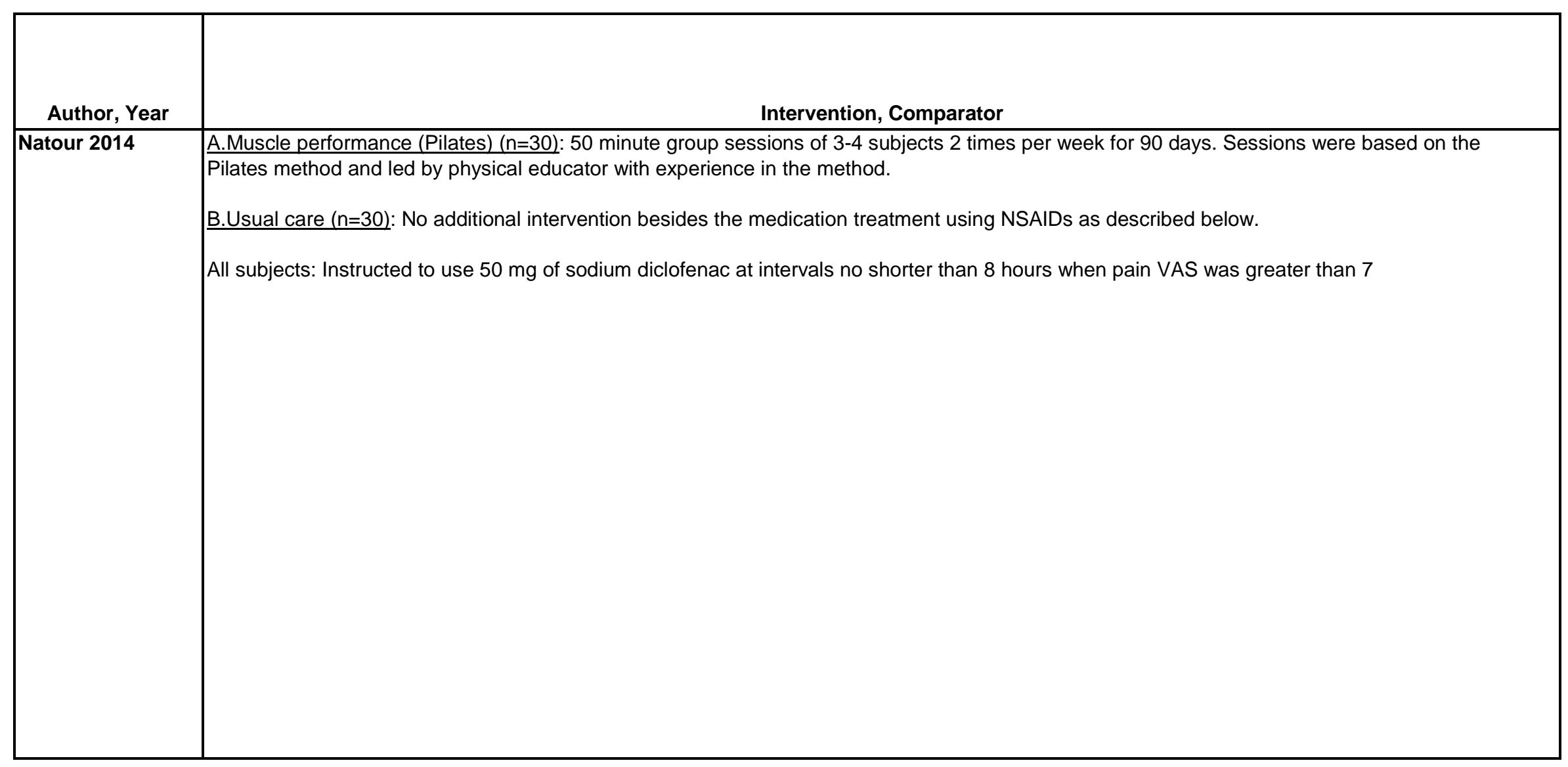




\begin{tabular}{|c|c|c|c|}
\hline Author, Year & Study Participants & Outcome Measures & $\begin{array}{c}\text { Duration of } \\
\text { Followup }\end{array}$ \\
\hline Natour 2014 & $\begin{array}{l}\text { A vs B } \\
\text { Age: } 48 \text { vs } 48 \\
\text { Female: } 80 \% \text { vs } 77 \% \\
\text { Employment: } \\
\quad \text { Unpaid work: } 30 \% \text { vs } 37 \% \\
\quad \text { Paid work: } 70 \% \text { vs } 60 \% \\
\quad \text { None: } 0 \% \text { vs } 3 \% \\
\text { Physical activity: } \\
\quad \text { Walking: } 37 \% \text { vs } 27 \% \\
\quad \text { Workout/dance: } 7 \% \text { vs } 13 \% \\
\quad \text { None: } 56 \% \text { vs } 60 \% \\
\text { RMDQ: } 12.1(5.2) \text { vs } 10.6(5.1) \\
\text { Pain VAS: } 5.5 \text { (5.2) vs } 5.8(2.1) \\
\text { SF-36 physical functioning: } 57.3(21.4) \text { vs } 58.8(23.7) \\
\text { SF-36 role physical: } 34.3(38.2) \text { vs } 42.7(40.7) \\
\text { SF-36 bodily pain: } 45.9(18.9) \text { vs } 42.9(21.4) \\
\text { SF-36 general health: } 64.4(18.8) \text { vs } 63.7(23.4) \\
\text { SF-36 vitality: } 54.6(21.5) \text { vs } 56.0(21.2) \\
\text { SF-36 social functioning: } 78.1(23.4) \text { vs } 78.6(28.2) \\
\text { SF-36 role emotional: } 73.3(28.2) \text { vs } 78.9(27.0) \\
\text { SF-36 mental health: } 60.1(23.9) \text { vs } 67.1(21.9)\end{array}$ & $\begin{array}{l}\text { RMDQ (0-24, higher score=higher disability) } \\
\text { Pain (0-10 VAS, higher score=higher pain) } \\
\text { SF-36 subscales (0-100, higher score=higher quality of } \\
\text { life) }\end{array}$ & $\begin{array}{l}\text { Short-term } \\
\text { followup } \\
3 \text { months }\end{array}$ \\
\hline
\end{tabular}




\begin{tabular}{|c|c|}
\hline Author, Year & \begin{tabular}{|c} 
Results - Subquestion a \\
(vs. sham, no treatment, waitlist, attention control)
\end{tabular} \\
\hline Natour 2014 & $\begin{array}{l}\text { A vs B, mean (SD) } \\
\text { Baseline } \\
\text { RDQ: } 10.58 \text { (5.12) vs. } 12.12(5.24) \\
\text { Pain }(0-10 \text { vAS): } 4.79(2.06) \text { vs. } 5.50(1.25) \\
\text { SF-36 physical functioning: } 58.75(23.69) \text { vs. } 57.29(21.36) \\
\text { SF-36 role physical: } 42.70(40.69) \text { vs. } 34.37(38.17) \\
\text { SF-36 bodily pain: } 42.91(21.40) \text { vs. } 45.91(18.87) \\
\text { SF-36 general health: } 63.66(23.37) \text { vs. } 64.37(18.81) \\
\text { SF-36 vitality: } 56.04(21.21) \text { vs. } 54.58(21.46) \\
\text { SF-36 social functioning: } 78.64(28.18) \text { vs. } 78.12(23.38) \\
\text { SF-36 role emotional: } 78.86(26.97) \text { vs. } 73.31(28.24) \\
\text { SF-36 mental health: } 67.06(21.85) \text { vs. } 60.06(23.85) \\
\\
\text { 3 months } \\
\text { RDQ: } 7.0 \text { (5.4) vs } 10.7(6.2), \text { difference }-3.6, p<0.001 \\
\text { Pain }(0-10 \text { vAS): } 4.2(2.8) \text { vs } 5.8(2.9), \text { difference }-1.6, p<0.001 \\
\text { SF-36 physical functioning: } 65.4(28.0) \text { vs } 59.6(19.0), \text { difference } 5.8, p=0.026 \\
\text { SF-36 role physical: } 56.4(34.8) \text { vs } 40.0(31.3), \text { difference } 16.4, p=0.086 \\
\text { SF-36 bodily pain: } 52.2(24.6) \text { vs } 43.9(29.1) \text {, difference } 8.3, p=0.030 \\
\text { SF-36 general health: } 65.2(22.2) \text { vs } 62.1(21.1) \text {, difference } 3.1, p=0.772 \\
\text { SF-36 vitality: } 60.3(23.4) \text { vs } 55.0(21.7), \text { difference } 5.3, p=0.029 \\
\text { SF-36 social functioning: } 86.0(22.8) \text { vs } 80.4(23.3), \text { difference } 5.6, p=0.096 \\
\text { SF-36 role emotional: } 82.6(24.2) \text { vs } 73.0(31.5), \text { difference } 9.7, p=0.165 \\
\text { SF-36 mental health: } 67.9(22.1) \text { vs } 65.3(23.1) \text {, difference } 2.6, p=0.243\end{array}$ \\
\hline
\end{tabular}




\begin{tabular}{|l|c|}
\hline Author, Year & $\begin{array}{c}\text { Results - Subquestion b } \\
\text { (vs. Pharmacological therapy) }\end{array}$ \\
\hline Natour 2014 & \\
& \\
& \\
\hline
\end{tabular}




\begin{tabular}{|l|c|l|}
\hline \multicolumn{1}{|c|}{ Author, Year } & $\begin{array}{c}\text { Results - Subquestion c } \\
\text { (vs. Exercise) }\end{array}$ & Adverse Events Including Withdrawals \\
\hline Natour 2014 & & $\begin{array}{l}\text { A vs B } \\
\text { Depression leading to withdrawal: } 3 \%(1 / 30) \\
\text { vs } 0 \% \text { (0/30) }\end{array}$ \\
& & \\
\end{tabular}




\begin{tabular}{|c|c|c|c|}
\hline Author, Year & Funding Source & Quality & Comments \\
\hline
\end{tabular}




\begin{tabular}{|c|c|c|c|}
\hline Author, Year & $\begin{array}{c}\text { Country } \\
\text { Number of Centers } \\
\text { Setting }\end{array}$ & Inclusion/Exclusion Criteria & $\begin{array}{c}\text { Number Randomized, } \\
\text { Analyzed } \\
\text { Attrition }\end{array}$ \\
\hline Nicholas 1991 & $\begin{array}{l}\text { Australia } \\
\text { Number of centers: } 1 \\
\text { Setting: Outpatient }\end{array}$ & $\begin{array}{l}20-60 \text { years old } \\
\text { Chronic non-malignant LBP >6 months duration } \\
\text { Not considered suitable for further invasive treatments } \\
\text { No insurance compensation claim due for settlement within } 12 \text { months } \\
\text { Able to read and speak English } \\
\text { Willing to participate in a research-oriented treatment program }\end{array}$ & $\begin{array}{l}\text { Randomized: } 58 \\
\text { Analyzed: } 39 \\
\text { Attrition: } 33 \%(19 / 58) \\
\end{array}$ \\
\hline
\end{tabular}




\begin{tabular}{|c|c|}
\hline Author, Year & Intervention, Comparator \\
\hline Nicholas 1991 & 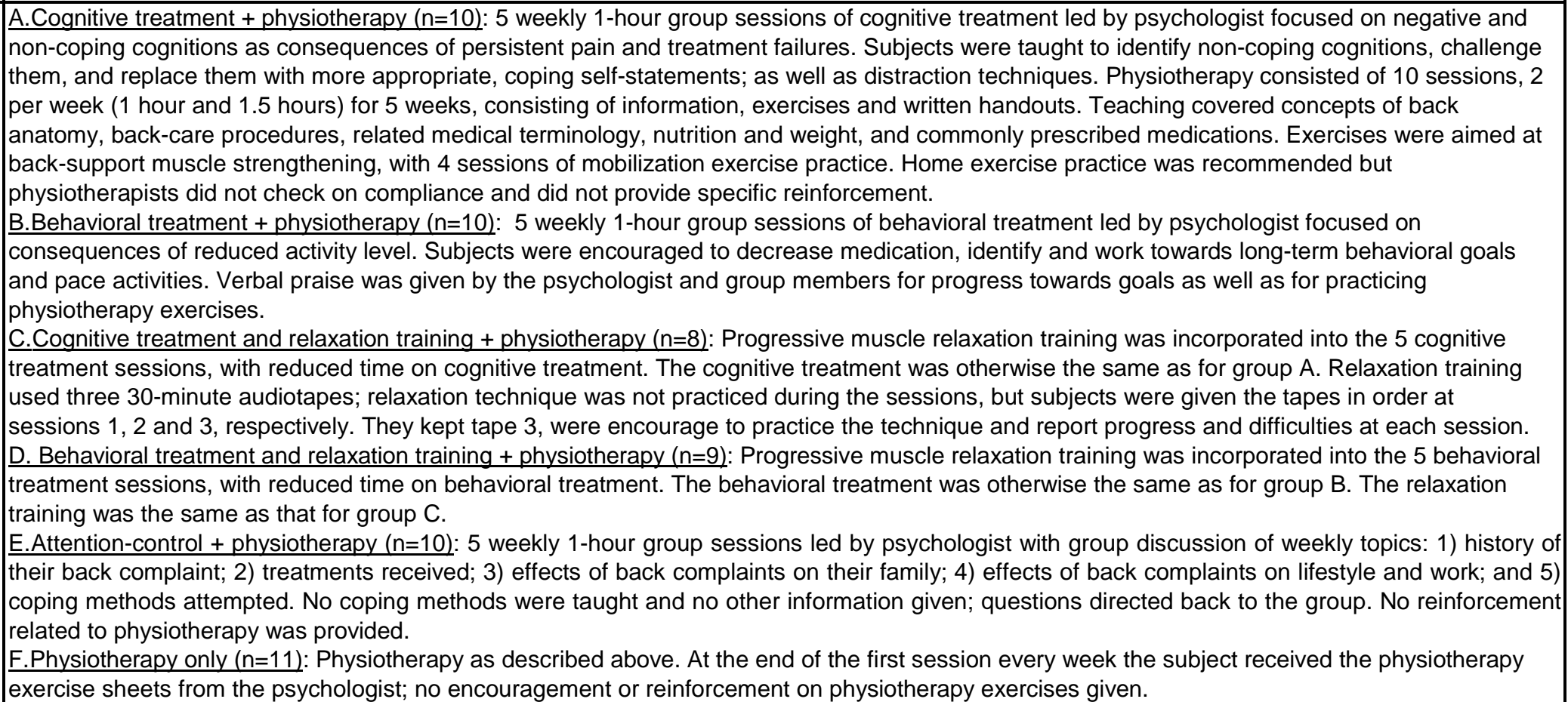 \\
\hline
\end{tabular}




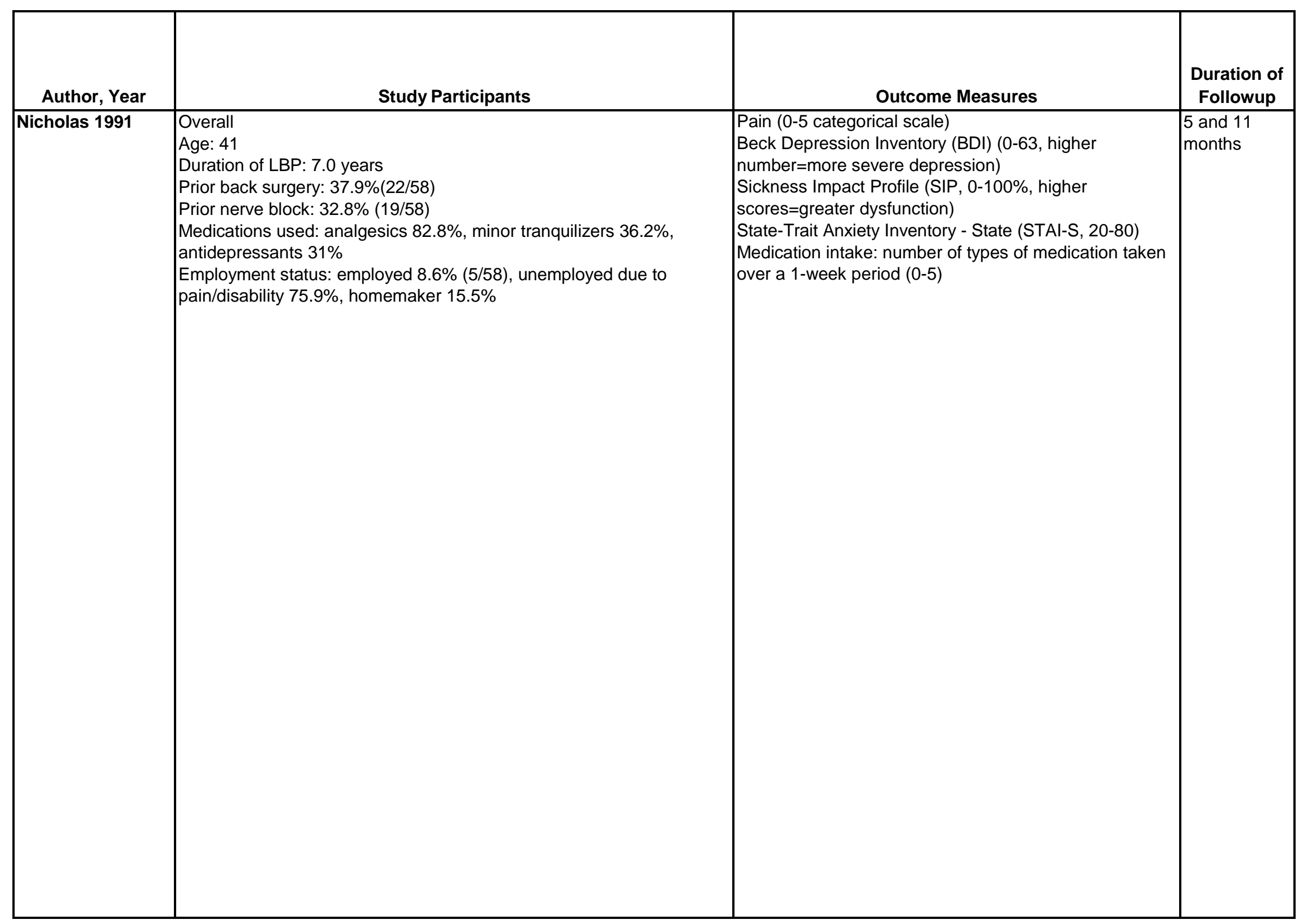




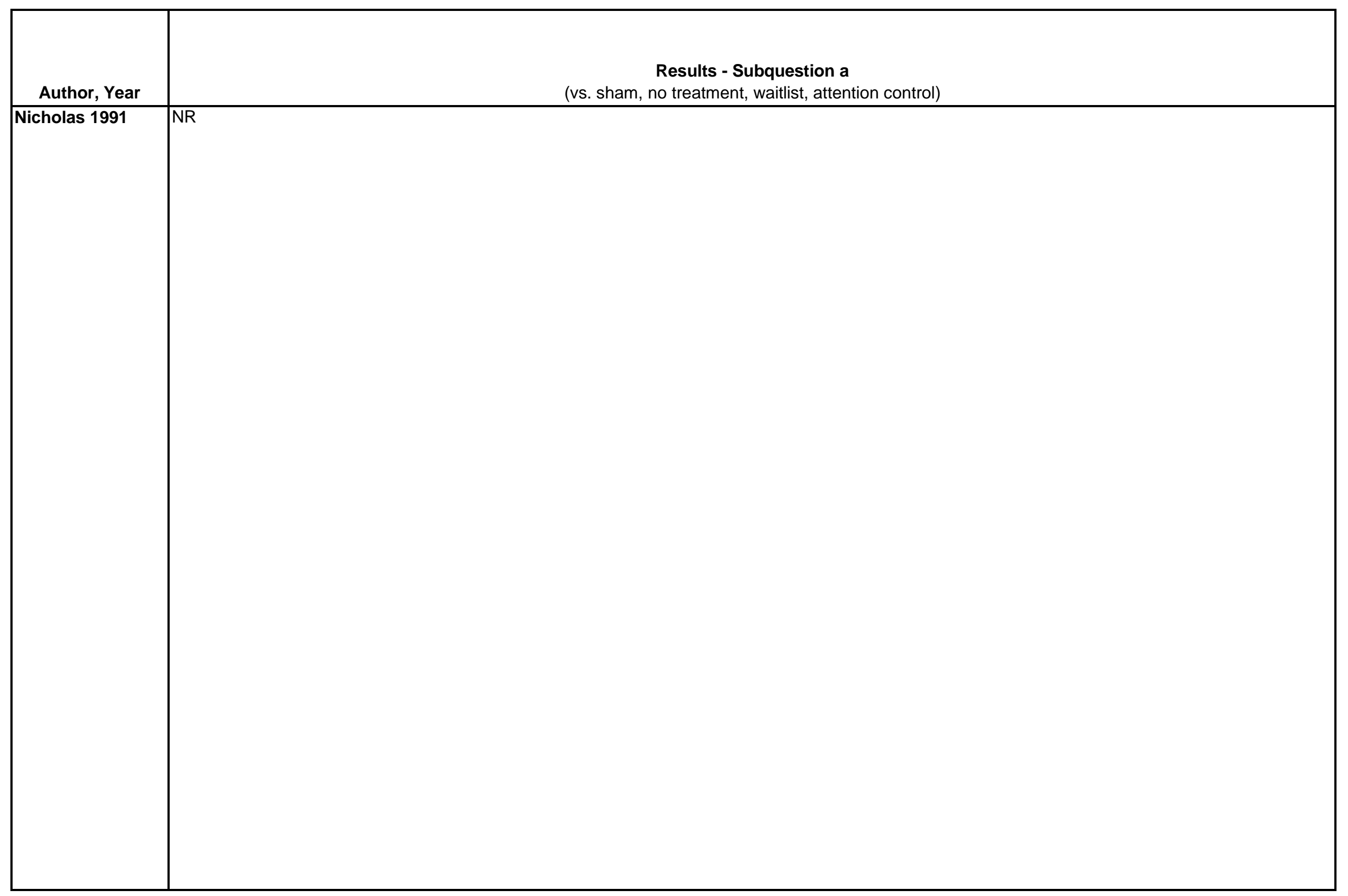




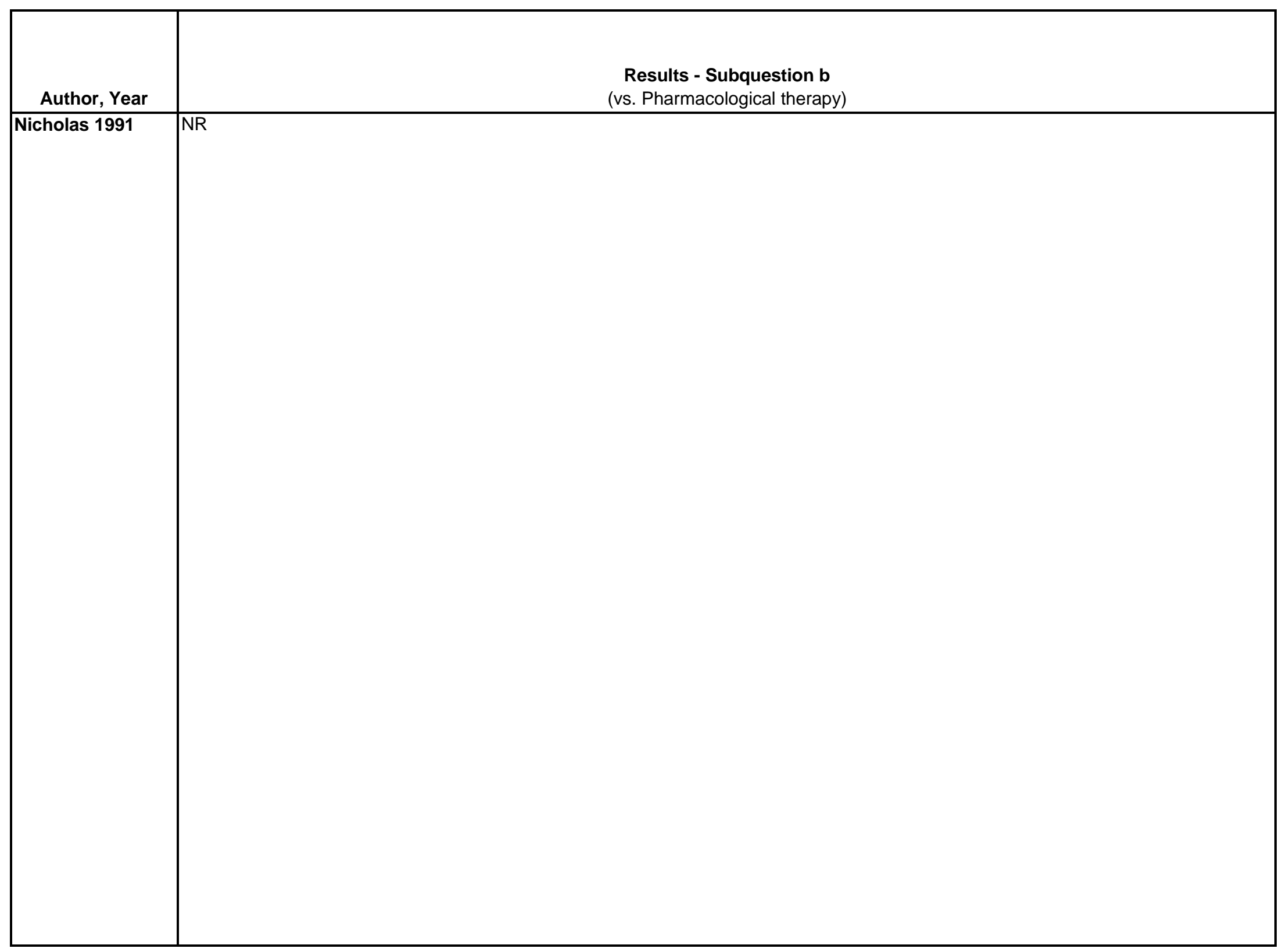




\begin{tabular}{|c|c|c|}
\hline Author, Year & $\begin{array}{l}\text { Results - Subquestion c } \\
\text { (vs. Exercise) }\end{array}$ & Adverse Events Including Withdrawals \\
\hline Nicholas 1991 & 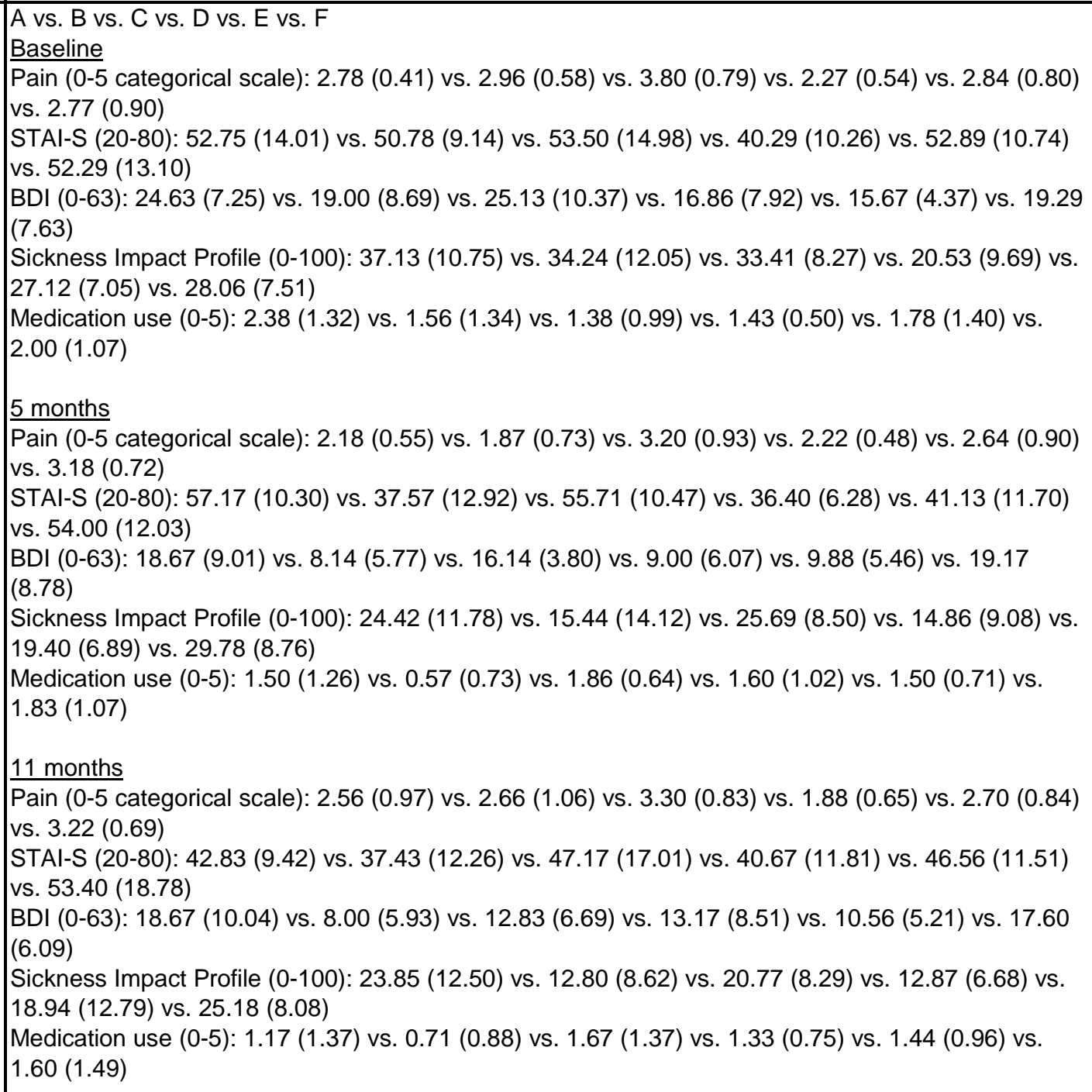 & $\begin{array}{l}\text { Overall } \\
\text { Withdrawal: } 17 \%(10 / 58) \text { at posttreatment; } \\
33 \% \text { (19/58) at } 6 \text { - and } 12 \text {-month follow ups } \\
\text { Withdrawal due to AEs: NR } \\
\text { Serious AEs: NR. "One [subject] died during } \\
\text { the followup period." } \\
\text { Nonserious AEs: NR }\end{array}$ \\
\hline
\end{tabular}




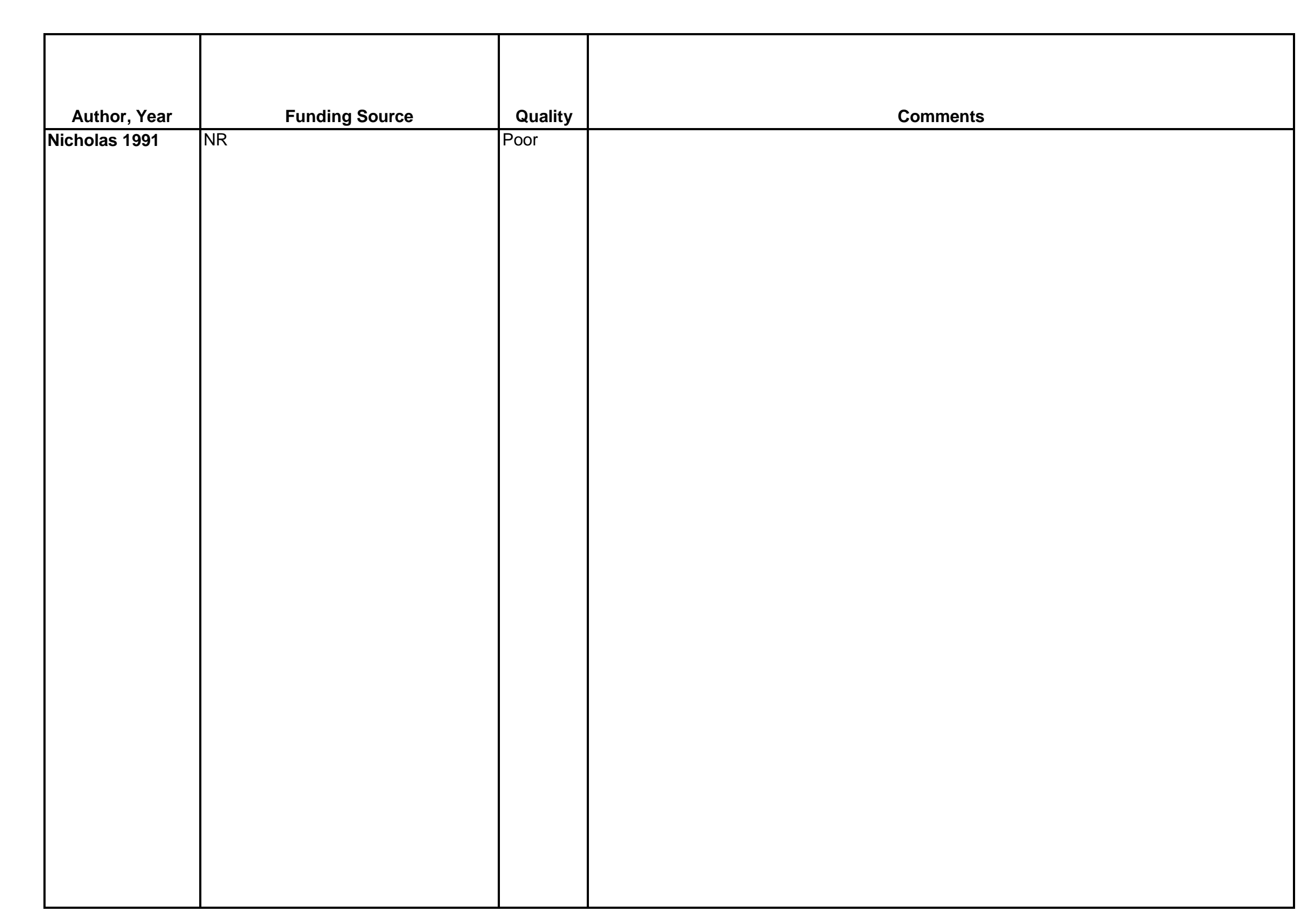

D-588 


\begin{tabular}{|c|c|c|c|}
\hline Author, Year & $\begin{array}{c}\text { Country } \\
\text { Number of Centers } \\
\text { Setting }\end{array}$ & Inclusion/Exclusion Criteria & $\begin{array}{c}\text { Number Randomized, } \\
\text { Analyzed } \\
\text { Attrition }\end{array}$ \\
\hline Nicholas 1992 & $\begin{array}{l}\text { Australia } \\
\text { Number of centers: } 1 \\
\text { Setting: Outpatient }\end{array}$ & \begin{tabular}{|l|}
$20-60$ years old \\
Chronic non-malignant LBP $>6$ months duration \\
Not considered suitable for further invasive treatments \\
No insurance compensation claim due for settlement within 12 months \\
Able to read and speak English \\
Willing to participate in a research-oriented treatment program
\end{tabular} & $\begin{array}{l}\text { Randomized: } 20 \\
\text { Analyzed: } 17 \\
\text { Attrition: } 15 \%(3 / 20)\end{array}$ \\
\hline Osteras 2014 & $\begin{array}{l}\text { Norway } \\
2 \text { centers } \\
\text { Outpatient }\end{array}$ & $\begin{array}{l}\text { ACR criteria for features of hand OA or uni-/bilateral OA in the first } \\
\text { carpometacarpal joint, FIHOA score } \geq 5 \\
\text { Exclude: Inflammatory rheumatic disease, steroid injection within } 2 \\
\text { mos, recent severe trauma, recent OA surgery, recent major surgery } \\
\text { of any type, cognitive dysfunction, language problems }\end{array}$ & $\begin{array}{l}\text { Randomized: } 130 \\
\text { Treated: } 124 \\
\text { Analyzed: } 119 \\
\text { Attrition: } 16 \%(21 / 130) \\
\text { *29\% in treatment group } \\
\text { vs. } 7 \% \text { in the control group }\end{array}$ \\
\hline Paolucci 2015 & Italy & $\begin{array}{l}\text { Inclusion: met ACR criteria (year NR) for FM and pharmacologic } \\
\text { treatment stable for } 3 \text { months } \\
\text { Exclusion: baseline FIQ score }<51 \text {, severe somatic or psychiatric } \\
\text { disorders that prevent physical loading, previous spine surgery, } \\
\text { vertebral fractures, sciatic pain, neoplasia, currently attending another } \\
\text { type of physical therapy, use of antidepressants }\end{array}$ & $\begin{array}{l}\text { Randomized: } 37 \\
\text { Analyzed: } 32 \\
\text { Treated: } 84 \%(16 / 19) \text { in A } \\
\text { Attrition: } 14 \%(5 / 37)\end{array}$ \\
\hline
\end{tabular}




\begin{tabular}{|c|c|}
\hline Author, Year & Intervention, Comparator \\
\hline Nicholas 1992 & $\begin{array}{l}\text { A.Cognitive-behavioral treatment (CBT), progressive muscle relaxation training, }+ \text { physiotherapy }(\mathrm{n}=10) \text { : CBT treatment in } 5 \text { weekly 1-hour group } \\
\text { sessions of cognitive treatment led by psychologist focused on negative and non-coping cognitions as consequences of persistent pain and } \\
\text { treatment failures. Subjects were taught to identify non-coping cognitions, challenge them, and replace them with more appropriate, coping self- } \\
\text { statements; as well as distraction techniques. Relaxation training used three } 30 \text {-minute audiotapes; relaxation technique was not practiced during } \\
\text { the sessions, but subjects were given the tapes in order at sessions } 1,2 \text { and } 3 \text {, respectively. Patients encouraged to practice the technique and } \\
\text { report progress and difficulties at each session. Physiotherapy consisted of } 10 \text { sessions, } 2 \text { per week ( } 1 \text { hour and } 1.5 \text { hours) for } 5 \text { weeks, consisting } \\
\text { of information, exercises and written handouts. Exercises aimed at back-support muscle strengthening, with } 4 \text { sessions of mobilization exercise } \\
\text { practice. Home exercise practice was recommended but physiotherapists did not check on compliance and did not provide specific reinforcement. } \\
\text { B.Attention-control ( } n=10)+ \text { physiotherapy: } 5 \text { weekly 1-hour group sessions led by psychologist who introduced a topic at each session and } \\
\text { encouraged group discussion. The topics were: } 1 \text { ) history of their back complaint; } 2 \text { ) treatments received; } 3 \text { ) effects of back complaints on their } \\
\text { family; } 4 \text { ) effects of back complaints on lifestyle and work; and 5) coping methods attempted. No coping methods were taught and no other } \\
\text { information given by the psychologist. The psychologist deflected questions back to the group, and did not give any reinforcement related to } \\
\text { physiotherapy. }\end{array}$ \\
\hline Osteras 2014 & $\begin{array}{l}\text { A.Exercise }(n=46) \text { : exercises to improve grip strength, improve thumb stability, and maintain finger range of motion, } 4 \text { group sessions } \\
\text { supplemented by for } 3 \text { times weekly at } 10 \text { repetitions (weeks 1-2) and } 15 \text { repetitions (weeks 3-12) at home } \\
\text { B. Usual care }(n=64) \text { : Subjects received no particular attention, referral, or treatment from the study. They were allowed to receive 'usual care' from } \\
\text { a general practitioner }\end{array}$ \\
\hline Paolucci 2015 & $\begin{array}{l}\text { A.exercise }(n=16): 1060 \text {-minute rehabilitation sessions, twice a week for } 5 \text { weeks. Low-impact aerobic training, } 60 \% \text { of maximum heart rate, for } 20 \\
\text { minutes; agility training and balance exercises, postural exercises, hip flexor strengthening, static stretching, diaphragmatic breathing, and } \\
\text { relaxation. } 84 \% \text { of participants in A completed all sessions. } \\
\text { B.Control }(n=16) \text { : No rehabilitation interventions, continued normal activities }\end{array}$ \\
\hline
\end{tabular}




\begin{tabular}{|c|c|c|c|}
\hline Author, Year & Study Participants & Outcome Measures & $\begin{array}{c}\text { Duration of } \\
\text { Followup }\end{array}$ \\
\hline Nicholas 1992 & $\begin{array}{l}\text { Overall } \\
\text { Age: } 44 \\
\text { Female: } 45 \%(9 / 20) \\
\text { Duration of LBP: } 5.5 \text { years } \\
\text { Previous treatments: back surgery } 45 \%(9 / 20), \text { physiotherapy } 85 \% \\
\text { (17/20), nerve block 35\% ( } 7 / 20) \\
\text { Medications used: analgesics } 80 \%(16 / 20), \text { minor tranquilizers 30\% } \\
\text { (6/20), antidepressants } 30 \%(6 / 20) \\
\text { Employment status: employed } 10 \%(2 / 20) \text {, unemployed due to } \\
\text { pain/disability } 65 \%(13 / 20), \text { homemaker } 25 \%(5 / 20)\end{array}$ & $\begin{array}{l}\text { Pain (0-5 categorical scale) } \\
\text { Beck Depression Inventory (BDI) (0-63, higher } \\
\text { number=more severe depression) } \\
\text { Sickness Impact Profile (SIP, } 0-100 \%) \\
\text { Medication intake: number of types of medication taken } \\
\text { over a 1-week period (0-5) }\end{array}$ & 5 months \\
\hline Osteras 2014 & $\begin{array}{l}\text { A vs B } \\
\text { Age: } 67 \text { vs } 65 \\
\text { Females: } 89 \% \text { vs } 91 \% \\
\text { Fulfilment of ACR criteria for hand OA: } 91 \% \text { vs } 91 \% \\
\text { Self-reported hip OA: } 39 \% \text { vs } 46 \% \\
\text { Self-reported knee OA: } 40 \% \text { vs } 51 \% \\
\text { Other rheumatic disease: } 13 \% \text { vs } 15 \% \\
\text { Severe mental distress: } 17 \% \text { vs } 39 \% \\
\text { FIHOA: } 10.8(5.0) \text { vs } 9.8(4.7) \\
\text { PSFS: } 3.5(2.4) \text { vs } 3.9(2.3) \\
\text { Hand pain NRS } 0-10: 4.2(2.1) \text { vs } 3.9(1.8) \\
\text { Patient global assessment affecting activity: } 4.3(1.9) \text { vs } 4.3(1.8) \\
\text { Patient global assessment affecting ADL: } 4.1(2.0) \text { vs } 3.9(2.0)\end{array}$ & $\begin{array}{l}\text { FIHOA (0-30, higher score=higher disability): PSFS (0- } \\
10 \text {, higher score=less disability): hand pain NRS (0-10, } \\
\text { higher score=greater pain): patient global assessment } \\
\text { of disease activity ( } 0-10 \text {, higher score=greater disease } \\
\text { activity): patient global assessment of disease activity } \\
\text { on ADL (0-10, higher score=great disease activity on } \\
\text { ADL): OARSI OMERACT (responder vs non-responder) }\end{array}$ & 3 months \\
\hline Paolucci 2015 & $\begin{array}{l}\text { A vs B } \\
\text { Age: } 50 \text { vs } 48 \\
\text { Female: } 100 \% \text { vs } 100 \% \\
\text { Duration of symptoms: NR } \\
\text { FIQ total: } 64.8(9.1) \text { vs } 63.9(9.3)\end{array}$ & $\begin{array}{l}\text { FIQ total score }(0-100, \text { higher scores=greater } \\
\text { impairment) }\end{array}$ & 3 months \\
\hline
\end{tabular}




\begin{tabular}{|c|c|}
\hline Author, Year & $\begin{array}{c}\text { Results - Subquestion a } \\
\text { (vs. sham, no treatment, waitlist, attention control) }\end{array}$ \\
\hline Nicholas 1992 & NR \\
\hline Osteras 2014 & 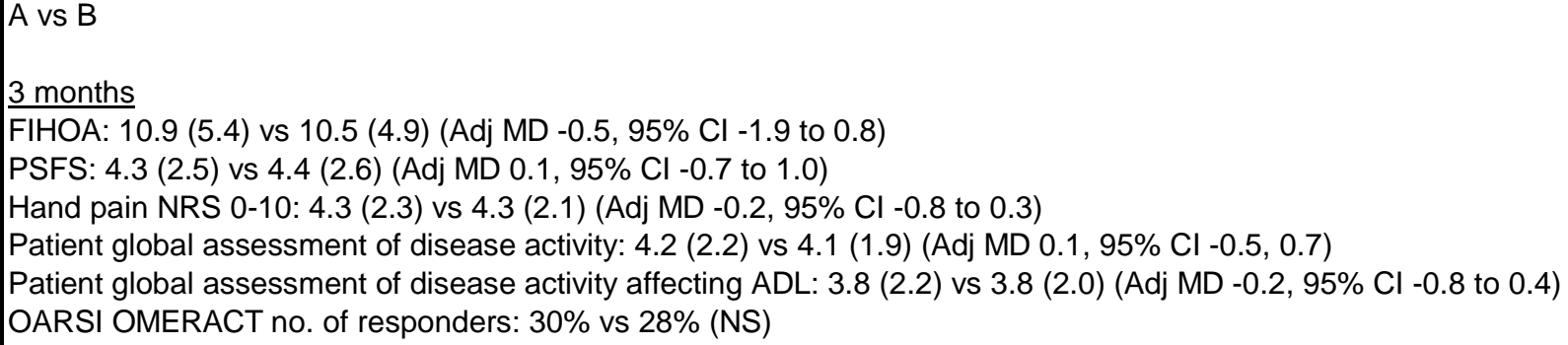 \\
\hline Paolucci 2015 & $\begin{array}{l}\text { A vs B } \\
3 \text { months: } \\
\text { FIQ total: } 53.8(10.7) \text { vs } 64.3(9.4), p=0.006 ; M D-10.50(95 \% \mathrm{Cl}-17.77,-3.23), p=0.006\end{array}$ \\
\hline
\end{tabular}




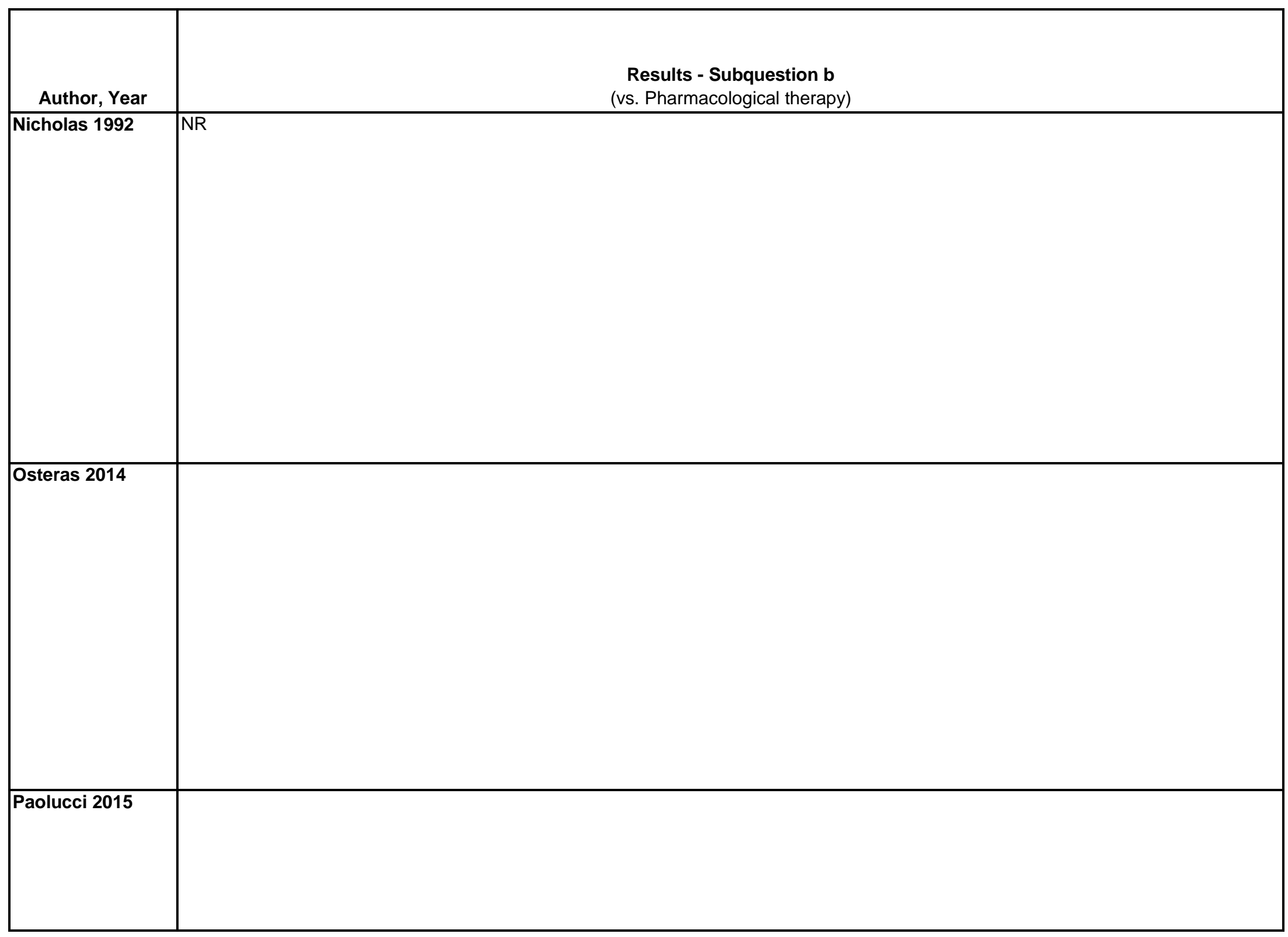

D-593 


\begin{tabular}{|c|c|c|}
\hline Author, Year & $\begin{array}{c}\text { Results - Subquestion c } \\
\text { (vs. Exercise) }\end{array}$ & Adverse Events Including Withdrawals \\
\hline Nicholas 1992 & $\begin{array}{l}\text { A vs. B. mean (SD) } \\
\text { Baseline } \\
\text { Pain (0-5 categorical scale): } 3.13(0.88) \text { vs. } 2.84(0.85) \\
\text { Beck Depression Inventory (0-63): } 17.33(7.41) \text { vs. } 20.44(10.62) \\
\text { Sickness Impact Profile }(0-100): 30.87(12.17) \text { vs. } 32.10(13.45) \\
\text { Using medication: } 100 \%(10 / 10) \text { vs. } 90 \%(9 / 10) \\
\\
5 \text { months } \\
\text { Pain intensity (0-5 categorical scale): } 2.89(0.64) \text { vs. } 2.75(1.11) \\
\text { Beck Depression Inventory (0-63): } 14.44(5.98) \text { vs. } 18.50(9.26) \\
\text { Sickness Impact Profile (0-100): } 18.30(11.18) \text { vs. } 25.31(14.34) \\
\text { Using medication: } 44 \%(4 / 9) \text { vs. } 88 \%(7 / 8)\end{array}$ & $\begin{array}{l}\text { A vs. B } \\
\text { Withdrawal: } 10 \% \text { (1/10) vs. } 20 \%(2 / 10) 6 \text { - } \\
\text { months } \\
\text { Withdrawal due to AEs: NR } \\
\text { Serious AEs: NR } \\
\text { Nonserious AEs: NR }\end{array}$ \\
\hline Osteras 2014 & & $\begin{array}{l}\text { Increased pain and inflammation in one } \\
\text { finger }(n=1) \\
\text { Increased pain and inflammation in all fingers } \\
(\mathrm{n}=2) \\
\text { Increased neck/shoulder pain }(\mathrm{n}=5) \text {, one } \\
\text { withdrawal from the study (note: study } \\
\text { reported all patients that experienced } \\
\text { increased neck/shoulder pain had a history of } \\
\text { neck/shoulder problems) } \\
\\
\text { Adverse events not broken down by } \\
\text { intervention group }\end{array}$ \\
\hline Paolucci 2015 & & $\begin{array}{l}\text { A vs B } \\
\text { Withdrawals: } 16 \%(3 / 19) \text { vs } 11 \%(2 / 18) \\
\text { Adverse events: } 0 \text { vs } 0\end{array}$ \\
\hline
\end{tabular}




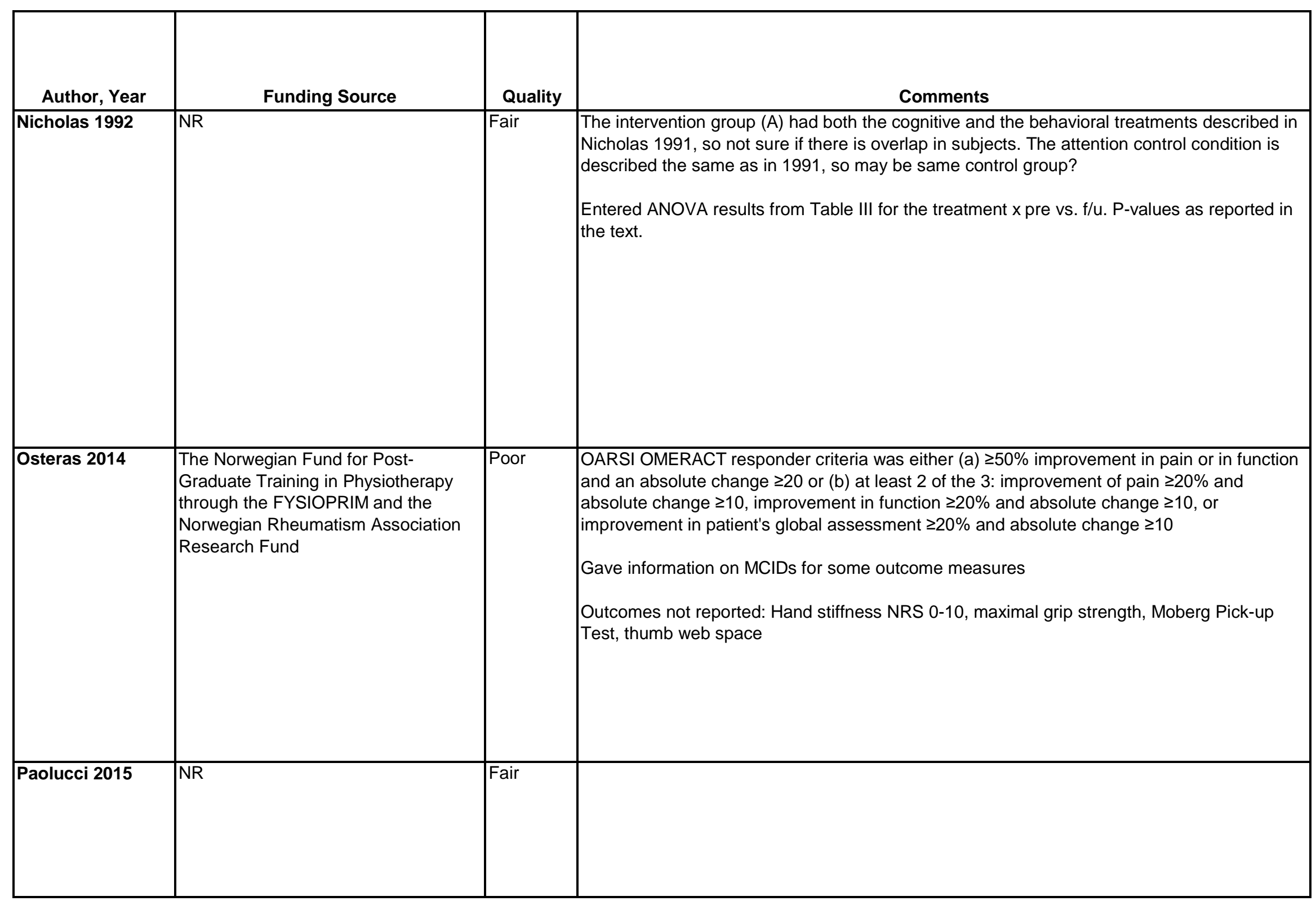




\begin{tabular}{|c|c|c|c|}
\hline Author, Year & $\begin{array}{l}\text { Country } \\
\text { Number of Centers and Setting }\end{array}$ & Inclusion/Exclusion Criteria & $\begin{array}{l}\text { Number Randomized, } \\
\text { Analyzed } \\
\text { Attrition }\end{array}$ \\
\hline Paolucci 2016 & $\begin{array}{l}\text { Italy } \\
1 \text { center } \\
\text { Outpatient }\end{array}$ & $\begin{array}{l}\text { Inclusion: Subjects with fibromyalgia who experienced } \\
\text { widespread pain for }>3 \text { months and pain with } 4 \mathrm{~kg} / \mathrm{cm}^{2} \\
\text { pressure at } 11 \text { or more of the } 18 \text { tender points, ages } 18 \text { to } \\
60 \text { years old, and VAS score }>3 \text { for pain. } \\
\text { Exclusion: presence of concomitant autoimmune or } \\
\text { hematologic diseases, psychiatric disorders, other causes } \\
\text { of chronic pain, and other diseases such as epilepsy and } \\
\text { tumors, pregnancy, pacemakers, participants currently } \\
\text { participating in another type of physical therapy, } \\
\text { overlapping painful conditions. }\end{array}$ & $\begin{array}{l}\text { Randomized: } 33 \\
\text { Analyzed: } 26 \\
\text { Attrition: } 21 \%(7 / 33)\end{array}$ \\
\hline
\end{tabular}




\begin{tabular}{|c|c|}
\hline Author, Year & Intervention, Comparator \\
\hline Paolucci 2016 & $\begin{array}{l}\text { Cross-over trial: patients randomized to receive A or B during the first treatment period then patients recevied opposite treatment during the } \\
\text { second treatment period (i.e., after crossing over; B vs. A) } \\
\text { A. Extremely low-frequency magnetic field first ( } n=16) \text { : } 3 \text { thirty minute sessions per week for } 4 \text { weeks ( } 12 \text { sessions total). Patients laid on a } \\
\text { bed with multi-low-frequency mattress that delivered a magentic field at an intensity of } 100 \text { uT and a multifrequency of } 1 \text { to } 80 \mathrm{~Hz} \text {. } \\
\text { B. Sham extremely low-frequency magnetic field first ( } n=17): 3 \text { thirty minute sessions per week for } 4 \text { weeks ( } 12 \text { sessions total). Patients laid } \\
\text { on a bed with multi-low-frequency mattress but no magnetic field was delivered. } \\
\text { Washout period: } 1 \text { month }\end{array}$ \\
\hline
\end{tabular}




\begin{tabular}{|c|c|c|c|}
\hline Paolucci 2016 & $\begin{array}{l}\text { A vs B } \\
\text { Age, years: } 50 \text { vs } 51 \\
\text { Female: } 100 \% \text { vs } 100 \% \\
\text { FM duration, years: } 7 \text { vs } 5 \\
\text { FIQ: } 58.7(11.3) \text { vs } 57.2(12.3) \\
\text { HAQ: } 0.7(0.3) \text { vs } 1.1(0.8) \\
\text { FIQ pain: NR } \\
\text { Pain VAS: } 4.9(1.4) \text { vs } 4.8(1.2) \\
\text { FAS: } 6.1(1.7) \text { vs } 6.4(1.4)\end{array}$ & $\begin{array}{l}\text { FIQ }(0-100 \text {, higher score=greater impact of } \\
\text { FM); HAQ (0-3, higher score=higher disability); } \\
\text { FIQ pain }(0-10 \text {, higher score=higher pain) pain } \\
\text { VAS (0-10, higher score=higher pain); FAS (0- } \\
\text { 10, higher score=higher pain) }\end{array}$ & 1 month \\
\hline
\end{tabular}




\begin{tabular}{|c|c|}
\hline Paolucci 2016 & $\begin{array}{l}\text { A vs } B \\
1 \text { month } \\
\text { FIQ: } 19.2(7.3) \text { vs } 57.9(12.5), p<0.001 \\
\text { Percent change from baseline in FIQ: }-67.3(9.9) \text { vs } 2.9(7.4), p<0.001 \\
\text { HAQ: } 0.3(0.2) \text { vs } 1.1(0.9), p=0.03 \\
\text { Percent change from baseline in HAQ: NR } \\
\text { FIQ pain: values NR, } p<0.001 \\
\text { Pain VAS: } 2.2(1.0) \text { vs } 5.3(1.3), p<0.001 \\
\text { Percent change from baseline in pain VAS: }-54.1(19.9) \text { vs } 6.3(16.0), p<0.001 \\
\text { FAS: } 3.2(1.2) \text { vs } 6.1(1.7), p<0.001 \\
\text { Percent change from baseline in FAS: }-46.5(17.3) \text { vs }-4.5(20.8), p<0.001 \\
\text { B vs A (after cross-over) } \\
1 \text { month } \\
\text { FIQ: } 25.1 \text { (8.5) vs } 53.9(8.7), p<0.001 \\
\text { Percent change from baseline in FIQ: }-56.0(9.4) \text { vs }-8.1(16.5), p<0.001 \\
\text { HAQ: } 0.7(0.7) \text { vs } 0.8(0.3), p=0.41 \\
\text { Percent change from baseline in HAQ: NR } \\
\text { Pain VAS: } 3.1 \text { (1.6) vs } 4.6(1.3), p=0.02 \\
\text { Percent change from baseline in pain VAS: }-39.7(26.0) \text { vs }-9.1(15.1), p=0.006 \\
\text { FAS: } 3.5(1.9) \text { vs } 6.2(1.0), p=0.002 \\
\text { Percent change from baseline in FAS: }-46.9(22.8) \text { vs }-1.2(15.4), p<0.001\end{array}$ \\
\hline
\end{tabular}




\begin{tabular}{|l|c|}
\hline Author, Year & $\begin{array}{c}\text { Results - Subquestion b } \\
\text { (vs. Pharmacological therapy) }\end{array}$ \\
\hline Paolucci 2016 & \\
& \\
& \\
\hline
\end{tabular}




\begin{tabular}{|c|c|c|}
\hline & $\begin{array}{l}\text { Results - Subquestion c } \\
\text { (vs. Exercise) }\end{array}$ & $\begin{array}{l}\text { Adverse Events Including Withdrawls } \\
\text { No side effects were recorded suring the studv }\end{array}$ \\
\hline \multirow{10}{*}{ Paolucci 2016} & & \\
\hline & & \\
\hline & & \\
\hline & & \\
\hline & & \\
\hline & & \\
\hline & & \\
\hline & & \\
\hline & & \\
\hline & & \\
\hline
\end{tabular}




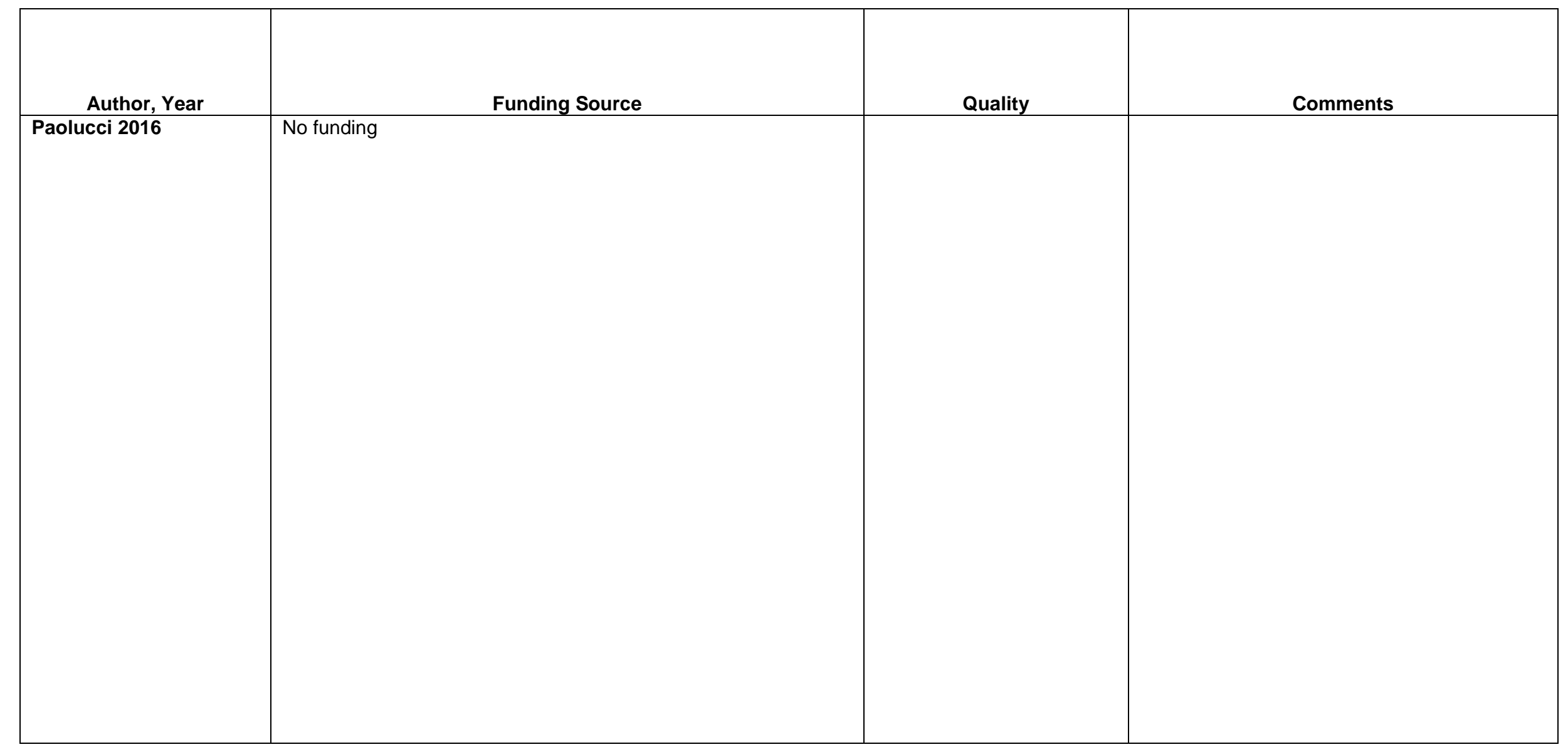




\begin{tabular}{|c|c|c|c|}
\hline Author, Year & $\begin{array}{c}\text { Country } \\
\text { Number of Centers } \\
\text { Setting }\end{array}$ & Inclusion/Exclusion Criteria & $\begin{array}{c}\text { Number Randomized, } \\
\text { Analyzed } \\
\text { Attrition }\end{array}$ \\
\hline $\begin{array}{l}\text { Pennix } 2001 \\
\text { FAST trial } \\
\text { (substudy in } \\
\text { patients with no } \\
\text { baseline ADL } \\
\text { disability) }\end{array}$ & $\begin{array}{l}\text { United States, } 2 \\
\text { centers, academic } \\
\text { medical centers }\end{array}$ & $\begin{array}{l}\text { Inclusion criteria: age } 60 \text { years or older; pain in the knee(s) on most } \\
\text { days of the month; difficulty with at least one of the following because } \\
\text { of knee pain: walking0.4 km; climbing stairs; getting in and out of a } \\
\text { car, bath, orbed; rising from a chair; or performing shopping, cleaning, } \\
\text { or self-care activities; and radiographic evidence of knee } \\
\text { osteoarthritis. } \\
\text { Exclusion criteria: baseline ADL disability; the presence of a medical } \\
\text { condition that precluded safe participation in an exercise program } \\
\text { (e.g., recent myocardial infarction or stroke, severe chronic obstructive } \\
\text { pulmonary disease, or congestive heart failure); inflammatory arthritis; } \\
\text { regular exercise participation (1 time per week for at least } 20 \text { minutes); } \\
\text { and inability to walk on a treadmill or walk, unassisted, } 128 \mathrm{~m} \text { in } 6 \\
\text { minutes. }\end{array}$ & $\begin{array}{l}\text { Randomized: } 250 * \\
\text { Treated: } 230 \\
\text { Analyzed: } 250 \\
\text { Attrition: } 0 \%(0 / 250) \\
\\
\text { *this article only included } \\
\text { patients from the FAST } \\
\text { trial would did not have } \\
\text { baseline ADL disability }\end{array}$ \\
\hline
\end{tabular}




\begin{tabular}{|c|c|}
\hline Author, Year & Intervention, Comparator \\
\hline $\begin{array}{l}\text { Pennix } 2001 \\
\text { FAST trial } \\
\text { (substudy in } \\
\text { patients with no } \\
\text { baseline ADL } \\
\text { disability) }\end{array}$ & 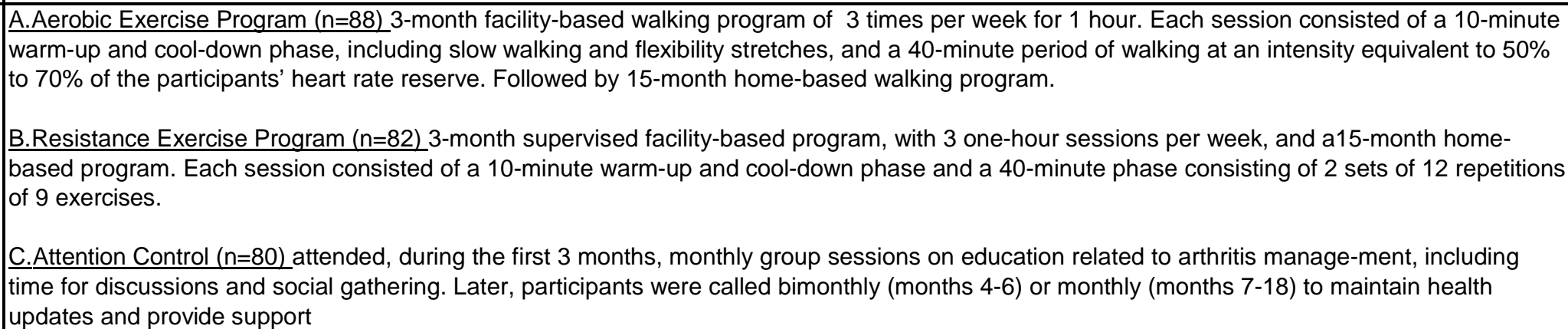 \\
\hline
\end{tabular}




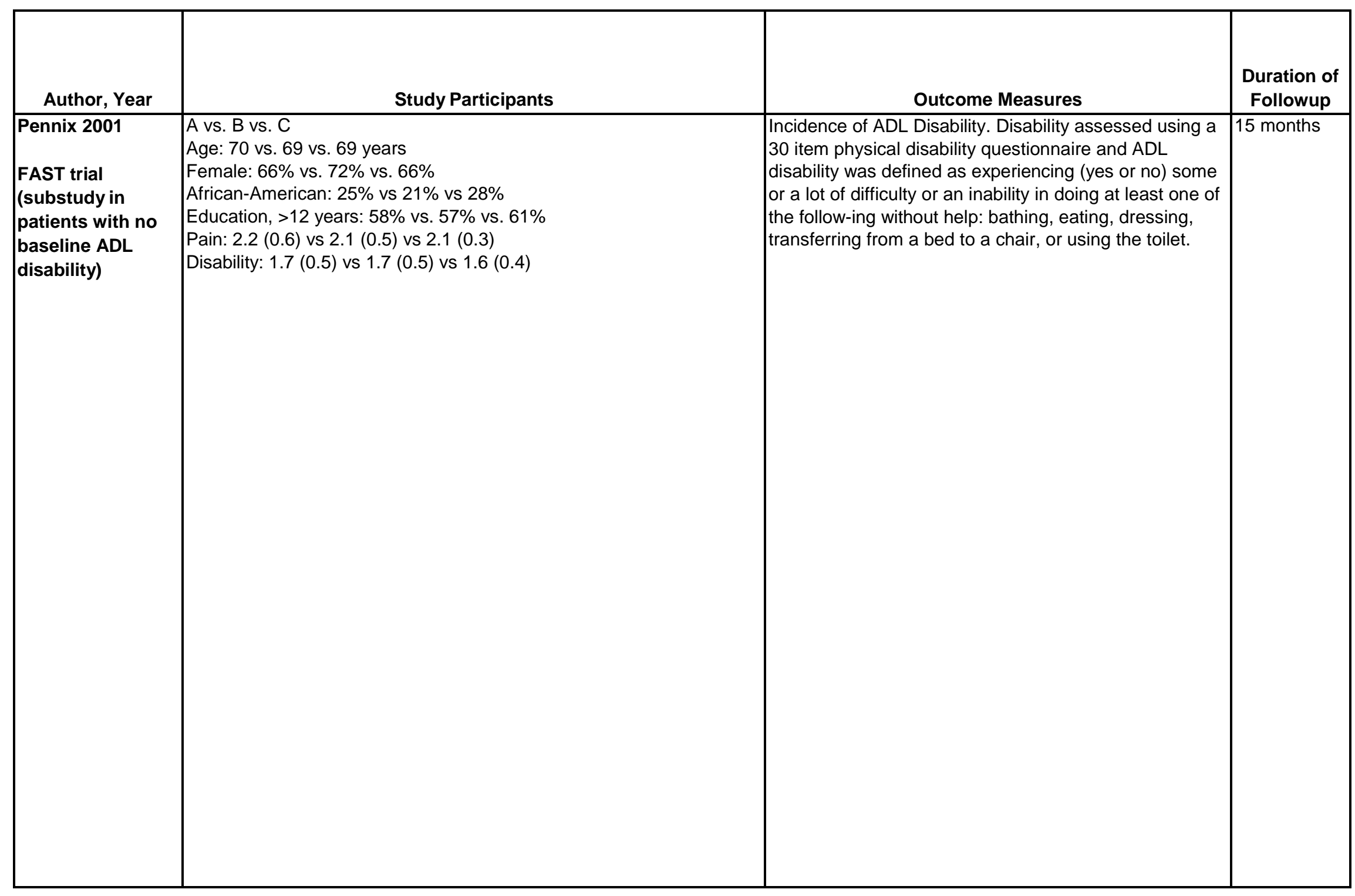




\begin{tabular}{|c|c|}
\hline Author, Year & $\begin{array}{l}\text { Results - Subquestion a } \\
\text { (vs. sham, no treatment, waitlist, attention control) }\end{array}$ \\
\hline $\begin{array}{l}\text { Pennix } 2001 \\
\text { FAST trial } \\
\text { (substudy in } \\
\text { patients with no } \\
\text { baseline ADL } \\
\text { disability) }\end{array}$ & 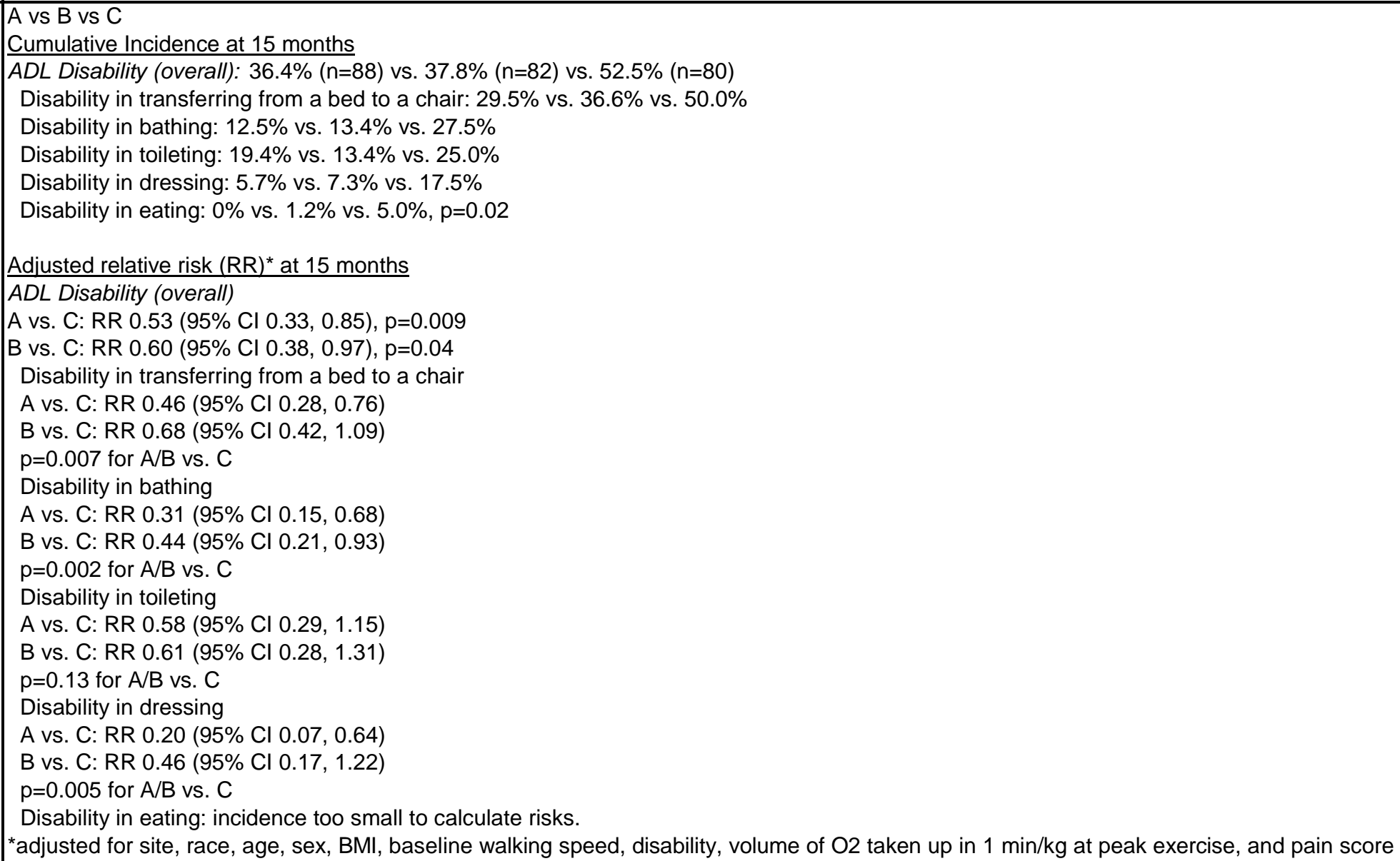 \\
\hline
\end{tabular}




\begin{tabular}{|l|l|}
\hline \multicolumn{1}{|c|}{ Author, Year } & \multicolumn{1}{c|}{$\begin{array}{c}\text { Results - Subquestion b } \\
\text { (vs. Pharmacological therapy) }\end{array}$} \\
\hline $\begin{array}{l}\text { Fennix 2001 } \\
\text { Fust trial } \\
\text { patients win } \\
\text { baseline ADL } \\
\text { disability) }\end{array}$ & NR \\
& \\
& \\
\hline
\end{tabular}




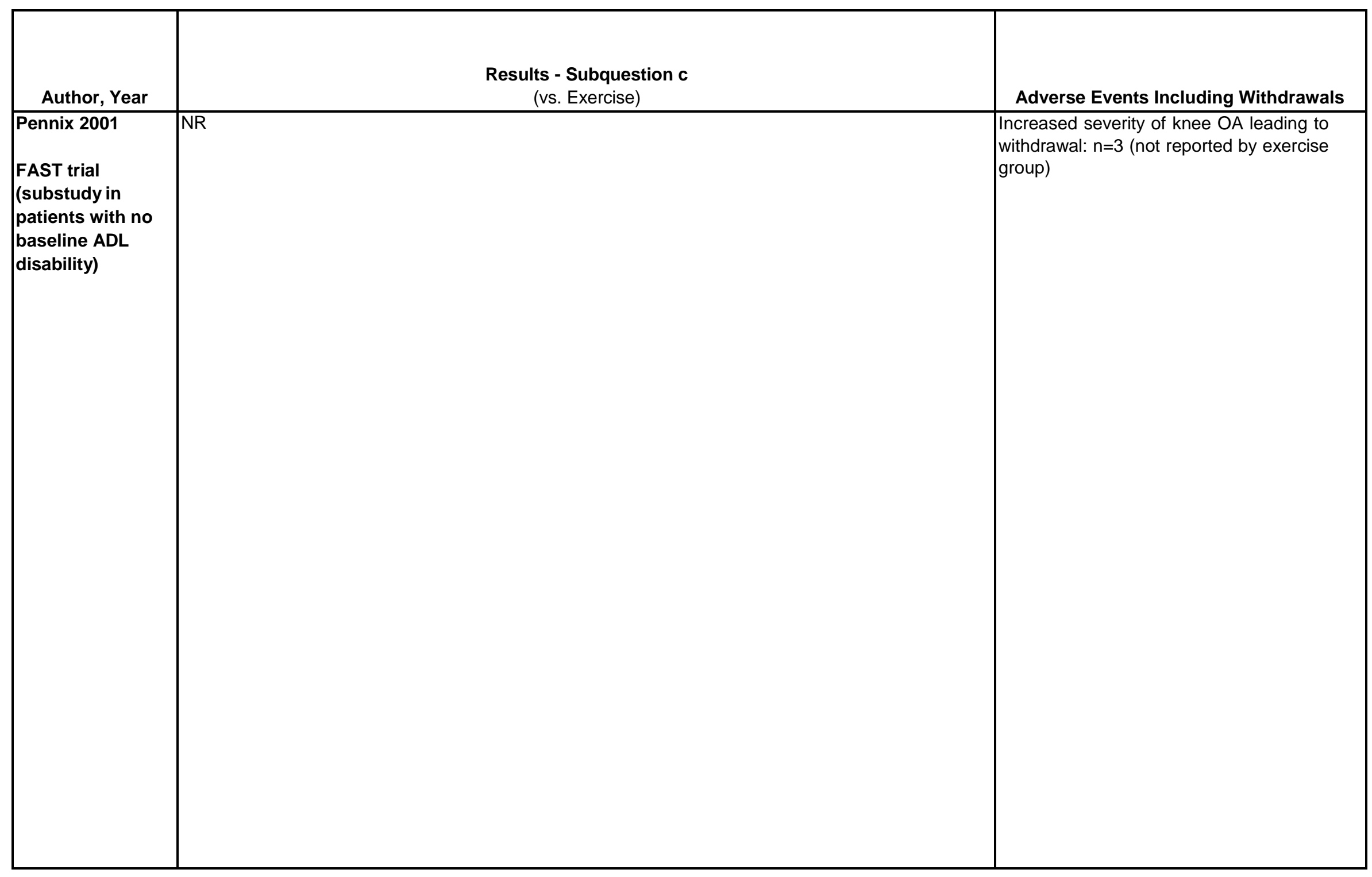




\begin{tabular}{|c|c|c|c|}
\hline Author, Year & Funding Source & Quality & Comments \\
\hline
\end{tabular}




\begin{tabular}{|c|c|c|c|}
\hline Author, Year & $\begin{array}{c}\text { Country } \\
\text { Number of Centers } \\
\text { Setting }\end{array}$ & Inclusion/Exclusion Criteria & $\begin{array}{c}\text { Number Randomized, } \\
\text { Analyzed } \\
\text { Attrition } \\
\end{array}$ \\
\hline $\begin{array}{l}\text { Pennix } 2002 \\
\text { FAST trial } \\
\text { (substudy looking } \\
\text { at baseline } \\
\text { depressive } \\
\text { symptoms) }\end{array}$ & $\begin{array}{l}\text { United States, } 2 \\
\text { centers, academic } \\
\text { medical centers }\end{array}$ & $\begin{array}{l}\text { Inclusion criteria: age } 60 \text { years or older; pain in the knee(s) on most } \\
\text { days of the month; difficulty with at least one of the following because } \\
\text { of knee pain: walking0.4 km; climbing stairs; getting in and out of a } \\
\text { car, bath, orbed; rising from a chair; or performing shopping, cleaning, } \\
\text { or self-care activities; and radiographic evidence of knee } \\
\text { osteoarthritis. } \\
\text { Exclusion criteria: the presence of a medical condition that precluded } \\
\text { safe participation in an exercise program (e.g., recent myocardial } \\
\text { infarction or stroke, severe chronic obstructive pulmonary disease, or } \\
\text { congestive heart failure); inflammatory arthritis; regular exercise } \\
\text { participation (1 time per week for at least } 20 \text { minutes); and inability to } \\
\text { walk on a treadmill or walk, unassisted, } 128 \mathrm{~m} \text { in } 6 \text { minutes. }\end{array}$ & $\begin{array}{l}\text { Randomized: } 439 \\
\text { Treated: } 439 \\
\text { Analyzed: } 407 \\
\text { Attrition: } 7 \%(31 / 438)\end{array}$ \\
\hline Perlman 2012 & United States & $\begin{array}{l}\text { Inclusion Criteria: } \\
\text { Eligible patients were men and women with radiographically } \\
\text { established OA of the knee who met American College of } \\
\text { Rheumatology criteria, were at least } 35 \text { years of age, and had a pre- } \\
\text { randomization score of } 40 \text { to } 90 \text { on the visual analog pain scale. } \\
\text { Patients with bilateral knee involvement had the more severely } \\
\text { affected knee (determined by the patient) designated as the study } \\
\text { knee. Subjects using NSAIDS or other medications to control pain } \\
\text { were included if their doses remained stable three months prior to } \\
\text { starting the intervention. } \\
\text { Exclusion Criteria: } \\
\text { Subjects were excluded if they suffered from rheumatoid arthritis, } \\
\text { fibromyalgia, recurrent or active pseudogout, cancer, or other serious } \\
\text { medical conditions. Subjects were also excluded if they had signs or } \\
\text { history of kidney or liver failure; unstable asthma; knee replacement of } \\
\text { both knees; reported recent use (4 weeks-1 year prior to enrollment) } \\
\text { of oral or intra-articular corticosteroids or intra-articular hyaluronate; or } \\
\text { knee arthroscopy or significant knee injury one year prior to } \\
\text { enrollment. A rash or open wound over the knee and regular use of } \\
\text { massage therapy (greater than once a month) also resulted in } \\
\text { exclusion from the study. }\end{array}$ & $\begin{array}{l}\text { Randomized: } 125 \\
\text { Treated: } 119 \\
\text { Completers: } 115 \\
\text { Analyzed: } 125 \\
\text { Attrition: } 8 \%(10 / 125)\end{array}$ \\
\hline
\end{tabular}




\begin{tabular}{|c|c|}
\hline Author, Year & Intervention, Comparator \\
\hline $\begin{array}{l}\text { Pennix } 2002 \\
\text { FAST trial } \\
\text { (substudy looking } \\
\text { at baseline } \\
\text { depressive } \\
\text { symptoms) }\end{array}$ & $\begin{array}{l}\text { A.Aerobic Exercise Program ( } n=149) \text { 3-month facility-based walking program of } 3 \text { times per week for } 1 \text { hour. Each session consisted of a } 10- \\
\text { minute warm-up and cool-down phase, including slow walking and flexibility stretches, and a } 40 \text {-minute period of walking at an intensity equivalent } \\
\text { to } 50 \% \text { to } 70 \% \text { of the participants' heart rate reserve. Followed by } 15 \text {-month home-based walking program. } \\
\text { B. Resistance Exercise Program ( } n=146 \text { ) 3-month supervised facility-based program, with } 3 \text { one-hour sessions per week, and a15-month home- } \\
\text { based program. Each session consisted of a 10-minute warm-up and cool-down phase and a } 40 \text {-minute phase consisting of } 2 \text { sets of } 12 \text { repetitions } \\
\text { of } 9 \text { exercises. } \\
\text { C. Attention Control ( } n=144 \text { ) attended, during the first } 3 \text { months, monthly group sessions on education related to arthritis manage-ment, including } \\
\text { time for discussions and social gathering. Later, participants were called bimonthly (months 4-6) or monthly (months } 7-18 \text { ) to maintain health } \\
\text { updates and provide support }\end{array}$ \\
\hline Perlman 2012 & 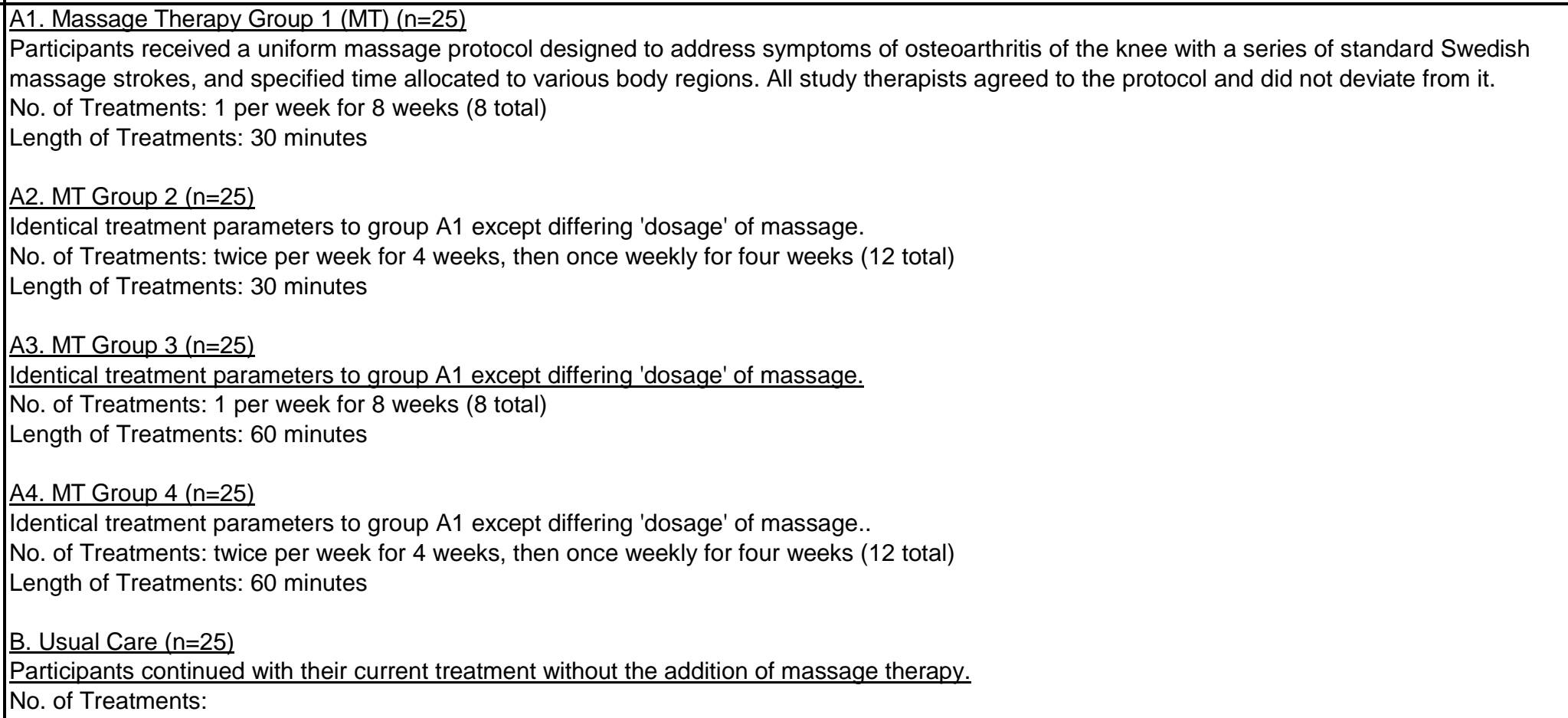 \\
\hline
\end{tabular}




\begin{tabular}{|c|c|c|c|}
\hline Author, Year & Study Participants & Outcome Measures & $\begin{array}{c}\text { Duration of } \\
\text { Followup }\end{array}$ \\
\hline $\begin{array}{l}\text { Pennix } 2002 \\
\text { FAST trial } \\
\text { (substudy looking } \\
\text { at baseline } \\
\text { depressive } \\
\text { symptoms) }\end{array}$ & $\begin{array}{l}\text { All participants (not reported separately by treatment group) } \\
\text { Age: } 69 \text { years } \\
\text { Female: } 70 \% \\
\text { Education, }>12 \text { years: } 56 \% \\
\text { High depressive symptomology on the CES-D (cutoff of } 5 \text { points): } 22 \% \\
\text { CES-D: } 2.74 \text { vs. } 2.74 \text { vs. } 2.74\end{array}$ & $\begin{array}{l}\text { Short Version of Center for Epidemiologic Studies } \\
\text { Depression (CES-D) (scale 0-18; higher score=more } \\
\text { depression); } \\
\text { 23-item self-report disability questionnaire (Scale 1-5; } \\
\text { higher score=greater disability); } \\
\text { Average knee pain during the past week for six different } \\
\text { activities of daily living on a Likert scale (Scale 1-6; } \\
\text { higher score=worse pain) }\end{array}$ & \begin{tabular}{|l|}
3 \\
(immediately \\
post \\
treatment), 6, \\
and 15 \\
months
\end{tabular} \\
\hline Perlman 2012 & $\begin{array}{l}\text { A1 vs. A2 vs. A3 vs. A4 vs. B } \\
\text { Age: } 70 \text { vs. } 62 \text { vs. } 63 \text { vs. } 64 \text { vs. } 64 \\
\text { Female: } 60 \% \text { vs. } 72 \% \text { vs. } 76 \% \text { vs. } 68 \% \text { vs. } 76 \% \\
\text { Race: } 92 \% \text { vs. } 88 \% \text { vs. } 76 \% \text { vs. } 80 \% \text { vs } 88 \% \text { white } \\
\text { Mean Duration of Chronicity: NR } \\
\text { Global (WOMAC): } 52.9(18.3) \text { vs. } 50.2(19.4) \text { vs. } 53.6(17.3) \text { vs. } \\
48.0(19.0) \text { vs. } 53.2(14.8) \\
\text { Pain (WOMAC): } 52.3(19.9) \text { vs. } 42.4(23.0) \text { vs. } 52.5(16.5) \text { vs. } 44.4(19.3) \\
\text { vs. } 46.3(15.4) \\
\text { Stiffness (WOMAC): } 53.4(24.1) \text { vs. } 58.6(21.1) \text { vs. } 58.4(24.7) \text { vs. } \\
51.2(24.4) \text { vs. } 62.8(18.2) \\
\text { Physical Function (WOMAC): } 52.9(17.9) \text { vs. } 49.5(19.5) \text { vs. } 49.8(19.7) \\
\text { vs. } 48.3(20.2) \text { vs. } 50.5(17.4) \\
\text { Pain (VAS): } 61.2(16.8) \text { vs. } 64.0(12.7) \text { vs. } 66.4(11.3) \text { vs. } 59.2(13.3) \text { vs. } \\
57.6(9.0)\end{array}$ & $\begin{array}{l}\text { Western Ontario and McMaster Universities } \\
\text { Osteoarthritis Index (WOMAC, higher scores indicate } \\
\text { greater pain, stiffness or functional limitation) } \\
\text { *no range for the scales provided } \\
\text { Pain (VAS, range } 0-100 \mathrm{~mm} \text { : higher scores indicate } \\
\text { severity of pain) }\end{array}$ & $\begin{array}{l}2 \text { and } 4 \\
\text { months }\end{array}$ \\
\hline
\end{tabular}




\begin{tabular}{|c|c|}
\hline Author, Year & $\begin{array}{c}\text { Results - Subquestion a } \\
\text { (vs. sham, no treatment, waitlist, attention control) }\end{array}$ \\
\hline $\begin{array}{l}\text { Pennix } 2002 \\
\text { FAST trial } \\
\text { (substudy looking } \\
\text { at baseline } \\
\text { depressive } \\
\text { symptoms) }\end{array}$ & $\begin{array}{l}\text { CES-D (Depressive Symptoms), average over time: } \\
\text { A vs C: } 2.12 \text { vs } 2.80, p<0.001 \\
\text { B vs C: } 2.59 \text { vs } 2.80, p=0.27 \\
\end{array}$ \\
\hline Perlman 2012 & 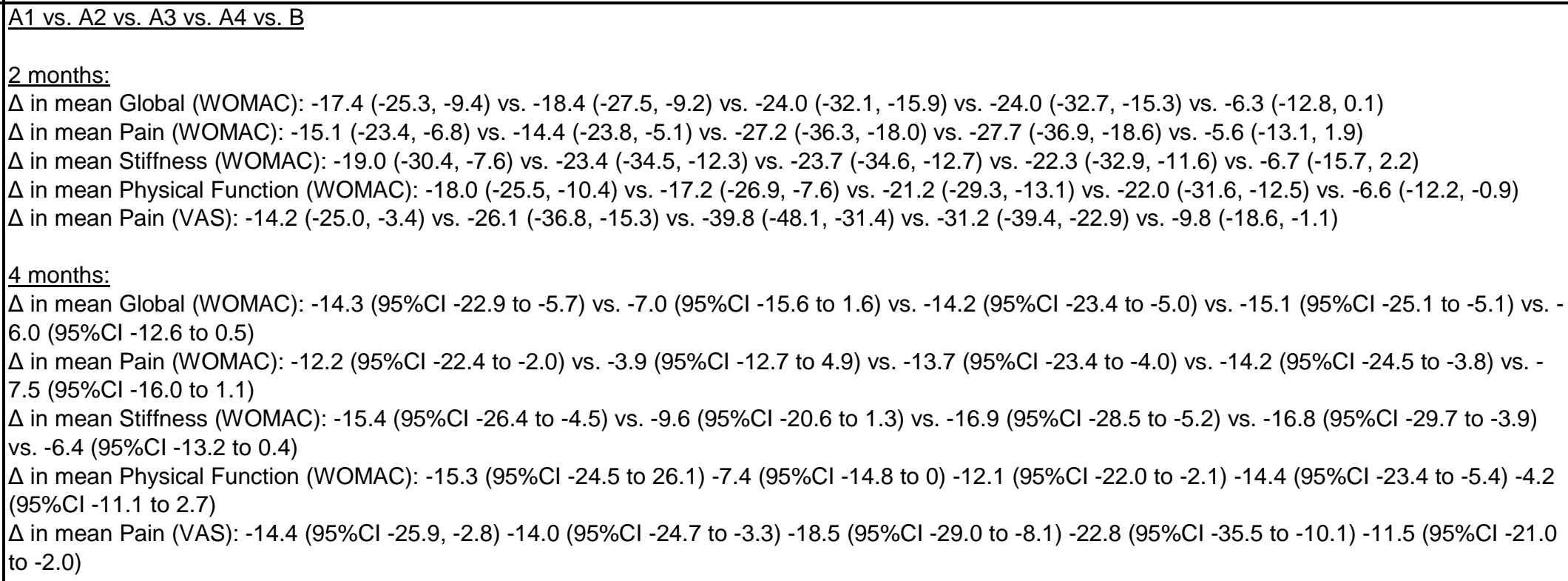 \\
\hline
\end{tabular}




\begin{tabular}{|l|l|}
\hline \multicolumn{1}{|c|}{ Author, Year } & \multicolumn{1}{c|}{$\begin{array}{c}\text { Results - Subquestion b } \\
\text { (vs. Pharmacological therapy) }\end{array}$} \\
\hline $\begin{array}{l}\text { Pennix 2002 } \\
\text { FAST trial } \\
\text { (substudy looking } \\
\text { at baseline } \\
\text { depressive } \\
\text { symptoms) }\end{array}$ & \\
\hline Perlman 2012 & NR \\
& \\
\hline
\end{tabular}




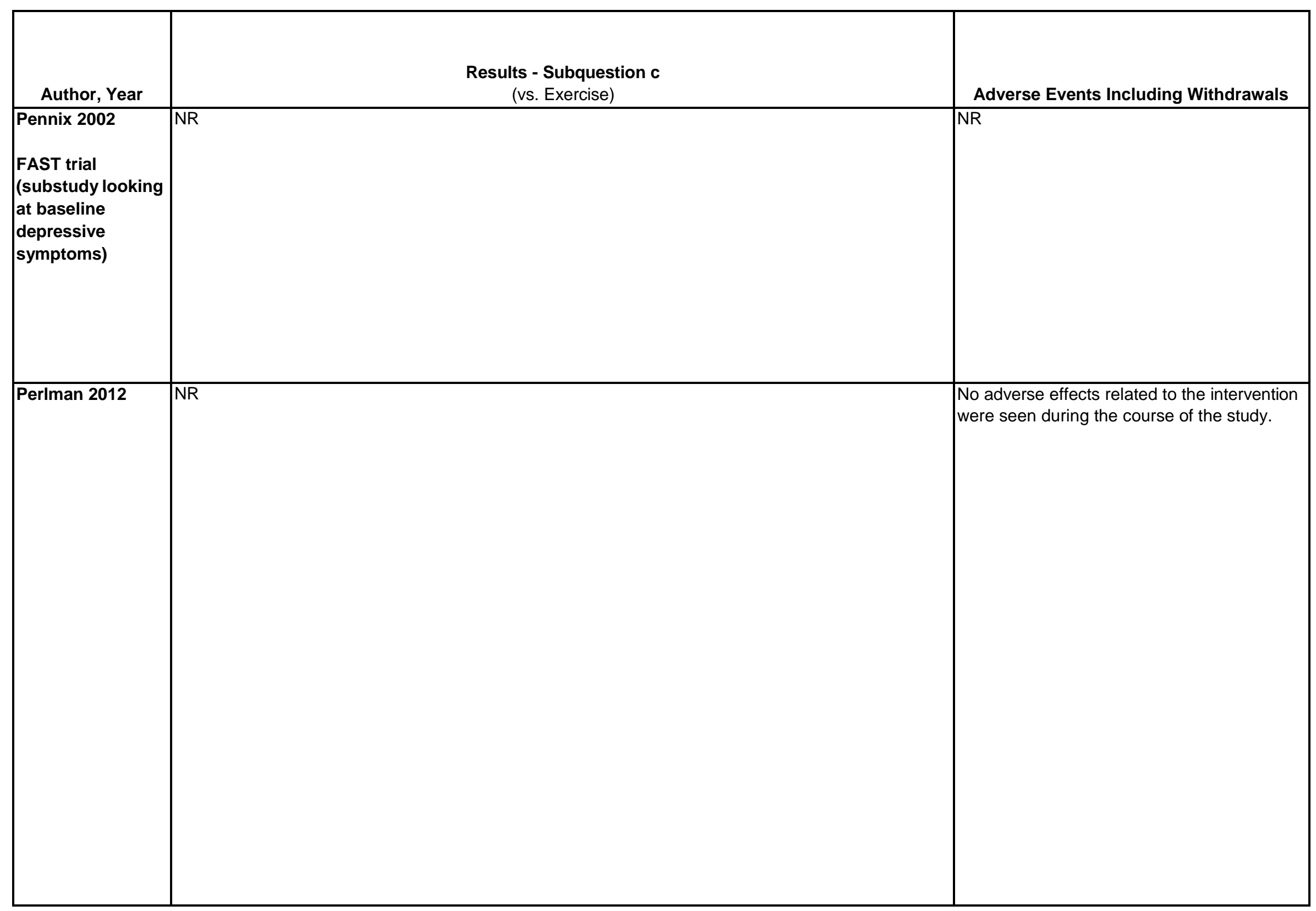




\begin{tabular}{|l|l|l|l|}
\hline \multicolumn{1}{|c|}{ Author, Year } & \multicolumn{1}{|c|}{ Funding Source } & Quality & \multicolumn{1}{|c|}{ Comments } \\
\hline Pennix 2002 & $\begin{array}{l}\text { Grant P60AG10484-01 from the } \\
\text { National Institute on Aging }\end{array}$ & Fair & Secondary analysis/outcome of original trial (Ettinger 1997) \\
$\begin{array}{l}\text { FAST trial } \\
\text { (substudy looking } \\
\text { at baseline } \\
\text { depressive } \\
\text { symptoms) }\end{array}$ & The Fitness Arthritis and Seniors Trial (FAST) \\
\hline Perlman 2012 & $\begin{array}{l}\text { "The publication was made possible } \\
\text { by grant number R01 ATO04623 from } \\
\text { the National Center for } \\
\text { Complementary and Alternative } \\
\text { Medicine (NCCAM at the National } \\
\text { Institutes of Health . The funders had } \\
\text { no role in study design, data collection } \\
\text { and analysis, decision to publish, or } \\
\text { preparation of the manuscript." }\end{array}$ & Fair & \\
& & & \\
\hline
\end{tabular}




\begin{tabular}{|c|c|c|c|}
\hline Author, Year & $\begin{array}{c}\text { Country } \\
\text { Number of Centers } \\
\text { Setting }\end{array}$ & Inclusion/Exclusion Criteria & $\begin{array}{c}\text { Number Randomized, } \\
\text { Analyzed } \\
\text { Attrition }\end{array}$ \\
\hline Poole 2007 & \begin{tabular}{|l} 
UK \\
Number of centers: 5 \\
reflexologists, 4 \\
therapists \\
Outpatient GP \\
surgeries or local \\
health center
\end{tabular} & $\begin{array}{l}\text { Age 18-65 years } \\
\text { Benign chronic LBP: an unresolved episode of LBP }>12 \text { weeks } \\
\text { duration } \\
\text { Exclude: } \\
\text { Pregnancy } \\
\text { Significant co-existing major medical illness } \\
\text { Diagnosed with significant co-existing psychiatric disorder } \\
\text { In litigation } \\
\text { Previous use of reflexology } \\
\text { Contraindication to reflexology, including recent surgery and } \\
\text { circulatory disorders of the lower limbs }\end{array}$ & $\begin{array}{l}\text { Randomized: } 243 \\
\text { Analyzed: } 156 \text { (6 months) } \\
\text { Attrition: } 36 \% \text { (87/243) }\end{array}$ \\
\hline Quilty 2003 & $\begin{array}{l}\text { UK, } 1 \text { community } \\
\text { setting }\end{array}$ & $\begin{array}{l}\text { Inclusion: chronic knee pain and radiographic evidence of } \\
\text { predominant PFJ involvement. } \\
\text { Exclusion: Advanced tibiofemoral joint changes, hip disease, previous } \\
\text { major knee surgery, fractures involving the knee joint or rheumatoid } \\
\text { arthritis. }\end{array}$ & $\begin{array}{l}\text { Randomized: } 87 \\
\text { Treated: } 82 \\
\text { Analyzed: } 82 \\
\text { Attrition: } 6 \%(5 / 87)\end{array}$ \\
\hline
\end{tabular}




\begin{tabular}{|c|c|}
\hline Author, Year & Intervention, Comparator \\
\hline Poole 2007 & $\begin{array}{l}\text { A: Respondent therapy (progressive muscle relaxation) }(n=54) \text { : Guided progressive muscle relaxation treatment instructing the participant to tense } \\
\text { then relax successive groups of muscles, focusing attention on the differential experience of each state. Groups of 1-4 participants. } 6 \text { treatments, } \\
\text { approximately } 1 \text { hour duration, over 6-8 weeks. } \\
\text { B. Reflexology ( } n=57) \text { : Morrell technique, application of firm but gentle compression to points of the feet thought to correspond to other parts of the } \\
\text { body. } 6 \text { treatments, approximately } 1 \text { hour duration, over 6-8 weeks. } \\
\text { C.Usual care }(n=45) \text { : Treatments per patient's physician (General Practitioner). Treatments included prescription medication, over the counter } \\
\text { medication, physiotherapy, massage, acupuncture, herbal remedies, TENS, pain management program, and no treatment (reported by participants } \\
\text { at end of the study). }\end{array}$ \\
\hline Quilty 2003 & $\begin{array}{l}\text { A. Physiotherapy }(n=40) \\
9 \text { sessions over a } 10 \text { week period lasting half an hour each carried out in a community setting. Patellar taping, } 7 \text { exercises (tailored to each patient), } \\
\text { posture correction, and footwear advice. All exercises were to be pain-free and performed } 10 \text { times each, } 5 \text { times a day. } \\
\text { B. Control ( } n=43) \text { : At the baseline visit all patients had a half-hour discussion with the physiotherapist concerning diagnosis, prognosis, } \\
\text { footwear, weight reduction, and activity. General exercise was encouraged but no specific quadriceps exercises were advised }\end{array}$ \\
\hline
\end{tabular}




\begin{tabular}{|c|c|c|c|}
\hline Author, Year & Study Participants & Outcome Measures & $\begin{array}{l}\text { Duration of } \\
\text { Followup }\end{array}$ \\
\hline Poole 2007 & $\begin{array}{l}\text { A vs. C } \\
\text { Age: } 46 \text { vs. } 47 \\
\text { Female: } 65 \% \text { vs. } 51 \% \\
\text { Duration of pain (months): } 128 \text { vs. } 115 \\
\text { Previous use of CAM: } 55 \% \text { vs. } 53 \%\end{array}$ & $\begin{array}{l}\text { SF-36 domains (0-100) } \\
\text { Oswestry Disability Index (ODI): (0-100\%; higher } \\
\text { percentage=greater impairment) } \\
\text { Beck Depression Inventory (BDI) (0-63, higher } \\
\text { score=more depressive symptoms) } \\
\text { Pain (0-100 VAS) }\end{array}$ & 4.5 months \\
\hline Quilty 2003 & $\begin{array}{l}\text { A vs B } \\
\text { Age: } 69 \text { vs } 67 \text { years } \\
\text { BMl: } 30 \text { vs } 30 \\
\text { WOMAC Function: } 27.4(12.2) \text { vs } 27.8(10.1) \\
\text { VAS pain: } 51.0(29.3) \text { vs } 53.4(25.9)\end{array}$ & $\begin{array}{l}\text { Overall pain in the most painful knee (Scale 0-100 mm } \\
\text { Visual Analog Scale) } \\
\text { Western Ontario and McMaster University OAindex } \\
\text { (WOMAC) function sub-score (Scale 0-68) }\end{array}$ & $\begin{array}{l}2.5 \text { and } 10.5 \\
\text { months }\end{array}$ \\
\hline
\end{tabular}




\begin{tabular}{|c|c|}
\hline Author, Year & $\begin{array}{c}\text { Results - Subquestion a } \\
\text { (vs. sham, no treatment, waitlist, attention control) }\end{array}$ \\
\hline Poole 2007 & 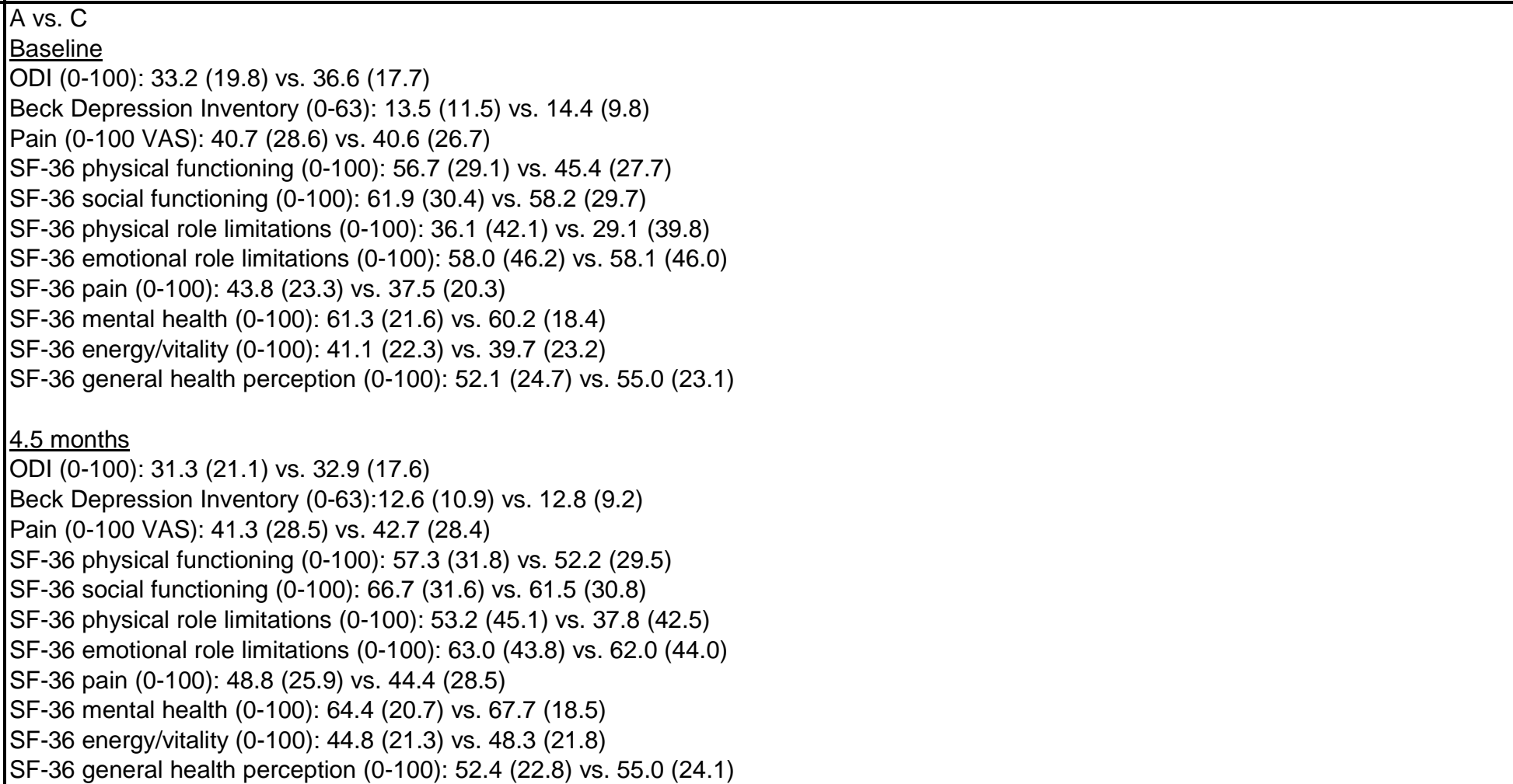 \\
\hline Quilty 2003 & 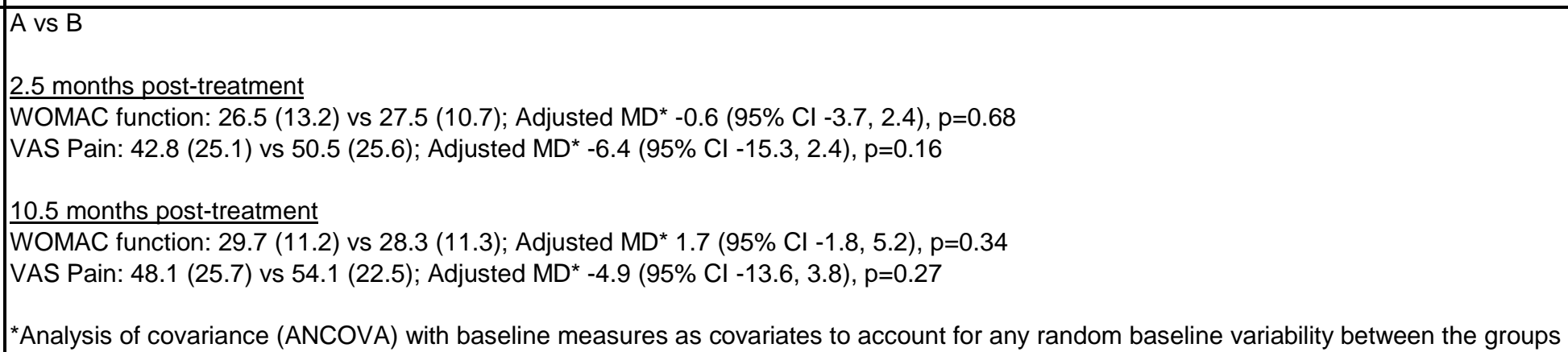 \\
\hline
\end{tabular}




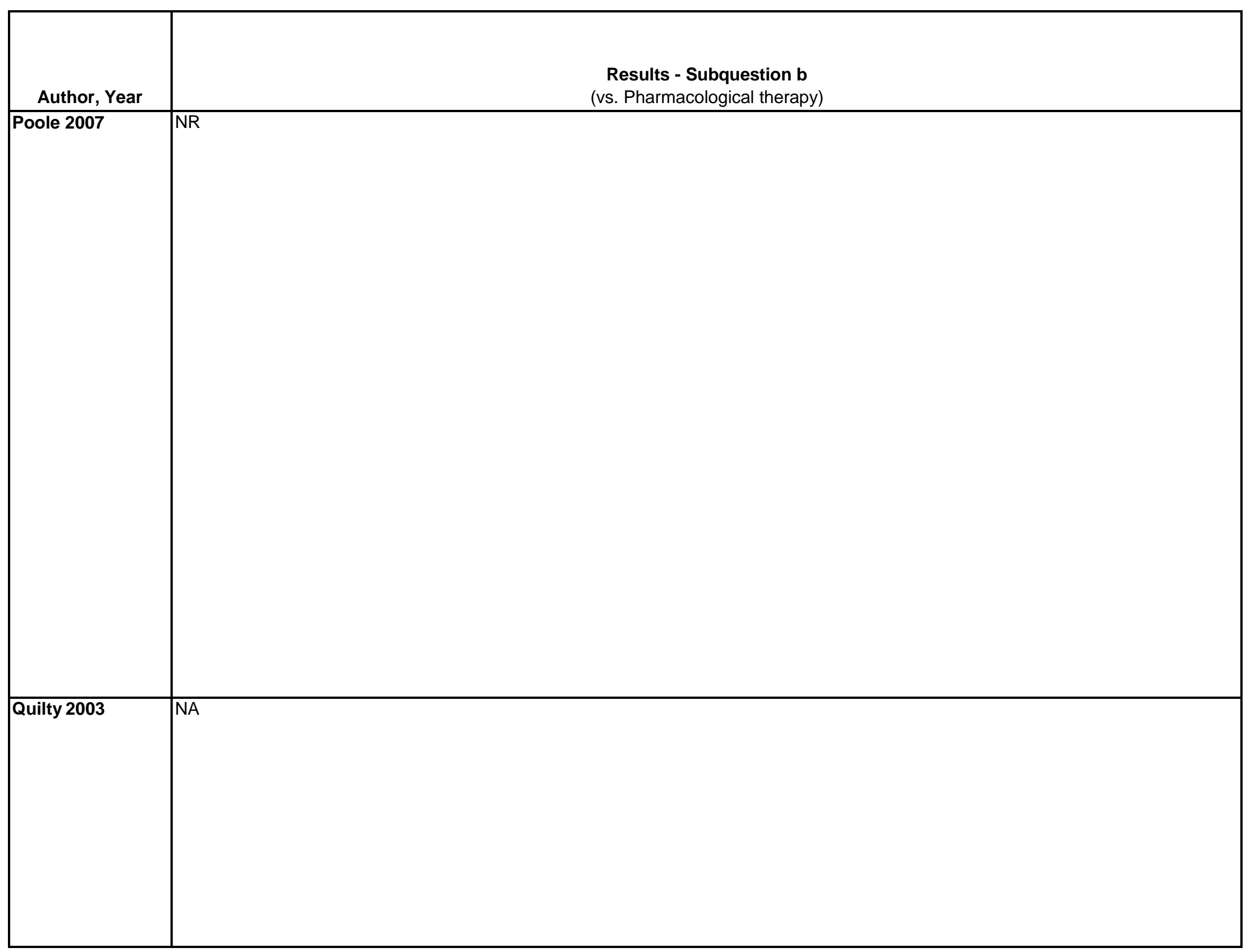

D-621 


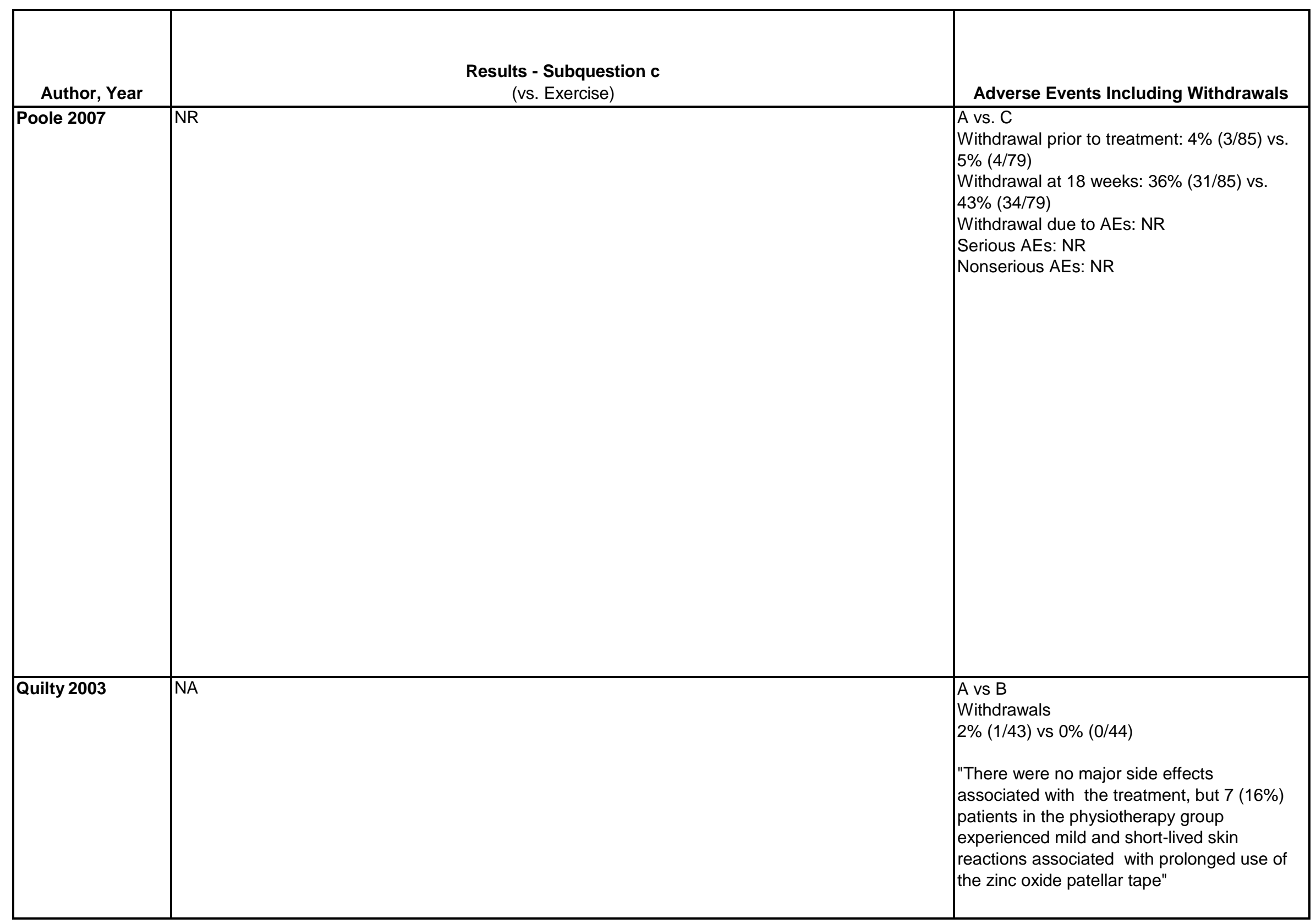




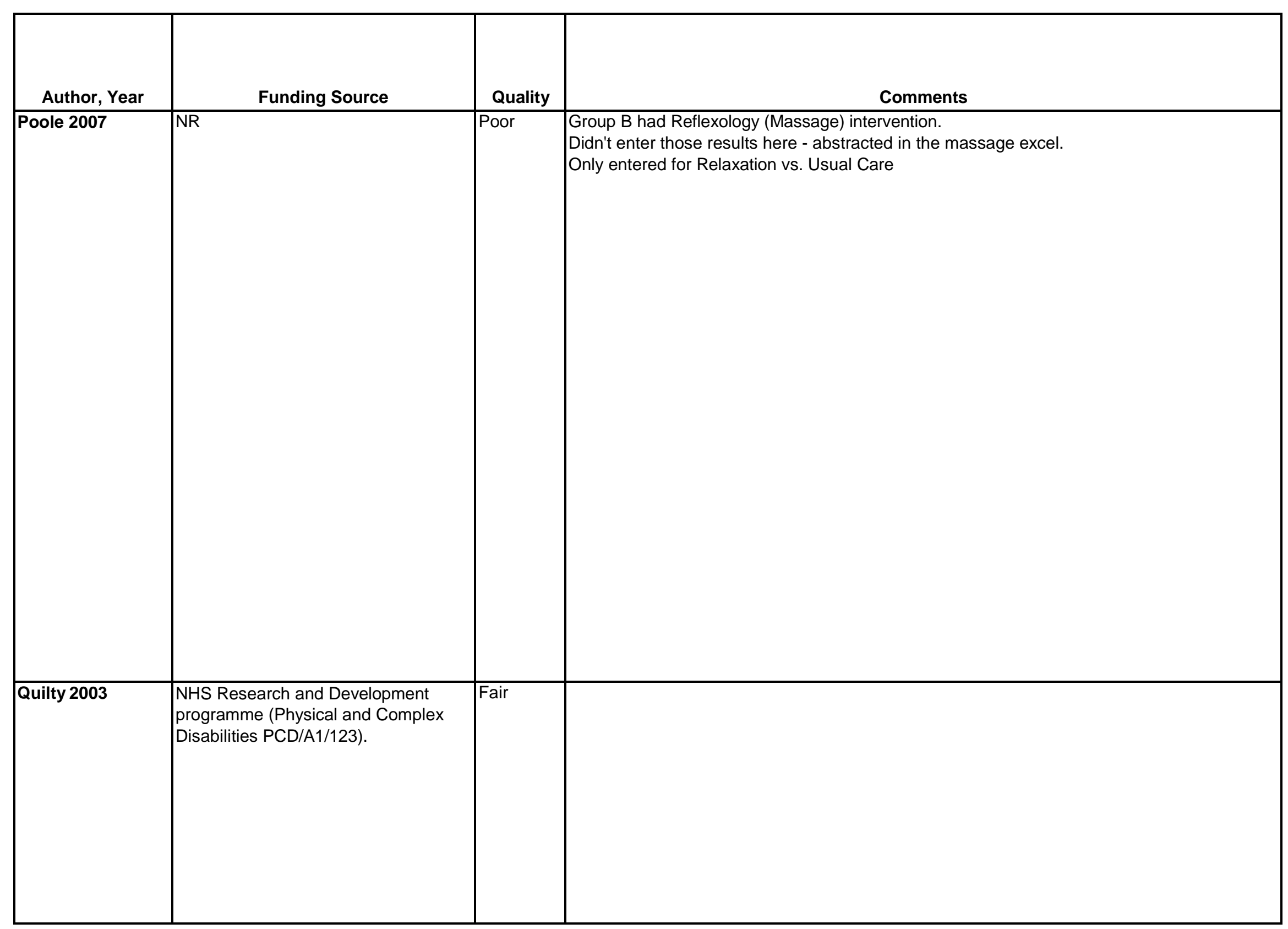




\begin{tabular}{|c|c|c|c|}
\hline Author, Year & $\begin{array}{c}\text { Country } \\
\text { Number of Centers } \\
\text { Setting }\end{array}$ & Inclusion/Exclusion Criteria & $\begin{array}{c}\text { Number Randomized, } \\
\text { Analyzed } \\
\text { Attrition }\end{array}$ \\
\hline Quinn 2008 & $\begin{array}{l}\text { UK } \\
\text { Number of centers: } 1 \\
\text { Outpatient }\end{array}$ & $\begin{array}{l}\text { Diagnosed with non-specific LBP } \\
\text { Any treatment for LBP stabilized for } 3 \text { months } \\
\text { Reflexology naive } \\
\text { Exclude: } \\
\text { Involvement in other research projects within } 3 \text { months }\end{array}$ & \begin{tabular}{|l|} 
Randomized: 15 \\
Treated: 15 \\
Analyzed: 15
\end{tabular} \\
\hline
\end{tabular}




\begin{tabular}{|l|l|}
\hline \multicolumn{1}{|c|}{ Author, Year } & \multicolumn{1}{c|}{ Intervention, Comparator } \\
\hline Quinn 2008 & $\begin{array}{l}\text { A: Reflexology: Pressure massage stimulation of numerous specific reflex points on the feet associated with the vertebrae of the spine and } \\
\text { surrounding musculature }(\mathrm{n}=7) \\
\text { B: Sham reflexology: Simple foot massage with stimulation of reflex points, avoiding vertebrae of the spine and surrounding musculature. (n=8) } \\
\text { Both groups received } 40 \text { minute weekly sessions for } 6 \text { weeks }\end{array}$ \\
\hline
\end{tabular}




\begin{tabular}{|l|l|l|l|}
\hline \multicolumn{1}{|c|}{ Author, Year } & \multicolumn{1}{|c|}{ Study Participants } & \multicolumn{1}{|c|}{ Outcome Measures } \\
\hline Quinn 2008 & $\begin{array}{l}\text { Age (median): } 42 \text { vs. } 45 \\
\text { Female: } 86 \% \text { vs. } 50 \% \\
\text { Pain visual analogue scale: } 4.7 \text { vs. 3.4 } \\
\text { RDQ: } 5 \text { vs. } 7.5 \\
\text { McGill pain scale: } 24 \text { vs. } 19\end{array}$ & $\begin{array}{l}\text { Duration of } \\
\text { Followup }\end{array}$ \\
\hline $\begin{array}{l}\text { Primary outcomes: } \\
\text { Pain Visual Analogue Scale: 10cm scale, higher } \\
\text { number = worse pain } \\
\text { Secondary outcomes: } \\
\text { RDQ: total score 0-24, higher number=worse function } \\
\text { McGill Pain questionnaire: total score 0-77, higher } \\
\text { number=worse pain } \\
\text { SF-36 health survey: total score 0-100, higher } \\
\text { number=better health quality of life }\end{array}$ \\
\end{tabular}




\begin{tabular}{|c|c|}
\hline Author, Year & $\begin{array}{c}\text { Results - Subquestion a } \\
\text { (vs. sham, no treatment, waitlist, attention control) }\end{array}$ \\
\hline Quinn 2008 & 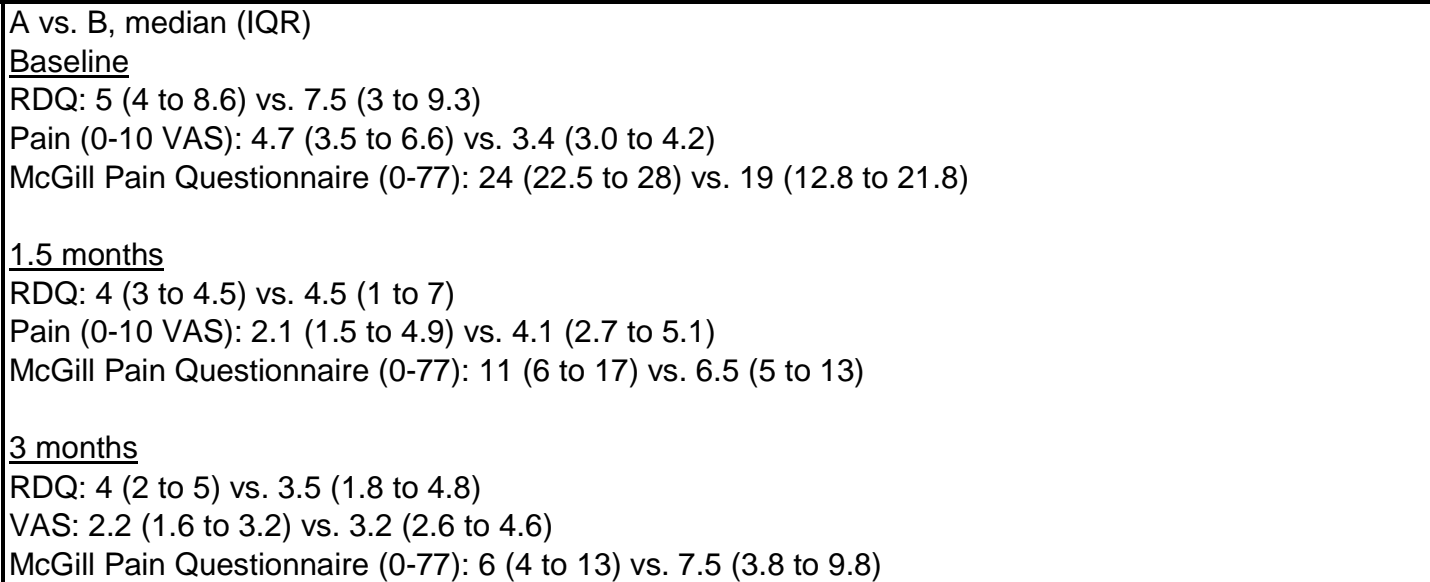 \\
\hline
\end{tabular}




\begin{tabular}{|c|c|}
\hline Author, Year & $\begin{array}{l}\text { Results - Subquestion b } \\
\text { (vs. Pharmacological therapy) }\end{array}$ \\
\hline Quinn 2008 & 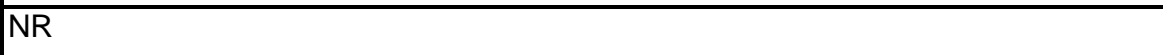 \\
\hline
\end{tabular}




\begin{tabular}{|l|l|l|l|}
\hline & & $\begin{array}{c}\text { Results - Subquestion c } \\
\text { (vs. Exercise) }\end{array}$ & Adverse Events Including Withdrawals \\
\hline Quinn 2008 & NR & $\begin{array}{l}\text { Adverse Events: None reported } \\
\text { Withdrawals: None }\end{array}$ & \\
& & & \\
& & & \\
\hline
\end{tabular}




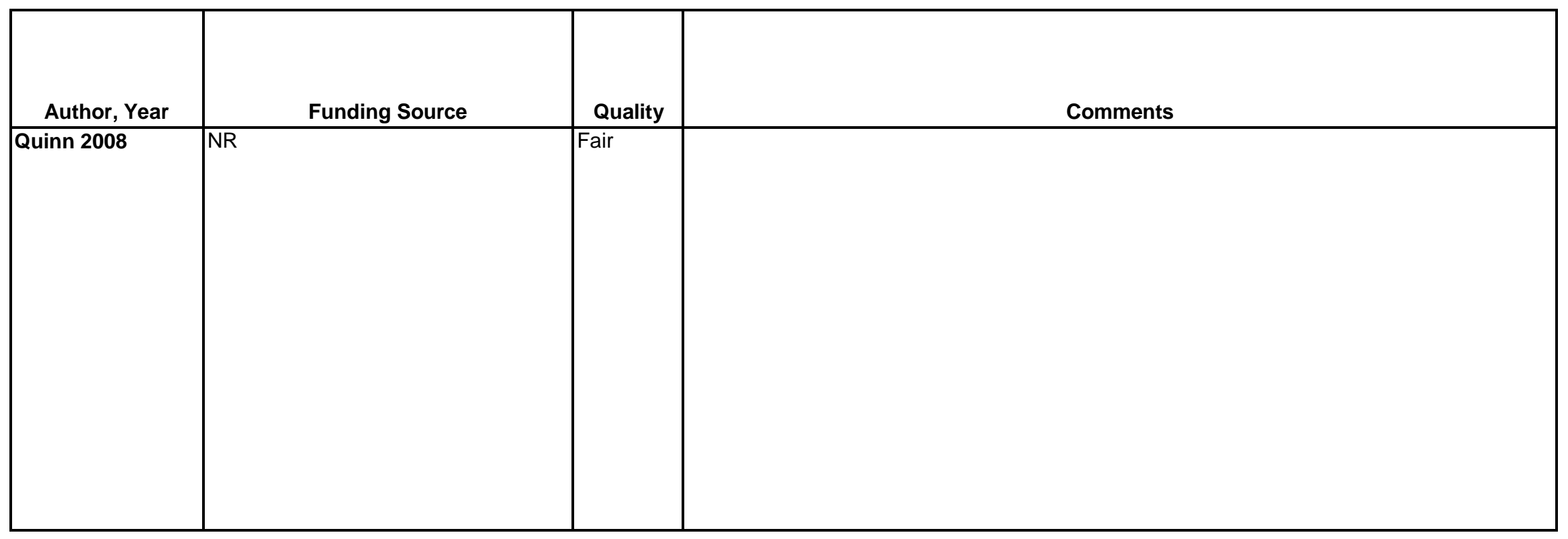

D-630 


\begin{tabular}{|c|c|c|c|}
\hline Author, Year & $\begin{array}{l}\text { Country } \\
\text { Number of Centers } \\
\text { Setting }\end{array}$ & Inclusion/Exclusion Criteria & $\begin{array}{l}\text { Number Randomized, } \\
\text { Analyzed } \\
\text { Attrition }\end{array}$ \\
\hline Redondo 2004 & \begin{tabular}{|l|} 
Spain \\
1 center \\
Tertiary care hospital
\end{tabular} & \begin{tabular}{|l|} 
Females with FM fulfilling ACR criteria \\
Exclude: Serious concomitant diseases
\end{tabular} & \begin{tabular}{|l|} 
Randomized: 40 \\
Treated: 40 \\
Analyzed: 31 \\
Attrition: $23 \%(9 / 40)$
\end{tabular} \\
\hline
\end{tabular}




\begin{tabular}{|c|c|}
\hline Author, Year & Intervention, Comparator \\
\hline Redondo 2004 & $\begin{array}{l}\text { A.Cognitive Behavior Therapy ( } n=21) \text { : One } 2.5 \text { hour session per week for } 8 \text { weeks. Sessions were designed to reduce distorted pain dimensions, to } \\
\text { cope with chronic pain, and to increase self-efficacy. Techniques included giving information about chronic pain, giving information about FM, } \\
\text { teaching relaxation techniques, and teaching coping strategies for chronic pain. Rate of compliance with sessions was mean }=72 \% \text {. } \\
\text { B.Exercise }(n=19): \text { Five } 45 \text { minute sessions of PE per week for } 8 \text { weeks. Each week consisted of } 1 \text { sessions of aquatic exercises, } 2 \text { sessions of } \\
\text { flexibility and endurance exercises, and } 2 \text { sessions of cardiovascular fitness exercises. At the end of the } 8 \text { week program, patients received } \\
\text { instructions to maintain daily physical exercises at home. Rate of compliance with sessions was mean }=84 \% \text {. } \\
\text { All subjects: Offered pharmacologic treatment of anti-inflammatory doses of ibuprofen or diclofenac, } 25 \mathrm{mg} \text { of amitriptyline a day, amd } \\
\text { acetaminophen. Patients were free to modify medication based on their clinical response }\end{array}$ \\
\hline
\end{tabular}




\begin{tabular}{|c|c|c|c|}
\hline Author, Year & Study Participants & Outcome Measures & $\begin{array}{c}\text { Duration of } \\
\text { Followup }\end{array}$ \\
\hline Redondo 2004 & \begin{tabular}{|l} 
A vs $B^{*}$ \\
Female: $100 \%$ vs $100 \%$ \\
FIQt: $52.0(12.0)$ vs $52.0(11.4)$ \\
FIQ pain: $7.3(2.3)$ vs $6.8(1.7)$ \\
FIQ depression: $5.2(3.0)$ vs $5.3(3.3)$ \\
FIQ anxiety: $6.4(3.4)$ vs $6.3(3.3)$ \\
Beck Anxiety Inventory: $24.1(12.3)$ vs $22.1(11.8)$ \\
Beck Depression Inventory: $19.2(12.0)$ vs $16.8(13.4)$ \\
SF-36 physical functioning: $41.9(22.3)$ vs $47.1(15.0)$ \\
SF-36 physical role: $16.7(26.6)$ vs $18.4(24.8)$ \\
SF-36 bodily pain: $23.3(15.7)$ vs $28.5(9.9)$ \\
SF-36 general health: $25.7(14.8)$ vs $39.0(17.4)$ \\
SF-36 vitality: $32.1(16.7)$ vs $31.3(17.3)$ \\
SF-36 social functioning: $55.3(25.8)$ vs $67.1(26.7)$ \\
SF-36 emotional role: $45.0(46.2)$ vs $64.9(40.8)$ \\
SF-36 mental health: $43.7(21.8)$ vs $49.9(24.5)$ \\
SF-36 health change: $4.2(0.7)$ vs $4.0(1.0)$
\end{tabular} & $\begin{array}{l}\text { FIQ (0-80, higher score=higher disability); FIQ pain (0- } \\
\text { 10, higher score=greater pain); FIQ depression (0-10, } \\
\text { higher score=greater depression); FIQ anxiety (0-10, } \\
\text { higher score=greater anxiety); Beck Anxiety Inventory (0 } \\
63 \text {, higher score=higher anxiety); Beck Depression } \\
\text { Inventory (0-63, higher scores=higher depression) SF- } \\
36 \text { subscales (0-100, higher score=higher quality of } \\
\text { health); SF-36 health change (0-5, higher score=more } \\
\text { negative health change) }\end{array}$ & $\begin{array}{l}6 \text { and } 12 \\
\text { months }\end{array}$ \\
\hline
\end{tabular}




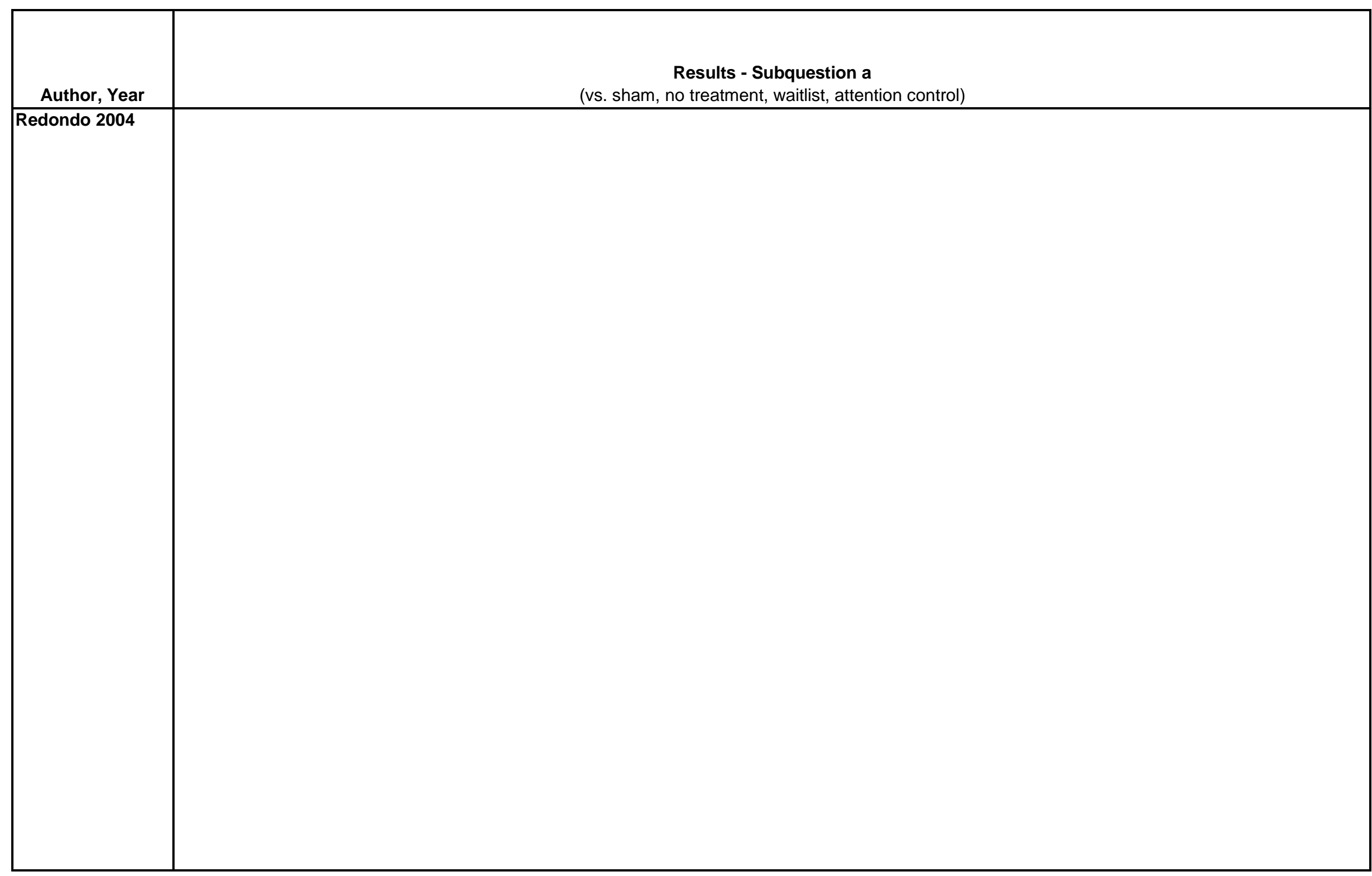




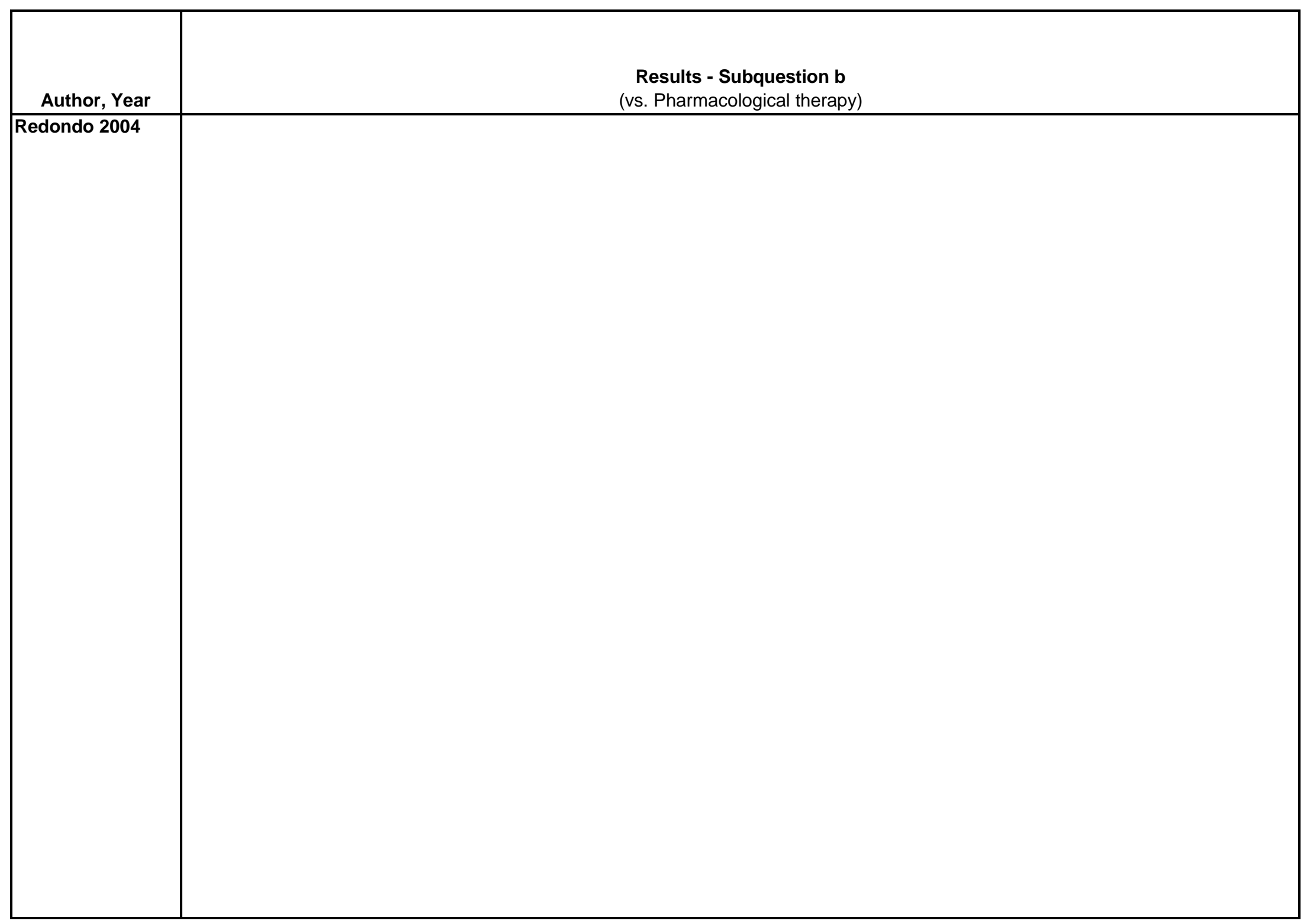

D-635 


\begin{tabular}{|c|c|c|}
\hline Author, Year & $\begin{array}{l}\text { Results - Subquestion c } \\
\text { (vs. Exercise) }\end{array}$ & Adverse Events Including Withdrawals \\
\hline Redondo 2004 & 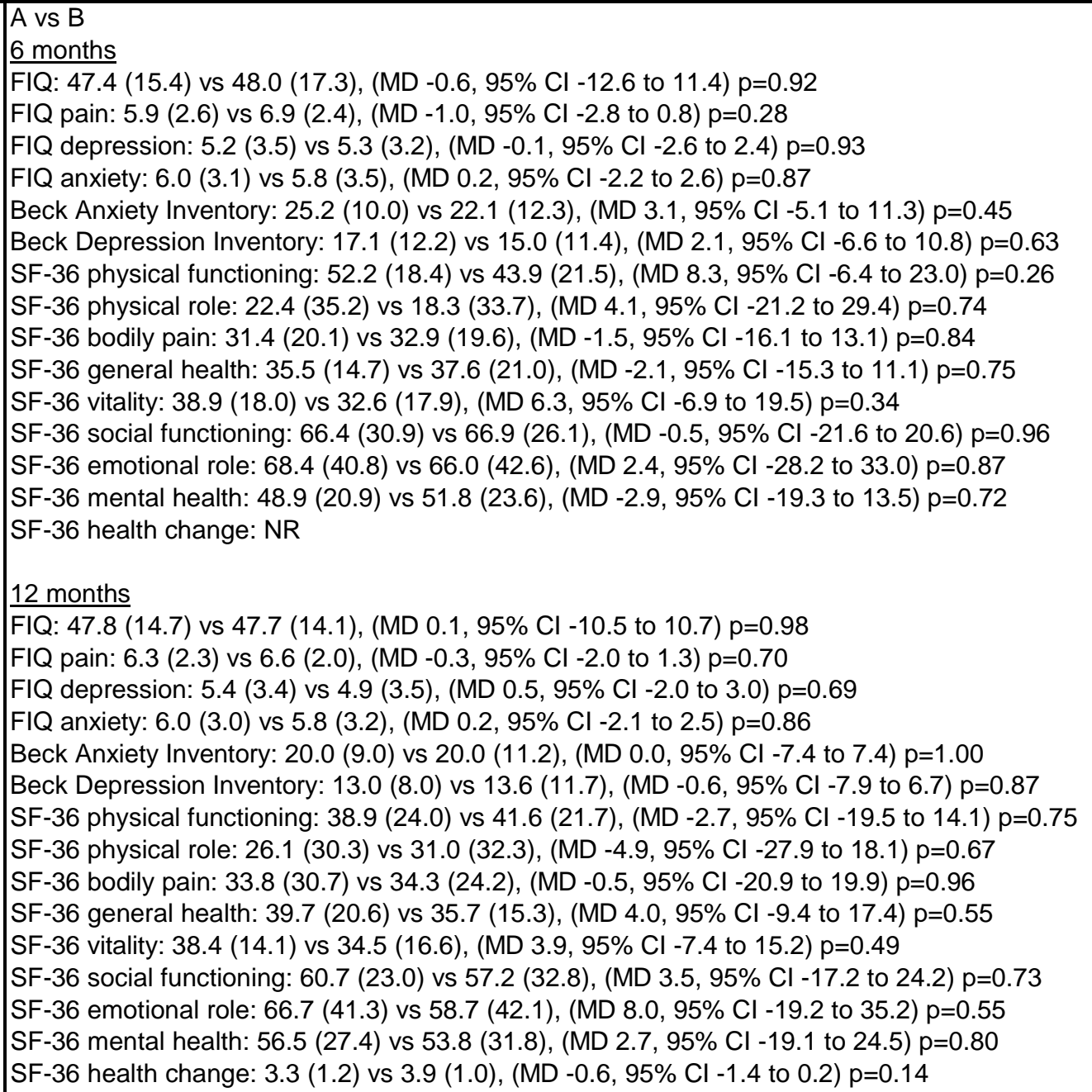 & NR \\
\hline
\end{tabular}




\begin{tabular}{|c|c|c|l|}
\hline Author, Year & Funding Source & Quality & \multicolumn{1}{|c|}{ Comments } \\
\hline Redondo 2004 & Poor & $\begin{array}{l}\text { *Authors state that baseline characteristics were measured but no demographics were } \\
\text { actually reported in the study } \\
\text { tIndividual subscales were also reported but only pain, anxiety, and depression were } \\
\text { abstracted separately } \\
\text { MDs and p values calculated. Baseline values of outcome measures may be different } \\
\text { enough to warrant adjusted analysis to be done }\end{array}$ \\
& & & \\
\hline
\end{tabular}




\begin{tabular}{|c|c|c|c|}
\hline Author, Year & $\begin{array}{c}\text { Country } \\
\text { Number of Centers } \\
\text { Setting }\end{array}$ & Inclusion/Exclusion Criteria & $\begin{array}{c}\text { Number Randomized, } \\
\text { Analyzed } \\
\text { Attrition }\end{array}$ \\
\hline $\begin{array}{l}\text { Rejeski } 2002 \\
\text { ADAPT Trial (same } \\
\text { trial as Messier } \\
\text { 2004; reports } \\
\text { quality of life } \\
\text { outcomes) }\end{array}$ & $\begin{array}{l}\text { United States } \\
1 \text { center } \\
\text { University } \\
\\
\end{array}$ & $\begin{array}{l}\text { Aged } 60 \text { or older, BMI greater or equal to } 28 \text {, knee pain on most days } \\
\text { of the month, sedentary lifestyle with less than } 20 \text { minutes of formal } \\
\text { exercise once a week for the past } 6 \text { months, self-reported difficulty in } \\
\text { at least one of the following activities due to knee pain: } 0.25 \text { mile walk, } \\
\text { climbing stairs, bending, stopping, kneeling, shopping, housecleaning, } \\
\text { radiographic evidence of tibio-femoral osteoarthritis, willingness to } \\
\text { undergo testing and intervention procedures } \\
\\
\text { Exclude: Serious medical condition preventing safe participation in an } \\
\text { exercise program, Mini-Mental score less than } 24 \text {, inability to complete } \\
18 \text { month study, inability to walk without a cane or assistive device, } \\
\text { participation in another research study, greater than or equal to } 14 \\
\text { alcoholic drinks per week, inability to complete protocol }\end{array}$ & $\begin{array}{l}\text { Randomized: } 158 \\
\text { Treated: NR } \\
\text { Analyzed: } 158 \\
\text { Attrition: }\end{array}$ \\
\hline Roche 2007/2011 & \begin{tabular}{|l|} 
France, inpatient \\
rehabilitation center
\end{tabular} & $\begin{array}{l}\text { Inclusion Criteria: } \\
\text { Eligibility for patients with nonspecific chronic LBP for at least } 3 \\
\text { months, age } 18 \text { to } 50 \text { years, on sick leave or at risk of work disability, } \\
\text { presently engaged in a nonlimited work contract, and having given } \\
\text { informed consent. } \\
\text { Exclusion Criteria: } \\
\text { Exclusion for LBP of specific origin (malignant, traumatic, infectious, } \\
\text { or inflammatory LBP, acute sciatica, spondylolisthesis), recent spinal } \\
\text { surgery (<4 months), cardiac or respiratory insufficiency (detected by } \\
\text { stress tests), neurologic impairment, a psychiatric disorder precluding } \\
\text { group therapy, and receiving disability pensions. }\end{array}$ & $\begin{array}{l}\text { Randomized: } 86 \\
\text { Treated: } 131 \\
\text { Analyzed: } 113 \\
\text { Attrition: } 14.4 \%(19 / 132)\end{array}$ \\
\hline
\end{tabular}




\begin{tabular}{|c|c|}
\hline Author, Year & Intervention, Comparator \\
\hline $\begin{array}{l}\text { Rejeski } 2002 \\
\text { ADAPT Trial (same } \\
\text { trial as Messier } \\
\text { 2004; reports } \\
\text { quality of life } \\
\text { outcomes) }\end{array}$ & $\begin{array}{l}\text { A.Exercise }(n=80) \text { : Three } 1 \text { hour sessions per week done at the study facility for } 4 \text { months. After } 4 \text { months, participants who wanted to do a home- } \\
\text { based program had the option to undergo a } 2 \text { month transition phase alternating between facility and home sessions, after which they carried out } \\
\text { the program at home. Sessions consisted of } 15 \text { minutes of aerobic exercises, } 15 \text { minutes of resistance-training, an additional } 15 \text { minutes of aerobic } \\
\text { exercises, and a } 15 \text { minute cool down phase. } \\
\text { B.Control }(n=78) \text { : } 1 \text { hour sessions monthly for three months consisting of presentations on osteoarthritis, obesity, and exercise and a question and } \\
\text { answer session. Monthly phone contact was maintained for months } 4-6 \text { and bimonthly phone contact was maintained for months } 7-18 \text {. During } \\
\text { phone calls, researchers gathered information on pain, medication, illnesses, and hospitalizations. On phone calls, participants were also able to } \\
\text { ask questions and voice concerns. }\end{array}$ \\
\hline Roche 2007/2011 & $\begin{array}{l}\text { A: Multidisciplinary intensive functional restoration Program ( } n=68) \text { : Patients in groups of } 6-8 \text { were exposed to an exercise program with a } \\
\text { physiotherapist including warm-up, stretching, flexibility training, aerobic exercises, and strengthening (with occupational therapist), muscular } \\
\text { endurance and coordination exercises, and balneotherapy sessions. Patients also received psychologist provided counseling. } 5 \text { days/week for } 5 \\
\text { weeks ( } 25 \text { total), } 6 \text { hours per day } \\
\text { B. Individualized exercise therapy ( } \mathrm{n}=64) \text { : Active exercise directed by physiotherapist including flexibility, stretching, strengthening, proprioception } \\
\text { exercises, endurance training. Home exercise program including jogging, swimming, stretching. } 3 \text { sessions/week for } 5 \text { weeks ( } 15 \text { total), } 1 \text { hour each }\end{array}$ \\
\hline
\end{tabular}




\begin{tabular}{|c|c|c|c|}
\hline Author, Year & Study Participants & Outcome Measures & $\begin{array}{l}\text { Duration of } \\
\text { Followup }\end{array}$ \\
\hline $\begin{array}{l}\text { Rejeski } 2002 \\
\text { ADAPT Trial (same } \\
\text { trial as Messier } \\
\text { 2004; reports } \\
\text { quality of life } \\
\text { outcomes) }\end{array}$ & $\begin{array}{l}\text { A vs B } \\
\text { Age: } 68 \text { vs } 69 \\
\text { Female: } 74 \% \text { vs } 67 \% \\
\text { Cardiovascular disease: } 16 \% \text { vs } 15 \% \\
\text { Diabetes: } 11 \% \text { vs } 9 \% \\
\text { SF-36 physical component score, mean (SE): } 34.5(1.1) \text { vs } 33.6(1.0) \\
\text { SF-36 mental component score, mean (SE): } 54.3(1.0) \text { vs } 52.7(1.3)\end{array}$ & $\begin{array}{l}\text { SF-36 physical component score (0-100, higher } \\
\text { score=higher quality of life); SF-36 mental component } \\
\text { score (0-100, higher score=higher quality of life) }\end{array}$ & $\begin{array}{l}6 \text { and } 18 \\
\text { months }\end{array}$ \\
\hline Roche 2007/2011 & $\begin{array}{l}\text { A vs B } \\
\text { Mean Age, years: } 41 \text { vs. } 39 \\
\text { Female, \%: } 32.4 \text { vs. } 37.5 \\
\text { Race: NR } \\
\text { History of spinal surgery, \%: } 23.5 \text { vs. } 18.8, p<0.05 \\
\text { Mean duration of symptoms: NR } \\
\text { No. of sick-leave days in the } 2 \text { yr. before treatment: } 185 \text { (149) vs. } \\
\text { 180(135) } \\
\text { Pain (0-10 VAS): } 4.7 \text { (2.1) vs. } 4.5 \text { (2.1) } \\
\text { Dallas Pain Questionnaire daily activities (0-100): } 51.8 \text { (SD not } \\
\text { reported) vs } 51 \text { (23.3) } \\
\text { Dallas Pain Questionnaire work and leisure (0-100): } 51.9 \text { (SD not } \\
\text { reported) vs. } 58 \text { (27.7) } \\
\text { Dallas Pain Questionnaire anxiety/depression (0-100): } 36.7 \text { (SD not } \\
\text { reported) vs. } 30.9 \text { (23.5) } \\
\text { Dallas Pain Questionnaire social interaction (0-100): } 30.7 \text { vs. } 27.4 \text { (SD } \\
\text { not reported) }\end{array}$ & $\begin{array}{l}\text { Primary } \\
\text { Dallas Pain Questionnaire, } 4 \text { subscales (0-100, higher } \\
\text { scores are more unfavorable) } \\
\text { Pain (0-10 VAS) } \\
\% \text { return to work } \\
\% \text { working full-time } \\
\text { days of sick leave } \\
\text { Anxiety/Depression Dallas Pain Questionnaire (DPQ- } \\
\text { Anxiety/Depression) }\end{array}$ & 10.75 months \\
\hline
\end{tabular}




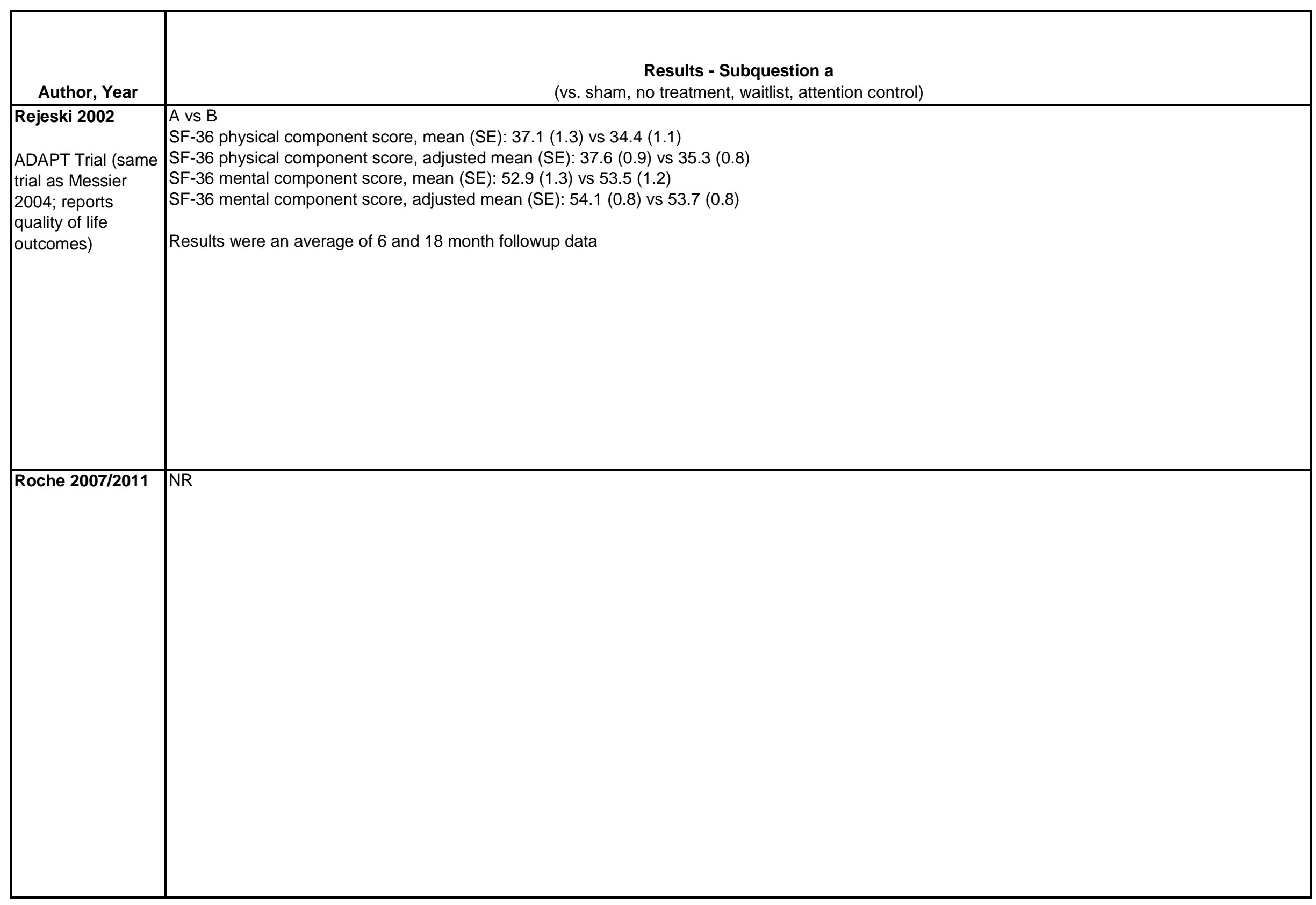




\begin{tabular}{|l|l|}
\hline \multicolumn{1}{|c|}{ Author, Year } & \multicolumn{2}{c|}{$\begin{array}{c}\text { Results - Subquestion b } \\
\text { (vs. Pharmacological therapy) }\end{array}$} \\
\hline $\begin{array}{l}\text { Rejeski 2002 } \\
\text { ADAPT Trial (same } \\
\text { trial as Messier } \\
\text { 2004 reports } \\
\text { quality of life } \\
\text { outcomes) }\end{array}$ & \\
\hline Roche 200712011 & NR \\
& \\
\hline
\end{tabular}




\begin{tabular}{|c|c|c|}
\hline Author, Year & $\begin{array}{l}\text { Results - Subquestion c } \\
\text { (vs. Exercise) }\end{array}$ & Adverse Events Including Withdrawals \\
\hline $\begin{array}{l}\text { Rejeski } 2002 \\
\text { ADAPT Trial (same } \\
\text { trial as Messier } \\
\text { 2004; reports } \\
\text { quality of life } \\
\text { outcomes) }\end{array}$ & & NR \\
\hline Roche 2007/2011 & 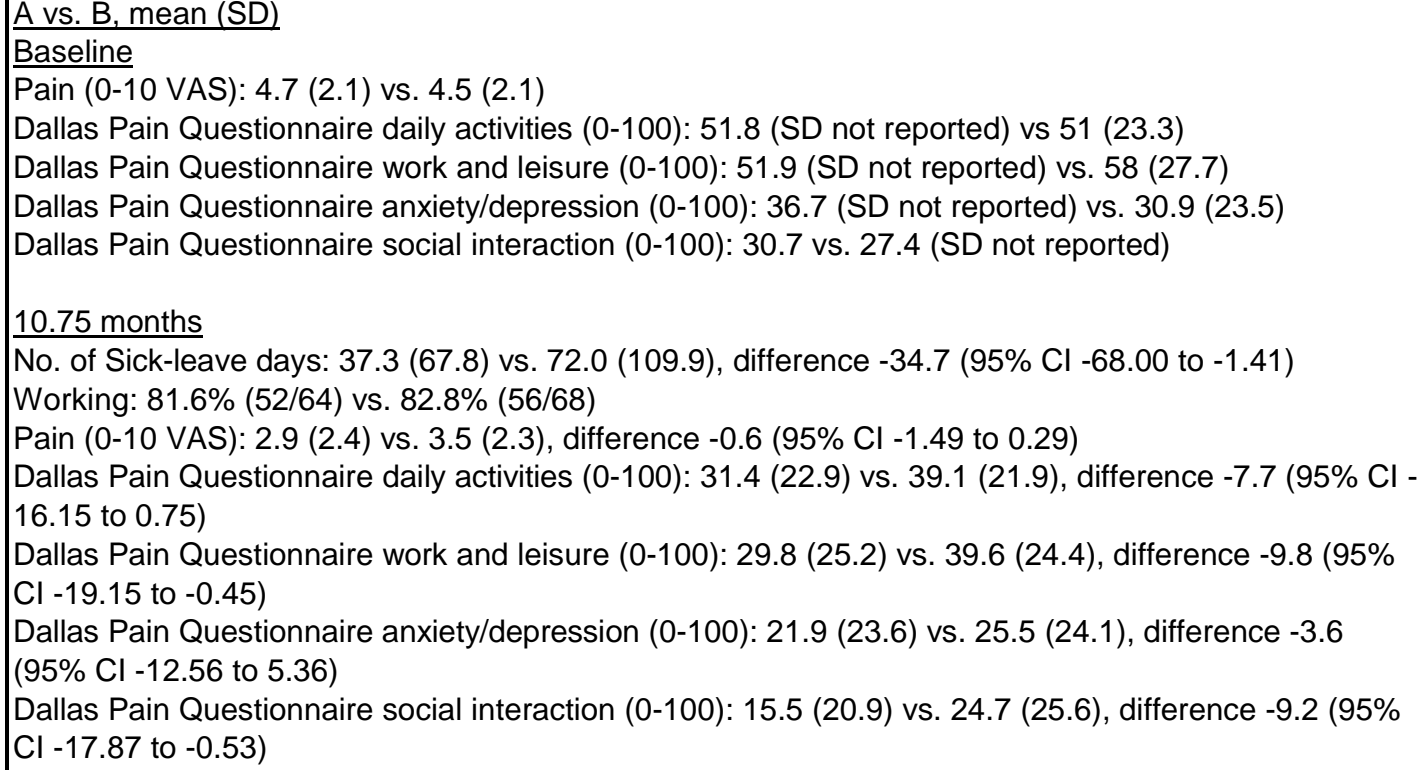 & NR \\
\hline
\end{tabular}




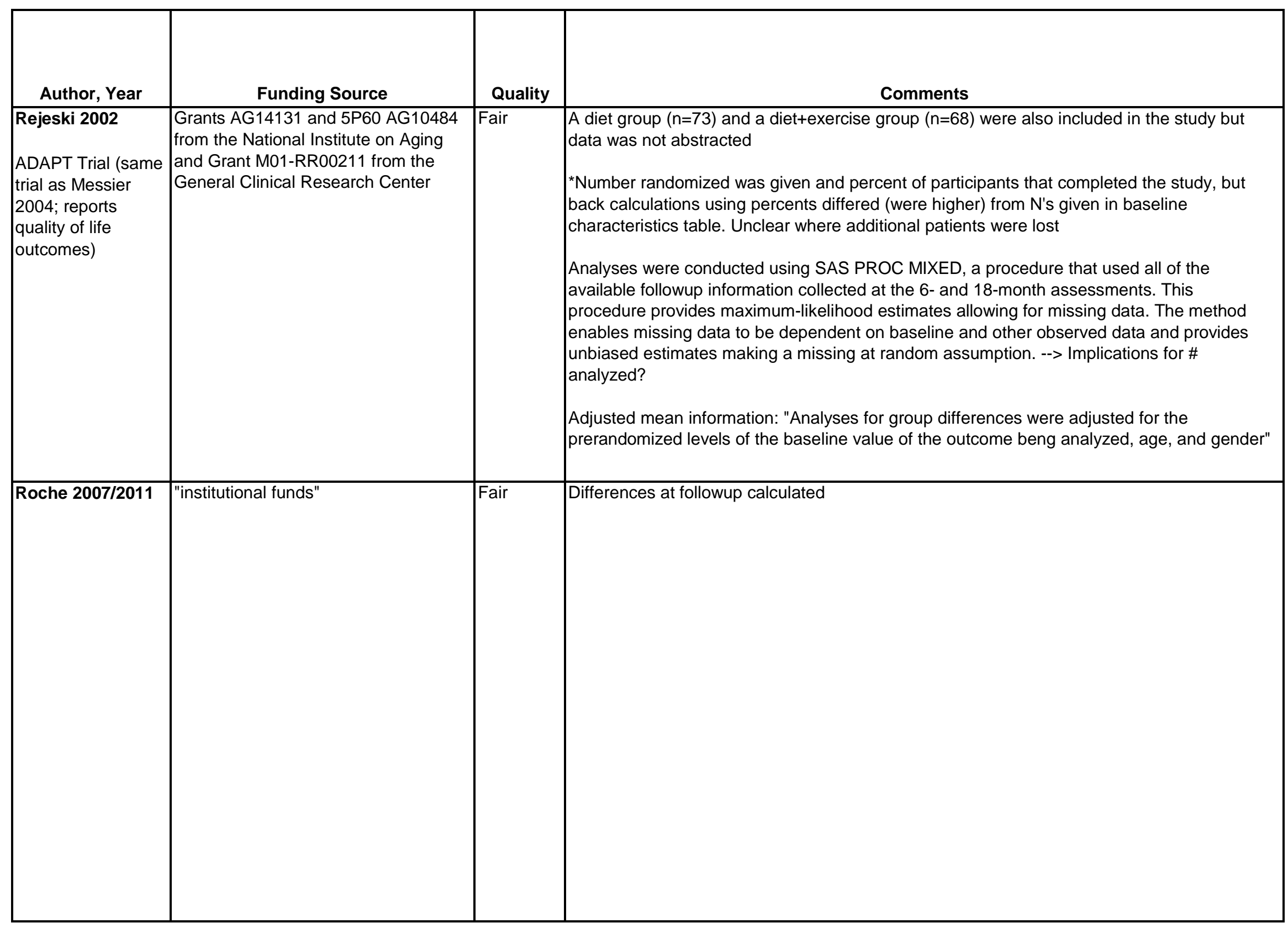




\begin{tabular}{|c|c|c|c|}
\hline Author, Year & $\begin{array}{c}\text { Country } \\
\text { Number of Centers } \\
\text { Setting }\end{array}$ & Inclusion/Exclusion Criteria & $\begin{array}{c}\text { Number Randomized, } \\
\text { Analyzed } \\
\text { Attrition }\end{array}$ \\
\hline Rosedale 2014 & $\begin{array}{l}\text { Canada } \\
\text { Number of centers } \\
\text { unclear } \\
\text { Outpatient }\end{array}$ & $\begin{array}{l}\text { Knee pain for longer than } 4 \text { months and a radiologically confirmed } \\
\text { diagnosis of knee OA. } \\
\text { Exclude: Unable to attend exercise physiotherapy } 2 \text { to } 3 \text { times per } \\
\text { week for } 2 \text { weeks, neurological conditions affecting lower extremities }\end{array}$ & $\begin{array}{l}\text { Randomized: } 180 \\
\text { Treated: } 158 \\
\text { Analyzed: } 124 \\
\text { Attrition: } 31 \%(56 / 180)\end{array}$ \\
\hline Rudolfsson 2014 & $\begin{array}{l}\text { Sweden } \\
\text { Outpatient setting } \\
2008\end{array}$ & $\begin{array}{l}\text { Swedish-speaking women, age range } 25-65 \text { years, with chronic }(>3 \\
\text { months) non-specific neck pain, disability, measured as }>9 \text { normalized } \\
\text { points of the first } 19 \text { items in the Disability Arm Shoulder Hand (DASH) } \\
\text { questionnaire } \\
\text { Excluded: onset or worsening of neck pain associated with trauma; } \\
\text { psychiatric, rheumatic, neurological, inflammatory, endocrine or } \\
\text { connective tissue disease; fibromyalgia; cancer; stroke; cardiac } \\
\text { infarction or diabetes type l; surgery or fracture to the back, neck, or } \\
\text { shoulder in the last } 3 \text { years or shoulder luxation in the last year; } \\
\text { strenuous exercise }>3 \text { times/week during the last } 6 \text { months. }\end{array}$ & $\begin{array}{l}\text { Randomized: } 108 \\
\text { Treated: } 101 \\
\text { Analyzed: } 85 \\
\text { Attrition: } 21 \% \\
\text { (23/108) }\end{array}$ \\
\hline Sahin 2010 & Turkey & $\begin{array}{l}\text { Chronic soft tissue neck pain } \geq 3 \text { months; } 18-65 \text { years of age; }>3 \text { in } 0- \\
10 \text { VAS pain scale; failed physical therapy, medical therapy or collar } \\
\text { for one month; no previous acupuncture therapy. } \\
\\
\text { Excluded: radicular pain, neurological deficits and disk herniation; } \\
\text { lumbar pain } \geq 3 \text { months with VAS }>5 \text {; radiological evidence of } \\
\text { narrowing of cervical neural foramen and facet osteoarthritis; fracture; } \\
\text { congenital neck deformities; spondylolysis or spondylolisthesis; } \\
\text { trauma, vertebral collapse, infection, malignancy, systemic disease, } \\
\text { thoracic outlet syndrome, temporomandibular joint dysfunction, spinal } \\
\text { cord surgery, psychotic disorder, pregnancy, previous use of } \\
\text { antineoplastic and immunosuppressive medications, bleeding } \\
\text { diathesis, physical or medical or manual therapy within a week before } \\
\text { study initiation. }\end{array}$ & $\begin{array}{l}\text { Randomized: } 31 \\
\text { Treated: } 31 \\
\text { Analyzed: } 29 \\
\text { Attrition: } 6 \% \\
(2 / 31)\end{array}$ \\
\hline
\end{tabular}




\begin{tabular}{|c|c|}
\hline Author, Year & Intervention, Comparator \\
\hline Rosedale 2014 & $\begin{array}{l}\text { A.Exercise }(\mathrm{n}=120) \text { : Program was based on the exercise-based treatment program Mechanical Diagnosis and Therapy (MDT). Subjects were } \\
\text { categorized as MDT derangement, meaning a direction of knee movement performed repeatedly had a positive and lasting effect on symptoms, or } \\
\text { to MDT nonresponder, accounting for subjects that did not have a lasting positive change from the repeated movements. The MDT derangement } \\
\text { group was given end-range exercises in the direction they had responded to, to be performed } 10 \text { times every } 2 \text { to } 3 \text { hours. The MDT nonresponder } \\
\text { group was given exercises to strengthen quadriceps and aerobic exercises. All subjects in the exercise group attended } 4 \text { to } 6 \text { physiotherapy } \\
\text { sessions, } 2 \text { to } 3 \text { assessment sessions lasting up to } 1 \text { hour and the rest followup sessions lasting } 20 \text { minutes, over a } 2 \text { week period. } \\
\text { B.Waiting list }(n=60) \text { : Subjects were followed up in the orthopedic department at the surgeon's discretion and continued receiving their usual care. }\end{array}$ \\
\hline Rudolfsson 2014 & $\begin{array}{l}\text { A.Massage }(n=28) \text { (classical) for the upper body including the back, neck and shoulders. Care was taken not to massage the affected body } \\
\text { regions too forcefully. } \\
\text { B.Neck coordination exercise ( } n=28 \text { ) performed with a newly developed training device designed to improve the fine movement control of the } \\
\text { cervical spine. The device, strapped to the head, consists of a plate with } 5 \text { exchangeable surfaces that allow for progression of task difficulty } \\
\text { (decreasing rolling resistance). The exercise task, performed in sitting, was to control the movement of a metal ball on the plate. Visual feedback } \\
\text { was provided via mirror. Training consisted of a basic training program and a progression program with } 12 \text { levels of increasing training dose, task } \\
\text { variability and difficulty. } \\
\text { C.Strength training ( } n=29 \text { ) with isometric and dynamic exercises targeting the neck and shoulder regions. Three exercises were isometric (15 } \\
\text { repetitions) and } 3 \text { dynamic ( } 2 \text { sets of } 15 \text { repetitions). Progressive resistance was given as strength increased during the sessions. Both intensity } \\
\text { and the extent of training were considered adequate to attain strength gains. } \\
\text { All } 3 \text { interventions consisted of } 22 \text { individually supervised single treatment sessions, } 30 \text { min each, distributed over } 11 \text { weeks }\end{array}$ \\
\hline Sahin 2010 & $\begin{array}{l}\text { A.Electro-acupuncture }(\mathrm{n}=13) 3 \text { sessions per week, each lasting for } 30 \text { minutes, } 10 \text { sessions in total. Local and distant acupuncture points used: } \\
\text { (BL10), BL60, LI4, TE5, GB20, GB21 and GV14. Electric needle stimulation for } 30 \text { minutes at low frequency }(\mathrm{I}-4 \mathrm{~Hz}) \text {, pulse width of } 200 \mid \text { is, } \\
\text { interrupted currents with high intensity. Deqi perception obtained. } \\
\\
\text { B.Sham acupuncture }(\mathrm{n}=16) 3 \text { sessions in a week, each lasting for } 30 \text { minutes, with } 10 \text { sessions in total. The sham acupuncture was similar to } \\
\text { needle placement in group A, but needles were inserted into points } 1-2 \mathrm{~cm} \text { away from meridian points in group A. Electrical stimulation was } \\
\text { administered as in group A until the patient perceived the current, after which it was switched off }\end{array}$ \\
\hline
\end{tabular}




\begin{tabular}{|c|c|c|c|}
\hline Author, Year & Study Participants & Outcome Measures & $\begin{array}{c}\text { Duration of } \\
\text { Followup }\end{array}$ \\
\hline Rosedale 2014 & $\begin{array}{l}\text { A vs B } \\
\text { Age: } 66 \text { vs } 64 \\
\text { Female: } 56 \% \text { vs } 60 \% \\
\text { Median comorbidities: } 3 \text { vs } 3 \\
\text { KOOS function: } 56 \text { (17) vs } 51 \text { (18) } \\
\text { KOOS function in sport and recreation: } 22 \text { (21) vs } 20 \text { (19) } \\
\text { KOOS pain: } 51 \text { (17) vs } 46(17) \\
\text { P4 pain scale: } 21(10) \text { vs } 23(8) \\
\text { KOOS knee symptoms: } 50(17) \text { vs } 48(21) \\
\text { KOOS quality of life: } 28 \text { (17) vs } 27 \text { (19) }\end{array}$ & $\begin{array}{l}\text { KOOS function subscale (0-100, higher score=higher } \\
\text { function); KOOS function in sport and recreation } \\
\text { subscale (0-100, higher score=higher function); KOOS } \\
\text { pain subscale (0-100, higher score=lower pain); P4 pain } \\
\text { scale (0-40, higher score=higher pain); KOOS knee } \\
\text { symptoms subscale (0-100, higher score=fewer } \\
\text { symptoms); KOOS quality of life subscale (0-100, higher } \\
\text { score=higher quality of life) }\end{array}$ & 2.5 months \\
\hline Rudolfsson 2014 & $\begin{array}{l}\text { A vs B vs C } \\
\text { Age: } 51 \text { vs } 52 \text { vs } 51 \text { years } \\
\text { Female: } 100 \% \text { vs } 100 \% \text { vs } 100 \% \\
\text { Weight (kg): } 73 \text { vs } 74 \text { vs } 74 \\
\text { Height (cm): } 167 \text { vs } 164 \text { vs } 165 \\
\text { Pain duration: } 120 \text { vs } 123 \text { vs } 84 \text { months (median) } \\
\text { Pain NRS (0-10), } 5 \text { vs } 6 \text { vs } 6 \text { (median) } \\
\text { NDI: } 26 \text { vs } 29 \text { vs } 31 \\
\text { SF-36 PCS: } 43 \text { vs } 39 \text { vs } 39 \text { (median) } \\
\text { SF-36 MCS: } 49 \text { vs } 52 \text { vs } 47 \text { (median) }\end{array}$ & Pain NRS (scale 0-10, higher score worse pain) & 6 months \\
\hline Sahin 2010 & $\begin{array}{l}\text { A vs B } \\
\text { Age: } 39 \text { vs } 35 \text { years } \\
\text { Female: } 100 \% \text { vs } 81 \% \\
\text { Not married: } 23 \% \text { vs } 25 \% \\
\text { University graduate: } 54 \% \text { vs } 94 \% \\
\text { BMl: } 23.9 \text { vs } 24.6 \\
\text { Pain with motion (0-10): } 7.38(1.61) \text { vs } 6.19 \text { (1.60) } \\
\text { Pain at rest: } 4.00 \text { (3.03) vs } 5.25(1.95)\end{array}$ & $\begin{array}{l}\text { Neck pain at rest and with motion in the last week } \\
\text { (scale 0-10, higher score worse pain) } \\
\text { Short-Form } 36 \text { (SF-36) (scale 0-100, higher } \\
\text { score=better QoL) }\end{array}$ & 3 months \\
\hline
\end{tabular}




\begin{tabular}{|c|c|}
\hline Author, Year & $\begin{array}{l}\text { Results - Subquestion a } \\
\text { (vs. sham, no treatment, waitlist, attention control) }\end{array}$ \\
\hline Rosedale 2014 & $\begin{array}{l}\text { A vs B } \\
\text { KOOS function: } 61 \text { (17) vs } 52 \text { (16), (Adj MD } 5,95 \% \mathrm{Cl} 1 \text { to } 9) \\
\text { KOOS function in sport and recreation: } 31 \text { (23) vs } 24 \text { (19), (Adj MD 6,95\% Cl } 0 \text { to } 11) \\
\text { KOOS pain: } 56 \text { (17) vs } 46 \text { (16), (Adj MD } 7,95 \% \mathrm{Cl} 3 \text { to } 11) \\
\text { P4 pain scale: } 24 \text { (8) vs } 21 \text { (10), (Adj MD }-2,95 \% \mathrm{Cl}-4 \text { to } 1) \\
\text { KOOS knee symptoms: } 56 \text { (17) vs } 52 \text { (19), (Adj MD } 2,95 \% \mathrm{Cl}-2 \text { to } 6) \\
\text { KOOS quality of life: } 34 \text { (19) vs } 32 \text { (19), (Adj MD } 1,95 \% \mathrm{Cl}-3 \text { to } 6)\end{array}$ \\
\hline Rudolfsson 2014 & \\
\hline Sahin 2010 & $\begin{array}{l}\text { A vs B } \\
3 \text { month outcomes } \\
\text { Pain with motion: } 4.50(2.48) \text { vs } 5.38(2.29), \mathrm{MD}-0.88(95 \% \mathrm{Cl}-2.70 \text { to } 0.94), \mathrm{p}=0.330 \\
\text { Pain at rest: } 4.00(2.97) \text { vs } 3.54(3.13), \mathrm{MD} 0.46(95 \% \mathrm{Cl}-1.88 \text { to } 2.80), \mathrm{p}=0.690\end{array}$ \\
\hline
\end{tabular}




\begin{tabular}{|l|l|}
\hline Author, Year & \multicolumn{2}{c|}{$\begin{array}{c}\text { Results - Subquestion b } \\
\text { (vs. Pharmacological therapy) }\end{array}$} \\
\hline Rosedale 2014 & \\
\hline Rudolfsson 2014 & \\
& \\
\hline Sahin 2010 & \\
\hline
\end{tabular}




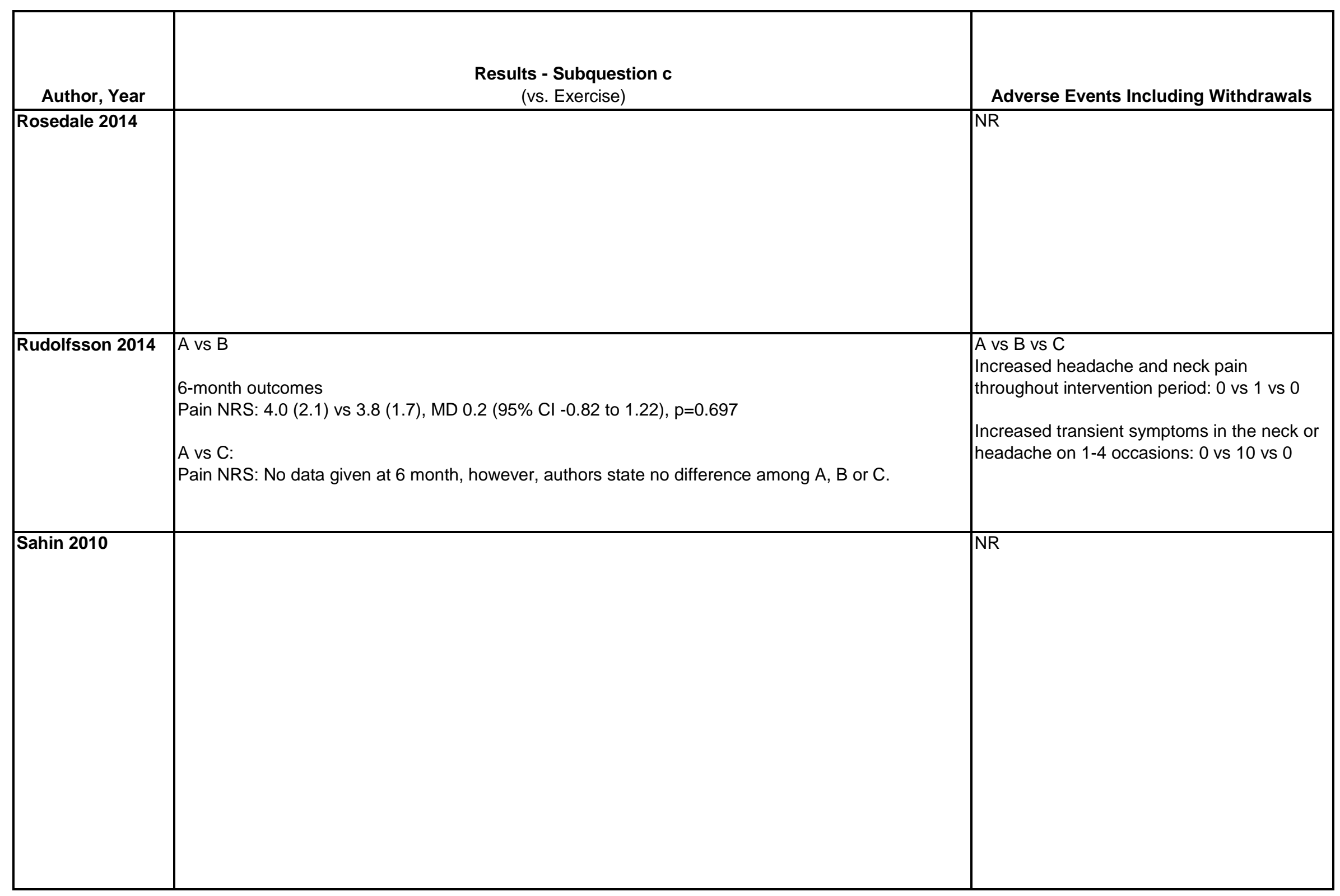




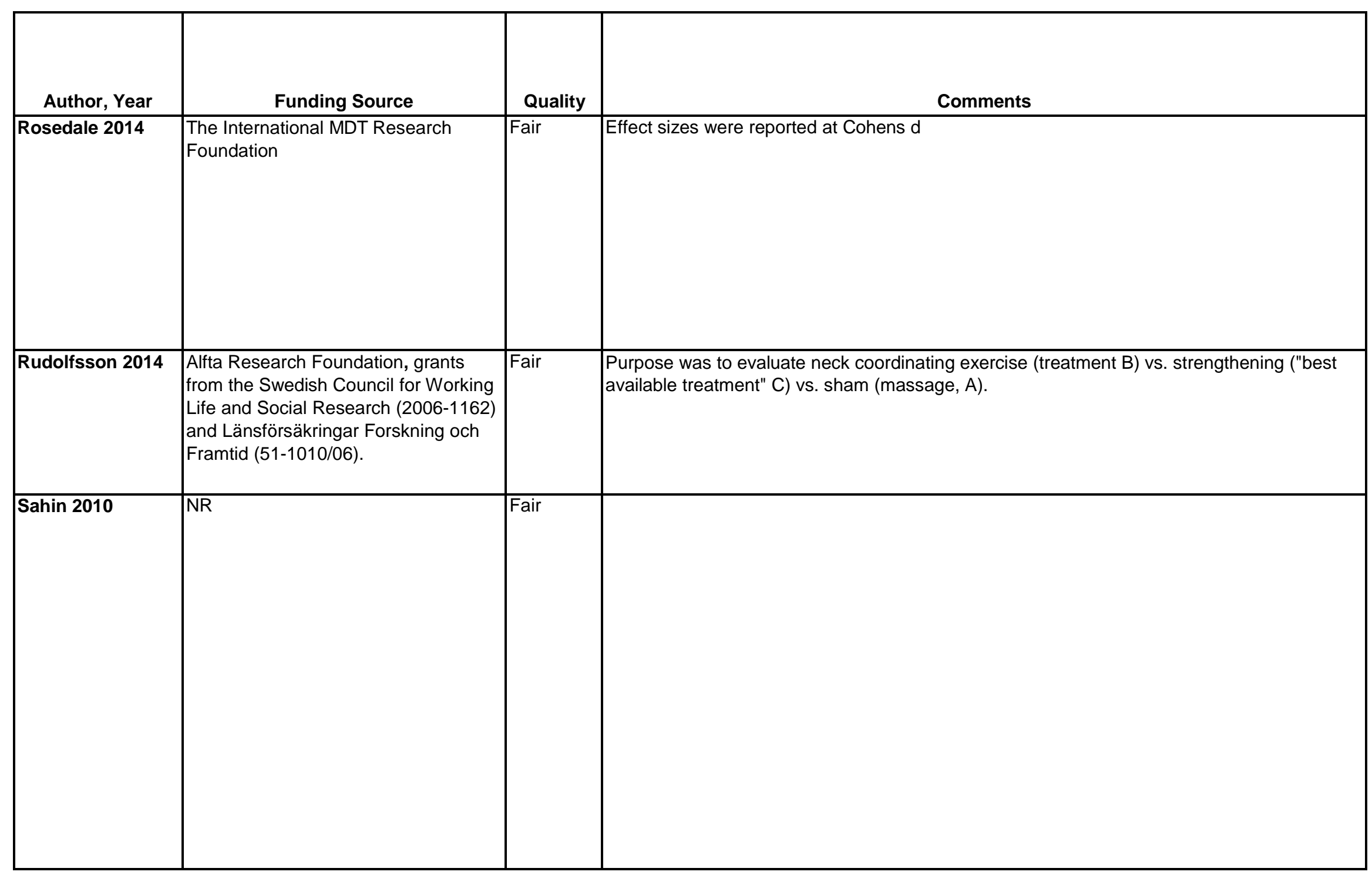




\begin{tabular}{|c|c|c|c|}
\hline Author, Year & $\begin{array}{l}\text { Country } \\
\text { Number of Centers } \\
\text { Setting }\end{array}$ & Inclusion/Exclusion Criteria & $\begin{array}{l}\text { Number Randomized, } \\
\text { Analyzed } \\
\text { Attrition }\end{array}$ \\
\hline Sanudo 2010 & $\begin{array}{l}\text { Spain } \\
\text { Recruited from } \\
\text { physician practices } \\
\text { and FM support } \\
\text { groups }\end{array}$ & $\begin{array}{l}\text { Women who met ACR } 1990 \text { criteria for FM } \\
\text { Exclusion: inflammatory rheumatic disease, severe psychiatric illness, } \\
\text { respiratory or cardiovascular disease that prevents physical exertion, } \\
\text { receiving psychological or physical therapy }\end{array}$ & $\begin{array}{l}\text { Randomized: } 64 \\
\text { Analyzed: } 55 \\
\text { Attrition: } 14 \%(9 / 64)\end{array}$ \\
\hline Sanudo 2012 & $\begin{array}{l}\text { Spain } \\
\text { Recruited from } \\
\text { physician practices } \\
\text { and FM support } \\
\text { groups }\end{array}$ & $\begin{array}{l}\text { Women who met ACR } 1990 \text { criteria for FM } \\
\text { Exclusion: inflammatory rheumatic disease, severe psychiatric illness, } \\
\text { respiratory or cardiovascular disease }\end{array}$ & $\begin{array}{l}\text { Randomized: } 41 \\
\text { Analyzed: } 15 \\
\text { Attrition: } 63 \%(26 / 41)\end{array}$ \\
\hline Sanudo 2015 & $\begin{array}{l}\text { Spain } \\
\text { Recruited from FM } \\
\text { support groups }\end{array}$ & $\begin{array}{l}\text { Inclusion: women with FM } \\
\text { Exclusion: pulmonary, cardiovascular, severe psychiatric, or } \\
\text { inflammatory rheumatic disease; attended psychological or physical } \\
\text { therapy or received exercise training in past year }\end{array}$ & $\begin{array}{l}\text { Randomized: } 32 \\
\text { Analyzed: } 28 \\
\text { Attrition: } 13 \% \text { (4/32) (4 } \\
\text { control subjects "excluded } \\
\text { from analysis by removal } \\
\text { of outliers") }\end{array}$ \\
\hline
\end{tabular}




\begin{tabular}{|c|c|}
\hline Author, Year & Intervention, Comparator \\
\hline Sanudo 2010 & $\begin{array}{l}\text { A.Supervised aerobic exercise }(n=18): 2 \text { sessions/week for } 24 \text { weeks of } 45-60 \text { minutes. Each session included warm-up, } 15-20 \text { minutes of steady- } \\
\text { state aerobic exercise, } 15 \text { minutes of interval training that included aerobic dance and jogging, and 5-10 minutes of cool down. } \\
\text { B. Supervised aerobic, muscle strengthening, and flexibility exercises ( } n=17) \text { : twice-weekly sessions for } 24 \text { weeks of aerobic and resistance } \\
\text { exercise with warmup, } 10-15 \text { minutes of aerobic exercise, } 15-20 \text { minutes of muscle strengthening exercise, and } 10 \text { minutes of flexibility exercises. } \\
\text { C. Usual care control ( } n=20) \text { : medical treatment for FM and continued normal daily activities, which did not include aerobic exercise. }\end{array}$ \\
\hline Sanudo 2012 & $\begin{array}{l}\text { A.Exercise }(n=13): \text { Twice-weekly } 45 \text { - to } 60 \text {-minute sessions of exercise (10-minute warmup, } 10-15 \text { minutes aerobic exercise, } 15-20 \text { minutes } \\
\text { muscle strengthening exercise, } 10 \text { minutes flexibility exercises) for } 6 \text { months. } \\
\text { B. Usual care }(n=12) \text { : usual medical care and normal daily activities, which did not include structured exercise. } \\
\text { Subjects alternated between } 6 \text { months of training and } 6 \text { months with no exercise intervention (asked not to participate in any structured exercise } \\
\text { program) for } 30 \text { months. }\end{array}$ \\
\hline Sanudo 2015 & $\begin{array}{l}\text { A.Aerobic exercise }(n=16) \text { : two sessions per week of } 45-60 \text { minutes, for } 24 \text { weeks. Each session included } 10 \text { minutes warmup, } 15-20 \text { minutes steady } \\
\text { state exercise at } 60-65 \% \text { of predicted maximum heart rate, } 15 \text { minutes of interval training at } 75-80 \% \text { of predicted maximum heart rate, and } 5-10 \\
\text { minutes cool down. } \\
\text { B. Usual care control }(n=12) \text { : normal activities, which did not include structured exercise. }\end{array}$ \\
\hline
\end{tabular}




\begin{tabular}{|c|c|c|c|}
\hline Author, Year & Study Participants & Outcome Measures & $\begin{array}{c}\text { Duration of } \\
\text { Followup }\end{array}$ \\
\hline Sanudo 2010 & $\begin{array}{l}\text { A vs C } \\
\text { Age: } 55.9(1.6) \text { vs } 56.6(1.9) \\
\text { FlQ: } 60.9 \text { (3.4) vs } 60.5(3.8) \\
\text { 6-minute walk test: } 512.2(15.9) \text { vs } 488.7(16.9) \\
\text { BDI: } 28 \text { (4) vs } 31(3) \\
\text { SF-36 total: } 36.1(2.9) \text { vs } 37.7(3.3) \\
\text { B vs C } \\
\text { Age: } 55.9(1.7) \text { vs } 56.6(1.9) \\
\text { FIQ: } 62.2(4.2) \text { vs } 60.5(3.8) \\
\text { 6-minute walk test: } 535.0(16.2) \text { vs } 488.7(16.9) \\
\text { BDI: } 25 \text { (3) vs } 31(3) \\
\text { SF-36 total: } 39.1(3.9) \text { vs } 37.7(3.3)\end{array}$ & $\begin{array}{l}\text { FIQ (0-100; higher scores=more severe symptoms and } \\
\text { disability) } \\
\text { 6-minute walk test: higher scores=greater distance } \\
\text { Beck Depression Inventory (BDI; 0-63, higher } \\
\text { scores=greater depression) } \\
\text { SF-36 (0-100, higher scores=better health-related } \\
\text { quality of life) }\end{array}$ & $\begin{array}{l}\text { Immediately } \\
\text { post- } \\
\text { intervention } \\
\text { (24 weeks) }\end{array}$ \\
\hline Sanudo 2012 & $\begin{array}{l}\text { A vs B } \\
\text { Female: } 100 \% \text { vs } 100 \% \\
\text { Pain duration NR } \\
\text { FIQ: } 58.6(12.2) \text { vs } 55.6(12.5) \\
\text { SF-36: } 41.4(14.7) \text { vs } 33.5(11.7) \\
\text { BDI: } 19.9(7.6) \text { vs } 20.4(7.7)\end{array}$ & $\begin{array}{l}\text { FIQ (0-80 without job-related items; higher scores = } \\
\text { more negative impact) } \\
\text { Beck Depression Inventory (BDI; 0-63, higher scores = } \\
\text { greater depression) } \\
\text { SF-36 (0-100, higher scores=better outcomes) }\end{array}$ & $\begin{array}{l}\text { Immediately } \\
\text { post 6-month } \\
\text { intervention } \\
\text { and at the } \\
\text { beginning } \\
\text { and end of } \\
\text { two more 6- } \\
\text { month } \\
\text { exercise } \\
\text { programs - }\end{array}$ \\
\hline Sanudo 2015 & $\begin{array}{l}\text { A vs B } \\
\text { Age: } 55 \text { vs } 58 \text { years } \\
\text { Female: } 100 \% \text { vs } 100 \% \\
\text { Race NR } \\
\text { Pain VAS: } 7.4 \text { vs } 7.2 \\
\text { Anxiety: } 6.9 \text { vs } 6.4 \\
\text { Depression: } 6.5 \text { vs } 7.1 \\
\text { Sleep disturbance: } 7.5 \text { vs } 8.4\end{array}$ & $\begin{array}{l}\text { Pain VAS (0-10 scale, higher scores=greater pain) } \\
\text { Anxiety VAS (0-10, higher scores=greater anxiety) } \\
\text { Depression VAS (0-10, higher scores=greater } \\
\text { depression) } \\
\text { Sleep VAS (0-10, higher scores=worse sleep) }\end{array}$ & $\begin{array}{l}\text { Immediately } \\
\text { post- } \\
\text { intervention } \\
\text { (24 weeks } \\
\text { from } \\
\text { baseline) }\end{array}$ \\
\hline
\end{tabular}




\begin{tabular}{|c|c|}
\hline Author, Year & $\begin{array}{c}\text { Results - Subquestion a } \\
\text { (vs. sham, no treatment, waitlist, attention control) }\end{array}$ \\
\hline Sanudo 2010 & $\begin{array}{l}\text { A vs } C \text {, mean improvement from baseline } \\
\text { FIQ: -8.8 (14) vs. NR; } p<0.05 \\
\text { BDI: }-8.5(8) \text { vs. NR; } p<0.01 \\
\text { SF-36 total: } 8.9 \text { (10) vs.NR; } p<0.05 \\
\text { B vs C, mean improvement from baseline } \\
\text { FIQ: }-8.8(12) \text { vs. NR; } p<0.01 \\
\text { BDI: -6.4 (4) vs. NR; } p<0.01 \\
\text { SF-36 total: } 8.4 \text { (11) vs. NR; } p<0.01\end{array}$ \\
\hline Sanudo 2012 & 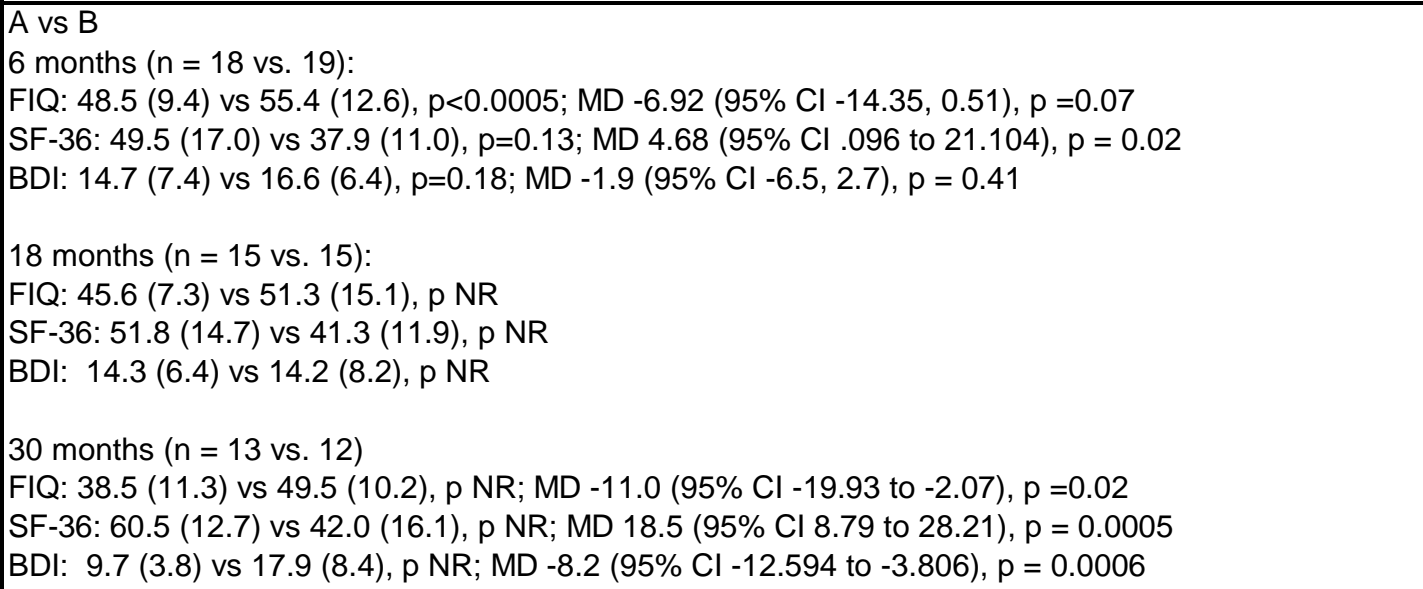 \\
\hline Sanudo 2015 & 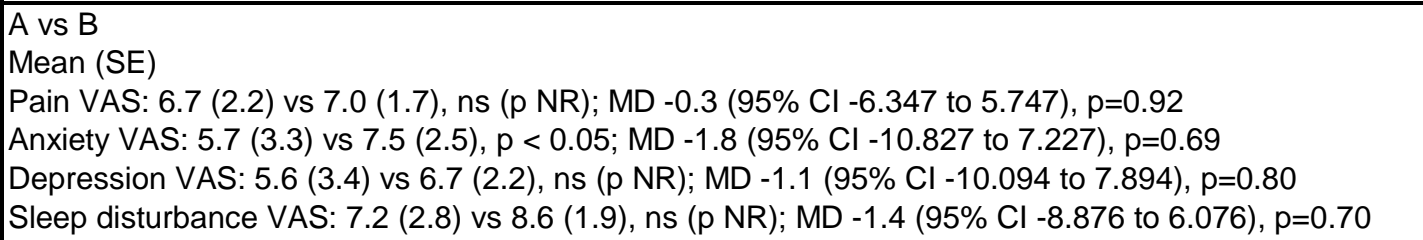 \\
\hline
\end{tabular}




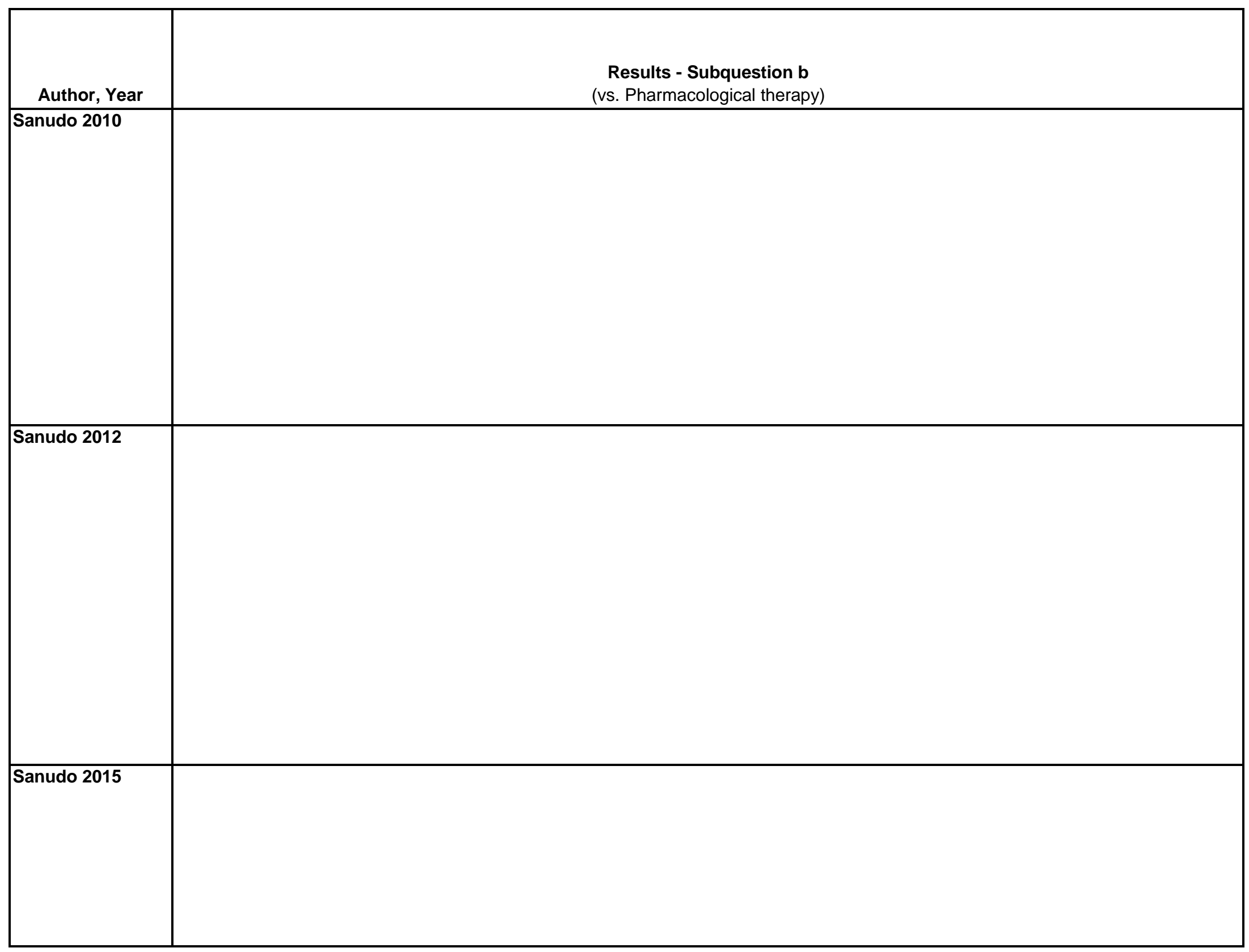

D-656 


\begin{tabular}{|c|c|c|}
\hline Author, Year & $\begin{array}{l}\text { Results - Subquestion c } \\
\text { (vs. Exercise) }\end{array}$ & Adverse Events Including Withdrawals \\
\hline Sanudo 2010 & & \begin{tabular}{|l} 
Adverse events: NR \\
Withdrawals: A vs C: $18 \%(4 / 22)$ vs $5 \%$ \\
$(1 / 21)$ \\
B vs C: $19 \%(4 / 21)$ vs $5 \%(1 / 21)$
\end{tabular} \\
\hline 保 & & $\begin{array}{l}\text { litst 6- } \\
\text { Withdrawalls: } \\
\text { A vs B: } 14 \%(3 / 21) \text { vs } 5 \%(1 / 20) \text { at first } \\
\text { month assessment; } 38 \%(8 / 21) \text { vs } 40 \% \\
\text { (8/20) at final assessment }\end{array}$ \\
\hline Sanudo 2015 & & $\begin{array}{l}\text { Adverse events: NR } \\
\text { Withdrawals: } 0\end{array}$ \\
\hline
\end{tabular}




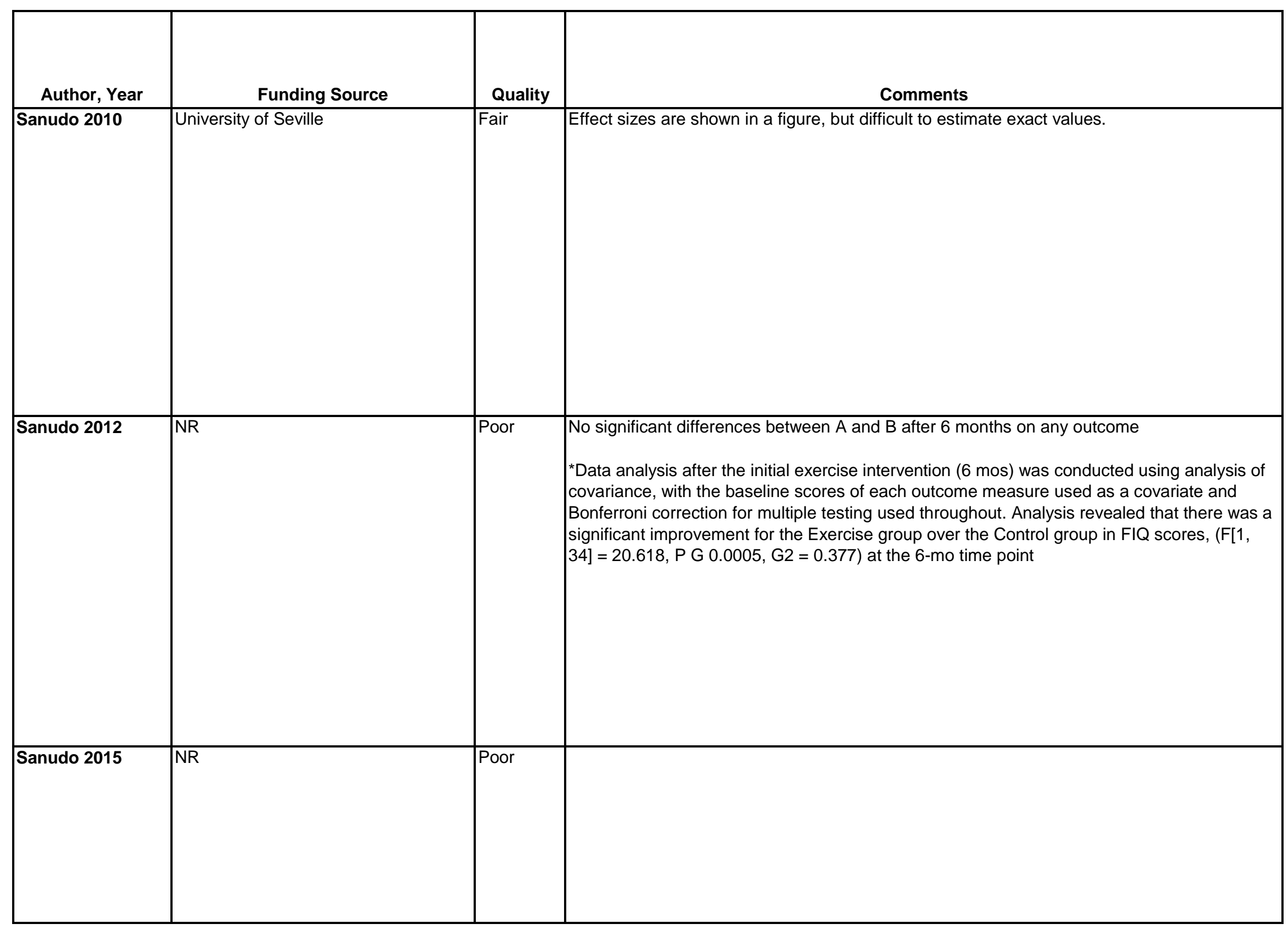




\begin{tabular}{|c|c|c|c|}
\hline Author, Year & \begin{tabular}{|c} 
Country \\
Number of Centers \\
Setting \\
\end{tabular} & Inclusion/Exclusion Criteria & $\begin{array}{c}\text { Number Randomized, } \\
\text { Analyzed } \\
\text { Attrition }\end{array}$ \\
\hline Saper 2017 & $\begin{array}{l}\text { US } \\
\text { Number of centers } 8 \\
\text { Outpatient }\end{array}$ & $\begin{array}{l}\text { Age } 18-64 \\
\text { Nonspecific low back pain } \\
\text { Duration at least } 12 \text { weeks } \\
\text { Average pain intensity in previous week of } 4 \text { or greater on a 0-10 } \\
\text { numerical rating scale } \\
\text { Exclude: } \\
\text { Specific causes of low back pain }\end{array}$ & $\begin{array}{l}\text { Randomized: } 320 \\
\text { Treated: } 307 \\
\text { Analyzed at } 26 \text { weeks: } 251 \\
\text { Analyzed at } 52 \text { weeks: } 258\end{array}$ \\
\hline Saral 2016 & $\begin{array}{l}\text { Turkey } \\
1 \text { center } \\
\text { Rehabilitation } \\
\text { department }\end{array}$ & $\begin{array}{l}\text { Inclusion: female, FM diagnosis based on } 1990 \text { ACR criteria, aged 25- } \\
60 \text { years old, followed up for } \geq 6 \text { months after FM diagnosis, pain } \\
\text { intensity } \geq 5 \text { on } 10 \mathrm{~cm} \text { VAS, presence of } \geq 5 \text { five years of primary school } \\
\text { education } \\
\text { Exclusion: previous diagnosis of an endocrine, neuromuscular, } \\
\text { infectious, or inflammatory disease, presence of hepatic or renal } \\
\text { disease, malignancy, history of severe trauma, advanced psychiatric } \\
\text { diseases, serious physical comorbidities, and pregnancy }\end{array}$ & $\begin{array}{l}\text { Randomized: } 66 \\
\text { Analyzed: } 59 \\
\text { Attrition: } 11 \%(7 / 66)\end{array}$ \\
\hline Schimmel 2009 & $\begin{array}{l}\text { Netherlands } \\
\text { Number of centers } 1\end{array}$ & $\begin{array}{l}\text { Patients with LBP for at least } 1 \text { year and one or more non-surgical } \\
\text { treatment. } \\
\text { Patients with previous surgical treatment and radicular leg pain. }\end{array}$ & $\begin{array}{l}\text { Randomized: } 60 \\
\text { Treated: } 60 \\
\text { Analyzed: } 60 \\
\text { Attrition: } 7 \%(4 / 60)\end{array}$ \\
\hline
\end{tabular}




\begin{tabular}{|c|c|}
\hline Author, Year & Intervention, Comparator \\
\hline Saper 2017 & $\begin{array}{l}\text { A:Hatha yoga ( } n=127) \text { : } 12 \text { weekly } 75-\text { minute Hatha yoga sessions including relaxation and meditation exercises, yoga breathing, and yoga } \\
\text { philosophy, yoga poses, and relaxation. Thirty minutes of daily home practice encouraged. Aids used to accommodate various physical abilities. } \\
\text { After } 12 \text { weeks patients randomized to weekly drop-in yoga classes (A1, maintenance) or home practice only (A2) } \\
\text { B: Exercise }(n=129): 1560 \text { minute appointments over } 12 \text { weeks, including supervised and individualized stabilization and aerobic exercise; patients } \\
\text { with high fear avoidance scores received the Back Book and reinforcement in psychologically informed principles. Patients given instructions and } \\
\text { supplies for home practice. After } 12 \text { weeks patients randomized to } 5 \text { booster sessions at } 4,6,8,10 \text {, and } 12 \text { months (B1, maintenance) or home } \\
\text { practice only (B2) } \\
\text { C: Education ( } n=64) \text { : Back Pain Helpbook, newsletter and } 5 \text { minute check-in call every } 3 \text { weeks. After } 12 \text { weeks, brief check-in call every } 6 \text { weeks }\end{array}$ \\
\hline Saral 2016 & $\begin{array}{l}\text { A. Long-term interdisciplinary group ( } \mathrm{n}=22) \text { : Patients had } 1 \text { full day session of a scientific and interactive educational program and } 1 \text { full day } \\
\text { session of an exercise education program. Patients had instructions to peform strengthening and stretchingexercises } 3 \text { days a week for } 20-30 \\
\text { minutes, as well as relaxation techniques twice a day for } 5 \text { days a week. Subjects also had a } 3 \text { hour session of CBT per week for } 10 \text { weeks. } \\
\text { B. Short-term interdisciplinary group ( } n=22) \text { : Over } 2 \text { full days, patients participated in education, exercise, and CBT. Patients had instructions to } \\
\text { peform strengthening and stretchingexercises } 3 \text { days a week for } 20-30 \text { minutes, as well as relaxation techniques twice a day for } 5 \text { days a week. } \\
\text { Subjects had two } 3 \text { hours CBT sessions. } \\
\text { C. Control group (n=22): Patients continued current medical treatments, normal daily living, and current physical activity levels }\end{array}$ \\
\hline Schimmel 2009 & $\begin{array}{l}\text { A.Intermittent traction }(n=31) \text { : Intermittent differential dynamics therapy: } 20 \text { sessions, } 6 \text { weeks, } 25-30 \\
\text { minutes, traction force } 50 \% \text { of body weight. } \\
\text { B.Sham ( } n=29) \text { : Similar treatment but at }<10 \% \text { body weight }\end{array}$ \\
\hline
\end{tabular}




\begin{tabular}{|c|c|c|c|}
\hline Author, Year & Study Participants & Outcome Measures & $\begin{array}{l}\text { Duration of } \\
\text { Followup }\end{array}$ \\
\hline Saper 2017 & $\begin{array}{l}\text { A vs. B vs. C } \\
\text { Age: } 46 \text { vs. } 46 \text { vs. } 44 \\
\text { Female: } 57 \% \text { vs. } 70 \% \text { vs. } 66 \% \\
\text { Race: } 20 \% \text { vs. } 16 \% \text { vs. } 17 \% \\
\text { Pain (0-10 NRS): } 7.1 \text { vs. } 7.2 \text { vs. } 7.0 \\
\text { Modified RDQ (0-23): } 13.9 \text { vs. } 15.6 \text { vs. } 15.0 \\
\text { SF- } 36 \text { physical component: } 36.2 \text { vs. } 35.2 \text { vs. } 36.6 \\
\text { SF- }-36 \text { mental component: } 43.4 \text { vs. } 41.4 \text { vs. } 42.3 \\
\text { Opioid use in past week: } 22 \% \text { vs. } 18 \% \text { vs. } 19 \%\end{array}$ & \begin{tabular}{|l|} 
Primary outcomes: \\
Modified RDQ (0-23) \\
Pain (0-10 NRS) \\
Medication use in previous week (yes/no) \\
Global improvement (7 point scale from extremely \\
worsened to extremely improved) \\
Patient satisfaction (5 point scale from very dissatisfied \\
to very satisfied) \\
SF-36 (0-100)
\end{tabular} & $\begin{array}{l}3.5,6.5 \text {, and } \\
9 \text { months }\end{array}$ \\
\hline Saral 2016 & $\begin{array}{l}\text { A vs B vs C } \\
\text { Age, years: } 38 \text { vs } 43 \text { vs } 44 \\
\text { Female: } 100 \% \text { vs } 100 \% \text { vs } 100 \% \\
\text { Symptom duration, months: } 69 \text { vs } 113 \text { vs } 88 \\
\text { FIQ: } 71.6(14.2) \text { vs } 67.7(12.0) \text { vs } 65.5(13.2) \\
\text { Pain VAS: } 8.2(0.9) \text { vs } 7.6(0.8) \text { vs } 7.5(0.9) \\
\text { BDI: } 23.4(11.0) \text { vs } 20.7(6.6) \text { vs } 21.4(10.4) \\
\text { SF-36 PCS: } 32.8(7.9) \text { vs } 36.5(8.7) \text { vs } 36.0(7.2) \\
\text { SF-36 MCS: } 30.4(11.7) \text { vs } 33.2(8.9) \text { vs } 36.1(9.8) \\
\text { Sleep VAS: } 7.2(2.8) \text { vs } 5.2(2.8) \text { vs } 5.8(2.7)\end{array}$ & $\begin{array}{l}\text { FIQ (0-100, higher score=greater impact of FM); pain } \\
\text { VAS (0-10, higher score=higher pain severity); BDI (0- } \\
63 \text {, higher score=higher severity of depression); SF-36 } \\
\text { PCS (0-100, higher score=higher quality of life); SF-36 } \\
\text { MCS (0-100, higher score=higher quality of life); sleep } \\
\text { VAS (0-10, higher score=lower quality of sleep) }\end{array}$ & \begin{tabular}{|l|}
6 months* \\
4 months \\
based on \\
intervention \\
group
\end{tabular} \\
\hline Schimmel 2009 & $\begin{array}{l}\text { A vs. B } \\
\text { Age (mean): } 42 \text { vs. } 46 \text { years } \\
\text { Female: } 39 \% \text { vs. } 52 \% \\
\text { Race: NR } \\
\text { Use of pain medication: } 48 \% \text { vs. } 51 \% \\
\text { Previous surgery: } 100 \% \text { vs. } 100 \% \\
\text { VAS low back pain (mean): } 61 \text { vs. } 53 \\
\text { ODI (mean): } 36 \text { vs. } 33 \\
\text { Total score SF- } 36 \text { (mean): } 52 \text { vs. } 53 \\
\text { VAS right leg pain (mean): } 37 \text { vs. } 33 \\
\text { VAS left leg pain (mean): } 27 \text { vs. } 31 \\
\text { Tampa score (mean): } 39 \text { vs. } 38\end{array}$ & $\begin{array}{l}\text { 100-mm VAS (unbearable pain intensity was recorded } \\
\text { as 100, and } 0 \text { indicated no pain at all) } \\
\text { Oswestry Disability Index (ODI, } \\
\text { effect of LBP on daily function } \\
\text { in ten domains) } \\
\text { Quality of life, Short-Form } 36 \text { (SF-36, assesses general } \\
\text { quality of } \\
\text { life in nine subscales) }\end{array}$ & 2 months \\
\hline
\end{tabular}




\begin{tabular}{|c|c|c|}
\hline Author, Year & \multicolumn{2}{|c|}{$\begin{array}{l}\text { Results - Subquestion a } \\
\text { (vs. sham, no treatment, waitlist, attention control) }\end{array}$} \\
\hline Saper 2017 & 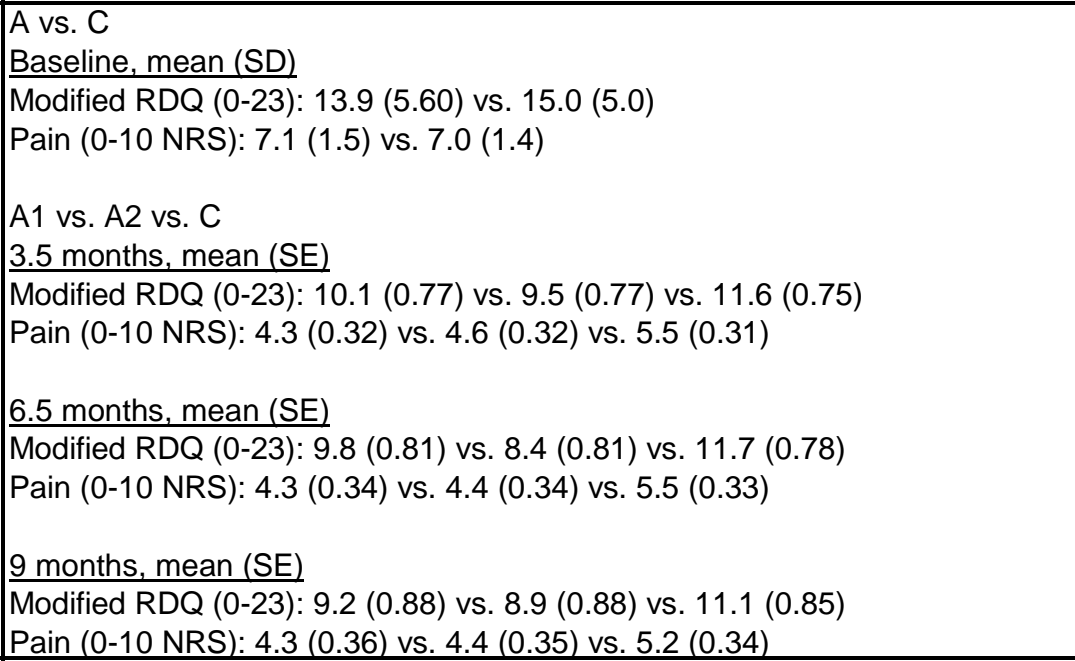 & \\
\hline Saral 2016 & 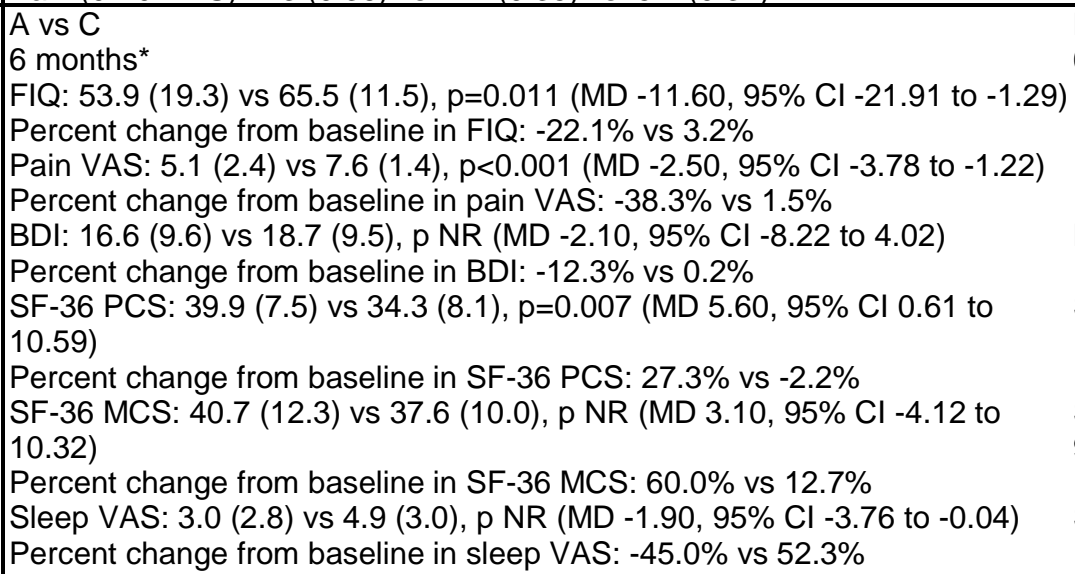 & 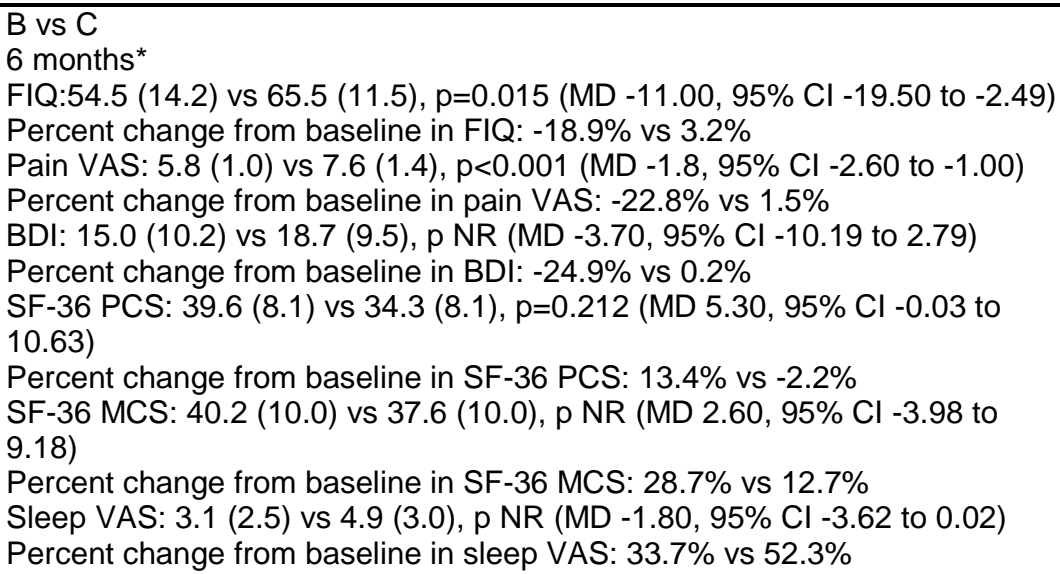 \\
\hline Schimmel 2009 & 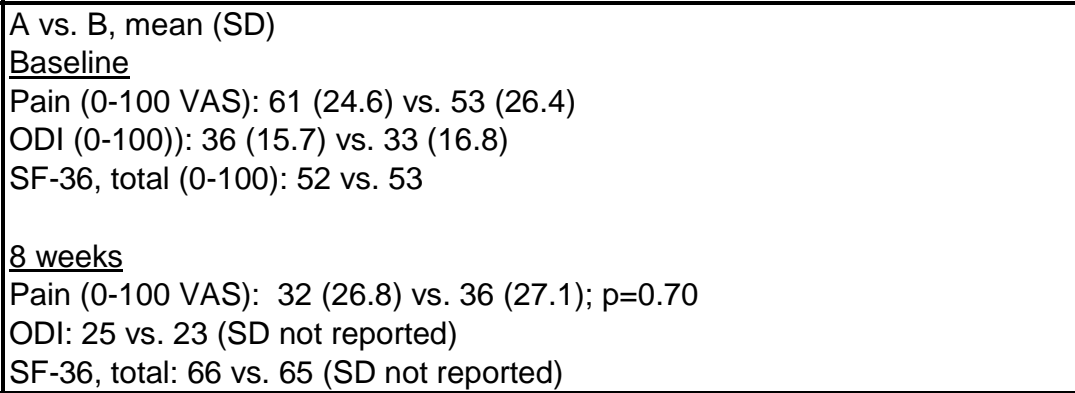 & \\
\hline
\end{tabular}




\begin{tabular}{|l|l|}
\hline \multicolumn{1}{|c|}{ Author, Year } & \multicolumn{2}{c|}{$\begin{array}{c}\text { Results - Subquestion b } \\
\text { (vs. Pharmacological therapy) }\end{array}$} \\
\hline Saper 2017 & NR \\
\hline Saral 2016 & \\
\hline Schimmel 2009 & NR \\
& \\
\hline
\end{tabular}




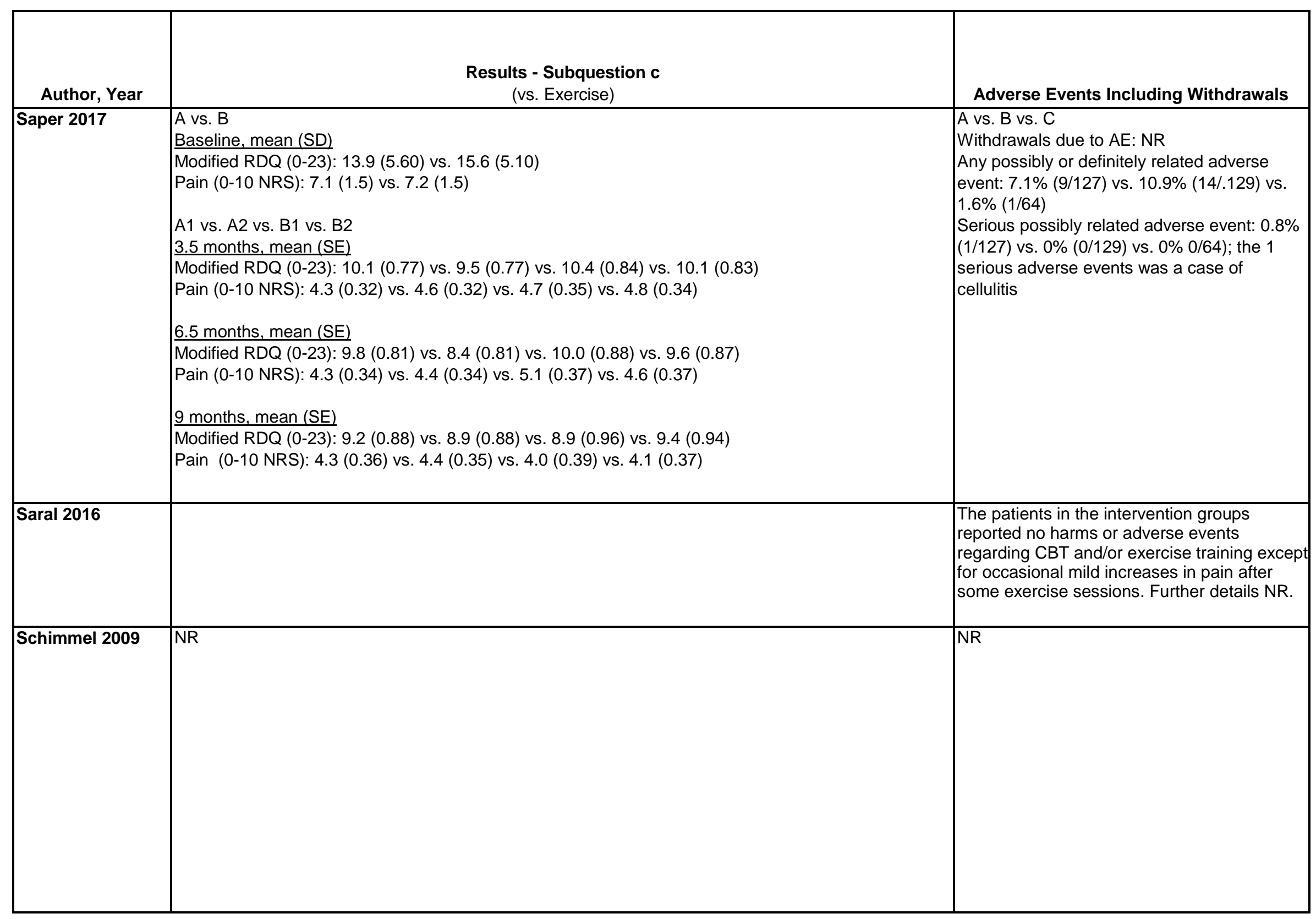




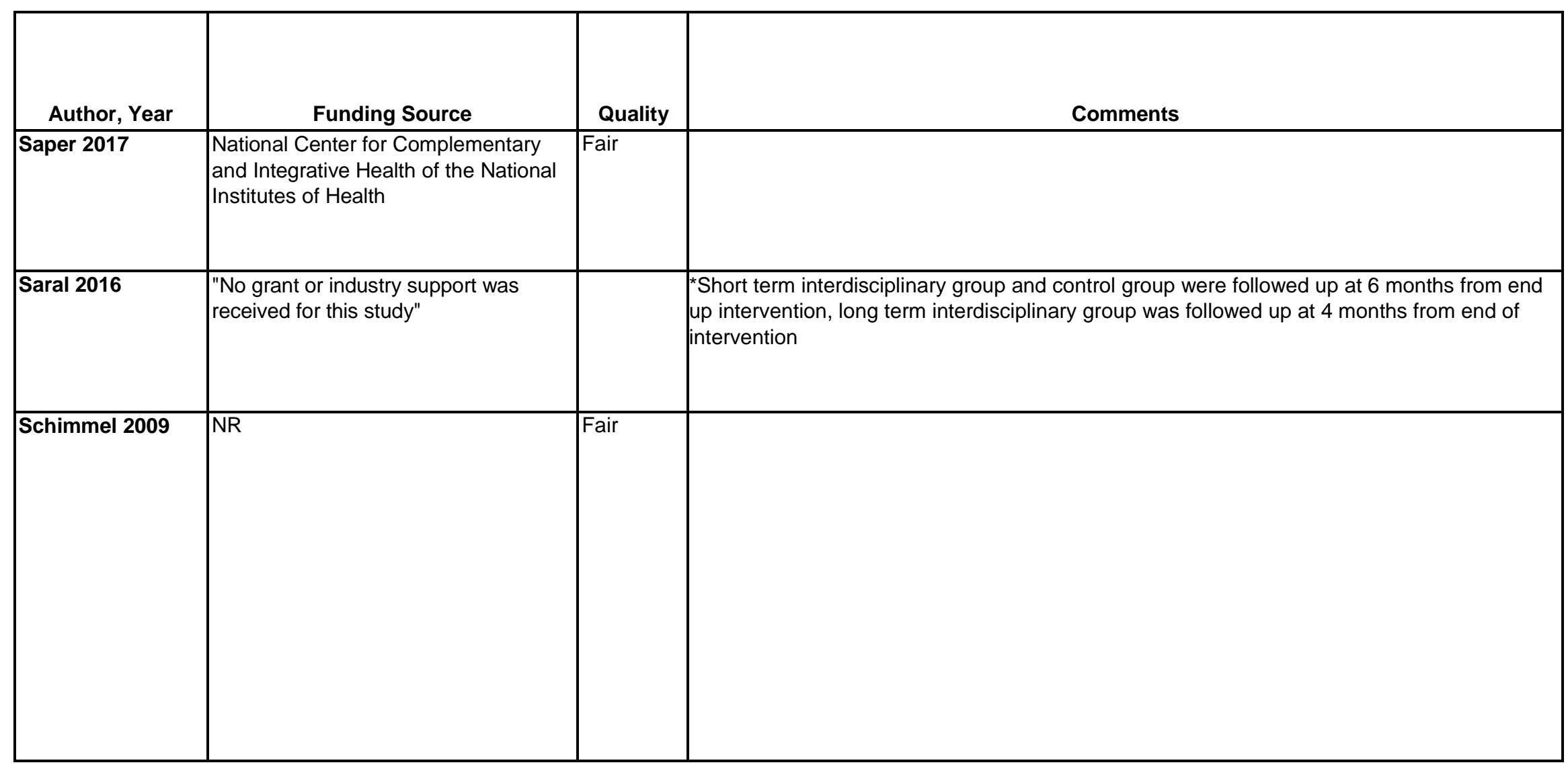




\begin{tabular}{|c|c|c|c|}
\hline Author, Year & $\begin{array}{c}\text { Country } \\
\text { Number of Centers } \\
\text { Setting }\end{array}$ & Inclusion/Exclusion Criteria & $\begin{array}{c}\text { Number Randomized, } \\
\text { Analyzed } \\
\text { Attrition }\end{array}$ \\
\hline Schmidt 2011 & Germany, single-site & $\begin{array}{l}\text { Inclusion Criteria: } \\
\text { Women aged 18-70 diagnosed with fibromyalgia according to } \\
\text { American College of Rheumatology criteria, along with German } \\
\text { language competency. } \\
\text { Exclusion Criteria: } \\
\text { Any life-threatening diseases, evidence of suppressed immune } \\
\text { functioning, or participation in other clinical trials. }\end{array}$ & \begin{tabular}{|l|} 
Randomized: 177 \\
Treated: 168 \\
Analyzed (ITT): 168 \\
Completers: 137 \\
Attrition: $5 \%(9 / 177)$
\end{tabular} \\
\hline
\end{tabular}




\begin{tabular}{|c|c|}
\hline Author, Year & Intervention, Comparator \\
\hline Schmidt 2011 & $\begin{array}{l}\text { A. Mindfulness-based Stress Reduction [MBSR] }(\mathrm{n}=53) \\
\text { 8-week group-based program with one } 2.5 \text { hour session/week and one } 7 \text { hour all-day session covering training in specific exercises and topics of } \\
\text { mindfulness practices. Participants were asked to complete daily practices of } 45-60 \text { minutes each } \\
\text { B.Active-control Intervention }(n=56) \\
\text { Controlled for nonspecific aspects of the MBSR program with similar meeting structure and format to MBSR treatment arm. Equivalent levels of } \\
\text { social support and weekly topical education was provided along with Jacobson Progressive Muscle Relaxation training and fibromyalgia-specific } \\
\text { gentle stretching exercises. Participants were asked to complete daily homework assignments with the same duration as MBSR group. } \\
\text { C. Waitlist (n=59) } \\
\text { Received no active treatment but were offered either intervention at the conclusion of the followup period. }\end{array}$ \\
\hline
\end{tabular}




\begin{tabular}{|c|c|c|c|}
\hline Author, Year & Study Participants & Outcome Measures & $\begin{array}{c}\text { Duration of } \\
\text { Followup }\end{array}$ \\
\hline Schmidt 2011 & 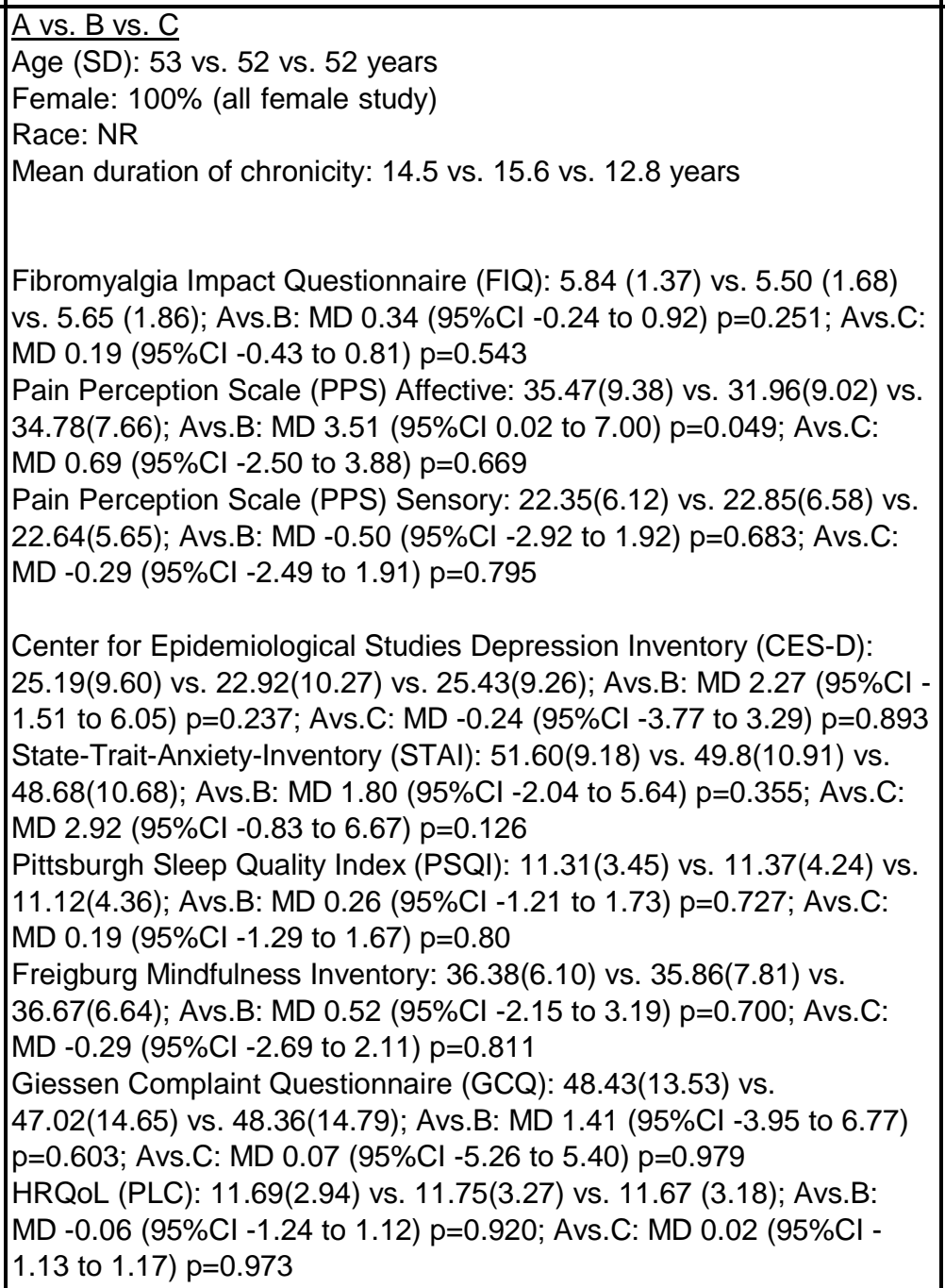 & $\begin{array}{l}\text { Primary: } \\
\text { Fibromyalgia Impact Questionnaire (FIQ) } \\
\text { Pain Perception Scale (PPS) } \\
\text { Secondary: } \\
\text { Center for Epidemiological Studies Depression } \\
\text { Inventory (CES-D, >23 indicates clinically relevant } \\
\text { depression) } \\
\text { State-Trait Anxiety Inventory Trait Subscale (STAI, } \\
\text { range 20-80: higher scores indicate higher anxiety } \\
\text { levels) } \\
\text { Pittsburgh Sleep Quality Index (PSQI, range 0-21: } \\
\text { higher scores indicate worse sleep) } \\
\text { Giessen Complaint Questionnaire (GCQ) } \\
\text { Quality of Life Profile for the Chronically III (PLC) } \\
\end{array}$ & 2 months \\
\hline
\end{tabular}




\begin{tabular}{|c|c|}
\hline Author, Year & $\begin{array}{c}\text { Results - Subquestion a } \\
\text { (vs. sham, no treatment, waitlist, attention control) }\end{array}$ \\
\hline Schmidt 2011 & 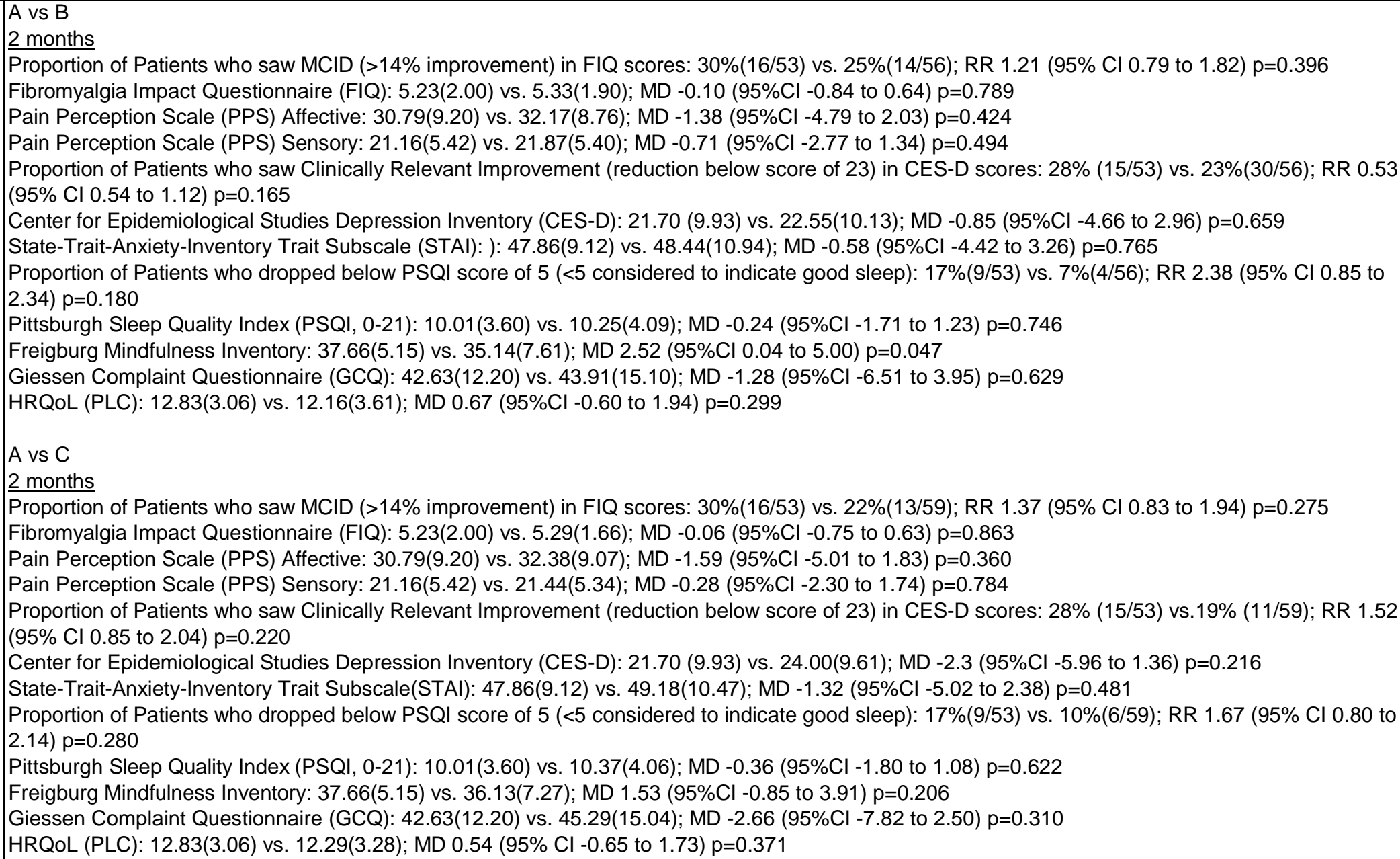 \\
\hline
\end{tabular}




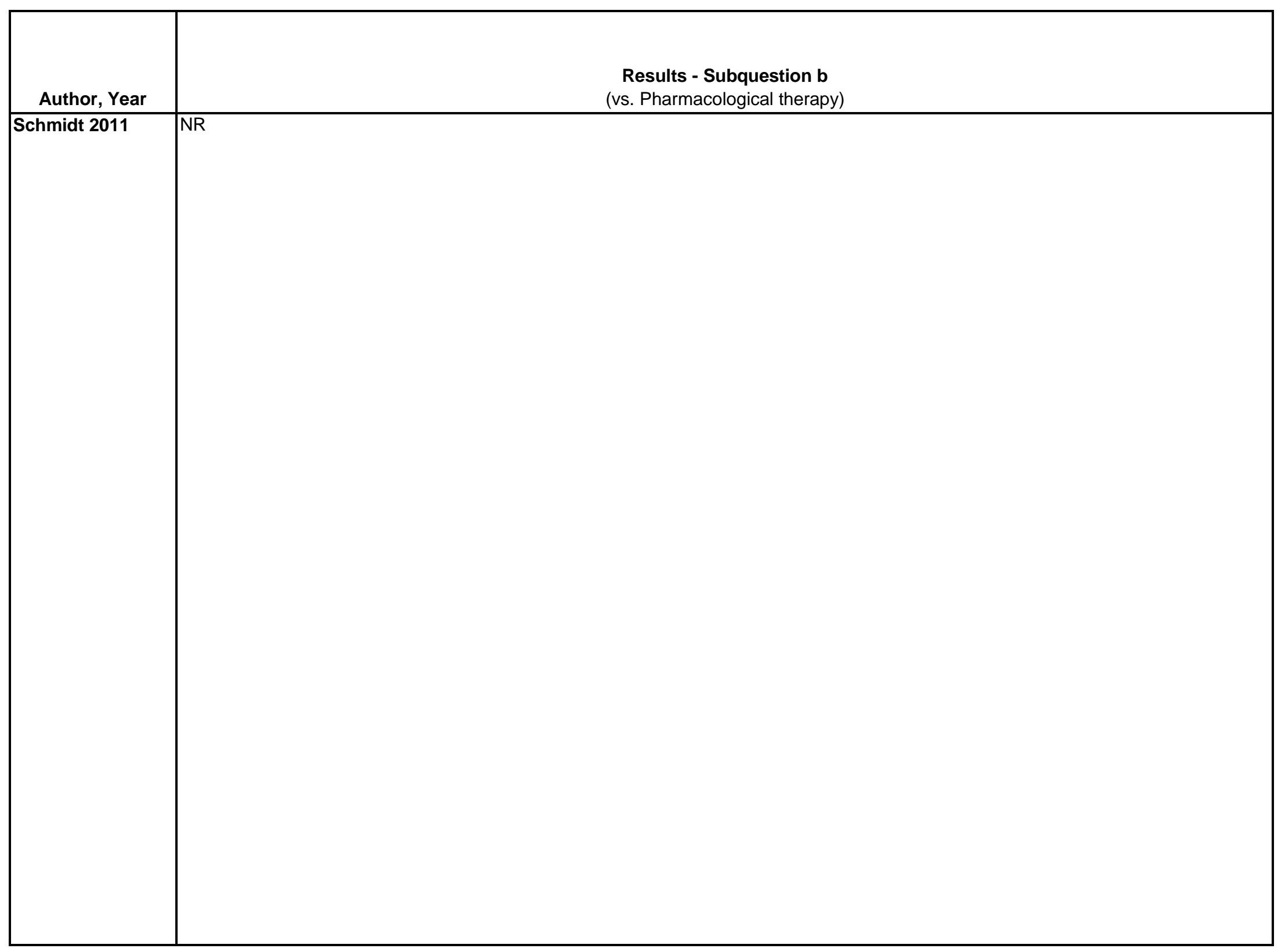

D-670 


\begin{tabular}{|c|c|c|}
\hline Author, Year & $\begin{array}{c}\text { Results - Subquestion c } \\
\text { (vs. Exercise) }\end{array}$ & Adverse Events Including Withdrawals \\
\hline Schmidt 2011 & 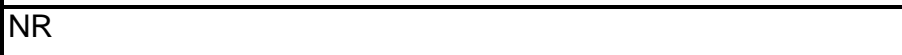 & NR \\
\hline
\end{tabular}




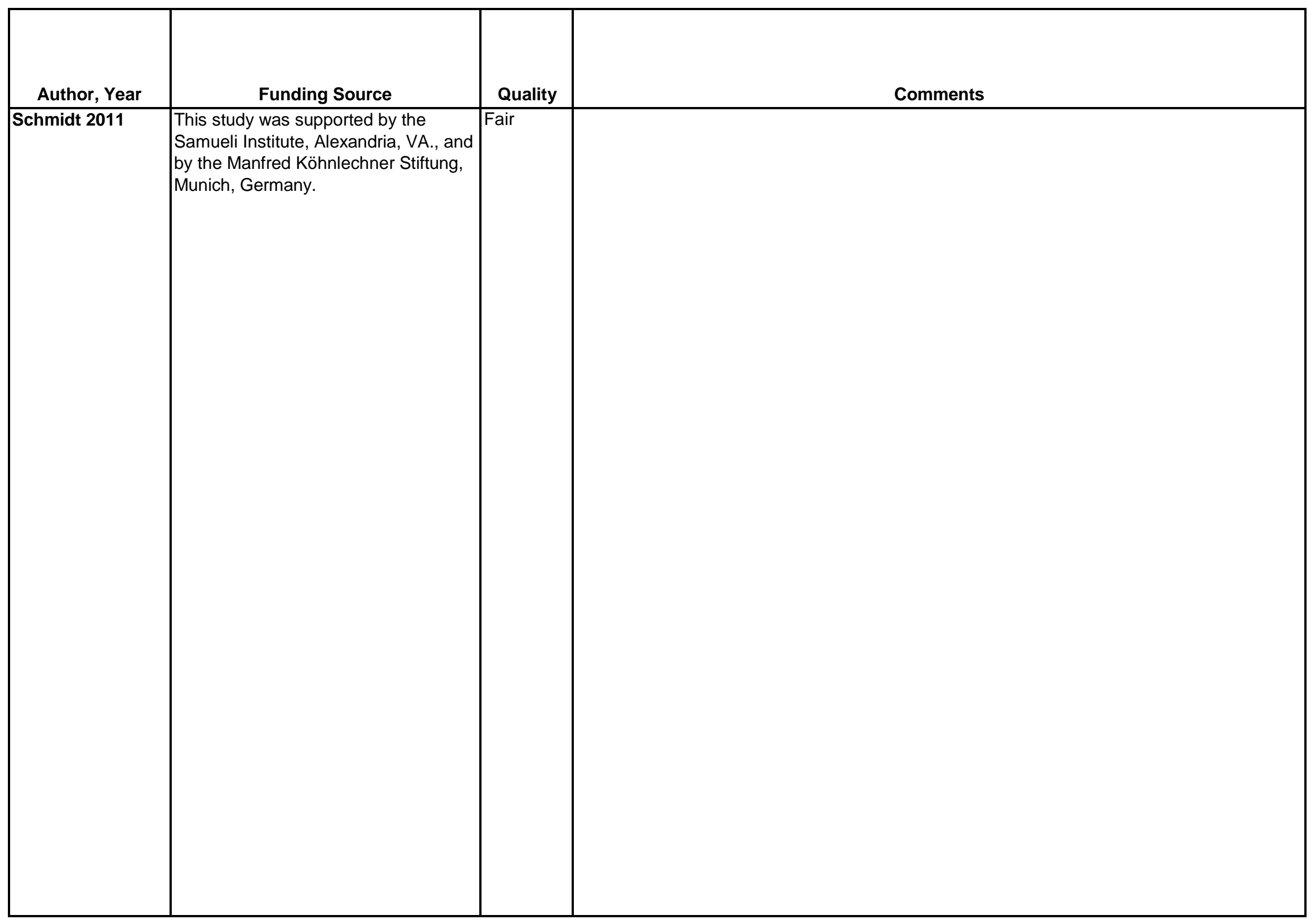

D-672 


\begin{tabular}{|c|c|c|c|}
\hline Author, Year & $\begin{array}{c}\text { Country } \\
\text { Number of Centers } \\
\text { Setting }\end{array}$ & Inclusion/Exclusion Criteria & $\begin{array}{c}\text { Number Randomized, } \\
\text { Analyzed } \\
\text { Attrition }\end{array}$ \\
\hline Seferiadis 2015 & $\begin{array}{l}\text { Sweden } \\
1 \text { center } \\
\text { Hospital }\end{array}$ & $\begin{array}{l}\text { Whiplash injury of WAD grades I, II, or III* for a minimum of } 1 \text { year } \\
\text { Exclude: Comorbidity that would increase possibility of harm from } \\
\text { intervention and/or measurement of outcomes }\end{array}$ & $\begin{array}{l}\text { Randomized: } 113 \\
\text { Treated: } 109 \\
\text { Analyzed: } 93 \\
\text { Attrition: } 18 \%(20 / 113)\end{array}$ \\
\hline
\end{tabular}




\begin{tabular}{|c|l|}
\hline Author, Year & \multicolumn{1}{c|}{ Intervention, Comparator } \\
\hline Seferiadis 2015 & $\begin{array}{l}\text { A.Basic body awareness therapy }(\mathrm{n}=57): 1.5 \text { hour sessions twice a week for } 10 \text { weeks. Sessions consisted of exercises based on activities of daily } \\
\text { living, meditation, and Tai Chi inspired exercises aiming to improve posture and increase efficient movement patterns } \\
\text { B.Exercise ( } \mathrm{n}=56): 1.5 \text { hour sessions twice a week for } 10 \text { weeks. Sessions consisted of } 45 \text { minutes of muscle strengthening, } 15 \text { minutes of } \\
\text { stretching, and } 20 \text { minutes of progressive muscle relaxation }\end{array}$ \\
\hline
\end{tabular}




\begin{tabular}{|c|c|c|c|}
\hline Author, Year & Study Participants & Outcome Measures & $\begin{array}{c}\text { Duration of } \\
\text { Followup }\end{array}$ \\
\hline Seferiadis 2015 & $\begin{array}{l}\text { A vs B } \\
\text { Age: } 47 \text { vs } 49 \\
\text { Female: } 66 \% \text { vs } 77 \% \\
\text { Duration of symptoms (years): } 10 \text { vs } 9 \\
\text { WAS classification: } \\
\quad 1: 0 \% \text { vs } 2 \% \\
\quad 2: 23 \% \text { vs } 28 \% \\
\quad 3: 77 \% \text { vs } 70 \% \\
\text { Neck Disability Index: } 20(8.9) \text { vs } 18.8(7.6) \\
\text { SF-36 physical functioning: } 67.5(21.3) \text { vs } 69.7(17.5) \\
\text { SF-36 role-physical: } 33.9(39.4) \text { vs } 24.5(39.2) \\
\text { SF-36 bodily pain: } 34.3(19.7) \text { vs } 35.2(18.2) \\
\text { SF-36 general health: } 54.7(22.5) \text { vs } 48.7(18.7) \\
\text { SF-36 vitality: } 39.5 \text { (23.9) vs 35.1 (22) } \\
\text { SF-36 social functioning: } 60(27) \text { vs } 59.4(27.2) \\
\text { SF-36 role-emotional: } 55.4(41.8) \text { vs } 51.7(44.5) \\
\text { SF-36 mental health: } 65.9(21.8) \text { vs } 62.7(24)\end{array}$ & $\begin{array}{l}\text { Neck Disability Index (0-50, higher scores=higher } \\
\text { disability) } \\
\text { SF-36 (0-100, higher score=higher quality of life) }\end{array}$ & 3 months \\
\hline
\end{tabular}




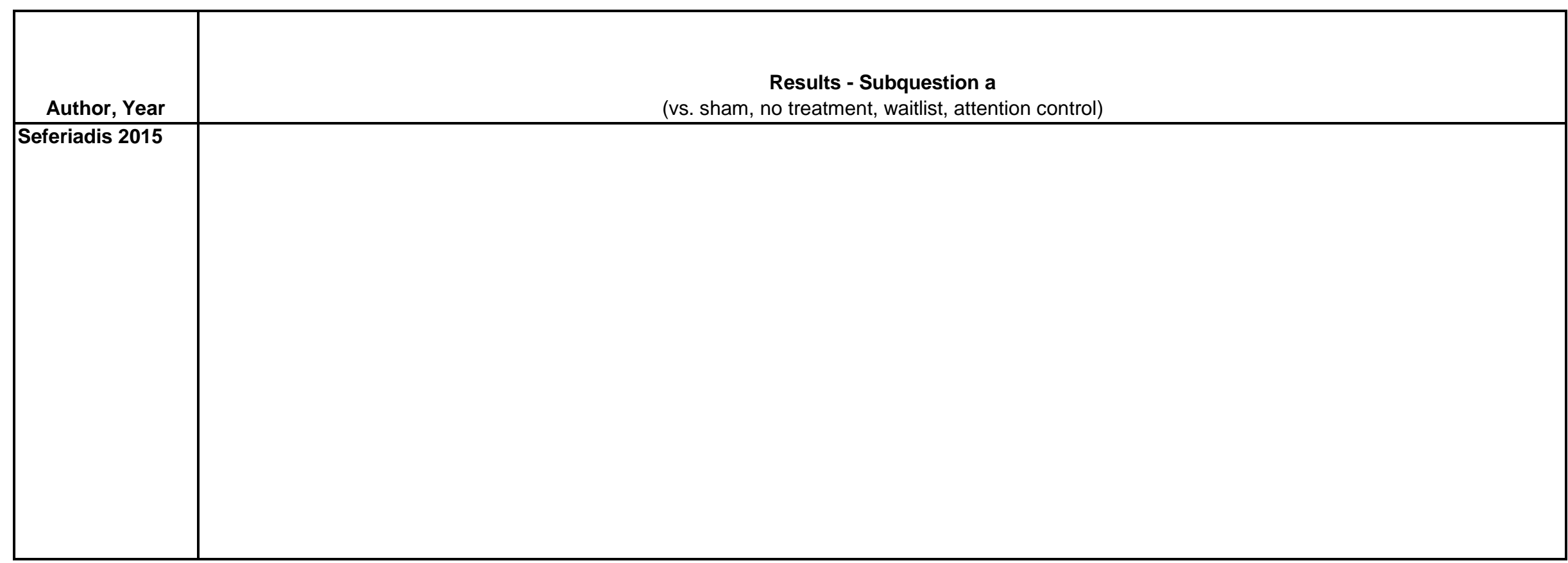




\begin{tabular}{|c|c|}
\hline Author, Year & $\begin{array}{c}\text { Results - Subquestion b } \\
\text { (vs. Pharmacological therapy) }\end{array}$ \\
\hline Seferiadis 2015 & \\
& \\
& \\
& \\
\hline
\end{tabular}




\begin{tabular}{|c|c|c|}
\hline Author, Year & $\begin{array}{l}\text { Results - Subquestion c } \\
\text { (vs. Exercise) }\end{array}$ & Adverse Events Including Withdrawals \\
\hline Seferiadis 2015 & $\begin{array}{l}\text { A vs. B } \\
\text { 3 months } \\
\text { Neck Disability Index: } \mathrm{MD}-2(95 \% \mathrm{Cl}-3.5 \text { to }-0.5) \text { vs. MD }-1 \text { ( } 95 \% \mathrm{Cl}-2.5 \text { to } 0.4) \\
\text { SF-36 physical functioning: } \mathrm{MD} 7.1(95 \% \mathrm{Cl} 3.7 \text { to } 11.4) \text { vs. MD } 0.5(95 \% \mathrm{Cl}-3.2 \text { to } 4.1) \\
\text { SF-36 role-physical: } \mathrm{MD} 17.5(95 \% \mathrm{Cl} 5.9 \text { to } 29) \text { vs. MD } 19(95 \% \mathrm{Cl} 9.3 \text { to } 28.6) \\
\text { SF-36 bodily pain: MD } 12.2(95 \% \mathrm{Cl} 6.9 \text { to } 17.6) \text { vs. MD } 4.9(95 \% \mathrm{Cl}-0.1 \text { to } 9.8) \\
\text { SF-36 general health: MD } 7.5(95 \% \mathrm{Cl} 2.4 \text { to } 12.6) \text { vs. MD } 4.5(95 \% \mathrm{Cl}-0.1 \text { to } 9) \\
\text { SF-36 vitality: MD } 7.3(95 \% \mathrm{Cl} 1 \text { to } 13.6) \text { vs. MD } 5.6(95 \% \mathrm{Cl}-0.5 \text { to } 11.6) \\
\text { SF-36 social functioning: MD } 13.3(95 \% \mathrm{Cl} 6.6-19.9) \text { vs. MD } 3.5(95 \% \mathrm{Cl}-3 \text { to } 9.9) \\
\text { SF-36 role-emotional: MD } 9.3(95 \% \mathrm{Cl}-2.3 \text { to } 21) \text { vs. MD } 4(95 \% \mathrm{Cl}-8.3 \text { to } 16.4) \\
\text { SF-36 mental health: MD } 2.8(95 \% \mathrm{Cl}-2 \text { to } 7.6) \text { vs. MD } 1.2(95 \% \mathrm{Cl}-3.6 \text { to } 5.9)\end{array}$ & $\begin{array}{l}\text { A vs B } \\
\text { No serious adverse effects } \\
\text { Non-serious adverse effects: } \\
\text { Any: } 14 / 53 \text { vs } 21 / 52 \text { (RR } 0.65,95 \% \mathrm{Cl} 0.37 \\
\text { to } 1.14 \text { ) } \\
\text { Increased pain: } 18 \%(10 / 57) \text { vs } 32 \%(18 / 56) \text {, } \\
\text { (RR 0.6, } 95 \% \mathrm{Cl} 0.3 \text { to } 1.1) \\
\text { Fatigue: } 4 \%(2 / 57) \text { vs } 0 \%(0 / 56) \\
\text { Increased headache: } 2 \%(1 / 57) \text { vs } 0 \%(0 / 56) \\
\text { Training soreness: } 2 \%(1 / 57) \text { vs } 0 \%(0 / 56) \\
\text { Back pain: } 0 \%(0 / 57) \text { vs } 2 \%(1 / 56) \\
\text { Hip pain: } 0 \%(0 / 57) \text { vs } 2 \%(1 / 56) \\
\text { Nausea: } 0 \%(0 / 57) \text { vs } 2 \%(1 / 56)\end{array}$ \\
\hline
\end{tabular}




\begin{tabular}{|c|l|c|l|}
\hline Author, Year & \multicolumn{1}{|c|}{ Funding Source } & Quality & \\
\hline Seferiadis 2015 & $\begin{array}{l}\text { Grants from The Health and Medical } \\
\text { Care Committee of the Region Vastra } \\
\text { Gotaland (VGFOUREG-11419, } \\
\text { VGFOUREG-24191, VGFOUREG- } \\
\text { 5525) and grants from the Research } \\
\text { and development council of the county } \\
\text { Sodra Alvsborg (VGFOUSA-162631, } \\
\text { VGFOUSA-38041, VGFOUSA-43901, } \\
\text { VGFOUSA-87931) }\end{array}$ & $\begin{array}{l}\text { Comments } \\
\text { VGAD grades made using Quebec classification } \\
\text { Outcomes not included: Tampa Scale of Kinesiophobia (pain-related fear of movement), } \\
\text { pain intensity Likert scale 0-5 (NR in text), pain frequency Likert scale 0-5 (NR in text), Body } \\
\text { Awareness Scale, ROM }\end{array}$ \\
& Outcomes reported as mean change within groups \\
\hline
\end{tabular}




\begin{tabular}{|c|c|c|c|}
\hline Author, Year & $\begin{array}{c}\text { Country } \\
\text { Number of Centers } \\
\text { Setting }\end{array}$ & Inclusion/Exclusion Criteria & $\begin{array}{c}\text { Number Randomized, } \\
\text { Analyzed } \\
\text { Attrition } \\
\end{array}$ \\
\hline Segal 2015 & $\begin{array}{l}\text { United States, multi- } \\
\text { site, outpatient clinic }\end{array}$ & $\begin{array}{l}\text { Inclusion Criteria: } \\
\text { Men and women age } 60 \text { and older with symptomatic knee } \\
\text { osteoarthritis and mobility disability. } \\
\text { Exclusion Criteria: } \\
\text { Exclusion of those with conditions other than knee OA which could } \\
\text { affect walking (e.g. amputation, severe back pain, severe peripheral } \\
\text { vascular or heart disease and neurological or developmental disease } \\
\text { including multiple sclerosis, Parkinson disease, myositis, rickets, or } \\
\text { lower limb musculoskeletal surgery in the previous } 6 \text { months). } \\
\text { Additionally, patients were excluded if they had undergone } \\
\text { corticosteroid injection either into a peripheral joint or into the spine in } \\
\text { the previous } 3 \text { months, or who anticipated inability to return for } \\
\text { followup were excluded. Other exclusion criteria were: medical } \\
\text { conditions that may preclude safe participation in the study protocol, } \\
\text { including but not limited to acute or terminal illness or unstable } \\
\text { cardiovascular condition (e.g., New York Heart Association class III or } \\
\text { IV congestive heart failure, clinically significant aortic stenosis, history } \\
\text { of cardiac arrest, use of a cardiac defibrillator, uncontrolled angina); } \\
\text { report of medical conditions that may impair ability to participate } \\
\text { including but not limited to pulmonary disease requiring the use of } \\
\text { supplemental oxygen; inability or unwillingness to comply with the } \\
\text { study protocol or be randomized; inability to obtain written clearance } \\
\text { for participation in the study by a physician; concurrent participation in } \\
\text { another observational or interventional research study; current } \\
\text { consumption of more than } 14 \text { alcoholic drinks per week; and/or } \\
\text { judgment of the principal investigator that participation would } \\
\text { endanger the safety of an individual. }\end{array}$ & $\begin{array}{l}\text { Randomized: } 58 \\
\text { Treated: } 54 \\
\text { Analyzed: } \\
3 \text { months }=77.6 \%(45 / 58) \\
9 \text { months }=72.4 \%(42 / 58) \\
\text { Attrition: } 27.5 \%(16 / 58)\end{array}$ \\
\hline
\end{tabular}




\begin{tabular}{|c|c|}
\hline Author, Year & Intervention, Comparator \\
\hline Segal 2015 & $\begin{array}{l}\text { A.Gait Training }(\mathrm{n}=24) \\
\text { Gait training sessions composed of guided strategies to optimize knee movements during treadmill walking, computerized motion analysis with } \\
\text { visual biofeedback. Additionally, on the basis of evaluation of strength, flexibility, trunk and lower limb range of motion and gait at the baseline visit, } \\
\text { a physical therapist instructed the participants in individualized home programs. } \\
\text { No. of Sessions: Twice weekly for } 12 \text { weeks ( } 24 \text { total) } \\
\text { Length of Sessions: } 45 \text { minutes each } \\
\text { B.Usual Care }(\mathrm{n}=18) \\
\text { Usual care for knee osteoarthritis and were not asked to make changes in their lifestyle (e.g., annual visit to their physician, use of pain } \\
\text { medications, knee surgery and/or physical therapy). Participants were asked to record twice weekly for } 3 \text { months in an Arthritis Foundation } \\
\text { symptom diary and once a week for the remaining } 9 \text { months of the study. }\end{array}$ \\
\hline
\end{tabular}




\begin{tabular}{|c|c|c|c|}
\hline Author, Year & Study Participants & Outcome Measures & $\begin{array}{c}\text { Duration of } \\
\text { Followup }\end{array}$ \\
\hline Segal 2015 & $\begin{array}{l}\text { A vs B } \\
\text { Age: } 70 \text { vs. } 69 \text { years } \\
\text { Female: } 76 \% \text { vs. } 53 \% \\
\text { Race: NR } \\
\text { Mean Duration of Chronicity: NR } \\
\\
\text { LLFDI basic lower limb function score: } 65.8(9.2) \text { vs. } 63.5 \text { (6.1) } \\
\text { KOOS Pain: } 62.7(10.8) \text { vs. } 59.8(13.1) \\
\text { KOOS Symptoms: } 60.1(16.8) \text { vs. } 63.0(13.6)\end{array}$ & $\begin{array}{l}\text { Late Life Function and Disability Instrument LLFDI: } \\
\text { Basic Lower Limb Function scores (LLFDI, range ) } \\
\text { Knee Injury Osteoarthritis Outcome Score Pain (KOOS, } \\
\text { range 0-100: higher scores represent severity of pain) } \\
\text { Knee Injury Osteoarthritis Outcome Score Symptoms } \\
\text { (KOOS, range 0-100: higher scores represent severity } \\
\text { of symptoms) }\end{array}$ & $\begin{array}{l}3 \text { and } 9 \\
\text { months }\end{array}$ \\
\hline
\end{tabular}




\begin{tabular}{|c|c|}
\hline Author, Year & $\begin{array}{c}\text { Results - Subquestion a } \\
\text { (vs. sham, no treatment, waitlist, attention control) }\end{array}$ \\
\hline Segal 2015 & $\begin{array}{l}\text { A vs. B } \\
\text { 3 months } \\
\text { Between group difference in change score compared with baseline } \\
\text { LLFDI basic lower limb function score: } 2.3(95 \% \mathrm{Cl}-1.8 \text { to } 6.3) p=0.265 \\
\text { KOOS Pain: } 3.7(95 \% \mathrm{Cl}-4.7 \text { to } 12.1) \mathrm{p}=0.384 \\
\text { KOOS Symptoms: } 6.2(95 \% \mathrm{Cl}-2.9 \text { to } 15.4) p=0.175 \\
\text { 9 months } \\
\text { Between group difference in change score compared with baseline } \\
\text { LLFDI basic lower limb function score: } 1.0(95 \% \mathrm{Cl}-7.4 \text { to } 9.4) p=0.809 \\
\text { KOOS Pain: } 7.2(95 \% \mathrm{Cl}-2.0 \text { to } 16.5) p=0.120 \\
\text { KOOS Symptoms: } 6.0(95 \% \mathrm{Cl}-6.2 \text { to } 18.2) p=0.327\end{array}$ \\
\hline
\end{tabular}




\begin{tabular}{|l|l|}
\hline Author, Year & \multicolumn{2}{c|}{$\begin{array}{c}\text { Results - Subquestion b } \\
\text { (vs. Pharmacological therapy) }\end{array}$} \\
\hline Segal 2015 & NR \\
& \\
& \\
\hline
\end{tabular}




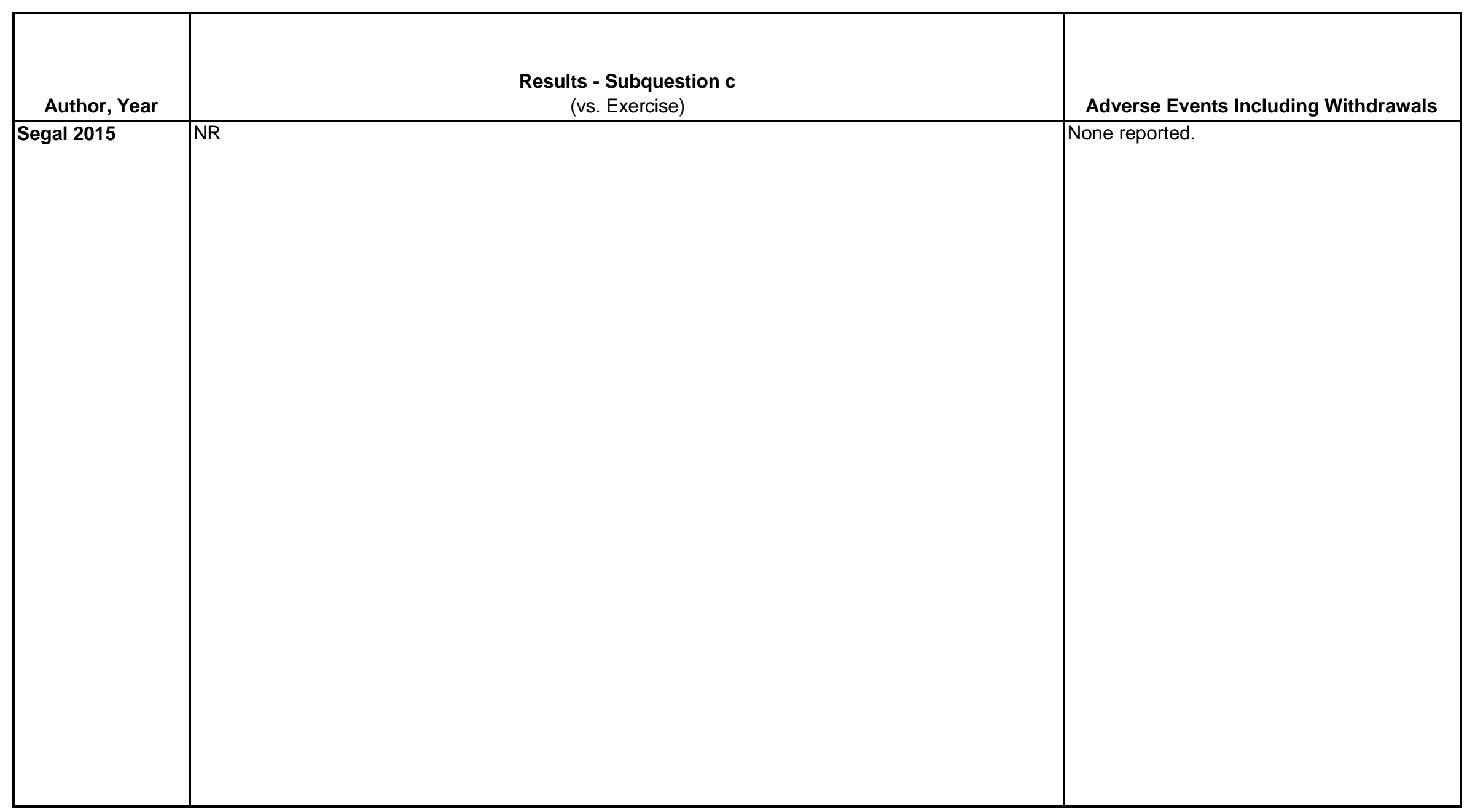




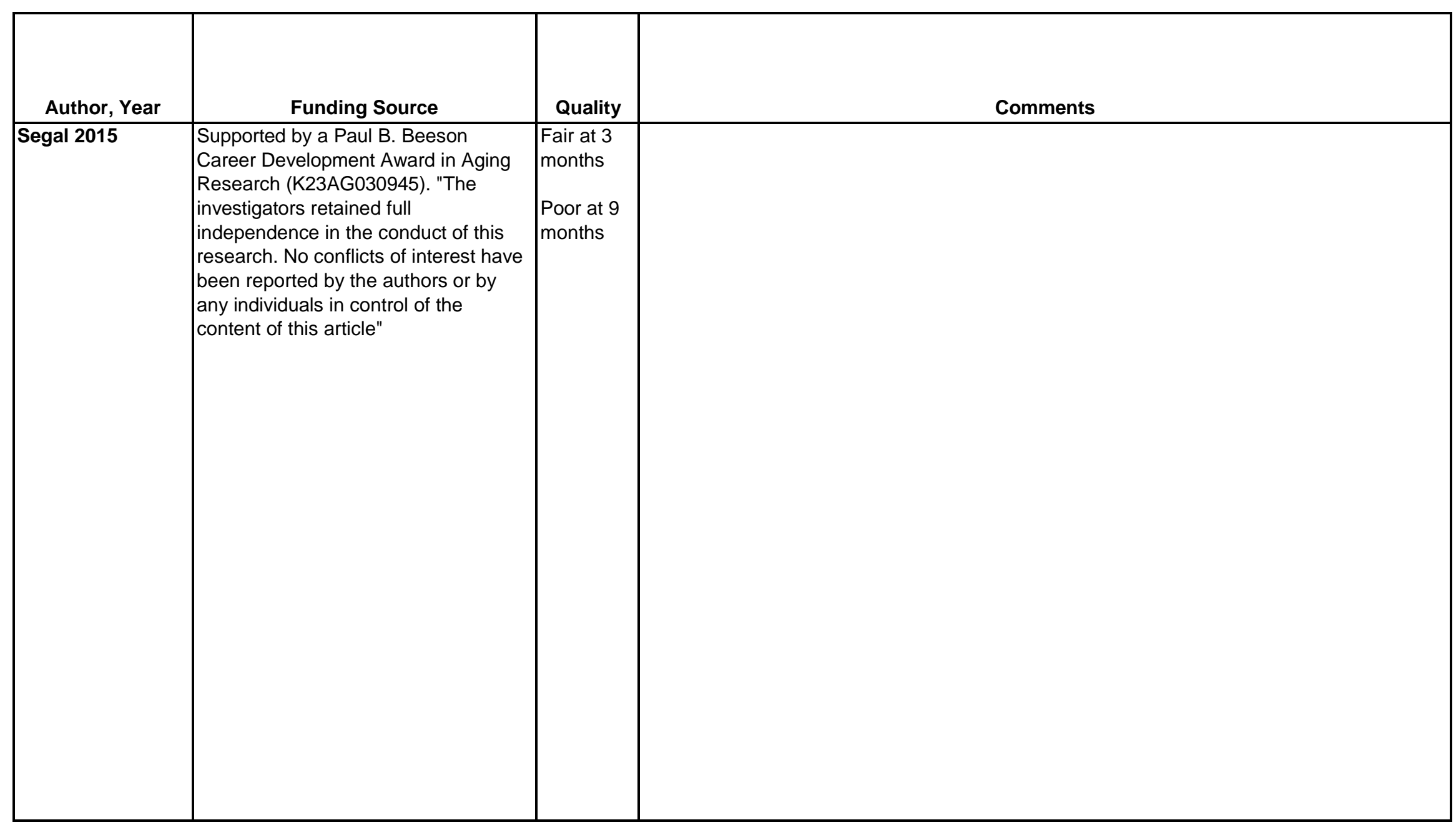




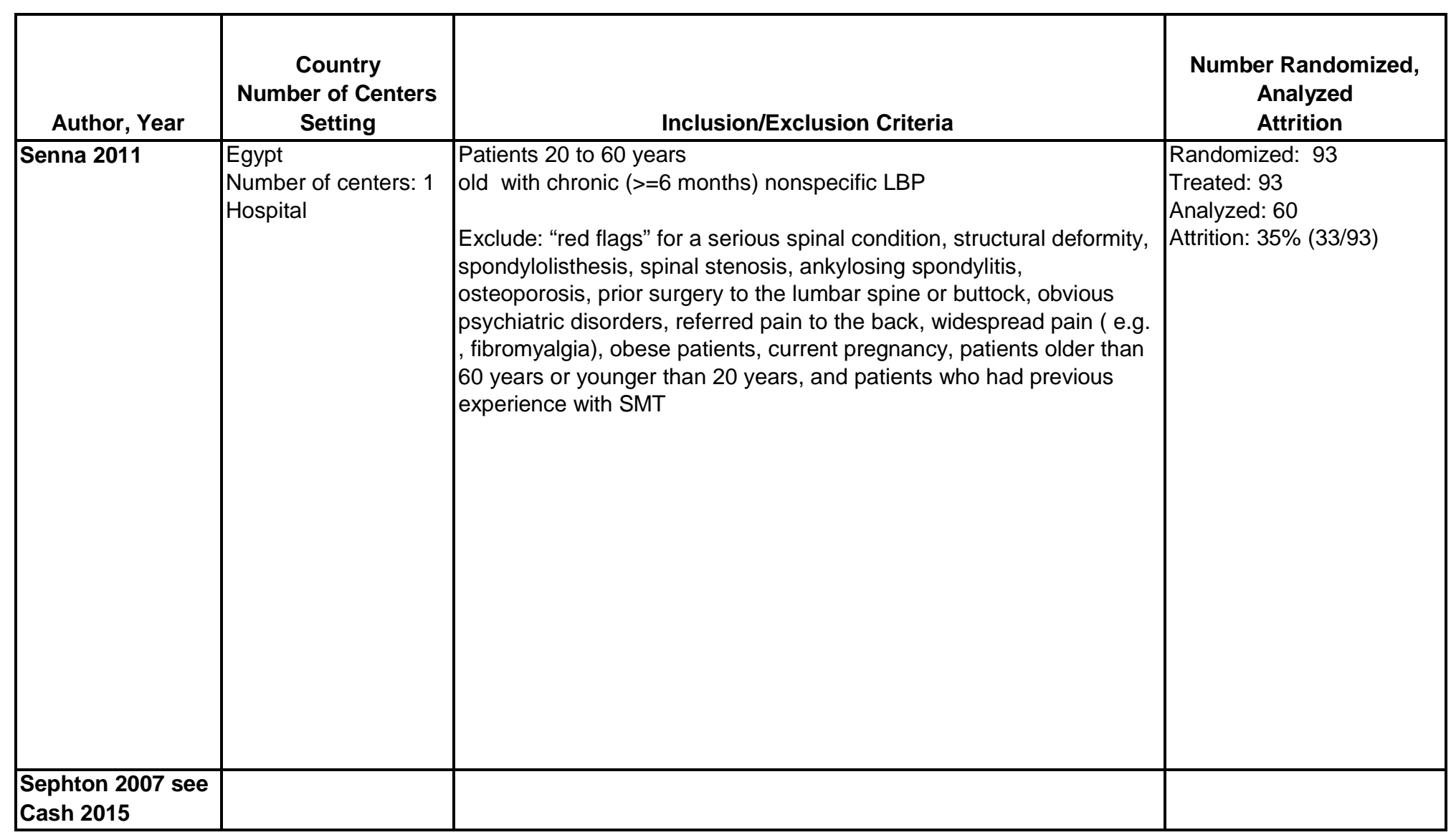




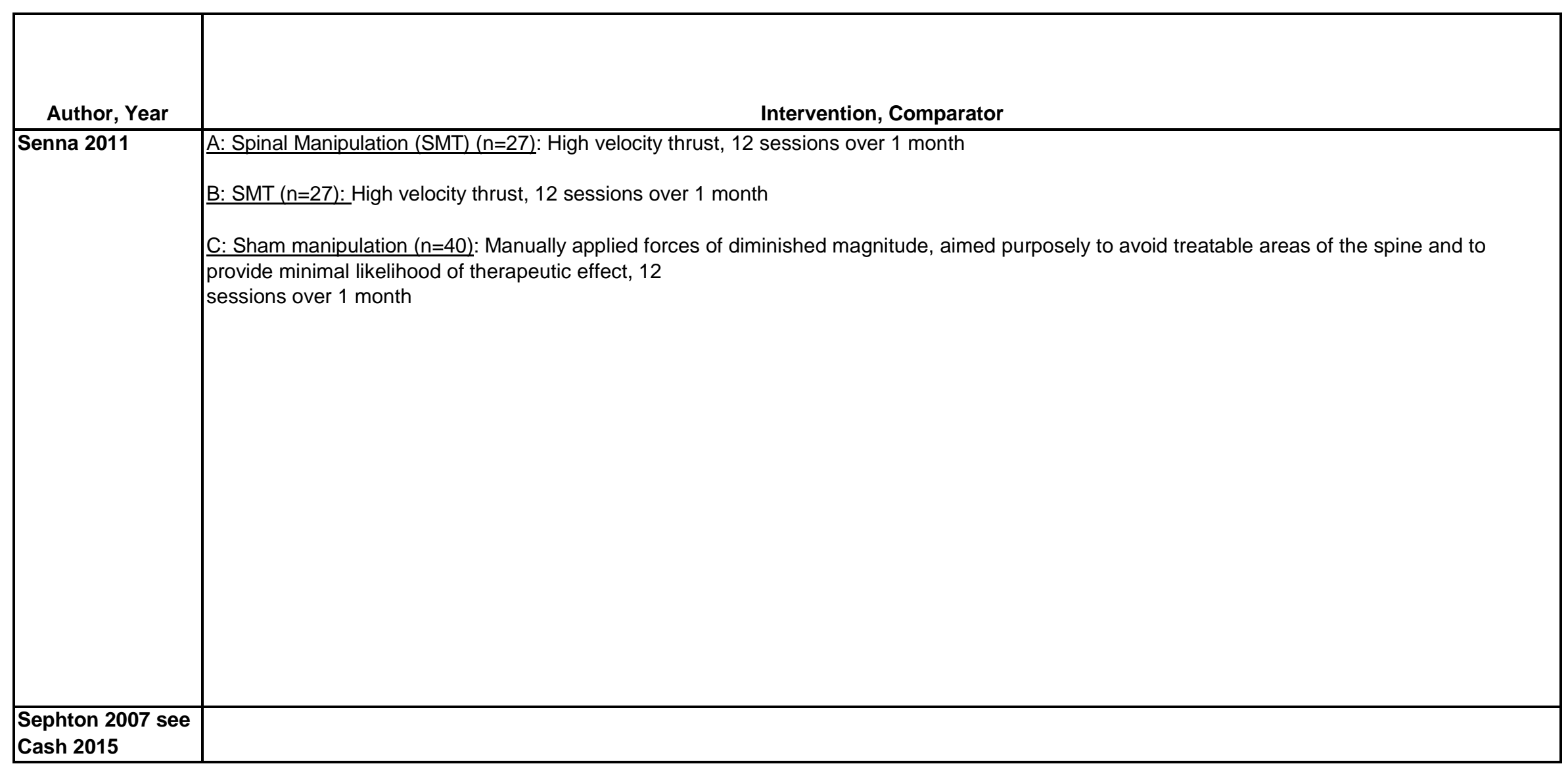




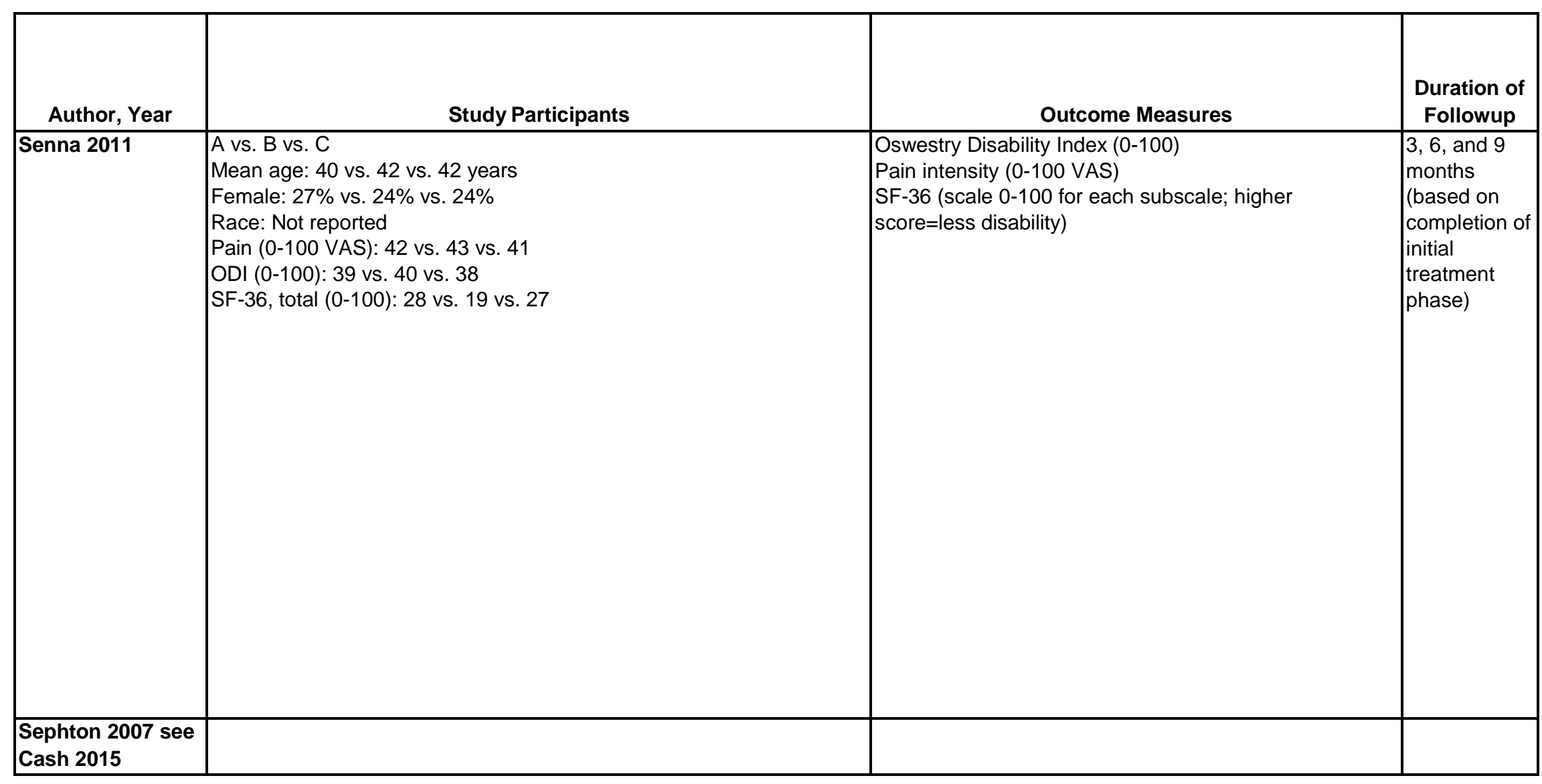




\begin{tabular}{|c|c|}
\hline Author, Year & $\begin{array}{l}\text { Results - Subquestion a } \\
\text { (vs. sham, no treatment, waitlist, attention control) }\end{array}$ \\
\hline Senna 2011 & 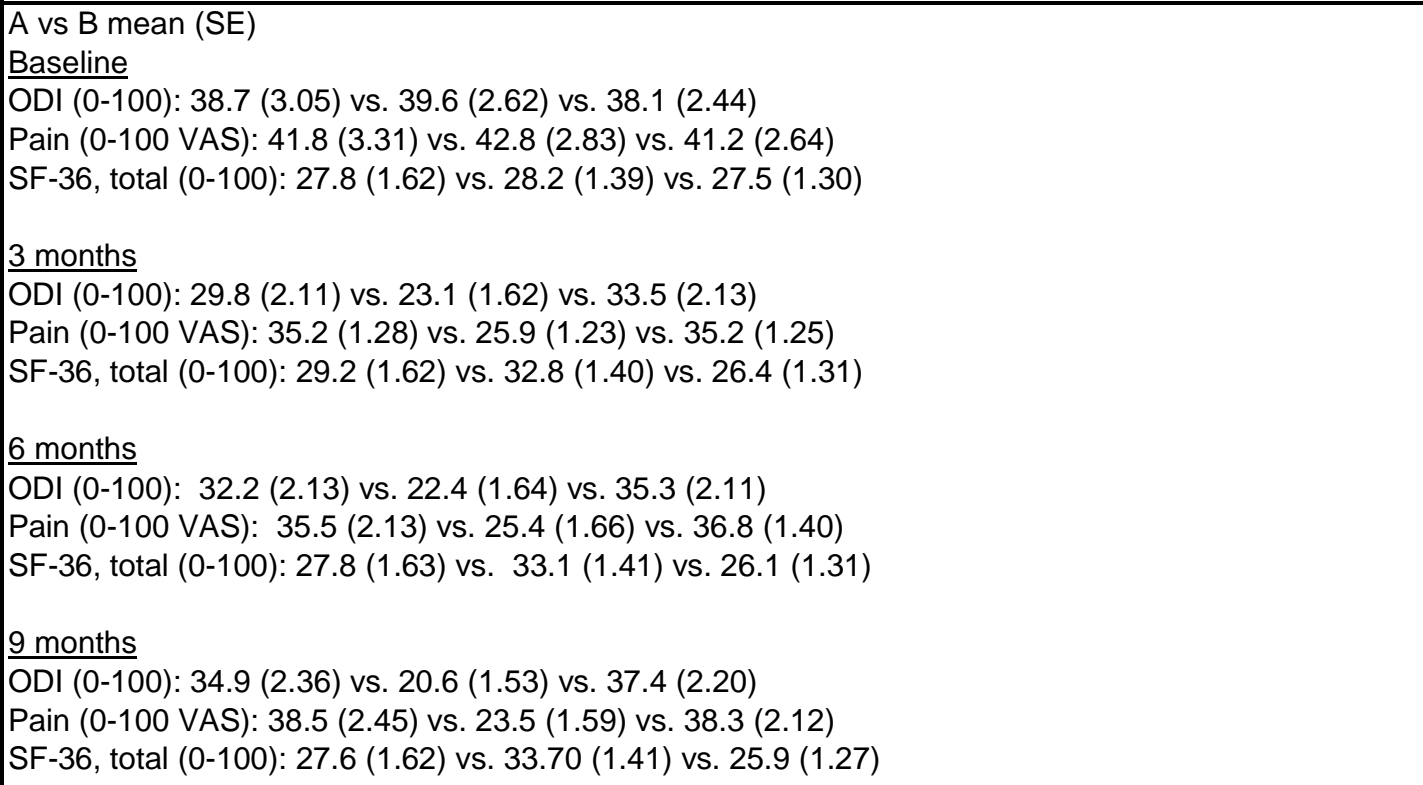 \\
\hline $\begin{array}{l}\text { Sephton } 2007 \text { see } \\
\text { Cash } 2015\end{array}$ & \\
\hline
\end{tabular}




\begin{tabular}{|l|l|}
\hline Author, Year & \multicolumn{1}{|c|}{$\begin{array}{c}\text { Results - Subquestion b } \\
\text { (vs. Pharmacological therapy) }\end{array}$} \\
\hline Senna 2011 & NR \\
& \\
\hline & \\
\hline
\end{tabular}




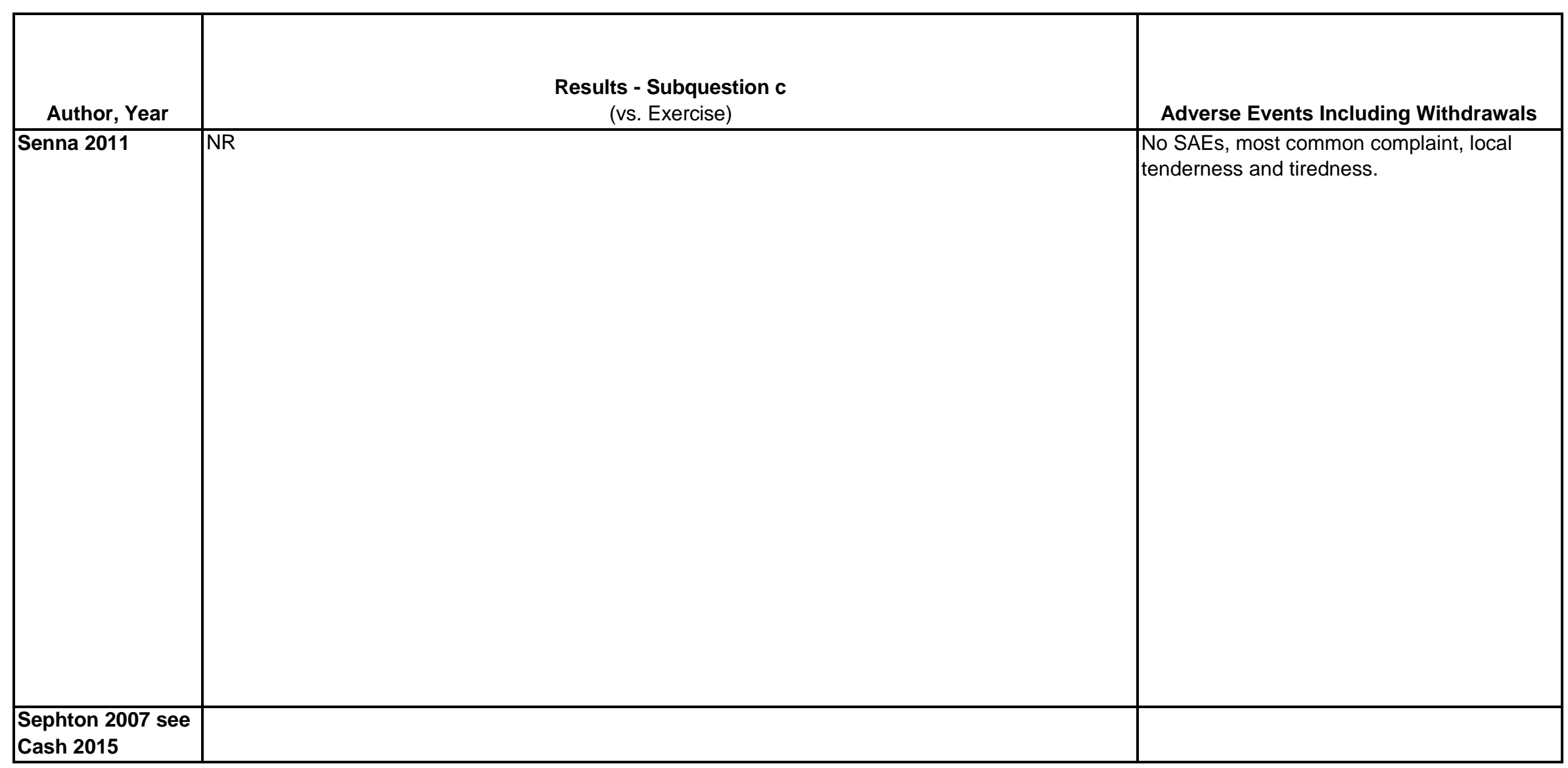




\begin{tabular}{|l|l|l|l|}
\hline & & & \\
Author, Year & Funding Source & Quality & \\
\hline Senna 2011 & None & Coor & \\
& & & \\
& & & \\
& & & \\
\hline $\begin{array}{l}\text { Sephton 2007 see } \\
\text { Cash 2015 }\end{array}$ & & & \\
\hline
\end{tabular}




\begin{tabular}{|l|l|l|}
\hline \multicolumn{1}{|c|}{ Author, Year } & \multicolumn{1}{|c|}{$\begin{array}{c}\text { Number of Centers and Setting } \\
\text { Sencan 2004 }\end{array}$} & $\begin{array}{l}\text { Number Randomized, } \\
\text { Analyzed } \\
\text { Attrition }\end{array}$ \\
\hline Setting NR & $\begin{array}{l}\text { Inclusion/Exclusion Criteria } \\
\text { Inclusion: Patients with FM diagnosis based on ACR 1990 } \\
\text { criteria, aged 18-50, with no other pharmacological } \\
\text { treatment or co morbid disease which was an inclusion } \\
\text { criteria stated in the study. } \\
\text { Exclusion: Patients with tumoral, infectious, metabolic, } \\
\text { cardiovascular, endocrine diseases, as well as those with } \\
\text { drug dependency were excluded from the study. }\end{array}$ & $\begin{array}{l}\text { Randomized: } 67 \\
\text { Analyzed: 60 } \\
\text { Attrition: 22.4\% (15/67) }\end{array}$ \\
\hline
\end{tabular}




\begin{tabular}{|l|l|}
\hline \multicolumn{1}{|c|}{ Author, Year } & \multicolumn{1}{c|}{ Intervention, Comparator } \\
\hline Sencan 2004 & $\begin{array}{l}\text { A. Exercise group ( } \mathrm{n}=14) \text { : three 40-minute aerobic exercise sessions per week for } 6 \text { weeks. Additionally, all patients were instructed to take } \\
\text { paracetamol as a rescue medication throughout the study. } \\
\text { B. Paroxetine }(\mathrm{n}=18) \text { : subjects given 20/mg paroxetine/day for } 6 \text { weeks. Additionally, all patients were instructed to take paracetamol as a } \\
\text { rescue medication throughout the study. } \\
\text { C. SHAM TENS ( } \mathrm{n}=20) \text { : Subjects were given placebo TENS with electrodes applied to two most painful tender points for } 20 \text { minutes, } 3 \\
\text { times/week for } 6 \text { weeks. Additionally, all patients were instructed to take paracetamol as a rescue medication throughout the study. }\end{array}$ \\
\hline
\end{tabular}




\begin{tabular}{|c|c|c|c|}
\hline Sencan 2004 & $\begin{array}{l}\text { A vs B vs. C } \\
\text { Age, years: } 35.4(9.6) \text { vs. } 35.6(9.4) \text { vs. } 35.5(7.8) \\
\text { Female: } 100 \% \text { vs. } 100 \% \\
\text { BMI (kg/height-m2): } 24.14(3.73) \text { vs. } 24.25(4.31) \\
\text { vs. } 24.60(2.64) \\
\text { Duration of symptoms, years: } 4.68 \text { (4.18) vs. } 6.53 \\
\text { (5.63) vs. } 5.10(4.68) \\
\text { VAS: } 6.85(1.23) \text { vs. } 6.62(1.42) \text { vs. } 7.70(1.72) \mathrm{cm} \\
\text { BDI: } 16.20(4.88) \text { vs } 20.80(5.25) \text { vs. } 18.50(5.31) \\
\text { Analgesic Consumption: } 9.65(2.2) \text { vs. } 7.10(1.65) \\
\text { vs. } 8.10(1.75)\end{array}$ & $\begin{array}{l}\text { Visual Analogue Scale (VAS 0-10cm, higher scores = higher } \\
\text { pain) } \\
\text { Beck Depression Inventory (BDI 0-63; higher scores=greater } \\
\text { depression) } \\
\text { Analgesic Consumption (mean daily analgesic consumption) }\end{array}$ & 6 months \\
\hline
\end{tabular}




\begin{tabular}{|c|c|}
\hline Sencan 2004 & $\begin{array}{l}\text { A vs C } \\
6 \text { months } \\
\text { VAS: } 4.75(1.21) \text { vs. } 5.01(1.91) ; M D-0.26(95 \% \mathrm{Cl}-1.46 \text { to } 0.94) p=0.660 \\
\text { BDI: } 9.95(2.81) \text { vs. } 15.15(3.21) ; \mathrm{MD}-5.2(95 \% \mathrm{Cl}-7.41 \text { to }-2.99) p<0.001 \\
\text { Analgesic Consumption: } 1.15(0.21) \text { vs. } 4.35(1.11) ; \text { MD }-3.17(95 \% \mathrm{Cl}-3.79 \text { to }-2.55) p<0.001\end{array}$ \\
\hline
\end{tabular}




\begin{tabular}{|c|c|}
\hline Author, Year & $\begin{array}{c}\begin{array}{c}\text { Results - Subquestion b } \\
\text { (vs. Pharmacological therapy) }\end{array} \\
\end{array}$ \\
\hline Sencan 2004 & $\begin{array}{l}\text { A vs. B } \\
6 \text { months } \\
\text { VAS: } 4.75(1.21) \text { vs. } 5.84(2.11) ; \mathrm{MD}-1.09(95 \% \mathrm{Cl}-2.37 \text { to } 0.19) \mathrm{p}=0.092 \\
\text { BDI: } 9.95(2.81) \text { vs. } 10.12(2.64) ; \mathrm{MD}-0.17(95 \% \mathrm{Cl}-2.09 \text { to } 1.75) \mathrm{p}=0.858 \\
\text { Analgesic Consumption: } 1.15(0.21) \text { vs. } 2.40(0.19) ; \mathrm{MD}-1.25(95 \% \mathrm{Cl}-1.39 \text { to }-1.11) \mathrm{p}<0.001\end{array}$ \\
\hline
\end{tabular}




\begin{tabular}{|l|l|l|}
\hline \multicolumn{1}{|c|}{ Author, Year } & \multicolumn{1}{|c|}{$\begin{array}{l}\text { Results - Subquestion c } \\
\text { (vs. Exercise) }\end{array}$} & \multicolumn{1}{c|}{ Adverse Events Including Withdrawls } \\
\hline Sencan 2004 & \multicolumn{1}{|c|}{$\begin{array}{l}\text { A vs B vs. C } \\
\text { Exclusions: } 7 / 67^{*} \\
\text { Withdrawals: } 30 \%(6 / 20) \text { vs } 10 \%(2 / 20) \text { vs. NR } \\
\text { Adverse Events: NR } \\
\text { *Seven patients due to transportation difficulties or drug intolerance were dropped from the } \\
\text { study and the study group consisted of } 60 \text { patients }\end{array}$} \\
& & \\
\end{tabular}




\begin{tabular}{|c|c|c|c|}
\hline Author, Year & $\begin{array}{c}\text { Country } \\
\text { Number of Centers } \\
\text { Setting } \\
\end{array}$ & Inclusion/Exclusion Criteria & $\begin{array}{c}\text { Number Randomized, } \\
\text { Analyzed } \\
\text { Attrition } \\
\end{array}$ \\
\hline Sherman 2009 & $\begin{array}{l}\text { USA } \\
\text { Group Health } \\
2004\end{array}$ & $\begin{array}{l}\text { Age } 20-64 \text { years of age, primary care for neck pain } \geq 3 \text { months. } \\
\text { Excluded: neck pain likely due to a non-mechanical cause (e.g., } \\
\text { metastatic cancer, fractured vertebrae, spinal stenosis); } 2 \text { ) complex } \\
\text { neck pain or neck pain potentially inappropriate for massage (cervical } \\
\text { radiculopathy, prior neck surgery, litigation for neck pain, motor } \\
\text { vehicle accident within past three months); unstable serious medical } \\
\text { or psychiatric conditions or dementia; minimal neck pain (rating }<3 \text { on } \\
0-10 \text { point bothersomeness scale) or neck pain lasting }<12 \text { weeks; } \\
\text { receiving other treatments for neck pain apart from medications; used } \\
\text { massage for neck pain within the last year; or could not speak or } \\
\text { understand English. }\end{array}$ & $\begin{array}{l}\text { Randomized: } 64 \\
\text { Treated: } 64 \\
\text { Analyzed: } 58 \\
\text { Attrition: } 9 \% \\
\text { (6/64) }\end{array}$ \\
\hline Sherman 2005 & $\begin{array}{l}\text { US } \\
\text { Number of centers } \\
\text { unclear } \\
\text { Outpatient }\end{array}$ & $\begin{array}{l}\text { Age } 20-64 \\
\text { Primary care visit for back pain } 3 \text { to } 15 \text { months prior to the study } \\
\text { Exclude: Complicated back pain (sciatica, previous back surgery, or } \\
\text { spinal stenosis); } \\
\text { Potentially attributable underlying diseases or conditions } \\
\text { Minimal pain (<3 on 0-10 "bothersomeness" scale); } \\
\text { Receiving other pack pain treatments or had participated in yoga or } \\
\text { exercise training for back pain in the past year; } \\
\text { Those with a possible disincentive to improve (workers; compensation } \\
\text { or litigation); } \\
\text { Unstable medical or severe psychiatric conditions or dementia }\end{array}$ & $\begin{array}{l}\text { Randomized: } 101 \\
\text { Treated: } 99 \\
\text { Analyzed at } 6 \text { weeks: } 92 \\
\text { Analyzed at } 12 \text { weeks: } 96 \\
\text { Analyzed at } 26 \text { weeks: } 95 \\
\text { Attrition at } 26 \text { weeks: } 6 \% \\
(6 / 101)\end{array}$ \\
\hline
\end{tabular}




\begin{tabular}{|c|c|}
\hline Author, Year & Intervention, Comparator \\
\hline Sherman 2009 & $\begin{array}{l}\text { A.Massage }(n=30) \text {, Swedish and clinical techniques and self-care recommendations; } 10 \text { massage treatments over a 10-week period (exact number } \\
\text { based on participant's clinical progress as determined by the licensed massage therapist and member of CAM practitioners, based on their findings } \\
\text { and the comments of the participant.) } \\
\text { B.Self-care book ( } n=28) \text { providing information on potential causes of neck pain, neck-related headaches, whiplash, recommended strengthening } \\
\text { exercises, body mechanics and posture, conventional treatment, complementary therapies for neck pain, and first aid for intermittent flare-ups. No } \\
\text { additional instruction about using the book was provided. }\end{array}$ \\
\hline Sherman 2005 & $\begin{array}{l}\text { A: Yoga ( } n=36) \text { : } 12 \text { weekly } 75 \text {-minute Viniyoga classes (median attended=9). Each class included a question-and-answer period, an initial and final } \\
\text { breathing exercise, } 5 \text { to } 12 \text { postures, and a guided deep relaxation. Postures were selected from } 17 \text { viniyoga postures. Each session had a specific } \\
\text { focus: strength-building, flexibility, and large-muscle movement; asymmetric poses; strengthening the hip muscles; lateral bending; integration; and } \\
\text { customizing a personal practice. Participants were asked to practice daily at home and were given handouts that described home practices, and } \\
\text { auditory compact discs to guide them through the sequence of postures with the appropriate mental focus. } \\
\text { B: Exercise }(n=35): 12 \text { weekly } 75 \text { minute classes (median attended=8) designed by a physical therapist to be different from what most participants } \\
\text { would have probably experienced in previous physical therapy sessions. Each class included educational talk, feedback from the previous week, } \\
\text { simple warm-ups to increase heart rate, repetitions of a series of } 7 \text { aerobic exercises and } 10 \text { strengthening exercises that emphasized leg, hip, } \\
\text { abdominal and back muscles. Repetitions of each exercise increased from } 8 \text { to } 30 \text { in increments of } 2 \text { over the course of the } 12 \text {-week series. The } \\
\text { strengthening exercises were followed by } 12 \text { stretches for the same muscle group. Each stretch was held for } 30 \text { seconds. Classes ended with a } \\
\text { short, unguided period of deep, slow breathing. } \\
\text { C: Attention control (self-care education) ( } n=30) \text { : Participants were mailed a copy of The Back Pain } \\
\text { Helpbook. The book emphasized such self-care strategies as adoption of a comprehensive fitness and strength program, appropriate lifestyle } \\
\text { modification, and guidelines for managing flare-ups. The study did not provide any instructions for using the book, many of the chapters concluded } \\
\text { with specific action items. }\end{array}$ \\
\hline
\end{tabular}




\begin{tabular}{|c|c|c|c|}
\hline Author, Year & Study Participants & Outcome Measures & $\begin{array}{c}\text { Duration of } \\
\text { Followup }\end{array}$ \\
\hline Sherman 2009 & \begin{tabular}{|l} 
A vs $B$ \\
Age: 47 vs 46 years \\
Female: $69 \%$ vs $69 \%$ \\
Attended some college: $81 \%$ vs $81 \%$ \\
White: $87 \%$ vs $81 \%$ \\
Married: $78 \%$ vs $59 \%$ \\
Income > $\$ 35,000: 74 \%$ vs $83 \%$ \\
Smoker: $9 \%$ vs $6 \%$ \\
Pain lasted > 1 year: $81 \%$ vs $81 \%$ \\
Symptom bothersome: $4.8(2.3)$ vs $4.9(1.8)$ \\
NDI: $14.2(5.0)$ vs $14.2(4.7)$ \\
SF-36 PCS: $46.0(5.6)$ vs $44.1(8.0)$ \\
SF-36 MCS: $51.9(7.0)$ vs $53.1(7.6)$
\end{tabular} & $\begin{array}{l}\text { NDI: (scale 0-50, higher score greater disability) } \\
\text { Bothersome numerical rating scale (scale, 0-10, higher } \\
\text { score=greater bothersome) } \\
\text { Short-Form } 36 \text { (SF-36) (scale 0-100, higher } \\
\text { score=better QoL) } \\
\text { Medication use }\end{array}$ & $\begin{array}{l}2.5 \text { and } 6.5 \\
\text { months }\end{array}$ \\
\hline Sherman 2005 & $\begin{array}{l}\text { A vs. B vs. C } \\
\text { Age: } 44 \text { vs. } 42 \text { vs. } 45 \\
\text { Female: } 69 \% \text { vs. } 63 \% \text { vs. } 67 \% \\
\text { Race: } 83 \% \text { vs. } 85 \% \text { vs. } 70 \% \text { white } \\
\text { Pain lasting >1 year: } 75 \% \text { vs. } 57 \% \text { vs. } 70 \% \\
\text { SF-36, physical: } 44 \text { vs. } 43 \text { vs. } 43 \\
\text { SF- } 36 \text {, mental health: } 53 \text { vs. } 54 \text { vs. } 53 \\
\text { RDQ: } 8.1 \text { vs. } 9.0 \text { vs. } 8.0 \\
\text { Exercise in past week (mean hours): } 3 \text { vs. } 3 \text { vs. } 3 \\
\text { Medication use for back pain in past week: } 58 \% \text { vs. } 57 \% \text { vs. } 50 \%\end{array}$ & $\begin{array}{l}\text { Primary outcomes: } \\
\text { Modified RDQ (0-23, higher score=more disability)) } \\
\text { Bothersomeness: (scale 0-10, higher score=more } \\
\text { bothersome) } \\
\text { Secondary outcomes: } \\
\text { General health status: SF-36 } \\
\text { Degree of restricted activity (3 questions) } \\
\text { Medication use }\end{array}$ & 3.5 months \\
\hline
\end{tabular}




\begin{tabular}{|c|c|}
\hline Author, Year & $\begin{array}{c}\text { Results - Subquestion a } \\
\text { (vs. sham, no treatment, waitlist, attention control) }\end{array}$ \\
\hline Sherman 2009 & $\begin{array}{l}\text { A vs B } \\
2.5 \text { months, mean difference }(95 \% \mathrm{Cl}) \\
\mathrm{NDI} \text {, mean difference: }-2.3(95 \% \mathrm{Cl}-4.7 \text { to } 0.15), \mathrm{p}=.066 \\
\mathrm{NDI}, \% \geq 5 \text { points: } 39 \% \text { vs } 14 \%, \mathrm{RR} 2.7(95 \% \mathrm{Cl} 0.99 \text { to } 7.5), \mathrm{p}=0.052 \\
\text { Bothersome score: }-1.2(95 \% \mathrm{Cl}-2.5 \text { to } 0.1), \mathrm{p}=0.081 \\
\text { Bothersome improvement } \geq 30 \%: 55 \% \text { vs } 25 \%, \mathrm{RR} 2.1(95 \% \mathrm{Cl} 1.04 \text { to } 4.2), \mathrm{p}=0.038 \\
\text { SF-36 PCS: } 52.8(\mathrm{Cl}, 53.0 \text { to } 53.7) \text { vs } 53.3(\mathrm{Cl}, 52.4 \text { to } 54.2), \mathrm{p}=0.982 \\
\text { SF-36 MCS: } 45.9(\mathrm{Cl}, 46.0 \text { to } 46.8) \text { vs } 45.3(\mathrm{Cl}, 44.2 \text { to } 46.4), \mathrm{p}=0.444 \\
6.5 \text { months } \\
\text { NDI, mean difference: }-1.9(95 \% \mathrm{Cl}-4.4 \text { to } 0.63), \mathrm{p}=0.14 \\
\text { NDI, \% } \geq 5 \text { points: } 57 \% \text { vs } 31 \%, \mathrm{RR} 1.8(95 \% \mathrm{Cl} 0.97 \text { to } 3.5), \mathrm{p}=0.061 \\
\text { Bothersome score: }-0.14(95 \% \mathrm{Cl}-1.5 \text { to } 1.2), \mathrm{p}=0.84 \\
\text { Bothersome improvement } \geq 30 \%: 43 \% \text { vs } 39 \%, \mathrm{RR} 1.1 \text { (95\% } \mathrm{Cl} 0.6 \text { to } 2.0), \mathrm{p}=0.80 \\
\text { SF-36 PCS and MCS: data not given, no statistical difference } \\
\text { Medication use: No change in group A, } 14 \% \text { increase in group B }\end{array}$ \\
\hline Sherman 2005 & 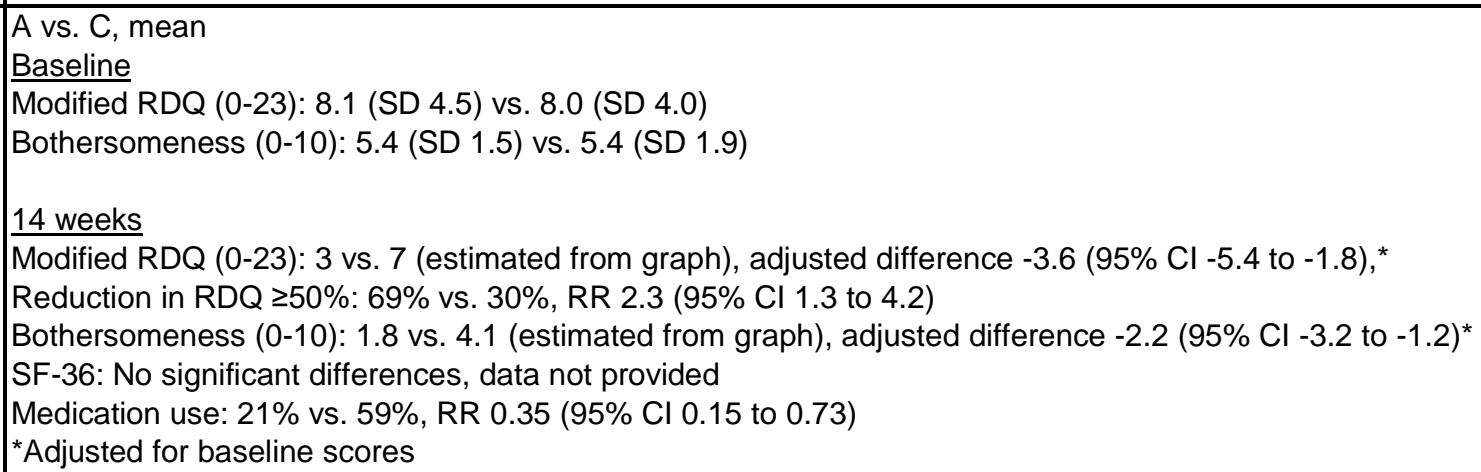 \\
\hline
\end{tabular}




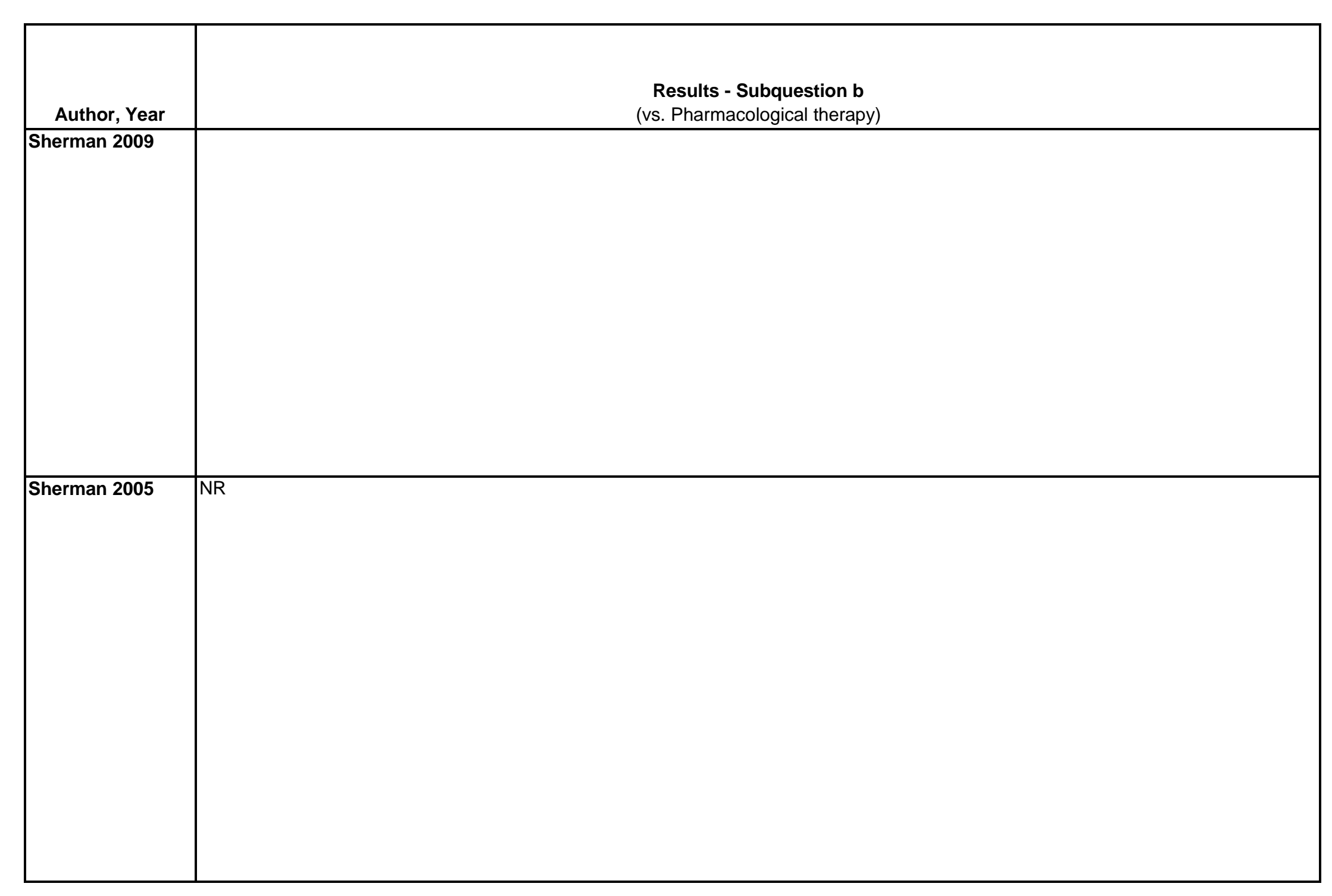




\begin{tabular}{|c|c|c|}
\hline Author, Year & $\begin{array}{c}\text { Results - Subquestion c } \\
\text { (vs. Exercise) }\end{array}$ & Adverse Events Including Withdrawals \\
\hline Sherman 2009 & & $\begin{array}{l}\text { No moderate or severe adverse experiences } \\
\text { reported } \\
\text { Mild adverse experiences: } \\
\text { Discomfort or pain during one or more } \\
\text { massages, } n=5 \\
\text { Increased soreness after treatment, } n=3 \\
\text { Nausea after each treatment } n=1\end{array}$ \\
\hline Sherman 2005 & $\begin{array}{l}\text { A vs. B, mean } \\
\text { Baseline } \\
\text { Modified RDQ (0-23): } 8.1 \text { (SD 4.5) vs. } 9.0 \text { (SD 4.1) } \\
\text { Bothersomeness: } 5.4 \text { (SD 1.5) vs. } 5.7 \text { (SD 1.9) } \\
14 \text { weeks } \\
\text { Modified RDQ (0-23): } 3 \text { vs. } 5 \text { (estimated from graph), adjusted difference }-1.5(-3.2 \text { to } 0.2)^{\star} \\
\text { Reduction in RDQ score } \geq 50 \%: 69 \% \text { vs. } 50 \%, \text { RR } 1.4 \text { (95\% Cl } 0.91 \text { to } 2.1) \\
\text { Bothersomeness: } 1.8 \text { vs. } 3.3 \text { (estimated from graph), adjusted difference }-1.4(95 \% \mathrm{Cl}-2.5 \text { to }-0.2)^{\star} \\
\text { SF-36: No significant differences, data not provided } \\
\text { Medication use: } 21 \% \text { vs. } 50 \%, \text { RR } 0.41 \text { ( } 95 \% \mathrm{Cl} 0.20 \text { to } 0.87) \\
{ }^{*} \text { Adjusted for baseline scores }\end{array}$ & $\begin{array}{l}\text { Adverse events NR } \\
\text { Withdrawals due to adverse events NR }\end{array}$ \\
\hline
\end{tabular}




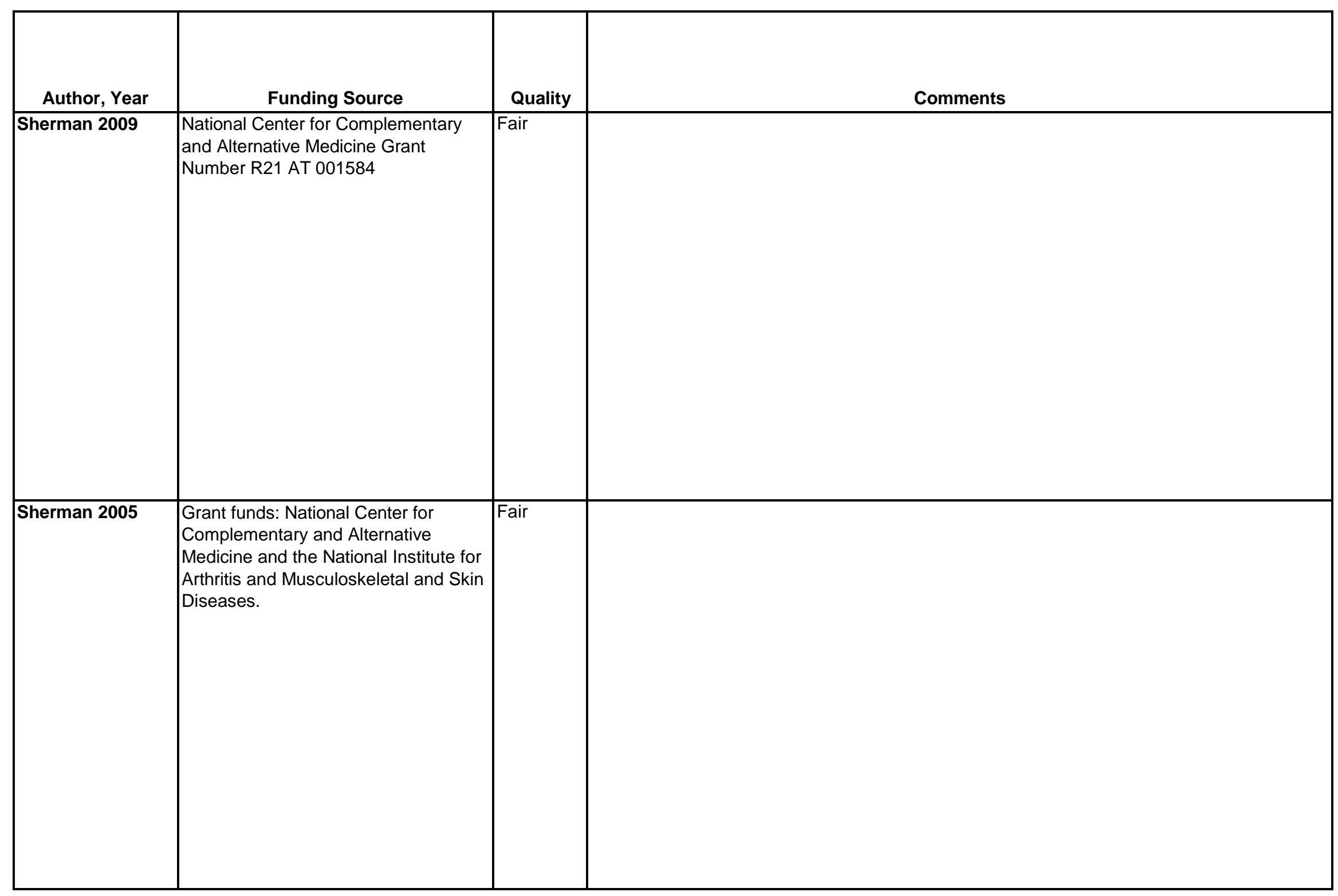




\begin{tabular}{|c|c|c|c|}
\hline Author, Year & \begin{tabular}{|c} 
Country \\
$\begin{array}{c}\text { Number of Centers } \\
\text { Setting }\end{array}$ \\
\end{tabular} & Inclusion/Exclusion Criteria & $\begin{array}{c}\text { Number Randomized, } \\
\text { Analyzed } \\
\text { Attrition }\end{array}$ \\
\hline Sherman 2011 & $\begin{array}{l}\text { US } \\
\text { Number of centers } 6 \\
\text { Outpatient }\end{array}$ & $\begin{array}{l}\text { Age 20-64 } \\
\text { ICD-9 diagnosis indicative of non-specific low back pain } \\
\text { Chronic low back pain persisting for at least } 3 \text { months } \\
\text { Pain bothersomeness rating of } \geq 3 \text { (0-10 scale) } \\
\text { Exclude: } \\
\text { Back pain attributed to a specific cause, } \\
\text { Complex back pain } \\
\text { Minimally painful at time of screening } \\
\text { Medical condition for which yoga or exercise were contraindicated } \\
\text { Major depression }\end{array}$ & \begin{tabular}{|l} 
Randomized: 229 \\
Treated: 228 \\
Analyzed at 6 weeks: 208 \\
Analyzed at 12 weeks: 206 \\
Analyzed at 26 weeks: 208 \\
Attrition at 26 weeks: $9 \%$ \\
$(21 / 229)$
\end{tabular} \\
\hline Somers 2012 & United States, & $\begin{array}{l}\text { Inclusion Criteria: } \\
\text { Participants were included if they: 1) reported knee pain on most days } \\
\text { of the month for at least the prior } 6 \text { months; } 2 \text { ) were over the age of } 18 \\
\text { years; 3) were overweight or obese (body mass index [BMI] P25 and } \\
642) ; 4 \text { ) met the American College of Rheumatology criteria for OA } \\
\text { and had radiographic evidence of OA affecting one or both knees } \\
\text { (knee X-rays were graded by an experienced reader) on the basis of } \\
\text { the Kellgren-Lawrence grading system (0-4; [28]); 5) had no other } \\
\text { major weight bearing joint affected by OA; } 6 \text { ) OA of the knee(s) was } \\
\text { considered the medical condition that contributed most to limitations in } \\
\text { their daily function as assessed by the health care provider; and 7) } \\
\text { were able to read and speak English. } \\
\\
\text { Exclusion Criteria: } \\
\text { Participants were excluded if they: 1) had a significant medical } \\
\text { condition that increased their risk of a significant adverse health event } \\
\text { during physical activity (e.g., myocardial infarction in the previous } 6 \\
\text { months, abnormal blood pressure response to exercise, etc.); 2) had } \\
\text { another known organic disease that would contraindicate safe } \\
\text { participation in the study (e.g., cancer); } 3 \text { ) had a non-OA inflammatory } \\
\text { arthropathy or another arthritic disorder (e.g., rheumatoid arthritis); 4) } \\
\text { used oral corticosteroids regularly; or 5) were participating in a regular } \\
\text { exercise or weight loss program. }\end{array}$ & $\begin{array}{l}\text { Randomized: } 111 \\
\text { Treated: } 89 \\
\text { Analyzed: } 111 \\
\text { Attrition: } \\
\text { post-treatment - } 12 / 60 \text { vs. } \\
10 / 51 \\
6 \text { month - } 17 / 60 \text { vs. } 14 / 51 \\
12 \text { month - } 21 / 60 \text { vs. } \\
14 / 51 \\
\text { Total - } 31.5 \% \text { (35/111) } \\
\end{array}$ \\
\hline
\end{tabular}




\begin{tabular}{|c|c|}
\hline Author, Year & Intervention, Comparator \\
\hline Sherman 2011 & $\begin{array}{l}\text { A: Viniyoga ( } n=92): 12 \text { weekly } 75 \text {-minute Viniyoga classes (median attended=10). Each class included a question-and-answer period, an initial and } \\
\text { final breathing exercise, } 5 \text { to } 12 \text { postures, and a guided deep relaxation. Postures were selected from } 17 \text { viniyoga postures. Each session had a } \\
\text { specific focus: strength-building, flexibility, and large-muscle movement; asymmetric poses; strengthening the hip muscles; lateral bending; } \\
\text { integration; and customizing a personal practice. Participants were asked to practice daily at home and were given handouts that described home } \\
\text { practices, and auditory compact discs to guide them through the sequence of postures with the appropriate mental focus. } \\
\text { B: Exercise ( } n=91) \text { : } 12 \text { weekly } 75 \text { minute classes (median attended=9) designed by a physical therapist to be different from what most participants } \\
\text { would have probably experienced in previous physical therapy sessions. Each class included educational talk, feedback from the previous week, } \\
\text { simple warm-ups to increase heart rate, repetitions of a series of } 7 \text { aerobic exercises and } 10 \text { strengthening exercises that emphasized leg, hip, } \\
\text { abdominal and back muscles. Repetitions of each exercise increased from } 8 \text { to } 30 \text { in increments of } 2 \text { over the course of the } 12 \text {-week series. The } \\
\text { strengthening exercises were followed by } 12 \text { stretches for the same muscle group. Each stretch was held for } 30 \text { seconds. Classes ended with a } \\
\text { short, unguided period of deep, slow breathing. } \\
\text { C: Attention control (self-care education) ( } n=30) \text { : Participants were mailed a copy of The Back Pain Helpbook. The book emphasized such self-care } \\
\text { strategies as adoption of a comprehensive fitness and strength program, appropriate lifestyle modification, and guidelines for managing flare-ups. } \\
\text { The study did not provide any instructions for using the book, many of the chapters concluded with specific action items. }\end{array}$ \\
\hline Somers 2012 & $\begin{array}{l}\text { A.Pain Coping Skills Training (PSCT) }(n=60) \\
\text { PCST strategies and education were delivered in group session by clinical psychologists. PCST is designed to decrease maladaptive pain } \\
\text { catastrophizing and enhance participants' ability to control and decrease pain by increasing use of adaptive coping strategies. } \\
\text { No. of Treatments: weekly for } 12 \text { weeks then every other week for the remaining } 12 \text { weeks (18 total) } \\
\text { Length of Treatments: } 60 \text { minutes each } \\
\text { B.Usual Care }(n=51) \\
\text { Participants assigned to this group continued to receive their routine care }\end{array}$ \\
\hline
\end{tabular}




\begin{tabular}{|c|c|c|c|}
\hline Author, Year & Study Participants & Outcome Measures & $\begin{array}{c}\text { Duration of } \\
\text { Followup }\end{array}$ \\
\hline Sherman 2011 & $\begin{array}{l}\text { A vs. B vs. C } \\
\text { Age: } 47 \text { vs. } 49 \text { vs. } 50 \\
\text { Female: } 67 \% \text { vs. } 63 \% \text { vs. } 60 \% \\
\text { Race: } 87 \% \text { vs. } 84 \% \text { vs. } 96 \% \text { white } \\
\text { Pain lasting >1 year: } 92 \% \text { vs. } 89 \% \text { vs. } 91 \% \\
\text { RDQ: } 9.8 \text { vs. } 8.6 \text { vs. } 9.0 \\
\text { Bothersomeness score: } 4.9 \text { vs. } 4.5 \text { vs. } 4.7 \\
\text { Back exercise in past week (mean hours): } 0.4 \text { vs. } 0.3 \text { vs. } 0.5 \\
\text { Medication use for back pain in past week: } 57 \% \text { vs. } 65 \% \text { vs. } 53 \%\end{array}$ & $\begin{array}{l}\text { Primary outcomes: } \\
\text { Modified RDQ (scale } 0-23, \text { higher score=more disability) } \\
\text { Bothersomeness: (scale } 0-10 \text {, higher score=more } \\
\text { bothersome) } \\
\text { Secondary outcomes: } \\
\text { Degree of restricted activity } \\
\text { Global rating of improvement }\end{array}$ & 3.5 months \\
\hline Somers 2012 & $\begin{array}{l}\text { A vs B } \\
\text { Age: } 58 \text { vs. } 58 \\
\text { Female: } 67 \% \text { vs. } 68 \% \\
\text { Race: } 62 \% \text { vs. } 61 \% \\
\text { Mean Duration of Pain: NR } \\
\text { Mean Physical Disability (AIMS): } 1.6(95 \% \mathrm{Cl} 1.3-1.8) \text { vs. } 1.6(95 \% \mathrm{Cl} \\
1.2-1.9) \\
\text { Mean Function (WOMAC): } 46.2(95 \% \mathrm{Cl} 41.1-51.3) \text { vs. } 46.1(95 \% \mathrm{Cl} \\
39.7-52.5) \\
\text { Mean Stiffness (WOMAC): } 54.7(95 \% \mathrm{Cl} 48.3-61.1) \text { vs. } 53.2(95 \% \mathrm{C} \\
46.0-60.7) \\
\text { Mean Pain (AIMS): } 5.6(95 \% \mathrm{Cl} 5.2-6.0) \text { vs. } 5.5(95 \% \mathrm{Cl} 4.9-6.1) \\
\text { Mean Pain (WOMAC): } 42.8(95 \% \mathrm{Cl} 42.1-53.3) \text { vs. } 43.4(95 \% \mathrm{Cl} \\
37.4-49.5) \\
\text { Mean Psychological (AIMS): } 2.9(95 \% \mathrm{Cl} 2.6-3.9) \text { vs. } 3.0(95 \% \mathrm{Cl} \\
2.6-3.4)\end{array}$ & $\begin{array}{l}\text { Primary } \\
\text { Arthritis Impact Measurement Scales (AIMS) } \\
\text { Western Ontario and McMaster Osteoarthritis Index } \\
\text { (WOMAC) } \\
\text { Physical Disability (AIMS, range 0-10: higher scores } \\
\text { indicating greater pain or disability) } \\
\text { Function (WOMAC, range 0-100: higher scores } \\
\text { indicating greater pain or disability) } \\
\text { Stiffness (WOMAC, range 0-100: higher scores } \\
\text { indicating greater pain or disability) } \\
\text { Pain (AIMS, range 0-10: higher scores indicating } \\
\text { greater pain or disability) } \\
\text { Pain (WOMAC, range 0-100: higher scores indicating } \\
\text { greater pain or disability) } \\
\text { Secondary } \\
\text { Psychological Disability (AIMS, range 0-10: higher } \\
\text { scores indicating greater pain or disability) }\end{array}$ & $\begin{array}{l}6 \text { and } 12 \\
\text { months }\end{array}$ \\
\hline
\end{tabular}




\begin{tabular}{|c|c|}
\hline Author, Year & $\begin{array}{c}\text { Results - Subquestion a } \\
\text { (vs. sham, no treatment, waitlist, attention control) }\end{array}$ \\
\hline Sherman 2011 & 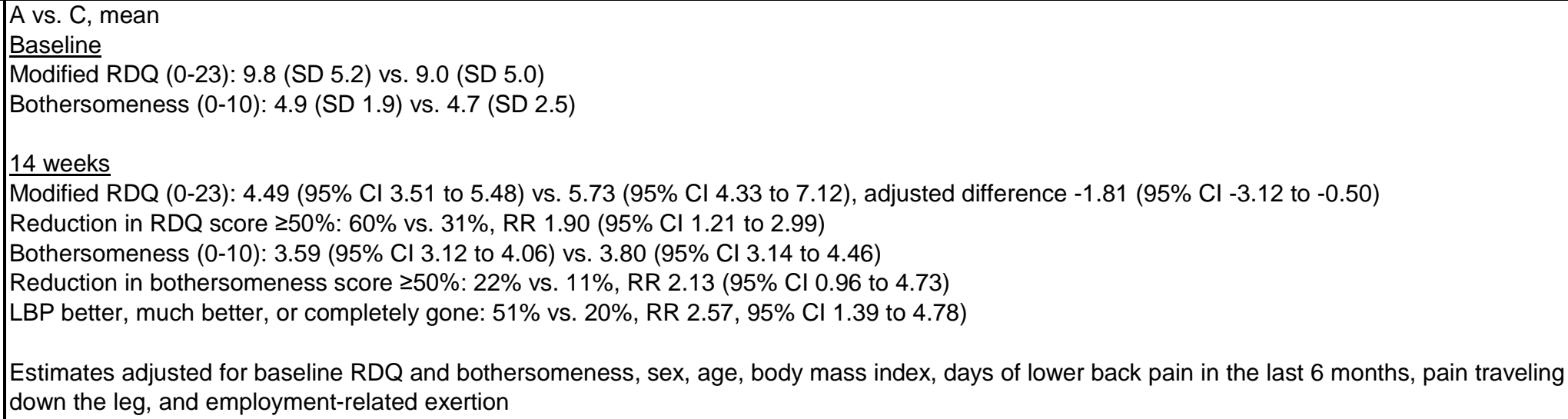 \\
\hline Somers 2012 & $\begin{array}{l}\text { A vs. B vs. C } \\
\text { Post-treatment Average (6-12 months) } \\
\text { Mean Physical Disability (AIMS): } 1.5(95 \% \mathrm{Cl} 1.3-1.6) \text { vs. } 1.5(95 \% \mathrm{Cl} 1.3-1.6) \text { vs. } 1.4(95 \% \mathrm{Cl} 1.2-1.6) \\
\text { Mean Function (WOMAC): } 35.2(95 \% \mathrm{Cl} 31.8-38.6) \text { vs. } 36.0(95 \% \mathrm{Cl} 32.6-39.3) \text { vs. } 37.5(95 \% \mathrm{Cl} 33.9-41.2) \\
\text { Mean Stiffness (WOMAC): } 44.5(95 \% \mathrm{Cl} 39.7-49.2) \text { vs. } 45.7(95 \% \mathrm{Cl} 41.2-50.2) \text { vs. } 46.4(95 \% \mathrm{Cl} 41.3-51.3) \\
\text { Mean Pain (AIMS): } 4.4(95 \% \mathrm{Cl} 4.1-4.8) \text { vs. } 4.7(95 \% \mathrm{Cl} 4.3-5.1) \text { vs. } 4.7(95 \% \mathrm{Cl} 4.3-5.1) \\
\text { Mean Pain (WOMAC): } 34.5(95 \% \mathrm{Cl} 30.8-38.2) \text { vs. } 35.5(95 \% \mathrm{Cl} 31.9-39.0) \text { vs. } 38.0(95 \% \mathrm{Cl} 34.1-41.8) \\
\text { Mean Psychological (AIMS): } 2.6(95 \% \mathrm{Cl} 2.4-2.8) \text { vs. } 2.5(95 \% \mathrm{Cl} 2.2-2.7) \text { vs. } 2.5(95 \% \mathrm{Cl} 2.3-2.8)\end{array}$ \\
\hline
\end{tabular}




\begin{tabular}{|l|l|}
\hline Author, Year & \multicolumn{1}{|c|}{$\begin{array}{c}\text { Results - Subquestion b } \\
\text { (vs. Pharmacological therapy) }\end{array}$} \\
\hline Sherman 2011 & $\mathrm{NR}$ \\
\hline Somers 2012 & $\mathrm{NR}$ \\
& \\
\hline
\end{tabular}




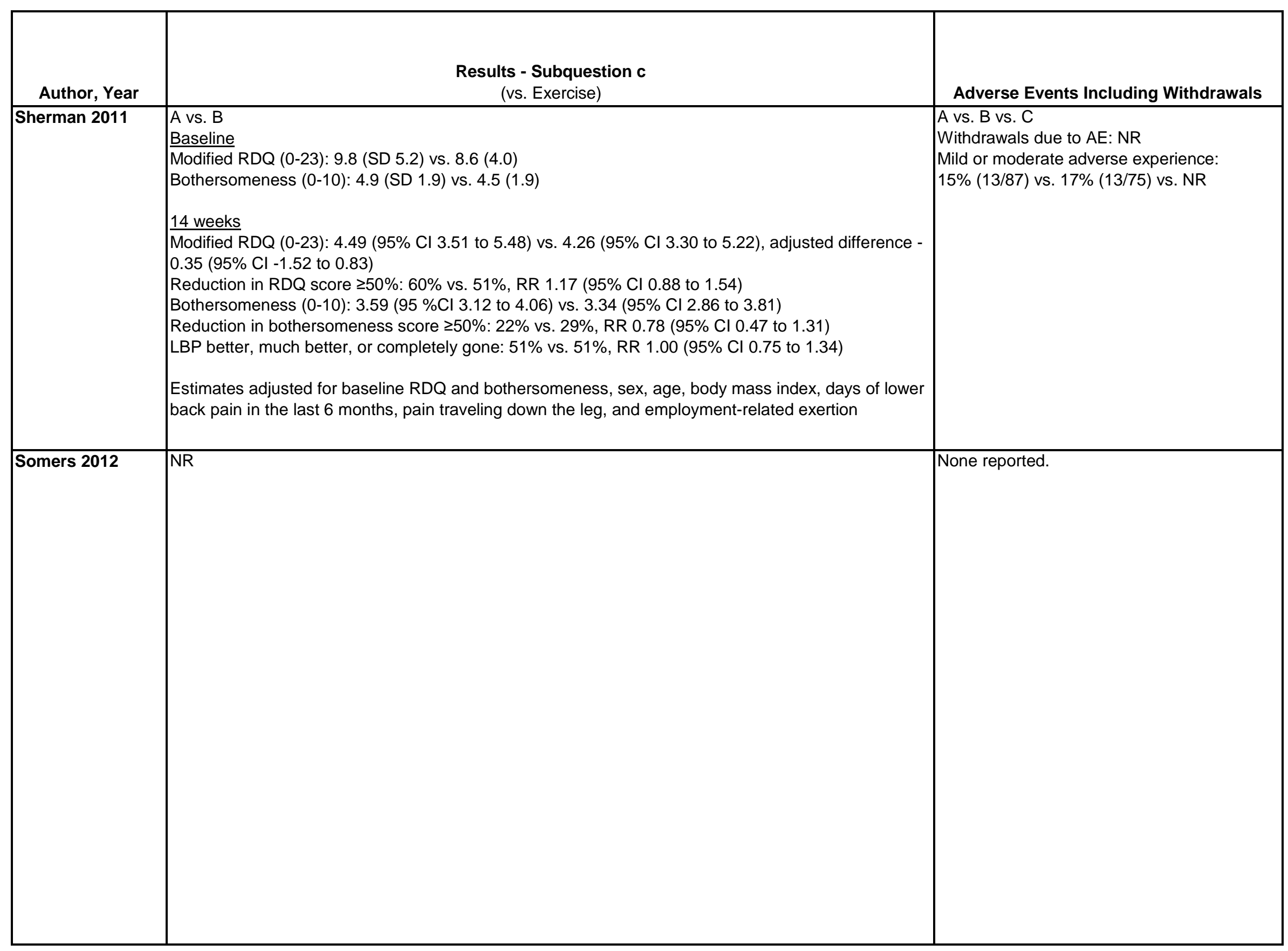




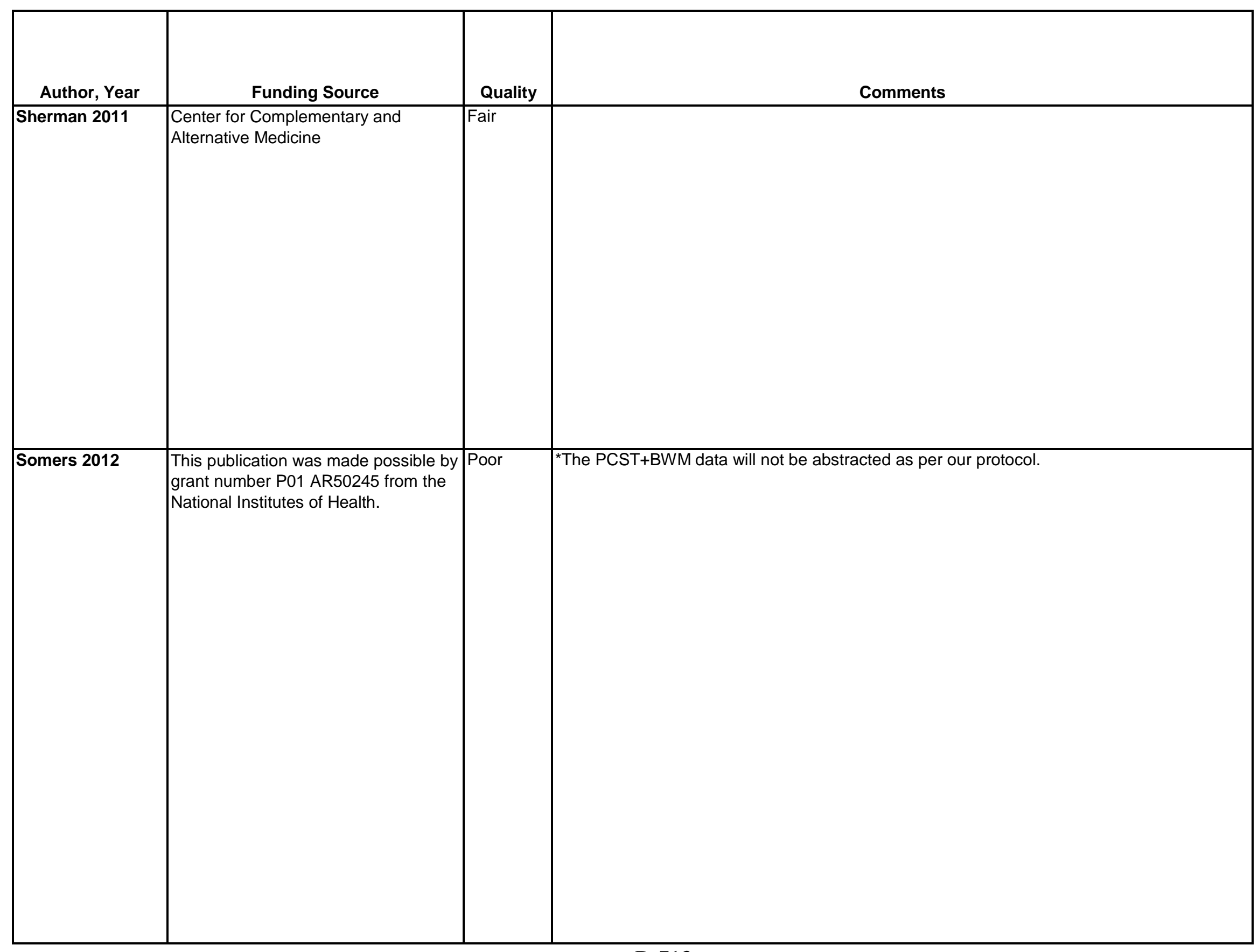




\begin{tabular}{|c|c|c|c|}
\hline Author, Year & $\begin{array}{c}\text { Country } \\
\text { Number of Centers } \\
\text { Setting }\end{array}$ & Inclusion/Exclusion Criteria & $\begin{array}{c}\text { Number Randomized, } \\
\text { Analyzed } \\
\text { Attrition }\end{array}$ \\
\hline Soriano 1998 & $\begin{array}{l}\text { Argentina } \\
\text { Number of centers: } \\
\text { NR } \\
\text { Unclear }\end{array}$ & $\begin{array}{l}\text { Patients older than } 60 \text { years, with chronic low back pain for more than } \\
3 \text { months. } \\
\text { Exclude: Patients with suspicion of cancer, osteomyelitis, gout, } \\
\text { Paget's or collagen disease, symptoms of neurological deficit in lower } \\
\text { limbs, or use of corticoids within } 30 \text { days. }\end{array}$ & $\begin{array}{l}\text { Randomized: } 85 \\
\text { Treated: } 71 \\
\text { Analyzed: } 71 \\
\text { Attrition: } 16 \%(14 / 85)\end{array}$ \\
\hline Stewart 2007 & $\begin{array}{l}\text { Australia } \\
2 \text { physiotherapy } \\
\text { clinics }\end{array}$ & $\begin{array}{l}\text { Presented for medical care of a whiplash-associated disorder grades } \\
\text { I-III } 1 \text { month after accident, at least "mildly" disabled with respect to } \\
\text { pre-injury status and have had significant pain or disability as } \\
\text { indicated by a score of at least } 20 \% \text { on any primary outcome } \\
\text { measures. Duration of symptoms, 3-12 months. } \\
\text { Exclude: Previous neck surgery, known or suspected serious } \\
\text { pathology, nerve root compromise, contraindication to exercise } \\
\text { (ACSM, 1995) severe or greater depressive symptoms as measured } \\
\text { by the Depression Anxiety Stress Scale (DASS), no neck radiograph } \\
\text { obtained since the accident and current physiotherapy neck treatment, } \\
\text { poor English comprehension. }\end{array}$ & $\begin{array}{l}\text { Randomized: } 134 \\
\text { Treated: } 134 \\
\text { Analyzed: } 125 \\
\text { Attrition: } 7 \%(9 / 134)\end{array}$ \\
\hline
\end{tabular}




\begin{tabular}{|c|c|}
\hline Author, Year & Intervention, Comparator \\
\hline Soriano 1998 & $\begin{array}{l}\text { A: GaAS laser }(n=38) \text { : Wavelength } 904 \mathrm{~nm} \text {, pulse frequency } 10,000 \mathrm{~Hz} \text {, pulse width } 200 \mathrm{nsec} \text {, peak power } 20 \mathrm{~W} \text {, average power } 40 \mathrm{~mW} \text {, } \\
\text { administered at dose of } 4 \mathrm{~J} / \mathrm{cm} 2 \text { per point to pain areas, } 5 \text { sessions a week for } 2 \text { weeks } \\
\text { B. Sham laser }(n=33)\end{array}$ \\
\hline Stewart 2007 & $\begin{array}{l}\text { A.Exercise plus advice ( } n=62): 6 \text { weeks of } 1 \text { hour graded exercise program based on behavioral theory and supervised by a physiotherapist, } 12 \\
\text { sessions total to include aerobic exercise, stretches, functional activities, activities to build speed, endurance and coordination, and trunk and limb } \\
\text { strengthening exercises, individualized home exercise program. } \\
\text { B.Advice alone ( } n=63 \text { ): Standardized education, reassurance and encouragement to resume light activity, given in } 1 \text { consultation and } 2 \text { followup } \\
\text { phone contacts. }\end{array}$ \\
\hline
\end{tabular}




\begin{tabular}{|c|c|c|c|}
\hline Author, Year & Study Participants & Outcome Measures & $\begin{array}{c}\text { Duration of } \\
\text { Followup }\end{array}$ \\
\hline Soriano 1998 & $\begin{array}{l}\text { A vs } \mathrm{B} \\
\text { Age: } 63 \text { vs. } 64 \text { years } \\
\text { Female: } 58 \% \text { vs. } 52 \% \\
\text { Pain score }(1 \text { to } 10): 7.9 \text { vs. } 8.1 \\
\text { Osteopenia: } 32 \% \text { vs. } 30 \% \\
\text { Osteophytes: } 63 \% \text { vs. } 66 \% \\
\text { Narrowing of disc space: } 34 \% \text { vs. } 33 \% \\
\text { Spondylolisthesis Grade I: } 5 \% \text { vs. } 3 \%\end{array}$ & $\begin{array}{l}\text { Pain score (percentage of relief: } 0-29 \%=\text { poor, } 30-59 \% \\
=\text { average, } 60-89 \%=\text { good, } 90-100 \%=\text { excellent) }\end{array}$ & $\begin{array}{l}\text { Intermediate } \\
\text { term } \\
6 \text { months }\end{array}$ \\
\hline Stewart 2007 & $\begin{array}{l}\text { A vs B } \\
\text { Age: } 44 \text { vs. } 43 \text { years } \\
\text { Female: } 73 \% \text { vs. } 62 \% \\
\text { Pain duration: } 9.5 \text { vs. } 8.6 \text { months } \\
\text { Pain intensity: } 5.2(2.0) \text { vs } 5.3(2.0) \\
\text { Bothersomeness: } 6.8(2.4) \text { vs } 7.1(2.3) \\
\text { Patient Specific Functional Scale (PSFS): } 3.9(1 . .7) \text { vs } 4.1 \text { (1.6) } \\
\text { NDI: } 18.2(6.3) \text { vs. } 19.7(6.9) \\
\text { SF-36 physical: } 36.4(9.9) \text { vs. } 36.8(8.6) \\
\text { SF-36 mental: } 49.0(11.0) \text { vs } 48.0(11.4) \\
\text { Global Perceived Effect (GPE): } 0.6(2.4) \text { vs } 0.3(2.4)\end{array}$ & $\begin{array}{l}\text { Pain intensity (box scale 0-10, higher score worse pain) } \\
\text { Bothersomeness (scale } 0-10 \text { ) } \\
\text { PSFS: average of } 3 \text { scores, all out of } 10 \text { (0 unable to } \\
\text { perform activity, } 10 \text { able to } \\
\text { perform activity at pre-injury level) } \\
\text { NDI: (scale } 0-50 \text {, higher score greater disability) } \\
\text { SF-36 physical and mental summary scores (scale 0- } \\
100 \text { for each) } \\
\text { GPE (scale }-5 \text { to } 5,-5 \text { vastly worse, } 0 \text { unchanged, } 5 \\
\text { completely recovered) } \\
\text { Adverse events }\end{array}$ & $\begin{array}{l}1.5 \text { months, } \\
12 \text { months }\end{array}$ \\
\hline
\end{tabular}




\begin{tabular}{|c|c|}
\hline Author, Year & $\begin{array}{c}\text { Results - Subquestion a } \\
\text { (vs. sham, no treatment, waitlist, attention control) }\end{array}$ \\
\hline Soriano 1998 & $\begin{array}{l}\text { A vs. B } \\
6 \text { months } \\
\text { No pain: } 44.7 \% \text { vs. } 15 \% ; p<0.01 \\
\text { Pain recurrence in subgroup of patients with a good or excellent response at end of treatment: } 35 \% \text { vs. } 70 \% ; p=N R\end{array}$ \\
\hline Stewart 2007 & 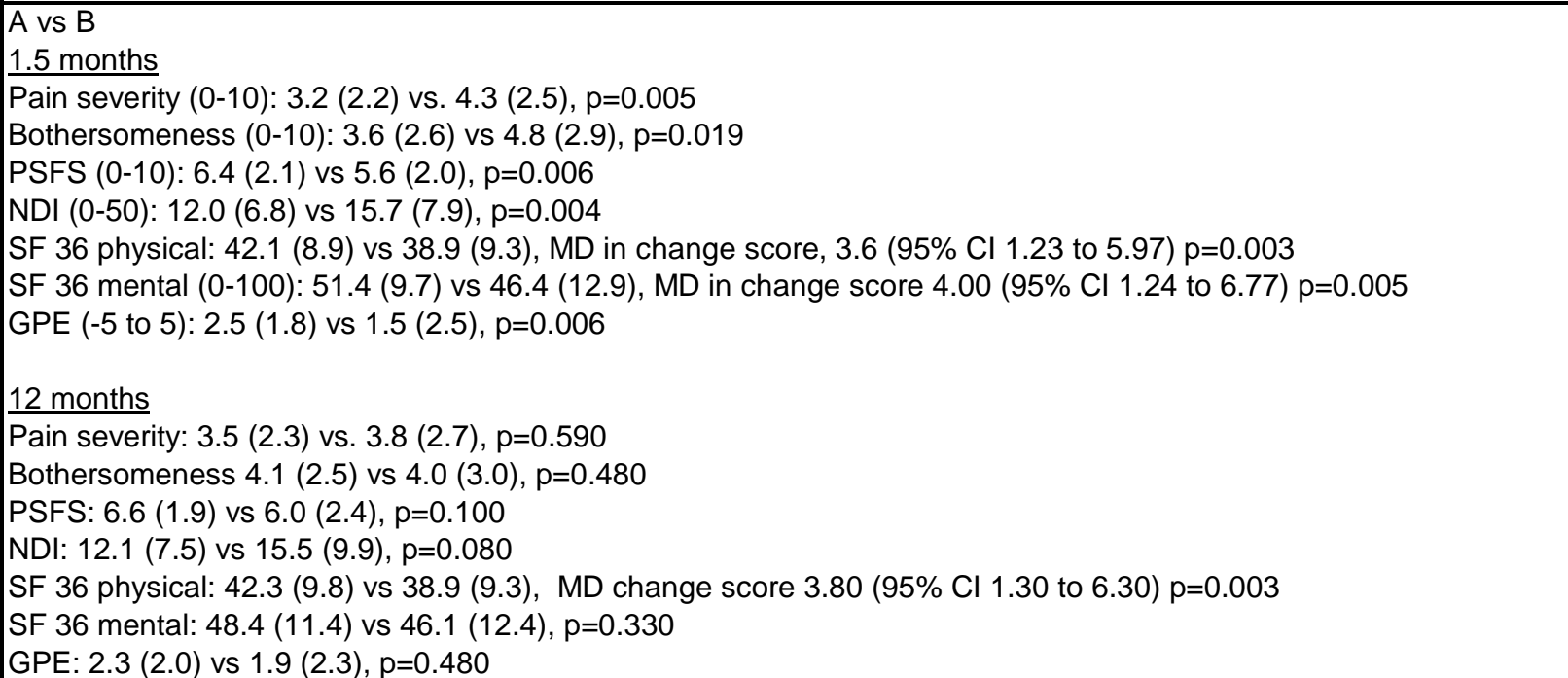 \\
\hline
\end{tabular}




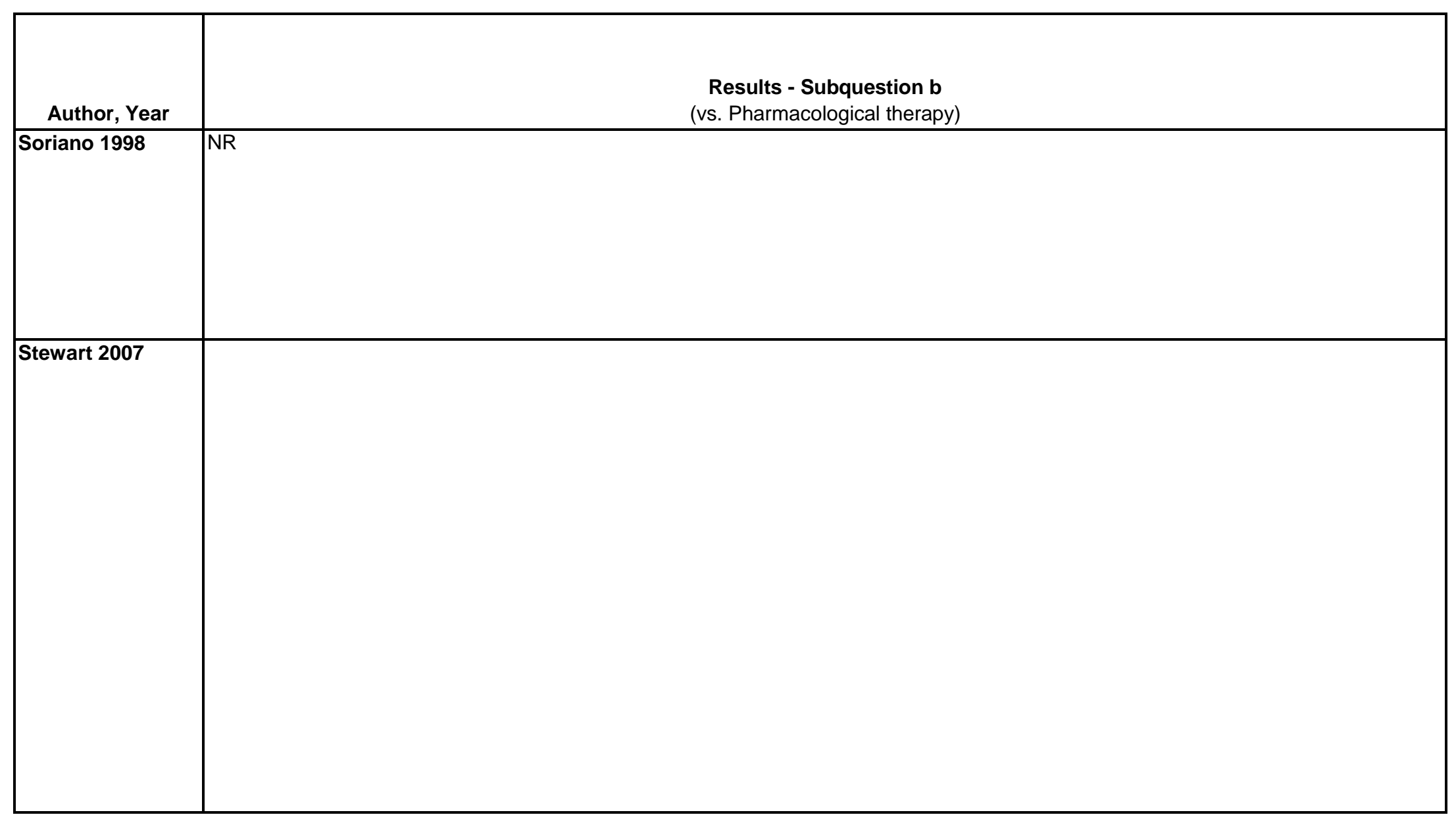




\begin{tabular}{|l|l|l|}
\hline Author, Year & \multicolumn{1}{|c|}{$\begin{array}{c}\text { Results - Subquestion c } \\
\text { (vs. Exercise) }\end{array}$} & Adverse Events Including Withdrawals \\
\hline Soriano 1998 & NR & $\begin{array}{l}\text { None (no cutaneous, ophthalmologic or } \\
\text { systemic side effects reported). }\end{array}$ \\
\hline Stewart 2007 & & $\begin{array}{l}\text { AEs: none requiring referral to medical } \\
\text { practitioner }\end{array}$ \\
& & $\begin{array}{l}\text { At 6 weeks subjects were asked if they } \\
\text { suffered any AEs. 13 (20\%) in the advice } \\
\text { plus exercise group answered 'yes', main } \\
\text { complaint was muscle pain with exercise (3), } \\
\text { knee pain (2) and lumbar spine pain (2). 12 } \\
\text { subjects (18\%) in the advice group answered } \\
\text { yes', main complaint was muscle pain (4) } \\
\text { increase in headaches (2) and ongoing pain } \\
\text { (2). }\end{array}$ \\
& \\
& & \\
\hline
\end{tabular}




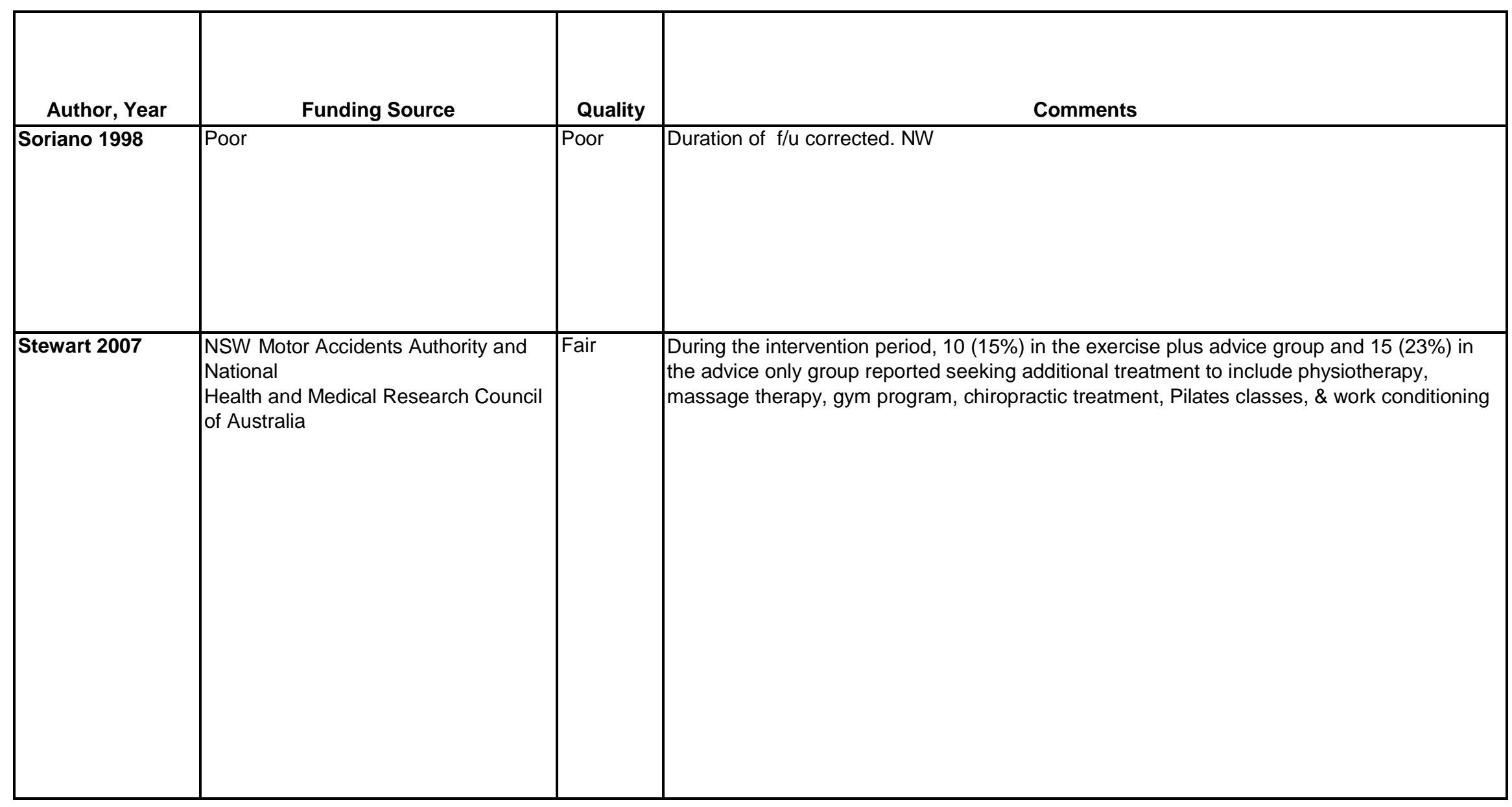




\begin{tabular}{|c|c|c|c|}
\hline Author, Year & $\begin{array}{c}\text { Country } \\
\text { Number of Centers } \\
\text { Setting }\end{array}$ & Inclusion/Exclusion Criteria & $\begin{array}{c}\text { Number Randomized, } \\
\text { Analyzed } \\
\text { Attrition }\end{array}$ \\
\hline Strand 2001 & Norway & $\begin{array}{l}\text { Inclusion Criteria: } \\
\text { Patients on }>8 \text { weeks sick leave with low back pain } \\
\text { Exclusion Criteria: } \\
\text { Pregnant, substance abuse, and illness conditions such as } \\
\text { progressive nervous system disease, serious cardiac disease, and } \\
\text { acute infection. }\end{array}$ & $\begin{array}{l}\text { Randomized: } 117 \\
\text { Treated: } 117 \\
\text { Analyzed: } 117 \\
\text { Attrition: } 0 \%(0 / 117)\end{array}$ \\
\hline Stukstette 2013 & $\begin{array}{l}\text { The Netherlands } \\
3 \text { centers } \\
\text { Outpatient }\end{array}$ & $\begin{array}{l}\text { ACR criteria for hand OA, hand OA was the most or second most } \\
\text { important problem, AUSCAN score } \geq 9 \\
\text { Exclude: Not willing to participate in a group treatment program }\end{array}$ & $\begin{array}{l}\text { Randomized: } 151 \\
\text { Treated: } 150 \\
\text { Analyzed: } 147 \\
\text { Attrition: } 3 \%(4 / 151)\end{array}$ \\
\hline
\end{tabular}




\begin{tabular}{|c|c|}
\hline Author, Year & Intervention, Comparator \\
\hline Strand 2001 & $\begin{array}{l}\text { A: Multidisciplinary rehabilitation ( } n=81) \text { : Physical training (strengthening, body awareness, aerobic fitness, relaxation), education, and cognitive } \\
\text { behavioral training (coping, responsibility for prescriptions, focus away from pain) and a workplace intervention. } 5 \text { days/week for } 4 \text { weeks, } 6 \\
\text { hours/day } \\
\text { B: Usual Care }(n=36) \text { : Usual care in community, did not follow a predefined treatment course. Most had physiotherapy ( } 76 \% \text {; and most had more } \\
\text { than } 24 \text { treatments) and } 32 \% \text { had alternative interventions (not further specified); } 14 \% \text { did not receive physiotherapy or alternative treatments }\end{array}$ \\
\hline Stukstette 2013 & $\begin{array}{l}\text { A.Multidisciplinary treatment program ( } \mathrm{n}=75): 4 \text { group based occupational therapy sessions } 2.5-3 \text { hours duration consisting of self-management } \\
\text { techniques, ergonomic principles, daily home exercises, splint (optional) } \\
\text { B.Waiting list ( } \mathrm{n}=72) \text { : Details NR } \\
\text { All patients: } 30 \text { minute explanation of written information about OA }\end{array}$ \\
\hline
\end{tabular}




\begin{tabular}{|c|c|c|c|}
\hline Author, Year & Study Participants & Outcome Measures & $\begin{array}{c}\text { Duration of } \\
\text { Followup }\end{array}$ \\
\hline Strand 2001 & \begin{tabular}{|l} 
A vs. B \\
Age: 45 vs. 42 \\
Female: $59 \%$ vs. $64 \%$ \\
Race: NR \\
BMI, kg/m2: $25.5(3.9)$ vs. $25.6(4.4)$ \\
Duration of symptoms (years): $10(10)$ vs. $9(7)$ \\
Disability Rating Index (0-100): $55.6(13.4)$ vs. $58.3(12.4)$ \\
Norwegian Pain Questionnaire $(0-106): 39.4(21.8)$ vs. $43.4(23.7)$ \\
Pain (0-100 VAS)): $48.3(19.6)$ vs. $53.0(21.4)$
\end{tabular} & $\begin{array}{l}\text { Primary: } \\
\text { Disability Rating Index (0-100, higher scores indicate } \\
\text { worse disability) } \\
\text { Norwegian Pain Questionnaire (0-106) } \\
\text { Pain (0-100 VAS) } \\
\text { Work (\% return to work) }\end{array}$ & 11 months \\
\hline Stukstette 2013 & $\begin{array}{l}\text { A vs B } \\
\text { Age: } 60 \text { vs } 58 \\
\text { Female: } 18 \% \text { vs } 16 \% \\
\text { Mean duration of diagnosis (yrs): } 4 \text { (6) vs } 4 \text { (7) } \\
\% \text { taking Opioids: } 3 \% \text { vs } 4 \% \\
\text { AUSCAN function: } 21.0(6.9) \text { vs } 21.8(6.3) \\
\text { Patient global assessment: } 49.5(25.1) \text { vs } 51.3(24.8) \\
\text { AUSCAN pain: } 10.4(3.4) \text { vs } 10.2(3.3) \\
\text { SF-36 physical score: } 39.5(7.3) \text { vs } 39.4(6.9) \\
\text { SF-36 mental score: } 49.7(9.0) \text { vs } 50.7(10.0)\end{array}$ & $\begin{array}{l}\text { AUSCAN function (0-36, higher score=greater } \\
\text { disability): patient global assessment of disease activity } \\
\text { (0-10, higher score=greater disease activity): OARSI } \\
\text { OMERACT (responder vs nonresponder): AUSCAN } \\
\text { pain (0-20, higher score=higher pain): SF-36 (0-100, } \\
\text { higher score=higher quality of life) }\end{array}$ & 3 months \\
\hline
\end{tabular}




\begin{tabular}{|c|c|}
\hline Author, Year & $\begin{array}{c}\text { Results - Subquestion a } \\
\text { (vs. sham, no treatment, waitlist, attention control) }\end{array}$ \\
\hline Strand 2001 & 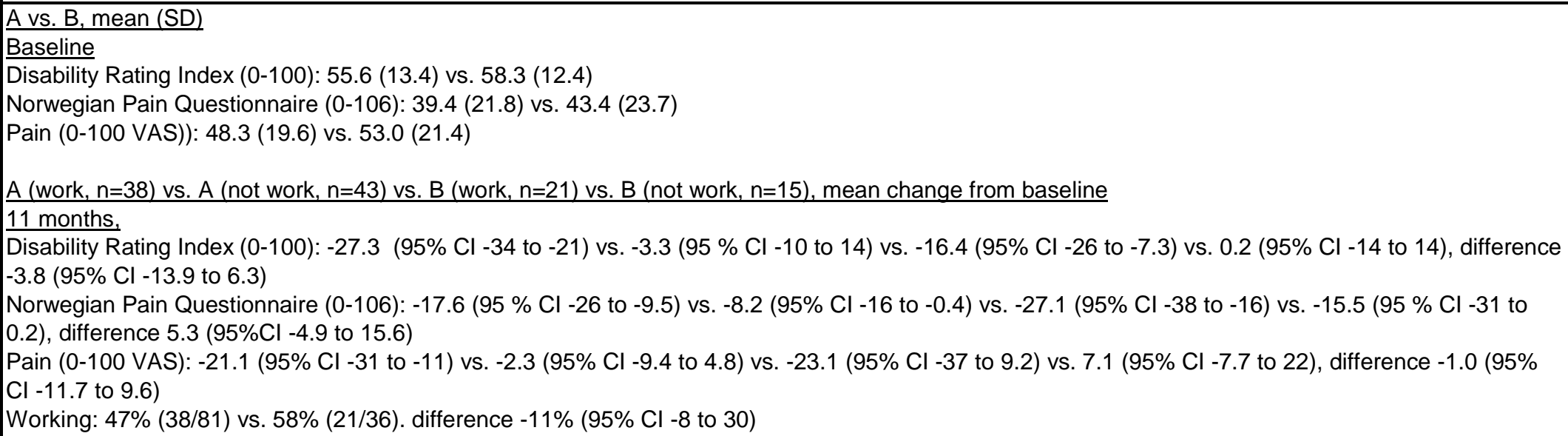 \\
\hline Stukstette 2013 & 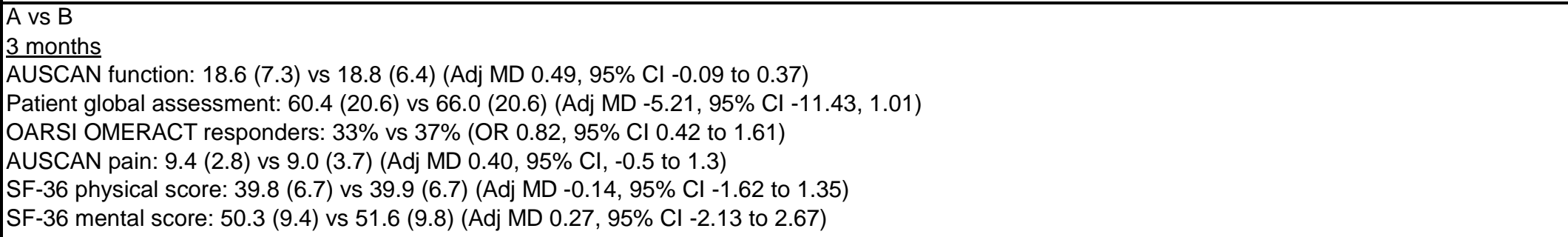 \\
\hline
\end{tabular}




\begin{tabular}{|l|l|}
\hline Author, Year & Results - Subquestion b \\
\hline Strand 2001 & (vs. Pharmacological therapy) \\
\hline Stukstette 2013 & \\
& \\
\hline
\end{tabular}

D-725 


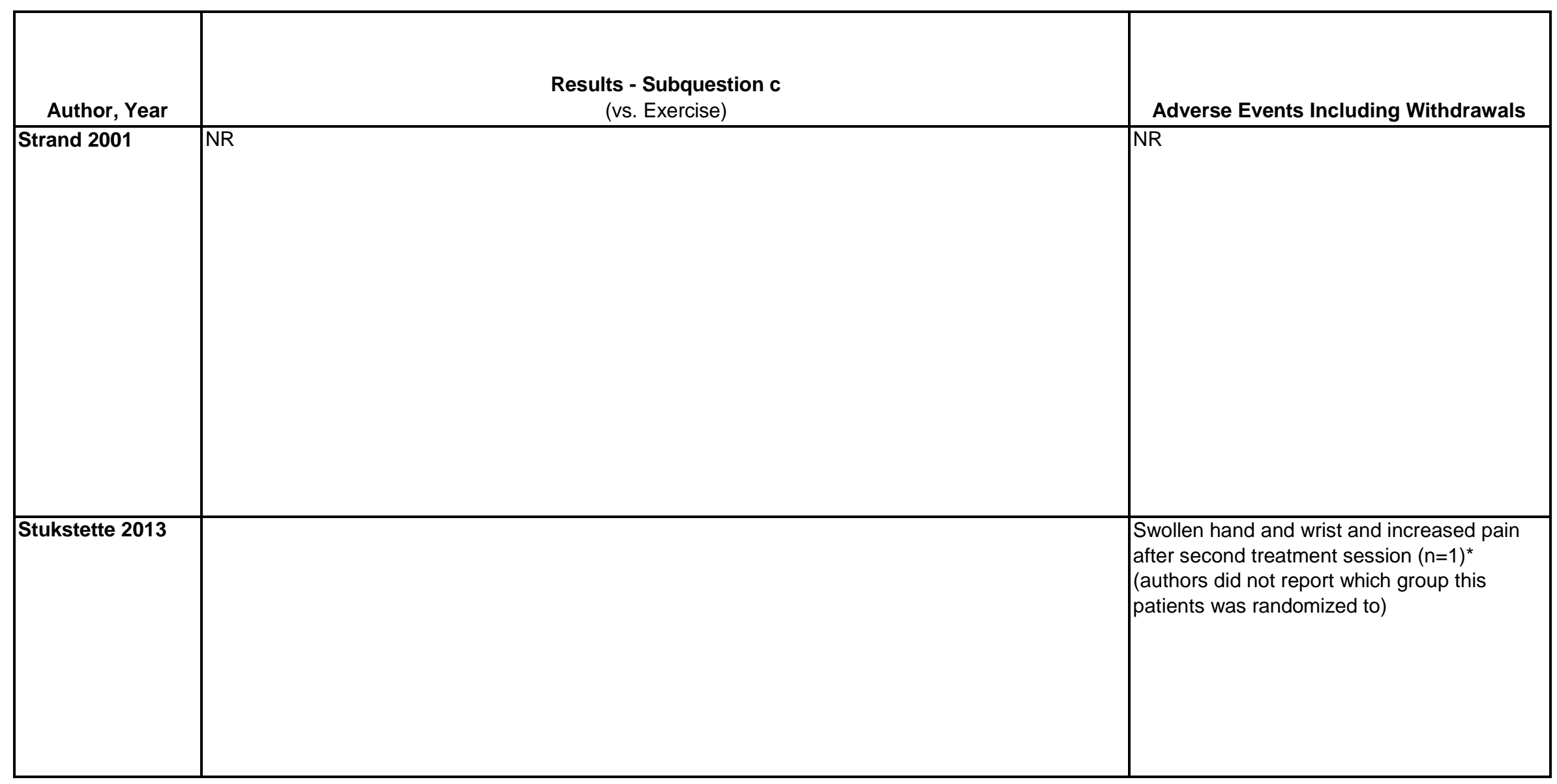




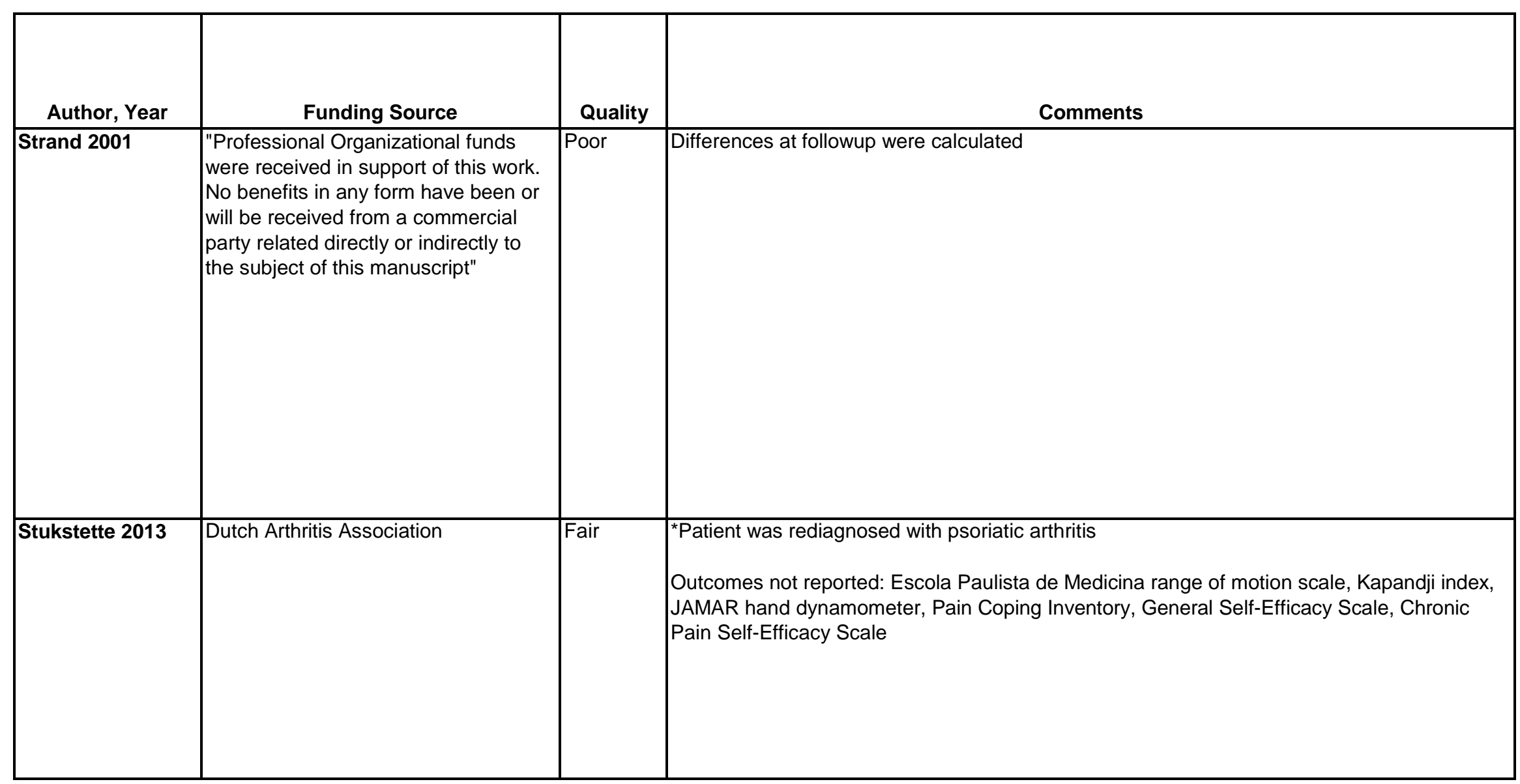




\begin{tabular}{|c|c|c|c|}
\hline Author, Year & $\begin{array}{c}\text { Country } \\
\text { Number of Centers } \\
\text { Setting }\end{array}$ & Inclusion/Exclusion Criteria & $\begin{array}{c}\text { Number Randomized, } \\
\text { Analyzed } \\
\text { Attrition }\end{array}$ \\
\hline $\begin{array}{l}\text { Suarez-Almazo } \\
2010\end{array}$ & $\begin{array}{l}\text { US, Texas. } \\
\text { Conducted through } \\
\text { Baylor and MD } \\
\text { Anderson with } 6 \\
\text { acupuncturists, } \\
\text { unclear number of } \\
\text { "sites" }\end{array}$ & $\begin{array}{l}\text { Inclusion Criteria: } 50 \text { years or older, radiographic knee OA using ACR } \\
\text { criteria, pain in the knee in the preceding } 2 \text { weeks } 3 / 10 \text { on VAS, no } \\
\text { prior acupuncture, stable NSAIDs and analgesics in the previous } \\
\text { month, 4) if receiving glucosamine, a stable dose for the past } 2 \\
\text { months, and no intraarticular knee injections in the previous } 2 \text { months. } \\
\text { Exclusion criteria: non stated other than inc criteria }\end{array}$ & $\begin{array}{l}\text { Randomized: } 560 \\
\text { Treated: } 527 \\
\text { Analyzed: } 494 \\
\text { Attrition: } 11.8 \%(66 / 560) \text { at } \\
12 \text { weeks }\end{array}$ \\
\hline Sullivan 1998 & $\begin{array}{l}\text { United States } \\
\text { Number of centers } \\
\text { unclear } \\
1 \text { hospital, multiple } \\
\text { GP clinics }\end{array}$ & $\begin{array}{l}\text { Over } 40 \text { years old, diagnosis of chronic, stable, primary OA in one or } \\
\text { both knees, knee pain occurring during weight-bearing activities for } \geq 4 \\
\text { months, radiographic evidence of primary OA of one or both knees, } \\
\text { use of NSAIDs } \geq 2 \text { days per week } \\
\text { Exclude: Serious medical conditions that were contraindications for } \\
\text { exercise, asymptomatic primary OA of one or both knees, dementia, } \\
\text { involvement in any program of regular exercise or study protocol }\end{array}$ & $\begin{array}{l}\text { Randomized: } 102 \\
\text { Treated: } 102 \\
\text { Analyzed: } 52 \\
\text { Attrition: } 49 \% \text { (50/102) }\end{array}$ \\
\hline
\end{tabular}




\begin{tabular}{|c|c|}
\hline Author, Year & Intervention, Comparator \\
\hline $\begin{array}{l}\text { Suarez-Almazo } \\
2010\end{array}$ & $\begin{array}{l}\text { A.Electroacupuncture }(n=153) \text { : Traditional Chinese Medicine points on the basis of clinical practice; TENS equipment emitted a dense disperse } \\
\text { wave impulse at } 50 \mathrm{~Hz} \text {, dispersing at } 15 \mathrm{~Hz}, 20 \text { cycles/minute. Voltage was increased slowly from } 5 \mathrm{~V} \text { to } 60 \mathrm{~V} \text { until maximal tolerance was achieved. } \\
\text { Patients rested for } 20 \text { minutes with continuing TENS. } \\
\text { B.Sham ( } n=302) \text { : instead of a dense disperse wave, a } 40 \mathrm{~Hz} \text { adjustable wave was used. Voltage was increased until the patient could feel it and } \\
\text { then immediately turned off. Patients rested for } 20 \text { minutes with the needles retained, but without TENS stimulation; sham points were outside the } \\
\text { relevant meridians; depth of needle placement was shallower than true electroacupuncture; } \\
\text { Both groups received } 20 \text { minute treatments } 2 / \text { week for } 6 \text { weeks, with } 12 \text { sessions in total } \\
\text { C. Waitlist control }(n=72) \\
\text { Note: this was a nested trial with acupuncture group randomized to high or low expectations and sham randomized to high or low expectations. }\end{array}$ \\
\hline Sullivan 1998 & $\begin{array}{l}\text { A.Exercise }(n=52): 3 \text { group sessions of } 10-15 \text { subjects per week were done for } 8 \text { weeks. Sessions were structured as a hospital-based supervised } \\
\text { fitness walking and supportive patient education program. Sessions consisted of stretching and strengthening exercises, expert speakers, group } \\
\text { discussions, instructions in safe walking techniques, and up to } 30 \text { minutes of walking. At the end of the } 8 \text { week treatment period, subjects were } \\
\text { encouraged to continue walking and given guidelines for managing individualized programs of fitness walking. } \\
\text { B. Usual care }(n=50) \text { : Subjects continued to receive the standard routine medical care they had been receiving prior to enrollment in the study. } \\
\text { Subjects were interviewed weekly during the } 8 \text { week treatment period about their functional and daily activities. }\end{array}$ \\
\hline
\end{tabular}




\begin{tabular}{|c|c|c|c|}
\hline Author, Year & Study Participants & Outcome Measures & $\begin{array}{c}\text { Duration of } \\
\text { Followup }\end{array}$ \\
\hline $\begin{array}{l}\text { Suarez-Almazo } \\
2010\end{array}$ & $\begin{array}{l}\text { A vs B vs. C } \\
\text { Age: } 64.5 \text { vs. } 64.5 \text { vs. } 64.1 \text { years } \\
\text { Sex (n, \% female): } 101(66 \%) \text { vs. } 195(65 \%) \text { vs. } 42(58.3 \%) \\
\text { Race (\% white): } 107(70 \%) \text { vs. } 204(68 \%) \text { vs. } 47(65.3 \%) \\
\text { Duration of symptoms: } 9.2 \text { vs. } 8.6 \text { vs. } 11.5 \text { years } \\
\text { WOMAC function: } 42.9(19.0) \text { vs. } 44.6(18.1) \text { vs. } 40.1(16.5) \\
\text { J-MAP: } 4.4(1.3) \text { vs. } 4.4(1.3) \text { vs. } 4.3(1.2) \\
\text { WOMAC pain: } 44.5(18.4) \text { vs. } 45.0(18.2) \text { vs. } 44.1(15.2) \\
\text { VAS pain: } 58.3(22.3) \text { vs. } 57.4(23.5) \text { vs. } 54.6(21.3) \\
\text { SF-12 PCS: } 35.0(9.9) \text { vs. } 33.5(8.7) \text { vs. } 35.3(8.4) \\
\text { SF-12 MCS: } 52.3(9.4) \text { vs. } 53.4(9.3) \text { vs. } 53.7(10.7)\end{array}$ & $\begin{array}{l}\text { WOMAC function subscale (scale unclear) } \\
\text { Joint-Specific Multidimensional Assessment of Pain (J- } \\
\text { MAP, range 1-7; higher scores=more pain) } \\
\text { WOMAC pain subscale (0-100; higher scores=greater } \\
\text { pain) } \\
\text { Average knee pain (VAS, 0-10; higher scores=greater } \\
\text { pain) } \\
\text { SF-12 PCS (scale 0-100; higher scores=better health) } \\
\text { SF-12 MCS (scale 0-100; higher scores=better health) }\end{array}$ & 1.5 months \\
\hline SuIIIVan 1998 & $\begin{array}{l}\text { A } 1 \text { Age: } 71 \text { vs } 68 \\
\text { Female: } 77 \% \text { vs } 90 \% \\
\text { AIMS physical activity subscale: } 6.3(2.2) \text { vs } 6.4(2.5) \\
\text { AIMS arthritis impact subscale: } 4.6(2.1) \text { vs } 4.5(2.5) \\
\text { AIMS pain subscale: } 4.9(2.1) \text { vs } 5.5(2.4) \\
\text { Pain VAS: } 4.1(2.6) \text { vs } 6.3(3.2) \\
\text { AIMS general health perception subscale: NR }\end{array}$ & $\begin{array}{l}\text { AIMS physIcal activity subscale (0-10, hIgner } \\
\text { score=higher disability); AIMS arthritis impact subscale } \\
\text { (0-10, higher score=higher impact); AIMS pain subscale } \\
\text { (0-10, higher score=higher pain); pain VAS (0-10, } \\
\text { higher score=higher pain); AIMS general health } \\
\text { perception subscale (0-10, higher score=worse health) }\end{array}$ & 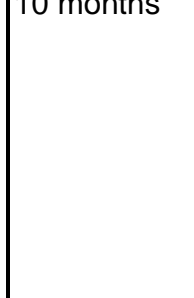 \\
\hline
\end{tabular}




\begin{tabular}{|c|c|}
\hline Author, Year & $\begin{array}{l}\text { Results - Subquestion a } \\
\text { (vs. sham, no treatment, waitlist, attention control) }\end{array}$ \\
\hline $\begin{array}{l}\text { Suarez-Almazo } \\
2010\end{array}$ & 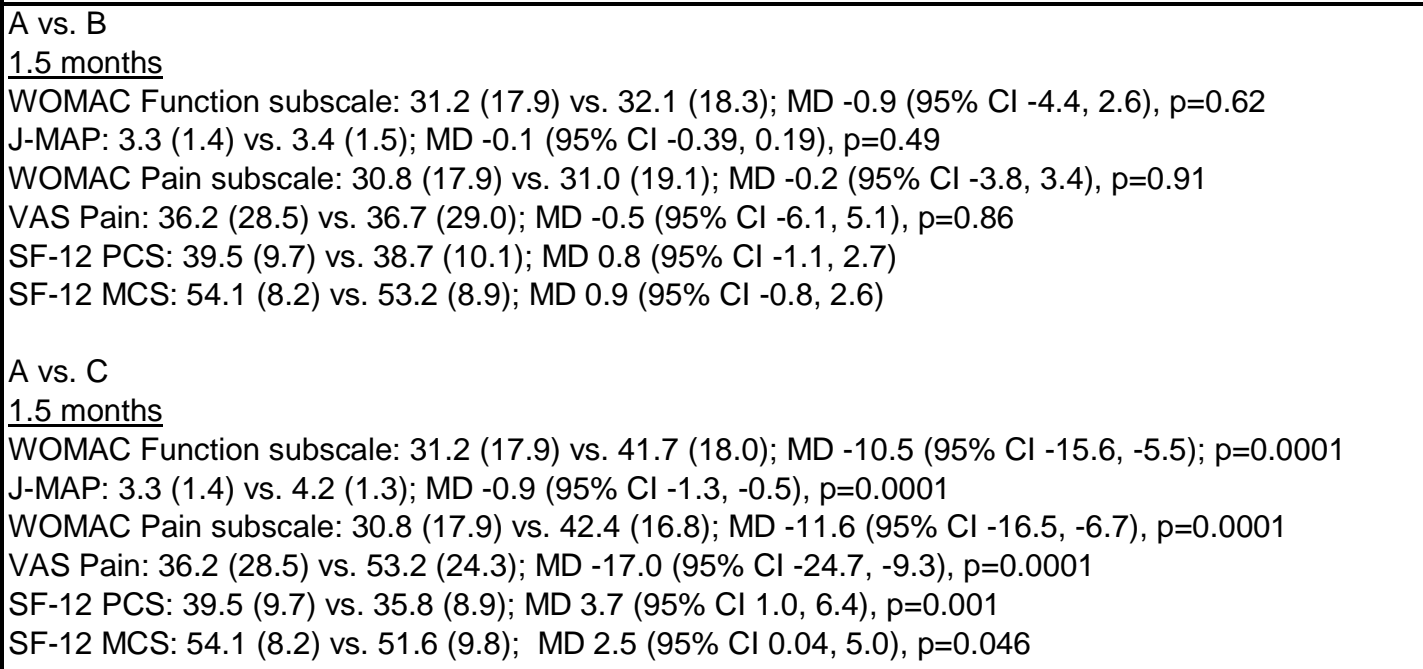 \\
\hline Sullivan 1998 & $\begin{array}{l}\text { A vs B } \\
\text { AIMS physical activity subscale: } 6.1(3.0) \text { vs } 6.2(2.8),(\mathrm{MD}-0.1,95 \% \mathrm{Cl}-1.7 \text { to } 1.5) \mathrm{p}=0.89 \\
\text { AIMS arthritis impact subscale: } 3.3(2.6) \text { vs } 3.8(2.1),(\mathrm{MD}-0.5,95 \% \mathrm{Cl}-1.8 \text { to } 0.8) \mathrm{p}=0.41 \\
\text { AIMS pain subscale: } 4.6(2.4) \text { vs } 5.5(2.1),(\mathrm{MD}-0.9,95 \% \mathrm{Cl}-2.2 \text { to } 0.4) \mathrm{p}=0.15 \\
\text { Pain VAS: } 5.0(2.8) \text { vs } 5.4(3.1),(\mathrm{MD}-0.4,95 \% \mathrm{Cl}-2.0 \text { to } 1.2) \mathrm{p}=0.60 \\
\text { AIMS general health perception subscale: } 3.7(2.8) \text { vs } 3.3(1.9),(\mathrm{MD} 0.4,95 \% \mathrm{Cl}-1.0 \text { to } 1.8) \mathrm{p}=0.52\end{array}$ \\
\hline
\end{tabular}




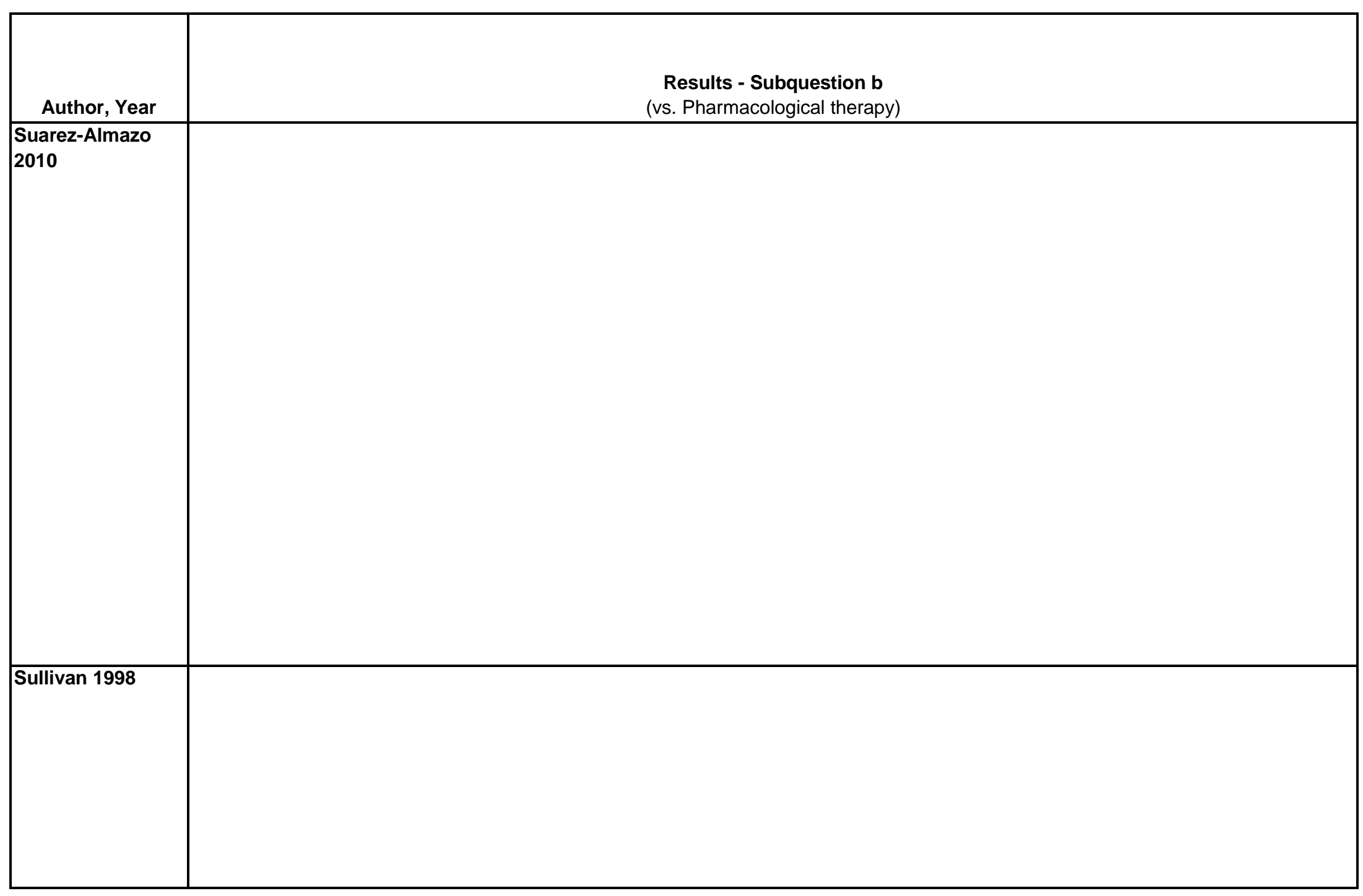

D-732 


\begin{tabular}{|c|c|c|}
\hline Author, Year & $\begin{array}{c}\text { Results - Subquestion c } \\
\text { (vs. Exercise) }\end{array}$ & Adverse Events Including Withdrawals \\
\hline $\begin{array}{l}\text { Suarez-Almazo } \\
2010\end{array}$ & & $\begin{array}{l}\text { AEs only reported for acupuncture groups } \\
\text { Exacerbation of knee pain: } \\
\text { TCA: } 7.2 \%(11 / 153) \\
\text { Sham: } 4.9 \%(15 / 302) \\
\text { RR } 1.4(95 \% \mathrm{Cl} 0.7,3.1), \mathrm{p}=0.34 \\
\text { Bruising at the needle site: } \\
\text { TCA: } 5.8 \%(9 / 153) \\
\text { Sham } 4.6 \%(14 / 302) \\
\text { RR } 1.3(95 \% \mathrm{Cl} 0.6,2.9) \\
\text { Muscle cramps: } \\
\text { TCA: } 0.7 \%(1 / 153) \\
\text { Sham: } 0.7 \%(2 / 302) \\
\text { RR } 0.99(95 \% \mathrm{Cl} 0.1,10.8) \\
\text { Headache: } \\
\text { TCA: } 0.7 \%(1 / 153) \\
\text { Sham: } 0 \%(0 / 302) \\
\text { RR not calculable } \\
\text { Infection at the needle site: } \\
\text { TCA: } 0.7 \%(1 / 153) \\
\text { Sham: } 0 \%(0 / 302) \\
\text { RR not calculable }\end{array}$ \\
\hline Sullivan 1998 & & $\mathrm{NR}$ \\
\hline
\end{tabular}




\begin{tabular}{|c|c|c|c|}
\hline Author, Year & Funding Source & Quality & Comments \\
\hline $\begin{array}{l}\text { Suarez-Almazo } \\
2010\end{array}$ & NIAMS, AHRQ & \begin{tabular}{|l} 
Good - \\
sham \\
Fair - \\
waitlist
\end{tabular} & $\begin{array}{l}\text { Also reported the following but not abstracted: Satisfaction with Knee Procedure (SKIP, } \\
\text { range 1-5), Timed Up and Go Test (TUG), Range of Motion (ROM). } \\
\text { Mean age and duration of knee pain for A vs. B were calculated using weighted means }\end{array}$ \\
\hline Sulivan 1998 & $\begin{array}{l}\text { Nasculoskeletal and Skin Diseases, } \\
\text { and the Arthritis Foundation }\end{array}$ & Proor & 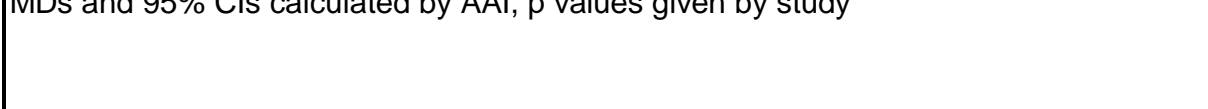 \\
\hline
\end{tabular}




\begin{tabular}{|c|c|c|c|}
\hline Author, Year & $\begin{array}{c}\text { Country } \\
\text { Number of Centers } \\
\text { Setting }\end{array}$ & Inclusion/Exclusion Criteria & $\begin{array}{c}\text { Number Randomized, } \\
\text { Analyzed } \\
\text { Attrition } \\
\end{array}$ \\
\hline Tak 2005 & $\begin{array}{l}\text { The Netherlands } \\
\text { Number of centers } \\
\text { unclear } \\
\text { Outpatient }\end{array}$ & $\begin{array}{l}55 \text { years or older, clinical diagnosis of OA, and living independently } \\
\text { Exclude: On waiting list for hip replacement, hip replacement within } \\
\text { previous year, inability to safely use fitness equipment, serious } \\
\text { depression or dementia, regular physical therapy treatment }\end{array}$ & $\begin{array}{l}\text { Randomized: } 109 \\
\text { Treated: } 94 \\
\text { Analyzed: } 94 \\
\text { Attrition: } 14 \%(15 / 109)\end{array}$ \\
\hline Tascioglu 2004 & $\begin{array}{l}\text { Turkey, university } \\
\text { hospital }\end{array}$ & $\begin{array}{l}\text { Inclusion Criteria: } \\
\text { Patients who had idiopathic knee OA according to American College } \\
\text { of Rheumatology criteria were recruited for the study. All patients had } \\
\text { Grade II to III bilateral knee OA confirmed radiologically according to } \\
\text { the Kellgren-Lawrence grading system. } \\
\text { Exclusion Criteria: } \\
\text { Exclusion for Kellgren-Lawrence Grade I and IV radiological changes, } \\
\text { knee joint disease other than OA, OA of the hip joint, osteoarthritic } \\
\text { involvement of the foot joints, serious concomitant systemic diseases, } \\
\text { intra-articular fluid effusion, previous physical therapy and intra- } \\
\text { articular corticosteroid or hyaluronic acid injections during the last six } \\
\text { months. }\end{array}$ & $\begin{array}{l}\text { Randomized: } 60 \\
\text { Treated: NR } \\
\text { Analyzed: NR } \\
\text { Attrition: NR }\end{array}$ \\
\hline
\end{tabular}




\begin{tabular}{|c|c|}
\hline Author, Year & Intervention, Comparator \\
\hline Tak 2005 & $\begin{array}{l}\text { A.Exercise }(n=45) \text { : Eight } 1 \text { hour weekly group sessions of strength training, information on a home exercise program, ergonomic advice, and } \\
\text { dietary advice } \\
\text { B.Standard of care }(n=49) \text { : Subject-initiated contact with their own GP }\end{array}$ \\
\hline Tascioglu 2004 & $\begin{array}{l}\text { A.Active Laser } 3 \text { joule }(\mathrm{n}=20) \\
\text { Participants were exposed to Low Level Laser Therapy (LLLT) to affected painful points. } \\
\text { No. of Treatments: } 1 / \text { day, } 5 \text { days/week for } 2 \text { week (10 treatments total) } \\
\text { No. of Treatment Points: } 5 \text { painful points, two minute irradiation per point (10 minutes total) } \\
\text { Total Dose: } 15 \text { joule, } 3 \text { joule per point ( } 150 \text { joule total) } \\
\text { Power Output: } 50 \mathrm{~mW} \text {, continuous } \\
\text { Wavelength: } 830 \mathrm{~nm} \\
\text { Laser Beam Diameter: } 1 \mathrm{~mm} \\
\text { Device: Endolaser } 476, \text { Enraf Nonius, Netherlands } \\
\\
\text { B.Active Laser } 1.5 \text { joule ( } \mathrm{n}=20) \\
\text { Participants were exposed to Low Level Laser Therapy (LLLT) to affected painful points. } \\
\text { No. of Treatments: } 1 / \text { day, } 5 \text { days/week for } 2 \text { week (10 treatments total) } \\
\text { No. of Treatment Points: } 5 \text { painful points, one minute irradiation per point ( } 5 \text { minutes total) } \\
\text { Total Dose: } 7.5 \text { joule, } 1.5 \text { joule per point (75 joule total) } \\
\text { Power Output: } 50 \mathrm{~mW}, \text { continuous } \\
\text { Wavelength: } 830 \mathrm{~nm} \\
\text { Laser Beam Diameter: } 1 \mathrm{~mm} \\
\text { Device: Endolaser } 476, \text { Enraf Nonius, Netherlands } \\
\text { C.Placebo Laser ( } \mathrm{n}=20) \\
\text { Identical treatment parameters except the device was rigged to appear operational but output energy }\end{array}$ \\
\hline
\end{tabular}




\begin{tabular}{|c|c|c|c|}
\hline Author, Year & Study Participants & Outcome Measures & $\begin{array}{c}\text { Duration of } \\
\text { Followup }\end{array}$ \\
\hline Tak 2005 & $\begin{array}{l}\text { A vs B } \\
\text { Age: } 68 \text { vs } 69 \\
\text { Female: } 64 \% \text { vs } 71 \% \\
\text { General health: } \\
\quad \text { Moderate/bad: } 40 \% \text { vs } 45 \% \\
\quad \text { Good/very good: } 60 \% \text { vs } 53 \% \\
\quad \text { No. of chronic conditions: } 2.6(1.8) \text { vs } 2.7(1.9) \\
\text { HHS: } 71.1(12.9) \text { vs } 71.0(13.3) \\
\text { GARS: } 22.8(5.4) \text { vs } 25.3(5.7) \\
\text { SIP-136 physical: } 7.2(9.2) \text { vs } 7.6(8.3) \\
\text { Pain VAS: } 3.8(2.1) \text { vs } 4.2(2.2) \\
\text { HHS pain subscale: } 27.9(8.1) \text { vs } 28.8(9.0) \\
\text { QoL VAS: } 7.0(4.3) \text { vs } 5.6(2.3) \\
\text { HRQoL: } 28.2(3.1) \text { vs } 27.3(2.4)\end{array}$ & $\begin{array}{l}\text { HHS (0-100, higher score=higher function); GARS (18- } \\
\text { 72, higher score=higher disability); SIP-136 physical (0- } \\
\text { 100, higher score=higher disability); pain VAS (0-10, } \\
\text { higher score=higher pain); HHS pain subscale (0-44, } \\
\text { higher score=less pain); QoL VAS (0-10, higher } \\
\text { score=higher QoL); HRQoL (7-39, higher score=higher } \\
\text { QoL) }\end{array}$ & 3 months \\
\hline Tascioglu 2004 & $\begin{array}{l}\text { A vs. B vs. C } \\
\text { Age: } 63 \text { vs. } 60 \text { vs. } 64 \\
\text { Female: } 70 \% \text { vs. } 75 \% \text { vs. } 65 \% \\
\text { Race: NR } \\
\text { Mean Duration of Chronicity: } 7.92(5.12) \text { vs. } 6.36(4.21) \text { vs. } 7.05(6.53) \\
\text { Mean Function (WOMAC): } 36.60(7.09) \text { vs. } 37.96(9.67) \text { vs. } 39.46 \\
(12.56) \\
\text { Mean Stiffness (WOMAC): } 4.12(3.01) \text { vs. } 4.64(1.89) \text { vs. } 4.45(2.51) ; \\
\text { Mean Pain (WOMAC): } 10.28(3.56) \text { vs. } 11.60(4.81) \text { vs. } 9.56(3.88) \\
\text { Mean Pain at Rest (VAS): } 39.08(14.86) \text { vs. } 41.55(16.65) \text { vs. } 37.92 \\
(11.00) \\
\text { Mean Pain at Movement (VAS): } 68.00(15.45) \text { vs. } 65.72(18.68) \text { vs. } \\
63.88(16.07)\end{array}$ & $\begin{array}{l}\text { WOMAC total (0-96: higher score=worse disability) } \\
\text { WOMAC function (0-68; higher score=worse function) } \\
\text { WOMAC Stiffness (0-8; higher score=worse stiffness) } \\
\text { WOMAC pain (0-20, higher score=greater pain) } \\
\text { Pain at Rest (VAS, 0-100; higher score=greater pain) } \\
\text { Pain at Activation (VAS, 0-100; higher score=greater } \\
\text { pain) }\end{array}$ & 6 months \\
\hline
\end{tabular}




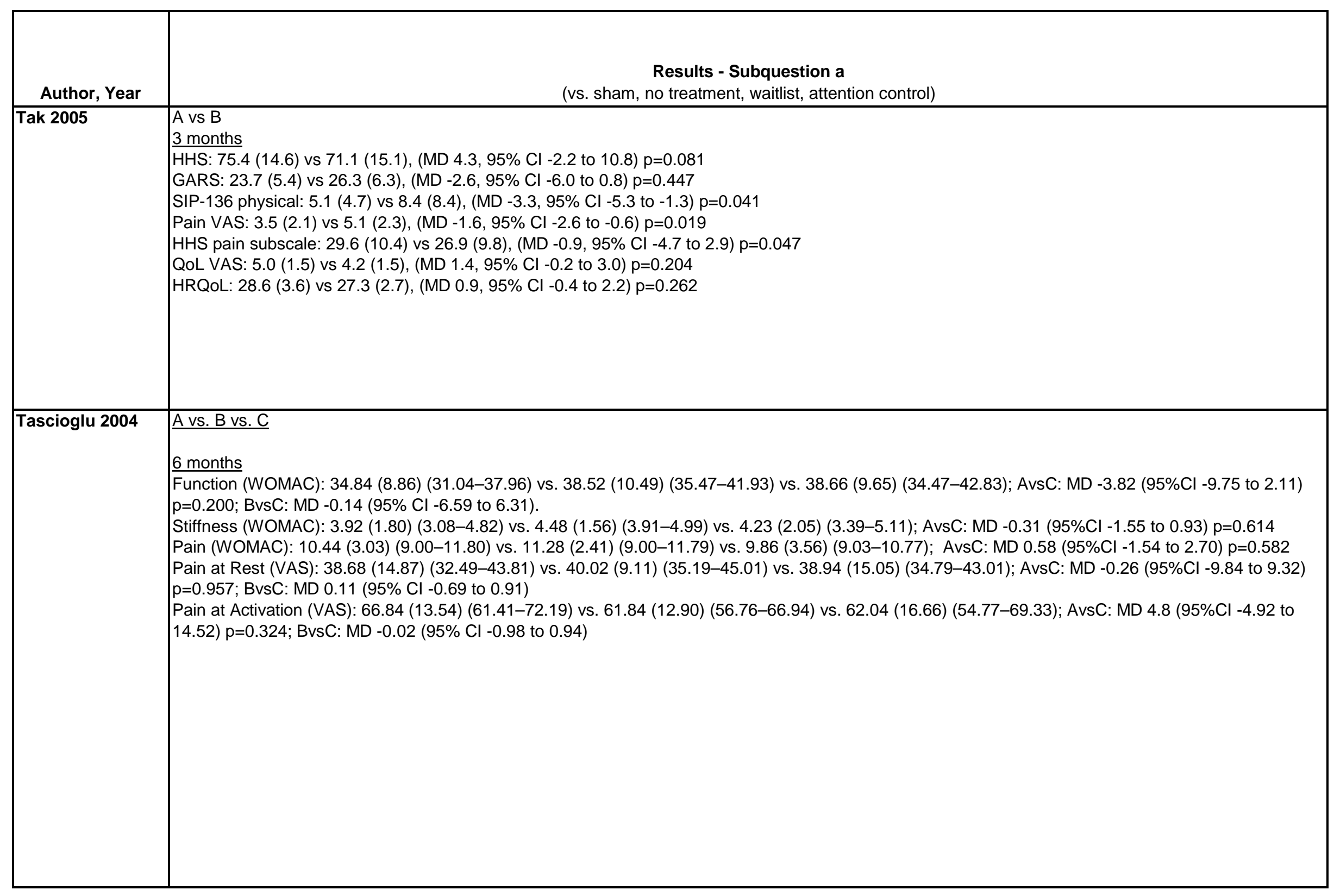




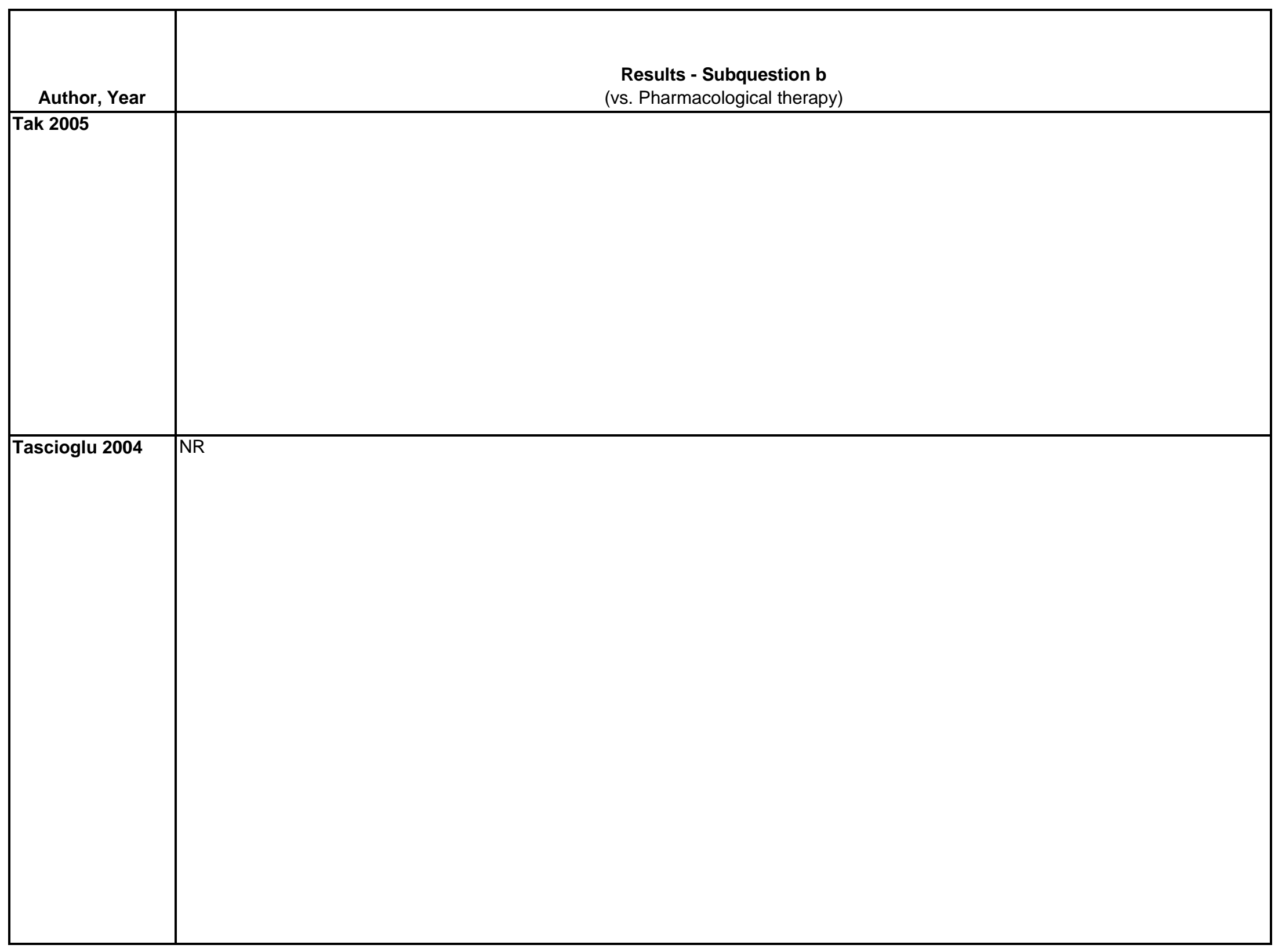

D-739 


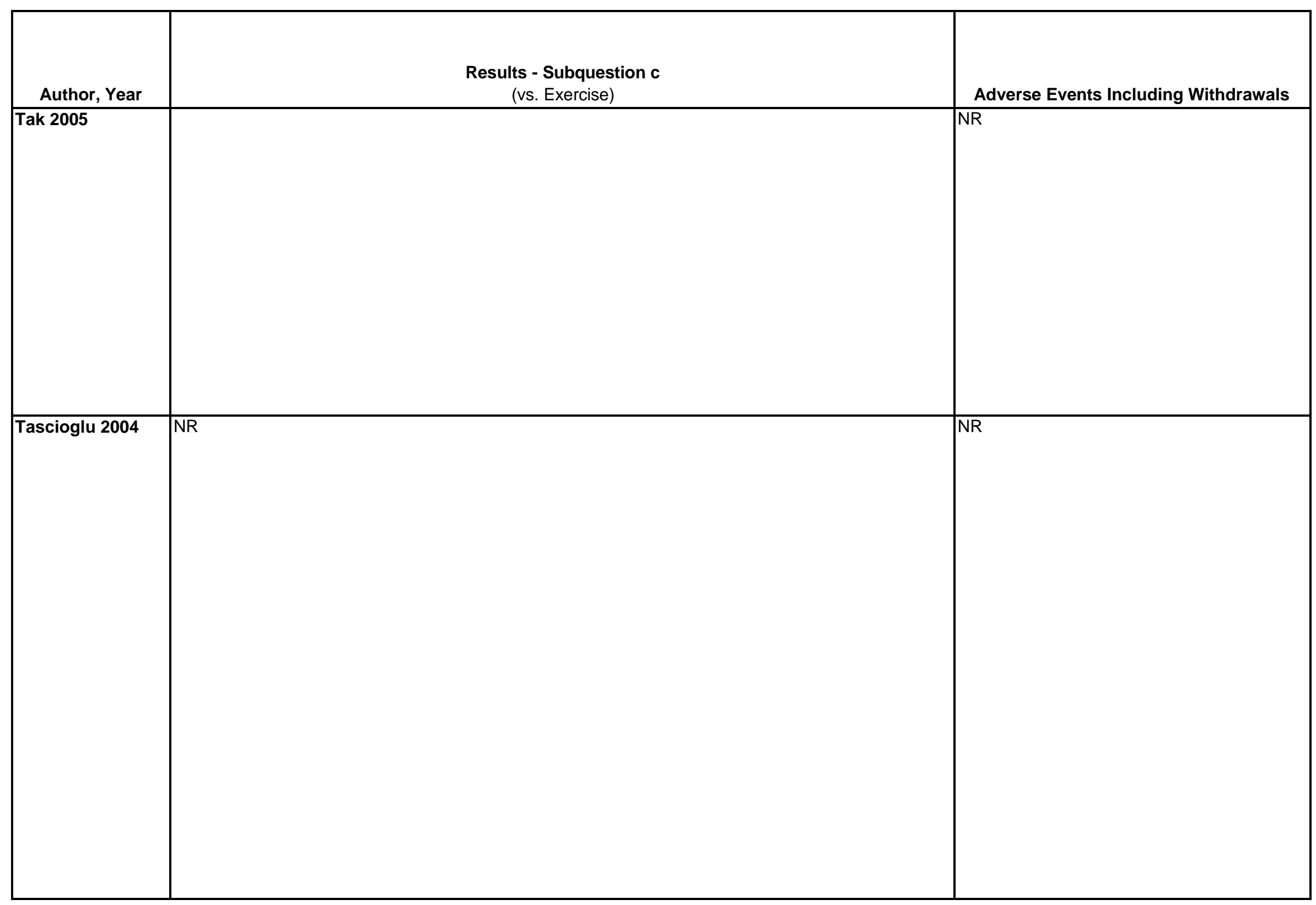




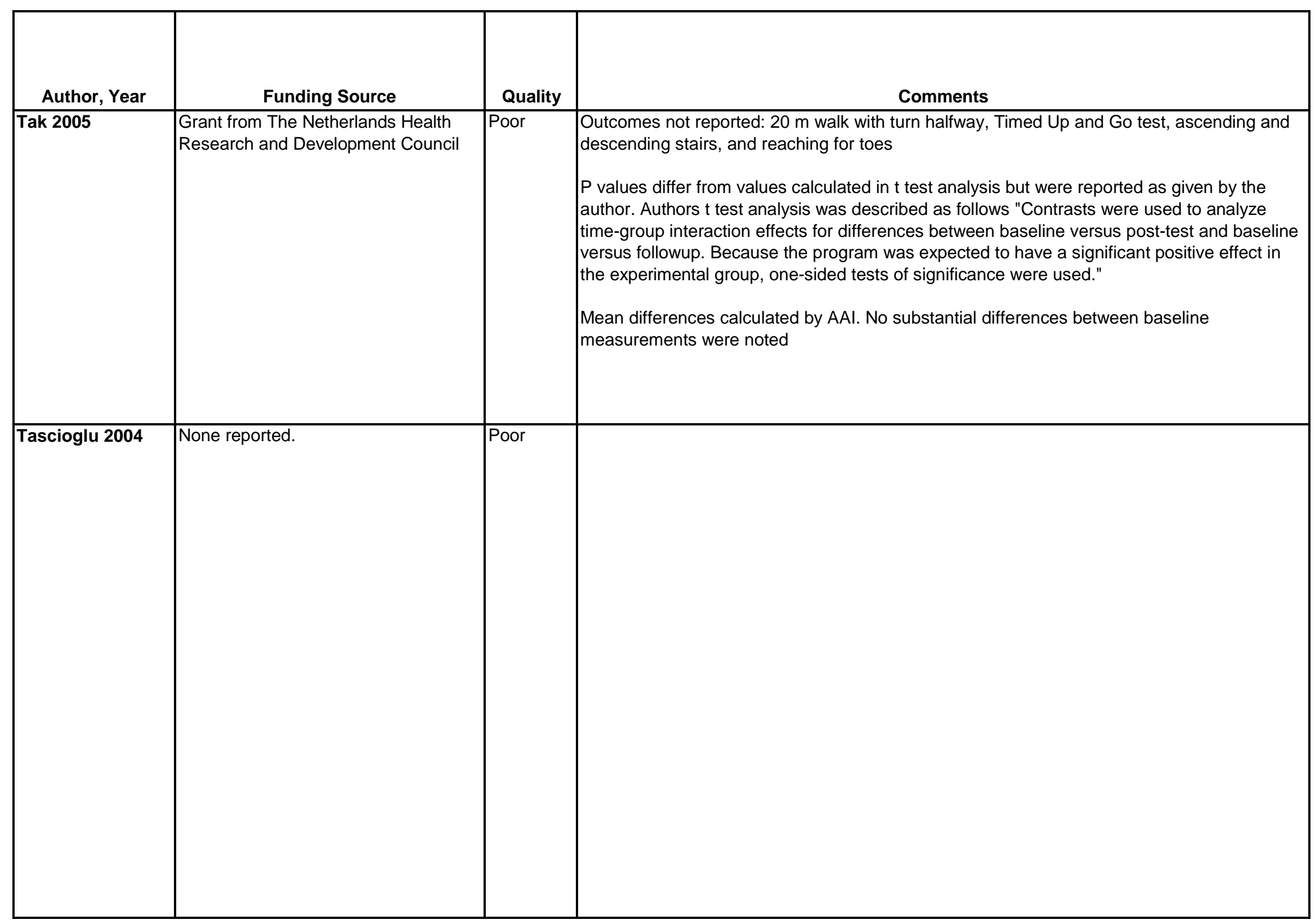




\begin{tabular}{|c|c|c|c|}
\hline Author, Year & $\begin{array}{c}\text { Country } \\
\text { Number of Centers } \\
\text { Setting }\end{array}$ & Inclusion/Exclusion Criteria & $\begin{array}{c}\text { Number Randomized, } \\
\text { Analyzed } \\
\text { Attrition }\end{array}$ \\
\hline Tavafian 2008 & \begin{tabular}{|l} 
Iran, single site, \\
research center
\end{tabular} & $\begin{array}{l}\text { Inclusion Criteria: } \\
\text { Age } 18 \text { years and over, chronic LBP (persisting for } 90 \text { days or more). } \\
\text { Exclusion Criteria: } \\
\text { Back surgery within } 2 \text { years, having complaint restricted to sacroiliac } \\
\text { joint, cervical or thoracic regions and congenital spine diseases. }\end{array}$ & $\begin{array}{l}\text { Randomized: } 102 \\
\text { Treated: } 102 \\
\text { Analyzed: } 74 \\
\text { Attrition: } 27.5 \% \text { (28/102) }\end{array}$ \\
\hline Tavola 1992 & $\begin{array}{l}\text { Italy, single site, } \\
\text { outpatient headache } \\
\text { center }\end{array}$ & $\begin{array}{l}\text { Inclusion criteria: } \\
\text { Diagnosis of muscle-tensive and tension-type headache, frequency of } \\
\text { headache episodes greater than once a week having a mean intensity } \\
\text { not less than 'moderate,' abstaining from other therapies previously } \\
\text { undertaken (except for non-narcotic analgesics). } \\
\text { Exclusion Criteria: organic pathology }\end{array}$ & $\begin{array}{l}\text { Randomized: } 30 \\
\text { Treated: } 30 \\
\text { Analyzed: } 30 \\
\text { Attrition: } 0 \%\end{array}$ \\
\hline
\end{tabular}




\begin{tabular}{|c|c|}
\hline Author, Year & Intervention, Comparator \\
\hline Tavafian 2008 & $\begin{array}{l}\text { A: Multidisciplinary program + medications ( } n=37) \text { : The back school program was a multidimensional and interdisciplinary educational regime } \\
\text { designed based on patients' characteristics, lifestyle and subsequent ability to cope; led by a rheumatologist. Included education in anatomy, } \\
\text { physiology, pathology of low back pain, self-care, health behaviors, biomechanics, lifestyle factors, and prevention. Additionally they were } \\
\text { accompanied by psychologist in coping skills, anger management, relaxation, and by a physiotherapist in stretching, strengthening, posture, and } \\
\text { functional movement advice (HEP). } 5 \text { sessions over } 4 \text { days, duration of sessions not reported; patient also received medications as described } \\
\text { below } \\
\text { B: Oral medication only }(n=37) \text { : Acetaminophen, NSAID and chlordiazepoxide, given under the supervision of the rheumatologist }\end{array}$ \\
\hline Tavola 1992 & $\begin{array}{l}\text { A: Acupuncture }(\mathrm{n}=15) \\
\text { No. of treatments: } 1 \text { treatment per week for } 8 \text { weeks } \\
\text { Type of needle: stainless steel, } 0.3 \mathrm{~mm} \text { diameter } \\
\text { Acupoints: placements made according to traditional Chinese medicine criteria on an individual basis } \\
\text { No. of needles: } 6-10 \\
\text { No. of insertions per needle: NR } \\
\text { Insertion depth: } 10-20 \mathrm{~mm} \\
\text { Time length of treatment: } 20 \text { minutes } \\
\\
\text { B: Sham ( } \mathrm{n}=15) \\
\text { No. of treatments: } 1 \text { treatment per week for } 8 \text { weeks } \\
\text { No. of needles: } 6-10 \\
\text { Acupoints: same regions, but not in specific acupoints } \\
\text { Insertion depth: } 2-4 \mathrm{~mm} \\
\text { Time length of treatment: } 20 \text { minutes }\end{array}$ \\
\hline
\end{tabular}




\begin{tabular}{|c|c|c|c|}
\hline Author, Year & Study Participants & Outcome Measures & $\begin{array}{l}\text { Duration of } \\
\text { Followup }\end{array}$ \\
\hline Tavafian 2008 & $\begin{array}{l}\text { A vs B } \\
\text { Age, year: } 43 \text { vs. } 45 \\
\text { Female, } \%: 100 \text { vs. } 100 \\
\text { Race: NR } \\
\text { Duration of symptoms (months): } 8.90 \text { vs. } 9.24 \\
\text { SF-36 Physical component summary (0-100): } 41.18 \text { (17.07) vs. } 42.29 \\
\text { (21.63) } \\
\text { SF-36 Mental component summary (0-100): } 47.52(28.77) \text { vs. } 47.68 \\
\text { (23.38) }\end{array}$ & $\begin{array}{l}\text { Secondary } \\
\text { SF-36 Physical component summary }(0-100) \\
\text { SF-36 Mental component summary }(0-100)\end{array}$ & $\begin{array}{l}3,6, \text { and } 12 \\
\text { months }\end{array}$ \\
\hline Tavola 1992 & $\begin{array}{l}\text { A vs. B } \\
\text { Age: } 33 \text { vs. } 33 \text { years } \\
\text { Female: } 87 \% \text { vs. } 87 \% \\
\text { Disease duration: } 8 \text { vs. } 8 \text { years } \\
\text { Mean frequency of headache attacks per month: } 18 \text { vs. } 17 \\
\text { Prior preventative treatments: NR } \\
\text { Medication overuse: NR } \\
\text { Mean analgesic use: } 12 \text { vs. } 12 \text { units/month } \\
\\
\text { Mean headache index (HI): } 4.3(3.9) \text { vs. } 4.5(3.4) \\
\text { Mean duration of attacks: } 3.3(1.5) \text { vs. } 4.4(3.2)\end{array}$ & $\begin{array}{l}\text { Responders, } 33 \% \text { and } 50 \% \text { thresholds (proportion of } \\
\text { patients with } \geq 33 \% \text { or } \geq 50 \% \text { improvement over baseline } \\
\text { on Headache Index Headache index (intensity X } \\
\text { duration } X \text { frequency/30) } \\
\text { Pain intensity (sum of the intensity of the attacks in a } \\
\text { month/number of attacks) } \\
\text { Duration of headache attacks (sum of the hours of } \\
\text { headache in a month/number of attacks) } \\
\text { Analgesic consumption (sum of the drugs taken per } \\
\text { month) }\end{array}$ & $\begin{array}{l}1,6 \text { and } 12 \\
\text { months }\end{array}$ \\
\hline
\end{tabular}




\begin{tabular}{|c|c|}
\hline Author, Year & $\begin{array}{c}\text { Results - Subquestion a } \\
\text { (vs. sham, no treatment, waitlist, attention control) }\end{array}$ \\
\hline Tavafian 2008 & 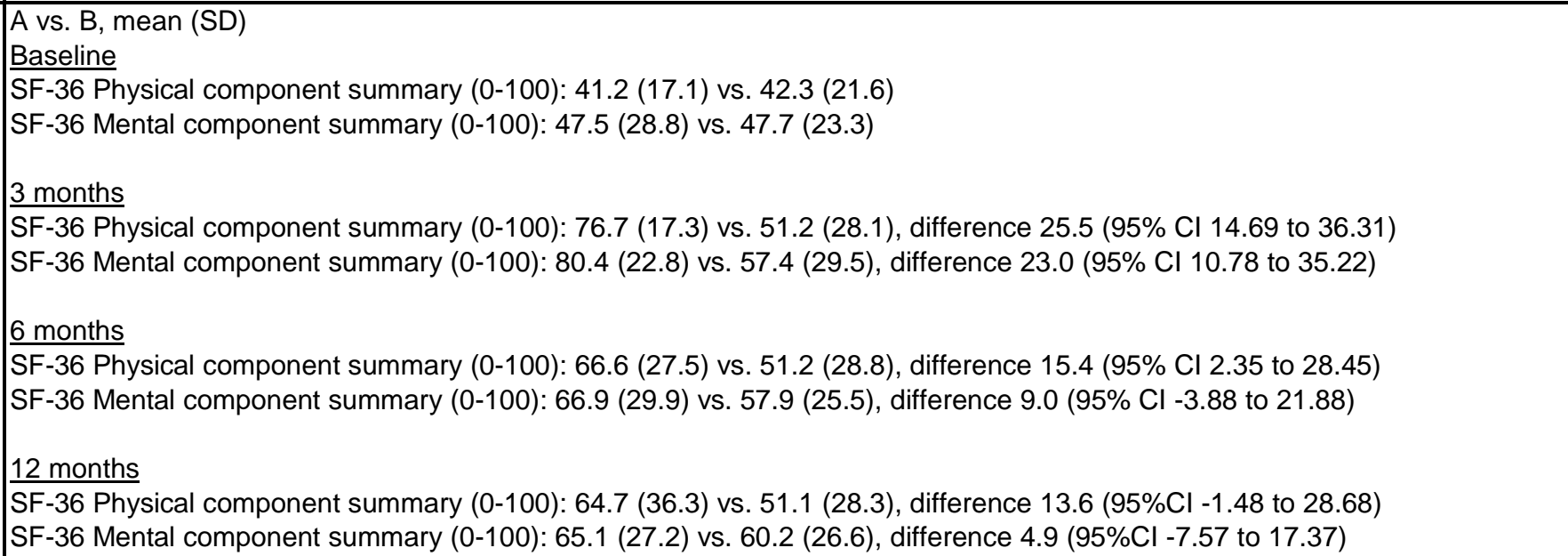 \\
\hline Tavola 1992 & 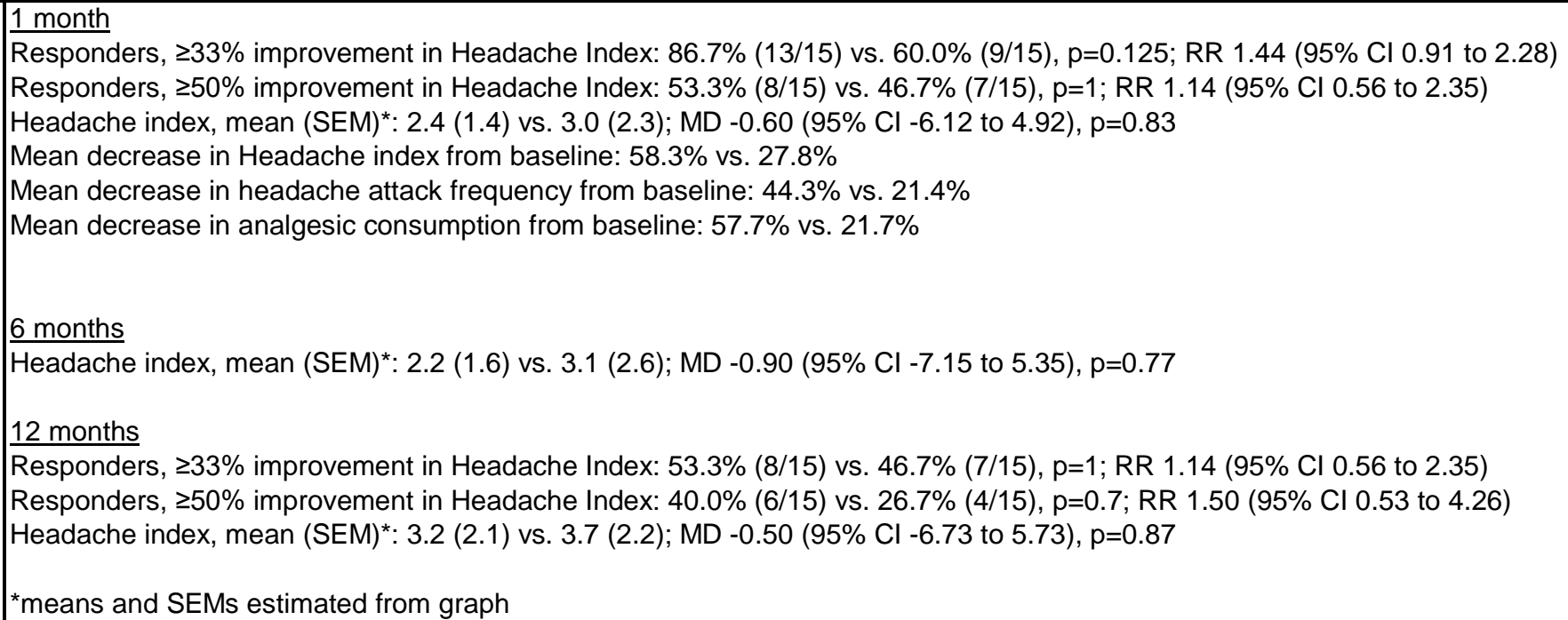 \\
\hline
\end{tabular}




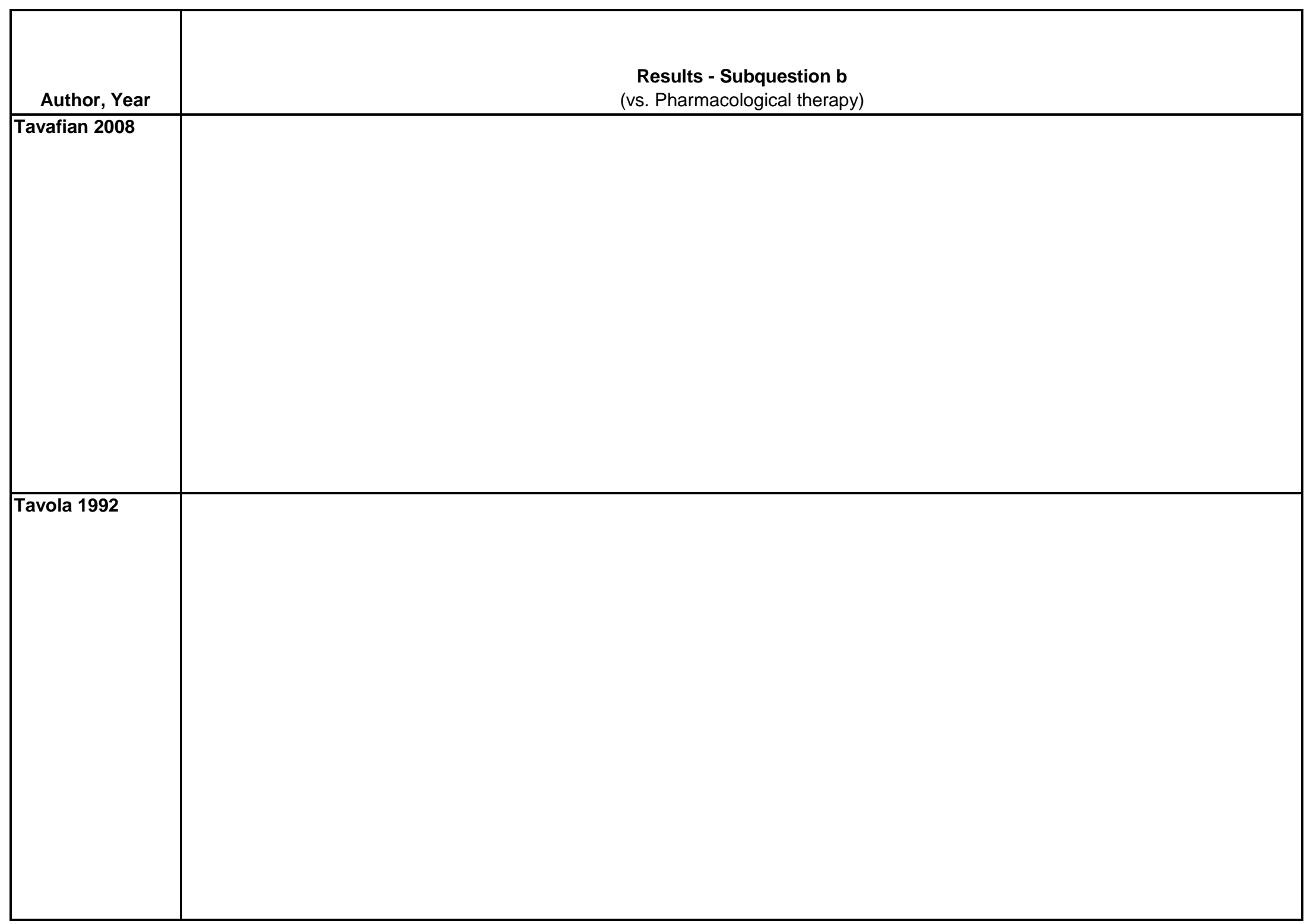

D-746 


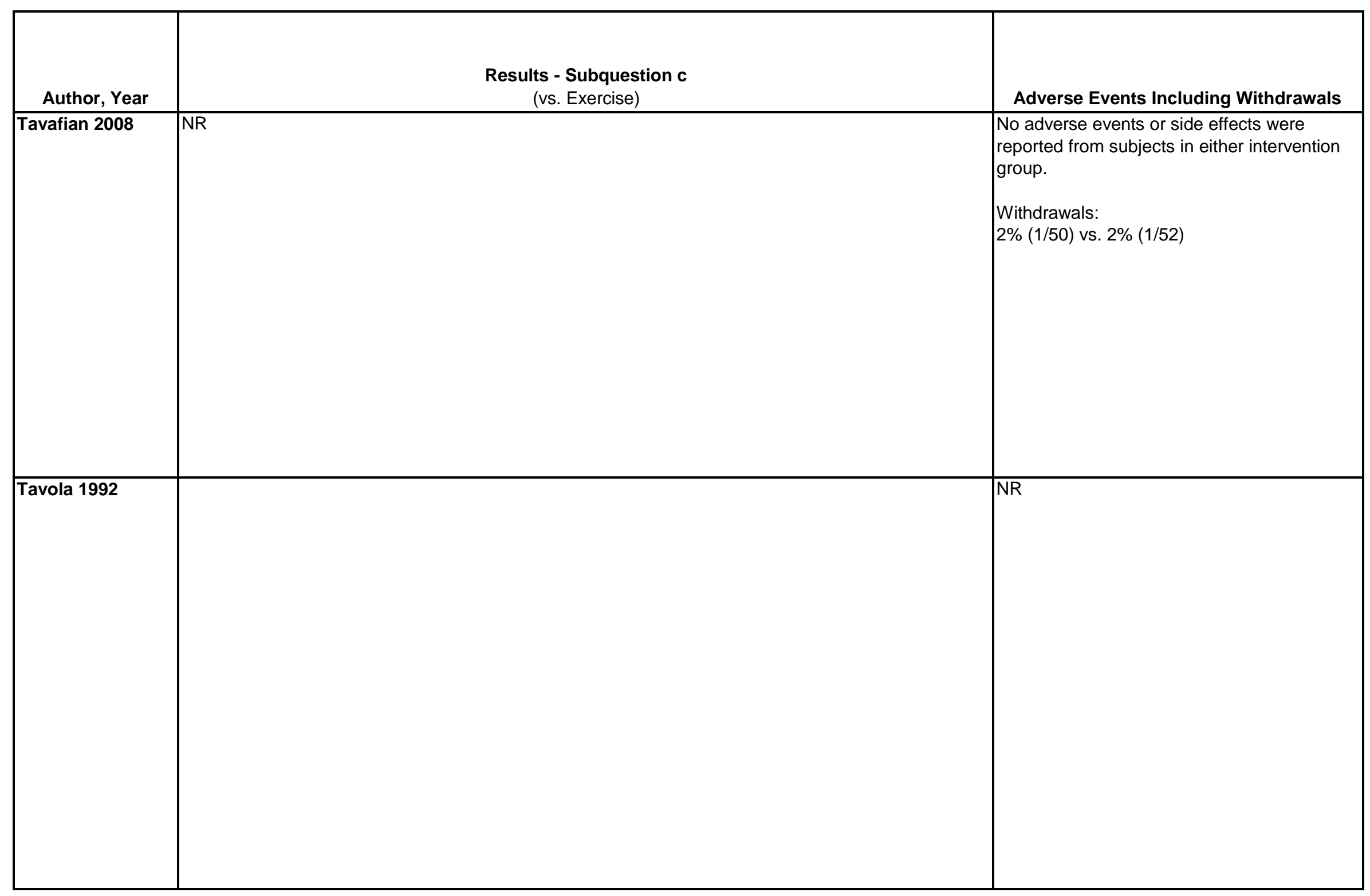




\begin{tabular}{|c|c|c|c|}
\hline Author, Year & Funding Source & Quality & Comments \\
\hline Tavafian 2008 & 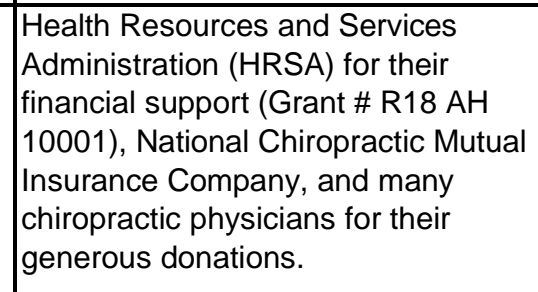 & oor & $\begin{array}{l}\text { The study reported all baseline and outcome values as mean (standard error). MD was } \\
\text { obtained with a SD calculated with the following equation [SD = SEM*Sart(n) ]. } \\
\text { Differences calculated by Spectrum, but studies appear to report SD not SE }\end{array}$ \\
\hline Tavola 1992 & NR & oor & \\
\hline & & & \\
\hline & & & \\
\hline & & & \\
\hline & & & \\
\hline & & & \\
\hline
\end{tabular}




\begin{tabular}{|c|c|c|c|}
\hline Author, Year & $\begin{array}{c}\text { Country } \\
\text { Number of Centers } \\
\text { Setting }\end{array}$ & Inclusion/Exclusion Criteria & $\begin{array}{c}\text { Number Randomized, } \\
\text { Analyzed } \\
\text { Attrition }\end{array}$ \\
\hline Teirlinck 2016 & $\begin{array}{l}\text { The Netherlands } \\
\text { General practitioners } \\
\text { Number of centers } \\
\text { unclear }\end{array}$ & $\begin{array}{l}45 \text { years or older, non-traumatic hip pain fulfilling ACR clinical criteria } \\
\text { for hip OA diagnosis } \\
\text { Exclude: Exercise therapy in the past } 3 \text { months, hip pain score }<3 \text { on } \\
\text { 11-point NRS, score of }<2 \text { on Algofunctional Index, hip surgery or on } \\
\text { waiting list, disabling co-morbidity, mentally incapable of participation }\end{array}$ & $\begin{array}{l}\text { Randomized: } 203 \\
\text { Treated: } 203 \\
\text { Analyzed: } 189 \\
\text { Attrition: } 7 \%(14 / 203)\end{array}$ \\
\hline Thamsborg 2005 & $\begin{array}{l}\text { Denmark, single-site, } \\
\text { outpatient }\end{array}$ & $\begin{array}{l}\text { Inclusion Criteria: } \\
\text { Patients older than } 45 \text { years with painful knee osteoarthritis of the } \\
\text { femorotibial compartment (fulfilling criteria of the American College of } \\
\text { Rheumatology) } \\
\text { Exclusion Criteria: } \\
\text { Inflammatory joint disease, acromegaly, Charcot's arthropathy, } \\
\text { haemochromatosis, Wilson's disease, ochronosis, terminal } \\
\text { illnesses/malignancies, pregnancy or lack of contraception use in } \\
\text { women of childbearing age, and use of pacemaker or any implanted } \\
\text { electrical device. Additionally, participants were excluded if they were } \\
\text { unable to understand/fill out the questionnaires, had received intra- } \\
\text { articular glucocorticoid or hyaluronic acid injection } 1 \text { month prior to } \\
\text { study entry, or had hip and/or lumbar spine OA with referred pain to } \\
\text { the study knee. }\end{array}$ & $\begin{array}{l}\text { Randomized: } 90 \\
\text { Treated: } 83 \\
\text { Analyzed: } 83 \\
\text { Attrition: } 7.7 \%(7 / 90)\end{array}$ \\
\hline
\end{tabular}




\begin{tabular}{|c|c|}
\hline Author, Year & Intervention, Comparator \\
\hline Teirlinck 2016 & $\begin{array}{l}\text { A.Exercise+usual care }(n=101) \text { : Maximum of } 12 \text { sessions over } 3 \text { months with each session } 30 \text { minutes long. Sessions consisted of information on } \\
\text { lifestyle adaptations, possible walking aids, appropriate postural loading of joints, and (in)appropriate pain behavior. Exercises performed during the } \\
\text { session focused on strengthening, increasing flexibility, and improving endurance. Three booster sessions occurred at } 2,4 \text {, and } 6 \text { months after the } \\
\text { initial } 3 \text { month treatment period. } \\
\text { B. Usual care }(n=102) \text { : Routine care provided by GP, which could include education, counselling, prescription of pain medication, additional } \\
\text { diagnostic tests, or referral to an orthopedic surgeon. Referral to a physical therapist was discouraged but not restricted } \\
\text { All patients: Received brochure with information about hip OA }\end{array}$ \\
\hline Thamsborg 2005 & $\begin{array}{l}\text { A.Pulsed Electromagnetic Fields (PEMF) }(\mathrm{n}=42) \\
\text { Two sets of two adjacent coils were placed on the medial and lateral regions of the study knee, with the interspace between the coils being at the } \\
\text { level of the koin line. The coils were placed on an insulating bandage of } 3-5 \mathrm{~mm} \text { thickness that could } \\
\text { No. of Treatments: daily treatment } 5 \text { days per week for } 6 \text { weeks ( } 30 \text { total } \\
\text { Length of Treatments: } 2 \text { hours each } \\
\text { Device: } \pm 50 \mathrm{~V} \text { in } 50 \mathrm{~Hz} \text { pulses changing voltage in } 3 \text { ms intervals. } \\
\text { B.Sham Electromagnetic Field ( } \mathrm{n}=41) \\
\text { Patients in the control group were subjected to a noneffective placebo electromagnetic field. } \\
\text { No. of Treatments: daily treatment } 5 \text { days per week for } 6 \text { weeks ( } 30 \text { total } \\
\text { Length of Treatments: } 2 \text { hours each }\end{array}$ \\
\hline
\end{tabular}




\begin{tabular}{|c|c|c|c|}
\hline Author, Year & Study Participants & Outcome Measures & $\begin{array}{l}\text { Duration of } \\
\text { Followup }\end{array}$ \\
\hline Teirlinck 2016 & $\begin{array}{l}\text { A vs B } \\
\text { Age: } 64 \text { vs } 67 \\
\text { Females: } 62 \% \text { vs } 55 \% \\
\text { High blood pressure: } 37 \% \text { vs } 44 \% \\
\text { Heart disease: } 17 \% \text { vs } 16 \% \\
\text { Lung disease: } 8 \% \text { vs } 9 \% \\
\text { Diabetes: } 10 \% \text { vs } 16 \% \\
\text { Knee OA: } 29 \% \text { vs } 31 \% \\
\text { Hand OA: } 29 \% \text { vs } 31 \% \\
\text { Rheumatoid arthritis: } 1 \% \text { vs } 5 \% \\
\text { Duration of symptoms, median (IQR): } 365 \text { (810) vs } 365(819) \\
\text { Pain medication used daily in past } 3 \text { months: } 21 \% \text { vs } 31 \% \\
\text { HOOS function: } 35.4(18.0) \text { vs } 32.2(17.5) \\
\text { HOOS pain: } 37.6(16.1) \text { vs } 38.9(15.7) \\
\text { ICOAP constant pain: } 5.4(3.5) \text { vs } 5.8(3.8) \\
\text { ICOAP intermittent pain: } 8.0(3.9) \text { vs } 8.4(4.3) \\
\text { ICOAP total pain: } 30.4(15.8) \text { vs } 32.2(7.5) \\
\text { EuroQol } 5 D-3 L: 0.79(0.12) \text { vs } 0.75(0.16)\end{array}$ & $\begin{array}{l}\text { HOOS function (0 to } 100 \text {, higher score=higher function); } \\
\text { HOOS pain (0 to } 100 \text {, higher score=lower pain); ICOAP } \\
\text { constant pain (0-20, higher score=higher pain); ICOAP } \\
\text { intermittent pain (higher score=higher pain); ICOAP } \\
\text { total pain (0-100, higher score=higher pain); EuroQol } \\
\text { 5D-3L (-0.329-1.0, higher score=higher quality of life) }\end{array}$ & $\begin{array}{l}3,6, \text { and } 9 \\
\text { months }\end{array}$ \\
\hline Thamsborg 2005 & $\begin{array}{l}\text { A vs B } \\
\text { Age: } 60 \text { vs. } 60 \\
\text { Female: } 47.6 \% \text { vs. } 61 \% \\
\text { Race: NR } \\
\text { Mean Duration of Chronicity (years): } 7.5(5.2) \text { vs. } 7.9(7.7) \\
\text { Analgesics Medication use: } 55 \%(23 / 42) \text { vs. } 61 \%(25 / 41) \\
\\
\text { Activities of Daily Living (WOMAC): } 43.83(1.93) \text { vs. } 46.49(2.21) \\
\text { Stiffness (WOMAC): } 5.74(0.29) \text { vs. } 5.85(0.28) \\
\text { Pain (WOMAC): } 13.15(0.57) \text { vs. } 14.49(0.54)\end{array}$ & $\begin{array}{l}\text { Primary } \\
\text { Western Ontario and McMaster Osteoarthritis Index } \\
\text { (WOMAC, higher scores indicate severity of pain, } \\
\text { stiffness and dysfunction) } \\
\text { Activities of Daily Living (WOMAC, range 0-85) } \\
\text { Joint Pain (WOMAC, range 0-25) } \\
\text { Stiffness (WOMAC, range 0-10) }\end{array}$ & 1.5 months \\
\hline
\end{tabular}




\begin{tabular}{|c|c|}
\hline Author, Year & $\begin{array}{c}\text { Results - Subquestion a } \\
\text { (vs. sham, no treatment, waitlist, attention control) }\end{array}$ \\
\hline Teirlinck 2016 & 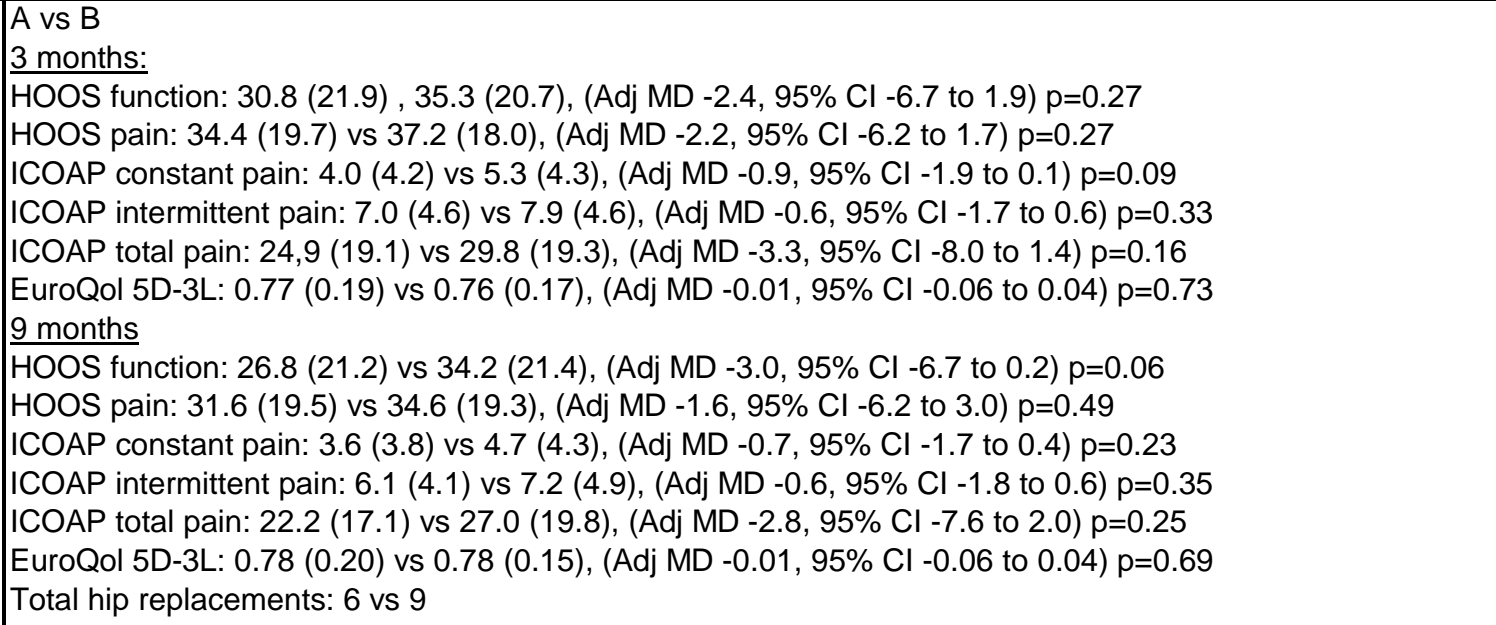 \\
\hline Thamsborg 2005 & $\begin{array}{l}\text { A vs. B } \\
1.5 \text { months } \\
\text { Activities of Daily Living (WOMAC): } 37.89(2.14) \text { vs. } 41.37(2.27) ; \mathrm{MD}-3.48(95 \% \mathrm{Cl}-4.44 \text { to }-2.51) \mathrm{p}=0.0001 \\
\text { Stiffness (WOMAC): } 4.81(0.32) \text { vs. } 5.15(0.30) ; \mathrm{MD}-0.34(95 \% \mathrm{Cl}-0.48 \text { to }-0.20) \mathrm{p}=0.0001 \\
\text { Joint Pain (WOMAC): } 11.40(0.57) \text { vs. } 12.24(0.63) ; \mathrm{MD}-0.84(95 \% \mathrm{Cl}-1.10 \text { to }-0.58) \mathrm{p}=0.0001\end{array}$ \\
\hline
\end{tabular}




\begin{tabular}{|l|l|}
\hline Author, Year & \multicolumn{1}{|c|}{$\begin{array}{c}\text { Results - Subquestion b } \\
\text { (vs. Pharmacological therapy) }\end{array}$} \\
\hline Teirlinck 2016 & \\
\hline Thamsborg 2005 & NR \\
& \\
& \\
\hline
\end{tabular}




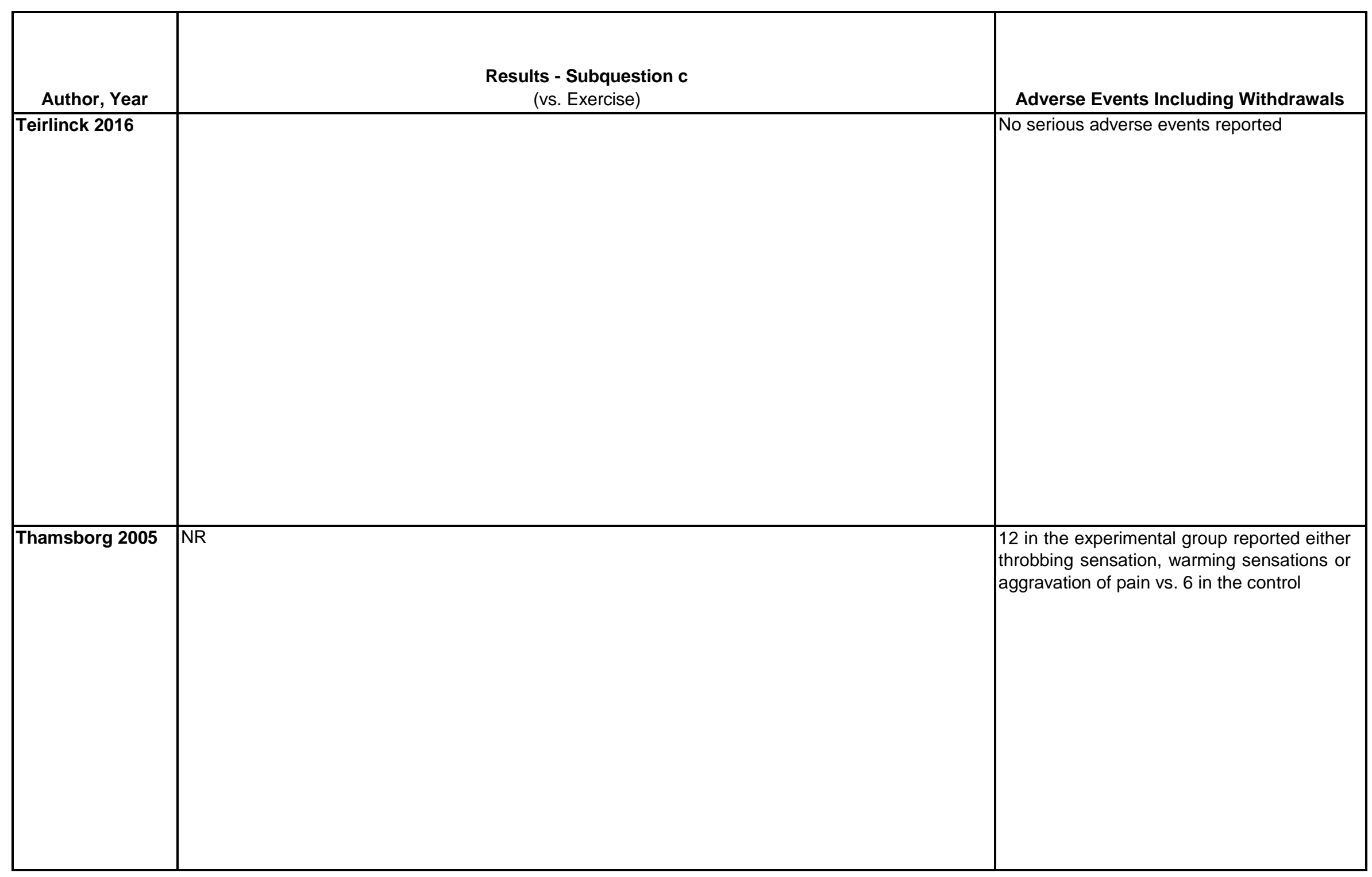




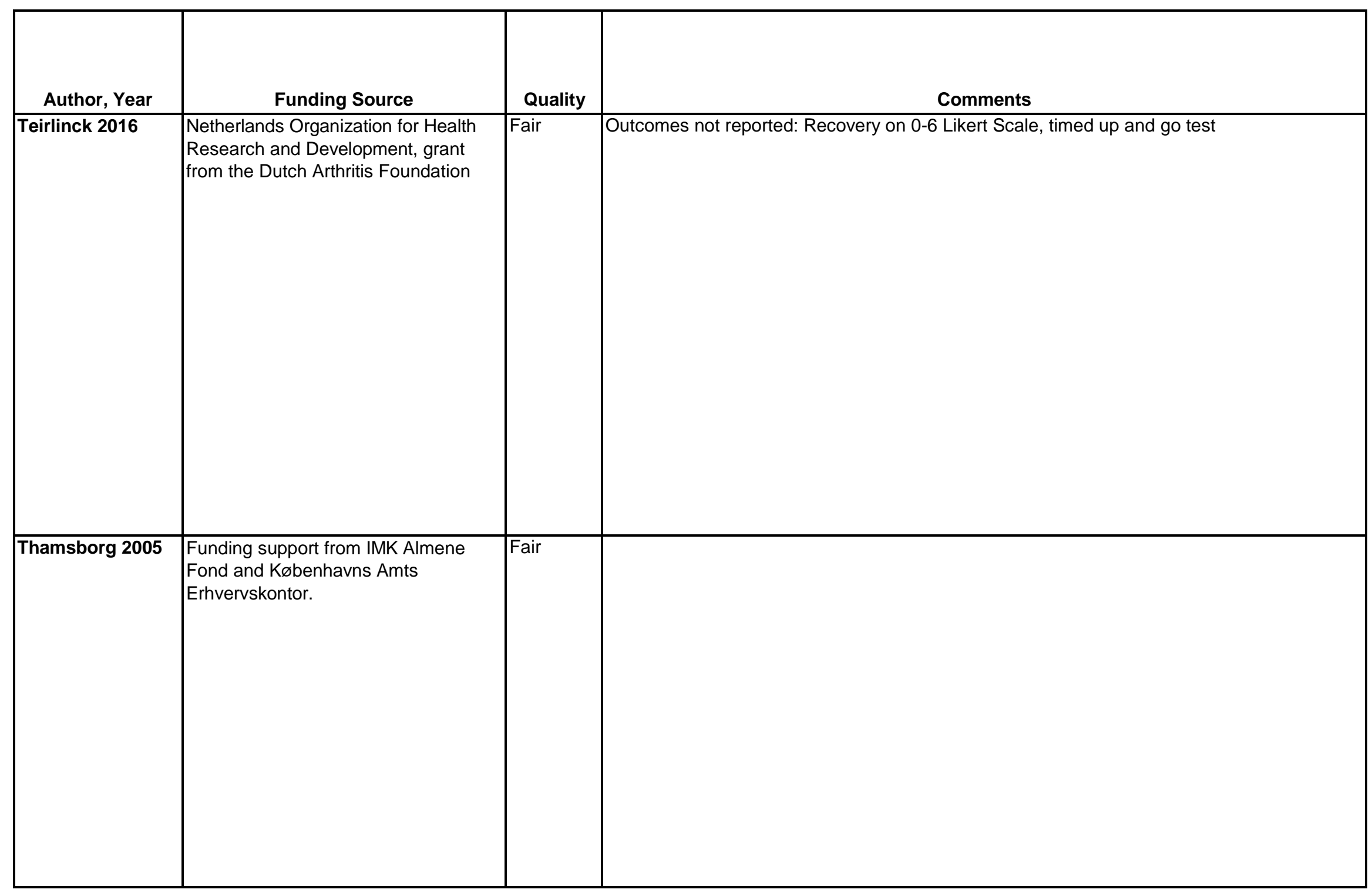




\begin{tabular}{|c|c|c|c|}
\hline Author, Year & $\begin{array}{c}\text { Country } \\
\text { Number of Centers } \\
\text { Setting }\end{array}$ & Inclusion/Exclusion Criteria & $\begin{array}{c}\text { Number Randomized, } \\
\text { Analyzed } \\
\text { Attrition }\end{array}$ \\
\hline Thieme 2006 & $\begin{array}{l}\text { Unclear } \\
10 \text { centers } \\
\text { Outpatient }\end{array}$ & $\begin{array}{l}\text { Married females with a diagnosis of FM fulfilling ACR criteria. Pain for } \\
\text { at least } 6 \text { months and spouses willing to participate. } \\
\text { Exclude: Inflammatory rheumatologic diseases, concurrent major } \\
\text { disease }\end{array}$ & $\begin{array}{l}\text { Randomized: } 125 \\
\text { Treated: } 125 \\
\text { Analyzed: } 125 \\
\text { Attrition: } 20 \%(25 / 125)\end{array}$ \\
\hline
\end{tabular}




\begin{tabular}{|c|c|}
\hline Author, Year & Intervention, Comparator \\
\hline Thieme 2006 & 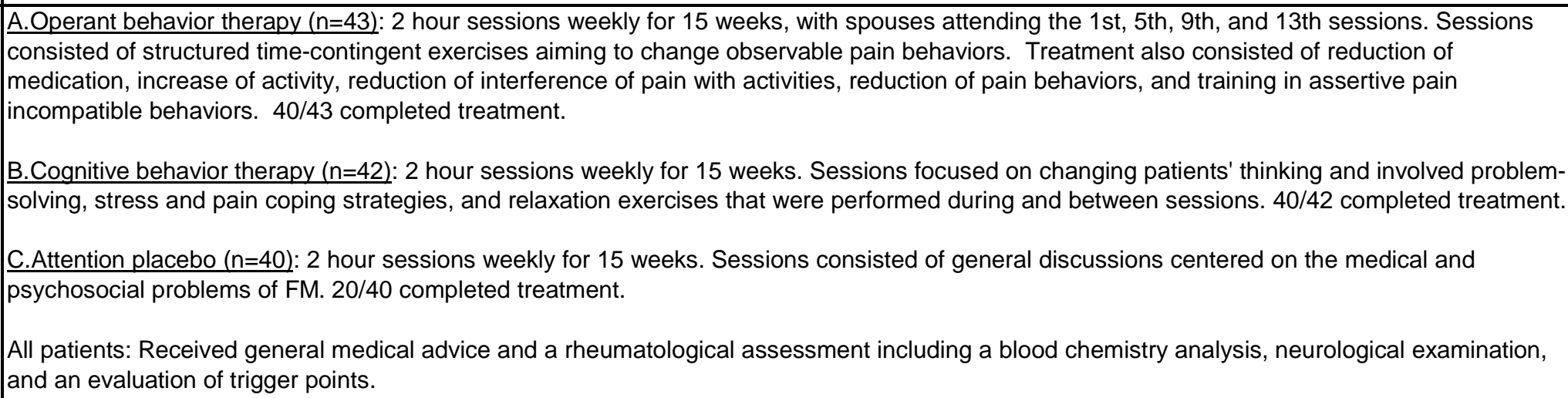 \\
\hline
\end{tabular}




\begin{tabular}{|c|c|c|c|}
\hline Author, Year & Study Participants & Outcome Measures & $\begin{array}{c}\text { Duration of } \\
\text { Followup }\end{array}$ \\
\hline Thieme 2006 & $\begin{array}{l}\text { A vs B vs C } \\
\text { Age: } 43 \text { vs } 49 \text { vs } 47 \\
\text { Female: } 100 \% \text { vs } 100 \% \text { vs } 100 \% \\
\text { Duration of symptoms, years: } 9.0 \text { vs } 9.1 \text { vs } 8.7 \\
\text { Number of physician visits: } 36.9(15.2) \text { vs } 30.6(16.2) \text { vs } 34.3(16.3) \\
\text { Occupational status: } \\
\quad \text { Working: } 40 \% \text { vs } 45 \% \text { vs } 50 \% \\
\quad \text { Unemployed: } 37 \% \text { vs } 38 \% \text { vs } 30 \% \\
\quad \text { Worker's compensation: } 7 \% \text { vs } 5 \% \text { vs } 8 \% \\
\quad \text { Retired: } 16 \% \text { vs } 10 \% \text { vs } 8 \% \\
\quad \text { Student: } 0 \% \text { vs } 2 \% \text { vs } 5 \% \\
\text { FIQ physical impairment: } 4.8(2.2) \text { vs } 4.4(2.1) \text { vs } 4.2(2.1) \\
\text { WHYMPI pain intensity:4.2 (1.0) vs } 4.2(0.8) \text { vs } 3.8(1.0) \\
\text { WHYMPI affective distress: } 3.2(1.4) \text { vs } 3.2(1.0) \text { vs } 3.5(1.3) \\
\text { WHYMPI solicitous spouse behavior: } 4.0(0.8) \text { vs } 3.3(1.6) \text { vs } 3.2(1.3) \\
\text { PRSS pain coping: } 3.0(1.0) \text { vs } 3.3(0.6) \text { vs } 2.9(0.7) \\
\text { PRSS pain catastrophizing: } 2.5(1.2) \text { vs } 2.3(0.9) \text { vs } 2.4(1.0)\end{array}$ & $\begin{array}{l}\text { FIQ physical impairment (0-10, higher score=higher } \\
\text { disability); pain intensity VAS (0-10, higher score=higher } \\
\text { pain) WHYMPI pain intensity (0-6, higher score=higher } \\
\text { pain); WHYMPI affective distress (0-6, higher } \\
\text { score=higher distress); WHYMPI solicitous spouse } \\
\text { behavior (0-6, higher score=lower spouse response); } \\
\text { PRSS pain coping (0-5, higher score=higher coping } \\
\text { ability); PRSS pain catastrophizing (0-5, higher } \\
\text { score=higher catastrophizing) }\end{array}$ & $\begin{array}{l}6 \text { and } 12 \\
\text { months }\end{array}$ \\
\hline
\end{tabular}




\begin{tabular}{|c|c|}
\hline Author, Year & $\begin{array}{c}\text { Results - Subquestion a } \\
\text { (vs. sham, no treatment, waitlist, attention control) }\end{array}$ \\
\hline Thieme 2006 & 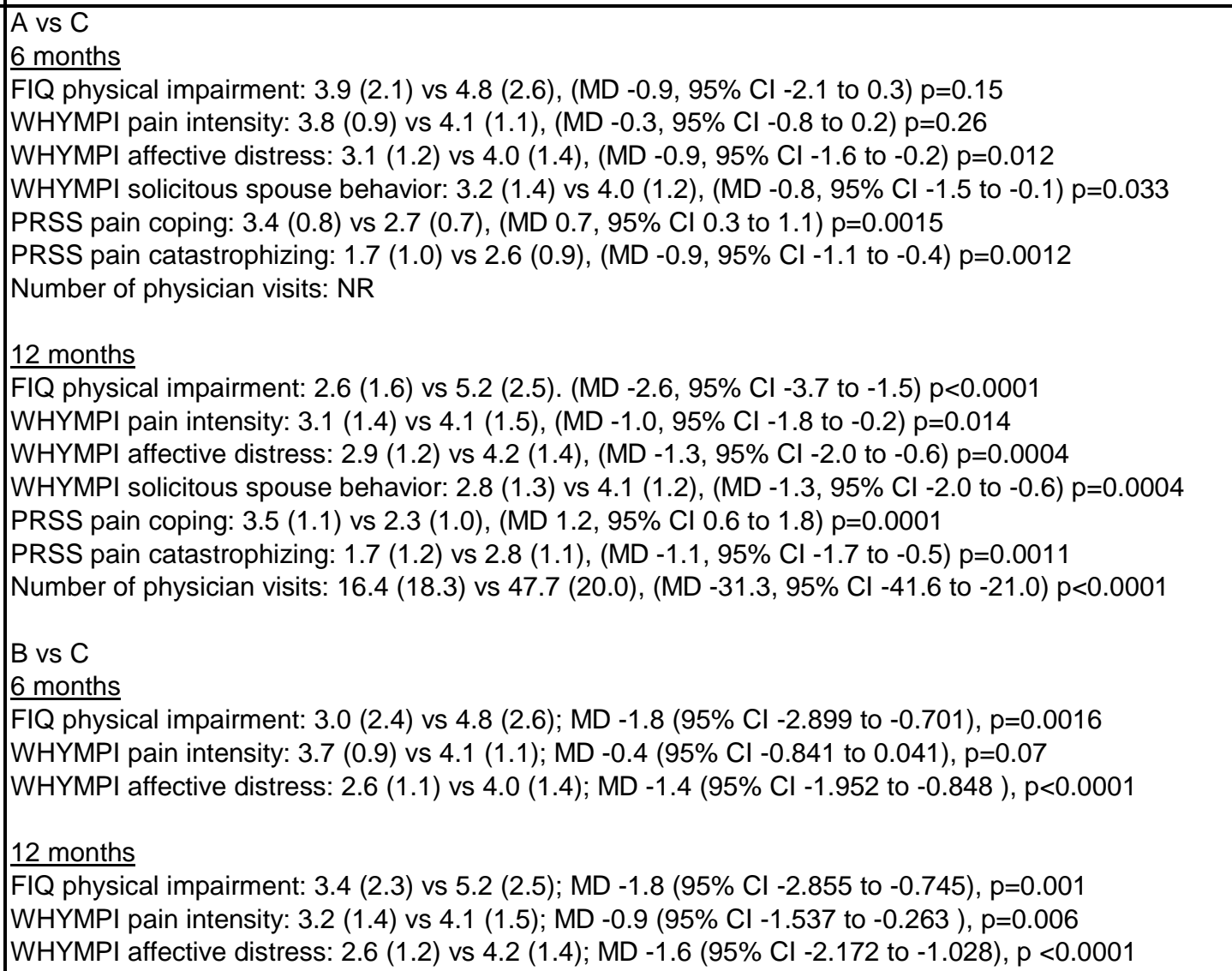 \\
\hline
\end{tabular}




$$
[-
$$




\begin{tabular}{|c|c|c|}
\hline Author, Year & $\begin{array}{l}\text { Results - Subquestion c } \\
\text { (vs. Exercise) }\end{array}$ & Adverse Events Including Withdrawals \\
\hline Thieme 2006 & & $\begin{array}{l}\text { Withdrawals: } \\
\text { 3/43 in A due to depression/lack of } \\
\text { motivation } \\
2 / 42 \text { in B due to depression } \\
\text { 20/40 in C due to worsening of symptoms }\end{array}$ \\
\hline
\end{tabular}




\begin{tabular}{|c|c|c|c|}
\hline Author, Year & Funding Source & Quality & Comments \\
\hline Thieme 2006 & $\begin{array}{l}\text { Grants from the Deutsche } \\
\text { Forshungsgemeinschaft to KT (Th 899- } \\
1 / 2 \text { and } 899 \text { 2/2) and HF (FL 156/26, } \\
\text { Clinical Research Unit } 107 \text { 'Learning, } \\
\text { plasticity and pain'), the Max-Planck } \\
\text { Aware for International Cooperation to } \\
\text { HF, and the National Institutes of } \\
\text { Health/National Institute of Arthritis } \\
\text { and Musculoskeletal and Skin } \\
\text { Diseases to DCT (AR44724 and AR } \\
47298\end{array}$ & Poor & \\
\hline
\end{tabular}




\begin{tabular}{|c|c|c|c|}
\hline Author, Year & $\begin{array}{c}\text { Country } \\
\text { Number of Centers } \\
\text { Setting }\end{array}$ & Inclusion/Exclusion Criteria & $\begin{array}{c}\text { Number Randomized, } \\
\text { Analyzed } \\
\text { Attrition }\end{array}$ \\
\hline Thomas 2002 & $\begin{array}{l}\text { UK } \\
2 \text { centers } \\
\text { General practitioner }\end{array}$ & $\begin{array}{l}\text { Aged } 45 \text { or over with knee pain on most days in the previous month } \\
\text { Exclude: Total knee replacement, lower limb amputation, permanent } \\
\text { cardiac pacemaker, no knee pain within the past week }\end{array}$ & $\begin{array}{l}\text { Randomized: } 786 \\
\text { Treated: NR } \\
\text { Analyzed: } 600 \\
\text { Attrition: } 24 \%(186 / 786)\end{array}$ \\
\hline Thomas 2006 & \begin{tabular}{|l|} 
UK \\
Number of centers: 21 \\
Setting: Outpatient \\
(private acupuncture \\
clinics and general \\
practices)
\end{tabular} & $\begin{array}{l}\text { Age 18-65 years } \\
\text { Non-specific LBP for } 4-52 \text { weeks } \\
\text { General practitioner assessment as suitable for primary care } \\
\text { management } \\
\text { Exclude } \\
\text { Current acupuncture treatment } \\
\text { Possible spinal disease (such as carcinoma) } \\
\text { Severe or progressive motor weakness } \\
\text { Prolapsed central disc } \\
\text { Past spinal surgery } \\
\text { Bleeding disorders (such as hemophilia) } \\
\text { Pending litigation }\end{array}$ & $\begin{array}{l}\text { Randomized: } 241 \\
\text { Analyzed: } \\
\text { - } 3 \text { months: } 217 \\
\text { - } 12 \text { months: } 215 \\
\text { - } 24 \text { months: } 182 \\
\text { Attrition: } 24 \%(59 / 241)\end{array}$ \\
\hline
\end{tabular}




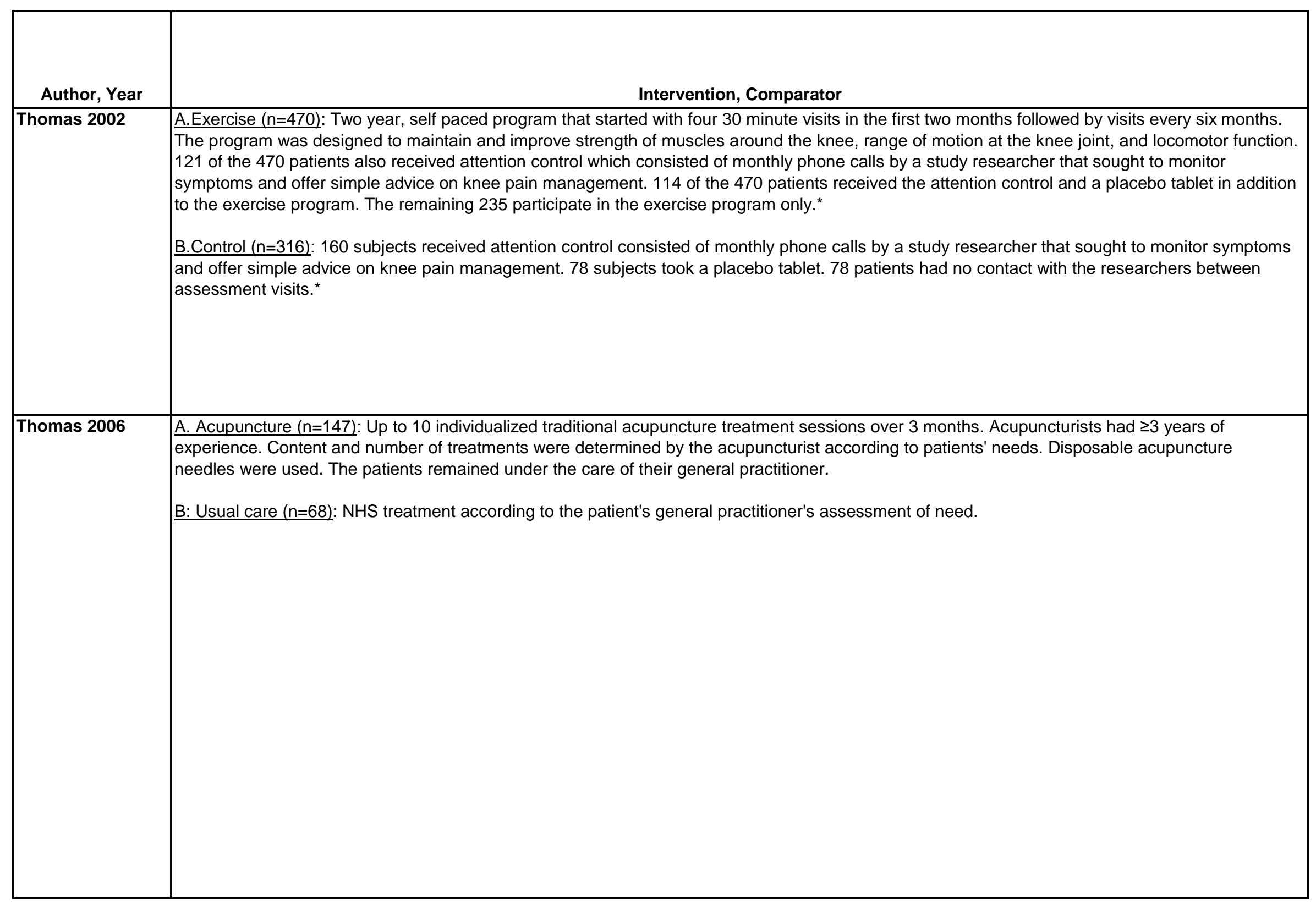




\begin{tabular}{|c|c|c|c|}
\hline Author, Year & Study Participants & Outcome Measures & $\begin{array}{c}\text { Duration of } \\
\text { Followup }\end{array}$ \\
\hline Thomas 2002 & $\begin{array}{l}\text { A vs } B \\
\text { Age: } 62 \text { vs } 62 \\
\text { Female: } 63 \% \text { vs } 66 \% \\
\text { WOMAC pain score: } 7.15 \text { vs } 7.35\end{array}$ & $\begin{array}{l}\text { WOMAC physical function (0-68, higher score=higher } \\
\text { disability); WOMAC pain (0-20, higher score=higher } \\
\text { pain); HADS depression (0-21, higher score=higher } \\
\text { depression); HADS anxiety (0-21, higher score=higher } \\
\text { anxiety); SF-36 (0-100, higher score=higher quality of } \\
\text { life) }\end{array}$ & $\begin{array}{l}\text { 6, 12, 18, } \\
\text { and 24 } \\
\text { months* }\end{array}$ \\
\hline Thomas 2006 & $\begin{array}{l}\text { A vs. B } \\
\text { Age: } 42 \text { vs. } 44 \\
\text { Female: } 62 \% \text { vs. } 58 \% \\
\text { Weeks with back pain: } 17.1 \text { vs. } 16.7 \\
\text { Baseline SF-36 physical functioning score: } 55.5 \text { vs. } 60.0 \\
\text { Baseline SF-36 bodily pain score: } 30.8 \text { vs. } 30.4 \\
\text { Baseline ODI: } 33.7 \text { vs. } 31.4 \\
\text { Baseline SF-MPQ present pain index: } 2.64 \text { vs. } 2.70 \\
\text { Number of previous episodes of LBP } \\
\text { - None: } 16 \% \text { vs. } 16 \% \\
\text { - 1-5: } 36 \% \text { vs. } 29 \% \\
\text { - >5: } 48 \% \text { vs. } 55 \% \\
\text { Presence of leg pain: } 67 \% \text { vs. } 59 \% \\
\text { Work status } \\
\text { - Full-time: } 52 \% \text { vs. } 56 \% \\
\text { - Part-time: } 25 \% \text { vs. } 28 \% \\
\text { - Housewife, retired, or student: } 14 \% \text { vs. } 15 \% \\
\text { - Permanently unable to work due to LBP: } 7 \% \text { vs. } 0 \% \\
\text { - Permanently unable to work due to other health reason: } 2 \% \text { vs. } 1 \% \\
\text { Drugs for LBP in past } 4 \text { weeks: } 88 \% \text { vs. } 90 \% \\
\text { Major health problems in addition to back pain: } 28 \% \text { vs. } 31 \% \\
\text { Ever used private acupuncture for any reason: } 13 \% \text { vs. } 9 \%\end{array}$ & $\begin{array}{l}\text { SF-36 bodily pain subscale }(0-100,100=\text { no pain) } \\
\text { Oswestry Disability Index (0-100, } 0=\text { no disability) } \\
\text { SF-McGill Pain Questionnaire Present Pain Index (0-5, } \\
0=\text { no pain) } \\
\text { Presence LBP or leg pain in the past } 12 \text { months } \\
\text { Medication use for LBP in the past } 4 \text { weeks }\end{array}$ & $\begin{array}{l}9 \text { months, } 21 \\
\text { months }\end{array}$ \\
\hline
\end{tabular}




\begin{tabular}{|c|c|}
\hline Author, Year & $\begin{array}{c}\text { Results - Subquestion a } \\
\text { (vs. sham, no treatment, waitlist, attention control) }\end{array}$ \\
\hline Thomas 2002 & $\begin{array}{l}\text { A (exercise) vs B (no exercise) } \\
6 \text { months } \\
\text { WOMAC physical function, mean difference }(95 \% \mathrm{Cl}) \text { : NR } \\
\text { WOMAC pain, mean difference }(95 \% \mathrm{Cl}):-0.6(-1.0 \text { to }-0.2), p=0.003 \\
\text { HADS: NR } \\
\text { SF-36: NR } \\
\text { 24 months } \\
\text { WOMAC physical function, mean difference }(95 \% \mathrm{Cl}):-2.6(-4.1 \text { to }-1.1), p=0.001 \\
\text { WOMAC pain: }-0.82(-1.3 \text { to }-0.3), p=0.001 \\
\text { HADS: NR (NS) } \\
\text { SF-36: NR (NS) }\end{array}$ \\
\hline Thomas 2006 & 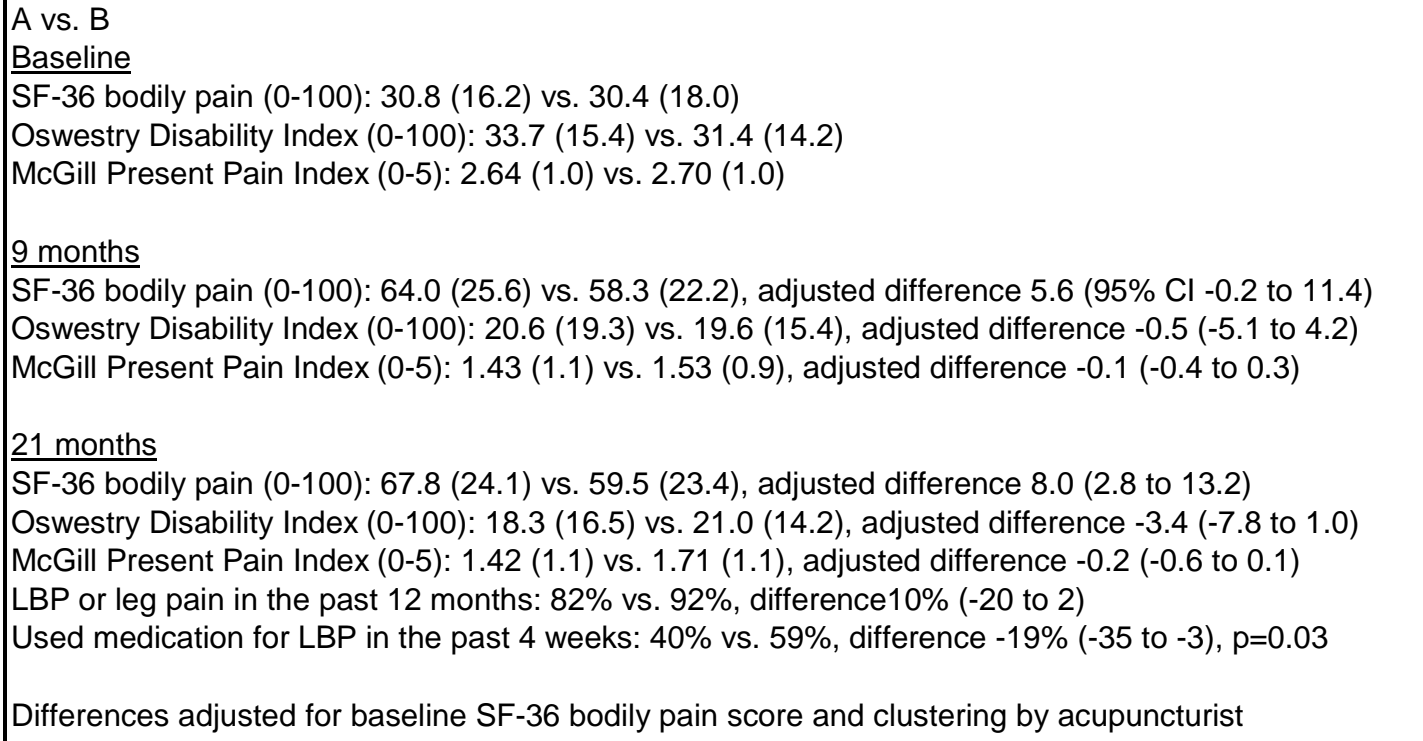 \\
\hline
\end{tabular}




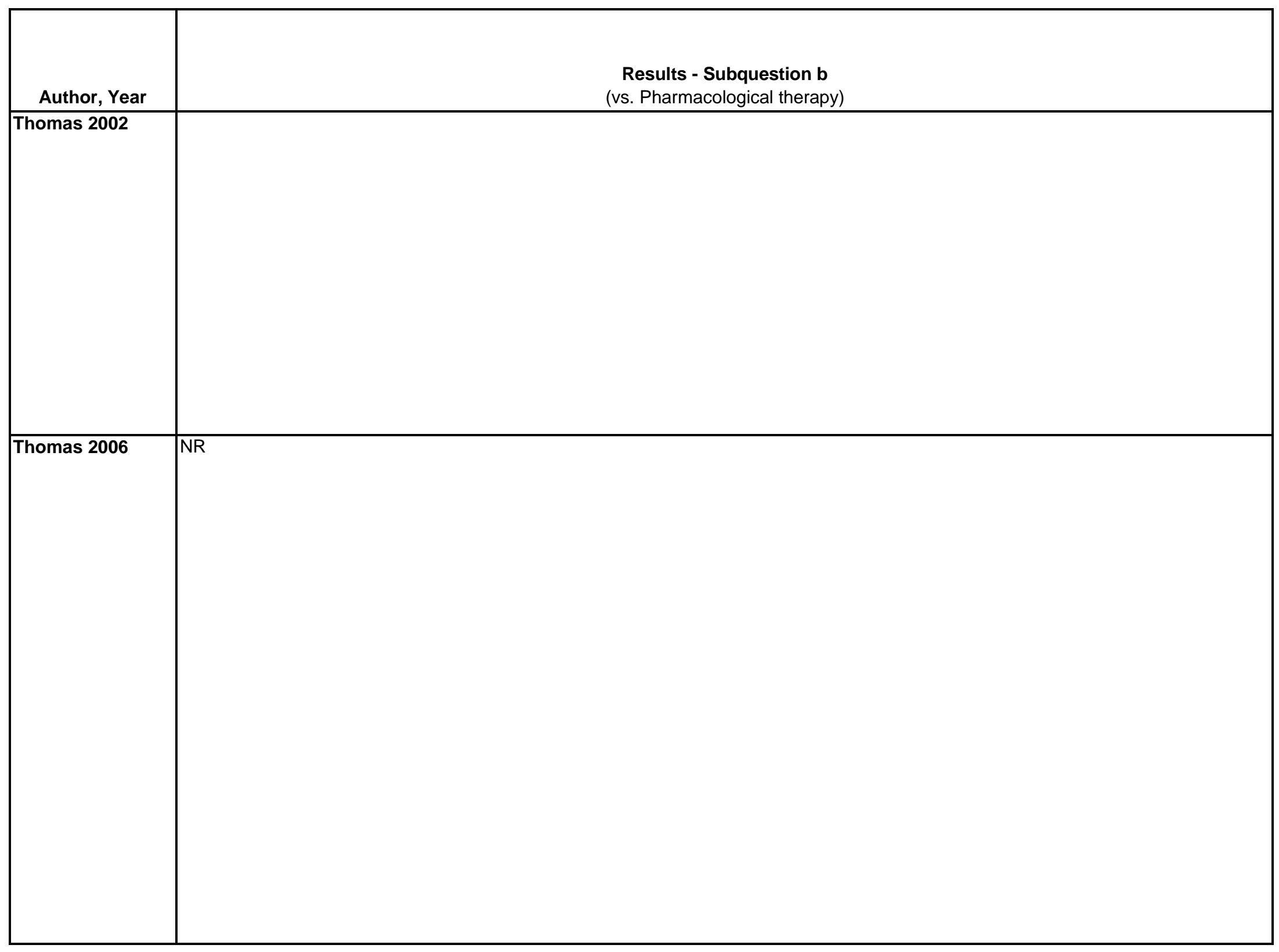

D-767 


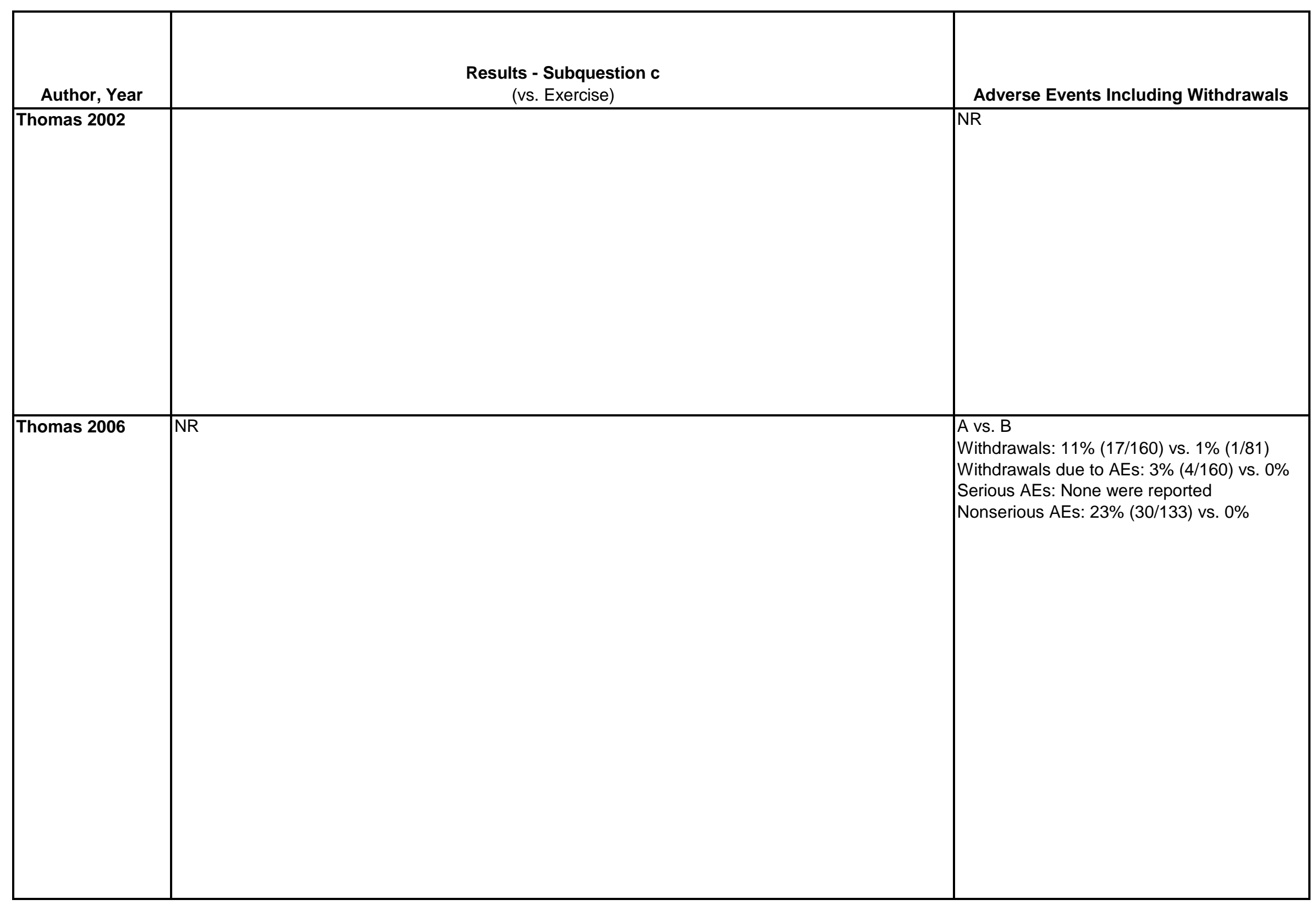




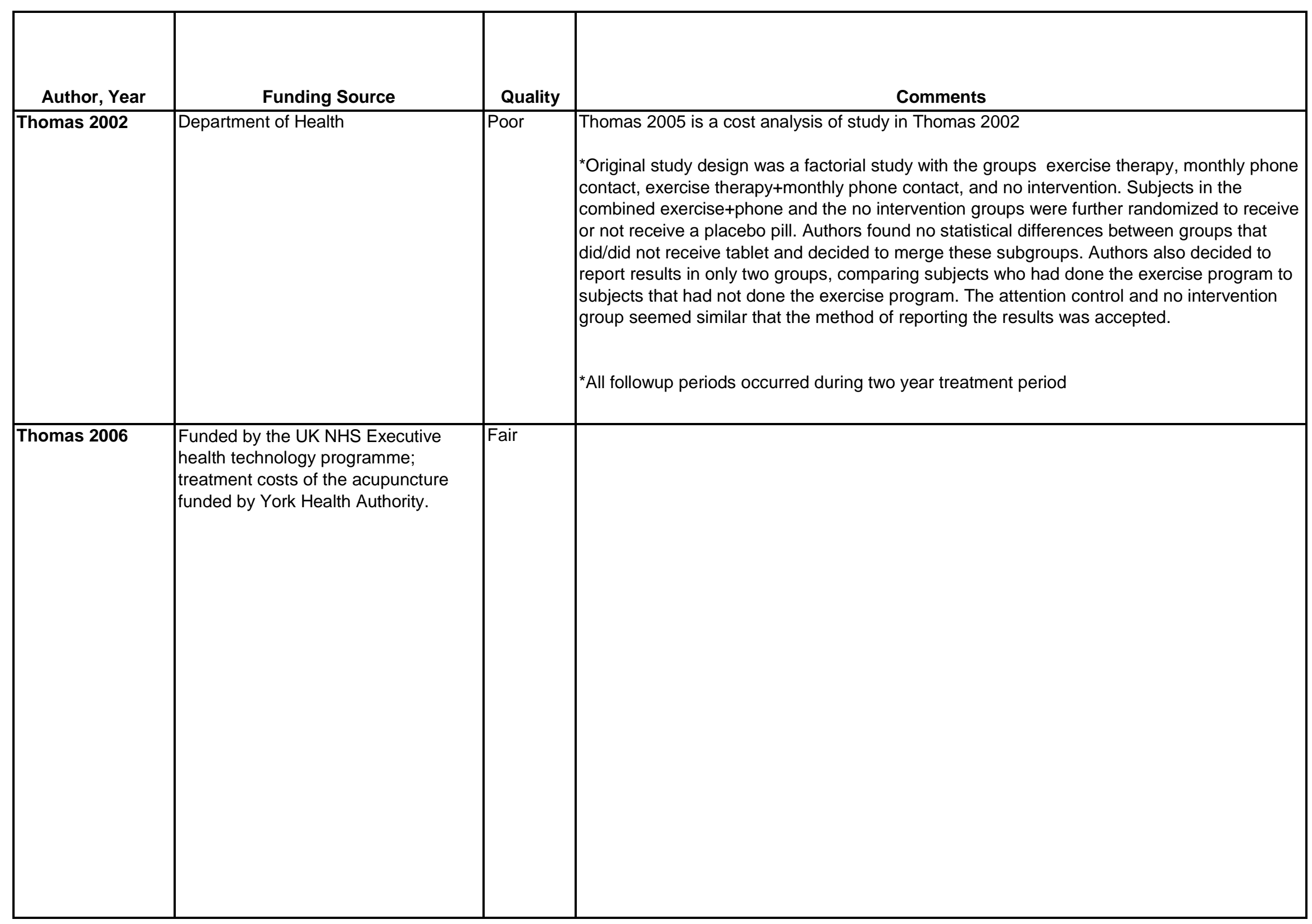




\begin{tabular}{|c|c|c|c|}
\hline Author, Year & $\begin{array}{c}\text { Country } \\
\text { Number of Centers } \\
\text { Setting }\end{array}$ & Inclusion/Exclusion Criteria & $\begin{array}{c}\text { Number Randomized, } \\
\text { Analyzed } \\
\text { Attrition }\end{array}$ \\
\hline $\begin{array}{l}\text { Thorstensson } \\
2005\end{array}$ & $\begin{array}{l}\text { Sweden } \\
\text { Number of centers } \\
\text { unclear } \\
1 \text { hospital, numerous } \\
\text { GPs }\end{array}$ & $\begin{array}{l}\text { Aged 35-65, diagnosis of radiographic osteoarthritis of Kellgren and } \\
\text { Lawrence grade III or more } \\
\text { Exclude: Inflammatory joint disease, anterior cruciate ligament injury, } \\
\text { injury to the menisci, hip symptoms more aggravating than knee } \\
\text { symptoms, knee replacement surgery within } 6 \text { months after study } \\
\text { initiation, co-morbidities not allowing exercise }\end{array}$ & $\begin{array}{l}\text { Randomized: } 65 \\
\text { Treated: } 61 \\
\text { Analyzed: } 46 \\
\text { Attrition: } 29 \%\end{array}$ \\
\hline Tilbrook 2011 & \begin{tabular}{|l|} 
UK \\
Number of centers \\
unclear \\
Outpatient/nonmedica \\
I setting \\
\\
\end{tabular} & $\begin{array}{l}\text { Age } 18-65 \\
\text { Visit for low back pain in prior } 18 \text { months } \\
\text { RDQ score } \geq 4 \\
\text { Musculoskeletal pain bounded by the lowest ribs and gluteal folds } \\
\text { Exclude: } \\
\text { Performed yoga in past } 6 \text { months } \\
\text { Could not get off floor unassisted } \\
\text { Pregnant } \\
\text { Life-threatening comorbid conditions } \\
\text { Prior spinal surgery } \\
\text { severe psychiatric problems or alcohol dependency } \\
\text { Indications of serious spinal neurologic abnormality }\end{array}$ & $\begin{array}{l}\text { Randomized: } 313 \\
\text { Treated: } 299 \\
\text { Analyzed at } 12 \text { months: } \\
272 \\
\text { Attrition: } 13 \%(41 / 313)\end{array}$ \\
\hline
\end{tabular}




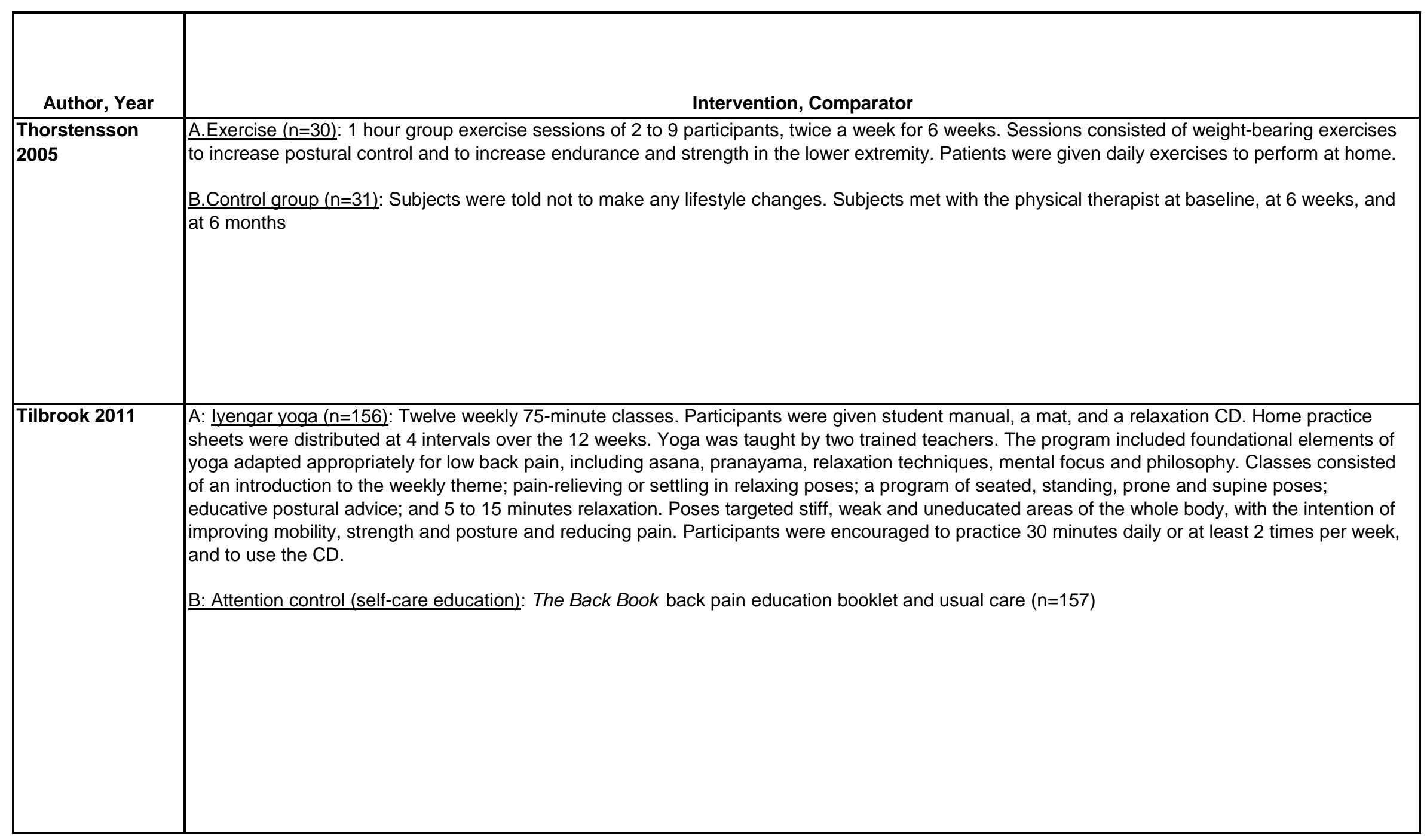




\begin{tabular}{|c|c|c|c|}
\hline Author, Year & Study Participants & Outcome Measures & $\begin{array}{c}\text { Duration of } \\
\text { Followup }\end{array}$ \\
\hline $\begin{array}{l}\text { Thorstensson } \\
2005\end{array}$ & $\begin{array}{l}\text { A vs B } \\
\text { Age: } 55 \text { vs } 57 \\
\text { Female: } 50 \% \text { vs } 52 \% \\
\text { KOOS pain: } 60(18) \text { vs } 64(19) \\
\text { KOOS ADL: } 69(18) \text { vs } 71(21) \\
\text { KOOS symptoms: } 63(20) \text { vs } 66(18) \\
\text { KOOS sports and recreation: } 34(31) \text { vs } 37(29) \\
\text { KOOS QOL: } 40(15) \text { vs } 46(21) \\
\text { SF-36 physical component score, mean }(95 \% \text { Cl): } 42.5 \text { (24.4 to } 57.5) \\
\text { vs } 43.8(24.2 \text { to } 57.3) \\
\text { SF-36 mental component score, mean }(95 \% \mathrm{Cl}): 55.6 \text { (40.2 to } 66.2) \\
\text { vs } 56.3 \text { ( } 37.0 \text { to } 67.0)\end{array}$ & $\begin{array}{l}\text { KOOS pain (0-100, higher score=lower disability); } \\
\text { KOOS ADL (0-100, higher score=lower disability); } \\
\text { KOOS symptoms (0-100, higher score=lower disability); } \\
\text { KOOS sports and recreation(0-100, higher score=lower } \\
\text { disability); KOOS QOL (0-100, higher score=lower } \\
\text { disability); SF-36 physical component score (0-100, } \\
\text { higher score=higher quality of life); SF-36 mental } \\
\text { component score (0-100, higher score=higher quality of } \\
\text { life) }\end{array}$ & 5 months \\
\hline Tilbrook 2011 & $\begin{array}{l}\text { A vs. B } \\
\text { Age: } 46 \text { vs. } 46 \\
\text { Female: } 68 \% \text { vs. } 73 \% \\
\text { Race: NR } \\
\text { Duration of back pain (median months): } 96 \text { vs. } 72 \\
\text { Medication use: } 57 \% \text { vs. } 55 \%\end{array}$ & $\begin{array}{l}\text { RDQ }(0-24) \\
\text { SF-12 (0-100) } \\
\text { Aberdeen Back Pain Scale (0-100) }\end{array}$ & $\begin{array}{l}3 \text { and } 6 \\
\text { months }\end{array}$ \\
\hline
\end{tabular}




\begin{tabular}{|c|c|}
\hline Author, Year & $\begin{array}{c}\text { Results - Subquestion a } \\
\text { (vs. sham, no treatment, waitlist, attention control) }\end{array}$ \\
\hline $\begin{array}{l}\text { Thorstensson } \\
2005\end{array}$ & $\begin{array}{l}\text { A vs B } \\
\text { KOOS pain, mean } \Delta(95 \% \mathrm{Cl}): 3.1(-1.9 \text { to } 8.2) \text { vs }-1.1(-6.6 \text { to } 4.4), \mathrm{p}=0.32 \\
\text { KOOS ADL, mean } \Delta(95 \% \mathrm{Cl}): 0.9(-3.8 \text { to } 5.6) \text { vs }-1.9(-7.7 \text { to } 3.9), \mathrm{p}=0.61 \\
\text { KOOS symptoms, mean } \Delta(95 \% \mathrm{Cl}): 1.0(-3.8 \text { to } 5.8) \text { vs }-3.4(-8.8 \text { to } 1.9), \mathrm{p}=0.31 \\
\text { KOOS sports and recreation, mean } \Delta(95 \% \mathrm{Cl}): 0.5(-10.1 \text { to } 11.2) \text { vs }-8.3(-19.5 \text { to } 2.8), \mathrm{p}=0.32 \\
\text { KOOS QOL, mean } \Delta(95 \% \mathrm{Cl}): 5.1(-0.7 \text { to } 11.0) \text { vs }-2.3(-9.5 \text { to } 4.9), \mathrm{p}=0.02 \\
\text { SF-36 physical component score, mean } \Delta(95 \% \mathrm{Cl}): 3.0(-5.9 \text { to } 16.3) \text { vs }-0.7(-14.8 \text { to } 9.8), \mathrm{p}=0.09 \\
\text { SF-36 mental component score, mean } \Delta(95 \% \mathrm{Cl}): 0.7(-18.1 \text { to } 13.2) \text { vs }-0.7(-16.8 \text { to } 12.8), \mathrm{p}=0.40\end{array}$ \\
\hline Tilbrook 2011 & $\begin{array}{l}\text { A vs. B } \\
\text { Baseline, mean (SD) } \\
\text { RDQ (0-24): } 7.84(3.96) \text { vs. } 7.75(4.72) \\
\text { Aberdeen Back Pain Scale (0-100): } 25.36(10.59) \text { vs. } 26.69(10.87) \\
\text { SF-12 PCS (0-100): } 44.41(9.13) \text { vs. } 44.04(9.45) \\
\text { SF-12 MCS (0-100): } 45.04(10.90) \text { vs. } 45.02(10.66) \\
\\
\text { 3 months (mean difference in change from baseline [95\% CI]) } \\
\text { RDQ: }-1.48(-2.62 \text { to }-0.33) \\
\text { Aberdeen Back Pain Scale }(0 \text { to } 100):-1.74(-4.32 \text { to } 0.84) \\
\text { SF-12 PCS: } 1.24 \text { (-0.83 to } 3.33) \\
\text { SF-12 MCS: } 2.02(-0.34 \text { to } 4.37) \\
\text { 6 months (mean difference in change from baseline [95\% CI]) } \\
\text { RDQ: }-1.57(-2.71 \text { to }-0.42) \\
\text { Aberdeen Back Pain Scale: }-0.73(-3.30 \text { to } 1.84) \\
\text { SF-12 PCS: } 0.80(-1.28 \text { to } 2.87) \\
\text { SF-12 MCS: } 0.42(-1.92 \text { to } 2.77)\end{array}$ \\
\hline
\end{tabular}




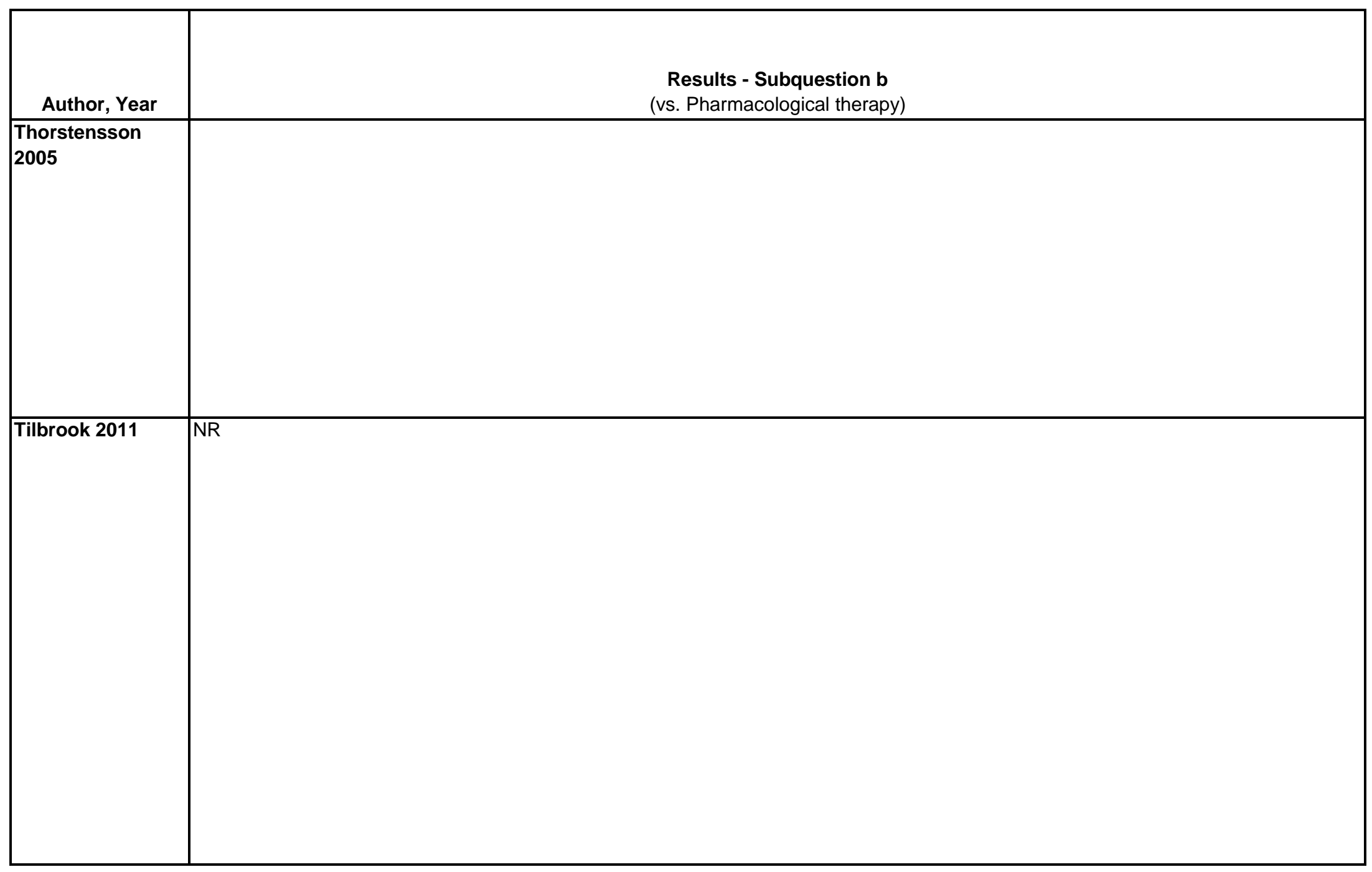

D-774 


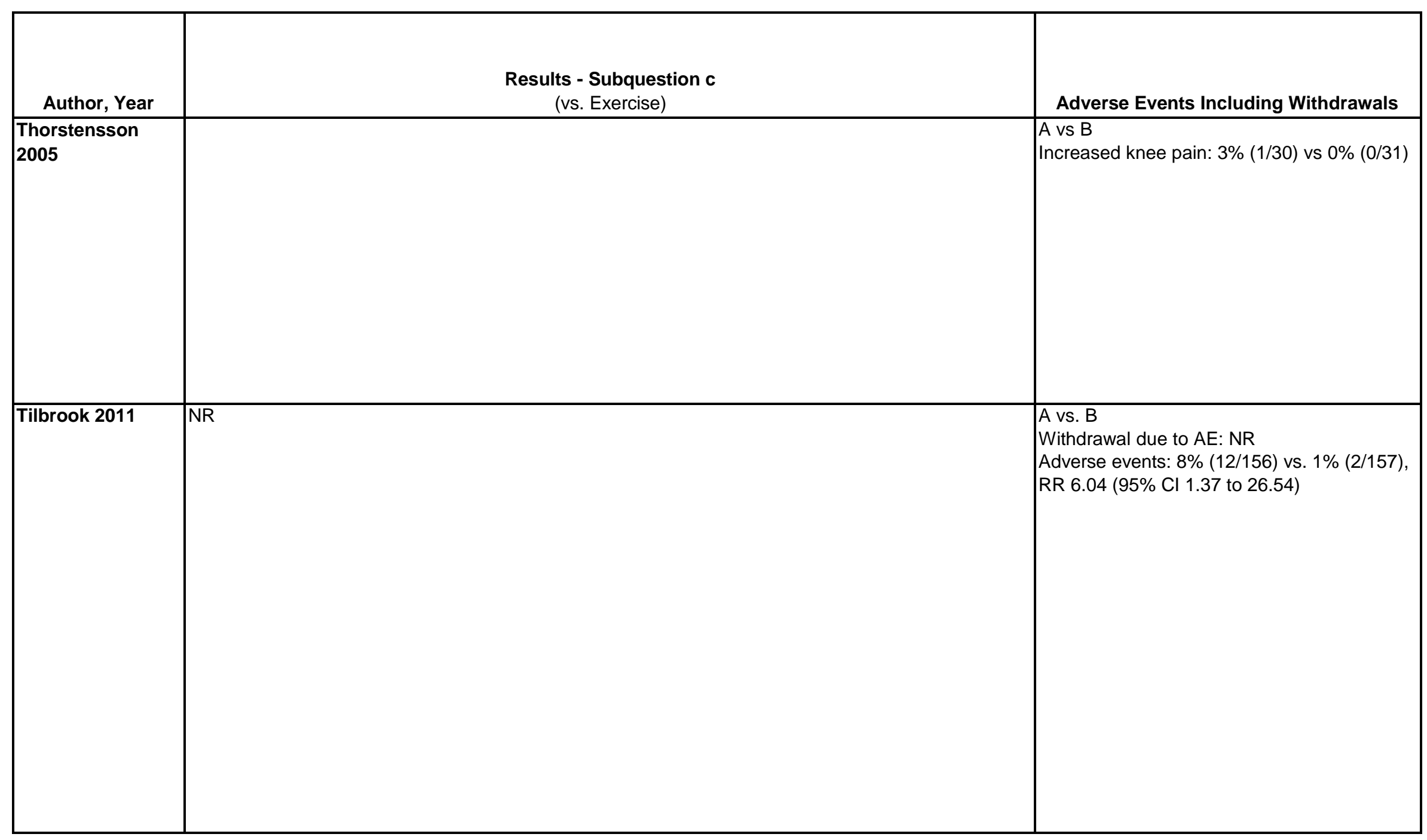




\begin{tabular}{|l|l|l|l|}
\hline \multicolumn{1}{|c|}{ Author, Year } & \multicolumn{1}{|c|}{ Funding Source } & Quality & \\
\hline $\begin{array}{l}\text { Thorstensson } \\
2005\end{array}$ & $\begin{array}{l}\text { Grants from the Vardal Foundation, } \\
\text { The Swedish Rheumatism Association } \\
\text { in Stockholm and Gothenburg, The } \\
\text { Swedish Research Council, The } \\
\text { Department of Research and } \\
\text { Development at Spenshult Hospital for } \\
\text { Rheumatic Diseases }\end{array}$ & Patients not treated were erroneously randomized \\
\hline Tilbrook 2011 & Grant funds: Arthritis Research UK & Fair & \\
\hline
\end{tabular}




\begin{tabular}{|c|c|c|c|}
\hline Author, Year & $\begin{array}{c}\text { Country } \\
\text { Number of Centers } \\
\text { Setting }\end{array}$ & Inclusion/Exclusion Criteria & $\begin{array}{c}\text { Number Randomized, } \\
\text { Analyzed } \\
\text { Attrition }\end{array}$ \\
\hline $\begin{array}{l}\text { Tomas-Carus } \\
20082009\end{array}$ & $\begin{array}{l}\text { Spain } \\
1 \text { site } \\
\text { Recruited by } \\
\text { advertisements in } \\
\text { newsletters of local } \\
\text { FM association }\end{array}$ & $\begin{array}{l}\text { Inclusion: FM diagnosis by ACR } 1990 \text { criteria } \\
\text { Exclusion: history of severe trauma, frequent migraines, peripheral } \\
\text { nerve entrapment, inflammatory rheumatic disease, severe psychiatric } \\
\text { illness; other disease that prevents physical loading; pregnancy; } \\
\text { attendance at another psychological or physical therapy or regular } \\
\text { physical exercise with more than one exercise session of } 30 \text { minutes } \\
\text { per week during a 2-week period in last } 5 \text { years. }\end{array}$ & $\begin{array}{l}\text { Randomized: } 33 \\
\text { Analyzed: } 30 \\
\text { Attrition: } 9 \%(3 / 33)\end{array}$ \\
\hline Trock 1994 & $\begin{array}{l}\text { USA } \\
3 \text { treatment centers in } \\
\text { two States }\end{array}$ & $\begin{array}{l}\geq 35 \text { years of age; pain and stiffness of } \geq 1 \text { year duration; radiographs } \\
\text { with evidence of disk space narrowing with osteophyte formation } \\
\text { and/or subchondral sclerosis in } \geq 1 \text { locations; or osteophyte formation } \\
\text { and subchondral sclerosis of facet joints. } \\
\\
\text { Excluded: Changed therapeutic regimen within } 1 \text { month before } \\
\text { evaluation; possible pregnancy; women of childbearing age not willing } \\
\text { to use contraception; unstable medical illness or cardiac pacemaker. }\end{array}$ & \begin{tabular}{|l|} 
Randomized: NR \\
Treated: 81 \\
Analyzed: 70 \\
Attrition: $14 \%$ \\
$(11 / 81)^{\star}$ \\
*Number at baseline used \\
for denominator
\end{tabular} \\
\hline
\end{tabular}




\begin{tabular}{|c|c|}
\hline Author, Year & Intervention, Comparator \\
\hline $\begin{array}{l}\text { Tomas-Carus } \\
20082009\end{array}$ & $\begin{array}{l}\text { A. Exercise }(n=15) \text { : Supervised training in a waist-high pool of warm water } 3 \text { times per week for } 8 \text { months. Each session was } 1 \text { hour and included } 10 \\
\text { minutes warmup, } 10 \text { minutes of aerobic exercise at } 60-65 \% \text { of maximal hart rate, } 20 \text { minutes of overall mobility and lower limb strength exercises } \\
\text { using water resistance and upper limb strength exercises without water resistance, another } 10 \text { minutes of aerobic exercise, and } 10 \text { minutes } \\
\text { cooldown. Heart rate was monitored using a pulse meter. Two subjects who failed to attend at least } 95 \% \text { of treatment sessions for personal } \\
\text { reasons were excluded from analysis. The rate of compliance with therapy sessions was } 93 \text { (standard deviation } 2 \text { ) times out of a maximum of } 96 \\
\text { sessions. } \\
\text { B.Control ( } n=15) \text { : For } 8 \text { months, participants continued their normal activities, which did not include exercise similar to that in A. One subject who } \\
\text { failed to attend for measurements for personal reasons was excluded from analysis. }\end{array}$ \\
\hline Trock 1994 & $\begin{array}{l}\text { A.Extremely low frequency pulsed electromagnetic fields ( } \mathrm{n}=38) \text {, <2 A with } 120 \mathrm{~V} \text {; applied with stepwise energy characteristics as follows: } 5 \mathrm{~Hz}, 0- \\
15 \text { gauss for } 10 \text { minutes; } 10 \mathrm{~Hz}, 15-25 \text { gauss for } 10 \text { minutes; and } 12 \mathrm{~Hz}, 15-25 \text { gauss for } 10 \text { minutes. Maximum number of pulses/burst was } 20 . \\
\text { B.Sham ( } \mathrm{n}=32 \text { ). Same setup but no electromagnetic field generated. } \\
\text { Treatments were given for } 30 \text { minute periods, } 3-5 \text { times per week for } 18 \text { treatments. }\end{array}$ \\
\hline
\end{tabular}




\begin{tabular}{|c|c|c|c|}
\hline Author, Year & Study Participants & Outcome Measures & $\begin{array}{c}\text { Duration of } \\
\text { Followup }\end{array}$ \\
\hline $\begin{array}{l}\text { Tomas-Carus } \\
20082009\end{array}$ & $\begin{array}{l}\text { A vs B } \\
\text { Age: } 51 \text { vs } 51 \\
\text { Female: } 100 \% \text { vs } 100 \% \\
\text { Symptom duration, years: } 20.1 \text { vs } 19.4 \\
\text { FIQ Total: } 6.1 \text { (1.2) vs } 6.3(1.3) \\
\text { FIQ Physical Function: } 3.0(1.5) \text { vs } 3.7(1.5) \\
\text { FIQ Pain: } 5.6(1.9) \text { vs } 6.4(2.3) \\
\text { FIQ Anxiety: } 6.5(2.7) \text { vs } 5.7(2.5) \\
\text { FIQ Depression: } 5.4(2.6) \text { vs } 6.0(2.1) \\
\text { STAI State Anxiety: } 45.1(9.9) \text { vs } 41.9(8.0) \\
\text { Additional measures reported in Tomas-Carus 2009: } \\
\text { SF-36 Physical Function: } 43.4(14.2) \text { vs } 32.8(19.8) \\
\text { SF-36 Bodily Pain: } 28.7(13.4) \text { vs } 20.8(19.2) \\
\text { SF-36 Mental Health: } 45.5(18.5) \text { vs } 51.2(26.2)\end{array}$ & $\begin{array}{l}\text { FIQ total score (0-10, higher scores=greater } \\
\text { impairment) } \\
\text { FIQ Physical Function (0-10, higher scores=greater } \\
\text { impact) } \\
\text { FIQ Pain (0-10, higher scores=greater impact) } \\
\text { FIQ Anxiety (0-10, higher scores=greater impact) } \\
\text { FIQ Depression (0-10, higher scores=greater impact) } \\
\text { State-Trait Anxiety Inventory (STAI) (20-80; higher } \\
\text { scores=greater anxiety) } \\
\text { Additional measures reported in Tomas-Carus 2009: } \\
\text { SF-36 Physical Function (0-100, higher scores=better } \\
\text { outcomes) } \\
\text { SF-36 Bodily Pain (0-100, higher scores=better } \\
\text { outcomes) } \\
\text { SF-36 Mental Health (0-100, higher scores=better } \\
\text { outcomes) }\end{array}$ & $\begin{array}{l}\text { Immediately } \\
\text { after } 8 \\
\text { months of } \\
\text { exercise }\end{array}$ \\
\hline Trock 1994 & $\begin{array}{l}\text { A vs B } \\
\text { Age: } 61 \text { vs } 67 \text { years } \\
\text { Female: } 71 \% \text { vs } 67 \% \\
\text { Weight (lb): } 161 \text { vs } 162 \\
\text { Duration of symptoms: } 7 \text { vs } 8 \text { years } \\
\text { Pain (0-100): } 72.02(18.45) \text { vs } 62.3(24.16) \\
\text { ADL difficulty } 11.94(5.63) \text { vs } 11.5(5.27)\end{array}$ & $\begin{array}{l}\text { Pain (VAS, 0-100, higher score worse pain) } \\
\text { ADL difficulty (scale, 0-24, higher score worse disability) } \\
\text { Patient assessment of improvement (scale, 0-100, } \\
\text { higher score greater the improvement) }\end{array}$ & 1 month \\
\hline
\end{tabular}




\begin{tabular}{|c|c|}
\hline Author, Year & $\begin{array}{c}\text { Results - Subquestion a } \\
\text { (vs. sham, no treatment, waitlist, attention control) }\end{array}$ \\
\hline $\begin{array}{l}\text { Tomas-Carus } \\
20082009\end{array}$ & $\begin{array}{l}\text { A vs B } \\
\text { 8 months } \\
\text { FIQ Total: } 5.2(1.6) \text { vs } 6.5(1.0), \mathrm{p}=0.017 ; \mathrm{MD} 45.5(95 \% \mathrm{Cl} 44.502 \text { to } 46.498), \mathrm{p}<0.0001 \\
\text { FIQ Physical Function: } 2.4(1.7) \text { vs } 3.7(2.0), \mathrm{p}=0.047 ; \mathrm{MD}-1.3(95 \% \mathrm{Cl}-2.688 \text { to } 0.088), \mathrm{p}=0.07 \\
\text { FIQ Pain: } 5.3(1.4) \text { vs } 6.6(1.8), \mathrm{p}=0.04 ; \mathrm{MD}-1.3(95 \% \mathrm{Cl}-2.506 \text { to }-0.094), \mathrm{p}=0.04 \\
\text { FIQ Anxiety: } 4.7(2.7) \text { vs } 6.6(2.1), \mathrm{p}=0.037 ; \mathrm{MD}-1.9(95 \% \mathrm{Cl}-3.709 \text { to }-0.091), \mathrm{p}=0.04 \\
\text { FIQ Depression: } 4.0(3.3) \text { vs } 6.1(1.7), \mathrm{p}=0.03 ; \mathrm{MD}-2.1(95 \% \mathrm{Cl}-4.063 \text { to }-0.137), \mathrm{p}=0.04 \\
\text { STAI State Anxiety: } 37.5(8.0) \text { vs } 44.4(8.9), \mathrm{p}=0.035 ; \mathrm{MD}-6.9(95 \% \mathrm{Cl}-13.229 \text { to }-0.571), \mathrm{p}=0.03 \\
\text { Additional measures reported in Tomas-Carus 2009: } \\
\text { SF-36 Physical Function: } 54.1 \text { (19.8) vs } 36.6(17.8), \mathrm{p}=0.017 ; \mathrm{MD} 17.5(95 \% \mathrm{Cl} 3.418 \text { to } 31.582), \mathrm{p}=0.02 \\
\text { SF-36 Bodily Pain: } 51.7(13.1) \text { vs 27.1 (20.9), } \mathrm{p}=0.001 ; \mathrm{MD} 24.6(95 \% \mathrm{Cl} 11.554 \text { to } 37.646), \mathrm{p}=0.0006 \\
\text { SF-36 Mental Health: } 67.3(21.4) \text { vs } 49(20.8), \mathrm{p}=0.025 ; \mathrm{MD} 18.3(95 \% \mathrm{Cl} 2.516 \text { to } 34.084), \mathrm{p}=0.02\end{array}$ \\
\hline Trock 1994 & \begin{tabular}{|l} 
A vs B \\
1 month outcomes: \\
Pain $(0-100): 25.87$ (30.22) vs $14.66(29.39), M D 11.21(95 \% \mathrm{Cl}-3.08$ to 25.50$) \mathrm{p}=0.122$ \\
ADL difficulty: 3.78 (7.35) vs $2.14(5.57), \mathrm{p}=\mathrm{NS}$ \\
Patients' assessment of improvement: 41.18 (35.88) vs 40.00 (32.27), $\mathrm{p}=\mathrm{ns}$
\end{tabular} \\
\hline
\end{tabular}




\begin{tabular}{|l|c|}
\hline \multicolumn{1}{|c|}{ Author, Year } & $\begin{array}{c}\text { Results - Subquestion b } \\
\text { (vs. Pharmacological therapy) }\end{array}$ \\
\hline $\begin{array}{l}\text { Tomas-Carus } \\
20082009\end{array}$ & \\
\hline & \\
\hline & \\
\hline
\end{tabular}

D-781 


\begin{tabular}{|l|c|l|}
\hline \multicolumn{1}{|c|}{$\begin{array}{c}\text { Results - Subquestion c } \\
\text { (vs. Exercise) }\end{array}$} & Adverse Events Including Withdrawals \\
\hline $\begin{array}{l}\text { Tomas-Carus } \\
2008 \text { 2009 }\end{array}$ & & $\begin{array}{l}\text { Avs B } \\
\text { Withdrawals: 2/ 17 (12\%) vs 0/16 } \\
\text { Adverse events: NR }\end{array}$ \\
\hline & & \\
\hline Trock 1994 & & \\
& & \\
\hline
\end{tabular}




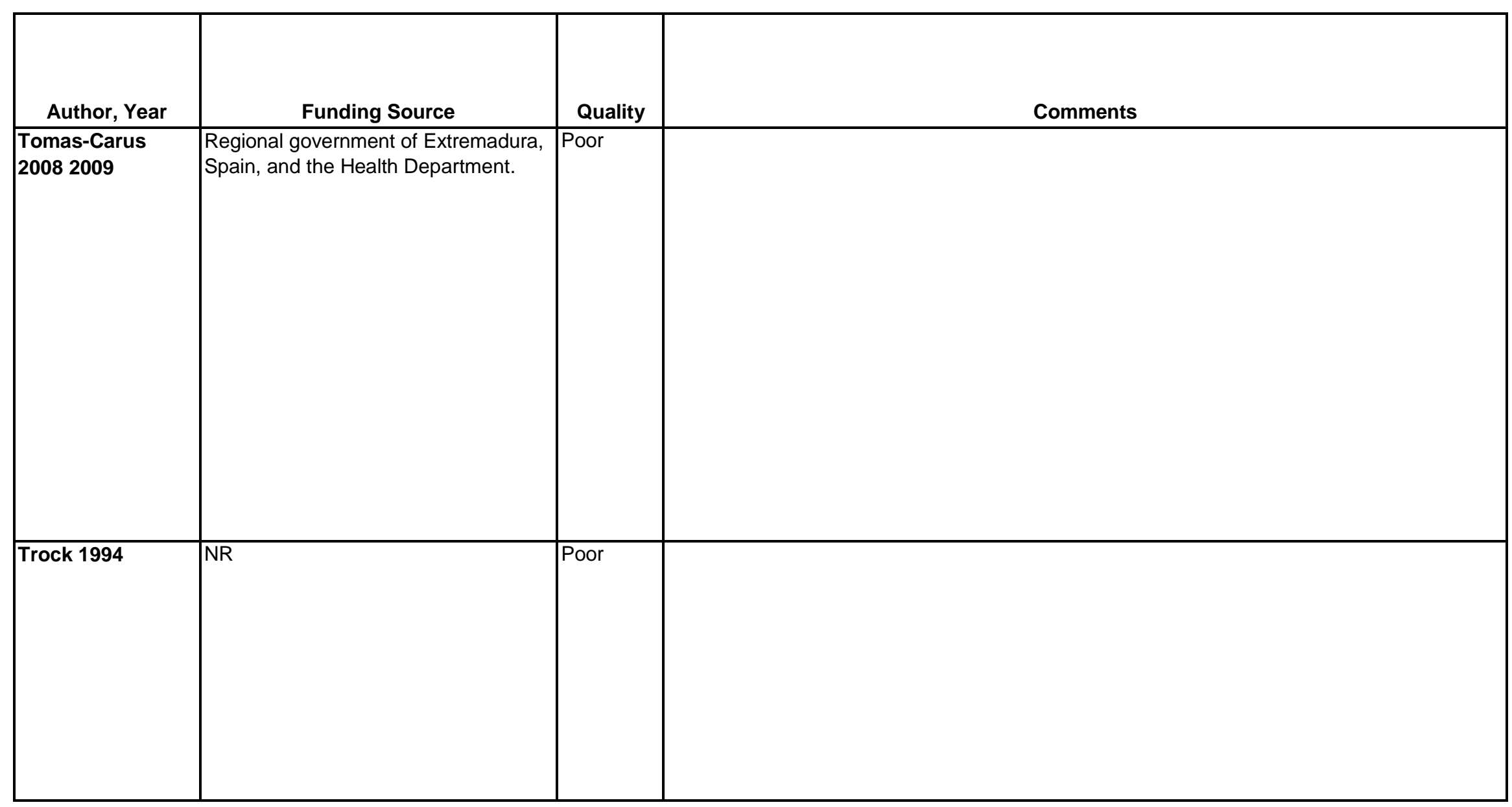




\begin{tabular}{|c|c|c|c|}
\hline Author, Year & $\begin{array}{c}\text { Country } \\
\text { Number of Centers } \\
\text { Setting }\end{array}$ & Inclusion/Exclusion Criteria & $\begin{array}{c}\text { Number Randomized, } \\
\text { Analyzed } \\
\text { Attrition }\end{array}$ \\
\hline Turner 1990 & $\begin{array}{l}\text { US } \\
\text { Number of centers: } \\
\text { Unclear } \\
\text { Outpatient }\end{array}$ & $\begin{array}{l}20-65 \text { years old } \\
\text { Currently married or cohabitating } \\
\text { Exclude } \\
\text { Current infectious medical disorder } \\
\text { Cardiovascular disease } \\
\text { Spine fracture or dislocation } \\
\text { Spondylolisthesis } \\
\text { Spine instability } \\
\text { Ankylosing spondylitis } \\
\text { Rheumatoid arthritis or connective tissue disease } \\
\text { History of cancer } \\
\text { Surgery in previous year } \\
\text { Nonspine limitation of lower extremity function } \\
\text { Leg pain with sciatic tension signs }\end{array}$ & $\begin{array}{l}\text { Randomized: } 49 \\
\text { Analyzed: } 31 \text { at } 6 \text { months, } \\
33 \text { at } 12 \text { months } \\
\text { Attrition: } 37 \%(18 / 49) \text { at } 6 \\
\text { months, } 33 \%(16 / 49) \text { at } 12 \\
\text { months }\end{array}$ \\
\hline $\begin{array}{l}\text { UK BEAM Trial } \\
\text { Team } 2004\end{array}$ & $\begin{array}{l}\text { United Kingdom } \\
\text { Number of centers: } 14 \\
181 \text { general practices } \\
\text { clinics }\end{array}$ & $\begin{array}{l}\text { Patients } 18 \text { and } 65 \text { years old, with LBP and a Roland disability score } \\
\text { of } \\
4 \text { or more, who experienced pain every day for } 28 \text { days before } \\
\text { randomization or for } 21 \text { out of the } 28 \text { days before randomization } \\
\text { and } 21 \text { out of the } 28 \text { days before that and agreed to } 3 \text { months of } \\
\text { treatment. } \\
\text { Exclude: Patients older than } 65 \text {, or those with a possibility of serious } \\
\text { spinal disorder, only pain below the knee, previous spinal surgery, } \\
\text { Roland disability score of } 3 \text { or less }\end{array}$ & $\begin{array}{l}\text { Randomized: } 1,334 \\
\text { Treated: } 1,334 \\
\text { Analyzed: } 1,334^{\star} \\
\text { Attrition: } 16 \%(1128 / 1334) \\
\text { *ITT }\end{array}$ \\
\hline
\end{tabular}




\begin{tabular}{|c|c|}
\hline Author, Year & Intervention, Comparator \\
\hline Turner 1990 & $\begin{array}{l}\text { A. Behavioral therapy ( } n=25) \text { : } 2 \text {-hour group sessions every week for } 8 \text { weeks, with spouses attending } 5 \text { sessions. Concepts of pain behaviors, well } \\
\text { behaviors, and the role of social reinforcers in maintaining pain behaviors were taught, and couples received communication training. Individual } \\
\text { patients set behavioral goals in areas affected by pain. Treatment included group discussion, role playing, and feedback with social reinforcement. } \\
\text { B. Exercise }(n=24) \text { : 2-hour sessions every week for } 8 \text { weeks. The exercise program aimed at increasing aerobic fitness through fast-walking/slow } \\
\text { jogging. Sessions consisted of discussion of progress and problems, instruction on stretching. Subjects engaged in aerobic exercise } 5 \text { times a week } \\
\text { on their own using a quota system. } \\
\text { C.Interdisciplinary - Behavioral plus Exercise ( } n=24) \text { : Subjects received the behavioral therapy intervention followed by the exercise intervention in } \\
\text { each session, for } 8 \text { weeks. Protocols were identical to the ones given to the individual intervention groups (A \& B, respectively). Spouses attended } 5 \\
\text { behavioral therapy sessions but did not participate in the exercise intervention. } \\
\text { D.Waitlist }(n=23) \text { : Patients waited } 8 \text { weeks after initial assessment thern were randomized to one of the } 3 \text { treatments }(A, B, \text { or } C) \text {. }\end{array}$ \\
\hline $\begin{array}{l}\text { UK BEAM Trial } \\
\text { Team } 2004\end{array}$ & $\begin{array}{l}\text { A: Manipulation ( } n=353) \text { UK chiropractic, osteopathic, and physiotherapy techniques including at least } 1 \text { high velocity thrusts, } 8 \text { treatments, } 20 \\
\text { minute sessions, } 12 \text { weeks } \\
\text { B: General practice care }(n=338) \\
\text { C: Exercise }(n=310) \text { group classes incorporating cognitive behavioral principles, } 8 \text { classes, } 60 \text { minute sessions for } 4-8 \text { plus a "refresher" class at } 12 \\
\text { weeks }(n=310) \\
\text { D: Manipulation and exercise combined ( } n=333), 12 \text { weeks }\end{array}$ \\
\hline
\end{tabular}




\begin{tabular}{|c|c|c|c|}
\hline Author, Year & Study Participants & Outcome Measures & $\begin{array}{c}\text { Duration of } \\
\text { Followup }\end{array}$ \\
\hline Turner 1990 & $\begin{array}{l}\text { Overall } \\
\text { Age: } 44 \\
\text { Female: } 48 \% \text { (46/96) } \\
\text { Duration of symptoms: } 12.9 \text { years } \\
\text { Previous back surgery: } 10 \% \text { (10/96) } \\
\text { Employment: } \\
\text { - Full or part time: } 73 \% \\
\text { Receiving financial compensation for pain: } 8 \% \\
\text { Involved or anticipating litigation related to pain } 11 \% \\
\text { no significant differences on any measure } \\
\\
\text { A vs. B vs. C vs. D } \\
\text { Baseline scores } \\
\text { Sickness Impact Profile: } 7.9 \text { vs. } 8.4 \text { vs. } 8.5 \text { vs. } 6.2 \\
\text { MPQ Pain Rating Index: } 21.0 \text { vs. } 19.4 \text { vs. } 25.5 \text { vs. } 21.2 \\
\text { Pain Behavior Observation Method: } 4.4 \text { vs. } 4.3 \text { vs. } 3.5 \text { vs. } 3.0 \\
\text { Pain Behavior Checklist: } 42.3 \text { vs. } 43.5 \text { vs. } 44.0 \text { vs. } 39.1 \\
\text { CES-D: } 10.4 \text { vs. } 12.0 \text { vs. } 12.4 \text { vs. } 10.5 \\
\text { no significant differences on any measure }\end{array}$ & $\begin{array}{l}\text { Sickness Impact Profile (SIP, 0-100, higher } \\
\text { score=higher disability) } \\
\text { McGill Pain Questionnaire Pain Rating Index (0-78, } \\
\text { higher score=more pain) } \\
\text { Center for Epidemiologic Studies - Depression Scale } \\
\text { (CES-D, 0-60, higher score=more depressive } \\
\text { symptoms) }\end{array}$ & $\begin{array}{l}6 \text { and } 12 \\
\text { months }\end{array}$ \\
\hline $\begin{array}{l}\text { UK BEAM Trial } \\
\text { Team } 2004\end{array}$ & $\begin{array}{l}\text { A vs. B vs. C. vs. D } \\
\text { Age: } 42 \text { vs. } 42 \text { vs. } 44 \text { vs. } 43 \text { years } \\
\text { Female: } 63 \% \text { vs. } 53 \% \text { vs. } 55 \% \text { vs. } 57 \% \\
\text { White: } 97 \% \text { vs. } 95 \% \text { vs. } 96 \% \text { vs. } 92 \% \\
\text { RDQ (0-24): } 8.9 \text { vs. } 9.0 \text { vs. } 9.2 \text { vs. } 8.9-9.1 \\
\text { SF-36 Physical component score: } 41 \text { vs. } 41 \text { vs. } 40 \text { vs. } 41 \\
\text { SF-36 Mental component score: } 45-46 \text { vs. } 47 \text { vs. } 45 \text { vs. } 46\end{array}$ & $\begin{array}{l}\text { RDQ }(0-24) \\
\text { Modified Von Korff disability scale(0-100, } 0=\text { best) } \\
\text { Modified Von Korff pain (0-100, } 0=\text { best) } \\
\text { SF-36 Physical component score (mean=50, SD=10, } \\
100=\text { best) } \\
\text { SF-36 Mental component score (mean=50, SD=10, } \\
100=\text { best) }\end{array}$ & 9 months \\
\hline
\end{tabular}




\begin{tabular}{|c|c|}
\hline Author, Year & $\begin{array}{c}\text { Results - Subquestion a } \\
\text { (vs. sham, no treatment, waitlist, attention control) }\end{array}$ \\
\hline Turner 1990 & NR \\
\hline $\begin{array}{l}\text { UK BEAM Trial } \\
\text { Team } 2004\end{array}$ & 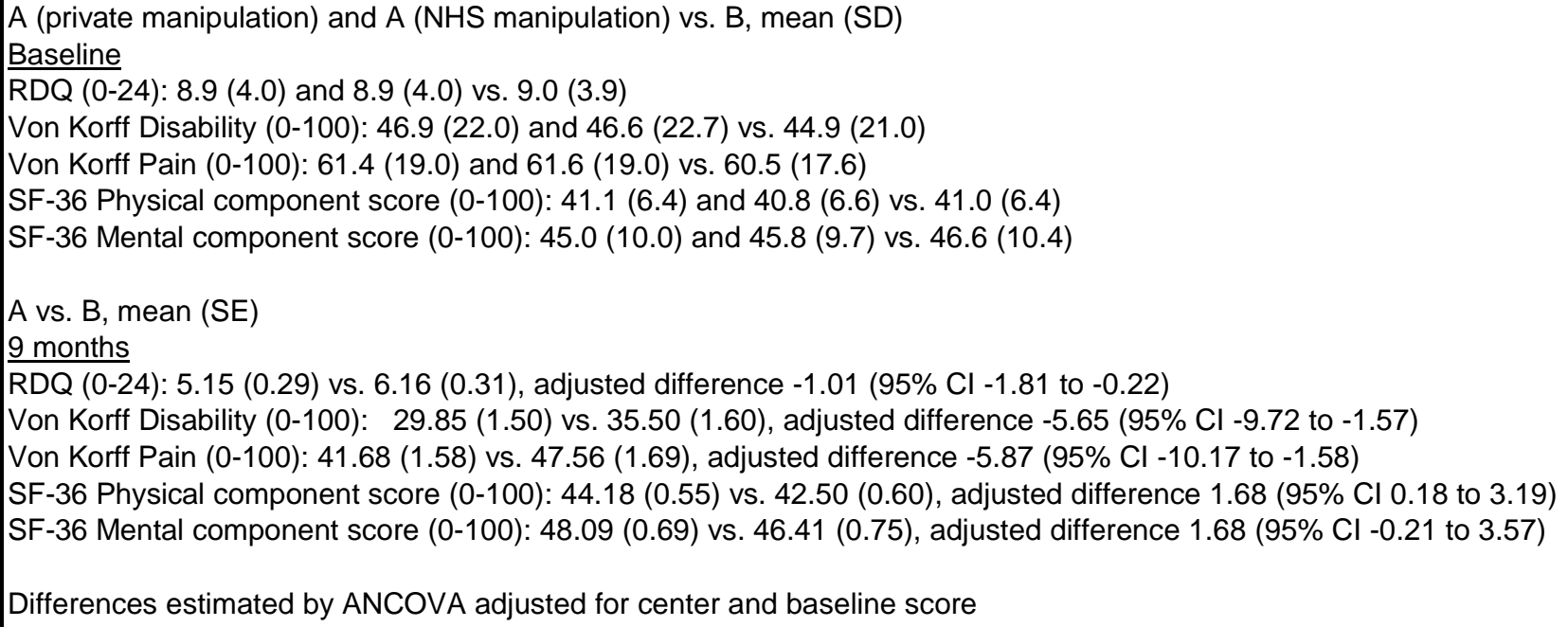 \\
\hline
\end{tabular}




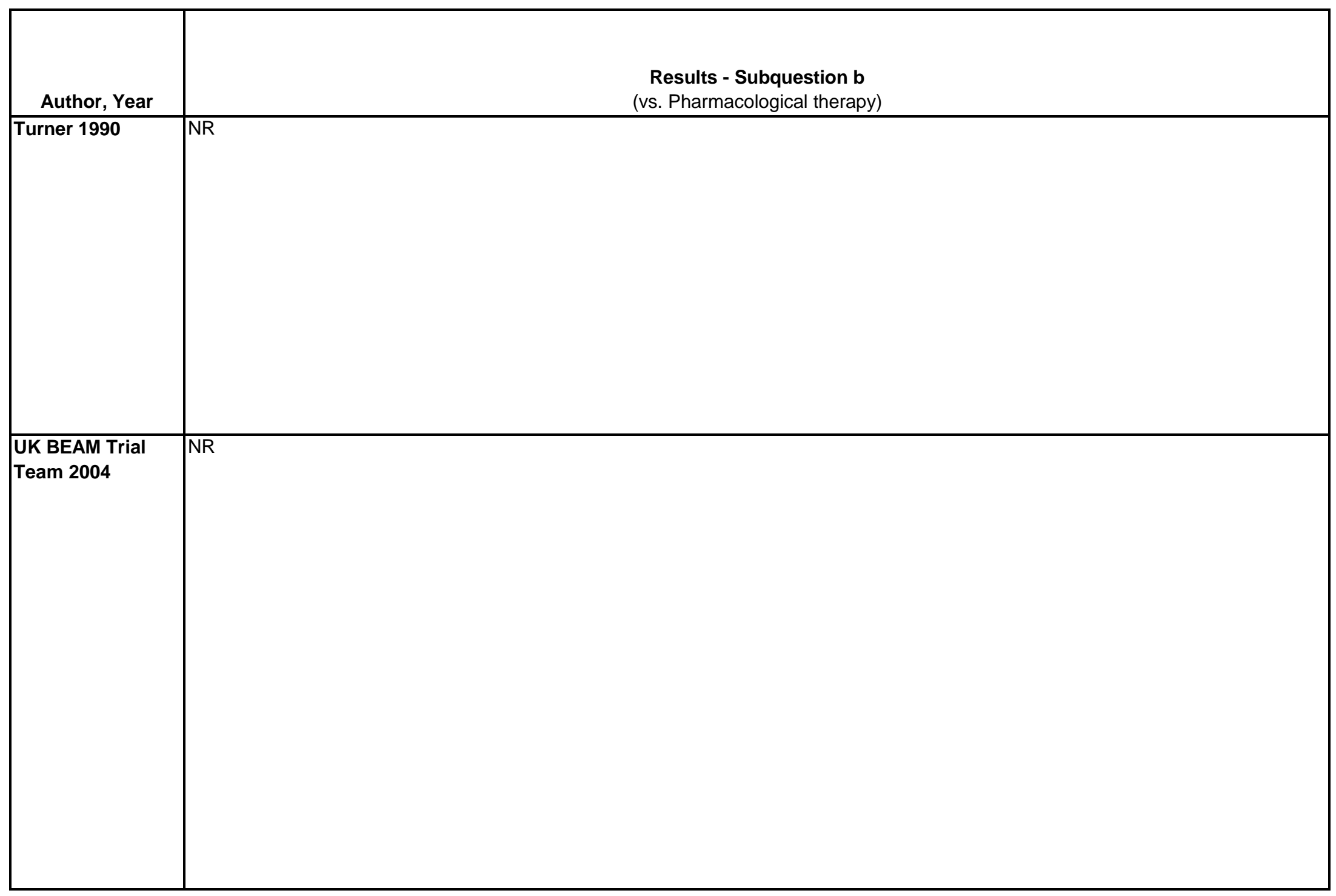

D-788 


\begin{tabular}{|c|c|c|}
\hline Author, Year & $\begin{array}{l}\text { Results - Subquestion c } \\
\text { (vs. Exercise) }\end{array}$ & Adverse Events Including Withdrawals \\
\hline Turner 1990 & $\begin{array}{l}\text { C vs. B } \\
\text { Baseline } \\
\text { McGill Pain Questionnaire Pain Rating Index (0-78): } 25.5(12.4) \text { vs. } 19.4 \text { (10.6) } \\
\text { Sickness Impact Profile (0-100): } 8.5(4.6) \text { vs. 8.4 (8.2) } \\
\text { Center for Epidemiologic Studies-Depression Scale (0-60): } 12.4 \text { (7.3) vs. } 12.0 \text { (7.7) } \\
\text { 6 months } \\
\text { McGill Pain Questionnaire Pain Rating Index (0-78): } 13.3(9.2) \text { vs. } 15.7(9.2) \\
\text { Sickness Impact Profile (0-100): } 4.5 \text { (4.7) vs. } 6.3(10.1) \\
\text { Center for Epidemiologic Studies-Depression Scale (0-60): } 8.3(7.9) \text { vs. } 9.3(8.3) \\
12 \text { months } \\
\text { McGill Pain Questionnaire Pain Rating Index (0-78): } 18.2(13.3) \text { vs. } 14.9(7.9) \\
\text { Sickness Impact Profile (0-100): } 4.8(3.4) \text { vs. } 4.7(7.9) \\
\text { Center for Epidemiologic Studies-Depression Scale (0-60): } 10.0(7.6) \text { vs. } 9.3(7.7)\end{array}$ & $\begin{array}{l}\text { C vs. B } \\
\text { Withdrawal at } 6 \text { months: } 42 \%(10 / 24) \text { vs. } \\
29 \%(7 / 24) \\
\text { Withdrawal at } 12 \text { months: } 42 \%(10 / 24) \text { vs. } \\
33 \%(8 / 24) \\
\text { Withdrawal due to AEs: NR } \\
\text { Serious AEs: NR } \\
\text { Nonserious AEs: NR }\end{array}$ \\
\hline $\begin{array}{l}\text { UK BEAM Trial } \\
\text { Team } 2004\end{array}$ & $\begin{array}{l}\text { A (private manipulation) and A (NHS manipulation) vs. B, mean (SE) } \\
\text { Baseline } \\
\text { RDQ (0-24): } 8.9(4.0) \text { and } 8.9(4.0) \text { vs. } 9.2(4.3) \\
\text { Von Korff Disability (0-100): } 46.9(22.0) \text { and } 46.6(22.7) \text { vs. } 47.7(22.6) \\
\text { Von Korff Pain }(0-100): 61.4(19.0) \text { and } 61.6(19.0) \text { vs. } 60.8(17.6) \\
\text { SF-36 Physical component score }(0-100): 41.1(6.4) \text { and } 40.8(6.6) \text { vs. } 40.5(6.7) \\
\text { SF-36 Mental component score }(0-100): 45.0(10.0) \text { and } 45.8(9.7) \text { vs. } 45.4(10.8) \\
\\
\text { A vs. C, mean (SE) } \\
9 \text { months } \\
\text { RDQ (0-24): } 5.15(0.29) \text { vs. } 5.74(0.31) \\
\text { Von Korff Disability (0-100): } 29.85(1.50) \text { vs. } 29.73(1.68) \\
\text { Von Korff Pain }(0-100): 41.68(1.58) \text { vs. } 41.54(1.84) \\
\text { SF-36 Physical component score (0-100): } 44.18(0.55) \text { vs. } 44.39(0.63) \\
\text { SF-36 Mental component score (0-100): } 48.09(0.69) \text { vs. } 46.77(0.81)\end{array}$ & No serious adverse events occurred. \\
\hline
\end{tabular}




\begin{tabular}{|l|l|l|l|}
\hline \multicolumn{1}{|c|}{ Author, Year } & \multicolumn{1}{|c|}{ Funding Source } & Quality & \\
\hline Turner 1990 & $\begin{array}{l}\text { Grants from the National Institute of } \\
\text { Neurological and Communicative } \\
\text { Disorders and Stroke (2 R01 NS } \\
\text { 19619 and P01 NS 16329) }\end{array}$ & Poor & Unclear if SIP scored on a 0-100 scale or alternative scale \\
\hline TK BEAM Trial & UK Medical Research Council (MRC) & Fair & \\
\hline
\end{tabular}




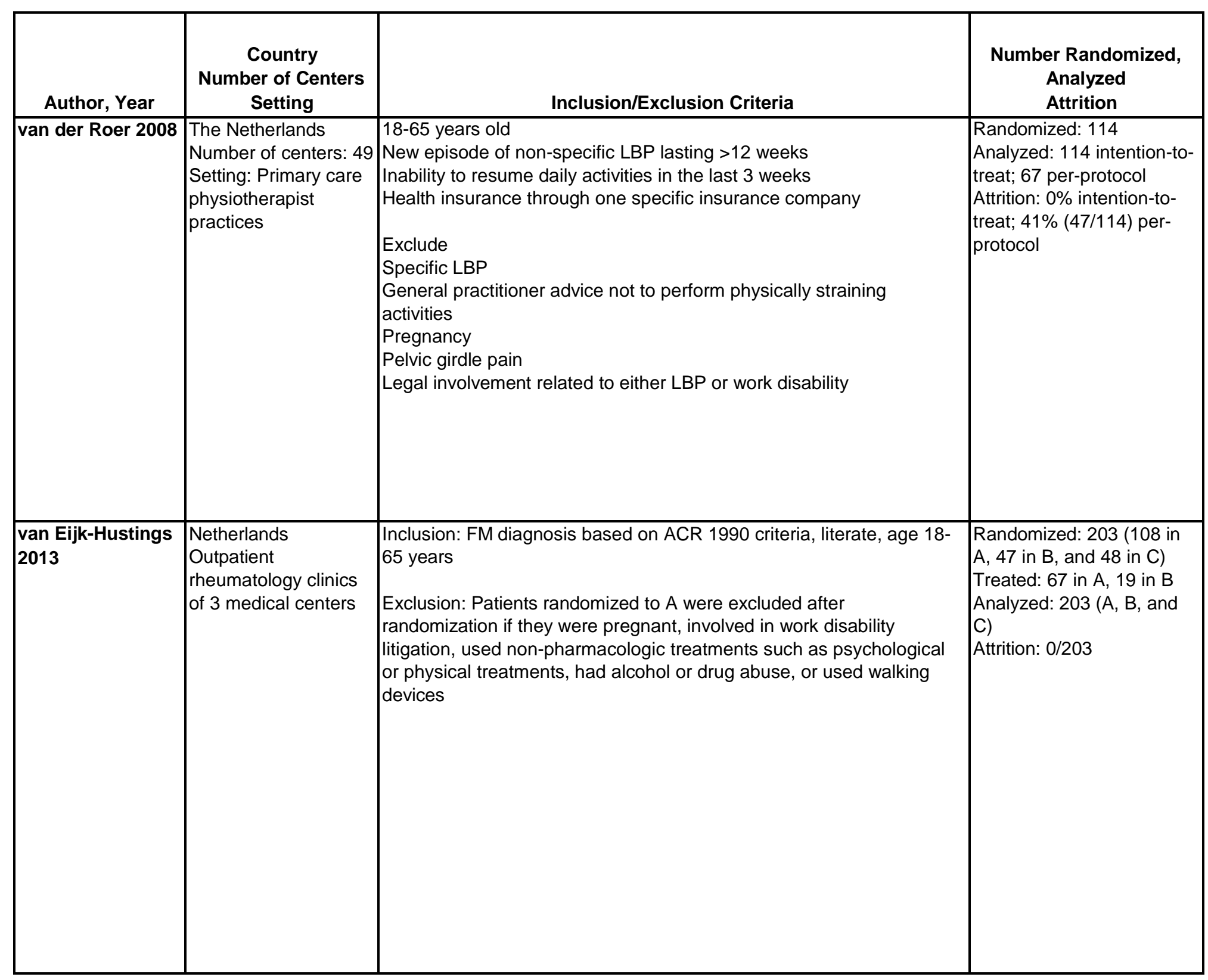




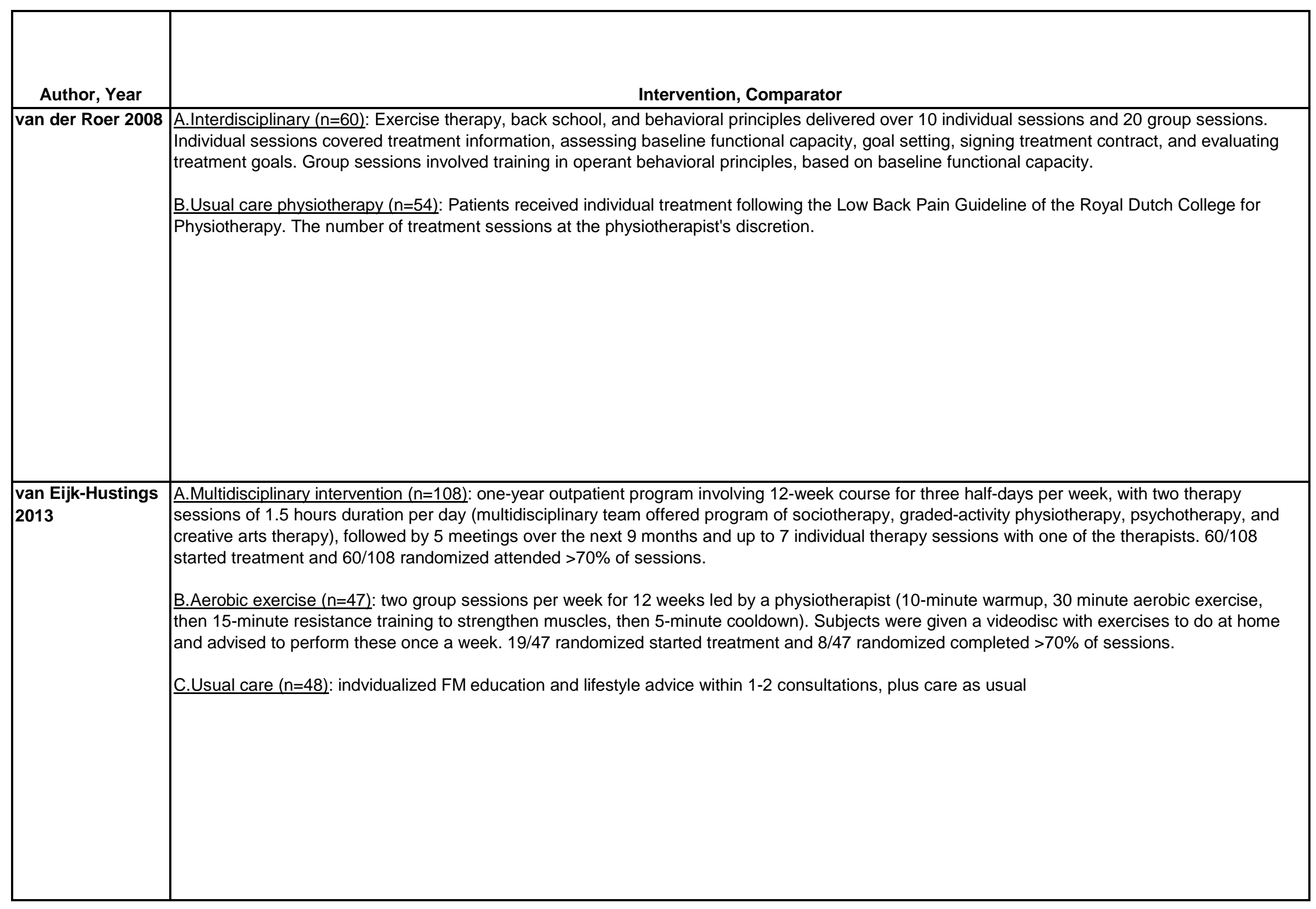




\begin{tabular}{|c|c|c|c|}
\hline Author, Year & Study Participants & Outcome Measures & $\begin{array}{c}\text { Duration of } \\
\text { Followup }\end{array}$ \\
\hline van der Roer 2008 & $\begin{array}{l}\text { A vs. B } \\
\text { Age: } 42 \text { vs. } 42 \\
\text { Female: } 55 \% \text { vs. } 48 \% \\
\text { Ethnic background: } \\
\text { - Dutch: } 48 \% \text { vs. } 35 \% \\
\text { - European immigrant: } 5 \% \text { vs. } 4 \% \\
\text { - Non-European immigrant: } 47 \% \text { vs. } 61 \% \\
\text { Duration of current episode, weeks: } 53.9 \text { vs. } 47.2 \\
\text { Paid work (\% yes): } 70 \% \text { vs. } 57 \%\end{array}$ & $\begin{array}{l}\text { Roland Morris Disability Questionnaire (RDQ, 0-24, } \\
\text { higher scores indicate worse health) } \\
\text { Pain (0-10 NRS) } \\
\text { Global Perceived Effect (GPE, 6-point scale from "much } \\
\text { worse" to "completely recovered") } \\
\text { Direct health care costs (12 months) }\end{array}$ & $\begin{array}{l}4 \text { and } 10 \\
\text { months }\end{array}$ \\
\hline $\begin{array}{l}\text { van Eijk-Hustings } \\
2013\end{array}$ & $\begin{array}{l}\text { A vs. B vs C: } \\
\text { Age: } 42 \text { for those who started treatment and } 41 \text { for those who did not } \\
\text { start treatment (group A) vs. } 44 \text { for those who started treatment and } \\
39 \text { for those who did not start treatment (group B) vs } 43 \text { (group C) } \\
\text { Female: } 94 \% \text { for those who started treatment and } 93 \% \text { for those who } \\
\text { did not start treatment (group A) vs. } 100 \% \text { (group B) vs } 98 \% \text { (group C) } \\
\text { Duration of FM symptoms (years): } 7.1 \text { for those who started treatment } \\
\text { and } 6.1 \text { for those who did not start treatment (group A) vs. } 6.2 \text { for } \\
\text { those who started treatment and } 7.3 \text { for those who did not start } \\
\text { treatment (group B) vs } 7.1 \text { (group C) } \\
\text { FIQ physical function: } 4.2 \text { (SE 0.2) vs 3.6 (SE } 0.2 \text { ) vs } 3.4 \text { (SE 0.3) } \\
\text { FIQ total: } 64.5 \text { (SE 1.4) vs } 60.0 \text { (SE 2.1) vs } 55.4 \text { (SE 2.3) } \\
\text { FIQ Pain: } 6.3 \text { (SE 0.2) vs } 6.2 \text { (SE 0.3) vs } 5.5 \text { (SE0.3) } \\
\text { FIQ Depression: } 5.2 \text { (SE 0.3) vs 4.8 (SE 0.3) vs } 4.2 \text { (SE 0.4) } \\
\text { FlQ Anxiety:5.9 (SE 0.3) vs } 4.9 \text { (SE 0.3) vs } 4.8 \text { (SE 0.4) } \\
\text { EQ-5D: } 0.36 \text { (SE 0.03) vs. } 0.41 \text { (SE 0.05) vs } 0.51 \text { (SE 0.04) }\end{array}$ & $\begin{array}{l}\text { FIQ total }(0-100 ; \text { higher scores=more negative impact) } \\
\text { and subscales }(0-10, \text { higher is worse) } \\
\text { FIQ pain }(0-10 \text {, higher scores=greater pain) } \\
\text { FIQ Depression (0-10, higher scores=greater } \\
\text { depression) } \\
\text { FIQ Anxiety: }(0-10, \text { higher scores=greater anxiety) } \\
\text { EQ-5D (-0.59 to } 1.00 \text {, with higher scores= better health) }\end{array}$ & 18 months \\
\hline
\end{tabular}




\begin{tabular}{|c|c|}
\hline Author, Year & \begin{tabular}{|c} 
Results - Subquestion a \\
(vs. sham, no treatment, waitlist, attention control)
\end{tabular} \\
\hline van der Roer 2008 & 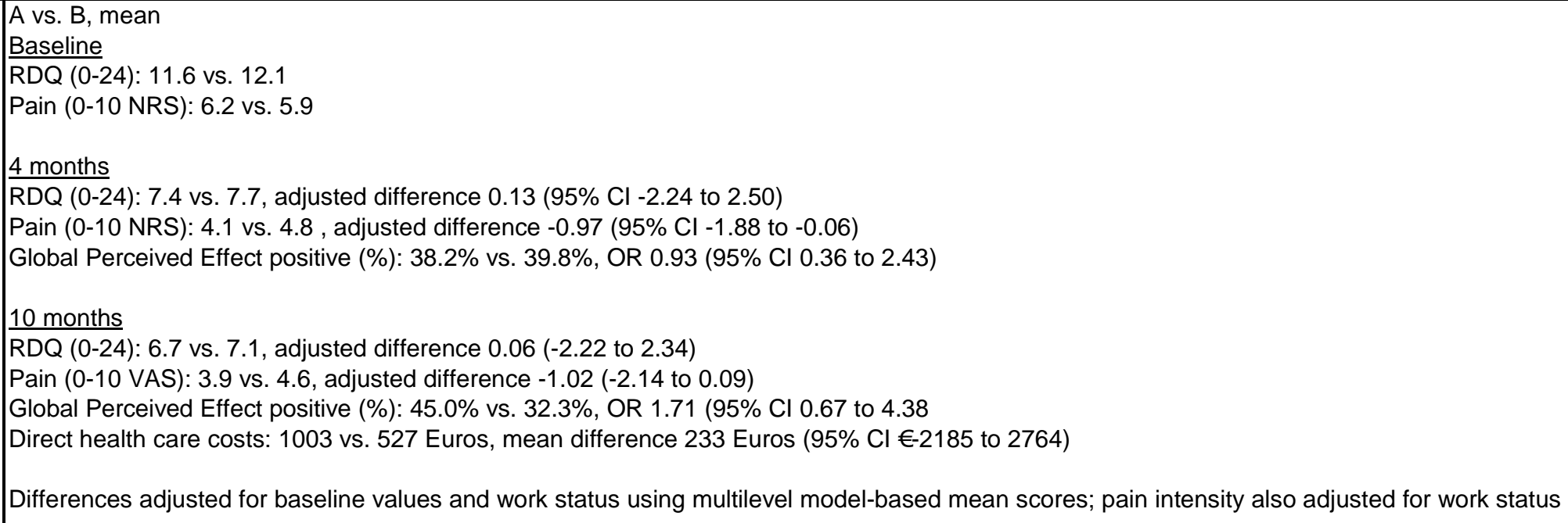 \\
\hline $\begin{array}{l}\text { van Eijk-Hustings } \\
2013\end{array}$ & 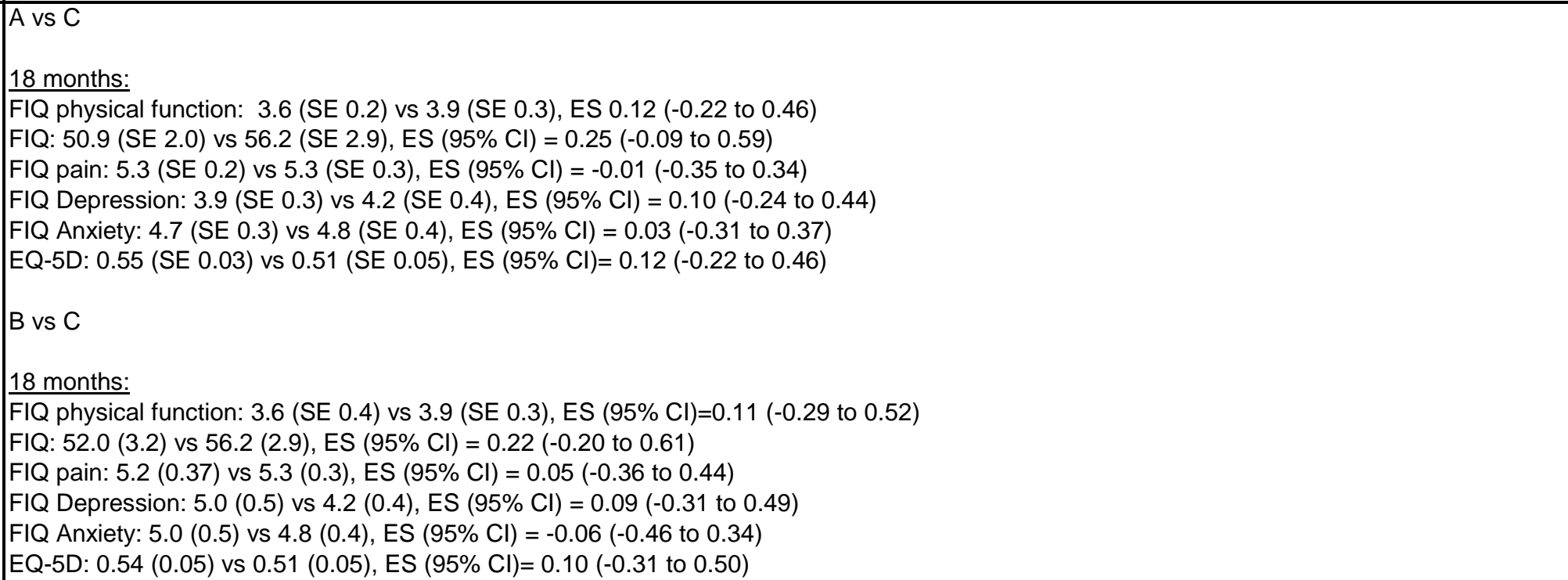 \\
\hline
\end{tabular}




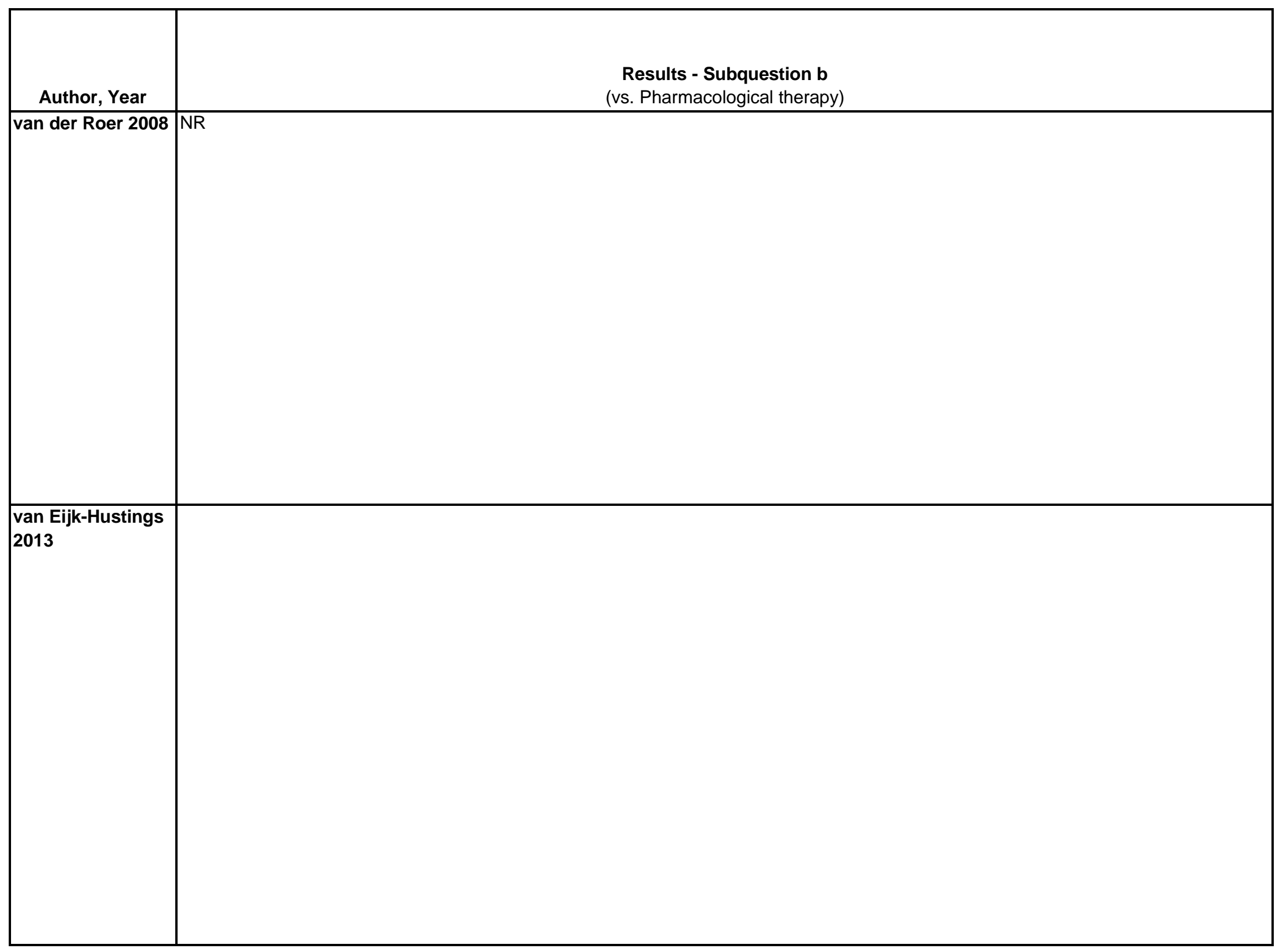

D-795 


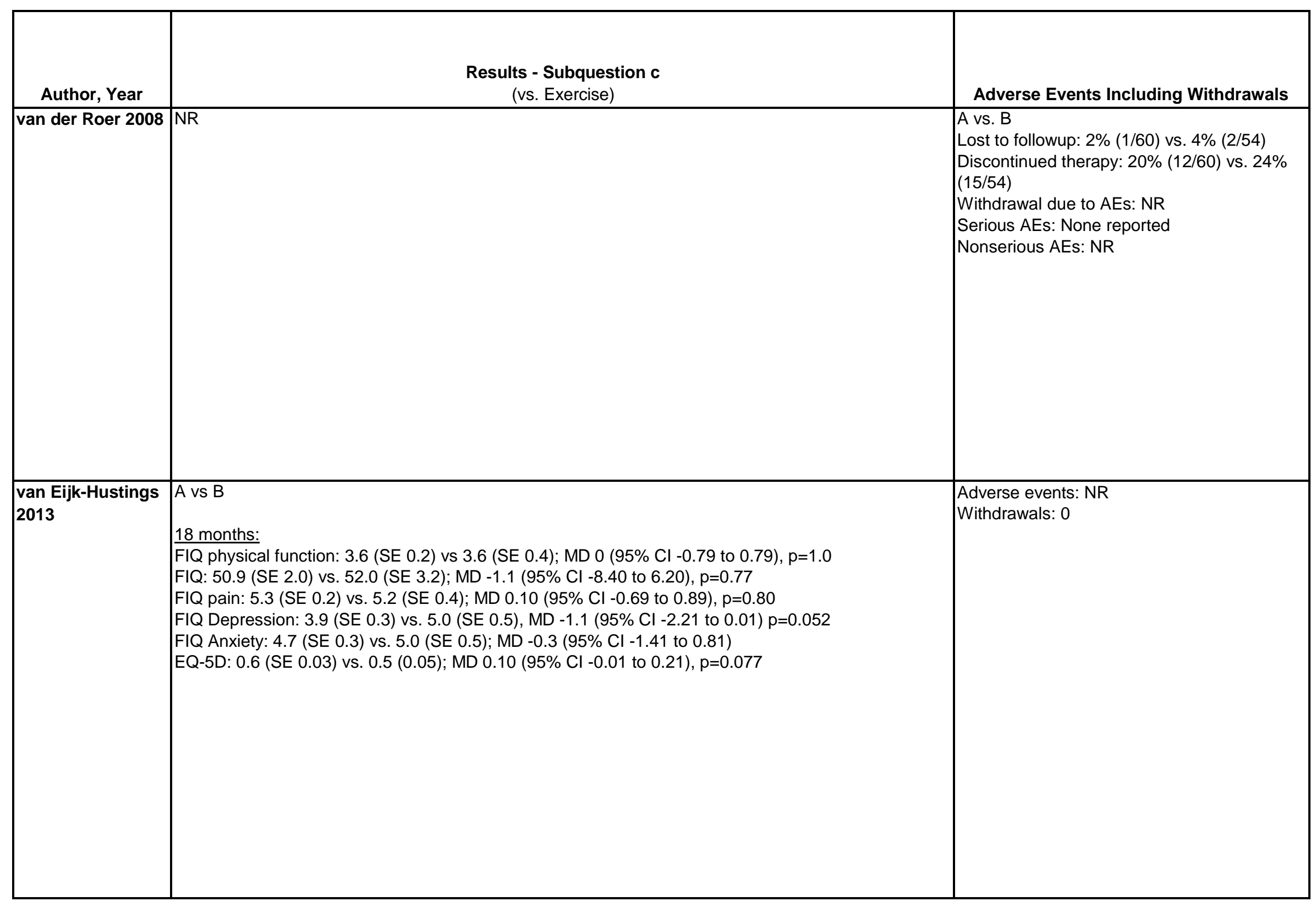




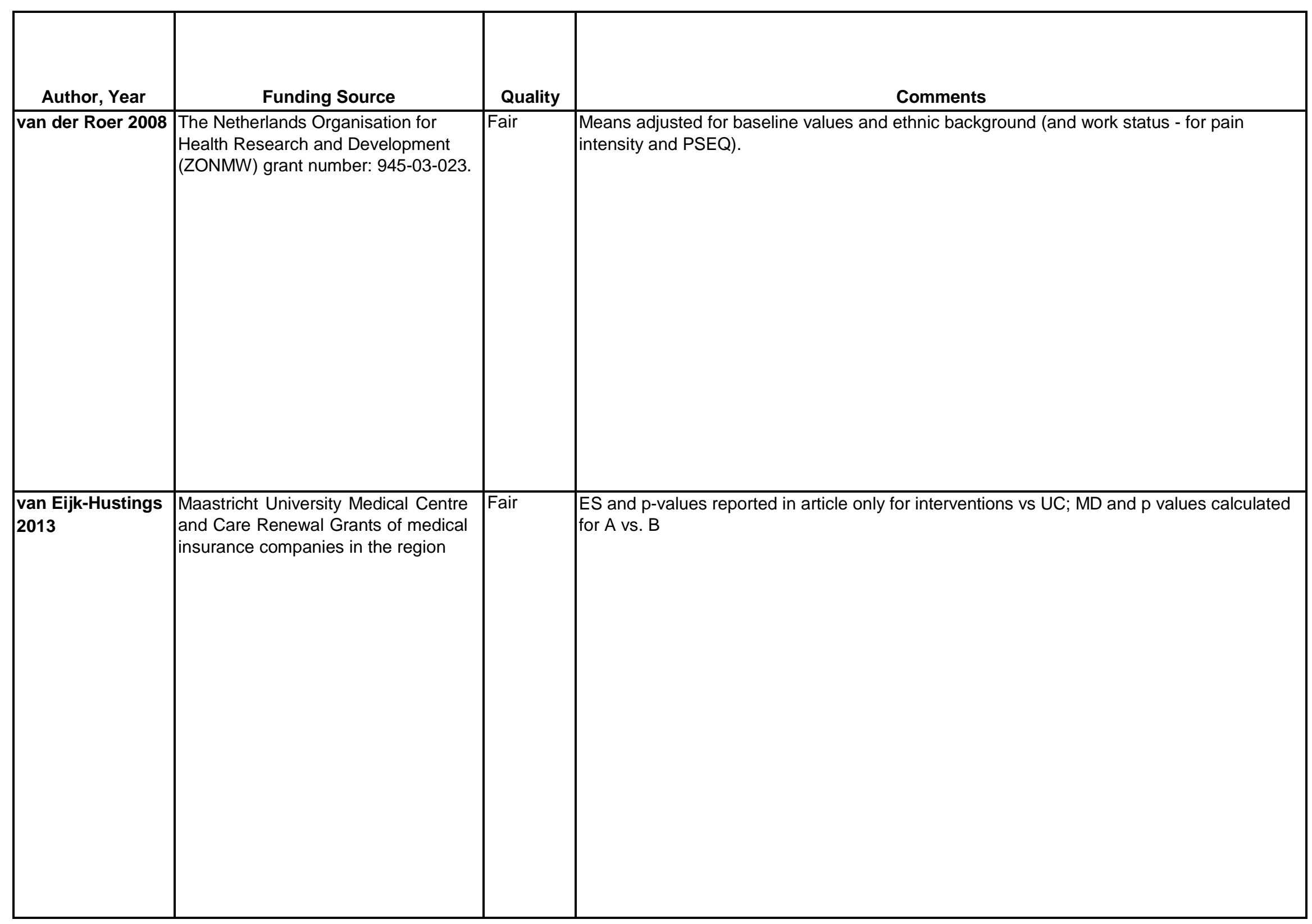




\begin{tabular}{|c|c|c|c|}
\hline Author, Year & $\begin{array}{c}\text { Country } \\
\text { Number of Centers } \\
\text { Setting }\end{array}$ & Inclusion/Exclusion Criteria & $\begin{array}{c}\text { Number Randomized, } \\
\text { Analyzed } \\
\text { Attrition }\end{array}$ \\
\hline van Santen 2002 & $\begin{array}{l}\text { The Netherlands } \\
2 \text { centers } \\
\text { Outpatient }\end{array}$ & $\begin{array}{l}\text { Female patients aged 18-60 years old, clinical diagnosis of FM } \\
\text { according to } 1990 \text { ACR criteria, living within } 30 \mathrm{~km} \text { of the clinical } \\
\text { centers } \\
\text { Exclude: Known comorbidity, localized myalgia, pregnancy, on waiting } \\
\text { list for elective surgery }\end{array}$ & $\begin{array}{l}\text { Randomized: } 143 \\
\text { Treated: } 129 \\
\text { Analyzed: } 118 \\
\text { Attrition: } 17 \%(25 / 143)\end{array}$ \\
\hline Vas 2006 & $\begin{array}{l}\text { Spain } \\
\text { Single Primary } \\
\text { Attention Healthcare } \\
\text { Center, 2002-2004 }\end{array}$ & $\begin{array}{l}\text { Outpatients } \geq 17 \text { years with symptomatic uncomplicated neck pain of } \\
\text { >3 months' duration, a motion-related neck pain intensity } \geq 30 \text { on a } \\
\text { visual analogue scale }(0-100 \mathrm{~mm}) \text {, no treatment during the week } \\
\text { preceding study onset. } \\
\\
\text { Excluded: Previous treatment with acupuncture; pain < } 30 \mathrm{~mm} \text { on VAS } \\
\text { (0-100 mm); neck pain classed as neuropathologic, infectious, } \\
\text { inflammatory, neoplasic, endocrine, metabolic or visceral; cervical } \\
\text { fracture or trauma; previous spinal surgery, non-specific fever, severe } \\
\text { psychiatric illness, severe disorder of overall health state, infectious } \\
\text { feverish disease, severe or generalized dermatopathy, malignant } \\
\text { tumor; incompatibility with the medication described in the protocol; } \\
\text { occupation-related lawsuit arising from neck pain; pregnancy; prior } \\
\text { recommendation for treatment with antineoplastic drugs, } \\
\text { corticosteroids, immunosuppressor drugs or opioids; inability or } \\
\text { unwillingness to follow instructions }\end{array}$ & $\begin{array}{l}\text { Randomized: } 123 \\
\text { Treated: } 115 \\
\text { Analyzed: } 85 \\
\text { Attrition:31\% } \\
(38 / 123)\end{array}$ \\
\hline
\end{tabular}




\begin{tabular}{|c|c|}
\hline Author, Year & Intervention, Comparator \\
\hline van Santen 2002 & $\begin{array}{l}\text { A.Fitness training ( } n=47) \text { : Group sessions of } 15-17 \text { patients for } 60 \text { minutes twice a week for } 24 \text { weeks consisting of aerobic exercises, stretching, } \\
\text { general flexibility and balance exercises, and isometric muscle strengthening. Subjects were encouraged to attend an additional third, } \\
\text { unsupervised, } 60 \text { minute session weekly and subjects were encouraged to use the sauna or swimming pool after all sessions. } 79 \% \text { (37/47) of the } \\
\text { subjects who completed the fitness program attended more than } 67 \% \text { of the training sessions. } \\
\text { B.Biofeedback ( } n=43 \text { ): Individual } 30 \text { minute sessions of electromyographic biofeedback and progressive muscle relaxation trianing } 2 \text { times per } \\
\text { week for } 8 \text { weeks. The progressive muscle relaxation technique was taught, with the biofeedback apparatus used as a tonometer to measure the } \\
\text { change in tension of the musculus frontalis. Subjects were encourage to practice techniques twice daily at home during the } 8 \text { weeks of treatment } \\
\text { and for } 16 \text { weeks afterwards. } 88 \% \text { (38/43) of the subjects who completed the biofeedback program attended more than } 67 \% \text { of the biofeedback } \\
\text { sessions } \\
\text { C.Usual care }(n=28) \text { : Subjects continued with usual care at the outpatient rheumatology department (analgesics NSAIDs, or tricyclic } \\
\text { antidepressants, if appropraite) but their general physicians were informed that aerobic exercises and relaxation should not be prescribed or } \\
\text { encouraged } \\
\begin{array}{l}\text { Subjects within each intervention group were randomized to receive an additional education program aimed at compliance with exercise or } \\
\text { biofeedback training. The program consisted of } 6 \text { sessions } 90 \text { minutes in length spread over } 24 \text { weeks and included information on FM, general } \\
\text { health education, self-management, relapse prevention principles, and the importance of the intervention the subjects were randomized to. }\end{array}\end{array}$ \\
\hline Vas 2006 & 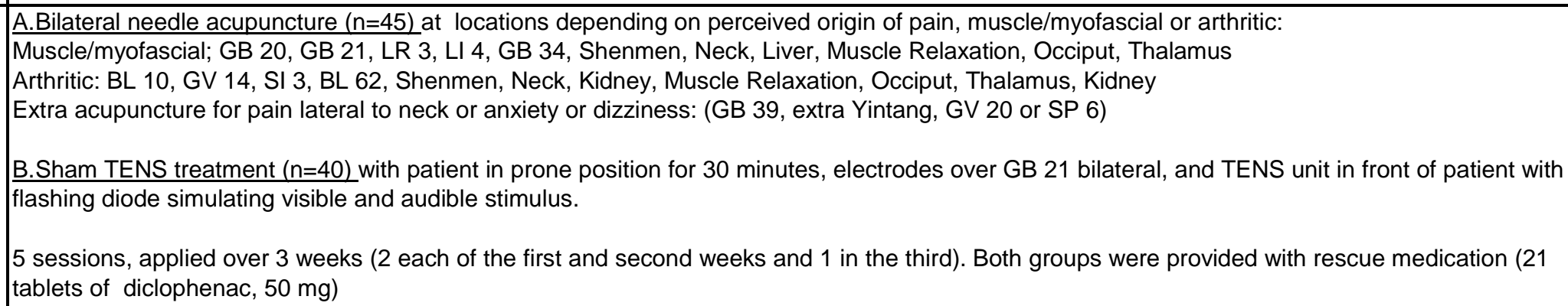 \\
\hline
\end{tabular}




\begin{tabular}{|c|c|c|c|}
\hline Author, Year & Study Participants & Outcome Measures & $\begin{array}{c}\text { Duration of } \\
\text { Followup }\end{array}$ \\
\hline van Santen 2002 & $\begin{array}{l}\text { A vs B vs C } \\
\text { Age: } 46 \text { vs } 44 \text { vs } 43 \\
\text { Female: } 100 \% \text { vs } 100 \% \text { vs } 100 \% \\
\text { Duration of symptoms: } 9.7 \text { vs } 10.1 \text { vs } 15.4 \text { years } \\
\text { SIP physical score: } 11.3(7.7) \text { vs } 11.4(11.2) \text { vs } 9.8(9.3) \\
\text { AIMS: } 1.9(2.1) \text { vs } 3.1(2.1) \text { vs } 5.4(2.0) \\
\text { Pain VAS: } 66.8(15.3) \text { vs } 59.1(18.5) \text { vs } 62.4(20.5) \\
\text { SCL-90-R Global Severity Index: } 182.4(48.0) \text { vs } 176.5(40.5) \text { vs } 183.9 \\
\text { (51.3) } \\
\text { SIP total score: } 14.4(7.8) \text { vs } 14.0(9.4) \text { vs } 11.4(9.4) \\
\text { SIP psychosocial score: } 16.3(11.8) \text { vs } 15.8(11.8) \text { vs } 18.1(13.9) \\
\text { Patient global assessment: } 2.8(0.7) \text { vs } 2.9(0.8) \text { vs } 3.0(0.8)\end{array}$ & $\begin{array}{l}\text { SIP physical score (0-100, higher score=higher impact } \\
\text { Arthritis Impact Measurement Scale (Dutch AIMS; 0-10, } \\
\text { higher score=higher impact) } \\
\text { Pain VAS (0-100, higher score=higher pain) } \\
\text { SCL-90-R Global Severity Index (higher score=more } \\
\text { severe psychological distress) } \\
\text { SIP total score (0-100, higher score=higher health- } \\
\text { related dysfunction) } \\
\text { SIP psychosocial score (0-100, higher score=higher } \\
\text { psychosocial dysfunction) } \\
\text { Patient global assessment (1-5, higher score=higher } \\
\text { general sense of well-being) }\end{array}$ & $\begin{array}{l}\text { Immediately } \\
\text { post- } \\
\text { intervention } \\
\text { (treatment of } \\
6 \text { months) }\end{array}$ \\
\hline Vas 2006 & $\begin{array}{l}\text { A vs B } \\
\text { Age: } 46 \text { vs } 47 \text { years } \\
\text { Female: } 75 \% \text { vs } 89 \% \\
\text { Intensive physical work: } 31 \% \text { vs } 21 \% \\
\text { Pain duration: } 47 \text { vs } 43 \text { months } \\
\text { Pain VAS with motion }(0-100): 68.7(14.3) \text { vs } 72.3(15.4) \\
\text { NPQ (0-100): } 52.7(14.0) \text { vs } 56.5(13.2) \\
\text { SF-36 PCS }(0-100): 36.7(9.7) \text { vs } 37.6(7.9) \\
\text { SF-36 MCS }(0-100): 38.7(13.0) \text { vs } 34.0(11.4)\end{array}$ & $\begin{array}{l}\text { Pain intensity with movement (scale 0-100, higher score } \\
\text { worse pain) } \\
\text { Northwick Park Neck pain Questionnaire (NPNQ) } \\
\text { (scale: 0-100\%, higher percentage the greater the } \\
\text { disability) } \\
\text { Short-Form } 36 \text { (SF-36) (scale 0-100, higher } \\
\text { score=better QoL) } \\
\text { Rescue medication use (scale none, occasional, } \\
\text { prescribed dose, above prescribed dose) }\end{array}$ & 6 months \\
\hline
\end{tabular}




\begin{tabular}{|c|c|}
\hline Author, Year & $\begin{array}{c}\text { Results - Subquestion a } \\
\text { (vs. sham, no treatment, waitlist, attention control) }\end{array}$ \\
\hline van Santen 2002 & $\begin{array}{l}\text { A vS C } \\
6 \text { months (mean change score }(95 \% \text { CI)): } \\
\text { SIP physical score: }-1.7(-3.7 \text { to } 0.3) \text { vs }-0.6(-2.9 \text { to } 1.7) \\
\text { AIMS: } 0.1(-0.6 \text { to } 0.8) \text { vs } 0.8(-1.8 \text { to }-0.2) \\
\text { Pain VAS: }-5.5(-10.9 \text { to }-0.1) \text { vs } 1.3(-4.5 \text { to } 7.1) \\
\text { SCL-90-R Global Severity Index: }-6.8(-20.1 \text { to } 6.5) \text { vs }-8.1(-19.8 \text { to } 3.6) \\
\text { SIP total score: }-1.9(-3.9 \text { to } 0.1) \text { vs }-1.4(-3.4 \text { to } 0.6) \\
\text { SIP psychosocial score: }-3.2(-6.2 \text { to } 0.2) \text { vs }-3.5(-7.0 \text { to } 0.0) \\
\text { Patient global assessment: } 0.5(0.2 \text { to } 0.8) \text { vs } 0.5(0.2 \text { to } 0.8) \\
\text { B vs C } \\
6 \text { months (mean change score }(95 \% \text { CI)): } \\
\text { SIP physical score: }-1.6(-3.4 \text { to } 0.2) \text { vs }-0.6(-2.9 \text { to } 1.7) \\
\text { Pain VAS: }-0.6(-6.5 \text { to } 5.3) \text { vs } 1.3(-4.5 \text { to } 7.1) \\
\text { SCL-90-R Global Severity Index: Data NR } \\
\text { AIMS: } 0.4(-0.1 \text { to } 0.9) \text { vs } 0.8(-1.8 \text { to }-0.2) \\
\text { SIP total score: }-2.3(-4.3 \text { to }-0.3) \text { vs }-1.4(-3.4 \text { to } 0.6) \\
\text { SIP psychosocial score: }-3.7(-4.9 \text { to }-2.5) \text { vs }-3.5(-7.0 \text { to } 0.0) \\
\text { Patient global assessment: } 0.3(0.0 \text { to } 0.6) \text { vs } 0.5(0.2 \text { to } 0.8)\end{array}$ \\
\hline Vas 2006 & $\begin{array}{l}\text { A vs } B \\
6 \text { months } \\
\text { (mean difference from baseline) } \\
\text { Pain VAS with motion }(0-100): 41.1(26.9) \text { vs } 26.8(25.9), M D 14.4(95 \% \text { Cl } 2.9 \text { to } 25.8), p=0.014 \\
\text { SF-36 PCS: }(0-100): 9.3(11.0) \text { v } 5.3(8.0), p=0.054 \\
\text { SF-36 MCS: }(0-100): 8.0(13.5) \text { vs } 5.2(14.1), p=0.351 \\
\text { Rescue med (none or occasional): } 87 \%(39 / 45) \text { vs } 68 \%(27 / 40), p=0.041\end{array}$ \\
\hline
\end{tabular}




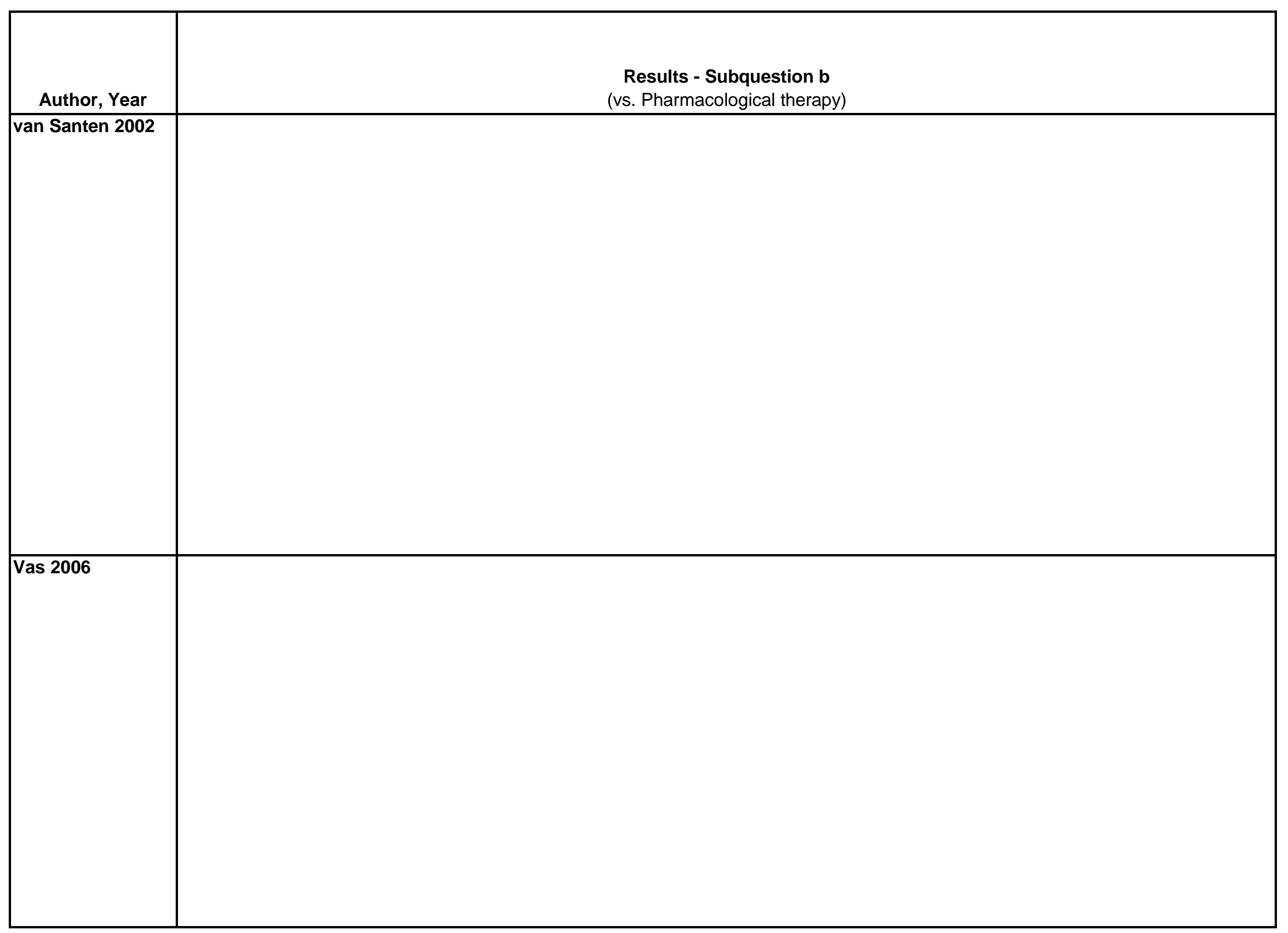

D-802 


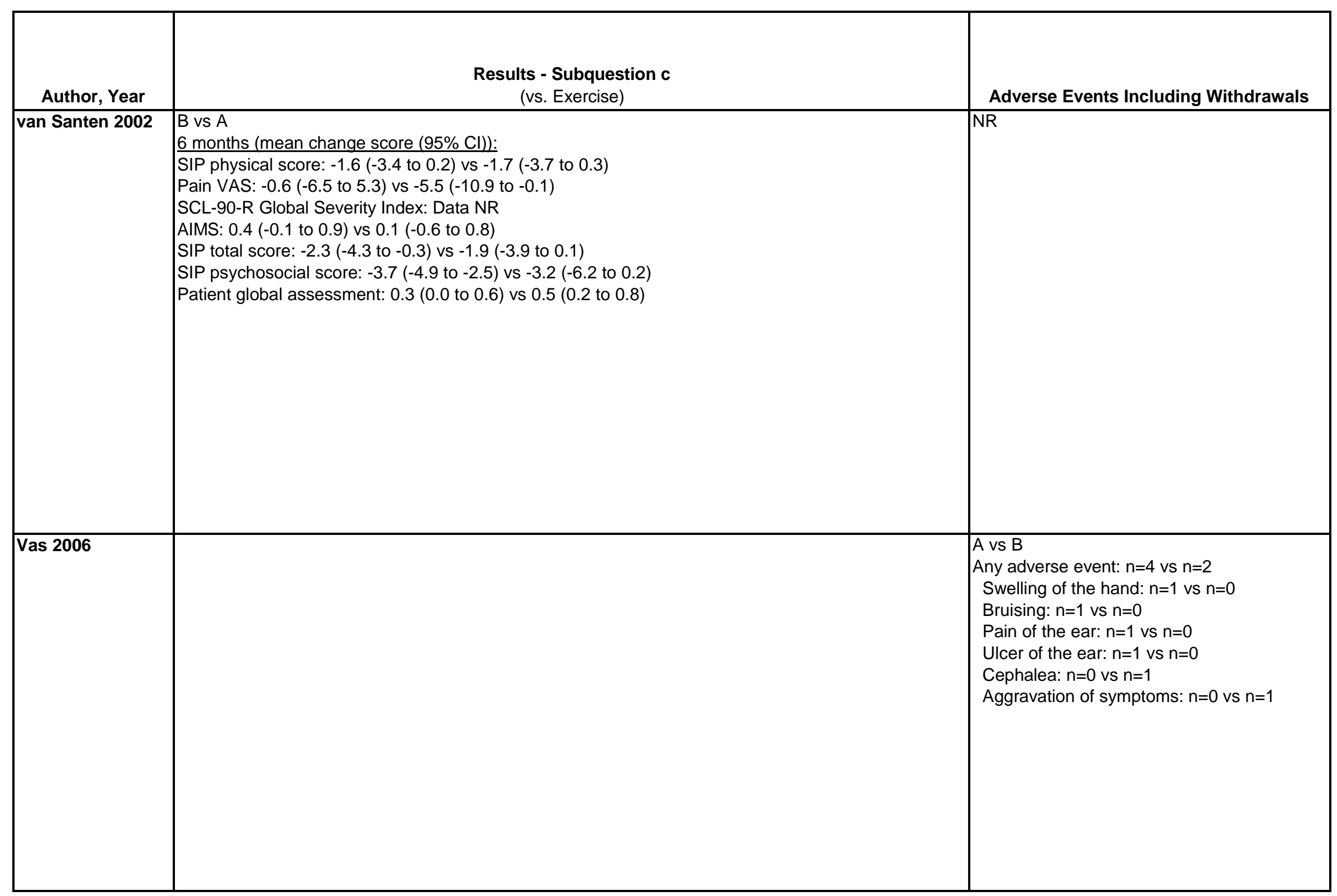




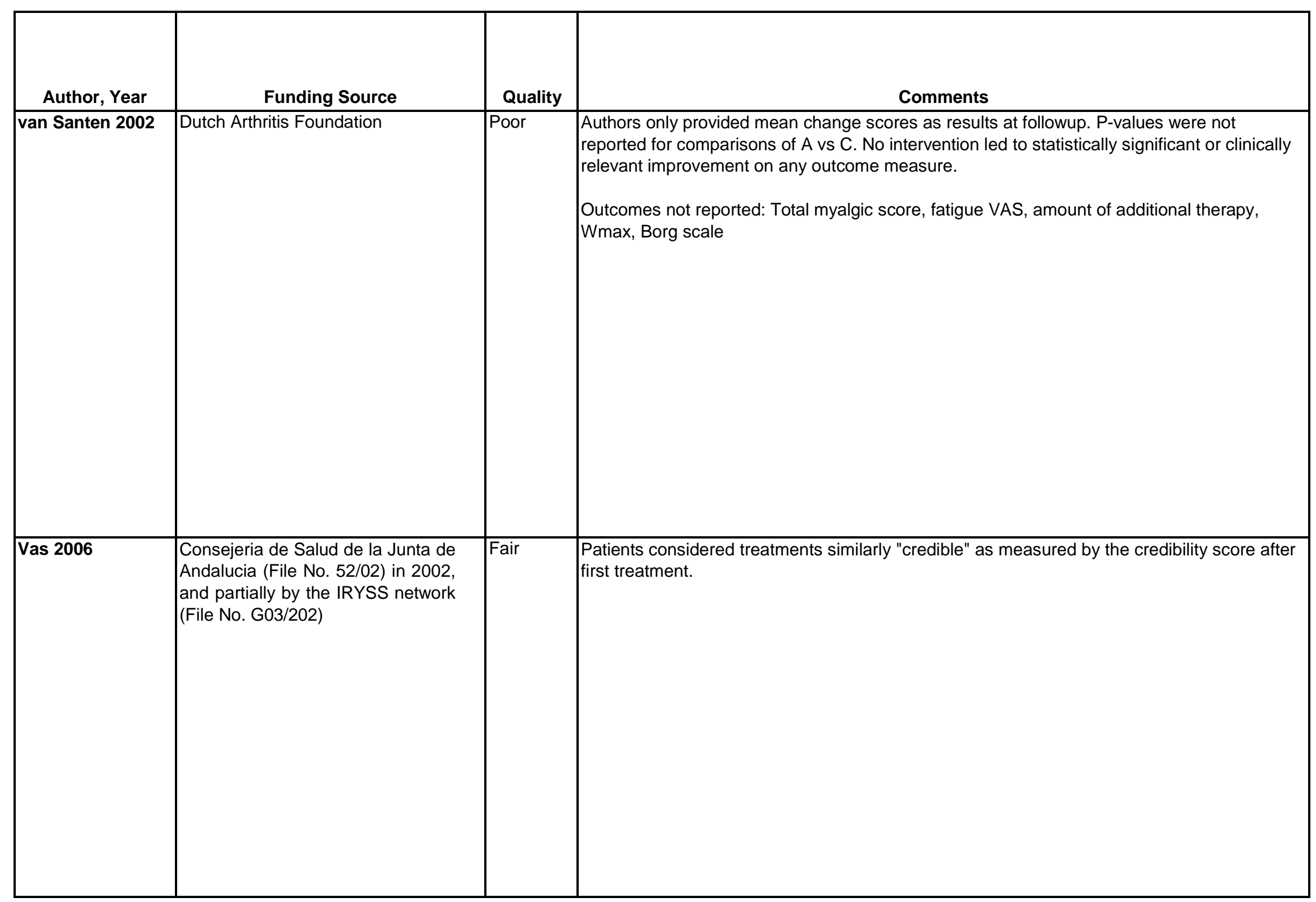




\begin{tabular}{|c|c|c|c|}
\hline Author, Year & $\begin{array}{c}\text { Country } \\
\text { Number of Centers } \\
\text { Setting }\end{array}$ & Inclusion/Exclusion Criteria & $\begin{array}{c}\text { Number Randomized, } \\
\text { Analyzed } \\
\text { Attrition }\end{array}$ \\
\hline Vas 2016 & $\begin{array}{l}\text { Spain, multicenter, } \\
\text { primary care }\end{array}$ & $\begin{array}{l}\text { Inclusion Criteria: } \\
\text { Patients included were over } 17 \text { years old, were diagnosed with } \\
\text { fibromyalgia according toe American College of Rheumatology } \\
\text { criteria, had not received acupuncture before and were referred by } \\
\text { their general practitioner. } \\
\\
\text { Exclusion Criteria: } \\
\text { Participants were excluded if they had chronic pain in relation to any } \\
\text { process other than fibromyalgia, were using anticoagulants or opiates, } \\
\text { were pregnant or a nursing mother, or were involved in occupational } \\
\text { litigation for reasons involving fibromyalgia. }\end{array}$ & $\begin{array}{l}\text { Randomized: } 164 \\
\text { Treated: NR } \\
\text { Analyzed: } \\
\text { Attrition: } \\
\text { Post-treatment: } 3.0 \% \\
\text { (5/164) } \\
\text { 3.75 months: } 5.4 \%(9 / 164) \\
9.75 \text { months: } 6.7 \% \\
(11 / 164)\end{array}$ \\
\hline Verkaik 2014 & \begin{tabular}{|l|} 
Netherlands \\
1 center \\
Type of center unclear
\end{tabular} & $\begin{array}{l}\text { FM diagnosis fulfilling } 1990 \text { ACR criteria of } 6 \text { years of less, ability to } \\
\text { travel and sit for } 1.5 \text { hours, and sufficient hearing } \\
\text { Exclude: Presence of psychiatric illness }\end{array}$ & $\begin{array}{l}\text { Randomized: } 70 \\
\text { Treated: } 65 \\
\text { Analyzed: } 53 \\
\text { Attrition: } 24 \% \text { (17/70) }\end{array}$ \\
\hline
\end{tabular}




\begin{tabular}{|c|c|}
\hline Author, Year & Intervention, Comparator \\
\hline Vas 2016 & $\begin{array}{l}\text { A.Acupuncture }(\mathrm{n}=80) \\
\text { Patients received acupuncture according to principles of Traditional Chinese Medicine from a trained medical expert. Patients also received } \\
\text { pharmacological treatment as prescribed by GP. } \\
\text { No. of Treatments: } 1 \text { session per week for } 9 \text { weeks ( } 9 \text { total) } \\
\text { Length of Treatments: } 20 \text { min each } \\
\text { Acupoints: NR } \\
\text { No. of Needles: NR } \\
\text { B.Sham Acupuncture }(n=82) \\
\text { Treatment and evaluation time were identical in both groups. The sham group received an acupuncture simulation on the dorsal and lumbar } \\
\text { regions, in which guide tubes for the same type of needle as used in the real acupuncture group were } \\
\text { applied to the body surface, but after removal of the } \\
\text { needles. Patients also received pharmacological treatment as prescribed by GP. }\end{array}$ \\
\hline Verkaik 2014 & $\begin{array}{l}\text { A.Guided imagery }(\mathrm{n}=33) \text { : Two } 1.5 \text { hour group sessions of } 6-12 \text { subjects. The first sessions consisted of group discussion, the theoretical } \\
\text { background of guided imagery, and instructions to practice at least one exercise daily for } 4 \text { weeks. Each exercise was a CD and contained } \\
\text { relaxation techniques, music, positive imagery, and pain management techniques. The second group session took place after the } 4 \text { weeks and } \\
\text { consisted of a group discussion. } \\
\text { B.Attention control }(n=37) \text { : Two } 1.5 \text { hour group sessions of } 6-12 \text { subjects held } 4 \text { weeks apart. Group sessions were a group discussion and did not } \\
\text { contain any information or training on guided imagery. }\end{array}$ \\
\hline
\end{tabular}




\begin{tabular}{|c|c|c|c|}
\hline Author, Year & Study Participants & Outcome Measures & $\begin{array}{l}\text { Duration of } \\
\text { Followup }\end{array}$ \\
\hline Vas 2016 & $\begin{array}{l}\text { A vs. B } \\
\text { Age (SD): } 52.3 \text { vs. } 53.2 \\
\text { Female: } 100 \% \text { vs. } 100 \% \\
\text { Race: } 98.8 \% \text { vs. } 98.8 \% \text { Spanish nationality } \\
\text { Mean duration of chronicity: } 5.89 \text { vs. } 5.76 \\
\\
\text { Fibromyalgia Impact Questionnaire (FIQ): } 71.7(11.0) \text { vs. } 70.1(14.2) \\
\text { Pain Intensity (VAS): } 79.3(11.0) \text { vs. } 75.8(13.3) \\
\text { HDRS: } 16.3(7.0) \text { vs. } 16.6(6.7) \\
\text { Short Form } 12 \text { Physical Component: } 28.5(8.3) \text { vs. } 31.0(8.4) \\
\text { Short Form } 12 \text { Mental Component: } 32.8(11.1) \text { vs. } 34.1(10.4)\end{array}$ & $\begin{array}{l}\text { Fibromyalgia Impact Questionnaire (FIQ, range 0-100: } \\
\text { higher scores indicate severity of symptoms) } \\
\text { Pain Intensity (VAS, range: 0-100; higher score=greater } \\
\text { pain) } \\
\text { Hamilton Depression Rating Scale (HDRS, range NR: } \\
\text { higher scores indicate severity of depression) } \\
\text { Short Form } 12 \text { Physical Component (SF-12, range 0- } \\
\text { 100: higher scores indicate optimal health status) } \\
\text { Short Form } 12 \text { Mental Component (SF-12, range 0-100: } \\
\text { higher scores indicate optimal health status) }\end{array}$ & $\begin{array}{l}3.75 \text { and } \\
9.75 \text { months }\end{array}$ \\
\hline Verkaik 2014 & $\begin{array}{l}\text { A vs B } \\
\text { Age: } 47 \text { vs } 48 \\
\text { Female: } 100 \% \text { vs } 97 \% \\
\text { Employment: } \\
\quad \text { Unemployed: } 35 \% \text { vs } 30 \% \\
\quad \text { < } 16 \text { hours weekly: } 9 \% \text { vs } 28 \% \\
\text { Between } 16 \text { and } 32 \text { hours weekly: } 44 \% \text { vs } 30 \% \\
\text { Between } 33 \text { and } 40 \text { hours weekly: } 9 \% \text { vs } 9 \% \\
\text { > } 40 \text { hours weekly: } 0 \% \text { vs } 3 \% \\
\text { Years since diagnosis: } \\
\quad 0-1: 53 \% \text { vs } 37 \% \\
\quad 2-4: 38 \% \text { vs } 48 \% \\
5-6: 9 \% \text { vs } 12 \% \\
\text { FIQ: } 53.7(2.7) \text { vs } 56.4(2.0) \\
\text { Pain VAS, mean }(95 \% \text { CI): } 5.9(5.3 \text { to } 6.3) \text { vs } 5.8(5.0 \text { to } 6.6)\end{array}$ & $\begin{array}{l}\text { FIQ }(0-100 \text {, higher score=lower function); pain VAS }(0- \\
10 \text {, higher score=higher pain) }\end{array}$ & 1.5 months \\
\hline
\end{tabular}




\begin{tabular}{|c|c|}
\hline Author, Year & $\begin{array}{c}\text { Results - Subquestion a } \\
\text { (vs. sham, no treatment, waitlist, attention control) }\end{array}$ \\
\hline Vas 2016 & $\begin{array}{l}\text { A vs. B } \\
\text { 3.75 months } \\
\text { Mean relative change Fibromyalgia Impact Questionnaire (FIQ): }-25.0(-29.8 \text { to }-20.2) \text { vs. }-11.2(-16.9 \text { to }-5.5) p<0.001 \\
\text { Mean relative change Short Form } 12 \text { Physical Component: } 37.0(27.8 \text { to } 46.3) \text { vs. } 15.5(7.8 \text { to } 23.3) p=0.001 \\
\text { Mean relative change Pain Intensity (VAS, range: } 0-100 \mathrm{~mm}):-23.6(-28.8 \text { to }-18.5) \text { vs. }-16.6(-22.7 \text { to }-10.5) p=0.047 \\
\text { Mean relative change Short Form } 12 \text { Mental Component: } 30.6(19.7 \text { to } 41.5) \text { vs. } 13.9(5.4 \text { to } 22.5) p=0.011 \\
\text { Mean relative change HDRS: NR } \\
9.75 \text { months } \\
\text { Mean relative change Fibromyalgia Impact Questionnaire (FIQ): }-22.2(-26.4 \text { to }-18.0) \text { vs. }-4.9(-10.2 \text { to } 0.5) p<0.001 \\
\text { Mean relative change Short Form } 12 \text { Physical Component: } 35.0(25.1 \text { to } 45.0) \text { vs. } 11.2(2.6 \text { to } 19.7) p<0.001 \\
\text { Mean relative change Pain Intensity (VAS, range: } 0-100 \mathrm{~mm}):-19.9(-24.6 \text { to }-15.1) \text { vs. }-6.2(-11.2 \text { to }-1.2) p<0.001 \\
\text { Mean relative change HDRS: }-19.1 \text { (-34.2 to }-3.9) \text { vs. }-5.9(-16.6 \text { to } 4.8) p=0.011 \\
\text { Mean relative change Short Form } 12 \text { Mental Component: } 23.0(13.7 \text { to } 32.4) \text { vs. } 9.4(1.9 \text { to } 16.9) p=0.013\end{array}$ \\
\hline Verkaik 2014 & $\begin{array}{l}\text { A vs B } \\
\text { FIQ: } 54.2(2.6) \text { vs } 53.0(2.5),(\mathrm{MD} 1.2,95 \% \mathrm{Cl}-0.2 \text { to } 2.6) \mathrm{p}=0.09 \\
\text { Pain VAS: NR* }\end{array}$ \\
\hline
\end{tabular}




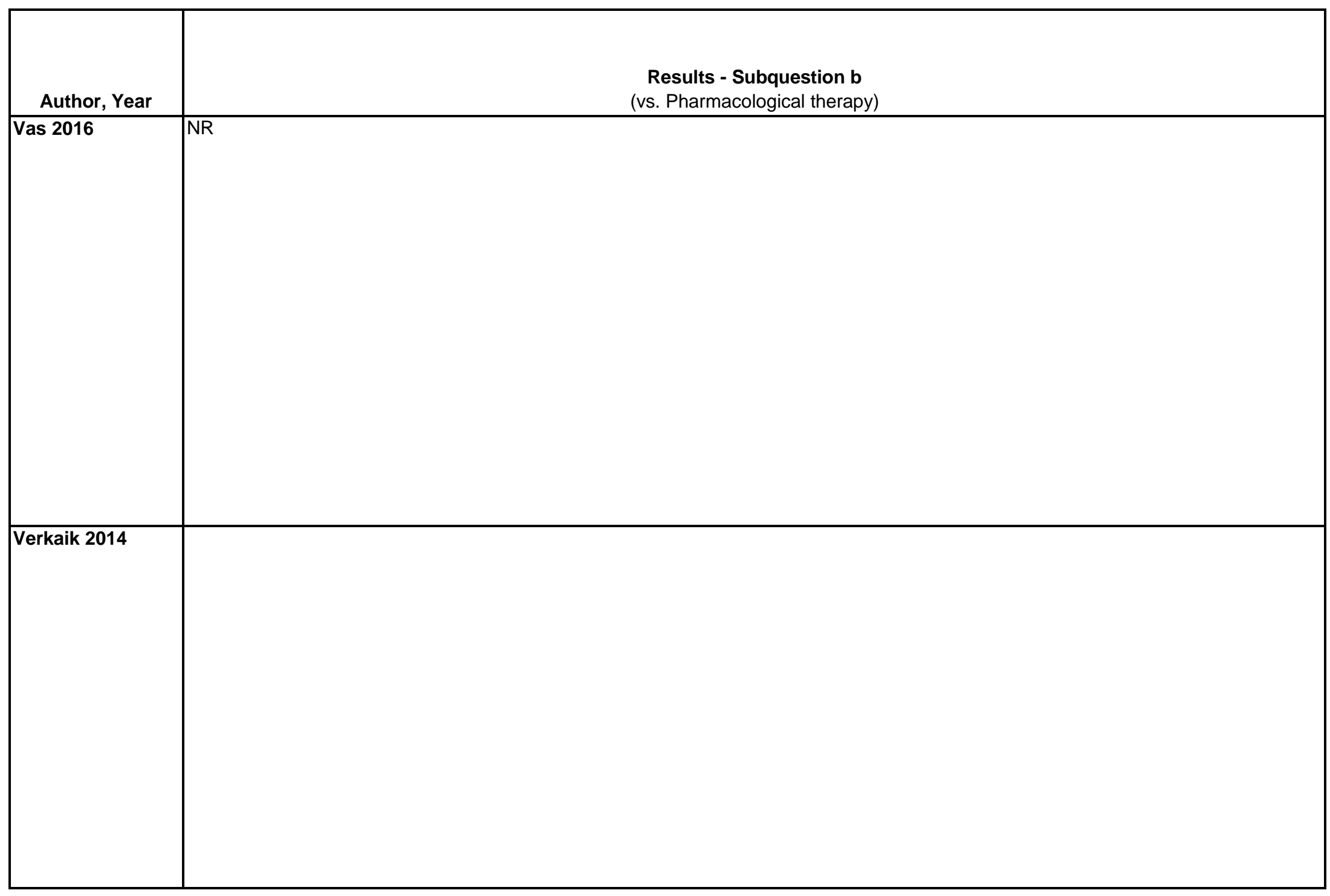

D-809 


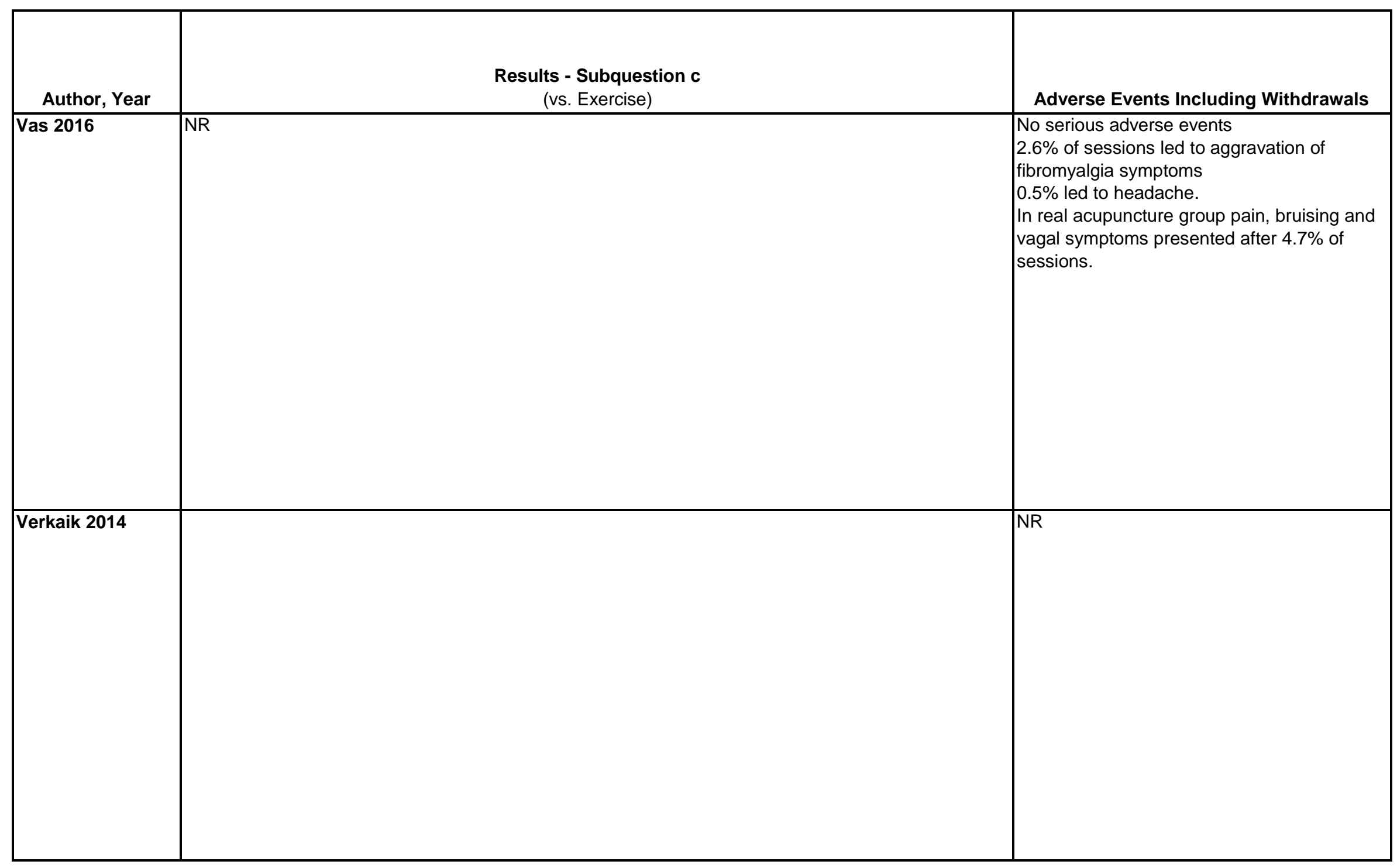




\begin{tabular}{|c|c|c|c|}
\hline Author, Year & Funding Source & Quality & Comments \\
\hline Vas 2016 & $\begin{array}{l}\text { This paper presents independent } \\
\text { research funded by the Spanish } \\
\text { Ministry of Health and Consumer } \\
\text { Affairs (Carlos III Health Institute, } \\
\text { project number PI10/00675) and by } \\
\text { the Andalusian Public Health System } \\
\text { (project number PI0436/09). The } \\
\text { funding agencies had no influence on } \\
\text { the design of the study, the analysis, } \\
\text { or the writing of the paper. }\end{array}$ & Good & \\
\hline Verkaik 2014 & Fonds NutsOhra & Poor & $\begin{array}{l}\text { *Study only reported pain VAS values for days } 1 \text { to } 26 \text { of the study period (intervention } \\
\text { lasted } 4 \text { weeks) } \\
\text { MD and p value calculated }\end{array}$ \\
\hline
\end{tabular}




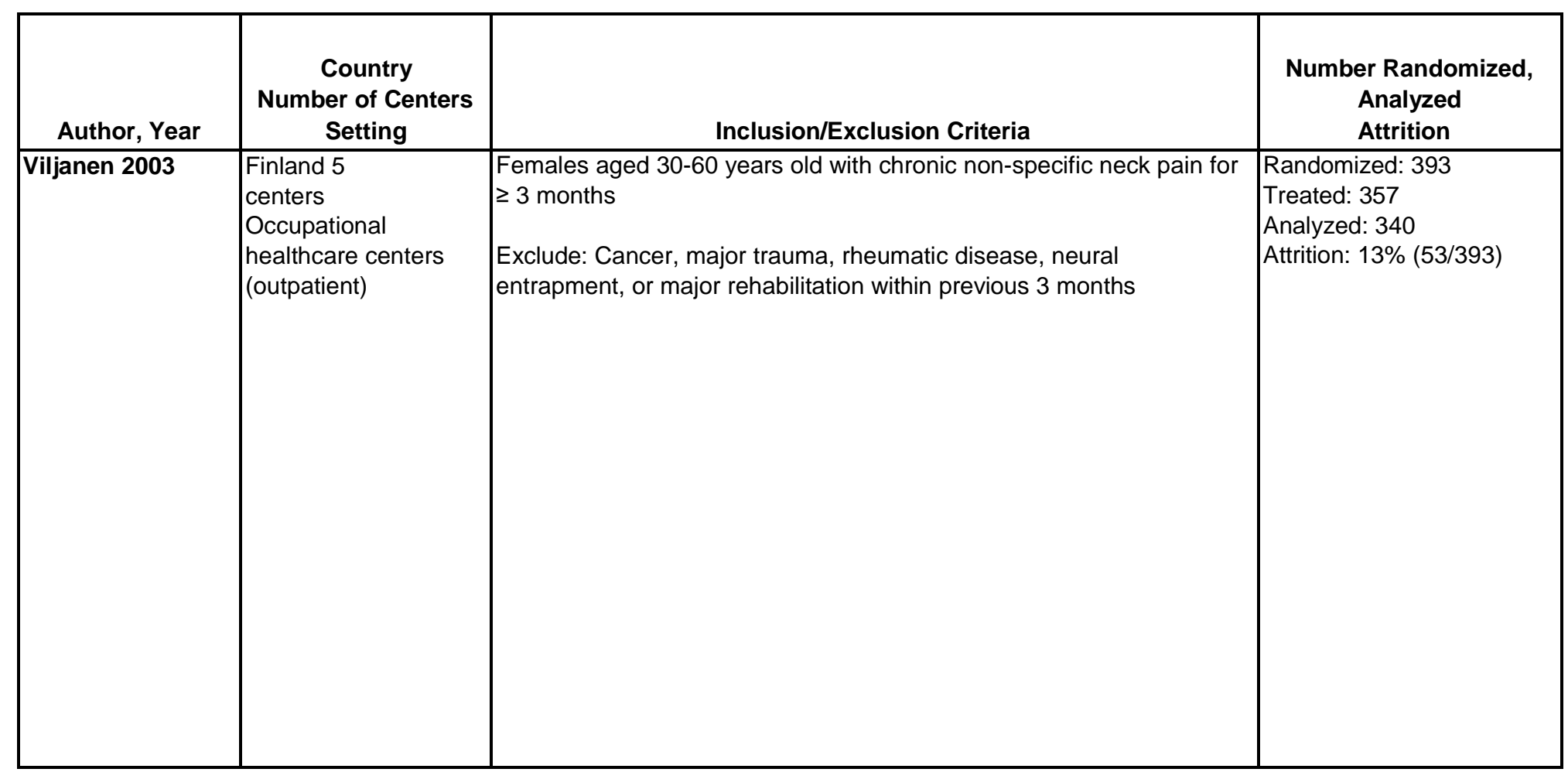




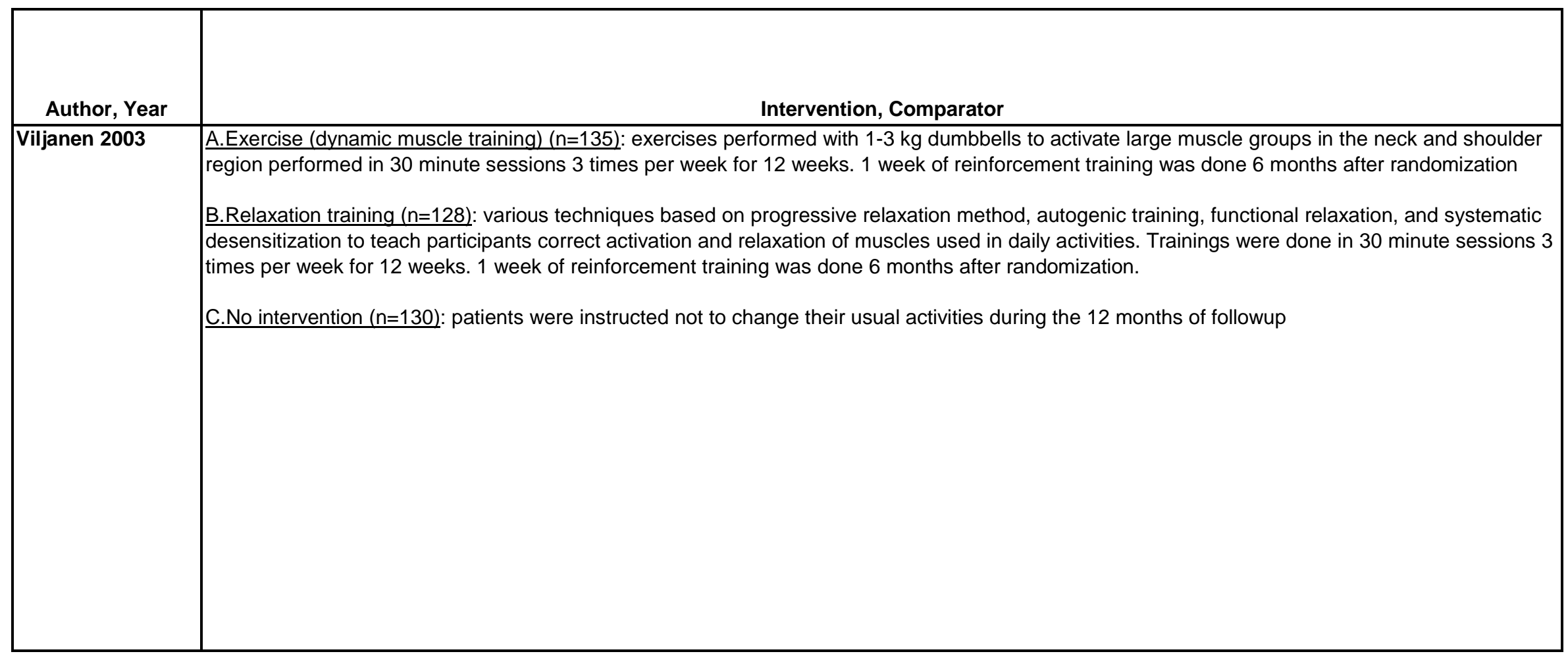




\begin{tabular}{|c|c|c|c|}
\hline Author, Year & Study Participants & Outcome Measures & $\begin{array}{l}\text { Duration of } \\
\text { Followup }\end{array}$ \\
\hline Viljanen 2003 & $\begin{array}{l}\text { A vs B vs C } \\
\text { Age: } 45 \text { vs } 43 \text { vs } 44 \text { years } \\
\text { Female: } 100 \% \\
\text { Performing physical activity } \geq 3 x / \text { week: } 44 \% \text { vs. } 34 \% \text { vs. } 41 \% \\
\text { Duration of office work: } 23 \text { vs. } 20 \text { vs. } 21 \text { years } \\
\text { Sedentary work }>6 \text { hours/day: } 76 \% \text { vs. } 75 \% \text { vs. } 73 \% \\
\text { Computer work >6 hours/day: } 33 \% \text { vs. } 39 \% \text { vs. } 35 \% \\
\text { Absent from work due to neck pain: } 12 \% \text { vs. } 12 \% \text { vs. } 12 \% \\
\text { Pain duration: } 11 \text { vs } 11 \text { vs } 10 \text { years } \\
\text { Neck disability scale }(0-80) 29(15.4) \text { vs } 29(14.3) \text { vs } 26(13.8) \\
\text { Pain VAS: } 4.8(2.3) \text { vs } 4.8(2.3) \text { vs } 4.1(2.2) \\
\text { Depression index: } 16(4.4) \text { vs } 16(4.9) \text { vs } 16(4.6)\end{array}$ & $\begin{array}{l}\text { Neck disability scale (0-80, higher score=higher } \\
\text { disability); pain VAS (0-10, higher score=higher pain); } \\
\text { depression index (10-40, higher score=more } \\
\text { depression) }\end{array}$ & \begin{tabular}{|l|}
3 and 9 \\
months
\end{tabular} \\
\hline
\end{tabular}




\begin{tabular}{|c|c|}
\hline Author, Year & $\begin{array}{c}\text { Results - Subquestion a } \\
\text { (vs. sham, no treatment, waitlist, attention control) }\end{array}$ \\
\hline Viljanen 2003 & 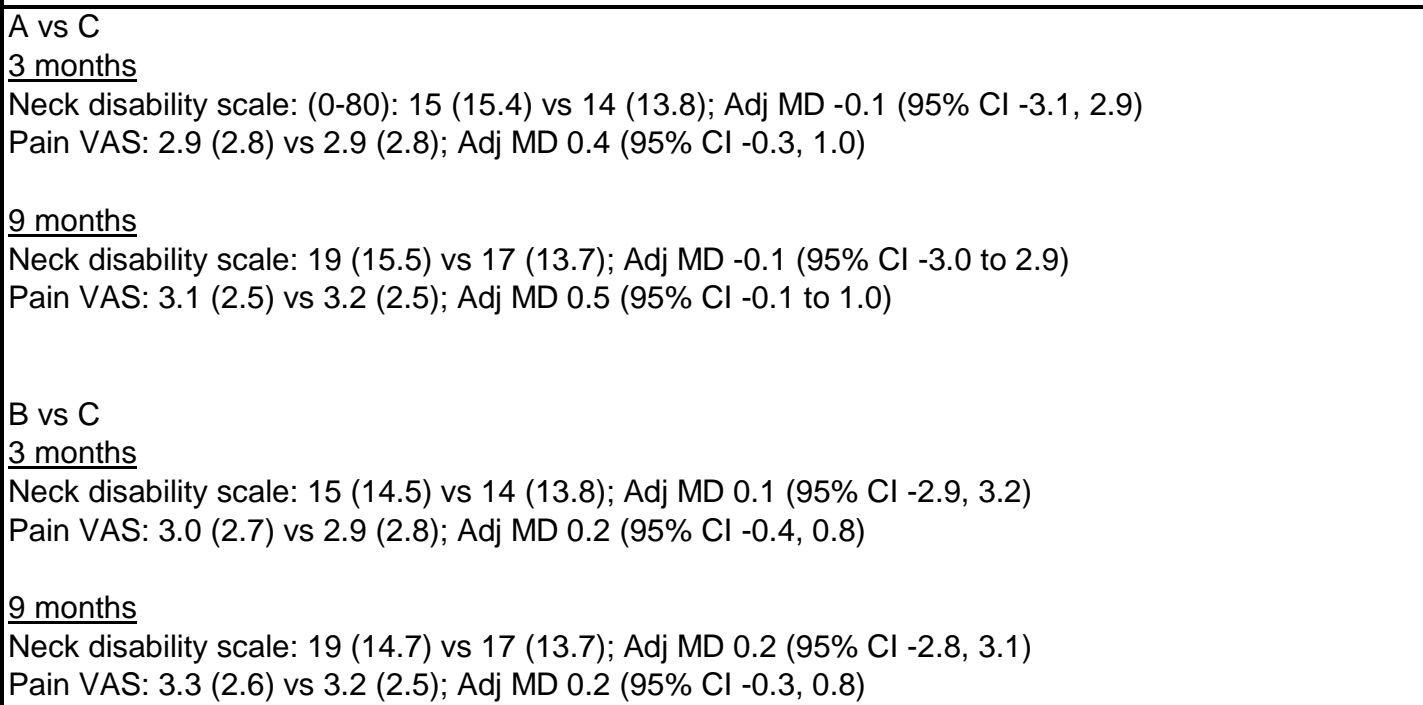 \\
\hline
\end{tabular}




\begin{tabular}{|l|c|}
\hline Author, Year & Results - Subquestion b \\
Viljanen 2003 & (vs. Pharmacological therapy) \\
\hline & \\
& \\
& \\
\hline
\end{tabular}

D-816 


\begin{tabular}{|c|c|c|}
\hline Author, Year & $\begin{array}{l}\text { Results - Subquestion c } \\
\text { (vs. Exercise) }\end{array}$ & Adverse Events Including Withdrawals \\
\hline Viljanen 2003 & 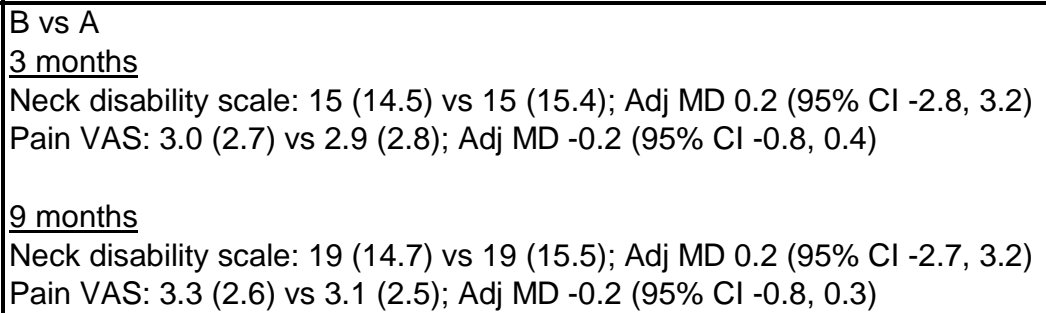 & NR \\
\hline
\end{tabular}




\begin{tabular}{|l|l|c|l|}
\hline Author, Year & \multicolumn{1}{|c|}{ Funding Source } & Quality & \multicolumn{1}{c|}{ Comments } \\
\hline Viljanen 2003 & $\begin{array}{l}\text { Finish work environment fund (project } \\
\text { No 96243) }\end{array}$ & Fair & $\begin{array}{l}\text { Results were reported comparing exercise (A) to control (C] and separately relaxation } \\
\text { training (B) to control (C]. } \\
\text { Outcomes not reported: subjective work ability, sick leave owing to neck pain, cervical ROM, } \\
\text { self reported recovery } \\
\text { Neck disability scale as reported by these authors is not the validated NDI measure; it is } \\
\text { comprised of 8 questions, each rated on a 0-10 VAS. While the authors refer to this as a } \\
\text { neck disability index, we use the term neck disability scale to avoid confusion with the } \\
\text { validated NDI. }\end{array}$ \\
& & \\
\hline
\end{tabular}




\begin{tabular}{|c|c|c|c|}
\hline Author, Year & $\begin{array}{c}\text { Country } \\
\text { Number of Centers } \\
\text { Setting }\end{array}$ & Inclusion/Exclusion Criteria & $\begin{array}{c}\text { Number Randomized, } \\
\text { Analyzed } \\
\text { Attrition }\end{array}$ \\
\hline Von Korff 2005 & $\begin{array}{l}\text { USA } \\
\text { Number of centers } \\
\text { unclear } \\
\text { Outpatient }\end{array}$ & $\begin{array}{l}\text { Primary care back pain patients } \\
\text { Age } 25-64 \\
\text { Endorsing } \geq 7 \text { activity limitations on the RDQ } \\
\text { Exclude: Patients being considered for back surgery } \\
\text { Currently being managed by a physical therapist or psychologist for } \\
\text { back pain }\end{array}$ & $\begin{array}{l}\text { Randomized: } 240 \\
\text { Treated: } 228 \\
\text { Analyzed: } 207 \\
\text { Attrition: } 14 \%(33 / 240)\end{array}$ \\
\hline
\end{tabular}




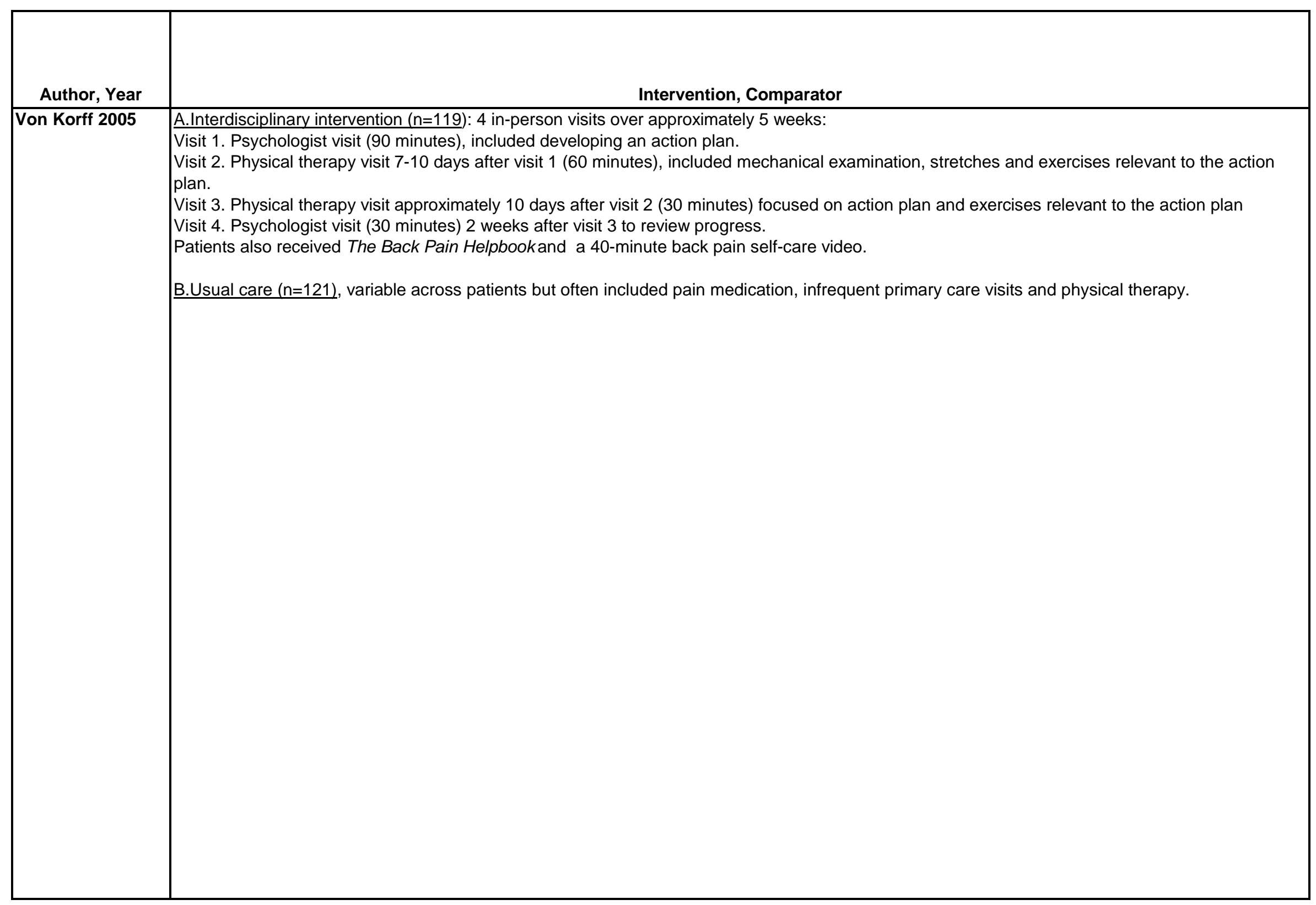




\begin{tabular}{|c|c|c|c|}
\hline Author, Year & Study Participants & Outcome Measures & $\begin{array}{c}\text { Duration of } \\
\text { Followup }\end{array}$ \\
\hline Von Korff 2005 & $\begin{array}{l}\text { A vs. B } \\
\text { Age (mean): } 50 \text { vs. } 50 \text { years } \\
\text { Female: } 65 \% \text { vs. } 60 \% \\
\text { Race: White: } 84 \% \text { vs. } 83 \% \\
\text { > } 90 \text { back pain days in } 6 \text { months: } 66 \% \text { vs. } 56 \% \\
\text { Chronic Pain Grade: Low pain intensity, Grade I: } 15 \% \text { vs. } 24 \% \\
\text { High pain with low activity limitations, Grade II: } 18 \% \text { vs. } 22 \% \\
\text { Moderate activity limitations, Grade III: } 23 \% \text { vs. } 25 \% \\
\text { Severe activity limitations, Grade IV: } 44 \% \text { vs. } 29 \%\end{array}$ & $\begin{array}{l}\text { Modified Roland Morris Disability Qu questionnaire } \\
\text { (modified RDQ, 0-23, higher number=worse function) } \\
\text { Pain (0-10 NRS) } \\
\text { SF-36 Mental Health (0-100, higher number=better } \\
\text { quality of life) } \\
\text { SF-36 Social Functioning (0-100) } \\
\text { Missed 30+ days from usual activities in prior } 3 \text { months } \\
\text { (yes/no) } \\
\text { On disability or workers compensation (yes/no) } \\
\text { Unable to work (yes/no) }\end{array}$ & $\begin{array}{l}4.5,10.5, \\
\text { and } 22.5 \\
\text { months }\end{array}$ \\
\hline
\end{tabular}




\begin{tabular}{|c|c|}
\hline Author, Year & $\begin{array}{l}\text { Results - Subquestion a } \\
\text { (vs. sham, no treatment, waitlist, attention control) }\end{array}$ \\
\hline Von Korff 2005 & 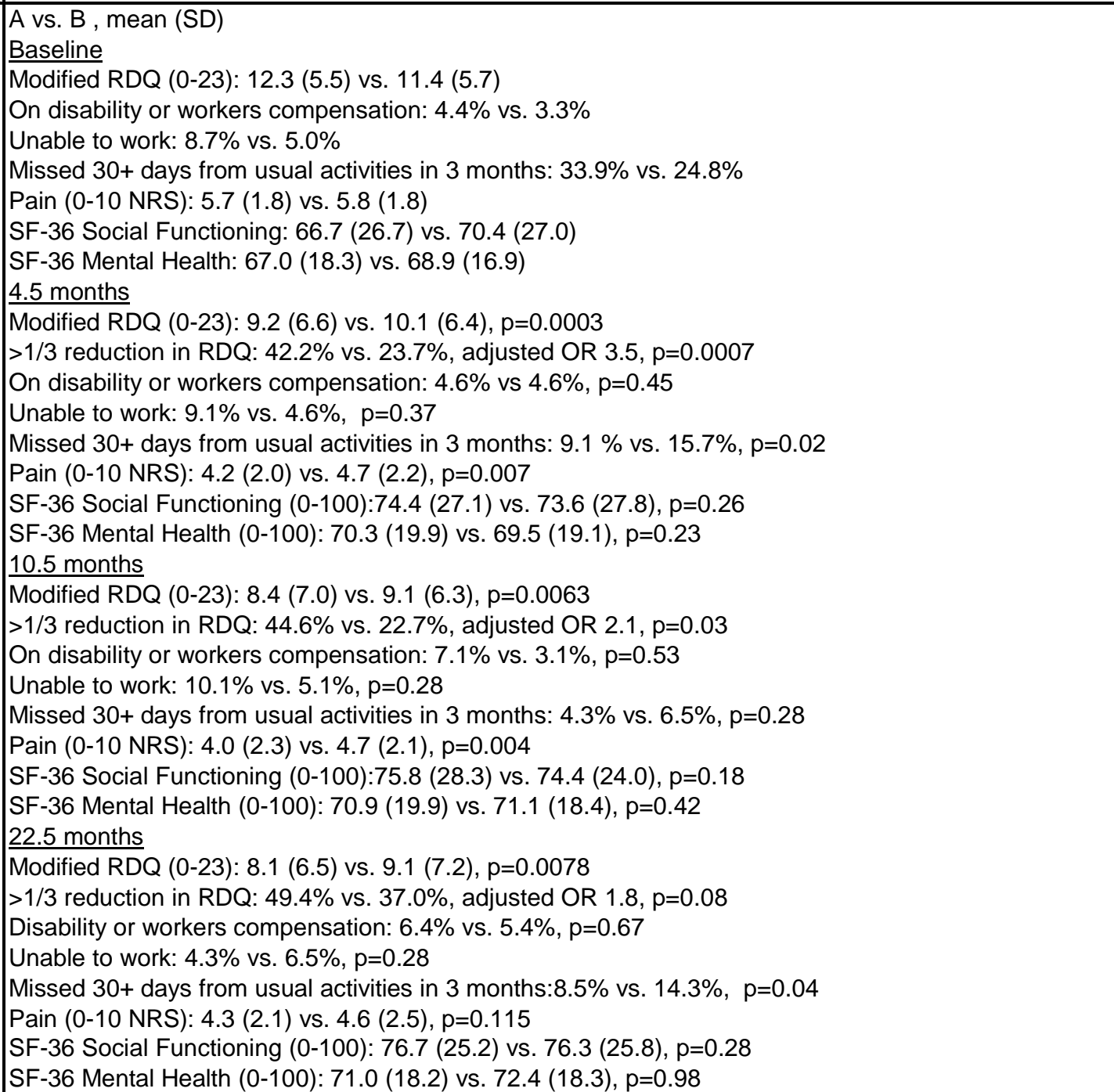 \\
\hline
\end{tabular}




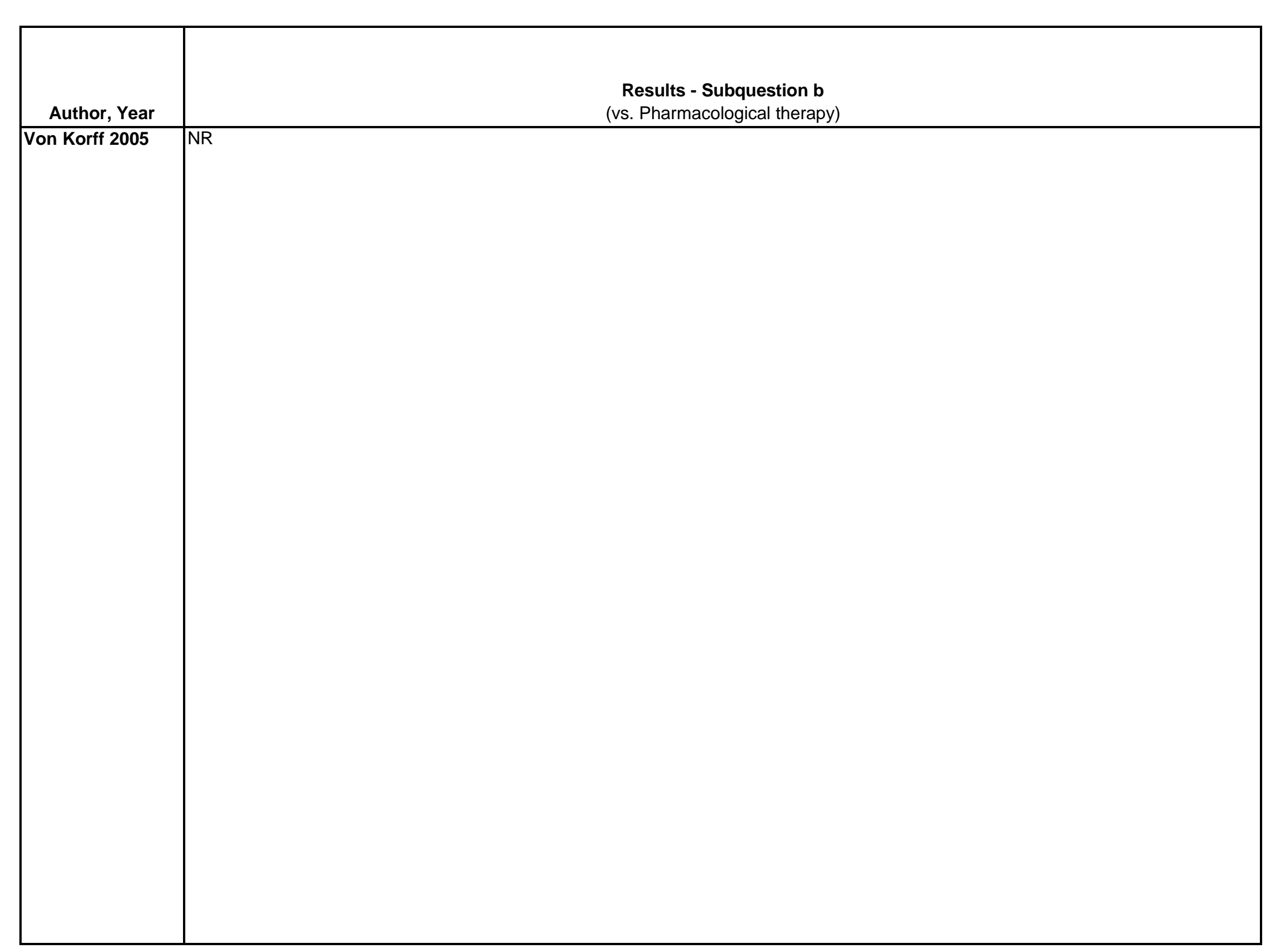




\begin{tabular}{|c|c|c|}
\hline Author, Year & $\begin{array}{c}\text { Results - Subquestion c } \\
\text { (vs. Exercise) }\end{array}$ & Adverse Events Including Withdrawals \\
\hline Von Korff 2005 & 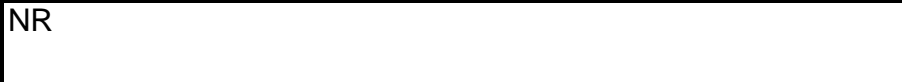 & $\begin{array}{l}\text { Withdrawals NR } \\
\text { AEs NR }\end{array}$ \\
\hline
\end{tabular}




\begin{tabular}{|c|c|c|c|}
\hline Author, Year & Funding Source & Quality & Comments \\
\hline Von Korff 2005 & $\mathrm{NIH}$ grant & Fair & $\begin{array}{l}\text { p-values adjusted for baseline value of the outcome variable, number of pain days and } \\
\text { graded chronic pain (Results - Subquestion a) }\end{array}$ \\
\hline
\end{tabular}




\begin{tabular}{|c|c|c|c|}
\hline Author, Year & $\begin{array}{c}\text { Country } \\
\text { Number of Centers } \\
\text { Setting }\end{array}$ & Inclusion/Exclusion Criteria & $\begin{array}{c}\text { Number Randomized, } \\
\text { Analyzed } \\
\text { Attrition }\end{array}$ \\
\hline Waling 2002 & $\begin{array}{l}\text { Sweden } \\
\text { Various work places } \\
\text { in the city of Umea, } \\
\text { number not reported }\end{array}$ & $\begin{array}{l}\text { Work related pain (pain related to work situation with such intensity } \\
\text { that working required extra effort) in the trapezius muscle, tenderness } \\
\text { at palpation, and limited motion of the cervical spine } \\
\text { Exclude: Diseases of other origin }\end{array}$ & $\begin{array}{l}\text { Randomized: } 126^{\star} \\
\text { Treated: } 103 \\
\text { Analyzed: } \\
6 \text { months: } 87 \\
\text { Attrition: } 31 \%(39 / 126) \\
14 \text { months: } 83 \\
\text { Attrition: } 34 \%(43 / 126) \\
3 \text { years: } 101 \\
\text { Attrition: } 20 \% \\
\text { (25/126) } \\
\text { 'Randomization of clusters } \\
\text { formed by selecting a time } \\
\text { that best fit participants' } \\
\text { schedule }\end{array}$ \\
\hline
\end{tabular}




\begin{tabular}{|c|c|}
\hline Author, Year & Intervention, Comparator \\
\hline Waling 2002 & $\begin{array}{l}\text { A.Strength training }(n=29): 3 \text { times per week for } 10 \text { weeks, } 1 \text { hour per session, of physiotherapist supervised strength training of neck and } \\
\text { shoulder muscles with loads of } 10 \text { to } 12 \text { maximal voluntary contractions, } 3 \text { sets. } \\
\text { B.Endurance training ( } n=28): 3 \text { times per week for } 10 \text { weeks, } 1 \text { hour per session, of physiotherapist supervised endurance training using arm- } \\
\text { cycling and arm exercises with rubber band resistance, } 30 \text { repetition maximum. } \\
\text { C. Coordination training }(n=25): 3 \text { times per week for } 10 \text { weeks, } 1 \text { hour per session, of physiotherapist supervised body awareness training focusing } \\
\text { on balance and postural stability similar to Tai Chi Chuan. } \\
\text { D. Reference group ( } n=21): 1 \text { time per week for } 10 \text { weeks, } 2 \text { hours per session of occupational nurse led stress management. }\end{array}$ \\
\hline
\end{tabular}




\begin{tabular}{|c|c|c|c|}
\hline Author, Year & \begin{tabular}{|c} 
Study Participants \\
\end{tabular} & Outcome Measures & $\begin{array}{l}\text { Duration of } \\
\text { Followup }\end{array}$ \\
\hline Waling 2002 & $\begin{array}{l}\text { A vs B vs C vs D } \\
\text { Age: } 38 \text { vs } 39 \text { vs } 38 \text { vs } 39 \text { years } \\
\text { Female: } 100 \% \text { all groups } \\
\text { Pain duration: } 6.3 \text { vs } 6.5 \text { vs } 6.6 \text { vs } 7.7 \text { years } \\
\text { Pain at present (0-100): } 26(21) \text { vs } 28(20 \text { vs } 33(21) \text { vs } 37(24) \\
\text { Pain in general }(0-100): 39(18) \text { vs } 40(21) \text { vs } 41(17) \text { vs } 43(19) \\
\text { Pain at worst }(0-100): 74(16) \text { vs } 70(17) \text { vs } 77(13) \text { vs } 75(21)\end{array}$ & $\begin{array}{l}\text { Pain at present (VAS scale 0-100, higher score worse } \\
\text { pain) } \\
\text { Pain in general (VAS scale 0-100, higher score worse } \\
\text { pain) } \\
\text { Pain at worst (VAS scale 0-100, higher score worse } \\
\text { pain) } \\
\text { Frequent neck-shoulder pain (\% with pain several } \\
\text { times/week or more) }\end{array}$ & $\begin{array}{l}6 \text { months, } \\
14 \text { months } \\
36 \text { months }\end{array}$ \\
\hline
\end{tabular}




\begin{tabular}{|l|l|}
\hline \multicolumn{1}{|c|}{ Author, Year } & \multicolumn{1}{c|}{$\begin{array}{c}\text { Results - Subquestion a } \\
\text { (vs. sham, no treatment, waitlist, attention control) }\end{array}$} \\
\hline Waling 2002 & $\begin{array}{l}\text { A vs B vs C vs } \mathrm{D} \\
\text { 6 months }\end{array}$ \\
\hline Frequent pain: $76 \%$ vs $91 \%$ vs $78 \%$ vs $73 \%, p=0.50$ \\
$\frac{14 \text { months }}{\text { Frequent pain: } 70 \% \text { vs } 80 \% \text { vs } 91 \% \text { vs } 56 \%, p=0.13}$ \\
$\begin{array}{l}36 \text { months } \\
\text { Pain at present: } 31(27) \text { vs } 22(26) \text { vs } 27(27) \text { vs } 16(19), p=0.073 \\
\text { Pain in general: } 32(22) \text { vs } 29(19) \text { vs } 29(21) \text { vs } 20(18), p=0.249 \\
\text { Pain at worst: } 61(27) \text { vs } 58(27) \text { vs } 57(28) \text { vs } 58(29), p=0.902 \\
\text { Frequent pain: } 47 \% \text { vs } 50 \% \text { vs } 58 \% \text { vs } 39 \%, p=0.66\end{array}$ \\
\hline
\end{tabular}




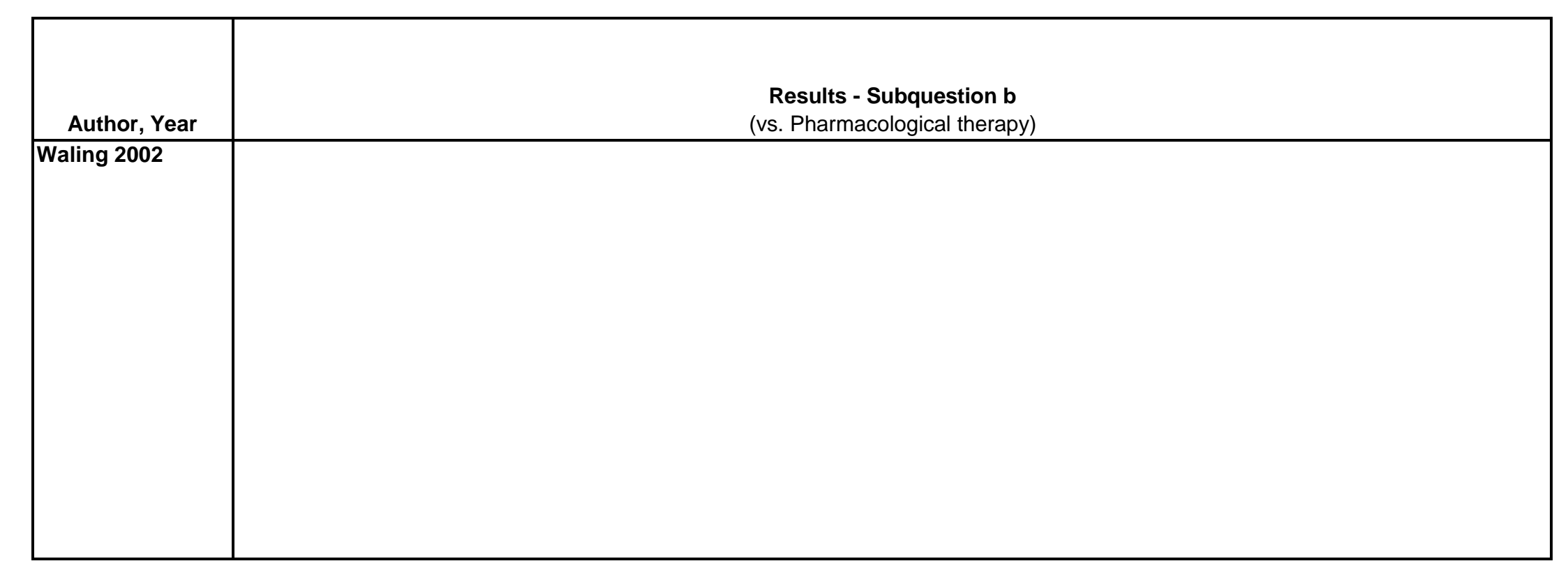

D-830 


\begin{tabular}{|l|c|l|}
\hline \multicolumn{1}{|c|}{ Author, Year } & $\begin{array}{c}\text { Results - Subquestion c } \\
\text { (vs. Exercise) }\end{array}$ & \\
\hline Waling 2002 & & \\
& & Adverse Events Including Withdrawals \\
\hline & & \\
& & \\
\hline
\end{tabular}




\begin{tabular}{|l|l|l|l|}
\hline \multicolumn{1}{|c|}{ Author, Year } & \multicolumn{1}{|c|}{ Funding Source } & Quality & \multicolumn{1}{c|}{ Comments } \\
\hline Waling 2002 & $\begin{array}{l}\text { The Swedish Council for Work Life } \\
\text { Research, Dnr 94-0315 and 97-0940 }\end{array}$ & Poor & $\begin{array}{l}\text { 6.6 month f/u pain results were estimated from figures, but were judged unreliable as } \\
\text { baseline and 3 year values differed from those given in table 3. }\end{array}$ \\
& & & \\
& & & \\
\end{tabular}




\begin{tabular}{|c|c|c|c|}
\hline Author, Year & $\begin{array}{c}\text { Country } \\
\text { Number of Centers } \\
\text { Setting }\end{array}$ & Inclusion/Exclusion Criteria & $\begin{array}{c}\text { Number Randomized, } \\
\text { Analyzed } \\
\text { Attrition } \\
\end{array}$ \\
\hline Wang 2009 & $\begin{array}{l}\text { United States, } \\
\text { hospital, single-site }\end{array}$ & $\begin{array}{l}\text { Inclusion Criteria: } \\
\text { Patients age } \geq 55 \text { years, body mass index (BMI) } \leq 40 \mathrm{~kg} / \mathrm{m} 2 \text {, Western } \\
\text { Ontario and McMaster Universities Osteoarthritis Index (WOMAC) } \\
\text { pain subscale score (visual analog version) }>40 \text { (range } 0-500 \text { ), and } \\
\text { fulfillment of the American College of Rheumatology criteria for knee } \\
\text { OA with radiographic Kellgren/Lawrence scale knee OA grade } 2 \text {. } \\
\\
\text { Exclusion Criteria: } \\
\text { Exclusion of individuals who had prior Tai Chi training or similar types } \\
\text { of alternative medicine like Qi Gong or yoga; individuals with serious } \\
\text { medical conditions, limiting their ability for full participation as } \\
\text { determined by primary care physicians; individuals with intraarticular } \\
\text { steroid injections in the previous } 3 \text { months, or reconstructive surgery } \\
\text { on the affected knee and any intraarticular hyaluronate injections in } \\
\text { the previous } 6 \text { months; and individuals unable to pass the Mini-Mental } \\
\text { examination (score <24). }\end{array}$ & $\begin{array}{l}\text { Randomized: } 40 \\
\text { Treated: } 40 \\
\text { Analyzed: } 40 \text { (ITT) } \\
\text { Attrition: } 0 \%(0 / 40)\end{array}$ \\
\hline
\end{tabular}




\begin{tabular}{|c|c|}
\hline Author, Year & Intervention, Comparator \\
\hline Wang 2009 & $\begin{array}{l}\text { A.Tai Chi }(n=20) \\
\text { Subjects in the tai chi group attended group tai chi classes where they learned } 10 \text { forms from the classic Yang style Tai Chi. They were also } \\
\text { instructed to practice Tai Chi at least } 20 \text { minutes per day at home with a Tai Chi DVD. Home practice continued after group sessions ended until } \\
\text { the } 48 \text { week followup. } \\
\text { No. of Treatments: } 2 / \text { week for } 12 \text { weeks ( } 24 \text { total) } \\
\text { Length of Treatments: } 60 \text { min/session } \\
\text { B.Attention Control }(n=20) \\
\begin{array}{l}\text { Subjects in the attention control group attended group classes where they received nutritional and medical information paired with } 20 \text { minutes of } \\
\text { stretching. Additionally, participants were instructed to practice at least } 20 \text { minute sof stretching exercises per day at home. } \\
\text { No. of Treatments: } 2 / \text { week for } 12 \text { weeks ( } 24 \text { total) } \\
\text { Length of Treatments: } 60 \text { min/session }\end{array}\end{array}$ \\
\hline
\end{tabular}




\begin{tabular}{|c|c|c|c|}
\hline Author, Year & Study Participants & Outcome Measures & $\begin{array}{c}\text { Duration of } \\
\text { Followup }\end{array}$ \\
\hline Wang 2009 & \begin{tabular}{|l} 
A vs B \\
Age: 63 vs. 68 \\
Female: $80 \%$ vs. $70 \%$ \\
Race: NR \\
Mean Duration of Chronicity: $9.7(7.0)$ vs. $9.7(8.3)$ years \\
\\
Pain (WOMAC): $209.3(58.5)$ vs. $220.4(101.0)$ \\
Stiffness (WOMAC): $105.7(37.3)$ vs. $120.7(50.4)$ \\
Physical Function (WOMAC): $707.6(246.9)$ vs. $827(258.8)$ \\
Patient VAS: $4.2(2.1)$ vs. $4.8(2.0)$ \\
Physician VAS: $4.8(1.7)$ vs. $5.8(2.2)$ \\
SF-36 PCS: $37.5(8.5)$ vs. $32.0(8.8)$ \\
SF-36 MCS: $51.4(12.2)$ vs. $50.8(12.6)$ \\
CES-D: $13.6(11.7)$ vs. $9.3(9.2)$
\end{tabular} & $\begin{array}{l} \\
\\
\text { Primary: } \\
\text { Western Ontario and McMaster Osteoarthritis Index } \\
\text { Overall (WOMAC VAS, range 0-2,400mm: higher } \\
\text { scores represent more pain, stiffness and disability) } \\
\text { Pain (WOMAC, range 0-500) } \\
\text { Stiffness (WOMAC, range 0-200) } \\
\text { Physical Function (WOMAC, range 0-1,700) } \\
\text { Patient Assessed Pain Global (VAS, range 0-10 cm: } \\
\text { higher scores indicate severity of pain) } \\
\text { Physician-Assessed Pain(VAS, range 0-10 cm: higher } \\
\text { scores indicate severity of pain) } \\
\text { Secondary: } \\
\text { Center for Epidemiologic Studies Depression Scale } \\
\text { (CES-D; score range 0-60, where } 0 \text { no dysphoria) } \\
\text { Short Form } 36 \text { Physical Component Summary Score } \\
\text { (SF-36 range 0-100, higher scores indicate improved } \\
\text { state) } \\
\text { Short Form } 36 \text { Mental Component Summary Score (SF- } \\
\text { 36 range 0-100, higher scores indicate improved state) }\end{array}$ & $\begin{array}{l}3 \text { and } 9 \\
\text { months }\end{array}$ \\
\hline
\end{tabular}




\begin{tabular}{|c|c|}
\hline Author, Year & $\begin{array}{c}\text { Results - Subquestion a } \\
\text { (vs. sham, no treatment, waitlist, attention control) }\end{array}$ \\
\hline Wang 2009 & 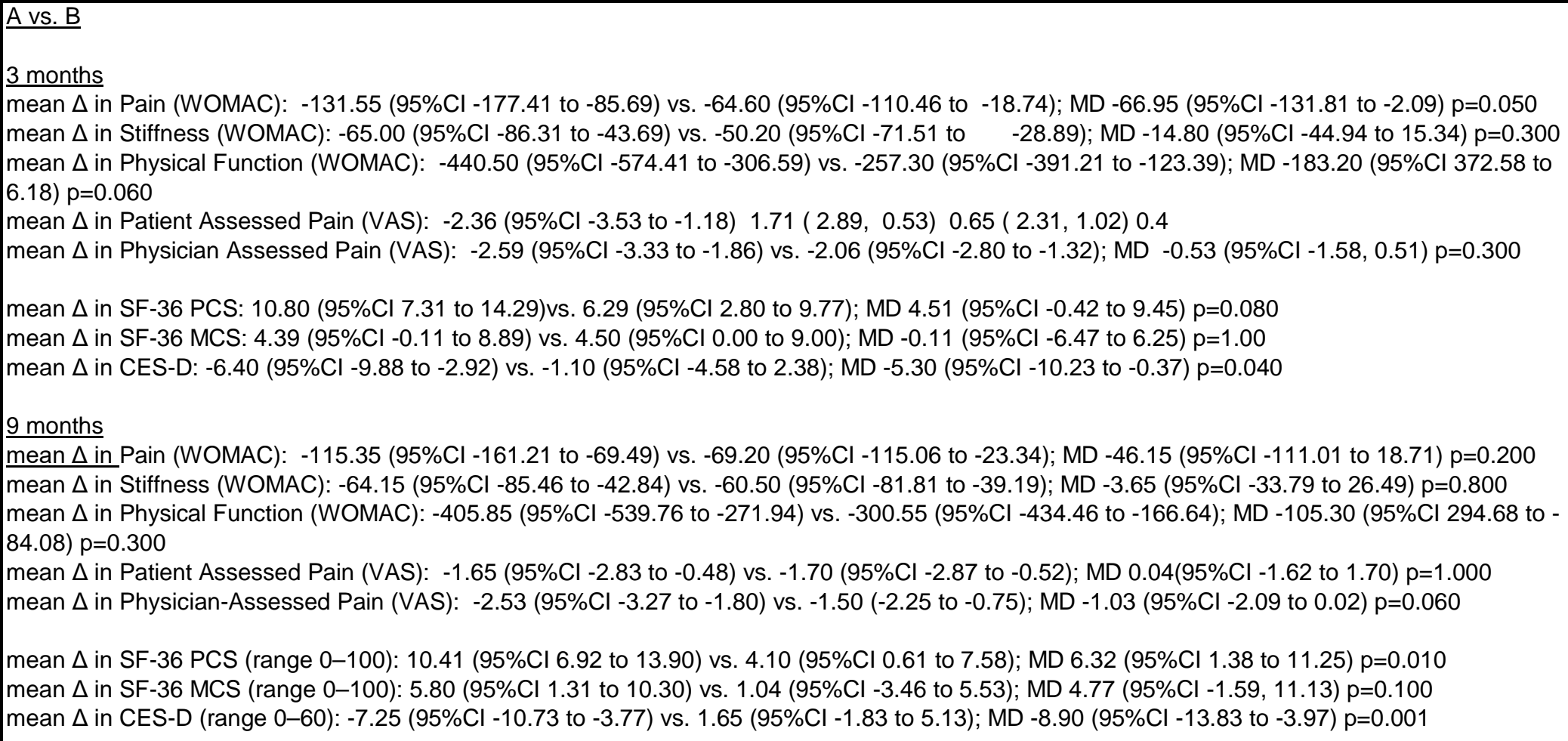 \\
\hline
\end{tabular}




\begin{tabular}{|l|l|}
\hline Author, Year & \multicolumn{2}{c|}{$\begin{array}{c}\text { Results - Subquestion b } \\
\text { (vs. Pharmacological therapy) }\end{array}$} \\
\hline Wang 2009 & NR \\
& \\
\hline
\end{tabular}




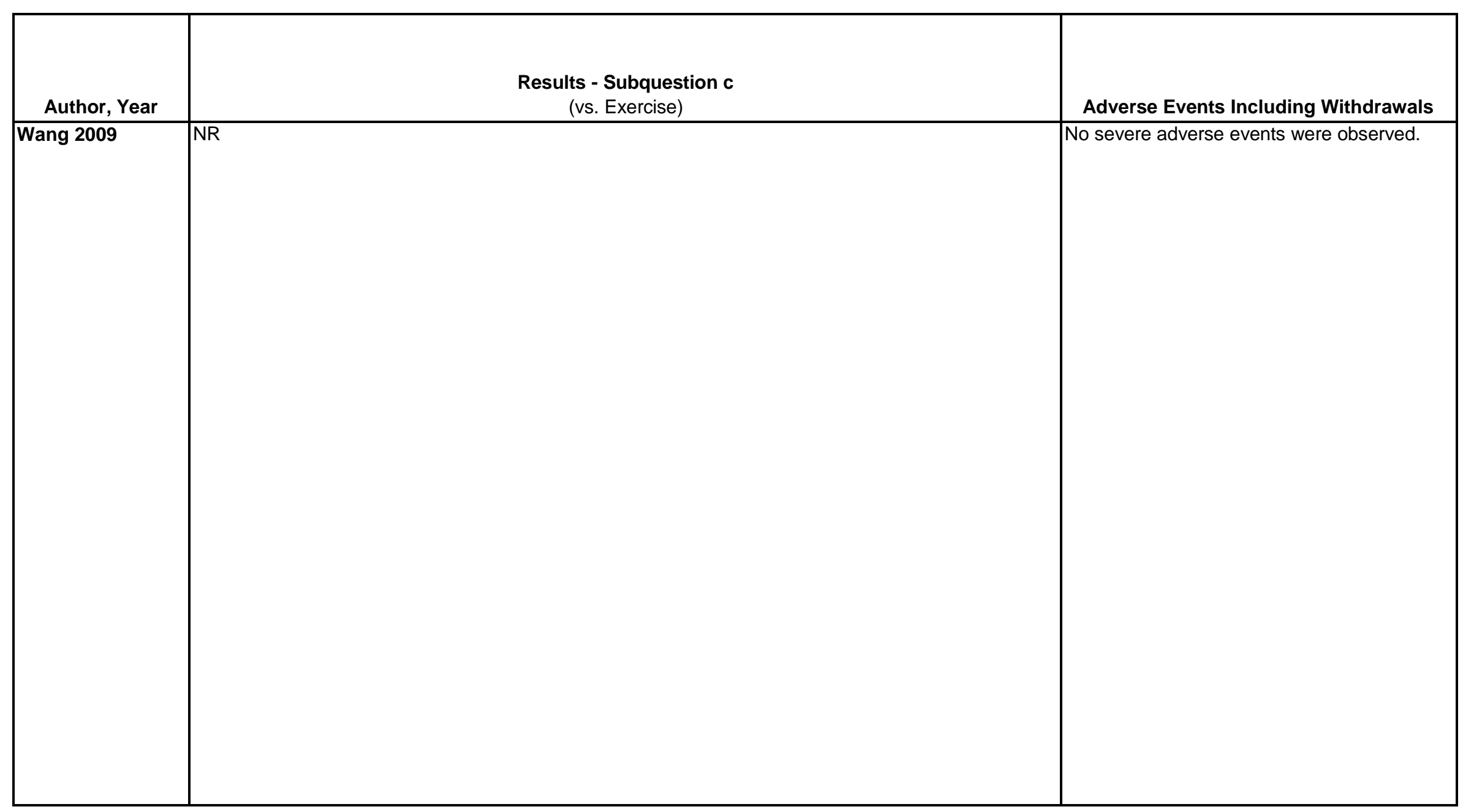




\begin{tabular}{|l|l|l|l|}
\hline \multicolumn{1}{|c|}{ Author, Year } & \multicolumn{1}{|c|}{ Funding Source } & Quality & \\
\hline Wang 2009 & $\begin{array}{l}\text { Supported by the National Center for } \\
\text { Complementary and Alternative } \\
\text { Medicine of the NIH (grant } \\
\text { R21AT002161). }\end{array}$ & Fair & \\
& & & \\
& & & \\
\end{tabular}




\begin{tabular}{|c|c|c|c|}
\hline Author, Year & $\begin{array}{c}\text { Country } \\
\text { Number of Centers } \\
\text { Setting }\end{array}$ & Inclusion/Exclusion Criteria & $\begin{array}{c}\text { Number Randomized, } \\
\text { Analyzed } \\
\text { Attrition }\end{array}$ \\
\hline Wang 2010 & $\begin{array}{l}\text { United States } \\
1 \text { center } \\
\text { Hospital }\end{array}$ & $\begin{array}{l}\text { Aged } 21 \text { or older, diagnosis of FM fulfilling } 1990 \text { ACR criteria } \\
\text { Exclude: Participation in tai chi training in the previous } 6 \text { months, } \\
\text { serious medical conditions that would limit participation, diagnosis of } \\
\text { medical conditions known to contribute to FM symptoms, positive } \\
\text { pregnancy test or plans to become pregnant during study period, a } \\
\text { Mini-Mental State Examination score less than or equal to } 24 \text {. }\end{array}$ & $\begin{array}{l}\text { Randomized: } 66 \\
\text { Treated: NR } \\
\text { Analyzed: } 59 \\
\text { Attrition: } 11 \%(7 / 66)\end{array}$ \\
\hline Weng 2009 & $\begin{array}{l}\text { Taiwan } \\
\text { Number of centers } \\
\text { unclear } \\
\text { Setting type NR }\end{array}$ & $\begin{array}{l}\text { Bilateral, moderate knee OA (Altman Grade II) } \\
\text { Exclude: Patients with hip joint OA or any hip problems with range of } \\
\text { motion limitations }\end{array}$ & $\begin{array}{l}\text { Randomized: } 132 \\
\text { Treated: } 132 \\
\text { Analyzed: } 103 \\
\text { Attrition: } 22 \% \text { (29/132) }\end{array}$ \\
\hline
\end{tabular}




\begin{tabular}{|c|c|}
\hline Author, Year & Intervention, Comparator \\
\hline Wang 2010 & $\begin{array}{l}\text { A.Tai chi }(n=33) \text { : } 60 \text { minutes sessions twice a week for } 12 \text { weeks. Sessions consisted of lessons covering } 10 \text { forms of the classic Yang style of tai } \\
\text { chi. Subjects were instructed to practice tai chi at home for at least } 20 \text { minutes a day and encouraged to maintain tai chi practice, using an } \\
\text { instructional DVD, during the followup period. } \\
\text { B. Control group ( } n=33) \text { : } 60 \text { minutes sessions twice a week for } 12 \text { weeks. Each session consisted of a } 40 \text { minute lesson on a topic relating to FM } \\
\text { followed by } 20 \text { minutes of supervised stretching of the upper body, trunk, and lower body. Subjects were instructed to practice stretching at home } \\
\text { for } 20 \text { minutes a day. } \\
\text { All subjects: Continued taking regular medications and encouraged to continue their routine activities during the 12-week intervention. Subjects } \\
\text { were asked to not take part in any new or additional exercise programs }\end{array}$ \\
\hline Weng 2009 & $\begin{array}{l}\text { A.Isokinetic exercise }(n=33): 3 \text { sessions a week for } 8 \text { weeks. Sessions consisted of sets of concentric and eccentric contractions at varying angular } \\
\text { velocities and start and stop angles. } \\
\text { B. No intervention }(n=33) \text { : Warm-up cycling for } 10 \text { minutes } \\
\text { All patients: Hot packs for } 10 \text { minutes and passive range of motion exercises }\end{array}$ \\
\hline
\end{tabular}




\begin{tabular}{|c|c|c|c|}
\hline Author, Year & Study Participants & Outcome Measures & $\begin{array}{c}\text { Duration of } \\
\text { Followup }\end{array}$ \\
\hline Wang 2010 & $\begin{array}{l}\text { A vs B } \\
\text { Age: } 50 \text { vs } 51 \\
\text { Female: } 85 \% \text { vs } 88 \% \\
\text { Duration of symptoms, years: } 11.8 \text { vs } 10.0 \\
\text { Medication use: } \\
\quad \text { Analgesics: } 88 \% \text { vs } 73 \% \\
\quad \text { Antidepressants: } 51 \% \text { vs } 45 \% \\
\quad \text { Anticonvulsants: } 27 \% \text { vs } 15 \% \\
\text { Muscle relaxants: } 27 \% \text { vs } 12 \% \\
\quad \text { Benzadiazepines: } 15 \% \text { vs } 9 \% \\
\text { Comorbidities: } \\
\quad \text { Heart disease: } 0 \% \text { vs } 0 \% \\
\quad \text { Hypertension: } 36 \% \text { vs } 18 \% \\
\quad \text { Diabetes: } 18 \% \text { vs } 3 \% \\
\text { FlQ: } 62.9 \text { (15.5) vs } 68.0(11.0) \\
\text { Patient global assessment VAS: } 5.8(2.3) \text { vs } 6.3(1.8) \\
\text { Physician global assessment VAS: } 5.7(1.9) \text { vs } 5.6(2.4) \\
\text { CES-D: } 22.6(9.2) \text { vs } 27.8(9.2) \\
\text { SF-36 physical component score: } 28.5(8.4) \text { vs } 28.0(7.8) \\
\text { SF-36 mental component score: } 42.6(12.2) \text { vs } 37.8(10.5) \\
\text { PSQI: } 13.9 \text { (3.1) vs } 13.5(3.7)\end{array}$ & $\begin{array}{l}\text { FIQ (0-100, higher score=more severe symptoms); } \\
\text { patient global assessment VAS (0-10, higher } \\
\text { score=higher pain); Physician global assessment VAS } \\
\text { (0-10, higher score=higher pain); CES-D (0-60, higher } \\
\text { scores=more severe depression); SF-36 physical } \\
\text { component score (0-100, higher score=higher quality of } \\
\text { life); SF-36 mental component score (0-100, higher } \\
\text { score=higher quality of life); PSQI (0-21, higher } \\
\text { scores=worse sleep quality) }\end{array}$ & 3 months \\
\hline Weng 2009 & $\begin{array}{l}\text { A vs B } \\
\text { Age (mean of all patients randomized): } 64 \\
\text { Female (mean of all patients randomized): } 75 \% \\
\text { Duration of symptoms (mean of all patients randomized): } 42.5 \text { months } \\
\text { Lequesne Index: } 7.3 \text { (2.5) vs } 7.1 \text { (1.8) } \\
\text { Pain VAS: } 4.7 \text { (1.6) vs } 4.5 \text { (1.5) }\end{array}$ & $\begin{array}{l}\text { Lequesne Index (0-24, higher score=higher severity); } \\
\text { pain VAS (0-10, higher score=higher pain) }\end{array}$ & 10 months \\
\hline
\end{tabular}




\begin{tabular}{|c|c|}
\hline Author, Year & $\begin{array}{c}\text { Results - Subquestion a } \\
\text { (vs. sham, no treatment, waitlist, attention control) }\end{array}$ \\
\hline Wang 2010 & $\begin{array}{l}\text { A vs B } \\
\text { FIQ mean } \Delta \text { from baseline }(95 \% \mathrm{Cl}):-28.6(-34.8 \text { to }-22.4) \text { vs }-10.2(-16.4 \text { to }-4.0),(\mathrm{MD}-18.3,95 \% \mathrm{Cl}-27.1 \text { to }-9.6) \mathrm{p}<0.001 \\
\text { Patient global assessment VAS mean } \Delta \text { from baseline }(95 \% \mathrm{Cl}):-2.4(-3.1 \text { to }-1.7) \text { vs }-0.7(-1.4 \text { to } 0.01),(\mathrm{MD}-1.7,95 \% \mathrm{Cl}-2.7 \text { to }-0.8) \mathrm{p}=0.001 \\
\text { Physician global assessment VAS, } \Delta \text { from baseline }(95 \% \mathrm{Cl}):-0.5(-1.2 \text { to } 0.1) \text { vs }(0.6)(0.03 \text { to } 1.2),(\mathrm{MD}-1.1,95 \% \mathrm{Cl}-2.0 \text { to }-0.2) \mathrm{p}=0.02 \\
\text { CES-D, } \Delta \text { from baseline }(95 \% \mathrm{Cl}):-6.5(-9.4 \text { to }-3.6) \text { vs }-2.4(-5.3 \text { to } 0.5),(\mathrm{MD}-4.1,95 \% \mathrm{Cl}-8.2 \text { to } 0.1) \mathrm{p}=0.05 \\
\text { SF-36 PCS, } \Delta \text { from baseline }(95 \% \mathrm{Cl}): 8.4(5.6 \text { to } 11.3) \text { vs } 1.5(-1.4 \text { to } 4.3),(\mathrm{MD} 7.0,95 \% \mathrm{Cl} 2.9 \text { to } 11.0) \mathrm{p}=0.001 \\
\text { SF-36 MCS, } \Delta \text { from baseline }(95 \% \mathrm{Cl}): 8.5(4.6 \text { to } 12.4) \text { vs } 1.2(-2.7 \text { to } 5.0),(\mathrm{MD} 7.3,95 \% \mathrm{Cl} 1.9 \text { to } 12.8) \mathrm{p}=0.009 \\
\text { PSQI, } \Delta \text { from baseline }(95 \% \mathrm{Cl}):-4.2(-5.8 \text { to }-2.7) \text { vs }-1.2(-2.7 \text { to } 0.4),(\mathrm{MD}-3.0,95 \% \mathrm{Cl}-5.2 \text { to }-0.9) \mathrm{p}=0.007\end{array}$ \\
\hline Weng 2009 & $\begin{array}{l}\text { A vs B } \\
\text { Lequesne Index: } 6.3 \text { (1.7) vs } 7.3(1.7) \\
\text { Pain VAS: } 3.6(1.6) \text { vs } 5.0(1.4)\end{array}$ \\
\hline
\end{tabular}




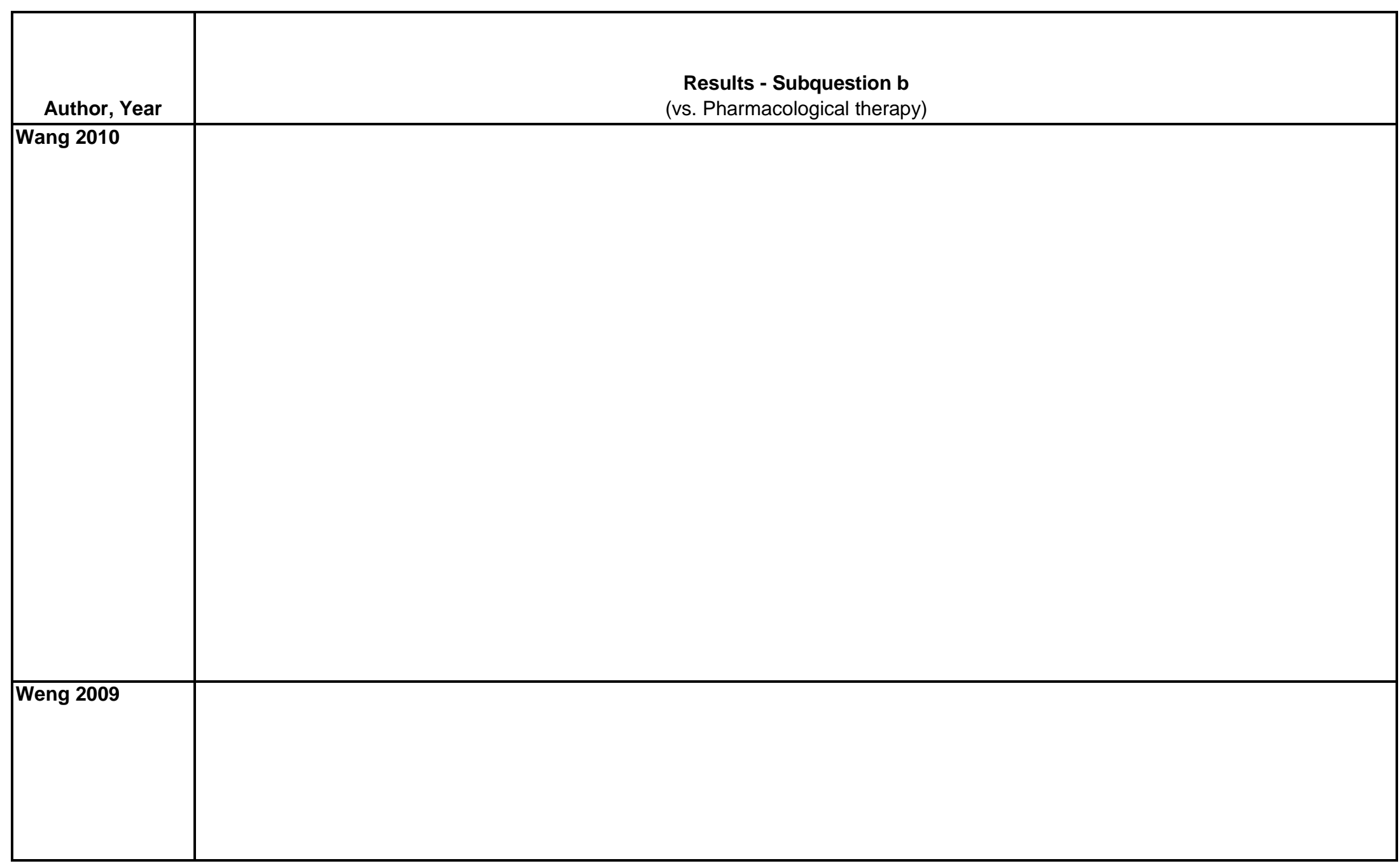

D-844 


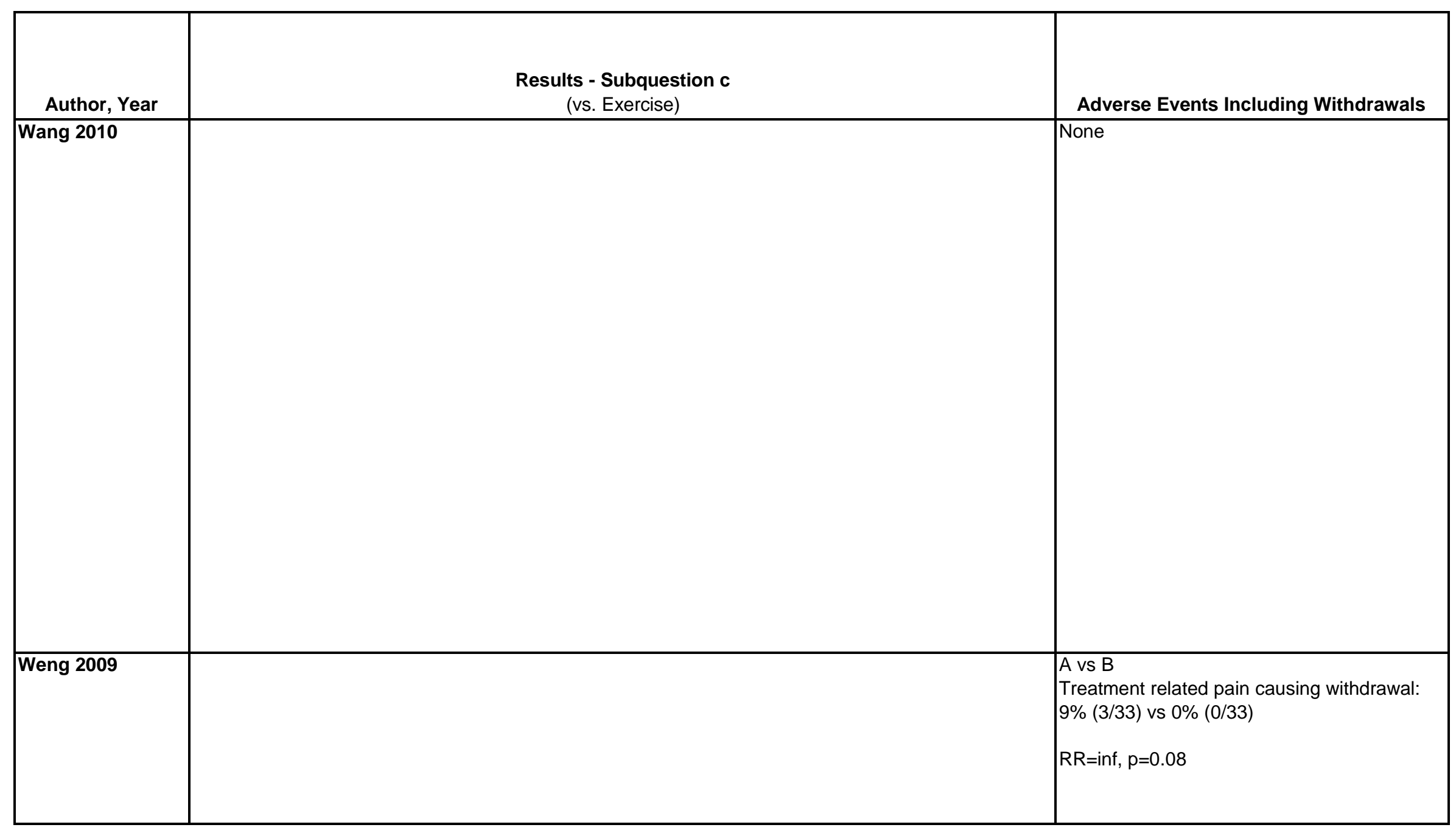




\begin{tabular}{|c|c|c|c|}
\hline Author, Year & Funding Source & Quality & Comments \\
\hline Weng 2009 & & Poor & $\begin{array}{l}\text { It looks like the study defined attrition as those that withdrew but did not include the patients } \\
\text { that discontinued treatment due to pain or the patients that they lost contact with. } \\
\text { Static stretching+isokinetic exercises }(n=33) \text { and PNF stretching+isokinetic exercises }(n=30) \\
\text { groups were also included in the study but were not included in data abstraction because } \\
\text { they were considered additive treatment }\end{array}$ \\
\hline
\end{tabular}




\begin{tabular}{|c|c|c|c|}
\hline Author, Year & $\begin{array}{c}\text { Country } \\
\text { Number of Centers } \\
\text { Setting }\end{array}$ & Inclusion/Exclusion Criteria & $\begin{array}{c}\text { Number Randomized, } \\
\text { Analyzed } \\
\text { Attrition }\end{array}$ \\
\hline White 2004 & $\begin{array}{l}\text { United Kingdom } \\
\text { Outpatient } \\
\text { departments of a } \\
\text { General and District } \\
\text { Hospital, } 199-2001\end{array}$ & $\begin{array}{l}18 \text { to } 80 \text { years of age, chronic mechanical neck pain, pain score }>30 \\
\text { mm onVAS (0-100) for } 5 \text { of } 7 \text { pretreatment days. } \\
\text { Excluded: pregnant patients, fracture or surgery to the neck, cervical } \\
\text { congenital abnormality, uncontrolled LBP, contraindication to } \\
\text { acetaminophen, systemic illness, ongoing neck-related litigation or } \\
\text { disability claims, current or recent manual neck treatment or steroid } \\
\text { use (oral or local injection). }\end{array}$ & $\begin{array}{l}\text { Randomized: } 135 \\
\text { Treated: } 125 \\
\text { Analyzed: } 124 \\
\text { Attrition:21\% } \\
\text { (29/135) } \\
\text { Randomized: } 135 \\
\text { Treated: } 135 \\
\\
6 \text { month } \\
\text { Analyzed: } 111 \\
\text { Attrition:18\% } \\
\text { (24/135) } \\
12 \text { month } \\
\text { Analyzed: } 107 \\
\text { Attrition: } 21 \%(28 / 135)\end{array}$ \\
\hline \multicolumn{4}{|l|}{$\begin{array}{l}\text { Wicksell } 2013 \text { - } \\
\text { see Jensen } 2013\end{array}$} \\
\hline Wigers 1996 & $\begin{array}{l}\text { Norway } \\
2 \text { center } \\
1 \text { outpatient, } 1 \text { patient } \\
\text { association }\end{array}$ & $\begin{array}{l}\text { Patients with generalized aching or stiffness involving } 3 \text { or more areas } \\
\text { in at least } 4 \text { out of } 15^{\star} \text { well-defined tender points for a minimum of } 3 \\
\text { months. } \\
\text { Exclude: Patients with pain thought to be related to trauma }\end{array}$ & $\begin{array}{l}\text { Randomized: } 60 \\
\text { Treated: NR } \\
\text { Analyzed: } 44 \\
\text { Attrition: } 27 \%(16 / 60)\end{array}$ \\
\hline
\end{tabular}




\begin{tabular}{|c|c|}
\hline Author, Year & Intervention, Comparator \\
\hline White 2004 & $\begin{array}{l}\text { A. Unilateral or bilateral Western needle acupuncture (n=70) at locations depending on pain distribution and tenderness, using the following points } \\
\text { Primary local neck: GB 20, 21; GV 14; secondary local neck: SI 12, 13 14; BL 9, 10; ST 11; SI 15, 16; BL 11, 41, 15, 17; GB 29; TE 16, 17; GV 15 } \\
\text { 16, 17; Primary distal points: LI 4, SI 3, GB 34, TE 5; secondary distal points: LI 11; SI 8; TE 10,36, 39, 40; BL 60; extra Luozhen } \\
\text { deqi obtained } \\
\text { B. Sham electroacupuncture (n=65) with audio and visual signals and up to } 8 \text { electrodes placed over acupuncture points simultaneously, but no } \\
\text { current through severed cables. } \\
\text { Both groups treated 2x/week for } 4 \text { weeks for } 20 \text { minutes each session, acetaminophen only for pain. }\end{array}$ \\
\hline \multicolumn{2}{|l|}{$\begin{array}{l}\text { Wicksell } 2013- \\
\text { see Jensen } 2013\end{array}$} \\
\hline Wigers 1996 & $\begin{array}{l}\text { A.Stress management }(n=20): 90 \text { minute group sessions of } 10 \text { patients done } 2 \text { times a week for } 6 \text { weeks followed by } 1 \text { session per week for the } \\
\text { next } 8 \text { weeks. Sessions consisted of equal portions of presentations stress mechanisms and strategies for improving quality of life, group } \\
\text { discussions on patients' experiences of stress and coping with pain, and relaxation training aimed at helping cope with stress and pain. } \\
\text { B. Aerobic exercise }(n=20): 45 \text { minute group sessions of } 10 \text { patients done } 3 \text { times a week for } 14 \text { weeks. The exercise program involved the whole } \\
\text { body and aimed to minimize eccentric muscle strain. Sessions consisted of training to music (further details not given) and aerobic games } \\
\text { C. Treatment as usual ( } n=20): \text { Subjects continued treatments they had been using at baseline. }\end{array}$ \\
\hline
\end{tabular}




\begin{tabular}{|c|c|c|c|}
\hline Author, Year & Study Participants & Outcome Measures & $\begin{array}{l}\text { Duration of } \\
\text { Followup }\end{array}$ \\
\hline White 2004 & $\begin{array}{l}\text { A vs B } \\
\text { Age: } 54 \text { vs } 53 \text { years } \\
\text { Female: } 66 \% \text { vs } 63 \% \\
\text { Pain score (0-100): } 49.6(12.3) \text { vs } 54.1(14.6) \\
\text { NDI: } 16.8(6.3) \text { vs } 17.2(6.1) \\
\text { SF-36 PCS: } 36.8(7.9) \text { vs } 36.3(9.3) \\
\text { SF-36 MCS: } 46.9(10.4) \text { vs } 48.3(9.9) \\
\text { Duration of symptoms: } 4.8 \text { vs } 7.7 \text { years }\end{array}$ & $\begin{array}{l}\text { NDI: (scale 0-50, higher score greater disability) } \\
\text { Pain intensity (scale, 0-10, higher score=greater pain) } \\
\text { Short-Form } 36 \text { (SF-36) (scale 0-100, higher } \\
\text { score=better QoL) }\end{array}$ & $\begin{array}{l}2,6 \text { and } 12 \\
\text { months }\end{array}$ \\
\hline \multicolumn{4}{|l|}{$\begin{array}{l}\text { Wicksell } 2013- \\
\text { see Jensen } 2013\end{array}$} \\
\hline Wigers 1996 & $\begin{array}{l}\text { A vs B vs C } \\
\text { Age: } 44 \text { vs } 43 \text { vs } 46 \\
\text { Female: } 90 \% \text { vs } 90 \% \text { vs } 95 \% \\
\text { Duration of symptoms (years): } 11 \text { (10) vs } 9 \text { (5) vs } 11 \text { (9) } \\
\text { Working status: } \\
\quad \text { Full time: } 25 \% \text { vs } 20 \% \text { vs } 20 \% \\
\quad \text { Part time: } 25 \% \text { vs } 35 \% \text { vs } 10 \% \\
\quad \text { Sick leave: } 30 \% \text { vs } 25 \% \text { vs } 30 \% \\
\quad \text { Disability pension: } 15 \% \text { vs } 20 \% \text { vs } 30 \% \\
\quad \text { Housewife or retired: } 5 \% \text { vs } 0 \% \text { vs } 10 \% \\
\text { Pain VAS: } 72 \text { (18) vs } 72(19) \text { vs } 65(17) \\
\text { Depression VAS: } 44 \text { (32) vs } 34 \text { (29) vs } 40(37)\end{array}$ & $\begin{array}{l}\text { Pain VAS (0-100, higher score=higher pain); depression } \\
\text { VAS (0-100, higher score=higher depression); global } \\
\text { subjective improvement }(0-4 \text {, higher score=higher } \\
\text { improvement) }\end{array}$ & 48 months \\
\hline
\end{tabular}




\begin{tabular}{|c|c|}
\hline Author, Year & $\begin{array}{c}\text { Results - Subquestion a } \\
\text { (vs. sham, no treatment, waitlist, attention control) }\end{array}$ \\
\hline White 2004 & $\begin{array}{l}\text { A vs } B \\
2 \text { months, } n=59 \text { vs } 59 \\
\text { NDI: } 11.0(6.3) \text { vs } 12.7(7.8), M D-1.7(95 \% \mathrm{Cl}-4.3 \text { to } 0.9), p=0.195 \\
\text { Pain }(0-100): 17.3(17.0) \text { vs } 23.2(20.7), \mathrm{MD}-5.9(95 \% \mathrm{Cl}-12.8 \text { to } 1.01), \mathrm{p}=0.09 \\
\text { SF- } 36 \text { physical: } 42.5(9.8) \text { vs } 43.8(10.0), \mathrm{p}=\mathrm{ns} \\
\text { SF-36 mental: } 52.5(8.6) \text { vs } 50.3(10.1), \mathrm{p}=\mathrm{ns} \\
\\
\text { 6 months, } \mathrm{n}=56 \text { vs } 53 \\
\text { NDI: } 9.9(7.0) \text { vs } 10.6(8.3), \mathrm{MD} 0.7(95 \% \mathrm{Cl}-3.61 \text { to } 2.21), \mathrm{p}=0.634 \\
\text { Pain }(0-100): 19.2(24.2) \text { vs } 21.0(24.4), \mathrm{MD}-1.8(95 \% \mathrm{Cl}-11.0 \text { to } 7.4), \mathrm{p}=0.700 \\
\\
12 \text { months, } \mathrm{n}=54 \text { vs } 53 \\
\text { NDI: } 8.9(6.6) \text { vs } 10.7(9.1), \mathrm{MD}-1.8(95 \% \mathrm{Cl}-4.84 \text { to } 1.24), \mathrm{p}=0.244 \\
\text { Pain }(0-100): 20.9(25.7) \text { vs } 24.36(26.7), \mathrm{MD}-3.46(95 \% \mathrm{Cl}-13.5 \text { to } 6.6), \mathrm{p}=496\end{array}$ \\
\hline \multicolumn{2}{|l|}{$\begin{array}{l}\text { Wicksell } 2013- \\
\text { see Jensen } 2013\end{array}$} \\
\hline Wigers 1996 & 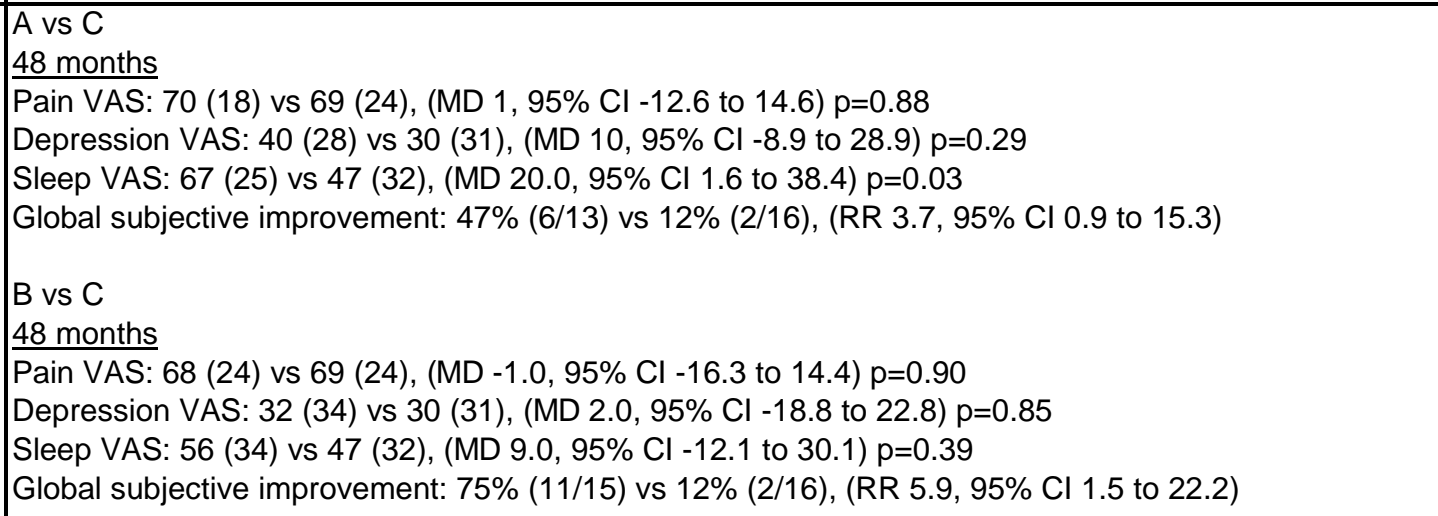 \\
\hline
\end{tabular}




\begin{tabular}{|l|l|}
\hline Author, Year & $\begin{array}{c}\text { Results - Subquestion b } \\
\text { (vs. Pharmacological therapy) }\end{array}$ \\
\hline White 2004 & \\
\hline Wicksell 2013- & \\
\hline Wigers 1996 & \\
& \\
\hline
\end{tabular}




\begin{tabular}{|c|c|c|}
\hline Author, Year & $\begin{array}{l}\text { Results - Subquestion c } \\
\text { (vs. Exercise) }\end{array}$ & Adverse Events Including Withdrawals \\
\hline White 2004 & & $\begin{array}{l}\text { Bruise at site of L1- } 4: n=1 \text { vs } n=0 \\
\text { Discomfort during treatment: } n=0 \text { vs } n=1 \\
\text { Dizziness after treatment: } n=1 \text { vs } n=1 \\
\text { Euphoria after treatment: } n=1 \text { vs } n=0 \\
\text { Faintness after treatment: } n=2 \text { vs } n=1 \\
\text { Mild headache after each treatment: } n=1 \text { vs } \\
n=1 \\
\text { Nausea on several occasions after treatment: } \\
n=0 \text { vs } n=1 \\
\text { Slight swelling of hand: } n=1 \text { vs } n=0 \\
\text { Tingling of thumb: } n=0 \text { vs } n=1 \\
\text { Tiredness on several occasions after } \\
\text { treatment: } n=0 \text { vs } n=1 \\
\text { Uncomfortable cold feeling from electrodes: } \\
n=0 \text { vs } n=1\end{array}$ \\
\hline \multicolumn{3}{|l|}{$\begin{array}{l}\text { Wicksell } 2013- \\
\text { see Jensen } 2013\end{array}$} \\
\hline Wigers 1996 & $\begin{array}{l}\text { A vs B } \\
48 \text { months } \\
\text { Pain VAS: } 70(18) \text { vs } 68(24),(M D 2,95 \% \mathrm{Cl}-11.6 \text { to } 15.6) \mathrm{p}=0.77 \\
\text { Depression VAS: } 40 \text { (28) vs } 32(34),(\mathrm{MD} 8,95 \% \mathrm{Cl}-11.9 \text { to } 27.9) \mathrm{p}=0.42 \\
\text { Sleep VAS: } 67(25) \text { vs } 56(34) \\
\text { Global subjective improvement: } 47 \% \text { (6/13) vs } 75 \%(11 / 15),(\mathrm{RR} 0.6,95 \% \mathrm{Cl} 0.3 \text { to } 1.2) \mathrm{p}=0.15\end{array}$ & NR \\
\hline
\end{tabular}




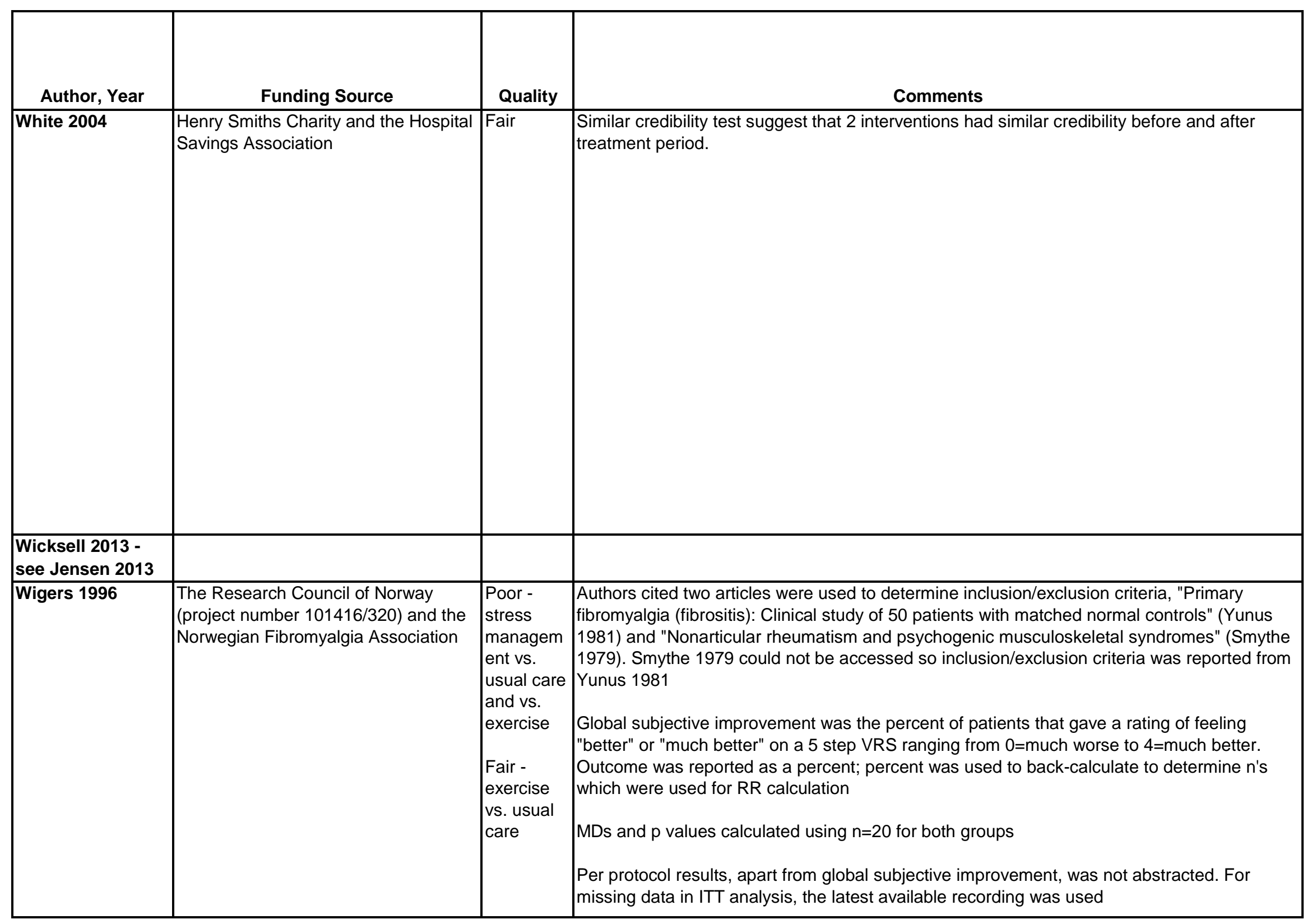




\begin{tabular}{|c|c|c|c|}
\hline Author, Year & $\begin{array}{c}\text { Country } \\
\text { Number of Centers } \\
\text { Setting }\end{array}$ & Inclusion/Exclusion Criteria & $\begin{array}{c}\text { Number Randomized, } \\
\text { Analyzed } \\
\text { Attrition }\end{array}$ \\
\hline Williams 2002 & $\begin{array}{l}\text { USA } \\
\text { Recruited from } \\
\text { registry of patients } \\
\text { being followed in } \\
\text { tertiary care } \\
\text { rheumatology clinic } \\
\text { specializing in FM }\end{array}$ & $\begin{array}{l}\text { Inclusion: meet } 1990 \text { ACR criteria for FM, age } 18+\text {, in standard } \\
\text { medical care at clinic for at least } 6 \text { months } \\
\text { Exclusion: severe physical impairment that precluded receiving CBT, } \\
\text { comorbid medical illnesses capable of causing worsening physical } \\
\text { function status, malignancy in past } 2 \text { years, history of psychosis, } \\
\text { current suicide risk or attempt in past } 2 \text { years, substance abuse in } \\
\text { past } 2 \text { years }\end{array}$ & $\begin{array}{l}\text { Randomized: } 145 \\
\text { analyzed: } 122 \\
\text { Attrition: } 16 \%(23 / 145)\end{array}$ \\
\hline Williams 2005 & $\begin{array}{l}\text { US } \\
\text { Number of centers } \\
\text { unclear } \\
\text { Outpatient }\end{array}$ & $\begin{array}{l}\text { Non-specific LBP with symptoms for }>3 \text { months } \\
>18 \text { years } \\
\text { Ambulatory } \\
\text { Exclude: } \\
\text { LBP due to nerve root compression, disc prolapse, spinal stenosis, } \\
\text { tumor, spinal infection, alkylosing spondylosis, spondylolisthesis, } \\
\text { kyphosis, or structural scoliosis } \\
\text { Presurgical candidates } \\
\text { Were involved in litigation or compensation } \\
\text { Body mass index }>35 \\
\text { Major depression or substance abuse } \\
\text { Practitioners of yoga }\end{array}$ & $\begin{array}{l}\text { Randomized: } 60 \\
\text { Treated: } 60 \\
\text { Analyzed at } 12 \text {-weeks: } 44 \\
\text { Analyzed at } 3 \text { months: } 42 \\
\text { Attrition: } 18 / 60(30 \%)\end{array}$ \\
\hline
\end{tabular}




\begin{tabular}{|c|c|}
\hline Author, Year & Intervention, Comparator \\
\hline Williams 2002 & $\begin{array}{l}\text { A.Group CBT plus Usual Care ( } \mathrm{n}=62): 6 \text { 1-hour group sessions delivered in 4-week period by clinical psychologist and focused on improving } \\
\text { functional status. Content included progressive muscle relaxation, imagery, activity pacing, pleasant activity scheduling, communication skills and } \\
\text { assertiveness training, cognitive restructuring, stress management and problem-solving. Median number of sessions attended }=4 \text { (range 2-6) } \\
\text { B. Usual Care ( } n=60) \text { : Standard pharmacological management of symptoms (typically low-dose tricyclic antidepressant medication, analgesics, } \\
\text { and/or antidepressants) plus suggestions to engage in aerobic fitness. }\end{array}$ \\
\hline Williams 2005 & $\begin{array}{l}\text { A: Yoga }(n=30): 16 \text { weekly } 1.5 \text { hour lyengar yoga classes. The classes consisted of } 29 \text { postures from the categories: supine, seated, standing, } \\
\text { forward bending, trists and inversions. Initially, restorative poses were done to relieve pain and muscle tension. Then poses were introduced to } \\
\text { lengthen muscles attached to the spine and pelvis, then standing poses to open the hips and groins and to teach how to use legs and arms to } \\
\text { lengthen pelvic and spinal tissues. Twists and inversions were also included. Participants gradually progressed from simple poses to progressively } \\
\text { more challenging poses. Participants were also encouraged to practice yoga at home for } 30 \text { minutes, } 5 \text { days per week. At the program end, } \\
\text { participants were encouraged to continue yoga therapy at home and through community classes. } \\
\text { B: Educational control }(n=30) \\
\text { Both groups received } 16 \text { weekly newsletters on back care and two } 1 \text { hour lectures of occupational/physical therapy education. }\end{array}$ \\
\hline
\end{tabular}




\begin{tabular}{|c|c|c|c|}
\hline Author, Year & Study Participants & Outcome Measures & $\begin{array}{l}\text { Duration of } \\
\text { Followup }\end{array}$ \\
\hline Williams 2002 & $\begin{array}{l}\text { A + B } \\
\text { Age, mean, years: } 47.7 \\
\text { Females: } 90 \% \\
\text { Race: White non-Hispanic } 88 \% \text {, black non-Hispanic 9\%, Hispanic 2\%, } \\
\text { Asian American } 1 \% \\
\text { Average years of education: } 16 \\
\text { Married: } 60 \% \\
\text { Compensation present or pending: } 28 \% \\
\text { McGill Pain Questionnaire sensory pain score (mean, scale NR): } 14.8 \\
\text { McGill Pain Questionnaire affective pain score (mean, scale NR): } 4.6 \\
\text { SF-36 Physical Component Summary Score (mean, 0-100): } 28.6\end{array}$ & $\begin{array}{l}\text { SF-36 Physical Component Summary Score (0-100, } \\
\text { higher scores=better functioning) } \\
\text { Short Form McGill Pain Questionnaire (MPQ) (scale } \\
\text { NR, higher scores=greater pain) }\end{array}$ & 12 months \\
\hline Williams 2005 & $\begin{array}{l}\text { A vs. } B \\
\text { Age: } 49 \text { vs. } 48 \\
\text { Female: } 65 \% \text { vs. } 70 \% \\
\text { White: } 90 \% \text { vs. } 92 \% \\
\text { Length of LBP (years): } 11.3 \text { vs. } 11.0 \\
\text { Medication use: } 45 \% \text { vs. } 50 \% \\
\text { Complementary and Alternative Medicine Use: } 35 \% \text { vs. } 25 \%\end{array}$ & $\begin{array}{l}\text { Pain Disability Index (7-70 scale, higher score indicates } \\
\text { higher disability) } \\
\text { Pain intensity, McGill Pain Questionnaire (0-10 VAS) } \\
\text { Present Pain Index (0-5 rating of pain) } \\
\text { Pain medication use }\end{array}$ & 3 months \\
\hline
\end{tabular}




\begin{tabular}{|c|c|}
\hline Author, Year & $\begin{array}{c}\text { Results - Subquestion a } \\
\text { (vs. sham, no treatment, waitlist, attention control) }\end{array}$ \\
\hline Williams 2002 & $\begin{array}{l}\text { A vs B } \\
12 \text { months } \\
\text { M (SD) NR } \\
\text { Proportion of subjects who improved more than } 12 \text { points from baseline on McGill Pain Questionnaire sensory scale: } 3.9 \% \text { vs } 7.2 \%, p>0.05 \\
\text { Proportion of subjects who improved more than } 5 \text { points from baseline on McGill Pain Questionnaire affective scale: } 9.2 \% \text { vs } 8.7 \%, p>0.05 \\
\text { Proportion of subjects who improved more than } 6.5 \text { points from baseline on SF-36 Physical Component Summary Score: } 25 \% \text { vs } 11.6 \%, O R=2.9, p \\
<0.05 ; \text { RR } 2.2(95 \% \mathrm{Cl} 0.98 \text { to } 4.99), p=0.047\end{array}$ \\
\hline Williams 2005 & 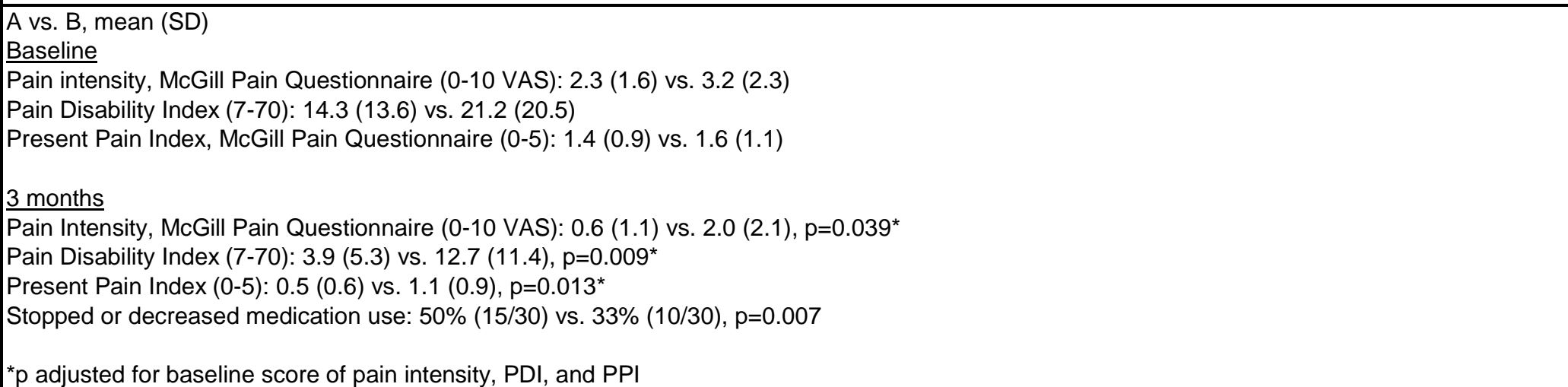 \\
\hline
\end{tabular}




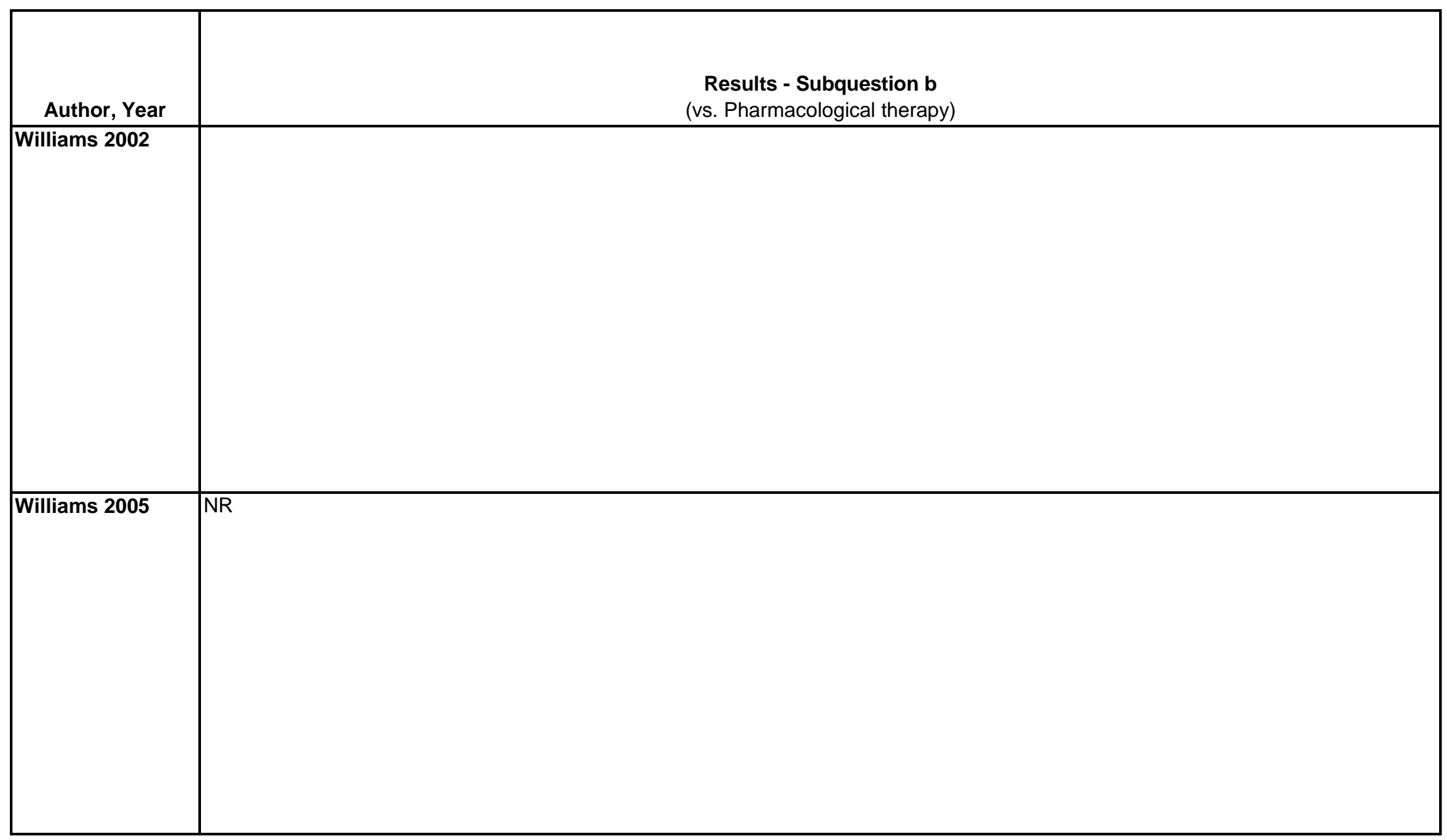

D-858 


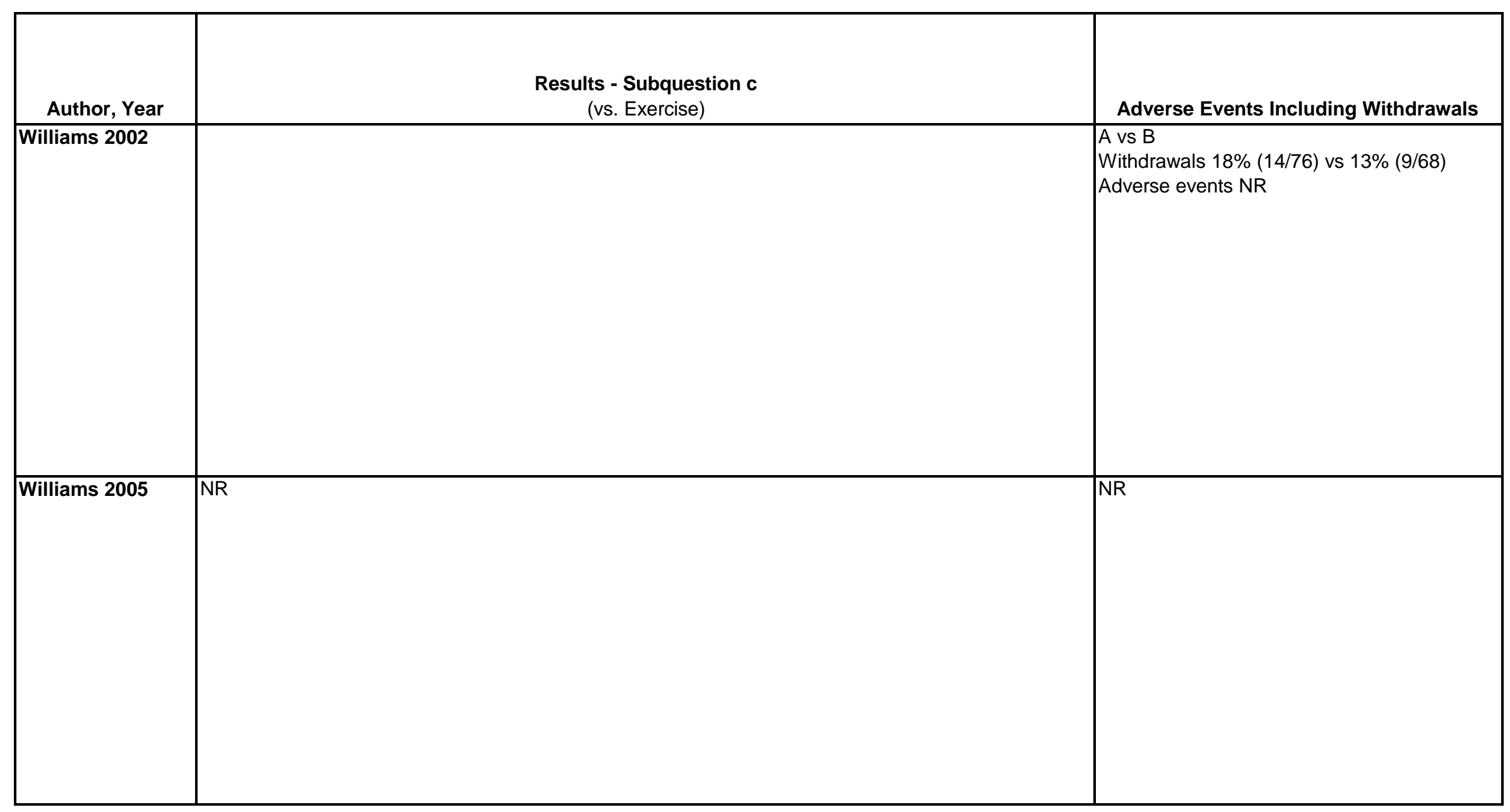




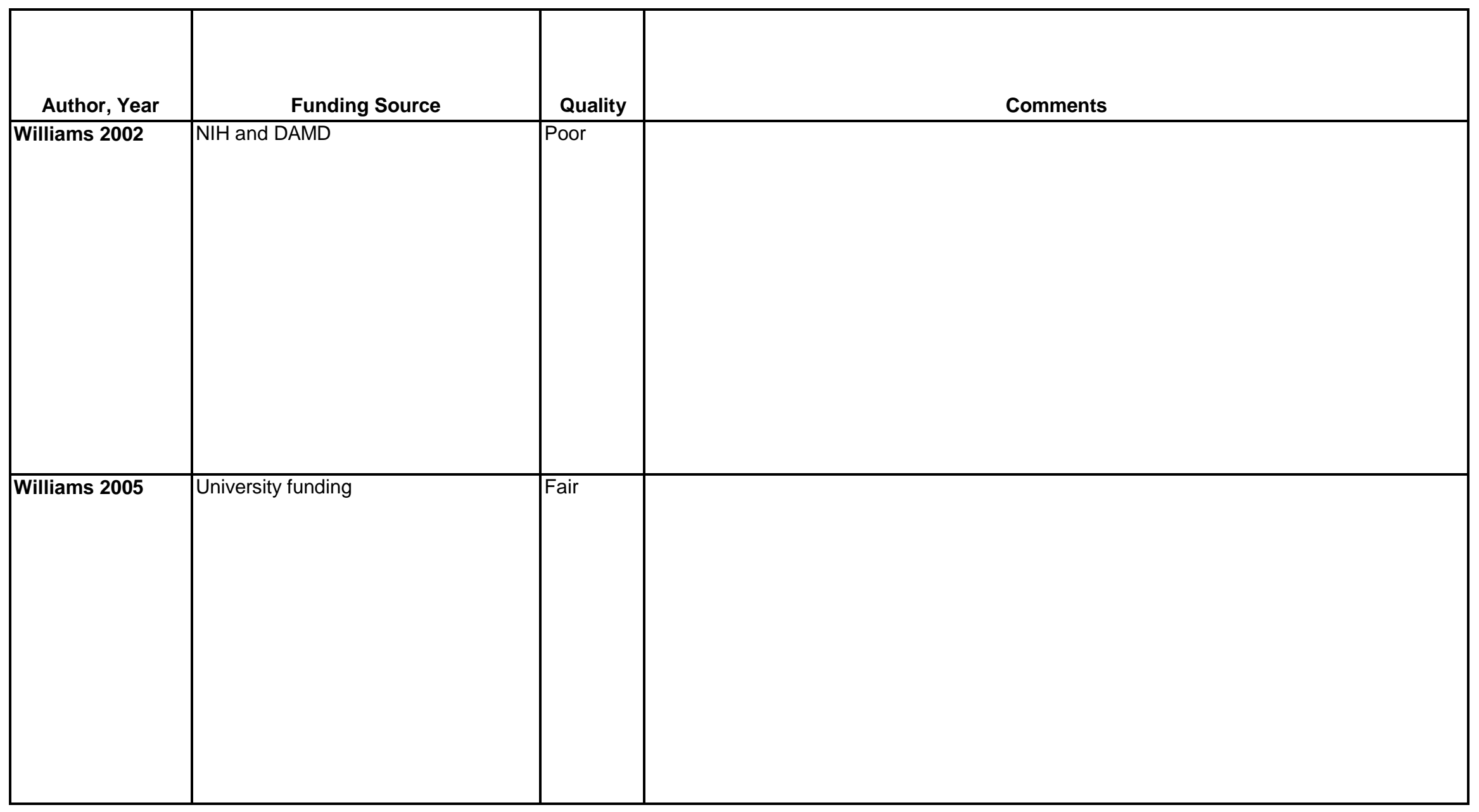

D-860 


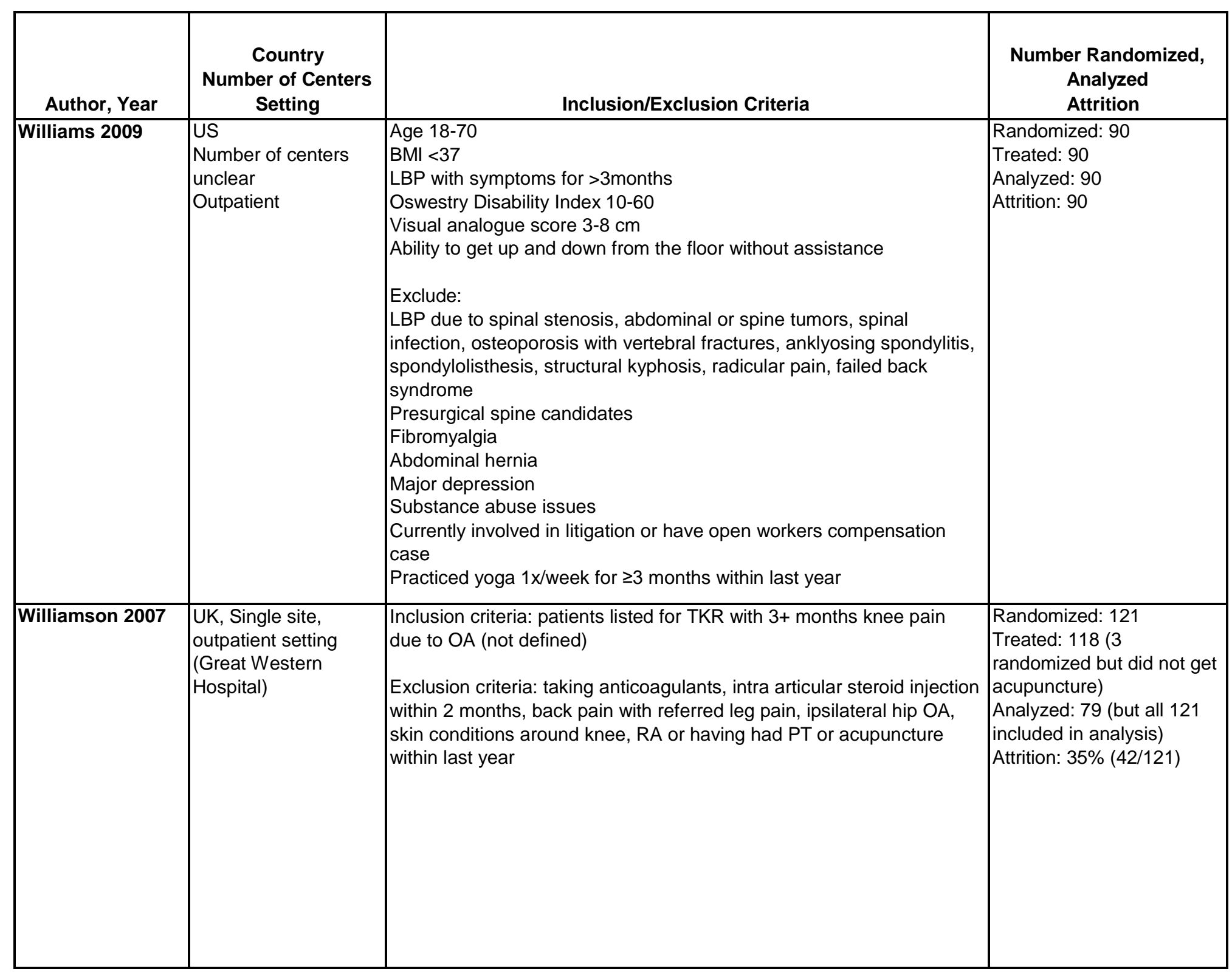




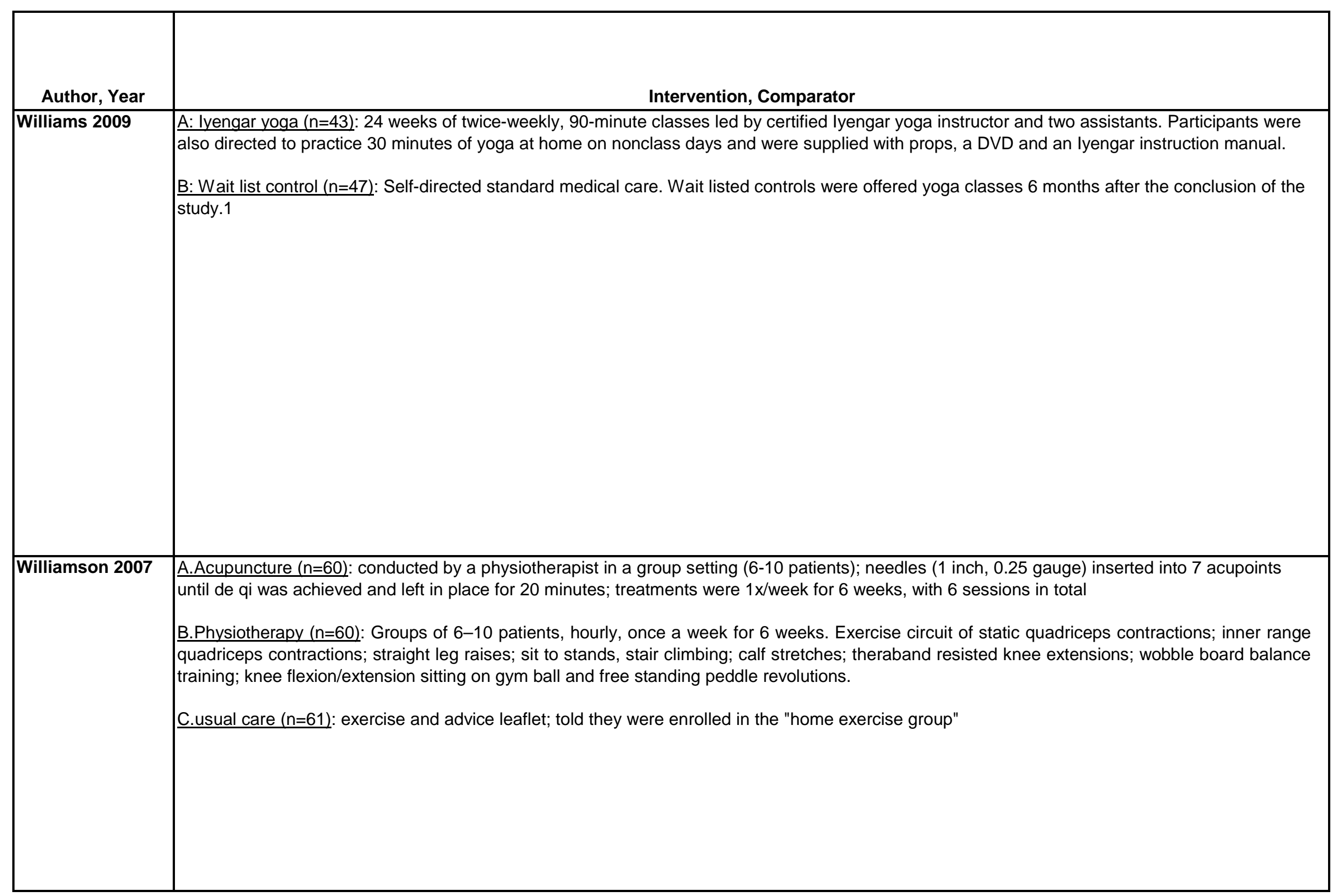




\begin{tabular}{|c|c|c|c|}
\hline Author, Year & Study Participants & Outcome Measures & $\begin{array}{c}\text { Duration of } \\
\text { Followup }\end{array}$ \\
\hline Williams 2009 & $\begin{array}{l}\text { Age: } 48 \text { vs. } 48 \text { years } \\
\text { Female: } 74 \% \text { vs. } 79 \% \\
\text { White: } 86 \% \text { vs. } 100 \% \\
\text { BMl: } 25.8 \text { vs. } 27.4 \\
\text { Taking medications for LBP: } 91 \% \text { vs. } 94 \% \\
\text { Months of current LBP: } 47 \text { vs. } 78 \\
\text { Months since first LBP: } 146 \text { vs. } 213, p=0.027\end{array}$ & $\begin{array}{l}\text { Oswestry Disability Index (0-100) } \\
\text { Pain intensity (0-100) } \\
\text { Beck Depression Inventory-Second Edition (0-63) }\end{array}$ & $\begin{array}{l}\text { Intermediate } \\
\text { term } \\
6 \text { months }\end{array}$ \\
\hline Williamson 2007 & $\begin{array}{l}\text { A vS B Vs. } \\
\text { Age: } 72 \text { vs. } 70 \text { vs. } 70 \text { years } \\
\text { Female: } 55 \% \text { vs. } 52 \% \text { vs. } 54 \% \\
\text { Caucasian: NR } \\
\text { Duration of symptoms: NR } \\
\text { WOMAC: } 50.9(15.7) \text { vs. } 50.2(17.8) \text { vs. } 51.1(16.4) \\
\text { OKS: } 40.2(7.7) \text { vs. } 39.3(8.7) \text { vs. } 40.5(8.6) \\
\text { Pain VAS: } 7.3(2.5) \text { vs. } 6.8(2.6) \text { vs. } 6.9(2.3) \\
\text { HAD Anxiety: } 7.3(4.3) \text { vs. } 7.5(4.9) \text { vs. } 6.7(3.6) \\
\text { HAD Depression: } 7.1(3.2) \text { vs. } 7.1(3.9) \text { vs. } 7.43(3.4)\end{array}$ & $\begin{array}{l}\text { Oxford Knee Scale (OKS, 12-60; higher score=worse } \\
\text { function) } \\
\text { Secondary: } \\
\text { Knee pain VAS (scale 0-10; higher score=greater pain) } \\
\text { Hospital Anxiety and Depression score (HAD, 0-21; } \\
\text { higher score=worse symptoms) }\end{array}$ & 1.5 montns \\
\hline
\end{tabular}




\begin{tabular}{|c|c|}
\hline Author, Year & $\begin{array}{l}\text { Results - Subquestion a } \\
\text { (vs. sham, no treatment, waitlist, attention control) }\end{array}$ \\
\hline Williams 2009 & $\begin{array}{l}\text { A vs. B, mean (standard error of the mean) } \\
\text { Baseline } \\
\text { Oswestry Disability Index (0-100): } 25.2(1.08) \text { vs. } 23.1(1.58) \\
\text { Pain (0-100 VAS): } 41.9(2.44) \text { vs. } 41.2(2.67) \\
\text { Beck Depression Inventory (0-63): } 9.2(0.92) \text { vs. } 8.3(0.89) \\
\text { 6 months } \\
\text { Oswestry Disability Index: } 19.3(1.94) \text { vs. } 23.5(1.80), p=0.001 \\
\text { Pain (0-100 VAS): } 22.2(3.96) \text { vs. } 38.3(3.09), p=0.0009 \\
\text { Beck Depression Inventory (0-63): } 4.6(0.84) \text { vs. } 7.8(1.00), p=0.0004\end{array}$ \\
\hline Williamson 2007 & 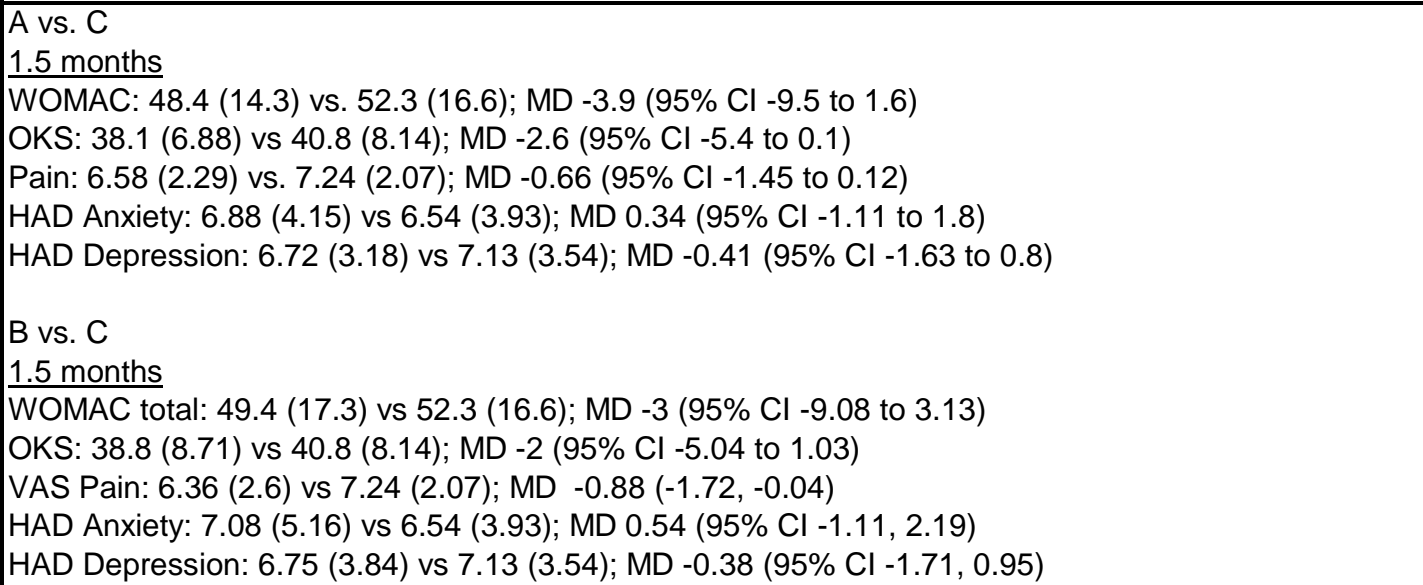 \\
\hline
\end{tabular}




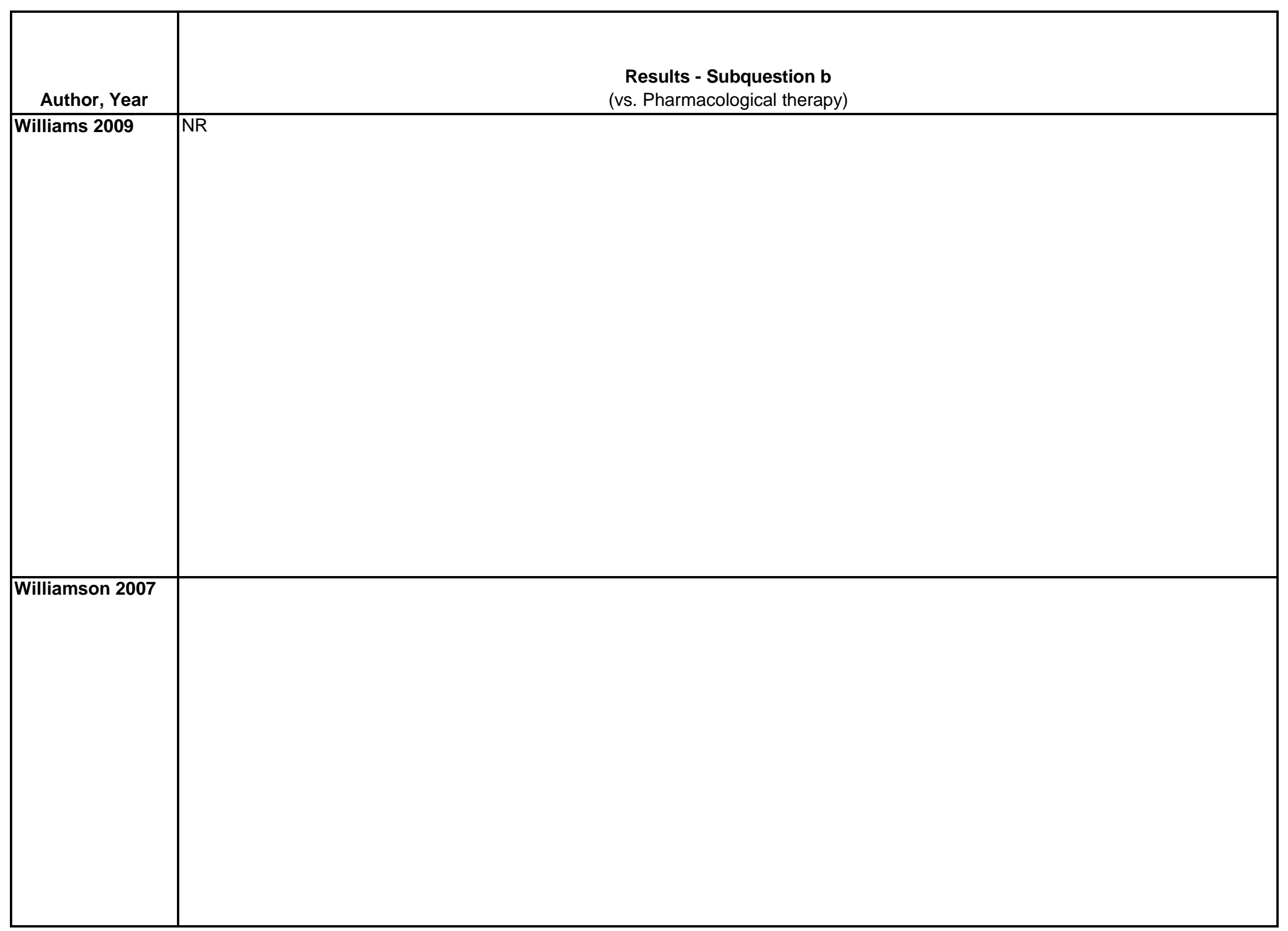

D-865 


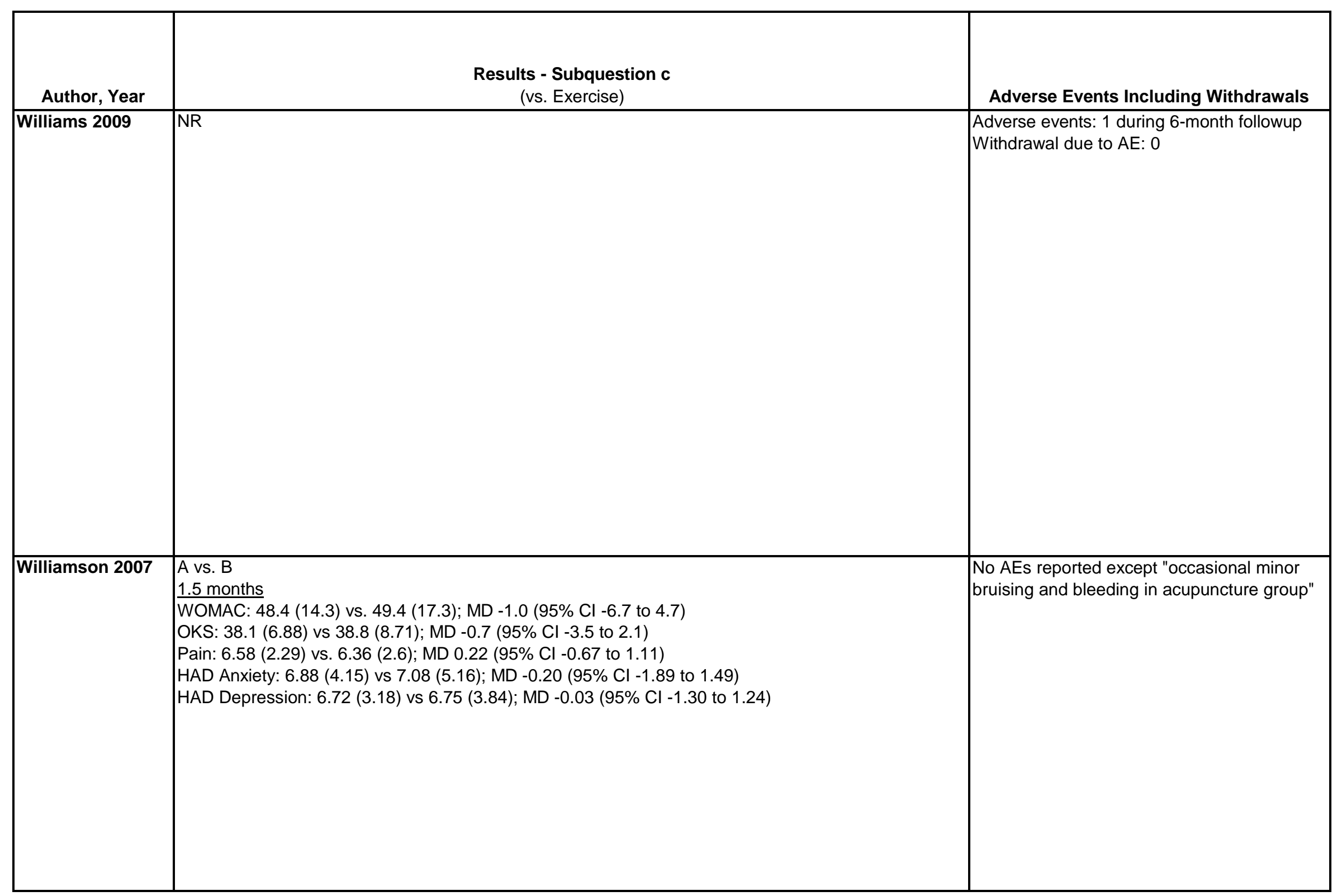




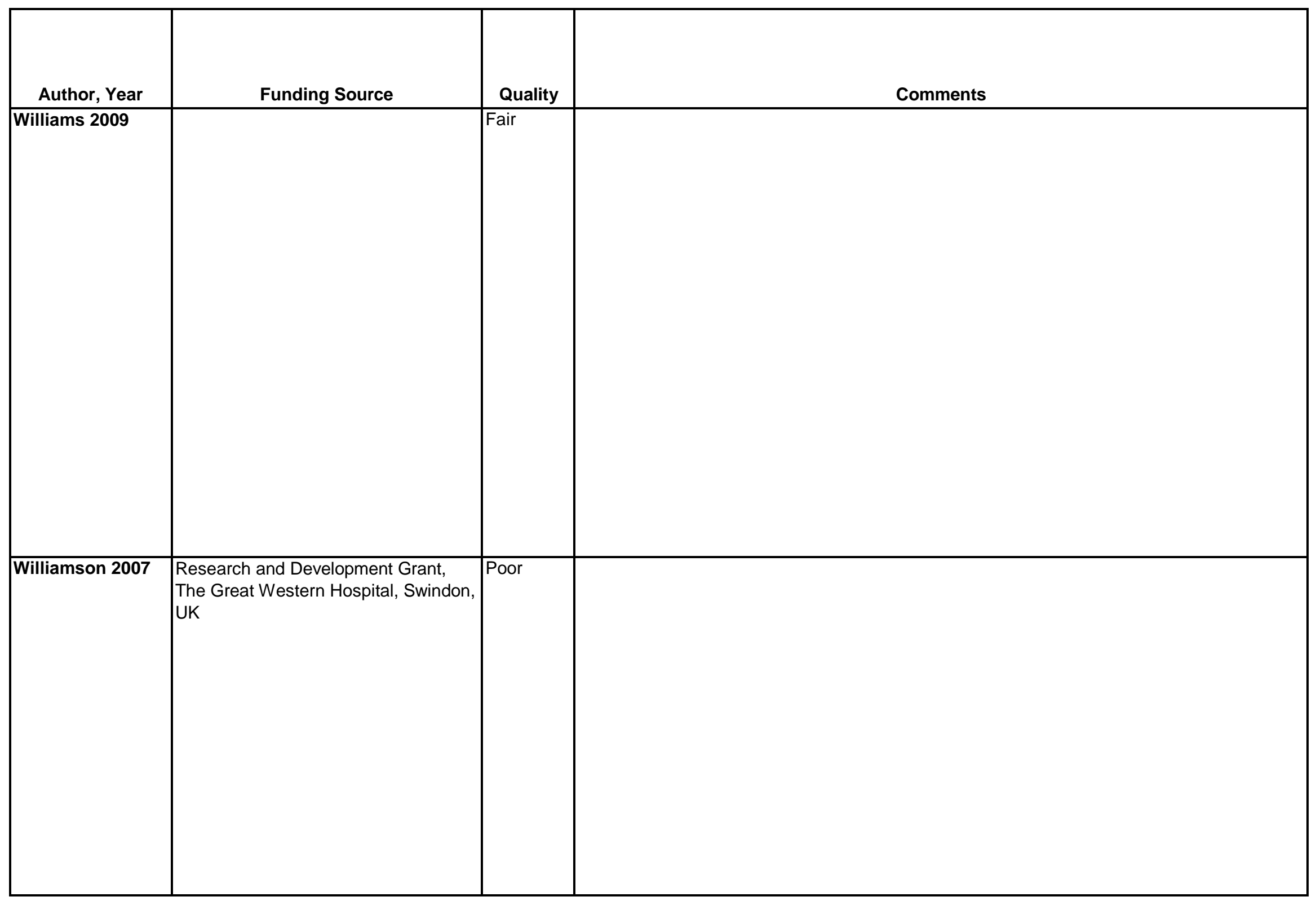

D-867 


\begin{tabular}{|c|c|c|c|}
\hline Author, Year & $\begin{array}{c}\text { Country } \\
\text { Number of Centers } \\
\text { Setting }\end{array}$ & Inclusion/Exclusion Criteria & $\begin{array}{c}\text { Number Randomized, } \\
\text { Analyzed } \\
\text { Attrition } \\
\end{array}$ \\
\hline Witt 2005 & $\begin{array}{l}\text { Germany, Number of } \\
\text { centers unclear }\end{array}$ & $\begin{array}{l}\text { Inclusion criteria: } 50-75 \text { years old, OA based on ACR criteria, } \\
\text { Kellgren-Lawrence grade } 2+\text { radiographic findings, average pain } \\
\text { intensity of } \geq 40 \text { on a } 100 \text { mm VAS in prior } 7 \text { days } \\
\text { Exclusion criteria: Knee pain due to inflammatory, malignant, or } \\
\text { autoimmune disease; serious valgus-defective or varus-defective } \\
\text { position; knee surgery or arthroscopy in the past year, } \\
\text { chondroprotective or intra-articular injection in the past } 4 \text { months, } \\
\text { systemic corticoid treatment or beginning of a new treatment for OAin } \\
\text { the past } 4 \text { weeks, local antiphlogistic treatment, acupuncture } \\
\text { treatment during the past } 12 \text { months, or PT or other treatments for } \\
\text { osteoarthritis knee pain (with the exception of NSAIDs) during the } \\
\text { previous } 4 \text { weeks, application } \\
\text { for pension or disability benefits, serious acute or chronic organic } \\
\text { disease or mental disorder, pregnancy or breastfeeding, and blood } \\
\text { coagulation disorders or coagulation-inhibiting medication other than } \\
\text { aspirin }\end{array}$ & $\begin{array}{l}\text { Randomized: } 226 \\
\text { Treated: } 224 \text { (2 } \\
\text { randomized but did not } \\
\text { complete baseline } \\
\text { questionnaires or get } \\
\text { acupuncture) } \\
\text { Analyzed: } 217 \text { (224 } \\
\text { included in ITT analysis } \\
\text { using LOCF) } \\
\text { Attrition: 4\% (9/226) }\end{array}$ \\
\hline Yildiz 2015 & $\begin{array}{l}\text { Turkey, outpatient } \\
\text { clinic }\end{array}$ & $\begin{array}{l}\text { Inclusion Criteria: } \\
\text { Patients between } 40 \text { and } 65 \text { years of age who were diagnosed with } \\
\text { bilateral stage } 2 \text { and } 3 \text { primary knee OA according to Kellgren- } \\
\text { Lawrence criteria, were enrolled in the study. } \\
\text { Exclusion Criteria: } \\
\text { Patients with secondary knee OA; active synovitis; symptomatic hip, } \\
\text { foot, and ankle disease; neurologic deficits in a lower extremity; recent } \\
\text { knee trauma; history of intraarticular steroid and/or hyaluronate } \\
\text { injection in the past } 6 \text { months; history of knee surgery or arthroscopy } \\
\text { to the knee joint in the last year; and application of physical treatment } \\
\text { to the knee in the last } 3 \text { months were excluded from the study. }\end{array}$ & $\begin{array}{l}\text { Randomized: } 90 \\
\text { Treated: } 90 \\
\text { Analyzed: } 90 \\
\text { Attrition: } 0 \%(0 / 90)\end{array}$ \\
\hline
\end{tabular}




\begin{tabular}{|c|c|}
\hline Author, Year & Intervention, Comparator \\
\hline Witt 2005 & $\begin{array}{l}\text { A. Acupuncture }(n=149) \text { : semi-standardized; patients received at least } 6 \text { local and at least } 2 \text { distant Traditional Acupuncture points; needle length } \\
\text { and diameter were at physcian's discretion; elicitation of de qi; needles stimulated manually at least once during each session } \\
\text { B. Minimal acupuncture }(n=75) \text { : superficial insertion of fine needles at non-acupuncture sites away from knee; manual stimulation of the needles } \\
\text { and provocation of de qi were avoided } \\
\text { Both groups underwent } 12 \text { sessions of } 30 \text { minutes duration, administered over } 8 \text { weeks; } \\
\text { In both groups, for patients with bilateral OA, both knees were needled with at least } 8 \text { out of } 10 \text { proposed points (at least } 16 \text { needles total); for } \\
\text { unilateral OA, the physician was able to choose unilateral or bilateral acupuncture. For unilateral acupuncture, the treatment had to be done with at } \\
\text { least } 8 \text { needles }\end{array}$ \\
\hline Yildiz 2015 & $\begin{array}{l}\text { A.Continuous Ultrasound ( } n=30) \\
\text { In addition to application of ultrasound therapy to affected leg(s), all patients were given a home exercise program and instructed to perform } \\
\text { isometric exercises and strengthening exercises } 3 \text { times/day for } 8 \text { weeks. } \\
\text { No. of Treatments: } 5 \text { days/week for } 2 \text { weeks ( } 10 \text { total) } \\
\text { Length of Treatments: } 5 \text { minutes } \\
\text { Area: anterior, medial and lateral areas of the knees } \\
\text { Frequency: } 1 \mathrm{MHz} \\
\text { Intensity: } 1.5 \mathrm{~W} / \mathrm{cm} 2 \\
\text { Device: } 5-\mathrm{cm} 2 \text { head (Enraf Nonius Sono plus } 492) \\
\text { B.Pulsed Ultrasound ( } n=30) \\
\text { Identical treatment protocol except device was set to a pulsed output. } \\
\text { Pulse Ratio: } 1: 5 \\
\text { C. Sham Ultrasound ( } n=30)\end{array}$ \\
\hline
\end{tabular}




\begin{tabular}{|c|c|c|c|}
\hline Author, Year & Study Participants & Outcome Measures & $\begin{array}{c}\text { Duration of } \\
\text { Followup }\end{array}$ \\
\hline Witt 2005 & $\begin{array}{l}\text { A vs. B } \quad \text { Age: } 65 \text { vs. } 63 \text { years } \\
\text { Female: } 70 \% \text { vs. } 65 \% \\
\text { Duration of symptoms: } 9.1 \text { vs. } 9.9 \text { years } \\
\text { Bilateral OA: } 74 \% \text { vs. } 77 \% \\
\text { Previous acupuncture treatment: } 9 \% \text { vs. } 7 \% \\
\text { Physiotherapy in past } 6 \text { months: } 15 \% \text { vs. } 9 \% \\
\text { Pharmacological intervention in past } 6 \text { months: } 29 \% \text { vs. } 36 \% \\
\\
\text { WOMAC: } 50.8(18.8) \text { vs. } 52.5(18.6) \\
\text { PDI: } 27.9(14.2) \text { vs. } 27.8(13.2) \\
\text { VAS pain: } 64.9(14.2) \text { vs. } 68.5(14.4) \\
\text { SF-36 Physical health: } 30.0(7.4) \text { vs. } 29.2(8.2) \\
\text { SF-36 Mental health: } 51.8(12.1) \text { vs. } 51.1(11.6) \\
\text { ADS: } 51.2(10.0) \text { vs. } 51.3(7.9)\end{array}$ & $\begin{array}{l}\text { WOMAC (scales unclear); } \\
\text { Pain Disability Index, German version (PDI, 0-10, higher } \\
\text { score=more severe disability related to pain); } \\
\text { SF-36 (0-100, higher score=better QoL); } \\
\text { Allgemeine Depressionsskala (ADS, Depression Scale, } \\
\text { scale unclear) } \\
\text { ×for bilateral OA, the knee defined at baseline as most } \\
\text { painful was the one assessed throughout entire study }\end{array}$ & $\begin{array}{l}4 \text { and } 10 \\
\text { months }\end{array}$ \\
\hline Yildiz 2015 & $\begin{array}{l}\text { A vs. B vs. C } \\
\text { Age: } 56 \text { vs. } 55 \text { vs. } 58 \\
\text { Female: } 83.3 \% \text { vs. } 80 \% \text { vs. } 86.6 \% \\
\text { Race: NR } \\
\text { Mean Duration of Chronicity: } 4.1 \text { vs. } 2.8 \text { vs. } 5.1 \text { years } \\
\\
\text { Lequesne Index Score: } 13.20(3.66) \text { vs. } 12.90(2.73) \text { vs. } 12.37(3.68) \\
\text { Pain on Movement (VAS) } 8.97(1.45) \text { vs. } 8.60(1.61) \text { vs. } 8.93(1.44) \\
\text { Pain at Rest (VAS): NR } \\
\text { Quality of Life (SF-36): NR } \\
\text { Sleep (VAS): NR }\end{array}$ & $\begin{array}{l}\text { Lequesne Function Index for Knee Osteoarthritis (range } \\
\text { 0-24, higher score=greater dysfunction) } \\
\text { Pain on Movement (VAS, 0-10) } \\
\text { Pain at Rest (VAS, 0-10) } \\
\text { SF-36 (0-100) } \\
\text { Sleep (VAS, 0-10) }\end{array}$ & 2 months \\
\hline
\end{tabular}




\begin{tabular}{|c|c|}
\hline Author, Year & $\begin{array}{l}\text { Results - Subquestion a } \\
\text { (vs. sham, no treatment, waitlist, attention control) }\end{array}$ \\
\hline Witt 2005 & 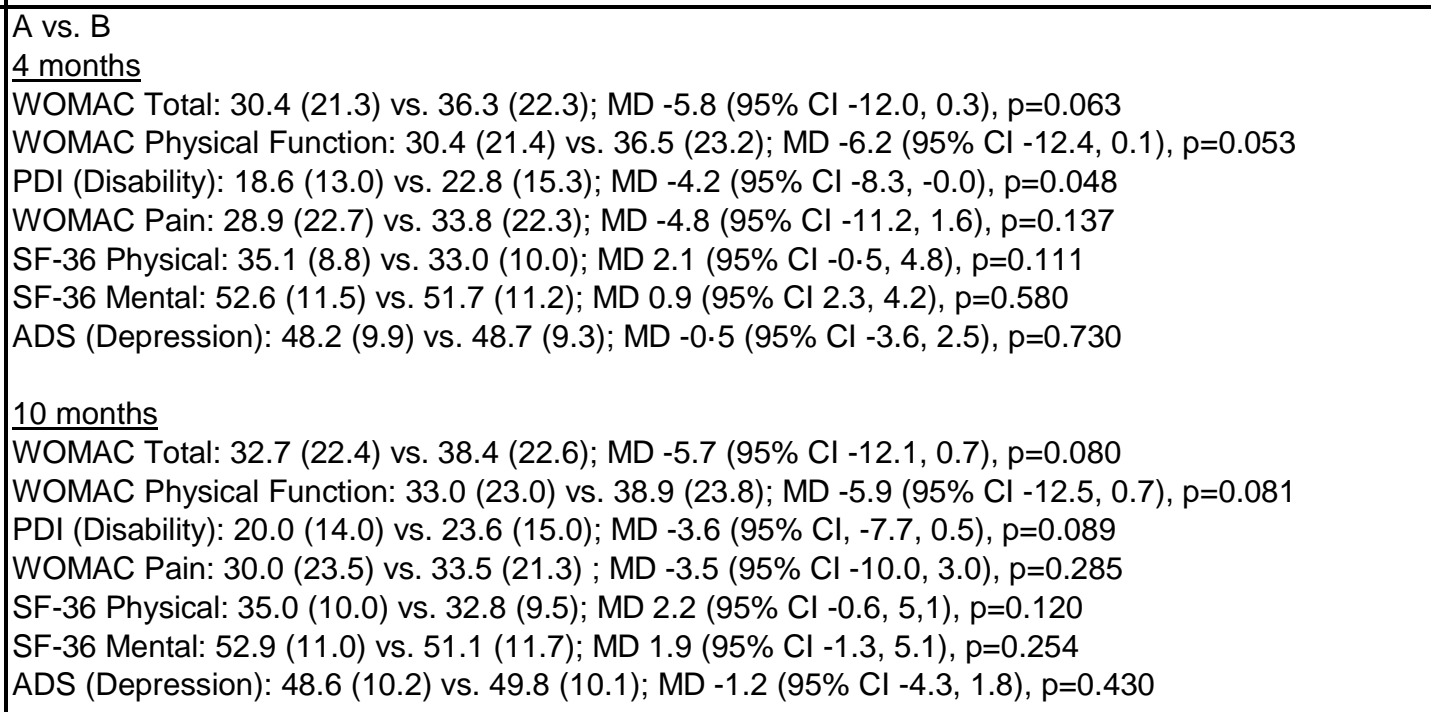 \\
\hline Yildiz 2015 & $\begin{array}{l}\text { A vs. C } \\
2 \text { months } \\
\text { Lequesne Index: } 5.45(3.43) \text { vs. } 11.73(4.53) \mathrm{p}<0.001 \text {; AvsC: MD }-6.2(95 \% \mathrm{Cl}-8.36 \text { to }-4.20) \\
\text { Pain on Movement (VAS): } 3.90(2.54) \text { vs. } 7.20(2.66) \mathrm{p}<0.001 ; \text { AvSC: MD }-3.3(95 \% \mathrm{Cl}-4.64 \text { to }-1.96) \\
\text { Pain at Rest (VAS): NR } \\
\text { Quality of Life (SF-36): NR } \\
\text { Sleep (VAS): NR } \\
\text { B vs. C } \\
\text { 2 months } \\
\text { Lequesne Index: } 6.02(3.14) \text { vs. } 11.73(4.53) \mathrm{p}<0.001 ; \text { BvsC: MD }-5.71(95 \% \mathrm{Cl}-7.72 \text { to }-3.70) \\
\text { Pain on Movement (VAS): } 3.83(2.61) \text { vs. } 7.20(2.66) \text { p<0.001; BvSC: } \mathrm{MD}-3.37(95 \% \mathrm{Cl}-4.73 \text { to }-2.01) \\
\text { Pain at Rest (VAS): NR } \\
\text { Quality of Life (SF-36): NR } \\
\text { Sleep (VAS): NR }\end{array}$ \\
\hline
\end{tabular}




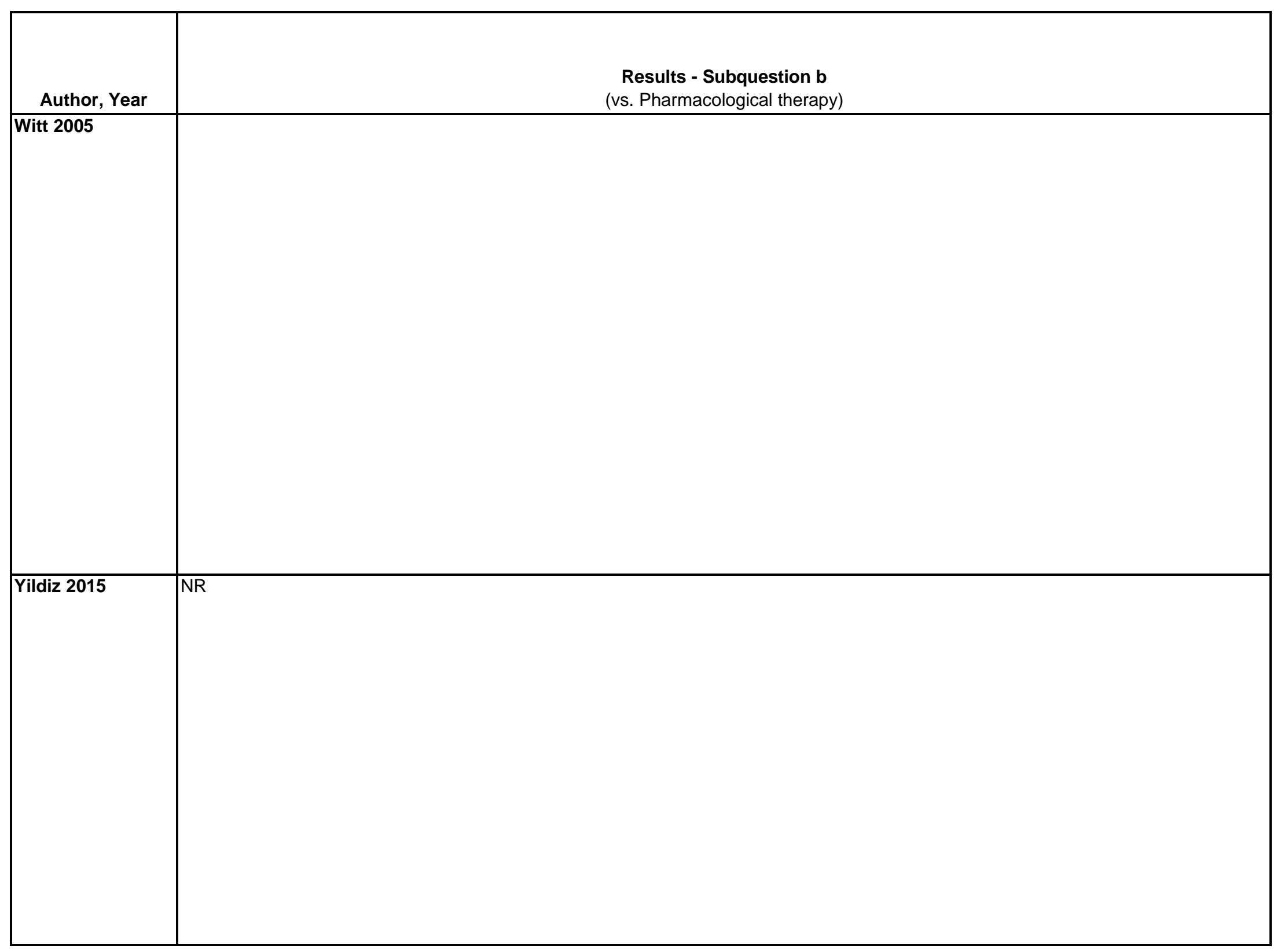




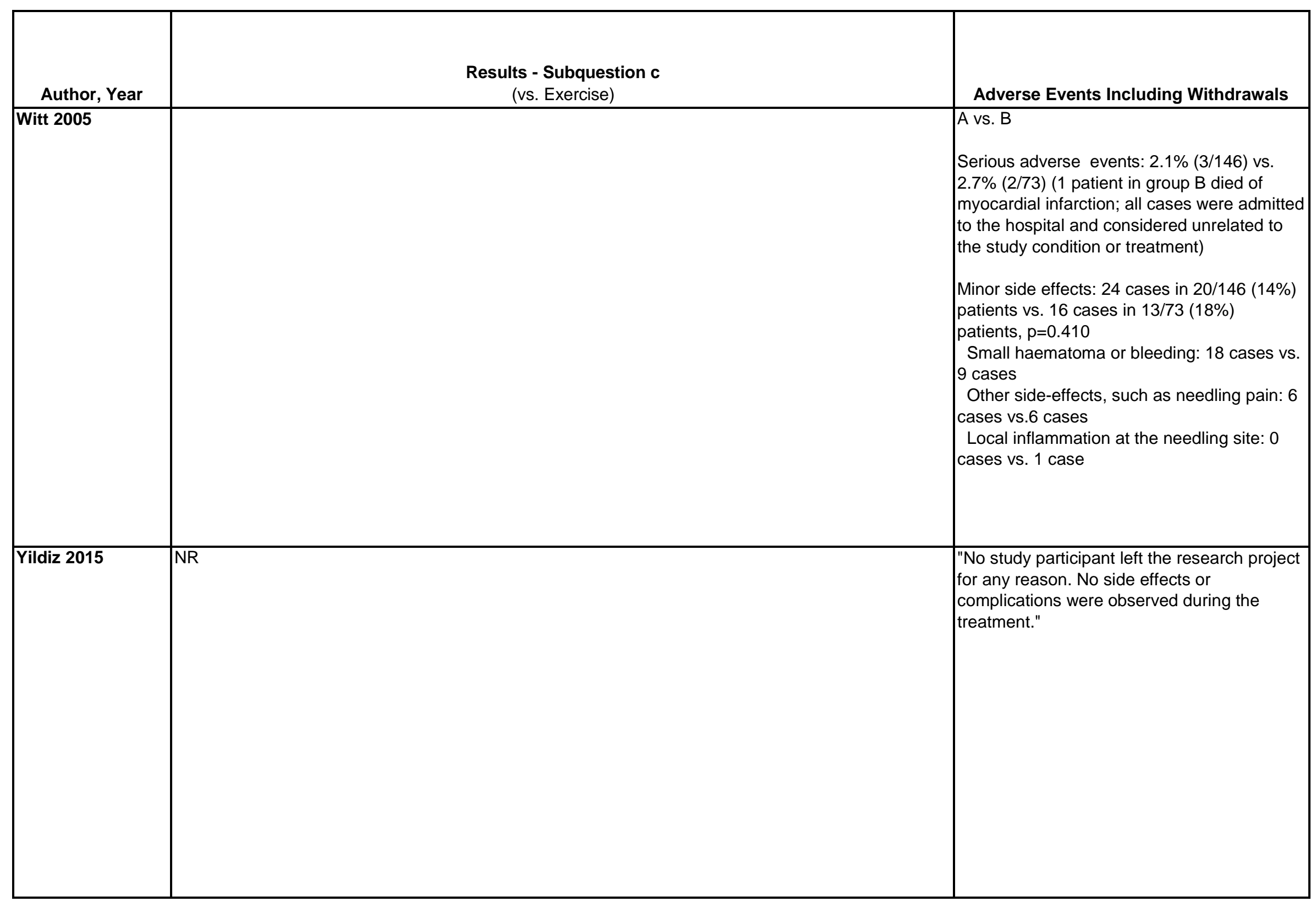




\begin{tabular}{|c|c|c|c|}
\hline Author, Year & Funding Source & Quality & Comments \\
\hline Witt 2005 & $\begin{array}{l}\text { Institute for Social Medicine, } \\
\text { Epidemiology and Health Economics }\end{array}$ & Fair & $\begin{array}{l}\text { This study had a third waitlist control arm that was excluded from this report because these } \\
\text { patients received } 12 \text { sessions of acupuncture after the } 8 \text { weeks (immediately post-treatment) } \\
\text { assessment; thus the only useable comparative data is immediately post-treatment which } \\
\text { does not meet our inclusion criteria. }\end{array}$ \\
\hline Yilddiz 2015 & NRR & Fair & \\
\hline & & & \\
\hline & & & \\
\hline & & & \\
\hline & & & \\
\hline & & & \\
\hline
\end{tabular}




\begin{tabular}{|c|c|c|c|}
\hline Author, Year & $\begin{array}{c}\text { Country } \\
\text { Number of Centers } \\
\text { Setting }\end{array}$ & Inclusion/Exclusion Criteria & $\begin{array}{c}\text { Number Randomized, } \\
\text { Analyzed } \\
\text { Attrition }\end{array}$ \\
\hline Yurtkuran 2007 & \begin{tabular}{|l|} 
Turkey, single \\
outpatient clinic
\end{tabular} & $\begin{array}{l}\text { Inclusion Criteria: } \\
50 \text { years or older } \\
\text { knee pain average severity of } 40 \text { or more on } 0-100 \text { VAS for } \geq 1 \text { month } \\
\text { prior, Kellgren and } \\
\text { Lawrence grade } 2 \text { and } 3 \text { KOA } \\
\text { Exclusion: knee surgery, serious valgus or } \\
\text { varus deformity or who had hormonal, metabolic, or systemic } \\
\text { rheumatologic problems leading to secondary KOA, PT in last } 6 \\
\text { months, oral analgesics in last } 4 \text { weeks }\end{array}$ & $\begin{array}{l}\text { Randomized: } 55 \\
\text { Treated: } 55 \\
\text { Analyzed: } 52 \\
\text { Attrition: } 5 \%(3 / 55)\end{array}$ \\
\hline Zgierska 2016 & $\begin{array}{l}\text { US } \\
\text { Number centers: } 1 \\
\text { Outpatient }\end{array}$ & $\begin{array}{l}21 \geq \text { years old treated with long-term opioids for chronic LBP } \\
\text { Exclude: prior experience with mindfulness meditation; inability to } \\
\text { consent for or reliably participate in study activities; diagnoses of } \\
\text { borderline } \\
\text { personality, bipolar, or delusional disorders; or current pregnancy }\end{array}$ & $\begin{array}{l}\text { Randomized: } 35 \\
\text { Treated: } 35 \\
\text { Analyzed: } 35 \\
\text { Attrition: } 0.02 \%(1 / 35)\end{array}$ \\
\hline Zhang 2013 & $\begin{array}{l}\text { Hong Kong } \\
2006-2009\end{array}$ & $\begin{array}{l}\text { Adult with chronic mechanical neck pain for } \geq 3 \text { months } \\
\text { Excluded: prior neck surgery, neurological deficits, history of } \\
\text { malignancy, congenital abnormality of the spine, systemic diseases, } \\
\text { and treatment by acupuncture in the last } 6 \text { months. }\end{array}$ & $\begin{array}{l}\text { Randomized: } 206 \\
\text { Treated: } 175 \\
\text { Analyzed: } 160 \\
\text { Attrition: } 22 \% \\
(46 / 206)\end{array}$ \\
\hline
\end{tabular}




\begin{tabular}{|c|c|}
\hline Author, Year & Intervention, Comparator \\
\hline Yurtkuran 2007 & $\begin{array}{l}\text { A. laser acupuncture ( } \mathrm{n}=27) \text { : infrared } 27 \mathrm{GaAs} \text { diyode laser instrument; output power of } 4 \mathrm{~mW}, 10 \mathrm{~mW} / \mathrm{cm} 2 \text { power density, } 0.4 \mathrm{~cm} 2 \mathrm{spot} \text { size, } 120- \\
\text { sec treatment time and } 0.48 \mathrm{~J} \text { dose per session. The irradiation was pulsed (duration of } 1 \text { pulse was } 200 \mathrm{nanosecond} \text { ), and only one point was } \\
\text { treated with contact application technique. Applied to the medial side of the knee to the acupuncture point (Sp9) on } \\
\text { the sural nerve. } \\
\text { B. sham laser acupuncture }(\mathrm{n}=25) \text { : performed in the same location and under the same conditions as the true laser acupuncture; patients could see } \\
\text { a red light but the machine was turned off } \\
\text { Both groups: } 5 \text { days per week for } 2 \text { weeks (total duration of therapy was } 10 \text { days) and } 20 \text { min per day; } 10 \text { sessions total. } \\
\text { In addition, all patients received a home-based, standardized exercise program }\end{array}$ \\
\hline Zgierska 2016 & $\begin{array}{l}\text { A. Mindfulness-based stress reduction ( } n=21): 8 \text { weekly } 2 \text { hour group sessions (mediation-CBT, "Mindfulness for Chronic Pain), plus } 30 \text { minutes/day, } \\
6 \text { days/week of at home practice } \\
\text { B. Usual care }(n=14) \text { : includes pharmacotherapy, safety, and treatment progress monitoring, treatment agreements, and referral to specialty care, } \\
\text { including physical therapy, and complementary therapies for pain and/or mental health }\end{array}$ \\
\hline Zhang 2013 & $\begin{array}{l}\text { A. Electro-acupuncture ( } \mathrm{n}=84 \text { ) with needles placed into } \mathrm{LI} 4, \mathrm{x} 2 \text {; SI3, x2; GB20,x2; GB21, x2; and Bailao and stimulated with electro-acupuncture } \\
\text { machine for } 45 \text { minutes. Two additional points could be chosen from tender points or acupuncture points immediately near the tender points. } \\
\text { B. Sham laser acupuncture }(\mathrm{n}=76) \text { was delivered via a mock laser pen that only emitted a red light. Each point was treated for } 2 \text { minutes, with the } \\
\text { pen at a distance of } 0.5 \text { to } 1 \mathrm{~cm} \text { from the skin. } \\
\text { Treatment } 3 \times \text { /week for } 3 \text { weeks }\end{array}$ \\
\hline
\end{tabular}




\begin{tabular}{|c|c|c|c|}
\hline Author, Year & Study Participants & Outcome Measures & $\begin{array}{c}\text { Duration of } \\
\text { Followup }\end{array}$ \\
\hline Yurtkuran 2007 & $\begin{array}{l}\text { A vs B } \\
\text { Age: } 52 \text { vs. } 53 \text { years } \\
\text { Female: } 96 \% \text { vs. } 96 \% \\
\text { Duration of symptoms: } 62 \text { vs. } 67 \text { months } \\
\text { WOMAC: } 66.53(17.6) \text { vs. } 51.31 \text { (18.9) } \\
\text { VAS pain on movement: } 6.47(1.6) \text { vs. } 6.06(2.2) \\
\text { NHP: } 8.79(3.8) \text { vs. } 8.06(4.5)\end{array}$ & $\begin{array}{l}\text { WOMAC (scale unclear; higher score=worse disability) } \\
\text { Knee Pain on movement (VAS, 0-100; higher score- } \\
\text { worse pain) } \\
\text { Nottingham Health Profile (NHP) QOL (0-38; higher } \\
\text { score=worse quality of life) }\end{array}$ & 3 months \\
\hline Zgierska 2016 & $\begin{array}{l}\text { Overall } \\
\text { Age: } 51.8 \text { years } \\
\text { Female: } 80 \% \\
\text { Race: NR } \\
\text { Medication use for pain: } 3 \text { months } \geq \\
\text { Severe pain related disability (mean): } 66.7 \\
\text { Moderate pain severity (mean): } 5.8 \\
\text { Morphine equivalent dose: } 148.3 \mathrm{mg} / \text { day } \\
\text { A vs B }\end{array}$ & $\begin{array}{l}\text { Oswestry Disability Index (0-100) } \\
\text { Brief Pain Inventory pain intensity }(0-10) \text { ) } \\
\text { Opioid dose (morphine-equivalent dose) mg/day, past } 28 \\
\text { days }\end{array}$ & 4.5 months \\
\hline Zhang 2013 & $\begin{array}{l}\text { A vs } \mathrm{B} \\
\text { Age: } 46 \text { years (whole population) } \\
\text { Female: } 70 \% \text { (whole population) } \\
\text { Duration: } 75 \text { months (whole population) } \\
\text { NPQ: } 40.7 \text { (Cl, } 38.6 \text { to } 42.9) \text { vs } 41.1 \text { (Cl, } 38.7-43.5) \\
\text { Pain with motion (0-100), } \\
\text { SF-36 PCS: } 52.5 \text { (Cl, } 51.5 \text { to } 53.4) \text { vs } 52.7(\mathrm{Cl}, 51.9 \text { to } 53.6) \\
\text { SF-36 MCS: } 43.8 \text { (Cl, } 42.9 \text { to } 44.8) \text { vs } 43.7(\mathrm{Cl}, 42.6 \text { to } 44.8)\end{array}$ & $\begin{array}{l}\text { Northwick Park Neck pain Questionnaire (NPQ) (scale: } \\
\text { 0-100\%, higher percentage the greater the disability) } \\
\text { SF-36 physical and mental summary scores (0-100, } \\
\text { higher score=better QoL) }\end{array}$ & $\begin{array}{l}3 \text { and } 6 \\
\text { months }\end{array}$ \\
\hline
\end{tabular}




\begin{tabular}{|c|c|}
\hline Author, Year & $\begin{array}{c}\text { Results - Subquestion a } \\
\text { (vs. sham, no treatment, waitlist, attention control) }\end{array}$ \\
\hline Yurtkuran 2007 & $\begin{array}{l}\text { A vs. B } \\
3 \text { months } \\
\text { WOMAC total: } 62.4 \text { (22.3) vs. } 50.6(23.6) ; \mathrm{MD} 11.8(95 \% \mathrm{Cl}-1.0,24.6), \mathrm{p}=0.07 \\
\text { WOMAC Physical Function: } 44.24(15.8) \text { vs. } 35.25(16.6) ; \mathrm{MD} 11.9(95 \% \mathrm{Cl} 2.9,20.9), \mathrm{p}=0.01 \\
\text { WOMAC Pain: } 13.47(5.8) \text { vs. } 11.50 \text { (6.0); MD } 2.0(95 \% \mathrm{Cl}-1.3,5.3) \\
\text { VAS Pain on movement: } 5.6(2.4) \text { vs. } 4.8(3.5) ; \mathrm{MD} 0.8(95 \% \mathrm{Cl}-0.9,2.5), \mathrm{p}=0.34 \\
\text { NHP: } 7.58 \text { (5.4) vs. } 6.44 \text { (6.3); MD } 1.14(95 \% \mathrm{Cl}-2.1,4.4), \mathrm{p}=0.49\end{array}$ \\
\hline Zgierska 2016 & $\begin{array}{l}\text { A vs. B } \\
4.5 \text { months, mean change from baseline } \\
\text { ODI: }-5.0 \text { ( } 95 \% \mathrm{Cl} 9.7,0.2) \text { vs. } 1.6(95 \% \mathrm{Cl}-4.3,7.4) \text {, mean difference in change from baseline }-6.5(95 \% \mathrm{Cl}-14.0,1.0) \\
\text { Brief Pain Inventory pain intensity: }-0.5(95 \% \mathrm{Cl}-1.1,0.02) \text { vs. } 0.5(95 \% \mathrm{Cl} 0.2,1.2) \text {, mean difference in change from baseline }-1.03(95 \% \mathrm{Cl}-1.9,-0.2) \\
\text { Opioid dose (mg morphine equivalents): }-10.1(95 \% \mathrm{Cl}-35.5,15.2) \text { vs. }-0.2(95 \% \mathrm{Cl}-31.4,30.9)\end{array}$ \\
\hline Zhang 2013 & $\begin{array}{l}\text { A vs B } \\
3 \text { month outcomes (mean and } 95 \% \mathrm{Cl} \text { ) } \\
\text { NPQ: } 32.9(\mathrm{Cl}, 30.3 \text { to } 35.4) \text { vs } 33.3(\mathrm{Cl} 30.1 \text { to } 36.5), \mathrm{p}=0.664 \\
\text { Pain with motion: } 46.6(\mathrm{Cl}, 42.2 \text { to } 51.0) \text { vs } 45.1(\mathrm{Cl}, 40.5 \text { to } 49.6), \mathrm{p}=0.617 \\
\text { SF-36 PCS: } 52.8(\mathrm{Cl}, 53.0 \text { to } 53.7) \text { vs } 53.3(\mathrm{Cl}, 52.4 \text { to } 54.2), \mathrm{p}=0.982 \\
\text { SF-36 MCS: } 45.9(\mathrm{Cl}, 46.0 \text { to } 46.8) \text { vs } 45.3(\mathrm{Cl}, 44.2 \text { to } 46.4), \mathrm{p}=0.444 \\
\\
\text { 6 month outcomes (mean and } 95 \% \mathrm{Cl}) \\
\text { NPQ: } 33.59(\mathrm{Cl}, 30.7 \text { to } 36.4) \text { vs } 34.3(\mathrm{Cl} 31.1 \text { to } 37.6), \mathrm{p}=0.808 \\
\text { Pain with motion: } 46.8(\mathrm{Cl}, 42.0 \text { to } 51.5) \text { vs } 43.6(\mathrm{Cl}, 38.8 \text { to } 48.4), \mathrm{p}=0.813 \\
\text { SF-36 PCS: } 53.0(\mathrm{Cl}, 52.0 \text { to } 53.9) \text { vs } 53.2(52.3 \text { to } 54.0), \mathrm{p}=0.559 \\
\text { SF-36 MCS: } 45.4(\mathrm{Cl}, 44.5 \text { to } 46.3) \text { vs } 44,4(\mathrm{Cl}, 43.4 \text { to } 45.4), \mathrm{p}=0.246\end{array}$ \\
\hline
\end{tabular}




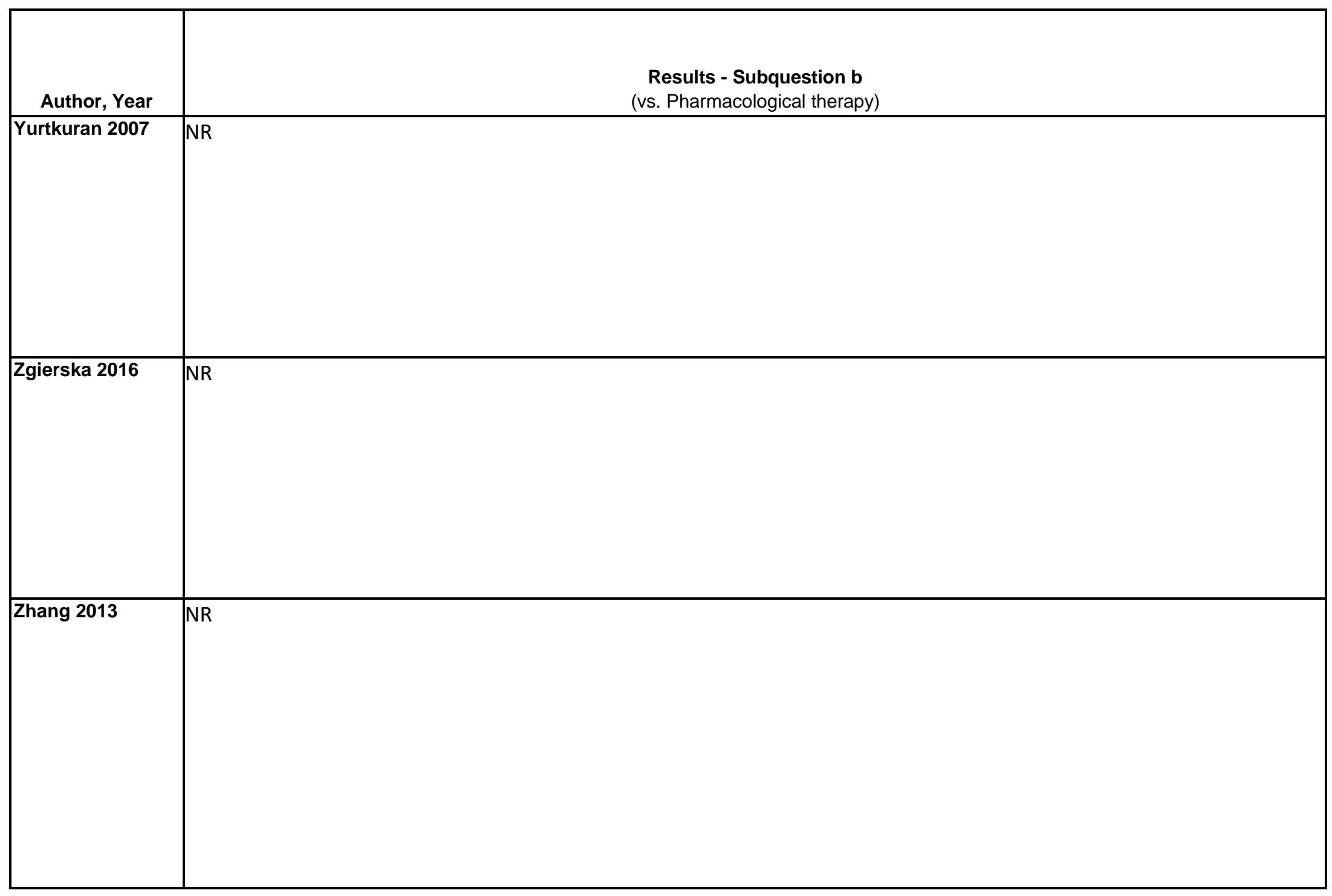

D-879 


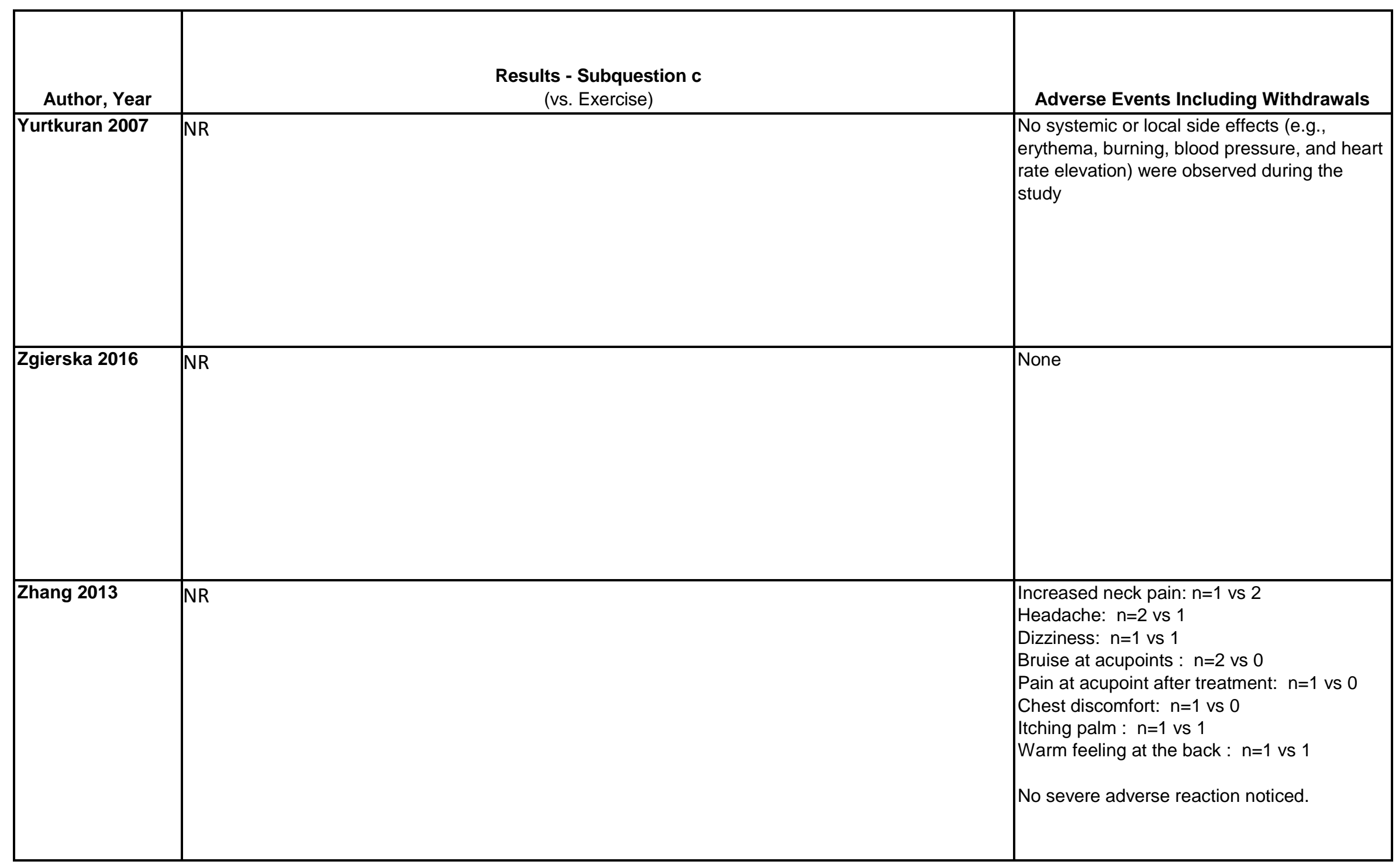




\begin{tabular}{|l|l|l|l|}
\hline Author, Year & \multicolumn{1}{|c|}{ Funding Source } & Quality & \\
\hline Yurtkuran 2007 & $\begin{array}{l}\text { Sponsored by University Research } \\
\text { Committee }\end{array}$ & Fair & \\
\hline Zgierska 2016 & $\begin{array}{l}\text { "K23AA017508 (NIH) National } \\
\text { Institute on Alcohol Abuse and } \\
\text { Alcoholism (NIAAA), and } \\
\text { University of Wisconsin-Madison" }\end{array}$ & Poor & \\
\hline Zhang 2013 & $\begin{array}{l}\text { Health and Health Services Research } \\
\text { Fund, Food and Health Bureau, Hong } \\
\text { Kong SAR Government (\#04060191), } \\
\text { School of Chinese Medicine of Hong } \\
\text { Kong }\end{array}$ & $\begin{array}{l}\text { Fair } \\
\text { lis= ; 3B= ; 5D-3L=3 level version of EQ-5D; ACR=American College of Rheumatology; ACSM=American College of Sports Medcine; ACT=Acceptance and }\end{array}$ \\
\hline
\end{tabular}

Commitment Therapy; ADAPT=The Arthritis, Diet, and Activity Promotion Trial; Adj=adjusted; ADL=Activities of Daily Living; ADS=Allgemeine Depressionsskala; $\mathrm{AE}=$ adverse event; $\mathrm{AHRQ}=$ Agency for Healthcare Research and Quality; AIMS=Arthritis Impact Measurement Scales; ALBA= ; ALF-LUA= ; AM=antidepressant medications; ANOVA=analysis of variance; $\mathrm{AP}=$ Arnold Peter; $\mathrm{AQoL}=$ assessment of quality of life; $\mathrm{AT}=$; $\mathrm{ATEP}=$ active trunk exercise program; AUSCAN=Australian/Canadian Osteoarthritis Hand Index; B2=B2 acupuncture point; BDI=Beck Depression Inventory; BDI-II= Beck Depression Inventory-II; BL10=BL10 acupuncture point; BL11=BL11 acupuncture point; BL12 =BL12 acupuncture point; BL16=BL16 acupuncture point; BL60=BL60 acupuncture point; BL62=BL62 acupuncture point; BL65=BL65 acupuncture point; Blvd=boulevard; BMI=body mass index; C4=C4 acupuncture point; CA=California;

$\mathrm{CAM}=$ complementary and alternative medicine; CAPES=Coordination for the Improvement of Higher Education Personnel; CBT=cognitive behavioral training; $\mathrm{CD}=$ compact disc; $\mathrm{CDC}=$ United States Centers of Disease Control and Prevention; CES-D=Center for Epidemiological Studies Depression Scale; $\mathrm{CI}=$ confidence interval; $\mathrm{cm} / \mathrm{CM}=$ centimeters; $\mathrm{COX}-2=$ cyclooxygenase-2; $\mathrm{CPEQ}=$ Comprehensive Pain Evaluation Questionnaire; $\mathrm{CPGS}=$ Von Korff Chronic Pain Grade Score; CTTH= ; DAK= ; $\mathrm{DAMD}=$; DANICA= ; DASS=Depression Anxiety Stress Scale; DFI=discrimination function index; diff=difference; Dr=drive; DU14=DU14 acupuncture point; $\mathrm{DVD}=$ digital versatile disc; $\mathrm{ELF}=$ extremely low frequency; EQ-5D= ; ES= ; ESWT=extracorporeal shock wave therapy; EuroQol= ; EVO=Engineering Virtual Organization; Ex-HN15=Ex-HN15 acupuncture point; F= ; FAST=The Fitness Arthritis and Seniors Trial; FD=flexion-distraction; FFbH-R=Funktionsfragebogen Hannover-Rücken; FIHOA=Functional Index for Hand Osteoarthritis; FIQ=Fibromyalgia Impact Questionnaire; Fl=floor; FM=fibromyalgia; FSI=Fatigue Symptom Inventory; f/u=followup; FYSIOPRIM= ; G= ; G2= ; GaAIAs=infrared emitting diodes; GaAs=gallium arsenide; GARS=Gilliam Autism Rating Scale; GB8=GB8 acupuncture point; GB12=GB12 acupuncture point; GB14=GB14 acupuncture point; GB20=GB20 acupuncture point; GB21=GB21 acupuncture point; GB34=GB34 acupuncture point; GB39=GB39 acupuncture point; GB41=GB41 acupuncture point; GB42=GB42 acupuncture point; GCQ=Giessen Complaint Questionnaire; 
GP=general practitioner; GPE=Global Perceived Effect; GRASS=gradient-recalled acquisition in a steady state; GSI=Global Severity Index; GV14=GV14 acupuncture point; GV20=GV20 acupuncture point; HA= ; HAD=Hospital Anxiety and Depression; HADS=Hospital Anxiety and Depression Scale; HAM-A=Hamilton Anxiety Rating Scale; HAM-D=Hamilton Rating Scale for Depression; HAQ= ; HARS=Hamilton Anxiety Rating Scale; HDI=Headache Disability Index; HDRS=Hamilton Depression Rating Scale; HEA=home exercise and advice; HEP= ; HFAQ=Hannover Functional Ability Questionnaire; HHS= ; HI=Headache Index; HIT-6=Headache

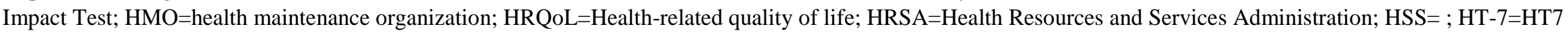

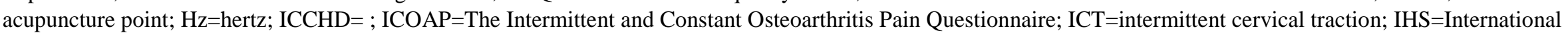
Headache Society; IL=Illinois; IMK= ; Inc=incorporated; inf= ; IQR=interquartile range; IRYSS=Investigación en Resultados y Servicios Sanitarios; ITT=intention to

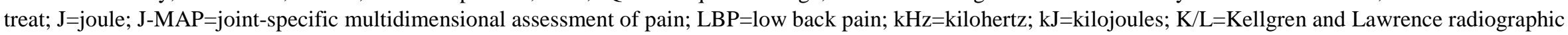
severity; km=kilometers; KOA=knee osteoarthritis; KOOS=Knee Injury and Osteoarthritis Outcome Score; KPS=Knee Pain Scale; KQ6=key question 6; L1=L1 acupuncture point; L2=L2 acupuncture point; L5=L5 acupuncture point; L14=L14 acupuncture point; LBO=Low Back Outcome Scale; LBP=low back pain; LI4=LI4 acupuncture point; LI5=LI5 acupuncture point; LI15=LI15 acupuncture point; LIV-3=LIV3 acupuncture point; LLC=limited liability corporation; LLFDI=Late-Life

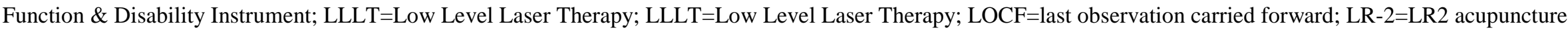
point; LR3=LR3 acupuncture point; LU7=LU7 acupuncture point; m=meters; mm=millimeters; MANOVA=Multivariate Analysis of Variance; MBSR=Mindfulnessbased Stress Reduction; MCD=Mean Duration of Chronicity; MCID=minimally clinically important difference; MCS=mental composite score; MD=Maryland; MDT=Mechanical Diagnosis and Therapy; METS=metabolic equivalents; mg=milligrams; MHz=MegaHertZ; MIDAS=Migraine Disability Assessment; mm=millimeters; MMSE=Mini-Mental Status Exam; mo/mos/MOS=months; MPI=Multidisciplinary Pain Inventory; MPQ=McGill Pain Questionnaire; ms= ; $\mathrm{mT}=$ massage therapy; $\mathrm{mW}=$ milliwatts; NCAAM=National Center for Complementary and Alternative Medicine; NCCAM=National Center for Complementary and

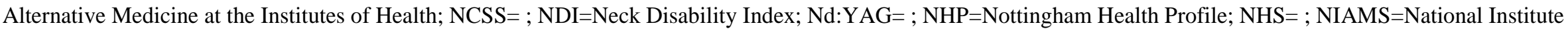

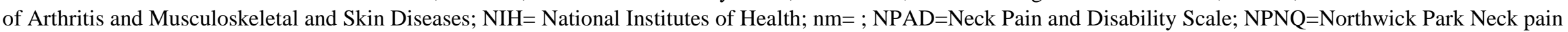

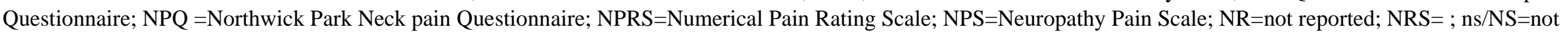
significant; NSAIDS=nonsteroidal anti-inflammatory drugs; NSCLBP=nonspecific low back pain; nsec=nanoseconds; NSW=New South Wales; NY=New York; O2=oxygen; OA=osteoarthritis; OARSI OMERACT=Osteoarthritis Research Society International ; ODI=Oswestry Disability Index; OKS=Oxford Knee Scale; OTC=over the counter; OTES=occipital transcutaneous electrical stimulation; P= ; P-6= ; PCS=physical composite score; PCD=Physical and Complex Disabilities; PCL=Quality of Life Profile for the Chronically Ill; PCS=physical composite score; PCST=pain coping skills training; PD= Power Density; PDI=Pain and Disability

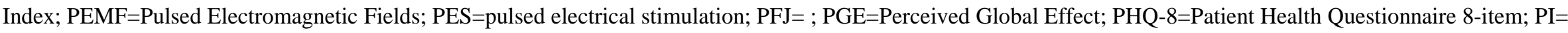
; PM\&R=Physical Medicine \& Rehabilitation; PMR=progressive muscle relaxation; PNF=proprioceptive neuromuscular facilitation; PPT= ; PRSS=Pain-Related Self

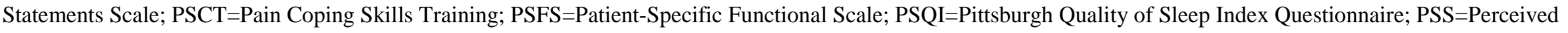

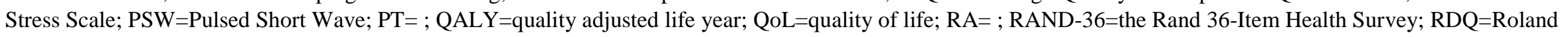

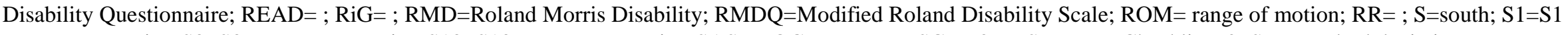
acupuncture point; S3=S3 acupuncture point; S13=S13 acupuncture point; SAS PROC MIXED= ; SCL-90-R=Symptom Checklist 90; SD=standard deviation;

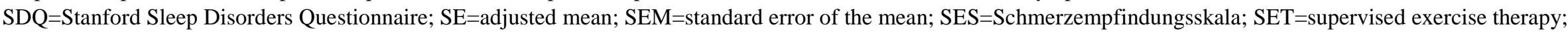
SF-12= ; SF-12v2=Short-Form 12v2; SI=small intestine acupuncture point; SI3=SI3 acupuncture point; SI4=SI4 acupuncture point; SI15=SI15 acupuncture point; SI9= SI9 acupuncture point; SI10=SI10 acupuncture point; SI11=SI11 acupuncture point; SI12=SI12 acupuncture point; SI14=SI14 acupuncture point; SIP=Sickness Impact

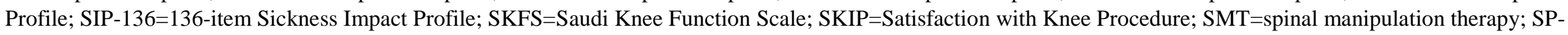
6=SP6 acupuncture point; SP9=SP9 acupuncture point; SR=systematic review; SSQ=Stanford Sleep Questionnaire; St=street; ST-36=ST36 acupuncture point; ST41=ST41 acupuncture point; STAI=State-Trait Anxiety Inventory; STAI-S=State-Trait Anxiety Inventory State Scale; STPI=State-Trait Personality Inventory; SWD=short wave diathermy; TAMMEF=Therapeutic Application of Musically Modulated Electromagnetic Field; TCA=traditional Chinese acupuncture; 
TCM=traditional Chinese medicine; TE5=TE5 acupuncture point; TE14=TE14 acupuncture point; TE15=TE15 acupuncture point; TE16=TE16 acupuncture point; TE17=TE17 acupuncture point; TENS=transcutaneous electrical nerve stimulation; TES=transcutaneous electrical stimulation; TKR=total knee replacement; TUG=Timed Up and Go Test; TW5=TW5 acupuncture point; TW8=TW8 acupuncture point; tx=treatment; UB2= UB2 acupuncture point; UB10=UB10 acupuncture point; UB60=UB60 acupuncture point; UK=United Kingdom; US=United States; USA=United States of America; UT=Utah; V= ; VAS=visual analogue scale; VGFOUREG= ; vs.=versus; VTR= ; VU= ; W=watts; WAD=whiplash-associated disorders; WHYMPI=West Haven-Yale Multidimensional Pain Inventory; wks= weeks; WL=waitlist; WOMAC=Western Ontario and McMaster Osteoarthritis Index; WPSI=Wahler Phsycial Symptoms Inventory; x2=twice; yrs=years; ZONMW=The Netherlands Organization for Health Research and Development. 


\section{Appendix E. Quality Assessment}

Table E-1. Quality assessment of randomized controlled trials See Appendix B. Included Studies for references.

\begin{tabular}{|c|c|c|c|c|c|c|c|c|c|}
\hline Author, Year & Randomization & $\begin{array}{l}\text { Concealed } \\
\text { Treatment } \\
\text { Allocation }\end{array}$ & $\begin{array}{c}\text { Intention-to- } \\
\text { Treat } \\
\text { Analysis }\end{array}$ & $\begin{array}{l}\text { Baseline } \\
\text { Group } \\
\text { Similarity }\end{array}$ & Patient Blinded & $\begin{array}{c}\text { Care } \\
\text { Provider } \\
\text { Blinded }\end{array}$ & $\begin{array}{l}\text { Outcome } \\
\text { Assessor / Data } \\
\text { Analyst Blinded }\end{array}$ & $\begin{array}{l}\text { Compliance } \\
\text { Acceptable in } \\
\text { All Groups }\end{array}$ & $\begin{array}{l}\text { Attrition } \\
\text { Reported }\end{array}$ \\
\hline Abbassi, 2012 & No & No & Yes & Yes & No & No & Unclear & Yes & Yes \\
\hline Abbott, 2013 & Yes & Yes & Yes & Yes & Unclear & No & Yes & Yes & Yes \\
\hline Ajimsha 2014 & Unclear & Unclear & Yes & Yes & Yes & No & Yes & Yes & Yes \\
\hline Al Rashoud 2014 & Yes & Yes & Unclear & Yes & Yes & Unclear & Yes & Unclear & No \\
\hline Alda 2011 & Yes & Yes & Yes & Yes & No & No & $\begin{array}{l}\text { Yes (CBO) No } \\
\text { (PRO) }\end{array}$ & Unclear & Yes \\
\hline Alfano 2001 & Yes & Unclear & No & Yes & $\begin{array}{l}\text { Yes (magnetic } \\
\text { field and sham } \\
\text { groups) } \\
\text { No (usual care } \\
\text { group) }\end{array}$ & Yes & $\begin{array}{l}\text { Yes (outcome } \\
\text { assessor) No } \\
\text { (data analyst) }\end{array}$ & Unclear & Yes \\
\hline Altan 2005 & Unclear & Unclear & Yes & No & Yes & Unclear & Yes & Yes & Yes \\
\hline Altan 2009 & Yes & Unclear & Yes & Yes & No & No & $\begin{array}{l}\text { Yes (CBO) No } \\
\text { (PRO) }\end{array}$ & Unclear & Yes \\
\hline Amris 2014 & Yes & Yes & Yes & Yes & No & No & No & Yes & Yes \\
\hline Andersen 2008 & Unclear & Unclear & Yes & Unclear & No & No & No & No & No \\
\hline Ang 2010 & Unclear & Unclear & Unclear & Unclear & No & No & No & Unclear & Yes \\
\hline Aslan Telci 2012 & Unclear & Unclear & Unclear & \begin{tabular}{|l} 
No \\
\end{tabular} & No & No & No & Unclear & No \\
\hline Assefi 2005 & Yes & Yes & Yes & \begin{tabular}{|l} 
Yes \\
\end{tabular} & Yes & No & Yes & Yes & Yes \\
\hline Banth, 2015 & Unclear & Unclear & Yes & Unclear & No & No & Yes & Unclear & Yes \\
\hline Baptista 2012 & Yes & Yes & Yes & No & No & No & No & Unclear & Yes \\
\hline Basford, 1999 & Yes & Unclear & Yes & \begin{tabular}{|l|} 
Yes \\
\end{tabular} & Yes & Yes & Yes & Yes & Yes \\
\hline Battisti 2004 & Unclear & Unclear & Unclear & Unclear & No & No & No & Yes & No \\
\hline $\begin{array}{l}\text { Bendix, 1995, } \\
1997,\end{array}$ & Yes (minimization) & Yes (minimization) & Yes & Yes & No & No & Yes & Unclear & Yes \\
\hline Bendix, 2000 & Yes (minimization) & Yes (minimization) & Yes & Yes & No & No & Yes & Unclear & Yes \\
\hline Bendix,1996, 1998 & Yes (minimization) & Yes (minimization) & Yes & Yes & No & No & Yes & Unclear & Yes \\
\hline Bennell, 2005 & Yes & Yes & Yes & Yes & Yes & No & Yes & Yes & Yes \\
\hline Bennell, 2016 & Yes & Yes & Yes & Yes & No & No & No & Yes & Yes \\
\hline Berman, 1999 & Yes & Yes & Yes & Yes & No & No & Unclear & Unclear & Yes \\
\hline Berman, 2004 & Yes & Yes & Yes & Yes & Yes & No & Yes & Yes & Yes \\
\hline Beurskens, 1997 & Yes & Yes & Yes & Yes & Yes & No & Yes & Yes & Yes \\
\hline Birch 1998 & Unclear & Unclear & Unclear & No & Yes/No* & No & Yes/No* & Yes & Yes \\
\hline
\end{tabular}




\begin{tabular}{|c|c|c|c|c|c|c|}
\hline Author, Year & $\begin{array}{c}\text { Attrition } \\
\text { Acceptable }\end{array}$ & $\begin{array}{c}\text { Attrition Between } \\
\text { Groups } \\
\text { Acceptable }\end{array}$ & $\begin{array}{c}\text { Timing of Outcome } \\
\text { Assessment in All } \\
\text { Groups Similar }\end{array}$ & $\begin{array}{c}\text { Registered or } \\
\text { Published Protocol }\end{array}$ & $\begin{array}{l}\text { Avoidance of } \\
\text { Selective } \\
\text { Outcomes } \\
\text { Reporting }\end{array}$ & Quality Rating \\
\hline Abbassi, 2012 & Yes & Yes & Yes & Unclear & Yes & Poor \\
\hline Abbott, 2013 & Yes & Yes & Yes & Yes & Yes & Fair \\
\hline Ajimsha 2014 & Yes & Yes & Yes & Unclear & Yes & Fair \\
\hline Al Rashoud 2014 & Unclear & Unclear & Yes & No & Yes & Fair \\
\hline Alda 2011 & Yes & Yes & Yes & Yes & Unclear & Fair \\
\hline Alfano 2001 & No & Yes & Yes & Unclear & Yes & $\begin{array}{l}\text { Fair (all } \\
\text { comparisons) }\end{array}$ \\
\hline Altan 2005 & Yes & Yes & Yes & No & Yes & Fair \\
\hline Altan 2009 & Yes & Yes & Yes & Unclear & Yes & Fair \\
\hline Amris 2014 & Yes & Yes & Yes & Yes & Yes & Fair \\
\hline Andersen 2008 & Unclear & Unclear & Yes & Yes & \begin{tabular}{|l|} 
Yes \\
\end{tabular} & Poor \\
\hline Ang 2010 & Yes & Yes & Yes & Yes & Unclear & Poor \\
\hline Aslan Telci 2012 & Unclear & Unclear & Yes & No & Yes & Poor \\
\hline Assefi 2005 & Yes & Yes & Yes & No & Yes & Good \\
\hline Banth, 2015 & No & Unclear & Yes & No & Unclear & Poor \\
\hline Baptista 2012 & Yes & \begin{tabular}{|l|} 
Yes \\
\end{tabular} & Yes & Yes & Unclear & Fair \\
\hline Basford, 1999 & Yes & Yes & Yes & Unclear & Yes & Fair \\
\hline Battisti 2004 & Unclear & Unclear & Yes & No & Yes & Poor \\
\hline $\begin{array}{l}\text { Bendix, 1995, 1997, } \\
1998\end{array}$ & \begin{tabular}{|l|} 
No $(22 \%$ at \\
12 months) \\
\end{tabular} & Yes & Yes & Unclear & Yes & Fair \\
\hline Bendix, 2000 & $\begin{array}{l}\text { No (22\% at } 1210 \\
\text { months) }\end{array}$ & Yes & Yes & No & Unclear & Fair \\
\hline Bendix,1996, 1998 & Yes & No & Yes & No & Yes & Fair \\
\hline Bennell, 2005 & Yes & No & Yes & No & Yes & Fair \\
\hline Bennell, 2016 & Yes & Yes & Yes & Yes & Yes & Fair \\
\hline Berman, 1999 & Yes & Yes & Yes & No & Yes & Fair \\
\hline Berman, 2004 & No & Yes & Yes & No & Yes & Fair \\
\hline Beurskens, 1997 & No & Yes & Yes & Unclear & Yes & Fair \\
\hline Birch 1998 & Yes & Yes & Yes & No & No & Poor \\
\hline
\end{tabular}




\begin{tabular}{|c|c|c|c|c|c|c|c|c|c|}
\hline Author, Year & Randomization & $\begin{array}{l}\text { Concealed } \\
\text { Treatment } \\
\text { Allocation }\end{array}$ & $\begin{array}{c}\text { Intention-to - } \\
\text { Treat } \\
\text { Analysis }\end{array}$ & $\begin{array}{l}\text { Baseline } \\
\text { Group } \\
\text { Similarity }\end{array}$ & $\begin{array}{l}\text { Patient } \\
\text { Blinded }\end{array}$ & $\begin{array}{c}\text { Care } \\
\text { Provider } \\
\text { Blinded }\end{array}$ & $\begin{array}{l}\text { Outcome } \\
\text { Assessor / Data } \\
\text { Analyst Blinded }\end{array}$ & $\begin{array}{l}\text { Compliance } \\
\text { Acceptable in } \\
\text { All Groups }\end{array}$ & $\begin{array}{l}\text { Attrition } \\
\text { Reported }\end{array}$ \\
\hline Blanchard 1990 & Unclear & Unclear & Unclear & Yes & Unclear & Unclear & No & Unclear & Yes \\
\hline Blodt, 2015 & Yes & Yes & Yes & No & No & No & Unclear & No ( $70 \%)$ & Yes \\
\hline Boline 1995 & Yes & Yes & Yes & Yes & No & No & No & Yes & Yes \\
\hline Bono 2015 & No & Yes & Yes & No & Yes & Yes & Yes & Yes & No \\
\hline Bourgault 2015 & Yes & Unclear & No & Yes & No & No & No & No & Yes \\
\hline Brinkhaus 2006a & Yes & Yes & Yes & Yes & Yes & No & Yes & Yes & Yes \\
\hline Brismee 2007 & Yes & Unclear & Yes & Yes & No & No & $\begin{array}{l}\text { Yes/No } \\
\text { (assessor } \\
\text { blinded/ patient } \\
\text { reported }\end{array}$ & Yes & Yes \\
\hline Bronfort, 2011 & Yes & Yes & Yes & Yes & No & No & Yes & Yes & Yes \\
\hline Brosseau, 2005 & Yes & Yes & Yes & Yes & Yes & Yes & Yes & Yes & Yes \\
\hline Brouwer 2006 & Yes & Yes & Yes & Yes & No & No & No & No & Yes \\
\hline Buckelew 1998 & Unclear & Unclear & Unclear & No & No & No & $\begin{array}{l}\text { Yes (CBO) No } \\
\text { (PRO) }\end{array}$ & Unclear & Yes \\
\hline Cakir 2014 & Yes & Yes & Yes & Yes & Yes & No & Yes & Unclear & Yes \\
\hline Carlsson 2001 & Unclear & Unclear & Yes & Yes & Yes & No & Yes & Unclear & Unclear \\
\hline $\begin{array}{l}\text { Cash 2015/Sephton } \\
2007\end{array}$ & Yes & Unclear & Yes & Yes & No & No & $\begin{array}{l}\text { Yes (CBO) No } \\
\text { (PRO) }\end{array}$ & No & Yes \\
\hline Castel 2012 & Unclear & Unclear & Yes & Yes & No & No & No & Yes & Yes \\
\hline Castel 2013 & Yes & Unclear & Yes & Yes & No & No & No & Unclear & Yes \\
\hline Castien 2011 & Yes & Yes & Yes & Yes & No & No & No & Yes & Yes \\
\hline Castro-Sanchez & Yes & Unclear & Yes & Yes & No & No & No & Yes & Yes \\
\hline Castro-Sanchez & Unclear & Unclear & Yes & Yes & No & No & No & Yes & Yes \\
\hline Cedraschi 2004 & Yes & Yes & No & Yes & No & No & No & No & Yes \\
\hline Chen, 2014 & Yes & Yes & Yes & Unclear & Unclear & No & Yes & Yes & No \\
\hline Cherkin 2001 & Yes & Unclear & Yes & Yes & No & No & Yes & Yes & Yes \\
\hline Cherkin 2009 & Unclear & Unclear & Yes & Yes & No & No & Yes & Yes & Yes \\
\hline Cherkin, 2011 & Yes & Yes & Yes & Yes & No & No & Yes & Yes & Yes \\
\hline Cherkin, 2016 & Yes & Yes & Yes & Yes & No & No & Yes & Yes & Yes \\
\hline Chiu 2011 & Yes & Yes & Yes & $\mathrm{No}^{*}$ & No & No & No & Unclear & Yes \\
\hline Cho 2013 & Yes & Yes & Yes & Yes & Yes & No & Unclear & Unclear & Yes \\
\hline Cho 2014 & Yes & Yes & Yes & No & No & No & No & Yes & Yes \\
\hline Chow 2006 & Yes & Yes & Yes & Yes & Yes & Yes & Yes & Yes & Yes \\
\hline
\end{tabular}




\begin{tabular}{|c|c|c|c|c|c|c|}
\hline Author, Year & $\begin{array}{c}\text { Attrition } \\
\text { Acceptable }\end{array}$ & $\begin{array}{c}\text { Attrition Between } \\
\text { Groups } \\
\text { Acceptable }\end{array}$ & $\begin{array}{c}\text { Timing of Outcome } \\
\text { Assessment in All } \\
\text { Groups Similar }\end{array}$ & $\begin{array}{c}\text { Registered or } \\
\text { Published Protocol }\end{array}$ & $\begin{array}{l}\text { Avoidance of } \\
\text { Selective } \\
\text { Outcomes } \\
\text { Reporting }\end{array}$ & Quality Rating \\
\hline Blanchard 1990 & Yes & $\begin{array}{l}\text { Yes - Relax only vs. } \\
\text { AC/WL No - CBT/relax } \\
\text { vs. AC/WL }\end{array}$ & Yes & No & Yes & Poor \\
\hline Blodt, 2015 & Yes & Yes & Yes & Yes & Yes & Fair \\
\hline Boline 1995 & Yes & No & Yes & No & Yes & Poor \\
\hline Bono 2015 & Unclear & Unclear & Yes & No & Yes & Poor \\
\hline Bourgault 2015 & No & No & Yes & Yes & Yes & Poor \\
\hline Brinkhaus 2006a & Yes & Yes & Yes & Yes & Yes & Good \\
\hline Brismee 2007 & No & No & Yes & No & Yes & Poor \\
\hline Bronfort, 2011 & Yes & Yes & Yes & Unclear & Yes & Fair \\
\hline Brosseau, 2005 & Yes & Yes & Yes & No & Yes & Good \\
\hline Brouwer 2006 & No & No & Yes & No & Yes & Poor \\
\hline Buckelew 1998 & Yes & Yes & Yes & Unclear & Yes & $\begin{array}{l}\text { Poor (all } \\
\text { comparisons) }\end{array}$ \\
\hline Cakir 2014 & Yes & Yes & Yes & No & No & Fair \\
\hline Carlsson 2001 & Unclear & Unclear & Unclear & Unclear & Yes & Poor \\
\hline Cash 2015/Sephton 2007 & No & No & Yes & Yes & No & Poor \\
\hline Castel 2012 & No & Yes & Yes & Unclear & Unclear & Poor \\
\hline Castel 2013 & No & No & Yes & No & Unclear & Poor \\
\hline Castien 2011 & Yes & Yes & Yes & Yes & Yes & Fair \\
\hline Castro-Sanchez & Yes & Yes & Yes & No & Yes & Fair \\
\hline Castro-Sanchez & Yes & Yes & Yes & No & Yes & Poor \\
\hline Cedraschi 2004 & \begin{tabular}{|l|} 
No \\
\end{tabular} & No & Yes & No & Unclear & Poor \\
\hline Chen, 2014 & Unclear & Unclear & Yes & No & Yes & Poor \\
\hline Cherkin 2001 & \begin{tabular}{|l} 
Yes \\
\end{tabular} & Yes & Yes & Unclear & Yes & Fair \\
\hline Cherkin 2009 & Yes & Yes & Yes & Yes & Yes & Fair \\
\hline Cherkin 2011 & Yes & Yes & Yes & Yes & Yes & Fair \\
\hline Cherkin, 2016 & No & Yes & Yes & Yes & Yes & Fair \\
\hline Chiu 2011 & $\mathrm{No}^{\star \star}$ & $\mathrm{No}^{\star \star}$ & Yes & No & Yes & Poor \\
\hline Cho 2013 & Yes & Yes & Yes & Yes & Yes & Fair \\
\hline Cho 2014 & Yes & Yes & Yes & Yes & Yes & Poor \\
\hline Chow 2006 & Yes & Yes & Yes & No & Yes & Good \\
\hline
\end{tabular}




\begin{tabular}{|c|c|c|c|c|c|c|c|c|c|}
\hline Author, Year & Randomization & $\begin{array}{l}\text { Concealed } \\
\text { Treatment } \\
\text { Allocation }\end{array}$ & $\begin{array}{c}\text { Intention-to- } \\
\text { Treat } \\
\text { Analysis }\end{array}$ & $\begin{array}{l}\text { Baseline } \\
\text { Group } \\
\text { Similarity }\end{array}$ & $\begin{array}{l}\text { Patient } \\
\text { Blinded }\end{array}$ & $\begin{array}{c}\text { Care } \\
\text { Provider } \\
\text { Blinded }\end{array}$ & $\begin{array}{c}\text { Outcome } \\
\text { Assessor I } \\
\text { Data } \\
\text { Analyst } \\
\text { Blinded }\end{array}$ & $\begin{array}{l}\text { Compliance } \\
\text { Acceptable in } \\
\text { All Groups }\end{array}$ & $\begin{array}{l}\text { Attrition } \\
\text { Reported }\end{array}$ \\
\hline Clarke-Jenssen & Yes & Yes & Yes & No & No & No & No & Yes & Yes \\
\hline Costa 2009 & Yes & Yes & Yes & Yes & $\begin{array}{l}\text { No (not } \\
\text { blinded to } \\
\text { exercise) }\end{array}$ & No & Yes & Yes & Yes (figure 1) \\
\hline Da Costa 2005 & Yes & Yes & Yes & Yes & No & No & No & Unclear & Yes \\
\hline Dias, 2003 & Yes & Unclear & Unclear & Yes & No & No & Yes & Unclear & Yes \\
\hline Dilek, 2013 & Yes & Yes & Yes & Yes & No & No & Yes & Unclear & Yes \\
\hline Djavid, 2007 & Unclear & Unclear & Yes & Yes & Yes & Yes & Yes & Yes & Yes \\
\hline Ebadi, 2012 & Yes & Yes & Yes & Yes & Yes & No & Unclear & Yes & Yes \\
\hline Ebneshahidi 2005 & Unclear & Unclear & Yes & No & Yes & No & Yes & Yes & Yes \\
\hline Edinger 2005 & Unclear & Unclear & Unclear & Unclear & No & No & No & Yes & Yes \\
\hline Ettinger 1997 & Yes & Yes & Yes & Yes & No & No & Yes & No & Yes \\
\hline Falcao 2008 & Yes & Unclear & Yes & Yes & No & No & No & Unclear & Yes \\
\hline Fary 2011 & Yes & Yes & Yes & Yes & Yes & Yes & Yes & No & Yes \\
\hline Ferreira, 2007 & Yes & Yes & Yes & Yes & No & No & Yes & Yes & Yes \\
\hline Fontaine 2010/2011 & Yes & No & Yes & Yes & No & No & Unclear & No & Yes \\
\hline Fukuda 2011 & Yes & Yes & Yes & Yes & Yes & \begin{tabular}{|l} 
No \\
(control) \\
Yes \\
(placebo \\
\end{tabular} & No & Yes & Yes \\
\hline Giannotti 2014 & Yes & Unclear & Yes & Yes & No & No & No & Unclear & Yes \\
\hline Gibson, 1985 & Unclear & Unclear & Yes & No & Yes & Yes & Yes & Unclear & Yes \\
\hline Giombini 2011 & Yes & Yes & Yes & Yes & Yes & No & Yes & Unclear & Yes \\
\hline Goldby 2006 & Yes & Unclear & Yes & Yes & No & No & Yes & Unclear & Yes \\
\hline Gowans 2001 & Unclear & Unclear & Yes & No & No & No & No & No & Yes \\
\hline Groessl 2017 & Yes & & Yes & Yes & No & No & No & No & Yes \\
\hline Gudavalli, 2006 & Yes & Yes & Yes & Yes & No & No & Yes & Unclear & Yes \\
\hline Gur 2004 & Yes & Unclear & Unclear & Yes & Yes & No & Unclear & Yes & Yes \\
\hline Gusi 2006 & Unclear & Unclear & Yes & Yes & No & No & No & Yes & Yes \\
\hline Haake 2007 & Yes & Yes & Yes & Yes & No & No & Unclear & Yes & Yes \\
\hline Haas, 2014 & Yes & Yes & Yes & Yes & No & No & Yes & \begin{tabular}{|l|} 
Yes \\
\end{tabular} & Yes \\
\hline Harkapaa, 1989 & Unclear & Unclear & Yes & Yes & No & No & No & Unclear & Yes \\
\hline Hegedus 2009 & Yes & Unclear & Unclear & Unclear & Yes & Yes & Unclear & Unclear & Yes \\
\hline Helminen 2015 & Yes & Yes & Yes & Yes & Yes & No & Yes & Unclear & Yes \\
\hline
\end{tabular}

\section{E-5}




\begin{tabular}{|c|c|c|c|c|c|c|}
\hline Author, Year & $\begin{array}{c}\text { Attrition } \\
\text { Acceptable }\end{array}$ & $\begin{array}{c}\text { Attrition Between } \\
\text { Groups } \\
\text { Acceptable }\end{array}$ & $\begin{array}{l}\text { Timing of Outcome } \\
\text { Assessment in All } \\
\text { Groups Similar }\end{array}$ & $\begin{array}{c}\text { Registered or } \\
\text { Published Protocol }\end{array}$ & $\begin{array}{l}\text { Avoidance of } \\
\text { Selective } \\
\text { Outcomes } \\
\text { Reporting }\end{array}$ & Quality Rating \\
\hline Clarke-Jenssen & Yes & Yes & Yes & No & Unclear & Fair \\
\hline Costa 2009 & Yes & Yes & Yes & Yes & Yes & Fair \\
\hline Da Costa 2005 & No & Yes & Yes & No & Yes & Fair \\
\hline Dias, 2003 & Yes & Yes & Yes & No & Unclear & Poor \\
\hline Dilek, 2013 & Yes & Yes & Yes & No & Yes & Fair \\
\hline Djavid, 2007 & Yes & Yes & Yes & Unclear & Yes & Fair \\
\hline Ebadi, 2012 & Yes & No & Yes & Yes & Yes & Fair \\
\hline Ebneshahidi 2005 & Yes & Yes & Yes & No & Yes & Fair \\
\hline Edinger 2005 & No & No & Yes & No & Unclear & Poor \\
\hline Ettinger 1997 & Yes & Yes & Yes & No & \begin{tabular}{|l|} 
Yes \\
\end{tabular} & Fair \\
\hline Falcao 2008 & Yes & Yes & Yes & No & Unclear & Fair \\
\hline Fary 2011 & Yes & Yes & Yes & Yes & Yes & Good \\
\hline Ferreira, 2007 & Yes & Yes & Yes & Yes & Yes & Fair \\
\hline Fontaine 2010/2011 & No & Yes & Yes & No & Unclear & Fair \\
\hline Fukuda 2011 & No & Yes & No & No & Yes & Poor \\
\hline Giannotti 2014 & No & No & Yes & Yes & Unclear & Poor \\
\hline Gibson, 1985 & No & $\begin{array}{l}\text { No }(21 \% \text { with } \\
\text { diathermy vs. } 6 \% \\
\text { with }\end{array}$ & Yes & Unclear & Yes & Poor \\
\hline Giombini 2011 & Yes & Yes & Yes & No & Yes & Fair \\
\hline Goldby 2006 & $\begin{array}{l}\text { Yes (>80\% at } \\
12 \text { months) } \\
\end{array}$ & No & Yes & Unclear & Yes & Fair \\
\hline Gowans 2001 & Yes & Yes & Yes & No & Unclear & Poor \\
\hline Groessl 2017 & No & Yes & Yes & Yes & Yes & Fair \\
\hline Gudavalli, 2006 & Yes & No & Yes & Unclear & Yes & Fair \\
\hline Gur 2004 & Yes & Yes & Yes & No & \begin{tabular}{|l|l} 
Yes \\
\end{tabular} & Fair \\
\hline Gusi 2006 & Yes & Yes & Yes & No & Unclear & Poor \\
\hline Haake 2007 & Yes & Yes & Yes & Yes & Yes & Fair \\
\hline Haas, 2014 & Yes & Yes & Yes & Yes & Yes & Fair \\
\hline Harkapaa, 1989 & Yes & Yes & Yes & No & Yes & Poor \\
\hline Hegedus 2009 & No & No & Yes & No & Yes & Poor \\
\hline Helminen 2015 & Yes & Yes & Yes & Yes & Yes & Fair \\
\hline
\end{tabular}




\begin{tabular}{|c|c|c|c|c|c|c|c|c|c|}
\hline Author, Year & Randomization & $\begin{array}{l}\text { Concealed } \\
\text { Treatment } \\
\text { Allocation }\end{array}$ & $\begin{array}{c}\text { Intention-to- } \\
\text { Treat } \\
\text { Analysis }\end{array}$ & $\begin{array}{l}\text { Baseline } \\
\text { Group } \\
\text { Similarity }\end{array}$ & $\begin{array}{l}\text { Patient } \\
\text { Blinded }\end{array}$ & $\begin{array}{c}\text { Care } \\
\text { Provider } \\
\text { Blinded }\end{array}$ & $\begin{array}{c}\text { Outcome } \\
\text { Assessor I } \\
\text { Data Analyst } \\
\text { Blinded }\end{array}$ & $\begin{array}{l}\text { Compliance } \\
\text { Acceptable in } \\
\text { All Groups }\end{array}$ & $\begin{array}{l}\text { Attrition } \\
\text { Reported }\end{array}$ \\
\hline Hinman, 2014 & Yes & Yes & Yes & Yes & $\begin{array}{l}\text { Yes (vs. } \\
\text { sham) } \\
\text { No (vs. no } \\
\text { treatment) }\end{array}$ & $\begin{array}{l}\text { Yes (vs. } \\
\text { sham) } \\
\text { No (vs. no } \\
\text { treatment) }\end{array}$ & Yes & Yes & Yes \\
\hline Ho 2017 & Yes & Yes & Yes & Yes & Yes & No & Yes & Yes & Yes \\
\hline Hoeksma 2004 & Yes & Yes & Yes & Yes & No & No & Yes & Yes & Yes \\
\hline Holroyd 1991 & Unclear & Unclear & Unclear & Yes & No & No & Unclear & Yes & Yes \\
\hline Holroyd 2001 & Yes & Yes & Yes & Yes & $\begin{array}{l}\text { Yes- } \\
\text { medication } \\
\text { component } \\
\text { s, No-for } \\
\text { stress } \\
\end{array}$ & Yes & Yes & Yes & Yes \\
\hline Hondras, 2009 & Yes & Unclear & Yes & Yes & No & No & Yes & Yes & Yes \\
\hline Huang, 2003 & Yes & Yes & Yes & Yes & Unclear & No & Unclear & Yes & Yes \\
\hline $\begin{array}{l}\text { Huang, 2005a Arth \& } \\
\text { Rheum }\end{array}$ & Yes & Yes & Yes & Yes & Unclear & No & Yes & Unclear & Yes \\
\hline $\begin{array}{l}\text { Huang, 2005b, } \\
\text { Archives PM\&R }\end{array}$ & Yes & Yes & Yes & Yes & Unclear & No & Yes & Yes & Yes \\
\hline $\begin{array}{l}\text { Jensen 2012/Wicksell } \\
2013\end{array}$ & Unclear & Yes & Unclear & Yes & No & No & No & Unclear & Yes \\
\hline Johnson 2007 & Yes & $\begin{array}{l}\text { Yes } \\
\text { (minimization) }\end{array}$ & Yes & Yes & No & No & No & No & Yes \\
\hline Jousset, 2004 & Unclear & Unclear & Yes & Yes & No & No & No & Unclear & Yes \\
\hline Jubb, 2008 & Yes & Yes & Yes & Yes & Yes & No & Yes & Unclear & Yes \\
\hline Juhakoski 2011 & Yes & Yes & Yes & Yes & No & No & $\begin{array}{l}\text { No/Yes } \\
\text { (primary } \\
\text { outcomes } \\
\text { were patient } \\
\text { reported and } \\
\text { patient's }\end{array}$ & $\begin{array}{l}\text { Yes/No (1st } \\
\text { year 86\%, 2nd } \\
\text { year 58\%) }\end{array}$ & Yes \\
\hline Kankaanpaa 1999 & Unclear & Unclear & Yes & Yes & No & No & No & Unclear & Yes \\
\hline Karst 2000 & Unclear & Unclear & Unclear & $\mathrm{No}^{*}$ & Yes & No & Yes & Yes & No \\
\hline Kayiran 2010 & Unclear & Unclear & Unclear & No & No & No & $\begin{array}{l}\text { Yes (CBO) No } \\
\text { (PRO) }\end{array}$ & Unclear & Yes \\
\hline Kayo 2012 & Yes & Yes & Yes & No & No & No & No & Unclear & Yes \\
\hline Kerr 2003 & Yes & Unclear & Yes & Yes & Unclear & No & Yes & No & Yes \\
\hline King 2002 & Yes & unclear & No & Unclear & No & No & No & No & Yes \\
\hline Lamb 2010/2012 & Yes & Yes & Yes & Yes & No & No & Unclear & No & Yes \\
\hline
\end{tabular}

E-7 


\begin{tabular}{|c|c|c|c|c|c|c|}
\hline Author, Year & $\begin{array}{c}\text { Attrition } \\
\text { Acceptable }\end{array}$ & $\begin{array}{c}\text { Attrition Between } \\
\text { Groups } \\
\text { Acceptable }\end{array}$ & $\begin{array}{c}\text { Timing of Outcome } \\
\text { Assessment in All } \\
\text { Groups Similar }\end{array}$ & $\begin{array}{c}\text { Registered or } \\
\text { Published Protocol }\end{array}$ & $\begin{array}{l}\text { Avoidance of } \\
\text { Selective } \\
\text { Outcomes } \\
\text { Reporting }\end{array}$ & Quality Rating \\
\hline Hinman, 2014 & Yes & Yes & Yes & Yes & Yes & $\begin{array}{l}\text { Good - vs. sham } \\
\text { Fair - vs. no } \\
\text { treatment }\end{array}$ \\
\hline Ho 2017 & Yes & Yes & No & Yes & Yes & Fair \\
\hline Hoeksma 2004 & Yes & Yes & Yes & Unclear & Yes & Fair \\
\hline Holroyd 1991 & Yes & No & Yes & No & Yes & Poor \\
\hline Holroyd 2001 & No & No & Yes & No & Yes & Poor \\
\hline Hondras, 2009 & Yes & No & Yes & Unclear & Yes & Fair \\
\hline Huang, 2003 & Yes & No & Yes & No & Yes & Poor \\
\hline Huang, 2005a Arth \& Rheum & Yes & Yes & Yes & No & Yes & Fair \\
\hline $\begin{array}{l}\text { Huang, 2005b, Archives } \\
\text { PM\&R }\end{array}$ & Yes & Yes & Yes & No & Yes & Fair \\
\hline Jensen 2012/Wicksell 2013 & No & Yes & Yes & No & Unclear & Fair \\
\hline Johnson 2007 & Yes & Yes & Yes & Yes & Yes & Fair \\
\hline Jousset, 2004 & Yes & Yes & Yes & No & Yes & Poor \\
\hline Jubb, 2008 & Yes & Yes & Yes & No & Yes & Fair \\
\hline Juhakoski 2011 & Yes & Yes & Yes & Yes & Yes & Fair \\
\hline Kankaanpaa 1999 & Yes & Yes & Yes & Unclear & Yes & Fair \\
\hline Karst 2000 & Unclear & Unclear & Yes & No & Yes & Poor \\
\hline Kayiran 2010 & Yes & Yes & Yes & Yes & Yes & Poor \\
\hline Kayo 2012 & No & Yes & Yes & Yes & Unclear & Fair \\
\hline Kerr 2003 & No & No & Yes & Unclear & Yes & Poor \\
\hline King 2002 & No & Unclear & Yes & No & Unclear & Poor \\
\hline Lamb 2010/2012 & Yes & Yes & Yes & Yes & Yes & Fair \\
\hline
\end{tabular}




\begin{tabular}{|c|c|c|c|c|c|c|c|c|c|}
\hline Author, Year & Randomization & $\begin{array}{l}\text { Concealed } \\
\text { Treatment } \\
\text { Allocation }\end{array}$ & $\begin{array}{c}\text { Intention-to- } \\
\text { Treat } \\
\text { Analysis }\end{array}$ & $\begin{array}{l}\text { Baseline } \\
\text { Group } \\
\text { Similarity }\end{array}$ & $\begin{array}{l}\text { Patient } \\
\text { Blinded }\end{array}$ & $\begin{array}{c}\text { Care } \\
\text { Provider } \\
\text { Blinded }\end{array}$ & $\begin{array}{c}\text { Outcome } \\
\text { Assessor I } \\
\text { Data } \\
\text { Analyst } \\
\text { Blinded }\end{array}$ & $\begin{array}{l}\text { Compliance } \\
\text { Acceptable in } \\
\text { All Groups }\end{array}$ & $\begin{array}{l}\text { Attrition } \\
\text { Reported }\end{array}$ \\
\hline Lambeek, 2010a & Yes & Yes & Yes & Yes & No & No & No & Yes & Yes \\
\hline Lansdown, 2009 & Yes & Yes & Yes & Yes & No & No & Unclear & \begin{tabular}{|l|} 
Yes \\
\end{tabular} & Yes \\
\hline Lansinger 2007 & Yes & Yes & Yes & Yes & No & No & No & Unclear* $^{*}$ & Yes \\
\hline Larsson 2015 & Yes & Yes & Yes & Yes & No & No & $\begin{array}{l}\text { Yes (CBO) } \\
\text { No (PRO) }\end{array}$ & No & Yes \\
\hline Lauche 2016 & Yes & Yes & Yes & Yes & No & No & No & Yes/No* & Yes \\
\hline Laufer 2005 & No & No & Yes & Yes & Yes & No & Yes & Yes & Yes \\
\hline Li 2017 & Yes & Yes & Yes & Yes & No & No & No & Unclear & Yes \\
\hline Liang 2011 & Yes & Yes & Unclear & Yes & Yes & No & Unclear & Yes & Yes \\
\hline Licciardone, 2013 & Yes & Yes & Yes & Yes & Yes & Unclear & Yes & Yes & Yes \\
\hline Little 2008 & Yes & Yes & Yes & Yes & No & No & Yes & Yes & Yes \\
\hline Lund, 2008 & Yes & Yes & Yes & Yes & No & No & Yes & Yes & Yes \\
\hline Lynch 2012 & Yes & Yes & Yes & Yes & No & No & No & Unclear & Yes \\
\hline MacPherson 2015 & Yes & Yes & Yes & Yes & No & No & No & Yes & Yes \\
\hline Mannerkorpi 2009 & Yes & Yes & Yes & Yes & No & No & No & No & Yes \\
\hline Martin 2006 & Unclear & Yes & Yes & Yes & Yes & No & Yes & Yes & Yes \\
\hline Martin 2012 & Yes & Unclear & Yes & Yes & No & No & No & No & Yes \\
\hline Mazzuca 2004 & Yes & Yes & Yes & Unclear & Yes & Yes & Unclear & Yes & Yes \\
\hline Messier, 2004 & Yes & Yes & Yes & Yes & No & No & Yes & No & Yes \\
\hline Miyamoto 2013 & Yes & Yes & Yes & No & No & No & No & Yes & Yes \\
\hline Monticone, 2013 & Yes & Yes & Yes & Yes & No & No & Yes & Unclear & Yes \\
\hline Monticone, 2014 & Yes & Yes & \begin{tabular}{|l|} 
Yes \\
\end{tabular} & Yes & No & No & Yes & Unclear & Yes \\
\hline Morone, 2009 & Yes & Yes & Unclear & Yes & No & No & Yes & Unclear & Yes \\
\hline Morone, 2016 & Yes & Yes & Unclear & Yes & No & No & Yes & Unclear & Yes \\
\hline Nambi 2014 & Yes & Unclear & Yes & Yes & No & No & Unclear & Yes & Yes \\
\hline Nassif 2011 & Yes & Unclear & Yes & Yes & No & No & No & Unclear & Yes \\
\hline Natour 2015 & Yes & Yes & Yes & Yes & No & No & No & \begin{tabular}{|l|} 
Yes \\
\end{tabular} & Yes \\
\hline $\begin{array}{l}\text { Nicholas } 1991 \\
\text { Behav }\end{array}$ & Unclear & Unclear & Yes & Yes & No & No & Unclear & Unclear & Yes \\
\hline $\begin{array}{l}\text { Nicholas 1992 Pain } \\
\text { 1992;48:339-47 }\end{array}$ & Unclear & Unclear & Yes & Yes & No & No & Unclear & Unclear & Yes \\
\hline Osteras, 2014 & Yes & Yes & Yes & No & No & No & Yes & No & Yes \\
\hline Paolucci 2015 & Yes & Unclear & Yes & Yes & No & No & No & Yes & Yes \\
\hline
\end{tabular}




\begin{tabular}{|c|c|c|c|c|c|c|}
\hline Author, Year & $\begin{array}{c}\text { Attrition } \\
\text { Acceptable }\end{array}$ & $\begin{array}{l}\text { Attrition } \\
\text { Between } \\
\text { Groups } \\
\text { Acceptable }\end{array}$ & $\begin{array}{l}\text { Timing of Outcome } \\
\text { Assessment in All } \\
\text { Groups Similar }\end{array}$ & $\begin{array}{c}\text { Registered or } \\
\text { Published Protocol }\end{array}$ & $\begin{array}{l}\text { Avoidance of } \\
\text { Selective } \\
\text { Outcomes } \\
\text { Reporting }\end{array}$ & Quality Rating \\
\hline Lambeek, 2010a & Yes & Yes & Yes & Yes & Yes & Fair \\
\hline Lansdown, 2009 & No & No & Yes & No & Yes & Poor \\
\hline Lansinger 2007 & No & No & No & Unclear & No & Poor \\
\hline Larsson 2015 & No & Yes & Unclear & Unclear & Yes & Poor \\
\hline Lauche 2016 & Yes/No** & Yes/No** & Yes & Yes & Yes & $\begin{array}{l}\text { Fair Tai chi vs wait list; } \\
\text { PoorTai chi vs Ex, Ex vs } \\
\text { waitlist }\end{array}$ \\
\hline Laufer 2005 & Yes & $\begin{array}{l}\text { No (High PSWD } \\
28 \% \text {, Low PSWD }\end{array}$ & Yes & No & Yes & Poor \\
\hline Li 2017 & Yes & Yes & Yes & Unclear & Yes & Fair \\
\hline Liang 2011 & Yes & Yes & Yes & Yes & Yes & Fair \\
\hline Licciardone, 2013 & Yes & Yes & Yes & Yes & Yes & Good \\
\hline Little 2008 & Yes & Yes & Yes & Yes & Yes & Fair \\
\hline Lund, 2008 & Yes & Yes & Yes & No & Yes & Fair \\
\hline Lynch 2012 & Yes & No & Yes & Yes & Yes & Fair \\
\hline MacPherson 2015 & Yes & Yes & Yes & Yes & Yes & Fair \\
\hline Mannerkorpi 2009 & No & Yes & Yes & No & Yes & Fair \\
\hline Martin 2006 & Yes & Yes & Yes & Unclear & Yes & Good \\
\hline Martin 2012 & No & Yes & Yes & No & Yes & Poor \\
\hline Mazzuca 2004 & Yes & Yes & Yes & No & Yes & Fair \\
\hline Messier, 2004 & Yes & Yes & Yes & No & Yes & Fair \\
\hline Miyamoto 2013 & Yes & Yes & Yes & Yes & Yes & Fair \\
\hline Monticone, 2013 & Yes & Yes & Yes & Unclear & Yes & Fair \\
\hline Monticone, 2014 & Yes & Yes & Yes & Unclear & Yes & Fair \\
\hline Morone, 2009 & Yes & Yes & Yes & Unclear & Yes & Fair \\
\hline Morone, 2016 & Yes & Yes & Yes & Yes & Yes & Fair \\
\hline Nambi 2014 & Yes & Yes & Yes & Unclear & Unclear & Fair \\
\hline Nassif 2011 & No & No & Yes & Unclear & Unclear & Poor \\
\hline Natour 2015 & Yes & \begin{tabular}{|l|} 
Yes \\
\end{tabular} & Yes & Unclear & \begin{tabular}{|l} 
Yes \\
\end{tabular} & Fair \\
\hline Nicholas 1991 Behav & No & Unclear & Yes & No & Yes & Poor \\
\hline $\begin{array}{l}\text { Nicholas 1992 Pain } \\
\text { 1992;48:339-47 }\end{array}$ & Yes & Yes & Yes & No & Yes & Fair \\
\hline Osteras, 2014 & No & No & Yes & Yes & Yes & Poor \\
\hline Paolucci 2015 & Yes & Yes & Yes & No & Unclear & Fair \\
\hline
\end{tabular}




\begin{tabular}{|c|c|c|c|c|c|c|c|c|c|}
\hline Author, Year & Randomization & $\begin{array}{l}\text { Concealed } \\
\text { Treatment } \\
\text { Allocation }\end{array}$ & $\begin{array}{c}\text { Intention-to- } \\
\text { Treat } \\
\text { Analysis }\end{array}$ & $\begin{array}{l}\text { Baseline } \\
\text { Group } \\
\text { Similarity }\end{array}$ & $\begin{array}{l}\text { Patient } \\
\text { Blinded }\end{array}$ & $\begin{array}{c}\text { Care } \\
\text { Provider } \\
\text { Blinded }\end{array}$ & $\begin{array}{l}\text { Outcome } \\
\text { Assessor I } \\
\text { Data } \\
\text { Analyst } \\
\text { Blinded }\end{array}$ & $\begin{array}{l}\text { Compliance } \\
\text { Acceptable in } \\
\text { All Groups }\end{array}$ & $\begin{array}{c}\text { Attrition } \\
\text { Reported }\end{array}$ \\
\hline Pennix, 2001 (FAST) & Yes & Yes & Yes & Yes & No & No & Yes & No & Yes \\
\hline Pennix, 2002 (FAST) & Yes & Yes & Yes & Yes & No & No & Yes & No & Yes \\
\hline Pennix, 2002 (FAST) & Yes & Yes & Yes & Yes & No & No & Yes & No & Yes \\
\hline Perlman 2012 & Yes & Yes & Yes & Unclear & No & No & No & Yes & Yes \\
\hline Poole 2007 & Yes (minimization) & $\begin{array}{l}\text { Yes } \\
\text { (minimization) }\end{array}$ & Yes & Yes & No & No & No & Unclear & Yes \\
\hline Quilty, 2003 & Yes & Yes & Yes & Yes & No & No & Yes & Yes & Yes \\
\hline Quinn 2008 & Yes & Unclear & Yes & Yes & Yes & No & Unclear & Yes & Yes \\
\hline Redondo 2004 & Yes & Unclear & Yes & Yes & No & No & No & Yes & Yes \\
\hline Rejeski, 2002 & Yes & Yes & Yes & Yes & No & No & Yes & No & Yes \\
\hline Rejeski, 2002 & Yes & Yes & Yes & Yes & No & No & Yes & No & Yes \\
\hline Roche, $2007 / 2011$ & Yes & Yes & Yes & Yes & No & No & No & Unclear & Yes \\
\hline Rosedale, 2014 & Yes & Yes & \begin{tabular}{|l} 
Yes \\
\end{tabular} & Yes & No & No & Yes & \begin{tabular}{|l} 
No \\
\end{tabular} & Yes \\
\hline Rudolfsson 2014 & Yes & Unclear & Unclear & Yes & No & No & Yes/No* & Unclear & Yes \\
\hline Sahin 2010 & Yes & Yes & \begin{tabular}{|l|} 
Yes \\
\end{tabular} & No & Yes & No & Yes & Yes & Yes \\
\hline Sanudo 2010 & Yes & Unclear & Yes & Yes & No & No & No & Yes & Yes \\
\hline Sanudo 2012 & Unclear & Unclear & No & Yes & No & No & No & No & Yes \\
\hline Sanudo 2015 & Unclear & Unclear & Yes & Unclear & No & No & No & Unclear & Yes \\
\hline Saper 2017 & Yes & Unclear & Yes & \begin{tabular}{|l} 
Yes \\
\end{tabular} & No & No & Yes & No & Yes \\
\hline Saral 2016 & Yes & Unclear & Yes & Yes & No & No & No & Unclear & Yes \\
\hline Schimmel, 2009 & Yes & Yes & Yes & Yes & Yes & No & Yes & Yes & Yes \\
\hline Schmidt 2011 & Yes & Yes & Yes & Yes & No & No & No & Yes & Yes \\
\hline Seferiadis 2015 & Yes & Yes & Yes & Yes & No & No & Yes/No* & No & Yes \\
\hline Segal 2015 & Yes & Yes & Yes & Unclear & No & No & No & Yes & Yes \\
\hline Senna, 2011 & Unclear & Yes & Yes & Yes & Yes & No & Yes & Unclear & Yes \\
\hline Sherman 2005 & Yes & Yes & Yes & Yes & No & No & Yes & Yes & Yes \\
\hline Sherman 2009 & Yes & Yes & Yes & Yes & No & No & No & Yes & Yes \\
\hline Sherman 2011 & Yes & Yes & Yes & Yes & No & No & Yes & Ye & Yes \\
\hline Somers 2012 & Yes & Yes & Yes & Yes & No & No & $\begin{array}{l}\text { Yes/No } \\
\text { (data }\end{array}$ & No & Yes \\
\hline Soriano, 1998 & Unclear & Unclear & No & Yes & Yes & Yes & Unclear & No & Yes \\
\hline Stewart 2007 & Yes & Yes & Yes & Yes & No & No & No & Yes & Yes \\
\hline Strand, 2001 & Unclear & Unclear & Yes & Yes & No & No & Yes & Unclear & Yes \\
\hline Stukstette, 2013 & Yes & Yes & Yes & Yes & No & No & Yes & Unclear & Yes \\
\hline $\begin{array}{l}\text { Suarez-Almazo, } \\
2010\end{array}$ & Yes & Yes & Yes & Yes & $\begin{array}{l}\text { Yes - sham } \\
\text { No - waitlist }\end{array}$ & $\begin{array}{l}\text { Yes - } \\
\text { sham }\end{array}$ & Yes & Unclear & Yes \\
\hline
\end{tabular}

E-11 


\begin{tabular}{|c|c|c|c|c|c|c|}
\hline Author, Year & $\begin{array}{c}\text { Attrition } \\
\text { Acceptable }\end{array}$ & $\begin{array}{c}\text { Attrition Between Groups } \\
\text { Acceptable } \\
\end{array}$ & $\begin{array}{c}\text { Timing of Outcome } \\
\text { Assessment in All } \\
\text { Groups Similar }\end{array}$ & $\begin{array}{c}\text { Registered or } \\
\text { Published Protocol } \\
\end{array}$ & $\begin{array}{c}\text { Avoidance of } \\
\text { Selective } \\
\text { Outcomes } \\
\text { Reporting } \\
\end{array}$ & Quality Rating \\
\hline Pennix, 2001 (FAST) & Yes & Yes & Yes & No & Yes & Fair \\
\hline Pennix, 2002 (FAST) & Yes & Yes & Yes & No & Yes & Fair \\
\hline Pennix, 2002 (FAST) & Yes & Yes & Yes & No & Yes & Fair \\
\hline Perlman 2012 & Yes & Yes & Yes & Yes & Yes & Fair \\
\hline Poole 2007 & No & No & Yes & No & Yes & Poor \\
\hline Quilty, 2003 & Yes & Yes & Yes & No & Yes & Fair \\
\hline Quinn 2008 & Yes & Yes & Yes & Unclear & Yes & Fair \\
\hline Redondo 2004 & No & Yes & Yes & No & Yes & Poor \\
\hline Rejeski, 2002 & Yes & Yes & Yes & No & Yes & Fair \\
\hline Rejeski, 2002 & Yes & Yes & Yes & No & Yes & Fair \\
\hline Roche, $2007 / 2011$ & Yes & No & Yes & Unclear & Yes & Fair \\
\hline Rosedale, 2014 & No & Yes & Yes & Yes & Yes & Fair \\
\hline Rudolfsson 2014 & No & Yes & Yes & Yes & Unclear & Fair \\
\hline Sahin 2010 & Yes & No & Yes & No & No & Fair \\
\hline Sanudo 2010 & Yes & Yes & Yes & Yes & Yes & Fair \\
\hline Sanudo 2012 & No & Yes & Yes & No & Unclear & Poor \\
\hline Sanudo 2015 & Yes & No & Yes & No & Yes & Poor \\
\hline Saper 2017 & Yes & Yes & Yes & Yes & Yes & Fair \\
\hline Saral 2016 & Yes & Yes & Yes & Yes & Yes & Fair \\
\hline Schimmel, 2009 & Yes & Yes & Yes & Unclear & Yes & Fair \\
\hline Schmidt 2011 & Yes & Yes (vs. attention control) & Yes & No & Yes & Fair \\
\hline Sencan 2004 & $\begin{array}{l}\text { Unclear(method } \\
\text { not described) }\end{array}$ & Unclear & Unclear & Yes & No & No \\
\hline Seferiadis 2015 & Yes & Yes & Yes & Yes & No & Fair \\
\hline Segal 2015 & No & $\begin{array}{l}\text { Yes (3 months) } \\
\text { No (9 months) }\end{array}$ & Yes & Yes & Yes & $\begin{array}{l}\text { Fair at } 3 \text { months Poor } \\
\text { at } 9\end{array}$ \\
\hline Sencan 2004 & No & Unclear & Yes & No & Yes & Poor \\
\hline Senna, 2011 & No & No & Yes & Unclear & Yes & Poor \\
\hline Sherman 2005 & Yes & Yes & Yes & Yes & Yes & Fair \\
\hline Sherman 2009 & Yes & Yes & Yes & No & Yes & Fair \\
\hline Sherman 2011 & Yes & Yes & Yes & Yes & Yes & Fair \\
\hline Somers 2012 & No & No & Yes & No & Yes & Poor \\
\hline Soriano, 1998 & No & No & Unclear & Unclear & Unclear & Poor \\
\hline Stewart 2007 & Yes & Yes & Yes & Yes & Yes & Fair \\
\hline Strand, 2001 & Yes & Yes & Yes & No & Yes & Poor \\
\hline Stukstette, 2013 & Yes & Yes & Yes & Yes & Yes & Fair \\
\hline $\begin{array}{l}\text { Suarez-Almazo, } \\
2010\end{array}$ & Yes & Yes & Yes & No & Yes & $\begin{array}{l}\text { Good - sham Fair - } \\
\text { waitlist }\end{array}$ \\
\hline
\end{tabular}

E-12 


\begin{tabular}{|c|c|c|c|c|c|c|c|c|c|}
\hline Author, Year & Randomization & $\begin{array}{l}\text { Concealed } \\
\text { Treatment } \\
\text { Allocation }\end{array}$ & \begin{tabular}{|c|} 
Intention-to- \\
Treat \\
Analysis \\
\end{tabular} & $\begin{array}{l}\text { Baseline } \\
\text { Group } \\
\text { Similarity }\end{array}$ & $\begin{array}{l}\text { Patient } \\
\text { Blinded }\end{array}$ & $\begin{array}{l}\text { Care } \\
\text { Provider } \\
\text { Blinded }\end{array}$ & $\begin{array}{c}\text { Outcome } \\
\text { Assessor / Data } \\
\text { Analyst Blinded }\end{array}$ & $\begin{array}{c}\text { Compliance } \\
\text { Acceptable in All } \\
\text { Groups }\end{array}$ & $\begin{array}{l}\text { Attrition } \\
\text { Reported }\end{array}$ \\
\hline Sullivan, 1998 & Unclear & Unclear & \begin{tabular}{|l|} 
Unclear \\
\end{tabular} & No & No & No & Yes & Unclear & Yes \\
\hline Tak 2005 & Yes & Unclear & Yes & Yes & No & No & $\begin{array}{l}\text { No/Yes (primary } \\
\text { outcomes were } \\
\text { patient reported } \\
\text { and patient's }\end{array}$ & No & Yes \\
\hline Tascioglu 2004 & Yes & Unclear & Unclear & Yes & Unclear & Yes & Yes & Unclear & No \\
\hline Tavafian, 2008 & Unclear & Unclear & Yes & Yes & No & No & No & Unclear & Yes \\
\hline Tavola 1992 & Unclear & Unclear & Unclear & Yes & Yes & No & Yes & Yes & Yes \\
\hline Teirlinck 2016 & Yes & Yes & Yes & Yes & No & No & No & $\begin{array}{l}\text { Yes/No (Yes during } \\
3 \text { month treatment } \\
\text { period; No for } \\
\text { booster sessions } \\
\text { during }\end{array}$ & Yes \\
\hline Thamsborg 2005 & Unclear & Unclear & Yes & Yes & Yes & No & Yes & Yes & Yes \\
\hline Thieme 2006 & \begin{tabular}{|l|} 
No \\
\end{tabular} & Unclear & Yes & Unclear & No & No & No & No & Yes \\
\hline Thomas 2006 & Yes & Yes & Yes & Yes & No & No & No & Yes & Yes \\
\hline Thomas, 2002 & Unclear & Unclear & Yes & Yes & Unclear & No & Yes & No & Yes \\
\hline Thorstensson, 2005 & Yes & Unclear & Unclear & Yes & No & No & Unclear & Yes & Yes \\
\hline Tilbrook 2011 & Yes & Yes & Yes & Yes & No & No & Yes & Yes & Yes \\
\hline $\begin{array}{l}\text { Tomas-Carus 2008/ } \\
\text { Tomas-Carus } 2009\end{array}$ & Unclear & Unclear & No & Unclear & No & No & No & Yes & Yes \\
\hline Trock 1994 & Yes & Yes & Unclear & No & Yes & No & Yes & Unclear & No \\
\hline Turner 1990 & Unclear & Unclear & Yes & Yes & No & No & No & Unclear & Yes \\
\hline $\begin{array}{l}\text { UK BEAM Trial } \\
\text { Team, } 2004\end{array}$ & Yes & Yes & Yes & Yes & No & No & No & No & Yes \\
\hline Van der Roer 2008 & Yes & Yes & Yes & Yes & No & No & $\mathrm{NO}$ & Unclear & Yes \\
\hline van Eijk-Hustings 2013 & Yes & Yes & Yes & Yes & No & No & No & No & Yes \\
\hline van Santen 2002 & Unclear & Unclear & Yes & No & No & No & $\begin{array}{l}\text { Yes (CBO) No } \\
\text { (PRO) }\end{array}$ & Unclear & Yes \\
\hline Vas 2006 & Yes & Yes & Yes & Yes & Yes & No & Yes & Yes & Yes \\
\hline Vas 2016 & Yes & Yes & Yes & Yes & Yes & No & Yes & Unclear & Yes \\
\hline
\end{tabular}




\begin{tabular}{|c|c|c|c|c|c|c|}
\hline Author, Year & $\begin{array}{l}\text { Attrition } \\
\text { Acceptable }\end{array}$ & $\begin{array}{c}\text { Attrition Between } \\
\text { Groups } \\
\text { Acceptable }\end{array}$ & $\begin{array}{c}\text { Timing of Outcome } \\
\text { Assessment in All } \\
\text { Groups Similar }\end{array}$ & $\begin{array}{c}\text { Registered or } \\
\text { Published Protocol }\end{array}$ & $\begin{array}{l}\text { Avoidance of } \\
\text { Selective } \\
\text { Outcomes } \\
\text { Reporting }\end{array}$ & Quality Rating \\
\hline Sullivan, 1998 & No & No & Yes & No & Yes & Poor \\
\hline Tak 2005 & No & Yes & Yes & Unclear & Yes & Poor \\
\hline Tascioglu 2004 & Unclear & Unclear & Yes & No & Yes & Poor \\
\hline Tavafian, 2008 & No & \begin{tabular}{|l|} 
Yes \\
\end{tabular} & Yes & Unclear & Yes & Poor \\
\hline Tavola 1992 & Yes & Yes & Yes & No & Yes & Poor \\
\hline Teirlinck 2016 & Yes & Yes & Yes & Yes & Yes & Fair \\
\hline Thamsborg 2005 & Yes & Yes & Yes & Yes & Yes & Fair \\
\hline Thieme 2006 & Yes & No & Unclear & No & Yes & Poor \\
\hline Thomas 2006 & Yes & Yes & Yes & Yes & Yes & Fair \\
\hline Thomas, 2002 & No & Yes & Yes & No & Unclear & Poor \\
\hline Thorstensson, 2005 & Yes & Yes & Yes & Yes & Yes & Fair \\
\hline Tilbrook 2011 & Yes & Yes & Yes & $\begin{array}{l}\text { Yes (see note at end } \\
\text { of text) }\end{array}$ & Yes & Fair \\
\hline $\begin{array}{l}\text { Tomas-Carus 2008/Tomas- } \\
\text { Carus } 2009\end{array}$ & Yes & Yes & Yes & No & Unclear & Poor \\
\hline Trock 1994 & Unclear & Unclear & Yes & No & Yes & Poor \\
\hline Turner 1990 & No & No & Yes & No & Yes & Poor \\
\hline $\begin{array}{l}\text { UK BEAM Trial Team, } \\
2004\end{array}$ & Yes & Yes & Yes & Yes & Yes & Fair \\
\hline Van der Roer 2008 & Yes & Yes & Yes & Yes & Yes & Fair \\
\hline van Eijk-Hustings 2013 & Yes & Yes & Yes & Yes & Unclear & Fair \\
\hline van Santen 2002 & Yes & No & Yes & Unclear & Yes & $\begin{array}{l}\text { Poor (all } \\
\text { comparisons) } \\
\end{array}$ \\
\hline Vas 2006 & No & Yes & Yes & No & Unclear & Fair \\
\hline Vas 2016 & Yes & Yes & Yes & Yes & Yes & Good \\
\hline
\end{tabular}




\begin{tabular}{|c|c|c|c|c|c|c|c|c|c|}
\hline Author, Year & Randomization & $\begin{array}{l}\text { Concealed } \\
\text { Treatment } \\
\text { Allocation }\end{array}$ & $\begin{array}{c}\text { Intention-to- } \\
\text { Treat } \\
\text { Analysis }\end{array}$ & $\begin{array}{l}\text { Baseline } \\
\text { Group } \\
\text { Similarity }\end{array}$ & $\begin{array}{l}\text { Patient } \\
\text { Blinded }\end{array}$ & $\begin{array}{c}\text { Care } \\
\text { Provider } \\
\text { Blinded }\end{array}$ & $\begin{array}{c}\text { Outcome } \\
\text { Assessor I } \\
\text { Data } \\
\text { Analyst } \\
\text { Blinded }\end{array}$ & $\begin{array}{l}\text { Compliance } \\
\text { Acceptable in } \\
\text { All Groups }\end{array}$ & $\begin{array}{l}\text { Attrition } \\
\text { Reported }\end{array}$ \\
\hline Verkaik 2014 & Yes & Unclear & Yes & Yes & No & No & No & Yes & Yes \\
\hline Viljanen 2003 & Yes & Yes & Yes & $\mathrm{No}^{*}$ & No & No & No & $\mathrm{No}^{\star \star}$ & Yes \\
\hline Von Korff, 2005 & Unclear & Unclear & Yes & Yes & No & No & Yes & Yes & Yes \\
\hline Waling 2002 & Unclear & Unclear & Yes & No & No & No & No & Unclear & Yes \\
\hline Wang 2009 & Yes & Yes & Yes & Yes & No & No & Yes & Yes & Yes \\
\hline Wang 2010 & Yes & Yes & Yes & No & No & No & $\begin{array}{l}\text { Yes (CBO) } \\
\text { No (PRO) } \\
\end{array}$ & No & Yes \\
\hline Weng, 2009 & Yes & Yes & Yes & Unclear & Unclear & No & Yes & Yes & Yes \\
\hline White 2004 & Yes & Unclear & Yes & Yes & Yes & No & Yes & Yes & Yes \\
\hline Wigers 1996 & Yes & Unclear & Yes & Yes & No & No & No & Unclear & Yes \\
\hline Williams 2002 & Unclear & Unclear & Unclear & Unclear & No & No & No & Unclear & Yes \\
\hline Williams 2005 & Yes & Unclear & Yes & Yes & No & No & Yes & Yes & Yes \\
\hline Williams 2009 & Unclear & Unclear & Yes & Yes & No & No & Yes & Yes & Yes \\
\hline Williamson, 2007 & Yes & Yes & Yes & Yes & No & No & Yes & Unclear & Yes \\
\hline Witt, 2005 & Yes & Yes & Yes & Yes & Yes & No & Yes & Unclear & Yes \\
\hline Yildiz 2015 & Yes & Unclear & Unclear & No & Yes & Yes & Unclear & Unclear & Yes \\
\hline Yurtkuran, 2007 & Yes & Unclear & Yes & Yes & Yes & No & Yes & Unclear & Yes \\
\hline Zgierska 2016 & Yes & Yes & Yes & No & No & No & Unclear & No & Yes \\
\hline Zhang 2013 & Yes & Unclear & Yes & Unclear & Yes & Yes & Yes & Yes & Yes \\
\hline
\end{tabular}




\begin{tabular}{|c|c|c|c|c|c|c|}
\hline Author, Year & $\begin{array}{c}\text { Attrition } \\
\text { Acceptable }\end{array}$ & $\begin{array}{c}\text { Attrition Between } \\
\text { Groups } \\
\text { Acceptable }\end{array}$ & $\begin{array}{l}\text { Timing of Outcome } \\
\text { Assessment in All } \\
\text { Groups Similar }\end{array}$ & $\begin{array}{c}\text { Registered or } \\
\text { Published Protocol }\end{array}$ & $\begin{array}{l}\text { Avoidance of } \\
\text { Selective } \\
\text { Outcomes } \\
\text { Reporting }\end{array}$ & Quality Rating \\
\hline Verkaik 2014 & No & Yes & Yes & Yes & Yes & Poor \\
\hline Viljanen 2003 & Yes & Yes & Yes & No & Yes & Fair \\
\hline Von Korff, 2005 & Yes & Yes & Yes & Unclear & Yes & Fair \\
\hline Waling 2002 & No & Yes & Yes & No & Yes & Poor \\
\hline Wang 2009 & Yes & Yes & Yes & Yes & Yes & Fair \\
\hline Wang 2010 & Yes & Yes & Yes & Yes & Yes & Fair \\
\hline Weng, 2009 & Yes & No & Yes & No & Yes & Poor \\
\hline White 2004 & No & Yes & Yes & No & Yes & Fair \\
\hline Wigers 1996 & No & $\begin{array}{l}\text { No (stress } \\
\text { management vs. } \\
\text { usual care and vs. } \\
\text { exercise) } \\
\text { Yes (exercise vs. } \\
\text { usual care) }\end{array}$ & Yes & Unclear & Yes & $\begin{array}{l}\text { Poor (stress } \\
\text { management vs. } \\
\text { usual care and vs. } \\
\text { exercise) } \\
\text { Fair (exercise vs. } \\
\text { usual care) }\end{array}$ \\
\hline Williams 2002 & Yes & Yes & Yes & No & Unclear & Poor \\
\hline Williams 2005 & No & No & Yes & Unclear & Yes & Fair \\
\hline Williams 2009 & Yes & No & Yes & Unclear & Yes & Fair \\
\hline Williamson, 2007 & No & No & Yes & No & Yes & Poor \\
\hline Witt, 2005 & Yes & Yes & Yes & Yes & Yes & Fair \\
\hline Yildiz 2015 & Yes & Yes & Yes & No & Yes & Fair \\
\hline Yurtkuran, 2007 & Yes & Yes & Yes & No & Yes & Fair \\
\hline Zgierska 2016 & Yes & Yes & Yes & Yes & Yes & Poor \\
\hline Zhang 2013 & No & Yes & Yes & No & Yes & Fair \\
\hline
\end{tabular}


Table E-2. Quality assessment of crossover trials

\begin{tabular}{|c|c|c|c|c|c|c|c|c|}
\hline Author, year & Randomization & $\begin{array}{l}\text { Concealed } \\
\text { treatment } \\
\text { allocation }\end{array}$ & $\begin{array}{l}\text { Intention- } \\
\text { to-treat } \\
\text { analysis }\end{array}$ & $\begin{array}{l}\text { Independent } \\
\text { or blind } \\
\text { assessment }\end{array}$ & $\begin{array}{c}\text { Appropriate } \\
\text { washout } \\
\text { period for } \\
\text { condition }\end{array}$ & $\begin{array}{l}\text { Attrition } \\
\text { reported }\end{array}$ & $\begin{array}{c}\text { Attrition } \\
\text { acceptable }\end{array}$ & $\begin{array}{c}\text { Number } \\
\text { completing } \\
\text { period } \\
\text { reported; } \\
\text { Attrition b/w } \\
\text { periods } \\
\text { acceptable } \\
(<10 \%)\end{array}$ \\
\hline Paolucci 2016 & Unclear & Unclear & Yes & Yes & Yes & Yes & $\begin{array}{l}\text { Yes - first } \\
\text { period; } \\
\text { No - second } \\
\text { period }\end{array}$ & Yes \\
\hline
\end{tabular}




\begin{tabular}{|c|c|c|c|c|c|c|c|}
\hline Author, year & $\begin{array}{l}\text { Results from } \\
\text { first phase } \\
\text { reported } \\
\text { separately }\end{array}$ & $\begin{array}{c}\text { Accounting for } \\
\text { missing data }\end{array}$ & $\begin{array}{l}\text { Use of methods } \\
\text { for within-subject } \\
\text { variation, } \\
\text { correlated data }\end{array}$ & $\begin{array}{c}\text { Analysis of } \\
\text { carryover effect }\end{array}$ & $\begin{array}{l}\text { Is there a } \\
\text { registered or } \\
\text { published } \\
\text { protocol }\end{array}$ & $\begin{array}{c}\text { Avoidance of } \\
\text { selective } \\
\text { outcomes } \\
\text { reporting }\end{array}$ & $\begin{array}{c}\text { Risk of bias } \\
\text { (Cochrane Back } \\
\text { Group }\end{array}$ \\
\hline Paolucci 2016 & Yes & No & Yes & No & Yes & Yes & Poor \\
\hline
\end{tabular}




\section{Appendix F. Exercise Categories}

Table F-1. Exercise and related intervention categories

\begin{tabular}{|l|l|}
\hline General category & Types included \\
\hline Muscle Performance & - Resistance training (strength, power or endurance exercises) \\
& - Sling exercise \\
& - Aquatic therapy/exercise \\
& - Musculoskeletal rehabilitation \\
- Pilates
\end{tabular}




\section{Appendix G. Strength of Evidence}

All outcomes were considered direct; therefore, the Directness domain is not shown on the strength of evidence tables.

See Appendix B. Included Studies for references.

\begin{tabular}{|c|c|c|c|c|c|c|c|c|c|}
\hline Intervention & Comparator & Outcome & $\begin{array}{c}\text { Number of RCTs } \\
\text { (patients) } \\
\text { Author Year } \\
\end{array}$ & $\begin{array}{c}\text { Study } \\
\text { Limitations }\end{array}$ & Consistency & Precision & $\begin{array}{l}\text { Reporting } \\
\text { Bias }\end{array}$ & $\begin{array}{l}\text { Strength } \\
\text { of } \\
\text { Evidence }\end{array}$ & $\begin{array}{l}\text { Findings, Direction, and } \\
\text { Magnitude of Effect }\end{array}$ \\
\hline \multirow[t]{5}{*}{ Exercise } & \multirow[t]{5}{*}{$\begin{array}{l}\text { Exercise vs. } \\
\text { usual care, } \\
\text { attention } \\
\text { control, or a } \\
\text { placebo } \\
\text { intervention }\end{array}$} & $\begin{array}{l}\text { Function } \\
\text { Short-term }\end{array}$ & $\begin{array}{l}6(\mathrm{~N}=553) \\
\\
\text { Costa } 2009 \\
\text { Goldby } 2006 \\
\text { Kankaanpaa } 1999 \\
\text { Miyamoto } 2013 \\
\text { Nassif } 2011 \\
\text { Natour 2014 }\end{array}$ & Moderate & Inconsistent & Precise & Undetected & Low & $\begin{array}{l}\text { Pooled SMD }-0.31(95 \% \mathrm{Cl} \\
-0.58 \text { to }-0.04) ;\left.\right|^{2}=57 \%\end{array}$ \\
\hline & & $\begin{array}{l}\text { Function } \\
\text { Intermediate- } \\
\text { term }\end{array}$ & $\begin{array}{l}3(\mathrm{~N}=332) \\
\text { Costa } 2009 \\
\text { Goldby 2006 } \\
\text { Kankaanpaa } 1999\end{array}$ & Moderate & Inconsistent & Imprecise & Undetected & Low & $\begin{array}{l}\text { Pooled SMD }-0.15(95 \% \mathrm{Cl} \\
-0.48 \text { to } 0.18) ; I^{2}=51 \%\end{array}$ \\
\hline & & $\begin{array}{l}\text { Function } \\
\text { Long-term }\end{array}$ & $\begin{array}{l}1(\mathrm{~N}=124) \\
\text { Goldby } 2006\end{array}$ & Moderate & Unknown & Imprecise & Undetected & Low & $\begin{array}{l}\text { Difference } 0.0(95 \% \mathrm{Cl}-11.4 \text { to } \\
11.4) \text { on the } 0 \text { to } 100 \mathrm{ODI}\end{array}$ \\
\hline & & $\begin{array}{l}\text { Pain } \\
\text { Short-term }\end{array}$ & $\begin{array}{l}6(\mathrm{~N}=553) \\
\text { Costa } 2009 \\
\text { Goldby 2006 } \\
\text { Kankaanpaa } 1999 \\
\text { Miyamoto 2013 } \\
\text { Nassif } 2011 \\
\text { Natour } 2014\end{array}$ & Moderate & Consistent & Precise & Undetected & Moderate & $\begin{array}{l}\text { Pooled difference }-0.81 \text { ( } 95 \% \\
\mathrm{Cl}-1.26 \text { to }-0.36 \text { ) on a } 0 \text { to } 10 \\
\text { scale; } 1^{2}=0 \%\end{array}$ \\
\hline & & $\begin{array}{l}\text { Pain } \\
\text { Intermediate- } \\
\text { term }\end{array}$ & $\begin{array}{l}3(\mathrm{~N}=332) \\
\text { Costa } 2009 \\
\text { Goldby } 2006 \\
\text { Kankaanpaa } 1999\end{array}$ & Moderate & Inconsistent & Imprecise & Undetected & Low & $\begin{array}{l}\text { Pooled difference }-1.37 \text { (95\% } \\
\text { Cl }-2.10 \text { to }-0.65) \text { on a } 0 \text { to } 10 \\
\text { scale; } I^{2}=34 \%\end{array}$ \\
\hline
\end{tabular}




\begin{tabular}{|c|c|c|c|c|c|c|c|c|c|}
\hline Intervention & Comparator & Outcome & $\begin{array}{l}\text { Number of RCTs } \\
\text { (patients) } \\
\text { Author Year }\end{array}$ & $\begin{array}{c}\text { Study } \\
\text { Limitations }\end{array}$ & Consistency & Precision & $\begin{array}{l}\text { Reporting } \\
\text { Bias }\end{array}$ & $\begin{array}{l}\text { Strength } \\
\text { of } \\
\text { Evidence }\end{array}$ & $\begin{array}{l}\text { Findings, Direction, and } \\
\text { Magnitude of Effect }\end{array}$ \\
\hline & & $\begin{array}{l}\text { Pain } \\
\text { Long-term }\end{array}$ & $\begin{array}{l}1(\mathrm{~N}=124) \\
\text { Goldby } 2006\end{array}$ & Moderate & Unknown & Imprecise & Undetected & Low & $\begin{array}{l}\text { Difference }-1.55 \text { on a } 0 \text { to } 10 \\
\text { scale }(95 \% \mathrm{Cl}-2.78 \text { to }-0.32)\end{array}$ \\
\hline & & Harms & $\begin{array}{l}2(\mathrm{~N}=240) \\
\text { Costa } 2009 \\
\text { Miyamoto } 2013\end{array}$ & Moderate & Consistent & Imprecise & Undetected & Low & $\begin{array}{l}\text { No evidence of increased risk } \\
\text { of serious harms }\end{array}$ \\
\hline \multirow[t]{6}{*}{$\begin{array}{l}\text { Psychological } \\
\text { Therapy }\end{array}$} & \multirow[t]{6}{*}{$\begin{array}{l}\text { Psychological } \\
\text { therapy vs. } \\
\text { usual care or } \\
\text { attention } \\
\text { control }\end{array}$} & $\begin{array}{l}\text { Function } \\
\text { Short-term }\end{array}$ & $\begin{array}{l}3(\mathrm{~N}=1,028) \\
\text { Cherkin } 2016 \\
\text { Lamb } 2010 \\
\text { Poole } 2007\end{array}$ & Moderate & Consistent & Precise & Undetected & Moderate & $\begin{array}{l}\text { Pooled SMD }-0.25(95 \% \\
\mathrm{Cl}-0.38 \text { to }-0.12) ; I^{2}=0 \%\end{array}$ \\
\hline & & $\begin{array}{l}\text { Function } \\
\text { Intermediate- } \\
\text { term }\end{array}$ & $\begin{array}{l}3(\mathrm{~N}=1,163) \\
\text { Cherkin } 2016 \\
\text { Johnson } 2007 \\
\text { Lamb } 2010 \\
\end{array}$ & Moderate & Consistent & Precise & Undetected & Moderate & $\begin{array}{l}\text { Pooled SMD }-0.25(95 \% \\
\mathrm{Cl}-0.37 \text { to }-0.13) ; 1^{2}=0 \%\end{array}$ \\
\hline & & $\begin{array}{l}\text { Function } \\
\text { Long-term }\end{array}$ & $\begin{array}{l}3(\mathrm{~N}=1,163) \\
\text { Cherkin } 2017 \\
\text { Johnson } 2007 \\
\text { Lamb } 2010 \\
\end{array}$ & Moderate & Consistent & Precise & Undetected & Moderate & $\begin{array}{l}\text { Pooled SMD }-0.27(95 \% \\
\mathrm{Cl}-0.39 \text { to }-0.15) ; 1^{2}=0 \%\end{array}$ \\
\hline & & $\begin{array}{l}\text { Pain } \\
\text { Short-term }\end{array}$ & $\begin{array}{l}3(\mathrm{~N}=1,028) \\
\text { Cherkin } 2016 \\
\text { Lamb } 2010 \\
\text { Poole } 2007 \\
\end{array}$ & Moderate & Consistent & Precise & Undetected & Moderate & $\begin{array}{l}\text { Pooled difference }-0.76 \text { ( } 95 \% \\
\mathrm{Cl}-0.99 \text { to }-0.53) \text { on a } 0 \text { to } 10 \\
\text { scale; } I^{2}=0 \%\end{array}$ \\
\hline & & $\begin{array}{l}\text { Pain } \\
\text { Intermediate- } \\
\text { term }\end{array}$ & $\begin{array}{l}3(\mathrm{~N}=1,163) \\
\text { Cherkin } 2016 \\
\text { Johnson } 2007 \\
\text { Lamb } 2010 \\
\end{array}$ & Moderate & Consistent & Precise & Undetected & Moderate & $\begin{array}{l}\text { Pooled difference }-0.71(95 \% \\
\mathrm{Cl}-0.94 \text { to }-0.48) ; I^{2}=0 \%\end{array}$ \\
\hline & & $\begin{array}{l}\text { Pain } \\
\text { Long-term }\end{array}$ & $\begin{array}{l}3(\mathrm{~N}=1,163) \\
\text { Cherkin } 2017 \\
\text { Johnson } 2007 \\
\text { Lamb } 2010 \\
\end{array}$ & Moderate & Consistent & Precise & Undetected & Moderate & $\begin{array}{l}\text { Pooled difference }-0.53(95 \% \\
\mathrm{Cl}-0.78 \text { to }-0.27) ; \mathrm{I}^{2}=0 \%\end{array}$ \\
\hline
\end{tabular}




\begin{tabular}{|c|c|c|c|c|c|c|c|c|c|}
\hline Intervention & Comparator & Outcome & $\begin{array}{l}\text { Number of RCTs } \\
\text { (patients) } \\
\text { Author Year }\end{array}$ & $\begin{array}{c}\text { Study } \\
\text { Limitations }\end{array}$ & Consistency & Precision & $\begin{array}{l}\text { Reporting } \\
\text { Bias }\end{array}$ & $\begin{array}{l}\text { Strength } \\
\text { of } \\
\text { Evidence }\end{array}$ & $\begin{array}{l}\text { Findings, Direction, and } \\
\text { Magnitude of Effect }\end{array}$ \\
\hline & $\begin{array}{l}\text { Psychological } \\
\text { therapy vs. } \\
\text { exercise }\end{array}$ & $\begin{array}{l}\text { Function } \\
\text { Intermediate- } \\
\text { and long-term }\end{array}$ & $\begin{array}{l}1(\mathrm{~N}=49) \\
\text { Turner } 1990\end{array}$ & High & Unknown & Imprecise & Undetected & Insufficient & $\begin{array}{l}\text { Insufficient evidence from } 1 \\
\text { poor-quality trial }\end{array}$ \\
\hline & & $\begin{array}{l}\text { Pain } \\
\text { Intermediate- } \\
\text { and long-term }\end{array}$ & $\begin{array}{l}1(\mathrm{~N}=49) \\
\text { Turner } 1990\end{array}$ & High & Unknown & Imprecise & Undetected & Insufficient & $\begin{array}{l}\text { Insufficient evidence from } 1 \\
\text { poor-quality trial }\end{array}$ \\
\hline \multirow[t]{7}{*}{$\begin{array}{l}\text { Physical } \\
\text { Modalities }\end{array}$} & $\begin{array}{l}\text { Short-wave } \\
\text { diathermy vs. } \\
\text { sham } \\
\text { diathermy }\end{array}$ & $\begin{array}{l}\text { Pain, } \\
\text { function, } \\
\text { harms }\end{array}$ & $\begin{array}{l}1(\mathrm{~N}=68) \\
\text { Gibson, } 1985\end{array}$ & High & Unknown & Imprecise & Undetected & Insufficient & $\begin{array}{l}\text { Insufficient evidence from one } \\
\text { poor-quality trial }\end{array}$ \\
\hline & \multirow{2}{*}{$\begin{array}{l}\text { Ultrasound } \\
\text { vs. sham } \\
\text { ultrasound }\end{array}$} & $\begin{array}{l}\text { Pain } \\
\text { Short-term }\end{array}$ & $\begin{array}{l}2(\mathrm{~N}=505) \\
\text { Ebadi } 2012 \\
\text { Licciardone } 2013\end{array}$ & Moderate & Consistent & Precise & Undetected & Low & No effects on pain in two trials \\
\hline & & Harms & $\begin{array}{l}1(\mathrm{~N}=455) \\
\text { Licciardone }\end{array}$ & Moderate & Consistent & Imprecise & Undetected & Low & $\begin{array}{l}\text { Any adverse event: RR } 1.03 \\
\text { (95\% Cl } 0.49 \text { to } 2.13) \\
\text { Serious adverse event: RR } \\
0.48 \text { ( } 95 \% \mathrm{Cl} 0.12 \text { to } 1.88)\end{array}$ \\
\hline & \multirow{2}{*}{$\begin{array}{l}\text { Low-level } \\
\text { laser therapy } \\
\text { vs. sham } \\
\text { laser }\end{array}$} & $\begin{array}{l}\text { Function } \\
\text { Short-term }\end{array}$ & $\begin{array}{l}1(\mathrm{~N}=56) \\
\text { Basford } 1999\end{array}$ & Moderate & Unknown & Precise & Undetected & Low & $\begin{array}{l}\text { Difference }-8.2(95 \% \mathrm{Cl}-13.6 \text { to } \\
-2.8) \text { on the } 0 \text { to } 100 \mathrm{ODI}\end{array}$ \\
\hline & & $\begin{array}{l}\text { Pain } \\
\text { Short-term }\end{array}$ & $\begin{array}{l}1(\mathrm{~N}=56) \\
\text { Basford } 1999\end{array}$ & Moderate & Unknown & Imprecise & Undetected & Low & $\begin{array}{l}\text { Difference }-16.0(95 \% \mathrm{Cl}-28.3 \\
\text { to }-3.7) \text { on a } 0 \text { to } 100 \text { scale }\end{array}$ \\
\hline & \multirow{2}{*}{$\begin{array}{l}\text { Low-level } \\
\text { laser therapy } \\
\text { vs. exercise } \\
\text { therapy }\end{array}$} & $\begin{array}{l}\text { Function } \\
\text { Intermediate- } \\
\text { term }\end{array}$ & $\begin{array}{l}1(\mathrm{~N}=35) \\
\text { Djavid } 2007\end{array}$ & Moderate & Unknown & Imprecise & Undetected & Low & $\begin{array}{l}\text { Difference }-4.4(95 \% \mathrm{Cl}-11.4 \text { to } \\
2.5) \text { on the ODI (0 to } 100 \text { scale })\end{array}$ \\
\hline & & $\begin{array}{l}\text { Pain } \\
\text { Intermediate- } \\
\text { term }\end{array}$ & $\begin{array}{l}1(\mathrm{~N}=35) \\
\text { Djavid } 2007\end{array}$ & High & Unknown & Imprecise & Undetected & Low & $\begin{array}{l}\text { Difference }-0.9(95 \% \mathrm{Cl}-2.5 \text { to } \\
0.7) \text { on a } 0 \text { to } 10 \text { scale }\end{array}$ \\
\hline
\end{tabular}




\begin{tabular}{|c|c|c|c|c|c|c|c|c|c|}
\hline Intervention & Comparator & Outcome & $\begin{array}{l}\text { Number of RCTs } \\
\text { (patients) } \\
\text { Author Year }\end{array}$ & $\begin{array}{c}\text { Study } \\
\text { Limitations }\end{array}$ & Consistency & Precision & $\begin{array}{l}\text { Reporting } \\
\text { Bias }\end{array}$ & $\begin{array}{l}\text { Strength } \\
\text { of } \\
\text { Evidence }\end{array}$ & $\begin{array}{l}\text { Findings, Direction, and } \\
\text { Magnitude of Effect }\end{array}$ \\
\hline & & Harms & $\begin{array}{l}3(\mathrm{~N}=162) \\
\text { Djavid } 2007 \\
\text { Basford } 1999 \\
\text { Soriano } 1998\end{array}$ & Moderate & Consistent & Imprecise & Undetected & Low & $\begin{array}{l}\text { No adverse events were } \\
\text { reported }\end{array}$ \\
\hline \multirow[t]{6}{*}{$\begin{array}{l}\text { Manual } \\
\text { Therapies }\end{array}$} & \multirow[t]{3}{*}{$\begin{array}{l}\text { Massage vs. } \\
\text { sham } \\
\text { massage, } \\
\text { usual care, or } \\
\text { attention } \\
\text { control }\end{array}$} & $\begin{array}{l}\text { Function } \\
\text { Short-term }\end{array}$ & $\begin{array}{l}4(\mathrm{~N}=642) \\
\text { Ajimsha } 2014 \\
\text { Cherkin } 2011 \\
\text { Poole } 2007 \\
\text { Quinn } 2008 \\
\end{array}$ & Moderate & Consistent & Imprecise & Undetected & Moderate & $\begin{array}{l}\text { Pooled SMD }-0.30(95 \% \\
\mathrm{Cl}-0.46 \text { to }-0.14) ; 1^{2}=0 \%\end{array}$ \\
\hline & & $\begin{array}{l}\text { Function } \\
\text { Intermediate- } \\
\text { term }\end{array}$ & $\begin{array}{l}3(\mathrm{~N}=713) \\
\text { Cherkin } 2001 \\
\text { Cherkin } 2011 \\
\text { Little 2008 }\end{array}$ & Moderate & Inconsistent & Imprecise & Undetected & Low & $\begin{array}{l}\text { Pooled SMD }-0.09(95 \% \\
\mathrm{Cl}-0.24 \text { to } 0.06) ; 1^{2}=0 \%\end{array}$ \\
\hline & & $\begin{array}{l}\text { Pain } \\
\text { Intermediate- } \\
\text { term }\end{array}$ & $\begin{array}{l}3(\mathrm{~N}=713) \\
\text { Cherkin } 2001 \\
\text { Cherkin } 2011 \\
\text { Little 2008 } \\
\end{array}$ & Moderate & Inconsistent & Imprecise & Undetected & Low & $\begin{array}{l}\text { Pooled difference }-0.01(95 \% \\
\mathrm{Cl}-0.40 \text { to } 0.38) ; I^{2}=0 \%\end{array}$ \\
\hline & \multirow[t]{2}{*}{$\begin{array}{l}\text { Massage vs. } \\
\text { exercise }\end{array}$} & $\begin{array}{l}\text { Function } \\
\text { Intermediate- } \\
\text { term }\end{array}$ & $\begin{array}{l}1(\mathrm{~N}=144) \\
\text { Little } 2008\end{array}$ & Moderate & Unknown & Imprecise & Undetected & Low & $\begin{array}{l}\text { Difference } 1.2(95 \% \mathrm{Cl}-1.47 \text { to } \\
3.87) \text { on the } 0 \text { to } 24 \text { Roland } \\
\text { Disability Questionnaire }\end{array}$ \\
\hline & & $\begin{array}{l}\text { Pain } \\
\text { Intermediate- } \\
\text { term }\end{array}$ & $\begin{array}{l}1(\mathrm{~N}=144) \\
\text { Little } 2008\end{array}$ & Moderate & Unknown & Imprecise & Undetected & Low & $\begin{array}{l}\text { Difference } 0.60(95 \% \mathrm{Cl}-0.67 \\
\text { to } 1.87) \text { on the } 0 \text { to } 10 \mathrm{Von} \\
\text { Korff pain scale }\end{array}$ \\
\hline & $\begin{array}{l}\text { Massage vs. } \\
\text { sham, usual } \\
\text { care, } \\
\text { attention } \\
\text { control, or } \\
\text { exercise } \\
\end{array}$ & Harms & $\begin{array}{l}4(\mathrm{~N}=787) \\
\text { Ajimsha } 2014 \\
\text { Cherkin } 2001 \\
\text { Cherkin } 2011 \\
\text { Little 2008 } \\
\end{array}$ & Moderate & Consistent & Imprecise & Undetected & Low & $\begin{array}{l}\text { Two trials reported no serious } \\
\text { adverse events; in four trials } \\
\text { the proportion of massage } \\
\text { patients with increased pain } \\
\text { ranged from }<1 \% \text { to } 26 \%\end{array}$ \\
\hline
\end{tabular}




\begin{tabular}{|c|c|c|c|c|c|c|c|c|c|}
\hline Intervention & Comparator & Outcome & $\begin{array}{l}\text { Number of RCTs } \\
\text { (patients) } \\
\text { Author Year }\end{array}$ & $\begin{array}{c}\text { Study } \\
\text { Limitations }\end{array}$ & Consistency & Precision & $\begin{array}{l}\text { Reporting } \\
\text { Bias }\end{array}$ & $\begin{array}{l}\text { Strength } \\
\text { of } \\
\text { Evidence }\end{array}$ & $\begin{array}{l}\text { Findings, Direction, and } \\
\text { Magnitude of Effect }\end{array}$ \\
\hline & \multirow[t]{3}{*}{$\begin{array}{l}\text { Traction vs. } \\
\text { sham traction }\end{array}$} & $\begin{array}{l}\text { Function } \\
\text { Short-term }\end{array}$ & $\begin{array}{l}2(\mathrm{~N}=211) \\
\text { Beurskens } 1997 \\
\text { Schimmel } 2009\end{array}$ & Moderate & Consistent & Imprecise & Undetected & Low & $\begin{array}{l}\text { Differences } 2 \text { points on the ODI } \\
\text { and } 0.7 \text { points on the Roland } \\
\text { Disability Questionnaire, } p>0.05 \\
\text { in both trials }\end{array}$ \\
\hline & & $\begin{array}{l}\text { Pain } \\
\text { Short-term }\end{array}$ & $\begin{array}{l}2(\mathrm{~N}=211) \\
\text { Beurskens } 1997 \\
\text { Schimmel } 2009\end{array}$ & Moderate & Consistent & Imprecise & Undetected & Low & $\begin{array}{l}\text { Differences }-4 \text { points in one trial } \\
\text { and } 4 \text { points in one trial, } p>0.05 \\
\text { in both trials }\end{array}$ \\
\hline & & Harms & No studies & -- & -- & -- & -- & -- & No evidence \\
\hline & \multirow{4}{*}{$\begin{array}{l}\text { Spinal } \\
\text { manipulation } \\
\text { vs. sham } \\
\text { manipulation, } \\
\text { usual care, } \\
\text { attention } \\
\text { control, or } \\
\text { placebo } \\
\text { intervention }\end{array}$} & $\begin{array}{l}\text { Function } \\
\text { Short-term }\end{array}$ & $\begin{array}{l}3(\mathrm{~N}=734) \\
\text { Haas } 2014 \\
\text { Hondras } 2009 \\
\text { Senna 2011 }\end{array}$ & Moderate & Inconsistent & Precise & Undetected & Low & $\begin{array}{l}\text { Pooled SMD }-0.34(95 \% \\
\mathrm{Cl}-0.63 \text { to }-0.05) ; 1^{2}=61 \%\end{array}$ \\
\hline & & $\begin{array}{l}\text { Function } \\
\text { Intermediate- } \\
\text { term }\end{array}$ & $\begin{array}{l}3(\mathrm{~N}=1,185) \\
\text { Haas } 2014 \\
\text { Senna } 2011 \\
\text { UK BEAM } 2004\end{array}$ & Moderate & Inconsistent & Precise & Undetected & Low & $\begin{array}{l}\text { Pooled SMD }-0.40(95 \% \\
\mathrm{Cl}-0.69 \text { to }-0.11) ; 1^{2}=76 \%\end{array}$ \\
\hline & & $\begin{array}{l}\text { Pain } \\
\text { Short-term }\end{array}$ & $\begin{array}{l}3(\mathrm{~N}=569) \\
\text { Gibson } 1985 \\
\text { Haas } 2014 \\
\text { Senna } 2011\end{array}$ & High & Inconsistent & Imprecise & Undetected & Low & $\begin{array}{l}\text { Pooled difference }-0.20(95 \% \\
\mathrm{Cl}-0.66 \text { to } 0.26) \text { on a } 0 \text { to } 10 \\
\text { scale; } I^{2}=58 \%\end{array}$ \\
\hline & & $\begin{array}{l}\text { Pain } \\
\text { Intermediate- } \\
\text { term }\end{array}$ & $\begin{array}{l}3(\mathrm{~N}=1,185) \\
\text { Haas } 2014 \\
\text { Senna } 2011 \\
\text { UK BEAM } 2004\end{array}$ & Moderate & Consistent & Precise & Undetected & Moderate & $\begin{array}{l}\text { Pooled difference }-0.64(95 \% \\
\mathrm{Cl}-0.92 \text { to }-0.36) ; I^{2}=0 \%\end{array}$ \\
\hline & \multirow[t]{2}{*}{$\begin{array}{l}\text { Spinal } \\
\text { manipulation } \\
\text { vs. exercise }\end{array}$} & $\begin{array}{l}\text { Function } \\
\text { Short-term }\end{array}$ & $\begin{array}{l}3(\mathrm{~N}=776) \\
\text { Bronfort } 2011 \\
\text { Ferreira } 2007 \\
\text { Gudavalli } 2006\end{array}$ & Moderate & Inconsistent & Imprecise & Undetected & Low & $\begin{array}{l}\text { Pooled SMD } 0.01(95 \% \\
\mathrm{Cl}-0.22 \text { to } 0.25) ; 1^{2}=62 \%\end{array}$ \\
\hline & & $\begin{array}{l}\text { Function } \\
\text { Intermediate- } \\
\text { term }\end{array}$ & $\begin{array}{l}4(\mathrm{~N}=1,467) \\
\\
\text { Bronfort } 2011 \\
\text { Ferreira } 2007 \\
\text { Gudavalli } 2006 \\
\text { UK BEAM } 2004\end{array}$ & Moderate & Inconsistent & Imprecise & Undetected & Low & $\begin{array}{l}\text { Pooled SMD } 0.02 \text { (95\% } \\
\mathrm{Cl}-0.13 \text { to } 0.18) ; 1^{2}=48 \%\end{array}$ \\
\hline
\end{tabular}




\begin{tabular}{|c|c|c|c|c|c|c|c|c|c|}
\hline Intervention & Comparator & Outcome & $\begin{array}{c}\text { Number of RCTs } \\
\text { (patients) } \\
\text { Author Year }\end{array}$ & $\begin{array}{c}\text { Study } \\
\text { Limitations }\end{array}$ & Consistency & Precision & $\begin{array}{l}\text { Reporting } \\
\text { Bias }\end{array}$ & $\begin{array}{l}\text { Strength } \\
\text { of } \\
\text { Evidence }\end{array}$ & $\begin{array}{l}\text { Findings, Direction, and } \\
\text { Magnitude of Effect }\end{array}$ \\
\hline & & $\begin{array}{l}\text { Pain } \\
\text { Short-term }\end{array}$ & $\begin{array}{l}3(\mathrm{~N}=776) \\
\text { Bronfort } 2011 \\
\text { Ferreira } 2007 \\
\text { Gudavalli } 2006\end{array}$ & Moderate & Inconsistent & Imprecise & Undetected & Low & $\begin{array}{l}\text { Pooled difference } 0.31(95 \% \\
\mathrm{Cl}-0.30 \text { to } 0.92) \text { on a } 0 \text { to } 10 \\
\text { scale; } I^{2}=60 \%\end{array}$ \\
\hline & & $\begin{array}{l}\text { Pain } \\
\text { Intermediate- } \\
\text { term }\end{array}$ & $\begin{array}{l}3(\mathrm{~N}=1,232) \\
\text { Bronfort } 2011 \\
\text { Ferreira } 2007 \\
\text { UK BEAM } 2004\end{array}$ & Moderate & Consistent & Imprecise & Undetected & Low & $\begin{array}{l}\text { Pooled difference } 0.22(95 \% \\
\mathrm{Cl}-0.09 \text { to } 0.52) ;\left.\right|^{2}=9.4 \%\end{array}$ \\
\hline & & Harms & $\begin{array}{l}7(\mathrm{~N}=2,201) \\
\\
\text { Bronfort } 2011 \\
\text { Ferreira } 2007 \\
\text { Gudavalli } 2006 \\
\text { Haas } 2014 \\
\text { Hondras } 2009 \\
\text { Senna } 2011 \\
\text { UK BEAM } 2004\end{array}$ & Moderate & Consistent & Precise & Undetected & Moderate & $\begin{array}{l}\text { No serious adverse events or } \\
\text { withdrawals due to adverse } \\
\text { events in } 7 \text { trials. } \\
\text { Nonserious adverse events } \\
\text { (primarily increased pain) } \\
\text { reported in } 3 \text { trials }\end{array}$ \\
\hline \multirow[t]{5}{*}{$\begin{array}{l}\text { Mindfulness } \\
\text { Practices }\end{array}$} & \multirow[t]{5}{*}{$\begin{array}{l}\text { Mindfulness- } \\
\text { based stress } \\
\text { reduction vs. } \\
\text { usual care or } \\
\text { attention } \\
\text { control }\end{array}$} & $\begin{array}{l}\text { Function } \\
\text { Short-term }\end{array}$ & $\begin{array}{l}\text { (N=577) } \\
\text { Cherkin } 2016 \\
\text { Morone } 2009 \\
\text { Morone } 2016 \\
\text { Zgierska } 2017\end{array}$ & Moderate & Inconsistent & Imprecise & Undetected & Low & $\begin{array}{l}\text { Pooled SMD }-0.25(95 \% \\
\mathrm{Cl}-0.53 \text { to } 0.04) ; 1^{2}=53 \%\end{array}$ \\
\hline & & $\begin{array}{l}\text { Function } \\
\text { Intermediate- } \\
\text { term }\end{array}$ & $\begin{array}{l}1(\mathrm{~N}=225) \\
\text { Cherkin } 2016\end{array}$ & Moderate & Unknown & Imprecise & Undetected & Low & $\begin{array}{l}\text { SMD }-0.20(95 \% \mathrm{Cl}-0.47 \text { to } \\
0.06)\end{array}$ \\
\hline & & $\begin{array}{l}\text { Function } \\
\text { Long-term }\end{array}$ & $\begin{array}{l}1(\mathrm{~N}=228) \\
\text { Cherkin } 2017\end{array}$ & Moderate & Unknown & Imprecise & Undetected & Low & $\begin{array}{l}\text { SMD }-0.20(95 \% \mathrm{Cl}-0.47 \text { to } \\
0.06)\end{array}$ \\
\hline & & $\begin{array}{l}\text { Pain } \\
\text { Short-term }\end{array}$ & $\begin{array}{l}4(\mathrm{~N}=577) \\
\\
\text { Cherkin } 2016 \\
\text { Morone } 2009 \\
\text { Morone } 2016 \\
\text { Zgierska } 2017\end{array}$ & Moderate & Consistent $^{a}$ & Precise & Undetected & Moderate & $\begin{array}{l}\text { Pooled difference }-0.76 \text { ( } 95 \% \\
\mathrm{Cl}-1.13 \text { to }-0.39) \text { on a } 0 \text { to } 10 \\
\text { scale; } I^{2}=29 \%\end{array}$ \\
\hline & & $\begin{array}{l}\text { Pain } \\
\text { Intermediate- } \\
\text { term }\end{array}$ & $\begin{array}{l}1(\mathrm{~N}=225) \\
\text { Cherkin } 2016\end{array}$ & Moderate & Unknown & Precise & Undetected & Low & $\begin{array}{l}\text { Difference }-0.75(95 \% \mathrm{Cl}-1.17 \\
\text { to }-0.33)\end{array}$ \\
\hline
\end{tabular}




\begin{tabular}{|c|c|c|c|c|c|c|c|c|c|}
\hline Intervention & Comparator & Outcome & $\begin{array}{l}\text { Number of RCTs } \\
\text { (patients) } \\
\text { Author Year }\end{array}$ & $\begin{array}{c}\text { Study } \\
\text { Limitations }\end{array}$ & Consistency & Precision & $\begin{array}{l}\text { Reporting } \\
\text { Bias }\end{array}$ & $\begin{array}{l}\text { Strength } \\
\text { of } \\
\text { Evidence }\end{array}$ & $\begin{array}{l}\text { Findings, Direction, and } \\
\text { Magnitude of Effect }\end{array}$ \\
\hline & & $\begin{array}{l}\text { Pain } \\
\text { Long-term }\end{array}$ & $\begin{array}{l}1(\mathrm{~N}=228) \\
\text { Cherkin } 2017\end{array}$ & Moderate & Unknown & Precise & Undetected & Low & $\begin{array}{l}\text { Difference }-0.32(95 \% \mathrm{Cl}-0.92 \\
\text { to } 0.28)\end{array}$ \\
\hline & & Harms & $\begin{array}{l}\text { (N=577) } \\
\text { Cherkin } 2016 \\
\text { Morone } 2009 \\
\text { Morone } 2016 \\
\text { Zgierska } 2017\end{array}$ & Moderate & Consistent & Imprecise & Undetected & Low & $\begin{array}{l}\text { One trial reported temporarily } \\
\text { increased pain in } 29 \% \text { of } \\
\text { patients undergoing MBSR and } \\
\text { three trials reported no adverse } \\
\text { events }\end{array}$ \\
\hline \multirow[t]{5}{*}{$\begin{array}{l}\text { Mind-Body } \\
\text { Practices }\end{array}$} & \multirow[t]{4}{*}{$\begin{array}{l}\text { Yoga vs. } \\
\text { attention } \\
\text { control or } \\
\text { wait list }\end{array}$} & $\begin{array}{l}\text { Function } \\
\text { Short-term }\end{array}$ & $\begin{array}{l}6(\mathrm{~N}=922) \\
\text { Groessl } 2017 \\
\text { Saper } 2017 \\
\text { Sherman } 2005 \\
\text { Sherman } 2011 \\
\text { Tilbrook } 2011 \\
\text { Williams } 2009\end{array}$ & Moderate & Consistent & Precise & Undetected & Moderate & $\begin{array}{l}\text { Pooled SMD }-0.50(95 \% \\
\mathrm{Cl}-0.72 \text { to }-0.29) ; I^{2}=54 \%\end{array}$ \\
\hline & & $\begin{array}{l}\text { Function } \\
\text { Intermediate- } \\
\text { term }\end{array}$ & $\begin{array}{l}3(\mathrm{~N}=584) \\
\text { Saper } 2017 \\
\text { Tilbrook } 2011 \\
\text { Williams } 2009 \\
\end{array}$ & Moderate & Consistent & Imprecise & Undetected & Low & $\begin{array}{l}\text { Pooled SMD }-0.33(95 \% \\
\mathrm{Cl}-0.49 \text { to }-0.16) ; 1^{2}=0 \%\end{array}$ \\
\hline & & $\begin{array}{l}\text { Pain } \\
\text { Short-term }\end{array}$ & $\begin{array}{l}5(\mathrm{~N}=770) \\
\text { Groessl } 2017 \\
\text { Saper } 2017 \\
\text { Sherman } 2005 \\
\text { Sherman } 2011 \\
\text { Williams } 2005 \\
\end{array}$ & Moderate & Consistent & Imprecise & Undetected & Low & $\begin{array}{l}\text { Pooled difference }-1.10 \text { (95\% } \\
\mathrm{Cl}-1.77 \text { to }-0.42) \text { on a } 0 \text { to } 10 \\
\text { scale; } I^{2}=74 \%\end{array}$ \\
\hline & & $\begin{array}{l}\text { Pain } \\
\text { Intermediate- } \\
\text { term }\end{array}$ & $\begin{array}{l}2(\mathrm{~N}=271) \\
\text { Saper } 2017 \\
\text { Williams } 2009\end{array}$ & Moderate & Consistent & Precise & Undetected & Moderate & $\begin{array}{l}\text { Pooled difference }-1.17(95 \% \\
\mathrm{Cl}-1.91 \text { to }-0.44) ; I^{2}=26 \%\end{array}$ \\
\hline & $\begin{array}{l}\text { Yoga vs. } \\
\text { exercise }\end{array}$ & $\begin{array}{l}\text { Function } \\
\text { Short-term }\end{array}$ & $\begin{array}{l}3(\mathrm{~N}=369) \\
\\
\text { Saper } 2017 \\
\text { Sherman } 2005 \\
\text { Sherman } 2011 \\
\end{array}$ & Moderate & Consistent & Imprecise & Undetected & Low & $\begin{array}{l}\text { Pooled SMD }-0.10(95 \% \\
\mathrm{Cl}-0.34 \text { to } 0.13) ; I^{2}=38 \%\end{array}$ \\
\hline
\end{tabular}




\begin{tabular}{|c|c|c|c|c|c|c|c|c|c|}
\hline Intervention & Comparator & Outcome & $\begin{array}{l}\text { Number of RCTs } \\
\text { (patients) } \\
\text { Author Year }\end{array}$ & $\begin{array}{c}\text { Study } \\
\text { Limitations }\end{array}$ & Consistency & Precision & $\begin{array}{l}\text { Reporting } \\
\text { Bias }\end{array}$ & $\begin{array}{l}\text { Strength } \\
\text { of } \\
\text { Evidence }\end{array}$ & $\begin{array}{l}\text { Findings, Direction, and } \\
\text { Magnitude of Effect }\end{array}$ \\
\hline & & $\begin{array}{l}\text { Function } \\
\text { Intermediate- } \\
\text { term }\end{array}$ & $\begin{array}{l}1(\mathrm{~N}=181) \\
\text { Saper } 2017\end{array}$ & Moderate & Unknown & Imprecise & Undetected & Low & $\begin{array}{l}\text { SMD }-0.01(95 \% \mathrm{Cl}-0.26 \text { to } \\
0.24)\end{array}$ \\
\hline & & $\begin{array}{l}\text { Pain } \\
\text { Short-term }\end{array}$ & $\begin{array}{l}4(\mathrm{~N}=429) \\
\text { Nambi } 2014 \\
\text { Saper } 2017 \\
\text { Sherman } 2005 \\
\text { Sherman } 2011\end{array}$ & Moderate & Inconsistent & Imprecise & Undetected & Low & $\begin{array}{l}\text { Pooled difference }-0.89(95 \% \\
\mathrm{Cl}-1.99 \text { to } 0.21) \text { on a } 0 \text { to } 10 \\
\text { scale; } I^{2}=92 \%\end{array}$ \\
\hline & & $\begin{array}{l}\text { Pain } \\
\text { Intermediate- } \\
\text { term }\end{array}$ & $\begin{array}{l}1(\mathrm{~N}=181) \\
\text { Saper } 2017\end{array}$ & Moderate & Unknown & Imprecise & Undetected & Low & $\begin{array}{l}\text { Difference } 0.30(95 \% \mathrm{Cl}-0.39 \\
\text { to } 0.99)\end{array}$ \\
\hline & & Harms & $\begin{array}{l}3(\mathrm{~N}=616) \\
\text { Saper } 2017 \\
\text { Sherman } 2011 \\
\text { Tilbrook } 2011 \\
\end{array}$ & Moderate & Consistent & Imprecise & Undetected & Low & $\begin{array}{l}\text { No difference in risk of any } \\
\text { adverse event; one trial } \\
\text { reported one serious adverse } \\
\text { event (cellulitis) }\end{array}$ \\
\hline & $\begin{array}{l}\text { Qi Gong vs. } \\
\text { exercise } \\
\text { therapy }\end{array}$ & $\begin{array}{l}\text { Function } \\
\text { Short-term }\end{array}$ & $\begin{array}{l}1(\mathrm{~N}=125) \\
\text { Blodt } 2015\end{array}$ & Moderate & Unknown & Imprecise & Undetected & Low & $\begin{array}{l}\text { Difference } 0.9(95 \% \mathrm{Cl}-0.1 \text { to } \\
\text { 2.0) on the } 0 \text { to } 24 \text { Roland } \\
\text { Disability Questionnaire }\end{array}$ \\
\hline & & $\begin{array}{l}\text { Function } \\
\text { Intermediate- } \\
\text { term }\end{array}$ & $\begin{array}{l}1(\mathrm{~N}=125) \\
\text { Blodt } 2015\end{array}$ & Moderate & Unknown & Precise & Undetected & Low & $\begin{array}{l}\text { Difference } 1.2 \text { (95\% Cl } 0.1 \text { to } \\
\text { 2.3) on the Roland Disability } \\
\text { Questionnaire }\end{array}$ \\
\hline & & $\begin{array}{l}\text { Pain } \\
\text { Short-term }\end{array}$ & $\begin{array}{l}1(\mathrm{~N}=125) \\
\text { Blodt } 2015\end{array}$ & Moderate & Unknown & Precise & Undetected & Low & $\begin{array}{l}\text { Difference } 7.7(95 \% \mathrm{Cl} 0.7 \text { to } \\
14.7) \text { on a } 0 \text { to } 100 \text { scale }\end{array}$ \\
\hline & & $\begin{array}{l}\text { Pain } \\
\text { Intermediate- } \\
\text { term }\end{array}$ & $\begin{array}{l}1(\mathrm{~N}=125) \\
\text { Blodt } 2015\end{array}$ & Moderate & Unknown & Imprecise & Undetected & Low & $\begin{array}{l}\text { Difference } 7.1(95 \% \mathrm{Cl}-1.0 \text { to } \\
15.2) \text { on a } 0 \text { to } 100 \text { scale }\end{array}$ \\
\hline & & Harms & $\begin{array}{l}1(\mathrm{~N}=125) \\
\text { Blodt } 2015\end{array}$ & Moderate & Unknown & Imprecise & Undetected & Low & $\begin{array}{l}\text { No difference in risk of adverse } \\
\text { events }\end{array}$ \\
\hline Acupuncture & $\begin{array}{l}\text { Acupuncture } \\
\text { vs. sham } \\
\text { acupuncture, } \\
\text { usual care, } \\
\text { attention } \\
\text { control, or a }\end{array}$ & $\begin{array}{l}\text { Function } \\
\text { Short-term }\end{array}$ & $\begin{array}{l}4(\mathrm{~N}=1,672) \\
\text { Brinkhaus 2006a } \\
\text { Cherkin } 2009 \\
\text { Cho } 2013 \\
\text { Haake } 2007\end{array}$ & Moderate & Inconsistent & Precise & Undetected & Low & $\begin{array}{l}\text { Pooled SMD }-0.22(95 \% \\
\text { Cl }-0.35 \text { to }-0.08) ;\left.\right|^{2}=44 \%\end{array}$ \\
\hline
\end{tabular}




\begin{tabular}{|c|c|c|c|c|c|c|c|c|c|}
\hline Intervention & Comparator & Outcome & $\begin{array}{l}\text { Number of RCTs } \\
\text { (patients) } \\
\text { Author Year }\end{array}$ & $\begin{array}{c}\text { Study } \\
\text { Limitations }\end{array}$ & Consistency & Precision & $\begin{array}{l}\text { Reporting } \\
\text { Bias }\end{array}$ & $\begin{array}{l}\text { Strength } \\
\text { of } \\
\text { Evidence }\end{array}$ & $\begin{array}{l}\text { Findings, Direction, and } \\
\text { Magnitude of Effect }\end{array}$ \\
\hline & \multirow[t]{6}{*}{$\begin{array}{l}\text { placebo } \\
\text { intervention }\end{array}$} & $\begin{array}{l}\text { Function } \\
\text { Interme- } \\
\text { diate-term }\end{array}$ & $\begin{array}{l}3(\mathrm{~N}=1,032) \\
\text { Brinkhaus 2006a } \\
\text { Cherkin 2001 } \\
\text { Cherkin } 2009\end{array}$ & Moderate & Inconsistent & Imprecise & Undetected & Low & $\begin{array}{l}\text { Pooled SMD }-0.08(95 \% \\
\mathrm{Cl}-0.36 \text { to } 0.20) ; 1^{2}=75 \%\end{array}$ \\
\hline & & $\begin{array}{l}\text { Function } \\
\text { Long-term }\end{array}$ & $\begin{array}{l}1(\mathrm{~N}=215) \\
\text { Thomas } 2006\end{array}$ & Moderate & Unknown & Imprecise & Undetected & Low & $\begin{array}{l}\text { Adjusted difference }-3.4(95 \% \\
\mathrm{Cl}-7.8 \text { to } 1.0) \text { on the } 0 \text { to } 100 \\
\text { ODI }\end{array}$ \\
\hline & & $\begin{array}{l}\text { Pain } \\
\text { Short-term }\end{array}$ & $\begin{array}{l}5(\mathrm{~N}=2,176) \\
\text { Brinkhaus 2006a } \\
\text { Carlsson } 2001 \\
\text { Cherkin } 2009 \\
\text { Cho } 2013 \\
\text { Haake } 2007\end{array}$ & Moderate & Consistent & Precise & Undetected & Moderate & $\begin{array}{l}\text { Pooled difference }-0.55(95 \% \\
\mathrm{Cl}-0.86 \text { to }-0.24) \text { on a } 0 \text { to } 10 \\
\text { scale; } I^{2}=30 \%\end{array}$ \\
\hline & & $\begin{array}{l}\text { Pain } \\
\text { Intermediate- } \\
\text { term }\end{array}$ & $\begin{array}{l}5(\mathrm{~N}=812) \\
\text { Brinkhaus 2006a } \\
\text { Carlsson } 2001 \\
\text { Cherkin } 2009 \\
\text { Cherkin } 2009 \\
\text { Thomas } 2006\end{array}$ & Moderate & Consistent & Imprecise & Undetected & Low & $\begin{array}{l}\text { Pooled difference }-0.25(95 \% \\
\mathrm{Cl}-0.67 \text { to } 0.16) \text { on a } 0 \text { to } 10 \\
\text { scale; } I^{2}=33 \%\end{array}$ \\
\hline & & $\begin{array}{l}\text { Pain } \\
\text { Long-term }\end{array}$ & $\begin{array}{l}1(\mathrm{~N}=215) \\
\text { Thomas } 2006\end{array}$ & Moderate & Unknown & Precise & Undetected & Low & $\begin{array}{l}\text { Difference }-0.83(95 \% \mathrm{Cl}-1.51 \\
\text { to }-0.15) \text { on a } 0 \text { to } 10 \text { scale }\end{array}$ \\
\hline & & Harms & $\begin{array}{l}6(\mathrm{~N}=2,525) \\
\text { Brinkhaus } 2006 \mathrm{a} \\
\text { Cherkin } 2001 \\
\text { Cherkin } 2009 \\
\text { Cho } 2013 \\
\text { Haake } 2007 \\
\text { Thomas } 2006\end{array}$ & Moderate & Consistent & Imprecise & Undetected & Low & $\begin{array}{l}\text { No evidence of increased risk } \\
\text { of serious harms }\end{array}$ \\
\hline $\begin{array}{l}\text { Multi- } \\
\text { disciplinary } \\
\text { Rehabilitation }\end{array}$ & $\begin{array}{l}\text { Multi- } \\
\text { disciplinary } \\
\text { rehabilitation } \\
\text { vs. usual care }\end{array}$ & $\begin{array}{l}\text { Function } \\
\text { Short-term }\end{array}$ & $\begin{array}{l}4(\mathrm{~N}=945) \\
\text { Bendix } 1996 \\
\text { Harkapaa } 1989 \\
\text { Lambeek } 2010 \\
\text { von Korff } 2005\end{array}$ & Moderate & Inconsistent & Precise & Undetected & Low & $\begin{array}{l}\text { Pooled SMD }-0.31 \text { (95\% } \\
\mathrm{Cl}-0.57 \text { to }-0.05) ; 1^{2}=70 \%\end{array}$ \\
\hline
\end{tabular}




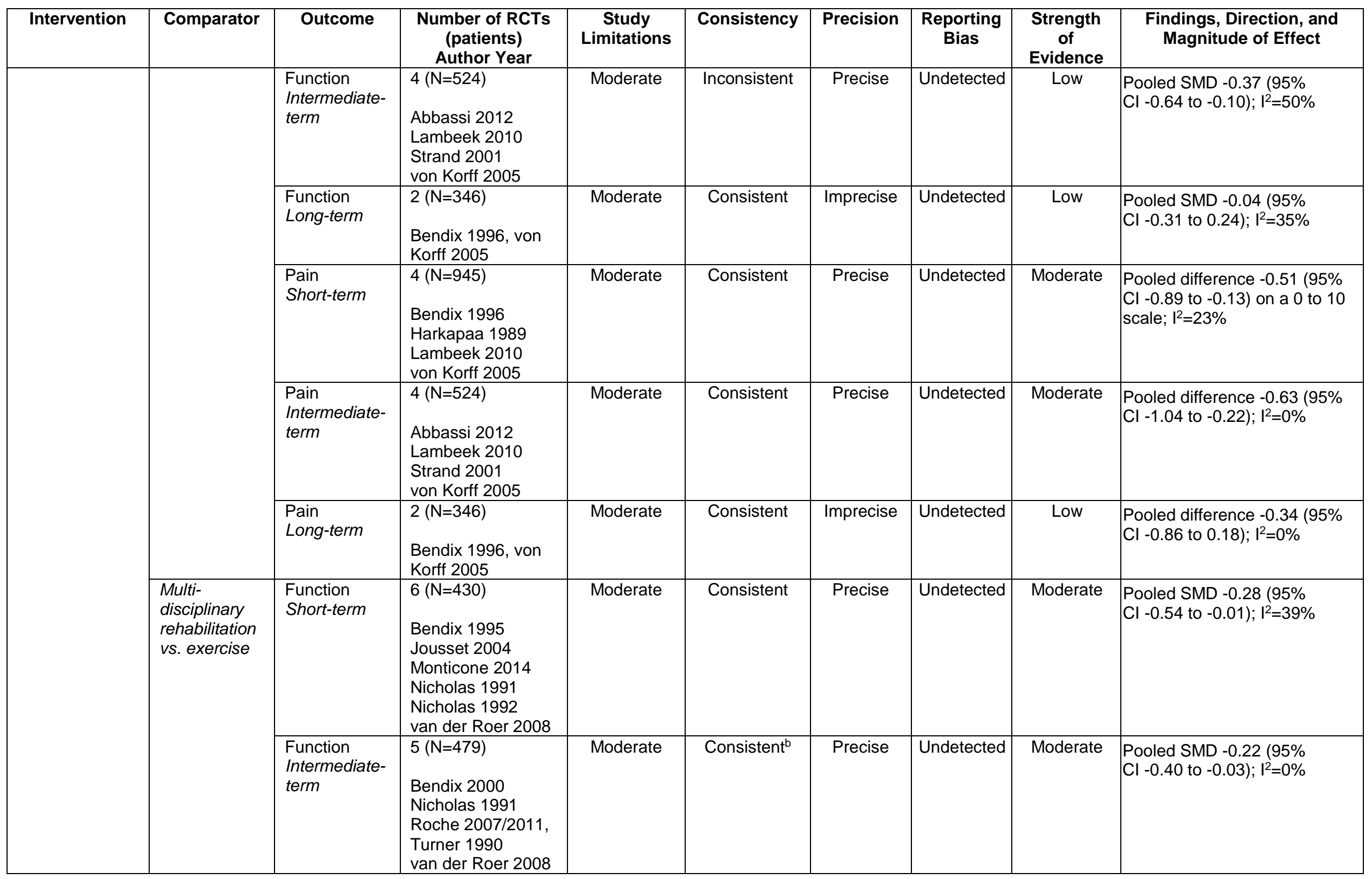




\begin{tabular}{|c|c|c|c|c|c|c|c|c|c|}
\hline Intervention & Comparator & Outcome & $\begin{array}{c}\text { Number of RCTs } \\
\text { (patients) } \\
\text { Author Year }\end{array}$ & $\begin{array}{c}\text { Study } \\
\text { Limitations }\end{array}$ & Consistency & Precision & $\begin{array}{l}\text { Reporting } \\
\text { Bias }\end{array}$ & $\begin{array}{l}\text { Strength } \\
\text { of } \\
\text { Evidence }\end{array}$ & $\begin{array}{l}\text { Findings, Direction, and } \\
\text { Magnitude of Effect }\end{array}$ \\
\hline & & $\begin{array}{l}\text { Function } \\
\text { Long-term }\end{array}$ & $\begin{array}{l}2(\mathrm{~N}=180) \\
\text { Bendix, 1995X } \\
\text { Turner 1990 } \\
\end{array}$ & Moderate & Consistent $^{b}$ & Imprecise & Undetected & Low & $\begin{array}{l}\text { Pooled SMD }-0.06(95 \% \mathrm{Cl} \\
-0.36 \text { to } 0.25) ; I^{2}=0 \%\end{array}$ \\
\hline & & $\begin{array}{l}\text { Pain } \\
\text { Short-term }\end{array}$ & $\begin{array}{l}6(\mathrm{~N}=430) \\
\\
\text { Bendix } 1995 \\
\text { Jousset } 2004 \\
\text { Monticone } 2014 \\
\text { Nicholas } 1991 \\
\text { Nicholas } 1992 \\
\text { van der Roer } 2008\end{array}$ & Moderate & Consistent & Precise & Undetected & Moderate & $\begin{array}{l}\text { Pooled difference }-0.75(95 \% \\
\mathrm{Cl}-1.18 \text { to }-0.31) \text { on a } 0 \text { to } 10 \\
\text { scale; } I^{2}=0 \%\end{array}$ \\
\hline & & $\begin{array}{l}\text { Pain } \\
\text { Intermediate- } \\
\text { term }\end{array}$ & $\begin{array}{l}5(\mathrm{~N}=479) \\
\text { Bendix 2000 } \\
\text { Nicholas } 1991 \\
\text { Roche 2007/2011, } \\
\text { Turner 1990 } \\
\text { van der Roer } \\
\end{array}$ & Moderate & Consistent $^{b}$ & Precise & Undetected & Moderate & $\begin{array}{l}\text { Pooled difference }-0.55(95 \% \\
\mathrm{Cl}-0.95 \text { to }-0.15) ; I^{2}=0 \%\end{array}$ \\
\hline & & $\begin{array}{l}\text { Pain } \\
\text { Long-term }\end{array}$ & $\begin{array}{l}2(\mathrm{~N}=180) \\
\text { Bendix, } 1995 \\
\text { Turner } 1990 \\
\end{array}$ & Moderate & Consistent $^{\mathrm{b}}$ & Imprecise & Undetected & Low & $\begin{array}{l}\text { Pooled difference } 0.00(95 \% \\
\mathrm{Cl}-0.94 \text { to } 0.95) ; \mathrm{I}^{2}=0 \%\end{array}$ \\
\hline & & Harms & $\begin{array}{l}2(\mathrm{~N}=94) \\
\text { Monticone } 2014 \\
\text { Tavafian } 2008\end{array}$ & High & Consistent & Imprecise & Undetected & Insufficient & $\begin{array}{l}\text { Insufficient data on harms from } \\
2 \text { trials, though no serious } \\
\text { harms were reported }\end{array}$ \\
\hline
\end{tabular}

a Outlier trial excluded, Banth 2015

b Outlier trial excluded, Monticone 2013 
Table G-2. Neck pain (KQ 2) strength of evidence

\begin{tabular}{|c|c|c|c|c|c|c|c|c|c|}
\hline Intervention & Comparator & Outcome & $\begin{array}{c}\text { Number of RCTs } \\
\text { (patients) } \\
\text { Author Year }\end{array}$ & $\begin{array}{c}\text { Study } \\
\text { Limitations }\end{array}$ & Consistency & Precision & $\begin{array}{l}\text { Reporting } \\
\text { Bias }\end{array}$ & $\begin{array}{l}\text { Strength } \\
\text { of } \\
\text { Evidence }\end{array}$ & $\begin{array}{l}\text { Findings, Direction and } \\
\text { Magnitude of Effect }\end{array}$ \\
\hline \multirow[t]{7}{*}{ Exercise } & \multirow[t]{7}{*}{$\begin{array}{l}\text { Exercise vs. } \\
\text { attention } \\
\text { control, no } \\
\text { treatment or } \\
\text { advice alone }\end{array}$} & $\begin{array}{l}\text { Function } \\
\text { Short-term }\end{array}$ & $\begin{array}{l}3(\mathrm{~N}=444) \\
\text { Stewart } 2007 \\
\text { Lauche } 2016 \\
\text { Viljanen } 2003\end{array}$ & Moderate & Inconsistent $^{\mathrm{a}}$ & Imprecise & Undetected & Low & $\begin{array}{l}\text { Pooled SMD, ( } 3 \\
\text { trials) }-0.23,95 \% \mathrm{Cl}-0.61 \\
\text { to } 0.15,1^{2}=72.6 \% \\
\text { Combination exercise only } \\
\text { (2 trials ), pooled } \\
\text { SMD }-0.44,95 \% \mathrm{Cl}-0.76 \text { to } \\
-0.09\end{array}$ \\
\hline & & $\begin{array}{l}\text { Function } \\
\text { Intermediate- } \\
\text { term }\end{array}$ & $\begin{array}{l}1(\mathrm{~N}=230) \\
\text { Viljanen } 2003\end{array}$ & Moderate & Unknown & Imprecise & Undetected & Low & $\begin{array}{l}\text { SMD 0.14, 95\% Cl -0.12, } \\
0.40)\end{array}$ \\
\hline & & $\begin{array}{l}\text { Function } \\
\text { Long-term }\end{array}$ & $\begin{array}{l}1(\mathrm{~N}=125) \\
\text { Stewart } 2007\end{array}$ & Moderate & Unknown & Imprecise & Undetected & Low & $\begin{array}{l}\text { SMD }-0.38,95 \% \mathrm{Cl}-0.74 \\
\text { to }-0.03\end{array}$ \\
\hline & & $\begin{array}{l}\text { Pain } \\
\text { Short-term }\end{array}$ & $\begin{array}{l}3(\mathrm{~N}=444) \\
\text { Stewart } 2007 \\
\text { Lauche } 2016 \\
\text { Viljanen } 2003\end{array}$ & Moderate & Inconsistent ${ }^{\mathrm{a}}$ & Imprecise & Undetected & Low & $\begin{array}{l}\text { Pooled difference }-0.72 \text {, } \\
95 \% \mathrm{Cl}-1.49 \text { to } 0.06 \\
\mathrm{I}^{2}=63.7 \% \\
\text { Combination exercise only } \\
\text { ( } 2 \text { two trials), pooled } \\
\text { difference }-1.12,95 \% \mathrm{Cl} \\
-1.82 \text { to }-0.43\end{array}$ \\
\hline & & $\begin{array}{l}\text { Pain } \\
\text { Intermediate- } \\
\text { term }\end{array}$ & $\begin{array}{l}2(\mathrm{~N}=353) \\
\text { Andersen } 2008 \\
\text { Viljanen } 2003 \\
\end{array}$ & Moderate & Consistent & Precise & Undetected & Low & $\begin{array}{l}\text { Pooled difference }-0.26 \text {, } \\
95 \% \mathrm{Cl}-0.70 \text { to } 0.19 \\
\mathrm{I}^{2}=0.0 \%\end{array}$ \\
\hline & & $\begin{array}{l}\text { Pain } \\
\text { Long-term }\end{array}$ & $\begin{array}{l}3(\mathrm{~N}=349) \\
\text { Stewart } 2007 \\
\text { Andersen } 2008 \\
\text { Waling } 2002\end{array}$ & Moderate & Inconsistent & Imprecise & Undetected & Low & $\begin{array}{l}\text { Pooled difference } 0.12,95 \% \\
\mathrm{Cl}-0.52 \text { to } 0.76, I^{2}=37.8 \%\end{array}$ \\
\hline & & Harms & $\begin{array}{l}2(\mathrm{~N}=201) \\
\text { Stewart } 2007 \\
\text { Lauche } 2016\end{array}$ & High & Consistent & Imprecise & Undetected & Low & $\begin{array}{l}\text { No evidence of increased risk } \\
\text { of serious harms }\end{array}$ \\
\hline
\end{tabular}




\begin{tabular}{|c|c|c|c|c|c|c|c|c|c|}
\hline Intervention & Comparator & Outcome & $\begin{array}{c}\text { Number of RCTs } \\
\text { (patients) } \\
\text { Author Year }\end{array}$ & $\begin{array}{c}\text { Study } \\
\text { Limitations }\end{array}$ & Consistency & Precision & $\begin{array}{l}\text { Reporting } \\
\text { Bias }\end{array}$ & $\begin{array}{l}\begin{array}{l}\text { Strength } \\
\text { of } \\
\text { Evidence }\end{array} \\
\end{array}$ & $\begin{array}{l}\text { Findings, Direction and } \\
\text { Magnitude of Effect }\end{array}$ \\
\hline & $\begin{array}{l}\text { Exercise vs. } \\
\text { pharmaco- } \\
\text { logical } \\
\text { therapy }\end{array}$ & $\begin{array}{l}\text { Pain, } \\
\text { Function, } \\
\text { Harms } \\
\text { Short- and } \\
\text { Intermediate- } \\
\text { term }\end{array}$ & $\begin{array}{l}1(\mathrm{~N}=40) \\
\text { Aslan Telci } 2012\end{array}$ & High & Unknown & Imprecise & Undetected & Insufficient & $\begin{array}{l}\text { Insufficient data from } 1 \text { poor } \\
\text { quality trial }\end{array}$ \\
\hline \multirow[t]{9}{*}{$\begin{array}{l}\text { Psychological } \\
\text { Therapies }\end{array}$} & \multirow[t]{4}{*}{$\begin{array}{l}\text { Relaxation } \\
\text { training vs. no } \\
\text { intervention }\end{array}$} & $\begin{array}{l}\text { Function } \\
\text { Short-term }\end{array}$ & $\begin{array}{l}1(\mathrm{~N}=258) \\
\text { Viljanen } 2003\end{array}$ & Moderate & Unknown & Imprecise & Undetected & Low & $\begin{array}{l}\text { Adjusted difference } 0.1 \text { (95\% } \\
\mathrm{Cl}-2.9 \text { to } 3.2 \text { ) on } 0-80 \text { scale }\end{array}$ \\
\hline & & $\begin{array}{l}\text { Function } \\
\text { Intermediate- } \\
\text { term }\end{array}$ & $\begin{array}{l}1(\mathrm{~N}=258) \\
\text { Viljanen } 2003\end{array}$ & Moderate & Unknown & Imprecise & Undetected & Low & $\begin{array}{l}\text { Adjusted difference } 0.2(95 \% \\
\mathrm{Cl}-2.8,3.1) \text { on } 0-80 \text { scale }\end{array}$ \\
\hline & & $\begin{array}{l}\text { Pain } \\
\text { Short-term }\end{array}$ & $\begin{array}{l}1(\mathrm{~N}=258) \\
\text { Viljanen } 2003\end{array}$ & Moderate & Unknown & Imprecise & Undetected & Low & $\begin{array}{l}\text { Adjusted difference } 0.2(95 \% \\
\mathrm{Cl}-0.4 \text { to } 0.8) \text { on } 0-10 \text { scale }\end{array}$ \\
\hline & & $\begin{array}{l}\text { Pain } \\
\text { Intermediate- } \\
\text { term }\end{array}$ & $\begin{array}{l}1(\mathrm{~N}=258) \\
\text { Viljanen } 2003\end{array}$ & Moderate & Unknown & Imprecise & Undetected & Low & $\begin{array}{l}\text { Adjusted difference } 0.2 \text { (95\% } \\
\mathrm{Cl}-0.3 \text { to } 0.8) \text { on } 0-10 \text { scale }\end{array}$ \\
\hline & \multirow[t]{4}{*}{$\begin{array}{l}\text { Relaxation } \\
\text { training vs. } \\
\text { exercise }\end{array}$} & $\begin{array}{l}\text { Function } \\
\text { Short-term }\end{array}$ & $\begin{array}{l}1(\mathrm{~N}=263) \\
\text { Viljanen } 2003\end{array}$ & Moderate & Unknown & Imprecise & Undetected & Low & $\begin{array}{l}\text { Adjusted difference } 0.2(95 \% \\
\mathrm{Cl}-2.8 \text { to } 3.2) \text { on } 0-80 \text { scale }\end{array}$ \\
\hline & & $\begin{array}{l}\text { Function } \\
\text { Intermediate- } \\
\text { term }\end{array}$ & $\begin{array}{l}1(\mathrm{~N}=263) \\
\text { Viljanen } 2003\end{array}$ & Moderate & Unknown & Imprecise & Undetected & Low & $\begin{array}{l}\text { Adjusted difference } 0.2 \text { (95\% } \\
\mathrm{Cl}-2.7 \text { to } 3.2 \text { ) on } 0-80 \text { scale }\end{array}$ \\
\hline & & $\begin{array}{l}\text { Pain } \\
\text { Short-term }\end{array}$ & $\begin{array}{l}1(\mathrm{~N}=263) \\
\text { Viljanen } 2003\end{array}$ & Moderate & Unknown & Imprecise & Undetected & Low & $\begin{array}{l}\text { Adjusted difference }-0.2 \text { (95\% } \\
\mathrm{Cl}-0.8 \text { to } 0.4) \text { on } 0-10 \text { scale }\end{array}$ \\
\hline & & $\begin{array}{l}\text { Pain } \\
\text { Intermediate- } \\
\text { term }\end{array}$ & $\begin{array}{l}1(\mathrm{~N}=263) \\
\text { Viljanen } 2003\end{array}$ & Moderate & Unknown & Imprecise & Undetected & Low & $\begin{array}{l}\text { Adjusted difference }-0.2(95 \% \\
\mathrm{Cl}-0.8 \text { to } 0.3) \text { on } 0-10 \text { scale }\end{array}$ \\
\hline & $\begin{array}{l}\text { Relaxation } \\
\text { training vs. no } \\
\text { intervention } \\
\text { or exercise }\end{array}$ & Harms & & & & & & & No evidence \\
\hline $\begin{array}{l}\text { Physical } \\
\text { Modalities }\end{array}$ & $\begin{array}{l}\text { Traction vs. } \\
\text { attention } \\
\text { control } \\
\end{array}$ & $\begin{array}{l}\text { Function, } \\
\text { Pain, Harms } \\
\text { Short-term } \\
\end{array}$ & $\begin{array}{l}1(\mathrm{~N}=79) \\
\text { Chiu } 2011\end{array}$ & High & Unknown & Imprecise & Undetected & Insufficient & $\begin{array}{l}\text { Insufficient evidence from one } \\
\text { poor-quality trial. }\end{array}$ \\
\hline
\end{tabular}




\begin{tabular}{|c|c|c|c|c|c|c|c|c|c|}
\hline Intervention & Comparator & Outcome & $\begin{array}{c}\text { Number of RCTs } \\
\text { (patients) } \\
\text { Author Year }\end{array}$ & $\begin{array}{c}\text { Study } \\
\text { Limitations }\end{array}$ & Consistency & Precision & $\begin{array}{l}\text { Reporting } \\
\text { Bias }\end{array}$ & $\begin{array}{l}\text { Strength } \\
\text { of } \\
\text { Evidence }\end{array}$ & $\begin{array}{l}\text { Findings, Direction and } \\
\text { Magnitude of Effect }\end{array}$ \\
\hline & & $\begin{array}{l}\text { Pain } \\
\text { Short-term }\end{array}$ & $\begin{array}{l}3(\mathrm{~N}=192) \\
\text { Chow } 2006 \\
\text { Gur } 2004 \\
\text { Altan } 2005\end{array}$ & Low & Consistent $^{b}$ & Imprecise & Undetected & Moderate & $\begin{array}{l}\text { Pooled difference }-1.81,(95 \% \\
\mathrm{Cl}-3.35 \text { to }-0.27) \text { on a } 0-10 \\
\text { scale: } I^{2}=76 \%\end{array}$ \\
\hline & & Harms & $\begin{array}{l}1(\mathrm{~N}=90) \\
\text { Chow } 2006\end{array}$ & Low & Unknown & Imprecise & Undetected & Low & $\begin{array}{l}\text { Adverse effects occurred with } \\
\text { similar frequency in both } \\
\text { groups. The most frequently } \\
\text { reported adverse effects in } \\
\text { the intervention group } \\
\text { included mild (78\%) or } \\
\text { moderate }(60 \%) \text { increased } \\
\text { neck pain, increased pain } \\
\text { elsewhere (78\%), mild } \\
\text { headache (60\%) and } \\
\text { tiredness }(24 \%) \text {. }\end{array}$ \\
\hline \multirow[t]{4}{*}{$\begin{array}{l}\text { Manual } \\
\text { Therapies }\end{array}$} & \multirow[t]{2}{*}{$\begin{array}{l}\text { Massage vs. } \\
\text { attention } \\
\text { control }\end{array}$} & $\begin{array}{l}\text { Function } \\
\text { Short-term }\end{array}$ & $\begin{array}{l}1(\mathrm{~N}=58) \\
\text { Sherman } 2009\end{array}$ & Moderate & Unknown & Imprecise & Undetected & Low & $\begin{array}{l}\text { Success ( } \geq 5 \text { points) RR } 2.7 \\
(95 \% \mathrm{Cl} .99 \text { to } 7.5)\end{array}$ \\
\hline & & $\begin{array}{l}\text { Function } \\
\text { Intermediate- } \\
\text { term }\end{array}$ & $\begin{array}{l}1(\mathrm{~N}=58) \\
\text { Sherman } 2009\end{array}$ & Moderate & Unknown & Imprecise & Undetected & Low & $\begin{array}{l}\text { Success ( } \geq 5 \text { points) RR } 1.8 \\
(95 \% \mathrm{Cl} .97 \text { to } 3.5)\end{array}$ \\
\hline & $\begin{array}{l}\text { Massage vs. } \\
\text { exercise }\end{array}$ & $\begin{array}{l}\text { Pain } \\
\text { Intermediate- } \\
\text { term }\end{array}$ & $\begin{array}{l}1(\mathrm{~N}=85) \\
\text { Rudolfsson } 2014\end{array}$ & Moderate & Unknown & Imprecise & Undetected & Low & $\begin{array}{l}\mathrm{MD} 0.2(95 \% \mathrm{Cl}-0.82 \text { to } 1.22) \\
\text { on the } 0-10 \mathrm{NRS}\end{array}$ \\
\hline & $\begin{array}{l}\text { Massage vs. } \\
\text { attention } \\
\text { control or vs. } \\
\text { exercise }\end{array}$ & Harms & $\begin{array}{l}2(\mathrm{~N}=143) \\
\text { Sherman } 2009 \\
\text { Rudolfsson } 2014\end{array}$ & Moderate & Unknown & Imprecise & Undetected & Low & $\begin{array}{l}\text { No evidence of increased risk } \\
\text { of serious harms }\end{array}$ \\
\hline \multirow[t]{2}{*}{$\begin{array}{l}\text { Mind-body } \\
\text { Practices }\end{array}$} & \multirow{2}{*}{$\begin{array}{l}\text { Alexander } \\
\text { Technique } \\
\text { plus usual } \\
\text { care vs. usual } \\
\text { care alone }\end{array}$} & $\begin{array}{l}\text { Function } \\
\text { Short-term }\end{array}$ & $\begin{array}{l}1(\mathrm{~N}=344) \\
\text { MacPherson } 2015\end{array}$ & Moderate & Unknown & Imprecise & Undetected & Low & $\begin{array}{l}\text { Difference }-5.56(95 \% \\
\mathrm{Cl}-8.33 \text { to }-2.78) \text { on } 0-100 \% \\
\text { scale }\end{array}$ \\
\hline & & $\begin{array}{l}\text { Function } \\
\text { Intermediate- } \\
\text { term }\end{array}$ & $\begin{array}{l}1(\mathrm{~N}=344) \\
\text { MacPherson } 2015\end{array}$ & Moderate & Unknown & Imprecise & Undetected & Low & $\begin{array}{l}\text { Difference }-3.92(95 \% \\
\mathrm{Cl}-6.87 \text { to }-0.97) \text { on } 0-100 \% \\
\text { scale }\end{array}$ \\
\hline
\end{tabular}




\begin{tabular}{|c|c|c|c|c|c|c|c|c|c|}
\hline Intervention & Comparator & Outcome & $\begin{array}{c}\begin{array}{c}\text { Number of RCTs } \\
\text { (patients) } \\
\text { Author Year }\end{array} \\
\end{array}$ & $\begin{array}{c}\text { Study } \\
\text { Limitations }\end{array}$ & Consistency & Precision & $\begin{array}{l}\text { Reporting } \\
\text { Bias }\end{array}$ & $\begin{array}{l}\text { Strength } \\
\text { of } \\
\text { Evidence }\end{array}$ & $\begin{array}{l}\text { Findings, Direction and } \\
\text { Magnitude of Effect }\end{array}$ \\
\hline & & Harms & $\begin{array}{l}1(\mathrm{~N}=344) \\
\text { MacPherson } 2015\end{array}$ & Moderate & Unknown & Imprecise & Undetected & Low & $\begin{array}{l}\text { No clear difference in the risk } \\
\text { of any non-serious adverse } \\
\text { event (e.g., pain and } \\
\text { incapacity, knee injury, } \\
\text { muscle spasm, and } \\
\text { complications after surgery): } \\
\text { RR } 2.25 \text { (95\% Cl } 1.00 \text { to } \\
5.04) \\
\text { No serious treatment-related } \\
\text { adverse events reported. }\end{array}$ \\
\hline & \multirow[t]{4}{*}{$\begin{array}{l}\text { Basic body } \\
\text { awareness } \\
\text { therapy vs. } \\
\text { exercise }\end{array}$} & $\begin{array}{l}\text { Function } \\
\text { Short-term }\end{array}$ & $\begin{array}{l}1(\mathrm{~N}=113) \\
\text { Seferiadis } 2016\end{array}$ & Moderate & Unknown & Imprecise & Undetected & Low & $\begin{array}{l}\text { Difference between groups in } \\
\text { mean change from } \\
\text { baseline }-1, p>0.05\end{array}$ \\
\hline & & $\begin{array}{l}\text { Function } \\
\text { Intermediate- } \\
\text { and long-term }\end{array}$ & $\begin{array}{l}1(\mathrm{~N}=139) \\
\text { Lansinger } 2007\end{array}$ & High & Unknown & Imprecise & Undetected & Insufficient & $\begin{array}{l}\text { Insufficient evidence from one } \\
\text { poor-quality trial }\end{array}$ \\
\hline & & $\begin{array}{l}\text { Pain } \\
\text { Intermediate- } \\
\text { and long-term }\end{array}$ & $\begin{array}{l}1(\mathrm{~N}=139) \\
\text { Lansinger } 2007\end{array}$ & High & Unknown & Imprecise & Undetected & Insufficient & $\begin{array}{l}\text { Insufficient evidence from one } \\
\text { poor-quality trial }\end{array}$ \\
\hline & & Harms & $\begin{array}{l}1(\mathrm{~N}=113) \\
\text { Seferiadis } 2016\end{array}$ & Moderate & Unknown & Imprecise & Undetected & Low & $\begin{array}{l}\text { No serious adverse effects } \\
\text { Any non-serious adverse } \\
\text { effects: RR } 0.65(95 \% \mathrm{Cl} 0.37 \\
\text { to } 1.14)\end{array}$ \\
\hline \multirow[t]{2}{*}{ Acupuncture } & \multirow[t]{2}{*}{$\begin{array}{l}\text { Acupuncture } \\
\text { vs. sham, } \\
\text { placebo or } \\
\text { usual care }\end{array}$} & $\begin{array}{l}\text { Function } \\
\text { Short-term }\end{array}$ & $\begin{array}{l}5(\mathrm{~N}=959) \\
\text { White } 2004 \\
\text { Liang } 2011 \\
\text { Zhang } 2013 \\
\text { MacPherson } 2015 \\
\text { Ho } 2017 \\
\end{array}$ & Moderate & Inconsistent & Precise & Undetected & Low & $\begin{array}{l}\text { Pooled SMD }-0.40(95 \% \\
\mathrm{Cl}-0.64 \text { to }-0.17) ; I^{2}=67.7 \%\end{array}$ \\
\hline & & $\begin{array}{l}\text { Function } \\
\text { Intermediate- } \\
\text { term }\end{array}$ & $\begin{array}{l}3(\mathrm{~N}=563) \\
\text { White } 2004 \\
\text { Zhang } 2013 \\
\text { MacPherson } 2015\end{array}$ & Moderate & Inconsistent & Imprecise & Undetected & Low & $\begin{array}{l}\text { Pooled SMD }-0.19 \text { (95\% } \\
\mathrm{Cl}-0.35 \text { to }-0.02) ; 1^{2}=0 \%\end{array}$ \\
\hline
\end{tabular}




\begin{tabular}{|c|c|c|c|c|c|c|c|c|c|}
\hline Intervention & Comparator & Outcome & $\begin{array}{c}\text { Number of RCTs } \\
\text { (patients) } \\
\text { Author Year }\end{array}$ & $\begin{array}{c}\text { Study } \\
\text { Limitations }\end{array}$ & Consistency & Precision & $\begin{array}{l}\text { Reporting } \\
\text { Bias }\end{array}$ & $\begin{array}{l}\text { Strength } \\
\text { of } \\
\text { Evidence }\end{array}$ & $\begin{array}{l}\text { Findings, Direction and } \\
\text { Magnitude of Effect }\end{array}$ \\
\hline & & $\begin{array}{l}\text { Pain } \\
\text { Short-term }\end{array}$ & $\begin{array}{l}4(N=490) \\
\text { Sahin } 2010 \\
\text { White } 2004 \\
\text { Liang } 2011 \\
\text { Zhang } 2013\end{array}$ & Moderate & Inconsistent & Precise & Undetected & Low & $\begin{array}{l}\text { Pooled difference }-0.27(95 \% \\
\mathrm{Cl}-0.59 \text { to } 0.05) \text { on a } 0-10 \\
\text { scale; } I^{2}=2 \%\end{array}$ \\
\hline & & $\begin{array}{l}\text { Pain } \\
\text { Long-term }\end{array}$ & $\begin{array}{l}1(\mathrm{~N}=107) \\
\text { White } 2004\end{array}$ & Moderate & Unknown & Imprecise & Undetected & Low & $\begin{array}{l}\text { Pooled difference }-0.35(95 \% \\
\mathrm{Cl}-1.34 \text { to } 0.64) \text { on a } 0-10 \\
\text { scale }\end{array}$ \\
\hline & $\begin{array}{l}\text { Acupuncture } \\
\text { vs. } \\
\text { pharmaco- } \\
\text { logical care }\end{array}$ & $\begin{array}{l}\text { Function } \\
\text { Short-term }\end{array}$ & $\begin{array}{l}1(\mathrm{~N}=30) \\
\text { Cho } 2014\end{array}$ & High & Unknown & Imprecise & Undetected & Insufficient & $\begin{array}{l}\text { Insufficient evidence due to } \\
\text { study limitations, unknown } \\
\text { consistency and imprecision } \\
\text { from one poor-quality study }\end{array}$ \\
\hline & & $\begin{array}{l}\text { Pain } \\
\text { Short-term }\end{array}$ & $\begin{array}{l}2(\mathrm{~N}=53) \\
\text { Birch } 1998 \\
\text { Cho } 2014\end{array}$ & High & Consistent & Imprecise & Undetected & Insufficient & $\begin{array}{l}\text { Insufficient evidence due to } \\
\text { study limitations and } \\
\text { imprecision from } 2 \text { poor } \\
\text { quality studies }\end{array}$ \\
\hline & $\begin{array}{l}\text { Acupuncture } \\
\text { vs. sham, } \\
\text { placebo, } \\
\text { usual care or } \\
\text { pharmaco- } \\
\text { logical care }\end{array}$ & Harms & $\begin{array}{l}5(\mathrm{~N}=907) \\
\\
\text { MacPherson } 2015 \\
\text { Vas } 2006 \\
\text { White } 2004 \\
\text { Liang } 2011 \\
\text { Zhang } 2013\end{array}$ & Moderate & Consistent & Precise & Undetected & Moderate & $\begin{array}{l}\text { No serious treatment-related } \\
\text { adverse events reported. } \\
\text { Most common non-serious } \\
\text { adverse effects included } \\
\text { numbness/ discomfort, } \\
\text { fainting and bruising. }\end{array}$ \\
\hline
\end{tabular}

$\mathrm{CI}$ = confidence interval; RCT = randomized controlled trial; RR = risk ratio; SMD = standardized mean difference.

a Outlier trial excluded, Li 2017b Heterogeneity is explained in part by the contribution of the good quality study; the others are fair. 
Table G-3. Knee osteoarthritis (KQ 3) strength of evidence

\begin{tabular}{|c|c|c|c|c|c|c|c|c|c|}
\hline Intervention & Comparator & Outcome & $\begin{array}{c}\text { Number of RCTs } \\
\text { (patients) } \\
\text { Author Year } \\
\end{array}$ & $\begin{array}{c}\text { Study } \\
\text { Limitations }\end{array}$ & Consistency & Precision & $\begin{array}{l}\text { Reporting } \\
\text { Bias }\end{array}$ & $\begin{array}{l}\text { Strength } \\
\text { of } \\
\text { Evidence }\end{array}$ & $\begin{array}{l}\text { Findings, Direction and } \\
\text { Magnitude of Effect }\end{array}$ \\
\hline \multirow[t]{4}{*}{ Exercise } & \multirow[t]{4}{*}{$\begin{array}{l}\text { Exercise vs. } \\
\text { usual care, } \\
\text { attention } \\
\text { control, or no } \\
\text { intervention }\end{array}$} & $\begin{array}{l}\text { Function } \\
\text { Short-term }\end{array}$ & $\begin{array}{l}7(\mathrm{~N}=641) \\
\text { Bennell } 2005 \\
\text { Quilty 2003 } \\
\text { Lund 2008 } \\
\text { Williamson } 2007 \\
\text { Rosedale 2014 } \\
\text { Thorstensson } 2005 \\
\text { Segal 2015 }\end{array}$ & Moderate & Consistent & Precise & Undetected & Moderate & $\begin{array}{l}\text { Pooled SMD }-0.25(95 \% \\
\left.\mathrm{Cl}-0.4 \text { to }-0.09,1^{2}=0 \%\right)\end{array}$ \\
\hline & & $\begin{array}{l}\text { Function } \\
\text { Intermediate- } \\
\text { term }\end{array}$ & $\begin{array}{l}9(\mathrm{~N}=637) \\
\text { Sullivan } 1998 \\
\text { Quilty 2003 } \\
\text { Messier 2004 } \\
\text { Huang 2005a } \\
\text { Huang 2005 b } \\
\text { Weng 2009 } \\
\text { Huang 2003 } \\
\text { Chen 2014 } \\
\text { Segal 2015 } \\
\end{array}$ & Moderate & Inconsistent ${ }^{\mathrm{a}}$ & Precise & Undetected & Low & $\begin{array}{l}\text { Pooled SMD }-0.78(95 \% \mathrm{Cl} \\
\left.-1.37 \text { to }-0.19, \mathrm{I}^{2}=91.4 \%\right)\end{array}$ \\
\hline & & $\begin{array}{l}\text { Function } \\
\text { Long-term }\end{array}$ & $\begin{array}{l}2(\mathrm{~N}=913) \\
\text { Messier } 2004 \\
\text { Thomas } 2002\end{array}$ & High & Consistent & Precise & Undetected & Low & $\begin{array}{l}\text { Pooled SMD }-0.24(95 \% \\
\left.\mathrm{Cl}-0.37 \text { to }-\left.0.11\right|^{2}=0 \%\right)\end{array}$ \\
\hline & & $\begin{array}{l}\text { Pain } \\
\text { Short-term }\end{array}$ & $\begin{array}{l}7(\mathrm{~N}=641) \\
\text { Bennell } 2005 \\
\text { Quilty 2003 } \\
\text { Lund 2008 } \\
\text { Williamson } 2007 \\
\text { Rosedale 2014 } \\
\text { Thorstensson } 2005 \\
\text { Segal 2015 }\end{array}$ & Moderate & Consistent & Precise & Undetected & Moderate & $\begin{array}{l}\text { Pooled difference on } 0-10 \\
\text { scale: }-0.44,(95 \% \mathrm{Cl}-0.82 \\
\left.\text { to }-0.05, \mathrm{I}^{2}=35 \%\right)\end{array}$ \\
\hline
\end{tabular}




\begin{tabular}{|c|c|c|c|c|c|c|c|c|c|}
\hline Intervention & Comparator & Outcome & $\begin{array}{c}\text { Number of RCTs } \\
\text { (patients) } \\
\text { Author Year }\end{array}$ & $\begin{array}{c}\text { Study } \\
\text { Limitations }\end{array}$ & Consistency & Precision & $\begin{array}{l}\text { Reporting } \\
\text { Bias }\end{array}$ & $\begin{array}{l}\text { Strength } \\
\text { of } \\
\text { Evidence }\end{array}$ & $\begin{array}{l}\text { Findings, Direction and } \\
\text { Magnitude of Effect }\end{array}$ \\
\hline & & $\begin{array}{l}\text { Pain } \\
\text { Intermediate- } \\
\text { term }\end{array}$ & $\begin{array}{l}9(\mathrm{~N}=638) \\
\\
\text { Sullivan } 1998 \\
\text { Quilty 2003 } \\
\text { Messier 2004 } \\
\text { Huang 2005a } \\
\text { Huang 2005b } \\
\text { Weng 2009 } \\
\text { Huang } 2003 \\
\text { Chen } 2014 \\
\text { Segal 2015 }\end{array}$ & Moderate & Inconsistent & Precise & Undetected & Low & $\begin{array}{l}\text { Pooled difference on a } 0-10 \\
\text { scale: }-1.61(95 \% \mathrm{Cl}-2.51 \text { to } \\
\left.-0.72, \mathrm{I}^{2}=91 \%\right)\end{array}$ \\
\hline & & $\begin{array}{l}\text { Pain } \\
\text { Long-term }\end{array}$ & $\begin{array}{l}2(\mathrm{~N}=914) \\
\text { Messier } 2004 \\
\text { Thomas } 2002\end{array}$ & High & Consistent & Precise & Undetected & Low & $\begin{array}{l}\text { Pooled difference on a } 0-10 \\
\text { scale: }-0.24(95 \% \mathrm{Cl}-0.72 \\
\left.\text { to } 0.24, I^{2}=55 \%\right)\end{array}$ \\
\hline & & Harms & $\begin{array}{l}7(\mathrm{~N}=1004) \\
\text { Bennell } 2005 \\
\text { Weng } 2009 \\
\text { Huang } 2003 \\
\text { Chen } 2014 \\
\text { Thorstensson } \\
\text { Ettinger } 1997 \\
\text { Abbott } 2013\end{array}$ & Moderate & Consistent & Precise & Undetected & Moderate & $\begin{array}{l}\text { One trial reported greater } \\
\text { temporary, minor increases in } \\
\text { pain in the exercise group } \\
\text { versus a sham group; } \\
\text { however, four trials found no } \\
\text { difference in worsening of } \\
\text { pain symptoms with exercise } \\
\text { vs. comparators. One trial } \\
\text { found no difference in falls or } \\
\text { deaths. }\end{array}$ \\
\hline \multirow[t]{2}{*}{$\begin{array}{l}\text { Psychological } \\
\text { Therapies }\end{array}$} & \multirow[t]{2}{*}{$\begin{array}{l}\text { CBT/pain } \\
\text { coping skills } \\
\text { training vs. } \\
\text { usual care }\end{array}$} & $\begin{array}{l}\text { Function, } \\
\text { Pain } \\
\text { Short-term to } \\
\text { long-term }\end{array}$ & $\begin{array}{l}2(\mathrm{~N}=222) \\
\text { Helminen } 2015 \\
\text { Somers } 2012\end{array}$ & Moderate & Consistent & Imprecise & Undetected & Low & $\begin{array}{l}\text { No differences in one fair } \\
\text { quality trial of CBT and one } \\
\text { poor quality trial of pain } \\
\text { coping skills training } \\
\text { averaged over } 6 \text { to } 12 \text { months } \\
\text { (intermediate to long term) } \\
\text { and } 1.5 \text { to } 10.5 \text { months (short } \\
\text { to intermediate term). }\end{array}$ \\
\hline & & Harms & $\begin{array}{l}2(\mathrm{~N}=222) \\
\text { Helminen } 2015 \\
\text { Somers } 2012 \\
\end{array}$ & Moderate & Consistent & Imprecise & Undetected & Low & $\begin{array}{l}\text { No adverse events observed } \\
\text { in two trials. }\end{array}$ \\
\hline
\end{tabular}




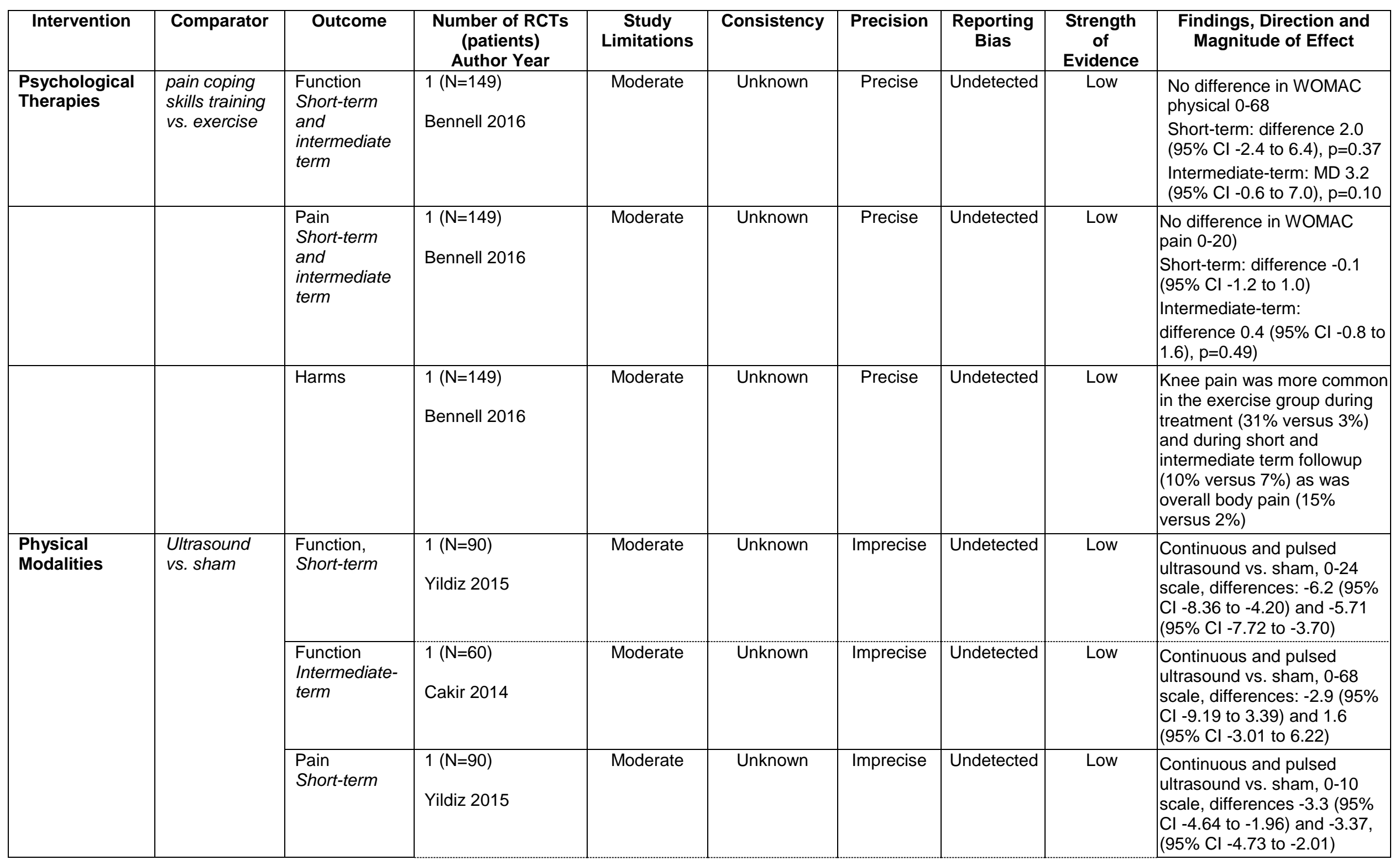




\begin{tabular}{|c|c|c|c|c|c|c|c|c|c|}
\hline Intervention & Comparator & Outcome & $\begin{array}{c}\text { Number of RCTs } \\
\text { (patients) } \\
\text { Author Year }\end{array}$ & $\begin{array}{c}\text { Study } \\
\text { Limitations }\end{array}$ & Consistency & Precision & $\begin{array}{l}\text { Reporting } \\
\text { Bias }\end{array}$ & $\begin{array}{l}\text { Strength } \\
\text { of } \\
\text { Evidence }\end{array}$ & $\begin{array}{l}\text { Findings, Direction and } \\
\text { Magnitude of Effect }\end{array}$ \\
\hline & & $\begin{array}{l}\text { Pain } \\
\text { Intermediate- } \\
\text { term }\end{array}$ & $\begin{array}{l}1(\mathrm{~N}=60) \\
\text { Cakir } 2014\end{array}$ & Moderate & Unknown & Imprecise & Undetected & Low & $\begin{array}{l}\text { Continuous and pulsed } \\
\text { ultrasound vs. sham, } 0-20 \\
\text { scale, differences: }-1.6(95 \% \\
\mathrm{Cl}-3.26 \text { to } 0.06) \text { vs. } 0.2(95 \% \\
\mathrm{Cl}-1.34 \text { to } 1.74) ; \text { also no } \\
\text { difference between groups for } \\
\text { other pain measures. }\end{array}$ \\
\hline & & Harms & $\begin{array}{l}2(\mathrm{~N}=150) \\
\text { Cakir } 2014 \\
\text { Yildiz } 2015\end{array}$ & Moderate & Unknown & Imprecise & Undetected & Low & $\begin{array}{l}\text { No adverse events reported } \\
\text { during the two trials }\end{array}$ \\
\hline & $\begin{array}{l}\text { TENS vS. } \\
\text { sham }\end{array}$ & $\begin{array}{l}\text { Function } \\
\text { Intermediate- } \\
\text { term }\end{array}$ & $\begin{array}{l}1(\mathrm{~N}=70) \\
\text { Fary } 2011\end{array}$ & Low & Unknown & Imprecise & Undetected & Low & $\begin{array}{l}\text { Difference in mean change } \\
-1.9(95 \% \mathrm{Cl}-9.7 \text { to } 5.9) \text { on } \\
\text { a } 0-100 \text { scale; } \\
\text { Proportion of patients who } \\
\text { achieved MCID }(\geq 9.1) \text { in } \\
\text { WOMAC function: } 38 \% \text { vs } \\
39 \% \text {, RR } 1.2(95 \% \mathrm{Cl} 0.6 \text { to } \\
2.2)\end{array}$ \\
\hline & & $\begin{array}{l}\text { Pain } \\
\text { Intermediate- } \\
\text { term }\end{array}$ & $\begin{array}{l}1(\mathrm{~N}=70) \\
\text { Fary } 2011\end{array}$ & Low & Unknown & Imprecise & Undetected & Low & $\begin{array}{l}\text { Dfference in mean change } \\
0.9(95 \% \mathrm{Cl}-11.7 \text { to } 13.4) \\
\text { on } 0-100 \mathrm{VAS} \text { and }-5.6 \\
(95 \% \mathrm{Cl}-14.9 \text { to } 3.6) \text { on } 0- \\
100 \text { WOMAC pain scale. } \\
\text { Proportion of patients who } \\
\text { achieved MCID }(\geq 20) \text { in pain } \\
\text { VAS: } 56 \% \text { vs } 44 \%, \text { RR } 1.3 \\
\text { (95\% Cl } 0.8 \text { to } 2.0)\end{array}$ \\
\hline & & Harms & $\begin{array}{l}1(\mathrm{~N}=70) \\
\text { Fary } 2011\end{array}$ & Low & Unknown & Imprecise & Undetected & Low & $\begin{array}{l}\text { No evidence of increased risk } \\
\text { of serious harms; no } \\
\text { differences between } \\
\text { treatments for harms (RR } \\
1.06,95 \% \mathrm{Cl} 0.38 \text { to } 2.97 \text { ) }\end{array}$ \\
\hline
\end{tabular}




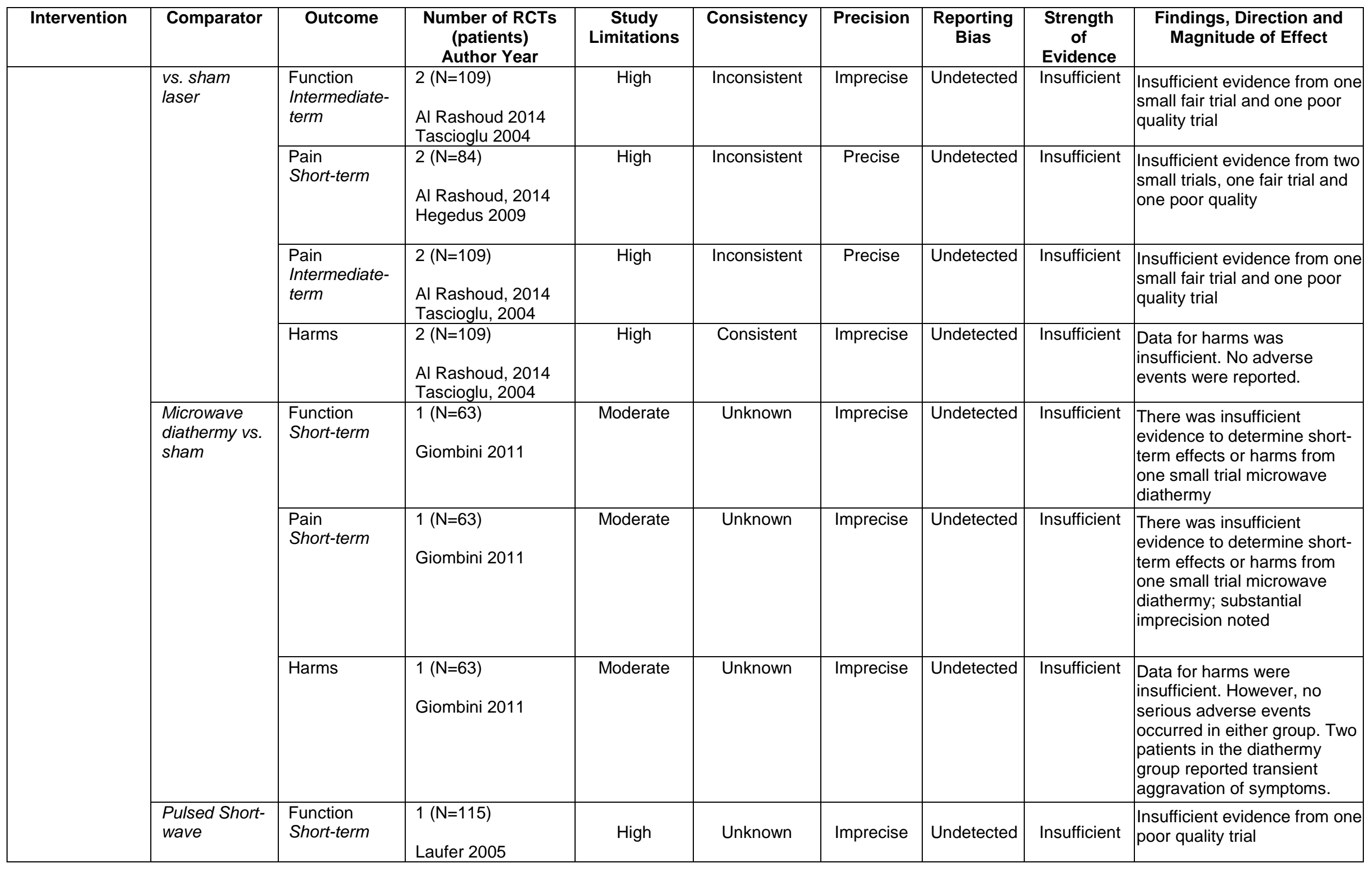




\begin{tabular}{|c|c|c|c|c|c|c|c|c|c|}
\hline Intervention & Comparator & Outcome & $\begin{array}{c}\begin{array}{c}\text { Number of RCTs } \\
\text { (patients) } \\
\text { Author Year }\end{array} \\
\end{array}$ & $\begin{array}{c}\text { Study } \\
\text { Limitations }\end{array}$ & Consistency & Precision & $\begin{array}{l}\text { Reporting } \\
\text { Bias }\end{array}$ & $\begin{array}{l}\text { Strength } \\
\text { of } \\
\text { Evidence }\end{array}$ & $\begin{array}{l}\text { Findings, Direction and } \\
\text { Magnitude of Effect }\end{array}$ \\
\hline & \multirow[t]{4}{*}{$\begin{array}{l}\text { Diathermy vs. } \\
\text { Sham }\end{array}$} & $\begin{array}{l}\text { Function } \\
\text { Long-term }\end{array}$ & $\begin{array}{l}1(\mathrm{~N}=86) \\
\text { Fukuda } 2011 \\
\end{array}$ & High & Unknown & Imprecise & Undetected & Insufficient & $\begin{array}{l}\text { Insufficient evidence from one } \\
\text { poor quality trial }\end{array}$ \\
\hline & & $\begin{array}{l}\text { Pain } \\
\text { Short-term }\end{array}$ & $\begin{array}{l}1(\mathrm{~N}=115) \\
\text { Laufer } 2005\end{array}$ & High & Unknown & Imprecise & Undetected & Insufficient & $\begin{array}{l}\text { Insufficient evidence from one } \\
\text { poor quality trial }\end{array}$ \\
\hline & & $\begin{array}{l}\text { Pain } \\
\text { Long-term }\end{array}$ & $\begin{array}{l}1(\mathrm{~N}=86) \\
\text { Fukuda } 2011\end{array}$ & High & Unknown & Imprecise & Undetected & Insufficient & $\begin{array}{l}\text { Insufficient evidence from one } \\
\text { poor quality trial }\end{array}$ \\
\hline & & Harms & $\begin{array}{l}2(\mathrm{~N}=201) \\
\text { Laufer } 2005 \\
\text { Fukuda } 2011\end{array}$ & High & Unknown & Imprecise & Undetected & Insufficient & $\begin{array}{l}\text { Data were insufficient for } \\
\text { harms. No adverse events } \\
\text { were reported by either trial. }\end{array}$ \\
\hline & \multirow[t]{3}{*}{$\begin{array}{l}\text { Electro- } \\
\text { magnetic } \\
\text { fields vs. } \\
\text { sham }\end{array}$} & $\begin{array}{l}\text { Function } \\
\text { Short-term }\end{array}$ & $\begin{array}{l}2(\mathrm{~N}=180) \\
\text { Battisti } 2004 \\
\text { Thamsborg } 2005\end{array}$ & Moderate & Consistent & Imprecise & Undetected & Low & $\begin{array}{l}\text { The fair quality trial: } \\
\text { (WOMAC) activities of daily } \\
\text { living subscale }(0-85) \text { mean } \\
\text { difference }-3.48(95 \% \mathrm{Cl} \text { - } \\
4.44 \text { to }-2.51)\end{array}$ \\
\hline & & $\begin{array}{l}\text { Pain } \\
\text { Short-term }\end{array}$ & $\begin{array}{l}2(\mathrm{~N}=180) \\
\text { Battisti } 2004 \\
\text { Thamsborg } 2005\end{array}$ & Moderate & Consistent & Imprecise & Undetected & Low & $\begin{array}{l}\text { The fair quality trial: } \\
\text { WOMAC-pain subscale }(0-25) \\
\text { versus sham, }-0.84(95 \% \mathrm{Cl}- \\
1.10 \text { to }-0.58) \text {. }\end{array}$ \\
\hline & & Harms & $\begin{array}{l}1(\mathrm{~N}=90) \\
\text { Thamsborg } 2005\end{array}$ & Moderate & Unknown & Imprecise & Undetected & Low & $\begin{array}{l}\text { More patients who received } \\
\text { real versus sham } \\
\text { electromagnetic field therapy } \\
\text { reported throbbing or } \\
\text { warming sensations or } \\
\text { aggravation of pain; however } \\
\text { the difference was not } \\
\text { significant (RR } 1.95,95 \% \mathrm{Cl} \\
0.81 \text { to } 4.71 \text { ) }\end{array}$ \\
\hline & \multirow[t]{2}{*}{$\begin{array}{l}\text { Superficial } \\
\text { heat vs. } \\
\text { placebo }\end{array}$} & $\begin{array}{l}\text { Pain } \\
\text { Short-term }\end{array}$ & $\begin{array}{l}1(\mathrm{~N}=52) \\
\text { Mazzuca } 2004\end{array}$ & Moderate & Unknown & Imprecise & Undetected & Insufficient & $\begin{array}{l}\text { Insufficient evidence from one } \\
\text { small, fair-quality trial }\end{array}$ \\
\hline & & Harms & $\begin{array}{l}1(\mathrm{~N}=52) \\
\text { Mazzuca } 2004\end{array}$ & Moderate & Unknown & Imprecise & Undetected & Insufficient & $\begin{array}{l}\text { Data was insufficient for } \\
\text { harms; no adverse events } \\
\text { were reported }\end{array}$ \\
\hline
\end{tabular}




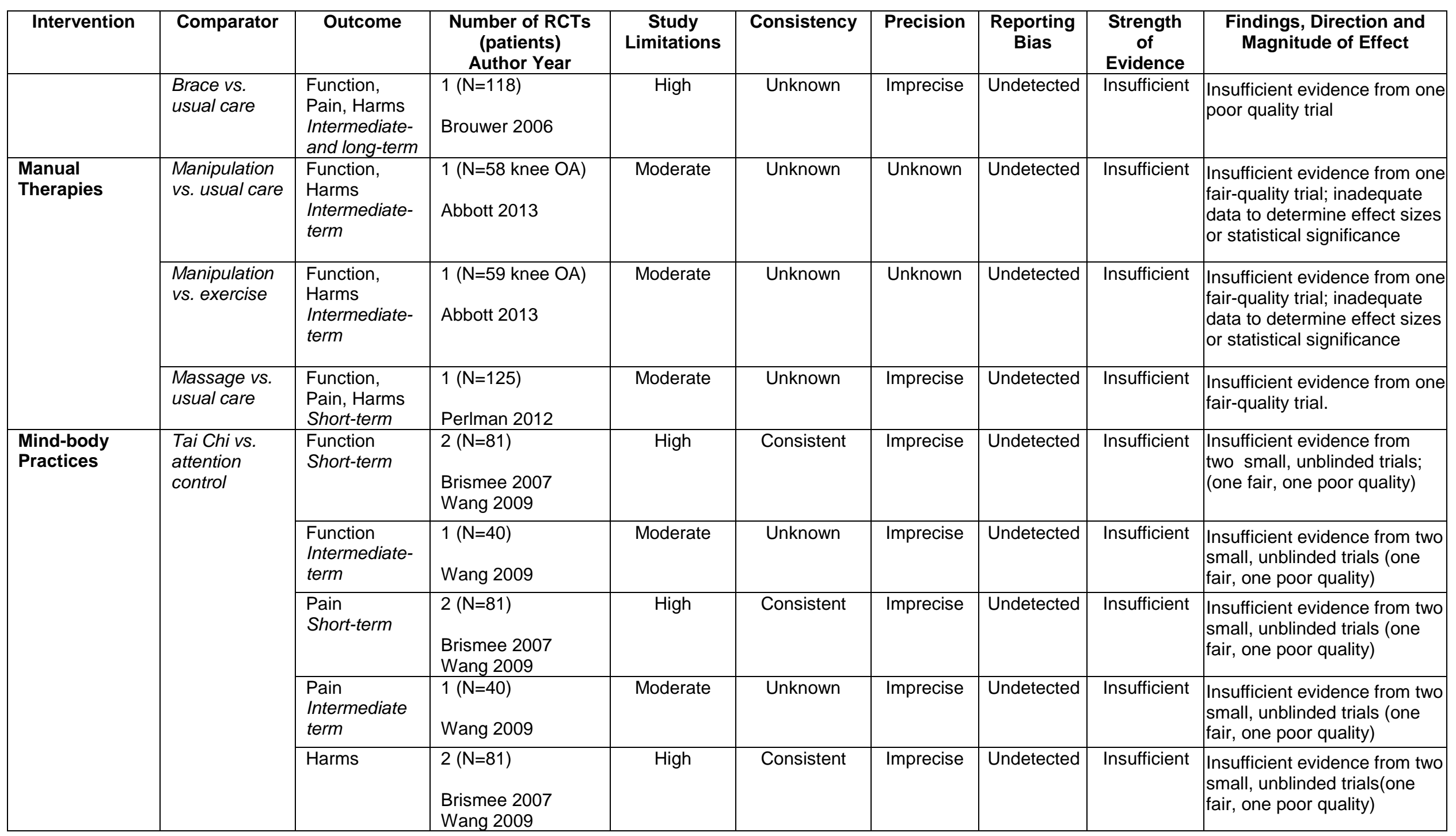




\begin{tabular}{|c|c|c|c|c|c|c|c|c|c|}
\hline Intervention & Comparator & Outcome & $\begin{array}{c}\text { Number of RCTs } \\
\text { (patients) } \\
\text { Author Year }\end{array}$ & $\begin{array}{c}\text { Study } \\
\text { Limitations }\end{array}$ & Consistency & Precision & $\begin{array}{l}\text { Reporting } \\
\text { Bias }\end{array}$ & $\begin{array}{l}\text { Strength } \\
\text { of } \\
\text { Evidence }\end{array}$ & $\begin{array}{l}\text { Findings, Direction and } \\
\text { Magnitude of Effect }\end{array}$ \\
\hline \multirow[t]{4}{*}{ Acupuncture } & \multirow[t]{4}{*}{$\begin{array}{l}\text { Acupuncture } \\
\text { vs. usual } \\
\text { care, no } \\
\text { treatment, } \\
\text { waitlist, or } \\
\text { sham }\end{array}$} & $\begin{array}{l}\text { Function } \\
\text { Short-term }\end{array}$ & $\begin{array}{l}4(\mathrm{~N}=871) \\
\text { Jubb } 2008 \\
\text { Suarez-Almazo } \\
2010 \\
\text { Yurturan } 2007 \\
\text { Witt } 2005\end{array}$ & Moderate & Inconsistent ${ }^{\mathrm{b}}$ & Precise & Undetected & Low & $\begin{array}{l}\text { Pooled SMD }-0.05,95 \% \mathrm{Cl} \\
-0.32 \text { to } 0.38)\end{array}$ \\
\hline & & $\begin{array}{l}\text { Function } \\
\text { Intermediate- } \\
\text { term }\end{array}$ & $\begin{array}{l}4(\mathrm{~N}=767) \\
\text { Berman } 2004 \\
\text { Lansdown } 2009 \\
\text { Witt 2005 } \\
\text { Hinman 2014 }\end{array}$ & Moderate & Consistent & Precise & Undetected & Moderate & $\begin{array}{l}\text { Pooled SMD }-0.15,95 \% \mathrm{Cl} \\
-0.31 \text { to } 0.02, \mathrm{I}^{2}=0 \%\end{array}$ \\
\hline & & $\begin{array}{l}\text { Pain } \\
\text { Short-term }\end{array}$ & $\begin{array}{l}6(\mathrm{~N}=1065) \\
\text { Berman } 1999 \\
\text { Jubb } 2008 \\
\text { Suarez-Almazo } \\
2010 \\
\text { Williamson } 2007 \\
\text { Witt 2005 } \\
\text { Yurturan } 2007\end{array}$ & Moderate & Inconsistent & Precise & Undetected & Low & $\begin{array}{l}\text { Pooled SMD }-0.27,95 \% \mathrm{Cl} \\
-0.56 \text { to } 0.02, I^{2}=75 \%\end{array}$ \\
\hline & & $\begin{array}{l}\text { Pain } \\
\text { Intermediate } \\
\text { term }\end{array}$ & $\begin{array}{l}4(\mathrm{~N}=767) \\
\text { Lansdown } 2009 \\
\text { Witt 2005 } \\
\text { Hinman } 2014 \\
\text { Berman 2004 }\end{array}$ & Moderate & Consistent & Imprecise & Undetected & Moderate & $\begin{array}{l}\text { Pooled SMD }-0.16,95 \% \mathrm{Cl} \\
\left.-0.31 \text { to }-0.02, \mathrm{I}^{2}=0 \%\right) ; \\
\text { Individually no trial reached } \\
\text { statistical significance. }\end{array}$ \\
\hline
\end{tabular}




\begin{tabular}{|c|c|c|c|c|c|c|c|c|c|}
\hline Intervention & Comparator & Outcome & $\begin{array}{c}\text { Number of RCTs } \\
\text { (patients) } \\
\text { Author Year }\end{array}$ & $\begin{array}{c}\text { Study } \\
\text { Limitations }\end{array}$ & Consistency & Precision & $\begin{array}{l}\text { Reporting } \\
\text { Bias }\end{array}$ & $\begin{array}{l}\text { Strength } \\
\text { of } \\
\text { Evidence }\end{array}$ & $\begin{array}{l}\text { Findings, Direction and } \\
\text { Magnitude of Effect }\end{array}$ \\
\hline & & Harms & $\begin{array}{l}9(\mathrm{~N}=1796) \\
\\
\text { Berman } 2004 \\
\text { Berman } 1999 \\
\text { Hinman } 2014 \\
\text { Jubb 2008 } \\
\text { Lansdown } 2009 \\
\text { Suarez-Almazo } \\
2010 \\
\text { Witt 2005 } \\
\text { Williamson } 2007 \\
\text { Yurtkuran } 2007\end{array}$ & Moderate & Consistent & Imprecise & Undetected & Moderate & $\begin{array}{l}\text { There is no apparent } \\
\text { difference in risk of serious } \\
\text { adverse events between any } \\
\text { form of acupuncture and the } \\
\text { control group. Worsening of } \\
\text { symptoms ( } 7 \%-14 \%) \text {, mild } \\
\text { bruising, swelling or pain at } \\
\text { the acupuncture site (1\%- } \\
18 \%) \text { were most common; } \\
\text { One case of infection at an } \\
\text { electroacupuncture site was } \\
\text { reported. }\end{array}$ \\
\hline & $\begin{array}{l}\text { Acupuncture } \\
\text { vs. exercise }\end{array}$ & $\begin{array}{l}\text { Function, } \\
\text { Pain, Harms } \\
\text { Short-term }\end{array}$ & $\begin{array}{l}1(\mathrm{~N}=120) \\
\text { Williamson }\end{array}$ & High & Unknown & Imprecise & Undetected & Insufficient & $\begin{array}{l}\text { Insufficient evidence from one } \\
\text { poor-quality trial. }\end{array}$ \\
\hline
\end{tabular}

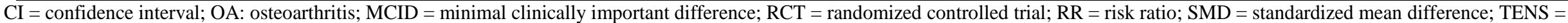
transcutaneous electrical stimulation; VAS = visual analog scale; WOMAC = Western Ontario and McMaster Universities Osteoarthritis Index.

a Outlier excluded, Dias 2003.

b Outlier excluded, Berman 1999.

c Estimate based on proximal likelihood methods. Results for all trials individually were not statistically significant. 


\begin{tabular}{|c|c|c|c|c|c|c|c|c|c|}
\hline Intervention & Comparator & Outcome & $\begin{array}{l}\text { Number of } \\
\text { RCTs } \\
\text { (patients) } \\
\text { Author Year }\end{array}$ & $\begin{array}{l}\text { Study } \\
\text { Limitations }\end{array}$ & Consistency & Precision & $\begin{array}{l}\text { Reporting } \\
\text { Bias }\end{array}$ & $\begin{array}{l}\text { Strength } \\
\text { of } \\
\text { Evidence }\end{array}$ & $\begin{array}{l}\text { Findings, Direction and } \\
\text { Magnitude of Effect }\end{array}$ \\
\hline \multirow[t]{6}{*}{ Exercise } & \multirow[t]{6}{*}{$\begin{array}{l}\text { Exercise vs. } \\
\text { usual care }\end{array}$} & $\begin{array}{l}\text { Function } \\
\text { Short-term }\end{array}$ & $\begin{array}{l}3(\mathrm{~N}=377) \\
\text { Juhakoski } 2011 \\
\text { Teirlinck } 2016 \\
\text { Tak } 2005\end{array}$ & Moderate & Consistent & Precise & Undetected & Low & $\begin{array}{l}\text { Pooled SMD }-0.33,95 \% \mathrm{Cl} \\
-0.53 \text { to }-0.12, \mathrm{I}^{2}=0 \%\end{array}$ \\
\hline & & $\begin{array}{l}\text { Function } \\
\text { Long-term }\end{array}$ & $\begin{array}{l}1(\mathrm{~N}=118) \\
\text { Juhakoski } 2011\end{array}$ & Moderate & Unknown & Imprecise & Undetected & Insufficient & $\begin{array}{l}\text { SMD }-0.37,95 \% \mathrm{Cl}-0.74 \text { to } \\
-0.01\end{array}$ \\
\hline & & $\begin{array}{l}\text { Pain } \\
\text { Short-term }\end{array}$ & $\begin{array}{l}3(\mathrm{~N}=371) \\
\text { Juhakoski } 2011 \\
\text { Teirlinck } 2016 \\
\text { Tak 2005 }\end{array}$ & Moderate & Inconsistent & Imprecise & Undetected & Low & $\begin{array}{l}\text { Pooled SMD }-0.34,95 \% \mathrm{Cl} \\
-0.63 \text { to }-0.04, \mathrm{I}^{2}=48.2 \%\end{array}$ \\
\hline & & $\begin{array}{l}\text { Pain } \\
\text { Intermediate- } \\
\text { term }\end{array}$ & $\begin{array}{l}2(\mathrm{~N}=307) \\
\text { Juhakoski } 2011 \\
\text { Teirlinck } 2016\end{array}$ & Low & Inconsistent & Imprecise & Undetected & Low & $\begin{array}{l}\text { Pooled SMD }-0.37,95 \% \mathrm{Cl} \\
-0.37 \text { to }-0.08, \mathrm{I}^{2}=0 \%\end{array}$ \\
\hline & & $\begin{array}{l}\text { Pain } \\
\text { Long-term }\end{array}$ & $\begin{array}{l}1(\mathrm{~N}=118) \\
\text { Juhakoski } 2011\end{array}$ & Moderate & Unknown & Imprecise & Undetected & Insufficient & $\begin{array}{l}\text { SMD }-0.25,95 \% \mathrm{Cl}-0.62 \text { to } \\
0.11\end{array}$ \\
\hline & & Harms & $\begin{array}{l}2(\mathrm{~N}=170) \\
\text { Tak } 2005 \\
\text { Abbott } 2013^{\mathrm{a}}\end{array}$ & High & Consistent & Imprecise & Undetected & Insufficient & $\begin{array}{l}\text { Insufficient data from two trials } \\
\text { although no serious harms were } \\
\text { reported in two trials. }\end{array}$ \\
\hline \multirow[t]{3}{*}{$\begin{array}{l}\text { Manual } \\
\text { Therapies }\end{array}$} & \multirow[t]{2}{*}{$\begin{array}{l}\text { Manipulation } \\
\text { vs. usual } \\
\text { care }\end{array}$} & $\begin{array}{l}\text { Function } \\
\text { Intermediate- } \\
\text { term }\end{array}$ & $\begin{array}{l}1(\mathrm{~N}=47) \\
\text { Abbott } 2013^{\mathrm{a}}\end{array}$ & Moderate & Unknown & Imprecise & Undetected & Insufficient & $\begin{array}{l}\text { Insufficient evidence from one } \\
\text { fair quality trial. No effect size } \\
\text { could be calculated. }\end{array}$ \\
\hline & & Harms & $\begin{array}{l}1(\mathrm{~N}=47) \\
\text { Abbott } 2013^{\mathrm{a}}\end{array}$ & Moderate & Unknown & Imprecise & Undetected & Insufficient & $\begin{array}{l}\text { No treatment-related serious } \\
\text { adverse events were detected }\end{array}$ \\
\hline & $\begin{array}{l}\text { Manipulation } \\
\text { vs. exercise }\end{array}$ & $\begin{array}{l}\text { Function } \\
\text { Short-term }\end{array}$ & $\begin{array}{l}1(\mathrm{~N}=109) \\
\text { Hoeksma } 2004\end{array}$ & Moderate & Unknown & Imprecise & Undetected & Low & $\begin{array}{l}\text { Adjusted difference } 11.1 \text { (95\% } \\
\mathrm{Cl} 4.0 \text { to } 18.6) \text { on } 0-100 \text { scale }\end{array}$ \\
\hline
\end{tabular}




\begin{tabular}{|c|c|c|c|c|c|c|c|c|c|}
\hline Intervention & Comparator & Outcome & $\begin{array}{l}\text { Number of } \\
\text { RCTs } \\
\text { (patients) } \\
\text { Author Year }\end{array}$ & $\begin{array}{l}\text { Study } \\
\text { Limitations }\end{array}$ & Consistency & Precision & $\begin{array}{l}\text { Reporting } \\
\text { Bias }\end{array}$ & $\begin{array}{l}\text { Strength } \\
\text { of } \\
\text { Evidence }\end{array}$ & $\begin{array}{l}\text { Findings, Direction and } \\
\text { Magnitude of Effect }\end{array}$ \\
\hline & & $\begin{array}{l}\text { Function } \\
\text { Intermediate- } \\
\text { term }\end{array}$ & $\begin{array}{l}2(\mathrm{~N}=155) \\
\text { Abbott 2013 } \\
\text { Hoeksma } 2004\end{array}$ & Moderate & Consistent & Imprecise & Undetected & Low & $\begin{array}{l}\text { Adjusted difference } 9.7,95 \% \\
\mathrm{Cl}, 1.5 \text { to } 17.9 \text { on } 0-100 \text { scale; } \\
\text { no effect size could be } \\
\text { calculated in the other trial but } \\
\text { direction of effect was similar }\end{array}$ \\
\hline & & $\begin{array}{l}\text { Pain } \\
\text { Short-term }\end{array}$ & $\begin{array}{l}1(\mathrm{~N}=109) \\
\text { Hoeksma }\end{array}$ & Moderate & Unknown & Precise & Undetected & Low & $\begin{array}{l}\text { Adjusted differences }-0.72(95 \% \\
\mathrm{Cl}-1.38 \text { to }-0.05) \text { for pain at rest } \\
\text { and }-1.21(95 \% \mathrm{Cl}-2.29 \text { to } \\
-0.25) \text { for pain walking on } 0-10 \\
\text { scale }\end{array}$ \\
\hline & & $\begin{array}{l}\text { Pain } \\
\text { Intermediate- } \\
\text { term }\end{array}$ & $\begin{array}{l}1(\mathrm{~N}=109) \\
\text { Hoeksma }\end{array}$ & Moderate & Unknown & Imprecise & Undetected & Insufficient & $\begin{array}{l}\text { Adjusted differences }-0.70(95 \% \\
\mathrm{Cl}-2.03 \text { to } 0.59) \text { for pain at rest } \\
\text { and }-1.27(95 \% \mathrm{Cl}-2.40 \text { to } \\
-0.19) \text { for pain walking on } 0-10 \\
\text { scale; impact on pain is unclear } \\
\text { from different measures }\end{array}$ \\
\hline & & Harms & $\begin{array}{l}2(\mathrm{~N}=155) \\
\text { Abbott 2013 } \\
\text { Hoeksma } 2004\end{array}$ & Moderate & Consistent & Imprecise & Undetected & Low & $\begin{array}{l}\text { No treatment-related serious } \\
\text { adverse events were detected } \\
\text { in one trial; similar rates of } \\
\text { study withdrawal due to } \\
\text { symptom aggravation were } \\
\text { seen in the second trial ( } 5 \% \text { vs. } \\
4 \% \text {; RR } 1.42,95 \% \mathrm{Cl} 0.25 \text { to } \\
8.16 \text { ) }\end{array}$ \\
\hline
\end{tabular}

$\mathrm{CI}$ = confidence interval; RCT = randomized controlled trial; RR = risk ratio; SMD = standardized mean difference.

${ }^{a}$ Authors did not provide data on the number of hip osteoarthritis patients for each intervention, only gave hip osteoarthritis population as a whole 
Table G-5. Hand osteoarthritis (KQ 3) strength of evidence

\begin{tabular}{|c|c|c|c|c|c|c|c|c|c|}
\hline Intervention & Comparator & Outcome & $\begin{array}{l}\text { N RCTs } \\
\text { (patients) }\end{array}$ & $\begin{array}{c}\text { Study } \\
\text { Limitations }\end{array}$ & Consistency & Precision & $\begin{array}{l}\text { Reporting } \\
\text { Bias }\end{array}$ & $\begin{array}{l}\text { Strength } \\
\text { of } \\
\text { Evidence }\end{array}$ & $\begin{array}{l}\text { Findings, Direction and } \\
\text { Magnitude of Effect }\end{array}$ \\
\hline Exercise & $\begin{array}{l}\text { Exercise vs. } \\
\text { usual care }\end{array}$ & $\begin{array}{l}\text { Function, Pain, } \\
\text { Harms } \\
\text { Short-term }\end{array}$ & $\begin{array}{l}1(\mathrm{~N}=130) \\
\text { Osteras }\end{array}$ & High & Unknown & Precise & Undetected & Insufficient & $\begin{array}{l}\text { Poor quality trial of exercise vs } \\
\text { waitlist High attrition rate in exercise } \\
\text { arm }(29 \%) \text {. }\end{array}$ \\
\hline \multirow[t]{4}{*}{$\begin{array}{l}\text { Physical } \\
\text { Modalities }\end{array}$} & \multirow{3}{*}{$\begin{array}{l}\text { Low level } \\
\text { laser therapy } \\
\text { vs. sham } \\
\text { intervention }\end{array}$} & $\begin{array}{l}\text { Function } \\
\text { Short-term }\end{array}$ & $\begin{array}{l}1(\mathrm{~N}=88) \\
\text { Brosseau }\end{array}$ & Low & Unknown & Imprecise & Undetected & Low & $\begin{array}{l}\text { No differences observed in one good } \\
\text { quality trial (difference } 0.2,95 \% \mathrm{Cl} \\
-0.2 \text { to } 0.6) \text {. }\end{array}$ \\
\hline & & $\begin{array}{l}\text { Pain } \\
\text { Short-term }\end{array}$ & $\begin{array}{l}1(\mathrm{~N}=88) \\
\text { Brosseau }\end{array}$ & Low & Unknown & Imprecise & Undetected & Low & $\begin{array}{l}\text { No differences observed in one good } \\
\text { quality trial (difference } 0.1,95 \% \mathrm{Cl} \\
-0.3 \text { to } 0.5 \text { ). }\end{array}$ \\
\hline & & Harms & $\begin{array}{l}1(\mathrm{~N}=88) \\
\text { Brosseau }\end{array}$ & Low & Unknown & Imprecise & Undetected & Low & $\begin{array}{l}\text { No serious adverse events identified } \\
\text { in one good quality trial. }\end{array}$ \\
\hline & $\begin{array}{l}\text { Superficial } \\
\text { heat } \\
\text { (paraffin) vs. } \\
\text { no treatment }\end{array}$ & $\begin{array}{l}\text { Function, Pain, } \\
\text { Harms Short- } \\
\text { term }\end{array}$ & $\begin{array}{l}1(\mathrm{~N}=56) \\
\text { Dilek }\end{array}$ & Moderate & Unknown & Imprecise & Possible & Insufficient & $\begin{array}{l}\text { Insufficient evidence from one small } \\
\text { trial }\end{array}$ \\
\hline \multirow[t]{3}{*}{$\begin{array}{l}\text { Multidisci- } \\
\text { plinary } \\
\text { Rehabilitation }\end{array}$} & \multirow[t]{3}{*}{$\begin{array}{l}\text { Multidisci- } \\
\text { plinary } \\
\text { rehabilitation } \\
\text { vs. waitlist }\end{array}$} & $\begin{array}{l}\text { Function } \\
\text { Short-term }\end{array}$ & $\begin{array}{l}1(\mathrm{~N}=151) \\
\text { Stukstette }\end{array}$ & Moderate & Unknown & Precise & Undetected & Low & $\begin{array}{l}\text { Adjusted difference } 0.49(95 \% \mathrm{Cl} \\
-0.09 \text { to } 0.37) \text {; } \\
\text { OASRI-OMERACT Responder: OR } \\
0.82 \text { ( } 95 \% \mathrm{Cl} 0.42 \text { to } 1.61)\end{array}$ \\
\hline & & $\begin{array}{l}\text { Pain } \\
\text { Short-term }\end{array}$ & $\begin{array}{l}1(\mathrm{~N}=151) \\
\text { Stukstette }\end{array}$ & Moderate & Unknown & Precise & Undetected & Low & $\begin{array}{l}\text { Adjusted difference } 0.40(95 \% \mathrm{Cl} \\
-0.5 \text { to } 1.3)\end{array}$ \\
\hline & & Harms & $\begin{array}{l}1(\mathrm{~N}=151) \\
\text { Stukstette }\end{array}$ & Moderate & Unknown & Imprecise & Undetected & Insufficient & No serious adverse events identified. \\
\hline
\end{tabular}

CI = confidence interval; OASRI-OMERACT = Osteoarthritis Research Society International-Outcome Measures in Rheumatology; OR = odds ratio; RCT = randomized controlled trial. 
Table G-6. Fibromyalgia (KQ 4) strength of evidence

\begin{tabular}{|c|c|c|c|c|c|c|c|c|c|}
\hline Intervention & Comparator & Outcome & $\begin{array}{c}\text { Number of RCTs } \\
\text { (patients) } \\
\text { Author Year }\end{array}$ & $\begin{array}{c}\text { Study } \\
\text { Limitations }\end{array}$ & Consistency & Precision & $\begin{array}{l}\text { Reporting } \\
\text { Bias }\end{array}$ & $\begin{array}{l}\text { Strength } \\
\text { of } \\
\text { Evidence }\end{array}$ & $\begin{array}{l}\text { Findings, Direction and } \\
\text { Magnitude of Effect }\end{array}$ \\
\hline \multirow[t]{4}{*}{ Exercise } & \multirow[t]{4}{*}{$\begin{array}{l}\text { Exercise vs. } \\
\text { usual care, } \\
\text { attention } \\
\text { control, or a } \\
\text { placebo } \\
\text { intervention }\end{array}$} & $\begin{array}{l}\text { Function } \\
\text { Short-term }\end{array}$ & $\begin{array}{l}7(\mathrm{~N}=410) \\
\text { King 2002 } \\
\text { Baptista } 2012 \\
\text { Kayo 2012 } \\
\text { Giannotti } 2014 \\
\text { Paolucci } 2015 \\
\text { Da Costa } 2005 \\
\text { Altan 2009 }\end{array}$ & Moderate & Inconsistent & Precise & Undetected & Low & $\begin{array}{l}\text { Pooled difference, }-7.61 \text { on } \\
\text { a } 0 \text { to } 100 \text { scale, } 95 \% \mathrm{Cl} \text {, } \\
\left.-12.78 \text { to }-2.43, \mathrm{I}^{2}=59.9 \%\right)\end{array}$ \\
\hline & & $\begin{array}{l}\text { Function } \\
\text { Intermediate- } \\
\text { term }\end{array}$ & $\begin{array}{l}8(\mathrm{~N}=461) \\
\text { Gowans } 2001 \\
\text { Sanudo } 2010 \\
\text { Mannerkofpi } 2009 \\
\text { Fontaine } 2011 \\
\text { Giannotti } 2014 \\
\text { Da Costa } 2005 \\
\text { Saunudo } 2012 \\
\text { Tomas-Carus } 2008\end{array}$ & Moderate & Consistent & Precise & Undetected & Moderate & $\begin{array}{l}\text { Pooled difference on } 0-100 \\
\text { scale, }-6.0495 \% \mathrm{Cl}-9.05 \\
\text { to }-3.03, \mathrm{I}^{2}=0 \%\end{array}$ \\
\hline & & $\begin{array}{l}\text { Function } \\
\text { Long-term }\end{array}$ & $\begin{array}{l}3(\mathrm{~N}=178) \\
\text { Van Eijk-Hustings } \\
2013 \\
\text { Fontaine } 2011 \\
\text { Sanudo } 2012\end{array}$ & Moderate & Consistent & Precise & Undetected & Low & $\begin{array}{l}\text { Pooled difference, on } 0-100 \\
\text { scale, }-4.33,95 \% \mathrm{Cl}-10.18 \\
\left.\text { to } 1.52, \mathrm{I}^{2}=0 \%\right)\end{array}$ \\
\hline & & $\begin{array}{l}\text { Pain } \\
\text { Short-term }\end{array}$ & $\begin{array}{l}6(\mathrm{~N}=337) \\
\text { Kayo } 2012 \\
\text { Buckelew } 1998 \\
\text { Gusi } 2006 \\
\text { Giannotti } 2014 \\
\text { Da Costa } 2005 \\
\text { Altan 20009 }\end{array}$ & Moderate & Consistent $^{a}$ & Precise & Undetected & Moderate & $\begin{array}{l}\text { Pooled difference }-0.89 \\
95 \% \mathrm{Cl}-1.32 \text { to }-0.46 \\
\mathrm{I}^{2}=0 \%\end{array}$ \\
\hline
\end{tabular}




\begin{tabular}{|c|c|c|c|c|c|c|c|c|c|}
\hline Intervention & Comparator & Outcome & $\begin{array}{c}\text { Number of RCTs } \\
\text { (patients) } \\
\text { Author Year }\end{array}$ & $\begin{array}{c}\text { Study } \\
\text { Limitations }\end{array}$ & Consistency & Precision & $\begin{array}{l}\text { Reporting } \\
\text { Bias }\end{array}$ & $\begin{array}{l}\text { Strength } \\
\text { of } \\
\text { Evidence }\end{array}$ & $\begin{array}{l}\text { Findings, Direction and } \\
\text { Magnitude of Effect }\end{array}$ \\
\hline & & $\begin{array}{l}\text { Pain } \\
\text { Intermediate- } \\
\text { term }\end{array}$ & $\begin{array}{l}7(\mathrm{~N}=327) \\
\text { Sanudo } 2015 \\
\text { Fontaine } 2011 \\
\text { Tomas-Carus } 2008 \\
\text { Giannotti } 2014 \\
\text { vanSanten } 2002 \\
\text { Da Costa } 2005 \\
\text { Sencan } 2004\end{array}$ & Moderate & Consistent & Precise & Undetected & Moderate & $\begin{array}{l}\text { Pooled difference }-0.41 \text {, on } \\
\text { a } 0-10 \text { scale, } 95 \% \mathrm{Cl}-0.87 \\
\text { to } 0.05, \mathrm{I}^{2}=9.5 \%\end{array}$ \\
\hline & & $\begin{array}{l}\text { Pain } \\
\text { Long-term }\end{array}$ & $\begin{array}{l}4(\mathrm{~N}=241) \\
\text { Wiggers } 1996 \\
\text { van Eijk-Hustings } \\
2013 \\
\text { Buckelew } 1998 \\
\text { Fontaine } 2011 \\
\end{array}$ & Moderate & Consistent & Precise & Undetected & Moderate & $\begin{array}{l}\text { Pooled difference }-0.18 \text {, } \\
95 \% \mathrm{Cl}-0.77 \text { to } 0.42 \\
\mathrm{I}^{2}=0 \%\end{array}$ \\
\hline & $\begin{array}{l}\text { Exercise vs. } \\
\text { pharma- } \\
\text { cologial } \\
\text { therapy }\end{array}$ & $\begin{array}{l}\text { Pain } \\
\text { Intermediate- } \\
\text { term }\end{array}$ & $\begin{array}{l}1(N=32) \\
\text { Sencan } 2004\end{array}$ & High & Unknown & Precise & Undetected & Insufficient & $\begin{array}{l}\text { Insufficient evidence from } \\
\text { one small, poor-quality trial }\end{array}$ \\
\hline
\end{tabular}




\begin{tabular}{|c|c|c|c|c|c|c|c|c|c|}
\hline Intervention & Comparator & Outcome & $\begin{array}{c}\text { Number of RCTs } \\
\text { (patients) } \\
\text { Author Year }\end{array}$ & $\begin{array}{c}\text { Study } \\
\text { Limitations }\end{array}$ & Consistency & Precision & $\begin{array}{l}\text { Reporting } \\
\text { Bias }\end{array}$ & $\begin{array}{l}\text { Strength } \\
\text { of } \\
\text { Evidence }\end{array}$ & $\begin{array}{l}\text { Findings, Direction and } \\
\text { Magnitude of Effect }\end{array}$ \\
\hline $\begin{array}{l}\text { Psychological } \\
\text { Therapies }\end{array}$ & $\begin{array}{l}\text { Psycho- } \\
\text { logical } \\
\text { therapy vs. } \\
\text { usual care, } \\
\text { waitlist, or } \\
\text { attention } \\
\text { control }\end{array}$ & $\begin{array}{l}\text { Function } \\
\text { Short-term }\end{array}$ & $\begin{array}{l}\text { CBT: } \\
2(\mathrm{~N}=97) \text { Pooled } \\
\text { Castel } 2012 \\
\text { Jensen } 2012 \\
2(\mathrm{~N}=96) \text { for RR } \\
\text { Ang 2010 } \\
\text { Castel } 2012 \\
\text { EMG Biofeedback: } \\
1(\mathrm{~N}=59) \\
\text { Buckelew } 1998 \\
\text { Imagery: } \\
1(\mathrm{~N}=70) \\
\text { Verkaik } 2014\end{array}$ & Moderate & Inconsistent & Imprecise & Undetected & $\begin{array}{l}\text { Low } \\
\text { (CBT) } \\
\text { Insufficient } \\
\text { (biofeed- } \\
\text { back, } \\
\text { imagery) }\end{array}$ & $\begin{array}{l}\text { Pooled mean difference } \\
-10.67,95 \% \mathrm{Cl}-17 \text { to }-4.30 \\
\mathrm{I}^{2}=0 \%, 0-100 \text { scale for } \\
\text { CBT; } \\
\text { More CBT recipients with } \\
\text { clinically important } \\
\text { improvement, } 2 \text { trials, } \mathrm{RR} \\
2.2(0.5 \text { to } 9.3) \text { and } \mathrm{RR} \\
2.8(1.3 \text { to } 6.1) \\
\text { No clear difference for } \\
\text { guided imagery ( } 1 \text { poor } \\
\text { quality trial) or EMG } \\
\text { biofeedback ( } 1 \text { poor quality } \\
\text { trial) }\end{array}$ \\
\hline
\end{tabular}




\begin{tabular}{|c|c|c|c|c|c|c|c|c|c|}
\hline Intervention & Comparator & Outcome & $\begin{array}{c}\text { Number of RCTs } \\
\text { (patients) } \\
\text { Author Year }\end{array}$ & $\begin{array}{c}\text { Study } \\
\text { Limitations }\end{array}$ & Consistency & Precision & $\begin{array}{l}\text { Reporting } \\
\text { Bias }\end{array}$ & $\begin{array}{l}\text { Strength } \\
\text { of } \\
\text { Evidence }\end{array}$ & $\begin{array}{l}\text { Findings, Direction and } \\
\text { Magnitude of Effect }\end{array}$ \\
\hline & & $\begin{array}{l}\text { Function } \\
\text { Long-term }\end{array}$ & $\begin{array}{l}\text { CBT: } \\
2(\mathrm{~N}=227) \\
\text { Williams } 2002 \\
\text { Thieme } 2006 \\
\text { EMG Biofeedback: } \\
1(\mathrm{~N}=59) \\
\text { Buckelew } 1998\end{array}$ & High & Inconsistent & Imprecise & Undetected & Insufficient & $\begin{array}{l}\text { Insufficient data from three } \\
\text { poor quality trials }\end{array}$ \\
\hline & & $\begin{array}{l}\text { Pain } \\
\text { Short-term }\end{array}$ & $\begin{array}{l}\text { CBT: } \\
3(\mathrm{~N}=125) \\
\text { Ang 2010 } \\
\text { Castel } 2012 \\
\text { Jensen } 2012 \\
\\
\text { EMG Biofeedback: } \\
1(\mathrm{~N}=53) \\
\text { Buckelew } 1998\end{array}$ & High & Consistent & Precise & Undetected & $\begin{array}{l}\text { Low } \\
\text { (CBT) } \\
\text { Insufficient } \\
\text { (biofeed- } \\
\text { back) }\end{array}$ & $\begin{array}{l}\text { Pooled mean difference } \\
-0.78,95 \% \mathrm{Cl}-1.30 \text { to } \\
-0.17,0-10 \text { scale for CBT; } \\
\text { No clear difference for } \\
\text { EMG biofeedback ( } 1 \text { poor } \\
\text { quality trial) }\end{array}$ \\
\hline & & $\begin{array}{l}\text { Pain } \\
\text { Intermediate- } \\
\text { term }\end{array}$ & $\begin{array}{l}\text { CBT: } \\
2(\mathrm{~N}=176) \\
\text { Alda 2011 } \\
\text { Castel } 2012 \\
\\
\text { EMG Biofeedback: } \\
1(\mathrm{~N}=65) \\
\text { Van Santen } 2002 \\
\end{array}$ & Moderate & Consistent & Precise & Undetected & $\begin{array}{l}\text { Low } \\
\text { (CBT) } \\
\text { Insufficient } \\
\text { (biofeed- } \\
\text { back) }\end{array}$ & $\begin{array}{l}\text { Pooled mean difference } \\
-0.44,95 \% \mathrm{Cl}-1.30 \text { to } 0.01 \text {, } \\
0-10 \text { scale for CBT; } \\
\text { Mean difference }-1.11,95 \% \\
\mathrm{Cl}-2.06 \text { to }-0.16 \text { for EMG } \\
\text { biofeedback ( } 1 \text { poor quality } \\
\text { trial) }\end{array}$ \\
\hline & & $\begin{array}{l}\text { Pain } \\
\text { Long-term }\end{array}$ & $\begin{array}{l}\text { CBT: } \\
1(N=40) \\
\text { Wiggers } 1996 \\
\text { EMG Biofeedback: } \\
1(N=53) \\
\text { Buckelew } 1998\end{array}$ & High & Consistent & Precise & Undetected & Insufficient & $\begin{array}{l}\text { Insufficient data from two } \\
\text { poor quality trials }\end{array}$ \\
\hline
\end{tabular}




\begin{tabular}{|c|c|c|c|c|c|c|c|c|c|}
\hline Intervention & Comparator & Outcome & $\begin{array}{l}\text { Number of RCTs } \\
\text { (patients) } \\
\text { Author Year }\end{array}$ & $\begin{array}{c}\text { Study } \\
\text { Limitations }\end{array}$ & Consistency & Precision & $\begin{array}{l}\text { Reporting } \\
\text { Bias }\end{array}$ & $\begin{array}{l}\text { Strength } \\
\text { of } \\
\text { Evidence }\end{array}$ & $\begin{array}{l}\text { Findings, Direction and } \\
\text { Magnitude of Effect }\end{array}$ \\
\hline & & Harms & $\begin{array}{l}2(\mathrm{~N}=195) \\
\text { Alda } 2011 \\
\text { Thieme } 2006\end{array}$ & High & Unknown & Imprecise & Undetected & Insufficient & $\begin{array}{l}\text { Data were insufficient; one } \\
\text { poor quality trial described } \\
\text { two withdrawals related to } \\
\text { depression in the CBT arm } \\
\text { and } 20 / 40 \text { for worsening of } \\
\text { symptoms in the attention } \\
\text { control arm. }\end{array}$ \\
\hline & \multirow[t]{5}{*}{$\begin{array}{l}\text { Psychologic } \\
\text { al therapy } \\
\text { vs. pharma- } \\
\text { cologial } \\
\text { therapy }\end{array}$} & $\begin{array}{l}\text { Function } \\
\text { Short-term }\end{array}$ & $\begin{array}{l}\text { CBT: } \\
1(\mathrm{~N}=60) \\
\text { Falco } 2008 \\
\text { EEG Biofeedback } \\
1(\mathrm{~N}=40) \\
\text { Kayiran } 2010\end{array}$ & Moderate & Inconsistent & Imprecise & Undetected & Insufficient & $\begin{array}{l}\text { Insufficient data from one } \\
\text { fair and one poor quality } \\
\text { trial }\end{array}$ \\
\hline & & $\begin{array}{l}\text { Function } \\
\text { Intermediate- } \\
\text { term }\end{array}$ & $\begin{array}{l}1(\mathrm{~N}=113) \\
\text { Alda } 2011(\mathrm{CBT})\end{array}$ & Moderate & Unknown & Precise & Undetected & Low & $\begin{array}{l}\text { Mean difference }-4.0 \text { on the } \\
0-100 \mathrm{FIQ}, 95 \% \mathrm{Cl}-7.7 \text { to } \\
-0.27\end{array}$ \\
\hline & & $\begin{array}{l}\text { Pain } \\
\text { Short-term }\end{array}$ & $\begin{array}{l}\text { CBT: } \\
1(\mathrm{~N}=60) \\
\text { Falco } 2008 \\
\text { EEG Biofeedback } \\
1(\mathrm{~N}=40) \\
\text { Kayiran } 2010\end{array}$ & Moderate & Inconsistent & Imprecise & Undetected & Insufficient & $\begin{array}{l}\text { Insufficient data from one } \\
\text { fair and one poor quality } \\
\text { trial }\end{array}$ \\
\hline & & $\begin{array}{l}\text { Pain } \\
\text { Intermediate- } \\
\text { term }\end{array}$ & $\begin{array}{l}1(\mathrm{~N}=113) \\
\text { Alda } 2011(\mathrm{CBT})\end{array}$ & Moderate & Unknown & Precise & Undetected & Low & $\begin{array}{l}\text { Difference } 0.2 \text { on a } 0-100 \\
\text { VAS, } 95 \% \mathrm{Cl}-4.0 \text { to } 4.4\end{array}$ \\
\hline & & Harms & $\begin{array}{l}1(\mathrm{~N}=113) \\
\text { Alda } 2011(\mathrm{CBT})\end{array}$ & Moderate & Unknown & Imprecise & Undetected & Low & $\begin{array}{l}\text { Withdrawals due to } \\
\text { adverse events, CBT vs. } \\
\text { pregabalin: } 0 \% \text { vs. } 5.5 \% \text {; } \\
\text { events included two } \\
\text { digestive problems, and } \\
\text { one dizziness }\end{array}$ \\
\hline
\end{tabular}




\begin{tabular}{|c|c|c|c|c|c|c|c|c|c|}
\hline Intervention & Comparator & Outcome & $\begin{array}{c}\text { Number of RCTs } \\
\text { (patients) } \\
\text { Author Year }\end{array}$ & $\begin{array}{c}\text { Study } \\
\text { Limitations }\end{array}$ & Consistency & Precision & $\begin{array}{l}\text { Reporting } \\
\text { Bias }\end{array}$ & $\begin{array}{l}\text { Strength } \\
\text { of } \\
\text { Evidence }\end{array}$ & $\begin{array}{l}\text { Findings, Direction and } \\
\text { Magnitude of Effect }\end{array}$ \\
\hline & & $\begin{array}{l}\text { Function } \\
\text { Intermediate- } \\
\text { term }\end{array}$ & $\begin{array}{l}\text { CBT: } \\
1(\mathrm{~N}=40) \\
\text { Redondo } 2004 \\
\text { EMG Biofeedback: } \\
1(\mathrm{~N}=114) \\
\text { Van Santen } 2002\end{array}$ & High & Consistent & Imprecise & Undetected & Insufficient & $\begin{array}{l}\text { Insufficient evidence from } \\
\text { two poor quality trials }\end{array}$ \\
\hline & & $\begin{array}{l}\text { Function } \\
\text { Long-term }\end{array}$ & $\begin{array}{l}\text { CBT: } \\
1(\mathrm{~N}=40) \\
\text { Redondo } 2004 \\
\text { Relaxation } \\
1(\mathrm{n}=130) \\
\text { Larsson } 2015 \\
\\
\text { EMG Biofeedback } \\
1(\mathrm{~N}=51) \\
\text { Buckelew } 1998\end{array}$ & High & Inconsistent & Imprecise & Undetected & Insufficient & $\begin{array}{l}\text { Insufficient evidence from } \\
\text { three poor quality trials; } \\
\text { inconsistency in findings } \\
\text { noted. }\end{array}$ \\
\hline & & $\begin{array}{l}\text { Pain } \\
\text { Short-term }\end{array}$ & $\begin{array}{l}1(\mathrm{~N}=51) \text { Buckelew } \\
\text { (EMG Biofeedback) }\end{array}$ & High & Unknown & Imprecise & Undetected & Insufficient & $\begin{array}{l}\text { Insufficient evidence from } \\
\text { one small, poor quality trial }\end{array}$ \\
\hline & & $\begin{array}{l}\text { Pain } \\
\text { Intermediate- } \\
\text { term }\end{array}$ & $\begin{array}{l}\text { CBT: } \\
1(\mathrm{~N}=40) \\
\text { Redondo } 2004 \\
\text { EMG Biofeedback: } \\
1(\mathrm{~N}=114) \\
\text { Van Santen } 2002\end{array}$ & High & Consistent & Imprecise & Undetected & Insufficient & $\begin{array}{l}\text { Insufficient evidence two } \\
\text { poor quality trials }\end{array}$ \\
\hline & & $\begin{array}{l}\text { Pain } \\
\text { Long-term }\end{array}$ & $\begin{array}{l}\text { CBT: } \\
2(\mathrm{~N}=80) \\
\text { Redondo } 2004 \\
\text { Wiggers } 1996 \\
\text { Relaxation } \\
1(\mathrm{n}=130) \\
\text { Larsson } 2015 \\
\text { EMG Biofeedback } \\
1(\mathrm{~N}=51) \\
\text { Buckelew } 1998\end{array}$ & High & Consistent & Imprecise & Undetected & Insufficient & $\begin{array}{l}\text { Insufficient evidence from } \\
\text { four poor quality trials }\end{array}$ \\
\hline
\end{tabular}




\begin{tabular}{|c|c|c|c|c|c|c|c|c|c|}
\hline Intervention & Comparator & Outcome & $\begin{array}{c}\text { Number of RCTs } \\
\text { (patients) } \\
\text { Author Year }\end{array}$ & $\begin{array}{c}\text { Study } \\
\text { Limitations }\end{array}$ & Consistency & Precision & $\begin{array}{l}\text { Reporting } \\
\text { Bias }\end{array}$ & $\begin{array}{l}\text { Strength } \\
\text { of } \\
\text { Evidence }\end{array}$ & $\begin{array}{l}\text { Findings, Direction and } \\
\text { Magnitude of Effect }\end{array}$ \\
\hline & & Harms & $\begin{array}{l}(\mathrm{N}=170) \\
\text { Larsson } 2015 \\
\text { Wiggers } 1996\end{array}$ & High & Consistent & Imprecise & Undetected & Insufficient & $\begin{array}{l}\text { Data were insufficient for } \\
\text { harms. In one trial no } \\
\text { patient had an adverse } \\
\text { event in relaxation group } \\
\text { compared to five }(7.5 \%) \text { in } \\
\text { the strengthening exercise } \\
\text { group (increased pain, } \\
\text { three of which withdrew). In } \\
\text { the other trial, withdrawals } \\
\text { due to adverse events were } \\
\text { similar between groups and } \\
\text { none of the events were } \\
\text { related to treatment. }\end{array}$ \\
\hline \multirow[t]{3}{*}{$\begin{array}{l}\text { Physical } \\
\text { Modalities }\end{array}$} & \multirow[t]{3}{*}{$\begin{array}{l}\text { Magnetic } \\
\text { fields vs. } \\
\text { usual care or } \\
\text { sham }\end{array}$} & $\begin{array}{l}\text { Function and } \\
\text { Pain } \\
\text { Short-term }\end{array}$ & $\begin{array}{l}(\mathrm{N}=33) \\
\text { Paolucci } 2016 \text { (cross- } \\
\text { over trial) }\end{array}$ & High & Unknown & Precise & Undetected & Insufficient & $\begin{array}{l}\text { Insufficient evidence from } \\
\text { one poor quality trial }\end{array}$ \\
\hline & & $\begin{array}{l}\text { Pain } \\
\text { Intermediate- } \\
\text { term }\end{array}$ & $\begin{array}{l}(\mathrm{N}=119) \\
\text { Alfano } 2001 \text { (parallel } \\
\text { trial) }\end{array}$ & Moderate & Unknown & Imprecise & Undetected & Low & $\begin{array}{l}\text { Difference }-0.6(95 \% \mathrm{Cl} \\
-1.9 \text { to } 0.7) \text { vs. sham and } \\
-1.0(95 \% \mathrm{Cl}-2.2 \text { to } 0.2) \text { vs. } \\
\text { usual care on a } 0-10 \mathrm{NRS}\end{array}$ \\
\hline & & Harms & $\begin{array}{l}(\mathrm{N}=119) \\
\text { Alfano } 2001 \text { (parallel } \\
\text { trial) }\end{array}$ & Moderate & Unknown & Imprecise & Undetected & Low & $\begin{array}{l}\text { No differences in adverse } \\
\text { events between the } \\
\text { functional and sham } \\
\text { magnetic groups (data not } \\
\text { reported); none of the } \\
\text { events were deemed to be } \\
\text { related to the treatments }\end{array}$ \\
\hline Massage & $\begin{array}{l}\text { Massage/ } \\
\text { myofascial } \\
\text { release vs. } \\
\text { sham }\end{array}$ & $\begin{array}{l}\text { Function } \\
\text { Intermediate- } \\
\text { term }\end{array}$ & $\begin{array}{l}1(\mathrm{~N}=94) \\
\text { Castro-Sanchez } \\
\text { 2011[a] }\end{array}$ & Moderate & Unknown & Imprecise & Undetected & Low & $\begin{array}{l}\text { Mean } 58.6 \text { (SD 16.3) vs. } \\
64.1 \text { (SD 18.1) on the FIQ } \\
(0-100 \text { scale), } p=0.048\end{array}$ \\
\hline
\end{tabular}




\begin{tabular}{|c|c|c|c|c|c|c|c|c|c|}
\hline Intervention & Comparator & Outcome & $\begin{array}{c}\text { Number of RCTs } \\
\text { (patients) } \\
\text { Author Year }\end{array}$ & $\begin{array}{c}\text { Study } \\
\text { Limitations }\end{array}$ & Consistency & Precision & $\begin{array}{l}\text { Reporting } \\
\text { Bias }\end{array}$ & $\begin{array}{l}\text { Strength } \\
\text { of } \\
\text { Evidence }\end{array}$ & $\begin{array}{l}\text { Findings, Direction and } \\
\text { Magnitude of Effect }\end{array}$ \\
\hline & & $\begin{array}{l}\text { Function } \\
\text { Long-term }\end{array}$ & $\begin{array}{l}1(\mathrm{~N}=94) \\
\text { Castro-Sanchez } \\
\text { 2011[a] }\end{array}$ & Moderate & Unknown & Imprecise & Undetected & Low & $\begin{array}{l}\text { Mean } 62.8 \text { (SD 20.1) vs. } \\
65.0(19.8) \text { on the FIQ (0- } \\
100 \text { scale), } p=0.329\end{array}$ \\
\hline & & $\begin{array}{l}\text { Pain } \\
\text { Short-term }\end{array}$ & $\begin{array}{l}1(\mathrm{~N}=64) \\
\text { Castro-Sanchez } \\
2011[\mathrm{~b}]\end{array}$ & High & Unknown & Imprecise & Undetected & Insufficient & $\begin{array}{l}\text { Insufficient evidence from } \\
\text { one poor quality trial }\end{array}$ \\
\hline & & $\begin{array}{l}\text { Pain } \\
\text { Intermediate- } \\
\text { term }\end{array}$ & $\begin{array}{l}2(\mathrm{~N}=158) \\
\text { Castro-Sanchez } \\
\text { 2011[a] } \\
\text { Castro-Sanchez } \\
\text { 2011[b] }\end{array}$ & Moderate & Inconsistent & Imprecise & Undetected & Insufficient & $\begin{array}{l}\text { Insufficient evidence from } \\
\text { one fair and one poor } \\
\text { quality trial due to } \\
\text { inconsistency in the } \\
\text { estimates }\end{array}$ \\
\hline & & $\begin{array}{l}\text { Pain } \\
\text { Long-term }\end{array}$ & $\begin{array}{l}1(\mathrm{~N}=94) \\
\text { Castro-Sanchez } \\
2011[\mathrm{a}]\end{array}$ & Moderate & Unknown & Imprecise & Undetected & Low & $\begin{array}{l}\text { MPQ sensory domain, } \\
\text { mean 18.2 (SD 8.3) vs. } \\
21.2(7.9) \text { on a } 0-33 \text { scale, } \\
\text { p=0.038; } \\
\text { MPQ evaluative domain, } \\
\text { mean } 23.2 \text { (SD } 7.6 \text { ) vs. } \\
26.7 \text { (SD 6.9) on a } 0-42 \\
\text { scale, p=0.036 }\end{array}$ \\
\hline & & Harms & $\begin{array}{l}1(\mathrm{~N}=94) \\
\text { Castro-Sanchez } \\
\text { 2011[a] }\end{array}$ & Moderate & Inconsistent & Imprecise & Undetected & Insufficient & $\begin{array}{l}\text { Data for harms were } \\
\text { insufficient; however, no } \\
\text { adverse effect occurred in } \\
\text { one fair quality trial }\end{array}$ \\
\hline \multirow[t]{2}{*}{$\begin{array}{l}\text { Mindfulness } \\
\text { Practices }\end{array}$} & \multirow{2}{*}{$\begin{array}{l}\text { Mindfulness- } \\
\text { based stress } \\
\text { reduction vs. } \\
\text { waitlist or } \\
\text { attention } \\
\text { control }\end{array}$} & $\begin{array}{l}\text { Function } \\
\text { Short-term }\end{array}$ & $\begin{array}{l}2(\mathrm{~N}=1258) \\
\text { Cash } 2015 \\
\text { Schmidt } 2011\end{array}$ & Moderate & Consistent & Precise & Undetected & Moderate & $\begin{array}{l}\text { No clear effect: difference } 0 \\
\text { to } 0.06 \text { on a } 0-10 \text { scale }\end{array}$ \\
\hline & & $\begin{array}{l}\text { Pain } \\
\text { Short-term }\end{array}$ & $\begin{array}{l}2(\mathrm{~N}=1258) \\
\text { Cash } 2015 \\
\text { Schmidt } 2011\end{array}$ & Moderate & Consistent & Precise & Undetected & Moderate & $\begin{array}{l}\text { No clear effect: } \\
\text { difference } 0.1 \text { on a } 0-100 \\
\text { VAS pain scale in one poor } \\
\text { quality trial; } \\
\text { difference }-1.38 \text { to }-1.59 \text { on } \\
\text { the affective and }-0.28 \text { to } \\
-0.71 \text { on the sensory } \\
\text { dimension (scales not } \\
\text { reported) of the Pain } \\
\text { Perception Scale in one } \\
\text { fair-quality trial }\end{array}$ \\
\hline
\end{tabular}




\begin{tabular}{|c|c|c|c|c|c|c|c|c|c|}
\hline Intervention & Comparator & Outcome & $\begin{array}{c}\text { Number of RCTs } \\
\text { (patients) } \\
\text { Author Year }\end{array}$ & $\begin{array}{c}\text { Study } \\
\text { Limitations }\end{array}$ & Consistency & Precision & $\begin{array}{l}\text { Reporting } \\
\text { Bias }\end{array}$ & $\begin{array}{l}\text { Strength } \\
\text { of } \\
\text { Evidence }\end{array}$ & $\begin{array}{l}\text { Findings, Direction and } \\
\text { Magnitude of Effect }\end{array}$ \\
\hline & & Harms & & & & & & & No evidence \\
\hline \multirow[t]{3}{*}{$\begin{array}{l}\text { Mind-Body } \\
\text { Therapies }\end{array}$} & \multirow[t]{3}{*}{$\begin{array}{l}\text { Tai Chi, } \\
\text { Qigong vs. } \\
\text { waitlist or } \\
\text { attention } \\
\text { control }\end{array}$} & $\begin{array}{l}\text { Function } \\
\text { Short-term }\end{array}$ & $\begin{array}{l}(\mathrm{N}=154) \\
\\
\text { Lynch } 2012 \\
\text { Wang } 2010\end{array}$ & Moderate & Consistent $^{\mathrm{b}}$ & Precise & Undetected & Low & $\begin{array}{l}\text { FIQ total score }(0-100) \text { : } \\
\text { Qigong, mean difference } \\
-7.5(95 \% \mathrm{Cl}-13.3 \text { to }-1.68) \\
\text { Tai chi, mean difference } \\
-23.5(95 \% \mathrm{Cl}-30 \text { to }-17) \\
\text { Heterogeneity may be } \\
\text { explained by duration and } \\
\text { intensity of intervention and } \\
\text { control group }\end{array}$ \\
\hline & & $\begin{array}{l}\text { Pain } \\
\text { Short-term }\end{array}$ & $\begin{array}{l}(\mathrm{N}=154) \\
\text { Lynch } 2012 \\
\text { Wang } 2010 \\
\end{array}$ & Moderate & Consistent $^{\mathrm{b}}$ & Precise & Undetected & Low & $\begin{array}{l}\text { Pooled difference }-1.54 \\
(95 \% \mathrm{Cl}-2.67,-0.41) \\
\mathrm{I}^{2}=75 \%, \text { scale } 0-10\end{array}$ \\
\hline & & Harms & $\begin{array}{l}(N=154) \\
\text { Lynch } 2012 \\
\text { Wang } 2010\end{array}$ & Moderate & Inconsistent & Unprecise & Undetected & Insufficient & $\begin{array}{l}\text { Data for harms were } \\
\text { insufficient. One trial } \\
\text { reported two adverse } \\
\text { events judged to be } \\
\text { possibly related to Qigong } \\
\text { practice: an increase in } \\
\text { shoulder pain and plantar } \\
\text { fasciitis; neither participant } \\
\text { withdrew from the study. In } \\
\text { the trial of Tai chi, no } \\
\text { adverse events were } \\
\text { reported. }\end{array}$ \\
\hline \multirow[t]{3}{*}{ Acupuncture } & \multirow[t]{3}{*}{$\begin{array}{l}\text { Acupuncture } \\
\text { vs. sham }\end{array}$} & $\begin{array}{l}\text { Function } \\
\text { Short-term }\end{array}$ & $\begin{array}{l}2(\mathrm{~N}=211) \\
\text { Vas } 2016 \\
\text { Martin } 2006\end{array}$ & Moderate & Consistent & Precise & Undetected & Moderate & $\begin{array}{l}\text { Pooled difference }-8.63 \\
(95 \% \mathrm{Cl} 12.12 \text { to }-5.13) \\
\mathrm{I}^{2}=0 \%, \text { scale } 0-100\end{array}$ \\
\hline & & $\begin{array}{l}\text { Function } \\
\text { Intermediate- } \\
\text { term }\end{array}$ & $\begin{array}{l}2(\mathrm{~N}=211) \\
\text { Vas } 2016 \\
\text { Martin } 2006\end{array}$ & Moderate & Consistent & Precise & Undetected & Moderate & $\begin{array}{l}\text { Pooled difference }-9.41 \\
\text { (95\% Cl }-13.96 \text { to }-4.85) \\
\mathrm{I}^{2}=27.4 \% \text {, scale } 0-100\end{array}$ \\
\hline & & $\begin{array}{l}\text { Pain } \\
\text { Short-term }\end{array}$ & $\begin{array}{l}3(\mathrm{~N}=297) \\
\text { Assefi } 2005 \\
\text { Martin } 2006 \\
\text { Vas } 2016\end{array}$ & Moderate & Inconsistent & Precise & Undetected & Low & $\begin{array}{l}\text { Pooled difference }-0.13 \\
\text { (95\% Cl }-1.06 \text { to } 0.79) \\
\mathrm{I}^{2}=72.0 \% \text {, scale } 0-10\end{array}$ \\
\hline
\end{tabular}




\begin{tabular}{|c|c|c|c|c|c|c|c|c|c|}
\hline Intervention & Comparator & Outcome & $\begin{array}{c}\text { Number of RCTs } \\
\text { (patients) } \\
\text { Author Year }\end{array}$ & $\begin{array}{c}\text { Study } \\
\text { Limitations }\end{array}$ & Consistency & Precision & $\begin{array}{l}\text { Reporting } \\
\text { Bias }\end{array}$ & $\begin{array}{c}\text { Strength } \\
\text { of } \\
\text { Evidence }\end{array}$ & $\begin{array}{l}\text { Findings, Direction and } \\
\text { Magnitude of Effect }\end{array}$ \\
\hline & & $\begin{array}{l}\text { Pain } \\
\text { Intermediate- } \\
\text { term }\end{array}$ & $\begin{array}{l}3(\mathrm{~N}=297) \\
\text { Assefi } 2005 \\
\text { Martin } 2006 \\
\text { Vas } 2016\end{array}$ & Moderate & Inconsistent & Precise & Undetected & Low & $\begin{array}{l}\text { Pooled difference }-0.53 \\
(95 \% \mathrm{Cl}-1.15 \text { to } 0.09), \mathrm{I}^{2}= \\
45.5 \%, \text { scale } 0-10\end{array}$ \\
\hline & & Harms & $\begin{array}{l}3(\mathrm{~N}=297) \\
\text { Assefi } 2005 \\
\text { Martin } 2006 \\
\text { Vas } 2016\end{array}$ & Moderate & Consistent & Precise & Undetected & Moderate & $\begin{array}{l}\text { Discomfort and bruising } \\
\text { were the most common } \\
\text { reported adverse events } \\
\text { and were more common in } \\
\text { the true acupuncture } \\
\text { groups. Discomfort was } \\
\text { substantially more common } \\
\text { for acupuncture or sham } \\
\text { needling ( } 61 \% \text { to } 70 \%) \\
\text { compared with simulated } \\
\text { acupuncture }(29 \%) \text {. } \\
\text { Vasovagal symptoms and } \\
\text { aggravation of fibromyalgia } \\
\text { symptoms were less } \\
\text { common (4\%, } 2.5 \text { of } \\
\text { sessions) }\end{array}$ \\
\hline \multirow[t]{2}{*}{$\begin{array}{l}\text { Multidisciplin } \\
\text { ary } \\
\text { Rehabilitation }\end{array}$} & \multirow[t]{2}{*}{$\begin{array}{l}\text { Multi- } \\
\text { disciplinary } \\
\text { rehabilitation } \\
\text { vs. usual } \\
\text { care or } \\
\text { waitlist }\end{array}$} & $\begin{array}{l}\text { Function } \\
\text { Short-term }\end{array}$ & $\begin{array}{l}3(\mathrm{~N}=381) \\
\text { Castel } 2013 \\
\text { Amris } 2014 \\
\text { Saral } 2016 \text { (“long- } \\
\text { term" intervention } \\
\text { arm)c }\end{array}$ & Moderate & Consistent $^{d}$ & Precise & Undetected & Low & $\begin{array}{l}\text { Pooled mean difference } \\
-6.52,95 \% \mathrm{Cl}-12.84 \text { to } \\
-0.21, \mathrm{I}^{2}=76.2 \% \text {, on } 0-100 \\
\text { FIQ } \\
\text { Proportion with clinically } \\
\text { meaningful improvement in } \\
\text { FIQ total score compared } \\
\text { with usual care at short } \\
\text { (OR } 3.1,95 \% \mathrm{Cl} 1.6 \text { to } 6.2 \text { ) }\end{array}$ \\
\hline & & $\begin{array}{l}\text { Function } \\
\text { Intermediate- } \\
\text { term }\end{array}$ & $\begin{array}{l}3(\mathrm{~N}=394) \\
\text { Martin } 2012 \\
\text { Castel } 2013 \\
\text { Cedraschi } 2004\end{array}$ & High & Consistent & Precise & Undetected & Low & $\begin{array}{l}\text { Pooled difference }-7.84, \\
95 \% \mathrm{Cl}-11.43 \text { to }-4.25, \\
\mathrm{I}^{2}=18.2 \% \\
\text { Proportion with clinically } \\
\text { meaningful improvement in } \\
\text { FIQ total score compared } \\
\text { with usual care at short } \\
\text { (OR } 3.1,95 \% \mathrm{Cl} 1.5 \text { to } 6.4 \text { ) }\end{array}$ \\
\hline
\end{tabular}




\begin{tabular}{|c|c|c|c|c|c|c|c|c|c|}
\hline Intervention & Comparator & Outcome & $\begin{array}{c}\text { Number of RCTs } \\
\text { (patients) } \\
\text { Author Year }\end{array}$ & $\begin{array}{c}\text { Study } \\
\text { Limitations }\end{array}$ & Consistency & Precision & $\begin{array}{l}\text { Reporting } \\
\text { Bias }\end{array}$ & $\begin{array}{l}\text { Strength } \\
\text { of } \\
\text { Evidence }\end{array}$ & $\begin{array}{l}\text { Findings, Direction and } \\
\text { Magnitude of Effect }\end{array}$ \\
\hline & & $\begin{array}{l}\text { Function } \\
\text { Long-term }\end{array}$ & $\begin{array}{l}2(\mathrm{~N}=311) \\
\text { Castel } 2013 \\
\text { van Ejik-Hustings } \\
2013\end{array}$ & Moderate & Consistent & Precise & Undetected & Low & $\begin{array}{l}\text { Pooled difference }-8.42 \text {, } \\
95 \% \mathrm{Cl}-13.76 \text { to }-3.08, \\
\mathrm{I}^{2}=24.9 \% \\
\text { Proportion with clinically } \\
\text { meaningful improvement in } \\
\text { FIQ total score compared } \\
\text { with usual care at short } \\
\text { (OR } 8.8,95 \% \mathrm{Cl} 2.5 \text { to } \\
30.9 \text { ) }\end{array}$ \\
\hline & & $\begin{array}{l}\text { Pain } \\
\text { Short-term }\end{array}$ & $\begin{array}{l}2(\mathrm{~N}=341) \\
\text { Castel } 2013 \\
\text { Amris } 2014\end{array}$ & Moderate & Consistent $^{\mathrm{e}}$ & Precise & Undetected & Low & $\begin{array}{l}\text { Pooled difference on } 0-10 \\
\text { scale }-0.24,95 \% \mathrm{Cl}-0.63 \text { to } \\
0.15, \mathrm{I}^{2}=0 \%\end{array}$ \\
\hline & & $\begin{array}{l}\text { Pain } \\
\text { Intermediate- } \\
\text { term }\end{array}$ & $\begin{array}{l}3(\mathrm{~N}=394) \\
\text { Martin } 2012 \\
\text { Castel } 2013 \\
\text { Cedraschi } 2004\end{array}$ & High & Consistent & Precise & Undetected & Low & $\begin{array}{l}\text { Pooled difference }-0.68 \text {, } \\
95 \% \mathrm{Cl}-1.07 \text { to }-0.30 \\
\mathrm{I}^{2}=0 \%\end{array}$ \\
\hline & & $\begin{array}{l}\text { Pain } \\
\text { Long-term }\end{array}$ & $\begin{array}{l}2(\mathrm{~N}=311) \\
\text { Castel } 2013 \\
\text { van Ejik-Hustings } \\
2013\end{array}$ & Moderate & Consistent & Precise & Undetected & Low & $\begin{array}{l}\text { Pooled difference }-0.25 \\
95 \% \mathrm{Cl}-0.68 \text { to } 0.17 \\
\mathrm{I}^{2}=0 \%\end{array}$ \\
\hline & & Harms & $\begin{array}{l}1(\mathrm{~N}=164) \\
\text { Cedraschi } 2004\end{array}$ & High & Unknown & Imprecise & Undetected & Insufficient & $\begin{array}{l}\text { Data were insufficient for } \\
\text { harms; however, one poor } \\
\text { quality trial reported that } \\
19 \% \text { (16/84) in the } \\
\text { multidisciplinary group } \\
\text { withdrew (versus } 0 \% \text { for } \\
\text { waiting list), two gave } \\
\text { increased pain as the } \\
\text { reason. Reasons for other } \\
\text { withdrawals were not given } \\
\text { and there was not } \\
\text { systematic reporting of } \\
\text { adverse events }\end{array}$ \\
\hline
\end{tabular}




\begin{tabular}{|c|c|c|c|c|c|c|c|c|c|}
\hline Intervention & Comparator & Outcome & $\begin{array}{c}\text { Number of RCTs } \\
\text { (patients) } \\
\text { Author Year }\end{array}$ & $\begin{array}{c}\text { Study } \\
\text { Limitations }\end{array}$ & Consistency & Precision & $\begin{array}{l}\text { Reporting } \\
\text { Bias }\end{array}$ & $\begin{array}{l}\text { Strength } \\
\text { of } \\
\text { Evidence }\end{array}$ & $\begin{array}{l}\text { Findings, Direction and } \\
\text { Magnitude of Effect }\end{array}$ \\
\hline & \multirow[t]{3}{*}{$\begin{array}{l}\text { Multi- } \\
\text { disciplinary } \\
\text { rehabilitation } \\
\text { vs. exercise }\end{array}$} & $\begin{array}{l}\text { Function } \\
\text { Long-term }\end{array}$ & $\begin{array}{l}1(\mathrm{~N}=155) \\
\text { van Eijk-Hustings } \\
2013\end{array}$ & Moderate & Unknown & Precise & Undetected & Low & $\begin{array}{l}\text { Difference }-1.10(95 \% \mathrm{Cl} \\
-8.40 \text { to } 6.20) \text { on a } 0-100 \\
\text { scale }\end{array}$ \\
\hline & & $\begin{array}{l}\text { Pain } \\
\text { Long-term }\end{array}$ & $\begin{array}{l}1(\mathrm{~N}=155) \\
\text { van Eijk-Hustings } \\
2013\end{array}$ & Moderate & Unknown & Precise & Undetected & Low & $\begin{array}{l}\text { Difference } 0.10(95 \% \mathrm{Cl} \\
-0.67 \text { to } 0.87) \text { on a } 0-10 \\
\text { scale }\end{array}$ \\
\hline & & Harms & $\begin{array}{l}1(\mathrm{~N}=155) \\
\text { van Eijk-Hustings } \\
2013\end{array}$ & Moderate & Unknown & Imprecise & Undetected & Insufficient & $\begin{array}{l}\text { Data were insufficient. } \\
\text { Harms not reported }\end{array}$ \\
\hline
\end{tabular}

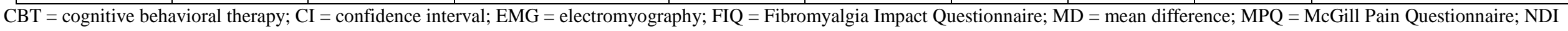
= Neck Disability Index; PSFS = Patient Specific Functional Scale; RCT = randomized controlled trial; RR = risk ratio; SD = standard deviation; VAS = visual analog scale.

${ }^{\text {a }}$ Outlier excluded, Baptista 2012.

${ }^{\mathrm{b}}$ Effect estimates go in the same direction even though magnitude of effect may differ

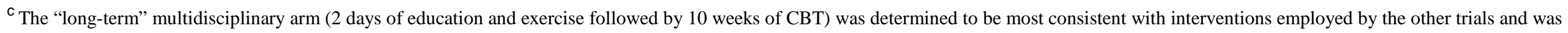

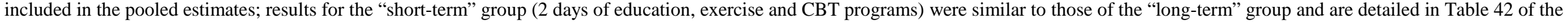
full report.

${ }^{d} \mathrm{I}^{2}>40 \%$ but not downgraded for inconsistency because direction of effect consistent across $>75 \%$ of trials or heterogeneity explainable in subgroup/stratified/sensitivity analyses.

e Outlier excluded, Saral 2016. 
Table G-7. Chronic tension headache (KQ 5) strength of evidence

\begin{tabular}{|c|c|c|c|c|c|c|c|c|c|}
\hline Intervention & Comparator & Outcome & $\begin{array}{c}\text { Number } \\
\text { of RCTs } \\
\text { (patients) } \\
\text { Author } \\
\text { Year }\end{array}$ & $\begin{array}{c}\text { Study } \\
\text { Limitations }\end{array}$ & Consistency & Precision & $\begin{array}{l}\text { Reporting } \\
\text { Bias }\end{array}$ & $\begin{array}{l}\text { Strength } \\
\text { of } \\
\text { Evidence }\end{array}$ & $\begin{array}{l}\text { Findings, Direction and } \\
\text { Magnitude of Effect }\end{array}$ \\
\hline \multirow[t]{8}{*}{$\begin{array}{l}\text { Psychological } \\
\text { Therapies }\end{array}$} & \multirow{4}{*}{$\begin{array}{l}\text { CBT vs. } \\
\text { waitlist, } \\
\text { attention } \\
\text { control, or } \\
\text { placebo }\end{array}$} & $\begin{array}{l}\text { Function } \\
\text { Short- and } \\
\text { intermediate } \\
\text { term }\end{array}$ & $\begin{array}{l}1(\mathrm{~N}=60) \\
\text { Holroyd } \\
2001\end{array}$ & High & Unknown & Precise & Undetected & Insufficient & $\begin{array}{l}\text { Insufficient evidence from one small } \\
\text { poor quality trial }\end{array}$ \\
\hline & & $\begin{array}{l}\text { Pain } \\
\text { Short-term }\end{array}$ & $\begin{array}{l}2(\mathrm{~N}=105) \\
\text { Holroyd } \\
2001 \\
\text { Blanchard } \\
1990 \\
\end{array}$ & High & Unknown & Precise & Undetected & Insufficient & $\begin{array}{l}\text { Insufficient evidence from two small } \\
\text { poor quality trials }\end{array}$ \\
\hline & & $\begin{array}{l}\text { Pain } \\
\text { Intermediate- } \\
\text { term }\end{array}$ & $\begin{array}{l}1(\mathrm{~N}=60) \\
\text { Holroyd } \\
2001\end{array}$ & High & Unknown & Precise & Undetected & Insufficient & $\begin{array}{l}\text { Insufficient evidence from one small } \\
\text { poor quality trial }\end{array}$ \\
\hline & & Harms & $\begin{array}{l}1(\mathrm{~N}=60) \\
\text { Holroyd } \\
2001\end{array}$ & High & Unknown & Precise & Undetected & Insufficient & $\begin{array}{l}\text { Insufficient evidence from one small } \\
\text { poor quality trial. The risk of } \\
\text { withdrawal due to adverse events } \\
\text { did not differ between CBT plus } \\
\text { placebo and placebo alone ( } 2 \% \text { vs. } \\
6 \%) \text {. }\end{array}$ \\
\hline & $\begin{array}{l}\text { Relaxation } \\
\text { vs. waitlist of } \\
\text { attention } \\
\text { control }\end{array}$ & $\begin{array}{l}\text { Pain, Harms } \\
\text { Short-term }\end{array}$ & $\begin{array}{l}1(\mathrm{~N}=55) \\
\text { Blanchard } \\
1990\end{array}$ & High & Unknown & Precise & Undetected & Insufficient & $\begin{array}{l}\text { Insufficient evidence from one small } \\
\text { poor quality trial }\end{array}$ \\
\hline & \multirow[t]{3}{*}{$\begin{array}{l}\text { CBT vs. } \\
\text { amitriptyline }\end{array}$} & $\begin{array}{l}\text { Function } \\
\text { Short- and } \\
\text { intermediate } \\
\text { term }\end{array}$ & $\begin{array}{l}1(\mathrm{~N}=60) \\
\text { Holroyd } \\
2001\end{array}$ & High & Unknown & Precise & Undetected & Insufficient & $\begin{array}{l}\text { Insufficient evidence from one small } \\
\text { poor quality trial }\end{array}$ \\
\hline & & $\begin{array}{l}\text { Pain } \\
\text { Short-term }\end{array}$ & $\begin{array}{l}2(\mathrm{~N}=96) \\
\text { Holroyd } \\
2001 \\
\text { Holroyd } \\
1991 \\
\end{array}$ & High & Unknown & Precise & Undetected & Insufficient & $\begin{array}{l}\text { Insufficient evidence from two small } \\
\text { poor quality trials }\end{array}$ \\
\hline & & $\begin{array}{l}\text { Pain } \\
\text { Intermediate- } \\
\text { term }\end{array}$ & $\begin{array}{l}1(\mathrm{~N}=60) \\
\text { Holroyd } \\
2001\end{array}$ & High & Unknown & Precise & Undetected & Insufficient & $\begin{array}{l}\text { Insufficient evidence from one small } \\
\text { poor quality trial }\end{array}$ \\
\hline
\end{tabular}




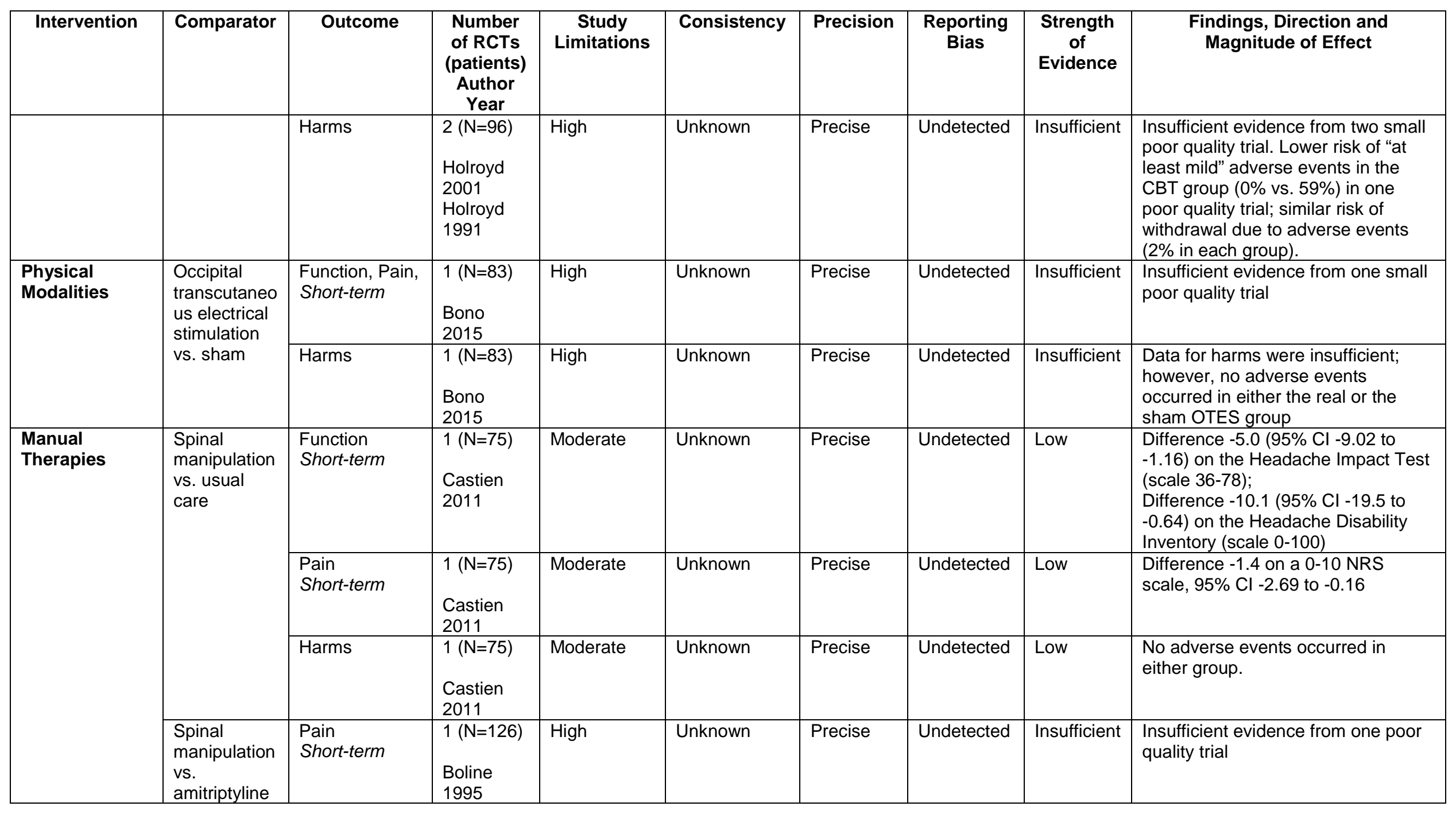




\begin{tabular}{|c|c|c|c|c|c|c|c|c|c|}
\hline Intervention & Comparator & Outcome & $\begin{array}{c}\text { Number } \\
\text { of RCTs } \\
\text { (patients) } \\
\text { Author } \\
\text { Year }\end{array}$ & $\begin{array}{c}\text { Study } \\
\text { Limitations }\end{array}$ & Consistency & Precision & $\begin{array}{l}\text { Reporting } \\
\text { Bias }\end{array}$ & $\begin{array}{l}\text { Strength } \\
\text { of } \\
\text { Evidence }\end{array}$ & $\begin{array}{l}\text { Findings, Direction and } \\
\text { Magnitude of Effect }\end{array}$ \\
\hline & & Harms & $\begin{array}{l}1(\mathrm{~N}=126) \\
\text { Boline } \\
1995\end{array}$ & High & Unknown & Precise & Undetected & Low & $\begin{array}{l}\text { Fewer adverse events with } \\
\text { manipulation versus amitriptyline } \\
\text { (RR } 0.05,95 \% \mathrm{Cl} 0.02 \text { to } 0.16 \text { ), } \\
\text { though the risk of withdrawal due to } \\
\text { adverse events was not significantly } \\
\text { different (RR } 0.16,95 \% \mathrm{Cl} 0.02 \text { to } \\
1.33 \text { ). Common complaints were } \\
\text { neck stiffness in the manipulation } \\
\text { group and dry mouth, dizziness, and } \\
\text { weight gain in the medication group }\end{array}$ \\
\hline \multirow[t]{5}{*}{ Acupuncture } & \multirow[t]{3}{*}{$\begin{array}{l}\text { Traditional } \\
\text { Chinese } \\
\text { needle } \\
\text { acupuncture } \\
\text { vs. sham }\end{array}$} & $\begin{array}{l}\text { Pain } \\
\text { Short-term }\end{array}$ & $\begin{array}{l}2(\mathrm{~N}=69) \\
\text { Karst } \\
2000 \\
\text { Tavola } \\
1992\end{array}$ & High & Consistent & Imprecise & Undetected & Insufficient & $\begin{array}{l}\text { Insufficient evidence from two small, } \\
\text { poor quality trials }\end{array}$ \\
\hline & & $\begin{array}{l}\text { Pain } \\
\text { Intermediate- } \\
\text { and long-term }\end{array}$ & $\begin{array}{l}1(\mathrm{~N}=30) \\
\text { Tavola } \\
1992\end{array}$ & High & Unknown & Imprecise & Undetected & Insufficient & $\begin{array}{l}\text { Insufficient evidence from one small, } \\
\text { poor quality trial }\end{array}$ \\
\hline & & Harms & & & & & & & No evidence \\
\hline & \multirow[t]{2}{*}{$\begin{array}{l}\text { Laser } \\
\text { acupuncture } \\
\text { vs. sham } \\
\text { laser }\end{array}$} & $\begin{array}{l}\text { Pain } \\
\text { Short-term }\end{array}$ & $\begin{array}{l}1(\mathrm{~N}=50) \\
\text { Ebneshahi } \\
\text { di } 2005\end{array}$ & Moderate & Unknown & Precise & Undetected & Low & $\begin{array}{l}\text { Median difference }-2 \text {, IQR } 6.3 \text {, on a } \\
0-10 \text { VAS scale for pain intensity } \\
\text { median difference }-8 \text {, IQR } 21.5 \text {, for } \\
\text { number of headache days per } \\
\text { month }\end{array}$ \\
\hline & & Harms & $\begin{array}{l}1(\mathrm{~N}=50) \\
\text { Ebneshahi } \\
\text { di } 2005\end{array}$ & Moderate & Unknown & Precise & Undetected & Low & $\begin{array}{l}\text { No adverse events occurred in } \\
\text { either group. }\end{array}$ \\
\hline
\end{tabular}

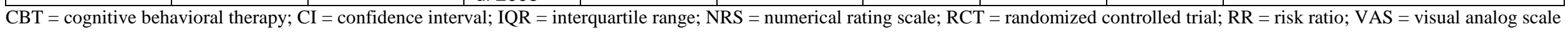




\section{Appendix H. Definitions for Magnitude of Effects}

Table H-1. Definitions for magnitude of effects, based on mean between-group differences

\begin{tabular}{|c|c|c|c|}
\hline Outcome & $\begin{array}{c}\text { Slight/Small } \\
\text { Magnitude of Effect }\end{array}$ & $\begin{array}{c}\text { Moderate } \\
\text { Magnitude of Effect }\end{array}$ & $\begin{array}{l}\text { Large/Substantial } \\
\text { Magnitude of Effect }\end{array}$ \\
\hline \multirow[t]{2}{*}{ Pain } & $\begin{array}{l}5-10 \text { points on a } 0 \text {-to } 100 \text {-point } \\
\text { VAS or the equivalent }\end{array}$ & $\begin{array}{l}>10-20 \text { points on a } 0 \text {-to } 100- \\
\text { point VAS or the equivalent }\end{array}$ & $\begin{array}{l}>20 \text { points on a } 0 \text {-to } 100 \text {-point } \\
\text { VAS or the equivalent }\end{array}$ \\
\hline & $\begin{array}{l}0.5-1.0 \text { points on a } 0 \text {-to } 10- \\
\text { point numerical rating scale or } \\
\text { the equivalent }\end{array}$ & $\begin{array}{l}>1-2 \text { points on a } 0 \text {-to } 10 \text {-point } \\
\text { numerical rating scale or the } \\
\text { equivalent }\end{array}$ & $\begin{array}{l}>2 \text { points on a } 0 \text {-to } 10 \text {-point } \\
\text { numerical rating scale or the } \\
\text { equivalent }\end{array}$ \\
\hline \multirow[t]{9}{*}{ Function } & 5-10 points on the ODI & $>10-20$ points on the ODI & $>20$ points on the ODI \\
\hline & $1-2$ points on the RDQ & $>2-5$ points on the RDQ & $>5$ points on the RDQ \\
\hline & 1-2 points on Lequesne Index & $\begin{array}{l}>2-5 \text { points on the Lequesne } \\
\text { Index }\end{array}$ & 5 points on the Lequesne Index \\
\hline & 5-10 points on the WOMAC & $>10-20$ points on the WOMAC & $>20$ points on the WOMAC \\
\hline & 5-10 points on the KOOS & $>10-20$ points on the KOOS & $>20$ points on the KOOS \\
\hline & 5-10 points on the NPQ & $>10-20$ points on the NPQ & $>20$ points on the NPQ \\
\hline & $\begin{array}{l}\text { 5-10 points on the FIQ Total } \\
\text { Score }\end{array}$ & $\begin{array}{l}>10-20 \text { points on the FIQ Total } \\
\text { Score }\end{array}$ & $\begin{array}{l}>20 \text { points on the FIQ Total } \\
\text { Score }\end{array}$ \\
\hline & $7.5-10$ points on the NDI & $>10-20$ on the NDI & $>20$ points on the NDI \\
\hline & $1.3-2.2$ on the PSFS & $23.3-2.6$ on the PSFS & $>2.6$ on the PSFS \\
\hline $\begin{array}{l}\text { Pain or } \\
\text { Function }\end{array}$ & $0.2-0.5 \mathrm{SMD}$ & $>0.5-0.8 \mathrm{SMD}$ & $>0.8 \mathrm{SMD}$ \\
\hline
\end{tabular}

ODI = Oswestry Disability Index; RDQ = Roland Morris Disability Questionnaire; SMD = standardized mean difference; VAS = visual analogue scale; WOMAC = Western Ontario and Mc Master Universities Osteoarthritis index; KOOS=Knee Injury and Osteoarthritis Outcome Score; NDI = neck disability index; NPQ = Northwick Park Questionnaire; PSFS = Patient-Specific Functional Scale; FIQ = Fibromyalgia Impact Questionnaire 